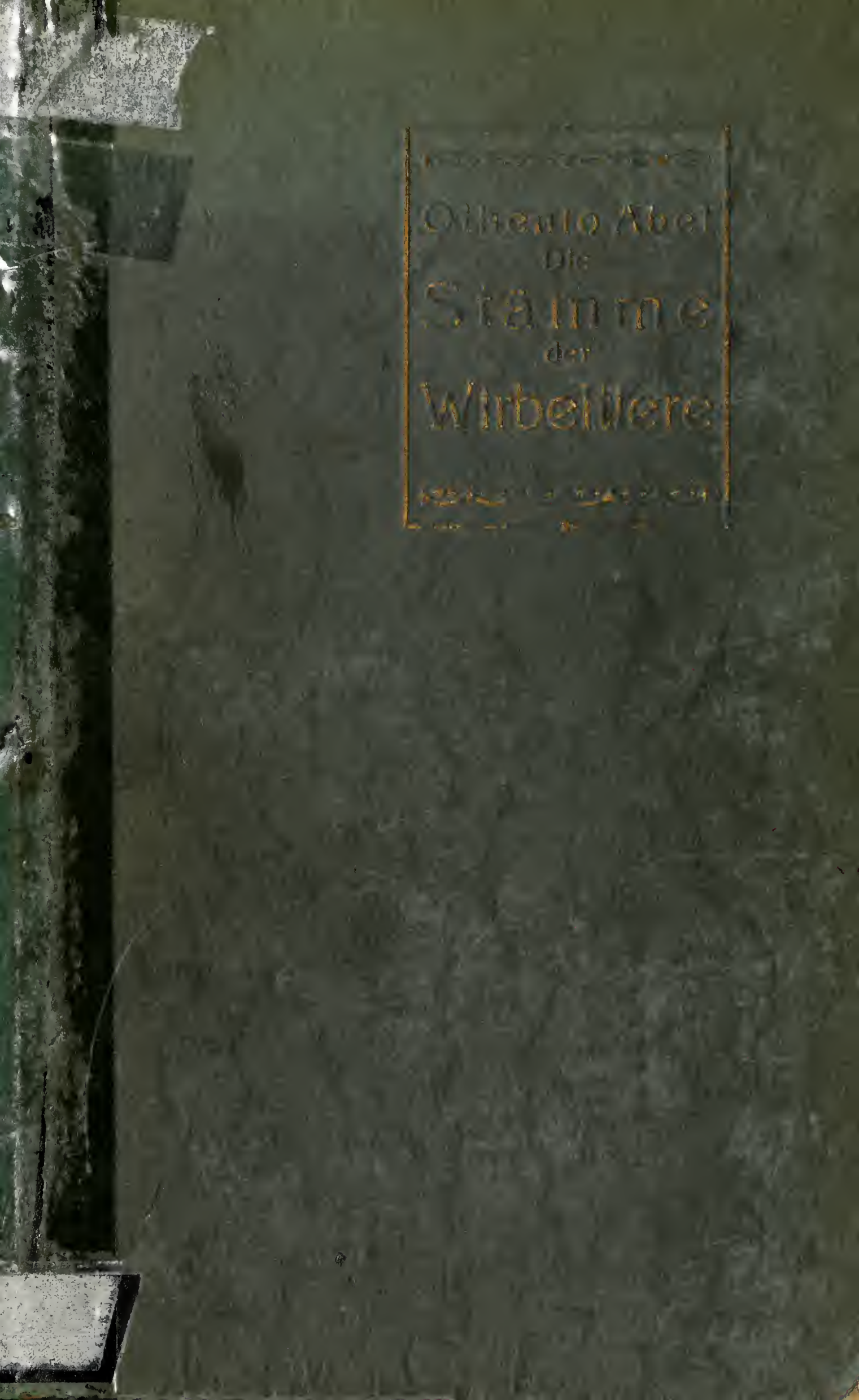







\title{
Die
}

\section{Stämme der Wirbeltiere}

Von

\section{Othenio Abel}

o. ö. Professor der Paläobiologie an der Universität Wien

\author{
Mit 669 Figuren im Text
}

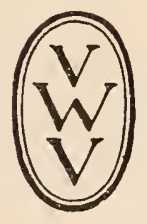

Berlin und Leipzig 1919

Vereinigung wissenschaftlicher Verleger Walter de Gruyter \& Co. 


\section{Copyright by}

Vereinigung wissenschaftlicher Verleger Walter de Gruyter \& Co. Berlin und Leipzig 1919. 


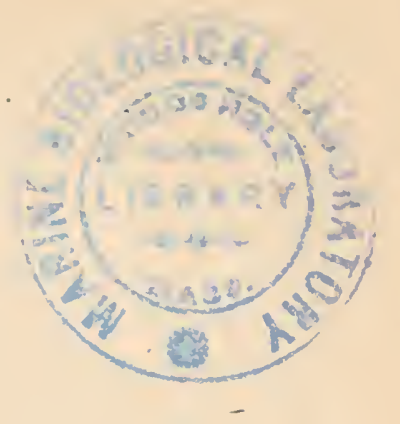

\section{Vorwort.}

Die ersten tastenden Versuche zur Aufhellung einer Stanmesgeschichte der Wirbeltiere haben sich auf die vergleichende Osteologie und allgemeine Anatomie der lebenden Formen beschränkt. Als später die Embryologie zu einer hohen Blüte gelangte, hat man mit ihrer Hilfe den Schlüssel zur Beantwortung vieler phylogenetischer Probleme zu finden gehofft und geglaubt. Die Stimmen, welche da und dort für eine eingehendere Berücksichtigung der paläontologischen Dokumente laut geworden sind, wurden von den eingeschworenen Vertretern der embryologischen Forschungsrichtung kaum beachtet und noch heute stehen viele bedeutende Zoologen auf dem Standpunkte, daß uns die Paläontologie nur einen sehr unvollständigen Aufschluß über die Vergangenheit der Tierwelt zu liefern vermag und daß die großen Erwartungen, welche man auf die Resultate der Paläozoologie gesetzt hatte, stark enttäuscht worden sind. Noch immer gilt für viele Zoologen als Grundsatz, daß die paläontologischen Urkunden zu selten, zu dürftig und zu schlecht erhalten sind, um aus ihnen weittragende phylogenetische Schlüsse ableiten zu können und sie vertiefen sich lieber in die Irrgänge morphologischer Spitzfindigkeiten, wofür die Geschichte der Forschungen über den Verbleib des Quadratums im Säugetierschädel ein treffendes Beispiel liefert.

Wer als Nichtfachmann die Mehrzahl der Publikationen über die fossilen Wirbeltierreste durchmustert, wird sich freilich zu der Ansicht hingezogen fühlen, daß aus den häufig sehr fragmentarisch erhaltenen fossilen Dokumenten keine zwingenden Beweise für oder gegen jene Anschauungen abgeleitet werden können, welche aus den Forschungen über die lebenden Wirbeltiere gewonnen worden sind. Dieses Gefühl der Unsicherheit und des Zweifels wird noch durch die wiederholt wechselnden Ansichten über die Deutung einzelner Reste von Seiten verschiedener Paläozoologen verstärkt, ebenso wie durch die häufig vorschnell ausgesprochenen Meinungen über die phylogenetische Stellung und Bedeutung verschiedener Formen. 
Wie jeder zu einer eigenen Forschungsrichtung ausgebaute Zweig der Biologie hat auch die Paläozoologie ihre eigenen Methoden ausgebaut und entwickelt. Das fossile Dokument hat für den, der nur mit vollständigen Objekten zu arbeiten gewöhnt ist und der morphologischen Rekonstruktion nicht bedarf, häufig nur den Wert eines unbestimmbaren Scherbens. Wir dürfen aber nicht vergessen, daß für den Historiker selbst ein fragmentärer Rest einer Urkunde oder einer Insclırift immer von höherem Werte sein und bleiben wird als die Anhaltspunkte für die hypothetische Rekonstruktion der Vergangenheit auf Grund der mündlichen Überlieferungen, die sich bis in die Gegenwart gerettet haben.

Freilich ist eine fragmentär erhaltene Urkunde für denjenigen, der nicht gewohnt ist, solche Reste zu lesen, zu ergänzen und zu deuten, vielfach ein Buch mit sieben Siegeln. Erst durch die sorgfältige Rekonstruktion der fragmentären fossilen Urkunde wird sie zu einem auch für die Fernerstehenden brauchbaren und verwertbaren Beweismittel. Daraus ergibt sich für den Paläozoolegen die Pflicht, das aus seinem engeren Forschungskreise stammende Beweismaterial für die Stammesgeschichte in leichter lesbarem, rekonstruiertem Zustande allgemein zugänglich zu machen.

Diese Erwägungen haben in mir den Entschluß gereift, eine zusammenfassende Darstellung der wichtigsten fossilen Dokumente aus der Stammesgeschichte der Wirbeltiere zu entwerfen und auf diese Weise den Beweis dafür zu liefern, daß die Paläozoologie der Wirbeltiere schon heute als die entscheidende Grundlage der Stammesgeschichte dieser Tiergruppe betrachtet werden muß. Die Achse der ganzen Darstellung konnte nur die vergleichende Osteologie der fossilen und lebenden Wirbeltiere sein, eine Forschungsrichtung, die in der letzten Zeit mehr und melır in die Hände der Paläozoologen übergegangen ist und unter den verschiedenen Zweigen der biologischen Forschung über lebende Wirbeltiere gegenwärtig stark in den Hintergrund gerückt erscheint.

Mit diesem hier skizzierten Grundplan, eine Übersicht der „Stämme der Wirbeltiere" zu entwerfen, mußte der Versuch verbunden werden, die verschiedenen fossilen und lebenden Stämme in ein „System“ zu bringen, um auf diese Weise einen leichteren Überblick zı ermöglichen. Da es vor allem darauf ankam, die Rolle festzulegen, welche die fossilen Vertreter der Wirbeltiere für deren Stanmesgeschichte spielen, durften sowohl jene Formen, die sich enge an die lebenden anschließen, als auch die lebenden Gruppen selbst nur in groben Umrissen dargestellt werden, wenn nicht der Umfang der Darstellung weit über das gesteckte Ziel hinausgreifen sollte. Einzelne besonders wiclitige Typen und Verbindungsglieder mußten eingehender besprochen werden als die Vertreter jener Gruppen, über deren Geschichte die fossilen Funde keinen anderen Auf- 
schlıß zu geben vermögen, als der durch die Untersuchungen über die lebenden Vertreter dieser Stänme gewonnen worden ist. Aus diesem Grunde sind beispielsweise die jüngeren Stämme der Teleostomen oder die der Vögel nur in großen Zügen umrissen worden, da die fossilen Gattungen und Arten bis jetzt zu keinen grundlegenden Verschiedenheiten der Ansichten über die Geschichte dieser Stänmme geführt haben. Die Säugetiere wurden zwar aus der Darstellung nicht ausgeschieden, aber kürzer behandelt, da es mir vor allem darauf ankan, die phylogenetischen Beziehungen der Fische, Amphibien und Reptilien darzulegen und weil icl außerdem erst vor kurzem die Phylogenie der Säugetiere in einem selbständigen Werke (,Die vorzeitlichen Säugetiere", Jena, bei G. Fisclier, 1914) besprochen habe, so daß ich auf dieses Buch verweisen darf.

Daß die hier gegebene Darstellung von den genetischen Zusammenhängen der einzelnen Gruppen in vielen Punkten von den bisherigen Ansichten über die Beziehungen zwischen den Stämmen und der Stelle ihrer Verzweigungen abweicht, darf nicht auf die Rechnung der Unvollständigkeit der fossilen Reste und ihrer Bedeutungslosigkeit für phylogenetische Fragen gestellt werden, wie dies so häufig zu geschehen pflegt. Der hauptsächlichste Grund für diese Verschiedenheiten unter den Ansichten der Paläozoologen liegt in der verschiedenen Bewertung der morplologisclien Merkmale, nicht in der verschiedenen Deutung derselben. Freilich sind auch die Deutungen der einzelnen Skelettelemente keineswegs immer dieselben und unterliegen in einzelnen Fällen weitgehenden Meinungsverschiedenheiten. Wer sicl in Einzelheiten jener Fragen, in deren Beantwortung, Deutung und phylogenetischen Bewertung ich von anderen Forschern abweiche, eingehender zu orientieren sucht, wird in dem nöglichst eingehenden Literaturverzeichnisse die weiteren Wege gewiesen finden.

Das wichtigste Hilfsmittel einer Darstellung, die den Zweck hat, über die bisher erreichten Ergebnisse der phylogenetischen Forschungen auf dem Gebiete der fossilen Wirbeltiere aufzuklären, nuß eine ausreichende Menge von Abbildungen sein. Diese Abbildungen nüssen, wie ich früher dargelegt habe, vor allen rekonstruktiv sein und möglichst klar die morphologischen Merkmale zur Schau tragen. Mehrere hundert Abbildungen habe ich für diese Darstellung selbst gezeichnet, entweder nach Originalen entworfen oder nach Originalabbildungen ungezeichnet oder aus solchen kombiniert, wenn bisher nur Detailbilder vorlagen. Ein anderer Teil der Abbildungen ist unmittelbar den Originalwerken entnommen.

Wer die Summe unserer bisherigen Kenntnisse von der phylogenetischen Bedeutung der fossilen Wirbeltiere mit dem Stande der Forschung vor etwa zwei Jahrzehnten vergleicht, wird sich dem Ein- 
drucke kaum entziehen können, daß auf diesem Gebiete eine gewaltige Arbeit geleistet und sehr bedeutende Fortschritte erzielt worden sind. Was in folgenden als ein Ausschnitt dieser Forschungsergebnisse der Paläozoologie mitgeteilt erscheint, wird bei einem weiteren Fortschritte unserer Forschungen zweifellos in manchen Punkten abgeändert und erweitert werden müssen, bis das von vielen Vertretern der biologischen Forschung angestrebte Ziel einer Stammesgeschichte der Wirbeltiere wenigstens in den Grundzügen als gelöst betrachtet werden darf. Hoffentlicl1 wird sich dabei immer mehr die Erkenntnis festigen, daß das letzte Wort bei den Lösungsversuchen dieser Probleme die Paläontologie zu sprechen hat, welche uns schon heute über verschiedene Probleme Aufschluß zu geben vermag, die bei der Beschränkung der phylogenetischen Forschungen auf die lebenden Formen stets in Dunkel gehüllt geblieben wären.

Mondsee, Oberösterreich, den 15. August 1919.

0. Abel. 


\section{Inhalt.}

Systematische Übersicht der erloschenen und der lebenden Familien der Wirbeltiere . . . . . . . . . . . . . . . . . . . . IX

Einleitung . . . . . . . . . . . . . . . . . . . . . . 1

Morphologische Vorbemerkungen . . . . . . . . . . . . . . . . . 17

I. Physiologische Bedeutung der Skelettbildungen . . . . . . . 17

II. Die heterogene Herkunft der Knochen: Ersatzknochen und Hautknochen . . . . . . . . . . . . . . . . . 20

11I. Die ersten Anfänge des Wirbelskeletts und dessen Differenzierung 21

IV. Aufbau und Gliederung des Wirbeltierschädels . . . . . . . 28

Die Stämme der Wirbeltiere . . . . . . . . . . . . . . . . . . . 63

Klasse: Rundmäuler (Cyclostomata) . . . . . . . . . . . . 63

Klasse: Fische (Pisces) . . . . . . . . . . . . . . . . 65

I. Unterklasse: Anaspida . . . . . . . . . . . . 65

Il. Unterklasse: Osteostraci . . . . . . . . . . . . 69

111. Unterklasse: Antiarchi . . . . . . . . . . . 86

IV. Unterklasse: Arthrodira . . . . . . . . . . . . . 92

V. Unterklasse: Elasmobranchii . . . . . . . . . 104

VI. Unterklasse: Acanthodei . . . . . . . . . . 147

VII. Unterklasse: Teleostomi . . . . . . . . . . 153

Klasse: Lurche (Amphibia) . . . . . . . . . . . . . . 220

Die stammesgeschichtliche Stellung der Amphibien . . . . . 220

Systematik der Amphibien . . . . . . . . . . . . . . 220

Die Morphologie der Wirbelsäule als Grundlage einer systematischen Gruppierung der Amphibien . . . . . . . . . 221

Die Terminologie der Wirbelkörper nach der Form . . . . . 232

I. Unterklasse: Stegocephalia (Stegocephalen) . . . . . 233

I1. Unterklasse: Anura (Froschlurche) . . . . . . . . 311

11I. Unterklasse: Urodela (Schwanzlurche) . . . . . . . 324

IV. Unterklasse: Apoda (Gymnophiona) . . . . . . . 332

Klasse: Kriechtiere (Reptilia) . . . . . . . . . . . . 333 
Seite

Klasse: Vögel (Aves) . . . . . . . . . . . . . . . 686

I. Unterklasse: Saururae . . . . . . . . . 693

II. Unterklasse: Ornithurae . . . . . . . . . . 695

Klasse: Säugetiere (Mammalia) . . . . . . . . . . . . 710

I. Unterklasse: Monotremata . . . . . . . . . 710

II. Unterklasse: Marsupialia . . . . . . . . . 710

III. Unterklasse: Placentalia . . . . . . . . . . 721

Morphologisches Register . . . . . . . . . . . . . . . . . . . . 878

Übersicht der Famlien und Unterfamilien, Ordnungen und Unterordnungen,

Klassen und Unterklassen . . . . . . . . . . . . . . . . 892

Verzeichnis der Gattungsnamen . . . . . . . . . . . . . . . . . . 897

Autorenregister . . . . . . . . . . . . . . . . . . . . . . . 910

\section{Berichtigungen.}

S. 129: Gemündinidae (statt Gemündenidae).

S. 151: Climatius scutiger (statt C. parexus).

S. 384: var. integra (statt var. integrum).

S. 389: (Zeile 9 von unten): $86,8 \mathrm{~cm}$ (statt $36,8 \mathrm{ccm}$ ).

S. 391: (Figurenerklärung): $H A$ (statt $H c$ ).

S. 392: (Nachtrag zur Figurenerklärung): $A c=$ Acetabulum.

S. 427: (Figurenerklärung): $F=$ Foramen magnum (statt Frontale).

S. 530: Baron F. Nopcsa machte mich nach Einsicht in die Aushängebogen auf die fehlerhafte Rekonstruktion des Hinterhauptes von Aetosaurus aufmerksan, die gelegentlich zu berichtigen sein wird.

S. 533: XV. Ordnung (statt XIX. Ordnung).

S. 554: XVI. Ordnung (statt XX. Ordnung). 


\section{Systematische Übersicht}

\section{der erloschenen und der lebenden Familien der Wirbeltiere.}

(Die erloschenen Familien und Gattungen sind durch einen * bezeichnet. Von jeder Familie ist nur je eine Gattung als Beispiel genannt, auch wenn diese Familie eine größere Zahl von Gattungen umfaßt.)

\section{Klasse: Rundmäuler (Cyclostomata).} Myxinidae: Myxine.

Petromyzodontidae: Petromyzon.

\section{Klasse: Fische (Pisces).}

\section{Unterklasse: Anaspida.}

*Lasaniidae: *Lasanius.

*Birkeniidae: *Birkenia.

*Pterolepidae: *Pterolepis.

I1. Unterklasse: Osteostraci.

*Coelolepidae: *Thelodus.

*Cephalaspidae: *Cephalaspis.

*Tremataspidae: *Tremataspis.

*Drepanaspidae: *Drepanaspis.

*Pteraspidae: *Pteraspis.

111. Unterklasse: Antiarchi.

*Asterolepidae: *Pterichthys.

IV. Unterklasse: Arthrodira.

*Coccosteidae: *Coccosteus.

*Mylostomidae: *Mylostoma.

*Ptyctodontidae: *Ptyctodus.

V. Unterklasse: Elasmobranchii.

1. Ordnung: Pleuropterygi.

*Cladodontidae: *Cladodus.

2. Ordnung: 1 chthyotomi.

*Pleuracanthidae: *Pleuracanthus.

3. Ordnung: Plagiostomi.

Notidanidae: Notidanus.

Chlamydoselachidae: Chlamydoselache.

Heterodontidae: Heterodontus.

Scyllidae: Scyllium.

Carchariidae: Carcharias.

Sphyrnidae: Sphyrna.

Lamnidae: Lamna.

Cetorhinidae: Cetorhinus.
Rhinodontidae: Rhinodon.

Spinacidae: Spinax.

Pristiophoridae: Pristiophorus.

Pristidae: Pristis.

Rhinidae: Rhina.

Rhinobatidae: Rhinobatus.

Rajidae: Raja.

Torpedinidae: Torpedo.

Trygonidae: Trygon.

Myliobatidae: Myliobatis.

*Gemuendinidae: *Gemuendina.

*Tamiobatidae: *Tamiobatis.

*Cochliodontidae: ${ }^{*}$ Cochliodus.

*Psammodontidae: *Psammodus.

*Petalodontidae: *Petalodus.

*Edestidae: *Helicoprion.

*Ptychodontidae: *Ptychodus.

4. Ordnung: Holocephali.

*Squalorajidae: *Squaloraja.

*Myriacanthidae: *Myriacanthus.

Chimaeridae: Chimaera.

VI. Unterklasse: Acanthodei.

*Acanthodidae: *Acanthodes.

Vil. Unterklasse: Teleostomi.

1. Ordnung: Crossopterygii.

*Osteolepidae: '*Osteolepis.

*Tarrasiidae: *Tarrasius.

*Holoptychiidae: *Holoptychius.

*Rhizodontidae: *Eusthenopteron.

*Onychodontidae: * Onychodus.

*Coelacanthidae: *Coelacanthus.

Polypteridae: Polypterus. 


\section{Ordnung: Dipneusti.}

Ctenodontidae: Neoceratodus.

\section{Ordnung: Actinopterygii.}

*Palaeoniscidae: *Palaeoniscus.

*Platysomidae: *Platysomus.

*Belonorhynchidae: *Belonorhynchus.

*Chondrosteidae: *Chondrosteus.

Polyodontidae: Polyodon.

Acipenseridae: Acipenser.

*Semionotidae: *Semionotus.

*Macrosemiidae: *Macrosemius.

*Pycnodontidae: *Mesodon.

*Pholidophoridae: *Pholidophorus.

* Pholidopleuridae: Pholidopleurus.

*Aspidorhynchidae: *Aspidorhynchus.

Amiidae: Amia.

*Pachycormidae: *Pachycormus.

* Oligopleuridae: *Oligopleurus.

Lepidosteidae: Lepidosteus.

*Leptolepidae: *Leptolepis.

Unterordnung: Malacopterygii.

Elopidae: Elops.

Albulidae: Albula.

Chanidae: Chanos.

*Plethodidae: *Plethodus.

Mormyridae: Mormyrus.

Hyodontidae: Hyodon.

Notopteridae: Notopterus.

Osteoglossidae: Osteoglossum.

Phractolaemidae: Phractolaemus.

Pantodontidae: Pantodon.

*Ctenothrissidae: ${ }^{*}$ Ctenothrissa.

*Saurodontidae: *Portheus.

Chirocentridae: Chirocentrus.

Clupeidae: Clupea.

Salmonidae: Salmo.

Alepocephalidae: Alepocephalus.

Stomiatidae: Malacosteus.

Gonorhynchidae: Gonorhynchus.

Cromeriidae: Cromeria.

Unterordnung: Ostariophysi.

Characinidae: Hydrocyon.

Cyprinidae: Cyprinus.

Gymnotidae: Gymnotus.

Siluridae: Silurus.

Callichthyidae: Callichthys,

Loricariidae: Loricaria.

Aspredinidae: Aspredo.

\section{Unterordnung: Symbranchii.}

Symbranchidae: Symbranchus.

Amphipnoidae: Amphipnous.
Unterordnung: Apodes.

Urenchelidae: *Urenchelys.

Anguillidae: Anguilla.

Nemichthyidae: Nemichthys.

Derichthyidae: Derichthys.

Synaphobranchidae: Synaphobranchus.

Saccopharyngidae: Saccopharynx.

Muraenidae: Muraena.

Unterordnung: Haplomi.

Galaxiidae: Galaxias.

Haplochitonidae: Haplochiton.

*Enchodontidae: *Enchodus.

Esocidae: Esox.

Dalliidae: Dallia.

Scopelidae: Scopelus.

Alepidosauridae: Alepidosaurus.

Cetomimidae: Cetomimus.

Kneriidae: Kneria.

*Chirothricidae: *Chirothrix.

Cyprinodontidae: Cyprinodon.

Amblyopsidae: Chologaster.

Stephanoberycidae: Stephanoberyx.

Percopsidae: Percopsis.

Unterordnung: Heteromi.

*Dercetidae: *Dercetis.

Halosauridae: Halosaurus.

Lipogenyidae: Lipogenys.

Notacanthidae: Notacanthus.

Fierasferidae: Fierasfer.

Unterordnung: Catosteomi.

Gastrosteidae: Gastrosteus.

Aulorhynchidae: Aulorhynchus.

*Protosyngnathidae: *Protosyngnathus.

Aulostomatidae: Aulostoma.

Fistulariidae: Fistularia.

Centriscidae: Centriscus.

Amphisylidae: Amphisyle.

Solenostomidae: Solenostoma.

Syngnathidae: Syngnathus.

Pegasidae: Pegasus.

Unterordnung: Percesoces.

Scombresocidae: Scombresox.

Ammodytidae: Ammodytes.

Sphyraenidae: Sphyraena.

Atherinidae: Atherina.

Mugilidae: Mugil.

Polynemidae: Pentanemus.

Tetragonuridae: Tetragonurus.

Stromateidae: Nomeus.

Icosteidae: 1costeus.

Ophiocephalidae: Ophiocephalus.

Anabantidae: Anabas.

Chiasmodontidae: Chiasmodon. 
Unterordnung: Anacanthini.

Macruridae: Macrurus.

Gadidae: Gadus.

Muraenolepididae: Muraenolepis.

\section{Unterordnung: Acanthopterygii.}

Berycidae: *Hoplopteryx.

Aphredoderidae: Aphredoderus.

Trachichthyidae: Trachichthys.

Holocentridae: Holocentrum.

Monocentridae: Monocentris.

Pempheridae: Pempheris.

Centrarchidae: Centrarchus.

Cyphosiidae: Cyphosus.

Lobotidae: Lobotes.

Toxotidae: Toxotes.

Nandidae: Nandus.

Percidae: Perca.

Acropomatidae: Propoma.

Serranidae: Serranus.

Anomalopidae: Anomalops.

Pseudochromididae: Pseudochromis.

Cepolidae: Cepola.

Hoplognathidae: Hoplognathus.

Sillaginidae: Sillago.

Sciaenidae: Sciaena.

Gerridae: Gerres.

Lactariidae: Lactarius.

Trichodontidae: Trichodon.

Latrididae: Latris.

Haplodactylidae: Haplodactylus.

Pristipomatidae: Pristipoma.

Sparidae: Dentex.

Mullidae: Mullus.

Scorpididae: Psettus.

Caproidae: Capros.

Chaetodontidae: Chaetodon.

Drepanidae: Drepane.

Acanthuridae: Acanthurus.

Amphacanthidae: Teuthis.

Osphromenidae: Osphromenus.

Embiotocidae: Ditrema.

Cichlidae: Cichla.

Pomacentridae: Pomacentrus.

Labridae: Tautoga.

Scaridae: Scarus.

Carangidae: Caranx.

Rhachicentridae: Rhachicentrum.

Scombridae: Scomber.

Trichiuridae: Thyrsites.

Paralepidae: Plagyodus.

*Palaeorhynchidae: *Palaeorhynchus.

Xiphiidae: Histiophorus.

Luvariidae: Luvarus.

Coryphaenidae: Coryphaena.

Bramidae: Bramis.
Zeidae: Zeus.

*Amphistiidae: *Amphistium.

Pleuronectidae: Pleuronectes.

Kurtidae: Kurtus.

Gobiidae: Gobius.

Echeneidae: Echeneis.

Caracanthidae: Micropus.

Scorpaenidae: Scorpaena.

Hexagrammidae: Hexagrammus.

Comephoridae: Anoplopoma.

Rhamphocottidae: Rhamphocottus.

Cottidae: Cottus.

Cyclopteridae: Cyclopterus.

Platycephalidae: Platycephalus.

Hoplichthyidae: Hoplichthys.

Agonidae: Agonus.

Triglidae: Trigla.

Dactylopteridae: Dactylopterus.

Trachinidae: Trachinus.

Percophidae: Percophis.

Leptoscopidae: Leptoscopus.

Nototheniidae: Notothenia.

Uranoscopidae: Uranoscopus.

Trichonotidae: Trichonotus.

Callionymidae: Callionymus.

Gobiesocidae: Sicyases.

Blenniidae: Blennius.

Batrachidae: Batrachus.

Pholididae: Pholis.

Zoarcidae: Zoarces.

Congrogadidae: Congrogadus.

Ophidiidae: Ophidium.

Podatelidae: Podateles.

Lamprididae: Lampris.

Veliferidae: Velifer.

Trachypteridae: Trachypterus.

Lophotidae: Lophotes.

Unterordnung: Opisthomi.

Mastacembelidae: Mastacembelus.

Unterordnung: Pediculati.

Lophiidae: Lophius.

Ceratiidae: Ceratias.

Antennariidae: Antennarius.

Gigantactinidae: Gigantactis.

Malthidae: Malthe.

Unterordnung: Plectognathi.

Triacanthidae: Triacanthus.

Triodontidae: Triodon.

Balistidae: Balistes.

Ostracionidae: Ostracion.

Tetrodontidae: Tetrodon.

Diodontidae: Diodon.

Molidae: Orthagoriscus. 


\section{Klasse: Lurche (Amphibia).}

1. Unterklasse: Stegocephalia.

1. Ordnung: Rhachitomi.

*Archegosauridae: *Archegosaurus.

*Trimerorhachidae: *Trimerorhachis.

*Eryopidae: *Eryops.

*Trematopsidae: *Trematops.

*Dissorophidae: *Cacops.

*Aspidosauridae: *Aspidosaurus.

*Zatrachyidae: *Zatrachys.

*Micropholidae: *Micropholis.

*Labyrinthodontidae: *Capitosaurus.

*Plagiosauridae: *Plagiosaurus.

2. Ordnung: Embolomeri.

*Cricotidae: *Cricotus.

3. Ordnung: Phyllospondyli.

*Branchiosauridae: *Branchiosaurus.

*Acanthostomatidae: *Acanthostoma.

4. Ordnung: Pseudocentrophori.

*Ceraterpetontidae: *Ceraterpeton.

*Ptyonidae: *Ptyonitus.

*Ophiderpetontidae: * Ophiderpeton.

*Molgophidae: *Molgophis.

*Phlegethontiidae: *Dolichosoma.

5. Ordnung: Gastrocentrophori.

*Microbrachidae: *Microbrachis.

*Hylonomidae: *Hylonomus.

*Limnerpetontidae: * Limnerpeton.
II. Unterklasse: Anura.

1. Ordnung: Aglossa.

Xenopodidae: Xenopus.

Pipidae: Pipa.

2. Ordnung: Phaneroglossa.

1. Unterordnung: Arcifera.

*Palaeobatrachidae: *Palacobatrachus.

Bufonidae: Bufo.

Discoglossidae: Alytes.

Pelobatidae: Pelobates.

Cystignathidae: Ceratophrys.

Hylidae: Hyla.

Amphignathodontidae: Amphignathodon.

Hemiphractidae: Ceratohyla.

2. Unterordnung: Firmisternia.

Ranidae: Rana.

Engystomatidae: Breviceps.

III. Unterklasse: Urodela.

*Paterosauridae: *Lysorophus.

*Hylaeobatrachidae: *Hylaeobatrachus.

Amphiumidae: *Andrias.

Salamandridae: Molge.

Proteidae: Protetus.

Sirenidae: Siren.

IV. Unterklasse: Gymnophiona (=Apoda).

Coeciliidae: Ichthyophis.

\section{Klasse: Kriechtiere (Reptilia).}

1. Ordnung: Cotylosauria

(Stammgruppe).

*Limnoscelidae: *Limnoscelis.

*Diadectidae: *Diadectes.

*Stephanospondylidae: *Stephanospondylus.

*Pantylidae: *Pantylus.

*Seymouriidae: *Seymonria.

*Sauravidae: *Eosauravus.

*Gymnarthridae: *Gymnarthrus.

*Pariotichidae: *Pariotichus.

*Captorhinidae: *Labidosaurus.

*Elginiidae: *Elginia.

* Pareiasauridae: *Pareiasaurus.

*Bolosauridae: *Bolosaurus.

2. Ordnung: Procolophonia.

*Procolophonidae: *Procolophon.
3. Ordnung: Pelycosauria. *Sphenacodontidae: *Dinetrodon. *Palaeohatteriidae: *Palaeohatteria. *Poliosauridae: *Varanosaurus.

*Ophiacodontidae: *Ophiacodon.

*Caseidae: *Casea.

*Edaphosauridae: *Edaphosaurus.

4. Ordnung: Deuterosauria.

*Deuterosauridae: *Denterosaurus.

5. Ordnung: Testudinata.

1. Unterordnung: Cryptodira.

*Triassochelyidae: *Triassochelys.

Chelydridae: Chelydra.

Cinosternidae: Cinosternum.

Dermatemydidae: Dermatemys.

Platysternidae: Platysternum.

Testudinidae: Testudo. 
Systemat. Übersicht der erloschenen und der lebenden Familien der Wirbeltiere. XIII

2. Unterordnung: Cheloniidea.

*Thalassemydidae: *Thalassemys.

Cheloniidae: Chelonia.

Dermochelyidae: Dermochelys.

3. Unterordnung: Pleurodira.

*Archaeochelyidae: *Proterochersis.

*Plesiochelyidae: *Plesiochelys.

*Amphichelyidae: *Pleurosternum.

*Miolaniidae: *Miolania.

Pelomedusidae: Podocnemis.

Chelyidae: Chelys.

4. Unterordnung: Trionychoidea.

Carettochelyidae: Caret tochelys.

Trionychidae: Trionyx.

6. Ordnung: Theriodontia.

1. Unterordnung: Therocephalia.

*Cynognathidae: *Cynognathus.

2. Unterordnung: Dromasauria.

*Dromasauridae: *Galepus.

3. Unterordnung: Dinocephalia.

*Dinocephalidae: *Delphinognathus.

4. Unterordnung: Dicynodontia.

*Dicynodontidae: *Dicynodon.

7. Ordnung: Rhynchocephalia. Sphenodontidae: Sphenodon.

*Pleurosauridae: *Pleurosaurus.

*Rhynchosauridae: *Rhynchosaurus.

*Sauranodontidae: *Sauranodon.

*Champsosauridae: *Champsosaurus.

8. Ordnung: Protorosauria.

*Protorosauridae: *Protorosaurus.

9. Ordnung: Mesosauria.

*Mesosauridae: *Mesosaurus.

10. Ordnung: Ichthyosauria.

*Ichthyosauridae: *Stenopterygius.

11. Ordnung: Sauropterygia.

*Nothosauridae: *Nothosaurus.

*Plesiosauridae: *Plesiosaurus.

*Elasmosauridae: *Elasmosaurus.

Pliosauridae: *Pliosaurus.

12. Ordnung: Placodontia.

*Placodontidae: *Placodus.

13. Ordnung: Parasuchia.

*Pelycosimiidae: *Erythrosuchus.

*Phytosauridae: *Mystriosuchus.

14. Ordnung: Pseudosuchia.

*Proterosuchidae: *Proterosuchus.

*Ornithosuchidae: *Ornithosuchus.

*Aëtosauridae: *Aëtosaurus.

*Scleromochlidae: *Scleromochlus.
15. Ordnung: Crocodilia.

*Teleosauridae: *Teleosaurus.

*Geosauridae: * Geosaurus.

*Pholidosauridae: *Pholidosaurus.

*Atoposauridae: *Alligatorellus.

Crocodilidae: Crocodilus.

Gavialidae: Gavialis.

16. Oednung: Rhamphorhynchoidea.

*Rhamphorhynchidae: *Rhamphorhynchus.

17. Ordnung: Pterodactyloidea.

*Pterodactylidae: *Pterodactylus.

*Ornithodesmidae: *Ornithodesmus.

*Ornithocheiridae: *Pteranodon.

18. Ordnung: Dinosauria (= Saurischia).

1. Unterordnung: Coelurosauria. *Podokesauridae: *Podokesaurus.

*Hallopidae: *Hallopus.

*Coeluridae: *Coelurus.

*Compsognathidae: *Compsognathus.

2. Unterordnung: Pachypodosauria.

*Zanclodontidae: *'Thecodontosaurus.

*Plateosauridae: *Plateosaurus.

3. Unterordnung: Theropoda.

*Anchisauridae: *Anchisaurus.

*Megalosauridae: *Megalosaurus.

*Spinosauridae: *Spinosaurus.

4. Unterordnung: Sauropoda.

*Diplodocidae: *Diplodocus.

*Atlantosauridae: *Brontosaurus.

*Cetiosauridae: *Haplocanthosaurus.

19. Ordnung: Ornithischia (= Orthopoda).

* Kalodontidae: *Iguanodon.

*Trachodontidae: *Trachodon.

*Stegosauridae: *Stegosaurus.

*Acanthopholidae: *Polacanthus.

* Ceratopsidae: *Triceratops.

20. Orduung: Araeoscelidia.

*Araeoscelidae: *Araeoscelis.

21. Ordnung: Lepidosauria.

1. Unterordnung: Lacertilia.

Geckonidae: Phyllodactylus.

Eublepharidae: Holodactylus.

Uroplatidae: Uroplates.

Pygopodidae: Pygopus.

Agamidae: Agama.

lguanidae: Iguana.

Zonuridae: Zonurus. 
Anguidae: Anguis.

Helodermatidae: Heloderma.

Varanidae: Varanus.

Teiidae: Tupinambis.

Amphisbaenidae: Amphisbaena.

Lacertidae: Lacerta.

Gerrhosauridae: Gerrhosaurus.

Scincidae: Scincus.

2. Unterordnung: Thalattos̊auria.

*Thalattosauridae: *Thalattosaurus.

3. Unterordnung: Dolichosauria.

*Dolichosauridae: *Adriosaurus.

4. Unterordnung: Mosasauria (= Pythonomorpha).

*Mosasauridae: *Mosasaurus.
5. Unterordnung: Rhiptoglossa.

Chamaeleonidae: Chamaeleo.

6. Unterordnung: Ophidia.

*Palaeophidae: *Palaeophis.

*Archaeophidae: *Archaeophis.

Typhlopidae: Typhlops.

Glauconiidae: Glauconia.

Boidae: Boa.

Pythonidae: Python.

Ilysiidae: Ilysia.

Uropeltidae: Uropeltis.

Colubridae: Tropidonotus.

Amblycephalidae: Amblycephalus.

Viperidae: Vipera.

\section{Klasse: Vögel (Aves).}

1. Unterklasse: Saururae.

Ordnung: Archaeornithes.

*Archaeopterygidae: *Archaeopteryx.

\section{Unterklasse: Ornithurae.}

1. Ordnung: Odontolcae.

*Hesperornithidae: *Hesperornis.

2. Ordnung: Odontormae. *Ichthyornithidae: *Ichthyornis.

3. Ordnung: Struthiones. Struthionidae: Struthio.

4. Ordnung: Aepyornithes. *Aepyornithidae: *Aepyornis.

5. Ordnung: Rheae.

Rheidae: Rhea.

6. Ordnung: Dinornithes. *Dinornithidae: *Dinornis.

7. Ordnung: Casuarii.

Casuariidae: Casuarius.

8. Ordnung: Apteryges.

Apterygidae: Apteryx.

9. Ordnung: Tinamif ormes.

Tinamidae: Crypturus.

10. Ordnung: Sphenisciformes. Spheniscidae: Aptenodytes.

11. Ordnung: Colymbiformes.

Podicipidae: Podiceps.

Colymbidae: Colymbus.

12. Ordnung: Procellariiformes. Procellariidae: Diomedea.
13. Ordnung: Ciconiformes.

1. Unterordnung: Steganopodes. Phaëtontidae: Phaëton.

Sulidae: Sula.

Phalacrocoracidae: Phalacrocorax.

Fregatidae: Fregata.

Pelecanidae: Pelecanus.

2. Unterordnung: Ardeae. Ardeidae: Herodias.

Scopidae: Scopus.

3. Unterordnung: Ciconiae. Ciconiidae: Ciconia.

Ibidae: Ibis.

4. Unterordnung: Phoenicopteri. Phoenicopteridae: Phoenicopterus.

*Odontopterygidae: *Odontopteryx.

14. Ordnung: Anseriformes.

1. Unterordnung: Gastornithidea. *Gastornithidae: * Gastornis.

2. Unterordnung: Palamedeae. Palamedeidae: Palamedea.

3. Unterordnung: Anseres.

Anseridae: Anser.

15. Ordnung: Falconiformes.

1. Unterordnung: Cathartae.

Cathartidae: Sarcorhamphus.

2. Unterordnung: Accipitres. Serpentariidae: Serpentarius.

Vulturidae: Vultur.

Falconidae: Aquila. 
16. Ordnung: Opist hocomi. Opisthocomidae: Opisthocomus.

17. Ordnung: Gallif ormes.

Mesoenidae: Mesoenas.

Turnicidae: Turnix.

Megapodiidae: Megapodius.

Cracidae: Ortalis.

Gallidae: Gallus.

*Palaeortycidae: *Palaeortyx.

*Gallinuloididae: *Gallinuloides.

18. Ordnung: Gruiformes.

Rallidae: Gallinula.

Gruidae: Grus.

Dicholophidae: Cariama.

*Phororacidae: *Phororacos.

Otididae: Otis.

Rhinochetidae: Rhinochetus.

Eurypygidae: Eurypyga.

Heliornithidae: Heliornis.

19. Ordnung: Charadriiformes.

1. Unterordnung: Limicolae.

Charadriidae: Charadrius.

Chionididae: Chionis.

Glareolidae: Glareola.

Thinocorythidae: Thinocorys.

Oedicnemidae: Oedichemus.

Parridae: Phyllopezus.

2. Unterordnung: Lari.

Laridae: Larus.

Alcidae: Uria.

3. Unterordnung: Pterocles.

Pteroclidae: Pteroclis.

4. Unterordnung: Columbae.

Columbidae: Columba.

*Dididae: *Didus.

20. Ordnung: Cuculif ormes.

1. Unterordnung: Cuculi.

Cuculidae: Cuculus.

Musophagidae: Turacus.

2. Unterordnung: Psittaci.

Trichoglossidae: Nestor.

Psittacidae: Ara.

\section{Ordnung: Coraciiformes.}

1. Unterordnung: Coraciae.

Coraciidae: Coracias.

Momotidae: Momotus.

Alcedinidae: Alcedo.

Upupidae: Upupa.

Strigidae: Bubo.
3. Unterordnung: Caprimulgi.

Steatornithidae: Steatornis.

Podargidae: Podargus.

Caprimulgidae: Caprimulgus.

4. Unterordnung: Cypseli.

Cypselidae: Cypselus.

Trochilidae: Trochilus.

5. Unterordnung: Colii.

Coliidae: Colius.

6. Unterordnung: Trogones.

Trogonidae: Trogon.

7. Unterordnung: Pici.

*Archaeotrogonidae: *Archaeotrogon.

Galbulidae: Galbula.

Capitonidae: Indicator.

Rhamphastidae: Rhamphastos.

Picidae: Picus.

22. Ordnung: Passeriformes.

1. Unterordnung: Anisomyodi.

Eurylaemidae: Eurylaemus.

Pittidae: Pitta.

Philepittidae: Philepitta.

Xenicidae: Acanthidositta.

Phytotomidae: Phytotoma.

Cotingidae: Cotinga.

Pipridae: Pipra.

Tyrannidae: Tyrannus.

Oxyruncidae: Oxyruncus.

Dendrocolaptidae: Phacelodomus.

Formicariidae: Pyriglena.

Pteroptochidae: Hylactes.

2. Unterordnung: Diacromyodi.

Menuridae: Menura.

Atrichornithidae: Atrichornis.

Hirundinidae: Hirundo.

Musicapidae: Musicapa.

Prunellidae: Prunella.

Troglodytidae: Troglodytes.

Pycnonotidae: Pycnonotus.

Campephagidae: Pericrocotus.

Ampelidae: Bombycilla.

Vireonidae: Vireosylva.

Prionopidae: Prionops.

Laniidae: Lanius.

Corvidae: Corvus.

Paradiseidae: Paradisea.

Dicruridae: Dicrurus.

Oriolidae: Oriolus.

Sturnidae: Sturnus.

Artamidae: Artamus.

Icteridae: Icterus.

Coerebidae: Coereba.

ingedi.

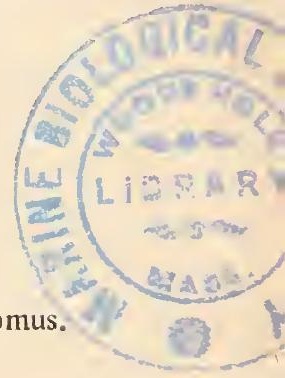


Tangaridae: Tangara.

Fringillidae: Passer.

Ploceidae: Ploceus.

Mniotiltidae: Dendroica.

Meliphagidae: Acanthogenys.

Nectariniidae: Nectarinia.

Drepanididae: Hemignathus.
Zosteropidae: Zosterops.

Dicaeidae: Dicaeum.

Paridae: Parus. .

Sittidae: Sitta.

Certhiidae: Certhia.

Motacillidae: Motacilla.

Alaudidae: Alauda.

\section{Klasse: Säugetiere (Mammalia).}

1. Unterklasse: Monotremata.

Ornithorhynchidae: Ornithorhynchus. Echidnidae: Echidna.

\section{Unterklasse: Marsupialia.}

1. Ordnung: Allotheria.

*Tritylodontidae: *Tritylodon.

*Plagiaulacidae: *Plagiaulax.

*Polymastodontidae: *Polymastodon.

*Polydolopidae: *Polydolops.

2. Ordnung: Diprotodontia.

Caenolestidae: Caenolestes.

Phalangeridae: Phalanger.

Phascolomyidae: Phascolomys.

3. Ordnung: Polyprotodontia.

*Dromatheriidae: $*$ Dromatherium.

*Triconodontidae: *Triconodon.

Dasyuridae: Thylacinus.

Didelphyidae: Didelphys.

Myrmecobiidae: Myrmecobius.

*Caroloameghiniidae: *Caroloameghinia.

\section{Unterklasse: Placentalia.}

1. Ordnung: Pant otheria.

*Amphitheriidae: *Amphitherium.

*Amblotheriidae: *Amblotherium.

*Dicrocynodontidae: *Dicrocynodon.

2. Ordnung: Insectivora.

1. Unterordnung: Dilambdodonta.

*Leptictididae: *Leptictis.

Talpidae: Talpa.

Soricidae: Sorex.

Erinaceidae: Erinaceus.

Macroscelididae: Macroscelides.

Tupaiidae: Tupaia.

Galeopithecidae: Galeopithecus.

*Adapisoricidae: *Adapisorex.

*Mixodectidae: *Mixodectes.

*Pantolestidae: *Pantolestes.

*Tillotheriidae: *Tillotherium.
2. Unterorduung: Zalambdodonta. Chrysochloridae: Chrysochloris. Centetidae: Centetes.

\section{Ordnung: Chiroptera.}

1. Unterordnung: Microchiroptera. Rhinopomidae: Rhinopoma.

Emballonuridae: Saccopteryx.

Noctilionidae: Cheiromeles.

Phyllostomidae: Vampirus.

Rhinolophidae: Rhinolophus.

Vespertilionidae: Vespertilio.

2. Unterordnung: Megachiroptera. Pteropodidae: Pteropus.

4. Ordnung: Carnivora.

1. Unterordnung: Acreodi.

*0xyclaenidae: *Deltatherium.

*Mesonychidae: *Mesonyx.

*Triisodontidae: *Triisodon.

2. Unterordnung: Pseudocreodi. *Hyaenodontidae: *Hyaenodon.

*Oxyaenidae: * Oxyaena.

3. Unterordnung: Eucreodi.

*Arctocyonidae: *Arctocyon.

*Miacidae: *Miacis.

Viverridae: Viverra.

Hyaenidae: Hyaena.

Felidae: Felis.

Mustelidae: Mustela.

Ursidae: Ursus.

Procyonidae: Procyon.

Canidae: Canis.

5. Ordnung: Pinnipedia.

Phocidae: Phoca.

Otariidae: Otaria.

Trichechidae: Trichechus.

6. Ordnung: Cetacea.

1. (Stammgruppe): Archaeoceti.

*Zeuglodontidae: *Zeuglodon.

*Microzeuglodontidae: *Microzeuglodon.

*Agorophiidae: *Agorophius.

*Patriocetidae: *Patriocetus. 
Systemat. Übersicht der erloschenen und der lebenden Fanilien der Wirbeltiere. XVII

2. Unterordnung: Mystacoceti.

Balaenopteridae: Balaenoptera.

Balaenidae: Balaena.

Rhachianectidae: Rhachianectes.

3. Unterordnung: Squaloceti. *Squalodontidae: *Squalodon.

Physeteridae: Physeter.

Acrodelphidae: Platanista.

*Eurhinodelphidae: *Eurhinodelphis. Ziphiidae: Ziphius.

4. Unterordnung: Delphinoceti.

Phocaenidae: Phocaena.

Delphinidae: Delphinus.

7. Ordnung: Xenarthra.

1. Unterordnung: Taeniodonta. *Stylinodontidae: *Psittacotherium.

2. Unterordnung: Anicanodonta.

* Gravigradidae: *Megatherium.

Myrmecophagidae: Myrmecophaga.

Bradypodidae: Bradypus.

3. Unterordnung: Hicanodonta. Dasypodidae: Dasypus.

8. Ordnung: Tubulidentata. Orycteropodidae: Orycteropus.

9. Ordnung: Pholidota.

Manidae: Manis.

10. Ordnung: Rodentia.

1. Unterordnung: Simplicidentata.

1. Sektion: Aplodontoidea.

Haplodontidae: Haplodon.

2. Sektion: Scinromorpha.

Castoridae: Castor.

Sciurilae: Sciurus.

Anomaluridae: Anomalurus.

3. Sektion: Myomorpha.

Jaculidae: Jaculus.

Heteronyidae: Dinodonys.

Geomyidae: Geomys.

Spalacidae: Spalax.

Bathyergidae: Bathyergus.

Muridae: Mus.

Myoxidae: Myoxus.

4. Sektion: Hystricomorpha.

Viscaciidae: Chinchilla.

Caviidae: Cavia.

Agutidae: Dasyprocta.
Dinomyidae: Dinomys.

Octodontidae: Octodon.

Coëndidae: Erethizon.

Hystricidae: Hystrix.

Ctenodactylidae: Ctenodactylus.

Pedetidae: Pedetes.

2. Unterordnung: Duplicidentata. 0chotontidae: Ochotona.

Leporidae: Lepus.

\section{Überordnung: Ungulata.}

(11.-22. Ordnung der Säugetiere.)

11. Ordnung (Stammgruppe der Ungulaten): Protungulata.

*Mioclaenidae: *Mioclaenus.

*Periptychidae: *Periptychus.

*Pantolambdidae: *Pantolambda.

Phenacodontidae: *Plienacodus.

*Meniscotheriidae: *Meniscotherium.

*Bunolitopternidae: *Didolodus.

12. Ordnu1ng: Artiodactyla.

1. Unterordnung: Hypoconifera.

*Dichobunidae: *Dichobune.

*Elotheriidae: *Elotherium.

2. Unterordnung: Caenotheria.

*Caenotheriidae: *Caenotherium.

3. Unterordnung: Euartiodactyla.

Suidae: Suls.

Hippopotamidae: Hippopotamus.

*Anthracotheriidae: *Anthracotherium.

*Anoplotheriidae: *Anoplotherimm.

* Oreodontidae: *Oreodon.

*Xiphodontidae: *Xiphodon.

Camelidae: Camelus.

Tragulidae: Tragulus.

*Hypertragulidae: *Blastomeryx.

Cervidae: Cervus.

Giraffidae: Camelopardalis.

Antilocapridae: Antilocapra.

Cavicornia: Bos.

13. Ordnung: Amblypoda.

*Coryphodontidae: *Coryphodon.

*Uintatheriidae: *Uintatherium.

14. Ordnung: Hyracoidea.

Hyracidae: Hyrax.

*Saghatheriidae: *Saghatherium.

15. Ordnung: Embrithopoda.

*Arsinoitheriidae: *Arsinoitherium.

Abel, Stämme der Wirbeltiere. 
XVIII Systemat. Übersicht der erioschenen und der lebenden Familien der Wirbeltiere.

16. Ordnung: Proboscidea.

*Moeritheriidae: *Moeritherium.

*Barytheriidae: *Barytherium.

*Dinotheriidae: *Dinotherium.

*Palaeomastodontidae: *Palaeomastodon. Elephantidae: Elephas.

*Desmostylidae: *Desmostylus.

17. Ordnung: Sirenia.

Halicoridae: Halicore.

Manatidae: Manatus.

18. Ordnung: Pyrotheria.

*Pyrotheriidae: *Pyrotherium.

19. Ordnung: Notoungulata.

1. Unterordnung: Typotheria.

*Notopithecidae: *Notopithecus.

*Interatheriidae: *Interatherium.

*Hegetotheriidae: *Hegetotherimm.

*Typotheriidae: *Typotherium.

2. Unterordnung: Toxodontia.

*Acoelodidae: *Acoelodus.

*Notohippidae: *Notohippus.

*Nesodontidae: *Nesodon.

*Toxodontidae: *Toxodon.

3. Unterordnung: Entelonychia.

*Notostylopidae: *Notostylops.

*Isotemnidac: *Isotemnus.

*Leontiniidae: *Leontinia.

*Homalodontotheriidae: *Homalodontotherium.

4. Unterordnung: Astrapotherioidea.

*Trigonostylopidae: *Trigonostylops.

*Albertogaudryiidae: *Albertogaudrya.

*Astrapotheriidae: *Astrapotherium.
20. Ordnung: Litopterna.

*Macraucheniidae: *Macrauchenia.

*Proterotheriidae: *Proterotherium.

*Adiantidae: *Adiantus.

21. Ordnung: Perissodactyla.

Tapiridae: Tapirus.

Rhinocerotidae: Rhinoceros.

Equidae: Equis.

*Titanotheriidae: *Titanotherium.

22. Ordnung: Ancylopoda. *Chalicotheriidae: *Chalicotherium.

23. Ordnung: Primates.

1. Unterordnung: Lemuroidea

$$
\text { (= Prosimiae). }
$$

*Notharctidae: *Pelycodus.

*Plesiadapidae: *Plesiadapis.

*Anaptomorphidae: *Anaptomorphis.

* Necrolemuridae: *Necrolemur.

*Adapidae: *Adapis.

Lemuridae: Lemur.

*Archaeolemuridae: *Archaeolemur. Chiromyidae: Chiromys.

Tarsiidae: Tarsius.

2. Unterordnung: Anthropoidea

$$
\text { (= Simiae). }
$$

1. Sektion: Platyrrhini.

Hapalidae: Hapale.

Cebidae: *Homunculus.

Callithrichidae: Callithrix.

2. Sektion: Katarrhini. Cynopithecidae: Cynopithecidae. *Parapithecidae: *Parapithecus. *Oreopithecidae: *Oreopithecus. Simiidae: *Dryopithecus. Hominidae: Homo. 


\section{Einleitung.}

Schon die ersten Versuche, die verwandtschaftlichen Beziehungen zwischen den einzelnen kleineren und größeren Gruppen des Tierreiches zu einem anschaulichen Bilde zu gestalten, haben zu Vergleichen der Geschichte der Tierwelt mit dem Wachstum eines reichverzweigten Baumes geführt. Dieser Vergleich war um so melır geeignet, die geschichtlichen Ereignisse im Laufe der Entwicklung der Tierwelt dem alfgemeinen Verständnisse näher zu rücken, als die „Stammbäume“ der Herrscherhäuser und Adelsgeschlechter eine gewolnte Vorstellung waren. So ist man demin auch inmmer wieder zu diesem Bilde zurückgekehrt, wenn auch verschiedene Einzelleiten bei dem Vergleiche nicht gut stimmen wollten; die Vorstellung eines „Stammrasens" oder "Stammschachtelhalms" usw. konnte den doch in den meisten Punkten treffenden Vergleich der Geschiclite des Lebens mit dem Wachstum eines Baunnes nicht ersetzen. Bei dicsem Bilde bleibend, konnte man den Vergleich auf die lebenden und abgestorbenen, gesunden und absterbenden Äste und Zweige ausdehnen und hat auch in graphischen Darstellungen pliylogenetischer Beziehungen diese Parallele fast ausnahmslos zur Regel genommen.

Wird die Geschichte der Tierwelt dem Wachstum eines reichverzweigten Baumes mit zahllosen dürren und vielen noch grünenden Ästen verglichen, so läßt sich auch das System der Tierwelt, soweit es nur die heute lebenden Formen umfaßt, einem horizontalen Querschnitt durch den Wipfel des Stammbaumes vergleichen. Dieser ,Wipfelquerschnitt" kann naturgemäß nur einen kleinen Teil aller Zweige und Äste des großen Lebensbaumes umfassen; das Querschnittsbild wird sich bedeutend verändern, wenn wir den Schnitt durch die Baumkrone um ein Stück tiefer legen, das heißt wemn wir z. B. niclit die lebende, sondern etwa die tertiäre Tierwelt zu einem „System" zu gruppieren versuchen. Die durch tiefer gelegene Teile der Stammbaumkrone gezogenen Querschnitte werden niclit nur dadurch vom

A bel, Stämme der Wirbeltiere. 
Wipfelquerschnitt verschieden sein, daß die verschiedenen Astschnitte näher zusammengerückt erscheinen, sondern es werden sich auch Querschnitte von vielen dürren Ästen zeigen, welche sich nicht bis zum Wipfel erstrecken und die den in früheren Zeiten erloschenen Zweigen des Tierstammes entsprechen.

Dieses Bild, das wir zu einer Veranschaulichung der Vorgänge im Laufe der Stammesgeschichte heranzuziehen pflegen, muß uns deutlich zum Bewußtsein bringen, daß es nur sehr sclıwer möglich ist, Phylogenie und Systematik zu einer ,systematischen .Phylogenie“ oder ,phylogenetischen Systematik“ zu verknüpfen.

Wiederholt ist der Versuch unternommen worden, zwischen Systematik und Phylogenie ein Kompromiß zustande zu bringen, in der Hoffnung darauf, daß dadurch in die Geschichte der Tierstämme Ordnung und Übersicht gebracht werden könnte. Das „,System“ des Tierreiches ist jedoch ein künstliches Gebilde, das ursprünglich als ein Ausdruck der Beziehungen zwischen den Astquerschnitten des Stanmbaumes geschaffen wurde. In der Tat können wir den Vergleich so weit treiben, daß wir die Querschnitte der kleinsten Zweige als ,Arten“, die Schnitte der sich zu Büscheln gruppierenden Artenzweige als "Gattungen" usw. ansehen. Aber diese Methode der systematischen Begriffsbildung, die zur Aufstellung eines „,Systems" des lebenden Tierreiches geführt hat, ist eben auf den Beziehungen aufgebaut, wie sie heute zwischen den Arten, Gattungen, Familien und Ordnungen bestehen.

Die ersten Funde fossiler Wirbeltiere führten zunächst zur Aufstellung neuer Arten, neuer Gattungen oder auch neuer Familien und Ordnungen. Solange ihre Zahl noch klein war, konnten sie im System der lebenden Tierwelt ohne Aufsehen untergebracht und eingeschoben. werden und ohne daß die Fehlerhaftigkeit dieses Vorganges den Systematikern recht zum Bewußtsein gekommen wäre. Als sich jedoch die Funde mehrten, sah man sich der Alternative gegenüber, entweder für eine jede neue ,Gattung“ oder eine andere systematische „Größe“, die nicht recht in den gegebenen Rahmen passen wollte, eine nette „Kiste“ zu zimmern, um einen Ausdruck Darwins zu gebrauchen, oder einem schon vorhandenen Begriff, z. B. einem Familienbegriff, durch „Erweiterung der Diagnose“ einen anderen Inhalt zu geben.

Beide Wege sind im Laufe der Entwicklung und des Ausbaues der Paläozoologie zu einer umfangreichen Wissenschaft betreten worden. Der erste Weg schien der bequemste zu sein und wurde und wird noch heute von vielen Autoren bevorzugt. Er hat dann eine Berechtigung, wenn über die verwandtschaftlichen Bezielnungen einer neu entdeckten Form ernste Zweifel bestehen; wenn dagegen die Verwandtschaftsverhältnisse der neuen Form klar zutage liegen, ist eine derartige 
Neuaufstellung von systematischen Kategorien als durchaus unstatthaft zu verwerfen. Sie schafft unnötigen Ballast und ist nur geeignet, die bereits crmittelten genetischen Beziehungen zwischen einzelnen Gruppen wieder zu verdunkeln.

Solange wir nur die verschicdenen Gattungen der Cephalaspiden, einer erloschenen Fanilie panzertragender paläozoischer Fische, kannten, war die Aufstellung der neuen Familie der Ateleaspidae für den obersilurischen Ateleaspis berechtigt, ja sogar notwendig, da wir über die genetischen Beziehungen zwischen Ateleaspis und den Cephalaspiden nur Vermutungen äußern konnten. Nun sind aber vor einigen Jahren im Obersilur Norwegens zwei Gattungen entdeckt worden, Aceraspis und Micraspis, welche nach den Untersuchungen J. Kiaers zweifellos als Zwischenformen anzusehen sind, die sich zwischen die Ateleaspiden und die Cephalaspiden einschieben. J. Kiaer hat für die Gattung Aceraspis die neue Familie der Aceraspidae errichtet, aber die Übergangsstellung derselben ausdrücklich betont. In diesem Falle scheint es jedoch ebenso wie in allen analogen Fällen das einzig Richtige zu sein, nicht nur von der Neugründung einer Familie abzusehen, sondern auch eine der beiden anderen Familien einzuziehen und alle Gattungen, die sich als Angehörige einer genetisch geschlossenen Gruppe erwiesen laben, in einer einzigen Fanilie zu vereinigen, in diesem Falle in der Familie der Cephalaspiden. Freilich muß die Diagnose dieser Familie entsprechend verändert und erweitert werden. Wir gelangen aber durch eine entsprechende Fassung der Faniliendiagnose zu dem Ergebnisse, daß die ,Familie“ zu einem phylogenetischen Begriff wird.

Wenn wir in diesem Sinne die Diagnose einer Familie derart formulieren, daß wir selbst weit verschiedene Anfangs- und Endglieder in ilur unterbringen können, wenn sie nur durch entsprechende Zwischenformen miteinander verknüpft erscheinen, so werden wir freilich dem Systematiker alten Schlages manchen Kummer bereiten, weil die „Bestimmung" einer Form dadurch bis zu einem gewissen Grade erschwert wird. Die Schwierigkeiten einer solchen Bestimmung werden aber noch dadurch gesteigert, daß sich überall dort, wo zahlireiche Gattungen aus den ersten Anfängen nahe verwandter Familien bekannt sind, die Gegensätze zwischen diesen „Wurzelgattungen“ verwischen und die Anfangsgattungen solcher Familien einander viel näher stehen als die Anfangs- und Endglieder innerhalb der einzelnen divergierenden Fanilien. So unterscheiden sich die Wurzelgattungen der Ungulatenordnungen der Perissodactyla, der Artiodactyla, der Ancylopoda, der Amblypoda und der Litopterna sehr wenig voneinander, während die Endglieder dieser Stämme als hochspezialisierte Typen sehr bedeutende Unterschiede aufweisen. Neben diesen Wurzelgattungen der einzelnen genannten Ordnungen stehen aber auch noch andere Formen, deren 
genetisclıe Beziehungen zu jüngeren Formenreilıen, einstweilen wenigstcns, nocl unaufgeklärt sind. Dies sind z. B. die Formen, die in den Familien der Periptychiden und Pleuraspidotheriiden eingereiht worden sind und die sich von den Wurzelgattungen der fünf früher genannten Ungulatenordnumgen nur wenig unterscheiden. Wir müssen uns also in diesem Falle wohl oder übel dadurch zu helfen versuchen, daß wir für alle diese Alnnenformen der fünf genannten Huftierordnungen wie auch für die Periptychiden und Pleuraspidotheriiden den Begriff einer ,S S ammgruppe" schaffen und in dieser alle Gattungen vereinigen, chne Rücksicht darauf, ob sie als Ahnengattungen jüngerer Fanilien nach-, gewiesen worden sind oder nicht. So sind wir zu der Aufstellung der „Stammgruppe“ der Condylarthra gelangt. Freilich liegt hier ein bewußtes Durchreißen sichergestellter phylogenetischer Verbände vor, aber dieser Vorgang ist wohl kaum zu umgehen. In diesen wie in allen analogen Fällen muß aber, wie ich schon in meinen ,Vorzeitlichen Säugetieren" (Jenla, bei G. Fischer, 1914, S. 27-34) dargelegt habe, durch die ausdrückliche Bezeichnung einer solchcn Gruppe als „Stammgruppe“ (z. B. Stammfamilie, Stammordnung u. dgl.) deutlich zum Ausdruck gebracht werden, daß hier eine Begriffsbildung vorliegt, die mit den sonstigen Begriffen einer Familie, Ordnung usw. nichts zu tun hat und mit diesen nicht auf eine gleiche systematisclue Stufe gestellt werden darf.

Mit Ausnahme dieser notgedrungenen künstlichen Durchreißung phylogenetischer Verbände ist aber jeder Versuch, einzelne Abschnitte eines einheitlichen Astes des Stammbaumes durch Aufstellung gesonderter „Familien“ zu zerschneiden, unbedingt zu verurteilen und muß energisch bekämpft werden. Wenn es auch kaum möglich ist, in einem ,Systen" die plıylogenetischen Beziehungen mit aller Klarheit zum Ausdrucke zu bringen, so müssen wir dech alles zu vermeiden suchen, was unnötigerweise zu einer Verschleierung von sichergestellten genetischen Verbänden beitragen könnte.

Aus denselben Gründen ist auch das Festlualten an den noch immer da und dort vertretenen Anschaungen über ,polypliyletiscle“" Gruppen auf das Scliärfste zu verurteilen. Das ,System" des Tierreiches ist ja niclıts Staries und Unabänderliches, sondern nur der jeweilige Ausdruck unserer Kenutnisse von den Verwandtschaftsverlıältnissen der kleineren und größeren Gruppen des Tierreiches oder soll sich doch wenigstens diesem ldeale nähern. Nun kann es aber keinem Zweifel unterliegen, daß wir in sehr vielen Fällen eine nahe Verwandtscliaft von Formen annehmen, die in der Tat nicht besteht. Man liat in früherer Zeit sehr viele systematische Gruppen unterschieden, die sich beim Fortschritte unserer Kenntnisse als durchaus unnatürliche Vereinigungen von lseterogenen Formen erwiesen liaben. Man hat 
sich daher gezwungen gesehen, derartige Begriffe, wie die "Cetomorphen“ für die.Wale und Sirenen, die „Ratiten" für die flugunfähigen Vögel, die „Aptera" für die flügellosen Insekten oder die „Parasita“ für die parasitischen Insekten, ebenso wie noch viele andere derartige Begriffe aus dem System auszuscheiden. Unser System steckt aber noch immer voll von derartigen unnatürlichen Verbänden und in jedenı Jahre wird irgendein derartiger Fall nachgewiesen. Wenn dies eintritt, dann gibt es nur eine einzige Möglichkeit, nämlich einen solchen Begriff unbedenklich über Bord zu werfen. Weil sich aber viele Systematiker von den ihnen vertraut gewordenen Vorstellungen und Namen nicht trennen wollen, so ist man auf den Ausweg verfallen, von einer, ,polyphyletischen Entstehung" derartiger Gruppen zu sprechen. Wenn der Nachweis dafür erbracht ist, daß eine bisher für monophyletisch gehaltene systematische Gruppe Formen mit gänzlich abweichender Vorgeschichte unfaßt, so muß sie auch systematisch in so viele Gruppen zerlegt werden, als verschiedene Stammeslinien vorliegen. Die Vorstellung von einer ,,polyphyletischen" Entstehung systematischer Gruppen ist eine widersinnige und muß aus unserem Vorstellungskreise endgültig verschwinden.

Wenn wir derart zu dem Begriffe einer Familie als einer phylogenetischen Einheit gelangen, so ist doch zu berücksichtigen, daß die verschiedenen Angehörigen einer solchen sehr häufig keine geschlossene Alnnenkette darstellen, sondern daß von einem Hauptstanm im Laufe der Stammesgeschichte mehr oder weniger seitliche Ausstrahlungen stattgefunden haben. Diese Seitenzweige kann man am besten als „Unterfamilien" bezeichnen, wenn sie nur eine untergeordnete Bedeutung besitzen und sich nur durch geringfügige morphologische $\mathrm{Ab}$ weichungen von dem Hauptstamm unterscheiden.

Mit dieser rein phylogenetischen Auffassung und Abgrenzung des Begriffes einer ,Familie“ sind wir aber noch nicht inlstande, die verwandtschaftlichen Beziehungen aller Äste des Stammbaumes klar zum Ausdrucke zu bringen. Wenn wir beim Bilde eines reichverzweigten Baumes bleiben und die Familien mit den Ästen desselben vergleichen, so müssen wir uns vor Augen halten, daß manche Äste einander näherstehen als andere Gruppen von Ästen oder Familien. Wir sind daher genötigt, diese Gruppen unter einem weiteren Begriffe zu summieren und gewisse, einander näherstehende Familien unter dem Begriffe einer „Ordnung“ zusammenzufassen. Zwischen die Kategorien der Familien und Ordnungen werden zuweilen noch die Begriffe der Unterordnungen und Überfamilien eingeschaltet, ebenso wie in einigen Fällen auch die Kategorie der Überordnung (z. B. Ungulata als Sammelbegriff für die verschiedenen Ordnungen der Huftiere) unterschieden wird. Daß alle Begriffe, die höher stelıen als die „Familie“, 
phylogenetische Vorstellungen sind, liegt auf der Hand. Anders steht die Frage nach dem Begriffe der „Gattung", der von den Systematikern der rezenten Tierwelt meist in deskriptivem, von den Paläontologen aber vorwiegend in phylogenetischem Sinne gebraucht wird.

In der Zeit der ersten Anfänge der wissenschaftlichen Systematik suchte man unter der Vorstellung eines ,Genus“ die nächstverwandten Arten zusammenzufassen. Daß der künstlich geschaffene Begriff einer „Gattung" ein engeres Verwandtschaftsverhältnis bezeichnen sollte und also nach unseren heutigen Ansichten eigentlich als ein phylogenetischer Begriff zu gelten hätte, geht schon aus der Definition Linnés hervor: „Genera tot dicimus, quot similes constructae fructificationes proferunt diversae species naturales." Der Ausbau der Systematik der lebenden Organismen hat den Begriff der Gattung zwar beibehalten, aber der Inhalt desselben hat im Laufe der Zeit manche Wandlung erfahren. In ganzen und großen hält man in den Kreisen der Systematiker, die sich die Klassifizierung der lebenden Organismen zum Ziele gesetzt haben, an der Vorstellung fest, daß die Gattungsgrenze eine Anzahl von Arten umfaßt, die in ,einigen wichtigeren" morphologischen Merknalen übereinstimmen. Mehr und mehr ist der Gattungsbegriff auf diesem Gebiete zu einem deskriptivsystematischen geworden.

Die Paläontologie hat von den Systematikern der lebenden Organismenwelt den Begriff des Genus ebenso wie den der Spezies zuerst unbedenklich übernommen. Der Gattungsbegriff ist von den Paläontologen lange Zeit hindurch in rein deskriptivem Sinne gebraucht worden und wird von den Systematikern der fossilen niederen Tiere, namentlich bei Mollusken usw. noch immer in diesem Sinne verwendet. Dagegen ist die mehr und mehr phylogenetischen Zielen zustrebende paläontologische Forschung auf dem Gebiete der Wirbeltiere schon frühzeitig vor die Aufgabe gestellt worden, gewisse Entwicklungsabschnitte einer Formenreihe durch bestimmte Begriffe zu umgrenzen. So ist man bald dazu gelangt, den Gattungsbegriff seines deskriptiven Charakters zu entkleiden und zu einem phylogenetischen umzugestalten. Vielfach bezeichnet man als ,Gattung“ in der Paläontologie ein bestimmtes, durch eine oder mehrere charakteristische Spezialisationen gekennzeichnetes Entwicklungsstadium einer Formenreihe, das entweder nur eine oder mehrere Arten umfaßt und das nach unten und nach oben an ein nächst tieferes und an ein nächst höheres Entwicklungsstadium anschließt. Die Abgrenzıng der Gattungen, wie sie bei der systematischen Analyse der Equiden, Physeteriden, Ziphiiden, Halicoriden, Rhinocerotiden usw. durchgeführt worden ist, mag als ein Beispiel für diesen Grundsatz bei der Trennung fossiler Gattungen dienen. 
Diese mehr und mehr rein phylogenetisch gewordene Auffassung von der Gattung als einem bestinmten Entwicklungsabschnitt einer Familie hat dazu geführt, daß die Grenzen dieser phylogenetischsystematischen Kategorien verhältnismäßig viel enger gezogen werden, als dies in der Systematik der lebenden Organismen der Fall ist, wo noch inmer die deskriptive Fassung und Abgrenzung der Gattung vorherrscht. Aus diesem Grunde ist der Gegensatz zwischen dem Begriffe einer lebenden Gattung und einer fossilen Gattung in den meisten Fällen sehr scharf. Es läßt sich, wenn wir zu dem Bilde eines Stammbaumes zurückkehren, die Vorstellung von dem Umfange und Inhalte einer fossilen Gattung einem durch zwei Querschnitte begrenzten Aststïcke, die von einer lebenden Gattung mehreren benachbarten Zweigdurchschnitten vergleichen. Selbstverständlich sind die Grenzen zwischen zwei fossilen Gattungen, die nach diesem Prinzipe unterschieden werden, rein willkürliche und nur dort scharf, wo vermittelnde Übergangsformen felılen. Wo der Übergang durch Zwischenformen geschlossen ist, bestehen keine scharfen Grenzen und können auch nicht bestehen; derartige scharfe Grenzen liegen nur bei jenen Gattungen vor, deren Arten zwar nebeneinander liegenden Zweig.querschnitten, aber nicht aneinander schließenden Aststücken entsprechen.

Durch diese wesentlich andere Auffassung von den Gattungsgrenzen der fossilen Formen ist auch eine Gewohnheit bedingt, die den Paläontologen vielfach zum Vorwurfe gemacht worden ist, nämlich die relativ enge Fassung des Gattungsbegriffes im Vergleiche zu der in der Regel viel weiteren Umgrenzung der rezenten Gattungen. Es kann nicht oft genug betont werden, daß in beiden Fällen die Abgrenzung einer Gattung reine Ansichtssache ist. Gleichwohl kann diese verschieden weite Fassung des Gattungsbegriffes unter Umständen manche Verwirrung anrichten. Wenn der Paläozoologe mehrere parallele Entwicklungsreilien ermittelt hat, deren einzelne Glieder er selbstverständlich mit eigenen Namen belegt, um schon auf diese Weise ihre phylogenetische Selbständigkeit zum Ausdrucke zu bringen, und wenn er mehrere dieser Reihen bis zu lebenden Gattungen zu verfolgen vermag, so werden die lebenden Gattungen als Endglieder dieser parallelen Reihen auch durch verschiedene Namen bezeiclmet werden müssen. Bei der Gewohnheit, die Grenzen der lebenden Gattungen weiter zu fassen als die der fossilen, tritt nun dann und wann der Fall ein, daß mehrere parallele Entwicklungsreihen sozusagen in einer einzigen rezenten Gattung münden. Hier ist nun wieder ein Fall gegeben, in dem die Vertreter polyphyletischer Entwicklungsanschauungen triumphierend den „Nachweis" eines neuentdeckten Beispiels einer polyphyletisch entstandenen Gattung erbracht zu haben glauben. Daß in 
solchen Fällen der Paläozoologe das Recht hat, auf der Auflösung der vermeintlich polyphyletischen Gattung zu bestehen, liegt auf der Hand. Derartige Beispiele liegen bei den Gattungen Equus, Rhinoceros und Elephas vor.

In allgemeinen muß man sich jedoch bestreben, ein Übereinkommen in diesen Fragen zu schaffen, da sonst die Verwirrung durch fortwährende Neubenennungen und Umbenennumgen von Tag zu Tag gesteigert wird. Andererseits ist freilich zu bedenken, daß durch das starre Festhalten an eingebürgerten Namen wie Ichthyosaurus, Plesiosaurus u. dgl. eine klare Übersicht über die Unterschiede der einzelnen, sehr verschiedenen Entwicklungslinien angehörenden Arten vielfach verschleiert wird. Die Haarspalterei darf aber nicht so "weit gehen, daß schließlich für jede Art eine eigene Gattung errichtet wird. Hier spielt leider eine sehr üble Gewohnheit mit, welche viele Paläontologen von den Zoologen und Botanikern übernommen haben und die darin besteht, bei Zitaten von Gattungs- und Artnamen diesen den Namen ilıres „Schöpfers" anzuhängen. Diese Gewohnheit hat bei vielen Systematikern die Untaufung und Neugründung von Gattungs- und Artnamen zu einer wahren Leidenschaft werden lassen, da viele Autoren auf diese Weise ihren Namen unsterblich zu machen hoffen. Schon Darwin ist gegen die Unsitte der Anhänğng des Autornamens an den Namen einer Gattung oder Art mit aller Schärfe, aber leider erfolglos zu Felde gezogen. Noch immer treiben viele Autoren auf diesem Gebiete ihr Unwesen, besonders jene, deren Name sonst wohl kaum mit den Fortschritten der Naturwissenschaften verknüpft werden würde.

Während somit die Begriffe der „Familie“ und der „Gattung“ ebenso wie die höheren Begriffe der „Ordnung" usw. durch die Arbeiten der Paläozoologen mehr und mehr zu phylogenetischen Vorstellungen geworden sind und sich über das niedere Niveau rein deskriptiver Unterscheidung erhoben haben, ist der Begriff der „Art“ auch bei den Paläontologen mehr oder weniger rein deskriptiv geblieben. Schon vor längerer Zeit hat $\mathrm{O}$. Jaekel ${ }^{1}$ diesen Gegensatz in der Auffassung des Artbegriffes und Gattungsbegriffes nälıer darzulegen versucht und kurze Zeit früher hat auch der französische Bryozoenforscher Canu einen analogen Standpunkt vertreten. Nach O. Jaekel sind die ,Arten“" jene systematischen Einheiten, die nach rein äußerlichen, mwesentlichen, für die Stammesgeschichte belanglosen Merkmalen zu unterscheiden sind, während die ,Gattungen“" durch die inneren, phylo-

1 O. Jaekel, Über verschiedene Wege phylogenetischer Entwicklung. Verhandlungen des $\mathrm{V}$. Internationalen Zoologen-Kongresses in Berlin, 1901. Neudruck bei G. Fischer, Jena, 1902. 
genetisch bedeutsamen Merkmale gekennzeichnet sein sollen. Auf die Schwierigkeit der Beantwortung der Frage, welche Merkmale als ,innere" und welche als ,äußere" zu verstehen seien, hat E. Dacqué " hingewiesen; gewiß ist in vielen Fällen dieser Unterschied klar zu erfassen, wie bei den lebenden Säugetieren, aber der Versuch einer Unterscheidung muß schon bei den fossilen Säugetieren versagen, von denen ja fast nur Skeletteile oder Gebisse vorliegen. Auch wenn wir z. B. an die lebenden Vögel denken, müssen wir zugeben, daß hier dieses Unterscheidungsprinzip völlig versagt, und das gleiche gilt für viele andere Gruppen. Ein passender Schlüssel ist damit auf keinen Fall gefunden. Hingegen kann man Dacqué kaum beipflichten, wenn er sagt: „Was sich Linné unter "Art" dachte, ist bei Jaekel "Gattung", was Jaekel aber "Art" nennt, ist bei anderen nur „,Varietät", ,,Subspezies" oder ,,Form11"."

Viele Forscher, die sich mit jenen Problemen der Biologie beschäftigen, welche außerhalb des durch Scheuklappen begrenzten engen Gesichtskreises der Systematiker alten Schlages und der Prioritätsschnüffler liegen, halten jede Erörterung über die Frage des Artbegriffes für unnütze Zeitverschwendung. ${ }^{2}$ Aber auch wenn man dieser Kardinalfrage der Systematik nicht die Bedeutung beilegt, wie sie ihr von einigen Lepidopterologen, Koleopterologen, Konchyliologen usw. zugeschrieben wird, so ist doch eine Beleuchtung dieser Meinungsdifferenzen auch für den Phylogenetiker keineswegs von untergeordneter Bedeutung. Es kann für den Architekten nicht gleichgültig sein, ob schlechte oder gute Maurer an den Fundamenten arbeiten, auf denen die Mauern seines Gebäudes ruhen sollen.

Schon in den sechziger Jahren des vergangenen Jahrhunderts, also zu einer Zeit, da die gesante wissenschaftliche Welt unter dem Einflusse des siegreich vordringenden Darwinismus stand, hat W. Waagen zum erstenmal den Versuch unternommen, ein Prinzip für die Unterscheidung der zeitlich aufeinander folgenden Arten aufzustellen. Von der Erkenntnis der Tatsache ausgehend, daß die Angehörigen einer

1 E. Dacqué. Zur systematischen Speziesbestimmung. Neues Jahrbuch für Mineralogie, Geologie und Paläontologie, Beilageband XXII, 1906, S. 639-685.

2 Indessen scheint mir auch andererseits der Ausspruch R. Hertwig s: ,Das Alpha tund Omega der Abstammungslehre ist der Artbegriff" (Die Abstammungslehre, in: Die Kultur der Gegenwart tısw., 111. Teil, 4. Abt., Bd. IV, 1914, S. 3) zu weitgehend zu sein. Man kann sich doch sehr eingehend mit phylogenetischen Untersuchungen beschäftigen, ohne auf eine bestimmte Definition der Spezies eingeschworen zu sein. Mit der Frage nach dem Verlanfe der Stammesgeschichte hat die engere oder weitere Fassung des Artbegriffes heute nichts mehr zu tun, da das Dogma von der ,Konstanz der Arten“ zu den endgiiltig iiberwundenen Standpunkten der Biologie gehört. 
geschlossenen Almenreilıe in aufeinander folgenden geologischen Horizonten bestimmte, wenn auch oft nur kleine Verschiedenheiten aufweisen, die sich schrittweise steigern, schlug W. Waagen ${ }^{1}$ für alle diese anemander schließenden und aufeinander folgenden Formen den Begriff einer „Kollektivart" vor, während er die einzelnen, voneinander oft nur unbedeutend verschiedenen, a ufeinander folgenden Formen dieser Kollektivart als ,Mutationen“ bezeichnete. Die einzelnen Mutationen benannte $W$. Waagen binär nach dem seit Linné für die Benennung der Spezies gebräuchlichen Vorgang. Genau genommen ist hier der Bcgriff der „Art" zum erstenmal in rein phylogenetischem Sinne gebraucht worden. Nach W. Waagen liegt im Begriffe der Varietät das Schwankende, im Begriffe der Mutation das Bleibende in der Geschichte einer Formenreilue. Die „Art" umfaßt daher im Sinne W. Waagens nicht nur eine Anzahl von nebeneinander lebenden Varietäten, sondern auch eine Anzahl von aufeinander folgenden Mutationen; es ist daher nach Waagen möglich, die Art nicht nur in horizontaler, sondern auch in vertikaler Richtung abzugrenzen.

Dicser Vorschlag, den W. Waagen zuerst an dem Beispiele des Ammonites subradiatus zu verwirklichen gesucht hat, fand nicht viel Beifall und Nachahmung. E. Dacqué verweist (l. c., S. 653) mit Recht darauf, daß es nur außerordentlich selten möglich ist, derartige Mutationen mit Sicherheit festzustellen und daß dies auch der Grund gewesen sein dürfte, weshalb sich der sonst gewiß gute Vorschlag Waagens nicht durchsetzen konnte. Dazu kommt noch, daß aus den Waagenschen Ausführungen nicht mit Sicherheit hervorgeht, wie er sich die gegenseitigen Abgrenzungen der aufeinanderfolgenden „Kollektivarten“ dachte, die ja doch auch durch fast unmerkliche Übergänge ebenso verknüpft sein müssen wie die Mutationen untereinander. Dies scheint mir auch der Hauptgrund dafür zu sein, daß die Waagensche Auffassung keinen rechten Anklang fand. Der Begriff der „Mutation" blieb in Zoologen- und Botanikerkreisen fast unbekannt und man wurde auf ihn erst wicder aufmerksam, als de Vries viel später neuerlich die Bezeichnung Mutation aufstellte.

Schon kurze Zeit nach dem Erscheinen der Waggensclıcn Arbeit finden wir bei M. Neumayr ${ }^{2}$ eine ganz andere Auffassung des Artbegriffes vom Standpunkte des Paläontologen aus. Die Aufstellung

1 W. Waagen, Formenreihe des Ammonites subradiatus. Beneckes Beiträge usw., Bd. II, 1869, S. 184.

2 M. Neumayr in M. Neumayr und C. M. Paul, Die Kongerien- und Paludinenschichten Slavoniens und deren Faunen. Abhandl. der k. k. geol. Reichsanstalt in Wien, Bd. VII, 1875, 3. Heft. 
und Abgrenzung einer Spezies soll nach Neumayr (1. c., S. 93) von jeder vorgefaßten Meinung über Konstanz oder Veränderlichkeit der Art sowie von ihrem Wesen unabhängig sein. Sie soll nur einen kleinen Formenkreis umfassen, der durcl ein bei zahlreichen Individuen immer wiederkehrendes, wenn auch unscheinbares Merkmal gekennzeichnet ist. Daraus geht hervor, daB Neumayr den Artbegriff in seiner Paludinenstudie nicht phylogenetiscl faßte wie W. Waagen und er selbst noch in seinen "Jurastudien" (1871) getan hatte, sondern rein deskriptiv. Diese Auffassung ist seither bei den Paläontologen, die sich mit der Beschreibung wirbelloser fossiler Tierreste beschäftigen, die herrschende geblieben. Aus ihr entsprangen und entspringen noch immer die zahllosen Speziesnamen, mit denen die Paläontologen die Literatur bereichert haben. Der Artbegriff wurde wieder zu einer „Kiste" in D́arwinschen Sinne, in die hineingesteckt wurde, was genau das für sie passende Maß hatte. Es ist das derselbe Standpunkt, den die weitaus meisten Systematiker der lebenden Tier- und Pflanzenwelt teilen. Viele haben freilich ein gewisses Taktgefühl dafür, weit die Unterscheidung von „Arten“ getrieben werden darf, um schließlich nicht jedes Individuum als eigene Art zu betrachten, und dieses Gefühl findet in der Botanik durch großen Reichtum des Untersuchungsmaterials eine wesentliche Unterstützung; bei dem häufig geübten Vorgange, unter dem Vorwande peinlichster Genauigkeit auf alle Unterschiede Rücksicht zu nehmen, käme man ja sonst dazu, jeden Fichtenbaum als eigene Art abzutrennen, da es ja zweifellos nicht zwei absolut bis in die letzten Einzelheiten übereinstimmende Individuen gibt. Wo jedoch nur wenige zu vergleichende Exemplare seltenerer Formen vorliegen, da feiert die „Speziesmacherei" wilde Triumphe. Die Zersplitterung der Arten in zahllose Spezies - ich erinnere an die von R. Hoernes und M. Auinger begonnene, aber unvollendet gebliebene Monographie der Pleurotomen aus dem Miozän des Wiener Beckens wird häufig ein ernstes Hindernis für die weitere gedeihliche Entwicklung der Unterscheidung der Angehörigen einer größeren Gruppe. Ein solches Gebiet der Systematik wird zum Schlusse gewölınlich der Tummelplatz von Dilettanten.

Daß die Abgrenzung mehrerer Spezies überhaupt nur bei nebeneinander stehenden Formen leicht möglich ist, aber auch da häufig auf Schwierigkeiten stößt, wie die erwähnten miozänen Pleurotomen des Wiener Beckens zeigen, die durch zahlreiche Übergänge verbunden sind, daß sie ferner bei zeitlich zwar aufeinander folgenden, aber gleichfalls durch Übergänge verbundenen Formen ebensowenig gelingen kann wie die ,,sichere Abgrenzung“ von Gattungen, ist für jeden, der einmal nit einem größeren Untersuchungsmaterial gearbeitet hat, etwas Selbstverständliches. Wer den unstillbaren Drang fühlt, einen oder 
mehrere Artnanen mit seinem Autornamen zu verknüpfen, finclet z. B. bei der Bearbeitung irgendeiner reicheren Ammonitenfauna aus der Trias und dem Jura der Alpen ein dankbares Arbeitsfeld. Einsichtigere Forscher haben diesen Übelstand der paläontologischen Systematik schon vor langer Zeit erkannt und hier ist wohl auch der Ausspruch M. Neumayrs anzuführen, der in seinen ,Stämmen des Tierreiches“ (Bd. 1, 1889, S. 67) betont, daß der Artbegriff in Sinne Linnés in der Paläontologie unanwendbar und unaufindbar sei und aus ihrem Bereiche verschwinden müsse.

Wir bedürfen aber zweifellos eines Ausdrucksmittels zur Ken11zeichnung einer Gruppe von Formen, die sich nur durch ganz unbecleutende Merkmale voneinander unterscheiden und durch Übergänge miteinander verbunden sind. Wo derartige Übergänge fehlen, wird man wohl gezwungen sein, diese abweichenden Typen mit selbständigen Namen zu versehen, aber dieser Vorgang wird in vielen Fällen nur als ein provisorischer angesehen werden müssen. Wenn durch weitere Funde da Material von verbindenden Übergangsgliedern wächst, wird eine Revision der ganzen Gruppe und ein Ausmerzen der überflüssig gewordenen Namen notwendig sein, wie dies z. B. bei den fossilen Zahnwalen aus dem Miozän von Antwerpen notwendig war. Der Grundsatz, der von einigen Systematikern vertreten wird, daß ,,zu einer Art säntliche Exemplare gehören, welche die in der ersten Diagnose festgestellten Merkmale besitzen"1, ist ganz unhaltbar. Wenn die Diagnose falsch war, wenn sie entweder zu enge oder zu weit gefaßt war, so müßten folgerichtig alle diese schlecht passenden Kisten ohne Möglichkeit einer Ausmerzung dieser lrrtümer als ewiger Ballast mitgeschleppt werden.

Daß wir irgendeine Bezeichnung und Begriffsbildung für eine Summe von Individuen haben müssen, die sich einander sehr ähnlich sehen, ist zweifellos. Wenn wir diese Bezeichnung und diesen Begriff

1 L. Plate hat in seiner wichtigen Abhandlung ,Prinzipien der Systematik mit besonderer Beriicksichtigung des Systems der Tiere" (Kultur der Gegenwart, III. Teil, 4. Abt., Bd. IV, 1914, S. 92-164) eine eingehende Kritik der verschiedenen Gesichtspunkte fiir die Aufstellung eines Artbegriffs gegeben. Seine Definition der "Art" lautet (im Anschluß an die Definition Doederleins aus dem Jahre 1902): ,Zu einer Art gehören sämtliche Exemplare, welche die in der Diagnose festgestellten Merkmale besitzen - wobei vorausgesetzt wird, daß die äußeren Verhältnisse sich nicht ändern --, ferner sämtliche davon abweichende Exemplare, die mit ihnen durch häıfig auftretende Zwischenformen innig verbunden sind, ferner alle, die mit den vorgenannten nachweislich in direktem genetischen Zusammenhang stehen oder sich durch Generationen fruchtbar mit ihnen paaren" (S. 120). Mag auch für den Zoologen diese Definition und Begriffsfassung brauchbar sein fïr den Paläozoologen ist sie es sicher nicht. 
dem der "Spezies" gleichsetzen, so ist wohl nichts gegen ein solches Übereinkommen einzuwenden; jedenfalls ist ein solcher Begriff ein unentbehrliches technisches Hilfsulttel der Biologie. Freilich ist es sehr fraglich, ob wir ein Übereinkommen über die Grundsätze erzielen werden können, nach denen eine „Art“ aufzustellen wäre. So wie die Dinge gegenwärtig liegen, ist der Gegensatz in den Anschanungen über die Grenzen einer ,Art" bei den Vertretern der verschiedenen biologischen Disziplinen sehr bedeutend, ja, es schwanken die Anschauungen bei der systematischen Klassifikation der einzelnen Gruppen des Tier- und Pflanzenreiches so sehr, daß kaum daran gedacht werden kann, ein allgemeingültiges Schema aufzustellen. Der Hauptunterschied in der verschiedenen Bewertung des Artbegriffes scheint darin zu liegen, daß der Systematiker vor allen Dingen danach strebt oder doch wenigstens danach streben soll, eine Identifizierung neu gefundener Individuen und ihre Einreihung in das System unter den Begriff einer Art zu ermöglichen, während der Phylogenetiker naturgemäß ganz andere Ziele verfolgt. Für den Systematiker der lebenden Organismen liegen die Verhältnisse viel günstiger als für den Paläozoologen; er sieht ja meist nur die Querschnitte durch die Äste des Stammbaumes, die auf dem Wipfelquerschnitt der Gegenwart liegen und ist viel eler in der Lage, ihre Grenzen in der Horizontalebene festzustellen als der Paläozoologe, der nur dort zwischen den Arten Vertikalgrenzen festzustellen vermag, wo die verbindenden Zwischenglieder fehlen. In den meisten Fällen - außer in jenen, wo wir eine eben entstandene oder entstehende Art vor uns liaben - sind die Horizontalgrenzen scharf, während die Vertikalgrenzen zwischen den genetisch miteinander verknüpften Arten - ich erinnere an Tetrabelodon angustidens, $T$. longirostris und $T$. arvernensis - rein künstliche sind. Würden derartige enge miteinander verknüpfte Kettenglieder einer Ahnenreihe häufiger sein, als sie es bis jetzt sind, so würde der Gegensatz in der Auffassung einer fossilen Art und einer rezenten Art viel klarer zum Ausdrucke kommen und auch die „Art" ebenso wic die „Gattung“ im paläontologischen Sinne nur Stückchen von Zweigen des Stammbaumes darstellen, die durch künstliche Vertikalgrenzen voneinander getrennt sind. Der Untersclied zwischen „Art" und „Gattung“ würde dann nur darin liegen, daß die erstere ein kleineres, die zweite dagegen ein größeres Stück eines Astes oder Zweiges des Stammbaumes repräsentiert.

Das gewaltige Heer der fossilen Formen ist einem wirr durcheinander liegenden Haufwerk von Aststücken zu vergleichen, deren ehemalige Verbindung zu ermitteln ist. In der Lösung dieses Problems liegt aber die Beantwortung der Frage nach den Verwandtschaftsbeziehungen und der Entstehung der lebenden Formen. Die morplio- 
logische, cmbryologische, physiologische und tiergeographische Forschung kann nur in beschränktem Maße auf die Frage der Vorgeschichte der lebenden Tierwelt eine Antwort geben; hicr gebührt das entscheidende Wort der Paläozoologie, und zwar gilt dies in erster Linie für die Wirbeltiere.

Wenn wir somit daran gehen, die genetischen Linien zu verfolgen, die von den ersten Anfängen des Wirbeltierstammes bis zu seinen lebenden Ausläufern fülıren, so muß die Darstellung der morphologischen Merkmale der fossilen Formen in den Vordergrund treten. Der folgende Versuch zielt in erster Linie dahin, die Ergebnisse der paläozoologischen Forschungen auf dem Gebiete der fossilen Wirbeltiere weiteren Kreisen zu erschließen und die morphologischen Gesichtspunkte für die Rekonstruktion der genetischen Linien darzulegen. Die reichen Funde paläozoischer Fische, Stegocephalen und Reptilien haben uns ein gewaltiges Tatsachenmaterial in die Hand gegeben, das uns gestattet, in vielen genetischen Fragen klarer zu sehen, als dies früher möglich gewesen ist. Die fossilen Formen sind aber in plyylogenetischer Hinsicht von sehr ungleichem Werte; mancher unvollständig erhaltene und seltene Rest ist unter Umständen weit wichtiger für die Phylogenie der Wirbeltiere, als so manches tadellos erhaltene Skelett. In einer Erörterung der phylogenetischen Bedeutung der fossilen Vertebraten ist daher eine entsprechende Auswahl der zu erörternden Formen unerläßlicl;; wer sich über die Bedeutung der fossilen Formen für den Ausbau der Stammesgeschichte zu unterrichten wünscht, hat wenig von der Aufzählung zahlloser Gattungs- und Artnamen, die oft nichts weiter besagen, als daß die paläozoologische Literatur leider noch immer mit viel unnützem Ballast beschwert ist.

Man hat in früherer Zeit viel von der ,Lückenhaftigkeit der paläontologischen Überlieferung" gesprochen, und dies ist ein sehr beliebtes Schlagwort geworden, namentlich in jenen Kreisen, in denen die Embryologie als das Um und Auf der phylogenetischen Forschung angesehen und den Ergebnissen der phylogenetischen Forschungen der Paläozoologen nur ganz geringe Beachtung geschenkt wird. Daß zahılreiche-fossile Arten nur in sehr unvollkommenen Resten bekannt sind, ist kein Zweifel; aber andererseits sind sehr viele fossile Wirbeltiere wenigstens in ihrem Skelettbau besser und vollständiger bekannt und sorgfältiger untersucht als so manche lebende Art. Das immer von neuem gedankenlos nachgesagte Schlagwort von der Lückenhaftigkeit der fossilen Urkunden muß durch das Gewicht der Tatsachen endlich zum Schweigen gebracht werden. Über die Vorgeschichte der Tetrapoden wird die Embryologie der rezenten Formen- kaum mehr wesentliche Erweiterungen unserer Kenntnisse zu erbringen imstande sein; die Zeit ist wohl für immer vorüber, da man es wagte, allein 
aus der Untersuchung der lebenden Reptilien zu Schlüssen über ihre Stammesgeschichte zu.gelangen. Hier kann man mit vollem Rechte die Waffe unkehren und darauf hinweisen, daß die lebenden Reptilien nur sehr dürftige Überreste eines einstmals reich verzweigt gewesenen Stammes darstellen, der seine Blüte im Paläozoikum und im Mesozoikum erreicht hat und sich seither in offenbarem Absterben befindet. Die zahlreichen rezenten Arten der Schildkröten, Eidechsen und Schlangen werden uns über die Verarmung des Reptilienstammes in der Gegenwart nicht hinwegtäuschen können, wenn wir die lebenden Ausläufer des Reptilienstammes mit seinen fossilen Vertretern vergleichen.

Viele Forscher sind der Meinung, daß die Fossilien in erster Linie als chronologische Dokumente zu bewerten seien und daß z. B. ein aus der Krideformation bekannt gewordenes Fossil infolge seines jüngeren Alters als der Nachkomme ciner der Trias angehörenden Form anzusehen sei. Dieses Betonen der chronologischen Aufeinanderfolge und die auf der zeitlichen Folge allein aufgebauten Sehlüsse sind als absolut fehlerhaft zu verwerfen. Sie können vielleicht zufällig mit dem tatsächlichen Entwicklungsgang zusammenstimmen, aber die chronologische oder stratigraphische Methode darf nie als ein brauchbarer und zum Ziel führender Weg der phylogenetischen Forschung betrachtet werden. Aufschlüsse über die genetische Entwicklung und die Vorgesclichte' der Lebewesen können wir einzig und allein nur aus der morphologischen Methode in Verbindung mit der paläobiologischen Analyse erwarten und erhoffen. Die Feststellung des geologischen Alters der fossilen Reste ist freilich keineswegs nebensächlicher Natur, sondern wird immer als ein wichtiges Hilfsmittel herangezogen werden müssen; wenn sich jedoch die Resultate der chronologischen und der morphologischen Untersuchung an widersprechen, so nuß unbedingt das Ergebnis der morphologischen Untersuchung entscheiden.

Die mangelhafte Unterscheidung von Bau und Form des Tierkörpers sowie einzelner Organe hat vielfach schwere 1rrtümer gezeitigt. Obwohl schon bei der Besprechung rezenter Formen da und dort darauf hingewiesen worden war, daß eine gleichartige Lebensweise eine gleichsinnige (konvergente), ja mitunter sogar eine durchaus gleichartige (parallele) Umbildung einzelner Organe oder selbst des ganzen Körpers bedingt, so ist doch erst von paläozoologischer Seite aus dieser Gesichtspunkt zu einer sorgfältig ausgebauten Forschungsmethode erhoben worden, die uns in den Stand setzt, die durch gleichartige Lebensweise bedingten Ähnlichkeiten odet Konvergenzerscheinungen in der Form von dem durch Verwandtschaft bedingten Ähnlichkeiten in Bau der Organismen scharf zu unterscheiden. So haben wir bereits 
eine ganze Rcihe von vermeintlichen Verwandtschaftsbeziehungen als eine Folgeerscheinung gleichartiger Anpassung von oft weit verschiedenen Formen an dieselbe Lebensweise zu entziffern vermocht; noch immer steckt aber unter den Deckmantel oberflächlicher, äußerer Ähnlichkeiten eine Fülle von Konvergenzerscheinungen verborgen, die wir einstweilen noch als Zeichen engerer Verwandtschaft zu deuten gewohnt sind. Rastloses Überprüfen der morphologischen Bezichungen unter steter Zuhilfenahme der paläobiologischen Analyse wird uns in stammesgeschichtlichen Fragen gewiß noch viele einstweilen merwartete Lösungen bringen. 


\section{Morphologische Vorbemerkungen.}

\section{Physiologische Bedeutung der Skelettbildungen.}

Unter Skelettbildungen in weiteren Sinne verstehen wir alle Hartteile des Wirbeltierkörpers, also nicht allein die Knochen, sondern auch die knorpeligen Elemente und die verhornten Epidermalbildungen (Haare, Federn, Schuppen, Nägel, Krallen, Hörner, Hautschilder, Hornschnäbel usw.), sowie die Zälıne.

Bei den Wirbellosen erscheinen Skelettbildungen selten als innere, sondern meist als äußere Bildungen, die man unter dem Namen „Außenskelett" zusammenfaßt. Bei den Wirbeltieren tritt dagegen das Außenskelett gegenüber dem Innenskelett an Bedeutung stark zurück, wenngleich bei den phylogenetisch ältesten Vertebraten, den Fischen, das Außenskelett entweder in Gestalt eines Schuppenpanzers oder eines aus Knochenplatten bestehenden Körperschutzes eine sehr wichtige Rolle spielt und unbeschuppte oder ungepanzerté Formen zu den Seltenheiten gehören. Auch bei den Stegocephalen und den zahlreichen Stämmen fossiler Reptilien sind Hautpanzerbildungen häufig anzutreffen, während sie unter den lebenden Vertebraten mit Ausnahme der Fische nur in den Gruppen der Schildkröten, der Xenarthra und der Krokodile in Gestalt von Knochenplatten ausgebildet, sonst aber sehr selten sind.

Das Außenskelett dient in den meisten Fällen als Schutzmittel gegen die Angriffe von Feinden und ist als solches in einigen Fällen zu extenen Ausbildungsstufen gelangt (z. B. bei den gepanzerten, pflanzenfressenden Ornithischiern Stegosaurus, Polacanthus). Auch das Innenskelett hat ursprünglich neben der Aufgabe, die Körperachse zu versteifen und dem Körper einen festeren Halt, ein ,Rückgrat" zu geben, den Charakter eines Schutzmittels besessen, denn die ersten auftretenden Skelettbildungen erscheinen als Unluüllung und somit als 
Scluutz der Chorda dorsalis und des Rückenmarkstranges sowie des Gehirns. Erst später treten zu diesen in der Körperachse liegenden Innenskelettbildungen (Wirbelsäule und Schädel) Verstärkungen der Gliedmaßen hinzu, zuerst in Gestalt von knorpeligen Trägern, später in Form von festen Knochen, welche zuerst nur die Aufgabe hatten, den Körper der ältesten Wirbeltiere beim ruhigen Liegen auf dem Grunde der Gewässer zu stützen; aus ilmen gingen Apparate hervor, die innstande waren, den Körper vorwärts zu schieben oder ihn doch bei seiner durch ein langsames und unbeholfenes Schlängeln bewirkten Vorwärtsbewegung zu unterstützen; daraus entwickelten sich im weiteren Verlaufe der Entfaltung des Wirbeltierstammes einerseits bei den Schwimmtieren Flossen, anderseits bei dem Übergange vom Wasserleben zum Landleben in strenger Abhängigkeit vom Gebrauch oder Nichtgebrauch der einzelnen Gliedmaßenteile die in den verschiedensten Richtungen spezialisierten Schieb-, Schreit-, Lauf- und Springfüße, die Grabfüße, Kletterfüße und Flugfüße oder Flügel; ein Wechsel der Lebensweise hatte immer wieder die Ungestaltung der Gliedmaßen im Gefolge, so daß aus Schreit- oder Schiebfüßen wieder Flossen wurden wie bei den Ichthyosauriern, Walen und Sirenen, ebenso wie auch aus dem Vogelflügel eine Ruderflosse entstehen konnte, wie sie der Pinguin besitzt; endlich sind bei Annahme einer wühlenden oder schlängelnden Lebensweise bei vielen Wirbeltieren die Extremitäten wieder verloren gegangen, wie bei den Aalen und Muränen unter den Fischen, den fußlos gewordenen Stegocephalen und den fast fußlos gewordenen lebenden Aalmolchen (Amphiuma) und den Armmolchen (Siren), den zahlreichen fußlos gewordenen Lacertiliern, den Schlangen usf. ${ }^{1}$ Bei den Vorfahren der Elasmobranchier waren die Lateralflossen ursprünglich Stützflossen (Pterygopodien) und aus diesenl sind erst bei Anpassung an das Freischwimmen die „Haifischflossen" entstanden; bei den Vorfahren der Teleostomen müssen, wie aus den morphologischen Verhältnissen der paarigen Flossen der ältesten Crossopterygier und der Dipneusten hervorgeht, gleichfalls Stützflossen ausgebildet gewesen sein, aus denen sich einerseits die Beinpaare der Tetrapoden, anderseits die Brust- und Bauchflossen der Teleostomen herausbildeten. Eine abweichende Entstehung der Flossen ist nur bei den Acanthodiern anzunelımen, wo die Seitenflossen wahrscheinlich aus einer lateralen Hautfalte hervorgegangen sind und ursprünglicln nicht zwei, sondern nicht weniger als sieben Lateralflossenpaare (bei Climatius) auftreten. Die Lateralflossen haben hier wolnl von Anfang an als Balanzierapparate, aber nie als Körperstützen funktioniert.

Zeigt uns dergestalt die vergleichende Analyse des knöchernen Glied-

1 O. Abel, Grundzüge der Paläobiologie der Wirbeltiere. Stuttgart, 1912. 
maßenskeletts der Wirbeltiere eine weitgehende Abhängigkeit der Form seiner einzelnen Elemente von ihrer Funktion, so treten uns dieselben Wechselbeziehungen auch in den verschiedenen Abschnitten des Achsenskeletts, wenn auch nicht mit derselben Deutlichkeit wie im Gliedmaßenskelett, entgegen, da die Funktionsmöglichkeiten dieser Skelettelemente beschränkter sind. Die Schwanzwirbel jener Typen, die sich mit Hilfe eines Ruderschwanzes im Wasser fortbewegen, wie die Ceraterpetontiden unter den Stegocephalen, erhalten lange Dornfortsätze, ebenso wie die der Fischottern und Wale unter den Säugern; Typen, welche einer besonders festen Verbindung der einzelnen Wirbel untereinander bedürfen, erhalten überzählige Gelenkverbindungen, wie die Phlegethontiiden unter den Stegocephalen und die mit ihnen nicht enger verwandten lebenden Blindwühlen; anderseits tritt in anderen Gruppen eine zunehmende Lockerung der Wirbelverbindungen auf, wie bei den Ichthyosauriern und bei den mit ihnen nicht verwandten Walen. Auch im Schädel macht sich die Abhängigkeit der Form von der Funktion der Kiefer und der Art der Nahrungserfassung überhaupt deutlich bemerkbar.

Bei der vergleichend-osteologischen Analyse des Wirbeltierskeletts, welche die Aufgabe hat, die verwandtschaftlichen Beziehungen der einzelnen Arten, Gattungen, Familien, Ordnungen und höleren systematischen Kategorien untereinander zu ermitteln, muß man sich daher sehr davor hüten, aus der Form der Skelettelemente einen Schluß auf die Verwandtschaft zu ziehen, da übereinstimmende Gestalten bei den Angehörigen der verschiedensten Gruppen auftreten können und sehr häufig nur die Folge einer gleichartigen Lebensweise, bzw. einer gleichsinnigen Funktion der Organe sind.

Bei eingehenderen. Vergleichen zeigt sich jedoch in den meisten Fällen, daß die Formähnlichkeit nur eine rein äußerliche ist und dá z. B. die Flossen wasserbewohnender Wirbeltiere in ihrer Gesamtform zwar eine oft überraschende Ähnlichkeit aufweisen, in ihrem Skelettbau aber durchaus verschieden sind. So sind die Skelettelemente der Brustflossen eines Haifisches, eines Thunfisches, eines Ichthyosaurus, eines Delphins, eines Dugongs, einer Phoca, eines Pinguins und einer Chelone im Aufbau und in der Anordnung sowie in den Größenverhältnissen der einzelnen Skelettelemente durchaus verschieden, soweit es sich überhaupt um homologe Elemente handelt (z. B. Humerus, Radius, Ulna, Carpalia, Metacarpalia und Phalangen) und nicht Skelettelemente vorliegen, die miteinander in keinen Vergleich gebracht werden können, weil sie keine homologen Bildungen sind (z. B. die Flossenstrahlen der Haifische und die Phalangen der Ichthyosaurier).

Die verwandtschaftlichen Beziehungen zwischen den verschiedenen Wirbeltieren können daher nur durch sorgfältige Analyse 
des anatomischen Baues ermittelt werden, wobei die gegenseitigen Lagebeziehungen der einzelnen Skelettelemente, ihr Spezialisationszustand, ihre Zahl und ihre Herkunft (ob Deckknochen, ob Knorpelknochen) zu berücksichtigen sind, kurz alle jene Merkmale, die man unter der Bezeichnung ,Bau“ des Skelettes zusammenzufassen pflegt, während die Form der Skelettelemente nur einen Schluß auf die Funktion und daraus auf die Lebensweise zuläßt, die bei den verschiedensten, nicht näher miteinander verwandten Arten dieselbe sein kann.

\section{Die heterogene Herkunft der Knochen: Ersatzknochen und Hautknochen.}

Die das Innenskelett der höheren Wirbeltiere zusammensetzenden knöchernen Elemente sind zwar zum größeren Teile aus Knorpelbildungen an jenen Stellen entstanden, die durch Zug oder Druck von Muskelsehnen oder Bändern besonders stark in Anspruch genommen wurden, aber es sind zu diesen ,Knorpelknochen" an vielen Stellen (z. B. im Schädel) Knochen hinzugetreten, die nicht in der Tiefe, sondern an der Oberfläche des Körpers, und zwar in der Haut, ihren Ursprung haben. Diese sekundär zum ursprünglichen oder primären Knorpelskelett hinzutretenden Knochen sind somit als Teile des Außenskeletts zu betrachten und so stellen sich gewisse, bei höheren Wirbeltieren zu Bestandteilen des Innenskeletts gewordene Knochen als ein späterer Zuwachs dar, wie es z. B. mit den meisten Knochen des Säugetierschädels der Fall ist. Dieser, heute dem Innenskelett angehörige Teil des Knochenskeletts ist zweifachen Ursprungs, indem sich einzelne Schädelknochen als Verknöcherungen des primären Knorpelschädels erweisen (z. B. das Basioccipitale und Exoccipitale), während andere Schädelknochen (z. B. das Frontale und Parietale) als Hautknochen zu betrachten sind, die erst später in so innige Verbindung mit den knöchernen Elementen des Knorpelschädels gelangten, daß man ohne Kenntnis der ontogenetischen Vorgänge und olne Rücksicht auf die einfacheren Verhältnisse bei den niederen Wirbeltieren nicht auf den Gedanken kommen würde, daß durchaus heterogene Elemente am Aufbau des Säıgetierschädels beteiligt sind.

Wir haben daher scharf zwischen jenen Knochen zu unterscheiden, die aus knorpeligen lnnenskelettelementen und jenen, die aus der Haut hervorgegangen sind. Die ersteren, die man gewöhnlich als Ersatzknochen oder Knorpelknochen bezeichnet, entstehen durch Anlagerung zarter Knochenlamellen an der Oberfläche des Knorpels, den sie allmählich verdrängen und ersetzen. Die andere Gruppe von Knochen, die Hautknochen oder Deckknochen, sind genetisch in ihrer Mehrzahl als verwachsene Schuppen oder Zähne anzusehen. 
Hautknochen (oder ,Belegknochen“) können jedoch auch (wie z. B. die ,Sesambeine" der Hand und des Fußes) aus der Verknöcherung einzelner Partien von Bändern, Sehnen und Membranen hervorgehen. Die Hautknochen treten zuweilen in so innige Verbindung mit den Elementen des primordialen Skelettes, daß sie uns natürliche Teile desselben vortäuschen können. Dies ist besonders dort möglich, wo die Knorpelbildungen des Innenskeletts in die Nähe der Körperoberfläche treten, wie es mit der knorpeligen Schädelkapsel der Fall ist. Un sie herum entstehen im Integument Knochenplatten, die sich zu einem Mosaik zusanmenfügen und so ein Schädeldach bilden; erst später verkalken zuerst einzelne Teile des Knorpelcraniums, dann immer mehr, bis wir z. B. im Schädel der Stegocephalen ein aus diesen beiden heterogenen Knochenstücken zusammengesetztes und scheinbar einheitliches Schädelskelett vor uns sehen.

Eine ebensolche Verbindung von Knorpelknochen und Hautknochen liegt im Flossenskelett der Knochenfische vor; die Träger der Flossenstrahlen sind verkalkte Knorpelelemente des Innenskeletts, die Flossenstrahlen selbst aber sind verknöcherte Hautbildungen, und trotzdem stehen beide heterogenen Elemente in inniger Verbindung.

\section{Die ersten Anfänge des Wirbelskeletts und seine Differenzierung.}

Ursprünglich war der langgestreckte Körper der ältesten Vertebraten nur von einem ungegliederten Strang, der Chorda dorsalis oder der Rückensaite, durchzogen, über welchem sich das Nervenrohır (Rückenmark und Gehirn) ausdehnte. Die Chorda ist als ungegliederter Strang noch heute bei einigen Fischen erhalten, wie bei den Holocephalen, Dipneusten, Polyodontiden und Acipenseriden, aber bei den übrigen Vertretern des großen Heeres der lebenden Fische und bei den übrigen Vertebraten ist sie anfangs durch knorpelige und später durch knöcherne Bildungen, die man in ihrer Gesantheit als Wirbelbildungen zusammenfaßt, zuerst eingeengt und schließlich, wie in den Wirbeln der erwachsenen Reptilien und Vögel, gänzlich verdrängt worden und wo sie noch in Rudimenten zwischen den Wirbeln der Säugetiere bestehen bleibt, spielt sie keine Rolle mehr.

Hingegen ist das Nervenrohr der Wirbeltiere, das ursprünglich so wie die Chorda ungeschützt war, schon frühzeitig von zuerst knorpeligen, dann von knöchernen Elementen des Innenskeletts umgeben und geschützt worden, welche sich aus einzelnen Spangen oder ,Bogenstücken" zu Halbringen oder Vollringen zusammenschlossen, um das Rückenmark und ein über demselben in der Mittellinie des Körpers dahinziehendes Längsband in sich aufzunehmen. Ebenso schließt sich 
auf der Unterseite der Chorda dorsalis um das unter ihr verlaufende Blutgefäß (die Aorta) ein aus knorpeligen und später knöchernen Bogenstücken gebildeter Ring. Diese Ausbildung ist, soweit dies die Befunde an noch lebenden primitiven Typen (z. B. beim Stör, Fig. 1) und an den fossilen Fischen zeigen, ausnahmslos der Entstehung eines knorpeligen oder knöchernen Wirbelkörpers vorangegangen.

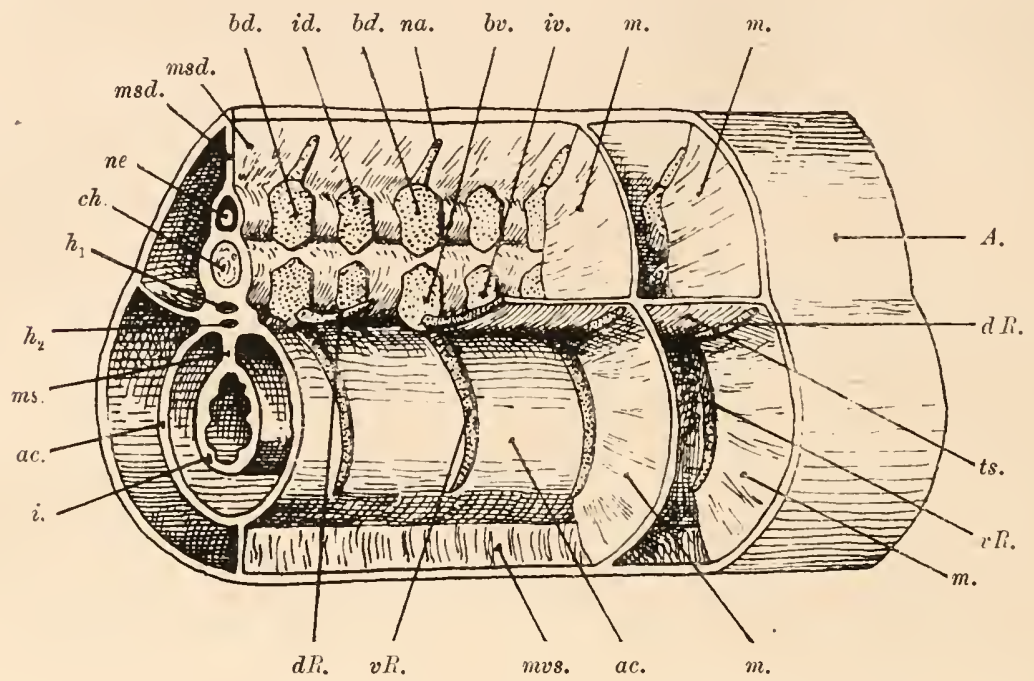

Fig. 1.

Schematische Darstellung der Wirbelbogenelemente, Rippen und Körpersepten eines gnathostomen Vertebraten; die Abbildung ist als Präparat gedacht, das ein Rumpfstück in schräger Seiten- und Vorderansicht zeigt (von links gesehen). Nach E. S. Goodrich, 1909 (umgezeichnet).

$a c$. = Außenwand der Leibeshöhle.

A. $=$ Außenwand des Rumpfes.

$b d .=$ Basidorsale.

$b v .=$ Basiventrale.

ch. $=$ Chorda dorsalis.

$h_{1}, h_{2}=$ Blutgefäße.

$i$. $=$ Darm.

id. $=$ Interdorsale.

iv. $=$ Interventrale. $m$. = Transversalseptum (Myocomma).

$m s$. = Mesenterium.

msd. = medianes Dorsalseptum

$m v s$. = medianes Ventralseptum.

$n a$. $=$ Neurapophyse.

ne. $=$ Rückenmark.

ts. $\quad=$ Transversalseptum.

$d R .=$ Dorsalrippe.

$v R .=$ Ventralrippe.

\section{Die Bogenelemente der Wirbel und die Rippen.}

(Fig. 1-3.)

Die Bogenstücke, welche zuerst in knorpeligem und später in knöchernem Zustande sich an die dorsale und an die ventrale Seite der Chorda anlegen, werden unter dem Namen Arcualia zusammengefaßt. Wir unterscheiden die oberhalb der Chorda liegenden Bogenstücke als dorsale Arcualia, die unter ilır gelegenen als ventrale Arcualia. 


\section{A. Dorsale Arcualia.}

1. Basidorsalia. - Die Basidorsalia umschließen das Rückenmark und bilden die Neurapophysen oder Neuralbogen. Ursprünglich paarig angelegt, verschmelzen sie im weiteren Verlaufe der Spezialisation des Wirbels im Laufe der Stammesgeschichte miteinander zu einem einheitlich erscheinenden Stücke. Sie sind unter allen Bogenelementen das wichtigste, das niemals durch ein anderes Bogenelement verdrängt wird, wohl aber, wie in den Wirbeln der Urodelen, sogar die Hauptmasse des Wirbels bilden kann.

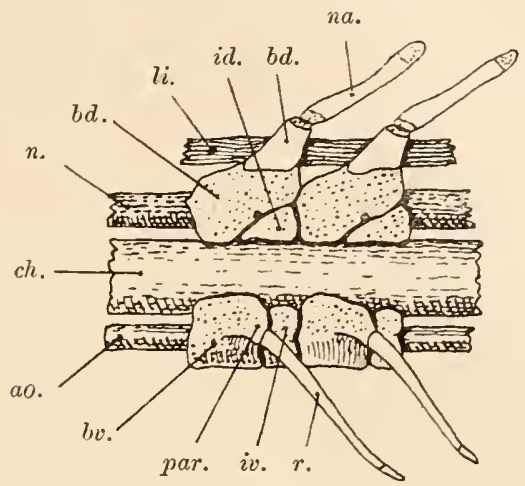

A.

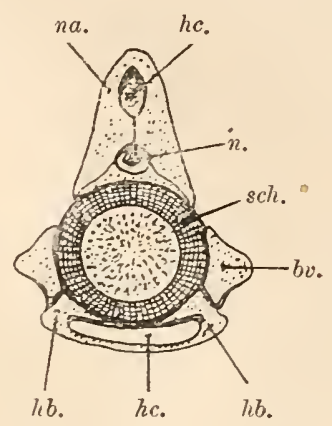

B.

Fig. 2.

A. Zwei Wirbel von Acipenser sturio L. aus der Rumpfregion, von der Seite gesehen. B. Ein Rumpfwirbel von Acipenser sturio L., quer durchschnitten, von vorne gesehen. Mit Benützung einer Zeichnung von E. S. Goodrich.

$\begin{aligned} a o . & =\text { Aorta. } \\ c h & =\text { Chordadorsalis } \\ \text { sch. } & =\text { Chordascheide. } \\ n . & =\text { Rückenmark. } \\ l i . & =\text { Longitudinalligament } . \\ n a . & =\text { Neurapophyse. } \\ b d . & =\text { Basidorsale. } \\ b v . & =\text { Basiventrale. }\end{aligned}$

2. Interdorsalia. - Zwischen je zwei aufeinanderfolgende Basidorsalia schiebt sich ein Paar Bogenstücke ein, welche den freien Raum auf der Oberseite des Rückenmarks zwischen den Basidorsalia zudecken.

3. Suprabasidorsalia. - Diese Stücke sind als Abschnürungen der Basidorsalia anzusehen, welche sich oben den Neurapophysen anschließen und die Neuraldornen bilden; sie stellen den oberen Abschluß des Dornfortsatzes dar.

4. Suprainterdorsalia. - Auch diese Stücke sind nur als abgeschnürte Teile anzusehen, und zwar als Abschnürungen der Interdorsalia; sie sind ebenso wie die Suprabasidorsalia paarig entwickelt 
und liegen über den Interdorsalia als Schlußsteine des knorpeligen oder knöchernen Daches des Rückenmarks zwischen den Neurapophysen.

\section{B. Ventrale Arcualia.}

1. Basiventralia. - Den Basidorsalia entsprechen auf der Ventralseite der Chorda die paarigen Basiventralia, welche die Aorta unschließen und die Hämapophyse oder den Hämalbogen bilden. Der Hämalbogen

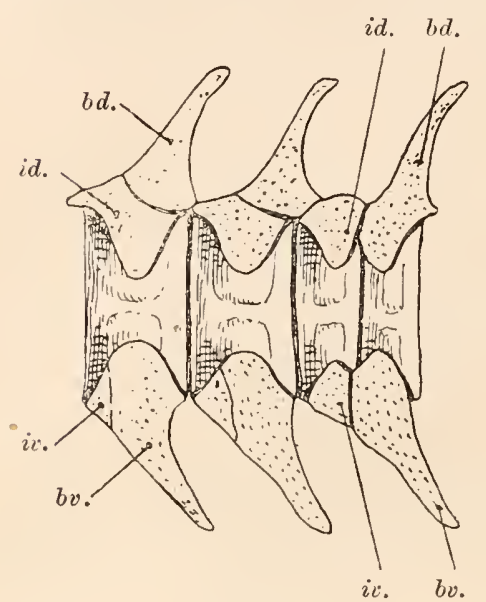

Fig. 3.

Drei Wirbel (zwei einfache und ein Doppelwirbel) von der Grenze zwischen Rumpf- 1 . Schwanzregion einer jungen, $7,5 \mathrm{~cm}$ langen Amia calva L. (Nach

H. Schauinsland, umgezeichnet.)

$$
\begin{aligned}
& b d .=\text { Basidorsale. } \\
& b v .=\text { Basiventrale. } \\
& i v .=\text { Interventrale. } \\
& i d .=\text { Interdorsale. }
\end{aligned}
$$

kommt dadurch zustande, daB sich an seitlichen, gegen unten gerichteten Fortsätzen dèr Basiventralia griffelförnige, spitz endende Rippen ansetzen, die als Ventralrippen (zum Unterschied von den Dorsalrippen) zu bezeichnen sind und die sich in der Caudalregion mit ihren freien Enden aneinanderlegen, so daß die Aorta von den zu einem ,Bogen“ vereinigten Ventralrippen unschlossen wird. Dieser Bogen wird als $\mathrm{Häm-}$ apophyse oder als unterer Dornfortsatz bezeichnet, das letztere dann, wenn er in feste Verbindung mit dem Wirbelkörper tritt (z. B. bei Stegocephalen und Urodelen).

2. Interventralia. - Die Interventralia korrespondieren mit den Interdorsalia auf der Dorsalseite der Chorda und sind zwischen je zwei Basiventralia eingeschaltet.

3. Costae ventrales $=$ Ventralrippen. - So wie die Suprabasidorsalia als Abschü̈rungen der Basidorsalia zu betrachten sind, kann man die Ventralrippen als Abschnürungen der Basiventralia ansehen. Wenn sie als freie, nach außen und unten abstehende, griffelförmige ,Rippen" entwickelt sind, so liegen sie der Innenseite der ventralen Rumpfmuskulatur an und umfassen den oberen Teil der Leibeshöhle; dies ist bei allen Teleostomen der Fall, während bei den Elasmobranchiern die freien Ventralrippen fehlen und homologe Bildungen nur in Gestalt von Hämapophysen entwickelt sind. Dagegen treten bei den Elasmobranchiern zwischen der dorsalen und der ventralen Rumpfmuskulatur in Horizontalseptum die Dorsalrippen auf, welche den Teleostomen meist fehlen. Hingegen sind alle übrigen rippentragenden Wirbeltiere in der präkaudalen Region der Wirbelsäule nur mit Dorsal- 
rippen ausgestattet, so daß sich hier ein fundamentaler Gegensatz ergibt, der aber z. B. durch Polypterus überbrückt wird, bei welchen Ventralrippen und Dorsalrippen vorhanden sind. Die Ventralrippen der höheren Vertebraten treten in der Kaudalregion der Wirbelsäule als Hämapophysen auf und es kommt nur in sehr seltenen Fällen (z. B. am vordersten Schwanzwirbel von Physeter macrocephalus) vor, daß die beiden Hälften der Hämapophysen getrennt bleiben, so daß sie dann als „Ventralrippen“ bezeichnet werden könnten.

4. Infraventralia. - In vereinzelten Fällen sind auch die ventralen Gegenstücke zu den Suprainterdorsalia beobachtet worden (z. B. in der Kaudalregion der Rochen); sie spielen keine besondere Rolle. Sie stellen Abschnürungen der Interventralia dar.

\section{Der Wirbelkörper.}

Ursprünglich war, wie schon erwähnt, der Wirbeltierkörper von einem ungegliederten Strang, der Chorda dorsalis, durchzogen, über welchem sich das Nervenroln (Rückenmark und Gehirn) erstreckte, Verhältnisse, wie sie uns noch heute bei Amphioxus entgegentreten, der aber keine Spur einer knorpeligen oder gar knöchernen Skelettbildung aufweist und sekundär den Schädel und die für die Wirbeltiere im strengeren Sinne bezeichnenden Sinnesorgane des Kopfes verloren lat.

Bei den höheren Wirbeltieren ist zwar die Chorda dorsalis noch vorhanden, aber sie wird durch die ursprünglich sie einfach umhüllenden, später differenzierten Wirbelbildungen im Verlaufe der stanmesgeschichtlichen Entwicklung zuerst eingeschnürt, dann aber immer mehr und mehr eingeengt, bis sie schließlich im erwachsenen Zustande der in dieser Hinsicht höchst spezialisierten Formen verloren geht und nur melır in der ontogenetischen Entwicklung eine Rolle spielt. Die Säugetiere, die man in der Mehrzahl ilurer morphologischen Merkmale als die höchst spezialisierten Wirbeltiere betrachten muß, verhalten sich jedoch im Reduktionsgrade der Chorda dorsalis primitiver als die lebenden Reptilien und Vögel, bei denen die Chorda innerhalb der Wirbelkörper und zwischen ilınen zugrunde geht; bei den Säugetieren bleibt in der Mitte der faserknorpeligen Zwischenwirbelscheiben (Intervertebralscheiben) noch ein gallertiger Rest der Chorda zwischen je zwei Wirbeln erhalten, während er allerdings im Bereiche des Wirbelkörpers selbst verloren geht.

Die Vorgänge, die zur Bildung von jenen Skelettelementen führen, die man unter dem Sammelnamen ,Wirbelkörper" oder ,Zentren" zu bezeichnen pflegt, sind sehr verschiedener Natur und zwar lassen sich zunächst zwei fundamental verschiedene Typen der Wirbelkörperbildung unterscheiden: die Wirbelkörperbildung durch Knorpelbildung und spätere Verkalkung der Chordafaserscheide (Chorda- 
wirbel), und die. Wirbelkörperbildung unter AusschluB der Chordascheide nur aus dem perichordalen, d. h. die Chorda umgebenden Bindegewebe (Bogenwirbel).

I. Chordawirbelkörper (= Chordazentren). - Im ersten Falle entsteht ein ,Wirbel" dadurch, daß in der faserigen Hüllschicht der Chorda dorsalis, der „Chordascheide“, in regelmäßigen Zwischenräumen Knorpelbildungen auftreten, die allmählich gegen das Innere der Chorda vordringen und sie an diesen Stellen abschnüren, so daß sie ein perlschnurartiges Aussehen erhält. Diese aus der Chordascheide hervorgehenden Wirbelkörper vergrößern sich nun wieder in verschiedener Weise, und zwar werden drei verschiedene Typen der Wirbelkörperbildung unterschieden, welche aus der Verknorpelung der Chordascheide hervorgehen.

Der einfachste Typus der Wirbelbildung tritt uns bei einzelnen heute noch lebenden Gruppen der Haifische entgegen. Bei Clnlamydoselache anguineus, einem Haifisch aus der japanischen Tiefsee, ist die Chorda im Schwanzabschnitte völlig einheitlich und durch keine Ringbildungen eingeschnürt; im vorderen Abschnitte der Chorda dorsalis treten jedoch in regelmäßigen Zwischenräumen je zwei aneinanderschließende Ringe auf, welche die Chorda einschnüren und nur im Mittelpunkt der ringförmigen Knochenscheiben einen schmalen Kanal für die Chorda freilassen.

Aus dem Grundtypus geht zunächst durch Ausbildung eines knöchernen Hohlzylinders um das Chordastück zwischen Vorder- und Hinterwand des Wirbelkörpers der zyklospondyle Wirbeltypus (Fig. 4, a) hervor, den wir bei den lebenden Haifischgattungen Acanthias und Scymnus, sowie bei dem unterliassischen Cestracioniden Palaeospinax antreffen, dem ältesten fossilen Fisch, bei dem ein vollständiger Wirbelkörper nachgewiesen werden konnte.

Vom zyklospondylen Typus zweigen nun zwei divergente Wege ab. Der eine führt zur Bildung eines tektospondylen Wirbels (Fig. 4,b), bei dem sich um die knöcherne Röhre in der Mitte des Wirbelzentrums konzentrisch immer weitere Kalkröhren legen; dies ist der Fall bei den Rochen und bei der Haifischgattung Rhina (Fig. 5, B). Auf dem zweiten Wege wird dagegen die weitere Verfestigung des Wirbels durch die Ausbildung radialer Knochenblätter bewirkt, die von der die Chorda umıschließenden zylindrischen Kalkröhre wie die Schaufeln eines Mühlrades ausstrahlen und auf der Vorder- und Hinterfläche des Zentrunis einen Stern bilden, weshalb dieser Typus die Bezeichnung asterospondyl (Fig. 4, c) erhalten hat. Wir treffen diesen Typus unter den lebenden Haifischen, z. B. bei den Gattungen Scyllium und Lamna(Fig. 5, A) an; er kommt bei den Rochen nicht vor.

Unter den Wirbeltieren ist es allein bei den Elasmobranchiern zur 
Ausbildung von Chordawirbeln gekommen, wälırend alle übrigen Wirbeltiere, soweit sie nicht überhaupt wirbelkörperlos sind (z. B. die Holocephali, Dipnoi, die meisten Crossopterygii, Chondrostei und Holostei) Wirbelkörper besitzen, die unter Ausschluß der Beteiligung der Chordascheide aus dem die Chorda umlhüllenden, ,perichordalen" Bindegewebe
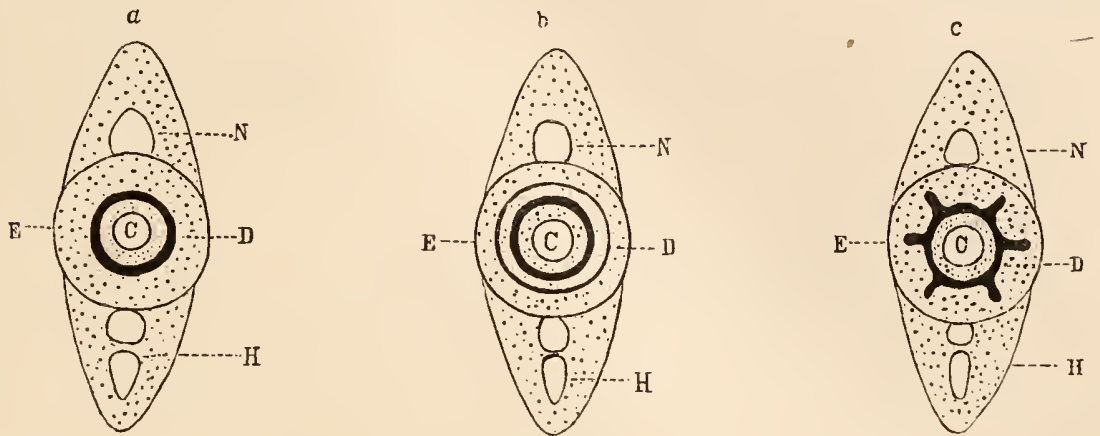

Fig. 4.

Schema eines zyklospondylen (a), eines tektospondylen (b) und eines asterospondylen Plagiostomenwirbels. (Nach C. Hasse.)

$C=$ Chordakanal. $D=$ Wirbelzentrum. $E=$ Elastica externa. $N=$ Neurapophyse. $H=$ Haemapophyse. Mit stärkerer schwarzer Farbe sind entweder die ringförmigen (in a und b) oder die sternförmigen Verknöcherungen (in c) gekennzeichnet.

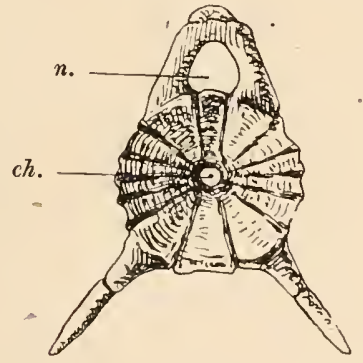

A.

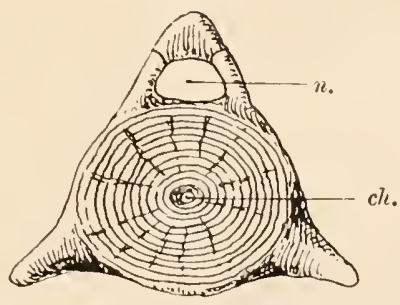

B.

Fig. 5.

A. Asterospondyler Wirbel von Lamna cornubica, Gm. B. Tektospondyler Wirbel von Rhina squatina, L. (Nach E. S. Goodrich.) $n=$ Rïckenmarkskanal (Neuralkanal), $c h=$ Chordakanal.

entstanden sind (Bogenwirbel). Von den Elasmobranchiern führt keine Brücke zu den Teleostomen und zu den höheren Wirbeltieren, sondern sie stellen einen sehr frülızeitig abgezweigten, einseitig spezialisierten und blind endigenden Hauptast des Wirbeltierstanmes dar.

11. Bogenwirbelkörper (= Bogenzentren). - Der zweite Weg der Bildung eines Wirbelkörpers ist von dem ersten grundverschieden. Hier wird zwar gleichfalls die Chorda dorsalis allmählich durch zuerst 
knorpelige und dann knöcherne Bildungen eingeschnürt und später verdrängt, aber diese Verknöcherung, die gleichfalls zur Bildung eines Wirbelzentrums führt, geht nicht von der Chordascheide, sondern vom perichordalen Bindegewebe aus und vollzieht sich durch das Wachstum der Bogenelemente, die wir schon kennen gelernt haben.

Die vier Paare von Bogenelementen beteiligen sich aber keineswegs immer in demselben Verhältnisse und Ausmaße an der Bildung der Wirbelkörper innerhalb der verschiedenen Wirbeltierstämme, sondern es gibt auch hier verschiedene Wege, auf denen ein Wirbelzentrum gebildet werden kann (vgl. die Tabelle der Wirbelbildung bei den Amphibien, Reptilien, Vögeln und Säugetieren).

Bei den prinitiveren Wirbeltieren finden wir stets Wirbelkörper, welche vorn und hinten tief kegelförmig ausgehöhlt sind; da die Hohlkegel ihre Spitzen gegeneinander kehren, so erhält ein solcher Wirbel eine Sanduhrform, und diese findet sich ebensowohl an den Chordawirbeln der Elasmobranchier wie an den Bogenwirbeln der Teleostomen. Man nennt diese bikonkaven Wirbelkörper,, a mphicoel". Auch bei den lıöheren Wirbeltieren kommen derartige amphicoele Wirbel vor (z. B. bei Ichthyosauriern und vielen paläozoischen Reptilien). Diese amphicoelen Reptilienwirbel sind jedoch keineswegs den amphicoelen Fischwirbeln homolog, die bei den Elasmobranchiern und bei den Teleostomen nach ganz verschiedenem Prinzip gebaut sind und also auch untereinander nicht homolog sein können. Der ,Wirbel" ist nur ein physiologischer, aber kein morphologischer Begriff; haben auch die ähnlich gestalteten amphicoelen Wirbel der Haifische, Knochenfische und Ichthyosaurier dieselbe Funktion, so ist doch ihre Genesis ganz verschieden (Chordawirbel und Bogenwirbel) und auch innerhalb der Gruppe der Formen mit Bogenwirbeln ist die Art des Aufbaues des Wirbels aus den Arcualia so ungleichartig, daß wir in diesem Falle die übereinstimmende Form der Wirbelkörper nur als eine Konvergenzerscheinung, aber nicht als einen Beweis der Verwandtschaft betrachten dürfen.

\section{Aufbau und Gliederung des Wirbeltierschädels.}

Von allen Hartteilen oder Skelettelementen des Wirbeltierkörpers fällt jenen, die siclı zum ,Schädel“ zusammenschließen, die weitaus bedeutungsvollste und wichtigste Aufgabe zu, da sie vor allem den Schutz des Gehirns und der mit demselben verbundenen Hauptsinnesorgane durchzuführen haben.

Zu diesen Hauptaufgaben des Schädels treten aber frühzeitig noch weitere. Die knorpelige Schädelkapsel ist als Schutzhülle des Gehirns und der'Hauptsinnesorgane ursprünglich von den das Vorderende des 
Darmrohres - die Mundöffnung - schützenden Skelettelementen vollständig getrennt, so daß die Skeletteile der Mundregion erst später mit dem „Primordialcranium“, d. i. der Schädelkapsel, in Verbindung treten. Primitiven Verhältnissen in dieser Hinsicht begegnen wir noch bei einzelnen lebenden Haifischen, wie z. B. beim Hundshai (Scyllium canicula, Fig. 6), wo nur das paarig auftretende Hyomandibulare in gelenkige Verbindung mit dem Knorpelcranium tritt, während das Palatoquadratum, gleichfalls ein paarig entwickelter Knochen, durch Ligamente an die Basis des Knorpelcraniums angeheftet ist.

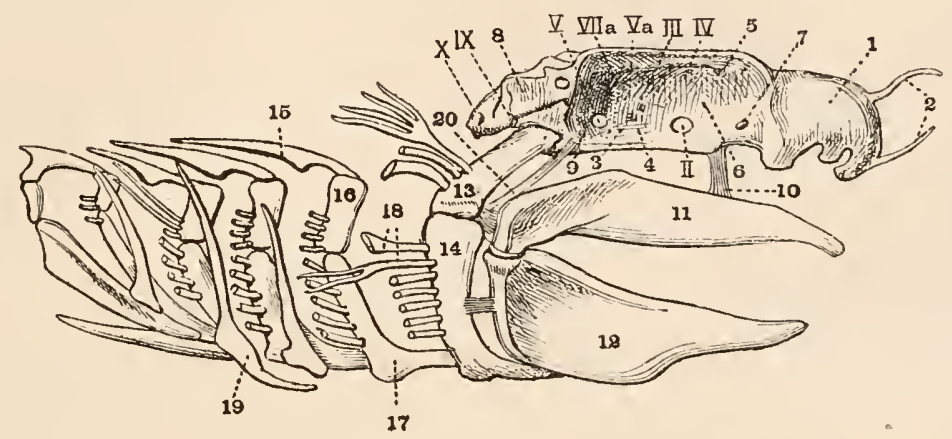

Fig. 6.

Seitenansicht des Schädels von Scyllium canicula, in $2 / 3$ nat. Gr. (Nach S. H. Reynolds.)

I. Nasenkapsel.

2. Rostrum.

3. Canalis interorbitalis.

7. Foramen für die Zungenbeinarterie.

5. Foramen für die Augenzweige des V. und VII. Nerven.

6. Foramen carotidicum (Austrittsstelle aus der Orbita).

7. Foramen orbitonasale.

8. Gehörkapsel.

9. Foramen carotidicum (Eintrittsstelle in die Orbita).

Io. Ligamentum ethmopalatinum.

II. Palato-Pterygo-Quadrat-Bogen.
I2. Meckelscher Knorpel.

I3. Hyomandibulare.

I.t. Ceratohyale.

15. Pharyngobranchiale.

I6. Epibranchiale.

I7. Ceratobranchiale.

18. Kiemenstrahlen (oberhalb ihrer Basis durchschnitten).

I9. Extrabranchiale.

20. Ligamentum praespiraculare.

$I I ., I I I ., I V ., V ., V a, V I I a, I X ., X$. bezeichnen die Austrittsstellen der betreffenden Schädelnerven.

Wir haben somit zunächst zwischen einer knorpeligen Umhüllung des Vorderendes des Nervenrohres bzw. des Gehirns und. der Hauptsinnesorgane und verschiedenen Skelettelementen $\mathrm{zu}$ unterscheiden, welche mit dem Vorderende des Darmrohres in Beziehung stehen und daher als das "Viszeralskelett" bezeichnet zu werden pflegen.

Das Viszeralskelett besteht ursprünglich aus einer großen Zahl von Kiemenbögen (das Vorhandensein von 14 Kiemenbögen bei dem Cyclostomen Bdellostoma ist als primitives Merkmal anzusehen), dann reduziert sich diese Zahl auf zehn (bei dem Anaspiden Pterolepis aus dem Obersilur Norwegens), besteht später (z. B. bei Lasanius [Fig. 30] 
und Thelodus [Fig. 34]) aus acht, dann aus sieben hintereinanderliegenden, knorpeligen Bögen, von denen die zwei vordersten mit den Mundteilen in Beziehung stehen und als der Kieferbogen und Zungenbeinbogen unterschieden werden; die fünf folgenden Bögen, welche an ihren Außenrändern feine Knorpelstrahlen tragen, die zur Stütze der Zwischenwände der Kiemenspalten dienen, werden als Kiemenbögen bezeichnet. Ursprünglich waren alle Viszeralbögen Kiemenbögen und die beiden vordersten sind erst später zum Kieferbogen und Zungenbeinbogen differenziert worden. In der Regel sind sieben Viszeralbögen bei den Elasmobranchiern (Fig. 6) vorhanden, aber bei einigen (z. B. bei Chimaera monstrosa) liegen dem Kieferbogen noch zwei Knorpelbögen jederseits auf, die Lippenknorpel, welche wahrscheinlich als die beiden vordersten, in den meisten Fällen verloren gegangenen Viszeralbögen anzusehen sind, so daß ihre Zahl hier ursprünglich neun betragen haben dürfte. Aus der Verschmelzung des Zungenbeinbogens oder des zweiten (regulären) Viszeralbogens mit den hinteren Kiemenbögen gehen bei den luftatmenden Wirbeltieren Bildungen hervor, die zur Zunge in innige Beziehung treten und den sog. Zungenbeinapparat bilden. Wenn auch dieser Zungenbeinapparat (Hyoidapparat) mit dem Schädel bei den Amphibien, Reptilien und Vögeln nicht in Verbindung tritt, so ist dies doch bei den Säugetieren der Fall und er kann daher als Bestandteil des Wirbeltierschädels mitgezählt werden.

Die knorpelige Schädelkapsel, die den eigentlichen Kern des Wirbeltierschädels bildet, ist bei den Cyclostomen in ihrer einfachsten und ursprünglichsten Ausbildung noch heute erhalten; sie ist in drei $\mathrm{Ab}$ schnitte gegliedert, die als Nasenregion, Augenregion und Ohrregion unterschieden werden, an welche sich unmittelbar die Wirbelsäule anschließt.

Bei den Elasmobranchiern bleibt zwar der die Hauptsinnesorgane und das Gehirn einschließende Schädel zeitlebens knorpelig, aber im linteren Abschnitt der Schädelkapsel ist bereits eine wichtige Veränderung nachweisbar, inden es hier durch Einbeziehung einer Anzahl von Wirbelelementen zur Bildung eines Hinterhauptes, einer Occipitalregion, gekommen ist, wie sich aus dem Verhalten der nummehr in den Gehirnabschnitt des Neuralrohres einbezogenen Nerven nachweisen läßt. Damit ist aber der Aufbau des Knorpelschädels keineswegs abgeschlossen; in weiteren Verlaufe der stammesgeschichtlichen Entwicklung der Wirbeltiere wird das bei den Elasmobranchiern, Teleostomen und Amplibien im großen und ganzen gleichartig gebaute Cranium beim Übergange zu den Amniotentypus noch um einige Wirbel, und zwar um drei, erweitert, wobei es zu der Ausbildung eines neuen Schädelnerven, des XII. (Nervus liypoglossus) kommt, der aus der Verschmelzung von drei Spinalnerven hervorgegangen ist. Diese in Laufe der 
Stammesgeschichte zweimal - zuerst bei den Fischen und zum zweitenmal bei den Amnioten - eingetretene Vergrößerung des Schädels durch Einbeziehung einiger Wirbel darf natürlich nicht mit der „Wirbeltheorie“ in Einklang gebracht werden, wie sie von Goethe und Oken vertreten wurde. ${ }^{1}$

Die bisher besprochenen Elemente des Wirbeltierschädels (primäre Gehirnkapsel, die vordersten Wirbel, das Viszeralskelett) sind ausnahmslos knorpeliger Natur oder, wenn sie bei höheren Wirbeltieren als Knochen auftreten, doch knorpelig präformiert. Sie gehören daher dem lnnenskelett an.

Außer den genannten Elementen des Innenskeletts beteiligen sich aber bei der Mehrzahl der Wirbeltiere auch noch Hautknochen an der Bildung des Schädelskeletts, die also dem Außenskelett angehören.

Bei den Fischen ist die Verbindung der Hautknochen mit den unter ihnen liegenden Elementen des Innenskeletts meist eine außerordentlich lockere, so daß die Trennung und Unterscheidung der Elemente des Außenskeletts und des Innenskeletts unschwer möglich ist. ${ }^{2}$ Auch bei den Amphibien ist die Verbindung der Knochen des Schädeldaches, das von Deckknochen (Hautknochen) gebildet wird, in den meisten Fällen durchaus lose, so daß die Unterscheidung des Außen- und Innenskeletts keinen wesentlichen Schwierigkeiten begegnet; aber es hat doch in einzelnen Fällen, wie bei der Unterscheidung der Dermosupraoccipitalia des Hautskeletts und des Supraoccipitale des Innenskeletts im Schädel einiger Stegocephalen ziemlich sorgfältiger Untersuchungen bedurft, um die Unterscheidung durchzuführen.

Unter den Deckknochen oder Hautknochen des Schädels werden meist zwei Gruppen unterschieden. Die erste Gruppe umfaßt die verschiedenen Hautverknöcherungen, welche auf der Oberseite des Schädels, dem eigentlichen ,Schädeldach", sowie an den Seiten des Schädels auftreten. Man bezeichnet diese Verknöcherungen als „Hautknochen“" im besonderen Sinne und trennt von ihnen jene Knochenplatten als ,Zahnknochen“ ab, welche aus der Verschmelzung von ursprünglich isolierten Zähnen zı kleineren oder größeren Knochenplatten hervor-

1 Nach dieser Theorie sollte der Schädel, z. B. der Schädel eines Säugetieres, aus der Vereinigung von mehreren Wirbeln hervorgegangen sein, und zwar sprach man von einem Occipital-, Parietal-, Frontal- und Nasalwirbel. Schon Th. H. Huxley und nach ihm C. Gegenbaur (1870) haben diese Theorie bekämpft und ihre Unhaltbarkeit erwiesen. Die Elemente der zum ursprïnglichen „Primordialcranium hinzutretenden Wirbel stecken ausschließlich im Hinterhaupt, und zwar sind vielleicht die Reste der beim Übergang zu.den Amnioten hinzugefügten Wirbel im Basioccipitale und Supraoccipitale der Reptilien zu suchen.

2 Von der Schwierigkeit, in einzelnen Fällen zu unterscheiden, ob Hautoder Knorpelknochen vorliegen, wird später die Rede sein. 
gegangen sind. Da jedoch die Zähne und die Plakoidschuppen der Haifische (der prinitivste Typus der Fischschuppen) homologe Bildungen darstellen, so daß man die Zähne der Mundhöhle ebensogut als ,,Mundhöhlenschuppen“ bezeichnen könnte wie die Plakoidschuppen der Körperoberfläche als ,Hautzähne“, so ist diese Unterscheidung von Hautknochen und Zahnknochen nicht sehr streng zu nehmen, weil es auch auf der Oberseite des Schädels durch Verschmelzung derartiger Plakoidschuppen-zur Bildung von Deckknochen gekommen ist. Gleichwoln ist die Unterscheidung von Hautknochen und Zahnknochen aus deskriptiven Gründen von Vorteil (vgl. diese Unterscheidung bei der Besprechung des Stegocephalenschädels).

Zu den schwierigsten Problemen der Morphologie gehört die Frage nach der Homologie der Deckknochen des Schädels bei den verschiedenen Klassen und Unterklassen der Wirbeltiere. Innerhalb der Amphibien und der Amnioten ist zwar die Frage der Homologie der einzelnen Elemente des Schädels mit wenigen Ausnahmen (z. B. Frage nach dem Verbleib des Quadratums der Reptilien in Säugetierschädel, Frage nach der Homologie des Mastoideunıs des Säugetierschädels usf.) befriedigend gelöst, aber die Homologisierung der Deckknochen des Amphibien- und des Teleostomensclıädels stößt noch immer auf große Schwierigkeiten und ist noch weit von ihrer Lösung entfernt. Ebenso ist es sehr zweifellaft, ob die Deckknochen des Schädels bei den verschiedenen Panzerfischen des Paläozoikums, welche verschiedenen Unterklassen der ,Fische" angehören, z. B. bei den Antiarchi und Arthrodiren, den Deckknochen der Crossopterygier homolog sind. Im allgemeinen läßt sich jedoch feststellen, daß die Zahl der Deckknochen bei den primitiven Formen größer ist als bei den höher stehenden Wirbeltieren und man kann diese Reduktion schon bei den Teleostomen, Stegocephalen und Reptilien verfolgen, wo die Zahl der einzelnen Deckknochen des Schädeldaches und des Unterkiefers ursprünglich sehr groß ist und allmällich teils durch Verschmelzung einzelner Elemente, teils durch Rudimentärwerden derselben inmer mehr abnimmt, wie der Schädelbau der Vögel und der Säugetiere zeigt. Ebenso weist auch der Schädel der Urodelen, Gymnophionen und Anuren eine wesentlich geringere Zahl von Deckknochen als der Schädel primitiver Stegocephalen auf.

Die Zusammensetzung des Dockknechenschädels der Teleostomen ist außerordentlich vorschiedenartig. Man hat wiederholt versucht, einen ,Fundamentalplan“ in Aufbaue des Schädeldaches, der Kieferregion usw. aufzufinden, aber alle diese Versuche müssen, einstweilen wenigstens, als fehlgeschlagen betrachtet werden. Ein Schädeltypus, wie er uns bei der Gattung Ania (Fig. 9-13) entgegentritt, ist keinesfalls prinitiv, obwohl dieser Typus von don Zoolegen in der Regel 
als der Ausgangstypus für die höher spezialisierten Teleostomen betrachtet wird. Wenn angenommen wird, wie dies meist zu geschehen pflegt, daß die zwischen den Augenhöhlen liegenden „Frontalia“, die vor ihnen liegenden „Nasalia“ und die hinter den Frontalia gelegenen „Parietalia“ als Grundelemente des Schädeldaches der Teleostomen zu

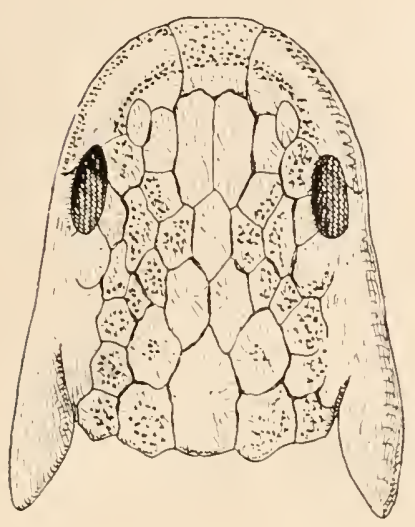

A.

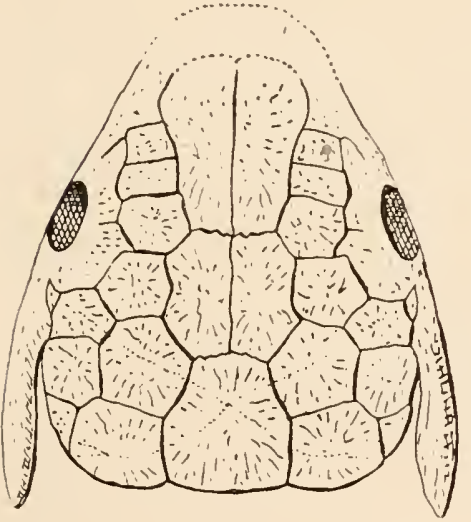

D.

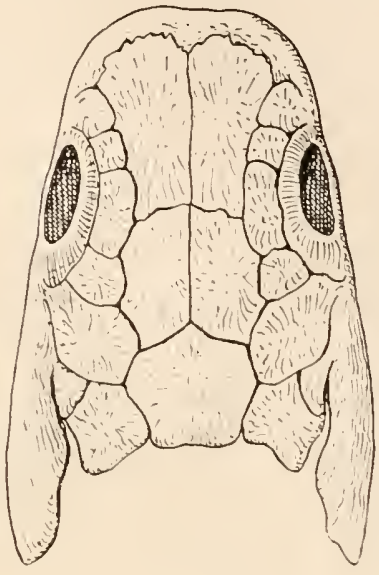

B.

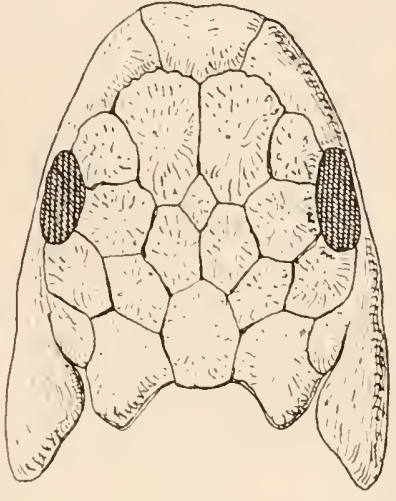

C.

Fig. 7.

Vergleiche zwischen den Schädeldächern von vier fossilen Dipneusten, um die divergente Entwicklung desselben bei Dipterus und Ctenodus einerseits und bei Scaumenacia und

Phaneropleuron anderseits zu zeigen.

A: Dipterus (Unterdevon bis Oberdevon).

B: Phaneropleuron (oberes Oderdevon).

C: Ctenodus (Karbon).

D: Scaumenacia (unteres Oberdevon).

(A bis C nach E. S. Goodrich, D nach L. Hussakof.)

betrachten sind, so ist dies durchaus unbegründet. Ursprünglich war der Teleostomenschädel von einer sehr großen Zahl kleiner, mosaikartig aneinanderstoßenden Platten bedeckt, wie das beispielsweise das Schädeldach des unterdevonischen Dipneusten Dipterus Valenciennesii (Fig. 7) zeigt; später trat im Laufe der Stammesgeschichte der einzelnen Stämme eine Verringerung der Plattenzahl infolge von Verschmelzungen der benachbarten Knochenplatten ein und es kam zur Bildung von wenigen, aber größeren Plattenpaaren oder Medianplatten 
in der Region des Schädeldaches. Daß diese Verringerung der Plattenzahl hauptsächlich durch eine Verschmelzung der Nachbarknochen zustande kam, darf wohl als sicher angenommen werden. Aber eingehendere Vergleiche zeigen, daß der Verschmelzungsprozeß nicht immer dieselben, sondern häufig verschiedene Elemente des Schädeldaches betroffen hat. Ein Vergleich der Schädeldecken von Dipterus (Fig. 7, A) mit Phaneropleuron (Fig. 7, B), Ctenodus (Fig. 7, C), Scaumenacia (Fig. 7, D) und Neoceratodus (Fig. 8) zeigt, daß die Wege,
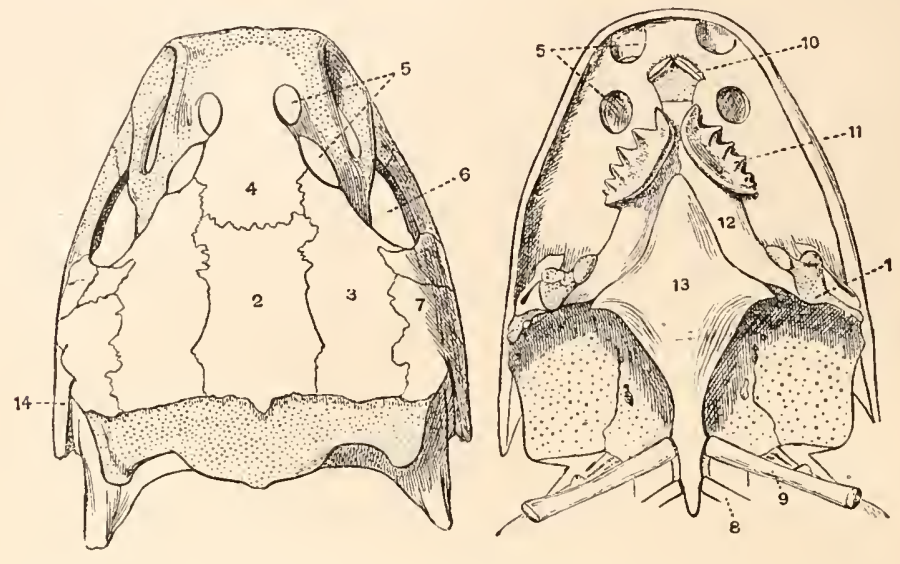

Fig. 8 .

Links Dorsalansicht, rechts Ventralansicht des Schädels von Neoceratodus miolepis (nach A. Günther, Deutung der Knochen abgeändert).

$I_{\text {. }}$ Knorpeliger Abschnitt des Quadratums, der mit dem Unterkiefer artikuliert.

2. Hintere Medianplatte (,,Scleroparietale"t).

3. - Lateralplatte (,Frontale“).

4. - Vordere Medianplatte (,Ethmoid").

5. - Nasenöffnungen.

6. - Orbita.
7. = Pteroticum (von anderen Autoren als ,Praeopercular“ und „Squamosum" bezeichnet).

8. = Zweite Rippe.

9. = Erste Rippe.

IO. = Vomerzähne.

$I x$. = Palato-pterygoidalzähne.

I2. = Palato-Pterygoideum.

I3. = Parasphenoideum.

I4. = Operculum.

die zur Herausbildung eines aus wenigeren Platten bestehenden Schädeldaches bei den Dipneusten geführt haben, durchaus verschieden waren und daß es sich lier nicht um homologe, sondern nur um konvergente Bildungen handelt. ${ }^{1}$ Aus der gleichartigen Lage der Knochenplatten und ihren gegenseitigen Beziehungen, ihrer Lage zwischen den Augenhöhlen usw. darf noch nicht der Schluß gezogen werden, daß

1 Einen weiteren, konvergenten Weg der Bildung eines Schädeldaches durch Verschmelzung zahlreicher Platten zu wenigen, großen Platten zeigt das von O. Jaekel (,Die Wirbeltiere“, 1911, p. 78, Fig. 81) abgebildete Schädeldach des permischen Dipneusten Conchopoma gadiforme, Kner, aus Lebach bei Saarbrücken. 
die als „Nasalia“, „Frontalia“, „Parietalia“ usw. bezeichneten Knochen in allen Fällen wirklich homolog sind.

Die gleichen Erscheinungen - die große Zahl mosaikartig aneinanderstoßender, kleiner Deckknochen im Schädeldache primitiver und ihre Verringerung im Schädeldache spezialisierter Typen - zeigen auch andere Stämme der Teleostomen. Wir finden z. B. bei Lepidosteus (F. Lepidosteidae), Macropoma (F. Coelacanthidae), Acipenser (F. Acipenseridae), Mesturus (F. Pycnodontidae), Polypterus (F. Polypteridae) usf. in verschiedenen Regionen des Deckschädels die Mosaikfelderung erhalten. Bei Acipenser (Fig. 14) ist dies der Fall in der Schnauzenregion, bei Mesturus (Fig. 15) in der Wangen- und Kehlregion, bei Macropoma (Fig. 16) in der Region zwischen Nasenloch, Oberkiefer, Augenhöhle und Schädeldach, bei Lepidosteus (Fig. 17) in der Oberkieferregion und im Praeopercularfelde, bei Polypterus zwischen Augenhöhle und Hinterhaupt (Fig. 18). Man hat sich in diesen und in analogen Fällen damit aus der Schlinge zu ziehen versucht, daß man eine sekundäre Teilung angenommen hat. Gegen eine derartige Annahme spricht aber ganz entschieden der Unistand, daß es sich in allen diesen Fällen durchwegs um primitivere Typen des Teleostomenstammes liandelt, welche wohl zweifellos die Mosaikfelderung dieser Schädelpartien von ihren Vorfahren übernommen haben. Die „Circumorbitalia“, „Supratemporalia" usf. sind z. B. derartige Erbstücke aus alter Zeit.

In einzelnen Fällen ist jedoch sekundär eine Vermehrung der Deckknochen im Schädeldache phylogenetisch jüngerer Teleostomen nachzuweisen. Derartige Beispiele bieten uns einzelne Welse, deren Deckschädel namentlich in der Wangen- und Augenregion sowie in der Kieferregion eine weitgehende Rückbildung der Deckknochen, in der Mitte des Schädeldaches aber eine weitgehende Verschmelzung der einzelnen Plattenpaare aufweist, so daß z. B. die „Parietalia“ nicht mehr als selbständige Knochen entwickelt sind. Bei Synodontis (Fig. 19) schließen sich nun an das „Supraoccipitale“, das sonst bei den jüngeren Actinopterygiern, und zwar allein bei diesen, unter den Fischen den hinteren Abschluß des Schädeldaches zu bilden pflegt, bei den älteren Actinopterygiern aber noch fehlt, mehrere sekundäre Hautknochen an, die eine Verlängerung des Schädeldaches über die vordersten Wirbel bilden. Hier liegt also zweifellos eine sekundäre Vermehrung der Deckknochen des Schädels vor, die aber mit der primären Vielzahl der Deckknochen bei primitiven Teleostomen nicht verwechselt werden darf.

Diese Erwägung droht allerdings, den vergleichenden osteologischen Untersuchungen über die Ableitung des Tetrapodenschädels vom Teleostomenschädel den Boden zu untergraben. Wenn wir uns darüber klar geworden sind, daß̣ der Ausgangspunkt für den Teleostomenschädel 
mit zahlreichen Deckknochen in einem Typus zu suchen ist, der eine aus noch zahlreicheren Mosaikschildern bestehende Schädelkapsel besaß und daß aus diesem Typus einerseits das große Heer der Teleostomen und anderseits die Tetrapoden hervorgegangen sind, so werden wir darauf verzichten müssen, in allen Einzelheiten Homologien zwischen den verschiedenen Knochen des Teleostomen- und des Tetrapodenschädels aufsuchen zu wollen. Viele dieser Knochen scheinen ja homolog zu sein, wie die Nasalia, Frontalia, Parietalia usw., aber wir sehen schon innerhalb des Teleostomenstammes der Dipneusten, daß die Deckplatten des Schädeldaches bei den einzelnen Gattungen aus dem Devon und Karbon nur zum Teile auf gleichen, zum anderen Teile aber auf ungleichen Wegen entstanden sind; so bilden Phaneropleuron und Scaumenacia die eine, Dipterus und Ctenodus eine zweite Entwicklungslinie innerhalb der Fanilie der Ctenodontiden (Fig. 7), wobei der Fortschritt in der Verschmelzung der Deckknochen des Schädels bei Ctenodus (Karbon) im Vergleiche zu Dipterus (Devon) sehr deutlich ist. Aber auch der leiseste Versuch einer Homologisierung der Schädelknochen z. B. bei Phaneropleuron einerseits und Ctenodus anderseits stößt auf sehr große, fast unüberwindliche Sclıwierigkeiten.

Innerhalb der einzelnen Stämme ist es aber freilich meist sehr gut möglich, Schritt für Schritt die Veränderungen der einzelnen Schäde Idachelemente, ihre Größenzunahme oder Größenabnahme, ihre Verschmelzung oder Teilung, Orimente und Rudimente zu unterscheiden. Über die Homologie der Deckschädelelemente bei den Amphibien, Reptilien, Vögeln und Säugetieren können nur in Einzelheiten ${ }^{1}$ Meinungsverschiedenleiten bestehen, in den Hauptfragen der Homologisierung dagegen nicht. Nur die Homologisierung der Knochen des Teleostomenschädels mit denen der höheren Vertebraten ist aus den oben gegebenen Darlegungen einstweilen nicht möglich und eine identische Benennung von Knochen, deren Homologisierung nur in besclıänktem Ausmaße möglich ist, geradezu fehlerhaft und irreführend.

Es sollte daher für die meisten Deckknochen der Teleostomen eine selbständige Nomenklatur begründet werden, soweit nicht bereits ohnedies für einzelne Elemente eigene Bezeichnungen vorliegen. Un dies möglich zu machen, müßte

1 Gegenwärtig bestehen die wichtigsten Meinungsdifferenzen in den Fragen nach der Homologie folgender Knochen bei den höheren Vertebraten: Squanosum, Prosquamosum, Supratemporale; Praefrontale, Lacrymale, Adlacrymale; Vomer, Praevomer, Parasphenoid; Orbitosphenoid, Alisphenoid, Epipterygoid; Quadratum, Tympanicum, Malleus. Die wichtigste Literatur über diese Fragen aus den letzten Jahren vgl. bei W. K. Gregory: Critique of Recent Work on the Morphology of the Vertebrate Skull, Especially in Relation to the Origin of Mammals. Journal of Morphology, Vol. XXIV, 1913, p. 1. 


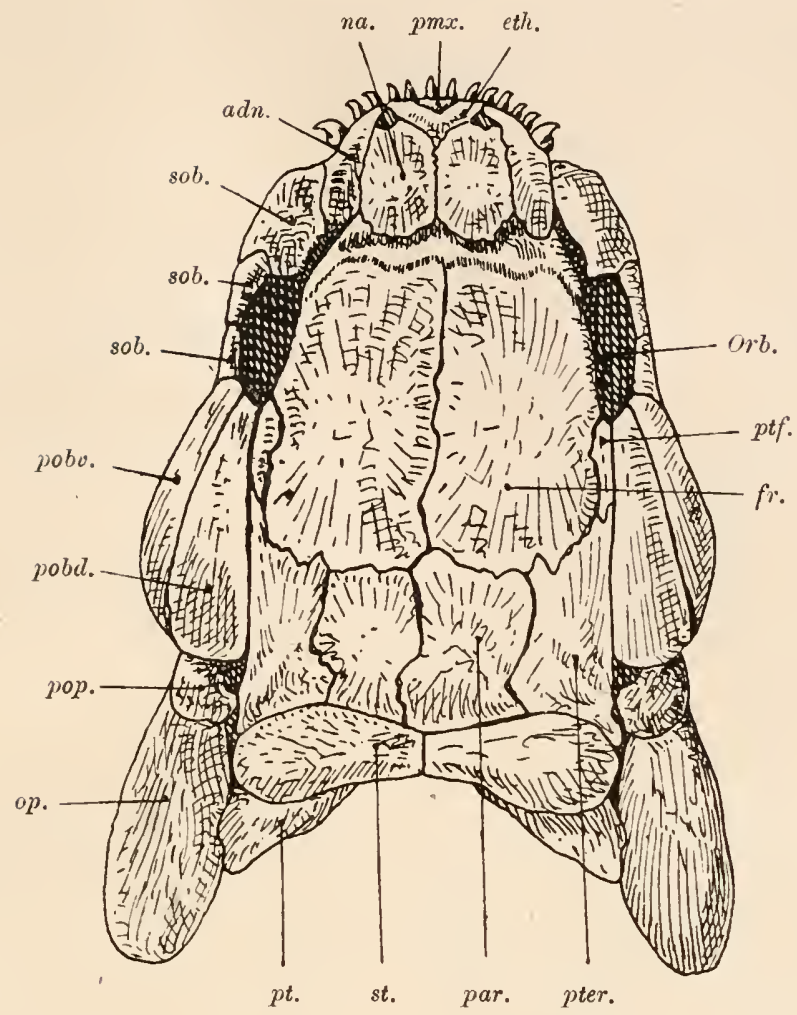

Fig. 9.

Schädelskelett von Amia calva, L., von der Oberseite. (Nach Allis aus Goodrich, unwesentlich abgeändert, teilweise die Bezeichnung der Knochen geändert.)

Erklärung der Abkürzungen (auch zu Figg. 10 und 11):
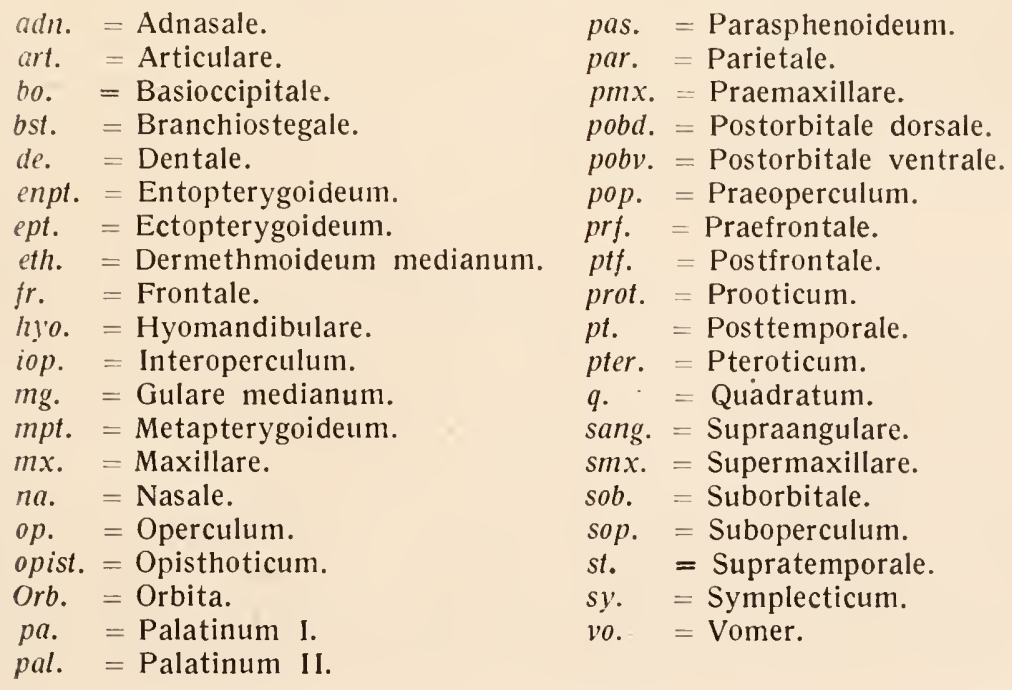
aber die vergleichende Osteologie des Teleostomenschädels von paläontologischer Grundlage aus in Angriff genommen werden, eine gewaltige Arbeit, welche die Kräfte zahlreicher Forscher in Anspruch nehmen und lange Zeit erfordern würde.

In den folgenden Darlegungen habe ich die bisher allgemein übliche Nomenklatur der Deckknochen des Teleostomenschädels einstweilen beibehalten, da das Hauptziel der Darstellung, die Verwandtschaftsverhältnisse der Fische

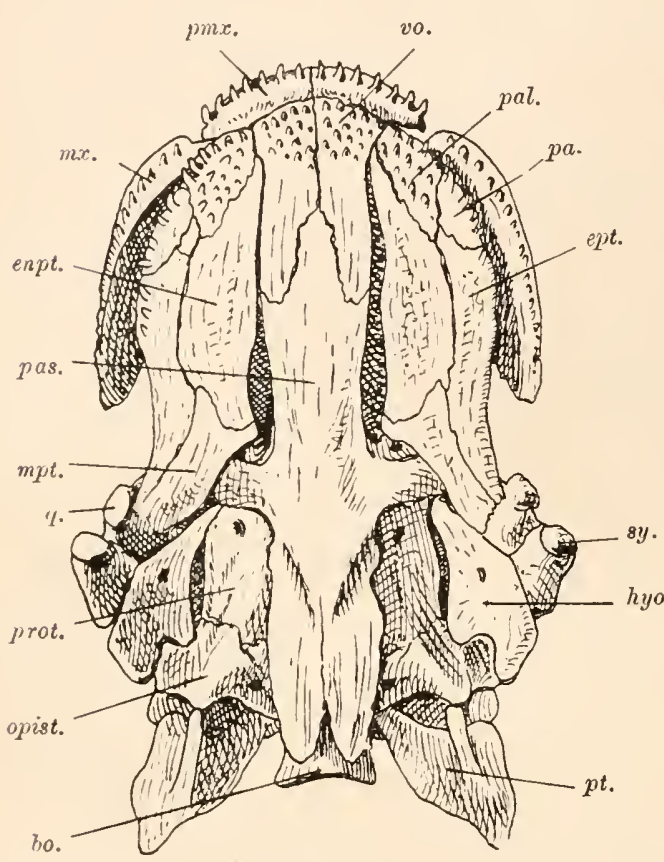

Fig. 10.

Schädelskelett von Amia calva, L., von der Unterseite. (Nach E. S. Goodrich.)

Erklärungen der Abkürzungen vgl. Fig. 9. einerseits und des höheren Vertebraten anderseits $z u$ erörtern, dadurch nicht berührt wird.

Die Knochen des Teleostomenschädels sind ihrer Entstehung nach entweder Ersatzknochen oder Hautknochen, aber es ist mitunter sehr schwierig, in einzelnen Fällen diese verschiedene Herkunft genau festzustellen. Schon einige Male ist beobachtet worden, daß ein Hautknochen in tiefere Lagen hinabsinken kann, dann mit dem Knorpelschädel in innige Verbindung tritt und schließlich als ein Knorpelknochen entwickelt wird. Dies ist z. B. der Fall mit dem Pteroticum (= ,Squamosum") der jüngeren Actinopterygier. Auch das Umgekehrte kann eintreten, daß ein Knorpelknochen zu einem Deckknoclien wird; dies ist nach den Untersuchungen von M. Sagemehl. (Morpholog. Jahrb., XVII, 1891, S. $556 \mathrm{ff}$.) beim Opisthoticum (- Intercalare) der Fall, das ursprünglich ein Knorpelknochen war und in dieser Ausbildung auch noch bei Amia auftritt, aber bei den meisten jüngeren Actinopterygiern nicht mehr mit dem Knorpel verbunden erscheint. Mitunter kommt es auch zu Verschmelzungen zweier heterogener, übereinanderliegender Knochen, wie dies mit dem Postfrontale (ursprünglich ein Deckknochen) und dem Sphenoticum (Knorpelknochen) der Fall ist; bei Amia sind beide Knochen 


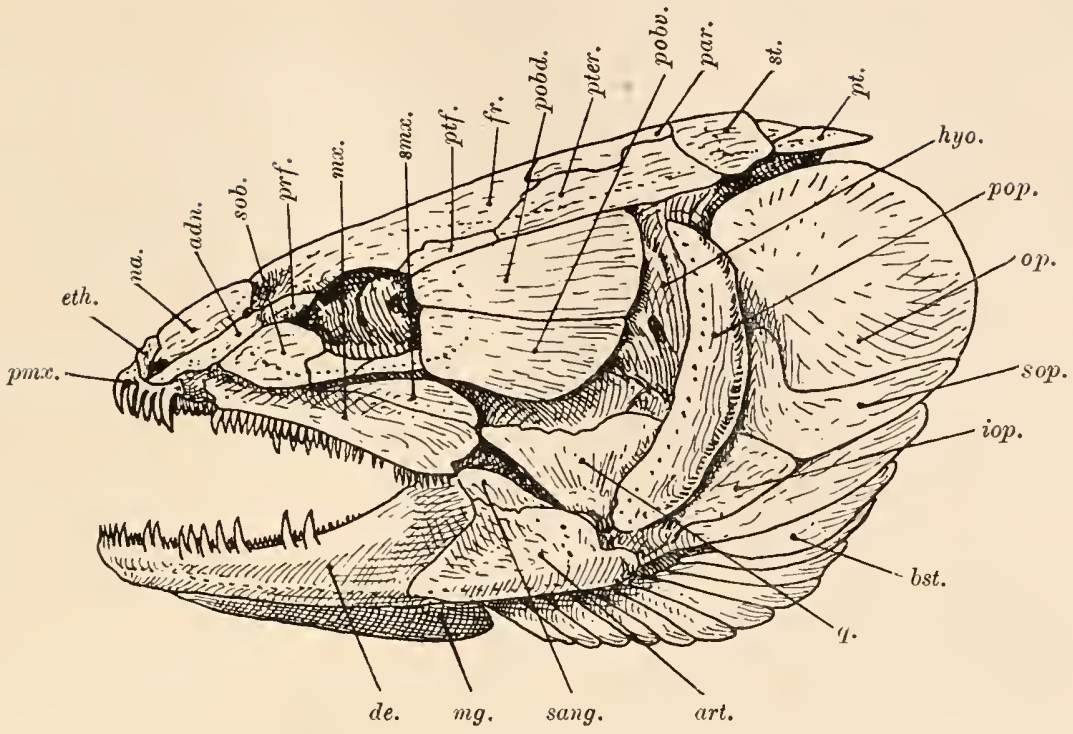

Fig. 11.

Schädelskelett von Amia calva, L., von der Seite gesehen. (Nach E. P. Allis aus E. S. Goodrich; Knochenbezeichnungen zum Teil abgeändert.)

Erklärung der Abkürzungen vgl. Fig. 9.
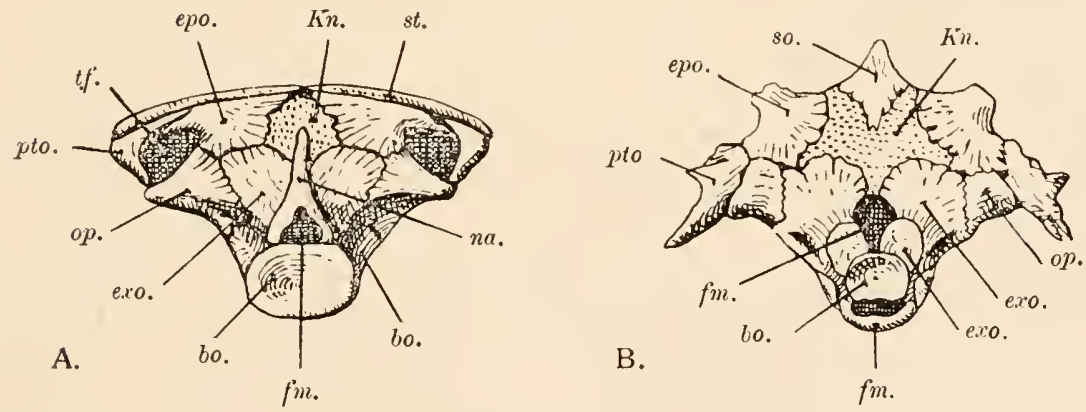

Fig. 12.

A. Hinterhaupt von Amia calva, L., Holozän. (Nach E. S. Goodrich.)

B. Hinterhaupt von Salmo salar, L., Holozän. (Nach C. Bruch.)

bo. $=$ Basioccipitale.

exo. = Exoccipitale.

epo. = Epioticum.

$f m$. = Foramen magnum.

$K n$. $=$ Knorpel des Hinterhauptes (Occipitalknorpel).

$n a .=$ Neurapophyse eines Wirbels, dessen Zentrum mit dem Basioccipitale verschmolzen ist. pa. = Parasphenoid; zwischen ihm und dem Basioccipitale der Augenmuskelkanal (Myodoma) sichtbar.

pto. = Pteroticum.

op. = Operculum.

so. = Supraoccipitale.

st. = Supratemporale.

$t f .=$ Temporalgrube. 
getrennt. ${ }^{1}$ Im Folgenden sollen die im Teleostomenschädel gewöhnlich unterschiedenen Knochen übersichtlich angeführt werden ${ }^{2}$ :

Basioccipitale (= Occipitale basilare), K. - Am Hinterende des Schädels die untere Grenze des Foramen magnum bildend; es unnschließt das Vorderende der Chorda. Seine Endfläche (Gelenkfläche) gegen den ersten freien Wirbel ist konkav und wie die Endfläche eines Wirbelkörpers gestaltet (z. B. Ania, Fig. 10 und $\left.12, b_{0}\right)$.

Exoccipitale (= Occipitale laterale), K. - Schließt seitlich an das Basioccipitale an und bildet die seitliche Begrenzung des Foramen magnum (z. B. Amia, Fig. 12 exo).

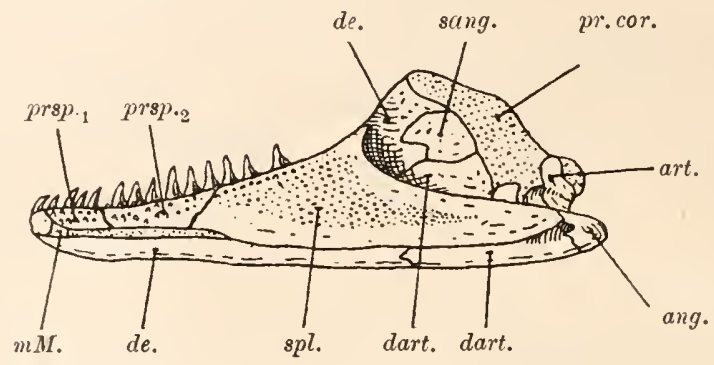

Fig. 13.

Unterkiefer von Amia calva, L.; Innenansicht des rechten Unterkieferastes. (Nach Allis, aus E. S. Goodrich; zum Teil abgeändert.)

ang. = Angulare.

art. $=$ Articulare.

dart. $=$ Dermarticulare.

de. $=$ Dentale.

$m M$. = Mentomandibulare pr. cor. $=$ Processus coronoideus.

prsp. $_{\cdot_{1}}=$ Praeoperculare anterius.

prsp.2 $_{2}=$ Praeoperculare posterius.

spl. $\quad \fallingdotseq$ Operculare.

sang. = Supraangulare.

Basisphenoideum, K. - Ursprünglich paarig, später unpaarig. Schließt vorne in der Mittellinie der Schädelbasis an das Basioccipitale nicht unmittelbar an, wie der gleich benannte Knochen der Tetrapoden, sondern ist von diesem durch das Prooticum getrennt (z. B. Salmo, Fig. 20, bsph.). Es fehlt häufig bei den jüngeren Actinopterygiern.

1 E. P. Allis, On Certain Homologies of the Squamosal, Intercalar, Exoccipital and Extrascapular Bones in Amia calva. Anatom. Anzeiger, XVI, 1899.

$\therefore \mathrm{K}=$ Knorpelknochen, $\mathrm{D}=$ Deckknochen. Mit Ausnahme weniger Knochen, wie z. B. Supraoccipitale, Postoccipitale, Basioccipitale, Mesethmoideum, Praeethmoideum, Dermethmoideum medianum und einiger medianer Platten in der Symphysenregion der Kiemenbögen sind alle Knochen des Teleostomenschädels paarig ausgebildet, die vorstehend genannten dagegen unpaarig. Die Vomeres, ursprünglich paarig, verschmelzen bei den phylogenetisch juingeren Actinopterygiern zu einem umpaarigen, medianen Knochen (Vomer). 
Parasphenoide $\mathbf{m}$, D. - Liegt über dem Basioccipitale und Basisphenoid und reicht nach vorne bis zu den Vomeres (z. B. Amia, Fig. 10, pas, Salno, Fig. 20, pas).

Vomer, D. - Stößt hinten an das Parasphenoid, vorne an das Praemaxillare. Mitunter bezahnt (z. B. Amia, Fig. 10, vo, Salmo, Fig. 20, vo).

Metapterygoideum, K. - Grenzt auf der Gaumenseite des Schädels vorne an das Entopterygoid und seitlich außen an das Ectopterygoid; hinten stößt es an das Quadratum und Hyomandibulare an (z. B. Amia, Fig. 10, mpt; Gadus, Fig. 21, Mp).

Entopterygoideum (= Mesopterygoideum), D. - Zwischen Palatinum, Ectopterygoid und Metapterygoid gelegen. Mitunter bezahnt; bei Amia zahnlos (Fig. 10, enpt).

Ectopterygoideum (= Pterygoideum), D. - Vorne an das Palatinum, innen an das Entopterygoid und Metapterygoid grenzend (z. B. Amia, Fig. 10, $e p t)$.

Palatinum (= Chondropalatinum, K). - Entsteht aus dem vorderen Abschnitt des endochondralen Palatoquadratum und ist zuweilen deutlich vom zahntragenden Dermopalatinum getrennt (z. B. Amia, Fig. 10, pal, pa).

Palatinum (= Dermopalatinum, D). - Zahntragender Haut-

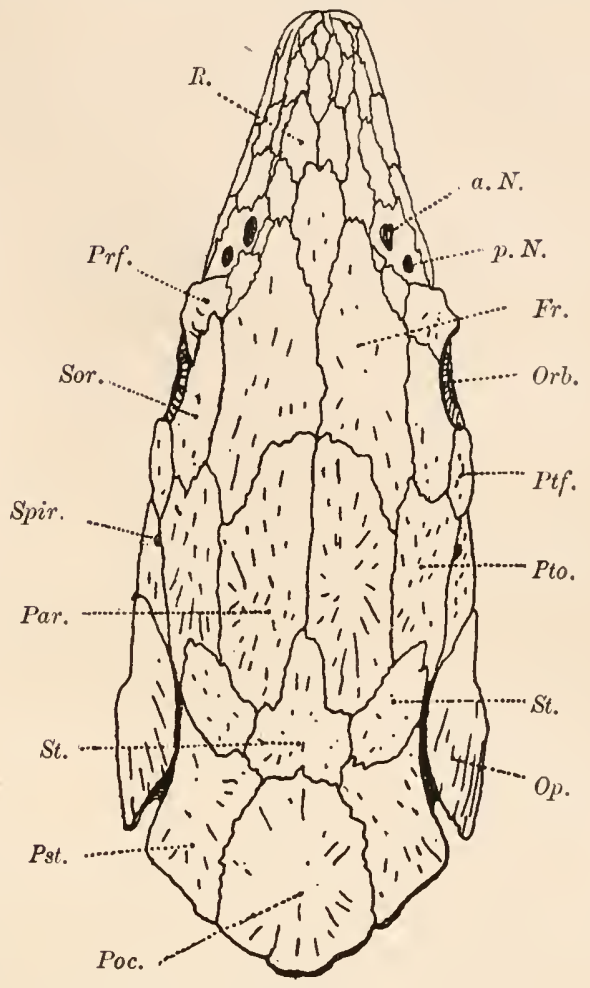

Fig. 14.

Schädeldach von Acipenser sturio, L., von oben gesehen. Die zahlreichen Plättchen der Rostralregion sind ebensowenig als Neuerwerbungen zu betrachten wie die zahlreichen Supratemporalia und Posttemporalia (Pst. u. Poc.). (Nach E. S. Goodrich.)

$$
\begin{aligned}
& \text { a. } . \text { = vordere Nasenöffnung. } \\
& \text { p. } . \text {. }=\text { hintere Nasenöffnung. } \\
& \text { Fr. }=\text { Frontale. } \\
& \text { Op. }=\text { Operculum. } \\
& \text { Par. }=\text { Parietale. } \\
& \text { Poc. }=\text { Postoccipitale }(=\text { medianes } \\
& \text { Prf. }=\text { Prasttemporale }) \\
& \text { Pst. }=\text { Posttemparale. } \\
& \text { Pto. }=\text { Pteroticum. } \\
& \text { R. }=\text { Rostralia. } \\
& \text { Sor. }=\text { Supraorbitale. } \\
& \text { Spir. }=\text { Spiraculare. } \\
& \text { St. }=\text { Supratemporale. }
\end{aligned}
$$

knochen; er kann einfach ausgebildet sein, aber zuweilen sind an seiner Stelle zwei, sogar drei Knochen vorhanden (ob die 


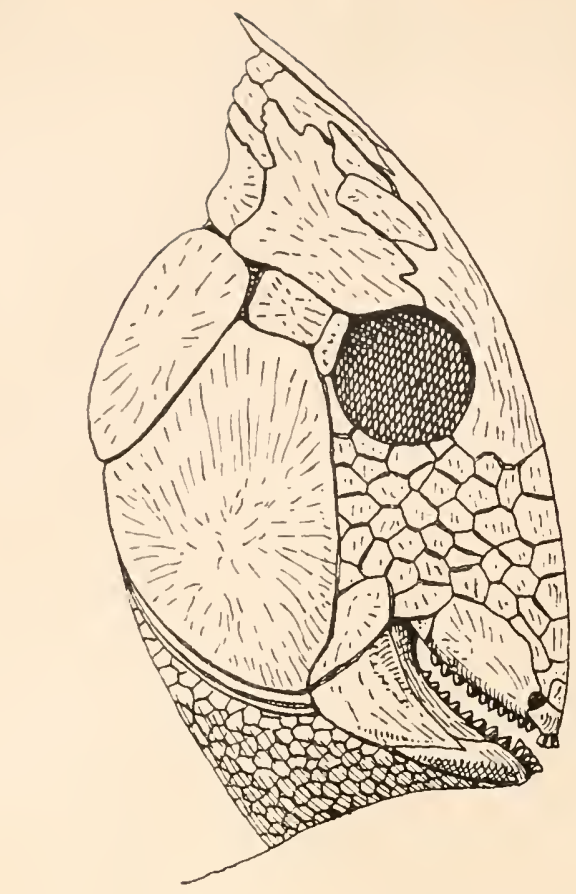

Fig. 15.

Rekonstruktion des Sçädels von Mesturus Leedsi, A. S. Woodward, aus dem oberen Jura (Oxford-Ton) von Peterborough in England, etwa $1 / 2$ nat. Größe. - (Nach A. Smith Woodward.)

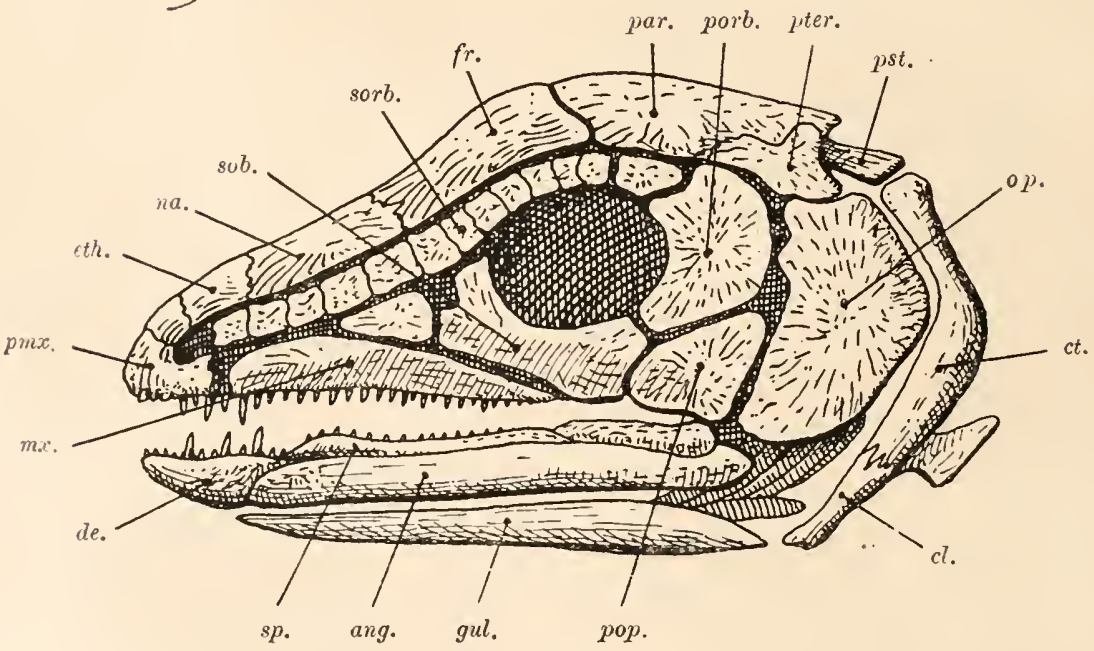

Fig. 16.

Rekonstruktion des Schädels von Macropoma Mantelli, Ag., aus der oberen Kreide Englands. (Nach E. S. Goodrich.)

ang. Angulare.

ct. $=$ Cleithrum.

cl. Clavicula.

de. Dentale.

eth. Ethmoideum.

fr. Frontale.

gul. Gulare laterale.

$m x$. Maxillare.

na. Nasale.

op. Operculum. pmx. = Praemaxillare.

pop. = Praeoperculum.

par. $=$ Parietale.

porb. = Postorbitale.

pst. $=$ Posttemporale.

pter. $=$ Pteroticum.

sob. $=$ Suborbitale.

$s o r b .=$ Supraorbitalplattenreihe.

$s p$. = Operculare. 
Mehrzahl primär oder sekundär, unsicher) (z. B. Amia, Fig. 10, $p a, p a l)$.

Alisphenoideum, K. - Tritt in der Regel hinten mit dem Prooticum und Sphenoticum, vorne mit dem Orbitosphenoid in Verbindung (z. B. Salmo, Fig. 20, as).

Fig. 17.

Schädel von Lepidosteus viridis, Gm., von der Seite gesehen. (Nach A. Smith Wood ward, abgeändert von E. S. Goodrich, 1909.)
An. = Adnasale.
Ang. = Angulare (Dermarticulare ?).
De. $\quad=$ Dentale.
En. $=$ Ethmonasale. $\left.{ }^{*}\right)$
E. $\quad=$ Ethmoideum.
Es. $=$ Extrascapulare.
Fr. $=$ Frontale.
Iop. = Interoperculum.
m. $\quad=$ Reihe der Máxillaria.
$N a . \quad=$ Nasale.
N. = Nasenöffnung.
Op. $=$ Operculum.
Orb. = Orbita.
Par. $=$ Parietale.
Pof. $=$ Postfrontale.
$P m x_{0}=$ Praemaxillare.
Po. $=$ Mosaikplatten der Praeoper- cularregion.
Pop. = Praeoperculum.
Porb. = Postorbitale.
Pter. = Pteroticum.
Sang. = Supraangulare.
Sorb. $=$ Suborbitale.
$S p b .=$ Supraorbitale.
Sop. = Suboperculum.
$S t_{1}=$ Supratemporale laterale.
$S t_{2} \quad=$ Supratemporale medianum.

*) Aus der Verschmelzung des Nasale mit einem Ethmoidalknochen entstanden.

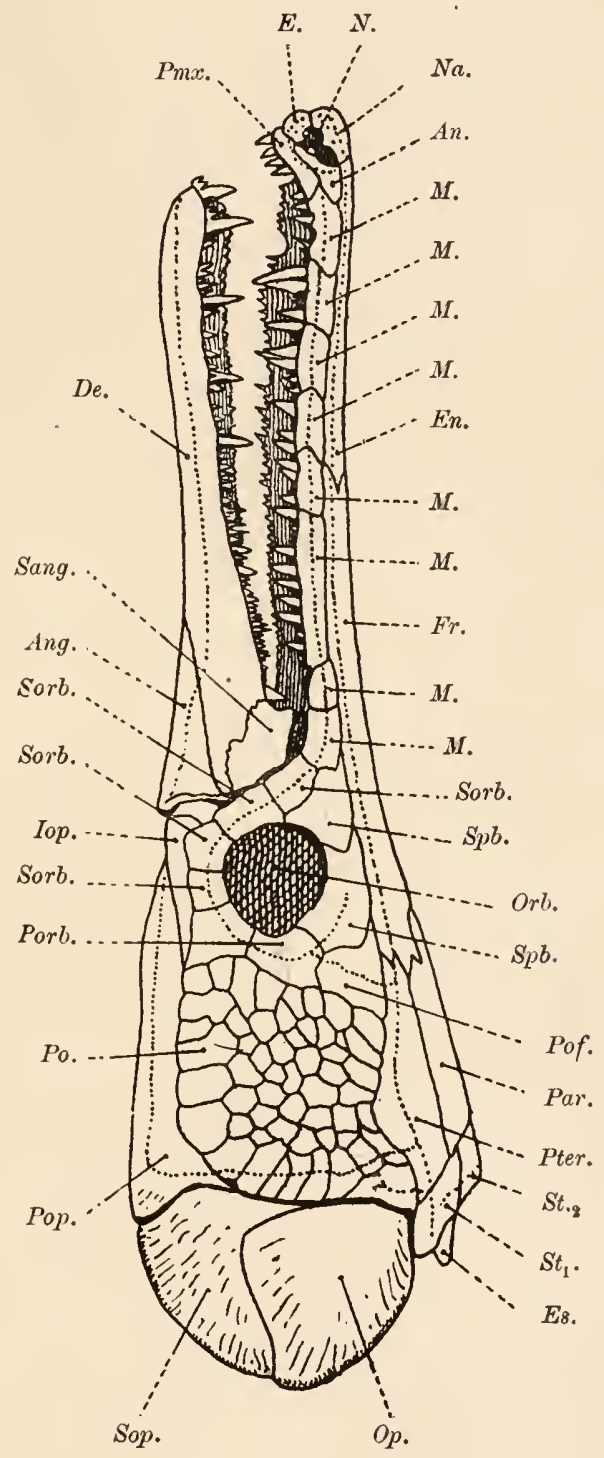

Orbitosphenoideum, K. - Liegt vor dem Alisphenoid und wird von einem großen Nervenloch durchbohrt (z. B. Salmo, Fig. 20, os). Prooticum (= Petrosum), K. - Liegt im vorderen Abschnitt der Gehörkapsel (z. B. Amia, Fig. 10, prot). 
Epioticum (= Occipitale externum), K. - Liegt an der oberen und inneren Seite der Gehörkapsel und tritt z. B. bei Amia mit dem Opisthoticum, Exoccipitale und Pteroticum in Grenzverbindung (z. B. Amia, Fig. 12, A, epo).

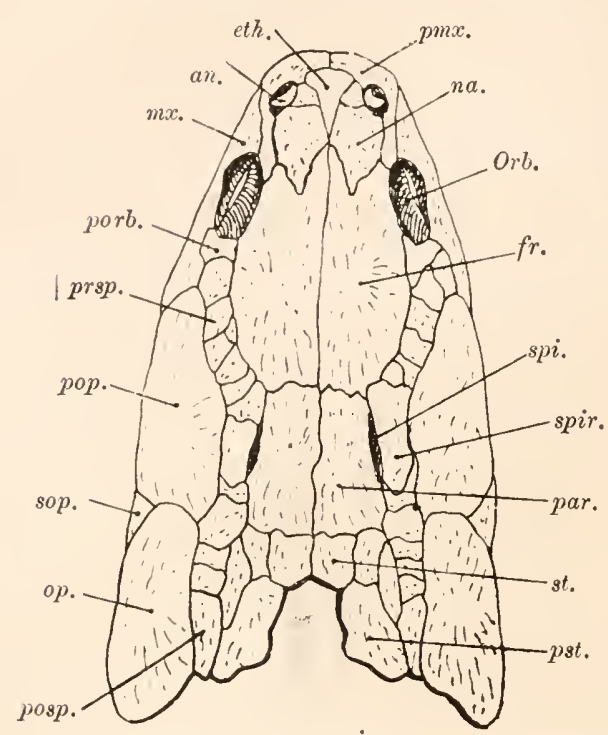

Fig. 18.

Schädeldach von Polypterus bichir, Geoff., von oben gesehen. (Nach J. Mïller, E. P. Allis und E. S. Goodrich.) Deutung der Knochen zum Teil abgeändert.

$\begin{array}{ll}\text { an. } & =\text { Adnasale. } \\ \text { eth. } & =\text { Ethmoideum. } \\ \text { fr. } & =\text { Frontale. } \\ m x . & =\text { Maxillare. } \\ \text { op. } & =\text { Operculum. } \\ \text { Orb. } & \text { Orbita. } \\ \text { par. } & \text { Parietale. } \\ \text { pmix. } & \text { Praemaxillare. } \\ \text { pop. } & \text { Praeoperculum. } \\ \text { porb. } & \text { Postorbitale. } \\ \text { posp. } & \text { Postspiracularia. } \\ \text { prsp. } & \text { Praespiracularia. } \\ \text { pst. } & \text { Posttemporale. } \\ \text { sop. } & \text { Suboperculum. } \\ \text { spi. } & \text { Spiraculum. } \\ \text { spir. } & \text { Spiraculare. } \\ \text { sl. } & \text { Supratemporale. }\end{array}$

Opisthoticum (= Intercalare), K. - Liegt hinter dem Prooticum und unter dem Pteroticum (z. B. Amia, Fig. 10, opist.).

Pteroticum (= Squamosum), K+D. - Zieht sich aus der Gehörregion auf die Oberseite des Schädeldaches hinauf, wo es mit dem Frontale, Parietale und Supratemporale in Grenzverbindung tritt (z. B. Amia, Fig. 10, pter; Fig. 12, A, pto). Sphenoticum (= dem basalen Abschnitt des ,Postfrontale" der Teleostomen, von diesem aber in einzelnen Fällen deutlich getrennt), K. - Liegt unter den Postfrontale (D) und vor dem Prooticum (z. B. Salmo, Fig. 22, 4).

Supraoccipitale $(=$ Occipitale superius), K. - Nur bei jüngeren Teleostomen ausgebildet, wo es als unpaariger Knochen den hinteren Abschluß des Schädeldaches bildet (z. B. Cyprinus, Fig.23, soc.).

Posttemporale, D. - Liegt als paariger Knoclien hinter dem Supratemporale an der hinteren Lateralecke des Schädeldaches (z. B. Anıia, Fig.9, 10, 11,pt). Supraten porale (= Extrascapulare), D. - Bei primitiveren Formen (z. B. Rhizodopsis, Polypterus) sind beiderseits mehrere S. vorhanden, mitunter aucl in der Mittellinie; einfach (z. B. bei Ania, Fig. 9, st). 
Postoccipitale (=medianes Supratemporale), D. - Medianer, unpaariger Knochen, der beim Stör hinter dem mittleren Supratemporale liegt und vielleicht mit einem primitiven, medianen Posttemporale identisch ist (Fig. 14, Poc).

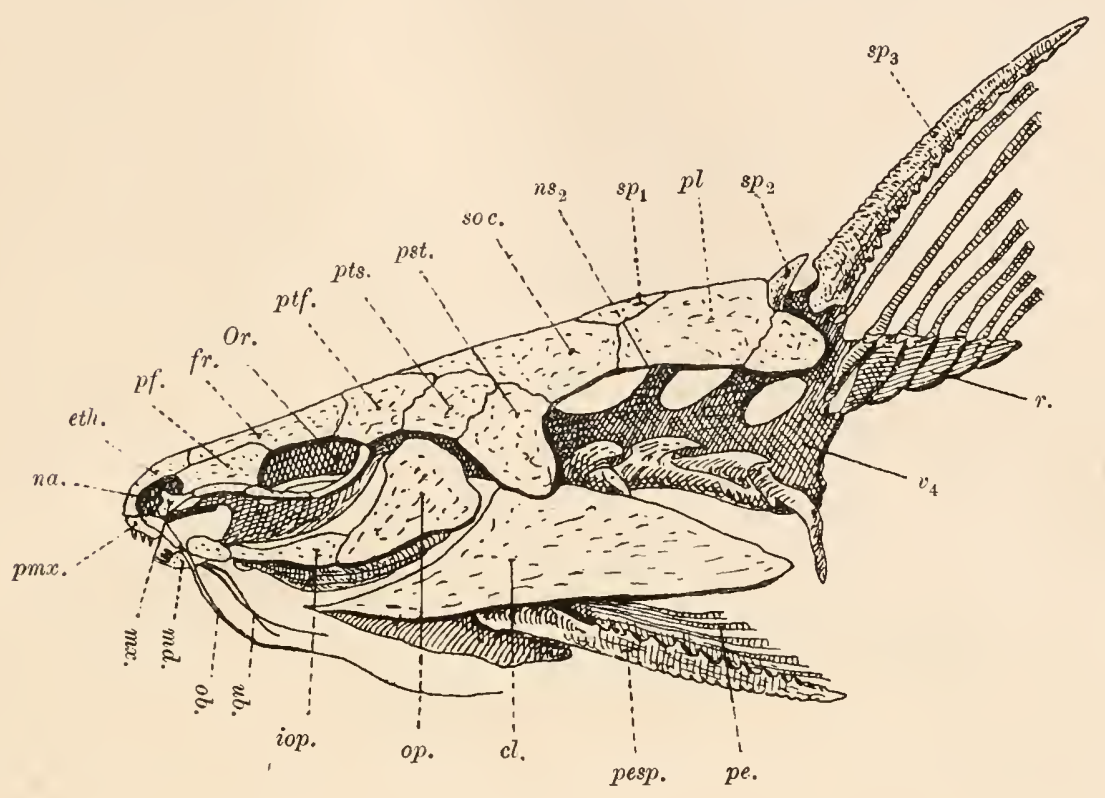

Fig. 19.

Synodontis schal, Schn. - Schädelskelett von der Seite gesehen. (Nach C. B. Br ühl, abgeändert von E. S. Goodrich.) - Die Kieferknochen sind stark reduziert, getrennte „Parietalia“ fehlen (wahrscheinlich mit dem Supraoccipitale verschmolzen), an das Schädeldach schließen sich mehrere neue Deckknochen ain, welche die vorderen Wirbel überdecken und sogar den ersten Dorsalstachel (?), $s p_{1}$, umschließen.

cl. $=$ Cleithrum.

eth. $=$ Mesethmoid.

fr. $=$ Frontale.

iop. = Interoperculum.

md. $=$ Mandibula.

$m x$. = Maxilla.

na. $\quad$ = Nasenöffnung.

$n s_{2} \quad=$ Neurapophyse des zweiten Wirbels.

$o b . \quad=$ Oberkieferbärtel.

op. = Operculum.

Or. = Orbita.

pesp. = erster Stachel der Pektoralflosse. pe. $=$ Pectoralis.

$p f . \quad=$ Praefrontale.

$p l . \quad=$ sekundärer Deckknochen .

pmx. = Praemaxillare.

ptf. $=$ Postfrontale

pts. = Pteroticum.

pst. $=$ Posttemporale .

$r . \quad=$ dorsale Radialia.

$s p_{1}, s p_{2}, s p_{3}=$ Stacheln der Dorsalis.

soc. = Supraoccipitale.

$u b . \quad=$ Mandibularbärtel.

$v_{4}=$ vierter $\mathrm{Wirbel}$, mit den vorderen "nbeweglich verbunden.

Parietale, D. - Meist getrennt vorhanden, aber mitunter (z. B. bei Siluridae) mit angrenzenden Knochen verschmolzen (z. B. Amia, Fig. 9, par).

Postfrontale, D. - Liegt über dem Sphenoticum, mit dem es in der 
Regel versclimilzt, grenzt bei Amia an das Frontale, Pteroticum und Postorbitale (Fig. 9, 11, ptf.).

Frontale, D. - Fast immer als getrennter, paariger Knochen entwickelt. Liegt auf dem Schädeldach zwischen den Augenhöhlen (z. B. Amia, Fig. 9, 11, fr).

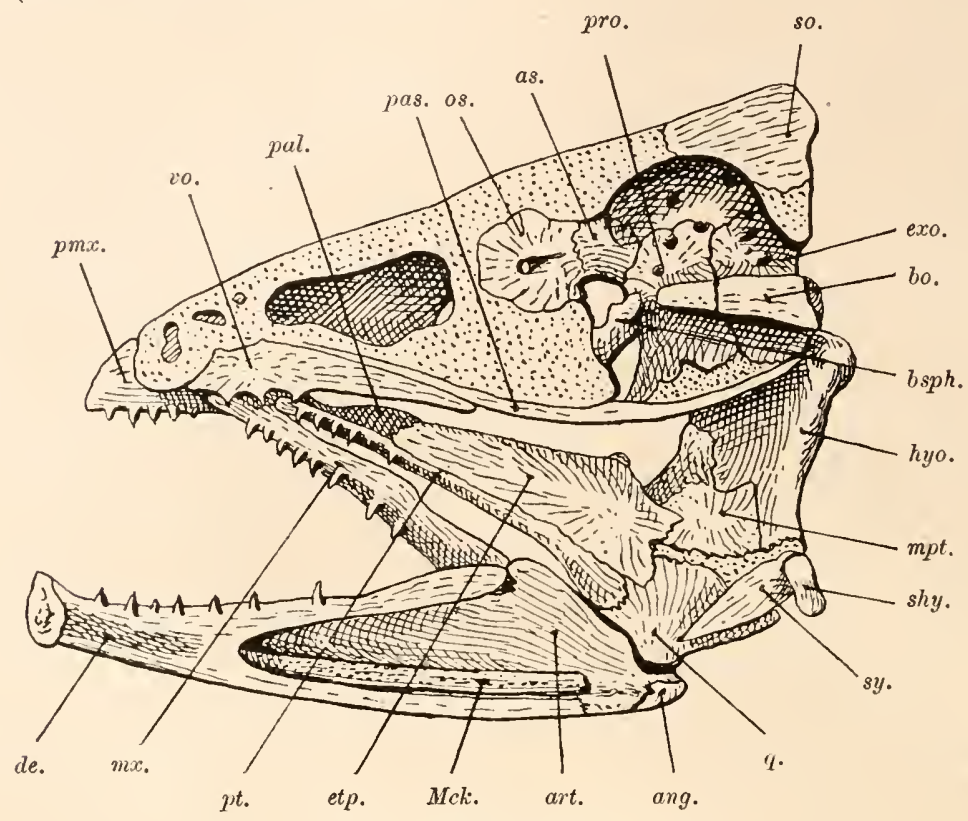

Fig. 20.

Schädel von Salmo salar, L. (Lachs), der Länge nach durchschnitten; Innenansicht der rechtsseitigen Schädelhälfte. (Nach C. Bruch, umgezeichnet.)

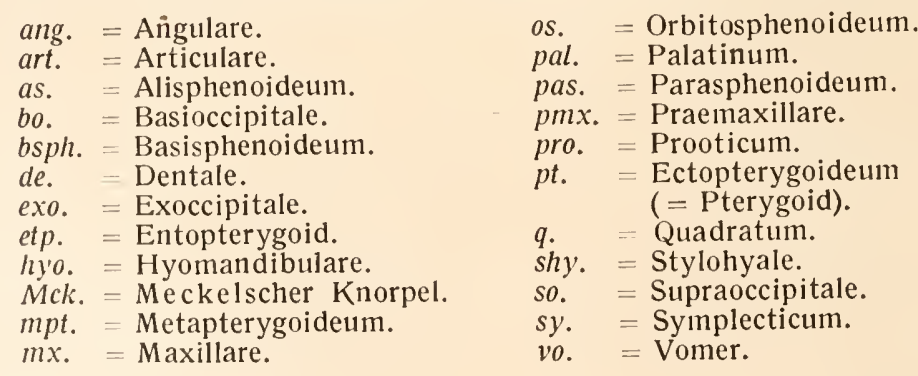

Praefrontale $(=$ Ectethmoideum $=$ Parethmoideum $=$ Ethmoideum laterale), D. - Bei Amia ein kleiner Knochen vor der Augenhöhle, zwisclien Frontale, Nasale, Adnasale und vorderstem Suborbitale (z. B. Amia, Fig. 11, prf).

Spiraculare, D. - Liegt als größter Knochen der Mosaikplattenreihe zwischen dem Parietale und Praeoperculum von Polypterus bichir (Fig. 18, spir.). 
Praespiracularia, D (nov. nom.). - Mit diesem Namen sind die kleinen knöchernen Mosaikplatten zu bezeichnen, die vor dem Spiraculare von Polypterus liegen (Fig. 18, prsp.).

Postspiracularia, D (nov. nom.). - Liegen hinter dem Spiraculare und reichen bis an den Hinterrand des Schädeldaches (Fig. 18, posp).

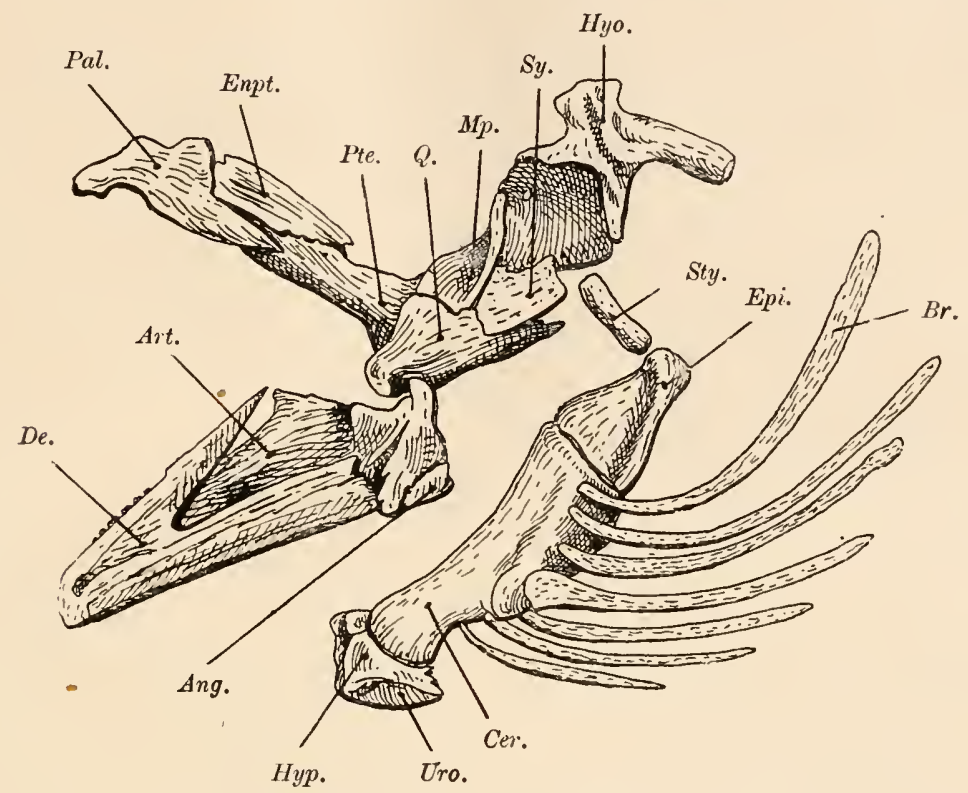

Fig. 21.

Unterkiefer und Hyoidbogen eines Dorsches (Gadus morrhua, L.), in $1 / 2$ nat. Gr.

(Nach S. H. Reynolds, Deutungen der Knochen zum Teil abgeändert.)

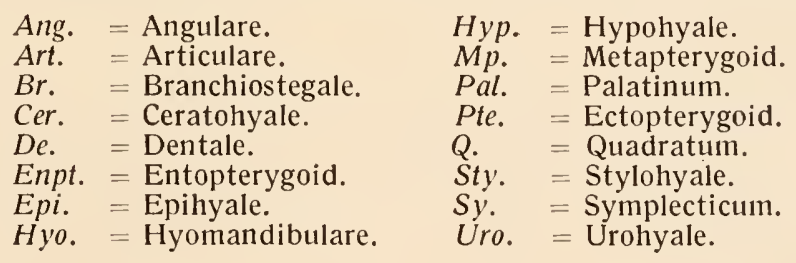

Postorbitale, D. - Entweder treten hinter dem die Augenhöhle unmittelbar anschließenden Ring kleiner Knochenplättchen (Circumlorbitalia oder Suborbitalia oder Supraorbitalia) viele Postorbitalia (z. B. Gadus, Fig. 24, pob) oder nur wenige (z. B. Lepidosteus, Fig. 17, Porb.) oder nur eines auf (z. B. Macropoma, Fig. 16, porb). Circumorbitalia, D. - Unter dieser Bezeichnung werden alle Mosaikplatten des inneren Augenringes zusammengefaßt. Mitunter unterscheidet man aber auch

Suborbitalia, D, als die vor und unter der Orbita liegenden und als 
Supraorbitalia, D, die über der Orbita liegenden kleineren oder größeren Knochenplättchen, während die vor der Orbita gelegenen Plättchen zuweilen auch als

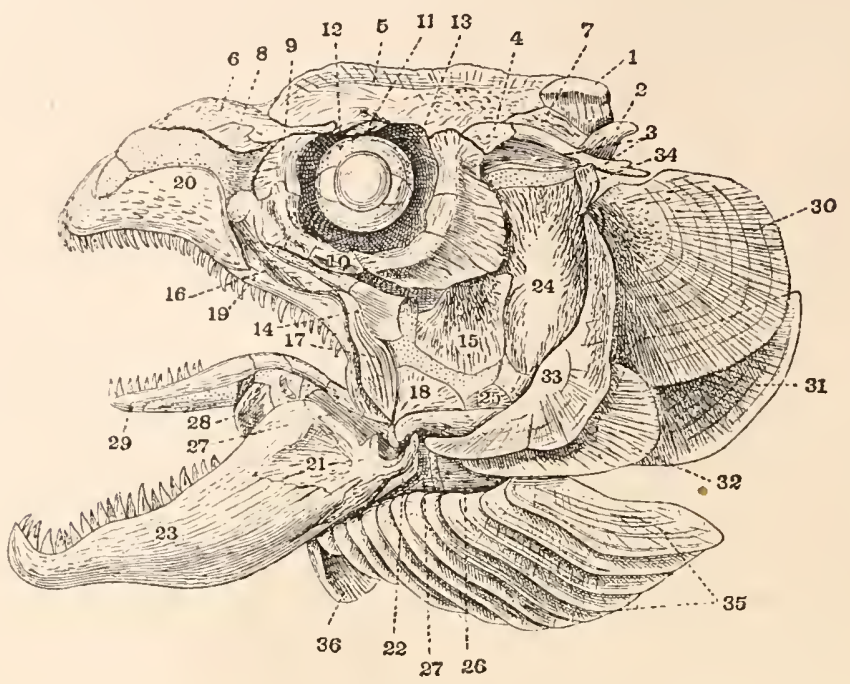

Fig. 22.

Seitenansicht des Schädels von Salmo salar. (Nach W. K. Parker.)

I. Supraoccipitale.

2. Epioticum.

3. Pteroticum.

4. Sphenoticum.

5. Frontale.

6. Dermethmoideum medianum.

7. Parietale.

8. Nasale.

9. Suborbitale.

IO. Suborbitale.

II. Supraorbitale.

I2. Knorpeliger Sclerotikalring.

I3. Verknöcherung im Sklerotikalring.

I4. Entopterygoideum.

I5. Metapterygoideum.

I6. Palatinum.

I7. Supermaxillare.

I8. Quadratum.
I9. Maxillare.

20. Praemaxillare.

$2 I$. Articulare.

22. Angulare.

23. Dentale.

24. Hyomandibulare.

25. Symplecticum.

26. Epihyale.

27. Ceratohyale.

28. Hypohyale.

29. Glossohyale.

3o. Operculum.

3I. Suboperculum.

32. Interoperculum.

33. Praeoperculum.

34. Supratemporale.

35. Branchiostegalia.

36. Urohyale.

An torbitalia, D, unterschieden werden (vgl. Fig. 17, sorb; Fig. 11, sorb; Fig. $24, s b o.)^{1}$

Nasale, D. - Liegt als paariger Knochen vor den Frontalia und bildet die hintere Grenze der Nasenöffnung (z. B. Amia, Fig. 9, na).

1 Als ,Antorbitale" wäre auch jener Knochen zu bezeichnen, der von vielen Autoren fälschlich mit dem Lacrymale der Tetrapoden homologisiert wird; es käme ïbrigens nur das Adlacrymale in Betracht, da Lacrymale = Praefrontale ist. 
Adnasale, D. - Liegt außerhalb seitlich von Nasale und bildet die Außengrenze der Nasenöffnung (z. B. Amia, Fig. 9, adnz.).

Laterallinienknochen, D. - Kleine Hantknochenplättchen im Bereiche der Laterallinie, die oberhalb des Hyomandibulare verläuft (z. B. Gadus, Fig. 24, lo).

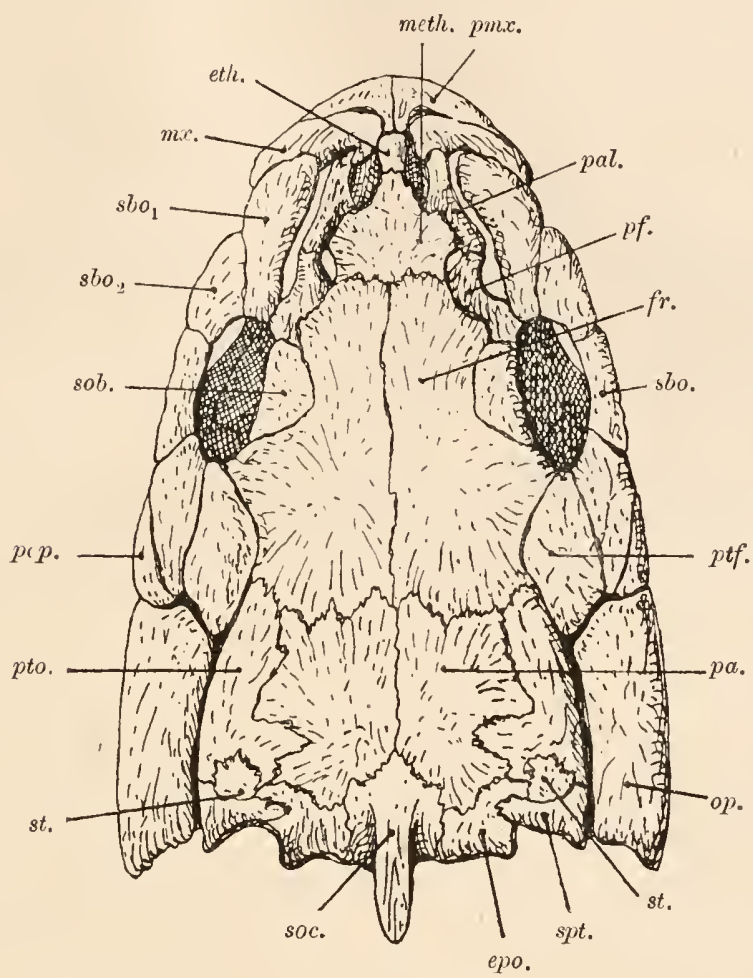

Fig. 23.

Schädeldach von Cyprinus carpio L., von oben gesehen. Deutung der Knochen nach E. S. Goodrich, 1909.

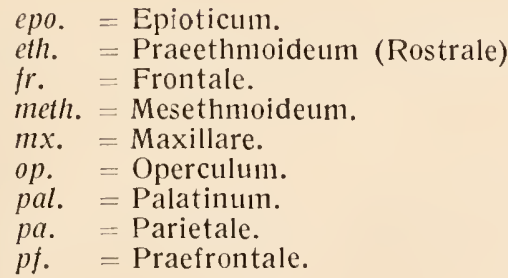
$p m x .=$ Praemaxillare
pop. = Praeoperculum.
pt $f .=$ Postfrontale.
pto. = Pteroticum.
$s b o_{1}, s b o_{2}=$ Suborbitalia.
sob. = Supraorbitale.
soc. $=$ Supraoccipitale
spt. $=$ Supratemporale
st. $=$ vorderes Supratemporale

Operculum, D. - Hauptknochen des (gewöhnlich) vier Knochenplatten umfassenden Kiemendeckel (Opercular-)Apparates und stets unter diesen zuhöchst gelegen (z. B. Ania, Fig. 11, op).

Suboperculum, D. - Liegt unter dem Operculum (z. B. Amia, Fig. 11, sop). 
Interoperculum (= Infraoperculum), D. - Liegt unter dem Suboperculum (z. B. bei Amia, Fig. 11, iop).

Praeoperculum, D. - Liegt vor den drei hinteren Opercularknochen (Operculum, Suboperculum, Interoperculum) und besitzt meist eine mondsichelförmige Gestalt (z. B. Amia, Fig. 11, pop).

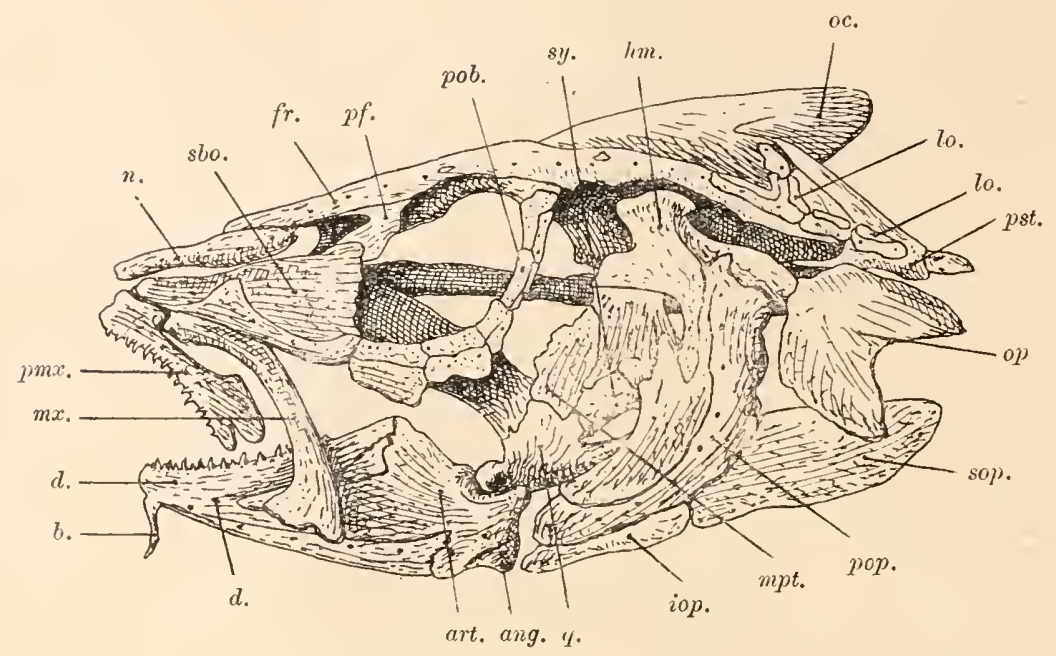

Fig. 24.

Schädel von Gadus morrhua L., der im Vergleiche mit dem von Amia (Fig. 11) eine beträchtliche Reduktion der Deckknochen in der Region hinter der Orbita zeigt und ferner durch die hochgradige Spezialisation der Kiefer auffällt. $\mathrm{Zu}$ beachten ist die Neubildung von kleinen Knochenplättchen im Bereiche der Seitenlinie (lo).

(Nach E. S. Goodrich, zum Teil nach F. J. Cole; unbedeutend abgeändert.)

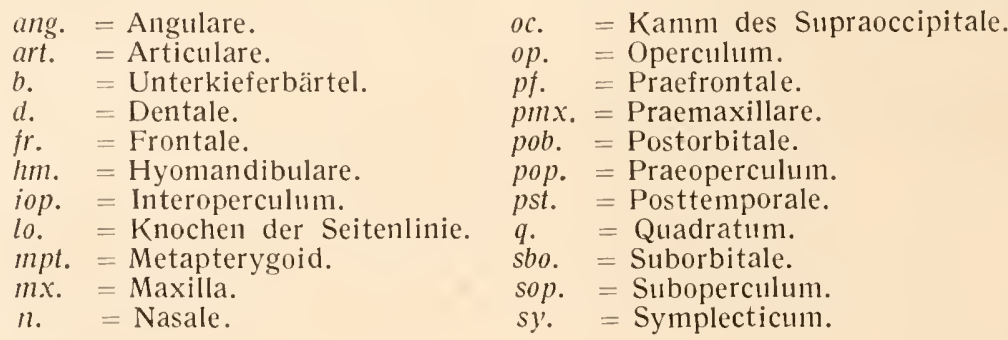

Supermaxillare ${ }^{1}$ (= Jugale), D. - Unter dieser Bezeiclnung wird mitunter ein über den Oberkieferknochen (Maxillare) liegender Hautknochen ausgeschieden. Von einer Homologie mit dem Supramaxillare oder Jugale der Tetrapoden kann wohl keine Rede sein (z. B. Amia, Fig. 11, smx; Salmo, Fig. 22, [17]).

1 Bisher meist Supramaxillare genannt und hier in Supermaxillare abgeändert, um jeden Irrtum auszuschließen. 
Maxillare, D. - Meist mit Zähnen besetzt. Walırscheinlich ident mit dem Supramaxillare der höheren Vertebraten (Tetrapoden). Es scheint, was nach den Verhältnissen bei Acipenser sturio (Fig. 14) und Lepidosteus (Fig. 17) zu schließen ist, aus der Verschmelzung einer größeren Zahl von kleinen Randplatten des Kiefers entstanden zu sein.

Praemaxillare, D. - Meist mit Zähnen besetzt. Bildet das Vorderende der Schnauze (z. B. Amia, Fig. 11, pmx).

Rostralia, D. - Kleine Mosaikplatten der Schnauzenregion (z. B. Acipenser, Fig. 14, R.).

Septomaxillare, D ? - Kleiner Knochen, der zuweilen in der Nasalkapsel auftritt (z. B. bei Amia). Vielleicht ist er in der Tat mit dem gleich benannten Knochen der höheren Vertebraten identisch. Mesethmoideum (= Ethmoideum medianum), K. - Mediane Verknöcherung des knorpeligen Primordialcraniums am Vorderende der Schädelbasis (z. B. Cyprinus, Fig. 23, meth.).

Dermethmoideum medianum, D. - Medianer Hautknochen über dem Mesethmoidalknorpel (z. B. Salmo, Fig. 22, [6]).

Praeethmoideum, D. - Das Vorderende der Ethmoidalregion ist in einigen Fällen mit einem kleinen, vor dem Mesethmoideum dermale gelegenen Knochen bedeckt; dieser Knochen ist nicht einem der Rostralia von Acipenser homolog, sondern eine sekundäre Neubildung (z. B. bei Cyprinus, Fig. 23, eth).

Hyomandibulare, K. - Einer der wichtigsten Knochen des Schädels. Tritt oben mit dem Knorpelcranium in (hyostyle) Verbindung ${ }^{1}$, vorne und unten grenzt es an das Metapterygoideum und Symplecticum und entsendet nach linten einen Fortsatz, der mit dem Operculum artikuliert (z. B. Gadus, Fig. 24, hm und 21, Hyo; Salıo, Fig. 20, hyo).

Symplecticum, K. - Zwischen Hyonandibulare und Quadratum gelegen (z. B. Gadus, .Fig. 24, sy und 21, Sy; Amia, Fig. 10, sy). ${ }^{2}$ Quadratum, K, - Bildet das Unterkiefergelenk und tritt mit dem Articulare in Verbindung (z. B. Gadus, Fig. 21, Q; Salmo, Fig. 20, q).

Articulare, K. - Verknöcherung des Hinterabschnittes des Meckelschen Knorpels; die Gelenkgrube gegen das Quadratum ist tief ausgehöhlt (z. B. Sain1o, Fig. 20, art; Gadus, Fig. 21, Art).

Angulare, D. - Liegt unter dem Articulare und bildet das hintere und untere Ende des Unterkiefers (z. B. Gadus, Fig. 21, Ang.; Salmo, Fig. 20, ang.; Amia, Fig. 13, ang).

1 Hauptsächlich mit dem Pteroticum, zum Teil auch mit dem Sphenoticum.

2 Fehlt bei Polypterus, den Welsen und Aalen. 
Dentale, D. - Der Hauptknochen des Unterkiefers, zahntragend (z. B. Amia, Fig. 13, de.; Gadus, Fig. 24, $d$; Salmo, Fig. 20, de).

C.

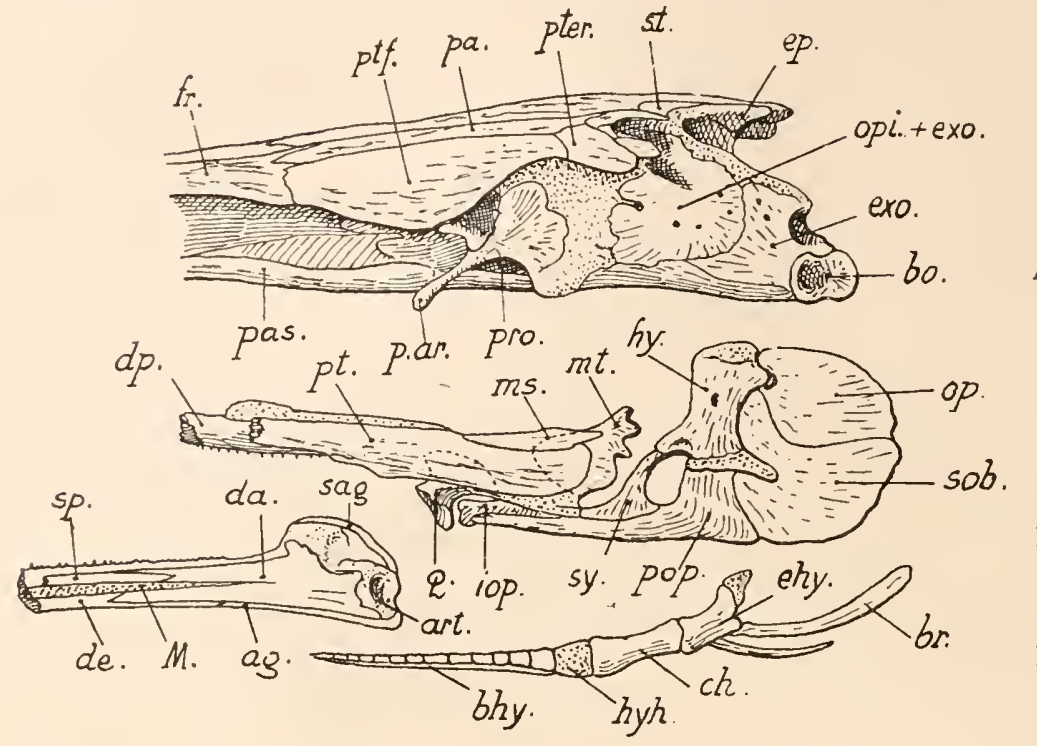

A.

B.

D.

Fig. 25. Lepidosteus osseus, L.

A. Schräge Seitenansicht des Hinterteiles des Schädels; B. Innenansicht des rechtsseitigen Opercularapparates und der an die Kiefer anschließenden Region, vorne abgebrochen; C. lmmenansicht des rechten Unterkiefers (Hinterende); D. Unterer Abschnitt des Hyoidbogens, zu B. gehörig. Knorpel punktiert. (Nach E. S. Goodrich, Deutung der Knochen zum Teil abgeändert.)

ag. = Angulare.

art. $=$ Articulare

bhy. = Basihyale.

bo. $=$ Basioccipitale.

$b r . \quad$ = Branchiostegale.

ch. $=$ Ceratohyale.

da. $=$ Postspleniale (?).

de. $=$ Dentale .

$d p . \quad=$ Dermopalatinum.

chy. = Epihyale .

ep. = Epioticum.

exo. = Exoccipitale (nach E. S. Goodrich Neurapophysen des vordersten Wirbels).

ir. $=$ Frontale .

hy. = Hyomandibulare .

$h y h$. = Hypohyale.

iop. = interoperculum.

M. = Meckelscher Knorpel.

ins. - Entopterygoid. mt. = Metapterygoid.

op. = Operculum.

opi. = Opisthoticum (nach E. S. Goodrich auch das Exoccipitale umfassend).

pa. $=$ Parietale .

p. ar. = Processus articularis für das Metapterygoid.

pas. $=$ Parasphenoid .

pop. $=$ Praeoperculum.

pro. $=$ Prooticum.

pt. = Ectopterygoid.

pter. = Pteroticum.

ptf. = Postfrontale.

$q . \quad=$ Quadratum.

sy. $\quad=$ Symplecticum.

sag. = Supraangulare.

sob. = Suboperculum.

sp. = Operculare.

st. $=$ Supratemporale.

Infradentale, D. - Unter dem Dentale liegen bei primitiven Teleostomen (z. B. bei den Crossopterygiern Rhizodopsis und Glyptolepis (Fig. 121) mlırere kleine Hautknochın. Bei den jüngeren Teleostomen sind sie verloren gegangen. 
Gulare laterale, D. - Bei primitiveren Teleostomen sind unterhalb der Infradentalia oder unmittelbar unter dem Dentale mehrere in einer Reihe stehende Kehlplatten (Jugularia) vorhanden. Das vorderste Element dieser Reihe pflegt vergrößert zu sein (z. B. bei Gonatodus, Fig. 27).
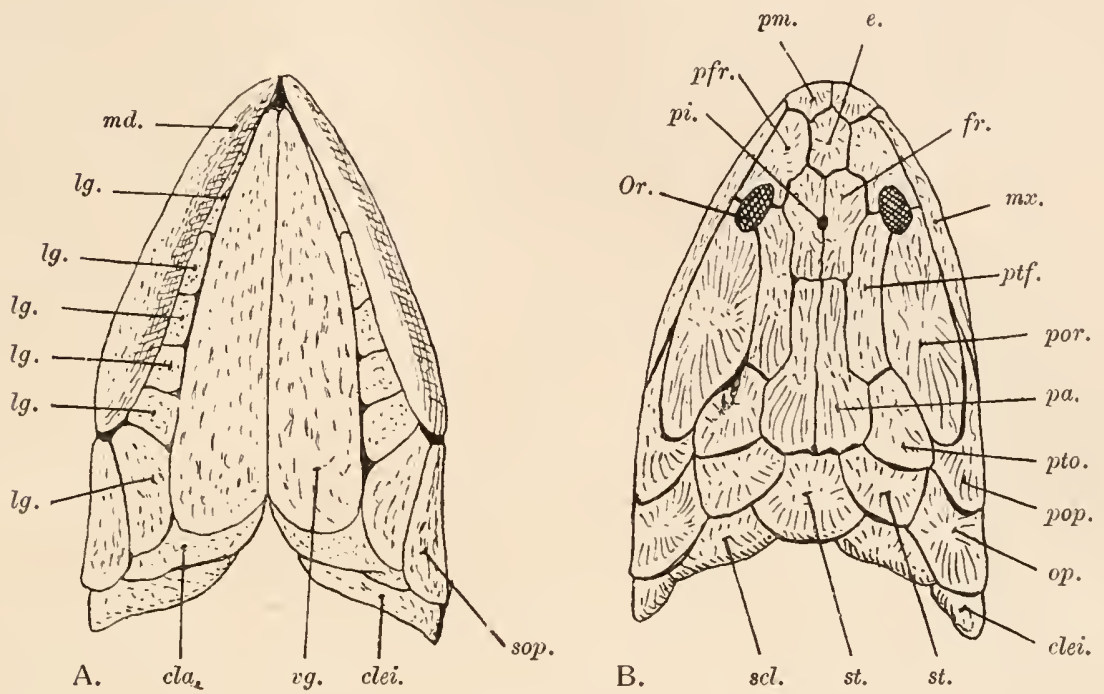

Fig. 26.

Schädel von Glyptopomus aus dem Old Red Sandstone Schottlands.

(Nach Th. H. Huxley, zum Teil abgeändert von E. S. Goodrich.)

A. Schädel von unten, B. Schädel von oben.

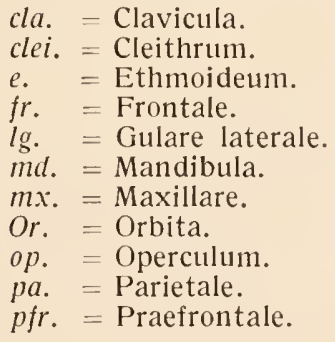

cla. = Clavicula.

cle . $_{\text {. }}$ Cleithrum.

fr. $=$ Frontale.

lg. $=$ Gulare laterale.

md. = Mandibula

op. $=$ Operculum

pfr. $=$ Praefrontale

$$
\begin{aligned}
& \text { pi. }=\text { Foramen pineale } \\
& \text { pm. } .=\text { Praemaxillare. } \\
& \text { pop. }=\text { Praeoperculum. } \\
& \text { por. }=\text { Postorbitale. } \\
& \text { ptf. }=\text { Postfrontale. } \\
& \text { pto. }=\text { Pteroticum. } \\
& \text { scl. }=\text { Supraclavicula. } \\
& \text { sop. }=\text { Suboperculum. } \\
& \text { st. } . \text { Supratemporale. } \\
& \text { vg. }=\text { Gulare ventrale. }
\end{aligned}
$$

Gulare medianum, D. - Unpaare Gularplatte, die das Verbindungsstück zwischen beiden lateralen Gularplattenreihen herstellt (z. B. Gonatodus, Fig. 27). Es ist noch vorhanden bei Amia (Fig. 11, mg), aber bei den jüngeren Actinopterygiern mit Ausnahme der Elopiden verloren gegangen. Es fehlt aber auch schon bei primitiveren Typen (z. B. bei Glyptopomus, Fig. 26).

Gulare ventrale, D. - Paarige Kehlplatten, die sich mitunter fast über die ganze Länge der Kehle erstrecken (z. B. Glyptopomus, Fig. 26, vg) und zwischen den Reihen der Gularia lateralia liegen. 
Mentomandibulare (= Mento-Meckelian Bone), K. - Verknöcherung des Vorderendes des Meckelschen Knorpels (z. B. Amia, Fig. 13, $m M$ ).

Operculare (= Spleniale), D. - Bezahnter Hautknochen auf der Innenseite des Unterkiefers. Bei primitiveren Teleostomen vorhanden; bei den älteren Actinopterygiern erhalten, z. B. bei Cheirodus, Polyodon, Amia, aber bei den phylogenetisch jüngeren Actinopterygiern verloren gegangen (Amia, Fig. 13, spl).

Praeoperculare anterius (nov. nom.), D. - Bezahnter Hautknochen auf der Innenseite des Unterkiefers. Nur bei primitiven Typen

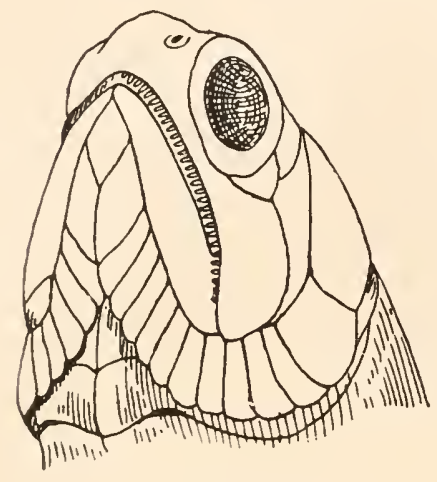

Fig. 27.

Unterseite des Schädels von Gonatodus punctatus, Ag., ein Palaeoniscide aus dem unteren Karbon von Wardie (Schottland). (Nach

R. H. Traquair, 1877.) vorhanden. Bildet das vorderste Element der Opercular(Splenial-) knochenreihe (z. B. Ania, Fig. 13, prsp. I).

Praeoperculare posterius, D (nov. nom.). - Bezahnter Hautknochen zwischen dem Praeoperculare anterius und dem Operculare (z. B. Amia, Fig. 13, prsp. 2).

Supraangulare, D. - Liegt auf der Außenseite zwischen Dentale und Articulare und auf der lnnenseite zwischen Dentale und Dermarticulare (z. B. Anila, Fig. 13, sang und 11, sang; Lepidosteus, Fig. 17, Sang). Bei den jüngeren Actinopterygiern fehlend.

Complementare (= Coronoideum), D. - Von verschiedenen Autoren wird das Vorhandensein dieses Knochens im Unterkiefer der Teleostomen angegeben, aber es ist fraglich, ob in diesen Fällen nicht eine Verwechslung mit dem Dermarticulare vorliegt.

Dermarticulare, D. - Dieser Knochen ist häufig mit den Articulare verwecliselt worden, ist aber ein von diesem unablängiger Hautknochen (seine Lage und Grenzen sind ersichtlich z. B. bei Amia, Fig. 13, dart; Lepidosteus, Fig. 17, Ang ?).

Praedentale (= Praesymphyseale), D. - Unpaarer, bezalnter Hautknochen an Vorderende des Unterkiefers von Aspidorhynchus (Fig. 166). Ähnliche (ob homologe?) Bildungen sind bei den Onychodontiden beobachtet worden. Die mediane Zahnreihe von Campodus scheint in morphologischer Hinsicht dem Praedentale der Onychodontiden und Aspidorhynchiden vergleichbar zu sein; in allen Fällen handelt es sich jedoch um sekundäre und 
nicht un prinäre Bildungen, die unabhängig voneinander entstanden sind.

Stylohyale (= Interhyale), K. - Das oberste Stück des Zungenbeinbogens (Hyoidbogens), das mit dem Symplccticum artikuliert (z. B. Salmo, Fig. 20, shy; Gadus, Fig. 21, Sty). ${ }^{1}$

Epiliyale, K. - Schließt unten an das Stylohyale an (z. B. Gadus, Fig. 21, Epi). ${ }^{2}$

Ceratohyale, K. - Schließt unten an das Epihyale an (z. B. Gadus, Fig. 21, Cer).

Hypohyale, K. - SchlieBt unten an das Ceratohyale an (z. B. Gadus, Fig. 21, Hypo).

Glossohyale (= Basihyale), K. - Die Hyoidbögen beider Körperhälften werden durch diesen median gelegenen, unpaaren, meist zahntragenden Knochen verbunden (z. B. Saln1o, Fig. 22 [29]). Urohyale (= Basibranchiostegale), K. - Zwischen den beiderseitigen Hypohyalia liegt eine mpaare dreieckige Platte, die nur bei den jüngeren Actinopterygiern beobachtet worden ist; wahrscheinlich sind jedoch die paarig entwickelten Knochen, die bei Polypterus an derselben Stelle liegen, dem Urohyale homolog (z. B. Salmo, Fig. 22 [36]; Gadus, Fig. 21, Uro).

Pharyngobranchiale, K. - Das oberste. Stück der Elemente (Branchiostegalia) je eines Kicmuluogens, in deı Regel nur bei den vordersten ausgebildet; ursprünglich auch an den hinteren vorhanden (z. B. Scyllium, Fig. 6 [15]). Die aus den vier vordersten Pharyngobranchialia verschmolzene, zahntragende Platte im Kiemenkorb von Gadus wird als Suprapharyngeale bezeichnet.

Epibranchiale, K. - Schließt sich als zweites Stück des Kiemenbogens unten an das Plaryngobranchiale an (vgl. Scyllium, Fig. 6 [16]).

Ceratobranchiale, K. - Schließt sich als drittes Stück des Kiemenbogens unten an das Epibrancliale an (vgl. Scyllium, Fig. 6 [17]). Hypobranchiale, K. - Schließt siclı in den vorderen Kiemenbögen als viertes Stück unten an das Ceratobranchiale an.

Basibranchiale (= Glossobranchiale), K. - Unpaares Verbindungsstück der bciderseitigen Hypobranchialia.

1 ,Since, however, the interhyal (stylohyal) probably corresponds to the epibranchial in the posterior arches, and should be called epihyal, it is possible that the ,epihyal" ossification below it does not represent an element found separate in the lower forms." (E. S. Goodrich, Fishes, I. c., 1909, p. 323.)

2 E. S. Goodrich (1. c., p. 272) identifiziert auch das Epihyale mit dem Interhyale (vgl. oben). 
Infrapharyngeale, K. - Unpaare, zahntragende Platte, zuweilen als obere Deckplatte des 4. und 5. Basibranchiale ausgebildet (z. B. bei Gadus).

Daß die Nomenklatur einzelner dieser Knochen des Teleostomenschädels sehr verschieden angewendet wird, wodurch manche Irrtümer entstehen müssen, und daß eine neue, gründliche Inangriffnahme der vergleichenden Osteologie des Teleostomenschädels eine dringende Notwendigkeit wäre, mag durch folgende Tabelle illustriert werden.

$\mathrm{Zu}$ den vorstehend angeführten Knochen treten in der Gruppe der Ostariophysi noch folgende Elemrente hinzu:

Ossicula Weberiana. - Unter diesem Namen bezeichnet man vier Knöchelchen, die in der Gruppe der Ostariophysi (Cyprinidae, Siluridae, Characinidae, Gymnotidae) in Kettenform die Schwimmblàse nit dem Gehörorgan verbinden. Da sie nur bei den Ostariophysi ausgebildet sind, stellen sie zweifellos eine Neuerwerbung vor, die diesen Stamme eigentümlich ist und sind daher für die Stanmesgeschichte der Fische von geringer Bedeutung. Man unterscheidet folgende Webersche Knöclıelclien: Tripus, Intercalarium, Scaphium, Claustrum. ${ }^{1}$

Tripus. - Wird als die modifizierte Rippe des 3. Wirbels betrachtet $\left(\mathrm{S} a g \mathrm{e} m \mathrm{eh} 1^{2}\right)$. Der hinterste der vier Wirbelknochen.

lintercalarium. - Wird (von Wright ${ }^{3}$ ) als der modifizierte Neuralbogen des 2. Wirbels betrachtet. Liegt vor dem Tripus und ist mit diesem wie mit dem vor ihm gelegenen Scaphium durch ein Ligament verbunden.

Scaplitum. - Wird von Wright als der modifizierte Neuralbogen des 1 . Wirbels angesehen.

Claustrum. - Wird von Wright als der modifizierte Dornfortsatz des 1. Wirbels angesehen. ${ }^{4}$

1 Wenn Tripus $=$ Malleus, Scaphium $=$ Stapes, Intercalarium $=$ Incus gestellt wird, so ist dieser Versuch einer Homologisierung nicht einmal durch gleiche physiologische Funktionen dieser Knochen berechtigt.

${ }^{2}$ M. Sagemehl, Beiträge zur vergleichenden Anatomie der Fische. Ill. und IV. Teil, Morphol. Jahrb. X, 1884 und XVII, 1891.

${ }^{3}$ R. R. Wright, On the Skull and Auditory Organ of the Siluroid Hyophthalmus. Transactions Roy. Soc. Canada, 1885.

${ }^{4}$ M. Sagemehl und ebenso B. Grassi betrachten das Claustrum als einen modifizierten Teil des Schädels. 


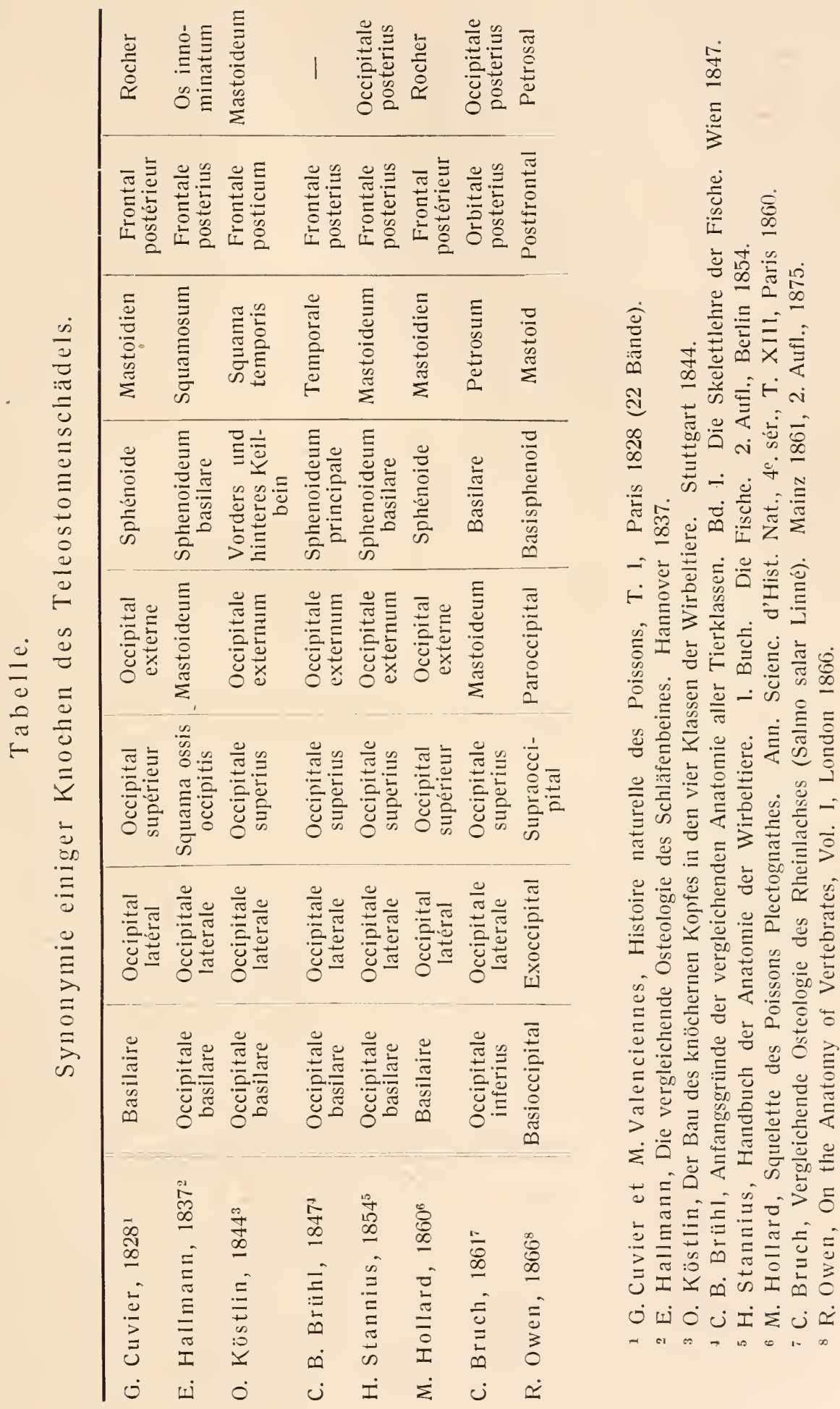




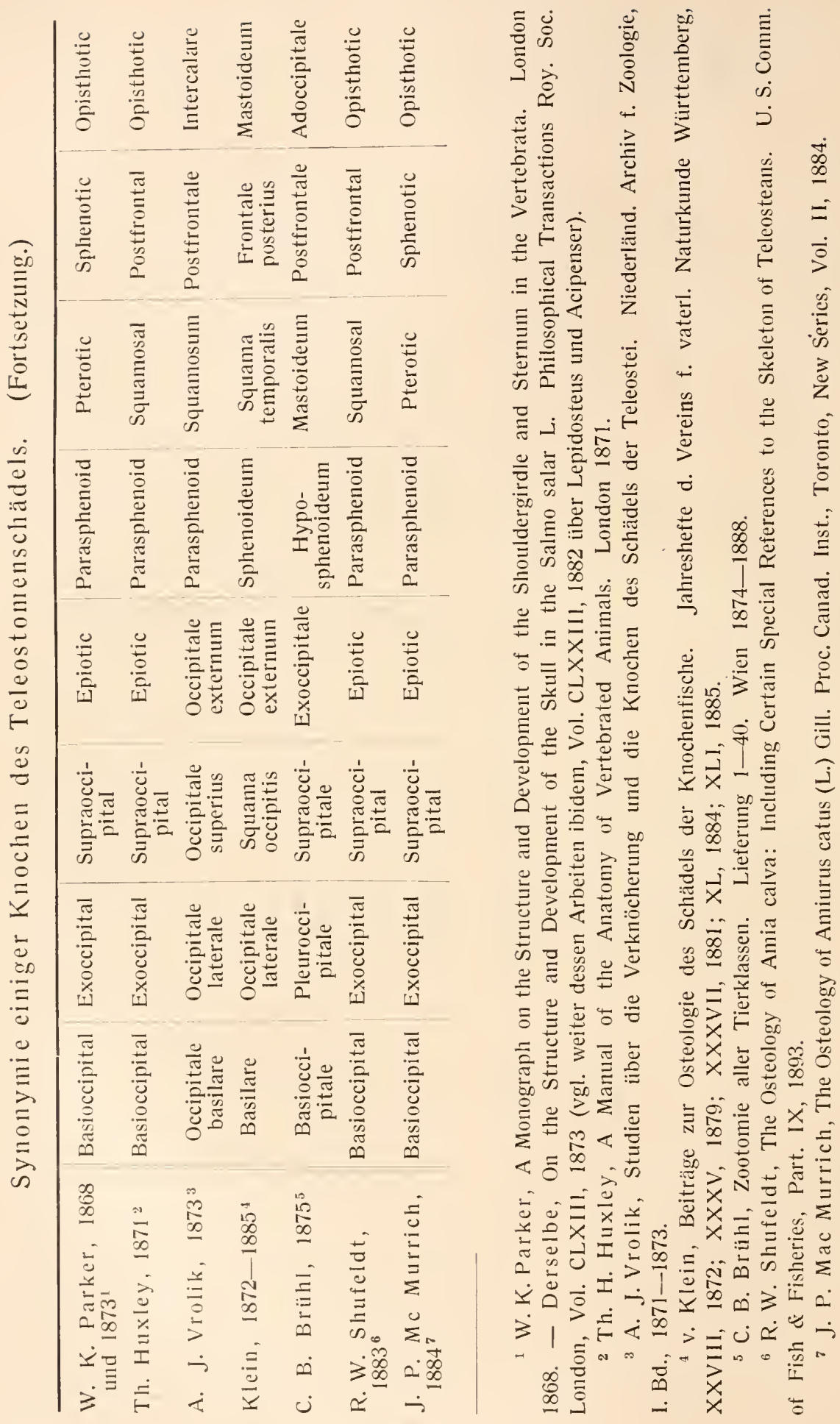




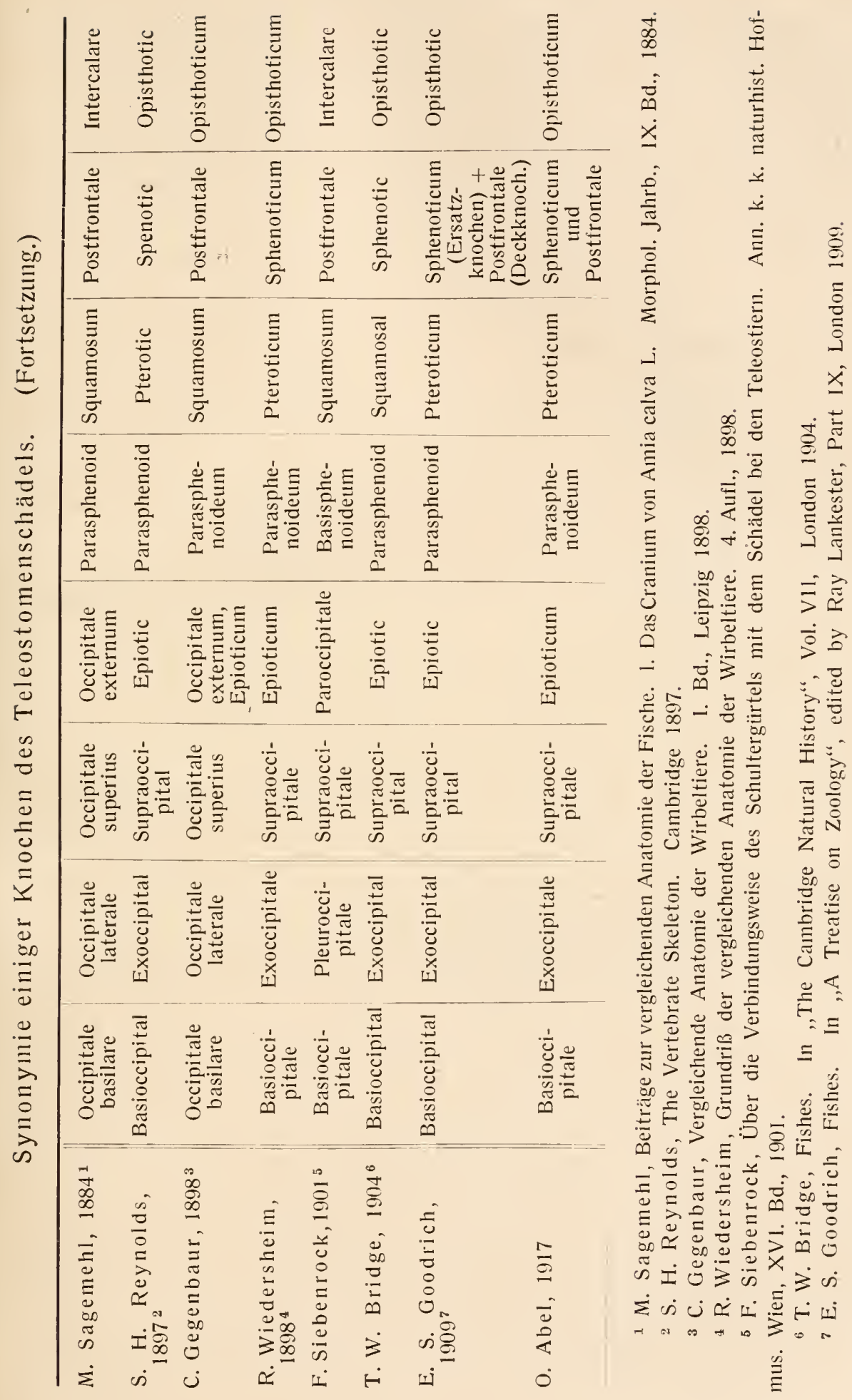


Bei den höheren Vertebraten (Reptilien, Vögelı und Säugetieren) treten aus dem Schädelraume (Schädelkapsel) zwölf Nervenpaare entweder durch separate oder durch für mehrere Nerven gemeinsame Öffnungen (Foramina) an der Schädelbasis aus. Meistens tritt der N. trigeminus mit seinen drei Ästen durcl je ein separates Foramen für jeden Ast aus. Wir haben folgende Schädelnerven bei den Reptilien, Vögelı und Säugetieren zu unterscheiden (Fig. 28):

I. Nervus olfactorius (Riechnerv), tritt in der Regel aus durch das Foramen olfactorium.

II. Nervus opticus (Sehnerv), tritt in der Regel aus durch das Foramen opticum.

III. Nervus oculomotorius (erster Augenbewegungsnerv), tritt in der Regel aus durch das Foramen oculomotorium oder durch das F. lacerum anterius.

IV. Nervus trochlearis (zweiter Augenbewegungsnerv), tritt in der Regel aus durch das Foramen trochleare oder durch das F. lacerum anterius.

V. Nervus trigeminus (= quintus) (dreigeteilter Nerv), tritt in der Regel aus durch das Foramen prooticum (mit allen drei $\ddot{\text { sten) }}$

oder, wenn jeder Ast für sich austritt, der erste Ast durch das Foramen lacerum anterius, der zweite Ast durch das Foramen rotundum, der dritte Ast durch das Foramen ovale.

VI. Nervus abducens (dritter Augenbewegungsnerv), tritt in der Regel aus durch das Foramen abducens oder durch das F. lacerum anterius.

VII. Nervus facialis (Gesichtsnerv), tritt in der Regel aus durch das Foramen stylomastoideum.

VIII. Nervus acusticus (Hörnerv), tritt in der Regel aus durch den Meatus auditorius internus oder durch das Foramen stylomastoideum.

IX. Nervus glossopharyngeus (Zungen-Racliennerv), tritt in der Regel aus durch das Foramen glossopharyngeum oder durch das F. lacerum posterius.

$X$. Nervus vagus (herumschweifender Nerv), tritt in der Regel aus durch das Foramen accessorium.

XI. Nervus accessorius (Beinerv), tritt in der Regel aus durch das Foranten accessorium.

X11. Nervus hypoglossus (Zungenfleischnerv), tritt in der Regel aus durch das Foramen condyloideum,

(eventuell in zwei Ästen) durch das F. cond. anterius und F. cond. posterius. 

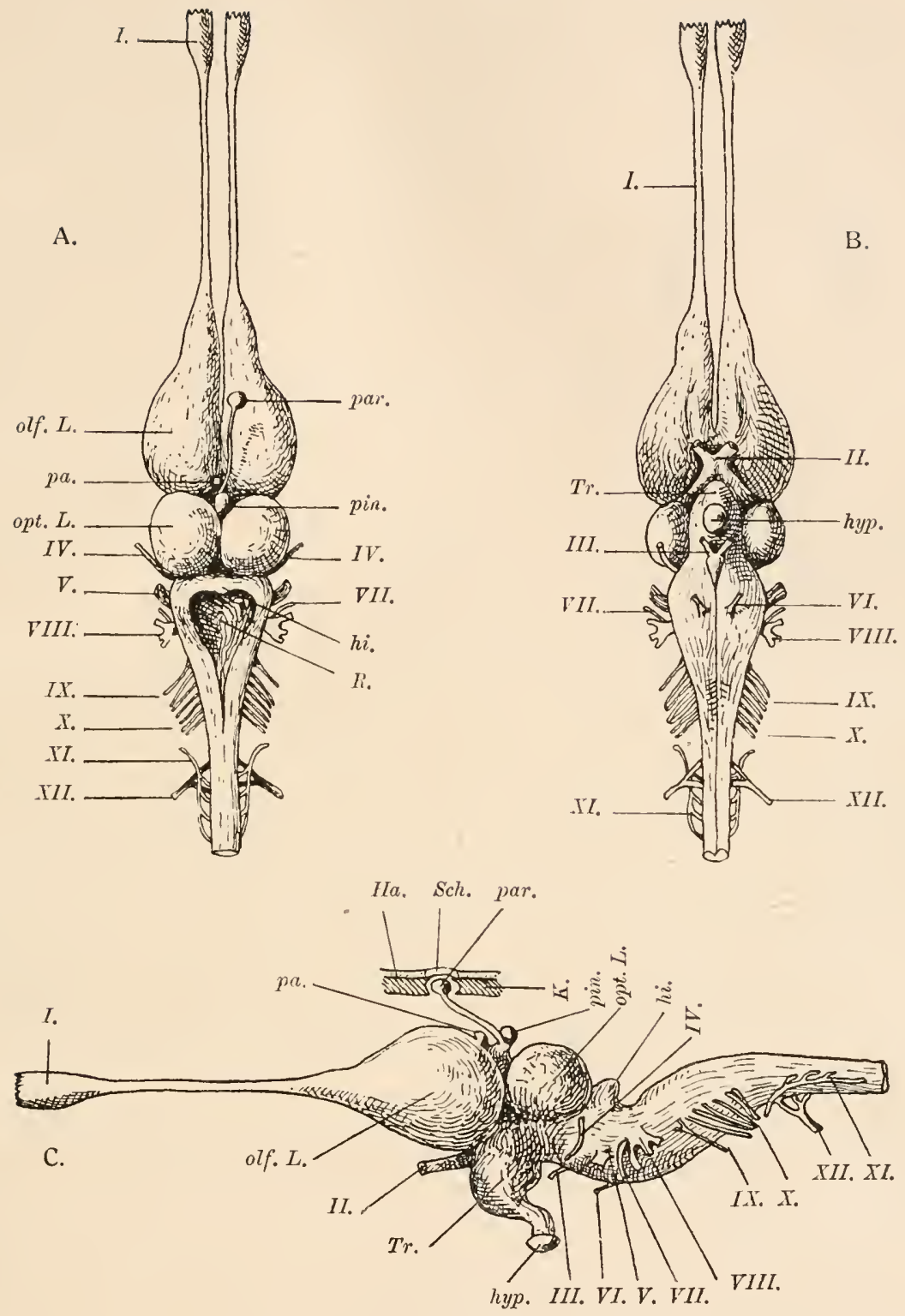

Fig. 28.

Reptiliengehirn, A von oben, B von unten, C von links gesehen. Etwas schematisiert.

(Nach J. E. V. Boas, zum Teil abgeändert.)
I.-XII. = Gehirnnerven.
par. $\quad=$ Parietalorgan (Parietalauge).
opt. $L .=$ Lobus opticus.
pin. $\quad=$ Pinealorgan (Epiphyse).
hi. $\quad=$ Hinterhirn (Cerebellum).
R. $\quad=$ Nachhirn
pa. $\quad=$ Paraphyse.
$K$. $\quad=$ Knochen des Schädeldaches,
hyp. $\quad=$ Hypophyse (Glandula pitui- taria).
Tr. = Trichter (Infundibulum).
olf. $L .=$ Lobus olfactorius.
Sch. $=$ Scheitelloch (Foramen parie- tale).
Ha. = Haut des Schädels. 
Unter diesen zwölf Nervenpaaren sind jedoch nur die vorderen zehn als ursprüngliche Schädelnerven zu betrachten, da bei den höheren

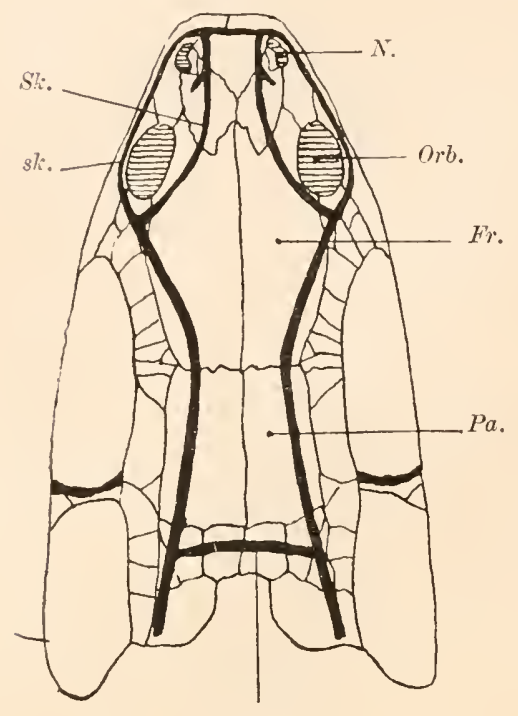

Fig. 29.

Die Schleimkanäle des Schädels von Polypterus. (Nach G. Baur und R.

H. Traquair, aus R. L. Moodie.)

$$
\begin{aligned}
& N .=\text { Nasenöfnung } . \\
& \text { Orb. }=\text { Orbita. } \\
& F r .=\text { Frontale. } \\
& P a .=\text { Parietale. } \\
& S k .=\text { Seitenkanal. }
\end{aligned}
$$

(Vgl. Fig. 26.)

Vertebraten durch Einbeziehung verschiedener Rückenmarksnerven in das Schädelinnere noch der XII. Nerv (Hypoglossus) dazugetreten ist, der aus der Vereinigung melsrerer Einzelnerven hervorging. Der X1. Nerv (Accessorius) ist als eine Abspaltung des X. (Vagus) anzusehen. Aus diesem Grunde unterscheidet man die zehn vorderen Nervenpaare als ,Urschädelnerven" "(paläokraniale Nerven), die den X1I. Nerven bildende Gruppe von Rückenmarks- oder Spinalnerven als „Neuschädel- nerven“ (neokraniale Nerven).

Der den Fischen eigentümliche „Seitennerv“ (Nervus lateralis), der vom X. Nerven aus abzweigt, steht mit der,,Seitenlinie“ oder dem,,,Seitenkanal" der Fische (Fig. 29) in Verbindung und repräsentiert ein Hautsinnesorgan. Er ist auch bei Amphibienlarven vorlanden und wahrscheinlich auch bei jenen Stegocephalen vorhanden gewesen, die auf dem Schädeldaclı die sog. ,,Schleimkanäle“ aufweisen; bei Micrerpeton caudatum aus dem Karbon von Illinois hat Moodie (1908) die Seitenlinie in der Schwanzregion nachweisen können, wo sie in ähnlicher Weise wie bei der Larve des lebenden Necturus maculatus ausgebildet ist. ${ }^{1}$

1 Roy L. Moodie, The Lateral Line System in Extinct Amphibia. The Journal of Morphology, Vol. XIX, 1908, p. $511^{\circ}$. 


\section{Die Stämme der Wirbeltiere.}

\section{Klasse: Rundmäuler (Cyclostomata).}

In der Gegenwart treten uns in den marinen Myxiniden und den marinen, fluviatilen und lacustrinen Petromyzodontiden Typen entgegen, deren allgemeine Organisation im Vergleiche zu den Fischen als außerordentlich tiefstehend $z u$ betrachten ist. Schon vor langer Zeit hat sie L. Agassiz (1857) von den „Fischen" getrennt und wenn sie auch in netuerer Zeit von manchen Forschern wieder diesem Stamme eingereiht werden, so kann doch keinem Zweifel unterliegen, daß sie sich in zahlreichen Merkmalen so durchgreifend von den Fischen unterscheiden, daß die phylogenetische Sonderstellung der Rundmäuler durch ilhre Abtrennung als eigene Klasse vollauf gerechtfertigt erscheint. Freilich ist ein Großteil ihrer morphologischen Merkmale auf Rechnung einer lochgradigen, einseitigen Spezialisation und nicht auf die primitive phylogenetische Stufe zu setzen, die sie den Fischen gegenüber einnehmen. Wenn wir, wie dies jetzt wohl allgemein geschieht, die Anaspida den Fischen zurechnen, so verschwinden manche der scharfen Gegensätze und wir werden zu der Annahme gedrängt, daß die Cyclostomen einen mit den Anaspiden aus gleicher Wurzel entsprossenen Stamm bilden, der sich allerdings schon sehr frülnzeitig abgezweigt und einseitig entwickelt hat. Das Fehlen der paarigen Flossen ist unter diesem Gesichtspunkte wohl als ein primäres Organisationsmerkmal anzusehen, aber andere Merkmale wie die aalförmige Körpergestalt, das Fehlen eines Schuppenkleides u. dgl. dürften wohl als sekundäre Spezialisationserscheinungen zul betrachten sein.

Der rein knorpelige Zustand des Skeletts der Cyclostomen ist woll gleichfalls als primitives Merkn1al zu bewerten. Nach den Untersuchungen von $\mathrm{H}$. Schauinsland scheinen sich in den segmentierten Partien der Wirbelsäule bei den Petromyzodontiden die Interdorsalia 
und Basidorsalia der Fische nachweisen zu lassen, doch ist die Homologie dieser Bogenelemente noch nicht gänzlich sichergestellt. Bei den Myxiniden fehlen die Arcualia gänzlich.

Die medianen Flossen bestehen entweder nur in einem niederen, un11 das Körperende geschlossen herumziehenden Hautsaum (z. B. bei Bdellostoma und Myxine) oder außer diesen noch aus zwei kleinen Dorsalflossen (z. B. bei Petromyzon fluviatilis). Die Medianflosse wird von Knorpelstrahlen gestützt, bei Myxine sind die terminalen Flossenstrahlen mit ihren Basen zu einer großen medianen Knorpelplatte vercinigt, die sich dorsal, terminal und ventral um die Chorda dorsalis legt. Auf Schritt und Tritt begegnen wir einer derartigen Mischung von sehr primitiven und hochspezialisierten Zuständen. Besonders deutlich tritt uns dies im Baue der Kiemenregion entgegen. Bei Bdellostoma sind 14 Paare freier und selbständiger Kiemenöffnungen vorhanden; diese lohe Zahl ist wohl nur als ein außerordentlich primitives Merkmal zu bewerten, in dem Bdellostoma viel tiefer steht als die Anaspiden. Aber bei Paramyxine sehen wir, daß die Zahl der Kiemenöffnungen bedeutend verringert ist (auf sechs) und daß sie sehr nahe zusammengerückt sind; hierbei sind die vorderen Kiemenöffnungen ersichtlich nach hinten verlagert worden. Bei Myxine endlich sind die bei Paramyxine noch offenen sechs Kiemenlöcher zu einer einzigen, sehr weit hinten liegenden Kiemenöffnung verschmolzen. Diese eigenartige Spezialisierung ist Gurch die bolirende Lebensweise bedingt; der ganze, von Bdellostoma über Paramyxine nach Myxine führende Unformungsprozeß der Kiemenregion ist daher als eine sekundäre Spezialisation und als Anpassung an die Lebensweise anzusehen. Obwohl sich die Inger (Myxine) in tote Fische einbohren und nicht Schlammwüller sind, wie die Aale, so ist doch die physiologische Bedeutung der Verkleinerung der Kiemenöffnung dieselbe wie bei den Aalen und Mutänen und somit als Konvergenzerscheinung zu betrachten.

Der Saugmund sowie die übrigen Merkmale der Mundregion z. B. Zunge, Hornzälne usf. - sind kaum als primitive, sondern als hoch spezialisierte Merkntale anzusehen. Freilich darf hierbei nicht übersehen werden, daß das Ansaugen eine Eigenschaft ist, die wir bei vielen Fischlarven und zwar namentlich bei solchen von primitiven Fischen vorfinden, wie die Larven von Amia, Lepidosteus, Acipenser, Lepidosiren und Protopterus zeigen. Das Vorhandensein eines Saugmundes bei Palaeospondylus Gunni aus den Caithress Flagstones (Unterdevon) von Schottland kann daher nicht als ein zwingender Grund zur Einreilunng dieses kleinen fossilen Fisches in die Klasse der Cyclostomen betrachtet werden, von der bisher noch keine fossilen Vertreter mit Siclerheit bekannt sind. 


\section{Klasse: Fische (Pisces).}

I. Unterklasse: Anaspida.

Aus dem obersten Silur Schottlands hat R. H. Traquair ${ }^{1}$ zwei Gattungen Fische beschrieben, welche zweifellos die primitivsten bisher bekanniten Vertreter der ganzen Klasse sind. Gliedmaßen fehlen den beiden Gattungen vollständig, das Innenskelett ist mit Ausnahme des bei Lasanius an allen Exemplaren deutlich nachweisbaren, aus acht ${ }^{2}$ Bögen bestehenden Kiemenkorbes nicht verkalkt gewesen und daher bei der Fossilisation zerstört worden. Bei Birkenia sind Schuppen vorhanden, die schienenförmig und in Längsreihen angeordnet sind. Die Oberfläche der Schuppen ist sehr fein gerunzelt; über ihre histologische Struktur läßt sich jedoch bei dem Erhaltungszustand der sehr zartkörperig gewesenen Reste kein Urteil abgeben.

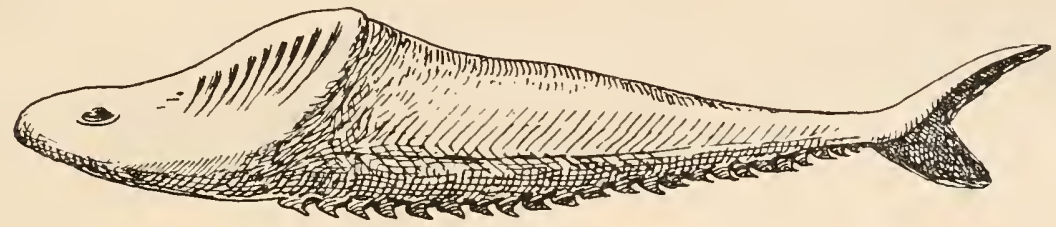

Fig. 30.

Rekonstruktion vọn 'Lasanius problematicus, Traquair, von links gesehen, in natiirlicher Größe. - Obersilur (Downtonian) Schottlands. (Orig.-Rekonst.)

Traquair hat eine Rekonstruktion von Birkenia entworfen, in der er die beiden dorsalen Längsschuppenreihen auf die rechte Körperseite projiziert; dies ist jedoch unrichtig, wie aus der entgegengesetzten Richtung der Schienen mit Sicherheit hervorgeht. Ebenso ist auch, wenigstens bei zwei der von Traquair abgebildeten Exemplare, ein Teil der ventralen Schuppenreihen, besonders in der vordersten Körperregion hinter dem Schädel, infolge Verdrückung bei der Fossilisation, auf die andere Körperseite hinübergequetscht, so daß das restaurierte Bild dieses Fisches ganz anders ist als die von Traquair entworfene Rekonstruktion. Jaekel ${ }^{3}$ hat die Ansicht ausgesprochen, daß Traquair die Rückenlinie mit der Bauchlinie verwechselt habe, aber diese

1 R. H. Traquair, Report on Fossil Fishes collected by the Geological Survey of Scotland in the Silurian Rocks of the South of Scotland. Transactions R. Soc. Edinburgh, Vol. XXXIX, Part 3, Nr. 32, 1899, p. 827-864, 5 pl. - Supplementary Report etc., ibidem, Vol. XL, Part 4, Nr. 33, 1904, p. 879-888, 3 pl.

${ }^{2}$ Bei Pterolepis (vgl. unten) sind beiderseits je zehn Kiemenöffnungen vorhanden.

3 O. Jaekel, Die Wirbeltiere. Berlin, 1911, p. 37.

Abel, Stämme der Wirbeltiere. 
Meinung berult auf einem Irrtum; die von Traquair angenommene Orientierung des Körpers von Birkenia elegans ist, abgesehen von der unrichtigen Deutung des Verlaufes und der Ausdehnung der Schienenreihen, richtig. ${ }^{1}$ Die Schienenschuppen scheinen sehr zart gewesen zu sein; die eigentünliche Richtung derselben an zwei Exemplaren, die Traquair abbildete, ist wolll auf eine Einsenkung der Weichteile in der vorderen Darmregion zurückzuführen. Daß die Reste dieses Fisches bei der Fossilisation stark geschrumpft sind, zeigt ein Vergleich der drei von Traquair abgebildeten Exemplare.

Die beiden Gattungen Birkenia und Lasanius sind in Süßwasserablagerungen gefunden worden und das gleiche ist auch bei den drei

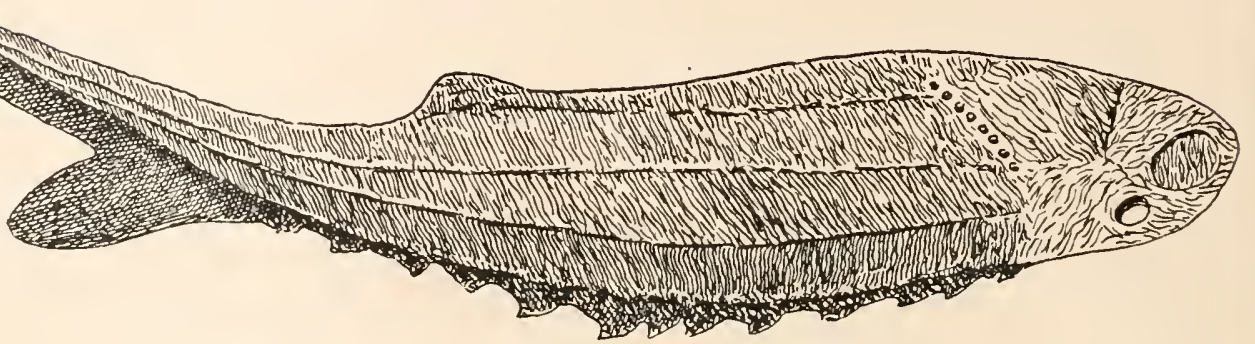

Fig. 31 .

Rekonstruktion von Birkenia elegans, Traquair, von rechts gesehen, in nat. Gr. Obersilur (Downtonian) Schottlands. (Orig.-Rekonst.)

Gattungen Pterolepis, Pharyngolepis und Rhyncholepis der Fall, die in gleichalten Schichten (Downtonian) bei Rudstangen in Norwegen (bei Christiania) entdeckt worden sind. Nach den vorläufigen Mitteilungen von J. Kiaer ${ }^{2}$ über diese Funde ist die Familie der Pterolepiden von den Birkeniiden durch eine andere Anordnung der Schuppenreihen verschieden, die in ihren Verlaufe den Myotomen entsprechen. Bei Pterolepis nitidus steht vor der Dorsalflosse ein auf einer Basalplatte ruhender Flossenstachel.

Die Stellung von Euphanerops longaevus, den A. Smith-Woodward ${ }^{3}$ aus dem Oberdevon von Quebec in Kanada besclurieb, ist fraglich. Kiaer stellt diese, einstweilen nur durch einen sehr schlecht er-

1 Auch Prof. J. Kiaer (Christiania) ist dieser Ansicht, wie er mir in einem Briefe (vom 27. XI. 1917) mitteilt.

J. Kiaer, A New Downtonian Fauna in the Sandstone Series of the Kristiania Area. A Preliminary Report. Videnskapsselskapets Skrifter, mat. nat. Kl., Kristiania, 1. Bd., 1911, Nr. 7, p. 17.

3 A. Smith Woodward, On a New Ostracoderm (Euphanerops longaevus) from the Upper Devonian of Scaumenac Bay, Province of Quebec, Canada. Ann. \& Mag. Nat. Hist., London, (VII), Vol. V, 1900, p. 416-418, 1 pl. 
haltenen Rest (l. c., S. 13) vertretene Gattung noch zu den Anaspiden, aber es ist wahrscheinlicher, daß O. P. Hay im Rechte ist, der (1902) die Familie der Euphaneropiden den Cephalaspiden anschließt.

Trotz mancher Verschiedenheiten zwischen diesen Gattungen stellen sie doch offenbar Vertreter einer allen übrigen Fischen gegenüberzustellenden Gruppe dar, die als die Unterklasse der Anaspida abgetrennt werden muß. Die Gründe, die für eine so scharfe Abtrennung von den Osteostraci sprechen, bestehen namentlich in dem Vorhandensein eines ventralen Flossensaumes, der aus dreieckigen, nach hinten gerichteten Hautlappen besteht. Die Funktion desselben ist wahrscheinlich in erster Linie die eines Richtung haltenden Ventralkieles gewesen, aber es ist auch möglich, daß die Lappen an der Lokomotion beteiligt waren. Der hauptsächliche Lokomotionsapparat der fusiform gestalteten und daher jedenfalls freischwimmenden oder ,nektonischen" Tiere ist aber gewiß die Terminalflosse gewesen, in deren oberen Lappen sich das Körperende fortsetzte, wie dies bei den weitaus meisten paläozoischen Fischen die Regel ist. Ein zwingender ethologischer oder morphologischer Grund für die Annahme Jaekels, daß sich das Körperende in den unteren Terminalflossenlappen in derselben Weise fortsetzte, wie dies bei den Ichthyosauriern oder den Thalattosuchiern der Fall war, liegt nicht vor.

Das auffallendste Merkmal dieser eigentümlichen Gattungen besteht neben dem Vorhandensein des ventralen Flossensaumes in dem vollständigen Fehlen der paarigen Flossen. Freilich fehlen sie auch bei allen Osteostraken, aber man könnte hier das Fehlen der paarigen Flossen eventuell als sekundären Verlust infolge des Überganges zur benthonischen Lebensweise ansehen, eine Auffassung, die ich allerdings mit Rücksicht auf das Fehlen der paarigen Flossen bei den fusiformen Pteraspiden nicht teilen kann. Bei den Anaspiden ist das Fehlen der paarigen Flossen kaum anders als ein ursprüngliches Verhalten anzusehen. Daß der mediane ventrale Hautlappensaum der Anaspiden den Ausgangspunkt der paarigen Flossen darstellt, die wir bei höherstehenden Fischen antreffen, ist aus verschiedenen Gründen durchaus unwahrscheinlich.

Die Anaspiden sind schwer in Beziehungen zu den anderen Unterklassen der Fische zu bringen. Am ehesten wäre es noch möglich, in ihnen die Ahnen der Osteostraci zu erblicken, mit denen namentlich Lasanius eine gewisse Ähnlichkeit in der allgemeinen Körpergestalt besitzt; über diese Frage könnten uns aber erst weitere Funde von Zwischenformen eine Gewißheit verschaffen. Der Besitz von acht Kiemenbogenpaaren, der bei Lasanius ebensowohl wie bei primitiven Osteostraken nachweisbar ist (z. B. bei Thelodus), scheint für ver- 
wandtschaftliche Beziehungen zu sprechen, über deren Grad sich jedoch nichts Bestimmtes sagen läßt.

\section{F. Lasaniidae.}

Lasanius. - Nur aus dem obersten Silur (Downtonian) von Schottland in zahlreichen Exemplaren bekannt. Die ventrale Hautlappenreihe besteht aus 18 oder mehr kleinen dreieckigen Zacken. Das Schädelprofil steigt ziemlich steil an und man muß den Körperabschnitt, der den eigentlichen Schädel und das Viszeralskelett umfaßt, im Vergleiche zu dem übrigen Körper als groß bezeichnen. Die von Traquair entworfene Rekonstruktion (zuerst 1898 entworfen und 1905 verbessert) gibt die Körpergestalt dieses eigentümlichen Fisches, von den1 zahlreiche Exemplare vorliegen, nicht glücklich wieder; die hier mitgeteilte Rekonstruktion (Fig. 30) wurde auf Grundlage der Originalabbildungen der Reste entworfen, die Traquair nach den Zeichnungen Greens als Lithographien veröffentlichte. In dieser neuen Rekonstruktion sind auch die Muskelzüge angedeutet, die an einem Exemplare zu beobachten sind. Die Haut scheint gerunzelt gewesen zu sein, wenigstens sind an einem Exemplar feine, parallele Runzeln sichtbar, welche eine gleichartige Richtung wie die Schienenschuppen von Birkenia aufweisen.

Bis jetzt sind zwei Arten (L. problenraticus und L. armatus) beschrieben worden. Beide waren Süßwasserbewohner.

\section{F. Birkeniidae.}

Von den Lasaniiden durch den Besitz einer kleinen Rückenflosse sowie der ausgedelnten Bepanzerung des ganzen Körpers mit feinrunzeligen Schienenschuppen unterschieden, die in vier Längsreihen die Körperflanken bedecken. Die Verzerrung der vorliegenden Exemplare hat bei der ersten Bearbeitung durch R. H. Traquair zu einer falschen Vorstellung von dem Verlauf und den Grenzlinien der Schuppenreihen geführt, die in der beigegebenen Abbildung (Fig. 31) berichtigt sind. Der Körper setzt sich in den oberen Lappen der tiefgegabelten Terminalflosse fort. Der ventrale Hautlappensaum umfaßt ungefähr 13 Lappen, deren mittlere am größten sind; ihre genaue Zahl steht nicht fest. Zwischen dem durch andere Art der Beschuppung vom Rumpf deutlich unterscheidbaren Kopf und dem Rumpfe stelıen acht kleine Öffnungen, die in einer von lintenoben nach vornunten herabziehenden Linie stehen und wahrscheinlich Kiemenöffnungen darstellen. Die Bepanzerung des Kopfes zerfällt deutlich in je zwei Paar lateraler Felder, die durch eine Mittellinie getremt sind. Welche Deutung wir den kleinen, paarigen Öffnungen nahe dem Unterrande des Schädels zuzusprechen haben, ist zweifelhaft; vielleicht sind es die Augenöffnungen. Vor und über ihnen liegt ein ovales Feld, dessen Bepanzerung eine andere ist als die der 
übrigen Schädelpartien; seine Bedeutung ist unaufgeklärt. Vielleicht ist es ein Spiraculum (vgl. die Spiracula der Elasmobranchier).

Eine Art (Birkerria elegans) ist in zahlreichen Exemplaren im obersten Silur Schottlands gefunden worden. Auch Birkenia war ein Süßwasserbewohner.

F. Pterolepidae. Von den Birkeniiden durch einen anderen Verlauf der Sclıppenreihen unterschieden, deren Längserstreckung der Richtung der Myotomen entspricht.

Pterolepis. - In Süßwasserbildungen des obersten Silur von Rudstangen bei Christiania. Zahlreiche Exemplare gefunden, die aber nech nicht näher beschrieben und abgebildet sind. Ventralschuppen zahlreicher als bei Birkenia, dadurch mehr an Lasanius erimnernd; vor der Dorsalflosse ein Flossenstachel. Zehn Kiemenöffnungen jederseits vorhanden. ${ }^{1}$ Körperlänge $10 \mathrm{~cm}$.

Pharyngolepis. - Vom gleichen Fundort. Körper langgestreckt, a lfförmig, bis $20 \mathrm{~cm}$ lang. Viel seltener als die vorige Gattung. Nur eine Art (Plr. oblongus) bis jetzt unterschieden. Die Dorsalflosse trägt keinen Stachel; der Kopf ist auf der Oberseite mit zahlreichen kleinen, auf der Unterseite mit großen Platten bedeckt.

Rhyncholepis. -- Vom gleichen Fundort. Körper klein, bis $7 \mathrm{~cm}$ lang, an Birkenia erinnernd. Die Art der Bedeckung des Kopfes mit Deckknochen erinnert nach J. Kiaer an die Anordnung dieser Platten bei den Crossopterygiern. Seiten und Unterseite des Kopfes tragen große Platten. Vor der Rückenflosse stehen zwei große flache Platten.

\section{Unterklasse: Osteostraci.}

Schon im oberen Silur Schottlands treten sehr eigentümliche Fische auf, die sich durch breiten, abgeflachten und dorsoventral komprimierten Vorderkörper als benthonische Typen erweisen. Bei den primitivsten Vertretern dieser Gruppe sind keine Panzerplatten oder Hautschilder vorhanden, sondern zahlreiche-Dentinschuppen oder „Hautzähne“, die an die Plakoidschuppen der Haifische erinnern; durch Verschmelzung dieser Einzelschuppen zu Platten entsteht bei spezialisierteren Gattungen zuerst ein mosaikartiger Panzer und schließlich können sich diese kleineren polygonalen Mosaikplatten zu größeren, scheinbar einheitlichen Plattenkomplexen vereinigen, wie dies im Kopfschild von Cephalaspis und anderen Gattungen der Fall ist.

Die hintere Körperhälfte bleibt bei allen bisher bekannten Formen, welche in dieser Gruppe zu vereinigen sind, schlank und spindelförmig und

1 Briefliche Mitteilung von Prof. Dr. J. Kiaer (Christiania) vom 27. Nov. 1917. 
läuft in eine gegabelte oder dreieckige, aber stets asyımmetrische ,,Schwanzflosse" (Terminalflosse) aus, deren Funktion eine epibatische ist. Bei einzelnen Typen (Drepanaspis, Pteraspis) sind dachziegelartige Schuppen vorhanden, deren Form bei Drepanaspis Fichtenzapfenschuppen ähnelt, während sie bei Pteraspis eine rhombische Form besitzen und an die Schuppenformen mesozoischer Teleostomen mit Ganoidschuppen erinnern. Bei Cephalaspis sind mehrere übereinanderliegende Schuppen zul längeren Schienenschuppen verschmolzen, deren Längsachse von oben nach unten (senkrecht zur Körperachse) verläuft; aber diese Schienenschuppen finden sich nur in der vorderen Rumpfregion, während die Schwanzregion mit zahlreichen kleinen Schuppen gepanzert ist. Auch hier, wie bei fast allen Fischen, sind somit die phylogenetisch prinitiveren Schuppentypen in der Schwanzregion erhalten.

Außer der schon erwähnten dreieckigen Terminalflosse (Drepanaspis, Ateleaspis, Cephalaspis) oder der tief gegabelten Terminalflosse (Thelodus, Lanarkia) ist bei einigen Osteostraken eine kleine Rückenflosse ausgebildet (Thelodus, Cephalaspis, Ateleaspis), die aber bei anderen Gattungen fehlt (z. B. bei Lanarkia, Drepanaspis und wahrscheinlich auch bei Pteraspis). Nur bei Aceraspis und Micraspis sind zwei getrennte Dorsalflossen beobachtet worden.- Die hintere dieser beiden Rückenflossen entspricht der Dorsalflosse von Cephalaspis; J. Kiaer ${ }^{1}$ hat die Ansicht ausgesprochen, daß die vordere Dorsalflosse von Aceraspis und Micraspis, die als die Vorläufer von Cephalaspis zu betrachten seien, in den medianen, stark entwickelten Dorsalkamm umgewandelt worden ist, wie er z. B. bei Cephalaspis Lyelli (nach E. S. Goodrich, 1909) auftritt. ${ }^{2}$ Dieser Dorsalkamm fehlt jedoch bei anderen Cephalaspisarten; z. B. bei C. Murchisoni. Ich möchte dem Vorhandensein oder Fehlen der vorderen. Darsalflosse kein allzu großes Gewicht beilegen; es genügt dieser Unterschied kaum zur Aufstellung einer eigenen Familie (Aceraspidae, Kiaer 1911) für Aceraspis und Micraspis.

Von parigen Flossen ist dagegen bei keinem einzigen Vertreter dieses Stammes die geringste Spur erhalten geblieben. Das Fehlen derselben ist kaum als Folge des Erhaltungszustandes zu betrachten; die paarigen Gliedmaßen sind bei den Osteostraken überhaupt nicht ausgebildet gewesen und haben ja auch anderen Gruppen der altpaläozoischen Fische (z. B. bei den Anaspiden und den Antiarchi) bestimunt gefehlt.

Die Augen liegen nur bei Thelodus und Lanarkia weit voneinander entfernt an den Seitenrändern des vorderen, stark verbreiterten Kopf-

1 J. Kiacr, A New Downtonian Fauna in the Sandstone Series of the Kristiania Area. Vidensk. Skrifter, mat.-nat. Kl., 1. Bd., Christiania 1911, Nr. 7, p. 16.

2 E. S. Goodrich, Vertebrata Craniata, I. Fasc., Part IX des ,"Treatise on Zoology“ von Ray Lankester, London, 1909, p. 201, Fig. 173. 
abschnittes dieser Formen, sind aber sonst meist einander stark genähert und liegen auf der Dorsalseite des Kopfes (Ateleaspis, Eukeraspis, Thyestes, Didymaspis, Cephalaspis, Trentataspis); bei den fusiformen Pteraspiden (Pteraspis und Cyathaspis) liegen sie an den Seiten des Kopfes. Drepanaspis ist vollständig blind gewesen, wie aus dem Fehlen der Augenhöhlen in dem Panzerdach des Schädels hervorgeht, das außer der Öffnung für die Mundspalte und einem Paar auf der Ventralseite des Kopfes gelegener sehr kleiner Öffnungen zum Durchtritt von Tentakeln keine anderen Öffnungen aufweist.

Die verwandtschaftlichen Beziehungen der Osteostraken untereinander sind durch die Untersuchungen der letzten Jahre etwas aufgehellt worden. Man hat früher alle panzertragenden Fische des älteren Paläozoikums als eine geschlossene Gruppe, die der „Panzerfische“ oder „Plakodermen“, betrachtet und als eine phylogenetische Einheit zusammengefaßt, in der auch die Asterolepiden (jetzt Antiarclii) und die Coccosteiden usw. (jetzt Arthrodira) mit eingeschlossen waren. Später wurden die Arthrodiren von den Plakodermen abgetrennt und zuerst den Dipneusten angegliedert; für die übrig gebliebenen „,Panzerfische" wurde die Bezeichnung Ostracodermi eingeführt. Als R. H. Traquair die eigentümlichen Birkeniiden im Obersilur von Lanarkshire als Vertreter der „Ordnung“ Anaspida beschrieb, wurden wieder diese beiden Formen den Ostrakodermen eingereiht und so blieb bis heute dieser systematische Begriff der Ostrakodermen oder Placodermen eine Sammelstelle für die Anaspida, Heterostraci (Coelolepidae, Genündenidae, Drepanaspidae, Pteraspidae), Osteostraci (Cephalaspidae, Tremataspidae) und Antiarchi. ${ }^{1}$ - Zweifellos sind also bisher sehr verschiedene Typen und Stänme in eine systematische Einheit vereinigt worden, wozu keine zwingenden Gründe vorliegen. Die Anaspida einerseits und die Antiarchi andererseits stellen so weit divergierende Stammesreihen dar, daß ihre Vereinigung mit den Gruppen der Heterostraci und Osteostraci eine höchst unnatürliche ist. Löst man diese beiden Gruppen, denen unbedenklich der Rang von Unterklassen zugeteilt werden kanı, da sie sich weit von den übrigen Unterklassen der „Fische“ im weiteren Sinne entfernen, aus dem Verbande der Heterostraci und Osteostraci los, so bleibt eine in sich geschlossene Gruppe zurück, für welche eine Trennung in zwei Abteilungen überflüssig, ja sogar fehlerhaft wäre, weil die Gegensätze zwischen ihnen keineswegs allzu groß sind. Ich schlage daher vor, die Gruppe der Heterostraci mit der der Osteostraci unter dem letzteren Namen zu vereinigen und die verschiedenen Formengruppen dieser größeren Abteilung als Familien zu unterscheiden.

1 Vgl. z. B. die Darstellung der fossilen Fische in E. Kokens Neubearbeitung des betreffenden Abschnittes von K. A. v. Zittel, Grundzüge der Paläontologie, 2. Aufl., 1911, p. 26-39. 


\section{F. Coelolepidae.}

Die beiden Gattungen Thelodus und Lanarkia, welche von R. H. Traquair in dieser Familie vereinigt worden sind, waren schon vor langer Zeit durch einzelne Schuppen bekannt, die unter verschiedenen Namen von Pander beschrieben worden waren. Beide

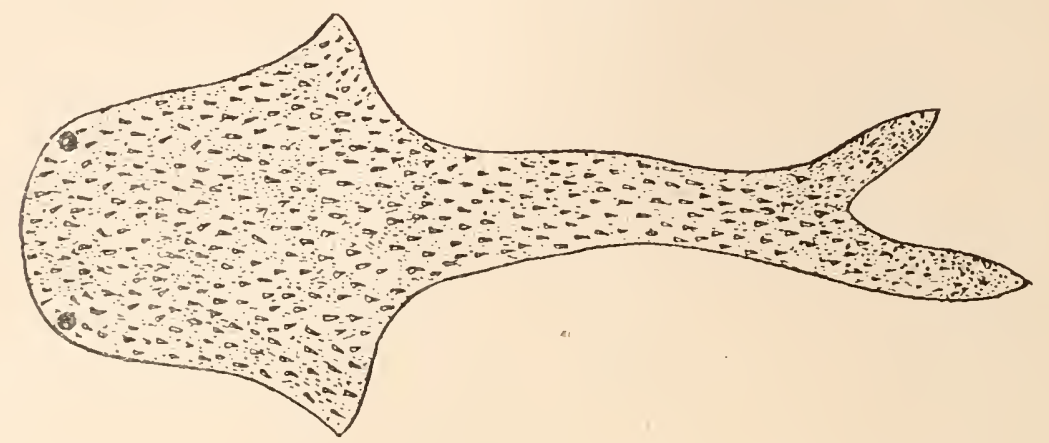

Fig. 32 .

Lanarkia spinosa, Traquair, aus dem obersten Silur (Downtonian) Schottlands, nat. Gr. (Nach R. H. Traquair.)

Gattungen repräsentieren Fische von sehr tiefstehender Organisation; der Vorderteil des Körpers ist rochenförmig verbreitert und ist seitlich in je einen dreieckigen Lappen ausgezogen, der Hinterteil ist langgestreckt, schlank, und läuft in eine tiefgegabelte, ungleichlappige Terminalflosse aus, deren oberer Lappen länger und größer ist als der

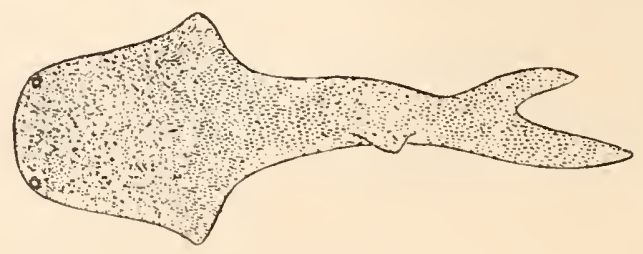

Fig. 33.

Rekonstruktion von Thelodus scoticus, Traqu., aus dem obersten Silur Schottlands. - Verkl. (Nach R. H. Traquair.)

untere. Lanarkia (Fig. 32) besaß keine anderen Flossen, Thelodus (Fig. 33) trug eine kleine dreieckige Rückenflosse. Die kleinen Augen standen bei beiden Gattungen weit voneinander getremnt nahe dem Vorderrand des Kopfabschnittes; paarige Flossen fehlten gänzlich. Der ganze Körper war mit kleinen Chagrinschuppen von Bau und Form primitiver Elasmobranchierschuppen (Hautzähnen) bedeckt. Ein Exemplar von Thelodus Pagei (Fig. 34) aus dem unteren Old Red Sandstone zeigt die Abdrücke von acht Kiemenbögen. 
Lanarkia. - Obersilur von Schottland (mehrere Arten).

Thelodus. - Obersilur und Unterdevon von Schottland, vereinzelte Schuppen im deutschen und baltischen Obersilur.

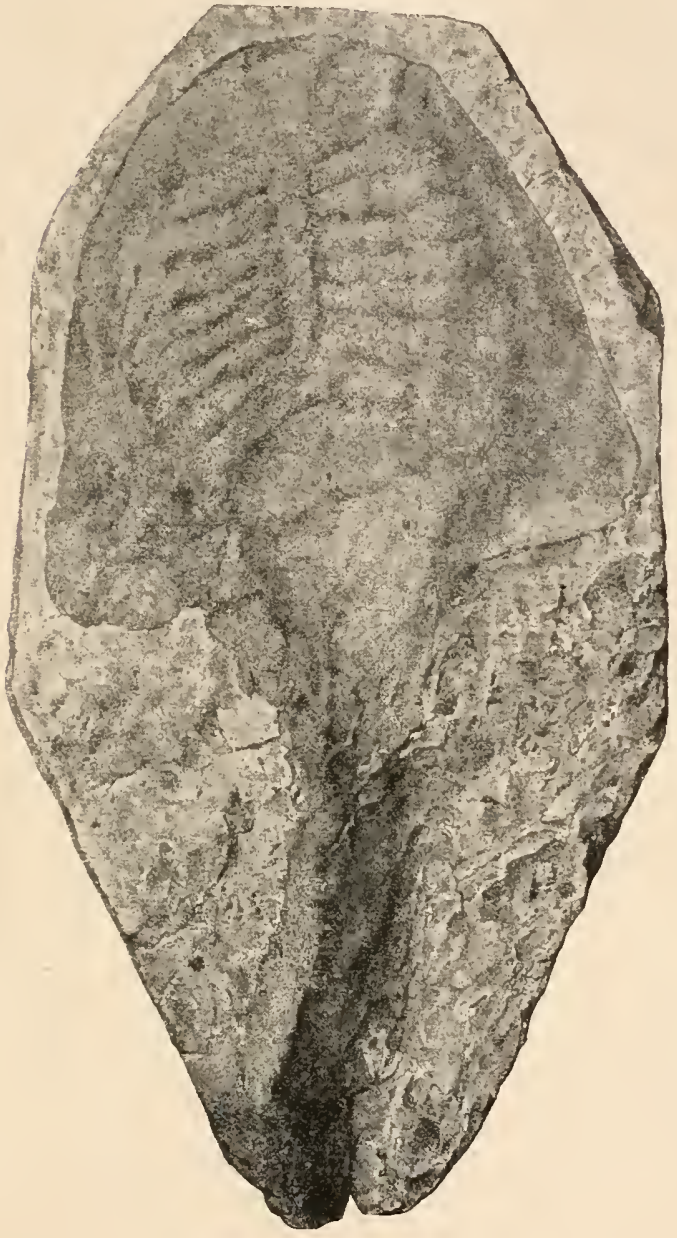

Fig. 34.

Thelodus Pagei, Powrie, aus dem unteren Old Red Sandstone von Turin Hill in Forfarshire, von der Dorsalseite, in etwa $1 / 2$ nat. Gr. (Nach R. H. Traquair:) Die Kiemenbögen haben hier eine ähnliche Anordnung wie bei Cephalaspis Murchisoni (Fig. 37).

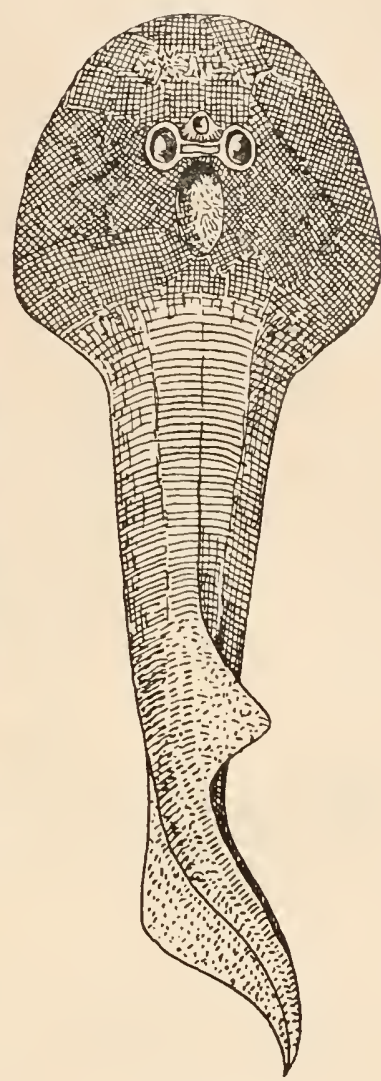

Fig. 35.

Rekonstruktion von Ateleaspis tesselata, Traquair, aus dem Obersilur (Downtonian Beds) von Seggholm und Birkenhead Burn in Schottland. (Orig.Rekonst. mit Benuitzung der Originalabbildungen sowie der Umrißrekonstruktion R. H.Traquairs, 1905.)

\section{F. Cephalaspidae.}

Alle Mitglieder dieser Familie (Ateleaspis, Aceraspis, Micraspis, Cephalaspis, Eukeraspis, Thyestes und Didymaspis) besitzen ein flaches Kopfschild, das bei den primitiveren Formen aus zahlreichen einzelnen polygonalen Plättchen besteht, die sich zu einem Mosaik zusammen- 
schlieBen (Ateleaspis, Fig. 35), während bei höher spezialisierten Formen (Cephalaspis Murchisoni, Fig. 36, A) der größte Teil dieser Schildchen zu einem einheitlichen Knochenplattenkomplex verschmolzen ist; bei Cephalaspis Lyelli ist diese Verschmelzung noch weiter vorgeschritten und das aus kleinen Mosaikplättchen bestehende hintere seitliche Abschlußfeld des Schädeldaches von Cephalaspis Murchisoni ist bei C. Lyelli zu einem, ,Horn“ des Kopfschildes geworden (Fig. 36, B). Dieses „Horn" ist bei Eukeraspis pustulifera enorm verlängert; es ist dagegen bei Thyestes (Fig. 39, 40) und Didymaspis sehr klein.

A.
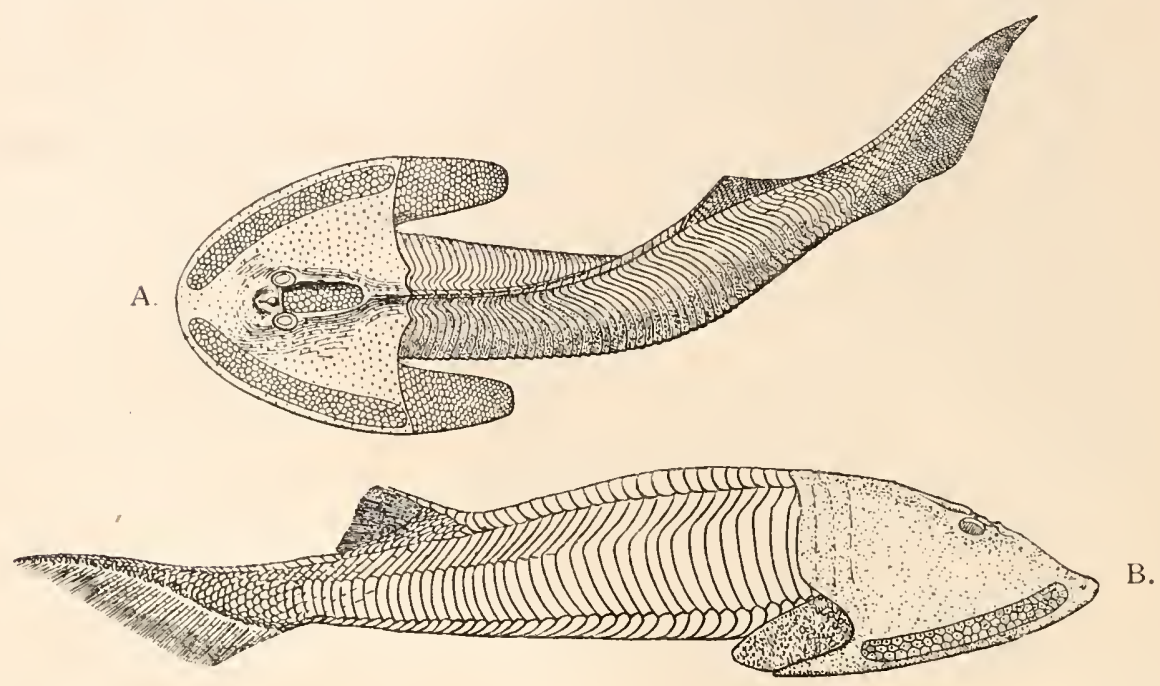

Fig. 36 .

A. Rekonstruktion von Cephalaspis Murchisoni, Egerton, aus den unterdevonischen Übergangsschichten des unteren alten Roten Sandsteins (Lower Old Red Sandstone Passage Beds) von Ledbury in Herefordshire; nach

A. Smith Woodward, 1906.

B. Rekonstruktion von Cephalaspis Lyelli, Ag., aus dem unterdevonischen Old Red Sandstone Schottlands. - Rekonst. von E. v. Stromer, 1912.

(Beide Figuren etwa in $1 / 2$ nat. Gr.)

Die beiden letztgenannten Gattungen stellen in Rahmen der Cephalaspiden einen einseitig spezialisierten Seitenzweig dar, bei dem sich die an das Kopfschild von Cephalaspis anschließenden vorderen drei bis vier Schienenschuppen zu einer Platte vereinigt zeigen, die bei Thyestes vom Kopfschild noch getrennt sein kann, aber in einzelnen Fällen mit denselben verschmilzt. Bei Didymaspis wird diese Scluienenschuppenplatte sehr groß, erreicht die Größe des Kopfschildes und erscheint mit diesem zu einem einheitlichen Gebilde verschmolzen.

Die Kopfschilder tragen sternförmige Höckerchen und erweisen sich, wie auch die besprochene Reihe von Ateleaspis bis Didymaspis 
zeigt, als Spezialisationen von Plakoidschuppen, die bei den Vorfahren als „Hautzälnne“ den Körper bedeckten (wie bei Thelodus oder Lanarkia).

Neuere Untersuchungen von A. S. Woodward (1906) über den Bau des Kopfschildes von Cephalaspis haben darüber Aufschluß gebracht $^{1}$, daß einzelne scharf abgegrenzte Abschnitte desselben aus locker zu einen Mosaik verbundenen Polygonalplatten bestehen, andere dagegen einen durch Verschmelzung solcher Platten entstandenen kompakten Schild darstellen. Diese Verschmelzung trat dort ein, wo die unter dem Panzer liegenden Weichteile nicht in beständiger Bewegung waren, während über den Kiemenspalten die Platten ein loses Mosaik bildeten, das bei der Fossilisation häufig verloren ging. Solche Mosaikfelder

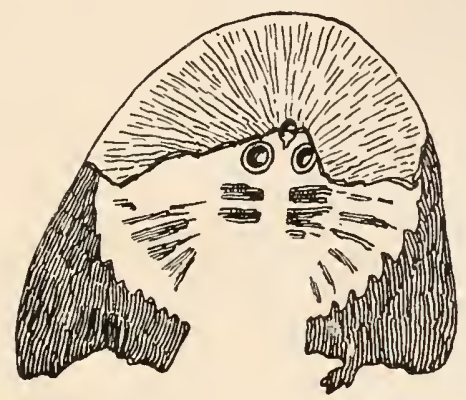

Fig. 37.

Kopfschild eines Cephalaspis Murchisoni Lank. aus dem Unterdevon Englands (Original im Museum für Naturkunde in Berlin) mit den deutlich erkennbaren Resten der Kiemenbögen und den Ausschnitten der Kiemenlöcher, von oben gesehen. $3 / 4$ nat. Gr. (Nach O. Jaekel, 1903).

Die Kiemenöffnungen liegen nicht auf der Dorsal-, sondern auf der Ventralseite des Kopfschildes. Die dunkel schraffierten, dreieckigen Lateralplatten sind die beiden ventralen Seitenschilder des Kopfpanzers, die sichtbar sind, weil der Dorsalschild hier abgebrochen ist.

begleiten bei Cephalaspis Murchisoni (Fig. 36, A) als ein breites Band den Außenrand des Kopfschildes, bilden die hinteren „Hörner" und finden sich außerdem in der Medianlinie hinter den einander stark genäherten Augen, wo sie eine muldenförmige Vertiefung (,postorbital valley", Lankester) ausfüllen. O. Jaekel hat (1903) die Frage aufgeworfen, ob dieses hinter den Augen gelegene vertiefte Feld nicht mit der ,Fossa rhomboidalis" oder "Rautengrube" des Gehirndaches höherer Wirbeltiere in Beziehung zu bringen wäre.

1 A. S. Woodward, The Study of Fossil Fishes. - Presidential Adress of the Geologists Association, London; Proc. Geol. Assoc., X1X., Parts 7 and 8, 1906 , pag. 268, fig. 2. 
Die morphologische Bedeutung der Gruben und Aufwölbungen in der Umgebung der Augenhöhlen ist noch unsicher. Die vor den Augen liegende unpaare mediane Grube ist vielleicht am ehesten (nach $\mathrm{O}$. Ja ekel, 1903) als die Öffnung für ein unpaares Riechorgan aufzufassen.

Die Lage der Kiemenbögen sowie die Querschnitte der Kiemenlöcher sind bei Cephalaspis Murchisoni (Fig. 37) einwandfrei beobachtet worden. Ihre Lage stimmt mit den Verhältnissen von Cyathaspis und mit den auf der Ventralseite des Kopfschildes von Eukeraspis gelegenen randlichen Kiemengruben durchaus überein. Ebenso sind die Öffnungen,

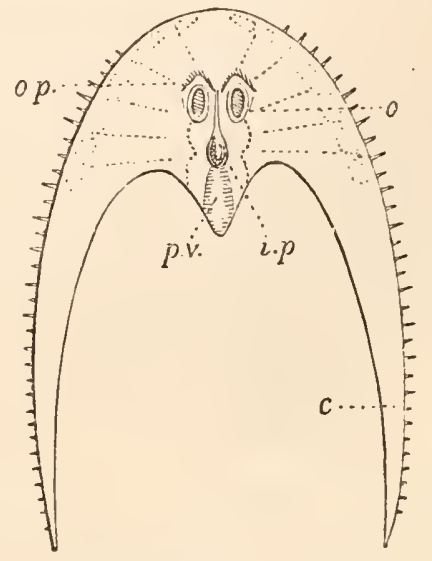

Fig. 38.

Rekonstruktion des Kopfschildes von Eukeraspis pustulifera, Ag., aus dem Obersilur von Ludlow in England. (Nach R. Lankester.)

$O$. $=$ Orbita.

o. $p .=$ Wulst vor der Orbita.

$i . p$. $=$ Wulst hinter den Augenhöhlen in der Mittellinie.

p. $u^{\prime}=$ mediane Furche.

c. $=$,Seitenhorn".

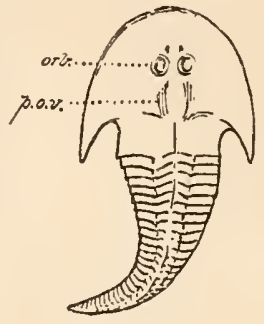

Fig. 39.

Thyestes Egertoni, aus dem unteren Teil des Old Red Sandstone von Herefordshire, England. Nat. Gr.

(Nach A. S. Woodward.)

orb. = Orbita,

p. o. v. = postorbitale Mulde.

die sich in bogenförmiger Reihe auf der Ventralseite des Kopfpanzers von Tremataspis (Fig. 41) finden, zweifellos als die Kiemenlöcher anzusehen.

Die Knochenplatten des Kopfschildes sind aus mehreren Schichten aufgebaut; die äußere Schicht, welche mit glänzenden Höckerchen ornamentiert ist und daher ein schmelzartiges Aussehen zeigt, besteht aus einer Modifikation des Dentins (Kosmin); die mittlere Schicht wird von einer grobzelligen, maschig strukturierten Osteodentinschichte, die unterste von einer dicliteren Dentinschicht mit zahlreichen Knochenkörperchen gebildet.

Die ersten Cephalaspiden erscheinen in Obersilur, die letzten verschwinden bereits im unteren Devon. 
Ateleaspis (Fig. 35). - Obersilur (Downtonian) von Seggholm in Schottland (A. tesselata, Traquair). ${ }^{1}$

Aceraspis. - Obersilur (Downtonian) Norwegens (A. robustus, Kiaer). - Eine Zwischenform zwischen Ateleaspis und Cephalaspis. Kopfschild mit breiten, biegsamen Laterallappen an Stelle der ,,Seitenhörner" des Kopfschildes von Cephalaspis Lyelli; C. Murchisoni würde zwischen dieser Art und Aceraspis ein Übergangsstadium bilden. Zwei'

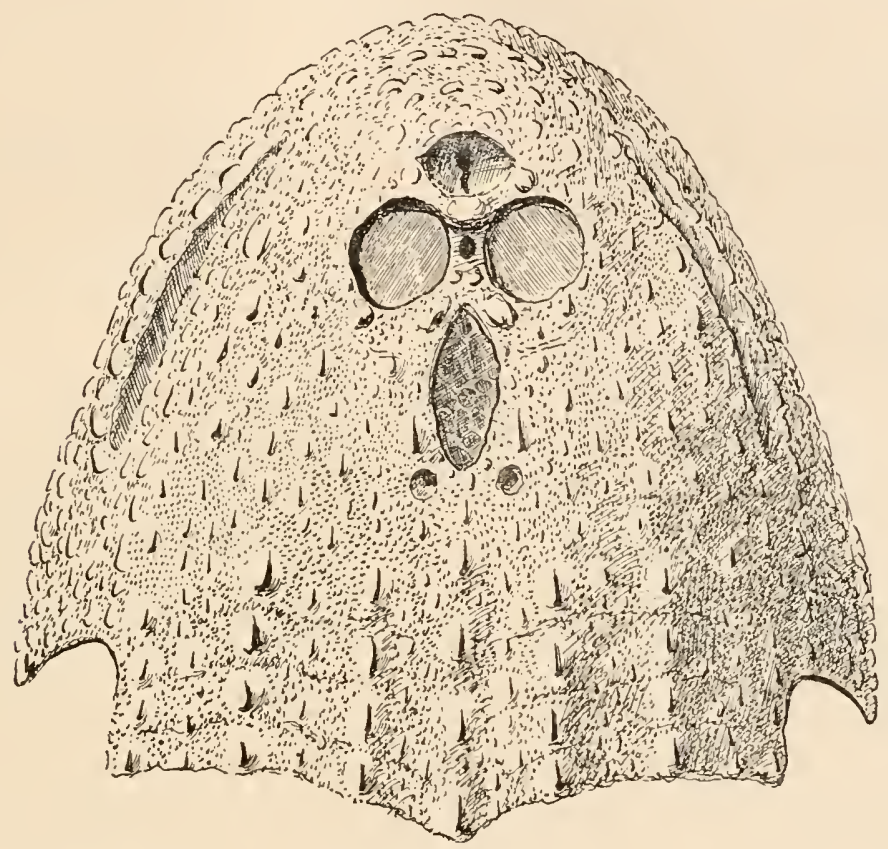

Fig. 40.

Rekonstruktion des Kopfschildes von Thyestes verrucosus, F. Schmidt, aus dem Obersilur von Oesel, etwa $4 / 1$ nat. Gr. (Nach O. Jaekel.)

Dorsalflossen vorhanden. Mehrere gut erhaltene Exemplare und viele mangethaft erhaltene Reste aufgefunden, aber noclı nicht näher beschrieben. ${ }^{2}$

Micraspis. - Obersilur (Downtonian) Norwegens (M. gracilis,

1 R. H. Traquair, Report on Fossil Fishes collected by the Geological Survey of Scotland in the Silurian Rocks of the South of Scotland. Transactions of the Royal Soc. Edinburgh, Vol. XXXIX. Part III. 1899, p. 834. - Supplementary Report, et' Ibidem. Vol. XL, Part IV, 1905, p. 883.

$2 \mathrm{~J}$. Kiaer, A New Downtonian Fauna in the Sandstone Series of the Kristiania Area. A Preliminary Report. Skrifter utgit av Videnskapsselskapet i Kristiania, 1911, I. Mat.-Nat. Kl., I. Bd., 1912, p. 16. 
Kiaer). ${ }^{1}$ Zwei Dorsalflossen; Seitenhörner nicht ausgebildet, an ihrer Stelle isolierte, biegsame Lappen entwickelt. Schwanzflosse heterozerk, sehr lang.

Ceplialaspis (Fig. 36, 37). - Von Obersilur bis zum Unterdevon (Unteres Old Red)...- Schottland, England, Kanada. Wichtigste Arten: C. Murchisoni, C. Lyelli. Bei der größten Art (C. magnifica, aus den Caithness flagstones Schottlands) erreichte der Kopfschild eine Länge voll $22 \mathrm{~cm} .^{2}$

Eukeraspis (Fig. 38). - Obersilur und unterstes Devon von Ludlow (E. pustulifera). ${ }^{3}$

Thyestes (= Auchenaspis) (Fig. 39, 40). - Obersilur von Ösel (Th. verrucosus) und Grenzschichten vom Obersilur zum Devon (Passage-Beds) in Schottland (Th. Egertoni). ${ }^{4}$

Didymaspis. - Obersilur Schottlands. ${ }^{5}$

\section{F. Tremataspidae.}

Von dieser merkwürdigen Gruppe ist nur eine Art, Tremataspis Schrencki, aus dem Obersilur der Insel Ösel bekannt. Der Vorderteil des Körpers ist in eine Knochenkapsel eingeschlossen, die dorsoventral abgeplattet ist; die Dorsalfläche der Kapsel besteht aus einem großen Schild, der an den Cephalothorax gewisser Krustazeen erinnert, mit

1 Skrifter utgit av Videnskapsselskapet i Kristiania, 1911, I. Mat.-Nat. KI., 1. Bd., 1912, p. 17.

2 E. R. Lankester, A Monograph of the Fishes of the Old Red Sandstone of Britain: Part I: The Cephalaspidae. Monographs of the Palaeontographical Society, London, Vol. XXI, 1867 und XXIII, 1869.

W. Patten, On the Structure of the Pteraspidae and Cephalaspidae. American Naturalist, Vol. XXXVII, 1903.

A. Smith Woodward, Catalogue of the Fossil Fishes in the British Museum. Vol. II, 1891, p. 177.

E. S. Goodrich, Vertebrata Craniata; in: Ray Lankester: A Treatise on Zoology, Part IX, London, 1909, p. 200.

M. Leriche, Contribution a l'Étude des Poissons fossiles du Nord de La France et des Régions voisines. Mémoires de la Soc. Géol. du Nord. T. V, 1906, p. 37.

T. W. Bridge, Fishes. The Cambridge Natural History, Vol. VII, 1904, p. 529.

A. Smith Woodward, The Study of Fossil Fishes. Proceedings of the Geologists Association, Vol. XIX, 1906, p. 268.

O. Jaekel, Tremataspis und Pattens Ableitung der Wirbeltiere von den Arthropoden. Zeitschrift Deutsch. Geol. Ges., 1903, p. 91 (Juliprotokoll).

${ }^{3}$ E. Ray Lankester, 1. c.

${ }^{4}$ F. Sclımidt, Über Thyestes verrucosus Eichw. und Cephalaspis Schrenckii Pand., nebst einer Einleitung ïber das Vorkommen silurischer Fischreste auf der Insel Ösel. Verhandl. Kais. Russ. Mineralog. Ges. St. Petersburg, (2), Vol. I, 1866, p. 217.

A. S. Woodward, Outlines of Vertebrate Palaeontology, London 1898, p. 11.

O. Jaekel, Die Wirbeltiere. Berlin, 19I1, p. 35.

5 E. Ray Lankester, I. c. 
denen Tremataspis von W. Patten ${ }^{1}$ in Beziehungen zu bringen versucht wurde, was aber einmütige Ablehnung gefunden hat. Der Kopfschild trägt zwei Augenöffnungen von ähnlicher Form und Lage wie die Cephalaspiden; zwischen den Augenhöhlen liegt ein kleines, loses, in der Mitte von der Epiphysenöffnung (Epidyse) durchbohrtes Plättchen, vor den Augen eine mediane Grube, die einer medianen Nasenöffnung entsprechen dürfte und deren Boden eine schlitzförmige, mediane Spalte aufweist. Hinter den Augenhöhlen liegt eine ovale Grube mit spongiösem

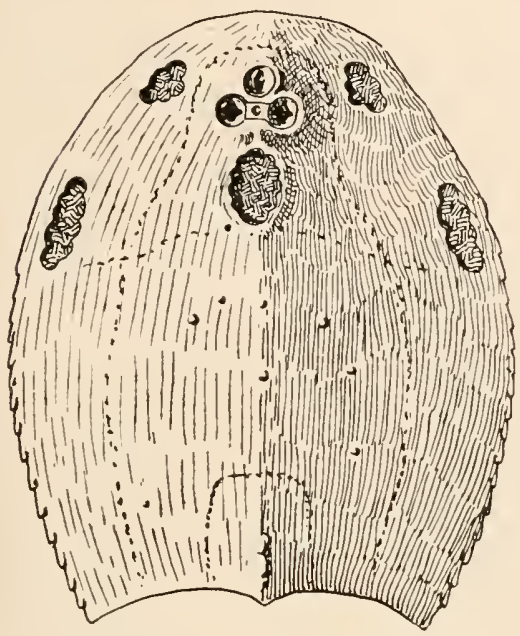

A.

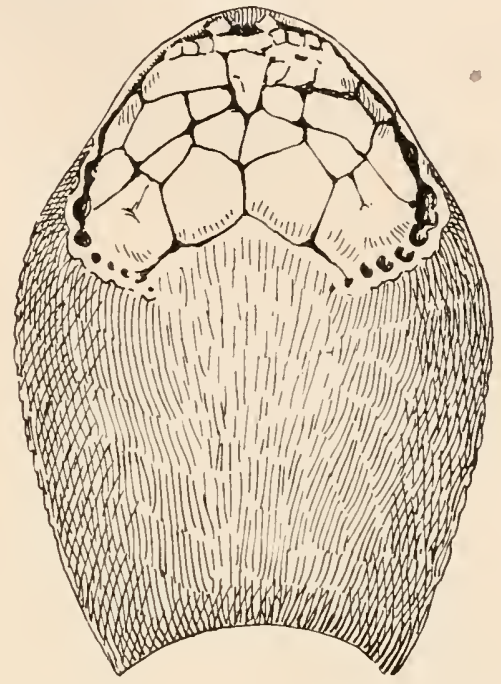

B.

Fig. 41 .

Panzer von Tremataspis Schrencki, Schmidt, aus dem Obersilur von Rootzikuill auf der Insel Ösel, in $3 / 2$ nat. Gr. A Oberansicht, B Ventralansicht des Panzers. (Nach O. Jaekel.)

Boden und nahe dem Seitenrand beiderseits je zwei unregelmäßig umgrenzte. Öffnungen, deren Boden gleichfalls spongiöse Beschaffenheit zeigt. Die Deutung dieser fünf Gruben mit spongiösem Boden ist ganz unsicher. O. Jaekel${ }^{2}$ hielt die Seitenlöcher für Durchtrittsstellen von Tentakeln, was aber ebenso unwahrscheinlich ist wie die Deutungen Pattens; dagegen hat die Deutung Rohons ${ }^{3}$ der beiden hinteren

$1 \mathrm{~W}$. Patten, On the Structure and Classification of the Tremataspidae. Mém. Acad. Sci. St. Pétersbourg, (8), Vol. XIII, 1903, p. 26. Derselbe, On the the Appendages of Tremataspis. American Naturalist, Vol. 37, 1903.

2 O. Jaekel, Tremataspis und Pattens Ableitung der Wirbeltiere von Arthropoden. Juliprotokoll d. Zeitschr. d. Deutschen Geol. Ges., 1903, p. 84.

3 J. V. Rohon, Die obersilurischen Fische von Ösel. Part I. Mémoires Acad. St. Pétersbourg, (7), Vol. XXXVIII, 1892, p. I; Part II, ibidem, (7), Vol. XLI, I893, p. 1. 
Öffnungen als Spiracula die größte Wahrscheinlichkeit für sich. Die Seitenränder sind vorn scharf, hinten zackig; die Ventralseite der Kopfkapsel trägt einen Kranz kleiner Öffnungen, deren Lage mit großer Wahrscheinlichkeit darauf schließen läßt, daß es sich um Kiemenöffnungen handelt. Der von ihnen umschlossene Vorderteil des Ventralschildes besteht aus polygonalen, lose aneinandergefügten Platten, den Oralplatten, die bis zur Mundspalte reichen, welche auf der Ventralseite liegt.

Die Augen sind, wie O. Jaekel zeigte, von zarten Sklerotikalplatten an den Rändern bedeckt gewesen, und zwar scheinen je vier solcher Plättchen vorhanden gewesen zu sein.

Das Kopfschild ist von zarten Schleimkanälen durchzogen, deren Verlauf nicht genau feststeht. Ihr wahrscheinlicher Verlauf ist in der beigegebenen Skizze (Fig. 41, A) durch punktierte Linien angedeutet.

Wie der hintere Teil des Körpers beschaffen war, ist ganz ungewiß. An ehesten werden wir an eine Körperform zu denken haben, wie sie Drepanaspis zeigt.

Das Tier ist jedenfalls ein benthonischer Meeresbewohner gewesen.

Tremataspis (Fig. 41). - Obersilur von Ösel (T. Schrencki).

\section{F. Drepanaspidae.}

Im unteren Devon von Gemünden in Rheinpreußen sind zahlreiche Reste von.Panzerfischen gefunden worden, die zwar flachgedrückt und durch den Gebirgsdruck stark verzerrt sind, aber doch die Einzelheiten ihres Außenskeletts sehr deutlich erkennen lassen. R. H. Traquair hat diese Fische (Drepanaspis gemündenensis, Schlüter, 1887) sehr eingehend beschrieben und rekonstruiert. ${ }^{1}$ Sie sind die einzigen bisher bekannten Vertreter der nach ihnen benannten Familie der Drepanaspiden.

Der Körper (Fig. 42, 43) ist in einen vorderen, größeren, dorsoventral stark komprimierten Kopf-Rumpfabschnitt und in einen hinteren Schwanzabschnitt getrennt. Der vordere Abschnitt ist in einen Panzer eingeschlossen, der aus einzelnen großen Knochenplatten mit dazwischenliegenden kleineren Platten besteht; die kleineren Platten bilden ein unregelnäßiges Mosaik. Alle Platten sind mit sternförmigen Höckerchen besetzt, ein Beweis dafür, daß sie aus der Verschmelzung von ursprünglich einzelnen Hautzähnen (Plakoidschuppen) hervorgegangen sind. Der Sclıwanz trägt dreieckige, nach hinten spitz zulaufende und sich dachziegelförmig deckende, skulpturierte Schuppen, deren Größe im Bereiche der relativ großen und breit dreieckigen Terminalflosse stark abnimmt; die Mittellinie des schuppentragenden Abschnittes ist

1 R. H. Traquair, The Lower Devonian Fishes of Gemünden. Transactions Royal Soc. Edinburgh, XL, Part 4, Nr. 30, 1903, p. 725 . Ibidem (Supplement), XLI, Part 2, Nr. 20, 1905, p. 469. 


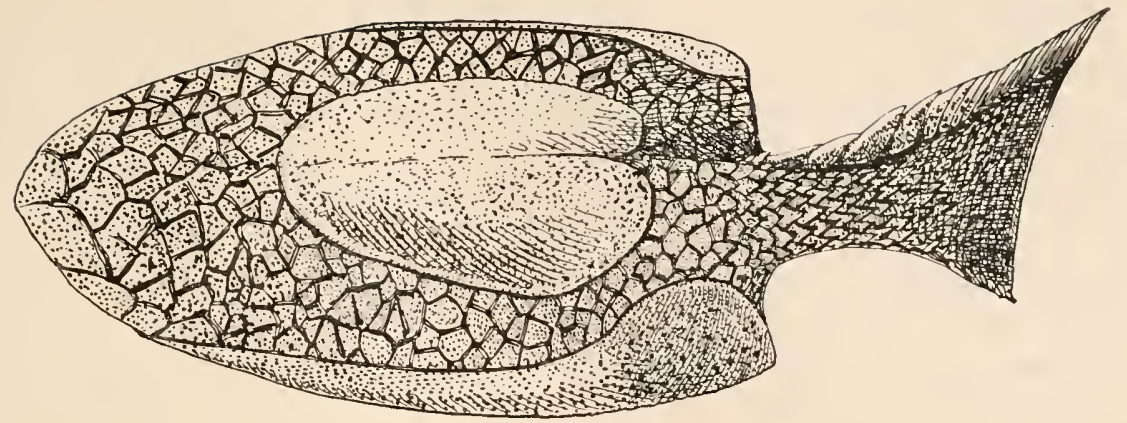

Fig. 42.

Rekonstruktion von Drepanaspis Gemündenensis, Schlüter, aus dem Unterdevon von Gemünden in Rheinpreußen, in etwa $1 / 5$ nat. Gr.; Ansicht schräge
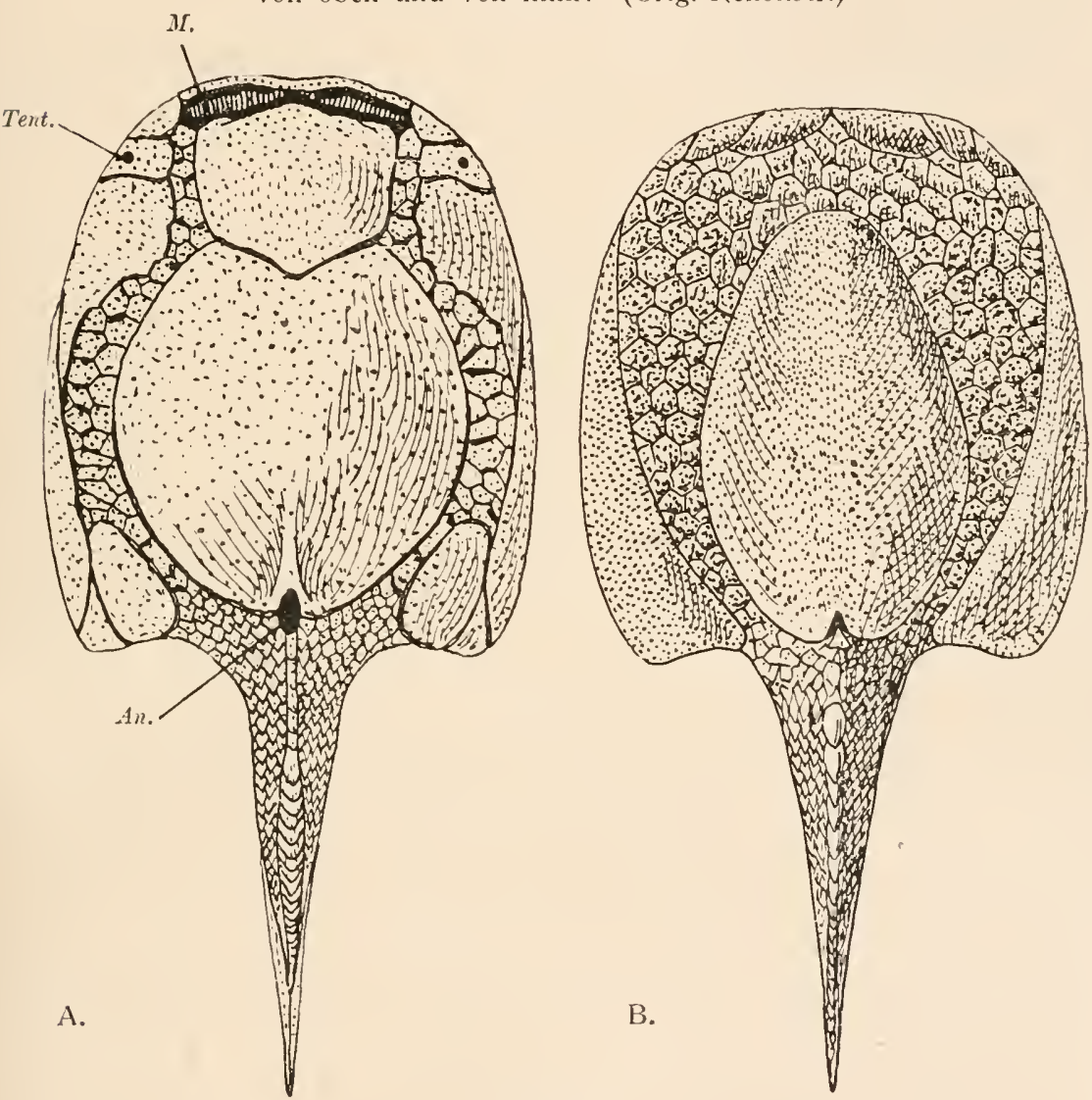

Fig. 43.

Rekonstruktion von Drepanaspis Gemündenensis, Schlïter, aus dem Unterdevon von Gemiunden in Rheinpreußen. A von der Unterseite, B von der Oberseite in ungefähr $1 / 5$ nat. Gr. (Rek. auf Grundlage der von R. H. Traqua ir mitgeteilten Photographien und Zeichnungen.)

M. = Mundspalte. An. = Afteröffnung. Tent. = Tentakelöffnung. (Die Augenhöhlen sind gänzlich obliteriert.) 
oben und unten mit stark entwickelten Firstschuppen (Fulkren) besetzt. Paarige Gliedmaßen oder paarige Flossen fehlen ebenso wie die Rücken- und Afterflossen. Die ventral gelegene Mundspalte ist breit, transversal gestellt, die Afteröffnung selır klein; Augenhöhlen fehlen gänzliclt, so daß Drepanaspis, wie ich $1908^{1}$ zeigte, blind gewesen sein 1muß. Die beiden kleinen Öffnungen, je eine seitlich und hinter dem Mundwinkel gelegen, dienten wahrșcheinlich zum Durchtritt von Tentakeln.2

Der Fisch war zweifellos ein benthonischer Meeresbewolner und dürfte, wie aus seiner totalen Blindheit zu schließen ist, im Schlamme eingewülılt gelebt haben.

Drepanaspis. - Unterdevon von Gemünden (Rheinpreußen).

\section{F. Pteraspidae.}

Wie bei den Drepanaspiden ist nur der vordere Teil des Körpers in einen Panzer eingeschlossen, während der hintere, frei bewegliche, Schuppen trug. Die Panzerplatten sind aber nicht, wie bei den Drepanaspidcn, abwechselnd kleiner und größer, so daß die großen medianen und lateralen Schilder von einem Mosaik kleiner Platten unterbrochen erscheinen, sondern der Vorderkörper ist nur von großen Platten eingeschlossen, die aus drei übereinander liegenden Schichten o hne Knochenzellen bestehen. Die Mittelschicht der Panzerplatten des Vorderkörpers besteht bei Pteraspis aus einem grobmaschigen Geflecht von Säulen und Blättern aus phosphorsaurem Kalk; die äußere, härtere Rindenschicht bestelıt aus Vasodentin, die innerste aus dünnen Lamellen von phosphorsauren Kalk. Diese Struktur der Platten des Vorderkörpers der Pteraspiden ist eine unter den Fischen einzig dastehende Erscheinung.

Die Mittelschicht der Panzerplatten . muß von Hautsinnesorganen durchsetzt gewesen sein, die in doppelten Porenreihen ausmünden, welche zueinander parallel verlaufen und makroskopisch als feine Streifen erscheinen. Außerdem wird die Oberfläche der größeren Platten von Schleinkanälen durchzogen, die M. Leriche ${ }^{3}$ auf der ntedianen Rückenplatte von Pteraspis Crouchi Lank. aus Nordfrankreich genau verfolgen konnte.

Der Vorderkörper läuft mitunter in ein langgestrecktes, schmalkegelförmiges Rostrum aus; am Hinterrande des Rückenschildes findet

1 O. Abel, Bau und Geschichte der Erde. Wien und Leipzig, 1909, ए. 97.

L. Dollo, La Paléontologie éthologique. Bull. Soc. Belge Géol. etc., XXIII, Bruxelles 1909, Mémoires, p. 393.

2 O. Abel, Palälobiologie der Wirbeltiere. 1912, p. 438.

${ }^{3}$ M. Leriche, Contribution a l'Étude des Poissons fossiles du Nord de La France. I. c., 1906, p. 30. 
sich bei Pteraspis (mit Ausnahme von P. Gosseleti) em beweglicher, medianer Rückenstachel eingelenkt. Ob sich eine Rückenflosse daran schloß, ist ungewiß. Vom Hinterkörper ist nur der vordere Teil besser erhalten, der mit rlombischen Schuppen besetzt war. Die Augenhöhlen waren bei Pteraspis sehr klein, bei Cyathaspis etwas größer, und standen seitlich. Diese Augenstellung in Verbindung mit der allgemeinen Gestalt des Vorderkörpers beweist, daß Pteraspis und die übrigen Gattungen dieser Familie keine schwerfälligen Bodenbewohner wie die Drepanaspiden waren, sondern ein höheres Maß von Beweglichkeit besessen haben müssen.

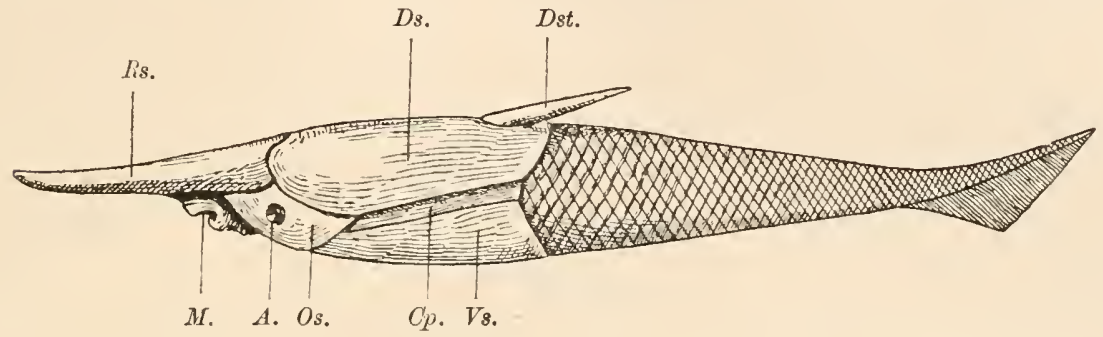

Fig. 44 .

Rekonstruktion von Pteraspis Crouchi, Lank., ats dem Unterdevon Nordfrankreichs und Englands, von der Seite gesehen, in $2 / 3$ nat. Gr. (Orig.-Rek. auf Grundlage der Abbildungen von A. Smith Woodward, R. H. Traquair und $M$. Leriche und tunter Benuitzung der von $M$. Leriche veröffentlichten Photographien der Originale.)
$M$. = Mundöffnung.
$V s .=$ Ventralschild.
A. $=$ Atıge.
Ds. $=$ Dorsalschild .
Os. = Augenschild.
Dst. $=$ Dorsalstachel.
$C p$. $=$ Cornutalschild.
Rs. = Rostrum.

Indessen spricht der Besitz des Rostrums dafür, daß z. B. Pteraspis Crouchi (F.g. 44, 45) eine bodenbewohnende Type war, die ihr Rostrum zum Aufstöbern der Beutetiere verwendete. Der Schwanz ist unbekannt, aber das Vorhandensein einer Schwanzflosse ist als wahrscheinlich anzunehmen. Von paarigen Flossen ist keine Spur vorhanden.

Pteraspis (= Palaeoteuthis, Archaeoteuthis, Scaphaspis) (F g. 44 bis 47). - Obersilur von England, Polen, Galizien, Schweden, Spitzbergen, Petschoraland, Nordamerika; Unterdevon von England, Schottland, Nordfrankreich, Belgien, Nordwestdeutschland (Eifel), Galizien. Von dieser weitverbreiteten Gattung werden zahlreiche Arten unterschieden (am besten bekannt Pteraspis Crouchi Lankester und Pt. rostrata Ag. aus dem Unterdevon Großbritanniens und Nordfankreichs). ${ }^{1}$

1 Ibidem (ausführliche Literatur über Cyathaspis, Pteraspis, etc.).

R. H. Traquair, Report on Fossil Fishes collected by the Geological Strvey 
Pteraspis Gosseleti Leriche (Fig. 46) aus dem Obersilur Englands besaß ein kurzes Rostrum, P. rostrata Ag. (Fig. 47) ein längeres, das längste P. Crouchi Lank. (Fig. 44, 45). Die Funktion des Rostrums dürfte wohl dieselbe wie bei rostrumtragenden, benthonischen Haifischen gewesen sein.

Der Panzer des Vorderkörpers bestand außer dem Rostrum und denn Dorsalstachel (der bei P. Gosseleti fehlt) noch aus einer großen medianen Dorsalplatte, einer ovalen medianen Ventralplatte, zwei von den Augenhöhlen durchbohrten Augenplatten und beiderseits je einer schmalen „Cornutalplatte“ (F“g. 44, Cp) zwischen dem Rückenschild uncl Bauchschild. Diese Cornutalplatte ist bei P. rostrata und P. Gosseleti im hinteren Teile von einem schrägstehenden Schlitz (Fig. 46, $S p$ ) durchbohrt, der als Austrittsstelle des Wassers bei der Kiemenatmung (also als Kiemenöffnung) gedeutet wurde. Diese Öffnung fehlt aber bei P. Crouchi vollkommen, wodurch bewiesen ist, daß sie nicht mit den Kiemenöffnungen identisch sein kann. Das Wasser muß aus den Kiemen an der Grenze zwischen dem Dorsalschilde und den Cornutalplatten ausgetreten sein, da die Richtung der Kiemenbögen von Cyathaspis integer (Fig. 48) gegen den Außenrand des Dorsalschildes gerichtet ist. Jedenfalls ist der Dorsalschild gegen die Cornutalplatten beweglich gewesen. Die Mundteile standen auf der Unterseite der Rostralplatte in einem zienlich großen Ausschnitt derselben. Löcher zum Durchtritt von Tentakeln, wie sie bei Drepanaspis zu beobachten sind, fehlen den Pteraspiden.

Die Spalte in den Cornutalplatten von Pteraspis rostrata und P. Gosseleti (Fig. 46 ı. 47) dürfte mit der Bewegungsfähigkeit der Platten gegeneinander zusammenhängen.

Paarige Flossen fehlen gănzlich. Im vorderen Teile des Hinterkörpers, knapp hinter dem Panzer des Vorderkörpers, sind rhombische Schuppen beobachtet worden, die wahrscheinlich den ganzen Hinterkörper bedeckten.

Palaeaspis (= Holaspis). - Eine Art im unteren Old Red Sandstone von Monmouthshire in Schottland und eine zweite Art aus dem Orerslur (Onondaga Group) von Pennsylvanien sind nur aus isoliurten Dorsalschildern bekannt, an deren Unterrändern die Augen-

of Scotland in the Silnrian Rocks of the South of Scotland. Transactions of the Roy. Soc. Edinburgh, Vol. XXXIX, 1899, p. 849. (Ausfiilhrliche Literatur.)

A. voul Alth, Über die paläozoischen Gebilde Podoliens and deren Versteinerungen. Abhandlmngen der K. K. Geologischen Reichsanstalt in Wien, VII. Bd., 1874, p. 1 .

Derselbe, Über die Zusammengehörigkeit der den Fischgattungen Pteraspis, Cyathaspis und Scaphaspis zugeschricbenen Schilder. Beiträge zurr Paläontologie und Geologie Österreich-Ungarns und des Orients, 11I. Bd., 1886, p. 61. 


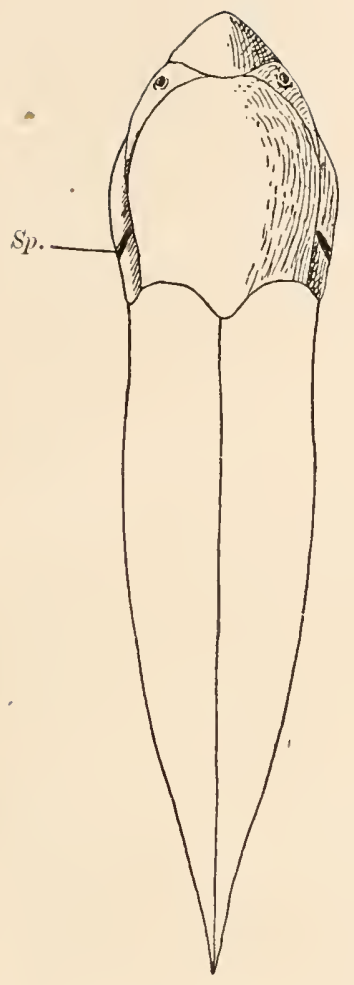

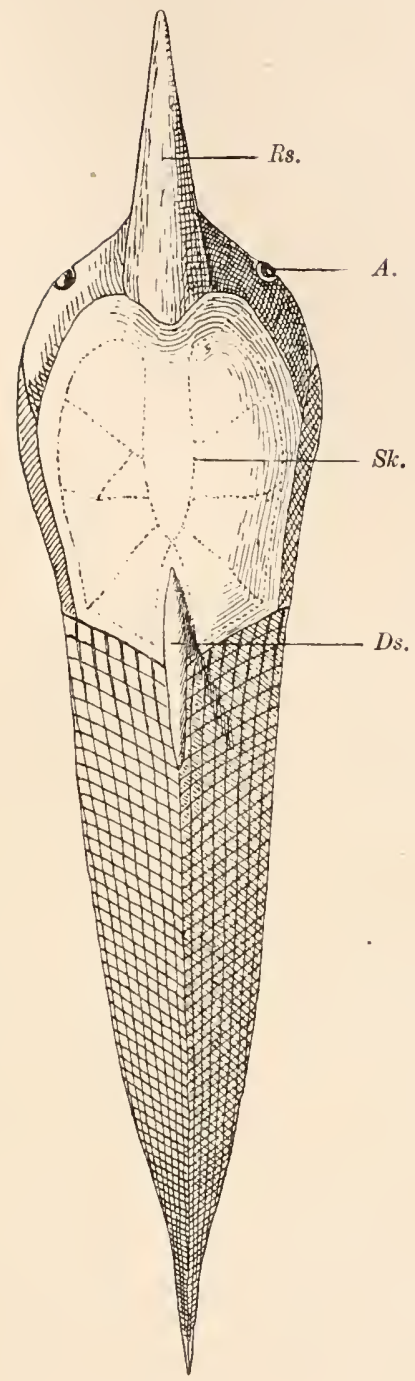

Fig. 45 .

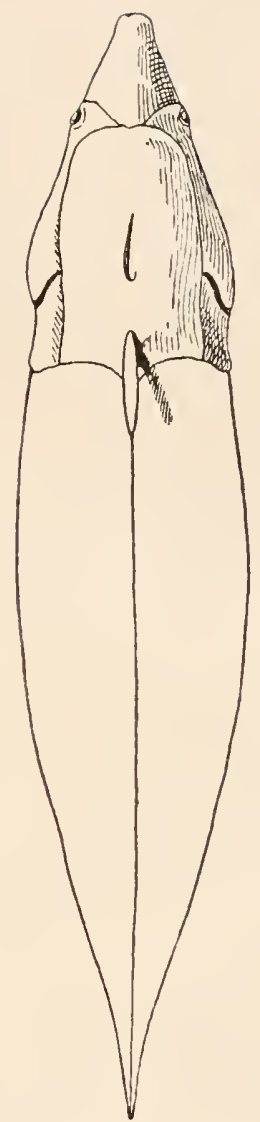

Fig. 47.

Fig. 46.

Fig. 45. Rekonstruktion von Pteraspis Crouchi, Lank., aus dem Unterdevon Nordfrankreichs und Englands, von oben gesehen.

Fig. 46. Rekonstruktion von Pteraspis Gosseleti, Leriche, aus dem Obersilur Nordfrankreichs, von oben gesehen.

Fig. 47. Rekonstruktion von Pteraspis rostrata, Ag., aus dem Unterdevon Belgiens, Englands und Nordfrankreichs, von oben gesehen. (Alle 3 Figuren sind Orig.-Rekonstr. in $\%$ nat. Gr.)

$A .=$ Auge. $R s .=$ Rostrum. $S k$. = Schleimkanäle.

Ds. = Dorsalstachel. $S p .=$ Schlitz in der Cornutalplatte. 
höhlen stehen. Dorsalstacheln fehlen. ${ }^{1}$ Die Annahme Claypoles ${ }^{2}$ von dem Vorhandensein paariger Flossen bei Palaeaspis beruht, wie

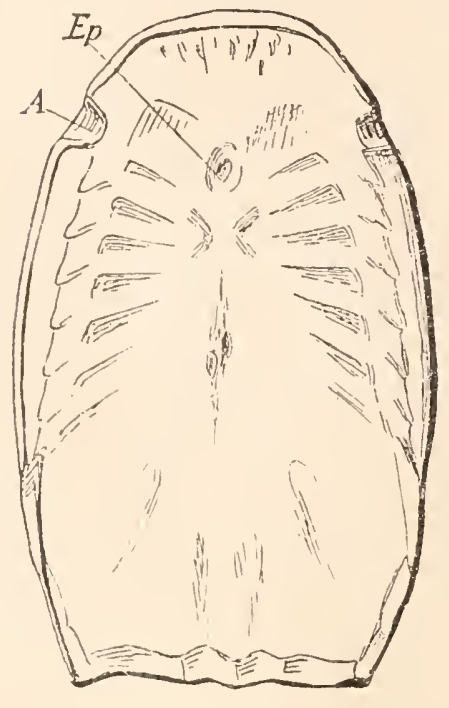

Fig. 48.

Innenfläche des Kopf- und Rückenpanzers von Cyathaspis integer, Kunth, aus dem obersilurischen Wenlockkalk (Moränengeschiebe) von Erkner bei Berlin, $3 / 2$ nat. Gr. (Nach O. Jaekel.) A. $=$ Augenhöhle. E. = Epiphysenloch. O. Jaekel ${ }^{3}$, B. Dean ${ }^{4}$ und R.H.Traquair ${ }^{5}$ gezeigt haben, auf einem Irrtum.

Cyathaspis (Fig. 48). - Die Augenhöhlen sind wie bei Palaeaspis in den Unterrand der Dorsalplatte eingeschnitten, deren Innenseite die Abdrücke von sieben Paar Kiemenbögen und der Epiphyse zeigt; der Körper war walzenförmig, die Rostralplatte kurz und stumpf gerundet. Einige Arten aus dem Obersilur Englands, Gotlands, Galiziens und aus NeuBraunschweig, sowie aus dem Unterdevon Schottlands und Nordfrankreichs bekannt. Ein gut erhaltenes Exemplar von C. integer ist in einem Moränengeschiebe (obersilurischer Wenlockkalk, wahrscheinlich aus Gotland stammend) bei Berlin gefunden worden. ${ }^{6}$

\section{Unterklasse: Antiarchi.}

Im Devon von Rußland, im Old Red Sandstone Schottlands, im Devon des Rheinlandes und im Devon von Kanada sind zahlreiche Reste eigentümlich organisierter Panzerfische aufgefunden worden, deren ver-

1 E. W. Claypole, Preliminary Note on some Fossil Fishes recently discovered in the Silurian Rocks of North America. American Naturalist, Vol. XVIII, 1884 , p. 1222.

Derselbe, On the Structure of the American Pteraspidian, Palaeaspis (Claypole), with Remarks on the Family. Quart. Journal Geol. Soc., London, Vol. XLVIII, 1). 542 .

2 Ibidem, p. 560, und: Fins of Palaeaspis americana. American Naturalist, Vol. XXVII, 1893, p. 375.

${ }^{3}$ O. Jaekel, Referat iiber E. W. Claypole, op. cit.: Nenes Jahrbuch f. Mir. etc., 1894, 1I. Bd., p. 466.

B. Dean, Fishes, Living and Fossil. New York, 1895, p. 71.

5 R. H. Traquair, I. c., Transactions Roy. Soc. Edinburgh, Vol. XXXIX, 1899, p. 853.

${ }^{6}$ M. Leriche, Contribution a l'Étude des Poissons fossiles du Nord de La France. 1. c., 1906, p. 22 (Literatur). Vgl. ferner insbesondere:

G. Lindström, On Remains of a Cyathaspis from the Silurian Strata of Got- 
wandtschaftliche Beziehungen $\mathrm{zu}$ den übrigen fossilen und lebenden Fischen lange Zeit hindurch nicht erkannt worden sind und auch heute noch nicht mit voller Klarheit zutage liegen. Daß sie einem Stamm der ,Fische“ angehören-müssen, geht aus dem Besitz von Schuppen in dem hinteren Teile des fischförmigen Körpers, sowie aus der Struktur der den Vorderteil des Körpers einhüllenden Knochenplatten hervor, die als verschmolzene Zälnne Zu deuten sind und als ,,Zahnknochen“ bezeichnet werden dürfen. Einige Gattungen, wie Bothriolepis, scheinen zwar schuppenlos gewesen zu sein, schließen sich aber im Bau und in der Anordnung der Knochenplatten wie im Besitze der eigentümlich organisierten „Seitenorgane" eng an die übrigen Gattungen an, die in der Gruppe der Asterolepiden zu einer Familie vereinigt werden müssen. Die Asterolepiden werden meistens als „Ordnung" der Plakodermen oder Ostrakodermen betrachtet; O. Jaekel ${ }^{1}$ ist der Ansicht, daß diese, von Cope als Antiarcha unterschiedene Gruppe in engeren verwandtschaftlichen Beziehungen zu den Arthrodiren steht, aber es scheint sich in den übereinstimmenden Merkmalen doch nur um konvergente oder parallele Anpassungen $\mathrm{zu}$ handeln, da den übereinstimmenden Merkmalen und Ähnlichkeiten ebensoviele durchgreifende Unterschiede gegenüberstehen. Die Seitenorgane können in keiner Weise mit den paarigen Extremitäten der Elasmobranchier und der Teleostomen in Vergleich gezogen werden und haben auch keineswegs die Funktion von Ruderorganen besessen, wie in früherer Zeit vielfach angenommen wurde, sondern sic haben höchstwahrscheinlich als Fangapparate gedient, wie wir sie von den Gespenstheuschrecken oder von Squilla mantis kemnen. Die Asterolepiden sind ausnahmslos benthonische, d. 1. grundbewohnende, Tiere gewesen, wofür nicht nur die Abplattung der Ventralseite des Körpers, sondern vor allem die auf die Oberseite des Schädels verschobenen, dicht beieinander liegenden Augen spreclsen. Der Gesamthabitus der Asterolepiden bewe'st, daß sie sich nuicht nur auf dem Meeresboden aufhielten, sondern mit dem Hinterteil ihres Körpers in den Bodenschlamm einwühlten. Die Ausbildung eines starken Knochenpanzers im Vorderteile des Körpers ist wahrscheinlich als ein Schutzmittel gegen die Angriffe der verschiedenen großen räuberischen Arthropoden dieser Zeit (z. B. die großen Merostomen) anzusehen, das durch mechanische Reize entstanden und auf dem Wege der Selektion ge-

land. Bihang till Kongl. Svenska Vetenskaps-Akademiens Handlingar, Vol. XXI, 1895.

O. Jaekel, Tremataspis und Pattens Ableitung der Wirbeltiere von den Arthropoden. I. c., 1903, p. 92.

Derselbe, Die Wirbeltiere. 1. c., 1911. (Cyathaspis integer wird zu Palaeaspis gestellt, p. 32.)

1 lbidem, p. 38. 
festigt worden sein dürfte, ebenso wie bei den zahlreichen anderen Panzerfischen des älteren Paläozoikums (Drepanaspidae, Pteraspidae, Ceplaalaspidae, Tremataspidae, Coccosteidae).

\section{F. Asterolepidae.}

Knorpelskelett unbekannt, aber wahrscheinlich ausgebildet gewesen. Körper im vorderen Teile mit dicken Knochenplatten gepanzert, die sich auf der Oberseite des Schädels zu einem geschlossenen Schilde zusammensclıließen, das gegen den Rumpfpanzer an einem transversal stehenden Gelenk bewegt werden konnte (Fig. 49). In der Mitte des Schädeldaches stehen die einander sehr genäherten Augen (Fig.50-52), die durch eine oder zwei kleine Platten getrennt sind. Vor den Augen

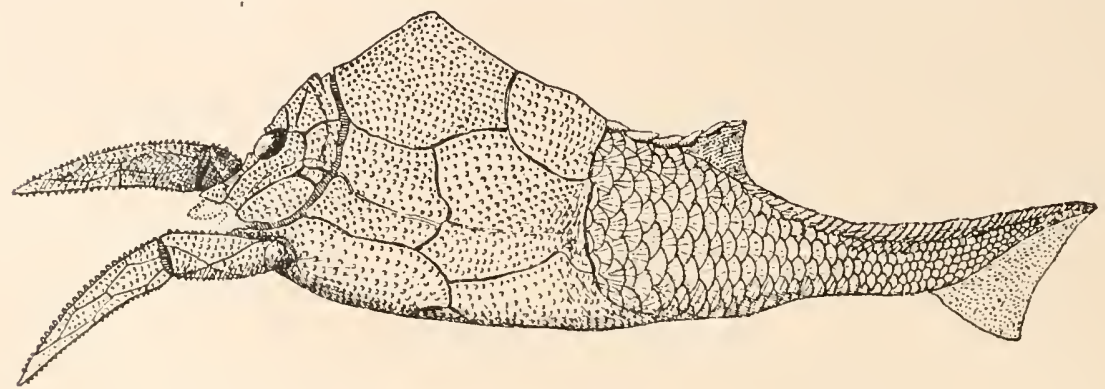

Fig. 49.

Rekonstruktion des Asterolepiden Pterichthys Milleri Ag., aus dem unteren Old Red Sandstone Schottlands. Seitenansicht in 4/s nat. Gr., auf Grundlage der Rekonstruktionen und Zeichnungen von R. H. Traquair und O. Jaekel, abgeändert von $\mathrm{O}$. Abel (1907).

liegt eine unpaare prämediane Platte, hinter ihnen eine unpaare postmediane Platte, an welche sich linten als Abschluß des Schädeldaches eine unpaare mittlere Occipitalplatte anlegt. Die Seitenteile des Schädeldaches werden von je vier Platten aufgebaut, von denen die Lateralplatte die größte ist; ihr legen sich hinten cine laterale Occipitalplatte und, weiter außen, eine Extralateralplatte an; zwischen diesen beiden Platten schiebt sich noch eine kleine Platte, die Angularplatte ein.

Das Rückenschild besteht aus einer vorderen und einer hinteren Medianplatte, von denen die vordere größer ist; seitlich von den Mittelplatten liegt beiderseits je eine vordere und hintere Seitenplatte.

Erscheint somit die Oberseite des Kopfschildes und Rückenpanzers durchaus symmetrisch gebaut, so fällt bei Betrachtung der Ventralseite des Panzers die asymmetrische Ausbildung der vier großen Ventralplatten auf, welche sich über eine kleine, rhombische Mittelplatte schieben. Der Ventralpanzer ist ein wenig länger als der Rückenpanzer.

In einem seichten Ausschnitt am Vorderrande des Ventralpanzers 
liegen bei Asterolepis und Pterichthys zwei kleine Platten, die Semilunarplatten; bei Bothriolepis ist nur eine unpaare Platte an dieser Stelle vorhanden. Vor diesen liegen die quere, ganz auf der Unterseite des Körpeṛs gelegene Mundspalte und vor ihr die paarigen Kiefer-

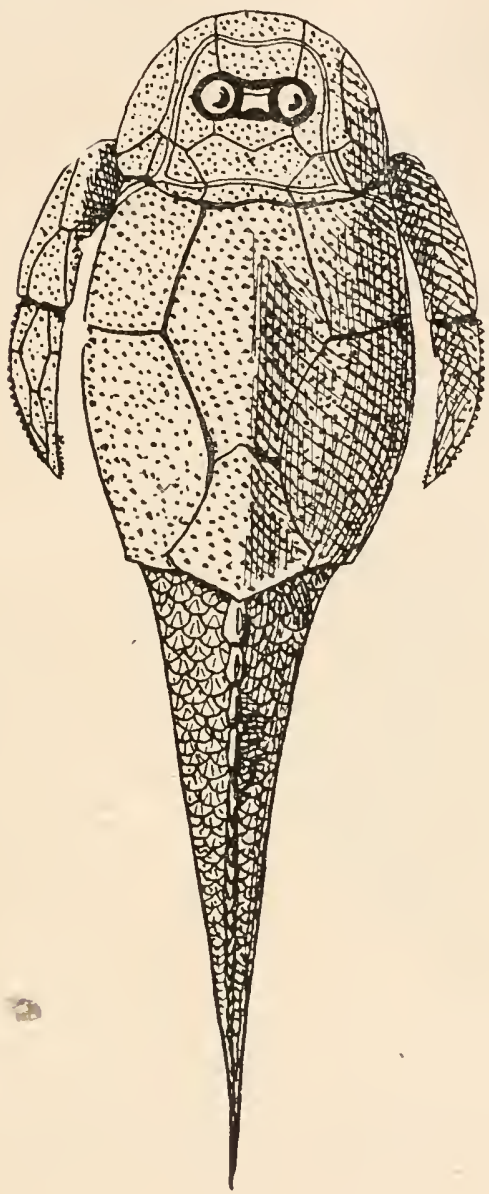

A.

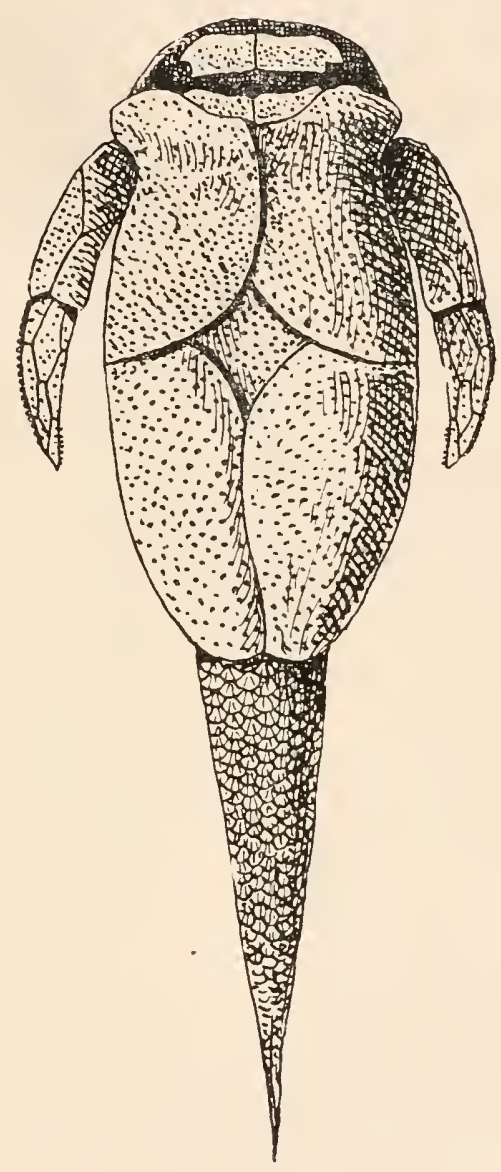

B.

Fig. 50.

Rekonstruktion von Pterichthys Milleri, Agassiz, aus dem unteren Old Red Sandstone Schottlands. A Dorsalansicht, B Ventralansicht ungefähr in natürlicher Größe. "(Nach R. H. Traquair, umgezeichnet.)

platten, die aber in keiner festen Verbindung mit dem Vorderrande des Kopfschildes stehen.

Auf der Oberseite des Schädeldaches läßt sich ein System von Seitenkanälen oder Schleimkanälen verfolgen, die sich auf die vordere und hintere Seitenplatte des Rückenschildes als „Seitenlinie" fortsetzen, wie R. H. Traquair 1904 gezeigt hat. Der Verlauf und die 
Ausbildung der Schleimkanäle unterliegt bei Asterolepis und Pterichthys einerseits und bei Bothriolepis andererseits beträchtlichen $\mathrm{Ab}$ weichungen.

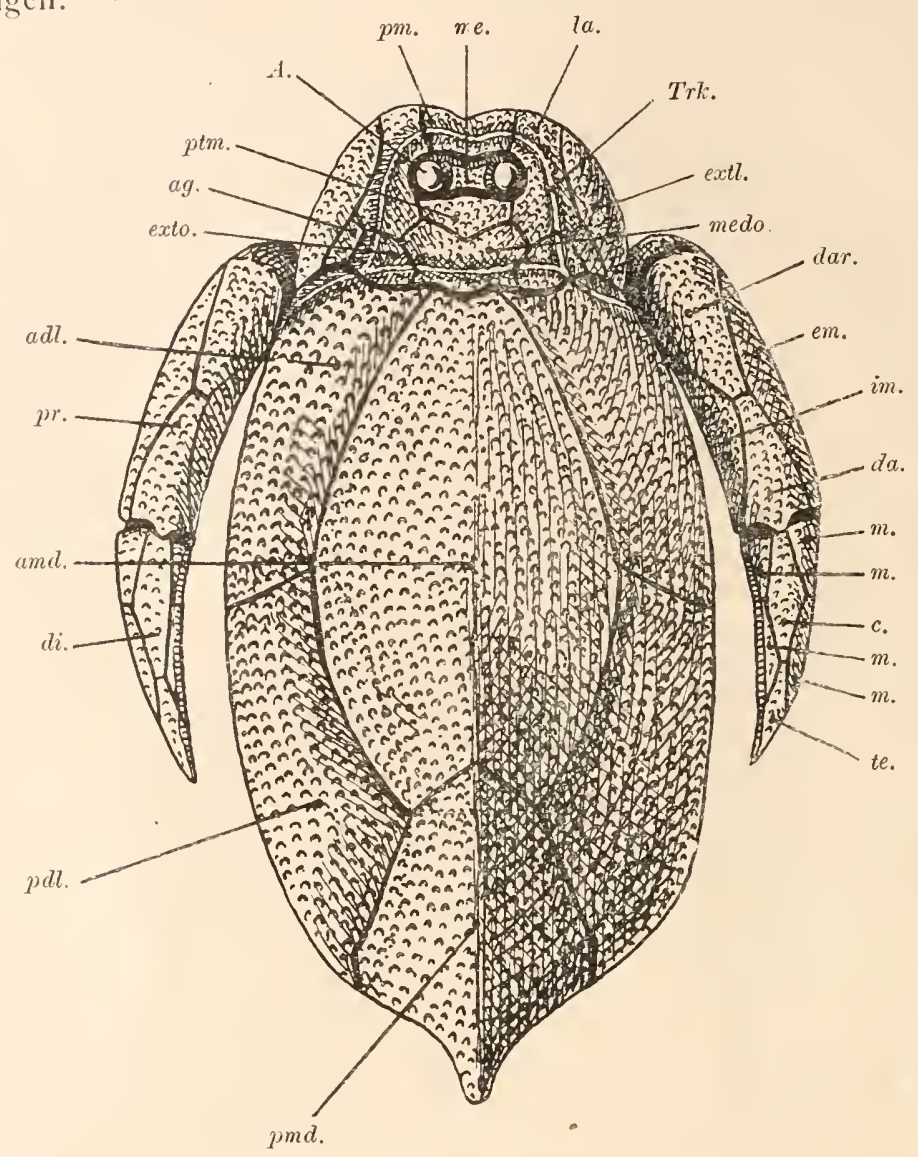

Fig. 51.

Rekonstruktion des Panzers von Asterolepis maxima, Ag., aus dem oberen Old Red Sandstone Schottlands, von oben gesehen (ungefähr $1 / 2$ nat. Gr.)

A. = Auge. $l a . \quad$ Lateralplatte.

adl. = vordere dorsale Lateralplatte. ' $m . \quad$ kleinere Deckplatten des Seiten-

ag. $=$ Angularplatte.

aind. $=$ vordere mediane Dorsalplatte.
$i . \quad$ Deckplatte des Seitenorgans.

da. $=$ Deckplatte des Seitenorgans.

dar. = Deckplatte des Seitenorgans.

di. = distales Segment des Seitenorgans.

em. - ämßere Platte des Seitenorgans.

extl. = Extralateralplatte.

exto. = Extraoccipitalplatte.

im. = innere Platte des Seitenorgans. organs.

me. = Medianplatte.

medo. = mittlere Occipitalplatte.

pm. = Prämedianplatte.

pmd. = hintere mediane Dorsalplatte.

pr. = proximales Segment des Seitenorgans.

pdl. $=$ hintere dorsale Lateralplatte.

te. $=$ Terminalplatte des Seitenorgans .

Trk. = Schleimkanal.

Das ,,Seitenorgan“ ist in einem Kugelgelenk, das als Sperrgelenk funktioniert, an der vorderen lateralen Ventralplatte eingelenkt. Es 
wird durch ein ,Ellbogengelenk" in einen proximalen und in einen distalen Abschnitt zerlegt; beide Abschnitte sind hohl und erinnern in dieser Hinsicht an die Scheren der Krustazeen. Der Panzer dieses Seitenorgans besteht aus zahlreichen kleinen Platten. Der Querschnitt des proximalen Abschnittes des Seitenorgans von Pterichthys ist dreieckig; es konnte dicht an den Körper angelegt werden und ist an dieser

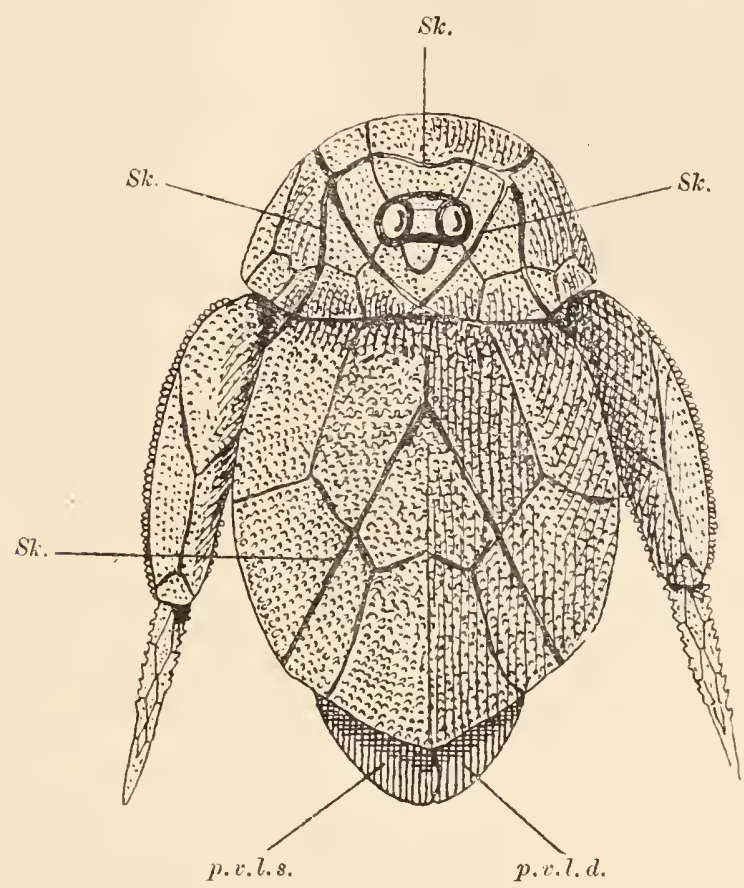

Fig. 52.

Rekonstruktion des Ruicken- und Schädelpanzers sowie der Seitenorgane von Bothriolepis canadensis, Whiteaves, aus dem Devon Kanadas, in nat. Gr. Die Panzerplatten der Ventralseite sind länger als der Rückenpanzer und daher in der Panzerrekonstruktion von oben sichtbar. (Rekonstruktion auf Grundlage eines Exemplars im geol. Institut der Wiener Universität und der Zeichnungen von R. H. Traquair, 1904.)

$S K .=$ Schleimkanäle. $\quad$ p.v.l.s. = linke hintere ventrale Lateralplatte. $p . v . l . d .=$ rechte hintere ventrale Lateralplatte.

Berührungsstelle abgeflacht. Im Tode waren die Seitenorgane meist weit vom Körper abgespreizt, aber diese Stellung ist nicht als normale Haltung anzusehen. Das lebende Tier hielt die ,,Seitenorgane“ wahrscheinlich meist nach vorn, wobei der proximale Abschnitt bei Asterolepis und Pterichthys nach oben, bei Bothriolepis nach unten sah. Diese Haltung steht in Zusammenhang mit dem Winkel, den die beiden Segmente des Seitenorgans miteinander bildeten; er war bei Pterichthys und Asterolepis nach unten geöffnet, bei Bothriolepis aber nach 
oben. Die Schneiden des distalen Segments waren mit scharfen Zälnchen besetzt, ebenso auch der Vorderrand des proximalen Segments bei Bothriolepis. Die Funktion des Seitenorgans kann nur die eines Fangapparates gewesen sein, der außerdem in einigen Fällen (z. B. bei Pterichthys productus) als Grabschaufel gedient haben dürfte. ${ }^{1}$

Der hintere Teil des Körpers war entweder mit Schuppen bedeckt (z. B. bei Pterichthys) oder nackt (bei Bothriolepis). Knapp hinter dem Rückenpanzer stand eine dreieckige Rückenflosse; die Schwanzflosse war heterozerk und breit dreieckig geformt.

Die ganze Gruppe stellt einen blind endenden Seitenast der Fische dar und ist nur aus dem Devon bekannt.

Pterichthys (F.g. 49-50). - Unterer Teil des Old Red Sandstone Schottlands, Mitteldevon der Eifel (Gerolstein). - P. Milleri Ag., P. Rhenanus Biyi., P. productus Ag. ${ }^{2}$

Asterolepis (F'g. 51). - Oberer Old Red Sandstone Schottlands und Devon Rußlands. - Während bei Pterichthys die Lateralplatten des Rückenpanzers die Medianplatte an den Rändern überlagern, überlagert hier die große Medianplatte die Ränder der Lateralplatten. $^{3}$

Microbrachius. - Unterer Old Red Sandstone Schottlands. Eine kleine Gattung mit sehr kurzen Seitenorganen. ${ }^{4}$

Bothriolepis (Fig. 52). - Oberer Old Red Sandstone Schottlands, Devon Kanadas. - Zahlreiche Arten. ${ }^{5}$

\section{Unterklasse: Arthrodira.}

Unter den zalılreichen panzertragenden Fischen des älteren Paläozoikums nehmen die Arthrodiren eine durchaus selbständige Stellung ein. O. Jaekel' hat versucht, sie mit den Antiarchi in genetische Beziehungen zu bringen und hat andererseits verwandtschaftliche Merkmale zwischen ihnen und den Acipenseriden feststellen zu·können ge-

1 O. Abel, Die Lebensweise der altpaläozoischen Fische. Verhandl, d. K. K. Zoolog.-Bot. Ges. in Wien, Bd. LVII, 1907, p. 164. Ich halte auch jetzt noch an der hier dargelegten Auffassung von der Funktion der Seitenorgane der Asterolepiden fest, obwohl Hoffmann (Paläontographica, 1911) eine andere Meinung vertritt.

2 R. H. Traquair, A Monograph of the Fishes of the Old Red Sandstone of Britain. (Unvollendet.) Part 11, London, Palaeontographical Society, 1894 und (Fortsetzung), ibidem, 1904 und 1906.

O. Jackel, Über die Organisation und systematische Stellıng der Asterolepiden. Zeitsclurift der Deutschen Geolog. Ges., Bd. LV, 1903, p. 41.

${ }^{3}$ R. H. Traquair, 1. c. 1894 . p. 71.

1 R. H. Traquair, I. c., 1904, p. 104.

R. 11. Traquair, J. c., p. 107.

${ }^{6}$ (). Jackel, Die Wirbeltiere. Berlin, 1911, p. 38. 
glaubt. Andere Forscher, wie C. R. Eastman ${ }^{1}$, haben die Arthrodiren in die Verwandtschaft der Dipneusten zu stellen versucht und diese Auffassung durch gewisse Ähnlichkeiten in der Ausbildung des Gebisses und der Art der Einlenkung des Unterkiefers zu begründen getrachtet. Keine dieser Theorien hat sich jedoch bis jetzt durchsetzen können. Die Ähnlichkeiten, die als Beweise für die Verwandtschaft mit den Antiarchi einerseits und den Dipneusten andererseits herangezogen wurden, stellen sich bei genauerer Betrachtung als Konvergenzerscheinungen heraus ${ }^{2}$, die keinen Schluß auf verwandtschaftliche Beziehungen gestatten, da zu tiefgreifende morphologische Unterschiede zwischen den verglichenen Gruppen bestehen. Jedenfalls waren die Arthrodiren marine Bodenbewohner, die mit ihrem durophagen Gebiß

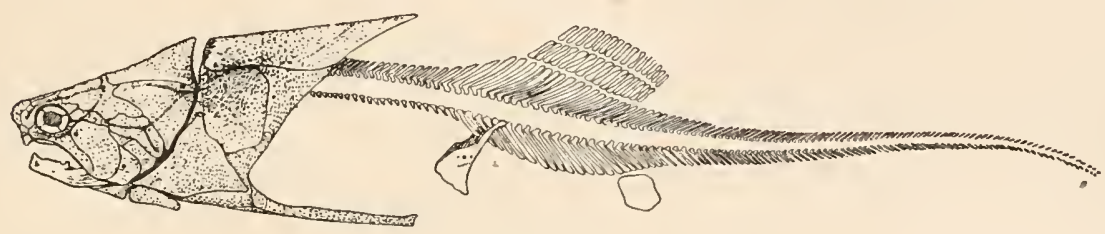

Fig. 53.

Rekonstruktion von Coccosteus decipiens Ag. aus dem Devon (Old Red Sandstone) Schottlands, stark verkleinert. - Rekonstruktion im wesentlichen nach R. H. Traquair, von E. v. Stromer in einigen Teilen abgeändert.

wahrscheinlich Muscheln und andere hartschalige Mollusken als Hauptnahrung verzehrten; daß sie benthonische Typen waren, geht ïbrigens auch aus dem macruriformen Körper hervor, der mit den lebenden Arten aus der Familie der Macruriden und den zahlreichen gleichartig an das benthonische Leben angepaßten Vertretern verschiedener Familien eine auffallende Ähnlichkeit zeigt (Fig. 53).

Man hat wiederholt den Versuch gemacht, die einzelnen Deckknochen des Arthrodirenschädels mit den Schädeldachplatten der Antiarchi und der Dipneusten zu homologisieren. Ebenso hat O. Jaekel versucht, die Ventralplatten des Rumpfpanzers mit den entsprechenden

1 C. R. Eastman, Dipnoan Affinities of Arthrodires. American Journal of Science, Vol. XXI, 1906, p. 131.

Derselbe, Mylostomid Dentition. Bulletin Mus. Comp. Zoology, Harvard Coll., Cambridge, Mass. Vol. L, 1907, p. 228: ,The combined evidence of the majority of characters of Arthrodires proves that they are spezialized Dipnoans."

2 Dies betrifft insbesondere die Autostylie des Unterkiefers, die im Laufe der Stammesgeschichte der Fische unabhängig von verschiedenen Stämmen erworben worden ist (bei Holocephalen, Dipneusten und bei Arthrodiren; bei der Selachiergattung Heterodontus [= Cestracion], vgl. Fig. 70, B, liegt ein Übergangsstadium von der hyostylen zur autostylen Kieferbefestigung vor). 
Platten von Pterichthys und den anderen Asterolepiden in Übereinstimmung zu bringen. Beide Versuche haben zu keinem überzeugenden Ergebnis geführt. Jaekel hat sogar die Schädeldachknochen einiger Coccosteiden aus dem Devon von Wildungen an der Ense (Fürstentum Waldeck in Deutschland) mit den Schädeldachelementen der Amphibien zu homologisieren versucht.

Das Schädeldach der Arthrodiren umfaßt eine größere Zahıl von Deckknochen, die lıäufig mit stark welligen oder zackigen Nahträndern ancinander stoßen. In der Mittellinie liegen drei unpaare Knochenplatten, die nach den allgemeinen Lagebeziehungen zu den Nasenöffnungen und den Augenhöhlen als ein unpaares Nasale, ein unpaares Frontale (dieser Knochen ist von der Epiphysenöffnung durchbohrt) und als ein unpaares Occipitale superius gedeutet wurden. Die parig entwickelten Platten zwischen den Augenhöhlen sieht Jaekel als die Lacrymalia an und glaubt weiter auch Postfrontalia, Jugalia, Supratemporalia und ,Epiotica“ neben den Quadratojugalia usf. unterscheiden zu können. Bei der gänzlich isolierten Stellung der Arthrodiren ist es jedoch katum möglich, derartige exakte Homologien feststellen zlı können, ebenso wie es auch nicht möglich ist, die Deckknochen des Teleostomenschädels oder des Amphibienschädels im Schädelskelett der Asterolepiden aufzufinden.

Im Schädeldach fallen vor allem die bei den meisten Arten stark vergrößerten Augenhöhlen auf, deren Öffnung durch vier sich zu einem Sklerotikalring zusammenschließenden Sklerotikalplatten eingeengt wird. Die großäugigen Typen dürften, wie Jaekel annimmt, Bewohner tieferer Wasserschichten gewesen sein. Die Augen standen meist seitlich, wie bei den lebenden Fischen des macruriformen Anpassungstyps, bei Macropetalichthys dagegen dorsal.

Die Bezahnung ist unverkennbar durophag, d. h. an die Zerkleinerung harter Nahrung angepaßt. Der Unterkiefer ist verknöchert und trägt fest mit dem Knochen verwachsene Zähne, die entweder scharfe Zacken bilden, wie sie uns in den Schnabelformen gewisser Sclildkröten und Raubvögel entgegentreten, oder in Gestalt von Reibplatten cntwickelt sind, die gleichfalls mit den benachbarten Knochen fest verwachsen. Es liegen also bei den Arthrodiren zwei verschiedene Ausbildungsformen des Gebisses vor, ein Brechscherengebiß and ein Reibgebiß. Der erste Typus ist z. B. bei Coccosteus und Rhamphodus (Fig. 54, 63), der zweite bei Mylostoma (Fig. 62) entwickelt. Dic Ähnliclıkeiten mit den Gebißformen der Chimäriden sind clurchaus oberflächlicher Natur und eine Folge konvergenter Anpassung an die gleichartige Nahrungsweise.

Der Kopfsclild der Coccosteiden war mit dem Rumpfpanzer gelenkig verbunden, und zwar ist an der vorderen Seitenplatte des Rücken- 
panzers ein kugeliger Gelenkkopf ausgebildet, der in eine Pfanne an Hinterrande einer Seitenplatte des Kopfschildes hineingreift (Fig. 59, 60). Bei einigen Gattungen ist zwischen Kopfschild und Rückenschild eine größere Lücke vorhanden, die auf eine relativ große Bewegungsfreiheit des Schädels in der Medianlinie hindeutet. In vereinzelten Fällen ist die Verbindung zwischen Kopf- und Rückenschild eine so feste geworden, daß de $e_{i}$ Kopf nicht nehr gegen den Rückenschild abgebogen werden konnte (so bei einer schmalköpfigen Type aus dem Devon von Wil(lungen).

Das Schnauzenende lief entweder keilförmig zu (z. B. bei Brachydirus, Fig. 54) oder war abgerundet (z. B. bei Pachyosteus, Fig. 57).

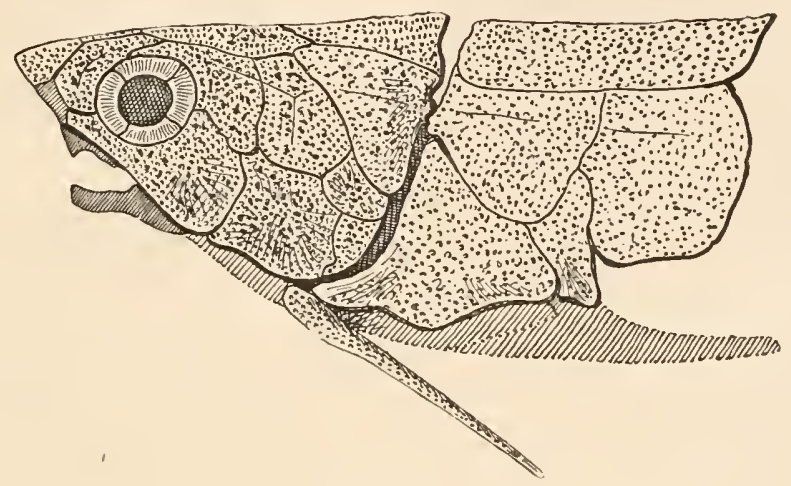

Fig. 54 .

Rekonstruktion des Schädel- und Rumpfpanzers von Brachydirus bickensis, Koenen, aus dem Oberdevon von Bicken und Wildungen in Deutschland, in $1 / 2$ nat. Gr. (Seitenansicht). (Nach O. Jaekel.)

An der Grenze zwischen Kopfschild und Rückenpanzer findet s.ch bei Brachydirus bickensis aus dem Devon Deutschlands (Nassau und Wildeck) ein langer Knochenstachel (Fig. 54) eingelenkt, der bei Coccosteus decipiens aus dem Old Red Sałdstone und bei Rhamphodus tetrodon aus dem Devon von Wildungen nur mehr in rudimentärem Zustande nachweisbar, bei anderen Gattungen (z. B. bei Pachyosteus) aber ganz verloren gegangen ist. Sowohl die morphologische als auch die physiologische Bedeutung dieses Stachels, den Jaeke! mit dem Seitenorgan der Asterolepiden vergleicht, ist noch maufgeklärt. Vielleicht handelt es sich um Tastapparate der benthonischen Typen. Jaekel nennt diesen Stachel „Spinale“.

Das Spinale lenkt bei Rhamphodus (Fig. 64) zwischen zwei Knochenplatten ein, von denen die untere nach Jaekel der Clavicula, die - obere dem Cleithrum des Schultergürtels der Fische entspricht; das auf dem Cleithrum oben sitzende Knochenstück bezeichnet Jaekel 
als „Collare“, doch ist dieses Stück vielleicht dasselbe, das bei den Teleostomen als „Supraclavicula“ unterschieden wird. Nach Jaekel ist das Spinale dem ersten Brustflossenstachel des Störs homolog, was aber zweifellos nicht der Fall ist, worauf schon E. Koken (1911) hinwies.

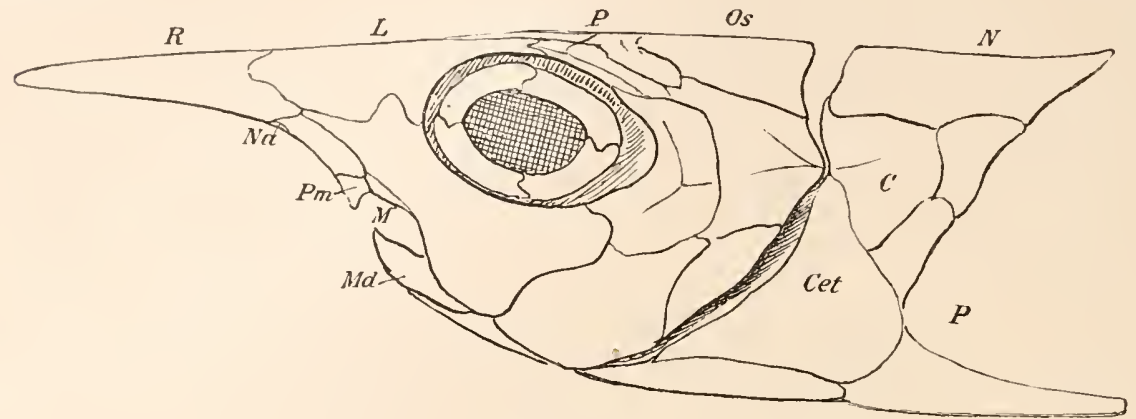

Fig. 55 .

Rekonstruktion des Kopfes von Oxyosteus aus dem Oberdevon von Wildungen, in Seitenansicht ( $1 / 2$ nat. Gr.). (Nach O. Jaekel.)
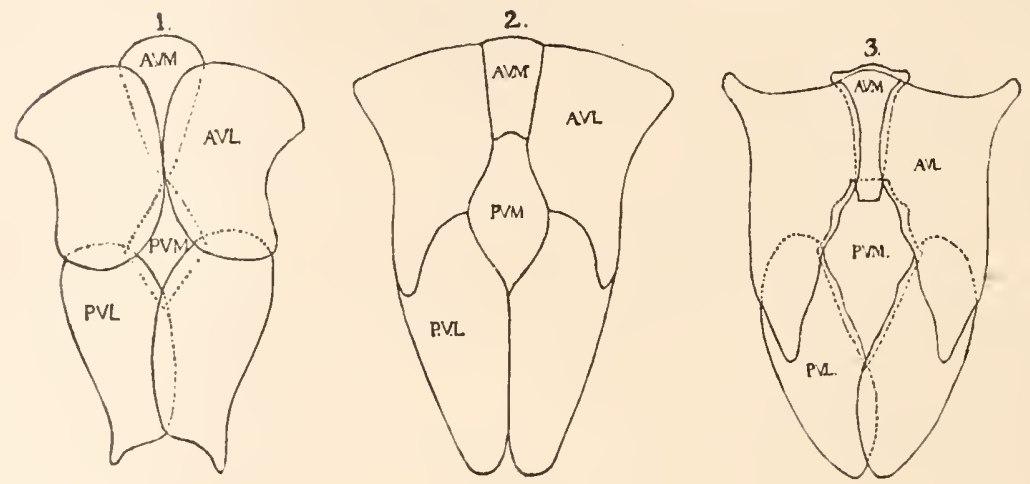

Fig. 56.

Rekonstruktion des Ventralpanzers von drei Arthrodiren: 1. Coccosteus decipiens, Ag.; 2. Dinichthys halmodeus (?), Clarke; 3. Dinichthys Newberryi (?), Clarke. (Nach Burnett Smith, 1909.)

AVM. - vordere Medianplatte (antero- AVL. = vordere Lateralplatte (anteroventro-medianum).

PVM. = hintere Medianplatte (postero- $\quad P V L .=$ hentro-laterale). ventro-medianum). ventro-laterale).

Brustflossen scheinen den Arthrodiren gefehlt zu haben, wenigstens ist bisher bei den vielen untersuchten Exemplaren nicht die geringste Andeutung eines Brustflossenskeletts gefunden worden. Hingegen ist ein wohlentwickeltes Becken bei Coccosteus decipiens (Fig. 53) nachgewiesen worden, mit dem an einigen besser erhaltenen Exemplaren 
auch knöcherne Flossenstrahlen artikulieren, so daß damit das Vorhandensein von Ventralflossen bei Coccosteus erwiesen ist. Wir kommen zum Verständnis dieser Verhältnisse, wenn wir die Funktion der Bauchflossen von Lepidosiren paradoxa mit der Funktion der Brustflossen dieses Dipneusten vergleichen. Die Ventralen sind hier ausgesprochene Bewegungsapparate, die mit der strahlenlosen Flossenseite dem Boden aufliegen und den Körper abwechselnd vorwärts schieben, während die Pektoralen hoch über dem Boden frei pendelnd getragen

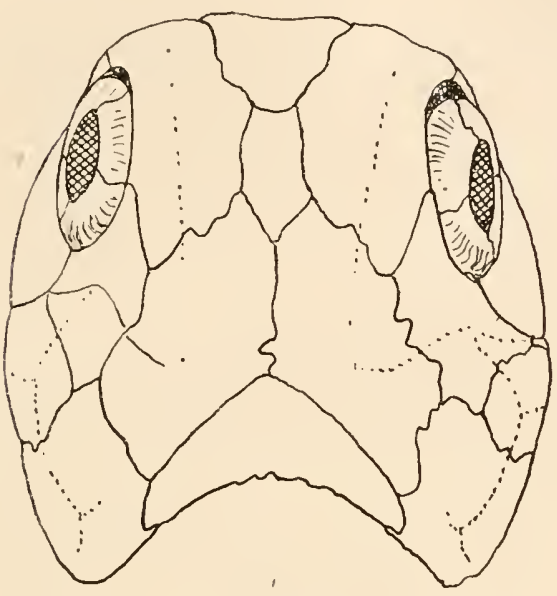

Fig. 57.

Dorsalansicht des Schädelpanzers von Pachyosteus bulla, Jkl., aus dem oberen Devon von Wildungen in Deutschland, $1 / 2$ nat. Gr. (Nach O. Jaekel.)

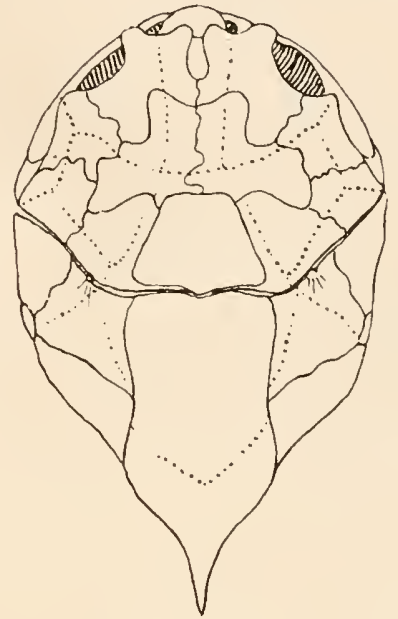

Fig. 58.

Dorsalansicht des Schädelund Rückenpanzers von Coccosteus decipiens, Ag., aus dem mittleren Devon Schottlands, in $1 / 3$ nat. Gr.

(Nach R. H. Traquair.)

Die Augenhöhlen sind dunkel schraffiert.

werden und nur als Tastorgane funktionieren. ${ }^{1}$ Vielleicht liegt auch bei Coccosteus eine analoge Funktion der Ventralen vor, die ihre starke Entwicklung und das gleichzeitige Fehlen der Pektoralen erklären würde.

Wahrscheinlich ist auch ein Paar Analflossen bei Coccosteus vorhanden gewesen; wenigstens würde diese Annahme das Auftreten einer medianen, rhombischen Knochenplatte in der Analregion verständlich machen. Flossenstrahlen sind allerdings nicht in Verbindung mit dieser Medianplatte erhalten.

1 Ich habe diese Schiebfunktion der Flossen an zwei Exemplaren von Lepidosiren paradoxa im Zoologischen Garten zu Frankfurt a. M. am 23. November 1913 und neuerlich am 23. November 1917 an einem Exemplar derselben Art beobachtet. 
Das Wirbelsäulenskelett bestelit aus wohlentwickelten oberen und unteren Bögen, welche ihre größte Höhe in der Region der Rückenflosse erreichen, die von zwei übereinander liegenden Reihen von knöchernen Flossenträgern gestützt wird; die untere Reihe dieser Träger ist wahrscheinlich den ,Basalia“, die obere den ,Radialia“ der Rückenflosse der Haifischembryonen homolog.

Der Körper trug keine Schuppen.

Die Knochen des Schädeldaches und des Rückenpanzers sind von zahlreichen Schleimkanälen durchzogen.

Einzelne Arten aus dem Devon Nordamerikas haben gewaltige Größe erreicht; der Schädel eines Exemplars von Dinichthys intermedius (F g. 60) ist nach Bashford Dean etwa $80 \mathrm{~cm}$ lang, so daß die Gesamtlänge des Tieres auf mindestens $4 \mathrm{~m}$ veranschlagt werden clarf; beträchtlich größer war Titanichthys, dessen Gesamtlänge 8 m überschritten haben dürfte. Die europäischen Vertreter, unter ihnen die häufigste Gattung Coccosteus, blieben meist weit hinter diesen riesigen Dimensionen zurück, nur die noch unvollständig bekannte Gattung Heterosteus aus dem Devon von Dorpat hat gleichfalls eine Körperlänge von etwa $3 \mathrm{~m}$ erreicht, wie aus der Dicke und Größe der isoliert gefundenen Knochenplatten zu schließen ist.

In Devon von Anacharras in Schottland (in den als Passage Beds bekannten Übergangsschichten vom Silur zum Devon) sind zahlreiche Exemplare eines winzigen Fisches (Fig. 65) entdeckt worden, der in der Regel nur 2,5 cm lang ist und dessen größte Exemplare die Länge von $5 \mathrm{~cm}$ nicht übersteigen. R. H. Traquair ${ }^{\mathbf{1}}$ hat diese Reste unter dem Namen Palaeospondylus Gunni beschrieben; ihre systematische Stellung ist trotz wiederholter ${ }^{2}$ sorgfältiger Untersuchungen der Reste, zuletzt durch W. J.Sollas ${ }^{3}$, noch immer unaufgeklärt. Die Hartteile der Reste sind in Steinkohle verwandelt und sind daher wahrscheinlich knorpelig gewesen. Die terminale Lage der Mundöffnung, die als ein Saugmund aufzufassen ist, hat zumeist die Vorstellung erweckt, daß es sich in Palaeospondylus um den ältesten Vertreter der Cyclostomen handeln könnte. Ich halte diese Auffassung für durchaus unbegründet und bin der Ansicht, daß es sich um die Larve eines Fisches handelt ${ }^{4}$, und zwar ist wohl in erster Linie an einen Vertreter der Arthrodiren zu denken. In denselben Schichten ist Coccosteus sehr häufig und zeigt

1 R. H. Traquair, Palaeospondylus Gumni. Proc. Roy. Phys. Soc. Edinburgh, Vol. XII, 1893. Proc. Zool. London, 1897.

${ }^{2}$ B. Dean, The Devonian Lamprey, Palaeospondylus Gunni etc. Mem. New York Acad. of Science, Vol. II, 1900.

${ }^{3}$ W. J. Sollas and J. B. J. Sollas, The Devonian Fish, Palaeospondylus Gunni, Traquair. Philosophical Transactions, London, Vol. CXCV1, 1903.

4 O. Abel, Grundzïge der Paläobiologie der Wirbeltiere. 1912, p. 479. 
übrigens auch denselben Erhaltungszustand der Verwandlung der knorpeligen Partien des Skeletts in Steinkohle. ${ }^{1}$ Die Frage nach der systematischen Stellung von Palaeospondylus kann aber einstweilen nicht sicher entschieden werden. ${ }^{2}$

\section{F. Coccosteidae.}

Alle Gattungen dieser Fanilie besitzen ein BrechscherengebiB mit scharfen Zacken und Schneiden zum Zerbrechen harter Nahrung (Mollusken, Krustazeen u. dgl.).

Coccosteus. - Von den europäischen Vertretern der Familie am besten bekannt. ${ }^{3}$ Körper makruriform (Fig. 53), Schädel meist kurz kegelförmig abgestutzt, aber mitunter stark verlängert (diese Formen sind wahrsclieinlich als „Gattungen“ abzutrennen). Bauchpanzer abgeflacht, ähnlich dem der Antiarchi, aus vier Platten bestehend, die eine rhombische Mittelplatte umschließen; außerdem ist aber noch (Fig. 56) eine vordere Medianplatte bei den Coccosteiden vorhanden, welche bei den Antiarchi stets fehlt. Diese Ähnlichkeit kann nicht als zwingender Beweis für eine Verwandtscliaft beider Stämme angesehen werden, denn , die räumliche Anordnung groBer Hautknochen in einer begrenzten Region des Körpers muß inmer eine gewisse Ähnlichkeit zeigen, die durch Konvergenz zu auffallender Übereinstimmung gesteigert werden kann" (E. Koken, 1911). ${ }^{4}$ Coccosteus ist nicht, wie mitunter angenommen wurde, eine ausschließliche Süßwassergattung gewesen, sondern unfaßt auch marine, benthonische Arten. Die Gattung ist durch mehrere Arten, von denen C. decipiens die häufigste ist, im Devon Europas vertreten (Old Red Sandstone Schottlands und Irlands, im Devon von Nassau, Wildeck, Eifel, Bölnmen, Rußland). Einzelne nordamerikanische Typen, die der Gattung Coccosteus eingereiht werden, wie Coccosteus (Protitanichthys) fossatus (Eastman,

1 W. J. Sollas and J. B. J. Sollas, An Account of the Devonian Fish, Palaeospondyltus Gunni, Traquair. Proc. Roy. Soc., Vol. LXXII, 1903, p. 98.

2 Fïr die Entscheidung dieser Frage ist das Vorhandensein einer deutlichen Segınentiertıng der Wirbelsätıle wichtig.

3 R. H. Traquair, On the Structure of Coccosteus decipiens, Agassiz. Proceed. Roy. Phys. Soc. of Edinburgh, Vol. X, 1890, p. 211. (Hier die wichtigste ältere Literatur.)

O. Jaekel, Über Coccosteus und die Beurteilung der Placodermen. Sitzungsberichte d. Ges. Naturf. Freunde zu Berlin, 1902,p. 103.

Derselbe, Netue Wirbeltierfunde ats dem Devon von Wildungen. Ibidem, 1906 , p. 73.

L. Hussakof, Notes on Devonic Fishes from Scaumenac Bay, Quebec. 1. An almost complete specimen of Coccosteus. New York State Museum Bulletin 158, VIII. Report of the Director of the Science Division, Albany, 1912, p. 127.

4 E. Koken, Neubearbeitung des Abschnittes „Pisces“ in K. A. von Zittels „,Grundzïge der Paläontologie (Paläozoologie)“, 2. Aufl., 1911, p. 80. 
1907) oder Coccosteus occidentalis stehen zwar der europäischen Gattung Coccosteus sehr nahe, sind aber doch eher der durch Titanichthys repräsentierten Formengruppe anzureihen. ${ }^{1}$

Fig. 59.

Selenosteus Kepleri, Dean aus den Cleveland Shales (Grenzschichten zwischen Oberdevon und Unterkarbon) Nordamerikas.

A. Kopfschild und Nackenschild von oben;

B. linker Unterkieferast von der Seite;

C. Ventralschild von unten.

Die von überlagernden Platten verdeckten Plattengrenzen sind durch punktierte Linien angedeutet.

(Nach B. Dean.)

$a d l .=$ Antero-dorso-laterale.

ar. $=$ Artikulationsstelle zwischen Kopf- u. Nackenschild.

$a v l .=$ Antero-ventro-laterale.

avm. = Antero-ventro-medianum.

c. = Centrale.

$d m .=$ Dorso-medianum.

co. = Occipitale externum.

$m$. = Marginale.

mo. = Occipitale medianum.

pi. $=$ Foramen pineale

pdl. $=$ Postero-dorso-laterale

pto. $=$ Postorbitale.

p $l_{\text {. }}=$ Postero-ventro-laterale.

pum. = Postero-ventro-medianum.

r. $=$ Rostrale.

(Stark verkleinert.)

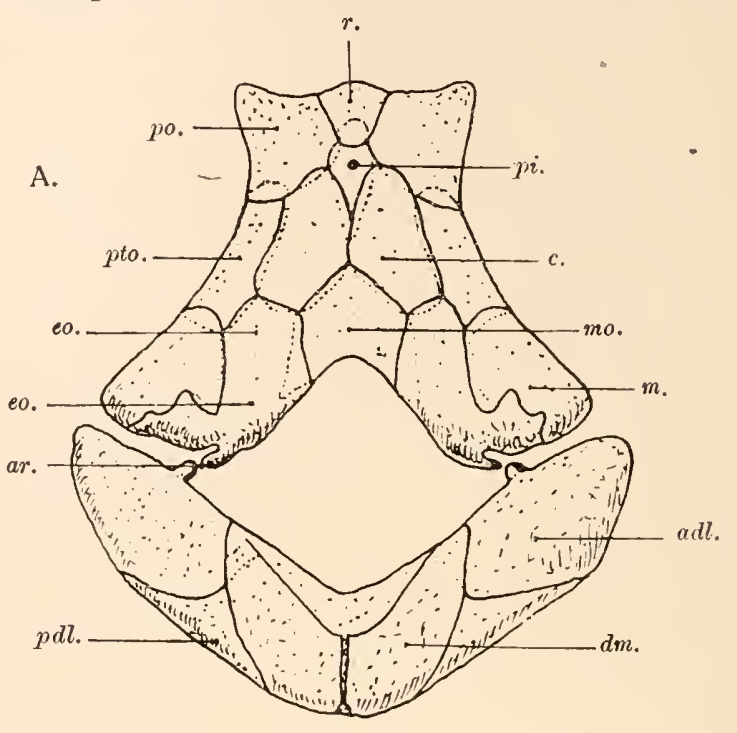

B.

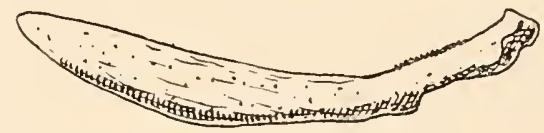

C.

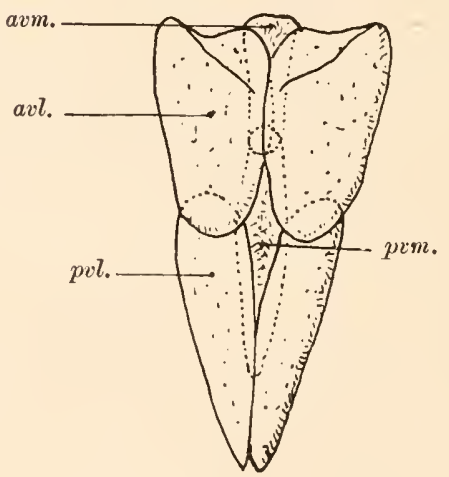

Dinichthys. - Kurze Rudimente der ,Spinalia“ vorhanden. Die starken Deckknochen des Schädels, die nicht wie bei Coccosteus

1 E. S. Goodrich unterscheidet $1909 \mathrm{im}$ IX. Bande des ,,Treatise on Zoology“, herausgegeben von Ray Lankester (p. 262), zwei große Gruppen der Arthrodira und zwar die Arthrothoraci (mit den Familien Coccosteidae, Selenosteidae, Dinichthyidae, Titanichthyidae, Mylostomidae) und die Temnothoraci (mit der Familic Homosteidac). Dagegen reiht er die Ptyctodontiden den Holocephalen an (p. 179). Die Systematik der Arthrodiren ist noch unsicher, da die meisten Gattungen nur schr unvollständig bekannt sind. 
mit Knöpfen oder Sternen besetzt, sondern glatt sind, verwachsen im Alter zu einem geschlossenen Dache. Eine kleine, mediane, zwischen den Augenhöllen gelegene Knochenplatte, die „Pinealplatte“, ist von einer kleinen Öffnung für das Pinealorgan durchbohrt und trägt auf der Innenseite eine sehr große Grube zur Aufnahme dieses Organs. Obere und untere Zahnplatten zu gewaltigen, scharfen Schneiden und Zacken ausgebildet. - Oberdevon Nordamerikas (Fig. 56, 60, 61). ${ }^{1}$

Fig. 60.

Rekonstruktion des Kopf- und Nackenschildes von Dinichthys intermedius, Newb., aus dem Oberdevon von Ohio, in $1 / 6$ nat. Gr.

(Nach Ch. R. Eastman.)

$A d l .=$ vordere dorsale Lateralplatte.

$C^{1}=$,Parietale“.

$C^{2}=$,Frontale".

Dm. = mittlere Dorsalplatte.

EO. = ,Epioticum".

M. = "Supratemporale" oder ,Marginale“.

MO. = "Supraoccipitale“"

$P$. $=$,Frontale "' (nach anderen ,Pineale“).

PDL. = hintere dorsale Lateralplatte.

PO. = ,Präfrontale".

PtO. = „Postorbitale" (nach O. Jaekel, ,Jugale").

R. = ,Rostrale“ (nach anderen ,Nasale“).

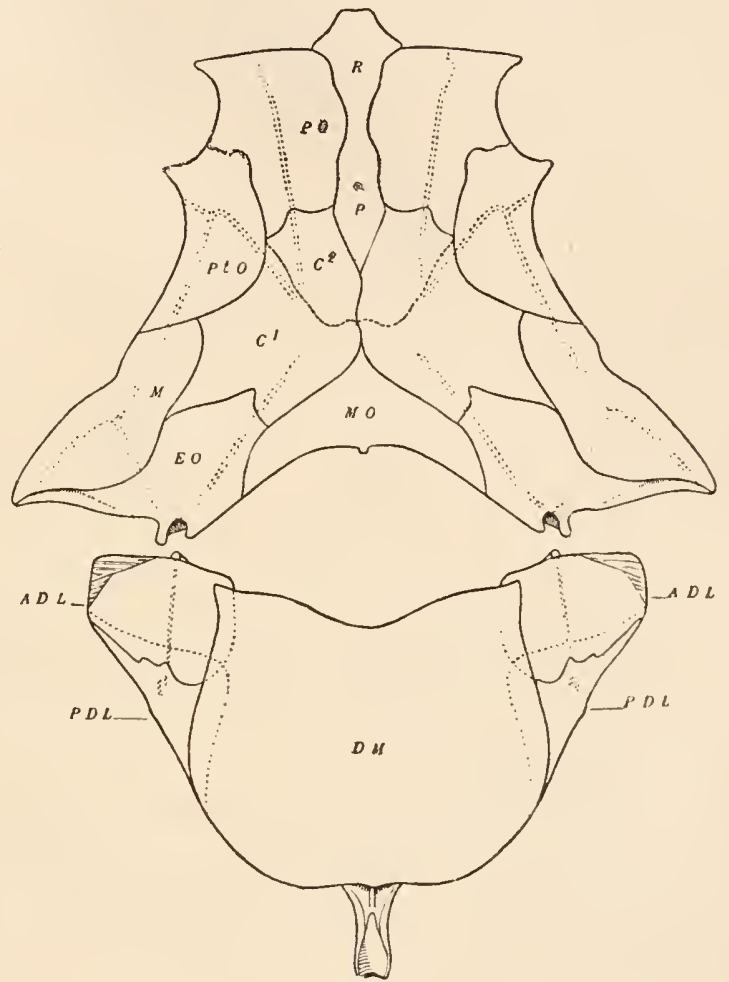

Oxyosteus. - Oberdevon von Wildungen in Deutschland. (Fig. 55.) $)^{2}$

1 B. Dean, Fishes, Living and Fossil. New York, 1895.

L. Hussak of, Studies on Arthrodira. Mem. Amer. Mus. Nat. Hist., Vol. IX, New York, 1906.

Ch. R. Eastman, Devonic Fishes of the New York Formations. New York State Museum, Memoir X. Albany, New York State Education Department, 1907.

E. B. Branson, Notes on the Ohio Shales an their Faunas. The University of Missouri Bulletin, Sci. Ser., Vol. 11, Nr. 2, Columbia, Miss., 1911, p. 23.

B. Smith, On Some Dinichthyid Armor Plates from the Marcellous Shale. Amer. Naturalist, Vol. XLIII, 1909, p. 588.

Derselbe, Notes on Some Little-Known Fishes from the New York Devonian. Proceed. Acad. Nat. Sci. Philadelphia, 1910, p. 656.

2 O. Jaekel, Die Wirbeltiere. Berlin 1911, p. 49, Fig. 37. 
Selenosteus. - Von S. Kepleri aus dem Oberdevon Nordamerikas Schädel- und Ventralschild bekannt. Die Augenöffnungen sind nicht von Knochenplatten umgeben, sondern ungeschützt (Fig. 59). ${ }^{1}$

Titanichthys, Macropetalichthys, Diplognathus, Liognathus im Oberdevon Nordamerikas, meist nur durch Zahnplatten bekannt.

Pachyosteus. - Im Oberdevon von Wildungen (Waldeck, Deutschland) (P. bulla). (Fig. 57). ${ }^{2}$

Brachydirus. - lin Oberdevon von Wildungen und von Bicken (Nassau, Deutschland) (B. bickensis). (Fig. 54.) ${ }^{3}$

Homosteus. - Old Red Sandstone, Schottland (H. Milleri). ${ }^{4}$

Heterosteus. - Devon von Dorpat. ${ }^{5}$

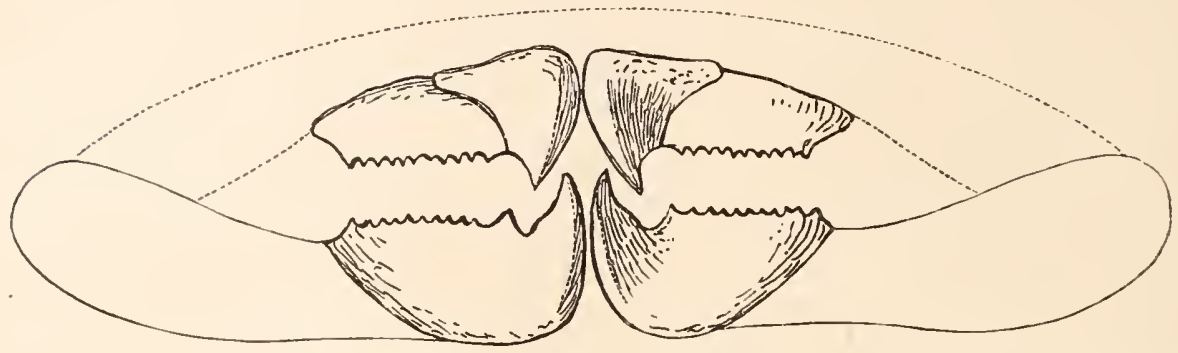

Fig. 61 .

Gebiß von Dinichthys Hertzeri, Newb., aus dem Devon (Huron Shales) von Delaware, Ohio, in $1 / 6$ nat. Gr. (Nach J. St. Newberry.)

\section{F. Mylostomidae.}

Alle Gattungen dieser Familie besitzen ein Reibgebiß, das im Oberkiefer aus zwei Paaren flacher, an die Reibplatten der Dipneusten oder Holocephalen erinnernder Mahlplatten und in Unterkiefer aus einem Paar solcher Platten besteht. Der Schädel (von Mylostoma variabile bekannt) scheint sehr flach gewesen zu sein; die Körperform der Mylostomiden ist unbekannt. Jedenfalls waren die Angehörigen dieser Familie durophage Grundbewohner des Meeres, die eine ähn-

1 B. Dean, On two New Arthrodires from the Cleveland Shale of Ohio. The Relationships of the Arthrognathi. Memoirs New York Acad. Science, Vol. II, 1901.

2 O. Jaekel, Nene Wirbeltierfunde aus dem Devon von Wildungen. Sitzungsberichte d. Ges. Naturf. Freunde Berlin, 1906, p. 78, Fig. 5.

8 Ibidem, p. 83, Fig. 10.

4 R. H. Traquair, The Extinct Vertebrata of Moray Firth Area. In: HarvieBrown \& Buckley, ,Vertebr. Fauna of the Moray Basin“, Vol. II, 1896, Pl. IV, Fig. 2.

5 Die Reste dieser noch nicht genauer bekannten Gattung fallen durch ilhre gewaltige Größe auf. Ein den Verf. zur Untersuchung vorliegendes Seitenorgan zeigt eine Zweiteilung und Gelenkbildung zwischen beiden Abschnitten ähnlich wie bei den Asterolepiden. 
liche Lebensweise wie die Holocephalen oder Rochen geführt haben dürften.

Mylos toma. - Oberdevon Nordamerikas (M. variabile). (Fig. 62). ${ }^{1}$

Dinomylostoma. - Oberdevon Nordamerikas (D. Beecheri). ${ }^{2}$

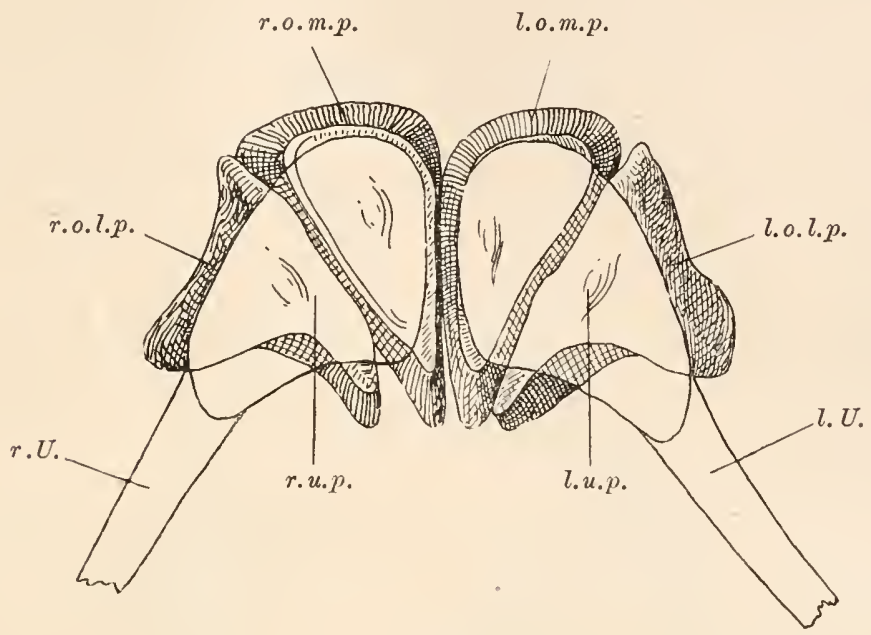

Fig. 62.

Oberes und unteres Gebiß von Mylostoma variabile Newberry, aus den Cleveland Shales von Sheffield in Ohio, N. Am.; beide Gebisse in Deckung gebracht, so daß die von der Gaumenfläche gesehenen oberen Zahnplatten vom Unterkiefer, der weiß gelassen wurde, gedeckt erscheinen.

(Nach C. R. Eastman, 1907.)
l. o.m.. . = linke obere Mittelplatte.
l.o.l. $p .=$ linke obere Seitenplatte.
$r . u . p .=$ rechte Unterkieferplatte.
r. o.m.. . = rechte obere Mittelplatte.
l. $u . p .=$ linke Unterkieferplatte.
r.o.l.. . $=$ rechte obere Seitenplatte.
r. $U .=$ rechter Unterkiefer.
l. $U$. = linker Unterkiefer.

\section{F. Ptyctodontidae.}

Alle Gattungen dieser Familie besitzen ein Scherengebiß, und zwar erinnert dasselbe in seiner Form an die Schnäbel von Raubvögeln und Schildkröten. Die Bezahnung besteht nur aus zwei Paaren von Zahnplatten, einem oberen und einem unteren, die mit ihren Vorderenden zusammenstoßen und auf diese Weise in hohem Grade den Eindruck eines Chelonier-soder Vogelschnabels hervorrufen (F'g.63). Von Skelett ist nur der Schultergürtel (von Rhamphodus tetrodon) bekannt, an dem ein rudimentäres Spinale einlenkt (F,g. 64).

1 C. R. Eastman, Mylostomid Dentition. Bull. Mus. Comp. Zool. Harvard College, Cambridge, Mass., Vol. L, Nr. 7, 1907, p. 211.

2 Derselbe, Structure and Relations of Mylostoma. Ibidem, Vol. L, Nr. 1, 1906 , p. 1. 
Die Struktur der Zahnplatten der Ptyctodontiden ist sehr eigenartig; sie werden aus harten, punktierten, übereinandergeschobenen Lamellen aufgebaut, deren Ebenen schräg zur Kaufläche stehen, während die Gefäßkanäle der Reibplatten des Holocephalengebisses senkrecht zur Kaufläche verlaufen. L. Dollo hat (1907) den Nachweis geführt, dlaß diese Familie den Arthrodiren einzureihen ist.

Ptyctodus. - Devon von Rußland, Belgien und Wisconsin (Nordamerika). ${ }^{1}$

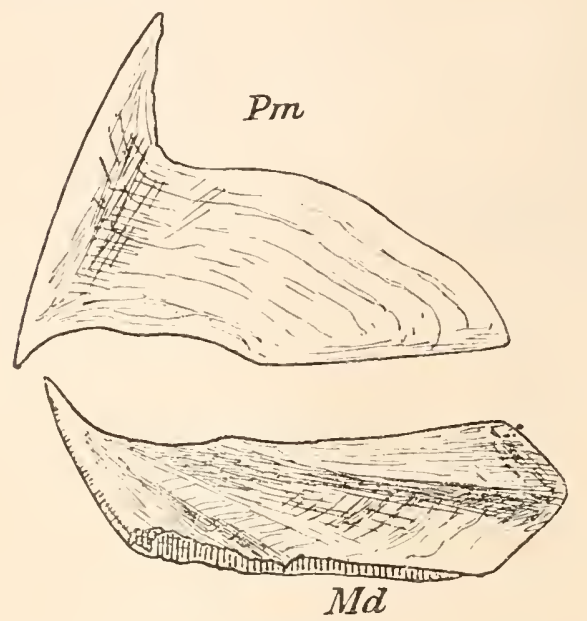

Fig. 63.

Gebiß von Rhamphodus tetrodon, Jkl., aus dem Oberdevon der Ense bei Wildungen in Deutschland, von außen gesehen.

(Nach O. Jaekel, 1906.)

Rhynchodus. - Devon Belgiens und Nordamerikas. ${ }^{2}$ Palaeomylus. - Devon Nordamerikas. ${ }^{3}$

Rhamphodus. - Devon von Wildungen, Deutschland (Fig. 63, 64). ${ }^{4}$

\section{Unterklasse: Elasmo- branchii.}

Die Unterklasse der Elasmobranchier liat in früheren Zeiten der Erdgeschichte zwar eine große Rolle gespielt, hat aber niemals die Bedeutung und die hohe Blüte der Teleostomen erreicht. Sie stehen noch heute in voller Entfaltung, wenn wir die lebenden Familien mit den ihnen zuzuteilenden fossilen Vertretern und den erloschenen Familien vergleichen. Im Gegensatz zu den Teleostomen sind die Elasmobranchier

1 Ch. H. Pander, Über die Ctenodipterinen des devonischen Systems. St. Petersburg, 1858, p. 48.

J. S. Newberry, Descriptions of Fossil Fishes. Report of the Geol. Survey of Ohio, Vol. 1, Part 2, 1873, p. 307.

L. Dollo, Les Ptyctodontes sont des Arthrodères. Bull. Soc. Belge de Géol., Pal. et d'Hydrol., T. XXI, 1907, p. 1. (Ausführliche Literatur.)

${ }^{2}$ Ch. R. Eastman, Dentition of Devonian Ptyctodontidae. Amer. Naturalist, Vol. XXXII, 1898, p. 473.

3 Ibidem, p. 545 .

4 O. Jaekel, Über Rhamphodıs, nov. gen., einen neuen devonischen Holocephalen von Wildungen. Sitzungsber. Ges. Naturf. Freunde, Berlin, 1903, p. 385.

Derselbe, Einige Beiträge zur Morphologie der ältesten Wirbeltiere. Ibidem. 1906, ก. 180.

L. Dollo, Les Ptyctodontes sont des Arthrodères. I. c., 1907, p. 1. 
als eine ausgesprochen konservative Gruppe zu bezeichnen, was schon daraus hervorgehen n11ag, daß wir eine ganze Reihe von heute noch lebenden Gattungen bis in die obere Kreide zurückverfolgen können. Die ganze Gruppe stellt einen in jeder Hinsicht selbständigen, großen Ast des Wirbeltierstammes dar, von dem keine Brücke zu den Teleostomen und auch keine Brücke zu den höheren Vertebraten führt. Die in früherer Zeit vielfach vertretene Auffassung, daß die Elasmobranchier eine „Vorstufe" der Knochenfische darstellen, ist heute ebensowenig mehr haltbar als die Versuche, aus den Flossen der Haifische (Fig. 66)

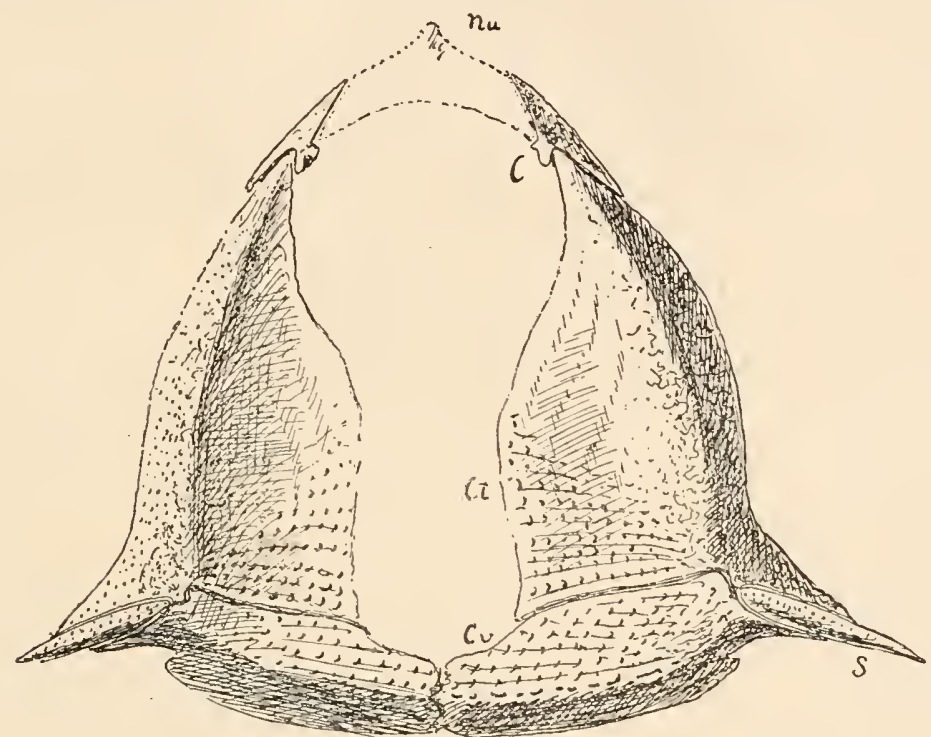

Fig. 64 .

Schultergürtel von Rhamphodus tetrodon, Jkl., aus dem Oberdevon von Wildungen (vgl. Fig. 63), in nat. Gr. (Nach O. Jaekel.)

$$
N u=\text { Nuchale. } \quad C=\text { Collare. } \quad C t=\text { Cleithrum. }
$$

$C v=$ Clavicula. $\quad S=$ Spinale.

die Flossen der Crossopterygier und Dipneusten oder der anderen Teleostomen (Fig. 67) und die Gliedmaßen der Amphibien abzuleiten. Der Aufbau der Wirbelzentren der Plagiostomen ist so eigenartig (Fig. 4, 5, 68, 69), daß er allein, ganz abgesehen von vielen anderen morphologischen Differenzen, jede Möglichkeit der Annahnne derartiger phylogenetischer Hypothesen ausschließt. Diese Auffassungen von den prinitiven Verhalten der Elasmobranchier im Vergleiche zu den Teleostomen und höheren Vertebraten beruhen hauptsächlich auf dem Vorhandensein prinitiver Hautschuppen (Plakoidschuppen) sowie auf der Tatsache, daß das Skelett der Elasmobranchier in wesentlichen knorpelig bleibt; gewisse Merkmale, wiie der primitive Bau der Terminalflosse, welche uns bei Vergleichen mit dem Terminalflossenbau der Teleostomen eine 
gute Vorstellung von der Entstehung spezialisierterer End-oder Terminalflossen vermittelt, reichen jedoch nicht aus, um die Elasmobranchier als die Ahnengruppe der Teleostomen anzusehen, da zahlreiche Spezialisationskreuzungen diesen primitiven Merkmalen gegenüberstehen. Wenn aber auch die Elasmobranchier und die Teleostomen divergente Ent-

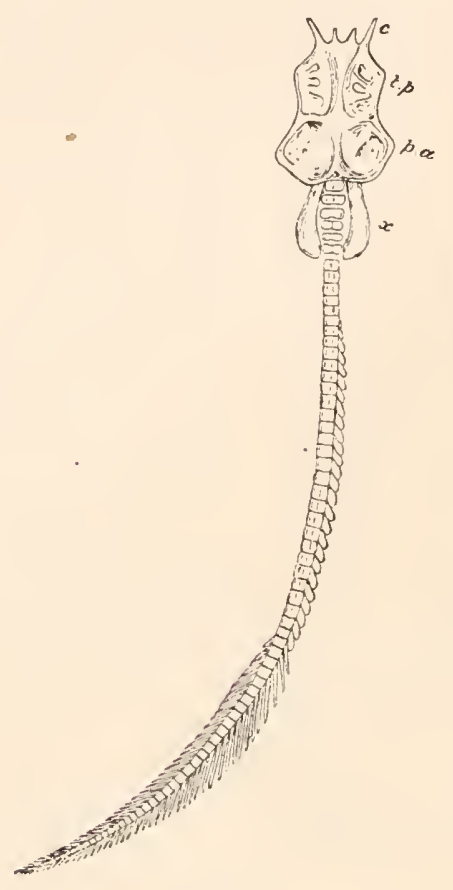

Fig. 65 .

Rekonstruktion vou Palaeospondylus Gunni, Traquair, aus den Übergangsschichten zwischen Silur und Devon von Caithness in Schottland. Die Körperlänge beträgt in der Regel etwa $2,5 \mathrm{~cm}$.

(Nach R. H. Traquair.) wicklungsreihen darstellen, so sind sie doch aller Wahrscheinlichkeit aus einer gemeinsamen Wurzel entsprossen und zwar muß die Spaltung derselben in eine sehr frühe geologische Zeit fallen. Bis heute liegen jedoch keine fossilen Formen vor, die allen Anforderungen einer Alinentype der beiden Stämme entsprechen würden. Im Gegensatze zu dem großen Heere der Knochenfische, das mit dem Mesozoikum zu immer ansteigender Blüte gelangt ist und sich in eine Unzahl von Familien gespalten hat, die in den verschiedensten Richtungen hohe Spezialisationsstufen erreicht haben, ist die Gruppe der Elasmobranchier verhältnisnüßig arm an Anpassungstypen. Sie sind im Vergleiche zu den vorwiegend zu Freischwimmern gewordenen Teleostomen fast durchaus Grundbewohner und haben es als ,Rochen" zu einer außerordentlich hohen Stufe der Anpassung an das benthonische Leben gebracht; nur ein relativ kleiner Teil ist zur nektonischen Lebensweise übergegangen, wobei freilich ausgezeichnete Schnellschwimmer, die „Haie“, aus dem Stamne der Plagiostomen hervorgegangen sind, die gleichzeitig zu den furchtbarsten Räubern der Meere gehören.

Die Mehrzahl der Elasmobranchier ist heite vivipar, d. h. die Jungen werden lebend zur Welt gebracht, während nur ein kleiner Teil ovipar geblieben ist, d. h. die Eier ablegt (Scylliidae, Heterodontidae, Rajidae, Chimaeridae). Von einem fossilen Chimäriden(Aletodus ferrugineus Ries aus dem unteren Dogger von Aalen in Württemberg) sind Eikapseln bekannt, die sich in ihrer Form eng an die Eikapseln cles lebenden Callorhynclus antarcticus anschließen. 
Unter den Merkmalen der Elasmobranchier sind als die wichtigsten folgende hervorzuheben:

1. Hautknochen kommen bei den Elasmobranchiern nicht zur Ausbildung. Auch bei den verwandten Acanthodiern bestehen die Hautverknöcherungen aus Vasodentin oder aus strukturlosen Lamellen ohne Knochenzellen, sind also den eigentlichen Belegknochen nicht vergleichbar.

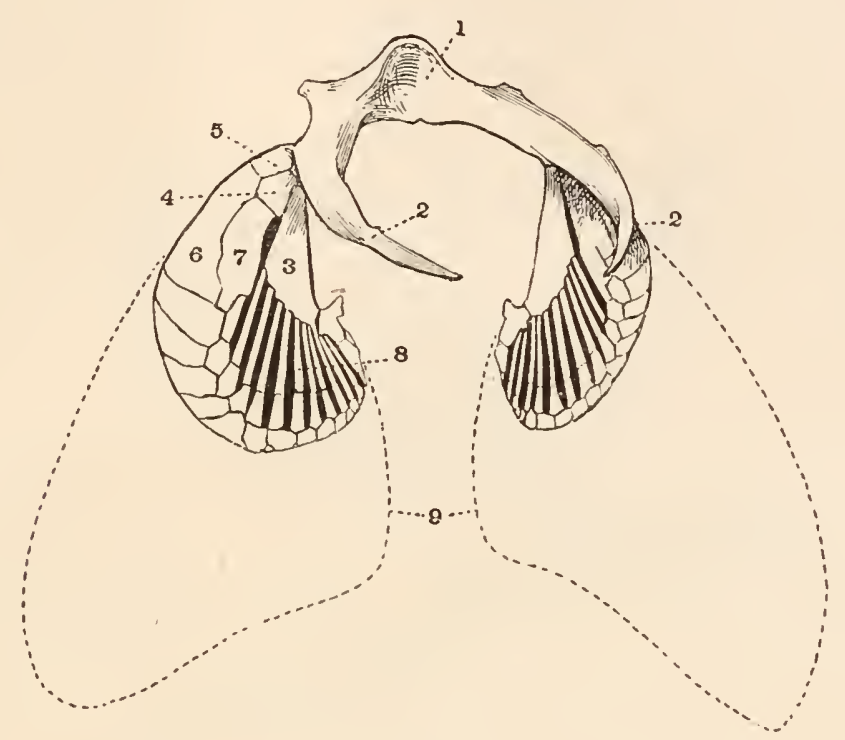

Fig. 66.

Schräge Dorsalansicht des Schultergïrtels und der beiden Brustflossen von Scyllium canicula, in $2 / 3$ nat. Größe. (Nach S. H. Reynolds.)

$I$. Mitte des Schultergiirtels.

2. Skapularabschnitt des Schultergürtels.

3. Metapterygium.

4. Mesopterygium.

5. Propterygium.

6. Propterygiales Radiale.
7. Mesopterygiales Radiale.

8. Metapterygiale Radialia.

9. Umriß der Pektoralen (punktiert), die durch Bindegewebsstrahlen von hornähnlicher Beschaffenheit gestützt werden.

2. Die Hautschuppen sind einfach, meist als "Plakoidschuppen“ entwickelt, die in Gestalt kleiner Zähnchen auf einem Sockel aufsitzen.

3. Die Wirbelsäule besteht bei den primitiveren Typen nur aus den oberen und unteren Bögen, später bildet sich auch ein Chordazentrum (vgl. S. 26) aus, wie bei den lebenden Plagiostomen, während die Chimäriden keine geschlossenen Wirbelkörper, sondern höchstens Ringzentren besitzen. Der Aufbau der Chordazentren (zyklospondyle, tektospondyle, asterospondyle Wirbelkörper) ist durchaus eigenartig.

4. Die Kiemenbögen (meist fünf, seltener [bei Notidanus] sechs oder sieben jederseits, bei Chlamydoselache sechs) stehen mit offenen Kiemenspalten in Verbindung. Bei der lebenden Gattung Chlamydose- 
lache sind wic bei den erloschenen Acanthodiern an den Kiemenspalten faltige Hautlappen entwickelt, die sich über die Kiemenspalten legen und dieselben schützen. Ein echter Operkularapparat (Kiemendeckel) ist unter den Elasmobranchiern $11 \mathrm{ur}$ bei den Holocephalen ausgebildet.

5. Die Aufnahme des Atemwassers geschieht bei den Elasmobranchiern mit Ausnahme der Holocephalen und einiger Lamniden hauptsächlich durch die ,,Spritzlöcher“ (spiracula), die .während des

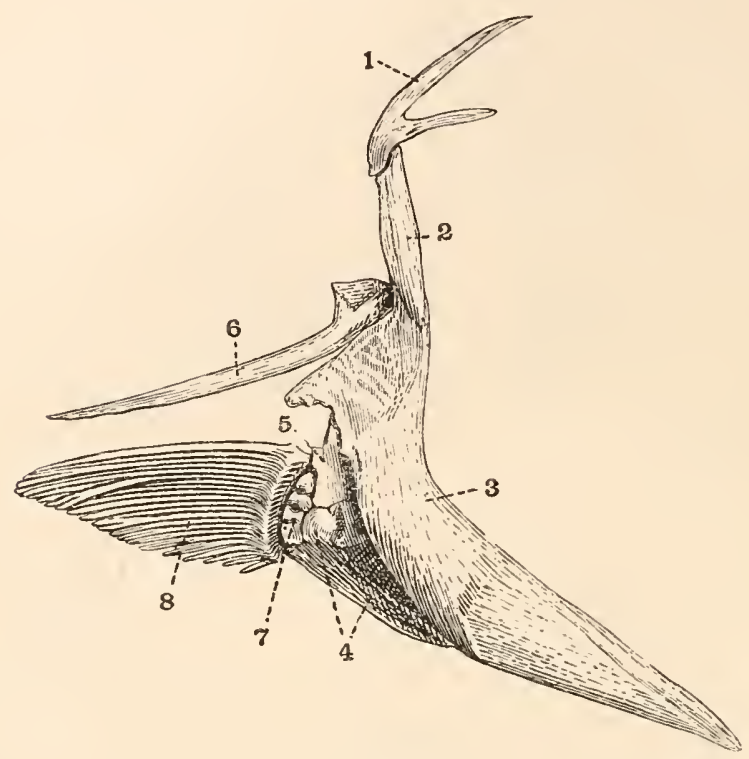

Fig. 67.

Rechte Hälfte des Schultergiirtels und der rechten Brustflosse eines Kabljaus (Gadus morrhua), in $1 / 2$ nat. Gr. (Nach S. H. Reynolds.)

I. Post temporale.

2. Supraclavicula.

3. Clavicula.

4. Coracoid.

5. Scapula.

6. Postclavicula.

7. Brachialia.

8. Dermale Flossenstrahlen.

Auspressens des Wassers aus den Kiemenspalten geschlossen werden. Bei fast allen übrigen Fischen wird das Atemwasser nur durch den Mund aufgenommen. Bei Polypterus und bei Acipenser sind noch funktionelle Spritzlöcher vorhanden, bei Lepidosteus und Amia sind sie rudimentär. Das Spritzloch liegt in der Regel unnittelbar hinter dem Auge.

6. Die Mundspalte der Elasmobranchier steht meist ventral, sehr selten terminal.

7. Die Verbindung des Unterkiefers mit dem Schädel ist bei den Elasmobranchiern in verschiedener Weise ausgebildet.

a) 1 m primitiven Zustand (z. B. bei Scylliun, Fig. 6) tritt der Unterkiefer mit dem linter ihm liegenden Hyomandibulare in Verbindung 
und wird vom Zungenbeinbogen getragen. Diese Befestigungsart, die auch bei den Rochen ausgebildet ist, wird als Hyostylie bezeichnet und ist jedenfalls die primitivste Befestigungsart des Unterkiefers mit dem Schädel.

b) Bei Notidanus (Fig. 70, A) ist das Hyomandibulare reduziert und der Unterkiefer tritt unmittelbar mit dem Palatoquadratum in Gelenkverbindung. Der Hyoidbogen hat seine selbständige Verbindung mit denı Schädel bewahrt; diese Befestigungsart wird als Amphistylie bezeichnet.

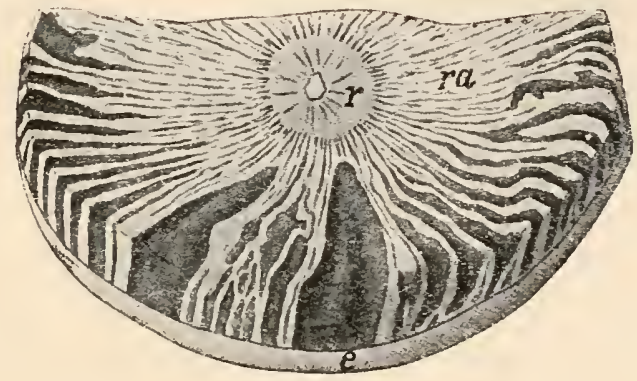

Fig. 68.

Quererschnitt durch die Mitte eines tektospondylen Plagiostomenwirbels: Oxyrhina Mantelli, Ag., obere Kreide (Niobraraschichten) von Kansas, in $2 / 3$ nat. Gr. (Nach C. R. Eastman, 1895.)

$r$ = ringförmige Verkalkung um die Chorda.

$r a=$ sternförmig ausstrahlende Kalkblätter.

$e=$ Rand der trichterförmig vertieften Endfläche.

c) Bei Heterodontus (Fig. 70, B) ist das Palatoquadratum in eine tiefe Grube an der Unter- und Außenseite des Knorpelschädels eingesenkt, mit demselben durch ein Ligament verbunden und steht in Gelenkverbindung mit dem Unterkiefer; hinter dem Palatoquadratum und dem Unterkiefer liegt das Hyomandibulare. Diese Art der Befestigung des Unterkiefers ist also vom hyostylen Typus verschieden und leitet zu jenen Typen hinüber, bei denen das Palatoquadratum mit denı Knorpelschädel vollkommen verschmolzen ist und sein Unterende das Unterkiefergelenk bildet. Die letztere Befestigungsart wird als Autostylie bezeichnet.

Die Autostylie findet sich unter den Elasmobranchiern bei den Holocephalen (Fig. 71), aber sie ist ganz unabhängig in verschiedenen anderen Stämmen entstanden (z. B. bei Arthrodiren und bei Dipneusten) und ist die Folge einer starken Inanspruchnahme des Gebisses bei quetschender, schneidender oder mahlender Funktion. Die Autostylie ist daher als eine wiederholt aufgetretene parallele Anpassung und nicht als Beweis einer engeren Verwandtschaft zu betrachten. 
8. Das Gebiß der Elasmobranchier ist entweder ein Fanggebiß oder ein aus diesen auf verschiedenen Wegen entstandenes Reibgebiß; las letztere bildete sich beim Übergange zu überwiegender oder ausschließlich hartkörperiger (durophager) Nahrungsweise aus.

9. Bei den Männchen der leben--

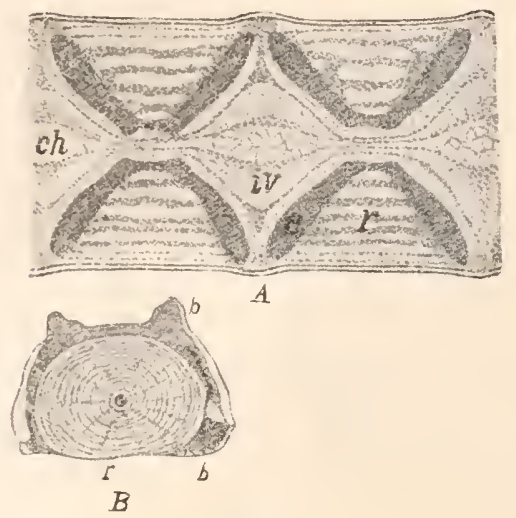

Fig. 69 .

A. Längsschnitt durch zwei Wirbel von Rhina vulgaris, lebend;

B. Querschliff durch die Mitte eines Wirbels derselben Gattung (Rhina spec.) aus der obersten Kreide von Maestricht in Holland. (Nach C. Hasse, 1882.)

$c h=$ Chorda dorsalis; innerhalb der durch dinkle Farbe gekennzeichneten Zentren eingeschnïrt, im Intervertebralraum iv von normaler Stärke; $r=$ ringförmige Verkalkungsschichten des tektospondylen Wirbels.

In Fig. B stellt $b$ die kalkige Bogenbasis dar. gelnen gelegentlich ins Süßwasser und nur vereinzelte Formen sind ausschließliche Süßwasserbewohner geworden (z. B. Carcharias nicaraguensis, ein etwa 311 langer Haifisch, im Nicaraguasee und im Rio San Juan).

\section{Ordnung: Pleuropterygii.}

Die Pleuropterygier stellen selir primitive Elasmobranchier dar, ohne aber als çigentliche Ahnengruppe der übrigen Ordnungen anfgefalst werden zu können. In vielen Punkten sind die Cladodontiden einseitig spezialisiert, sind aber trotzdem als jener Zweig der Elasmobranchier zu betrachten, der die meisten altertümlichen Merkmale umfaßt. Ob er in jüngeren Familien seine Fortsetzung findet, ist zweifelhaft. 
Das hervorstechendste Merkmal dieser Gruppe sind die paarigen Flossen.

In der Brustflosse von Cladodus Neilsoni Traquair aus dem Karbonkalk von East Kilbride in Schottland (Fig. 73) ist eine lange, aus einzelnen Segmenten bestehende, gegliederte Flossenachse vorlıanden. Vergleichen wir das Skelett der Brustflosse von Cladodus mit dem eines
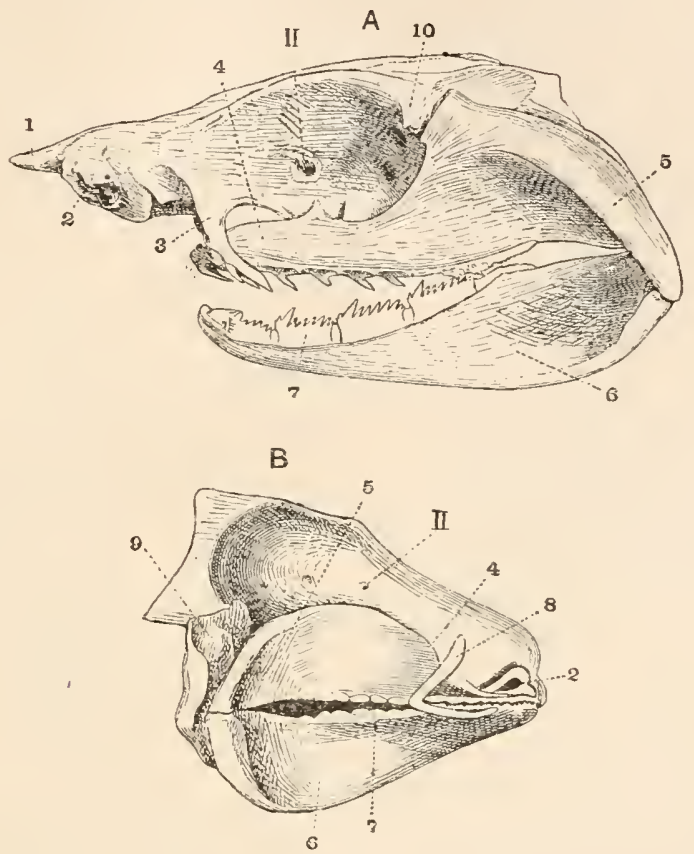

Fig. 70 .

A. Amphistyler Schädel von Notidanus (nach S. H. Reynolds), in $1 / 2$ nat. Gr. B. Schädel von Heterodontus (Übergang von der Hyostylie zur Autostylie) (nach C. Gegenbaur), in $1 / 3$ nat. Gr.

I. Rostrum.

2. Nasenkapsel.

3. Processus ethmopalatinus.

4. Palatinalabschnitt des PalatoPterygo-Quadratum.

5. Quadratumabschnitt desselben Bogens.
6. Meckelscher Knorpel.

7. Zähne.

8. Lippenknorpel.

9. Hyomandibulare.

IO. Processus postorbitalis.

II. Foramen opticum.

Hundshaies (Scyllium canicula, Fig. 66), so sehen wir, daß sich an den sichelförmigen Schultergürtel des letzteren eine Reihe polygonaler Knorpelstücke anlegt, die ihrer Reihenfolge nach als Propterygium, Mesopterygium und Metapterygium bezeichnet werden. An diese Elemente reihen sich die Radialia an, eines an das Propterygium, eines an das Mesopterygium und zwölf an das Metapterygium; dann folgt weiter nach außen noch eine größere Zahl polygonaler Knorpelstücke; an diese schließen sich endlich hornartige Bindegewebsstrahlen 
(nicht Hornstrahlen!) als Spreizen des übrigen, plattig verbreiterten Abschnittes der Brustflosse an.

Bei Cladodus Neilsoni setzt sich an das Knorpelstück der Brustflosse, das von Traquair ${ }^{\mathbf{1}}$ mit dem Metapterygium identifiziert wurde, eine lange Reihe von zylindrischen Knorpelstücken an, die in der Verlängerung der Hauptachse der Flosse liegen (Fig. 73).

Dieselben Verhältnisse, die an der Brustflosse von Cladodus Neilsoni zu beobachten sind, konnten von $\mathrm{O}$. Jaekel an den Beckenflossen

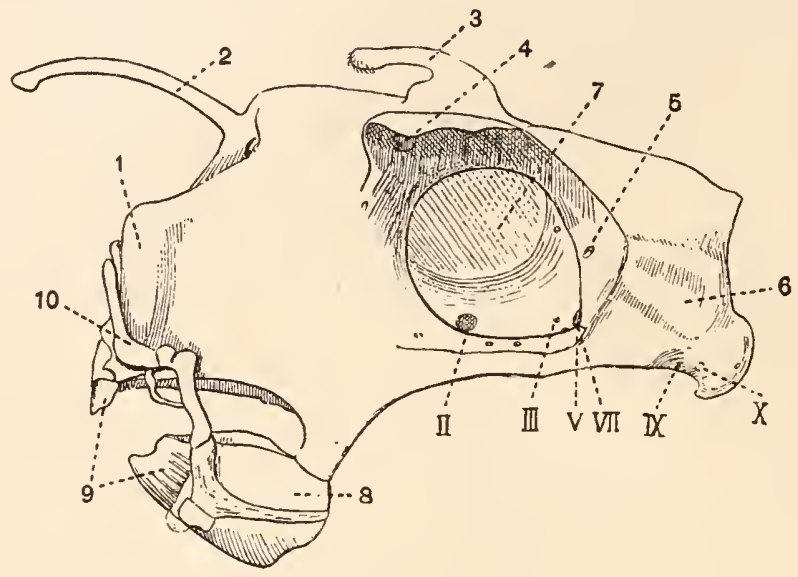

Fig. 71 .

Autostyler Schädel eines Männchens von Chimaera monstrosa. (Nach Hubrecht, aus Reynolds.)

I. Nasenkapsel.

2. Knorpeliger Nasenstachel.

3. Erektiler Kopfstachel.

4. Foramen für den Austritt der Augennerven aus der Orbita.

5. Foramen für die Eintrittsstelle des Augenastes des V. Nerven.

6. Gehörkapsel.
7. Septum interorbitale.

8. Unterkiefer, mit dem Schädel durch einen Fortsatz des Palato-PterygoQuadratbogens verbunden.

9. Zähne.

To. Lippenknorpel.

$I I ., I I I ., V ., V I I ., I X ., X .=$ Foramina für die betreffenden Schädelnerven

von Cladodus Fyleri aus den Cleveland Shales von Ohio (Grenzschichten zwischen dem Devon und Karbon) festgestellt werden (Fig. 72). An die ziemlich großen Beckenhälften setzt sich jederseits am Hinterende des Beckens ein Metapterygium an, vor dem noch ein kleines Knorpelstück liegt, das als Propterygium gedeutet werden kann. An das Metapterygium gliedern sich in analoger Weise wie in der Brustflosse zylindrische Knorpelstücke an, welche die Hauptachse der Flosse bilden. Diese gegliederten Knorpelstäbe werden als Pterygopodien bezeichnet.

1 R. H. Traquair, On Cladodus Neilsoni (Traquair) etc. Transactions Geol. Soc. Glasgow, XI, 1897, p. 41, pl. IV. 
Nur im vordersten Teile der Brust- und Bauchflosse setzen sich außen an die Metapterygien und die Propterygien einfache Radialia an; die Pterygopodien scheinen frei geendet $\mathrm{zu}$ haben und nicht in die Flossenfläche einbezogen gewesen zu sein.

Das Ende der ventralen Pterygopodien von Cladodus Fyleri ist kolbenförmig verdickt und scheint feine Krallen getragen $\mathrm{zu}$ haben, wie dies auch bei den Pleuracanthiden beobachtet worden ist. Dies deutet darauf hin, daß das Pterygopodium hier bereits als Klammerorgan bei der Begattung funktioniert haben dürfte.

Das Pterygopodium der Cladodontiden stellt aller Wahrscheinlichkeit nach die primäre Hauptachse der Brust- und Bauchflossen dar, an welche sich erst sekundär die Radialia angeschlossen haben.

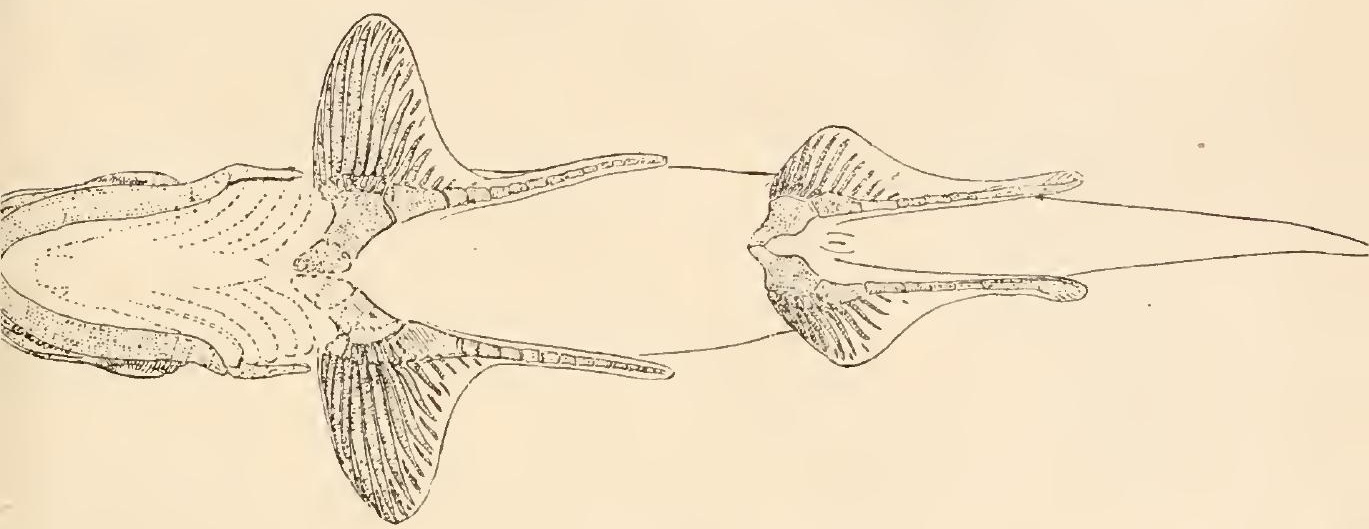

Fig. 72.

Rekonstruktion von Cladodus (Cladoselache) Fyleri Newb. aus dem Devon Cleveland shales) von Ohio, Nordamerika, von unten gesehen. Stark verkleinert. (Nach O. Jaekel, 1909.)

Ursprünglich sind die Gliedmaßen der Cladodontiden bzw. ihrer Ahnen wohl ebensolche Bewegungsorgane gewesen, wie sie uns, freilich als Derivate von Schwinmflossen, bei Lepidosiren unter den Dipneusten entgegentreten, wo sie abwechselnd den Körper des auf dem Boden liegenden Fisches vorwärts schieben. Die erste Ausbildung der paarigen Gliedmaßen der Elasmobranchier dürfte sonach auf Kriechorgane, und zwar auf segmentierte Pterygopodien zurückgehen, wie sie im Flossenskelett der Cladodontiden noch erhalten sind. Cladodus ist jedenfalls ein benthonischer Typ gewesen und hat wahrscheinlich die Pterygopodien in analoger Weise wie Lepidosiren verwendet.

Daraus darf nun freilich nicht der Schluß gezogen werden, daß alle paarigen Fischflossen auf analoge oder homologe Pterygopodialbildungen zurückgeführt werden können. Die später zu besprechenden Verhältnisse des Flossenbaues der Acanthodier sprechen dafür, daß die Flossen 
in diesem Falle als Versteifungen einer lateralen Hautfalte anzusehen sind, was insbesondere durch das Auftreten von ein bis fünf überzähligen Flossenpaaren zwischen den beiden normalen Flossenpaaren, also zwischen den Brust- und Bauchflossen, sehr wahrscheinlich gemacht wird. Die primäre Entstehung paariger Flossen wäre somit auf zwei verschiedenen Wegen vor sich gegangen; bei den Ahnen der Pleuropterygier

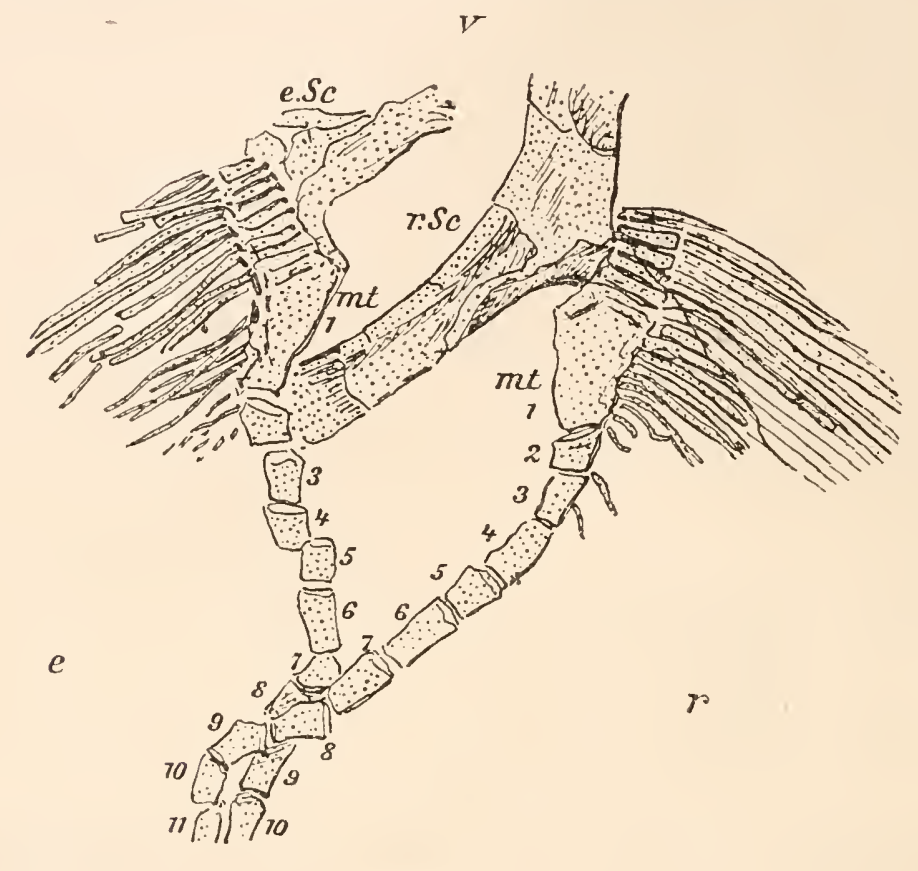

负

Fig. 73.

Brustflossenskelett von Cladodus Neilsoni Traqu. aus dem Kohlenkalk von East Kilbride (Schottland). (Nach R. H. Traquair.)

$v$. = vorne. $\quad$ e. Sc. = linke Scapula.

e. $=$ links. $\quad$ r.Sc. $=$ rechte Scapula.

$r$. = rechts. $m t .=$ Metapterygium.

$h$. = hinten. $\quad I-I O=$ knorpelige Segmente des Metapterygiums. $(1 / 2$ nat. Gr.)

sind die Flossen, wie ich hier zu zeigen versucht habe, aus Kriechapparaten hervorgegangen, deren letzte Reste bei den leute noch lebenden Elasmobranchiern nur mehr in Gestalt der „Claspers“ und in den drei Elementen Metapterygium, Mesopterygium und Propterygium erhalten sind. Ebenso sind auch die paarigen Flossen der Crossopterygier auf Stützapparate benthonischer Vorfahren zurückzuführen, wovon noch später die Rede sein wird; ihre Spezialisierung zu Flossen ist jedoch in grundverschiedener Weise erfolgt. 
Die beiden wichtigsten Vertreter dieser Gruppe gehören einer einzigen Gattung (Cladodus, Agassiz = Cladoselache, Dean) an.

\section{F. Cladodontidae.}

Außer dem schon besprochenen Bau der Flossen mit den langen Pterygopodien ist der Bau und die Form der Terminalflosse besonders auffallend. Die Chorda dorsalis wendet sich am Hinterende des Körpers nach oben und setzt sich bis zur Spitze des oberen Endes der Terminalflosse fort, die somit dem heterozerken ${ }^{1}$ Typus entspricht (Fig.74). Über der Chorda sind in der Terminalflosse Knorpelbögen (Neurapophysen) ausgebildet, die eine Reihe großer Knorpelstrahlen tragen; ebensolche Strahlen legen sich an die Unterseite der Chorda an, nur sind sie hier schlanker und in größerer Zahl vorhanden. Der Hinterrand der Terminalflosse verläuft fast gerade und senkrecht zur Körperachse.

Die Zahl der Kienenspalten ist unsicher; sicher beobachtet sind fünf, möglicherweise sind aber noch zwei weitere vorhanden gewesen (Dean hatte neun angenommen). Die Zähne (Fig. 75) sind je nach ihrer Lage in den Kiefern verschieden geformt; zwischen einer Form mit hoher Hauptspitze und zwei kleinen basalen Nebenspitzen und einer Form mit niederer Hauptspitze und sechs (jederseits drei) lohen Nebenspitzen gibt es alle Übergänge. Die Mundspalte stand terminal (Fig. 72). Ob Spritzlöcher vorhanden waren, ist noch unsicher. Die Augen waren von zahlreichen Sklerotikalplatten ringförmig umschlossen. Die Haut war mit kleinen Hautzähnchen dicht übersät; vor der Terminalflosse stand beiderseits je eine

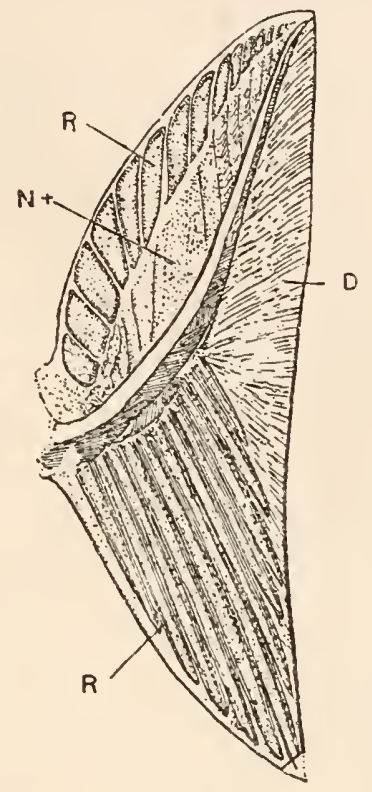

Fig. 74 .

Terminalflosse von Cladodus Fyleri aus dem Oberdevon von Ohio, in etwa

$1 / 2$ nat. Gr.

(Nach B. Dean.)

$D=$ Flossenhaut.

$N+=$ Neurapophysen der Caudalwirbel.

$R \quad=$ endoskeletale Knorpelstrahlen der Terminalflosse. horizontale Hautfalte, die Steuerkiele (wie z. B. bei Lamna, beim Thunfisch [Thunnus] und der Makrele [Scomber]) bilden und in physiologischer Hinsicht den vertikalen Steuerkielen der Wale (z. B. Phocaena, Megaptera) vergleiclıbar sind. Die Befestigungsart des Unterkiefers war hyostyl.

1 Über die Terminologie der Flossentypen nach Form, Bau und Funktion vgl. O. Abel, Paläobiologie der Wirbeltiere, 1912, p. 104-113. 
Cladodus (= Cladoselache). (Fig. 72-75.) - Die besten Exemplare aus den Grenzschichten des Oberdevons und Karbons von Ohio sowie aus dem Kohlenkalk von East Kilbride in Schottland bekannt; außerden in Oberdevon von Wildungen (nach O. Jaekel), im Karbon von England, Irland, Belgien und Rußland aufgefunden. Die größten Exemplare erreichten eine Länge von $2 \mathrm{~m}^{1}{ }^{1}$
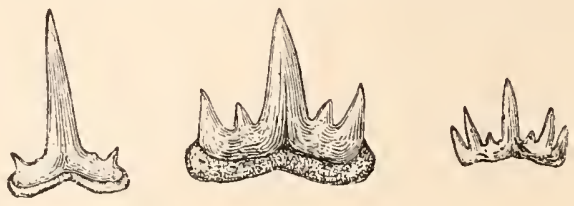

Fig. 75 .

Zähne von Cladodus, in $1 / 2$ nat. Gr., aus verschiedenen Regionen der Kiefer. (Nach B. Dean.)

\section{Ordnung: Ichthyotomi.}

Die Pleuracanthiden, welche eine in manchen Punkten hochspezialisierte, in anderen Merkmalen aber noch sehr tiefe and primitive Stellung unter den Elasmobranchiern einnehmen, stehen in der Gesantsumme ihrer morphologischen Merkmale etwa in der Mitte zwischen den Pleuropterygiern und den Plagiostomen und sind wohl an besten als eigene Ordnung zu umgrenzen. Im Bau der Flossen erweisen sie sich als höher spezialisiert als die Pleuropterygier, da sich an das Pterygopodium der Brustflosse bereits hintere Strahlen angesetzt haben, wodurcl die Brustflosse haifischähnlicher wird. Die Bauchflosse schließt sich dagegen in ihrem Bau noch immer näher an die Bauchflosse von Cladodus als an die Bauchflossentypen der Plagiostomen an.

1 B. Dean, Contributions to the Morphology of Cladoselache (Cladodus). Journal of Morphology, Vol. 1X, 1894, p. 87.

Derselbe, A New Cladodont from the Ohio Waverly, Cladoselache Newberryi, n. sp. Transactions New York Acad. Science, Vol. XIII, 1894, p. 115.

Derselbe, Fishes, Living and Fossil. New York, 1895, p. 79.

Derselbe, Sharks as Ancestral Fishes. Natur. Science, Vol. VIII, I896, p. 245.

E. W. Claypole, The Cladodont Sharks of the Cleveland Shale. Amer. Geologist, XI, 1893, p. 325.

Derselbe, On a New Specimen of Cladodus Clarki. Ibidem, XV, 1895, p. 1.

Derselbe, The Cladodonts of the Upper Devonian of Ohio. Geolog. Magazine, (4), Vol. II, 1895, p. 473.

Derselbe, On the Structure of the Teeth of the Devonian Cladodont Sharks. Proc. Amer. Microscop. Soc., XVI, 1895, p. 191.

O. Jaekel, Über die Beurteilung der paarigen Extremitäten. Sitzungsber. kgl. preuß. Akad. d. Wiss., Bd. XXVI, Berlin, 1909, p. 707.

R. H. Traquair, On Cladodus Neilsoni (Traquair), from the Carboniferous Limestone of East Kilbride. Transactions of the Geol. Soc. of Glasgow, Vol. XI, 1897, Part 1, p. 41. 
Stellt somit der Bau der paarigen Flossen wahrscheinlich ein Zwischenstadium zwischen den Pleuropterygiern und den Plagiostomen dar, so ist der Bau der medianen Flossen durchaus abweichend von beiden Gruppen und kann nur als die Folgeerscheinung einer eigenartigen Lebensweise angesehen werden, die am ehesten mit jener der lebenden Macruriden zu vergleichen ist. Der Rumpf wird von einem niedrigen Flossensaum umgeben, der hinter dem Schädel beginnt und, nur von einer Einkerbung unterbrochen, bis zum spitz endenden Schwanzende läuft, sich von hier auf die Unterseite wendet und nach vorne ungefähr bis zu der Linie reicht, die durch die auf der Rückenseite vorhandene Einkerbung des Flossensaumes bezeichnet wird. Vor dem Ende des ventralen Flossensaumes, der ebenso wie längs der ganzen Rückenlinie von zwei übereinanderstehenden Reihen knorpeliger Flossenstrahlen gestützt wird, stehen zwei einander genäherte schmale Flossen mit knorpeligen Trägern, die vielleicht untereinander und mit dem ventralen Flossensaum vereinigt waren.

Diese Verhältnisse sind unmöglich als primitive zu deuten; es liegt offenbar eine sekundäre Verlängerung der Rückenflosse vor, die ursprünglich von der Caudalis getrennt war, wie die Einkerbung des dorsalen Saumes beweist, und es ist der ganze Abschnitt des Flossensaumes, welcher von der auf der Dorsalseite gelegenen Einkerbung angefangen bis zum Körperende und von da auf der Ventralseite bis zur Analflosse reicht, der Caudalis der Plagiostomen gleichzustellen. Es ist also die Terminalflosse hier allein von der Caudalis gebildet, ein Fall, der sonst bei keiner Gruppe der lebenden Fische zu beobachten ist, wenn wir von den Cyclostomen absehen.

Die Chorda persistiert und wird oben und unten von verkalkten Bögen begleitet; irgendwelche Andeutungen einer Wirbelzentrenbildung fehlen gänzlich.

Der Knorpelschädel trägt mitunter einen großen, entweder glatten (Anodontacanthus) oder gezähnelten (Pleuracanthus) Nackenstachel, der bei Chondrenchelys fehlt. Hinter dem Palatoquadratum liegt ein schmächtiges, schlankes Hyomandibulare; ob die Gelenkverbindung amphistyl oder hyostyl war, ist noch zweifelhaft. Von den Kiemenspalten sind nur fünf vorhanden, so daß in dieser Hinsicht die Pleuracanthiden höher spezialisiert gewesen sind als z. B. Notidanus unter den lebenden Plagiostomen. Die Mundspalte liegt nicht auf der Ventralseite, sondern terminal, verhält sich also in dieser Hinsicht primitiv. Die Zähne tragen zwei divergierende starke Spitzen, zwischen denen ein kleiner Zacken steht, sind also hoch spezialisiert.

Die Haut war vollständig nackt.

Die Pleuracanthiden stellen somit eine auf primitiver Basis vom Hauptstamme der Elasmobranchier abgezweigte und einseitig speziali- 
sierte Gruppe dar, die nicht als die Ahnengruppe der Plagiostomen betrachtet werden darf. Da sie nur aus Süßwasser- und Brackwasserablagerungen, aber nicht aus marinen Schichten bekannt sind, dürfen sie als Süßwassertypen angesehen werden.

\section{F. Pleuracanthidae.}

Pleuracanthus. - Karbon und Perm von Deutschland (Fig. 76), Österreich, Frankreich und England, Perm von Texas. ${ }^{1}$

Anodontacantluus. - Karbon Englands. ${ }^{2}$

Chondrenchelys. - Karbon Schottlands. ${ }^{3}$

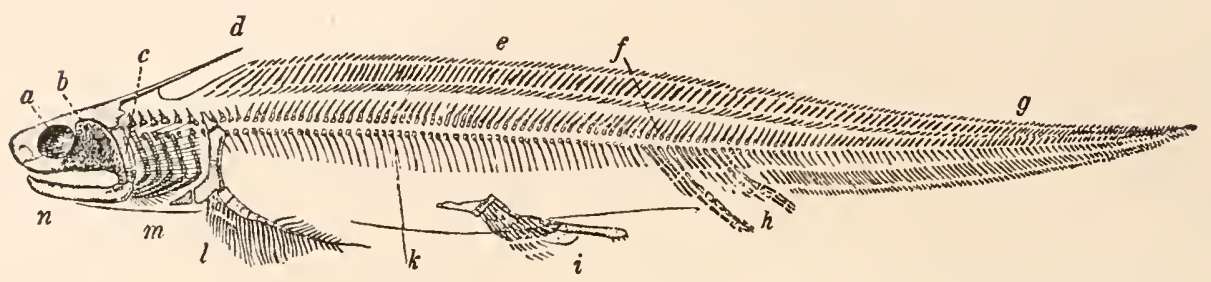

Fig. 76.

Rekonstruktion von Pleuracanthus sessilis, Jordan, ơ aus dem unteren Perm von Lebach bei Saarbrïcken, in 1/6 nat. Gr. (Nach O. Jaekel, 1906.)
$a=$ Augenhöhle.
$b=$ Palatoquadratum.
$c=$ Hyomandibulare.
$d=$ Kopfstachel.
$e=$ Träger der Rückenflosse.
$t$ - verkalkte obere Wirbelbögen.
$g=$ Terminalflosse.
$h=$ Afterflosse.
$i=$ Bauchflosse mit Begattungsstachel (Clasper).
$k=$ untere Wirbelbögen.
$l=$ Brustgiirtel und Brustflosse.
$m=$ Kiemenbögen.
$n=$ Mandibulare.

\section{Ordnung: Plagiostomi.}

Die Plagiostomen umfassen eine große Zahl von lebenden und eine verhältnismäßig kleine Zahl fossiler Familien. Die meisten lebenden

${ }^{1}$ Ch. Brongniart, Sur un nouveau Poisson fossile du terrain houiller de' Commentry (Allier), Pleuracanthus Gaudryi. Bull. Soc. Géol. France (3), T. XVI, Paris 1886, p. 546. - Comptes Rendus, Paris, 23. Avril 1888.

Derselbe, Études sur le terrain houiller de. Commentry. Faune ichthyologique. I. partie. 1888. 38 Seiten.

O. Jaekel, Neue Rekonstruktionen von Pleuracanthus sessilis und von Polyacrodus Hauffianus. Sitzungsber. Ges. Naturf. Freunde, Berlin 1906, p. 155 (Literatur).

2 J. W. Davis, On the Fossil Fish-Remains of the Coal-Measures of the British Islands. Part I: Pleuracanthidae. Transactions Roy. Dublin Soc. (2), Vol. IV, 1892, p. 703.

${ }^{3}$ R. H. Traquair, Notes on Carboniferous Selachii. Geological Magazine (3), Vol. V, London 1888, p. 103.

A. Smith Woodward, Catalogue of the Fossil Fishes in the British Museum. Part. I (Elasmobranchii). London 1889, p. 15. 
Familien stehen, wie aus ihrer großen Artenzahl hervorgeht, noch in voller Blüte; einige Familien umfassen nur wenige Vertreter, wie die altertümlichen Notidaniden oder die Chlamydoselachiden, während z. B. die Carchariiden oder die Lamniden zahlreiche Arten zählen.

Man hat in früherer Zeit unter den Plagiostomen zwei große Gruppen unterschieden, die Selachier oder echten Haifische und die Batoidei oder Rochen. Für diese Unterscheidung waren aber Merkmale gewällt worden, welche sich zum Teil auf beide Gruppen verteilt finden, wie der Bau der Wirbelkörper, oder solche Merkmale, die als typische Anpassungserschei-

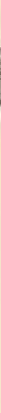

Fig. 77.

Skelett von Hybodus Hauffianus, E. Fraas, mit erhaltener Haut, aus dem oberen Lias von Holzmaden, Württemberg, in $1 / 8$ nat. Gr. (Nacl1 E. Koken 1907, aus E. v. Stromer, 1912.)

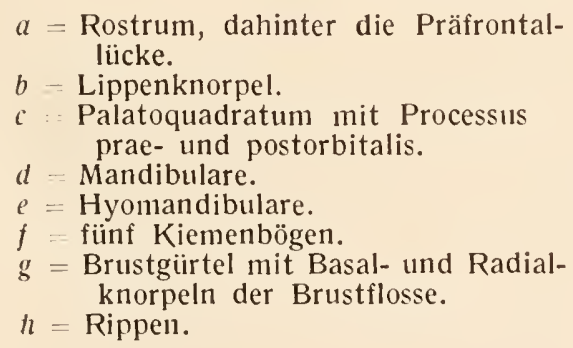
lïcke.

$b$ - Lippenknorpel.

c : Palatoquadratum mit Processus prae- und postorbitalis.

$d=$ Mandibulare.

$e=$ Hyomandibulare .

$f=$ fünf Kiemenbögen.

$g$ = Brustgüirtel mit Basal- und Radialknorpeln der Brustflosse.

$h=$ Rippell.

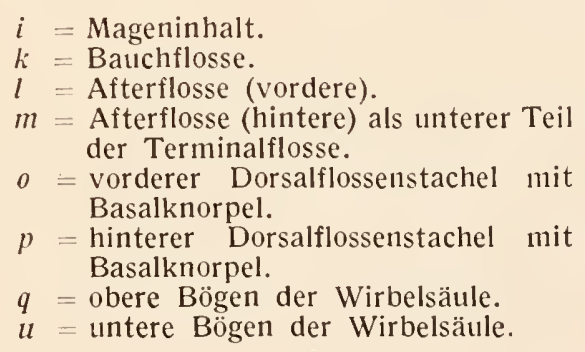

$k=$ Bauchflosse.

$l=$ Afterflosse (vordere) .

$m=$ Afterflosse (hintere) als unterer Teil der Terminalflosse.

$o=$ vorderer Dorsalflossenstachel mit Basalknorpel.

Basalknorpel.

$u=$ untere Bögen der Wirbelsäule.

nungen an die benthonische Lebensweise angesehen werden müssen, wie die dorsoventral abgeflachte Körpergestalt in Verbindung mit der Verbreiterung der Brustflossen, die Reduktion des Schwanzes und der Analflosse, die Lage der Kiemenspalten, das durophage Gebiß usw. Fortgesetzte Untersuchungen haben uns darüber aufgeklärt, daß aus einem Grundstamm mit zyklospondylem Wirbelkörperbau und nur geringfügigen Anpassungen an das benthonische Meeresleben einerseits durch Annalıme einer rein nektonischen Lebensweise die Typen der schnellschwimmenden Haifische, andererseits durch Fortsetzung der benthonischen Lebensweise die Rochen entstanden sind. Man darf aber nicht die Gesamtsumme der nektonischen Typen der Summe der rein benthonischen Typen als systematische Kategorien gegen- 
überstellen; „Haifische“ und „Rochen" stellen nur zwei verschiedene Anpassungstypen des Plagiostomenstammes dar, die wicderholt auf verschiedenen Wegen entstanden sind. Auch die Spezialisierung des Wirbelkörperbaues ist bei den verschiedenen Familien der Plagiostomen ganz unabhängig voneinander erfolgt. Der Ausgangstypus ist der Typus der einfachen Sanduhrwirbelbildung, den Hasse als ,zyklospondyl“ bezeichnet hat. Aus diesem Typus sind einerseits die ,asterospondylen“, andererseits die ,tektospondylen“" Wirbeltypen hervorgegangen. In großen und ganzen zeigt sich freilich, daß die ehemalige systematische Kategorie der ,Rochen" einen tektospondylen Wirbelbau, die Hauptmasse der ,Haifische“ einen asterospondylen Wirbel-

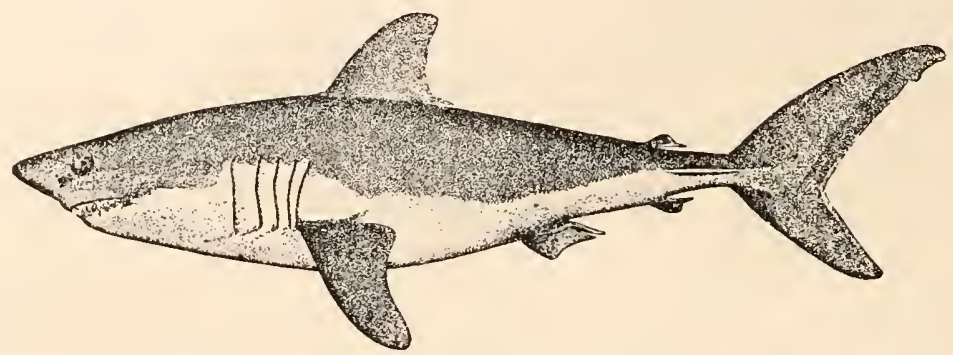

Fig. 78.

Lamna cornubica; Holozän. $1 / 27$ nat. Gr. (Nach B. Dean.)

bau besitzt, aber es bestehen verschiedene Ausnahmen, wie die zyklospondylen Wirbel der Ptychodontiden und die tektospondylen Wirbel der Rhiniden. Dazu kommt, daß wir heute auch aus anderen Merkmalen mit Sicherheit erschließen können, daß die verschiedenen rochenförmigen Typen unabhängig voneinander entstanden sind, so daß die „Rochen“ oder Batoidei schon aus diesem Grunde eine unnatürliche, weil ,,polyphyletische“ Gruppe bilden, die unbedingt aufgelöst werden muß, wie alle künstlichen, systematischen Gruppen, die Formen von verschiedener phylogenetischer Herkunft umfassen.

A. Lebende Familien.

1. F. Notidanidae (Grauhaie).

Fossil vom Jura an. - Lebende Type: Heptanchus (sieben Kiemenspalten, amphistyl, Chordazentren einfach, Andeutungen von Asterospondylie in den Schwanzwirbeln von Notidanus, vivipar). (Fig.70, A.)

\section{F. Chlamydoselachidae.}

Fossil vom Pliozän an. - Lebende Type: Chlamydoselache (sechs Kiemenspalten, hyostyl, Chordazentren wie bei den Notidaniden, aber in der Schwanzregion noch primitiver gebaut, viv:par). - Fossil im Pliozän von Toscana. 


\section{F. Heterodontidae (Doggenhaie).}

Fossil vom Unterkarbon an. - Lebende Type: Heterodontus = Cestracion (fünf Kiemenspalten, ovipar, Übergang zur Autostylie, Chordascheide bei den ältesten Typen [z. B. Hybodus] unverkalkt; später asterospondyl. Schädel des Männchens mit Kopfstacheln [bei Hybodus] oder mit zwei stark vorspringenden Kammleisten [Heterodontus]. Zwei Dorsalflossen, jede mit starkem Stachel am Vorderrand. - Ältester Vertreter der Familie: Ctenacanthus costellatus aus dem Unterkarbon von Schottland. - Hybodus (Trias bis Kreide). - Acrodus (Trias bis Kreide). - Paracestracion (Tithon Bayerns). - Von Campodus (Ober-

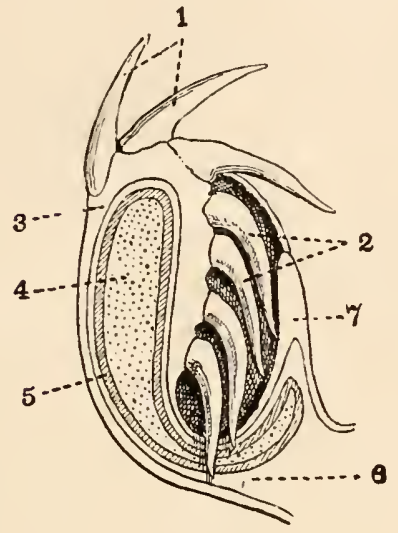

Fig. 79 .

Längsschnitt durch den Kiefer eines Haifisches (Odontaspis americanus).

(Nach S. H. Reynolds.)

I. Zähne in Funktion.

2. Zähne in Reserve.

3. Haut.

4. Kieferknorpel.

5. Kalkkruste des Kieferknorpels.

6. Bindegewebe.

7. Schleimhaut des Mundes.

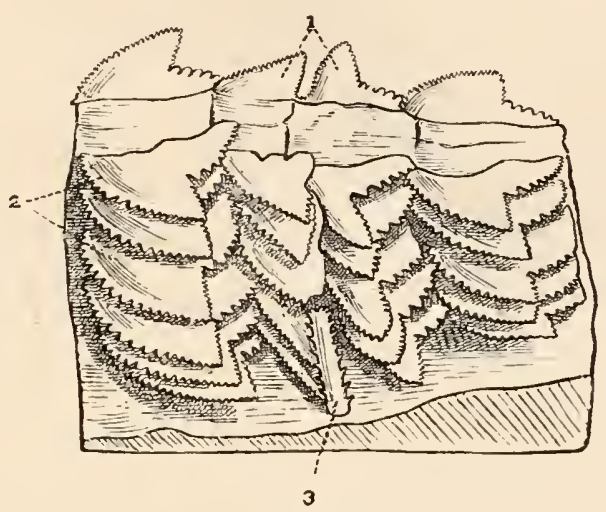

Fig. 80 .

Teil des Unterkiefers eines Carchariiden (Galeus), um die Lage der Ersatzzähne zu zeigen. (Nach R. Owen, aus Reynolds.)

I. Zähne in Funktion.

2. Zähne in Reserve.

3. Bruchstiick des Schwanzstachels eines Trygon, der den Kiefer verletzte und das Wachstum der Zähne behinderte.

karbon Nordamerikas) ist nur das Gebiß bekannt, das sich dem Heterodontustypus anschließt. (Fig. 70, B, und 77.)

\section{F. Scylliidae (Hundshaie).}

Fossil vom Tithon (oberer weißer Jura) an. - Lebende Type: Scyllium (fünf Kiemenspalten, hyostyl, asterospondyl, ovipar). - (Fig. 6, 66.)

\section{F. Carchariidae (Menschenhaie).}

Fossil von der Kreide an. - Lebende Type: Carcharias (asterospondyl, vivipar). - Zahlreiche lebende Arten (20 Gattungen mit zusammen etwa 60 Arten). Die Gattung Galeus (z. B. G. canis) ist eine benthonische Type (Fig. 80). 
6. F. Sphyrnidae (Hammerhaie).

Fossil vom Miozän an (in Europa und Nordamerika). - Lebende Type: Sphyrna.

7. F. Lamnidae (Riesenlaaie).

Fossil vom Jura an, inn Tertiär sehr häufig. - Lebende Haupttypen: Lamma, Odontaspis, Oxyrhina, Alopecias, Carcharodon (astero-
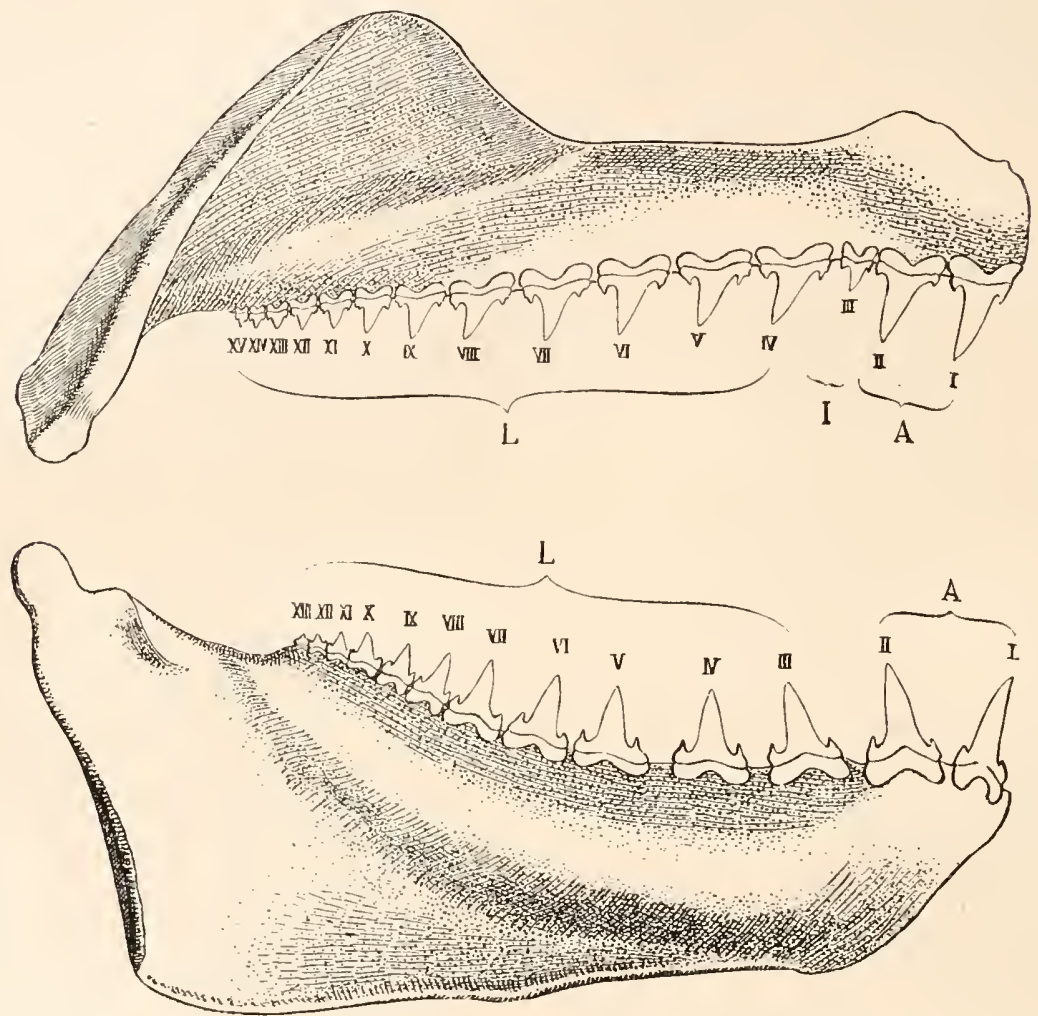

Fig. 81 .

Die Formverschiedenheiten der Zähne von. Lamna cornubica, L., Holozän, die die Unhaltbarkeit der allẹn auf Form- und Größenunterschiede errichteten fossilen Arten zeigen. (Nach M. Leriche.) $A=$ Vorderzähne. $\quad I=$ Zwischenzähne. $L$ - Lateralzähne.

spondyl, vivipar, Schwanz mit Lateralkielen vor der Terminalflosse, Spritzlöcher zuweilen felılend). - Die Zähne von Carcharodon megalodon (Eozän bis Pliozän, vielleicht von verschiedenen Arten herrührend) erreichen eine Höhe von $15 \mathrm{~cm}$. Sie wurden wiederholt bei Dredschzügen im Gebiete des roten Tiefseetons an der Oberfläche des Meeresbodens gefischt. - (Fig. 5, 78, 79, 81, 82.) 


\section{F. Cetorhinidae (Sonnenhaie).}

Fossil vom Pliozän an, vielleicht auch schon inn älteren Tertiär. Einzige lebende Art: Cetorhinus (= Selache) maximus, Körperlänge $13 \mathrm{~m}$ erreichend. Das Futter des harmlosen Riesen besteht aus kleinen pelagischen Fischen und Evertebraten. Die Zähne sind klein, kegelförmig und in sehr großer Zahl vorhanden.

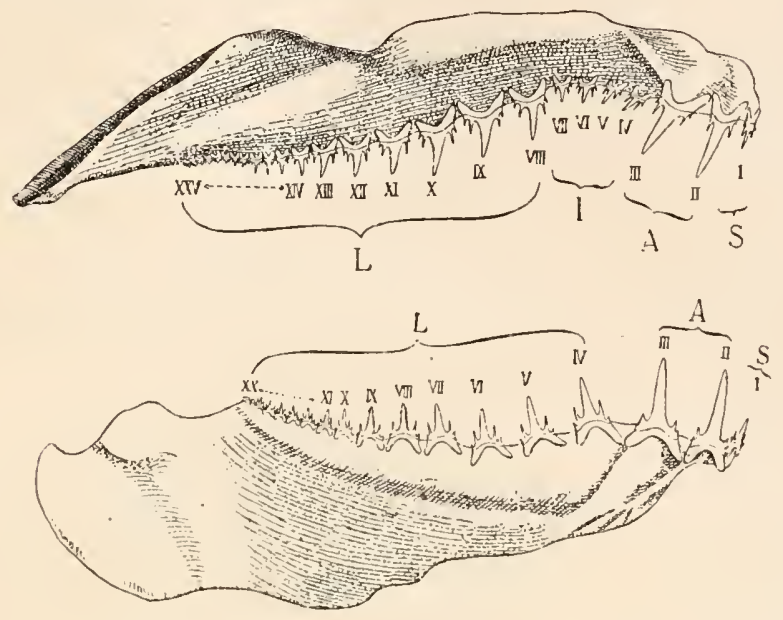

Fig. 82 .

Die Größenunterschiede der Fangzähne im Ober- und Unterkiefer von Odontaspis ferox, Risso, Holozän, von rechts gesehen. Nur die äußeren Zähne abgebildet.

(Nach M. Leriche.)
$S=$ Zähne der Symphysenregion
$A=$ große Vorderzähne.
$I=$ kleine Internediärzähne.
$L=$ Lateralzähne.

\section{F. Rhinodontidae.}

Nur eine lebende Gattung bekannt, die den größten lebenden Vertreter der Haitische (Rhinodon) mit ungefähr 16 m größter Körperlänge enthält. Die Zähne sind klein und kegelförnig wie bei Cetorhinus und die Tiere sind gleichfalls harmlos.

\section{F. Spinacidae (Dornhaie).}

Fossil von der oberen Kreide an. - Lebende Haupttype: Spinax. (Zyklospondyl. Vivipar. Bei mehreren Gattungen steht vor jeder der beiden Dorsalflossen ein kräftiger Stachel, der bei mehreren anderen Gattungen fehlt.) - Die lebende Gattung Centrophorus tritt schon in der oberen Kreide des Libanon auf.

\section{F. Pristiophoridae.}

Fossil von der oberen Kreide an. - Lebende Type: Pristiophorus. (Tektospondyl. Vivipar. Kiemenspalten lateral gestellt. Schädel in ein langes Rostrum ausgezogen, das dorsoventral abgeflacht ist, auf der 
Unterseite ein Paar sehr langer Tentakel trägt und an den Seitenrändern mit Zähnen besetzt ist; das Rostrum dient als Apparat zum Durchpflügen des Meeresbodens.) Die fossile Type aus der oberen Kreide des Libanon ist noch nicht benannt und beschrieben.

\section{F. Pristidae (Sägefische).}

Fossil von der oberen Kreide an. -- Lebende Type: Pristis. (Tektospondyl; Kientenspalten ventral gelegen; vivipar; Schädel mit langen Rostrum wie bei Pristiophorus (Fig. 83, 84). Gleichfalls benthonische

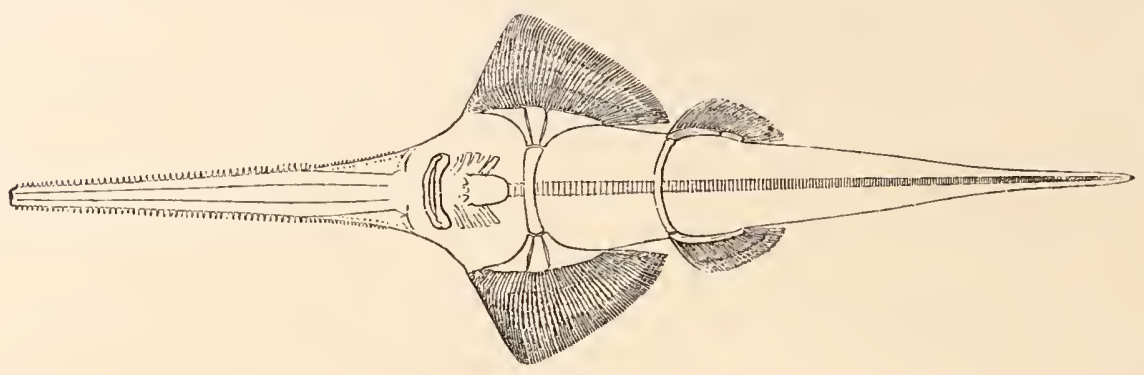

Fig. 83.

Rekonstruktion von Sclerorhynchus atavus, ein Pristide aus der oberen Kreide des Libanon, in $1 / 7$ nat. Gr. (Nach A. Smith Woodward.)

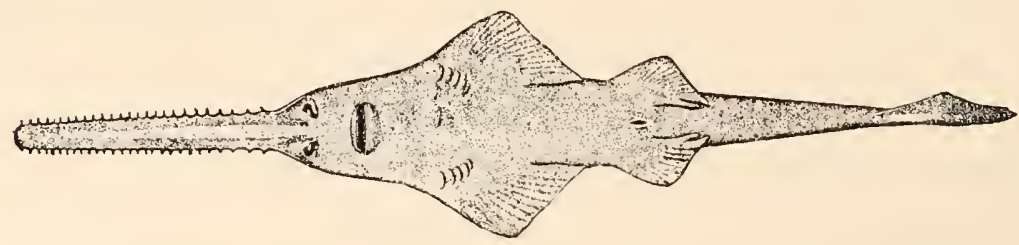

Fig. 84 .

Ventralansicht von Pristis pectinatus, lebend.

Typen von gleicher Lebensweise wie Pristiophorus.) Der älteste bekannte Pristide aus der oberen Kreide des Libanon ist Sclerorhynchus atavus. Eine Riesenform aus dem Obereozän Ägyptens ist Propristis Scliweinfurthi (Fig. 85).

\section{F. Rhinidae (Meerengel).}

Fossil von oberen Jura an. - Lebende Type: Rhina (= Squatina). (Tektospondyl. Vivipar. Zwei Dorsalflossen; Analflosse fehlt. Körper dorsoventral abgeflacht und die Brust- und Bauchflossen verbreitert, aber der Kopf vorn abgerundet und der ganze Körper mehr haifischähnlich (Fig. 86), weshalb diese Familie früher meist den ,,echten Haifischen" angeschlossen wurde, mit denen die Meerengel auch die laterale Lage der Kiemenspalten gemein haben, was jedoch nur ein Anpassungs- 
A.
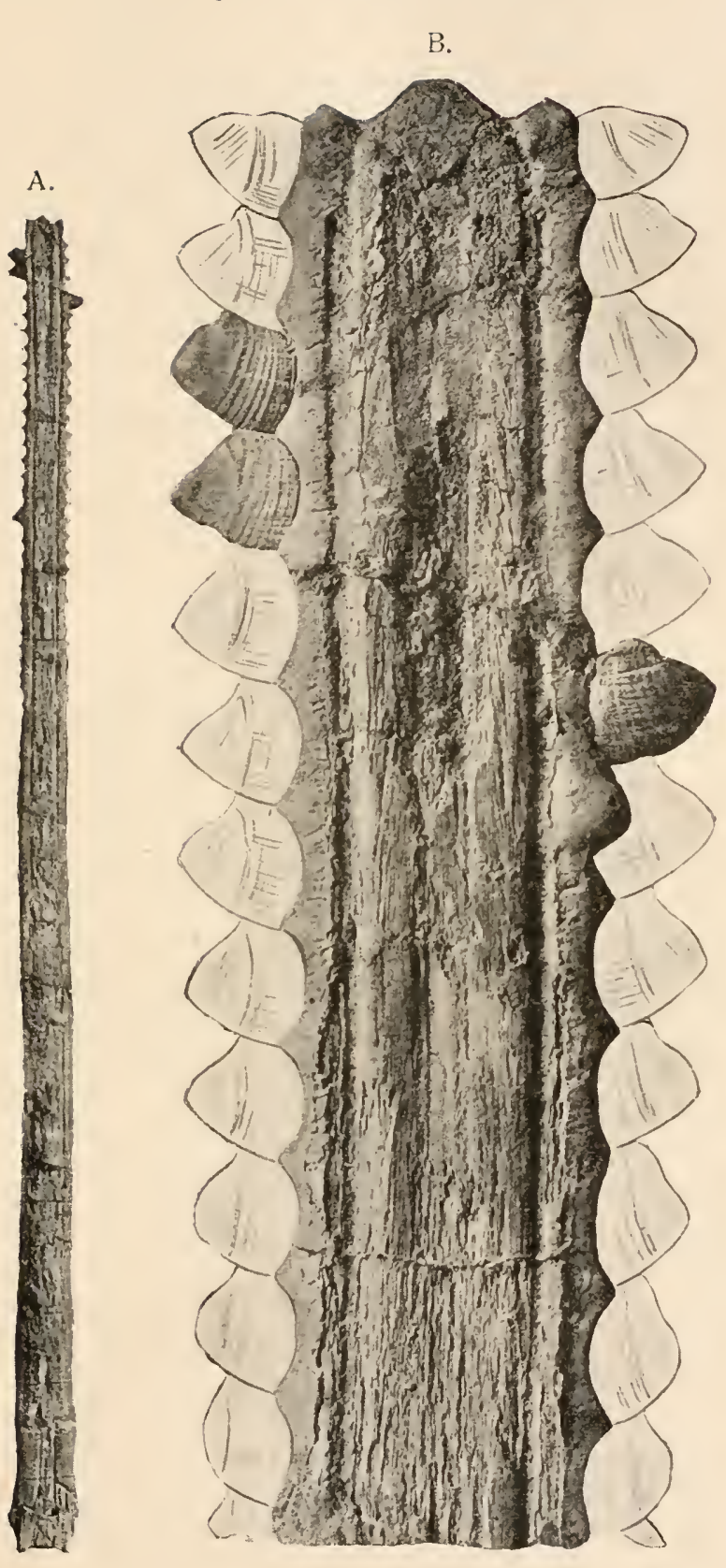

C.

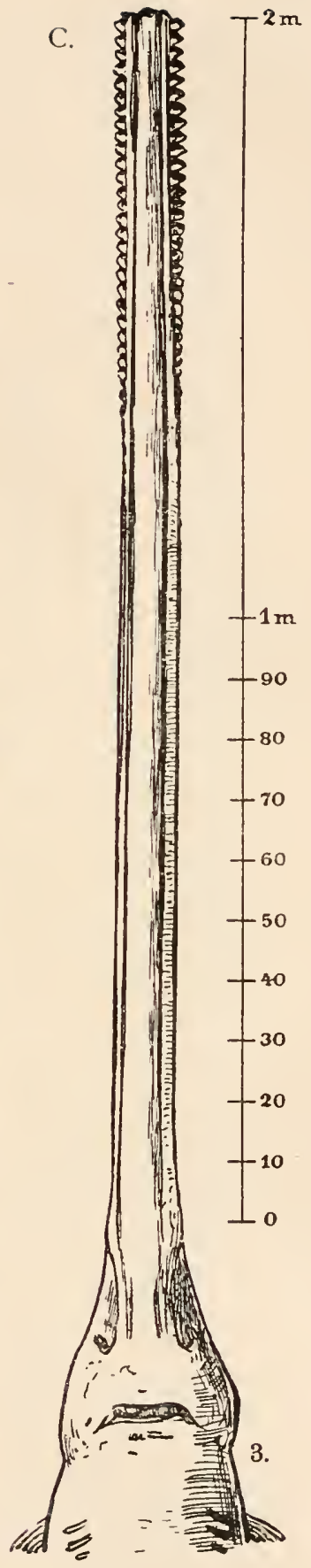

Fig. 85

Propristis Schweinfurthi, Dames, aus der oberen Mokattamstufe (Obereozän) des Fayûm, Ägypten. - A. Gesamtansicht des Rostrums; B. Vorderende der Säge mit den ergänzten Zähnen der ,Säge" in $2 / 3$ der nat. Größe; C. Rekonstruktion des Schädels, von der Unterseite gesehen. (Nach E. Fraas.) 
merkmal von untergeordneter Bedeutung ist.) - Ganze, gut erhaltene Skelette sind in den lithographischen Schiefern Bayerns nicht selten (z. B. Fig. 87).

\section{F. Rhinobatidae.}

Fossil vom oberen Jura an. - Lebende Type: Rhinobatus. (Tektospondyl. Vivipar. Kiemenspalten ventral gelegen. Schädel in eine

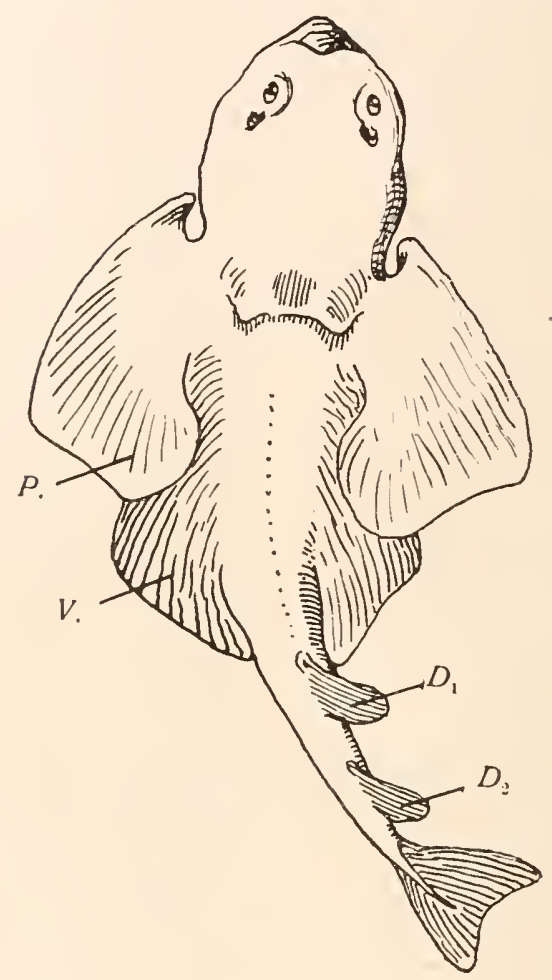

Fig. 86.

Rhina squatina (F. Rhinidae). Holozän. P. = Pectoralis. $\quad D_{1}=$ vordere Dorsalis. $V$. = Ventralis. $\quad D_{2}=$ hintere Dorsalis. dreieckige, breite, dorsoventral abgeflachte Spitze ausgezogen.) Die gut erhaltenen Exemplare aus dem oberen weißen Jura Bayerns (z. B. Rhinobatus mirabilis) oder aus dem Obereozän des Monte Bolca in Oberitalien unterscheiden sich nur in untergeordneten Merkmalen von den lebenden Arten. (Fig. 88.)

15. F. Rajidae (Glattrochen).

Fossil von der oberen Kreide an (Cyclobatis, Raja). - Die fossilen Arten schließen siclı eng an die lebenden an (Fig. 89). (Körper dorsoventral stark abgeflacht, aber der Vorderkörper allmählich in den Schwanz übergelend, ohne Analflosse, Schwanzflosse reduziert oder ganz verloren gegangen. Zwei sehr kleine Rückenflossen, weit hinten gelegen, Kiemenspalten ventral. Ovipar.)

16. F. Torpedinidae (Zitterrochen).

Fossil vom Obereozän an. Lebende Type: Torpedo. (Im Gegensatz zu der rhombischen Geștalt des Vorderkörpers der Rajiden ist der Vorderkörper hier scheibenförmig (Fig. 90), oft fast von kreisrundem Umriß. Der Vorderkörper geht allmählich in den Schwanzteil ïber, der zwei kleine Rückenflossen und eine kleine Schwanzflosse trägt. Kiemenspalten ventral. Vivipar.) - Eine der lebenden Gattung Narcine angehörige Art (N. Molini Jkl.) im Obereozän des Monte Bolca.

17. F. Trygonidae (Stachelroclien).

Fossil von der oberen Kreide an. - Lebende Type: Trygon. (Im Gegensatz zu den vorher besprochenen Familien mit stark abgeflachtem 


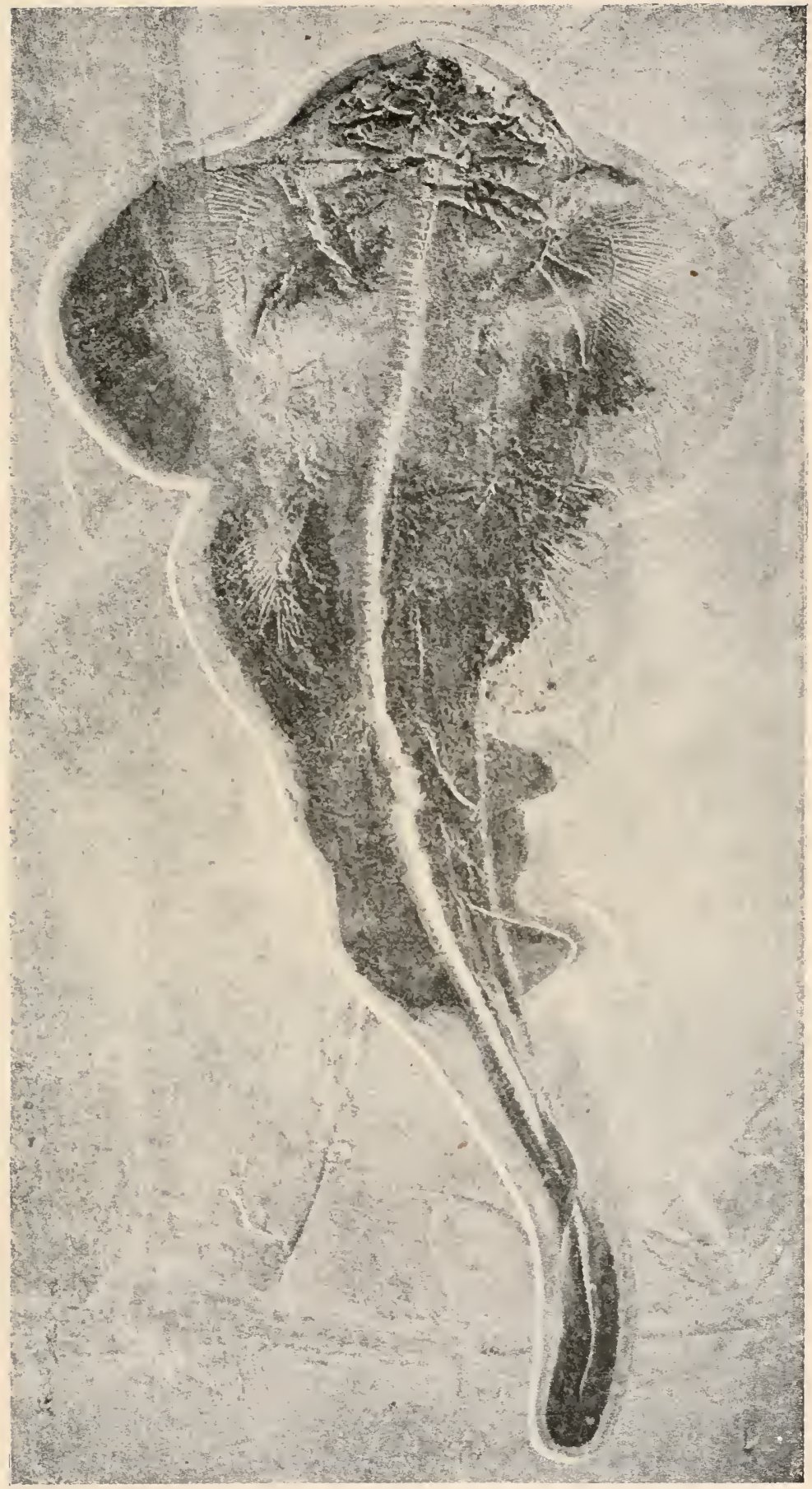

Fig. 87. Rhina alifera, Münster, aus den Plattenkalken des obersten Jura von Nusplingen in Württemberg. Stark verkleinert. Original im Senckenberg-Museum zu Frankfurt a. M. (Nach F. Drevermann.) 
Körper stoßen die Brustflossen (Fig. 93) vor der Schnauze zusanmmen, während sie bei den Rhinobatiden, Rajiden und Torpediniden nur seitlich an das Rostrum angeheftet sind. Der Schwanz ist als peitschenförmiges oder stark verkürztes Gebilde [Pteroplatea] scharf vom Vorderkörper abgesetzt und trägt meist einen gezähnten Stachel (Fig. 91, 92) an Stelle einer Dorsalflosse. Vivipar.) - Von Urolophus sind Reste aus der oberen Kreide bekannt, von Trygon aus dem Eozän des Monte Bolca in Oberitalien.

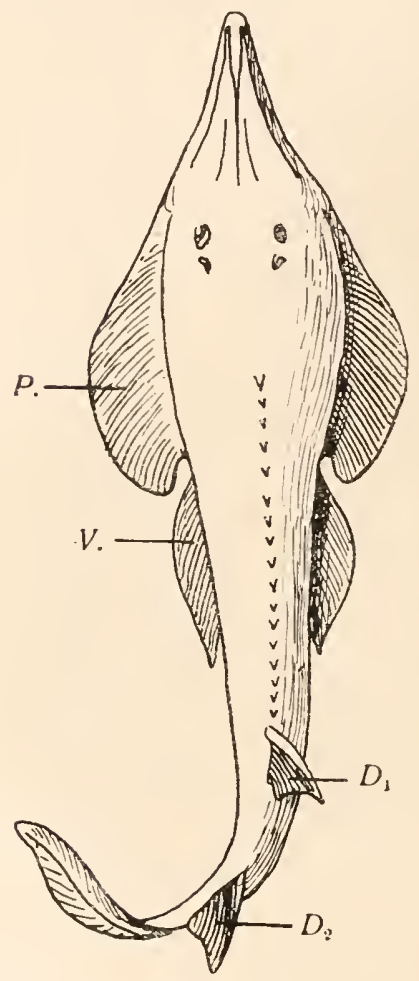

Fig. 88.

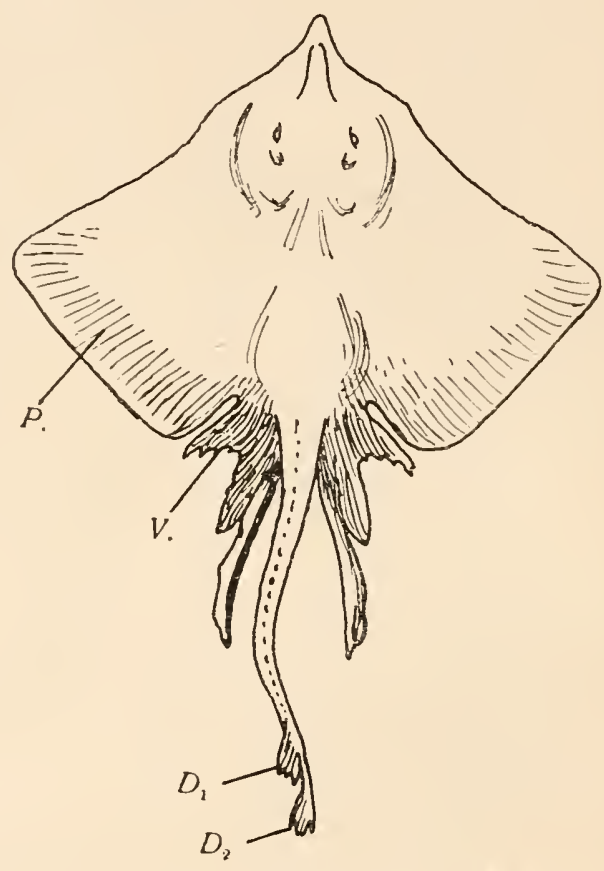

Fig. 89.

Rhinobatus granulatus (F. RhinoRaja laevis (F. Rajidae). Holozän. batidae). Holozän.

$P$. = Pectoralis, $V_{.}=$Ventralis, $D_{1}$ vordere, $D_{2}$ hintere Dorsalis.

\section{F. Myliobatidae (Meeradler).}

Fossil vom Untereozän an. - Lebende Type: Myliobatis. (Brustflossen und Scliwanzteil sowie Dorsalstacheln wie bei den Trygoniden, aber Brustflossen zu beiden Seiten des Kopfes unterbrochen (Fig. 93) und weiter vorn wieder ausgebildet. Scliwanz extrem verlängert, peitschenartig. Vivipar. Gebiß aus großen, zu einem geschlossenen Mosaik vereinigten Platten bestehend (Fig. 96), während die Zähine 
der Trygoniden klein sind. Die Myliobatiden sind zweifellos die Nachkommen der Trygoniden, aber nur jene Formen kommen als Ahnentypen in Betracht, bei denen der Schwanz nicht verkürzt ist wie bei Pteroplatea altavela.) — Aus dem Eozän und jüngeren Abteilungen des Tertiärs ist eine große Zahl von Arten bekannt, die meist zu lebenden Gattungen gehören (Fig. 94, 95).

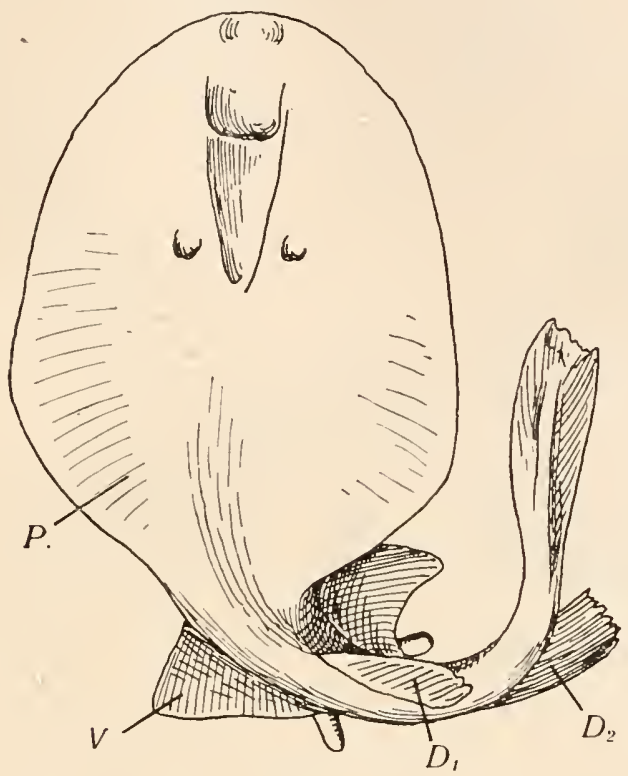

Fig. 90.

Ein blinder Tiefseerochen, Benthobatis Moresbyi (F. Torpedinidae). Abyssale Region des Indischen Ozeans (Küste von Travancore, in einer Tiefe von 430 Faden). - Die Augen sind atrophiert; die auf dem Rücken sichtbaren paarigen Gruben sind die Spirakeln. (Nach A. Alcock, 1898.)

$P .=$ Pectoralis. $\quad V .=$ Ventralis. $D_{1}$ und $D_{2}$ vordere und hintere Dorsalis

B. Erloschene Familien.

\section{F. Gemuendenidae.}

Im Unterdevon von Gemünden (Rheinpreußen) ist ein verhältnismäßig gut erhaltener, freilich stark verdrückter Rest eines Fisches gefunden worden (Fig. 97), den R. H. Traquair (1903) als Gemündina Stürtzi beschrieb und mit Vorbehalt in Beziehung zu den Chimäriden brachte. ${ }^{1}$ Eine Reihe von Merkmalen spricht für die Einreihung dieses eigentümlichen Typus in die Elasmobranchier. Auf der einen Seite des

1 R. H. Traquair, The Lower Devonian Fishes of Gemünden. Transactions Roy. Soc. Edinburgh, XL, Part 4, Nr. 30, 1903, p. 734. 


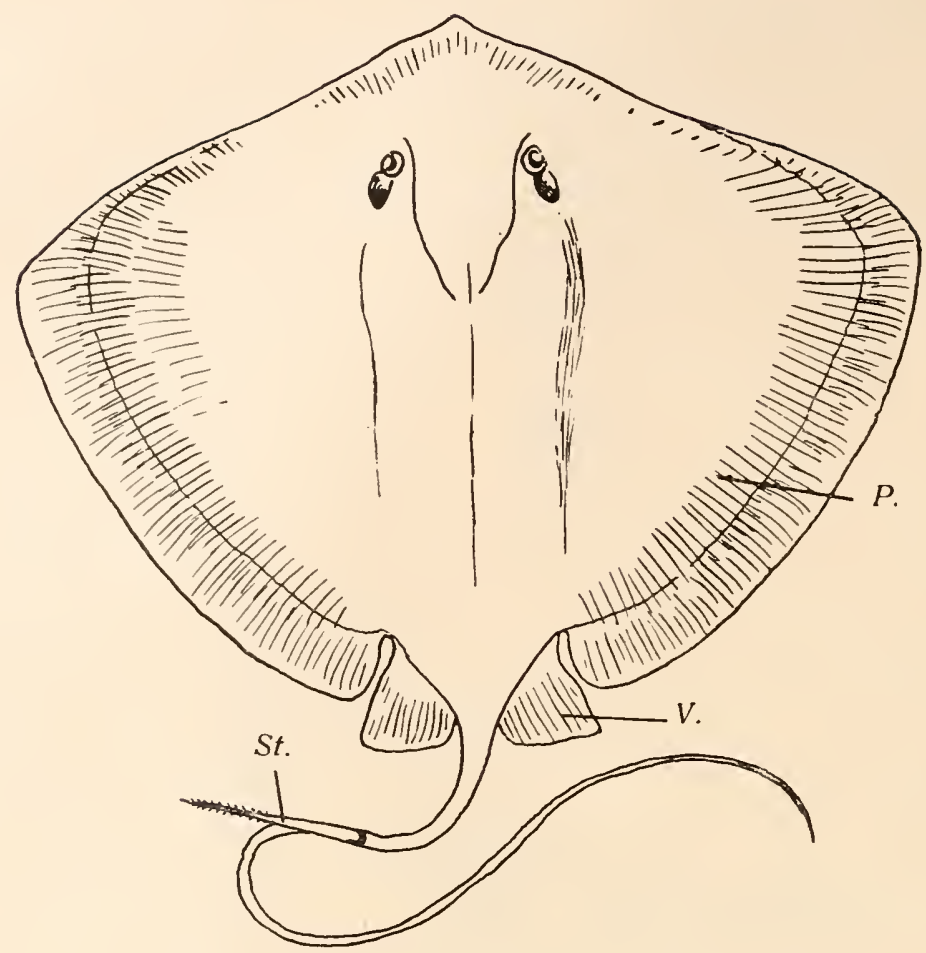

Fig. 91.

Trygon uarnak (F. Trygonidae). Holozän.

$P_{0}=$ Pectoralis $\quad V_{.}=$Ventralis. St. $=$Dorșalflossenstachel.

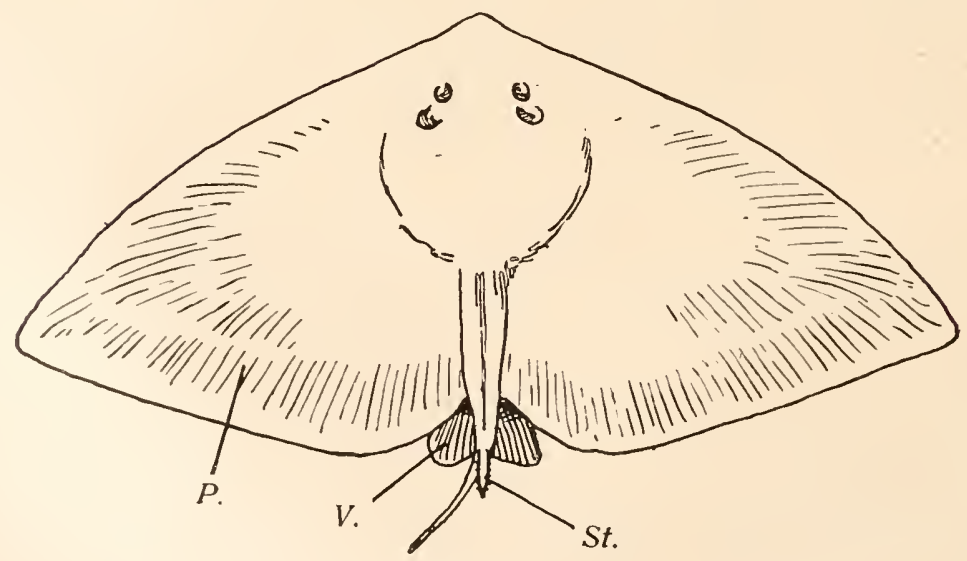

Fig. 92.

Pteroplatea altavela (F. Trygonidae), - Holozän.

P. = Pectoralis. $\quad V .=$ Ventralis. St. = Dorsalflossenstachel. 
Restes, die Traquair wohl mit Recht als die Ventralseite bezeichnet, sind in der Vorderregion des dorsoventral stark abgeflachten Vorderkörpers auf der Schieferplatte deutlich umgrenzte Skeletteile zu beobachten, die dem Kopfskelett angehören müssen; an den bogenförmigen
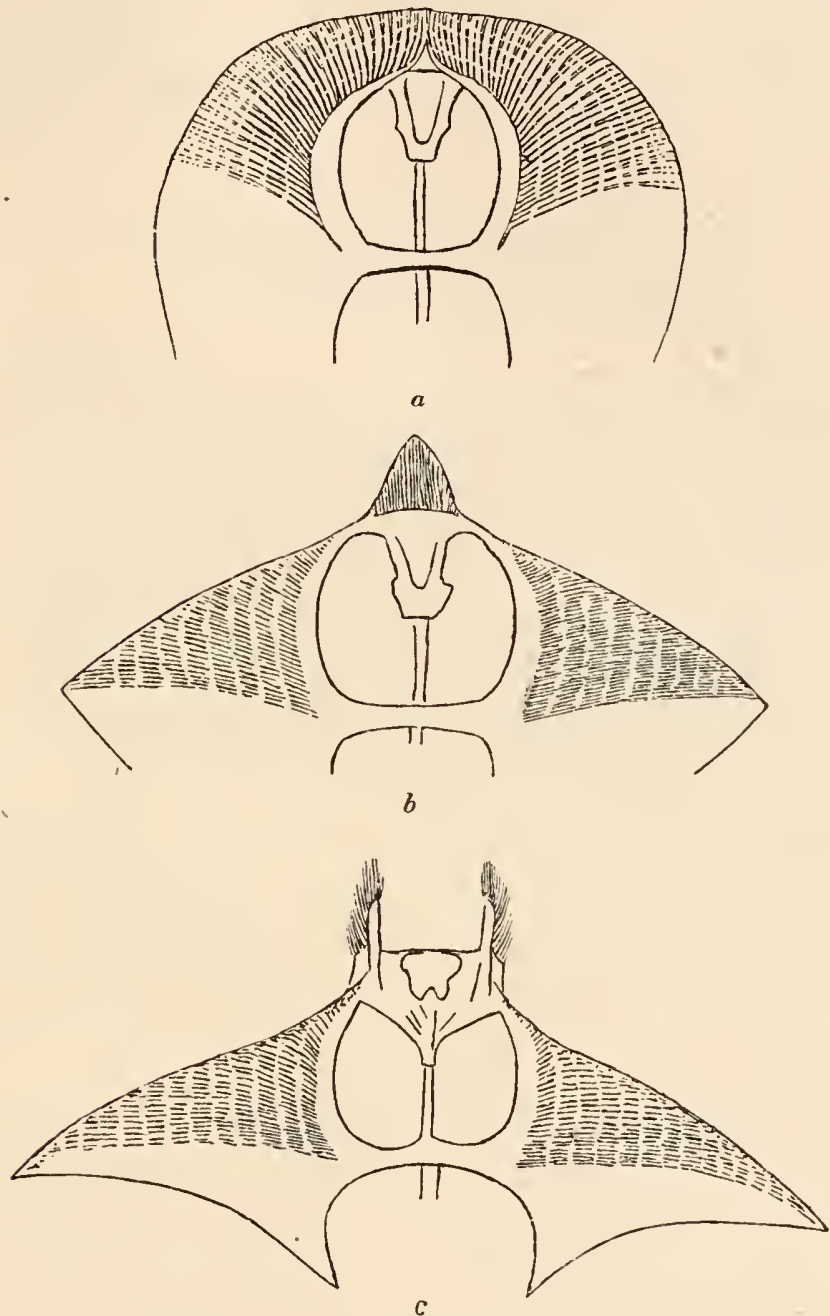

Fig. 93.

Der vordere Zusammenschluß der Brustflossen $a$ bei Trygon, $b$ bei Myliobatis, $c$ bei Ceratoptera. (Nach O. Jaekel.)

Ausschnitt am Hinterrande des Schädelskeletts legt sich beiderseits je eine deutlich abgegrenzte sichelförmige Spange an, die vielleicht als Schultergürtelspange zu deuten ist. Die Mundspalte liegt dorsal, die kleinen, einander stark genäherten Augen gleichfalls. Die Wirbelsäule zeigt eine deutliche Segmentierung. Die Seitenteile des Vorderkörpers 


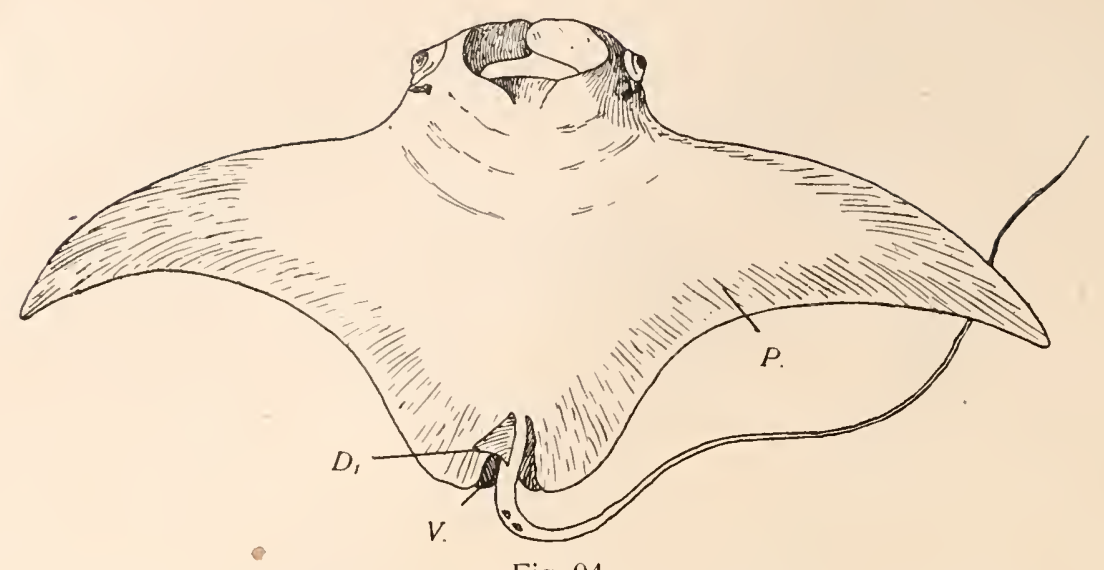

Fig. 94.

Ceratoptera vampyrus (F. Myliobatidae). - Holozän. - Spannweite der Brustflossen etwa $6 \mathrm{~m}$.

$P$. = Pectoralis. $\quad V .=$ Ventralis $\quad D .=$ Dorsalis.

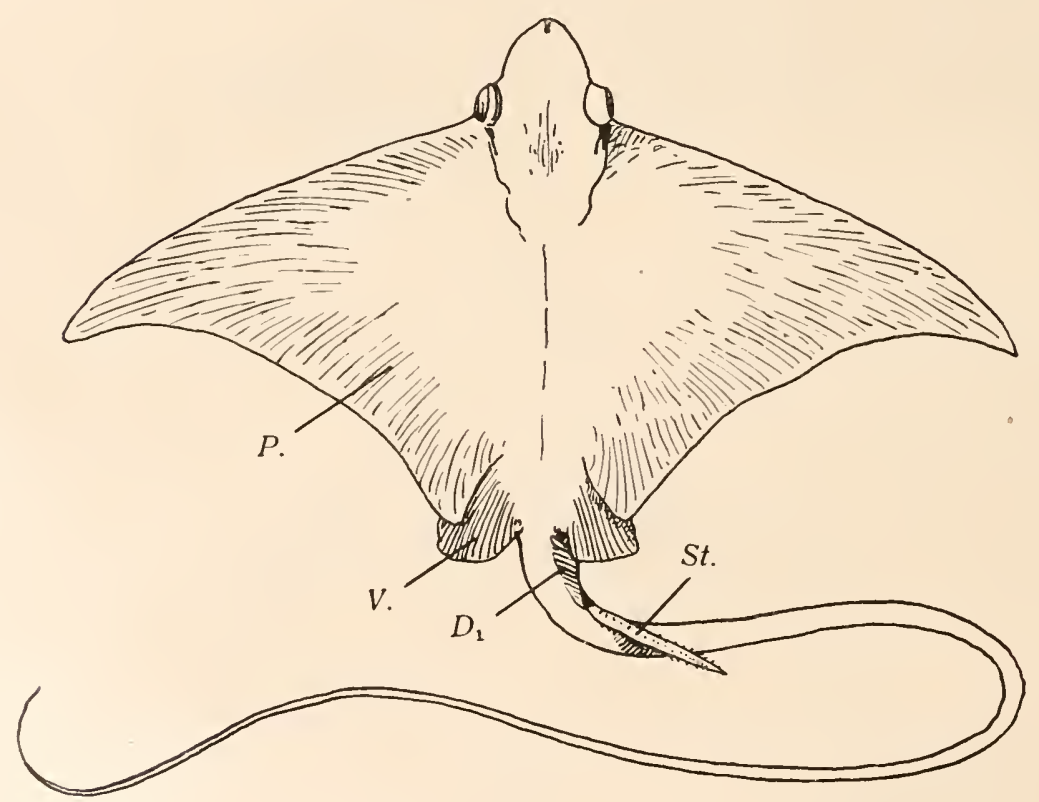

Fig. 95.

Myliobatis aquila (F. Myliobatidae). - Holozän.

$$
\begin{array}{ll}
P_{0}=\text { Pectoralis. } & D_{1}=\text { vordere Dorsalis. } \\
V .=\text { Ventralis. } & S t .=\text { Dorsalflossenstachel. }
\end{array}
$$

scheinen den Brustflossen zu entsprechen; Spuren von Ventralen oder einer Dorsalis sind nicht zu beobachten. Das Hinterende des Körpers fehlt. Der Körper ist mit zahlreichen kleinen Höckern (Hautzähnchen?) 
bedeckt. - Über die Bezielıungen zu den einzelnen Fanilien und Faniliengruppen läßt sich nichts Bestimmtes sagen; wahrscheinlich gehört Gemündina einem durchaus selbständigen Ast des Elasmobranchierstamilles an.

\section{F. Tamiobatidae.}

Auch diese Fanilie, die durch eine einzige Art (Tamiobatis vetustus Eastman) aus dem Oberdevon von Kentucky repräsentiert wird, ist

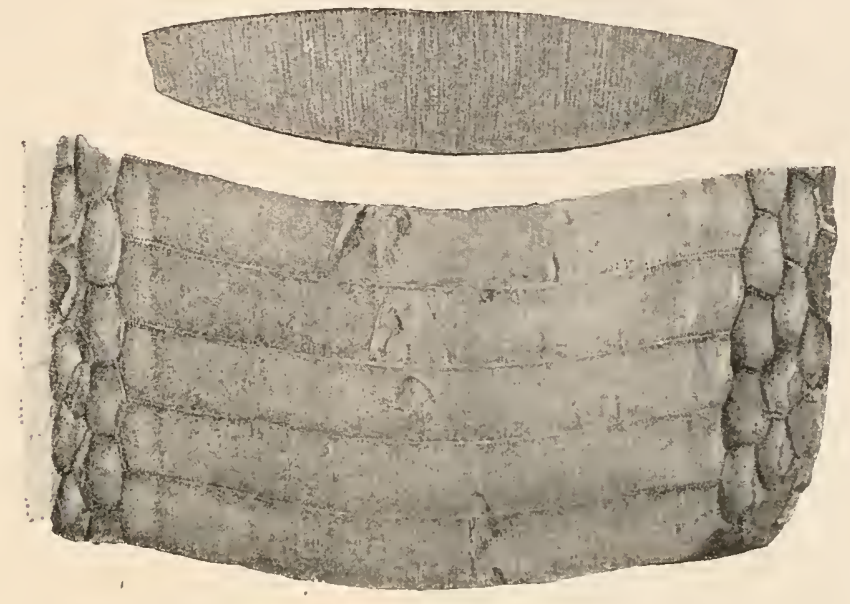

Fig. 96.

Myliobatis Pentoni A. S. Woodw., aus den mitteleozänen Nummulitenkalken (untere Mokattamstufe) des Mokattamgebirges bei Kairo. Unten: Teil des unteren Gebisses, von der Kaufläche" gesehen. Oben: Längsschnitt durch eine mittlere Zahnplatte des Unterkiefers. $2 / 3$ nat. Gr. (Nach A. Smith Woodward.)

von ganz unsicherer systematischer Stellung. Tamiobatis stellt jedenfalls einen benthonischen Elasmobranchier dar, doch ist die Beziehung dieser depressiformen Type zu den Rochenfanilien einstweilen unaufgeklärt. Möglicherweise haben wir in den Taniobatiden einen selbständigen Ast der Elasmobranchier, bzw. der Plagiostomen zu erblicken. ${ }^{1}$

\section{F. Cochliodontidae.}

Von den verschiedenen Typen, die in dieser Familie vereinigt werden, sind fast nur Zähne oder Flossenstacheln bekannt. Die Zahnplatten scheinen aus der Verschmelzung benachbarter Einzelzähne aus ver-

1 Von Tamiobatis vetustus ist nur der Schädel bekannt; er besteht aus schwach verkalktem Knorpel.

C. R. Eastman, Tamiobatis vetustus: A New Form of Fossil Skate. American Journal of Science, 4. ser., Vol. IV, Nr. 20, 1897, p. 85. 
schiedenen Zahnreihen hervorgegangen zu sein. Nur von einer einzigen Gattung und Art (Menaspis armata ${ }^{1}$ aus dem Kupferschiefer von Lonau am Harz und von Mansfeld) ist der ganze Körper bekannt (Fig. 98), der mit langen, gekrümmten Stacheln besetzt war. Cochliodus, Deltoptychius, Streblodus, Sandalodus, Deltodus, Psephodus usw. sind Namen für verschiedene Typen von Zahnplatten, die im Karbon von Europa und Nordamerika gefunden worden sind. ${ }^{2}$ (Fig. 99-100.)

A.

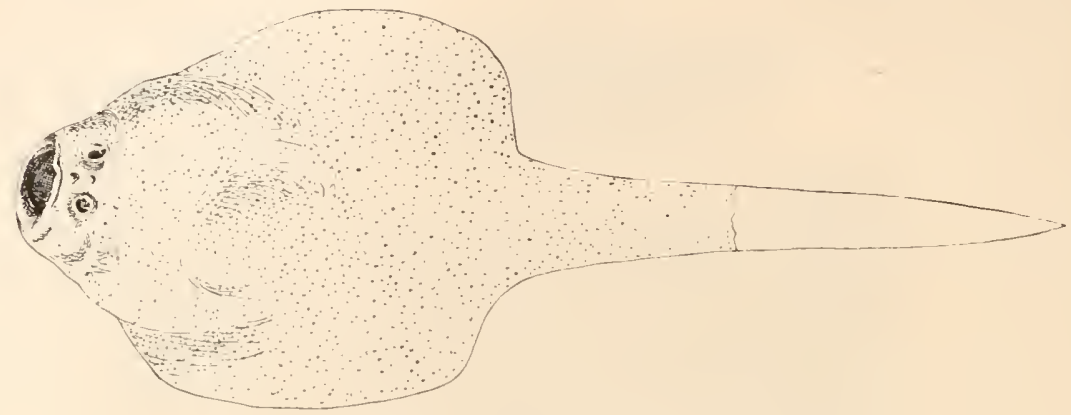

B.

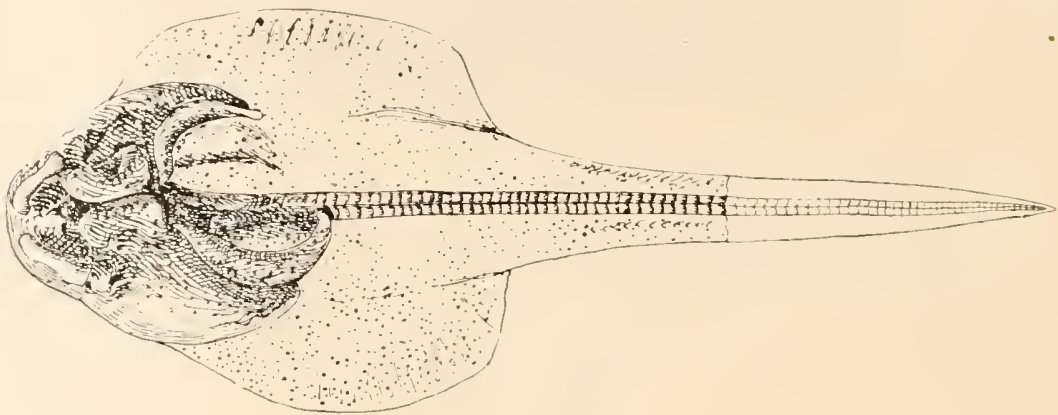

Fig. 97.

A. Rekonstruktion von Gemündina Stürtzi, Traqu. (Dorsalansicht), aus dem Unterdevon von Gemünden in Rheinpreußen. - B. Unterseite desselben Exemplars. Gezeichnet nach den von R. H. Traquair mitgeteilten Photographien des Originals. - Reduziert auf $1 / 3$ nat. Gr. (Orig.-Rekonstruktion.)

$\mathrm{Ob}$ die Cochliodontiden in näheren verwandtschaftlichen Beziehungen zu irgendeiner der heute noch lebenden Familien der Elasmobranchier stehen, ist durchaus zweifelhaft.

1 O. Jaekel, Über Menaspis armata Ewald. Sitzungsber. Ges. Naturf. Freunde, Berlin, 1891, p. 115.

2 A. Smith-Woodward, The Evolution of Sharks Teeth. Natural Science, Vol. I, Nr. 9, November 1892, p. 671. 


\section{F. Psammodontidae.}

Auch die systematische Stellung dieser Familie ist ganz unsicher; sie wurce für verschiedene Zahntypen errichtet, die durch ihre breite, sehr flache Form und ihre punktierte oder fein gerunzelte Oberfläche gekennzeichnet sind. Die quadratischen oder rechteckigen Zälne standen in mehreren Längsreihen in den Kiefern. lhre Funktion dürfte wohl dieselbe wie die der Zahnplatten der Myliobatiden gewesen sein. - Wichtigste Gattung: Psammodus (Karbon. von Groß- britannien und Nordamerika).

\section{F. Petalodontidae.}

Das Gebiß der Gattungen dieser Familie ist gleichfalls an die durophage Lebensweise angepaßt; daß die Tiere benthonisch lebten, geht auch aus der allgemeinen Körperform von Janassa bituminosa (Fig. 101) aus dem permisclien Kupferschiefer Deutschlands hervor, die.eine auffallende Ähnlichkeit mit den Körperformen der lebenden Rochen aufweist, ohne aber mit einer der lebenden Familien nälher verwandt $\mathrm{zu}$ sein. Die Bauchflossen von Janassa besaßen an der Vorderseite einen kleinen, von der Flosse losgelösten Fortsatz, den Jaekel als „Lauffinger“ bezeichnet.

Die Zähne der Petalodontiden sind sehr eigentiunlich gestaltet und weichen von

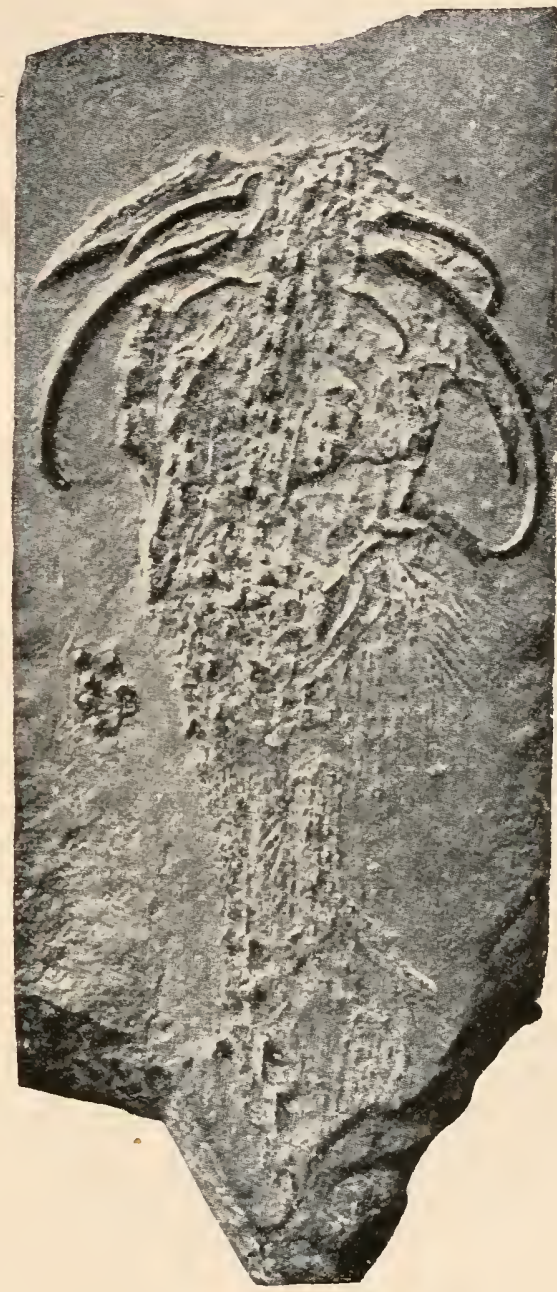

Fig. 98.

Menaspis armata, Ewald, aus dem permischen Kupferschiefer des Martinsschachtes im ,Glückauf“-Revier bei Mansfeld in Thüringen, etwa in $2 / 3$ nat. Gr. (Nach O. Jaekel.) allen bekannten Elasmobranchiergebissen durchaus ab. Die Wurzel ist von der Krone scharf getrennt; die Krone selbst ist im Längsschnitt S-förmig gekrümmt, wie dies namentlich aus dem Gebiß von Janassa klar zu ersehen ist. 
Zahlreiche Gattungen, alle aus dem Karbon und.Perm von Europa und Nordamerika.

Janassa. - Permischer Kupferschiefer und Zechstein Deutschlands (Fig. (101).

Petalodus. - Karbon von Europa und Nordamerika.

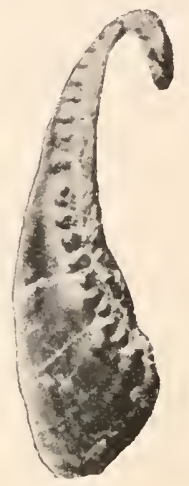

a

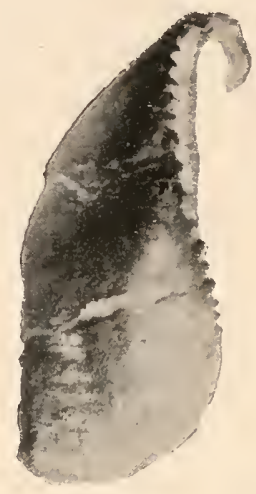

b

Fig. 99.

Psephodus dubius, A. S. Woodward, aus dem unteren Dinantien (Karbon) von Saint-Aubin (Nordfrankreich), a: linke Zahnplatte des Unterkiefers, von vorne gesehen, b: dieselbe, von der Mundseite gesehen. Nat. Gr. (Nach M. Leriche.)
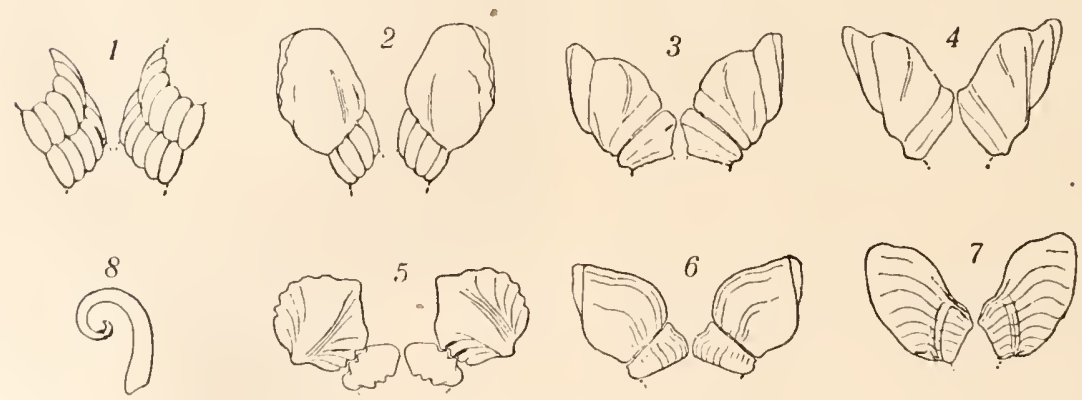

Fig. 100.

Die Entstehnng der Dentalplatten fossiler Elasmobranchier durch i is Verschmelzung von Einzelzähnen. (Nach A. Smith Woodward.)

I. Heterodontus Philippi.

2. Psephodus magnus.

3. Cochliodus contortus.

4. Deltoptychius acutus.

5. Pleuroplax Rankini.

( $I$ aus dem Holozän, $2-8$ aus der Steinkohlenformation.)

\section{F. Edestidae.}

In dieser Familie werden verschiedene Typen von sehr merkwürdigen und ilırer Natur nach zum Teil noch strittigen Gebilden 
vereinigt, die sich in der einfachsten und primitivsten Ausbildung als hintereinanderstehende Zähne darstellen, deren Vasodentinsockel verwachsen sind; so entsteht ein im Profil bananenförmiger, im Quer-

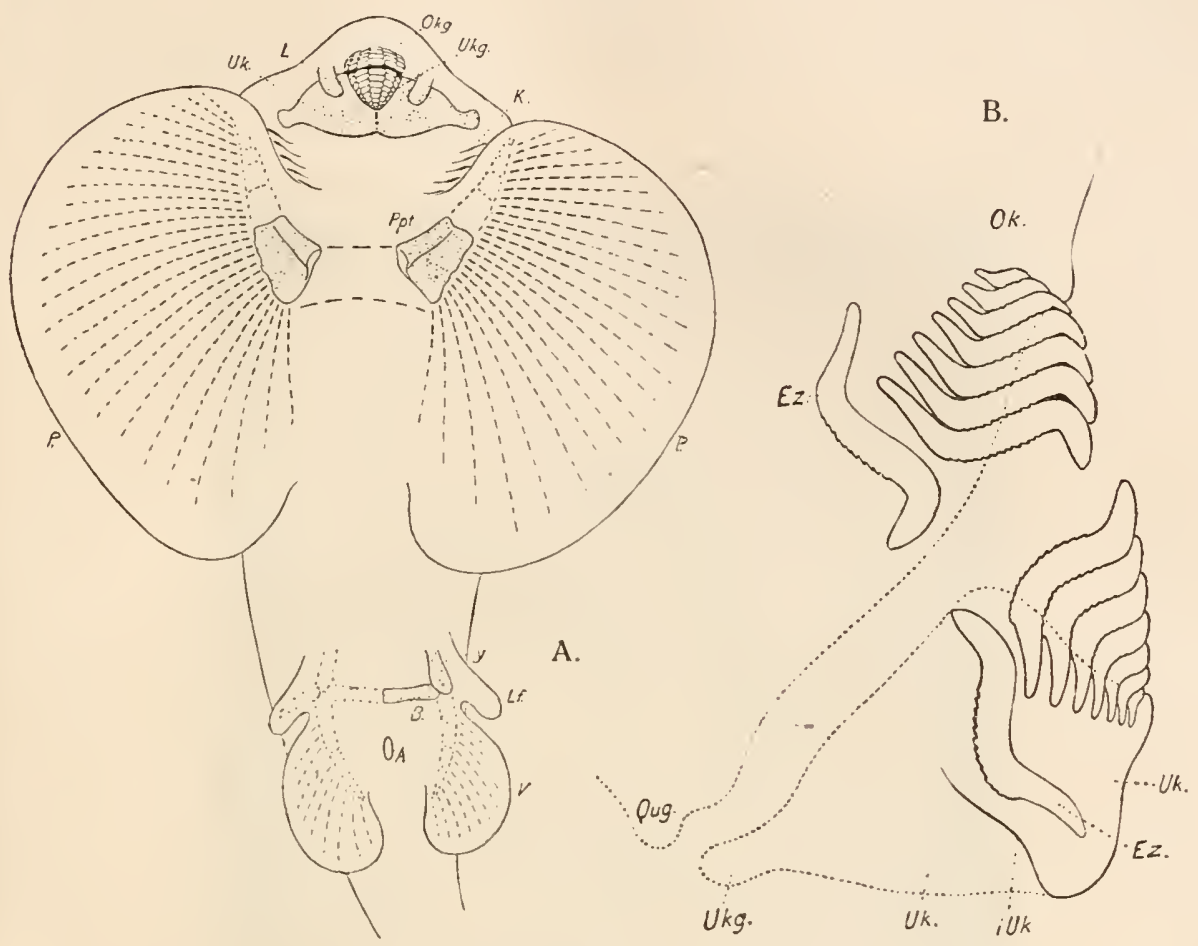

Fig. 101.

Janassa bituminosa, Schlotheim, ein Petalodontide aus dem permischen Kupferschiefer Deutschlands; A. Rekonstruktion der Unterseite in 1/2 nat. Gr., B. Längsschnitt in der Symphyse durch das Gebiß des Ober- und Unterkiefers, vergrößert. (Nach O. Jaekel.)

Fig. A :

L: $\quad=$ Lippenknorpel.

$U k .=$ Unterkiefer.

Ukg. = Unterkiefergebiß.

$O \mathrm{~kg} .=$ Oberkiefergebiß .

$K . \quad=$ Kiemenspalten.

Ppt. = Propterygium.

$P . \quad=$ Pectoralis

$V . \quad=$ Ventralis.

Lf. = ,Lauffinger".

A. $=$ After.
B. $=$ Basalknorpel der Bauchflosse $(V)$.

$y$. $\quad=$ Beckenelement (als Stütze des Lauffingers?).

Fig. B:

$O k .=$ Oberkiefer.

$U k_{0}$. = Unterkiefer.

$E z .=$ Ersatzzähne.

$i U k$. = Innenrand des Unterkiefers in der medianen Symphysenebene.

$U \mathrm{~kg} .=$ Unterkiefergelenk.

Qug. = Gelenk am Palatoquadratum.

schnitt eiförmiger Körper, der bilateral symmetrisch gebaut und auf einer Seite in der Medianebene mit scharfen, an den Schneiden tief gekerbten Zahnrändern besetzt ist (z. B. Edestus crenulatus, Hay, aus dem Karbon von Illinois). Über den Typus Toxoprion mit stärker 
gekrümmten Profil fülırt die Entwicklung zu den hochspezialisierten Typen Lissoprion und Helicoprion, bei denen der zahntragende Scliaft zu einer bilateralsymmetrischen Spirale geworden ist (Fig. 102). Vielleicht spielen bei dem Krümmungsgrade auch Altersunterschiede eine Rolle. ${ }^{1}$ Jedenfalls standen die Spiralen frei aus dem Körper hervor; wahrscheinlich sind es eigenartige Flossenstacheln, die vielleicht vor der Dorsalflosse standen und als Angriffswaffen dienten. ${ }^{2}$ Die syste-

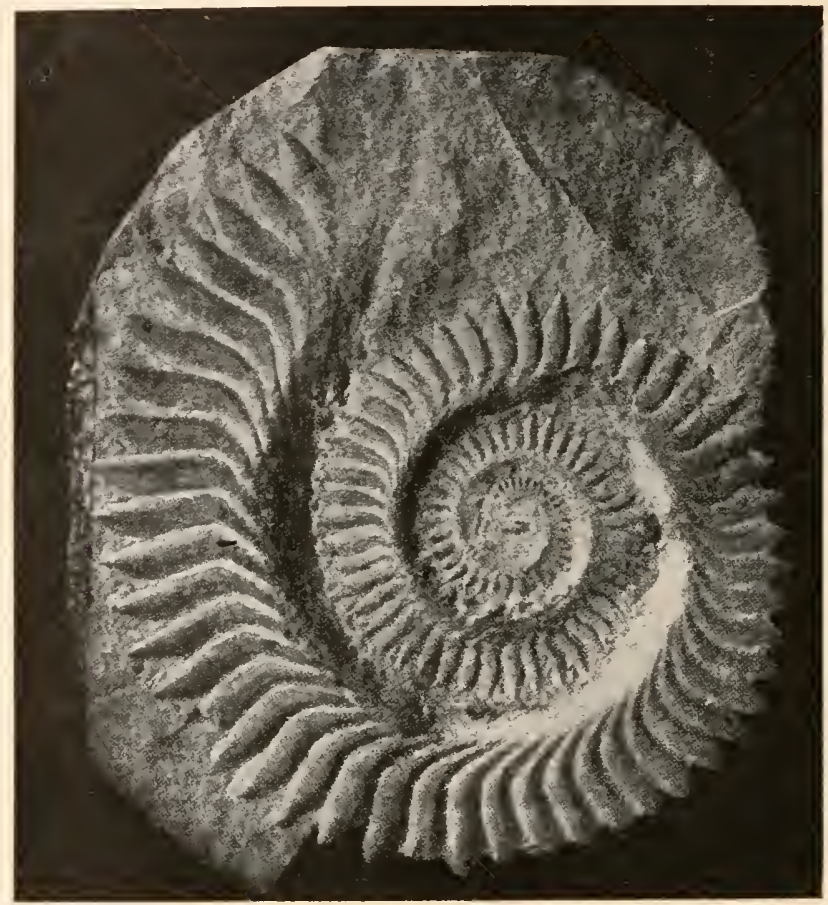

Fig. 102.

Spiralstachel von Helicoprion Bessonowi, Karpinsky, aus dem unteren Perm (Artinskische Stufe) Rußlands, in $1 / 2$ nat. Gr. (Nach A. Karpinsky.)

matische Stellung der Edestiden ist noch zweifelhaft; sie dürften einen Zweig der Plagiostomen bilden.

Edestus. - Karbon Nordamerikas (llinois, Nevada, Indiana, Arkansas) und unteres Perm Rußlands (Artinskstufe von Moskau).

Toxoprion. - Oberkarbon Nordamerikas (Nevada) und Karbon (?) Australiens.

1 O. Abel, Paläobiologie der Wirbeltiere. 1912, p. 567-568.

2 O. P. Hay, On the Nature of Edestus and Related Genera, with Descriptions of one New Genus and three New Species. Proc. U. S. Nat. Mus., Washington, XXXVil, 1909, p. 57. 
Lissoprion. - Oberkarbon Nordamerikas (Idaho und Wyoming). Die Spirale trägt 86 Zähne.

Helicoprion. - Unteres Perm (Artinskstufe) von Moskau. H. Bessonowi ${ }^{1}$ erinnert an die offene Spirale eines Crioceras; die Gesamtzahl der Zähne beträgt etwa 180, der Durchmesser der Spirale $26 \mathrm{~cm}$ (Fig. 102).

\section{F. Ptychodontidae.}

Die Gebisse der Gattungen dieser Fanilie - die Hauptgattung ist Ptychodus - bestehen aus sehr zahlreichen, flachen, subquadratischen Zahnplatten, welche nicht als verschmolzene Einzelzähne, sondern als verbreiterte Zahnindividuen aufzufassen sind. Die Kaufläche der Zähne trägt in der Mitte starke Querrunzeln, an den Rändern sind

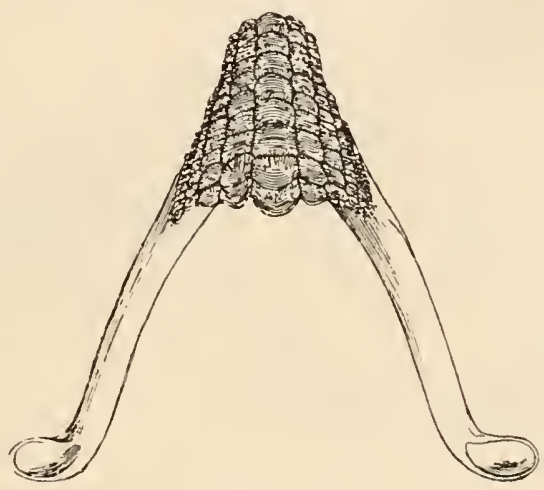

Fig. 103.

Rekonstruktion des Unterkiefers und des unteren Gebisses von Ptychodus decurrens, Ag., aus der obersten Kreide von Sussex in England, in $1 / 2$ nat. Gr. (Nach A. Smith Woodward.)

die Runzeln feiner und wechseln mit dichtstehenden Tuberkeln ab. Im Oberkiefer steht in der Medianlinie eine Reihe sehr kleiner Zähne, während im Unterkiefer (Fig. 103) die mediane Reihe die größten Zahnplatten des Unterkiefers enthält. Das Gebiß beweist die durophage und somit benthonische Lebensweise dieser Formen, welche nur aus der mittleren und oberen Kreide bekannt sind; die näheren verwandtschaftlichen Verhältnisse in Rahmen der Elasmobranchier konnten bisher nicht festgestellt werden. Die Wirbel sind zyklospondyl gebaut. Mit den Myliobatiden stehen sie in keinem engeren Verwandtschaftsverhältnis.

1 A. Karpinsky, Über die Reste von Edestiden und die neue Gattung Helicoprion. Verh. K. Russ. Mineral. Ges. St. Petersburg (2), XXXVI, Nr. 2, 1899. 


\section{Ordnung: Holocephali.}

Obwohl die ältesten Holocephalen erst aus dem unteren Lias bekannt sind, so kann es doch kaum einem Zweifel unterliegen, daß diese Gruppe der Fische ein viel höheres geologisches Alter besitzt. Sie stellen einen frühzeitig von dem gemeinsamen Ausgangsstamm der Elasmobranchier abgezweigten Ast dar, der sich in anderer Richtung als die Plagiostomen spezialisiert hat.

Die wichtigsten Merkmale der Holocephalen bestehen in der von den Plagiostomen durchaus verschiedenen Art der Zusammenensetzung und des Aufbaues der Wirbelsäule; die Chorda dorsalis ist persistent und die Wirbel bestehen aus knorpelig bleibenden Basidorsalia, Supradorsalia und Interdorsalia, sowie (bei spezialisierteren Typen) aus einfachen Ringzentren von der Form eines durchbohrten Damenbrettsteins (Fig. 107). Rippen fehlen. Der Schädel ist autostyl (Fig. 71),

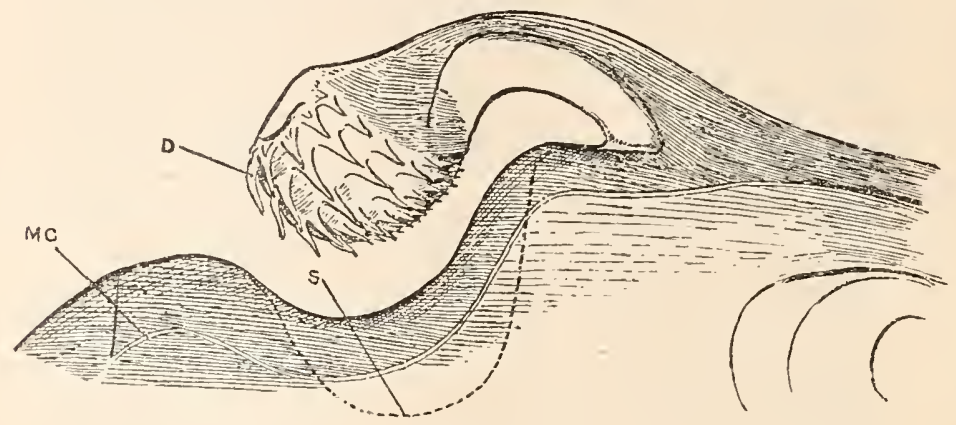

Fig. 104.

Kopfstachel eines Männchens von Chimaera Colliei, rezent;

nach B. Dean. ( $6 / 1$ nat. Gr.)

$D=$ Zähne des Kopfstachels. $M C$. = Schleimkanal.

$S=$ Boden der Grube für den Stirnstachel.

d. h. der Unterkiefer lenkt am Palatoquadratum ein, das ebenso wie das Hyomandibulare mit dem Knorpelcranium unbeweglich verschmolzen ist. Statt der offenen fünf bis sieben Kiemenspalten der Plagiostomen ist nur eine einzige vorhanden, die durch einen dem Operkularapparat der Teleostomen in physiologischer Hinsicht entsprechenden Apparat geschützt wird. Spritzlöcher fehlen. Das Gebiß ist an die durophage Nahrungsweise angepaßt und besteht ans je einem großen Unterkieferzahn jecterseits, denn oben zwei, mitunter auch drei Zähne jederseits gegenüberstehen. Die Zähne sind von sehr charakteristischer Form, plattenförmig und nit einem oder mehreren Buckeln versehen; diese ermöglichen daler aucl die Bestimmung vereinzelt gefundener fossiler Zähne, zunnal auch ihre Struktur eine eigenartige ist. Die Zähne 
bestehen aus Vasodentin und sind von zahlreichen feinen Kanälen durchsetzt, deren Achse zur Reibfläche senkrecht steht.

Die Flossen entsprechen ihrem Aufbau nach durchaus den Flossen der Plagiostomen.

Der Schädel einiger lebenden Holocephalen (z. B. Callorhynchus, Harriotta) ist vorn in ein Rostrum verlängert, das die Aufgabe hat; den Meeresboden nach Beutetieren zu durchstöbern. Ähnliche Bildungen sind auch bei den fossilen Formen (z. B. bei Acanthorhina, Myriacanthus) vorhanden. Bei den Männchen der lebenden Chimäriden steht auf der Dorsalseite des Schädels ein medianer, nach vorn einklappbarer und in einer Grube versenkbarer, bezahnter Stachel (Fig. 104); bei fossilen

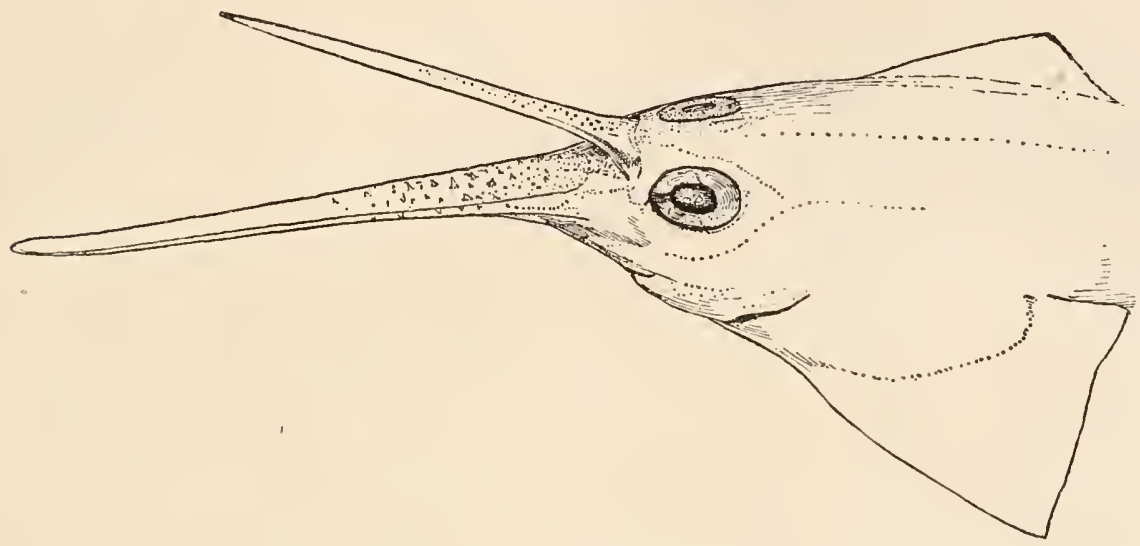

Fig. 105.

Rekonstruktion des Schädels von Squaloraja polyspondyla, Ag., $\sigma^{7}$, aus dem unteren Lias von Dorsetshire in England, in etwa $1 / 3$ nat. Gr. (Nach B. Dean.)

Formen (z. B. bei Myriacanthus und Squaloraja) ist dieser Kopfstachel zuweilen in ein langes, spitzes, mit widerhakenartigen Zähnen besetztes Horn ausgezogen, das auch hier wahrscheinlich nur den Männchen zukanı (Fig. 105, 108, 109). Diese Stacheln besitzen eine weite Pulpahöhle. Auch vor der vorderen Rückenflosse steht fast immer ein langer, kräftiger Stachel. Die Haut ist entweder nackt oder mit kleinen Hautzälnnen besetzt.

Die Holocephalen sind heute ausnahmslos Grundbewolnner und dasselbe gilt für alle bekannten fossilén Formen.

\section{F. Squalorajidae.}

Die allgemeine Körperform erinnert an die lebende Gattung Harriotta. Das Rostrum ist sehr lang, spitz und dorsoventral komprimiert; beim Mäninchen ist ein sehr langer, nach vorn gerichteter Kopfstachel vorhanden. Die vordere Dorsalflosse trägt keinen Stachel. 
Squaloraja. - Unterer Lias von Dorsetshire, England (Fig. 105 bis 107). ${ }^{1}$

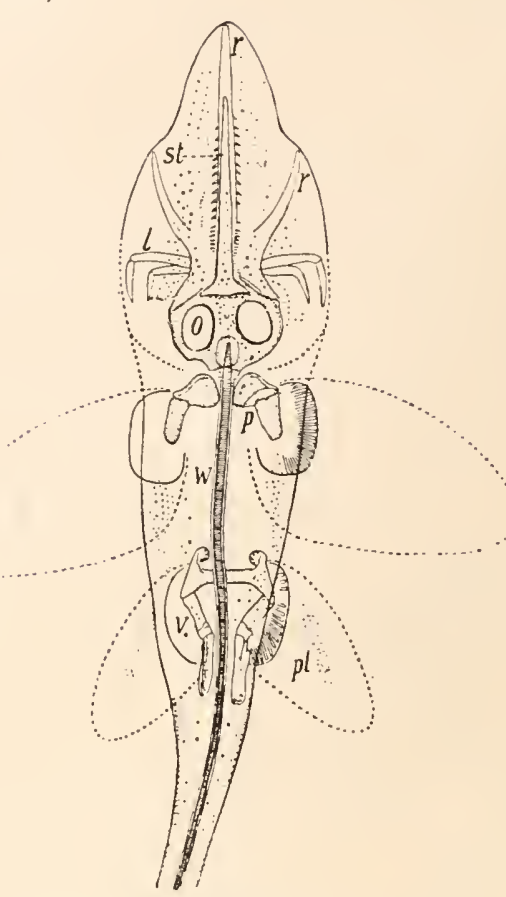

Fig. 106.

Rekonstruktion des vorderen Körperabschnittes von Squaloraja polyspondyla, Ag., $\not{\not}$, aus dem unteren Lias von Dorsetshire in England, etwa in $1 / 4$ nat. Gr.

(Nach B. Dean, 1906.)

l. = Lippenknorpel (?). $0 .=$ Orbita. $p_{.}=$Schultergïrtel. $\quad r .=$ Rostralknorpel, am mittleren kleine Seitenstacheln. st. = Knorpelstachel am Kopfe des Männchens. $v .=$ Beckengïrtel. $\quad w .=$ Kalkringzentren um die Chorda dorsalis. $p l .=$ Plakoidschuppen.

\section{F. Myriacanthidae.}

Vor der Rückenflosse ein großer, hohler Stachel. A. Smith Woodward gibt für Myriacanthus das Vorhandensein eines unpaaren Präsymphysealzahnes an, bei Chimaeropsis scheint nach Zittel etwas Ähnliches der Fall zu sein. Die Frage bedarf indessen mit Rücksicht auf die Beobachtungen von E. Fraas an Acanthorhina Jaekeli noch der Aufklärung. Das Männchen von Myriacanthus besaß einen sehr großen Kopfstachel, Acanthorhina nur einen kleinen. Der Schädel trägt mehrere laterale Hautplatten, die aus der Verschmelzung von Hautzähnen hervorgegangen sein dürften.

Myriacanthus. - Unterer Lias Englands, oberer Lias Schwabens (Fig. 108). ${ }^{2}$

Acanthorhina. - Oberer Lias von Holzmaden in Schwaben (Fig. 109). ${ }^{3}$

Chimaeropsis. - Oberer Jura (Tithon) Bayerns. ${ }^{4}$

1 A. Smith Woodward, Catalogue of the Fossil Fishes in the British Museum. - Part. II, 1891, p. 40.

O. M. Reis, On the Structure of the Frontal Spine and the Rostro-Labial Cartilages of Squaloraja and Chimaera. - Geol. Magazine (4), Vol. II, London 1895, p. 385 .

2 A. Smith Woodward, On the Myriacanthidae - an Extinct Family of Chimaeroid Fishes. - Ann. Mag. Nat. Hist. (6), Vol. IV, London 1889, p. 275.

Derselbe, Catalogue of the Fossil Fishes, 1. c., p. 43. - On a New Species of the Chimaeroid Fish, Myriacanthus paradoxus, from the Lower Lias near Lyme Regis (Dorset). - Quart. Journal Geol. Soc. London, Vol. LXII, 1906, p. 1.

E. Fraas, Chimaeridenreste aus dem oberen Lias von Holzmaden. - Jahreshefte d. Ver. f. Vaterländ. Naturkunde in Württemberg, 1910, p. 61.

3 Ibidem, S. 55.

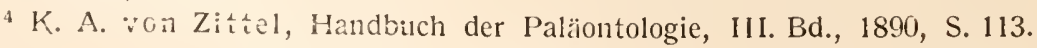




\section{F. Chimaeridae.}

Fossil vom braunen Jura an. Drei lebende Gattungen (Chimaera, Callorhynchus, Harriotta). Ovipar. Fossile Eikapseln (Fig. 112) aus dem

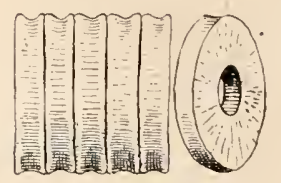

Fig. 107.

Wirbelzentren von Squaloraja polyspondyla, Ag., aus dem unteren Lias von Dorsetshire, England.

(Nach E. S. Goodrich.)

braunen Jura von Heiningen in Württemberg und aus der oberen Kreide von Wyoming ${ }^{1}$ bekannt. Schnauze stumpf (Chimaera, Fig. 71) oder zugespitzt (Harriotta) oder mit hakenförmig nach unten und hinten

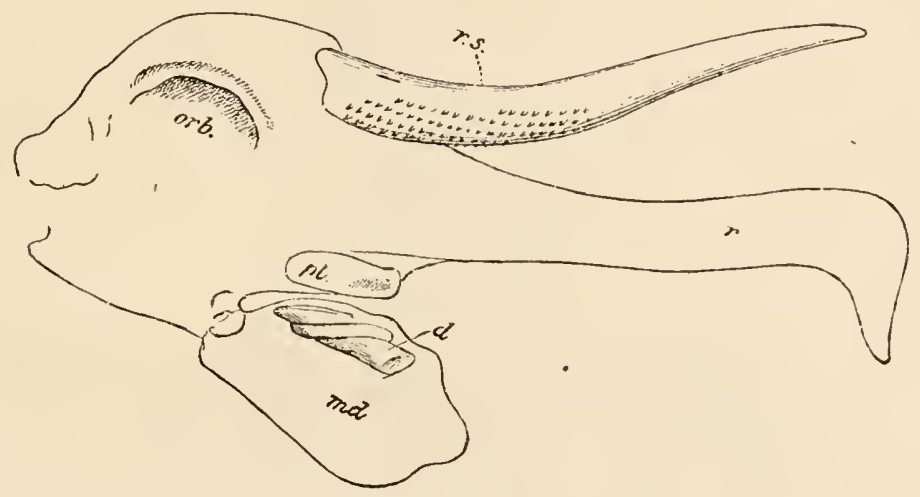

Fig. 108.

Rekonstruktion des Kopfes von Myriacanthus granulatus, ơ, aus dem unteren Lias von Dorsetshire, England, etwa in $1 / 3$ nat. Gr.

(Nach A. Smith Woodward.)
$r .=$ Rostrum.
$p l .=$ Palatinalzahnplatte.
i. = linke Unterkieferzahnplatte,
orb. = Orbita .
Gaumenansicht.
$r s$. = Kopfstachel des Männchens.

umgebogenem Rostrum (Callorhynchus). Die Gegensätze zu den beiden fossilen Familien sind ziemlich untergeordneter Natur und bestehen

1 o. Jaekel, Über jurassische Zähne und Eier von Chimaeriden. - Neues Jahrbuch f. Mineral. ısw., Bei!.-Dd. XIV, 1901, S. 551.

B. Dean, A Chimaeroid Egg-Capsule from the North American Cretaceous. - Mem. Amer. Mus. Nat. Hist., New York, Vol. IX, 1909, p. 265. 
inı wesentlichen nur in Unterschieden des Gebisses. Während die Zalınplatten der Squalorajiden und Myriacanthiden verhältnismäßig dünn sind, und die Reibflächen keine scharf umrissenen Grenzen

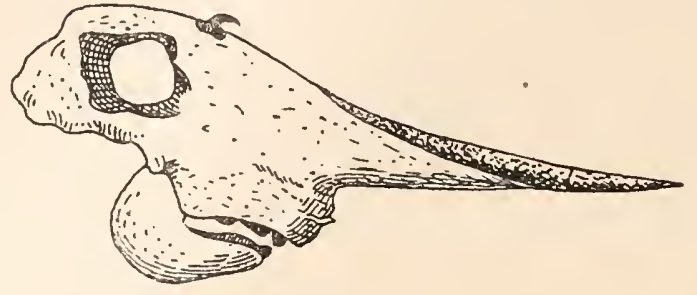

Fig. 109.

Rekonstruktion des Schädels von Acanthorhina Jaekeli, E. Fraas, aus dem oberen Lias von Holzmaden in Württemberg, in $1 / 4$ nat. Gr.

(Nach E. Fraas.)

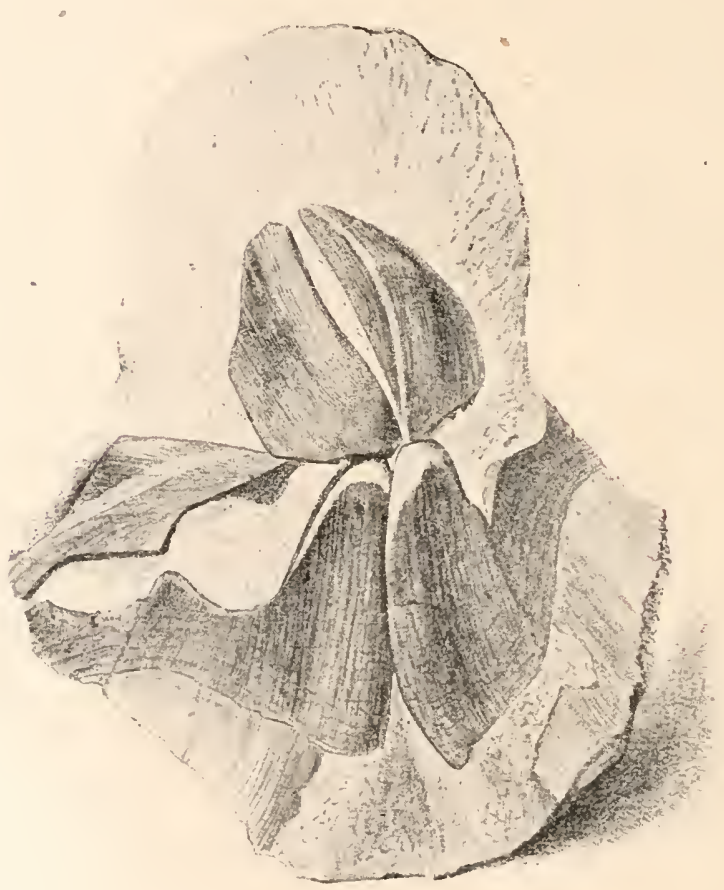

Fig. 110.

Vorderansicht des oberen und unteren Gebisses von Ischyodus Schübleri, Qu., aus dem oberen Jura von Kelheim in Bayern, in $3 / 4$ nat. Gr.

(Nach L. v. Am mon.)

aufweisen, sind die Zahnplatten der Chimäriden sehr dick und haben scharf abgegrenzte „Zahnbuckel“, d. h. Reibflächen (Fig. 111). (Die Substanz der Zahnplatten ist von der Struktur der Zahnbuckel verschieden. 
Die erstere besteht aus einem schwanmigen, sclıwach verkalkten Gewebe, die zweite ist eine dichte, gefäßreiche Modifikation des Dentins. Das Gebiß der Chimäriden stellt daher einen im Vergleiche zu den Squalorajiden und Myriacanthiden vorgeschritteneren Spezialisationsgrad dar.
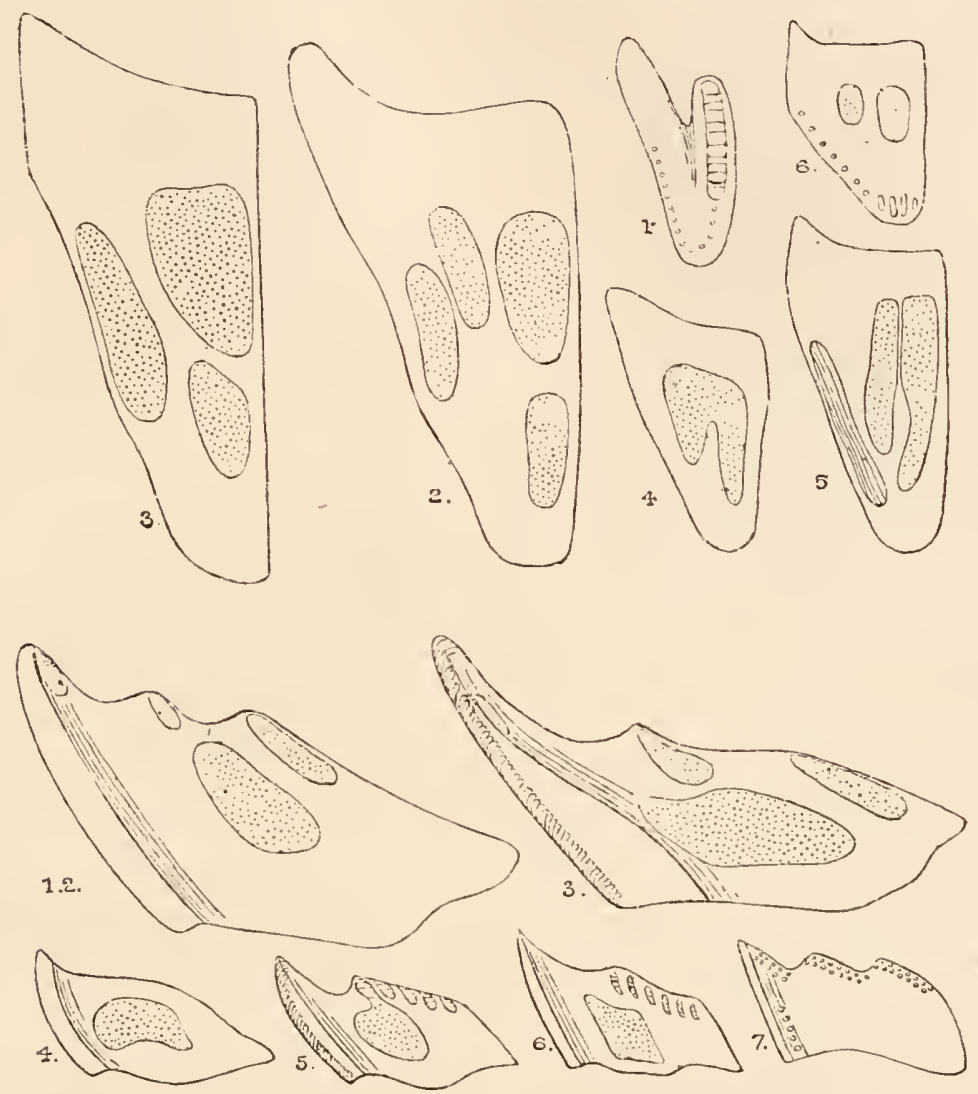

Fig. 111 .

Oben: Gaumenansicht der linken Gaumenzähne. Unten: Innenansicht des rechten

Unterkieferzahnes melırerer fossiler und rezenter Chimäriden. Schematisch.

(Nach A. S. Woodward, aus dem Brit. Mus. Catal.)

I. Ganodus (Jura).

2. Ischyodus (Jura und Kreide).

3. Edaphodon (Kreide und Eozän).

4. Callorhynchus (Holozän).
5. Elasmodus (Eozän und Oligozän).

6. Chimaera (Holozän).

7. Elasmodectes (oberer Jura und Kreide).

Die Lage und Zahl der Zahnbuckel ist bei den einzelnen Gattungen sehr verschieden und ermöglicht eine leichte Trennung der verschiedenen fossilen Formen. Hautplatten fehlen dem Schädel der Chimäriden.

Ischyodus. - Vom braunen Jura bis zur oberen Kreide aus Europa, Nordamerika und Neuseeland bekannt. Im lithographischen 
Schiefer Bayerns sind melirere wohlerhaltene Skelette gefunden worden (Fig. 110, 111). ${ }^{1}$

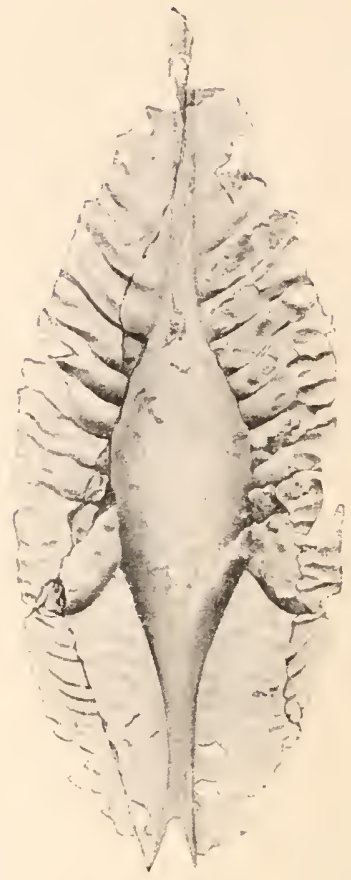

A.

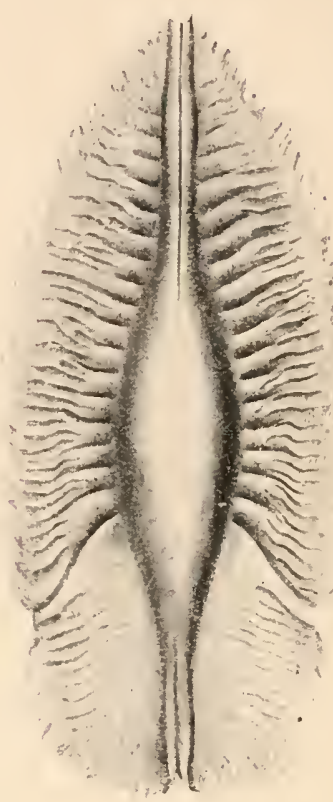

B.

Fig. 112.

A. Eikapsel eines Chimäriden aus dem Braunen Jura $\beta$ von Heiningen in Wuirttemberg. B. Eikapsel von Callorhynchus antarcticus, bei Talcahuano an der chilenischen Küste in 10 Faden Tiefe auf Schlammboden gefischt. Fig. A und $B$ in $1 / 2$ nat. Gr. (Nach O. Jaekel.)

1 A. Smith Woodward, On the Skeleton of a Chimaeroid Fish (Ischyodus) from the Oxford Clay of Christian Malford, Wiltshire. - Ann. Mag. Nat. Hist., London (6), Vol. IX, 1892, p. 94.

L. von Ammon, Über neue Stïcke von Ischyodus, - Berichte d. naturwiss. Ver. zu Regensburg, 5. Heft für die Jahre 1894-1895; Regensburg 1896, S. 252.

Derselbe, Ein schönes Exemplar von Ischyodus avitus. - Geognost. Jahreshefte, X11. Jahrg., Münclen 1899, S. 1.

E. Philippi, Über Ischyodus suevicus, nov. sp. - Ein Beitrag zur Kenntnis der fossilcn Holocephalen. - Palaeontographica, XLIV. Bd., 1897, p. 1.

A. Smith Woodward, On a New Chimaeroid Fin-Spine from the Portland Stone. - Proceedings of the Dorset History and Antiquarian Ficld Club, Vol. XXVII, Dorchester, 1906, p. 1. S. 540

O. Jaekel, Über jurassische Zähne und Eier von Chimaeriden, 1. c., 190I,

M. Leriche, Révision de la Faune ichthyologique des Terrains crétacés du Nord de la France. - Annales des la Soc. Géol. du Nord, T. XXXI, Lille 1902, p. 125 . 
Ganodus. - Brauner Jura Englands (Fig. 11!). ${ }^{1}$

Edaphodon.. - Obere Kreide bis Eozän Englands und Nordamerikas, Bernsteinformation Ostpreußens (Fig. 111). ${ }^{2}$

Leptomylus. - Oberste Kreide Nordamerikas. ${ }^{3}$

Elasmodus. - Obere Kreide Englands, Bernsteinformation Ostpreußens (Fig. 111). ${ }^{4}$

Chimaera. - Vom Tertiär an (Fig. 71, 104, 111).

Callorhynchus. - Vom Tertiär an (Fig. 112).

\section{Unterklasse: Acanthodei.}

Die Stellung dieser sehr eigentümlichen und nur aus dem Devon, Karbon und Perm bekannten Gruppe der Fische ist sehr verschieden beurteilt worden. In früherer Zeit wurden sie meist zu den Ganoiden gestellt; später hat man sie nach dem Vorschlage von A. SmithWo odward und O. M. Re is den Elasmobranchiern eingereiht. O. Jaekel betrachtet die Acanthodier als eine Unterklasse (Proostea) seiner ,,Klasse“ der Teleostomata, hebt aber den Mangel von Knochenzellen in den Skelettbildungen der Acanthodier besonders hervor.

Auf jeden Fall weist die Gruppe der Acantlodier eine so große Zahll eigenartiger morphologischer Merkmale auf, daß sie als ein durchaus selbständiger $\mathrm{Zweig}$ der Fische $\mathrm{zu}$ betrachten ist. $\mathrm{Zu}$ einer Zeit, da man unter den Fischen im engeren Sinne nur die beiden Hauptabteilungen der Knorpelfische oder Elasmobranchier und der Knochenfische oder Teleostomen unterschied und unter den letzteren die primitiveren Formen als die Gruppe der Ganoiden zusammenfaßte, konnte man zweifeln, ob man die Acanthodier den Elasmobranchiern oder den Ganoiden einreihen solle. Heute weiß man, daß die Elasmobranchier nicht als die Ahnen der Teleostomen betrachtet werden dürfen und die Frage nach der systematischen Stellung der Acanthodier hat dadurch eine ganz andere. Bedeutung als früher erlangt, da man sie mehr oder weniger als eine Übergangsgruppe zwischen den Elasmobranchiern und den Teleostomen betrachtete.

Gegen die Einreihung in die Elasmobranchier spricht vor allem der gänzlich verschiedene Aufbau der paarigen Flossen. Die Ent-

1 E. T. Newton, The Chimaeroid Fishes of the British Cretaceous Rocks. Memoirs of the Geol. Survey of the United Kingdom, Monogr., IV, 1878, p. I.

2 Ibidem.

A. Smith Woodward, Catalogue of the Fossil Fishes, 1. c., T. II.

3 L. Hussakof, The Cretaceous Chimaeroids of North America. - Bull. Amer. Mus. Nat. Hist., New York, Vol. XXXI, 1912, p. 195 (Literatur!).

4 E. T. Newton, 1. c. 
stehung derselben ist bei den Acanthodiern auf einem ganz anderen Wege vor sich gegangen als bei den Elasmobranchiern, nämlich nicht aus einem Pterygopodium, wie dies Cladodus zeigt, sondern aus einem lateralen Hautsaum, von dem zwischen den beiden Lateralflossenpaaren (Brustund Bauchflossen) bei Clinatius, Diplacanthus usw. noch eine Anzalıl (fünf bis ein Paar) überzälliger Lateralflossen als Rudimente erhalten

A.

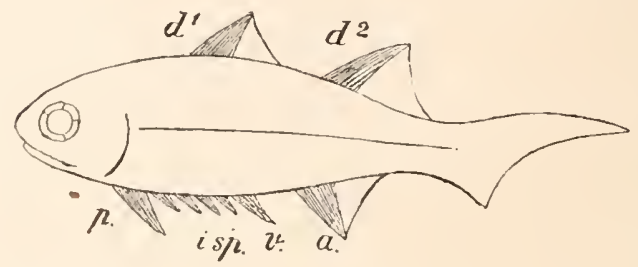

C.

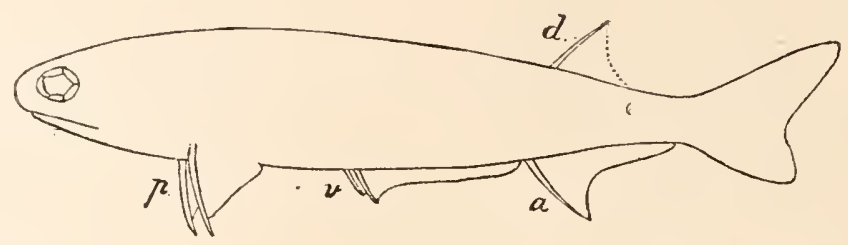

D.

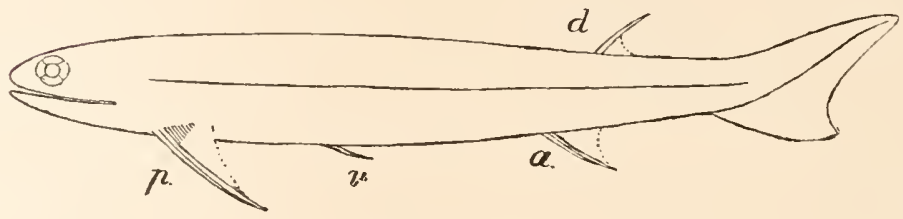

Fig. 113.

Umrißlinien von vier verschiedenen Acanthodiern.

A. Climatius scutiger, Egerton (unterer Old Red von Forfarshire, Schottland).

B. Mesacanthus Mitchelli, Egerton (unterer Old Red von Forfarshire, Schottland).

C. Acanthodes sulcatus, Agassiz (Unterkarbon von Edinburgh).

D. Acanthodes gracilis, Roemer (unteres Perm Böhmens).

(Nach A. Smith Woodward, 1916.)

$d_{1}, d_{2}=$ Dorsalis. $a=$ Analis. $p=$ Pectoralis. $v=$ Ventralis.

$i . s p$. = ïberzählige Lateralflossen bzw. Flossenstacheln.

sind. Auch die Art der Beschuppung des Körpers ist von der bei allen Elasmobranchiern bekannten Plakoidbeschuppung sehr verschieden. Andererseits bestehen wieder durchgreifende Gegensätze zu den Teleostomen in Bau der Kiefer und des Kiemengerüstes, sowie in der selır eigentünlichen Mikrostruktur des lnnenskelettes, ferner in dem Fehlen typischer „Verknöchermingen“, an deren Stelle nur eine Knorpelverkalkung stattfindet (O. M. Reis). Reis hat ausdrücklich hervorgehoben, daß im Hautskelett der Acanthodier keine Spur von Übergängen zum Typus der "Ganoiden" feststellbar sind. Wir werden daher die Stellung der 
Acanthodier unter den übrigen Stämmen der Fische am besten dadurcl zum Ausdrucke bringen, wenn wir sie als eine den Elasmobranchiern und den Teleostomen dem Range nach gleichwertige Gruppe und als einen durchaus selbständigen Ast des Fischstammes betrachten tind als Unterklasse abtrennen.

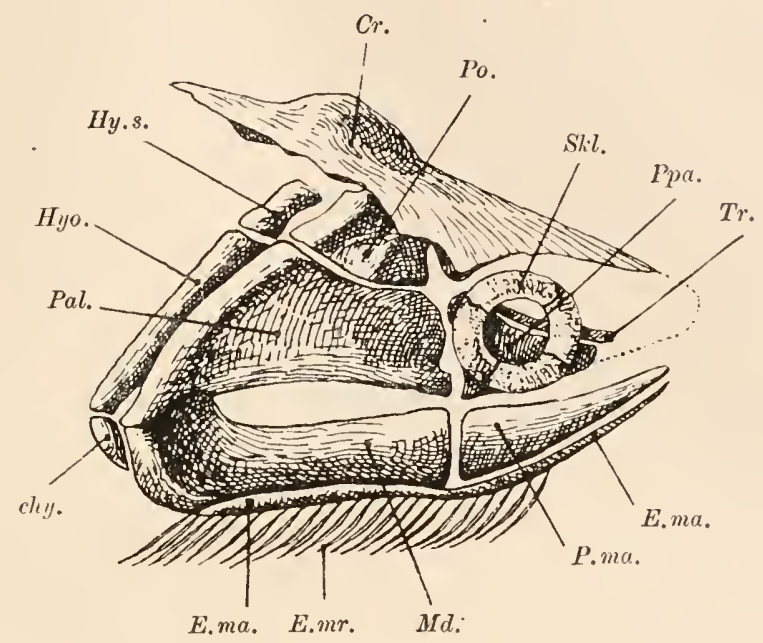

Fig. 114.

Schädelskelett von Acanthodes Bronni, Ag., aus dem Perm Deutschlands, von rechts gesehen in nat. Gr. (Rekonstruktion von O. M. Reis, 1896, umgezeichnet und unbedeutend abgeändert.)

\begin{tabular}{|c|c|c|c|}
\hline$C r$. & $=$ Dorsaler Vorsprung des $\mathrm{K}$ & $H y . s$. & „Epihyomandibulare“ (Reis \\
\hline & $\begin{aligned} & \text { kraniums. } \\
= & \text { Ceratobran }\end{aligned}$ & $\begin{array}{l}\text { Md. } \\
\text { Pal. }\end{array}$ & = Unterkiefer (Mandibulare). \\
\hline & $\begin{array}{l}\text { 1913; fehlt in der Zeichnung } \\
\text { von Reis). }\end{array}$ & $\begin{array}{l}\text { P. ma. } \\
\text { Po. }\end{array}$ & $\begin{array}{l}\text { =Praemandibulare" (Reis). } \\
\text { = Postorbitalfortsatz. }\end{array}$ \\
\hline ma. & $\begin{array}{l}=\text {,extramandibulärer Stachel“" } \\
\text { (Reis). }\end{array}$ & Ppa. & $\begin{array}{l}=\text { "Praepalatoquadratum" } \\
\text { (Reis). }\end{array}$ \\
\hline$m r$. & $\begin{aligned}= & \text { extramandibuläre Strahlen } \\
& \text { (Reis). } \\
= & \text { Hyomandibulare. }\end{aligned}$ & $\begin{array}{l}\text { Skl. } \\
\text { Tr. }\end{array}$ & $\begin{array}{l}=\text { Sklerotikalring. } \\
=, \text { Trabeculare" (Reis). }\end{array}$ \\
\hline
\end{tabular}

Am genautesten ist Acanthodes Bronni aus den Perm Deutschlands bekannt, dessen Skelett von O. M. Reis sehr eingehend untersucht wurde (Fig. 114, 115).

Die Acanthodier besitzen einen fusiformen Körper mit heterozerker Terminalflosse und einer Analflosse, deren Vorderrand durch einen starken Stachel gestützt wird. Ebensolche Stacheln finden sich auch an den Vorderrändern aller anderen Flossen, mit Ausnahme der Terminalflosse. Bei den ursprünglicheren Gattungen sind zwei, bei den spezialisierteren Gattungen nur eine Dorsalflosse vorhanden, und zwar entspricht die letztere der hinteren Rückenflosse von Climatius.

Zwischen der Brust- und der Bauchflosse von Climatius sind jeder- 
seits fünf bis vier, bei Parexus vier, bei Diplacanthus und Mesacanthus nur eine überzählige Flosse jederceits vorhanden; bei Acanthodes und den mit dieser Gattung näher verwandten Formen sind dicse überzälligen Flossen verloren gegangen (Fig. 113).

Das Kieferskelett (Fig. 114) zeigt im Vergleiche zu den Elasmobranchiern und zu den Teleostomen ganz abweichende Verhältnisse. Ein großes Palatoquadratum tritt in Gelenkverbindung mit dem Unterkiefer; vom Palatoquadratum ist ein vorderes Stück (= ,Präpalatoquadratum", Reis) abgetrennt, ebenso ein vorderes Stück (= „Prämandibulare“, Reis) vom Unterkiefer. Unter diese beiden Stücke, die den Unterkiefer bilden, legt sich ein dünner, langer Stab, der ,extramandibuläre Stachel" (Reis). Hinten schließen sich an den Kieferbogen drei Stücke des Zungenbeinbogens an, dessen Mittelstück das längste ist und das als Hyomandibulare zu bestimmen ist. Vom Knorpelcranium sind meistens nur einzelne Abschnitte verkalkt; mitunter läßt sich an einzelnen Exemplaren von Acantlıdes Bronni die Schädeldecke in ilıren Umrissen gut beobachten; ein vom Palatoquadratum abgetrennter Fortsatz, der „Postorbitalfortsatz“ (Reis) springt nach unten vor und stellt die Verbindung mit dem Palatoquadratum her. ${ }^{1}$ Das Auge war durch vier zu einem Ringe geschlossene Sklerotikalplatten geschützt und liegt über dem Präpalatoquadratum. Zälme fehlen den Acanthodiden mit Ausnahme von Ischnacanthus und Acanthodopsis vollständig. Ein medianes, schmales Skelettstück der Region der Schädelbasis bezeichnet Reis als „Trabeculare“ (Fig. 114, Tr.). Die Wirbelsäule von Acanthodes ist nur in der Schwanzregion schwach verkalkt und besteht hier aus oberen und unteren Bögen. Von den Flossen ist außer den Stachelı des Vorderrandes fast immer nur die Beschuppung des hinter denl Stachel liegenden Flossenlappens erhalten, sehr selten sind auch Spuren feiner Flossenstrahlen sichtbar. Von den fünf Kiemenrögen sind meistens nur die drei vorderen verkalkt.

Die Skeletteile von Acanthodes zeigen, soweit sie nicht dem dermalen Außenskelett angehören, eine eigentünliche histologische Struktur; eine diclıte äußere Lage ist von einer porösen inneren schon makroskopisch zu unterscheiden. In der äußeren Lage treten spindelförmige Zellen auf, die aber keine echten Knochenzellen, sondern verknöcherte Bindegewebszellen des faserigen Bindegewebsknorpels sind (O. M. Reis). Die Struktur dieser AuBenschicht ist grobfaserig; alle Blutgefäßkanäle fehlen. Dic innere Schiclıt zeigt ein Haufwerk unregelnäßiger Hohlräume, deren Stützen eine kugelig-knollige Form zeigen und die sich daher von der

1 O. M. Reis betrachtet diesen Fortsatz als Bestandteil des Craniums bzw. der Schädeldecke und vergleicht ihn mit dem Postorbitalfortsatz von Notidanus (Heptanchus). O. Jaekel sieht ihn dagegen als Element des Kieferbogens an und dies scheint richtig zu sein. 
gewöhnlichen Prismenstruktur der Haifischknochen durchaus unterscheiden. Nur mit der Wirbelstruktur der Elasmobranchier hat diese Struktur einige Ähnlichkeit. Die Schuppen von Acantlodes besitzen keine Pulpa und es tritt kein Gefäßkanal in den Basalteil der Schuppe ein. Die Schuppen bestehen nur aus Dentin. Sie schließen sich zu einem geschlossenen Panzer aus kleinen, regelmäßigen, quadratischen Plättchen zusammen. Die Flossenstacheln tragen keine Schmelzschicht. Das Rumpfschuppenkleid zeigt eine laterale und eine ventrale Seitenlinie. Auf dem Schädel sind nur die dorsalen Teile beschuppt; Mundteile, Wangen, Unterkiefer und die Kiemenregion von Acanthodes sind schuppenlos (F:g. 115).

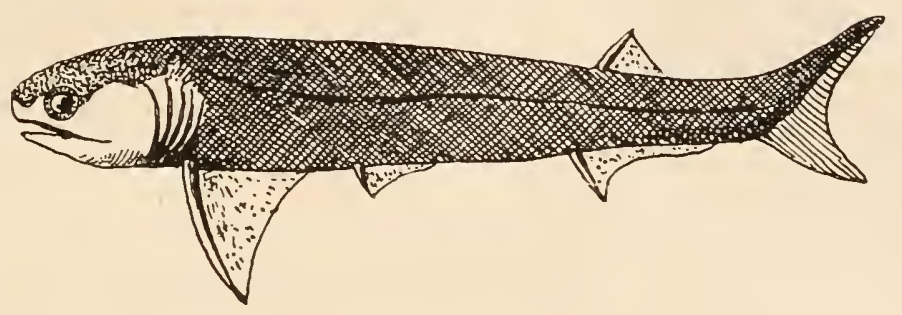

Fig. 115.

Rekonstruktion von Acanthodes Bronni, Ag., aus dem Perm Dentschlands. $1 / 3$ nat. Gr. (Umrißlinien nach der Rekonstruktion von A. Sinith Woodward, aber Schädelregion abgeändert.)

Die Acanthodier sind vom Unterdevon bis zum Perm bekannt; die größte vertikale Verbreitung hat Acanthodes.

Eine Unterscheidung verschiedener Familien unter den Acanthodiern auf Grundlage der Zahl der Lateralflossen und Dorsalflossen ist unmögliclı, da die Gattungen nur durch graduell verschiedene Merkmale voneinander getrennt sind und einem geschlossenen Formenkreise angehören.

\section{F. Acanthodidae.}

Climatius. - Unterdevon von Nordamerika und Schottland. Zwei Dorsalflossen vorhanden. Zwischen den Brustflossen und Banchflossen jederseits fünf bis vier Nebenflossen (fünf bei C. Mac Nicoli, vier bei C. parexus). ${ }^{1}$ (Fig. 113, A).

1 J. Powrie, On the Fossiliferous Rocks of Forfarshire and their Contents. - Quart. Journ. Geol Soc., Vol. XX, 1864, p. 413.

Derselbe, On the Earliest Known Vestiges of Vertebrate Life. - Transactions Geol. Soc. Edinburgh, Vol. I, 1869, p. 284.

A. Smith Woodward, Catalogue of the Fossil Fishes in the British Museum. - Part. 11., London 1891, p. 1 (Literatur!).

Derselbe, Outlines of Vertebrate Palaeontology for Students of Zoology. Cambridge Biol. Ser., London I898, p. 36.

E. Ray Lankester, Rekonstruktion von Climatius macnicoli in ,Guide to 
Parexus. - Unterdevon von Schottland. Vier Paar Nebenflossen, zwei Dorsalflossen. ${ }^{1}$

Diplacanthus. - Unterdevon von England und Kanada. Nur ein Paar überzälliger Lateralflossen, zwei Rückenflossen, die vordere höher als die hintere.2

Mesacanthus. - Unterdevon von Schottland. - Vordere Dorsalflosse verloren gegangen, die über der Analis stehende hintere Dorsalis vorhanden. Ein überzähliges Lateralflossenpaar zwischen Pectoralen und Ventralen vorhanden. ${ }^{3}$ (Fig. 113, B.)

Acanthodes. - Vom Devon bis Perm Europas. Im Unterdevon von Neubraunschweig und im Oberdevon von Kanada. Vordere Dorsalis fehlt; laterale Zwischenflossen gänzlich verloren gegangen. ${ }^{4}$ Kiefer gänzlich zahnlos (z. B. bei A. Bronni aus dem Perm Deutschlands).

Acanthodopsis. - Oberkarbon von Northumberland. ${ }^{5}$ - Kiefer im Gegensatz zu Acanthodes jederseits nit $6-8$ kegelförmigen Zähnen besetzt. A. Wardi.

Ischnacanthus. - Unterdevon Schottlands. - Kiefer mit kräftigen Zähnen besetzt, zwischen welchen kleinere stehen. Die Zälıne

the Gallery of Fishes in the Departiment of Zoology of the British Museum (Natural History)", herausgegeben von E. Ray Lankester, London 1908, p. 25.

A. Smith Woodward, The Study of Fossil Fishes. - Proceed. of the Geologists Assuciation, London, Vol. XIX, 1906, p. 271.

1 J. Powrie, I. c.

2 Vgl. die zul Climatius angegebene Literatur und außerdem:

A. Smith Woodward and C. D. Sherborn, A Catalogue of British Fossil Vertebrata. - London 1890, p. 65.

R. H. Traquair, The Extinct Vertebrata of Moray Firth Area; aus HarvieBrown \& Buckley, Vertebrate Fauna of the Moray Basin, Vol. II, p. 235-285, Edinburgh 1896, Pl. II, Fig. 1 (Rekonstruktion von Diplacanthus striatus).

${ }^{3}$ P. G. Egerton, British Fossils. - Memoirs of the Geological Survey of the United Kingdom (10), 1861, p. 51.

A. Smith Woodward, The Study of Fossil Fishes. - 1. c., 1906, p. 271.

${ }^{4}$ K. A. von Zittel, Handbuch der Paläozoologie. - 111. Bd., 1893, p. 165 (Literatur).

Vgl. außerdem:

O. M. Reis, Über Acanthodes Bronni Agassiz. - Schwalbes Morphologische Arbeiten, Jena, VI. Bd., 1896, p. 143.

Derselbe, Illustrationen zur Kenntnis des Skelettes von Acanthodes Bronni, Ag. - Abhandl. d. Senckenberg. Naturf. Ges. Zu Frankfurt a. M., 1895, XIX. Bd., S. 49.

A. Smith Woodward, The Study of Fossil Fishes, I. c., 1906, p. 271.

O. Jaekel, Die Wirbeltiere. - Berlin 1911, S. 70.

A. Smith Woudward, Outlines of Vertebrate Palaeontology, I. c., 1898, "p. 35.

${ }^{5}$ A. Hancock and $T h$. Atthey, Notes on the Remains of Some Reptiles and Fishes from the Shales of the Northumberland Coal Field. - Ann. Mag. Nat. Hist., London, (4), Vol. I, 1868, p. 364. 
scheinen mit den Hautverkalkungen in den oberen und unteren Kiefern verschmolzen zul sein.

Cheiracanthus. - Unterdevon Schottlands und Kanadas. ${ }^{1}$ Selır ähnlich Acanthodes, aber Dorsalflosse weiter-vorne gelegen.

\section{Unterklasse: Teleostomi.}

Die Teleostomen bilden den Hauptzweig des Fischstammes. Sie sind bis in das untere Unterdevon zurückzuverfolgen und haben sich von einem gemeinsamen Ausgangsstanm schon sehr frühzeitig in verschiedene Hauptgruppen gespalten, von denen die im Jura zuerst erscheinenden ,Teleostier“2 sich zu einer außerordentlich hohen Blüte aufgeschwungen haben, die heute noch anhält. Dieser erst in später Zeit erreichten Blüte der Teleostomen, insbesondere der Teleostier, entspricht das Zahlenverhältnis der bis heute bekannten Familien; 10 erloschenen Familien aus dem Kreise der Teleostier stehen etwa 165 lebende Familien gegenüber. Die verschiedene Bewegungsart, der verschiedene Aufenthaltsort und die verschiedene Lebensweise der Teleostomen hat zur Ausbildung der verschiedenartigsten Gestalten, manchmal zur Entstehung von geradezu abenteuerlichen Formen geführt, wie sie uns namentlich bei den Tiefseefischen und überhaupt bei den Fischen mit verminderter Eigenbewegung entgegentreten und in der einseitigen Ausbildung gewisser durch die Lebensweise bedingter Spezialisationen die Elasmobranchier weit übertreffen. Merkwürdigerweise finden wir aber unter den Teleostomen verhältnismäßig wenige Typen, die sich den dorsoventral stark deprimierten Formen unter den Elasnobranchiern zur Seite stellen lassen; Typen von ähnlich hohem Anpassungsgrad an das benthonische Leben, wie sie uns in den Rochen und Myliobatiden entgegentreten, sind bei den Teleostomen überhaupt nie zur Ausbildung gelangt, was vielleicht damit zusammenhängt, daß dieser Stamm der Fische seit jelıer das freischwimmende Leben bevorzugt hat.

Die morphologischen Merkmale der Teleostomen bestehen vor allem in der bei den ältesten Formen noch fehlenden, aber dann in

1 R. H. Traquair, The Extinct Vertebrata of the Moray Firth Area. I. c., 1896, p. 235-285, Pl. I1, Fig. 2 (Cheiracanthus Murchisoni).

Derselbe, Notes on the Devonian Fishes of Campelitown \& Scammenac Bay in Canada. - Proceed. Roy. Soc. Edinburgh, Vol. XII, 1893, p. 112 (Ch. costellatus).

2 Als ,Teleostei“" pflegte man bisher den Kreis der phylogenetisch jüngeren Actinopterygier zusammenzufassen. Es läßt sich jedoch dieser systematische Begriff aus dem Grunde nicht aufrecht erhalten, weil die Spezialationsstufe der ,Teleostier" von verschiedenen Stämmen unabhängig voneinander erworben wurde, wie weiter unten noch eingehender dargelegt werden soll. 
den verschiedenen Stämmen einsetzenden und weit vorgeschrittenen Verknöcherung des Skelettes. Der Knorpelschädel und die Elemente des Kieferbogens werden von Hautknochen überdeckt, von denen die mittleren Deckknochen des Schädeldaches, die man mit den Nasalia, Frontalia und Parietalia der höheren Vertebraten zu vergleichen pflegt, die konstantesten sind, ebenso wie an der Schädelbasis zwei mediane Knochen, das Parasphenoid und ein medianer „Vomer", fast stets vorhanden sind.

Die Befestigung des Unterkiefers mit dem Schädel ist nit einziger Ausnahme der Dipneusten hyostyl geblieben, was mit der Funktion der Kiefer zusammenhängt. Die Autostylie der Dipneusten ist sekundärer Natur und durch die Ausbildung der zum Zerquetschen und Zerreiben der Nahrung bestimnnten Zahnplatten bedingt.

Die Kiemenspalten werden bei allen Teleostomen durch Kiemendeckelplatten (Operkularplatten) geschützt.

Die paarigen Flossen sind schon bei den ältesten bekannten Teleostomen vorhanden, und zwar stehen die Ventralflossen ursprünglich abdominal, wandern aber bei einzelnen Typen nach vorn und stehen dann thorakal, können aber noch weiter nach vorn rücken und vor den Brustflossen zu stehen kommen (jugulare und mentale Stellung der Ventralen). Bei einigen Stämmen sind die Ventralflossen funktionslos geworden und ganz verloren gegangen, bei anderen haben sie die Rolle von Stenerorganen verloren und sind zu Saugscheiben, Tastorganen usw. umgeformt worden?. Die Brustflossen gehen nur sehr selten verloren, z. B. bei den aalförmigen, sich nur schlängelnd fortbewegenden Muränen. In einigen Fällen konnte der Nachweis erbracht werden, daß die Ventralen aus der thorakalen und selbst aus der jugularen Stellung wieder in die abdominale Lage zurückgekehrt sind, wie dies Dollo für die Atheriniden zeigen konnte.

Die Brustflossen werden von einem wohlentwickelten, sekundären Schultergürtel getragen, die Bauchflossen hängen an einem reduzierten Beckengürtel, der mitunter ganz fehlen kann. Die Frage der Ableitung der Flossen der Teleostomen von primitiveren Formen ist noch immer ungelöst; jedenfalls ist es sicher, daß sie von den Flossentypen der Elasmobranchier nicht abgeleitet werden können. Die Hautstrahlen der paarigen und der unpaarigen Flossen dürften n11odifizierte Schuppen oder "Lepidotrichia“ sein, während die Flossenstrahlen der Elasmobranchier hornartige Bindegewebsfäden sind.

Der Körper der Teleostomen ist ursprünglich beschuppt gewesen; der Verlust der Schuppen bei verschiedenen Stämmen ist unbedingt als sekundär anzusehen, ebenso wie das Vorhandensein von knöchernen Rumpfplatten, von denen Dollo gezeigt hat, daß sie inmer auf ein nacktes Vorstadiun folgen, wie z. B. bei den Panzerwelsen. Die auf Grund der Ausbildung von ,Ganoidschuppen“ in früherer Zeit all- 
gemein gemachte Unterscheidung von „Ganoidei“ einerseits und den "Teleostei“" mit Zykloid- und Ktenoidschuppen anderseits hat sich als unhaltbar erwiesen, seitdem die Erkemntnis gereift ist, daß die Ganoidbeschuppung eine Vorstufe der Zykloid- und Ktenoidbeschuppung darstellt, die von verschiedenen Stämmen unabhängig erworben wurde.

Die Stammgruppe der Teleostomen sind ohne Zweifel die Crossopterygier. Aus ihnen sind die Dipneusten hervorgegangen, deren älteste Vertreter sich kaum wesentlich von den Crossopterygiern unterscheiden; die verschiedenen Merkmale, durch die sich die Dipneusten von den übrigen Teleostomen unterscheiden, sind ausschließlich als eine Folge der veränderten Lebensweise anzusehen und sind keineswegs so durchgreifend, daß die Ausscheidung der Lungenfische aus der Unterklasse der Teleostomen gerechtfertigt wäre. ${ }^{1}$ Die Autostylie der Dipneusten ist sekundär erworten und steht in kausalem Zusammenhang mit der Ausbildung ihres Gebisses; die Unformung der Schwimnblase zu einer Lunge, die Ausbildung innerer Nasenöffnungen und die eigentümlichen Spezialisationen des Herzens sind Folgen der veränderten Lebensweise. Da sie, wie Dollo (1895) gezeigt hat, unter keinen Unständen als die Alınen der Amphibien angesehen werden dürfen, sondern einen blind endigenden Seitenast der Teleostomen darstellen, so liegt kein zwingender Grund vor, sie aus dem Verbande der Teleostomen herauszureißen und etwa als eigene „Unterklasse“ der Fische anzusehen. Sie werden daher im folgenden als eine der Stammgruppe der Crossopterygier anzureihende Ordnung der Teleostomen besprochen werden.

Die Crossopterygicr spielen unter den Teleostomen dieselbe Rolle, wie die Condylarthra unter den Huftieren; sie bilden die Wurzelgruppe der jüngeren Stänme, die sich zu verschiedenen Zeiten vom Hauptstanmme der Teleostomen losgelöst haben und selbständig geworden sind. Diese jüngeren Familion hat man in verschiedoner Weise zusammenzufassen und zu gruppieren versucht; man hat Überordnungen, Ordnungen, Unterordnungen, Kohorten, Hauptordnungen, Nebenordnungen, Vorphasen und Hauptphasen, Vorstufen, Hauptstufen und Oberstufen usw. unter den Teleostomen unterschieden und hat auf diese

1 Daß der Besitz von Lungen oder lungenartig fullktionierenden Organen der Kiemenregion an und für sich zu keiner Sonderstellung irgendeiner damit versehenen Gruppe der Fische berechtigt, geht schon daraus hervor, daß nicht die Dipneusten allein derartige Einrichtungen besitzen. Solche Fälle sind Amphipnous cuchia (der „Cuchia-Aal“"), die Welsgattung Saccobranchus, ferner Anabas ınd Ophiocephalus 11. a. Diese in morphologischer Hinsicht sehr ungleichwertigen Einrichtungen befähigen die Tiere, atmosphärische Luft zu atmen und es ist somit diese Fähigkeit unter den Fischen nicht allein von den Dipneusten erworben worden. Eine ïbersichtliche Darstellung dieser Frage findet sich in T. W. Bridge, Fishes. (The Cambridge Natur. Hist., Vol. VII, London, 1904, pag. 292-296.) 
Weise die verwandtschaftlichen Beziehungen zwischen den einzelnen Familien zum Ausdrucke im ,System“ zu bringen versucht. Dies hat jedoch vielfach ganz falsche Vorstellungen von den Beziehungen der einzelnen Stämme zueinander erweckt und zur Schaffung von durchaus unnatürlichen Verbänden geführt.

Ebenso wie die seinerzeit von Agassiz aufgestellte Gruppierung in ,Ganoidei“ mit Ganoidschuppen einerseits und in ,Teleostei“ mit Zykloid- oder Ktenoidschuppen andererseits nicht mehr aufrecht erhalten werden kann, seitdem man zur Erkenntnis gelangt ist, daß keine scharfen Grenzen bestehen und alle Teleostier einmal die Stufe der Ganoidbeschuppung durchlaufen haben, der Besitz oder das Felılen von Ganoidschuppen also nicht als Kennzeichen von scharf geschiedenen Gruppen verwertet werden darf, so ist dies auch mit jenen morphologischen Merkmalen der Fall, die zur Aufstellung der systematischen Kategorien der ,Chondrostei" und „Holostei“" geführt haben. Diese noch heute in der Systematik der Fische übliche Unterscheidung beruht im wesentlichen auf der Gegenüberstellung von graduell verschiedenen Spezialisationen, welche die verschiedenen Stämme zum Teil ganz unablıängig voneinander durchlaufen haben. So ist das Verhalten der Beschuppung in der Schwanzregion der ,Chondrostei“ (z. B. Paläonisciden, Platysomiden, Chondrosteiden, Polyodontiden und Acipenseriden) auch noch bei den primitiveren Stämmen der „Holostei“ (z. B. Semionotiden) ganz dasselbe; die Schuppen, welche den hinteren Körperabschnitt überdecken, der sich in den oberen Schwanzflossenlappen fortsetzt, sind von den Schuppen der-Körperflanken durch eine scharfe Grenzlinie getrennt und der Verlauf ihrer Reihen ist ganz verschieden. Dieser scharfe Gegensatz verschwindet bei jenen Typen, welche einen lomozerken Terminalflossenbau aufweisen, in dem die primäre Caudalis verkümmert ist. Mit dem Schwunde der Caudalis geht auch die Beschupptung des Körperendes verloren, wie wir an Lepidotus oder Dapedius deutlich verfolgen können. Diese Unterschiede sind also unbedingt nur gradueller Natur; alle höher organisierten Fische haben cinmal das Stadium des bei den ,Chondrostei“ noch deutlich ausgebildeten heterocerken Terminalflossenbaues durchlaufen. Eine systematische Unterscheidung, welche sich allein auf dieses Merkmal stützt, würde dem Versuche vergleichbar sein, die Säugetiere mit brachyodontem (nicedrigkronigem) Gebiß den Säugetieren mit hypsodontem (hoch-o kronigem) Gebils gegenüberzustellen und auf diese Unterschiede zwei große systematische Grippen zu gründen. Mit den übrigen Merkmalen, wolche zur Kennzeichnung der Gruppen der Chondrostei, Holostei and Teleostei verwendet werden, verhält es sich ganz genau so wie mit der eben besproclienen Frage der Beschuppung. Es kann wohl keinem Zweifel unterliegen, daß zu verschiedenen Zeiten der Erdgeschichte 
vom Hauptstamme der Teleostomen immer neue Seitenäste abgezweigt sind, die sich auf entsprechend tieferer oder höherer allgemeiner Organisationsstufe selbständig weiter entwickelt haben. In großen und ganzen läßt sich sagen, daß die in älterer Zeit abgezweigten Stämme, etwa die vom Unterdevon bis zum Perm sich zut selbständigen Gruppen ausbildenden Paläonisciden (Unterdevon bis Unterkreide) und Platysomiden (Karbon und Perm) eine gewisse Summe gemeinsamer Merkmale aufweisen, die sie von den in jüngerer Zeit abgezweigten Stänmmen unterscheiden; aber diese Gruppen zusammen mit den wahrscheinlich aus den Paläonisciden entstandenen Stören oder „Knorpelganoiden" "als eine „Ordnung der Chondrostei“ den jüngeren Stämmen gegenüberstellen zu wollen, entbehrt jeder Berechtigung und ist nur geeignet, falsche Vorstellungen von den Beziehungen der "Chondrostei" zu den ,Holostei“ zu erwecken, unter welchem Namen alle Stämme zusammengefaßt werden, die sich zwischen dem Perm und dem Jura vom Hauptstanme der Teleostomen abgetrennt haben, also zu einer Zeit, da die allgemeine Organisation der ganzen Gruppe schon auf einer höheren Stufe angelangt war. Diese Seitenäste, deren wichtigste Vertreter die Senionotiden und Pycnodontiden waren, erreichten ihre Blüte in der Trias- und Jurazeit, gingen in der Kreide sichtlich zurück und leben nur mehr in Gestalt von wenigen Nachzüglern, wie Amia und Lepidosteus, noch in der Gegenwart fort.

Alle Familien der Teleostomen, die seit denı jura vom Hauptstamme der Teleostomen abgezweigt sind, faßt man gewölnnlich unter dem systematischen Begriff der ,"Teleostier" zusammen. Dies ist die noch heute in voller Blüte stehende Gruppe der Teleostomen. Unter ihnen lassen sich wieder vier Kategorien von Unterordnungen unterscheiden, die durch die phylogenetisch aufeinanderfolgenden Unterordnungen der Malacopterygii, Haploni, Acanthopterygii und Plectognathi gekennzeichnet sind, und zwar scheinen die Beziehungen dieser Unterordnungen zueinander etwa die folgenden zu sein (nach G. A. Boulenger, 1904):

11. Opisthomi

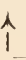

9. Anacanthini

$\hat{i}$

7. Catosteomi 个
13. Plectognathi

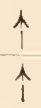

10. Acanthopterygii

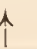

5. Haplomi

6. Heteromi

$\hat{i}$
12. Pediculati



8. Percesoces

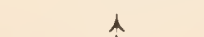

4. Apodes

3. Symbranchii 
Abweichend von den in neuerer Zeit üblichen Gruppierungen der Teleostomen fasse ich in folgenden die Gruppen der Chondrostei, Holostei und Teleostei als eine einheitliche Gruppe zusammen, wie dies schon B. Dean (1895) und A. S. Woodwaid (1898) getan haben, und zwar als die Ordnung der Actinopterygii.

Unter den Teleostomen unterscheide ich folgende Abteilungen:

I. Ordnung: Crossopterygii (Stammgruppe).

I1. Ordnung: Dipneusti.

III. Ordnung: Actinopterygii.

\section{Ordnung: Crossopterygii (Stammgruppe der Teleostomen).}

Die Benennung dieser Gruppe als Crossopterygii oder „Quastenflosser" ist sehr bezeichnend, da die Angehörigen dieser Gruppe durch einen zwar graduell verschiedenen, aber in den Hauptzügen doch gleichartigen Bau der Flossen gekennzeichnet sind. Die primitivsten Zustände des Flossenbaues treffen wir bei den Holoptychiiden an, die den ältesten Dipneusten sehr nahe stehen. Bei ihnen wird die Brustflosse von einem langen, zentralen, gegliederten Aclsenstab durchzogen, an den sich in biserialer Anordnung Strahlen anschließen, welche als Stützen der Seitenteile der Flosse dienen. Diese Flossenstrahlen werden auch als „Lepidotrichia" bezeichnet; sie sind, wie Goodrich wahrscheinlich gemacht hat, als modifizierte Schuppen anzusehen. Der zentrale Achsenstab der Brustflosse ist beschuppt. Während die Brustflosse der Holoptychiiden und der ältesten Dipneusten spitz zuläuft, treten bei anderen Crossopterygiern Modifikationen in der Richtung ein, daß der zentrale Achsenstab eine Verkürzung erfährt und die Lepidotrichia eine fächerförmige Anordnung erhalten (z. B. bei Osteolepis, Undina, Polypterus, Calamoichthys). Eine andere Modifikation des prinitiven Brustflossentyps zeigt die Flosse von Eusthenopteron, die am Hinterrande gerade abgestutzt ist und dadurch in der äußeren Form den normalen Actinopterygierflossen ähnlich wird. Das knorpelige Skelett der zentralen Brustflossenachse ist nur von Eusthenopteron genauer bekannt. Das Achsenskelett der Brustflosse von Neoceratodus scheint den primitiven Bau der Crossopterygierflosse bis lieute bewalırt zu laben.

Ähnlich wie die Brustflossen sind die Bauchflossen der Crossopterygier geformt und gebaut gewesen, doch sind sie im allgemeinen kürzer als die Brustflossen, und zwar ist diese Verkürzung besonders bei jenen Formen ausgeprägt, die wir als freischwimmende und nicht einen großen Teil ihres Lebens auf dem Boden liegende Typen ansprechen mïssen.

Auch die beiden Rückenflossen und die freie Analflosse (die Analis 11.; die Analis 1. ist mit der Caudalis schon bei den primitivsten 
Formen zu einer einheitlichen Terminalflosse vereinigt) besitzen ein beschupptes, zentrales Achsenskelett.

Die Terminalflosse ist ursprünglich ausgesprochen epibatisch und heterozerk (z. B. bei Holoptychius), später isobatisch und rhipidizerk (z. B. bei Glyptolaemus, Undina, Eusthenopteron).

Die Schuppen der Crossopterygier sind entweder von rhombischer Form (Osteolepidae, Polypteridae) oder ihr freier Hinterrand ist halbkreisförmig abgerundet (zykloid), wie bei den Holoptychiiden, Rhizodontiden und Coelacanthiden. Im ersten Falle stehen die Schuppen in Reihen nebeneinander, während sie sich bei den Formen mit Zykloidschuppen dachziegelartig decken. Nur bei den Polypteriden ist eine Schicht Ganoin als äußere Bedeckung der Schuppen vorhanden, die eine Schmelzschicht vortäuscht, aber nur eine Knochenschicht darstellt; dagegen sind bei den Osteolepiden usf. die Schuppen mit einer Außenschichte bedeckt, welche als Kosmin bezeichnet wird und eine epidermale, also eine echte Schmelzbildung darstellt. Bei den Rhizodontiden geht dieser Kosminbelag in der Regel wieder verloren.

Die Wirbelsäule der Crossopterygier ist nur in untergeordneter Weise verknöchert. Bei einigen Formengruppen treten in der Schwanzregion ringförmige Verknöcherungen (Ringzentren) auf, wie bei den Osteolepiden; bei den Rhizodontiden finden sich in der Abdominalregion einiger Gattungen derartige Ringwirbel; bei Eusthenopteron sind außerdem in der Schwanzregion die oberen und die unteren Bögen verkalkt. Aus derartigen Ringwirbeln sind die amplicoelen Vollwirbel der lebenden Polypteriden hervorgegangen. Dagegen sind bei den Holoptychiiden ebenso wie bei den Coelacanthiden nur die oberen und unteren Bögen verknöchert und es treten überhaupt keine Ringwirbelbildungen bei diesen Formen auf. Der Knorpelschädel ist ursprünglich mit einer auffallend großen Zahl von relativ kleinen Deckknochenplatten bedeckt, welche meist mit Höckerchen oder Runzèln von Kosmin besetzt sind. Im Verlaufe der phylogenetischen Entwicklung tritt, unabhängig voneinander bei Osteolepiden und Rhizodontiden, eine Verschmelzung dieser kleinen, mosaikartig aneinander passenden Plättchen zu einzelnen großen, medianen oder paarigen Platten ein, ganz ebenso wie dies im Verlaufe der Stammesgeschichte der Dipneusten nachzuweisen ist, unter denen Dipterus Valenciennesii aus dem unteren Unterdevon ein mosaikartig aus vielen Platten zusammengesetztes Schädeldach besitzt, während bei Ceratodus und Neoceratodus das Schädeldach nur aus wenigen Platten besteht. Diese Verschmelzung betrifft hauptsächlich den mittleren Teil des Schädeldaches, während an den Seitenflächen (Wangen-, Augen- und Kiemendeckelregion) die kleineren Platten erhalten bleiben. Die Kehlregion ist durch den Besitz zweier großer Kehlplatten (,Gularplatten“) gekennzeichnet, wie dies besonders 
gut bei Rhizodopsis zu beobachten ist; hier findet sich vor diesen beiden Platten noch eine mediane, kleinere Kehlplatte und zwischen diesen und dem Unterkiefer sowie der untersten Kiemendeckelplatte eine größere Zahl von kleinen, lateralen Kehlplatten.

Der Kiemendeckelapparat der Crossopterygier ist einfacher gebaut als bei den Actinopterygiern. So besteht z. B. bei Gadus morrhua (Fig. 24) der Operkularapparat aus dem Operculum als Hauptstück, dem sich hinten und unten das Suboperculum, vorn und unten das Interoperculum und vorn das Praeoperculum anschließen. Bei den Crossopterygiern setzen meist nur drei Platten den Operkularapparat zusammen, und zwar scheint in diesen Fällen das Interoperculum zu fehlen. Die beiden beständigsten Operkularplatten scheinen das Operculum und das Suboperculum zu sein. Die Deckknochen des Schultergürtels schließen sich an den Hinterrand des Operkularapparates an.

Das Kiefergelenk ist hyostyl.

Bemerkenswert ist das Auftreten eines Pinealforamens zwischen den als „Frontalia“ gedeuteten Platten des Schädeldaches.

Das Gebiß besteht aus mehr oder weniger kegelförmigen, mitunter ein wenig gekrümmten Zähnen, die bei den einzelnen Stämmen durch Einfaltungen kompliziert erscheinen. Bei den Osteolepiden sind die Zähne einfach gebaut und weisen nur an der Basis Längseinfaltungen auf; etwas weiter nach oben atusgedehnt sind diese Falten bei den Rhizodontiden, und einen sehr hohen Spezialisationsgrad haben die Zähne der Holoptychiiden erreicht, den man als die ,dendrodonte" Zahnstruktur zu bezeichnen pflegt; diese kommt dadurch zustande, daß an 'Stelle der Pulpa von der Basis gegen die Spitze viele konvergente Kanäle verlaufen, die erst in der Nähe der Spitze zu einer zentralen Höhle zusammenfließen. Von den vertikalen Kanälen und von der aus ihrer Vereinigung in der Nähe der Spitze gebildeten ,Pseudopulpa" strahlen radial gegen die Peripherie des Zahnes viele feine, sich nach außen immer weiter verzweigende Röhrchen büschelförmig aus, von denen wieder kleine Seitenäste abzweigen, so daß auf dem Querschnitt eines solchen Zahnes ein Gewirr von Kanälen und Falten sichtbar ist, das in auffallender Weise an die ,labyrinthodonte" Zahnstruktur der Stegocephalenfamilie der Labyrinthodontidae aus der Gruppe der Rhachitomi crinnert (Fig. 116 und 117). Bei vielen Crossopterygiem sind einzelne Zühnne des Gebisses durch besondere Größe von den anderen verschieden und können als Fangzähne gedeutet werden.

Die Crossopterygier und die ilmen sehr nahestehenden ältesten Dipneusten (Dipterus Valenciennesii) umfassen jedenfalls verschiedene, schon vor dem tuntersten Devon, also gewiß schon im Obersilur, getremte Stammreihen, die auf eine noch unbekannte gemeinsame Wurzel zurückgehen müssen. Der wesentlichste Unterschied zwischen 
den ältesten Dipneusten und den Crossopterygiern des unteren Devons besteht in der verschiedenen Ausbildung des Gebisses, das bei den Dipneusten schon sehr frühzeitig an die eigenartige Nahrungsweise dieser Ordnung (vgl. p. 174) adaptiert erscheint, während das Gebiß der unter dem systematischen Begriff der Crossopterygier zusammengefaßten Formenreihen stets ein Fanggebiß geblieben ist. Die verschiedenen Fanilien der Crossopterygier weisen so zahlreiche Spezialisationskreuzungen auf, daß sie nicht voneinander abgeleitet werden können. So z. B. sind die Zähne der sonst so einseitig und hoch spezialisierten

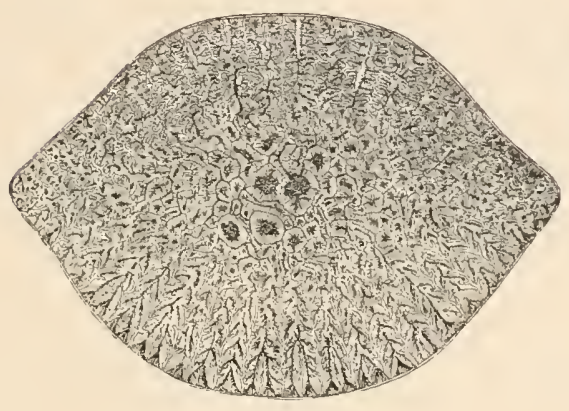

Fig. 116.

Querschnitt durch einen Zahn von Holoptychius (Dendrodus) biporcatus, Ag., aus dem Devon von Aa, Livland. Stark

vergr. (Nach Ch. Pander.)

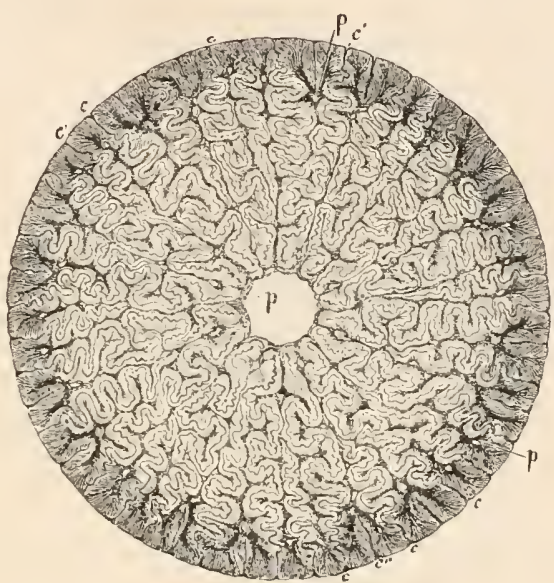

Fig. 117.

Querschnitt durch einen Zahn von Mastodonsaurus Jaegeri, einem Stegocephalen aus der oberen Trias Deutschlands. Ungefähr $2 / 1$ nat. Gr. (Nach R. Owen.) $p=$ Pulpa und Pulpaausstïlpungen. $c=$ Zahnzement.

Coelacanthiden und Polypteriden einfacher gebaut als die der unterdevonischen Formen und dieser einfache Zahmbau ist sicher als ein primitives Verhalten anzusehen.

\section{F. Osteolepidae.}

Schuppen rhombisch, mit dickem Kosminbelag, einander entweder nicht überlagernd, oder rhomboidisch mit schwach abgerundetem, freiem Hinterrand, der die hintere Schuppe überdeckt. Achse der Brustflossen kurz. Im Schädeldach ist fast immer ein Pinealforamen vorhanden, die mittleren Schädeldachknochen sind mehr oder weniger miteinander verwachsen. Terminalflosse epibatisch bis isobatisch, wobei sich die Wirbelsäule bis zum Ende der Flosse in gerader Linie fortsetzt (Glyptopomus), während sie bei den epibatischen Terminalflossentypen (Osteo- 
lepis, Thursius) nach oben aufgebogen ist. In der Schwanzregion Ringzentren ausgebildet. Zähne einfach, nur an der Basis gefaltet. Osteolepis. - Mittlerer Teil des Old Red Sandstone (Unterdevon) Schottlands (Fig. 118). ${ }^{1}$ Schwanzflosse epibatisch.

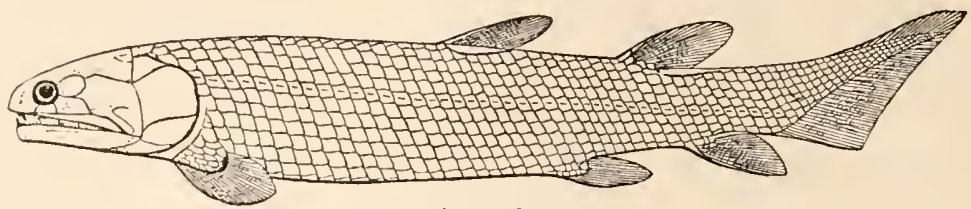

Fig. 118.

Rekonstruktion von Osteolepis macrolepidotus aus dem Old Red Sandstone (Devon) des Gebietes des Moray Firth in Schottland. (Nach R. H. Traquair.)

Thursius. - Ebendaher. ${ }^{2}$ Schwanzflosse epibatisch.

Diplopterus. - Ebendaher (Fig. 119). ${ }^{3}$ Schwanzflosse beinahe isobatisch, Wirbelsäulenende nur noch schwach nach oben gerichtet.

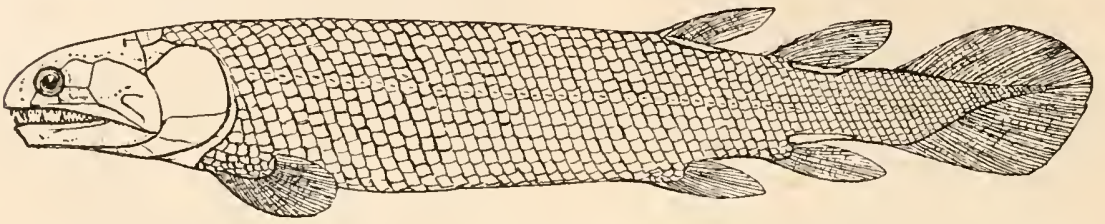

Fig. 119.

Rekonstruktion des Diplopterus Agassizii aus dem Old Red Sandstone (Devon) des Moray-Firth-Gebietes in Schottland. (Nach R. H. Traquair.)

Glyptopomus. - Oberer Teil des Old Red Sandstone (Oberdevon) Schottlands und Devon Pennsylvaniens (Fig. 26). ${ }^{4}$ Schwanzflosse isobatisch.

${ }^{1}$ R. H. Traquair, The Extinct Vertebrata of Moray Firth Area. - Aus Harvie-Brown \& Buckley: „Vertebrate Fauna of the Moray Basin“, Vol. II, Edinburgh, 1896, p. 235-285, Pl. III, Fig. 2.

2 A. Geikie, On the Old Red Sandstone of Western Europe. - Transactions Roy. Soc. Edinburgh, Vol. XXVIII, 1878, p. 451.

R. H. Traquair, Notes on the Nomenclature of the Fishes of the Old Red Sandstone of Great Britain. - Geological Magazine, (3), Vol, V, 1888, p. 516.

${ }^{3}$ R. H. Traquair, The Extinct Vertebrata of Moray Firth Area. - I. c., Pl. 1II, Fig. 3.

Derselbe, Adress to the Zoological Section of the British Association of the Advancement of Science. - Bradford, 1900, p. 10.

4 A. Smith Woodward, Catalogue of the Fossil Fishes in the British Museum. Part 11, 1891, p. 389.

Th. H. Huxley, Glyptolaemus Kinnairdi. - Memoirs of the Geological Survey of the United Kingdom (X), 1861, p. 41.

Derselbe, Preliminary Essay upon the Systematic Arrangement of the Fishes of the Devonian Epoch. - Ibidem, p. 1.

O. Abel, Grundzuige der Pa!äobiologie, 1912, p. 108, 112. 
Parabatrachus (= Ectostereorhachis). - Karbon und Perm von England, Kansas, Texas uni Ohio, vielleicht auch in Neuschottland. ${ }^{1}$

\section{F. Tarrasiidae.}

Der einzige Vertreter dieser Familie ist ein kleiner, kaum $6 \mathrm{~cm}$ langer Fisch aus dem Unterkarbon von Tarras Foot und Glencartholm in Eskdale (Schottland). Der Rücken trägt an Stelle zweier getrennter Dorsalflossen einen kontinuierlichen hohen Hautsaum, der das Körperende umzieht und bis zur Analflosse reicht, wie dies bei den höher spezialisierten Dipneusten der Fall ist. Die Bauchregion trägt keine Schuppen, wohl aber die Schwanzregion, die nit viereckigen, dicken, sehr kleinen Schmelzschuppen gepanzert ist. Der Bau der Flossenträger weicht von den der übrigen Crossopterygier bedeutend ab. - Nur eine Art, Tarrasius problematicus. ${ }^{2}$

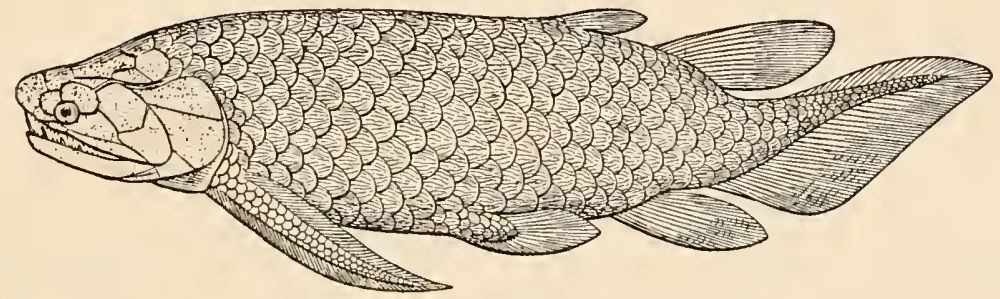

Fig. 120.

Rekonstruktion von Holoptychius Flemingi aus dem Old Red Sandstone Schottlands, $1 / 8$ nat. Gr. (Nach R. H. Tı aquair.)

\section{F. Holoptychiidae.}

Schuppen mit Kosminschichte, zykloid, sich dachziegelartig deckend. Achse der Brustflossen lang, spitz zulaufend, primitiver als bei den Osteolepiden gebaut. Bauchflossen kurz, kaum halb so lang als die Brustflossen, mit fächerförmig stehenden Lepidotrichien. Ein Pinealforamen fehlt. Schädeldachknochen nicht zu medianen, großen Platten verschmolzen. Terminalflosse schwach epibatisch, ausgesprochen hetozerk. In der Wirbelsäule nur die oberen und unteren Bögen verknöchert, keine Ringzentren vorhanden. Zahnreihe aus spitzigen, kegelförmigen Zähnen bestehend, sehr stark spezialisiert, labyrintho-

1 Über die Literatur bezüglich dieser Gattung vgl. O. P. Hay, Bibliography and Catalogue of the Fossil Vertebrata of North America. - Bul'etin No. 179 of the U. S Geol. Survey, Washington, 1902, p. 362.

2 R. H Traquair, Report on the Fossil Fishes collected by the Geologica Survey of Scotland in Eskdale and Liddesdale. Part I. - Transactions Roy. Soc. Ed'nburgh, Vol. XXX, 1881, p. 61, Pl. 1V, Figg. 4-6.

Derselbe, Observations on some Fossil Fishes from the Lower Carboniferous Rocks of Eskdale. - Annales Mag. Nat. Hist, London, Vol. VI, 1890. 
dont oder ,dendrodont" (Holoptychiidae = Dendrodontidae). Einzelne Arten erreichen eine Länge von fast $70 \mathrm{~cm}$.

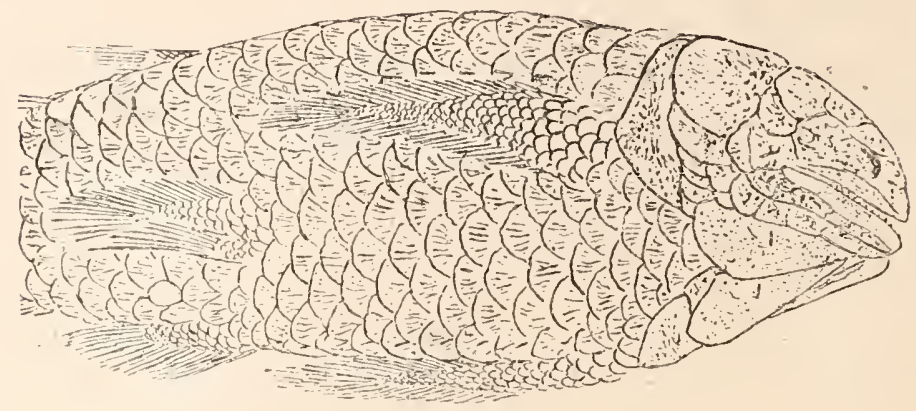

Fig. 121.

Vorderteil des Körpers von Glyptolepis macrolepidotus aus dem Mitteldevon Schottlands, schräge von tmten gesehen, um den allmählichen Übergang der Bauchschuppen in die Schuppen der Flossenachsen zu zeigen. $3 / 1$ nat. Gr. (Nach O. Jaekel.)

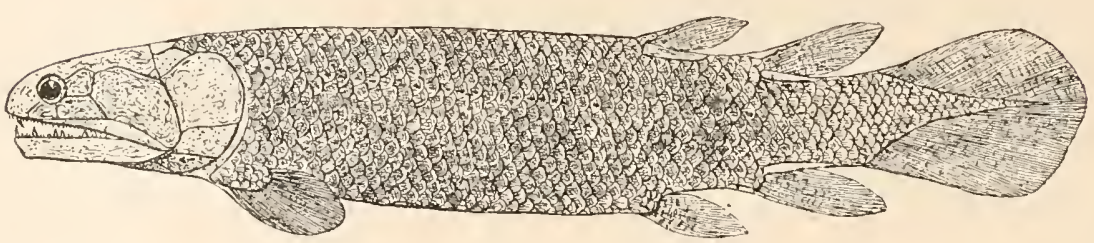

Fig. 122.

Gyroptychius, aus dem Old Red Sandstone des Moray-Firth-Gebietes in Schottland, rekonstruiert von R. H. Traquair, 1896.

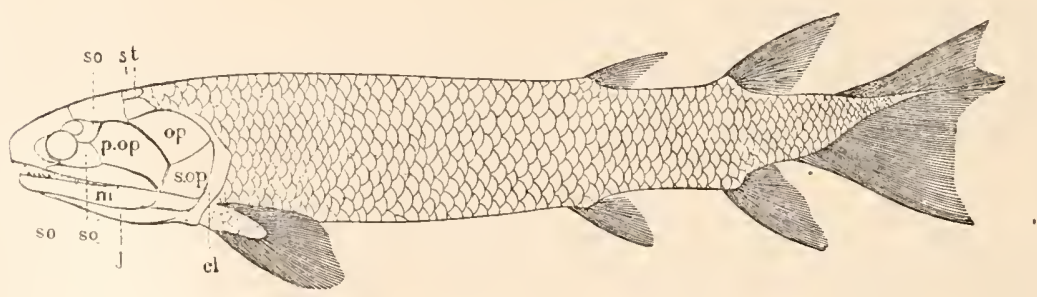

Fig. 123.

Rekonstruktion des Tristichopterus alatus, aus dem Old Red Sandstone (Devon) Schottlands, (Nach R. H. Traquair.)

$\begin{array}{llll}\text { so. } & \text { Suborbitale. } & \text { s. op. } & \text { Suboperculum. } \\ \text { st. } & \text { Supratemporale. } & m . & \text { Mandibula. } \\ \text { p. op. } & \text { Praeoperculum. } & j . & \text { Gulare. } \\ \text { op. } & \text { Operculum. } & \mathrm{cl} . & =\text { Clavicula. }\end{array}$

Holoptychius (= Dendrodus). - Hauptverbreitung im Oberdevon (oberer Old Red) Schottlands, ferner im Devon Belgiens, Böhmens, 
der Eifel, der russischen Ostseeprovinzen, Pennsylvaniens, New Yorks, Neuschottlands, Kanadas. Zahlreiche Arten (Fig. 116, 120). ${ }^{1}$

Glyptolepis. - Old Red Sandstone Schottlands (Fig. 121). ${ }^{2}$

\section{F. Rhizodontidae.}

Wie die vorige Familie, aber im Bau der Brustflossen spezialisierter, weil diese nur eine kurze Achse besitzen; Zähne weniger hoch spezialisiert als bei den vorhergehenden Familien. In der Wirbelsäule sind Ringzentren vorhanden.

Die Beschuppung erweist sich im Vergleiche zu den Osteolepiden als spezialisiert, da die meisten Gattungen gerundete (nicht mehr rhonbische) und kosminlose Schuppen besitzen; gelegentlich kommt (bei Rhizodopsis) Kosmin als Schuppenbelag und (bei Gyroptychius) als Belag der Flossenstrahlen vor.

Gyroptychius. - Devon (Old Red Sandstone) Schottlands. Die Körperform, Lage, Form und Größe der Flossen und der allgemeine Habitus erinnert in hohem Grade an Diplopterus (Fig. 122). ${ }^{3}$

Tristichopterus. - Unterdevon Schottlands (Fig. 123). ${ }^{4}$

Eustlienopteron. - Oberdevon von Quebec, Kanada. Körperlänge des größten bisher bekannten Exemplars 1 nl (Fig. 124). ${ }^{5}$

Megalichthys (= Rhizodus). - Die bedeutende Größe der Zähne (ihre Länge kann bis $10 \mathrm{~cm}$ betragen) beweist die für Crossopterygier

1 J. V. Rohon, Die Dendrodonten des devonischen Systems in RuBland. Mémoires de l'Acad. Imp. St. Pétersbourg (7), Vol, XXXVI, 1889, p. 1.

R. H. Traquair, On the Systematic Position of the „Dendrodont" Fishes. - Geological Magazine (3), Vol. VI, 1889, p. 490.

Derselbe, The Extinct Vertebrata of Moray Firth Area. - I. c., 1896, Pl. II, Fig. 4.

J. S. Newberry, The Palaeozoic Fishes of North America. - Monographs U. S. Geol. Survey, Vol. XVI, 1889, p. 100-115.

E. D. Cope, On New Palaeozoic Vertebrata from Illinois, Ohio, and Pennsylvania. - Proceed. Amer. Philosoph. Soc., Vol. XXXVI, 1897, p. 71.

R. H. Traquair, Notes on the Devonian Fishes of Campbelltown and Scaumenac Bay in Canada. - Geological Magazine (3), Vol. X, 1893, p. 123 und 265 (als Glyptolepis quebecensis beschrieben).

- 2 O. Jaekel, Über die Beurteilung der paarigen Extremitäten. - Sitzungsberichte d. Kgl. Preußischen Akademie der Wissenschaften, 1909, p. 718, Fig. 10.

${ }_{3}$ R. H. Traquair, The Extinct Vertebrata of Moray Firth Area. - 1. c., Pl. III, Fig. 1.

4 R. H. Traquair, On the Structure and Affinities of Tristichopterus alatus, Egerto11. - Transactions Roy. Soc. Edinburgh, Vol. XXV11, 1875, p. 383.

5 L. Hussakof, Notes on Devonic Fishes from Scaumenac Bay, Quebec. Bulletin of the New York State Museum, Albany, No. 158, 1912, p. 131. (Abbildung eines vorzüglich erhaltenen Exemplars in nat. Gr.)

J. F. Whiteaves, lllustrations of the Fossil Fishes of the Devonian Rocks of Canada. - Part II, Transactions Roy. Soc. Canada, Vol. VI, Sect. 4 (1888), 1889 , p. 78. 
ungewöhnliche Körperlänge dieser Typen, die aus dem Karbon von Schottland, England and Nordamerika nachgewiesen sind. ${ }^{1}$ Type: M. Hibberti, Ag.

Rhizodopsis. - Karbon von Europa (England, Schottland und Schlesien). ${ }^{2}$

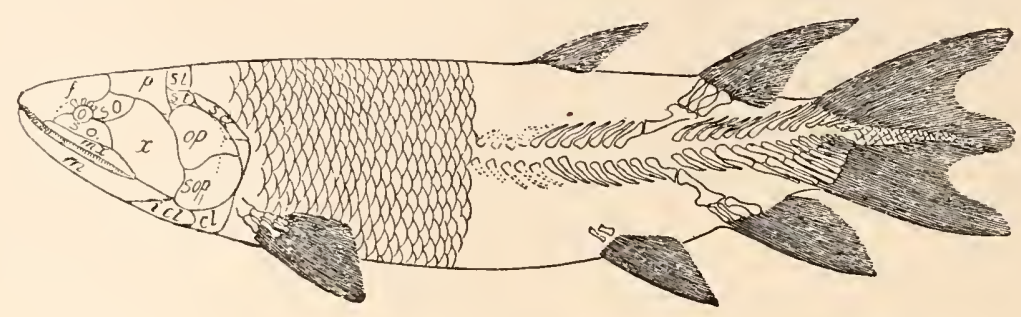

Fig. 124.

Rekonstruktion von Eusthenopteron Foordi, aus dem Oberdevon der Scaumenac Bay in Kanada, in $1 / 4$ nat. Gr. (Nach White aves.)

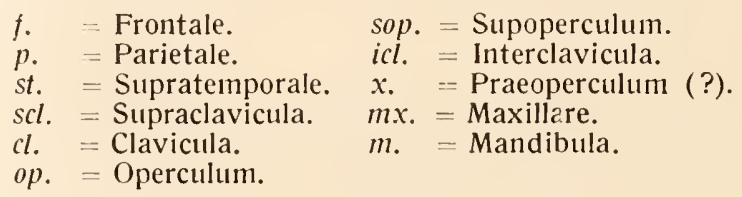

\section{F. Onychodontidae.}

Schuppen zykloid. Das wichtigste Merkmal dieser nur durch eine Gattung aus dem Deven Nordamerikas bekannten Gruppe sind die großen, unpaaren, auf einem mediancn Präsymphysealknochen des Unterkiefers stehenden Zähne, welche die ïbrigen Zähne um das Zehnfache ihrer Länge übertreffen. Wahrscheinlich handelt es sich

1 R. H. Traquair, Remarks on the Genus Megalichthys (Agassiz), with Description of a New Species. - Proceed. Roy. Phys. Soc. Edinburgh, Vol. VIII, 1884, p. 67.

J. St. Newberry, Description of Several New Genera and Species of Fossil Fishes from the Carboniferous Strata of Ohio. - Proceed. Acad. Nat. Sciences Philadelphia, Vol. VIll, 1856, p. 99.

Derselbe, The Palaeozoic Fishes of North America. - Monographs of the U. S. Geol. Survey, Vol. XVI, 1889, p. 191.

Der Bau und die Form der Terminalflosse von Megalichthys bildet eine Zwischenstufe zwischen dem isobatischen (spezialisierten) und dem epibatischen (primitiven) Terminalflossentypus, wie aus den Untersuchungen Traquairs über Megalichthys laticeps (I. c., 1884, S. 71) hervorgeht. Megalichthys schließt sich am engsten an Osteolepis an und steht dieser Gattung näher als den devonischen Gattungen Gyroptychius, Tristichopterus und Eusthenopteron.

2 R. H. Traquair, On the Cranial Osteology of Rhizodopsis. - Transactions of the Roy. Soc. of Edinburgh, Vol. XXX, 1881, p. 167. 
in diesen medianen, großen Zähnen um Angriffswaffen, ähnlich wie bei den Edestiden (z. B. Edestus, Helicoprion).

Onychodus. - Devon von Ohio, New York, Manitoba. ${ }^{1}$

\section{F. Coelacanthidae.}

Schuppen zykloid, knöchern, aber dünn, mit sehr zarter Schmelzlage bedeckt. Der Operkularapparat besteht nur aus einem großen Operculum. Terminalflosse isobatisch, von sehr eigentümlicher Gestalt: aus einer Ausgangsform, wie sie uns bei Glyptopomus entgegentritt, wo bereits der über dem Körperende liegende Teil der Caudalis dieselbe Größe wie die unter dem Körperende liegende Analis erreicht hat, sind folgende weiteren Stadien abzuleiten: Coelacanthus, Macropoma, Undina, Diplurus. Bei der letztgenannten Gattung ist die Wirbelsäule weit ïber ihr ursprüngliches Ende hinausgewachsen, so daß die neu entstandene Endflosse, die sich an dieser Verlängerung gebildet hat, den Charakter einer selbständigen Schwanzflosse erhalten hat.

Während somit die Region der Terminalflosse bei den Coelacanthiden einen sehr hohen Grad von Spezialisation erreicht hat, verhält sich sowohl das aus ganz einfachen Kegelzähnen bestehende Gebiß als auch die Verknöcherung der Wirbel durchaus primitiv; selbst bei den Coelacanthiden der oberen Kreide (Macropoma) sind nur die oberen und unteren Bögen verkalkt, aber niemals Wirbelzentren zur Ausbildung gelangt.

Eine sehr merkwürdige und in ihrer physiologischen Bedeutung noch unaufgeklärte Erscheinung tritt uns in der Verknöcherung der Schwimmblase entgegen. Die Wände der Schwimmblase bestehen aus sechs Längsreihen von rhombischen Kalkplatten, die sich schuppenförmig übereinanderlegen, und zwar derart, daß der Vorderrand einer solchen, aus dünnen Kalklamellen aufgebauten Platte sich über den Hinterrand der vorhergehenden Platte schiebt. Auf der Innenseite ist die Wandung der Schwimmblase von einem System von verdickten Leisten bedeckt, die sich zu einem netzartigen Geflecht vereinigen, und zwar herrscht in der Art der Kreuzung dieser Verdickungen die rhombische Form vor. Der Verlauf dieses Netzwerkes im Inneren der Schwimmblase der Coelacanthiden erinnert auffallend an den Bau der Lungenwände von Lepidosiren, so daß es wahrscheinlich ist, daß die

1 J. S. Newberry, The Paleozoic Fishes of North America. - 1. c., p. 56, 71, 99. Die Zugehörigkeit der Reste aus dem Devon Englands ist unsicher. (E. T. Newton, Note on a New Species of Onychodus from the Lower Old Red Sandstone of Fairfax. - Geol. Magazine (3). Vol. IX, 1892, p. 5I. - R. H. Traquair, Notes on Palaeozoic Fishes. - Ann. Mag. Nat. Hist., London (7), Vol. II, 1898, p. 68. - A. S. Woodward, Note sur l'Helicoprion et les Édestides. - Bull. Soc. Belge de Géologie etc., T. XIII, I899, p. 232.) 
Funktion der Schwimmblase eine gleichartige war und daß somit auch die Coelacanthiden ,Lungenfische“ waren. Ein sicheres Urteil ist in dieser Frage jedoch einstweilen nicht möglich, wenn auch der allgemeine Körpertypus der Coelacanthiden entschieden dafür spricht, daß sie eine ähnliche Lebensweise geführt haben wie die Dipneusten. Auch die Nasenregion der Coelacanthiden weist in vielen Punkten eine Übereinstimmung mit den Dipneusten auf.

Das Hyomandibulare ist mit dem Palatoquadratum verwachsen.

Die Wirbelsäule zeigt, wie bereits betont, keine Verknöcherungen außer den oberen und unteren Bögen.

Die Zälıne sind klein und zart; die Tiẹre sind jedenfalls nicht durophag gewesen. Die Augen sind durch einen Kranz von zalılreichen, kleinen Sklerotikalplatten geschützt.

$\mathrm{Zu}$ den auffallendsten Merkmalen der Coelacanthiden gehört das Vorhandensein von gabelförmigen Knochenplatten als Träger der Dorsalflossen und der Analflosse; der Träger der vorderen Dorsalflosse ist besonders breit. Von diesen Trägern gehen unmittelbar die Strahlen der medianen Flossen aus.

Die Ventralflossen stehen nicht mehr in ihrer ursprünglichen, abdominalen Lage, sondern sind nach vorn gegen den Thorax verschoben.

Jedenfalls stellt die ganze Familie einen einseitig hoclsspezialisierten Stamm dar, der auf primitiver Basis vom Hauptstamme der Crossopterygier abgezweigt ist. Die ältesten Gattungen sind aus dem Karbon, die jüngsten aus der oberen Kreide bekannt.

Coelacanthus. - Karbon von England, Ohio und llinois; Perm von England und Deutschland; obere Trias von Lunz in Niederösterreich und aus der Kapkolonie. Mehrere Arten, bis $30 \mathrm{~cm}$ Länge erreichend. ${ }^{1}$

Graphiurus. - Eine Art aus der oberen Trias von Raibl in Kärnten bekannt. ${ }^{2}$

Diplurus. - Eine Art aus der Trias von New Jersey und Connecticut bekannt. ${ }^{3}$

1 O. M. Reis, Die Coelacanthinen, mit besonderer Berücksichtigung der im weißen Jura Bayerns vorkommenden Gattungen. - Paläontographica, Bd. XXXV, 1888 , p. 1.

Derselbe, Coelacanthus lunzensis, Teller. - Jahrbuch d. K. K. Geol. Reichsanstalt, Wien, Bd. L, 1900, S. 187.

R. Broom, The Fossil Fishes of the Upper Karroo Beds of South Africa. Annals of the South African Museum, Vol. V11, 1909, p. 253.

2 R. Kner, Die Fische der bituminösen Schiefer von Raibl in Kärnthen. Sitzungsberichte der K. Akad. der Wissenschaften, Wien, Bd. LIII, 1866, p. 152.

${ }^{3}$ Ch. R. Eastman, Triassic Fishes of Connecticut. - State of Connecticut, St. Geol. and Nat. Hist. Surv., Bull. No. 18, Hartford, 1911, p. 44. 
Undina. - Lias Englands (U. gulo), oberer Jura Bayerns (lithographischer Schiefer) und Frankreichs. Mehrere, bis $45 \mathrm{~cm}$ lange Arten (Fig. 125). ${ }^{1}$

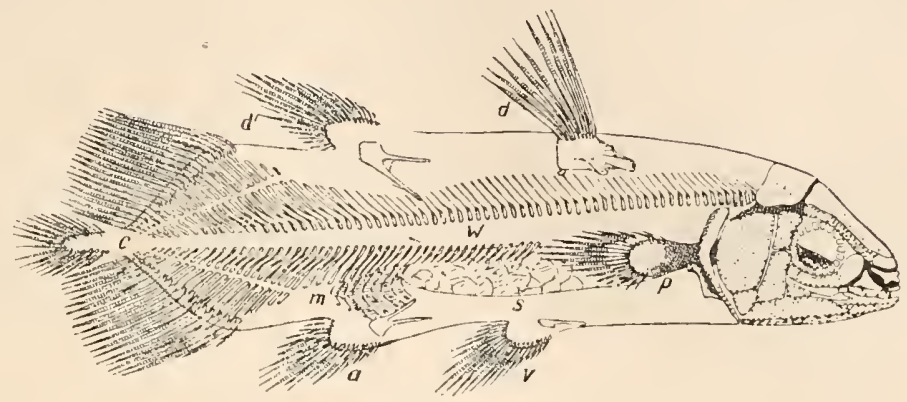

Fig. $125 \mathrm{a}$.

Rekonstruktion von Undina acutidens, Reis, aus dem oberen Jura von Solnhofen, Bayern, in $1 / 4$ nat. Gr. (Nach O. Reis.)

$$
\begin{aligned}
& a=\text { Analis. } \quad c=\text { Terminalis. } \\
& d, t^{\prime}=\text { vordere und hintere Dorsalis. } s=\text { verknöcherte Schwimumblase. } \\
& P \text { Pectoralis. } \quad m \text { - versteinerte Muskeln. } \\
& v \text { = Ventralis. } \quad \cdots=\text { Region der Chorda dorsalis }
\end{aligned}
$$

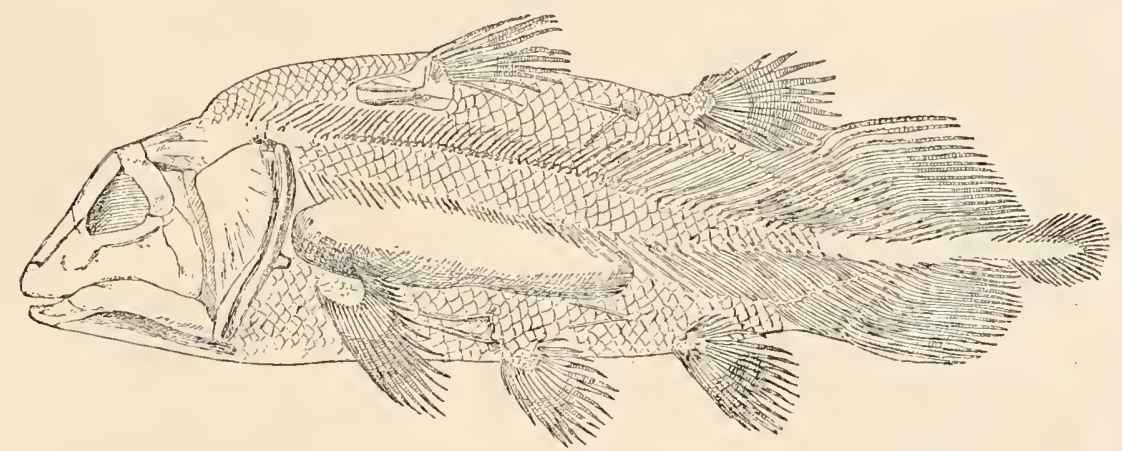

Fig. 125 b.

Undina penicillata, Münster, cin Coelacanthide aus dem oberen Jura von Zandt bei Eichstätt, in $1 / 3$ nat. Gr. (Nach K. A. von Zittel.)

Macropoma..- Mittlere und obere Kreide von Frankreich, Norddeutschland, Böhmen, England. ${ }^{2}$ (Fig. I6.)

Mawsonia. - Untere Kreide von Bahia (Brasilien). Schuppen scheinen gänzlich zu fehlen. ${ }^{3}$

1 O. M. Reis, Die Coelacanthinen, usw., I. c.

2 A. Smith Woodward, Outlines of Vertebrate Palaeontology, 1898, p. 78.

3 J. Mawson and A. S. Woodward, On the Cretaceous Formation of Bahia (Brazil), and on Vertebrate Fossils collected therein. - Quart. Journ. Geol. Soc., London, Vol. LXIII, 1907, p. 134.

A. S. Woodward, On some Fossil Fishes discovered by Prof. Ennes de Souza in the Cretaceous Formation at Ilhéos (State of Bahia), Brazil. - Ibidem, Vol. LXIV, 1908, p. 358. 


\section{F. Polypteridae.}

Die heute noch in Afrika lebenden Polypteriden sind fossil nur aus dem Eozän Ägyptens bekannt. ${ }^{1}$ Sie stellen einen gleichfalls schon in sehr früher Zeit vom Hauptstamme der Crossopterygier abgezweigten Seitenast dar, der z. B. in der Ausbildung eines aus rhombischen,
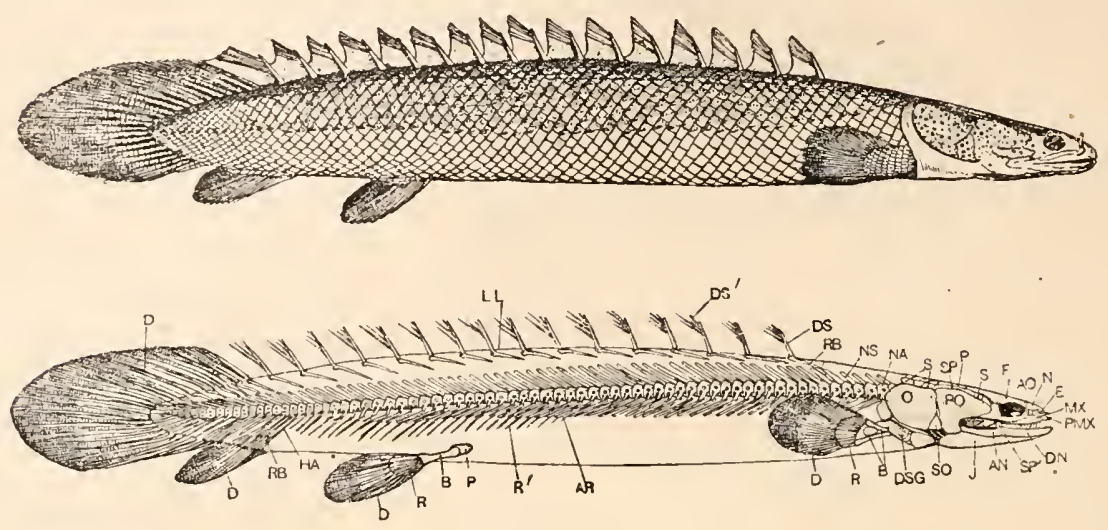

Fig. 126.

Vollansicht und Skelettansicht von Polypterus bichir, Holozän.

Ungefähr $1 /$ s nat. Gr. (Nach B. Dean.)

\begin{tabular}{|c|c|c|}
\hline \multicolumn{3}{|l|}{$\Lambda$} \\
\hline$A O$ & $\begin{array}{l}\text { Angurare. } \\
=\text { Antorbitale. }\end{array}$ & $=$ Maxillare. \\
\hline$A R$ & $=$ Rippen. & $=$ Nasale. \\
\hline$B$ & $=$ Basalia der paarigen Flossen. & $=$ Neuralboges \\
\hline & $=$ Träger der Term & physe. \\
\hline DN & $=\mathrm{De}$ & lum. \\
\hline$D$ & $\begin{array}{l}\text { Iflossenstachel (modifi- } \\
\text { Schuppe). }\end{array}$ & $\begin{array}{l}P= \\
P M X=\end{array}$ \\
\hline$D S^{\prime}$ & $\begin{array}{l}=\text { Sekundäre Strahlen (Haut- } \\
\text { strahlen) der Dorsalis. }\end{array}$ & $\begin{array}{l}=\text { Radialia der paarigen Flossen. } \\
=\text { Rippen. }\end{array}$ \\
\hline DS & Hautschuppen. & $=$ Träger der Analflosse. \\
\hline & $=$ Ethmoideum. & $=$ Knochen der Spiracularlinie. \\
\hline & $=\mathrm{Fr}$ & = Suboperculum. \\
\hline$H$ & $\begin{array}{l}=\text { Haemalbögen } . \\
=\text { Gulare. }\end{array}$ & $\begin{array}{l}=\text { Spiraculum. } \\
=\text { Spleniale. }\end{array}$ \\
\hline
\end{tabular}

dicken Schuppen bestehenden Panzers primitiv ist, aber durch die Ausbildung einer die Scluppen bedeckenden Ganoinlage (vgl.p. 159) sich von allen anderen Fanilien des Stammes sehr bestimmt unterscheidet. Das Innenskelett ist stark verknöchert, die Wirbelzentren amphicoel. Spritzlöcher sind vorhanden. Die Schwimmblase ist paarig ausgebildet. Das Skelett der Brustflosse ist von dem aller übrigen Crossopterygier verschieden, ebenso sind keine getrennten, großen Dorsalflossen, sondern eine große Zalıl kleiner Flossen vorhanden,

1 E. von Stromer, Die Fischreste des mittleren und oberen Eozäns von Ägypten. I. Teil. - Beiträge zur Paläontologie und Geologie Österreich-Ungarns und des Orients, Bd. XVIII, 1905, S. 184. 
deren Skelett sehr eigenartig ist' (Fig. 126). Inn Schädeldach fällt das Vorhandensein zahlreicher kleiner Knochenplatten (Spiracularia) zwischen den mittleren Knochen des Schädeldaches und der Wangenregion auf (Fig. 18). Von den lebenden Gattungen Polypterus und Calamoichthys erreicht die erstere die bedeutende Länge von $120 \mathrm{~cm}$. Beide Gattungen sind Grundbewohner der großen afrikanischen Ströme; Polypterus tritt im Stromgebiete des Nil und des Kongo auf, Calamoichthys bewohnt nur verschiedene Flüsse Westafrikas. Aus dem Obereozän Ägyptens hat E. Stromer einzelne Schuppen beschrieben, die keine nähere Bestimmung zulassen, aber als Belege für das, Vorkommen von Polypteriden in Afrika auch in früherer Zeit von Bedeutung sind. Außerhalb des afrikanischen Kontinentes sind niemals auch nur dürftige Spuren dieser Familie fossil nachgewiesen worden und es ist anzunehmen, daß sie einen seit sehr langer Zeit, wahrscheinlich schon seit dem Paläozoikum, isolierten und auf Afrika beschränkten Stamm darstellen.

\section{Ordnung: Dipneusti (= Dipnoi).}

Man hat häufig die Ansicht vertreten, daß die Lungenfische oder Dipneusten die Ahnen der Amphibien und somit eine Übergangsgruppe zwischen den Fischen und den Tetrapoden darstellen.

Diese Anschauung ist, wie Dollo (1895) gezeigt hat, unhaltbar. Die Dipneusten stellen einen Seitenzweig der Teleostomen dar, der von den Crossopterygiern seinen Ausgang genommen hat; die Ähnlichkeiten zwischen ihnen und den Amphibien sind durchaus auf Rechnung analoger Anpassung an das amphibiotische Leben zu setzen, ohne daß es möglich wäre, eine theoretische Brücke zwischen den beiden Gruppen zu schlagen. Die Dipneusten sind einseitig so hoch spezialisiert, daß schon seit der Entstehung der Dipteriden keine Abzweigung in der Richtung zu den Amphibien erfolgt sein kann. Um so weniger darf daran festgehalten werden, daß etwa Neoceratodus oder eine andere der heute lebenden Dipneustengattungen den Weg der Entstehung der Amphibien aus den Fischen zeigt oder gar die Ansicht verfochten werden, daß eine dieser lebenden Gattungen als ein „missing link“ zwischen Fischen und Tetrapoden anzusehen ist.

Die Ausbildung einer Lunge aus der Schwimmblase, die wir schon bei den Crossopterygiern antreffen, in Verbindung mit der Reduktion des Kiemendeckelapparats und der Entstehung innerer Nasenöffnungen kann nicht ausreichen, den Dipneusten- im System eine exzeptionelle Stellung zu verschaffen. Ich habe darum die Dipneusten als selbständige Ordnung der Teleostomen unmittelbar hinter den Crossopterygiern eingereiht, in der Meinung, daß durch diese Anordnung im System 
die verwandtschaftlichen Beziehungen der Dipneusten viel klarer zum Ausdrucke kommen als durch eine Loslösung von den Teleostomen und ,Erhebung“ zu einer eigenen ,Unterklasse“ oder sogar „Klasse“, wozu keine genügende Berechtigung vorliegt.

Das wichtigste Merkmal, das die Dipneusten ebensowohl von den Crossopterygiern wie von den Actinopterygiern und von den Amphibien unterscheidet, ist das Gebiß. Im Ober- und Unterkiefer finden sich keine isolierten, kegelförmigen Zähne, sondern nur Zahnplatten vor, die zwar bei Lepidosiren und Protopterus im Unterkiefer verloren gegangen, sonst aber bei allen Dipneusten vorlanden sind, und zwar steht ein Paar auf den Gaumenplatten (den Pterygopalatina) und das zweite diesem gegenüber im Unterkiefer; bei Neoceratodus (Fig. 8, 127) trägt

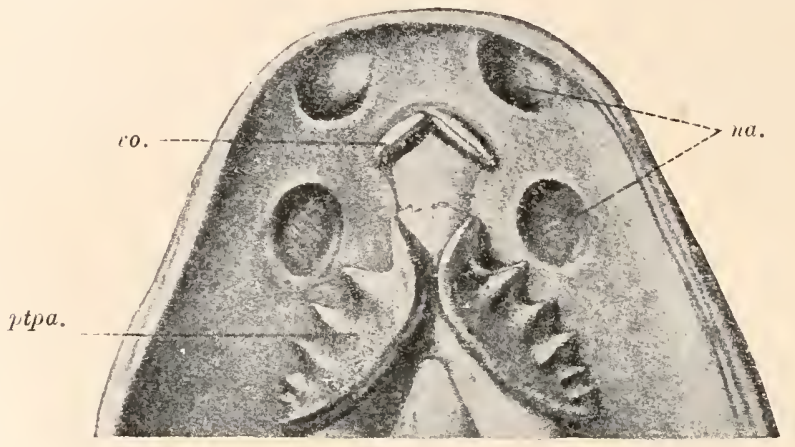

Fig. 127.

Gaumenfläche eines erwachsenen Neoceratodus Forsteri in $2 / 3$ nat. Gr.

(Nach R. Semon, 1899.)

na. $=$ Nasenlöcher. $v_{0}=$ Vomerzahnplatte. ptpa. = Ptery opal tinalzc hnplatte.

auch der Vomer jederseits ein Paar kleiner, meißelförniger Zähnchen, denen keine Antagonisten im Unterkiefer gegenüberstehen. Die Zalınplatten sind, wie sich ontogenetisch nachweisen läßt, aus der Verwachsung von Einzelzähnen hervorgegangen, und zwar entsprechen die sechs Kämme der oberen Zahnplatte von Neoceratodus ebensovielen Einzelzähnen, die beim Embryo noch getrennt sind (Fig. 128).

\section{$\mathrm{Zu}$ Fig. 128.}

A. Gaumenfläche des Oberkiefers. - $v_{1}, v_{2}, v_{3}$ drei getrennte Zähne an der Stelle des späteren Vomerzahns. $a_{1}-a_{4}, b_{1}-b_{3}, c_{1}-c_{2}$ bezeichnen einzelne, in drei Reihen angeordnete Zähne, die später zu der großen Pterygopalatinalplatte verschmelzen; jede dieser beiden Platten besteht daher aus 9 Einzelzähnen, deren Basen zwar verwachsen, deren Spitzen aber frei sind.

B. Gaumenfläche des Unterkiefers. $-x_{1}-x_{5}$ und $o_{1}-o_{3}$ zwei getrente Reihen von Einzelzähnen, die später zu einer einheitlichen Zahnplatte jederseits verschmelzen; zul diesen treten noch die Zähne $q_{1}, p_{1}$ und $p_{2}$. Der unpaare Zahn $y$ ist von R. Semon in zwei Fällen auch in paariger Ausbildung beobachtet worden. 
Das Gebiß von Neoceratodus hat einen Typus beibehalten, der schon im Devon bei den ältesten bekannten Dipneusten ausgebildet war. Es ist kein durophages Gebiß, wie z. B. das Gebiß der Rochen oder der verschiedenen durophagen lebenden und fossilen Elasmobranchier, sondern ein Gebiß, das nach R. Semon zum Abschneiden, Zerquetschen. und Zerreiben weicher Wasserpflanzen und der auf ihnen und zwischen ihnen lebenden Organismen dient. Die scharf hervortretenden Kämme der Zahnplatten von Neoceratodus sind also in physiologischer Hinsicht an ehesten den hohen Höckern der Malılzähne der Flußpferde oder von Bothriopsis oder von Moeritherium zu vergleichen. Bei der großen Ähnlichkeit zwischen den Formen der Zahnplatten der lebenden und der fossilen Dipneusten dürfen wir wohl annehmen, daß auch die fossilen Typen dieselbe Nahrungsweise geführt haben wie Neoceratodus, also im wesentlichen Pflanzenfresser gewesen sind, die aber außerdem eine karnivore Nahrung nicht verschmäht haben. Einzelne fossile Typen (Phaneropleuron, Uronemus und vielleicht auch Scaumenacia) müssen die sonst bei den Dipneusten vorherrschende Lebensweise dahin abgeändert haben, daß sie wieder die karnivore Nahrung bevorzugt haben. Dies geht daraus hervor, daß sich schon bei Phaneropleuron, wo eine kammtragende breite Zahnplatte in jedem Kiefer auftritt, die äußeren Höcker derselben derart spezialisiert zeigen, daß sie mit einer marginalen Reihe von Einzelzähnen verwechselt werden konnten; bei der noch höher spezialisierten Gattung Uronemus sind die ktenodonten Zahnplatten des Oberkiefers, die auf dem Palato-Pterygoid standen, gänzlich bis auf vereinzelt stehende runde Höckerchen verloren gegangen und nur die marginale Tuberkelreihe übrig geblieben, während das Palato-Pterygoid schon durch seine flache, verbreiterte Gestalt beweist, daß auf ihm früher nicht nur einzelne Tuberkeln, sondern Zahnplatten befestigt waren. Die marginalen Tuberkeln der Kiefer von Uronemus sind mit ihren Basen verschmolzen und zweifellos die letzten funktionellen Reste der ktenodonten Zahnplatten. Hier liegt also zwar eine Rückkehr zur ehemaligen rein karnivoren Nahrungsweise der Crossopterygier vor, aber der morphologische Bau dieser als Fanggebiß funktionierenden Tuberkeln ist von der Reihe der Einzelzähne, wie sie die Ahnen der Dipneusten besaßen, durchaus verschieden (Beispiel für das Gesetz von der Nichtumkehrbarkeit der Entwicklung). ${ }^{1}$

Unter den Dipneusten werden in der Regel mehrere Familien unterschieden, deren Abgrenzung jedoch bis in die letzte Zeit strittig gewesen ist. So ist man allmählich'dazu gekommen, für die Gattung

${ }^{1}$ L. Dollo, Sur la Phylogénie des Dipneustes. - Bull. Soc. Belge de Géologie, Paléont. etc., T. IX, Bruxelles 1895, pag. 116. 
Dipterus und ihre nächsten Verwandten die Familie der Dipteriden zu errichten, und liat als Grund der Trennung von der Familie der Phaneropleuriden das Fehlen der marginalen Bezahnung bei den Dipteriden angegeben; da aber Traquair nachgewiesen hat, daß das Gebiß dieser

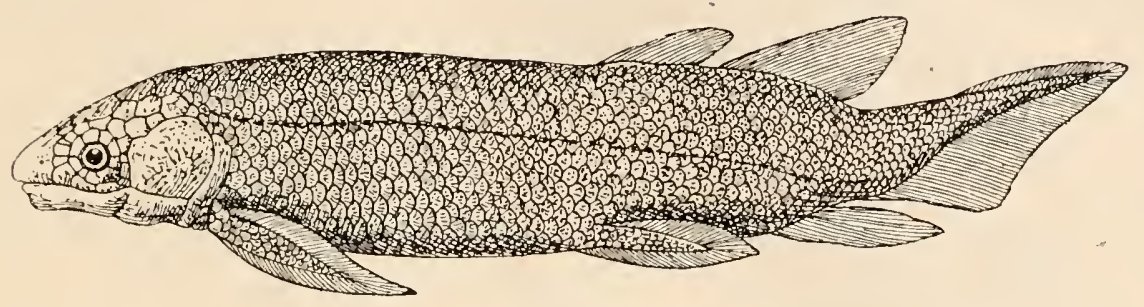

Fig. 129.

Dipterus Valenciennesii, Sedg. et Murch., aus dem Old Red Sandstone (unteres Unterdevon) Schottlands, in $1 / 4$ nat. Gr. (Nach R. H. Traquair.)

auch unter dem Namen der Ctenodontiden vereinigten Phaeneropleuridengattungen sich nicht fundamental, sondern nur graduell von dem der Dipteriden unterscheidet, so fällt dieser Grund für eine Trennung der Ctenodontiden und Dipteriden weg, die somit in einer Familie unter

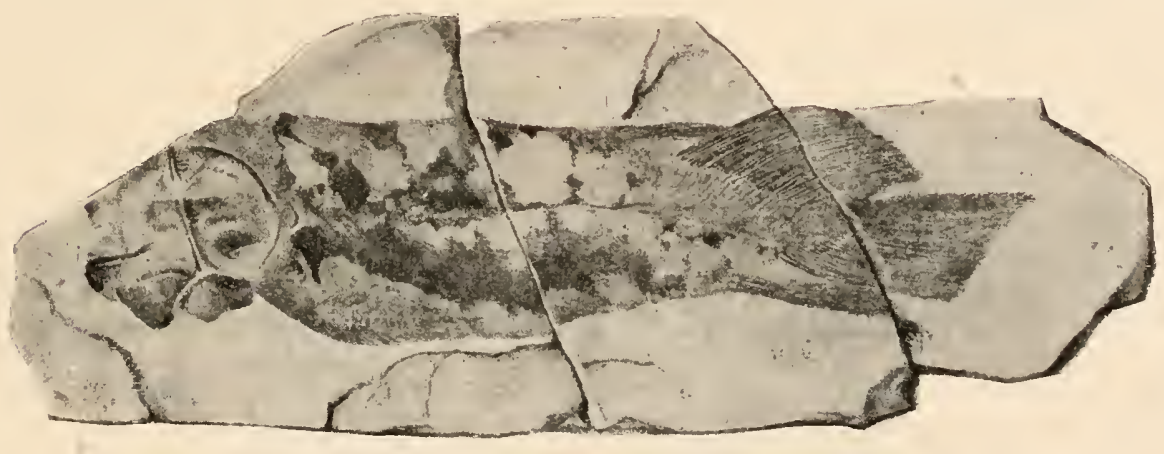

Fig. 130 .

Dipterus macropterus, Traquair, aus dem Old Red Sandstone (oberes Unterdevon) von Caithness in Schottland. $2 / 3$ nat. Gr. (Nach R. H. Traquair.)

dem Namen der Ctenodontiden zu vereinigen wären. Traquair hat weiter die Ansicht vertreten, daß die Gattung Uronemus durch die eigentümliche Spezialisation ihres Gebisses eine separate Stellung unter den Dipneusten einnimmt. ${ }^{1}$ Aus seinen Darlegungen geht jedoch, wie Dollo später gezeigt hat, klar hervor, daß die Spezialisation des Gebisses von Uronemus nur ein höheres Spezialisationsstadium des bei

1 R. H. Traquair, Notes on the Devonian Fishes of Campelltown and Scaumenac Bay in Canada, No. 3. - Geolog. Magazine, London, Dec. III., Vol. X, 348, 1893, pag. 264. 

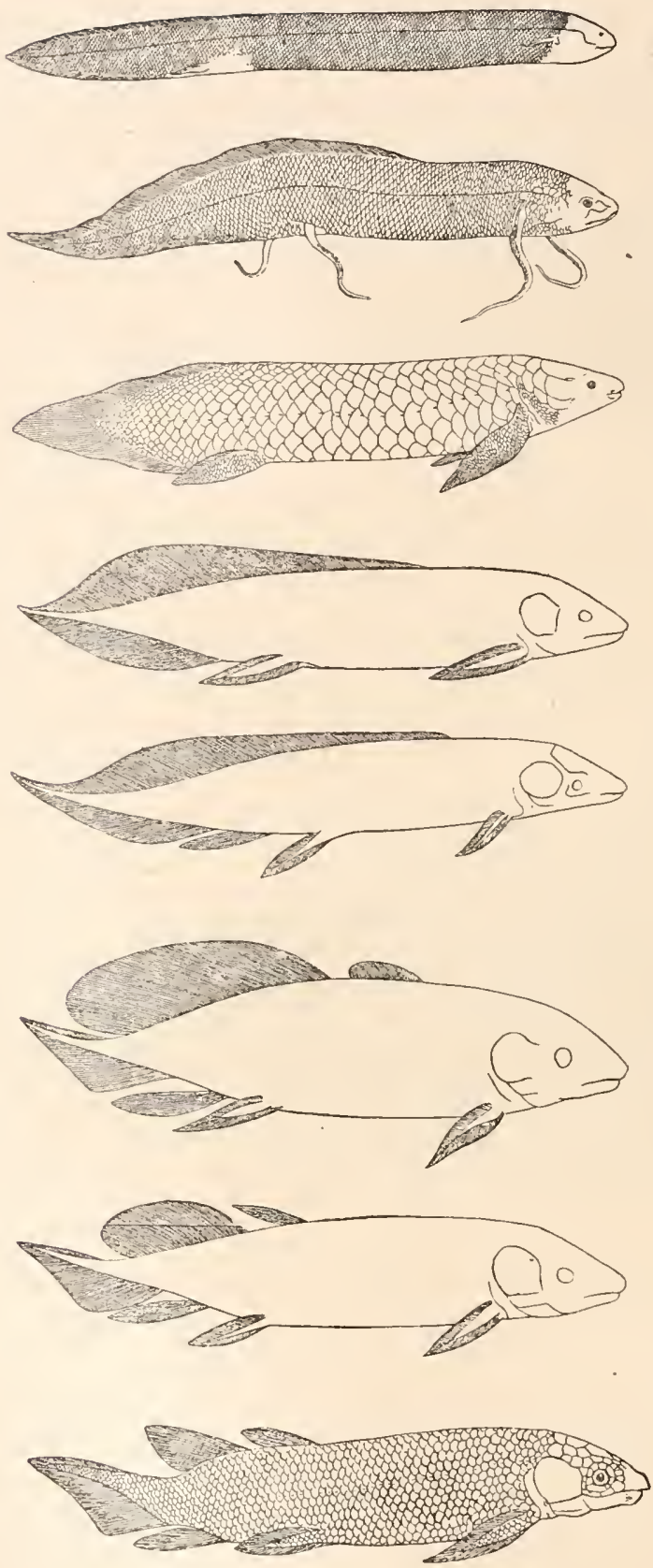

Fig. 131.
Lepidosiren paradoxa, Fitzinger; Holozän, Süiamerika.

Protopterus annectens, Owen; Holozän, Afrika.

Neoceratodus Forsteri, Krefft;

Holozän, Australien.

Uronenuis lobatus, Agassiz; Unterkarbon, Schottland.

Phaneropleuron Andersoni, Huxley; uberes Oberdevon, Schottland.

Scaumenacia curta, Whiteaves; unteres Oberdevon, Kanada.

Dipterus macropterus, Traquair; oberes Unterdevon, Schottland.

Dipterus Valenciennesi, Sedgwick et Murchison; unteres Unterdevon, Schottland.

Die Stufenreihe der Dipueusten, nach L. Dollo, 1895.

Phaneropleuron eingeschlagenon Weges sei. Es liegt also auch kein - Grund dafür vor, die Familie der Uronemiden von den Ctenodontiden 
zu trennen. Die drei lebenden Gattungen Neoceratodus (auf die kleinen Flußgebiete des Burnett- und Mary-River an der Küste Queenslands beschränkt), Lepidosiren (Südamerika) und Protopterus (Westafrika) sind freilich so sehr voneinander verschieden, daß man sie als Vertreter dreier verschiedener Familien ansehen könnte; Lepidosiren und Protopterus

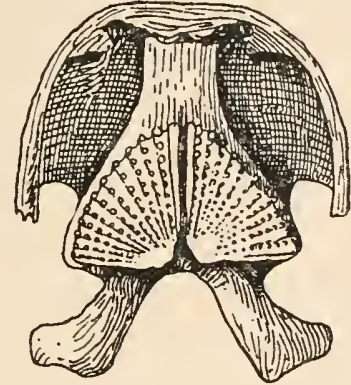

Fig. 132.

Oberes Gebiß und Kiefer von Dipterus Valenciennesii, Sedgw. et Murch., aus dem unteren Unterdevon (Lower Old Red) Schottlands, in nat. Gr., von der Gaumenseite gesehen. (Nach A. Smith Woodward.)

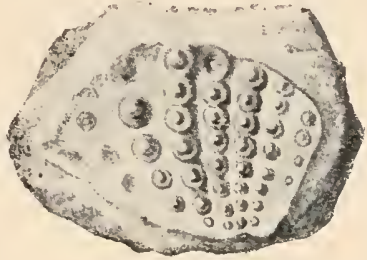

Fig. 133.

Oberflächenansicht einer Zahnplatte von Dipterus tuberculatus aus dem Devon, in $8 \frac{1}{2}$ facher Vergrößerıng. (Nach Ch. H. Pander.)

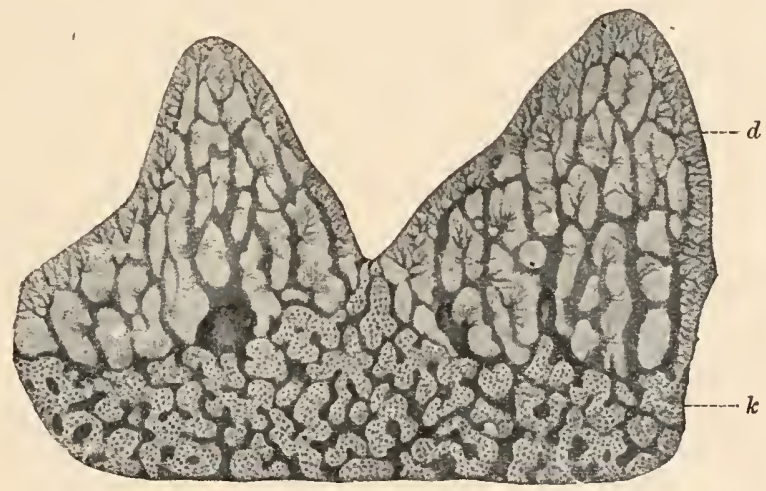

Fig. 134 .

Längsschliff durch zwei nebeneinanderstehende Spitzen einer Zahnplatte von Dipterus tuberculatus, aus dem Devon, stark vergr. (Nach Ch. Pander.) $d=$ Dentin. $k=$ Knochen.

stehen sich einander etwas näher und sind darum meist in einer Familie, den Lepidosirenidae, vereinigt worden. Die Gegensätze zu den Ctenodontiden sind jedoch gleichfalls nur gradueller Natur und es entspricht wohl den verwandtschaftlichen Beziehungen zwischen den lebenden und fossilen Dipneusten besser, alle bekannten Gattungen nur in einer einzigen Familie, den Ctenodontiden, zusammenzufassen. 
Die älteste Dipnenstengattung Dipterus steht den Crossopterygiern des Devons viel näher als den lebenden Dipneusten. Die paarigen Flossen entsprechen durchaus dem Typus der schmalen, schlanken, zweizeilig bestrahlten Seitenflosse, wie wir sie bei Holoptychius (Fig. 120) kennen gelernt haben. Der Körper ist mit zykloiden, schmelzbedeckten Schuppen (Kosminschuppen) gepanzert, die vier medianen Flossen (vordere und hintere Dorsalis, Terminalis [= Caudalis + Analis prima] und Analis secunda) sind ursprünglich getrennt und erst im Laufe der plyylogenetischen Entwicklung tritt, wie Dollo $1895^{1}$ überzeugend dargelegt

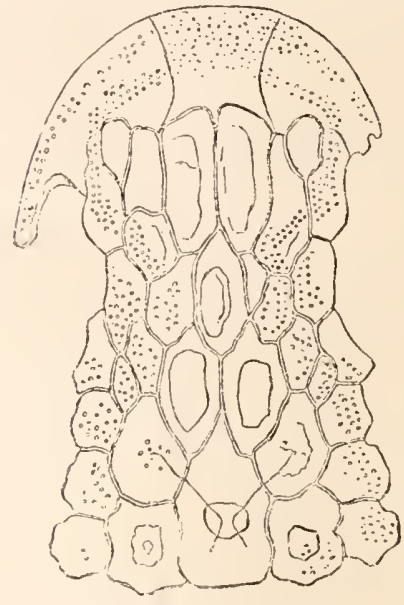

Fig. 135.

Mosaikpanzer des Schädels von Dipterus Valenciennesii, aus dem unteren Unterdevon Schottlands, in nat. Gr. (Nach Ch. Pander.)

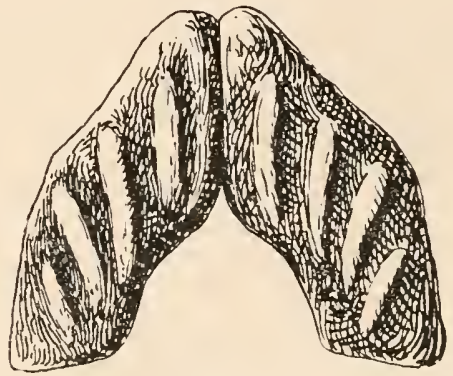

Fig. 136.

Die beiden Zahnplatten des Unterkiefers von Palaedaphus insignis, Van Ben. et de Kon., aus dem Devon von Lüttich, Belgien. $1 / 4$ nat. Gr. (Nach P. J. van Beneden und L. G. de Koninck.)

hat, eine Vereinigung dieser getrennten Medianflossen zu einem medianen Hautsann ein, wie er bei den lebenden Gattungen ausgebildet ist (Fig. 131). Im Schädel sind ursprünglich Gularplatten vorhanden, aber bei den jüngeren Typen sind sie verloren gegangen. Das Schädeldach bestand bei Dipterus (Fig. 135, 7 A.) aus einer großen Zahl von einzelnen, zu einem Mosaik vereinigten Platten, die sich bei den jüıgeren Gattungen zu größeren Deckknochen zısanıınenschließen, wie dies z. B. Neoceratodus (Fig. 8) zeigt; einen parallelen Vorgang haben wir auch bei den Crossopterygiern verfolgen können. Die Wirbelsäule ist immer auf einer tiefen Stufe stehen geblieben; zur Bildung von knöchernen Wirbelkörpern ist es bei den Dipnensten nie gekommen. 
Die Verknöcherung beschränkt sich auf die oberen und unteren Bögen sowie auf die Rippen und Flossenträger.

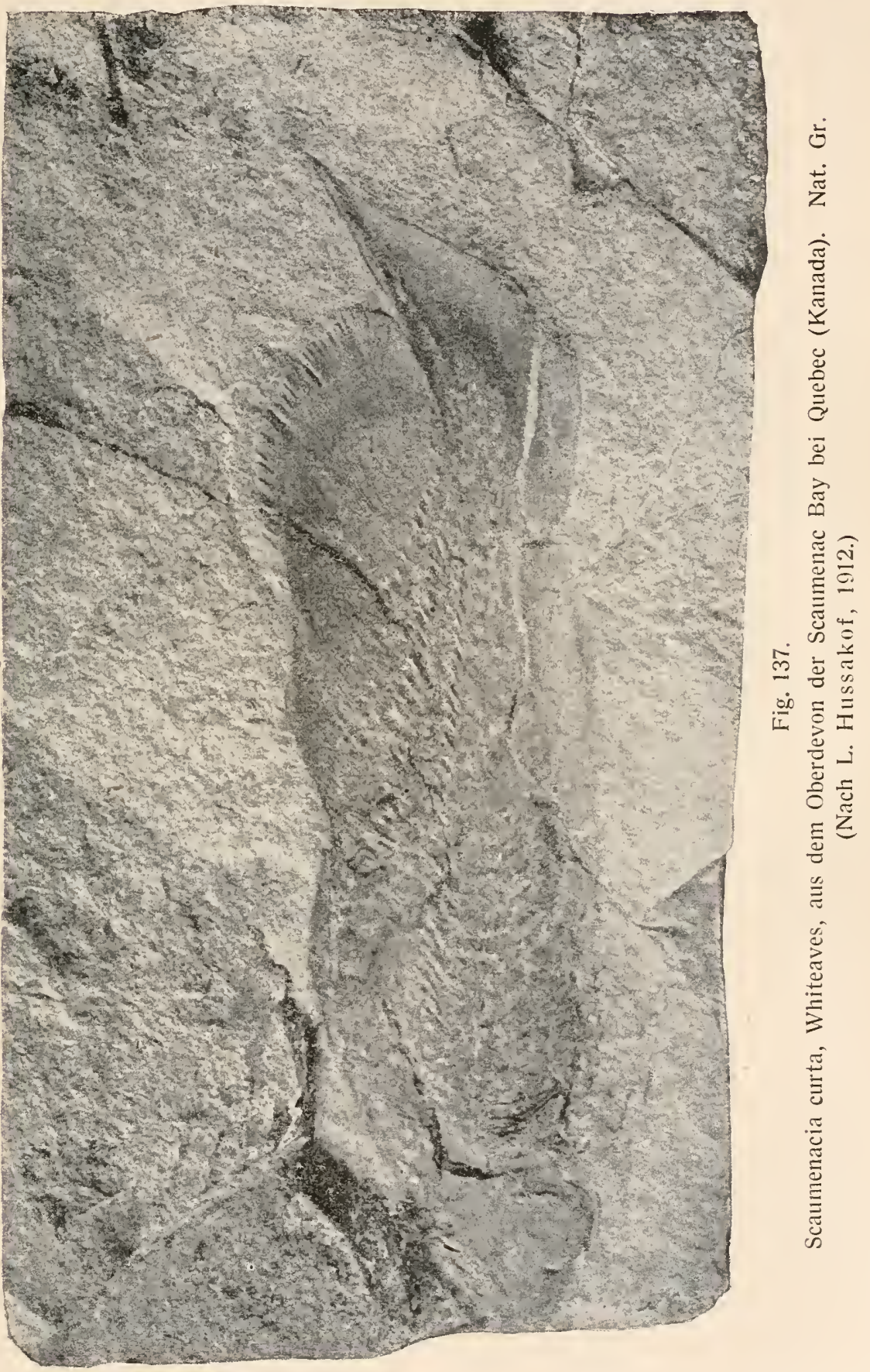




\section{F. Ctenodontidae.}

Dipterus. - Vom unteren Unterdevon bis zum Oberdevon. Häufig im Old Red Sandstone Schottlands (D. Valenciennesii in unteren Unterdevon, D. macropterus im oberen Unterdevon). Zahlreiche Arten inn Devon von Pennsylvanien, Iowa und New York. Die Zahnplatten tragen etwa zehn bis zwölf fächerförmig ausstrahlende Känn11e n11 aufsitzenden Tuberkelı (Fig. 7 A, 129-135). ${ }^{1}$

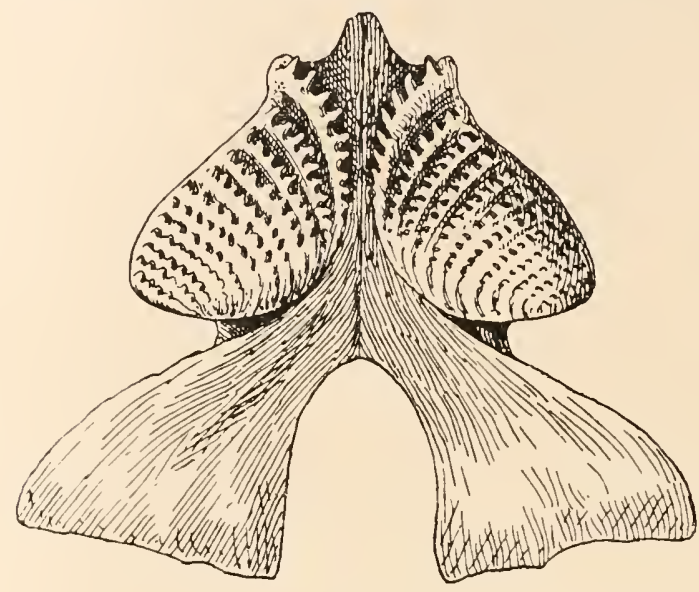

Fig. 138.

Unterkiefer mit den beiden Zahnplatten von Ctenodus tuberculatus, Atthey, aus dem Karbon von Newsham, England. 1/3 nat. Gr. (Nach A. Hancock und Th. Atthey, unbedeutend abgeändert und ergänzt.)

Palaedaphus. - Oberdevon (Frasnien) Belgiens. Nur die Zahnplatten bekannt, die eine beträchtliche Größe erreichen können (Länge (ler oberen Zahnplatte von P. devoniensis $135 \mathrm{~mm}$ ). Vier Radialkämme auf den Zahnplatten vorhanden, die zwei mittleren bei P. Abeli zu je einem scharfschneidenden Höcker ungeformt (Fig. 136). ${ }^{2}$

Scaumenacia. - Unteres Oberdevon, Kanada. Hintere Rückenflosse beträchtlich vergrößert, in dieser Hinsicht zwischen Dipterus

1 Eine ausführliche Literaturïbersicht in O. P. Hay, Bibliography and Catalogue of the Fossil Vertebrata of North America. - Bull. No. 179, U. S. Geol. Survey, Washington, 1902, p. 351.

Vgl. ferner: R. H. Traquair, The Extinct Vertebrata of Moray Firth Area. - In Harvie-Brown \& Buckley, Vertebrate Fauna of the Moray Basin. Edinburgh, 1896.

Derselbe, A New Species of Dipterus. - Geol. Magazine, London (3), Vol. VI, 1889, p. 97.

${ }^{2}$ L. Dollo, Sur un Dipneuste nouveau de grandes dimensions, découvert dans le Dévonien supérieur de la Belgique. - Bull. Acad. Roy. Belg., Bruxelles 1913, p. 15 . 
macropterus und Phaneropleuron Andersoni einen Übergang bildend. Äußere Reihe der Zalınplattenhöcker wie eine marginale Zahnreihe funktionierend (Fig. 7 D, 131, 137). ${ }^{1}$

$$
\text { Phaneropleuro11.--Oberes }
$$
Oberdevon von Schottland. Die hintere Rückenflosse ist mit der Terminalflosse verschmolzen. Gebiß ähnlich wie bei Scaumenacia spezialisiert (Fig. $7 \mathrm{~B}$, 131). ${ }^{2}$

Uronemus. - - Unterkarbon von Schottland. Alle Medianflossen $\mathrm{zu}$ einem einheitlichen Hautsaum verschmolzen. PalatoPterygoidea ohne Zahnplatten, nur mit einzelnen Tuberkeln und einer marginalen Höckerreilhe besetzt, welche aus den basal untereinander verschmolzenen Randzacken der rudimentär gewordenen Zahnplatten besteht (Fig. 131). ${ }^{3}$

Ctenodus. - Karbon von England, Schottland und (?) Böhmen. Zahnplatten mit zahlreichen fast parallelen, gezähnten oder gekerbten Kämmen (Fig. 7 C, 138). ${ }^{4}$

Sagenodus. - Karbon und Perm von Ohio, lllinois, Texas, Kansas, Pennsylvanien, Rußland. Zähne nit drei bis zehn

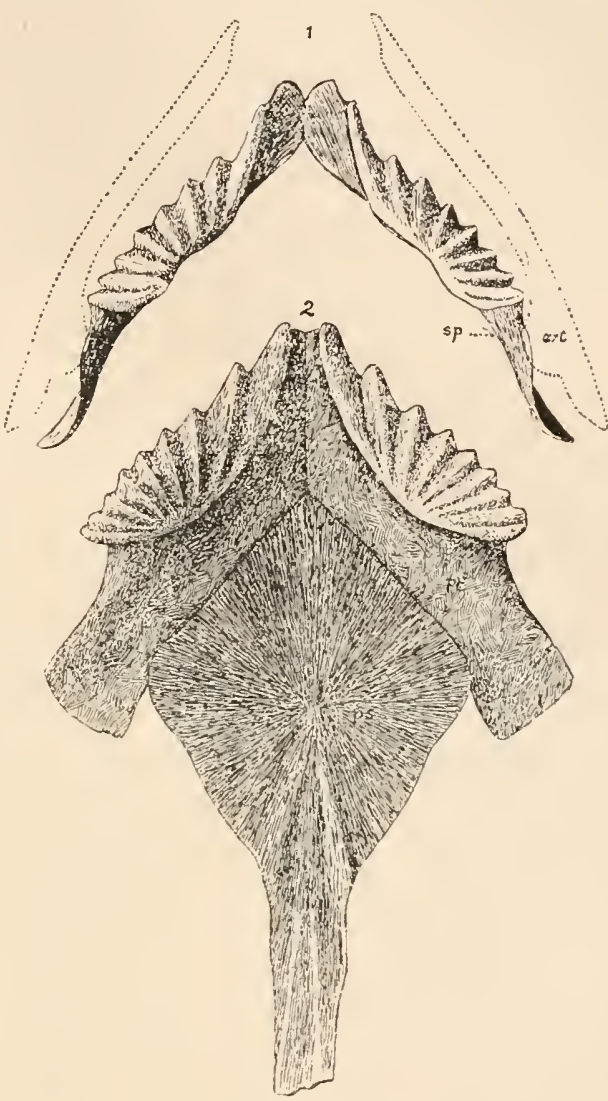

Fig. 139.

Das untere (1) und obere Gebiß (2) von Sagenodus Copei, Williston, aus dem Karbon von Kansas, in nat. Gr. (Nach S. W. Williston.)

$s p=$ Spleniale.

$a r t=$ Articulare.

1 L. Hussakof, Notes on Devonic Fishes from Scaumenac Bay, Quebec. New York State Museum Bulletin No. 158, Albany, 1912, p. 134.

2 R. H. Traquair, On Phaneropleuron Andersoni (Huxley) and Uronemus lobatus (Agassiz). - Journal of the Roy. Geol. Soc. Ireland. 1871, Vol. III, p. 45.

3 R. H. Traquair, Notes on the Devonian Fishes of Campelltown and Scaumenac Bay in Canada, No. 3. - Geol. Mag., London, Dec. 11I, Vol. X, 1893, p. 264.

4 A. Hancock and Th. Atthey, Notes on the Various Species of Ctenodus obtained from the Shales of the Northumberland Coal Field. - Nat. Hist. Transactions Northumberland and Durham, Vol. III, 1868, p. 54.

Dieselben, A Few Remarks on Dipterus and Ctenodus, etc. - Ibidem, Vol. IV, 1872, p. 397. 


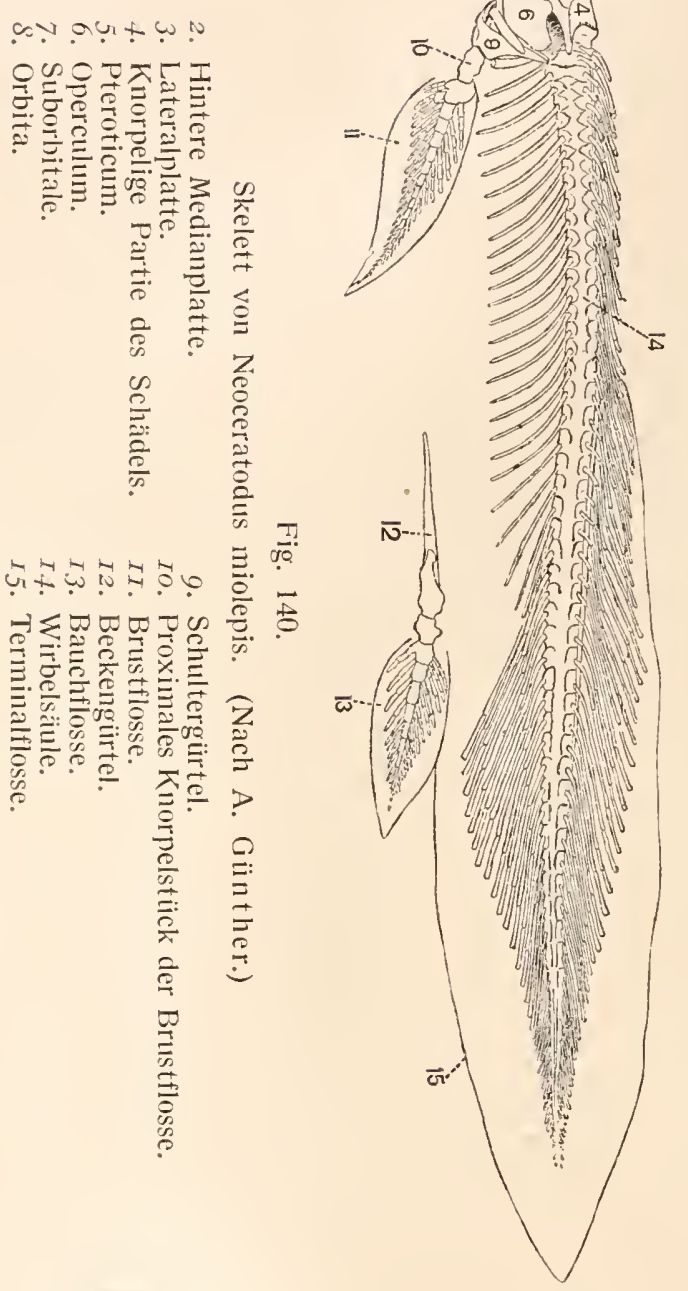

Kämmen, die mitunter gezähnt, mitunter glatt sind. Die Schuppen besitzen keine Ganoinschicht mehr und nähern sich in dieser Hinsicht den Schuppen der lebenden Dipneusten (Fig. 139). ${ }^{1}$

Ceratodus. - Von der Trias bis zum Eozän.

Ceratodus besitzt eine sehr große horizontale und vertikale Verbreitung. Ceratoduszähne sind wiederholt in der Trias von Europa gefunden worden, einmal sogar ein wohlerhaltener Schädel in der oberen Trias von Lunz in Niederösterreich $^{2}$; aus dem Jura Europas kennt man nur wenige Reste (aus dem Dogger Englands), aus späterer Zeit sind aus Europa keine Ceratodusreste bekannt. In Afrika tritt Ceratodus zuerst an der Wende der Perm- und Triaszeit auf (Kapkolonie) ${ }^{3}$ und hat noch in der oberen Kreide im Zentrum der westlichen Sahara gelebt. ${ }^{4}$ Aus Nordamerika kennt

1 S. W. Williston, A New Species of Sagenodus from the Kansas CoalMeasures. - Kansas Univ. Quarterly, Vol. VIII, 1899, p. 175.

2 F. Teller, Über den Schädel eines fossilen Dipnoers, Ceratodus Sturii, nov. spec., aus den Schichten der oberen Trias der Nordalpen. - Abhandl. K. K. Geol. Reichsanstalt Wien, XV. Bd., 1891, 3. Heft, S. 1.

${ }^{3}$ A. Smith Woodward, On Atherstonia, etc., and on a Tooth of Ceratodus from the Stormberg Beds of the Orange Free State. - Ann. Mag. Nat. Hist., 1889.

H. G. Seclcy, On Ceratodus Kannemeyeri (Seeley). - Geol. Mag., London 1897.

R. Broom, The Fossil Fishes of the Upper Karroo Beds of South Africa. Annals South African Museum, Vol. VII, 1909, p. 253.

4 E. Haug, Documents scientifiques de la Mission Saharienne. - Paléontologie. - Publ. Soc. Géographie, Paris 1905, p. 819. 
man Ceratoduszälnne aus dem oberen Jura von Wyoming ${ }^{\mathbf{1}}$, in Südamerika ist ein Zahn in Schichten gefunden worden, die wahrscheinlich dem Eozän angehören. ${ }^{2}$ Auch in Ostindien ${ }^{3}$ ist Ceratodus aus der Trias in vier Arten nachgewiesen, und daß die Gattung schon im Mesozoikum in Australien lebte, ist durcl den Fund eines Zahnes in unteren Jura von Victoria belegt. ${ }^{4}$ Die Gattung Neoceratodus, die heute nur mehr den Burnett- und Maryfluß in Queensland bewolnt, war noch in der Quartärzeit im Gebiete des Darlingflusses in Neusüdwales heimisch. ${ }^{5}$

Daraus geht hervor, daß Ceratodus einst eine weltweite Verbreitung: besaß und seit dem Mesozoikum langsam, aber sicher seinem völligen Aussterben entgegengeht.

Neoceratodus. - Lebend in Queensland (Volksnane „Djelleh" ${ }^{6}$ ) (Fig. 8, 127, 128, 140).

Lepidosiren. - Lebend in Südamerika.

Protopterus. - Lebend in Afrika; im Unteroligozän Ägyptens eine Art nachgewiesen (P. libycus).

\section{Ordnung: Actinopterygii.}

Während sich die Dipneusten in den wichtigsten morphologischen Merkmalen auf' das engste an die Crossopterygier anschließen und ihre abweichenden Merkmale nur als die Folgen der vorgeschrittenen Anpassung an die grundbewolnende, rulige und träge Lebensweise in

1 O. C. Marsh, New Species of Ceratodus, from the Jurassic. - A Americ. Journal of Science (3), Vol. XV, 1878, p. 76.

W. C. Knight, Some New Jurassic Vertebrates from Wyoming. - Ibidem (4), Vol. V, 1898, p. 186.

2 F. Ameghino, Les Formations sédimentaires du Crétacé supérieur et du Tertiaire du Patagonie. - Anales del Museo Nacional de Buenos Aires. - T. XV, Buenos Aires, 1906, p. 71.

E. von Stromer, Über das Gebiß der Lepidosirenidae und die Verbreitung tertiärer und mesozoischer Lungenfische. - Richard Hertwig-Festschrift, Jena, G. Fischer, II. Bd., 1910, S. 622.

3 Th. Oldham, On Some Fossil Fish-Teeth of the Genus Ceratodus, from Maledi, South of Nagpur. - Mem. Geol. Survey of India, Vol. 1, 1859, p. 295.

4 A. Smith Woodward, On a Tooth of Ceratodus and a Dinosaurian Claw from the Lower Jurassic of Victoria, Australia. - Ann. Mag. Nat. Hist., London (7), Vol. XVIII, 1906, p. 1.

${ }^{5}$ R. Semon, Verbreitung, Lebensverhältnisse und Fortpflanzung des Ceratodus Forsteri. - Zoolog. Forschungsreisen in Australien. - 1. Bd., Denkschriften d. Med. naturw. Ges. in Jena, IV. Bd., 1893, p. 17.

${ }^{6}$ Der Name ,Barramunda" bezieht sich auf die Teleostomenart Osteoglossum Leichhardti aus dem Flußgebiete des Dawson und Fitz Roy, aber nicht auf Neoceratodus. 
Verbindung mit der eigentümlichen Ernährungsart und der Atmung durch die zu einer Lunge veränderte Schwimmblase anzusehen sind, haben sich die Actinopterygier in anderer Richtung spezialisiert. Zwar scheinen in einzelnen Merkmalen zwischen den Crossopterygiern und den Actinopterygiern tiefgreifende Gegensätze zu bestehen, die den Gedanken nahe legen könnten, daß sie zwei getrennte und nicht enger miteinander verknüpfte Stämme der Fische darstellen, aber verschiedene andere Gründe sprechen doch wieder dafür, daß auch die Actinopterygier aus primitiven Crossopterygiern in sehr alter Zeit hervorgegangen sind. Die Entstehung der Actinopterygier liegt jedenfalls sehr weit zurück, da wir schon im Devon in Cheirolepis einen zwar in vielen Punkten sehr primitiven Teleostomen aus der Gruppe der Actinopterygier vor uns haben, der aber bereits in den bezeichnenden Merkmalen der Ordnung - Bau der paarigen Flossen und dem Vorhandensein von Branchiostegalplatten - einen auffallenden Gegensatz zu den Crossopterygiern bildet.

Ein Merkmal, das die Crossopterygier und Actinopterygier scharf scheidet und das bisher niemals in seiner vollen Bedeutung gewürdigt worden ist, besteht in dem Verhalten der Beschuppung des Körperendes im Gegensatz zu der Beschuppung des übrigen Körpers. Während bei den Crossopterygiern die Schuppenreihen des ganzen Körpers eine gleichsinnige Orientierung zeigen und in parallelen Reihen von vorn oben nach hinten unten über die Körperflanken herabziehen, ist der Schuppenkomplex der Kaudalregion der älteren Actinopterygier durch eine andere Richtung der Schuppenreihen strenge von der Beschuppung des übrigen Körpers getrennt, und zwar ist die Grenzlinie vollkommen gerade (Fig. 141) und läuft stets, wenn das Körperende die Achse des oberen Schwanzflossenlappens bildet, von vorn oben nach hinten untẹn; wo durch Reduktion des Körperendes aus dem heterozerken Terminalflossentypus der homozerke hervorgegangen ist, wie dies bei der Hauptmasse der lebenden Fische der Fall ist, sind auch die Schuppen der bei den älteren Actinopterygiern scharf abgesetzten Terminalflossenregion verloren gegangen. Die Verkümmerung dieses Abschnittes läßt sich in einigen Familien (z. B. bei den Pycnodontiden und Semionotiden) schrittweise verfolgen (Fig. 157, 159).

Der Gegensatz im Verlaufe der Schuppenreilıen, der in vielen Fälleı auch noch durch eine verschiedene Form der Schuppen in der Kaudalregion und der Schuppen der übrigen Körperteile gesteigert wird, ist zweifellos durch eine verschiedene Funktion der Muskulatur bedingt, welche unter den betreffenden Schuppengruppen liegt. Dieser Gegensatz in der Funktion der Rumpf- und Schwanzmuskulatur nuß durchaus scharf sein, da sich sonst ein allmählicher Übergang zwischen beiden Schuppengruppen feststellen ließe und eine durchaus geradlinige Grenze, 
wie sie in allen Fällen besteht, undenkbar wäre. Dies kann nur dadurch erklärt werden, daß der Schwanz starke Lateralschläge ausführte, während der Körper verlıältnismäßig starr gehalten wurde. Wo keine scharfe Grenze zwischen der Beschuppung des Schwanzes und des Rumpfes zu beobachten ist, wie bei den Dipneusten und bei den Crossopterygiern, ist eine derartige Funktionstrennung der beiden Körperabschnitte nicht anzunehmen und es muß daher die Lokomotion nicht durch die Schwanzflosse allein bewirkt, sondern durch ein Schlängeln des ganzen Körpers wesentlich unterstützt worden sein, wie dies ja auch bei den lebenden Dipneusten und Polypteriden in der Tat zu beobachten ist. Solange die Terminalflosse der Actinopterygier epibatisch funktionierte, blieb dieses Verhältnis zwischen dem beschuppten Körperende als Achse des oberen Terminalflossenlappens und dem unteren Terminalflossenlappen bestehen, aber bei dem Übergange zur isobatischen Funktion der Terminalflosse bei der Hauptmasse der Teleostomen wurde der obere Lappen der Terminalflosse kleiner und das Körperende mit den eigentümlich angeordneten Schuppen allmählich reduziert.

Die besprochenen Verschiedenheiten im Bau der Terminalflosse bei den Actinopterygiern in Gegensatze zu den Crossopterygiern und Dipneusten sind also dadurch bedingt, daß die Actinopterygier einen Stamm darstellen, der in sehr früher Zeit zur ausgesprochen nektonischen, schnellschwimmenden Lebensweise überging (Paläonisciden) und daß erst später wieder durch Annalıme anderer Bewegungsarten infolge eines anderen Aufenthaltsortes, anderer Nahrung usw. die Funktion der Terminalflosse eine andere wurde, wobei sich der homozerke Terminalflossenbau in seinen verschiedenen Varianten entwickelte.

Daß schon die ältesten Actinopterygier von der trägen, halbbenthonischen Lebensweise der Crossopterygier zu der nektonischen übergegangen sind, geht auch mit voller Klarheit aus dem Bau und aus der Form der paarigen Flossen hervor. Bei den Crossopterygiern besaßen die paarigen Flossen noch eine ,Trägerfunktion“, wie dies Semon ${ }^{1}$ treffend genannt hat, und diese Funktion ist auch heute noch bei den Dipneusten erhalten, wo sie sogar bei Lepidosiren in eine Kriech-

1 R. Semon, Weitere Beiträge zur Physiologie der Dipnoerflossen, auf Grund neuer, von Mr. Arthur Thomson, an gefangenen Exemplaren von Ceratodus angestellten Beobachtungen. - Zool. Anzeiger, XXII. Bd., 1899, S. 294-300. - Derselbe, Beobachtungen iiber den australischen Lungenfisch im Freileben und in der Gefangenschaft. - Blätter f. Aquarien- u. Terrarienkunde, 1908, Nr. 21. - Hier hebt R. Semon hervor, daß beim australischen Lungenfisch in den Flossen bereits ein ,Ellbogengelenk“ und ein ,Kniegelenk“ deutlich entwickelt ist. Ebenso ist schon frïher auch bei Protopterus eine ,Trägerfunktion" der paarigen Flossen beobachtet worden (J. E. Gray, Observations on a Living African Lepidosiren in the Crystal Palace. Proc. Zool. Soc. London, XXIV, 1856). 
funktion ${ }^{1}$ übergegangen ist. Schon bei der Trägerfunktion der paarigen Flossen kommint es zur Entwicklung eines deutlichen Knicks in der Mitte der Gliedmaßen, also eines ,Ellbogengelenks“ und eines „Kniegelenks". Flossen, welche nur zur Erhaltung des Gleichgewichts und zum Steuern dienen und höchstens bei langsanem Schwimmen auch als Ruder verwendet werden, bedürfen keines geknickten oder gegliederten Achsenstabes; daher geht schon bei den mehr an das nektonische Leben angepaßten Crossopterygiern die beschuppte Achse der paarigen Flossen mehr und mehr zurück und es bildet sich z. B. schon bei Osteolepis eine Flossenform heraus, die an jene der Actinopterygier erinnert (Fig. 118).

Diese Reduktion des Achsenteiles der paarigen Flossen ist bei den ältesten bekannten Actinopterygiern (Cheirolepis) schon sehr weit vorgeschritten, was darauf hindeutet, daß der Übergang zur nektonischen Lebensweise dieser Formen schon in sehr früher geologischer Zeit, vielleicht schon im oberen Silur, erfolgt sein muß. Wir müssen annehmen, daß die Abzweigung der Actinopterygier von den Crossopterygiern noch zu einer Zeit stattfand, da die Scluppen selır klein und von quadratischer Form waren, weil die Beschuppung von Cheirolepis kaum als spezialisiert, sondern, was die GröBe und Form der Schuppen betrifft, als sehr primitiv anzusprechen ist.

Eine weitere Eigentümlichkeit aller Actinopterygier ist der Ersatz der Gularplatten, wie sie z. B. Rhizodopsis zeigt, durch zahlreiche sich dachziegelartig deckende Branchiostegalplatten oder ,Kiemenstrahlen“" Die ïbrigen Merkmale unterscheiden sich im wesentlichen nur in gradueller Hinsicht von jenen der Crossopterygier.

\section{F. Palaeoniscidae.}

Alle Gattungen dieser Fanilie besitzen einen fusiformen, mitunter etwas erhöhten und lateral komprimierten Körper, erreichen jedoch n:emals die hohe, stark lateral komprimierte Körpergestalt der Platysomiden. Bei Cheirolepis ist der ganze Körper mit dichtstehenden, sehr klemen rlombischen Schuppen bedeckt, bei den übrigen Gattungen herrschen große, rlımbische Schuppen vor; zykloide Schuppenformen treten zwar auf, sind aber auBerordentlich selten (Coccolepis, Trissolepis). Die Beschuppung des Schwanzes ist stets scharf von der Beschuppung der Körperflanken abgesetzt und die Schuppenreihen beider Regionen weisen eine andere Richtung auf; ïberdies ist auch die Schuppenform der Schwanzregion dadurch unterschieden, daB die Rhomben spitzwinkeliger zu sein pflegen und mitunter eine geringere

1 Nach meinen Beobachtungen im Zoologischen Garten zu Frankfurt a. M. an 23. November 1913. 
Größe besitzen als die Flankenschuppen. Vor den medianen Flossen sind in der Regel sehr starke Stützschuppen oder ,Fulkren“ ausgebildet.

Die Terminalflosse ist ursprünglich heterozerk und epibatisch, und zwar ist dieser Typus auch bei der jüngsten bekannten Gattung aus dem Wealden, Coccolepis, noch erhalten. In der Trias von Connecticut, New Jersey, Virginia, Massaclusetts, der Kapkolonie, von Neusüdwales und Europa treten jedoch einige Gattungen (Redfieldius, Dictyopyge) auf, deren Terminalflosse sich dem homozerken Typus nähert und eine

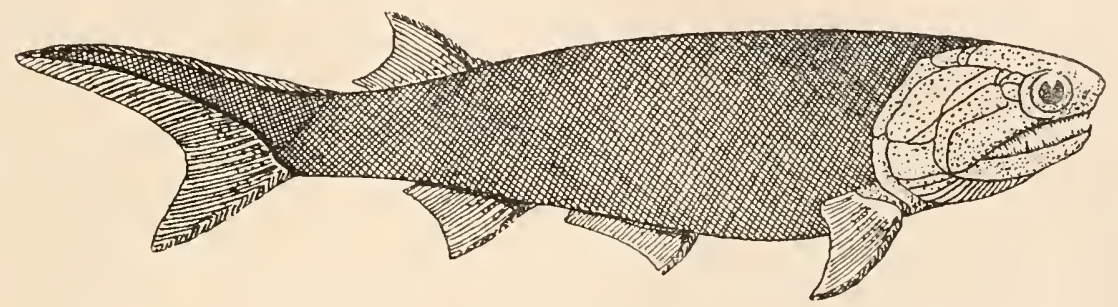

Fig. 141.

Rekonstruktion von Cheirolepis Traillii, aus dem unteren Old Red Sandstone (Unterdevon) von Nordschottland, in etwa $1 / 1$ nat. Gr. (Nach R. H. Traquair.)

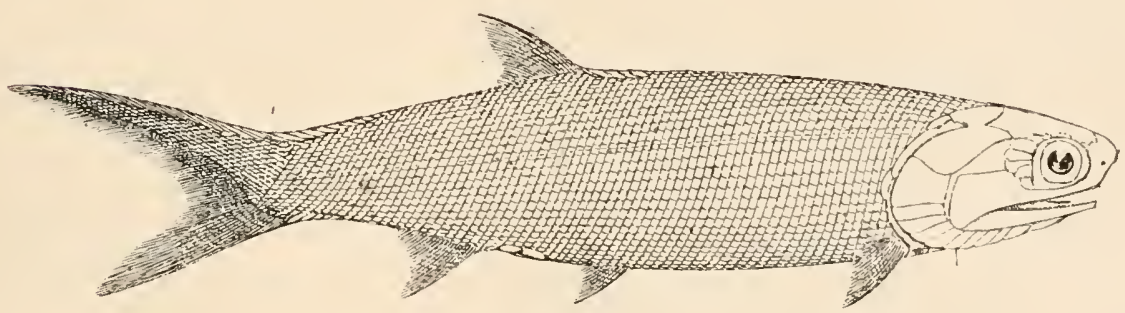

Fig. 142.

Rekonstruktion von Palaeoniscus macropomus, Ag., aus dem oberen Perm Deutschlands, in $1 / 2$ nat. Gr. (Körperlänge etwa $22 \mathrm{~cm}$.). (Nach R. H. Traquair.)

Reduktion des mit rhombischen Schuppen besetzten Schwanzendes der übrigen Paläonisciden aufweist. Diese früher als „Catopteriden“ zusammengefaßten Gattungen beweisen, daß sich der Übergang von der Heterozerkie zur Homozerkie unabhängig voneinander in verschiedenen Stämmen vollzogen hat und daß dieser Gegensatz im Bau der Terminalflosse nur verschiedene Spezialisationsstufen in der Anpassungsreihe der Teleostomen-Terminalen darstellt.

Die Wirbelsäule besitzt nienlals verknöcherte Zentren. Ebenso sind die Rippen unverknöcliert gewesen (Fig. 170, B).

Der Schädel ist mit zahlreichen Hautknochen bedeckt, die sich zu einer geschlossenen Kapsel über dem Knorpelschädel zusammenschließen. Der Kiemendeckelapparat besteht aus einenı großen Operculum und einem 
darunter liegenden Suboperculum, an welches sich zahlreiche Bran-

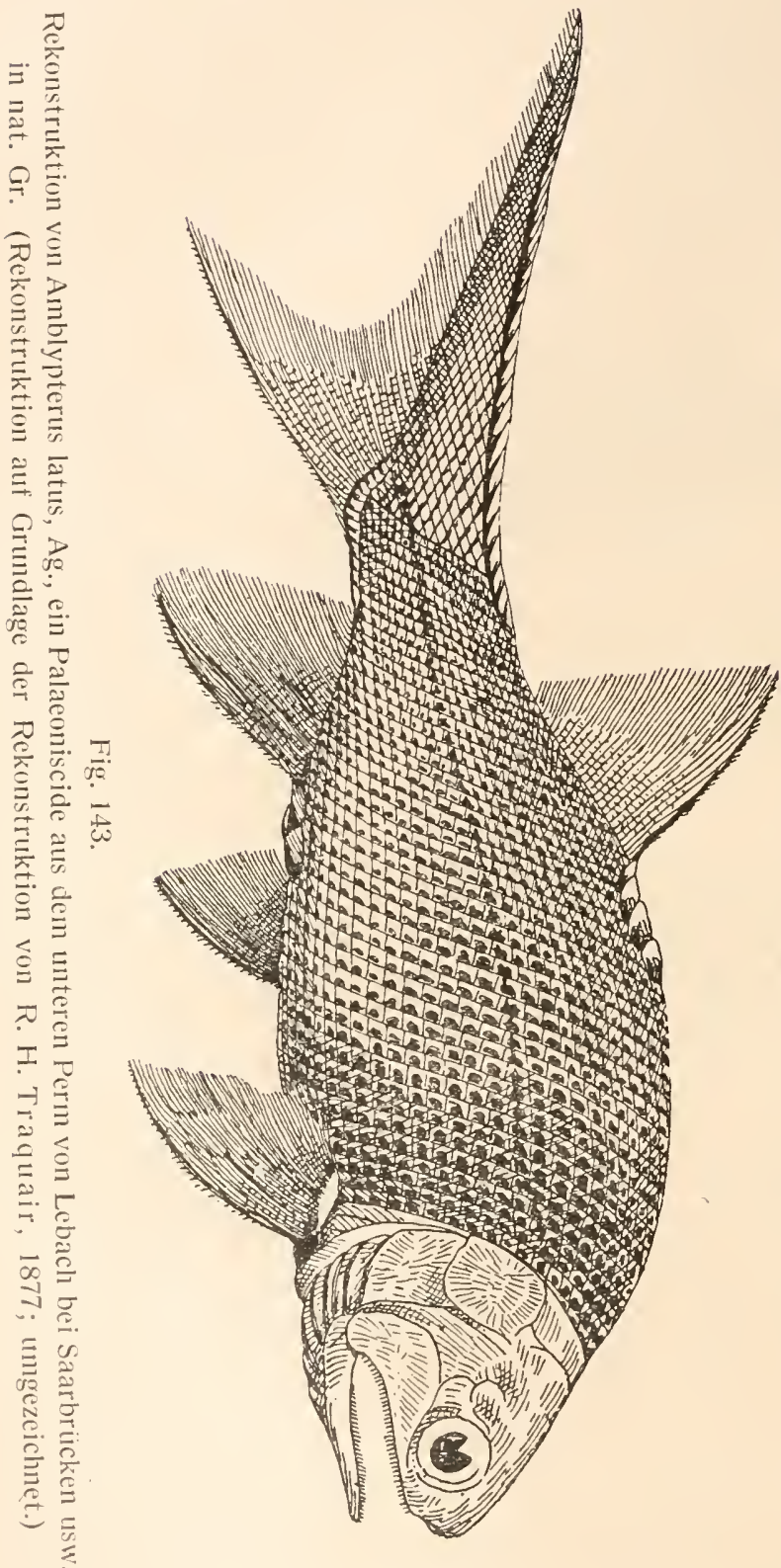
chiostegalplatten anschließen; vor dem Operculum und Suboperculum liegt ein Praeoperculum. An dieses schließt sich ein zahntragendes Maxillare und weiter vorn ein Praemaxillare an. Die Augenhöhle wird an ihrem Hinterrande von zahlreichen Suborbitalia umsäumt, ebenso der Oberrand der Orbita. Gegen die Mitte des Schädeldaches zu folgen zunächst das Squamo-. sum, über diesem das Parietale und vor diesem das Frontale, dem sich vorn ein ,Frontale anterius" (= Lacrymale ? $)^{1}$ und zuletzt ein Nasale anschließen.

Die ersten Paläonisciden erscheinen im Mitteldevon Schottlands, erreichen im unteren Perm ilıre Blüte und gehen von da an wieder zurück. Der jüngste Vertreter der Familie ist Coccolepis macropterus aus der unteren Kreide (Wealden) von Bernissart in Belgien mit zykloiden Schuppen auf den Körperflanken, aber rlıombischen Schuppen in der Schwanzregion (Fig. 144, 145 .

1 Dieser Knochen wird von anderen Autoren als ,Ethmoideum dermale laterale" (= Praefrontale, vgl. p. 46) bezeichnet. Seine Homologien sind noch fraglich. Von einer Homologie mit dem Lacrymale der Tetrapoden kann kaum die Rede sein. 
Cheirolepis. - Mitteldevon (nittleres Old Red) Schottlands und Rußlands, Oberdevon von Quebec, Kanada (Fig. 141). ${ }^{1}$

Palaeoniscus. - Sehr häufig im Perm Deutschlands (Kupferschiefer), Frankreichs, Englands, Rußlands (Fig. 142). ${ }^{2}$

Elonichthys. - Karbon von Europa und Neubraunscliweig, Perm von Europa und Nordamerika. ${ }^{3}$

Gonatodus. - Karbon Schottlands (Fig. 27). ${ }^{4}$

Amblypterus. - Perm Europas (Fig. 143). ${ }^{5}$

Trissolepis. - Perm Böhmens. ${ }^{6}$

Redfieldius (= Catopterus). - Trias Nordamerikas. ${ }^{7}$

Dictyopyge. - Trias von Virginia und Connecticut, Europa (Basel und Franken), Kapkolonie, Neusüdwales. ${ }^{8}$

Coccolepis. - Zuerst im unteren Lias Englands ${ }^{9}$, zuletzt im

1 R. H. Traquair, On the Structure and Systematic Position of the Genus Cheirolepis. - Ann. Mag. Nat. Hist. London (4), Vol. XV, 1875, p. 237.

2 R. H. Traquair, The Ganoid Fishes of the British Carboniferous Formations. - Palaeontographical Society, 1877, Part 1, p. 13.

Derselbe, On the Agassizian Genera Amblypterus, Palaeoniscus, Gyrolepis and Pygopterus. - Quarterly Journal of the Geological Society, London, Vol. XXXIII, 1877 , p. 548.

3 R. H. Traquair, The Ganoid Fishes etc:, l. c., p. 47.

L. M. Lambe, Palaeoniscid Fishes from the Albert Shales of New Brunswick. Canada Department of Mines, Geol. Survey Branch, Memoir No. 3, Ottawa, 1910, p. 22.

4 R. H. Traquair, The Ganoid Fishes, etc., 1. c., Pl. 11, Fig. 4, 5.

${ }^{5}$ R. H. Traquair, On the Agassizian Genera etc., I. c.

${ }^{6}$ A. Fritsch, Fauna der Gaskohle und der Kalksteine der Permformation Böhmens. - III. Bd., 1895.

7 Ch. R. Eastman, Triassic Fishes of Connecticut. - State of Conn., State Geol. and Nat. Hist. Surv., Bull. 18, Hartford 1911, p. 47 (Literatur).

Eastman faßt die drei Gattungen Redfieldius (die nach ihm als Catopterus zu bezeichnen ist), Dictyopyge und Perleidus in der Familie Catopteridae zusammen. Ich kann diese Gattungen nur als höher spezialisierte Glieder der Familie der Palaeonisciden betrachten, da die Unterschiede fast nur in dem höheren, dem horozerken Terminalflossentypus sich nähernden Spezialisationsgrad der Schwanzflosse bestehen.

8 Ibidem, p. 55 (Literatur).

Weitere Literatur ïber Redfieldius und Dictyopyge vgl. in O. P. Hay, Bibliography and Catalogue of the Fossil Vertebrata of North America. - Washington, Bull. 179 of the U. S. Geol. Surv., 1902, p. 370.

R. Broom, The Fossil Fishes of the Upper Karroo Beds of South Africa. Annals South African Mus., Vol. VII, 1909, p. 262.

9 A. Smith Woodward, Notes on Some Ganoid Fishes from the English Lower Lias. - Annals Mag. Nat. Hist., London, Vol. V, 1890, p. 432. 
Wealden von Bernissart in Belgien. ${ }^{1}$ Auch aus dell Jura von Neusüdwales $^{2}$ nachgcwiesen (Fig. 144, 145).

\section{F. Platysomidae.}

Der Körper dieser Fisclie ist sehr hoch, und zwar lassen sich die Spezialisationssteigerungen bei den karbonischen und permischen Gattungen sehr gut verfolgen. Die Körperflanken sind schon bei der ältesten bekannten Gattung, die auf Paläonisciden zurückgeht, mit Schuppen bedeckt, die höher als breit sind; diese Zerrung der Schuppen nimmit mit der Zunalume der Körperhöhe ständig zu. Bei Dorypterus sind die Schuppen bis auf die normal bleibenden Schuppen des Schwanzendes fast ganz verloren gegangeil und es sind nur einige wenige ventrale

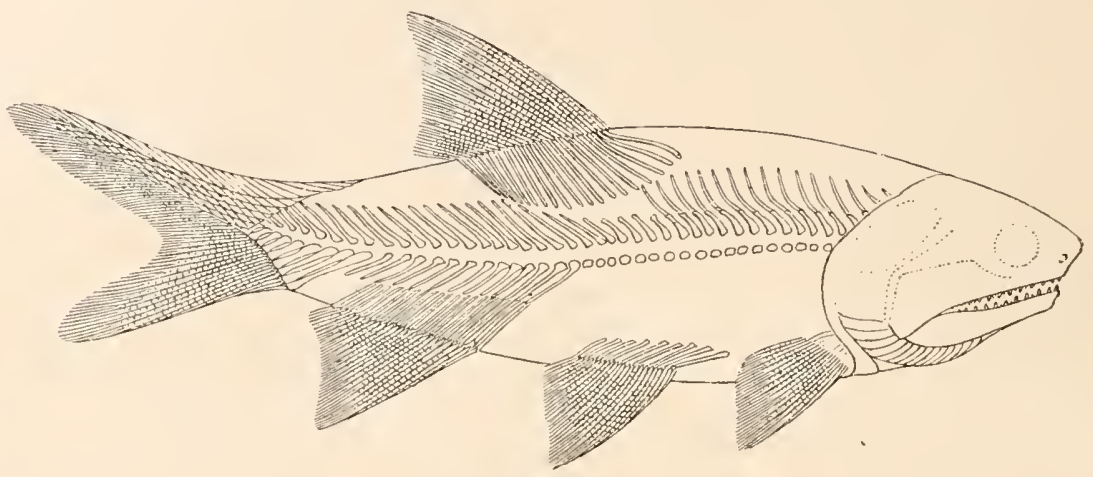

Fig. 144.

Rekonstruktion des Skelettes von Coccolepis macropterus Traqu., aus dem Wealden von Bernissart, Belgien. Körperlänge etwa $25 \mathrm{~cm}$. (Nach R. H. Traquair.)

Schuppen stehen geblieben, die unmittelbar an den Schädel anschließen. Die paarigen Flossen nehmen mit der zunehmenden Ausbildung der hohen Köıperform beständig an Größe ab, die Bauchflossen werden in die jugulare Lage verschoben und gehen bei Cheirodus gänzlich verloren, während sie bei Dorypterus noch vorhanden sind, aber liier vor den Brustflossen in jugularer Lage stehen. Die Schwanzflosse ist tief gabelförmig ausgeschnitten und gleichlappig bei den an höchsten stehenden Formen, während sie bei Eurynotus noch ungleichlappig ist. Die Dorsalis und Analis sind ursprünglich (Eurynotus) sehr ungleich groß, aber allmählich nehmen sie gleiche Form und Größe an. Der Adaptationstypus der Platysoniden ist derselbe wie bei vielon lebenden

1 R. H. Traquair, Les Poissons Wealdiens de Bernissart. - Mémoires du Musée d'Hist. Nat. de Belgique, Bruxelles, 1911, p. 9.

${ }^{2}$ A. Smith Woodward, The Fishes of the Talbragar Beds, - Memoirs Geol. Surv. New South Wales, Palleontology, No. 9, Sydney, Vol. IX, 1895, p. 4. 
Riffischen aus den Fanilien der Scorpididen (z. B. Psettus) oder Cliaetodontiden (z. B. Platax) oder den Brachsen aus der Familie der Cypriniden (z. B. Abranis), und findet sich auch bei den fossilen Pycnodontiden vertreten. Meist sind derartig hochkörperige Fische Riffbewohner, aber derselbe Typus tritt auch bei den benthonisch lebenden Brachsen unserer Süßwasserflüsse und Seen auf und ist dalier, ebenso wie die Ausbildung von Kugelformen oder Nadelformen, als eine Folgeerscheinung der Verminderung der Eigenbewegung im allgemeinen anzusehen. Ein Fingerzeig zur Ermittlung der Lebensiweise ist die Ausbildung des Gebisses der verschiedenen hochkörperigen Typen; wo die Zähne zu Schnäbeln oder zu Reibplatten umgeformt sind, liegen Riffbewohner vor, die eine durophage Nahrungsweise fülıren oder geführt haben, während bei den gründelnden Fischen wie bei den Braclis?n der Mund vorstreckbar und die Nahrungsweise mala-
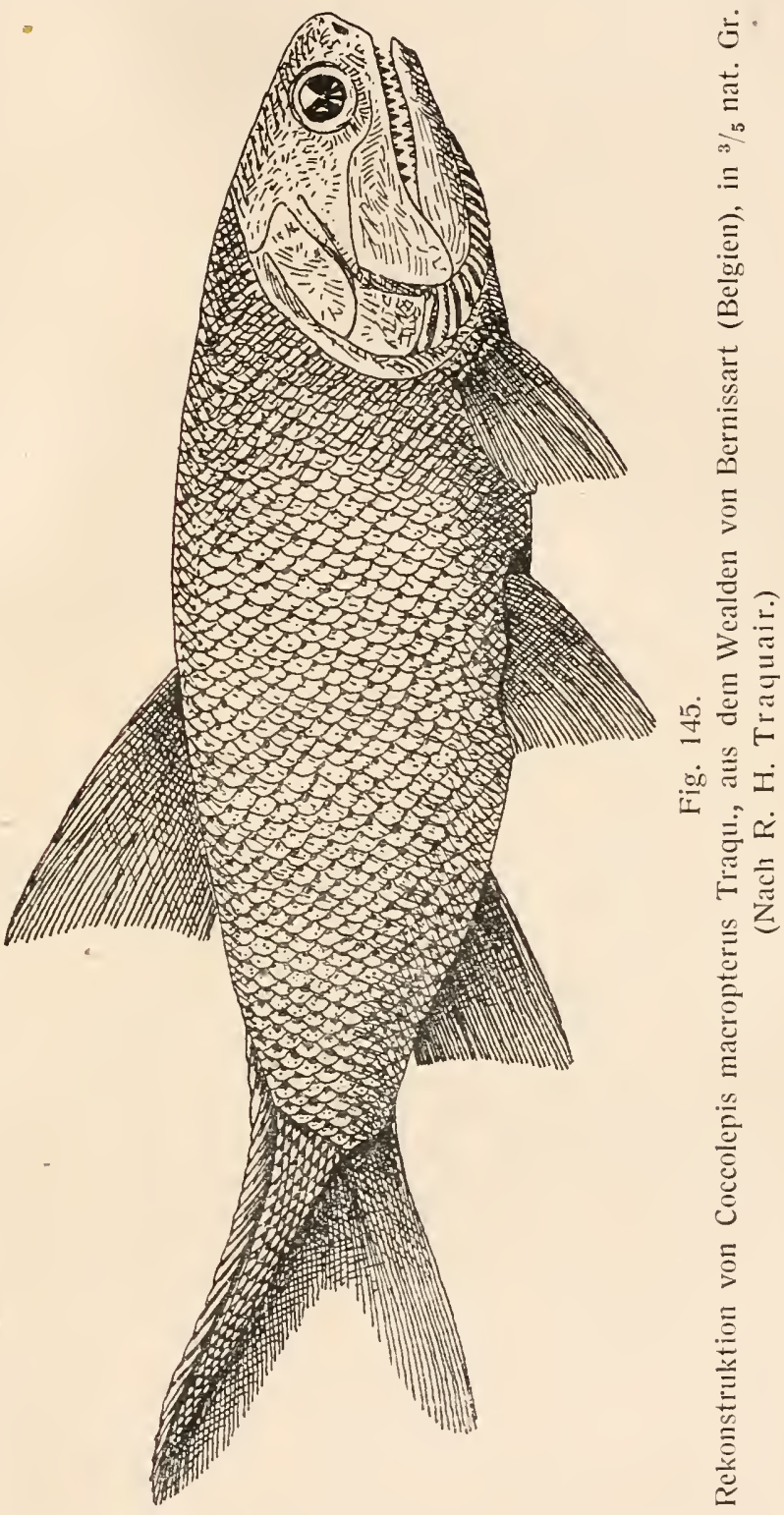

kophag ist. Da die Platysoniden stumpfkonische und niedrige Zähne besaßen, scheinen sie durophage Riffische gewesen zu sein.

Eurynotus. - Unterkarbon von Schottiand und Belgien (Fig. 146). ${ }^{1}$

1 R. H. Traquair, On the Structure and Affinities of the Platysomidae. Transactions of the Roy. Soc. of Edinburgh, Vol. XXIX, 1879, p. 348. 


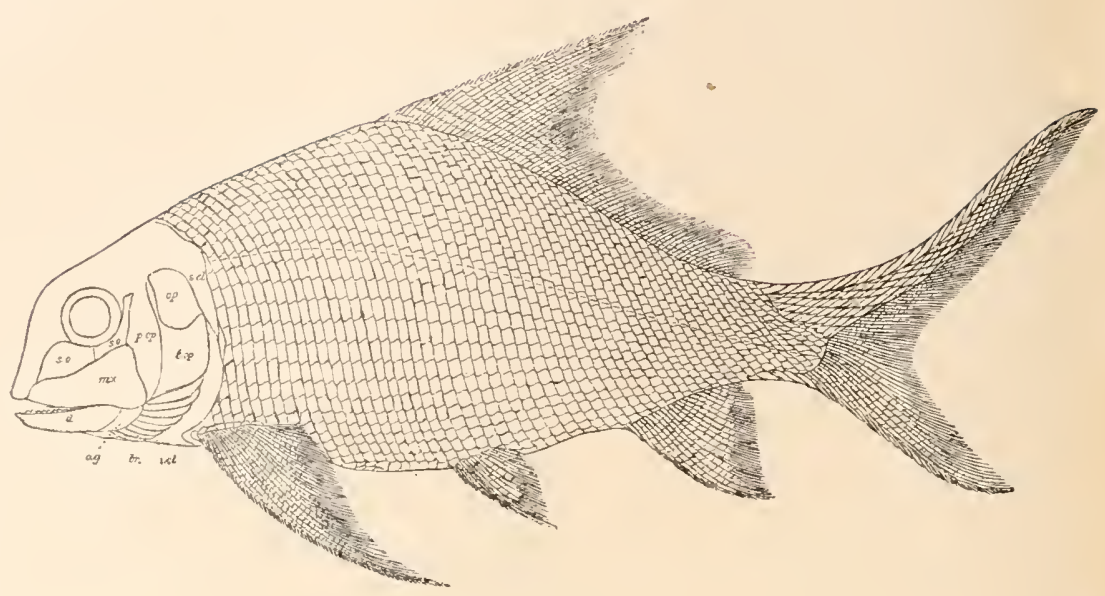

Fig. 146.

Rekonstruktion von Eurynotus crenatus, Ag., aus dem Unterkarbon Schottlands, in etwa $2 / 3$ nat. Gr. (Nach R. H. Traquair.)

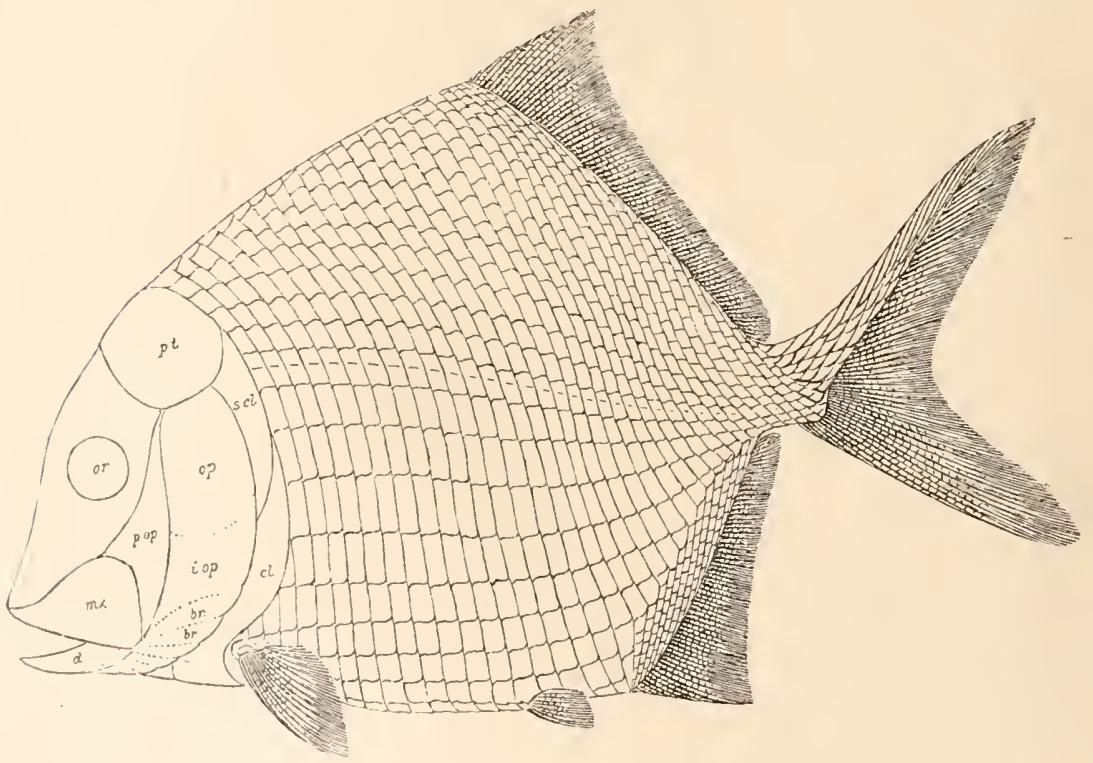

Fig. 147.

Rekonstruktion von Platysomus striatus, Ag., aus dem Perm (Magnesian limestone) Englands. Nat. Gr. (Nach R. H. Traquair.) 


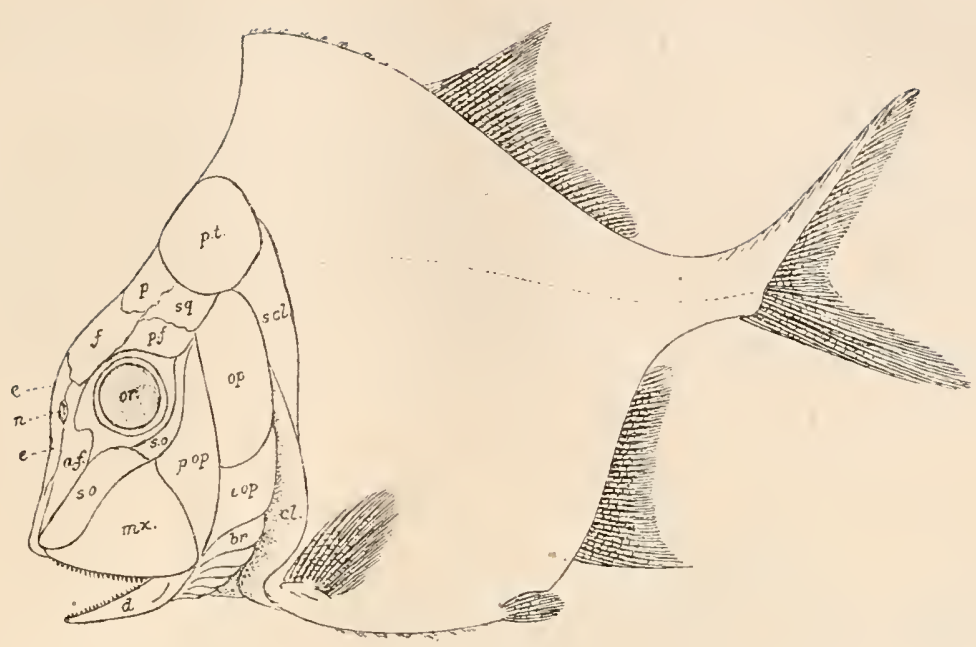

Fig. 148 .

Rekonstruktion von Platysonus parvulus, Ag., aus dem Karbon Englands, in nat. Gr. (Schuppen nicht eingezeichnet.) (Nach R. H. Traquair.)

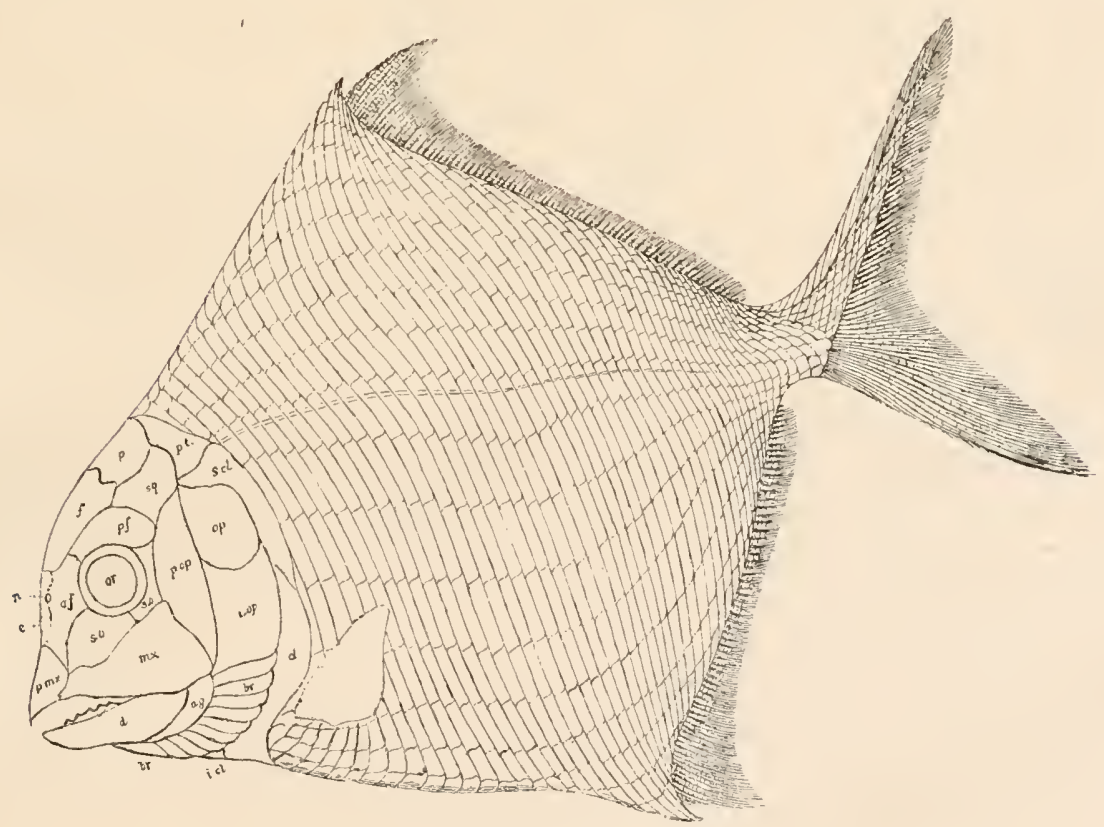

Fig. 149.

Rekonstruktion von Cheirodus granulosus, Young, auf Grund mehrerer Exemplare aus dem Karbon von North Staffordshire, England, in ungefähr $2 / 3$ nat. Gr. (Nach R. H. Traquair.) 
Mesolepis. - Unterkarbon von Schottland. ${ }^{1}$

Platysomus. - Karbon und Perm von England und Deutschland (Fig. 147, 148). ${ }^{2}$

Cheirodus. - Oberkarbon von England (Fig. 149). ${ }^{3}$

Dorypterus. - Perm von Deutschland. Außenskelett stark reduziert, lnnenskelett sehr kräftig ausgebildet, aber die Wirbelsäule ohne verknöcherte Zentren. Bauchflosse klein, jugular. Reduktion der Schuppen an Vorderende des Abdomens ähnlich wie bei Mesodon unter den Pycnodontiden (Fig. 150). ${ }^{4}$

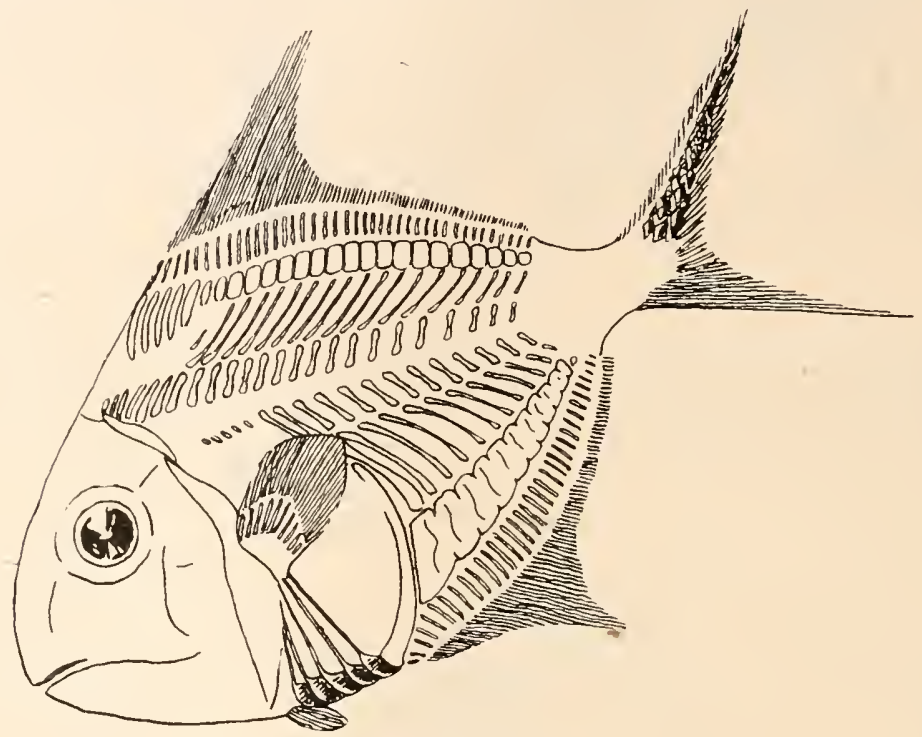

Fig. 150.

Rekonstruktion von Dorypterus Hofmanni, Germar, aus dem permischen Kupferschiefer von Riechelsdorf in Hessen, in nat. Gr. (Nach O. M. Reis, 1892.)

\section{F. Belonorhynchidae.}

Die Stellung dieser Familie ist unsicher; die Persistenz der Chorda und die sehr schwache Verknöcherung der Wirbelbögen beweist jedoch, daß sie schon frühzeitig vom Hauptstamme der Teleostomen abgezweigt ist. Neben diesen primitiven Verhältnissen im Bau der Wirbelsäule bestehen jedoch hochgradige Spezialisationen im Bau der Schwanzflosse, in der Beschuppung, in der Schnauze usw. Die Chorda setzt sich geradlinig in die Terminalflosse fort, ähnlich wie dies bei den Coelacanthiden

1 R. H. Traquair, On the ... Platysomidae, I. c. p. 355.

2 Ibidem, p. 368.

3 lbiden, p. 363.

${ }^{4}$ O. M. Reis, Zur Osteologie und Systematik der Belonorhynchiden und Tetragonolepiden. - Geognostische Jahreshefte, Jahrgang 1891, 1892, p. 167. 
der Fall ist; die Terminalflosse selbst ist gleichlappig oder ,,isobatisch". Der Körper ist bis auf vier Längsreihen von Schuppen nackt; es ist eine dorsale, eine ventrale und jederseits eine laterale Reihe großer, sich dachziegelartig deckender Schuppen vorhanden. Brustflossen und Bauchflossen sind klein und stehen weit voneinander ab. Der Schädel läuft in eine lange, spitze Schnauze aus, die ein Raubgebiß trägt. Die Dorsal- und Analflosse stehen einander gegenüber wie bei den Hechten oder bei Belone oder bei Lepidosteus (sagittiformer Raubfischtypus).

Saurichthys. - Obere Trias der Alpen und der Lombardei. ${ }^{1}$

Belonorhynchus. - Jura von England, Württemberg, Neusüdwales (Fig. 151). ${ }^{2}$

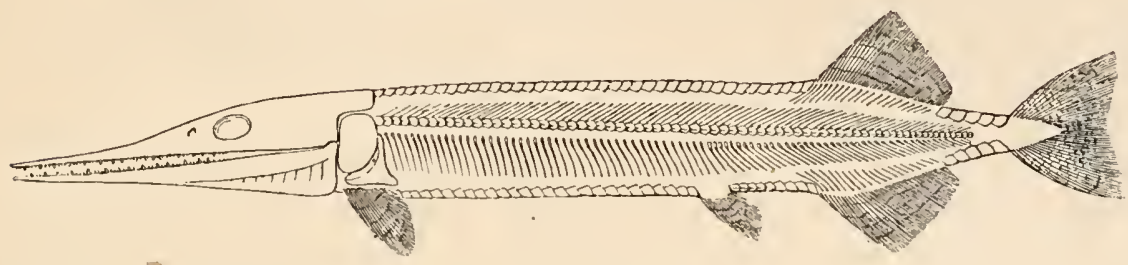

Fig. 151 .

Rekonstruktion von Belonorhynchus gigas aus den Hawkesburyschichten (Trias?) von Gosford, Neusïdwales, in $1 / 4$ nat. Gr. (Nach A. S. Woodward.)

\section{F. Chondrosteidae.}

Von primitiven Teleostomen, wahrscheinlich von Paläonisciden, hat sich eine Familie abgezweigt, von der wir nur einen Vertreter aus dem unteren Lias Englands kennen (Chondrosteus acipenseroides) und einen zweiten aus dem oberen Lias (Gyrosteus mirabilis). Die Wirbelsäule ist nur unvollständig verknöchert und besitzt keine knöchernen Zentren, sondern nur obere und untere Bögen. Die Schuppen sind bis auf den äußersten Kaudalabschnitt, der die Achse des oberen Schwanzflossenlappens bildet, verloren gegangen; dort sind noch rhombische Schuppen mit Ganoinbedeckung in derselben Anordnung wie bei den Paläonisciden erhalten. Rippen fehlen. Vom Knorpelschädel scheint nur das Hyomandibulare verknöchert gewesen zu sein; dagegen sind verschiedene Deckknochen vorhanden (Fig. 152). Die Schnauze lief in ein Rostrum aus, das den kleinen, zahnlosen Mund ziemlich weit überragte. Der Schultergürtel war ebenso wie bei Acipenser gebaut. Chondrosteus erreichte eine bedeutende Größe; einzelne Reste lassen

1 O. M. Reis, l. c. p. 143.

2 A. Smith Woodward, Outlines of Vertebrate Paleontology, 1898, p. 88. 
auf eine Länge von 2 11 schließen. ${ }^{1}$ Gyrosteus mirabilis aus dem oberen Lias Englands dürfte eine Länge von 6-7 m erreicht haben. ${ }^{2}$

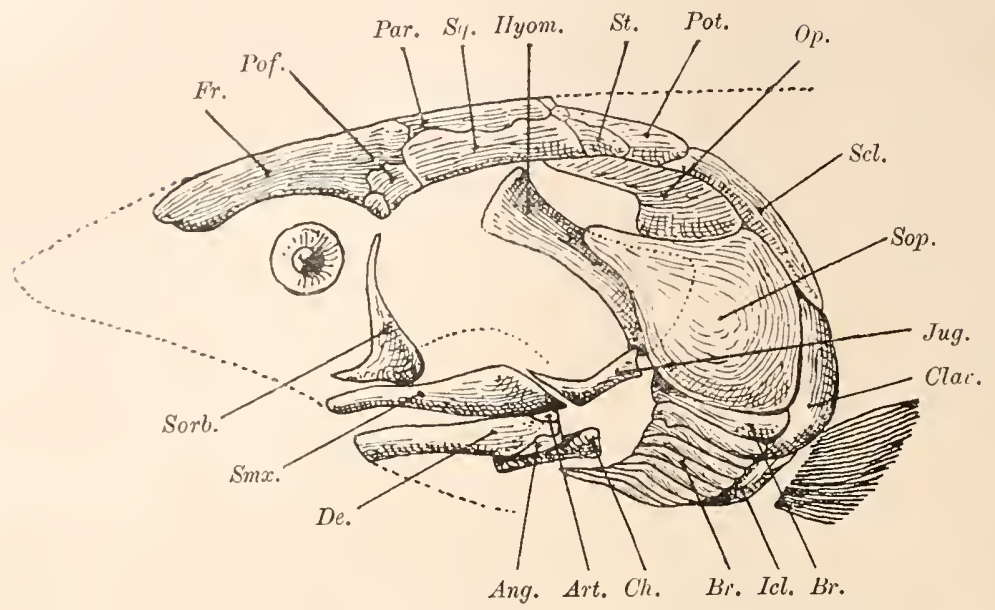

Fig. 152.

Rekonstruktion des Schädels von Chondrosteus acipenseroides, Ag., aus dem Unterlias von Dorsetshire und Leicestershire, in $1 / 4$ nat. Gr. (Nach R. H. Traquair, unwesentlich abgeändert; umgezeichnet.)

\begin{tabular}{|c|c|c|c|}
\hline $\begin{array}{l}\text { Ang. } \\
\text { Art. } \\
\text { Br. } \\
\text { Ch. } \\
\text { Clav. } \\
\text { De. } \\
\text { Fr. } \\
\text { Hyom. } \\
\text { Icl. } \\
\text { Jug. }\end{array}$ & $\begin{array}{l}=\text { Angulare. } \\
=\text { Articulare. } \\
=\text { Branchiostegalia. } \\
=\text { Ceratohyale. } \\
=\text { Clavicula. } \\
=\text { Dentale. } \\
=\text { Frontale. } \\
=\text { Hyomandibulare. } \\
=\text { Interclavicula. } \\
=\text { Jugale. }\end{array}$ & $\begin{array}{l}\text { Op. } \\
\text { Par. } \\
\text { Pof. } \\
\text { Pot. } \\
\text { Scl. } \\
\text { Smx. } \\
\text { Sop. } \\
\text { Sorb. } \\
\text { Sq. } \\
\text { St. }\end{array}$ & $\begin{array}{l}=\text { Operculumı. } \\
=\text { Parietale. } \\
=\text { Postfrontale. } \\
=\text { Posttemporale. } \\
=\text { Supraclavicula. } \\
=\text { Supramaxillare. } \\
=\text { Suboperculum. } \\
=\text { Suborbitale. } \\
=\text { Squamosum. } \\
=\text { Supratemporale. }\end{array}$ \\
\hline
\end{tabular}

\section{F. Polyodontidae.}

Die primitive Beschuppung ist bei den lebenden Gattungen nur auf dem die Aclıse des oberen Schwanzflossenlappens bildenden Körperende erhalten, sonst ist der Körper nackt; bei Crossopholis sind noch

1 R. H. Traquair, Notes on Chondrosteus acipenseroides, Agassiz. - Geol. Magazine, London (3), Vol. IV, 1887, p. 248.

A. Smith Woodward, On the Paleontology of Sturgeons. - Proceed. Geol. Assoc., Vol. XI, 1889, p. 24.

M. Browne, On a Fossil Fish (Chondrosteus) from Barrow-on-Soar, hitherto recorded nnly from Lyme Regis. - Transactions Leicester Lit. and Phil. Soc., $1889,1 \% .16$.

2 A. Smith Woodward, On the Fossil Fishes of the Upper Lias of Whitby. - Part IV. - Proc. Yorkshire Geol. and Polytechn. Society (2), Vol. XIII, 1899, p. 455 . 
ausgedehntere Reste der ehemaligen Beschuppung vorhanden. Die Schnauze ist hochgradig spezialisiert, entweder konisch (Psephurus) oder von der Gestalt des Schnabels eines Löffelreihers (Polyodon). Der weite Mund ist noch mit kleinen Zähnen bewaffnet.

Crossopholis. - Eozän von Wyoming. Die Schuppen sind nicht nur auf den Schwanzteil beschränkt, sondern finden sich auch noch auf den Körperflanken; sie stehen hier noch in schiefen Reihen, ohne sich jedoch zu berühren, da sie zu dünnen, granulierten, kleinen Scheibchen reduziert sind (Crossopholis magnicaudatus). ${ }^{1}$

\section{F. Acipenseridae.}

Auch bei den Stören ist die primitive, rhombische Ganoidbeschuppung nur noch auf dem Körperende erhalten, das sich bis zum Ende des oberen Schwanzflossenlappens (der Caudalis s. s.) fortsetzt. Die fünf Knochenplattenreihen (eine dorsale und beiderseits zwei laterale Reihen) sind nicht etwa aus Schuppen hervorgegangen, wie mitunter angenommen wird, sondern diese Platten sind, wie Dollo(1904) gezeigt hat, ${ }^{2}$ Neuerwerbungen nach Durchlaufung eines nackten Zwischenstadiums, wie dies sehr klar auch bei den Welsen und Cottiden usw. zu verfolgen ist. Die Acipenseriden sind also hinsichtlich der Bepanzerung nicht primitiver, sondern spezialisierter als die Polyodontiden.

Die Kiefer sind gänzlich zahnlos geworden.

Der älteste , fossile Rest ist Acipenser toliapicus aus dem Untereozän (Londonton) von Sheppey in Kent (England).

\section{F. Semionotidae.}

Im Perm Englands tritt ein kleiner Fisch auf, der den ältesten Vertreter der im Mesozoikum zu hoher Blüte gelangenden Familie bildet (Acentrophorus); ursprünglich fusiform gestaltet wie die Paläonisciden, deren Nachkommen die Semionotiden sein dürften, nehmen sie im weiteren Verlaufe der Stanmesgeschichte der Familie eine allmählich immer höhere und lateral stark komprimierte Körperform an und zwar hat sich dieser Entwicklungsvorgang, wie es scheint, mehrere Male wiederholt. Das Gebiß besteht urprünglich aus einfachen, griffelförmigen Stiftzähnen auf den äußeren zahntragenden Kieferknochen, doch tritt allmählich eine Differenzierung des Gebisses zu einem Mahlgebiß ein. Die hinteren und inneren Zähne erhalten halbkugelförmige Kronen und stellen sich als Apparate dar, die trefflich geeignet sind, harte Nahrung zu zerreiben; die vordersten Zähne sind zuweilen durch

1 E. D. Cope, On Two New Forms of Polyodont and Gonorhynchid Fishes from the Eocene of the Rocky Mountains. - Memoirs Nat. Acad. Sci., Vol. III, 1886 , p. 161.

2 L. Dollo, Expédition Anfarctique Belge.-Poissons. - Anvers, 1904, p. 139. 
cine Lïcke (,Diastem“) von den Mahlzähnen getrennt und wirkten offensichtlich als Apparate zum Abbrechen von Korallenästen u. dgl., wie dies namentlich bei Lepidotus palliatus aus dem oberen Jura Bayerns zul sehen ist (Fig. 157).

Die Schuppen sind mit einer dicken Lage von Ganoin bedeckt und stehen auf den Körperflanken in schiefen Reihen; es ist aber auch in vielen Fällen ein Rest der ehemals ausgedehnteren Beschuppung des Schwanzendes vorhanden, das sich in den oberen Lappen der Terminalflosse fortsetzt, aber im Vergleiche zu den Paläonisciden wesentlich reduziert ist. Dadurch erhält die Terminalflosse mehr und mehr eine gleiclılappige Form, sie wird isobatisch und homozerk.

Alle Flossen tragen an ihren Vorderrändern starke Fulkren und die Flossenstralılen sind meist dichotom gegabelt.

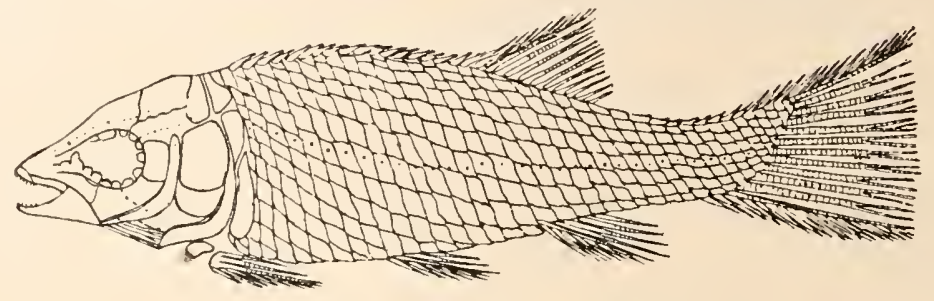

Fig. 153.

Rekonstruktion von Semionotus capensis, A. Smith Woodward, aus der obersten Trias (unterer Lias?) der Oranje Kolonie (Stormbergschichten). (Nach Schellwien, aus E. v. Stromers Lehrbuch der Paläozoologie.)

Die Schuppen der Semionotiden sind ursprünglich rhombisch(Fig. 153) und greifen auf der Innenseite derart ineinander, daß sich eine dem Vorderrande folgende, spindelförmige Verdickung mit der anschließenden verkeilt. Diese Leisten werden mitunter so kräftig, daß sie auch auf der Außenseite der Schuppen als Rippen ausgeprägt sind, die den Eindruck hervorrufen, als ob über den Schuppenpanzer schräge Rippen von vorn oben nach linten unten herabziehen würden. Nur bei Aetheolepis (Fig. 155) kommen in der hinteren Körperregion zykloide Schuppen vor, die durch Übergänge mit den rhombischen Schuppen des Vorderkörpers verbunden sind.

Die Verknöcherung der Wirbelsäule ist bei den Semionotiden durch verschiedene Stadien vertreten. Dapedius (Fig. 159, B; 170, C) weist in der Spezialisation cer Wirbelsäule eine tiefe Stufe auf, da nur die oberen und unteren Bögen verknöchert sind und die Chorda persistent ist; dagegen finden wir bei Tetragonolepis die Chorda von Pleurozentren und Hypozentren umgeben. Innerhalb der Gattung Lepidotus zeigen die ältesten Arten keine Verknöcherungen im Bereiche der Chordascheide, aber bei den jüngeren und höher spezialisierten Arten des 
Wealden (Unterkreide) sind bereits Ringwirbel zur Ausbildung gelangt. Es ist dies ein deutlicher Beweis dafür, daß die Verknöcherung der Wirbelsäule eine Spezialisation darstellt, die von verschiedenen Stämmen ganz unabhängig erreicht wurde und daß dieselbe Spezialisationsstufe der Wirbelsäule keinen Maßstab für die Beurteilung der ver-

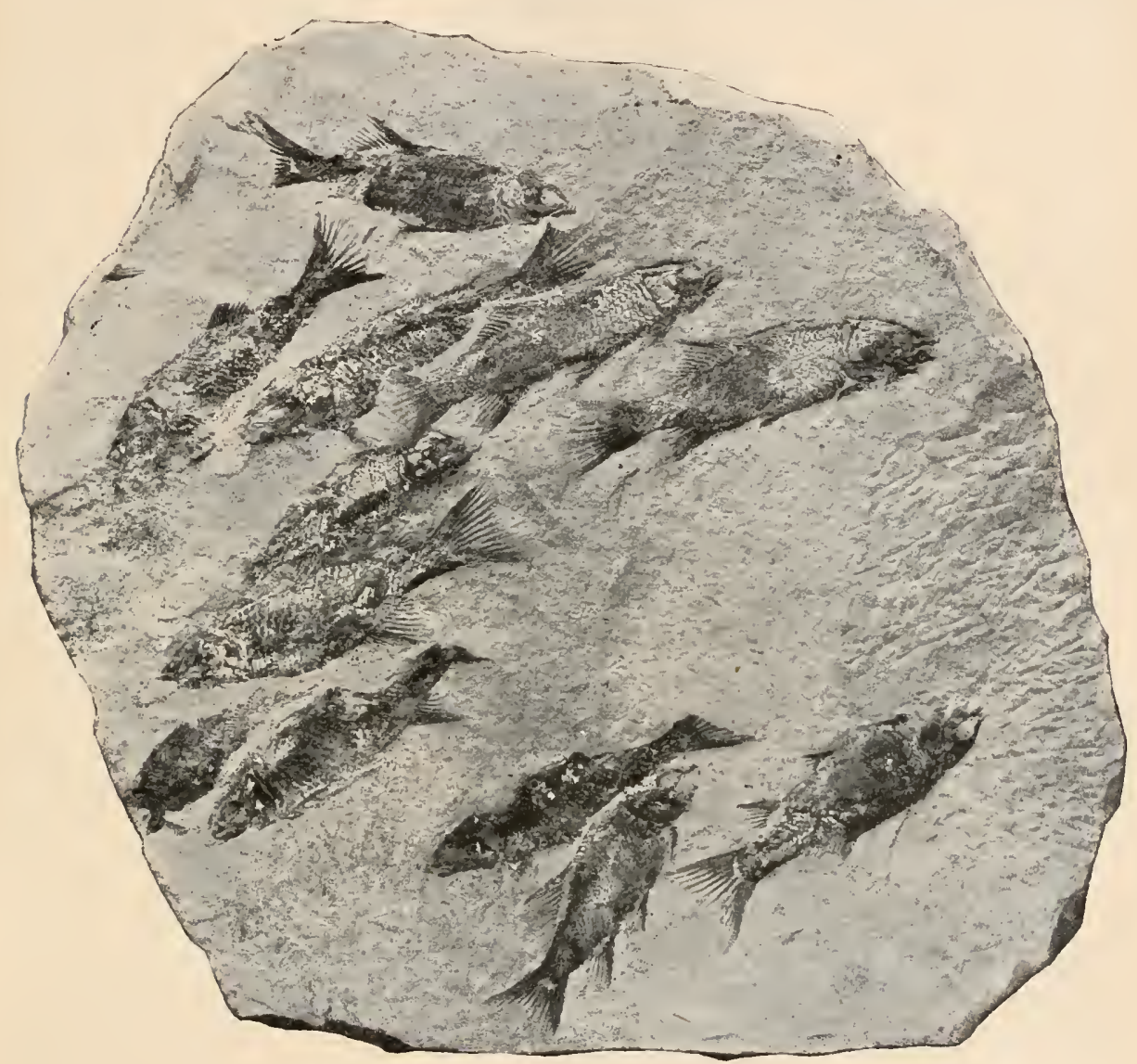

Fig. 154 .

Sandsteinplatte mit zahlreichen Exemplaren von Semionotus capensis, A. S. Woodward, aus der Karooformation (unterer Lias?) der Kapkolonie. - Original im Senckenberg-Museum zu Frankfurt a. M. - (Stark verkleinert.)

wandtschaftliche̊n Beziehungèn zwischen den einzelnen Stammeslinien bilden darf.

Die Semionotiden erscheinen im Perm, erreichen in der Jurazeit eine hohe Blüte und verschwinden wieder in der Kreidezeit.

Acentrophorus. - Die älteste bisher bekannte Gattung der Familie. Von Semionotus nur durch das Fehlen einer besonders vorstehenden Reihe von Dorsalschuppen unterschieden. Perm von Eng- 
land, Schottland, Sachsen, Böhmen und vielleicht auch in der Trias von Massachusetts. ${ }^{1}$

Semionotus. - In der Trias weit verbreitet: Ostalpen, Deutschland, Nordamerika, Kapkolonie, Neusüdwales. Der Körper ist mit dicken Schuppen gepanzert, mäßig hoch und trägt auf dem Rücken eine Reile hoher, gekielter Schuppen (Fig. 153, 154). ${ }^{2}$

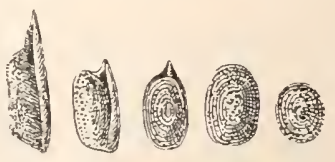

Fig. 155.

Schuppen von Actheolepis mirabilis aus dem Jura von Neu-Süd-Wales, in 1/2 nat. Gr. Links Schuppen aus der vorderen, rechts aus der hinteren Körperregion, die bereits den zykloiden Typus erreicht haben. (Nach A. Smith Woodward.)

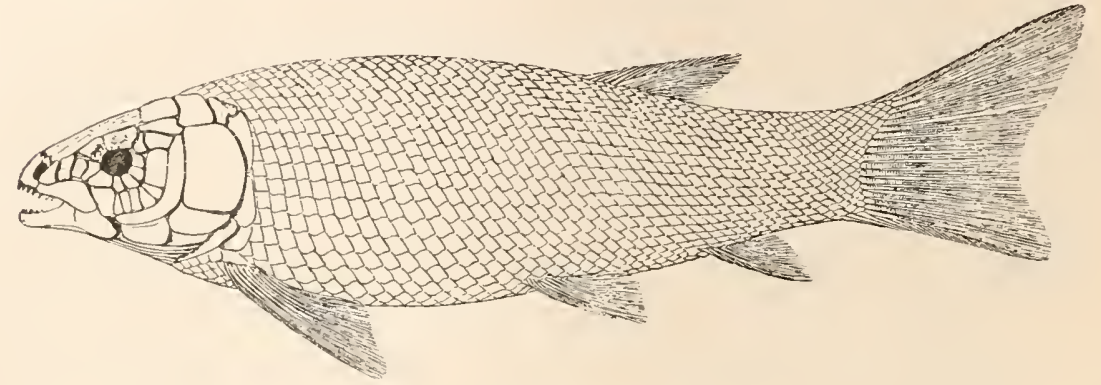

Fig. 156.

Rekonstruktion von Lepidotus elvensis, Blainv., aus dem oberen Lias von Holzmaden in Wiirttemberg, in $1 / 5$ nat. Gr. (Nach O. Jaekel.)

Dollopterus. - Trias (oberer Muschelkalk) von Isserstedt bei Jena. - Die Brustflossen sind enorm verlängert und erreichen eine Länge von $10 \mathrm{~cm}$ bei einer Körperlänge von $16 \mathrm{cml}$ (ohne Terminalflosse). Das Tier war ein Flugfisch. ${ }^{3}$

1 R. H. Traquair, On the Agassizian. Genera Amblypterus, etc. -- Quarterly Journal Geol. Soc. London 1877, p. 565.

A. Sinith Woodward, Outlines of Vertebrate Palaeontology. - 1898, p. 96.

2 E. Schellwicn, Über Semionotus, Ag. — Schriften der Physikal-Ökonom. Ges. zu Königsherg, XL11. Bd., 1901.

O. Abel, Paläobiologie der Wirbeltiere, 1912, S. 98.

E. Hennig, Eine neue Platte mit Semionotus capensis. - Sitzungsberichte der Ges. Naturf. Freunde, Berlin 1915, S. 49.

K. Gorjanovic-Kramberger, Die obertriadische Fischfauna von Hallein in Salzburg. - Beiträge zur Paläontologie und Gcol. Öst.-Ung. u. d. Orients, XV111. Bd., 1905, S. 195.

3 O. Abel, Fossile Flugfische. - Jahrbuch der K. K. Geol. Reichsanstalt, Wien, LV1. Bd., 1906, S. 48. 
Actheolepis. von Neusüdwales. Schuppen auf dem Vorderkörper rhombisch, nach hinten allmählich in zykloide Schuppen übergehend (Fig. 155). ${ }^{1}$

Colobodus.

Mittlere und obere Trias Deutschlands, der Ostalpen und Italicns. - Körper ziemlich hoch, seitlich komprimiert, Rücken- und Afterflosse groß und hoch, Schuppen am Hinterrande gezackt, Zähne habbugelig, ein durophages Gebiß bildend. ${ }^{2}$

Lepidotus.

Körper lateral komprimiert, bei einigen Arten sehr hoch ( $z$. B. bei L. palliatus), Brust- und Bauchflossen relativ klein; im Schwanzabschnitt die primitive $\mathrm{Be}$ schuppung des Kaudalendes in der Achse des oberen Terminalflossenlappens deutlich von der Beschuppung der Körperflanken abgesetzt.

\section{Obere Trias oder Jura (Hawkesburyschichten)}

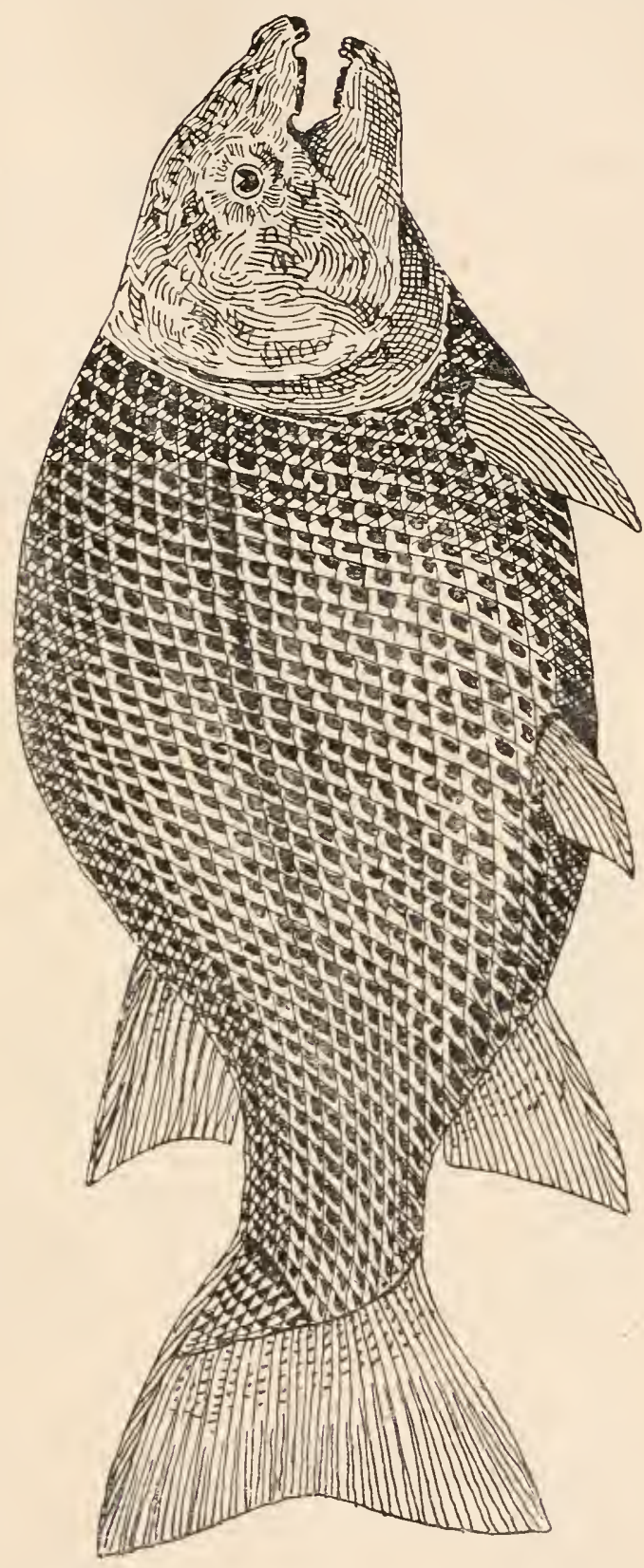

1 A. Smith Woodward, The Fossil Fishes of the Hawkesbury Series at Gosford, New South Wales. - Memoirs Geol. Soc. New South Wales, Paläont., No. 4, Sydney 1890 , p. 1.

2 K. Gorjanovic-Kramberger, Die obertriadische Fischfauna von Hallein in Salzburg. - I. c., S. 198 (Literatur). 
Gebiß heterodont, vorn mit dicken Stiftzähnen zum Abbrechen von Korallenästen u. dgl., hinten mit halbkugeligen Mahlzähnen, die ein dichtgedrängtes Pflaster bilden. Die Gattung erscheint zuerst in der oberen Trias Schlesiens, wird im Lias sehr häufig und gehört zu den häufigsten Fischen des oberen Jura Europas. Sie ist außerdem aus dem Jura Ostindiens und des Kongostaates, aus dem Wealden DeutschOstafrikas und Belgiens und aus der Kreide Brasiliens nachgewiesen worden (Figg. 156, 157). ${ }^{1}$

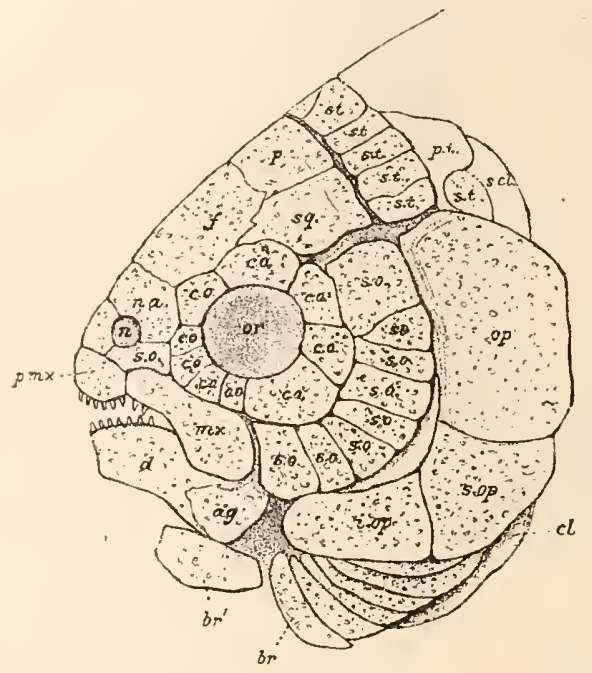

Fig. 158.

Rekonstruktion des Schädels von Dapedius. (Nach R. H. Traquair.)
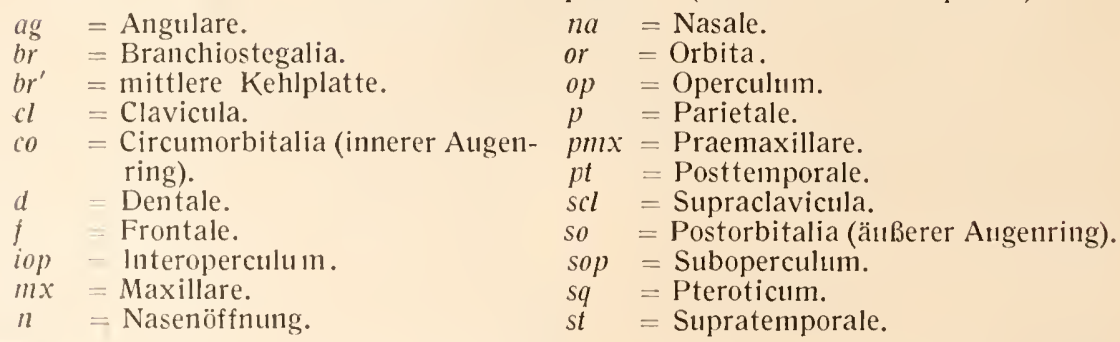

1 F. Priem, Étnde sur le Genre Lepidotus. - Annales de Paléontologie, T. III, Paris 1908, p. 8.

R. H. Traquair, Les Poissons Wealdiens de Bernissart. - Mém. Mus. Hist. 11at. de Belgique, 1911, p. 16.

A. Smith Woodward, On some Fossil Fishes discovered by Prof. Ennes de Souza in the Cretaceous Formation at Ilhéos (State of Bahia), Brazil. - Quart. Jotrn. Geol. Soc., London 1908, Vol. LXIV, p. 359.

M. Leriche, Les Poissons des Couches du Lualaba, Congo Belge. - Revue Zool. Afrique, T. 1, Bruxelles 1901.

E. Hennig, Die Fischreste unter den Funden der Tendaguruexpedition. Archiv fuir Biontologie, III. Bd., 4. Heft, 1914, S. 295. 
Dapedius. - Die ersten, allerdings problematischen Spuren dieser Gattung treten in der oberen Trias der Alpen und Italiens auf; die Blütezeit von Daped'us fällt in den Lias von Mitteleuropa. Der Körper dieser Formen ist hoch, stark lateral komprimiert und von in die

A.

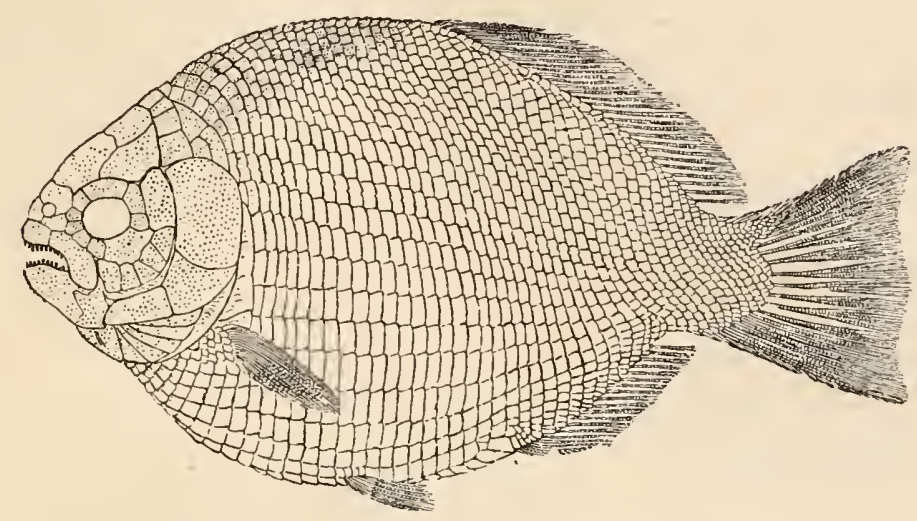

B.

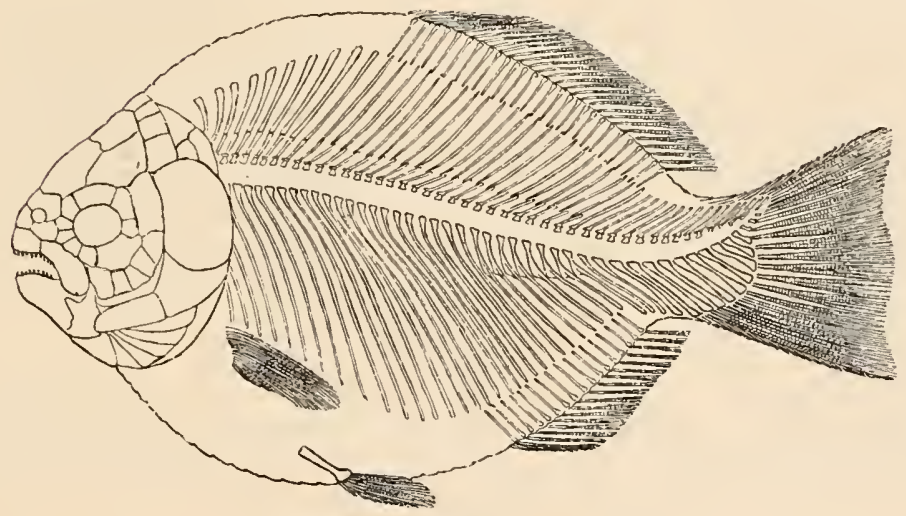

Fig. 159.

Rekonstruktion von Dapedius politus aus dem Unterlias von Dorsetshire in England, $1 / 4$ nat. Gr. A. Rekonstruktion des Schuppenkleides, B. Rekonstruktion des Skelettes. (Nach A. Smith Woodward.)

Höhe gezogenen, stark glänzenden Schuppen bedeckt. Der Knorpelschädel ist verknöchert. Orbita von zahlreichen kleinen Suborbitalplatten umsäumt. Zwischen den Branchiostegalplatten eine Gularplatte vorhanden. Deckknochen mit glänzenden Höckern, die aus Ganoin bestehen. Zähne nicht wie bei Lepidotus spezialisiert, sondern keulenförmig (Fig. 158, 159).

Stellt auch Dapedius in der Gestalt des Körpers und der Form der Dorsalflosse und Analflosse, ferner in der stärkeren Reduktion 
des nit prinären Schuppen bedeckten Achsenteiles des oberen Terminalflossenlappens eine höhere Spezialisationsstufe dar als Lepidotus, so ist er doch in anderen Merkmalen primitiver, so daß beide Gattungen getrennte Formenkreise darstellen, die von einer gemeinsamen Wurzel entsprossen sind. ${ }^{1}$

Tetragonolepis. - Oberer Lias von Deutschland und England, Kota-Malerischichten Ostindiens. Der Körper ist sehr hoch und erreicht mitunter ein fast kreisrundes Profil; er ist stark komprimiert. Die paarigen Flossen sind sehr klein, die Bauchflossen stehen weit vorn. Die Wirbelsäule weist gut entwickelte Pleurozentren und Hypozentren auf. Die Flankenschuppen sind sehr hoch und fast zu Schienenschuppen geworden. ${ }^{2}$

\section{F. Macrosemiidae.}

Die Macrosemiiden stellen einen auf die Semionotiden zurückzuverfolgenden Ast des Teleostomenstammes dar, der frühzeitig zu einer ausgesprochen nektonischen Lebensweise übergegangen ist und daher eine Reihe von Spezialisationsmerkmalen erworben hat, die den Semionotiden fehlen. Hierzu gehört z. B. das Auftreten einer zweiten Dorsalis bei den Gattungen Propterus und Notagogus und die Ausbildung einer fächerförmigen, schwach ausgeschnittenen oder gerade abgestutzten Terminalflosse bei Notagogus, der auch darin sich spezialisiert erweist, daß die ursprünglich rhombischen Schuppen zykloid geworden sind. Die Chorda ist bei den primitiveren Typen von Pleurozentren und Hypozentren, bei Propterus und Notagogus von Knochenringen unschlossen. Die ersten Vertreter dieser Familie sind aus dem Jura, die jüngsten aus der oberen Kreide bekannt.

Macrosemius. - Oberer Jura Europas. Die Rückenflosse begimnt schon hinter den Nacken und reicht bis zur Schwanzwurzel. ${ }^{3}$

Propterus. - Oberer weißer Jura Bayerns. ${ }^{4}$

Notagogus. - Oberer weißer Jura bis untere Kreide Europas. ${ }^{5}$

1 A. Smith Woodward, Catalogue of the Fossil Fishes in the British Museum, Vol. I11, London 1895.

2 Ibiclem.

3 A. Smith Woodward, Outlines of Vertebrate Palaeontology. - 1898, p. 101 .

Ältere Literatur (vgl. besonders A. Wagner), siehe bei K. A. von Zittel, Handbuch der Paläozoologie, 111. Bd., 1890, p. 201.

${ }^{4}$ A. Wagner, Monographie der fossilen Fische aus dem lithographischen Schiefer Bayerns. - Abhandl. d. Math.-Plıys. Klasse d. Kgl. Bayr. Akad. d. Wiss., IX. Bd., Miunchen 1863, S. 645.

${ }^{5}$ R. H. Traquair, Les Poissons Wealdiens de Bernissart. - I. c., 1911, p. 26. 


\section{F. Pycnodontidae.}

Die Herkunft und nähere Verwandtschaft dieser eigentümlichen und sehr hoch spezialisierten Fische ist unsicher, doch ist es an wahrscheinlichsten, daß sie auf Semionotiden zurückgehen. Sie treten zum ersten Male im unteren Lias auf und haben, wie Reste aus dem Schiefer des Monte Bolca in Oberitalien beweisen, noch im Obereozän Europas gelebt.

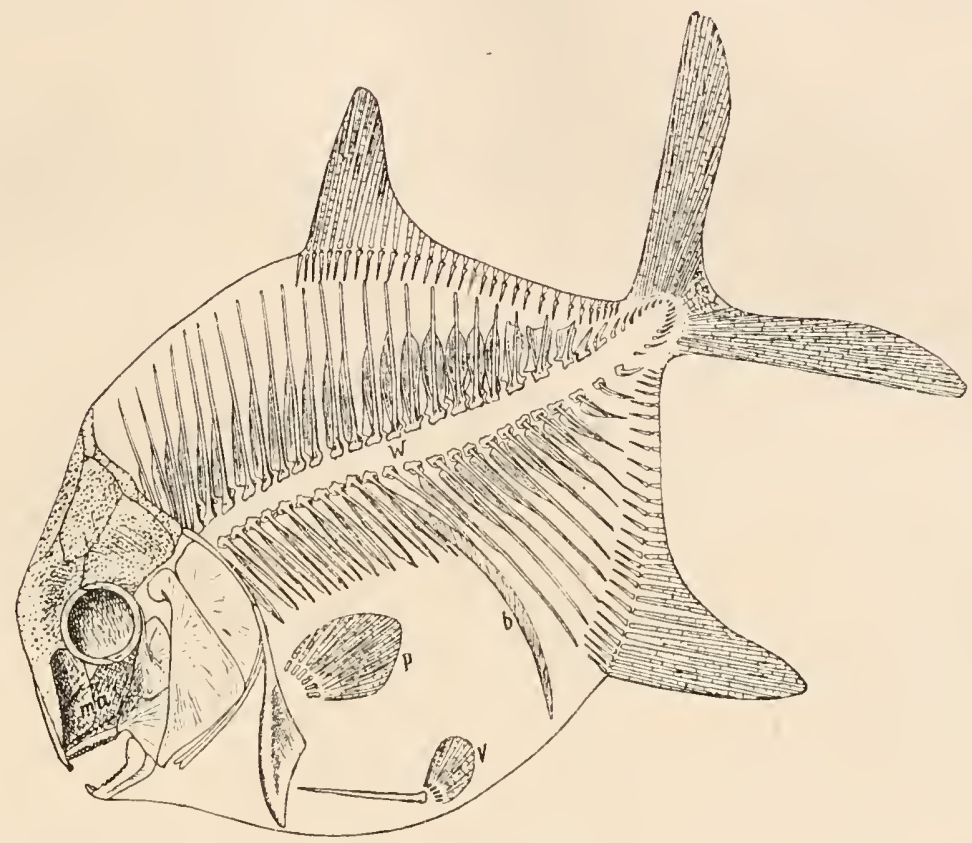

Fig. 160 .

Rekonstruktion von Gyrodus hexagonus, Blainv., aus dem obersten Jura (lithograph. Schiefer) von Solnhofen in Bayern. (Nach E. Hennig, 1906.)

Alle Gattungen der Familic besitzen einen sehr hohen, lateral extrèn komprimierten Körper mit gegenüberstehender, gleich großer Dorsalis und Analis, welche verschiedene Formen aufweisen, aber immer symmetriscl gestaltet sind. Das Gebiß ist ein hochspezialisiertes Mahlund Reibgebiß. Die Schuppen sind rhombische Ganoinschuppen; sie gehen im Verlaufe der Stammesgeschichte der Pycnodontiden allmählich verloren und bleiben zuerst auf die vordere Körperhälfte, zuletzt nur auf den vordersten Bauchteil knapp hinter der Kehle reserviert. Die Schwanzflosse enthält nur mehr Rudimente des Paläoniscidenschwanzes und ist daher als homozerk zu bezeichnen. Sie ist entweder breit fächerförmig wie bei Mesodon oder tief ausgeschnitten mit sehr spitzen Flossenenden wie bei Microdon. Bei den genannten Gattungen 
sind von den Schuppen in der vorderen Körperlıälfte außer den Schuppen hinter der Kehlregion noch die Spindeln übrig geblieben, mit denen die Schuppen der Semionotiden an der Innenseite untereinander befestigt sind; diese Spindeln ziehen als schräge Knochenleisten über die

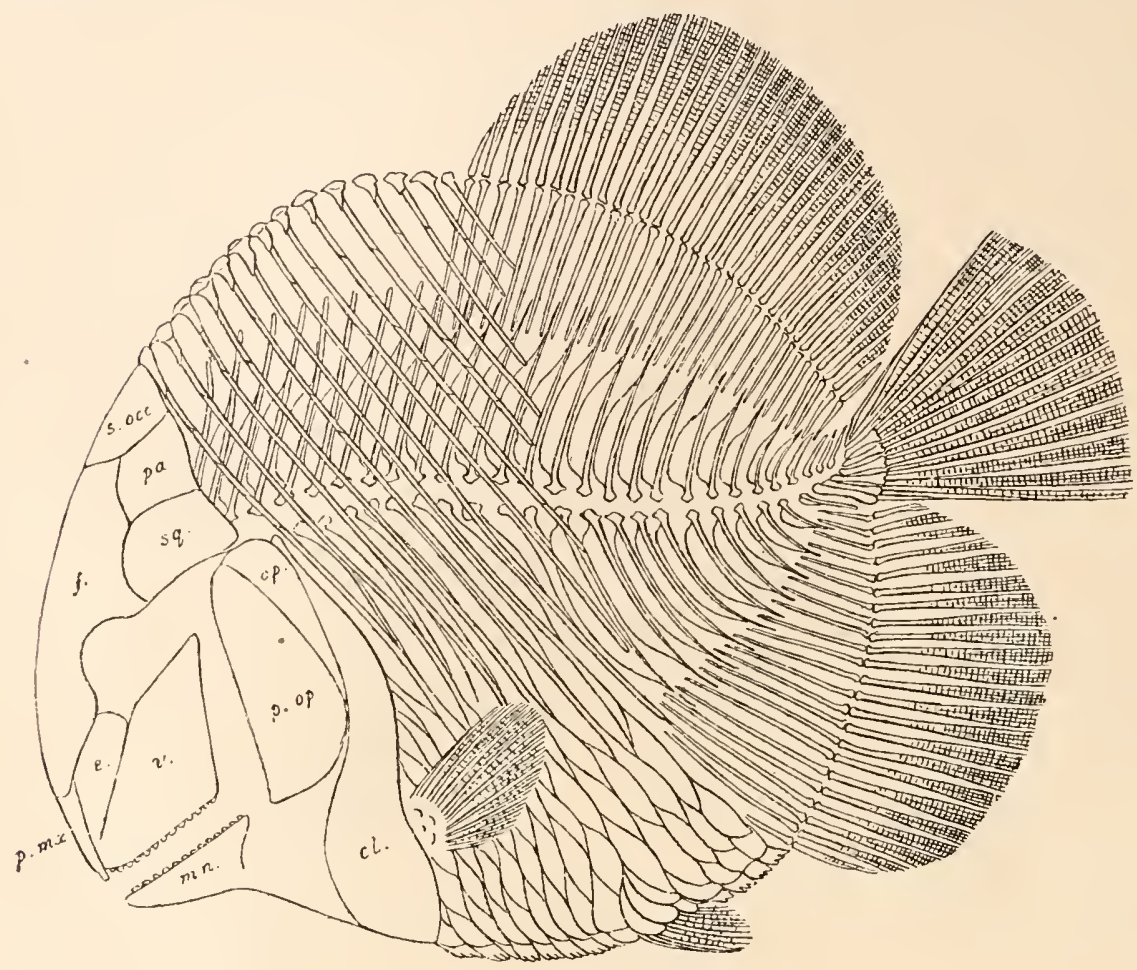

Fig. 161 .

Rekonstruktion des Skelettes von Mesodon bernissartensis, Traqu., aus dem Wealden von Bernissart in Belgien, nat. Gr. - Die Beschuppung ist stark reduziert; nur in der Abdominalregion ist der geschlossene Schuppenpanzer erhalten, während im vorderen Teile der Körperflanken nur die Basalleisten erhalten geblieben sind, mit denen die Schuppen ineinandergreifen (,Hautrippen“). Die Schwanzregion ist gänzlich schuppenlos geworden. (Nach R. H. Traquair.)

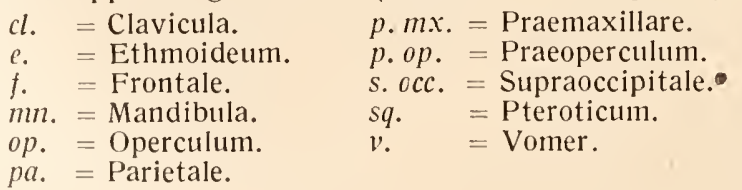

Seitenrumpfmuskulatur herab. Die Wirbelsäule besitzt selbst bei der jüngsten Gattung (Pycnodus aus dem Mitteleozän des Monte Bolca) keine knöchernen Zentren, wohl aber sehr stark verknöcherte obere und untere Bögen. Vom Operkularapparat ist nur mehr das Operculum und Praeoperculum vorhanden. 
Gyrodus. - Vom braunen Jura bis zur oberen Kreide Europas (Fig. 160). ${ }^{1}$

Microdon. - Weißer Jura Europas urd von Texas. ${ }^{2}$

Mesturus. - Weißer Jura Europas (Fig. 15). ${ }^{3}$

Mesodon. - Trias bis untere Kreide Europas (Fig. 161). ${ }^{4}$

Coelodus. - Vom Jura bis zur oberen Kreide Europas; obere Kreide von Syrien, Kansas, Texas und Oklahoma. ${ }^{5}$

Palaeobalistum. - Obere Kreide des Libanon, Frankreichs, Brasiliens (Sergipe del Rey), Mitteleozän des Monte Bolca in Oberitalien. ${ }^{6}$

Pycnodus. - Mitteleozän des Monte Bolca (Oberitalien), Eozän von Tunis; vielleicht auch in der oberen Kreide und im Tertiär Nordamerikas. ${ }^{\top}$

1 E. Hennig, Gyrodus und die Organisation der Pycnodonten. - Palaeontographica, LI11. Bd., 1906.

Vgl. die Literaturangaben über Pycnodontiden bei K. A. von Zittel, Handbuch der Paläozoologie, I1]. Bd., 1890, S. 236.

$2 \mathrm{~V}$. Thiollière, Description des poissons fossiles provenant des gisements coralliens du Jura dans le Bugey. - Paris et Lyon 1854-1873, 2 vols.

3 A. Smith Woodward, The Pycnodont Fish Mesturus. - Ann. Mag. Nat. Hist. London 1896, (6), Vol. XVII, p. 1.

4 R. H. Traquair, Les Poissons Wealdiens de Bernissart. - l. c., 1911, p. 29.

5 J. J. Heckel, Beiträge zur Kenntnis der fossilen Fische Österreichs. Denkschriften der math.-nat. Klasse d. K. Akad. d. Wiss., XI. Bd., Wien 1856, p. 187.

F. Priem, Sur des Pycnodontes et des Squales du Crétacé supérieur du bassin de Paris. - Bull. Soc. Géol. de France (3), XXVI, Paris 1898, p. 229.

E. D. Cope, New and Little Known Paleozoic and Mesozoic Fishes. - Journ. Acad. Sciences, Philadelphia 1894, (2), Vol. IX, p. 447.

S. W. Williston, Some Fish-Teeth from the Kansas Cretaceous. - Kanșas Univ. Quarterly, Vol. IV, 1900, p. 27.

J. W. Gidley, Some New American Pycnodont Fishes. - Proceed. U. S. Nat. Mus., Vol. 46, 1913, p. 447.

L. Hussakof, A New Pycnodont Fish, Coelodus syriacus, from the Cretaceous of Syria. - Bull. Amer. Mus. Nat. Hist., Vol. XXXV, 1916, p. 135.

${ }^{6}$ A. Smith Woodward, Catalogue of the Fossil Fishes of the British Museum. - Vol. III, 1895, p. 275.

Derselbe, Notes on some Upper Cretaceous Fish-Remains from the Provinces of Sergipe and Pernambuco, Brazil. - Gẻological Magazine, London 1907, p. 193.

7 Die ältere Literatur über Pycnodus siehe in O. P. Hay: Bibliography of the Fossil Vertebrata of North America, 1902, p. 373. - Vgl. ferner:

F. Priem, Sur les Poissons fossiles des Phosphates d'Algérie et de Tunisie. - Bull. de la Soc. Géol. de France (4), T. III, 1903, p. 402.

Ch. R. Eastman, Les Types de Poisșons fossiles du Monte Bolca au Muséum d'Histoire naturelle de Paris. - Mémoires Soc. Géol. de France, Paris 1905, T. XIIl, Fasc. 1, p. 10. 


\section{F. Pholidophoridae.}

Die Pholidophoriden sind eine Familie, die Gattungen von meist sehr geringer Körpergröße umfaßt. Die ersten Pholidophoriden erscheinen in der unteren Trias (Pholidophorus) und verschwinden wieder im oberen Jura.

Die meisten Gattungen der Pholidophoriden (in der bisherigen Fassung) besitzen einen fusiformen Körper, der an den Flanken mit hohen Schienenschuppen gepanzert ist, die besonders bei Pholidopleurus eine bedeutende Höhe erreichen. Die Chorda persistiert und ist von knöchemen Pleurozentren und Hypozentren umhüllt, die sich zuweilen zu geschlossenen Ringen vereinigen.

Aus der Lage und Form der medianen Flossen in Verbindung mit der sehr geringen- Größe der Batuchflossen lassen sich wichtige Schlüsse über die Herkunft der Familie ableiten. Wir haben bei den Semionotiden und ebenso auch in einigen anderen Fällen gesehen, daß sich hohe Schienenschuppen nur dort ausbilden, wo der Körper von der fusiformen Gestalt zur hochkörperigen und lateral komprimierten Type übergegangen ist. Bei diesem Übergang, der z. B. auch bei den Platysomiden Schritt für Schritt verfolgt werden kann, treten zwei Merkmale in inniger Verbindung auf: erstens die Reduktion der Bauchflossen und zweitens die Verschiebung der Dorsalis und Analis nach hinten, wobei diese Medianflossen zu langen Flossensäumen mit höherem Vorderrand ausgezogen werden. Alle drei Merkmale: Schienenschuppen, Verlust der Ventralen und Ausbildung eines Dorsalflossensaumes und Analflossensaumes finden wir bei der Gattung Pholidopleurus aus der Alpentrias wieder; der Körper ist aber hier nicht hoch, sondern fusiform. Die fusiforme Körpergestalt von Pholidopleurus muß daher sekundär erworben worden sein, und zwar nach Durchlaufung eines hochkörperigen Vorstadiums. Da die Spuren einer derartigen durchgreifenden Anpassung, wie es die Ausbildung der hochkörperigen, lateral komprimierten Fischform darstellt, nicht gänzlich verwischt werden können (Dollosches Irreversibilitätsgesetz), so sind noch bei Pholidopleurus in den Schienenschuppen, in Verlust der Ventralen und in der Form und Lage der Dorsalis und Analis die Merkmale erkennbar, welche als Erbstücke aus einer früheren Zeit erhalten geblieben sind, in der die Vorfahren von Pholidopleurus eine Körperform wie Cheirodus besessen haben müssen.

Auch die Gattung Pleuropholis mit sehr kleinen Bauchflossen, langen, einander gegenüberstehenden Dorsal- und Analflossen und sehr hohen Schienenschuppen muß auf hochkörperige Ahnen zurückgehen. Da aber die Ventralen hier noch erhalten sind, so muß Pleuropholis von einer Alnenform abgezweigt sein, bei der die Ventralen noch nicht verloren gegangen waren, und es muß der Ausgangstypus in einer Ahnen- 
form gesucht werden, die beiläufig die Spezialisationsstufe von Platysomus, aber noch nicht die von Cheirodus erreicht hatte.

Da alle Plolidophoriden die Körperflanken mit mehr oder weniger hohen Schienenschuppen gepanzert haben, so sind wohl alle Gattungen aus hochkörperigen Vorfahren hervorgegangen. Der Zeitpunkt der Abzweigung der ältesten Pholidophoriden von primitiven Actinopterygiern dürfte in die obere Permzeit zu verlegen sein. Aus dieser Zeit kennen wir zwar noch keine Formen, die als Ahnen der Pholidophoriden in Betracht kommen könnten; erst in der Trias von Neusüdwales und von Südafrika (obere Karrooschichten der Kapkolonie) treten uns sehr kleine, hochkörperige Fische entgegen, wie Cleithrolepis minor von $72 \mathrm{~mm}$ größter Körperlänge, die ich als die ältesten, bzw. primitivsten Pholidophoriden betrachten möchte; Cleithrolepis ist bisher den Paläonisciden eingereiht worden. Eine verwandte Gattung ist das zwerghafte Hydropessum Kannemeyeri aus der oberen Trias der Kapkolonie, dessen Körperlänge $62 \mathrm{~mm}$ bei einer Körperhöhe von $52 \mathrm{~mm}$ beträgt.

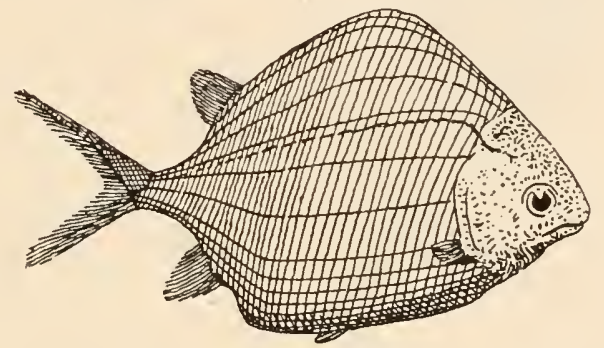

Fig. 162 .

Rekonstruktion von Cleithrolepis minor, Broom, aus der Triastormation (Karrooformation) der Kapkolonie, in nat. Gr. (Orig.-Rekonstr. auf Grundlage der von R. Broom mitgeteilten Photographie des Originals.)

Diese beiden Gattungen aus der oberen Trias Afrikas zeigen jedoch ganz verschiedene Spezialisationen. Cleithrolepis besitzt nur eine kleine Rücken- und Afterflosse, während beide Flossen bei Hydropessum einen langen Saum bilden. Die beiden Gattungen vertreten also ungefähr die Spezialisationsstufen der beiden Ahnentypen, von denen sich einerseits die sich um Peltopleurus, andererseits die sich um Pholidopleurus gruppierenden Gattungen abgetrennt haben müssen. In der bisherigen Fassung der Pholidophoriden waren also zwei auf verschiedene Ausgangsformen zurückgehende Stämme vereinigt worden, die nummehr zu trennen sind, und zwar in die Familie der Pholidophoriden und in die Fanilie der Pholidopletriden.

Als Unterscheidungsmerkmal der Pholidophoriden von den Pholidopleuriden hat die geringe Größe der Dorsalis und Analis zu gelten, wie sie auch Cleithrolepis zeigt. Beide Flossen erfahren später bei den Fall- 
schirmfischen aus den Gattungen Thoracopterus und Gigantopterus eine sehr weitgehende Reduktion. Bei den Pholidopleuriden ist die Dorsalis und Analis als langer Hautsaum entwickelt, wie dies schon bei Hydropessum zu beobachten ist.

Cleithrolepis. - Obere Trias der Kapkolonie und von Neusüdwales (Fig. 162). ${ }^{1}$

Pholidophorus. - Untere Trias bis oberer Jura von Europa, Sibirien, Süddakota, Südafrika (Kapkolonie), Wealden Belgiens. ${ }^{2}$

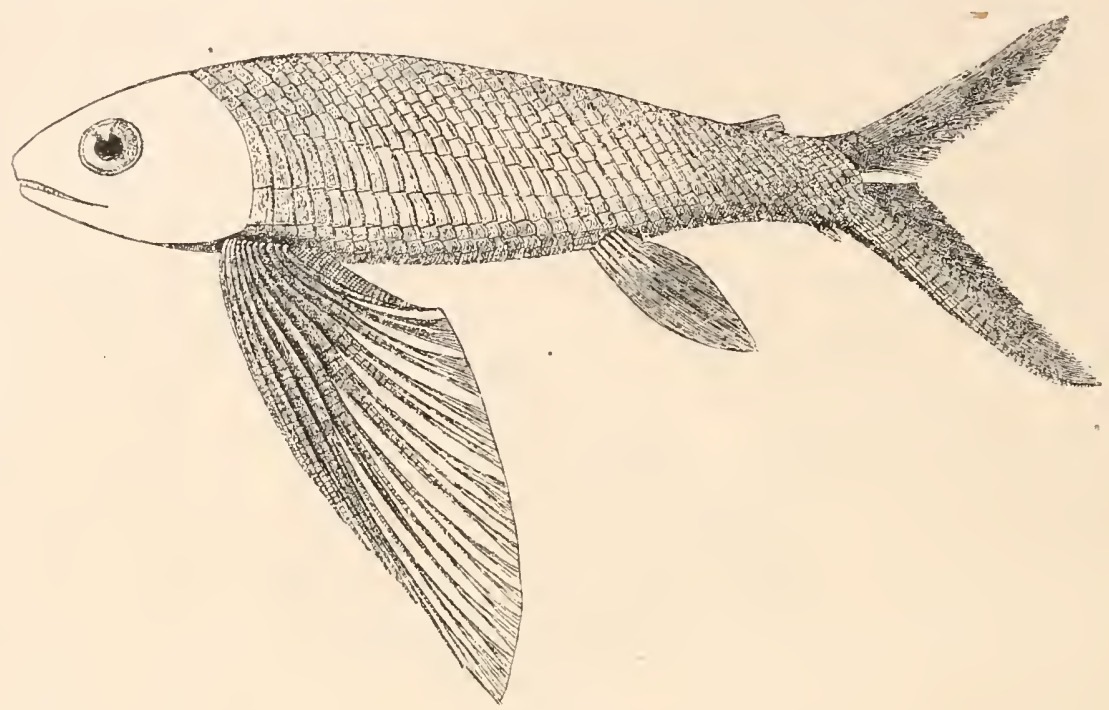

Fig. 163.

Thoracopterus Niederristi, Bronn, ein fossiler Flugfisch aus der Trias der Alpen. Nat. Gr. (Nach O. Abel.)

Thoracopterus. - Obere Trias der Alpen und von Giffoni bei Salerno. Die Terminalflosse ist tief gegabelt, der untere Lappen größer als der obere (hypobatischer Terminalflossentypus wie bei der Gattung Exocoetus). Brustflossen enorm vergrößert. Lebensweise dieselbe wie bei den lebenden Fallschirmfischen oder „Flugfischen“ aus der Gruppe der Exocoeten. Dorsal- und Analflosse rudimentär (Fig. 163). ${ }^{3}$

1 R. Broom, The Fossil Fishes of the Upper Karroo Beds of South Africa. Annals of the South African Museum, Vol. VI1, 1909, p. 266.

2 O. Abel, Fossile Flugfische. - Jahrbuch der K. K. Geol. Reichsanstalt Wien, LVI. Bd., 1906, p. 17.

Außer der I. c. genannten Literatur vgl. ferner:

R. Broom, 1. c. supra, p. 267.

R. H. Traquair, Les Poissons Wealdiens de Bernissart. - Mém. Mus. Roy. d'Hist. Nat. Belg., 191 I, p. 43.

3 O. Abel, Fossile Flugfische, I. c., 1906, p. 1. 
Gigantopterus. - Sehr ähnlich der vorigen Gattung. ${ }^{1}$

Peltopleurus. - Obere Trias der Alpen. ${ }^{2}$

\section{F. Pholidopleuridae.}

Hydropessum. - Obere Trias der Kapkolonie (Fig. 164). ${ }^{3}$ Pholidopleurus. - Obere Trias der Alpen (Fig. 165). ${ }^{4}$

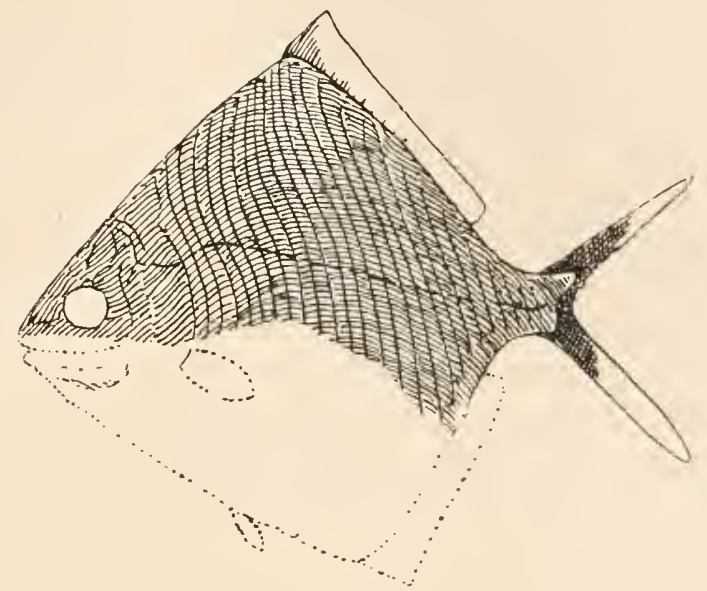

Fig. 164 .

Hydropessum Kannemeyeri, Broom, aus der Trias (Karrooformation) der Kapkolonie, in nat. Gr. (Nach R. Broom, ergänzt.)

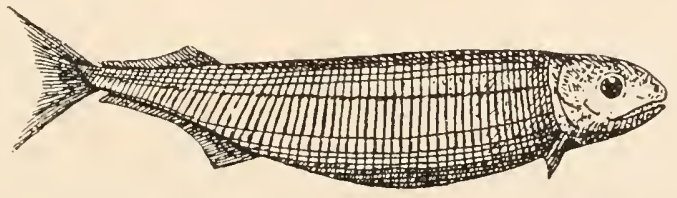

Fig. 165.

Rekonstruktion von Pholidopleurus typus, Bronn, aus der oberen Trias von Raibl in Kärnten, in nat. Gr. (Orig.-Rekonstr.)

Pleuropholis. - Oberer weißer Jura von Bayern und Frankreich, Wealden Belgiens. ${ }^{5}$

\section{F. Aspidorhynchidae.}

Die verwandtschaftlichen Beziehungen dieser Fannilie, welche durch die hochspezzialisierten Gattungen Aspidorhynchus und Belonostomus

1 O. Abel, Fossile Flugfische, 1. c., p. 39.

2 Literatur über Peltopleurus vgl. bei O. Abel, Fossile Flugfische, I. c., p. 7.

${ }^{3}$ R. Broom, I. c. supra, p. 266.

${ }^{4}$ Literatur bei O. Abel, Fossile Flugfische, I. c., S. $6-8$.

5 R. H. Traquair, Poissons Wealdiens de Bernissart, I. c., 1911, p. 45. 
vertreten ist, konnten bis jetzt noch nicht mit Sicherheit ermittelt werden, aber es ist sehr wahrscheinlich, daß sie auf die Pholidophoriden zurückgehen, mit denen sie manche Übereinstimmung aufweisen. Die Beschuppung besteht aus drei übereinanderstehenden Längsreihen sehr hoher Schienenschuppen, welche oben und unten von Längsreihen kleinerer, rhombischer Schuppen begleitet werden, also in derselben Weise wie bei den Pholidophoriden und Pholidopleuriden. Die Dorsalis und die Analis sind klein und stehen einander gegenüber, die Terminalflosse ist tief gegabelt und homozerk gebaut. Die Brustflosse ist etwas größer als die Bauchflosse, aber beide sind klein.

Der Ganoinbelag einzelner Schuppengruppen ist reduziert, die Wirbel entweder zart und ringförmig, oder stärker verknöchert (Aspidorhynchus); die Chorda tritt aber in diesem Falle noch durch den Wirbelkörper durch (Belonostonus). Die Schnauze ist sehr stark verlängert und läuft in ein spitzes, schwertförmiges Ende wie bei Histiophortus gladius aus. In Unterkiefer ist ein selbständiger Präsymphysealknochen (Praedentale) zur Ausbildung gelangt, die Zähne sind spitz und zahlreich, was auf die Raubtiernatur der Tiere schließen läßt.

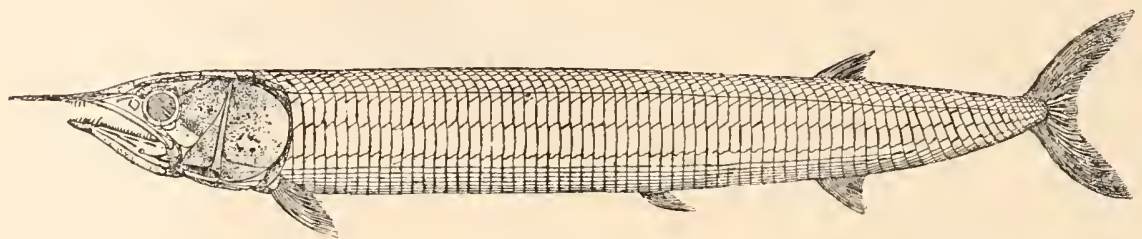

Fig. 166.

Rekonstruktion von Aspidorhynchus acutirostris, Ag., aus dem obersten Jura von Solnhofen in Bayern, in $1 / 5$ nat. Gr. (Nach P. Assmann.)

Aspidorhynchus. - Vom braunen Jura Englands bis zum Tithon Bayerns. Auch im weißen Jura von Frankreich gefunden (Fig. 166). ${ }^{1}$

Belonostomus. - Vom oberen weißen Jura Bayerns und Frankreichs bis zur oberen Kreide Europas, Ostindiens, Mexikos, Brasiliens und Queenslands. ${ }^{2}$

\section{F. Amiidae.}

In der oberen Trias der Alpen erscheinen die ersten, allerdings etwas zweifelhaften Spuren eines Stanmes der Teleostomen, der sich inn Jura zur Blüte entfaltet und von da an zurückgeht; der letzte lebende Nachzügler ist der von den südlichen Teilen der Vereinigten Staaten bis zum Huron- und Eriesee verbreitete Süßwasserfisch Amia calva. Ebenso

1 P. Assmann, Über Aspidorhynchus. - Archiv für Biontologie, I. Bd., 1906.

2 O. M. Reis, Über Belonostomus, Aspidorhynchus und ihre Beziehungen zum lebenden Lepidosteus. - Sitzungsber. d. K. Bayr. Akad. d. Wiss., II. KI., München 1887. 
wie in anderen selbständigen Stänmen lassen sich auch hier gewisse Spezialisationsstufen von Formation zu Formation verfolgen, wie die allmählich zunehmende Verknöcherung der Wirbelsäule, der Übergang von der Heterozerkie zur Homozerkie und der Übergang von rhombischen kleinen Ganoinschuppen zu ganoinlosen Zykloidschuppen. Man hat die Formen, welche verschiedenen Spezialisationsstufen angehören, zu Familien gruppiert, aber dieser Vorgang entbehrt der Berechtigung; es liegt kein zwingender Grund für eine Trennung der "Caturiden" von den ,Amiiden" vor und nur die einseitig spezialisierten Pachycormiden mit langem, spitzem Rostrum nehmen eine isolierte Stellung ein.

Ursprünglichere Gattungen, wie Caturus, zeigen noclı die wesentlichen Merkmale aller primitiven Stämme, die im Mesozoikum vom Hauptstanme der Teleostomen abgezweigt sind und sich selbständig entwickelt haben. Es waren seit jeher sclulankkörperige, räuberische, schnellschwimmende Fische, die am ehesten in ilırem Habitus mit Lachsen verglichen werden können.

Eugnathus. - Weißer Jura Süddeutschlands. Ganoinschuppen dick, rhombisclı. Chorda ohne verknöcherte Halbringe (Fig. 168).

Caturus. - Jura Europas (England und Deutschland), vielleicht schon in der Trias und vielleicht noch in Wealden. Die Wirbelsäule ist sehr unvollkommen verknöchert, höchstens sind kleine Pleurozentren und Hypozentren vorhanden. Die Schuppen sind rhombisch mit abgerundeten Rändern, bilden also ein Übergangsstadium zum Zykloidschuppentypus:

Osteorhachis. - Basidorsalia als Neurapophyse einem kräftigen, von den Interdorsalia gebildeten Pleurozentrum aufsitzend, das die Gestalt eines Hufeisens besitzt; an die Hinterseite legt sich das von den Basiventralia gebildete, gleichfalls hufeisenförmige Hypozentrum, das die Rippen trägt. Der Chordakanal bleibt weit offen. - Vom Lias bis zum oberen Jura Englands (Fig. 167).

Eurycormus. - Weißer Jura Süddeutschlands und Englands. Schuppen dünn, Chorda von Pleurozentren und Hypozentren umschlossen, die sich in Schwanzabschnitt zu Halbwirbeln zusammenschließen.

Megalurus. - Weißer Jura von Deutschland, England, Frankreich. Schuppen sehr dünn, zykloid; Wirbelkörper kräftig verknöchert, noch bis in den oberen Terminalflossenlappen hineinreichend, im vorderen Teile der Wirbelsäule aus keilförmig ineinandergreifenden und alternierenden Pleurozentren und Hypozentren aufgebaut, im Kaudalabschnitt jedoch aus zwei „Halbwirbeln" bestehend, von denen der vordere die oberen und unteren Bogen sowie die Rippen trägt (Hypozentrum), während der lintere Halbwirbel nur zur Ausfüllung des Zwischenraumes zwischen zwei Hypozentren dient. Die Rückenflosse 
beginnt über den Bauchflossen und reicht bis in die Linie der Afterflosse.

Amia. - Zuerst in Eozäı Europas; lebend in Nordanerika. Wirbelbau wie bei Megalurus. Die Rückenflosse ist größer als bei der

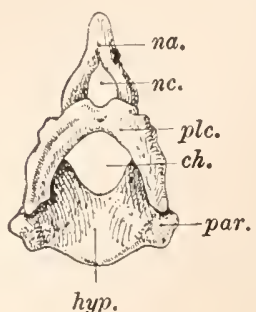

A.

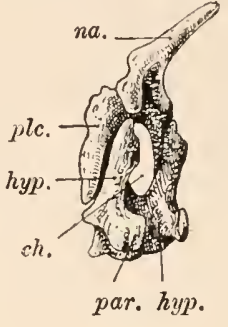

B.

Fig. 167.

Wirbel von Osteorhachis Leedsi, A. Smith Woodward (F. Eugnathidae), aus dem oberen Jura (Oxfordton) von Peterborough in England. Nach E. S. Goodrich, 1909.

A. von vorne, B. schräge von hinten und von der Seite.
$n a .=$ Neurapophyse
nc. : = Neuralkanal.
$p l c .=$ Pleurozentrum.
$c h \cdot=$ Kanal für die Chorda dorsalis.
hyp. $=$ Hypocentrum.
par. = Parapophyse

vorigen Gattung und erstreckt sich fast doppelt so weit. Bei Megalurus und Amia ist die Schwanzflosse nicht ausgeschnitten, sondern deltoid, bei Megalurus mit spitzen, bei Amia mit gerundeten Ecken.

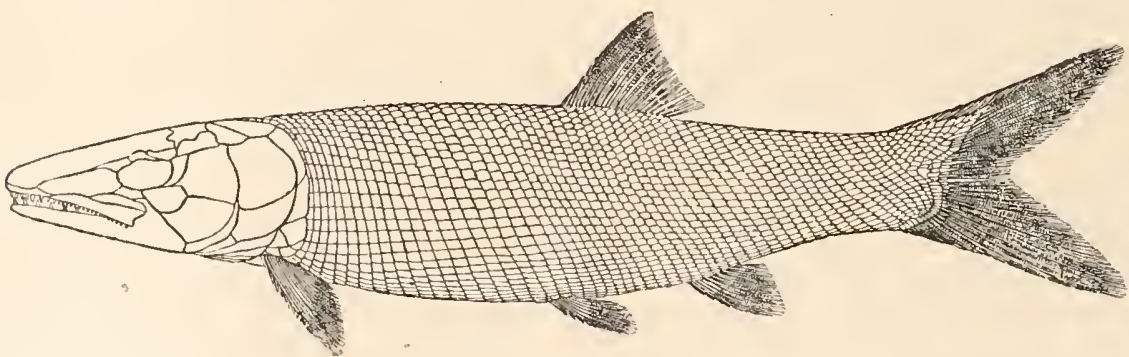

Fig. 168.

Rekonstruktion von Eugnathus orthostomus, Ag., aus dem unteren Lias Südenglands, in etwa $1 / 5$ nat. Gr. (Nach A. Smith Woodward.)

\section{F. Pachycormidae.}

Die Pachycormiden sind mit den Amiiden sehr nahe verwandt und entweder aus primitiven Vertretern der Aniiden oder doch aus sehr nahen Verwandten derselben hervorgegangen. Das wesentlichste Kennzeichen dieser Familie besteht in der spitzen Schnauze, die an Aspidorlyynchus oder an die lebenden Schwertfische (Histiophorus) erinnert. Die Verknöcherung der Wirbelsäıle bleibt auf einer tiefen 
Stufe stehen, da z. B. bei Hypsocormus überhaupt nur die oberen und unteren Bögen verkalkt waren und Ansätze zur Bildung knöcherner Wirbelkörper nicht nachweisbar sind; die Schuppen derselben Gattung sind außerordentlich klein, und da nicht anzunehmen ist, daß sie sich sekundär verkleinert haben, so ist dieses Merkmal als ein primitives anzusehen. Dies würde dafür sprechen, daß die Pachycormiden von Formen mit einem Schuppenkleid wie etwa Cheirolepis unter den Paläonisciden ihren Ursprung genommen haben. Auch bei der Gattung Pachycormus sind die Schuppen rhombisch und auffallend klein. Die Terminalflosse ist bei allen Gattungen der Familie sehr tief ausgeschnitten und groß; auffallend ist die geringe Größe der Bauchflossen, die bei Euthynotus weit nach vorn gerückt sind und bei Asthenocormus ganz fehlen. Ein eigentümliches Merkmal der Familie sind die zahlreichen Branchiostegalstralilen, deren Zahl jederseits bis auf 40 steigen kann.

Pachycormus. - Lias und Jura Englands, Deutschlands und Frankreichs.

Euthynotus. - Lias Deutschlands.

Hypsocormus. - Weißer Jura Bayerns und Englands.

Asthenocormus. - Weißer Jura Bayerns.

\section{F. Oligopleuridae.}

Die verwandtschaftlichen Beziehungen der in dieser Familie vereinigten Gattungen sind nicht befriedigend ermittelt. Die Spezialisationen der Oligopleuriden sind im allgemeinen als ziemlich vorgeschritten zı bezeichnen, da die Schuppen dünn und zyklöid, die Wirbelsäıle nit vollständig verknöcherten Zentren versehen ist und der Schädeldachbau dem der höher spezialisierten Teleostomen aus der Gruppe der Actinopterygier entspricht. Primitiv ist allein das Verhalten des Körperendes, das sich in den oberen Schwanzflossenlappen fortsetzt, so daß also der Übergang von der Heterozerkie zur Homozerkie bei den Angehörigen dieser Familie noch nicht vollzogen ist.

Die ersten Vertreter der Oligopleuriden erscheinen im oberen Jura und die letzten verschwinden in der oberen Kreide.

Oligopleurus. - Weißer Jura Deutschlands und Frankreichs, untere Kreide Italiens, der Insel Wight und Bernissart in Belgien.

Spathiurus. - Obere Kreide, Libanon.

\section{F. Lepidosteidae.}

Die. Lepidosteiden stellen eine in der Gegenwart noch durch den Knochenhecht (Lepidosteus osseus) vertretene Familie von altertünlichem Gepräge dar, deren prinitive Merkmale vor allem in der Mosaikfelderung einzelner Schädelpartien, in dem Vorhandensein rhombischer Ganoidschuppen und in dem Besitze einer heterozerken Terminalflosse bestehen, in die sich das beschuppte Körperende bis zum Ende des 
oberen Terminalflossenlappens - der ursprünglichen Caudalis - fortsetzt. Die Wirbelsäule ist stark verknöchert.

Obwohl die ältesten Lepidosteiden erst aus dem Eozän bekannt sind, kann es doch keinem Zweifel unterliegen, daß diese Familie einen schon im Mesozoikum und zwar schon verhältnismäßig frühzeitig vom Hauptstamme der Actinopterygier abgezweigten Ast darstellt, der in den erwähnten Merkmalen auf primitiver Stufe stehen geblieben ist und sich in anderen Merkmalen progressiv entwickelt hat.

Lepidosteus. - Erscheint zuerst im Eozän Europas und Nordamerikas, lebte in Europa noch bis zum Pliozän und bewohnt heute nur mehr die südlichen Teile Nordamerikas, Nordmexikos und Kubas (Fig. 25). Vielleicht schon im oberen Jura (Atlantosaurus Beds) Nordamerikas.

Diesen Fanilien der Actinopterygier, die auf primitiver Basis vom Hauptstamme abgezweigt sind, schließt sich das gewaltige Heer der jüngeren Familien an, von denen nur eine ganz verschwindend geringe Zahl gänzlich erloschen ist: Leptolepidae, Plethodidae, Ctenothrissidae, Saurodontidae, Tomognathidae, Enchodontidae, Chirothricidae, Dercetidae, Protosyngnathidae, Palaeorhynchidae und Amphistiidae, also etwa der sechzehnte Teil aller jüngeren Actinopterygierfamilien, die man meist unter dem Begriffe der, ,Teleostier" zu vereinigen pflegt (z. B. Fig. 169, 170).

E. S. Goodrich dat (1909) die Merkmale der Teleostier in folgender Reihung zusammengefaßt: 1. Der Verlust der Ganoinlage der Schuppen; 2. die gerundete Form der sich dachziegelartig deckenden, dünnen Schuppen; 3. die einfache Ringform oder Sandulırform der Wirbelkörper; 4. die Zwischenmuskelknochen; 5. die homozerke Terminalflosse mit Hypuralknochen; 6. die vorgeschrittenere Reduktion der Radialia in den Lateralflossen; 7. die stachelartige Postclavicula; 8. die Ausbildung des „Supraoccipitale“, d. i. eines Knochens, der hier nach M. A. Willcox möglicherweise als modifizierte Neurapophyse eines oder mehrerer Wirbel anzusehen ist; 9. der unpaarige Vomer; 10. die Vereinfachung des Unterkiefers, in dem das Supraangulare und Spleniale verloren gegangen sind, so daß nur das Dentale, Angulare und Articulare ïbrig bleiben; 11. das Fehlen von besonderen Wangenplatten und Verlust des Gulare medianum; 12. Vorhandensein eines medianen Urolıyale. Die übrigen, von Goodrich angeführten Merkmale sind nicht osteologischer Natur. Alle vorstehend genannten Eigentümlichkeiten sind aber zweifellos nur graduelle Unterschiede der jüngeren Actinopterygierfamilien in Vergleiche zu den älteren und da sie unablıängig von verschiedenen Stämmen erworben worden sein müssen, wie zalılreiche Spezialisationskreuzungen zeigen, würde eine 
Gruppierung der jüngeren Actinopterygier in eine scheinbare systematische Einheit, nämlich unter dem Sammelbegriff der „Teleostier", ganz falsche Vorstellungen von ihren Beziehungen zu den Stamm-
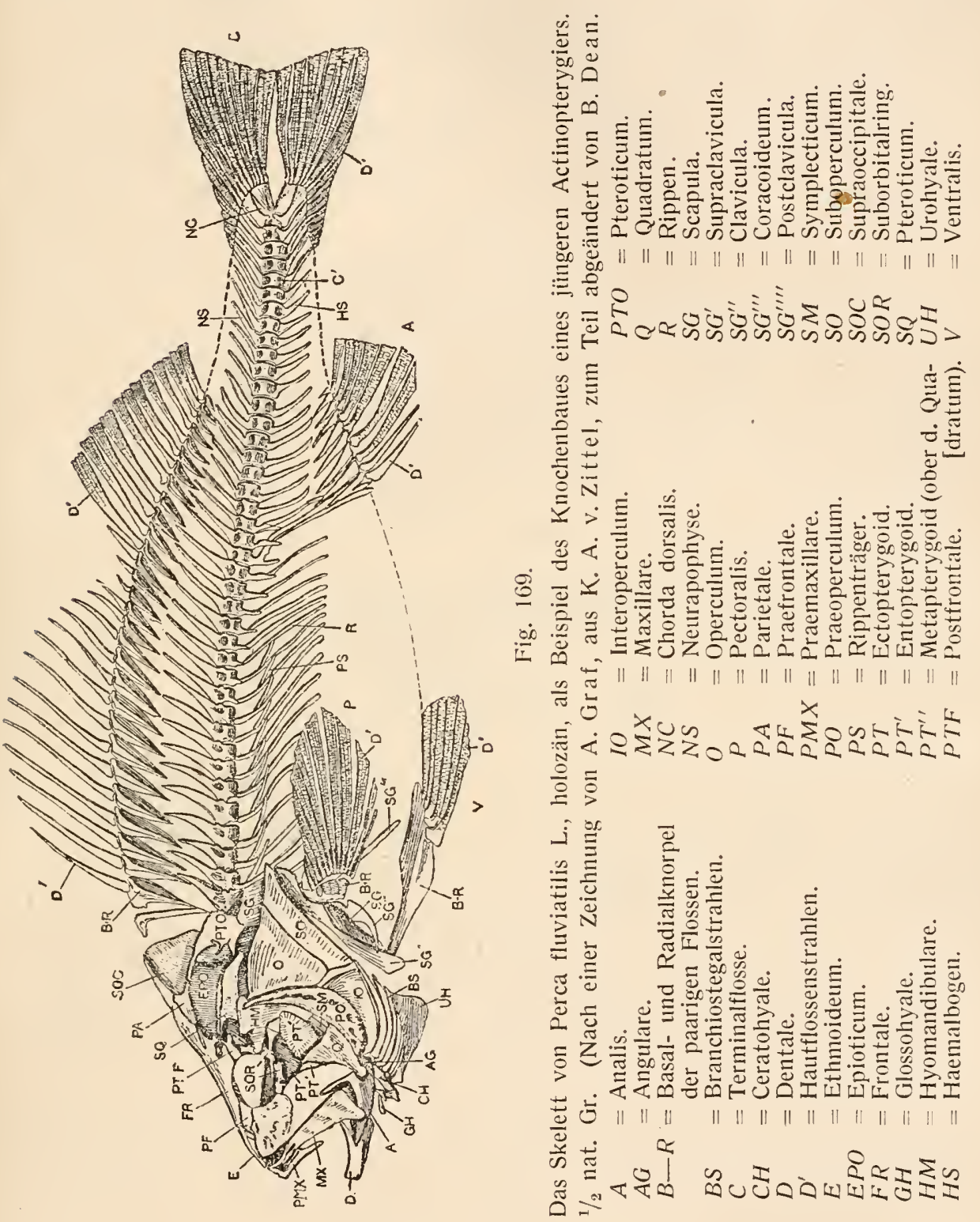

gruppen erwecken und sollte daher überhaupt nicht mehr angewandt werden.

Ebenso wie sich bei den eingehender besprochenen älteren Fanilien der Actinopterygier unabliängig voneinander in den einzelnen Stämmen 
D.

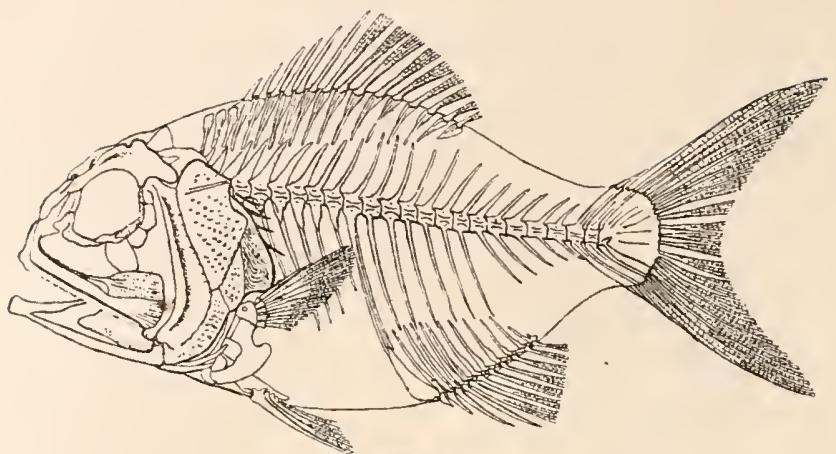

C.

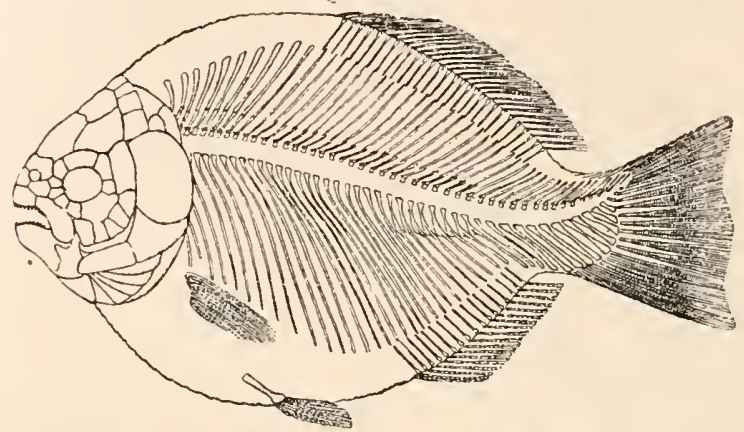

B.

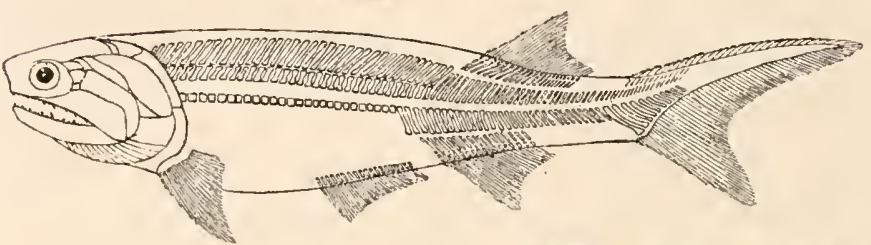

A.

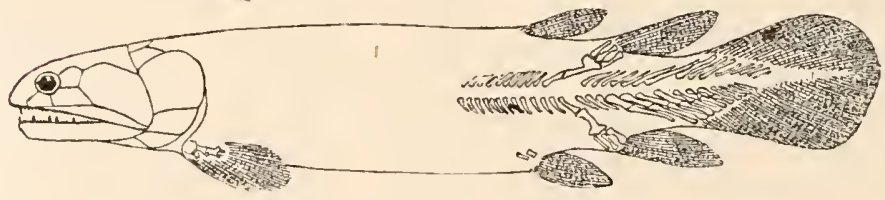

Fig. 170.

Schema zur Darstellung der vier aufeinanderfolgenden Hauptstufen der Wirbelsäulenverknöcherung bei den Teleostomen. (Nach A. Smith Woodward, 1906.) A: Typus eines Crossopterygiers, charakteristisch für das Devon; die Wirbelsäule nut im hinteren Abschnitte verknöchert und zwar auch hier nur die oberen und unteren Bögen.

B: Typus eines Palaeonisciden, charakteristisch für das Karbon und Perm; die Wirbelsäule zwar fast der ganzen Länge nach verknöchert, aber noch keine Wirbelkörper ausgebildet.

C: Typus eines Semionotiden (Dapedius), charakteristisch für die Trias und den Jura; die Verknöcherung des Gesamtskeletts ist weiter vorgeschritten, aber die Wirbelzentren sind noch immer unverknöchert.

D: Typus eines juingeren Actinopterygiers aus der Familie der Beryciden (Hoplopteryx), charakteristisch für die Kreide und die jüngeren Formationen; das Skelett ist hochgradig verknöchert, von Spezialisationen fallen u. a. die Lage des unter das Maxillare geschobenen Praemaxillare und die weit nach vorn verschobene Ventralis auf; die Wirbelzentren sind solid verknöchert. Dieser Typus entspricht der Entwicklungsstufe der Mehrzahl der modernen Teleostomen. 
parallele Spezialisationen vollzogen haben, ist dies auch bei den jüngeren Familien der Fall gewesen. Derartige parallele Spezialisationen finden sich z. B. in der Schwimmblase ausgeprägt. Ursprünglich offen und durch den Ductus pneumaticus mit der Mundhöhle in Verbindung, kann diese Verbindung unterbrochen und die Schwimmblase geschlossen werden, ja, sie kann sogar gänzlich verloren gehen. Der prinitivere Zustand, bei welchen die Schwimmblase noch einen offenen Kommunikationskanal besitzt, wird der ,physostome“ genannt; er findet sich bei allen Actinopterygiern wäh'end des embryonalen Lebens, im erwachsenen Zustand noch bei den Gruppen der Malacopterygier, Ostariophysi, Apodes und Haplomi. Dagegen ist die Schwimmblase abgeschlossen bei den folgenden Gruppen: Heteromi, Catosteomi, Acanthopterygii, Opisthomi, Pediculati, Jugulares und Plectognathi, welche somit den „physoclisten“ Zustand der Schwimmblase repräsentieren.

Es ist jedoch nicht möglich, diese beiden Spezialisationsgegensätze in der systematischen Gruppierung zum Ausdruck zu bringen, da dadurch ganz falsche Vorstellungen von den verwandtschaftlichen Beziehungen der „Physostomen“ und „Physoclisten“ ausgelöst würden und es ist daher in der letzten Zeit diese Gruppierung wenig in Anwendung gebracht worden. Alle Physoclisten müssen einmal das physostome Stadium durchlaufen haben, aber das Aufgeben desselben ist wiederholt unabhängig voneinander in den einzelnen Gruppen eingetreten und kann daher nicht als systematisches Unterscheidungsmerkmal verwertet werden.

Die Zahl der bisher bekannten lebenden Arten aus der Gruppe der jüngeren Actinopterygier (= Teleostei aut.) dürfte gegenwärtig die Ziffer 12000 bereits überschritten haben. Wenn auch in der Kreide und in tertiären Ablagerungen sehr zahlreiche fossile Arten gefunden worden sind, so bleibt doch ihre Zahl weit hinter jener der lebenden Arten zurück und bildet nur einen sehr kleinen Bruchteil derselben. 


\section{Klasse: Amphibia (Lurche).}

\section{Die stammesgeschichtliche Stellung der Amphibien.}

Die Lurche nehmen eine vermittelnde Stellung zwischen den Fischen und Reptilien ein. Die Vertreter der noch lebenden Amphibienstämme, die Coèciliiden (Blindwühlen), Urodelen (Schwanzfurche) uind Anuren (Froschlurche) können jedoch nicht als Ausgangsformen oder selbst als Ausgangsgruppen für die höheren Wirbeltiere angesehen werden; als eine solche Übergangsgruppe kann nur der Kreis der Stegocephalen in Betracht kommen. Zwischen den primitivsten Vertretern dieser Stammgruppe der Stegocephalen und den primitivsten Reptilien aus der Gruppe der Cotylosauria bestehen überhaupt keine scharfen Grenzen, soweit dies aus der morphologischen Vergleichung beider Gruppen gefolgert werden kann, und wo Gegensätze vorliegen, sind sie nur gradueller Natur. Eine scharfe Scheidewand zwischen einer primitiven Stegocephalenform, wie Trimerorhachis, und einer primitiven Cotylosaurierform, wie Seymouria, ist durchaus unnatürlich, da auch der gastrozentrale Wirbeltypus von einem rhachitomen abzuleiten ist. Während also die Lücken zwischen der Stammgruppe der Amphibien und der Stammgruppe der Reptilien durch die paläontologischen Funde der letzten Jahre als nahezu geschlossen betrachtet werden können, ist es noch nicht gelungen, die Anschlußstelle der Stegocephalen an die Fische mit voller Sicherheit zu ermitteln, wenn auch die Beweisgründe für die engere Verwandtschaft der Stegocephalen und der Crossopterygier durch neuere Forscliungen an Kraft gewonnen haben. Die in früherer Zeit vielfach verfochtene und teilweise noch heute verteidigte Hypothese der Abstammung der Stegocephalen von den Lungenfischen oder Dipneusten ist als endgültig abgetan zu betrachten. ${ }^{1}$

\section{Systematik der Amphibien.}

Die drei lebenden Stämme der Amphibien sind die Coeciliidae (Blindwühlen), welche die selbständige Ordnung der Gymnopliona bilden, ferner die Urodela (Schwanzlurche) mit den Fanilien der Amphiumidae (Fisclımolche), Salamandridae (Molche), Proteidae (Olme) und Sirenidae (Armmolche) und endlich die Ordnung der Anura (Frosch-

${ }^{1}$ L. Dollo, Sur la Phylogénie des Dipneustes. - Bull. Soc. Belge de Géologie, Paléont. etc., T. IX, Bruxelles 1895 , pag. 79. 
lurcle) mit zahlreichen Fanilien, die sich auf die Unterordnungen der Aglossa und der Phaneroglossa verteilen. Die Phaneroglossa werden in die beiden Gruppen der Arcifera (Schiebbrustfrösche) und Firmisternia (Starrbrustfrösche) eingeteilt.

Von den Coeciliiden kennt man keine fossilen Reste; die Urodelen sind jedoch bis in das Perm Nordamerikas zurïckverfolgt worden, da die Gattung Lysorophus nummehr als Urodele erkannt worden ist. Die ältesten Anurenreste sind in oberen Jura Spaniens und Nordamerikas gefunden worden; ob die noch ungenügend bekannte Form Pelion Lyelli $(W y m a n)^{1}$ in die Ahnenreihe der Frösche gehört, ist noch eine offene Frage. Wenn dies der Fall wäre, so würden sich die Anuren bis in das Oberkarbon hinab verfolgen lassen.

Die Urodelen wurzeln ebenso wie die Gymnophionen und die Anuren in der großen Stammgruppe der Stegocephalen, die sich schon sehr frühzeitig in divergente Äste gespalten hat, von denen die meisten schon nach kurzer Blütezeit noch in der Permzeit erloschen sind, während nur wenige Nachzügler noch bis zum Ende der Triaszeit lebten, in der sie allerdings die größten Körperdinensionen erreichten, die von Amphibien bekannt geworden sind. Die Urodelen sind in vielen Punkten mit den Branchiosauriden der Karbon- und Permzeit so nahe verwandt, daß sie jetzt von den meisten Forschern als die Nachkommen derselben angesehen werden. Die Kreise der Urodelen und der Stegocephalen schneiden sich also im Bereiche der Branchiosauriden, ein Fall, der die Schwierigkeiten beleuchtet, die phylogenetischen Beziehungen zwischen zwei genetisch verknüpften Gruppen inı "System" zum Ausdruck zu bringen. Wenn wir nur die sicher den Urodelen und Anuren einzureihenden fossilen Gattungen aus dem Bereiche der Stegocephalen ausscheiden, aber alle anderen in dieser "Stammgruppe" vereinigt lassen, so werden die Bezielıungen der noch lebenden Amphibienstämme zu den fossilen Ordnungen und Familien der Amphibien am besten zum Ausdruck gelangen.

\section{Die Morphologie der Wirbelsäule als Grundlage einer systematischen Gruppierung der Amphibien.}

Schon bei Besprechung der Fische haben wir gesehen, daß der Begriff des ,Wirbels" kein morphologisch eindeutiger ist. Auch bei den höheren Wirbeltieren, die summarisch als Tetrapoden bezeichnet

1 j. Wyman: On some Remains of Batrachian Reptiles discovered in the Coal Formation of Ohio, etc. - Americ. Journal of Science, $2^{\circ}$ ser., XXV., New Haven, 1858. p. 158. - R. L. Moodie, The Dawn of Quadrupeds in North America. The Popular Science Monthly, Vol. LXXII, June 1908, p. 562, Fig. 1. 
werden, sind die Wirbel bei den einzelnen Gruppen keineswegs homolog.

Wenn auch bei den meisten höheren Wirbeltieren der Wirbel ein einheitliches Ganzes zu bilden scheint, so ist dies doch durchaus nicht der Fall. Aus der Entwicklungsgeschichte der Wirbel ergibt sich mit voller Klarheit, daß sie zwar auf einen gemeinsamen Ausgangstypus zurückgehen, der durch vier Páare knorpeliger Bogenelemente gekennzeichnet ist, daß aber die weitere Spezialisation dieser vier Bogenpaare auf divergenten Wegen erfolgt ist. Eine eingehende Verfolgung der Spezialisationsgeschichte dieser vier Paare von ursprünglichen Bogenelementen führt daher zu wichtigen Aufschlüssen über die verwandtschaftlichen Beziehungen zwischen den verschiedenen Gruppen, welche je ihren eigenen Spezialisationsweg in Aufbau der Wirbelsäule eingeschlagen haben.

H. Gadow kam bei seinen embryologischen Forschungen über die Morphogenie der Wirbel zu dem Ergebnis, daß der Ausgangstypus des Tetrapodenwirbels von vier Paaren knorpeliger Bogenelemente (Arcualia) gebildet wird. Diese sind:
1. Zwei Basidorsalia,
2. zwei Basiventralia,
3. zwei Interdorsalia,
4. zwei Interventralia.

Diese vier, bzw. acht ursprünglich getrennten Bogenelemente erfuhren in Laufe der Stammesgeschichte folgende divergente Spezialisationen bei den Tetrapoden:

\section{Rhachitomer Typus.}

Die vier Paar Bogenelemente verharren in getrenntem Zustande, so daß der Wirbelkörper aus mehreren Stücken zusammengesetzt erscheint; treten im Verlaufe der Stammesgeschichte Verwachsungen einzehner Elemente der Rumpfregion auf, so ist doch der ursprüngliche Zustand des sog. ,, Schnittwirbels" noch in der Schwanzregion zu beobachten.

Wir haben in einem solchen Wirbel zu unterscheiden:

1. Die Basidorsalia. - Sie bilden den oberen Wirbelbogen oder die „Neurapophyse“. Sie sind meistens miteinander verschmolzen, aber zuweilen (z. B. in den Rückenwirbeln von Trimerorhachis insignis) noch getrennt (Fig. 171, 172, 173).

${ }^{1} \mathrm{H}$. Gadow, On the Evolution of the Vertebral Column of Amphibia and Amniota. - Philosophical Transactions of the Royal Society London, Vol. CLXXXVII, 1896, p. 1-57 (Literatur, p. 53-57). 


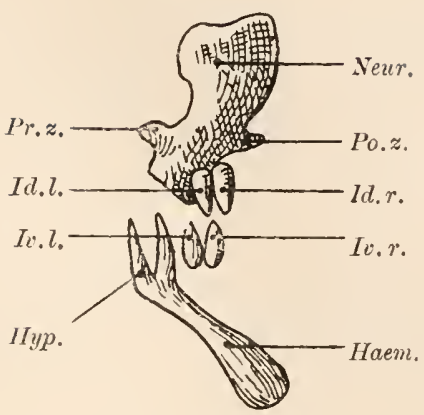

Fig. 171.

Schematische Seitenansicht eines Schwanzwirbels von Archegosaurus, von links gesehen. Der Wirbel ist verdriickt; daher ist die Gabel des Hypozentrums sichtbar und die zwei Paare der Interarcua'ia (Interventralia und Interdorsalia) liegen nebeneinander.

Haem. = Haemapophyse. $\quad I . r .=$ rechtes Interventrale.

Hyp. = Hypocentrum. Neur. = Neurapophyse.

Id. $l$. $=$ linkes Interdorsale. $\operatorname{Pr} . z .=$ Praezygapophyse.

Id. $r$. = rechtes Interdorsale. Po. z. $=$ Postzygapophyse.

Iv. $l$. $=$ linkes Interventrale.

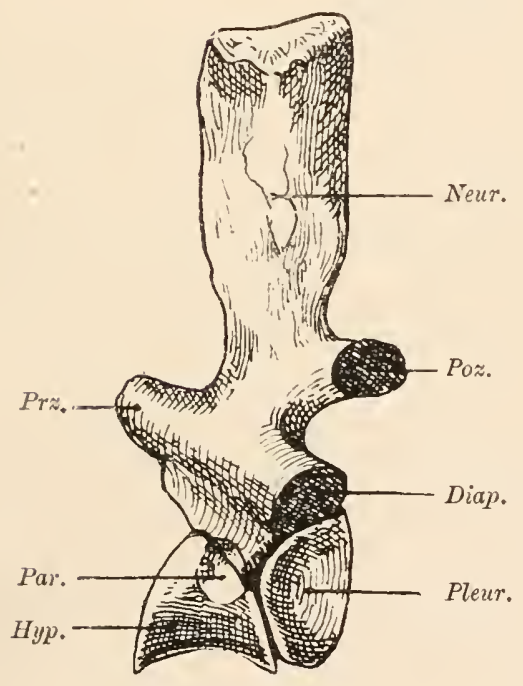

Fig. 172.

Dorsalwirbel von Eryops, von links gesehen, in $2 / 3$ nat. Gr.; aus dem Perm Nordamerikas. (Nach S. W. Williston.) Bezeichnungen wie in Fig. 171, dazu noch:

$$
\begin{aligned}
& \text { Par. }=\text { Parapophyse. } \\
& \text { Diap. }=\text { Diapophyse. } \\
& \text { Pleur. }=\text { Pleurozentrum. } \\
& \text { Prz. }=\text { Praezygapophy.e. } \\
& \text { Poz. }=\text { Postzygapophyse. }
\end{aligned}
$$

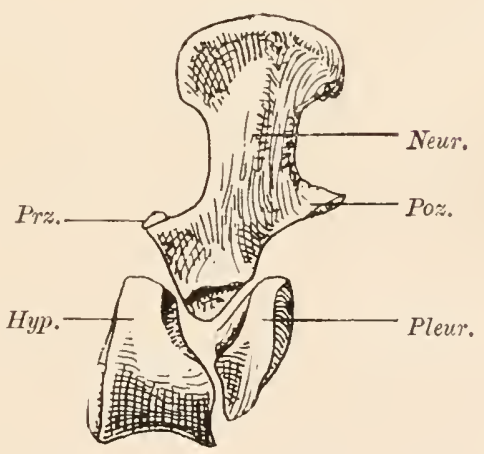

Fig. 173.

Hinterer Rumpfwirbel von Archegosaurus Decheni, aus dem Perm von Lebach bei Saarbrïcken, von links gesehen, in nat.Gr.

(Nach O. Jaekel.)

Prz. = Praezygajophyse.

Poz. = Postzygapophyse.

Hyp. = Hypocentrum.

Pleur. = Pleurocentrum.

Neur. = Neurapophyse. 
2. Die Basiventralia. - Sie liegen vor und unter den Basidorsalia. Sie verschmelzen meistens untereinander (Fig. 172, 173) zu einer unpaarigen Masse, dem ,Hypozentrum" (= Interzentrum), bleiben aber zuweilen noch getrennt (z. B. an den Schwanzwirbeln von Archegosaurus, Fig. 171).

3. Die Interdorsalia. - Sie liegen über und hinter den Basiventralia, bleiben in der Schwanzregion bei Archegosaurus, Chelydosaurus und Sphenosaurus getrennt und entsprechen dem ,oberen Paar der Pleurozentren" (Fig. 171, Id.r., Id.l.).

4. Die Interventralia. - Sie liegen unter den Interdorsalia, bleiben zuweilen (z. B. bei Archegosaurus, Fig. 171, Chelydosaurus und Sphenosaurus) getrennt und entsprechen dem ,unteren Paar der Pleurozentren" (= Intercentra pleuralia).

Aus diesem Grundtypus geht einerseits infolge Verschmelzung einiger und der Reduktion anderer Elemente der stereospondyle Typus hervor, andererseits durch Ausbildung von zwei hintereinanderliegenden Wirbelkörperscheiben ein „Doppelwirbel“, der als embolomerer Typus unterschieden wird.

\section{I. Stereospondyler Typus.}

Während der primitive rhachitome Wirbel vier Paar getrennter Bogenelemente umfaßt, tritt in einem Stamme schon in Unterkarbon (bei Loxomma) und im Oberkarbon (bei Anthracosaurus) und weiter bei den jüngsten Stegoceplıalen der Triasformation (z. B. Mastodonsaurus, Metopias, Capitosaurus, Labyrinthodon, Plagiosaurus) eine Spezialisation des Wirbelbaues ein, die mit der Herausbildung eines scheinbar einheitlichen Wirbels endet. Dieser ,stereospondyle" Wirbel umfaßt jedoch noch zwei Paar der ursprünglichen Bogenelemente, die miteinander fest verwachsen sind; das sind die Basidorsalia (Neurapophyse) und die Basiventralia (Hypozentrum). Dagegen sind die lnterdorsalia und die Interventralia (Pleurocentra) durch Reduktion verloren gegangen. Bei Mastodonsaurus scheinen die Pleurozentren wenigstens noch in knorpeligem Zustande als Rudimente vorhanden gewesen zu sein, da beim Aneinanderstoßen der Wirbelkörper zwischen je zweien eine Lücke übrigbleibt, die mit Knorpelmasse ausgefüllt gewesen sein muß.

\section{Embolomerer Typus.}

Während der stereospondyle Wirbel durch Reduktion der Pleurozentren und durch die Verschmelzung von Hypozentrum und Neurapophyse (d. h. Basiventralia + Basidorsalia) zustande kommt, bildete sich, allerdings selır selten, bei anderen Stegocephalen ein Doppelzylinder oder ein „Doppelwirbel“ aus (F"g. 174). Der vordere Zylinder bildet den 
eigentlichen Wirbelkörper, der die oberen und unteren Bogenstücke sowie die Querfortsätze für die Rippen trägt; der hintere Zylinder dient nur als Ausfüllungsmasse oder ,, Intervertebralmasse“. Der vordere Zylinder entspricht den vereinigten Basidorsalia (Neurapophyse) und Basiventralia (Hypozentrums), der hintere Zylinder den vereinigten Interdorsalia und Interventralia (= oberes und unteres Paar der Pleurozentren).

Derartige „Doppelwirbel“ sind nur bei zwei Gattungen (Cricotus und Diplovertebron) bekannt und zeigen eine auffallende Übereinstimmung mit den Doppelwirbeln der Schwanzregion einzelner Fische, und zwar z. B. nit jenen der lebenden Amia calva (Fig. 3) oder des oberjurassischen Amiaden Eurycormus speciosus. Auch bei den Fischen ist diese Erscheinung der „Embolomerie“ sehr selten.

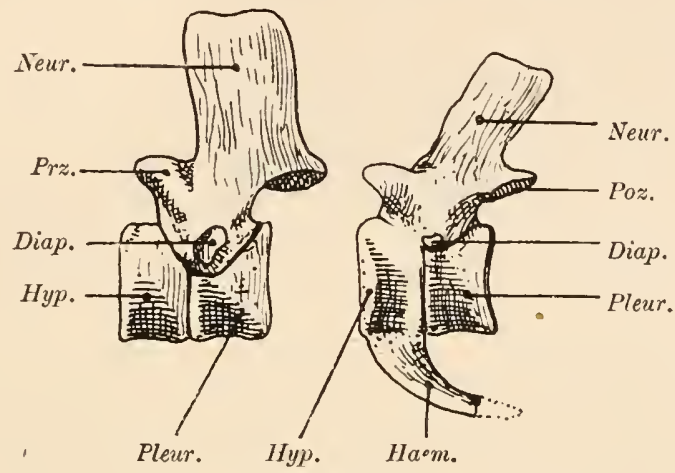

Fig. 174.

Links: Dorsalwirbel, rechts: Caudalwirbel von Cricotus, aus dem Perm von Texas. Beide Wirbel sind von links gesehen. $1 / 2$ nat. Gr. (Nach S. W. Williston.) Diap. - Diapophyse. Haem. = Haemapophyse. Prz. = Praezygapophyse. Hyp. = Hypocentrum. Poz. = Postzygapophyse.

Neur. = Neurapophyse.

\section{Pseudozentraler Typus.}

Dieser Typus wird in der Gegenwart durch die Wirbel der Urodelen repräsentiert. Der Wirbelkörper besteht bei ilnnen aus den Basiventralia (Hypozentrum) und den in der Jugend getrennten, im Alter mit ihnen verschmolzenen Basidorsalia (Neurapophyse). Beide Bogenpaare verwachsen miteinander zu einem einheitlichen Wirbel, während die beiden hinteren Bogenpaare (Interdorsalia und Interventralia) knorpelig bleiben, vom Aufbau des knöchernen Wirbels ausgeschlossen sind und den ,,Intervertebralknorpel" bilden.

Mitunter (Rumpfwirbel der Urodelen) wird aber der Wirbelkörper nur von den Basidorsalia allein gebildet, welche die Basiventralia gänzlich verdrängt haben. Zwischen diesem Typus und jenem, bei welchem 
auch noch die Basiventralia am Aufbau des Wirbels beteiligt sind, finden sich vielfache Übergänge.

Einem primitiveren Typus als dem Wirbeltypus der lebenden Urodelen begegnen wir bei den fossilen Gattungen Branchiosaurus, Melanerpeton und Pelosaurus. Hier besteht der Wirbelkörper aus zwei sclıwach ossifizierten Knochenblättern, die sich um die Chorda dorsalis legen und den Basiventralia (Hypozentrum) entsprechen, die somit hier noch paarig ausgebildet sind. Dorsal treten die Basiventralia mit den Basidorsalia in Verbindung. Der Wirbelkörper wird in einem solchen Falle (z. B. bei Branchiosaurus) zı gleichen Teilen von den Basiventralia und den Basidorsalia gebildet; die Interdorsalia und Interventralia nehmen an der Bildung des Wirbels auch hier keinen Anteil.

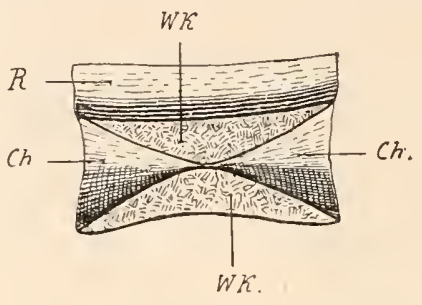

Fig. 175.

Thyrsidium fasciculare, Cope. Oberkarbon von Linton, Ohio. Wirbelkörper der Länge nach bis zur Mitte durchgebrochen, Neurapophysen entfernt; der im Leben von der Chorda und dem Rückenmark erfüllte Hohlraum ist hier von Gestein eingenommen.

Wk. = Wirbelkörper. $\quad R .=$ Rückenmark. $\quad C h .=$ Chorda dorsalis

Dieser Wirbelkörpertypus, bei welchem dic Pleurozentren gänzlich vom Aufbau des knöchernen Wirbels ausgeschlossen sind, die Basidorsalia dagegen die Hauptrolle spielen, ist von H. Gadow als „Pseudozentrum" bezeichnet worden.

Der primitive Zustand, welchen wir in den Wirbeln von Branchiosaurus antreffen, ist als „Blattwirbeltypus" oder "phyllospondyler" Typus unterschieden worden, bildet aber ebenso nur eine Entwicklungsstufe des pseudozentralen Wirbeltyps, wie die einheitlich verknöcherten Urodelenwirbel. Man hat früher diese ,Vollwirbler" mit ,ganzem" oder ,holospondyle n1" Wirbel den Plyyllospondylen gegenübergestellt; später sind sogar die Amphibien mit einheitlich ossifiziertem, bikonkavem und oft sanduhrförmigem (vgl. Fig. 175) Wirbelkörper als „lepospondyle" Formen unterschieden worden, ja man hat sie sogar als ,Lepospondyla“ (Zittel) den ,Temmospondyla“ (= Schnittwirbler, Jaekel) gegenübergestellt. Heute weiß man, daß der Begriff der Lepospondyla ein unnatürlicher, weil rein künstlicher ist, und daß ein Teil der ,Lepospondyla" (Ophiderpetontiden, Molgophiden, Phlegethontiiden, Ptyoniden 
und Ceraterpetontiden) dem pseudozentralen Wirbeltypus angehört, während der andere Teil der ,Lepospondyla“ dem gastrozentralen Wirbeltypus einzureihen ist.

\section{Notozentraler Typus.}

Dieser Wirbeltypus ist ausschließlich im Stamme der Anuren ausgebildet. Ursprünglich sind auch hier, wie die ontogenetische Entwicklung zeigt, vier Paare von Bogenelementen vorhanden gewesen; im weiteren Verlaufe des Wachstums, das in diesem Falle die Stammesgeschichte wiederspiegelt, nehmen die Interdorsalia außerordentlich $\mathrm{zu}$, verdrängen allmählich die Interventralia und bilden schließlich die Hauptmasse des Wirbelkörpers, während die Basiventralia (welche mit den Basidorsalia zu einer kompakten Masse verschmelzen) auf die vordere oder kraniale Hälfte des Wirbelkörpers beschränkt bleiben. Die Basiventralia können aber auch ganz verloren gehen (z. B. bei Pipa, Bombinator, Xenopus). In diesem Falle besteht der Wirbel nur mehr aus den Interdorsalia und den Basidorsalia.

H. Gadow hat diesen Wirbelkörpertypus, bei welchem das Zentrum aus den lnterdorsalia und den Basiventralia oder aus den Interdorsalia allein besteht, ,Notozentrum" genannt.

Bei normaler Ausbildung entsenden die Basiventralia jederseits einen lateralen Fortsatz (Querfortsatz) zur Rippenartikulation, außerdem ventrale Fortsätze, die als Hämapophysen in der Schwanzregion eine V-förmige Spange bilden, welche das ventral von der Wirbelsäule verlaufende Blutgefäß umschließt.

\section{Vl. Gastrozentraler Typus.}

Dem gastrozentralen Typus gehört nur ein kleiner Teil der fossilen Stegocephalen, aber alle Reptilien, Vögel und Säugetiere an. Er ist dadurch gekennzeichnet, daß die Hauptmasse des Wirbelkörpers aus den Interventralia besteht, während die Basiventralia (Hypozentrum) vom Aufbau des Wirbelkörpers meist gänzlich ausgeschlossen sind und nur mehr in Gestalt loser Hämapophysen (=Os en $\mathrm{V}=$ Chevron Bones) mit der Unterseite des Zentrums in Verbindung treten.

Die Basidorsalia bilden auch bei den Angehörigen dieses Wirbeltypus wie immer die Neurapophyse, während die Interdorsalia vollständig verloren gegangen sind.

H. Gadow nennt das dergestalt ausschließlich aus den Interventralia aufgebaute Zentrum das "Gastrozentrum".

Bei den lebenden Amphibien tritt dieser Wirbeltypus nicht auf; unter den fossilen Amphibien ist er bisher nur bei den Hylonomiden und Microbrachiden (Fig. 176) nachgewiesen. Wahrscheinlich ist er auch bei den Limnerpetontiden ausgebildet. 


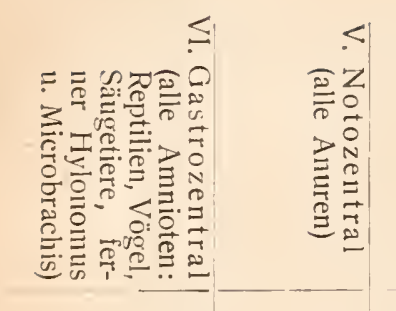

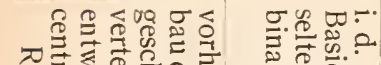

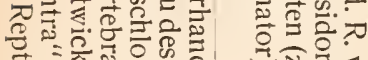

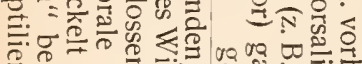
$\cong$ ․․․

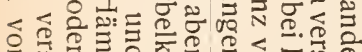

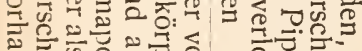

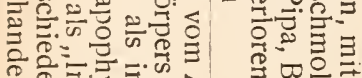

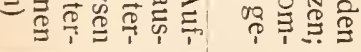

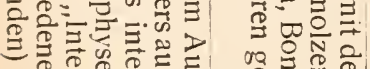

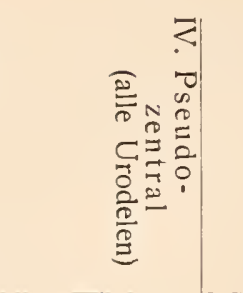

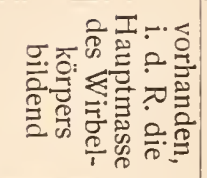

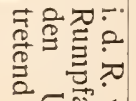

동ㅎㅁ

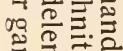

긍

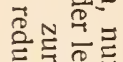

촉. 륭:

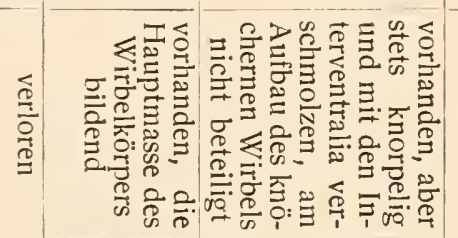

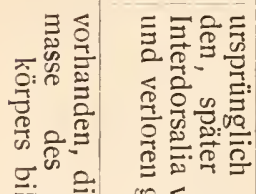

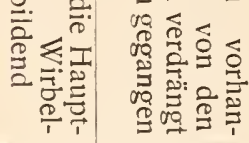

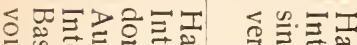

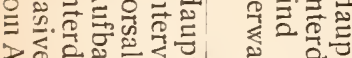

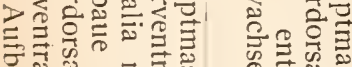

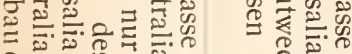
के № $\left.{ }^{\infty}\right)$

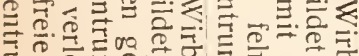
管

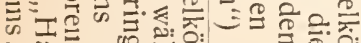

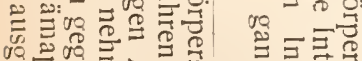

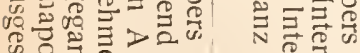

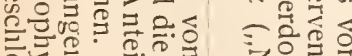

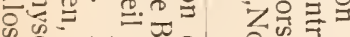

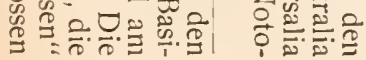

$\frac{2}{\frac{6}{6}}$

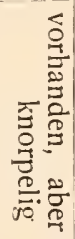

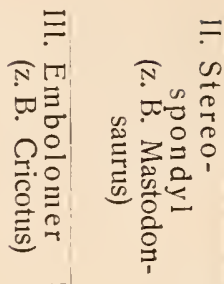
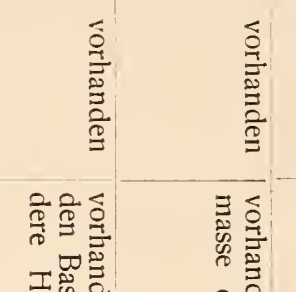

可: 竞:

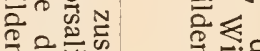

言虽

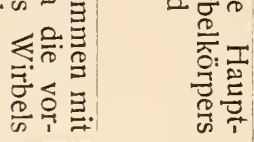
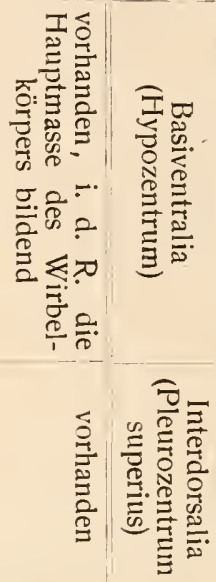

을켱

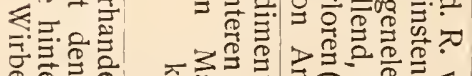

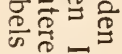

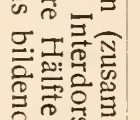

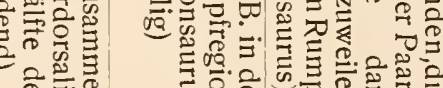

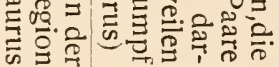

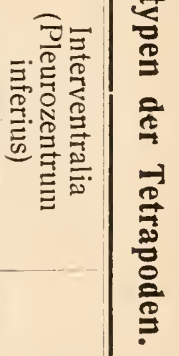


Zweifellos ist auch dieser Typus von einem primitiven Typus abzuleiten, bei dem alle vier Bogenelemente vorhanden waren, und geht also auf den rhachitomen Typus zurück.

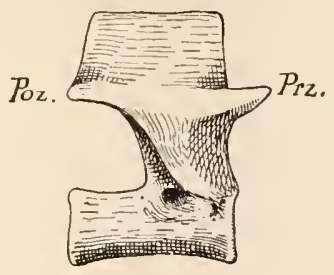

Fig. 176.

Microbrachis Pelikani, Fritsch. Oberkarbon von Nürschan, Böhmen.

Rumpfwirbel, von rechts gesehen. Vergr. (Nach H. Schwarz.) Prz. = Präzygapophyse. $\quad P o z_{0}=$ Postzygapophyse.

Die Wirbel der Amphibien treten untereinander in gelenkige Verbindung, und zwar sind normal an der Vorderseite des Wirbels die paarigen Präzygapophysen und an der Hinterseite die gleichfalls paarigen Postzygapophysen (Fig. 176-183) ausgebildet. Die Post-

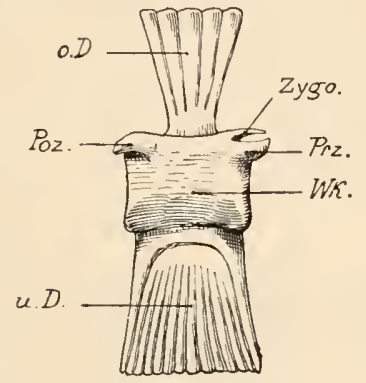

Fig. 177.

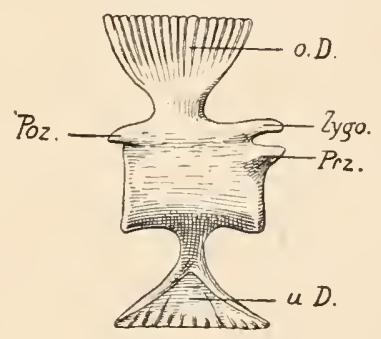

Fig. 178.

Oestocephalus remex, Cope. Oberkarbon von Linton, Ohio. Schwanzwirbel, von rechts gesehen. Vergr.

o. D. = oberer Dornfortsatz.

$u . D$. = unterer Dornfortsatz.

Prz. = Präzygapophyse.

Poz. = Postzygapophyse .

Zygo. = Zygosphen .

$W k$. = Wirbelkörper.

Ptyonius Vinchellianus (?), Cope. Oberkarbon von Linton, Ohio. Schwanzwirbel, von rechts gesehen. Vergr. (Nach H. Schwarz.)

o. D. = oberer Dornfortsatz.

u. D. = unterer Dornfortsatz.

Prz. = Präzygapophyse.

Poz. = Postzygapophyse.

Zygo. = Zygosphen .

zygapophysen greifen von oben nach unten in die Präzygapophysen des hinten oder kaudal anschließenden Wirbels ein und liegen dementsprechend etwas höher. Beide Zygapophysenpaare entspringen von der Neurapophyse.

Außer dieser normalen Art von Gelenkverbindung zwischen zwei anschließenden Wirbeln treten in vereinzelten Fällen (z. B. bei Urocordylus, 
Ptyonius, Oestocephalus, Diplocaulus) überzählige Gelenkverbindungen im Neurapophysenabschnitt, und zwar oberhalb der Zygapophysen auf (Fig. 177-180, 183). Über der Präzygapophyse entspringt in diesem Falle ein kranialwärts gerichteter, keilförmiger, unpaarer, medianer

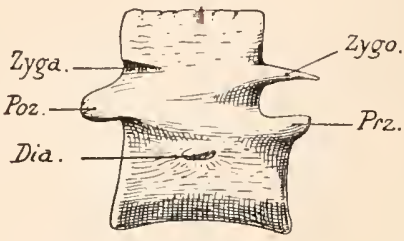

Fig. 179.

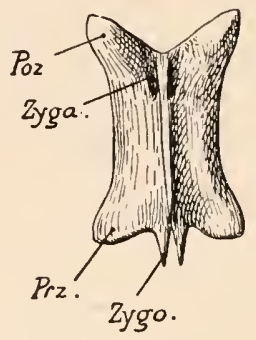

Fig. 180.
Ptyonius pectinatus, Cope. Oberkarbon von Linton, Ohio. Rumpfwirbel, von rechts gesehen. Vergr.

(Nach H. Schwarz.)

Zyga. = Zygantrum.

Zygo. = Zygosphen.

Prz. = Präzygapophyse

Poz. = Postzygapophyse.

Dia. = Diapophyse.

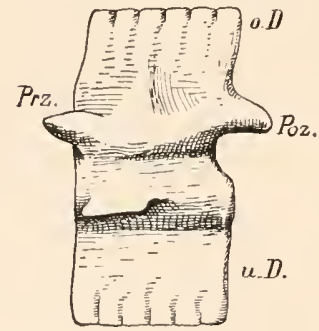

Fig. 181 .

Scincosaurus crassus, Fritsch.

Oberkarbon von Nürschan, Böhmen. Schwanzwirbel, von links gesehen. Vergr.

(Nach H. Schwarz.)

Prz. = Präzygapophyse.

Poz. = Postzygapophyse.

o. D. $=$ oberer Dornfortsatz.

ul. D. = unterer Dornfortsatz.

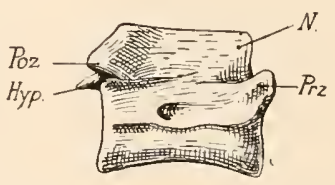

Fig. 182.

Phlegethontia linearis, Cope. Oberkarbon von Linton, Ohio. Rumpfwirbel, von rechts gesehen. Vergr. (Nach H. Schwarz.)

Prz. = Präzygapophyse.

Poz. = Postzygapophyse .

$N . \quad=$ Neurapophyse.

Hyp. = Hyposphen.

Fortsatz (Zygosphen) von der Neurapopliyse, der in eine gleichfalls median gelegene Vertiefung (Zygantrum) an der Hinterseite der Neurapophyse des vorausgehenden Wirbels über den Postzygapopliysen eingreift. Mitunter kommt es jedoch zu einer Spaltung des Zygosphens; in diese Gabel schiebt sich der hintere Kamm der Neurapophyse hinein 
und die Gelenke für das Zygosphen werden von keilförmig nach vorn sich zuspitzenden Gruben an den Außenseiten der Neurapophyse gebildet, wie dies bei Ptyonius der Fall ist (Fig. 180, Zygo u. Zyga). Bei

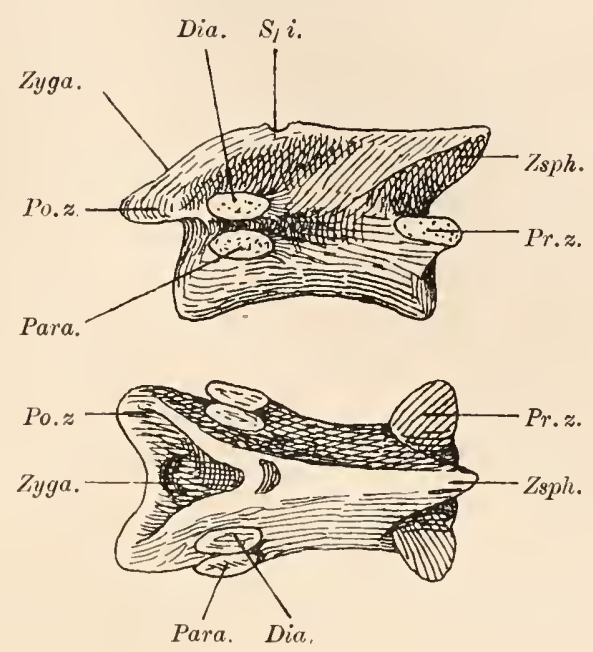

Fig. 183.

Wirbel von Diplocaulus, aus dem Perm von Texas; oben: Ansicht von rechts, unten: Ansicht von oben. Nat. Gr. (Nach F. Broili.)
Dia. = Diapophyse.
Para. = Parapophyse.
Po.z. = Postzygapophyse.
$\operatorname{Pr} . \dot{z} .=$ Praezygapophyse.
Zyga. = Zygantrum.
Zsph. = Zygosphen

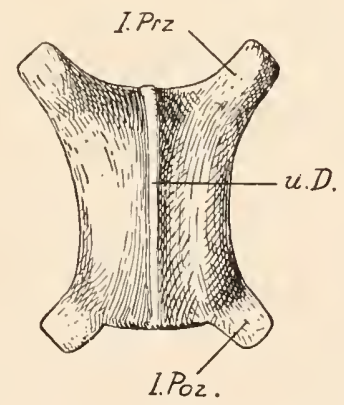

Fig. 184.

Dolichosoma longissimum, Fritsch. Oberkarbon von Nürschan, Böhmen.

Wirbel, von unten gesehen. Vergr. (Nach H. Schwarz.)

I. Prz. = Infra-Präzygapophyse. $\quad$ I. Poz. = Infra-Postzygapophyse. u. D. = unterer Dornfortsatz.

den Phlegethontiiden tritt (bei Phlegethontia) an Stelle des Zygosphens und Zygantrums eine akzessorische mediane Gelenkverbindung auf, bei welcher der Zapfen an Hinterende der Neurapophyse, die Vertiefung am Vorderende derselben steht. Dieser mediane, kaudalwärts stehende 
Zapfen wird Hyposphen, die ilhn, aufnehmende Vertiefung des anschließenden Wirbels Hypantrum genannt (Fig. 182).

In einigen Fälleıı (z. B. bei Phlegethontia und Dolichosoma unter den Stegocephalen, sowie bei den lebenden Blindwühlen) sind auch an der Ventralseite der Wirbelkörper überzählige paarige Gelenkfortsätze ausgebildet, für welche die Bezeichnung , Infrazygapophysen“ anzuwenden wäre. Ein Wirbel von Dolichosoma (Fig. 184) gibt, von der Ventralseite gesehen, ein ähnliches Bild, wie derselbe Wirbel von der Oberseite, nur besteht ein wichtiger Unterschied darin, daß die vorderen Gelenkfortsätze der Unterseite die hinteren des vorhergehenden Wirbels überlagern, während die vorderen Gelenkfortsätze der Oberseite (Präzygapophysen) von den hinteren des vorhergehenden Wirbels (Postzygapophysen) überlagert werden. Durch diese akzessorischen Gelenkverbindungen wird die Verbindung der Wirbel untereinander eine außerordentlich feste.

\section{Die Terminologie der Wirbelkörper nach der Form.}

Die Wirbelkörper besitzen in allgemeinen eine zylindrische Gestalt, aber ihre Endflächen sind entweder flach oder konvex oder konkav, so daß wir eine Anzahl verschiedener Typen zu unterscheiden haben ${ }^{1}$, die in der systematischen Gruppierung der Reptilien eine wichtige Rolle spielen. Diese Typen sind:

\begin{tabular}{|c|c|c|c|c|c|}
\hline \multicolumn{2}{|c|}{ Form der Endflächen } & \multirow{2}{*}{ Linsentypen } & \multirow{2}{*}{$\begin{array}{c}\text { Terminologie } \\
\text { nach Owen }\end{array}$} & \multirow{2}{*}{$\begin{array}{l}\text { Terminologie } \\
\text { nach Wieland }\end{array}$} & \multirow{2}{*}{ Beispiele } \\
\hline vordere & hintere & & & & \\
\hline flach & flach & plan & amphiplatyan & platyan & Plesiosauria usw. \\
\hline konvex & konvex & bikonvex & bikonvex & cyrtean & $\begin{array}{c}\text { erster Kaudal- } \\
\text { wirbel von Diplo- } \\
\text { docus }\end{array}$ \\
\hline konkav & konkav & bikonkav & amphicoel & coelian & $\begin{array}{l}\text { Ichthyosauria, } \\
\text { Stenosaurus usw. }\end{array}$ \\
\hline flach & konkav & planokonkav & platycoel & platycoelian & Metriorhynchus \\
\hline konkav & flach & konkavplan & - & coeloplatyan & $\begin{array}{l}\text { erster Sakral- } \\
\text { wirbel der leben- } \\
\text { den Krokodilier }\end{array}$ \\
\hline konkav & konvex & konkavkonvex & procoel & coelocyrtean & Mosasauria \\
\hline konvex & konkav & konvexkonkav & opisthocoel & cyrtocoelian & Streptospondylus \\
\hline $\begin{array}{l}\text { sattel- } \\
\text { förmig }\end{array}$ & $\begin{array}{l}\text { sattel- } \\
\text { förmig }\end{array}$ & - & - & $\begin{array}{l}\text { ephippisch, } \\
\text { platyhippisch } \\
\text { usw. }\end{array}$ & Vögel \\
\hline
\end{tabular}

1 G. R. Wieland, The Terminology of Vertebral Centra. - Amer. Journ. of Science (4), VIII, 1899, p. 163. 


\section{Unterklasse: Stegocephalia (Stegocephalen).}

\section{Der Schädelbau der Stegocephalen.}

Unı den Schädelbau der Stegocephalen richtig erfassen und verstelıen zu können, ist es nötig, eine der fossilen Typen als Ausgangspunkt der morphologischen Analyse zu wählen, da der Schädel der lebenden Urodelen, Anuren und Gymnophionen auf divergenten Entwicklungswegen entstanden und einen zu hohen Spezialisationsgrad erreicht hat, um als Grundlage der Darstellung gewählt werden zu können. Wie wir später sehen werden, hat der Gymnophionenschädel nur scheinbar die meisten altertümlichen Züge des Stegocephalenschädels unter den drei genannten Stämmen bewahrt (vgl. S. 332).

Das wesentliche Kennzeichen des ursprünglichen Stegocephalenşchädels besteht in denl geschlossenen Schädeldach, denl die für fast alle Reptilien bezeichnenden Schläfendurchbrüche fehlen. Allerdings konınt es bei einigen Stegocephalengattungen (z. B. bei Cacops und Trenlatops) durch das Vorrücken der am Hinterrande des Schädeldaches gelegenen Ohröffnung und den hinteren Abschluß derselben - durch das Tabulare zu der Bildung einer Schädelöffnung, die an die obere Temporalöffnung der Reptilien erinnert, aber sie isto derselben nicht homolog.

Der knöcherne Schädel oder das Schädelskelett besteht aus einer Anzahl von Knorpelknoclien, d. h. solchen, die knorpelig präformiert sind, und aus einer Anzahl von Deckknochen oder Belegknochen, welche in der Haut entstehen und somit als Hautverknöcherungen zu betrachten sind. Da die Knorpelknochen dadurch entstehen, daß die Knochenmasse den vorher zur Ausbildung gelangten Knorpel allmälılich verdrängt oder richtiger ersetzt, so werden sie auch als „Ersatzknochen“ bezeichnet.

Unter den Deckknochen werden zwei Kategorien unterschieden. Die erste Gruppe von Knochen gehört dem Bereiche der Oberseite und der Seitenflächen des Knorpelschädels an und umfaßt Knochen, welche in der Haut entstanden sind und sich später in die Tiefe gesenkt haben. Diese. Gruppe kann als die Gruppe der Hautknoclien bezeichnet werden.

Die zweite Gruppe der Deckknochen hat O. Hertwig (1874) als Zahnknochen bezeichnet, d. 1. sie sind nach dieser Auffassung aus der Verwachsung von Einzelzähnen entstanden. Sie gehören der Mundund Gesichtsregion des Schädels an. 


\title{
Der Aufbau des Stegocephalenschädels.
}

\section{Die' Deckknochen des Schädels. ${ }^{1}$}

\author{
A. Hautknochen.
}

Nasale. Vorn an das Praemaxillare stoßend, den Hinterrand der vorderen Nasenöffnung bildend, dann an das Supramaxillare grenzend. Dann wendet sich die Außengrenze des Nasale einwärts, stößt an der Knickungsstelle mit der vorderen Spitze des Adlacrymale zusammen, läuft dem Lacrymale ein Stück weit entlang und biegt an der Grenze gegen das Frontale scharf nach vorn und innen in der Richtung zur Mittellinie ab.

Internasale. Ein umpaarer Knochen, vor dem Vorderende beider Nasalia und zwischen den Praemaxillaria gelegen. Er ist bis jetzt nur bei Micropholis Stowi, Huxley, aus der Trias der Kapkolonie beobachtet worden. Ob er als ein gelegentlich auftretender Schaltknochen (= Interkalarknochen $=$ Os Wormianum) anzusprechen ist oder, wie Broili (1916) meint, als eine Verknöcherung des Ethmoidknorpels anzusehen ist, muß einstweilen unentschieden bleiben.

Frontale. Vorn an das Nasale, außen an das Lacrymale stoßend, weiter den vorderen Teil des Innenrandes der Augenhöhle bildend, dann an das Postfrontale stoßend und von hier senkrecht auf die Mittellinie nach innen längs der Naht gegen das Parietale laufend.

Parietale. Vorn an das Frontale, außen zuerst an das Postfrontale, damn an das Supratemporale stoßend, dann in fast rechten Winkel gegen die Mittellinie abbiegend und längs des Vorderrandes des Dermosupraoccipitale gegen die Mittellinie ziehend,

Dermosupraoccipitale. ${ }^{2}$ Das Dermosupraoccipitale stößt vorn an das Parietale, seitlich an das Supratemporale und das hinter demselben liegende Tabulare und bildet, paarig entwickelt, den Mittelteil des Hinterrandes des Schädeldaches. Es bildet ferner den Oberrand des Foramen magnum und stößt an der Hinterwand des Schädeldaches mit dem Supraoccipitale zusammen.

1 Als Beispiel und zur Einführung in die Morphologie der. Deckknochen des Schädels ist hier der Schädel von Capitosaurus nasutus H. v. Meyer aus dem Buntsandstein Deutschlands (Untertrias) zugrunde gelegt, obwohl die hier zu beobachtenden Verhältnisse keineswegs bei allen Stegocephalen dieselben sind. Schädel und Unterkiefer dieses rhachitomen Stegocephalen haben als Gipsabgiisse weite Verbreitung gefunden, weshalb dieser Typus als Grundlage gewählt wurde.

${ }^{2}$ Früher meist mit dem Supraoccipitale verwechselt, das jedoch ein Knorpelknochen und kein Deckknochen ist. Eine andere, von R. Broom in den letzten Jahren neu eingeführte Bezeichnung ist ,Postparietale“. Der Name „, Dermosupraoccipitale" wurde von Miall 1878 aufgestellt und neuerdings von F. v. Huene (1913) wieder in Erinnerung gebracht. 
Centroparietale. Dieser unpaare Knochen liegt zwischen den Parietalia und den Dermosupraoccipitalia (= Postparietalia) von Aphaneramn11a rostratum, A. S. Woodward, aus der Trias von Spitzbergen. ${ }^{1}$

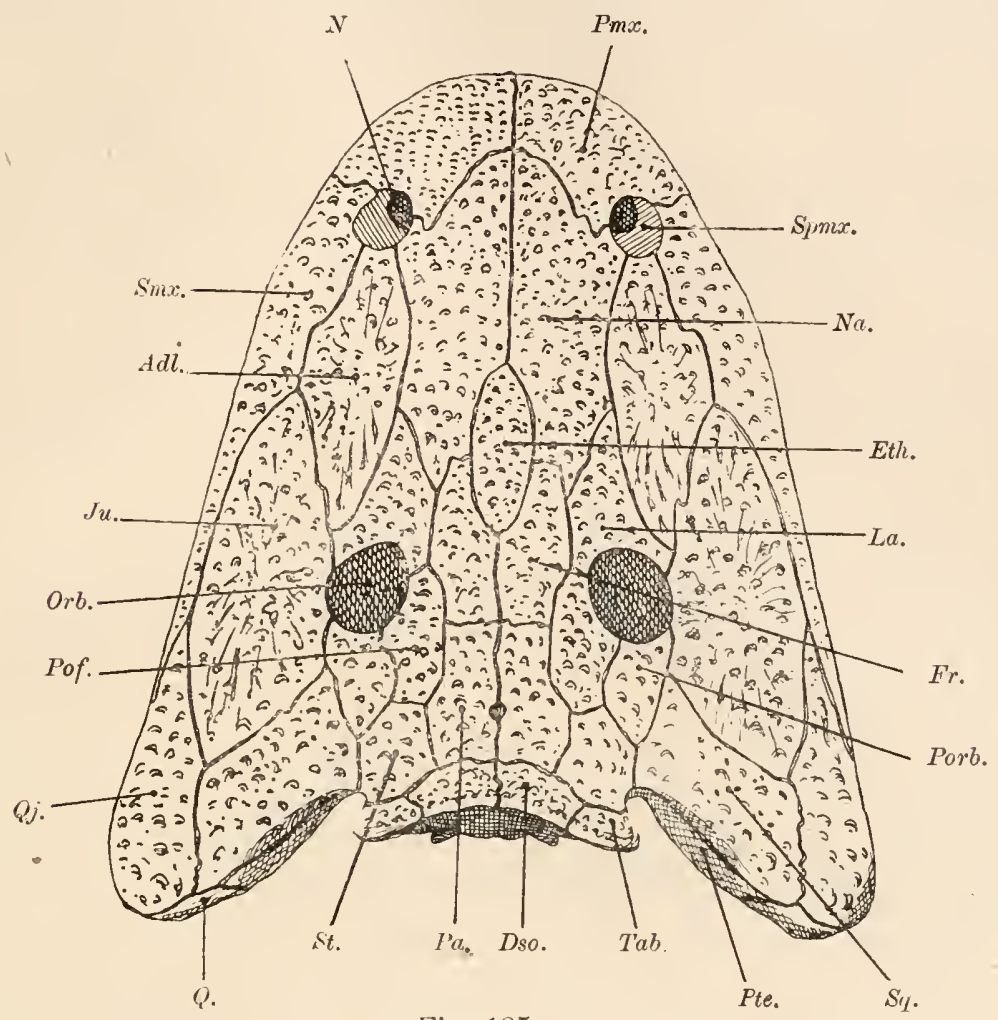

Fig. 185.

Schädel von Eryops megacephalus, Cope, aus dem Perm von Texas; Dorsalansicht des Schädeldaches in $1 /$ nat. Gr. '(Nach R. Broom, 1913.)
Adl. = Adlacrymale.
Pof. $=$ Postfrontale
Dso. = Dermosupraoccipitale. Porb. = Postorbitale.
Eth. = Ethmoidale.
Pte. = Pteroticum.
Fr. - Frontale.
Ju. $\quad=$ Jugale.
La. = Lacrymale.
$N$. = Nasenöffnung.
$\begin{array}{ll}\text { Q. } & =\text { Quadratum. } \\ \text { Qj. } & =\text { Quadratojugale. }\end{array}$
Smx. = Supramaxillare.
Na. $=$ Nasale.
Orb. = Orbita
$P a . \quad=$ Parietale.
Spmx. = Septomaxillare.
$S q . \quad=$ Squamosum .
St. = Supratemporale
Tab. = Tabulare.

Pmx. $=$ Praemaxillare .

Da er bisher bei keinem einzigen anderen Vertebraten aufgefunden worden ist, dürfte es sich höchstwahrscheinlich um einen akzessorischen, überzähligen Schaltknochen oder Nahtknochen (Os Wormianum)

1 C. Wiman, Über die Stegocephalen aus der Trias Spitzbergens. -- Bull. Geol. Inst. Upsala, X1II, 1914, p. 18. 
handeln. Seine Lage unterscheidet ihn vom Interparietale der Reptilien und Säugetiere wie auch vom Praeparietale der Reptilien (zwischen die Parietalia und Frontalia eingeschalteter medianer Knochen, gleichfalls ein „Nahtknochen“, der bei Lystrosaurus, Dicynodon, Gordonia, Gorgonops, Galepus nachgewiesen wurde). ${ }^{1}$

Tabulare. ${ }^{2}$ An das Dermosupraoccipitale schließt sich hinten das Tabulare an, welches zapfenförmig nach hinten und außen vorspringt. Vorn grenzt es an das Supratemporale, weiter außen an das Squamosum und tritt auf der Schädelhinterwand mit dem unter ihm liegenden Exoccipitale in Verbindung.

Intertemporale. ${ }^{3}$ Dieser paarige, bei Capitosaurus fehlende Knochen ist Z. B. bei Trimerorhachis insignis (Fig. 202) selbständig entwickelt, wo er vom Postfrontale, Postorbitale, Supratemporale und Parietale ringsum eingeschlossen wird. Er findet sich auch bei Gephyrostegus (Fig. 230, Jsq).

Supratemporale. ${ }^{4}$ Bei Capitosaurus wird dieser Deckknochen vom Parietale, Postfrontale, Postorbitale, Squamosum, Tabulare und Dermosupraoccipitale ringsum eingeschlossen und stößt daher nit sechs Knochen zusammen.

Squamosum. ${ }^{5}$ Dieser Knochen grenzt innen an das Tabulare, weiter vorn an das Supratemporale, Postorbitale, außen an das Jugale und an das hinter diesem sich anschließende Quadratojugale, und stößt ạn der Hinterwand des Schädels mit dem Opisthoticum und Pterygoideum zusammen.

Quadratojugale. Das Quadratojugale bildet in der Regel die hintere Außenecke des Schädeldaches, tritt vorn mit dem Jugale, innen mit dem Squamosum und unten an der Schädelhinterwand mit dem Quadratum in Verbindung.

1 F. Broili, Unpaare Elemente im Schädel von Tetrapoden. - Anatom. Anzeiger, XL1X, 1917, p. 566.

2 Die Bezeichnung Tabulare stammt von E. D. Cope. Später wurde von Cope der Terminus , intercalare“ für diesen Knochen angewendet, der aber schon für zwei andere Skelettelemente vergeben ist. R. Broom hat nun in den letzten Jalıren die Bezeichnung „Postparietale“ angewendet. Die Bezeichnung als „Epioticum" ist unrichtig, da die Epiotica Knorpelknochen, die Tabularia aber Hautknochen sind.

3 O. Jaekel bezeichnet ihn nach dem Vorschlag Baurs als ,,Intersquamosum“ (bei Gephyrostegus bohemicus); vgl. Fig. 230, Isq. - Dieser Knochen entspricht jedoch offenbar dem Supratemporale (fälschlich als Squamosum bezeichnet) von Capitosaurus nasutus (vgl. H. Schroeder, Ein Stegocephalenschädel von Helgoland. Jahrb. Kgl. Preuß. Geol. Landesanstalt, XXXI1I. Bd., 1913, Taf. 17, p. 243).

4 Irrtiimlich wird dieser Knochen häıfig mit dem Squamosum identifiziert.

5 Nach dem Vorsclilage von G. Baur (1895) wiederholt als ,, Prosquamosum“ bezeichnet, so zuletzt von H. Schroeder (1913). 
Jugale. Das Jochbein nimmt an Außenrande des Schädeldaches einen relativ großen Raum ein. Es grenzt vorn an das Supramaxillare, weiter innen und hinten an das Adlacrymale, weiter nach hinten an das Lacrymale, bildet einen Teil des Außenrandes der Augenhöhle, tritt weiter mit den Postorbitale in Verbindung, trifft hinter diesem mit dem Squamosum und an seinem hinteren Ende mit dem Quadratojugale zusanmen.

Postorbitale. Dieser Deckknochen bildet einen großen Teil des Hinterrandes der Augenhöhle und grenzt von innen nach außen zuerst an das Postfrontale, dann an das Supratemporale, Squamosum und Jugale.

Postfrontale. Ein relativ kleiner Knochen zwischen Frontale, Parietale, Supratemporale und Postorbitale, der einen Teil des Augenhöhleninnenrandes bildet.

Lacrymale. ${ }^{1}$ Zwischen dem Frontale, Nasale, Adlacrymale und Jugale liegend und den Vorderrand der Orbita bildend.

Adlacrymale. ${ }^{2}$ Dieser Knochen liegt zwischen dem Supramaxillare, Jugale, Lacrymale und Nasale (bei Capitosaurus) und bildet hier einen Teil der Begrenzung des Nasenloches.

Septomaxillare ${ }^{3}$ (= Intranasale, Gaupp). Dieser bisher meist übersehene kleine Knochen ist in der Regel nur in der Tiefe der vorderen Nasenöffnung unter deren Hinterrand sichtbar. Er ist bei vielen Stegocephalen nachgewiesen (z. B. bei Eryops, Trimerorhachis, Zatrachys) und findet sich auch inı Froschschädel (z. B. bei Rana temporaria) vor.

Scleroticalia. Der Augapfel vieler Stegocephalen wird durch eine Reihe kleiner Hautknochenplättchen geschützt, welche sich ringförmig aneinanderlegen. Ihre Zahl ist sehr verschieden, scheint aber bei den. Branchiosauriden am größten gewesen zu sein. Der durch diese Scleroticalia gebildete Knochenring wird als ",Sklerotikalring" bezeichnet. Bei Stereocyclops, einem lebenden Engmaulfrosch, ist ein Sklerotikalring festgestellt worden.

1 Früher fast allgemein als ,Praefrontale" bezeichnet, bis zuerst $O$. Jaekel (1903) und später E. Gaupp (1910) nachwiesen, daß dieser Knochen dem lacrymale der Säugetiere homolog ist.

2 Von E. Gaupp (1910) so benannt an Stelle des ,Lacrymale“. O. Jaekel hatte 1905 die Bezeichnung ,Postnasale“ vorgeschlagen, die aber unglücklich gewählt ist und daher keinen Anklang gefunden hat.

${ }^{3}$ Von E. D. Cope als ,turbinated bone“ bezeichnet. Die Benennung ,Septomaxillare" stammt von Swinnerton und Howse. 
B. Zahnknochen.

Parasphenoideum (= Parabasale, Gaupp). Das Parasphenoid ist ein unpaarer Knochen, dessen hinterer Teil als Platte entwickelt ist, die seitlich mit den Pterygoidea in Verbindung tritt. Diese Platte ist zuweilen (z. B. bei Acanthostoma, Dawsonia, Zatrachys) mit kleinen

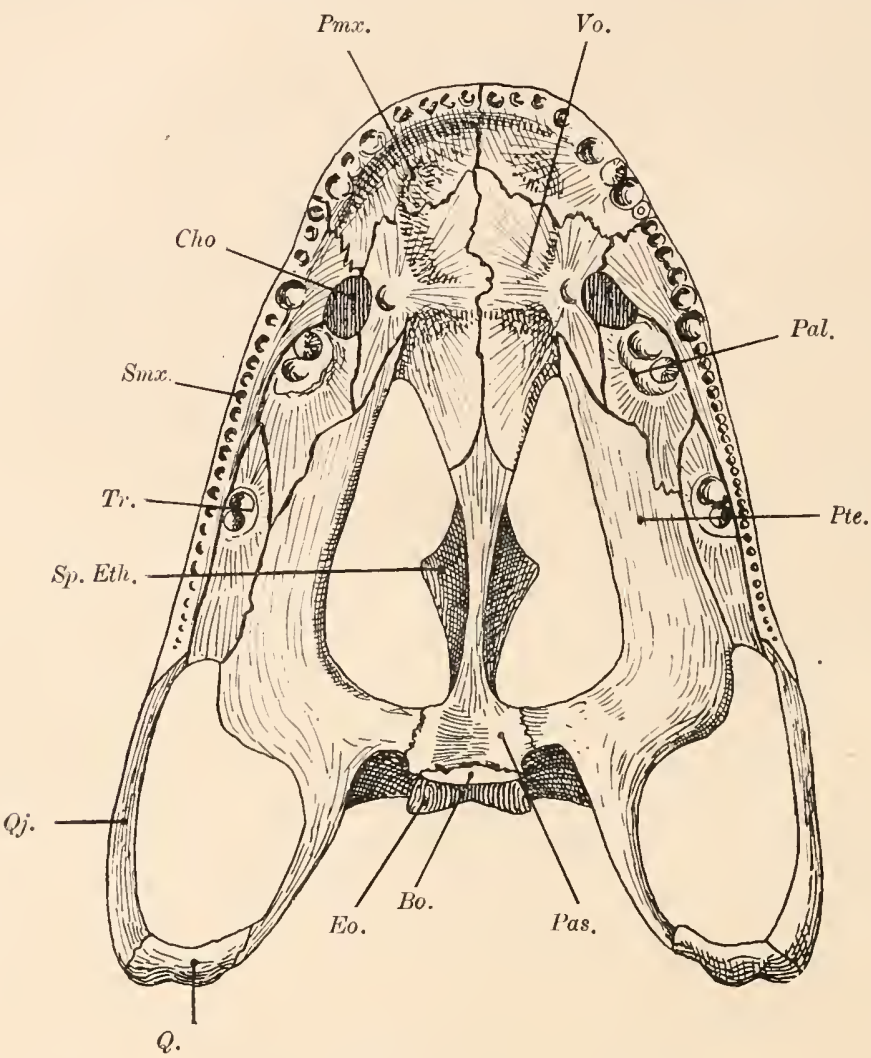

Fig. 186.

Unterseite des Schädels von Eryops megacephalus, Cope, aus dem Perm Nordamerikas, in $1 / 4$ nat. Gr. (Nach R. Broom, 1913.)
Bo. $=$ Basioccipitale.
Q. $\quad$ = Quadratum.
Cho. = Choane
Qj. $\quad=$ Quadratojugale.
Eo. = Exoccipitale
Smx. = Supramaxillare.
Pal. = Palatinum.
$S p . E t h .=$ Sphenethmoid.
Pas. $=$ Parasphenoid
Tr. $\quad=$ Transversum.
Pmx. = Praemaxillare.
Vo. $=$ Vomer.

Pte. $=$ Pterygoid .

Zähnen besetzt, bei anderen (z. B. bei Trematosaurus) wie ein Schädeldachknochen skulpturiert, bei anderen (z. B. Branchiosaurus) glatt. Nach vorn läuft das Parasphenoid in einen langen, sehr schlanken Stiel (Processus cultriformis) aus, der die mittlere Trennungs- 
leiste der beiden außerordentlich großen Gaumenöffnungen bildet. An das Vorderende des langen Parasphenoidstiels legen sich seitlich die kleinen Palatina und vor diesen die (ursprünglich paarigen) Vomeres all.

Palatinum. Das Palatinum der Stegocephalen trägt meist eine der Zahnreihe des Oberkiefers parallele Zahnreihe, grenzt außen an das Supramaxillare, hinten und innen an das Pterygoid und tritt vorn (z. B. bei Acanthostoma, wo es zahlreiche Zähne trägt, oder bei Cyclotosaurus, wo es eine Reihe Zähne trägt) nit dem Vomer in Verbindung. An seiner linteren Außenecke trifft es mit dem Quadratojugale zusammen.

Pterygoideum. Das Pterygoid stößt innen mit breiter Nahtfläclıe an das Parasphenoid und entsendet nach vorn einen meist sehr schlanken, zarten, spangenförmigen Fortsatz, der mit den Palatinum in Verbindung tritt. Zuweilen grenzt es vorn aucl1 an den Vomer. Das Hinter- und Außenende grenzt an das. Exoccipitale. Das Pterygoid ist mitunter bezahnt (z. B. bei Zatrachys, Dawsonia, Acanthostoma und Batrachiderpeton).

Transversum $\quad(=$ Ectopterygoideum $=$ Transpalatinum $)$ Vom Pterygoid, Palatinum und Supramaxillare durch Nälıte getrennt. Es trägt (z. B. bei Diplocaulus, Fig. 228) mitunter eine Reile kleiner Zähne, die sich auf das Palatinum fortsetzt, bei Acanthostoma außerdem einen größeren „Fangzalı". Das Transversum ist derselbe Knochen, der im Krokodilschädel als ,,Transpalatinum" bezeichnet wird.

Vomer (= Praevomer, Broom). Auch der Vomer erweist sich durch seine Bezahnung als Zahnknoclen. Entweder trägt er (z. B. bei Capitosaurus, Mastodonsaurus, Cyclotosaurus) neben einer Reihe kleiner Zähne noch ein bis zwei Paar großer, kegelförmiger Fangzähne, oder er ist (z. B. bei Acanthostoma, Zatrachys) mit sehr zahlreichen Zälnnen bedeckt. Er grenzt außen an das Praemaxillare, Supramaxillare und das Palatinum, und tritt hinten in der Mittellinie des Schädels 111it dem Parasphenoid in Verbindung.

Praemaxillare. Das Vorderende der Schnauze bildend. Es grenzt hinten an das Supramaxillare und an den Vomer und trägt eine Zahnreihe.

Supraniaxillare. Der Oberkieferknochen stößt vorn an das Praemaxillare, innen an das Palatinum und den Vomer und hinten an das Quadratojugale. Er trägt eine Zalınreihe.

\section{Die Knorpelknochen des Schädels.}

Dic Knorpelknochen werden gewöhnlich in vier Gruppen zusammengefaßt: 1. Occipitalia (Hinterlauptbeine), 2. Otica (Olnrknoclıen), 3. Sphe- 
noidalia (Keilbeine), 4. Ethmoidalia (Siebbeine). Dazı treten aber noch das Quadratum und das Epipterygoid, welche dem Gebiete des Kieferbogens angehören und aus dem Palatoquadratum hervorgegangen sind.

Supraoccipitale. Das unpaarige Supraoccipitale ist ein echter Ersatzknochen und dari daher nicht mit dem Dermosupraoccipitale verwechselt werden. Es ist bisher nur bei Gymnarthrus nachgewiesen, wo es zwischen den Dermosupraoccipitalia und den Exoccipitalia an der Hinterwand des Schädels sichtbar ist. Sonst scheint es bei den Stegocephalen im knorpeligen Zustande verharrt zu haben; an seiner Stelle ist meist eine Lücke an der Schädelhinterwand sichtbar.

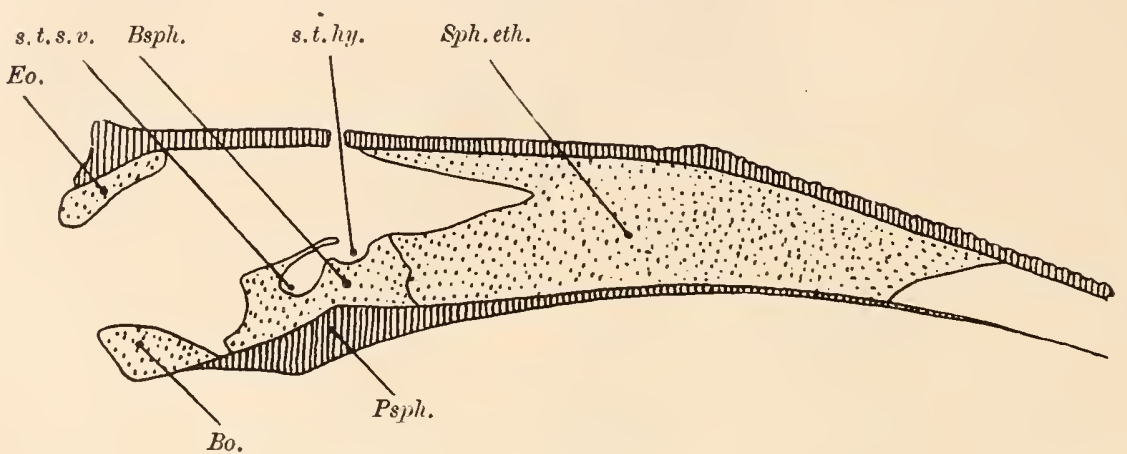

Fig. 187.

Längsschnitt durch den Schädel von Eryops megacephalus, Cope, ungefähr in

$1 / 2$ nat. Gr. (Nach R. Broom, 1913.)

Die Deckknochen sind senkrecht schraffiert, die Knorpelknochen punktiert dargestellt.

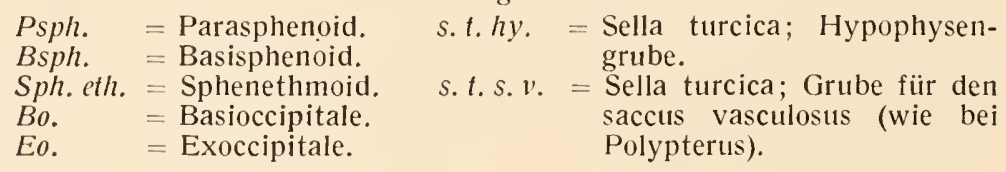

Exoccipitale (= Occipitale laterale). Dieser paarig entwickelte Knochen stößt oben an das Dermosupraoccipitale (wenn es nicht durch das Supraoccipitale von ihm getrennt wird), außen und seitlich an das Prooticum und unten an das Basioccipitale. Die Exoccipitalia bilden den Hauptteil der Unfassung des Foramen magnum (Hinterhauptsloch), sowie die Kondylen (Gelenkhöcker = Condylus occipitalis) des Hinterhauptes.

Basioccipitale. Ein unpaarer Knochen, der sich zwischen die Exoccipitalia an der Schädelbasis einschiebt und vorn mit dem Basisphenoid in Verbindung tritt. In Vergleich zu dem bei den Stegocephalen stets großen Basisphenoid ist das Basioccipitale sehr klein und daher schwer nachzuweisen.

Basisphenoideum. Gleichfalls ein unpaarer Knochen der Schädelbasis, der sich vorn an das Basioccipitale anlegt und an seiner der Unter- 
seite des Gehirns zugekehrten Oberseite eine tiefe Grube (für die Hypophyse des Zwischenhirns), die Fossa pituitaria oder Sella turcica (Türkensattel), aufweist.

Sphenethmoideum. Dieser unpaare Knorpelknochen bildet an der Schädelbasis die vordere Fortsetzung des Basisphenoids und füllt den Zwischenraum zwischen dem Parasphenoid und den Schädeldach aus. Sein Hinterende ist zur Aufnahme des Vorderendes des Gehirns tief ausgehöhlt. Dieser Abschnitt entspricht vielleicht dem Präsphenoid der Säugetiere (R. Broom, 1913).

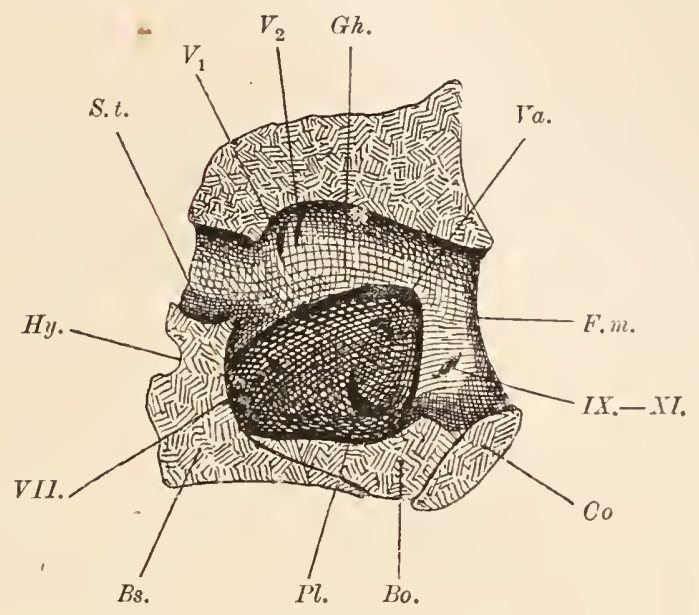

Fig. 188.

Eryops spec. Perm von Nordamerika. Längsschnitt durch den hinteren Teil der Schädelkapsel; Ansicht der rechtsseitigen Hälfte derselben von innen, Decke und Basis der Gehirnkapsel durchschnitten. Originalzeichnung in $3 / 4$ nat. Gr. auf Grund der von F. v. Huene (1912) veröffentlichten Skizzen der Präparate Nr. 4178 und 4188

in Am. Mus. Nat. Hist. (New York). Erklärungen nach v. Huene.

\begin{tabular}{|c|c|c|}
\hline$V_{1}$ und & $=$ Austrittsstellen des N. trige- & S.t. = Sella turcica. \\
\hline VII. & $\begin{aligned} & \text { minus. } \\
= & \text { Austrittsstelle des N. facialis }\end{aligned}$ & $\begin{aligned} H y^{\prime} \cdot & =\text { Hypodyse }(\text { Hypophysen- } \\
\text { grube) } & \text {. } \\
V q & =\text { Venenloch }\end{aligned}$ \\
\hline & $=$ Austrittsstelle des IX. bis & $\begin{array}{l}\text { Condylus occipitalis. } \\
\text { Basioccipitale. }\end{array}$ \\
\hline $\mathrm{Pl}$. & $\begin{array}{l}=\text { Austrittsstelle der perilym- } \\
\text { phatischen Gefäße. }\end{array}$ & $\begin{array}{l}\text { Bs. }=\text { Basisphenoid. } \\
\text { Gh. }=\text { Gehirnhöhlenraum. }\end{array}$ \\
\hline$m$ & $=$ Foramen magnum. & \\
\hline
\end{tabular}

Ethmoidale. Bei verschiedenen Stegocephalen, z. B. bei Eryops ${ }^{1}$ aus dem Perm Nordamerikas, bei Osteophorus Roemeri.H. v. Meyer aus dem Perm von Löwenberg in Schlesien ${ }^{2}$, bei Trematosaurus Sobeyi

1 R. Broom, Studies on the Permian Temnospondylous Stegocephalians of North America. - Bull. Am. Mus. Nat. Hist., XXXI1, Nov. 1913, p. 585 und 591.

2 H. v. Meyer, Osteophorus Roemeri aus dem Rotliegenden von KleinNeuendorf in Schlesien. - Palaeontographica, VII. Bd., 1859, p. 101. 
Haughton aus der Trias Südafrikas ${ }^{1}$ und bei Ricnodon aus der oberkarbonischen Gaskohle von Nürschan in Böhmen² tritt zwischen den Nasalia und Frontalia in der Medianebene des Schädels ein unpaarer Knochen auf, der als Internasofrontale (H. v. Meyer, 1859), Nasofrontale oder neuerdings von D. M. S. Watson (1913) als Interfrontale bezeichnet worden ist. Schon H. v. Meyer sprach die Vermutung aus, daß es sich hier um eine Verknöcherung des Siebbeines (Ethmoideums) zu handeln scheine, die bei den Anuren und Gymnophionen (z. B. bei Siphonops) an derselben Stelle des Schädeldaches

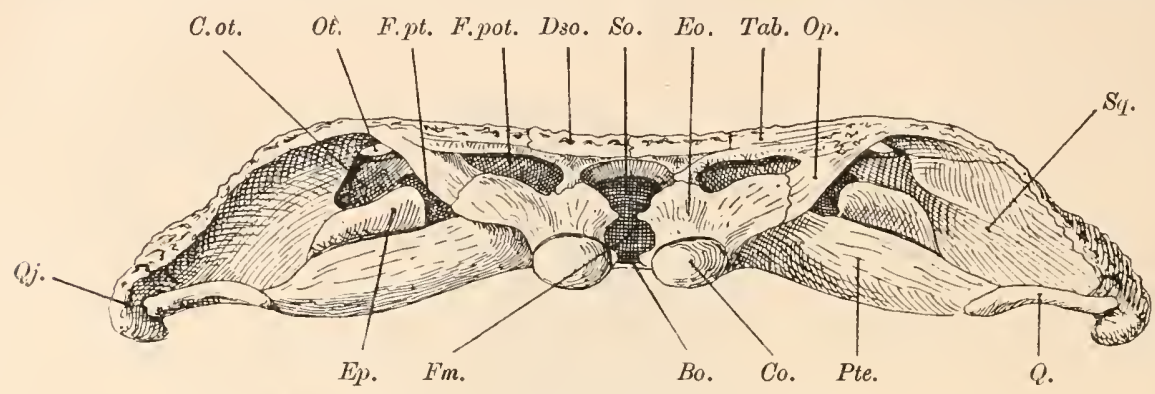

Fig. 189.

Hinterhaupt von Cyclotosaurus posthumus E. Fraas aus dem oberen Keuper (Stubensandstein) von Pfaffenhofen in Württemberg. (Ungefähr $1 / 2$ nat. Gr.) Nach E. Fraas, 1913.
So. Öffnung der Schädelwand, die
beim lebenden Tiere durch ein
knorpeliges Supraoccipitale ver- schlossen war.
Q. $\quad=$ Quadratum.
Qj. = Quadratojugale.
Ep. = Epioticum.
Op. = Opisthoticunl.
Bo. = Öffnung, die beim lebenden Tiere durch das knorpelig ge- bliebene Hinterende des Basi- occipitale verschlossen war.
Ot. = sekundär zu einem Fenster ver- schlossener Otikalschlitz.
C. ot. = Oticalgrube.
F. $m$. = Foramen magnum.
$F . p t .=$ Fenestra pteroccipitalis.
Dso. $\quad$ Dermosupraoccipitale.
Tab. $=$ Tabulare.
Sq. $\quad$ = Squamosum.
F. pot. $=$ Fenestra posttemporalis
Pte. = Pterygoideum.
Co. $=$ Condylus occipitalis.
Eo. = Exoccipitale.

zwischen den Deckknochen zum Vorschein kommit. Nach den kritischen Vergleichen, die F. Broili (1917) durchfülırte ${ }^{3}$, ist dieser mediane Knochen des Stegocephalenschädels als eine Ossifikation des Ethmoidalknorpels anzusehen und daher als Ethmoidale zu bezeichnen. Mit dem Sphenethmoideum kann es nicht wohl identifiziert werden (Broili, 1917).

1 S. H. Haughton, Investigations in South African Fossil Reptiles and Amphibia; Part 1: On a New Species of Trematosaurus. - Ann. South Afr. Mus., XII, 1915, Part 2.

2 D. M. S. Watson, On Micropholis Stowi, Huxley, a Temnospondylous Amphibian from South Africa. - Geol. Magazine, Dec. V, Vol. X, London 1913, p. 341.

${ }^{3}$ F. Broili, Unpaare Elemente im Schädel von Tetrapoden. - Anat. Anzeiger, XLIX. Bd., 1917, p. 574. 
Orbitosphenoideum. Dieser paarig entwickelte Knochen liegt an der Schädelbasis und bildet z. B. bei Cyclotosatïus posthumus (von E. Fraas, 1913, als Alisphenoid bezeichnet, das bei den Amphibien bisher n:cht beobachtet wurde) das Verbindungsstück zwischen dem Parasphenoid und dem ursprünglich knorpelig präformierten primären Schädel (Hirnschädel). Diese Verbindung findet dort statt, wo vom Frontale aus jederseits ein Wulst nach innen, hinten und unten zum Parasphenoid hin abbiegt.

Epioticum (=Felsenbein nach Quenstedt). Ein paarig entwickelter Knochen der Gehörregion, der unter den Stegocephalen bis jetzt mit Sicherheit nur bei Cyclotosaurus posthumus E. Fraas (1913) nachgewiesen werden konnte (Fig. 189). - Es nimmt hier an der Bildung der Wand des Gehörganges teil, der in einer allseitig geschlossenen Öffnung (Fenestra oticalis) auf der Oberseite des Schädeldaches ausmündet. Es wird jedenfalls auch bei anderen Stegocephalen bei genauerer Untẹrsuchung nachgewiesen werden können. Der häufig als Epioticum bezeichnete Knochen des Schädeldaches ist dagegen identisch mit dem Tabulare und als solches zu bezeichnen.

Opisthoticum (= Paroccipitale). Dieser paarig entwickelte Knochen bildet einen Teil der Schädelhinterwand (z. B. bei Capitosaurus und Eryops) und wird vom Tabulare überdeckt.

Prooticum. Es ist kleiner als das Opisthoticum (z. B. bei Eryops) und bildet bei dieser Gattung einen kurzen Kanm unter dem Hinterende des Parietale (Fig. 216).

Sphenoticum. Ein kleines, wahrscheinlich knorpeliges Element des Schädels von Lyrocephalus Euri (Trias Spitzbergens), welches das Prooticum mit dem Supratemporale und Parietale verbindet, scheint nach C. Wiman (1916) dem Sphenoticum zu entsprechen.

Stapes (= Columella auris). Der Stapes ist bei zalılreichen Stegocephalen erhalten (z. B. bei Lonchorhynchus, Eryops usw.). Er verschließt die Fenestra ovalis und ist als relativ langer, gerader Knochenstab entwickelt (Fig. 216).

Quadratum. Das Quadratum ist ein Ersatzknochen des Gelenkteiles des knorpeligen Palatoquadratums und bildet das Gelenk gegen den Unterkiefer. Es ist bei den Stegocephalen verhältnismäßig klein; vorn innen stößt es an das Pterygoid, außen und oben an das Quadratojugale.

Epipterygoideum (= Columella cranii). Das Epipterygoid ist die Verknöcherung des vorderen oder pterygoidalen Abschnittes des knorpeligen Palatoquadratums. Es erscheint bei Lyrocephalus Euri Wiman als ein zapfenförmiger, vom Pterygoid schräg nach innen und unten gerichteter Fortsatz des Pterygoids, von dem es jedoch deutlich getrennt ist. Es ist auch bei Eryops nachgewiesen. Vielleicht ist es auch bei Anaschisma und Gondwanosaurus vorhanden gewesen. 


\section{Die Deckknochen des Unterkiefers. ${ }^{1}$}

Dentale. Dieser Knochen ist ebenso wie die sog. Zahnknochen des Schädels aus einer Verwachsung von ursprünglich einzelstehenden Zälnnen hervorgegangen. Das Dentale bildet den äußereñ, das gleichfalls (nach O. Hertwig) als Zahnknochen aufzufassende Spleniale den inneren Zahnbogen des Unterkiefers. Auf dem Oberrande des Dentale steht in der Regel eine Reihe kegelförmiger, gleichgroßer Zähne. Es nimmit das Vorderende des Unterkiefers allein ein, dehnt sich hauptsächlich auf der Außenseite und Oberseite des Unterkiefers aus und läuft nach hinten spitz zu. Innen stößt es an das Spleniale, weiter hinten an drei schmale Knochen, vorn zuersî an das Praecoronoid, dann an das Intercoronoid und zuletzt an das Complementare. An der Außenseite des Unterkiefers legt sicl das Dentale vorn auf das Spleniale, dann auf das Praearticulare, dann zieht sein Unterrand längs der oberen Grenze des Angulare nach oben und keilt im Supraangulare aus.

Spleniale (= Operculare). Dieser zweite "Zahnknochen" ist bei den Stegocephalen zahnlos; sein Vorderende nimmt noch an der Symphyse, wenn auch nur in untergeordnetem Maße, Anteil, während der Hauptabschnitt derselben dem Dentale zufällt. Das Spleniale bildet sodann auf der Innenseite den Unterrand des Unterkiefers, bis es vom Postspleniale abgelöst wird, an dessen oberer Grenze es nach oben zieht, wo sich das Intercoronoid und Praecoronoid keilförmig zwischen das Dentale und Spleniale einschieben. Das Spleniale ist z. B. beim lebenden Urodelen Necturus maculatus, bei Siredon usw. bezahnt.

Praecoronoid. Ein schmaler, schlanker Knochen zwischen den Dentale, Spleniale und Intercoronoid, der an der Innenwand des Unterkiefers liegt.

Intercoronoid. Es grenzt vorn an das Praecoronoid, unten an das Spleniale, Postspleniale und Praearticulare, hinten an das Complementare und oben an das Dentale. Es liegt gleichfalls an der Innenwand des Unterkiefers.

Praearticulare (= Goniale). An der Innenwand des Unterkiefers gelegen. Sein Oberrand bildet die untere Begrenzung des Hauptkanals, welcher den knöchernen Unterkiefer durchzieht (Canalis cartilaginis Meckelii $=$ Canalis primordialis) und der den primordialen Unterkiefer

1 Als Grundlage fuir die nachfolgende Analyse diente vor allem die Mitteilung von G. W. Willist on (Journ. of Geology, XXII, Nr. 4, May-June 1914, p. 364 bis 419), in welcher festgestellt wird, daß der Terminus Postspleniale (Williston) vor der Bezeichnung Praeangulare (Broom) die Priorität hat; ebenso ist die Bezeichnung Epicoronoid (Watson) einzuziehen. Die Verhältnisse der Unterkieferknochen zueinander sind am klarsten bei Trimerorhachis Alleni Case (Fig. 203) cder bei Eryops megacephalus aus dem Perm von Texas zu beobachten (Fig. 190). 
$(=$ Meckelscher Knorpel = Cartilago Meckelii) einschließt. Seine Grenzlinie stößt hinten an das Articulare, unten an das Angulare und Praeangulare, keilt zwischen diesem und dem darüber liegenden Intercoronoid aus und läuft unter dem Complementare wieder zur Öffnung des Canalis primordialis zurück.

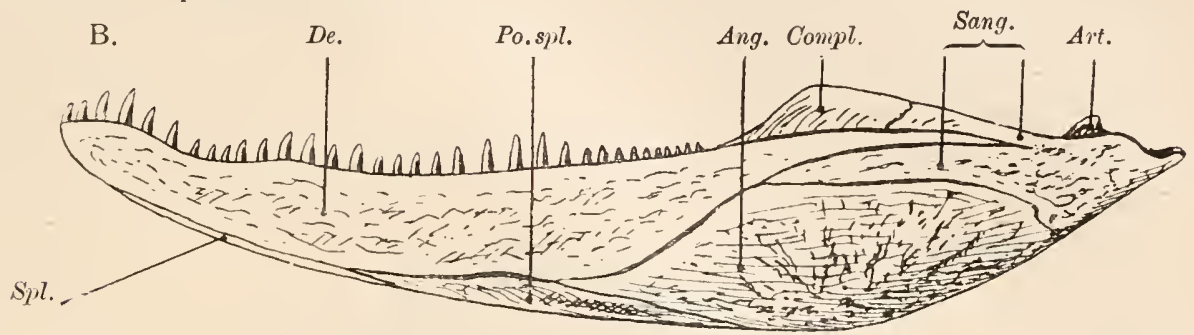

A.

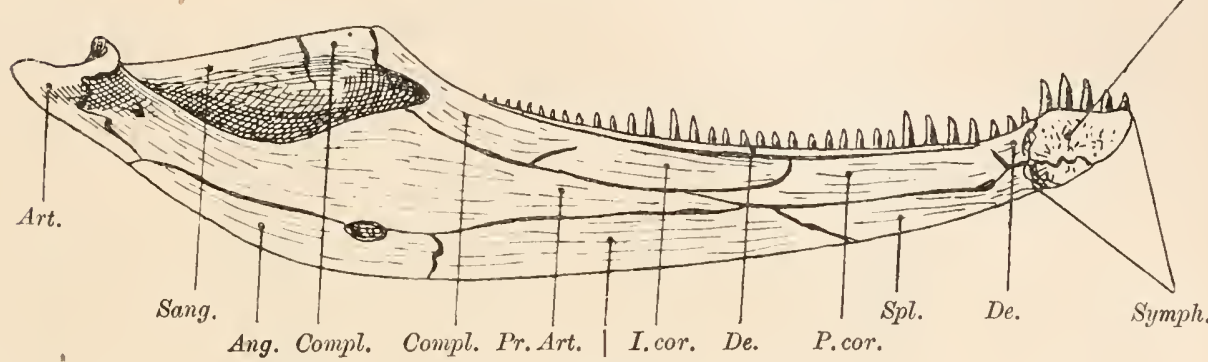

Po.spl.

Fig. 190 .

Unterkiefer von Eryops megacephalus, Cope, A von innen, B von außen gesehen; aus dem Perm von Texas. 1/4 nat. Gr. (Nach R. Broon, 1913.)

De. $\quad=$ Dentale.

Spl. $=$ Spleniale $(-$ Operculare $)$.

P. cor. = Praecoronoid.

I. cor. $=$ Intercoronoid.

Pr. Art. = Praearticulare $(=$ Goniale $)$.

Ang. = Angulare.
Po. spl. = Postspleniale $(=$ Praeangulare $)$.

Sang. $=$ Supraangulare.

Compl. $=$ Complementare $(=$ Coronoid $)$.

Art. $=$ Articulare.

Symph. = Symphyse.

Angulare. Dieser große Knochen liegt fast zur Gänze an der Außenseite des Unterkiefers, bildet aber auch noch als schmale Leiste einen Teil seines Unterrandes. Auf der Außenseite stößt es unten und vorn an das Postspleniale, oben an das Dentale und Supraangulare, wendet sich mit seinem Hinterende an Articulare nach unten und auf die Innenseite des Unterkiefers, wo es unter dem Praearticulare weiterläuft und wieder mit dem Postspleniale zusammentrifft.

Postspleniale (= Praeangulare). Zum größeren Teil auf der Innenwand des Unterkiefers ausgebreitet, aber auch an der Außenwand gut entwickelt. Die Grenze zieht auf der Außenseite des Kiefers vom Spleniale zum Dentale, senkt sich hinten unter das Angulare, taucht auf der Innenwand wieder auf und zieht unter dem Praearticulare und Intercoronoid wieder zum Spleniale. 
Supraangulare. An der höchsten Stelle des Unterkiefers gelegen. Es bildet auf der Innenwand des Unterkiefers einen großen Teil der Wand des Canalis primordialis, grenzt vorn an das Complementare, hinten an das Articulare und unten an das Angulare. Das Dentale sendet einen langen Keil nach hinten in das Supraangulare.

Complementare $(=$ Coronoid $\doteq$ Epicoronoid). Sein Hinterrand bildet -auf der Innenwand des Unterkiefers die vordere Begrenzung. des Eintrittsloches des Canalis primordialis. Oben stößt es an das Dentale, vorn an das Intercoronoid, unten an das Praearticulare; hinten tritt es mit dem Supraangulare in Verbindung. Auf der Außenseite wird es vom Dentale unterschoben.

\section{Die Knorpelknochen des Unterkiefers.}

Articulare. Das Articulare ist die Ersatzossifikation am Gelenkende des Meckelschen Knorpels und tritt mit dem Quadratum des Schädels in Gelenkverbindung. Seine Nachbarknochen sind auf der Innenseite des Unterkiefers das Angulare und Praearticulare, auf der Außenseite das Angulare und Supraangulare.

Mentomandibulare (Gegenbaur, 1898). Während das Articulare die Ersatzverknöcherung des Hinterendes des Meckelschen Knorpels darstellt, ist dieser Knochen aus der Ossifikation des Vorderendes dieses Knorpels entstanden. Er ist bei fossilen Stegocephalen noch nicht nachgewiesen; beim lebenden Siredon ist er selbständig ausgebildet, bei Rana mit dem Dentale verschmolzen (E. Gaupp, 1911).

\section{Die Zähne der Stegocephalen.}

Die Stegocephalen tragen in der Regel auf dem Praemaxillare, Supramaxillare und Dentale Zähne, doch sind auch verschiedene andere Knochen des Gaumendaches (Vomer, Palatinum, Pterygoid, Transversum, Parasphenoid), in einigen Fällen (z. B. Necturus, Siredon) auch das Spleniale mit Zähnen besetzt. Vollkommen zahnlos sind nur einige Ánuren.

Die Zähne sind meist spitzkegelförmig oder stumpfkegelförmig, selten lateral komprimiert (Cricotus), und meist von gleicher Größe; es kommen jedoch bei vielen fossilen Formen neben den die Hauptmasse des Gebisses bildenden kleineren Zähnen einige wenige große vor, die als ,Fangzähne“ bezeichnet zu werden pflegen. Die Hauptmasse des Zahnes besteht aus Dentin; der untere Teil der Außenseite des Zahnkegels ist mit Zement bedeckt, der obere Teil ist mit einem Überzug von Email oder Schmelz versehen.

Mitunter geht die einfache Kegelform der Zähne durch Ausbildung einer Vorder- und Hinterkante in den Typus eines zweischneidigen 
Zahnes mit linsenförmigem Querschnitt über. Häufig sind die Zähne längsgefaltet oder wenigstens längsgestreift; diese Faltenbildung ist durch sternförmig von der Zahnhöhle (Pulpa) ausstrahlende Ausstülpungen bedingt. Bei höher spezialisierten Zahntypen erfahren diese Ausbuchtungen der Pulpa eine weitere Fältelung; zwischen die radial stehenden D.ntinwände schiebt sich von der Außenwand des Zahnes Zement ein und füllt mit eigentümlichen wellenförnigen oder an ein Labyrinth erinnernden zahllosen Falten das Innere des Zahnes aus, was bei den ,Labyrinthodonten“ (z. B. bei Mastodonsaurus) den

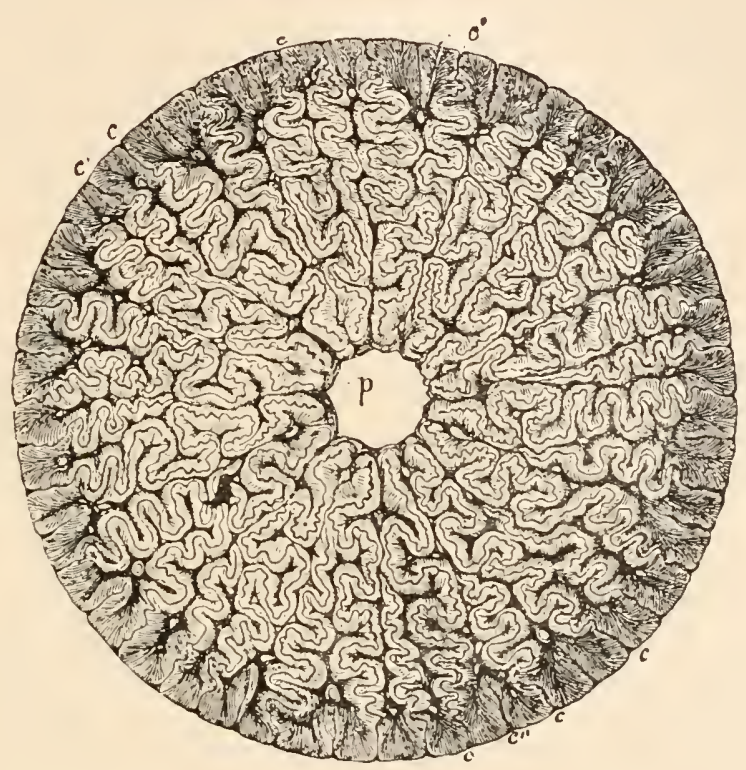

Fig. 191.

Querschnitt durch einen Zahn von Mastodonsaurus Jaegeri, einem Stegocephalen aus der oberen Trias Deutschlands, stark vergrößert. (Nach R. Owen.) $p=$ Pulpahöhle. $\quad c=$ Zahnzement.

hö̀chsten Grad der Ausbildung erreicht (Fig. 191). Diese Zalmstruktur gleicht in hohem Grade jener gewisser Crossopterygier (z. B. bei der devonischen Gattung Holoptychius). Auch in anderer Hinsicht besteht eine auffallende Übereinstinnmung mit den Crossopterygiern. Wo größere Fangzähne entwickelt sind (z. B. bei Loxomma), ist in der unmittelbaren Nähe des funktionellen Zahnes eine seichte Grube im Knochen zu sehen, in welcher ein früher funktioneller Zahn stand, der aber abgenützt und ausgefallen ist. Mitunter sieht man in der Tiefe der Zahngrube einen neuen Zahn zur Entstehung kommen, manchmal steht der neue Zahn neben dem noch funktionierenden (Fig. 186). Genau dieselbe Art des Zahnersatzes findet unter den Crossopterygiern bei Megalichthys oder 
bein lebenden Lepidosteus statt. Niemals erfolgt der Zahnersatz durch einen unter dem alten Zahn entstehenden neuen, sondern stets neben demselben. Alveolen fehlen den Stegocephalen; entweder erscheinen die Zähne auf den zahntragenden Knochen unmittelbar aufgewachsen oder es bildet sich um ihre Basis ein ringförmiger Knochenwall, so daß sie in seichten Gruben stehen (z. B. bei Loxomma).

Nacl der verschiedenen Art der Verbindung der Zähne mit den sie tragenden Knochen unterscheidet man daher bei den Stegocephalen folgende Typen:

1. Akrodonte Zahnbefestigung. Der Zahnsockel sitzt dem freien Kieferrande auf und ist mit diesem verwachsen.

2. Pleurodonte Zahnbefestigung. Der Zahn ist an dem etwas erhöhten Innenrande des Kiefers mit der Außenseite seiner Wurzel befestigt, so daß die Innenseite der Wurzel freiliegt und nur vom Zahnfleisch verdeckt wird.

3. Protothekodonte Zahnbefestigung. Der Zahnsockel sitzt in einer seichten Grube oder der Zahn steht mit seinen Nachbarn in einer seichten Rinne; der Sockel ist mit dem Knochen verwachsen.

Die thekodonte Zalmbefestigung (Ausbildung selbständiger Alveolen für jeden Zahn), wie sie bei Reptilien auftritt (vgl. unten die $\mathrm{C}_{0}$ tylosauria, S. 334) ist bei den Stegocephalen noch nicht ausgebildet.

\section{Die Öffnungen des Stegocephalenschädels.}

Orbita (= Augenhöhle). Die größte Öffnung des Schädeldaches der Stegocephalen. An ihrer Umrandung nehmen hauptsächlich folgende Schädelknochen Anteil: Lacrymale, Postfrontale, Postorbitale, Jugale. Zuweilen erreicht jedoch auch das Adlacrymale den vorderen Orbitalrand (z. B. bei Zatrachys). Auch das Frontale kann an der Umrandung teilnehmen (z. B. bei Diplocaulus).

Naris (= Nasenöffnung; obere oder vordere N. = Naris anterior, untere oder hintere $\mathrm{N}$. = Naris posterior $=$ Choane). Die Nasenöffnungen sind bei den Stegocephalen immer paarig entwickelt und liegen fast immer an Vorderende des Schädeldaches (weit nach hinten geschoben nur bei Lonchorhynchus Öbergi aus der Trias Spitzbergens) jederseits zwischen dem Praemaxillare und dem Nasale. Das Adlacrymale nimmt zuweilen an der Begrenzung des vorderen Nasenloches Anteil (z. B. bei Eryops). Stets sind die Nares anteriores kleiner als die Augenhöhlen.

Die gleichfalls paarigen unteren oder hinteren Nasenöffnungen auf der Gaumenseite des Schädels werden in der Regel jederseits vom Praemaxillare, Vomer, Palatinum und Supramaxillare umrahmt. 
Fenestra internasalis (= Fazialgrube). In einigen Fällen ist bei Stegocephalen eine unpaare, mediane Öffnung in der Nasalregion in Gestalt eines Schlitzes in Schädeldach vorhanden, die sowohl auf der Oberseite des Schädels wie auf seiner Unterseite sichtbar ist (Fenestra internasalis superior et F. i. inferior). Dies ist auch zuweilen bei lebenden Urodelen der Fall (z. B. bei Molge cristata); bei einigen permischen Gattungen (z. B. bei Acanthostoma, Dasyceps, Zatrachys, Trematops) ist diese Öffnung von auffallender Größe. Nach Analogie der lebenden Gattungen darf man vermuten, daß die Fazialgrube eine Drüse einschloß, die ein klebriges Sekret absonderte, das auf die Zunge floß und den Fang flüchtiger Beutetiere erleichterte (Fig. 211).

Fenestra praeorbitalis (= Wangengrube). Bei Trematops (Fig. 208) schließt sich an die vordere Nasenöffnung eine langgestreckte Grube an, die sich gegen die Orbita hin erstreckt und allseits abgeschlossen ist. Bei Loxomma tritt dagegen eine Verschmelzung der Wangengrube mit der Augenöffnung ein, während die Nasenöffnung separiert bleibt. Möglicherweise diente diese Grube auch hier zur Aufnahme einer Schleim absondernden Drüse.

Fenestra palatinalis $(=$ Fenestra mediopalatinalis $=$ Gaumengrube). Die meisten Stegocephalen besitzen eine sehr große Gaumeingrube, die in der Mittellinie durch das Parasphenoid in eine rechte und linke Hälfte zerlegt wird. Gewölnnlich wird diese Grube vorn von den Vomeres und seitlich von den Pterygoidea begrenzt, doch kann sich auch das Supramaxillare an der seitlichen Begrenzung beteiligen. Als Extren für eine sehr große Gaumengrube in Verhältnis zum Schädel kann Branchiosaurus, als Extrem für eine sehr kleine Diplocaulus gelten.

Fenestra basitemporalis ${ }^{1}$ (= Gaumenschläfengrube ${ }^{2}$ ). Durch das Pterygoid von der Gaumengrube getrennt, folgt weiter hinten und außen eine meist dreieckig ungrenzte Grube, welche hinten vom Quadratum, außen vom Quadratojugale und innen vom Pterygoid begrenzt wird. Diese Grube ist bein lebenden Tier jedenfalls mit Muskeln erfüllt gewesen und die Ausdehnung derselben hat wahrscheinlich später in einigen, aber nicht in allen Fällen zu einer weiteren Aushöhlung der Innenseite des Schädeldaches und sonit zur Bildung einer echten Schläfenöffnung an den Seiten des Schädeldaches geführt, was aber bei den Stegocephalen bis jetzt nicht beobachtet worden ist.

Fenestra posttemporalis (= hintere Schläfenöffnung). An der Hinterwand des Stegocephalenschädels öffnet sich eine meist schmale,

1 Neue Bezeichnung (vgl. Fig. 193, ü̈.).

2 Die Bezeichnung ,,untere Schläfenöffnung", wie sie Boas (1914) anwendet, führt leicht zu Verwechslungen mit der unteren, seitlichen Schläfenöffnung der Reptilien und ist daher besser zu vermeiden. 
langgestreckte Spalte zwischen dem Tabulare, Opisthoticum und Exoccipitale; unter Unständen kann sich auch das Dermosupraoccipitale und Supraoccipitale an der Begrenzung dieser Spalte beteiligen (z. B. bei Capitosaurus). Diese Öffnung ist auch auf der Unterseite des Schädels sichtbar (z. B. bei Cyclotosaurus) und führt in die weite, beim lebenden Tier von Muskelmasse ausgefüllt gewesene Schläfenhöhlung (Fig. 189, 205. 2.9).

A.

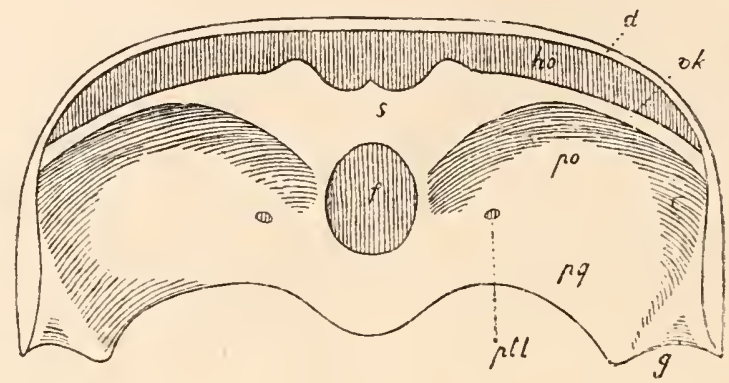

B.

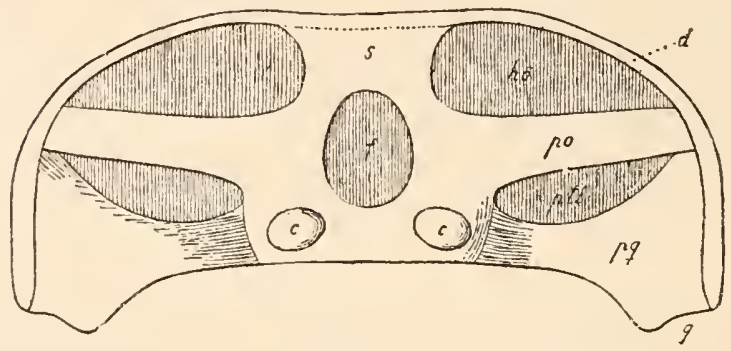

Fig. 192.

A: Schädel von Neoceratodus, von hinten gesehen; B: Schädel eines

Stegocephalen (schematisiert), von hinten gesehen.

(Nach J. E. V. Boas.)

c. $=$ Condylus occipitalis.

d. $=$ Schädeldach .

f. $=$ Foramen magnum.

g. = Gelenkfläche gegen den Unter kiefer.

hö. = Fenestra posttemporalis (hintere Schläfenöffnung). $p t l .=$ Fenestra pteroccipitalis (Pteroccipitalliicke).

po. = Gegend des Opisthoticum (Par- occipitale).

$p q .=$ Palatoquadratum.

$q . \quad$ = Quadratum.

$s . \quad=$ Hinterhaupt. $v k$. = vorspringende Kante des Knorpelschädels von Ceratodus.

Fenestra pteroccipitalis. Die Pteroccipitallücke liegt unterhalb und meist außerhalb von der Fenestra posttemporalis und führt in die Schläfenhöhle. Sie wird in der Regel oben und innen vom Opisthoticum und Exoccipitale, unten und außen vom Pterygoid begrenzt. Sie kann gegen die Schädelbasis herab und nach vorn verschoben sein (Fig. 189, 205, 219).

Cavum oticale (= Ohrengrube). Bei vielen Stegocephalen ist bei Betrachtung des Schädeldaches von der Oberseite am Hinterrand 
des Daches ein Einschnitt vorhanden, der die Lage der äußeren Ohröfnung anzeigt. In dieser Einkerbung (Incisura oticalis oder Ohrenschlitz) lag das Trommelfell, dessen Existenz wir nach Analogie der Verhältnisse bei den Anuren annehmen dürfen. An das Trommelfell (Membrana tympani) schloß sich eine im äußeren Abschnitt wahrscheinlich knorpelige, schädeleinwärts aber verknöcherte und bei einigen Stegocephalen gut erhaltene Columella auris $=$ Stapes an, die das ovale Fenster der Gehörblase des Schädels (Fenestra ovalis) verschloß, wie die Verhältnisse bei Eryops und anderen Gat-

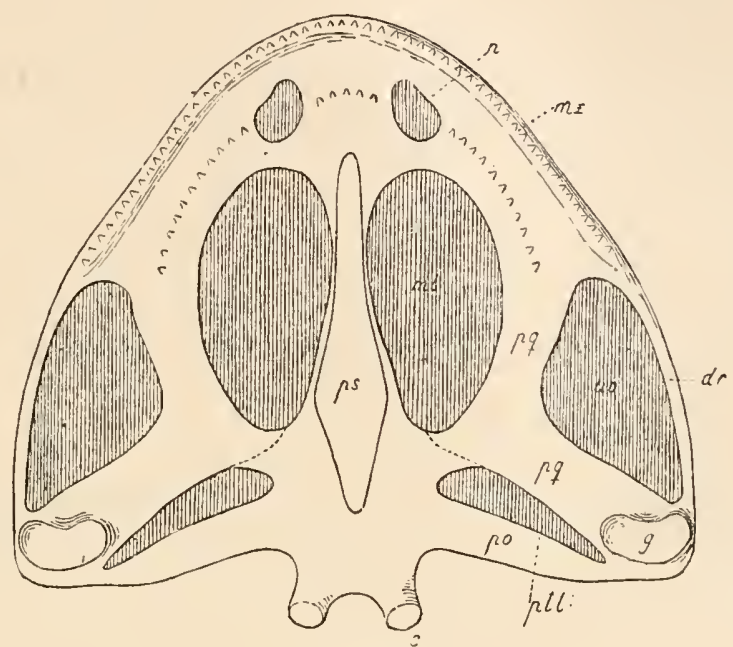

Fig. 193.

Unterseite eines Stegocephalenschädels, schematisiert.

(Nach J. E. V. Boas, 1914.)

Öffnungen:

$n$. = hintere Nasenöffnung (Choane).

$\mathrm{ml}$. = Fenestra palatinalis $(=\mathrm{F}$. mediopalatinalis = Gaumengrube).

$u \ddot{0}$. = Fenestra basitemporalis $(=$ Gaumenschläfengrube $=$, ,untere Schläfenöfnung" nach Boas).

ptl. = Fenestra pteroccipitalis.
Knochen:

$$
U x \text {. = Supramaxillare. }
$$

$p q$. = Palatoquadratum.

g. = Quadratum.

po. = Gegend des Opisthoticum.

ps. $=$ Parasphenoid.

c. = Condylus occipitalis, vom Exoccipitale gebildet.

tungen zeigen. Der ganze Raum zwischen den Trommelfell bzw. der Incisura oticalis einerseits und der Fenestra ovalis andererseits kann als das Cavum oticale oder die Ohrengrube bezeichnet werden. Mitunter reicht die Incisura oticalis als tiefe Einkerbung weit nach vorn in das Schädeldach hinein (z. B. bei Broiliellus), sie kann aber auch durch die seitliche Expansion des Tabulare gegen hinten zu einem Fenster verschlossen werden, so daß es zu der Bildung einer den Schläfenöffnungen ähnlichen, aber mit diesen nicht homologen Öffnung kommt. Diese an die Temporalgruben der Reptilien erinnernde Lücke (= Pseudo- 
temporalgrube) ist z. B. bei Cacops, Trematops und Cyclotosaurus nachgewiesen (Fig. 208-210, 189).

Sehr eigentümliche Verhältnisse liegen bei Diplocaulus vor, wo die Ohrenschlitzgrube auf der Unterseite des Schädels liegt, so daß daraus der Schluß gezogen werden darf, daß das Trommelfell, wenn es überhaupt vorhanden war, auf der Unterseite des Schädels lag (Fig. 228).

Apertura intermaxillaris (= Fangzahnloch). Bei den stereospondylen Stegocephalen sind im Unterkiefer große Fangzähne entwickelt, von denen je einer am Vorderende jedes Kieferastes steht. Diese Zähne greifen entweder in konische Vertiefungen der Gaumenseite der Praemaxillaria, ohne sie zu durchbrechen (z. B. bei Cyclotosaurus), oder sie durchbrechen das Schädeldach und treten auf der Oberseite des Schädels frei hervor. Dies ist der Fall z. B. bei Metopias, Trematosaurus, Mastodonsaurus, Peltostega (Fig. 212, Ap.int., Fig. 218).

Foramen parietale $(=$ Parietalöffnung $=$ Scheitelloch $)$. Bei fast allen Stegocephalen ist in der Mittellinie des Schädels zwischen den Parietalia eine kleine kreisrunde Öffnung für das Parietalorgan des Zwischenhirns (= Parietalauge, verschieden vom Pinealorgan! vgl. Fig. 28, S. 61) vorhanden. Es fehlt an alten Schädeln bei einzelnen Arten, die in Jugendzustand noch ein offenes Foranen parietale besitzen (z. B. bei Diplocaulus, Trimerorlachis, Sclerocephalus), wo es durch seitliches Überwuchern der Parietalia verschlossen worden ist.

Foramen magnum (= Hinterhauptsloch). Die Umrisse des Foramen magnum der Stegocephalen sind von sehr verschiedener Gestalt. Das an den verschiedenen Schädeln sichtbare Loch ist mitunter durch seitliche Vorsprünge in zwei Abteilungen (z. B. bei Metopias, Mastodonsaurus) oder sogar in drei übereinanderliegende Abschnitte (bei Cyclotosaurus robustus und, allerdings nicht so deutlich, auch bei Peltostega Erici) geteilt. Es scheint, daß nicht diese ganze Öffnung, sondern nur ein Teil derselben dem Foramen magnum entspricht, und daß bei den beiden letztgenannten Arten der obere Teil des Loches von einem knorpelig gebliebenen Abschnitt des Supraoccipitale, der untere von einem knorpeligen Teil des Basioccipitale zu Lebzeiten des Tieres ausgefüllt wurde.. Bei Cyclotosaurus stantonensis würde der obere Teil der Öffnung im Hinterhaupt gleichfalls einem Knorpelabsclnnitt des Supraoccipitale entsprechen, während das Basioccipitale hier zur Gänze verknöchert ist.

Foramen quadrati. An der Hinterwand des Schädels einiger Stegocephalen (z. B. bei Capitosaurus und Anaschisma) liegt eine Öffnung, die dem Foramen quadrati der Reptilien homolog ist. Sie liegt an der Grenze zwischen dem Quadratum und dem Quadratojugale. 
C. Wiman liat sie (1916) auch bei Peltostega Erici (Trias von Spitzbergen) nachgewiesen (Fig. 219, F.q.).

Nervenöffutungen. Die Deutung der Nervenlöcher des Stegocephalenschädels ist noch unsicher. Meist sind neben dem Condylus occipitalis an dessen Außenrand ein oberes und ein unteres Loch jederseits vorhanden. Der Nervus vagus (X.) tritt wahrscheinlich durch das obere Foramen in Gesellschaft einiger anderer Nerven aus. Nach den Untersuchungen v. Huenes an Eryops ist die Austrittsstelle des Nervus facialis, der durch den Canalis Fallopii läuft, nachgewiesen. Zwei andere Öffnungen an der Innenwand der Gehörblase, die nacls außen und vorn fülıren, deutet v. Huene als ein Venenloch und eine Austrittsstelle der perilymphatischen Gefäße (Fig. 188, Pl.). Oberhalb der Gehörblase und über der Sella turcica, aber ein wenig hinter derselben, liegt eine Öfnung, die Huene als Foramen prooticum, d. h. als Austrittsstelle des Nervus trigeminus deutet. An der Außenseite der Ssluädelkapsel von Eryops ist unterhalb des Foramen prooticum eine Öffnung, die Huene als die Austrittsstelle des Nervus oculomotorius ansieht, und ein kleines Stück vor dieser liegt ein Foramen, das wahrscheinlich als das Foramen opticum anzusehen ist.

\section{Der Bau des Brust-Schultergürtels und der Vordergliedmaßen der Stegocephalen.}

Ebenso wie der Schädel der Stegocephalen ein zum Teil aus Hautknochen und zum Teil aus Ersatzknochen aufgebautes Skelett besitzt, ist auch das Skelett des Schultergürtels der Stegocephalen aus heterogenen Elementen aufgebaut. Die Verhältnisse bei den lebenden Urodelen und Anuren zeigen, daß ein Teil der den Schultergürtel und den Sternalabschnitt zusammensetzenden Elemente knorpelig bleibt; dasselbe ist für die Stegocephalen anzunehmen, bei denen nur ein Teil dieser Elemente verknöchert war und daher erhalten bleiben konnte, während die Knorpel bei der Fossilisation zerstört worden sind.

Bei den Stegocephalen bilden die Knochen des Brust-Schultergürtels einen auf der Außenseite meist stark skulpturierten Kehlbrustpanzer.

Die Elemente des Brust-Schultergürtels der Stegocephalen sind folgende (Fig. 194-196):

1. Interclavicula. Dieser unpaarige Knochen, der seinem Ursprunge nach als Hautknochen zu betrachten ist, zeigt häufig (z. B. bei Archegosaurus, Diceratosaurus) die für Hautknochen bezeichnende, grubige Oberflächenskulptur. Seine Umrisse sind meist rhombisch, aber mitunter läuft er nach hinten in einen medianen, stielförmigen Fortsatz aus (z. B. bei Melanerpeton). 
2. Clavicula. Ein paarig ausgebildeter Hautknochen, der gleichfalls (z. B. bei Archegosaurus, Diceratosaurus) grubig skulpturiert sein

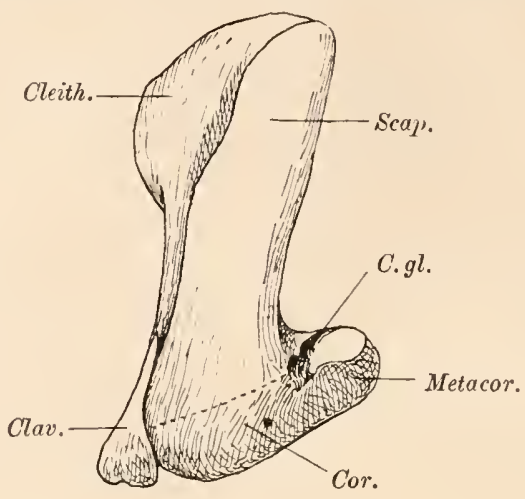

Fig. 194.

Linker Schultergürtel von Eryops, von außen gesehen. Perm von

Texas. $2 / 9$ nat. Gr. (Nach S. W. Williston.)
Cleith. = Cleithrum
C. $g l$. = Cavitas glenoidalis.

Clav. = Clavicula.

Scap. = Scapulare.

Cor $=$ Coracoid.

Metacor. $=$ Metacoracoid.

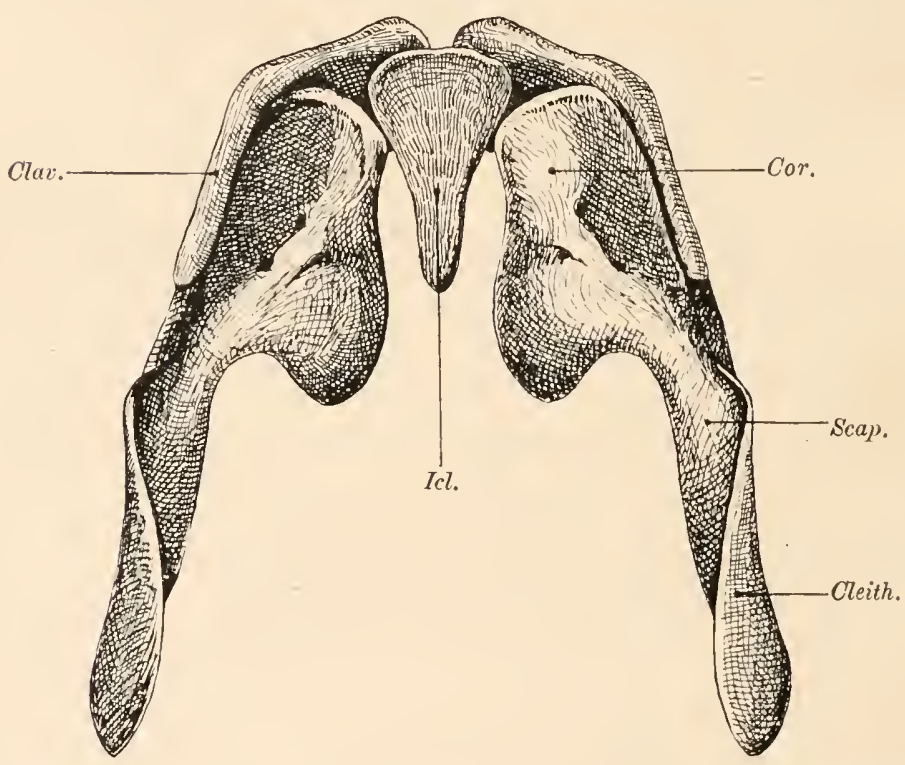

Fig. 195.

Schultergürtel von Cacops aspidephorus, Will., aus dem Perm von Texas, von oben gesehen, in $2 / 3$ nat. Gr. (Nach S. W. Williston.)
Cor. $=$ Coracoid.
Cleitl. = Cleithrum.
Icl. $=$ Interclávicula
Clav. = Clavicula.
Scap. = Scapulare.

kann oder eine glatte Oberfläche besitzt. Die Claviculae schieben sich sehr liäufig über den Außenrand der Interclavicula gegeneinander vor, 
so daß die Interclavicula, von der Ventralseite betrachtet, von den Claviculae überlagert erscheint.

3. Cleithrum (= Supraclavicula). Auch dieser paarige Knochen zeigt in seltenen Fällen eine grubige Außenskulptur (z. B. bei Diceratosaurus und Archegocaurus) und erweist sich daher als Hautknochen.

4. Scapulare. Diesen fünf Hautknochen schließt sich ein paarig entwickelter Ersatzknochen an, der den dorsalen Abschnitt des BrustSchultergürtels bildet und der kräftigste Knochen der ganzen Gruppe zul sein pflegt.

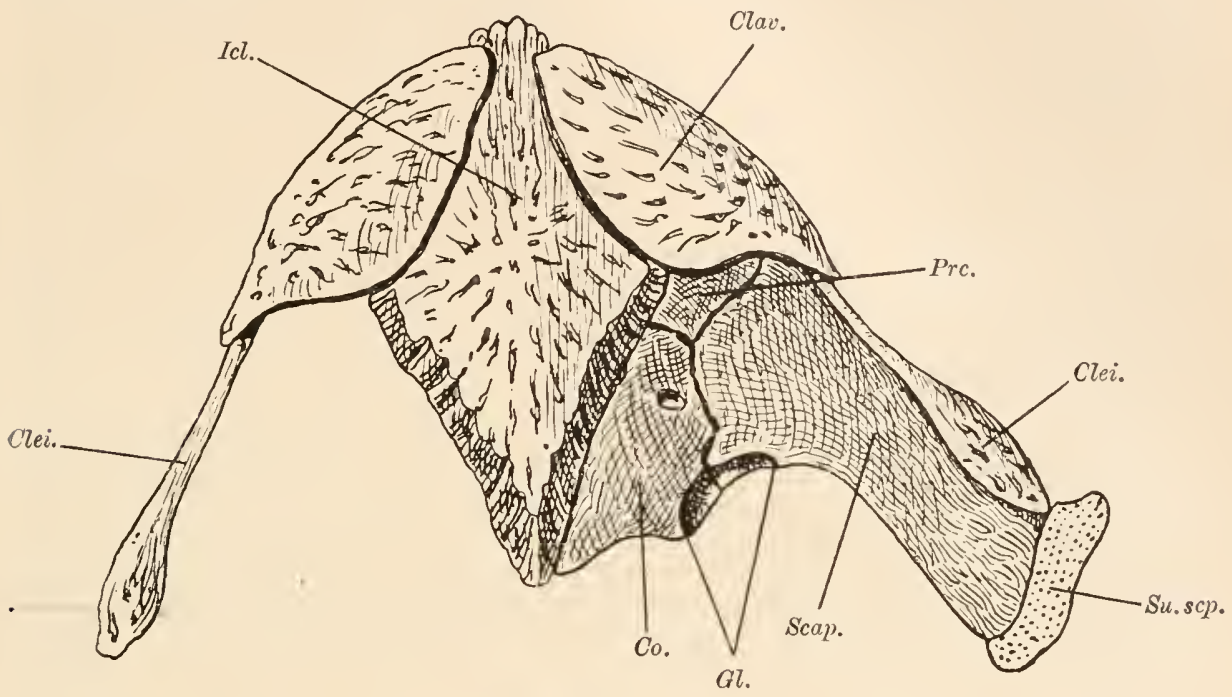

Fig. 196.

Rekonstruierte Unteransicht des Schultergïrtels von Archegosaurus.

(Nach O. Jaekel.)

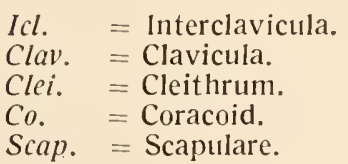

Su.scp. $=$ Suprascapulare.

Gl. $=$ Gelenkgrube (cavitas glenoidalis) für den Kopf des Humerus.

Prc. $=$ Praecoracoid.

5. Coracoideum. Ein weiterer Ersatzknochen ist das paarig ausgebildete Coracoid, das mit dem Ventralende des Scapulare in Verbindung tritt.

6. Metacoracoideum. Das hintere Ende des Coracoids scheint ein selbständiger Knochen zu sein (z. B. bei Eryops) und ist jedenfalls als ein Ersatzknochen anzusehen.

7. Praecoracoideum. Zwischen dem Scapulare, Coracoid, der Interclavicula und Clavicula einiger Stegocephalen (z. B. Archegosaurus, Cacops) findet sich eine Lücke, die von einem Knorpelstück ausgefüllt gewesen sein dürfte, das dem Praecoracoid der lebenden Amphibien entspricht. 
Bei den meisten plumpkörperigen Stegocephalen ist der BrustSchultergürtel sehr kräftig entwickelt, geradezu enorm z. B. bei Cacops. Einen ganz anderen Typus zeigt dagegen der Brust-Schultergürtel z. B. bei Diceratosaurus und bei Metopias usw. Dagegen ist diese Region bei den Branchiosauriden relativ zart gebaut. Wahrscheinlich sind die Elemente dieses Skelettabschnittes bei der letztgenannten Gruppe vorwiegend knorpelig gewesen.

Das Armskelett der Stegocephalen umfaßt den Humerus (= Oberarmknochen), Radius (= Speiche), Ulna (= Elle), sowie eine Anzahl Carpalia (= Handwurzelknochen), Metacarpalia (= Mittelhandknochen) und Phalangen (= Fingerknöchel). Eine Verwachsung von Radius und Ulna ist bei den Anuren eingetreten. Die Gelenkenden der Armknochen sind in der Regel unverknöchert. Mitunter ist das Unterende des Humeruis von einem Foramen entepicondyloideum durchbohrt. Der Humerus vieler Stegocephalen besitzt eine sehr merkwürdige Gestalt, indem das obere (proximale) Stück der Diaphyse gegen das untere (distale) um $90^{\circ}$ gedreht ist (z. B. bei Dissorophus, Eryops).

Vom Carpus sind, soweit bekannt, nur bei Archegosaurus, Actinodon, Cacops, Trematops und Eryops die Elemente in verknöchertem Zustand erhalten gebliebein, sonst aber infolge ihrer knorpeligen Konsistenz bei der Fossilisation verloren gegangen. Die größte Zahl von Elementen weist der Carpus von Eryops megacephalus aus dem Perm von Texas auf. Er besteht hier aus elf getrennten Stücken (nach E. C. Case, 1911), deren Deutung noch nicht sichergestellt ist. Sowohl S. W. Williston als E. C. Case sind der Ansicht, daß die Hand von Cacops, Trematops und Eryops fünffingerig gewesen ist. Von diesen scheidet zunäclist Cacops aus, da nur zwei Reihen Carpalia und einige vereinzelte Phalangen im Zusammenhang vorliegen und die fünffingerige Hand nur rekonstruiert ist (S. W. Williston, 1910). Bei Trematops sind neun Carpalia erhalten (S. W. Williston, 1909), aber die Fingerknochen fehlen gänzlich. In der Rekonstruktion sind sie zwar so angeordnet, daß fünf Finger anzunehmen wären, aber dies ist einstweilen noch sehr fraglich. Auch bei Eryops scheinen nach den von E. C. Case (1911) mitgeteilten Abbildungen nicht melnr als vier Metacarpalia erhalten zul sein. Da von Archegosaurus feststeht, daß er nur vier Finger besaß und das gleiche für alle übrigen Stegocephalen gilt, bei denen die Finger nicht rekonstruiert, sondern wirklich erhalten sind, so muß einstweilen daran festgehalten werden, daß kein Stegocephale bekannt ist, der mehr als vier Finger besaß. 


\section{Der Bau des Beckengürtels und der hinteren Gliedmaßen der Stegocephalen.}

Das Becken der Stegocephalen ist in der Regel nur an einem, sehr selten (z. B. bei Cacops) an zwei Sakralwirbeln befestigt. Es besteht aus folgenden Elementen:

1. Ilium. Meist schlank und keulenförmig; zuweilen (z. B. bei Cricotus) besitzt es einen langen hinteren Fortsatz. Sein Unterende nimmt immer an der Bildung der Gelenkpfanne (Acetabulum) für den Kopf des Oberschenkelknochens Anteil.

2. Ischịm. Wie das Ilium stets an der Bildung des Acetabulums beteiligt. Ilium und Ischium sind bei den Stegocephalen stets verschmolzen.

3. Pubis. Meist ist das Pubis mit den beiden anderen Beckenknochen vereinigt, kann aber auch, wenn auch nur sehr selten (z. B. bei Metopias [Fig. 217] oder bei Mastodonsaurus) frei sein und ist in diesen Falle sehr klein. In einigen Fällen ist es an der Bildung des Acetabulums beteiligt, meist aber von demselben ausgeschlossen. Niemals ist das Pubis knorpelig, wie dies für die lebenden Amphibien Regel ist. Zuweilen findet sich ein Hüftbeinloch oder Foramen obturatorium.

Das Hinterfußskelett der Stegocephalen umfaßt das Femur (Oberschenkelknochen), die Tibia (Schienbein) und die Fibula (Wadenbein). Eine Verwachsung der beiden Unterschenkelknochen, wie sie bei den Anuren stattfindet, ist bei den Stegocephalen nicht beobachtet worden.

Der Tarsus (Fig. 197) ist in den meisten Fällen knorpelig gewesen und daher nicht erhalten. Bei einigen Formen, wie z. B. bei Trematops (Fig. 197), umfaßt der Tarsus (Fußwurzel) zwölf getrennte Elemente und weist einen sehr eigentümlichen Bau auf. Bei dieser Gattung liegen vier Reihen von Tarsalelementen übereinander:

Obere Reihe: Intermedium.

Zweite Reihe: Fibulare, Centrale 4, Tibiale.

Dritte Reihe: Centrale 3, Centrale 2, Centrale 1.

Untere Reihe: Tarsale 5, Tarsale 4, Tarsale 3, Tarsale 2, Tarsale 1.

Dieselbe Zahl von Tarsalelementen ist von Baur bei Archegosaurus nachgewiesen worden.

Die hohe Zahl der Fußwurzelknochen ist jedenfalls eine sehr eigenartige Erscheinung und wahrscheinlich durch eine eigentïmliche Funktion der Fußwurzel bedingt, die durch die große Zahl der Tarsalia einen hohen Grad von Biegungsfähigkeit erhalten hat. Älnnliche Verhältnisse wie in der Fußwurzel von Trematops kehren bei der Reptiliengattung Ophiacodon wieder. 
Die Phalangenzahlen der fünf Zehen scheinen schwankend gewesen zu sein. Jedenfalls ist bei den genauer bekannten Formen stets die vierte Zehe die längste und trägt die meisten Plıalangen. Bei Ceraterpeton Galvani aus dem Karbon von Kilkenny (Irland) tragen der erste bis fünfte Zehenstrahl 2, 3, 4, 4, 3 Phalangen; bei Trematops (Fig. 197) war die Phalangenformel (nach S. W. Williston) 2, 3, 3, 4, 3, dürfte aber auch hier dieselbe wie bei Ceraterpeton gewesen sein

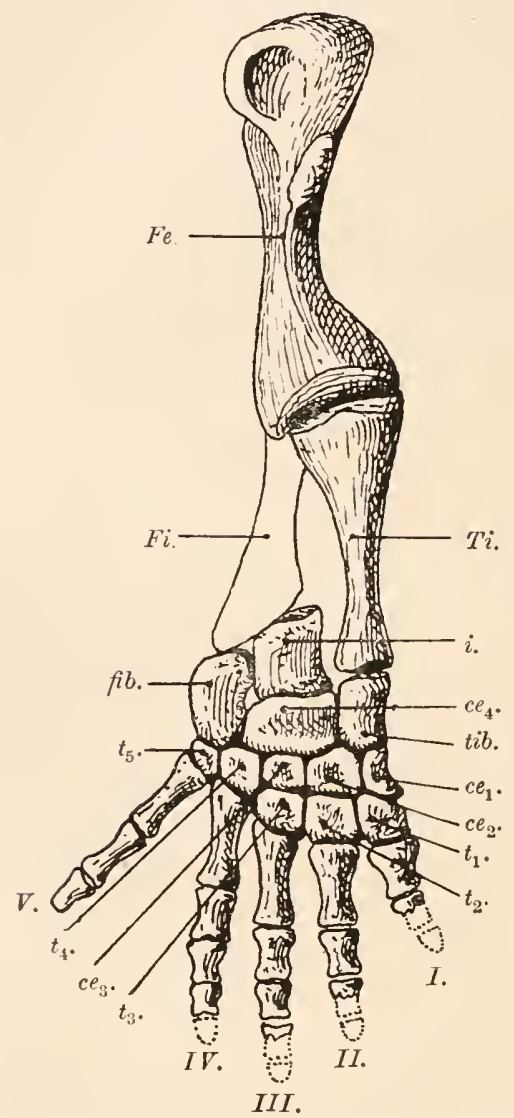

Fig. 197.

Linker Hinterfuß von Trematops Milleri, Will., aus dem Perm von Texas, von der Palmarseite gesehen. (Nach S. W. Williston.)

$F e .=$ Femur.

$F i$. $=$ Fibula.

$T i$. = Tibia.

fib. $=$ Fibulare

$i$. $=$ Intermedium.

tib. = Tibiale.

$\mathrm{Ce}_{1}, \mathrm{Ce}_{2}, \mathrm{Ce}_{3}, \mathrm{ce}_{4}=$ Centrale I bis Centrale IV.

$t_{1}, t_{2}, t_{3}, t_{4}, t_{5}=$ Tarsale $\mathrm{I}$ bis Tarsale $V$.

I. $-V .=$ erster bis fünfter Zehenstrahl.

(vgl. Fig. 223); bei Pelosaurus (Fig. 222) betrug sie 2, 2, 3, 4, 3. Im Hinterfuß von Diceratosaurus punctolineatus (von O. Jaekel als Arm beschrieben) sind in den vorderen drei Zehen 2, 3, 3 ( +1 fehlende) Phalangen erhalten; die Phalangenzahl der hinteren Zehen ist unsicher, da auf der von Jaekel untersuchten Platte die Hinterfüße beider Körperhälften durcheinandergeworfen zu sein scheinen.

Bei einigen Stegocephalen sind die Hinterfüße sehr kräftig ausgebildet (z. B. Trematops, Cacops), bei anderen (z. B. Metopias, Fig. 217) dagegen auffallend schwach und nur zum unbeholfenen Fortschieben 
des Körpers durch ein „Stenmkriechen“ geeignet. Bei den schlangenförmigen Stegocephalen sind sie verkümmert oder fehlen gänzlich; bei Diplocaulus sind die Hinterbeine stärker verkümmnert als die Vorderbeine.

\section{Die Rippen der Stegocephalen.}

Die Rippen (Costae) der Stegocephalen (Fig. 198) treten in der Regel durch zwei Gılenklıösker mit dem Wirbel in Verbindung. Dar am Oberend ¿ der Rippe stehende Höcker wird das Capitulum, das auf dəm Dorsalrande und über dem Capitulum liegende Höckerchen das Tuberculum genannt. Die konkave Gelenkfläche des Wirbels, die zur Aufnahme des Tuberculums bestimmt ist (fovea pro tuberculo costae), liegt am Wirbel oberhalb der Grube zur Aufnahme des Capitulums (fovea pro capitulo costae), und zwar liegt das Tuberkulargelenk des

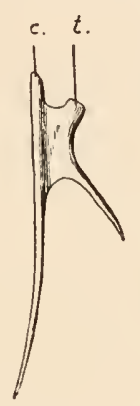

A.

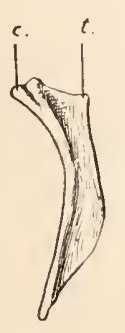

B.

Fig. 198.

A: Ophiderpeton vicinum, Fritsch. Oberkarbon von Niirschan, Böhmen. Rippe.

B: Molgophis spec., Cope. Oberkarbon von Linton, Ohio. Rippe.

Beide Fig. vergr. (Nach H. Schwarz.)

$c .=$ Capitulum costae. $\quad t .=$ Tuberculum costae.

Wirbels am Ende eines Fortsatzes, der als die Diapophyse bezeichnet wird, während der untere, das Capitulargelenk tragende Fortsatz als Parapophyse benannt zu werden pflegt. „Diapophyse“ und „Parapophyse" sind somit Bezeichnungen, welche die Beziehung des Wirbels zur Rippe andeuten, sind aber keineswegs als homologe Bildungen des Wirbels zu betrachten, da z. B. die Parapophysen der rhachitomen Stegocephalen von den Basiventralia, die Parapophysen der Reptilien usw. aber von den Interventralia gebildet werden.

Bei vielen fossilen Stegocephalen (z. B. bei Branchiosaurus) scheinen die Oberenden der Rippen samt Tuberculum und Capitulum zu fehlen; sie sind jedoch jedenfalls auch hier, freilich in knorpeligem Zustande, vorhanden gewesen. 
Sehr häufig zeigen die Rippen größerer Stegocephalen eine starke Verbreiterung des unteren (distalen) Endes (z. B. Metoposaurus, Metopias); bei vielen Gattungen ist der Mittelteil der Rippe zu einem flügelartigen Fortsatz verbreitert, welcher die hintere Rippe erreicht (z. B. bei Euchirosaurus, Archegosaurus, Mastodonsaurus); bei Ophiderpeton (Fig. 198, A) ist dieser Fortsatz lang. Diese Fortsätze, deren Rudimcnte (= Proc. recurvati, A. M. von Fejerváry, 1918) bei den Anuren noch vorhanden sind, funktionieren jedenfalls in derselben Weise wie die Processus uncinati der Vögel und einiger Reptilien (z. B. der Krokodile) und sind auch wahrscheinlich diesen Fortsätzen homolog.

Mit denn Becken tritt meist nur ein einziger Wirbel in Verbindung, der Sakralwirbel, der eine kurze, meist etwas kräftigere Rippe trägt als die anderen Wirbel; am distalen Ende dieser Sakralrippe ist das Becken befestigt. Bei einzelnen Familien (z. B. Dissorophidae) sind jedoch zwei Sakralwirbel vorhanden.

Bei den Anuren sind die Rippen rudimentär geworden und meist mit den Wirb In verschmolz n (Fig. 242, Proc. trans.). Nur die Gymnophionen, die auch in anderen Merkmalen primitiv geblieben sind, besitzen noch kräftige Rippen, die kräftigsten unter den lebenden Amphibien.

\section{Die Hautverknöcherungen der Stegocephalen.}

Während bei den lebenden Amphibien mit Ausnahme der in den Schädel, Unterkiefer und Brust-Schultergürtel einbezogenen Hautknochen in der Regel keine Hautverknöcherungen auftreten, waren solche bei den Stegocephalen weit verbreitet und scheinen nur bei wenigen Formen gefehlt zu haben (z. B. bei Molgophis und Pelion). Unter den lebenden Amphibien sind nur einige Formen zu nennen, bei denen auf dem Rücken kalkige Schilder oder Platten auftreten. Dies ist der Fall beim Schmuckhornfrosch (Ceratophrys ornata Bell.), dessen Rücken ein festes Knochenschild trägt; bei Dermatonotus Mülleri Blgr. und Stereocyclops incrassatus Cope, die zu den Engmaulfröschen gehören, scheiden dorsale Hautdrüsen eine an der Luft zu einem Panzer erhärtende Flüssigkeit aus, die als Schutzmittel gegen die Bisse von Termiten gedeutet wird, von denen sich diese Tiere ernähren. Bei einem anderen Engnaulfrosch (Brachycephalus ephippium Spix) ist ein knöcherner Rückenpanzer vorhanden, der mit den Dornfortsätzen des 2. bis 7. Rückenwirbels fest verwachsen ist und auffallend an den Rückenpanzer der Stegocephalengattungen Cacops, Aspidosaurus und Dissorophus erinnert. Stereocyclops besitzt überdies einen knöchernen Sklerotikalring.

Bei den meisten Stegocephalen ist die Bauchseite des Rumpfes mit knöchernen Schuppen bedeckt (z. B. bei Crossotelus, Archegosaurus usf.), welche meist die Form dünner Spindeln besitzen und sich 
zu Reihen aneinanderschließen, die nach vorn konvergieren und in der Mittellinie des Bauches zusammentreffen: Aus diesen Hautrippen entstanden später bei den Reptilien die knöchernen „Ventralrippen“ (= Sternalrippen = Bauchrippen); unter den lebenden Urodelen sind sie nur bei der Gattung Menobranchus, aber in rudimentärem Zustande, vorhanden.

Bei Cacops und einigen anderen Stegocephalen aus dem Perm Nordamerikas liegen über den Dornfortsätzen der Rückenwirbel skulpturierte Knochenplatten, die in einigen Fällen (z. B. Dissorophus) an die Knochengürtel der Gürteltiere erinnern und so wie diese und ebenso auch wie die Rückenplatten von Ceratophrys und Brachycephalus als eine Folge der grabenden Lebensweise anzusehen sind.

Die Hautverknöcherungen der Stegocephalen treten außer in der Forn von Deckknochen in der Schädelregion in zwei verschiedenen Formen auf: als Schuppen, die in Laufe der Stammesgeschichte zu Stäbchen oder Knochenleisten umgeformt werden (Bauchschuppen und Bauchrippen) und als Platten, welche jedoch wahrscheinlich nichts anderes als zu größeren Stücken vereinigte Schuppen darstellen und somit als eine höhere Spezialisationsstufe der Schuppen zu betrachten sind.

Ob die „Kammplatten“, welche knöcherne Stäbe mit kammartiger Zähnung des einen Endes darstellen, wirklich als Kopulationsorgane des Männchens zu betrachten sind (A. Fritsch, 1883 und 1901), die zum Festhalten des Weibchens bei der Begattung dienten ${ }^{1}$, ist nach netueren Untersuchungen wieder fraglich geworden. ${ }^{2}$ Möglicherweise sind es überlaupt keine Stegocephalenreste, sondern Fisclureste (Kopulationsorgane von Selachiern).

\section{Die Körperformen und die Lebensweise der Stegocephalen.}

Allgemeine Körperform. - Die Hauptmasse der Stegocephalen besaß ursprünglich eine salamander-oder molchförnige Körpergestalt mit vier ungefähır gleich langen, in Verhältnis zur Körperlänge kurzen Gliedmaßen und einem Schwanz, der in primitiven Zustande ungefähr die Länge des übrigen Körpers erreicht haben dürfte, so daß das Becken beiläufig in halber Körperlänge stand. Diese Verhältnisse sind also etwa dieselben gewesen, wie sie bei den lebenden Molchen noch heute erhalten sind.

1 Roy L. Moodie, The Clasping Organs of Extinct and Recent Amphibia. Biological Bulletin, XIV., March 1908, p. 249.

2 H. Schwarz, Über die Wirbelsäule und die Rippen holospondyler Stegocephalen. Beitr. z. Paläont. 11. Geol. Öst.-Ung. ınd des Orients, XX1., 1908, p. 67. 
Sowohl die Verkürzung des Schwanzes, die bis zu einer Verkünmmerung führen kann (z. B: Eryops, Cacops usf.), sowie die Verlängerung des Schwanzes, die schon bei Typen wie. Ceraterpeton aus dem Oberkarbon lrlands zu beobachten ist, sind sonit als sekundäre Spezialisationen anzusehen. Ebenso ist die durch Vermehrung der Rumpfwirbel und der Schwanzwirbel erreichte extreme Verlängerung des Rumpfes, die zuerst zu aalförnigen und später zu schlangenförmigen Typen (z. B. Dolichosoma nit 150 Wirbeln, bei den lebenden Coeciliiden bis zu 300 Wirbeln) führt, als eine sekundäre anzusehen. Die Verlängerung des Rumpfabschnittes mit den weit nach hinten gerückten Beckengürtel tritt uns unter den lebenden Stegocephalen z. B. bei Proteus und bei Amphiuma entgegen.

Eine sehr merkwürdige Körperform hat Diplocaulus besessen; ein sehr großer, extrem flacher und durch die weitausladenden Seitenzacken mondsichelförmig gewordener Schädel sitzt einem Rumpfe mit sehr kleinen und schwachen Vorder- und Hinterbeinen auf, so daß die Körperform von Diplocaulus in der Tat eine Ähnlichkeit mit der einer Froschlarve besitzt, mit der sie mehrfach verglichen wurde.

Form, Bau und Funktion der Wirbel. - Die verschiedene Bewegungsart der Amphibien kommt sehr deutlich in der Form der Wirbel und der Art ihrer Gelenkverbindungen zum Ausdruck.

Bei den schlangenförmigen „Aistopoden" sind ebenso wie bei den lebenden Gymnophionen, den fußlos gewordenen Lacertiliern und den Schlangen die Extremitäten verloren gegangen und die Lokomotion wird allein durch die Schlängelung des Körpers bewirkt. Dies hat die Ausbildung einer großen Gleichförmigkeit und eine Erhölung der Wirbelzahl, dann aber auch eine eigentümliche Gelenkverbindung zur Folge; die bei den Gymnophionen und den fossilen Aistopoden auftretenden akzessorischen Gelenke an der Ventralsëite der Wirbelkörper ermöglichen zwar eine leichte laterale Verschiebung derselben, verhindern aber eine Verschiebung in dorsoventraler Richtung. Eine weitere Übereinstimmung zwischen den „Aistopoden“ und Gynn10phionen besteht in der Gestalt der niedrigen, breiten Neurapophysen, die nur einen stumpfen Kiel an Stelle des sonst meist hohen Dornfortsatzes besitzen; auch die Querfortsätze sind in beiden Gruppen sehr kurz. Diese Ähnlichkeiten sind als eine Folge weitgehender Konvergenz, aber nicht als Beweis enger Verwandtschaft $\mathrm{zu}$ betrachten.

Während bei den „Aistopoden“ und Gymnophionen die Wirbel sehr gleichförnig sind, sind bei den Ptyoniden und Ceraterpetontiden die Rumpf- und Schwanzwirbel außerordentlich formverschieden. Die Schwanzwirbel sind sehr stark lateral kompriniert und besitzen hohe obere und untere Dornfortsätze, so daß der Schwanz sehr hoch und lateral stark komprimiert gewesen sein muß. Diese Wirbelformen 
finden sich auch bei den lebenden Wassermolchen, sind jedoch bei diesen nicht so extren ausgebildet, wie bei den Ptyoniden. Die Ursache dieser Formverschiedenheit der Rumpf- und Schwanzwirbel liegt in der Funktion des Schwanzes als Ruderorgan, wobei sich derselbe starr verhält und nur in einem von der Sakralregion gebildeten Scharnier zwar in mediolateraler Richtung, aber nicht in dorsoventraler Richtung bewegt werden kann. Dieses Scharniergelenk ist z. B. bei Urocordylus zu beobachten.

Die Verfestigung der Ptyonidenwirbel kommut durch die Ausbildung starker akzessorischer Gelenkfortsätze (Zygosphen und Zygantrum) zustande. Bei Scincosaurus fehlen jedoch diese Gelenke und die Verfestigung wird durch ein enges Aneinanderschließen der Dornfortsätze erreicht.

Form, Bau und Funktion der GliedmaBen. - Die Mehrzahl der lebenden und fossilen Amphibien besitzt beide Gliedmaßenpaare; sie sind bei einigen lebenden (z. B. Coeciliidae) und fossilen (z. B. Phlegethontiidae) Gruppen gänzlich verloren gegangen, sind bei anderen nur zum Teil verloren (z. B. die Hinterbeine von Siren lacertina, welche noch kleine Arme besitzt) oder sind bei einigen aalförmigen Typen, wenn auch stark reduziert, noch erhalten (z. B. bei Proteus).

Unter den molch- und salamanderförmig gebauten Stegoceplalen ist sowohl bei den kurzschwänzigen Formen (z. B. Seeleya pusilla, Branchiosaurus amblystomus, Amphibamas grandiceps) als auch bei den langschwänzigen Typen (z. B. Ceraterpeton Galvani, Scincosaurus crassus) die hintere Gliedmaße fast ebenso lang als die vordere, aber doch unverkennbar etwas stärker. Dieses Verhältnis ist nahezu dasselbe wie bei den lebenden Molchen und Salamandern, und wir sind daher zu der Annahme berechtigt, daß die Funktionen der beiden Gliedmaßenpaare auch bei jenen Stegocephalen, die ein gleiches Längenund Stärkeverlıältnis der Extremitäten aufweisen, dieselben wie bei den analog geformten lebenden Typen gewesen sind.

Die Fortbewegung der landbewohnenden Salamander (z. B. Salamandra maculosa) ist sehr langsam und unbeholfen; der Feuersalamander setzt die Gliedmaßen abwechselnd und sehr langsam vor und wirft dabei seinen Körper in S-förniger Krümmung abwechselnd nach links und rechts. Die Vorder- und Hinterbeine sind gleichsinnig gebeugt, während z. B. bei den Säıgetieren der Winkel des Ellbogengelenks nach vorn und der des Kniegelenks nach hinten geöffnet ist. Die Finger sind nach vorn, die Zehen nach vorn und einwärts gerichtet. Beim Ausschreiten wird zuerst der linke Vorderfuß, dann der rechte Hinterfuß, dann der rechte Vorderfuß und zuletzt der linke Hinterfuß vorgesetzt; Hand und Fuß treten mit voller Sohlenfläche auf. Die Hinterbeine sind etwas größer und stärker als die Arme. 
Ein Vergleich des Hand- und Fußskeletts der lebenden Molche und Salamander mit dem der Stegocephalen aus der Gruppe der Brancliosauriden (z. B. Pelosaurus laticeps oder Branchiosaurus amblystomus) zeigt einige auffallende Abweichungen. In der Regel liegen die kleinen Tiere derart auf den Schieferplatten, daß die Dorsalfläche der Hinterfüße nach unten und die Sohlenfläche nàch oben gekehrt ist; mitunter kommen ganz auffallende Verdrehungen vor (z. B. bei Pelosaurus usf.). Dagegen ist die Dorsalfläche der Hand stets nach oben gekehrt.

Ferner ist der vierte Finger- und Zehenstrahl deutlich länger als die benachbarten Finger oder Zehen und enthält eine Phalange mehr. Dadurch nähert sich dieser Gliedmaßenbau dem der meisten Reptilien, unter denen die Verlängerung des vierten Zehenstrahls am klarsten bei den Eidechsen in Erscheinung tritt. Diese Zehenverlängerung des vierten Strahles in Hand und Fuß hängt mit der vorwiegend schiebenden Funktion der Extremitäten zusammen. Hände und Füße werden zwar auch bei den Eidechsen abwechselnd vorgesetzt und berühren auch hier mit der ganzen Sohlenfläche den Boden, aber die Fortbewegung geschieht durch ein Strecken der im Ellbogen- oder Kniegelenk gebeugt aufgesetzten Extremität, wobei die Hand- und Fußfläche fest auf dem Boden verankert bleibt. Danit steht die nach vorn konvexe Bogenkrümmung der Finger und namentlich der Zehen im Zusammenhang. Eine besondere Aufgabe fällt der fünften Zehe zu, die bei den Eidechsen von den vier vorderen deutlich getrennt und nach hinten abgespreizt ist. In Moment des Streckens des Hinterfußes, da der Körper nach vorn geworfen wird, drückt die fünfte Zehe nach innen tnd hinten auf den Boden und verstärkt so die Gewalt des Abstoßens noch dann, wenn schon der Tassus den Boden verlassen hat.

Diese Fortbewegung der Eidechsen ist also im Wesen eine schicbende. Aus dem Schiebkriechen ist ein Schieblaufen geworden; bei einzelnen Geckonen, z. B. bei Otocryptis, ist die Bewegung in eine springende übergegangen, wobei die stark verlängerten Hinterbeine gleichzeitig und nicht melır abwechselnd gestreckt werden. Eine Folgeerscheinung dieses Übergangs zur Sprungbewegung ist die Reduktion der 5. Zehe und eine geänderte Winkelstellung der Hinterbeine.

Die primitivste Gliedmaßentype, die wir bei Stegocephalen kennen, tritt uns z. B. bei Pelosaurus oder Branchiosaurus, überhaupt in der Gruppe der Phyllospondyli entgegen. Auf diesen Typus lassen sich alle übrigen Gliedmaßentypen der fossilen und lebenden Amplibien zurückführen; die Annahme, daß die rudimentären Gliedmaßen von Proteus oder Amphimma etwa wegen ilhrer Kürze und Zartheit sowie wegen ihrer geringen Finger- und Zehenzahl, die bis auf zwei herab- 
sinken kann, als der Ausgangspunkt einer mehrfingerigen Extrenität angesehen werden müsse, ist entschieden abzulehnen.

Bei den vorwiegend aquatischen Molchen übernehmen die Hinterbeine neben dem lateral komprinierten Ruderschwanz die Rolle von Lokomotionsapparaten und wirken gelegentlich als Ruder, wälırend die Vorderfüße sich nur in ganz untergeordnetem Maße an der Lokomotion beteiligen; dieser Körpertypus tritt uns z. B. bei Archegosaurus entgegen.

Die Finger und Zehen bleiben bei den lebenden Molchen mit wenigen Ausnahnen frei beweglich und sind nicht durch Sclıwimmhäute verbunden.

Dagegen finden wir große Schwinmhäute in der Gruppe der Anuren an Hinterfuß entwickelt, so z. B. bei dem ausschließlich aquatischen Spornfrosch Afrikas (Xenopus laevis Daud.), aber auch bei der nur zur Laichzeit ins Wasser gehenden, sonst landbewohnenden Knoblauchskröte (Pelobates fuscus Laur.). Bei denı südamerikanischen Kletterfrosch (Phyllomedusa) sind die Schwimmhäute neuerlich verloren gegangen.

Bei jenen Anuren, welche die springende und schwinnende Lebensweise aufgegeben haben und zu schwerfälligen Landtieren geworden sind, die nur sehr unbeholfen kriechen, aber sich dafür meist sehr geschickt durch oft messerscharfe, schaufelförmige Grabschwielen an der Fußwurzel mit dem Hinterende des Körpers voran in den Boden eingraben können (z. B. Breviceps nossoambicus Ptis.), sind die Schwimmhäute entweder stark reduziert oder gänzlich verloren gegangen.

Eine sehr merkwürdige und unter den lebenden Amphibien ohne Gegenstück dastehende Spezialisation weist der Gliedmaßenbau nehrerer permischer Stegocephalen auf.

Der Brust-Schultergürtel einiger paläozoischer Stegocephalen aus der Unterordnung der Rhachitomen ist außerordentlich kräftig gebaut (z. B. bei Cacops, Eryops, Desmospondylus). Die Arme sind kurz und gedrungen, der Carpus verknöchert. Der Humerus ist außer durch seine auffallende Kürze dadurch gekennzeichnet, daß sein oberer und unterer Abschnitt komprimiert erscheinen und daß diese beiden Abschnitte um $90^{\circ}$ gegeneinander gedreht sind. Zweifellos ist die an der Außenseite des Schultergürtels entspringende und an den Armknochen inserierende Muskulatur ungewöhnlich kräftig gewesen.

Die Stellung des Humerus muß bei diesen Formen horizontal und fast senkrecht zur Körperachse gewesen sein; die Unterarmknochen dürften in einem fast rechten Winkel gegen den Humerus abgebogen und nach unten gerichtet gewesen sein, während die zur Gänze dem Boden aufruhende Handfläche nach innen gerichtet war, wie dies die grabenden und kriechenden Anuren der Gegenwart zeigen (z. B. Pyxicephalus adspersus). 
Die Fortbewegung dürfte in der Art vor sich gegangen sein, daß die starke Schultermuskulatur den Körper ein wenig in die Hölıe hob und ein kurzes Stück vorwärts schob; wenn die Bauclffäche wieder dem Boden aufruhte, setzte das zweite Tempo ein. Die Hinterbeine dürften eine ähnliche, aber mehr schiebende Funktion besessen haben; die Zehen sind wahrscheinlich nicht nach innen, sondern nach außen gerichtet gewesen. Dieser Erklärungsversuch würde die starke Verknöcherung von Carpus und Tarsus bei diesen Formen verständlich machen.

Derselbe Gliedmaßentypus kehrt bei paläozoischen Reptilien wieder (unter den Pelycosauriern bei Ophiacodon, unter den Cotylosauriern z. B. bei Limnoscelis, Diadectes, Diasparactus, Seymouria).

Cacops, Eryops und Desmospondylus haben wahrscheinlich ihre Vorderbeine auch zum Graben benützt, wofür die Ausbildung eines starken Panzers über den Rückenwirbeln spricht, der z. B. bei Dissorophus multicinctus so auffallend an die Panzerplatten der Gürteltiere erinnert, daß ihn E. D. Cope (1895) als ,batrachian armadillo" beschrieb.

Diese Art der Fortbewegung, die wir für Cacops usw. annehmen müssen, unterscheidet sich wesentlich vom Schiebkriechen und ist vielmehr als ein Stemmkriechen zu bezeichnen.

Die verschiedenen Bewegungsarten der lebenden ${ }^{1}$ und fossilen Amphibien (bei erwachsenen Individuenl) sind folgende:

1. Kriechen auf dem Lande (z. B. *Salamandra maculosa, Hylonomus).

2. Schiebkriechen auf dem Lande (z. B. Branchiosaurus).

3. Stemmkriechen auf dem Lande (z. B. Cacops, Desmospondylus).

4. Wühlen auf dem Lande (z. B. * Ichthyophis, Ophiderpeton).

5. Schlängeln und Wühlen (z. B. Dolichosoma longissinumu).

6. Schwimmen (z. B. *Proteus anguineus, *Molge cristata, Archegosaurus Decheni, Lonchorhynchus Öbergi, Urocordylus, Ptyonius, Oestocephalus, Scincosaurus, Ceraterpeton, Diplocaulus).

7. Springen (z. B. *Rana temporaria, *Chorophilus ormatus).

8. Springen und Scliwimmen (z. B. *Rana esculenta).

9. Springen und Klettern (z. B. *Hyla faber, *Phyllonedusa theringi).

10. Springen und Fallschirmfliegen (z. B. *Rhacophorus Reinwardti).

1 Über die Lebensweise der hier genannten lebenden, mit einem * bezeichneten Arten vgl. F. Werner, Neubearbeitung von „Brehms Tierleben“, IV. Bd., 1912. 
11. Wühlen und Schwimmen (z. B. *Amphiuma means, * Siren lacertina).

12. Krieclien und Graben (z. B. *Pyxicephalus adspersus, * Rhinophrynus dorsalis, *Breviceps mossambicus).

13. Schwimmen und Kriechen (z. B. * Megalobatrachus maxinus).

14. Tasten und Kriechen (z. B. * Typlllomolge Rathbuni).

Aufenthaltsorte der Stegocephalen. - Die erwachsenen Amphibien sind entweder Süßwasser- oder Landbewohner oder bringen ihr Leben teils im fließenden oder stehenden Wasser, teils auf dem Lande zu. Ihre ursprüngliche Heimat sind wahrscheinlich seichte Landsümpfe und Strandsümpfe gewesen, in denen die lichtscheuen Tiere während der Nacht auf Beute ausgingen. Daß sich die kleineren Formen, wie z. B. die Branchiosauriden, tagsüber an geschützten Orten verbargen, beweisen die wiederholten Funde solcher Formen in den Stämmen von Sigillarien und Lepidodendren Neuschottlands. Andere haben sich walırscheinlich in den Schlamm eingewühlt und erst in der Dunkelheit ihre Verstecke verlassen.

In der letzten Zeit sind in der Trias Spitzbergens langschnauzige, offenbar an das Wasserleben angepaßte Stegocephalen beschrieben worden (z. B. Lonchorhynchus und Aphanerannma), die möglicherweise Meeresbewohner gewesen sind. Es ist jedoch anzunelnimen, daß diese Typen'erst in erwachsenen Zustande das Meer aufsuchten und ihre Larvenzeit wie alle Stegocephalen in Süßwasser verbrachten.

Bei Lonchorhynchus spricht für das Wasserleben außer der bei lebhaften Wasserräubern sehr häufig auftretenden Schnauzenverlängerung vor allem die seitliche Lage der Augen, welche auch bei einer vor kurzem entdeckten Gattung von unsicherer systematischer Stellung (Chenoprosopus Milleri, Mehl 1913, Perm von Neumexiko) zu beobachten ist. Die nach hinten verschobenen Nasengänge bei Lonchorliynchus beweisen, daß das Tier eine mehr horizontale Schwimmstellung besaß als jene aquatischen Reptilien, welche eine scliräge (klinonektonische) Körperhaltung beim Schwimmen einnehmen, wie z. B. die Molche, und daher auch dann, wenn ilıre Schnauzen beträchtlich verlängert sind, die Nasenlöcher anı Vorderende der Schnauze beibehalten, weil dieses zuerst aus denı Wasser auftaucht (z. B. bei denı lebenden Gavialis gangeticus, Crocodilus cataphractus und den fossilen Krokodiliern Metriorhynchus, Geosaurus, Teleosaurus usf.). - Nur bei jenen aquatischen Wirbeltieren, welche beim Schwimmen eine horizontale Körperstellung einnehmen, werden die äußeren Nasenöffnungen gegen die Schädelkapsel, also nach hinten, verschoben (z. B. bei Walen und Sirenen) und das gleiche müssen wir daher auch als Folge der horizontalen Schwimmstellung bei fossilen Wirbeltieren annehmen 
(z. B. bei Lonchorhynchus. Phytosaurus $[=$ Belodon $]$, Ichthyosaurus, Thalattosaurus, Mesosaurus usf.).

Die Ablagerungen der Permzeit in Texas sind wohl am ehesten als Schichten zu deuten, die sich in sumpfigen Deltaniederungen gebildet haben. Obwohl Einschwenmungen vom Hinterlande her in solchen Deltabildungen häufig auftreten, so spricht doch die ganze Art des Vorkonmens dafür, daß die Stegocephalen in diesen Gegenden bodenständig waren.

Die Fährten, welche als „Chirotherium" seit langer Zeit aus dem Perm und der Trias bekannt sind und früher meistens als Fußabdrücke von Stegocephalen gedeutet wurden, gehören wahrscheinlich Dinosauriern an, da diese Fährten stets einen auffallenden Größenunterschied von Hand und Fuß zeigen, einem Tiere mit fünffingeriger kleiner Hand angehörten und in einzelnen Fällen sicher von bipeden Wirbeltieren in den Schlamm eingedrückt worden sind.

\section{Nahrungsweise der Stegocephalen.}

Die lebenden Amphibien sind ausnahmslos Raubtiere. Die kleineren leben von Wassertieren der verschiedensten Gruppen, von Würmern, Insektenlarven und erwachsenen Insekten, kleinen Krustazeen, Schnekken usf., während größere Arten, wie der japanische Riesensalamander, sich hauptsächlich von Fischen, Fröschen, Würmern und Insekten ernähren oder, wie mehrere Riesenfrösche, auch auf größere Tiere, wie Frösche, Eidechsen, Schlangen, Mäuse und Vögel Jagd machen. Rana Guppyi (Salomoninseln), dessen Weibchen bis $21 \mathrm{~cm}$ lang wird, nährt sich ausschließl.ch von großsn Krebsen. Da viele Frösche vorwiegend von Molchen und anderen Fröschen leben, so dürfen wir von den größeren Stegocephalen der Vorzeit vermuten, daß sie namentlich auf Fische, Krebse und Stannesgenossen, wohl auch auf kleinere Reptilien Jagd machten. In diesem Zusammenhang gewinnt eine Beobachtung Powers besonderes Interesse, daß bei jenen Axolotllarven (Amblystoma tigrinum), die sich gewöhnt hatten, ihre Artgenossen zu verzelıren, im Gebiß einzelne große Fangzähne zur Ausbildung gelangten. Das Vörhandensein ähnlicher großer Fangzähne bei vielen fossilen Stegocephalen, namentlich bei den Labyrinthodontiden, spricht somit dafür, daß sie sich vorwiegend von größeren Beutetieren ernälrten. Ein sehr auffallend gestaltetes Gebiß besaß Cricotus, dessen dichtstehende Zähne lateral komlprimiert sind und scharfe Schneiden tragen, die sich zu einer Säge ancinanderschließen.

\section{Die Kiemen der Stegocephalen.}

Wahrscheinlich haben alle Stegocephalen so wie die lebenden Amphibien ein Larvenstadium mit Kiemenatmung durchlaufen. Bei einigen 
Stegocephalen sind Reste von Kiemen oder Kiemenbogenzähnchen nachgewiesen worden, so z. B. bei Branchiosaurus und Archegosaurus, aber nur bei jugendlichen lndividuen. Bei dem ältesten bisher bekannten Urodelen, Lysorophuts tricarinatus Cope aus dem Perm von Nordamerika, sind auch noch im erwachsenen Zustande vier Branchialbögen in verknöcherten Zustande nachweisbar, so daß daraus hervorgeht, daß dieses Tier eine perennibranchiate, ausschließlich aquatische Lebensweise geführt haben muß, weil es zeitlebens auf dem Larvenstadium stehen blieb.

\section{Das Seitenliniensystem und die Schleimkanäle der Stegocephalen.}

Bei den Fischen und Cyclostomen ist ein System merkwürdiger Hautsinnesorgane ausgebildet, welche auf dem Kopfe und an den Körperflanken in bestimminter Anordnung stehen und z. B. bei Knochenfischen auch äuBerlich in der sog. ,, Seitenlinie" sichtbar sind, weshalb dieser Hautsinnesorgankomplex den Namen ,Seitenliniensystem" (Lateralliniensystem) erhalten hat. Die physiologische Bedeutung dieser Organe ist noch immer nicht zur Gänze aufgeklärt; gegenwärtig wird gewöhnlich angenommen, daß der Apparat zur Wahrnehmung von Erschütterungen dient, die sich in Form von Wellenbewegungen im Wasser fortpflanzen. Nach den Untersuchungen von G. H. Parker (1904) über die Funktion des Laterallinienorgans bei den Fischen ist es sehr wahrscheinlich, daß dieses Sinnesorgan eine Aufgabe zu erfüllen hat, die ungefähr zwischen den Organen für dèn Tastsinn und jenen für den Gehörsinn die Mitte hält. ${ }^{1}$

Diese Organe liegen bei den Knochenfischen in schleinabsondernden Kanälen (,Schleimkanälen") unter der Haut, und sind in Rinnen der Kopfknochen sowie in einem Kanal eingebẻttet, der die Schuppen durchbohrt; meist verläuft die Seitenlinie mehr oder weniger geradlinig oder folgt parallel dem Dorsalprofile des Fischrumpfes in der Mitte der Flanke, aber zuweilen ist sie scharf ungeknickt ${ }^{2}$ und sogar manchmal in einen oberen und unteren Abschnitt getrennt. ${ }^{3}$ Bei Tiefseefischen gelangen im Zusammenhange mit den Laterallinienorganen Leuchtapparate zur Ausbildung (z. B. bei Porichthys 350 Photophoren jederseits).

1 G. H. Parker, The Function of the Lateral Line Organs in Fishes. Bull. of the Bureau of Fisheries, XXIV, 1904, p. 185.

2 Z. B. bei dem lebenden Pleuronectiden Lepidoblepharon ophthalmolepis Weber (1913) aus der Arafura-See bei den Kei-Inseln. (Max Weber, Die Fische der Siboga-Expedition. Leiden, 1913, p. 422, Taf. VI, Fig. 7.)

3 Z. B. bei Tilapia Dolloi. (T. W. Bridge: Fishes. In ,The Cambridge Natural History“, Vol. VII, 1904, p. 152, Fig. 93.) 
In typischen Fällen zerfällt das Lateralliniensystem der Fische in folgende Abschnitte, z. B. bei Gadus:

1. Lateralkanal (längs der Körperflanken und dem Hinterhaupt. Innerviert vom Nervus lateralis maior).

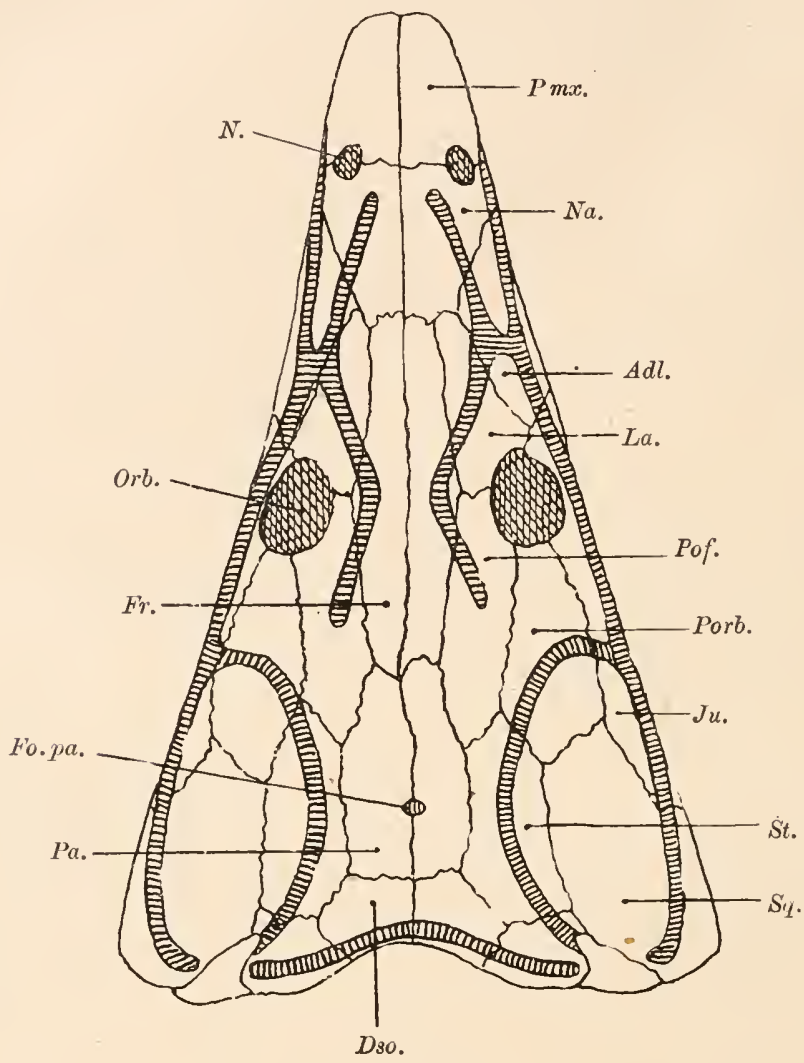

Fig. 199.

Die Schleimkanäle (horizontal schraffiert) des Schädeldaches von Trematosaurus Brauni, Burm., in $2 / 5$ nat. Gr.
Adl. = Adlacrymale.
Orb. = Orbita.
Dso. $\quad=$ Dermosupraoccipitale.
$P a . \quad=$ Parietale
Fo. $p a .=$ Foramen parietale.
Pmx. = Praemaxillare.
$\mathrm{Fr} . \quad=$ Frontale
Pof. $=$ Postfrontale.
Ju. $=$ Jugale.
La. $=$ Lacrymale.
N. $\quad=$ Nasenöffnung.
Porb. = Postorbitale.
Na. $\quad=$ Nasale.
Sq. $\quad$ = Sqamosum.
St. $=$ Supratemporale.

2. Supraorbitalkanal (oberhalb des Auges. Innerviert vom Ramus ophthalmicus des Nervus facialis).

3. Infraorbitalkanal (unterhalb des Auges. Innerviert vom Ranus buccalis und R. oticalis des $\mathrm{N}$. facialis). 
4. Operculo-Mandibularkanal (= Hyonlandibularkanal) (folgt der Außenseite des Unterkiefers und zieht sich in die Operkularregion hinauf. Innerviert vom Ramus mandibularis ext. des N. facialis).

Diese Längskanäle sind häufig durch quere Kommissuren verbunden, die auf der Oberseite des Schädels verlaufen (z. B. Supraorbitalkommissur bei Gadus, Occipitalkommissur bei Polypterus, Fig. 29.)

Dieselben Schleimkanäle finden sich auch bei den Amphibien, und zwar sind sie bei den lebenden meist nur in rudimentärem Zustande, selten wohlausgebildet vorhanden (z. B. bei Necturus). Genau dieselbe Anordnung und Ausbildung dieser Kanäle ist bei Micrerpeton caudatun Moodie aus dem Karbon von lllinois nacligewiesen worden.

Hingegen zeigt der Schädel der meisten Stegocephalen viel tiefere und breitere Kanäle, als dies bei den Fisclien der Fall ist. Ganz besonders scharf sind diese Kanäle auf dem Schädeldach der Labyrinthodontiden ausgeprägt (Fig. 199). Wie R. L. Moodie (1908) gezeigt hat, sind diese Kanäle den Schleimkanälen des Fischschädels homolog. Bei den Branchiosauriden ist nur in der Schwanzregion das Lateralliniensystem ausgebildet (Micrerpeton), während der Schädel keine Schleimkanäle trägt.

$\mathrm{Ob}$ die Funktion der Schleimkanäle der Labyrinthodontiden dieselbe war wie bei den Fischen, ist sehr zweifelhaft. Wahrscheinlich dienten sie nur dazu, die Haut schleimig zu erhalten und das Austrocknen derselben zu verhindern, denn die großen Labyrinthodontiden, bei denen die Schleimkanäle besonders groß und scharf ausgeprägt sind, dürften wohl der Mehrzahl nach schwerfällige Landtiere, aber keine ausschließlich aquatischen Formen gewesen sein.

\section{Ordo: Rhachitomi ( $=$ Temnospondyli).}

Wirbel ursprünglich aus mehreren freibleibenden Elementen (Basidorsalia, Basiventralia, Interdorsalia, Interventralia) zusammengesetzt (rhachitomer Wirbeltypus), später durch Verschmelzung der Basidorsalia und Basiventralia unter gleichzeitiger Reduktion der Interdorsalia und Interventralia (stereospondyler Wirbeltypus) zu einem einheitlichen, vorn und hinten ausgehöhlten (amphizölen) Körper verschmelzend. Die ersten Vertreter des Stammes im Unterkarbon (hier schon stereospondyle Typen), die jüngsten in der Trias. Ausgestorben. ${ }^{1}$

1 Eine eingehende Literaturübersicht, welche die Arbeiten ïber paläozoische Amphibien und Reptilien bis zum Jahre 1888 umfaßt, findet sich in: L. von Ammon, Die permischen Amphibien der Rheinpfalz. - München 1889. Die späteren Arbeiten sind weit zerstreut; die neuere Literatur (bis 1911) ist, soweit sie sich auf die nordamerikanischen Funde bezieht, enthalten in: E. C. Case, Revision of the Amphibia and Pisces of the Permian of North America. - Carnegie Institution of Washington, Publication No. 146, 1911. 


\section{F. Archegosauridae.}

Körper langgestreckt, bis 1,5 $\mathrm{m}$ und darüber erreichend; hierher gehört die größte bekannte Stegocephalengattung des Karbons, Sclerocephalus. Der Schwanz ist lang und seitlich komprimiert, was in Verbindung mit der Schnauzenverlängerung einzelner Arten (z. B. Arclıego-

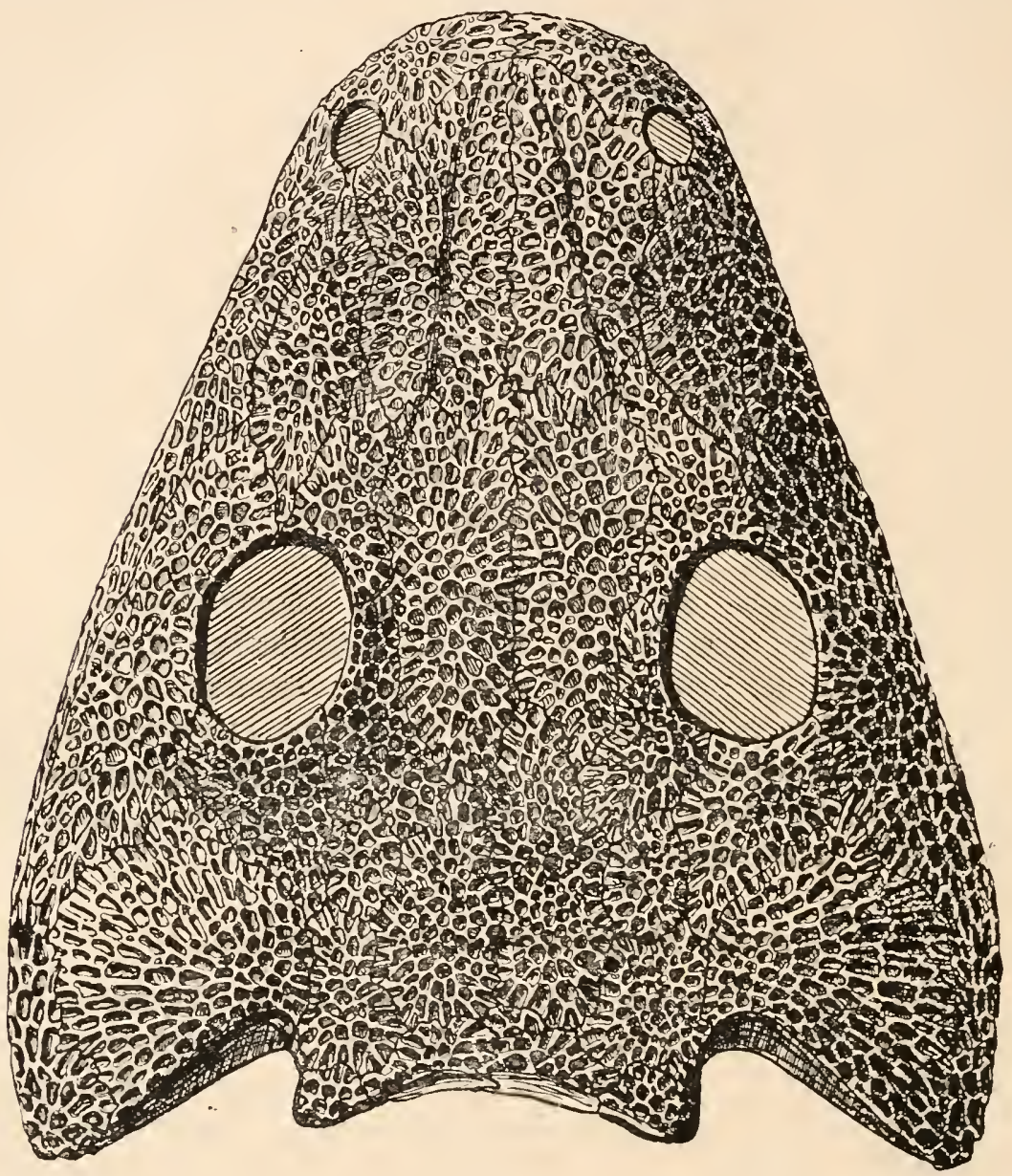

Fig. 200.

Rekonstruktion des Schädeldaches eines Archegosauriden (vgl. Chelydosaurus Vranyi, Fritsch), aus dem untersten Perm von Braunau, Böhmen. 1/2 nat. Gr.

(Nach O. Jaekel.)

saurus Decheni Gdf.) für eine aquatische Lebensweise dieser Formen spricht. Auch bei den im Alter langschnauzigen Arten ist jedoch der Schädel in der Jugend stumpf dreieckig. Die Augenhöhlen meist im hinteren Schädeldrittel gelegen, wenn der Schädel ausgewachsen ist, bei jungen lndividuen in halber Schädellänge, meist oval, nur bei Sclero- 
cephalus kreisrund. Augenhöhlen dưrch Sklerotikalplatten geschützt. Hinterhaupt in der Jugend unverknöchert. Nasenlöcher an Vorderende der Schnauze. In der Jugend äußere Kiemen (bei Archegosaurus) nachgewiesen. Brustschultergürtel kräftig. Vorderfüße vierfingerig, Hinterfüße fünfzehig (Archegosaurus); Arme schwächer als die Hinterbeine (Archegosaurus). Bauchpanzer vorhanden, aus schmalen, spindeloder leistenförmigen Hautschuppen (Sternalrippen) bestehend. Wirbel von typisch rhachitomem Bau. Schädelknochen in der Regel sehr stark skulpturiert (vgl. Fig. 200).

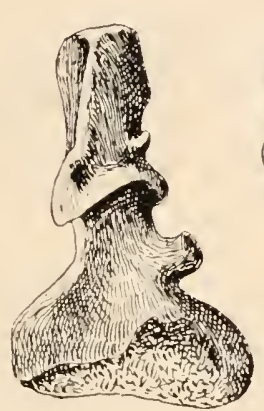

a

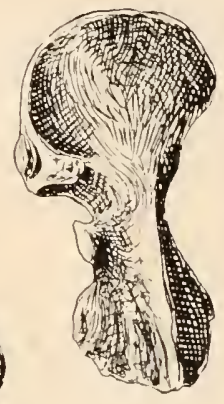

b

Fig. 201.

Actinodon Rochei, Gaudry, ein Archegosauride aus dem Perm von Autun, Frankreich. Humerus, a. von vorne, b. von der Seite, in $1 / 2$ nat. Gr. (Nach A. Gaudry.)

Sclerocephalus. - Schädel sehr breit, stark skulpturiert, Augenhöhlen kreisrund, klein, im hinteren Drittel der Schädellänge, weit voneinander getrennt. - Oberkarbon von Bölnmen (Gaskohle von Nürschan), Perm Deutschlands (Pfalz und Sachsen). ${ }^{1}$

Osteophorus. - Der Schädel besitzt große Ähnlichkeit mit dem von Sclerocephalus, unterscheidet sich aber von diesen durch das Vorhandensein eines ,Internasofrontale“, eines medianen Knochens zwischen den Nasenbeinen und Stimbeinen. Vielleicht ist aber dieser Knochen einem „Schaltknochen“ gleichzusetzen, dem nur eine individuelle oder höchstens spezifische Bedeutung zuzusprechen ist. - Mittleres Rotliegendes (Permi) Schlesiens. ${ }^{2}$

Actinodon. (= Euclirosaurus). - Nahe verwandt mit Sclero-

1 F. Broili, Über Sclerocephalus aus der Gaskohle von Nürschan und das Alter dieser Ablagerungen. - Jahrbuch der K. K. Geol. Reichsanstalt in Wien, LVIII. Bd., 1908, p. 51.

2 H. von Meyer, Osteophorus Roemeri aus dem Rotliegenden von KleinNeuendorf in Schlesien. - Paläontographica, VII. Bd., 1859, p. 101. 
cephalus, aber Augenhöhlen groß und weiter vorn gelegen. - Perm von Frankreich (Autun). ${ }^{1} \quad$ (Fig. 201.)

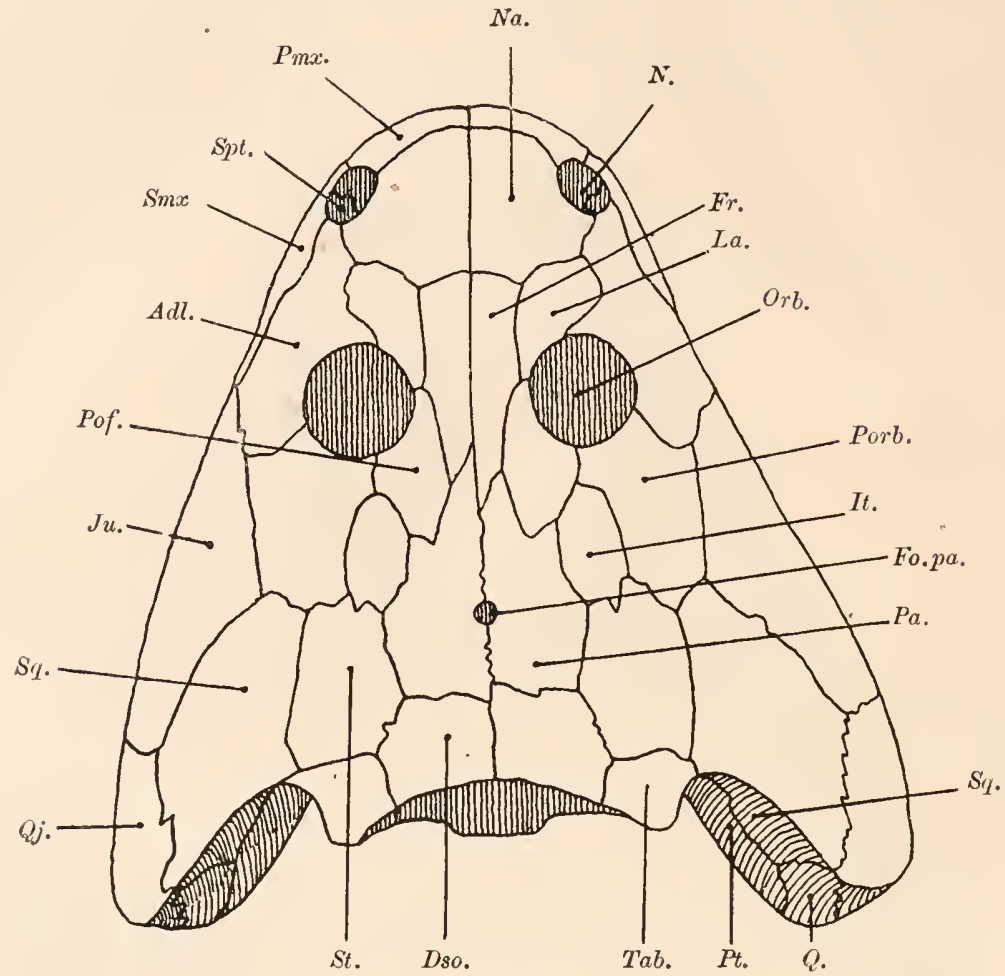

Fig. 202.

Schädeldach von Trimerorhachis insignis, Cope, aus dem Perm von Texas, Rekonstruktion in $1 / 2$ nat. Gr. mit Benützung der von R. Broom, F. v. Huene und S. W. Williston veröffentlichten Abbildungen. Das Vorhandensein eines Septomaxillare ist hier nach Analogie von Trimerorhachis mesops angenommen.
Adl. = Adlacrymale.
Pmx. = Prämaxillare.
Dso. $=$ Dermosupraoccipitale
Pof. $=$ Postfrontale.
Fr. $\quad=$ Frontale
Porb. $=$ Postorbitale
Fo. $p a .=$ Foramen parietale
It. $=$ Intertemporale.
Pt. $\quad=$ Pterygoid.
Ju. $=$ Jugale
La. = Lacrymale.
Q. $\quad=$ Quadratum.
N. $\quad=$ Nasenöffnung.
Na. $\quad=$ Nasale
Orb. = Augenöffnung
Qj. $\quad=$ Quadratojugale
Smx. = Supramaxillare.
Spt. = Septomaxillare.
Sq. = Squamosum.
St. = Supratemporale
$P a . \quad=$ Parietale.
Tab. = Tabulare.

Archegosaurus. - Gehört zu den häufigsten und daher bestbekannten Stegocephalen. - Perm Deutschlands (Sphärosideritknollen

1 A. Gaudry, L'Actinodon. - Nouvelles Archives du Muséum d'Histoire nat. - T. $X, 2^{e}$ série, 1887.

A. Thévenin, Les plus anciens Quadrupèdes de la France. - Annales de Paléontologie, T V., Paris 1910 (hier die ältere Literatur). 
des Rotliegenden von Lebach bei Saarbrücken; Rotliegendes von Sachsen; Karbon von Kaschmir). ${ }^{1}$ (Fig. 171, 173, 196.)

Cochleosaurus. - Dermosupraoccipitale löffelförmig verlängert. Oberes Karbon von Böhmen (Gaskohle von Nürschan). ${ }^{2}$

Chelydosaurus. - Unterstes Perm von Braunau in Böhmen (Fig. 200). ${ }^{3}$

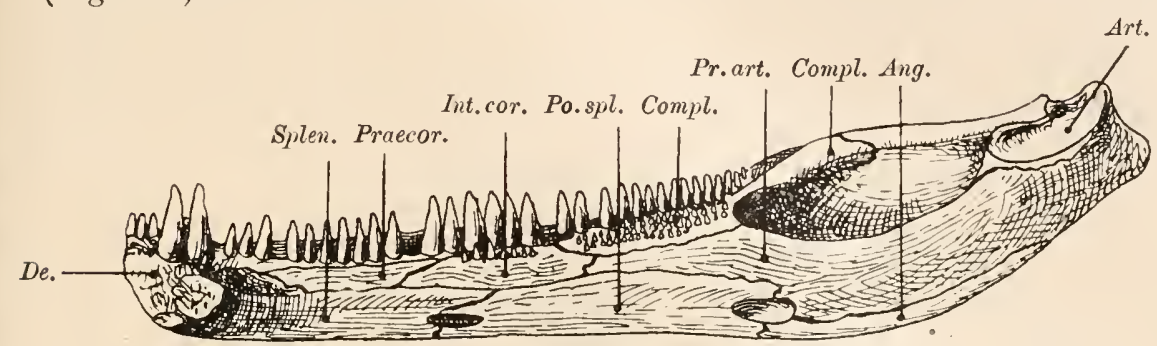

B.

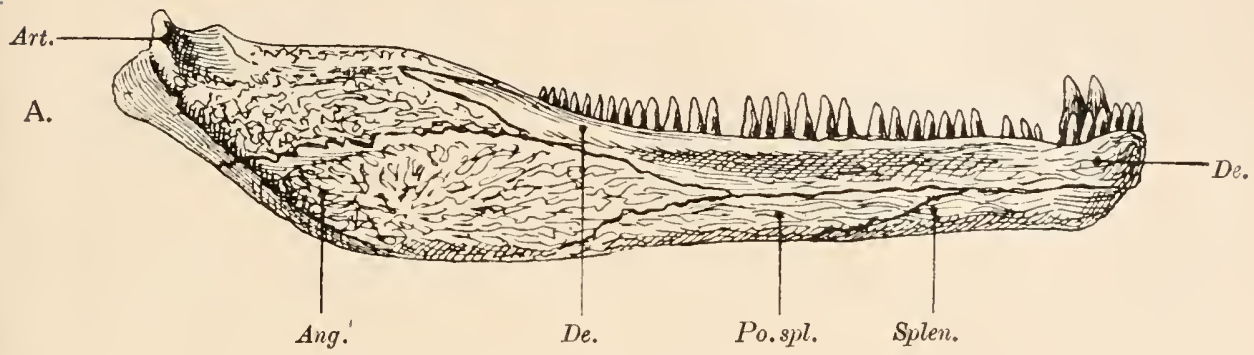

Fig. 203.

Rechter Unterkieferast von Trimerorhachis Alleni, Case, aus dem Perm von Texas, in $4 / 9$ nat. Gr. A. Außenansicht; B. Innenansicht. (Nach S. W. Williston.)
Ang. = Angulare.
Praecor, = Praecoronoid.
Art. = Articulare.
Pr. art. = Praearticulare.
Compl. $=$ Complementare.
Po. spl. $=$ Postspleniale.
De. $\quad=$ Dentale.
Spl. $\quad=$ Spleniale

Int. cor. = intercoronoid

\section{F. Trimerorhachidae.}

Gesamtlänge $1 / 2-111$. Schädel flach, mit Schleimkanälen. Augen weit vorn gelegen, nach oben gerichtet. Intertemporale vorhanden. Condylus occipitalis einfach, konkav. Pleurozentren klein, Dornfort-

1 Das Hauptwerk über Archegosaurus ist: H. von Meyer, Reptilien aus der Steinkohlenformation in Deutschland. - Paläontographica, VI. Bd., 1857, p. 59.

Über den Bau der Wirbel von Archegosaurus vgl. O. Jaekel, Über die Klassen der Tetrapoden. - Zoolog. Anzeiger, XXXIV. Bd., 1909, p. 201.

2 F. Broili, Beobachtungen an Cochleosaurus bohemicus Fritsch. - Paläontographica, LIl. Bd., 1905, p. 1.

3 A. Fritsch, Die Fauna der Gaskohle und der Kalksteine der Permformation Böhmens. - I. Bd. 1883, II. Bd. 1885-1889. 
sätze kurz. 31 präsakrale Wirbel, alle rippentragend, Sakralrippen nicht differenziert. Körper mit dünner, biegsamer, Knochenplättchen tragender Haut bedeckt. Scapula kurz, breit; Cleithrum fehlt. Claviculae und Interclavicula als schildförmige, skulpturierte Platten entwickelt. Gliedmaßen klein, schwach ossifiziert. Finger und Zehen sowie die Elemente des Carpus und Tarsus sind unbekannt; vielleicht waren sie knorpelig. Bei zahlreichen Exemplaren sind die Ilia bekannt; diese Knochen sind sehr klein und waren nach den Untersuchungen Willistons nicht fest mit dem Sacrum verbunden. Pubis und Ischium sind

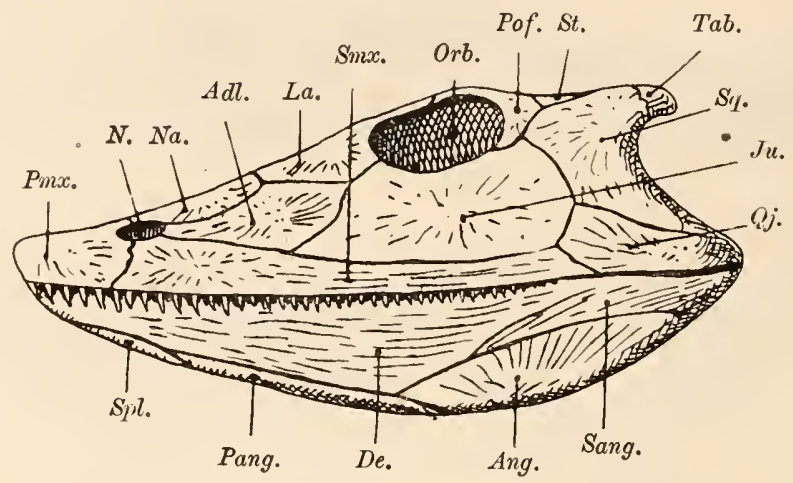

Fig. 204.

Seitenansicht des Schädels von Eryops anatinus, Broom, aus dem Perm von Texas, in $1 / 2$ nat. Gr. (Nach R. Broom.)

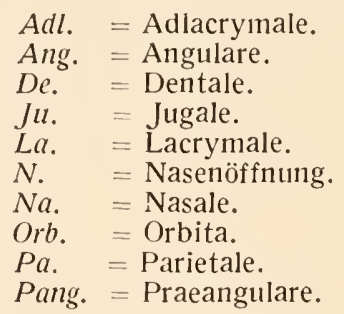

Pof. $=$ Postfrontale.

Pmx. = Praemaxillare.

Qj. $\quad=$ Quadratojugale.

Sang. = Supraangulare.

Smx. = Supramaxillare.

Spl. $=$ Spleniale.

Sq. $\quad=$ Squamosum.

St. $=$ Supratemporale.

Tab. = Tabulare.

Pang. $=$ Praeangulare .

wahrscheinlich unverknöchert gewesen. Knapp bei dem hinteren Ende des Unterkiefers ist bei einem Exemplar ein flacher Knochen beobachtet worden, der ein ungewöhnlich großes Hyoid oder Epibranchiale darstellen dürfte. Dieser Unustand sowie die Reduktion des Beckens, die sich in gleicher Weise beim lebenden Necturus findet, sprechen nach Williston dafür, daß Trimerorhachis ein aquatisches und zwar ein perennibranchiates Tier war, bei dem der knorpelige Zustand der unteren Beckenelemente sowie von Hand und Fuß eine sekundäre Anpassung an das Wasserleben nach Analogie von Necturus darstellt. 
Trimerorhachis. - Perm von Texas und Oklahoma. ${ }^{1}$ (Fig. 202, 203.)

\section{F. Eryopidae.}

Große Tiere von $1 / 2-3 \mathrm{~m}$ Länge. Schädel flachgedrückt, mit Schleinkanälen. Interfrontale vorhanden. Zwei Hinterhauptskondylen. Otikalschlitz klein. Scapula groß, mit großem Cleithrum. Interclavicula und Clavicula mit rauher Oberfläche, Schultergürtel sehr kräftig.

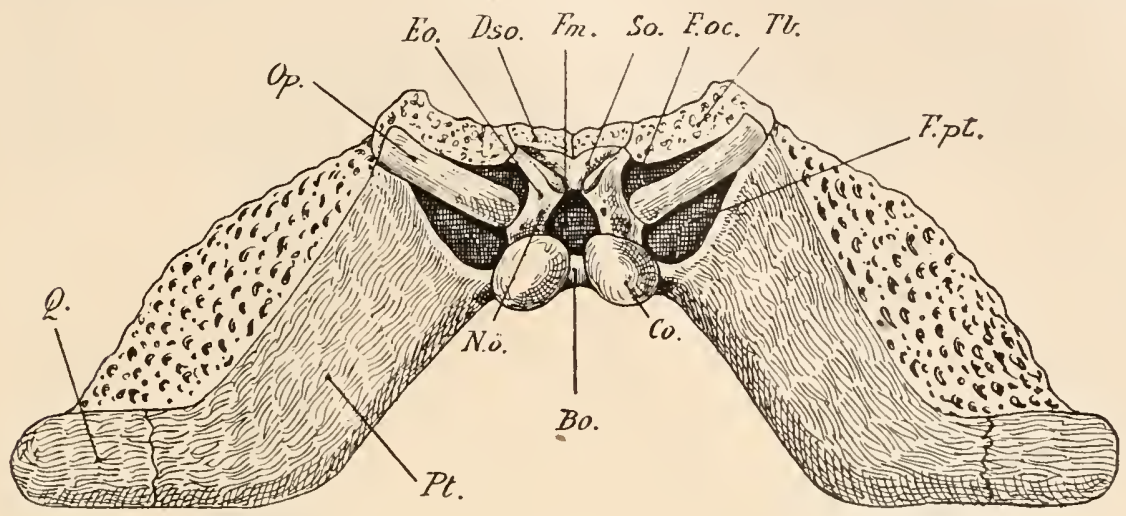

Fig. 205.

Hinterhaupt von Eryops megacephalus, Cope, aus dem Perm von Texas, in etwa $1 / 4$ nat. Gr. (Neue Rekonstruktion auf Grundlage verschiedener Abbildungen, namentlich von S. W. Williston, E. C. Case, R. Broom, C. Wiman u. F. v. Huene.)

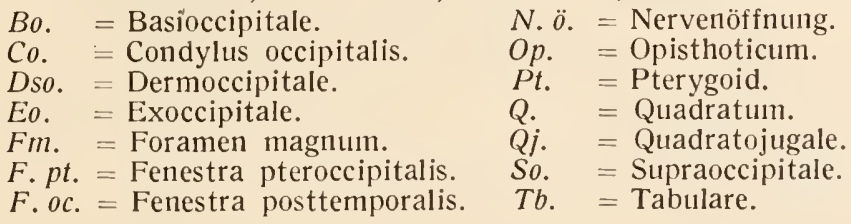

Ein Sakralwirbel. Rippen mit Processus uncinatus versehen. (Fig. 172, 185-188, 190, 194, 204-206.)

Eryops. - Perm von Texas, Oklahoma, Neumexiko. ${ }^{2}$

1 S. W. Williston, The Primitive Structure of the Mandible in Amphibians and Reptiles. - Journal of Geology, Vol. XXI, 1913, p. 625.

Derselbe, Trimerorhachis, a Permian Temnospondyl Amphibian. - Ibidem, Vol. XX111, 1915, p. 246.

Derselbe, The Skeleton of Trimerorhachis. - Ibidem, XXIV, 1916, p. 291.

Derselbe, Synopsis of the American Permocarboniferous Tetrapoda. Contributions from Walker Museum, Vol. I, 1916, p. 206.

2 E. C. Case, Revision of the Amphibia and Pisces of the Permian of North America. - Carnegie Institution, Washington, Nr. 146, 1911, p. 91.

F. von Huene, Beiträge zur Kenntnis des Schädels von Eryops. - Anatomischer Anzeiger; XLI. Bd., 1912, p. 98.

R. Broom, Studies on the Permian Temnospondylous Stegocephalians of North America. - Bulletin American Mus. Nat. Hist., New York, Vol. XXXI1, 1913,p. 579.

S. W. Williston, Contributions from Walker Museum, Vol. 1, 1916, p. 200. 


\section{F. Trematopsidae.}

Plumpe, kurzschwänzige, großköpfige Formen von etwa $1 / 2$ bis 111 Körperlänge. Schädel nicht flachgedrückt, sondern gewölbt; Augenhöhlen etwa in halber Schädellänge gelegen. Interfrontale und Intertemporale fehlen. Keine Schleimkanäle vorhanden. An Vorderende der Schnauze eine mediane Fenestra internasalis; die Nasenöffnungen mit je einer großen Fenestra praeorbitalis in Verbindung; das weit nach vorn reichende Cavum oticale durch einen vom Tabulare und Squamosum gegen das Quadratojugale gerichteten Vorsprung gegen hinten abgeschnürt und geschlossen (Pseudotemporalgrube). Zwei Kondylen.

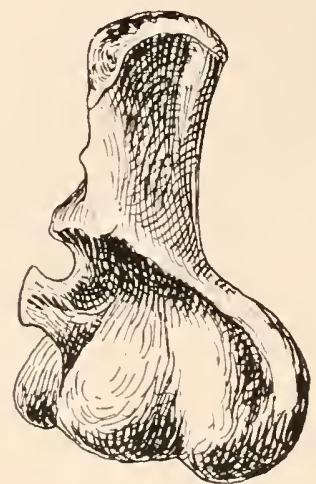

Fig. 206.

Rechter Humerus von Eryops $(1 / 3$ nat. Gr.).

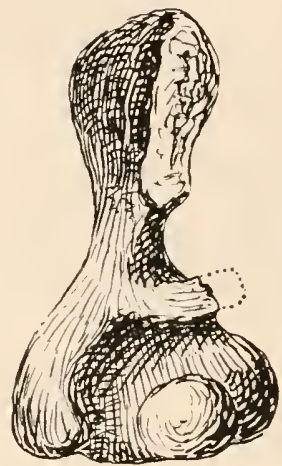

Fig. 207.

Linker Humerus von Trematops Milleri $(2 / 3$ nat. Gr.).

Mehrere Paar größere Fangzähne auf Vomer, Palatinum und Supramaxillare. Kein Hautpanzer auf dem Rücken, Claviculae und Interclavicula olne Skulptur. Becken- und Gliedmaßenknochen ähnlich wie bei Eryops gebaut, Carpus verknöchert (9 Elemente), Tarsus ebenso (12 Elemente). Phalaingenformel der Hand unsicher (vielleicht 5 Finger vorhanden ?), Zehenphalangenformel: 1, 2, 3, 4, 2. 23-25 präsakrale Wirbel, 2 Sakralwirbel.

Trematops. - Ein fast vollständiges Skelett bekannt. Perm von Texas. ${ }^{1}$ (Fig. 197, 207, 208.)

\section{F. Dissorophidae.}

Plumpe, gepanzerte, kurzschwänzige Formen, terrestrisch, wahrscheinlich Grabtiere. Körperlänge etwa $1 / 2 \mathrm{~m}$. Schädel plump, etwas

1 S. W. Williston, New or little-known Permian Vertebrates: Trematops, New Genus. - Journal of Geology, Vol, XVII, 1909, p. 636. 
deprimiert; Schleinkanäle, Interfrontale und Intertemporale fehlen. Otikalgrube geschlossen. Halswirbel und Rückenwirbel von je einem Paar Knochenschilder bedeckt, das vordere glatt, das lintere skulpturiert. Scapula mit großem Cleithrum in Verbindung, Schultergürtel kräftig, ebenso das Becken. 21 präsakrale Wirbel, 2 Sakralwirbel.

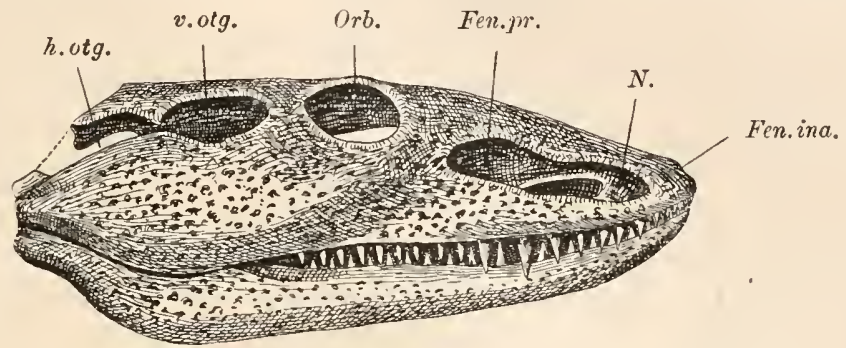

Fig. 208.

Schädel von Trematops Milleri, Will., aus dem Perm von Texas, in $1 / 3$ nat. Gr. (Nach S. W. Williston.)
h. ofg. = hinterer Abschnitt des Cavum Orb. $\quad=$ Orbita. oticale.
v. otg. = vorderer Abschnitt des Ca-
Cav. $p r .=$ Fenestra praeorbitalis. vum oticale.
N. $\quad$ Naris
Cav. ina. $=$ Fenestra internasalis.

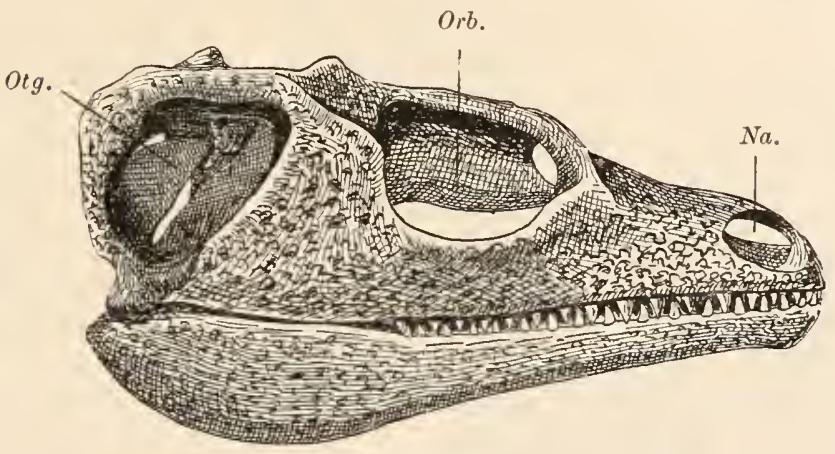

Fig. 209.

Schädel von Cacops aspidephorus, Will., aus dem Perm von Texas, $1 / 2$ nat. Gr. (Nach S. W. Williston.)

Otg. = Cavum oticale (dirch den hinteren Abschluß zu einer Pseudotemporalgrube geworden, vgl. p. 251). Orb. = Orbita. $N a .=$ Naris.

Cacops. - Panzerplatten über der Wirbelsäule nicht verschmolzen, seitlich nicht weit über die Neurapophysen vorspringend. Melırere Skelette bekannt. - Perm von Texas. ${ }^{1}$ C. aspidephorus (Fig. 195, 209, 210).

1 S. W. Williston, Cacops, Desmospondylus; New Genera of Permian Vertebrates. Bulletin of the Geological Society of America, Vol. XXI, 1910, p. 249. 


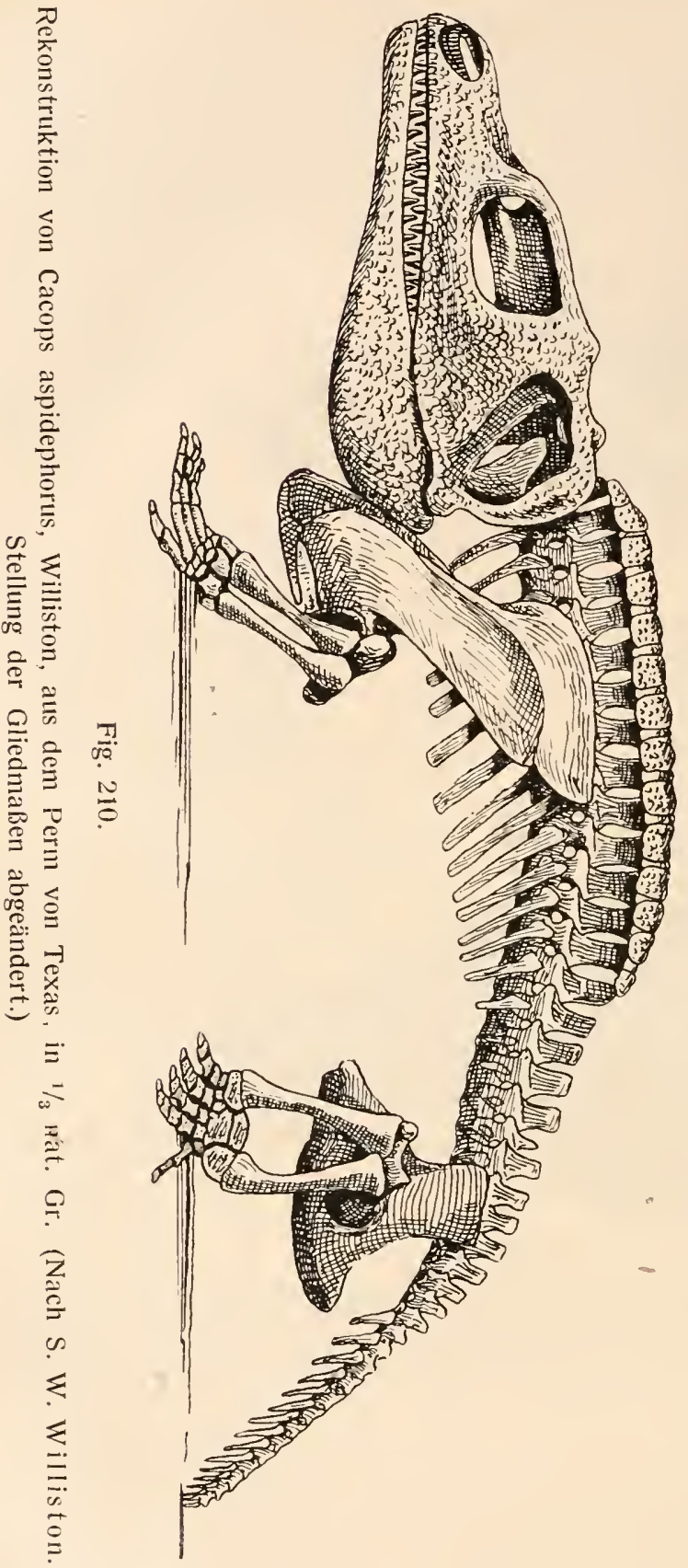

Dissorophus. Panzerplatten über den ganzen Rücken ausgedehnt, gürteltierartig angeordnet, wahrscheinlich noch schwach beweglich. Größter Teil des Skeletts bekannt. - Perm von Texas. ${ }^{1}$ D.multicinctus.

\section{F. Aspidosauridae.}

Den Dissoropliden nahe verwandt, aber Otikalgrube noch offen und nur je eine Panzerplatte über jedem Wirbel vorhanden.

Broiliellus. Schädel und große Teile des Skeletts bekannt. Vorderste Panzerplatte des Rückens groß. - Perm von Texas. ${ }^{2} \quad$ B. texensis.

Aspidosaurus. - Schädel, Panzer und übrige Skeletteile großenteils bekannt. Rücken-Panzerplatten dachfirstartig gebaut, aneinanderstoßend. A. Glascocki, A. ichton, A. apicalis, A.110vomexicanus. Perm von Texas. ${ }^{3}$

1 S.W. Williston, Dissorophus. Journal of Geology, Vol. XVIII, 1910, p.526. -

2 S.W.Williston, Broiliellus, A New Genus of Amphibians from the Permian of Texas. Journal of Geology, Vol. XXII, 1914, p. 49.

${ }^{3}$ F. Broili, Permische Stegocephalen und Reptilien aus Texas. Paläontographica, Bd. LI, 1904, p. 40. 
Alegeinosaurus. - Schädel unbekannt. - Permı von Texas. ${ }^{1}$ A. aphthitos.

\section{F. Zatrachydae.}

Schädel außerordentlich flach, mit großer Fenestra internasalis. Augenhöhlen relativ klein, weit hinten gelegen, mit den vorderen Nasenöffnungen durch einen Wulst verbunden, so daß der mittlere Teil des Schädeldaches eingesenkt erscheint; außerhalb dieses Wulstes ist das Schädeldach gleichfalls grubig vertieft. Schädeldach hinten in Zacken verlängert; die äußeren vom Quadratojugale gebildet, die inneren vom Tabulare. Bei Platyhystrix ist überdies auch das Dermosupraoccipitale hinten in einen Zacken verlängert. Zähne zahlreich, klein, chagrinartig. Dornfortsätze der Wirbel skulpturiert, entweder lateral als Träger für Panzerplatten verbreitert (Zatrachys) oder enorm verlängert, an die Dornfortsätze der Pelycosaurier erinnernd (Platyhystrix). Gliedmaßen, Schulter- und Beckengürtel unbekannt. Körperlänge zwischen $1 / 2$ und $1 \mathrm{~m}$.

Zatrachys. - Perm von Texas. ${ }^{2}$ Z. serratus, etc. (Fig. 211).

Dasyceps. - Perm von Kenilworth, England. ${ }^{3}$ D. Bucklandi.

Platyhystrix. - Perm von Neumexiko. ${ }^{4}$ P. rugosus.

\section{F. Micropholidae.}

Aus den Procolophonschichten der Kapkolonie sind mehrere Reste eines sehr merkwürdigen kleinen Stegocephalen bekannt geworden, für den Huxley schon 1859 den Namen Micropholis Stowi aufstellte. Erst 1913 hat uns jedoch D. M. S. Watson ${ }^{5}$ mit dem Schädelbaue dieser Form genauer bekannt gemacht. Micropholis ist der jüngste rhachitome Stegocephale, von den vollständigere Reste vorliegen (die Schichten mit Procolophon gehören der unteren oder mittleren Trias an), da im württembergischen Keuper bisher nur vereinzelte Wirbelreste von rhachitomem Bau gefunden worden sind. Die Eigentümlichkeiten von Micropholis bestehen in der eigenartigen Anordnung der Knochen des

1 E. C. Case, Revision of the Amphibia and Pisces of the Permian of North America. - 1. c., 1911, p. 60.

2 Ibidem, p. 48. - R. Broom, Studies of the Permian Temnospondylous Stegocephalians of North America. - Bull. Amer. Mus. Nat. Hist., XXXI1, 1913, p. 592.

${ }^{3}$ F. von Huene, Neubeschreibung des permischen Stegocephalen Dasyceps Bucklandi (Lloyd) aus Kenilworth. - Geologische und paläont. Abhandl., N. F. Bd. VIII (G. R. Bd. X1I), 1910, p. 325.

4 S. W. Williston, American Permian Vertebrates. - Chicago, 1911, p. 135.

Derselbe, Contributions from Walker Museum, I. c., 1916, p. 204.

5 D. M. S. Watson, Micropholis Stowi, Huxley, a Temnospondylous Amphibian from South Africa. - Geol. Magazine, London 1913, p. 340. 
Schädeldaches, dem Vorhandensein eines Internasale in einer Grube zwischen den Prämaxillarien vor den Nasenbeinen, den enormen Palatinalgruben (größer als bei irgendeiner anderen rhachitomen Type), der Gelenkverbindung der Pterygoidea mit dem Basisphenoid statt mit dem Parasphenoid, der schwachen Ausbildung der Claviculae und Cleithra, dem schwachen Humerus und dem Verluste der Schleimkanäle auf dem Schädeldache. Die Herkunft der Micropholiden ist unbekannt.

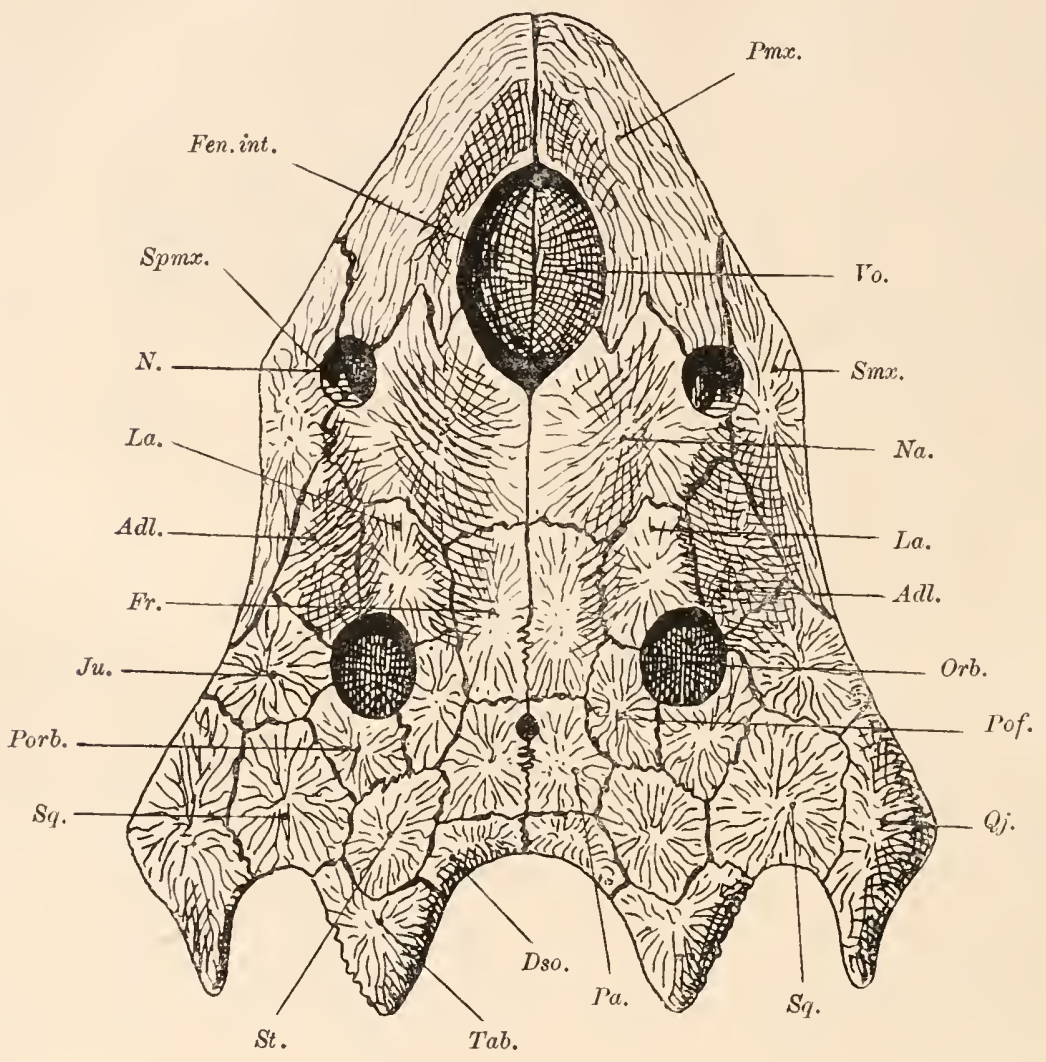

Fig. 211.

Dorsalansicht des Schädeldaches von Zatrachys microphthalmus, Cope, aus dem

Perm Nordamerikas, in $4 / 5$ nat. Gr. (Nach R. Broom, 1913.)

Vo. $=$ Vomer. Fen . int. = Fenestra internasalis. Spmx. = Septomaxillare.

Die übrigen Bezeichnungen der Knochen wie in Fig. 202.

\section{F. Labyrinthodontidae.}

In dieser Gruppe, welche jedenfalls zalılreiche verschiedene Stämnne umfaßt, deren Unterschiede und deren Geschichte aber noch nicht aufgeklärt sind, sind jene rhachitomen Stegocephalen vereinigt, welche einen stereospondylen Wirbeltypus (s. oben) aufweisen. Der erste Vertreter 
(Loxomma) erscheint bereits im unteren Karbon (in Eisenstein von Gilmerton in Schottland), ein Beweis für das bedeutend höhere Alter der Stegocephalen, als meist angenommen wird; ihre Entstehung fällt jedenfalls schon in die Devonformation und liegt vielleicht noch weiter zurück.

Das Hinterhaupt ist fast gänzlich verknöchert (nur das Supraoccipitale und Basioccipitale ist häufig knorpelig geblieben). Das Schädeldach ist meist von tiefen Schleimkanälen durchfurcht, die zwischen den Augen- und Nasenhöhlen die Gestalt einer Lyra zeigen. Sklerotikalplatten und Bauchpanzerplatten (Bauchrippen) fehlen. Bei vielen jüngeren Fornen sind die Fangzähne sehr kräftig; die unteren durchbrechen die Zwischenkiefer entweder gänzlich oder passen in tiefe Gruben derselben hinein, ohne auf der Oberseite des Schädeldaches auszutreten, wenn die Kiefer zusanmengeklappt sind. Zuweilen sind größere Präorbitalöffnungen vorhanden, die mit den Augenhöhlen verbunden sind (Loxomma), mitunter sind die vorderen Nasenöffnungen mit den Durchbruchsöffnungen der Unterkieferzähne zu einer gemeinsamen Öffnung verbunden (Anaschisma). Einige Gattungen besitzen eine stark verlängerte Schnauze (z. B. Lonchorhynchus, Aphaneramma). Zu dieser Gruppe gehören die größten bekannten Stegocephalen (Mastodonsaurus mit $1 \mathrm{~m}$ Schädellänge). Der Brustschultergürtel ist sehr kräftig, aber die Gliedmaßen klein. Die Gruppe, welche in dieser Fassung unnatürlich ist, da sie jedenfalls zahlreiche Stämme umfaßt, enthält langkörperige und langschwänzige Gattungen, sowie plumpe, kurzschwänzige Typen; die ersteren dürften im erwachsenen Zustande eine narine Lebensweise geführt haben, die letzteren Landtiere gewesen sein. Man hat in früherer Zeit fünffingerige und fünfzehige Fährten (Chirotheriunfährten) mit den Labyrinthodontiden in Beziehung zu bringen versucht, aber diese Fährten, die namentlich im Rotliegenden und in der Trias (Buntsandstein) Deutschlands häufig gefunden werden, können nicht auf Stegocephalen bezogen werden, sondern dürften wohl von Dinosauriern herrühren, da unter ihnen die Fährten bipeder Typen auftreten, die Labyrinthodontiden wie überhaupt alle Stegocephalen niemals biped gewesen sind und nie mehr als vier Finger aufweisen. Auch der Größenunterschied der Hand- und Fußfährten spricht für die Deutung von Chirotherium als Dinosaurierfährten.

Loxomma. - Schädel, Wirbel und Rippen bekannt. Augenhöhlen vorn mit der Präorbitalöffnung zusammenfließend; die von den Schleimkanälen des Schädeldaches gebildete „Lyra" vorn durch Querfurche verbunden. - In Unterkarbon von Schottland, Oberkarbon Böhmens und Englands. ${ }^{1}$ (Fig. 212.)

1 Th. H. Huxley, On New Labyrinthodonts from the Edinburgh Coalfield: 1. Note respecting the Discovery of A New and Large Labyrinthodont (Loxomma 
Anthracosaurus. - Oberkarbon von England. ${ }^{1}$ A. Russelli.

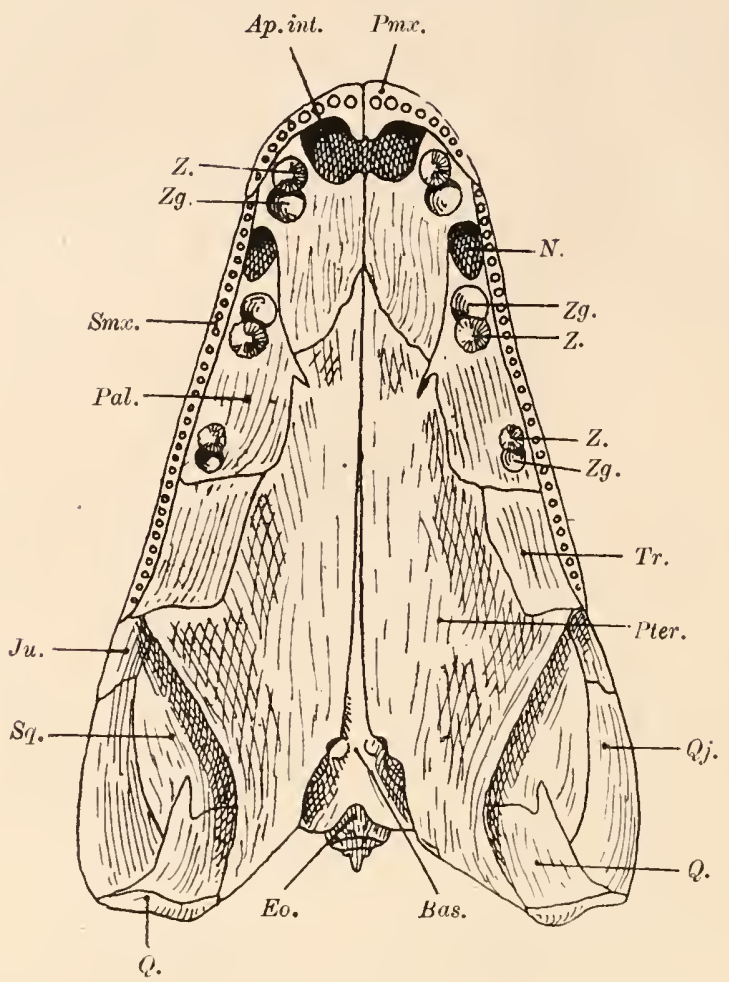

Fig. 212.

Unteransicht des Schädels von Loxomma, in $1 / 4$ nat. Gr.

(Nach D. M. S. Watson.)

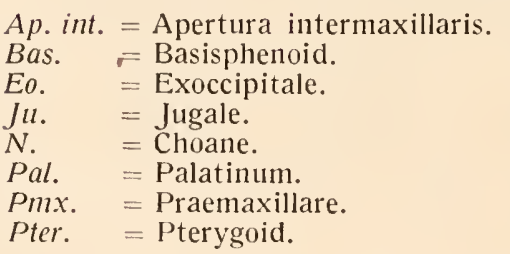

Q. $\quad$ = Quadratum.

Qj. = Quadratojugale.

Smx. = Supramaxillare.

Sq. $=$ Squamosum.

Tr. = Transversum.

$Z$. $=$ Zahn.

$Z g . \quad=$ Zahngrube (Stelle des ausgefallenen Zahns).

Allmani) in the Gilmerton Ironstone. - Quarterly Journal Geol. Soc., Vol. XVIII, London 1862, p. 291.

A. Hallcock and Th. Atthey, On the Occurence of Loxomma Allmani in the Northumberland Coalfield. - Ann. Mag. Nat. Hist., London, 4. Ser., Vol. V, p. 374 .

D. M. S. Watson, The Larger Coal Measure Amphibia. - Memoirs and Proceedings of the Manchester Literary and Philosophical Society, Vol. LVIl, 1912-1913, Manchester, 1912, p. 1.

1 Th. H. Huxley, Description of Anthracosaurus Russelli, a New Labyrinthodont from the Lanarkshire Coalfield. - Quart. Journ. Geol. Soc., London, Vol. XIX, 1863, p. 52. 
Pteroplax. - Karbon von Northumberland. ${ }^{1}$ P. Russelli (Atthey, non Huxley!).

Anaschisma. - Augen weit vorn gelegen, Ohrenschlitze kaum angedeutet. Die vordere Nasenöffnung ist jederseits mit der Apertura intermaxillaris vereinigt. - Trias Nordamerikas. ${ }^{2}$ A. Browni.

Trematosaurus. - Schädel mit langgestreckter Schnauze. Trias Deutschlands (Buntsandstein von Bernburg) und Trias (?) der Kapkolonie. ${ }^{3}$ (Fig. 199, 213.)

A phane ramma. - Schädel mit langgestreckter, schlanker Schnauze. - Trias (Posidonomyenschiefer) von Spitzbergen. ${ }^{4}$

Lonchorhynchus. - Schnauze sehr verlängert; langschnauzigste Stegocephalengattung, die bisher bekannt ist. Nasenlöcher weit hinten gelegen, vorderer Abschnitt des Rostrums nur von den Prämaxillaren gebildet. Jedenfalls aquatischer Räuber, wahrscheinlich Fischjäger; dürfte ebenso wie Aphaneramma im erwachsenen Zustand eine marine Lebensweise geführt haben. - Trias (Posidonomyenschiefer) von Spitzbergen. ${ }^{5}$. (Fig. 214, 215.)

Tertrema. - Schnauze lang, schmal, aber kürzer als bei Lonchorhynchus. Wahrscheinlich dieselbe Lebensweise wie Lonchorhynchus. Trias (Posidonomyenschiefer von Spitzbergen). ${ }^{6}$

1 A. Hancock and Th. Atthey, Notes of the Remains of some Reptiles and Fishes from the Shales of the Northumberland Coalfield. - Ann. Mag. Nat. Hist., London, 4. Ser., Vol.' I, -p. 260.

D. M. S. Watson, I. c., p. 1.

2 E. B. Branson, Structure and Relationsships of the American Labyrinthodontidae. - Journal of Geology, Vol. XIII, 1905, p. 568.

${ }^{3}$ H. Burmeister, Die Labyrinthodonten aus dem Bunten Sandstein von Bernburg, zoologisch geschildert. - Berlin 1849.

O. Jaekel, Die Wirbeltiere. - Berlin 1911, p. 112. (Abbildung einer Rekonstruktion des Schädels von Trematosaurus Brauni.) Vgl. auch O. Jaekel, Über die Klassen der Tetrapoden. - Zoologischer Anzeiger, 1909, S. 197.

K. A. von Zittel, Handbuch der Paläozoologie, Ill. Bd., S. 356 und 401.

F. Drevermann, Über einen Schädel von Trematosaurus. - Centralbl. f. Min. u w., 1914, Nr. 20.

S. H. Haughton, Investigations in South African Fossil Reptiles and Amphibia. - I. On a New Spezies of Trematosaurus (T. Sobeyi). - Annals South Afric. Museum, Vol. XII, Part II, 1915, p. 47.

4 A. Smith Woodward, On Two New Labyrinthodont Skulls of the Genera Capitosaurus and Aphaneramma. - Proceed.Zool. Soc., London 1904, Vol. Il, p. 173.

C. Wiman. Über die Stegocephalen aus der Trias Spitzbergens. - Bulletin of the Geological Institute of Upsala, Vol. XIII, 1914, p. 17.

5 Ibidem, p. 14.

c. Wiman, Neue Stegocephalenfunde aus dem Posidonomyaschiefer Spitzbergens. - Ibidem, Vol. XIII (2), 1916, p. 220.

Derselbe, Über die Stegocephalen Tertrema und Lonchorhynchus. - Ibidem, Vol. XIV, 1917, p. 238.

${ }^{6}$ C. Wiman, l. c., 1914 , p. 21. - 1. c., 1917, p. 229. 


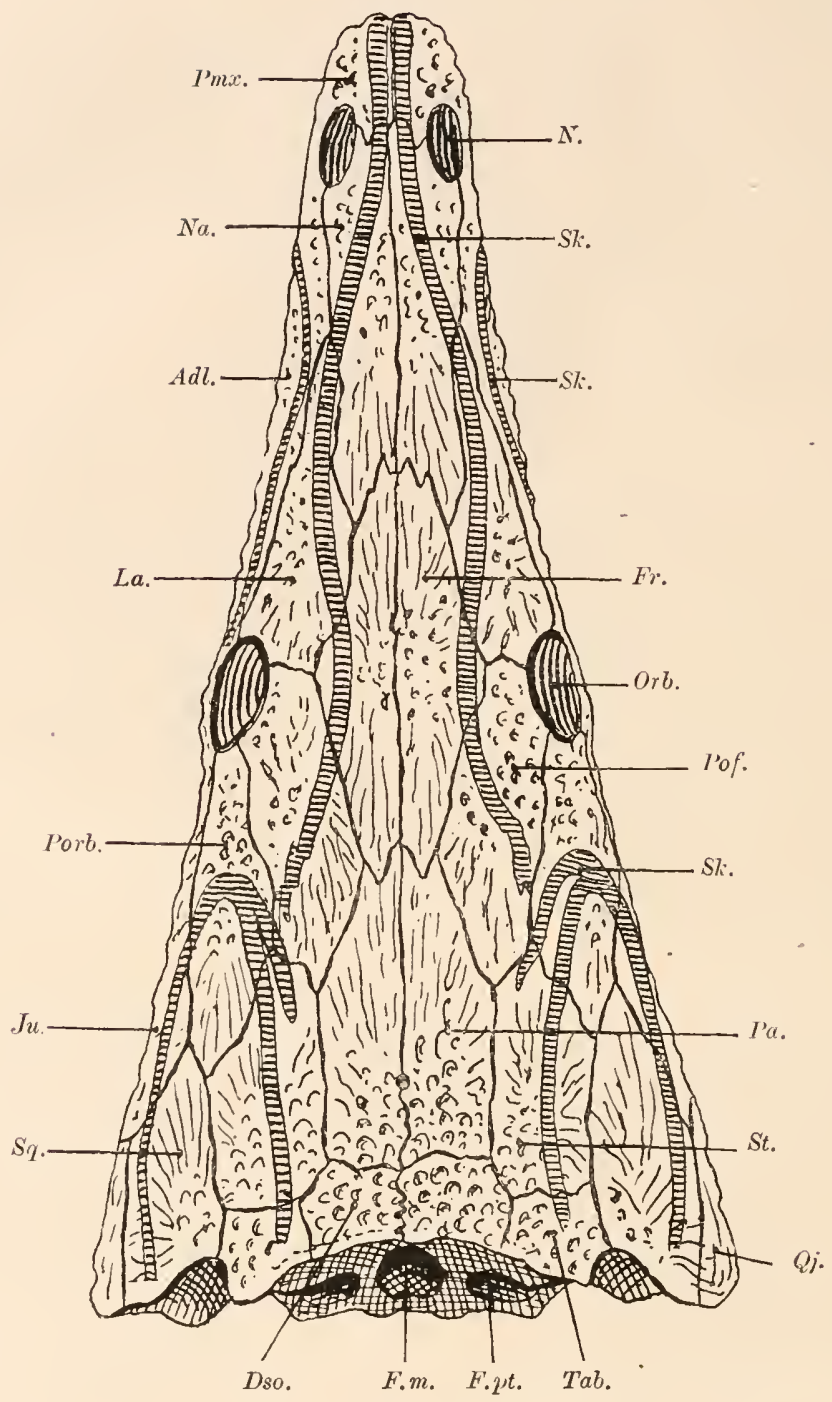

Fig. 213.

Schädeldach von Trematosaurus Brauni, Burm., aus dem oberen Buntsandstein von Bernburg, in $1 / 2$ nat. Gr. (Nach O. Jaekel.)

Adl. = Adlacrymale.

Dso. = Dermosupraoccipitale.

$F . m$. = Foramen magnum.

$F . p t$. $=$ Fenestra pteroccipitalis

Fr. $=$ Frontale

Jil. $=$ Jugale.

La. $=$ Lacrymale.

N. = Nasenöffnung.

Na. - Nasale.

Orb. = Orbita .
$P a . \quad=$ Parietale

$P m x$. = Praemaxillare

Pof. = Postfrontale.

Porb. = Postorbitale.

Qj. = Quadratojugale.

Sk. = Schleimkanal.

Sq. = Squamosum.

St. $=$ Supratemporale.

$T a b .=$ Tabulare. 
Peltostega. - Deckknochen des Schädels jeder für sich schildförnig konvex. Foramen parietale in einer dreieckigen, glatten Vertiefung gelegen. - Trias von Spitzbergen. ${ }^{1}$

Lyrocephalus. - Schleimkanäle des Schädeldaches außerordentlich stark vertieft. - Trias von Spitzbergen. ${ }^{2}$ (Fig. 216.)

Metopias. - Schädel breit, Schnauze stumpf. Augen weit vorn gelegen. Fast das ganze Skelett bekannt. - Obere Trias (Keuper) von Hanweiler bei Stuttgart. ${ }^{3}$ (Fig. 217.)

Cyclotosaurus. - Ohrenschlitz hinten zu einer Pseudotemporalgrube (Cavum oticale) geschlossen. - Trias (Keuper) von Württemberg und von Stanton in Staffordshire. ${ }^{4}$ (Fig. 189, 218, 219.)

Capitosaurus. - Ohrenschlitze klein, offen. Nasalia auffallend groß. - Trias Deutschlands, Spitzbergens und Südafrikas. ${ }^{5}$

Mastodonsaurus. - Größter aller bekannten Stegocephalen, Schädel etwa $1 \mathrm{~m}$ lang. - Trias Deutschlands (Buntsandstein, Muschelkalk und Keuper). ${ }^{6}$ (Fig. 117, 191, 220.)

1 C. Wiman, I. c., 1916, p. 210.

2 C. Wiman, Über das Hinterhaupt der Labyrinthodonten. - Ibidem, Vol. XII, 1912, p. 1. - Derselbe, I. c., 1914, p. 10; 1916, p. 216.

3 E. Fraas, Die Labyrinthodonten der schwäbischen Trias. - Paläontographica, XXXVI. Bd., 1889, p. 1.

Derselbe, Fïhrer durch die Kgl. Naturaliensammlung zu Stuttgart. I. Die geognostische Sammlung Württembergs. - 3. Auflage, Stuttgart 1910, S. 30.

4 E. Fraas, 1. c. 1889.

A. Smith Woodward, On Two New Labyrinthodont Skulls, etc., I. c., P. Z. S., 1904, 11, p. 170. - Der Schädelrest gehört, worauf schon H. Schröder 1913 (Jahrbuch Kgl. Preuß. Geol. Landesanstalt, XXXIII. Bd., S. 256) aufmerksam machte, wegen der Pseudotemporalgrube nicht zu Capitosaurus, sondern zu Cyclotosaurus.

F. Broili (Über Capitosaurus arenaceus Münster. - Centralblatt für Min. usw., 1915, p. 574) vertritt die Meinung, daß Capitosaurus jüngere, Cyclotosaurus dagegen ältere Individuen eines enge zusammengehörigen und zu einer einzigen Gattung gehörigen Formenkreises umfaßt. Nach ihm ist der Verschluß des bei Capitosaurus offenen Ohrenschlitzes eine Alterserscheinung und darf daher nicht als Unterscheidungsmerkmal zweier Gattungen benuitzt werden. Da mir ïber diese Frage die Akten noch nicht geschlossen zu sein scheinen, so habe ich hier die beiden Gattungen Capitosaurus und Cyclotosaurus einstweilen noch getrennt gehalten.

E. Fraas, Neue Labyrinthodonten aus der schwäbischen Trias. - Paläontographica, LX. Bd., 1913, p. 275.

5 H. Schröder, Ein Stegocephalenschädel von Helgoland. - Jahrbuch der Kgl. Preußischen Geologischen Landesanstalt, XXX111. Bd., Berlin 1913, p. 232. (Hier die ältere Literatur einzusehen.)

C. Wiman, 1. c. 1914, S. 21. (Bruchstïck eines Schädeldaches.)

R. Broom, Notice of some New South African Fossil Amphibians and Reptiles. - Annals South African Museum, Vol. V1I, Part I11, 1909, p. 271. (Capitosaurus africanus, n. sp.)

- E. Fraas, Die Labyrinthodonten der schwäbischen Trias. - I. c., 1889. (Hier die ältere Literatur.) 


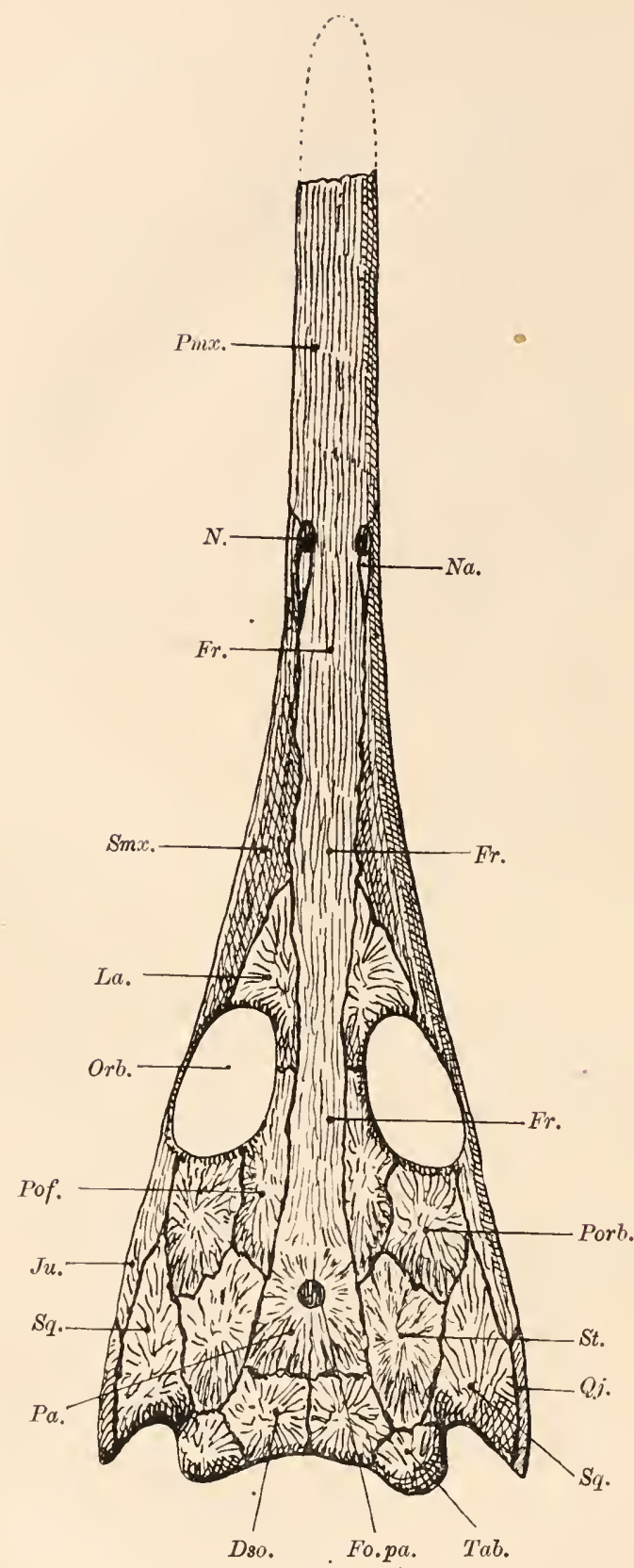

Fig. 214.

Schädeldach von Lonchorhynchus Öbergi, Wiman, aus der Trias Spitzbergens, von oben in $1 / 2$ nat. Gr. (Orig.-Rekonstruktion auf Grundlage der Abbildungen von C. Wiman, 1914 und 1916.)

Fo. $p a .=$ Foramen parietale.

Die iibrigen Abkürzungen wie in Fig. 213.

\section{F. Plagiosauridae.}

O. Jaekel hat (1913) aus der oberen Trias von Halberstadt einen sehr merkwürdigen Stegocephalen, Plagiosaurus depressus, beschrieben, dessen Schädelbau mit der schon seit längerer Zeit bekannten Gattung Plagiosternum in zahlreichen Merkmalen übereinstimmt, so daß beide Gattungen in derselben Familie vereinigt werden müssen. Besonders auffallend ist bei Plagiosaurus jedoch die Skelettzusammensetzung des Unterkiefers sowie die an Dermochelyden erinnernde Panzerung des Rumpfes, ferner der Bau der großen Interclavicula und die Art des Wirbelaufbaues. O. Jaeke I hat aus dem Verhalten der bisher noch nicht eingehender beschriebenen Wirbed den Schluß gezogen, daß Plagiosaurus nicht zu den teminospondylen Stegocephalen, sondern zu den Stegocephalen mit „Vollwirbeln" zu stellen sei und zwar reiht O. Jaekel diese Gattung seinen Microsauria ein, die sich zum Teile mit der hier unterschiedenen Gruppe der Pseudocentrophori decken. Wenn es auch mit Rücksicht auf die erwähnten Merkmale von Plagiosaurus, wozu noch die Zweiköpfigkeit der Rippen kommt, nicht wohl möglich ist, diese 
Gattung und die ihr sehr nahestehende Gattung Plagiosternum in die Familie der Labyrinthodontiden einzureihen, so scheint docl

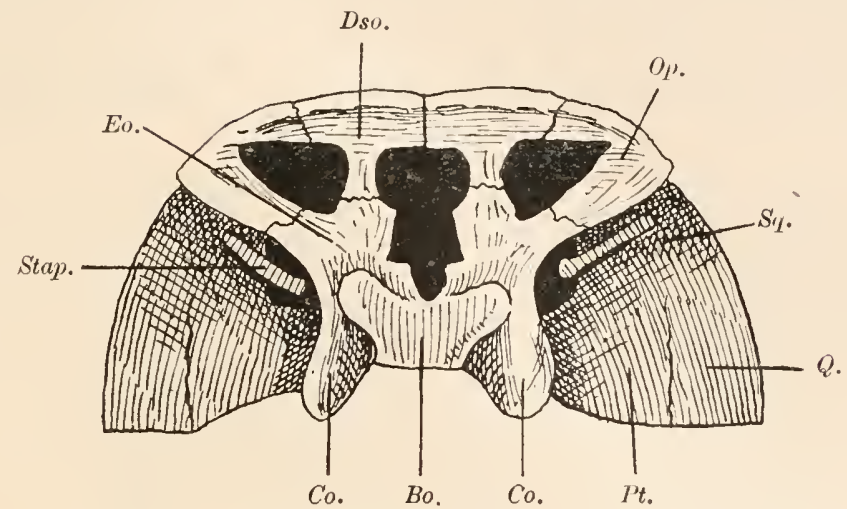

Fig. 215.

Hinterhaupt von Lonchorhynchus Öbergi, Wiman, aus der Trias Spitzbergens, in $2 / 3$ nat: Gr. Die mittlere der drei schwarz gehaltenen Öffnungen ist das Foramen magnum (beim lebenden Schädel kleiner, weil zum Teil von knorpeligen Knochen umgrenzt, die bei der Fossilisation verloren gingen), die beiden seitlichen oberen sind die Fenestrae posttemporales, die beiden seitlichen unteren, in welche der Stapes hineinfiihrt, die Ohrengruben.
Bo. $=$ Basioccipitale.
Co. = Condylus occipitalis.
Pt. = Pterygoid.
Dso. $=$ Dermosupraoccipitale.
Q. $\quad=$ Quadratum.
Eo. - Exoccipitale.
Sq. $=$ Squamostum.
Op. = Opisthoticum.
Stap. $=$ Stapes.

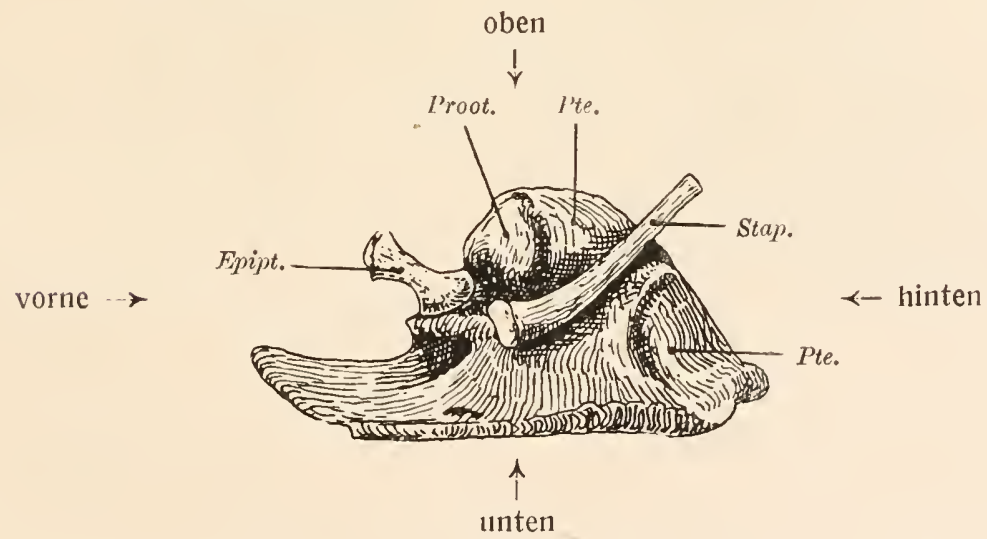

Fig. 216.

Präparat der rechten Ohrregion von Lyrocephalus Euri, Wiman, aus der Trias Spitzbergens, von innen gesehen. 2/3 nat. Gr. (Nach C. Wiman, 1914.)

$$
\begin{array}{ll}
\text { Epipt. }=\text { Epipterygoid. } & \text { Pte. }=\text { Pterygoid } . \\
\text { Proot } .=\text { Prooticum. } & \text { Stap. }=\text { Stapes } .
\end{array}
$$

nach der Beschreibung Jaekels nur ein stereospondyler Wirbeltypus, aber weder ein pseudozentraler nocli ein gastrozentraler Typus 
vorzuliegen. Die Plagiosauriden sind daher wohl nur als ein erloschener und sehr eigenartig spezialisierter Seitenzweig der Rhachitomi (in unserem Sinne) zu betrachten. Für den stereospondylen Wirbel (vgl. S. 224) ist es bezeichnend, daß der Wirbel scheinbar einheitlich ist, aber doch die Basidorsalia und die Basiventralia umfaßt, während die

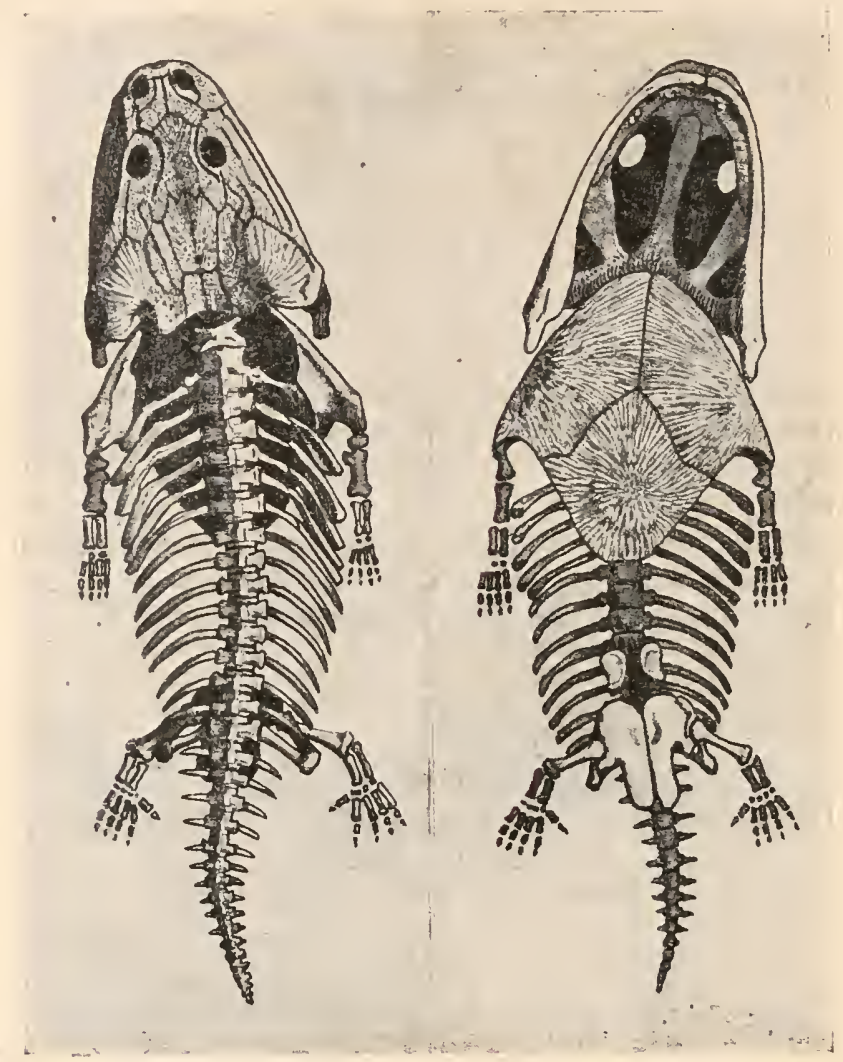

A.

B.

Fig. 217.

Skelett von Metopias diagnosticus, H. v. Meyer, aus dem Keuper von Hanweiler bei Winnenden in Württemberg. A: Riickenansicht, B: Bauchansicht des Originals im Kgl. Naturalienkabinett zu Stuttgart. Schädellänge $45 \mathrm{~cm}$. (Nach E. Fraas.)

Interventralia verloren gegangen sind und dies ist auch bei Plagiosaurus der Fall. Die bestehenden Unterschiede des Wirbelbaues sowie der übrigen Skeletteile von Plagiosaurus rechtfertigen jedoch zweifellos die Abtrennung einer selbständigen Familie, aber nur innerhalb der Rhachitomen und nicht außerhalb derselben. 
Plagiosaurus. - Obere Trias von Halberstadt. - Schädel flach, breit, von halbkreisförmigen Unriß, mit großen Augenhöhlen. Unterkiefer einen dünnen Bogen bildend, mit doppelter Zahnreihe und schuppenartigen Deckknochen auf der Außen- und Unterseite des Dentale. Interclavicula sehr groß und breit, mit seitlichen Gelenkzapfen

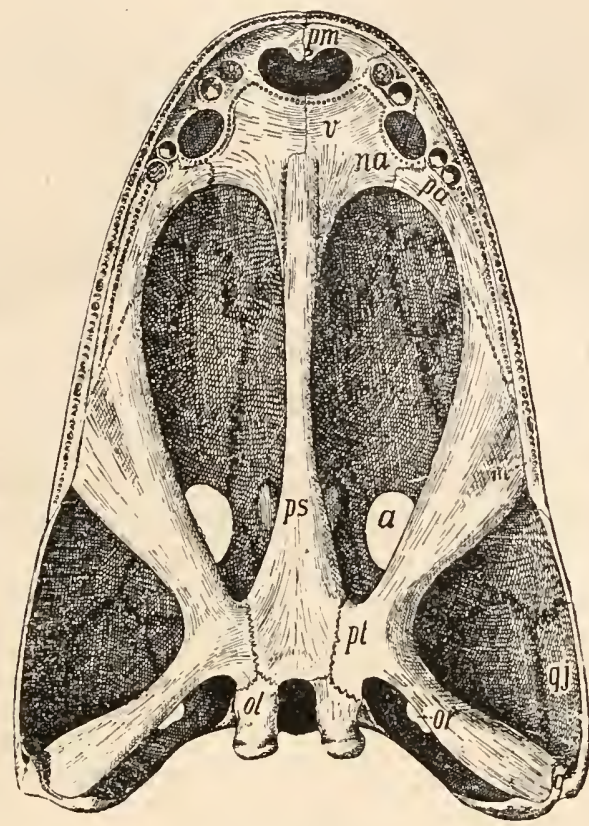

Fig. 218.

Unteransicht des Schädels von Cyclotosaurus robustus, H, von Meyer, aus der oberen Trias der Umgebung Stuttgarts, ungefähr in $1 / 6$ nat. Gr. (Nach E. Fraas.) a. = Orbita (von unten gesehen).

$m$. = Supramaxillare.

na. = Choane.

ol. $=$ Exoccipitale.

$o r$. = Cavum oticale (durch den hinteren Abschluß als ,Pseudotemporalgrube" erscheinend).

$p a .=$ Palatinum (trägt vorne jederseits 2 Fangzähne und eine zur Supramaxillarreihe parallele innere Zahnreihe).

- pm. = Praemaxillare (zwischen beiden pm und den beiden $v$ die Apertura intermaxillaris für die Fangzähne des Unterkiefers sichtbar).

ps. = Parasphenoid.

pt. = Pterygoid.

$q . \quad$ Q Quadratum.

$q j . \quad=$ Quadratojugale.

$v . \quad=$ Vomer (bezahnt).

für die Claviculae. Rumpf dorsal und ventral mit einem aus Polygonalplatten bestehenden kräftigen Panzer. Alle Hautknochen mit hohen Dornen besetzt, ebenso auch die Schuppen. Rippen zweiköpfig, an den oberen Bögen und an der Grenze zweier Wirbel einlenkend, die nur aus den Basiventralia und Basidorsalia bestehen. Körperform unbekannt. ${ }^{1}$

1 O. Jaekel, Über die Wirbeltierfunde in der oberen Trias von Halberstadt. - Paläontolog. Zeitschrift, Berlin, I. Bd., 1913, p. 202. 
Plagiosterıum. - Schädel selır breit und kurz, von auffallender Gestalt. - Trias von Schwaben (oberer Muschelkalk und unterer Keuper). ${ }^{\mathbf{1}}$ (Fig. 221.)

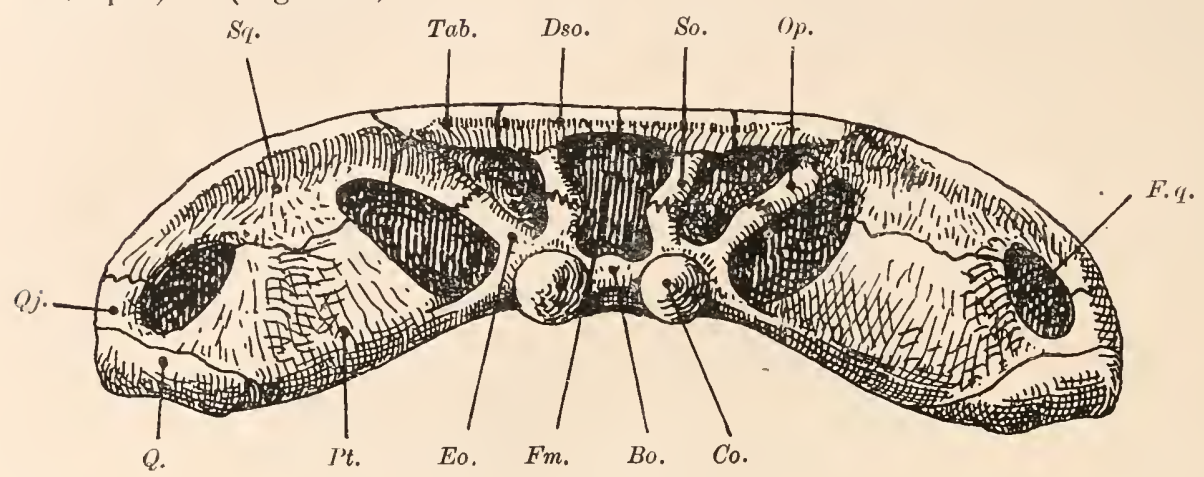

Fig. 219.

Hinterhaupt von Cyclotosaurus stantonensis, A. S. Woodward, aus dem interen Keuper von Stanton bei Uttoxeter, England. - Rekonstruktion in $2 / 3$ nat. Gr., mit Beniitzung der Abbildungen von A. Smith Woodward (1904), F. v. Huene (1910) und C. Wiman (1912).
Bo. $=$ Basioccipitale.
Co. $=$ Condylus occipitalis.
Dso. = Dermosupraoccipitale.
Eo. = Exoccipitale.
$F m$. = Foramen magnum
$F . q .=$ Foramen quadrati.
Op. = Opisthoticum.

Pt. = Pterygoid.

Q. $=$ Quadratum.

Qj. = Quadratojugale.

So. $=$ Supraoccipitale.

$S q . \quad=$ Squamosum .

Tab. = Tabulare.

(Vgl. dazu Fig. 189, S. 242).

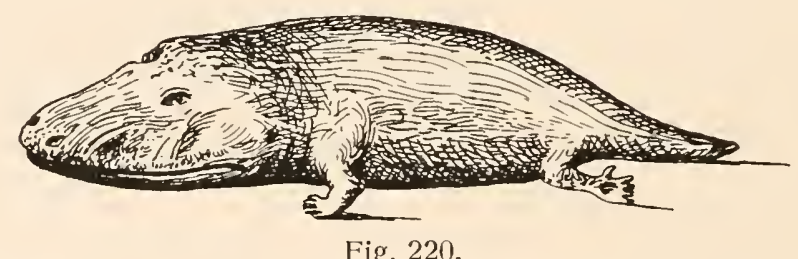

Fig. 220.

Rekonstruktion von Mastodonsaurus giganteus, Jaeger, ein Stegocephale von etwa $3 \mathrm{~m}$ Länge aus dem Keuper Württembergs. (Rek. von O. Abel, 1911.)

\section{Ordo: Embolomeri.}

Wirbel ursprüngliclı wie jener der Rhachitomi auf einen Ausgangstypus mit vier Paar getrennter Bogenelemente zurückgehend, aber einseitig derart spezialisiert, daß die Basiventralia als „Hypozentrum“,

1 E. Fraas, Die schwäbischen Triassaurier nach dem Material der kgl. Naturaliensammlung in Stuttgart zusammengestellt. - Festgabe zur 42. Versammlung der Deutschen Geologischen Gesellschaft in Stuttgart, 1896, S. 8.

Derselbe, Neue Labyrinthodonten aus der schwäbischen Trias. - Paläontographica, LX. Bd., 1913, S. 277. 
die Interdorsalia + Interventralia als „Pleurozentrum" je eine gleichgroße flachzylindrische Wirbelhälfte bilden. Nur aus dem Oberkarbon und Perm bekannt.

\section{F. Cricotidae.}

Schlanke, aquatische Stegocephalen von 1-2 m Körperlänge. Schädel nit verlängerter, vorn abgerundeter Schnauze, Nasenlöcher

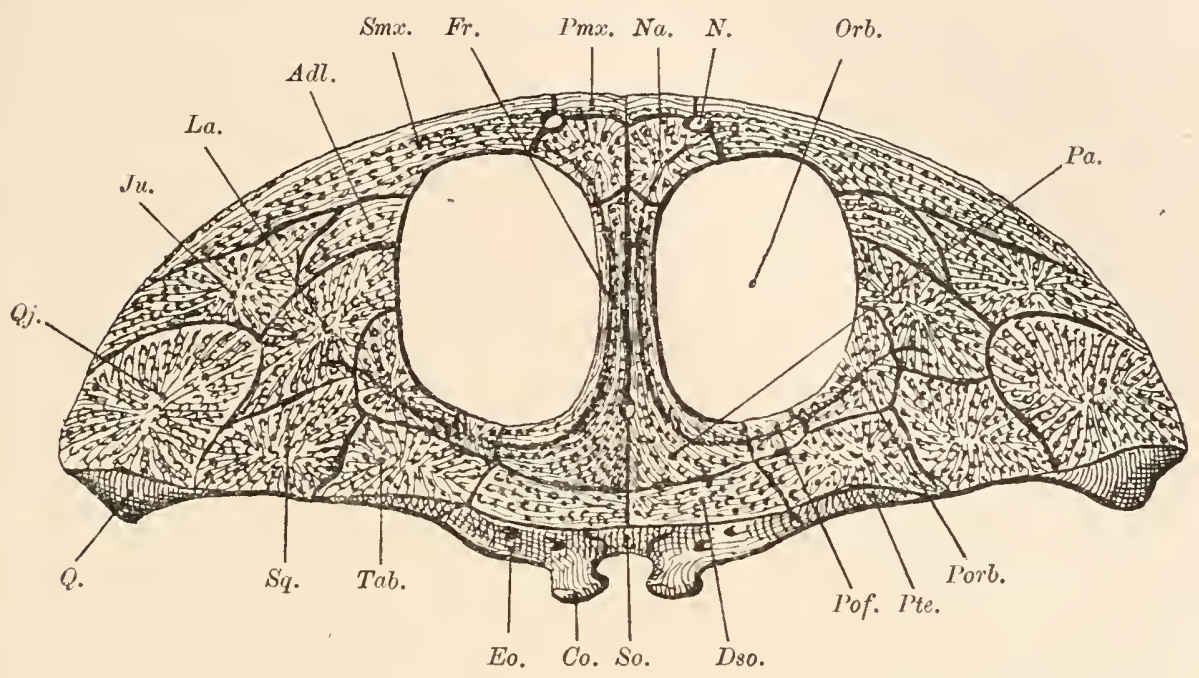

Fig. 221.

Dorsalansicht des Schädels von Plagiosternum granulosım, E. Fraas, aus dem Bonebed (obere Trias) von Crailsheim in Wiirttemberg. Länge der Schädeldecke $20 \mathrm{~cm}$, Breite $50 \mathrm{~cm}$ (ıngefähr). (Nach E. Fraas, 1913; Zeichnung ergänzt und die Bezeichnungen der Knochen zum Teil abgeändert.)

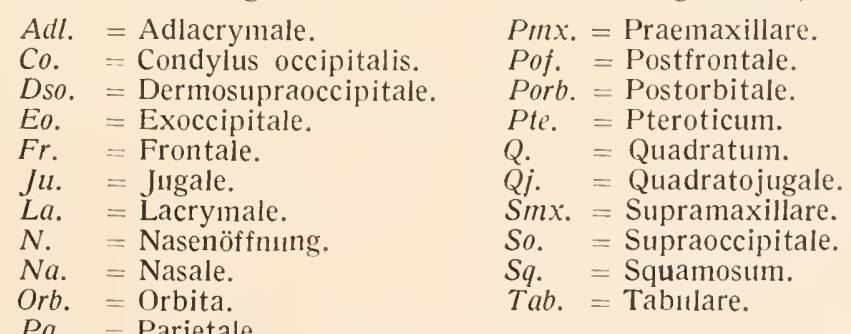

ähnlich wie bei Lonchorhynchus nicht am Vorderende der Schnauze, sondern weiter außen gelegen, Augenhöhlen seitlich. Schwanz lang, schlank. Ilium mit Verlängerung des Hinterabschnittes. Bauchschuppen vorhanden, Schädel mit Schleimkanälen.

Cricotus. - Zähne dichtgedrängt, mit scharfer Schneide. Schädel und Wirbel gut, Gliedmaßen nur fragmentarisch bekannt, letztere 
jedenfalls sehr kurz. Lebensweise vielleicht krokodilartig. - Perm von Texas, lllinois und Kansas. ${ }^{1}$ (Fig. 174.)

Diplovertebron. - Einzelne Wirbel, Fragmente des Schädels und der Gliedmaßen bekannt; die Wirbel ähneln stark jenen von Cricotus. - Oberkarbon Böhmens (Gaskohle von Nürschan). ${ }^{2}$

\section{Ordo: Phyllospondyli.}

Die bezeichnenden Merkmale dieser 'Gruppe der Stegocephalen liegen im Bau der Wirbelsäule.

Während wir bei den bisher besprochenen Gruppen der Stegocephalen einen zwar aus verschiedenen Bogenelementen aufgebauten, aber doch massiven, knöchernen Wirbel fanden, besteht der Wirbel jener Formen, die als Phyllospondyli unterschieden werden, zwar auch aus verschiedenen Bogenelementen, aber ein Teil derselben ist ,neutralisiert" und bildet die knorpelige Intervertebralmasse, während der andere Teil der Bogenelemente nur in Gestalt von dünnen, sehr zarten Knochenblättchen entwickelt ist, die einen Schutz der Chorda dorsalis und des Rückennarks darstellen. Die erwähnte Intervertebralmasse wird von den vereinigten Interdorsalia und Interventralia gebildet, der knöcherne Wirbel dagegen von den Basidorsalia und den Basiventralia, und zwar spielen dabei die Basidorsalia die Hauptrolle; die Basiventralia unschließen nur je ein unteres Viertel der Chorda. Die Querfortsätze für die Rippenartikulation werden von den Basidorsalia und den Basiventralia gemeinsam gebildet.

Dieser Wirbeltypus ist daher nicht fundamental, sondern nur graduell von dem Wirbeltypus verschieden, den wir bei den lebenden Urodelen vorfinden. Da auch die übrigen morphologischen Merkmale keine scharfen Gegensätze zu jenen der Urodelen darstellen, so wäre es vielleicht richtiger, die Gruppe der Phyllospondyli mit den Urodelen zu vereinigen und als eine primitive Gruppe derselben in das System

1 E. C. Case, Revision of the Amphibia and Pisces of the Permian of North America. - Carnegie Institution of Washington, Publ. No. 146, Washington 1911, p. 145 .

R. Broom, Studies on the Permian Temnospondylous Stegocephalians of North America. - Bulletin of the American Museum of Natural History, Vol. XXXII, 1913, p. 564.

S. W. Williston, Synopsis of the American Permocarboniferous Tetrapoda. - Contributions to the Walker Museum, Vol. I, Chicago 1916, p. 209.

${ }^{2}$ A. Fritsch, Fauna der Gaskohle und der Kalksteine der Permformation Böhmens. - I1. Bd., Prag 1885. 
einzureihen. Aus den oben (S. 221) dargelegten Gründen ist es jedoch zweckmäßiger, die Phyllospondyli einstweilen als einen Zweig der Stamminruppe der Stegocephalen aufzufassen und sie in diesen1 Zusammenhange zu besprechen.

Alle Phyllospondylen besaßen eine nur vierfingerige Hand, aber einen fünfzehigen Fuß.

Das Seitenliniensystem der Gattung Micrerpeton scheint ähnlich wie bei der Larve des lebenden Necturus gewesen zu sein.

Die Zähne waren einfach gebaut und besaßen eine große Pulpa.

Die ersten Phyllospondylen kennt man aus dem Karbon, die letzten aus dem Perm.

\section{F. Branchiosauridae.}

Salamanderförmige Stegocephalen mit kurzem, breitem, sehr flachen Schädel mit unverknöcherter Hinterwand, Carpus und Tarsus knorpelig; Hinterfuß in der Regel mit der Sohlenfläche nach oben gewendet. Pubis knorpelig und daher nicht erhalten. Gebiß aus zahlreichen feinen Zähnchen bestehend. Wirbel aus zwei Paar verknöcherten Bogenelementen (Basidorsalia und Basiventralia) aufgebaut, die das Rückenmark und die Chorda dorsalis umhüllen. Der Dornfortsatz trägt jederseits eine Präzygapophyse und eine Postzygapophyse. Karbon und Perill.

Branchiosaurus. - Kleine,

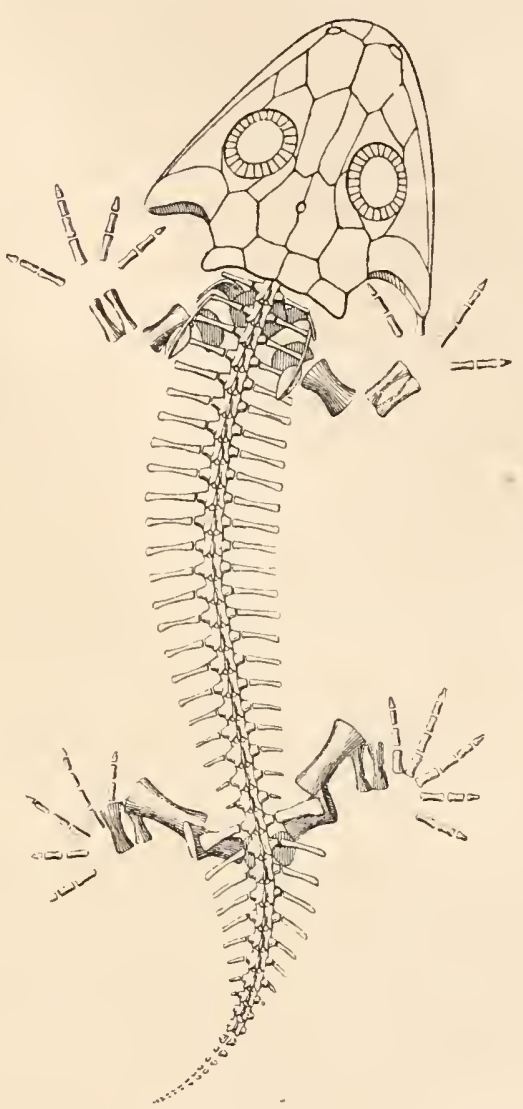

Fig. 222.

Pelosaurus laticeps, Credner, aus dem permischen Kalkstein von Niederhäßlich bei Dresden. (Nach H. Credner.) salamanderförmige, in der Jugend aquatische, im erwachsenen Zustand wahrscheinlich terrestrische Tiere, die zwischen den Sumpfpflanzen ihre Nahrung suchten, die aus Würmern, Insekten usw. bestanden haben dürfte. Der Schwanz war selır kurz und umfạßte nur etwa 15 Wirbel, gegen 20-26 der Präsakralregion. Die erhaltenen Larven besitzen Kiemenbögen, die den erwachsenen Tieren fehlen. Außerordentlich häufig im Oberkarbon Böhmens (Nürschan), im Perm von Niederhäßlich bei Dresden, Braunau in Böhmen, 
Lebach bei Saarbrücken u. a. Orten Deutschlands, sowie in Perm Frankreiclıs (Autuu). ${ }^{1}$

Pelosaurus. - Kopf sehr groß, Adlacrymale noch vorhanden, das bei Branchiosaurus fehlt. - Pernı von Deutschland und Frankreich. ${ }^{2}$ (Fig. 222.)

Melanerpeton. - Tiefer Otikalschlitz vorhanden, Hinterhaupt weit zurückspringend. - Perm von Sachsen, Böhmen und Mähren. ${ }^{3}$

Micrerpeton. - Oberkarbon von Illinois. ${ }^{4}$

Pelion. - Ein einziges Exemplar aus dem Oberkarbon von Linton in Olio bekannt. Oberarm und Oberschenkel sehr lang, Hand vierfingerig, Wirbel unvollkommen verknöchert, Schädeldach breit, vorn breit abgerundet. Schwanz unbekannt, aber wahrscheinlich kurz. ${ }^{5}$

\section{F. Acanthostomatidae.}

Verhältnismäßig große Formen von salamanderartiger Körpergestalt. Schädeldach breit, flach, vorn breit abgerundet, skulpturiert; Augenhöhlen in der hinteren Hälfte des Schädeldaches gelegen, Nasenöffnungen durch weiten Zwischenraun getrennt, in der Mitte zwischen ihnen ein großes Cavum internasale. Pränaxillare, Supranıxillare, Voner, Palatinum, Transversum bezahnt, und zwar stehen auf den drei letztgenannten Knochen einzelne größere Fangzähne (nach O. Jaekel).

Acanthostoma. - Perm von Niederhäßlich bei Dresden. ${ }^{6}$

1 H. Credner, Die Stegocephalen und Saurier aus dem Rotliegenden des Plauenschen Grundes bei Dresden. - Zeitschrift der Deutschen Geolog. Ges., 1881, p. 303,$575 ; 1883$, p. 275,$277 ; 1886$, p. 576.

A. Fritsch, Fauna der Gaskohle, usw., - I. c., I. Bd., p. 69.

A. Thévenin, Les plus anciens Quadrupèdes de la France. - Ann. de Paléont., T. I, Paris 1906.

${ }^{2}$ H. Credner, I. c., V. Teil, 1885, p. 706; III. Teil, 1883, p. 214.

${ }^{3}$ H. Credner, I. c., IV. Teil, 1883, p. 289; V. Teil, 1885, p. 694.

4 R. L. Moodie, The Dawn of Quadrupeds in North America. - The Popular Science Monthly, Vol. LXX11, 1908, p. 558.

Derselbe, The Lateral Line System in Extinct Amphibia. - Journal of Morphology, Vol. X1X, 1908, p. 511. - The Ancestry of the Caudate Amphibia. American Naturalist, Vol. XLII, 1908, p. 361. - The Carboniferous Amphibia of North America. - Transactions of the Academy of Kansas, Vol. XXI1, 1909.

5 J. Wyman, On Some Remains of Batrachian Reptiles discovered in the Coal Formation of Ohio. - The American Journal of Science and Arts (2), Vol. XXV, 1858 , p. 158.

R. L. Moodie, The Dawn of Quadrupeds etc. - I. c., p. 562.

${ }^{6}$ H. Credner, Die Stegocephalen und Saurier usw., 1. c., IV. Teil, Zeitschrift d. Deutschen Geol. Ges., XXXV. Bd., 1883, p. 277. 


\section{Ordo: Pseudocentrophori (110V.).}

Die systematische Abgrenzung dieser Gruppe ist bisher sehr unsicher gewesen. Ich vereinige in dieser Gruppe alle jene Formen, welche keine Blattwirbel mehr besitzen, wie die Branchiosauriden, sondern Vollwirbel mit Pseudozentren, wie sie auch für die Urodelen kennzeichnend sind. Aus denselben Gründen, die für die Einreihung der Phyllospondyli in die Stegocephalen maßgebend sind, sind auch dié in der Gruppe der Pseudocentrophori zusammengefaßten Familien der Ceraterpetontiden, Ptyoniden, Ophiderpetontiden, Molgophiden und Phlegethontiiden den Stegocephalen anzugliedern.

Die primitivsten Formen enthält die Familie der Ceraterpetontiden, soweit dies die Spezialisation der Gliedmaßen betrifft. Sie sind hier noch wollentwickelt (z. B. bei Ceraterpeton Galvani), werden aber schon bei den jüngeren Gattungen der Fanilie (Diplocaulus) rudimentär, sind auch bei den Ptyoniden stark reduziert und bei den Ophiderpetontiden, Molgophiden und Phlegethontiiden gänzlich verloren gegangen. Mit der Reduktion der Gliedmaßen geht die Längenzunahme des bei den Ceraterpetontiden und Ptyoniden sehr stark komprimierten Schwanzes Hand in Hand; dabei gehen aber die hohen oberen und unteren Dornfortsätze, welche für diese beiden Fanilien sehr bezeichnend sind, verloren, und bei den gänzlich fußlos gewordenen Ophiderpetontiden, Molgophiden und Phlegethontiiden (=,Aistopoda“) sind die unteren Dornfortsätze ebenso wie die oberen zu schwachen Kielen verkümmert und der ganze Wirbel infolge noch hinzutretender Reduktion der Querfortsätze sandulırförmig geworden. Diese Veränderungen müssen durch eine Änderung der Bewegungsart und des Aufenthaltsortes bei den fußlos gewordenen Formen in Gegensatz zu den Ceraterpetontiden und Ptyoniden bedingt sein. Die beiden letzteren Familien waren Wasserbewohner und haben einen Ruderschwanz besessen, während die fußlos gewordenen Formen eine Lebensweise wie die lebenden Blindwühlen geführt haben müssen, die im erwachsenen Zustande Landtiere sind und sich in den Boden einwühlen. Der stark verbreiterte Schädel von Diplocaulus spricht in Verbindung mit den auf die Dorsalseite des Schädeldaches verschobenen Augen dafür, daß diese Tiere auf dem Grunde von Gewässern lebten.

\section{F. Ceraterpetontidae.}

Langgestreckte Formen mit kleinen, bei den höchstspezialisierten Gattungen (Diplocaulus) rudimentär gewordenen Exfremitäten. Die Augen des dorsoventral abgeplatteten Schädels liegen auf der Oberseite desselben; nur bei Batrachiderpeton ist der Schädel gewölbt und 


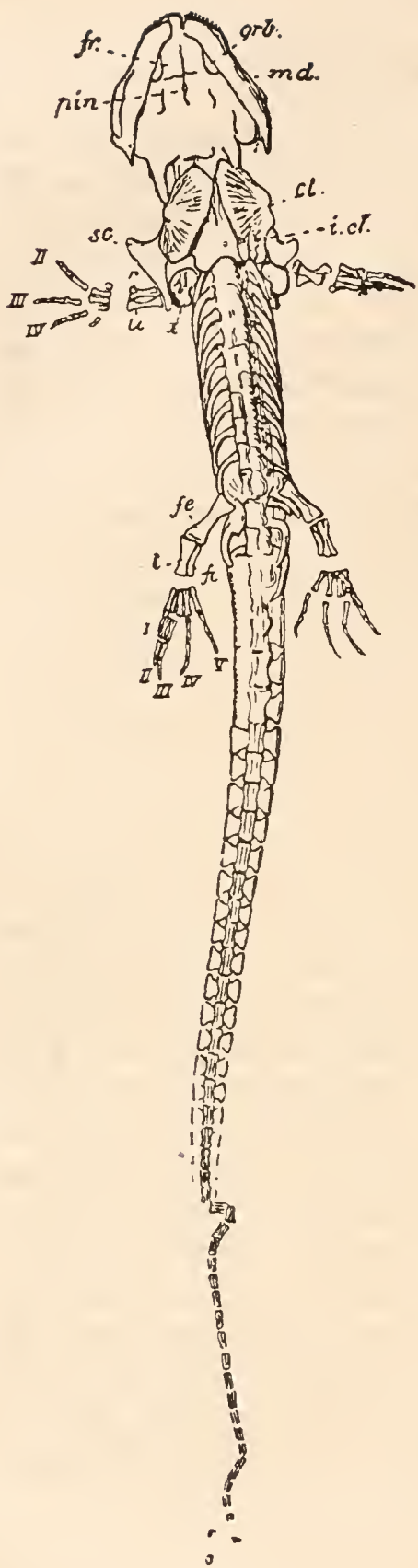

Fig. 223.

Ceraterpeton Galvani, Huxley. Oberkarbon von Castlecomer bei Kilkenny, Irland. Ventralansicht des Skelettes in nat. Gr. (Nach A. Smith Woodward.) die Augen liegen auf den Seiten desselben. Bei allen Gattungen dieser Familie ist der Scliädel an den Hinterecken in Hörner ausgezogen, die bei den verschiedenen Gattungen aus verschiedenen Elementen bestehen. Bei Ceraterpeton springt der Seitenrand des Schädeldaches bis zum Quadratojugale nach außen vor, wendet sich dann nach einwärts, bildet eine Einbuchtung und wendet sich dann noch einmal nach hinten, wo das Tabulare als spitzer Kegel ziemlich weit nach hinten vorspringt. Bei Batrachiderpeton ist das Schädeldach gewölbt, so daß in der Oberansicht die Bucht zwischen Quadratojugale und Squamosum nicht sichtbar ist, sondern nur in der Seitenansicht; sie ist hier bedeutend kleiner als bei Ceraterpeton, während das weit llach hinten vorspringende Horn nicht nur vom Tabulare, sondern auch vom Squamosum gebildet wird. Bei Diplocaulus ist das Horn noch größer geworden und außer dem Tabulare und Squamosum auch noch das an den Außenenden verzerrte Dermosupraoccipitale und das Parietale jederseits in die Bildung des ,Horns“ miteinbezogen

\begin{tabular}{|c|c|}
\hline \\
\hline & \\
\hline & von unten her bloßgelegt, $d$ \\
\hline & $\begin{array}{l}\text { die Schädelbasis weggebroche } \\
\text { ist). }\end{array}$ \\
\hline & Foramen parietale. \\
\hline & Orbita. \\
\hline & $=$ Unterkiefer. \\
\hline & $=$ Clavicula. \\
\hline$c l$. & $=$ Interclavicula. \\
\hline & = Scapula. \\
\hline & Coracoid oder Humerus. \\
\hline & $\begin{array}{l}=\text { Radius. } \\
=\text { Ulna. }\end{array}$ \\
\hline & $\begin{array}{l}=\text { Ulna. } \\
=\text { Femur. }\end{array}$ \\
\hline & $=$ Tibia. \\
\hline & $\begin{array}{l}=\text { Fibula. } \\
=1 .-5 . \mathrm{Ze}\end{array}$ \\
\hline
\end{tabular}


worden. Bei Diceratosaurus ist die Bildung des „Horns" durch die Verschmelzung von Tabulare, Squamosum und Postorbitale zustande gekommen. O. Jaekel hat dieses aus verschiedenen Deckknochen verschmolzene Horn als „Perisquamosum" bezeichnet.

$\mathrm{Ob}$ bei Scincosaurus derartige Hörner vorhanden waren, ist noch zweifelhaft und darum auch die systematische Stellung dieser Gattung unsicher. Der Bau der Wirbel würde allerdings für eine Einreihung in die Familie sprechen.

Die Wirbel der Ceraterpetontiden unterscheiden sich im Rumpfabschnitt und Schwanzabschnitt sehr bestimmt durch das Verhalten der Neurapophysen und der Hämapophysen. Nur im Schwanzabschnitt treten lange, meist an ihren distalen Enden fächerförmig verbreiterte untere Dornfortsätze (Hämapophysen) auf, welche ebenso wie die distalen Enden der Neurapophysen gekerbt zu sein pflegen. Die Neurapophysen der Schwanzwirbel sind immer sehr hoch; bei den Dorsalwirbeln ist es nur nit Ausnahme von Diplocaulus ebenso. Die Sakralregion ist durch eine abweichende Gestalt der Wirbel sehr genau gekennzeichnet; besonders deutlich ist dieser Formunterschied des Sakralwirbels bei Diplocaulus.

Der Brustschultergürtel der Ceraterpetontiden ist kräftig, aber die Arme sind kurz und schwach; die Hände sind vierfingerig ${ }^{1}$ und klein. Ebenso sind auch die Hinterbeine sehr zart; bei Diplocaulus sind beide Gliedmaßenpaare rudimentär, das hintere melır als das vordere. Hand- und Fußwurzel waren unverknöchert.

Ceraterpeton. - Kleine molchartige Type mit außerordentlich verlängerten Schwanz, der die dreifache Rumpflänge aufweist. 15 bis 20 Präsakralwirbel, etwa 75 Schwanzwirbel vorhanden. Schädeldach breitdreieckig, vorn gerundet. Körperlänge 18-20 cml. - Oberkarbon von Kilkenny (Irland) und Staffordshire (England). ${ }^{2}$ C. Galvani (F:g. 223).

Diceratosaurus. - Größer als die vorgenannte Gattung. Schwanz beträchtlich verlängert, bis zu 100 Wirbel. 12 Präsakralwirbel. Die Dornfortsätze der Rumpfwirbel tragen skulpturierte Verbreiterungen, welche als Träger von Hautknochen dienten. Die Querfortsätze der Dorsalwirbel sind sehr lang, die Rippen einköpfig und kräftig. Zygosphen und Zygantrum vorhanden. Schädel breit, flach, Augen groß, ganz auf der Dorsalseite des Schädeldaches gelegen, Schnauze vorn breit abgestutzt. Hörner des Schädeldaches aus dem Postorbitale, Squa-

1 Dies ist bei Ceraterpeton Galvani nach den Abbildungen von A. SmithWoodward vollkommen sicher. Die von Jaekel beschriebene fünffingerige Hand von Diceratosaurus ist der Hinterfuß. Die von Fritsch für Scincosaurus angenommene fünffingerige Hand ist rekonstruiert.

2 A. Smith Woodward, Ceraterpeton Galvani, Huxley. - Geological Magazine (4), Vol. IV, 1897, p. 293. 


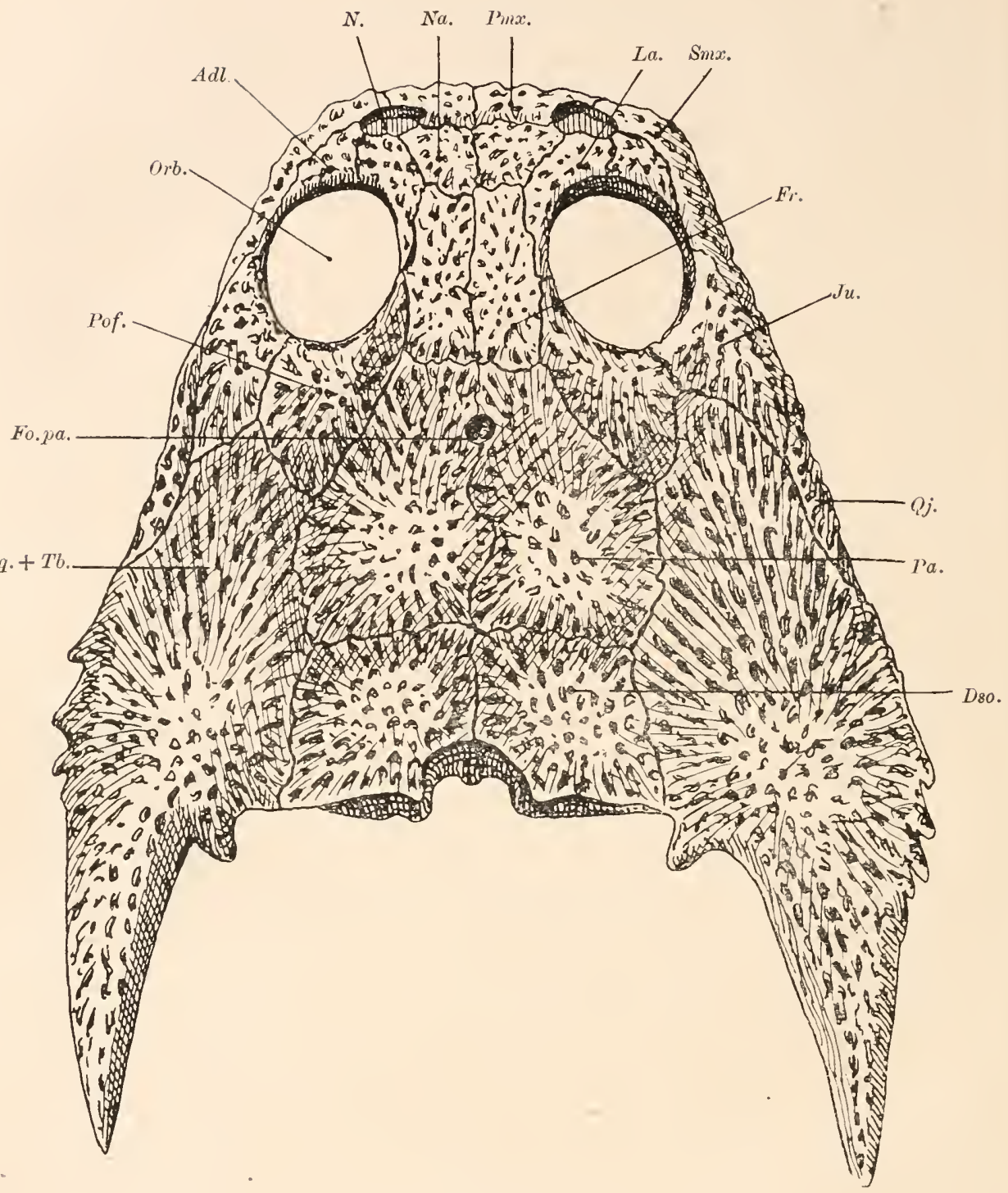

Fig. 224.

Schädeldach von Diceratosaurus punctolineatus, Cope, aus der Karbonformation

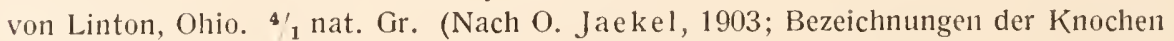
zum Teil abgeändert.)
Adl. $=$ Adlacrymale.
Orb. $\quad=$ Orbita.
Dso. $\quad=$ Dermosupraoccipitale.
$P a . \quad=$ Parietale
Fo. pa. = Foramen parietale.
$\mathrm{Fr} . \quad=$ Frontale.
Ju. $\quad=$ Jugale.
La. = Lacrymale.
N. = Nasenöffnung.
Na. $\quad=$ Nasale.
Pmx. = Praemaxillare.
Pof. $\quad=$ Postfrontale.
Porb. $+S q .+T b .=$ Postorbitale + Squamosum + Tabulare.
Qj. = Quadratojugale.
Simx. = Supramaxillare. 
mosum und Tabulare gebildet. - Oberkarbon von Linton, Ohio. ${ }^{1}$ D. punctolineatus (Fig. 224).

Scincosaurus. - Systematische Stellung unsicher, weil noch ungenügend untersucht. Schwanzwirbel mit quadratisch verbreiterten,

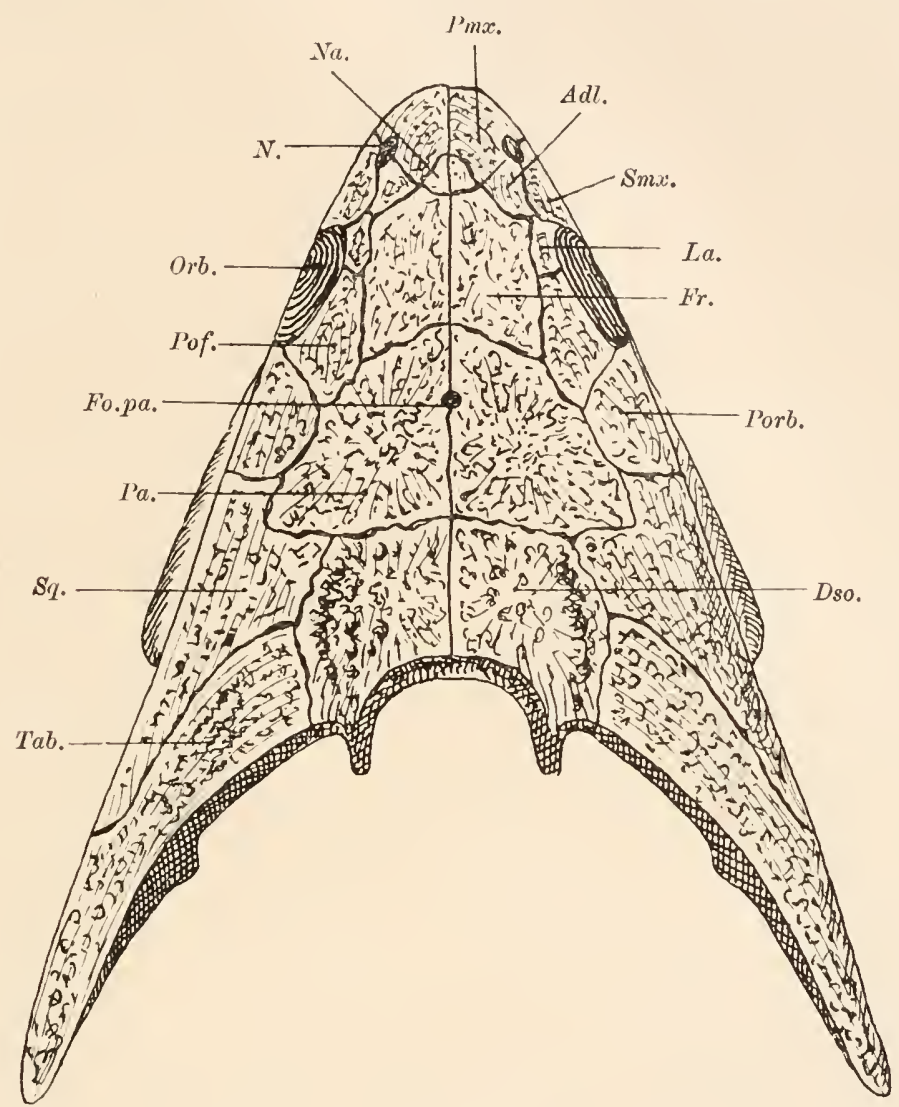

Fig. 225.

Dorsalansicht des Schädeldaches von Batrachiderpeton lineatum, Hanc. et Atth., aus dem Oberkarbon Englands, in $1 \frac{1}{2}$ nat. Gr.

(Nach D. M. S. Watson, 1913.)

\begin{tabular}{|c|c|c|c|}
\hline $\begin{array}{l}\text { Adl. }= \\
\text { Dso. }= \\
\text { Fr. }= \\
\text { Fo.pa. }= \\
\text { La. } \\
\text { N. } \\
\text { Na. }=\end{array}$ & $\begin{array}{l}=\text { Adlacrymale. } \\
=\text { Dermosupraoccipitale. } \\
=\text { Frontale. } \\
=\text { Foramen parietale. } \\
=\text { Lacrymale. } \\
=\text { Nasenöffnung. } \\
=\text { Nasale. }\end{array}$ & $\begin{array}{l}\text { Orb. } \\
\text { Pa. } \\
\text { Pmx. } \\
\text { Pof. } \\
\text { Porb. } \\
\text { Smx. } \\
\text { Tab. }\end{array}$ & $\begin{array}{l}=\text { Orbita. } \\
=\text { Parietale. } \\
=\text { Praemaxillare. } \\
=\text { Postfrontale. } \\
=\text { Postorbitale. } \\
=\text { Supramaxillare. } \\
=\text { Tabulare. }\end{array}$ \\
\hline
\end{tabular}

an den distalen Kanten gekerbten oberen und unteren Dornfortsätzen. Schädeldach breit, flach, von halbeiförmigem Umriß. Bauchseite be-

1 O. Jaekel, Über Ceraterpeton, Diceratosaurus und Diplocaultis. - Neues Jahrb. f. Min. usw., 1903, 1. Bd., p. 109. 
schuppt. Carpus und Tarsus verknöchert. - Oberkarbon von Nürschan in Böhmen. ${ }^{1}$ S. crassus (Fig. 181).

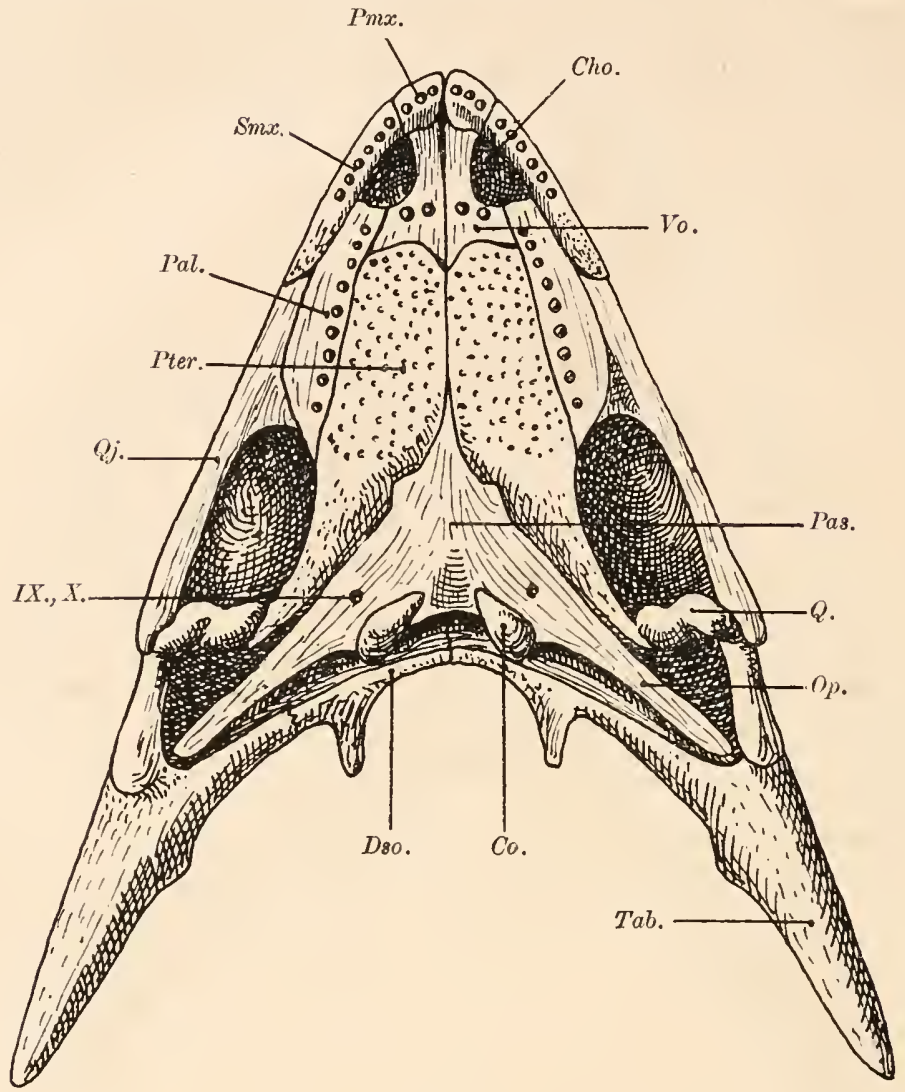

Fig. 226.

Unterseite des Schädels von Batrachiderpeton lineatum, Hanc. et Attl., Oberkarbon Englands, $1 \frac{1}{2}$ nat. Gr. (Nach D. M. S. Watson, 1913.)
Co. = Condylus occipitalis.
Q. $\quad$ = Quadratum.
Cho. = Choane.
Qj. $\quad=$ Quadratojugale.
Dso. = Dermosupraoccipitale. Smx. = Supramaxillare.
Op. $\quad=$ Opisthoticum.
Pal. $\quad=$ Palatinum
Tab. $\quad=$ Tabulare.
Pas. = Parasphenoid
Pmx. = Praemaxillare.
Vo. $\quad=$ Vomer
$I X ., X .=$ Austrittsstellen des IX. und
Pter. $=$ Pterygoid.

Batrachiderpeton. - Schädeldach dreieckig, schwach gewölbt; Augen an den Seitenflächen des Schädels gelegen. Prämaxillare, Supra-

1 A. Fritsch, Fauna der Gaskohle und der Kalksteine der Permformation Böhmens. - 11. Bd., 1885.

H. Schwarz, Über die Wirbelsäule und die Rippen holospondyler Stegocephalen (Lepospondyli Zitt.). - Beiträge zur Geol. und Paläont. Öst.-Ung. u. d. Orients, XXI. Bd., Wien 1908, S. 88. 
maxillare, Palatinum, Vomer und Pterygoid bezahnt. Unterkiefergelenke und Hinterhauptsgelenke ungefähr in derselben Linie gelegen, Schädeldach nach hinten beiderseits in je ein großes, spitzes Horn ausgezogen, das hauptsächlich vom Tabulare und zu einem kleinen Teile auch vom Squamosum gebildet wird. Brustschultergürtel kräftig, Interclavicula breit, scheibenförmig; die breiten Claviculae treten mittels eines spitzen Fortsatzes mit den T-förmigen Cleithren in Verbindung. Gliedmaßen und Wirbel unbekannt. - Oberkarbon Englands. ${ }^{1}$ B. lineatum (Fig. 225, 226).

Diplocaulus. - Hochspezialisierte Gattung. Der Schädel ist sehr niedrig, dabei sehr stark verbreitert und an den hinteren Außenecken in lange Hörner ausgezogen. Die Augenhöhlen sind klein und liegen auf der Oberseite des Schädeldaches nahe beieinander. Die Nasenöffnungen sind ebenfalls sehr klein und liegen an Vorderrande des Schädeldaches. Das Foramen parietale ist bei jungen Individuen offen, bei erwachsenen geschlossen. Die durch die beiden Unterkiefergelenke des Schädels gelegte Linie liegt weit vor den Kondylen des Hinterhauptes. Außer den Kieferknochen sind die Vomeres, Palatina und der vordere Teil der Transversa mit kleinen Zähnen besetzt. Das Parasphenoid ist stark in die Länge gestreckt; es trennt die beiden mediopalatinalen Gruben. Das Postorbitale ist vorhanden und wird von folgenden Knochen begrenzt: Postfrontale, Jugale, Squamosum, Parietale und gelegentlich auch von Quadratojugale. Wirbel einheitlich, amphizöl, jederseits mit zwei Gelenkfortsätzen für die zweiköpfigen Rippen, mit Zygosphen und Zygantrun. 16 präsakrale Wirbel, ein Sakralwirbel, wahrscheinlich eine größere Zahl von Schwanzwirbeln, die aber nur zum Teile bekannt sind. . Die präsakralen Wirbel unterscheiden sich in ihrer allgemeinen Form sehr bestinmmt vom Sakralwirbel, dessen Ventralseite eine tiefe Aushöhlung trägt; er steht mit seinem verdickten und rauhen Hinterende durch eine zahnförmig verlaufende Sutur mit dem ersten Schwanzwirbel in Verbindung. Der 18. Wirbel (1. Schwanzwirbel) trägt zuerst hohe Dornfortsätze, und zwar eine Neurapophyse und eine Hänlapophyse, deren distale Enden verbreitert und gekerbt sind. Brustschultergürtel stark, aber die Arme reduziert; noch stärker reduziert sind jedoch die Hinterbeine. Die Schwanzregion scheint auf der Dorsalseite und auf der Ventralseite mit Panzerplatten bedeckt gewesen zu sein, da der 18. Wirbel in ähnlicher Weise wie bei Diceratosaurus skulpturierte Verbreiterungen an den distalen Enden der Dornfortsätze trägt. Der Humerus besitzt ein Foramen entepicondyloideum.

1 D. M. S. Watson, Batrachiderpeton lineatum Hancock \& Atthey, a CoalMeasure Stegocephalian. - Proceed. Zool. Soc. London, 1913, p. 949. 
Nur aus dem Perm von Texas, Illinois und Oklahoma bekannt. (Fig. 183, 227, 228.)

\section{F. Ptyonidae.}

Schädel langgestreckt, dreieckig, mit spitz zulaufender Schnauze, ohne Hörnerbildung an den hinteren Außenecken des Schädeldaches. Augenhöhlen auf der Dorsalseite-gelegen, Nasenlöcher groß. Gliedmaßen schwach entwickelt, verkümmert, während der Schwanz außerordentlich verlängert ist (bis zu 80 Wirbel bei Urocordylus). Dornfortsätze der Schwanzwirbel fächerartig erweitert und gekerbt. Zygosphen und Zygantrum vorhanden.

Urocordylus. - Oberkarbon von Kilkenny (Irland) und Nürschan (Böhmen). ${ }^{1}$

Ptyonius. - Oberkarbon von Linton (Ohio) und Nürschan (Böhmen). ${ }^{2} \quad$ (Fig. 178, 179, 180.)

Oestocephalus. - Oberkarbon von Linton (Ohio) und Nürschan (Böhmen). ${ }^{3}$ (Fig. 177.)

\section{F. Ophiderpetontidae.}

Körper sehr lang, blindwühlenähnlich, bis zu 100 Wirbel unfassend. Querfortsätze der Wirbel sehr kräftig entwickelt, Rippen zweiköpfig. Rücken und Bauch gepanzert. Proximaler Abschnitt der Rippen auffallend verbreitert. Schädel unvollständig bekannt. Gliedmaßen fehlen vollständig, ebenso der Brustschultergürtel.

Ophiderpeton. - Oberkarbon von Kilkenny (Irland) und Nïrschan (Böhmen). ${ }^{4}$ (Fig. 198, A.)

Thyrsidium. - Oberkarbon von Linton (Ohio). ${ }^{5}$ (Fig. 175.)

1 Th. H. Huxley, On a Collection of Fossil Vertebrata from the Jarrow Colliery of Kilkenny, Ireland. - Transactions Royal Irish Academy Dublin, Vol. XXIV, 1867, p. 353.

H. Schwarz, Über die Wirbelsäule und die Rippen holospondyler Stegocephalen (Lepospondyli Zitt.). - Beiträge zur Paläontologie und Geologie ÖsterreichUngarns und des Orients, XXI. Bd., 1908, S. 79.

2 E. D. Cope, Synopsis of the Extinct Batrachia from the Coal Measures. Report of the Geol. Survey of Ohio, Palaeontology, II, 1875, p. 350.

H. Schwarz, I. c., p. 82 .

${ }^{3}$ E. D. Cope, 1. c., 1875 , p. 366.

H. Schwarz, 1. c. p. 86 .

4 Th. H. Huxley, I. c., 1867.

A. Fritsch, Fauna der Gaskohle und der Kalksteine der Permformation Böhmens. - I. Bd., 1880, S. 119; IV. Bd., 1901, S. 88.

H. Schwarz, 1. c. S. 67.

5 E. D. Cope, I. c., 1875, p. 365.

H. Schwarz, 1. c., 1908, S. 70. 


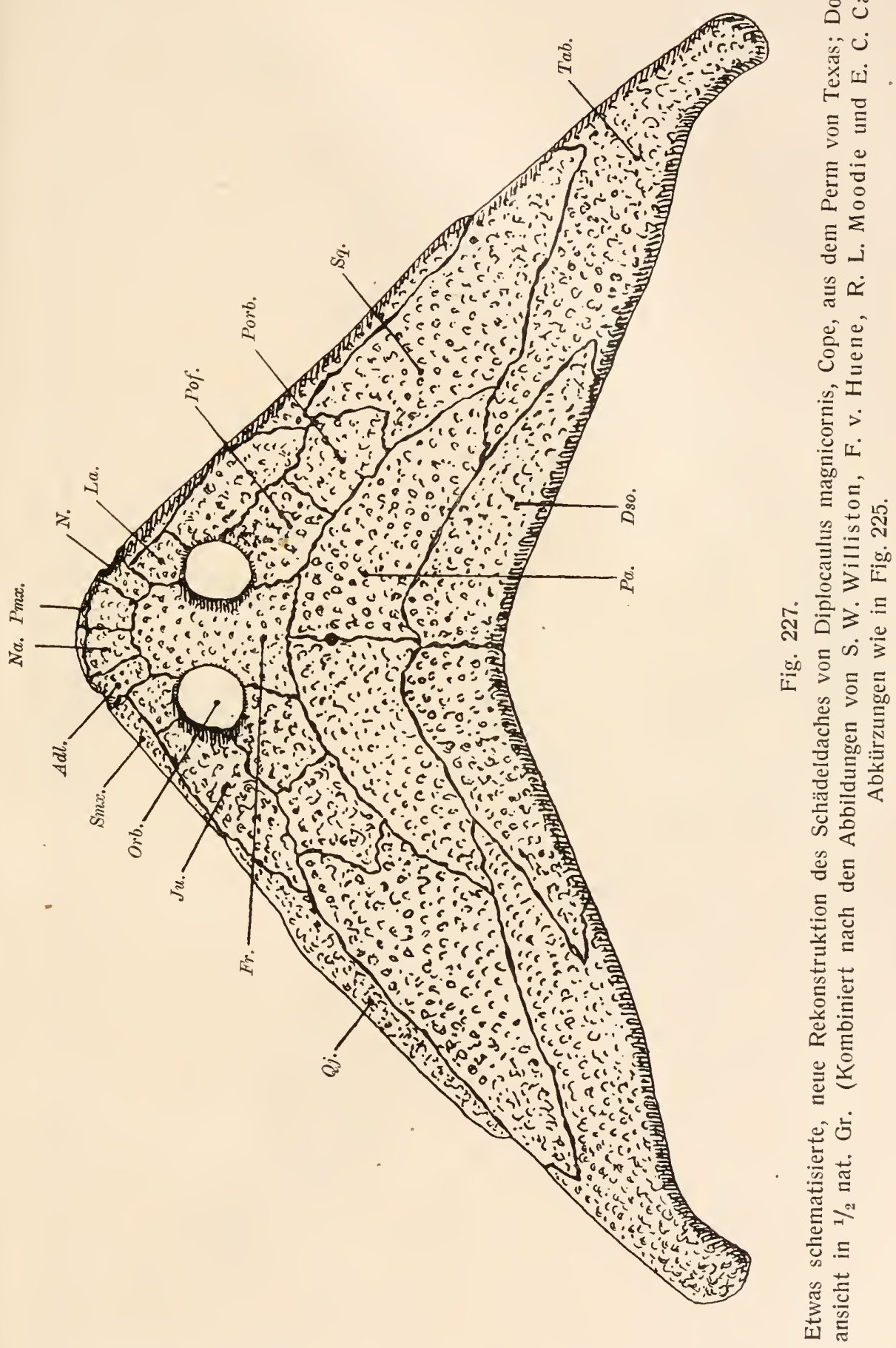



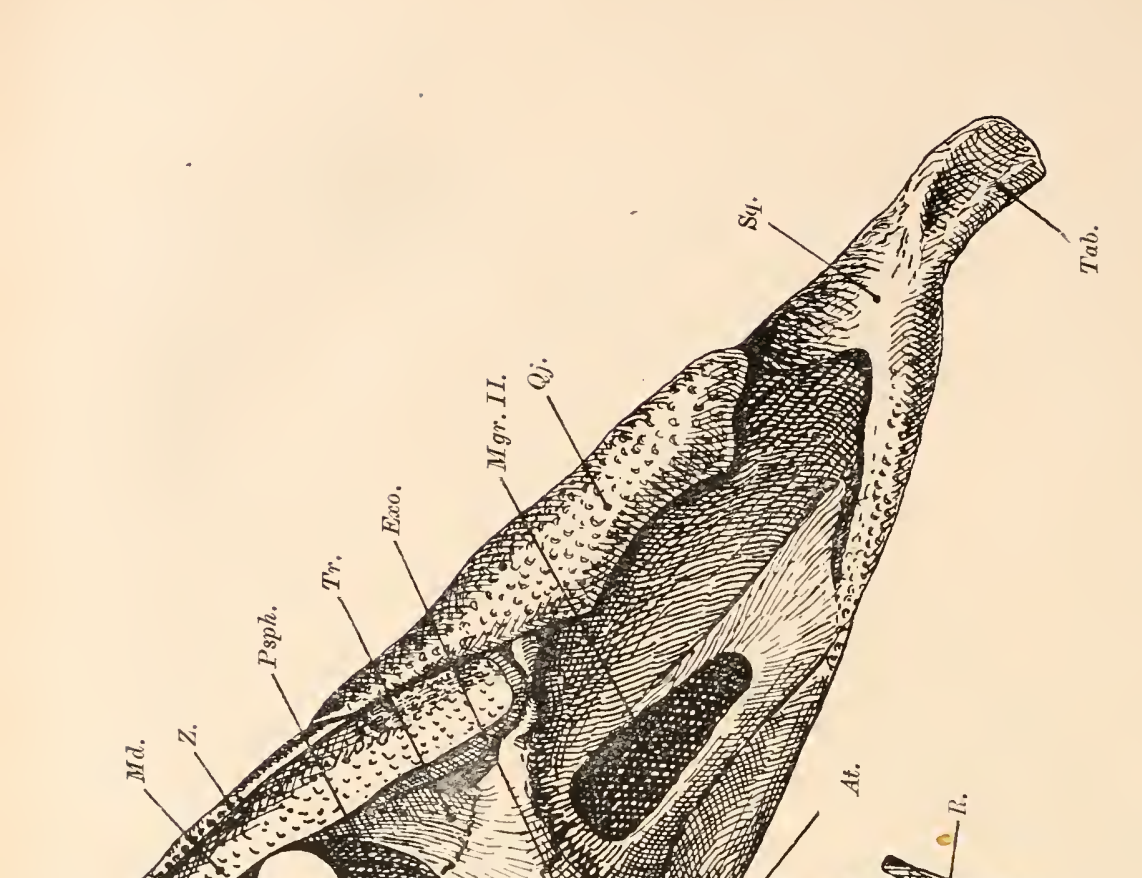

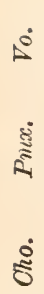




\section{F. Molgophidae.}

Wie die vorige Familie, aber Wirbel mit starker Seitenleiste; Rippen sehr kräftig. Schuppen fehlen.

Molgophis. - Oberkarbon von Linton (Ohio). ${ }^{1}$ (Fig. 198, B.)

\section{F. Phlegethontiidae.}

Fußlos und blindwühlenähnlich wie die beiden vorhergehenden Familien, aber Rippen sehr schwach verknöchert, fischgrätenartig, Hautschuppen sehr zart oder fehlend; Wirbel an der Ventralseite mit überzähligen, paarigen Gelenkfortsätzen (Infrapräzygapophysen [nom. nov.] und Infrapostzygapophysen [nom. nov.]), Querfortsätze schwach entwickelt. Die Ventralseite des Wirbelkörpers trägt einen medianen Kiel.

Phlegethontia. - Die akzessorische Wirbelverfestigung wird durch einen medianen Zapfen verstärkt, der am Hinterrande der Neurapophyse steht (das Zygosphen steht sonst am Vorderrande der Neurapophyse), und der als Hyposphen bezeichnet wird, das sicl in eine entsprechende Vertiefung (Hypantrum) am Vorderrande des hinten anschließenden Wirbels einfügt. Der obere Dornfortsatz (Neurapophyse) ist sehr niedrig und gerade abgestutzt. - Oberkarbon von Linton (Ohio). ${ }^{2}$ (Fig. 182.)

Dolichosoma, - Schädel relativ schmal, dreieckig, Schnauze spitz zulaufend. Unterkiefer lang, schlank. Der langgestreckte, blindwühlenförmige Körper enthält angeblich bis zu 150 Wirbel, deren untere Gelenkfortsätze stärker entwickelt sind als bei der vorher besprochenen Gattung. Während aber dort außer den normalen Zygapopliysen und

Zı Fig. 228.

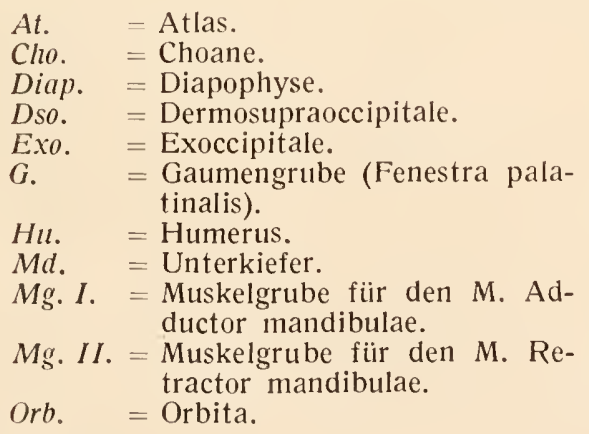
Par. = Parapophyse
Pal. = Palatinum.
Pmx. = Praemaxillare.
Psph. = Parasphenoid.
Pte. $\quad=$ Pterygoid.
Q. $\quad=$ Quadratum.
Qj. $\quad=$ Quadratojugale.
R. $\quad=$ Rippe (zweiköpfig).
Smx. = Supramaxillare.
Sq. = Squamosum.
Tab. = Tabulare.
Tr. $\quad=$ Transversum.
Vo. = Vomer.
Z. $\quad$ Zahnreihe des Oberkiefers.

1 E. D. Cope, 1. c., 1875, S. 365.

H. Schwarz, 1. c., 1908, S. 73.

2 E. D. Cope, 1. c., 1875, S. 367.

H. Schwarz, I. c., 1908, S. 74 . 
den überzähligen Infrazygapophysen noch ein Hyposphen vorhanden ist, fehlt hier das letztere. Die Wirbel sind sehr gleichförmig gebaut.

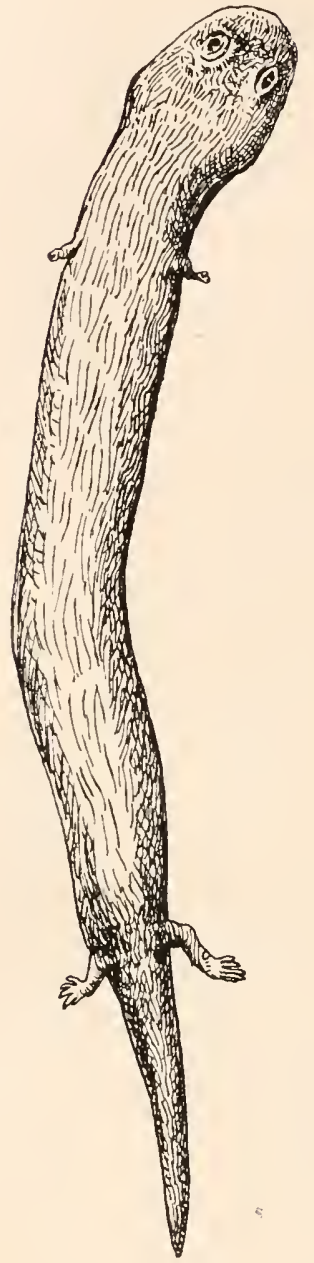

Fig. 229.

Rekonstruktion von Microbrachis Pelikani Fr., aus der oberkarbonen Gaskohle von Nürschan (Böhmen), in nat. Gr. (Original.) Bei einigen Arten sind Schuppen vorhanden. - Oberkarbon von Kilkenny (Irland) tund Nüršchan (Böhmen). ${ }^{1}$ (Fig. 184.)

\section{Ordo: Gastrocentrophori (nov.).}

Nur bei einem kleinen Teile der fossilen Amphibien ist ein Wirbeltypus vorhanden, der für die Amnioten die ausschließliche Regel bildet und der dadurch gekennzeichnet ist, daß die Hauptmasse des Wirbelzentrums aus den Interventralia aufgebaut ist, welche das ,Gastrozentrum" bilden. Die Basiventralia sind als selbständige Hämapophysen entwickelt und treten mit dem Wirbelkörper nur in lockere Verbindung. Trotz dieses übereinstimmenden Wirbelbaues der Amnioten und dieser wenigen Gattungen, die in der Gruppe der Stegocephalen als selbständige Ordnung unterschieden werden müssen, können die bisher bekannten Formen dieser Ordnung nicht als unmittelbare Vorfahren der Reptilien angesehen werden, da sie einseitig spezialisiert sind. Alle hierher gehörigen Gattungen besitzen einen langgestreckten Körper und einen sehr kurzen Schwanz, der höchstens die halbe Rumpflänge erreicht. Die Gattung Microbrachis ähnelt in ihrer allgemeinen Körperform außerordentlich der lebenden Gattung Amphiuma (Aalmolch), kann aber wegen ihres abweichenden Wirbelbaues nicht als Vorfahrentype dieser Gruppe der lebenden Amphibien in Betracht kommen.

\section{F. Microbrachidae.}

Kleine, schlanke, an Amphiuma erinnernde

Formen mit sehr kurzem Schwanz, der kaum die halbe Rumpflänge erreicht und verkümmerten Extremitäten; die Arme sind viel stärker reduziert als die Hinterbeine. Die Augen liegen auf der Oberseite des skulpturierten Schädeldaches und stehen weit

1 Th. H. Huxley, 1. c., 1867.

H. Schwarz, l. c., 1908, S. 76 . (Hier die weitere Literatur.) 
vorn. Rumpfrippen schwach gebogen, zweiköpfig. Bauchschuppen vorhanden. Der Schwanz ist konisch verjüngt, nicht komprimiert, und somit kein Ruderschwanz wie z. B. bei den Ptyoniden; die kleinen Tiere sind wahrscheinlich ebenso wie Amphiuma Schlammwühler gewesen. Microbrachis._-Oberkarbon von Nürschan (Böhmen). ${ }^{1}$ (Fig. 176, 229.)

\section{F. Hylonomidae.}

Von der vorhergehenden Fannilie wenig verschieden, vielleicht mit ihr zusammenfallend.

Hylonomus. - Oberkarbon von South Joggins (Neuschottland), Oberkarbon von Nürschan und Kounova (Böhmen), Perm von Niederhäßlich bei Dresden. ${ }^{2}$

\section{F. Limnerpetontidae.}

Wie die vorhergehende Familie kaum von den Microbrachiden zu trennen. Limnerpeton. - Oberkarbon, Nürschan. ${ }^{3}$

Amphibamus. - Oberkarbon, Illinois. ${ }^{4}$

1 A. Fritsch, Fauna der Gaskohle und der Kalksteine der Permformation Böhmens. - I. Bd., 1883, S. 174.

H. Schwarz, Über die Wirbelsäule und die Rippen holospondyler Stegocephalen (Lepospondyli Zitt.). — Beiträge zur Paläontologie und Geologie Österr.-Ungarns u. d. Orients, XXI. Bd., Wien 1908, S. 91.

O. Jaekel, Über die Klassen der Tetrapoden. - Zool. Anzeiger, Bd. XXXIV, 1909, S. 206, 208, 209. (Zu der Diagnose der Haplosauri ist zu bemerken, daß Microbrachis einen auffallend kurzen Schwanz besitzt, während für diese Gruppe nach O. Jaekel ein langer Schwanz bezeichnend sein soll.)

Derselbe, Die Wirbeltiere. - Berlin 1911, S. 119.

2 J. W. Dawson, On a terrestrial Mollusk, a Chilognathus Myriapod, and some New Species of Reptiles from the Coal-Measure of Nova Scotia. - Quart. Journ. Geol. Soc., Vol. XVI, 1860, p. 274.

Derselbe, On the Results of Recent Explorations of Erect trees containing Animal Remains in the Coal Formation of Nova Scotia. - Philos. Transactions Roy. Soc., London, Vol. CLXX1II, Part. 2, 1882, p. 621.

A. Fritsch, Fauna der Gaskohle uws., I. Bd., 1883, S. 88.

H. Credner, Die Stegocephalen und Saurier aus dem Rotliegenden des Plauenschen Grundes bei Dresden. - Zeitschrift d. Deutschen Geol. Ges., 1885 (V. Teil, S. 724) und 1890 (IX. Teil, S. 240).

H. Schwarz, 1. c., 1908, S. 98.

3 A. Fritsch, Fauna der Gaskohle usw., I. Bd., 1883, S. 147.

4 E. D. Cope, On Amphibamus grandiceps, a New Batrachian from the CoalMeasures. - Proc. Acad. Nat. Sci., Philadelphia, 1865, p. 134.

Derselbe, Supplement to the Description of Vertebrates. - Geol. Survey Illinois, Vol. II, 1866, p. 135.

R. L. Moodie, The Dawn of Quadrupeds in North America. - The Popular Science Monthly, Vol. LXXII, 1908, p. 563.

Derselbe, The Mazon Creek, Illinois, Shales and their Amphibian Fauna. Amer. Journ. Science, Vol. 34, 1912, p. 277 (Übersicht der Amphibienfauna der Mazon Creek Shales). 


\section{Incertae sedis.}

Gephyrostegus. - Diese Gattung von unsicherer systematischer Stellung, die in einem Exemplar aus der oberkarbonen Gaskohle von Nürschan vorliegt, ist durch die seitliche Aushöhlung des Schädels an der Stelle der Temporalgruben und der Verdünnung der Schädelwand

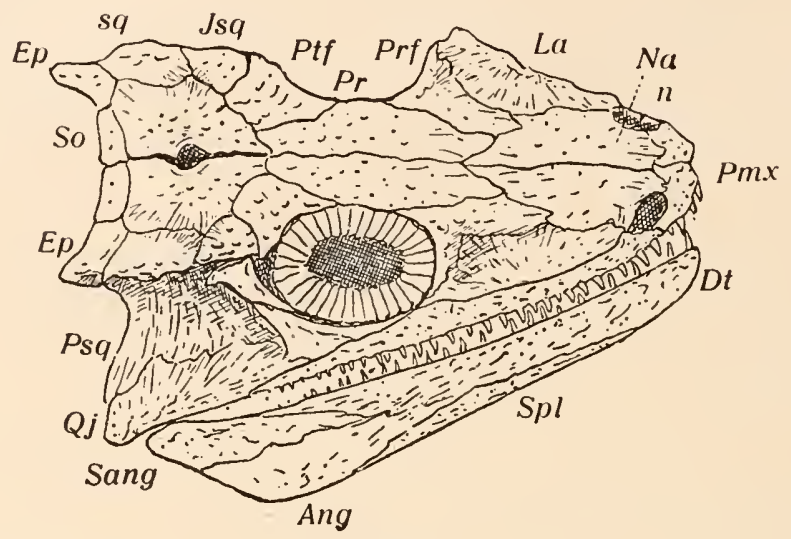

Fig. 230.

Seitenansicht des schief zusammengedrückten und daher auch die Oberseite des Schädeldaches zeigenden Schädels von Gephyrostegus bohemicus, Jaekel, aus dem obersten Karbon der Gaskohle von Nürschan in Böhmen, in $2 / 3$ nat. Gr. (Zeichnung von O. Jaekel, Deutung der Knochen im folgenden zum Teil

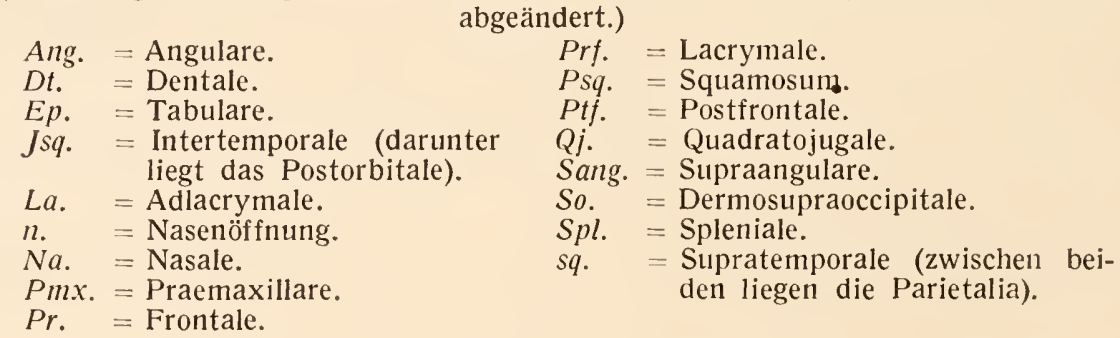

an den eingebuchteten Stellen bemerkenswert. Die von Jaekel geäußerte Vermutung, $\mathrm{daß}$ diese Gattung einen Übergangstypus zu den Reptilien darstellt, ist jedoch unhaltbar, weil die Temporalgruben der Reptilien auf einem anderen Wege entstanden sind. ${ }^{1}$ (Fig. 230.)

Chenoprosopus. - Perm (Miller Bone-Bed) von Neumexiko. Bisher nur der Schädel bekannt; es ist noch nicht möglich gewesen,

1 O. Jaekel, Über einen neuen paläozoischen Tetrapodentypus, Gephyrostegus bohemicus, n. g. n. sp. - Zeitschrift d. Deutschen Geol. Ges., LIV. Bd., 1902, S. 127.

Derselbe, Die Wirbeltiere, 1. c., 1911, S. 137. 
diese eigentümliche Type einer der bisher bekannten Familien oder größeren systematischen Abteilungen der Stegocephalen einzureihen. M. G. Mehl (1913) stellt die Gattung zu den Rhachitomen, hebt aber gewisse Reptilienmerkmale und scharfe Unterschiede der Gaumenregion im Vergleich zul den Rhachitomen hervor ${ }^{\mathbf{1}}$; S. W. Williston (1916) reiht Chenoprosopus der Familie der Cricotidae ein ${ }^{2}$ (Fig. 231.)
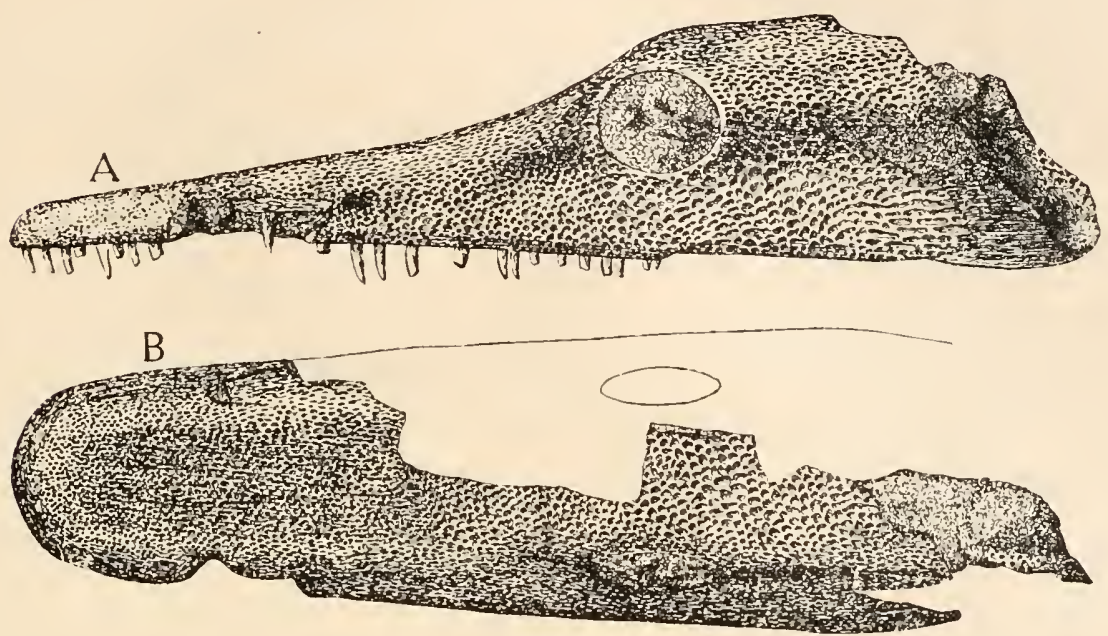

Fig. 231 .

Chenoprosopus Milleri, Mehl; aus dem Permokarbon am Poleo Creek bei Arroyo de Agua (Neumexiko). A: Schädel von links, B: von oben gesehen. Schädellänge $288 \mathrm{~mm}$. (Nach M. G. Mehl, 1913.)

\section{Unterklasse: Anura (Froschlurche).}

\section{Allgemeine Kennzeichen des Stammes.}

Das hervorragendste Kennzeichen aller Angehörigen des ganzenStammes ist der im erwachsenen Zustande schwanzlose ${ }^{\mathbf{3}}$, gedrungene Körper, dessen Schwanzwirbel zu einem dolchförmigen, in der Mittel-

1 M. G. Mehl, Description of Chenoprosopus Milleri gen. et spec. nov. (In: E. C. Case, S. W. Williston and M. G. Mehl, Permo-Carboniferous Vertebrates from New Mexico.) - Carnegie Institution of Washington, Publ. 181, Washington 1913, p. 11.

2 S. W. Williston, Synopsis of the American Permocarboniferous Tetrapoda. Contributions from Walker Museum, Vol. 1, Nr. 9, Chicago 1916, p. 209.

3 Nur bei dem Discoglossiden Ascaphus Truei aus Nordamerikas tritt, wie mir mein Freund Professor Dr. F. Werner mitteilt, im erwachsenen Zustande ein ziemlich langes Schwanzrudiment auf, das bei drei erwachsenen $\sigma^{-1}$ beobachtet worden ist und somit keine zufällige atavistische Bildung darstellt. 


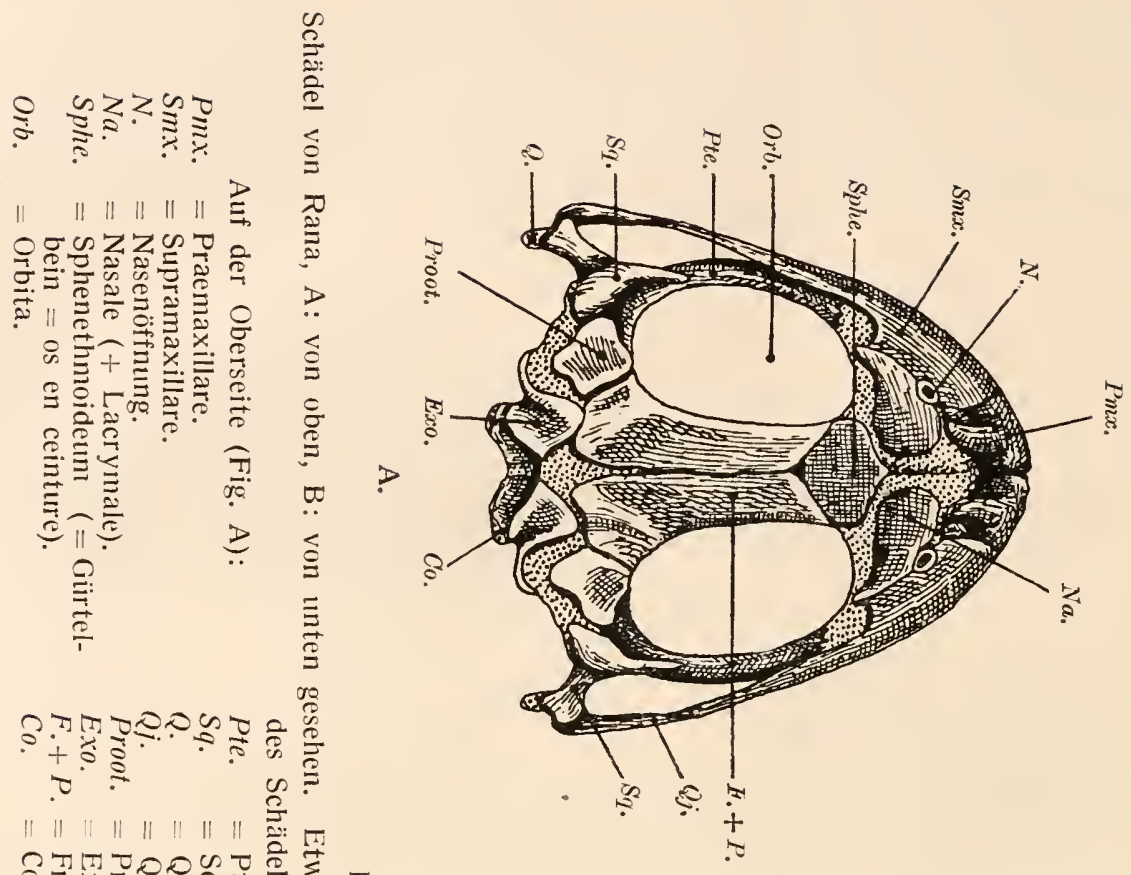

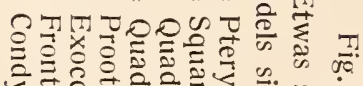

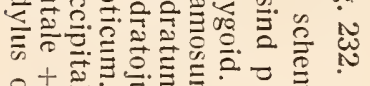

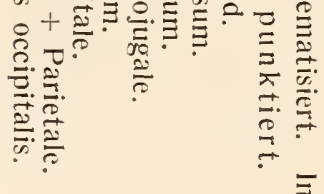

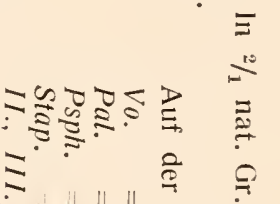

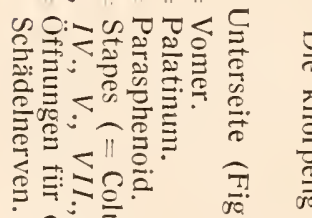

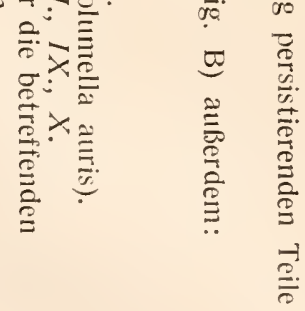

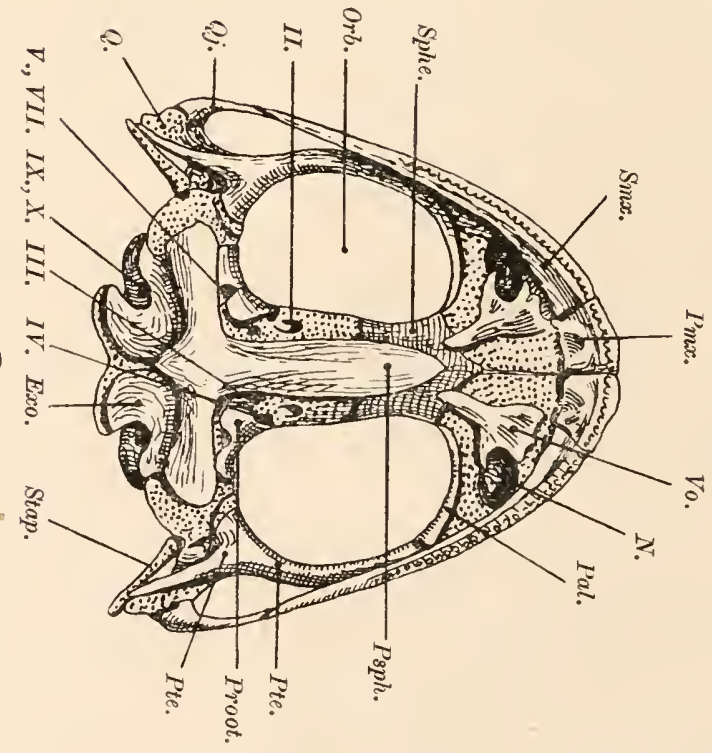


linie des Körpers zwischen den langgestreckten Hüftbeinen liegenden Knochen (Coccyx oder Urostyl) verschmolzen sind. Das Foramen parietale ist nie vorlanden. ${ }^{?}$

\section{Schädelbau der Anuren.}

Das Dach des Anurenschädels ist bei spezialisierten Vertretern des Stammes vom Stegocephalenschädel namentlich dadurch verschieden, daß die einzelnen Deckknochen nicht zu einem Mosaik vereinigt sind und in Nähten aneinanderstoßen, sondern entweder frei bleiben oder in verschieden hohem Grade untereinander verwachsen, soweit sie nicht durch Reduktion verloren gegangen sind (Fig. 232). Die

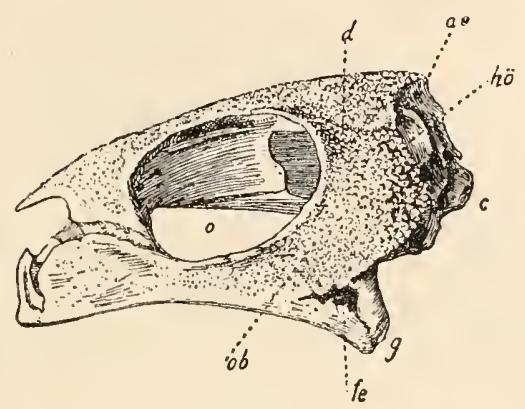

Fig. 233.

Schädel von Pelobates cultripes.

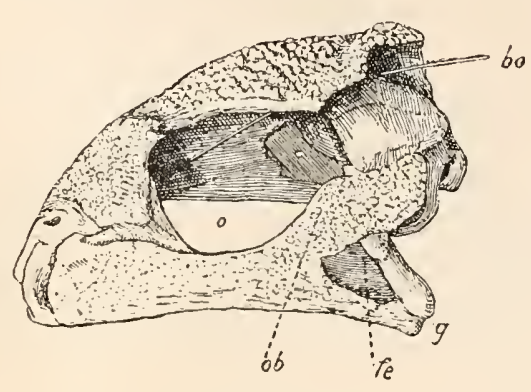

Fig. 234.

(Nach J. E. V. Boas.)

ao. = hintere Öffnung für den Kanal der $f_{e}$. = Seitenfenster im Schädeldach

Arteria occipitalis.

bo. $=$ Borste, in den Kanal bei der Öffnung ao eingefiihrt.

$0 . \quad$ = Orbita.

$c .=$ Condylus occipitalis.

g. = Gelenkfläche gegen den Unterkiefer.

$o b .=$ Briicke zwischen $o$ und $f e$.

hö. = Fenestra posttemporalis.

allgemeine Schädelform erinnert dagegen in hohem Grade an die der Stegocephalen, weit mehr als dies bei den Urodelen und Gymmophionen der Fall ist. Meist ist der Anurenschädel sehr flach und breit, kann aber in einzelnen Fällen stark gewölbt und hoch sein (z. B. bei Ceratohyla, Pelobates, Ceratophrys).

Das Schädeldach der Stegocephalen besitzt keine Durchbrüche

1 Das Fehlen des Foramen parietale bei den Anuren ist um so auffallender, als sie noch ein unpaares, median gelegenes ,Stirnorgan" besitzen, das zwischen der vorderen Hälfte beider Augen liegt und unter den einheimischen Fröschen am besten bei Rana temporaria entwickelt ist. Zu dem Stirnorgan führt ein Verbindungsstrang aus der Hirnhöhle durch die Naht zwischen den Frontoparietalia; dieser Strang umfaßt ein Blutgefäß und einen markhaltigen Nerventraktus. (Vgl. über diese Frage E. Gaupp, Anatomie des Frosches, 3. Abt., 2. Aufl., 1904, S. 758-762, Literatur S. 922.) - Ob dieses „Stirnorgan“ der Frösche dem Parietalorgan der Reptilien homolog ist, ist eine noch unentschiedene Frage. 
oder Fenster in der Schläfenregion, die den Temporalgruben der Reptilien vergleichbar sind; die Öffnungen in dieser Schädelregion bei Cyclotosaurus, Cacops und Trematops sind durch den hinteren Verschluß der Incisura oticalis entstanden und können nicht mit den Temporalfenstern der Reptilien homologisiert werden. Dagegen treten bei einzelnen Anuren Spalten in der Schläfenregion, und zwar an den Seiten des Schädeldaches auf, die bei Pelobates cultripes (Fig. 233) noch klein, bei Pelobates fuscus (Fig. 234) aber schon bedeutend größer

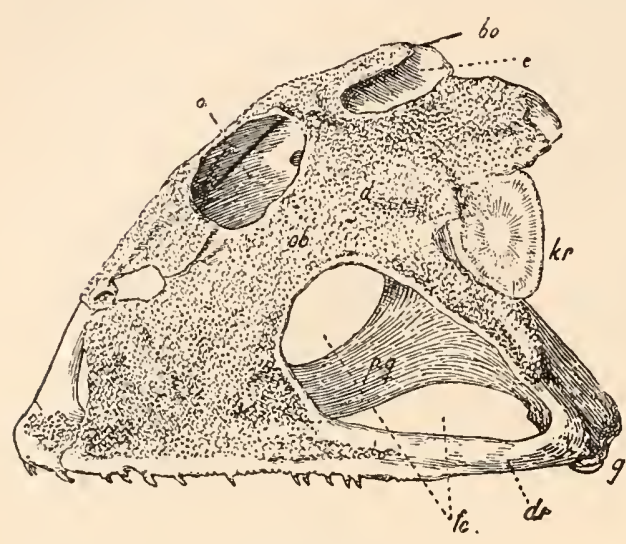

Fig. 235.

Ceratophrys dorsata.

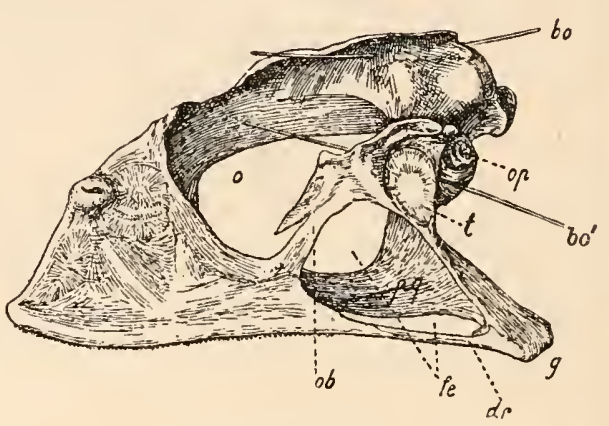

Fig. 236.

Ceratophrys Boiei.

(Nach J. E. V. Boas.)

bo. = Borste, durch den Kanal der Arteria occipitalis geführt.

$b o^{\prime}=$ Borste durch die Fenestra pteroccipitalis.

d. $=$ Schädeldach .

$d r$. = Seitenrand des ehemals geschlossenen Schädeldaches.

e. = Inzisur des Schädeldaches am Hinterrand. fe. $=$ Seitenfenster im Schädeldach.

g. $=$ Kiefergelenkfläche.

$k r$. = knorpeliger Rahmen des Trommelfelles.

o. $=$ Orbita

$o b .=$ knöcherne Brïcke zwischen $o \mathrm{u}$. fe.

$o p$. = Operculum.

$p q$. = Palatoquadratımı.

t. $=$ Tronmelfell.

sind und sich z. B. bei Ceratohyla fasciata (Fig. 241), Ceratophrys Boiei (Fig. 236) und Ceratophrys dorsata (Fig 235) zu großen Tennporalfenstern erweitert zeigen. Noch größer ist dieses Scliläfenfenster bei Calyptocephalus Gayi (Fig. 237), wo es ebenso wie in den vorstehend genannten Fällen allseitig verschlossen und von der Orbita durch eine breite Brücke getrennt ist. Bei Bufo (Fig. 238) und Rana (Fig. 239) schwindet diese Brücke, so daß die Augenhöhle und das Schläfenfenster zusammenfließen, wobei aber noch ein Rest des Schädeldaches die Stelle der ehemaligen Brücke bezeichnet. ${ }^{1}$

1 J. E. V. Boas, Die Schläfeniiberdachung und das Palatoquadratum in ihrem Verhältnis zum iibrigen Schädel bei den Dipnoern und den terrestren Wirbeltieren. - Morpholog. Jahrbuch, Bd. XLIX, 2. Heft, 1914, S. 229. 
Mit dem Schwunde des Schädeldaches über der Schläfenhöhle, wie es bei Rana und den meisten lebenden Anuren eingetreten ist, erscheint der die Temporalhöhlung ausfüllende Muskel (Adductor mandibulae posterior longus $=M$. temporalis aut.) nebst dem Musculus ptery-

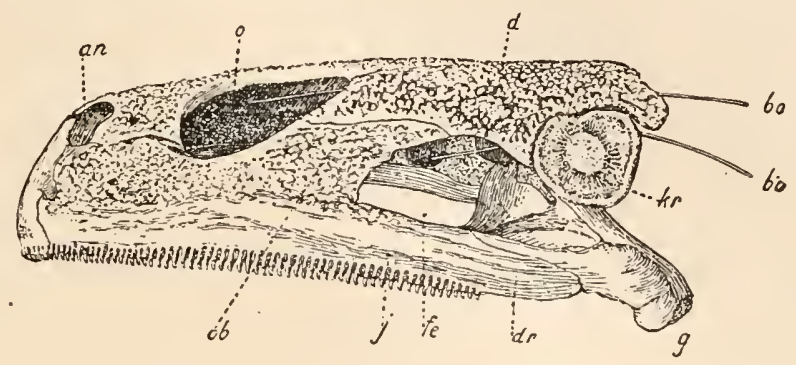

Fig. 237.

Schädel von Calyptocephalus Gayi von links. (Nach J. E. V. Boas.)

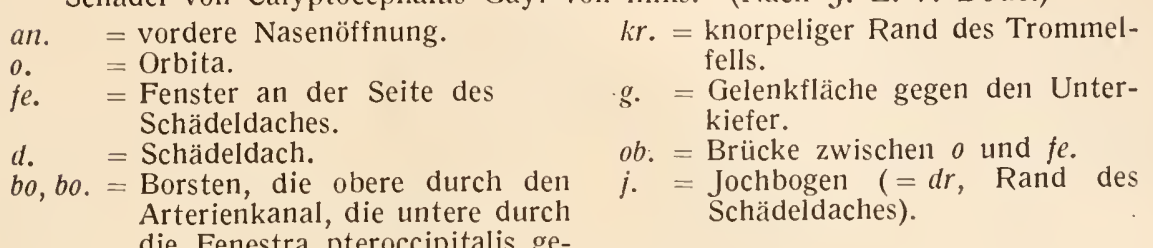
die Fenestra pteroccipitalis geführt.

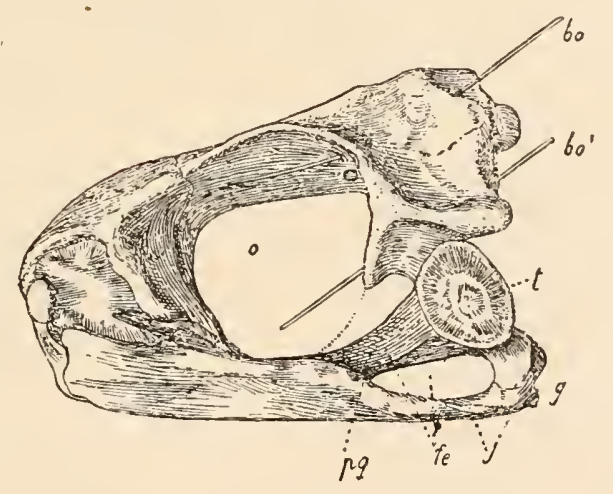

Fig. 238.

Schädel von Bufo agua. (Nach J. E. V. Boas.)

bo. = Borste durch den Kanal der Arteria g. = Gelenkfläche gegen den Unterkiefer. occipitalis.

fe. Seitenfenster im 'Schädeldach.

$b o^{\prime}=$ Borste durch die Fenestra pter- $j .=$ Jochbogen.

occipitalis.

t. $=$ Trommelfell.

$o$. = Orbita.

$p q .=$ Palatoquadratum.

goideus unbedeckt (dasselbe ist nach J. E. V. Boas auch bei Pelobates fuscus und Ceratophrys Boiei der Fall) und der Musculus rhomboideus ant. heftet sich an eine Faszie, die über den $M$. adductor nandibulae post. long. hinwegzieht. 
Die Incisura oticalis ist bei Hemiphractus scutatus (Fig. 240) und Ceratohyla fasciata (Fig. 241) als tiefe Einbuchtung vorhanden und wird vom Trommelfell verschlossen. Durch diese'Lage des Otikalschlitzes wie durch das völlig geschlossene, fensterlose Schädeldach ist der Schädel von Hemiphractus scutatus außerordentlich stegocephalenähnlich (J. E. V. Boas, 1914), eine Ähnlichkeit, die durch die grubige Skulptur des Schädeldaches noch gesteigert wird. Das Schädel- und Schläfendach der Hemiphractiden ist nach den eingehenden Untersuchungen von Boas nicht als sekundäre Neubildung, sondern als ein Erbstück von den Stegocephalen anzuselien. -

Auch die Unterseite des Anurenschädels weist in vielen Merkmalen eine auffallende Übereinstimmung mit den Schädeln von Stegocephalen auf, was besonders durch den langen Processus cultriformis des Para-

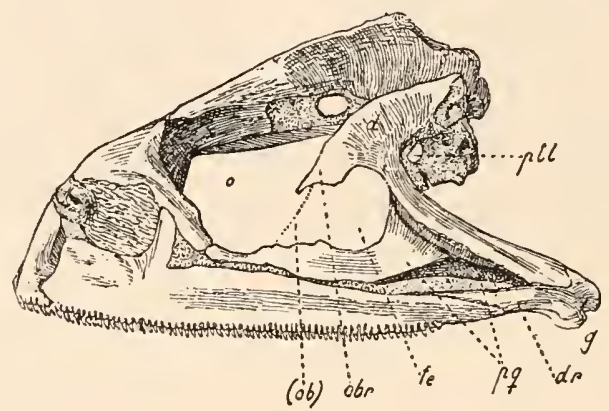

Fig. 239.

Schädel von Rana mugiens, Trommelfell und Gehörknöchelchen weggenommen. (Nach J. E. V. Boas.)

$o .=$ Orbita.

$f_{0}=$ Fenster im Schläfendach, infolge Reduktion der bei Ceratophrys (Fig. 236) vorhandenen Knochenbrïcke mit der Orbita vereinigt.

$$
\begin{aligned}
& o b r .=\text { letzter Rest dieser Briicke. } \\
& p q .=\text { Palatoquadratum. } \\
& d r .=\text { Seitenrand des Schädeldaches. } \\
& g . \\
& \text { ptl. }=\text { Kiefergelenkfläche. }
\end{aligned}
$$

sphenoids zum Ausdrucke kommt, der die beiden großen Gaumenfenster an der Unterseite der Schädelkapsel trennt. Eine Pteroccipitallücke ist auch bei den Anuren vorhanden, doch ist sie meist sehr klein.

Unter den Spezialisationen, welche für den Anurenschädel bezeichnend sind, sind hervorzuheben: die Verwachsung des Frontale und Parietale zu einem Frontoparietale, das von dem der anderen Schädelhälfte meist getrennt bleibt; nur bei den Aglossa sind beide Frontoparietalia miteinander verschmolzen. Die Lacrymalia (= Praefrontalia aut.) verwachsen meistens mit den Nasalia oder fehlen in einigen Fällen gänzlich. Infolge der Verschmelzung des Lacrymale mit dem Nasale erscheint dieser Knochen relativ groß. Das Sphenethmoideum ist groß, ringförmig und legt sich wie ein Gürtel um das Vorderende des knor- 
peligen Primordialschädels, weshalb es auch als „Gürtelbein“ oder ,,os en ceinture" bezeichnet wird. Die Vomeres liegen als isolierte Knochenplatten auf der Unterseite des Knorpelschädels und bedecken zum Teil das Sphenethmoid, das auf der Schädeloberseite entweder freiliegt oder an seinem Vorderrande von den Nasalia bedeckt wird (Fig. 232).

Der Gesantcharakter der Knochenbedeckung des Anurenschädels läßt sich dahin zusammenfassen, daß bei den spezialisierteren Typen wie z. B: Rana oder Bufo die Knorpelknochen ebensowohl wie die Belegknochen stark reduziert sind und mehr oder weniger als isolierte Platten auftreten.

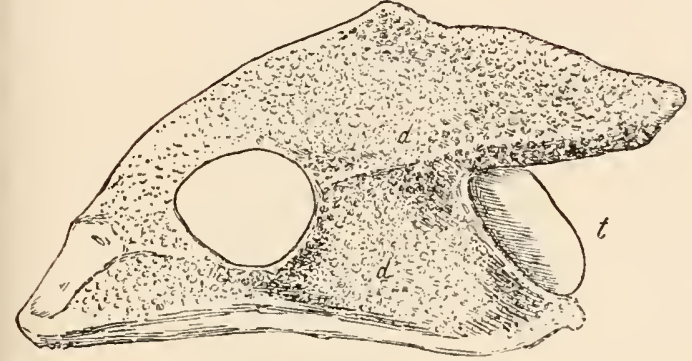

Fig. 240.

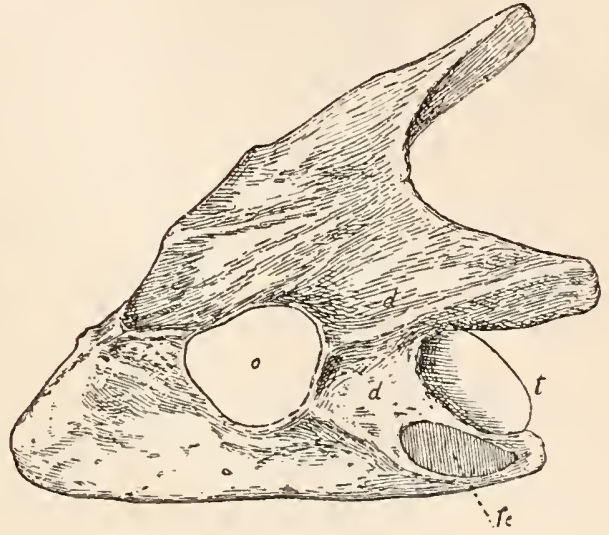

Fig. 241.

Schädel von Hemiphractus scutatus, Spix. Schädel von Ceratohyla fasciata, Peters. Beide etwas gedreht, so daß sie von links und ein wenig von oben gesehen erscheinen.

Beide Schädel sind noch von der Haut bedeckt. (Nach J. E. V. Boas.)
d. = Schädeldach.
o. = Orbita.
fe. $=$ Fenster im Schläfendach .
$t .=$ Trommelfell.

Von Einzelheiten ist das Vorhandensein eines Septomaxillare (= Intranasale, Gaupp, 1896) im Schädel von Rana hervorzuheben, das sich aber wahrscheinlich auch bei vielen anderen Anuren nachweisen lassen dürfte.

Die Fenestra ovalis $(=\mathrm{F}$. vestibuli) der Olırkapsel wird durch eine ovale Knochenplatte, das Operculum, verschlossen, nit welcher ein dünnes Stäbchen, das Plectrum, in Verbindung steht. Operculum und Plectrum sind Teile des Stapes (= Columella auris), dessen distales Ende mit dem Trommelfell in Verbindung tritt, das in einem Knorpelring (Annulus tympanicus) ausgespannt ist. ${ }^{1}$

\section{S. 679 .}

1 E. Gaupp, Anatomie des Frosches, 3. Abt., 2. Aufl., Braunschweig, 1904, 


\section{Wirbelsäule und Rippen der Anuren.}

Der Aufbau des Wirbels der Anuren ist von dem der übrigen Amphibien durchaus verschieden; er

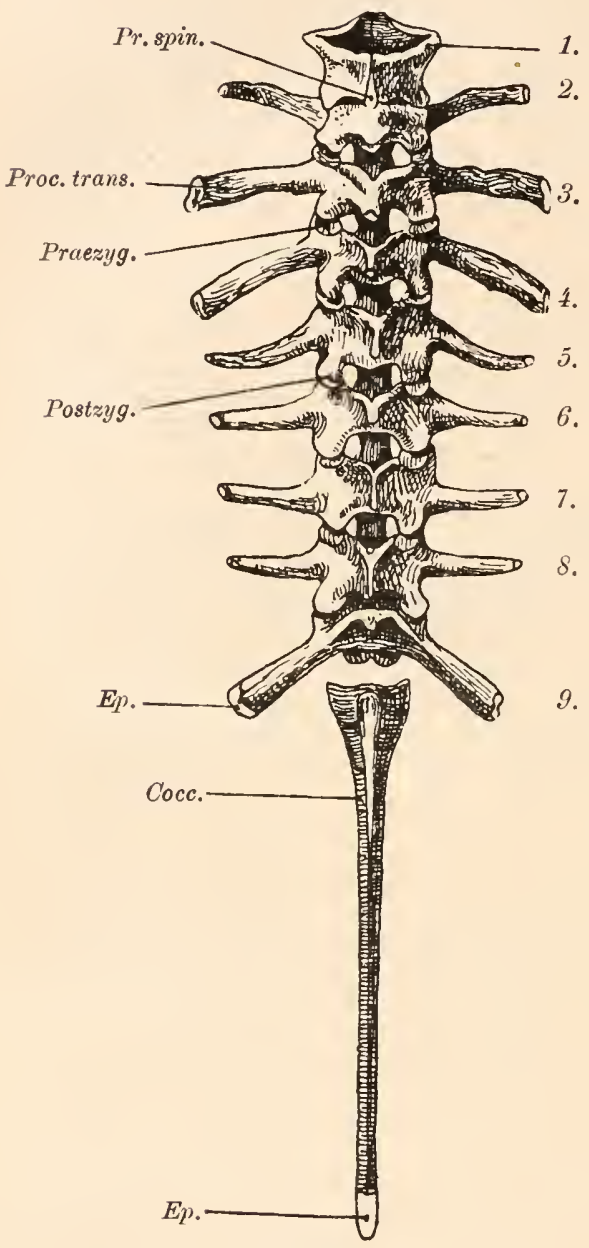

Fig. 242.

Wirbelsäule von Rana esculenta, von oben gesehen. $2 / 1$ nat. Gr.

(Nach E. Gaupp.)

$I-9 \quad=$ Wirbel.

Pr.spin. - Processus spinosus.

Proc.trans. = Processus transversus.

Praezyg. - Praezygapophyse.

Postzyg. $\quad=$ Postzygapophyse.

Ep.

Cocc.

$=$ Epiphysen.

- Coccyx. bildet den notozentralen Typus (s. oben), d. h. die Wirbel umfassen in der Regel nur drei Paar Bogenelemente (die Interventralia sind verloren gegangen) oder, wenn auch die Basiventralia (z. B. bei Pipa und Bombinator) verloren gehen, nur zwei Paare (Basidorsalia und Interdorsalia), von denen die Interdorsalia als Notozentrum die Hauptmasse des Wirbelkörpers bilden. Jedenfalls geht dieser Wirbeltypus auf einen primitiven rhachitomen Typus zurück.

Als "Halswirbel" kann man nur den ersten, an den beiden Condyli occipitales des Hinterhauptes einlenkenden bezeichnen, der jedoch mit dem Atlas der Reptilien, Vögel und Säugetiere nicht homolog ist (H. Gadow, 1896); dies hängt danit zusammen, daß den Amphibien der X11. Schädelnerv (i. e. aus dem Schädel austretende Nerv) fehlt. Der XII. Schädelnerv der Ammioten ist dem ersten Spinalnerven der Amplibien homolog und erst später in das Schädelinnere einbezogen worden.

Außer dem einzigen Halswirbel liegen zwischen dem Schädel und dem Sacrum, das in der Regel von einem, selten von zwei (Pelobates, Pipa, Hymenochirus) Wirbeln gebildet wird, meist 7 Wirbel, so daß wir meist 8 präsakrale Wirbel bei den Anuren antreffen (bei Pelobates fuscus 9, bei Pipa 7, bei Hymenochirus 5). Das Steißbein (Coccyx $=$ Os coccygeum) ist aus der 
weitgehenden Verschmelzung von 12 Schwanzwirbeln hervorgegangen (Fig. 242, 243).

Freie Rippen sind nur an den vordersten Wirbeln der Discoglossiden und bei den Larven der Aglossa nachgewiesen; die langen Querfortsätze (Processus transversi) der Anurenwirbel sind die Rudimente der Rippen (A. M. von Fejerváry, Verh. Zool. Bot. Gıs. Wien, 1918, S. 114).

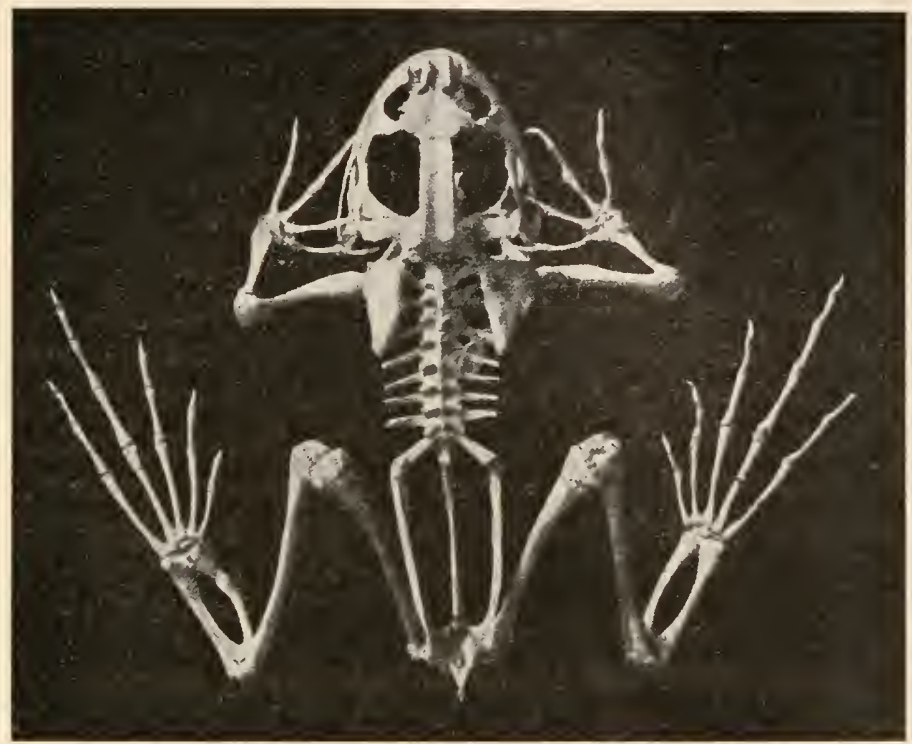

Fig. 243.

Skelett von Rana ridibunda Pallas. Tuldscha. (Nach O. Abel, 1912.)

\section{Brustschultergürtel und Vordergliedmaßen der Anuren.}

Der Brustschultergürtel der Anuren unterscheidet sich von dem der Stegocephalen vor allem durch das Fehlen eines Cleithrum, sowie durch eine andere Anordnung der einzelnen, von den Stegocephalen ererbten Elemente.

Dem Scapulare schließt sich ein zum Teile verkalkter, zum Teile knorpelig gebliebener Knochen, das Suprascapulare, an, das sich in starker Wölbung wie ein Schild um das Vorderende des Thorax auf dessen Dorsalseite legt und mit seinem ventralen Ende an das Scapulare stößt. Vom Ventralende des Scapulare zweigt nach vorn die Clavicula, nach hinten das Coracoid ab; die Clavicula verbindet sich mit dem Praecoracoid, das Coracoid mit dem Epicoracoid. Die Grenzen zwischen Praecoracoid und Epicoracoid sind nicht scharf zu erkennen, aber da in beiden Elementen beim erwachsenen Frosche getrennte Verkalkungen 
auftreten, so ist ihre Selbständigkeit wahrscheinlich, wenn auch nicht sicher.

In der Mittellinie treten die Elemente des Brustbeinabschnitts mit dem Schultergürtel derart in Verbindung, daß sich vorn an die beiden Praecoracoidea das Episternum (ein unpaariger Knorpelknochen, der mit der Interclavicula der Stegocephalen nicht homolog ist) und hinten an die beiden Epicoracoidea das Sternum (=Xiphisternum) anschließt. Beide Sternalelemente bleiben zum Teil knorpelig, so daß in ihnen eine Pars ossea von der Pars cartilaginea zu unterscheiden ist (Fig. 244, 245).

Im Armskelett fällt vor allem die vollständige Verschmelzung von Radius und Ulna zu einem einzigen Knochen auf, der aber die Herkunft aus zwei Elementen stets deutlich erkennen läßt. In der Hand ist der Daumen als Oriment entwickelt, das in Gestalt eines Griffels der Handflächenseite (Volarseite) des Carpale I. aufsitzt. An der Vorderseite des Metacarpale II. ist eine Tuberosität ausgebildet, die nur beim Männchen auftritt und als Muskelansatzstelle des in der Brunstzeit sehr stark werdenden Musculus abductor indicis longus dient. Die Carpalia III, IV, V sind untereinander verwachsen, das Radiale auffallend groß und an die Vorderseite der Hand verschoben (Fig. 246).

\section{Beckengürtel und Hintergliedmaßen der Anuren.}

Das Becken der Anuren unterscheidet sich von dem der Stegocephalen vor allem durch die enorme Verlängerung der Ilia, ihre Lage zur Wirbelsäule und die Ausbildung des Coccyx, der sich in eine Grube auf der Oberseite der Ilia an ihrer hinteren Vereinigungsstelle hineinlegt.

Ebenso wie die beiden Knochen des Unterarmes sind auch Tibia und Fibula miteinander vollständig in ihrer ganzen Länge verwachsen, loch ist die ursprüngliche Grenze beider Knochen durch eine Rinne (Sulcus intermedius) gekennzeichnet. Das Mittelstück besitzt eine Markröhre, die oberen und unteren Enden aber je zwei, so daß also die Wand zwischen beiden Knochen nur in der Mitte des Knochens fehlt. Im Tarsus sind Tibiale (= Astragalus) und Fibulare (= Calcaneus) außerordentlich verlängert und repräsentieren in physiologischer Hinsicht einen Unterschenkel; die proximalen und distalen Enden beider Knochen werden von einer gemeinsamen Epiphyse unfaßt. Vor der ersten Zehe liegt ein Praehallux, ebenso wie der Daumen der Frösche ein Oriment, der die knöcherne Grundlage des Fersenlı̈̈ckers an Innenrande des Froschfußes bildet́ und bei jenen Arten besonders stark entwickelt ist, welche mit ihren Hinterbeinen graben. Der Praehallux umfaßt ein Metatarsale und zwei Phalangen (Fig. 247). 


\section{Fossile Überreste}

\section{der Anuren.}

Obwohl die Anuren schon in früher Zeit von der Stammgruppe der Stegocephalen abgezweigt sein müssen, so finden sich doch die ältesten fossilen Vertreter derselben erst in der Juraformation Spaniens und Nordamerikas, bei denen die wesentlichen Anurenmerkmale in derselben Ausprägung wie bei den lebenden vorhanden zu sein scheinen, soweit die Erhaltung der Reste ein Urteil darüber zuläßt.

Alle bisher bekannten fossilen Anuren gehören dem Stamme der Phaneroglossa an; die Mehrzahl dieser Formen sind Arciferen, nur ein kleiner Bruchteil gehört den Firmisterniern an.

Die Kreideformation hat bisher keine Anurenreste geliefert; im Tertiär sind sie häufiger und von zahlreichen Fundorten Europas bekannt. Im Eozän von Ostindien (bei
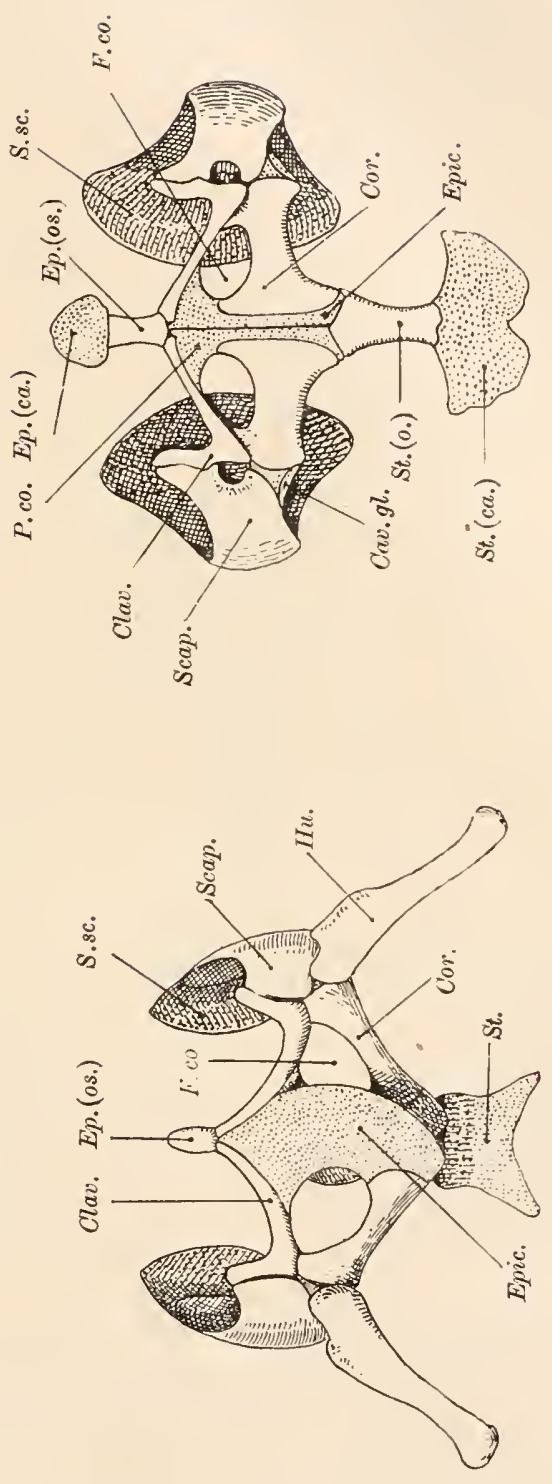

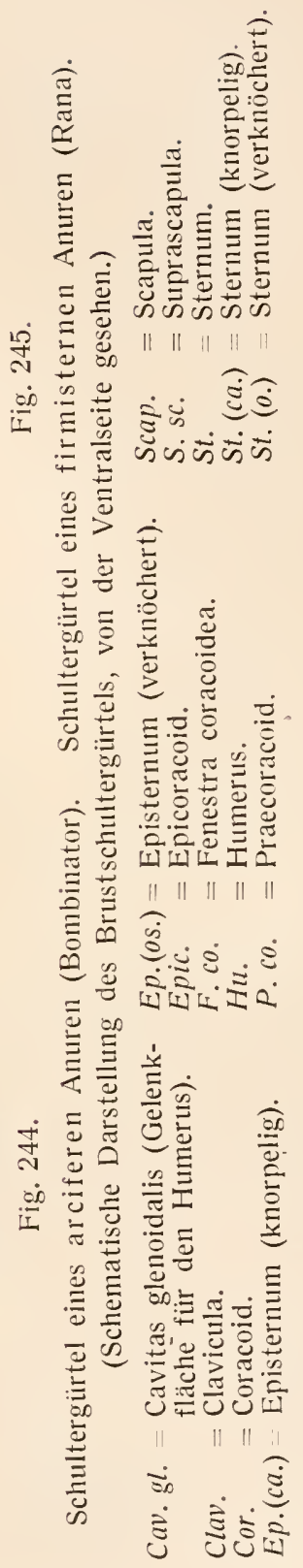


Bombay) und im Eozän Nordamerikas (Wyoming) sind vereinzelte Reste gefunden worden.

Die fossilen Anuren verteilen sich auf folgende Familien ${ }^{1}$ :

I. Ordnung: Aglossa (Zungenlose).

F. Xenopodidae (fossil unbekannt).

F. Pipidae (fossil unbekannt).

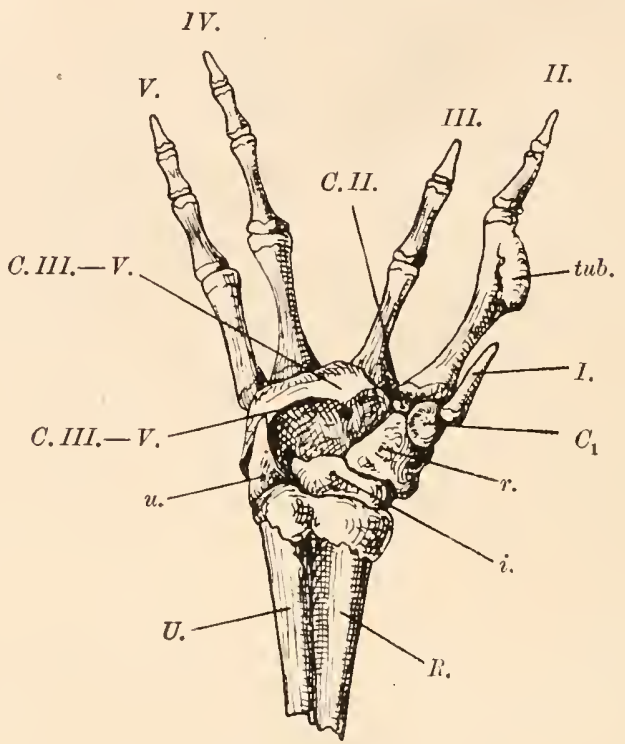

Fig. 246.

Rechte Hand eines Männchens von Rana esculenta von der Volarseite. Vergrößert. Nach E. Gaupp (Bezeichnungen der Knochen teilweise abgeändert).
$u$. = Uinare.
$i$. $=$ Intermedium.
II. $-\mathrm{V}$. = Finger $\mathrm{II}-\mathrm{V}$.
$r .=$ Radiale.
$U$. = Ulna.
C. $I I . \quad=$ Carpale $I I$.
$R_{\text {. }}=$ Radius
$I$. = Oriment des Daumens
C. $I I I .-V .=$ Carpale $I I I+I V+V$. tab.
= Tuberosität des Metacar- pale II zum Ansatz des Musculus abductor indicis (Metacarpale I). longus.

\section{Ordnung: Phaneroglossa (Zungenfrösche).}

\section{Erste Reihe: Arcifera.}

F. Palaeobatrachidae.

Palaeobatrachus Gaudryi Vidal (oberer Jura Spaniens).

Verschiedene Arten aus dem Oligozän Oberitaliens und Deutschlands und aus dem Miozän Deutschlands und Böhmens.

1 In der folgenden Liste sind nur die wichtigsten Formen angefuihrt. 
F. Bufonidae.

Eobatrachus agilis Marsh (oberer Jura [Como Beds] von Wyoming).

Bufo serratus Filh. (alttertiäre Phosphorite des Quercy).

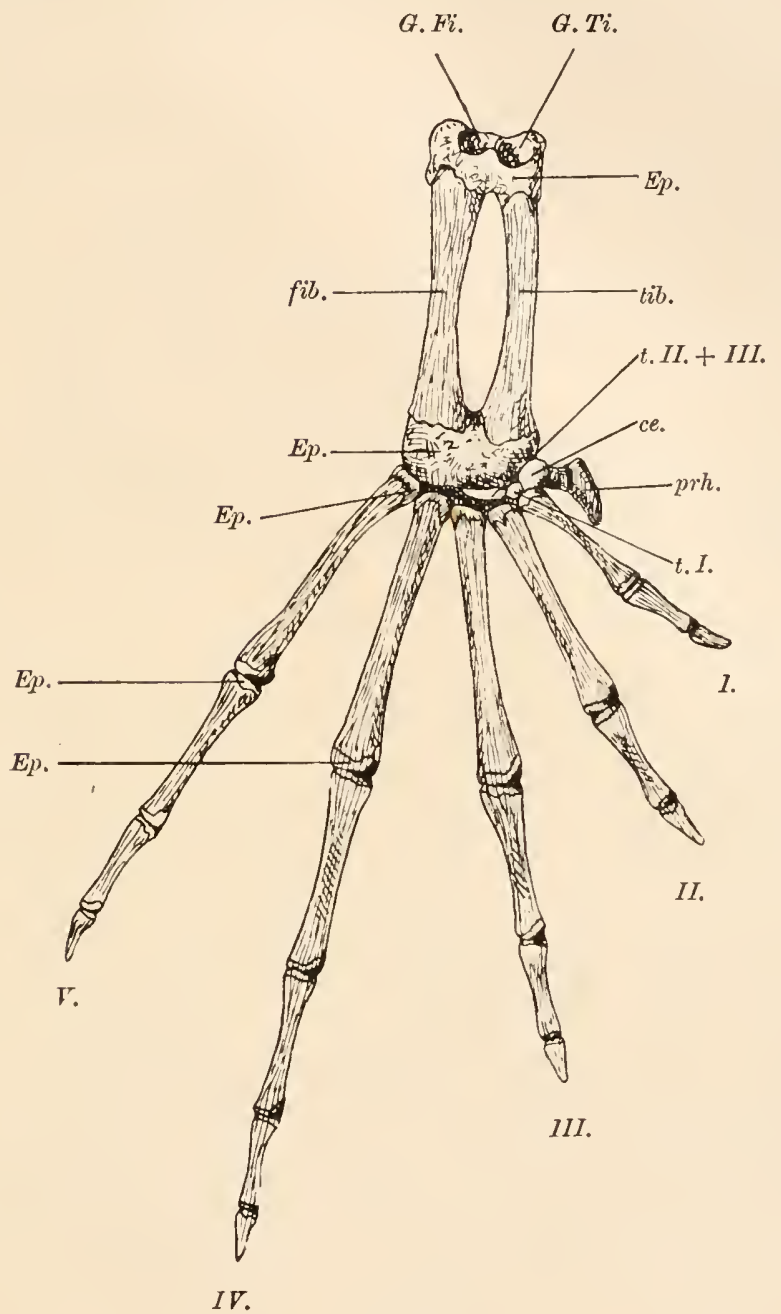

Fig. 247.

Rechter Hinterfuß von Rana esculenta, Dorsalseite, in $2 / 1$ nat Gr. Nach E. Gaupp.

G. Fi. = Gelenkfläche für die Fibula. I.-V. = Zehe $\mathrm{I}-\mathrm{V}$.

$G . T i$. = Gelenkfläche für die Tibia. prh. $=$ Praehallux.

fib. $=$ Fibulare.

tib. $=$ Tibiale.

Ep. $=$ Epiphysen.

t. II. $+I I I .=$ Cuneiforme $\mathrm{II}+\mathrm{III}$.

t. $I . \quad=$ Cuneiforme $\mathrm{I}$.

ce. $\quad=$ Centrale.

F. Discoglossidae.

Protopelobates gracilis Bieb. (Oberoligozän Böhmens).

Alytes Troscheli H. v. Mey. (Untermiozän von Rott bei Bonn). 
Pelophilus Agassizii Tschudi (Obermiozän von Öningen).

Latonia Seyfriedi H. v. Mey. (Obermiozän von Öningen).

F. Pelobatidae.

Pelobates Decheni Trosch. (Untermiozän von Rott bei Bonn).

P. fuscus Wagl. (rezent, auch im deutschen Plistozän).

F. Cystignathidae.

Vertreter der lebenden Gattungen Ceratophrys und Leptodactylus im Plistozän Brasiliens.

F. Hylidae (fossil unbekannt).

F. Amphignathodontidae (fossil unbekannt).

F. Hemiphractidae (fossil unbekannt).

Zweite Reihe: Firmisternia.

F. Ranidae.

Oxyglossus pusillus Owen (Eozän von Bombay).

Rana (zahlreiche Arten, seit dem Alttertiär bekannt).

F. Engystomatidae (fossil unbekannt). .

\section{Unterklasse: Urodela (Schwanzlurche).}

In der allgemeinen Körperform, im Bau des Schädels und der Gliedmaßen haben sich die Urodelen von den Stegocephalen weniger weit entfernt als die Anuren. Ein wesentliches Spezialisationsmerkmal liegt in der Reduktion des Schläiendaches, das bei den am höchsten spezialisierten Typen ganz verloren gegangen ist, so daß die die Schläfenhöhlen füllende Muskulatur freiliegt, während bei weniger hoch spezialisierten Typen zwei übereinanderliegende Schläfenfenster zur Ausbildung gelangt sind, die an die entsprechenden Durchbrüche des Reptilienschädels erinnern (z. B. bei Dienryctilus viridescens). Vom Schädeldach sind in der Regel noch die Nasalia, Lacrymalia, Frontalia, Parietalia sowie die Kieferknochen übrig geblieben, während die Adlacrymalia sehr selten erhalten sind; auch die Supramaxillaria können ganz fehlen. Die Palatina treten sehr oft in feste Verbindung mit den Vomeres. Die Parietalia stoßẹı unnittelbar an die Exoccipitalia, so daß die Dermosupraoccipitalia und das Supraoccipitale unterdrückt erscheinen. Das Parasphenoid ist groß und breit, Quadratum und Squamosum verknöchert, aber das Quadratojugale zu einem Ligament reduziert. Die Pterygoidea sind groß und nehmen in einzelnen Fällen (z. B. Cryptobranchus und Megalobatrachus) einen großen Raum an der Basis der Schläfenlı̈lıle ein. Die Basisplatte des Stapes (Operculum) ist verknöchert. Alle Zahnknochen können bezahnt sein. Ein Parietalforamen fehlt bei allen Urodelen (Fig. 248). 

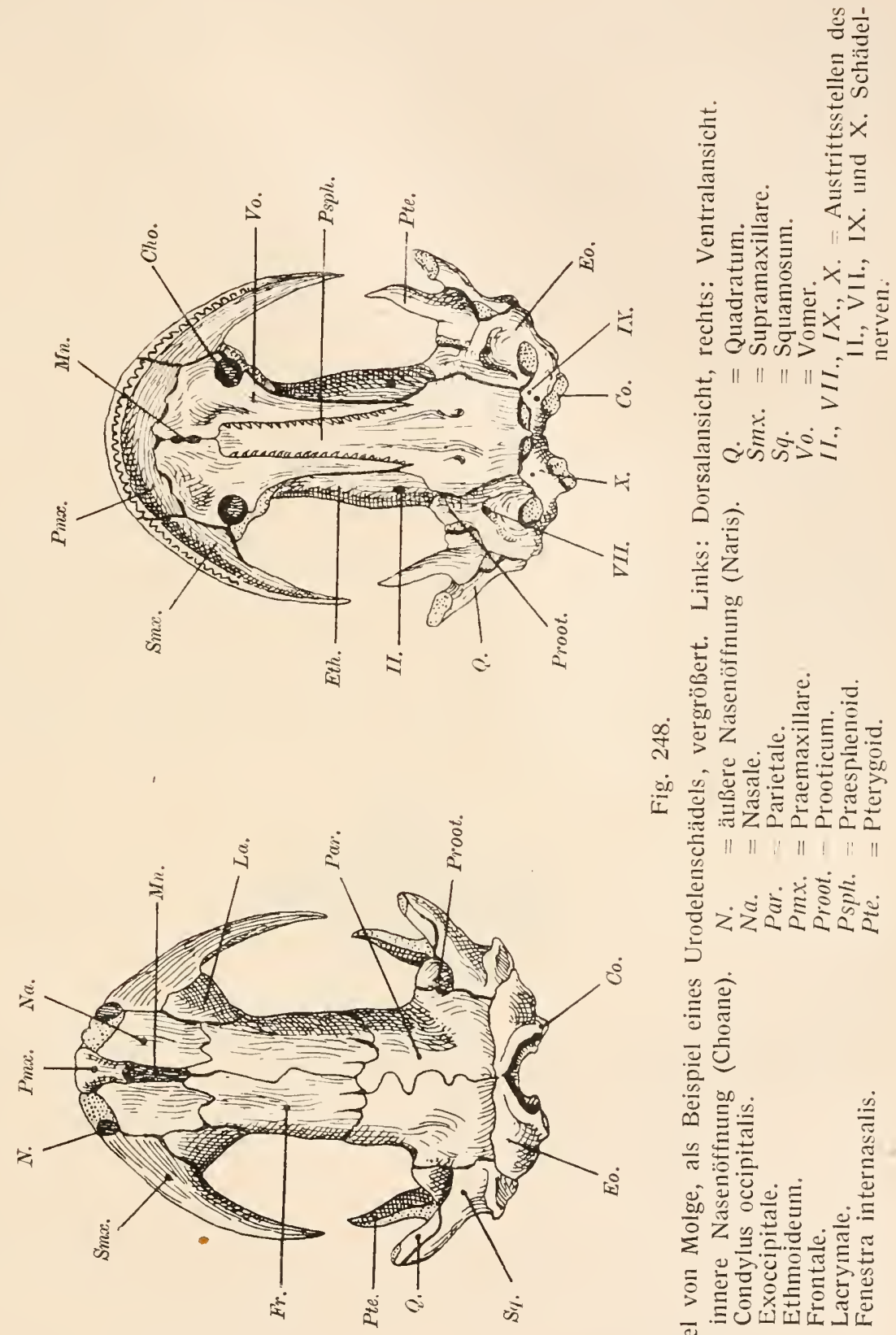

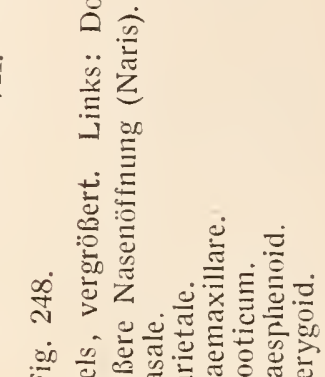
我 क

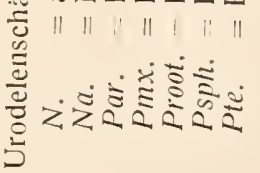

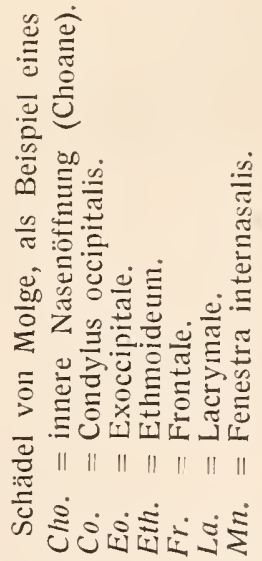


Der Schultergürtel ist einfacher gebaut als bei den Anuren; die Coracoide schieben sich in ähnlicher Weise übereinander wie dies bei den Schiebbrustfröschen (Arcifera) der Fall ist. Der größte Teil des Schultergürtels der Urodelen bleibt knorpelig.

Im Beckengürtel bleibt das Pubis stets knorpelig. Der vorn sich gabelnde knorpelige Fortsatz am Vorderende des Pubis, der fälschlich als „Epipubis“ bezeichnet zu werden pflegt, scheint bei den lungenatmenden Salamandern zur Atmung in Beziehung zu stehen, da er den lungenlosen, hautatmenden Salamandern fehit.

Die Hand besitzt nie mehr als vier Finger, kann aber bei spezialisierten Formen infolge Reduktion einzelner Finger ein zweifingeriger Stumnel werden (bei Amphiuma means).

Der FuB ist ursprünglich fünfzehig, doch kann die Zehenzahl (bei Amphiuma) auf drei, ja sogar auf zwei (bei Proteus) herabsinken.

Die ältesten Vertreter der Urodelen sind die Lysorophiden, deren einziger Vertreter (Lysorophus tricarinatus) im unteren Perm von Illinois, Texas und Oklahoma in zahlreichen Exemplaren gefunden wurde. Der zweitälteste Urodele ist Hylaeobatrachus Croyi aus dem Wealden von Bernissart (Belgien); vereinzelte Molche sind aus der oberen Kreide Nordamerikas bekannt. Aus dem Tertiär Europas liegt eine größere Zahl fossiler Urodelen, darunter der berühmte Andrias Scheuchzeri aưs dem Miozän von Öningen (Baden) vor.

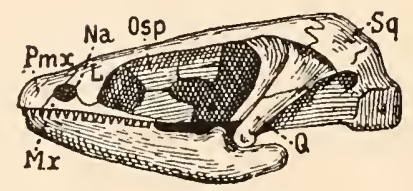

Fig. 249.

Rekonstruktion des Schädels von Lysorophus tricarinatus, Cope, aus dem

Perm von Texas. $2 / 1$ nat. Gr. (Nach E. C. Case, 1908.)

$\begin{array}{llll}P m x . & =\text { Praemaxillare. } & O s p . & =\text { Interorbitalseptum. } \\ N a . & =\text { Nasenöfnung. } & S q . & =\text { Squamosum. } \\ M x . & =\text { Supramaxillare. } & Q . & \text { Q Quadratum. } \\ L . & =\text {, Lacrymale“. } & & \end{array}$

\section{Übersicht der fossilen Urodelen.}

\section{F. Pateroșauridae.}

Während die Branchiosauriden in Schädelbau noch durchaus die Charaktere der Stegocephalen zeigen und daher in Rahmen dieser Stanmmgruppe keine unnatürliche Stellung einnehmen, tritt uns in der Gattung Lysorophus aus dem Perm von Texas, Illinois und Oklahoma eine Form entgegen, die sich im Schädelbau so enge an die lebenden 
Urodelen anschließt, daß sie im Zusammenlang mit dieser Gruppe besprochen werden muß. $\mathrm{Zu}$ den wesentlichen Unterschieden des Lyso-

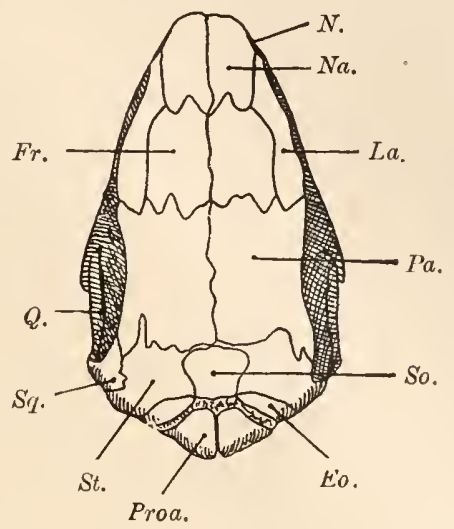

Fig. 250.

Rekonstruktion des Schädeldaches des ältesten Urodelen, Lysorophus tricarinatus, Cope, aus dem Perm Nordamerikas, in $3 / 1$ nat. Gr. (Nach S. W. Williston, 1908, mit einigen Abänderungen von F. von Huene, 1913; kombiniert.)
Eo. $=$ Exoccipitale.
Proa. = Proatlas.
Fr. $=$ Frontale
Q. $\quad=$ Quadratum.
La. $=$ Lacrymale.
So. $=$ Supraoccipitale.
$N . \quad=$ Naris (Nasenöffnung)
$N a . \quad=$ Nasale.
$P a . \quad=$ Parietale.
Sq. $=$ Squamosum.
St. $=$ Supratemporale.

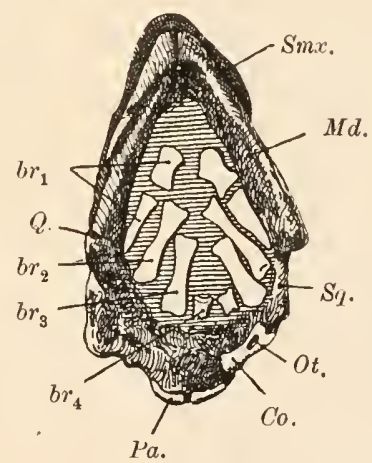

Fig. 251.

Unteransicht eines Schädels von Lysosophus tricarinatus, Cope, aus dem Perm Nordamerikas, mit den verkalkten Resten der Kiemenbögen, in $5 / 2$ nat. Gr. (Nach einer Photographie von S. W. Williston; umgezeichnet und etwas schematisiert.)
$b r_{1} b r_{2}, b r_{3}, b r_{4}=$ erster bis vierter
$P a . \quad=$ Parietale.
Kiemenbogen.
Co. = Condylus occipitalis.
Md. = Unterkiefer.
Ot. = Ohröffnung.
Q. $\quad=$ Quadratum,
Smx. = Supramaxillare.
Sq. $=$ Squamosum.

rophusschädels von dem der Stegocephalen gehört die allgeneine Vereinfachung desselben, die vor allem durch den Verlust des Parietal- 


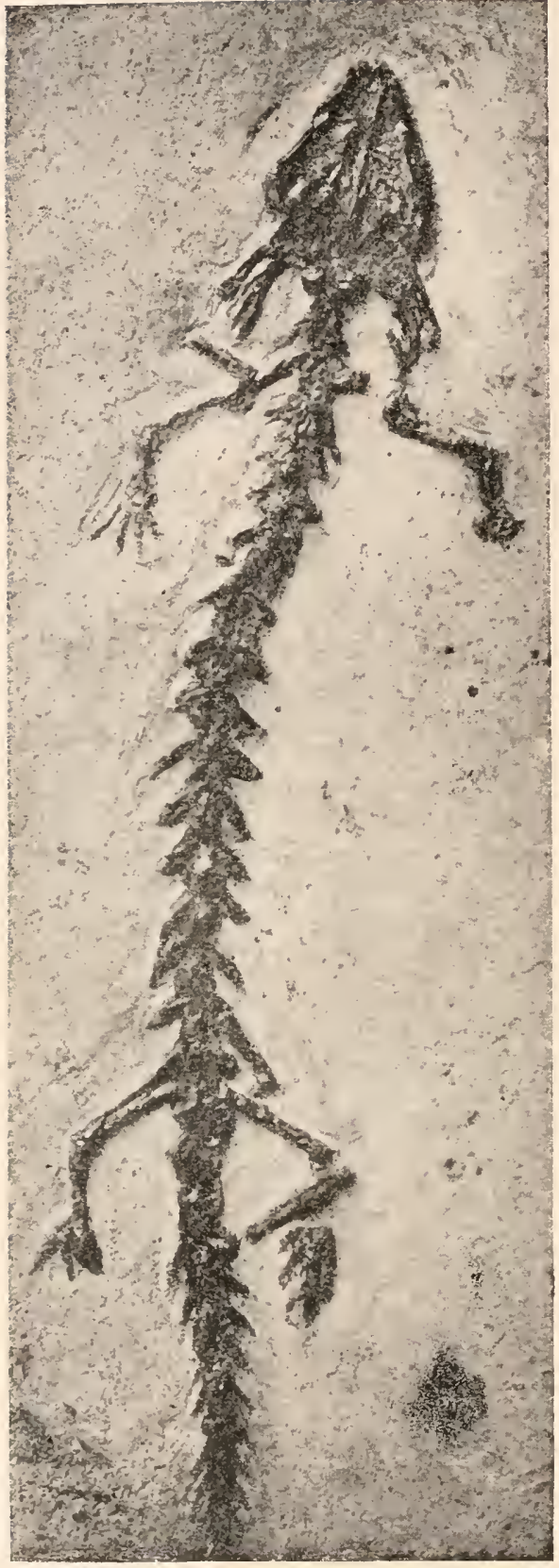

Fig. 252.

Hylaeobatrachus Croyi, Dollo, ein fossiler Molch aus dem Wealden (Unterkreide) von Bernissart, Belgien, in $2 / 1$ nat. Gr. (Nach L. Dollo.) foramens, der Quadratojugalia, Jugalia, Postfrontalia, Adlacrymalia und Tabularia zum Ausdrucke kommt; ferner ist statt der getrennten Dermosupraoccipitalia ein unpaares Supraoccipitale vorhanden (ob die Dermosupraoccipitalia in diesen Element stecken, ist noch fraglich); das Vorhandensein von vier Paaren verknöcherter Branchialia (Fig. 251), von denen S. W. Williston zwei Ceratobranchialia und vier Paar Epibranchialia unterscheidet, beweist unbedingt nebst dem doppelten Condylus die Zugehörigkeit zu den Amphibien, unter denen wieder nur die Urodelen in Betracht kommen. Besonders die Schläfengegend zeigt in Form und Lage überraschende Ähnlichkeit mit den modernen Salamandern.

Die Nasenöffnungen sind sehr klein und liegen weit vorn, die Augenhöhlen liegen an der Seite des Schädels. Die Augen müssen sehr klein gewesen sein.

Die Wirbel sind tief amphicöl und tragen laterale Kiele; ihr Bau ist urodelenartig. Die Rippen sind fast durchaus zweiköpfig. Von den Extremitäten sind nur dürftige Reste bekannt; sie waren im Verhältnis zum Körper zien1lich klein.

Der Unterkiefer erreichte etwa zwei Drittel der Schädellänge; jedes Dentale trägt etwa 12 Zälnne, die anf die vorderen zwei Fünftel der Unterkieferlänge beschränkt sincl.

Lysorophus. - Unteres Perm von Nordamerika (Illinois, Texas, 
Oklahoma). ${ }^{1}$ - Zahlreiche Schädel bekannt. Die Körperlänge von L. tricarinatus Cope hat kaum mehr als $20 \mathrm{~cm}$, gewölınlich nur $15 \mathrm{~cm}$, betragen, wovon etwa $1,5 \mathrm{~cm}$ auf die Schädellänge entfallen. Das Tier ist perennibranchiat gewesen, d. h. es hat den Kiemenapparat das ganze Leben hindurch beibehalten. Irgendein Schluß auf einen genetischen Zusammenhang von Lysorophus mit den lebenden perennibranchiaten Urodelen darf daraus nicht abgeleitet werden, da die Beibehaltung der Larvencharaktere (Neotenie) in verschiedenen Stämmen unabhängig voneinander erfolgt ist und die Folgeerscheinung einer parallelen Anpassung an das Wasserleben darstellt. Lysorophus dürfte nach S. W. Williston (1908) ein Schlanmwühler gewesen sein und die Art des Vorkommens spricht dafür, daß zahlreiche Individuen beinı Austrocknen von Tümpelı und Sümpfen verendeten (Fig. 249-251).

\section{F. Hylaeobatrachidae.}

Nur eine einzige Art in einem Exemplar aus dem Wealden von Bernissart (Belgien) bekannt. Der schlanke, vorn spitz zulaufende Schädel besitzt verknöcherte Supramaxillaria; beiderseits sind drei Paar verknöcherter Kiemenbögen erhalten, das Tier war somit perennibranchiat. Die Gliedmaßen sowie die Gesamtform des Körpers sind salamanderartig.

1 Die im Anfange fragliche systematische Stellung der Gattung Lysorophus und ihre verschiedene Deutung als Reptil oder als Urodele hat in den letzten Jahren zu einer lebhaften Diskussion Anlaß gegeben. Die wichtigsten Publikationen über diese Fragen sind folgende:

F. Broili, Stammreptilien. - Anatomischer Anzeiger, XXV. Bd., 1904, S. 586 (hier die ältere Literatur).

E. C. Case, Notes on the Skull of Lysorophus tricarinatus. - Bulletin Amer. Mus. Nat. Hist. New York, Vol. XXIV, 1908, p. 531.

F. Broili, Systematische und biologische Bemerkungen zu der permischen Gattung Lysorophus. - Anatomischer Anzeiger, XXX111. Bd., 1908, S. 290.

S. W. Williston, Lysorophus, a Permian Urodele. - Biological Bulletin, Vol. XV, 1908, p. 229.

E. C. Case, Revision of the Amphibia and Pisces of the Permian of North America. - Carnegie Institution of Washington, Publ. No. 146, 1911, p. 68 und 141.

S. W. Williston, New Permian Reptiles: Rhachitomous Vertebrae. - Journal of Geology, Vol. XV11I, 1910, p. 585 (600).

Derselbe, Primitive Reptiles, a Review. - Journal of Morphology, Vol. XX111, 1912, p. 660.

M. Finney, The Limbs of Lysorophus. - Ibidem, p. 664.

F. von Huene, Über Lysorophus aus dem Perm von Texas. - Anatom. Anzeiger, XL111. Bd., S. 389.

Derselbe, The Skull Elements of the Permian Tetrapoda in the American Museum of Natural History, New York. - Bull. Amer. Nat. Hist. New York, Vol. XXXIII, 1913, p. 372.

S. W. Williston, Synopsis of the American Permocarboniferous Tetrapoda. - Contributions from Walker Museum, Vol. I, 1916, p. 211. 
Hylaeobatrachus. - Wealden Belgiens. H. Croyi. ${ }^{1}$ (Fig. 252).

\section{F. Amphiumidae.}

Andrias. - Nahe verwandt mit dem Schlammteufel (Cryptobranchus alleghaniensis) und dem japanischen Riesensalamander (Megalobatrachus maxinus). Die größten Exemplare, die man aus den miozänen Süßwassermergeln von Öningen in Baden kennt, erreichen $120 \mathrm{~cm}$ Körperlänge (Andrias Scheuchzeri). ${ }^{2}$ Eine kleinere Art (Andrias Tschudii) ${ }^{2}$ ist in der miozänen Braunkohle von Rott bei Bonn gefunden worden. Auch aus dem Oberoligozän von Bilin (Böhmen) ist ein Andriasrest (A. bohenicus) bekannt geworden. ${ }^{3}$

\section{F. Salamandridae.}

Hierher gehören wahrscheinlich alle übrigen bisher bekannten fossilen Urodelen, deren sichere Zuweisung zu einer der lebenden Unterfamilien bisher nur in jenen Fällen gelungen ist, in denen sich die fossilen Formen eng an lebende Arten anschließen. ${ }^{4}$

Scaplierpeton. - Obere Kreide (Judith River Beds) Nordamerikas. - Dürftige Reste von unsicherer Stellung, vielleicht mit den lebenden Querzahnmolchen (Amblystomatinen) verwandt. ${ }^{5}$

Megalotriton. - Alttertiäre Phosphorite (Obereozän und Oligozän) des Quercy in Frankreich. - Vereinzelte, große Wirbel und Gliedmaßenreste von unsicherer systematischer Stellung. ${ }^{6}$

Polysemia. - Miozän (Braunkohle) von Orsberg bei Erpel im Siebengebirge bei Bonn. ${ }^{7}$ - $\mathrm{Zu}$ den echten Molchen gehörend. Weitere fossile Molche (Salamandrinen) sind:

1 L. Dollo, Note sur le Batracien de Bernissart. - Bull. Mus. Roy. d'Hist. Nat. de Belgique, T. III, 1884, p. 85.

${ }^{2}$ H. von Meyer, Zur Fauna der Vorwelt. Fossile Säugetiere, Vögel und Reptilien aus dem Molassemergel von Oeningen. - Frankfurt a. M. 1845, S. 18, Taf. VIII-X.

${ }^{3}$ G. C. Laube, Andriasreste aus der böhmischen Braunkohlenformation. Abhandlungen des Vereins ,Lotos" in Prag, I. Bd., 1897, 2. Heft, S. 1.

Derselbe, Neue Andriasreste aus den Tonen von Preschen bei Bilin. „:Lotos“, Sitzungsber., Prag 1909, LVII. Bd.

${ }^{4}$ Eine Zusammenstellung der fossilen Salamandriden findet sich in dem von J. F. Pompeckj verfaßten Abschnitt ïber fossile Amphibien im ,Handwörterbuch der Naturwissenschaften", Jena (G. Fischer), I. Bd., S. 340.

${ }^{5}$ E. D. Cope, On Some Extinct Reptiles and Batrachia from the Judith River and Fox Hill Beds of Montana. - Proceed. Acad. Nat. Sciences, Philadelphia 1876, p. 353.

${ }^{6}$ G. de Stefano, Sui Batraci Urodeli delle Fosforiți del Quercy. - Boll. Soc. Geol. Ital., Roma, XXI1, 1903, p. 40.

K. A. von Zittel, Handbuch der Paläozoologie, 11I. Bd., 1890, S. 420.

${ }_{7} \mathrm{H}$. von Meyer, Salamandrinen aus der Braunkohle an Rhein und in Böhmen. - Paläontographica, V1I. Bd., 1860, S. 58. 
Heliarchon. - Braunkohle von Rott bei Bonn.. ${ }^{1}$

Archaeotriton. - Basalttuff von Altwarnsdorf und Diatomaceenschiefer von Sulloditz in Bölımen. ${ }^{2}$

Molge. - Mehrere Arten aus dem Miozän Frankreichs (Sansans), Böhmens (z. B. im Halbopal von Luschitz) und des Rheinlandes (Braunkohle von Erpel bei Bonn). ${ }^{3}$

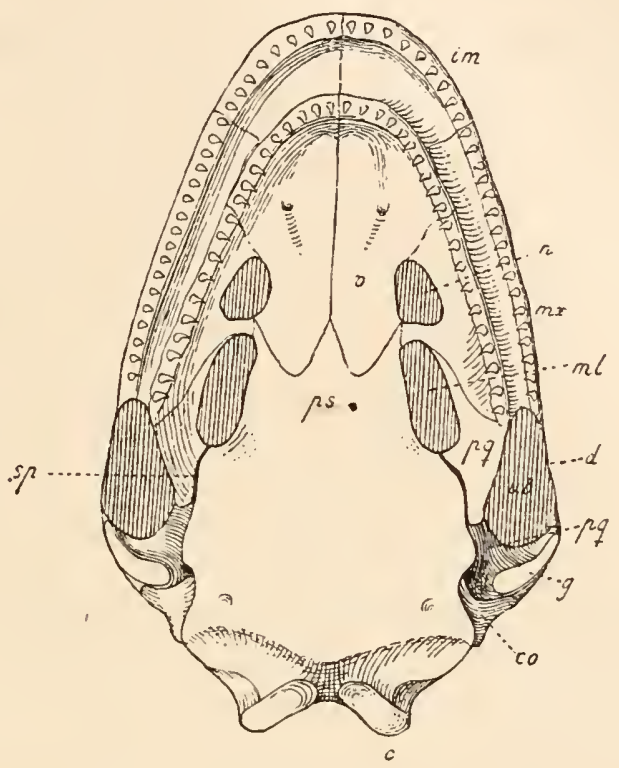

Fig. 253.

Ichthyophis glutinosus, Schädel von der Unterseite. (Nach J. E. V. Boas.)

c. = Condylus occipitalis.

co. $=$ Columella auris.

d. $=$ Rand des Schädeldaches.

g. $=$ Kiefergelenkfläche.

im. = Praemaxillare

$m x$. = Supramaxillare.

$m l .=$ Fenestra palatinalis $n$. $=$ Choane.

$p q$. = Palatoquadratum

ps. = Parasphenoid (mit den Nachbarknochen verwachsen).

$u \ddot{o} .=$ Fenestra basitemporalis.

$\nu .=$ Vomer .

Orthophya. - Miozän von Öningen (Baden). Eine blindwühlen-

1 H. von Meyer, Heliarchon furcillatus, ein Batrachier aus der Braunkohle von Rott im Siebengebirge. - Paläontographica, X. Bd., 1863, S. 292.

$2 \mathrm{H}$. von Meyer, Salamandrinen aus der Braunkohle am Rhein und in Böhmen. - Paläontographica, V11. Bd., 1860, S. 69.

G. C. Laube, Amphibienreste aus dem Diatomaceenschiefer von Sulloditz. - „Lotos“, Sitzungsber., XLVI. Bd., Prag 1898, S. 2.

${ }^{3}$ H. von Meyer, I. c., 1860 , S. 64. 
ähnliche, wahrscheinlich fußlose Type mit sclınalem, spitzem Schädel. Systematische Stellung unsicher. ${ }^{1}$

\section{F. Proteidae.}

Fossil unbekannt.

\section{F. Sirenidae.}

Fossil unbekannt.

\section{Unterklasse; Apoda (= Gymnophiona).}

F. Coeciliidae (z. B. Ichthyophis, Fig. 253).

Fossil unbekannt.

Dieser Stamm der Amphibien bildet einen einseitig spezialisierten Seitenast der Amphibien, der frühzeitig von den Stegocephalen abgezweigt sein dürfte. Die Ähnlichkeiten, die der Coeciliidenschädel mit dem Schädeltypus eines primitiven Stegocephalen aufweist, sind jedoch nur scheinjare; der Schädęl des Coeciliiden ist nicht „stegal“, wie z. B. Trimerorhachis (Fig. 202) oder Eryops (Fig. 204), sondern ist als ,pseudostegal“ zu bezeichnen, da er $\mathrm{zu}$ diesem Zustand einer geschiossenen Schädelkapsel erst nach Durchlaufung des Urodelenschädelstadiums zurückgekehrt ist. Dies beweisen die Anordnung und Lage der Schädelmuskulatur sowie die Vereinfachung und Begrenzung der Schädelknochen. Es liegt also hier ein analoger Fall vor wie z. B. bei Chelonia unter den Schildkröten.

Die Ausbildung des ,pseudostegalen“ Zustandes ist bei den Coeciliiden als eine Anpassung an die wühlende Lebensweise anzusehen.

1 H. von Meyer, Die Fauna der Vorwelt usw., I. c. 


\section{Klasse: Reptilia.}

\section{Stammgruppe: Cotylosauria.}

Das bezeichnendste Merkmal aller Formen, die dieser Stammgruppe der Reptilien angehören, ist das allseits geschlossene Schädeldach, das im Gegensatz zu dem mit Schläfendurchbrüchen versehenen zygalen Schädel (Fig. 254) als ein „,stegales“ zu bezeichnen ist. Im Bau des Schädels schließen sich die Cotylosaurier unmittelbar an die primitiveren Stegocephalen an; die Elemente des Schädels und Unterkiefers, die wir z. B. bei Trimerorhachis finden, sind mit wenigen Ausnahmen auch noch im Cotylosaurierschädel vertreten, so daß also im Schädelbau zwischen den primitiveren Vertretern der beiden großen Gruppen der Wirbeltiere keine anderen als graduelle Unterschiede bestehen. Gegen die Hypothese, zwischen den rhachitomen Stegocephalen und den Cotylosauriern eine direkte genetische Verbindung anzunehmen, spricht die verschiedene Spezialisierung im Aufbau des Wirbelkörpers keineswegs; sie zeigt nur, daß beide Gruppen zwar unbedingt aus einer gemeinsamen Wurzel entsprossen sind, aber schon frühzeitig selbständige Wege eingeschlagen haben. Wahrscheinlich fällt der Zeitpunkt dieser Spaltung an den Beginn der Steinkolilenformation; da ums ältere Tetrapodenreste bis jetzt nicht bekannt sind, so kann darüber keine Vermutung geäuBert werden, ob die Trennung der Rhachitomen von den Cotylosauriern vielleicht schon in der Devonformation vor sich gegangen ist.

Neben dem stegalen Charakter des Cotylosaurierschädels ist die rauhe Skulptur der Schädelknochen ein wichtiges und gleichfalls primitives Merkmal. Außer den auch in höher spezialisierten Reptilienstämmen vorhandenen Schädelelementen sind die Adlacrymalia, Postorbitalia, Septomaxillaria, Epipterygoidea, Opisthotica, Quadratojugalia, Dermosupraoccipitalia und Supratemporalia bei der Mehrzahl der Cotylosaurier als selbständige, paarige Knochen vorhanden; die Tabularia sind bei der Gattung Seymouria nachgewiesen, die auch ein Intertemporale wie einige rhachitome Stegocephalen besitzt. Auch bei anderen Cotylosauriern (z. B. bei Bolbodon, Diadectes, Chilonyx, Captorhinus, Gymnarthrus usw.) sind die Tabularia beobachtet worden. Bei Seymouria ist ein tiefer Otikalschlitz wie bei den Stegocephalen vorhanden. Die Adlacrymalia der Cotylosaurier sind groß und reichen vom Hinterrand der Nasenöffnung bis zum Vorderrand der Augenhöhle. 
Die Zähne sind ihrer Befestigungsart nach bei den Cotylosauriern entweder als protothekodont oder thekodont zu bezeichnen; die letztere Befestigungsart besteht in der Einpflanzung der Zähne in sepa-

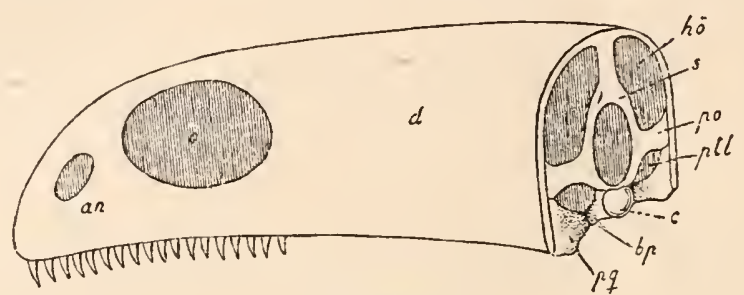

A Cotylosaurier.

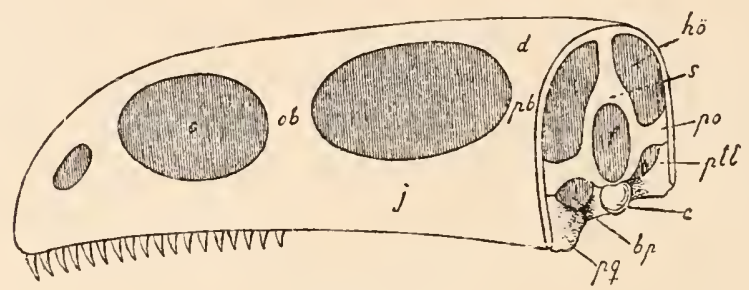

$B$ Pelycosaurier.

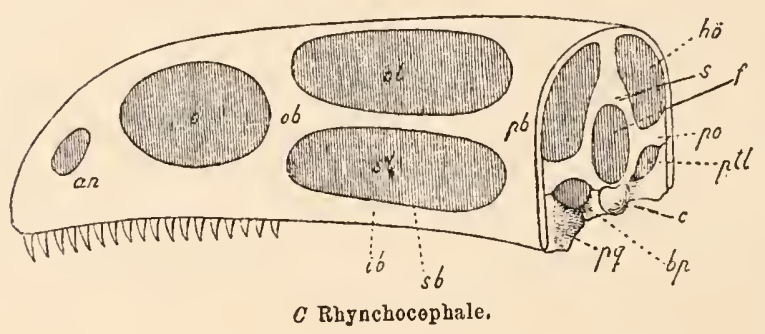

Fig. 254.

Schematische Darstellung des Schädels dreier verschiedener Reptilientypen, $\iota \mathrm{m}$ die relative Lage der Fenster in der Schläfengegend $(d)$ und am Hinterhaupt zu zeigen. (Nach J. E. V. Boas, 1914.)
an. = Nasenöffnung.
o. = Orbita.
$o b$. = Brücke zwischen der Orbita und den Schläfengruben.
$o l .=$ obere Temporalgrube .
sl. $=$ untere Temporalgrube.
$s b .=$ oberer Schläfenbogen.
$i b .=$ unterer Schläfenbogen.
c. $=$ Condylus occipitalis.
s. $=$ Hinterhaupt.
$h \ddot{o} .=$ Fenestra posttemporalis.
$f .=$ Foramen magnum.
$p t l .=$ Fenestra pteroccipitalis.
$b p .=$ Basipterygoidfortsatz.
$p q .=$ Palatoquadratum.
po. = Opisthoticum.
$j . \quad=$ Jochbogen.
$p b$. = hinterer Schläfenbogen.

raten Alveolen, was einen höheren Spezialisationsgrad gegenüber der protothekodonten Bezahnung darstellt, die sich schon bei Stegocephalen findet. Zähne stehen auf den Praemaxillaria, Supramaxillaria, Vomeres, Pterygoidea, Palatina und im Unterkiefer auf dem Dentale. 

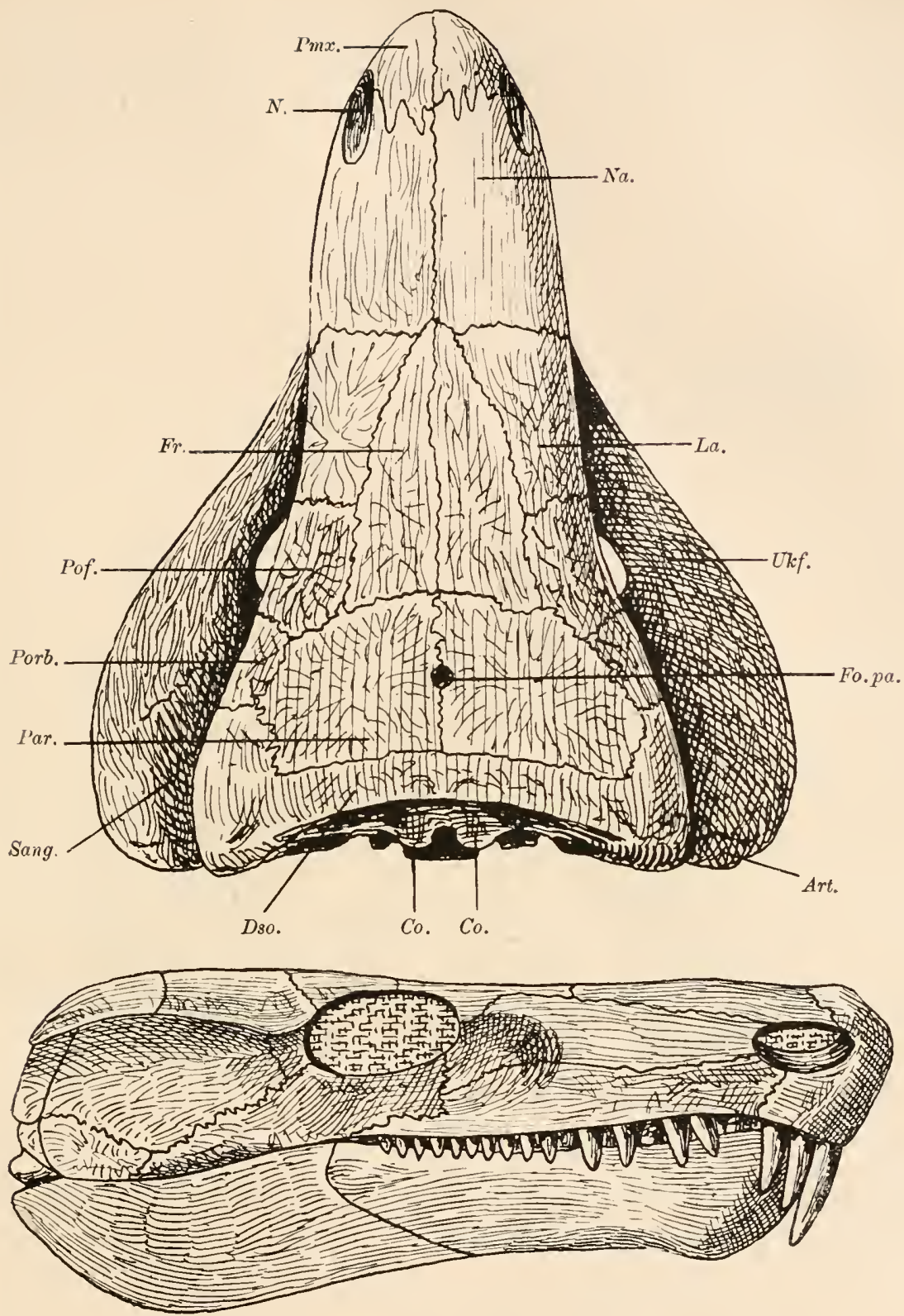

Fig. 255.

Rekonstruktion des Schädels und Unterkiefers (Oberansicht und Ansicht von rechts) von Limnoscelis paludis, Will., aus dem Perm von Texas, in $2 / 5$ nat. Gr.

(Nach S. W. Williston.)

\begin{tabular}{|c|c|c|c|}
\hline $\begin{array}{l}\text { Art. } \\
\text { Co. } \\
\text { Dso. } \\
\text { Fo. pa. } \\
\text { Fr. } \\
\text { La. } \\
\text { N. }\end{array}$ & $\begin{array}{l}=\text { Articulare. } \\
=\text { Condylus occipitalis. } \\
=\text { Dermosupraoccipitale. } \\
=\text { Foramen parietale. } \\
=\text { Frontale. } \\
=\text { Lacrymale. } \\
=\text { Nasenöffnung. }\end{array}$ & $\begin{array}{l}\text { Na. } \\
\text { Par. } \\
\text { Pmx. } \\
\text { Pof. } \\
\text { Porb. } \\
\text { Sang. } \\
\text { Ukf. }\end{array}$ & $\begin{array}{l}=\text { Nasale. } \\
=\text { Parietale. } \\
=\text { Praemaxillare. } \\
=\text { Postfrontale. } \\
=\text { Postorbitale. } \\
=\text { Supraangulare. } \\
=\text { Unterkiefer. }\end{array}$ \\
\hline
\end{tabular}


Das Transversum ist bis jetzt nicht nachgewiesen.

Der starke Brustschultergürtel enthält die Interclavicula und die Claviculae, die niemals skulpturiert sind, ferner die im Alter verschmol-

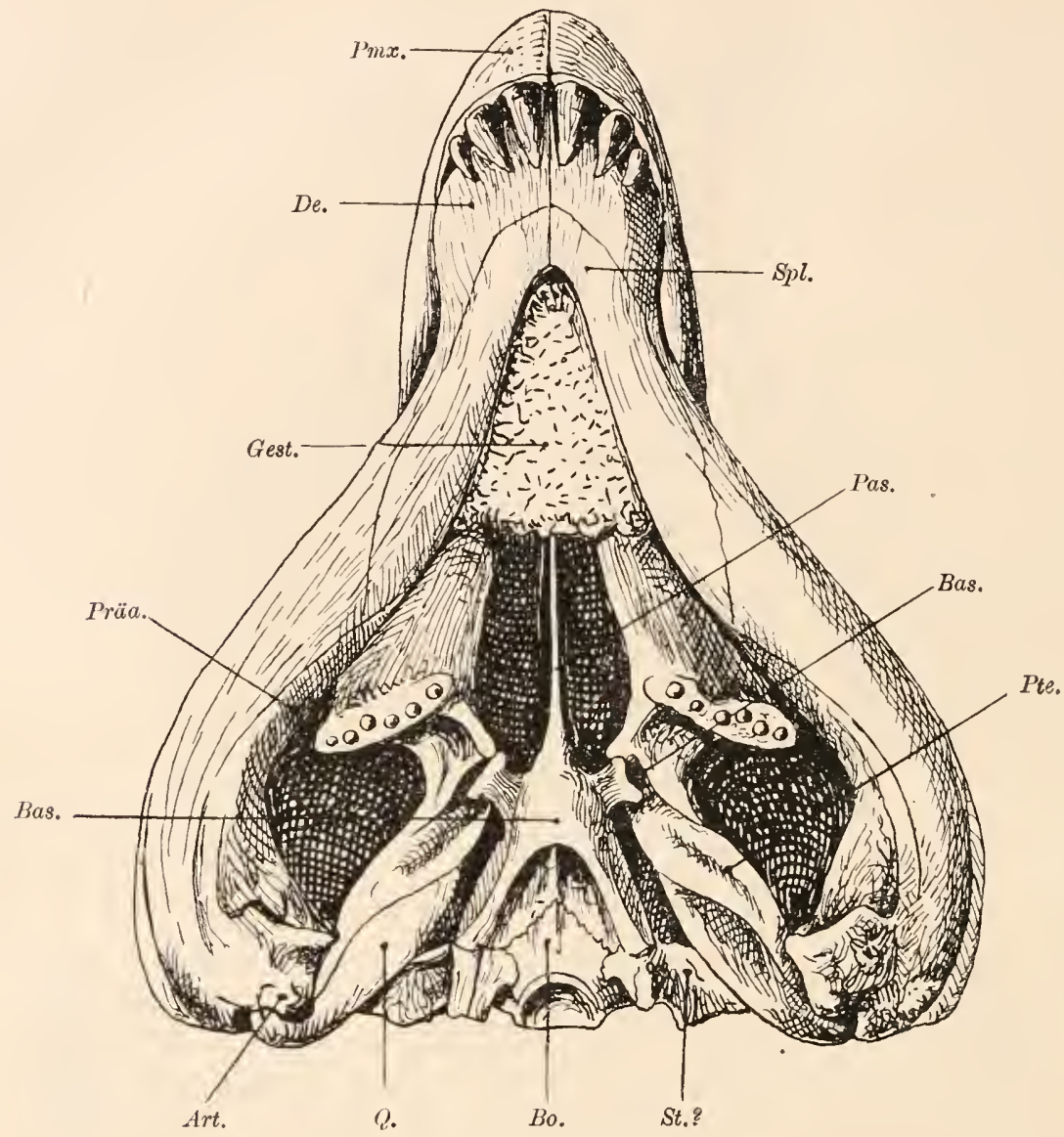

Fig. 256.

Unteransicht des Schädels und Unterkiefers von Limnoscelis paludis, Will., aus dem Perm von Texas, in $2 / 5$ nat. Gr. (Nach S. W. Williston.)
Art. = Articulare.
Pmx. = Praemaxillare.
Bas. = Basisphenoid.
Präa. = Präarticulare
Bo. $\quad=$ Basioccipitale.
Pte. $=$ Pterygoid.
De. $\quad=$ Dentale.
Q. $\quad=$ Quadratum.
Gest. = Gesteinsrest.
Spl. $=$ Spleniale.
Pas. = Parasphenoid.
St. ? = Supratemporale (?).

zenen Coracoidea, Metacoracoidea und Scapulae. Ein Cleitlırum ist zuweilen vorhanden (z. B. bei Limnoscelis).

Das Becken ist inmer von einem Foramen obturatorium durchbohrt; Pubis und Ischium sind plattenförmig verbreitert. 
Der Humerus ist wie bei vielen fossilen Stegocephalen am Oberund Unterende plattig verbreitert, und zwar liegen diese proximalen und distalen Platten in verschiedenen Ebenen. Der Carpus umfaßt die drei proximalen Elemente (Radiale, Intermedium und Ulnare),
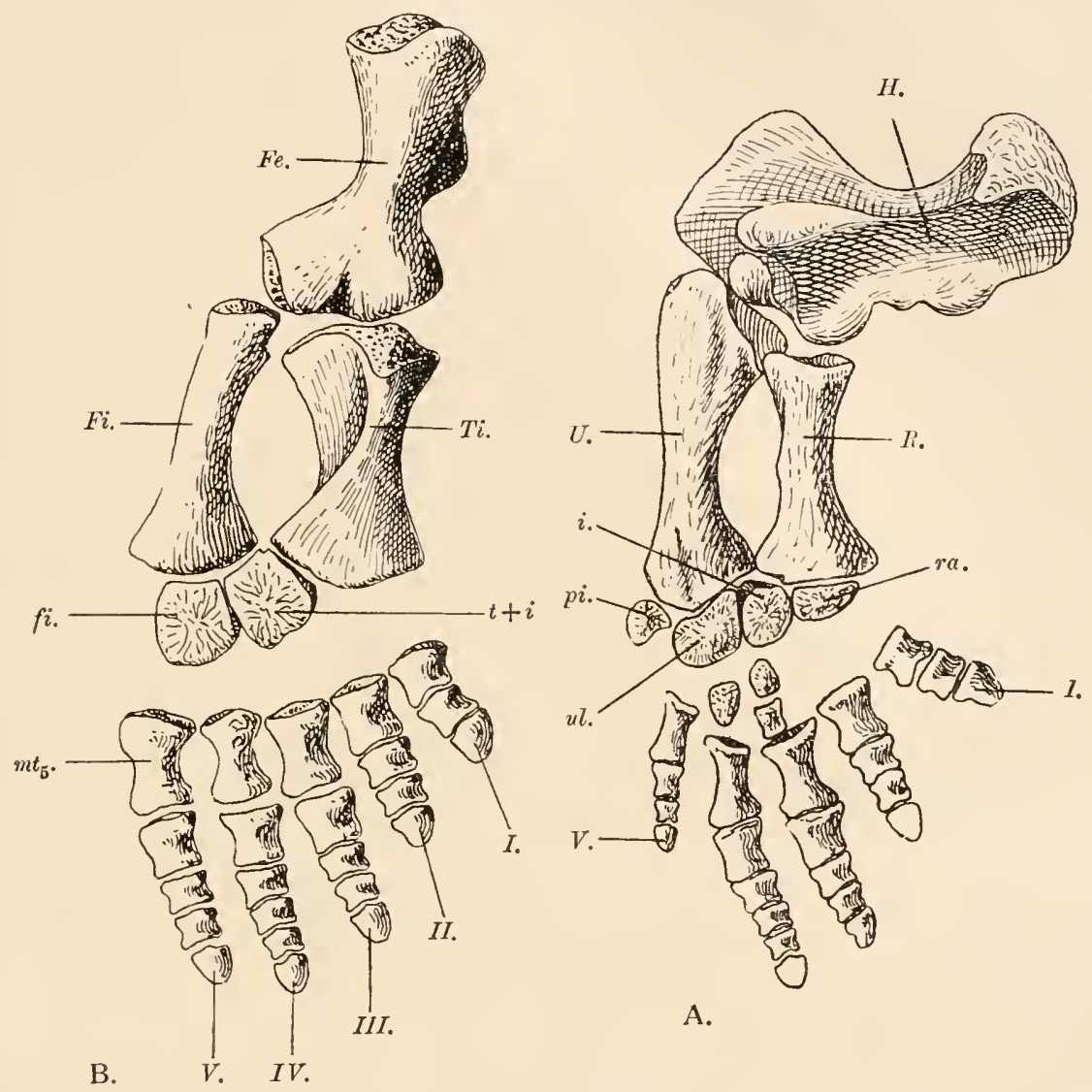

A.

Fig. 257.

A: Rechter Vorderfuß, B: rechter Hinterfuß von Limnoscelis paludis, Will. (vgl. Fig. 255 u. 256), von der Dorsalseite in $2 / 5$ nat. Gr. (Nach S. W. Williston.)
$\mathrm{Fe}$. $=$ Femur.
$F i$. = Fibula.
H. $=$ Humerus.
$i$. $\quad=$ Intermedium (carp.).
R. $=$ Radius.
$U . \quad=$ Ulna.
fi. $=$ Fibulare.
$t+i=$ Tibiale + Intermedium(tars.).
pi. $\quad=$ Pisiforme
ra. $=$ Radiale.
ul. $\quad=$ Ulnare.
mt $_{5}$. $=$ Metatarsale $\mathrm{V}$.
$I .-V .=$ Erster bis fünfter Finger bzw. Zehe.

ferner ein Pisiforme und Centrale und die fünf distalen Carpalia. Der Tarsus umfaßt außer dem Calcaneus (= Fibulare) und dem Astragalus (= Intermedium + Tibiale + Centrale) noch fünf distale Tarsalia, von denen einige zuweilen unverknöchert bleiben. Hand und Fuß sind fünf- 
fingerig bzw. fünfzehig, die Finger und Zehen meist stämmig und kurz, zuweilen aber (z. B. bei Eosauravus) lang und eidechsenartig gestellt. Die Phalangenformel ist 2, 3, 4, 5, 3 (4) in Hand und FuB, auch in jenen Fällen, wo die Zehen stark verkürzt sind und nicht mehr zum Schiebkriechen, sondern nur zum Stemmkriechen und Graben verwendet werden (z. B. bei Diadectes).

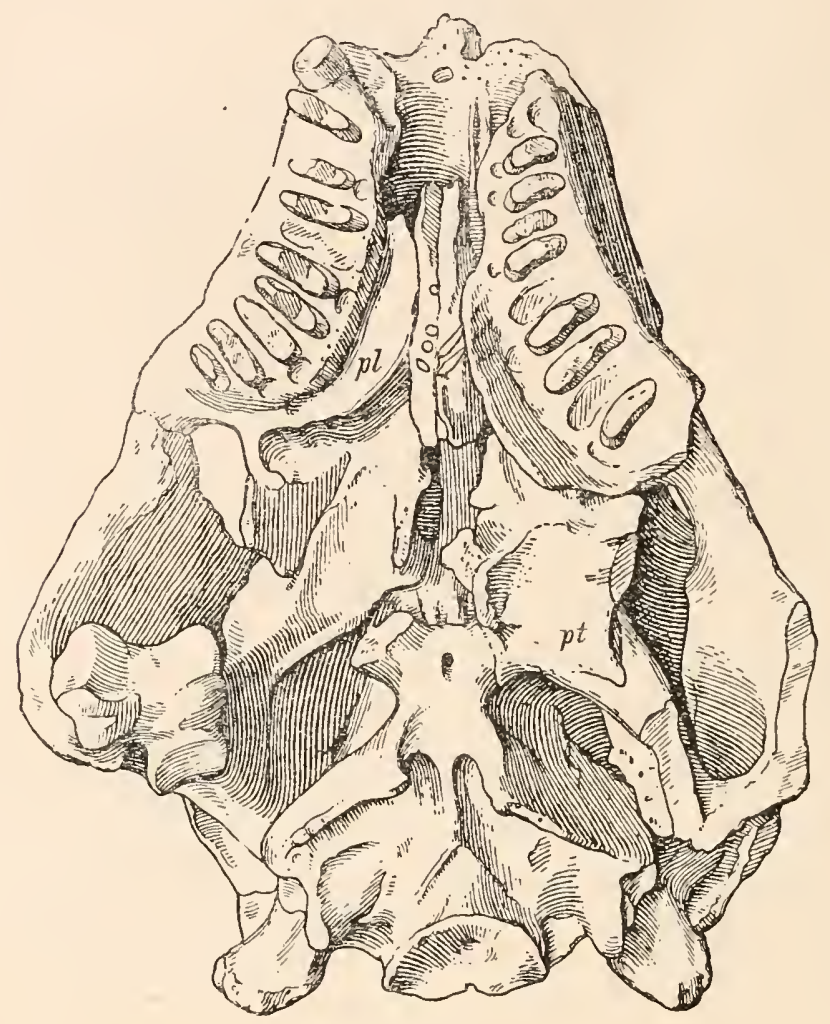

Fig. 258.

Diadectes phaseolinus, Cope. Perm von Texas. Schädel, von unten gesehen. $1 / 2$ nat. Gr. (Nach E. C. Case.)

\section{F. Limnoscelidae.}

Langgestreckte, langschwänzige Reptilien von etwa 2 m Körperlänge; räuberische Sumpf- oder Süßwasserbewohner. Dermosupraoccipitalia und Tabularia groß, anf der Oberseite des Schädeldaches gelegen. Supratemporalia vorhanden. Hinterhauptscondylus konkav. Schädeldach selır flach, Augenhöhlen seitlich gestellt, von oben her nicht sichtbar. Unterkieferäste breit ausladend, sehr stark geschwungen. Die Zähne des Zwischenkiefers sehr groß. Rippen einköpfig. Ein kleines Cleithrum vorhanden. Carpalia und Tarsalia unvollständig verknöchert. Fuß kurz und breit, Endphalangen hufförmig. 
Limnoscelis. - Perm von Neumexiko. - Mehrere vollständige Skelette bekannt. ${ }^{1}$ (Fig. 255-257.)

\section{F. Diadectidae.}

Robust gebaute Tiere von 1 bis $3 m$ Körperlänge, mit sehr kräftigen Brustschultergürtel und einköpfigen, starken Rippen, von denen die vorderen plattenartig erweitert sind und sich dachziegelartig überdecken. Diese Reptilien sind wahrscheinlich Grabtiere gewesen, die eine weichkörperige Nahrung zu sich nahmen, die aus Insekten, Würmern usw. bestanden haben dürfte; das Gebiß ist zweifellos nicht kar-

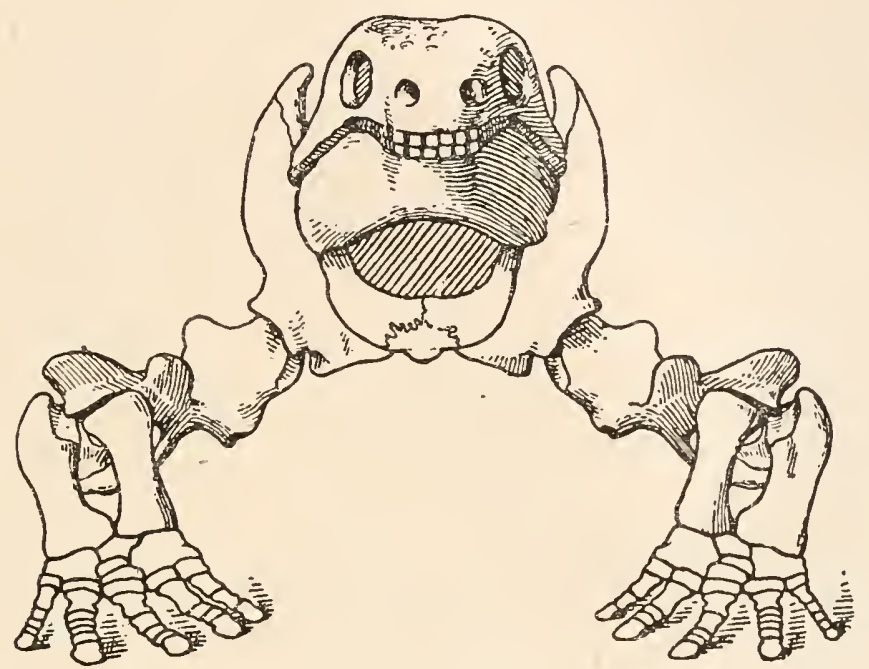

Fig. 259.

Diadectes phaseolinus, Cope. Perm von Texas. Rekonstruktion des Skelettes, von vorne gesehen. 1/6 nat. Gr. (Nach E. C. Case.)

nivor. Bei einigen Formen mag sekundär eine herbivore Ernährungsart eingetreten sein (O. Abel, 1912). ${ }^{2}$ Die vorderen Gliedmaßen sind sehr kräftig, die Hand trug fünf verkürzte Finger init der Phalangenformel 2, 3, 4, 5, 4 und war digitigrad, ebenso der Hinterfuß (E. C. Case, 1910).

In Schädel fällt das große Parietalforamen auf; die Knochen des Schädeldaches sind rauh skulpturiert. Dermosupraoccipitalia, Tabularia und Supratemporalia sind vorhanden. Vorderzähne schneidezahnartig, die hinteren als transversale Wülste entwickelt, an die Zahnformen der Xenarthren (z. B. an Hyperleptus) erinnernd.

1 S. W. Williston, American Permian Vertebrates. - Chicago, 1911, p. 23.

Derselbe, Synopsis of the American Permocarboniferous Tetrapoda. - Contributions from Walker Museum, Chicago, Vol. 1, No. 9, 1916.

2 O. Abel, Paläobiologie der Wirbeltiere. - 1912, p. 130. 
21 oder mehr Präsakralwirbel, 1-2 Sakralwirbel. Cleithrum vorhanden. Bauchrippen fehlen.

Diadectes. - Perm von Texas und Neumexiko. - Fast das ganze Skelett bekannt. ${ }^{1}$ (Fig. 258 260.)

Diasparactus. - Perm von Neumexiko. - Fast das ganze Skelett bekannt. ${ }^{2}$ (Fig. 261.)

Diadectoides. - Perm von Texas. - Zähne, Wirbel, Hinterbeine bekannt. ${ }^{3}$

Animasaurus. - Perm von Neumexiko. - Nur der Schädel bekannt. ${ }^{4}$

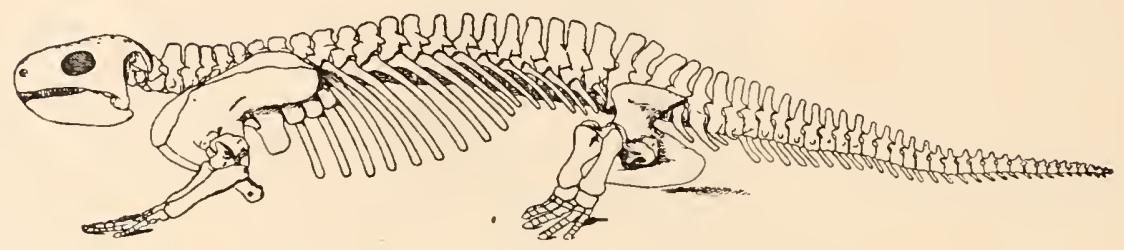

Fig. 260.

Rekonstruktion des Skelettes von Diadectes phaseolinus, Cope, aus dem Perm von Texas. Ungefähr $1 / 30$ nat. Gr. (Nach E. C. Case.)

\section{F. Stephanospondylidae.}

Diese Familie ist bisher nur durch die Gattung Stephanospondylus aus dem Perm Sachsens vertreten. Der Schädel ist flach, sein Umriß in der Oberansicht abgerundet dreieckig; er ist skulpturiert und besitzt ein großes Foramen parietale. Im Supramaxillare stehen zwei(?) Reihen von Backenzähnen, die durch einen größeren Zahn, der funktionell einem Canin entspricht, von den Greifzähnen des Zwischenkiefers getrennt werden. Diese Greifzähne sind einfache Kegelzähne, wälnrend die „Mahlzähne" eine quer zur Kieferachse stehende Krone besitzen, die einen ovalen Querschnitt zeigt, ähnlich wie dies bei Diadectes der Fall ist; die Krone ist unterhalb der Basis eingeschnürt.

1 E. C. Case, A Revision of the Cotylosauria of North America. - Carnegie Institution of Washington, Publication No. 145, 1911, p. 67.

2 E. C. Case, New or Little Known Reptiles and Amphibians from the Permian (?) of Texas, - Bull. Am. Mus. Nat. Hist. New York, Vol. XXVIII, Art. 17, 1910, p. 175.

E. C. Case and S. W. Williston, Description o: a Nearly Complete Skeleton of Diasparactus zenos Case. - Carnegie Inst. Washington, Publ. No. 181, 1913, p. 17.

3 E. C. Case, A Revision of the Cotylosauria etc., 1. c. 1911, p. 26.

4 E. C. Case and S. W. Williston, A Description of the Skulls of Diadectes lentus and Animasaurus carinatus. - American Journal of Science, Vol XXXIII, April 1912, p. 345. 
Zwei untereinander verwachsene Sakralwirbel. Coracoid und Procoracoid frei, das erstere verlängert. Cleithrum groß. Wirbel mit sehr kräftigen, massiven Dornfortsätzen. Die Finger tragen Krallen.

Stephanospondylus. - Perm von Sachsen. ${ }^{1}$ (Fig. 262.)

\section{F. Pantylidae.}

Kleinere Tiere von etwa 0,5 m Körperlänge. Schädel schildkrötenälnnlich. Praemaxillare, Supramaxillare und Dentale mit einfacher Zahnreihe, aber die ganze, aus den Vomeres, Palatina und Pterygoidea ge-
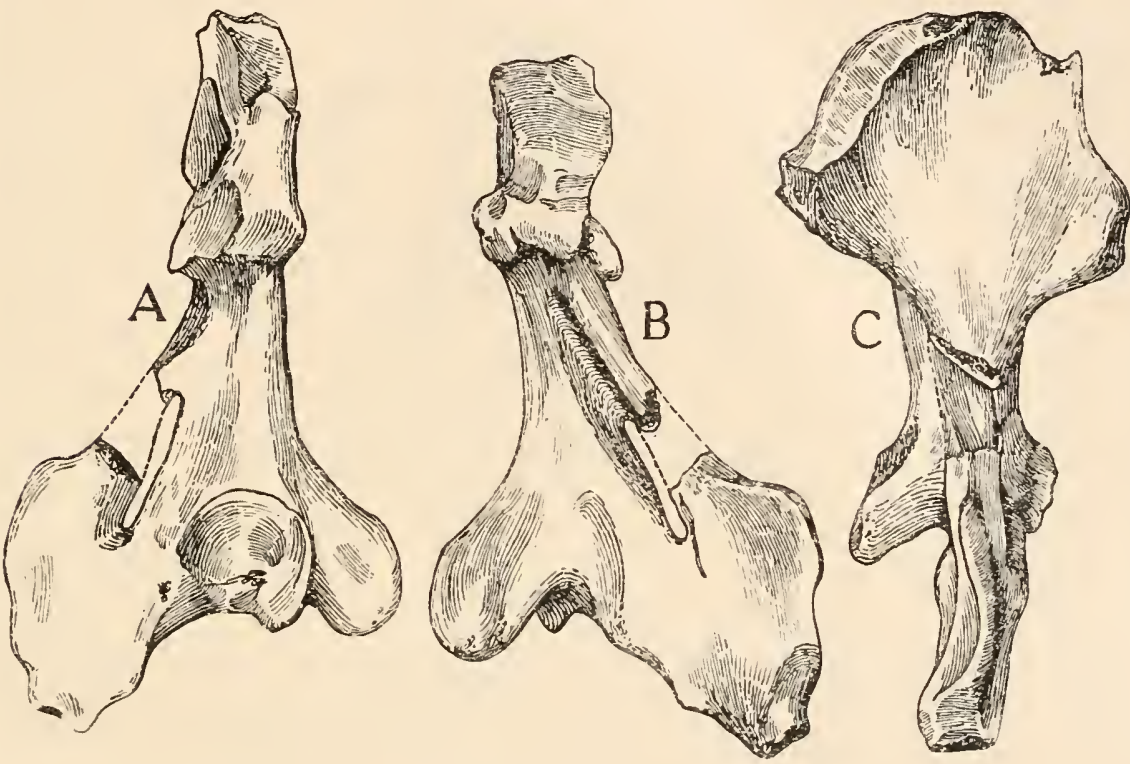

Fig. 261.

Diasparactus zenos, Case; aus dem roten, tonigen Sandstein (Permokarbon) von El Cobre Cañon in der Landschaft Rio Arriba, Neumexiko. 1/2 nat. Gr.

Linker Hunerus A von vorne, B von hinten, C von innen gesehen.

(Nach E. C. Case und S. W. Williston, 1913.)

bildete Gaumenplatte mit einem dichten Zahnpflaster bedeckt, ebenso das Complementare im Unterkiefer, der sehr kräftig gebaut ist. Parietalloch fehlt. Alle Schädeldachknochen ebenso wie die Außenseite des Unterkiefers rauh skulpturiert. Supratemporale und Tabulare vorhanden. Rippen zweiköpfig. Körper wahrscheinlich zur Gänze mit kleinen, dünnen, mosaikartig aneinanderschließenden Knochenplatten

1 R. Stappenbeck, Über Stephanospondylus n. g. und Phanerosaurus H. v. M. - Zeitschrift der Deutschen Geologischen Gesellschaft, Bd. LVII, 1905, p. 379 . 
gepanzert. Interclavicula abweichend von allen anderen Reptilien gebaut, an Ornithorhynchus erinnernd. Gliedmaßen auffallend schlank und zart. Das Tier war jedenfalls durophag und dürfte eine wühlende Lebensweise geführt haben, worauf namentlich die Schädelform linweist.

Pantylus. - Perm von Texas. - Erst seit 1916 genauer bekannt (S. W. Williston, Contr. Walker Museum, Chicago, Vol. I, Nr. 9, p. 165). ${ }^{1}$ (Fig. 263-264.)

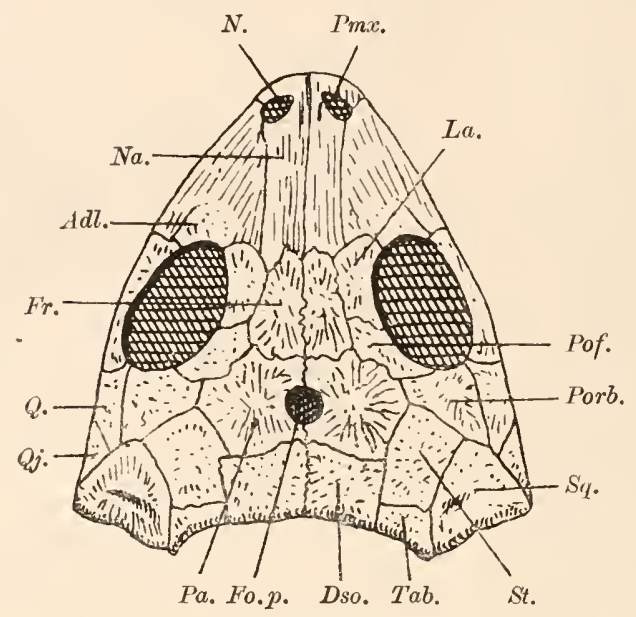

Fig. 262.

Dorsalansicht des Schädeldaches von Stephanospondylus pugnax, Stapp.,

aus dem Perm Sachsens. (Nach R. Stappenbeck.)

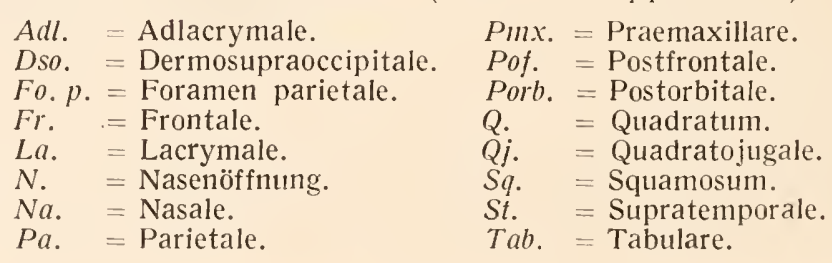

\section{F. Seymouriidae.}

Terrestrische, wahrscheinlich insektivore Reptilien von etwa $1 / 211$ Körperlänge. Der Schädel ist von dreieckigem Umriß in der Oberansicht und besitzt ein lntertemporale, Supratemporale und Tabulare. Zwischen den Parietalien ist ein Parietalforanen vorlanden. An den Hinterecken des Schädels ist eine Otikalkerbe vorhanden, ähnlich wie bei vielen Stegocephalen. Die Zähne sind schlank und kegelförmig

1 Vgl. außerdem: R. Broom, On the Cotylosau ian Genus Pantylus Cope. - Bull. Amer. Mus. Nat. Hist., Vol. XXX11, Art. 35, 1913, p. 527. 
und stehen in einfacher Reihe auf den Praemaxillarien, Supramaxillarien und denı Dentale; die vorderen Zähne sind nicht vergrößert. In der Wirbelsäule sind 23 Präsakralwirbel und ein Sakralwirbel vorhanden;

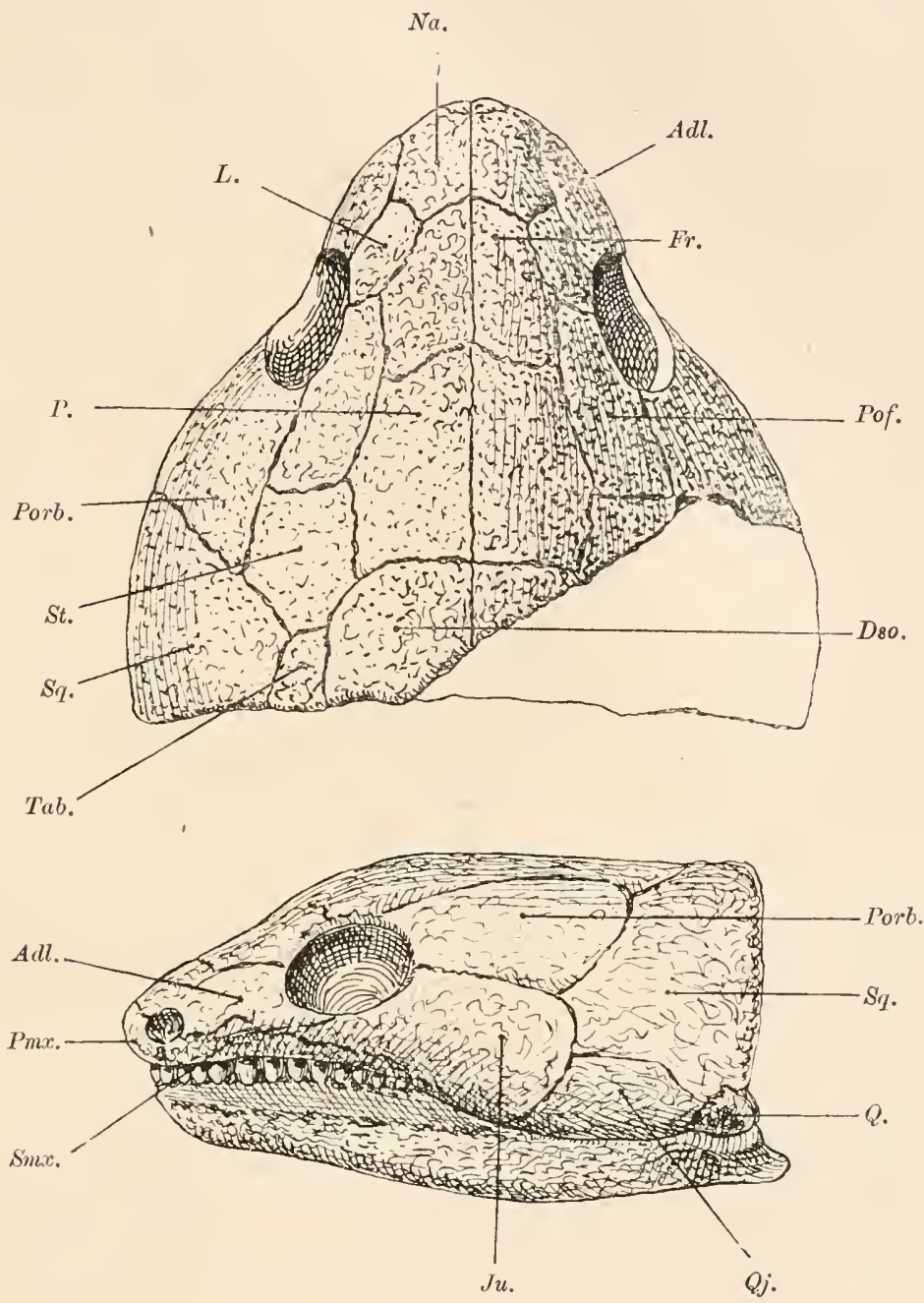

Fig. 263.

Schädel von Pantylus cordatus, Cope, aus dem Perm von Texas; Oberansicht und Seitenansicht in $3 / 4$ nat. Gr. (Nach S. W. Williston, 1916.)

Smx. = Supramaxillare.

Ju. $=$ Jugale.

Die übrigen Abkürzungen wie in Fig. 262.

der Schwanz ist nur unvollständig bekannt, war aber jedenfalls kurz. Alle Rippen sind zweiköpfig. Ein Cleithrum felılt. Die Gliedmaßen sind kurz und stämmig. 
Seymouria. - Perm von Clear Fork, Texas. ${ }^{1}$ (Fig. 265.)

\section{F. Sauravidae.}

Schlanke Reptilien von geringer Körpergröße, etwa $30 \mathrm{~cm}$ lang. Der Schädel ist unbekannt. Die allgemeinen Verhältnisse des Rumpfes und der Extremitäten sprechen dafür, daß das Tier - es ist nur eine Art bekannt - eine eidechsenartige Lebensweise führte. Die Hinter-

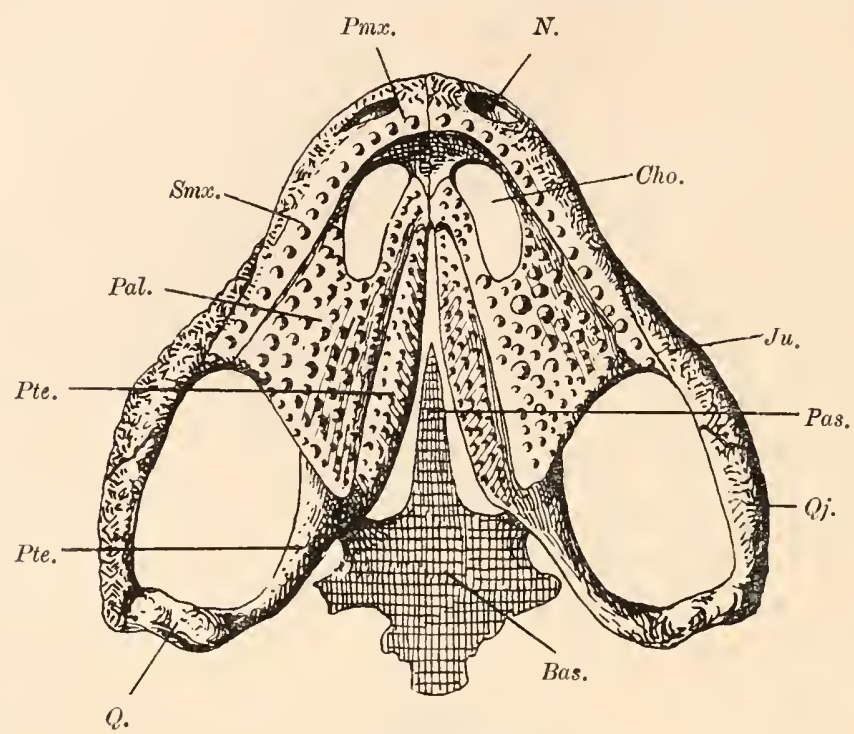

Fig. 264.

Unterseite des Schädels von Pantylus cordatus, Cope, aus dem Perm von Texas (vgl. Fig. 263). 3/1 nat. Gr. Die Praemaxillaria (Pmx.), Supramaxillaria $(\operatorname{Smx}$.$) , Palatina (Pal.), Pterygoidea (Pte.) sowie die$ vor den Pterygoidea zwischen den Choanen liegenden Vomeres tragen zahlreiche Zähne. (Nach S. W. Williston.)
Bas. = Basisphenoid.
Pmx. = Praemaxillare
Cho. = hintere Nasenöffnung (Choane).
Pt. $\quad=$ Pterygoid
$J u . \quad=$ Jugale .
Q. $\quad=$ Quadratum.
$N . \quad=$ vordere Nasenöffnung (Naris).
Qj. $\quad=$ Quadratojugale.
Pal. = Palatinum
Pas. = Parasphenoid.
Smx. = Supramaxillare.

beine sind typische Schiebfüße mit sehr langer vierter und fast gleichlanger fünfter Zehe, die nach hinten gerichtet war, wie im Schiebfuß der schnellaufenden lebenden Eidechsen.

1 S. W. Williston, Restoration of Seymouria baylorensis Broili, an American Cotylosaur. - Journal of Geology, Vol. XIX, No. 3, 19I1, p. 232.

Derselbe, Restorations of some American Permocarboniferous Amphibians and Reptiles. - Journal of Geology, Vol. XXII, No. I, 1914, p. 57.

Derselbe, Synopsis of the American Permocarboniferous Tetrapoda, I. c., Contributions fıom Walker Museum, Vol. 1, No. 9, p. 215. 
S. W. Williston ${ }^{1}$ vereinigte Eosauravus, Sauravus, Hylonomus und Petrobates zu einer systematischen Einheit, für die er die Bezeichnung ,Microsauria“ wählte, die von Dawson (1863) für Hylonomus aufgestellt worden war. ${ }^{2}$ ln Jahre 1916 führt er Eosauravus als Vertreter der Fanilie der Sauravidae im Rahmen der Cotylosaurier an, ohne Hylonomus und Petrobates zu erwähnen. ${ }^{3}$ Hylonomus haben wir (vgl. S. 309) als Vertreter der F. Hylonomidae neben den Microbrachiden und Limnerpetontiden als einen Zweig der neuen Amphibienordnang Gastrocentrophori unterschieden. Ob und inwieweit von diesen

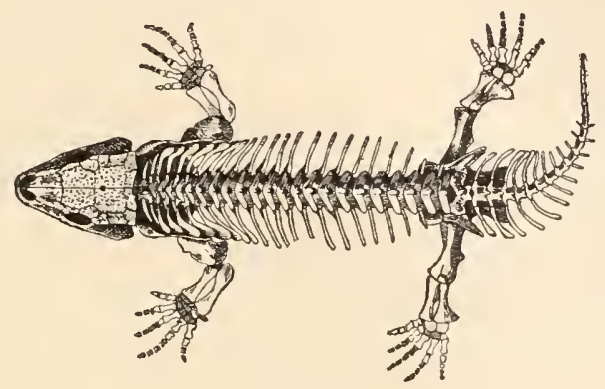

Fig. 265.

Skelett von Seymouria baylorensis, Broili, aus dem Perm von Texas. Ungefähr $1 / 3$ nat. Gr. (Nach S. W. Williston.)

eine Verbindung zu den Sauraviden führt, müssen neue Funde und Untersuchungen klarstellen; einstweilen können wir darüber keine Sicherheit erlangen.

Eosauravus. - Steinkohlenformation von Ohio. ${ }^{4}$

\section{F. Gymnarthridae.}

Die in dieser Fannilie vereinigten Arten sind sehr klein und erreichten kaum $20 \mathrm{~cm}$ Körperlänge. Die Zähne des Zwischenkiefers sind nicht verlängert, die des Oberkiefers größer und bei Gymnarthrus in Querschnitt oval, bei Cardiocephalus mit scharfer Schneide. Dermosupraoccipitalia und Tabularia vorhanden.

1 S. W. Williston, Primitive Reptiles: A Review. - Journal of Morphology, Vol. XXIII, 1912, p. 655.

2 J. W. Dawson, Air Breathers of the Coal Period. - New York und London 1863, p. 47.

${ }^{3}$ S. W. Williston, Synopsis of the American Permocarboniferous Tetrapoda. - Contrib. Walker Museum, Vol. I, No. 9, Chicago, 1916, p. 217.

${ }^{4}$ Früher mit Isodectes punctulatus identifiziert. Vgl. insbesondere: E. C. Case, A Revision of the Cotylosauria of North America. - Carnegie Institution, No. 145, 1911, p. 31. 
Gymnarthrus. - Perm von Texas. - G. Willoughbyi. ${ }^{1}$ Cardiocephalus. - Perm von Texas. - C. Sternbergii. ${ }^{2}$

\section{F. Pariotichidae.}

Diese Fanilie steht nach den Untersuchungen von Williston(1916) in nahen Beziehungen zu den Captorhiniden; die vorderen Zälne sind nach rückwärts gekrümmt und stehen entweder in einfachen oder mehrfachen Reihen auf den Kieferknochen. Der Schädel ist flach, von dreieckigem Umriß, und besitzt (bei Pariotichus) ein relativ großes Parietalloch. Die Oberfläche der Schädelknochen ist grubig skulpturiert. Die Tiere erreichten nur eine geringe Körpergröße, die größten Exemplare werden $1 \mathrm{~m}$ lang.

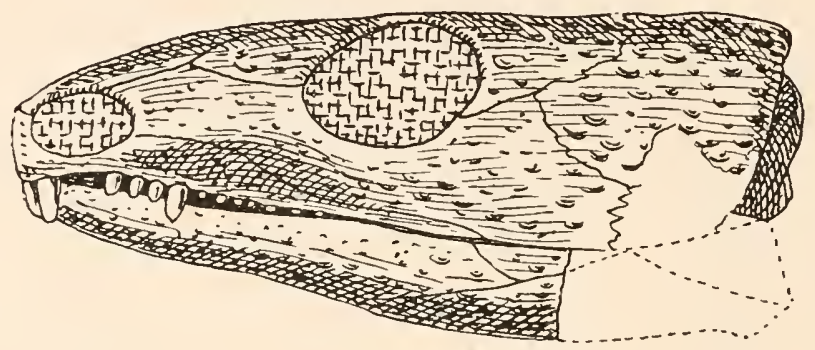

Fig. 266.

Seitenansicht des Schädels von Pariotichus aguti, Cope, aus dem Perm von Texas. Nat. Gr. (Nach E. B. Branson.)

Pariotichus. - Perm von Texas. ${ }^{3}$ P. laticeps (Fig. 266).

Isodectes. - Perm von Texas. ${ }^{4}$ I. megalops (Fig. 267).

\section{F. Captorhinidae.}

Kleine Tiere von $1 / 4$ bis $1 \mathrm{~m}$ Körperlänge. Sclıädel in der Oberansicht breit dreieckig. Parietalloch klein. Supratemporale felılt. Auf

1 E. C. Case, New or little known Reptiles and Amphibians from the Permian (?) of Texas. - Bull. Amer. Mus. Nat. Hist., Vol.XXVIII, 1910, p. 177.

S. W. Williston, Contributions from Walker Museum, l. c. 1916, p. 217.

2 F. Broili, Permische Stegocephalen und Reptilien aus Texas. - Paläontographica, Bd. LI, 1904, p. 45.

S. W. Williston, Contributions from Walker Museum, 1. c., 1916, p. 219.

${ }^{3}$ S. W. Williston, New or Little Known Permian Vertebrates. - Pariotichus. - Biological Bulletin, Vol. XVII, No. 3, August 1909, p. 241.

E. B. Branson, Notes on the Osteology of the Skull of Pariotichus. Journal of Geology, Vol. XIX, No. 2, 1911, p. 135.

4 E. C. Case, A Revision of the Cotylosauria of North America. - 1. c., Washington, 1911, p. 92.

S. W. Williston, The Osteology of Some American Permian Vertebrates. Part 11. - Contributions from Walker Museum, Vol. I, No. 9, 1916, p. 176 und 219. 
dem Palatinum kleine Zähne. Die Zähne stehen auf den Kiefern in einer oder in mehreren Reihen, in Oberkiefer zwei oder mehr Reihen. Gliedmaßen gedrungen, Schwanz kurz. Die Zähne des Zwischenkiefers sind verlängert und nach hinten gekrümml, besonders kräftig bei Labidosaurus.

Captorhinus. - Perm von Texas und Oklahoma. - Mehrere fast vollständige Skelette bekannt. Zähne im hinteren Teile der Supramaxillaria in zwei bis vier Reihen. ${ }^{1}$ C. angusticeps.

Labidosaurus. - Perm von Texas. - Praemaxillare stark nach unten gebogen, mit drei großen Schneidezähnen jederseits. ${ }^{2}$ L. hannatus (Fig. 268).

\section{F. Elginiidae.}

Die einzige Art (Elginia mirabilis) aus dem permischen Sandstein von Cuttie's Hillock bei Elgin in Schottland ist nur durch den Schädel bekannt, der durch die zalılreichen Knochenzapfen auffällt, die namentlich auf dem hinteren Teile des Schädels sehr groß sind und nacl hinten abstehen, wodurch der Habitus jenen der lebenden Agamidengattung Moloch oder der lebenden Iguanidengattung Phrynosona sehr ähnlich wird, bei denen aber die

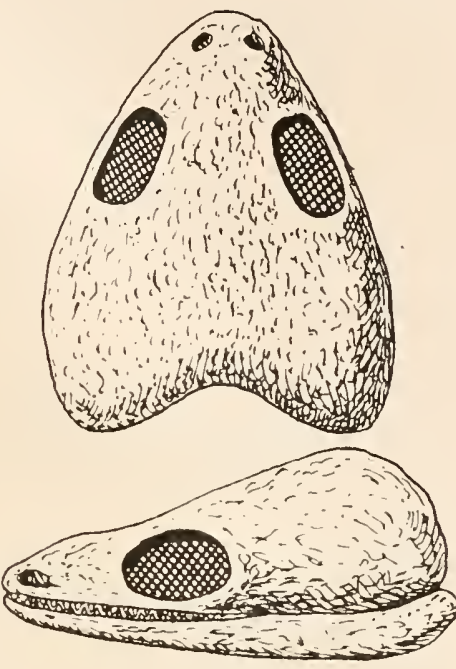

Fig. 267.

Oberansicht und Seitenansicht des SchädeIs von Isodectes aus dem Perm von Texas; $11 \frac{1}{2}$ nat. Gr. (Nach S. W. Williston, 1916.) Stacheln keine knöcherne Unterlage besitzen und reine Hornbildungen sind. Die Zahnkronen sind etwas gezähnelt und die Basis der Krone eingeschnürt. Die Lebensweise der Tiere dürfte jener der erwähnten lebenden Lacertiliergattungen Moloch und Phrynosona ähnlich gewesen sein.

1 E. C. Case, A Revision of the Cotylosauria of North America, 1. c., p. 93.

S. W. Williston, Contributions from Walker Museum, 1. c., 1916, p. 219.

2 E. C. Case, A Redescription of Pariotichus (Labidosaurus in Lit.) incisivus Cope. - Zoological Bulletin, Vol. II, No. 5, Boston 1899.

F. Broili, Ein montiertes Skelett von Labidosaurus hamatus Cope, einem Cotylosaurier aus dem Perm von Texas. - Zeitschrift der Deutschen Geol. Gesellschaft, Bd. LX, 1908, S. 63.

S. W. Williston, The Skull of Labidosaurus. - The American Journal of Anatomy, Vol. X, No. 1, 1910, p. 69.

Derselbe, Restorations of some American Permocarboniferous Amphibians and Reptiles. - Journal of Geology, Vol. XX11, 1914, p. 65. 
Elginia. - Perm Schottlands. ${ }^{1}$ E. mirabilis (Fig. 269).

\section{F. Pareiasauridae.}

Die Pareiasauriden waren ziemlich große Reptilien - Pareiasaurus Baini erreichte eine Körperlänge von etwa $3 m$ - und besaßen einen plumpen Körper mit kurzen, sehr stämmigen Gliedmaßen. Der Schädel trägt eine kräftig ausgesprochene Skulptur aus Höckern und Gruben; am Unterrande des Unterkiefers steht ein kleiner Höcker am Vorderende, ein großer Knochenzapfen etwa in halber Länge des Unterkiefers. Diese Zapfen sind wohl am ehesten als Muskelansatzstellen zu deuten.

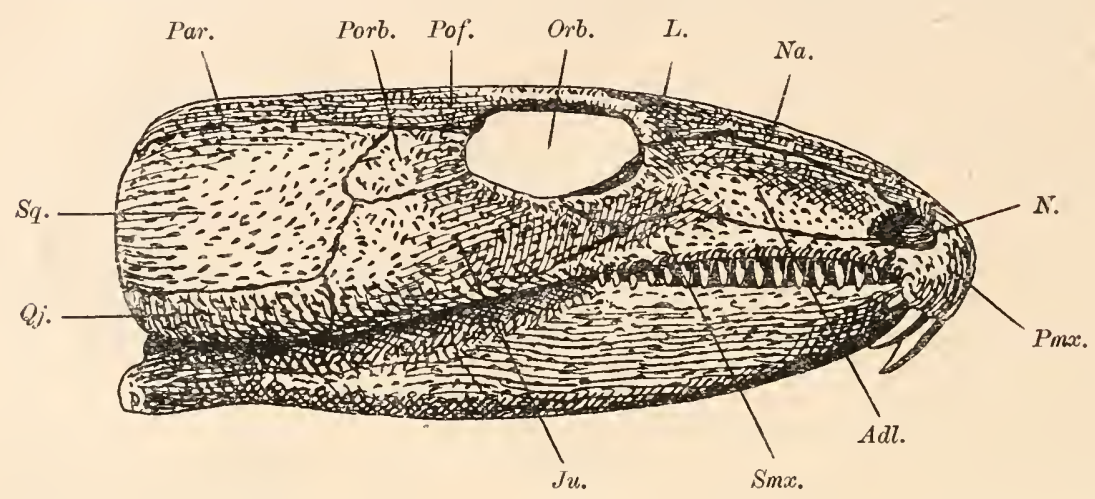

Fig. 268.

Seitenansicht des Schädels von Labidosaurus hamatus, Cope(?) aus dem Perm von Texas, in $1 / 2$ nat. Gr. (Nach S. W. Williston, 1916.) Abkiirzungen wie in Fig. 263.

Der Rücken ist mit mehreren Reihen von Knochenplatten gepanzert. In der Wirbelsäule finden sich zwischen den Wirbelkörpern Hypozentren (Interzentren) eingeschaltet. Die Krallenphalangen der Finger und Zehen, deren Phalangenzahl noch unsicher ist $(2,3,4,5,3$ ?), sind stark gebogen und krallenartig geschärft.

Pareiasaurus. - Perm von Südafrika und Nordrußland. ${ }^{2}$ P. Baini (Fig. 270).

Propappus. - Perm von Südafrika. - Der ganze Rücken dicht 111it Knochenplatten gepanzert. ${ }^{3}$

1 E. T. Newton, On Some New Reptiles from the Elgin Sandstone. Philosophical Transactions of the Roy. Society, London 1893, Vol. CLXXXIV, p. 431.

2 Bis jetzt sind vier nahezu vollständig erhaltene Skelette bekannt. Letzte Mitteilung (hier die ältere Literatur!) von E. C. Case: A Revision of the Cotylosauria of North America. - 1. c. 1911, p. 53. Über die Phalangenzahl vgl. das folgende Zitat.

${ }^{3}$ Der größte Teil eines großen Skelettes bekannt: R. Broom, Contributions to South African Paleontology. On the Pareiasaurian Genus Propappus. - Annals South African Museum, Vol. IV, 1908, p. 351. - Vgl. auch E. C. Case, I. c., 1911, p. 54 . 


\section{F. Bolosauridae.}

Kleine Tiere, unvollständig bekannt und provisorisch den Cotylosauriern eingereiht, vielleicht aber zu den Pelycosauriern gehörig.
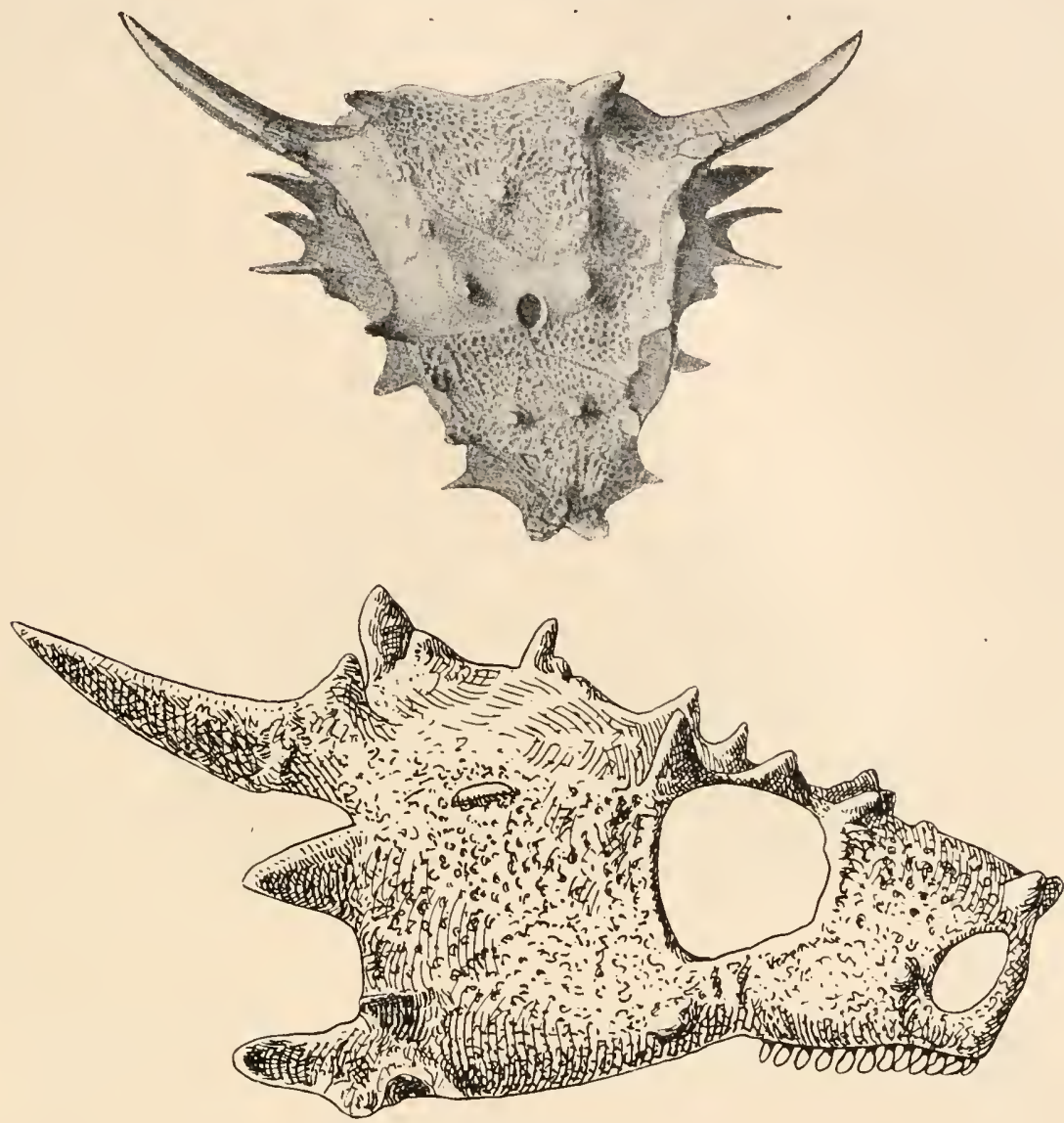

Fig. 269.

Oberansicht und Seitenansicht des Schädels von Elginia mirabilis, Newt., aus dem Perm (unterer Teil des New Red Sandstone) von Elgin, Schottland. Seitenansicht in $1 / 2$ nat. Gr. (Nach E. T. Newton; Zähne und Temporalregion in der vorl. Rekonstruktion ergänzt.)

Bolosaurus. - Perm von Texas. - Backenzähne transversal verbreitert und mit vorspringendem Höcker an der Außenseite der oberen Backenzähne und an der Innenseite der unteren. ${ }^{1}$ B. striatus.

${ }^{1}$ E. C. Case, A Revision of the Cotylosauria of North America. - 1. c., 1911, p. 89.

R. Broom, On the Structure and Affinities of Bolosaurus. - Bulletin Amer. Mus. Nat. Hist., New York, Vol. XXXII, 1913, p. 509.

S. W. Williston, Contributions from Walker Museum, l. c., 1916, p. 214. 


\section{Ordnung: Procolophonia.}

Von den Cotylosauriern hauptsächlich dadurch verschieden, daß eine mit der Orbita verschmolzene große Temporalöffnung (Orbito-Temporalöffnung) vorhanden ist, während das Schädeldaclı der Cotylosaurier stets geschlossen bleibt. Ein weiterer wichtiger Unter-

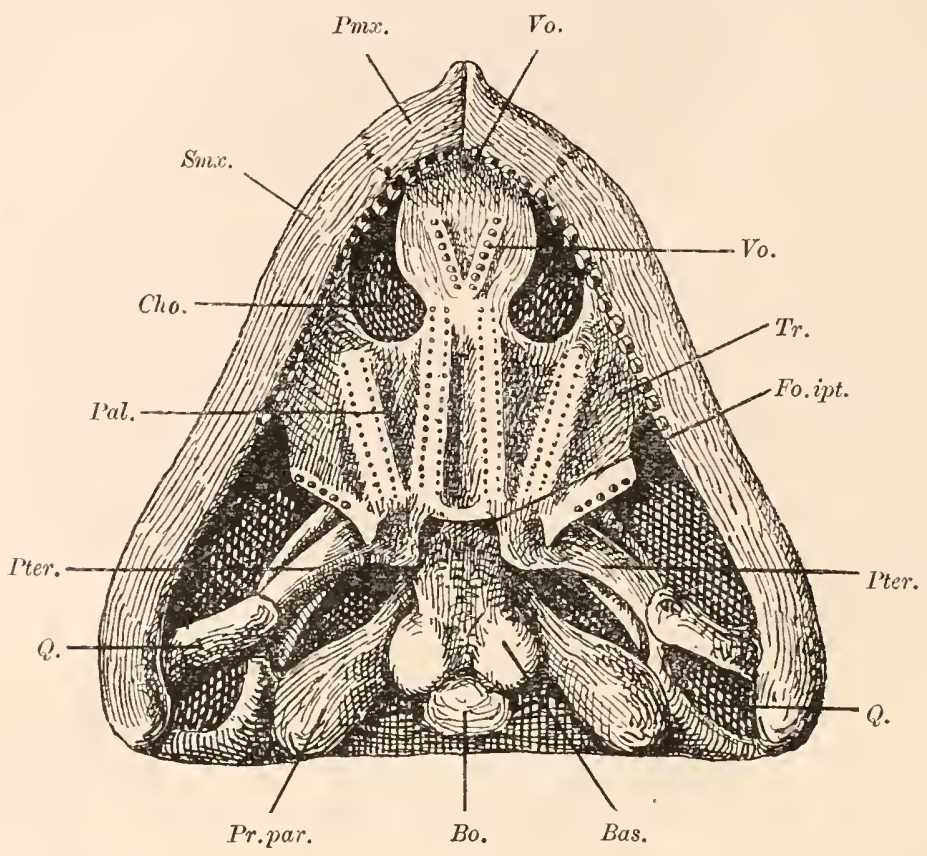

Fig. 270 .

Gaumenansicht des Schädels von Pareiasaurus Baini, Seeley, aus dem Perm Sïdafrikas, ungefähr in $1 / 6$ nat. Gr. (Rekonstruktion auf Grundlage verschiedener Abbildungen; nach R. Broom, 1910; H. G. Seeley, 1893; A. S. Woodward, 1898; E. T. Newton, 1894; insbesondere nach J. Versluys, 1912.)
Bas. $\quad=$ Basisphenoid.
Bo. $=$ Basioccipitale
Cho. = Choane.
Pter. $\quad=$ Pterygoid.
Fo. ipt. $=$ Fossa interpterygoidea
Pal. $\quad=$ Palatinum.
Pmx. = Praemaxillare.
Pr. par. = Processus paroccipitalis.
Q. $\quad=$ Quadratum.
Sinx. = Supramaxillare.
Tr. $=$ Transversum.
Vo. $=$ Vomer.

schied besteht in der Ausbildung des Brustschultergürtels. Die Interclavicula ist T-förmig (ähnlich wie bei Diadectes), n11 den Claviculae nicht verwachsen, und die großen scheibenförmigen Coracoide und Procoracoide sind allseitig frei. Bei Procolophon (und wahrscheinlich ebenso bei den übrigen Procolophonia) liegen zwischen Parietale und Quadratum drei, bei den Cotylosauriern aber vier Knoclien; der verloren gegangene scheint das Supratemporale zu sein, da der am 
Hinterrande des Schädeldaches vorspringende Stachel dem Tabulare entsprechen dürfte. Die Dermosupraoccipitalia sind vorhanden.

Das Becken sowie beide Gliedmaßenpaare sind in den Hauptzügen ebenso wie bei den Cotylosauriern gebaut. Abdominalrippen sind bei Procolophon, Koiloskiosaurus und Telerpeton nachgewiesen.

Vier Gattungen aus der unteren und mittleren Trias von Deutschland, Schweiz, Schottland und Südafrika bekannt. Allen gemeinsam

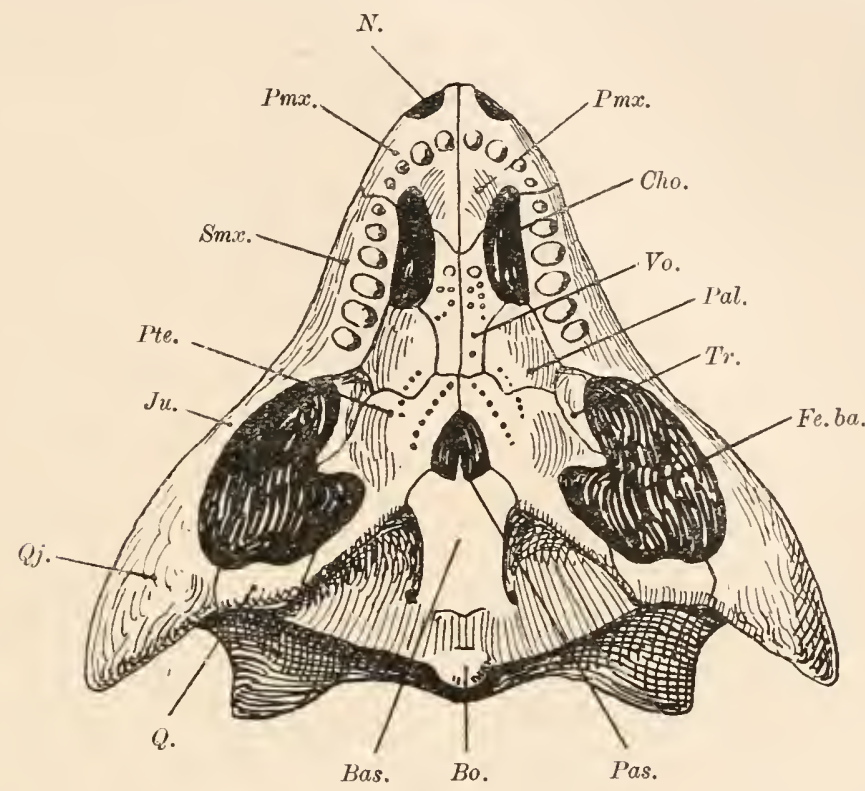

Fig. 27I.

Reskonstruktion der Unterseite des Schädels von Procolophon trigoniceps, Owen, aus dem Perm der Kapkolonie, in nat. Gr. (Vielleicht $0^{7}$ ?)

(Nach R. Broom.)

$F e . b a .=$ Fenestra basitemporalis.

Die ïbrigen Abkürzungen wie in Fig. 270 u. 264.

ist die dreieckige Schädelform, das flache Schädeldach, eine hohe Schnauze, ein relativ großes Parietalloch und starke Stacheln am Hinterrande des Schädeldaches, die bei Sclerosaurus an längsten sind. Die Nasenlöcher liegen an Schuauzenende.

Procolophon. - Trias (Karooformation) von Südafrika. ${ }^{1}$ P. trigoniceps (Fig. 271).

1 R. Broom, On the Affinities of the Primitive Reptile Procolophon. Proceedings of the Zool. Soc., 1905, I, p. 212.

Derselbe, A Comparison of the Permian Reptiles of North America with those of South Africa. - Bulletin American Mus. Nat. Hist., New York, Vol. XXVIII, 1910 , p. 203. 
Sclerosaurus. - Untere Trias (Buntsandstein) von Basel, Schweiz.

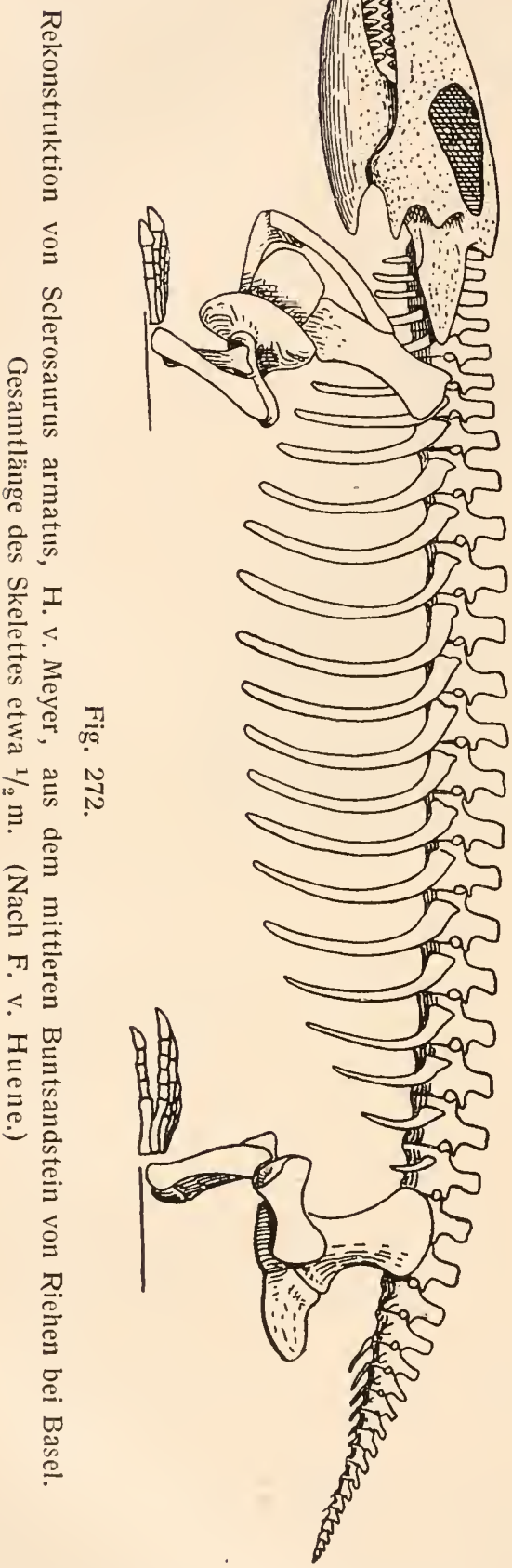

- Rücken gepanzert. ${ }^{1}$ S. armatus (Fig. 272).

Telerpeton.- Mittlere Trias von Elgin, Schottland. ${ }^{2}$ T. elginense (Fig. 273).

Koiloskiosaurus.- Untere Trias (Buntsandstein) bei Koburg, Deutschland. $^{3} \quad$ K. coburgiensis (Fig. 274).

\section{Ordnung: Pelycosauria.}

Mit Ausnahne der Ophiacodontiden, bei denen zwei laterale Schläfengruben auftreten, ist in dieser Gruppe nur eine seitliche Schläfengrube jederseits vorhanden, die der unteren Temporalgrube von Sphenodon entspricht (obere Begrenzung vom Postorbitale und Squamosum, untere vom Jugale und Squamosum gebildet; die untere Spange ist jedoch bei Varanosaurus aus der Familie der Poliosauriden verloren gegangen, ein Merkmal, das außer bei Varanosaurus auch bei den Sauropterygiern und bei den Squamata auftritt und in diesen drei Fällen ganz unabhängig erworben worden ist).

1 F. von Huene, Übersicht iiber die Reptilien der Trias. - Geologische und Paläontologische Abhandlungen, N. F. Bd. Vl (G. R. Bd. X), 1902, p. 23.

Derselbe, Die Cotylosauria der Trias. - Paläontographica, LIX. Bd., 1912 , p. 94.

2 F. von Huene, Die Cotylosauria der Trias. - Paläontographica, LIX. Bd., 1912, p. 82.

${ }^{3}$ F. von Huene, Ibidem, p. 70. 
Im. Schädel sind Septomaxillare, Adlacrymale, Postorbitale, Quadratojugale, Squamosum und Epipterygoid immer vorhanden. Das Foramen parietale ist stets vorhanden, das Ectopterygoid (= Trans-
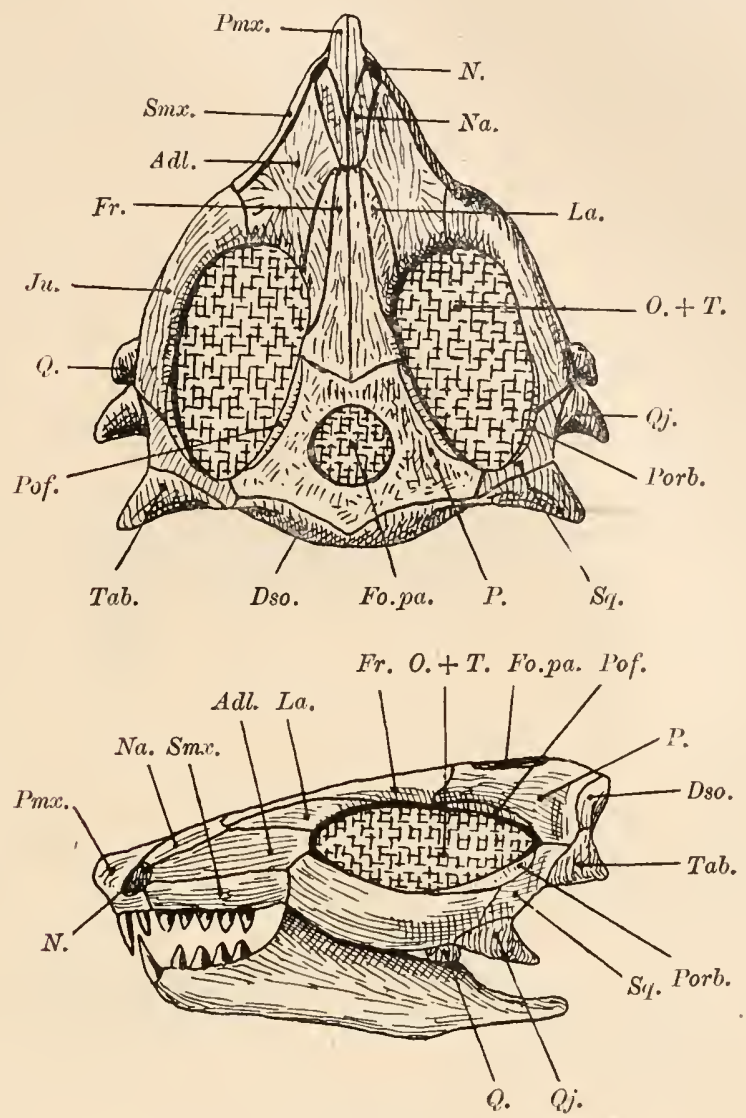

Fig. 273.

Oberansicht und Seitenansicht des Schädels von Telerpeton elginense, Mant., aus der Trias von Elgin, Schottland, in nat. Gr. (Rekonstruiert.) (Nach F. von Huene.)

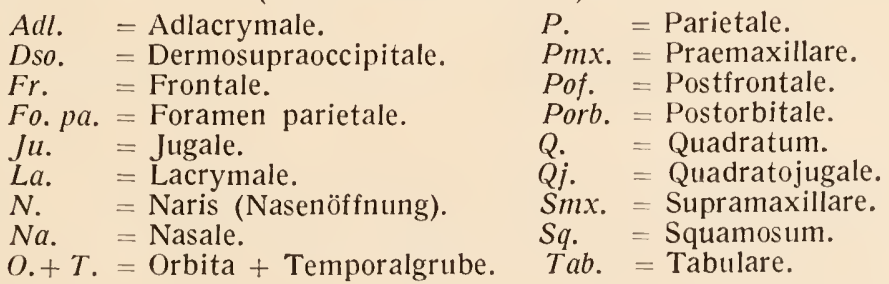

versum) bis jetzt nicht nachgewiesen. Im Unterkiefer ist das Praearticulare vorhanden und von den Nachbarknochen getrennt; das Complementare $(=$ Coronoid $=$ Epicoronoid $)$ ist verlängert; das Spleniale 
nimmt an der Symphyse teil. - Bei verschiedenen Pelycosauriergattungen sind die Dermosupraoccipitalia nachgewiesen worden und wahrscheinlich sind auch in einigen Fällen die Tabularia und Supratemporalia vorhanden.
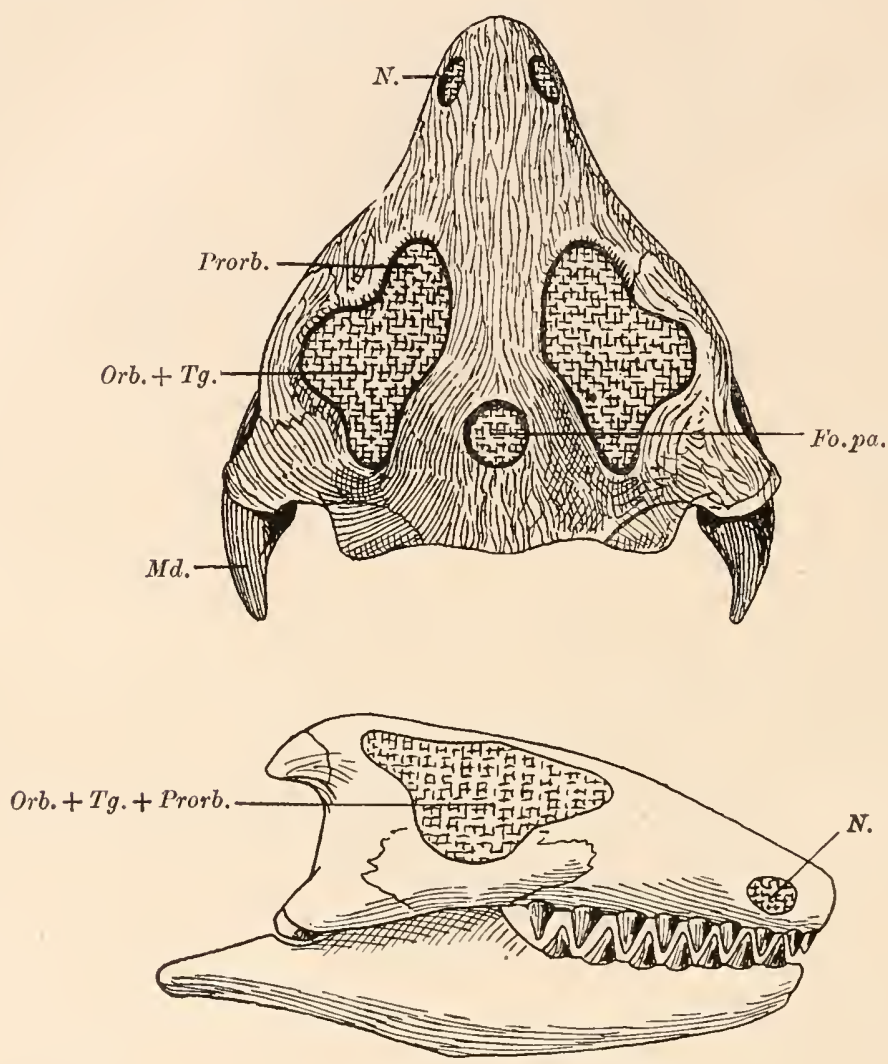

Fig. 274.

Schädel von Koiloskiosaurus coburgiensis, Huene, aus dem Buntsandstein von Coburg, in nat. Gr., von oben und von der Seite gesehen.
N.
Prorb. $=$ Nasenöffnung.
Orb. = Augenöffnung.
Prorb. = Präorbitaloffn
Tg. $=$ Schläfengrube.
Fo. $p a .=$ Foramen parietale
Md. = Unterkiefer.

Der Halsabschnitt umfaßt 6-7 Wirbel; alle Wirbel einschließlich der Kaudalregion besitzen getrennte Hypozentren (= Interzentren) bzw. Hämapophysen. Der Proatlas artikuliert mit dem Atlas und den Exoccipitalia. - Die Rippen sind zweiköpfig; das Tuberculum lenkt an der Diapophyse ein, das Capitulum artikuliert intervertebral.

Der Brustschultergürtel ist robust gebaut; Clavicula und Interclavicula vorhanden; Coracoid, Metacoracoid und Scapula im Alter 
verschmolzen. Foramen supraglenoideum und Foramen supracoracoideum vorlianden. - Beckenknochen abgeflacht, ein kleines Foranen obturatoriun meistens vorhanden, das Acetabulum undurchbohrt.

Gliedmaßen länger als bei den Cotylosauriern, fünffingerig und fünfzehig, mit stark verknöchertenı Carpus (Radiale, Intermedium, Ulnare, Centraliạ, fünf distale Carpalia) und Tarsus (6-9 Elemente). Centrale und Tarsale quintum selten unverknöchert. Zehen meist kurz, gerade gestreckt, nur in wenigen Fällen (z. B. Ophiacodon) nach vorn gebogen, in umgekehrter Richtung wie bei den Lacertiliern. Phalangenformel: 2, 3, 4, 5, 3 (4) in Hand und Fuß.

Die zahlreichen Familien, die nach dem Vorschlage von S. W. Willi ston (1916) in der Gruppe der ,Theromorpha“" = Pelycosauria) zu vereinigen sind, stellen aber keineswegs eine natürliche, systematische Einheit im Vergleiche mit anderen Reptilordnungen (z. B. Crocodilia, Squamata, Ichthyosauria usf.) dar. Aller Wahrscheinlichkeit nach gehören sie sehr verschiedenen Stänmmen an, die in der Wurzel der Cotylosaurier, der „Stanmmgruppe“ der Reptilien, zusammenlaufen. Man hat früher zwischen den „Cotylosauriern" und „Theromorphen" tiefgreifende Unterschiede feststellen zu können vermeint, aber es ist nichts davon übrig geblieben als der Unterschied, daß die Cotylosaurier keine Schläfengruben besitzen, also noch ein stegales Schädeldach tragen, während sich bei den ,.Theromorphen" bereits eine Schläfengrube entwickelt hat, das Schädeldach also zygal geworden ist. Diese Bildung einer Temporalgrube, welche der unteren Schläfengrube von Sphenodon entspricht, ist aber wohl nur ein Merkmal, das den Charakter einer Entwicklungsstufe repräsentiert, die von sehr verschiedenen Nachkommen der Cotylosaurier durchlaufen werden konnte. Wenn wir noch Ophiacodon berücksichtigen, so finden wir sogar schon einen o beren Schläfendurchbruch, wenn auch erst sehr klein, in Ausbildung, so daß wir hier einen Übergang zu den Reptilien mit doppelten Schläfengruben vor uns sehen. Diese Schläfengruben sind aber, wie wir später zeigen werden, bei den verschiedenen Reptilienstämmen ganz unabhängig voneinander entstanden und untereinander keinesfalls homolog, da ihre Begrenzung sehr verschieden ist; in einigen Stämmen entsteht die untere zuerst, in anderen die obere, wieder in anderen bildet sich eine Temporalgrube aus, die den Raum der oberen und unteren einnimmt usf. Die Bezeichnung eines Reptils als ,theromorph" ist also nur in Sinne einer höheren Entwicklungsstufe im Vergleiche zu den primitiven ,cotylosauriden“ Reptilien aufzufassen und anzuwenden. Dab die theromorphen Reptilien nicht nur hinsichtlich ihrer Temporalgruben, sondern aich in ihren übrigen osteologischen Merkmalen auf einer höheren Spezialisationsstufe als die Cotylosaurier stehen, geht aus der Diagnose der einzelnen Familien hervor. 
Die hier als „Pelycosauria“ zusammengefaßten Stämme haben zum Teil extreme Spezialisationen erreicht, wie die Sphenacodontiden (z. B. Dimetrodon) und Edaphosauriden (z. B. Naosaurus). Diese Stämme finden in den jüngeren Reptilienfamilien keine Fortsetzung und sind gänzlich erloschen.

\section{F. Sphenacodontidae (Marsh $=$ Clepsydropidae Cope).}

Karnivore, terrestrische Reptilien von 1 bis $3 \mathrm{~m}$ Körperlänge. Zälıne kegelförmig, lateral komprimiert, mit scharfen Spitzen; Zähne ungleich groß (anisodont), zwischen Supramaxillare und Praemaxillare in der Zahnreihe eine Lücke (Diastema). Dermosupraoccipitalia, Tabularia und Supratemporalia vorhanden (nach F. v. Huene, 1913). Unterkiefer am Hinterrande mit tiefer Einkerbung. Schädel im ganzen hoch und schmal.

Wirbel mit verlängerten Dornfortsätzen, extrem verlängert bei Dimetrodon, bei den anderen Gattungen kürzer. 27 Präsakralwirbel, 3 Sakralwirbel. 11 Karpalknochen, 8 Tarsalknochen. Endphalangen spitz, gekrümmt.

Dimetrodon. - Perm von Texas und Oklahoma. - Neurapophysen die 25 fache Höhe des Wirbelkörpers erreichend. Zähne mit krenelierten Schneiden. Fast das ganze Skelett bekannt. ${ }^{1}$ (Fig. 275-278.)

Sphenacodon. - Perm von Neumexiko. - Dornfortsätze höchstens sechsmal so hoch als der Wirbelkörper. Ränder der Zähne glatt. Nicht so gut bekannt wie die vorige Gattung. ${ }^{2}$

Clepsydrops. - Perm von Illinois und Texas. - Dornfortsätze niederer als bei Dimetrodon, Schwanz lang. Wirbel, Schädelfragmente, Gliedmaßenreste bekannt. ${ }^{3}$

1 E. C. Case, Revision of the Pelycosauria of North America. - Carnegie Institution of Washington, Publication No. 55, 1907, p. $43 \mathrm{ff}$.

Derselbe, Desription of a Skeleton of Dimetrodon incisivus Cope. - Bull. Amer. Mus. Nat. Hist., Vol. XXVIII, 1910, p. 189.

F. von Huene, A Comparison of the Permian Reptiles of North America with those of South Africa. - Ibidem, p. 224.

Derselbe, Das Hinterhaupt von Dimetrodon. - Anatomischer Anzeiger, 1913 , p. 519.

R. Broom, A Further Comparison of the South African Dinocephalians with the American Pelycosauria. - Bull. Amer. Mus. Nat. Hist., Vol: XXXI1I, 1914, p. 135 .

S. W. Williston, The Osteology of Some American Permian Vertebrates. Journal of Geology, Vol. XX1I, 1914, p. 413.

Derselbe, Synopsis of the American Permocarboniferous Tetrapoda. - Contributions from Walker Museum, Chicago, Vol. I, 1916, p. 222.

2 E. C. Case and S. W. Williston, Permocarboniferous Vertebrates from New Mexiko. - Chapter VI. - Carnegie Instit., Washington, Publ. No. 181, 1913, p. 61.

${ }^{3}$ E. C. Case, Revision of the Pelycosauria. - I. c., 1907, p. $37 \mathrm{ff}$. 

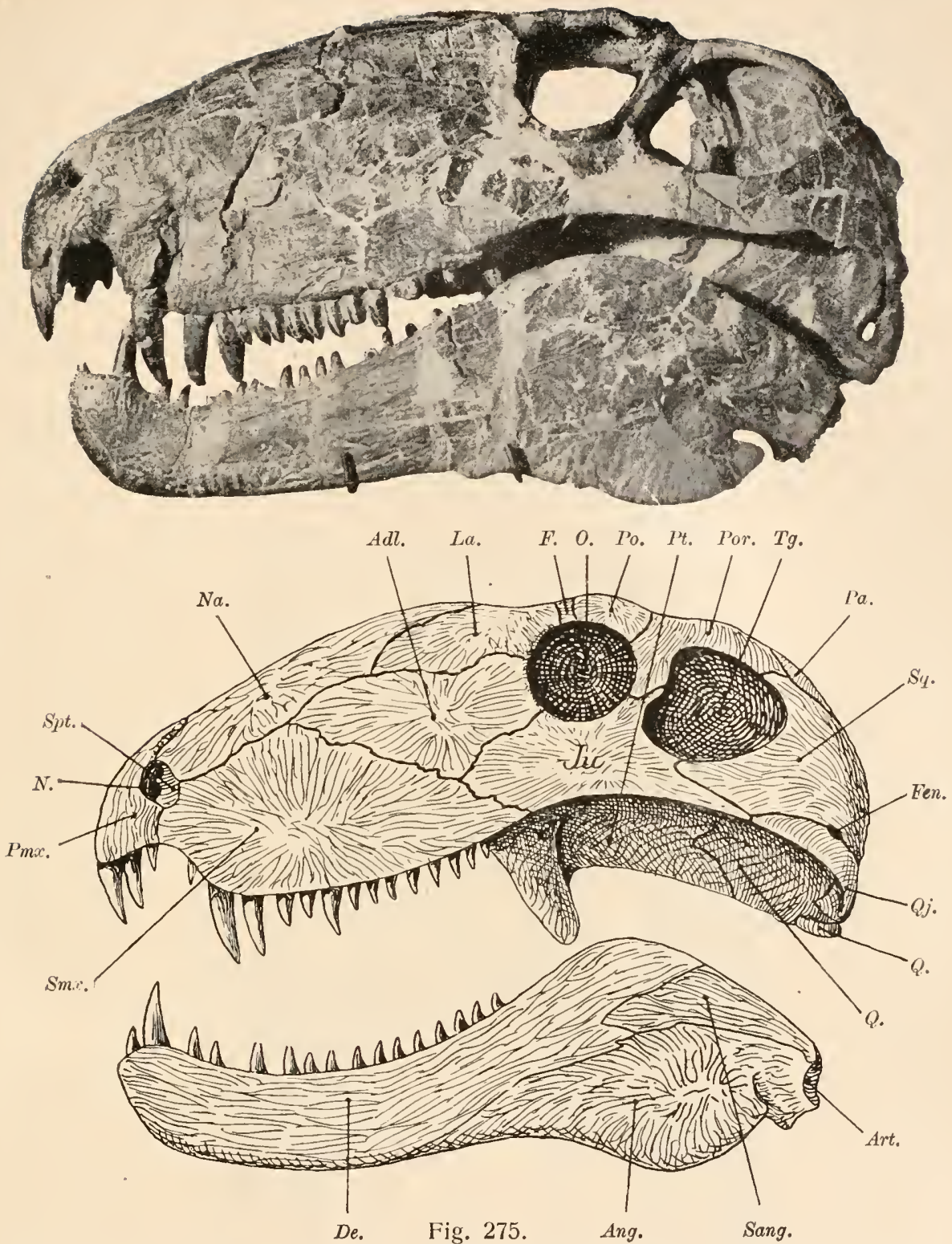

Schädel und Unterkiefer von Dimetrodon incisivus, Cope, aus dem Perm von

Texas, rekonstruiert. $1 / 3$ nat. Gr. (Im wesentlichen nach R. Broom, 1910.)

Adl. $=$ Adlacrymale.

Ang. = Angulare.

Art. = Articulare.

De. $\quad=$ Dentale.

F. $\quad=$ Frontale

Fen. $=$ Fenster zwischen Sq. u. Qj.

Ju. $=$ Jugale.

La. $=$ Lacrymale.

N. $=$ Naris.

$N a .=$ Nasale.

O. = Orbita
$P a .=$ Parietale

Pmx. = Praemaxillare.

Po. = Postfrontale.

Por. = Postorbitale.

Q. $\quad=$ Quadratum.

Qj. = Quadratojugale.

Sang. = Supraangulare.

Smx. = Supramaxillare.

Spt. $=$ Septomaxillare.

Sq. $=$ Squamosum.

$T g .=$ Temporalgrube. 


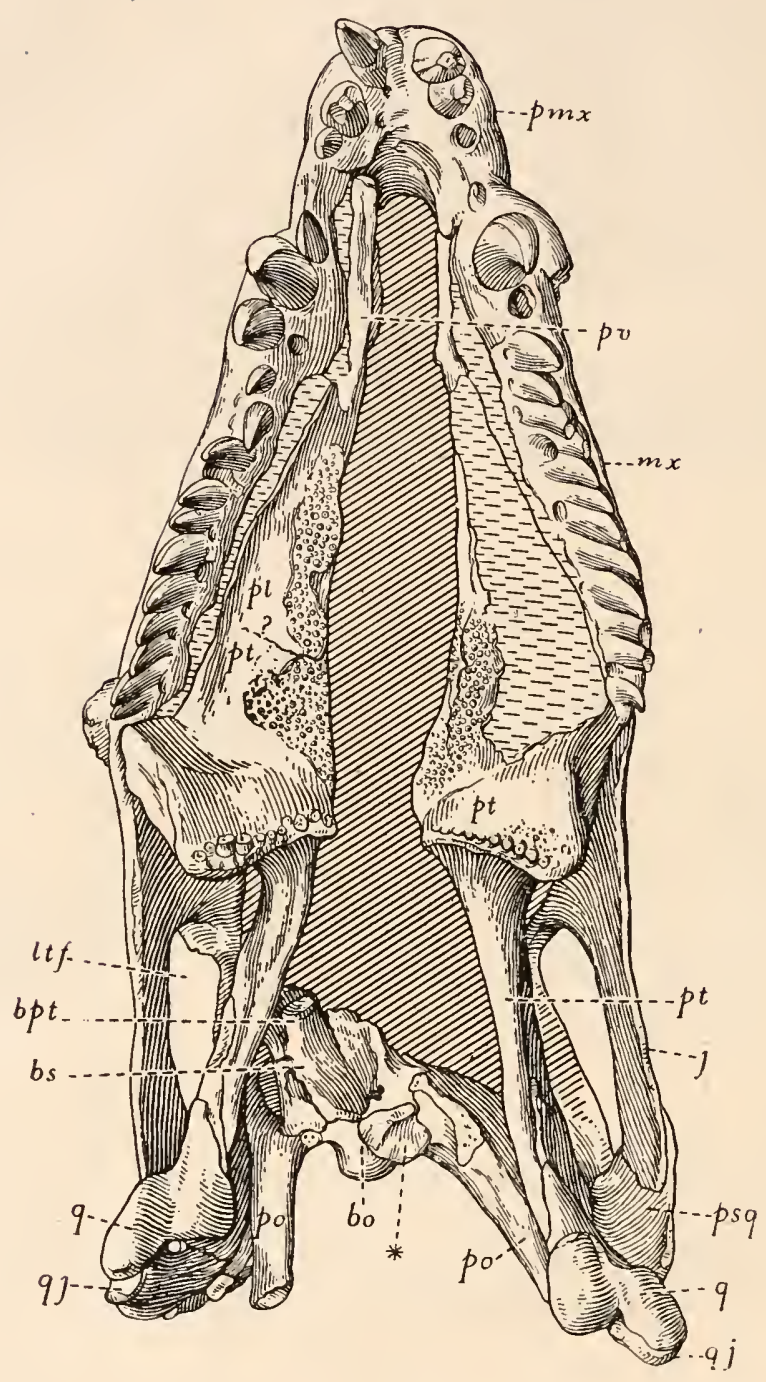

Fig. 276.

Unteransicht eines Schädels von Dimetrodon incisivus, Cope, aus dem Perm von Texas. $3 / 8$ nat. Gr. (Nach E. C. Case.)
pmx. = Praemaxillare.
pv. $=$ Vomer.
bs. $\quad=$ Basisphenoid.
$m x$. = Supramaxillare.
po. = Opisthoticum.
pt. $=$ Pterygoid .
pl. $=$ Palatinum.
$q . \quad=$ Quadratum.
j. $=$ Jugale
ltf. = Fenestra temporalis lat. $p s q .=$ Squamosum
bpt. $=$ Processus basipterygoideus. ${ }^{*}=$ Facette auf dem Basisphenoid bo. = Basioccipitale. für den Kopf des Stapes. 


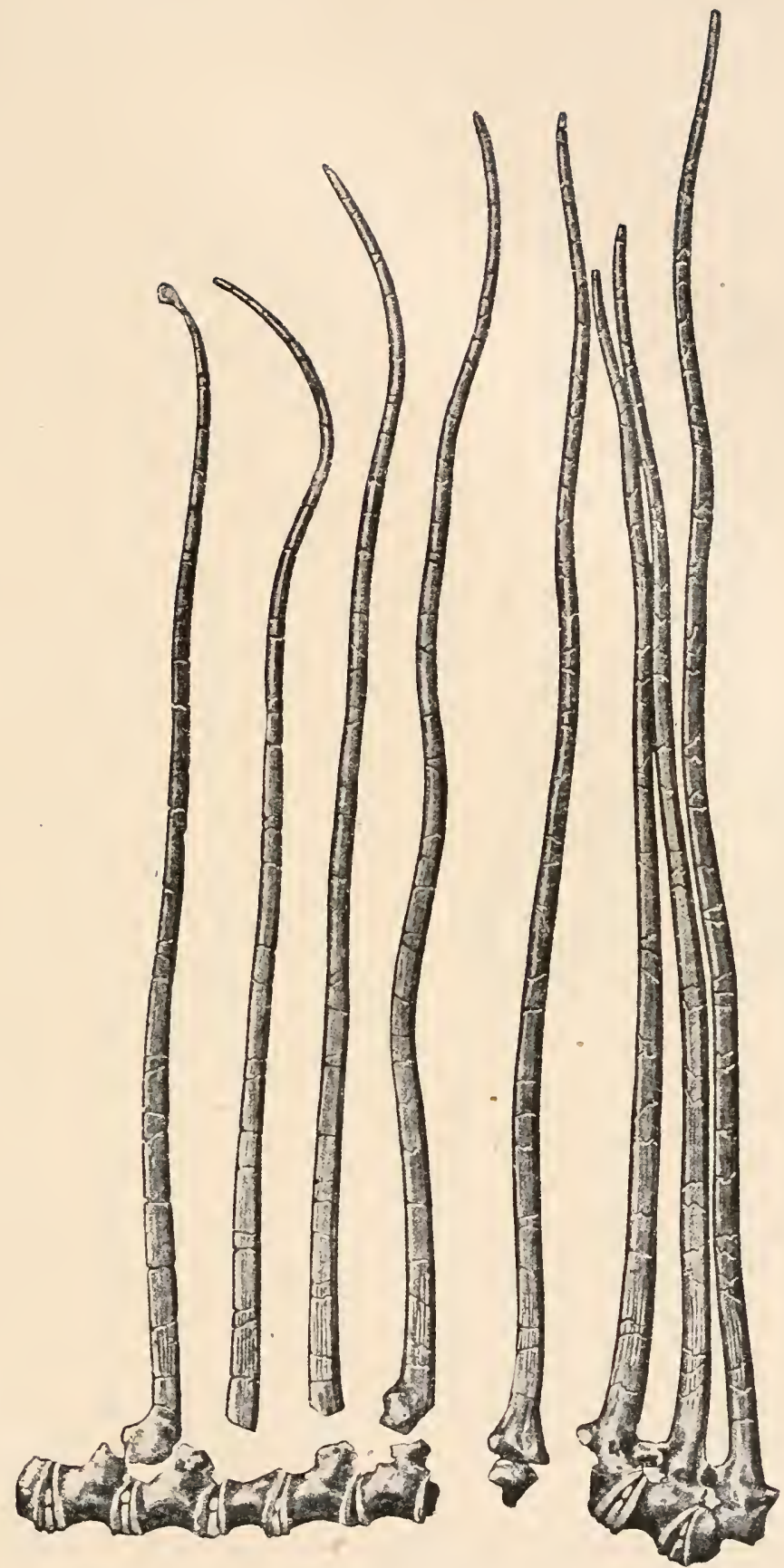

Fig. 277.

Rïcken- und Lendenwirbel von Dimetrodon macrospondylus, Cope, aus dem Perm von Texas, von der Seite gesehen. - Höhe des Wirbels mit dem höchsten Dornfortsatz: $64 \mathrm{~cm}$. (Nach E. C. Case.) 
Tetraceratops. - Perm von Texas. - Schädel mit zwei Höckerpaaren für Hörner auf den Lacrymalia und Nasalia. Gebiß mit Diastenı. ${ }^{1}$ (Fig. 279.)

\section{F. Palaeohatteriidae.}

Diese Familie ist von G. Baur für die Gattung Palaeohatteria aus denl Pern von Niederhäßlich bei Dresden errichtet worden. Man

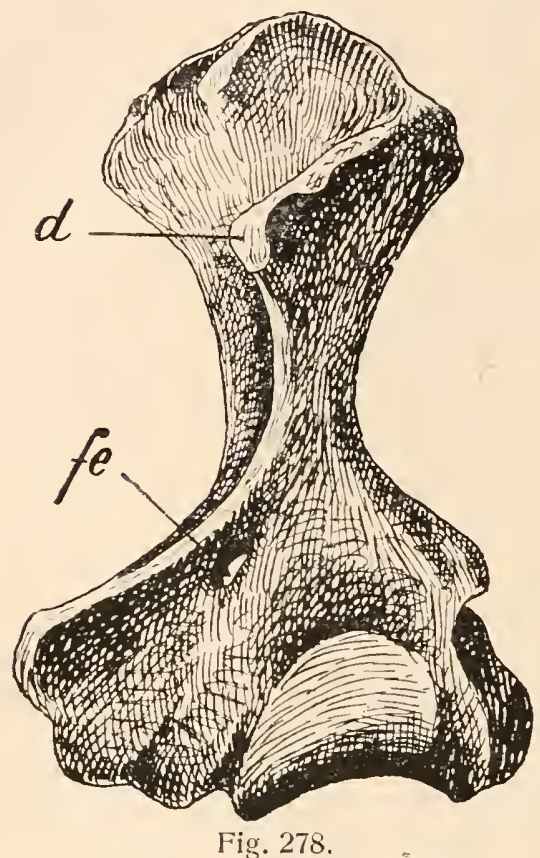

Vorderansicht des linken Humerus von Dimetrodon incisivus, Cope, aus dem Perm von Texas, in $1 / 2$ nat. Gr. (Nach E. C. Case.)

d. $=$ Muskelleiste.

$f e .=$ Foramen entepicondyloideum. hat fast allgemein bis in die letzte Zeit daran festgehalten, daß Palaeohatteria als eine primitive Rhynchocephalengattung anzusehen sei. $\mathrm{Zu}$ dieser unrichtigen Auffassung, deren Unhaltbarkeit S. W. Williston (1914) gezeigt hat ${ }^{2}$, führte namentlich die falsche Beobachtung der Temporalregion. Palaeohatteria besitzt nicht, wie früher angenommen wurde, zwei Paar Temporalgruben, sondern nur die untere Temporalgrube, bzw. eine Öffunng im Schädeldach, die der unteren Temporalgrube von Sphenodon homolog ist.

Palaeohatteria erreichte eine Länge von 40 bis $45 \mathrm{~cm}$ und war, wie aus dem Gebiß hervorgeht, ein Raubtier; seine Lebensweise war terrestrisch. Der Schultergürtel und das Becken, beide von S. W. Williston (1914) auf Grund einer Revision der Leipziger Originale neu dargestellt, beweisen die Zugehörigkeit zu den Theromorphen und besitzen die meiste Ähnlichkeit mit den entsprechenden Skelettelementen von Varanops und Ophiacodon. Die Rippen sind einköpfig wie bei Ophiacodoll. Auf 27 Präsakralwirbel folgen 3 Sakralwirbel. Die Chorda persistiert in der Achse der aus amplicölen Hülsenwirbeln

1 W. D. Matthew, A Four-Horned Pelycosaurian from the Permian of Texas. - Bull. Amer. Mus. Nat. Hist., Vol. XXIV, 1908, p. 183.

2 S. W. Williston, The Osteology of Some American Permian Vertebrates I. Journal of Geology, Vol. XXII, No. 4, May-June 1914 (Contributions from the Walker Museum, Vol. I, No. 8), p. 396-398. Auf die Ähnlichkeit mit den Sphenacodontiden hat schon v. Huene (1910) hingewiesen. 
bestehenden Wirbelsäule; zwischen den Wirbelkörpern sind Hypozentren (= lnterzentren) vorhanden, die in der Kaudalregion als Hänapophysen ausgebildet sind.

Palaeohatteria. - Perm Sachsens. ${ }^{1}$ (Fig. 280.)

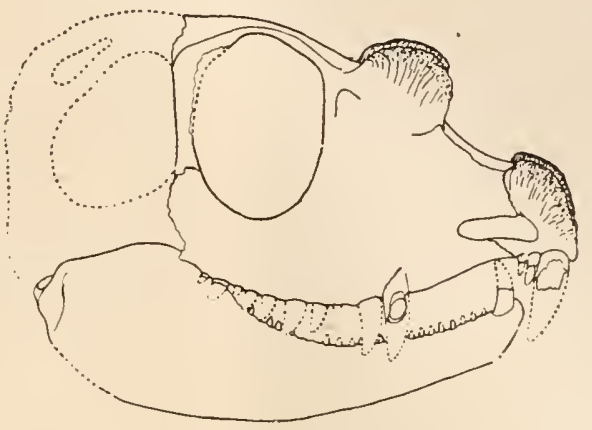

Fig. 279.

Rekonstruktion des Schädels eines vierhörnigen Pelycosauriers,

Tetraceratops insignis, Matthew, ans dem Perm von Texas.

$2 / 3$ nat. Gr. (Nach W. D. Matthew.)

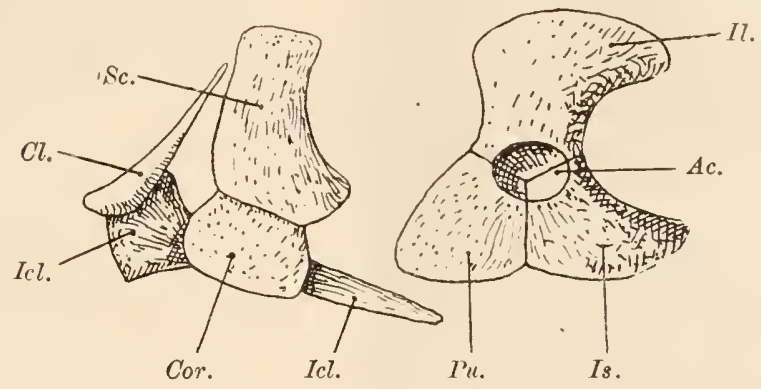

Fig. 280.

Palaeohatteria Iongicaudata, Credner. Schultergürtel (links) und Beckengürtel (rechts), beide der linken Körperhälfte angehörig, von der Seite gesehen. Perm von Niederhäßlich bei Dresden. (Nach S. W. Williston, 1914.)
Sc. $=$ Scapulare.
Il. $=$ llium.
$C l$. = Clavicula.
Pu. $=$ Pubis.
$I c l .=$ Interclavicula.
Cor.$=$ Coracoid.
Is. = Ischium.
Ac. $=$ Acetabulum

\section{F. Poliosauridae.}

Insektivore oder karnivore Reptilien von 1 bis 1,5 m Körperlänge.

1 H. Credner, Die Stegocephalen und Saurier aus dem Rothliegenden des Plauenschen Grundes bei Dresden. - VII. Teil. Zeitschrift d. Deutsch. Geol. Ges., XL. Bd., 1888, p. 490. 


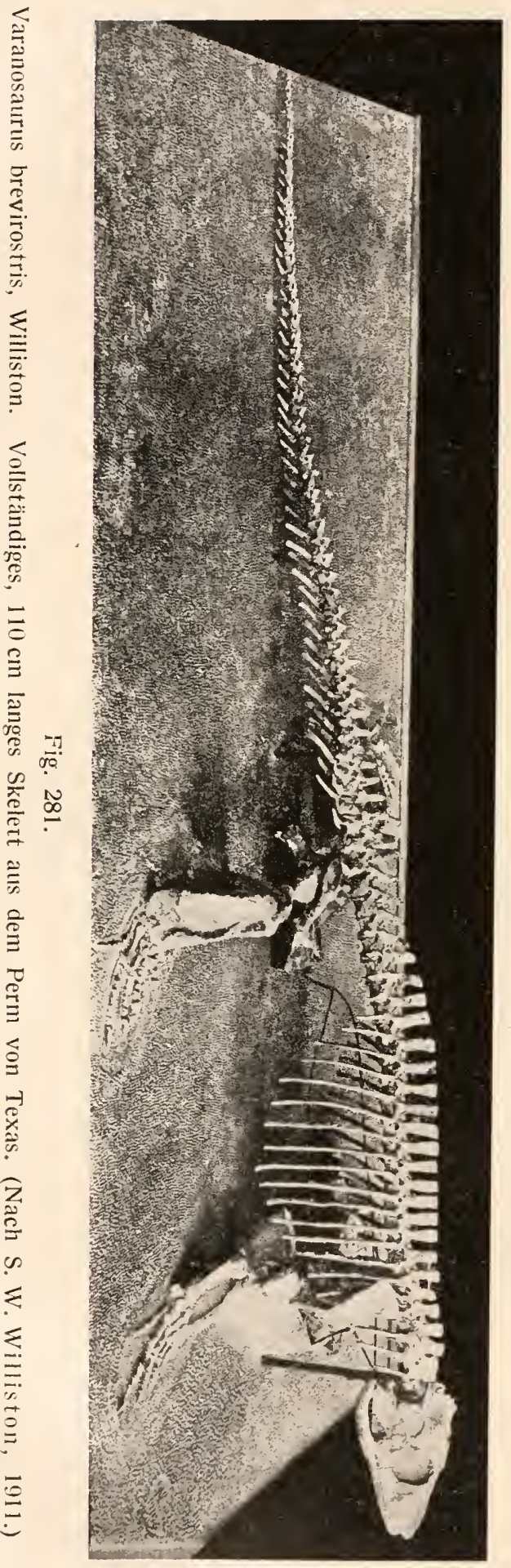

Schädel verlängert, schmal, nicht in die Höhe gezogen. Dermosupraoccipitalia vorhanden (ob auch Tabularia und Supratemporalia?). 27 Präsakralwirbel, 2 Sakralwirbel. Schwanz lang. Dornfortsätze höchstens dreimal so hoch als der Wirbelkörper. Cleithrum fehlt. Rippen zart. Klauen zugespitzt.

Varanops. - Perm von Texas. - Mehrere vollständige Skelette bekannt. Rippen zweiköpfig. Temporalgrube groß. In jeder Kieferlälfte

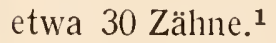

Varanosaurus. - Perm von Texas. - Schädel länger als bei Varanops. Bis 50 Zähne in jeder Kieferhälfte. Rippen einköpfig. ${ }^{2}$ (Fig. 281, 282.)

1 S. W. Williston, Synopsis etc., I. c., 1916, p. 225.

2 Derselbe, American Permian Vertebrates. - Chicago, 1911, p. 85.

F. Broili, Permische Stegocephalen und Reptilien ats Texas. - Paläontographica, LI. Bd., 1904, p. 71 .

E. C. Case, Revision of the Pelycosauria. - I. c., 1907, p. 79.

F. Broili, Über den Schädelbau von Varanosaurus acutirostris. - Zentralbl. f. Mineral. usw., 1914, p. 27.

D. M. S. Watson, Notes on Varanosaurus acutirostris, Broili. - Ann. and Mag. Nat. Hist., London (8), Vol. XIII, 1914, p. 297.

F. Broili, Unpaare Elemente im Schädel der Tetrapoden. - Anatomischer Anzeiger, IL. Bd., 1916, p. 563. 
Poliosaurus. - Perm von Texas. - Etwa 30 Kegelzähne in jeder Kieferhälfte. Vielleicht nur Jugendform einer anderen Gattung, da das Skelett teilweise knorpelig geblieben war. ${ }^{1}$
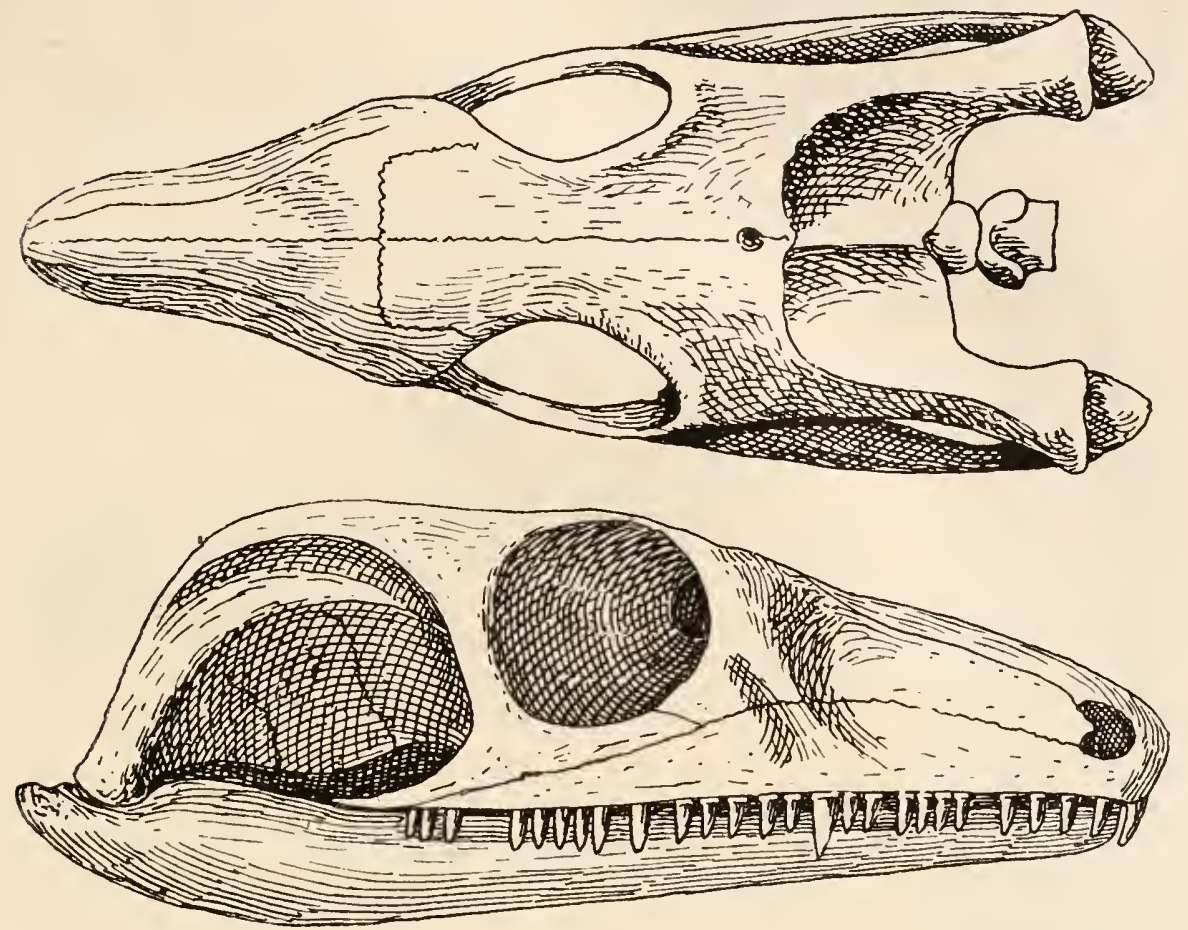

Fig. 282.

Rekonstruktion des Schädels von Varanosaurus brevirostris, Will., aus dem Pernı von Texas. "Oberansicht und Seitenansicht in $2 / 3$ nat. Gr. (Nach S. W. Willis ton.)

Mycterosaurus. - Perm von Texas. - Im Jahre 1914 wurde an Mitchel-Creek ein gut erhaltener Schädel nebst einigen schlecht erhaltenen anderen Skelettresten entdeckt. Der Bau des Schädels beweist nach den Untersuchungen von S. W. Williston (1915 und 1916) seine Zugehörigkeit zu den Pelycosauriern, doch ist die Einreihung in die Familie der Poliosauridae einstweilen noch als provisorische anzusehen, da im Baue der Zähne Unterschiede bestehen. Der allgemeine Charakter des Schädels stimmt am besten mit dem von Varanosaurus überein. ${ }^{2}$ (Fig. 283.)

1 E. C. Case, Revision of the Pelycosauria, 1. c., p. 18.

S. W. Williston, American Permian Vertebrates. - I. c., p. 80.

Derselbe, Synopsis usw., I. c., 1916, p. 225.

2 S. W. Williston, A New Genus and Species of American Theromorpha: Mycterosaurus longiceps. - Journal of Geology, Vol. XXIII, 1915, p. 554. 


\section{F. Ophiacodontidae.}

Küstentiere oder Tieflandbewohner von etwa $2 \mathrm{~m}$ Körperlänge, karnivor oder insektivor. Schädel auffallend hoch, lang und schmal. Zahnreihe geschlossen, Zähne spitz kegelförnig. Orbita weit hinten gelegen, fast dreieckig, dahinter eine sehr kleine obere und unter dieser eine größere untere Temporalgrube, beide durch Postorbitale und Squamosum getrennt. Dornfortsätze niedrig, 27 Präsakralwirbel und 2 Sakral-
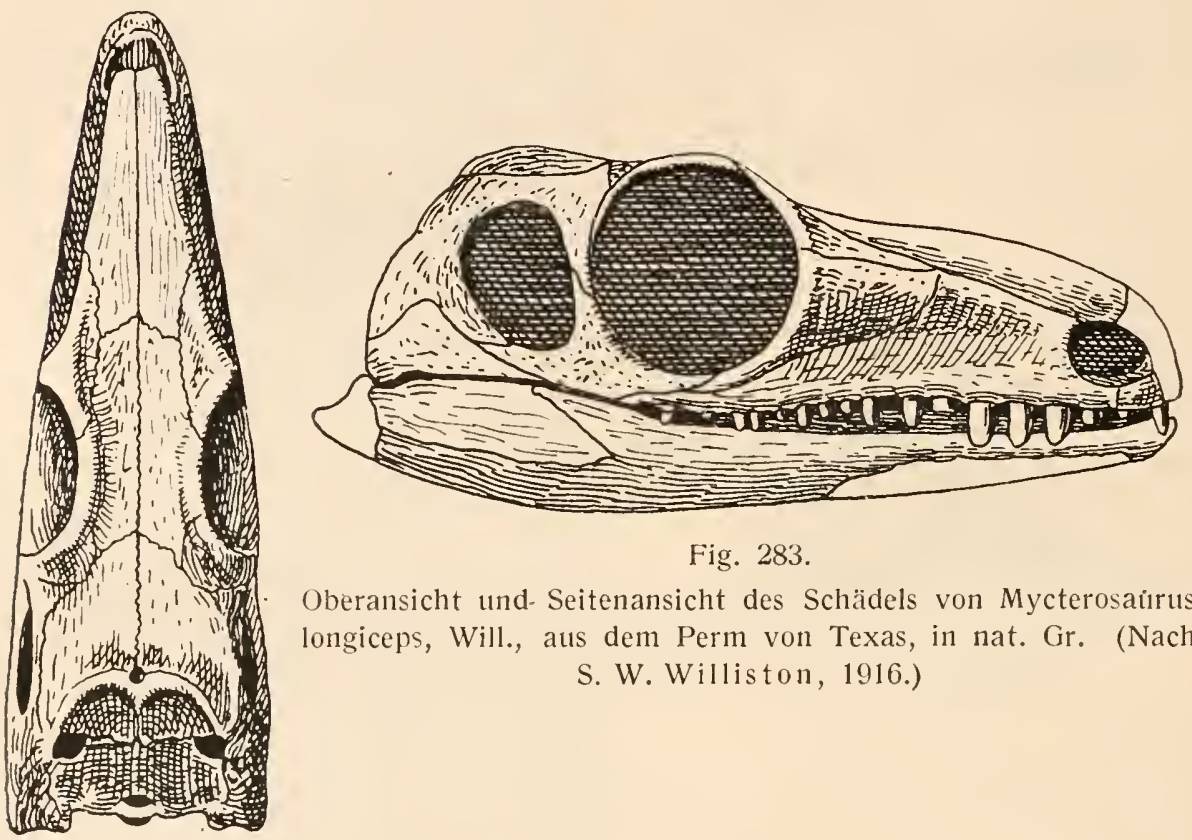

Fig. 283.

Oberansicht und- Seitenansicht des Schädels von Mycterosaürus longiceps, Will., aus dem Perm von Texas, in nat. Gr. (Nach S. W. Williston, 1916.)

wirbel, Schwanz lang. Rippen einköpfig. Brustschultergürtel kräftig; Carpus und Tarsus sehr kräftig und stark verknöchert; Zelıen kurz, relativ schwach, nach vorn einen konkaven Bogen bildend. Bauchrippen vorhanden.

Ophiacodon. - Perm von Neumexiko. - Ein fast vollständiges Skelett bekannt, aber Schädel stark verdrückt. Vielleicht identisch nit der Gattung Theropleura aus dem Perm von Texas. ${ }^{1}$ (Fig. 284 -287.)

\section{F. Caseidae.}

Die Tiere, die ungefähr 1 m Körperlänge erreichten, dürften Pflanzenfresser gewesen sein, da sie sehr kräftige Zähne mit abgerundeten, stumpfen Spitzen besaßen. In jedem Kiefer standen etwa 11 Zähne. Der

1 S. W. Williston and E. C. Case, Description of a Nearly Complete Skeleton of Ophiacodon, Marsh. - Permocarbonif. Vertebr. from New Mexiko. - Carnegie Instit. Publ. 181, 1913, p. 37. 


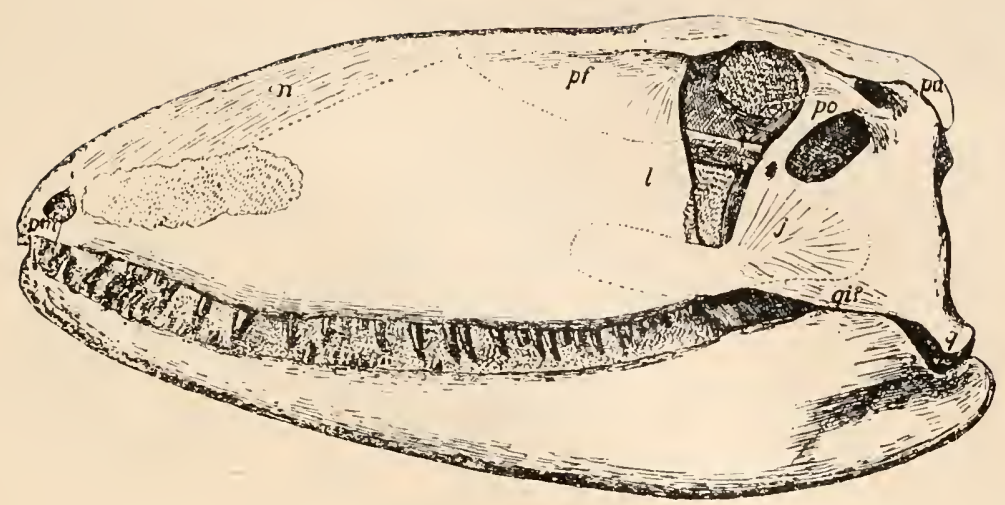

Fig. 284.

Ophiacodon mirus, Marsh; aus dem Permokarbon von Neumexiko. Die Knochengrenzen sind zum Teil recht zweifelhaft; ebenso ist die Deutung der Knochen unsicher. $Z u$ beachten sind die beiden kleinen Schläfengruben hinter der birnförmigen Augenhöhle und das kleine Nasenloch sowie der enorme Gesichtsteil des Schädels bei großer Schnauzenhöhe. 1/3 11at. Gr.

(Nach S. W. Williston und E. C. Case, 1913.)

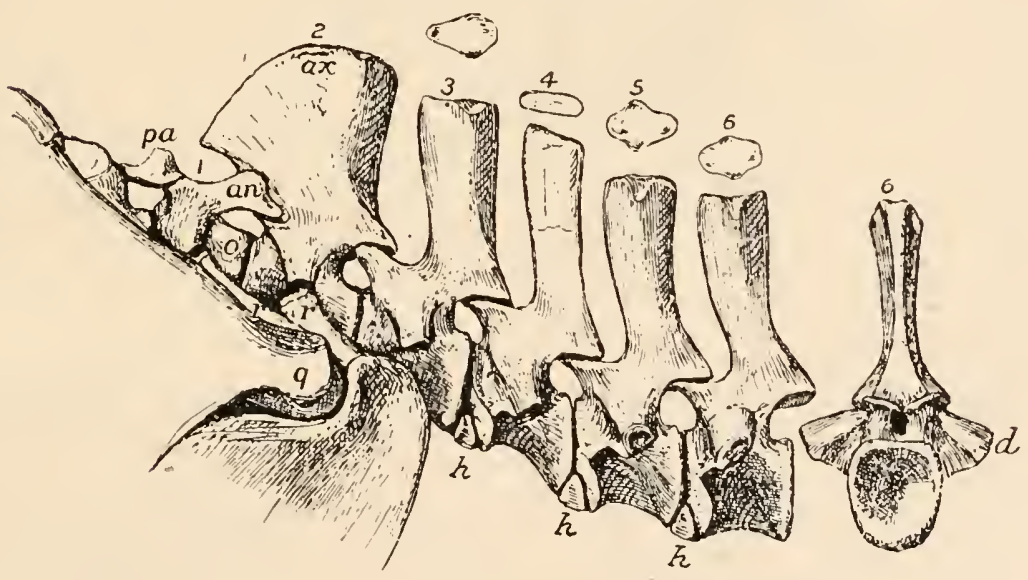

Fig. 285.

Ophiacodon mirus, Marsh; aus dem Permokarbon von Neumexiko. - Die Halswirbel 1-6 von der Seite gesehen; über ihnen die dorsalen Endflächen der Neurapophysen 3-6 von der Oberseite gesehen; rechts der 6 . Halswirbel von vorne. Links ist ein Teil des Hinterhauptes und Unterkiefers sichtbar. $1 / 2$ nat. Gr. (Nach S. W. Williston und E. C. Case.)

pa. $=$ Proatlas.

an. = Neurapophyse des Atlas.

$a x .=$ Axis (Epistropheus).

o. $=$ Processus odontoideus des Epistropheus. $q .=$ Quadratum.

d. $=$ Diapophyse.

$r, r .=$ Rippen.

h. $=$ Basiventrale (Haemapophyse $=$ Hypozentrum = Interzentrum). 
Schädel ist kurz, breit und hoch. Palatinum und Complementare $\left(=\mathrm{C}_{0}\right.$ ronoid aut.) dicht mit kleinen, kegelförmigen Zähnchen besetzt. Ein großes Parietalloch vorhanden. Dermosupraoccipitalia und Tabularia

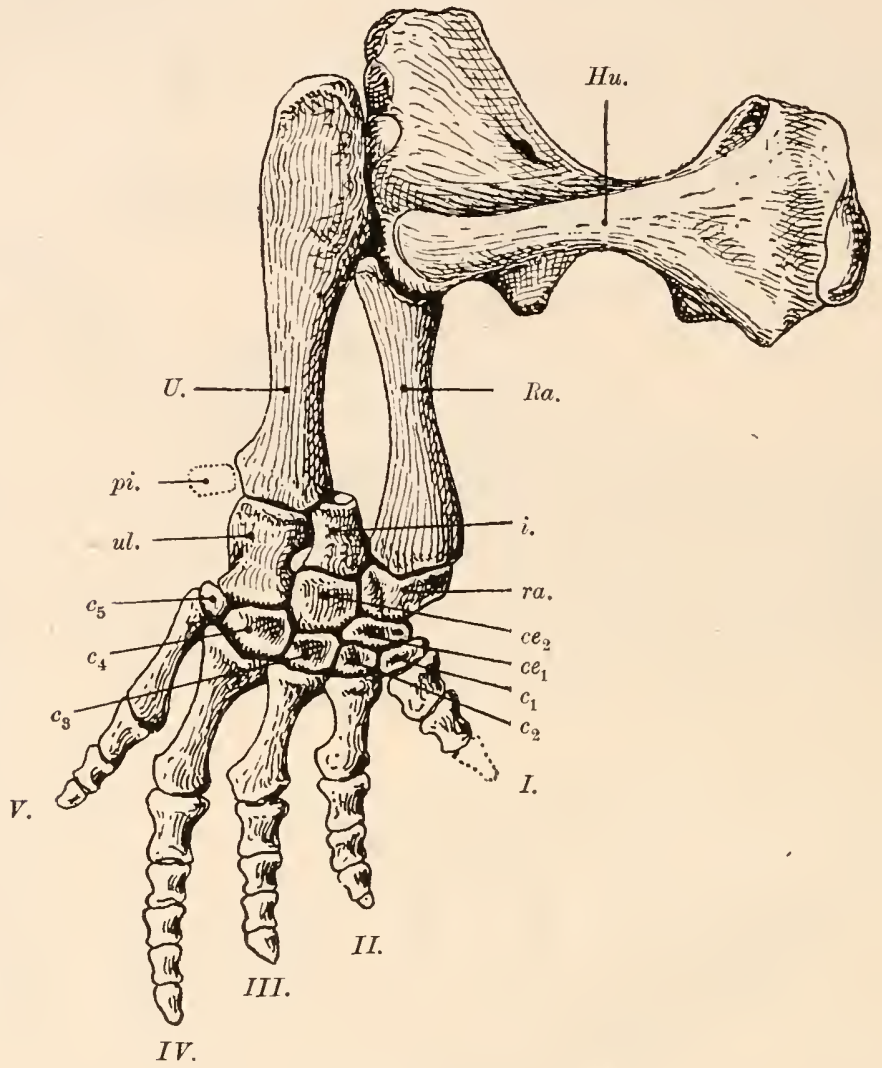

Fig. 286

Rechter Arm von Ophiacodon mirus, Marsh, aus dem Permokarbon von Neumexiko. $1 / 2$ nat. Gr. (Nach S. W. Williston und E. C. Case, 1913.)

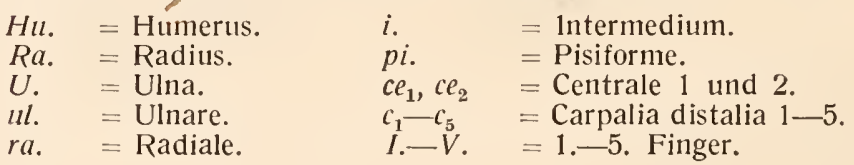

nachgewiesen. Schwanz sehr lang, 25 Präsakral- und 3 Sakralwirbel. Vorderbeine verhältnismäßig kurz und stämmig, Schultergürtel kräftig. Eine Art (Casea Broilii) im Perm von Texas, ${ }^{1}$ (Fig. 288.)

1 S. W. Williston, The Skulls of Araeoscelis and Casea, Permian Reptiles. - Journal of Geology, Vol. XXI, 1913, p. 743.

Derselbe, American Permian Vertebrates. - 1911, p. 112. 


\section{F. Edaphosauridae.}

Die beiden in dieser Familie zu vereinigenden Gattungen (Edaphosaurus und Naosaurus) sind früher mit den Sphenacodontiden (z. B.

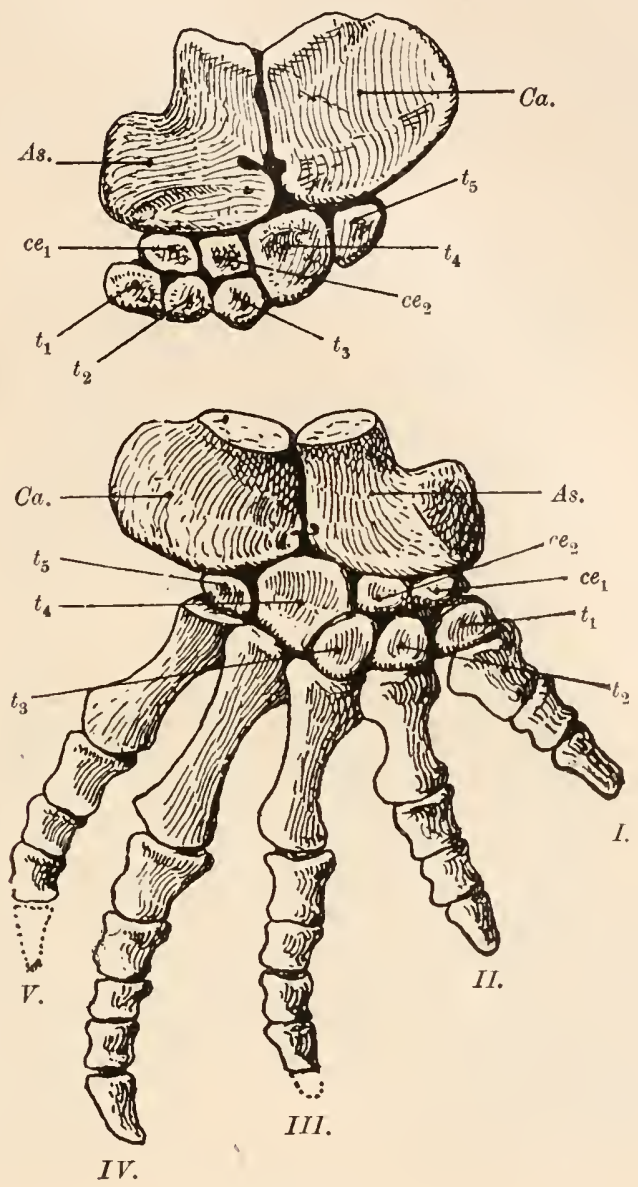

Fig. 287.

Rechter Hinterfuß von Ophiacodon mirus, Marsh, aus dem Permokarbon von Neumexiko; oben: Tarsus von der Dorsalseite, unten: Hinterfuß von der Plantarseite. $1 / 2$ nat. Gr. (Nach S. W. Williston und E. C. Case.)
As. = Astragalus.
Ca. $\quad=$ Calcaneus
$c e_{1}, c e_{2}=$ Centrale 1 und 2 .
$t_{1}-t_{5}=$ Tarsale $1-5$.
$I_{1}-V_{0}=1 .-5$. Zehe.

Dimetrodon) zu einer Familie vereinigt worden, wozu namentlich die analoge Spezialisation der Wirbel geführt hatte, deren Dornfortsätze zu enorm verlängerten Spießen ausgezogen sind. An dem im amerikanischen Museum montierten Skelett des „Naosaurus claviger" waren irrtümlich ein Schädel und die Gliedmaßen von Dimetrodon mit der 
Wirbelsäule von Naosaurus kombiniert worden; neue Funde im Jahre 1911 im Perm von Texas zeigten jedoch, daß Edaphosaurus von Dimetrodon und den Sphenacodontiden überhaupt weit verschieden ist und daß Edaphosaurus und Naosaurus einer Familie angehören, die sich in sehr wesentlichen Merkmalen von den Sphenacodontiden unterscheidet. Wahrscheinlich waren die Edaphosauriden terrestrische Tiere, die aber keine räuberische Lebensweise führten, sondern wahrscheinlich herbivor, vielleicht auch insektivor gewesen sind. Der Schädel ist kurz

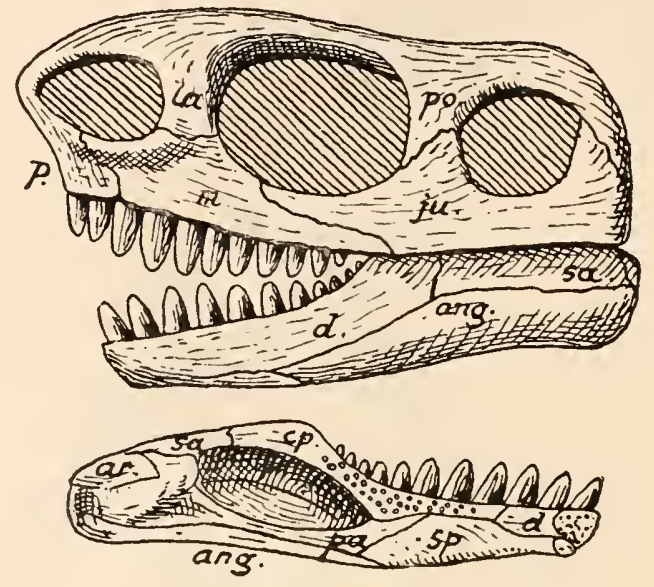

Fig. 288.

Casea Broilii, Will. Perm von Texas. Schädel und Unterkiefer von links, darunter Innenansicht des linken Unterkieferastes. Nat. Gr.

(Nach S. W. Williston.)

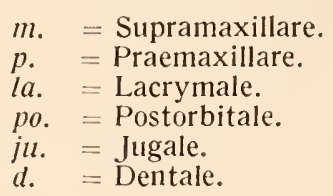

$m$. = Supramaxillare.

p. = Praemaxillare

la. $=$ Lacrymale

ju. = Jugale.

d. $=$ Dentale.

$$
\begin{aligned}
& \text { ang. }=\text { Angulare. } \\
& a r .=\text { Articulare } \\
& s a .=\text { Supraangulare } \\
& c p .=\text { Complementare } \\
& s p .=\text { Spleniale. } \\
& p a .=\text { Praearticulare. }
\end{aligned}
$$

und hoch, dabei relativ schmal und trägt auf den Palatinen und Pterygoiden sowie auf den Vomeres (nach R. Broom, 1910) zahlreiche kleine Zähne, ebenso auf den Kieferknochen. Die Schläfengrube ist sehr groß und wird oben vom Parietale und Squamosum, unten von Jugale und Squamosum begrenzt. Zwischen Jugale, Quadratojugale und Squamosum soll sich nach R. Broom (1910) eine kleine Spalte befinden, ähnlich wie sie auch bei Dimetrodon auftreten soll (nach Broom, 1910), aber die Untersuchungen über neue Funde im Perm von Neumexiko durch S. W. Williston und E. C. Case (1913) haben diesen Befund nicht bestätigen können. Die Rückenwirbel tragen sehr hohe; spitze Dornfortsätze, die den Wirbelkörper um das Zehn- bis Zwanzig- 
fache an Höhe übertreffen und vielleicht durch einen Hautkanm verbunden waren; diese Dornfortsätze waren wieder mit transversalen

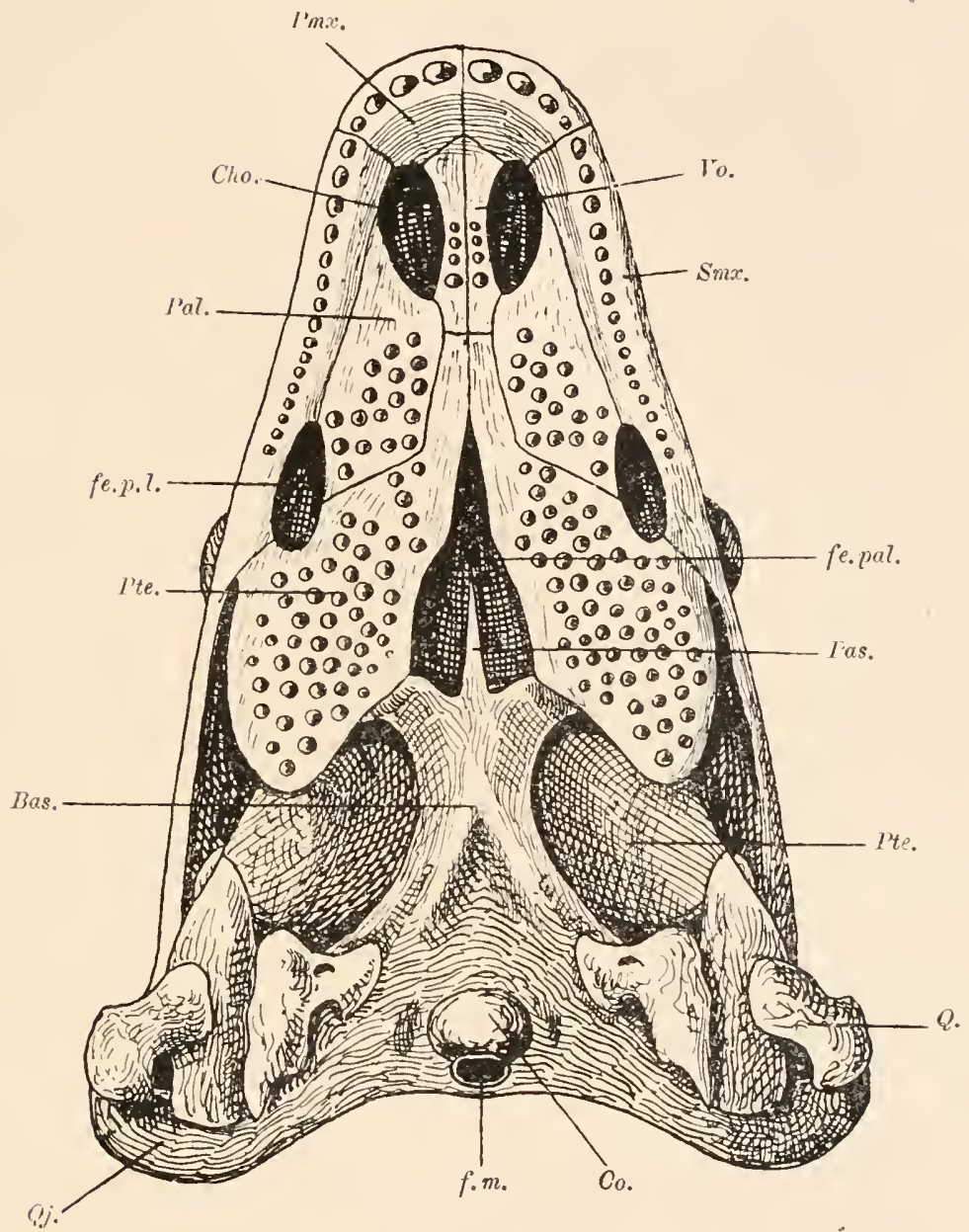

Fig. 289.

Unterseite des Schädels von Edaphosaurus pogonias, Cope, aus dem Perm von Texas; Rekonstruktion in 2/3 nat. Gr. (Nach R. Broom, 1910, ungezeichnet.)

\begin{tabular}{|c|c|c|c|}
\hline $\begin{array}{l}\text { Bas. } \\
\text { Cho. } \\
\text { Co. } \\
\text { fe. pal. } \\
\text { fe.p.l. } \\
\text { f.m. } \\
\text { Pal. }\end{array}$ & $\begin{array}{l}=\text { Basisphenoid. } \\
=\text { Choane. } \\
=\text { Condylus occipitalis. } \\
=\text { Fenestra palatinalis. } \\
=\text { Fenestra palat. lateralis. } \\
=\text { Foramen magnum. } \\
=\text { Palatinum. }\end{array}$ & $\begin{array}{l}\text { Pas. } \\
\text { Pmx. } \\
\text { Pte. } \\
\text { Q. } \\
\text { Qj. } \\
\text { Simx. } \\
\text { Vo. }\end{array}$ & $\begin{array}{l}=\text { Parasphenoid. } \\
=\text { Praemaxillare. } \\
=\text { Pterygoid. } \\
=\text { Quadratum. } \\
=\text { Quadratojugale. } \\
=\text { Supramaxillare. } \\
=\text { Vomer. }\end{array}$ \\
\hline
\end{tabular}

Stacheln besetzt, welche wahrscheinlich frei nach den Seiten vorstanden und eine Hornscheide trugen. Die Rippen sind zweiköpfig, der Schwanz sehr lang; das Sacrum unfaßt zwei Wirbel. Der Hinterfuf 
ist unbekannt. Es ist zweifellaft, ob die beiden Gattungen Edaphosaurus und Naosaurus nicht ident sind.

Edaphosaurus. ${ }^{1}$ - Naosaurus. - Zuerst im Oberkarbon Böhmens (ein Wirbel ${ }^{2}$ ), dann im Perm (Rotliegenden) Deutschlands ${ }^{3}$ und im Perm von Texas, Neumexiko und Ohio. E. pogonias, E. novomexicanus (ein vortrefflich erhaltener Schädel nebst anderen Skelettresten), ${ }^{4}$ E. cruciger, N. claviger $^{5}$, N. microdus sind die wichtigsten Arten. (Fig. 289-292.)

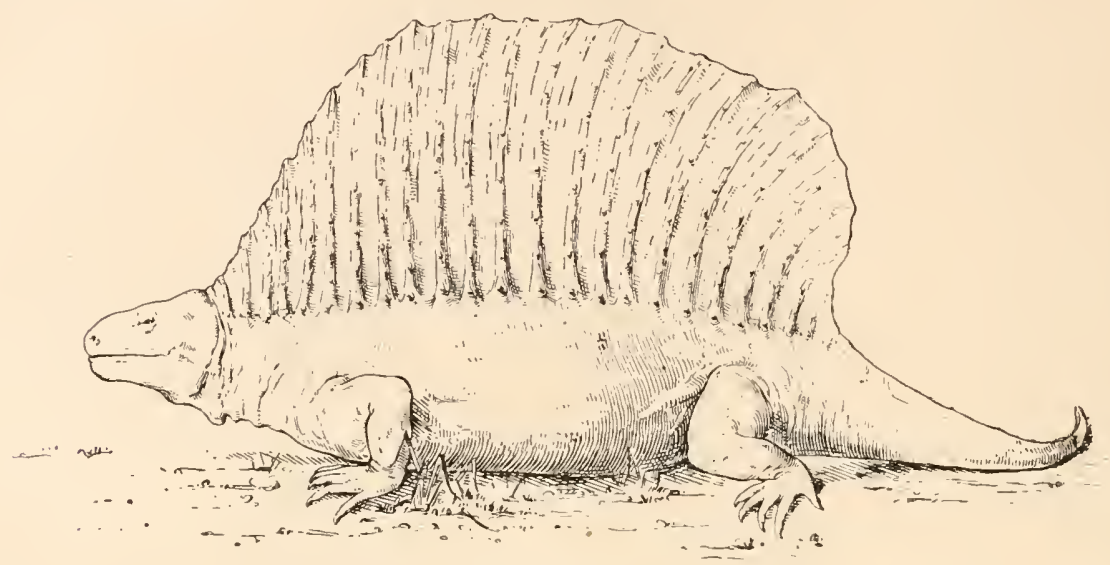

Fig. 290.

Rekonstruktion von Edaphosaurus cruciger, Cope, aus dem Perm von Texas. Körperlänge ıngefähr $182 \mathrm{~cm}$. (Nach E. C. Case, 1914.)

Ctenosaurus. Untere Trias (Buntsandstein) von Rheinhausen bei Göttingen. Nur aus Wirbeln mit naosaurusartigen Dornfortsätzen bekannt. $^{6}$

1 E. C. Case, Revision of the Pelycosauria. - I. c. 1907.

R. Broom, Permian Reptiles of North America and South Africa. - Bull. Anı. Mus. Nat: Hist., Vol. XXVIII, 1910, p. 221.

E. C. Case, Restoration of Edaphosaurus cruciger, Cope. - Amer. Naturalist, Vol. XLVIII, 1914, p. 117.

S. W. Williston, Synopsis of the American Permocarboniferous Tetrapoda, I. c., 1916, p. 230.

2 A. Fritsch, Fauna der Gaskohle und der Kalksteine der Permformation Böhmens. - Bd. I, J883, S. 29; Bd. III, 1885, S. 121; Bd. IV, 1895, S. 86.

3 O. Jaekel, Naosaurus Credneri im Rotliegenden von Sachsen. - Zeitschr. Deutsch. Geol. Ges., LXII. Bd., 1910, S. 526 (Monatsberichte).

${ }^{4}$ S. W. Williston and E. C. Case, A Description of Edaphosaurus, Cope. - Permo-Carbonif. Vert. from New Mexiko. - Carnegie Institution, Publ. 181, p. 71.

${ }^{5}$ H. F. Osborn, A Mounted Skeleton of Naosaurus, a Pelycosaur from the Permian of Texas. - Bull. Amer. Mus. Nat. Hist., Vol. XXIII, 1907, p. 265.

${ }^{6}$ F. von Huene, Neue Beschreibung von Ctenosaurus aus dem Göttinger Buntsandstein. - Centralblatt f. Mineral. usw., 1914, S. 496. 


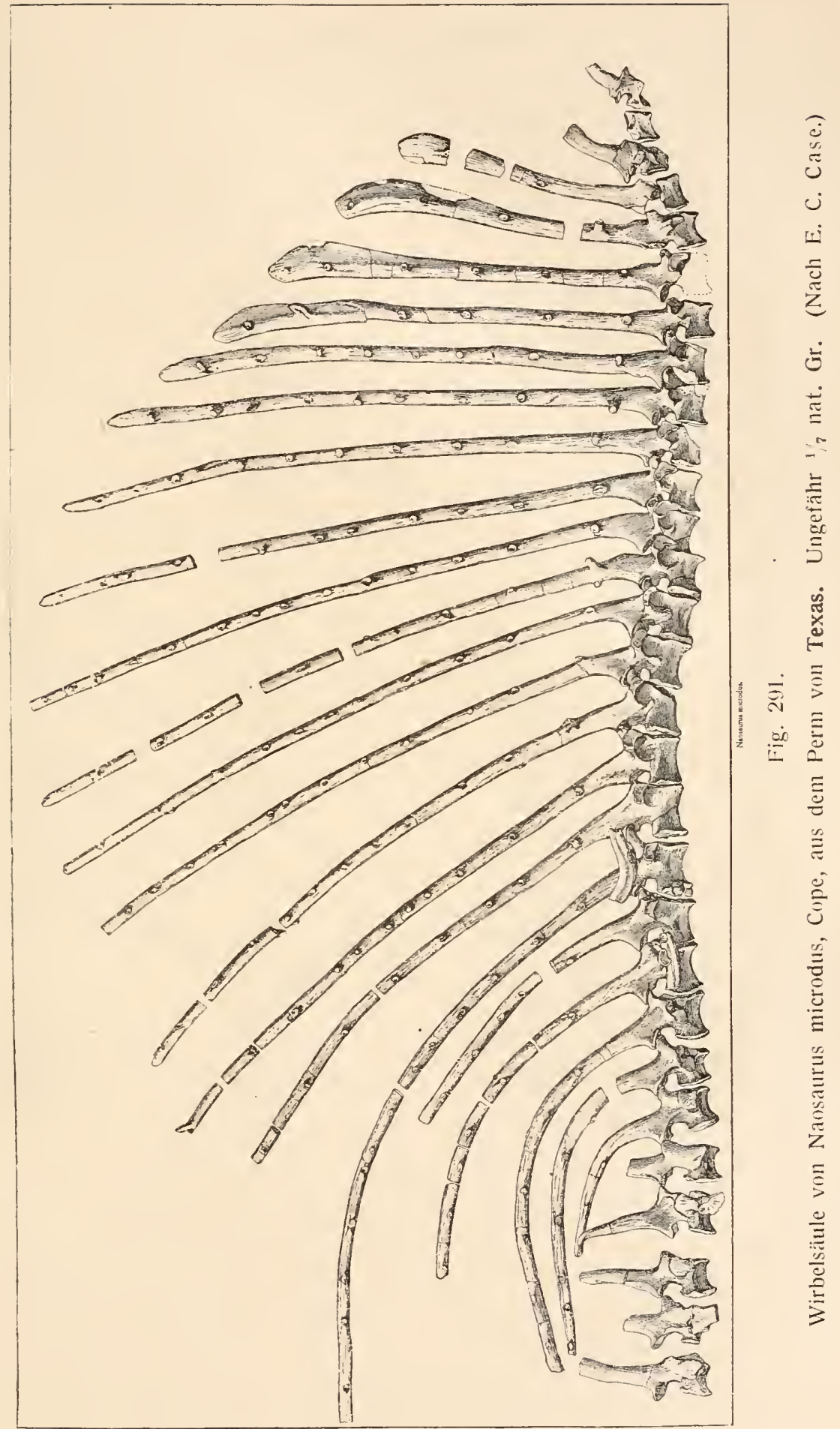




\section{Ordnung: Deuterosauria.}

Im Perm Rußlands sind Reste von Reptilien gefunden worden, die zu zwei Gattungen gehören, für welche die Namen Deuterosaurus und Rhopalodon aufgestellt worden sind. Obwohl der Schädel beidel Typen unvollständig erhalten ist, so ließ sich doch namentlich durch

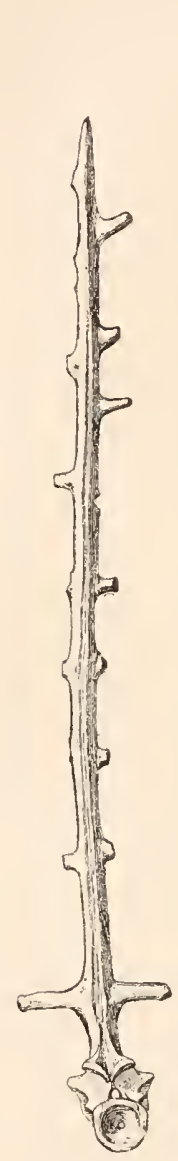

A.

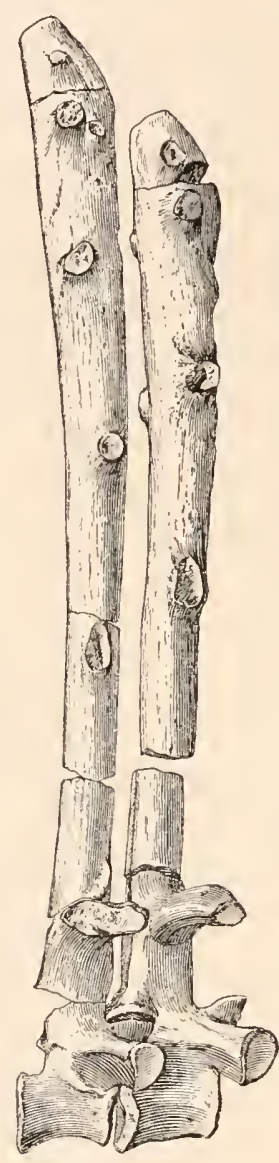

B.

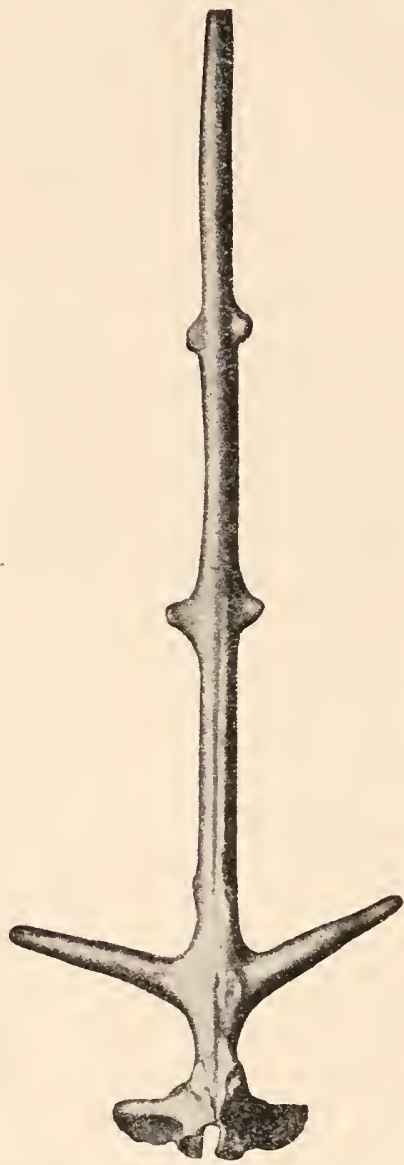

C.

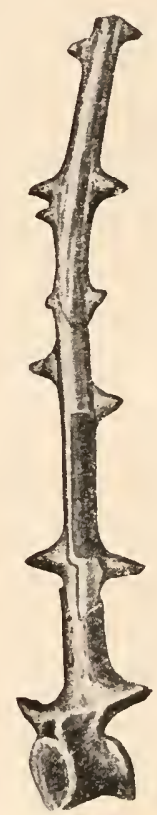

D.

Fig. 292.

A: Vorderansicht des 8. Wirbels von Naosaurus microdus, Cope. Perm von Texas. 1/6 nat. Gr.

B: Seitenansicht zweier Wirbel (hintere Halswirbel oder vordere Brustwirbel) von Naosaurus claviger, Cope. Perm von Texas. 1/6 nat. Gr.

C: Neurapophyse eines Rückenwirbels von Naosaurus microdus, Cope. Perm von Texas. $1 / 3$ nat. Gr.

D: Schräge Seitenansicht eines Wirbels von Naosaurus mirabilis, Fritsch. Oberkarbon von Kounova, Böhmen. 1/6 nat. Gr.

(A-C nach E. C. Case, D nach A. Fritsch.) 
die Untersuclumgen von Huenes feststellen, daß der Aufbau der Seitenwände des Scluädeldaches durchaus eigenartig ist und keinen Anschlub von Denterosaurus an andere Ordnungen gestattet; diese Eigentünlichkeiten bestelıen in der Lage und Form der einzigen Schläfenöffunng, welche der oberen Temporalgrube der Reptilientypen mit zwei lateralen Schläfenöffnungen entspriclıt. Ähnliche Verhältnisse sind unter den zahlreiclıen lebenden und fossilen Stämmen der Reptilien nur noch bei den Placodontiern und bei den Ichthyosaurien bekannt, mit denen jedoch die Gattung Deuterosaurus ebensowenig wie mit Araeoscelis vereinigt werden kann, bei welcher Gattung ein sekundärer Verschlub der unteren Tenporalgrube eingetreten ist. Die meiste Ähnlichkeit in der Form, Lage und unteren Begrenzung der Schläfengrube von Deuterosaurus sclıeint nuit den Schädeln einzelıer Sclıildkrötengattungen vorzuliegen, doch bestehen auch hier so grobe Unterschiede, dab die Sonderstellung von Deuterosaurus als Vertreter einer selbständigen Reptilienordnung gerechtfertigt erscheint. Mit den Sanropterygiern sind keine engeren Beziehungen nachweisbar, ebensowenig mit den Placodontiern.

Der Sclädel ist auffallend kurz und hoch und trägt in den Zwiscluenkicfern jederseits fünf, in Supranaxillare dagegen nur zwei große, in der Form an die groben, gezälnelten Zälne der Splrenacodontiden erinnernde Zähne. Überhanpt bestelıen zu dieser Gruppe der Pelycosaurier verschiedene Beziehungen; da jedoch die Pelycosaurier nur eine untere Schläfengrube besitzen, deren Oberrand von Postorbitale gebildet wird, so scheiden sie mbedingt ans einem engeren Vergleich mit Denterosaturus atus.

Die Verhältnisse der Schädelbasis sind noch zu ungenügend bekannt, tuin darans weittragende Schlüsse auf die verwandtschaftlichen Beziehnngen zu anderen Reptiliengruppen ableiten zu können. Die Choanen von Denterosanrus und Rhopalodon liegen mach Seeley zienlich weit hinten und werden von den Vomeres getremnt, die bei Deuterosaurus sehr klein, bei Rhopalodon anffallend grob sind; wälnend sie bei Deuterosaurus durch die Palatina von den Pterygoidea getrenut erscheinen, stoben sie bei Rhopalodon mit ilnen zusammen, so dab die Palatina bei dieser Gattung seitwärts abgedrängt erscheinen wie bei den Phytosauriern. Die Zähne von Denterosaurus stimunen nach Huene in Form und Kerbung auch mit jenen von Erythrosuchus aus der Fanilie der Pelycosimiiden (Parasuchiern) ïberein, so daß wir also Bezielıungen zu verschiedenen Reptilicnordnungen in Schädel von Deuterosaurus feststellen könurell.

In der Wirbelsäule fehlen die Hypozentren (lnterzentren) in der hinteren Hälfte des Rückens; die Wirbelkörper sind kurz. Die vorderen Rippen sind zweiköpfig, die hinteren einköpfig. 
Eine sehr auffallende und bisher kaunı gewürdigte Tatsache liegt in der häufigen Verschmelzung der Rippen mit den Wirbeln, was den Gedanken an zum mindesten ähnliche Verhältnisse wie bei den Schildkröten nahelegt, ohne daß jedoch daraus weitere Schlüsse abgeleitet werden könnten.

In Extrenitätenskelett bestehen Ähnlichkeiten zwischen den Deı1terosauriern und den Sphenacodontiden; ehenso ist der Schultergürtel jenem der Sphenacodontiden ähnlich. Auch der Armbau ist in beiden Gruppen nahezu derselbe, soweit sich aus den erhaltenen Resten der Deuterosauriden etwas über diese Beziehungen entnehmen läßt (Humerus und Ulna erhalten). Auch das Becken ist älnliclı wie bei Dimetrodon gebaut, zeigt aber auch nach Huene Ähnlichkeiten mit den Parasuchiern.

Soweit sich aus don bisherigen Beobachtungen und Vergleichen ein Urteil gewinnen läßt, nelımen die Deuterosauriden keine hoch spezialisierte Stellung ein, sondern vereinigen eine Reihe von Merkmalen prinitiver Art. Ob sie eine durchaus selbständige Stellung beibehalten haben oder ob von einzelnen, noch unbekannten Vertretern dieser Gruppe eine Brücke zıi anderen Ordnungen hinüberfülırt, kann heute noch nicht ernstlich erörtert werden.

Deuterosaurus. - Perm Rußlands. ${ }^{1}$ (Fig. 293.)

Rhopalodon. - Perm Rußlands. ${ }^{2}$ Schr unvollkommen bekannt.

Außerdem mehrere auf dürftige Reste errichtete Gattungen, deren Stellung ganz unsicher jst.

\section{Ordnung: Testudinata $(=$ Chelonia $)$.}

Die Schildkröten bilden einen selır alten Zweig des Reptilienstannmes, von dem leute noch etwa 232 Arten leben (nach F. Siebenrock, 1909). Ihre genetischen Beziehungen zu den ältesten und prinitivsten Reptilien sind bis in die letzte Zeit sehr unklar gewesen und erst vor kurzem ist durch die Entdeckung einer sehr primitiven Schildkröte (Triassochelys dux) in der oberen Trias von Halberstadt, die von O. Jaekel (1916) eingehend beschrieben wurde, etwas mehr Licht in die bisher dunkle Frage nach der Herkunft der Schildkröten verbreitet worden.

Das hauptsächlichste Merkmal aller Schildkröten besteht in der Ausbildung einer knöchernen Kapsel (Theca), die den Rumpf umschließt

1 F. von Huene, Über Erythrosuchus, Vertreter der neuen Reptilordunng Pelycosimia. - Geologische und paläontologische Abhandlungen, N. F. Bd. X (G. R. Bd. XIV), Jena 1911, S. 38.

E. C. Case, Revision of the Pelycosauria. - Carnegie Institution of Washington, Publ. No. 55, 1907, p. 67.

2 F. von Huene, 1. c. p. 40. 
und sich in ein Rückenschild (Carapax) und Bauchschild (Plastron) gliedert. Die Terminologie der Panzerelemente ist folgende.

In Carapax haben wir zunächst eine mediane Reihe von Knoclıenplatten zu unterscheiden. Der erste und zweite Rückenwirbel wird von einer meist quer verlängerten Platte, der Nackenplatte oder Nuchalplattc überdeckt, an welche sich als horizontale Deckplatten die Neuralplatten anschließen; meist sind acht oder neun solcher Neural-

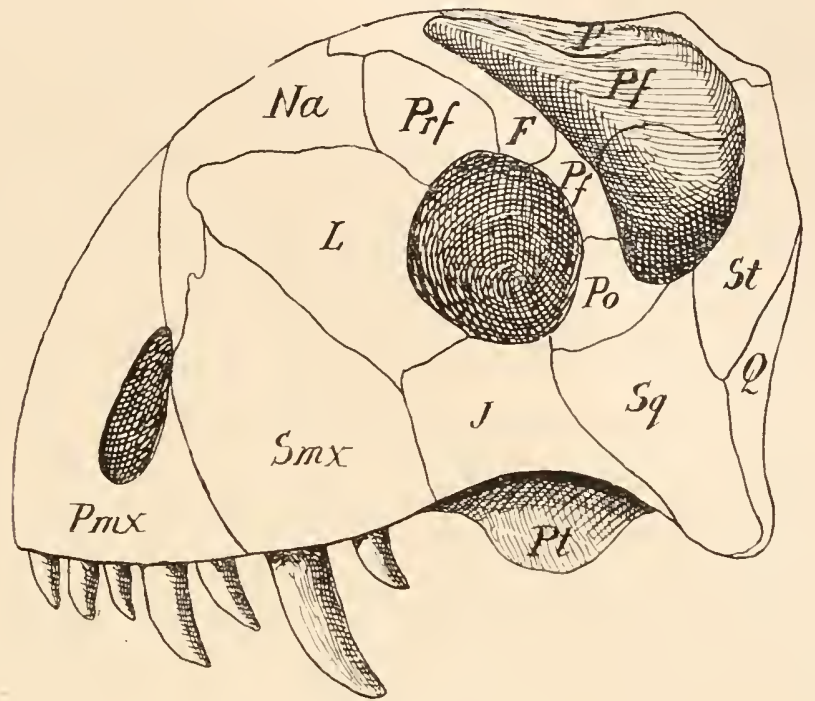

Fig. 293.

Rekonstruktion des Schädels von Deuterosaurus, aus dem Perm Rußlands, in $2 / 3$ nat. Gr. Rekonstruktion auf Grundlage der Zeichnung F. v. Huenes (1911).

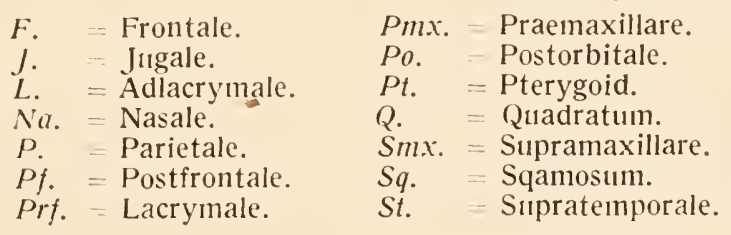

platten vorhanden. Sie legen sich auf die Neurapophysen des 3. bis 10. Rückenwirbels. An die Neuralplatten schließen sich die medianen Pygalplatten (bis drei) an, die meist zu einer versclmolzen sind.

An diese medianen Knochenplatten schließen sich seitlich die paarigen Rippenplatten oder Kostalplatten an, die sich über die Rippen legen und mit ihnen in so feste Verbindung treten, daß sie meist als die verbreiterten Rippen selbst angesehen worden sind.

Die Bildung der Kostalplatten setzt mit den 3. Rückenwirbel ein (O. Jaekel, 1916), und zwar sind ursprünglicl neun Paar Kostalplatten vorhanden gewesen, wie Triassochelys dux zeigt; daß bei den 
lebenden Schildkröten in der Regel nur acht Rippenpaare mit dem Carapax in Verbindung treten, hat seinen Grund darin, daß die beiden letzten in der Regel verschmolzen sind, weshalb die ,achte" Kostalplatte meist die doppelte Breite der vorhergehenden (siebenten) Kostalplatte besitzt.

Der Rand des Carapax wird von einer größeren Zahıl von Randplatten oder Marginalplatten gebildet, die bei den Trionychoidea fehlen.

Der knöcherne Carapax wird von hornigen, großen Mittelschildern und kleineren Randschildern derart überdeckt, daß deren Grenzen nicht mit den Grenzen der Neural-, Kostal- und Marginalplatten zusammenfallen, sondern diesen Grenzlinien ausweichen. Dadurch wird eine stärkere Verfestigung des ganzen Panzers bewirkt. Man unterscheidet die mittlere Reihe von Hornscliildern als die Vertebralscuta; an sie schließt sich beiderseits je eine Reilue von Lateralscuta (oder Costalscuta) und außen die Marginalscuta an. Außerden war aber noch bei Triassochelys zwischen den Reihen der Marginal- und Lateralscuta eine dritte Reille, die der Submarginalscuta, vorhanden, die z. B. bei Proganochelys Quenstedti aus der oberen Trias (mittlerer Keuper) Württembergs nur mehr vorn und hinten erhalten geblieben, aber in der Mitte ausgefallen ist; bei den jüngeren Schildkröten sind die Submarginalscuta ganz verloren gegangen. Die Hornplatte über dem Nuchale bezeiclunet man als Nuchalscutum, die über dem Pygale als Pygalscutum. Sie gehören der Reihe der Marginalscuta an.

Der Bauchschild oder das Plastron unterscheidet sich vom Rückenschild in erster Linie durch das Fehlen einer medianen, durchlaufenden Reihe von Knoclıenplatten. In Plastron einer pleurodiren Schildkröte liegen vorn die paarigen Klavikularplatten oder Epiplastra, die (nach O. Jaekel, 1916) den Claviculae homolog sind; an ihren Hinterrand legt sich das mediane Entoplastron an, das der Interclavicula der Cotylosaurier homolog ist und den einzigen medianen Knochen des Plastrons bildet. Dann folgt ein Paar Hyoplastra und diesem ein Paar Hypoplastra; den hinteren Abschlub des Bauchpanzers bilden die beiden Xiphiplastra. Die Hornschilder, welche sich dem Bauchpanzer auflegen, werden als Armschilder oder Brachialscuta, clie folgenden als Pectoralscuta (Brustschilder), A bdominalscuta (Baucl-selhilder) und Femoralscuta (Schenkelschilder), die beiden hintersten als Analscuta bezeichnet. Die vordersten nennt man Kehlplatten oder Gularscuta. Zuweilen ist auch ein Intergularscutum vorlaanden. Bei der obertriadischen Gattung Proterochersis (aus dem Keuper Württembergs) treten Kaudalscuta und Interkaudalscuta auf, die bisher bei keiner anderen Schildkröte beobachtet worden sind (Fig. 319). 
Die morplologisclue Zusammensetzung des Carapax ist noch strittig. Nach J. Versluys (1914) besteht der Carapax aus dermalen Elementen, dic teils einer tieferen Schicht, teils einer höheren Schicht der Lederhaut ilıren Ursprung verdanken; die ersten wären als thekale, dic zweiten als epithekale Hautverknöcherungen zu bezeiclmen. Als thehale Elemente betrachtet J. Versluys die Costalia und Neuralia (das Nuchale und die Pygalia gehören dazu), ferner die Claviculae (Epiplastron), die Interclavicula (Entoplastron) und die Bauchrippen, welche nach O. Jaekel (1916) an der Bildung des Bauchpanzers von Triassochelys entscheidenden Anteil nehmen (Fig. 304). Als epithekale Elemente sind die Marginalia anzusehen. O. Jaekel (1914) betrachtet dagegen sowolnl die Neuralia als auch die Costalia als Bestandteile des Innenskeletts und nimme mit A. Goette (1899) an, daß die Kostalplatten keine Auflagerungen auf den Rippen, sondern Verbreiterungen der Rippen selbst sind, wälırend die Neuralia die oberen plattenförmigen Verbreiterungen der Neurapophysen darstellen (Fig. $3 \subset 0$. $307-312,314,318,319$ ).

Eine selır merkwïndige V'eränderung hat der Schultergürtel der Schildkröten erfahren. Bei den primitivsten bisher bekannten Sclildkröten, T, assochelys und Proganochelys aus der oberen Trias, ist noch das Cleithrum vorluanden (Fig. 305), geht aber schon bei den Juraformen verloren. Die noch vorhandenen Elemente des Schultergürtels der lebenden Schildkröten bestehen in Coracoid und in der Scapula. Ein Präcoracoid fehlt; der mit diesen verwechselte Knochen ist nur ein von der Scapula aus entspringender Fortsatz, der Processus acromialis; dieser ist ein naclı vorwärts und innen gewendeter stielartiger Fortsatz, der als Oriment schón bei Tliassochelys dux nachweisbar ist (O. Jaekel, 1916); Das Oberende der Scapula scheint sich bei Trassochelys in ein Suprascapulare fortgesetzt zu luaben.

Das Sacrlim wird in der Regel von zwei, mitunter ancl von meln Wirbeln gebildet. Das llimm ist mit dem Sacrum verschmolzen; Pubis und Ischium bleihen entweder frei oder verbinden sich (bei den Pleurodiren) mit dem-Bauchsclild (Fig. 306).

Die GliedmaBen sind bei den Landschildkröten plump und stämmig, bei den Seeschildkröten zu Flossen umgeformt, und zwar sind die Vorderflossen viel gröBer als die Hinterflossen (Fig. 3:2). Nu bei den Trionychoidea sind überzählige Phalangen über die für die Schildkröten normale Phalangenzahl (2, 3, 3, 3, 3) an vierten Finger- und Zehenstralıl zu beobachten; bier treten $4-5$ Plabangen auf, bei Cycloderma und Cyclanorbis kann der vierte Finger sogar 6 Phalangen tragen. Bei den langflossigen Cheloniden ist dagegen dic Phalangenformel normal $(2,3,3,3,3)$, doch sind die Plualangen enornu verlängert.

Der Schäde l besitzt zahlreiche auffallende Spezialisationsmerkmale. 


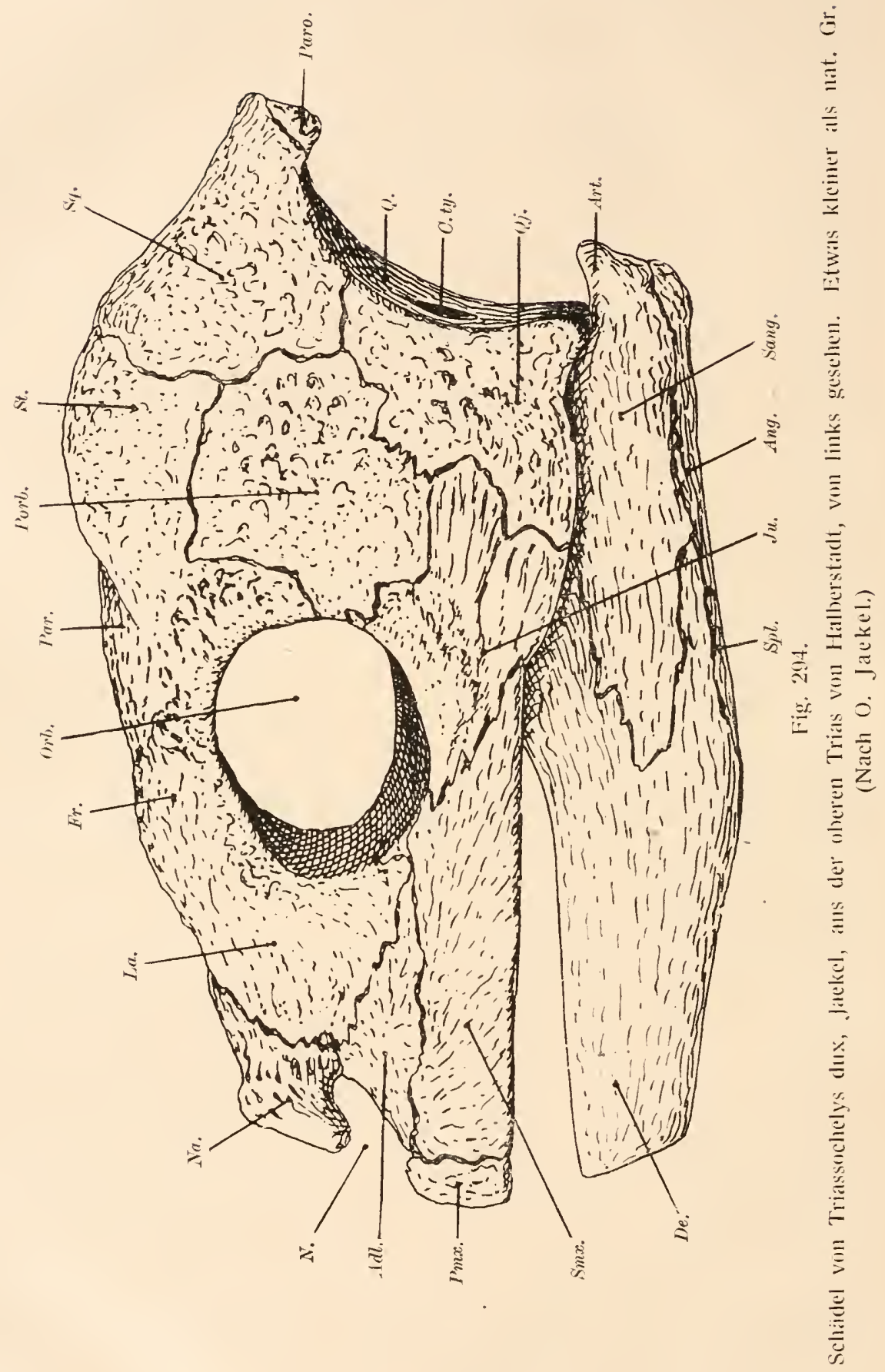


Zu Fig. 294.

Adl. Aólacrymale.

Ang. Angulire.

Art. = Articulare

C. $t y^{\prime}$ = Cavum tympani.

De. $=$ Dentale.

Fr. = Frontale.

Ju. = Jugale.

La. = Lacrymale.

N. = Naris

Na. = Nasale.

Orb. = Orbita.
Par. = Parietale.

Paro. $=$ Paroccipitale.

Pmx. = Praemaxillare

Porb. $=$ Postorbitale,

Q. $\quad=$ Quadratum.

Qj. = Quadratojugale.

Sang. = Supraangulare.

Smx. = Supramaxillare.

$S p l .=$ Spleniale.

$S q . \quad=$ Squamosum.

St. $=$ Supratemporale .

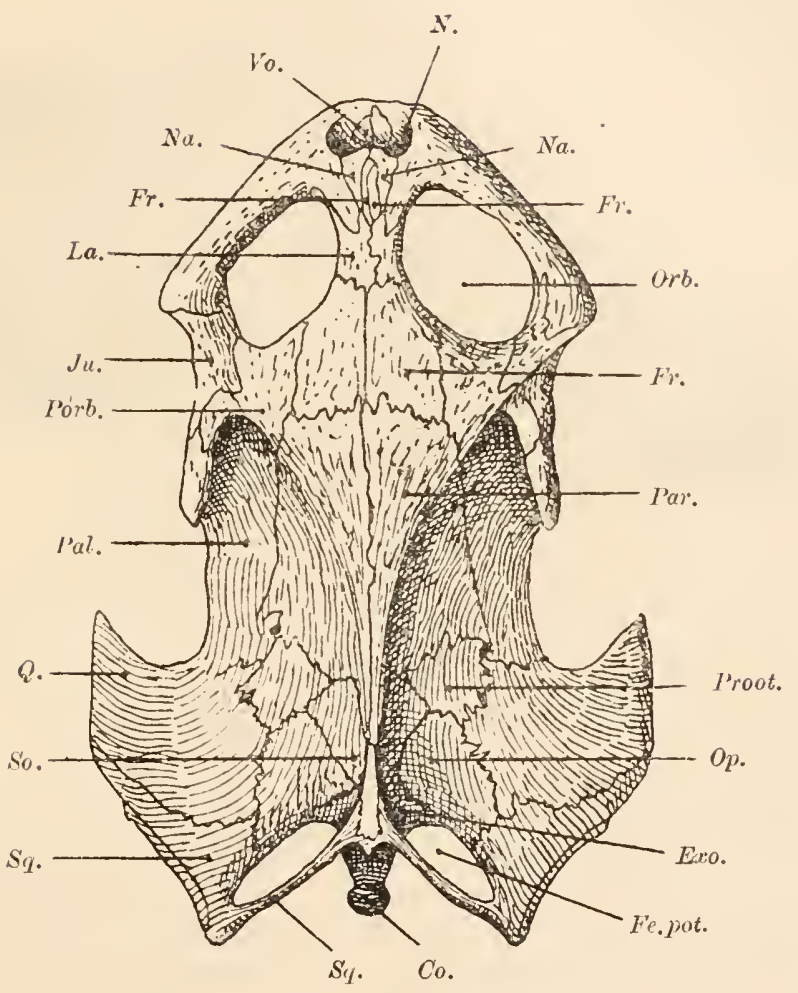

Fig. 295.

Schädel von Hydromedusa Maximiliani, Mikan, aus Brasilien und São Paulo; Dorsalansicht in nat. Gr. (Nach O. Jaekel; Deutungen der Knochen zum Teil abseänc'ert auf Grundlage von Untersuchungen an Hydromedusaschädeln im k. k. Naturh. Hofmus. in Wien.)
Proot. = Prooticum.
Op. = Opisthoticum.
So. $\quad=$ Supraoccipitale.
Exo. = Exoccipitale.
Co. $=$ Condylus occipitalis.
$\mathrm{Fe}$. pot. = Fenestra posttemporalis.

(Die übrigen Abkürzungen wie in Fig. 294.) 

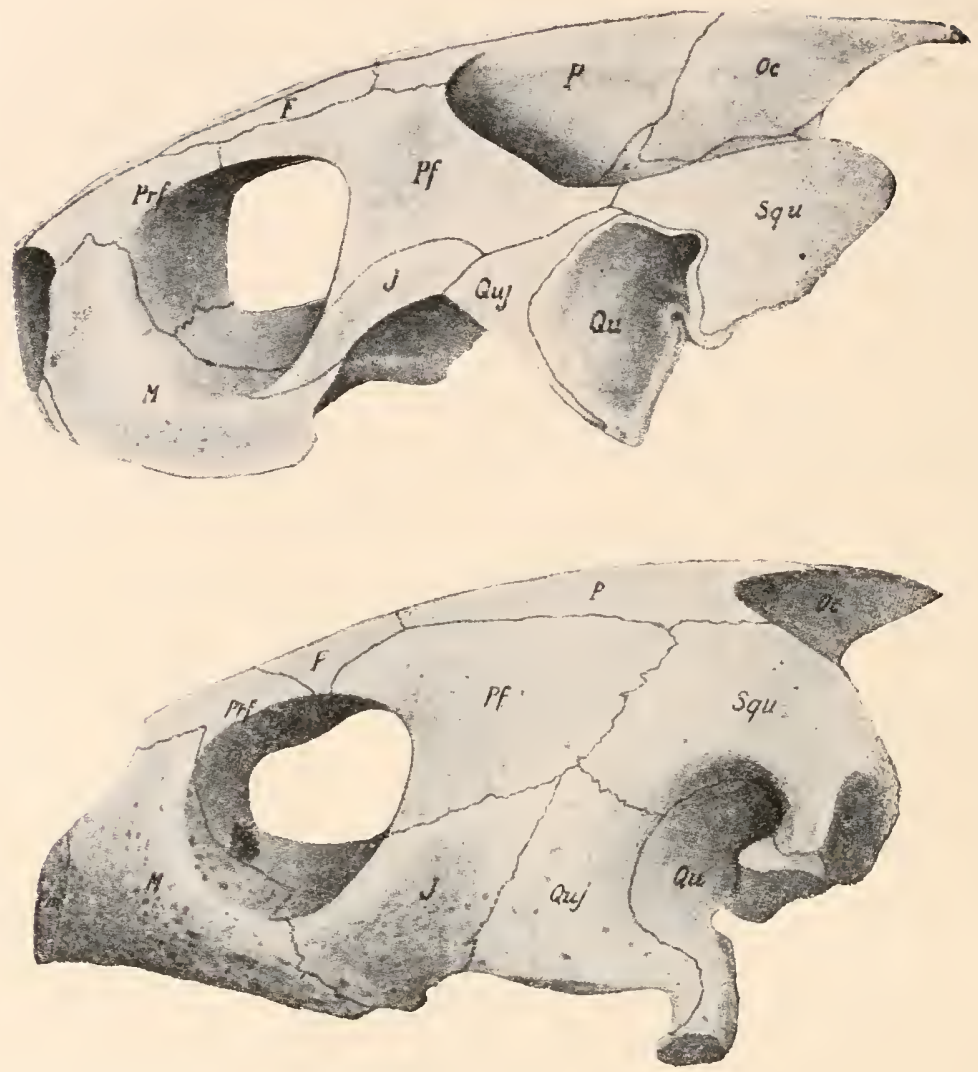

Fig. 296.

Oben: Emys orbicularis L.; unten: Chelonia mydas, L.

(Nach C. Rabl.)

Der primitivere Schädeltypus ist durch Emys, aber nicht, wie C. Rabl meint, durch Chelonia repräsentiert. Aus dem stegalen Schädeltypus von Triassochelys (Fig. 294) entwickelte sich durch Erweiterung der Posttemporalöffunng nach vorne die große, bis zum Scheitelkamm reichende Mnskelgrube, die somit cine ganz andere Entstehungsgeschichte besitzt als die ,obere Temporalgrube“ der meisten spezialisierten Reptilien. Bei Chelonia ist diese Posttemporalgrube, deren obere Querspange (vgl. Hydromedusa, Fig. 295) schon bei Emys fehlt, sekundär verschlossen worden. Der ,pseudostegale" Verschlul, wird durch seitliches Wachstum des Postfrontale, Parjetale und Squamosum gebildet.

Erklärung der Abkürzungen Fig. 296-299:

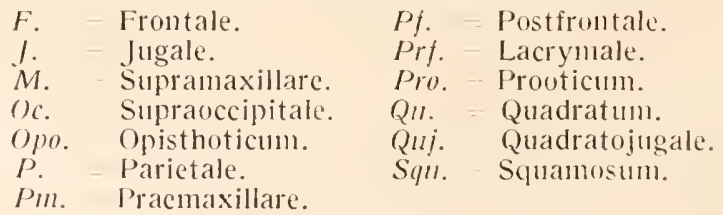


Durch den Fund von Ti iassochelys (Fig. 294) und die von O. Jaekel durchgeführte morphologische Analyse des Schädels darf es jetzt als feststehend betrachtet werden, daß die Schildkröten von Vorfahren mit einen vollständig geschlossenen Schädeldach ohne seitliche Temporalgruben abstanmen, wie dics beim Sclıädel der Cotylosaurier der Fall ist. Nur die Hinterseite des Schädels ist von einem Paar großer Posttemporalöfnungen durchbrochen, die vom Squamosum, Supraoccipitale und Paroccipitale umrahnut werden (Fig. 301).

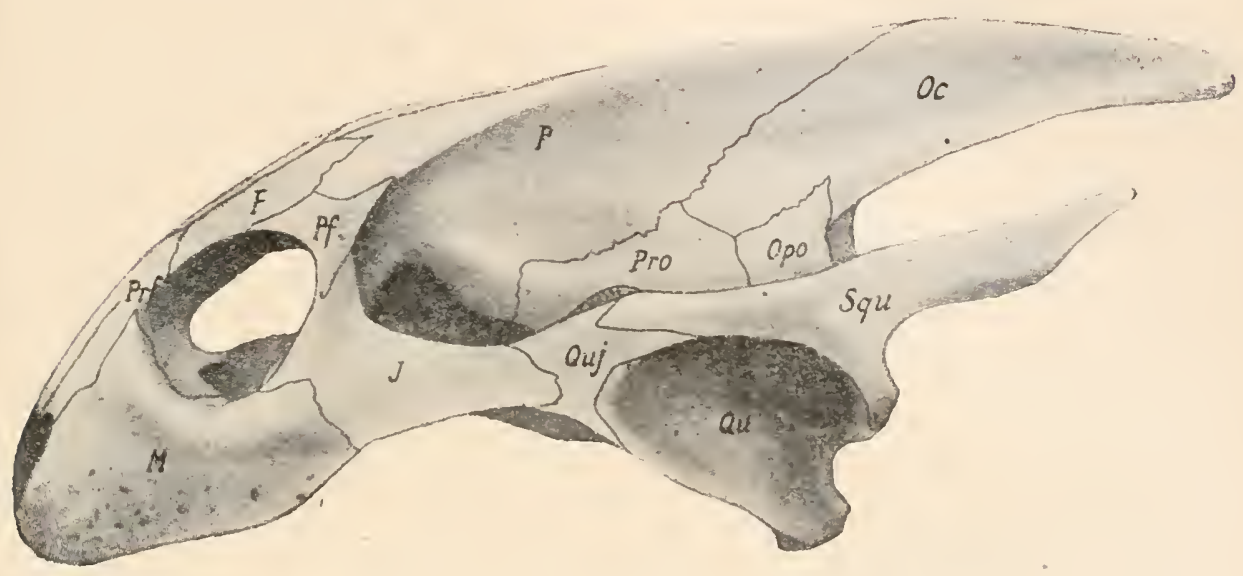

Fig. 297.

Trionyx cartilagineus, Bodd. (Nach C. Rabl.)

Gekennzeichnet durch enorme Erweiterung der Posttemporalgrube nach vorne und Ausdehnung des medianen Schädelkammes nach hinten. Diescr Typus stellt eine höhere Spezialisationsstufe der z. B. durch Emys gekennzeichneten Anpassungsrichtung dar.

In der Regel wird diese Posttemporalöffnung nach vorn erweitert, wobei es zur Bildung einer großen Temporalgrube konmt, deren Lage ziemlich genau dieselbe ist wie bei den Reptilien mit oberer Schläfenöffnung; aber die Spange, die sonst diese obere Schläfengrube abschließt, geht meist verloren und ist nur in wenigen Fällen erhalten, wie in der Familie der Chelyiden, z. B. bei Hydromedusa (Fig. 295), wo sie vom Parietale und Squanısum gebildet zu werden pflegt (sie felılt bei Chelodina).

Die sehr differente Forn der Temporalregion des Schildkrötenschädels hat zu verschiedenen Theorien über die Entstehung der lateralen Temporalgruben und der Wanderung des Jochbogens quer über die Schädelwand von unten vorn (z. B. Trionyx, Fig. 297) nach oben hinten (z. B. Hydromedusa, Fig. 295) Veranlassung gegeben (vgl. die Arbeiten von C. Rabl 
$[1903]^{1}$, J.E.V.Boas $[1914]^{2}$ usw.). Hierbei ist meist nicht berücksichtigt worden, aus welchen Elementen die betreffende Schädelwand und die angeblich wandernde Spange aufgebaut ist. Von einigen Autoren ist der Schädel von Chelon a (Fig. 296) als ein primitiver, dem Cotylosaurierschädel vergleichbarer Typus betrachtet worden ${ }^{3}$, aber die Lagerung der Knochen zeigt deutlich, daß es sich hier um eine sekundäre Schläfendachbildung handelt, die O. Jaekel mit dem Terminus ,tegal" zum Unterschied vom primär ,stegalen“ Typus der Stegocephalen und Cotylosaurier bezeichnet hat. Es ist aber auch noch ein zweiter Weg zur Bildung eines sekundären Schläfendaches bei den Schildkröten nachzuweisen, und dieser liegt bei Podocnemis vor, wo eine sekundäre laterale Verbreiterung des Parietale mit dem Jugale und Quadratojugale in Verbindung tritt, während das sekundäre Schläfendach bei Chelon a vom Parietale. Postfrontale und Squamosum gebildet wird. Dieser sekundäre Verschlub der oberen Temporalgrube scheint nach O. Jaekel eine Folgeerscheinung aquatischer Lebensweise zu sein.

Der bogenförmige Ausschnitt, den wir an vielen Schildkrötenschädelı unterhalb der vom Postfrontale, Jugale, Postorbitale (?) und Quadratojugale gebildeten unteren Abschlußspange der oberen Temporalgrube finden, kann unmöglich der ,unteren“ Temporalgrube der Reptilien homolog sein, da ja die Knochen, welche sonst den unteren Abschluß dieser Öffnung bilden, bei den Schildkröten den Oberrand dieses Ausschnittes bilden. Dieser Ausschnitt ist z. B. bei Testudo (Fig. 298, B) sehr weit und groß; sein Vorderrand wird vom Supramaxillare gebildet. Mitunter fehlt der Joclıbogen vollständig (z. B. bei Teriapene, Fig. 298).

Zähne fehlen den jüngeren Schildkröten gänzlich; nur bei T.iassoclıelys dux stehen dichtgedrängte kleine Zähne auf dem Parasphenoid, den Pterygoidea und dem Vomer (?) und bilden eine Art Hechel. Diese Zähne besitzen eine Kegelform mit abgerundeter Spitze. Außerdem sind bei Triassochelys dux sowohl in den oberen als in den unteren Kieferrinnen rudimentäre Zähne entdeckt worden, die in kleinen Zahnhöhlen liegen (O. Jaekel, 1916). Die rudimentären Zälıne des Oberkiefers und Unterkiefers haben den Schmelzüberzug verloren. Die Befestigungsart ist als eine tliekodonte zu bezeichnen (vgl. p. 248).

Die stets vereinigten äußeren Nasenöffnungen liegen immer weit vorn am Sclnauzenende; die Augenhöhlen sind groß. Die Kiefer

${ }^{1}$ C. Rabl, Über einige Probleme der Morphologie. - Verhandl. d. Anatom. Ges., XVII. Vers. zu Heidelberg 1903, S. 154.

2 J. E. V. Boas, Die Schläfenïberdachung und das Palatoquadratum in ihrem Verhältnis zum iibrigen Schädel bei den Dipnoern und den terrestren Wirbeltieren. - Morpholog. Jahrbuch, 19I4, S. 286.

3 C. Rabl, I. c., S. 167. 


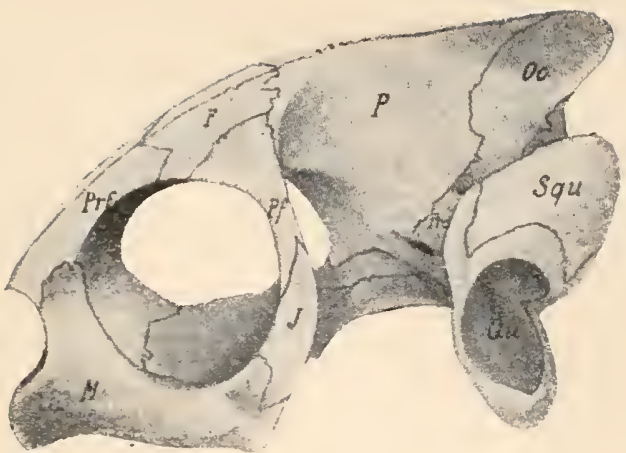

C.

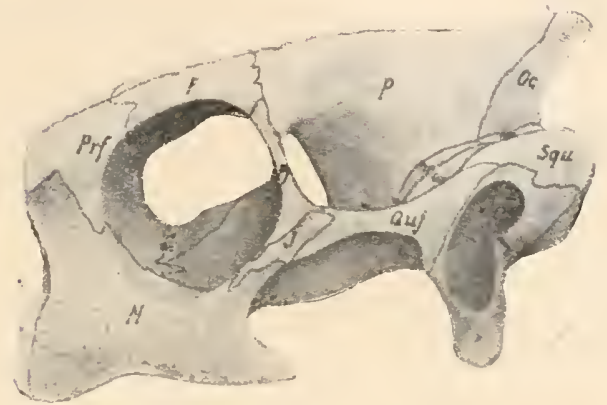

B.

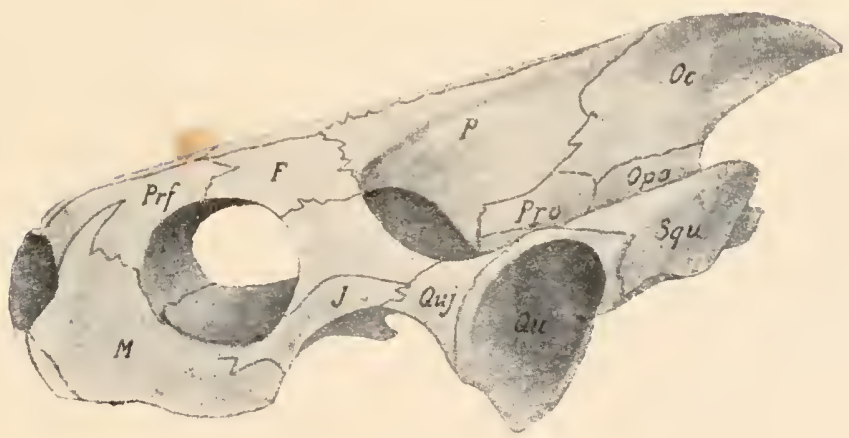

A.

Fig. 298.

A: Geoemyda punctularia, Daud. Suidamerika. - B: Testudo oculifera, Kuhl. Siidafrika. - C: Terrapene ornata, Ag. Nordamerika. (Nach C. Rabl.)

Die primitivste Form dieser Reihe (hinsichtlich des Verhaltens des Jochbogens) ist Geoemyda. Der tiefe, bogenförmige Einschnitt am Unterrande des Jochbogens darf keinesfalls mit der , ,unteren Temporalgrube“ der mit zwei normalen, lateralen Schläfengruben versehenen Reptilien identifiziert werden, da in diesen Fällen der vom Jugale und Quadratojugale gebildete Jochbogen die untere Grenzspange der ,unteren" Temporalgrube bildet. Bei Geoemyda noch kräftig, ist der Jochbogen bei Testudo sehr zart gebaut, bei Terrapene aber gänzlich verloren gegangen, so daß dieser Ausschnitt mit der Posttemporalgrube zu einer einheitlichen, weiten Muskelgrube zusammenfließt. 
besitzen schmeidende Ränder und sind von Hornscheiden überdeckt. Die Praemaxillaria sind rudimentär und liegen vor den äußeren Nasenöfnungen. Sie sind schon bei Tiiassochelys sehr klein. Im Hinterhaupt nehmen die Paroccipitalia einen groben Raum ein.

Die Schildkröten bilden einen geschlossenen Stamm, dessen Entstehung vielleicht noch in die Permzeit zurïckreicht; die nemeren morphologischen Untersuchungen über diese Gruppe festigen die Ansicht immer mehr, daßs sie auf die Cotylosaurier zurückgehen und viełleicht kurze Zeit hindurch ein Pelycosaurierstadium durchlaufen haben,

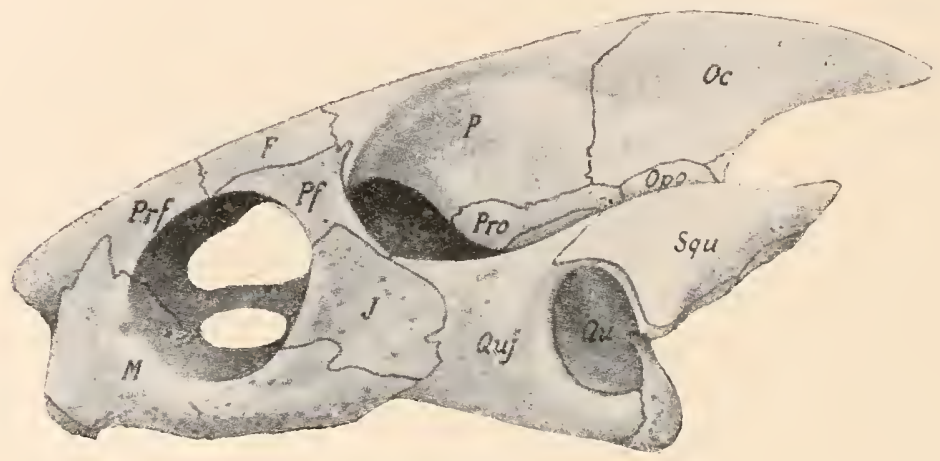

Fig. 299.

Cinosternum scorpioides L., var. integrum, Leconte. Sïdamerika.

(Nach C. Rabl.)

Charakteristisch für diese Schädeltype ist die Höhe des Jochbogens. Dieser Zustand ist als ein sekundärer zu betrachten und von einem Typus abzuleiten, bei dem der Jochbogen niedriger, aber der untere bogenförmige Ausschnitt (wie z. B. bei Geoennyda) vorhanden war. Die Erhöhung des Jochbogens ist hier durch ein sekundäres Wachstum von Supramaxillare, Jugale und Quadratojugale zustande gekommen und zwar wird der Hauptteil dieses sekundär vergrößerten Jochbogenabschnittes vom Quadratojugale gebildet.

wobei sie die Reduktion der Phalangen und eine obere Temporalgrube erwarben. Die ältesten Schildkröten sind zweifellos nicht aquatische, sondern terrestrische, und zwar aller Wahrscheinlichkeit nach grabende Tiere gewesen, die bei dieser Lebensweise einen Panzer erlhielten, älnnlich wie wir dies für die Vorfahren der Gürteltiere annehmen müssen. Die ältesten bekanıten Schildkröten Tiassochelys, Proganochelys und Proterochersis sind schon mit Rücksicht auf den gewölbten Carapax als Landschildkröten zu betrachten. Untor diesen ist der Stanum der Cryptodira der primitivere; die noch lebenden Testudiniden gehören zu den primitivsten Vertretern der lebenden Testudinaten, da sie die meisten altertümlichen Merkmale bewahrt haben. Dagegen sind die Cheloniidea ein spezialisierter Seitenzweig des Schildkrötenstammes. 
Die Trionychoidea haben sich wahrscheinlich sehr früh (viel frülıer als in der Kreide) von Landschildkröten abgezweigt und sind als konservative Gruppe auf der früh erreichten Spezialisationshöhe, die sie heute einnehmen, stehen gebliehen. Der letzte Hauptzweig des Schilcl-

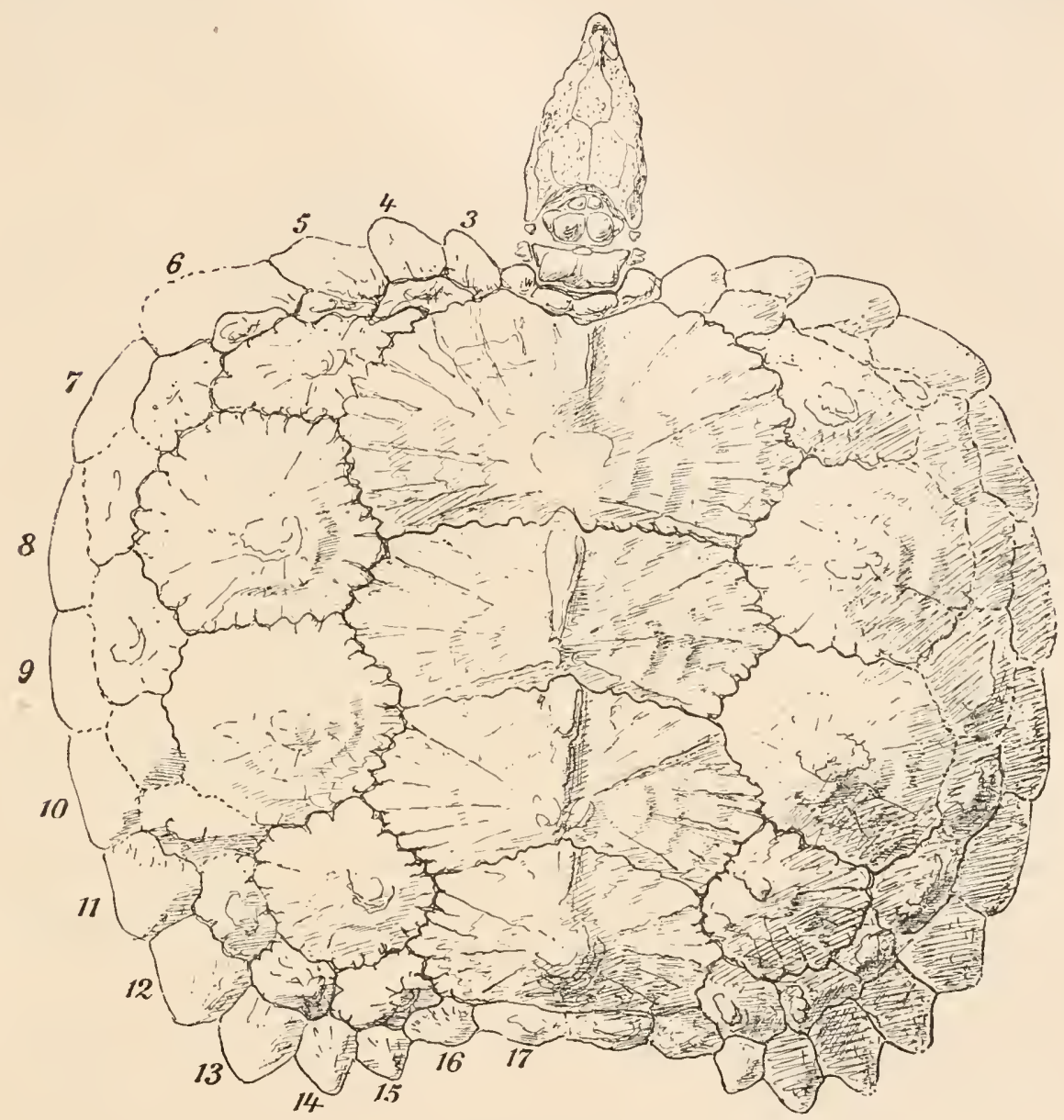

Fig. 300 .

Oberansicht des Carapax von Triassochelys dux, Jaekel, obere Trias von Halberstadt. Die gegenwärtige größte Breite von $60 \mathrm{~cm}$ war im Leben geringer, da` der Gesteinsdruck den Carapax in die Breite gedrückt hat. (Nach O. Jaekel.) $3-I 7=$ Marginalia.

krötenstammes, die Pleurodiren, muß sich gleichfalls schon sehr frülızeitig von den Cryptediren getrennt haben; die obertriadische Gattung Proterochersis zeigt in der festen Verwachsung des Beckens mit dem Plastron unverkennbare Pleurodirenmerkmale und darf als der älteste Vertreter der Pleurodiren betrachtet werden. 


\section{Unterordnung: Cryptodira.}

Kopf und Hals vertikal in die Schale zurückzielıbar, keine oder nur kurze Querfortsätze an den Halswirbeln vorhanden; Becken mit dem Plastron nicht fest verbunden; letzteres mit 11 oder 12 Hornschildern bedeckt; Gliednaßen mit Klump- oder Schwimmfüßen versehen, an denen 4-5 Krallen vorhanden sind; Phalangen mit Kondylen; Schale mit Hornschildern bedeckt. (Nach F. Siebenrock, 1909.)

\section{F. Triassochelyidae.}

Triassochelys. - Obere Trias(Keuper) von Halberstadt. ${ }^{1}$ - Schäclel, Carapax und Plastron sowie das Innenskelett fast vollständig, Gliedmaßen unvollständig bekannt. Der Carapax umfaßt 9 Kostalien, mehr als 30 Marginalien und 12 Neuralien, deren vorderste zu einem Nuchale verwachsen sind; die Pygalia liegen dem Sacrum auf. Zahlreiche marginale Hornschilder, die in zwei parallelen Kränzen die vier großen Neuralscuta und die beiderseits von diesen liegenden vier kleinen Lateralscuta umrahmen; der innere Kranz ist als die Reihe der Submarginalscuta anzusehen (Fig. 300).

Das Bauchschild (Fig. 304) ist hauptsächlich aus verwachsenen Bauchrippen zusammengesetzt. lm Schultergürtel ist ein Cleithrum vorhanden; die Scapula ist in einen kurzen Akromialfortsatz verlängert (Fig. 305).

Der Schädel trägt nit Ausnahme der großen posttemporalen Durchbruclusöffnungen keine Temporalgruben, ist also stegal gebaut (Fig. 294, $301)$.

Auf dem Parasphenoid, den Vonteres und Pterygoidea stehen Zähne, die eine Hechel bilden (Fig. 302). Außerdem sind in den Zahnrinnen des Ober- und Unterkiefers kleine, in Alveolen steckende Zahnrudimente zu beobachten (Fig. 303).

Die Deckknochen des Unterkiefers sind normal entwickelt, aber miteinander verwachsen.

Nur eine Art(Triassochelys dux) in einem Exemplar bekannt (Fig. 300). Die Länge des Carapax beträgt in der Mittellinie $54 \mathrm{~cm}$, die größte Länge erreicht er seitlich von der vorn und hinten eingebuchteten Mittellinie

1 O. Jaekel, Die Wirbeltierfunde aus dem Keuper von Halberstadt. II. Teil: Testudinata. - Paläontologische Zeitschrift, II. Bd., Berlin 1916, S. 88.

Da der von O. Jaekel aufgestellte Name „Stegochelys“ bereits vor längerer Zeit von R. Lydekker für eine andere fossile Schildkröte aufgestellt wurde (auch von Zittel in seinem Handbuch der Paläozoologie, III. Bd., S. 546 angeführt), so ist eine andere Benennung dieses neuen Schildkrötentyps aus der Trias von Halberstadt notwendig geworden. O. Jaekel hat mir auf eine diesbeziigliche Anfrage 1917 mitgeteilt, daß er nummehr den Namen Triassochelys für die von ihm als Stegochelys dux beschriebene Gattung und Art vorschlägt. 
mit $65 \mathrm{cml}$. Der $15 \mathrm{~cm}$ lange Schädel ist sehr stark verknöchert und wird in dieser Hinsicht nur von der Gattung Miolania übertroffen.

Proganochelys. - Obere Trias (Keuper) Württembergs. ${ }^{1}$ Älnlich Triassochelys, aber unvollständig bekannt. Die Reihe der Subnarginalia auf den vorderen und hinteren Teil des Carapax beschränkt, in der

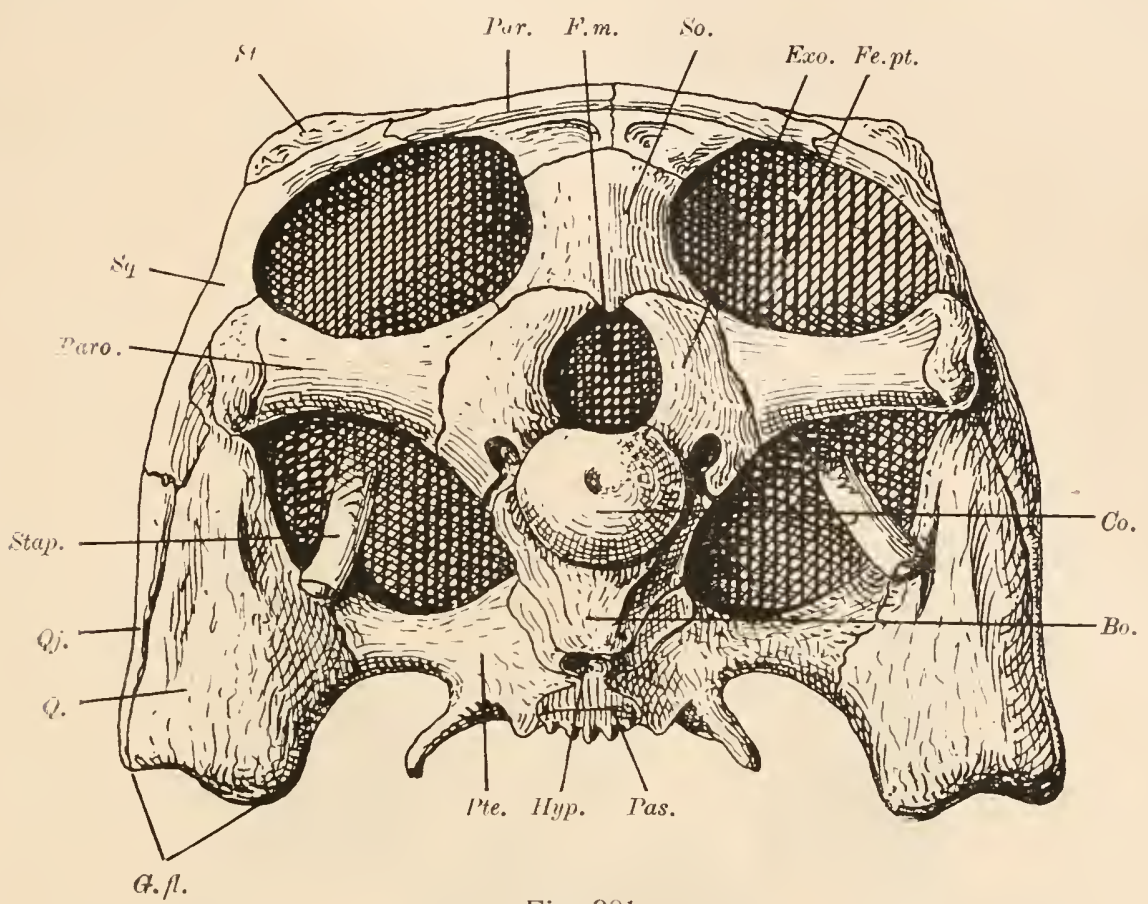

Fig. 301.

Hinteransicht des Schädels von Triassochelys dux, Jaekel, aus der oberen Trias von Halberstadt. Etwas kleiner als nat. Gr. (Nach O. Jaekel.)

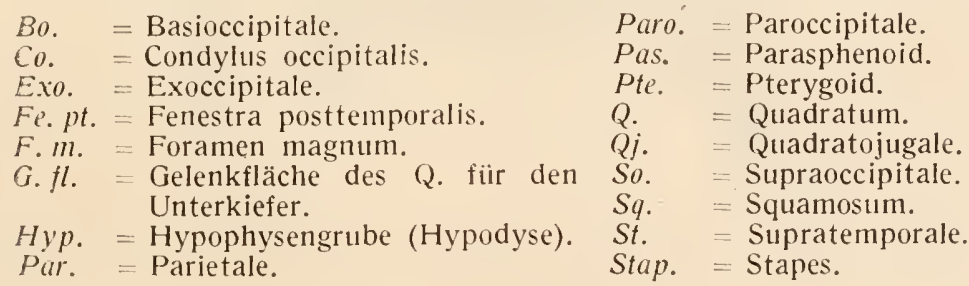

Mitte des Randes verloren gegangen. Die Marginalia an den Hinterecken zu groBen Kegelhöckern ausgezogen (Fig. 307). Das Becken ist unbekannt. E. Fraas hatte eine pleurodirenartige Verbindung des Beckens mit dem Plastron angenommen, doch ist dies sehr zweifelhaft.

1 E. Fraas, Proganochelys Quenstedti Baur (Psammochelys keuperiana Qu.). - Ein neuer Fund der Keuperschildkröte aus dem Stubensandstein. - Jahreshefte des Vereins für vaterländische Naturkunde in Württemberg, LV. Bd., 1899, S. 401. 


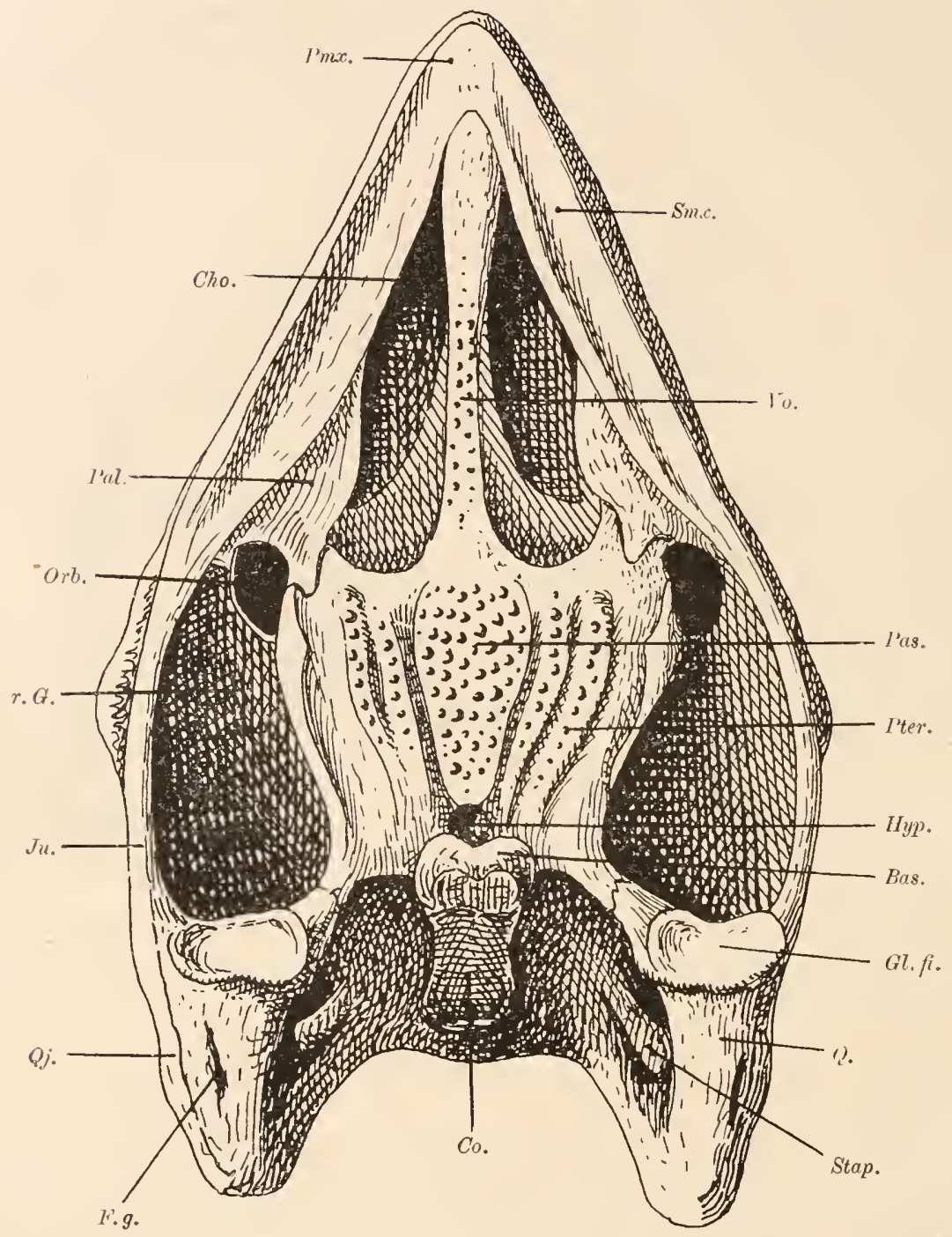

Fig. 302.

Unterseite des Schädels von Triassochelys dux, Jaekel, aus der oberen Trias von Halberstadt, in nat. Gr. (Nach O. Jaekel, 1916.)

\begin{tabular}{|c|c|c|}
\hline $\begin{array}{l}\text { Bas. } \\
\text { Cho. } \\
\text { Co. } \\
\text { F.q. } \\
\text { Gi.tl. }\end{array}$ & $\begin{array}{l}\text { Basisphenoid. } \\
\text { Choane. } \\
\text { Condylus occipitalis. } \\
\text { Foramen quadrati. } \\
=\text { Gelenkfläche des Q. für } \\
\text { den Unterkiefer. } \\
=\text { Hypophysengrube. } \\
=\text { Jugale. } \\
=\text { Palatinum. }\end{array}$ & $\begin{array}{l}\text { Pas. }=\text { Parasphenoid. } \\
\text { Pmx. }=\text { Praenaxillare. } \\
\text { Pter. }=\text { Pterygoid. } \\
\text { Q. }=\text { Quadratum. } \\
\text { Qj. }=\text { Quadratojugale. } \\
r . G .=\text { rechte Gaumengrube. } \\
\text { Smx. }=\text { Supramaxillare. } \\
\text { Stap. }=\text { Stapes. } \\
\text { Vo. }=\text { Vomer. }\end{array}$ \\
\hline
\end{tabular}


Die übrigen fossilen Vertreter der Cryptodiren, unter denen namentlich die Gattung Testudo häufiger (in Oberpliozäı Ostindiens durch die - Riesenform Testudo Atlas mit 2 m Carapaxlänge und im Pliozän von Serrat (Ostpyrenäen) durch T. Perpiniana mit 1,20 m Carapaxlänge) vertreten ist, die auch schon unteroligozäne Riesenformen unfaßt (Testudo

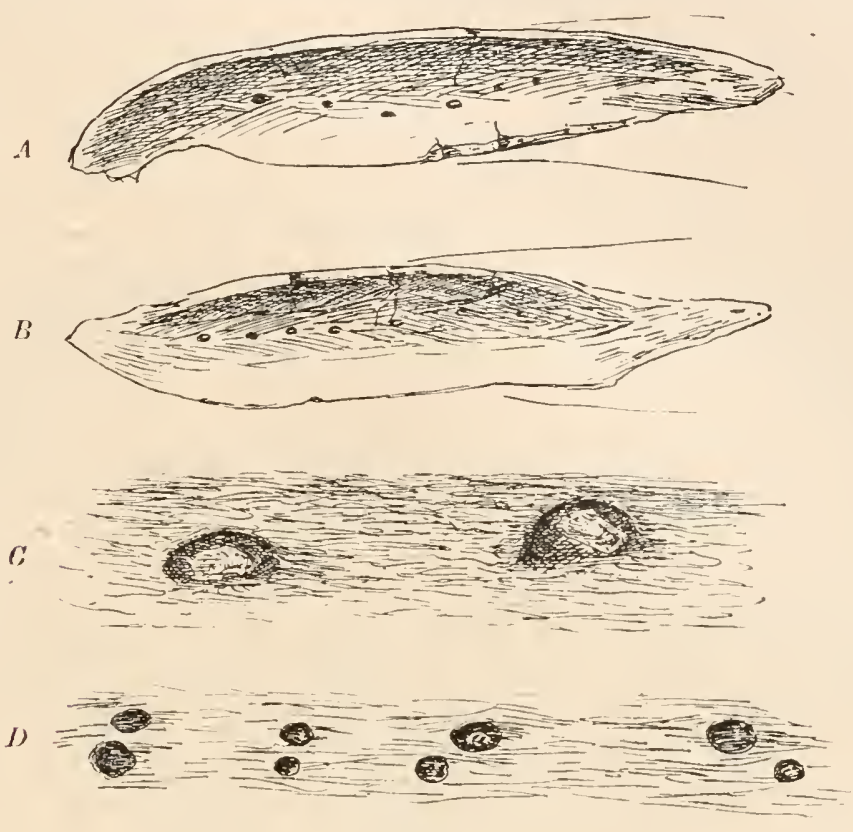

Fig. 303.

Die rudimentären Zahnanlagen von Triassochelys dux, Jkl., aus der oberen

Trias von Halberstadt. (Nach O. Jaekel, 1916.)

A: Schnabelrinne des rechten Unterkiefers (nat. Gr.).

B: Schnabelrinne des linken Unterkiefers (nat. Gr.). In der Mitte der Schnabelrinne die Reihe der kleinen Zahngruben.

C: Zwei diecer Zahngruben in 20facher Vergrößerung.

D: Ein Teil der Doppelreihe der Zahngruben des rechten Oberkiefers, 10fach vergröhert.

Ammon aus Ägypten mit 36,8 cm Carapaxlänge, Fig. 308), bieten geringen Aufschluls über den Verlauf der Stammesgeschichte der einzelnen Fanilien. Von den lebenden Familien der Cryptodiren (Chelydridae, Cinosternidae, Dermatemydidae, Platysternidae und Testudinidae) sind mit Assuahme der Clielydriden und Platysterniden fossile Vertreter bekannt.

2. Unterordnug: Chelonidea.

Die Cheloniidea bilden einen Seitenzweig der Schildkröten, der von Landleben zum Meeresleben übergegangen ist. Die verbindenden 
schon bei den Sumpfschildkröten und Süßwasserschildkröten (z. B. Enys) verloren und macht bei den Hochseeschildkröten mehr und mehr einer flachen, herzförmigen Gestalt Platz. Die Verbindung des Rückenschildes nit dem Bauchschilde lat sich gelockert und es ist bei den marinen Typen zu einer Reduktion der Außenenden der Costalia und des Kernes des Plastrons gekommen; wir können diesen Prozeß der Reduktion der Verknöcherung bei den fossilen Thalassemydiden, Chelo-

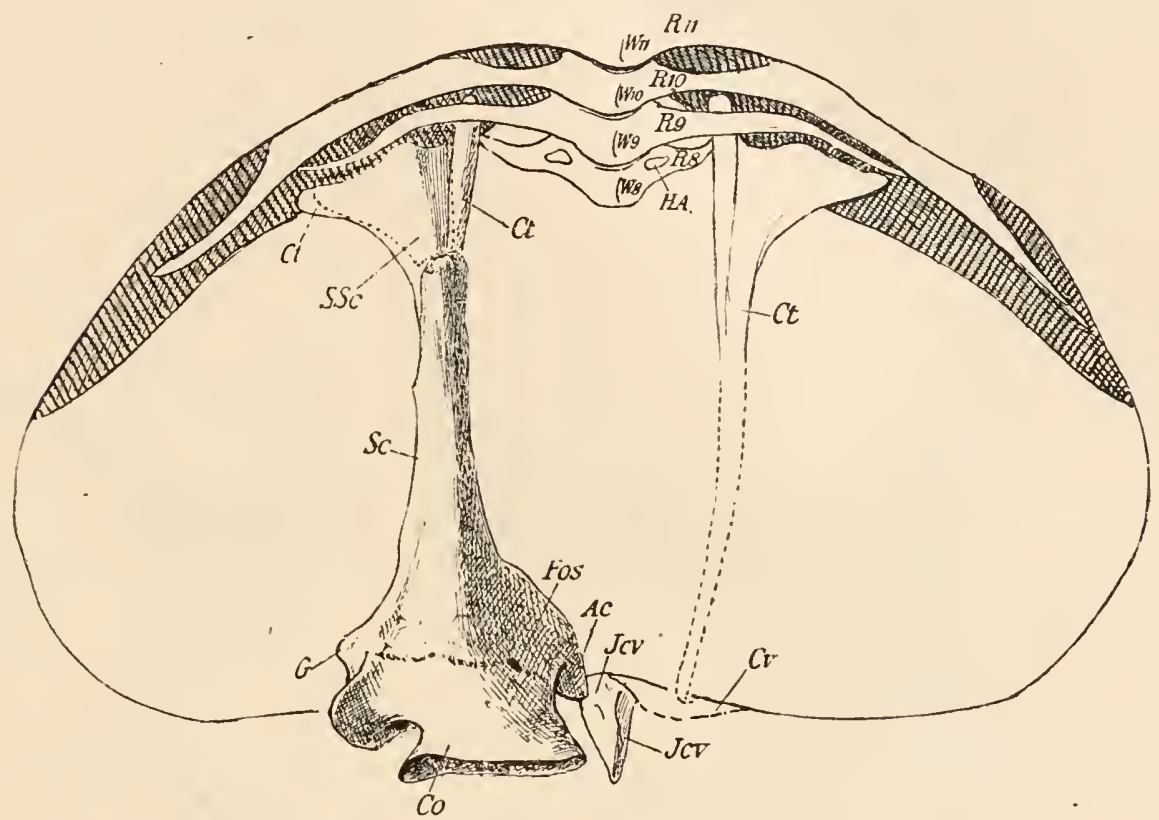

Fig. 305 .

Die Einfiigung des Schulterapparates unter den Rückenpanzer bei Triassochelys dux, Jkl., aus der oberen Trias von Halberstadt. (Nach O. Jaekel, 1916.)

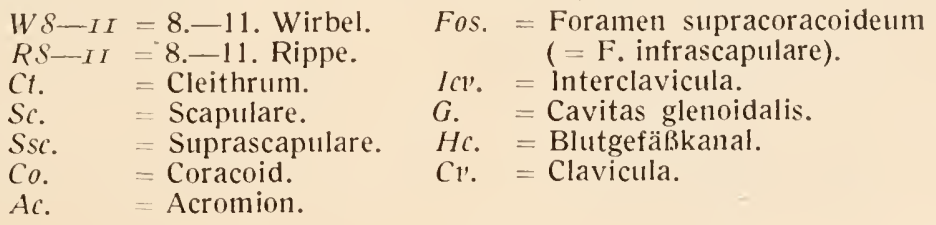

niiden und Dermochelyiden in seinen verschiedenen Stufen deutlich verfolgen. Im weiteren Verlaufe wird der Carapax auf einen schmalen medianen Schild reduziert (z. B. bei Allopleuron aus der oberen Kreide von Holland und Belgien), der noch von einem Kranz schwacher Marginalia umgeben ist; wenn aber auch die Kostalplatten verloren gegangen sind, bleiben doch noch die Rippen selbst erhalten (z. B. Archelon ischyros aus der Oberkreide von Dakota). In Bauchschild werden die einzelnen Elemente voneinander getrennt, die in der Mitte 
des Plastrons entstelende Fontanelle wird immer größer, und sclıließlich bleibt vom Plastron nur ein schmaler Knochenring übrig, der von den Claviculae, den Hyoplastra, Hypoplastra und Xiphiplastra gebildet wird. Dieses Stadium der Reduktion des knöchernen Bauchschildes ist an weitesten bei der lebenden Gattung Dermochelys vor-

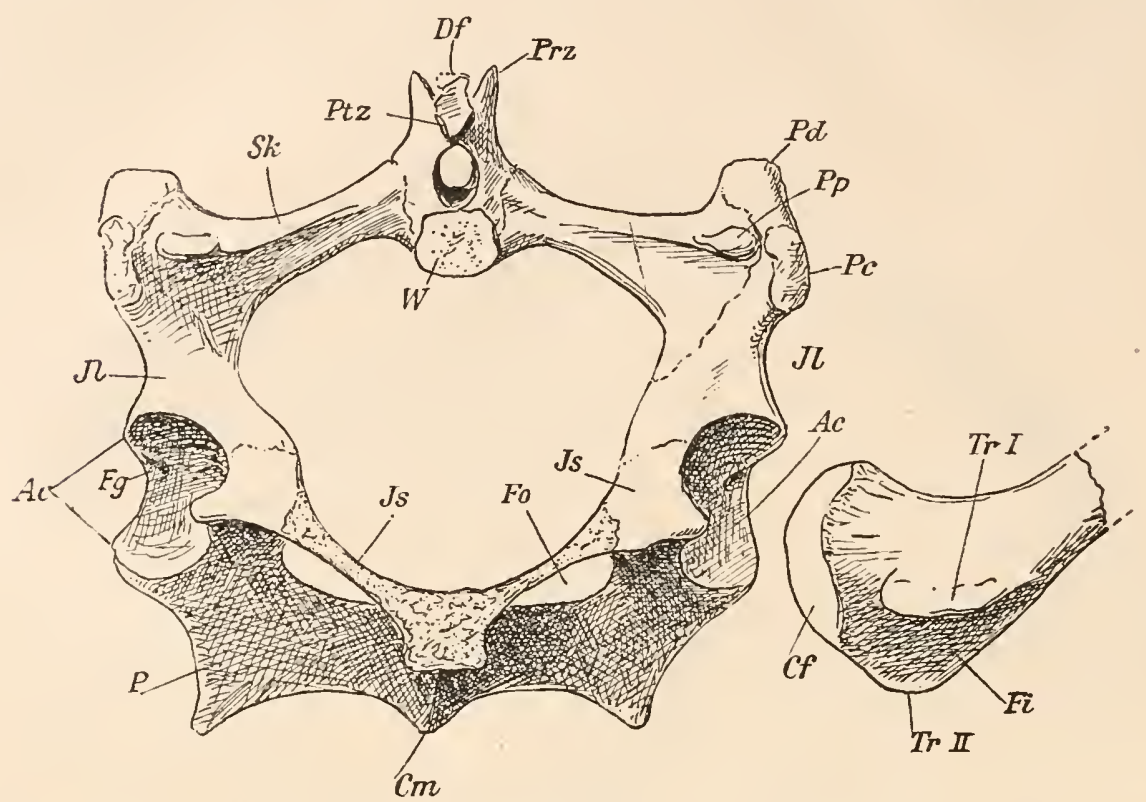

Fig. 306 .

Beckengürtel von. Triassochelys dux, Jaekel, aus der oberen Trias von Halberstadt. $2 / 3$ 11at. Gr. Hinteransicht. (Nach O. Jaekel, 1916.)

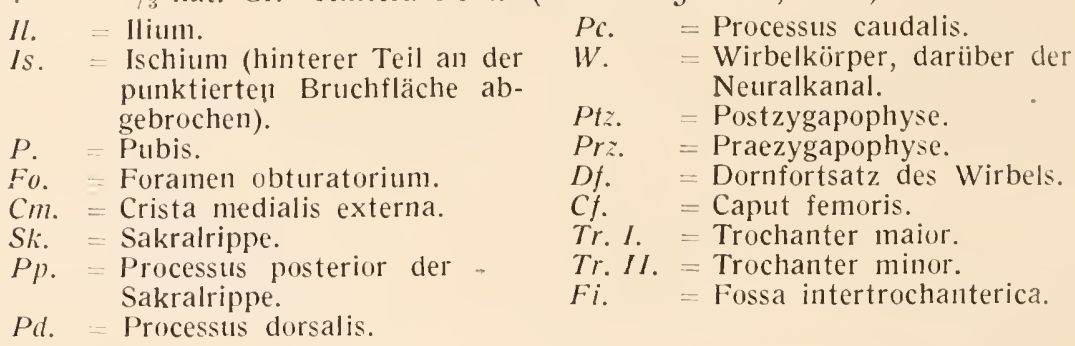

geschritten; bei ilur ist vom ehemaligen Carapax nichts mehr übrig geblieben als die Nuchalplatte.

Wir finden jedoch in den häutigen, mosaikartig gefeldertenRückenschild der Lederschildkröte (Dermochelys coriacea) sehr zarte Knochenplättchen, die kalkig und durch zackige Nähte verbunden sind. Auch auf der Bauchseite liegen kleine Knochenkörperchen in der Haut, aber sie schließen sich nicht zu einem Mosaik zusammen, sondern liegen ganz unregelmäßig verstrent in der Haut. 
Diese Mosaikplättchen in der Rückenlıaut und die knöchernen Tuberkeln in der Banchlnaut sind enenso wie die noch vorhandenen, zarten Randplättclın (Marginalia) nicht als Rudimente des primären Carapax und Plastrons, sondern als Rudimente eines ïber diesem vorhanden gewesenen sekundären Knochenschildes anzusehen. Während

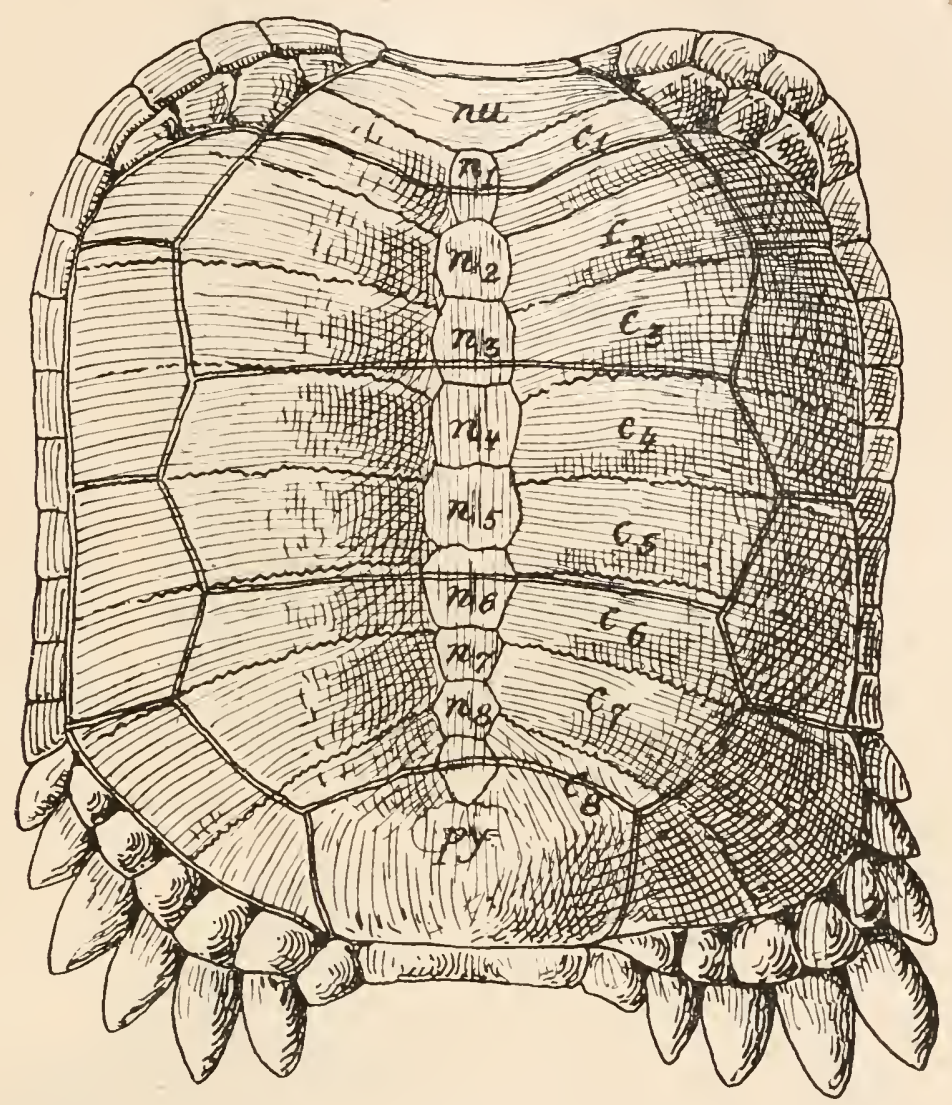

Fig. 307 .

Carapax von Proganochelys Quenstedti, Baur, aus dem obersten Keuper Württembergs. (Nach E. Fraas.) Die Grenzlinien der (nicht erhaltenen) Hornschilder sind durch doppelte Linien bezeichnet.
nur. = Nuchalplatte.
$n_{1}-n_{8}=$ Neuralplatten.
pl. = Pygalplatte.
$c_{1}-c_{8}=$ Costalplatten.

der Carapax und das Plastron mit Ausnahne der Marginalia in einer tieferen Schicht, der-Lederhaut, der ,thekalen" Schicht, gebildet werden, gehört dieser sekundäre Panzer einer höheren Schicht der Lederhaut, der ,epithekalen" Schicht, an.

Da sich der epithekale Panzer bei Dermochelys gleichfalls in Stadium vorgeschrittener Reduktion befindet, so nuıß die Lederschildkröte von 

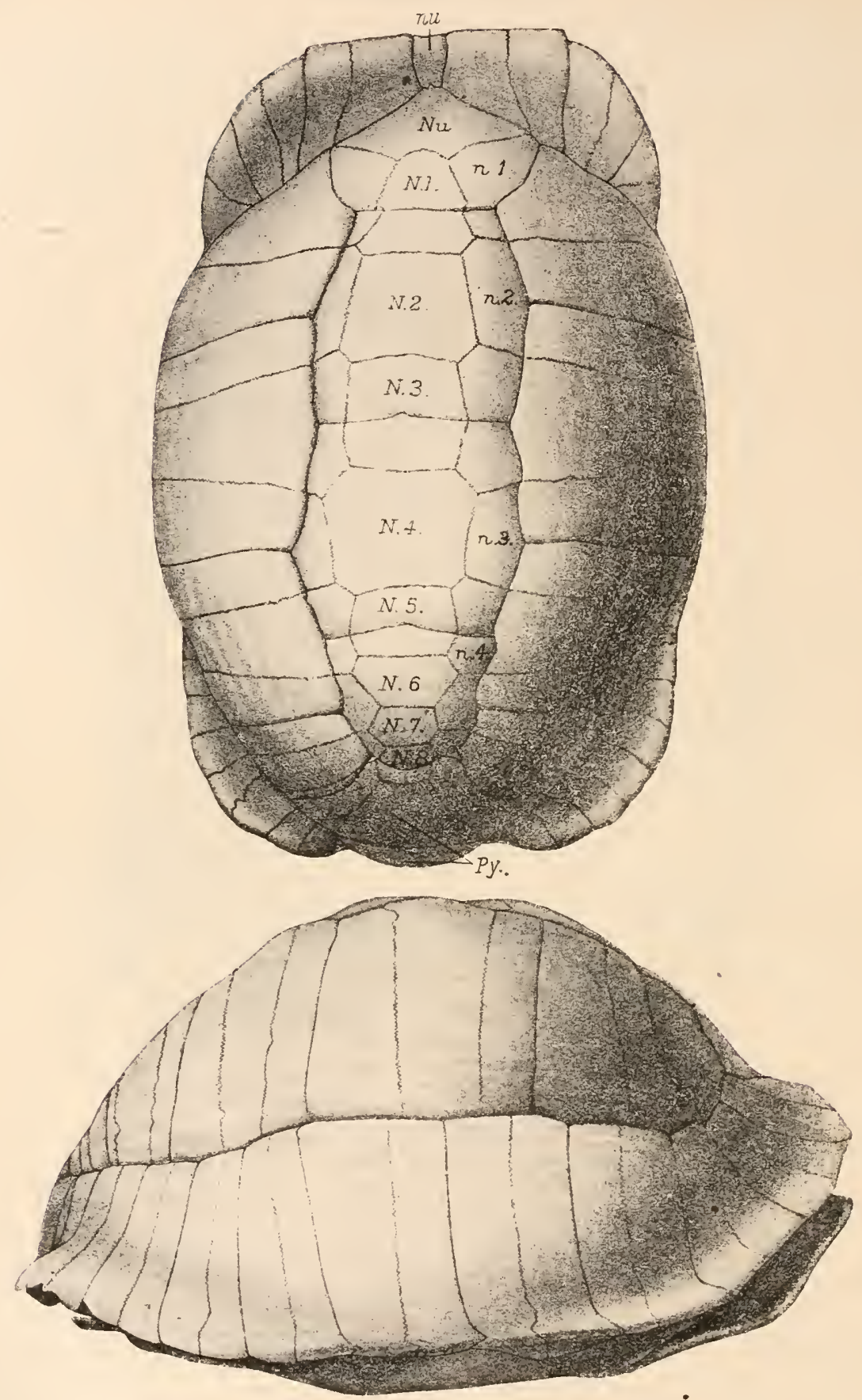

Fig. 308.

Knochenpanzer von Testudo Ammon, Andrews, aus dem Unteroligozän des Fayum (Nord von Birket-el-Qurun), Ägypten. Karapaxlänge $86,8 \mathrm{~cm}$. (NachC.W.Andrews.) $N u$. = Nuchalplatte (Knochen). $N_{1}-N_{8}=$ Neuralplatte (Neurale) I.-VIII. (Knochen). nu. = Nuchal-, $n_{1}-n_{4}=$ Neuralscutum. $P y^{\prime}=$ vordere u. hintere Pygalplatte (Knochen). 
Ahnen abstanmen, die einen funktionellen sekundären Rückenschild und Bauchschild über den Rudimenten des primären Carapax und Plastron besaß $B$. Wir kennen derartige Typen in der Gattung Psephophorus (Fig. 315), die vom Eozän bis zum Oberpliozäı lebte und eine gtwaltige Größe erreichte; da Psephophorus Scaldii aus dem Mittelpliozän von Antwerpen die riesige Testudo (Colossochelys) Atlas (mit $2 \mathrm{~m}$ Carapaxlänge) noch bedeutend übertraf, so war sie die größte bisher bekannte fossile Schildkröte. Bei dieser ist ein aus dicken Knochenplatten bestehender Mosaikpanzer vorhanden, der bei den Alnnen von Dermocliclys in gleicher Weise ausgebildet gewesen sein muß.

L. Dollo ${ }^{1}$ hat (1901) dargelegt, daß die wechselvolle Geschichte des Panzers bei den Vorfahren von Dermoclielys dadurch zu erklären ist, daß eine zweimalige, von einer Rückkehr zum Küstenleben unterbrochene Wanderung in die Hochsee eingetreten sein muß. Die Reduktion des primären, bei der terrestrischen Lebensweise erworbenen Panzers (Carapax und Plastron) ist eine Folge des Aufenthaltes in der Hochsee und läßt sich bei den Thalassemydiden und Cheloniiden schrittweise verfolgen (Fig. 309-312, 314). Von derartigen hochspezialisierten Hoclıseeformen aus dem Stamme der Cheloniiden muß ein Seitenzweig zur littoralen Lebensweise zurückgekehrt sein und bei dieser den sekundären, epithekalen Mosaikpanzer erworben haben. Dermochelys ist aber wieder zu einem Hochseebcwolmer geworden, bedarf also des sekundären Knochenschildes ebensowenig wie des primären und hat daher auch den zweiten verloren.

In der obercn Kreide Nordamerikas sind einige Cheloniidea gefunden worden, bei denen auf dem thekalen Carapax entweder vereinzelte modiane Knochenplatten aufsitzen, die der epithekalen Lederhautschicht entstammen (z. B. bei Toxochelys Bauri drei epithekale Knochinhöcker auf den Neuralia, Fig. 310) oder die eine geschlossene Reihe ven Knochenplatten in der Mcdianlinie bilden (z. B. Arcleelon ischyros, Fig 312). Diese Typen zeigen uns den Weg, auf dem die Entstehung von Psephophorus und Dermochelys vor sich gegangen ist.

Der Schädel der Cheloniidea hat im Laufe der Stammesgeschichte eine wichtige Veränderung durclı die Ausbildung eines sekundären Sclläfendaches erfahren, das bei den Gattungen aus der Kreideformaticn ncch nicht so wcit ausgebildet ist als bei Chelonia, wo das sekundäre Schläfendach vollständig die Temporalgrube überdeckt. Die „,absteigenden Fortsätze“2 der Parietalia sind bei den Thalassemydiden noch nicht in der Weise ausgebildet wie bei den jüngeren Cheloniidea.

${ }^{1}$ L. Dollo, Sur l'Origine de la Tortue Luth. - Bull. Soc. Roy. Sciences médicales et naturelles de Bruxelles, 1901.

2 O. Jaekel hat diese Teile der Parietalia, die zur seitlichen Umwandung der Gehirnkapsel dienen, als ,Entomella“ bezeichnet (1916). 


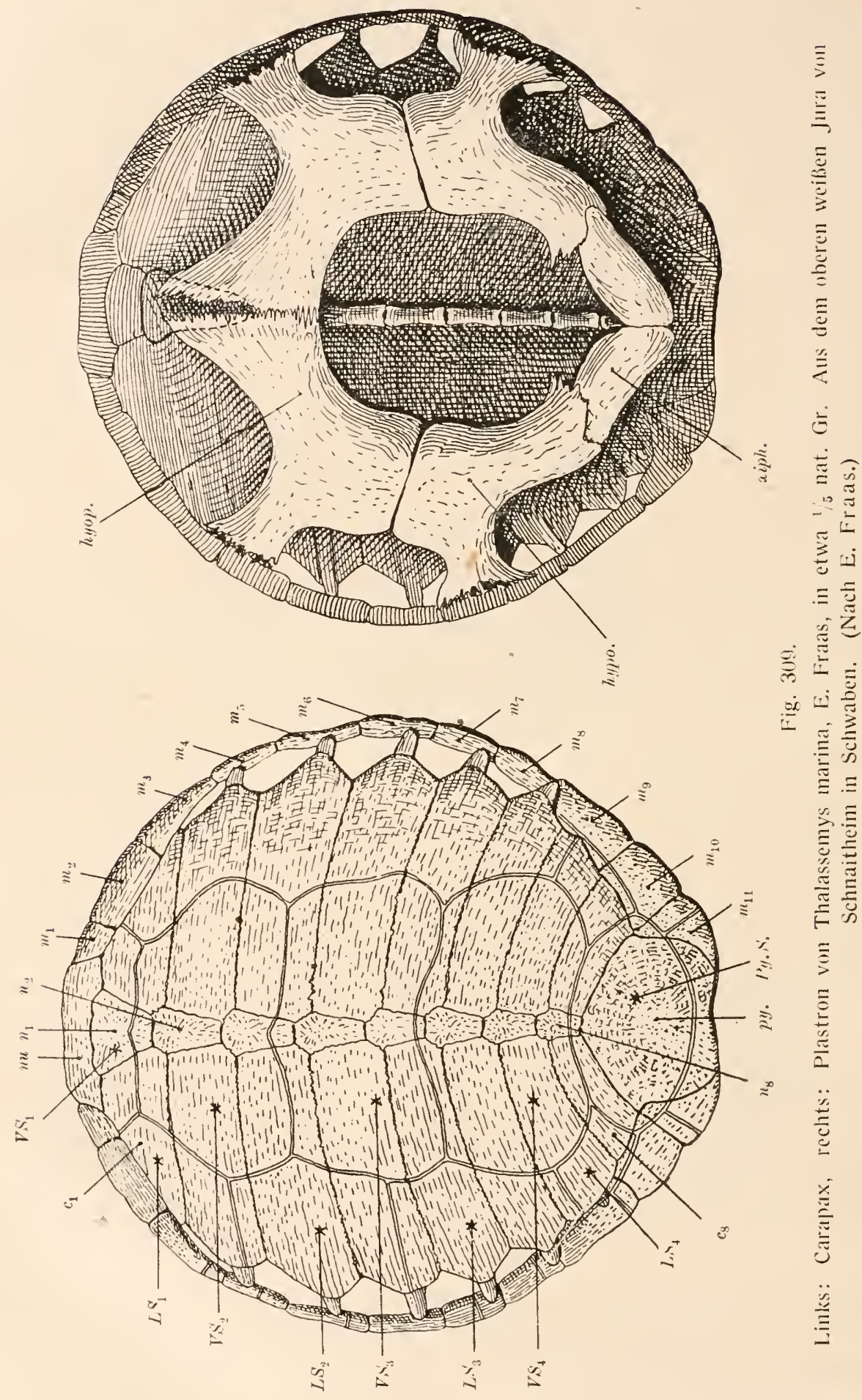


Die Gliedmaßen sind zu Flosstn ungewandelt und besonders die Hände verlängert worden.

Die verschicdenen Gattungen der Cheloniidea sind in zahlreiche Fanilien aufgeteilt wordon, deren Abgrenzung jedoch keine sehr scharfe ist, da eine Reihe von Zwischenformen vorliegen. Die ,Familien“ der Cheloniidea stellen im wesentlichon nur aufeinanderfolgende Entwicklungsstufen dar, die jeweils eine Zahl von Gattungen enthalten, die infolge von Spezialisationskreuzungen aus der Alnnenreihe vieler jüngerer Gattungen ausscheiden; da aber die Nachkommen der verschiedenen, einer dieser Entwicklungsstufen angehörenden Gattungen sich wieder selbständig zu der nächstfolgenden Stufe weiterentwickelt haben, so zerschneidet das bisherige "System" die genetischen Linien an mehreren Stellen. Wenn im folgenden die Gruppierung der Cheloniidea in die - Familien der Thalassemydidae, Cheloniidae und Dermochelyidae beibehalten wurde, so soll damit nicht gesagt sein, daß die erstgenannte „Familie" einen selbständigen Ast bildet. Die Familien der Protostegiden, Toxochelyiden, Propleuriden und Lytolomiden vereinige ich mit der Familie der Clıeloniiden, da kein zwingender Grund für die Abtrennung dieser Familien vorliegt.

\section{F. Thalassemydiden."}

Die Thalassemydiden bilden die Stammgruppe der jüngeren Cheloniidea und sind in allgemeinen durch geringe Spezialisationshölı jener Anpassungen gekonnzeichnet, die sich in gesteigerter Form bei den Cheloniiden und Dermochelyiden vorfinden. Sie bilden die Brücke zu den Emydinen, einer Unterfamilie der Testudiniden, und beweisen die Herkunft der Cheloniidea von den Cryptodiren. Die Glicdmaben waren noch emysartig; die Zehen und Finger endeten mit Krallen und waren kurz, aber im Carapax sind bereits Fontancllen infolge Reduktion der randlichen Partien der Costalia vorhanden, wälırend im Plastron die zentrale Fontanelle auftritt. Der Rückenschild ist nur noch bei Chelonides aus dem oberen Jura Norddeutschlands stärker gewölbt, zeiğt aber

\section{Zu Fig. 309.}

Die Grenzen zwischen den Skelettelementen sind durch einfache Nahtlinien, jene der darüber liegenden Hornschilder durch doppelte Linien gekennzeichnet. Die Lage der Hornschilder ist durch kleine Sterne bezeichnet.

\begin{tabular}{|c|c|c|c|}
\hline & $\begin{array}{l}\text { Knochenschilder: } \\
=\text { Nuchalplatte. }\end{array}$ & $\begin{array}{l}\text { hypo. } \\
\text { xiph. }\end{array}$ & $\begin{array}{l}=\text { Hypoplastron. } \\
=\text { Xiphiplastron. }\end{array}$ \\
\hline $\begin{array}{l}p y . \\
n_{1}-n_{8}\end{array}$ & $\begin{array}{l}=\text { Pygalplatte. } \\
=\text { Niuralplatten } 1-8 .\end{array}$ & & Hornschilder: \\
\hline $\begin{array}{l}c_{1}, c_{8} \\
m_{1}-m_{11} \\
h y y^{\prime} o p\end{array}$ & $\begin{array}{l}=\text { Costalplatten } 1 \text { und } 8 \\
=\text { Marginalplatten } 1-11 . \\
=\text { Hyoplastron. }\end{array}$ & $\begin{array}{l}V S_{1}-V S_{4} \\
L S_{1}-L S_{4} \\
P y . S .\end{array}$ & $\begin{array}{l}=\text { Vertebralscutum } 1-4 . \\
=\text { Lateralscutum } 1-4 . \\
=\text { Pygalscutum. }\end{array}$ \\
\hline
\end{tabular}


bereits die ersten Anpassungen an das Meeresleben in kleinen Fontanellen zwischen den Rippenenden und einer großen zentralen Fontanelle des Plastrons. Einen anderen Typus repräsentiert Idiochelys aus dem oberen Jura Frankreichs und Bayerns, da der Rückenschild zwar sehr flach und thalassemysartig gebaut ist, das Plastron aber keine zentrale Fontanelle aufweist. Hier liegen also zweifellos Spezialisationskreuzungen vor. Eine weitere, bereits höher spezialisierte Gattung ist Thalassemys (Fig. 309) aus dem oberen Jura Deutschlands und der Schweiz, und noch weiter spezialisiert ist Eurysternum aus gleichalterigen Bildungen Bayerns und Frankreichs; bei dieser Gattung ist das sekundäre Schläfendach bereits vollständig geschlossen.

Die Entstehung der Thalassenydiden aus den Emydinen und sonit die Abzweigung der Clıcloniidea von den Cryptodira dürfte in diese Zeit des oberen Jura oder der unteren Kreide fallen; in der Wealdenform Chitracephalus liegt bereits eine Type vor, die in den wesentlichen Merknalen durchaus den Charakter der primitiveren Cheloniiden aufweist.

Chelonides. - Oberer Jura von Hannover. ${ }^{1}$

Idiochelys. - Oberer Jura von Kelleim und Cerin."

Thalassemys. - Oberer Jura von Solothurn und Neuenburg in der Schweiz, Scluaitheim in Schwaben. ${ }^{3}$ (Fig. 309.)

Eurysternum (- Acichelys). - Oberer Jura von Kelhein, Solnhofen und Cerin. ${ }^{4}$

1 G. A. Maack, Die bis jetzt bekannten fossilen Schildkröten und die im oberen Jura bei Kelheim (Bayern) und Hannover neu aufgefundenen ältesten Arten derselben. - Paläontographica, XV111. Bd., 1869, S. 193.

A. Portis, Über fossile Schildkröten aus dem Kinmeridge von Hannover. Ibidem, XXV. Bd., 1878, S. 125.

W. Oertel, Beiträge zur Kenntnis der oberjurassichen Schildkrötengattung Hydropelta. - Centralblatt f. Min. usw., 1915, S. 347.

2 H. von Meyer, Zur Fauna der Vorwelt. Reptilien aus dem lithographischen Schiefer des Jura in Deutschland und Frankreich. - Frankfurt a. M., 1860.

${ }^{3}$ L. Ruetimeyer, Die fossilen Schildkröten von Solothurn und der übrigen Juraformation. Mit Beiträgen zur Kenntnis von Bau und Geschichte der Schildkröten im Allgemeinen. - Netle Denkschriften der Schweizerischen Gesellschaft f. Naturwissenschaften, XXV. Bd., 1873. (Hier Verweise auf die ältere Literatur.)

E. Fraas, Thalassemys marina E. Fraas aus dem oberen weißen Jura von Schnaitheim nebst Bemerkungen ïber die Stammesgeschichte der Schildkröten. - Jahreshefte d. Ver. f. vaterländische Naturkunde in Württemberg, 1903, S. 72.

4 L. Lortet, Les Reptiles fossiles du Bassin du Rhône. - Archives dı Musée d'hist. nat. de Lyon, T. V., 1892, p. 3.

K. A. von Zittel, Bemerkungen ïber die Schildkröten des lithographischen Schiefers in Bayern. - Paläontographica, XXIV. Bd., 1877, S. 175.

$\mathrm{Zu}$ dieser Gattung gehört der größte Teil der unter dem Namen Hydropelta (z. B. H. Meyeri) beschriebenen Arten (vgi. W. Oertel, 1. c., 1915, S. 347). 
Chitraceplialus. - Unteıe Kreide (Wealden) von Bernissart in Belgien. ${ }^{1}$

Sontiochelys. - Untere Kreide vom Monte Santo bei Görz. ${ }^{2}$

\section{F. Cheloniidae.}

Der Rückenschild z:igt an den Rändern große Fontanellen zwischen den Rippen, die sich in Laufe der Stammesgeschichte immer weiter gegen die Wirbelsäule zu ausdehnen, bis sie bei Protosphargis dieselbe erreicht haben. Ebenso ist die zentrale Fontanelle des Plastrons bei den älteren Cheloniiden noclı relativ klein, erweitert sich aber bei den jüngeren und besonders bei Protosphargis derart, daß die Hyoplastra, Hypoplastra und Xiphiplastra nur mehr einen Ring bilden, der vorn durch

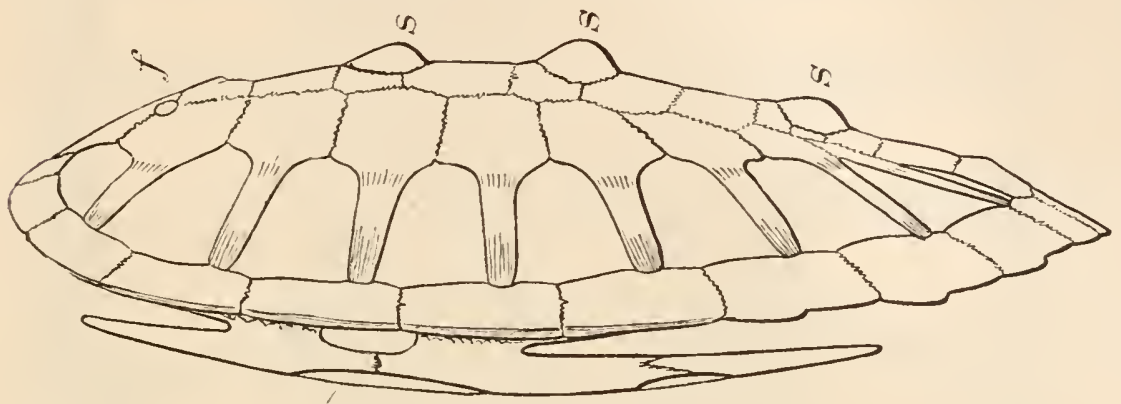

Fig. 310 .

Carapax und Plastron von Toxochelys Bauri Wieland aus der oberen Kreide vun Gove County (Kansas), von der Seite gesehen. Länge etwa $53 \mathrm{~cm}$.

(Nach G. R. Wieland, 1905.)

$j .=$ Foramen postnuchale. $s .=$ die drei epithekalen Buckel der Mittellinie.

das getrennte Entoplastron abgeschiossen wird. Der Schädel weist den schon bei Eurysternum vollzogenen sekundären Verschluß des Schläfendaches in verschieden hohem Grade auf. Carapax und Plastron, die schon bei Thalassemys nicht mehr miteinander verwachsen waren (E. Fraas, 1903), sind bei den sich um Toxochelys gruppierenden Gattungen nur mehr locker miteinander verbunden, wälnrend bei der lebenden Chelonia die Verbindung durch Ligamente bewerkstelligt wird.

Die Brücke zu den Thalassemydiden wird durch die Gattungen Osteopygis, Lytoloma und einige verwandte Gattungen gebildet. Die Brücke zu den Dermochelyiden bilden vielleicht Archelon und Protosphargis, so

1 L. Dollo, Première Note sur les Chéloniens de Bernissart. - Bulletin du Musée Royal d'Histoire naturelle de Belgique, T. III, 1884, p. 63.

2 G. Stache, Sontiochelys, ein neuer Typus von Lurchschildkröten (Plenrodiren) aus der Fischschieferzone der unteren Karstkreide des Monte Santo bei Görz. - Verhandl. d. K. K. Geol. Reichsanstalt in Wien, 1905, S. 285. 
daß also keine scharfen Grenzen zwischen diesen drei Fanilien bestehen und die Differenzen nur gradueller Natur sind. Würde an der bisher geübten Methode der Errichtung von Fanilien innerhalb des Kreises

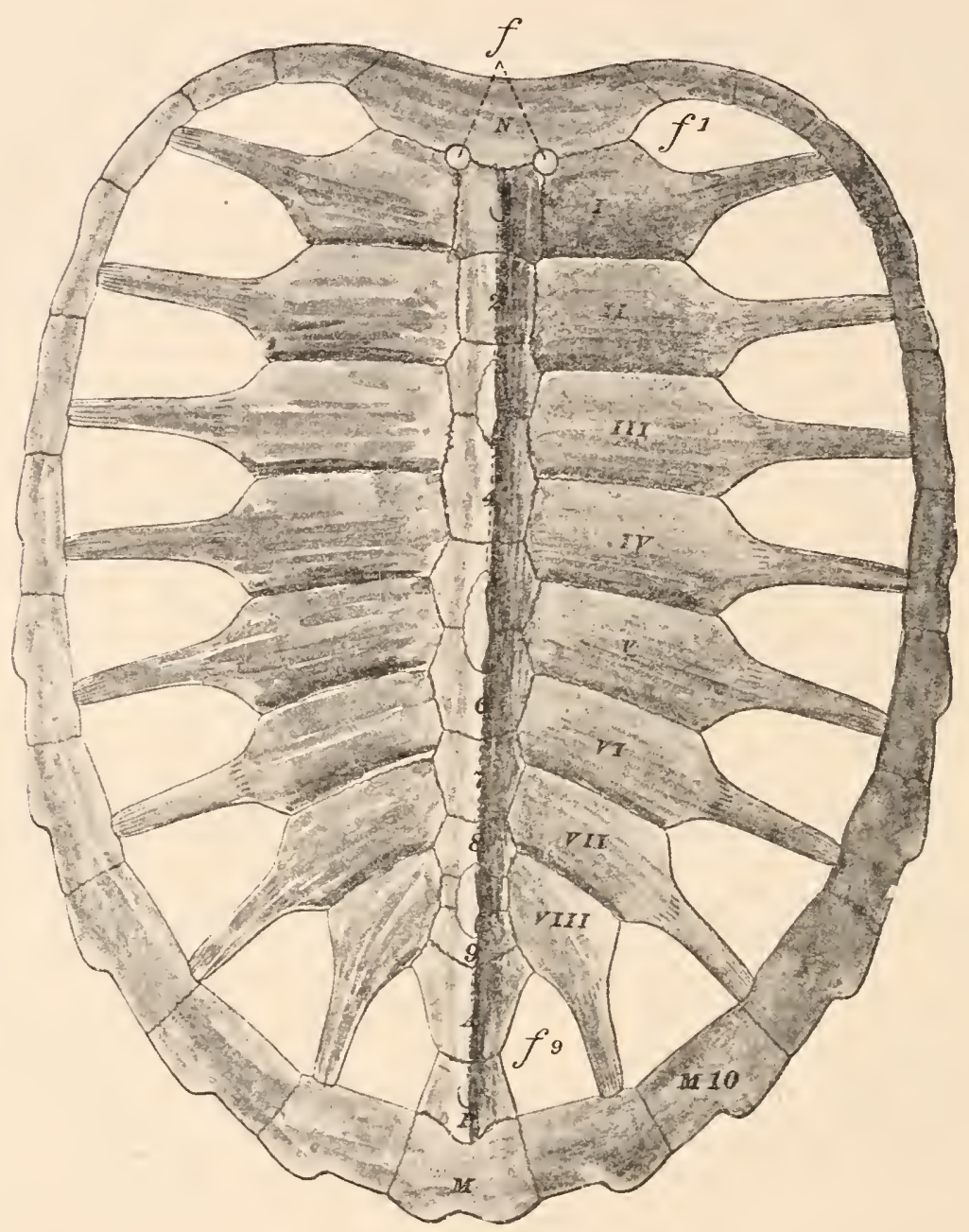

Fig. 311 .

Carapax von Toxochelys Bauri, Wieland, aus der oberen Kreide (Niobrara Cretaceous) von Gove County in Kansas. Länge etwa $53 \mathrm{~cm}$.

(Nach G. R. Wieland, 1905.)
t. $=$ Foramina postnuchalia. $\quad I .-V I I I .=$ Costalia I.-VIII.
$f_{1}$ und $f_{9}=$ Laterale Fontanellen. $\quad N . \quad$ = Nuchalplatte.

der Cheloniidea festgehalten werden, so müßte schließlich für jede einzelne der vielen fossilen Gattungen eine separate Fanilie errichtet werden. 
Osteopygis. - Obere Kreide Nordamerikas. - Carapax ohne Fontanellen, Plastron mit kleiner zentraler Fontanelle. Man kann in Zweifel sein, ob diese Gattung als ein noch in der Kreide lebender Vertreter der Stammgruppe der Thalassemydiden anzusehen oder den Cheloniiden einzureihen ist. ${ }^{1}$

Lytoloma. - Obere Kreide (Cenoman) bis Obereozän Belgiens, Englands, Nordamerikas, Afrikas (Tunis). - Ca:apax n11 randlichen Fontanellen zwischen den Marginalien und den Costalplatten. Die Syn1physe des Unterkiefers ist ungewönlich lang. Das Tier lebte (nach L. Dollo, 1903) littoral und war durophag (conchifrag). Lytoloma bildet wahrscheinlich das Endglied eines Seitenastes der Cheloniiden. ${ }^{2}$

Toxochelys. - Untere Kreide (Aptien) Hannovers ${ }^{3}$ und obere Kreide Nordamerikas. - Kurze Symphyse des Unterkiefers ${ }^{4}$ (Fig.310, 311).

1 G. R. Wieland, Structure of the Upper Cretaceous Turtles of New Jersey: Adocus, Osteopygis, and Propleura. - American Journal of Science, Vol. XVII, 1904 , p. 118.

2 L. Dollo, Première Note sur les Chéloniens Landeniens (Éocène inférieur) de La Belgique. - Bulletin du Musée Roy. d'Hist. Nat. de Belgique, T. IV, 1886, p. 129. (Als Pachyrhynchus Gosseleti beschriebener Unterkiefer von Lytoloma Gosseleti, Dollo.)

Im Naturhistorischen Museum zu Brüssel befinden sich aus dem Untereozän von Erquelinnes (Belgien) die Reste von mehr als 25 Individuen von Lytoloma Gosseleti, von denen 13 montiert sind. Sie sind noch nicht eingehender beschrieben (L. Dollo, Bulletin Soc. Belge de Géologie etc., T. XXI, 1907, p. 83).

Derselbe, Eochelone brabantica, Tortue marine nouvelle du Bruxellien (Eocène moyen) de La Belgique. - Bull. Acad. Roy. de Belgique, 1903, pag. 62 The Fossil Vertebrates of Belgium. - Annals of the New York Academy of Sciences, Vol. XIX, 1909, p. 99.

Vgl. ïberdies: O. P. Hay, The Fossil Turtles of North America. - Carnegie Institution of Washington, Publication Nr. 75, 1908. (Ausführliche Literatur iiber die fussilen Schildkröten Nordamerikas.)

3 W. Oertel, Toxochelys gigantea nov. sp., eine neue Schildkröte aus dem Aptien von Hannover. - VII. Jahresbericht d. Niedersächsischen Geol. Vereins zu Hannover, 1914, S. 91. Von dieser Art liegt zwar nur ein Schädel vor, der aber nach Oertel der nordamerikanischen Art Toxochelys procax so nahe steht, daß die neue Art zweifellos als Vertreter dieser früher nur aus der oberen Kreide Nordamerikas bekannten Gattung anzusehen ist.

Vgl. ferner O. P. Hay, I. c. sowie die folgenden Arbeiten:

4 G. R. Wieland, Notes on the Cretaceous Turtles, Toxochelys and Archelon, with a Classification of the Marine Testudinata. - American Journal of Science, Vol. XIV, 1902, p. 95.

Derselbe, A New Niobrara Toxochelys. - American Journal of Science, Vol. XX, 1905, p. 325 .

O. P. Hay, Description of two Species of Fossil Turtles, Toxochelys stenopora and Chisternon? interpositum, the latter hitherto unknown. - Proceed. U. S. National Museum, Vol. XXXVI, 1909, p. 191. 


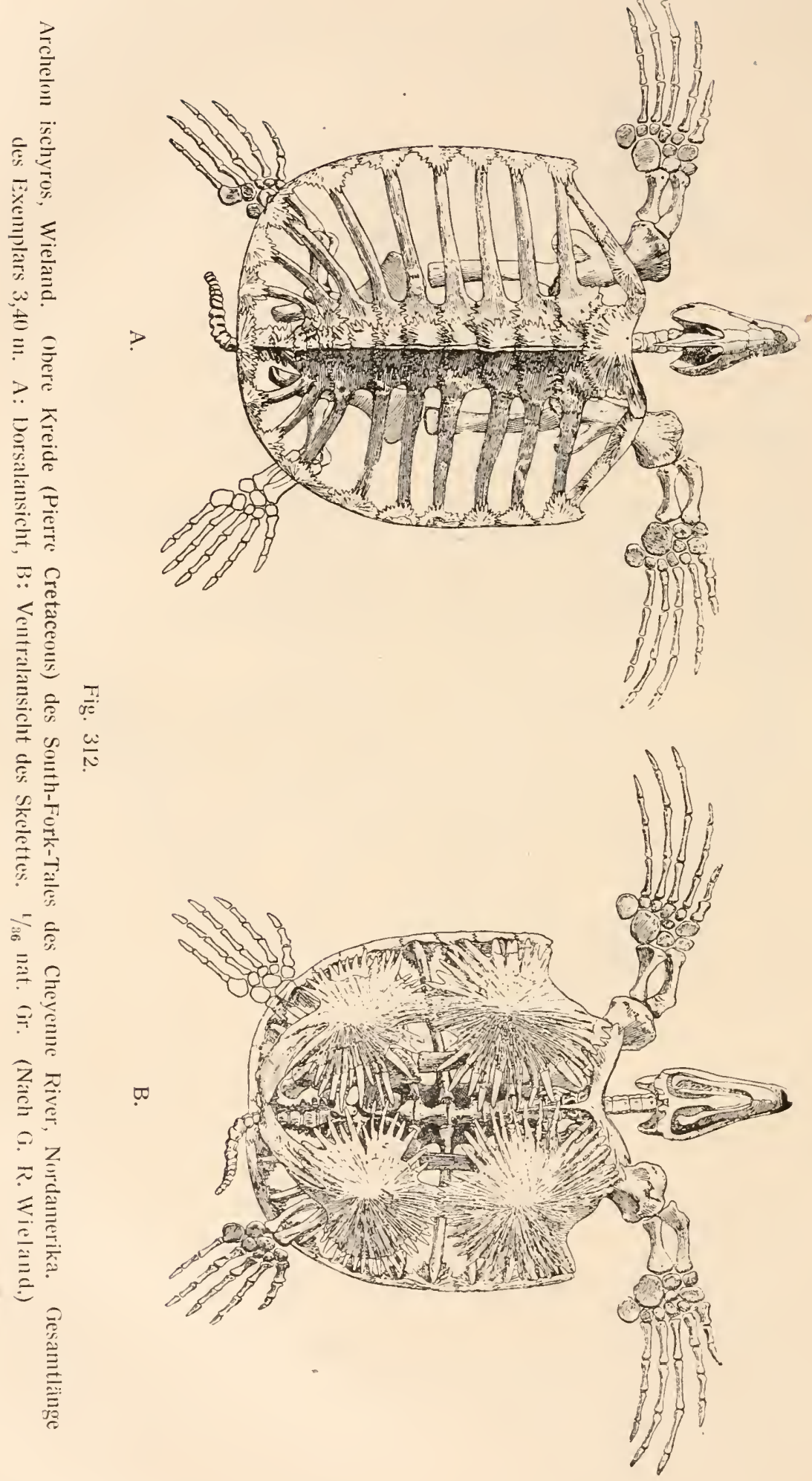


Protostega. - Obere Kreide Nordamerikas. ${ }^{1}$ strichtien). ${ }^{2}$

Allopleuron. - Obere Kreide Belgiens (Obersenon und Mae-

Archelon. - Obere Kreide Nordanerikas. ${ }^{3}$ A. ischyros erreichte eine Länge von etwa 4,25 m (Schädellänge $1 \mathrm{~m}$ ). (Fig. 312-313.)

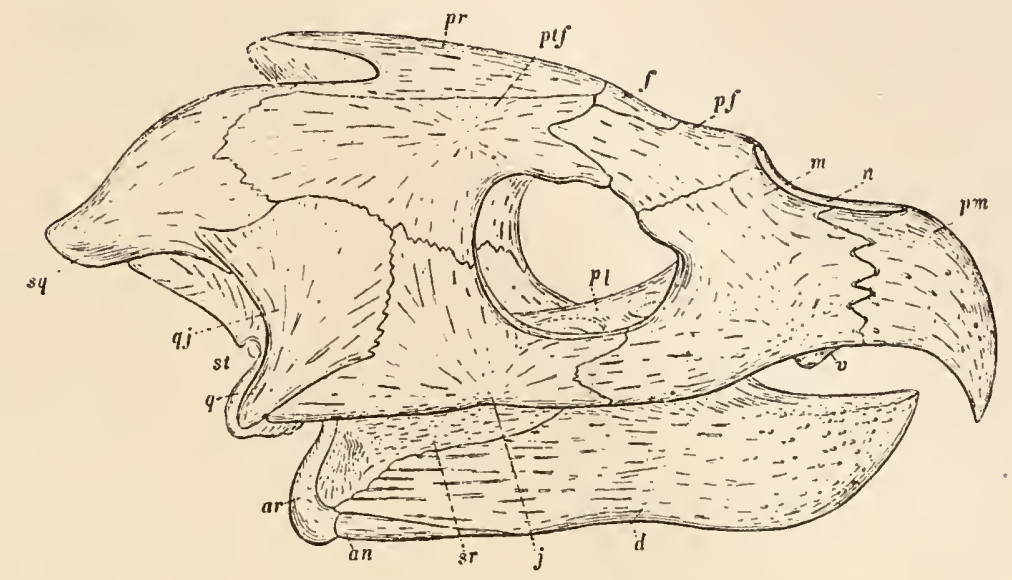

Fig. 313 .

Schädelrekonstruktion von Archelon ischyros, Wieland, aus der oberen

Kreide vom Cheyenne River in Süddakota (Fort Pierre Cretaceous).

Schädellänge $1 \mathrm{~m}$ erreichend. (Nach G. R. Wieland, 1900.)

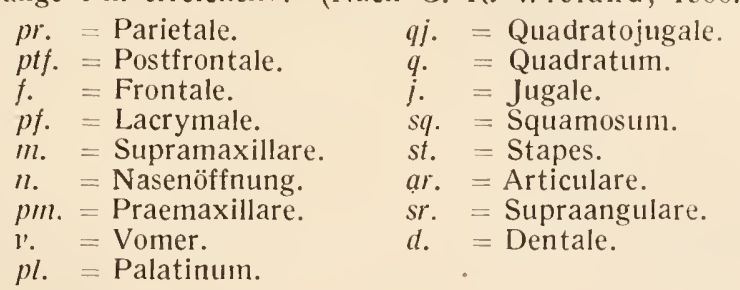

Protosphargis. - Obere Kreide Oberitaliens (Verona). ${ }^{4}$ (Fig. 314.)

1 G. R. Wieland, Revision of the Protostegidae. - American Journal of science, Vol. XXVII, 1909, p. 101.

2 T. C. Winkler, Des Tortues Fossiles conservées dans le Musée Teyler et dans quelques autres Musées. - Archives du Musée Teyler, Vol. II, 1869.

${ }^{3}$ G. R. Wieland, The Skull, Pelvis, and Probable Relatioships of the Hugh . Turtles of the Genus Archelon from the Fort Pierre Cretaceous of South Dakota. American Journal of Science (4), Vol. IX, 1900, p. 237.

Derselbe, Revision of the Protostegidae. - Ibidem (4), Vol. XXVII, 1909, p. 101.

4 G. Capellini, Le Piastre marginali della Protosphargis veronensis. Rendiconto delle Sessioni della R. Accademia delle Scienze dell'Istituto di Bologna. Vol. II, 1898, p. 97. 
Argillochelys. - Untereozän Belgiens und Englands. ${ }^{1}$ Eochelone. - Mitteleozän von Brabant (Belgien). ${ }^{2}$ Oligochelone. - Mitteloligozän von Boom (Belgien)。 ${ }^{3}$ Thalassochelys. - Lebend.

Chelonia. - Lebend (Fig. 296).

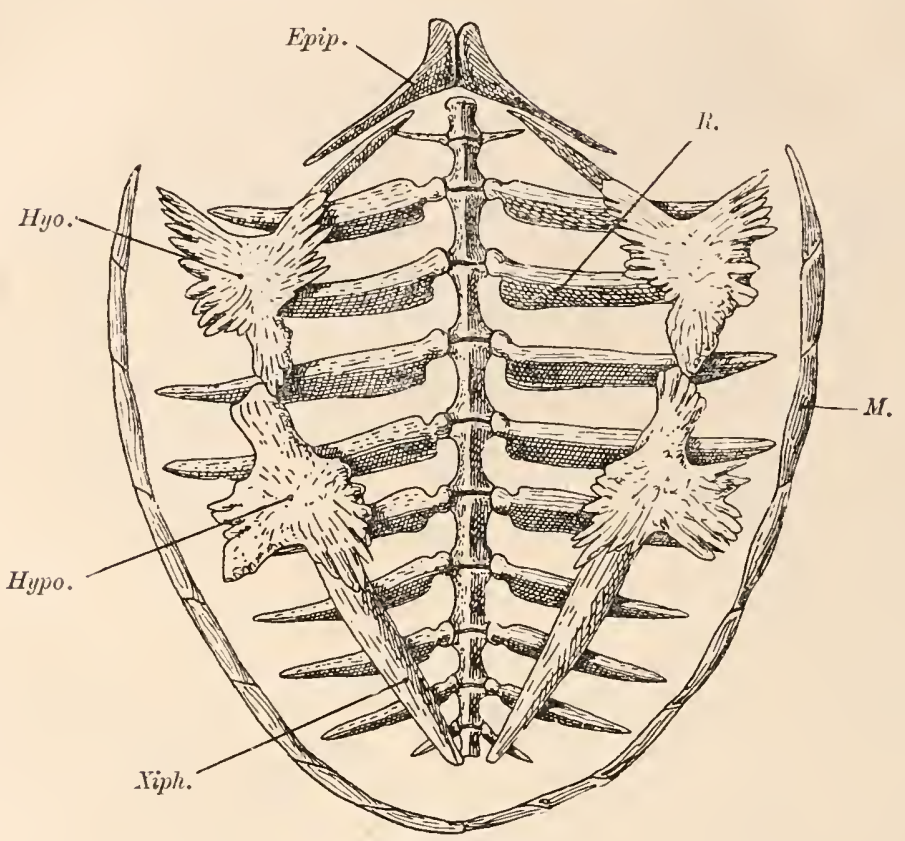

Fig. 314 .

Protosphargis veronensis, Capellini, aus der oberen Kreide von Verona, in $1 / 16$ nat. Gr.
R. $=$ Rippen.
Hyo. = Hyoplastron.
M. = Marginalia.
Hypo. = Hypoplastron.
Epip. = Epiplastron
Xiph. $=$ Xiphiplastron.

\section{F. Dermochelyidae.}

Sind auch die Gattungen, welche die Almenformen der Dermochelyiden bilden, bisher noch nicht bekannt, so ist doch der Weg vollkommen klargelegt, den die Entwicklung dieser Familie aus den Cheloniiden genommen hat. Vielleicht wurzeln die Dermochelyiden in den älteren Thalassemydiden, so daß die weitgehenden Ähnlich-

1 R. Lydekker, Catalogue of the Fossil Reptilia and Amphibia in the British Museum. I11. Chelonia. - 1889, p. 40.

2 L. Dollo, Eochelone brabantica etc., - 1. c., 1903.

3 L. Dollo, The Fossil Vertebrates of Belgium. - 1. c. 1909, p. 114.

Der im Briisseler Museum aufbewahrte Rest (vollständiger Carapax und Gliedmaßenknochen) ist noch nicht näher beschrieben. 
keiten der Cheloniiden und Dermochelyiden nur als Folgen paralleler Entwicklung anzusehen wären; dafür würden das Vorhandensein einer

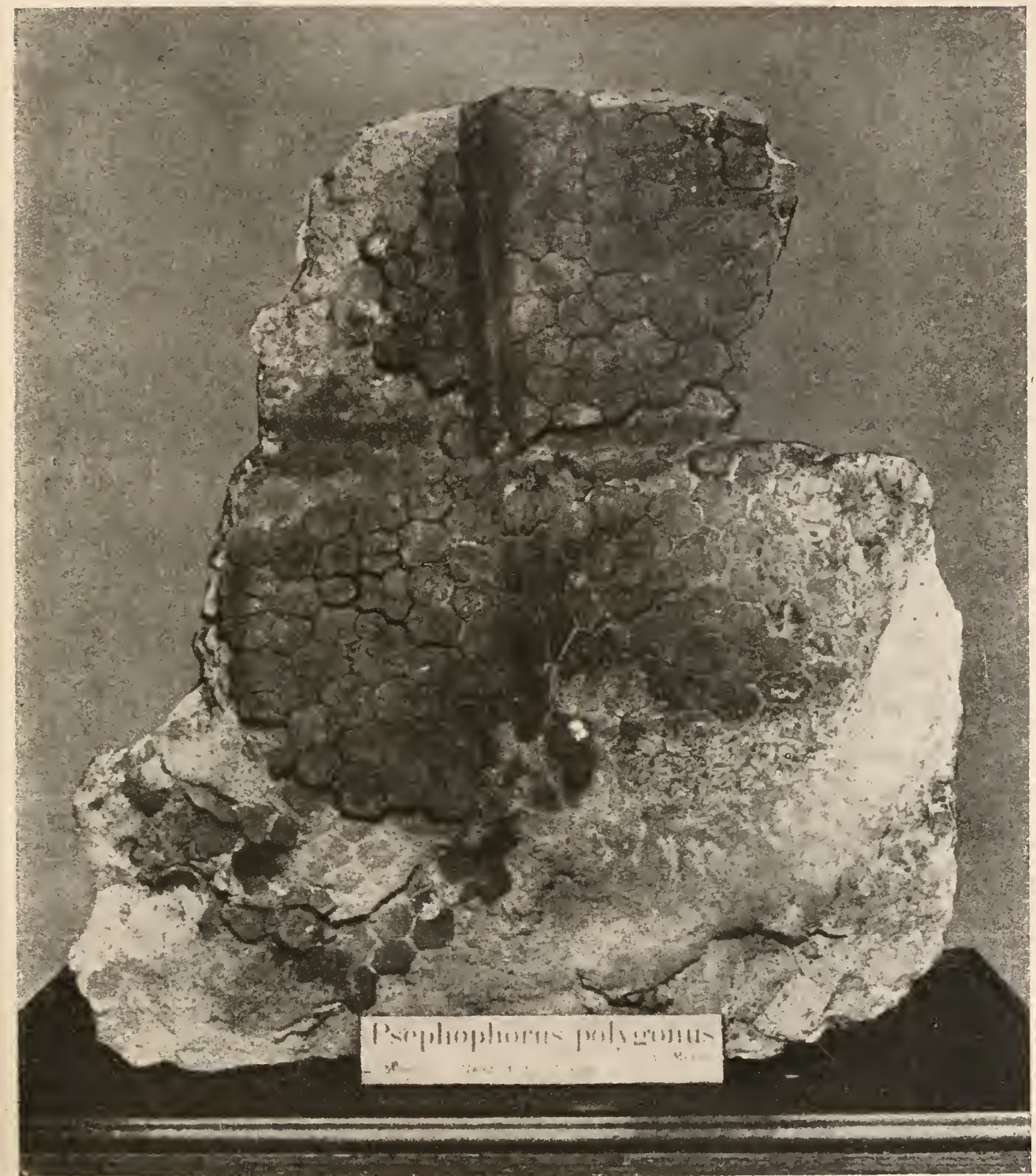

Fig. 315.

Psephophorus polygonus, H. v. Meyer. Bruchstiick des Carapax (Original von H. v. Meyer und H. G. Seeley) aus dem kieseligen, miozänen Sandstein des Thebener Kobels bei Neudorf a. d. March, Ungarn. Original in der k. k. Geol. Reichsanstalt in Wien. Phot.: Ing. F. Hafferl. (Die untere Hälfte des Stückes war nach der Entdeckung des Fundes verschleppt worden und wurde durch einen Zufall 25 Jahre später zustande gebracht. — 1/s nat. Gr.) 
starken ersten Rippe, das Fehlen der absteigenden Parietalplatten als Teile der Seitenwand des Schädeldaches und das eigentünliche Verlaalten des Parasphenoids (J. Versluys, 1909 und 1914) sprechen. Die Frage der Abzweigungsstelle der Dermochelyiden sowie des Zeitpunktes derselben muß weiteren Untersuchungen vorbehalten bleiben, doch kann schon jetzt an der nahen Verwandtschaft der Cheloniiden und der Dermochelyiden kein Zweifel mehr bestehen. Als wesentliches Kennzeichen der Gruppe kann man die Ausbildung des sekundären, epithekalen Panzers ansehen, der bei Dermochelys wieder im Verschwinden begriffen ist; unter diesem Gesichtspunkte würde vielleicht auch Archelon in diese Familie zu stellen sein, aber es ist ja immerhin möglich, daß hier ein paralleler Spezialisationsweg bei zwei verschiedenen Stänmen vorliegt.

Psephophorus. -- Vom Mitteleozän bis zum Mittelpliozän Europas (Oberfozän Ägyptens, Miozän Nordamerikas). - Epithekaler Panzer als Mosaikschild entwickelt, dessen Platten sehr dick sind. ${ }^{1}$ (Fig. 315.)

Dermochelys. - Lebend. - Der Schädel der Gattung Pseudosphargis (Oberoligozän Norddeutschlands) ist Dermochelys ähnlich, aber durch den Besitz der Pterygoidflügel an der Seitenwand der Gehirnkapsel verschieden, so daß die Stellung dieser Gattung unsicher ist; sie gehört vielleicht zu den Cheloniiden.. ${ }^{2}$ (Fig. 316.)

\section{Unterordnung: Pleurodira.}

Das wesentlichste Merkmal des Pleurodirenskeletts liegt in der festen Verbindung des Beckens mit dem Bauchschild (Fig. 317); dazu kommt die Ausbildung kräftiger Querfortsätze an den Halswirbeln und die Art des Verbergens des Schädels unter den Panzerschutz. Während

1 H. G. Seeley, Nate on Psephophorus polygonus H. v. Meyer. - Quarterly Journal of the Geol. Soc. London, Vol. XXXVI, 1880, p. 406.

L. Dollo, Première Note sur les Chéloniens Oligocènes et Néngènes de La Belgique. - Bull. Mus. Roy. d'Hist. Nat. Belg., t. V., 1888, p. 59.

Derselbe, Sur l'Origine de la Tortue Luth (Dermochelys coriacea). - Bull. de la Soc. Roy. des Sciences médicales et naturelles de Bruxelles, 1901, p. 1.

2 H. Voelker, Über das Stamm-, Gliedmaßen- und Hautskelett von Dermochelys coriacea L. - Zool. Jahrbücher, Abt. f. Anatomie, XXX111. Bd., 1913, S. 431 (ausfuihrliche Literatur).

J. Versluys, Ein großes Parasphenoid bei Dermochelys coriacea. - Zgol. Jahrbiicher, XXVIII. Bd., 1909, S. 283.

Derselbe, On the Phylogeny of the Carapace, and on the Affinities of the Leathery Turtle, Dermochelys coriacea. - British Association etc., Birmingham 1913.

Derselbe, Über die Phylogenie des Panzers der Schildkröten und über die Verwandtschaft der Lederschildkröte (De mochelys coriacea). - Paläontologische Zeitschrift, Berlin 1914, 1. Bd., S. 321. 
Reptilia.
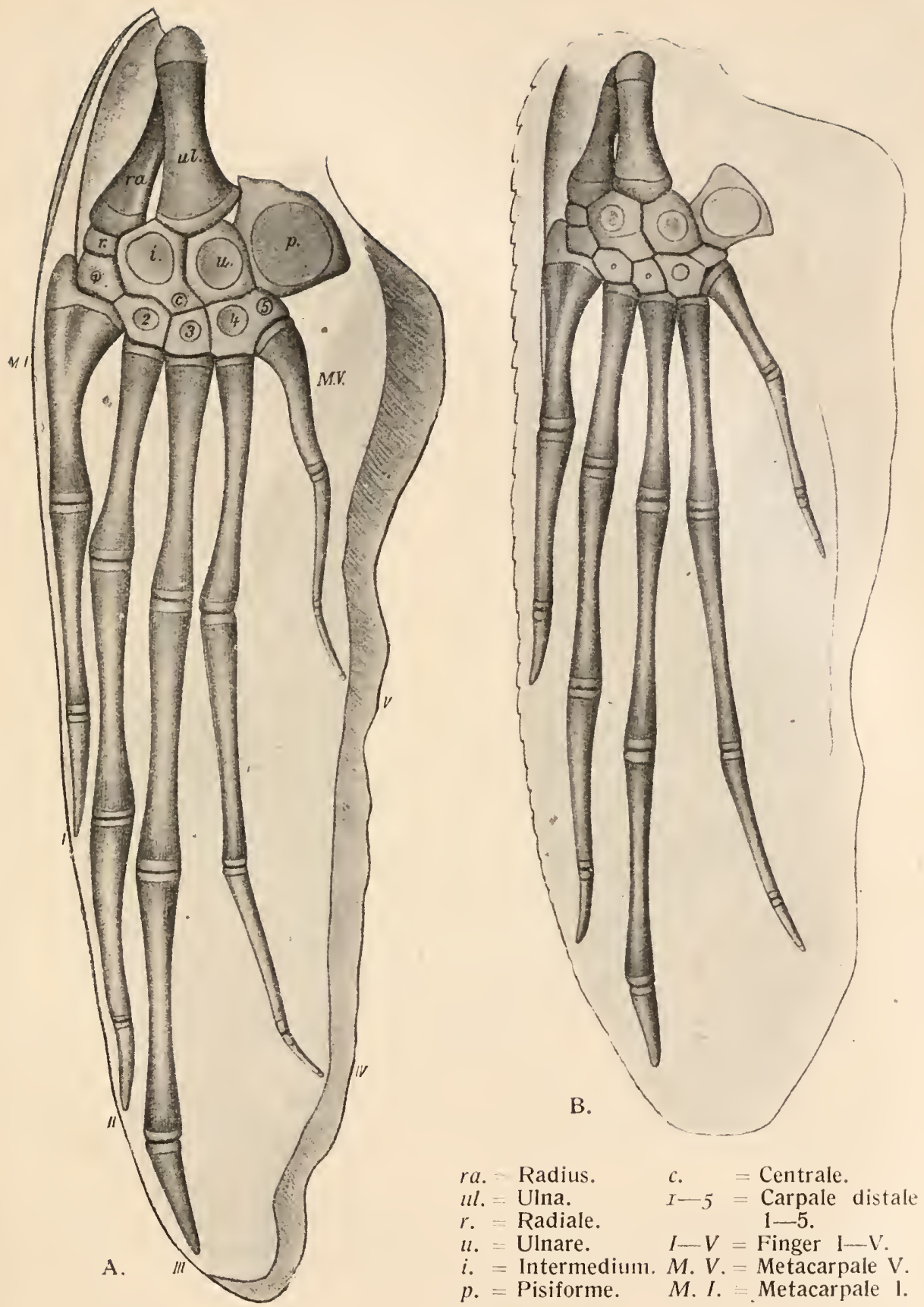

Fig. 316.

Dermochelys coriacea, L. - Linke Hand von der Dorsalfläche gesehen (links: älteres, rechts: juingeres Tier). $Z_{u}$ beachten ist die Grenze zwischen dem Carpale 4 und c. 5 bei dem jüngeren Tier, ebenso die Grenze zwischen dem Intermedium und Centrale, so daß darats die ursprïngliche Trennung dieser beim erwachsenen Tier verschmolzenen Carpalelemente bewiesen ist. Fig. A in $1 / 1, B$ in 11/1 nat. Gr. (Nach H. Völker, 1913.) 
bei den Cryptodiren der Kopf durch eine in der Medianebene sich vollziehende Biegung der Halswirbel zurückgezogen wird, wird Kopf und Hals bei den Pleurodiren seitlich umgebogen, um so zwischen Carapax und Plastron verborgen zu werden. Diese Fähigkeit steht mit der starken Ausbildung der Querfortsätze der Halswirbel (Muskelansatzstellen) in Zusammenlang.

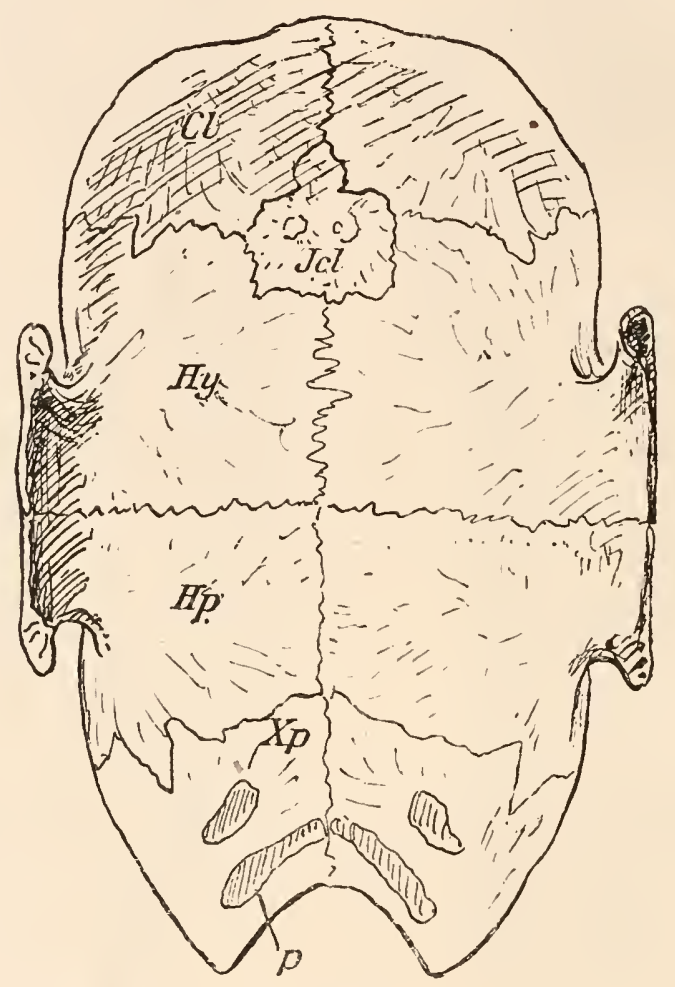

Fig. 317.

Plastron einér pleurodiren Schildkröte, von der Bauchseite gesehen. (Nach O. Jaekel.)

Cl. = Epiplastra ( = Claviculae $)$.

$I c l$. = Entoplastron $(=$ Interclavicula). $X p .=$ Xiphiplastra (auf ihnen $p=$ die Hy. = Hyoplastra. Ansatzflächen fïr das Becken).

Alle lebenden Pleurodiren sind Wasserbewohner; sie verlassen das Wasser entweder nie oder doch nur zeitweilig. Daher sind auch bei allen Pleurodiren Scliwimmfüße ausgebildet.

Die systematiscle Bestimmung der fossilen Vertreter der Pleurodiren kann nur dann nit Sicherheit erfolgen, wenn entweder die Übereinstimnnung des Panzerbanes mit lebenden Gattungen über jeden Zweifel erlaben ist, oder wemn die Anheftung des Beckens an das Plastron (Fig. 317, 320) oder der Bau der Halswirbel benbachtet werden kann. 


\section{F. Archaeochelyidae.}

Die älteste pleurodire Schildkröte ist Proterochersis robusta, die E. Fraas (1913) aus dem Keuper Württembergs beschrieb. Der Carapax ist hoch gewölbt; das Becken ist sehr kräftig und mit dem Cara-

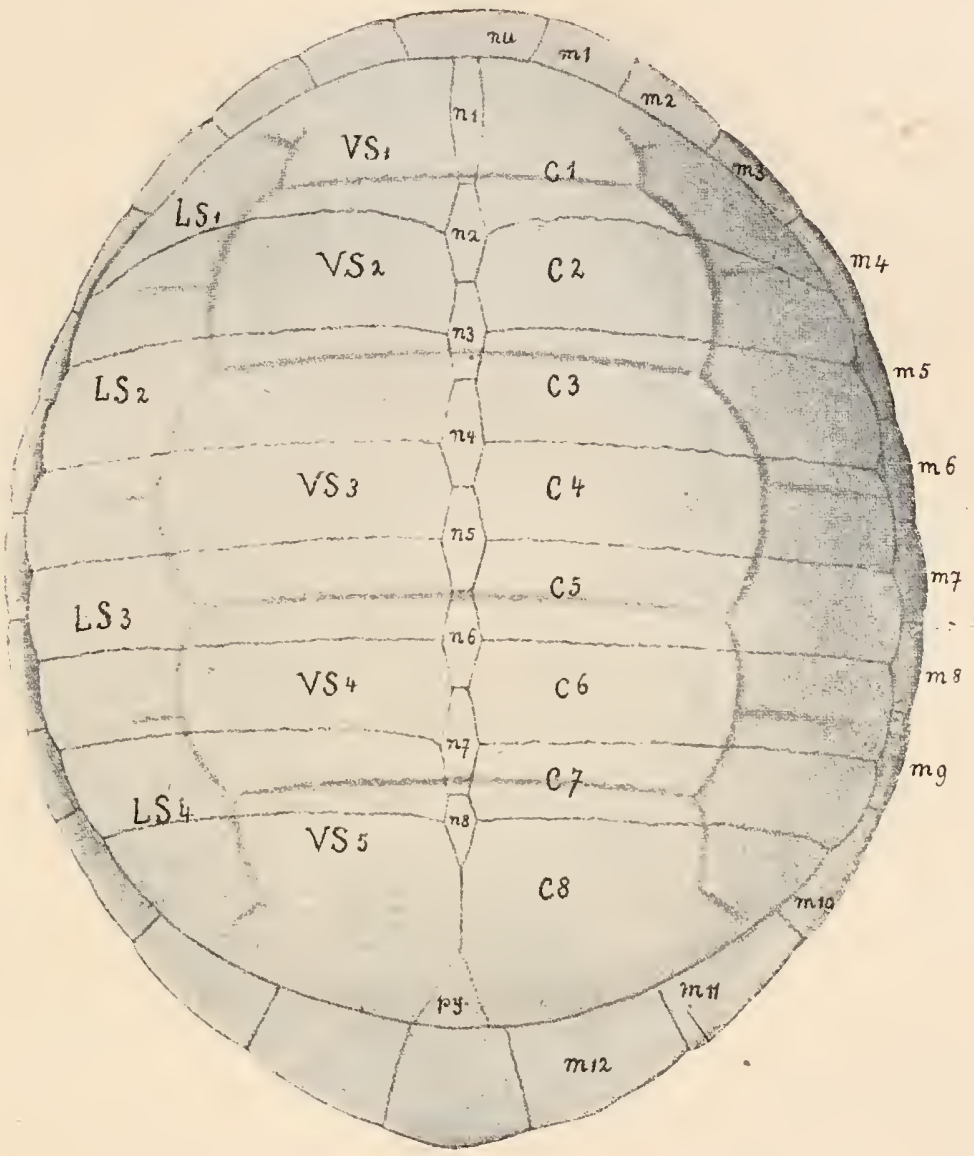

Fig. 318.

Proterochersis robusta E. Fraas, die älteste pleurodire Landschildkröte aus dem Stubensandstein von Rudersberg in Württemberg (obere Trias). Carapax, von oben gesehen, rekonstruiert. Ungefähr $1 / 3$ nat. Gr.

(Nach E. Fraas, 1913.)

$\begin{array}{lll}\text { mu. } & =\text { Nuchalplatte. } & m^{1}-m^{12}=\text { Marginalplatten. } \\ n^{1}-n^{8}=\text { Neuralplatten. } & V S_{1}-V S_{5}=\text { Vertebralscuta. } \\ p^{\prime} . & =\text { Pygalplatte. } & L S_{1}-L S_{1}=\text { Lateralscuta. } \\ c^{1}-c^{8} & =\text { Costalplatten. } & \end{array}$

pax und Plastron fest verwachsen. Im Plastron finden sich zwischen den Hyoplastra und Hypoplastra zwei Paar Mesoplastra eingeschaltet. Das Vorhandensein derselben ist als ein prinitives Merkmal anzusehen (E. Fraas, 1913). Die hohe Wölbung der Schale spricht dafür, daß das Tier eine Landschildkröte war. 
Proterochersis. - Obere Trias Württembergs ${ }^{1}$ (Fig. 318, 319).

\section{F. Plesiochelyidae.}

Aus dem oberen Jura Deutschlands und der Schweiz liegen mehrere

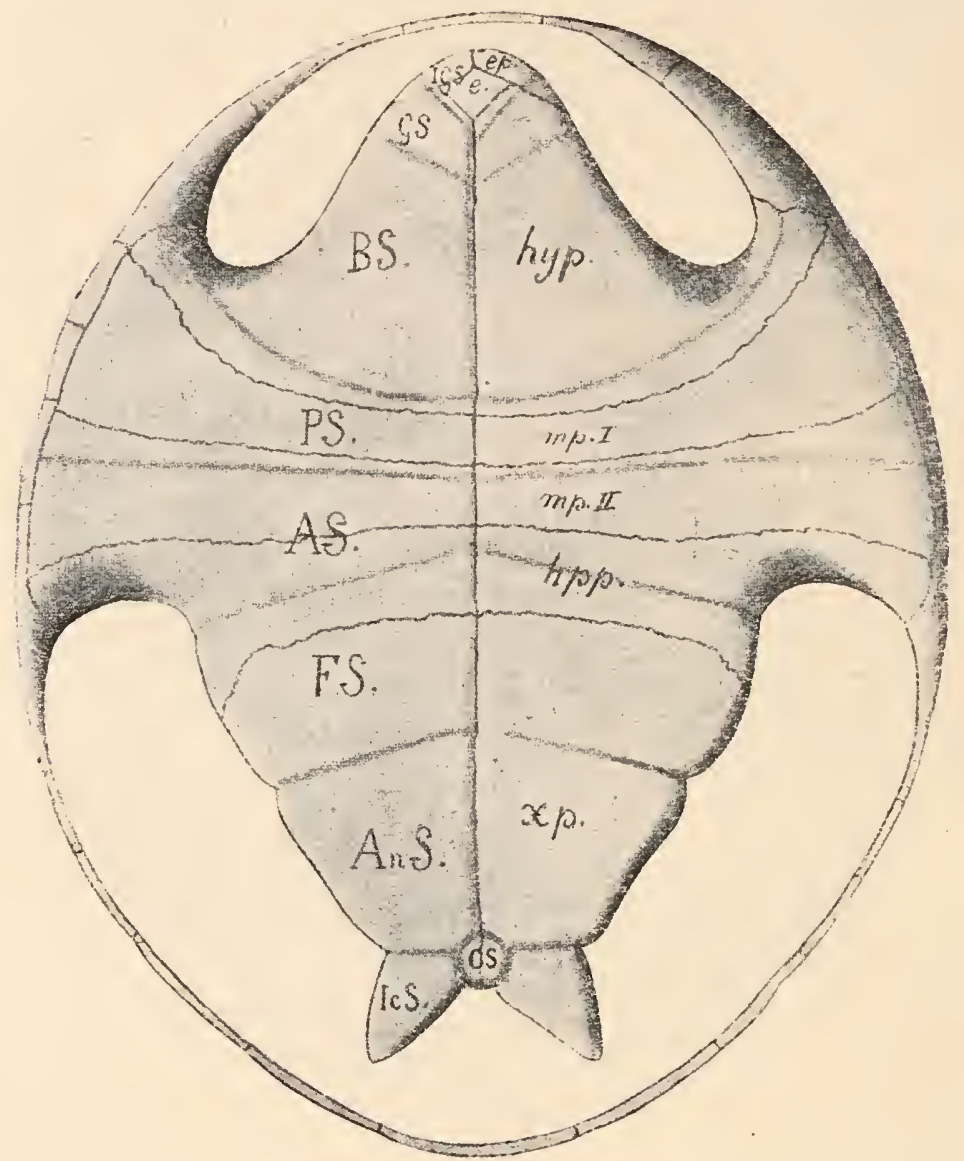

Fig. 319.

Plastron von Proterochersis (vgl. Fig. 318.)

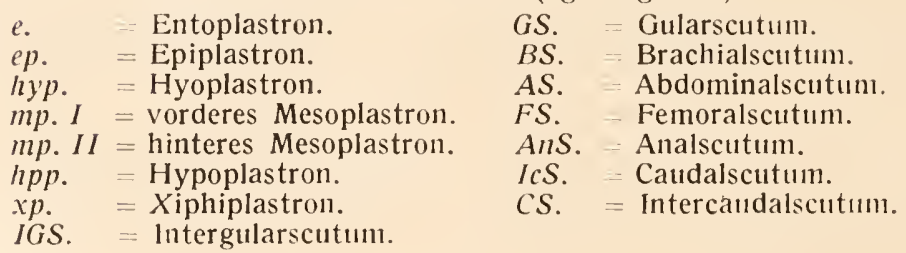

Arten vor, deren Zugehörigkeit zu den Pleurodiren aus der Verwachsung des Beckens mit dem Plastron hervorgeht. Diese Arten verteilen sich

1 E. Fraas, Proterochersis, eine pleurodire Schildkröte aus dem Keuper. Jahreshefte des Vereins f. Vaterländische Naturkunde in Wïrttemberg, 1913, S. 13. 
auf die Gattung Plesiochelys einerseits und die Gattung Craspedochelys anderseits.

Der Rückenschild von Plesiochelys ist kreis- oder herzförmig und ziemlich stark gewölbt, so daß daraus zu entnehmen ist, daß die Anpassung an das Wasserleben bei dieser Artengruppe noch nicht sehr weit vorgeschritten war. Bei Craspedochelys ist die Schale schwach gewölbt und bei einzelnen Arten nahezu flach; so daß also diese Gattung bereits ein vorgeschritteneres Anpassungsstadium an. das Wasserleben darstellt. Daß sich der Anpassungsprozeß an das Wasserleben auch in anderen Teilen des Skelettes der Plesiochelyiden benterkbar macht, geht u. a. aus dem Vorhandensein einer zentralen Fontanelle im Plastron von Craspedochelys und bei mehreren Arten von Plesiochelys hervor. Das Mesoplastron fehlt.

Die Tiere erreichten eine stattliche Größe; einige Plesiochelysarten besaßen eine Schale von $50 \mathrm{~cm}$ Rückenlänge.

Da die Beziehungen der beiden Gattungen zu der Fanilie der lebenden Chelyiden noch nicht ganz sicher stehen, so müssen die beiden Gattungen Plesiochelys und Craspedochelys provisorisch als Vertreter einer selbständigen Familie betrachtet werden, bis durch weitere Funde die genetische Zusammengehörigkeit mit den heute auf Südamerika, Australien und Neuguinea beschränkten Chelyiden sichergestellt ist.

Plesiochelys. - Oberer Jura von Hannover ${ }^{1}$, Solothurn und Neuenburg (Schweiz)." Wahrscheinlich Sïßwasserbewohner.

Craspedochelys. - Oberer Jura von Solothurn." Wahrscheinlich Süßwasserbewohner.

\section{F. Amphichelyidae.}

Die Familie der Amphichelyiden ist bisher ein Sammelbegriff für verschiedene Gattungen von unsicherer systematischer Stellung gewesen, die ausgeschieden werden müssen (z. B. Platychelys, Glyptops mit einem Becken, das nicht mit dem Plastron verwachsen ist). Als typische Vertreter der Familie sind die Gattungen Pleurosternum und Baëna zu betrachten (F. Pleurosternidae, Hay), bei denen nur ein Mesoplastron zwischen den Hyoplastron und Hypoplastron jederseits eingeschoben ist. Der Carapax ist abgeflacht, ein Zeichen dafür, daß diese Gruppe bereits an das Wasserleben angepaßt gewesen ist.

1 G. A. Maack, I. c., Paläontographica, XVIII. Bd., I869.

2 L. Ruetimeyer, Die fossilen Schildkröten von Solothurn und der iibrigen Juraformation. - Denkschriften der Schweizerischen Naturforschenden Ges., XX.V. Bd., 1873.

${ }^{3}$ E. Fraas, Thalassemys marina, etc., 1. c., 1903, p. 88.

4 L. Ruetimeyer, 1. c.; E. Fraas, 1. c. 
Pleurosternum. - Oberer Jura und Wealden von Norddeutschland. - Carapax sehr flach. ${ }^{1}$ (Fig. 320.)

Baёna. - Eozän (Wasatch ınd Bridger) Nordamerikas (Wyoming und Neumexiko). ${ }^{2}$

\section{F. Miolaniidae.}

Diese Familie ist für die eigenartig spezialisierte, riesige Gattung Miolania errichtet worden, die aus dem Pliozän (Plistozän?) von Neusüdwales, aus den Plistozän von Queensland und Lord Howe Island, sowie aus Schichten unbestimmten Alters (Eozän?) Patagoniens bekannt geworden. Aus Patagonien und Queensland liegt $j$ ? ein trefflich

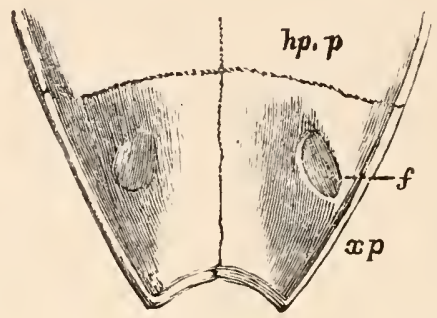

Fig. 320.

Innenansicht des Hinterendes des Plastrons von Pleurosternum Bullocki, einer pleurodiren Schildkröte aus dem oberen Jura (Purbeck) von Dorsetshire.

$$
\begin{aligned}
& 1 / 4 \text { nat. Gr. (Nach R. Lydekker.) } \\
& f . \quad=\text { Ansatzstelle für das Pubis. } \\
& x p . \quad=\text { Xiphiplastron. } \\
& h p . p .=\text { Hypoplastron. }
\end{aligned}
$$

erhaltener Schädel vor, der am Hinterrande mit langen kegelförmigen Zapfen besetzt ist, ähnlich wie der Schädel von Elginia Mirabilis (Fig. 269). Das Aussehen des Tieres, dessen Schwanz in eine knöcherne, stachelige Scheide eingehïllt war (ähnlich wie bei Glyptodon), mag sich dem der lebenden Matamata (Chelys fimbriata) Südamerikas und zum Teil der stachelhalsigen Type Platemys Spixii aus Südamerika genähert haben.

Miolania. - Plistozän von Queensland, Lord Howe Island, Neu-

1 R. Owen, A Monograph of the Fossil Chelonian Reptiles of the Wealden Clays and Purbeck Limestones. - Palaeontographical Society, Vol. VII, 1853.

A. Grabbe, Beitrag zur Kenntnis der Schildkröten des Deutschen Wealden. — Zeitschrift d. Deutschen Geol. Ges., XXXVI. Bd., 1884, S. 17.

A. Smith Woodward, Outlines of Vertebrate Palaeontology. - 1898, p. 172.

2 E. D. Cope, The Vertebrata of the Tertiary Formations of the West. Book 1, Report of the U. S. Geological Survey of the Territories, Washington, 1884, p. 146. 
südwales (hier Pliozän?) und Schichten unbestimunten Alters in Patagonien. - Schädelbreite am Hinterende $58 \mathrm{~cm}^{1}$ (Fig. 321.)

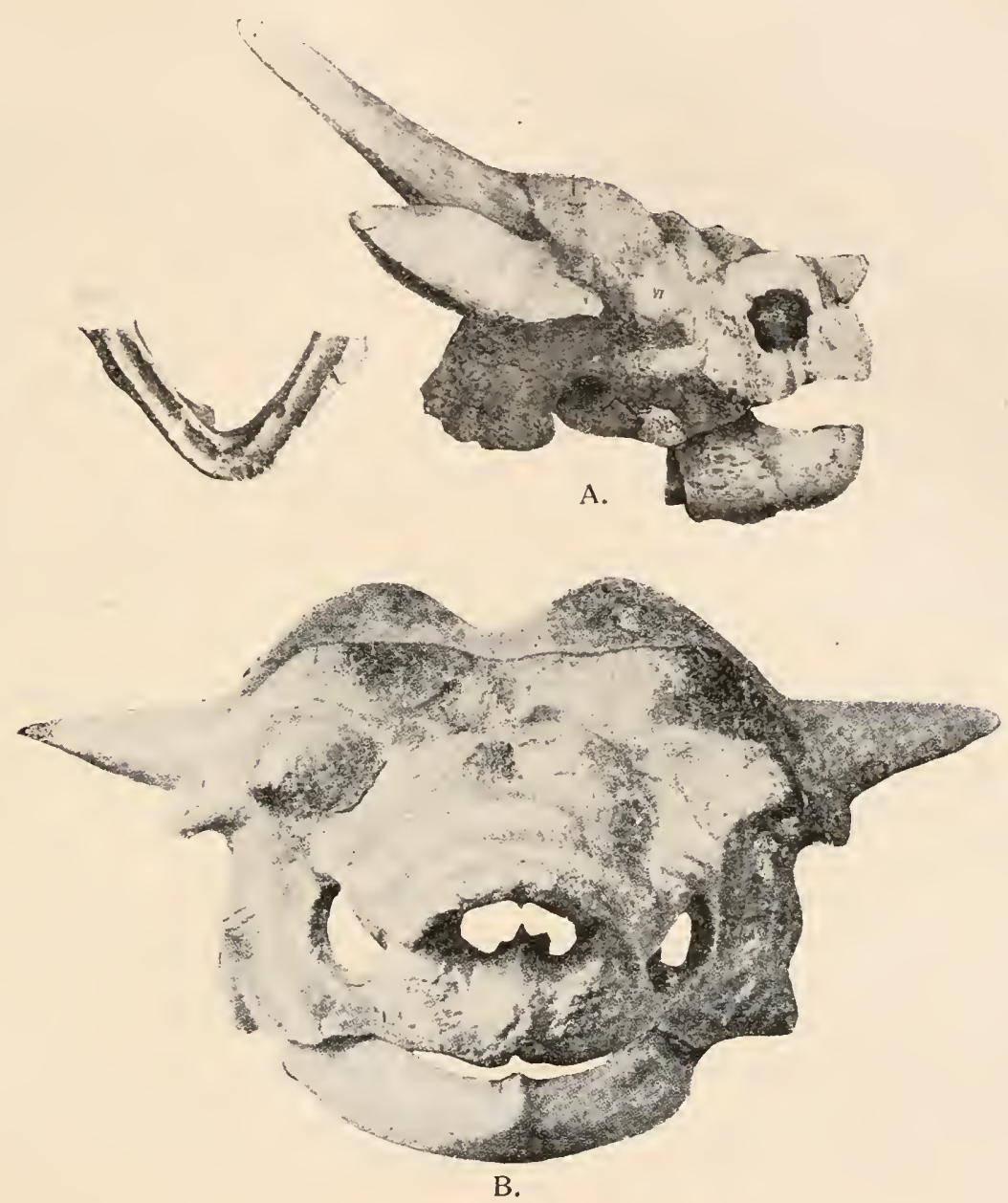

Fig. 321.

A: Miolania argentina, Amgh., Schädel und Unterkiefer in 1/\& nat. Gr. Aus dem roten Eozän(?) -Sandstein von Chubut, Argentinien (geol. Alter unsicher. (Nach A. Smith Woodward.)

B: Miolania Oweni, A. S. W., aus dem Plistozän von Queensland. (Nach A. Smith Woodward.) Stark verkl.

1 R. Owen, Description of Fossil Remains of Two Species of a Megalanian Genus (Meiolania) from Lord Howe's Island. -- Philosophical Transactions Roy. Soc., London 1886, Vol. CLXXVII, p. 471.

G. A. Boulenger, On the Systematic Position of the Genus Miolania, Owen (Ceratochelys, Huxley). - Proceed. Zool. Soc., London 1887, p. 554.

A. Smith Woodward, On some Extinct Reptiles from Patagonia, of the 
Die übrigen fossilen Pleurodiren geben über die Stammesgeschichte dieser Gruppe keine wesentlichen Aufschlüsse. Die systematische Stellung vieler Gattungen ist sehr unsicher.

\section{Unterordnung: Trionychoidea.}

Die Trionychoidea sind eine sehr alte Gruppe, die sich frülızeitig vom Hauptstamme der Schildkröten abgezweigt und einseitig spezialisiert hat. Dafür spricht das Auftreten vieler sehr primitiver Merkmale neben eigenartigen, den anderen Schildkröten fehlenden Spezialisationen. Der Hals wird in der Medianebene in die Schale zurückgezogen und mit dieser Gewohnheit steht auch die schwache Ausbildung der, Querfortsätze der Halswirbel in Zusammenhang. Das Becken ist mit dem Plastron nicht verwachsen. Die Gliedmaßen sind zu Flossen ausgebildet, die Schnauze endet in einem Rüssel und der Carapax sowie das Plastron haben die Hornschilder verloren. Die Marginalia sind entweder vorhanden (Carettochelyidae) oder fehlen (bei den meisten Trionychidae); zuweilen sind die Marginalia ohne Verbindung mit dem Carapax im hinteren Abschnitt des Lederschildes als Rudimente erhalten geblieben (Emyda). Besonders bezeichnend ist die rauhe, grubige Skulptur der Panzerplatten des Carapax und des Plastrons.

Die ersten Trionychiden treten in der oberen Kreide Nordamerikas auf̣; im Tertiär waren sie weit verbreitet und sind aus Europa, Afrika, Ostindien und Nordamerika beschrieben worden. Fast jeder neue Fund einer Trionychide wurde zu einer eigenen Art gestempelt, so daß heute bereits ungefähr 80 Artnamen für fossile Vertreter der Gattung Trionyx aufgestellt worden sind. ${ }^{1}$ Die Mehrzahl dieser „Arten“ wird jedoch einzuziehen sein. Über die Phylogenie der Trionychoidea geben diese Reste, wenigstens nach den bisher vorliegenden Untersuchungen, keinen Aufschluß.

Die lebenden Trionyxarten (z. B. Fig. 297) sind Süßwasserbewohner und fehlen nur in Australien und Südamerika, von wo sie auch nicht durch fossile Vertreter bekannt sind.

Genera Miolania, Dinilysia, and Genyodectes. - Proceedings Zoological Society, London 1901, Vol. 1, p. 169.

R. Etheridge, On the Occurrence of the Genus Meiolania in the Pliocene Deep Lead at Canadian, near Gulgong. - Records of the Geol. Survey of New Soutl Wales, Vol. I, 1889, p. 149.

L. Dollo, Expédition Antarctique Belge: Poissons. - Anvers, 1904, p. 223. (Hier die weitere Literatur.)

1 Eine (nicht ganz vollständige) Übersicht iiber die bis 1891 beschriebenen fossilen ,Arten" der Gattung Trionyx findet sich bei A. Negri: Trionici eocenici ed oligocenici del Veneto. - Memorie della Soc. Italiana delle Scienze, T. VIII, Napoli 1892, p. 5. Einen Überblick ïber die zahlreichen ,Arten" ans der engeren Verwandtschaft von Trionyx protriunguis gibt W. Teppner (Centralblatt f. Min., Geol. u. Pal., 1914, p. 628). 


\section{Ordnung: Theriodontia.}

Die Theriodontier stellen eine Gruppe von Reptilien dar, die in manchen Merkmalen mit den Sphenacodontiden verwandt zu sein scheinen, ohne daß sich jedoch direkte genetische Beziehungen zwischen beiden Stämmen nachweisen ließen. Der Hauptstamm der Theriodontier ist die im Perm und in der Trias zu hoher Blüte gelangte Gruppe der Therocephalia, die sich in einer ähnlichen Richtung wie die Säugetiere entwickelt haben und mit ihnen so zahlreiche Übereinstimmungen aufweisen, daß wiederholt der Gedanke von einem ummittelbaren genetischen Zusammenhang der Theroceplialier und der Säugetiere aufgetauclit ist.

An die Therocephalia schließen sich noch drei weitere Stammesreihen (Dinocephalia, Dromasauria und Dicynodontier) an, die mit ihnen zur Ordnung der Theriodontier vereinigt werden können, da sie in vielen Merkmalen des Skelettbaues übereinstimmen.

Die Theriodontier stellen also in dieser Umgrenzung einen Reptilstamm dar, der sich durch folgende gemeinsame morphologische Merkmale kennzeichnet:

Die Schädelknochen weisen niemals eine Skulptur wie jene der Cotylosaurier oder mancher Theromorphen auf. An den Schläfen ist eine einzige große Temporalgrube zur Ausbildung gelangt; außerdem ist eine kleine Temporalgrube unterhalb der großen in einigen wenigen Fällen beobachtet worden. Diese untere Temporalgrube kam im Stamme der Theriodontier nie zur vollen Ausbildung und ist auf einige Formen besclıränkt geblieben, wo sie nur den Charakter einer kleinen Spalte zwischen dem Jugale und Squamosum besitzt (z. B. Fig. 326 u. 335). Die große vorhandene Temporalgrube entspricht daher jedenfalls der oberen Temporalgrube jener Reptilien, bei denen zwei laterale Temporalgruben ausgebildet worden sind.

Der Schädel ist fast immer sehr schlank und lang; die Praemaxillaria sind kurz, die Supramaxillaria groß, und zwar reichen die letzteren ziemlich hoch an der Schädelseite hinauf. Septomaxillaria sind immer vorhanden. Die Nasalia sind lang und reichen an den Schädelseiten tief hinab. Mit einziger Ausnahme von Delphinognathus (Fig. 335). fehlt bei allen Theriodontiern das Quadratojugale, und das Squamosum drängt das inmmer kleiner werdende Quadratum ganz herab, so daß es namentlich bei den triadischen Therocephalia, die man früher meist unter dem Namen Cynodontia zusammengefaßt und den primitiveren Gattungen des Perms gegenübergestellt hat, rudimentär wird. Bei allen Theriodontiern stoßen die Vomeres mit den Pterygoidea zusanmen und drängen daleer die Palatina ganz zur Seite. Ein Interparietale und die Tabularia sind (nach Watson, 1913) immer vor- 
handen. Das Postorbitale und Postfrontale liegt an der vorderen Ecke der Temporalgrube.

Die Wirbel sind amphicöl, zwei bis vier setzen das Sacrum zusammen. Das Becken weist ein geschlossenes Acetabulum auf und die drei Elemente (Ilium, Pubis und Ischium) sind durch Nälıte fest miteinander verbunden. Im Humerus ist ein Foramen entepicondyloideum vorhanden. Die Phalangenzahl ist in Hand und Fuß auf zwei im ersten Strahl ınd auf drei in allen übrigen Fingern und Zehen reduziert.

Die Theriodontier erscheinen zuerst in Perm und sterben in der Trias ohne Nachkommen aus.

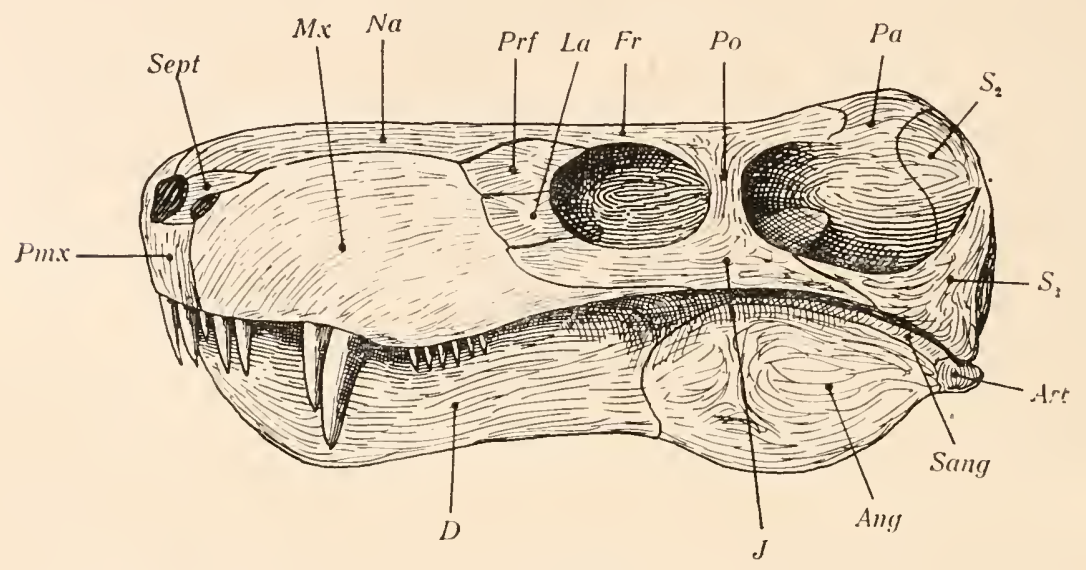

Fig. 322.

Schädel eines permischen Therocephaliers, Aloposaurus gracilis, Broom.

Kapkolonie. 3/4 nat. Gr. (Nach R. Broom.)

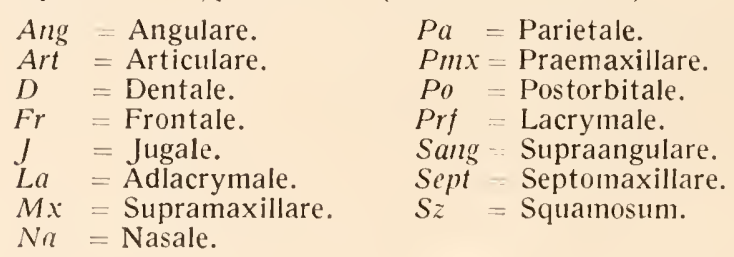

1. Unterordnung: Therocephalia.

Diese Gruppe der Theriodontier gehört zu denl merkwürdigsten fossilen Reptilien. Die überwiegende Mehrzahl der in diese Gruppe gehörenden Formen ist an die ränberische Lebensweise in einer Weise angepaßt gewesen, daß eine ïberraschende Ähnlichkeit in Gebiß, in der allgemeinen Schädelform, in der Körpergestalt usf. zustande kanı. Nur wenige Gattungen, wie Diademodon, sind nach Durchlaufung einer karnivoren Vorstufe zur Herbivorie übergegangen.

Die auffallendste Säugerähnlichkeit des Schädels bestelıt in der 
Differenzierung des Gebisses in Greifzähne, Reißzähne und Scherenzähne, die den lnzisiven, Kaninen und Molaren der Säugetiere funktionell entsprechen. Die Greifzälnne sind dicht gedrängt ınd ihre Zahl schwankt von acht (bei Alopecodon) bis zu vier (z. B. bei Cynognathus, Galesáurus usf.). Die den Caninen oder Eckzähnen entsprechenden großen Reißzälnne stehen wie bei den Säugetieren am Vorderende des Supramaxillare und die unteren Antagonisten vor ihnen. Die unteren Reißzähne greifen aber nicht wie bei den Säugetieren an den oberen

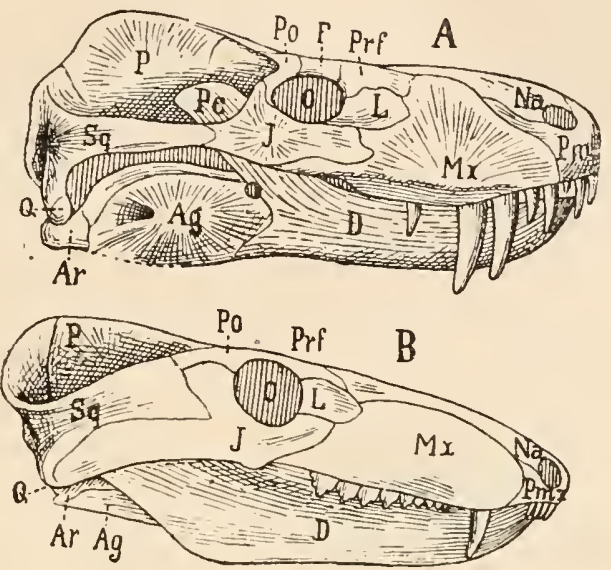

Fig. 323.

Vergleich zweier Therocephalierschädel, un die Verschiedenheiten des

Aufbaues des Jochbogens zu zeigen:

A: Lycosuchus Vanderrieti, Broom. Perm der Kapkolonie.

B: Cynognathus platyceps, Seeley. Trias der Kapkolonie.

$\begin{array}{ll}\quad(1 / 4 \text { nat. Gr. } & \text { Nach } \mathrm{R} . \text { Broom. }) \\ A g=\text { Angulare. } & O=\text { Orbita. } \\ A r=\text { Articulare. } & P=\text { Parietale. } \\ D=\text { Dentale. } & P c=\text { Processus coronoideus. } \\ F=\text { Frontale. } & P m=\text { Praemaxillare. } \\ J=\text { Jugale. } & P o=\text { Postorbitale. } \\ L=\text { Adlacrymale. } & P r f=\text { Lacrymale. } \\ M x=\text { Supramaxillare. } & Q=\text { Quadratum. } \\ N a=\text { Nasale. } & S q=\text { Squamosum. }\end{array}$

Eckzähnen vorbei und legen sich nicht auf die Außenseite der Supramaxillaria, sondern greifen in Gruben vor den oberen Eckzähnen in die Gaumenfläche der Supramaxillaria ein. Meist sind oben jederseits zwei Reißzähne hintereinander entwickelt (z. B. Fig. 322 u. 323), seltener nur einer jederseits (z. B. bei Cynognathus, Fig. 326). Hinter den Eckzähnen folgen kleinere Zähne, welche die Aufgabe des Zerkleinerns der Beutetiere haben und als Scherenzähne funktionieren. Bei den höher spezialisierten Gattungen sind sie dreispitzig, bei den primitiveren einspitzig. 
Snux. Na. La. Adl. Fr. Ju. Pof. Porb. Par.

I'mx.

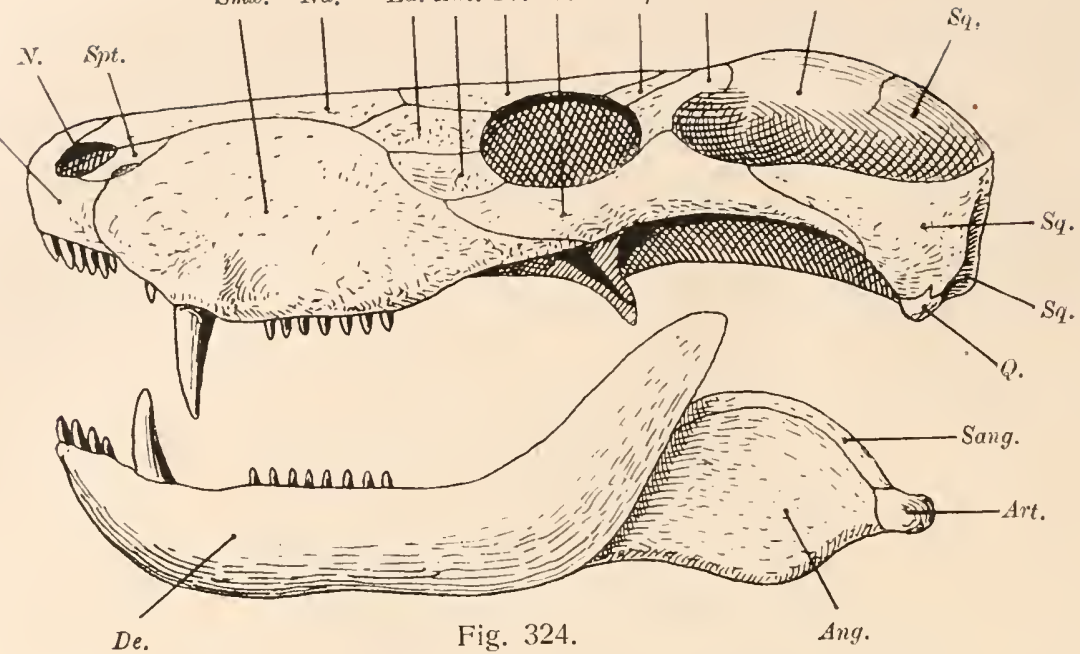

$S q$

Par.

Iu. Porb. Orb. Ju.

Smx. Na.

$N^{\top}$

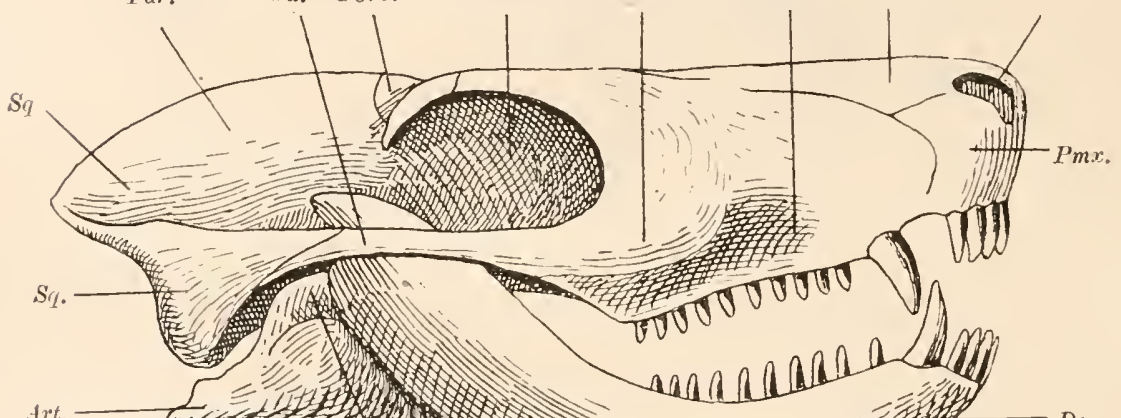

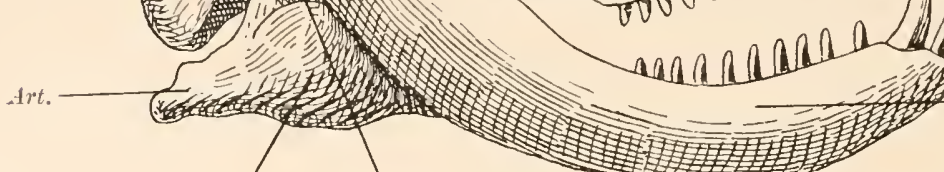

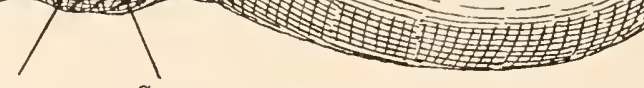

Ang. Sang. Fig. 325.

Par. u.T.n. Porb. Pof.

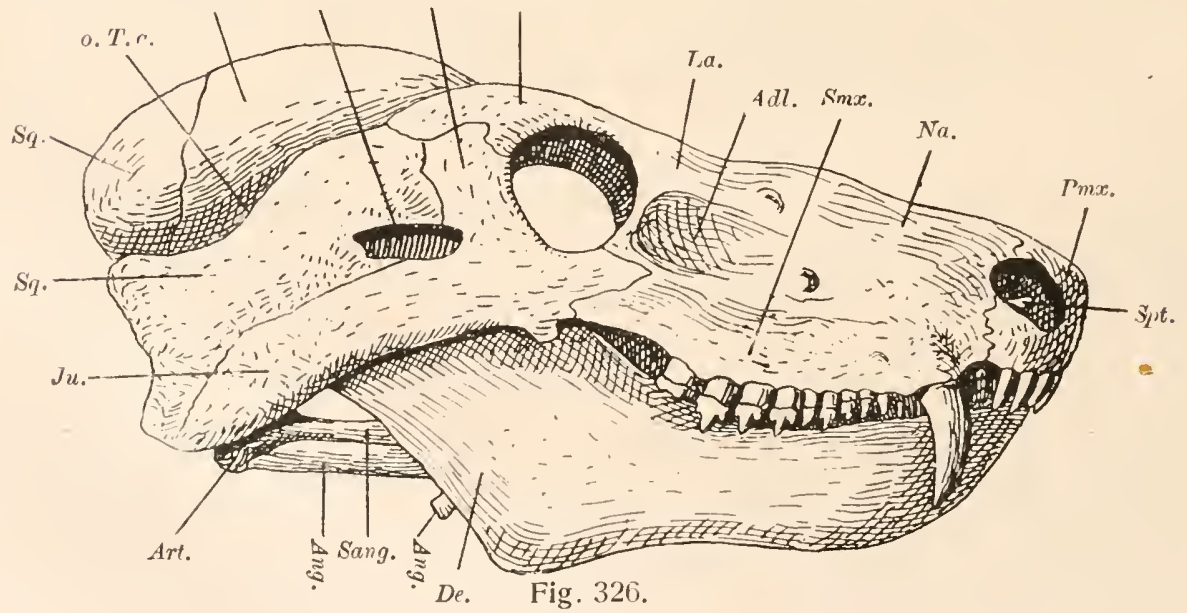


Mit der geänderten Gebißfunktion steht eine wesentliche Veränderung des Unterkieferbaues in kausalem Zusammenhang (Fig. 324 -328). Das Dentale hat eine gewaltige Vergrößerung auf Kosten aller anderen Unterkieferknochen erfahren und es ist zur Ausbildung eines Processus coronoideus des Dentale gekommen, der durchaus an den Kronenfortsatz des Säugetierunterkiefers gemahnt. Die von den älteren Wirbeltieren ererbten Elemente: Articulare, Praearticulare, Angulare, Supraangulare, Spleniale und Complementare sind zwar noch vorhanden, werden aber bei den jüngeren Therocephaliern stark reduziert. Articulare, Angulare, Supraangulare und Pracarticulare liegen bei di sen in einer Grube an Hinterende und auf der Innenseite des Dentale (Fig. 328) und sind so locker mit diesem verbunden, daß sie bei der Fossilisation sehr leicht aus dem Verbande mit dem Dentale herausfallen und verloren gehen.

Die Ausbildung des Kronenfortsatzes des Dentale sowie die allgemeine Form dieses Unterkieferelementes spricht dafür, daß die Ausbildung des Massetermuskels und des bei den Sängern auf dem Kronenfortsatz inserierenden Temporalnuskels bei den Therocephaliern dieselbe oder doch sehr ähnlich war wie bei den Säugetieren.

Die Schädelkapsel ist sehr klein und das Gehirn wenig differenziert gewesen, wie aus den Ausgüssen der Hirnhöhle hervorgeht.

\section{Zu Fig. $324-326$.}

Die Schädel und Unterkiefer dreier Therocephalier aus dem Perm und der Trias der Kapkolonie, die die allmähliche Reduktion der hinteren Unterkieferpartie (mit Articulare, Angulare und Supraangulare) zeigen.

Fig. 324. Scylacosaurus Sclateri, Broom; Perm Siidafrikas (Kapkolonie), in $4 / 2$ nat. Gr. (Nach R. Broom.)

Fig. 325. Bauria cynops, Broom; Trias Südafrikas (Kapkolonie); in $3 / 4$ nat. Gr. .(Nach R. Broom.)

Fig. 326. Cynognathus crateronotus, Seeley; aus den oberen Beaufortschichten (Trias) der Kapkolonie, etwa in 1/4 nat. Gr. (Neue Rekonstruktion des Schädels auf Grundlage der Abbildungen des Schädels nach A. Smith Woodward, 1898, und des Unterkiefers [nach der beendeten Präparation] nach D. M. S. Watson, 1912; das Original im Brit. Mus. Nat. Hist. in London.)

$\begin{array}{ll}\text { Ang. } & =\text { Angulare. } \\ \text { Art. } & =\text { Articulare. } \\ \text { Adl. } & =\text { Adlacrymale. } \\ \text { De. } & \text { Dentale. } \\ \text { Fr. } & \text { Frontale. } \\ \text { Jul. } & =\text { Jugale. } \\ \text { La. } & =\text { Lacrymale. } \\ \text { N. } & =\text { Nasenöffnung. } \\ \text { Na. } & =\text { Nasale. } \\ \text { Orb. } & =\text { Orbita. } \\ \text { o. T.g. } & \text { obere Temporalgrube. }\end{array}$

Par. = Parietale.

Pmx. = Praemaxillare.

Pof. $\quad=$ Postfrontale.

Porb. = Postorbitale.

Q. $\quad=$ Quadratum.

Simx. = Supramaxillare.

Spt. $\quad=$ Septomaxillare.

Sq. $\quad$ = Squamosum.

Sang. = Supraangulare

u. T. $g .=$ untere Temporalgrube. 
An die Schädelkapsel schließen sich die lateralen, sehr großen und weiten Temporalgruben an, welche für eine starke Ausbildung der in diesen Höhlen liegunden Muskulatur sprechen. Diese großen Temporalgruben werden tunten von einen starken Jochbogen begrenzt, der aus dem Postorbitale, Jugale und Squanosum aufgebaut wird. Zwischen dem Jugale, Squamosum und Postorbitale liegt bei einzelnen Formen, wie bei Cynognathus, eine kleine Fissur, die der unteren Temporalgrube der Reptilien mit oberen und unteren lateralen Temporalgruben homo$\log$ ist (Fig. 326).

Der Gelenkhöcker der Therocephalier ist ursprünglich einköpfig, später doppelt, und zwar kommt diese Verdoppelung dadurch zustande, daß das Basioccipitale nach vorn ausweicht (Fig. 331).

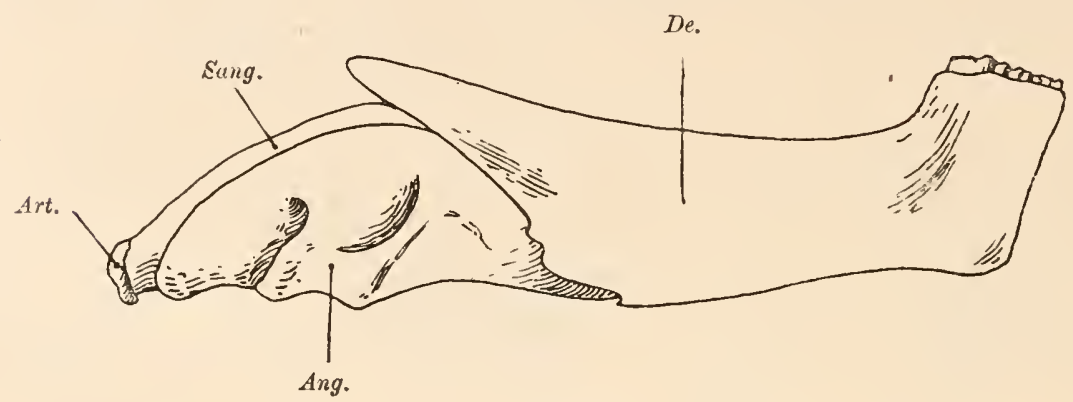

Fig. 327.

Außenansicht des rechten Unterkieferastes von Scymuosuchus Whaitsi, Broom, in $1 / 2$ nat. Gr. (Zähne nicht eingezeichnet.) (Nach D. M. S. Watson.) $\begin{array}{ll}\text { Ang. }=\text { Angulare } & \text { De. }=\text { Dentale. } \\ \text { Art. }=\text { Articulare. } & \text { Sang. }=\text { Supraangulare. }\end{array}$

Die Schädelbasis bietet besonders im Abschnitt der Choanen wichtige Eigentünlichkeiten dar. Bei den permischen Therocephaliern ist der Gaumen noch primitiv gebaut; die Choanen werden durch die Vomeres (nach Broom „Praevomeres“, aber giwiß ident mit den Vomeres der Stegocephalen und Cotylosaurier sowie der übrigen höheren Wirbeltiere) getrennt, welche sich nach hinten zwischen die Palatina einkeilen und mit dem Vorderende der Pterygoidea zusammenstoßen. Bei den jüngeren Therocephaliern der Trias ist ein sekundärer Gatmen zur Ausbildung gelangt, indem die Choanen von zwei Platten überbrïckt werden, die von den Palatina entspringen. Dadurch wird die Gaumenplatte sekundär verlängert und die Öffnung der Choanen weiter nach hinten verlegt. Auf dem Palatinum sind in einigen Fällen (bei Cynognathus und Diademodon) sehr kleine, diclitstelıende Zähnchen zu beobachten, ebenso auf dem Pterygoid (bei Scylacosaurus, Fig. 329). Zwischen dem Palatinum, Pterygoid und Supramaxillare ist noch ein kleines Transversum vorhanden; zwischen Transversum, Palatinum und Pterygoid liegt 
eine Lücke, die bei Scylacosaurus groß, bei Diademodon aber rudimentär ist (Fig. 330). Die äußeren Nasenöffnungen sind nur bei Galesaurus zu einer einzigen Öffnung verschmolzen, sonst sind sie getrennt. Das Quadratum ist bei den permischen Therocephaliern zwar auch schon verkleinert, doch nimmt die Reduktion dieses Knochens bei den tria-
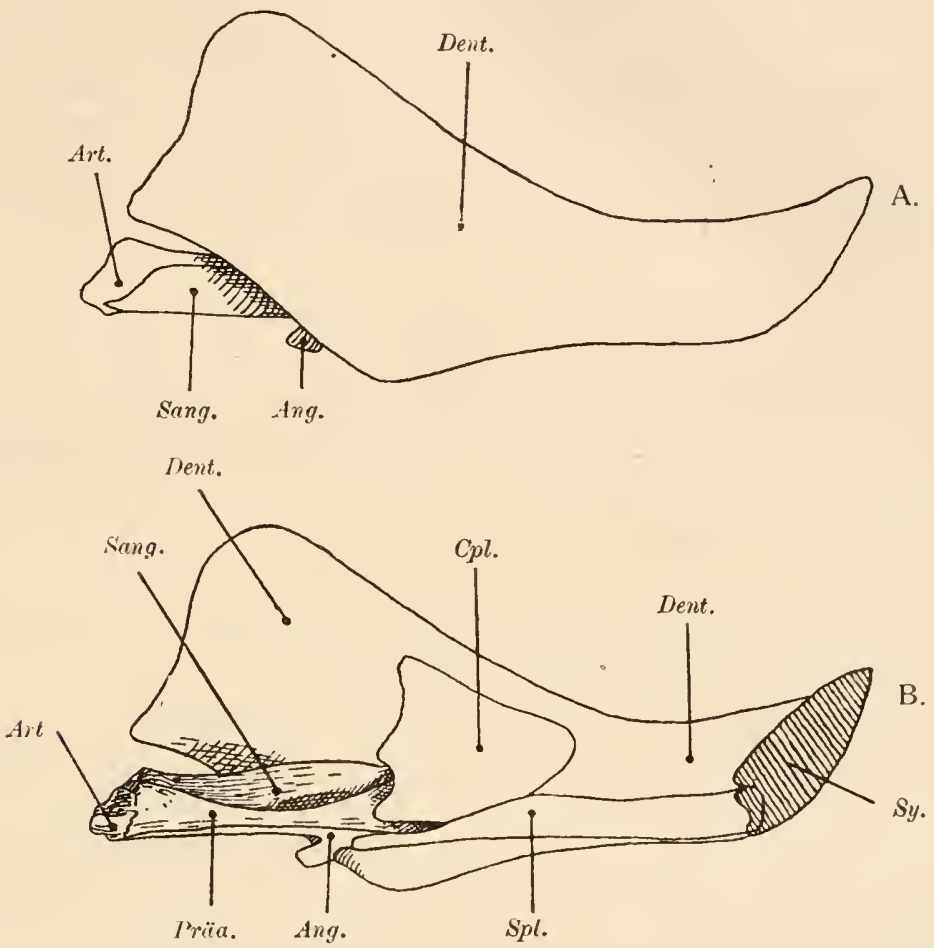

Fig. 328.

A. Rechter Unterkieferast von Cynognathus crateronotus, Seel., aus der Trias der Kapkolonie, von außen gesehen. Die Zähne sind nicht dargestellt.

B. Linker Unterkieferast desselben Tieres, von innen gesehen.

Beide Figuren in 1/4 nat. Gr. (Nach D. M. S. Watson.) .

Ang. $=$ Angulare.
Art. $=$ Articulare.
Cpl. $=$ Complementare.
Dent. $=$ Dentale.
Präa. $=$ Präarticulare.

Sang. = Supraangulare

$S p l .=$ Spleniale.

Sy. $\quad=$ Symphyse.

dischen Gattungen stark zu. Der Hauptknochen dieses Schädelabschnittes, in dem sonst, z. B. bei den Stegocephalen und Cotylosauriern, das Quadratum und das Quadratojugale die Hauptrolle spielen, wird bei den Therocephaliern von Squanosum eingenommen.

Die Therocephalier unfassen jedenfalls verschiedene Familien, die sich zum Teil ganz einseitig spezialisiert haben, deren Merkmale und Unterschiede aber bis jetzt noch nicht scharf abzugrenzen sind. $\mathrm{Zu}$ 
diesen einseitigen Spezialisationen gehört z. B. das sekundär herbivore Gebiß von Diademodon und Gomphognathus, die einem Seitenast angehören; dazu gehört ferner die Reduktion der Knochenspange zwischen der Orbita und der Temporalgrube bei Bauria; ein weiteres einseitiges Spezialisationsmerkmal ist die Verschmelzung der beiden Frontalia zu einem medianen, unpaarigen Knochen und die schon erwähnte Vereinigung beider Nasen öfnungen zu einer einzigen bei Galesaurus usf.

Trotz dieser Verschiedenheiten in Einzelleiten, die das Vorhandensein verschiedener Entwicklungsreihen im Rahmen der Therocephalia beweisen, bieten sie doch in ihrer Gesamtheit èine überraschende Fülle von Merkmalen dar, die wir unter den Säugetieren wiederfinden. Diese sind:

1. Das Vorhandensein eines einzigen Jochbogens, der vom Squamosum und Jugale gebildet wird (Owen, Seeley, Broom, Watson).

2. Die Differenzierung des Gebisses in Greifzähne (Inzisiven1), Reißzähne (Caninen) und Mahlzähne (Molaren) (Owen, Seeley, Broom, Watson).

3. Die Art der Einpflanzung der Zähne in Alveolen (Owen, Seeley, Wats on).

4. Das Vorhandensein eines sekundären Gaumens bei den jüngeren Therocephaliern (Seeley, Broom, Watson).

5. Das Vorhandensein eines medianen Parasphenoids. Außerdem sind in vorderen Teile des Gaumens die paarigen Vomeres vorlanden, welche von Broom als „Praevomeres" bezeichnet werden, aber zweifellos mit den als Vomeres bei den Amphibien unterschiedenen Knochen homolog sind, die wieder, von verschiedenen Forschern in der letzten Zeit dargelegt wurde ${ }^{1}$, ebenso wie mit den unpaarigen Vomer der Schildkröten, mit denı unpaarigen Vomer der Säugetiere homolog sind.

6. Die starke Reduktion des Quadratums (Seeley, Broom, Watson).

7. Die starke Reduktion der Unterkieferelemente mit Ausnahme des Dentale (Seeley, Broom, Watson).

1 Die Bezeichnung, Praevomer" hat R. Broom aufgestellt (On the Homblogy of the Palatine Process of the Mammalian Praemaxillary. - Proc. Linnean Soc. New South Wales (X), 1895; On the Mamınalian and Reptilian Vomerine Bones. - Ibidem, 1902). Seither ist diese Bezeichnung in der paläontologischen Literatur häufig angewandt worden. Der ,,Vomer" der Säugetiere wird jedoch in einzelnen Fällen (z. B. bei Homo und Didelphis) noch parig angelegt und verschmilzt hier erst im Laufe der Ontogenie. Da außer diesem Vomer (= Praevomeres, Broom) bei Didelphis auch ein Rudiment des Parasphenoids nachgewiesen werden konnte, ist für die Unterscheidung der „Praevomeres" der Reptilien und des ,Vomer" der Säugetiere kein Grund mehr vorhanden.

Vgl. dariiber insbesondere F. von Huene: Ein ganzes Tylosaurusskelett. Geol. 1. Paliont. Abhandl., N. F. Bd. VIII (G. R.. Bd. XII), 1910, p. 309. 
8. Das Vorhandensein eines langen äußeren Gehörganges (Meatus auditorius externus) (Gregory, Watson).

9. Die Ausbildung eines doppelten Gelenkkopfes des Hinterlnauptes bei den triadischen Therocephaliern (Seeley, Watson).

10. Die allgemeine Form und Anordnung der Absclnnitte der Wirbelsäule (Seeley, Watson).

11. Die auffallende Säugetierähnlichkeit der Scapula und des Sclultergürtels überhaupt (Seeley, Broon, Watson, Gregory).

12. Die Gestalt des Humerus, der ein Foramen entepicondyloideum besitzt (Owen, Seeley, Broom, Watson, Giegory).

13. Das Vorhandensein eines Olecranons in der Ulna (Seeley, Watson).

14. Der Bau der Handwurzel (Seeley, Bardeleben, Broom, Watson, Gregory).

15. Die Reduktion der Phalangen in den Fingern und Zehen und das Vorluandensein derselben Phalangenformel wie bei den normalen Säugetieren (2, 3, 3, 3, 3) (Broon, Osborn, Watson).

16. Der Aufbau des Sacrums aus mehr als zwei Wirbeln (Owen, Seeley, Watson).

17. Der Bau des Beckens (Owen, Seeley, Broom, Watson).

18. Der Bau des Tarsus (Broom, Watson, Giegory).

19. Die Kleinheit der Fenestra vestibuli (Watson).

20. Die ventrale Lage des inneren Ohres (bei Theromus beobachtet) (W a ts 0 11).

21. Das Vorlandensein zahlreicher Gefäßlöcher an der Seite der Gehirnkapsel, nur mit dem Gefäßsystem dieser Region des Insektivorenschädels vergleiclıbar (Watson).

22. Der einmalige Zahnwechsel der Inzisiven, Caninen und Prämolaren (bei Diademodon, naclı R. Broom 1913).

Trotz dieser großen Zahl von Säugetiermerkmalen kömnen die Therocephalia aus dem Grunde nicht als die Alnengruppe der Säugetiere betrachtet werden, weil sie in wichtigen Merkmalen, wie in Bau des Gehirns und der Schädelkapsel, von den Säugetieren weit verschieden sind. Wir dürfen jedoch aus der Tatsache, daß die Therocephalier eine so große Menge von Säugetiermerkmalen aufweisen, darauf schließen, daß sie zusammen mit den Säugetieren von gemeinsamen Alınen abstammen. Da die ältesten Therocephalier im Perm auftreten, so muß der Zeitpunkt der Entstehung der Säugetiere in annähernd dieselbe Zeit wie die Abtrennung der Therocephalia fallen. Beide Stänmme sind auf kleine Reptilien zurückzuführen, die aus der Gruppe der Cotylosaurier entstanden sind. Während jedoch die Säugetiere erst viel später zur Blüte gelangten und das ganze Mesozoikum 
hindurch auf einer tiefen Entwicklungsstufe verharrten, entwickelten sich die Therocephalier sehr rasch zu hoher Blüte, um aber schon in der Trias zu erlöschen, ohne daß es ihnen gelungen wäre, sich im Kampfe mit den anderen Raubtieren des Reptilienstanmes erfolgreich zu beloupten; aus der Trias sind die Therocephalia bisher nur aus der Kapkolonie bekannt und selbst in reichen Fossillagern dieser Formation ist in Europa oder Nordamerika nie die geringste Spur ilırer Anwesenheit entdeckt worden, während sie im Perm auch aus Europa nachgewiesen werden konnten. Das Hauptlager der Therocephalier sind die dem Perm zuzurechnenden unteren und die der Trias angehörenden oberen Beaufortschichten Südafrikas (Kapkolonie).

Die wichtigsten Gattungen sind ${ }^{1}$ : 329).

Scylacosaurus. - Perm Südafrikas. - Z. B. S. Sclateri (Fig. 324,

Scaloposaurus. - Perm Südafrikas. - Z. B. S. constrictus, der

1 Die wichtigste Literatur iber diese interessante und für die Frage nach der Abstammung der Säugetiere sehr wichtigen Gruppe der Reptilien ist folgende:

R. Broom, On the Development and Morphology of the Marsupial Shoulder Girdle. - Transactions Royal Society Edinburgh, Vol. XXXIX, Part III, 1899, p. 749 .

- On the Mammalian and Reptilian Vomerine Bones. - Proc. Linnean Society New South Wales, 1902, Part IV, p. 545.

- On the Structure of the Palate in the Primitive Theriodonts. - Geological Magazine, London (4), 1903, Vol. X, p. 343.

- On the Classification of the Theriodonts and their Allies. - Report of the Sonth African Assosiation of the Advancement of Science, Vol. I, 1903, p. 1.

- On an almost perfect Skull of a New Primitive Theriodont (Lycosuchus Vanderrieti). - Transactions Sonth African Philosoph. Suc., Vol. XIV, 1903, p. 197.

- The Origin of the Mammalian Carpus and Tarsus. - Ibidem, Vol. XV, 1904, p. 89 .

- On the Structure of the Theriodont Mandible, and on its Mode of Articulation with the Skull, - Proc. Zool. Soc., London 1904, Vol. I, p. 490.

- On the Use of the Term Anomodontia. - Records of the Albany Museum, South Africa, Vol. I, 1905, p. 266.

- Preliminary Notice of some New Reptiles collected by Mr. Alfred Brown at Aliwal North, S. Africa. - Ibidem, p. 269.

- On some Points in the Anatomy of the Theriodont Reptile Diademodon. - Proc. Zool. Soc., London 1905, Vol. I, p. 96.

- Reptiles of the Karrooformation. - In: A. W. Rogers, ,An Introduction to the Geology of Cape Colony", London 1905, p. 228.

- On a New Cynodont Reptile (Aelurosuchus Browni). - Transactions South African Phil. Soc., Vol. XVI, 1906, p. 376.

- Some Recent Advances in South African Paleontology. - Science, N. S., Vol. XXVI, 1907, p. 796.

- On the Origin of Mammals. - Report of the Brit. and Sonth Africa Assoc., Vol. 111, 1907, p. 1. 
kleinste bekannte Therocephale, dessen Schädellänge kaun $5 \mathrm{~cm}$ beträgt. Das Angulare ist noch groß, aber der Kronenfortsatz des Dentale bereits stark entwickelt.

Lycosuchus. - Perm Südafrikas. - Z. B. L. Vanderrieti (Fig. 323).

R. Broom, On the Geological Horizons of the Vertebrate Genera of the Karrooformation. - Records of the Albany Museum, Vol. II, 1907, p. 156.

- The origin of the Mammal-like Reptiles. - Proc. Zool. Soc., London 1907, p. 1047.

- On the Interrelationships of the Known Therocephalian Genera. - Annals of the South African Museum, Vol. IV, Part IV, 1908.

- Notice of some new South African Fossil Amphibians and Reptiles. - Ibidem, Vol. VII, Part 111, 1909, p. 270.

- On the Shoulder Girdle of Cynognathus. - lbidem, p. 283.

- An Attempt to determine the Horizons of the Fossil Vertebrates of the Karruo. - lbidem, p. 285.

- The Skull of Tapinocephalus. - Geological Magazine, London 1909, p. 400.

- A Comparison of the Permian Reptiles of North America with those of South Africa. - Bulletin Amer. Mus. Nat. Hist., Vol. XXVIII, Art. 20, 1910, p. 197.

- Observations on some Specimens of South African Fossil Reptiles preserved in the British Museum. - Transactions Royal Soc. South Africa, Vol. II, Part I, 1910 , p. 19.

- On the Structure of the Skull in Cynodont Reptiles. - Proc. Zool. Soc., London 1911, p. 893.

- On some New South African Permian Reptiles. - Ibidem, p. 1073.

- On some New Carnivorous Therapsids. - Bulletin Amer. Mus. Nat. Hist., New York, Vol. XXXII, 1913, p. 557.

- On Evidence of a Mammal-like Dental Succession in the Cynodont Reptiles. lbidem, p. 465.

R. Owen, On some Reptilian Fossils from South Africa. - Quart. Journal Geol. Soc., London 1860, Vol. XVI, p. 49.

- Descriptive and Illustrative Catalogue of the Fossil Reptilia of South Africa in the Collection of the British Museum. - London 1876.

W. K. Gregory, The Orders of Mammals. - Bulletin of the Amer. Mus. Nat. Hist., Vol. XXVII, 1910, p. 113.

- Critique of Recent Work on the Morphology of the Vertebrate Skull, Especially in Relation to the Origin of Mammals. - Journal of Morphology, Baltimore 1913, Vol. XXIV, No. 1, p. 1.

H. G. Seeley, Researches on the Structure, Organization, and Classification of the Fossil Reptilia. - Part IX, On the Therosuchia. - Philosophical Transactions, Roy. Soc., London 1895, Vol. CLXXXV B, p. 987.

- Ibidem, Part 1X, Sect. 2, p. 1019.

- Ibidem, Part IX, Sect. 4, Vol. CLXXXVI, 1895, p. 1.

- Ibidem, Part IX, Sect. 5, Vol. CLXXXVIII, 1895, p. 59.

D. M. S. Watson, The Skull of Diademodon, with Notes on those of some other Cynodonts. - Annals and Magazins of Natural History (8), Vol. V111, 1911, p. 293. On some Features of the Structure of the Therocephalian Skull. - Ibidem (8), Vol. XI, 1913, p. 65.

A. Smith Woodward, Outlines of Vertebrate Paleontology. - Cambridge 1898, p. 150 . 
Aloposaurus. - Perm Südafrikas. - Z. B. A. gracilis. Sçhädellänge $12 \mathrm{~cm}$ (Fig. 322).

Alopecodon. - Perm Südafrikas. - 8 Greifzähne, 2 Reißzähne und 8 Mahlzähne oben jederseits vorhanden.

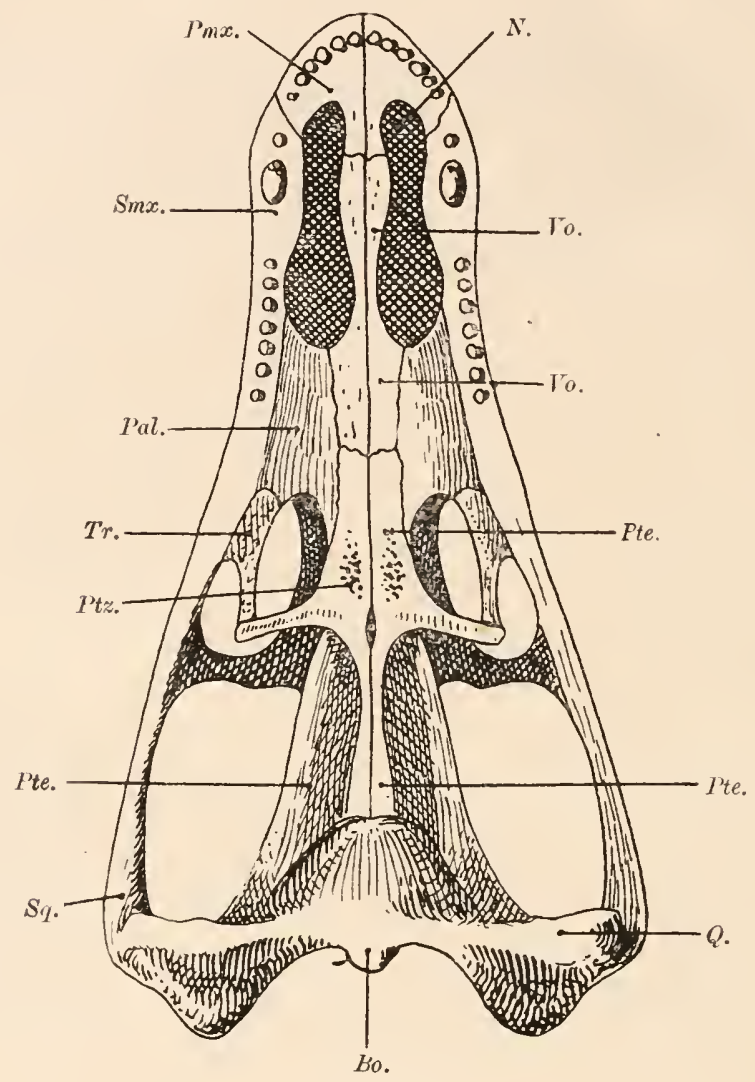

Fig. 329.

Gaumenansicht des Schädels von Scylacosaums Sclateri, Broom, ein Therocephalier aus dem Perm Sïdafrikas; rekonstruiert in $4 / 7$ nat. Gr. (Nach R. Broom, 1910.)

\begin{tabular}{|c|c|c|c|}
\hline $\begin{array}{l}\text { Bo. } \\
\text { N. } \\
\text { Pal. } \\
\text { Pmx. } \\
\text { Pte. }\end{array}$ & $\begin{array}{l}=\text { Basioccipitale. } \\
=\text { Choane. } \\
=\text { Palatinun. } \\
=\text { Praemaxillare. } \\
=\text { Pterygoid. }\end{array}$ & $\begin{array}{l}\text { Q. } \\
\text { Smx. } \\
\text { Sq. } \\
\text { Tr. } \\
\text { Vo. }\end{array}$ & $\begin{array}{l}=\text { Quadratum. } \\
=\text { Supramaxillare. } \\
=\text { Squamosum. } \\
=\text { Transversum. } \\
=\text { Vomer. }\end{array}$ \\
\hline
\end{tabular}

Scymnosuchus. - Perm Südafrikas. Z. B. S. Whaitsi. - Angulare noch groß (Fig. 327).

- Lycosaurus. - Perm Südafrikas. - Übergangstype zu den jüngeren Gattungen. 
Inostranzewia. - Perm Rußlands (noch nicht eingehend beschric ben).

Cynognathus. - Trias Südafrikas. - Z. B. C. crateronotus (Fig. 323, 326, 328, 331).

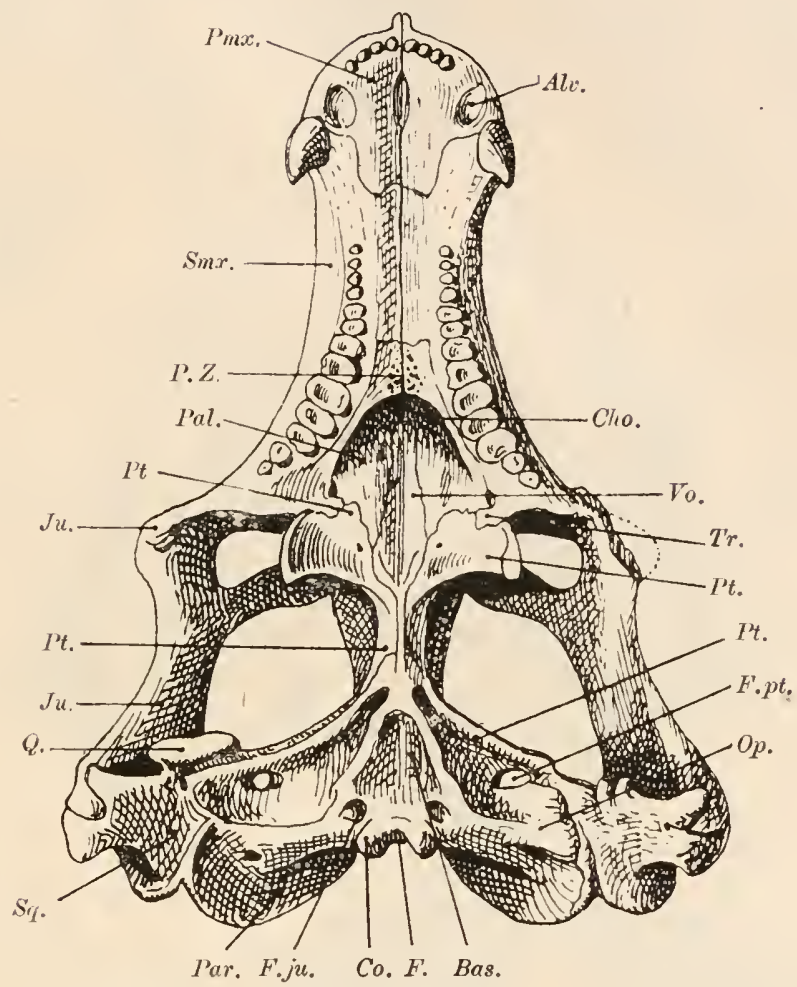

Fig. 330.

Rekonstruktion der Unterseite des Schädels von Diademodon Browni, Seeley, aus der Trias Südafrikas (Kapkolonie). 4/5 nat. Gr. ( $\mathrm{lm}$ wesentlichen nach D. M. S. Watson, ergänzt im Vorderteile der Kiefer nach Gomphognathus minor, Broom, aus der Trias der Kapkolonie; Einzelheiten zum Teil nach

\section{R. Broom.)}

Alv. = Alveole vor dem Reißzahn. P. $Z$. = Palatinalzähne.

Bas. = Basisphenoid.

Co. = Condylus occipitalis.

Par. $=$ Parietale.

Cho. = Choane .

$F$. $\quad$ Frontale

Pmx = Praemaxillare

$F . j u$. $=$ Foramen jugulare

$F . p t$. $=$ Foramen pterygopalatinum.

$J u . \quad=$ Jugale.

Op. = Opisthoticum

Pt. $\quad=$ Pterygoid.

Q. $=$ Quadratum.

Smx. = Supramaxillare.

$S q . \quad=$ Squamosum.

Tr. $=$ Transversum

Pal. $=$ Palatinum.

Bauria. - Trias Sülafrikas. - Z. B. B. cynops (Fig. 325).

Gomphognathus. - Trias Südafrikas. - Z. B. G. polyphagus. 
Diademodon. - Trias Südafrikas. - Z. B. D. Browni. Herbivor. - 4 Greifzähne, 1 Reißzahn, 12 Mahlzähne (bei D. platyrhinus).

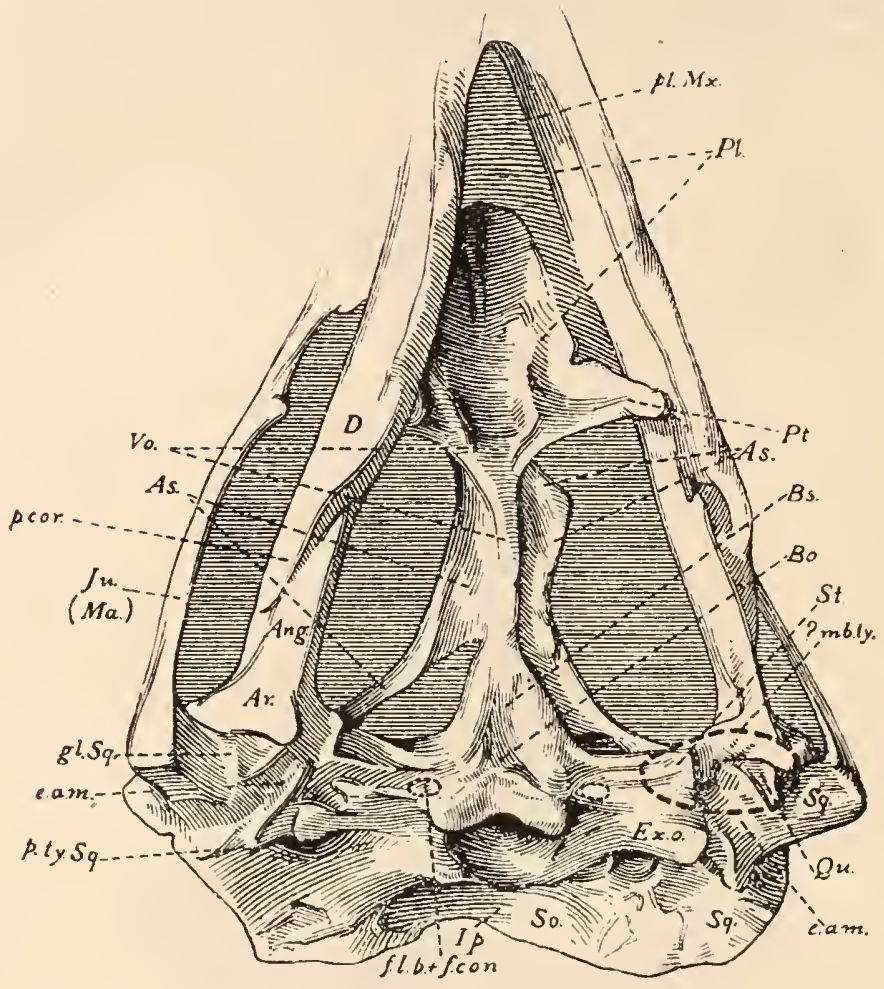

Fig. 331 .

Unterseite des Schädels von Cynognathus platyceps, Seeley, aus der Trias der Kapkolonie. Ungefähr $1 / 2$ nat. Gr. (Nach W. K. Gregory, 1913.)

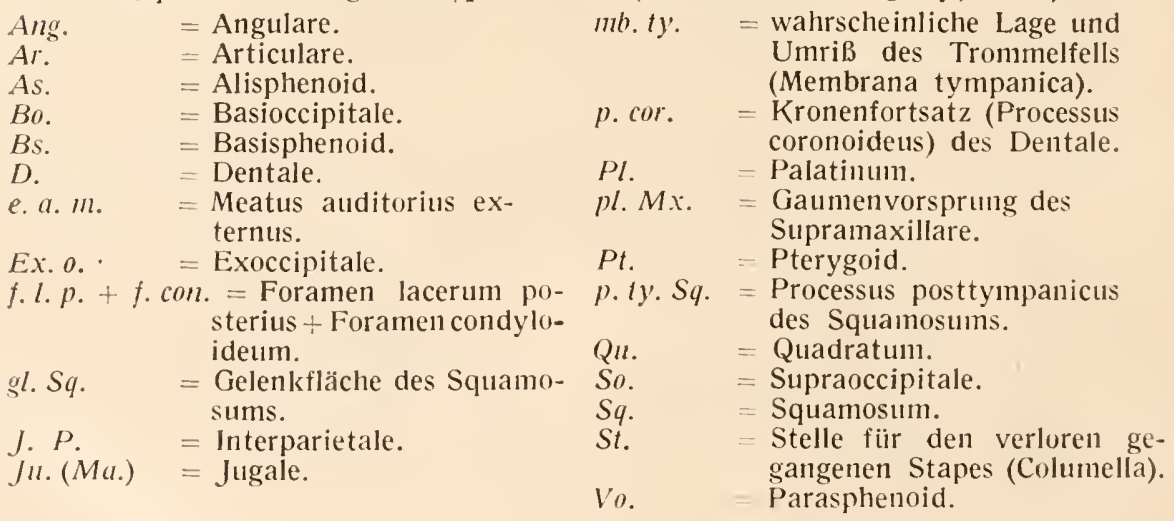

Nach R. Broom (1913) ist bei Diademodon ein Zalmwechsel in derselben Weise wie bei den Säugetieren zu beobachten; wenn das Tier seinen Reifezustand erreicht, so werden die Greifzähne, Reißzähne und 


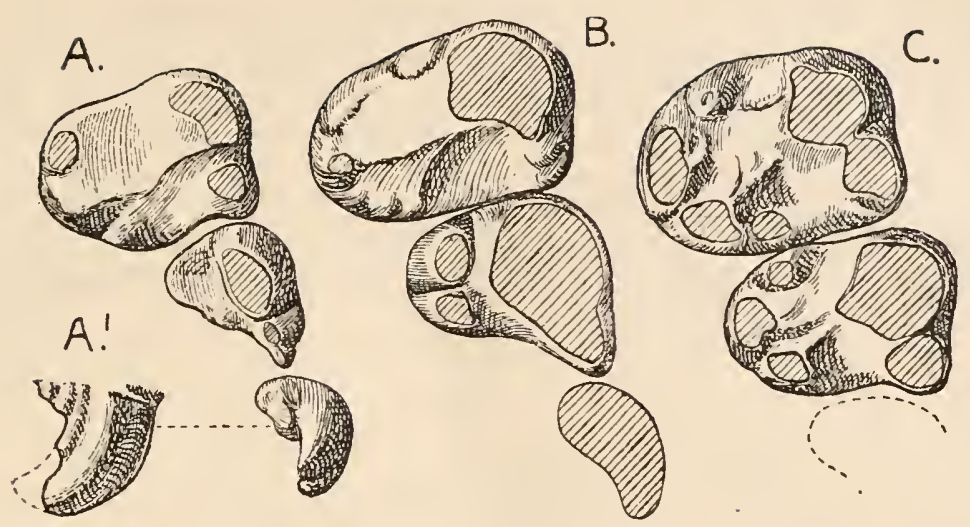

Fig. 332.

A. Die drei letzten Backenzähne von Diademodon Browni, von der Kaufläche gesehen (vgl. Fig. 330).

A'. Seitenansicht des letzten Backenzahns von D. Browni.

B. Die drei letzten Backenzähne. von Diademodon entomophonus.

C. Die zwei vorletzten Backenzähne von Diademodon mastacus.

Alle Figuren in $3 / 1$ nat. Gr. Die Reste stammen aus den ,Red Beds" bei der Farm Witkop (Distrikt Albert der Kapkolonie), die wahrscheinlich der obersten Trias angehören. (Nach D. M. S. Watson, 1913.)

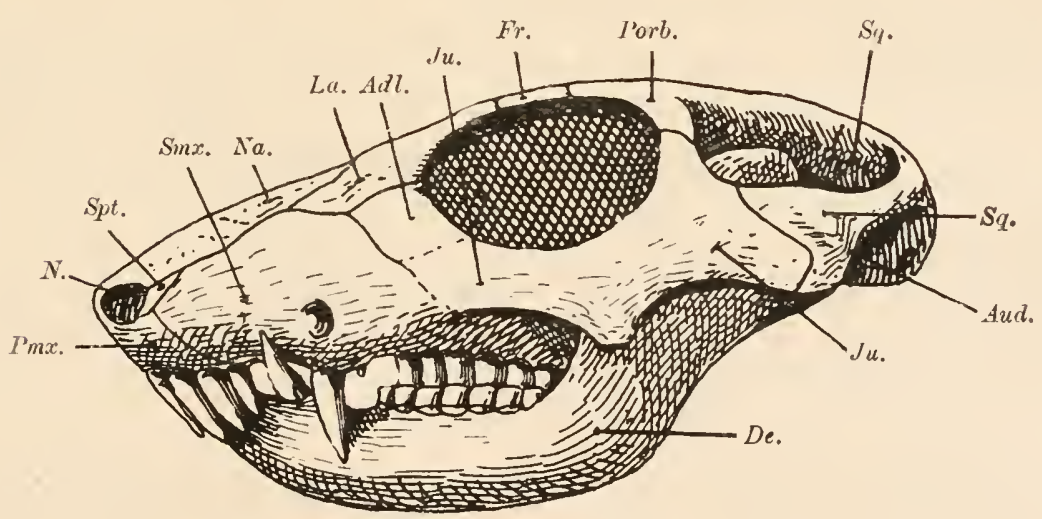

Fig. 333.

Seitenansicht des rekonstruierten Schädels von Sesamodon Browni, Br. des säugetierähnlichsten der bisher bekannten Therocephalier aus der Trias der Kapkolonie.

(Nach R. Broom, 1911.)

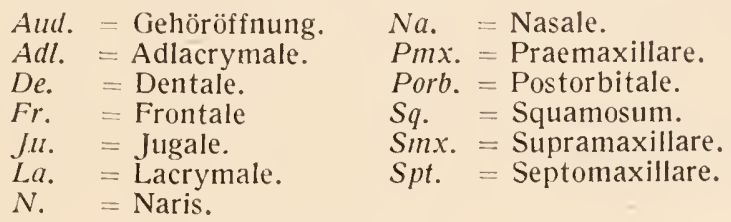


der vordere Teil der Mahlzähne durch 4 lızisiven, 1 Canin und 4 Prämolaren ersetzt, während die der ersten Dentition angehörenden Molaren stehen bleiben und nicht gewechselt werden, also die hinteren 8 Mahlzähne der ersten Dentition (Fig. 320, 332).

Sesamodon. - Trias Südafrikas. - S. Browni. Diese Art ist unter den Therocephaliern die säugetierähnlichste. Die Zalınformel umfaßt Greifzähne, Reißzähne, Backenzähne; die Differenzierung des Gebisses steht in innigem Zusammenhang mit der Form und dem Bau

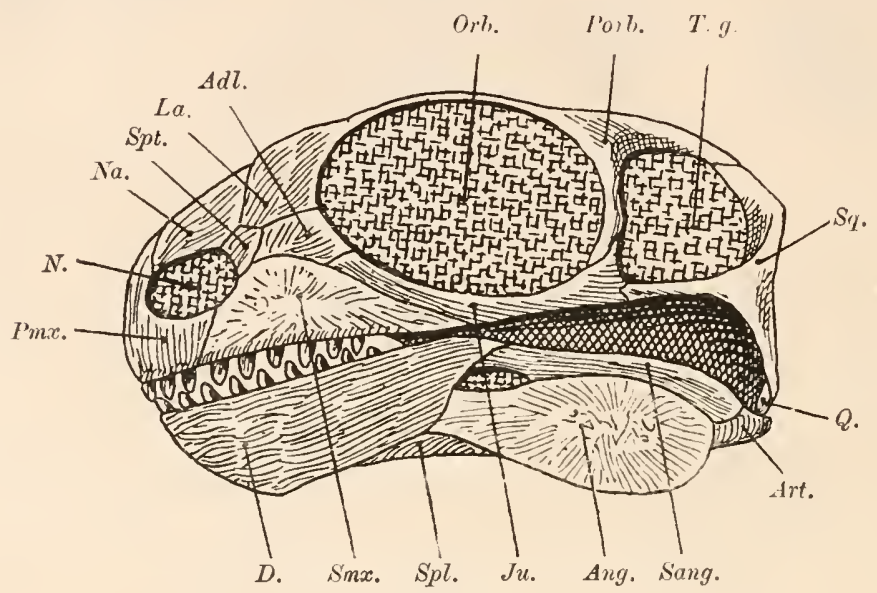

Fig. 334.

Rekonstruktion des Schädels von Galepus Jouberti, Broom, aus dem Perm Südafrikas. $5 / 3$ nat. Gr. (Nach R. Broom.)
Adl. = Adlacrymale.
$P m x$. = Praemaxillare.
Ang. = Angulare.
Porb. = Postorbitale.
Art. = Articulare.
D. = Dentale
Ju. = Jugale.
Q. $\quad$ = Quadratum.
La. = Lacrymale.
Sang. = Supraangulare.
$N$. = Nasenöffnung
Spl. $=$ Spleniale .
$\mathrm{Na}$. $=$ Nasale.
Spt. = Septomaxillare.
Orb. = Orbita.
$S q . \quad=$ Squamosum.
$T . g .=$ Temporalgrube

des Unterkiefers, in dem das Dentale auf Kosten der anderen Mandibularelemente sehr stark entwickelt und ein starker Kronenfortsatz ausgebildet ist. Der Unterkiefer konnte (nach Broom, 1. c., 1911, p. 916) eine anteroposteriore Bewegung ausführen; W. K. Gregory (The Orders of Manmmals, 1910, 1, c., p. 119 und 220) nimmt dagegen eine mediolaterale Bewegungsfähigkeit des_Unterkiefers an. Die laterale Verbreiterung der Kronen der Backenzähne scheint dafür zu sprechen, daß Sesamodon Browni ein herbivores Tier war. Als direkter Ahne der Säugetiere kann es aber trotz der vielen und großen Ähnlichkeiten nicht in Betracht kommen (Fig. 333). 
2. Unterordnıng: Dromasauria.

Die wichtigsten Kennzeichen dieser Unterordnung sind das Fehlen des Quadratojugale (wie bei den Therocephaliern) und die Ausbildung eines langen Astes des Squanosums, der nach unten vorspringt und an seinem Ende ein kleines Quadratum trägt (wie bei den Dicynodontiern). Die Augenhölılen sind außerordentlich vergrößert. Der Gesantlıabitus des Schädels erinnert an Eidechsen. In Schädeldach ist ein großes Parietalloclı vorlanden. In Unterkiefer ist das Angulare und Supraangulare gut entwickelt und beide Knoclıen nehmen fast dieselbe Länge wie das Dentale ein. Reißzähne sind nicht ausgebildet und alle Zähne von gleicher Gestalt und Größe. Der Schultergürtel ist ebenso gebaut wie bei den Therocephaliern, aber das Vorhandensein eines Cleithrums ist zweifelhaft. Die Phalangenformel ist: 2, 3, 3, 3, 3. Abdominalrippen sind vorlıanden. Galechirus besitzt einen Sklerotikalıing.

\section{F. Dromasauridae.}

Galechirus. - Pernu von Süllafrika. ${ }^{1}$ G. Scholtzi.

Gale pus. - Perm von Südafrika. - Schädellänge ungefälır 40 1mm. ${ }^{2}$ G. Jouberti (Fig. 334).

\section{Unterordnung: Dinoceplualia.}

Die Dinocephalier sind durch einige Gattungen aus dem Perm der Kapkolonie vertreten; ob die als Eubrachiosaurus aus der Trias Nordamerikas beschriebenen Reste dieser Gruppe einzureihen sind, ist sehr fraglich. Obwohl die einzelnen Gattungen bisher nur unvollständig bekannt sind, so läßt sich doch aus den vorhandenen Schädelresten schließen, daß sie einen Seitenzweig der Theriodontier bilden, der sich schon sehr frülnzeitig von den Therocephaliern getrennt haben muß, da bei Delphinognathus noch ein Quadratojugale vorhanden ist, das den Therocephaliern fehlt. Es scheint jedoçl, daß Tapinocephalus kein Quadratojugale mehr besessen hat. Der Schädel der Dinocephalier ist verhältnismäßig. kurz und hoch und die Bezalunung scluwach ausgebildet. Ebenso wie bei einigen Therocephaliern findet sich auch bei Delphinognathus eine kleine laterale Temporalgrube unterlıalb der großen lateralen Ten-

1 R. Broom, On Some New Reptiles from the Karroobeds of Victoria west, South Africa. - Transactions South African Phil. Soc., Vol. XVIII, 1907, p. 31.

2 R. Broom, A Comparison of the Permian Reptiles of North America with those of South Africa. - Bulletin Amer. Mus. Nat. Hist., New York 1910, Vol. XXVIII, p. 205.

Derselbe, On the Structure of the Skull in Cynodont Reptiles. - Proc. Zool. Soc., London 1911, p. 893. 
poralgrube, woraus hervorgeht, daß auch bei den Dinocephaliern die letztere nur der oberen Temporalgrube der Reptilien mit doppelten Lateralgruben in der Schläfenregion entspricht. Die Augenlıöhle ist bei Delphinognathus und Tapinocephalus, den an besten bekannten Gattungen, relativ klein.

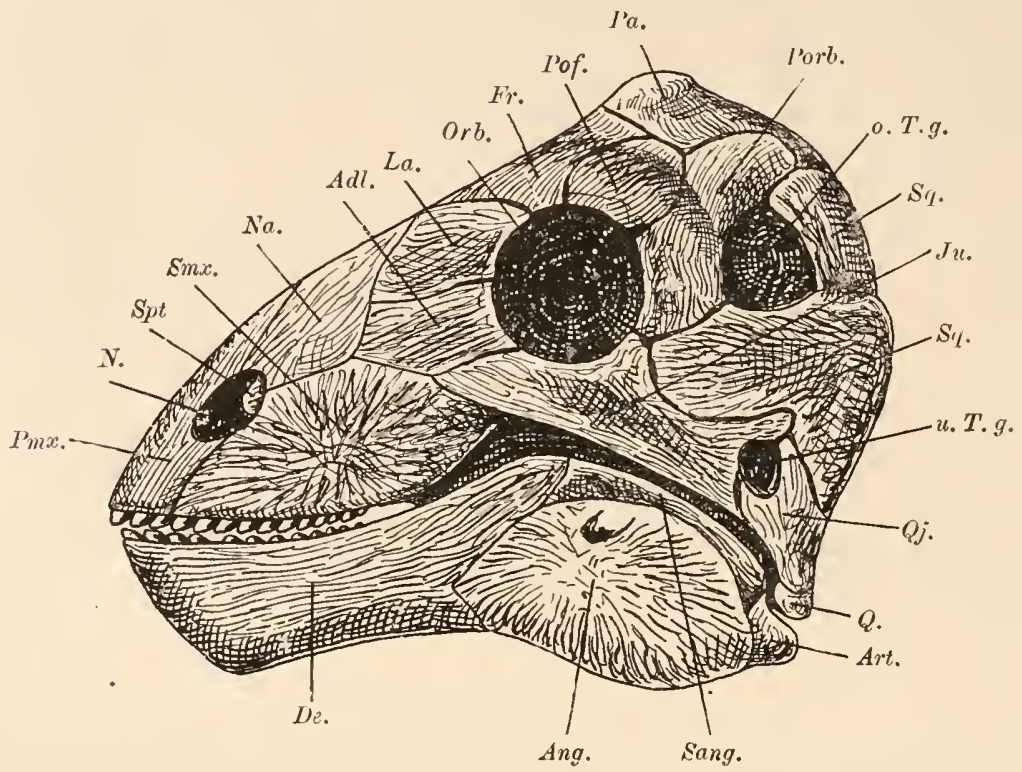

Fig. 335.

Rekonstruktion des Schädels von Delphinognathus conocephalus, Seeley, aus dem Perm Südafrikas, in $1 / 4$ nat. Gr. (Nach R. Broom.)

\begin{tabular}{|c|c|c|c|}
\hline $\begin{array}{l}\text { Adl. } \\
\text { Ang. } \\
\text { Art. } \\
\text { De. } \\
\text { Fr. } \\
\text { Jir. } \\
\text { La. } \\
\text { N. } \\
\text { Na. } \\
\text { Orb. }\end{array}$ & $\begin{array}{l}=\text { Adlacrymale. } \\
\text { = Angulare. } \\
\text { = Articulare. } \\
\text { = Dentale. } \\
\text { = Frontale. } \\
\text { = Jugale. } \\
\text { = Lacrymale. } \\
=\text { Nasenöffnung. } \\
\text { = Nasale. } \\
=\text { Orbita. } \\
\text { = obere Temporalgrube. }\end{array}$ & $\begin{array}{l}\text { Pa. } \\
\text { Pof. } \\
\text { Porb. } \\
\text { Pmx. } \\
\text { Q. } \\
\text { Qj. } \\
\text { Smx. } \\
\text { Spt. } \\
\text { Sang. } \\
\text { Sq. }\end{array}$ & $\begin{array}{l}=\text { Parietale. } \\
=\text { Postfrontale. } \\
=\text { Postorbitale. } \\
=\text { Praemaxillare. } \\
=\text { Quadratum. } \\
=\text { Quadratojugale. } \\
=\text { Supramaxillare. } \\
=\text { Septomaxillare. } \\
=\text { Supraangulare. } \\
=\text { Squamosum. } \\
=\text { untere Temporalgrub }\end{array}$ \\
\hline
\end{tabular}

\section{F. Dinocephalidae.}

Die wichtigsten Gattungen sind:

Delphinognathus. - Perm von Südafrika. - Bezahnung aus kleinen, gleichförnıig gestalteten Zähnen bestehend. Die Wirbel erinnern durch die starke Entwicklung der Querfortsätze an jene von Dimetrodon. Der Schultergürtel umfaßt eine große Scapula, Coracoid und Präcoracoid. Das Cleithrum ist schwach entwickelt, die Clavicula 
und Interclavicula sehr kräftig. Bauchrippen scheinen zu fehlen. ${ }^{1}$ D. conocephalus (Fig. 335).

Tapinocephalus. - Perm von Südafrika. - Schädelkapsel hoch, gewölbt, Schnauze kurz, vorn abgerundet, mit kleinen, gleichgroßen Zähnen. Die Hinterwand des Schädels springt weit über das Foramen magnum nach hinten schüsselförmig vor. Die Vomeres trennen die Palatina und treten mit den Vorderenden der Pterygoidea in Verbindung. ${ }^{2}$ T. Atherstoni.

Sy. D.

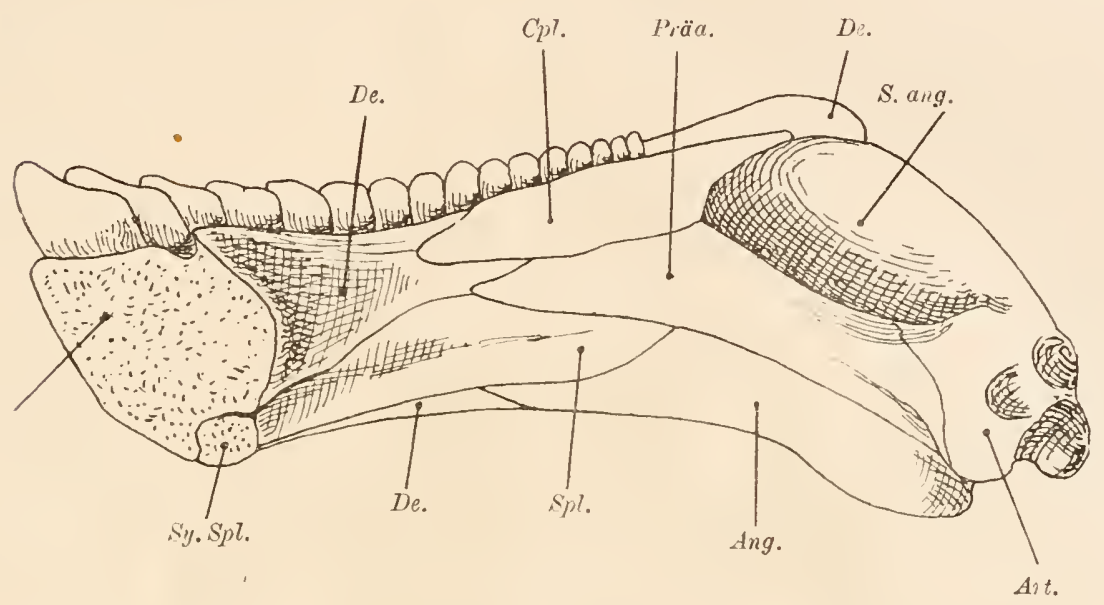

Fig. 336.

Innenseite des rechten Unterkiefers von Moschognathus Whaitsi, Broom, aus dem Perm Siidafrikas (Karrooformation der Kapkolonie), in $2 / 5$ nat. Gr. (Nach R. Broom, 1914.)

$\begin{array}{llll}\text { Ang. } & =\text { Angulare. } & S p l . & =\text { Spleniale. } \\ \text { Art. } & =\text { Articulare. } & S y . D . & \text { Symphysenabschnitt } \\ \text { Cpl. } & =\text { Complementare. } & & \text { des Dentale. } \\ \text { De. } & =\text { Dentale. } & S y . S p l . & \text { Symphysenabschnitt } \\ \text { Präa. } & =\text { Praearticulare. } & & \text { des Spleniale. } \\ \text { S. } \text { ang. } & =\text { Supraangulare. } & & \end{array}$

Moschops. - Perm von Südafrika. - M. capensis.

Moschognathus. - Perm von Südafrika. - M. Whaitsi ${ }^{3}$ (Fig. 336). Gorgonops. - Perm von Südafrika. ${ }^{4}$ - In der Art der Verbindung der Praemaxillaria mit den Supramaxillaria besteht eine auffalfende

1 R. Broom, A Comparison etc., 1. c., supra, 1910, p. 206.

2 R. Broom, The Skull of Tapinoceplialus. - Geological Magazine, London 1909 , p. 400.

${ }^{3}$ R. Broom, A Further Comparison of the South African Dinocephalians with the American Pelycosaurs. - Bulletin Amer. Mus. Nat. Hist., New York 1914, Vol, XXX111, p. 137.

${ }^{4}$ D. M. S. Watson, On Some Features of the Structure of the Therocephalian Skull. - Ann. Mag. Nat. Hist., London 1913, Ser. 8, Vol. X1, p. 72. 
Übereinstimmung mit den primitiven Therocephaliern einerseits und den Sphenacodontiden andererseits, so daß dieses Verhalten als ein primitives

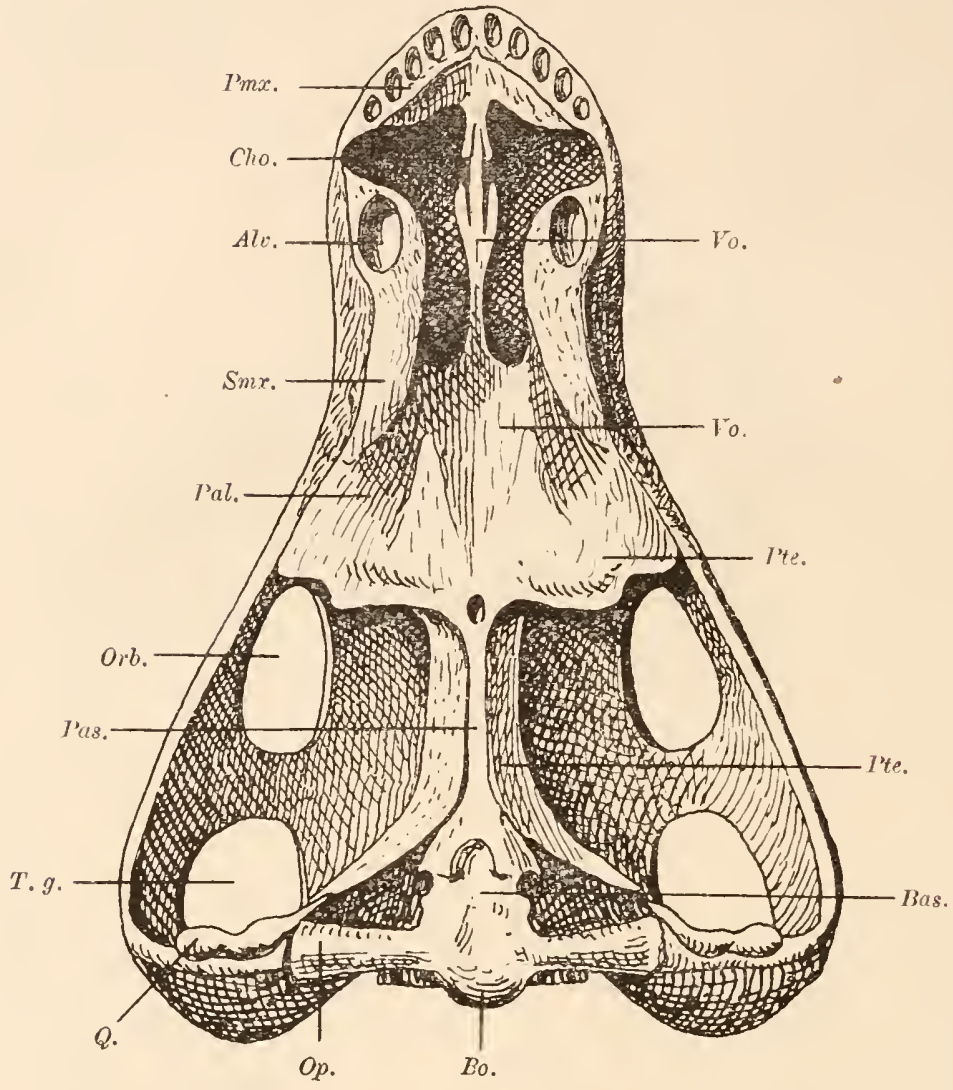

Fig. 337.

Gaumenansicht des Schädels von Gorgonops torvus, Broom, aus dem Perm Südafrikas (Endothiodon Beds der Beaufortgruppe der Karrooformation), kombiniert mit dem unvollständigen Schädel eines Gorgonopsiden (Scymnosuchus Whaitsi?) aus denselben Schichten, in 1/2 nat. Gr. (Nach D. M. S. Watson, 1913, aber die Deutung der Knochen hier zum Teil abgeändert.)

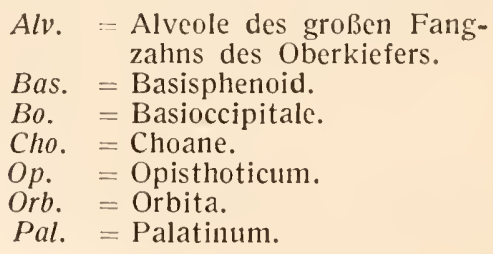

Pas. = Parasphenoid.

Pmx. = Praemaxillare.

Pte. $=$ Pterygoid.

Q. $\quad=$ Quadratum.

Smx. = Supramaxillare.

T.g. $=$ Temporalgrube.

Vo. $=$ Vomer .

zu betrachten sein dürfte. Allerdings scheint dieses Merkmal, da es sich bei den Cotylosauriern nicht vorfindet, unabhängig voneinander bei den verschiedenen primitiven Stämmen entstanden zu sein (Watson, 
1913). Watson meint, $d a ß$ die Vomeres nicht mit cem medianen „Vomer" der Sängetiere verweclıselt werden dürfen; dies gehe aus dem Verhalten der Vomeres bei Gorgonops wie auch aus dem Vergleiche mit anderen Therapsidenschädeln hervor, wo man in einigen Fällen zwischen den Vomeres deutlich einen medianen Knochen feststellen kann, der -dem Parasphenoid der primitiven Tetrapoden homolog ist. Diese Auffassung beruht hauptsächliclı auf der Voraussetzung, daß das Parasphenoid der Stegoceplaalen und Reptilien mit dem Vomer der Säugetiere identisch ist und daß die ,Praevonteres" den Säugetieren felılen, Indessen ist diese Ansicht kaum aufrecht zu halten, denn die Praevomeres sind wahrscheinlich dem bei den Säugetieren unpaarigen Vomer homolog (vgì. oben) und das Parasphenoid scheint bei den Säugern zu fehlen. In dieser Frage sind noch fortgesetzte Untersuchungen erwünscht, um zu einer Klärung zu gelangen.

In Oberkiefer steht jederseits ein stark vergrößerter Reißzahı. Im Zwischenkiefer sind fünf Greifzähne jederseits in. Funktion, aber es ist zweifelhaft, ob hinter den großen Reißzähnen nocl funktionelle Mahlzähne standen. Wir dürfen wohl annehmen, daß Gorgonops eine Form repräsentiert, die der Vorstufe der Dicynodontier angehört, welche alter Wahıscheinlichkeit nach mit den Dinocephaliern genetisch verbunden sind und einen aus ihnen hervorgegangenen, hochspezialisierten Seitenast darstellen. G. torvus. (Fig. 337).

\section{Unterordnung: Dicynodontia.}

Die Dicynodontier stellen einen einseitig spezialisierten Stamm der Reptilien dar, der eine Reihe von Gattungen unfaßt, die man als die Sirenen unter den Reptilien bezeichnen könnte. Sie gehören dem Kreise der Theriodontia an und scheinen mit den Dinocephaliern am nächsten verwandt zu sein. Dafür würde vor allem das Vorlıandensein des langen, nach unten gerichteten Astes des Squamosums sprechen, an dessen unterem Ende ein sehr kleines Quadratum die Gelenkverbindung mit den1 Unterkiefer herstellt.

Das schon auf den ersten Blick auffallende Kennzeichen des Schädels der Dicynodontier ist der eigentümlich herabgebogene Zwischenkiefer, der bei allen Gattungen dieser Unterordnung gänzlich zahnlos geworden ist. Im Oberkiefer ist meist ein einziger großer Zahn jederseits ausgebildet, der an der Stelle der Reißzähne der Therocephalia und des Reißzahnes von Gorgonops stelit und mit demselben zweifellos homolog ist. Er fehlt jedoch in vielen Fällen; es ist die Vermutung ausgesprochen worden, daß die zahnlosen Formen, wie z. B. Udenodon, nur die Weibchen der zahntragenden Formen, wie Dicynodon, vorstellen, da die sonstigen Unterschiede zwischen den bezahnten Dicynodonten und den 
zahnlosen Udenodonten nur ganz geringfügiger Natur sind. Bei den prini-

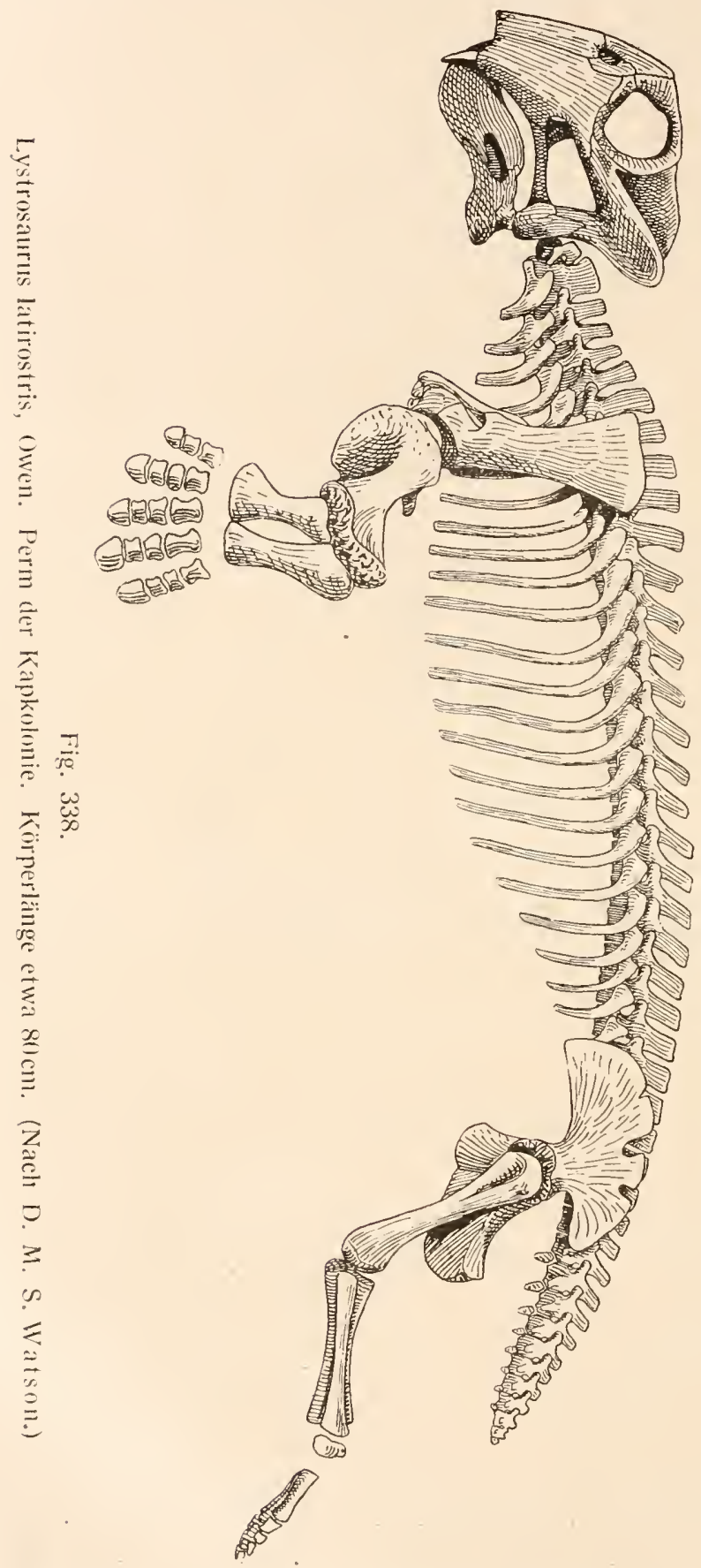
tiveren Gattungen (z. B. bei Endothiodon) stehen hinter dem Eckzahn noch kleinere Mahlzähne, aber bei den liöher spezialisierten Formen sind diese ganz verloren gegangen.

Die Praemaxillaria sind untereinander verschmolzen und es ist wahrscheinlich, dab sie, ebenso wahrscheinlich anch der Unterkiefer, mit einen Hornschnabel bedeckt gewesen sind. Es ist aber andererseits zu bedenken, daß bei einem kleinen, von O. Jaekel beschriebenen Dicynodonten (Udenodon pusillus) auf einer Seite des Schädels noch ein Zahnrudiment (des Reißzalunes) zul beobachten ist, das der anderen Seite gänzlich fehlt, und dies scheint mir dafür zu sprechen, daß Dicynodon von Udenodon generisch verschieden ist.

Die Choanen sind ziemlich weit nach hinten gerückt, und zwar kommt diese Verschiebung in ähnlicher Weise wie bei den jüngeren 
Therocephaliern durch die Ausbildung eines sekundären Gaumens zustande, der von den Palatina und den Supramaxillaria gebildet wird.

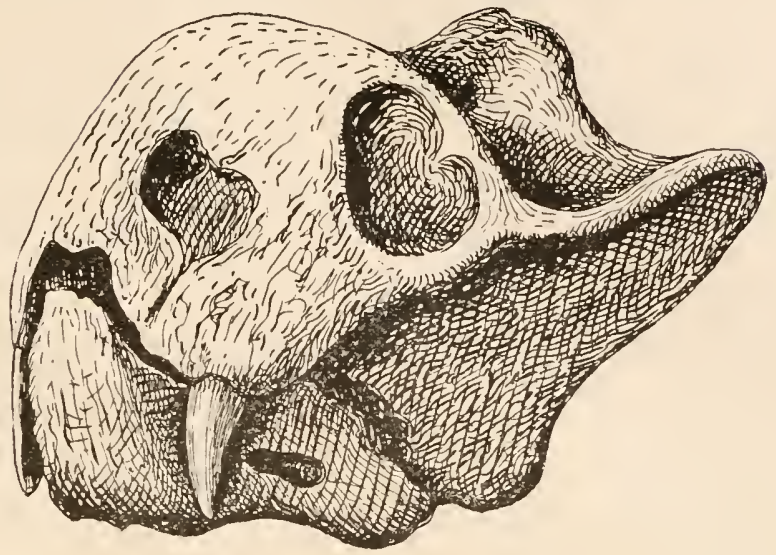

Fig. 339 .

Schräge Seiten- und Vorderansicht des Schädels von Sagecephalus pachyrhynchus, Jaekel, aus der Karrooformation (untere Trias) Siidafrikas, in ıngefähr $1 / 5$ nat. Gr. (Nach O. Jaekel.)

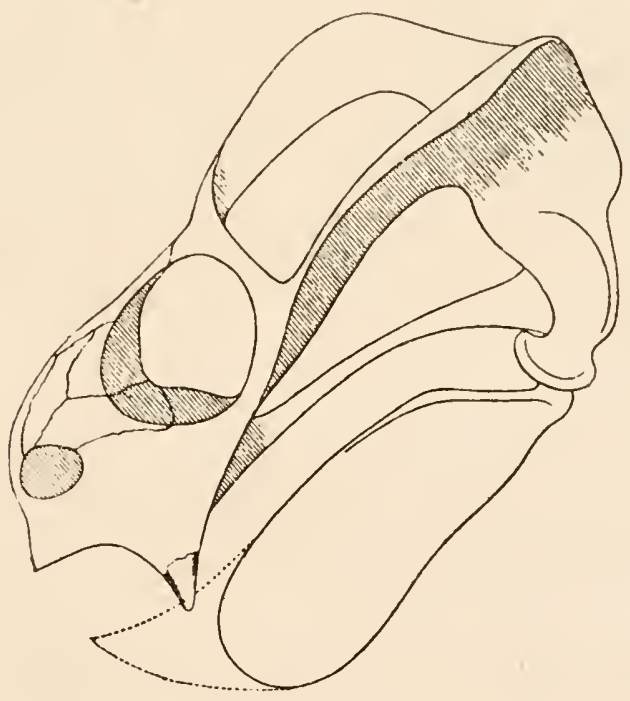

Fig. 340 .

Gordonia Traquairi, Newt., aus dem Perm von Cutties Hillock bei Elgin in Schottland. Etwa $1 / 2$ nat. Gr. Rekonstruktion des Schädels in Seitenansicht. (Nach E. T. Newton.)

Die Ausbildung eines sekundären Gaumens ist also jedenfalls unabhängig voneinander bei den Therocephaliern und bei den Dicynodontiern 
erfolgt; Gorgonops hat noch weit vorn liegende Choanen und verhält sich also in dieser Hinsicht gegenüber den Dicynodonten als die primitivere Vorstufe. Der Condylus occipitalis ist aber bei den Dicynodontiern nicht wie bei den Theroceplaliern durch das Ausweichen des Basioccipitale nach vorn doppelt geworden, sondern ist noch funktionell einfach, wenn er auch sehr deutlich, seinen Aufbau aus drei Stücken (beide Exoccipitalia und das Basioccipitale) zeigt.
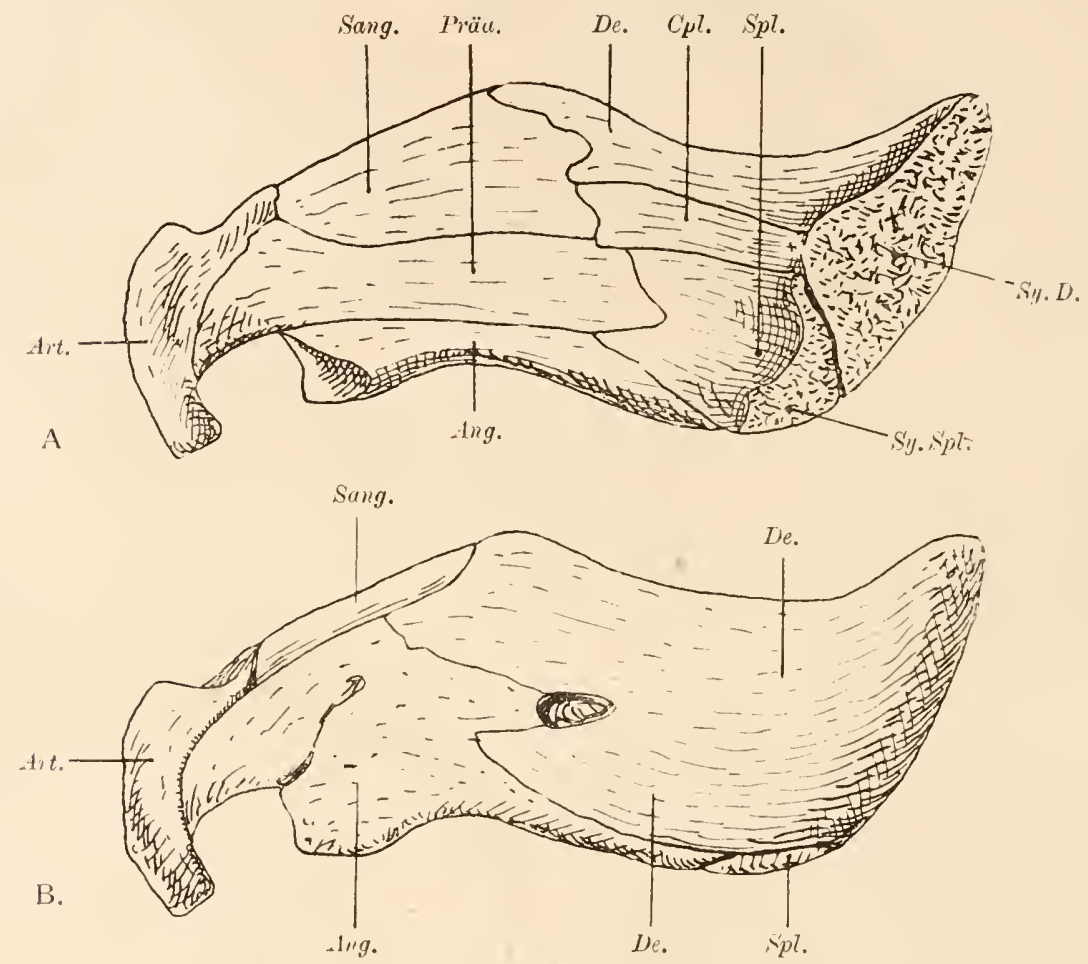

Fig. 341 .

A. Linker Unterkieferast von Dicynodon, aus dem Perm der Kapkolinine, in $1 / 2$ nat. Gr., von innen gesehen.

B. Rechter Unterkieferast desselben Exemplars, von außen gesehen. (Nach D. M. S. Watson.) Abkiirzungen wie in Fig. 336.

Die kleinen Olıröffnungen liegen auf der Hinterseite des Schädels. Anı vollständigsten ist das Skelett von Lystrosaurus latirostris bekannt. Die Wirbelsäule ist bei dieser Art sehr kräftig gebaut und umfaßt 25 Präsakralwirbel, 6 Sakralwirbel und 10 Kaudalwirbel.

Der Schultergürtel unfaßt die drei Elemente Scapula, Coracoid und Präcoracoid; an Vorderrande der Scapula findet sich ein dem Acromion der Säugetierscapula vergleichbarer Fortsatz. Das Becken besitzt in einigen Punkten eine auffallende Ähnlichkeit mit den Säugetierbecken, und zwar besteht diese Älnılichkeit hauptsächlich in der 
Art der Nalıtverbindung der drei Elemente des Beckens, sowie in Vorhandensein eines Foramen obturatorium zwischen dem Pubis und Ischium. Die Gliedmaßen waren kurz und stänınig und hatten die Phalangenformel $2,3,3,3,3$.

Daß die Dicynodonten Wasserbewohner waren, ist als sicher anzunehmen; eine ganze Reihe von Anpassungen, die D. M. S. Watson bei Lystrosaurus latirostris analysiert hat, sprechen dafür, daß es Tiere waren, die dieselbe oder doch eine sehr ähnliche Lebensweise wie die Sirenen geführt haben. Die Älnnlichkeit des Schädels mit der besonders bei Lystrosaurus an die Stoßzahnbildung der Halitheriiden und Halicoriden (hier ist es ein Schneidezahn) erinnernden Stellung und Form

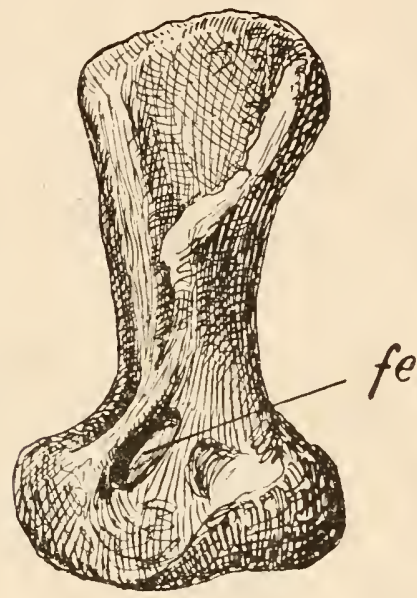

A.

Fig. 342 .

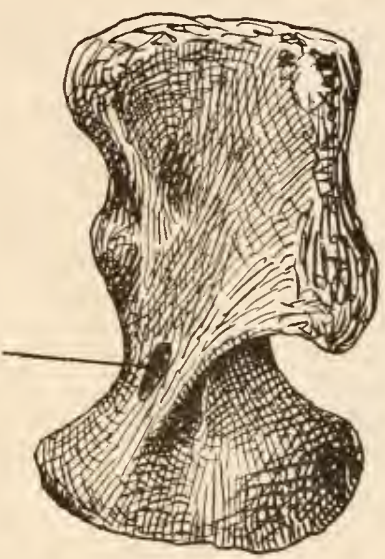

B.

A. Humerus von Dicynodon pardiceps, Owen, aus dem Perm der Kapkolonie.

B. Humerus von Udenodon (= Platypodosaurus) robustus, Owen, ebendaher.

(Nach R. Owen.)

fe. = Foramen entepicondyloideum.

des Eckzahnes in Verbindung mit einer Reduktion des übrigen Gebisses, wie bei Rhytina, spricht dafür, daß die Nahrungsweise der Dicynodonten eine ähnliche war wie bei den Seekühen. Die Tiere waren aber keinesfalls in derselben Weise wie die Sirenen zum Scliwimmen befähigt, da der Schwanz kurz und plump ist und keine Anzeichen des Vorhandenseins einer Schwanzflosse trägt, und beide Gliedmaßenpaare vorhanden sind. Es ist daher wahrscheinlich, daß dieser ganz einseitig spezialisierte und nur auf das Perm und die Trias beschränkte Zweig des Reptilstammes eine Lebensweise in Sümpfen und ruhigen Strömen führte, wie heute die Flußpferde oder die fluviatilen Lamantine und daß sich diese schwerfälligen Tiere, deren Größe zwischen einer Ratte und einenı kleinen Flußpferd schwankte, von Wasserpflanzen genährt haben. 


\section{F. Dicynodontidae.}

Endothiodon. - Schon 1876 beschrieb R. Owen aus dem Perm der Kapkolonie eine Gattung aus der Verwandtschaft von Dicynodon, um welche sich einige später entdeckte Gattungen (z. B. Esoterodon,

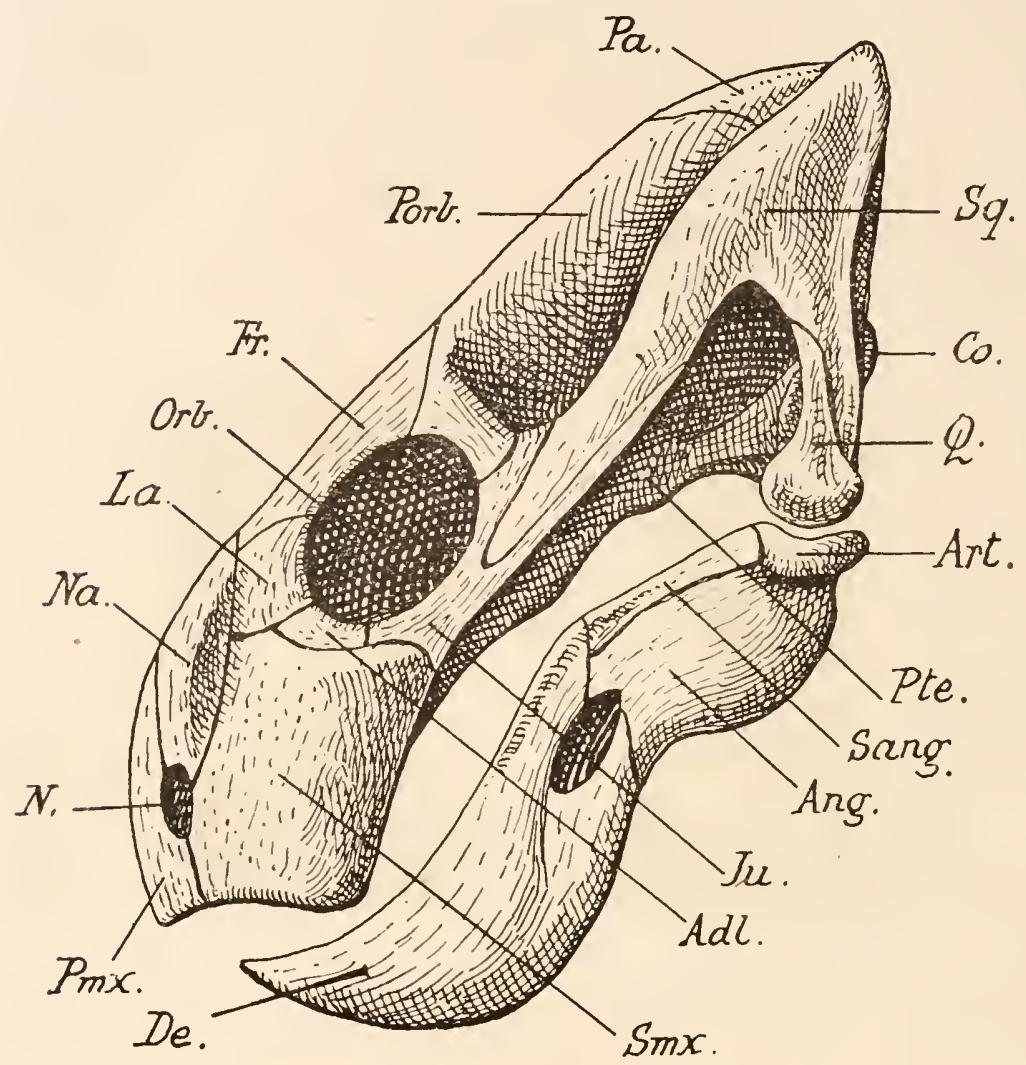

Fig. 343.

Udenodon gracilis, Broom. Perm Südafrikas. Nat. Gr. Schädel in normaler Stellung zur Horizontalebene. (Nach R. Broom.)

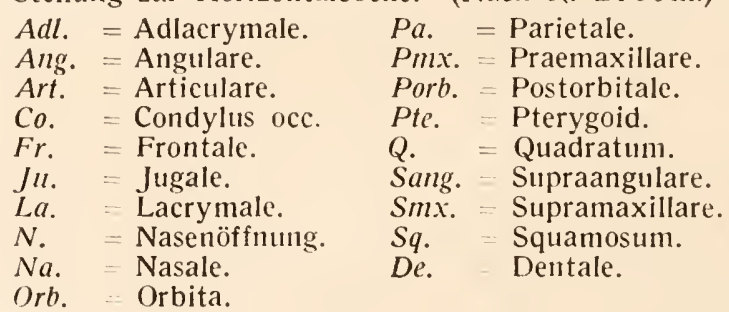

Cryptocynodon, Opisthoctenodon, Pristerodon) gruppieren. Das wesentliche Kennzeichen dieser Gattungen ist der geringere Spezialisationsgrad des Gebisses im Vergleiche zu den Gattungen Lystrosaurus, Dicynodon, Udenodon, Gordonia, Cistecephalus usw., bei denen entweder 
Esoterodon und Opisthoctenodon dagegen nicht. Vielleicht liegen hier wirklich nur sexuelle Unterschiede vor. ${ }^{1}$

Die obun genannten, nur aus dem Perm Südafrikas bekannten Gattungen sind meist als geschlossene Familie (Endothiodontidae) den Dicynodontiden gegenübergestellt worden. Diese Trennung scheint mir

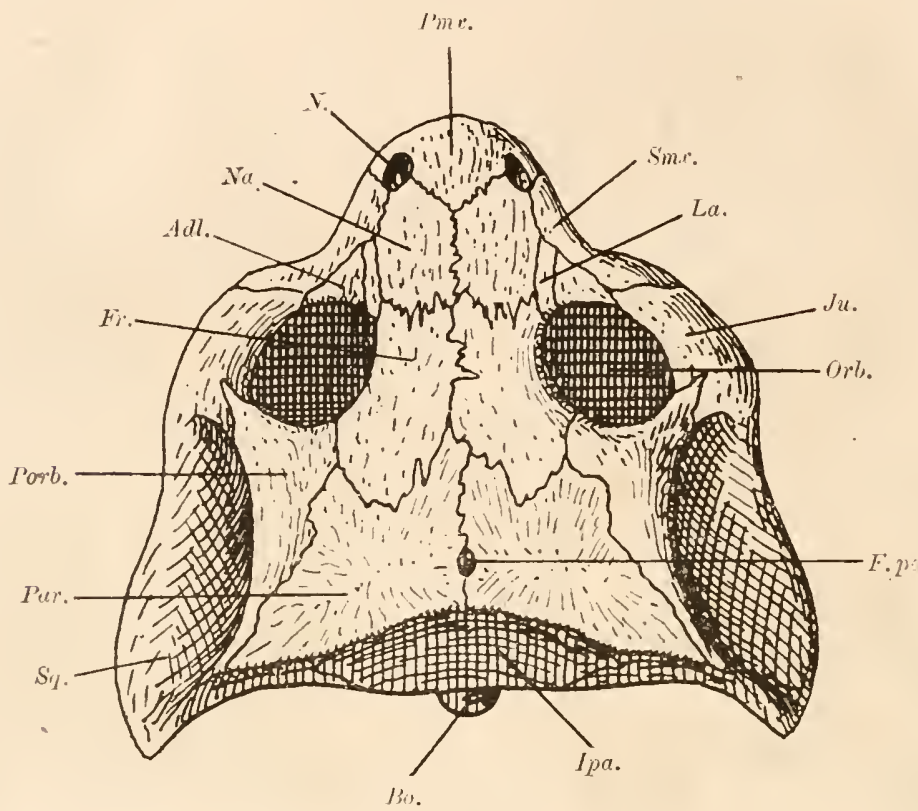

Fig. 345 .

Rekonstruktion des Schädels von Cistecephalus microrhinus, ()wen, ein Dicynodontide ans dem Perm (Karrooformation) der Kapkolonie. Nat. Gr.

(Nach R. Broom.)

Adl. - Adlacrymale.

Ipa. - Interparietale.

Die übrigen Abkiirzungen wie in Fig. 344.

nicht genügend begründet und nur geeignet, das Bild von den engen Bezichungen der beiden Gattungsgruppen zu verwischen, die sich allein durch graduelle Differenzen in der Spezialisation des Gebissts unterscheiden.

Lystrosaurus. - Perm von Südafrika und Ostindien. - Wichtigste

1 R. Broom, A Comparison of the Permian Reptiles of North America with those of South Africa. - Bulletin of the Ainerican Museum of Natural History. Vol. XXVIII, 1910, p. 211. 
Arten: L. declivis, L. latirostris. Nasenlöcher weit nach hinten bis in die Nähe der Orbita verschoben. ${ }^{1}$ (Fig. 338.)

Sageceplialus. - Untere Trias der Kapkolonie. ${ }^{2}$ (Fig. 339.)

Gordonia. - Perm von Cutties Hillock bei Elgin in Schottland. ${ }^{3}$ (Fig. 340.)

Dicynodon. - Perm und Trias von Südafrika. ${ }^{4}$ (Fig. 341, 342.) Udenodon. - Perm und Trias von Südafrika. ${ }^{5}$ (Fig. 343, 344.)

Cistecephalus. - Perm von Südafrika. - Eine vollständig zahı!los gewordene Form mit stark verkürztem Schädel. ${ }^{6}$ (Fig. 345.)

\section{Ordnung: Rhynchocephalia.}

Man liat seit dem genaueren Bekanntwerden der lebenden Gattung Sphenodon (- Hatteria) in Neuseeland die phylogenetische Bedeutung der Rhynchocephalen allgemein sehr hoch eingeschätzt. Durch die Untersuchungen v. Huenes ist mit dieser althergebrachten Vorstellung gründlich aufgeräumt worden; es sind wohl primitive Stammeslinien, die sich schon in früher Zeit von den Cotylosauriern losgelöst haben, aber sie haben sich einseitig entwickelt und niemals zu besonderer

${ }^{1}$ D. M. S. Watson, The Skeleton of Lystrosaurus. - Records of the Albany Museum, Vol. 1I, p. 287.

Derselbe, The Limbs of Lystrosaurus. - Geological Magazine, London (5), Vol. X, 1913, p. 256.

Derselbe, Some Notes on the Anomodont Brain Case. - Anatomischer Anzeiger, XLIV. Bd., 1913, p. 210.

2 O. Jaekel, Die Wirbeltiere. - Berlin 1911, p. 191, Fig. 209 (ohne nälere Beschreibung).

${ }^{3}$ E. T. Newton, Some New Reptiles from the Elgin Sandstone. - Philosophical Transactions of the Royal Society, Vol. CLXXXIV (B), London I893, p. 431.

4 J. B. J. Sollas and W. J. Sollas, A Study of the Skull of a Dicynodon by Means of Serial Sections. - Philosophical Transactions of the Royal Soc. Vol. CCIV (B), London 1913, p. 201. (Hier Zitate der älteren Literatur.)

D. M. S. Watson, On Some Reptilian Lower Jaws. - Ann. Mag. Nat. Hist., Vol. X, London 1912 (8), p. 575. - Udenodon wird von Watson als das Weibchen von Dicynodon angesehen.

5 O. Jaekel, Über den Schädelbau der Dicynodonten. - Sitzungsberichte der Ges. Naturforschender Freunde in Berlin, 1904, p. 172.

R. Broom, A Comparison of the Permian Reptiles of North Anerica with those of South Africa. - Bull. Amer. Mus. Nat. Hist., Vol. XXV11I, 1910, p. 212.

6 lbidem, p. 213.

R. Broom, Observations on Some Specimens of South African Fossil Reptiles Preserved in the British Museum. - Transactions of the Royal Soc. of South Africa. Vol. 11, Part I, 1910, p. 24: „Cistecephalus .... is evidently the last Stage in the Development of the Dicyrodonts". 
Blïte entfaltet. Seitdem die Cotylosaurier genauer bekannt geworden sind und dem Vorhandensein der beiden Temporalgruben bei Sphenodon und seinen Vorfahren nicht mehr die große phylogenetische Bedeutung wie früher zugeschrieben werden kann, stellen sicl eben die Cotylosaurier als die Ahnengruppe der höheren Reptilien dar, von denen eine große Zahl verschiedener Stammesreihen abgezweigt sind.

Außer der durch Sphenodon in der Gegenwart vertretenen Gruppe der echten Rhynchocephalen oder Sphenodontiden sind in der Ordnung der Rhynchocephalen noch folgende Fanilien zu unterscheiden: die Sauranodontiden, die Rhynchosauriden, die Champsosauriden und die Acrosauriden. Die Thalattosauriden, die früher vielfach mit den Rhynchocephaliern vereinigt worden sind, erweisen sich jetzt nach eingehenderen Untersuchungen als eine Gruppe der Lepidosauria, die schon in sehr früher Zeit, wahıscheinlich schon im Perm, neben den Rhynchocephalen auftreten und einen von diesen ganz unabhängigen Stannm der Reptilien darstellen, der sich in ähnlicher Richtung wie die gleichfalls aus den Lepidosauriern hervorgegangenen Mosasaurier (= Pythonomorphen) abgezweigt und an das Meeresleben angepaßt hat, ohne aber die Trias zu überleben, in der er entstanden ist.

\section{F. Sphenodontidae.}

In Schädel sind zwei übereinanderliegende Ttumporalgruben vorhanden, die untere vom Jugale und Quadratum nebst Quadratojugale gebildete Spange als unterer Abschluß der unteren Temporalgrube ist wohl entwickelt. Die Nasenlöcher sind getrennt, das Foramen parietale klein. Das Quadratum ist mit dem Schädeldach unbeweglich verbunden. Die Wirbelsäule weist inn erwachsenen Zustande noch Reste der Chorda auf; die Wirbel sind amphizöl und auf der Ventralseite finclen sich Hypozentren ausgebildet. Das Supramaxillare, Palatinum und Dentale tragen dreieckige abgeplattete Zälnne, das Praemaxillare ist zalmlos oder trägt einen schneidenden Zahn, der stark nach unten vorspringt. Bei Polysphenodon sind Praenaxillare, Supramaxillare, Palatinum, Pterygoid und Transversum mit zahlreichen stumpfkonischen Zähnen besetzt, was auf eine durophage Lebensweise hindeutet. Bauchschuppen sind woln "bei allen Sphenodontiden vorhanden gewesen, aber nur bei cinigen nachgewiesen.

Eifelosaurus. - Untere Trias (Buntsandstein) der Eifel. ${ }^{1}$ Brachyrhinodon. - Mittlere Trias von Elgin in Schottland.

1 O. Jaekel, Üher ein neues Reptil aus dem Buntsandstein der Eifel. Zeitschrift d. Deutschen Geol. Ges., LVI. Bd., 1904, S. 90.

2 F. von Huene, Über einen echten Rhynchocephalen aus der Trias von Elgin, Brachyrhinodon Taylori. - Neues Jahrbuch f. Min. usw., 1910, 11. Bd., S. 29. Derselbe, Der zweite Fund des Rhynchocephalen Brachyrhinodon in Elgin. - Ibidem, 1912, I. Bd., S. 51. 


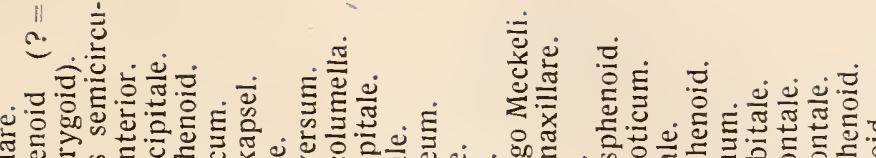

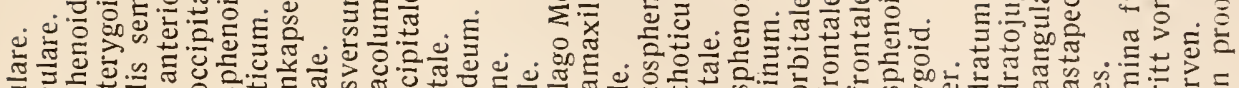

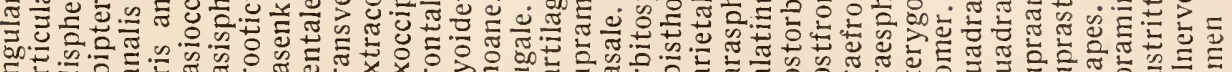

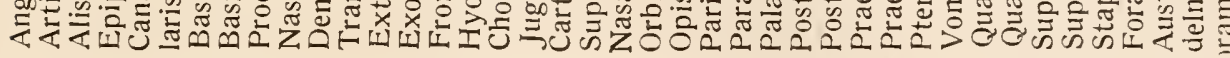

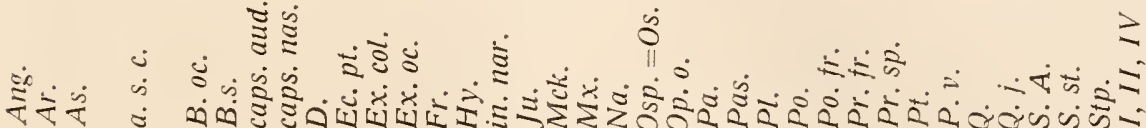

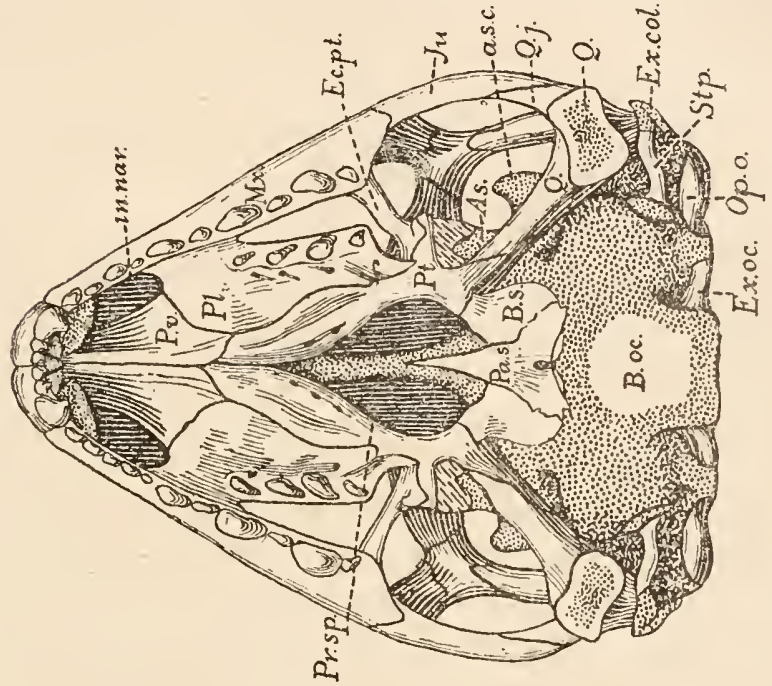

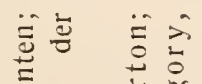

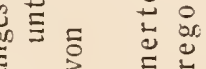

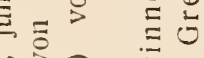

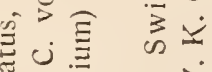

的芯

Е.ं

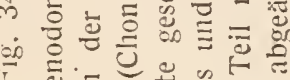

I $\cong$ :

के

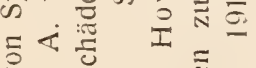

$>$ प

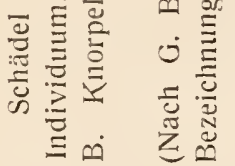
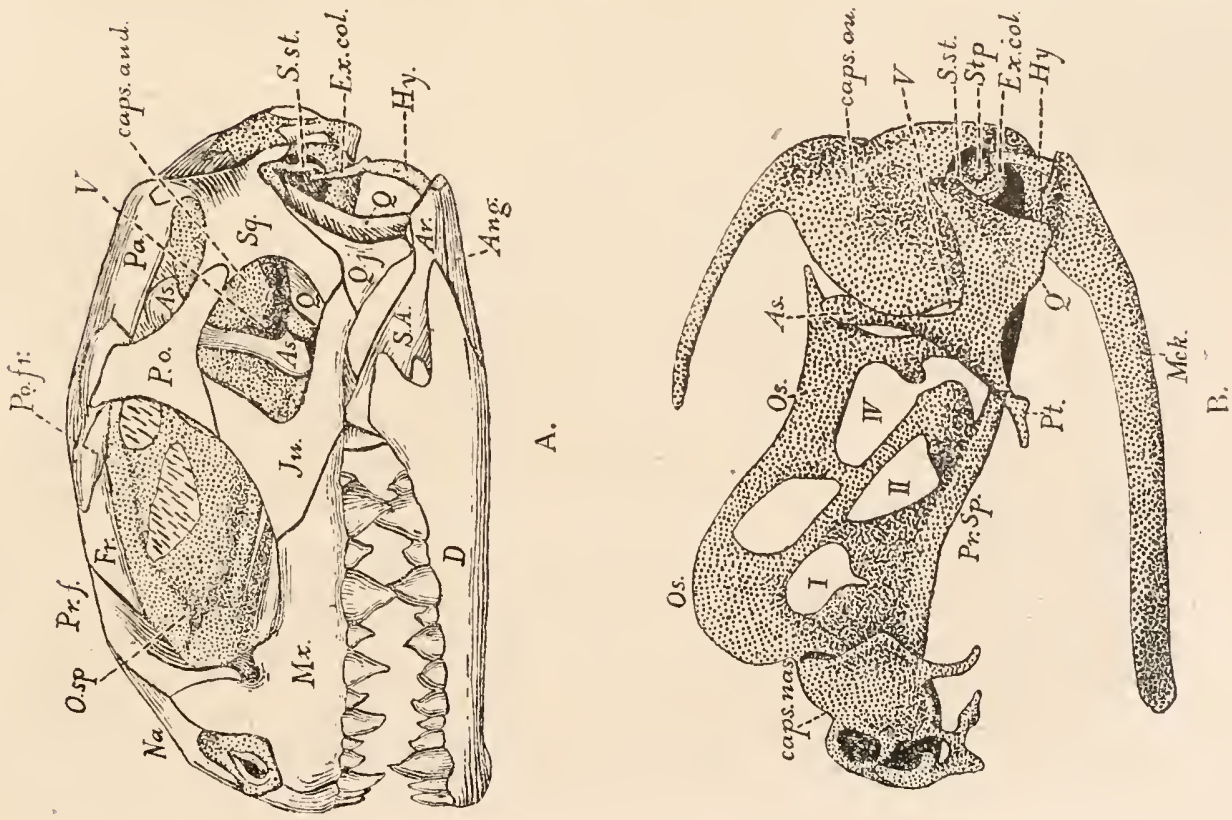
Polysphenodon. - Obere Trias (nittlerer Keuper) von Hannover. ${ }^{1}$ (Fig. 347, A).

Homoeosaurus. - Oberer Jura Bayerns, Englands und Hannovers. ${ }^{2}$

Sphenodon. - Lebend in Neuseeland; auf einige kleine lnseln in der Plentybai an der Nordinsel beschränkt, sonst erlosclıen. (Fig.346.)

\section{F. Pleurosauridae.}

Diese Familie ist durch eine kleine Gattung aus dem oberen Jura Europas vertreten, die sich einseitig an das Meeresleben angepaßt hat und einen sehr langen Körper (nit über 45 Präsakralwirbeln) und kleine Flossen besitzt. Der allgemeine Habitus erinnert am meisten an den der Mosasaurier.

Pleurosaurus. - Oberer Jura von Bayern und Frankreich. ${ }^{3}$ Junge Individuen wurden als Acrosaurus beschrieben. ${ }^{4}$

\section{F. Rhynchosauridae.}

Eine hochspezialisierte Gruppe, die sich von prinitiven Rhynchocephalen abgezweigt und einseitig differenziert hat. Als die wesentlichsten Kennzeichen der Familie können die zu einer einzigen Öffnung vereinigten Nasenlöcher, die sehr merkwürdige, schmabelartig nach unten abgebogene Form der Zwischenkiefer und das nach oben scharf aufgebogene Unterkieferende in Verbindung mit der durophagen Bezahnung. des Supramaxillare und des Dentale gelten; die Palatina und Praemaxillaria sind unbezahnt. Das Supratemporale scheint zu fehlen. Die Begrenzung der Augenhöhle unterliegt bei den einzelnen Gattungen durchgreifenden Verschiedenheiten; das vorgeschrittenste Stadium scheint bei Stenometopon aus der mittleren Trias von Elgin vorzuliegen. Beide Temporalgruben sind wohl ausgebildet.

Hyperodapedon. - Mittlere Trias von Elgin in Schottland und Ostindien. ${ }^{5}$ (Fig. 347, B.)

1 O. Jaekel, Die Wirbeltiere. - Berlin 1911, S. 146 . (Eine eingehendere Beschreibung fehlt noch.)

${ }^{2}$ L. von Ammon, Über Homoeosaurus Maximiliani. - Abhandl. der math. phys. Klasse d. Kgl. Bayrischen Akad. d. Wiss., XV. Bd., Mïnchen 1885, S. 499.

${ }^{3}$ W. Dames, Beitrag zur Kenntnis der Gattung Pleurosaurus H. v. Meyer.

Gitzungsber. d. Akad. d. Wiss. zu Berlin, XLII. Bd., 1896, S. 1107.

4 A. Andreae, Acrosaurus Frischmanni H. v. Mey. - Ein dem Wasserleben angepaßter Rhynchocephale von Solnhofen. - Ber. d. Senckenberg. Ges. Frankfurt a. M., 1893, S. 21.

5 Th. H. Huxley, Further Observations on Hyperodapedon Gordoni. Quarterly Journal Geolog. Soc., Vol. XLIII, London 1887, p. 675.

R. Burckhardt, On Hyperodapedon Gordoni. - Geological Magazine, Dec. IV, Vol. VII, London 1900, p. 486.

G. A. Boulenger, On Reptilian Remains from the Trias of Elgin. - Philosophical Transactions R. Soc., Vol. CXCVI (B), London, 1903, p. 176. 


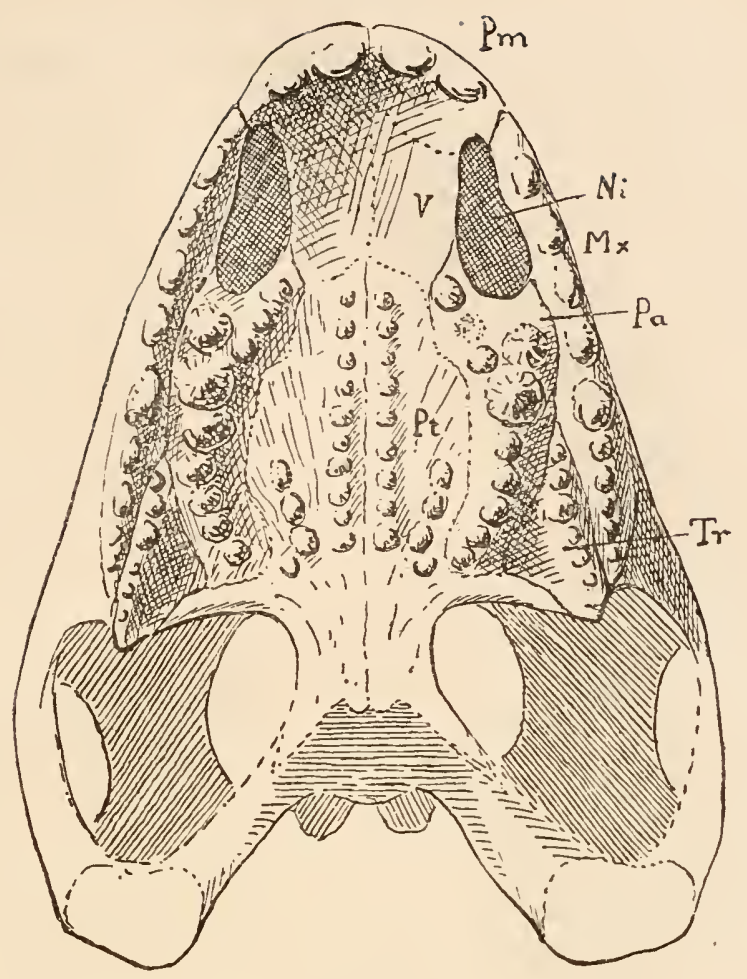

Fig. $347 \mathrm{~A}$.

Gaumenansicht des Schädels von Polysphenodon Mülleri, Jaekel, aus der oberen Trias (mittlerer, Keuper) von Fallersleben (Hannover), 4 mal vergr. (Nach O. Jaekel.) $P m$. = Praemaxillare (bezahnt). $\quad P a$. - Palatinum (bezahnt).

$M x$. = Supramaxillare (bezahnt). $\quad P t . \quad=$ Pterygoideum (bezahnt).

$V . \quad=$ Vomer.

Ni. $=$ Choane.

$T r$. = Transversum (bezahnt).

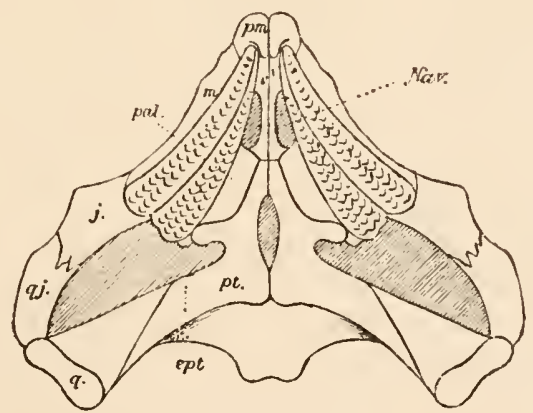

Fig. 347 B.

Gáumenansicht des Schädels ${ }^{\top}$ von Hyperodapedon Gordoni, Huxley, aus der mittleren Trias von Elgin in Schottland, in $1 / 4$ nat. Gr., rekonstruiert.

(Nach G. A. Boulenger, 1903.)
pm. = Praemaxillare.
pt. = Pterygoid.
$m$. = Supramaxillare.
$j$. $=$ Jugale
v. $=$ Vomer .
Nav. = Choanen .
$q j .=$ Quadratojugale.
pal. $=$ Palatinum.
$q . \quad=$ Quadratum.
ept. = Transversum. 
Rhynchosaurus. - Obere Trias von Grinsill bei Shrewsbury, England. ${ }^{1}$ (Fig. 348.)

Stenometopon. - Mittlese Trias von Elgin in Schottland." (Fig. 349.)

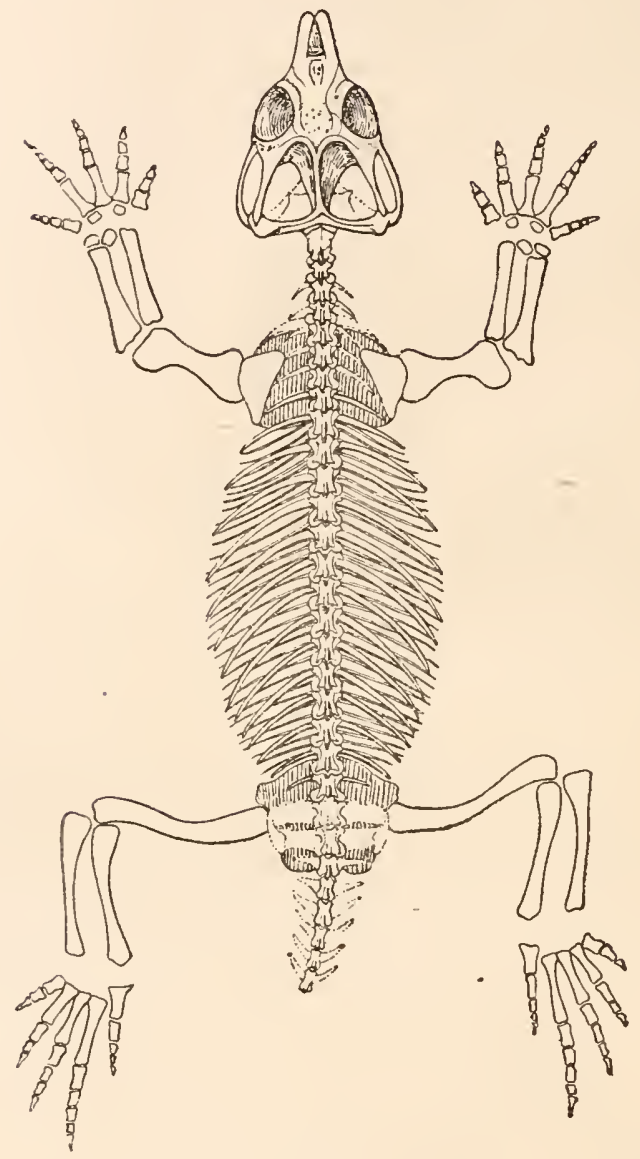

Fig. 348 .

Rhynchosaurus articeps, Owen, aus der oberen Trias von Grinsill bei Shrewsbury (England). Rekonstruktion in $2 / 3$ nat. Gr. (Nach A. Smith Woodward.)
Howesia. - Trias vol Südafrika. ${ }^{3}$

\section{F. Sauranodontidae.}

Nur eine einzige, stark aberrante und einseitig spczialisierte Gattung repräsentiert diesen Seitenzweig der Rhynchocephalen, der sicl in ähnlicher Weise wie die Rhynchosauriden entwickelt hat. Die Kiefer und Palatina sind gänzlich zahnlos geworden, schnabelartig gekrümmt und besitzen scharfe, schneidende Ränder, die jedenfalls mit Hornscheiden bedeckt gewesen sind. Ein Foramen parietale fehlt ebenso wie bei den Rhynchosauriden; die Postorbitalia sind groß lind vielleicht mit den Postfrontalia verschmolzen. Das Schädeldach trägt zwei laterale Temporalgruben. Der Schwanz ist lang.

Das geologische Alter (oberster Jura) würde den Gedanken nahelegen, daß Sauranodon ein hoclispezialisiertes Endglied der Rhynchosauriden ist; dagegen spriclıt aber der primitive Bau der Nasenregion, in der die Nasenöffuungen

1 A. Smith Woodward, On Rhynchosaurus articeps. - Report of the 70 th. Meeting of the British Association Advancement Science (York, 1906), London 1907, p. 1.

2 G. A. Boulenger, 1. c. 1903, p. 179.

${ }^{3}$ R. Broom, The South African Diaptosaurian Reptile Howesia. - Proceedings Zoological Society, London 1906, p. 591. 
weit voneinander getrennt sind, da sich die Praemaxillaria und Nasalia zwischen sie einschieben, während bei den Rhynchosauriden die äußeren Nasenöffnungen vereinigt sind. Trotz der nahen Verwandtschaft von Sauranodon mit den Rhynchosauriden ist diese Gattung daher als Vertreter eines selbständigen Seitenzweiges anzusehen, der zwar mit den Rhynchosauriden in einer gemeinsamen Wurzel zusammenläuft, aber schon frühzeitig eigene Entwicklungswege eingesclılagen hat.
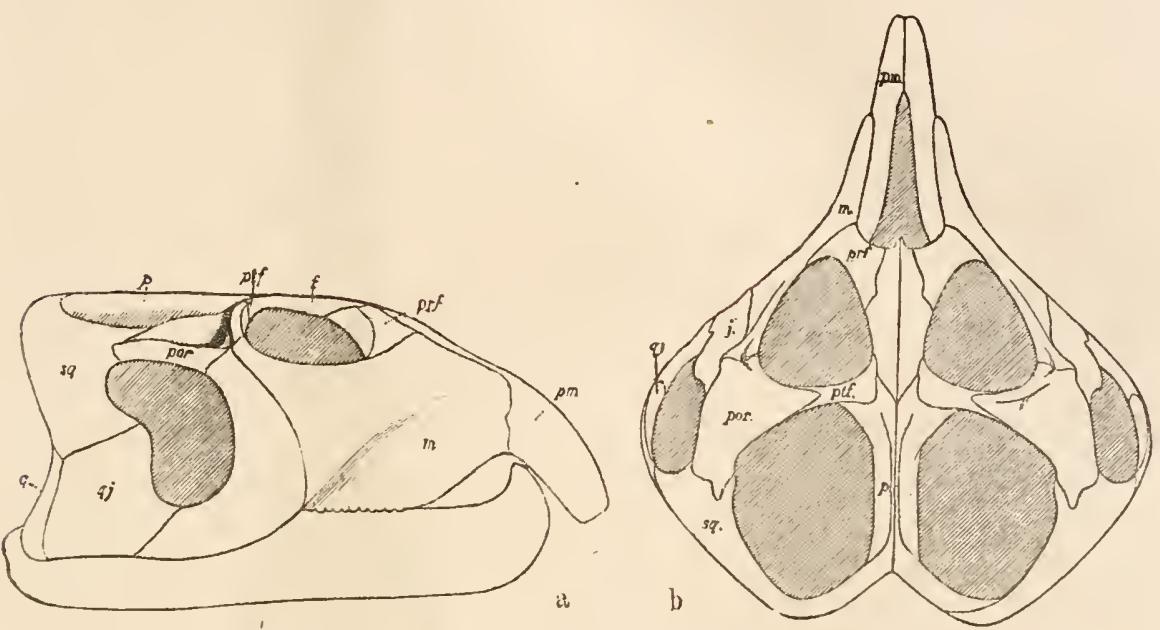

Fig. 349 .

a. Seitenansicht, b. Oberansicht des Schädels von Stenometopon Taylori, Bonlenger, aus der mittleren Trias von Elgin (Schottland), rekonstruiert in 1/, nat. Gr. (Nach G. A. Boulenger, 1903.)

pm. $=$ Praemaxillare.
m. $=$ Supramaxillare
prf. $=$ Lacrymale.
f. $=$ Frontale.
ptf. $=$ Postfrontale.
por. $=$ Postorbitale.
$j . \quad=$ Jugale.
qj. - Quadratojugale.
$s q . \quad$ = Squamosum.
p. Parictale.
q. Quadratum.

por. = Postorbitale.

Sauranodon. - Oberster Jura von Cerin in Frankreich. ${ }^{1}$ S. incisivus, Jourdan.

\section{F. Champsosauridae.}

Von dieser Familie sind zwei Gattungen aus der oberen Kreide und dem unteren Eozän Nordamerikas und Europas (Nordfrankreichs und Belgiens) bekannt; es waren aquatische, krokodilähnliche Reptilien, die siclı wahrscheinlich schon frühzeitig von den Sphenodontiden

1 L. Lortet, Les Reptiles fossiles du Bassin du Rhône. - Arch. Mus. d'Hist. Nat. de Lyon, T. V., 1892, p. 1.

F. v. Huene, Über einen echten Rhynchocephalen aus der Trias von Elgin, Brachyrhinodon Taylori. - Neues Jahrbuch f. Mineral, usw., 1910, 11. Bd., S: 50: 
abgezweigt und einseitig differenziert haben. Auf den Kieferknochen stehen spitzige Zähne, kleine Zähnchen stehen außerdem auf den Vomeres, Palatina, Pterygoidea und Transversa. Das Foramen parietale ist verloren gegangen. Die Nasenlöcher stehen terminal. Die allgemeine Form des Schädels erinnert an einen Gavialschädel. In

Fig. 350 .

Unteransicht des Schädels von

Champsosaurus laramiensis,

B. Brown, aus der obersten Kreide

(Laramie Beds) von Montana,

Nordamerika, in $1 / 6$ nat. Gr.

(Nach B. Brown.)

Praemaxillare (bezahnt).

$b=$ Supramaxillare (bezahnt).

$c=$ Ethmoideum.

$d$ = Choane.

$e=$ Vomer (bezahnt).

$f$ = Palatinum (bezahnt).

$g=$ Orbita (von unten gesehen), unter ihr die Fenestra palatinalis.

$h$ = Pterygoideum (bezahnt).

$i$ - Jugale.

$k=$ Transversum.

$l=$ Postorbitale.

$m=$ Postfrontale.

$n=$ obere Temporalgrube.

$\theta=$ untere Temporalgrube.

$p=$ Quadratojugale.

$q$ = Quadratum.

$r$ Squamosum.

$s=$ Exoccipitale.

$t=$ hinterer Fortsatz des Parietale. $u=$ Basisphenoid $u$. Basioccipitale.

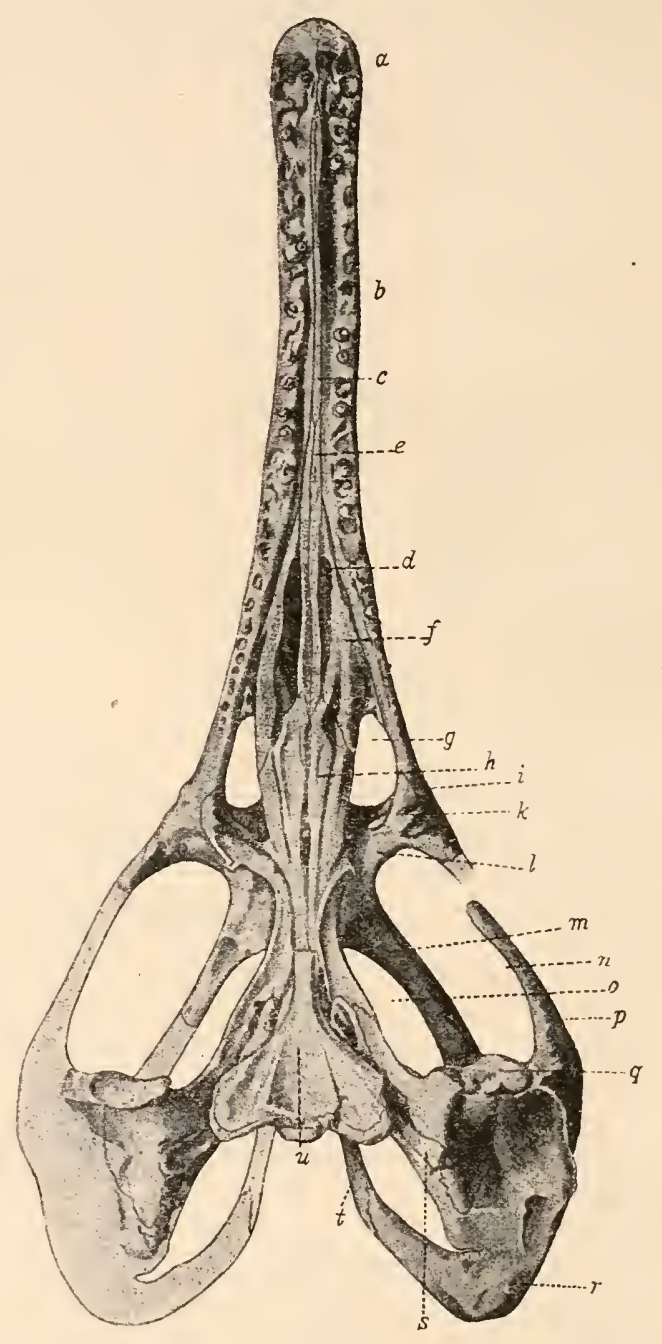

Halswirbelabschnitt sind Hypozentren vorhanden, der Bauch war durch Bauchrippen geschützt. Die Tiere waren Süßwasserbewohner.

Champsosaurus. - Obere Kreide (Laramie Beds) von Montana und unteres Eozän (Puerco Beds) von Neumexiko. ${ }^{1}$ (Fig. 350.)

1 B. Brown, The Osteology of Champsosaurus, Cope. - Memoirs Amer, Mus. Nat. Hist., Vol. IX, Part I, 1905, p. 1. 
Simoedosaurus. - Obere Kreide und unteres Eozän von Belgien and Nordfiankreich. ${ }^{1}$

\section{VIIL. Ordnung: Protorosauria.}

Die Grundlage dieser Ordnung ist die Gattung Protorosaurus. Das erste Exemplar wurde 1706 im permischen Kupferschiefer von Suhl (Thüringen) gefunden; Ch. M. Spener beschrieb den Rest als fossiles Krokodil. Seither sind von diesem Reptil zahlreiche Exemplare gefunden worden, aber nur der erste Fund umfaßt auch den Schädel, dessen Bau noch immer nicht ganz klargestellt ist. Nach den neuen Untersuchungen von S. W. Williston (1914) ist kein zwingender Grund zur Annahme vorhanden, daß der Schädel außer der unteren auch eine obere Temporalgrube besaß; auch ist das von Seeley angenommene Vorhandensein einer Präorbitalöffnung zweifelhaft. Wir sind daher bei der systematischen Bestimmung dieser Gattung fast ausschließlich auf die Merkmale der Wirbelsäule und des Gliedmaßenskeletts angewiesen. Vergleiche mit anderen Reptilordnungen haben schon seit langer Zeit auf gewisse Beziehungen zu den Lepidosauriern hingewiesen und die neueren Untersuchungen Willistons haben diese Vermutungen bestärkt. Mit den Rhynchocephalen scheinen sie nicht näher verwandt zu.sein. Wichtig ist das Vorhandensein von Hohlräumen in den Gliedmaßenknochen. In großen und ganzen ist von Protorosaurus viel zu wenig bekannt, als daß weittragende phylogenetische Schlüsse auf Vergleichen zwischen den Protorosauriern und den anderen Reptilordnungen aufgebaut werden könnten; indessen scheint es von Vorteil, die Gattung Protorosaurus als Vertreter einer eigenen Ordnung zu unterscheiden, da sie sich in die übrigen nicht ohne Zwang einreihen läBt. Ob Aphelosaurus aus dem Perm von Autun in Frankreich an Protorosaurus anzuschließen ist, muß einstweilen unentschieden bleiben.

Protorosaurus. - Oberes Perm (Kupferschiefer) Deutschlands und Magnesian Limestone Englands (Durham). ${ }^{2}$

1 L. Dollo, Première Note sur le Simoedosaurien d'Erquelinnes. - Bull. Mus. Roy. d'Hist. Nat. de Belgique. - T. III, 1884, p. 151.

V. Lemoine (Drei kurze Mitteilungen über Funde von Simoedosaurus im untersten Eozän Frankreichs), Comptes Rendus, Acad. Sci. Paris, T. XCVIII, 1884, p. 697 und 1011; ibidem, 1885, p. 753.

2 S. W. Williston, The Osteology of Some American Permian Vertebrates. - Journal of Geology, Vol. XXII, 1914, p. 394.

Von der älteren Literatur über dieses oft erwähnte Reptil vgl. insbesondere H. G. Seeley, On Protorosaurus Speneri. - Philos. Transactions, Vol. CLXXVIII, London 1887. 


\section{Ordnung: Mesosauria (= Proganosauria).}

In Perm von Südamerika, Südafrika und Deutsch-Südwestafrika treten zwei Gattungen auf (Stereosternum und Mesosaurus), welche unter den Reptilien eine ziemlich isolierte Stellung einnelnmen. Man lat diese Gattungen mit den Sauropterygiern, Ichthyosauriern und mit den Rliynchocephalen in Beziehungen zu bringen versucht, doch ist bisher über ilhre systematische Stellung noch keine Einigung erziclt worden. Die richtigste Auffassung scheint mir die v. Huene's zu sein, der die Mesosaurier sowohl von Protorosaurus wie von den Rhynchocephalen scharf scheidet und dagegen auf eine Anzahl von mit den Ichthyosauriern übereinstimmenden Merkmalen hinweist. Freilich ist

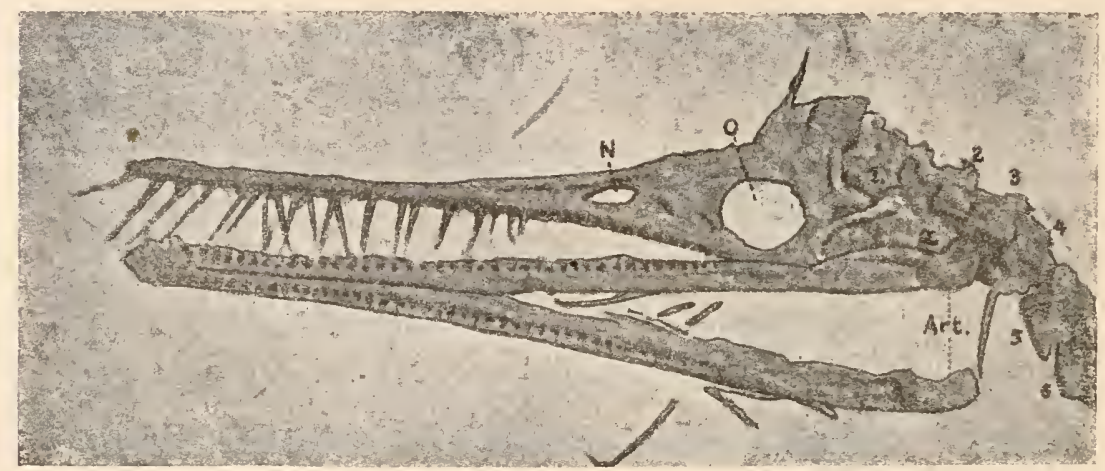

Fig. 351 .

Schädel von Mesosaurus brasiliensis Mc Gregor aus dem Perm von lraty, sidlich von Ponto Grossa im Staate Parana. Nat. Gr. (Nach J. H. Mc Gregor, 1908.)
N. = Nasenöffnung.
Art. = Articulare.
O. - Orbita.
$T-6=$ die 6 vorderen Halswirbel.
Q. Quadratum.

mit Entschiedenheit zu betonen, daß. weder die Ichthyosaurier von Mesosauriern abgeleitet werden dürfen, noch umgekelırt; es ist dagegen wahrscheinlich, daß die Mesosaurier der Wurzel des Ichthyosaurierstanmes nahestehen und sich wie diese zwar an das Wasserleben frülzeitig angepaßt haben, aber in einer ganz anderen'Richtung als die Ichthyosȧurier. Die Ähnlichkeiten zwischen den Mesosauriern und Ichthyosauriern bestehen vor allem in der Art des Eingreifens der Nasalia zwischẹn die Praemaxillaria, in der Bezahnung der langgestreckten Vomeres, die sich vor den Choanen zwischen die Pränaxillarien einschieben, in der Form des Quadratunis und in dem Felılen einer unteren Schläfénbrücke. Dagegen ist die weit nach hinten verschobene Lage der Nasenöffunngen als eine bloße Konvergenzerscheinung 
infolge vorgeschrittener Anpassung an das Wasserleben zu deuten. Andererseits bestehen Konvergenzen mit den Sauropterygiern in der Pachyostose der Rippen; die Lokomotionsart scheint an ehesten mit jener der Meereskrokodile vergleichbar zu sein, da die Hinterbeine vieł stärker entwickelt sind als die Vorderbeine. Die Zähne sind selır lang und spitz und bilden ein Fanggebiß; sie stehen in Alveolen und sind dicht gedräıgt. Die plattenförnıige Ausbildung des Brust- und Beckengürtels erimnert wieder an ähnliche Spezialisationen der Sauropterygier. Die Mesosaurier besaßen Bauchrippen.

\section{F. Mesosauridae.}

Die beiden bekannten Gattiingen sind Süßwasserbewohner gewesen.

Stereosternum. - Perm vor Sào Paulo und Parana in Südbrasilien, Paraguay und Uruguay, Perm von Südafrika (Fig. 352, 385, B).

Mesosaurus. - Verbreitung dieselbe wie die der vorigen Gattung, außerdem noch im Perm von DeutsclSüdwestafrika. ${ }^{1}$ (Fig. 351.)

\section{Ordnung: Ichthyosauria.}

ln der Triasformation erscheinen die ersten Vertreter eines Reptilienstammes, der in so hohem Maße an das Wasserleben angepaßt war, dab. nicht nur im allgemeinen Habitus, sondern auch in vielen einzehnen Merkmalen weitgehende

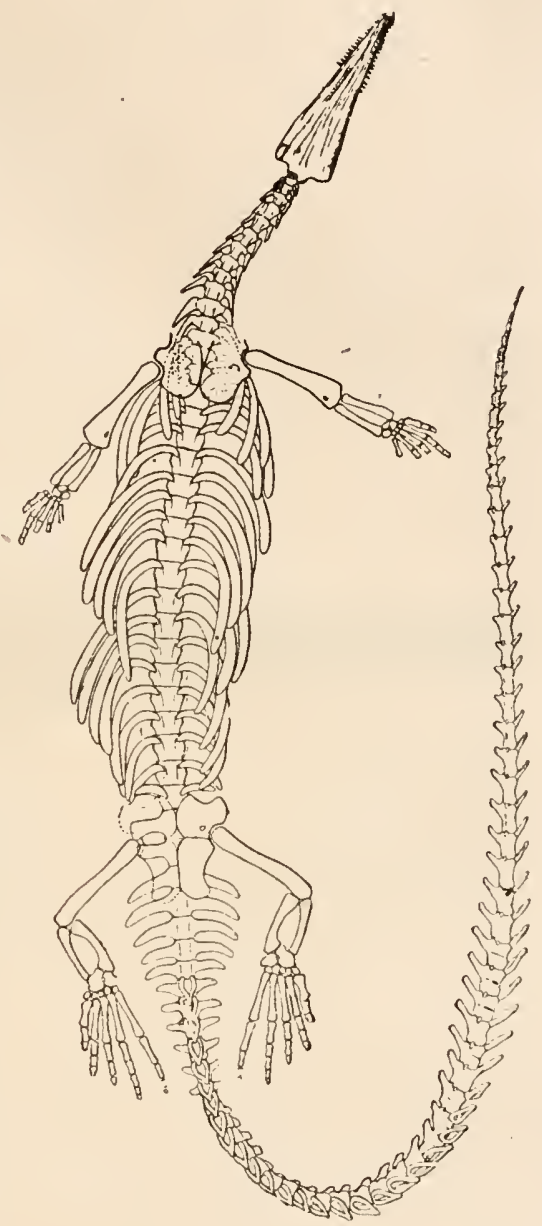

Fig. 352.

Stereosternum tumidum, Cope, aus den Perm von Sã Paulo, in ungefähr $1 / 2$ nat. Gr., von der Ventralseite gesehen. (Nach J.H. Mc Gregor.) Ähnlichkeiten mit den Fischen und Walen aufgetreten sind, die jedoch nur als Konvergenzerscheinungen bewertet werden dürfen. Der Schädel läuft in eine spitze, delphin-

1 Die Literatur iber Stereosternum und Mesosaurus ist enthalten in: E. von Stromer, Die ersten fossilen Reptilreste aus Deutsch-Südwestafrika und ihre geologische Bedeutung. - Centralbl. f. Min. usw, 1914, S. 530. 
ähnliche Schnauze aus, die Nasenlöcher sind weit nach hinten gegen das Schädeldach zu verschoben, der Körper ist in hohem Grade delphinförnnig geworden, die paarigen Gliedmaßen sind zu Flossen umgeformt, (s hat sich eine Rückenflosse und eine Schwanzflosse ausgebildet, die Wirbel zeigen eine sehr vereinfachte, fischähnliche, kurze, amphizöle Gestalt, der Körper ist nackt geworden usf.

Die Ichthyosaurier gehörten im Jura zu den häufigsten Meeresreptilien und können wohl als die damaligen "Beherrscher der Meere" angesehen werden. Ihre Reste liegen zu Tausenden in den Ablagirungen des süddeutschen und englischen Lias begraben; im oberen Jura bereits seltener, nehmen sie in der Kreidezeit sichtlich an Häufigkeit ab und verschwinden schon vor dem Ausgange der Kreideformation aus allen Meeren, olne Nachkommen zu hinterlassen.

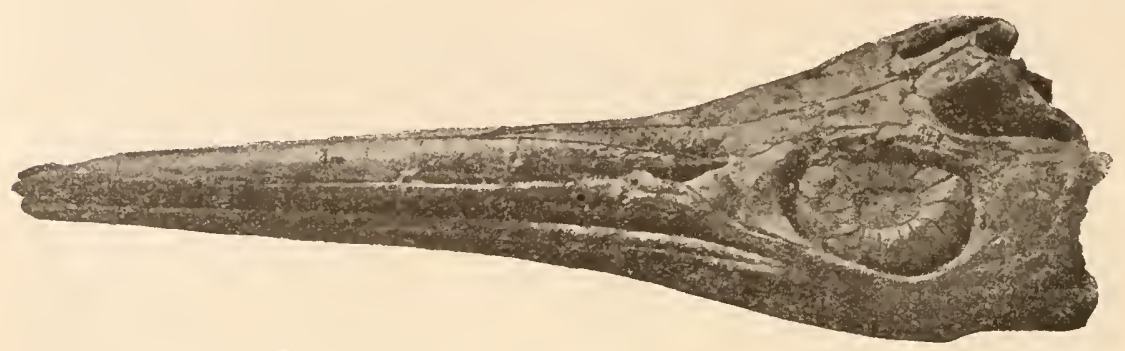

Fig. 353.

Schädel von Stenopterygius acutirostris, Owen, aus dem uberen Lias von Holzmaden, Württemberg; Länge 1,28 m. (Nach E. Fraas, 1913.) (Grundlage für die Rekonstruktion Fig. 354.)

Als Grundlage der Besprechung der Morphologie des Schädels wähle ich den Schädel eines Ichthyosauriers aus dem oberen Lias, Stenopterygius acutirostris Ow. ${ }^{1}$ (Fig. 353 - 356.)

Die Schnauze (Fig.354) ist selır lang und nimmt fast zwei Dritteile der Schädellänge ein; sie ist mit sehr zahlreichen, kräftigen Zähnen bewaffnet, die ein Fanggebiß bilden. Die Zwischenkiefer und Nasalia sind stark in die Länge gezogen, das Nasenloch ist weit nach linten gerückt und von der großen, durch einen Sklerotikalring geschützten, lateral gelegenen Augenhöhle nur durch das große Adlacrymale getrennt. Der Oberrand der Orbita wird von einem klcinen Lacrymale gebildet, an das sich hinten, gleichfalls an der oberen Begrenzung der Orbita teilnehmend, ein Postfrontale anschließst; der Hinterrand der Orbita wird von Postorbitale begrenzt, an das sich, den Unterrand der Augenhölıle bildend, das Jugale anschließt. Das Jugale keilt sich vorn zwischen

1 E. Fraas, Ein unverdrückter Ichthyosaurusschädel. - Jahreshefte d. Ver: f. vaterländ. Naturkunde in Württemberg, 1913, S. 1. 


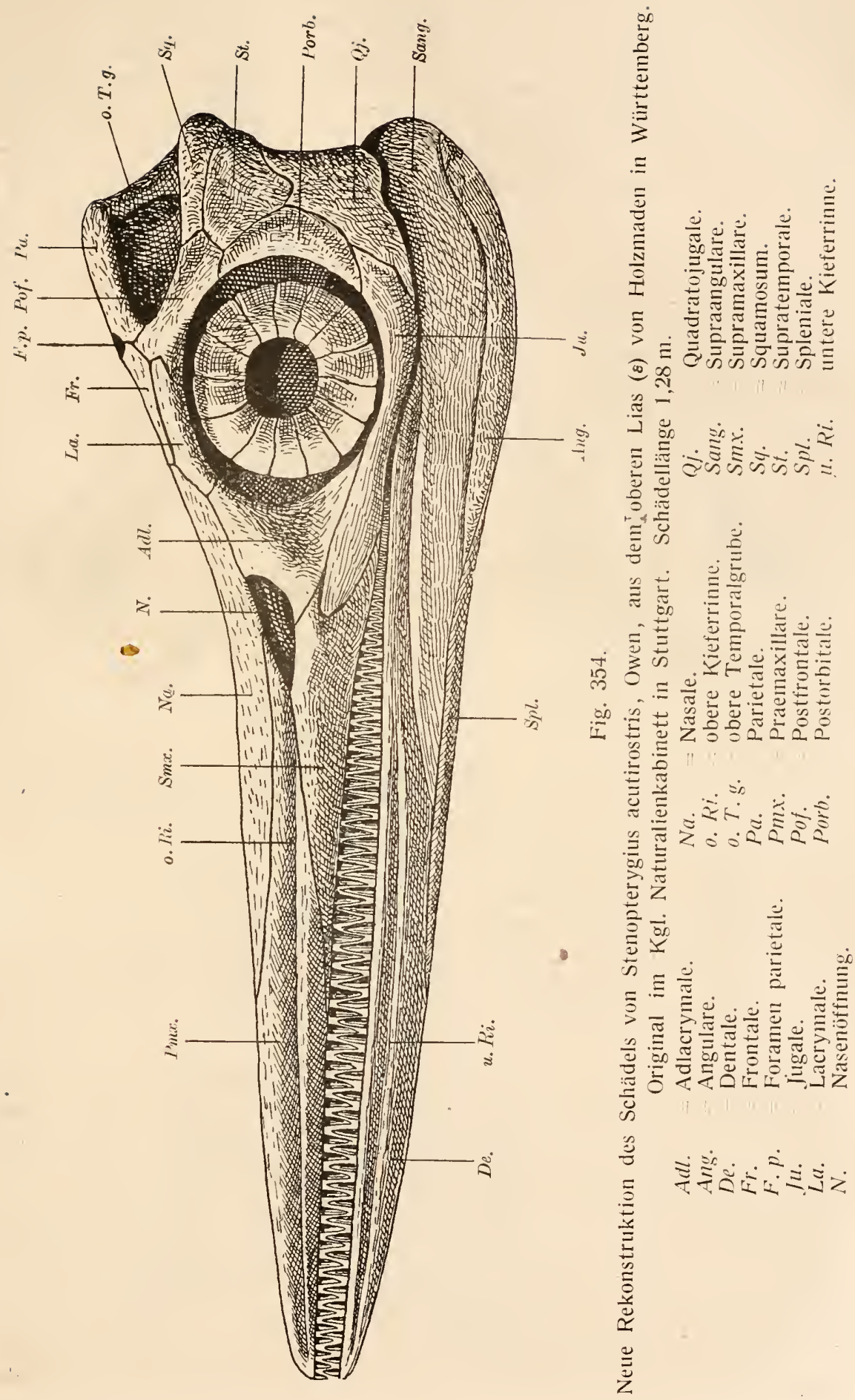


das Adlacrymale und das Supramaxillare ein und schiebt sicl mit seinem Hinterende zwischen das Postorbitale und das Quadratojugale, das die lintere Außenecke des Schädels bildet. Das Quadratum liegt auf der Hinterseite des Schädels und ist im Seitenprofil daher nicht sichtbar. Der Hirnteil des Schädeldaches wird von den paarigen Frontalia und Parietalia gebildet; das Parietalforamen liegt an der Stelle, wo die Frontalia und Parietalia in der Mittellinie zusammenstoßen.

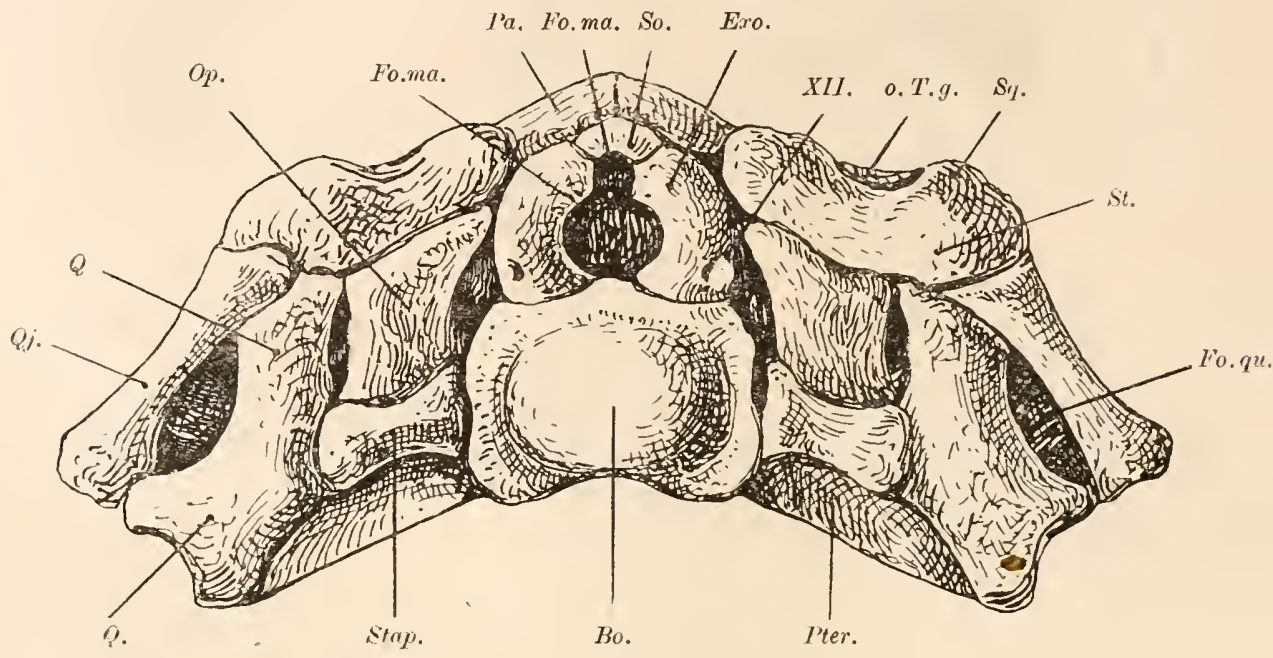

Fig. 355.

Hinteransicht des Schädels von Stenopterygitus acutirostris Owen (vgl. Fig. 353, 354, 356). (Originalrekonstruktion.)

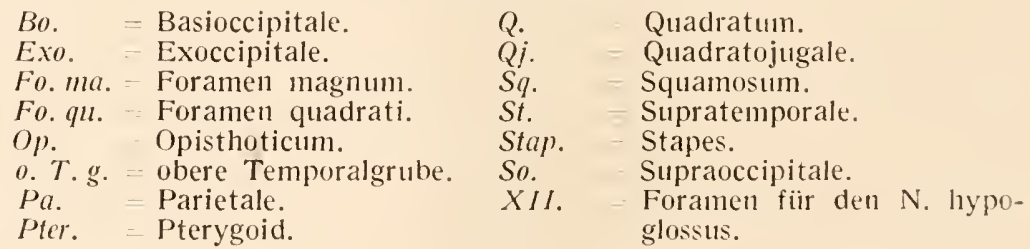

Wälıend die einzelnen Knochen der Seitenwände und der Oberseite des Schädeldaches enge zusammenschließen und weiche, sanft gerundete und geglättete Oberflächenformen besitzen, fällt uns bei Betrachtung der Hinterseite des Schädels (Fig. 355) die klobige Gestalt der einzelnen Knochen auf, die nur in losen Verband stehen und zwischen sich zalılreiche Lücken frei lassen. Der größte Knochen des Schädeldacles ist das Basioccipitale, das allein den Gelenkkopf des Hinterhauptes, den Condylus occipitalis, bildet. Die äußerste Mittelspitze des Basioccipitale beteiligt sich an der Begrenzung des Foramen magnum, aber die Seitenränder desselben werden von den Exoccipitalia 


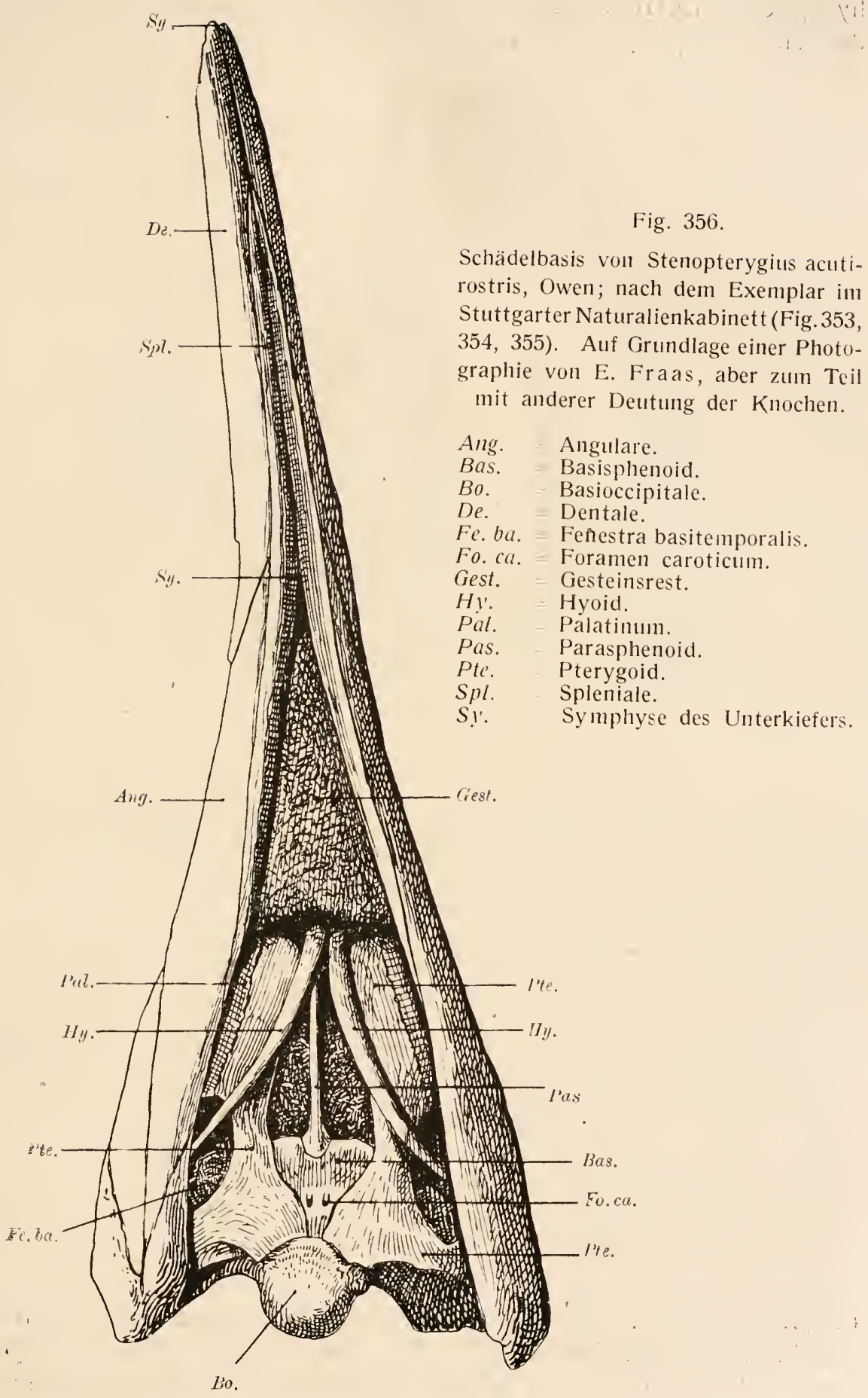


gebildet, die von einem kleinen Loch, der Austrittsstelle des Nervus hypoglossus (XII) durchbohrt sind; das Schlußstück der Öffnung des Hinterhauptsloches wird von einem auffallend kleinen Supra-

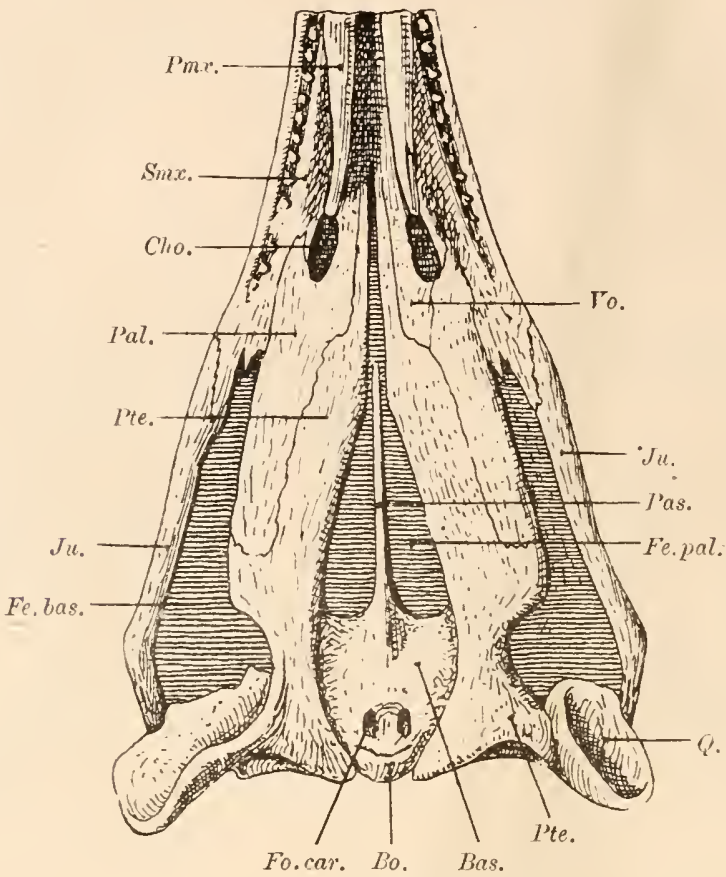

Fig. 357.

Gaumenfläche der hinteren Schädelpartie von Stenopterygius longifrons, ()wen, aus dem oberen Lias der Normandie. - Mit Benützung der Abbildungen von R. Owen Innd A. Smith Woodward, aber wesentlich abgeändert; ebenso die Deutung der Knochen abgeändert. J. Versluys faßte (1912) die Hinterenden der Praemaxillaria $(P m x)$ als die Palatina und die Palatina $(P a l$.$) als Transversa auf, ebenso wie$ E. Fraas (1913) und F. Broili (1917) im Gegensatze zu seiner früheren Deutung (Neubearbeitung von Zittels Grundzügen der Palaeontologie, 1911, I1. Bd., S. 223, Fig. 363). Ich pflichte v. Huene bei, wenn er (1916, S. 64) betont, daß bei den Ichthyosauriern ein Transversum bis jetzt nicht sicher nachgewiesen ist, entgegen der Auffassung von J. Versluys, E. Fraas und F. Broili. Neue Untersuchungen dieser Schädelregion werden uns darüber Aufklärung bringen miissen:

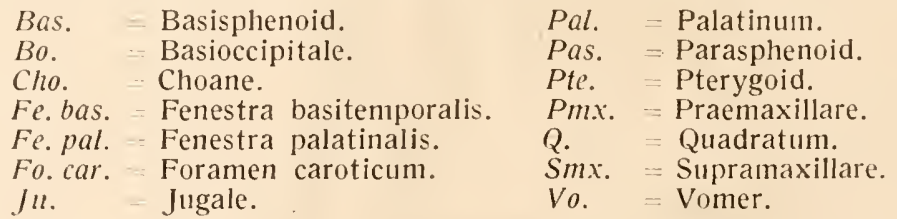

occipitale gebildet. Über dem Supraoccipitale werden in der Hinteransicht die kleinen Parietalia sichtbar, an die sich seitlich die Squamosa und unter diesen die Supratumporalia anschließen, deren Grenzen 
gegen das Squamosum nicht immer deutlich zu sehen sind. An das Supratemporale legt sich das schon in der Besprechung cer Seitenansicht des Schädels crwälınte Quadratojugale an; innerhalb von diesem liegt das Quadratum mit der Gelenkfläche für das Articulare des Unterkiefers. Zwischen dem Quadratum und dem Basioccipitale wird die Verbindung durch das Pterygoid hergestellt. In der Lïcke zwischen Pterygoid, Quadratum, Squamosum, Exoccipitale und Basicccipitale

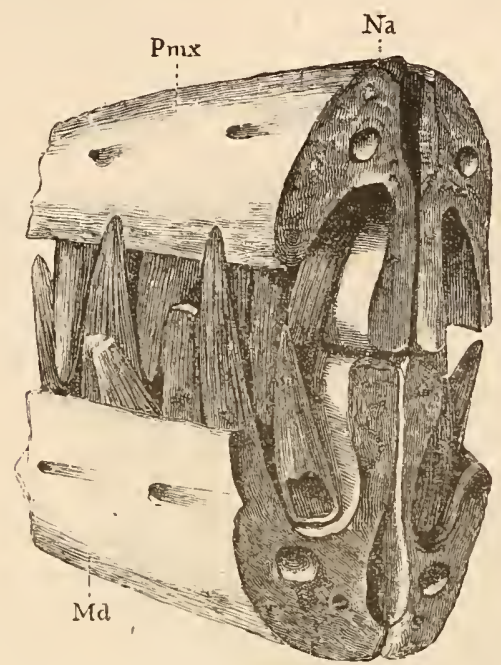

A.

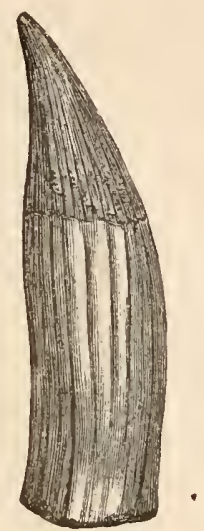

B.

Fig. 358.

A. Schnauzenfragment von Ichthyosaurus Quenstedti, Zittel; im Bohnerz von Melchingen auf sekundärer Lagerstätte gefunden (aus Schichten des oberen Jura umgelagert). (Nach F. A. Quenstedt.)

$N a=$ Nasale, $P m x=$ Praemaxillare, $M d=$ Unterkiefer.

B. Zahn von Eurypterygius communis, Conyb.; aus dem unteren Lias von Lyme Regis in Dorsetshire, England. Nat. Gr. (Nach K. A. von Zittel.)

liegen zwei Otikalknoclıen; der untere, cier nit seiner Außenseite in eine Grube des Quadratums hineinpaßt und sich an das Basioccipitale anlegt, ist der Stapes, der obere, größere Knochen das Opisthoticum.

Die Schädelbasis (Fig. 356) bietet bei Stenopterygius acutirostris Aufschluß über eine Reilıe wichtiger Merkmale. An das Basioccipitale cchließt sich vorn das unpaarige Basisphenoid an, das die Gestalt eines Dreieckes mit nach hinten gerichteter Spitze und nach vorn gerichteter Basis besitzt. Darauf folgt weiter vorn das dolchförmig gestaltete Parasphenoid, das die große Fenestra palatinalis teilt; seitlich schließt sich an das Basisphenoid das Pterygoid an, das den Innenrand der Fenestra basitemporalis bildet. 
Das Basisphenoid von Stenopterygius acutirostris weist zwei Foramina auf, welche als die Austrittsstellen der geteilten Carotis interna anzusehen sind.

An das Pterygoid schließt sich vorn das Palatinum und seitlich davon gegen innen der paarig ausgebildete Vomer an. ${ }^{1}$ Zwischen Vomer, Palatinum und dem Supramaxillare liegt die innere Nasenöffnung (Choane), deren Vorderrand bei St. acutirostris wahrscheinlich ebenso wie bei den meisten ïbrigen Ichthyosauriern von den Hinterenden der Praemaxillarien gebildet wird. (Fig. 357.)

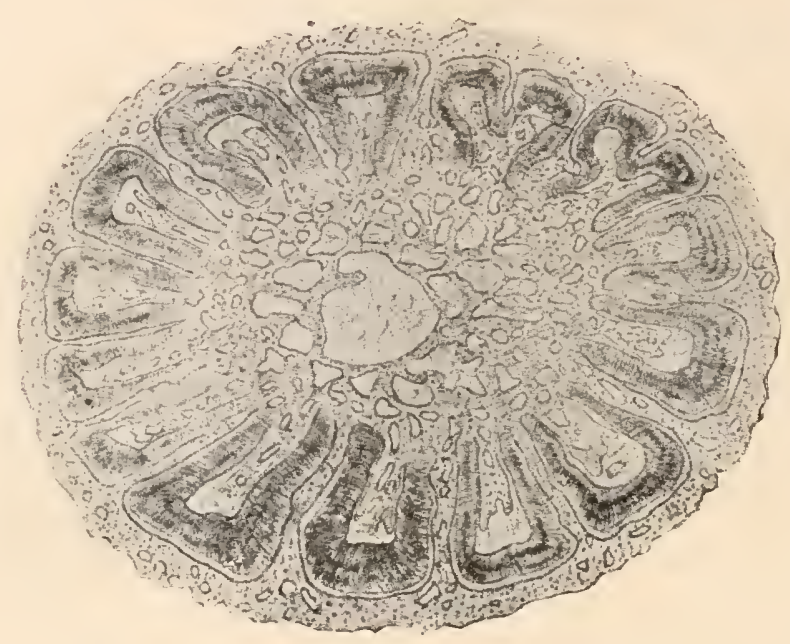

Fig. 359 .

Horizontalschliff durch die Basis der Zahnkrone von Ichthyosaurus crassicostatus, Theodori, aus dem oberen Lias Württembergs. 8: I nat. Gr. - In der Mitte Querschnitt der Pulpahöhle, in welche von außen her Radialfalten (Dentinsubstanz) vorspringen. Außen und innen Knochensubstanz (Cement). (Nach E. Fraas, 1891.)

Bei denn (Fig. 356) abgebildeten Schädel sind die beiden rippenartig gebogenen Zungenbeine oder Hyoidea erhalten geblieben.

Der Unterkiefer der Ichthyosaurier zeigt verschiedene Eigentümliclıkeiten in Vergleiclie mit den Cotylosauriern und den ïbrigen primitiveren Reptilien. Zu diesen gehört in erster Linie das Fehlen des Complementare ( Coronoid), das durch ein großes Praearticulare ersetzt wird, mit dem es luäufig verwechselt worden ist. Das Articulare ist sehr klein, legt sich an die innere Seite des Supraangulare und fällt beim Fossilisationsprozeß leicht aus dem Verbande mit den übrigen Knochen des Unterkiefers. Außer den genannten Elementen des Unterkiefers sind noch vorlıanden: Dentale, Spleniale, Angulare, Supraangulare.

1 In Fig. 356 ist diese Partie der Schädelbasis von Gestein (Gest.) verdeckt. 
A.

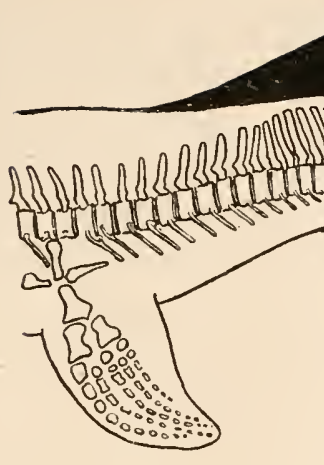

B.

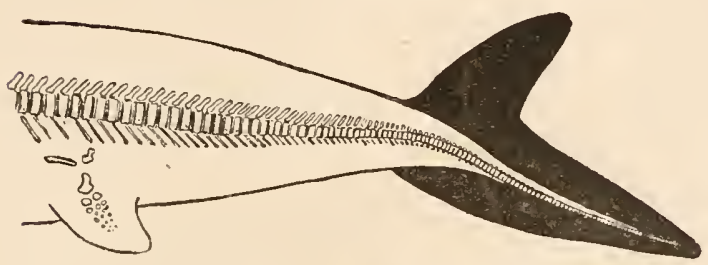

Fig. 360.

c.

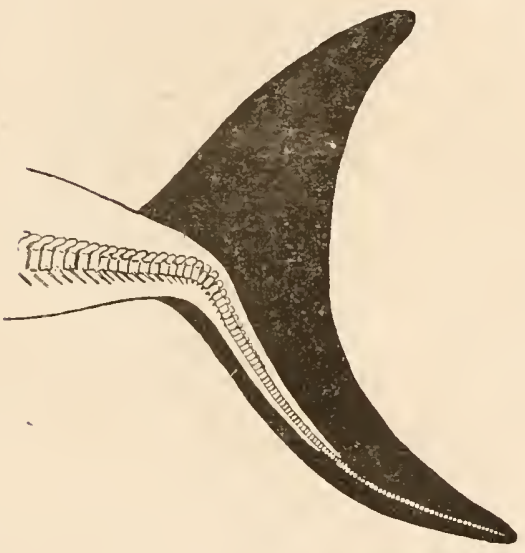

Die phylogenetische Entwicklung der Schwanzflosse bei den 1chthyosauriern.

A. Mixosaurus Nordenskjöldi Wiman. Trias (Muschelkalk) von Spitzbergen. (Nach C. Wiman, 1910.)

B. Ichthyosaurus (Stenopterygius) quadriscissus, Quenst., Jugendstadium. Oberer Lias $(\varepsilon)$ Wiirttembergs. (Nach E. Fraas, 1911.)

C. Dieselbe Art, erwachsenes Exemplar. Ebendaher. (Nach E. Fraas, 1910.)

D. Ichthyosaurus trigonus, var. posthumus. Oberer weißer Jura (Tithon) von Solnhofen, Bayern. (Nach F. Bauer, 1898.)

(Nach E. Fraas, 1911.) 
Die geringe Entwicklung des Articulare sowic die schwache Ausbildung des Kiefergelenkes überhaupt beweist, daß das Gebiß (Fig. 352-359), welches aus spitzen, bei jüngeren Gattungen in einer gemeinsamen. tiefen Rinne stehenden kegelförmigen Zähnen bestand (Fig. 358), nur zum Ergreifen, aber nicht auch zum Zerbeißen der Beute diente. Bei den ältesten Gattungen steckten die Zähne in Alveolen und erst später trat ihre Lockerung ein.

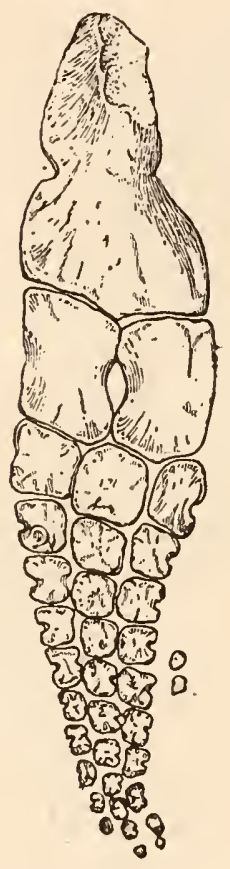

Fig. 361 .

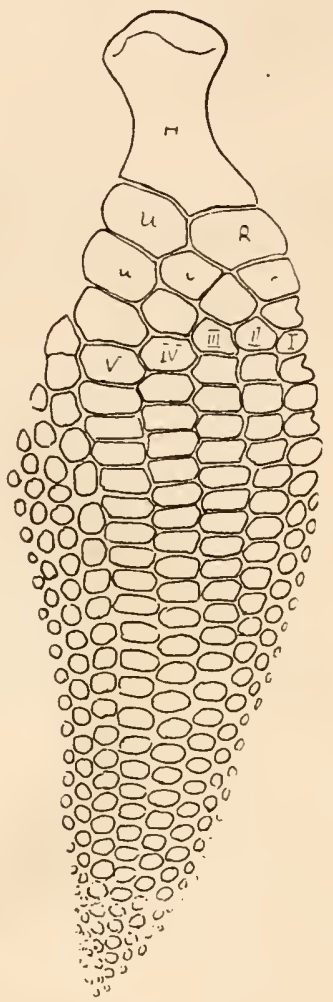

Fig. 362.
Linke Vorderflosse von Merriamia Zitteli aus der Trias Kaliforniens. $1 / 2$ nat. Gr.

(Nach J. C. Merriam.)
Rechte Vorderflosse von Eurypterygius communis, Conyb., var. hyperdactyla Jaekel. Unterer Lias von Lyme Regis, England. (Original im Kgl. Naturalienkabinett zu Stuttgart.) Verkl. (Nach O. Jaekel.)

Der Rumpf der Ichthyosaurier war im allgemeinen von der Form eines Delphinrumpfes, doch bestehen insofern Unterschiede zwischen den einzelnen Arten und Gattungen der Ichthyosaurier, daß wir gedrungenere und langgestreckte Rumpfformen unterscheiden können. Die Wirbelsäule besteht aus einer sehr großen Zahl amphizöler Wirbel, die durch ihre Kürze auffallen. Die Wirbelsäule setzt sich als Achse 
des unteren Schwanzflossenlappens bis zum Ende der Terminalflosse fort; bei Mixosaurus, dem primitivsten bekannten Ichthyosauier aus der mittleren Trias, ist die Abknickung des Schwanzendes, das sich in die Terminalflosse fortsetzt, sehr gering, nimmt bei den Liasformen rasch zu und erreicht ihren höchsten Grad bei den Ichthyosauriern des oberen Jura, wo eine starke Reduktion der Schwanzwirbel des unteren Schwanzflossenlappens einsetzt, die sich bei den Kreideichthyosauriern noch weiter vorgeschritten zeigt. ${ }^{1}$ (Fig. 360.)

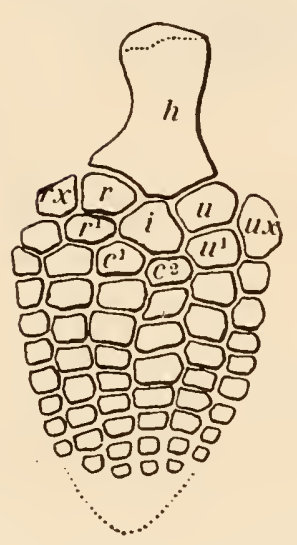

Fig. 363.

Vorderflosse von Eurypterygius extremus, Boulenger, aus dem Kimmeridge der Gegend von Bath in England.

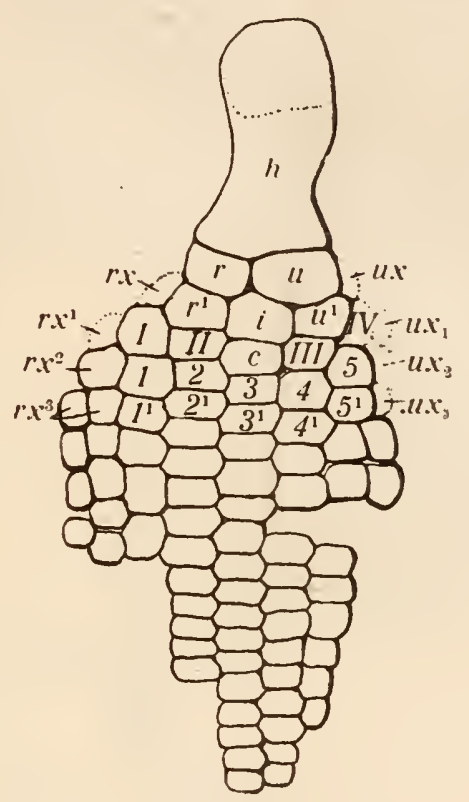

Fig. 364.

Linke Vorderflosse von Eurypterygius platydactylus, Broili, aus der oberen Unterkreide (Aptien) Hannovers. (Nach F. Broili.) Unterarm und proximale Carpalreihe desselben Stückes: vgl. Fig. 367.

Zwischen den vordersten Wirbeln finden sich an der Ventralseite Hypozentren (= Interzentren) ausgebildet, wie dies auch bei Cotylosauriern und anderen primitiven Reptilien zu beobachten ist.

1 F. Bauer, Die Ichthyosaurier des oberen Weißen Jura. - Paläontographica, XLIV. Bd., 1898, S. 283.

F. Broili, Ein neuer Ichthyosaurus aus der norddeutschen Kreide. - Ibidem, LIV. Bd., 1907, S. 139.

E. Fraas, Embryonaler Ichthyosaurus mit Hautbekleidung. Jahreshefte d. Ver. f. vaterländ. Naturkunde in Württemberg, 67. Jahrg., 1911, S. 480. 
Bei den älteren Ichthyosauriern der Trias sind ebenso wie bei den Juraichthyosauriern die Rippen in der vorderen Rumpfregion zweiköpfig und gehen erst in der Beckenregion in einköpfige Rippen über. ${ }^{1}$

Bei jüngeren Ichthyosauriern tritt infolge der starren Kopflaltung ebenso wie bei den marinen Zahnwalen eine Verschmelzung der vorderen Halswirbel ein. ${ }^{2}$

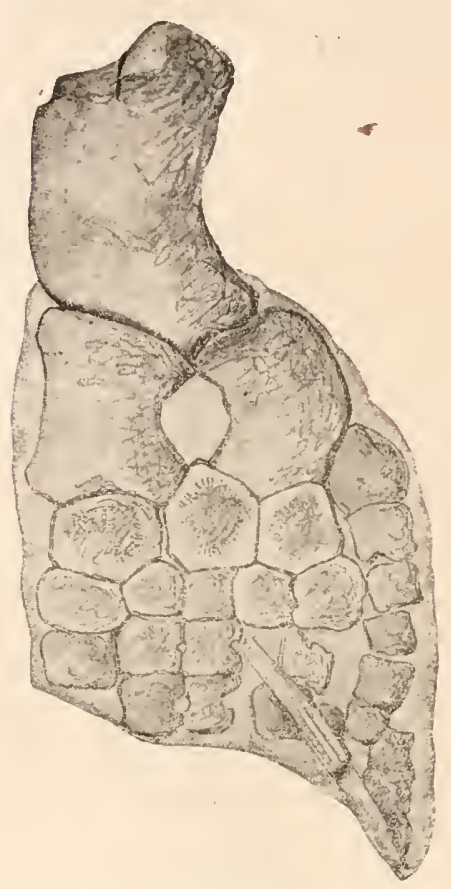

Fig. 365 .

Brustflosse von Mixosaurus Nordenskjöldi, Huike, aus dem ,oberen Saurierniveau" (mittlere Trias) von Middelhook im Isfjord auf Spitzbergen, in $1 / 2$ nat. Größe. (Nach

C. Wiman, 1910.)

Die Gliedmaßen der Ichthyosaurier sind zu Flossen umgeformt, und zwar lassen sich bei dieser Untwandlung aus den Extremitäten der landbewohnenden Vorfahren der Ichthyosaurier zwei Wege unterscheiden. Der erste Weg führt zur Ausbildung einer langen, spitzen, schmalen Flosse (z. B. Fig. 361) unter Verringerung der Finger- und Zehenzanl, der zweite Weg führt zur Entstehung breiter, kurzer Flossen (z. B. Fig. 362, 263, 364) unter Neubildung von Fingerstrallen (Hyperdaktylie). Bei der primitivsten Iclrthyosauriertype, die wir kemnen, Mixosaurus, sind die drei Elemente des Ober- und Unterarmes (Fig. 365) und die drei Elemente des Ober- und Unterschenkels (Fig. 266) noch deutlich als solche zu erkennen, wenn sie auch schon weitgehende Anpassungen an das Wasserleben und eine Unnformung der ganzen Gliedmaßen zu Flossen zeigen; aber bei den jüngeren Ichthyosauriern geht diese Uniformung der Gliedmaßen zu Flossen so weit, daß sich die Knochen des Unterarmes und des Unterschenkels kaum meln wesentlich von den Knochen des Carpus und Tarsus unterscheiden (Fig. 267 ). Die einzelnen, nitunter irrgulärn (Fig. 68) Fingerstrahlen bestehen aus einer selur großen Zahl von Phalangen, sowohl bei den breitflossigen

1 F. v. Huene, Beiträge zur Kenntnis der Ichthyosaurier im deutscinen Muschelkalk. - Paläontographica, LXI1. Bd., 1916, S. 1 (Literatur).

F. Broili, Einige Bemerkungen über die Mixosauridae. - Anatom. Anzeiger 1916 , S. 474.

2. F. Broili, Ein neuer Ichthyosaurus usw., I. c., 1907, S. 143.

O. Abel, Grundzïge der Paläobiologie der Wirbeltiere. - 1912; S. 466. 
(latipinnaten) als auch bei den schmalflossigen (longipinnaten) Typen; in einigen Fällen ist jedoch im Vergleich zu den Ausgangsformen der Ichthyosaurier, wie sie uns etwa in den Cotylosauriern entgegentreten, eine weitgehende Reduktion der Phalangen in den noch vorhandenen Fingern und Zehen zu verzeichnen (z. B. Ophthalmosaurus) (Fig.369, 370).

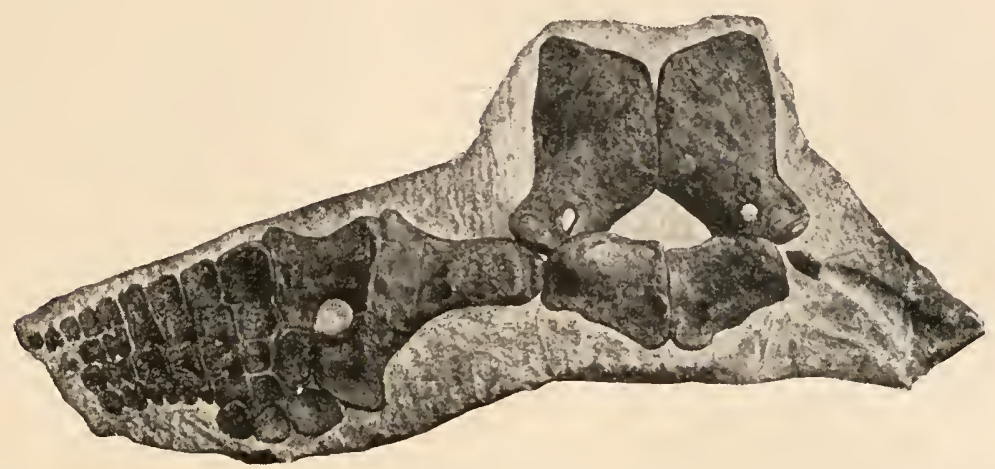

Fig. 366.

Beckengürtel und Hinterflosse von Mixosaurus Nordenskjöldi, Hulke, aus der mittleren Trias von Middelhook im Isfjord auf Spitzbergen, in $1 / 2$ Nat. Gr. (Nach C. Wiman, 1910.)

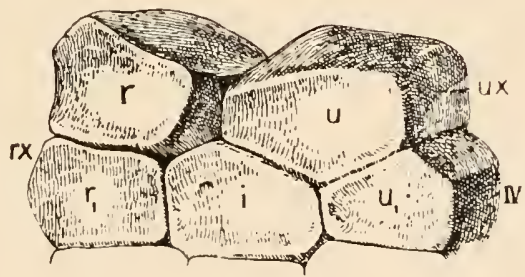

Fig. 367.

Unterarm und proximale Carpalreihe von Eurypterygius platydactylus, Broili, aus dem Aptien (obere Unterkreide) Hannovers (vgl. Fig. 364). 1/2 11at. Gr. (Nach F. Broili.)

$r .=$ Radius. $\quad r_{1}=$ Radiale.

$U$. $=$ Ulna.

$i_{\text {. }}=$ Intermedium.

$r x$. Gelenkfläche für das radiale Sesambein. $u_{1}=$ Ulnare.

$u x$. Gelenkfläche für das ulnare Sesambein. $I V .=$ Gelenkfläche für das Pisiforme.

Der Schultergürtel der Ichthyosaurier ist sehr kräftig gebaut. An ein medianes, ursprünglich dreieckiges ınd später T-förmiges Mittelstück, das der Interclavicula entspricht, legen sich zu beiden Seiten die großen Coracoide an, die zusammen mit der Scapula das Armgelenk bilden. An die Scapula und den vorderen, quer verbreiterten Teil der Interclavicula legt sich beiderseits eine schlanke, stabförmige Clavicula an. 
Der Beckengürtel der ältesten Ichthyosaurier hat noch große Älınlichkeit mit jenem der tetrapoden Landreptilien der Permzeit. Zunächst lockert sich bei der Anpassung an das Wasserleben die Verbindung des Iliums mit der Wirbelsäule, das zu einem schmalen Stab wird, später senkt sich das Becken immer melır herab und steht bei den Liasichthyosauriern nicht melır mit der Wirbelsäule in Verbindung. Die Hinterextremitäten sind stets kleiner als die Vorderextremitäten und unterliegen bei den meisten Gattungen und Arten aus jüngerer Zeit einer fortschreitenden Reduktion, die besonders stark bei Ophthalmosaurus zum Ausdruck kommt. Bei dieser Gattung sind Pubis und Ischium völlig miteinander verwachsen, aber vom llium getrennt;

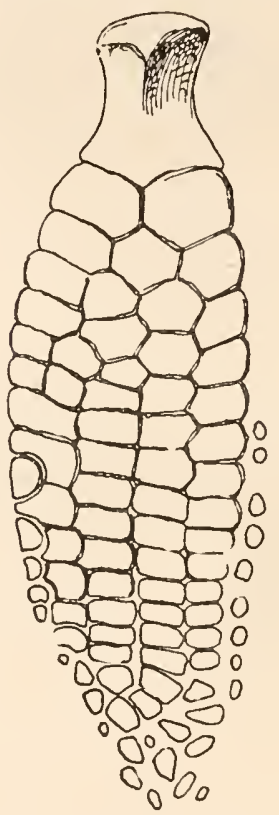

Fig. 368.

Abnormale Ichthyosaurierflosse aus dem Unterlias von Street, Somersetshire. Wahrscheinlich = Eurypterygius intermedius (Guide of Fossil Reptiles, Brit. Mus. Nat. Hist., London, 1910, p. 39, Fig. 38, A).

Orig.-Zeichnung nach einem Abguß im Brit. Mus. Nat. Hist., Nr. 2562.

in dem plattentörmigen, aus der Verschmelzung von Pubis und Ischium hervorgegangenen Knochen ist ein kleines Foramen obturatorium sichtbar (Fig. 371).

Zwischen den beiden Gliedmaßenpaaren sind sehr zalılreiche, dünne, schwach gebogene Bauclırippen ausgebildet.

Die häutige Rückenflosse, die an mehreren Exemplaren aus dem deutschen Oberlias freipräpariert werden konnte, hatte dieselbe Form wie die Rückenflosse der Delphine der Gegenwart (Fig. 372 -374).

In der Kehlregion einzelner Exemplare aus dem deutschen oberen Lias ist ein runder Sack erhalten, der wahrsclıeinlich als Kehlsack zu deuten ist ${ }^{1}$; seine Funktion ist jedoch noch fraglich (Fig. 372, 374).

1 O. Abel, Paläobiologie der Wirbeltiere. - 1912. p. 422. Ich habe hier die 
Bei zahlreichen Exemplaren hat man in der Leibeshöhle junge Tiere gefunden, die wiederholt zu der Vorstellung geführt haben, daß es sich in allen derartigen Fällen um Embryonen handelt, die nit der Mutter zugrunde gegangen sind. Indessen sind in einzelnen dieser Fälle

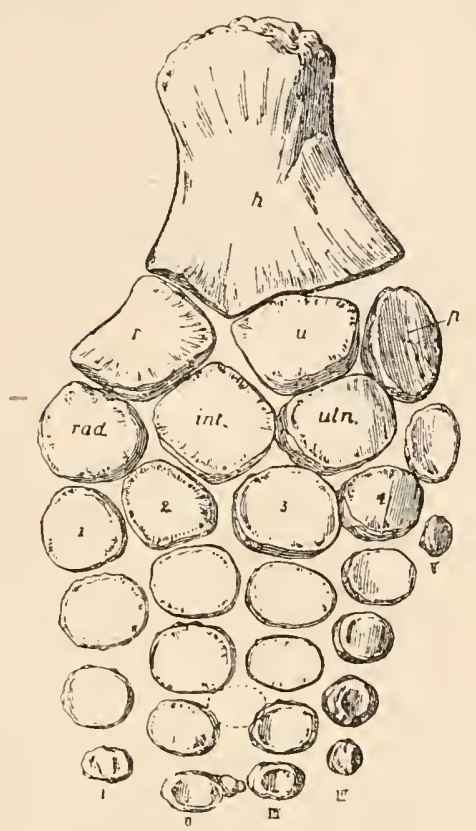

Fig. 369.

Linke Vorderflosse von Ophthalmosaurus icenicus, Seeley, aus dem Oxfordien von Peterborough in England, $1 / 6$ nat. Gr.

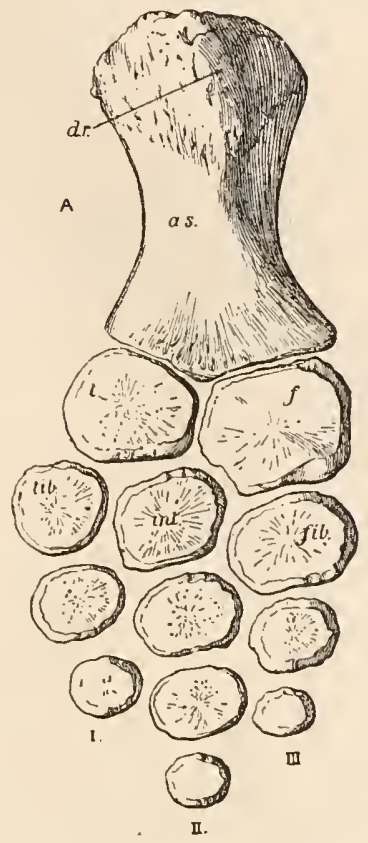

Fig. 370 .

Ventralansicht der rechten Hinterflosse derselben Art, $1 / 6$ nat. Gr.

(Nach C. W. Andrews, 1910.)

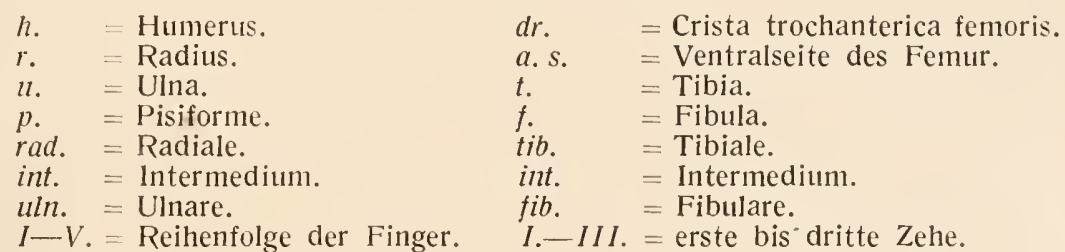

die Jungen verschieden groß und liegen zun Teil so weit vorn in der Leibeshöhle, daß es sich wohl nur um gefressene Junge handelı kann. Möglicherweise liegen in einigen Fällen wirklich Embryonen vor; daß die Ichthyosaurier vivipar gewesen sind, ist übrigens auch ohne Nach-

Vermutung ausgesprochen, daß es sich in dem Kehlsack entweder um eine Schallblase oder um eine Einrichtung handelt, die mit der Nahrungsaufnahme in irgendeinem Zusammenhange steht. 
weis von dem Vorhandensein von erhaltenen Embryonen nahezu sicher, da die Lebensweise eine Fortpflanzung auf oviparem Wege als unwahrschcinlich erscheincn läßt. ${ }^{1}$

Die Nahrung der Ichthyosaurier bestand in Fischen, Belemmiten und anderen Cephalopoden, wie erhaltene Speisereste in der Magengegend beweisen. An einzelnen Fundstellen von Ichthyosauriern sind ihre Exkremente häufig (Koprolithen). ${ }^{2}$

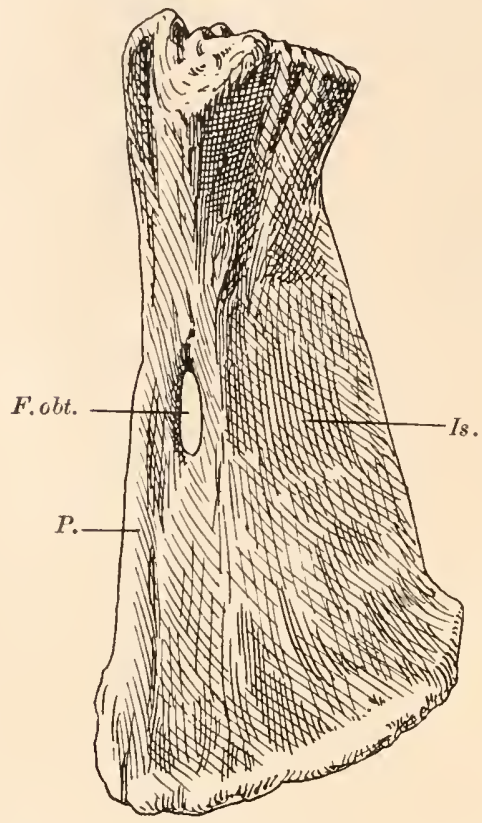

Fig. 371.

Pubis + Ischium von Ophthalmosatmu: icenicus, Seel., aus dem Oxfordien Englands. $1 / 2$ nat. Gr.

(Nach C. W. Andrews.)

Is. $\quad$ = Ischium.

P. $=$ Pubis.

F. obt. = Foramen obturatorium.

Die Körperlänge der Ichthyosaurier schwankte zwischen 1 1nl und $12 \mathrm{~m}$. Der größte Ichthyosaurier dürfte I. trigonodon gewesen sein; ein $2 \mathrm{~m}$ langer Schädel dieser Art wurde im oberen Lias Frankens gefunden.

Schon in Rhät lebten riesige Ichthyosaurier, wie das gewaltige Unterkieferfragment aus dem Bonebed von Aust Cliff am Severn bei Bristol beweist, das F. von Huene (1912) beschrieb ${ }^{3}$. Dieses Tier könnte vielleicht noch größer gewesen sein als Ichthyosaurus trigonodon, doch sind einstweilen genauere Schätzungen ummöglich.

${ }^{1} \mathrm{~W}$. Branca, Sind alle im Inneren von Ichthyosauren liegenden Jungen ausnahmslos Embryonen? - AbhandI. Kgl. Preuß. Akad. d. Wiss., 1907, S. 1.

Derselbe, Nachtrag zur Embryonenfrage bei Ichthyosaurus. - Sitzungsber. Kgl. Preıß. Akad. d. Wiss., XV111. Bd., 1908, S. 392.

O. Abel, Paläobiologie der Wirbeltiere. 1912. S. 75.

2 Viele der unter dem Namen ,Ichthyosaurierkoprolithen" beschriebenen Exkremente diirften jedoch von Fischen herriihren.

${ }^{3}$ F. v. Huene, Der Unterkiefer eines riesigen Ichthyosauriers aus dem englischen Rhät. - Centralbl. f. Mineral. usw., 1912, S. 61. 
Man hat ursprünglich sowohl die Arten mit kurzen und breiten Flossen wie die Arten mit langen und schmalen Flossen in einer Gattung (Ichthyosaurus) vereinigt und faßt auch heute noch sehr heterogene Typen unter diesem Namen zusammen. Es kann jedoch keinem Zweịfel mnterliegen, daß es sich in den Breitflossern und in den Sclmul-

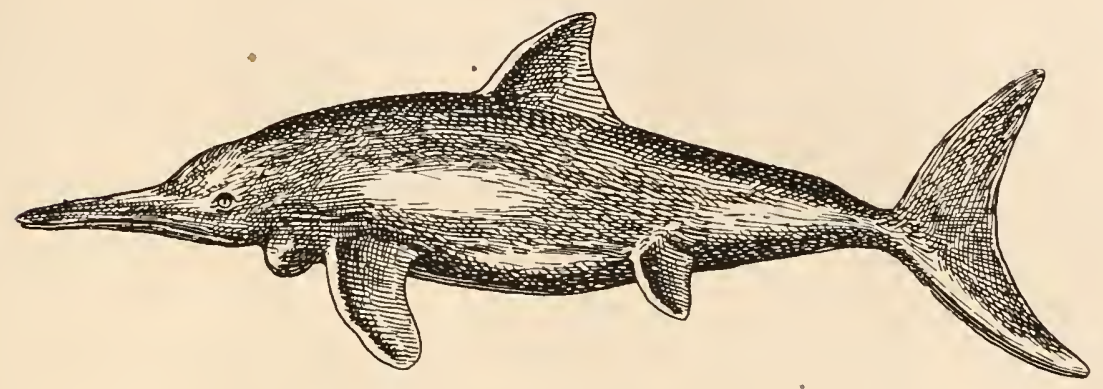

Fig. 372 .

Rekonstruktion von Stenopterygius quadriscissus, Quenstedt, aus dem oberen Lias Wirttembergs, auf Grundlage des Originals im Senckenberg-Musemm z11 Frankfurt a. M. (vgl. Fig. 374). (Nach O. Abel, 1912.)

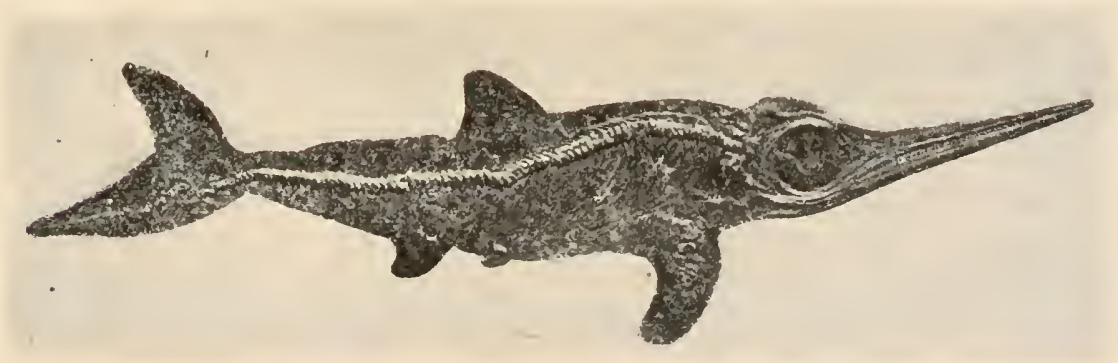

Fig. 373.

Stenopterygius quadriscissus, Qu. (emend. E. Fraas). Sehr junges Exemplar von $50 \mathrm{~cm}$ Körperlänge. - Oberer Lias von Holzmaden in Württemberg. Original im Kgl. Naturalienkabinett zu Stuttgart. (Nach E. Fraas, 1911.)

flossern (diese Unterscheidung deckt sich inicht ganz mit den systematischen Gruppen der Latipinnati und Longipinnati) um Vertreter zweier durchaus divergenter Stammesreihen handelt, welche ebenso scharf voneinander geschieden sind, wie etwa die breit- und kurzflossigen Balaeniden von den lang- und schmalflossigen Balaenopteriden unter den Bartenwalen. O. Jaekel hat daher schon 1904 vorgeschlagen $^{1}$, die

1 O. Jaekel, Eine neute Darstellung von Ichthyosaurus. - Zeitschrift der Deutsch. Geol. Ges., LVI. Bd., 1904, S. 32. 

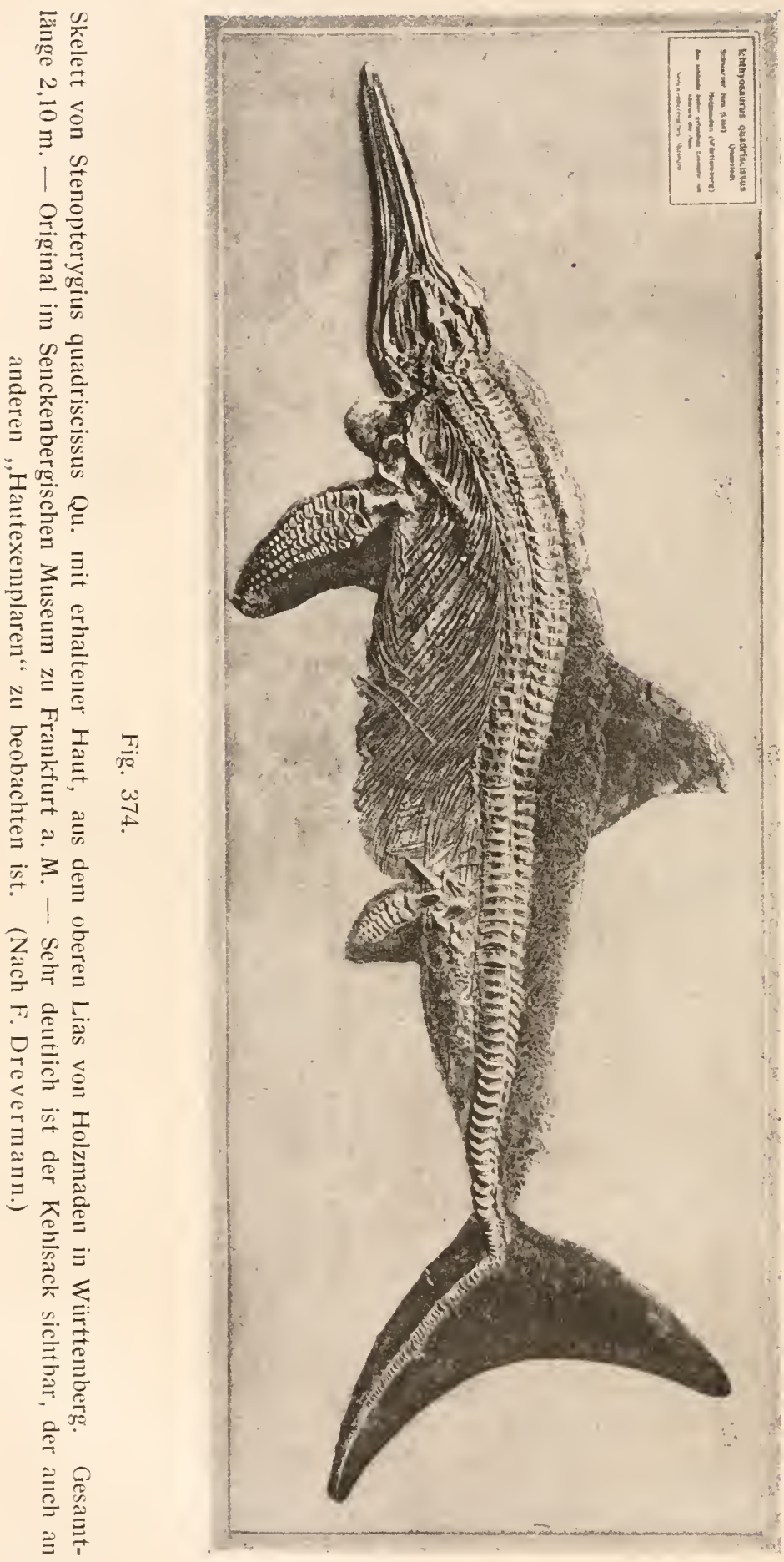
Breitflosser unter den Iclithyosauriern unter dem Namen Eurypterygius und die Schmalflosser unter dem Namen Stenopterygius zusammenzufassen, doch hat sich dicse Bezeichnung gegenüber dem eingebürgerten Namen Ichthyosaurus noch nicht durchzusetzen vermocht. Jedenfalls ist dieses Merkmal des Flossenbaues̃ zur Unterscheidung der Ichthyosaurusarten von viel größerer Wichtigkeit, als etwa die verschiedene Schnauzenlänge, die bei 1 . breviceps aus dem unteren Lias Englands extrem kurz, bei I. campylodon aus dem Gault des Rounddown Tumnel bei Dover extrent lang ist. Eine sehr merkwürdig differenzierte Gattung mit enorm verlängerter Schnauze und kurzem Unterkiefer, die in dieser Hinsicht eine überraschende Konvergenz mit dem langschnauzigen Zahnwal Eurhinodelphis aus dem Obermiozän von Antwerpen aufweist, habe ich (1909) als ,Eurhinosaurus" abgetrennt. ${ }^{1}$

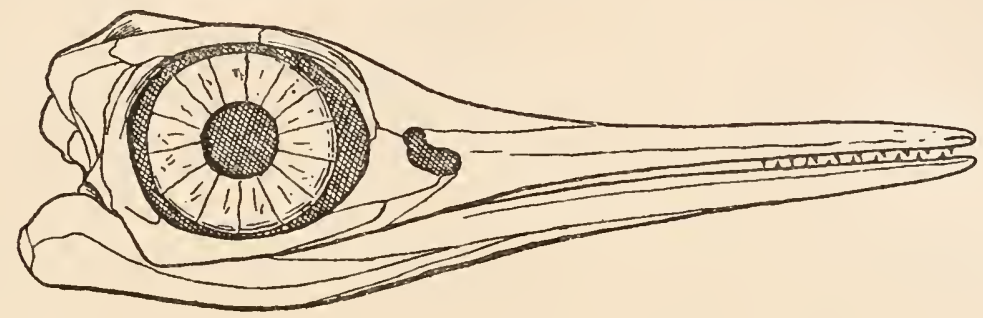

Fig. 375.

Rekonstruktion des Schädels von Ophthalmosaurus icenicus, Seeley, eines Ichthyosauriers aus dem Oxfordien Englands mit riesigen Augenhöhlen und breitem Sklerotikalring. Schädellänge etwa $1 \mathrm{~m}$. Gebiß rudimentär. (Nach C. W. Andrews.)

Bei der oberjurassischen Gattung Ophthalmosaurus mit außerordentlich vergrößerten Augenhöhlen sind die Zähne sehr klein ınd auf die vordersten Teile der Kiefer beschränkt. Es liegt hier eine parallele Anpassung mit den sekundär zahnarm gewordenen Zahnwalen vor, und zwar ist als die Ursache dieser Gebißreduktion wohl der Übergang von der ichthyophagen zur ausschließlich teuthophagen Ernälırung, d. i. Cephalopodennalırung, anzusehen. ${ }^{2}$ (Fig. 375.)

Die Ichthyosaurier stammen nicht direkt von den Cotylosauriern ab, sondern von einer Ahnengruppe, bei der bereits ein oberes Schläfenloch jederseits zur Ausbildung gelangt war. Huene hat es (1916) wahrscheinlich zu machen versucht, daß die direkten Alnen auf der Spezialisationsstufe der Poliosauriden gestanden und diesen sehr ähnlich waren, ${ }^{3}$

1 O. Abel, Cetaceenstudien. I. Mitteilung. - Sitzungsber. d. Kais. Akad. d. Wiss., Wien, CXV1II. Bd., math. nat. K1., 1909, S. 245.

2 O. Abel, Paläobiologie der Wirbeltiere, S. 526.

${ }^{3} \mathrm{~F}$. von Huene, Beiträge zur Kenntnis der Ichthyosaurier im deutschen Muschelkalk. - Paläontographica, XLII. Bd., 1916, S. 63. 
aber dagegen spricht vor allem, daß die Poliosauriden nur eine untere, aber keine obere Temporalgrube besessen haben, so daß die Ichthyosaurier mit ihrer oberen Temporalgrube und fehlenden unteren Temporalgrube nicht auf den Sclıädeltypus von Varanosaurus usf. zurückgehen können. Auch ist der hintere steile Absturz ${ }^{\circ}$ des Schädeldaches von Varanosaurus so eigenartig, daß an eine Ableitung der Ichthyosaurier von varanosaurusartigen Theromorplen nicht gedacht werden kann. Indessen mag zugegeben werden, daß die langgestreckte, sclmmale und spitz zulaufende Schädelform von Varanosaurus acutirostris unverkenubare Ähnlichkeiten

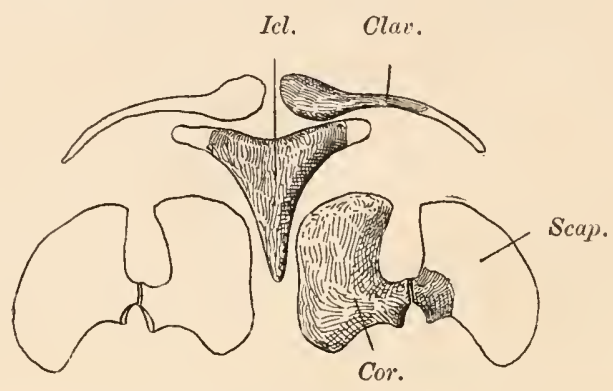

Fig. 376.

Schultergiirtel von Mixosaurus atavus, Quenst., aus der mittleren Trias Deutschlands, in $1 /$, nat. Gr.; kombiniert und rekonstruiert von F. v. Huene, 1916.
Icl. $=$ Interclavicula .
Clas. = Clavicula.
Scap. = Scapulare.
Cor. $=$ Coracoid

(Vgl. daztı die Kritik F. Broili's (1917, Anat. Anz., 49. Bd., S. 484), in welcher die Richtigkeit dieser Rekonstruktion bestritten wird.)

mit dem Schädel der primitiven Ichthyosaurier aufweist, aber diese Ähnlichkeiten sind höchstens auf Rechnung einer analogen Nahungsweise zu setzen.

Zwischen den Mesosauriern und Ichthyosauriern bestehen keine verwandtschaftlichen Beziehungen und die vorhandenen Ähnliclıkeiten sind teils als Folge der aquatischen Lebensweise beider Stämme, teils als gemeinsam von den Alnen ererbte Merkmale anzusehen. Wir müssen die Alnen der Ichthyosaurier in primitiven Reptilien der Theromorplenstufe aus der Permzeit suchen, die jedoch bis heute unbekannt geblieben sind. ${ }^{1}$

1 Gegen die Ableitung der Ichthyosaurier von Mesosaurus oder Stereosternum sprechen vor allem die in ganz anderer Richtung entwickelten Anpassungen an das Wasserleben bei den beiden Gruppen. Während die Mesosaurier den Molchtypus antweisen, haben die Ahnen der Ichthyosaurier zweifellos schon sehr friihzeitig die Riclitung zum Torpedotypus eingeschlagen, ohne daß irgend ein Merkmal dafür sprechen wiirde, daß die Vorstufe der Ichthyosaurier von molchförmigen Typen gebildet worden und diese Anpassungsform an das Schwimmen später mit der fusiformen Körpergestalt vertauscht worden wäre. Vgl. hieriiber auch Stromer, Die ersten fossilen Reptilreste aus Dentsch-Siidwestafrika nnd ihre geologische Bedentung. - Centralblatt f. Min., usw., 1914, S. 538. 
Mixosaurus. - Die Reste dieser kleinen, höchstens 1 m Körperlänge erreichenden Gattung sind bisher aus der Trias der Lombardei, Spitzbergens, Deutsclulands und Nevadas bekannt geworden. Das Schwanzende ist nur wenig abgebogen, so daß die Schwanzflosse sehr niedrig gewesen sein muß. Die Zähne stecken in Alveolen, nicht in einer Zahnrinnc. Die Interclavicula (Fig. 376) ist dreieckig, die Flossen breit und kurz, die Vorderflosse viel größer als die Hinterflosse, die Knochen des Oberarms und Oberschenkels, des Unterarms und Unterschenkels verhältnismäßig primitiv gebaut und in ilırer Form noch deutlich von den proximalen Elementen des Carpus und Tarsus unterschieden. M. atavus: Deutschland, unterer Muschelkalk; M. Nordenskjöldi: Spitzbergen, oberer Muschelkalk; M. Cornalianus: obere Trias der Lombardei; M. Fraasi: mittlere Trias von Nevada und einige andere Arten. ${ }^{1}$ (Fig. 365, $366,376,377$.

Cymbospondylus. - Mittlere Trias von Nevada, Muschelkalk Deutschlandis. - Der Schädel zeigt in Bau der Region zwischen den Augenhöhlen wesentliche Verschiedenheiten, die besonders in dem verschiedenen Größenverhältnis der Frontalia und Nasalia zum Ausdruck kommmen. Die Tiere waren relativ groß (Sclädellänge etwa $1 \mathrm{ml}$ ). Der Schwanz war wie bei Mixosaurus nur wenig nach unten gebogen. In der Länge der Arm- und Beinknochen ist C. noch primitiv. Die Vorderund Hinterflossen sind etwa gleich groB. Ob sie breit und kurz waren, ist noch zweifellhaft." (Fig. 378.).

Merriamia. - Obere Trias von Kalifornien. - Die Flossen sind sehr schmal und lang und enthalten in der Vorderflosse nur drei funktionelle Fingerstrahlen nebst Rudimenten eines vierten Fingerstrahls; die Hinterflosse ist kleiner als die Vorderflosse. In dieser Hinsicht ist

1 E. Repossi, Il Mixosauro degli Strati Triasici di Besano in Lombardia. Atti Soc. Italiana, XLI. Bd., Milano 1902, p. 361.

J.C. Merriam, Triassic Ichthyosauria with Special Reference to the American Forms. - Memoirs of the University of California, Vol. I, 1908.

C. Wiman, Ichthyosaurier aus der Trias Spitzbergens. - Bulletin of the Geol. Inst. of Upsala, Vol. X, 1910, p. 124 (Literatur p. 144).

Derselbe, Über Mixosaurus Cornalianus Bass. sp. - Ibidem, Vol. XI, 1912, p. 230 (Literatur p. 240).

Derselbe, Notes on the Marine Triassic Reptile Fanna of Spitzbergen. University of California Publications, Bull. of the Department of Geology, Vol. X, 1916, p. 63 (Literatur p. 73).

F. von Huene, Beiträge zur Kenntnis der Ichthyosaurier im deutschen Muschelkalk. - Paläuntographica, LXII. Bd., 1916, p. I (Literatur p. 66).

F. Broili, Einige Bemerkungen ïber die Mixosauridae. - Anatomischer Anzeiger, XLIX. Bd., 1916, S. 474.

2 Vgl. außer der oben genannten Abhandlung Merriams anch seine Studie: The Types of Limb-Structure in the Triassic Ichthyosauria. - Americ. Journal of Science (4), Vol. XIX, New Haven 1905, p. 23. 
also Merriamia bereits höher spezialisiert als die mangelhaft bekannte Gattung Toretocnemus, bei der die Hinterflossen ebenso lang oder etwas länger sind als die Vorderflossen; Toretocnemus ist in der oberen Trias Kaliforniens gefunden worden. ${ }^{1}$ (Fig. 361.)

Fig. 377 .

Rekonstruktion des Schädels von Mixosaurus atavus, Quenst., aus der Mitteltrias (HomomyenMergel des Wellendolomits bei Simmozheim, Schwarzwald) Deutschlands, von oben gesehen. $1 / 2$ nat. Gr.

(Nach F. v. Huene, 1916.)

$$
\begin{aligned}
& \text { Adl. = Adlacrymale. } \\
& \text { Bo. = Basioccipitale. } \\
& \text { Fr. = Frontale } \\
& \text { Fo. p. = Foramen parietale } \\
& \text { Ju. }=\text { Jugale. } \\
& \text { La. = Lacrymale. } \\
& \text { N. }=\text { Nasenöffnung. } \\
& \text { Na. = Nasale. } \\
& \text { Orb. = Orbita. } \\
& P a . \quad=\text { Parietale. } \\
& \text { Pmx = Praemaxillare } \\
& \text { Porb. }=\text { Postorbitale } \text {. } \\
& \text { Q. } \quad=\text { Quadratum. } \\
& \text { Qj. = Quadratojugale. } \\
& \text { Smx. = Supramaxillare. } \\
& S q . \quad=\text { Squamosum. } \\
& \text { Sta. = Stapes. } \\
& \text { S. } t .=\text { Supratemporale. } \\
& \text { T. } g .=\text { Temporalgrube. }
\end{aligned}
$$

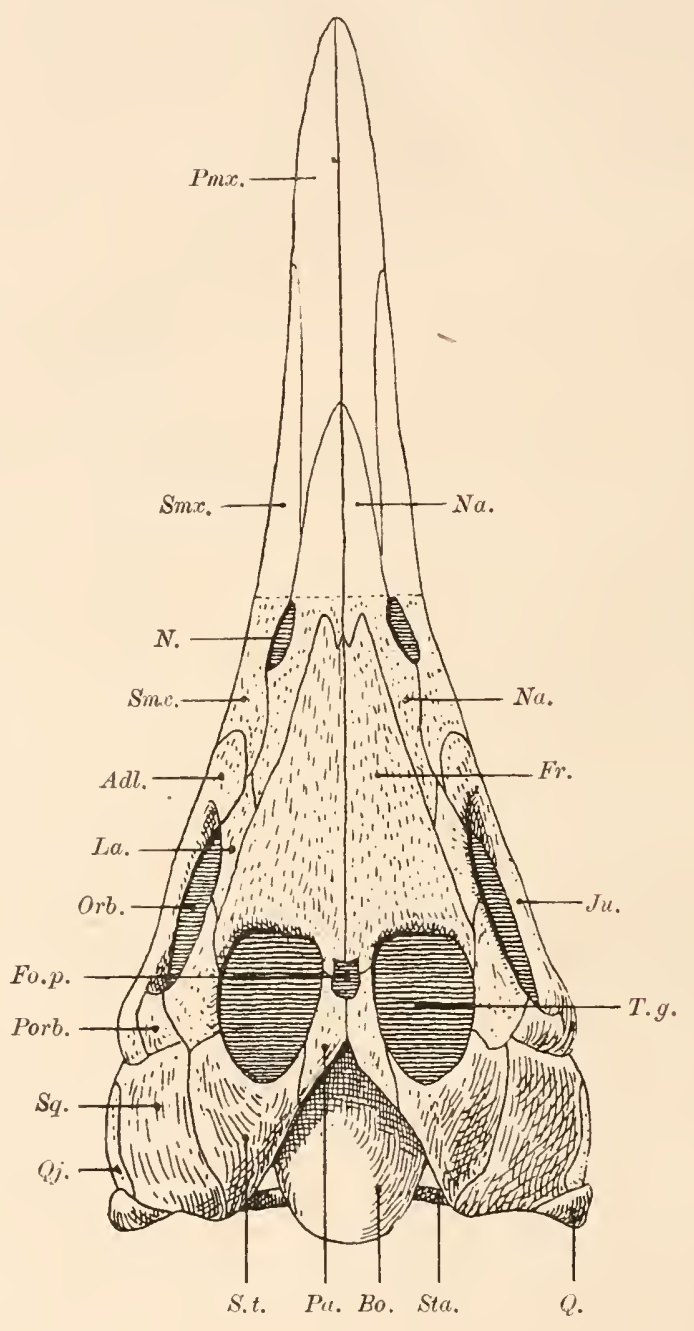

Shastasaurus. - Obere Trias Kaliforniens. - Nur zwei bis drei Fingerstrahlen in der sehr schmalen Vorderflosse, welche die rudimentäre Hinterflosse bedeutend an Länge übertrifft. ${ }^{2}$

Eurypterygius $(=$ Ichthyosaurus e. p., Gruppe der polydaktylen

1 Ibidem und J. C. Merriam, i. c. suprá.

2 J. C. Merriam, 1. c. 1908. 
Ichthyosaurier). ${ }^{1}$ - Weit verbreitet, vom unteren Lias bis zur oberen

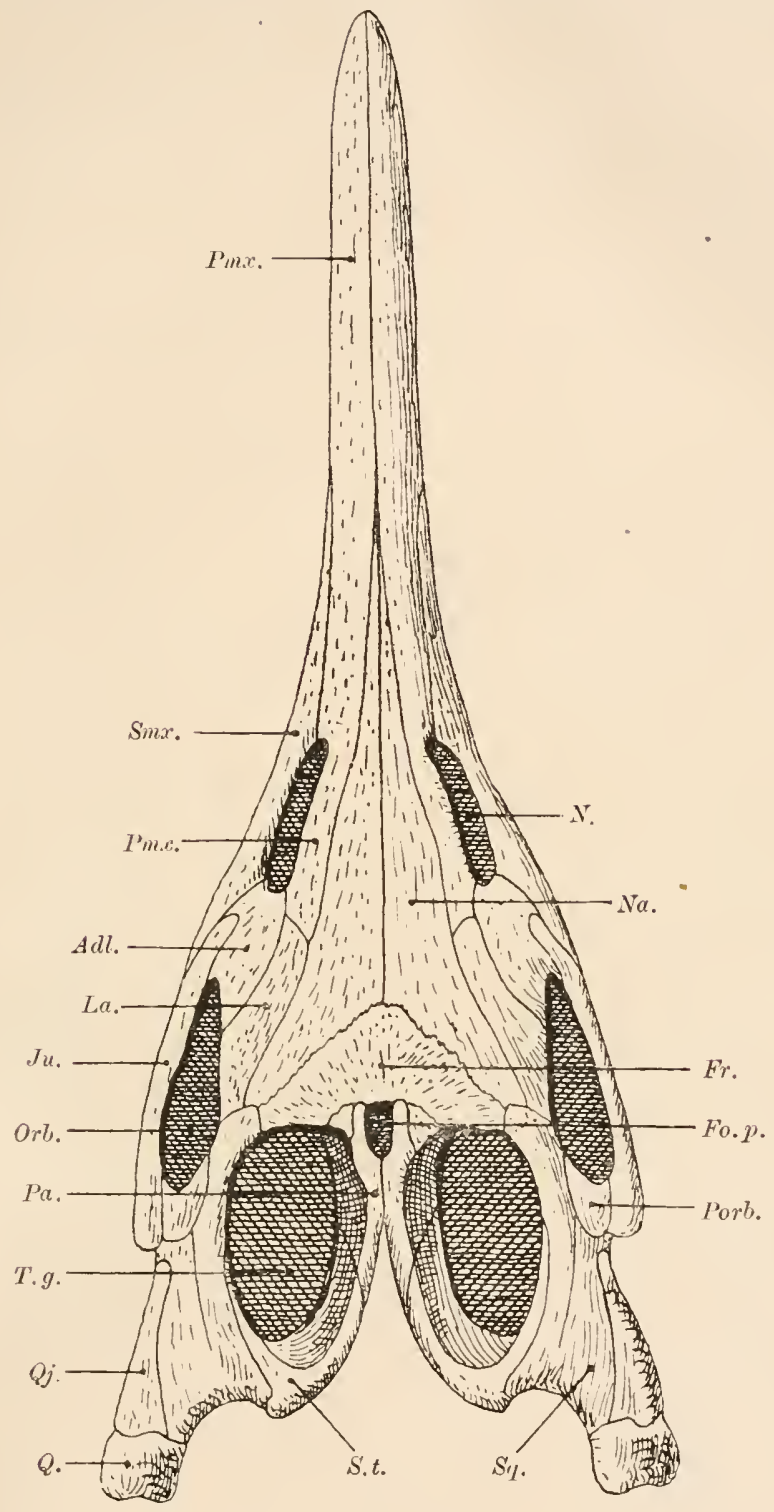

Fig. 378 .

Rekonstruktion des Schädels von Cymbospondylus spec. aus der mittleren Trias Kaliforniens, von oben gesehen. $1 /$, nat. Gr. (Nach'J. C. Merriam.) Abkürzungen wie in Fig. 377. Kreide. Diese Gattung kann unmöglich von den wenigfingerigen (oligodaktylen) Triasichthyosauriern abstanlmen, da sie nicht nur ihre normale, von den Landreptilien ererbte Fingerzahl besaß, sondern die Flossenbreite im Laufe der Stammesgeschichte der Gattung nocl beständig vermehrte. Wahrscheinlicl stecken auch noch nach der Abtrennung von Eurlinosaurus und Stenopterygius in der Gattung Eurypterygius mehrere verschiedene Gattungen, deren Abgrenzung aber einstweilen noch nicht möglich ist und eingehendere morphologische Vergleiche aller bekannten Arten voraussetzt, die bis heute noch fehlen.

Die Gattung Eurypterygius ist wahrscheinlich aus einer der primitiven Gattungen Mixosaurus oder Cymbo-

1 O. Jaekel, Eine neue Darstellung von Ichthyosaurus. - Sitzungsberichte d. Deutschen Geol. Ges., Zeitschrift d. Deutsch. Geol. Ges., LVI. Bd., 1904, S. 32. 
spondylus hervorgegangen; die schmalflossigen, oligodaktylen, hochspezialisierten Gattungen Merriamia, Shastasaurus usw. kommen nicht als Ahnenformen in Betracht und stellen jedenfalls einen blinden Seitenast der lchthyosaurier dar, da die Juraichthyosaurier, die sich einerseits um Eurypterygius, andererseits um Stenopterygius gruppieren, in ihrem Flossenbau auf breitflossige Ahnen mit voller Finger- und Zehenzahl zurückgehen und daher nicht von Formen mit reduzierten Fingern und Zehen abgeleitet werden können.

Sclıon bei den im Lias auftretenden Arten der Gattung Eurypterygius sind Ulna, Radius, Tibia und Fibula sehr stark modifiziert und haben die Form der angrenzenden Carpalia bzw. Tarsalia angenommen. Im weiteren Verlauf der Stammesentwicklung der Gattung keilt sich das Intermediun immer weiter zwischen Radius und Ulna ein und erreicht schon bei E. extremus aus dem unteren Lias Englands den Unterrand des Humerus. Durch Vermehrung der Fingerstrahlen bzw. der Längsreihen von Plıalangen können bis zu elf Strahlen in der Brustflosse von E. communis auftreten. Die Art der Vermehrung unterliegt groBen Schwankungen selbst innerhalb der Arten, wie Vergleiche der Flossen von E. communis zeigen. Die Vermehrung der Plialangenreilhen findet llauptsächlich an der ulnaren Seite der Hand, aber auch, freilich in schwächerem Maße, an der Vorderseite oder Radialseite der Hand statt.

Die Gattung Eurypterygius entspricht nicht genau der Gruppe der „Latipinnati“, da diese nicht nur durch breite, kurze Flosse, sondern namentlich dadurch gekennzeichnet sein soll, dab vom intermedim der Handwurzel zwei Fingerstrahlen ausgehen, wälırend bei den ,,Longipinnati" nur ein einziger Fingerstralıl in "der Mitte der Vorderflosse stehen soll; nach dieser Auffassung soll bei den "Latipinnati“ der dritte Finger verdoppelt sein und statt des einen Centrale bei den Longipinnati sollen zwei Centralia vorhanden sein. Da jedoch die Bestimmung der betreffenden Knochen als „Centralia“ außerordentlich zweifelhaft ist, kommit diese systematische Gliederung kaum in Betracht. Dagegen scheint es, daß Flossentypen wie die des E. extremus einem anderen Stanme angehören als die Flossentypen, wie sie uns bei E. platydactylus entgegentreten, und es ist daher wahrscheinlich, daß aucl in der Gattung Eurypterygius weit melır Gattungen stecken als man bisher anzunehmen pflegt. ${ }^{1}$

Zu den breitflossigen lchthyosauriern (Eurypterygius) sind z. B. zur rechnen:

E. intermedius (unterer Lias Englands) (Fig. 368).

E. Conybeari (unterer Lias Englands),

1 Die Literatur iiber Ichthyosaurier ist sehr unfangreich. G. Baur, E. D. Cope, R. Owen und E. Fraas haben zahlreiche Ablandlungen über diese Reptilien 
E. communis (oberer Jura Englands [Kimmeridge]) (Fig. 358 B, 362).

E. extremus (oberer Jura [Kimmeridge] Englands). ${ }^{1}$ (Fig. 363.)

E. platydactylus (untere Kreide [Neokon und Aptien] Norddeutschlands) (Fig. 364, 367) usf.

Stenopterygius (= Ichthyosaurus e. p., Gruppe der oligodaktylen Ichthyosaurier). - Hauptverbreitung im Lias. ${ }^{2}$ - Die Ichthyosaurier des süddeutschen oberen Lias aus den schwarzen Schiefern und Kalken von Holzmaden, Boll und anderen Fundorten in Süddeutschland gehören zu den Ichthyosauriern, die meist eine reduzierte und nur selten die normale Fingerzahl aufweisen und nur in wenigen Fällen an der

veröffentlicht. Zn den wichtigsten derselben, in denen auch die weitere Literatur nachzusehen ist, gehören:

E. Fraas, Die Ichthyosaurier der siiddeutschen Trias und Juraablagerungen. Tübingen 1891.

- Die Hautbedeckung von Ichthyosaiurus. - Jahreshefte d. Ver. f. Vaterländ. Naturkunde in Wiirttemberg, L. Bd., 1894, S. 493.

- Ein unverdriickter Ichthyosaurusschädel. - Ibidem, 1913, S. 1.

G. Baur, On the Morphology and Origin of the Ichthyopterygia. - American Naturalist, Vol. XXI, 1887, p. 837.

R. Lydekker, Note on the Classification of the Ichthyopterygia. - Geolog. Magazine (3), Vol. V, 1888, p. 309.

R. Owe 11, Monograph of the Fossil Reptilia of the Liassic Formations. - Part III (Ichthyopterygia). - Palaeontographical Society, Vol. XXXV, London 1881, p. 83.

G. Baur, Die Palatingegend der Ichthyosauria. - Anat. Anzeiger, X. Bd., 1895, S. 456.

R. Lydekker, Catalogue of the Fossil Reptilia and Amphibia in the British Museum. - Part 11. - 1889.

O. P. Hay, Bibliography and Catalogue of the Fossil Vertebrata of North America. - Bull. 179 of the U. S. Geol.-Survey, Washington 1902, p. 461 (ausführliche Literatur, besonders ïber Proteosaurus, Home [Type: P. platyodon, Conyb.)].

F. Broili, Ein neuer Ichthyosaurus aus der norddeutschen Kreide. - Paläontographica, LIV. Bd., 1907, S. 139.

- Neue Ichthyosaurierreste aus der Kreide Norddeutschlands und das Hypophysenloch bei Ichthyosauriern. - Ibidem, LV. Bd., I909, S. 295.

E. von Stromer, Neue Forschungen ïber lungenatmende Meeresbewohner. Fortschritte der naturw. Forschung, II. Bd., Berlin u. Wien 1910, S. 101.

1 Das geologische Alter des von G. A. Boulenger (A Paddle of a New Species of Ichthyosaur. - Proc. Zool. Soc., London 1904, p. 424) beschriebenen Restes war unbekannt, ebenso wie der Fundort; als wahrscheinlich wurde angenommen, daß der Rest aus dem unteren Lias der Gegend von Bath stamme. Da ein zweites, allerdings nicht so vollständiges Exemplar im oberen Jura (Kimmeridge) von Swindon in England gefunden wurde, wie C. W. Andrews (Marine Reptiles of the Oxford Clay. - Vol. I, 1910, p. 54) berichtet, so ist es wahrscheinlich, daß diese Art dem oberen und nicht dem unteren Jura angehört, wofür ja auch, wie Andrews hervorhebt, der extrem hohe Spezialisationsgrad der Flosse spricht.

2 O. Jaekel, Eine neue Darstellung von Ichthyosaurus. - Zeitschrift der Deutschen Geol. Ges., LVI. Bd., 1904, S. 32. 
ulnaren Seite der Hand überzählige Phalangenreihen besitzen. Die

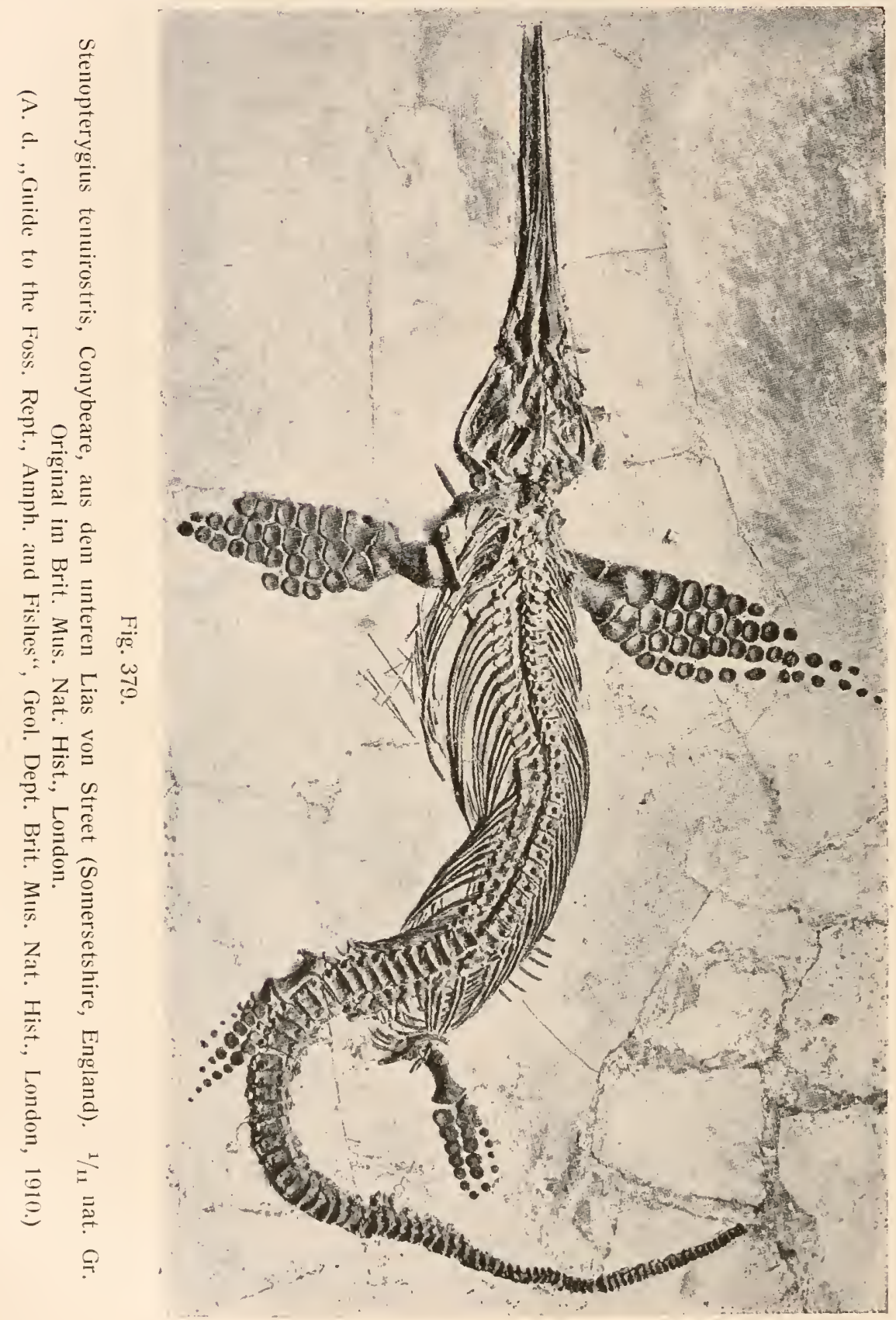

Flosse kann dabei (vgl. St. tenuirostris, Fig. 379) sehr breit und groß sein, ist aber oft klein (St. quadriscissus, Fig. 380). Hierher gehören 
die häufigsten Ichthyosaurierartcu St. quadriscissus, St. tenuirostris, St. acutirostris, St. Iongifrons, St. platyodon. Wahrscheinlich wird auch die Gattung Stenopterygius in mehrere Gattungen zu zerlegen sein, doch sind erst genauere Untersuchungen darüber erforderlich.

Eurhin os aurus. - Oberer Lias Württembergs und Englands. ${ }^{1}$ Schnauze enorm verlängert, den kurzen Unterkiefer weit überragend, Flossen dreifingerig, lang und schmal, die vorderen Flossen länger als dic hinteren..$^{2}$ Die Schnauzenlänge des etwa 5 ml langen Tieres erreichte, von der Spitze bis zum Nasenloch gemessen, über $1 \mathrm{~m}$. - E. longirostris und E. longipes mit Flossen von ïber 1 inl Länge. ${ }^{3}$

10 . Abel, Cetaceenstudien. 1. Mitteilung: Das Skelett von Eurhinodelphis Cocheteuxi aus dem Obermiozän von Antwerpen. - Sitzungsberichte d. K. Akad. d. Wiss. Wien, math. nat. K1., CXVI11. Bd., 1909, S. 245.

2 Die Vorderflossen eines von B. Hauff präparierten ,Hautexemplars“ aus dem Lias von Holzmaden von $4 \mathrm{~m}$ Körperlänge sind $80 \mathrm{~cm}$, die Hinterflossen nur $60 \mathrm{~cm}$ lang. (Nach einer Mitteilung von E. Fraas an F. König. - F. König: Fossilrekonstruktionen. - Miinchen, bei Dultz u. Co., 1911, S. 41.) Zittel hatte hervorgehoben, daß die Hinterflossen bei diesem Typus länger seien als die Vorderflossen, was sich nunmehr als unrichtig erwiesen hat.

${ }^{3}$ K. A. von Zittel, Handbuch der Paläozoologie. - III. Bd., S. 470.

Das Verhältnis zwischen Rostrum und Unterkiefer, das auffallend an den miozänen Zahnwal Eurhinodelphis aus dem Boldérien von Antwerpen erinnert, ist an einem trefflich erhaltenen Schädel des Stıttgarter Naturalienkabinetts sehr gut zu beobachten.

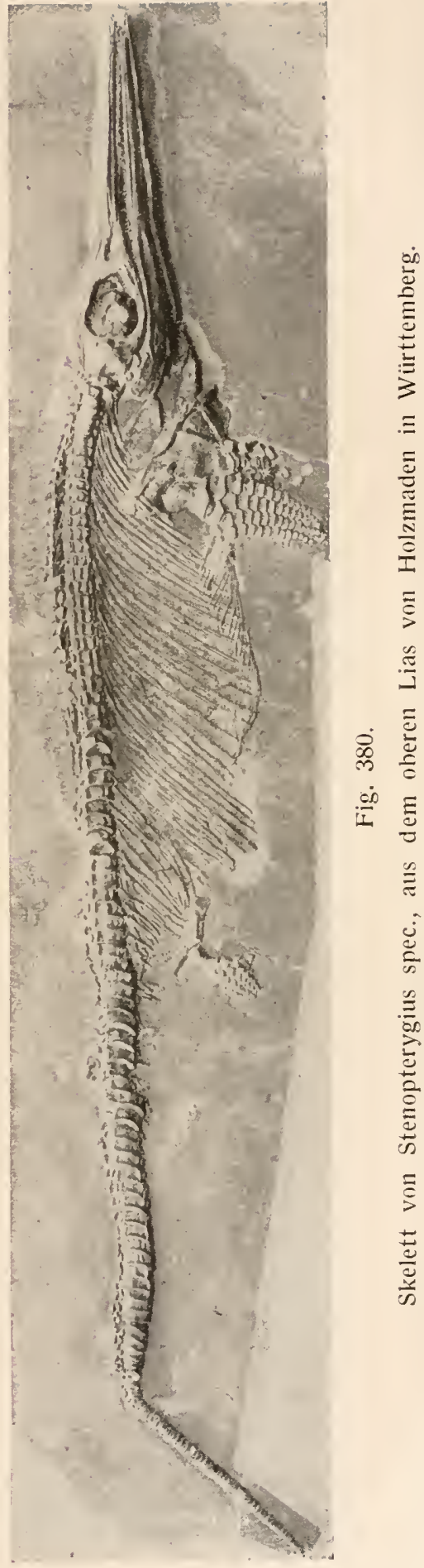


Ophthalmosaurus. - Oberer Jura von England und Nordanterika, vielleicht noch in der oberen Kreide Englands. - Augenhöhlen sehr groß, Knochenspange hinter den Augenhöhlen stark reduziert. Supramaxillare klein, zahnlos, Praemaxillare sehr lang. Zähne nur in den Zwischenkiefern und im vorderen Teile der Unterkiefer,

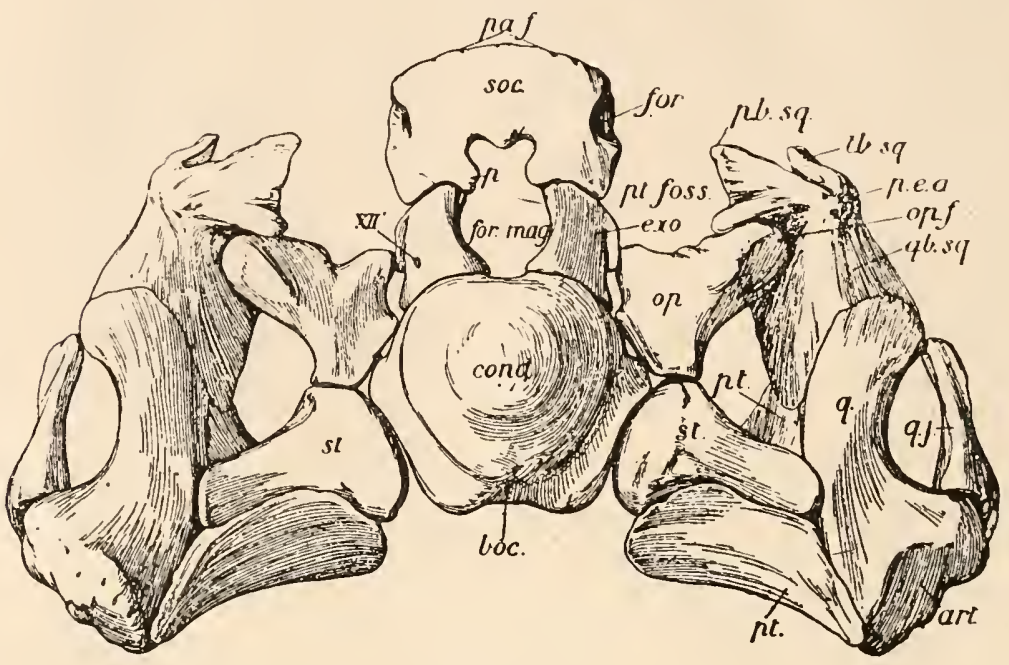

Fig. 381 .

Hinterhaupt von Ophthalmosaurus icenicus, Seeley, aus dem Oxfordien von Peterborough, England. $1 / 3$ nat. Gr. (Nach C. W. Andrews.)

art.

boc.

cond. $=$ Condylus occipitalis.

exo. $=$ Exoccipitale.

for. $\quad=$ Foramen im Supraoccipitale.

for. mag. = Foramen magnum.

op. $\quad=$ Opisthoticum.

$o p . f . \quad=$ Facette für das Opisthoticun (am Squamosum).

p. = = Fortsatz des Supraoccipitale, in das Foramen magnum vorspringend. pa. $f .=$ Facette am Supraoccipitale für die Parietalia.

p. b. $s q .=$ Parietalast des Squamosums.

p. e. $a$. $=$ hinterer Ast des Squamosums.

pt. $\quad=$ Pterygoid.

pt. foss. $=$ Fenestra posttemporalis.

$q . \quad=$ Quadratum.

q.b. sq. = Quadratast des Squamosums.

soc. $\quad$ Supraoccipitale.

st. $\quad$ Supratemporale.

t. b. sq. - Temporalast des Squamosums.

$X I I$. Foramen für den hinteren Ast des N. hypoglossus.

sehr klein, locker in der Zahnrinne stehend und daher bei der Fossilisation leicht ausfallend. Vordere Halswirbel verschmolzen. Dornfortsätze der Wirbel lateral stark komprimiert, breit. Vorderflossen breit oval, sehr kurzfingerig, nur mit vier Fingern in Funktion ${ }^{1}$, der fünfte

1 C. W. Andrews bildete 1910 (A Descriptive Catalogue of the Marine Reptiles of the Oxford Clay, Pl. 11, Fig. 4) die linke Vorderflosse eines Ichthyosauriers unter dem Namen Ophthalmosaurus icenicus ab, ohne sich in Texte darauf zu beziehen (das Exemplar wurde erst nach dem Drucke des Textes gefunden). Die Flosse ist 
rudimentär. Hinterflossen viel kleiner als die vorderen, außerordentlich reduziert, nur mehr drei kurze Zehenstrahlen umfassend. Pubis und Ischium verschmolzen, mit kleinem Foramen obturatorium.

O. icenicus. - Oberer Jura (Oxfordien) Englands. ${ }^{1}$ (Fig. 369, 370, $371,375,381)$.

Die Ichthyosaurier der Kreide werden unter dem Sammelbegriff „, Ichthyosaurus" zusammengefaßt, gehören aber wahrscheinlich ebenso verschiedenen Gattungen an wie die Juraichthyosaurier. I. campylodon ist aus der Kreide Englands, Frankreichs und Rußlands bekannt; andere Reste aus den Kreideablagerungen Europas werden zu verschiedenen Arten gestellt. Vereinzelte Reste von Ichthyosauriern sind in der Kreide von Australien und Neuseeland, ein riesiges Schnauzenfragment in der Kreide von Ceram und einzelne Wirbel in der Kreide Ostindiens gefunden worden.

\section{Ordnung: Sauropterygia.}

Die Sauropterygier bilden eine Gruppe von Reptilien, die sich von terrestrischen Vorfahren abgezweigt haben und zur marinen Lebensweise übergegangen sind. Abweichend von der Mehrzahl der sekundär aquatisch gewordenen Vertebraten ist der Schwanz der Sauropterygier nicht als Lokomotionsorgan verwendet und daher verkürzt worden; die Fortbewegung geschah ausschließlich mit Hilfe der zu großen, langen und schmalen Ruderflossen ungeformten Gliedmaßen, die wohl in ähnlicher Weise funktioniert haben wie die Flossen der Meeresschildkröten, an die auch die ganze Körpergestalt erinnert. Freilich sind diese Ähnlichkeiten rein äußerlicher Natur und ebenso als Konvergenzerscheinungen anzusehen wie die allgemeine Ähnlichkeit des Körpertypus der Delphine, Ichthyosaurier und Haifische.

Die Geschichte der Sauropterygier ist heute in den Grundzügen als aufgeklärt anzusehen. Die primitivsten Typen unter den Sauropterygiern sind nächst den Trachelosauriden die Nothosauriden, die man vielfach, aber mit Unrecht, als die Ahnen der Plesiosaurier betrachtet. In vielen Merkmalen, wie z. B. in Bau der Giiedmaßen, der Wirbelsäule, des Schultergürtels und Beckens usw. primitiv, stellen sie im Bau der Schädelbasis hochspezialisierte Typen dar, während die Plesiosaurier im Bau des Gaumens eine tiefere Spezialisationsstufe als die Notho-

polydaktyl und zwar besteht sie aus acht Fingerstrahlen, die teilweise durch Teilung eines einfachen Strahls verdoppelt sind. Ob diese Flosse zu Ophthalmosaurus icenicus gehört, scheint mir sehr zewifelhaft, da die anderen Abbildungen eine aúsgesprochene Oligodaktylie beider Flossen zeigen.

1 Ibidem, p. 2. 
sauriden einnehmen, sonst aber die entsprechend höhere Spezialisationsstufe des Sauropterygierstammes repräsentieren.

Unter den Plesiosauriern sind wieder ganz verschiedene Spezialisationsreihen zu unterscheiden. Wir kennen kurzschnauzige Formen mit starkem Rechengebiß, wie z. B. Simolestes vorax; andere Schädeltypen erinnern in hohem Grade an Krokodile, z. B. Pliosaurus ferox; wieder andere, wie z. B. Trinacromerum bentonianum (Fig. 399), besitzen lange, schmale Schnauzen. Diese verschiedenen Schmauzenformen zeigen bereits, daß die Nahrungsweise der Plesiosaurier ziemlich verschieden gewesen sein muß, da Formen, wie Simolestes, benthonische Beutetiere gefressen haben müssen, während Trinacromerum ein schnelischwimmender Fischjäger gewesen sein dürfte. Bei der Gruppe der durch Elasmosaurus markierten Formen tritt eine außerordentliche Verlängerung des Halses ein, der (bei Elasmosaurus selbst) die unter Wirbeltieren einzig dastehende Zahl von 76 Halswirbeln erreicht und den Körper beträchtlich an Länge übertrifft (Hals: Rumpf $=23: 9$ ), so daß das rekonstruierte Bild dieses Reptils einen ganz verzerrten Eindruck hervorruft. Daß dieses Tier gleichfalls vorwiegend von benthonischen Tieren lebte, geht wohl daraus hervor, daß in der Magengegend von Elasmosaurus Snowii Gastrolithen (d.s. verzehrte und im Magen geschliffene Kieselsteine) gefunden worden sind. Der lange Hals der Elasmosaurier ist daher mit den langen Hälsen verschiedener gründelnder Wasservögel in Parallele zu stellen.

Die Verschiedenheiten des Brustgürtels bei den Nothosauriden und bei den Plesiosauriden, die zuweilen als Grüncle für die Divergenz beider Stämme angeführt werden, sind nur gradueller Natur und durch die verschiedene Funktion der Arme bedingt; dagegen ist es unmöglich, den Gaumentypus der Plesiosauriden auf den der Nothosauriden zurückzuführen, so daß wir die Nothosauriden als einen blind endenden Seitenzweig der Sauropterygier ansehen müssen, deren Hauptstamm von den Plesiosauriden gebildet wird. Die Nothosaurier sind nur aus der Trias bekannt; die ersten dürftigen Reste der Plesiosaurier treten im Muschelkalk auf, aber erst im Lias erscheinen die nitunter prachtvoll erhaltenen Skelette von Plesiosaurus, die dieses Reptil neben den Ichthyosauriern zu den populärsten genuacht und schon seit langer Zeit wiederlolt den Gegenstand wissenschaftlicher Untersuchungen gebildet haben. Trotzdem sind noch manche Fragen aus der Stammesgeschichte der Plesiosauriden, namentlich die verwandtschaftlichen Beziehungen der jurassischen zu den kretazischen Gattungen, dringend einer Aufklärung bedürftig.

\section{F. Trachelosauridae.}

Die neuerliche Untersuchung eines Reptilienskelettes aus den Bunt- 
sandstein (untere Trias) von Bernburg im Herzogtum Anhalt ${ }^{1}$ hat ergeben, daß in ihn ein Sauropterygier von sehr geringer Spezialisationshöhe vorliegt. F. Broili, der die nicht zum Abschlusse gebrachten Untersuchungen $^{2}$ E. Fischers beendete und herausgab, legt dar, daß es sich um eine Type handelt, die zwar in vielen Punkten, so z. B. in Baue des Beckens geradezu als eine Vorstufe von Nothosaurus zu betrachten ist, aber in anderen, wie im Baue der Halswirbelsäule, bereits einen höheren Spezialisationsgrad als Nothosaurus erreicht hat.

Der Halswirbelabschnitt der Wirbelsäule umnfaßt etwa 20 (21 ?) Wirbel, war also auffallend lang. In dieser Hinsicht sowie in der Art der Gelenkverbindung der Halsrippen allein mit dem Wirbelkörper schließt sich Trachelosaurus Fischeri, wie F. Broili diesen Saurier genannt hat, enge an die übrigen Sauropterygier an; dagegen unterscheidet er sich von diesen sehr bestimmint durch die Größenabnalıme der Rückenwirbel im Vergleiche mit den hinteren Halswirbeln. Ferner sind bei den Nothosauriden, die wir bisher als die prinitivsten Sauropterygier betrachteten, die Wirbelkörper und Dornfortsätze in der Halsregion nur sehr locker verbunden, bei Trachelosaurus dagegen durch feste Gelenke vereinigt. Es liegen also in diesen beiden Spezialisationen zwischen Trachelosaurus und den Nothosauriden ,Spezialisationskreuzungen" vor, die uns daran verhindern, Trachelosaurus als unmittelbaren Vorläufer bzw. Ahnen der Nothosauriden anzusehen, obwohl der Bau des Iliums einer Vorstufe des Nothosaurideniliums entspricht. Trachelosaurus ist daher nach F. Broili als der Vertreter einer bisher unbekannt gewesenen Gruppe der Sauropterygier anzusehen, die eine selbständige Entwicklungsreihe repräsentiert und sich weder in die Nothosauriden noch in die Plesiosauriden fortgesetzt hat.

Obwohl Broili ans der Form des Iliums die Annahme einer terrestrischen Lebensweise von Trachelosaurus zu begründen versucht, so scheint mir doch für diese Annahnse kein zwingender Grund vorzuliegen. In den Anfangsstufen der Anpassung an das Wasserleben macht sich namentlich in jenen Fällen, in denen die Hinterextremitäten - nicht funktionslos werden, sondern noch als Ruder fungieren, nur eine sehr geringe Veränderung des Beckens bemerkbar. Die allgemeine Körperform scheint, wie aus den Ausführungen Broilis zu schließen ist, der eines Lariosaurus zienılich ähnlich gewesen zu sein.

1 F. Broili und E. Fischer, Trachelosaurus Fischeri nov. gen. nov. spec. Ein newer Saurier aus dem Buntsandstein von Bernburg. - Jahrbuch der Königl. Preußischen Geologischen Landesanstalt für 1916, Berlin 1917, XXXVII. Bd., p. 359.

2 Dr. E. Fischer fiel im Gefecht von Fréconrupt (Vogesen) am 21. August 1914. F. Broili gab dem neuen Typus den Artnamen. 


\section{F. Nothosauridae.}

Die Nothosaurier zeigen zwar auch schon deutlich die ersten Anpassungsstufen an das Wasserleben, aber die Gliedmaßen besitzen,

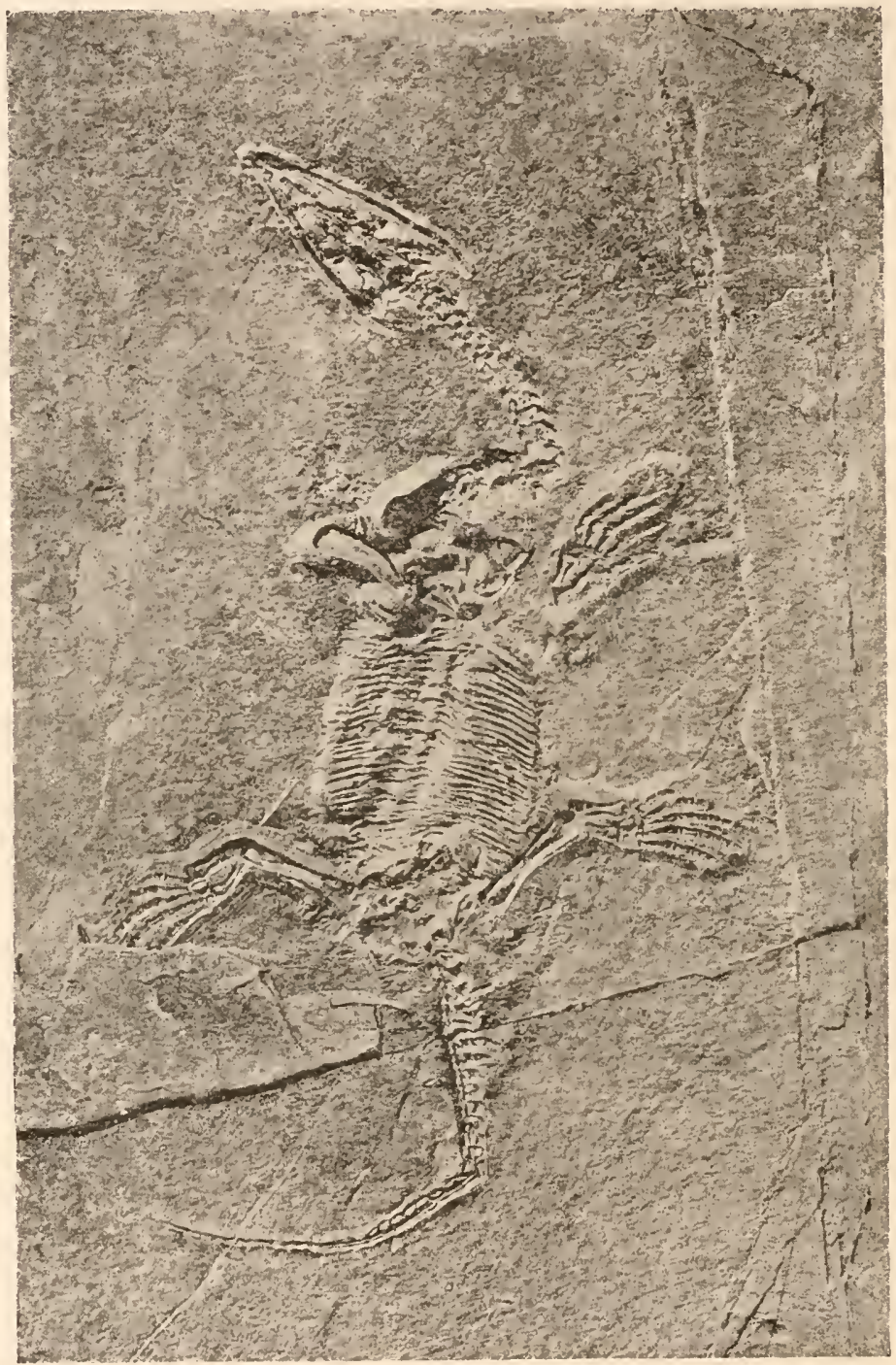

Fig. 382.

Lariosaurus Balsami, Curioni (von der Bauchseite), aus dem Muschelkalk (mittlere Trias) von Perledo am Comersee. Original im SenckenbergMuseum zut Frankfurt a. M. Ungefähr $1 / 2$ nat. Gr. (Junges Tier.) (Nach F. Drevermann.)

wie z. B. Lariosaurus Balsani (Fig. 382) zeigt, noch durchaus den allgemeinen Charakter, wie iln terrestrische Vertebraten aufweisen; 
freilich wurden sowohl die Hand als auch der Fuß bereits als Flossen verwendet. Die Hauptknochen der Gliedmaßen sind noch relativ lang, der Unterarm auffallend massiv; überhaupt sind Hand und FuB, ziemlich zart und klein im Verhältnis zu den übrigen Abschnitten der Gliedmaßen. Bei der höher spezialisierten Gattung Proneusticosaurus

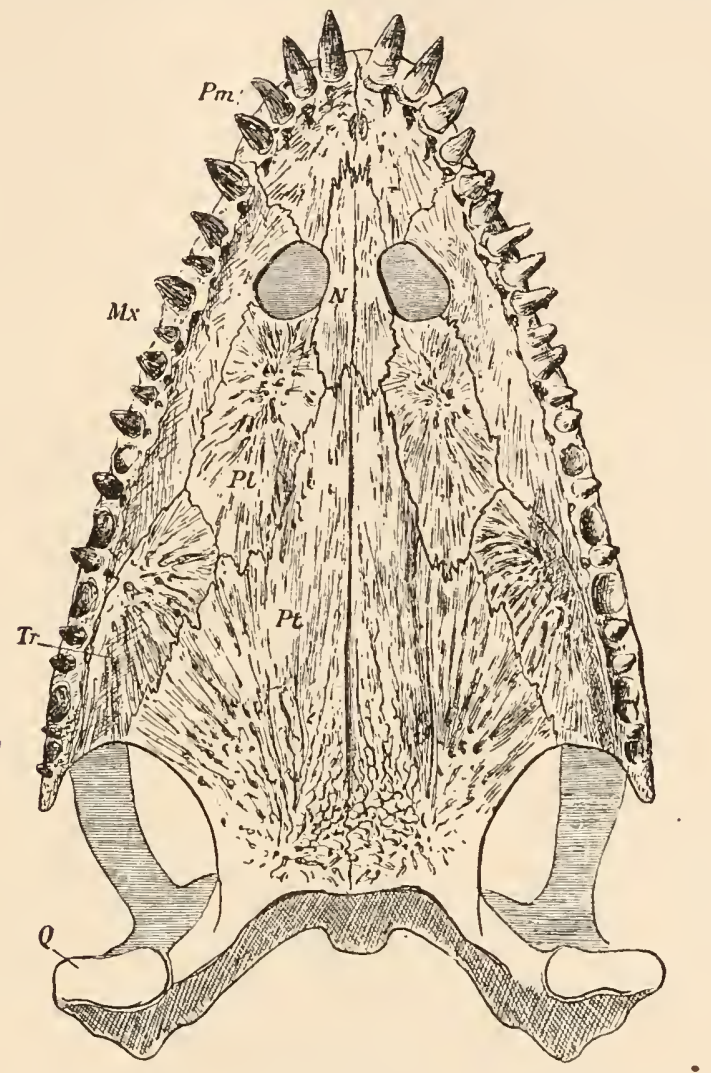

rig. 383.

Gaumenansicht des Schädels von Simosaurus Gaillardoti, H. v. Meyer, aus der mittleren Trias (oberer Muschelkalk) von Crailsheim in Wuirttemberg, in $1 / 2$ nat. Gr. (Nach O. Jaekel.)

$$
\begin{aligned}
& P m=\text { Praemaxillare. } \quad P t=\text { Pterygoideum. } \\
& M x=\text { Supramaxillare. } \quad T r=\text { Transversum. } \\
& N=\text { Vomer. } \quad Q=\text { Quadratum. } \\
& P l=\text { Palatinum. }
\end{aligned}
$$

(Der hintere Teil des Schädels ist ergänzt.)

sind Hand und Fuß bereits zu typischen Flossen geworden, weisen aber noch keine Verlängerungen der Finger- und Zehenstrahlen auf.

Der Schädel ist bei einigen Gattungen (z. B. Lariosaurus, Simosaurus) (Fig. 383) kurz und breit, bei Nothosaurus (Fig. 384) lang und schmal. Die Nasenlöcher sind vom Vorderende der Schnauze weg gegen hinten verschoben, die Nasalia verkümmert; das Vorderende der Schnauze 
wird allein von den Praemaxillaria gebildet. Die Frontalia und Parietalia sind verwachsen, die Parietalia sehr schmal; zwischen ihnen steht ein Foramen parietale.

Die oberen Temporalgruben (Fig. 384) sind sehr groß und drängen die Parietalia in der Mittellinie zu einem schmalen Kamm zusammen (bei

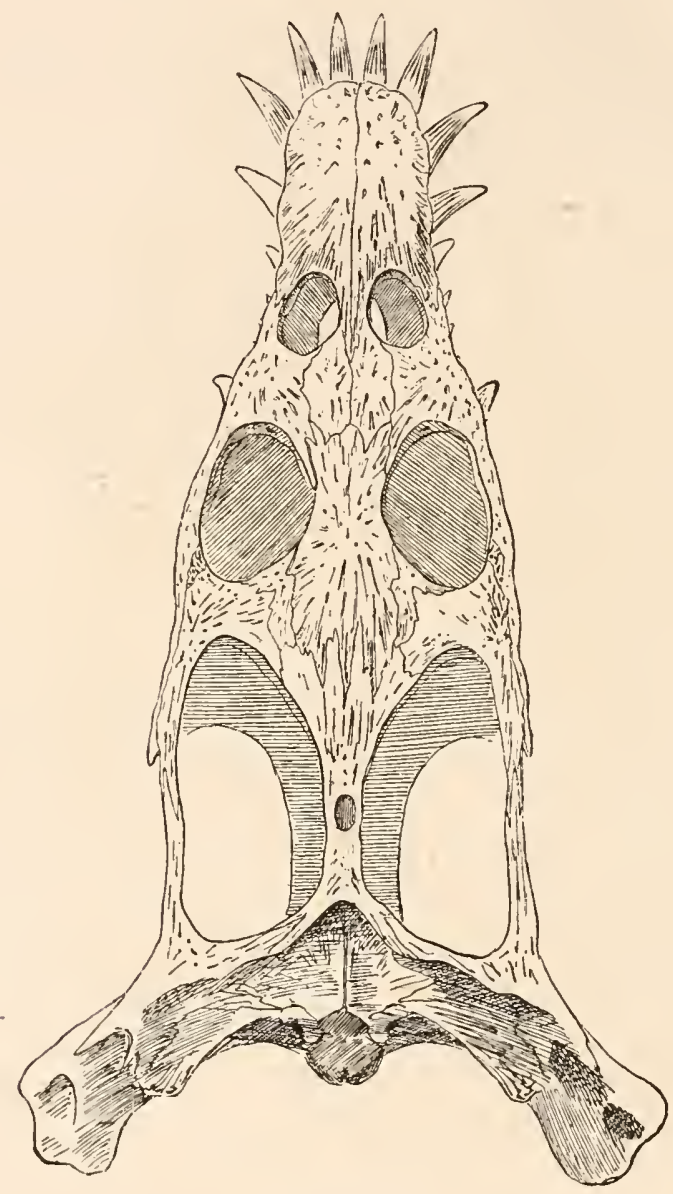

Fig. 384 .

Oberansicht des Schädels von Nothosaurus cfr. Friedericianus, v. Fritsch, aus der Mitteitrias (unterer Muschelkalk) von Mühlhausen in Thüringen. $2 / 3$ nat. Gr. (Nach O. Jaekel.)

Nothosaurus; bei Simosaurus ist der mediane Parietalabschnitt breiter). Diese obere Temporalgrube wird unten von einer Knochenspange abgeschlossen, die vom Squamosum und Postorbitale gebildet wird; die untere Temporalgrube ist vorhanden, aber unten geöffnet, und diesem spezialisierten Zustand entspricht auch das Fehlen des Jugale und Quadrato- 
jugale. Diese Verhältnisse der Temporalregion beweisen, daß die Sauropterygier von Vorfahren abstammen müssen, die beide Schläfengrubenpaare besaßen. Der Schädel der Nothosauriden war durchaus unbeweglich (akinetisch).

Ganz eigentümliche Verhältnisse zeigt der Bau des Gaumens (Fig. 383). Die beiden Vomeres $(N)$ trennen die Choanen und die an deren Hinterrand beginnenden Palatina; an das Hinterende der Vomeres schließen sich die Pterygoidea an, welche eine gewaltige Ausdehnung besitzen und bis an das Hinterende der Schädelbasis reichen, so daß weder das Parasphenoid noch das Basisphenoid bei der Betrachtung der Schädelunterseite sichtbar sind. Zwischen den Pterygoidea bleibt bei Simosaurus Gaillardoti eine sehr schmale Spalte frei; bei Nothosaurus schließen sie fest aneinander. An den Seiten der Pterygoidea schiebt sich zwischen

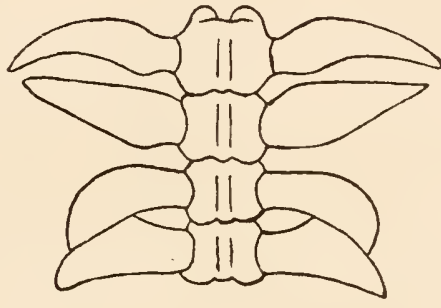

A

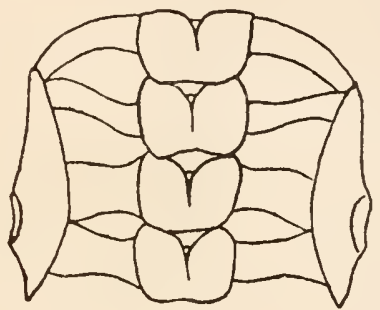

B

Fig. 385.

A: Pronetusticosaurus Madelungi, Volz, aus dem untersten Muschelkalk von Sacrau in Oberschlesien; B: Stereosternum (nach Sceley). Die beiden Figuren sind auf gleiche Größe gebracht, um den Vergleich zu erleichtern. In Fig: A ist der letzte Brustwirbel, beide Lendenwirbel und der erste Sakralwirbel dargestellt, in Fig. B das Sacrum und beide Ilia. (Nach W. Volz.)

ihnen und den Supramaxillaria jederseits ein Transversum ein. Zähne stehen nur auf den Praemaxillaria, Supramaxillaria und Dentalia; sie sind spitzkegelförmig (Nothosaurus) oder stumpfkegelförmig (z. B. Simosaurus), und zwar sind die vorderen größer; besonders stark sind die Größendifferenzen der Zähne bei Nothosaurus, wo die Zwischenkieferzälnne die hinteren Supramaxillarzähne beträchtlich an Länge übertreffen.

Die Wirbel sind platycoel. Bei Proneusticosaurus (Fig. 385) und verwandten Formen ist eine auffallende Verdickung (Pachyostose) der Wirbel, und zwar namentlich ihrer Fortsätze, zı beobachten. Der Halsabschnitt umfaßt bei Nothosaurus 22 Wirbel, ebensoviel bei Lariosaurus (20-21), aber Neusticosaurus besitzt nur 16 Halswirbel. Die Rippen sind einköpfig; die sehr kräftigen Bauchrippen bilden ein dichtes Geflecht. 
Der Brustgürtel(Fig. 386) besteht aus einer kleinen Interclavicula, an die sich die beiden Claviculae anschließen; mit der Scapula ist die Clavicula jederseits durch eine Quernaht verbunden. Die Scapula entsendet einen kräftigen Ast nach oben und hinten und tritt mit dem größten Knochen des Schultergürtels, dem Coracoid, in feste Nahtverbindung. Die Coracoidea stoßen median zusammen, so daß zwischen dem Clavicularabschnitt und Coracoidabschnitt des Schultergürtels eine weite Öffnung freibleibt, in der vielleicht knorpelige Praecoracoidea lagen.

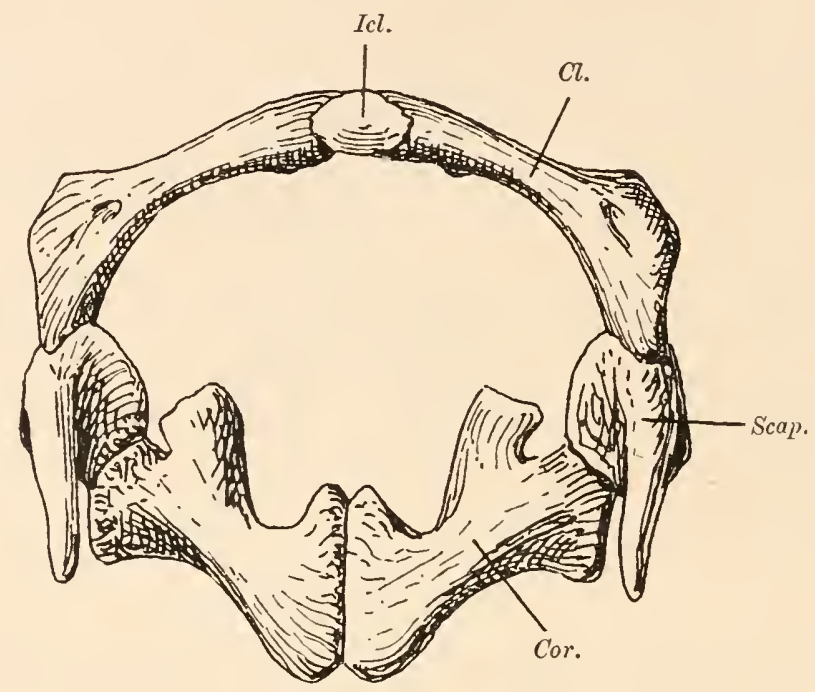

Fig. 386.

Schulterguirtel von Nothosaurus mirabilis, Münster, aus dem Muschelkalk (mittlere Trias) von Bayreuth, in $1 / 4$ nat. Gr.; von der Dorsalseite gesehen.

(Nach K. A. v. Zittel.)
Icl. = Interclavicula.
Scap. = Scapula.
Cl. = Clavicula.
Cor. $=$ Coracoid.

Das Becken, das aus den relativ locker verbundenen normalen Elementen besteht, ist bei Proneusticosaurus mit sechs Sakralwirbeln fest verbunden.

Lariosaurus. - Muschelkalk (nittlere Trias) der Lombardei. Die Pterygoidea sind bei Jugendexemplaren noch nicht in der Mitte geschlossen; daraus ergibt sich, daß im Bau des Gaumens diese Gattung unter den Nothosauriden die tiefste Stellung einnimmt. Die allgemeinen Verhältnisse des Körpers weisen trotz vielfacher Ähnlichkeiten mit Landreptilien bereits deutliche Sauropterygiermerkmale auf; die Bauchrippen bilden ein dichtes Geflecht, und zwar schließen sich je drei (eine mediane und je eine laterale) zu einer Querspange zu- 
sammen. Die Größe des Tieres war gering; die Körperlänge erwachsener Exemplare erreicht kaum $1 \mathrm{~m}^{1}$ (Fig. 382).

Nothosaurus. - Vom Buntsandstein (untere Trias) bis zur Lettenkohle (obere Trias) Deutschlands. Die Körperlänge einzelner Arten erreicht $3 \mathrm{~m}$, andere, wie N. Friedericianus, blieben, wie aus den Schädelmaßen hervorgeht, weit hinter dieser Zahl zurück. Hand und Fuß sind noch immer unbekannt, obwohl bereits zahlreiche Skelette gefunden worden $\operatorname{sind}^{2}$ (Fig. 384, 386).

Partanosaurus. - Mittlere Trias (Partnachschichten) Vorarlbergs. P. Zitteli. ${ }^{3}$

Anarosaurus. - Muschelkalk von Remkersleben bei Magdeburg ${ }^{4}$ (Fig. 387).

Proneusticosaurus. - Muschelkalk (mittlere Trias) Schlesiens ${ }^{5}$ (Fig. 385).

Simosaurus. - Mitteltrias und Obertrias Deutschlands ${ }^{6}$ (Fig. 383).

\section{F. Plesiosauridae.}

Schon die ältesten Plesiosauriden, von denen wir vollständigere Reste besitzen, zeigen sehr weit vorgeschrittene Anpassungen an das Wasserleben. Die Gliedmaßen sind zu langen, schmalen Flossen ausgebildet, und zwar sind alle vier Flossen ungefähr gleich groß. Der Körper bleibt bei allen Plesiosauriern plump und war auf der Bauchseite abgeflacht; die Elemente des Schultergürtels, des Beckengürtels und der Bauchrippen bilden in funktioneller Hinsicht einen geschlossenen Bauchpanzer, der sich zwar in ethologischer, aber keineswegs in morphologischer Hinsicht mit dem Bauchpanzer der Schildkröten vergleichen läßt.

1 W. Deecke, Über Lariosaurus und einige andere Saurier der lombardischen Trias. - Zeitschrift der Deutschen Geolog. Ges., XXXVIII. Bd., 1886, S. 170.

G. A. Boulenger, On a Nothosaurian Reptile from the Trias of Lombardy, apparently referable to Lariosaurus. - Transactions Zoological Soc., London 1896, Vol. XIV, p. 1.

2 E. Koken, Beiträge zur Kenntnis der Gattung Nothosaurus. - Zeitschrift der Deutschen Geolog. Ges., XLV. Bd., 1893, S. 337.

O. Jaekel, Über den Schädelbau der Nothosauriden. - Sitzungsber. d. Ges. Naturforsch. Freunde in Berlin, 1895, S. 60.

3 Th. Skuphos, Über Partanosaurus Zitteli und Microleptosaurus Schlosseri aus den Vorarlberger Partnachschichten. - Abhandlungen der K. K. Geol. Reichsanstalt in Wien, XV. Bd., 1893.

4 W. Dames, Anarosaurus pumilio. - Zeitschrift d. Deutschen Geol. Ges., XLII. Bd., 1890, S. 74.

$5 \mathrm{~W}$. Volz, Proneusticosaurus, eine neue Sauropterygiergattung aus dem unteren Muschelkalk Oberschlesiens. - Paläontographica, XLIX. Bd., 1902, p. 121.

6 O. Jaekel, Über den Schädelbau der Nothosauriden. - I. c., p. 68. 


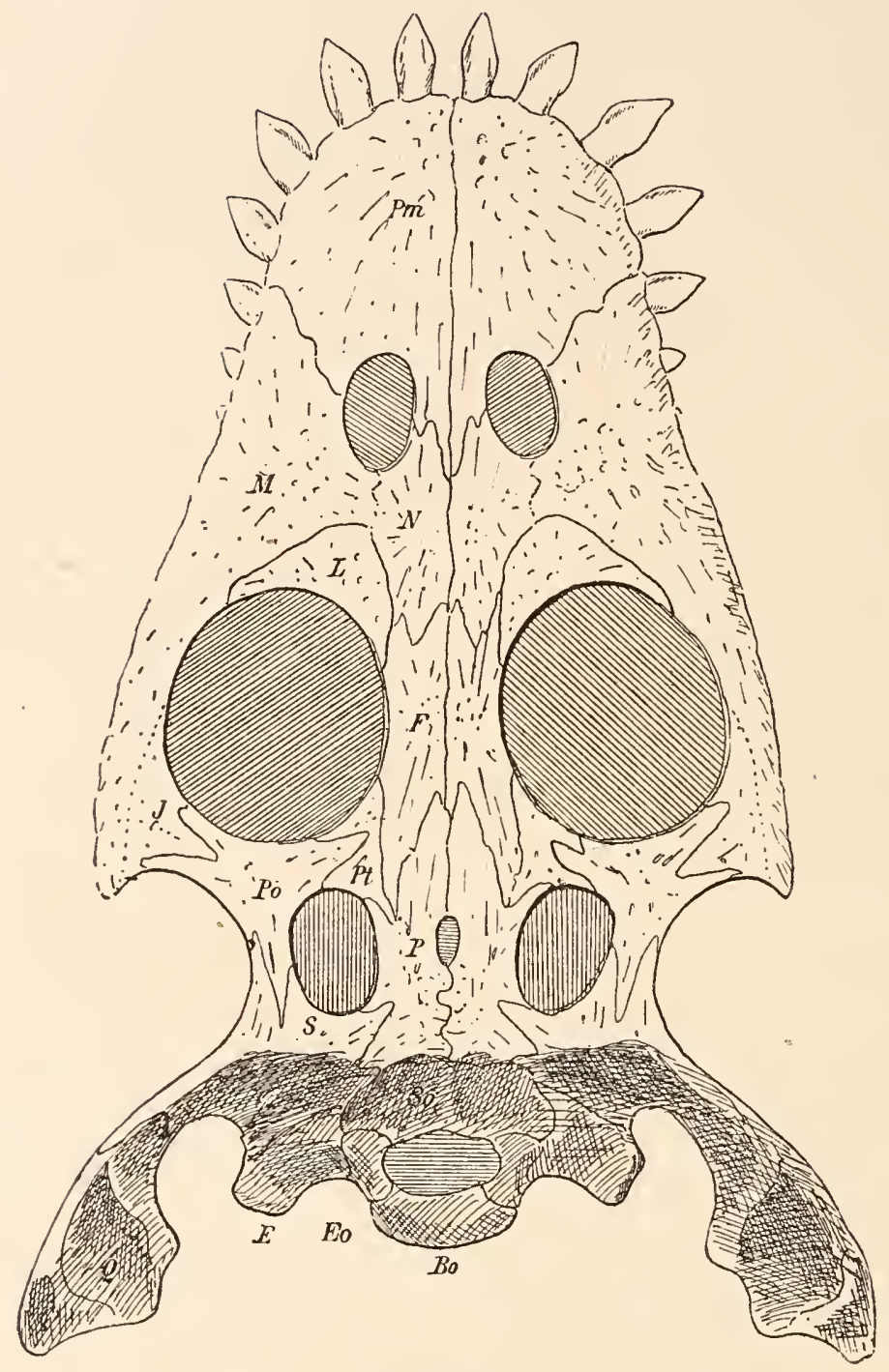

Fig. 387.

Oberansicht des Schädels von Anarosaurus pumilio, Dames, aus dem Muschelkalk (mittlere Trias) von Remkersleben. Vergr. 4:1. (Nach O. Jaekel.)

$$
\begin{array}{llrl}
P m & =\text { Praemaxillare. } & & P=\text { Parietale. } \\
M & =\text { Supramaxillare. } & & S=\text { Squamosum. } \\
N & =\text { Nasale. } & & \text { So }=\text { Supraoccipitale. } \\
L & =\text { Lacrymale } & & Q=\text { Quadratum. } \\
F & =\text { Frontale. } & E & =\text { Epioticum. } \\
J & =\text { Jugale. } & & E 0=\text { Exoccipitale } \\
P o & =\text { Postorbitale. } & & B o=\text { Basioccipitale. } \\
P t & =\text { Postfrontale. } & &
\end{array}
$$

Im Sclı̈̈del (Fig. 388-390) sehen wir die äußeren Nasenöffnungen zienlich weit nach hinten verschoben - sie stehen knapp vor den Augen- 
höhlen - und sind schr klein. Die oberen Schläfengruben werden wie bei den Nothosauriden unten vom Squanosum und Postorbitale abgeschlossen, die untere Temporalgrube ist in iltren oberen Grenzen deutlich erkennbar, aber die untere Spange fehlt, wie bei den Nothosauriden. Im Gegensatz zu den Nothosauriden ist bei den Plesiosauriern noch ein Jugale vorhanden, das jedoch nicht die spitze Zacke am Vorderende der unteren Temporalgrube bildet; diese wird entweder vom Supramaxillare eingenommen und über diesem liegt das Jugale, oder das Jugale erreicht zwar den Unterrand, bildet aber keinen Zacken. Das Vorhandensein des Jugale ist ebenso wie der Bau des Gaumens als ein primitives Merkmal im Vergleich mit den Nothosauriden anzusehen. Der Gaumen (Fig. 390) enthält außer den Clioanen noch eine mediane Lücke zwischen den Pterygoidea, weiter hinten wird das Parasphenoid zwischen den Pterygoidea sichtbar und läßt zwischen sich und ihnen jederseits die „Parasphenoidallücke" frei. An den Grenzen der Pterygoidea gegen die großen Palatina ist meist noch eine schmale Lücke beiderseits vorhanden.

Das Quadratum ist klein und fest mit den angrenzenden Knochen verbunden.

Die Zähne stehen in tiefen Alveolen (Fig. 390, 391), und zwar nur in einer Reihe.

Der Brustgürtel (Fig. 392, 393) bietet ein wesentlich verschiedenes Bild als bei den'Nothosauriden dar. Dic Coracoidea sind sehr bedeutend vergrößert und stoßen vorn entweder nur an die Scapulae, mit denen zusammen sie ein ovales Loch umschließen (z. B. bei Plesiosaurus Guilelmi imperatoris) oder sie enden in der Mittellinie spitz und die ovale Lücke bleibt vorn offen (bei Plesiosaurus Hawkinsi). Die Interclavicula ist verschieden groß entwickelt, tritt entweder mit den Coracoidea und den Claviculae oder nur mit den letzteren in Verbindung. Ob das Procoracoid in dem vorderen Fortsatz der Scapula zu suchen ist, das den vorderen Abschluß des Foramens zwischen Coracoid und Scapula bei Plesiosaurus Guilelmi imperatoris bildet, ist fraglich. Der Brustgürtel ist fast bei jeder Plesiosaurierart verschieden geformt und ist zur Bestimmung der einzelnen Art trefflich geeignet, da seine Verhältnisse innerhalb der einzelnen Arten ziemlich konstant bleiben. Die Unterschiede betreffen besonders den Clavicularabschnitt und treten z. B. bei einem Vergleich der aus dem Oxfordien Englands bekannten Plesiosaurier sehr deutlich zutage.

Der Bau der Vorderflossen und Hinterflossen ist auffallend ähnlich und die Verschiedenheiten des Flossenbaues unter den einzelnen Arten sind in beiden Flossenpaaren merkwürdigerweise gleichsinnig. Stets ist der Humerus und das Fenur sehr lang und kräftig gebaut; die Knochen des Unterarms und Unterschenkels sind bei den Liasformen viel kürzer (etwa halb so lang) und in ihrer Form bei den älteren Gattungen deutlich 
Die Stämme der Wirbeltiere.
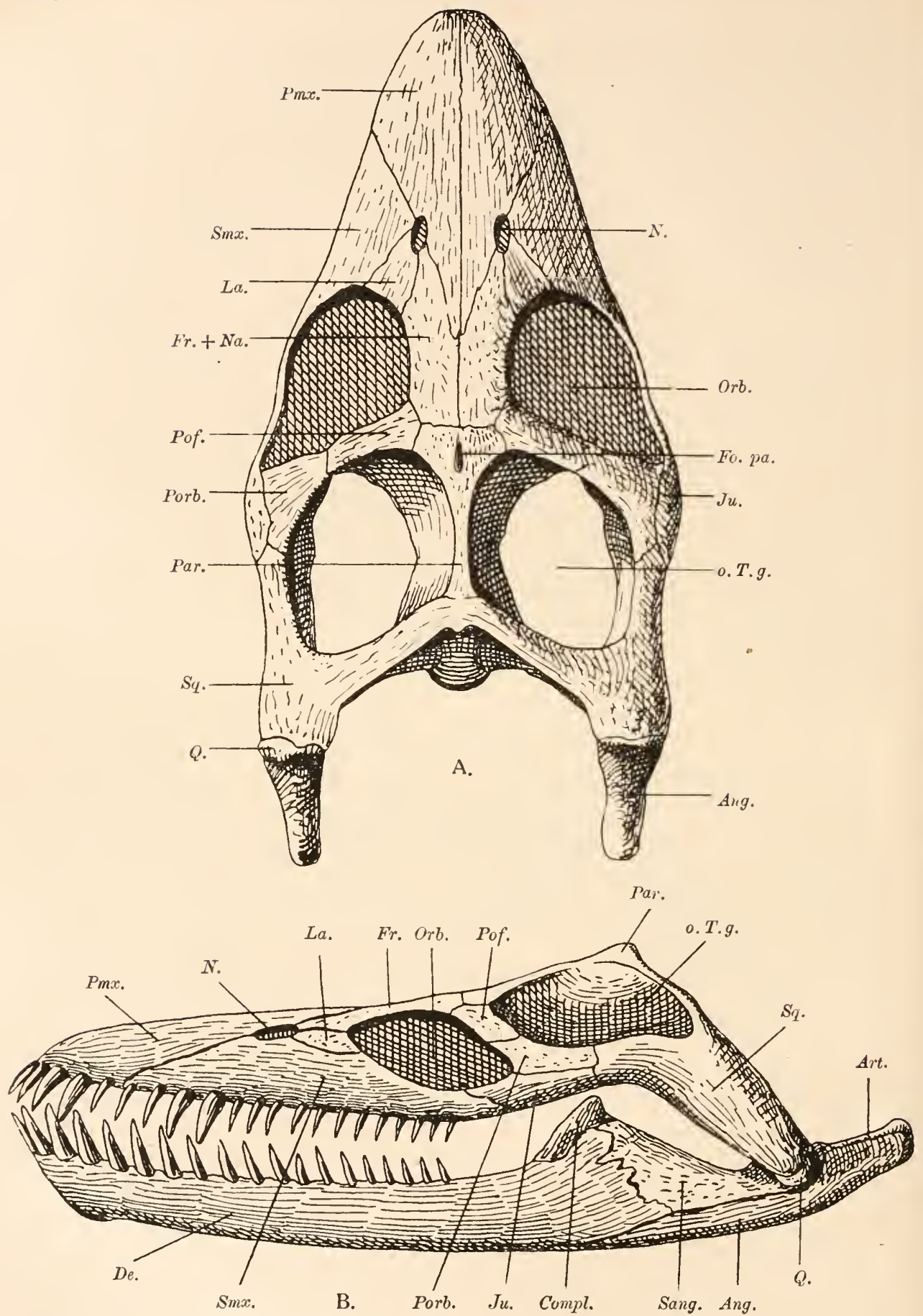

Fig. 388.

Rekonstruktion des Schädels von Muraenosaurus in $1 / 3$ nat. Gr. Oxfordien von Fletton bei Peterborough, England. (Nach C. W. Andrews, 1910.) $A$ von oben, B von links gesehen. 
von den Carpalia und Tarsalia verschieden, ebenso wie diese von den Metapodien leicht unterschieden werden können, was z. B. bei den Ichthyosauriern nur sehr schwer möglich ist. In manchen Fällen (z. B. bei Cimoliasaurus Bernardi) kommt es zur Ausbildung akzessorischer Elemente am Ulnarrande der Flossen, die eine feste Verriegelung der knöchernen Flossenelemente herbeiführen. Immer enden die Flossen spitz, wobei der vierte Strahl in Hand und Fuß der längste bleibt.

Bei den Gattungen des oberen Jura und der Kreide sind die Knochen des Unterarms und Unterschenkels sehr stark verkürzt und zu Platten ungeformt, die sich in ihrer allgemeinen Form nicht mehr so leicht von den Carpalia oder Tarsalia unterscheiden lassen (z. B. Cryptocleidus, Fig. 395, und Cimoliasaurus, Fig. 396). Die Metapodien und Phalangen behalten aber auch bei diesen hochspezialisierten Plesiosauriern ihre ursprüngliche Gestalt bei, wie sie die Liasplesiosaurier zeigen.

Das Becken ist ventral stark abgeplattet; die Pubes verwachsen meist vollständig in der Mittellinie untereinander, ebenso die Ischia; auch die Pubes und Ischia verwachsen untereinander und bilden das Acetabulum, während das Ilium in den meisten Fällen nicht an der Bildung der Gelenkgrube für den Oberschenkel teilnimmt.

Die Wirbelsäule enthält eine große Zahl platycoeler Wirbel, deren größte Zahl auf den Halsabschnitt entfällt; das Maximum wird mit 76 Halswirbeln bei Elasmosaurus erreicht. Der Hals enthält auch bei den kurzhalsigen Formen mehr Wirbel als bei den Nothosauriden; der Scliwanz ist verkünmert und umfaßt gewöhnlich etwa 40 kleine Wirbel. Eine Schwanzflosse ist kaum vorhanden gewesen, obwohl ihr Vorhandensein in verschiedenen Rekonstruktionen angenommen worden ist.

Plesiosaurus. - Die ersten, aber noch zweifelhaften Spuren treten im deutschen Muschelkalk auf; die Hauptverbreitung erreicht die Gattung in unteren Lias Englands (Lyme Regis, Charmouth und Street) und im oberen Lias Süddeutschlands (Holzmaden, Banz, Altdorf usw.); auch in oberen Lias Englands.(z. B. Whitby) treten Plesiosaurier auf. Aus England kennt man fast 30 verschiedene Arten. Aus

Zı Fig. 388.

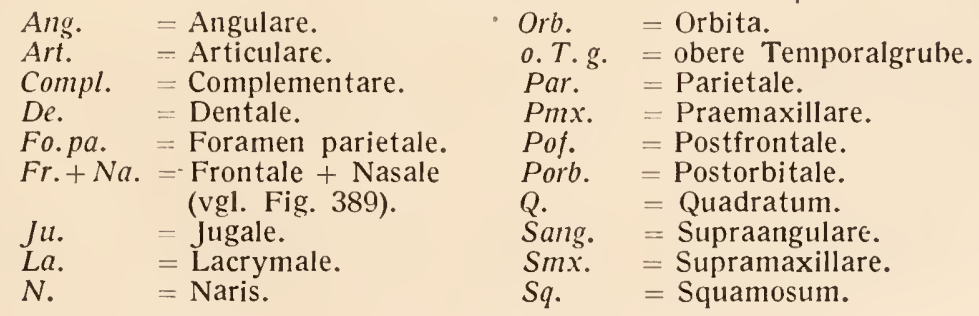


jüngeren Ablagerungen ist die Gattung nicht sicher nachgewiesen, da die verschiedenen, als $P$. beschriebenen Wirbel und anderen Skelettreste möglicherweise zu anderen Gattungen gehören. ${ }^{1}$

Die wesentlichen Kennzeichen der Gattung liegen im Bau und in der allgemeinen Form des Schädels und Schultergürtels. Im allgemeinen

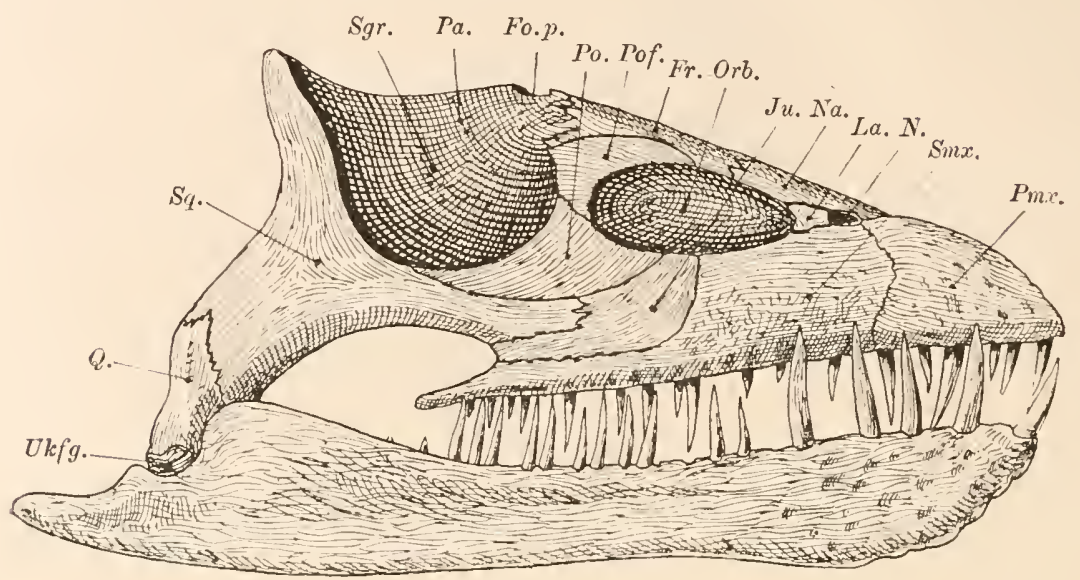

Fig. 389.

Seitenansicht des Schädels von Plesiosaurus Guilelmi Imperatoris, Dames, aus dem oberen Lias von Holzmaden in Wiirttemberg, in $2 / 3$ nat. Gr.

(Nach E. Fraas.)

\begin{tabular}{|c|c|c|c|}
\hline $\begin{array}{l}\text { Fo.p. } \\
\text { Fr. } \\
\text { Ju. } \\
\text { La. } \\
\text { N. } \\
\text { Na. } \\
\text { Orb. } \\
\text { Pa. }\end{array}$ & $\begin{array}{l}=\text { Foranen parietat } \\
=\text { Frontale. } \\
=\text { Jugale. } \\
=\text { Lacrynale. } \\
=\text { Naris. } \\
=\text { Nasale. } \\
=\text { Orbita. } \\
=\text { Parietale. }\end{array}$ & $\begin{array}{l}\text { Po. } \\
\text { Pof. } \\
\text { Prnx. } \\
\text { Q. } \\
\text { Sgr. } \\
\text { Smx. }\end{array}$ & $\begin{array}{l}=\text { Postorbitale. } \\
=\text { Postfrontale. } \\
=\text { Praemaxillare. } \\
=\text { Quadratum. } \\
=\text { Schläfengrube. } \\
=\text { Supramaxillare. } \\
=\text { Squamosum. } \\
=\text { Unterkiefergeler }\end{array}$ \\
\hline
\end{tabular}

kann P. als eine langialsige Type mit kleinem Kopf bezeichnet werden. Die schönsten bisher bekannten Exemplare wurden 1893 und $1906 \mathrm{im}$ oberen Lias von Holzmaden aufgefunden; das erste wird in Berlin.

${ }^{1}$ W. Dames, Die Plesiosaurier der süddeutschen Liasformation. - Abhandl. d. Kgl. Akad. d. Wiss., Berlin 1895, S. 1.

E. Fraas, Plesiosaurier aus dem oberen Lias von Holzmaden. - Paläontographica, LVII. Bd., 1910, p. 105. (Literatur!)

R. Lydekker, Catalogue of the Fossil Reptilia and Amphibia in the British Museum. - Part. I1, London 1889. (Literatur!)

R. Owen, Monograph of the Fossil Reptilia of the Liassic Formations. Part 1. Sauropterygia. - Palaeontographical Society, London 1865, Vol. XVII, p. 1 .

W. J. Sollas, On a New Species of Plesiosaurus (P. Conybeari) from the Lower Lias of Charmouth, etc. - Quarterly Journal Geol. Soc. London, Vol. XXXVII, p. 440 . 
das zweite in Stuttgart aufbewahrt (Plesiosaurus Guilelmi imperatoris, Fig. 389). - Ein sehr schönes, fast vollständiges Skelett von Plesiosaurus dolichodeirus wurde schon vor langer Zeit (1824) im unteren Lias von Lyme Regis gefunden und von Conybeare beschrieben; die Abbildung dieses Skelettes ist weit verbreitet worden. Die Körperlänge der verschiedenen Arten schwankt zwischen 2 und 5 m (Fig. 389, 391, 392, 394).

Thaumatosaurus. - Vom unteren Lias bis zum Malm aus Deutschland, England und Frankreich sowie aus dem Jura (Gondwanastufe) Ostindiens bekannt. Von Plesiosaurus namentlich durch die Kürze des Halses und durch den großen Schädel verschieden. Ein prachtvolles Skelett wurde 1906 in dem dem oberen Lias angehörenden harten Kalkstein von Holzmaden unmittelbar über den weichen Schiefern gefunden, die das Hauptlager der Reptilienreste von Holzmaden bilden ${ }^{1}$ (Fig. 390, 391, B.).

Muraenosaurus. - Oxfordien Englands. - Schädel klein, sehr breit und kurz, niedrig, mit etwa 24 Zähnen in jeder Kieferlaälfte. Hals lang; 44 Halswirbel. Unterkiefersymphyse sehr kurz, jederseits im Unterkiefer etwa 20 Zähne. Das Jugale erreicht zwar den Unterrand des Schädels, bildet aber keinen Zacken als Rest der unteren Schläfenspange, die vollständig obliteriert ist. Die Pterygoidea schließen in der Mittellinie nicht aneinander, sondern lassen zwischen sich eine lange, schmale Spalte frei; diese Spalte wird in ihrem hinteren Teile durch das langgestreckte Parasphenoid haloiert, dem sich hinten das Basisphenoid und Basioccipitale anschließen. Das Basisphenoid bildet das Verbindungsstïck zwischen den beiden gegen die Quadrata divergierenden Flügel der Pterygoidea und füllt den Raum zwischen diesen Ästen vollständig aus ${ }^{2}$ (Fig. 388).

Muraenosaurus verhält sich also im Bau des Gaumens zweifellos primitiver als z. B. Thaumatosaurus victor, wo die Pterygoidea vor und hinter der durch das Parasphenoid zweigeteilten Lücke in der Mittellinie des Schädels zusammenstoßen (Fig. 390). Schon aus diesem Verhalten der Gaumenregion geht klar hervor, daß Muraenosaurus trotz seines jüngeren geologischen Alters und trotz einzelner Spezialisationssteigerungen im Vergleiche zu Thammatosaurus und Plesiosaurus nicht der Alne dieser beiden Gattungen sein kann, denn das Verhalten der Pterygoidea bei Thaumatosaurus beweist deren hölere Spezialisation gegenüber Muraenosaurus. Es liegen somit hier Spezialisationskreuzungen vor, aus denen die Divergenz des durch Thaumatosaurus einerseits

1 E. Fraas, 1. c., supra, p. 123.

2 C. W. Andrews, A Descriptive Catalogue of the Marine Reptiles of the Oxford Clay. - London, British Museum of Natural History, 1910, p. 77. 


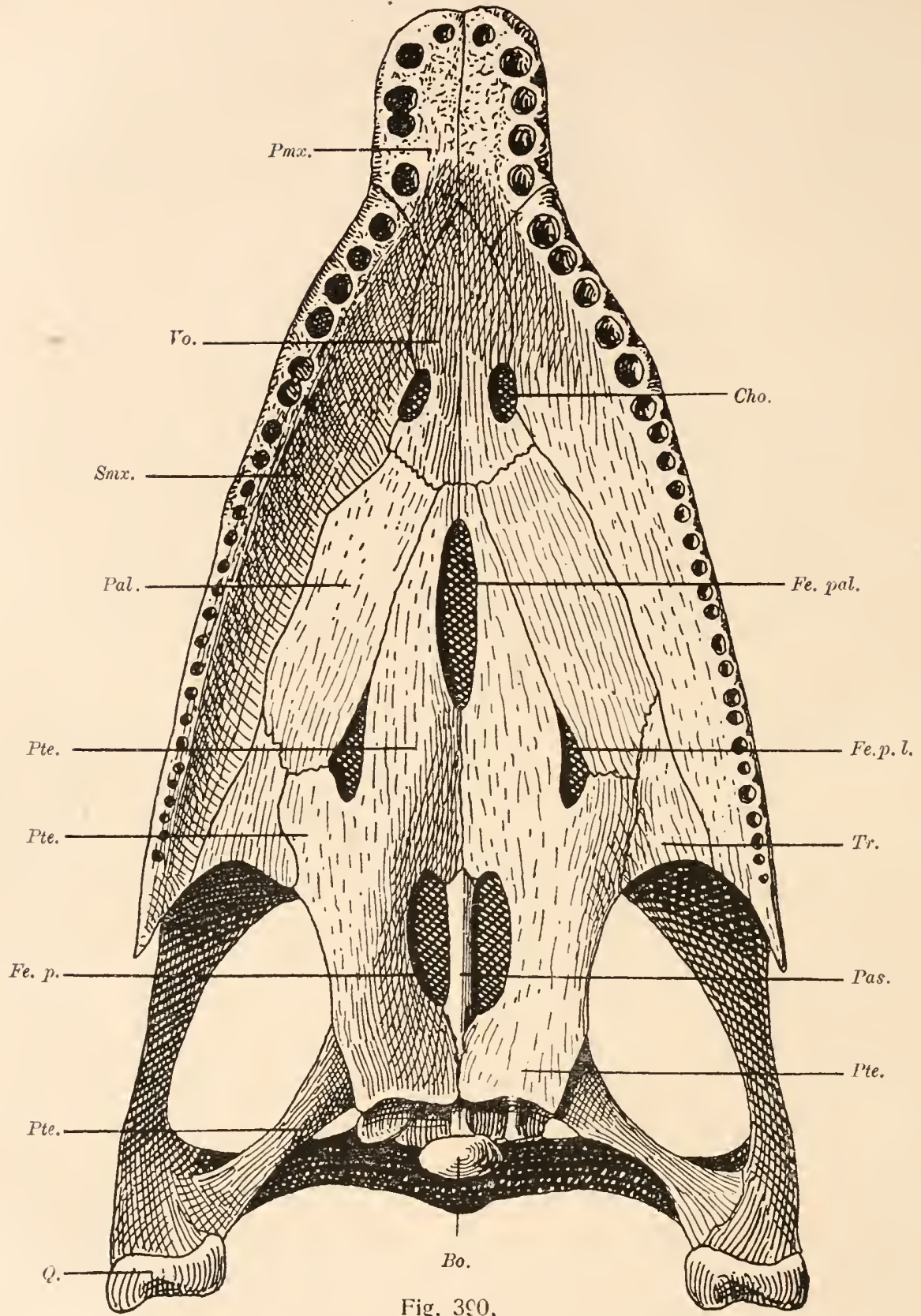

Gaumenansicht des Schädels von Thaumatosaurus Victor, E. Fraas, aus dem oberen Lias von Holzmaden in Württemberg, in 1/2 nat. Gr. (Nach E. Fraas, 1910.) Bo. = Basioccipitale. $\quad$ Pmx. = Praemaxillare.

Cho. = Choane. Pte.$=$ Pterygoid.

$F e$. p. $\quad=$ Fenestra palatinalis posterior. $Q . \quad=$ Quadratum.

Fe. pal. = Fenestra palatinalis anterior. Smx. = Supramaxillare.

$F e . p . l .=$ Fenestra palatinalis lateralis. $T r .=$ Transversum.

Pal. $\quad$ = Palatinum. Vo. $\quad$ = Vomer.

Pas. $\quad=$ Parasphenoid. 
und durch Muraenosaurus andererseits vertretenen Stammes hervorgeht.

An den Muraenosaurustypus der Gaumenbildung schließen sich mehrere weitere Gattungen an, die sich in derselben Weise wie Muraenosaurus prinitiv verhalten, da die Pterygoidea in der Mittellinie

C.

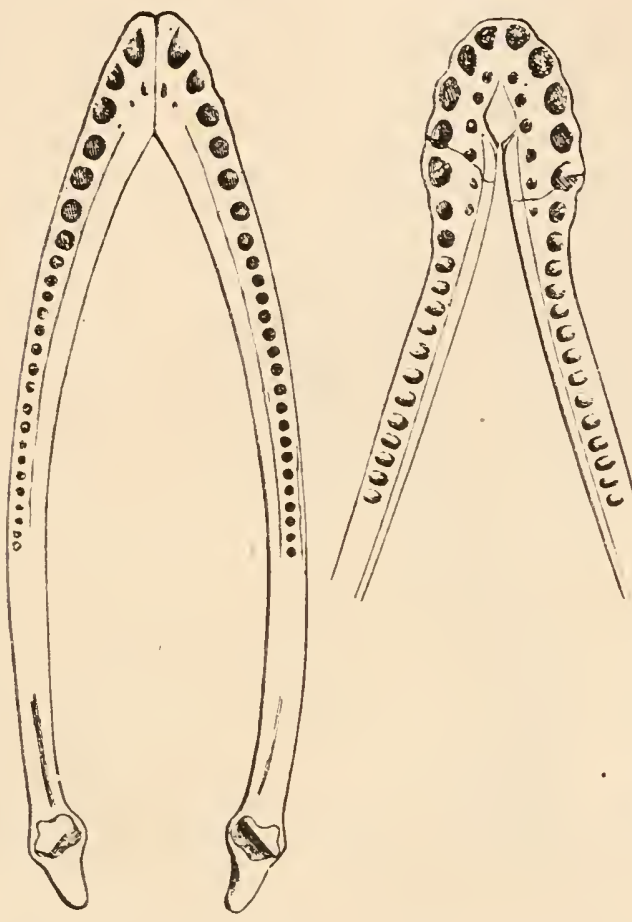

B.

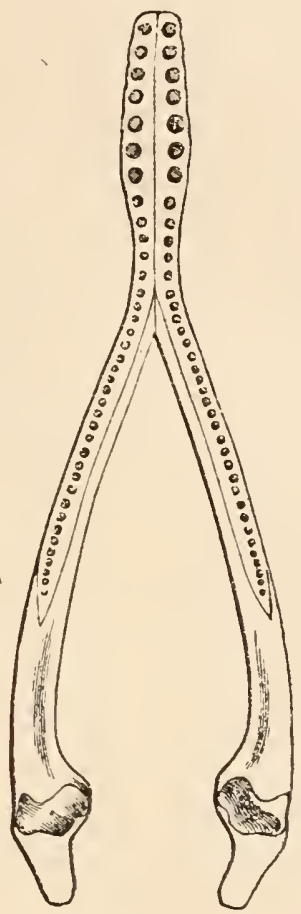

Fig. 391.

Kieferformen dreier verschiedener Plesiosaurier. A: Unterkiefer von Peloneustes philarchus, aus dem Oxfordien von Peterborough, England; $1 / 8$ nat. Gr. B: Unterkiefer von Thaumatosaurus indicus, ans dem Oberjura Ostindiens, 1/2 nat. Gr.; C: Unterkiefer von Plesiosaurus dolichodeirus, aus dem Unterlias von Lyme Regis in England, $1 / 1$ nat. Gr. (Aus dem Guide Foss. Reptiles uș., Brit. Mus. Nat. Hist.

$$
\text { London, 1910, Fig. 31, p. 35.) }
$$

Die Kieferformen B und A beweisen, daß die Tiere Muschelfresser gewesen sein müssen. Der Typus A crinnert an die Unterkicferform der Schildkrötengattung Lytoloma.

picht zusammenstoßen; hierher gehört z. B. Tricleidus aus dem Oxfordien Englands und eine Reihe anderer Gattungen, M. Leedsi von Peterborough in England.

Cryptocleidus. - Oxfordien Englands. - Hals relativ kurz (32 Halswirbel), Halsrippen einköpfig; dies ist im Verogleich zu Plesiosaurus und Thaumatosaurus, bei denen die Halsrippen zweiköpfig sind, 
als ein Spezialisationsfortschritt zu betrachten, während andererseits im Bau des Schädels primitivere Verhältnisse vorliegen. Schädel kurz, plump, relativ klein. Mehrere trefflich erhaltene Skelette aus dem Oxfordien von Fletton bei Peterborough bekannt. C. oxoniensis ${ }^{1}$ (Fig. 395, 398).

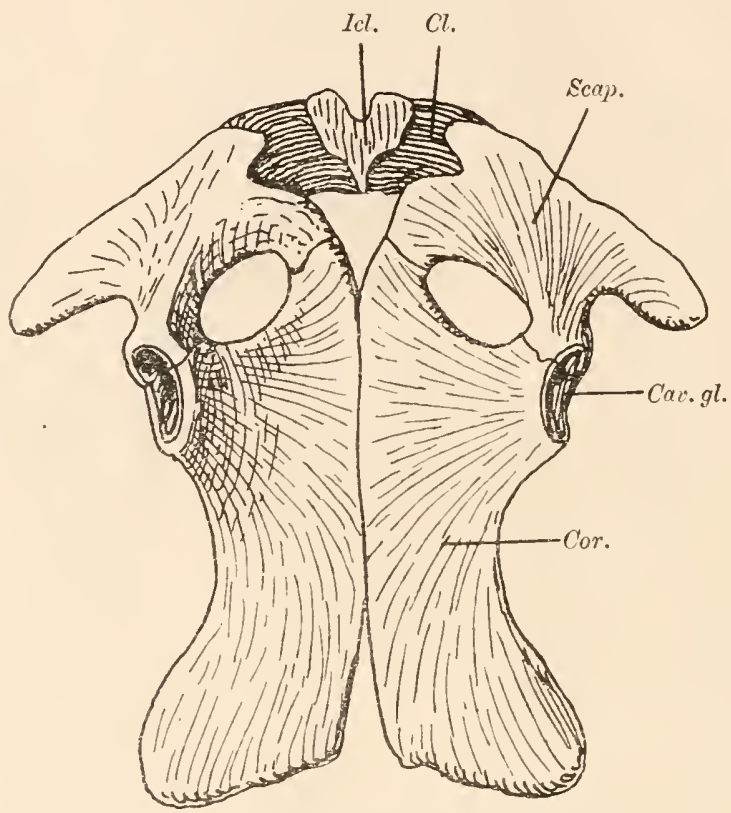

Fig. 392.

Schulterguirtel von Plesiosaurus GuileImi imperatoris, Dames, aus dem oberen Lias von Holzmaden in Württemberg, von der Ventralseite gesehen. 1/6 nat. Gr. (Nach E. Fraas.)
Icl. $=$ Interclavicula.
Cl. $=$ Clavicula .
Scop. = Scapula .
Cav.gl. = Cavitas glenoidalis (Gelenk-
Cor. = Coracoid. flache für den Humerus).

Pliosaurus. - Oxfordien Englands. - Schädel relativ groß, ähnlich dem eines langschnauzigen Krokodils, Hals kurz, mit zweiköpfigen Rippen. Die Pterygoidea schließen hinter der Parasphenoidallücke zusammen und entsenden gegen die Quadrata lange, schlanke Äste. Das Jugale erreicht den Unterrand des Schädels, ohne einen Zacken, wie z. B. bei Thaumatosaurus, zu bilden. P. ferox. ${ }^{2}$

Peloneustes. - Oxfordien Englands. - Schädelform ähnlich wie bei Pliosaurus. P. philarchus. Unterkiefersymplıyse lang ${ }^{3}$ (Fig.391, A).

1 C. W. Andrews, A Descriptive Catalogue of Marine Reptiles of the Oxford Clay. - 1. c., 1910 , p. 164.

2 Derselbe, Ibidem, Part II, London 1913, p. 2.

3 Ibidem, p. 34. 
Simolestes. - Oxfordien Englands. - Schädel kurz, breit, Unterkieferäste stark nach außen gebogen; Kiefer am Vorderende mit langen, spitzen Zähnen besetzt, die eine Fangreihe bilden und weit nach außen vorspringen. S. vorax. ${ }^{1}$

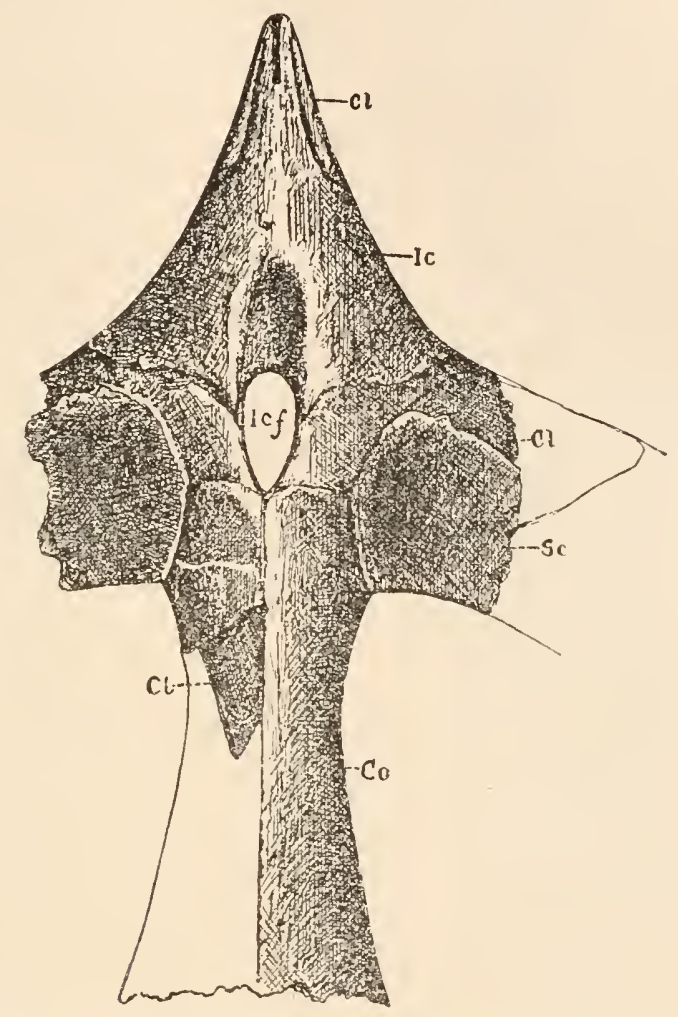

Fig. 393.

Schultergürtel von Trinacromerum bentonianum, Cragin, aus der oberen Kreide von Kansas, in $2 / 6$ nat. Gr. (Nach S. W. Williston.)
$\mathrm{Cl}=$ Clavicula.
$C_{0}=$ Coracoid.
$I c t=$ Foramen interclaviculare.
ic $=$ Interclavicula.
$S c=$ Scapula.

\section{Brancasaurus. - Wealden Westfalens. ${ }^{2}$}

1 C. W. Andrews, Ibidem, Part. II, London 1913, p. 25.

2 Th. Wegner, Brancasaurus Brancai Wegner, ein Elasmosauride aus dem Wealden Westfalens. - Branca-Festschrift, Berlin 1914, S. 235. (Übersicht der bisher aus der Kreide Europas bekannten Plesiosauriden und ihrer Unterschiede sowie ausführliche Literatur.) Aus Europa sind bisher ungefähr 30 verschiedene Arten beschrieben, die sich voneinander $z$. T. sehr wesentlich unterscheiden, aber von Wegner sämtlich unter dem Gattungsnamen Plesiosaurus zusammengefaßt werden. Die Mehrzahl dieser „Arten" ist freilich auf ganz dürftigen Resten, meist nur auf einzelne Halswirbel, einige andere ,Arten“ auf einzelne Brustwirbel und andere auf 
Elasmosaurus. - Obere Kreide Nordamerikas. - Hals enorm verlängert, bis 76 Halswirbel. ${ }^{1}$ Die Halslänge verhält sich zur Körperlänge (3 11 ) wie 23: 9 (Fig. 397).

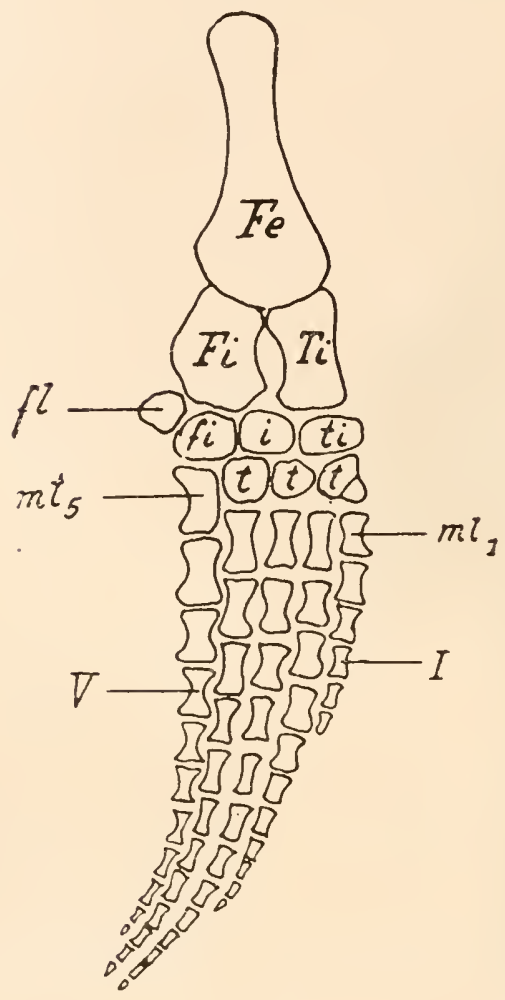

Fig. 394.

Hinterflosse von Plesiosaurus Guilelmi imperatoris, Dames, aus dem oberen Lias von Holzmaden in Württemberg. 1/10 nat. Gr. (Nach E. Fraas.)

$\begin{array}{ll}F e & =\text { Femur. } \\ F i & =\text { Fibula. } \\ T i & =\text { Tibia. } \\ f i & =\text { Fibulare. } \\ i & =\text { Intermedium. } \\ t i & =\text { Tibiale. } \\ t & =\text { Tarsalia } 1 .-3 . \\ f l . & =\text { Flabella (fibulares Sesam- } \\ & \text { bein). } \\ m t_{1}, m_{5} & =\text { Metatarsale I., V. } \\ l, V & =\text { erste und fünfte Zehe. }\end{array}$

einzelne Gliedmaßenknochen errichtet und stellen eigentlich nur einen sehr lästigen Ballast der Literatur dar. Hoffentlich wird einmal eine von phylogenetischen Gesichtspunkten in Angriff genommene Monographic der Plesiosauriden mit diesem wertlosen Material grïndlich aufräumen, das gegenwärtig eine klare Übersicht der Plesiosauriden und einen Einblick in ihre Geschichte nahezu unmöglich macht.

1 Auch aus Nordamerika ist eine größere Zahl von Plesiosaurierarten beschrieben worden; die letzte Zusammenstellung aus dem Jahre 1908 von S. W. Williston (Journal of Geology, Vol. XVI, 1908, p. 736) führt 4 Arten (Plesiosaurus shirleyensis, Pantosaurus striatus, Megalneusaurus rex, Cimoliasaurus laramiensis) aus dem oberen marinen Jura von Wyoming und 32 Arten aus der Kreide an. Auch von diesen Arten sind sehr viele auf ganz ungenügende und schlecht erhaltene Reste errichtet worden.

Die Gattung Elasmosaurus ist jetzt verhältnismäßig am besten bekannt. S. W. IVilliston, North American Plesiosaurs, Elasmosaurus, Cimoliasaurus, and Polycotylus. - The American Journal of Science (4), Vol. XXI, 1906, p. 221. Vgl. auch S. W. Williston, North American Plesiosaurs, Part I, Publication Nr. 73 of the Field Columbian Museum, Geol. Ser., Vol. II, Chicago 1903. 


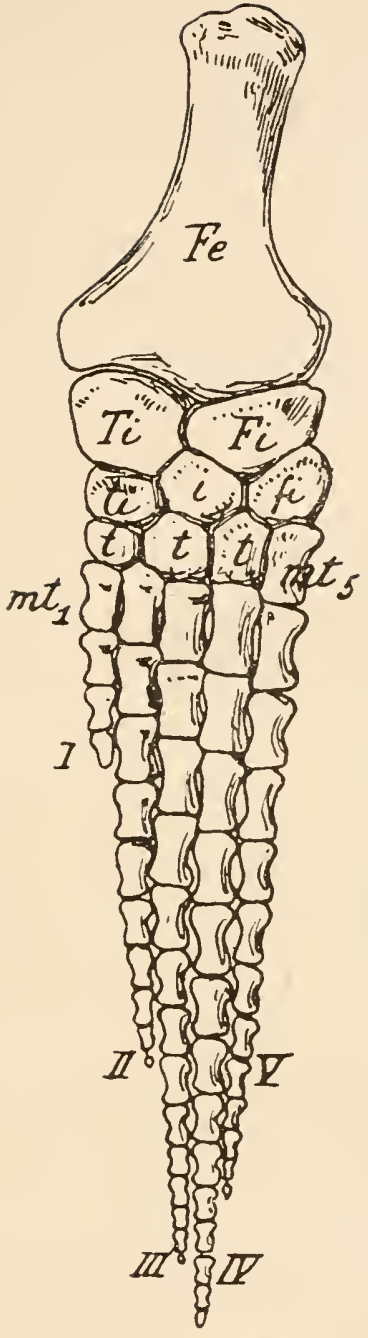

Fig. 395.

Hinterflosse von Cryptocleidus oxoniensis, Phil., aus dem oberen Jura (Oxfordien) Englands. 1/7 nat. Gr.

(Nach C. W. Andrews, 1910.)

$$
\begin{aligned}
F e . & =\text { Femur. } \\
F i . & =\text { Fibula. } \\
\text { Ti. } & =\text { Tibia. } \\
t i . & =\text { Tibiale. } \\
\text { fi. } & =\text { Fibulare } \\
t . & =\text { Tarsale I. } \\
m t_{5 .} & =\text { Metatarsale V. } \\
I .-V . & =1 .-5 . \text { Zehe. }
\end{aligned}
$$

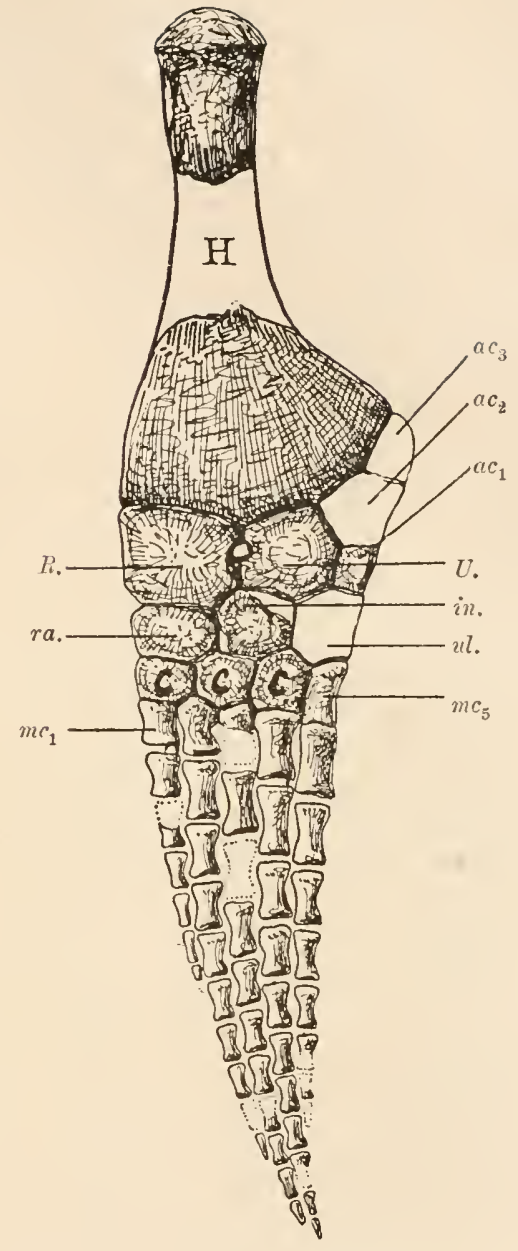

Fig. 396.

Vorderflosse von Cimoliasaurus Bernardi, Owen, aus der oberen Kreide von Isjum, Gouvernement Charikow, Rußland. Stark verkleinert, (Nach $\mathrm{A}$. Riabinin.)

$$
\begin{array}{ll}
H . & =\text { Humerus. } \\
R . & =\text { Radius. } \\
U . & =\text { Ulna. } \\
r a . & =\text { Radiale. } \\
\text { ul. } . & =\text { Ulnare. } \\
\text { in. } & =\text { Intermedium. } \\
a c_{1}-a c_{3} & =\text { Akzessorische Sesambeine. } \\
m c_{5} . & =\text { Metacarpale V. } \\
m c_{1} . & =\text { Metacarpale I. } \\
C . & =\text { die drei distalen Carpalia. }
\end{array}
$$




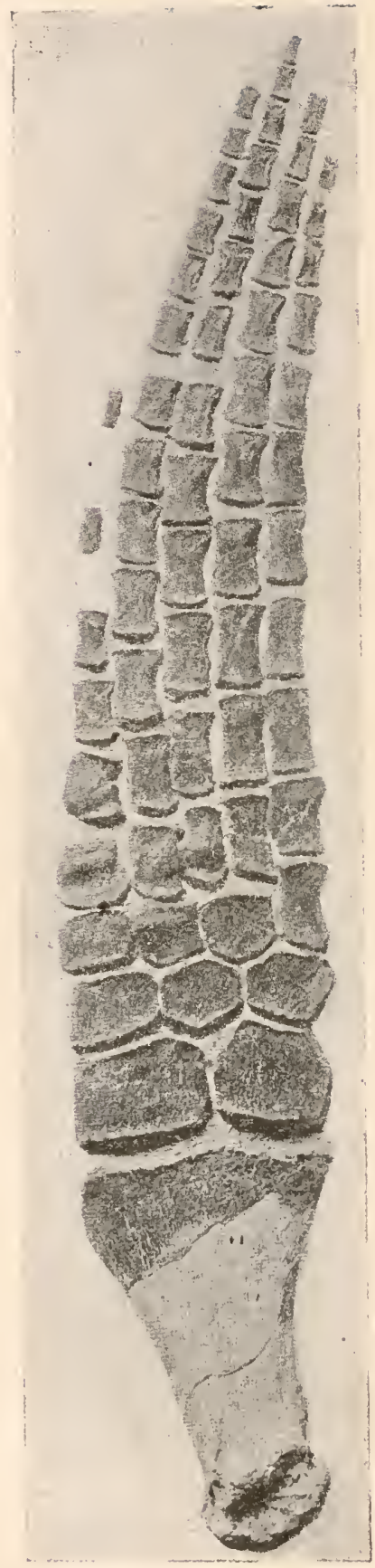

Fig. 397.

Rechte Hinterflosse von Elasmosaurus ischiadicusWilliston, obere Kreide (Niobrara Cretaceous) von Kansas. (Nach S.W.Williston, 1906.)
Trinacromerum. - Obere Kreide von Kansas. - Schädel außerordentlich lang und schmal, Unterkiefersymphyse sehr lang, Hals fast ebenso lang als der Kopf, nur etwa 19-23 Wirbel umfassend ${ }^{1}$ (Fig. 393, 399).

Brachauchenius. - Obere Kreide Nordamerikas. - Schädellänge etwa $1 \mathrm{~m}$, Unterkiefersymphyse sehr kurz, Hals nur aus 13 Wirbehn bestehend, an denen einköpfige Rippen artikulieren. ${ }^{2}$

Die Zahl der unterscheidbaren Gattungen und Arten der Plesiosaurier ist zwar sehr groß, aber es ist bisher noch nicht gelungen, die phylogenetischen Beziehungen zwischen ihnen aufzuklären. ${ }^{3}$ Jedenfalls umfaßt dieser Stanm eine größere Reihe von selbständigen Formenreihen, die schon selir frühzeitig, wahrscheinlich schon im unteren Jura, divergiert haben dürften. Die durch Elasmosaurus vertretene und bis auf Muraenosaurus zurückreichende Formenreilie ist vielleicht am besten in der Familie der Elasmosauridae, die Gattungen Trinacromerum und

1 S. W. Williston, North American Plesiosaurs: Trinacromerum. - Journal of Geology, Vol. XVI, 1908, p. 715.

2 S. W. Williston, The Skull of Brachatlchenius, with Observations on the Relationships of the Plesiosaurs. - Proceedings of the U. S. Nat. Mus. Washington, Vol. XXXII, 1907, p. 477.

3 S. W. Williston'hat schon 1902 (,,On Certain Homoplastic Characters in Aquatic Air-breathing Vertebrates." - Kansas University Science Bulletin, Vol. I, Nr. 9, 1902, p. 259) die Allpassungsmerkmale der Plesiosaurier, deren graduelle Steigerung einen Aufschluß über die phylogenetische Stellung und die Gruppierung der einzelnen Stämme vermitteln kann, angeführt. Bei der großen Menge der bisher bekannten Reste von Plesiosauriden ist es verwunderlich, daß gerade über die Geschichte dieser seit so langer Zeit bekannten Reptiliengruppe noch immer kein klares Bild gewomnen werden konnte, obwohl alle Voraussetzungen dafür gegeben zu sein scheinen. 
Polycotylus ${ }^{1}$, denen nocl Piratosaurus ${ }^{2}$ anzuschließen wäre (nach S. W. Williston, 1908), in der Familie der Polycotylidae zu vereinigen. Pliosaurus und Brachauchenius scheinen einen geschlossenen Stamm, die Familie der Pliosauridae, zu bilden. Über diese Fragen kann jedoch, da noch inmer eine Monographie der Sauropterygia fehlt, einstweilen kein abschlieBendes Urteil gefällt werden. Einzelne der bisher beschriebenen Gattungen und, Arten clürften selbständigen Formenreihen angehören, wie z. B. Cimoliasaurus Bernardi, Owen (Fig. 396), abel

1 S. W. Williston, 1. c., Amer. Journ. of Science, Vol. XXI, 1906, p. 233.

2 J. Leidy, Cretaceous Reptiles of the United States. - Smithsonian Contribution to Knowledge, Nr. 192, 1864, p. 29.

S. W. Will is ton (1.c., Journal of Geology, Vol. XVI, 1908, p. 735) bezeichnet es als möglich, daß diese Gattung mit Polycotylus oder Trinacromerum identisch sein könnte. Sie ist nur auf duirftige Reste begründet.

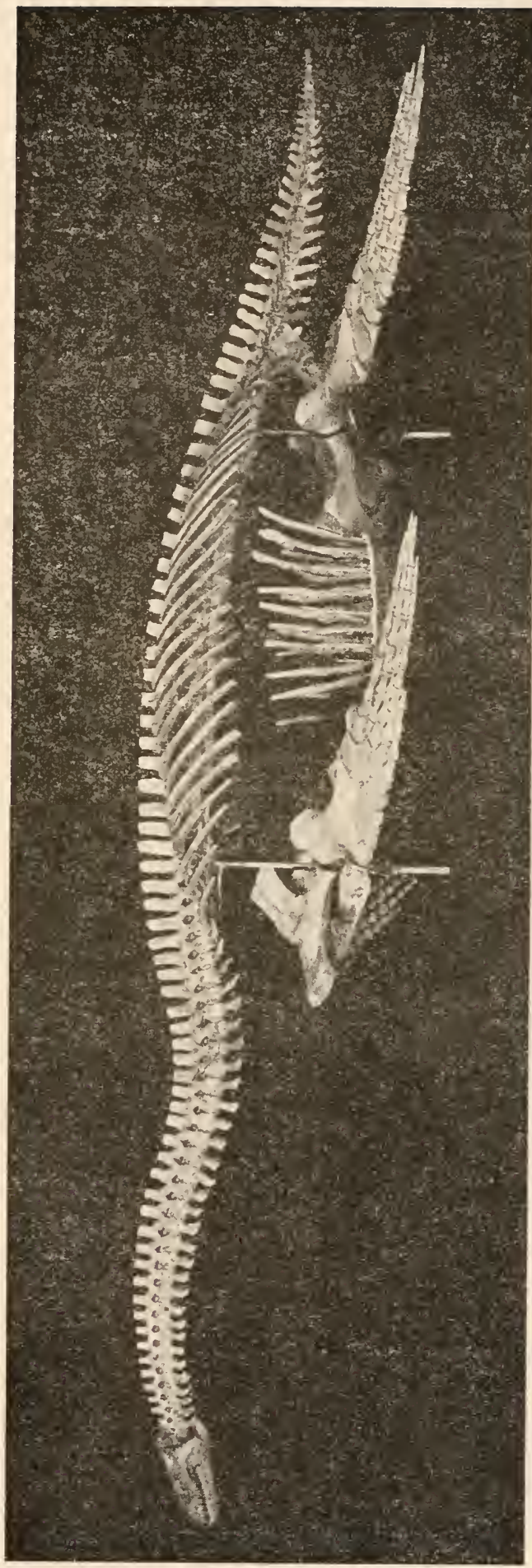




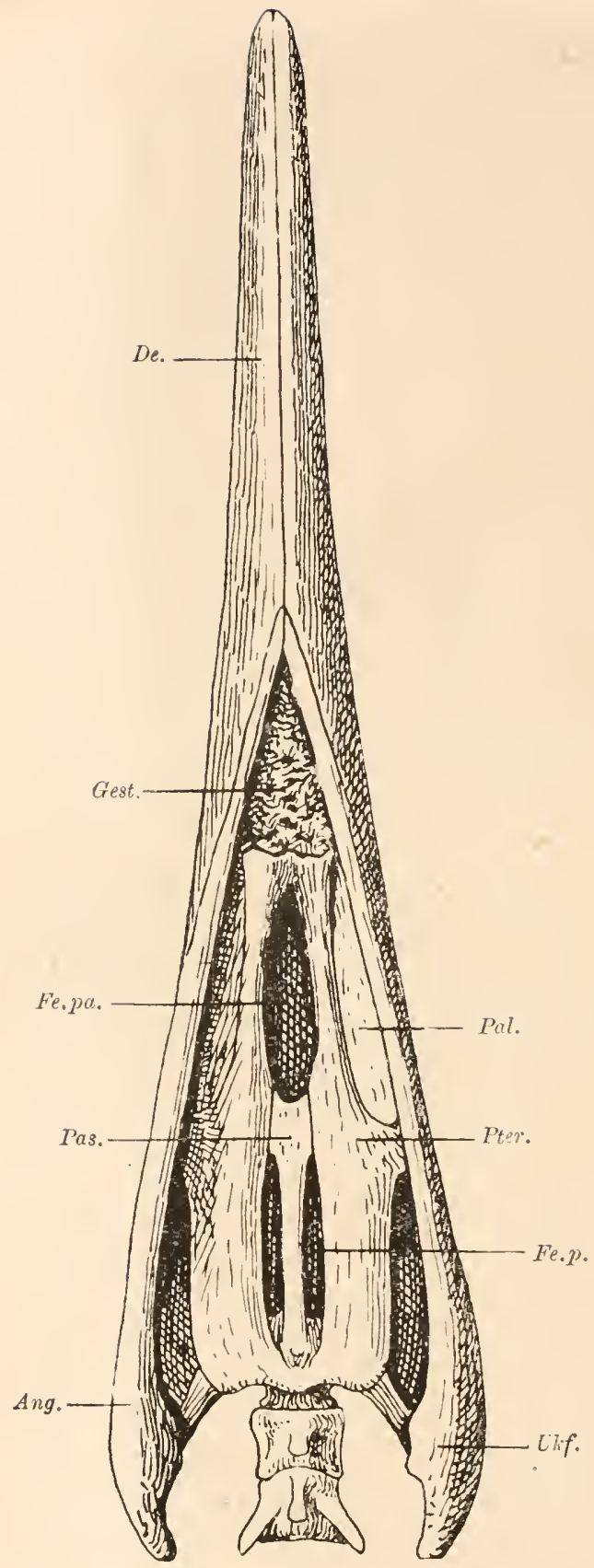

Fig. 399.

Unterseite des Schädels und Unterkiefers von Trinacromerum bentonianum, Cragin, aus der mittleren Kreide (Upper Benton Cretaceons) von Kansas. 1/6 nat. Gr. (Nach S. W. Williston, unbedeutend abgeändert.) das bisher vorliegende Material ist noch nicht nach einheitlichen Gesichtspunkten untersuclit worden, so daß wir über die Gruppe der Plesiosaurier trotz der zallureichen Reste nur sehr ungenügend unterrichtet sind.

\section{Ordnung: Placodontia.}

Die Placodontier, die durclı die beiden Hauptgattungen Placodus und Placochelys sowie durch die Gattung Cyamodus repräsentiert werden, stellen einen sehr einseitig spezialisierten, schon auf prinitiver Basis abgezweigten Stamn der Reptilien dar, der sich an das Wasserleben angepaßt hatte und eine duropliage Lebensweise führte.

Der Schädel besitzt nur ein Schläfenloch jederseits, das der oberen Temporalgrube der Reptilien mit zwei Paar Temporalgruben entspricht; die untere Begrenzung dieser Temporalgrube wird voln Postfrontale, Postorbitale und Supratemporale gebildet, und zwar ist diese untere $\mathrm{Ab}$ schlußspange - der Jochbogen - auBerordentlich hoch und sehr kräftig gebaut. Die auffallende Hölie des Joclifortsatzes des Squamosums legt den Gedanken nahe, daß vielleicht hier ebenso wie bei Araeoscelis ein sekundärer Verschlub der bei den Vorfalıren 
der Placodontier vielleicht offen gewesenen unteren Temporalgrube vorliegt.

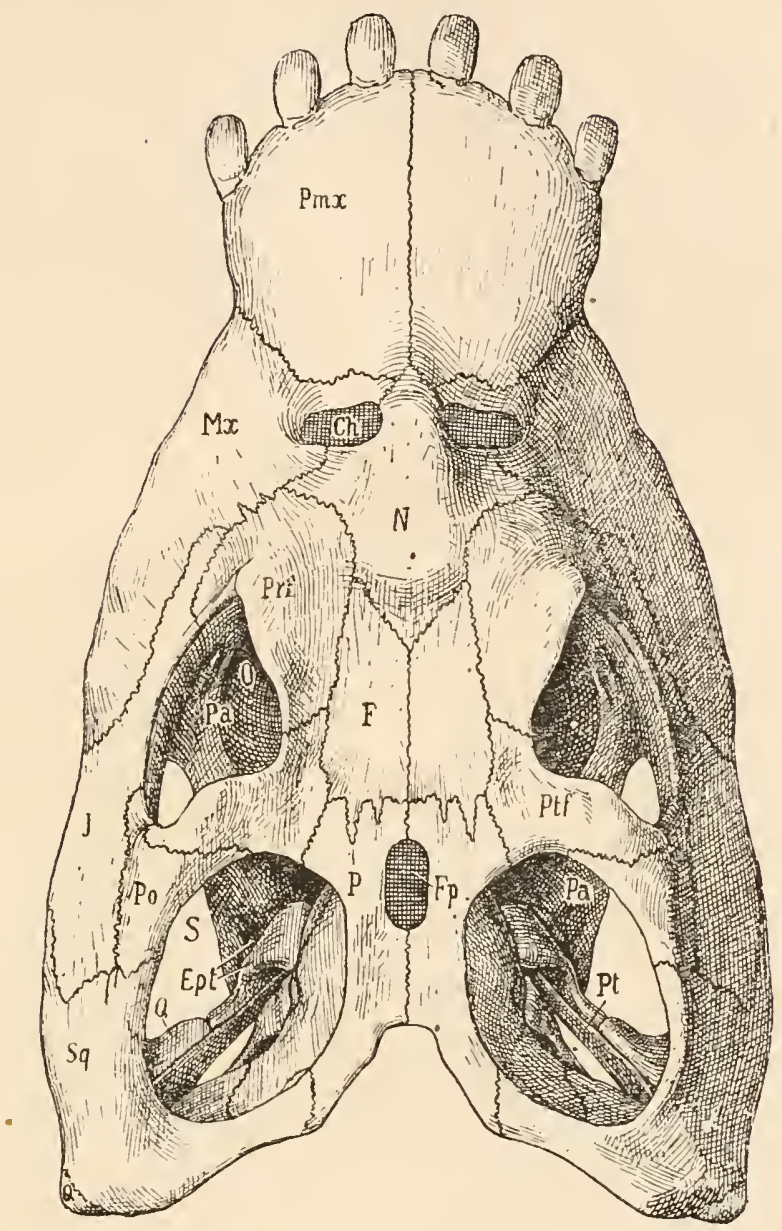

Fig. 400.

Schädel von Placodus gigas, Ag., aus dem Muschelkalk (mittlere Trias) von Kulmbach in Bayern (Oberfranken), von oben gesehen, in $1 / 2$ nat. Gr.

Nach F. Broili.

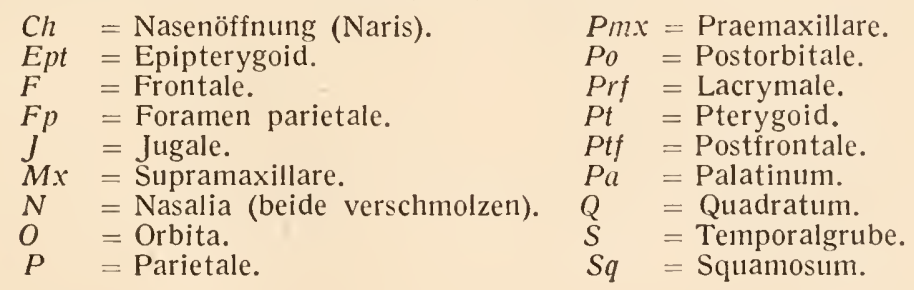

Zwischen den Parietalia liegt ein bei Placodus großes, bei Placochelys kleines Foramen parietale. Die äußeren Nasenöffnungen sind 
weit nach hinten geschoben; an sie schließen sich hinten die Nasalia an, die bei Placodus in der Mittellinie verschmolzen sind. Die Choanen

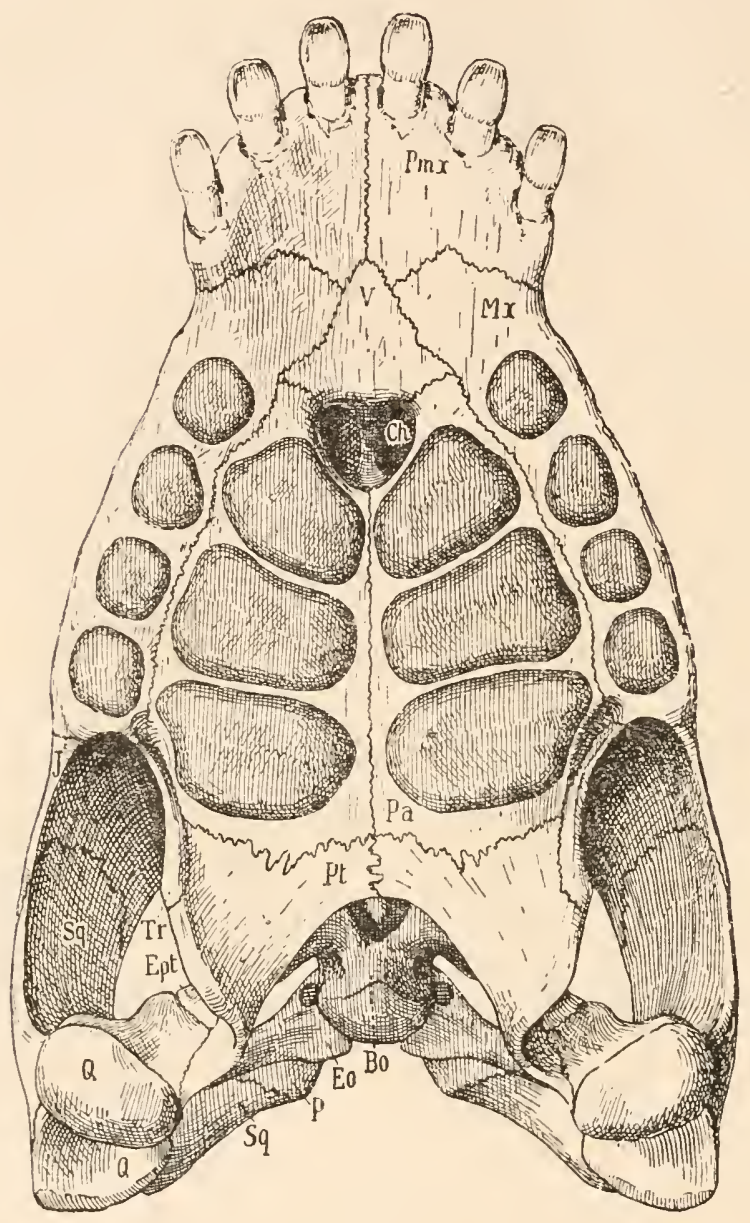

Fig. 401.

Placodus gigas, Ag., aus dem Muschelkalk (mittlere Trias) von Kulmbach in Bayern. $1 / 2$ nat. Gr. Schädel von der Unterseite. (Nach F. Broili.)

\begin{tabular}{|c|c|c|c|}
\hline & $=$ Basioccipitale. & $P_{a}$ & $=$ Palatinum. \\
\hline & = Choane. & $P t$ & = Pterygoid \\
\hline & $=$ Exoccipitale & $P$ & $=$ Parietale. \\
\hline$E p t$ & $=$ Epipterygoid. & $Q$ & Quadratum. \\
\hline & sale. & $S q$ & Squamosum. \\
\hline & - Praemaxillare. & V & = Vomer. \\
\hline
\end{tabular}

liegen fast genau unter den oberen Nasenöffnungen. Ein Adlacrynale felılt, ebenso ein Quadratojugale, dagegen ist ein Supratemporale vorhanden, das mit dem unter ilm liegenden Squamosum verschmolzen 


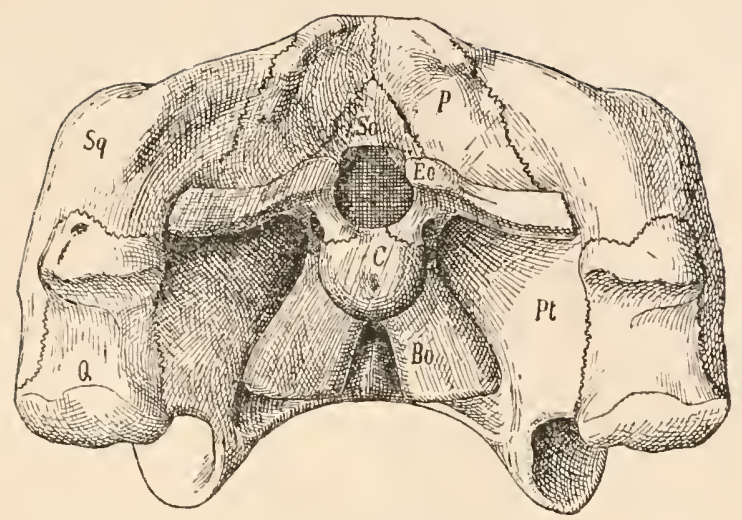

Fig. 402.

Schädel von Placodus gigas, Ag., aus dem Muschelkalk von Kulmbach in

Bayern. $1 / 2$ nat. Gr. (Nach F. Broili.)

$B o=$ Basioccipitale. $\quad P t=$ Pterygoid.

$C=$ Condylus occipitalis. $\quad Q=$ Quadratum.

$E_{0}=$ Exoccipitale. $\quad S_{q}=$ Squamosum.

$P=$ Parietale. $\quad$ So $=$ Supraoccipitale.

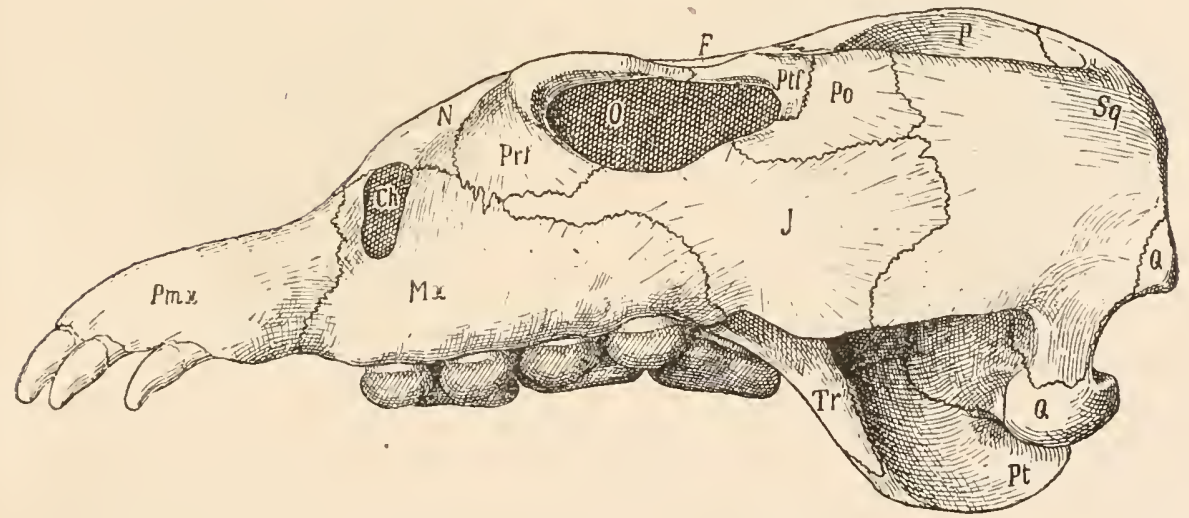

Fig. 403.

Placodus gigas, Ag.; Mitteltrias (Muschelkalk) von Kulmbach in Oberfranken (Bayern). $1 / 2$ nat. Gr. (Nach F. Broili.)

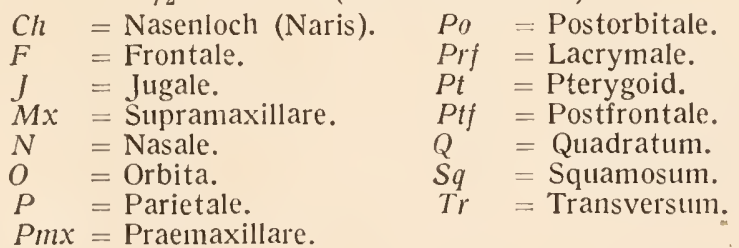

ist. Der Zwischenkiefer ist bei Placodus sehr groß und vorn breit abgerundet; er trägt bei dieser Gattung jederseits drei, bei Cyamodus 
nur zwei Zälnne; bei Placochelys ist er zugespitzt, schmal und vollständig zahnlos.

Sowohl der Oberkiefer als das Palatinum ist mit großen Zahn-

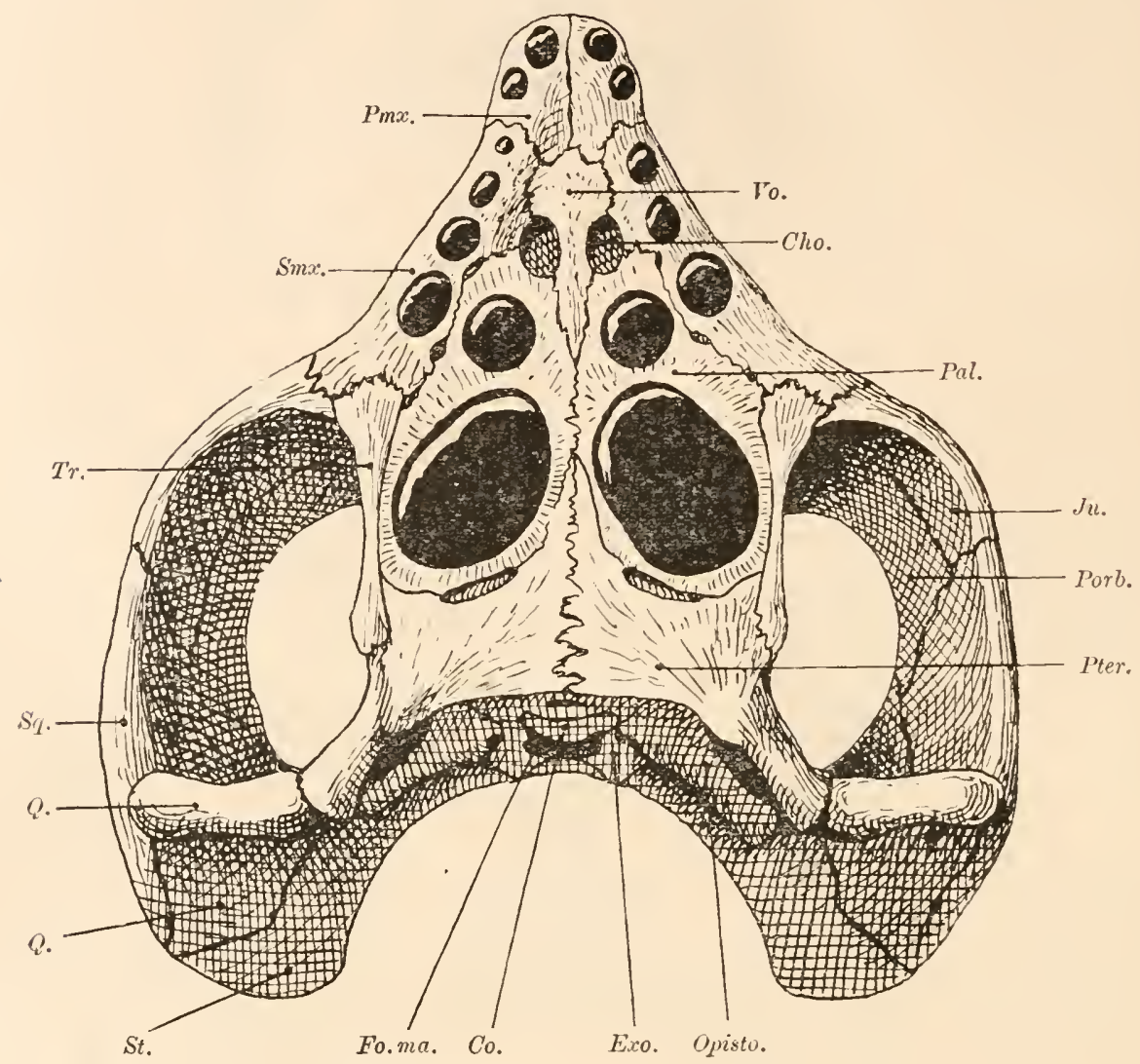

Fig. 404.

Gaumenseite des Schädels von Cyamodus tarnowitzensis, Gürich, aus dem unteren Muschelkalk Oberschlesiens. Etwas kleiner als nat. Gr. (Nach O. Jaekel, Bezeichnungen der Knochen zum Teil nach $F$. v. Huene abgeändert.)
Cho. = Choane.
Porb. = Postorbitale.
Co. $\quad$ Condylus occipitalis.
Pter. Pterygoid.
Exo. = Exoccipitale.
Q. $\quad=$ Quadratum.
Fo.ma. = Foramen magnum.
Smx. Supramaxillare.
Jll. $\quad=$ Jugale.
Opisto. = Opisthoticum.
Pal. $\quad=$ Palatinum.
Prix. $=$ Praemaxillare .
Sq. $\quad=$ Squamosum.
St. $\quad=$ Supratemporale
Tr. $=$ Transversum.
Vo. $\quad=$ Vomer

platten besetzt; die Zahl, Lage und relative Größe ist bei den drei Gattungen verschieden. Unter den großen Platten bilden sich die Ersatzzähne aus. Wälırend die Vorderzähne von Placodus in ähnlicher Weise funktioniert haben dürften wie bei Lepidotus, nämlich als ein 
Apparat zum Loslösen und Ergreifen von hartschaligen Mollusken u. dgl. vom Meeresgrunde, wurde diese Rolle bei Placochelys von dem als Stöberapparat oder Pflug dienenden Zwischenkiefern übernommen.

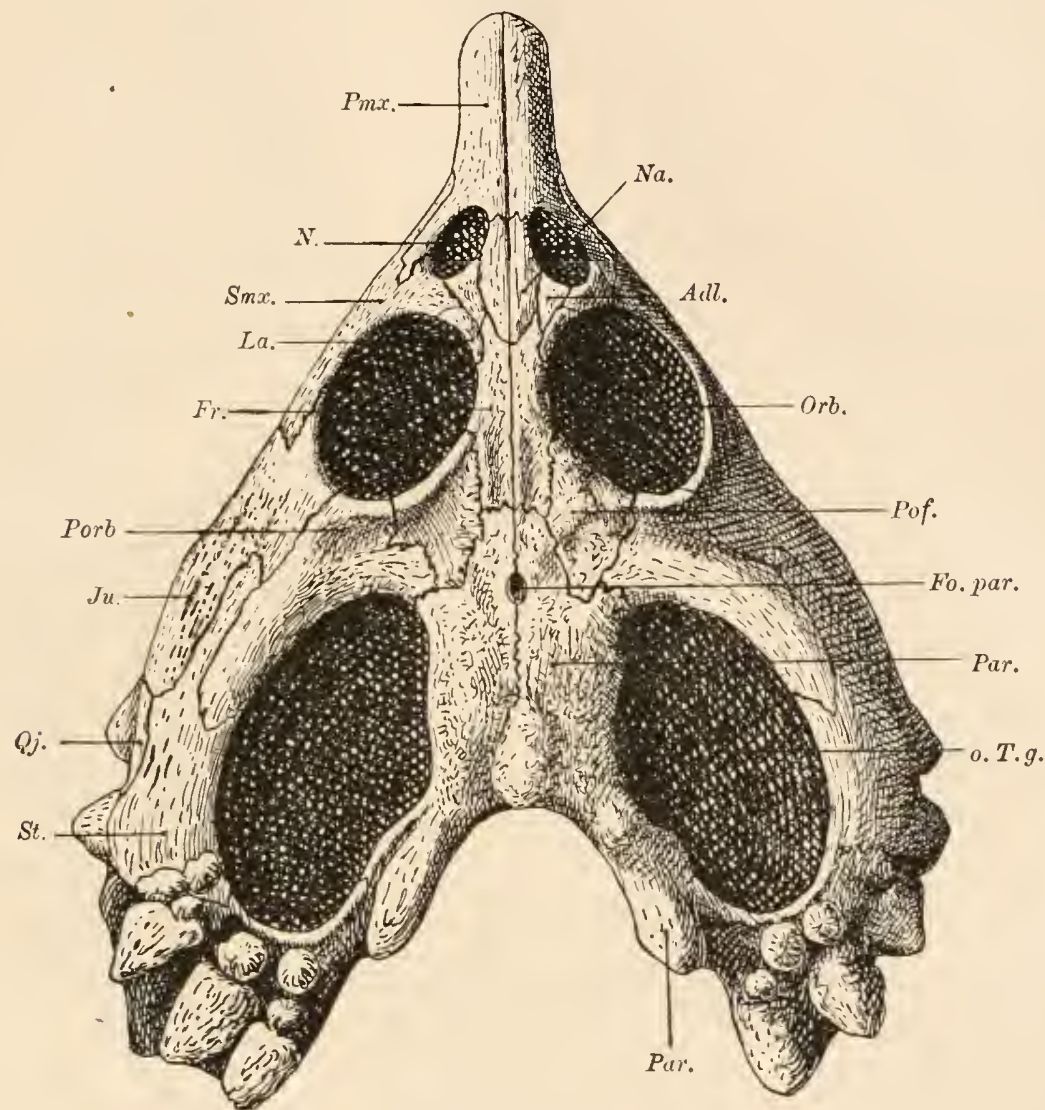

Fig. 405.

Dorsalansicht des Schädels von Placochelys placodonta, Jaekel, aus der oberen Trias des Jerusalemberges am Plattensee, Ungarn. 2/3 nat. Gr. (Nach O. Jaeke1, 1907; teilweise abgeändert und mit anderen Deutungen einzelner Knochen.)

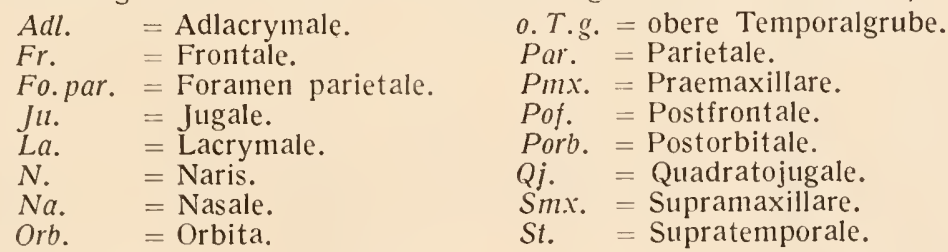

Das Skelett ist bisher nur von Placochelys z. T. bekannt; die Wirbel sind flach amphizoel und durch eine eigentümliche, viereckige Grube auf dem Boden des Neuralkanals der Halswirbel gekennzeichnet. Sie ist bei allen vorliegenden Halswirbeln beobachtet worden; ihre Bedeutung 
ist unbekannt. - Placodus besaß (nach einer vorläufigen Mitteilung von F. Drevermann 1915 über den Fund eines fast vollständigen

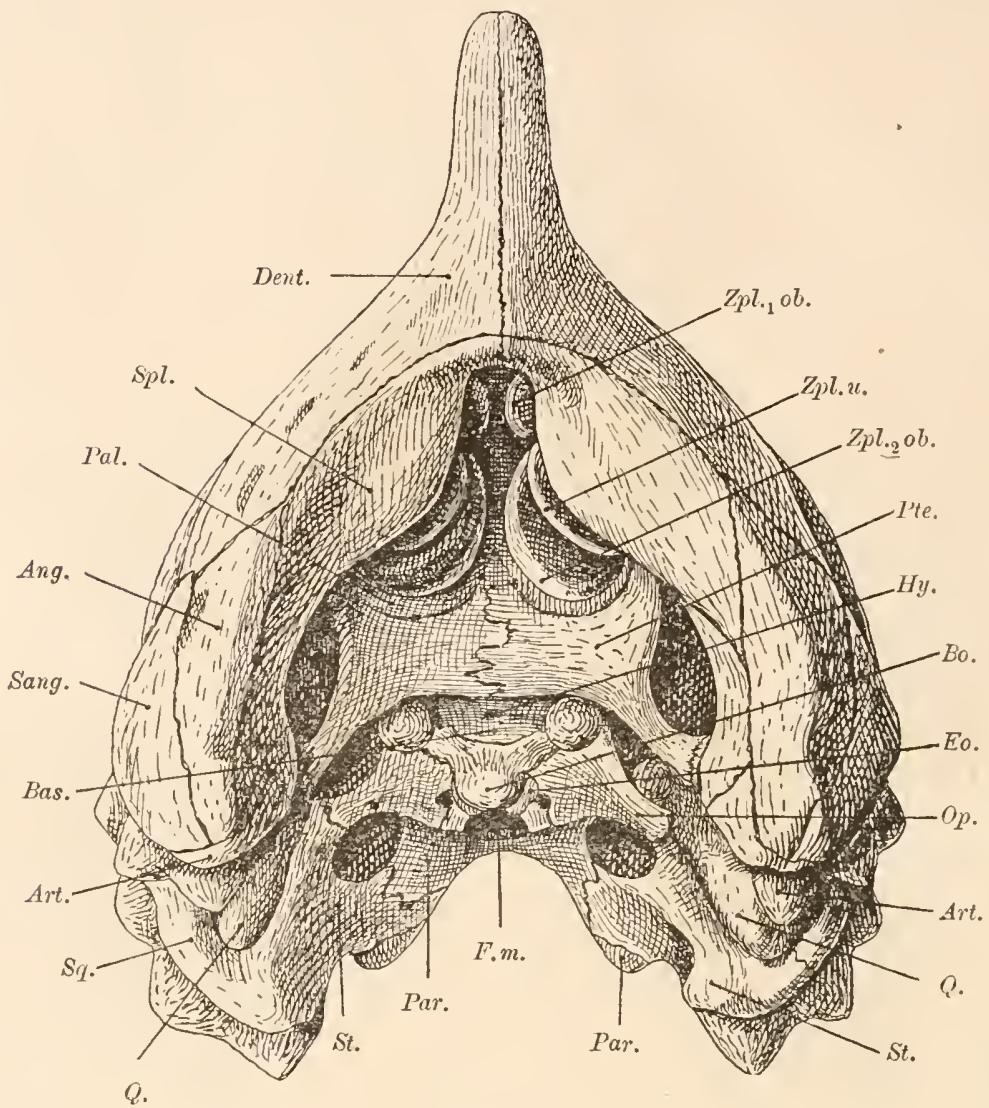

Fig. 406.

Unteransicht des Schädels und Unterkiefeıs von Placochelys placodonta, Jaekel, aus der oberen Trias (Keuper) des Jerusalemberges bei Veszprém am Plattensee, Ungarn. $2 / 3$ nat. Gr. (Nach O. Jaekel; Bezeichnungen zum Teil abgeändert.)
Ang. = Angulare.
Art. = Articulare.
Par. $\quad=$ Parietale.
Bas. = Basisphenoid.
Pte. $\quad=$ Pterygoid.
Bo. $=$ Basioccipitale
Q. $\quad=$ Quadratum.
De. $\quad=$ Dentale
Sang. = Supraangulare.
Eo. = Exoccipitale.
Sq. $\quad=$ Sqamosum.
$F \cdot m$. = Foramen magnum
St. $\quad=$ Supratemporale.
$H y .=$ Hypophysengrube.
Spl. $\quad=$ Spleniale.
Op. = Opisthoticum.
$Z p l_{1} . o b$. = obere vordere Zahnplatte.
Pal. = Palatinum.
$Z p l_{2} . o b .=$ obere hintere Zahnplatte.
Zpl. $u$. = untere Zahnplatte.

Placodusskeletts) tief amphizoele Wirbel, die früher als Anomosaurus beschricben worden waren.

Der Brustkorb von Placochelys bestand aus kräftigen Rippen, die einen starken, knöchernen Hautpanzer trugen; dieser Panzer ist aus 


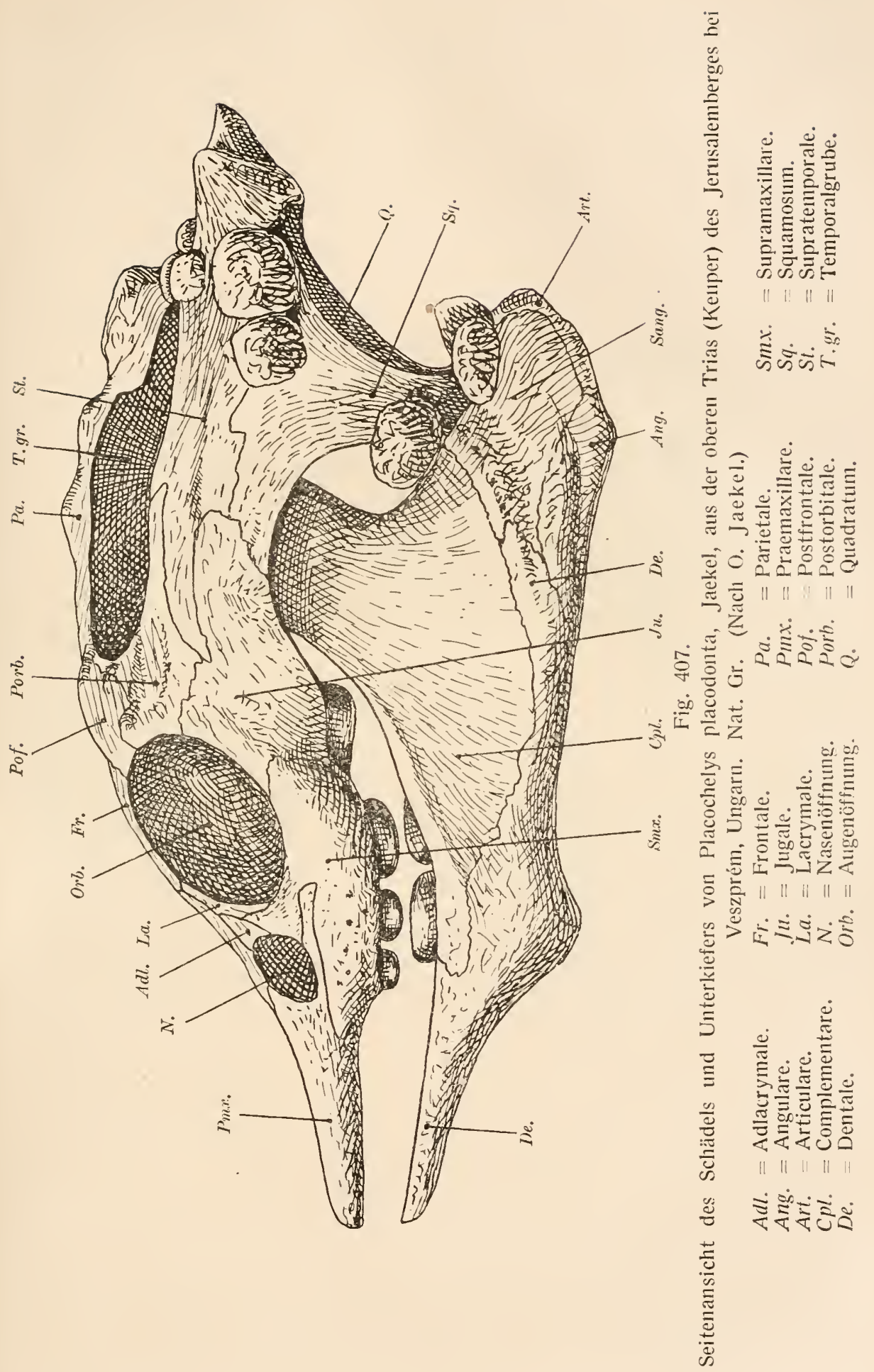


zahlreichen Buckelı von verschiedener Größe zusanmengesetzt. Außerdem waren wohlentwickelte Bauchrippen vorhanden.

Brust- und Beckengürtel sowie Gliedmaßenreste sind bei dem bisher noch nicht beschriebenen Skelett aus dem Muschelkalk von Heidelberg erhalten. Das Becken ist plattenförmig, was für eine ventrale $\mathrm{Ab}$ plattung des Körpers älnnlich wie bei den Plesiosauriern spricht. Die Placodontier dürften schwerfällige Schwimmintiere und Bewohner des

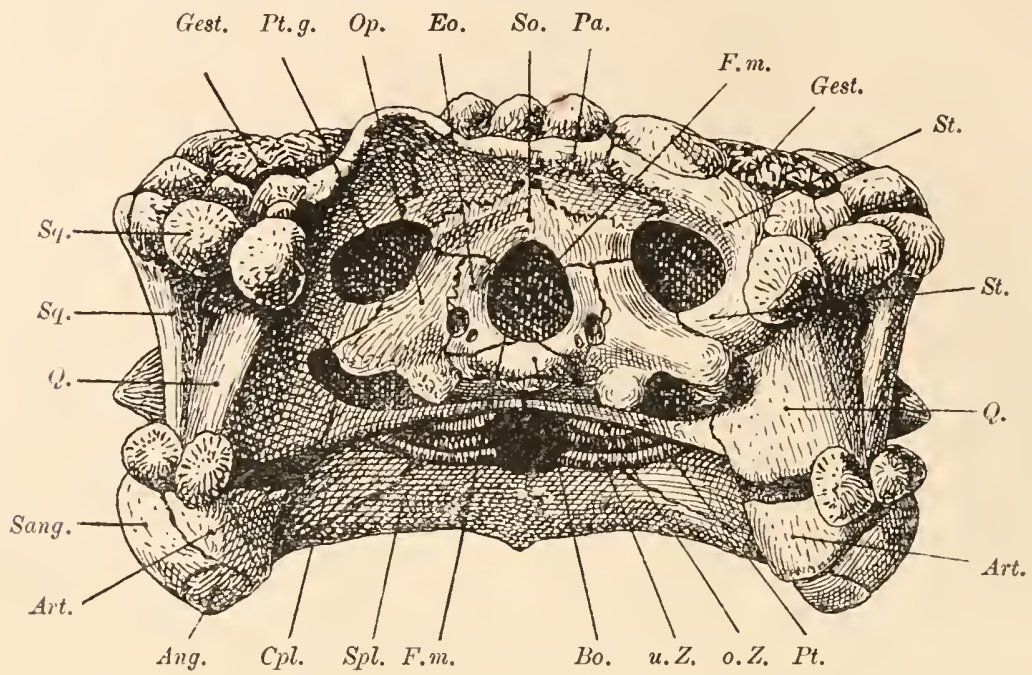

Fig. 408.

Hinteransicht des Schädels und Unterkiefers von Placochelys placodonta, Jaeke!. Vgl. Fig. 406 und 407. (Nach O. Jaekel, Bezeichnungen zum Teil abgeändert.)

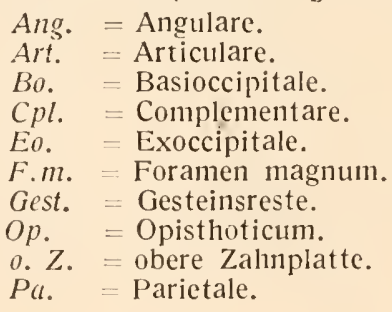

Pt. = Pterygoid.

Pt.g. = Fenestra pteroccipitalis

Q. $=$ Quadratum.

Sang. $=$ Supraangulare.

So. - Supraoccipitale.

Spl. $=$ Spleniale.

Sq. $=$ Squamosum.

St. $=$ Supratemporale.

It. $Z$. = untere Zahnplatte.

Meeresstrandes oder der Flachsee gewesen sein, die sich von Musclieln ernährten.

Placodus. - Mittlere Trias (Muschelkalk) Deutschlands, namentlich von Bayreuth und Heidelberg ${ }^{1}$ (Fig. 400-403).

I F. Broili, Zur Osteologie des Schädels von Placodus. - Paläontograplica, LIX. Bd., 1912, p. 147.

O. Jaekel, Placochelys placodonta aus der Obertrias des Bakony. - Resultate der wissenschaftlichen Erforschung des Balatonsees. - I. Bd., I. Teil, Paläont. Anhang, Budapest 1907. (Hier die ältere Literatur.)

F. von Huene, Über Erythrosuchus, Vertreter der neuen Reptilordnung Pely- 
Cyamodus. - Mittlere Trias (Muschelkalk) Deutschlands ${ }^{1}$ (Fig. 404).

Placochelys. - Obere Trias (Keuper) von Veszprém am Plattensee (Ungarn) ${ }^{2}$ (Fig. 405-408).

\section{Ordnung: Parasuchia.}

Aus der Triasformation sind mehrere Gattungen bekannt, die sich in zwei scheinbar scharf geschiedene Gruppen teilen, deren erste durch die Gattungen Erythrosuchus und Scaphonyx, und deren zweite durch die langschnauzigen Phytosauriden gebildet wird. Trotz der äußerlich sehr auffallenden Verschiedenheiten in der Schädelform beider Gruppen - die erste besitzt einen hohen, kurzen Schädel mit terminalen Nasenlöchern, die zweite einen Schädel mit enorm verlängerter Schnauze und mit nach hinten geschobenen Nasenlöchern - ist doch im Bau des Skeletts eine so weitgehende Übereinstimmung der Angehörigen beider Gruppen vorlanden, daß sie zusammen als Vertreter einer geschlossenen Ordnung, der Parasuchia, anzusehen sind.

Es kann ja wohl keinem Zweifel unterliegen, daß die langschnauzigen Phytosauriden von kurzschnauzigen Vorfahren abstammen, bei denen die Nasenlöcher an Vorderende der Schnauze lagen, wie dies für alle primitiven Reptilien gilt. In der Schnauzenform und in der Lage der Nasenlöcher verhält sich also die Gruppe Erythrosuchus und Scaphonyx primitiv im Vergleich zu den Phytosauriden, welche sicher ein Stadium durchlaufen haben müssen, wie es die Gattung Erythrosuchus repräsentiert. Freilich kommt diese Gattung selbst ebensowenig wie Scaphonyx als direkte Alnenform in Betracht, da sie ungefähr dasselbe geologische Alter wie die bereits langschnauzig gewordenen Phytosaurier besitzt, und es klafft zwischen Erythrosuchus und Mesorhinus immerhin eine große Lücke. Alle Unterschiede zwischen der durch Erythrosuchus und Scaphonyx vertretenen Gruppe und den Phytosauriden sind aber nur gradueller Natur und es besteht kein zwingender Grund, die erste Gruppe als selbständige Ordnung (Pelycosimia) abzutrennen, wie dies Huene (1911) vorgeschlagen hat.

\section{F. Pelycosimiidae.}

Die Pelycosimiiden besitzen einen relativ hohen Schädel, der in der Oberansicht einen dreieckigen Umriß besitzt. Bezeichnend für den

cosimia. - Geolog. und paläontol. Abhandl., N. F. Bd. X (G. R. Bd. XIV), Jena 1911, p. 44.

F. Drevermann, Über Placodus. Vorläufige Mitteilung. - Centralbl. f. Mineral. usw., 1915, S. 402.

1 O. Jaekel, 1. c., S. 9.

2 O. Jaekel, I. c., 1902.

A bel, Stämme der Wirbeltiere. 
Bau des Schädeldaches, der auch bei den Phytosauriden in den Grundzügen überliefert erscheint, ist das Vorhandensein von fünf Paar Öffnungen auf dem Schädeldach: Nasenöffnungen, Präorbitalöffnungen, Orbitae, untere Temporalgruben und obere Temporalgruben. Die Prä-

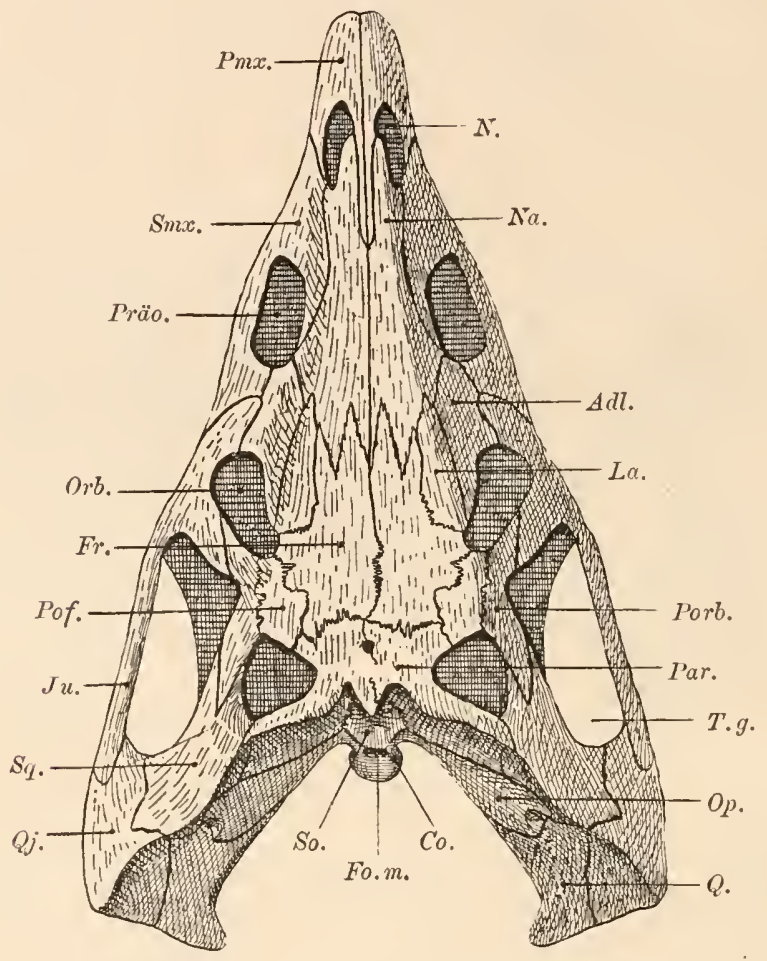

Fig. 409.

Oberansicht des Schädels von Erythrosuchus africanus, Broom, aus der Trias der Kapkolonie, in $1 / 10$ nat. Gr. (Nach F. von Huene.)

\begin{tabular}{|c|c|c|}
\hline $\begin{array}{l}\text { Adl. } \\
\text { Co. } \\
\text { Fr. } \\
\text { Fo.m. } \\
\text { Jli. } \\
\text { La. } \\
\text { N. } \\
\text { Na. } \\
\text { Op. } \\
\text { Orb. } \\
\text { Par }\end{array}$ & $\begin{array}{l}=\text { Adlacrymale. } \\
=\text { Condylus occipitalis. } \\
=\text { Frontale. } \\
=\text { Foramen magnum. } \\
=\text { Jugale. } \\
=\text { Lacrymale. } \\
=\text { Nasenöffnung. } \\
=\text { Nasale. } \\
=\text { Opisthoticum. } \\
=\text { Orbita. } \\
=\text { Parietale }\end{array}$ & 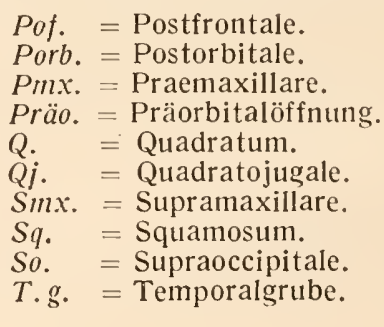 \\
\hline
\end{tabular}

orbitalöffnungen liegen in lialber Länge zwischen den Nasenöffnungen und den Augenhölılen.

Der Schädel von Erythrosuchus ist sehr groß (96 cm Länge und $60 \mathrm{~cm}$ größte Höhe samt dem Unterkiefer). Der Schädel verschmälert sich stark nach vorn und die Schnauze läuft spitz zu. Das Skelett 
stimmt mit dem der Phytosauriden in den Hauptpunkten überein, aber der Körper war plumper und offenbar an das Wasserleben nicht in dem Grade angepaßt, wie dies bei den Phytosauriden der Fall war.

Erythrosuchus. - Trias der Kapkolonie. - Außer dem Schädel zahlreiche Teile des übrigen Skeletts bekannt. E. africanus (Fig. 409). ${ }^{1}$

Scaphonyx. - Trias Brasiliens (Rio Grande do Sul). - Nur Wirbel und dürftige Gliedmaßenreste bekannt, die Erythrosuchus sehr ähnlich sind. S. Fischeri. ${ }^{2}$

\section{F. Phytosauridae.}

Die Phytosauriden stellen eine sehr einseitig spezialisierte Gruppe der Parasuchier dar, die ausschlieBlich auf die Trias beschränkt zu sein scheint, da in jüngeren Formationen niemals auch nur der geringste Rest gefunden worden ist, der auf diese Familie bezogen werden könnte.

Die allgemeine Körperform der Phytosauriden war die der lebenden langschnauzigen Krokodile, und es ist wiederholt durch diese Ähnlichkeit die falsche Vorstellung erweckt worden, daß es sich in diesen krokodilälınlichen Reptilien der Triaszeit um Vorläufer der echten Krokodile handle. Die genaueren morphologischen Vergleiche haben uns jedoch mit einer jeden Zweifel ausschließenden Entschiedenheit gezeigt, daß die Spezialisationen zwar im großen und ganzen in ähnlicher Weise wie bei den Krokodilen verlaufen sind, daß aber in den Einzelheiten tiefgreifende Gegensätze bestehen, die eine genetische Verknüpfung der Phytosaurier und der Krokodilier vollkommen ausschließen.

Zu diesen Gegensätzen gehört vor allen der für die Phytosauriden überaus charakteristische Bau der Schnauze und die Lage der äußeren Nasenöffnungen. Während bei den Krokodilen die verlängerte Schnauze hauptsächlich von den Supramaxillaria gebildet wird, besteht die verlängerte Schnauze der Plytosauriden fast ausschließlich aus den enorm verlängerten Zwischenkiefern. Ferner liegen die Nasenlöcher bei allen Krokodilen, auch bei den hochgradig an das Wasserleben angepaßten Formen, am Vorderende der Schnauze (eine Folgeerscheinung der klinonektonischen Körperhaltung der Krokodile beim Schwimmen), während die Nasenlöcher der Phytosauriden weit nach hinten verschoben sind. Dies beweist, daß die Phytosauriden beim Schwimmen und ruhigen Liegen im Wasser eine horizontale Stellung eingenommen haben müssen, da nur in diesem Falle die Verschiebung der Nasenöffnungen nach hinten und oben erfolgt.

1 F. von Huene, Über Erythrosuchus, 1. c., S. 3.

2 A. Smith Woodward, On some Fossil Reptilian Bones from the State of Rio Grande do Sul. - Revista do Museo Paulista, Vol. VII, Sao Paulo 1907, p. 46. F. von Huene, l. c., 1911, p. 25. 


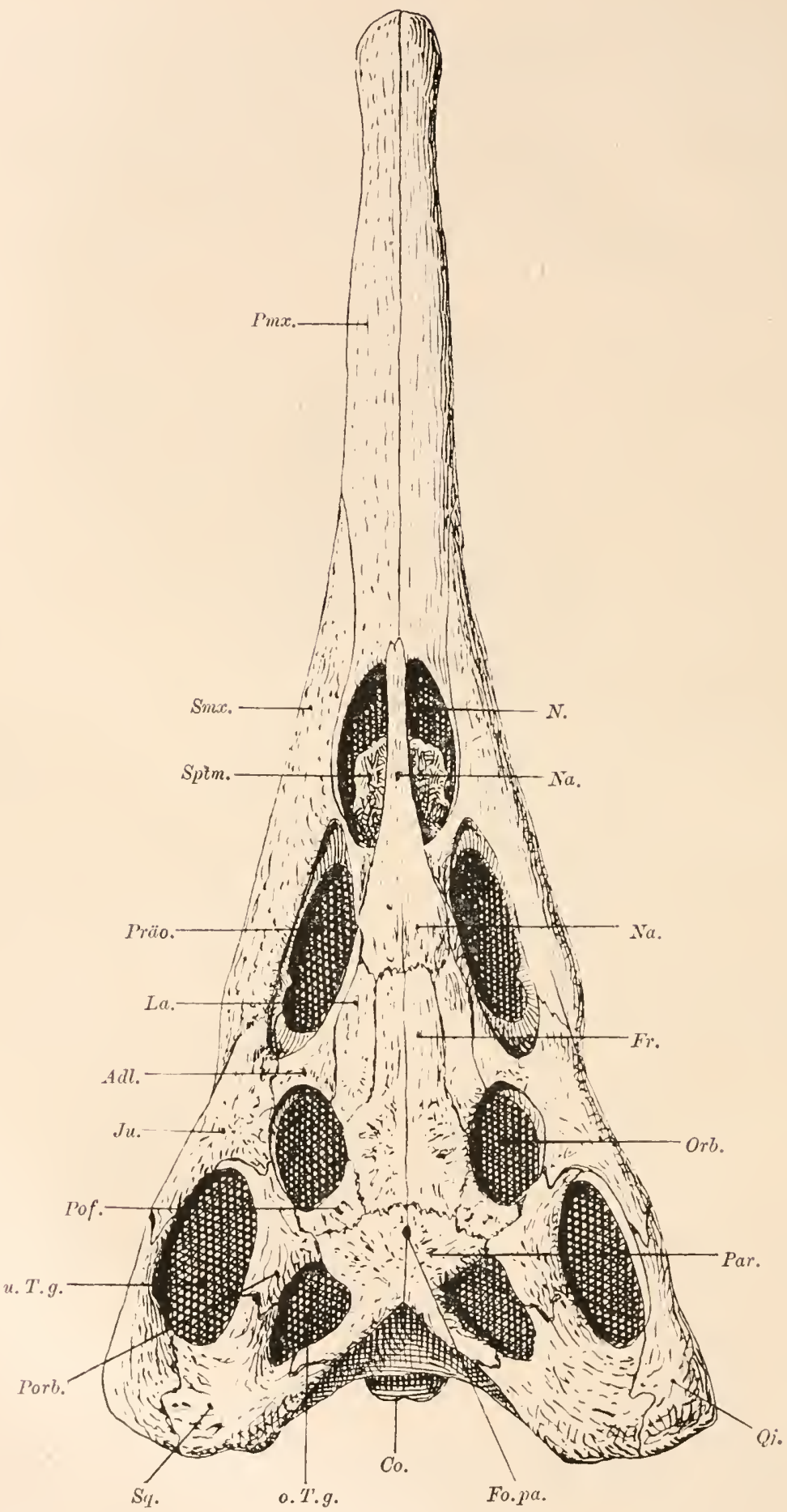

Fig. 410. 
Ein weiteres wichtiges Kennzeichen der Phytosauriden ist das Vorhandensein von großen Präorbitalöffnungen. Diese Öffnungen werden von den Pterygoidmuskẻln ausgefüllt, die zum Hinterende des Unterkiefers ziehen und die, wie Huene (1911) ausführt, bei den Phytosauriden besonders kräftig entwickelt gewesen sein müssen.

Das Schädeldach der Phytosauriden besitzt zwei große laterale Temporalgruben, von denen die obere die kleinere ist. Bei der primitiven Phytosauridengattung Mesorhinus wird die obere Temporalgrube hinten von langen Fortsätzen der Parietalia abgeschlossen, aber in Verlaufe der phylogenetischen Entwicklung der Phytosaurier gehen diese Fortsätze verloren und der hintere Abschluß dieser Grube wird nur von den Squamosa gebildet, so daß diese Spange viel tiefer liegt und die oberen Temporalgruben, z. B. bei Phytosaurus, viel tiefer gegen das Foramen magnum herabreichen als dies bei der Gattung Mesorhinus der Fall ist.

Ein weiterer Unterschied der Phytosauriden von den Krokodilen liegt in der zunehmenden Verkleinerung der postpalatinalent Gaumendurchbrüche bei den Phytosauriden, während bei den Krokodilen der umgekehrte Weg verfolgt werden kann; bei diesen nehmen sie im Laufe der Stammesgeschichte beständig an Größe zu.

Der Gaumen der Phytosauriden zeigt nach Huene viele altertün1liche Züge, die an ähnliche Verhältnisse bei den Cotylosauriern erinnern. Verschiedene Merkmale der Schädelbasis finden sich bei den Sphenacodontiden wieder, wie z. B. die Form und Ausbildung des Quadratums und die Zusammensetzung des Unterkiefers. Ferner ist die Interclavicula der Phytosauriden jener der Sphenacodontiden sehr ähnlich und eine weitere Übereinstimmung beider Gruppen besteht im Bau des Beckens, das überhaupt altertümliches Gepräge zeigt. Das Femur hat zum Teil seine altertümliche Form bewahrt und unterscheidet sich dadurch von Femur der Krokodile, das den Typus zeigt, wie wir ihn bei den Dinosauriern und Ornithischiern, Pterosauriern und Vögeln finden; dieser Unterschied ist aber nur gradueller Natur.

\section{Zu Fig. 410.}

Dorsalansicht des Schädels von Mesorhinus Fraasi, Jaekel, aus dem mittleren Buntsandstein (untere Trias) von Bernburg in Deutschland, rekonstruiert in etwa $2 / 5$ nat. Gr.

\begin{tabular}{|c|c|c|c|}
\hline $\begin{array}{l}\text { Adl. } \\
\text { Co. } \\
\text { Fo.pa. } \\
\text { Fr. } \\
\text { Ju. } \\
\text { La. } \\
\text { N. } \\
\text { Na. } \\
\text { o. T.g. } \\
\text { Orb. }\end{array}$ & $\begin{array}{l}=\text { Adlacrymale. } \\
=\text { Condylus occipitalis. } \\
=\text { Foramen parietalt. } \\
=\text { Frontale. } \\
=\text { Jugale. } \\
=\text { Lacrymale. } \\
=\text { Nasenöffnung. } \\
=\text { Nasale. } \\
=\text { obere Temporalgrube. } \\
=\text { Orbita. }\end{array}$ & $\begin{array}{l}\text { Par. } \\
\text { Pmx. } \\
\text { Pof. } \\
\text { Porb. } \\
\text { Präo. } \\
\text { Q. } \\
\text { Smx. } \\
\text { Sptm. } \\
\text { Sq. } \\
\text { t. T. g. }\end{array}$ & $\begin{array}{l}=\text { Parietale. } \\
=\text { Praemaxillare. } \\
=\text { Postfrontale. } \\
=\text { Postorbitale. } \\
=\text { Präorbitalöffnung. } \\
=\text { Quadratojugale. } \\
=\text { Supramaxillare. } \\
=\text { Septomaxillare. } \\
=\text { Squamosum. } \\
=\text { untere Temporalgrub }\end{array}$ \\
\hline
\end{tabular}




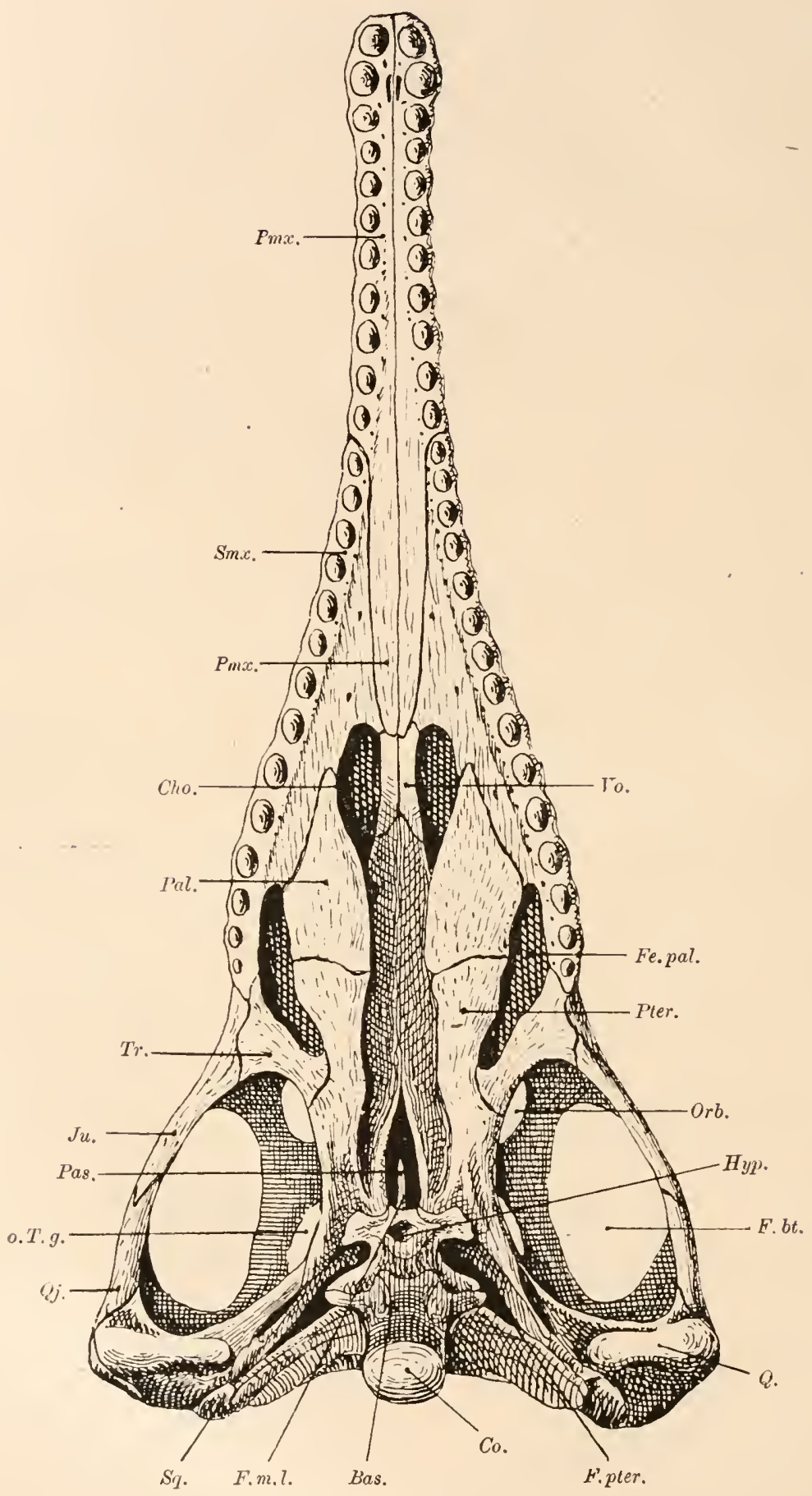

Fig. 411 . 
Die Geschichte dieses ẹigentümlich spezialisierten Stammes liegt also in den Hauptzügen klar vor uns: sie stellen einen blind endigenden Ast des Reptilienstammes dar, der die Vorstufe der Pelycosimiiden durchlaufen und sich in ähnlicher Richtung wie die Krokodile an das Wasserleben angepaßt hat.

Mesorhinus. - Der älteste und zugleich primitivste Plyytosaurier aus dem mittleren Buntsandstein von Bernburg in Deutschland (untere 'Trias). - Die Nasenlöcher liegen etwa in halber Schädellänge, die hintere Abschlußspange der oberen Temporalgruben wird von langen Fortsätzen der Parietalia gebildet. Die Präorbitalgruben liegen hinter den äußeren Nasenöffnungen. Ein kleines Foramen parietale ist vorhanden. ${ }^{1}$ (Fig. 410-411).

\section{Stagonolepis. - Mittlere Trias von Elgin (Schottland).}

Phytosaurus (= Belodon). - Obere Trias (Keuper) von Württemberg und anderen Orten Süddeutschlands, Trias von Neumexiko, Nordkarolina, Pennsylvanien, Texas und Connecticut. ${ }^{3}$

\section{Zu Fig. 411.}

Unteransicht des Schädels von Mesorhinus Fraasi, Jaekel, aus dem mittleren Buntsandstein (untere Trias) von Bẹrnburg in Deutschland, rekonstruiert in etwa ${ }^{2} / 5$ nat. Gr.

(Nach O. Jaekel.)

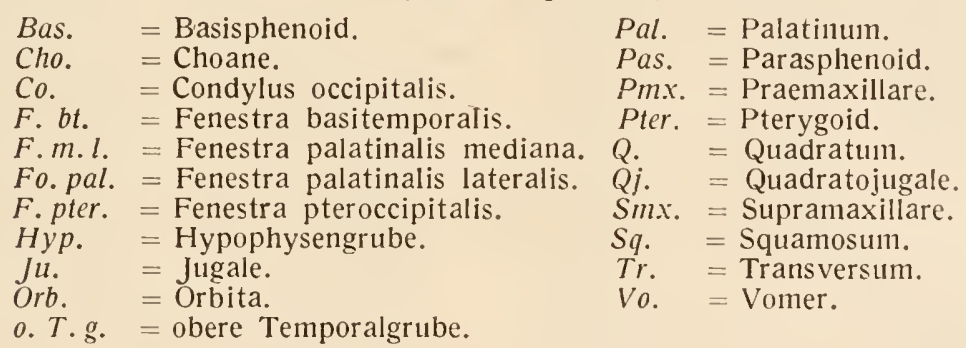

1 O. Jaekel, Über einen neuen Belodonten aus dem Buntsandstein von Bernburg. - Sitzungsber. d. Ges. Naturforsch. Freunde zu Berlin, 1910, Nr. 5, S. 197.

2 Th. H. Huxley, On Stagonolepis Robertsoni, and on the Evolution of the Crocodilia. - Quart. Journ. Geol. Soc. London, XXX1, 1875, p. 423.

Derselbe, The Crocodilian Remains found in the Elgin Sandstones usw. Memoirs of the Geolog. Survey of the United Kingdom, Monographs, III, London 1877.

F. von Huene, Beiträge zur Kenntnis und Beurteilung der Parasuchier. Geol. u. Palaeont. Abh., (N. F. Bd. X), G. R. Bd. XIV, Jena 1911, S. 109.

${ }^{3}$ H. v. Meyer, Der Schädel des Belodon aus dem Stubensandstein des oberen Keupers. - Palaeontographica, X. Bd., 1863, p. 227.

Derselbe, Palaeontographica, VII. Bd., 1861, p. 253 und ibidem, XIV, 1865, p. 99.

E. Fraas, Führer durch die Kgl. Naturaliensammlung zu Stuttgart, I. Die geogn. Sammlung Württembergs. - 3. Aufl., 1910. - p. 38, Fig. 28 (Photographien 
Der Schädel läuft stets in eine außerordentlich verlängerte Schnauze aus, die bei Ph. Kapffii sehr hoch, bei Ph. Plieningeri dagegen niedrig, in beiden Fällen aber sehr stark lateral komprimiert ist. Der Rücken von Phytosaurus Kapffii war mit zwei Längsreihen großer, bis $30 \mathrm{~cm}$ langer Platten gepanzert, die seitlich von je einer Reihe kleinerer Platten begleitet waren (Fig. 412).

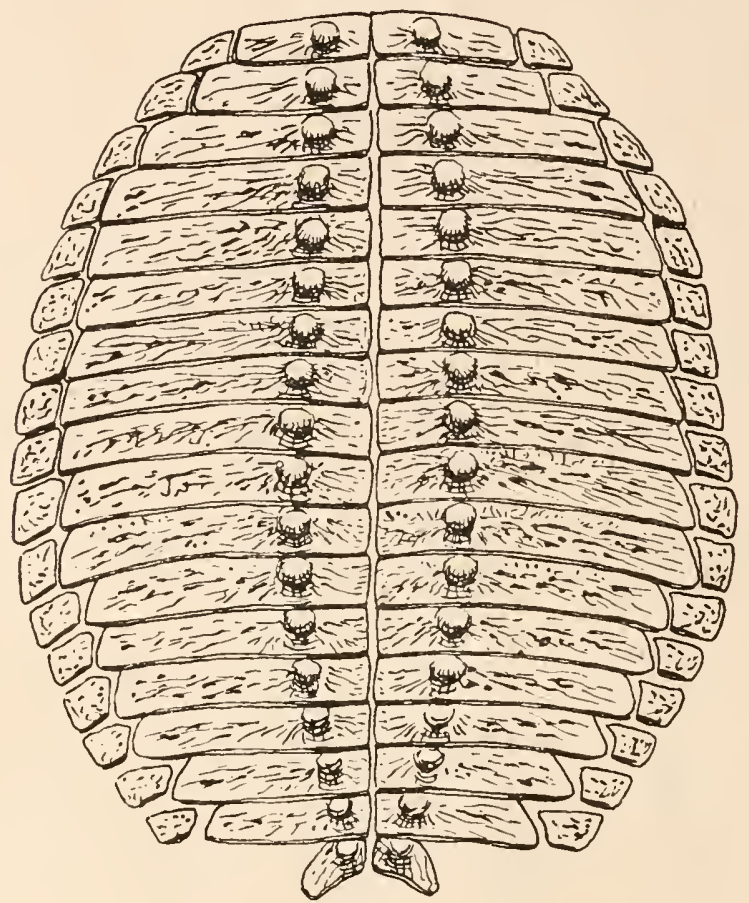

Fig. 412.

Rückenpanzer von Phytosaurus Kapffii, H. v. Meyer, aus der oberen Trias der Umgebung von Stuttgart (Wiirttembarg). Stark verkleinert. (Rekonstruktion unter Benuitzung der älteren Abbildungen von $\mathrm{H}$. von Meyer und der neueren Rekonstruktion (1913) von F. von Huene.)

Es werden mehrere Arten unterschieden, unter denen Ph. Kapffii (Fig. 413, A) die bekannteste ist; eine weitere, ziemlich vollständig

von Mystriosuchus planisostris und Phytosaurus Kapfii); Fig. 24: Rekonstruktion beider Formen.

Mc. Gregor, The Phytosauria with Special Reference to Mystriosuchus and Rhytidodon. - Memoirs Americ. Mus. Nat. Hist., Vol. IX, 1906. (Hier die ältere Literatur.)

F. v. Huene, I. c. supra.

Derselbe, Vorläufige Mitteilung ïber einen neuen Phytosaurusschädel aus dem schwäbischen Keuper. - Centralbl. f. Min. usw., 1909, S. 583. 
bekannte Art ist Ph. Plieningeri (Fig. 413, B; 414), beide aus dem deutschen Keuper.

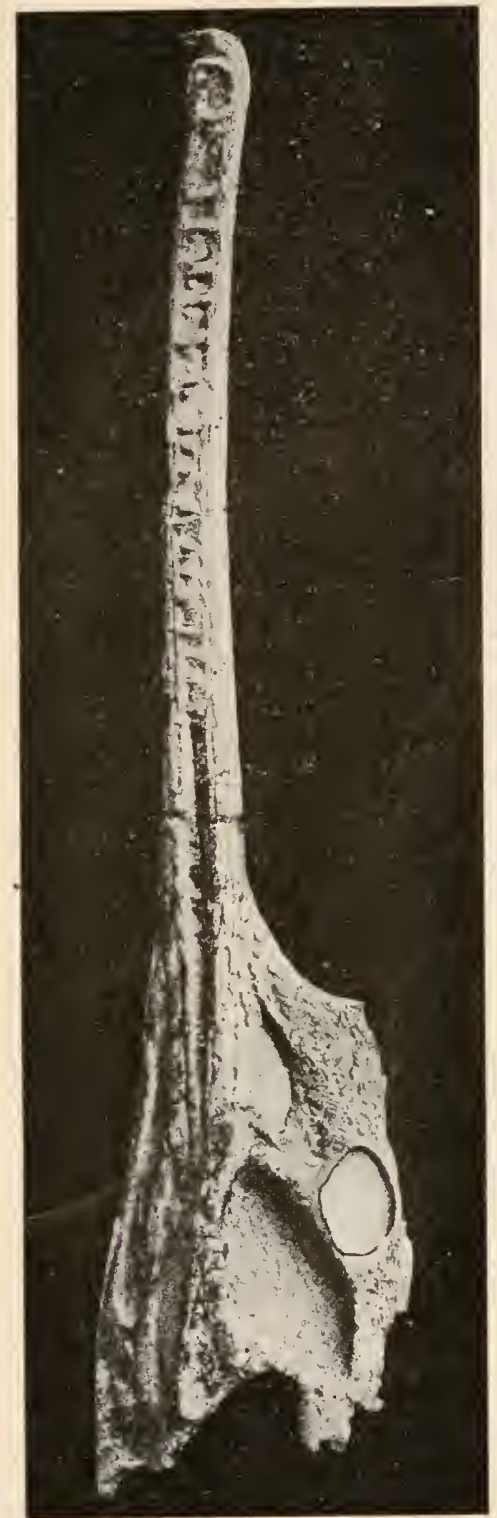

A.

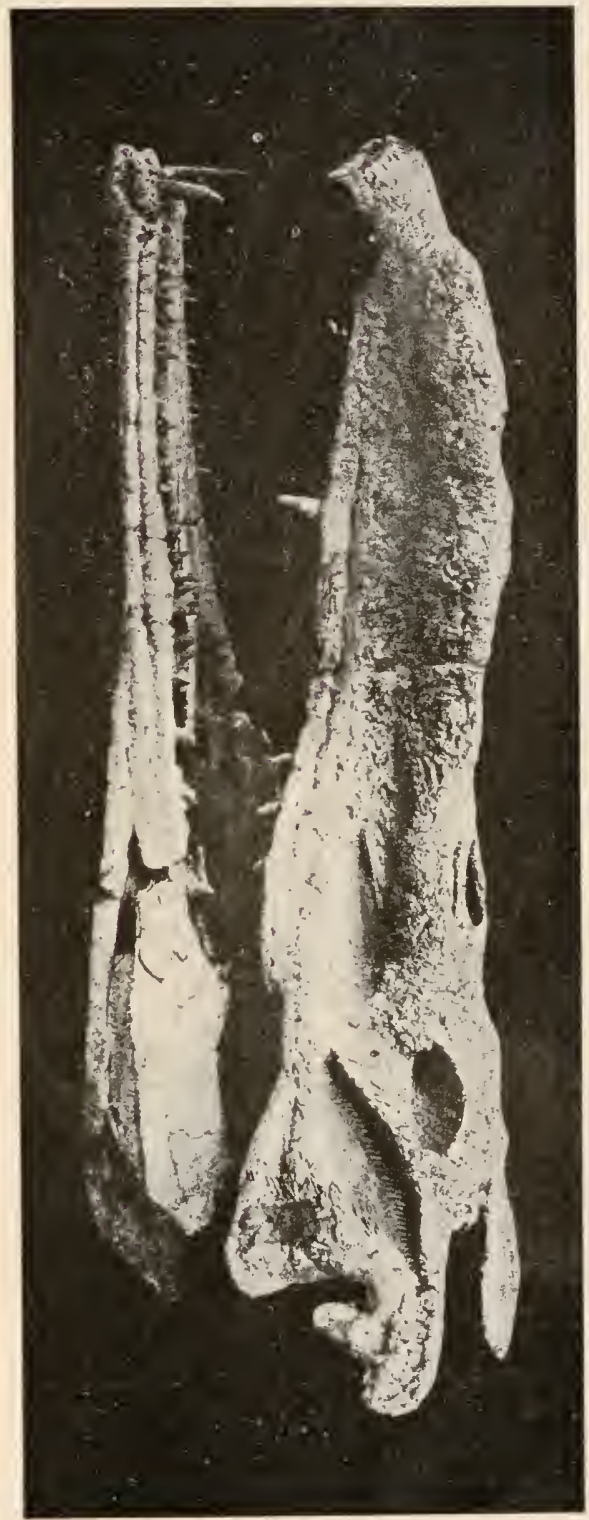

B.

Fig. 413.

A. Seitenansicht des Schädels von Mystriosuchus planirostris, H. v. Meyer, aus der oberen Trias Württembergs (vgl. Fig. 415).

B. Seitenansicht des Schädels von Phytosaurus Kapffi, H. v. Meyer, ebendaher (vgl. Fig. 414 und 412).

Beide Originale im Kgl. Naturalienkabinett zu Stuttgart. (Nach E. Fraas.) 
Mystriosuchus (= Rutiodon). - Keuper Württembergs und der Schweiz; obere Trias Nordamerikas. - Von Phytosaurus hauptsächlich durch die abweichende Bepanzerung verschieden, die auf dem Rücken aus vier Reihen unregelmäßig quadratischer Platten besteht. Die Panzerplatten beider Gattungen sind mit starker, grubiger Skulptur versehen. Während die Platten bei Phytosaurus dachziegelartig übereinander greifen, liegen sie bei der zweiten Gattung nebeneinander. M. planirostris ${ }^{1}$, M. (Rutiodon) carolinensis, M. (R.) manchattanensis ${ }^{2}$ (Fig. 415).

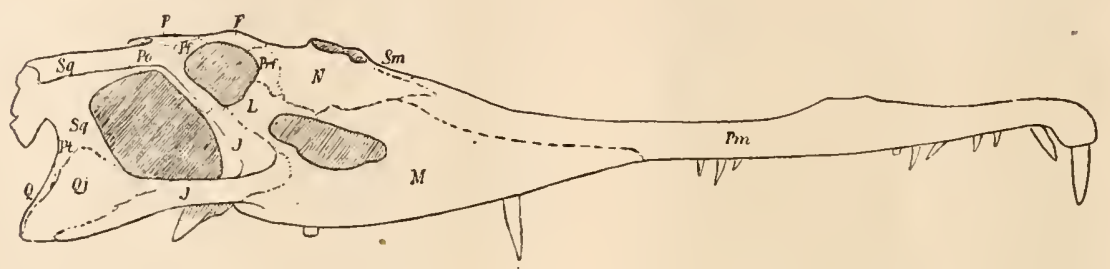

Fig. 414.

Phytosaurus Plieningeri, H. v. Meyer, Schädel von rechts. Aus dem Stubensandstein (obere Trias) von Trossingen in Württemberg. Original in der Universitätssammlung in Tübingen. Ungefähr $1 / 10$ nat. Gr. (Nach F. v. Huene.)

$P m=$ Praemaxillare.

$M=$ Supramaxillare.

$\mathrm{Sm}=$ Septomaxillare.

$N=$ Nasale.

$\operatorname{Prf}=$ Lacrymale.

$L=$ Adlacrymale.

$J=$ Jugale.

Qj = Quadratojugale.

$S q=$ Squamosum.

$P t=$ Pterygoid (auch der unterhalb des Jochbogens unter demBuchstaben $J$ vorspringende Fortsatz ist das $P t)$.

$P_{0}=$ Postorbitale.

$P f=$ Postfrontale.

$P=$ Parietale.

$F=$ Frontale.

(Die kraterförmige Öffnung oberhalb des Buchstabens $N$, hinter dem $S m$, ist die Nasenöffnung.)

Parasuclius. - Trias Ostindiens. ${ }^{3}$

1 Nach E. Fraas besteht die Bepanzerung von Phytosaurus aus zwei medianen Reihen sehr schmaler, aber langer (bis $30 \mathrm{~cm}$ langen) Knochenplatten, die sich mit ihren Längsseiten iiberdecken. Dagegen besteht der Panzer von Mystriosuchus aus vier medianen Reihen subquadratischer Platten von sehr unregelmäßigem Umriß. Dieselbe Anordnung der Platten wie Mystriosuchus zeigt auch ,Rutiodon" aus der Trias Nordamerikas.

Über die Literatur bzgl. Mystriosuchus vgl. die Literatur ïber Phytosaurus.

2 Mc. Gregor, The Phytosauria, usw., 1. c., 1906.

F. von Huene, A New Phytosaur from the Palisades near New York. Bulletin Amer. Mus. Nat. Hist., New York, XXXII, 1913, p. 275.

3 Über die Beziehungen dieser ziemlich fragmentären Reste zu den übrigen Phytosauriden vgl. F. von Huene, Beiträge zur Kenntnis und Beurteilung der Parasuchier, 1. c., 1911, p. 104. 


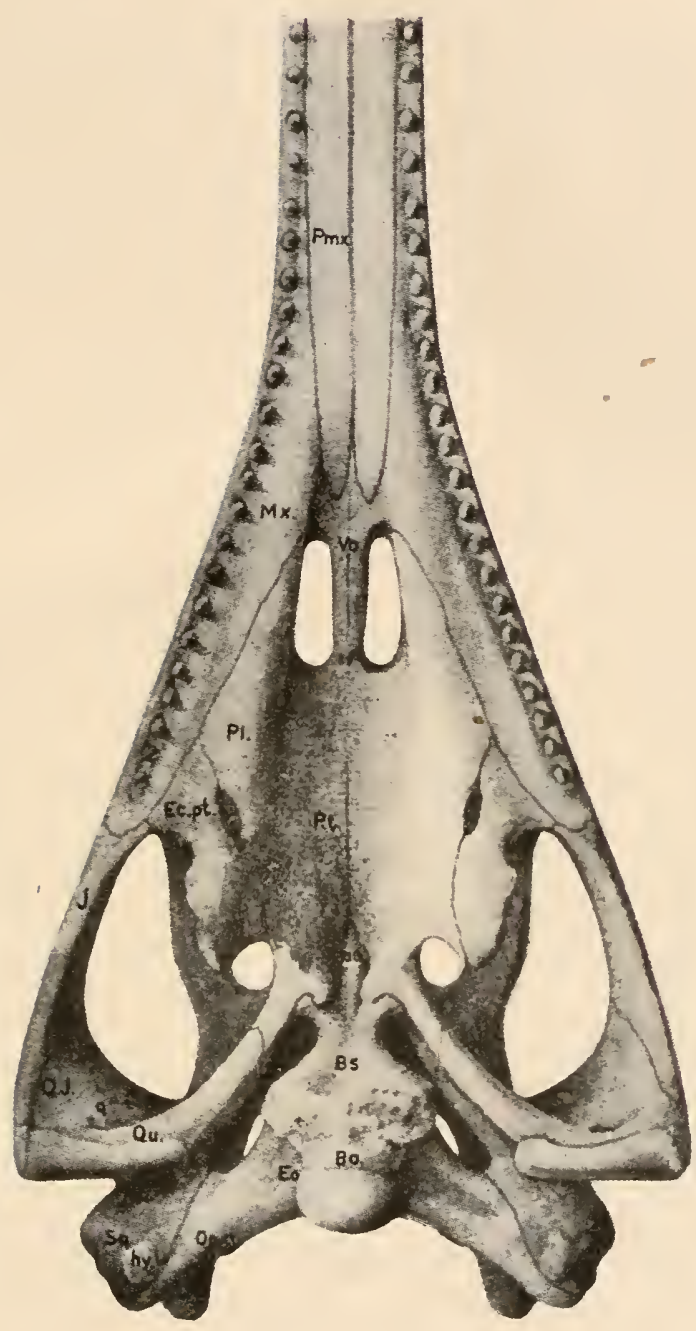

Fig. 415.

Mystriosuchus planirostris, H. v. Meyer; Gaumenansicht des Schädels (ohne Schnauzenende). Aus dem Stubensandstein (obere Trias) von Württemberg. (Nach Mc Gregor, 1906.)

Bo = Basioccipitale.

$B s=$ Basisphenoid.

Pas (keilförmiger Fortsatz vor $B s$ )

$=$ Parasphenoid.

$P t=$ Pterygoid.

$P l \quad=$ Palatinum.

$E c p t=$ Transversum.

$M x=$ Supramaxillare.
Pmx $=$ Praemaxillare.

$V_{0},=$ Vomer .

$J=$ Jugale.

Qj = Quadratojugale.

$Q \quad=$ Quadratum.

$S q=$ Squamosum.

$E_{0}=$ Exoccipitale.

Opo = Opisthoticum (Paroccipitale). 


\section{Ordnung: Pseudosuchia. ${ }^{1}$}

Die Pseudosuchier stellen eine in phylogenetischer Hinsicht außerordentlich wichtige Gruppe der Reptilien dar. Sie umfassen verschiedene Gattungen, die in Triasablagerungen, vorwiegend in Europa, gefunden worden sind und sich in verschiedene Fanilien gruppieren. Am längsten und besten bekannt ist Aëtosaurus ferratus, der 1875 in einer Gruppe von 24 Individuen auf einer fast 2 qm messenden Schichtplatte des Stubensandsteins (oberer Keuper = oberste Trias) bei Heslach in der Nähe von Stuttgart entdeckt wurde; das größte Exemplar dieser prachtvoll erhaltenèn Tiere erreicht $86 \mathrm{~cm}$ Körperlänge. Später sind in der Trias von Elgin in Schottland sowie in der Trias der Kapkolonie, endlich auch in Nordamerika weitere Reste von verschiedenen Pseudosuchiern entdeckt worden.

Wie F. v. Huene gezeigt hat, ist die Ordnung der Pseudosuchier als die Stamngruppe einer Reihe weiterer Äste des Reptilienstammes anzusehen, die eine große Bedeutung erlangt haben. Als Nachkommen der Pseudosuchier sind, wie die morphologischen Vergleiche ergeben, die Dinosaurier und Ornithischier, die Pterosaurier, Krokodile und Vögel anzusehen. Die Parasuchia sind mit ihnen nahe verwandt, dürften aber schon früher abgezweigt sein und mit den Pseudosuchiern in einer gemeinsamen Wurzel zusammenlaufen. Es ist kaum anzunehmen, daß die Divergenz aller dieser Äste erst in der Triaszeit erfolgt ist; die Pseudosuchier sind aller Wahrscheinlichkeit nach schon mit den wesentlichen Merkmalen dieser Entwicklungsstufe in Perm vorhanden gewesen und die Abzweigung der Dinosaurier fällt sicher in eine frühere Zeit als die Triasformation.

Wenn wir die Aëtosauriden mit den Phytosauriden vergleichen, so sehen wir, daß zwischen diesen beiden Gruppen, abgesehen von den aquatischen, einseitigen Anpassungen der Pliytosauriden, keine durchgreifenden Unterschiede bestehen. Man könnte daher die Pseudosuchier und die Parasuchier, wie dies in letzter Zeit von G. Heilmann (1916) und von F. von Nopcsa (mündliche Mitteilung) angcnommen wird, in eine einheitliche Gruppe, in die der „Parasuchier“ zusammenfassen. lch möchte jedoch an der Unterscheidung beider Gruppen festhalten und in den „Parasuchiern“ die an das Wasserleben, in den "Pseudosuchiern" die an das Landleben angepaßten Stämme zusammenfassen, die zwar aus einer gemeinsanen

1 Huene betrachtet die Pseudosuchier als die Ahnengruppe der ,Archosaurier". Unter dem Begriff der „Archosaurier“ werden die Saurischier, Ornithischier, Pterosaurier, Krokodile und Vögel von F. v. Huene (1914) zusammengefaßt. Diese Gruppierung ist hier nicht angewendet. 
Wurzel entsprossen sind, aber frühzeitig divergente Entwicklungsbahinen eingeschlagen haben.

Die wesentlichsten Kennzeichen des Schädels, der von Aëtosaurus, Euparkeria und Ornithosuchus gut, von Scleromochlus und Stegomus nur mangelhaft bekannt ist, bestehen im Vorhandensein einer größeren Zahl von Durchbruchsöffnungen des Schädeldaches. Außer den äußeren Nasenöffnungen und den Augenhöhlen findet sich zwischen diesen beiden Öffnungen jederseits eine sehr große Präorbitalgrube, die bei Scleromochlus und Aëtosaurus kleiner ist als die Augenhölle, bei Ornithosuchus aber die Augenhöhle beträchtlich an Größe übertrifft. Entweder sind beide lateralen Schläfengruben, die verschiedene Größe besitzen (z. B. ist bei Aëtosaurus die obere, bei Scleromochlus die untere größer) getrennt oder sie fließen infolge Reduktion der liauptsächlich vom Postorbitale gebildeten Grenzspange in eine einzige Öffnung zusammen (z. B. bei Ornithosuchus). Die ehemaligen Unrisse der oberen und der unteren Temporalgrube sind aber auch hier wenigstens in groben Zügen noch $\mathrm{zu}$ erkennen. Der Unterkiefer trägt an der Außenseite eine große Öffnung, wie sie auch bei den Krokodilen auftritt.

Einzelheiten des Schädels von Aëtosaurus ferratus sind noch immer nicht genügend aufgeklärt. Namentlich ist die Frage offen, welches der beiden Knochenstücke inı Bereiche der äußeren Nasenöffnung als das Septomaxillare zu deuten ist, das am Oberende der Nasenöffnung liegende oder das weiter vorn sichtbare Knochenstückchen. Daß ein Supraorbitale, wie es O. Fraas seinerzeit für Aëtosaurus angenommen hatte, fehlt, hat v. Huene (1914) gezeigt. Eine auffallende Eigentümlichkeit des Aëtosaurenschädels sind die großen Nasalia und die sehr kleinen, verkümmerten Praemaxillaria; die gleichen Verhältnisse sind bei Stegomus zu beobachten. Beiden Gattungen fehlt ein Parietalforamen. Dagegen weisen die Schädel sowie die übrigen Skeletteile der Proterosuchiden, Ornithosuchiden und Scleromoclıliden gegenüber Aëtosaurus wesentliche Unterschiede auf. Besonders eigenartig ist die Spezialisation der Gliedmaßen von Scleromochlus, die unverkennbar als Sprungbeine funktionierten! Huene vermutet, daß Scleromochlus ein Fallschirmıeptil war, das auf Bäumen lebte. Die Ähnlichkeit zwischen Scleromochlus und der lebenden arborikolen Agamidengattung Otocryptis ist in der Tat eine so auffallende, daß wir eine analoge Lebensweise auch für den fossilen Pseudosuchier Scleromochlus annehmen dürfen.

Die-Lebensweise der verschiedenen Gattungen der Pseudosuchier ist, wie aus den Körperformen und der Gliedmaßengestalt der bisher näher bekannten Gattungen zu erschließen ist, ziemlich verschiedenartig gewesen. Aëtosaurus scheint von langschnauzigen, phytosaurier- 
ähnlichen Vorfahren abzustammen und die aquatische Lebensweise mit einer terrestrischen vertauscht zu haben, während Stegomus noch ein halbaquatisches Tier gewesen zu sein scheint; Ornithosuchus ist wohl eine terrestrische Type gewesen, ebenso wie Euparkeria.

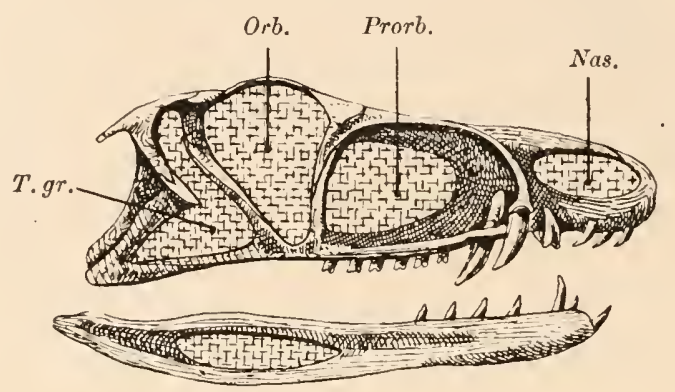

Fig. 416.

Rekonstruktion des Schädels von Ornithosuchus Woodwardi, E. T. Newton, aus der mittleren Trias von Elgin (Schottland) in $1 / 2$ nat. Gr.

(Nach E. T. Newton, 1894.)
$T . g r .=$ die beiden miteinander ver $-O r b .=$ Orbita. schmolzenen Temporalgruben Prorb. = Präorbitalöffnung. (obere und untere). Nas. = Nasenöffnung.

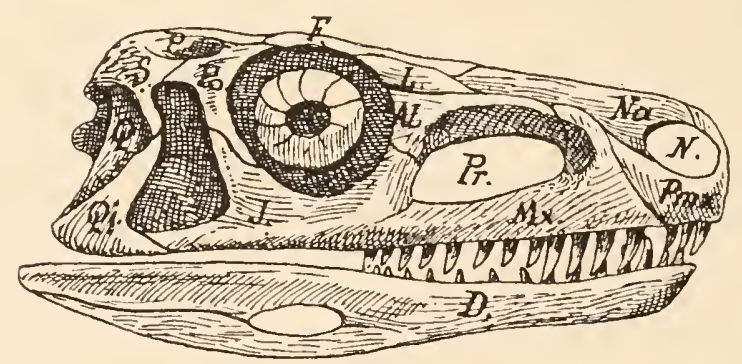

Fig. 417.

Euparkeria capensis, Broom, ein Pseudosuchier aus der Trias der Kapkolonie. Schädel von rechts gesehen. (Nach R. Broom, 1913, umgezeichnet von G. Heilmann, 1916.)
Al. = Adlacrymale.
$\mathrm{Na} . \quad=$ Nasale.
D. $\quad=$ Dentale.
F. $\quad=$ Frontale
$P . \quad=$ Parietale
J. = Jugale.
L. = Lacrymale.
$P m x$. = Praemaxillare.
$M x$. = Supramaxillare
N. $=$ Naris.
Po. $\quad=$ Postorbitale.
Pr. = Präorbitalöffnung.
Q. $\quad=$ Quadratum.
Qj. $\quad=$ Quadratojugale.

\section{F. Proterosuchidae.}

Proterosuchus. - Trias der Kapkolonie. - Durch die Bezahnung der Vomeres und Pterygoidea erweist sich die Gattung in dieser Hinsicht sehr primitiv. Die Zälnne stehen am Innenrande des Ober- 
kiefers (wie bei Scleromochlus, Erpetosuchus, Ornithosuchus). Die Orbita wird unten durch das Jugale begrenzt. Ein großer Präorbitaldurchbruch ist vorhanden. Die große Öffnung an der Außenfläche des Unterkiefers fehlt. Ein Complementare fehlt. ${ }^{1}$

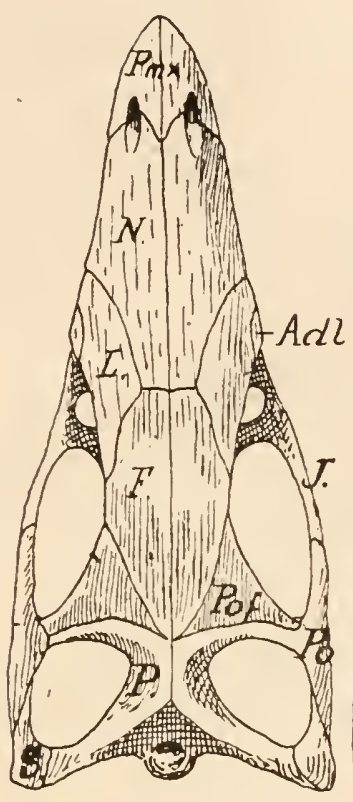

A.

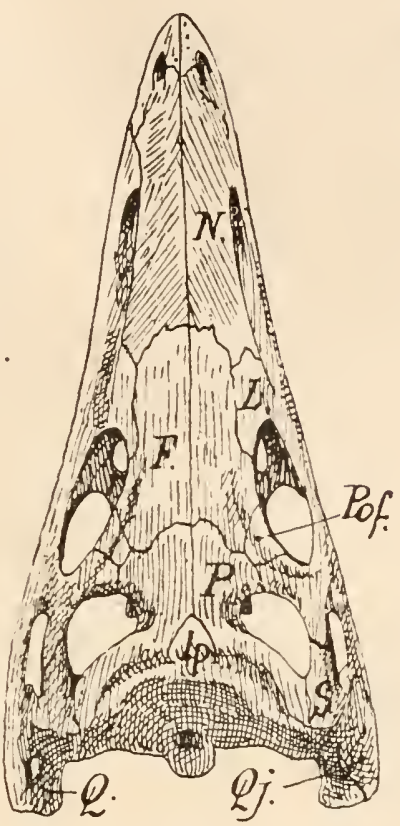

B.

Fig. 418 .

Oberansicht des Schädels (rekonstruiert), A: von Anchisaurus colurus, Marsh (Trias Nordamerikas) und B: von Euparkeria capensis, Broom (Trias der Kapkolonie). Beide Schädel auf dieselbe Länge reduziert, ım den Vergleich der Knochengrenzen zu erleichtern. (Nach G. Heilmann, 1916.)

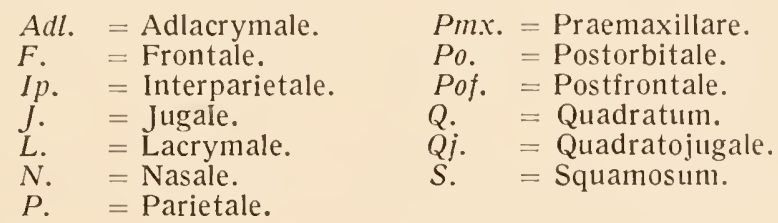

Erpetosuchus. - Mittlere Trias von Lossiemouth bei Elgin (Schottland). - Sehr ähnlich der vorigen Gattung. Zwei Paar Schläfenlöcher vorhanden; obere rundlich, untere dreieckig, Präorbitalöffnung groß.

1 R. Broom, On a New Reptile (Proterosuchus Fergusi) from the Karroo Beds of Tarkastad, S. Afr. - Annals of the South African Mus., Vol. IV, 1904, p. 159. 
Choanen weit vorn. Der Rücken ist nit zwei Plattenreihen ähnlich wie bei Aëtosaurus gepanzert. ${ }^{1}$

\section{F. Ornithosuchidae.}

Euparkeria. - Trias der Kapkolonie. - Ein wohl erhaltener Schädel sowie einige andere Skeletteile (z. B. Becken) bekannt. Im Schädel (Fig. 417, 418), der massiver gebaut ist als jener von Ornithosuchus (Fig. 416), fällt das gerundete Schnauzenprofil auf. Die beiden

A.

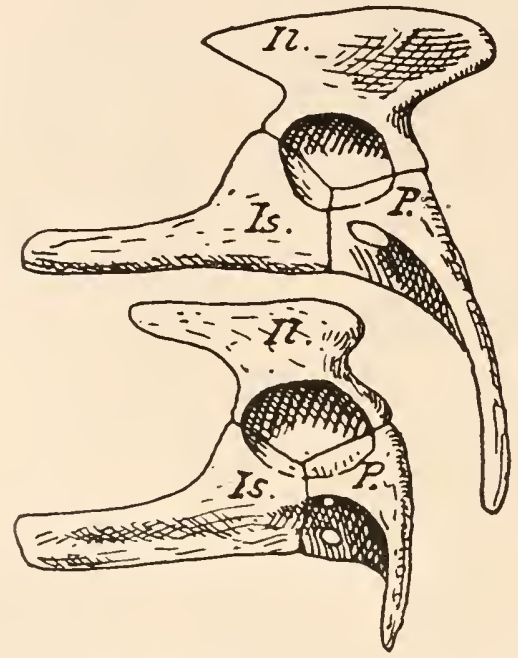

Fig. 419.

Rechte Beckenhälfte zweier Pseudosuchier. A: Ornithosuchus Woodwardi, E. T. Newton (mittlere Trias von Elgin, Schottland) und B: Euparkeria capensis, Broom (Trias der Kapkolonie), beide von außen gesehen. (Nach G. Heilmann, 1916.)

$$
\text { Il. = Ilium. } \quad P \text {. = Pubis. } I s .=\text { Ischium. }
$$

Temporalgruben sind noch getrennt, die Präorbitalöffnung groß; das Auge ist durch einen Sklerotikalring geschützt. Das Becken (Fig. 419)

1. Das geologische Alter der Stagonolepisschichten von Lossiemouth bei Elgin entspricht nach Huene der deutschen Lettenkohle und ist daher als mittlere Trias zıl bezeichnen.

F. von Huene, Eine Zusammenstellung über die englische Trias und das Alter ihrer Fossilien. - Centralbl. f. Min. usw., 1908, S. 9.

Derselbe, Über die reptilfiihrenden Sandsteine bei Elgin in Schottland. Ibidem, 1913, S. 617.

Über Erpetostuchus vgl. E. T. Newton, Reptiles from the Elgin Sandstone. Description of two new Genera. - Plilosophical Transact. Roy. Soc. London (B), Vol. 185, 1894, p. 573.

F. von Huene, Beiträge zur Geschichte der Archosaurier. - Geol. und Paläont. Abhandl. (N. F. Bd. X111), G. R. Bd. XVIl, 1914 (Literatur). 
erimnert in der allgemeinen Form, namentlich aber durch die Rückwärtskrümmung des Pubis in auffallender Weise an das Becken der Ornithopoden, ebenso wie das Becken von Ornithosuchus, und ist deshalb von besonderer Bedeutung für die Frage nach den Verwandtschaftsbeziehungen zwischen den Pseudosuchiern, Ornithischiern und Dinosauriern. ${ }^{1}$ (Fig. $\left.417,418,419.\right)$

Ornithosuchus. - Mittlere Trias von Lossiemouth bei Elgin (Schottland). - Die Choanen weit nach hinten geschoben. Schnauze vorn in Profil abgerundet. Sehr große Präorbitaldurchbrüche vorhanden. Obere und untere Temporalgrube miteinander verschmolzen. Rücken mit zwei Reihen Panzerplatten, deren Längsachse nicht quer zur Körperachse steht wie bei den Proterosuchiden und Aëtosauriden, sondern parallel zur Körperachse verläuft; ilıre Form ist fast quadratisch. ${ }^{2}$ (Fig. 416, 419.)

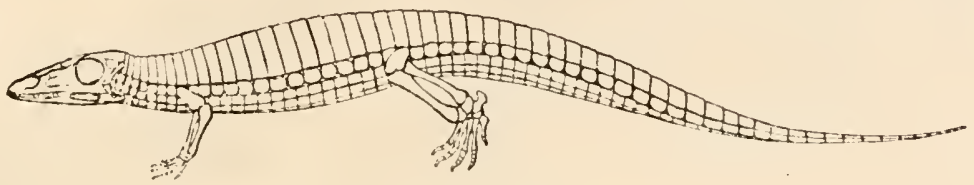

Fig. 420 .

Rekonstruktion von Aëtosaurus ferratus, O. Fraas, aus dem Keuper Württembergs; Panzer der Gliedmaßen weggelassen. (Nach O. C. Marsh, 1896.)

\section{F. Aëtosauridae.}

Aëtosaurus. - Oberste Trias Württembergs. - Inı Schädel fällt die spitz zulaufende Schnauze auf, in der die Praemaxillaria rudimentär sind; die Septomaxillaria scheinen vorhanden zu sein. Die äußeren Nasenöffnungen sind lang und schmal. Zwischen ihnen und den Augenhöhlen liegen Präorbitalöffnungen. Ein Paar oberer und ein Paar unterer Temporalgruben vorhanden. Lacrymale kleiner als das Adlacrymale. Nasalia auffallend groß und lang, bis zur Scluauzenspitze reichend; die Länge der Nasalia in Verbindung mit der Reduktion der Praemaxillaria scheint für eine sekundäre Verkürzung der Schnauze zu sprechen. Das Parietalforamen fehlt. Der Rücken ist mit zwei Längsreihen von großen Knochenplatten gepanzert, deren Längsachse quer

1 R. Broom, On the South African Pseudosuchian Euparkeria and allied Genera. - Proceed. Zool. Soc., London 1913, Vol. II.

G. Heilmann, Fuglenes Afstamning. - Kjöbenhavr, 1916, p. 342-354.

2 E. T. Newton, Reptiles from the Elgin Sandstone. - I. c., 1894.

F. von Huene, Beiträge zur Geschichte der Archosaurier. - 1. c., p. 14.

R. Broom, Proceed. Zool. Soc. London 1913. 
zur Körperaclıse verläuft; die Körperflanken trugen kleinere Panzerplatten, ebenso der Bauch. Die Zehen des Hinter- und Vorderfußes waren bekrallt, beide Gliedmaßen fünfzehig, aber die fünfte Zehe trägt nur rudimentäre Phalangen. Der Körper besaß Eidechsenform; die Wirbelsäule umfaßt 28 Präsakralwirbel und 2 Sakralwirbel, sowie eine

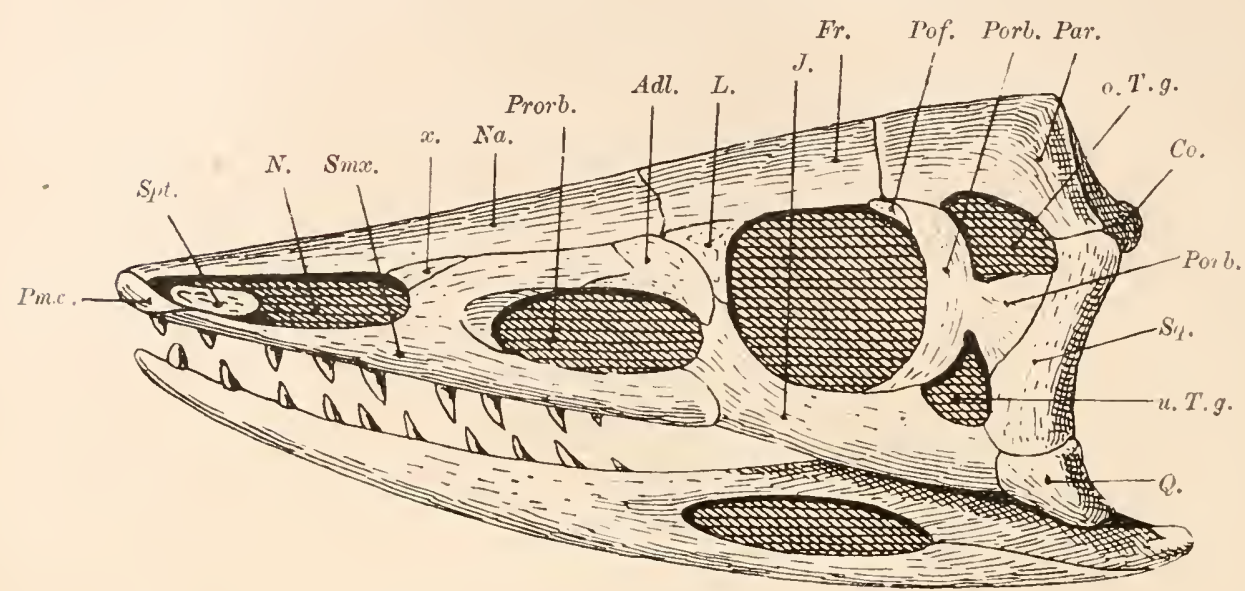

Fig. 421.

Rekonstruktion des Schädels von Aëtosaurus ferratus, O. Fraas, aus dem Keuper (obere Trias) von Heslach bei Stuttgart. Etwa nat. Gr. (Neue Rekonstruktion nach den Originaleı in Stuttgarter Naturalienkabinett unter Beniutzung der Zeichnungen von F. von Huene, 1914.)

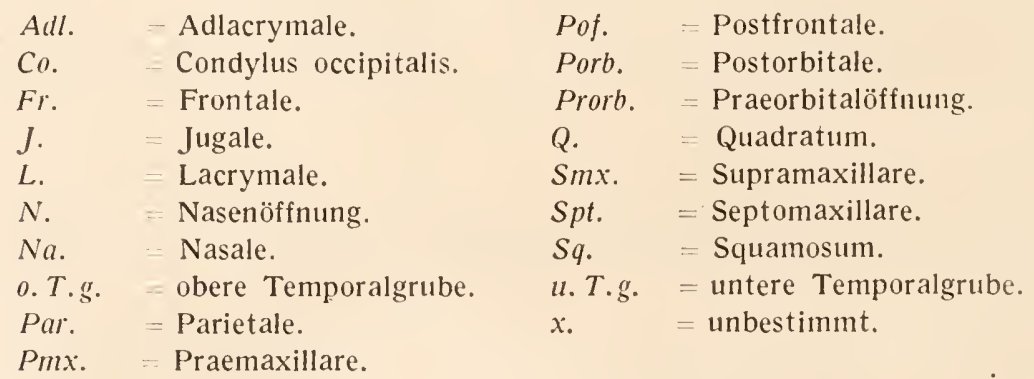

größere Zalıl Schwanzwirbel. Eine Art mit besonders breitem Schwanz wurde von E. Fraas (1907) als A. crassicauda beschrieben.

Eine Eigentümlichkeit der Wirbel von Aëtosaurus besteht in der ungewöhnlich starken Ausbildung der Querfortsätze der Schwanzwirbel, die rippenartig gebogene Spangen darstellen. Diese sonst bei den Reptilien unbekannte Erscheinung dürfte mit der schweren Bepanzerting und der trotz derselben großen Beweglichkeit des Tieres in ursächlichem Zusammenhang stehen, da die Schwanz- und Rumpfnuskeln 

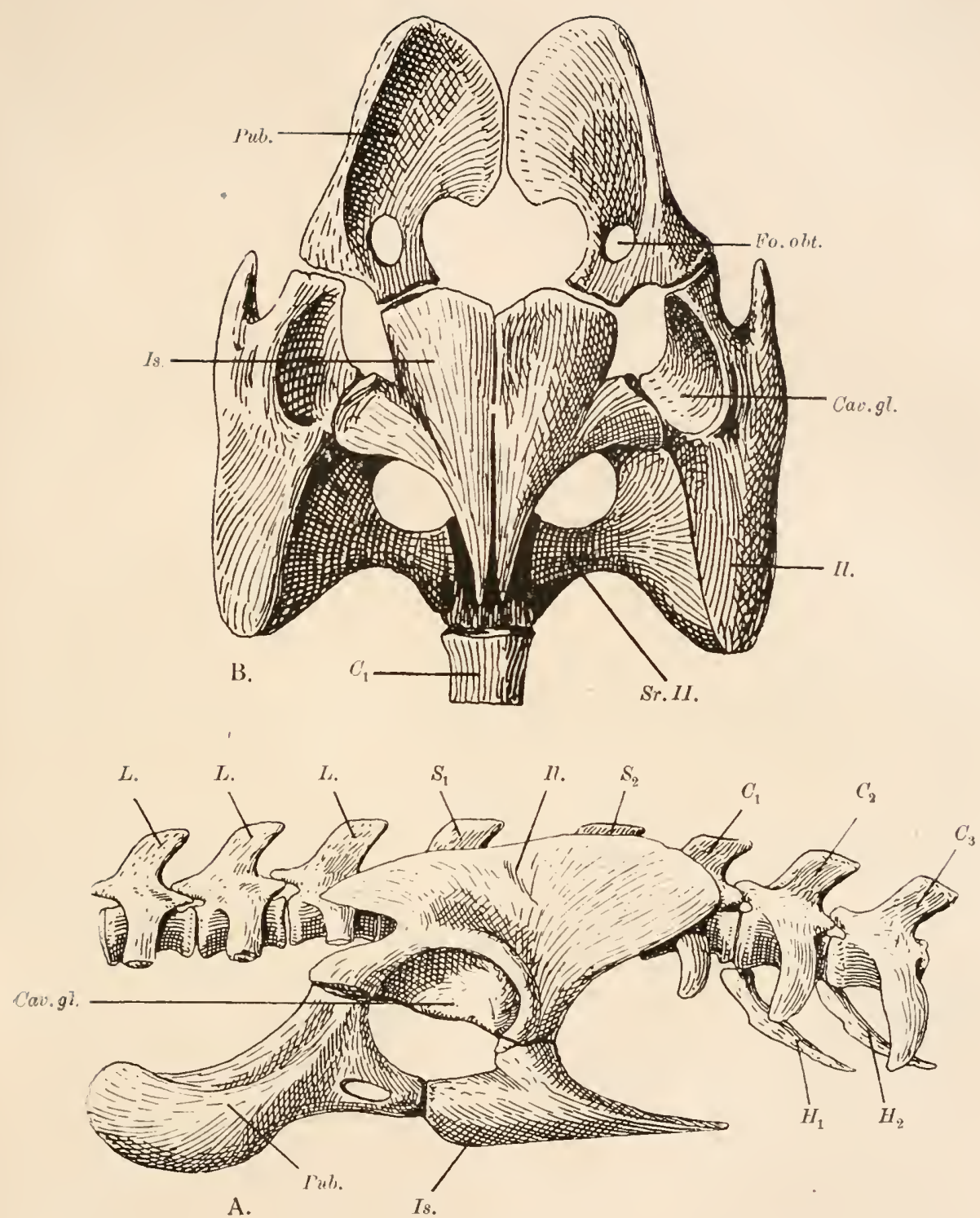

Fig. 422.

Das Becken und die anschließenden Teile der Wirbelsäule von Aëtosaurus crassicauda, E. Fraas, aus dem oberen Stubensandstein (obere Trias) von Pfaffenhofen in Wirttemberg; A: von der linken Seite, B: von unten gesehen. Nat. Gr. (Nach E. Fraas, 1907.)
L. Lendenwirbel.
$S_{1}, S_{2}=$ Sakralwirbel.
$C_{1}, C_{2}, C_{3}=$ Caudalwirbel.
Cav.gl. = Gelenkpfanne für das Femur.
Sr. II. = zweite Sakralrippe.
Fo.obt. = Foramen obturatorium.
$\begin{array}{ll}\text { Il. } & =\text { Ilium. } \\ \text { Pub. } & =\text { Pubis. }\end{array}$
Is. $\quad$ Istorium
$H_{1}, H_{2}=$ Haemapophysen. 
an den starken Querfortsätzen ihre Stützpunkte finden. Das Becken ist von A. crassicauda gut bekannt. ${ }^{1}$ (Fig. 420-422.)

Stegomus. - Newark. Red Sandstone (Trias) von New Haven, Connecticut. - Außer dürftigen Schädel-; Gliedmaßen- und Wirbelresten die Abdrücke der Rücken- und einiger Seitenśchilder bekannt, die mit Aëtosaurus nahe übereinstimmen. ${ }^{2}$

Dyoplax. - Keuper Württembergs. ${ }^{3}$

\section{F. Scleromochlidae.}

Scleromochlus. - Mittlere Trias von Lossiemouth bei Elgin (Schottland). - Das kleine Tier, von dem mehrere Exemplare bekannt sind, die uns heute eine Rekonstruktion auf breiterer Grundlage ermöglichen, als dies A. Smith Woodward (1907) möglich war ${ }^{4}$, fällt durch die ungewöhnliche Länge der Gliedmaßen auf, die das Reptil zu einem Springtier stempeln. Sehr auffallend ist die Länge der Arme, die Huene (1914) als Zeichen für ein arborikoles Kletterleben betrachtet. ${ }^{5}$ Der verhältnismäßig große Schädel besitzt eine obere kleine und eine untere große Schläfenöffnung; die größte Öffnung des Sclıädels ist die Augenhöhle, vor der eine große, nur durch eine schmale Brücke von der Orbita getrennte Präorbitalöffnung liegt. Vor dieser ist die vordere Nasenöffnung zu ergänzen. Die Kiefer sind, wie Huene nachwies, bezahnt gewesen. Hals und Rumpf sind kurz, der Schwanz sehr lang. Das Tier war ein Sohlengänger; die fünfte Zehe ist verkürzt, die übrigen Zehen sind sehr stark verlängert, auch die zu ihnen gehörenden Metatarsalia. Tibia und Fibula sind sehr schlank und liegen dicht aneinander. Die Unterarmknochen sind gleichfalls sehr schlank und lang.

1 O. Fraas, Aëtosaurus ferratus Fr., die gepanzerte Vogelechse aus dem Stubensandstein bei Stuttgart. - Jahreshefte des Vereins f. Vaterl. Naturkunde in Württemberg, XXXIII. Bd., 1877, p. 1.

O. C. Marsh, The Dinosaurs of North America. - XVI. Annual Report of the U. S. Geological Survey, Washington 1896, p. 231.

O. Jaeke I, Die Wirbeltiere. - Berlin 1911, p. 164 (Rekonstruktion des Scluädels).

F. von Huene, Beiträge zur Geschichte der Archosaurier, I. c., p. 18.

E. Fraas, Aetosaurus crassicauda n. sp. nebst Beobachtungen ïber das Becken der Aetosaurier. - Jahresh. des Ver. f. Vaterl. Naturk. in Württemberg, 1907, p. 101.

2 O. C. Marsh, A new Belodont Reptile (Stegomus) from the Connecticut River Sandstone. - Amer. Journ. Science, Vol. II, 1896, p. 59.

K. B. Emerson and F. B. Loomis, Stegomus longipes, a New Reptile from the Triassic Sandstones of the Connecticut Valley. - Ibidem, 1904, p. 377.

F. von Huene, Beiträge zur Geschichte der Archosaurier, I. c., p. 17.

${ }^{3}$ O. Fraas, Dyoplax arenaceus, ein neuer Keupersaurier. - Jahreshefte d. Ver. f. Vaterländ. Naturkunde in Württemberg, XXIII, 1867, S. 108.

4 A. Smith Woodward, On a New Dinosaurian Reptile (Scleromochlus Taylori, gen. et spec. nov.) from the Trias of Lossiemouth, Elgin. - Quart. Journ. Geol. Soc., London, Vol. LXIII, 1907, p. 140.

${ }^{5}$ F. von Huene, Beiträge zur Geschichte der Archosaurier, I. c., p. 4. 
Auffallend ist die große Länge des Unterarmes (vgl. Fig. 423). Die kleine Hand war nit scharfen Krallen bewehrt und die Finger wurden gespreizt gehalten. Die Gesamtanpassung des Reptils erinnert in lohem Grade an den Habitus von Otocryptis bivittata (ein springender, arborikoler Agamide von Ceylon). ${ }^{1}$ Die Reduktion der fünften Zelıe sowie die Gesantverhältnisse der Gliedmaßen sind fast genau dieselben. Ich meine daler, daß wir nicht gezwungen sind, für Scleromochlus eine fallschirmtierartige Lebensweise anzunelmmen, wemn auch aus analog gebauten Typen Fallschirmreptilien sehr leicht entstehen komnten. Scleromochlus Taylori (nur eine Art bekannt) Fig. 423).

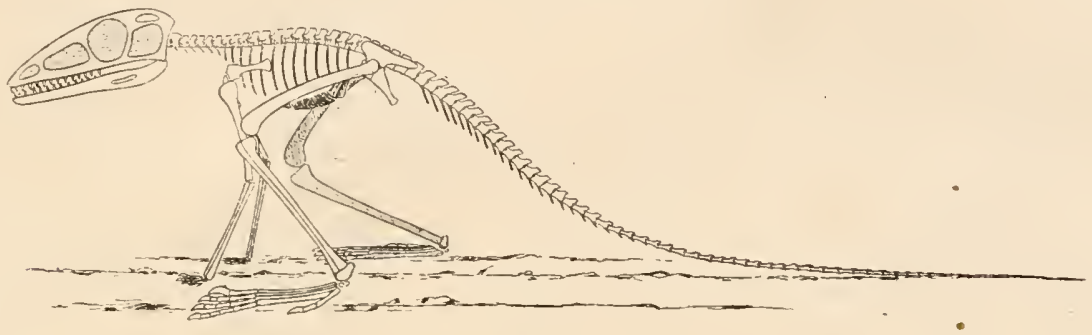

Fig. 423.

Rekunstruktion von Scleromochlus Taylori, A. S. Woodward, aus dem Stagonolepissandstein (mittlere Trias) von Lossiemouth bei Elgin (Schottland). Ungefähr 1/. nat. Gr. (Nach F. von Huene, 1914.)

\section{Ordnung: Crocodilia.}

Die Krokodile bilden eine sehr einseitig spezialisierte Ordnung der Reptilien, die nur einen geringen Formenschatz umfaßt und deren Spezialisationen sich in relativ sehr engen Grenzen bewegen. Sie besitzen sämtlich die Körperform, die vom Nilkrokodil allgemein bekannt ist und die Unterschiede kommen äußerlich fast nur in der verschiedenen Länge der Schnauze und in der verschiedenen Länge des Schwanzes zum Ausdruck. Die überwiegende Mehrzahl der Krokodile der Vorzeit war an das Leben in Sümpfen, Strömen und Seen, also an das Leben im Sülßwasser angepaßt und eine ausgesprochen marine Lebensweise ist nur bei den erloschenen Familien der Teleosauriden und der Geosauriden nachweisbar, welche im allgemeinen Bau des Körpers und der Schädelform Älınlichkeiten mit den Parasuchiern aufweisen, aber von diesen durch tiefgreifende morphologische Gegensätze weit verschieden sind.

Die wichtigsten Kennzeichen der Krokodile bestehen in der Lage der äußeren Nasenlöcher und ihrer Verschmelzung ${ }^{2}$ am vorderen

1. O. Abel, Grundzïge der Paläobiologie der Wirbeltiere. - 1912, S. 217.

2 In einigen Fällen (z. B. bei Geosaurus suevicus und auch bei einzelnen lebenden Krokodilen) kann die Nasenhöhle durch zwei Zapfen der Praemaxillaria, die in der 
Schnauzenende, selbst bei den langschmauzigen Teleosauriden, Geosauriden und Gavialiden; die inneren Nasenlöcher sind weit nach linten verschoben, und zwar kommt diese Verlagermng dadurch zustande, daß die Supramaxillaria und Palatina unter den ursprïnglich weit vorn liegenden Choanen ein Dach bilden, so daß ihre Ausmündung an das Hinterende dieses sekundären Gaumens zu liegen kommint (Fig. 424). Diese Art der Daclıbildung unter den Choanen ist für die älteren Krokodile bezeichnend und Huxley hat für alle Formen mit dieser Bauart des sekundären Gaumens die systematische Gruppe der ,Mesosuchia“ errichtet; bei den weiter vorgeschritteneren, jüngeren und höler spezialisierten Krokodiliern nehmen jedoch auch noch die Pterygoidea an dem Aufbau des sekundären Gaumens Anteil, so dap bei diesen Gattungen die Choanen noch weiter nach hinten verschoben sind tund in näclıster Nähe des Hinterlauptes in die Mundhöhle ausmünden.

Ebenso kann auch das Verhalten der Präorbitalöffntungen nicht als Merkmal zur Unterscheidung der Fanilien verwendet werden; bei den auf prinitiver Stufe abgezweigten und einseitig an das nektonische Meeresleben angepaßten Teleosanriden sind noch kleine Präorbitalöfnungen vorhanden, bei den Geosauriden fehlen sie, aber bei den Goniopholiden (z. B. bei Notosuchus) sind sie noch vorhanden. Derartige Merkmale geben uns einen Anhaltspunkt zur Feststellung des Zeitpunktes der Abzweigung der einzelnen Fanilien vom Hauptstamme der Krokodilier, aber es sind nur graduelle und keine tiefgreifenden Unterschiede.

Ein scharfer Gegensatz, auf den erst C. W. Andrew's (1913) aufnerksan gemacht hat, besteht dagegen zwischen den Gattungen mit und ohne Transversalforamen. Bei Hylaeochampsa, einem Krokodil aus den Wealden Englands, ist das Transversum von einer sehr großen Öffnung durchbohrt, deren Rudimente bei allen lebenden Krokodilen in Gestalt einer kleinen Durchbohrung des Transversums nachweisbar sind. Bei verschiedenen Gattungen (Pholidosaurus, Bernissartia und Goniopholis) fehlt jede Spur dieser Durchbohrung des Transversums und da sich diese Gattungen in der Bildung des sekundären Gaumens als ,Mesosuchier" verhalten, ist es wahrscheinlich, daß sie überhaupt nicht in die Ahnenreihe der Crocodiliden gehören. Es wird daher geboten sein, die Gattung Hylaeochampsa als prinitive Crocodiliden-

Mittellinie gegencinander wachsen und sich zu einem Kamm verbinden, sekundär in zwei Teile zerlegt werden, so daß die Nasenöfnungen wieder paarig angelegt scheinen. Diese Bildung darf nicht mit der primären Doppelanlage verwechselt werden. Bei den Atoposauriden kommt eine sekundäre Teilung der vereinigt gewesenen Nasenlöcher dadurch zustande, daß sich von den Nasalia Fortsätze in die Nasenöffnung einschieben und diese halbieren. 
Reptilia.

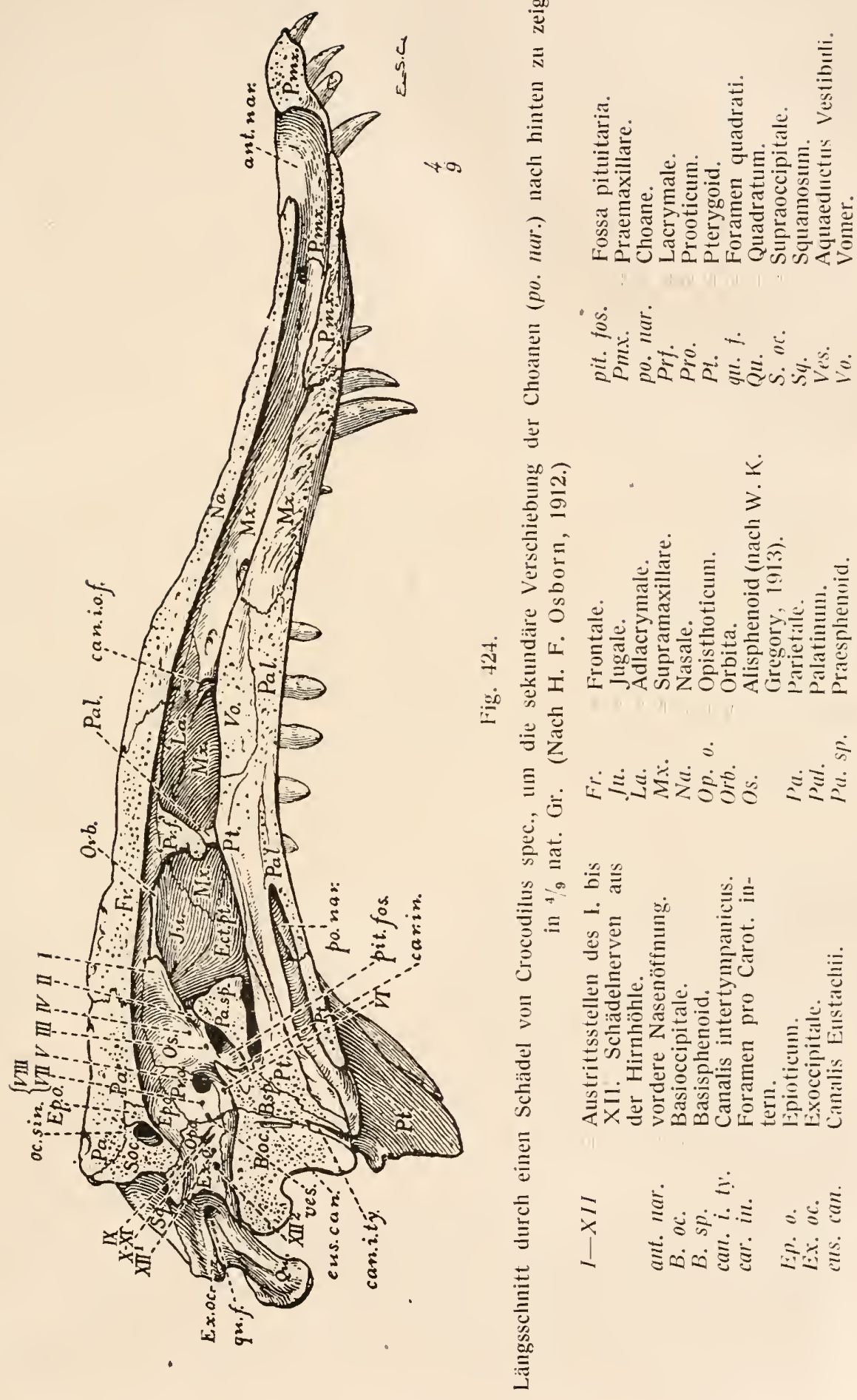


gattung anzusehen und den Begriff der Fanilie „Crocodilidae" entsprechend zu erweitern, während die Formen mit durchaus verschiedenem Băl des Transversums als eine selbständige Gruppe anzusehen sind, welche sich früher vom Hauptstamme abgezweigt hat und auf primitiver Stufe der Gaumenbildung stehen geblieben ist. Diese Gruppe möclıte ich als die Familie der Pholidosauriden bezeichnen und mit den Goniopholiden vereinigen.

Ein Parietalforamen fehlt allen Krokodilen; das Quadratum ist unbeweglich mit den angrenzenden Knochen verbunden.

Fast immer sind zwei Paar ,, lateraler" Schläfengruben vorhanden, von denen die oberen auf dem, namentlich bei den phylogenetisch jüngeren Gattungen quadratisch abgeflachten Schädeldach liegen (Fig.430). Die unteren Schläfenöffnungen sind meist sehr groB, ihre untere $\mathrm{Ab}$ schlußspange ist immer vorhanden. Bei manchen Alligatoren sind die oberen Temporalgruben sekundär verloren gegangen und geschlossen.

Die verschiedene Länge der Schnauze bildet keinen durchgreifenden und systematiscl verwertbaren Unterschied; man hat zwar früher ,Brevirostres" und "Longirostres" zu unterscheiden versucht, ist aber von diesem Gliederungsversuche wieder abgekommen, da mannigfache Übergänge zwischen lang- und kurzschnauzigen Gattungen und Arten bestehen.

Ein wesentliches Kennzeichen aller Krokodilier und zugleich ein fundamentaler Unterschied gegenüber den Parasuchia liegt im Aufbau der Schnauze, die bei den Krokodilen hauptsächlich von den Supramaxillaria gebildet wird, die z. B. bei den langschnauzigen Teleosauriden oder bei den Gavialiden bis nahe an das Vorderende des Schädels reichen, während bei den Phytosauriden die langen Rostren (z. B. bei Plhytosaurus und Mystriosuchus) in der Hauptsache von den enorm verlängerten Prämaxillarien gebildet werden.

Von besonderen Eigentünlichkeiten des Krokodilschädels wären die halbkugeligen Knochenblasen zu erwähnen, welche bei den Gavialen seitlich von den inneren Nasengängen oberluałb des sekundären Gaumens aufsitzen und mit den Gängen kommunizieren. Es scheint sich hier um Luftbehälter zu handelı.

Der Unterkiefer weist die normalen Elemente auf (Dentale, Spleniale, Angulare, Supraangulare, Articulare und Complementare).

In der Wirbelsäule ist die Art der Gelenkverbindung der Rippen mit dem Querfortsatz des Wirbelkörpers sehr eigenartig, denn die Rippe artikuliert sowolıl mit dem Tuberculum als mit dem Capitulum ausschließlich an Querfortsatz. Diese Art der Gelenkverbindung ist schon bei den Teleosauriden (z. B. bei Steneosaurus) zu beobachten. Die Form des Wirbelzentrums ist bei den mesozoischen Gattungen mitunter zylindrisch und mitunter amphicöl, während bei alten jüngeren 
Krokodilen die Wirbelkörper an Vorderende ausgehöhlt (procöl) sind und nur einige Ausnahmen davon innerhalb der Wirbelsäule vorkoṇmen (Atlas, Epistropheus, zweiter Sakralwirbel, erster Kaudalwirbel).

Selır eigentiumlich ist der Aufbau des Beckens der Krokodilier. Das llium ist ein dicker, massiver Knochen, der an seiner lnnenseite mit zwei Sakralwirbeln in Verbindung tritt; die Verbindung wird durch zwei Paar Sakralrippen ${ }^{1}$ bewerkstelligt. Unten tritt es mit dem Ischium und Pubis in Verbindung und alle drei Elemente beteiligen sich an der Bildung des Acetabulums. Zwischen ihnen liegt das Foramen acetabuli. Das niit dem Ischium verschmolzene Pubis ist hochgradig reduziert und besteht aus unverknöchertem Knorpel. Der gewöhnlich als „Pubis" gedeutete Knochen ist (nach S. H. Reynolds, 1897) ein dem Becken ursprünglich fremdes Element und wird von Seeley als Präpubis, von Reynolds als „Epipubis“" bezeichnet; es erstreckt sich schräg nach vorn und besitzt eine spatelförmige Gestalt.

Huene hat daraus den Schluß gezogen, daß dieser zweifellos selbständige Beckenknochen der Krokodile, der als „Präpubis“ oder „Epipubis" zu bezeichnen ist, als ein Beweis dafür anzusehen ist, daß die Krokodile ein Vorfahrenstadium durchlaufen laben, bei welchem das Pubis, wie z. B. bei den Vögeln, nach hinten gewendet wurde; Huene nimmt geradezu an, daßs die Vorfahren der Krokodile, eine Zeitlang wenigstens, eine bipede Lebensweise wie die Vögel oder Dinosaurier oder Ornithischier gefülırt lıaben. Das Problem der Entstehung des Epipubis scheint mir noch nicht genügend aufgeklärt, um einen

I Die ,Sakralrippen“ sind, wie O. Jaekel (Sitzungsber. d. Ges. naturf. Freunde, Berlin, 1906, S. 9) und F. v. Huene (Anatom. Anzeiger, 33. Bd.i Jena, 1908, S. 378) gezeigt haben, den Querfortsätzen homolog, aber Huene nimmt an, daß dies nur fiir die dorsale Hälfte der Sakralrippen gilt, während ihre untere von „Costoiden“ (d. s. interprotovertebrale Verknöcherungen der oberen Rippenenden) gebildet wird. Die ,Costoide" (der Terminus und seine Definition stammt von P. Albrecht, 1882) sind als Homologa jener Rippenabschnitte anzusehen, aus denen im Laufe der Ontogenese das Capitulum und das Collum costae hervorgehen. Eine Trennung der Costoide von den Rippen habe ich an den Querfortsätzen der hinteren Brtustwirbel bei einigen Zahnwalen (z. B. Eurhinodelphiden, Physeteriden, Ziphiiden) nachweisen künnen, wo sie mit dem Wirbelkörper verschmelzen und die von mir als ,Merapophysen" (= Parapophyse + Costoid) bezeichneten Fortsätze bilden, an denen die einköpfig gewordenen Rippen mit ihrem Tuberculum artikulieren. Bei anderen Zahnwalen trennt sich das Costoid gleichfalls von der Rippe ab, verschmilzt aber als ein nach unten und innen gerichteter Zacken mit der Diapophyse, die in diesem Falle mit dem Tuberculum der Rippe artikuliert; in den zuerst erwähnten Fällen einer Merapophysenbildung wird die Diapophyse rudimentär und ist als funktionsloses Knöpfchen ober der Merapophyse an den Übergangswirbelı nachzuweisen (O. Abel, Sitzungsher. K. Akad. d. Wiss. Wien, 118. Bd., Wien, 1909, S. 247). 
zwingenden Schluß auf die bipede Gangart der Krokodilierahnen zu gestatten. ${ }^{1}$

Eine weitere Eigentünlichkeit der Krokodile liegt in der abnormen Verlängerung der drei proximalen Carpalia (Radiale, Pisiforme, Ulnare).

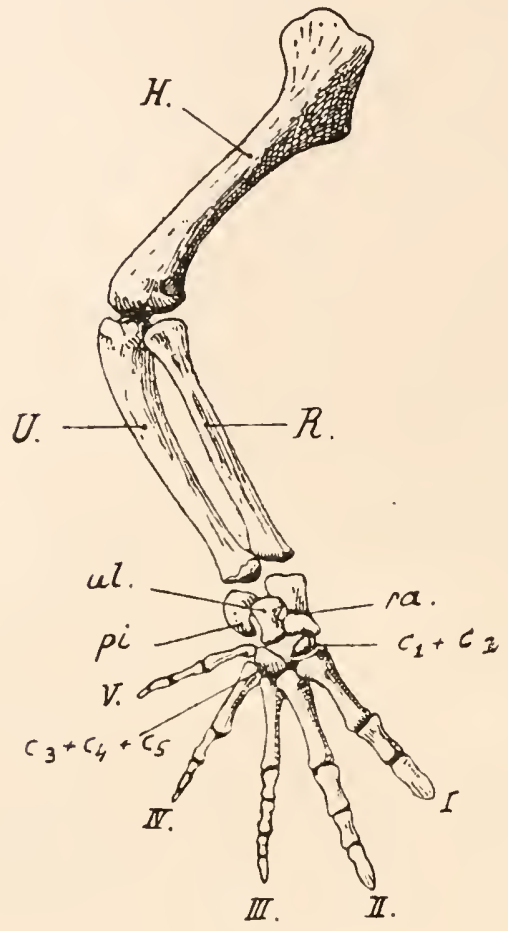

Fig. 425.

Rechtes Armskclett von Caiman latirostris, Dand.; lebend in Siidamerika.

(Nach S. H. Reynolds.)

$\begin{array}{ll}H . & \text { Himerus. } \\ U . & \text { Ulna. } \\ R . & \text { Radius. } \\ u l . & \text { Ulnare. } \\ \text { ra. } & \text { Radiale. } \\ p i . & \text { Pisiforme. } \\ C_{1}+C_{2} & \text { Carpale }(1+2) . \\ C_{3}+C_{1}+C_{5} & \text { Carpale }(3+4+5) .\end{array}$

(Fig. 425.) Huene bringt diese Verlängerung in Verbindung mit der Rückkehr von der bipeden Lebensweise der Vorfahren; nach seiner Meinung wurde der Arm der Krokndilieralnen verkürzt und als die Rückkenr zur tetrapoden Gangart eintrat, wurden die Carpalia verlängert, ım auf diese Weise die ganze Extremität zu verlängern. ${ }^{2}$

Dic Verlängerung der drei proximalen Carpalia der Krokodilland ist zweifellos sekundär entstanden. Sie ist aber, wit mir scheint, eine Folge des Überganges zu der für die Krokodile und für andere aquatische Wirbeltiere aigentünlichen Schwimnbewegung nach Art der Molche (,Molchtypus", Abel). Bei dieser Schwimmart werden die Vorderflossen in anderer Weise als z. B. bei den Walen, Ichthyosauriern usw. also bei den Tieren, die nach denn Torpedotyp gebaut sind, gebraucht. Eine analoge Verlängerung ist im Carpus der Cheloniiden zu beobachten (O. A be l, Paläobiologie, 1912, S. 165). Auch bei den Krokodilen scheint dic mechanische Ursache der Verlängerung der drei proximalen Carpalknochen dieselbe zu sein wie bei den Meeresschildkröten.

1 Es mag daranf hingewiesen werden, daß analoge Bildungen in Becken der lungenlosen Salannander vorkommen, bei denen eine Beziehnng zwischen dem Vorhandensein der Epipubes und der Hautatmung vermutet wird.

${ }^{2}$ F. von Huene, Beobachtungen iiber die Bewegungsart der Extremitäten bei Krokodilen. - Biolog. Centralblatt, XXX111. Bd., Angust 1913, S. 408. F. v. Huene hat ïbersehen, daß ich in meiner "Paläobiologie der Wirbeltiere" (1912, S. 217) die Frage der Lokomotion der Krokodile sowohl auf dem festen Land wie im Wasser (ibidem, S. 133 und 208) erörtert habe. 
Von großer Wichtigkeit für die ganze Frage der Abstamumung der Krokodile und der Lebensweise ihrer Vorfahren scheint mir das Längenverhältnis der Finger der Alligatorhand zu sein, das mit den entsprechenden Verhältnissen in der Hand der primitiven Dinosaurier durchaus übereinstimmit. Ich behalte mir vor, auf diese Frage an anderer Stelle ausfülırlicher zurückzukommen. ${ }^{1}$

Die ältesten Krokodile besitzen ausnahmslos lange Schnauzen und kurzschnauzige Typen treten erst im obersten Jura auf. Ob diese Verkürzung, wie aus der geologischen Verbreitung zu erschließen wäre, eine sekundäre ist, oder ob uns nur einstweilen ältere kurzsclnnauzige Typen unbekannt sind, ist gleichfalls eine noch offene Frage.

Die Krokodile sind ann nächsten mit den Pseudosuchiern verwandt und müssen schon in der Trias die wesentlichen Merkmale der Ordnung besessen haben; ilıre Blüte fällt in die Jura- und Kreidezeit. Die ersten Krokodile treten in Lias auf, doch reicht ihre Geschichte jedenfalls viel weiter, gewiß bis in die Trias zurück. Sie müssen von Formen abstammen, die zwei Paar lateraler Temporalgruben und ein Paar Präorbitalgruben besaßen, also etwa in ähnlicher Weise gebaut gewesen sind wie Aëtosaurus. Die Pseudosuchier gehen auf primitive Rhynchocephalen wie Palaeohatteria oder Protorosaurus zurück und somit sind auch die Wurzeln dés Krokodilstanmes bis zu den Rliynchocephalen zurückzuverfolgen.

\section{F. Teleosauridae.}

Rostrum enorm verlängert, Schädel dadurch dem eines Gavials oder eines Phytosauriers sehr ähnlich. Schnauze fast ausschließliclı vou den Supranaxillaria gebildet, Praemaxillaria selır klein, auf das äußerste Schnauzenende beschränkt. Die Nasalia keilen vorn in den Supramaxillaria aus. Lacrymalia sehr klein, Adlacrymalia grof. Obere Temporalgruben fast quadratisch, groß, Augenhöhlen auf der Oberseite des Sclıädels gelegen, viel kleiner als die Temporalgruben. Mitunter ist eine in Verschwinden begriffene Präorbitalöffnung zu beobachten. Die Vorderfüße sind außerordentlich stark reduziert, die Hand verkümmnert; die Tiere schwanmmen hauptsächlich durch laterale Ruderschläge des kräftigen Schwanzes, unterstützt von Ruderschlägen der Hinterbeine (Molchtypus). Der Körper war (nit Ausnahne von Dyrosaurus) mit starken Knochenplatten gepanzert, welche wahrscheinlich Hornschilder trugen; auf dem Rücken standen zwei bis vier Reihen größerer Platten (Fig. 428), auf den Flanken und dem Bauche viele

1 Die Hand der Krokodile ist bei den verschiedenen Gattungen ziemlich verschieden gebaut; z. B. bestehen zwischen Crocodilus und Alligator bedeutende Gegensätze. 


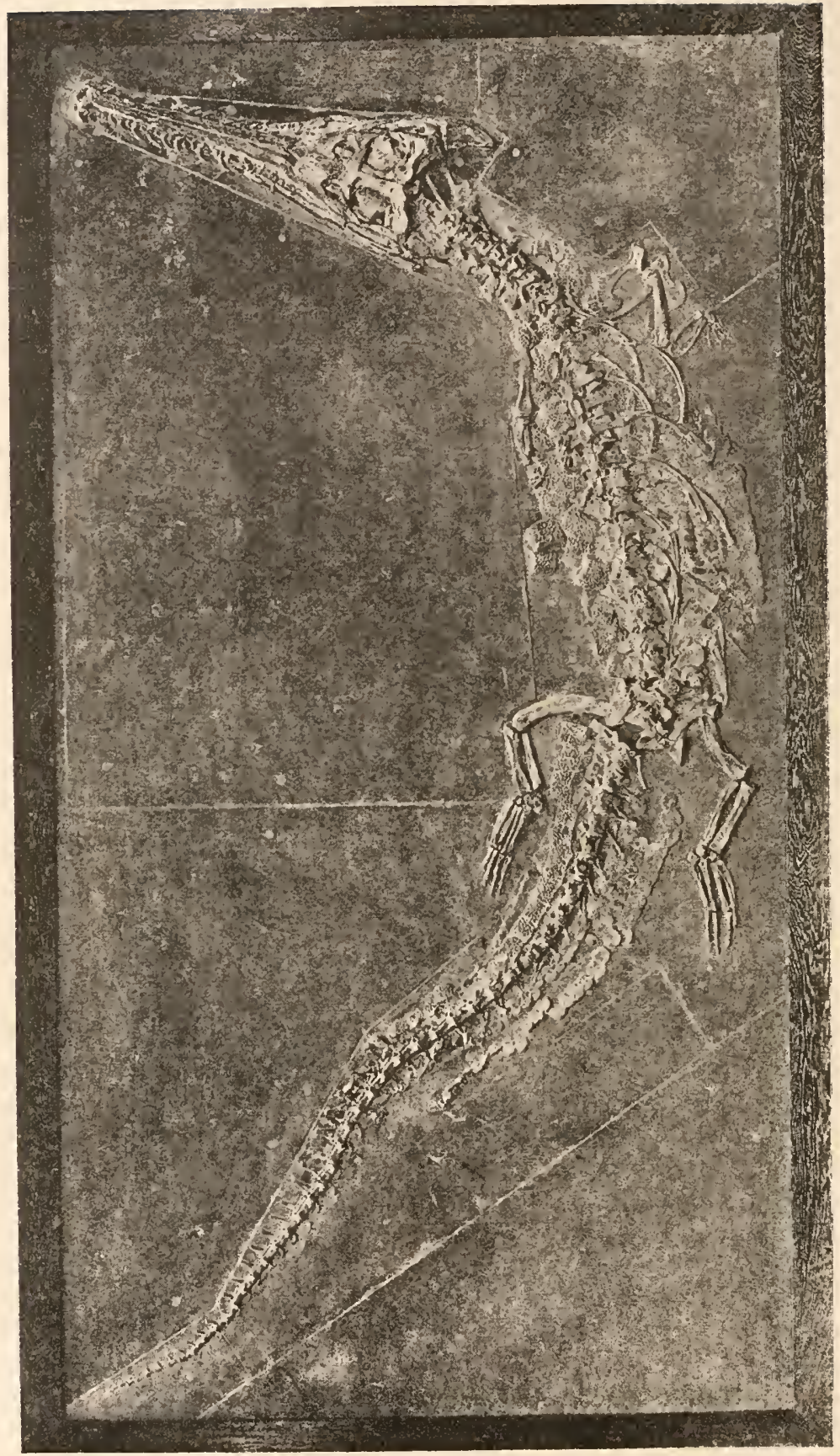

Fig. 426.

Mystriosaurus bollensis, Cuvier, ein Teleosauride aus dem oberen Lias von Holzmaden in Wirttemberg. Original in Senckenberg-Museum zu Frankfurt a. $M$. Stark verkleinert. - (Nach F. Drevermann.) 
Reihen kleinerer Platten. Die Tiere dürften ausschließliche Meeresbewohner gewesen sein und sich höchstens am Strande nach Art der

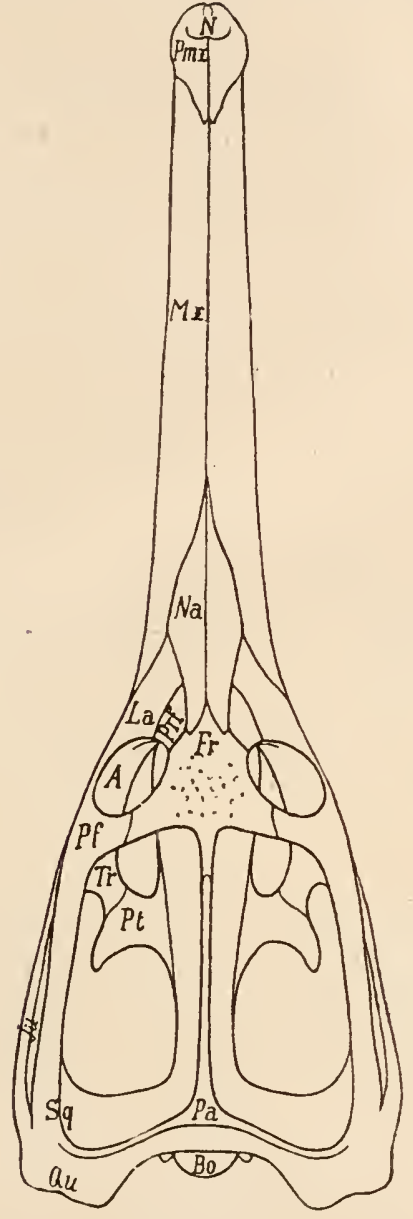

Fig. 427.

Stenosaurus Larteti Desl., var. Kokeni Auer, aus dem Oxfordien (oberer Jura) von Peterborough in England. Etwa

1\% nat. Gr. (Nach E. Auer, 1909.)

$N$ - Nasenöffnumg $A$ A

$M x=$ Supramaxillare. $P f=$ Postfrontale .

$\mathrm{Na}=$ Nasale. $\quad \mathrm{Tr}=$ Transversum.

$L a=$ Adlacrymale. $\quad P t=$ Pterygoid.

Prf $=$ Lacrymale. $\quad J u=$ Iugale.

$S q=$ Squamosım. $\quad B J=$ Basioccipitale.

$P Q=$ Parietale. $\quad Q u=$ Quadratum.
Pmx = Praemaxillare. Fr. $=$ Frontale.

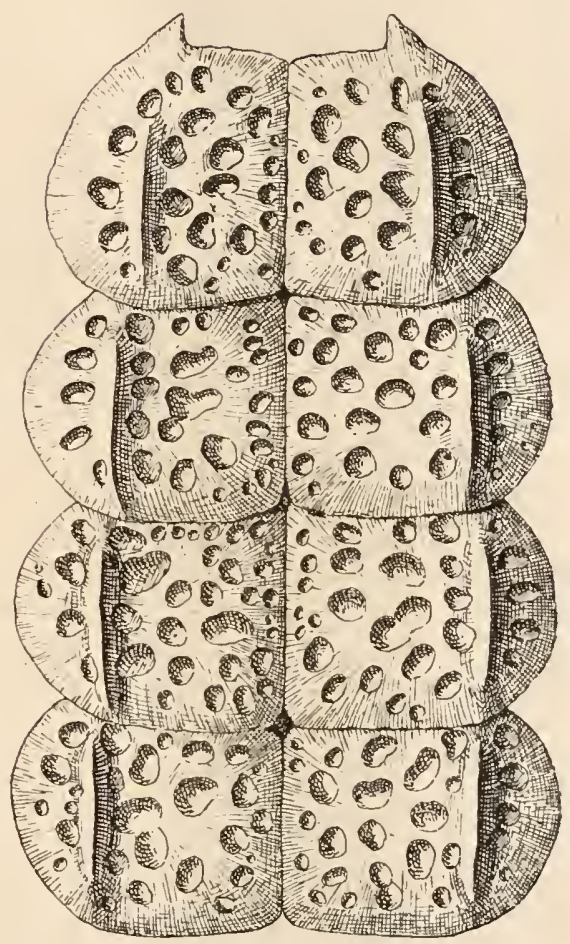

Fig. 428.

Außenansicht (Rückenansicht) von vie: Paaren Panzerplatten der mittleren Rückenreihe von Stenosaurus Larteti aus dem Oxfordien (oberer Jura) von Peterborough in England. $3 /$, nat. Gr.

(Nach E. Auer.)

Robben gesonnt haben. In den Kiefern trugen die Tiere zalılreiche Fangzähne, besonders große am Vorderende der Schnauze (Fangrechen). Sie lebten in Afrika noch inn Eozän. 
Pelagosaurus. - Oberer Lias Nordfrankreichs und Württen:-

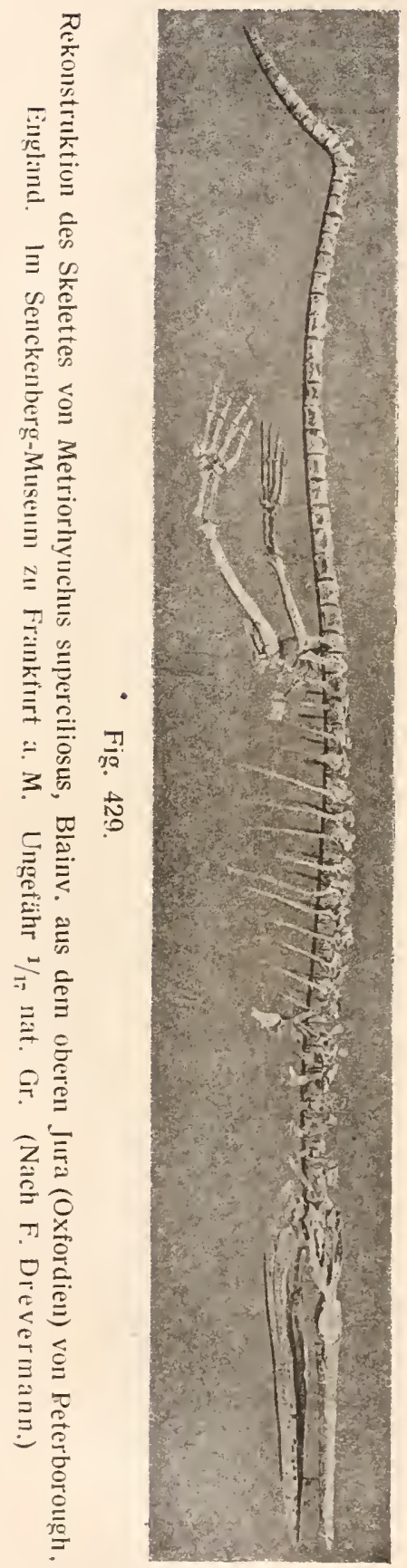
bergs. - Kleine Formen, bei denen die Augen mehr lateral stehen als bei Mystriosaurus. ${ }^{1}$

Mystriosaurus. - Oberer Lias von Württemberg (Boll und Holzmaden) und Banz in Franken. Körperlänge von M. bollensis etwa 4 111. Zahlreiche Arten 2 (Fig.426).

Steneosaurus. - Oberer Jura (Oxfordien) Englands und Frankreichs. Ist jedenfalls als der Nachkomme von Mystriosaurus anzusehen, von dem er nur wenig verschieden ist. Indessen bestehen Unterschiede in der Form der Choanenbegrenzung, ferner sind die Frontalia der Liasgattung größer und die Temporalgruben kleiner. - Zahlreiche. Arten ${ }^{3}$ (Fig. 427-428).

Mycterosuchus. - Oxfordien von Peterborough in England. - Rostrum

1 J.A. Deslongchamps-Eudes, Mémoires sur les Téléosauriens de l'Epoque jurassique du Département du Calvados. - Mémoires de la Soc. Linnéenne de Normandie, T. XIII, 1864.

E. Deslomgchamp-Eudes, Note sur les Reptiles fossiles appartenant à la famille des Téleosauriens, dont les débris ont été recueillis dans les assises jurassiques de Normandie. Bull. Soc. Géol. de France, T. XXVII, 1870, p. 299.

Derselbe, Notes Paléontologiques. - Bd. I, 1863-1869.

${ }^{2}$ H. G. Bronn und J. J. Kaup, Abhandlungen über die gavialartigen Reptilien der Liasformation. - Stuttgart, 1841.

A. Wagner, Die fossilen Überreste'gavialartiger Saurier aus der Liasformation. - Abh. Kgl. bayr. Akad. d. Wiss., Mïnchen 1850, V. Bd., S. 516,555 .

E. d'Alton und H. Burmeister, Der fossile Gavial von Boll. - Halle 1854.

3 E. Auer, Über einige Krokodile der Juraformation. - Palaeontographica, 55. Bd., 1909, S. 217 (ausführliche Literatur!).

C. W. Andrews, A Descriptive Catalogue of the Marine Reptiles of the Oxford Clay. - Part 11, London 1913, p. 80. 
stark verlängert und scliarf vom übrigen Schädel abgesetzt. Zälıne nach abwärts gerichtet, Schädelkapsel groß, obere Temporalgrube groß. ${ }^{1}$ Teleosaurus. - Oberer Jura von Frankreich und England. Sehr ähnlich der vorigen Gattung, aber Zähne mehr nach außen gestellt, Schädelkapsel kleiner, obere Temporalgrube kleiner. ${ }^{2}$

Congosaurus. - Marines Untereozän (Montien) von Landana, Belg.-Congo. - Ein 3,50 m langes; fast vollständiges Skelett bekannt, das bisher nur in einer vorläufigen Mitteilung L. Dollos (1914) beschrieben, aber bisher noch nicht abgebildet wurde. Die Skelettmerkmale stimmen in den wesentlichen Punkten mit jenen der übrigen Teleosauriden überein, doch unterscheidet sich diese Gattung von den übrigen durch den Besitz von vier dorsalen Längsreihen von Panzerplatten sowie die viereckigen, sich dachziegelartig deckenden ventralen Panzerplatten, -weshalb L. Dollo die Gattung als Vertreter einer eigenen Familie (Congosauridae) betrachtet (C. Bequaerti). ${ }^{3}$

Dyrosaurus. - Plosphate von Gafsa (Tumis); (nach F. von Nopcsa)' auf sekundärer, nach $A$. Thevenin auf primärer Lagerstätte, im letzteren Falle also gleichfalls eozän). - Von Congosaurus hauptsächlich durch das Fehlen des Hautpanzers, die längere Schnauze, die Länge der Nasalia und die längere Unterkiefersymphyse verschieden (D. phosphaticus).

\section{F. Geosauridae.}

Wie die Teleosauriden an das Meeresleben angepaßt,. aber in verschiedener Richtung höher spezialisiert, z. B. in der Ausbildung einer Schwanzflosse, deren unterer Lappen von dem ähnlich wie bei den Ichthyosauriern abgeknickten Sclıwanz gestützt wird. Vorderflosse hochgradig spezialisiert, viel kleiner als die zu Ruderfüßen umgestalteten Hinterbeine. Nasalia groß, an der Zusanmensetzung des Rostrums einen relativ großen Anteil nehmend, mitunter die Praemaxillaria erreichend. Lacrymalia sehr groß. Wirbelkörper mit schwach konkaven Endfläclım. Die Hautbepanzerung felılt vollständig; das Auge trug

C. W. Andrews, I. c. p. 135.

2E. Deslongchamps-Eudes, Notes paléontologiques, T. 1, 1863-1869.

E. Auer, I. c., p. 224.

${ }^{3}$ L. Dollo, Sur la Découverte de Téléosauriens tertiaires au Congo. - Bull. Acad. Roy. Belgique, Bruxelles, Juillet 1914, p. 288.

${ }^{3}$ F. v. Nopcsa, Remarques au sujet de la note de M. Thevenin sur le Dyrosaurus. - Compte Rendu Somm. Séances Soc. Géol. France, 1911, p. 162.

o. Abel, Grundzüge der Paläobiologie der Wirbeltiere, 1912, S. 64 . Nach einer mündlichen Mitteilung hält Nopcsa an seiner Auffassung von der sekundären Lagerstätte der Dyrosaurusreste in Tunis fest.

5 A. Thevenin, Le Dyrosaurus des Phosphates de Tunisie. - Annales de Paléontologie, T. VI, 1911, p. 95. 
einen Sklerotikalring. Die Familie umfaßt mehrere Gattungen, von denen die älteste (Metriorhynchus) zuerst in Dogger auftritt; die jüngste Gattung (Neustosaurus) ist im Neokom Frankreichs und Norddeutscl1lands gefunden worden.
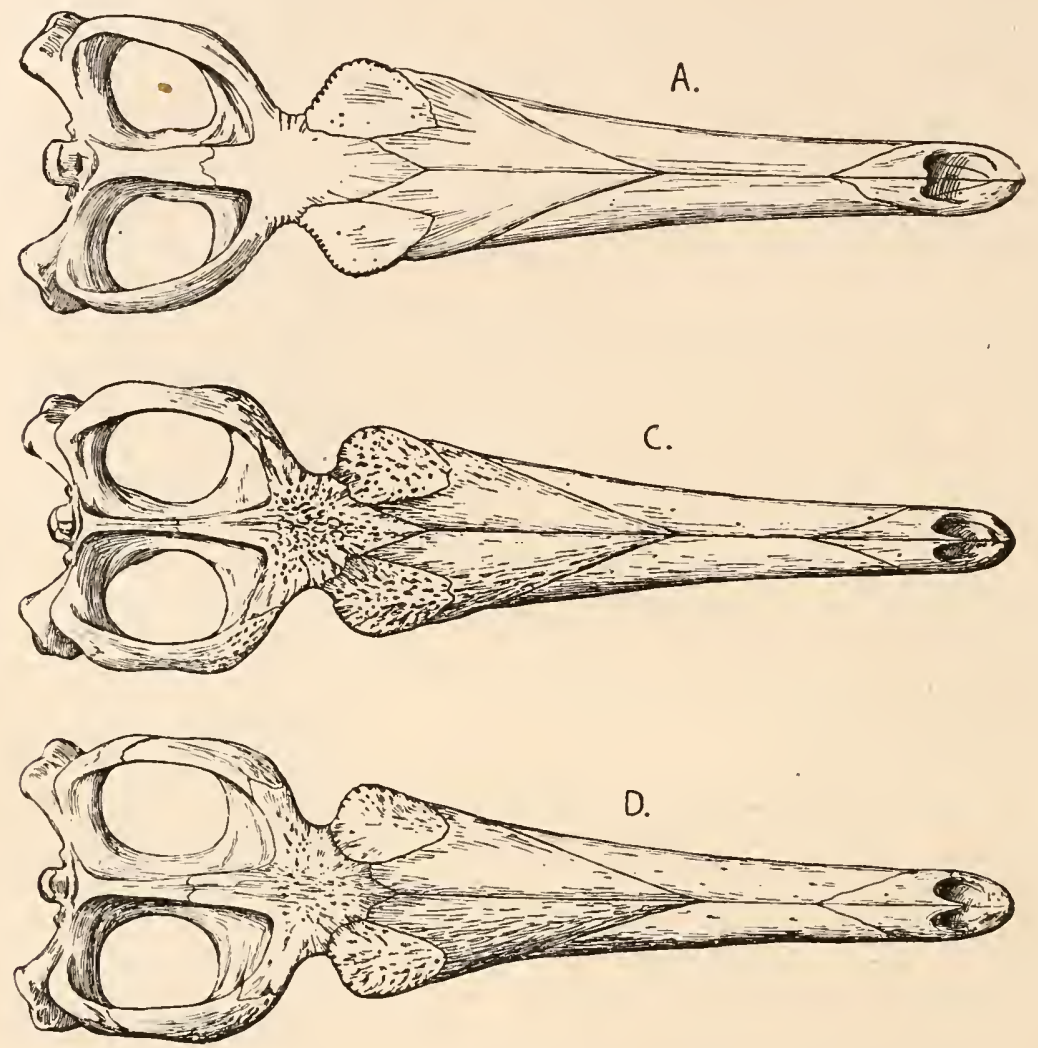

Fig. 430.

Schmalschnauzige Schädeltypen von Metriorhynchus aus dem oberen Jurz (Oxfordien) von Peterborough (England). (Nach C. W. Andrews.)
A: Metriorhynchus laevis, Andr.
C: Metriorhynchus superciliosus, Blairv.
D: Metriorhynchus Moreli, Desl.

(Das Schädeldach von $\mathbf{M}$. laevis ist glatt, die der beiden anderen Typen sind skulpturiert.)

Metriorhynchus. - Oberer Dogger und Oxfordien Englands unci Nordfrankreichs, Jura von Patagonien. (Fig. 429-431). ${ }^{1}$

Dacosaurus. - Oberer Malın von Deutschland, England, Frankreich. Von Metriorhynchus durch geringere Länge der Tibia und Fibula 

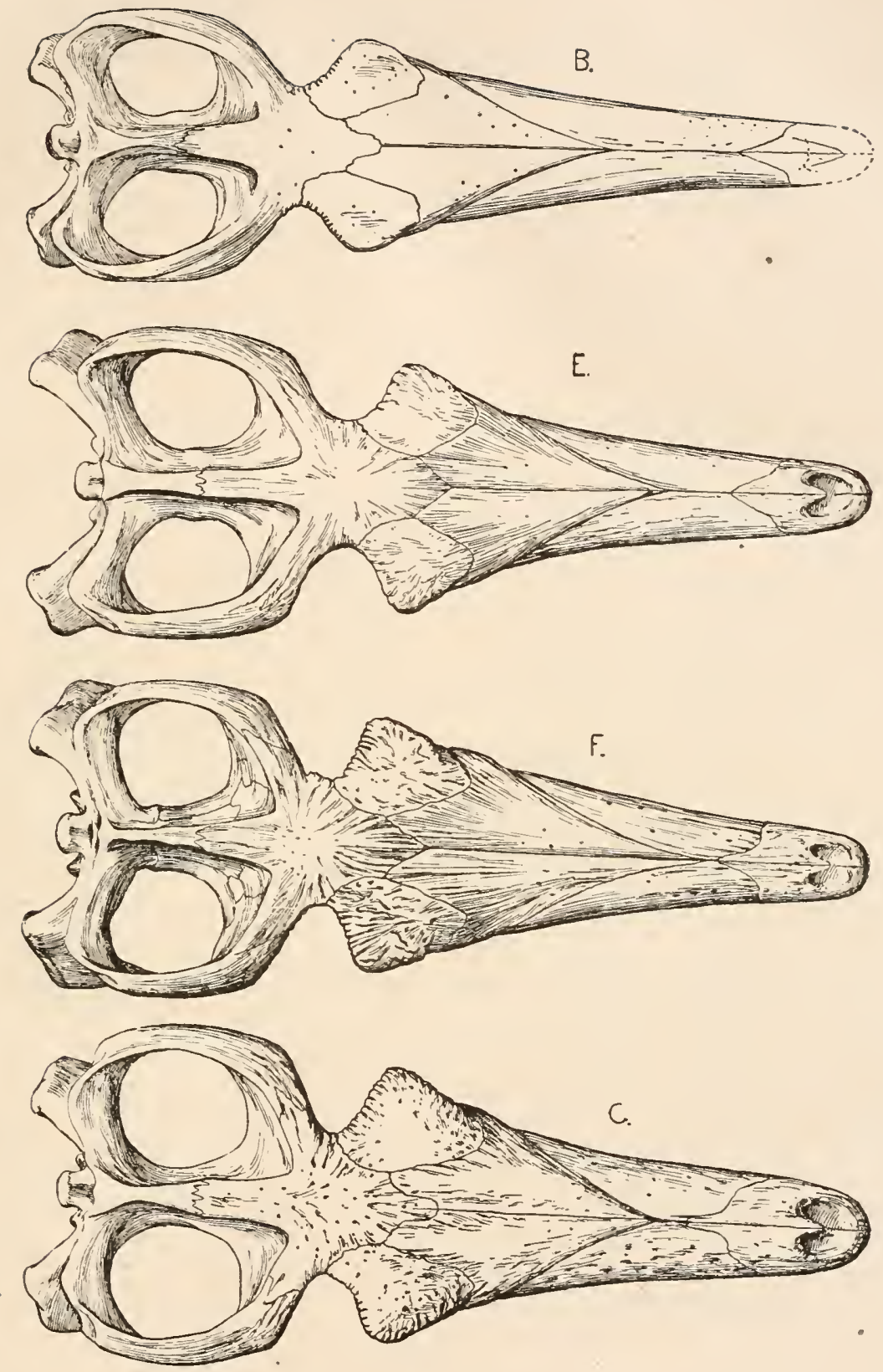

Fig. 431.

Breitschnauzige Schädeltypen von Metriorhynchus aus dem oberen Jura (Oxfordien) von Peterborough (England). (Nach C. W. Andrews.)

B: Metriorhynchus Leedsi, Andr.

E: Metriorhynchus cultridens, Andr.

F: Metriorhynchus brachyrhynchus, Desl.

G: Metriorhynchus durobrivense, Lyd.

(Das Schädeldach der Type B ist glatt, die der anderen sind skulpturiert.) $\mathrm{Abel}$, Stämme der Wirbeltiere. 
im Vergleich zum Femur, die stärkere Reduktion der Vorderflosse und das Vorhandensein scharfer Zahnschneiden unterschieden; alle diese Merkmale stellen einen höheren Spezialisationsgrad dar. Dacosaurus ist die geologisch jüngere Gattung und der Nachkomme von Metriorhynchus. In Staufen bei Giengen wurde ein etwa $6 \mathrm{~m}$ langes Skelett von D. maximus gefunden (Schädellänge $1 \mathrm{~m}$ ). ${ }^{1}$

Geosaurus. - Oberer Malm Süddeutschlands. Schädel langschnauzig, Nasenlöcher durch eine sekundäre Scheidewand getrennt, Augenhöhlen groß, Augen mit Sklerotikalring. Schädelknochen nicht skulpturiert. Vorderflossen hochgradig spezialisiert, Knochen des Radialrandes zu Platten umgeformt, die hinteren vier Finger verkümmert. Schwanzende stark nach unten gebogen, an der Abknickungsstelle durch hohe Dornfortsätze und Hämapophysen verstärkt. Körperlänge der am besten bekannten Art (G. suevicus) etwa $2 \mathrm{~m}$. - G. suevicus, G. giganteus, G. gracilis (Fig. 432-433). ${ }^{2}$

Geosaurus und Dacosaurus gehören verschiedenen Entwicklungslinien an, die auf eine gemeinsame Wurzel zurückgehen.

\section{F. Pholidosauridae.}

Außer den Teleosauriden und Geosauriden werden gewöhnlich noch folgende Familien der Krokodilier unterschieden: die Macrorhynchiden (z. B. Pholidosaurus), die Atoposauriden (z. B. Alligatorium, Atoposaurus), die Goniopholiden (z. B. Goniopholis, Bernissartia, Notosuchus), die Gavialiden (z. B. Tomistoma, Gavialis) und die Crocodiliden (z. B. Crocodilus, Diplocynodon, Alligator). Diese Gliederung ist heute kaum mehr in diesem Unfange und mit bei den ehemaligen Definitionen der Gruppen aufrechtzuhalten. Die Gegensätze zwischen den älteren und jüngeren Krokodilen, die in der Gaumenbildung und in der Amphicölie oder Procölie der Wirbel (die primitiven Formen sind alle amphicöl, die jüngeren alle procöl) zutage treten, sind nur gradueller Natur; das ,Mesosuchier"-Stadium der Wirbelsäule und der Gaumenbildung müssen alle jüngeren Krokodile mubedingt durchlaufen haben. Anders steht es mit dem Bau des Transversums und der Durchbohrung desselben. Bei Hylaeochampsa vectiana aus dem englischen Wealden (Unterkreide) ist das Transversum von einen großen Foramen durchbohrt, dessen Rudimente sich nach C. W. Andrews (1913) bei

1 E. Fraas, Die Meerkrokodile (Thalattosuchia) des oberen Jura unter spezieller Berïcksichtigung von Dacosaurus und Geosaurus. - Palaeontographica, 49. Bd., 1902 , p. 1.

2 Ibidem.

L. von Ammon, Über jurassische Krokodile aus Bayern. - Geognost. Jahreshefte, München 1906, XVIII. Jahrg., S. 55.

C. W. Andrews, 1. c., Titelbild. 


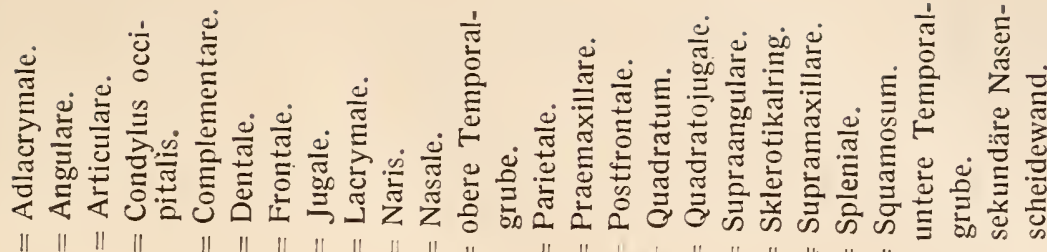

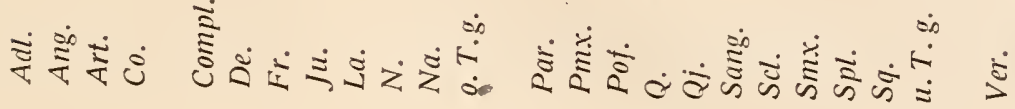
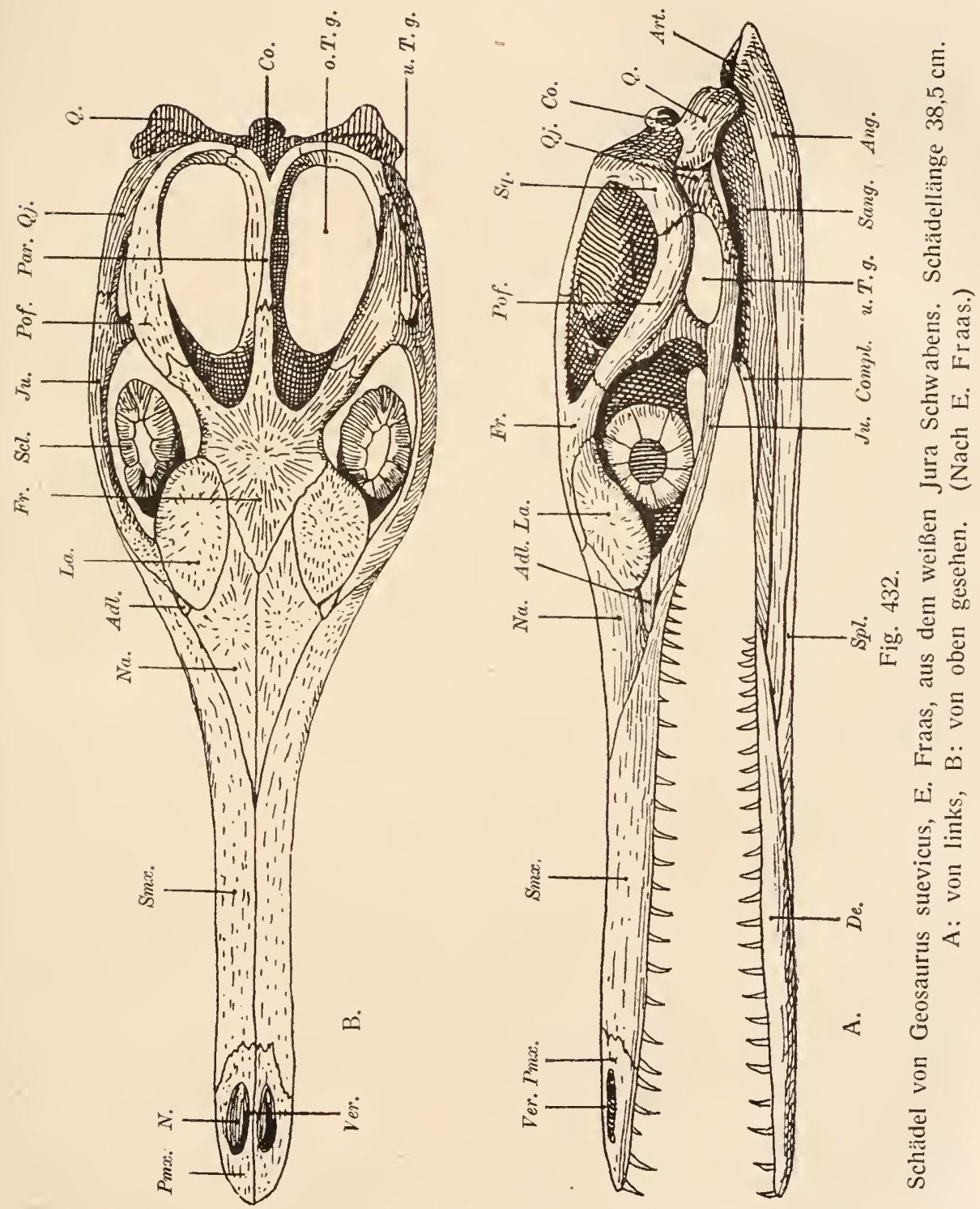
allen lebenden Krokodilen in Gestalt einer kleinen Durchbohrung noch nachweisen lassen; bei Goniopholis und Bernissartia, wie auch bei Pholidosaurus ist dagegen keine Spur einer Gabelung oder Durchbohrung des Transversums wahrzunehmen. Diese Gründe haben Andrews dazu geführt, jede direkte Verbindung dieser Gruppe der Krokodilier mit den echten Krokodilen abzulehnen, welche mit der Gattung Hylaeochampsa beginnen. Içh vereinige im folgenden die Gattungen Pholidosaurus, Goniopholis, Bernissartia, Notosuchus und die weiteren mit diesen näher verwandten Gattungen in der Familie Pholidosauridae.

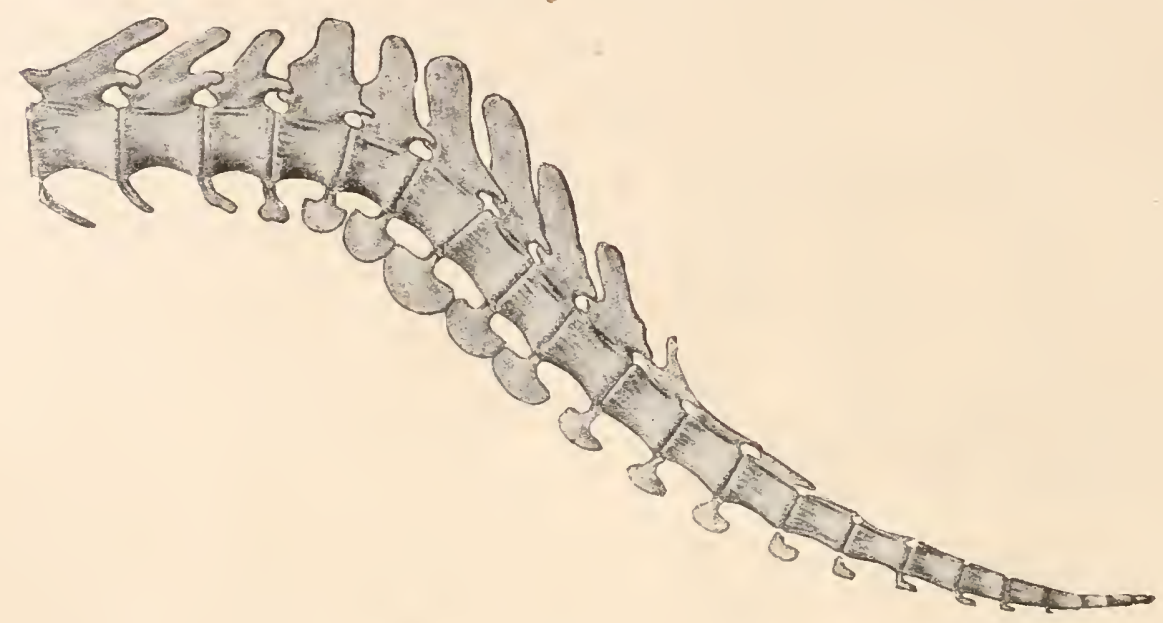

Fig. 433.

Schwanzende von Geosaurus suevicus, E. Fraas, aus dem Tithon (oberer weißer Jura) von Nusplingen. Zu beachten: Schlußsteinform der Wirbel an der Knickungsstelle, Achsenrichtung der Dornfortsätze, Verstärkung der Haemapophysen an der Knickungsstelle. $1 / 2$ nat. Gr. (Nach E. Fraas.)

Die Kennzeichen dieser Familie bestehen somit in dem undurchbohrten Transversum und in allgemein primitiveren Verlıalten der Clroanenregion und der Wirbelsäule.

Pholidosaurus. - Wealden von Hannover und England. Die Nasalia erreichen, sich nach vorn in den Supramaxillaria auskeilend, die hinteren Spitzen der Praemaxillaria. Die Palatina bilden den Vorderrand der Choanen, ihre Seitenränder werden von den Pterygoidea begrenzt. ${ }^{1}$

1 G. Jaffé, Über Pholidosaurusreste aus dem Naturhistorischen Museum in Lïbeck. - Mitteil. d. Geograph. Ges. und des Naturhist. Mus. in Lübeck (2), 25. Heft, 1911.

D. M. S. Watson, Notes on Some British Mesozoic Crocodiles. - Mem. and Proceed. of the Manchester Liter. and Phil. Soc., Manchester 1911, Vol. 55, Nr. 18.

Derselbe, On the Skull and Part of the Skeleton of a Crocodile from the 
Goniopholis. - Wealden von England und Belgien, Kreide von Brasilien und Nordamerika. Choanenbildung ähnlich wie bei Pholidosaurus. ${ }^{1}$

Bernissartia. - Wealden von Bernissart in Belgien. ${ }^{2}$

Notosuchus. - Oberste Kreide von Patagonien. ${ }^{3}$

\section{F. Atoposauridae.}

Ein Seitenzweig der Krokodilier, der dadurch besonders gekennzeichnet ist, daß sich die Nasalia nach vorn in die Nasenöffnung einschieben und durch ein von ihren Vorderenden gebildetes Septum die Nasenöffnung teilen. Der Wirbelbau ist primitiv. Die kleinen Formen (Alligatorellus wird nur $22 \mathrm{~cm}$ lang) besitzen einen stumpfschnauzigen, sehr kurzen Schädel und sehr große, die oberen Temporalgruben um das Dreifache ïbertreffende Augenhöhlen.

Alligatorium. - Oberer Jura Süddeutschlands und Frankreichs. ${ }^{4}$ Alligatorellus. - Oberer Jura Frankreichs. ${ }^{5}$

A toposaurus. - Oberer Jura Süddeutschlands und Frankreichs. ${ }^{6}$

Middle Purbeck of Swanage, with a Description of a New Species (Pholidosaurus laevis), and a Note on the Skull of Hylaeochampsa. - Ann. Magaz. Nat. Hist., London (8), Vol. XI, 1913, p. 485.

1 R. Owen, Monograph of the Fossil Reptilia of the Wealden and Purbeck Formations. - Suppl. VII1. - Palaeont. Soc., 1878, p. 8.

J. W. Hulke, Note on two Skulls from the Wealden and Purbeck Formations. - Quart. Journ. Geol. Soc., London 1878, Vol. XXXIV, p. 377.

R. W. Hooley, On the Skull and Greater Portion of the Skeleton of Goniopholis crassidens from the Wealden Shales of Atherfield (Isle of Wight). - Quart. Journ. Geol. Soc., Vol. LXIII, 1907, p. 50.

L. Dollo, Première Note sur les Crocodiliens de Bernissart. - Bull. Mus. Roy: Hist. Nat. Belg., T. II, 1883, p. 309.

A. Smith Woodward, On two Mesozoic Crocodilians from the Red Sandstones of the Territory of Neuquen (Argentine Republic). - Anales del Museo de La Plata. - Palaeont. Argentina, Vol. IV, La Plata, 1896, p. 18 (=Cynodontosuchus).

W. J. Holland, A New Crocodile from the Jurassic of Wyoming. - Annals of the Carnegie Museum, Vol. 1II, 1905, Nr. 3, p. 431.

2 L. Dol10, 1. c. 1883, p. 321.

3 A. Sinith Woodward, I. c., 1896, S. 6.

4 L. Lortet, Les Reptiles fossiles du Bassin du Rhône. - Archives du Musée d'Hist. nat. de Lyon, T. V, 1892, p. 108.

K. A. von Zittel, Handbuch der Paläontologie, III. Bd., S. 675.

L. von Ammon, Über jurassische Krokodile aus Bayern. - Geognost. Jahreshefte, München 1905, 18. Jahrg., München 1906, S. 56 (Alligatorium franconicum).

5 L. Lortet, 1. c. (Alligatorellus Beaumontei).

${ }^{6}$ L. Lortet, I. c.

H. von Meyer, Zur Fauna der Vorwelt. Reptilien aus dem lithographischen Schiefer des Jura in Deutschland und Frankreich. - IV. Bd., Frankfurt a. M. 1860, S. 114. (Atoposaurus Oberndorferi aus Kelheim, A. Jourdani aus Cerin.) 


\section{F. Crocodilidae.}

Durch durchbohrtes Transversum gekennzeichnet. Schon die älteste, in diese Familie einzureihende Gattung Hylaeochampsa besitzt procöle Wirbel; die Choanen liegen sehr weit hinten und werden auch vorn nicht mehr von den Palatina, sondern von den Pterygoidea begrenzt. Die Familie umfaßt kurzschnauzige und langschnauzige Formen, die keine natürlichen Gruppen bilden, da die Verkürzung des Rostrums wiederholt unabliängig erfolgt ist. Von den Crocodiliden sind relativ spät die Gavialiden abgezweigt, deren Anpassungstypus mit dem der Phytosauriden und der Teleosauriden übereinstimmt; die Ähnlichkeiten der Körperform, Schädelform, Schnauzenform und Zahnrechenbildung sind nur als Konvergenzerscleinungen zu bewerten.

Hylaeochampsa. - Wealden von England. - Choanen weit hinten gelegen, vorn und seitlich von den Pterygoidea begrenzt; die Grenze der Pterygoidea gegen die Palatina liegt weit vorn. Großes Transversum mit großem Transversalforamen. Wirbel procöl (Andrews, 1913). - H. vectiana. ${ }^{1}$

Libycosuchus. - Unterstes Cenoman der Libyschen Wüste. Ein 16,5 cm langer Schädel nebst Unterkiefer und einigen amphicölen Wirbeln bekannt. Ein bezeichnendes Merkmal sind die großen, tief herabreichenden Flügel der Pterygoidea, zwischen denen die kleinen Choanen austreten. Die Transversa sind groß und kräftig; das große Transversalforamen von Hylaeochampsa fehlt, scheint aber durch eine kleine, in der Abbildung Stromers (1914) angedeutete Öffnung ersetzt zu werden. Die Transversa stoßen vorn mit den Palatina zusammen. Im sekundären Gaumendach liegt beiderseits von den die mittlere Brücke bildenden Palatina je eine große Suborbitalöffnung. Die äußeren Nasenöffnungen werden von einem Septum gespalten, das wahrscheinlich von den Nasalia gebildet wird. Die Sclnnauze ist breit und kurz, der Unterkiefer in seinem vorderen Drittel, die Oberkiefer bis zur Grenze mit den Transversa bezahnt. Wahrscheinlich eine terrestrische Type. Libycosuchus brevirostris. Unterstes Cenoman Ägyptens (Fig. 434). ${ }^{2}$

Deinosuchus. - Eine Riesenform von etwa 10-13 m Körperlänge aus der oberen Kreide von Montana (D. Hatcheri). ${ }^{3}$

Crocodilus. - In der oberen Kreide Europas. Zahlreiche

1 C. W. Andrews, 1. c., Ann. Mag. Nat. Hist., 1913, p. 492.

2 E. v. Stromer, Ergebnisse der Forschungsreisen Prof. E. Stromers in den Wüsten Ägyptens. - I1. Teil. - Abh. Kgl. Bayr. Akad. d. Wiss., München 1914, XXVII. Bd., 3. Abh.

${ }^{3}$ W. J. Holland, Deinosuchus Hatcheri, a New Genus and Species of Crocodile from the Judith River Beds of Montana. - Annals Carnegie Museum, Pittsburgh, Vol. VI, 1909, p. 281. 
Reptilia.

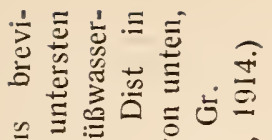

至

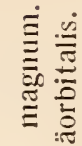

竞咅

मீं

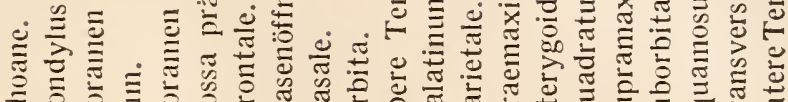

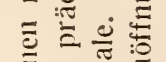

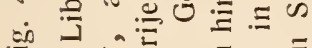

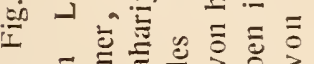

$\stackrel{0}{0}$

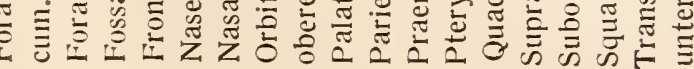

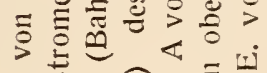

点 $=\widehat{\bar{z}} \cong$

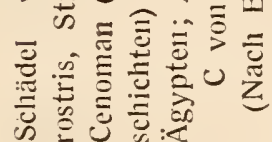

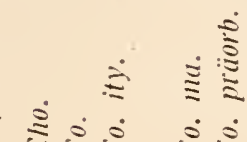

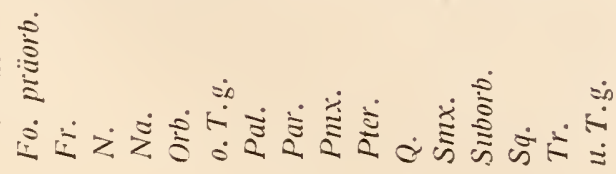
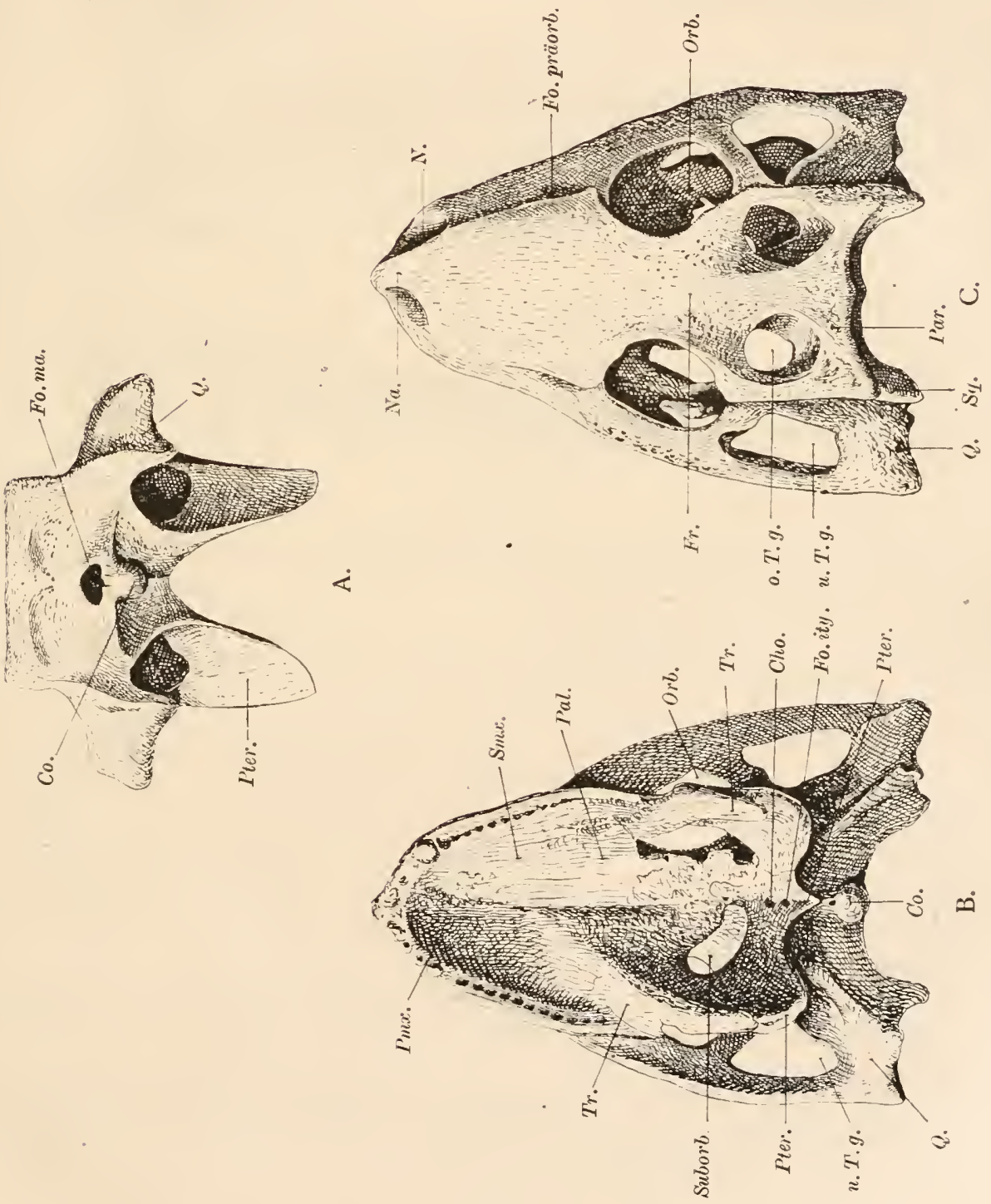
fossile Reste aus dem Tertiär von Europa, Nordafrika, Nordamerika, Ostindien. Lebend in Afrika, Asien und Amerika (Fig. 435).

Die Zwischenkiefer besitzen jederseits zwei tiefe Gruben für die beiden vordersten Unterkieferzähne; der vierte Unterkieferzahn fügt sich in einen seitlichen, tiefen Ausschnitt des Oberkiefers ein. Eine knöcherne Nasenscheidewand fehlt.

Oste olaemus. - Eine lebende Art (O. tetraspis) in Afrika zwischen dem $9^{0}$ nördl. Br. und $7^{0}$ südl. Br. - Nasenöffnungen durch knöcherne Scheidewand getrennt.

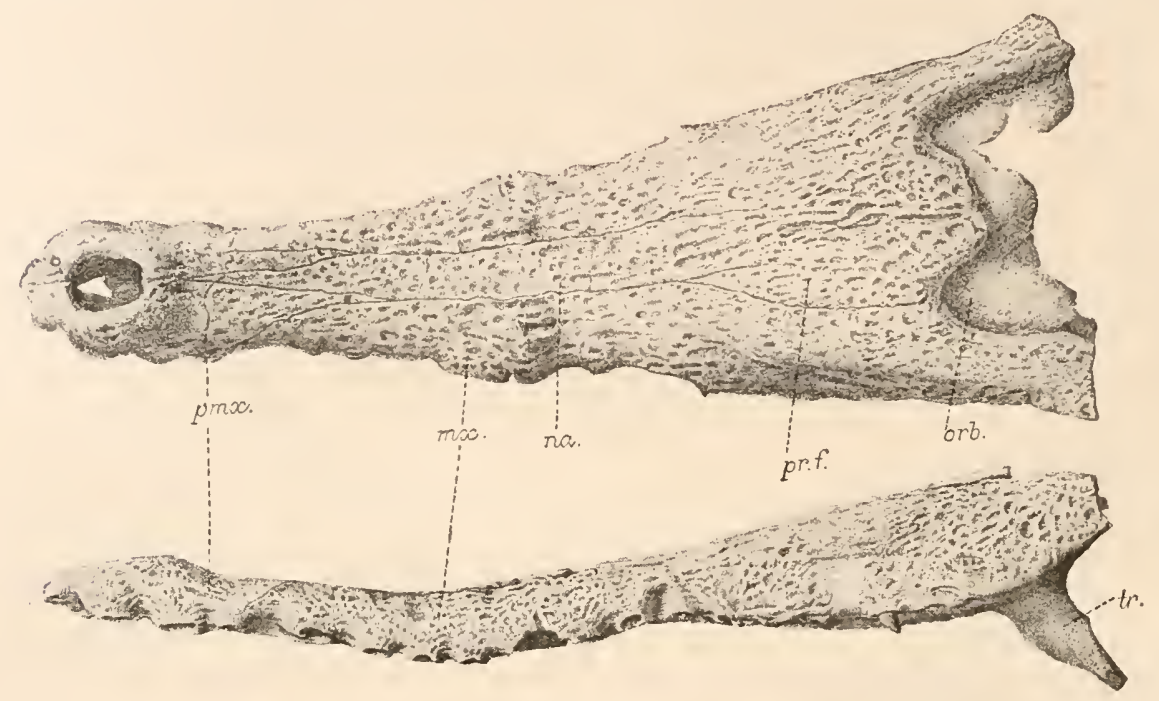

Fig. 435.

Crocodilus articeps, Andrews, aus dem Unteroligozän des Fayûm, Ägypten. (Länge des Schädelrestes: $43 \mathrm{~cm}$. (Nach C. W. Andrews.)

$$
\begin{aligned}
& p m x .=\text { Praemaxillare } \quad p r . f .=\text { Lacrymale } . \\
& m x . \text { = Supramaxillare. } \text { orb. }=\text { Orbita } . \\
& \text { na. = Nasale. } t r .=\text { Transversum. }
\end{aligned}
$$

Leidyosuchus. - Obere Kreide von Wyoming und Canada. Nach Ch. W. Gilmore (1910) nimmt die Gattung eine Zwischenstellung zwischen Crocodilus und Alligator ein und zwar steht sie dem ersten näher; der vierte Unterkieferzahn greift jedoch nicht in einen seitlichen Ausschnitt, sondern in eine Grube auf der Unterseite des Oberkiefers ein (wie bei den Alligatoren). ${ }^{1}$

1 L. M. Lambe, On a New Crocodilian Genus and Species from the Judith River Formation of Alberta. - Transactions Roy. Soc. Canada (3), Vol. 1, 1909, p. 219.

Ch. W. Gilmore, Leidyosuchus Sternbergii, a New Species of Crocodile from the Ceratops Beds of Wyoming. - Proceed. U. S. Nat. Musetım, Washington, Vol. XXXVIII, 1910, p. 485. 
Diplocynodon. - Eozän von Neunexiko, Eozän bis Miozän Europas. ${ }^{1}$

Der dritte und vierte Unterkieferzahn greifen in einen seitlichen Aussclinitt des Oberkiefers ein.

Caiman. - Keine knöcherne Nasenscheidewand; außer dem Rückenpanzer ein Bauchpanzer aus dachziegelartig sich deckenden Knochenplatten vorhanden (älnnlich wie bei Congosaurus, vgl. S. 543). Mehrere Arten, lebend in Mittel- und Südamerika (Fig. 425).

Alligator. - Lebend in China und Nordamerika. Die Nasenöffnungen sind durch ein Septum zweigeteilt, das von den Nasalia gubildet wird. Ebenso wie beim Caiman greift der vierte Unterkieferzahn in eine Grube auf der Unterseite des Oberkiefers ein. In den Bauclschildern fehlen die Hautknochen.

\section{F. Gavialidae.}

In jeder Hinsicht die hoclspezialisierten Nachkommen der Crocodiliden: Wirbel procöl, Choanen fast an Hinterende der Schädelbasis liegend und von den Pterygoidea begrenzt, Bauchpanzer verloren gegangen usw. Die Nasalia liegen weit hinten, durch die das Rostrum fast zur Gänze zusammensetzenden Supramaxillaria von den Prämaxillaria getrennt.

Thoracosaurus. - Obere Kreide von New Jersey, Frankreich und Holland. Vor den Augenliöhlen sind bei Th. neocaesariensis aus New Jersey Präorbitalöffnungen vorhanden, die bei anderen Arten (Th. macrorhynchus aus Maastricht) fehlen. ${ }^{2}$

Tomistoma. - Vom Obereozän Ägyptens an; lebend im indomalaiischen Archipel und in Hinterindien. (Fig. 436-437). ${ }^{3}$

1 A. Pomel, Note sur des animaux fossiles découverts dans le Département de l'Allier. - Bull. Soc. Géol. France (2), 1847, p. 383.

R. Ludwig, Fossile Crocodiliden aus der Tertiärformation des Mainzer Beckens. - Palaeontographica, Suppl. I1I, 1877, p. 1.

K. A. Redlich, Wierbeltierreste aus der böhmischen Braunkohlenformation. Jahrbuch d. K. K. Geol. Reichsanstalt, Wien 1902, 52. Bd., S. 135 (Literatur).

E. D. Cope, The Reptiles of the American Eocene. - Amer. Naturalist, Vol. XVI, 1882, p. 986.

2 E. Koken, Thoracosaurus macrorhynchus, Bl., aus der Tuffkreide von Maastricht. - Zeitschr. d. Deutschen Geol. Ges., 40. Bd., 1888, S. 754.

${ }^{3}$ F. Toula und J. A. Kail, Über einen Krokodilschädel aus den Tertiärablagerungen von Eggenburg in Niederösterreich. - Denkschriften d. Kais. Akad. d. Wiss., Wien, math.-nat. Cl., 50. Bd., 1885, S. 299 (Literatur).

G. Capellini, Sul Coccodrilliano Garialoide (Tomistoma calaritanus) scoperto nella Collina di Cagliari. - Memorie R. Accad. dei Lincei (4), Vol. V1, 1890, p. 507.

C. W. Andrews, A Descriptive Catalogue of the Tertiary Vertebrata of the Fayûm, Egypt. - London 1906, Brit. Mus. Nat. Hist., p. 267. 
Gavialis. - Fossil im Pliozän Ostindiens (eine 15 m lange Riesenform), lebend in Ostindien und Birma.

\section{Ordnung: Rhamphorhynchoidea.}

Bei der Gruppe der zu Hautflüglern gewordenen Reptilien, die wir bisher als die Gruppe der „Pterosauria“ zu bezeichnen gewohnt waren, tritt uns ein vollkommen analoger Fall wie bei der ehemaligen Gruppe der „Dinosaurier“ entgegen. Zwei Stämme, die in einer gemeinsamen Ahnengruppe wurzeln, haben sich von verschiedenen Gattungen

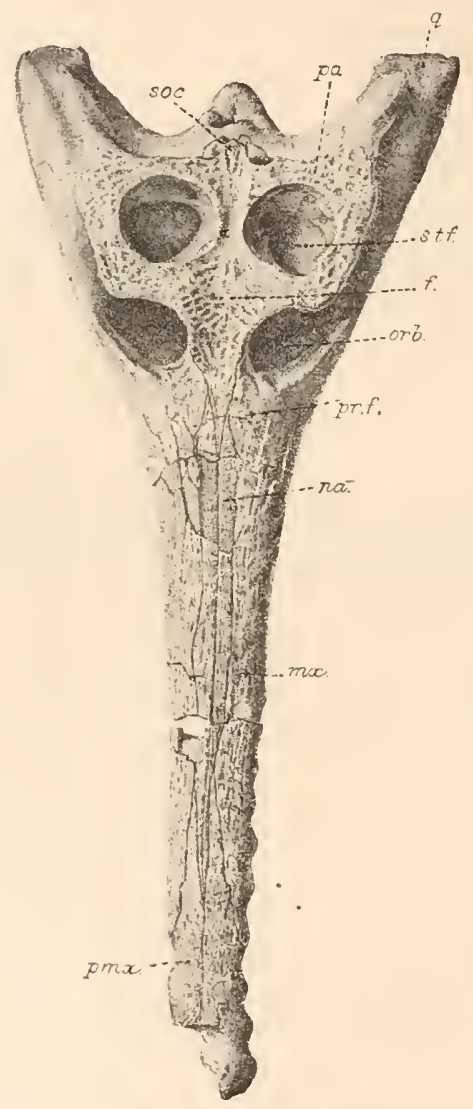

Fig. 436.

Tomistoma africanum, Andrews, aus dem Obereozän (Qasr-el-Sagha-Schichten) des Fayûm, Ägypten. Schädellänge: $106 \mathrm{~cm}$.

(Nach C. W. Andrews.)

pmx. = Praemaxillare.

$m x$. = Supramaxillare.

na. $=$ Nasale.

pr.f. = Lacrymale.

orb. = Orbita.

f. $=$ Frontale

s.t.f. = obere Temporalgrube.

pa. ${ }^{\prime}=$ Parietale

soc. $=$ Supraoccipitale.

$q . \quad=$ Quadratum.

aus zu Flugtieren weiter entwickelt und infolge Annahme einer gleichartigen Lebensweise so viele übereinstimmende Anpassungsmerkmale erhalten, daß man sie in eine einheitliche Gruppe vereinigen zu müssen geglaubt hat. Bei dem Fortschreiten unserer Kenntnisse von der Organisation der „Pterosaurier" hat sich jedoch gezeigt, daß schon die ältesten Vertreter zwei durchaus verschiedene Entwicklungswege eingeschlagen liaben und daß wir keine Zwischenform kennen, welche diese beiden 


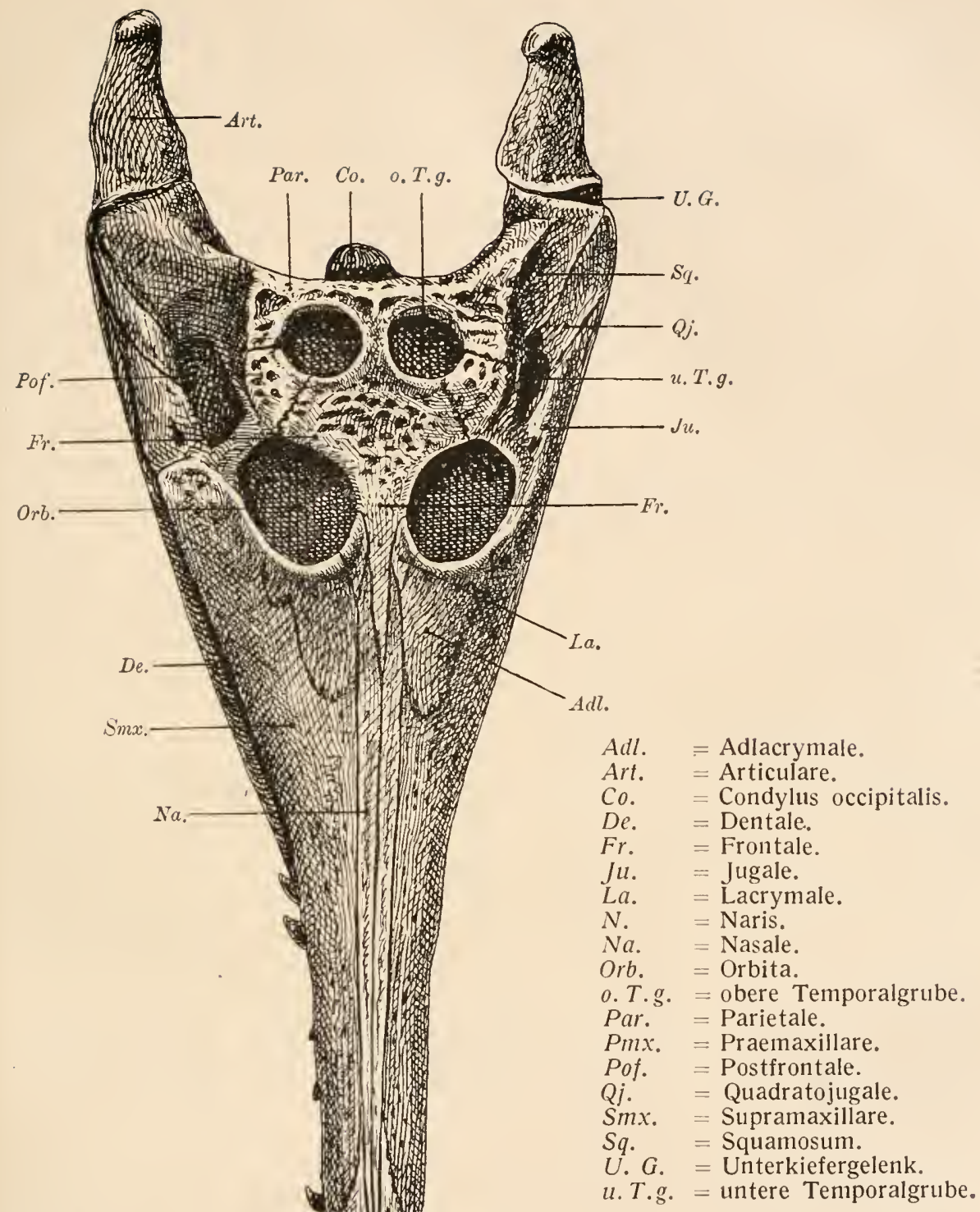

Fig. 437.

Dorsalansicht des Schädels eines fossilen Gavials, Tomistoma calaritanum, Capellini, aus dem Miozän von Cagliari (Sardinien). Schädellänge $75 \mathrm{~cm}$. (Neue Rekonstruktion auf Grundlage der von G. Capellini mitgeteilten Abbildungen des Restes, aber gegen diese wesentlich abgeändert und die Deutung der Knọchen berichtigt. $\mathrm{Zu}$ beachten: die geringe Größe des quadratischen Mittelstückes des Schädeldaches im Vergleiche zu Tomistoma africanum, Andr., Fig. 436.) 
Stämme verbinden würde. Bei der einen Gruppe wird der Flug, der zuerst ein Fallschirmflug war und dann in cinen Drachenflug überging, auf ganz andere Weise bewerkstelligt als bei der zweiten Gruppe, die vom Fallschirmflug zum Flatterflug und erst sehr spät zum Drachenflug übergegangen ist. In der ersten Gruppe, die durch die Gattung Rhamphorhynchus (Fig. 442) repräsentiert wird, spielt der lange sehnige Schwanz mit einem terminalen rhombischen Steuersegel eine außerordentlich wichtige Rolle und ist niemals im Verlaufe der Geschichte dieses Stammes reduziert worden; bei der zweiten Gruppe, die durch die Gattung Pterodactylus (Fig. 446) gekennzeichnet ist, hat der Schwanz ebenso wie bei den Fledermäusen keine Funktion beim Fluge ausgeübt und ist schon frühzeitig rudimentär geworden. Diese beiden Lösungen des Flugproblems sind von den Rhamphorhynchoidea und bei den Pterodactyloidea ganz unabhängig durchgeführt worden und können durch, keine Zwischenform überbrückt werden. Aus diesem Grunde müssen wir die stets spitz- und schmalflügelig gebliebenen, langschwänzigen Rhamphorhynchoidea und die zuerst kurzflügelig, später langflügelig, aber immer breitflügeligen und kurzschwänzigen Pterodactyloidea als zwei scharf geschiedene Gruppen, als selbständige „,Ordnungen" der Reptilien betrachten.

Wir kennen in der Gegenwart einen Fall, der uns zeigt, daß von verschiedenen Gattungen einer Stammgruppe ganz unablıängig dieselbe Lebensweise eingeschlagen wird, die zu konvergenten Anpassungen fülırt und zu der falschen Vermutung fülıren könnte, daß die betreffenden, durch parallele und konvergente Anpassungen sehr ähnlich gewordenen Typen eine gesclılossene „Familie“ bilden. Unter den lebenden Beuteltieren gibt es drei Fallschirmbeutler: Acrobates, Petauroides und Petaurus. Dicse drei Gattungen bilden in der genannten Reihenfolge drei aufeinanderfolgende Anpassungsstufen, die aber gewisse Spezialisationskreuzungen aufweisen, so daß eine direkte genetische Verknüpfung der drei Gattungen ausgeschlossen ist. Studien über das Gebiß haben O. Thomas gezeigt, daß Acrobates aus der Phalangeridengattung Distoechurus, Petaurus aus der Phalangeridengattung Gymnobelideus und Petauroides aus der Phalangeridengattung Pseudochirus hervorgegangen ist. Dieser gut untersuchte Fall ist zweifellos nicht der einzige in der Stammesgeschichte, sondern wahrscheinlich der normale Vorgang. Wenn nun die betreffenden Stammgattungen einander niclit so nahe stehen als die drei genannten Stammgattungen für Acrobates, Petaurus und Petauroides, sondern sich z. B. schon durch längeren oder verkürzten Schwanz unterscheiden, so werden wohl zahlreiche ähnliche, ja sogar homologe Veränderungen der Organisation in Verlaufe der Stammesgeschichte der abgezweigten Typen auftreten, aber die grundlegenden Verschiedenheiten im Schwanze bestehen bleiben. 
So ist woln auch die ,Zweistännmigkeit" der Dinosaurier und die „Zweistämmigkeit" der Pterosaurier zu erklären und ein analoger Fall scheint bei der Spaltung des Reptilstammes in die Zweige der Theriodontier und der Säugetiere vorzuliegen; wir werden als weitere Beispiele die Placodontier und die Sauropterygier heranziehen dürfen und werden zweifellos bei fortschreitender Vertiefung unserer morphologischen Kenntnisse von den fossilen Wirbeltieren die Zahl dieser Fälle noch sehr bedeutend vermehren können. Es wäre aber fehlerhaft, nach gelungenem Nachweise von der tiefen Spaltung zweier oder mehrerer Stämme bis in eine Stanmgruppe noch an der ehemaligen Gruppenbezeichnung

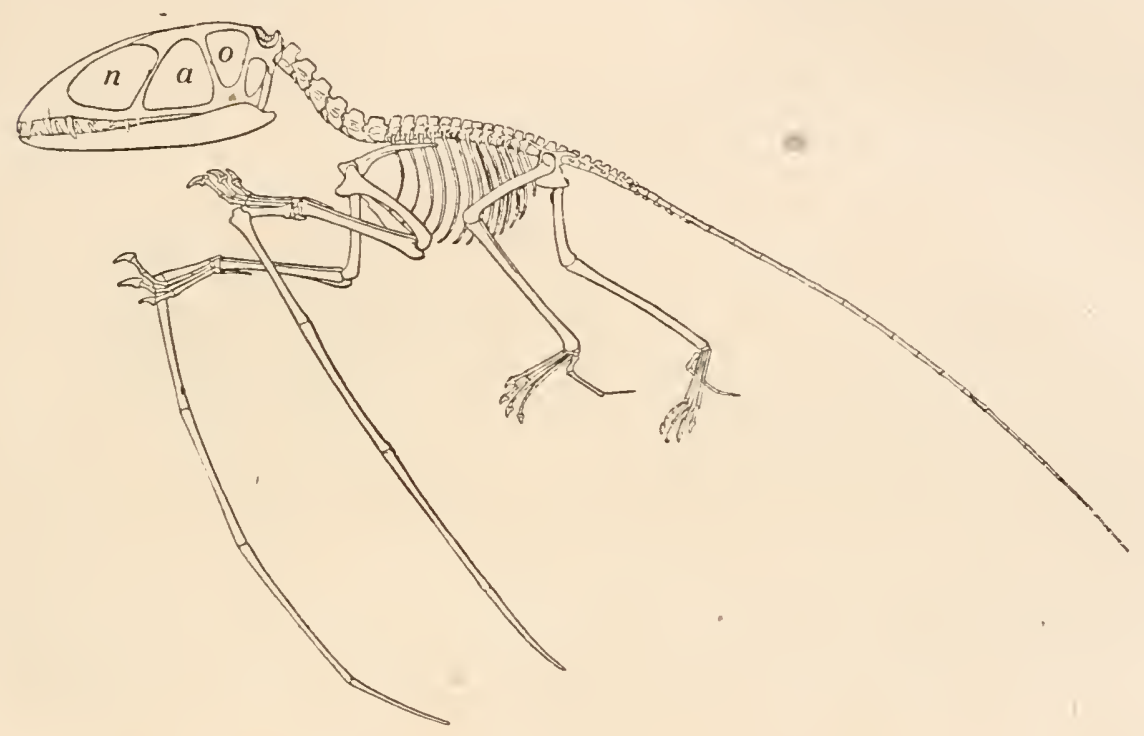

Fig. 438.

Rekonstruktion von Dimorphodon macronyx, Owen, aus dem unteren Lias von Dorsetshire. Etwa $1 / 9$ nat. Gr. (Nach R. Owen, abgeändert von Ridewood.)
a. = Orbita.
$a .=$ Präorbitalöffnung.
$n$. = Nasenöffnung.

und den alten Gruppenbegriff festzuhalten, da durch ein solches Vorgehen die tatsächlichen genetischen Beziehungen nicht nur verschleiert, sondern unrichtig dargestellt und ein verzerrtes Bild liefern wïrden. Aus diesem Grunde ist auch der Sammelbegriff der Pterosaurier aufzugeben und durch die Ordnungsbegriffe Rhanphorhynchoidea und Pterodactyloidea zu ersetzen.

Die Rhamphorhynchoidea besitzen, wie oben erwälınt, ausnahmslos einen langen Schwanz; das Metacarpale des vierten Fingers, der enorm verlängert und zu einem ,Flugfinger" geworden ist, der allein den häutigen Flügel spannt, ist stets kürzer als der halbe Vorderarm (Fig. 438). Eine große, von der Nasenöffnung getrennte Präorbitalöffnung ist immer 
vorhanden. Ein weniger wichtiges Merkmal liegt im Gebisse und in den Kieferformen. Bei den ältesten Gattungen (Dimorphodon) ist der Schädel auffallend groß und hoch mit breiten Kiefern, bei den späteren wird die Schnauze außerordentlich spitz. Mit dem Spitzerwerden der Schnanze steht das Kleinerwerden der Präorbital- und Nasenöffnung in Zusammenhang. Bei fortschreitender Spezialisation wird der Schädelbau immer leichter und zarter (Fig. 439), er wird aber bei keinem Vertreter der Rhamphorhynchoidea zu dem nur mehr aus schlanken, zarten Knochenspangen bestehenden „Traversenschädel“, wie dies Ornithodesmus latidens aus der Ordnung der Pterodactyloidea in so extremer Weise zeigt (Fig. 447).

Es sind zwei Paare seitlicher Schläfengruben vorhanden; die unteren werden z. B. bei Scaphognathus vorn vom Postorbitale, unten vom Quadratojugale und hinten von Quadratum und oben vom Squanosum

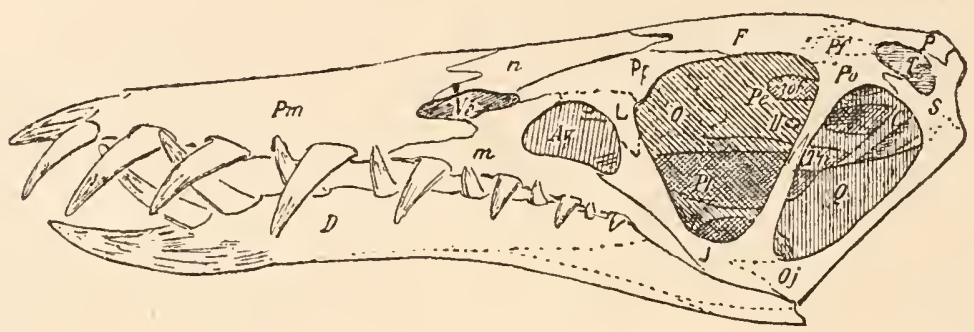

Fig. 439 .

Rekonstruktion des Schädels von Rhamphorhynchus spec., von links gesehen. Oberer Jura (Tithon) Bayerns. $3 / 4$ nat. Gr. (Nach O. Jaekel.)

begrenzt. Die oberen Temporalgruben sind sehr klein und werden von den unteren durch eine vom Squamosum gebildete Spange getrennt. An der Hinterseite des Schädels liegt, vom Foranen magnum durch breite Paroccipitalfortsätze getrennt, jederseits eine kleine hintere Schläfengrube (Fenestra posttemporalis). Das Quadratum und der Gaumen waren bei allen Rhamphorhynchoidea unbeweglich mit dem Schädeldach verbunden; der Schädel war also akinetisch; für eine auch nur geringe Bewegungsfähigkeit liegen auch bei Scaphognathus keine Anzeichen vor.

Am Oberrande der Orbita kann ein kleines Suborbitale auftreten (z. B. bei Scaphognathus und Campylognathus). Ein Septomaxillare ist bei Scaphognathus nachgewiesen.

In der Ausdehnung und Begrenzung der einzelnen Elemente des Schädeldaches bestehen bei den verschiedenen Gattungen ziemlich weitgehende Unterschiede. Stets liegen jedoch die Choanen ziemlich genau unter den äußeren Nasenöffnungen; sie werden in der Medianlinie durch die Vomeres getrennt, während die Palatina seitlich von 
ihnen liegen und hinten mit den vorderen Spangen der Pterygoidea zusammenstoßen. Das Basisphenoid spaltet sich vorn zu einer Gabel, deren Enden mit den Transversa in Verbindung treten.

Die Kiefer tragen schlanke, meist stark nach vorn gerichtete Zähne. Die Unterkieferäste sind in der Symphyse in der Regel fest verschmolzen. Ein Kronenfortsatz felllt.

Inı Schultergürtel fällt vor allem das breite, außen in der Mittellinie gekielte Sternum auf, dessen Ausbildung und Form durch die starke Entwicklung der Brustmuskeln bedingt und als eine Anpassung an den Flug anzusehen ist. Das Sternum tritt mit den Rippen in feste Verbindung. Von den Elementen des Schultergürtels sind nur die Scapula und das Coracoid vorhanden.

Das Armskelett hat durchgreifende Veränderungen erfahren. Der Humerus ist kurz, stämmig und zeigt kräftige Muskelleisten. Die beiden Unterarmknochen sind häufig doppelt so lang als der Oberarm. Die Ulna gelenkt an einer Querrolle des distalen Humerusendes. Die Handwurzel war nach E. v. Stromer (1913) zweireihig; die Beweglichkeit in derselben scheint gering gewesen zu sein.

Der Metacarpus umfaßt vier Metapodien (1., 2., 3., 4. Metacarpale, das 5. fehlt), von denen das des vierten Fingers, der den Flugfinger bildet, weitaus das stärkste ist. Die drei vorderen Metacarpalia liegen als dünne, zarte, Griffel dicht aneinander und enden in kleine, bekrallte Phalangen, deren Krallen kopfwärts gerichtet waren. Von der Handwurzel entspringt ein zweiteiliger Spannknochen, der vielfach mit dem ersten Finger verwechselt wurde. Entscheidend für die Beurteilung der Fingerzälllung sind die Phalangenzahlen:

Finger:

Normalzahl bei Reptilien

Rhamphorhynchoidea und Pterodactyloidea
I. II. III. IV. V.

$\begin{array}{lllll}2 & 3 & 4 & 5 & 3\end{array}$

$\begin{array}{lllll}2 & 3 & 4 & 4 & 0\end{array}$

Daß im vierten Finger nur 4 Phalangen auftreten, erklärt sich aus dem Schwunde der Krallenphalange. Die einzelnen Phalangen hatten fast keine Bewegungsfähigkeit gegeneinander; das Hauptgelenk des Flugfingers liegt zwischen der Grundphalange und dem Metacarpale. Ein olecranonartiger Fortsatz am Proximalende der Grundphalange verhindert eine Überbiegung des Gelenks.

Die Flughaut, die sich an dem Flugfinger ausspannte, war schmal und trug gerade Falten, die gegen die Spitze verliefen. Die zarte Endphalange des Flugfingers war ein wenig nach vorn aufgebogen und muß elastisch gewesen sein.

Sehr bemerkenswerte Eigentümlichkeiten zeigt das Becken. Das Ilium ist lang und niedrig und das Pubis ist mit dem Ischium fest verwachsen; zwischen den beiden letzteren Knochen ist ein Foramen ob- 
turatorium bei Rhamphorhynchus und Dimorphodon zu sehen, das ebenso auch bei den Pterodactyloidea auftritt. Außerdem ist aber noch ein Knochen vorhanden, der zweifellos dem Praepubis der Krokodile entspricht und der sowohl im Becken der Rhamphorhynchoidea wie in dem der Pterodactyloidea auftritt. Diese Übereinstimnung mit dem Beckenbau der Krokodile ist sehr auffallend; es scheint hier nicht, wie v. Huene (1914) vermutet, eine Neuerwerbung der Flugsaurier vorzuliegen, die als eine bessere Stütze der Eingeweide funktionierte, sondern dürfte wohl als ein Ahnenmerkmal anzusehen sein, das in gleicher Weise bei den Krokodilen auftritt, aber allen anderen Reptiliengruppen fehlt. Die Praepubes sind bei den Rhamphorhynchoidea bandförnilg untereinander verbunden, während die Puboischia nicht verschmelzen; bei den Pterodactyloidea verschmelzen dagegen die Puboischia und die Praepubes bleiben frei.

Die Hinterbeine sind schlank; der Unterschenkel ist länger als das Femur. Nur die Tibia ist noch funktionell, die Fibula ist rudimentär und griffelartig zugespitzt; sie erreicht kaum die halbe Länge der Tibia. In Tarsus sind zwei übereinanderliegende, aus mehreren verschmolzenen Elementen bestehende Fußwurzelknochen vorhanden. Der Hinterfuß ist funktionell fünfzehig, und zwar war die fünfte Zehe nach hinten abgebogen; schon bei Dimorphodon, aber ebenso bei Rhamphorhynchus ist diese Abbiegung deutlich zu sehen. Diese Zehe diente als Spannknochen wie der Sporn an Calcaneus der Fledermäuse, und zwar muß sie das Uropatagium gespannt haben, das sich zwischen den Hinterfüßen und dem Schwanz ausspannte. Die Stellung der Füße bei gespreizten Flughäuten muß also derart gewesen sein, daß die Zehen nach hinten gerichtet waren; dies bedingt eine Fußstellung, wie bei den Fledermäusen. Bei den Pterodactyloidea ist die Stellung der HinterfüBe anders gewesen; die fünfte Zehe ist bei ihnen verkümmert. Die Zehengliederformel ist 2, 3, 4, 5, 2 für den 1.-5. Zehenstrahl.

Die Wirbelsäule besteht aus 7 sehr langen und kräftigen Halswirbeln (bei Rhamphorhynchus), denen sich die rasch an Größe abnehmenden Brustwirbel anschließen (in der Regel 14); dann folgen zwei rippenlose Lendenwirbel, die den Pterodactyloidea fehlen. Alle präsakralen Wirbe! sind procöl und erinnern dadurch an die Wirbel der jüngeren Krokodilier. Ebenso ist die Art der Gelenkverbindung der Rippen mit den Querfortsätzen auffallend krokodilartig. Das Sacrum besteht bei den Rhamphorhynchoidea konstant aus 4 Wirbeln.

Der Schwanz ist bei allen Rhamphorhynchoidea sehr lang und war vollkommen steif, wie aus dem dichten Sehnengeflecht hervorgeht, das den Schwanz umhüllt und das schon bei den ältesten Typen vorhanden war. Diese Sehnenstränge waren verknöchert und haben in ähnlicher Weise wie bei den Ornithischiern in der Rumpfregion oder bei Archae- 
opteryx in der Schwanzregion die Biegung der betreffenden Abschnitte der Wirbelsäule verhindert.

Die Rhamphorhynchoidea erscheinen, falls sich die noch unvollkommen bekannte Gattung Tribelesodon als ein echter Rhamphorhynchoide erweisen sollte, was wahrscheinlich ist, zuerst in der oberen Trias und verschwinden im oberen Jura.

Tribelesodon. - Obere Trias von Besano (Lombardei). ${ }^{1}$

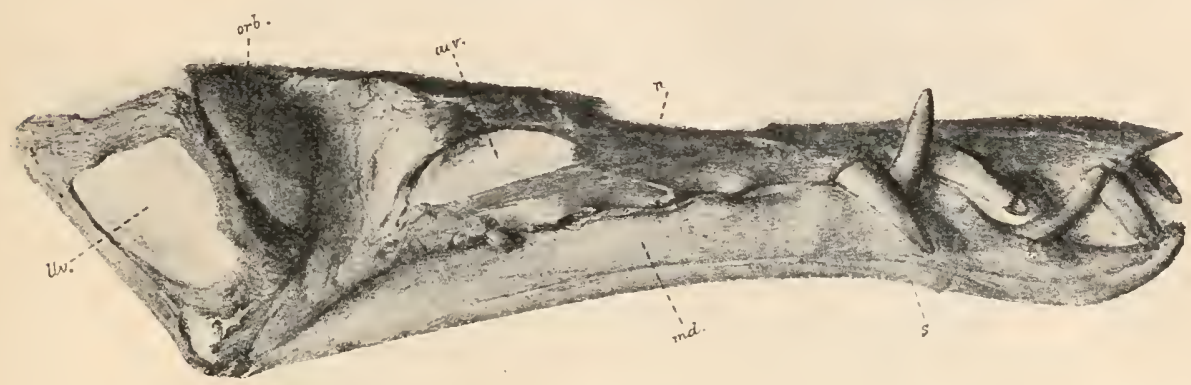

Fig. 440 .

Schädel von Rhamphorhynchus longiceps, A. Smith-Woodward, aus dem lithographischen Schiefer von Eichstätt in Bayern. Etwa $3 / 5$ nat. Gr.

(Nach A. Smith Woodward.)

aov - Fenestra praeorbitalis. $\quad m d=$ Unterkiefer.

orb $=$ Orbita.

ltv = seitliche Temporalgrube.

$s=$ Hinterende der Symphyse des Unterkiefers. $n$ Nasenöffnung.

$Z_{\|}$beachten ist die Abwärtsbiegung des Unterkieferendes und die relative Größe der Fangzähne im Vorderteil der Schnauze.

\section{Dimorplodon. - Unterer Lias von Lyme Regis (England)²} (Fig. 438).

1 F. Bassani, Sui fossili e sull' età degli schisti bituminosi triasici di Besano di Lombardia. - Atti della società italiana di scienze naturali XXIX, Milano, 1886.

${ }^{2}$ R. Owen, On a New Genus (Dimorphodon) of Pterosauria. - Repoits of the British Association Advanc. Science, 1858, p. 97.

Derselbe, On the Vertebial Characters of the Order Pterosauria, as exemplified in the Genera Pterodactylus (Cuvier) and Dimorphodon (Owen). - Plilosoph. Transactions Roy. Soc., London 1860, Vol. CXLIX, p. 161.

Derselbe, Monograph of the Fossil Reptilia of the Liassic Formations. Part II, Pterosauria. - Palaeontographical Society, London 1870, Vol. XX1II. p. 41.

H. G. Seeley, Remarks on Professor Owen's Monograph on Dimorphodon. Ann. Mag. Nat. Hist., London (4), Vol. V I, 1870, p. 129.

Derselbe, The Ornithosauria. - Cambridge 1870. - (Hier eingehende Bibliographie iiber Pterosauria, p. 129-132.)

Derselbe, The Ornithosaurian Pelvis. - Ann. Mag. Nat. Hist., London (6), Vol. V1I, 1891, p. 249.

A. Smith Woodward, Vertebrate Palaeontology, l. c. Cambridge 1898, p. 226. 
Campylognathus. - Oberer Lias von Holzmaden (Württemberg). ${ }^{1}$ Scaphognathus. - Oberer Lias von Whitby (England) ${ }^{2}$; oberel Jura Bayerns."

Dorygnathus. - Oberer Lias Württembergs. ${ }^{4}$

Rhamphorliynchus. - Oberer Jura (Tithon) Bayerus und Württembergs" (Fig. 439-442).

1 F. Plieninger, Campylognathus Zitteli. Ein neuer Flugsaurier ans dem Lias Schwabens. - Palaeontographica, Bd. 4I, 1895, p. 193. (Ausfuihrliche Bibliographie über Pterosaurier.)

Derselbe, Die Pterosaurier der Juraformation Schwabens. - Palaeontographica, Bd. 53, 1907, p. 217. (Ausfiihrliche Bibliographie iiber Pterosaurier.)

2 E. T. Newton, On the Skull, Brain, and Anditory Organs of a New Species of Pterosaurian (Scaphognathus Purdoni) from the Upper Lias, near Whitby, Yorkshire. - Philos. Transactions, Roy. Soc. London 1889, Vol. 179, p. 503.

${ }^{3}$ K. A. von Zittel, Handbuch der Palaeozoologie, III. Bd., S. 796.

${ }^{4}$ A. Wagner, Fische und Saurier im oberen wie unteren Lias. - Sitzungsberichte d. Kgl. bayr. Akad. d. Wissenschaften, München 1860, S. 48.

F. Plieninger, Die Pterosaurier der Juraformation Schwabens, I. c., 1907, S. 225 .

${ }^{5}$ H. von Meyer, Pterodactylus (Rhamphorhynchus) Gemmingi. - Palaeontographica, I. Bd., 1851, p. 1. - VII. Bd., 1860, p. 79.

Derselbe, Zur Fauna der Vorwelt. - Reptilien aus dem lithographischen Schiefer des Jura in Deutschland und Frankreich. - Frankfurt a. M., 1860, S. 67.

O. C. Marsh, The Wings of Pterodactyles. - Amer. Journ. Science (3), Vol. XX111, 1882, p. 251.

K. A. von Zittel, Über Flugsaurier aus dem lithographischen Schiefer Bayerns. - Palaeontographica, Bd. XXIX, 1882, p. 47.

T. C. Winkler, Note sur une espèce de Rhamphorhynchus du Musée Teyler. - Archives dı Musée Teyler, Haarlem (2), Vol. I, 1883, p. 219.

A. Smith Woodward, On Two Skulls of the Ornithosaurian Rhamphorhyıchus. - Ann. Mag. Nat. Hist., London (7). Vol. IX, 1902, p. 1.

F. Plieninger, l. c., 1907, p. $238 \mathrm{ff}$.

K. Wanderer, Rhamphorhynchus Gemmingi. - Palaeontographica, Bd. LV, 1908 , p. 195.

L. von Ammon, Über ein schönes Flughautexemplar von Rhamphorhynchus. - Geognostische Jahreshefte (1908), Muinchen 1909, S. 227.

F. König, Notizen zu einigen plastischen Rekonstruktionsversuchen (Habitusmodellen) von Flugsauriern, speziell Rlamphorhynchus. - Anticu. Katalog Nr. 24 von Schönhut, München 1910 .

E. von Stromer, Bemerkungen zur Rekonstruktion eines Flugsaurierskelettes. - Zeitschrift d. Deutschen Geol. Ges., 62. Bd., 1910, S. 85.

O. Abel, Grundziige der Palaeobiologie. - 1912, S. $300 \mathrm{ff}$.

Derselbe, Über den Erwerb des Flugvermögens. - Vorträge des Vereins zur Verbreitung naturw. Kennt. in Wien, 52. Jahrg., 8. Heft, Wien 1912, S. 14.

E. von Stromer, Rekonstruktionen des Flugsauriers Rhanphorhynchus Genmingi H. v. M. - Netres Jálurbuch f. Mineralogie usw., 1913, II. Bd., S. 49.

O. Jaekel, Die Flïgelbildung der Flugsaurier und Vögel. - Anatom. Anzeiger, Jena 1915, S. 1. 


\section{Ordnung: Pterodactyloidea.}

Auf die grundlegenden Unterschiede zwischen dieser Ordnung und den Rhamphorhynchoidea ist schon früher eingegangen worden. $\mathrm{Z}_{1}$
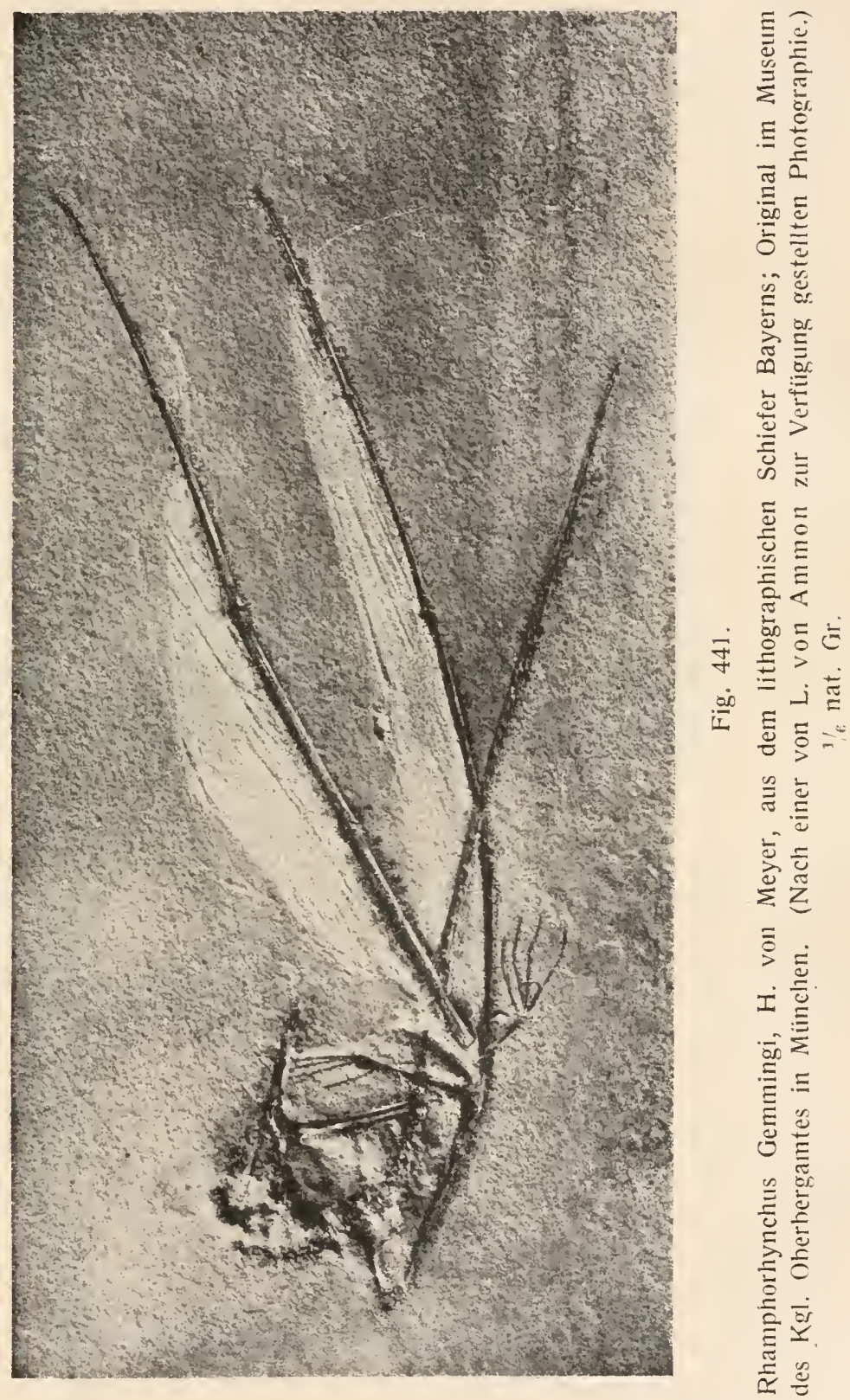

diesen Differenzen gehört in erster Linie die Reduktion des Schwanzes, die andere Stellung des Hinterfußes mit dem reduzierten fünften Zehen- 


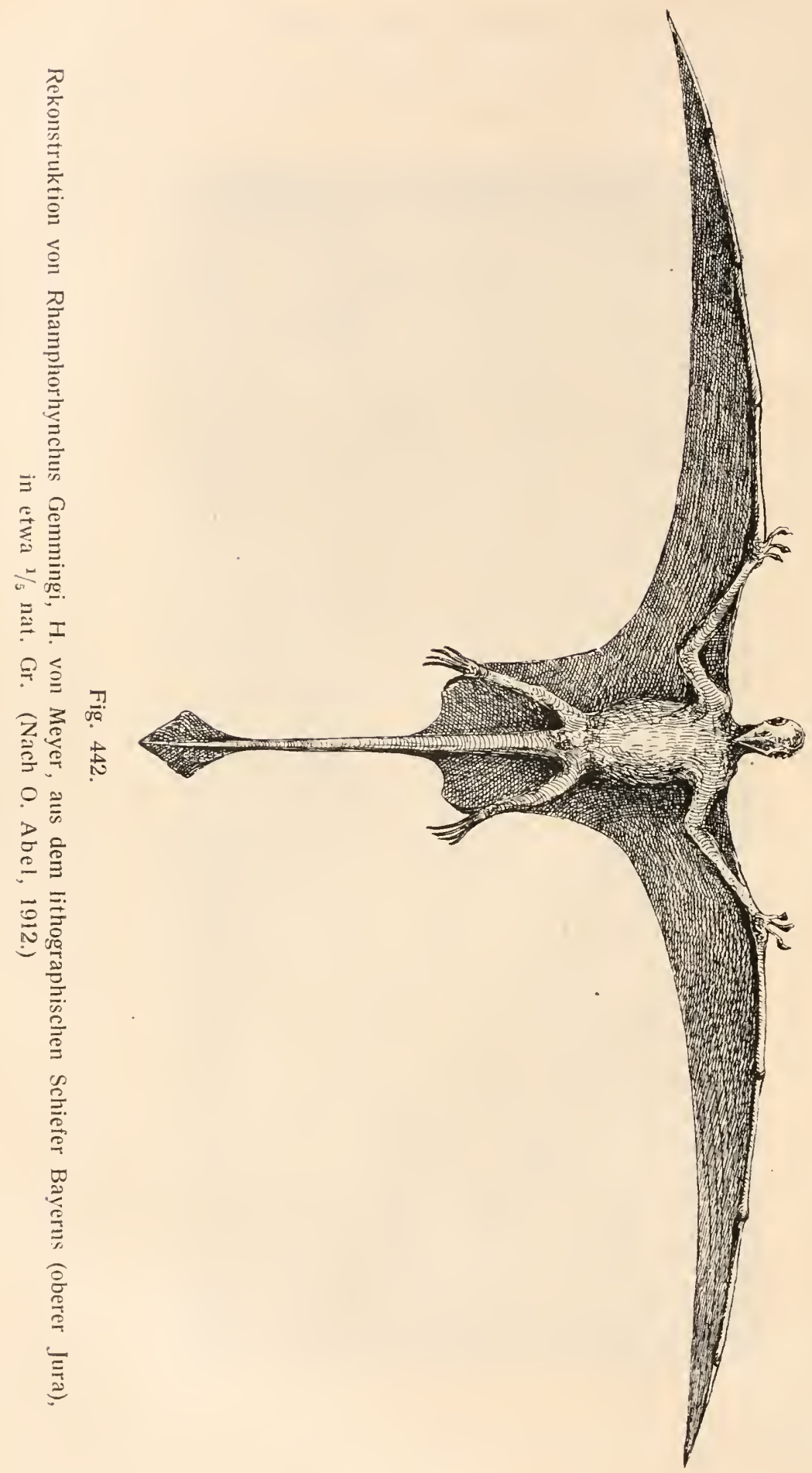


strahl, die Verschmelzung der beiden Puboischia in der Symphyse und die bedeutende Länge des Metacarpus, der beinahe die Länge des Unterarms erreicht. Die Vereinigung der Präorbital- mit der Nasenöffnung kann aus dem Grunde nicht als fundamentaler Gegensatz betrachtet werden, da sie nur eine Spezialisationssteigerung gegenüber den Rhamphorhynchoidea, aber keine Spezialisationskreuzung darstellt und überlıaupt nur bei einer Familie auftritt. Ebenso kann auch die hölere Zalıl der Sakralwirbel niclıt in die Reihe der die beiden Ordnungen trennender Unterschiede aufgenommen werden.

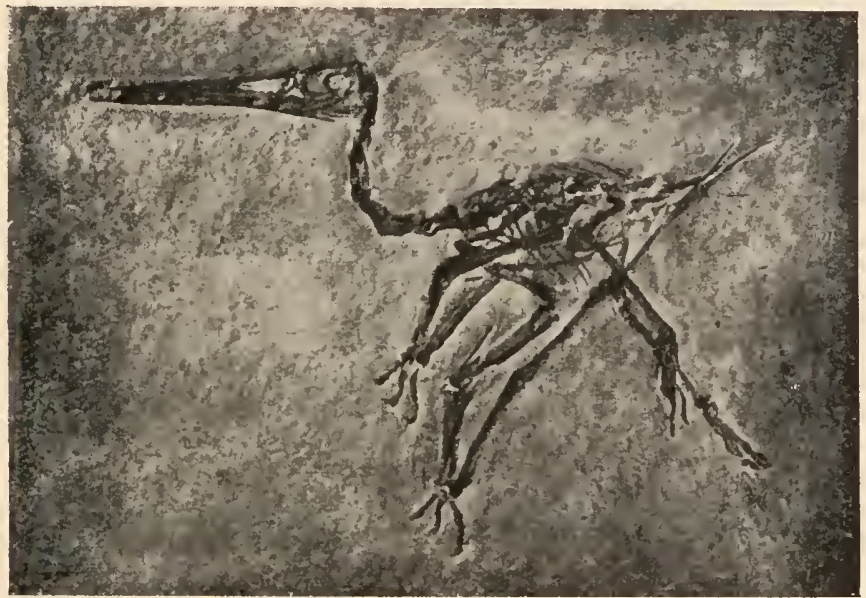

Fig. 443.

Pterodactylus scolopaciceps, H. v. Meyer, aus den lithographischem Schiefer von Eichstätt in Bayern. Etwa $1 / 2$ nat. Gr. (Nach O. Abel, 1912.)

Die Pterodactyloidea, die von Beginn ihrer Geschichte an ihre eigenen Wege gegangen sind, sind in keinen älteren Ablagerungen als aus dem oberen weißen Jura mit Sicherheit nachgewiesen, müssen aber jedenfalls schon in der Trias vorhanden gewesen sein. In der Kreideformation treten hochspezialisierte Gattungen auf, die verschiedenen Seitenzweigen des Stammes der Pterodactyloidea angehören; der eine dieser Seitenzweige sind die unterkretazischen Ornithodesmidae nit dem merkwürdigen Ornithodesmus latidens aus dem Wealden der Insel Wight, der zweite Seitenzweig sind die Ornithocheiridae der oberen Kreide Europas und Nordamerikas, die sich wieder in die Pteranodontinae und in die Nyctosaurinae gespalten haben. Diese Gruppe umfaßt mit Pteranodon ingens, der eine Spannweite der Flügel von über 8 m erreichte, die größten Flugtiere aller Zeiten. Die Pterodactyliden sind aus jüngeren Ablagerungen als Tithon (oberster Jura) un- 
bekannt, die Ornithocheiriden sind nur von der unteren bis zur oberen Kreide bekannt.

\section{F. Pterodactylidae.}

Der Scliädel ist in eine langgestreckte Sclmauze ausgezogen, deren Bezahnung im allgemeinen schwach ist; eine stärkere Bezalnnung hat z. B. Pterodactylus Iongicollum, eine schwächere P. suevicus, so daß wir schon hier eine Reduktion des Gebisses beobachten können, die bei den Ornithodesmiden und Ornithocheiriden viel weiter vorgeschritten ist und schließlich mit der gänzlichen Zahnlosigkeit der Kiefer endet (z. B. Pteranodon).

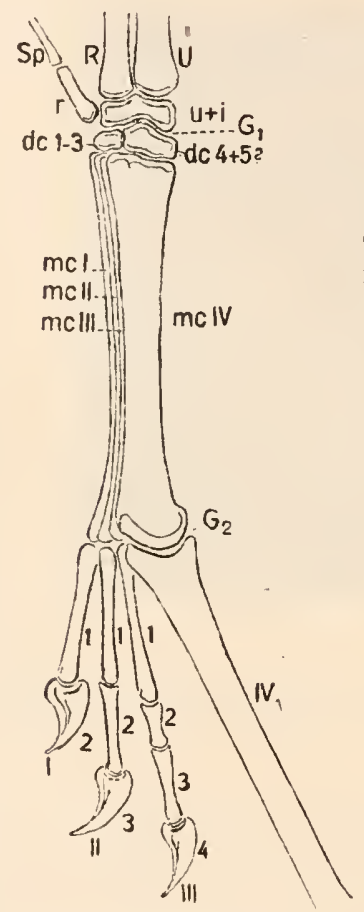

Fig. 444.

Schematische Darstellung des linken Handskelettes eines Pterodactylıs, um die allgemeinen Lageverhältnisse der Handelemente zu zeigen. (Nach O. Jaekel, zum Teil Deutung der Elemente nach O. Abel.)

$\begin{array}{ll}d c & =\text { distale Carpalia. } \\ G_{1} & \text { Gelenk zwischen der proximalen } \\ & \text { und der distalen Reihe der Car- } \\ & \text { palia. } \\ G_{2} & \text { Gelenk des Flugfingers. } \\ m c & \text { Metacarpalia. } \\ r & \text { Sesambein (Sehnenknochen), } \\ & \text { proximaler Spannknochen. } \\ R & \text { Radius. } \\ S p & \text { distaler Spannknochen (Sesan- } \\ u+i \quad & \text { bein }=\text { Sinare + Intermedium }+ \text { Ra- } \\ & \text { diale. } \\ U & \text { Ulna. } \\ I-I V \quad & \text { I.- IV. Finger. }\end{array}$

Die Präorbitalöffnung ist mit der Nasenöffnung vereinigt, ebenso ist die Spange zwischen der Orbita und der Präorbitalöffnung unterbrochen, so daß eine einzige große laterale Schädelöffnung vorliegt, die durch zwei spitz endende Spangenreste vor der Orbita in einen vorderen und hinteren Teil zerlegt wird. Außerdem ist nocl eine langgestreckte, schmale untere und eine kleine obere Schläfenöffnung vorhanden.

lin Flugfinger sind die Phalangengelenke in viel höheren Grade beweglich gewesen als bei den Rhamphorhynchoidea, so daß der Flugfinger cine mehrfaclie Knickung aufweist und vielleicht zusammengelegt werden konnte. Diese Knickung der Phalangengelenke ist an vielen Skeletten deutlich zu beobachten und ist an den hier abgebildeten 
rekonstruierten Skelett von Pterodactylus spectabilis zum Ausdruck gebracht (Fig. 445, 446).

Das Sternum ist relativ klein. Die Puboischia sind wahrscheinlich immer in der Mittellinie verwachsen, was in der Zeichnung fehlerhaft dargestellt ist. Der fünfte Zehenstralıl ist rudimentär.

Pterodactylus. - Oberer (weißer) Jura Süddeutschlands und Frankreichs, vielleicht auch in Kimmeridgien Englands. ${ }^{1}$ (Fig. 443-446).

\section{F. Ornithodesmidae.}

Ornithodesmus. - Wealden der Insel Wight, England. Schädel aus zarten Traversen aufgebaut, Suturen der Knochen fast ganz obliteriert. Zälne auf den vordersten Teil der Kiefer bescluränkt, Nasenöfnung durch eine Spange von der Präorbitalöffnurig getrennt; auBerdem eine hintere Präorbitalöffnung vorhanden, die nit der Orbita zusammenfließt; ihre ehemalige Trennungsspange gegen die Orbita ist noch deutlich erkennbar. Eine schmale untere und kreisförmige obere Temporalöffnumg vorhanden.

Die vorderen Rückenwirbel sind zum Teil zu einem ,Notaritum“ verschmolzen, was wolnl auch bei den Ornithocheiriden, aber nicht bei den Pterodactyliden der Fall ist; das Oberende der Scapula artikuliert in einer Grube an der Seitenwand des Notariums, das durch die verwachsenen Neurapophysen von 6 Wirbeln gebildet wird. Außerdem noch 6 freie Dorsalwirbel vorhanden. Der Mittelliandknochen des Flugfingers erreicht die halbe Länge des Vorderarms² (Fig. 447).

1 H. v. Meyer, Zur Fauna der Vorwelt, 1. c.

Derselbe, Pterodactylus spectabilis aus dem litlographischen Schiefer von Eichstätt. - Palaeontographica, Bd. X, 1861, p. 1.

A. Wagner, Beschreibung einer neten Art von Ornithocephalus, usw. Abhandl. d. Kgl. Bayr. Akad. d. Wiss., München 185I, VI. Bd., S. 132.

Derselbe, Neue Beiträge zur Kenntnis der urweltlichen Fauna des lithographischen Schiefers. - Ibidem, VIII. Bd., 1858, S. 415.

T. C. Winkler, Le Pterodactylus Kochi Wagn. dı Musée Teyler. - Archives du Musée Teyler, Hạarlen, T. 111, 1874, p. 377.

K. A. von Zittel, Über Flugsaurier aus den lithographischen Schiefer Bayerns. - Palaeontographica, XXIX. Bd, 1882, p. 49.

O. Fraas, Über Pterodactylus stevicus. - Ebenda, XXV. Bd., 1878, S. 163.

F. Plieninger, Die Pterosaurier der Juraformation Schwabens. - Ebenda, L.1II. Bd., 1907, p. 209.

O. Abel, Über den Erwerb des Flugvermögens. - Vorträge d. Vereins zur Verbreitung naturwiss. Kenntnisse, Wien 1912, 52. Jalırgang.

Derselbe, Grundzïge der Paläobiologie, 1912, S. 321.

F. Broili, Über Pterodactylus micronyx, H. v. Meyer. Zeitschrift der Deutschen Geol. Ges., 64. Bd., 1912, S. 492.

2 R. W. Hooley, On the Skeleton of Ornithodesmus latidens, an Ornithosaur from the Wcalden Shales of Atherfield (Isle of Wight). - Quart. Journ. Geol. Soc. London 1913, Vol. LXIX, p. 372. 

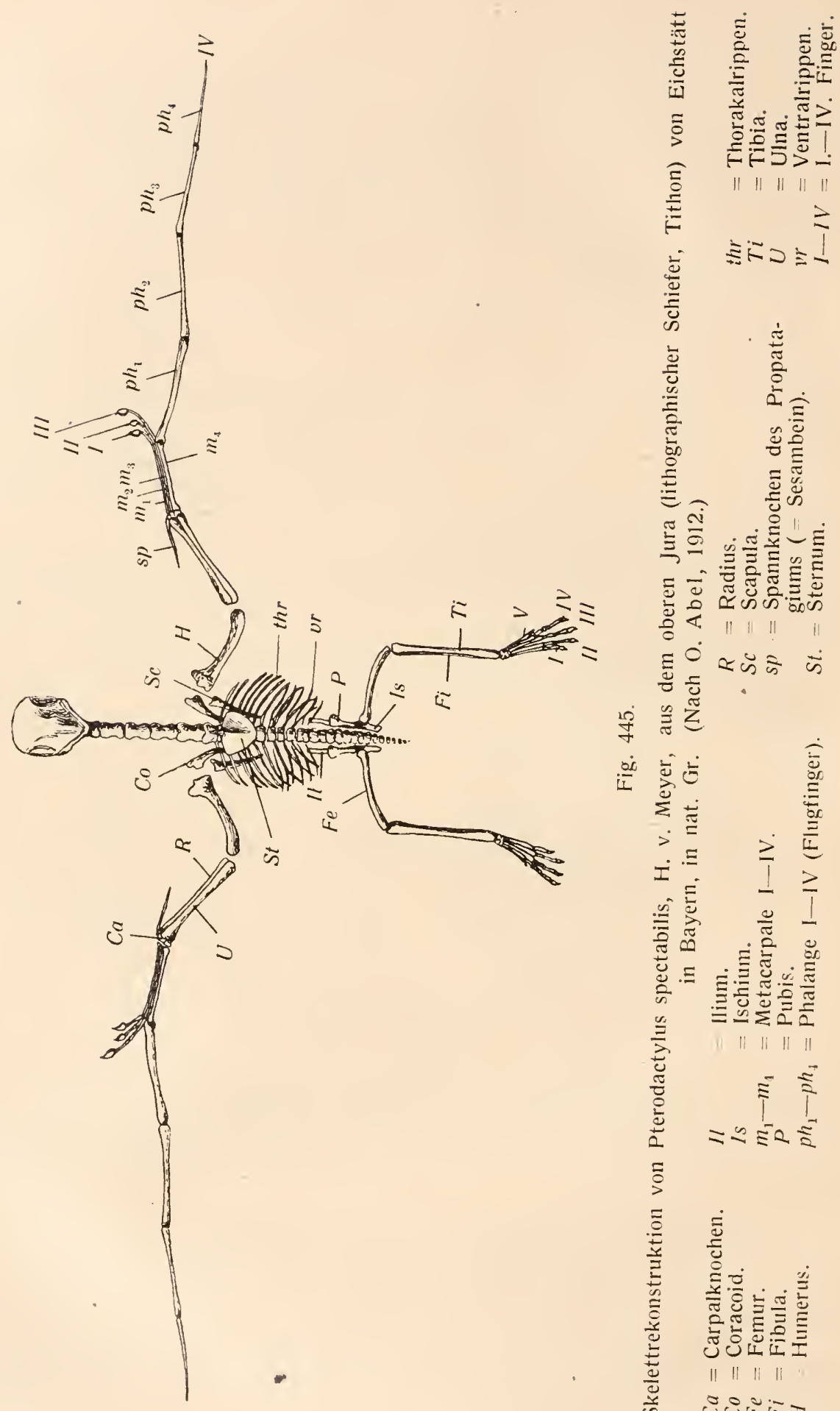

竞

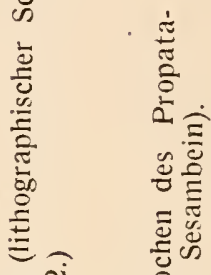

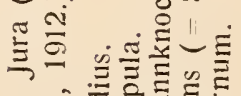

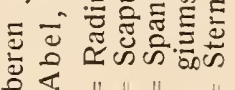
\& \|\|\|\|

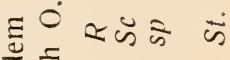
定孚 $\dot{0}$ $\therefore \dot{0}$

I. $\geq$

产 营.

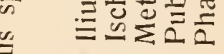
岁 || || $\mid \|$ 范

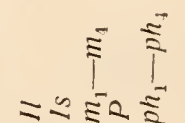

$2 \approx-ミ 2 ミ$

5

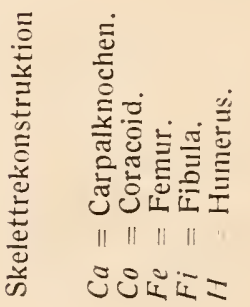




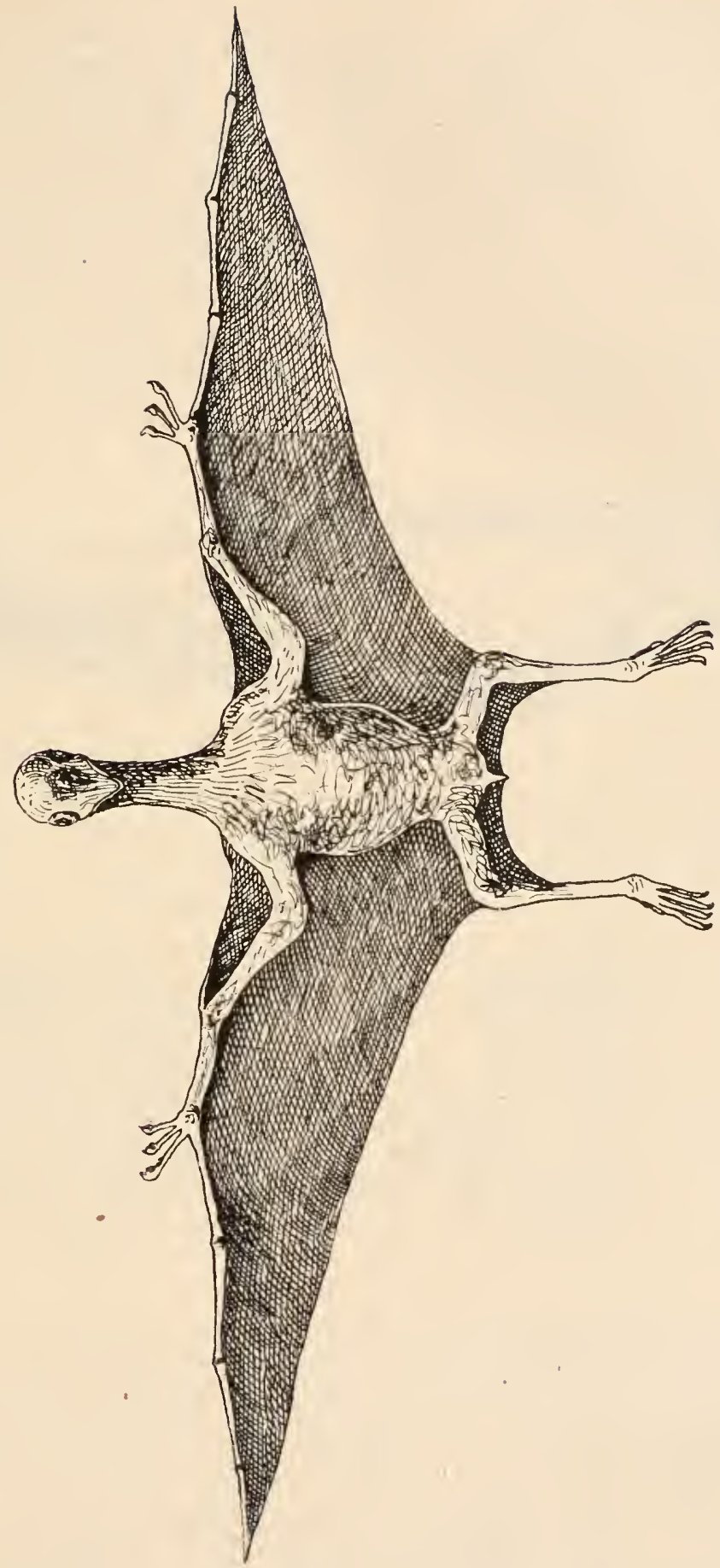

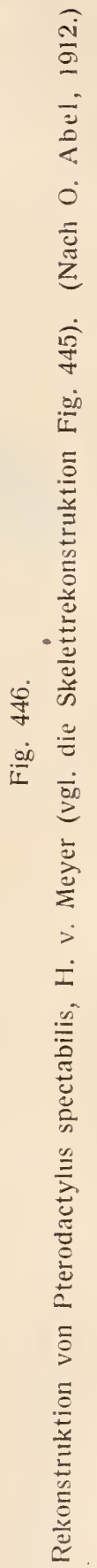




\section{F. Ornithocheiricae.}

Bei den Ornithocheiriden ist die Orbita vollständig umgrenzt und somit von der Präorbitalöffnung abgeschlossen. Ein Notarium (3 bis 8 Wirbel) ist vorhanden; bei den Nyctosaurinen tritt die Scapula nicht mit ihm in Verbindung, wohl aber bei den Pteranodontinen, und zwar lier ebenso wie bei Ornithodesmus. Der Schädel ist nur bei Ornithocheirus bezahnt, sonst zahnlos, mit langer, spitz zulaufender Schnauze. Die proximale Tarsusreihe ist mit der Tibia versclinolzen (Tibiotarsus). Vom fünften Zehenstrahl ist nur ein kleines Metatarsalrudinent erhalten. Die Zehen sind sehr lang; besonders lang sind die Metatarsen.

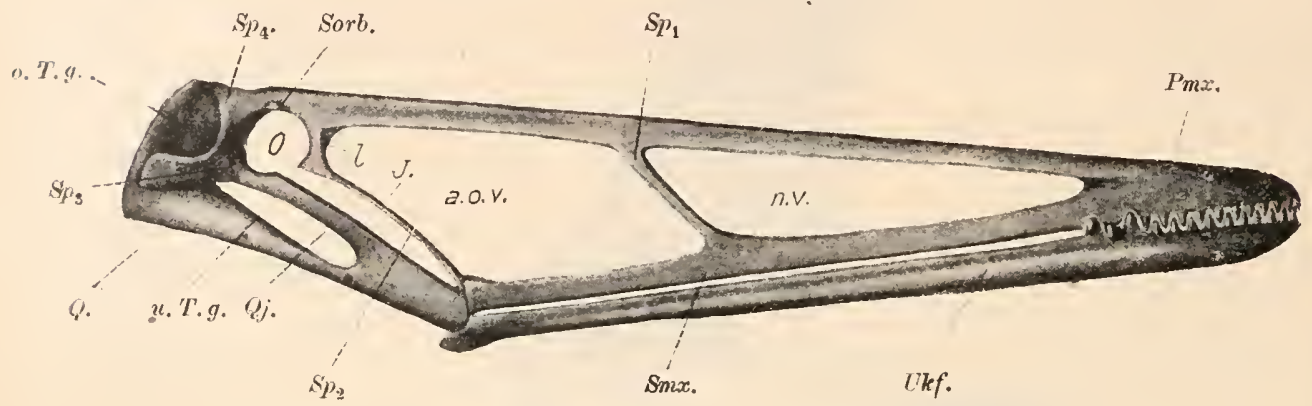

Fig. 447.

Rekonstruktion des Schädels von Ornithodesmus latidens, Seeley, aus der Unterkreide (Wealden) von Atherfield auf der Insel Wight. 1/5 nat. Gr.

(Nach R. W. Hooley, 1913.)

$\begin{array}{ll}J . & =\text { Jugale. } \\ \text { Pmx. } & =\text { Praemaxillare. } \\ \text { Smx. } & =\text { Supramaxillare. } \\ \text { Q. } & =\text { Quadratum. } \\ \text { Qj. } & =\text { Quadratojugale. } \\ O . & =\text { Orbita. } \\ o . T . g . & =\text { obere Temporalgrube. } \\ \text { u.T.g. } & =\text { untere Temporalgrube. } \\ \text { a.o.v. } & =\text { Fenestra praeorbitalis. } \\ \text { n.v. } & =\text { Fenestra nasalis (Nasen- } \\ \text { Ukf. } & \text { öffnung). }\end{array}$

$S p_{1}$. = Spange zwischen Praeorbitalgrube und Nasalgrube.

$S p .=$ Spange zwischen Praeorbitalgrube u. der Suborbitalgrube.

$S p_{3 .} . \quad$ - Spange zwischen oberer und unterer Temporalgrube.

$S p_{1} .=-$ Spange zwischen der Orbita u. der oberen Temporalgrube.

Sorb. - Supraorbitale (?).

l. $\quad$ Lacrymale, zugleich Spange zwischen Orbita und Praeorbitalgrube.

ebenso einzelne Grundphalangen, während in der dritten Zehe die zweite, in der vierten Zehe die zweite und dritte Plıalange auffallend verkürzt sind; die distal anschließenden Plıalangen sind wieder lang. Ebenso ist in der Hand die zweite Phalange des dritten Fingers verkürzt. Derartige Spezialisationen treten besonders in den Gliedmaßen arborikoler Tiere, z. B. bei den Batmfaultieren auf (Bradypus, Choloepus), und dies deutet auf eine arborikole Lebensweise der Vorfahren hin. Das Sternum ist gekielt, das Auge war durch einen Sklerotikalring geschützt. 
Die Fübe sind wahrscheinlich beim Fluge enge aneinander geschlossen gehalten worden ${ }^{1}$; die Hinterbeine sind zwar sehr schwach gebaut, aber verlängert und dürften dem Hinterende des Plagiopatagiums zum Ansatz gedient haben. Der Schwanz ist hochgradig rudimentär, ebenso der ganze Rumpf im Verhältnis zum enorm entwickelten Arm, Hals und Kopf.

Die weitgehendste Spezialisation hat der Schädel von Pteranodon erfahren; er läuft nach hinten in einen sehr zarten, dünnen, extrem verlängerten Kamm aus, der wahrscheinlich beim Fluge als Steuer gedient hat. Bei der Kleinheit des Rumpfes und der relativ enormen Größe des Schädels und der Kiefer ist anzunehmen, daß die Tiere einen Kehlsack besessen haben, in dem eine Vorverdaumug stattfand. Das Vorkommen spricht dafür, daß die Tiere eine marine Lebensweise ähnlich wie der Albatros (Diomedea) führten und nach Fischen jagten.

Unterfamilie Nyctosaurinae.

Schädel ohne Hinterhauptskamm, Scapula nicht an Notarium einlenkend. Kiefer zahnlos. Nur 3 Rückenwirbel zu einent Notarimm verschmolzen.

Nyctosaurus ( - Nyctoclactylus). - Obere Kreide von Kansas. Schwingenweite ttwa $2 \mathrm{~m}$. Nur 3 Wirbel zu einem Notarium verschmolzen. Die hinteren Rippen schlank, einköpfig; sie waren vielleicht abgespreizt und bildeten Stïtzen des Plagiopatagiums, ähnlich wie die Rippen von Draco volans. ${ }^{2}$ (Fig. 448).

Unterfamilie Pteranodontinae.

Schädel mit langem Hinterhauptskamm, Scapula anı Notarium einlenkend, Kiefer bei primitiveren Typen (Ornithocheirus) bezahnt, bei spezialisierten (Pteranodon) unbezahnt. 8 Rückenwirbel zu einem Notariun verschmolzen.

Ornithocheirus. - Wealden bis Oberkreide Englands. ${ }^{3}$

1 O. Abel, Die Lösung des Flugproblems bei den Tieren der Vorzeit. „Urania“, Wochenschrift für Volksbildung, Wien, 27. Mai 1916, S. 309. (Habitusbilder und neue Rekonstruktion von Pteranodon.)

2 S. W. Williston, The Skull of Nyctodactylus. - Journal of Geology, Vol. X, 1902, p. 525 .

F. von Huene, Beiträge zur Kenntnis des Schädels einiger Pterosaurier. Geol. und Paläont. Abhandl., N. F. Bd. XIII (G. R. Bd. 17), 1914, S. 57.

S. W. Williston, Kansas Pterodactyls. - Part I und II. Kansas Univ. Quarterly, Vol. 1, 1892, p. 1; Vol. II, 1893, p. 79.

3 H. G. Seeley, The Ornithosauria, an Elementary Study of the Bones of Pterodactyles usw.; Cambridge 1870, p. 84.

Dersclbe, Dragons of the Air. - London 1901, p. 176.

R.W. Hooley, On the Ornithosaurian Genus Ornithocheirus, with a Review of the Specimens from the Cambridge Greensand in the Sedgwick Museum, Cambridge. - Ann. Mag. Nat. Hist., London (8), Vol. XIII, 1914, p. 529. 
Die Stämme der Wirbeltiere.

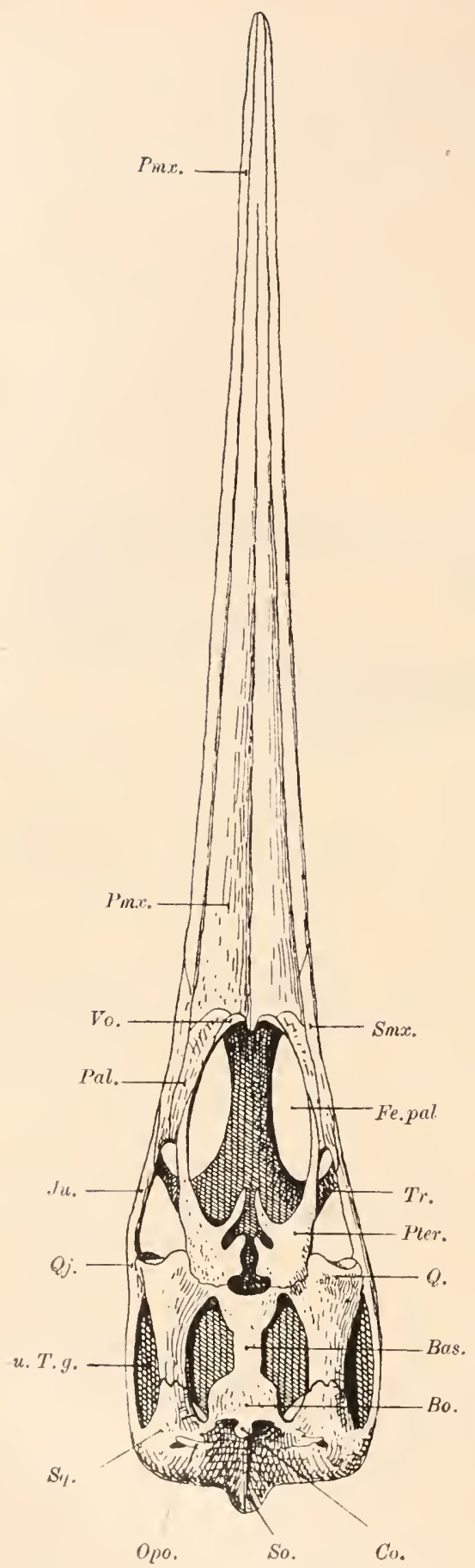

Fig. 448.

Unteransicht des Schädels von Nyctosaurus gracilis, Will., aus der oberen Kreide (Nicbrara Cretaceous) von Kansas. Etwas mehr als $1 / 2$ nat. Gr. (Nach S. W. Williston, mit Ergänzungen von F. von Huene; umgezeichnet.)

Bas. $\quad=$ Basisphenoid.

Bo. $\quad$ Basioccipitale.

Co. Condylus occipitalis.

Fe. pal. Fenestra palatina.

Jll. Jugale.

Opo. Opisthoticum.

Pal. - Palatinum.

Pmx. Praemaxillare.

Pter. Pterygoid.

Q. Quadratum.

Qj. Quadratojugale.

So. Supraoccipitale.

Simx. Supramaxillare.

Sq. $=$ Squamosum.

u. T. g. = untere Temporalgrube.

Vo. $=$ Vomer.

R. W. Hooley unterscheidet (1914) unter den bisher unter dem Gattungsnamen Oinithocheirus vereinigten Arten mehrere selbständige 
Gruppen und stellt für einige Arten die Gattungsnamen Lonchodectes und Amblydectes auf; unter Hinzuziehung der schon von Owen abgetrennten Gattung Criorhynchus würden sich nach Hooley innerhalb der „Ornithocheiriden“ zwei Unterfamilien unterscheiden lassen. Die erste (Ornithocheirinae) würde die Gattungen Ornithocheirus und Lonchodectes, die zweite (Criorhynchidae) die Gattungen Criorhynchus und

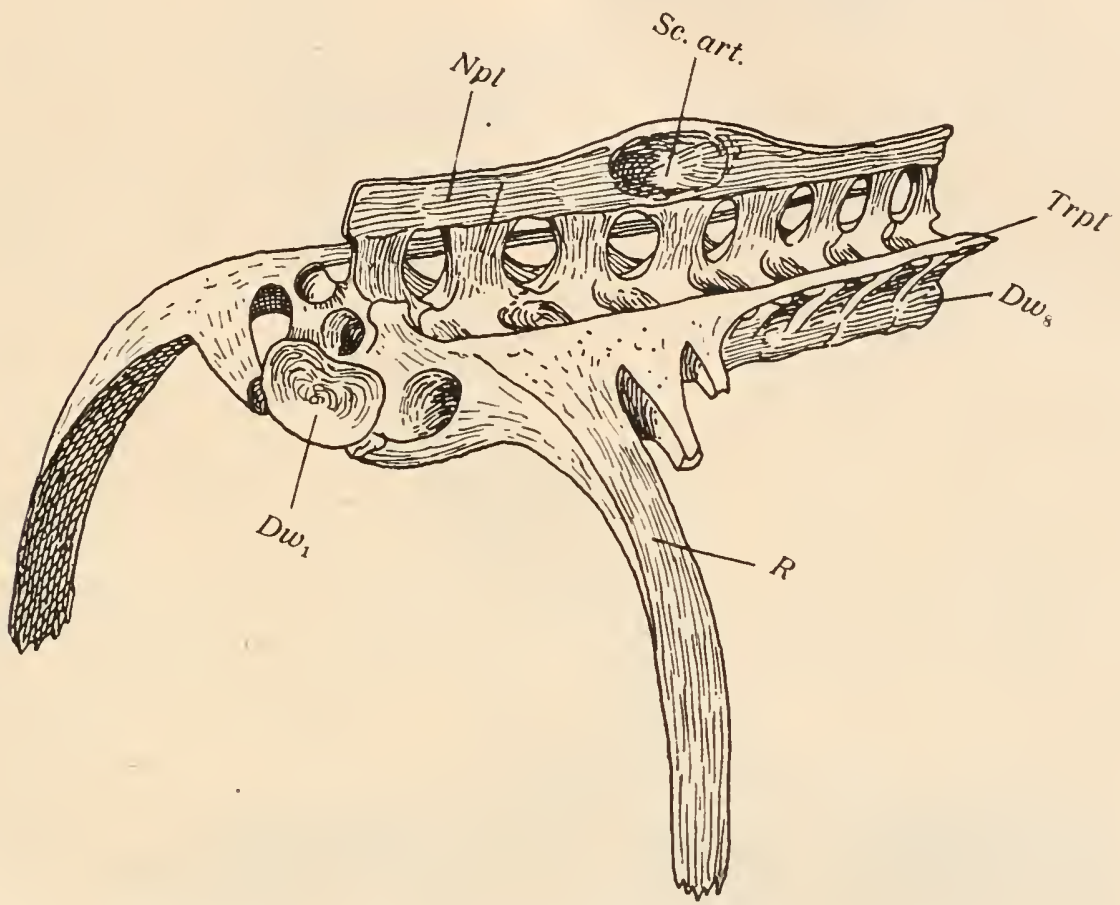

Fig. 449.

Notarium (Komplex, aus acht verschmolzenen Riickenwirbeln bestehend) von Pteranodon ingens, Marsh, aus der Oberkreide von Kansas. (Nach G. F. Eaton.) Npl. = die zu einer Platte verschmol- Sc. art. = Gelenkfläche fïr die Scapula zenen Neurapophysen der acht $D w_{1}=$ Vorderfläche des ersten Rücken . Wirbel.

$T r . p l .=$ die zul einer Transversalplatte $D v^{\prime}=$ achter Riickenwirbel. verschmolzenen Querfortsätze, $R$. = Ripp?. mit denen die Rippen conssif:ziert sind.

Amblydectes enthalten. Ich kann dieser Gruppierung ebensowenig beipflichten wie der von Hooley (1913) aufgestellten Systematik der Flugsaurier, in welcher Pteranodon und Ornithocheirus mit Nyctosaurus und Rhamphorhynchus zu einer geschlossenen Unterordnung vereinigt werden. Die Unterschiede der von Hooley unterschiedenen „Gattungen" innerhalb des Ornithocheiruskreises sind jedenfalls außerordentlich gering; der größte Unterschied besteht in den Längenverschiedenheiten der vorderen und hinteren Zähne. 
Pteranodon. - Oberkreide von Kansas, Nordamerika. - Spannweite der Flügel über $8 \mathrm{~m}$ erreichend, meist nur $6,5 \mathrm{~m}$ betragend. ${ }^{1}$ (Fig. 449-452).

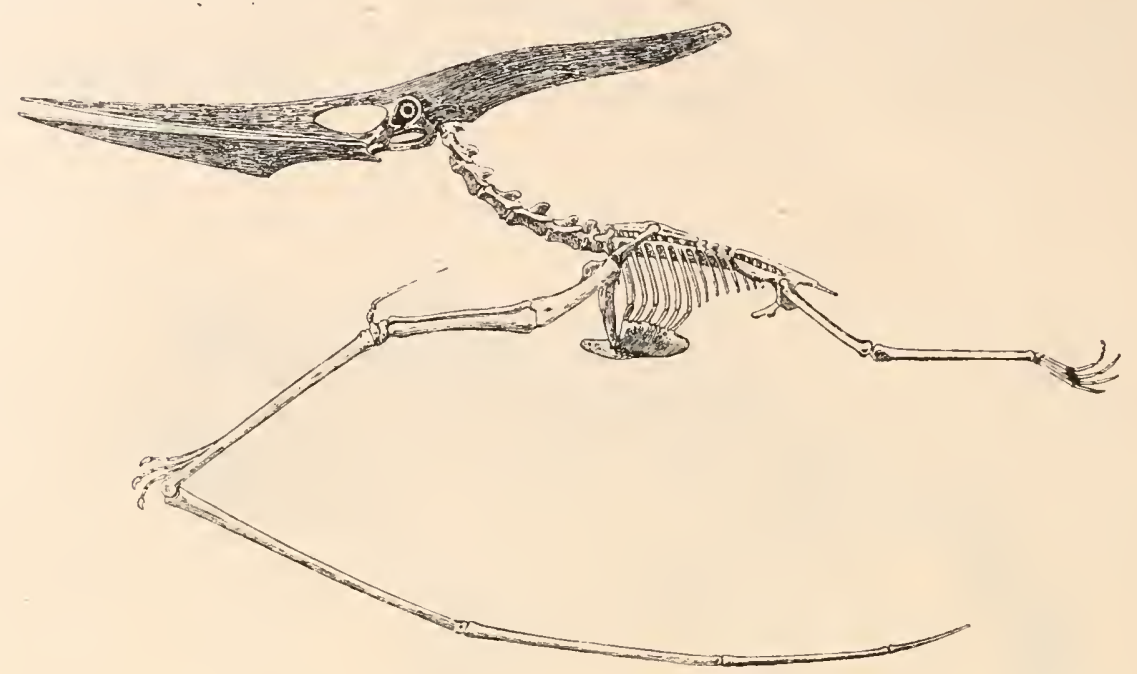

Fig. 450 .

Rekonstruktion von Pteranodon ingens, Marsh, aus der oberen Kreide von Kansas. Die Spannweite der Fliggel erreichte iiber $8 \mathrm{~m}$. (Nach G. F. Eaton.)

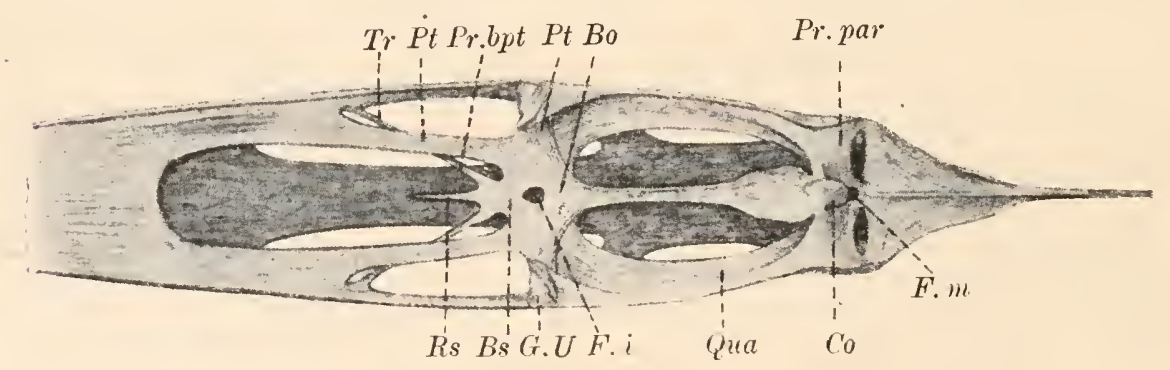

Fig. 451.

'Gaumenregion des Schädels von Pteranodon ingens, von unten gesehen, in 1/4 nat. Gr. (Nach G. F. Eaton, Deutungen der Knochen zum Teil nach J. Versluys.)

\begin{tabular}{|c|c|c|c|}
\hline Bo & Basioccipitale. & Pr. bpt & Basipterygoidfortsatz (?). \\
\hline Bs & Basisphenoid. & Pr. par & Prucessus paroticus. \\
\hline & Condylus occipitalis. & Pt & = Pterygoid. \\
\hline 8 & Foramen intertympanicum. & Qua & Quadratum. \\
\hline.$m$ & $\begin{array}{l}\text { Foramen magnum. } \\
\text { Gelenkfläche fiir den Unter- }\end{array}$ & $\begin{array}{l}\text { Rs } \\
T r\end{array}$ & $\begin{array}{l}\text { Rostrum sphenoidale. } \\
=\text { Transversum. }\end{array}$ \\
\hline
\end{tabular}
kiefer,

1 G. F. Laton, Osteology of Pteranodon. - Memoirs Conn. Academy of Arts and Sciences, Vol. I1, New Haven, Conn., 1910.

S. W. Williston, Kansas Pterodactyls, 1. c.

Derselbe, Restoration of Ornithostoma (Pteranodon). - Kansas Univ. Quarterly, Vol. VI, 1817, p. 35. Ältere Literatur bei F. Plieninger, 1907 (s. oben). 

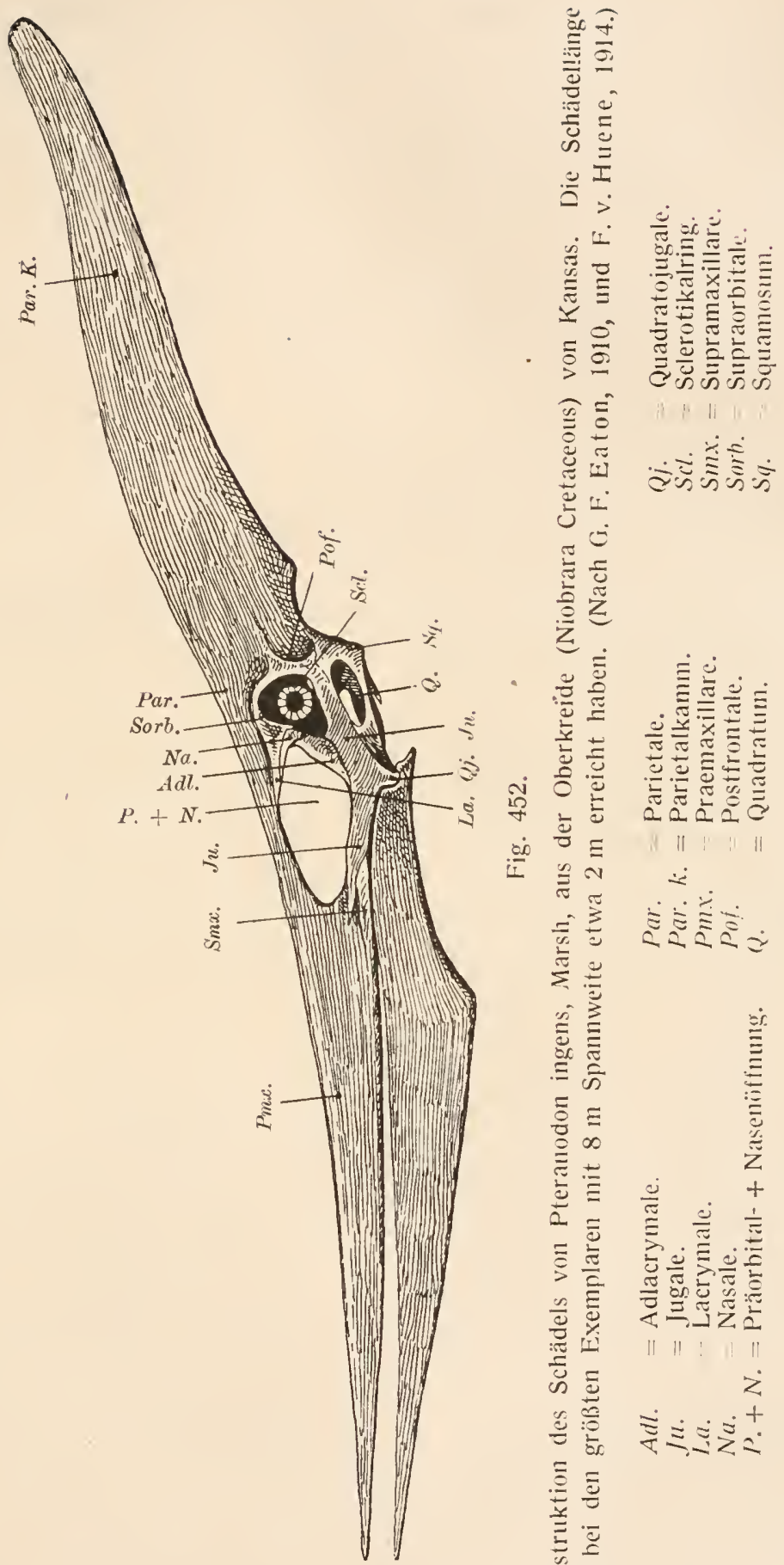

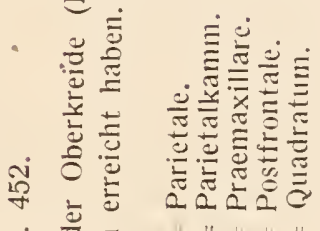

को

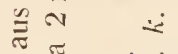

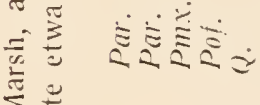

突

离

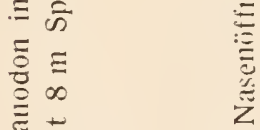

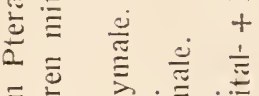

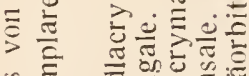

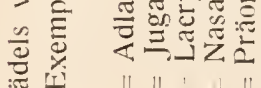

i

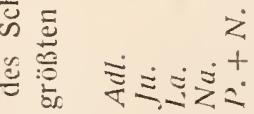

产 


\section{Ordnung: Dinosauria (= Saurischia).}

Unter dieser Bezeichnung ist nur ein Teil der zahlreichen Gattungen und Familien zusammenzufassen, die bisher unter dem Sammelbegriff der „Dinosaurier" vereinigt worden sind. Schon seit längerer Zeit hat man bei fortschreitender Erforschung des Skelettbaues der in dieser Gruppe vereinigten Gattungen die Gegensätze erkannt, die zwischen den ,"Theropoden" und ,Sauropoden" einerseits und den „Praedentata" (= Orthopoda) andererseits bestehen. Durch die Untersuchungen v. Huenes ist dieser Gegensatz zwischen den beiden Gruppen noch schärfer zur Geltung gekommen. Seit ihrer Abzweigung von der einstweilen noch unbekannten Ahnengruppe sind die beiden Stämme getrennte Wege gegangen und nicht aus einer primitiven Gruppe der „,Dinosaurier" später divergiert. Da es überaus wahrscheinlich ist, daß sich die Entwicklung der beiden Stämme nicht aus einer einzigen Stamngruppe vollzogen hat, sondern daß es zwei schon im Vorfahrenstadium der Dinosaurier sehr verschiedene Gattungsgruppen waren, die als Wurzeln der beiden Stämme zu betrachten sind, so dürfen wir wohl daran festhalten, daß die ,Dinosaurier" als einheitliche Ordnung aufzulösen sind. Für die erste Gruppe mag der Name "Dinosauria“ beibehalten werden, während die zweite als „Ornithischia“ abzutrennen ist. Die letzteren besitzen nach F. V. Huene engere verwandtschaftliche Beziehungen zu den Krokodilen, Pterosauriern und Vögeln, die den Dinosauriern (- Saurischiern) fehlen, so daß nach seiner Auffassung daraus hervorgeht, daß die Wurzel dieser vier Stämme eine gemeinsame und von der Wurzel der Dinosaurier verschiedene ist. ${ }^{1}$

1 F. von Nopcsa, ,Über Dinosaurier. - 1. Notizen iiber die Systematik der Dinosaurier" (Centralblatt f. Mineralogie, usw., 1917, S. 203) wendet sich gegen das Fallenlassen des Namens „Dinosaurier", wie ich dies gleichfalls vertreten habe. (O. Abel, „Die Dinosaurier und Ornithischier Nordamerikas". - Die Naturwissenschaften, 4. Jahrg., 1916, 32. und 33. Heft, S. 469-498.) Dagegen hat B. Brown (,Corythosaurus casuarius, a New Crested Dinosaur". - Bull. Amer. Mus. Nat. Hist., New York 1914) vorgeschlagen, den Namen ,Dinosauria“ ganz fallen zu lassen, da sich unsere jetzigen Kenntnisse von den phylogenetischen Beziehungen nicht mehr mit dem alten Begriffe der Dinosaurier vereinigen lassen. Dies wäre ja in der Tat die richtige Konsequenz der von v. Huene (,Das natïrliche System der Saurischia“. - Centralblatt f. Miı., usw., 1914, S. 154) dargelegten „Zweistämmigkeit" der „Dinosaurier" und würde jeden Versuch ausschließen, in ihnen eine ,polyphyletische" Gruppe zu erblicken. Erfahrungsgemäß läßt sich aber eine derartig eingebürgerte systematische Bezeichnung nicht leicht ausrotten; ich habe daher (1. c., 1916, S. 471) vorgeschlagen, ,fïr die Ordnung der Saurischia den althergebrachten Namen, „Dinosaurier" zu reservieren und für die zweite Ordnung den Namen ,Ornithischia" anzuwenden." Ich kann meinem Freunde Baron Nopcsa leider nicht darin folgen, in den Dinosauriern den systematischen Begriff einer ,Überordnung“ zn erblicken; er hat in den Gesprächen, die wir ïber 
Die entscheidenden Merkmale und Unterschiede zwischen den Dinosauriern und den Ornithischiern bestehen vor allem im Bau des Beckens. Bei den Dinosauriern ist das Pubis nach vorn gerichtet, schlank und mitunter in der Mittellinie verwaclısen (z. B. bei Plateosaurus), ähnlich wie dies bei den Ischia der Fall ist. Bei den Ornithischiern (= Praedentata) ist dagegen das Pubis ebenso wie bei den Vögeln nach hinten gerichtet nnd legt sich als dünner, schlanker Knochenstab unter das gleichfalls stark verlängerte, stabförmige Ischinm, wie dies in typischer Ausbildung z. B. bei Iguanodon oder Camptosaurus zu beobachten ist. Dies ist jedoch nur bei den bipeden Typen der Fall; die sekundär quadruped gewordenen Ornithischier (z. B. Triceratops, Stegosaurus, Ankylosaurus) zeigen ein abwaichendes Verhalten, indem bei diesen Formen das Pubis entweder verdickt ist und zusammen mit dem Ischium ein in physiologischer Hinsicht einheitliches Skelettstück bildet (Stegosaurus) oder rudimentär wird (Triceratops) oder ganz verloren geht (Ankylosaurus). Diese Umbildungen des Pubis bei den sekundär quadrupeden Typen beweisen den kausalen Zusammenhang zwischen der bipeden Körperhaltung und der Ausbildung eines schlanken, unter dem Ischium liegenden Pubis, wie wir es auch bei den Vögeln antreffen. ${ }^{1}$

Der nach vorne ge ichtete Beckenknochen der Ornithischier, der frülıer mit den' Pubis homologisiert wurde, ist dagegen als eine. Neuerwerbung anzusehen und als Processus pseudopectinealis zu bezeichnen. Mit Ausnahme von Ankylosaurus, bei welchem dieser Knochen I udimentär ist, finden wir ihn bei den Ornithischiern stets deutlich entwickelt. Es bildet einen vor der Gelenkpfanne (Acetabulum) gèlegenen Fortsatz, der aber nicht mit an derselben Stelle liegenden Processus pectinealis der Vögel homolog ist; dieser gehört dem llium an,

diese Frage führten, auf den Fall der Pterosaurier hingewiesent. Auch hier bin ich aber für eine möglichst scharfe Trennung beider unabhängig voneinander ent- standenen Stämme (Rhamphorhynchoidea und Pterodactyloidea). Die Systematik darf nicht zu einem starren Rahmen werden, sondern muß als elastisches Band sich den Ergebnissen der stanımesgeschichtlichen Forschungen anzuschmiegen trachten.

1 Das nach hinten gerichtete Pubis der Ornithischier ist früher meist als ein neues, dieser Reptilgruppe eigentïmliches Gebilde betrachtet und als ,Postpubis“ bezeichnet worden, während man den nach vorne gerichteten Beckenast mit dem Pubis homologisierte. Sonach würde hier ein Fall konvergenter Anpassung vorgelegen haben, wie ich dies in meiner ,,Paläobiologie der Wirbeltiere“ (1912, S. 269) darzulegen versuchte. Da aber seither gewichtige Gründe dafür geltend gemacht worden sind, daß der vordere Beckenast der Ornithischier nicht dem Pubis entspricht, sondern als ,Processus pseudopectinealis“ eine Neuerwerbung, der hintere Pıbisast aber das ehemalige, nur ebenso wie bei den Vögeln nach hinten gewendete Pubis darstellt, so liegt hier kein Fall einer konvergenten, sondern einer parallelen Anpassung vor. 
während der entsprechende Fortsatz des Ornithischierbeckens dem Bereiche des Pubis angehört. Er ist daher als ,Processus pse $u d 0$. pectinealis" zu unterscheicen (F. Nopcsa, 1905). ${ }^{1}$ An ihm heftete sich wahrscheinlich ebenso wie bei den Vögeln der Musculus ambiens an. Im Gegensatze zu den konvergierenden Pubes, die in der Medianebene zusammenstoßen, divergieren die Processus pseudopectineales stark nach außen gegen die Rippen (Fig. 504, S. 638).

Ein weiterer Gegensatz zwischen den Dinosauriern und Ornithischiern lieğt im Bau des Gesichtsteiles des Schädels, der bei den Ornithischiern sehr eigentümliche Spezialisationen erfahren hat. Dagegen verhält sich der Gehirnteil des Schädels in beiden Gruppen ziemlich gleich. Auch die Wirbelsäule und die Rippenartikulation weist wenig Verschiedenheiten in beiden Gruppen auf (v. Huene, 1914). Die Kieferteile des Ornithischierschädels sind infolge des Überganges von der karnivoren zur herbivoren Nahrungsweise sehr stark modifiziert; die Kieferenden wurden (mit Ausnahme von Hypsilophodon) zahnlos und von einen Hornsclnabel bedeckt, während in Unterkiefer ein neuer Knochen (Praedentale) in der Symphysenregion auftrat. Die Umformung der Praemaxillaria und die Ausbildung eines hohen Kronfortsatzes im Unterkiefer der Ornithischia sind als Folgen der geänderten Gebißfunktion zu betrachten.

Ein wichtiger Unterschied beider Gruppen liegt ferner in der Ausbildung starker Sehnenverknöcherungen längs der Wirbelsäule der Ornithischier, die den Dinosauriern fehlen. Dagegen fehlen den Ornithischiern die Bauchrippen, die bei den Dinosauriern vorhanden sind.

Die Dinosaurier zerfallen in zahlreiche Familien, die sich in mehrere Unterordnungen (Coelurosauria, Pachypodosauria, Theropoda und Sauropoda) trennen lassen.

Eine der auffallendsten Eigenschaften der Dinosaurier ist ihre gewaltige Körpergröße; auch die Oruithischier haben zahlreiche Riesenformen aufzuweisen, die aber doch hinter den riesigen Typen wie Brontosaurus, Brachiosaurus, Diplodocus, Tyrannosaurus usf. zurückbleiben. Dieser enorme Wuchs steht nach neueren Untersuchungen F. v. Nopcsas mit einer auffallenden Vergrößerung der Hypo-

a F. von Nopcsa, Notes on British Dinosaurs. Part 1: Hypsilophodon. Geological Magazine, London 1905, p. 203.

Derselbe, Über Dinosaurier: 3. Über die Pubis der Orthopoden. - Centralblatt f. Mineralogie usw., 1917, Nr. 15 und 16, S. 348 (Literatur).

F. v. Huene, Beiträge zur Lösung der Praepubisfrage bei Dinosauriern und anderen Reptilien. - Anat. Anzeiger, XXXI1I. Bd., 1908, S. 401.

Dersclbe, Beiträge zur Geschichte der Archosaurier. - Geol. u. Paläont. Abhandl., N. F., Bd. XII1 (G. R. Bd. XV11), 1. Heft, Jena 1914, S. 38.

G. Heilmann, Fuglenes Afstaming. - Kobenhavn 1916. 
physe des Gehirns in Zusanmenhang. Eine gleichartige Hypertrophie der Hypophyse findet sich auch bei jener Art des Riesenwuchses, die in der pathologischen Anatonie als Akromegalie bezeichnet zu werden pflegt. Freilich ist durch den Nachweis der Hypertrophie der Hypophyse bei Dinosauriern und Ornithischiern, die in der Tat mit ilırem Riesenwuchs in kausalem Verhältnis zu stehen scheint, die Frage nach der Ursache dieser Hypophysenvergrößerung noch nicht gelöst. ${ }^{1}$

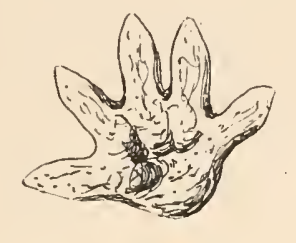

Fig. 453.

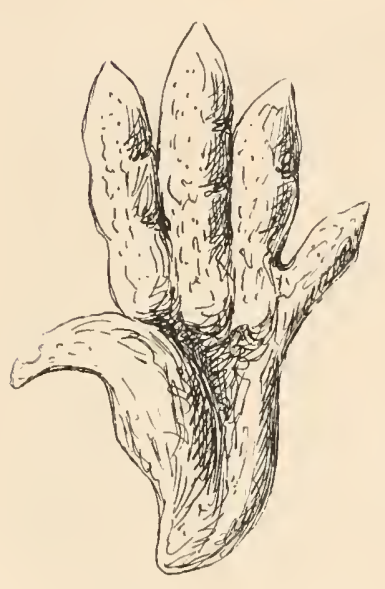

Fährte eines Dinosauriers (Chirotherium storetonense) aus der Trias von Storeton, Cheshire, England. Oben: die kleine Handfährte, unten: die große Fuß fährte mit seitlich abstehendem Hallux (Großzehe) und starkem Ballen der Großzehe, der beweist, daß sie den iibrigen Zehen opponiert werden konnte.

Nach dem Original im Brit. Mus. Nat. Hist., London, unter Beniitzung der Abbildungen von H. G. Morton (1897) gezeichnet. 1/, nat. Gr. (Aus O. Abel, Paläobiologie der Wirbeltiere.)

Die Dinosaurier haben in verschiedenen Landbildungen und Sumpfbildungen zahlreiche Fährten hinterlassen (Fig. 453 und 496). Man kennt solche Fährten schon aus der Permformation, doch sind sie besonders häufig in der Trias (Buntsandstein) Frankens, Thüringens, Frankreichs und Englands und in Wealden Englands und Hannovers. Auch aus der Trias Nordamerikas (Connecticut und Massachusetts), dem Jura von Wyoming und Colorado, sowie aus Südafrika (Karooformation von New Port bei Middleburg in der Kapkolonie) sind Dinosaurierfährten bekannt; die aus der Trias stammenden Abdrücke wurden früher größtenteils als Fährten großer Stegocephalen betrachtet. Es kann indessen, wie ich schon 1912 ausgeführt habe², kaum einem Zweifel unterliegen, daß die als „Chirotherium" beschriebenen Fährten von

1 F. von Nopcsa, Über Dinosaurier: 2. Die Riesenformen unter den Dinosauriern. - Centralblatt f. Mineralogie usw., 1917, S. 332.

2 O. Abel, Paläobiologie der Wirbeltiere, 1912, S. 68. 
Tieren hervorgebracht worden sind, deren hintere Gliedmaßen fast dreimal so stark ansgebildet waren wie die vorderen; es können also nur Dinosaurier als Erzenger dieser Fälnrten in Betracht kommen und diese Auffassung erhält ihre besondere Stütze durch die Entdeckung eines „Chirotherium", dessen Fährte nur aus den Abdrücken der Hinterfüße bestelit, die hintereinander in gerader Linie in den Schlamm eingedrückt erscheinen. Diese Fährte ${ }^{1}$ kann nur von einem bipeden Tier eingedrückt worden sein. Die Stellung und Haltung der Großzehe in den Chirotherinmfährten stimmt vollkommen mit der von mir $1910^{\circ}$ und 1912 dargelegten Auffassung überein, daß die Dinosaurier von arborikolen, d. i. baumbewohnenden Vorfahren mit opponierbarer Großzehe abstammen, einer Auffassung, an der ich auch heute trotz der von F. v. Huene und F. von Nopcsa gemachten Einwände festhalte.

\section{Unterordnung: Coelurosauria.}

Diese Unterordnung umfaßt mehrere triadische Gattungen, die durch den leichten, durch Hohlräume in den Wirbeln und Gliedmaßen auffallenden, vogelähnlichen Knochenbau, den enorm verlängerten Schwanz. die großen, langen, zu Sprungbeinen modifizierten Hinterbeine mit sehr stark verlängertem Metatarsus und eine schmale, lange Hand gekennzeichnet sind. Diese Formen verteilen sich auf die beiden Familien der Podokesauriden und der Hallopiden; es sind mit Ausnahme von Tanystrophaeus conspicuus aus dem Muschelkalk Deutschlands kleine Formen von der Größe eines Marders. Bei den jurassischen Cöluriden ist der Unterschenkel und der Metatarsus gleichfalls sehr lang; sie unterscheiden sich nur unwesentlich von den älteren Familien, erreichen aber bedeutendere Körpergröße. Ebenso bestehen keine scharfen Gegensätze im Skelettbau zwischen den Compsognathiden, die von der oberen Trias bis zur oberen Kreide lebten, und den älteren Familien; bei der jüngsten Gattung Ornithomimus aus der oberen Kreide der Vereinigten Staaten und Kanadas ist der Metatarsus in hohenı Grade vogelähnlich geworden.

Die Tiere waren wahrscheinlich bipede Steppenspringer, die sich ähnlich springend und hüpfend wie die Känguruhs weiterbewegten: alle waren karnivor.

\section{F. Podokesauridae.}

Saltopus. - Trias von Elgin in Schottland. ${ }^{3}$

1 O: Abel, Paläobiologie der Wirbeltiere, S. 275, Fig. 201.

2 O. Abel, Die Vorfahren der Vögel und ihre Lebensweise. - Verhandlungen d. K. K. Zool. Bot. Ges. Wien, LX1. Bd., 1911, S. 144.

${ }^{3}$ F. von Huene, Ein primitiver Dinosaurier aus der mittleren Trias von Elgin. - Geologische und paläontologische Abhandlungen, Neue Folge, Bd. VIl: (G. R. Bd. XI1), 6. Heft, Jena 1910, S. 317 .. 
Podokesaurus. - Trias von Connecticut. - P. holyokensis. ${ }^{1}$ Tanystrophaeus. - Trias Deutschlands. ${ }^{2}$

\section{F. Hallopidae.}

Hallopus. - Trias von Canyon City, Colorado. - Nur durch die Kürze des Pubis von der vorigen Fannilie verschieden, falls der Knochen richtig gedeutet ist. ${ }^{3}$

\section{F. Coeluridae.}

Coelurus. - Oberer Jura Nordamerikas. ${ }^{4}$

Aristosuchus. - Wealden Englands. ${ }^{5}$

\section{F. Compsognathidae.}

Procompsognathus. - Dieser älteste Vertreter der Compsognathiden wurde im Frühjahre 1909 in der oberen Trias von Pfaffenhofen in Württemberg entdeckt. Das ungefähr $75 \mathrm{~cm}$ lange Skelett schließt sich in den Hauptmerkmalen enge an Compsognathus aus dem Tithon der Pfalz an. Alle Knochen sind dünnwandig und hohl; der Tarsus scheint knorpelig gewesen zu sein. ${ }^{6}$

Compsognathus. - Oberer Jura von Jachenhausen in der Oberpfalz (Bayern)., - Ein cinziges Exemplar bekannt. Das Tier erreichte

1 M. Talbot, Podokesaurus holyokensis, a New Dinosaur from the Triassic of the Connecticut Valley. American Journal of Science, Vol. XXXI, 1911, p. 469.

F. von Huene, Beiträge zur Geschichte der Archosaurier. - Geologische und paläontologische Abhandlungen, Jena, Neue Folge, Bd. XIII (G. R. Bd. XVII), 1. Heft, I914, S. 31.

2 F. von Huene, Die Dinosaurier der europäischen Triasformation mit Berïcksichtigung der außereuropäischen Vorkommnisse. - Geologische und paläontologische Abhandlungen, Supplementband I, 1907-1908.

3 F. von Huene and R. S. Lull, On the Triassic Reptile, Hallopus victor, Marsh. American Journal of Science, Vol. XXV, 1908, p. 113.

F. von Huene, Beiträge zur Geschichte der Archosaurier, 1. c., 1914, S. 22.

1 E. D. Cope, A Contribution to the History of the Vertebrata of the Trias of North America. - Proceedings Amer. Philosophical Society, Vol. XXIV, Nr. 26, p. 209 .

F. von Huene, Über die Dinosaurier der außereuropäischen Trias. - Geologische und paläontologische Abhandlungen, Neue Folge, Bd. VIII (G. R. Bd. XII), 2. Heft, 1906 , S. 118.

; H. G. Seeley, On Aristosuchus pusillus (Owen), being turther Notes on the Fossils described by Sir R. Owen as Poikilopleuron pusillus. - Quarterly Journal Geological Society London, Vol. XLI11, 1887, p. 221.

${ }^{6}$ E. Fraas, Die neuesten Dinosaurierfunde in der schwäbischen Trias. Die Naturwissenschaften, 1. Jahrgang, 45. Heft, 7. November 1913, S. 1097.

F. von Huene, Das natiirliche System der Saurischia. - Centralblatt für Mineralogie usw., 1914, S. 155. 


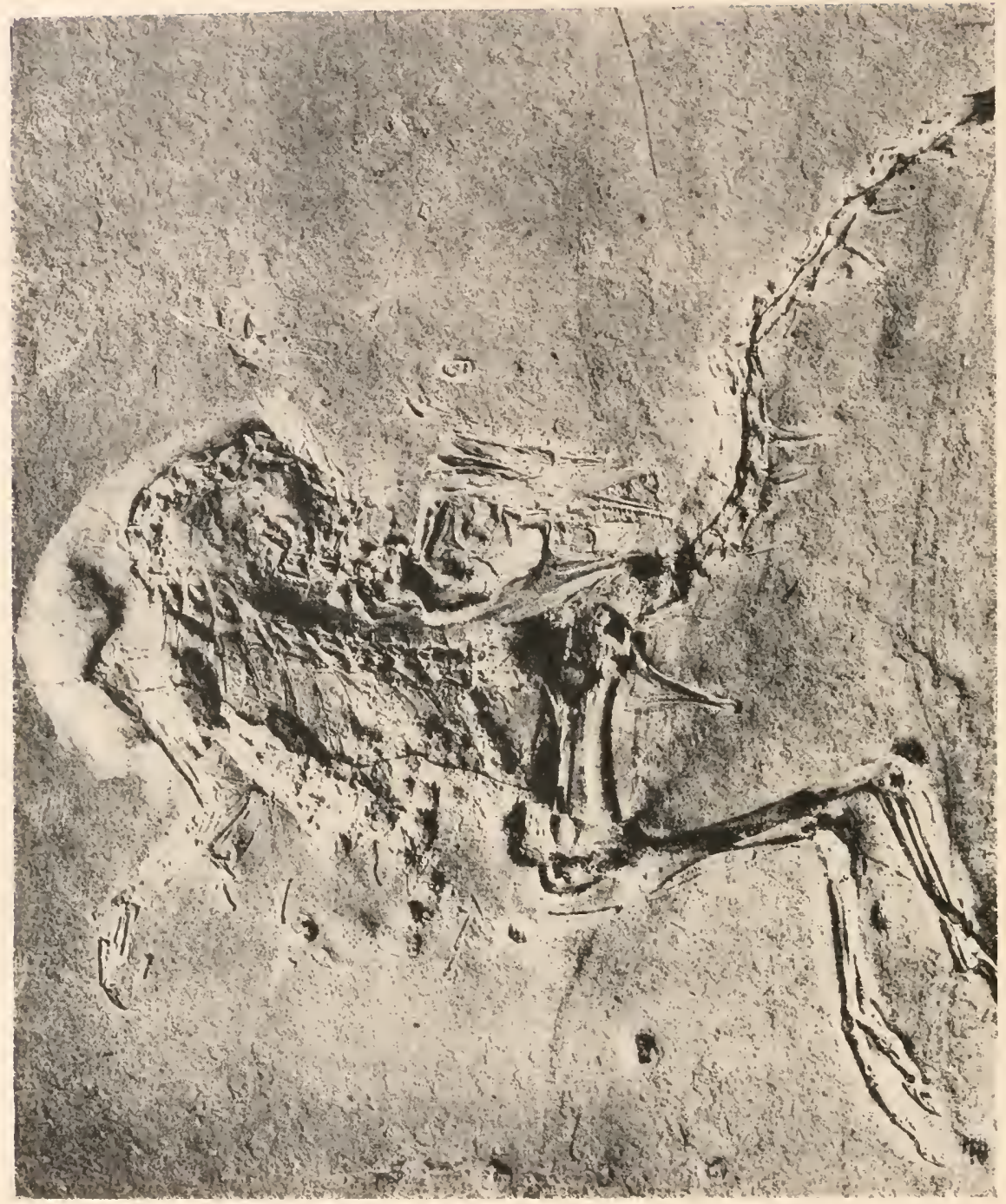

Fig. 454 .

Skelett von Compsognathus longipes, Wagner, ans den lithographischen Schietern (oberer Jura) von Jachenhausen in der Oberpfalz, Bayern. (Nach F. von Huene.) $1 / 2$ nat. Gr.

Der Scluädel und Hals des Tieres sind gegen den Rïcken zurïckgebogen; das Tier ist jedenfalls in bereits stark verwestem Zustande in die Rifflagune von Jachenhausen eingeschwemmt worden, wobei die Zehenkrallen der Hinterfüße auf dem weichen Schlamm schleiften und die auf der rechten Bildseite sichtbaren Rinnen auf der schlammoberfläche hervorbrachten. In der Leibeshöhle liegen die zwischen den Rippen (in der Plotographie nicht deutlich) sichtbaren Reste eines gefressenen Reptils, das früher fälschlich als Embryo gedeutet wurde. 
im erwachsenen Zustand die Größe einer Katze. In der Leibeshölıle des Restes liegen Reste eines kleinen, gefressenen Reptils ${ }^{1}$ (Fig. 454). Ornithomimus. - Obere Kreide Nordamerikas. Mehrere kleinere und größere Arten² (Fig. 455).

Ornitholestes. - Obere Kreide Nordamerikas. - Im Schädel sind jederseits zwei Orbitalöffnungen vorhanden. Die Finger sind lang;

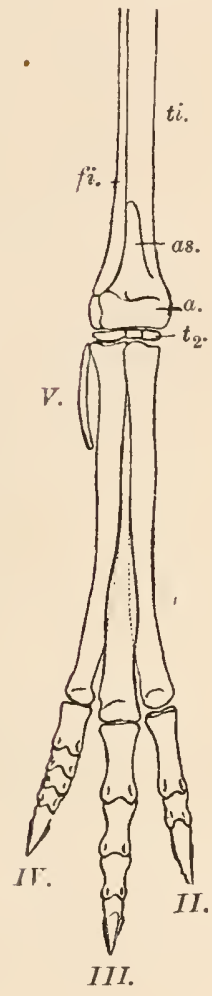

Fig. 455 .

Rechter Hinterfuß von Ornithomimus altus, Lambe. ein Compsognathide aus der oberen Kreide (BellyRiver-Series) von Canada; die Gesamtlänge des

Tieres wird auf etwa $6,5 \mathrm{~m}$ geschätzt.

(Nach L. M. Lambe.)

a. $\quad=$ Astragalus und Calcaneus.

as. $\quad$ aufsteigender Ast des Astragalus (vgl. Fig. 456).

fi. $\quad$ Fibula.

ti. $\quad$ Tibia

t. = distale Tarsalia.

$\ddot{I I}$. - V. $=$ zweiter bis fünfter Zehenstrahl.

' A. Wagner, Compsognathus. - Abhandlungen der Kgl. Bayerischen Akademie der Wissenschaften in München, II. Klasse, IX. Bd., 1861, S. 94.

K. A. von Zittel, Handbuch der Paläozoologie, 111. Bd., 1890, S. 734.

F. von Nopcsa, Neues über Compsognathus. - Jahrbuch für Mineralogie ısw., Beilageband XVI, 1903, S. 476.

F. von Huene, Der vernutliche Hautpanzer des Compsognathus longipes. Ibidem, Jahrgang 1901, Bd. 1, S. 157.

O. C. Marsh, The Dinosaurs of North America. 1896, p. 228.

3 O. C. Marsh, The Dinosaurs of North America. - 1. c. p. 204.

H. F. Osborn and L. M. Lambe, On Vertebrata of the Mid-Cretaceous of the North West Territory. - Geological Survey of Canada, Contributions to Canadian Palaeontology, Vol. 111, Ottawa 1902, p. 50. 
der fünfte fehlt, der vierte ist verkümmert. Das Tier erreichte eine Länge voll 2,22 m. $^{1}$

2. Unterordnung: Pachypodosauria. (Stammgruppe der Theropoden und Sauropoden.)

ln dieser Gruppe vereinigt W. D. Matthew (1915) nur drei Familien (Anchisauridae, Zanclodontidae, Plateosauridae), wälnrend F. v. Huene (1914) alle nicht zu den Coelurosauriern gehörenden Familien in der von ihm aufgestellten Unterordnung der Pachypodosaurier zusammenfaßt. Wenn auch derartige systematische Gruppierungen mehr oder weniger Sache der persönlichen Auffassung und der Konvention sind und es ziemlich gleichgültig ist, ob eine Familie zum "Range“ einer Unterordnung ,erhoben" wird oder niclst, so verschafft doch die Gruppierung und Einteilung von Gattungen in systematische Kategorien höherer Ordnung eine Vorstellung von den genetischen Beziehungen und Verbänden oder soll doch wenigstens diese Vorstellung zu erwecken trachten; die verwandtschaftlichen Beziehungen werden ja niemals in einem „Systen" dargestellt werden können, weil die vertikalen, genetischen Linien durch die künstlichen Grenzen der systematischen Gruppen immer gewaltsam zerrissen und quer durchschnitten werden.

So ist es auch sehr schwer, ja fast unmöglich, in der systematiscluen Gruppierung die Stellung der Pachypodosauria zu den beiden weiteren Gruppen, den Theropoden und Sauropoden, so zum Ausdruck zu bringen, daß die genetischen Beziehungen dieser drei Gruppen zueinander klar zutage treten. Die triadischen Pachypodosaurier, die z. B. durch die Gattungen Plateosaurus, Sellosaurus und Zanclodon repräsentiert werden, stellen nach den neueren Untersuchungen über die Stammesgeschichte der Dinosaurier die Alnnengruppe der Theropoden einerseits und der Sauropoden andererseits dar; beide Ausstrahlungen der Stammgruppe sind mit ihr derart durch Übergänge verbunden, daß eine scharfe Unterscheidung der Pachypodosaurier von ihren Nachkommen auf Schwierigkeiten stößt. Diese Schwierigkeiten müssen überall dort zutage treten, wo Bindeglieder zwisclıen größeren Gruppen bekannt werden, so wie dies mit der Cetaceengattung Patriocetus der Fall ist, welche den Übergang von den Archäoceten zu den Mystacoceten vermittelt (S. 753).

Unter den Pachypodosauriern ist eine Gruppe zu unterscheiden, welche den Übergang zu den räuberischen Theropoden (Anchisauriden und Megalosauriden) bildet; das sind die Zanclodontiden. Whr Gebib

- 1 H. F. Osborn, Ornitholestes Hermanni. - Bulletin American Museum of Natural History, Vol. XIX, 1903.

W. D. Matthew, Dinosaurs. - New York (American Museum of Natural History), 1915 , p. 55. 
besteht aus sichelförmig gebogenen, rückwärts gekrümnten, komprinierten und mit schneidenden Rändern versehenen Zähnen, die auf eine räuberische Nahrungsweise hindeuten. Der Schädel dieser Gattungen ist verhältnismäBig groß. Von Gattungen dieser Gruppe wären besonders zu nemnen Zanclodon, Teratosaurus und Gresslyosaurus.

Die zweite Gruppe der Pachypodosaurier unterscheidet sich von der ersten nur in scheinbar unwesentlichen Merkmalen, wie in der relativen Kleinheit des Schädels und der Zahnform; hier sind die Zähne spatelför!nig und tragen gekerbte Ränder (,,Spitzkerbung" der Zahnränder). Diese Formen scheinen bereits in einer Übergangsperiode von der Fleischnahrung zur Pflanzennahrung zu stehen und bilden die Wurzel der herbivoren Sauropoden; sie können, obwohl sie neuerlich von F. v. Huene in zahlreiche Familien zerlegt worden sind, als die Fanilie der Plateosauriden zusammengefaßt werden.

Wenn auch die extrem spezialisierten Endglieder der Theropoden (z. B. Tyrannosaurus) und der Sauropoden (z. B. Diplodocus) beträchtlich verschieden sind und sich somit eine starke Divergenz beider Entwicklungslinien feststellen läßt, so sind doch die Unterschiede der Zanclodontiden und der Plateosauriden noch so unbedeutend, daß sié wohl zusammen in einer Gruppe vereinigt werden kömnen, die man als die „Stammgruppe“ der Theropoden und der Sauropoden bezeichnen muls. In System ist dieses Verhältnis nicht zum Ausdruck zu bringen; daher werden von einigen Forschern die Anchisauriden zu den Pachypodosauriern gestellt (W. D. Matthew, 1915), wälnrend sie von anderen in der Unterordnung der Theropoden neben die Megalosauriden gestellt werden. Ein künstlicher, unnatürlicher Schnitt durch die Stammeslinie ist in beiden Fällen vorlanden und es kann sich bei einem Streite um die Legung der Grenzlinie wohl nur mehr darum handeln, welches Übel das kleinere ist und eine halbwegs bessere Vorstellung von den verwandtschaftlichen Beziehungen vermittelt. ${ }^{1}$

1 O. Jaekel hat 1913 (Über die Wirbeltierfunde in der oberen Trias von Halberstadt. Paläont. Zeitschrift, 1. Bd., Berlin, Heft 1, S. 197) vorgeschlagen, die Dinosaurier nach ihrer Nahrungsweise und die durch dieselbe bedingten Anpassungen in drei Stämme zu gliedern: 1. Therophagi (Raubdinosaurier), 2. Allophagi (omnivore Dinosaurier), 3. Phy tophagi (herbivore Dinosaurier). Nach dieser Auffassung wïrden die Plateosauriden den Allophagi, die Zanclodontiden den Therophagi anzugliedern sein. Da aber die Zanclodontiden und die Plateosauriden sich nur in geringfügigen Punkten unterscheiden, so ist es doch vielleicht besser, sie in einer „Stammgruppe“ vereinigt zu lassen, ebenso wie wir den Kreis der Protungulata als Stammgruppe der Ungulaten aufrechterhalten, obwohl wir die Wurzeln der jüngeren Ungulatenstämme bis zu den einzelnen Familien der Protungulata zurückverfolgen können. - Die neue Einteilung in Therophagi, Allophagi und Phytophagi wäre übrigens ganz überflüssig, da ja schon J. B. Hatcher (1903) nach denselben Gesichtspunkter die Theropoda, Sauropoda und Praedentata unterschieden hatte (Osteology of Haplocanthosaurus, etc. Memoirs Carnegie Museum, II, Nr. 1, Nov. 1903, p. 47). 
Wählen wir zur Besprechung eines Pachypodosauriertyps den in der Trias von Halberstadt entdeckten und von O. Jaekel (1913) beschriebenen Plateosaurus longiceps, so fällt uns vor allem die eigentünnliche Körperhaltung auf. Das Tier war zweifellos biped; dies gelıt aus dem Größenumterschiede der Hinter- und Vorderextremität, der Ausbildung eines selır kräftigen Schreitfußes und der eigentümlichen Spezialisierung der Hand hervor, welche keinesfalls als Schreithand, sondern nur als Greifhand gedient haben kann. Der erste Finger ist der stärkste und die folgenden nehmen an Stärke rasch ab; der zweite ist der längste der ganzen Hand, ihm folgt an Länge der dritte Finger; der vierte und fünfte Finger sind zwar noch vorlanden, aber stark verkümmert. Der Grundplan des Handbanes, wie ilnn die Plateosauriden und ebenso auch die Zanclodontiden (z. B. Gresslyosanrus Plieningeri) zeigen, ist selbst in unbedeutenden Einzelheiten fast derselbe und ist fast identisch mit dem Bau der Vogelhand, nur mit dem Unterschiede, daß in dieser der vierte und fünte Finger verloren gegangen tnd nur die drei vorderen der Pachypodosaurierhand ïbrig geblieben sind. Die Übereinstimmung der Form beweist nicht nur eine gleichartige Funktion der Hand bei den Pachypodosauriern und den Vorfahren der Vögel, sondern spricht auch bei der morphologischen Identität der Elemente für eine nahe Verwandtschaft der Vogelahnen mit den Pachypodosauriern oder deren unnittelbaren Vorfahren. Auch bei den Vögeln ist ausnahmslos der zweite Finger der längste, während der erste der kürzeste, aber der stärkste ist und bei Archaeopteryx, die nocl alle drei Finger bekrallt hatte, die stärkste Kralle trägt.

Dieser Bau der Hand ist uns schon bei den Compsognathiden begegnet; da er also sowohl im Stanme der Coelurosauria als in dem der Pachypodosaurier auftritt, so scheint die Gruppe der Dinosatırier überhaupt von einer Stanmoruppe abzustanmen, bei welcher bereits diese Spezialisationsrichtung der Hand eingeschlagen war. Von dieser uns bis heute noch unbekannten Vorfahrengruppe der Dinosaurier, die als Avidinosaurier zu bezeichnen wären, stammen auch die Vögel ab.

Die Spezialisation des Handbaues, die wir schon bei den ältesten Dinosauriern finden, kann nur als eine Anpassung an das Klettern gedeutet werden; die Hand funktionierte als Greifhand. Von den arborikolen Vorfahren der Dinosaurier und Vögel, welche bereits eine bipede Gangart besessen haben müssen, sind die Dinosaurier zur terrestrischen Lebensweise zurückgekelırt, während die Vogelahnen arborikol geblieben und bei dieser Lebensweise zuerst zu Fallschirnutieren und später zu aktiven Flugtieren geworden sind.

Ein wesentlicher Unterschied zwischen den Dinosaturiern und den Vögeln liegt im Bau des Beckens. Bei den Dinosauriern ist das Becken in den Hanptzügen ebenso wie bei den primitiven terrestrischen Rep- 
tilien gebaut; das llium verbindet sich mit mehreren Sakralwirbeln. das Pubis ist nach vorn und unten, das Ischium nach linten und unten gerichtet. Bei den Vögeln hat dagegen das Pubis eine ganz veränderte Lage und Beziehung zum lschium erhalten. Es wird, wie die Untersuchungen von N. G. Lebedinsky (1913) gezeigt und dadurch die Beobachtungen der früheren Forscher, namentlich Mehnerts (I888) bestätigt haben, als getrennter, mit dem Ischium divergierender Strahl angelegt und wendet sich erst in Laufe der ontogenetischen Entwicklung nach-rückwärts, um sich als schmale, dünne Spange unter das Ischiunı zu schieben. Ein kleiner Fortsatz oberhalb des Vorderendes des Pubis, der Processus pectinealis des Vogelbeckens, gehört jedoch bereits dem llium an und ist als eine Nenerwerbung der Vögel anzusehen.

Auch bei den Ornithischiern ist das Pubis, wie schon früher dargelegt wurde, ebenso wie bei den Vögeh nach hinten gewendet und schiebt sich bei den bipeden Typen als schlanker Knochenstab unterdas gleichfalls sehr verlängerte Ischium. Der Processus pectinealis fehlt hier, wird aber durch den in funktioneller Hinsicht gleichsinnig funktionierenden Processus, pseudopectinealis vertreten, an dem sich der Musculus ambiens angesetzt haben dirfte.

Da sowohl die Mehrzahl der Dinosaurier (Saurischier) als auch die weitaus überwiegende Melırzah! der Ornithischier (Orthopoda) biped gewesen sind, so ersçheint dieser Gegensatz in der Struktur des Beckens bei den beiden Gruppen, von denen die eine in weitgehender Weise den Vögeln ähnelt, außerordentlich auffallend. Es scheint, daß hier zwei ganz ve:schiedene Gangarten vo:liegen, über deren Unterschiede wit jedoch bis jetzt keine klaren Vorstellungen gewinnen konnten. Vielleicht hängt der Gegensatz des Beckenbaues mit einer verschiedenen Inanspruchnahme des Schwanzes zusammen. Wir wissen, daß der Schwanz bei der Fortbewegung der Vögel auf festem Boden keine Rolle spielt und daher verkümmert ist. Dagegen ist der Schwanz bei der bipeden Känguruhs ein wichtiges Hilfsmittel der Lokomotion. Bei den Ornithischiern scheint der Schwanz beim Schreiten und Laufen in fieier Balance gehalten worden zu sein und daher finden wir hier vielleicht die Ursache für die analoge Beckenbildung der Ornithischier und derVögel, während die Dinosaurier, soweit es sich um zweibeinige Typen handelt, sich eher nach Art der Känguruhs fortbewegt haben dürften..

Der lange, sehr kräftige Schwanz ist ein wichtiges Kennzeichen der Pachypodosaurier. Er war jedenfalls sehr beweglich und steht darin in scharfem Gegensatz zum Schwanze der Ornithischier, in dem sich, ebenso wie im Rumpfabschnitt der Wirbelsäule, Sehnenverknöcherungen an die Sèitenflächen der Dornfortsätze anlegen und auf diese Weise eine Seitwärtsbewegung oder Vertikalbewegung der Wirbelsäule mit Ausnahme des Halsabschnittes fast unmöglich machen (z. B. Iguanodon). 
Diese Verhältnisse bei den Ornithischiern erinnern an die Starrheit der Wirbelsäule, die im Laufe der Stammesgeschichte bei den Vögeln eingetreten ist.

Die Zahl der Halswirbel von Plateosaurus (nach O. Jaekel nur 11 einschließlich des Proatlas) ist verhältnismäßig gering. Im ganzen sind 24 schwach amphicöle Präsakralwirbel vorhanden, so daß auf den Thorax 13 Wirbel entfallen. Die tiefer amphicölen Halswirbel tragen zweiköpfige Rippen (mit Ausnahme des Proatlas); der letzte Präsakralwirbel ist rippenlos und könnte daher als Lendenwirbel bezeichnet werden. Alle Rippen sind zweiköpfig.

Die Zanclodontiden sind in sicher bestimmbaren Resten nur aus der Trias Europas bekannt; da auch Thecodontosaurus, von dem früher nur sehr unvollständige Reste vorlagen, auf Grund eines fast vollständigen, von E. Fraas in der oberen Trias von Pfaffenhofen ausgegrabenen und einstweilen nur vorläufig beschriebenem Skelettes von Th. diagnosticus dieser Familie einzureihen ist, erstreckt sich ihr Verbreitungsgebiet auch auf Nordamerika, Südafrika, Australien und vielleicht auch auf Ostindien.

Die Plateosauriden sind nur aus der Trias Europas bekannt; die systematische Stellung von Euskelosaurus aus der Trias Südafrikas ist unsicher.

\section{F. Zanclodontidae}

Die Zähne sind. messerförmig mit scharfen Schneiden und ein wenig nach hinten gekrümmit.

Zanclodon. - Obere Trias Deutschlands. ${ }^{1}$

Gresslyosaurus. - Trias Deutschlands und der Schweiz ${ }^{2}$ (Fig. 456, 457).

Teratosaurus. - Obere Trias Deutschlands. Bei einem Exemplar, das F. v. Huene 1915 beschrieb (Fig. 458), ist das Bauchrippengeflecht unvergleichlich schön und vollständig erhalten geblieben. ${ }^{3}$

Thecodontosaurus. - Obere Trias Europas; unvollständige Reste auch aus Südafrika, Australien und Nordamerika bekannt. Das fast vollständige Skelett gehörte nach E. Fraas einem etwa 2 ml langen, schlankkörperigen Raubdinosaurier an. Das Vorhandensein einer typischen Greifhand spricht entschieden gegen die Auffassung einer ausschließlich tetrapoden Gangart dieser Tiere, wie sie E. Fraas (1913)

1 F. von Huene, Die Dinosaurier der europäischen Triasformation mit Beriicksichtigung der außereuropäischen Vorkommnisse. - Geologische und paläontologische Abhandlungen, Supplementband I, Jena .1907-1908.

2 Ibidem.

${ }^{3}$ F, von Huene, Beiträge zur Kenntnis einiger Saurischier der schwäbischen Trias. - Neues Jahrbuch fïr Mineralogie usw., 1915, I. Bd., S. 1. 
annahm. Atuch scheint mir kein zwingender Grund für die Annahme einer plantigraden Stellung des Hinterfußes vorzuliegen. ${ }^{1}$

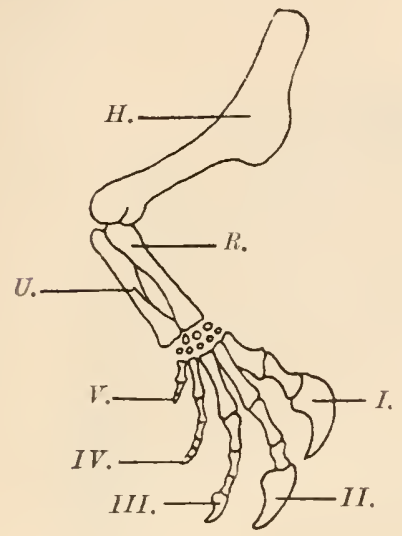

Fig. 456 .

Rechte Hand von Gresslyosaurus Plieningeri, Huene, aus dem oberen Keuper von Degerloch bei Stuttgart. Rekonstruiert. Nach F. v. Huene, unwesentlich abgeändert (vgl. O. Abel, Paläobiologie d. W., 1912,

S. 338).

H. = Humerus.

$U . \quad=$ Ulna.

R. $=$ Radius.

I. $-\mathrm{V} .=$ I. $-\mathrm{V}$. Finger.
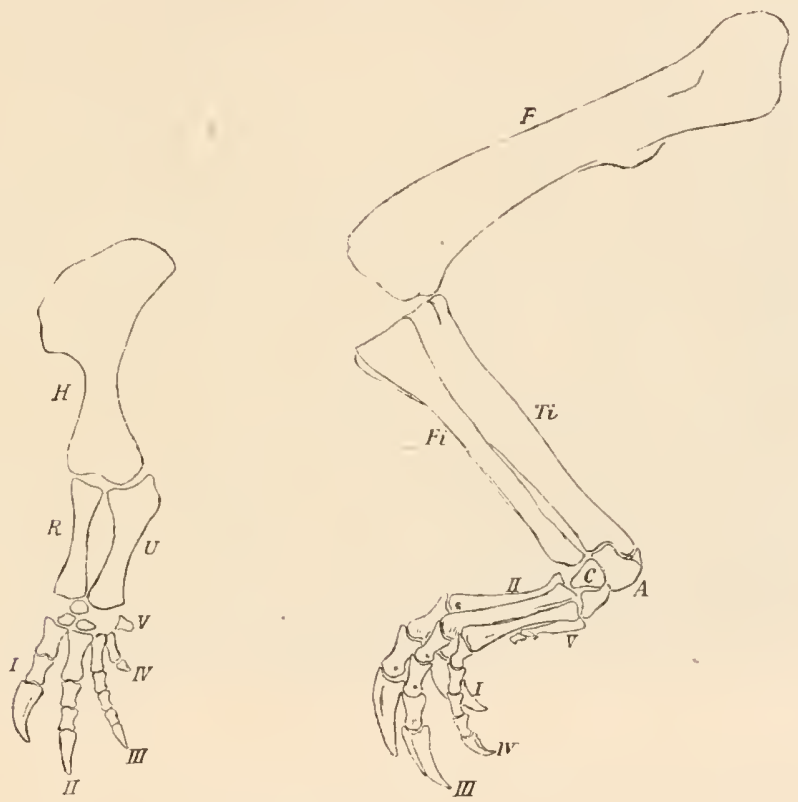

Fig. 457.

Links: Vorde:fuß, rechts: Hinterfuß von Gresslyosaurus Torgeri, Jaekel, aus der oberen Trias (Keuper) von Halberstadt. 1/12 nat. Gr.

(Nach O. Jaekel.)

$$
\begin{array}{rlrl}
I-V & =\begin{array}{ll}
\text { 1. bis V. Finger } \\
\text { bzw. Zehe. }
\end{array} & & F=\text { Femur. } \\
H & =\text { Humerus. } & F i=\text { Tibia. } \\
R & =\text { Radius. } & & A=\text { Astragalus. } \\
U & =\text { Ulna. } & C & \text { Calcaneus. }
\end{array}
$$

1 E. Fraas, Die neuesten Dinosaurierfunde in der schwäbischen Trias. Die Naturwissenschaften, I. Jahrgang, 1913, 45. Heft, 7. November 1913, S. 1097. 


\section{F. Plateosauridae.}

Die Zähne sind spatelförnig mit spitzen, zur Zahnachse paralle! stehenden kleinen Zacken an den schneidenden Rändern (.,Spitzkerbung“) (Fig. 459).

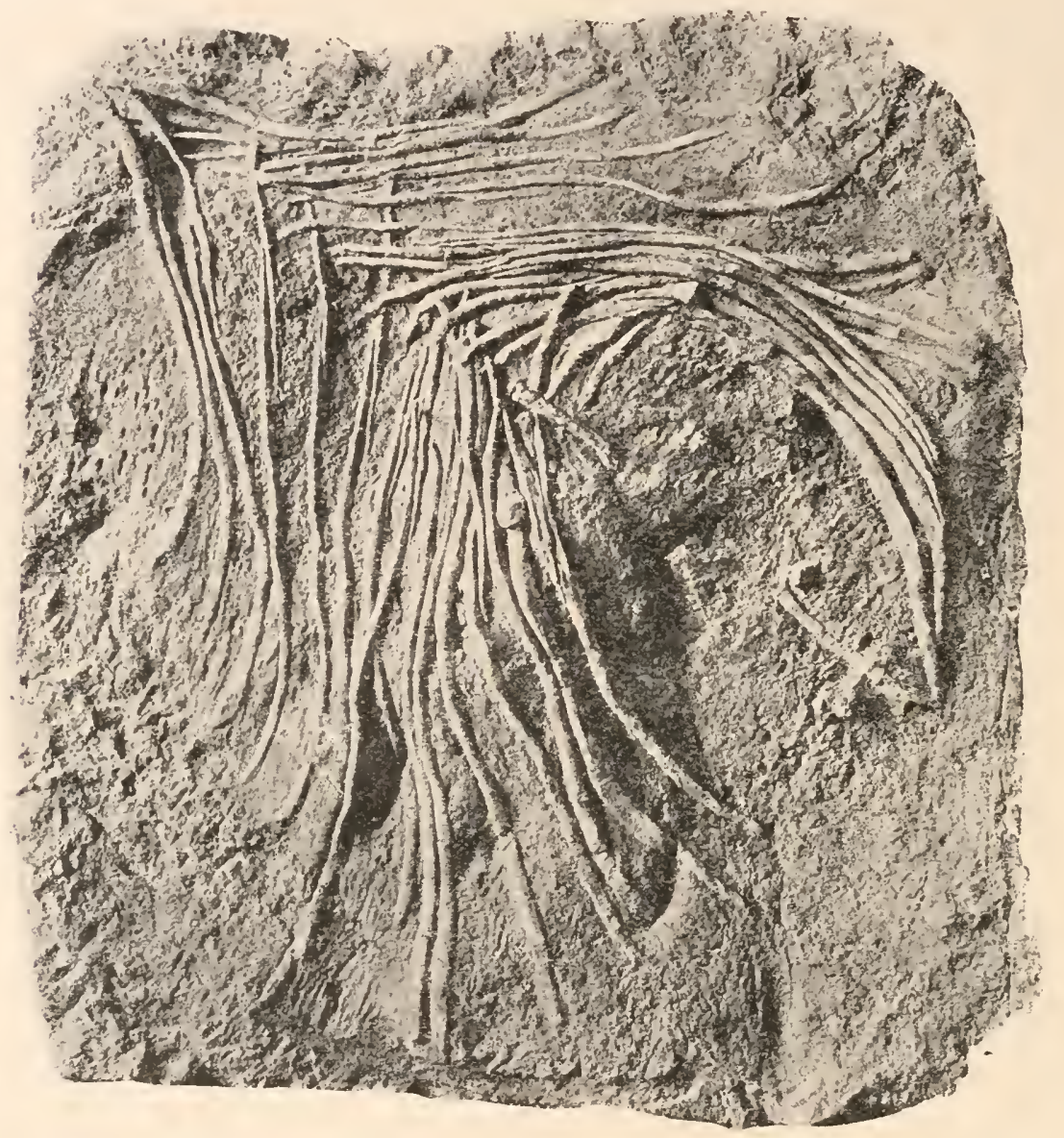

Fig. 458.

Vollständiger Bauchpanzer (Bauchrippen) von Teratosaurus suevicus, H. v. Meyer, aus dem Stubensandstein (Obertrias) von Trossingen in Württemberg, in natïrlicher Lage im Gestein, ungefähr 1/7 nat. Gr. (Nach F. v. Huene, 1915.)

Plateosaurus. - Obere Trias Deutschlands und Frankreiclss. In der Trias von Halberstadt sind mehrere prachtvoll erhaltene Skelette gefunden worden. - Mehrere Arten; die Tiere erreichten stattliclie Größe. Der Oberschenkel einer Art ist 1,17 m lang. ${ }^{1}$

1 E. Fraas, Ibidem, S. 1097.

o. Jaekel, Über die Wirbeltierfunde in der oberen Trias von Halberstadt. Paläontologische Zeitschrift, I. Bd., 1. Heft, 1913, S. 155. 
Der vollständigste Fund eines Plateosaurus ist neben den Halberstadter Funden das Skelett von P. intéger (= trossingensis), das E. Fraas 1912 ausgrub und 1913 (vorläufig) beschrieb. Die Körperlänge des Tieres beträgt 5,75 m. E. F raas ninmut auch für diesen Dinosaurier an, daß er sich bei ruhigen Schreiten auf alle vier Beine stützte und nur bei schnellen Laufe ausschließlich auf den plantigraden Hinterbeinen fortbewegte. Die vorgeschrittene Reduktion der beiden äuBeren Finger sowie der ganze Bau der Hand spricht jedoch für eine Greifhand, die meinas Erachtens für einen tetrapoden Gang ganz ungeeignet war. $\mathrm{Ob}$ der Oberschenkel wirklich so stark seitwärts gerichtet war, wie dies E. Fraas annahm, und ob das Tier rein plantigrad war, was ich gleichfalls für zweifelhaft halte, müssen weitere Untersuchungen aufklären. Keinesfalls waren sie, wie E. Fraas annahm; Raubtiere, sondern zweifellos Pflanzenfresser (Fig. 459, 460).

Sellosaurus. - Obere Trias Deutschlands. Die Gattung steht Plateosaurus sehr nalıe. In den Keuperschiclsten (obere Trias) vo11 Trossingen in Württemberg sind in den letzten Jahren mehrere Skelettreste verschiedener Arten entdeckt worden, die ein gutes Bild von dem Habitus dieser Tiere vermitteln. Sellosaurus war etwas schlanker und wahrscheinlich schnellfüßiger als der plumpere Plateosaurus. ${ }^{1}$

Die Körperlıaltung der Plateosauriden ist kaum die gewesen, welche F. v. Huene (1908) und O. Jaekel (1913) für diese Tiere annelımen; sie muß viel steiler gewesen sein, wie dies in der nemen Rekonstruktion (Fig. 469) zum Ausdruck zu bringen versucht wurde. Da die Tiere fast ausschließlich auf den Hinterbeinen gegangen sein dürften, so ist diese steilere Stellung der Wirbelsäule zu dieser Gangart, bei welcher der Schwanz nachgeschleift worden sein muß, unbedingt erforderlich." Plateosaurus ist kaum als ein schnellfüßiges Tier, sondern als ein relativ schwerfälliges Schreittier anzusehen, wäh end die Gattung Sellosaurus die schnellfüßigeren Arten der Plateosauriden umfassen dürfte.

\section{Unterordnung: Theropoda.}

Die Theropoden stellen eine Gruppe dar, die sich aus den Zanclodontiden weiter entwickelt und zu furchtbaren Raubtieren ausgebildet hat, die mit Tyrannosaurus rex aus der obersten Kreide Nordamerikas eine gewaltige Größe erreichten (Körperlänge fast $10 \mathrm{~m}$, Schädellänge 1,21 111, Höle des Tieres in aufgerichteter Stellung über dem Boden 5,49 m, Höhe des Knies über dem Boden 1,83 m). Die ältesten Vertreter des Theropodenstammes, die sich noch enge an die Zanclodontiden

1 Favon Huene, Beiträge zur Kenntnis einiger Saurischier der schwäbischen Trias. - Neues Jahrbuch für Mineralogie usw., 1915, I. Bd., S. 1. 


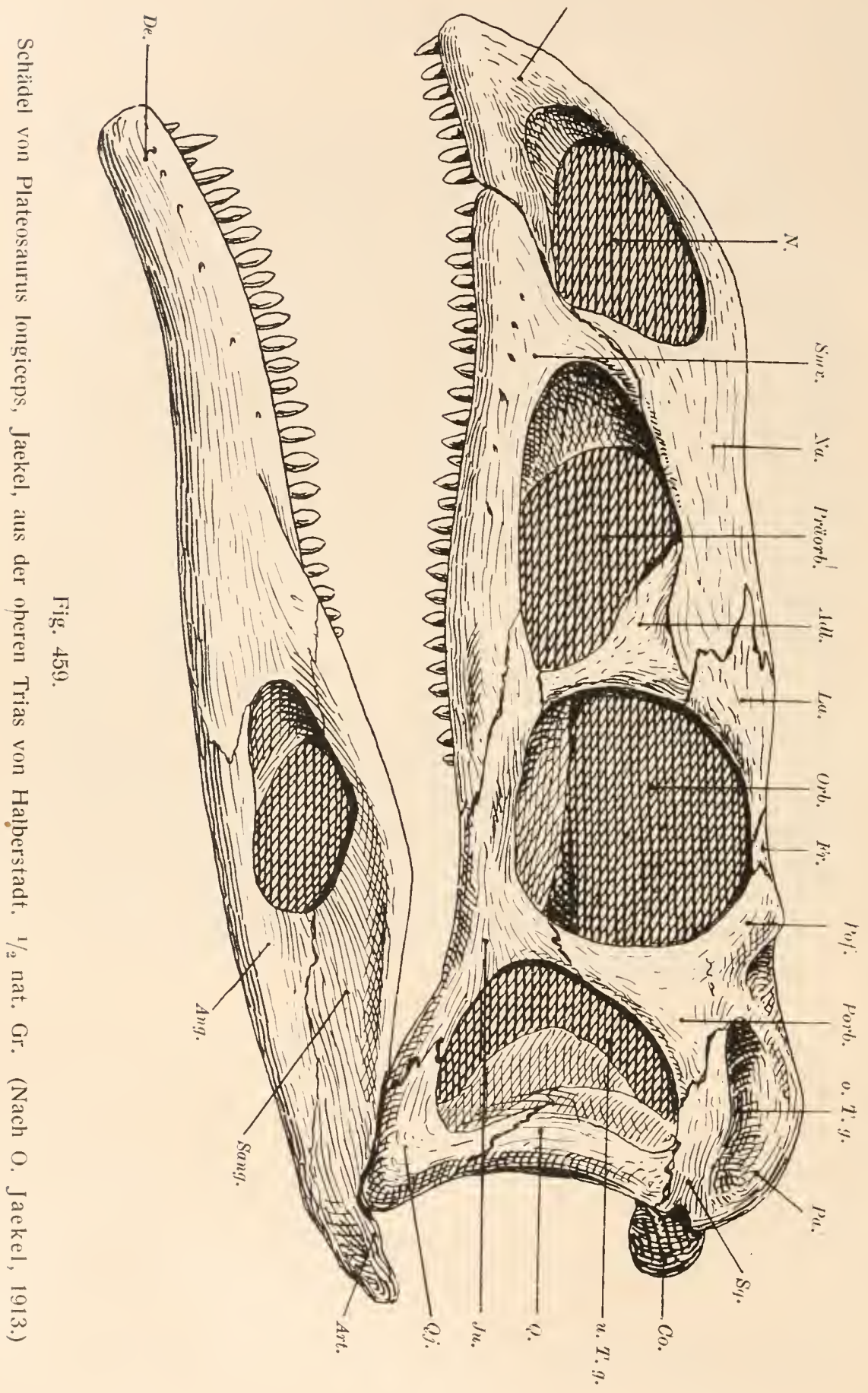


anschließen, werden durch die Anchisauriden aus der Trias Nordanerikas repräsentiert, die noch einen relativ kleinen Schädel besaßen; schon bei ihnen tritt eine eigentümliche Spezialisation der Hand auf, die eine Steigerung der schon bei den Pachydoposauriern zu beobachtenden Ausbildung einer Greifzange oder Enterhakens darstellt, der in den Körper des Beutetieres eingeschlagen wurde. Bei der jüngsten Gattung Tyrannosaurus ist jedoch der Arm hochgradig verkümmert (nur ein winziger Humerus bekannt, der etwa den dritten Teil der Femurlänge erreicht), der Schädel dagegen enorm vergrößert worden. Der Fuß ist schon bei Anchisaurus funktionell dreizehig gewordenl, da die fünfte Zehe rudimentär ist und das Metatarsale $\mathrm{V}$. distal stummelförmig olnne Gelenkrolle endet; die erste Zehe stand, wie die Fälırte von Anchisaurus (= Anchisauripus) beweist, nach hinten ab und berührte noch mit ihrer Krallenphalange den Boden. Bei Allosaurus aus dem oberen Jura Nordamerikas ist die erste Zehe noch weiter verkümmert und das Metatarsale I in ein oberes und ein unteres Rudiment aufgelöst; das letztere trägt noch die verkürzten Phalangen samt einer Kralle, der fünfte Zehenstrahl ist aber hier vollständig verloren gegangen. Bei Tyrannosaurus ist der Hinterfuß $\beta$ ähnlich wie bei Allosaurus gebaut.

Im Schädel ist entweder nur eine Präorbitalöffnung (Anchisaurus) oder eine große Präorbitalöffnung unmittelbar vor der Orbita und vor dieser eine klein'e vorhanden; unter der äußeren Nasenöfnung steht noch eine dritte sehr kleine Präorbitalöffnung (bei Allosaurus und Tyrannosaurus). ${ }^{1}$ Ein Postorbitale ist vorhanden; das Lacrymale ist sehr klein und derart gelegen, daß es als Gelenk zwisclıen dem vorderen und hinteren Abschnitt des metakinetischen Schädels fungieren kann, wie J. Versluys (1910) gezeigt hat. Das Lacrymale paßt bei Allosaurus in eine seichte, aber selır glatte Gelenkgrube des Postorbitale, das mit dem Postfrontale verschmolzen sein dürfte; bei Tyrannosaurus

Zu Fig. 459.

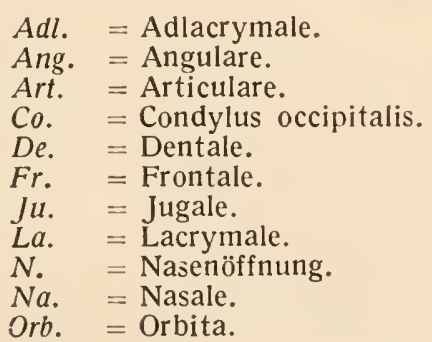

o.T.g. = obere Temporalgrube.

$\begin{array}{ll}\text { Pa. } & =\text { Parietale. } \\ \text { Pmx. } & =\text { Praemaxillare. } \\ \text { Pof. } & =\text { Postfrontale. } \\ \text { Porb. } & \text { = Postorbitale. } \\ \text { Präorb. } & \text { Präorbitalöffntung. } \\ \text { Q. } & =\text { Quadratum. } \\ \text { Qj. } & =\text { Quadratojugale. } \\ \text { Sang. } & =\text { Supraangulare. } \\ \text { Smx. } & =\text { Supramaxillare. } \\ \text { Sq. } & =\text { Squamosum. } \\ \text { u. T.g. } & =\text { untere Temporalgrube. }\end{array}$

1 Bei Tyrannosaurus ist auch im Jugale unterhalb des hinteren Präorbitaldurchbruches ein kleines Foramen vorhanden. 


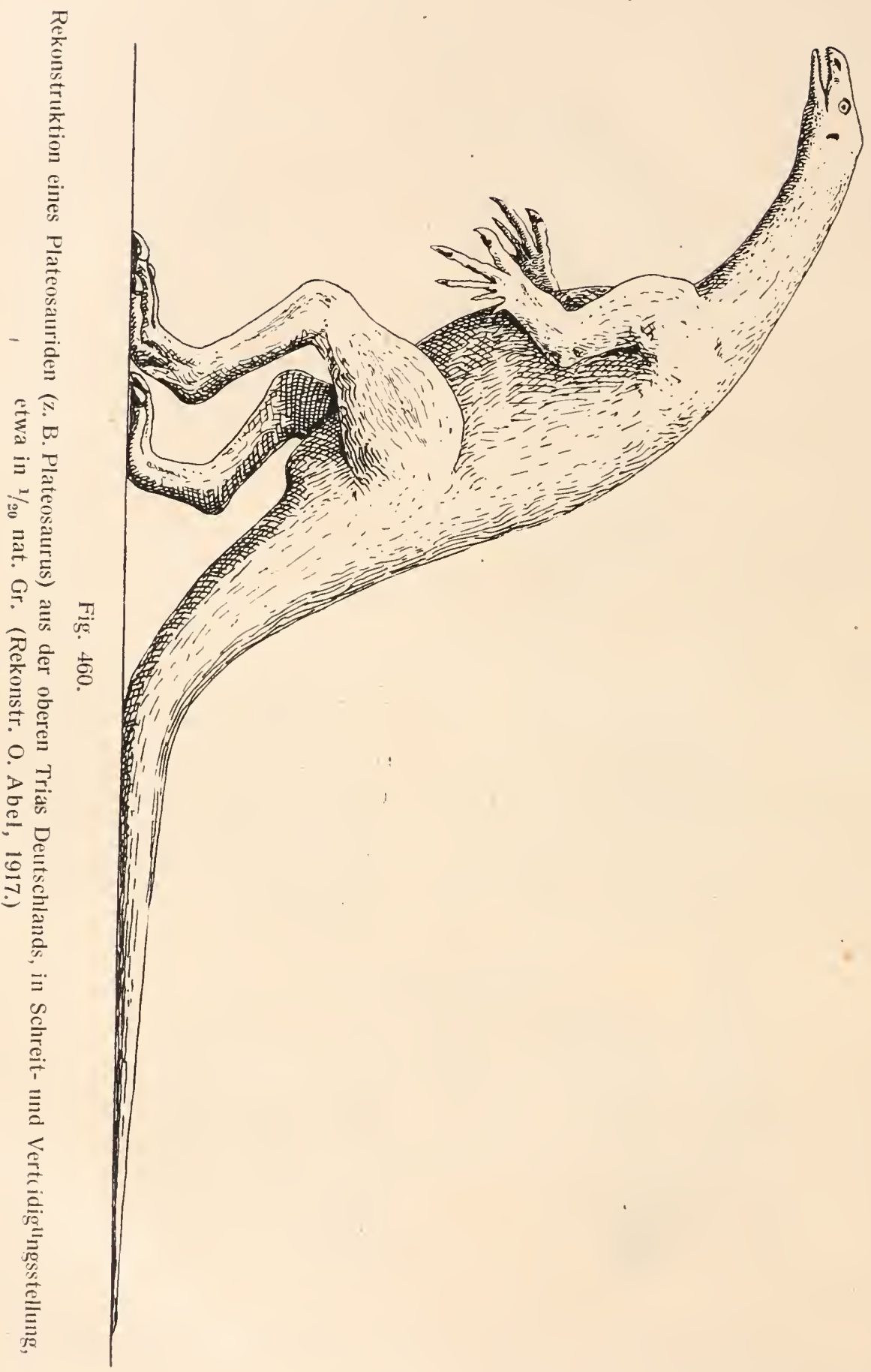


trägt das Postorbitale eine sehr rauhe, knopfartige Verdickung an der Stelle, wo bei Allosaurus das Lacrymal-Postorbitalgelenk liegt.

Ein europäischer Vertreter der Megalosauriden ist der gewaltige Megalosaurus. Er ist zwar nur aus unvollständigen Resten bekannt, aber die vorliegenden lassen darauf schließen, daß diese Tiere eine enorme Körpergröße besaßen, da z. B. das Femur eine Länge voll 1 m aufweist, so daß Megalosaurus beinahe die Größe von Tyrannosaurus (Femurlänge $130 \mathrm{~cm}$ ) erreicht haben dürfte.

Das Skelett der Theropoden ist sehr leicht gebaut, die Gliedmaßenknochen sind hohl (wie dies schon bei den Zanclodontiden der Fall ist) und zuweilen finden siclı auch in Inneren der Wirbel große Höhlungen.

Die Wirbel sind amphicöl oder platycöl bei den älteren Formen; bei den Megalosauriden werden die Halswirbel opisthocöl, wälırend. die Rückenwirbel amplricöl bleiben.

Die Megalosauriden reichen von der Trias bis zur obeisten Kreide.

\section{F. Anchisauridae.}

Anchisaurus. - Trias von Nordamerika (Connecticut). Das Tier erreichte eine Länge von etwa $1 \mathrm{~m}$. Seine Fälırte ist als ,Anchisauripus" beschrieben worden ${ }^{1}$ (Fig. 4!8, A, 461-462).

\section{F. Megalosauridae.}

Von den Anchisauriden nur durch graduelle Differenzen verschieden, so daß beide Familien besser zu vereinigen wären. Die stark komprimierten, schneidenden Zälne sind nach hinten gerichtet.

Megalosaurus. - Die am weitesten verbreitete Gattung, die aber wahrscheinlich nur ein Sammelbegriff für vereinzelt gefundene Reste ist, die sich auf verschiedene Gattungen verteilen. Die ältesten Megalosaurusreste treten im interen Lias von Lyme Regis in England auf; die vollständigsten Reste sind in Dogger von Minchinhampton, Stonesfield und Enslow (England) gefunden worden. Weitere Reste

1 F. von Huene, Die Dinosaurier der außereuropäischen Trias. - Geologische und paläontologische Abhandlungen, Neue Folge, Bd. VIII (G. R. Bd. XII), 2. Heft, Jena 1906, S. 102 (Literatur).

Derselbe, Die Dinosaurier der europäischen Triasformation, I. c., 1907-1908.

Derselbe, Nachträge zu meinen friiheren Beschreibungen triassischer Saurischia. - Geologische und paläontologische Abhandlungen, Neue Folge, Bd. XIII (G. R. Bd. XVII), Jena 1914, S. 69.

R. S. Lull, Fossil Footprints of the Jura-Trias of North America. - Me-moirs of the Boston Society of Natural History, Boston 1904, p. 461. (Ausfiihrliche Fährtenliteratur.)

O. Abel, Grundziige der Paläobiologie der Wirbeltiere, 1912, S. 69 und 271. Vgl. hier auch die Ausführungen iiber die Funktion der Hand als Reißwaffe (S. 589) sowie die Ableitung von Anchisaurus von baumbewohnenden Vorfahren (S. $402 \mathrm{ff}$.). 


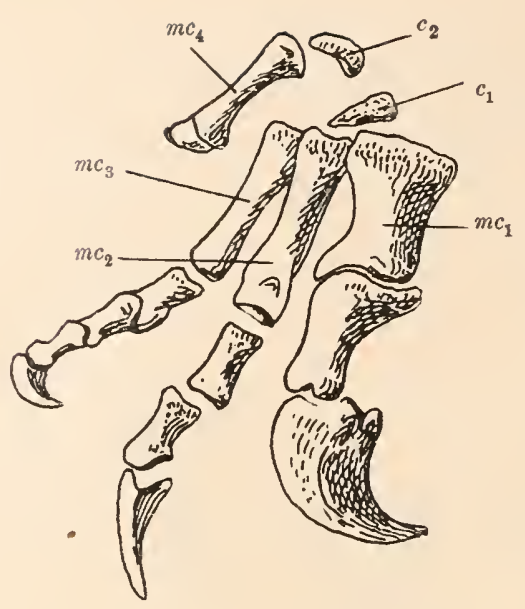

Fig. 461 .

Rechte Hand von Anchisaurus colurus, Marsh, aus dem Connecticutsandstein von Manchester, Conn. (Nord-Amerika). Die Finger liegen in unnatürlicher, verquetschter Stellung im Gestein; die Hand ist nach Fig. 460 zu ergänzen. 1/2 nat. Gr. (Nach F. v. Huene, 1914.)

$c_{1}, c_{2}=$ Carpalia.

$m c_{1}, m c_{2}, m c_{3}, m c_{1}=$ Metacarpale I-IV.

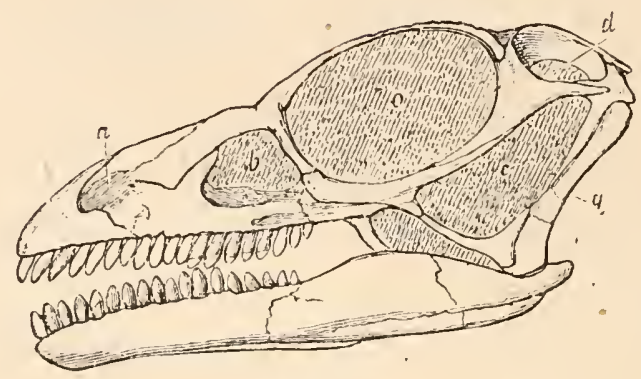

Fig. 462.

Schädel von Anchisaurus colurus, Marsh, aus der oberen Trias (Connecticut RedSandstone) von Manchester, U.S.A. 1/2 nat. Gr.

(Nach O.C. Marsh.)

$a=$ Nasenöffnung.

$b=$ Fenestra praeorbitalis.

$c=$ untere Temporalgrube.

$$
\begin{aligned}
& d=\text { obere Temporalgrube. } \\
& o=\text { Orbita. } \\
& q=\text { Quadratum. }
\end{aligned}
$$

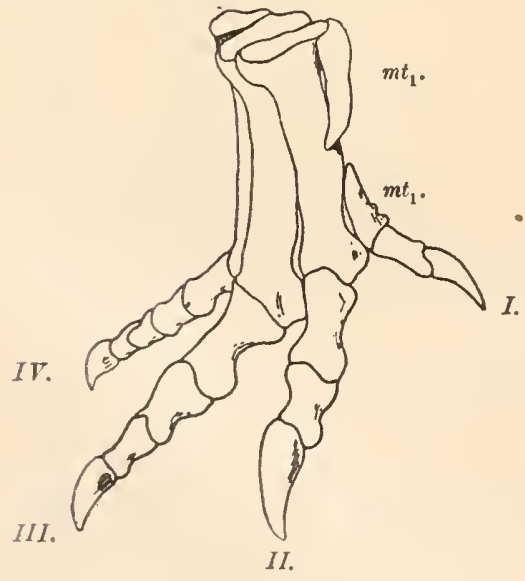

Fig. 463.

Rechter Hinterfuß von Allosaurus aus dem oberen Jura (Atlantosaurus Beds) Nordamerikas. (Nach H. F. Osborn.)

$m t_{1}=$ Rudimente des ersten Metatarsale. I. $-V .=$ erste bis fünfte Zehe. 
sind im Oxfordien und in höheren Stufen des oberen Jura Englands, im Wealden Belgiens, Englands und Deutschlands und in verschiedenen Ablagerungen der oberen Kreide entdeckt worden (Gosauschichten in Niederösterreich und Siebenbürgen, obere Kreide von Ostindien, Madagaskar und Australien).

Der am vollständigsten bekannte Schädelrest von Megalosaurus (M. Bradleyi) ist durch A. S. Woodward (1910) aus dem Great Oolite

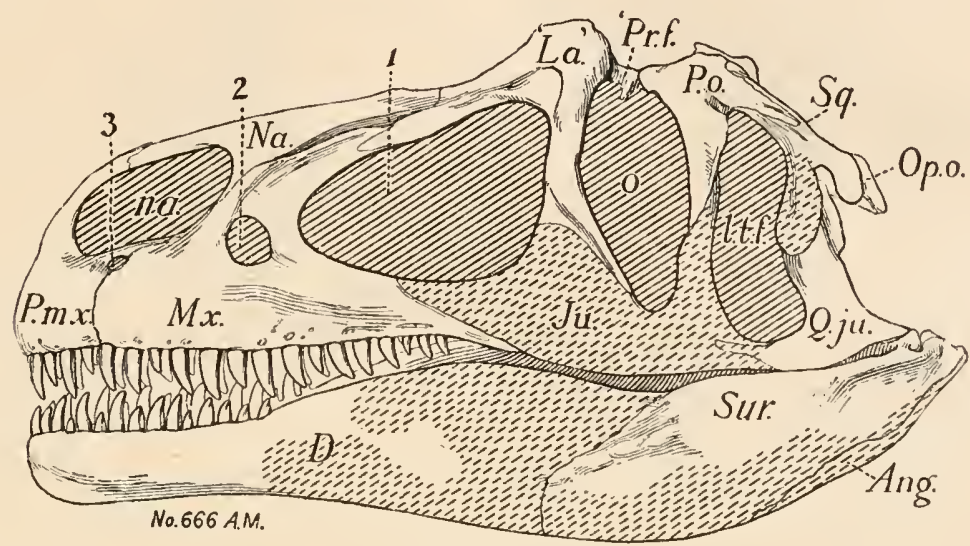

Fig. 464.

Schädel von Allosaurus agilis aus den Atlantosaurus Beds Nordamerikas, rekonstruiert. Die rekonstruierten Teile sind schraffiert. (Nach H. F. Osborn.)

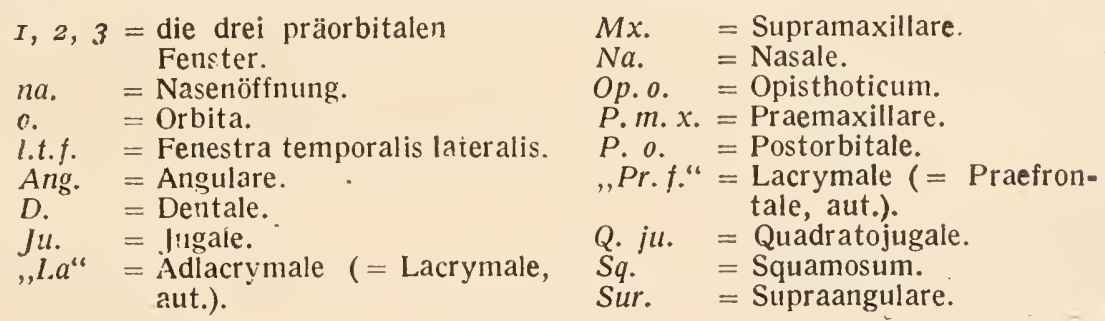

(Dogger) von Minchinhampton in Gloucestershire beschrieben worden. Der Schädel trägt einen Kanm wie Ceratosaurus, aber Megalosaurus (M. Bucklandi und M. Bradleyi) besitzt jederseits vier, Ceratosaurus dagegen nur drei Prämaxillarzähne. Die Rumpfwirbel von Megalosaurus trugen außerordentlich hohe Dornfortsätze. ${ }^{1}$

1 A. Smith Woodward, On a Skull of Megalosaurus from the Great Oolite of Minchinhampton (Gloucestershire). - Quarterly Journal of the Geological Society of London, Vol. LXVI, 1910, p. 111 (Literatur).

Die ältere Literatur ïber Megalosaurus findet sich, wenn auch nur zum Teile, in der Bibliographie der fossilen Vertebraten Nordamerikas von O. P. Hay (Bulletin of the U. S. Geological Survey, Nr. 179, Washington, 1902, p. 487). 
Allosaurus. - Atlantosaurus Beds (oberer Jura) Nordamerikas. Körperlänge $7-10 \mathrm{~m}^{1}$

Creosaurus. - Ebendaher. ${ }^{2}$

Ceratosaurus. - Ebendaher. Auf den Nasenbeinen ein hoher dreieckiger Kamm. Körperlänge $4-5 \mathrm{~m}^{3}$ (Fig. 465).

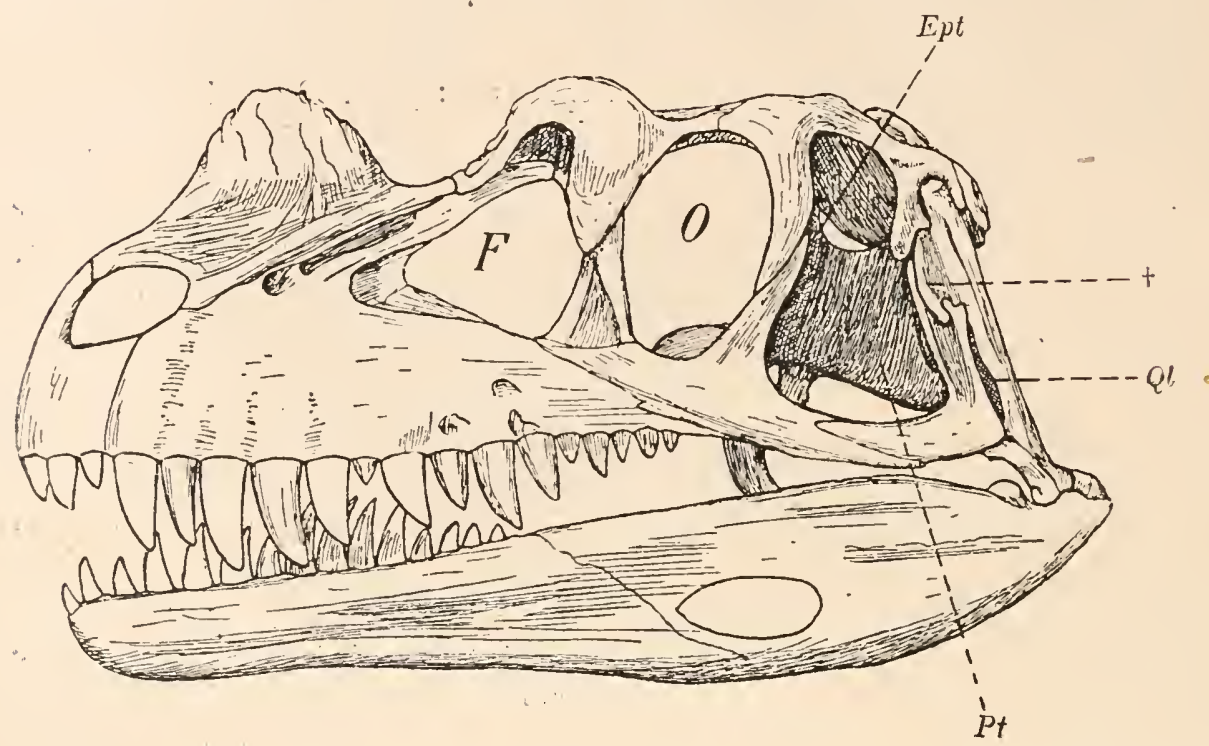

Fig. 465.

Schädel von Ceratosaurus nasicornis aus den Atlantosaurus Beds Nordamerikas (Colorado). Der Schädel trug einen medianen Kamm auf den Nasenbeinen und ein Hornpaar vor den Augen. (Nach O. C. Marsh, aus J. Versluys.)
Ept $=$ Epipterygoid.
$F=$ Fenestra praeorbitalis.
$P t=$ Pterygoid.
$Q l=$ Foramen quadrati.
$O=$ Orbita .
$t=$ Fortsatz des Quadratums.

1 H. F. Osborn, Fore and Hind-Limbs of Carnivorous Dinosaurs from the Jurassic of Wyoming. - Dinosaur Contributions, Nr. 3. - Bulletin of the American Museum of Natural History, Vol. X11, 1899, p. 161.

W. L. Beasley, A Carnivorous. Dinosaur: A Reconstructed Skeleton of a Huge Saurian. - Scientific American, New York, 14. Dezember 1907, Vol. XCVII, p. $437-447$.

H. F. Osborn, Crania of Tyrannosaurus and Allosaurus. - Memoirs of the Anerican Museum of Natural History, New Series, Vol. 1, Part 1, New York 1912 , p. 1.

${ }^{2}$ H. F. Osborn, The Skull of Creosaurus. - Bulletin of the American Museum of Nat. Hist., New York, Vol. XIX, 1903, p. 697.

J. Versluys, Streptostylie bei Dinosauriern nebst Bemerkungen über die Verwandtschaft der Vögel und Dinosaurier. - Zoologische Jahrbücher, Abt. für Anatomie und Ontogenie der Tiere. XXX. Bd., 1910, S. 181.

3 O. P. Hay, On Certain Genera and Species of Carnivorous Dinosaurs, with Special Reference to Ceratosaurus nasicornis. - Proceedings of the U. S. National Museum, Vol. XXXV, 1908, p. 351. 
Dryptosaurus (= Laelaps). - Vielleicht schon im oberen Jura (Atlantosau; us Beds) Nordamerikas; häufig in der oberen Kreide von Montana und New Jersey; auch in der obersten Kreide von Kanada (Edmonton Series). ${ }^{1}$

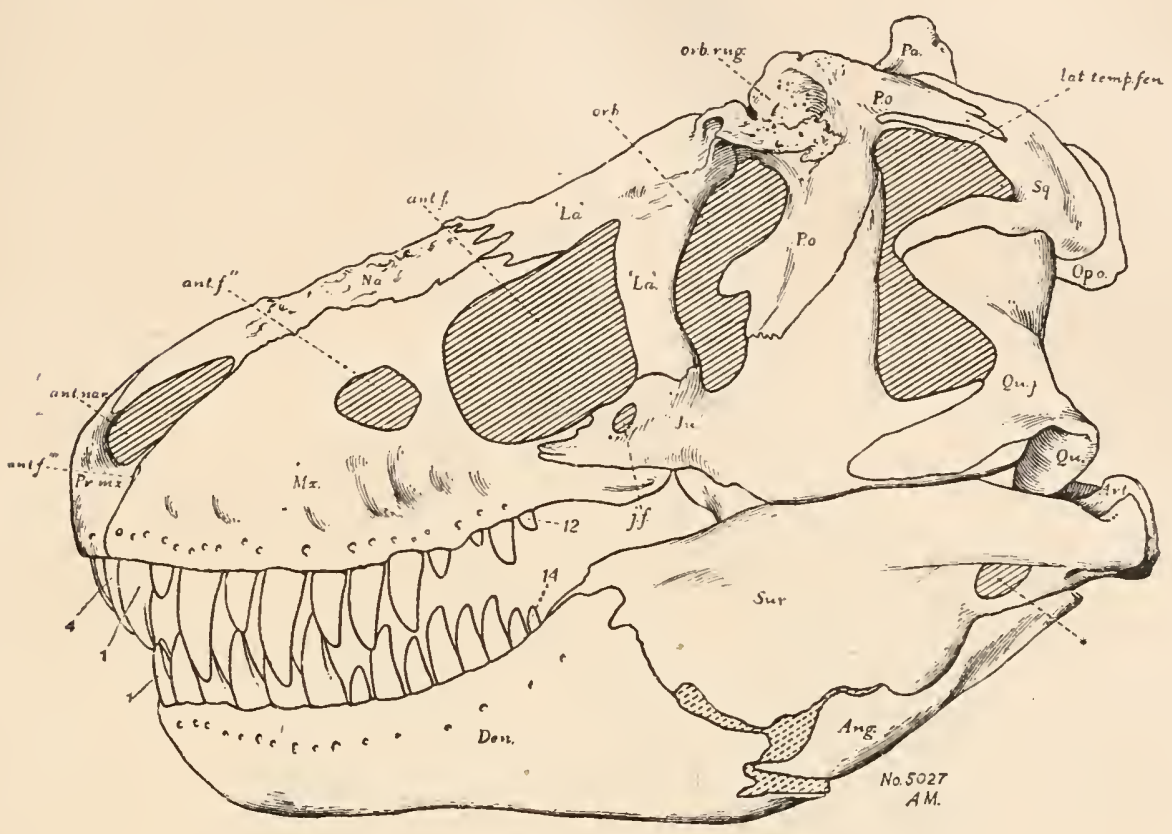

Fig. 466.

Schädel von Tyrannosaurus rex aus der oberen Kreide (Laramie-Beds) von Montana.

Schädellänge des Exemplars 5027 d. Am. Mus. Nat. Hist. in New York 1,21 m.

(Nach H. F. Osborn.)
$I, I 2, I_{4}=$ Zähne des Ober- und Unter- kiefers.
$4 \quad=$ vicrter Inzisiv des 7wischen- kiefers.
Ang. = Angulare.

Art. $=$ Articulare

ant. $f$, ant. $f . .^{\prime \prime}$ ant. $f .^{\prime \prime \prime}=$ die drei antorbitalen Fenster.

ant. nar. = vordere Nasenöffiumg.

Den. $\quad=$ Dentale.

j.f. $\quad=$ Fenestra jugalis

Ju. $\quad=$ Jugale.

, La $^{6} \quad$ = Adlacrymale ( = Lacrymale aut.).

lat. temp. fen. = Fenestra temporalis lateralis.

$M x$ = Supramaxillare.
Na. $\quad=$ Nasale.

Opo. = Opisthoticum.

orb. $\quad=$ Orbita.

orb. rug. = Knochenwucherung (wahrscheinlich Hornsockel) oberhalb der Augenhöhle.

Pa. $\quad=$ Parietale.

Po. $\quad=$ Postorbitale.

Pr. $m x .=$ Praemaxillare.

Qu. $\quad=$ Quadratum.

Quj. = Quadratojugale.

Sq. $\quad=$ Squamosum.

Sur. $\quad=$ Supraangulare.

* $\quad=$ Fenster im Supraangulare.

Anm. Die rauh skulpturierte Oberfläche des Nasale spricht dafür, daß hier ein medianer Kamm aufsaß.

1 L. M. Lambe, On Dryptosaurus incrassatus (Cope), from the Edmonton Series of the North West Territory. - Geological Survey of Canada, Contributions to the Canadian Palaeontology, Vol. III, Ottawa 1904, p. 1. 
Tyrannosaurus. - Oberste Kreide (Laramieschichten) von Montana (Nordamerika) ${ }^{1}$ (Fig. 466-472).

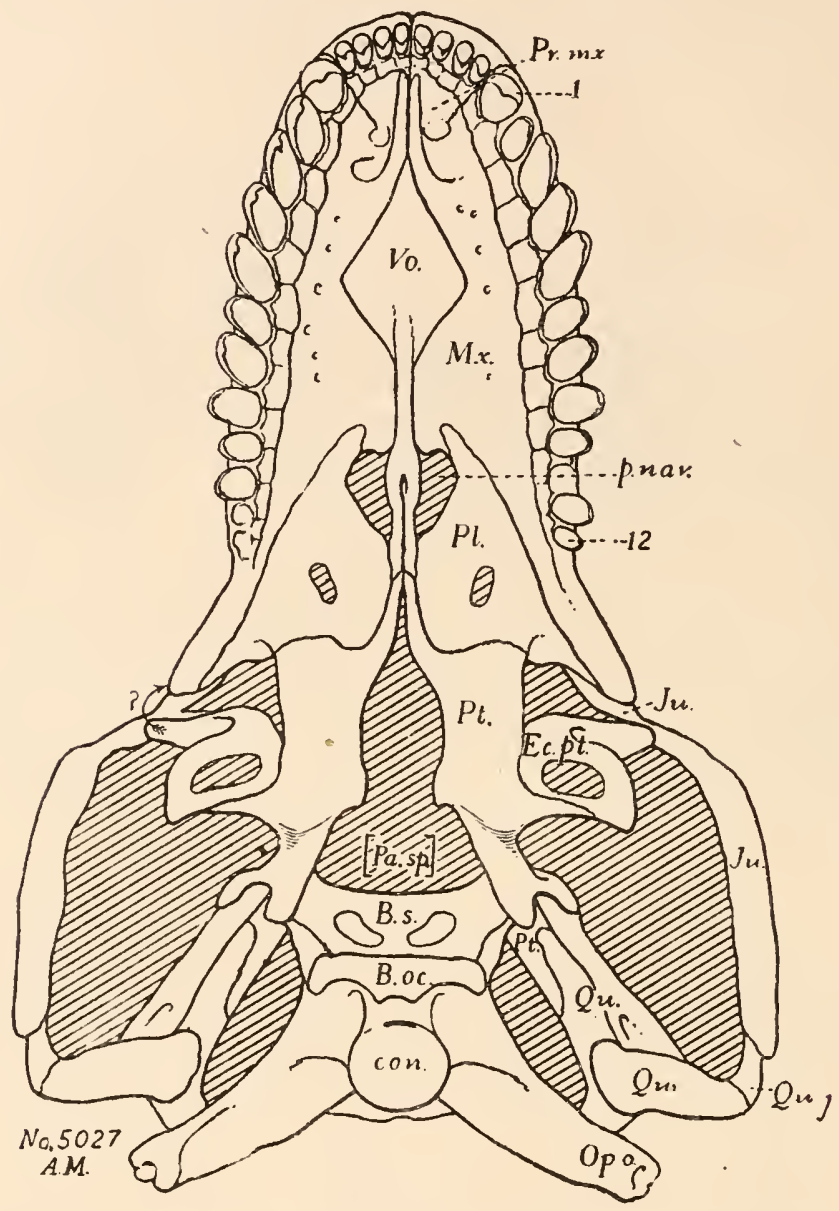

Fig. 467.

Gaumenfläche des Schädels von Tyrannosaurus rex aus der oberen Kreide von Montana, rekonstruiert. (Nach H. F. Osborn.)

I U. $x 2=1$. und 12. Zahn des linken Oberkiefers.

B. $o c$. = Basioccipitale.

B. $s .=$ Basisphenoid.

con. = Condylus occipitalis.

Ec. pt. = Ectopterygoid.

$J u . \quad=$ Jugale.

$M x$. = Supramaxillare.

Op. o. = Opisthoticum ( = Parnccipitale).
$[P a . s p \cdot]=$ Lage des Parasphenoids. Pl. $\quad=$ Palatinum.

p. nar. $=$ Choane.

Pr. $m x .=$ Praemaxillare.

Pt. $\quad=$ Pterygoid .

Qu. $\quad=$ Quadratum.

Qu.j. = Quadratojugale.

Vo. $=$ Vomer.

1 H. F. Osborn, Tyramosaurus and Other Cretaceous Dinosaurs. Bulletin of the American Museum of Natural History, Vol. XXI, 1905, p. 259. - Derselbe, Tyrannosaurus, Upper Cretaceous Carnivorous Dinosaur (Second Communication). Ibidem, Vol. XXII, 1906, p. 281. - Derselbe, Tyrannosaurus, Restoration and 


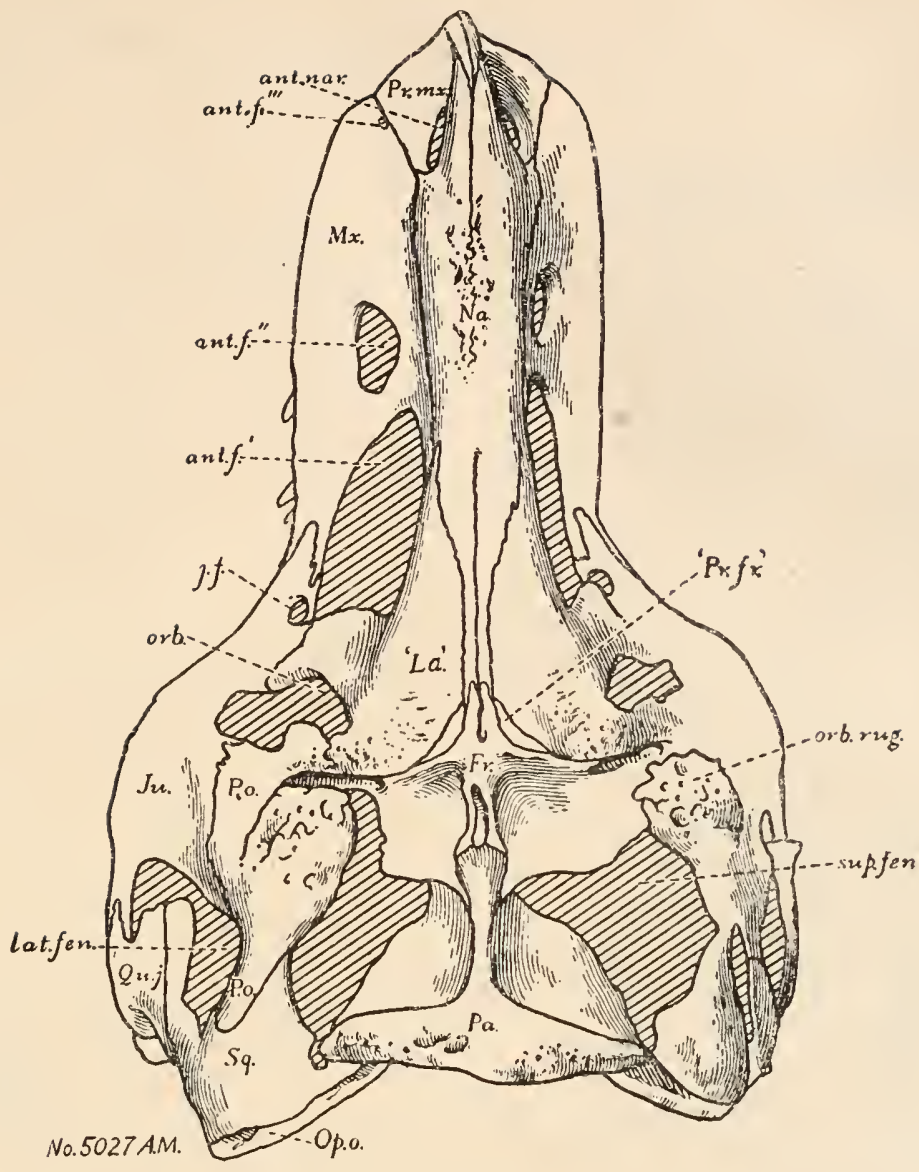

Fig. 468.

Oberansicht des Schädels von Tyrannosaurus rex aus der oberen Kreide von Montana, rekonstruiert. (Nach H. F. Osborn.)

\section{Schädelöffnungen:}

ant. nar. = vordere Nasenöffnung. ant..$^{\prime}$, ant. $f .^{\prime \prime}$, ant..$^{\prime \prime \prime}$

$=$ die drei präorbitalen Fenster.

$j . f . \quad=$ Fenster im Jugale.

orb. $=$ Orbita.

lat. fen. = Fenestra temporalis lateralis. sup.fen. $=$ Fenestra temporalis superior.

Schädelknochen:

Fr. $\quad=$ Frontale.

Ju. $\quad=$ Jugale.

"La." = Adlacrymale ( = Lacrymale, aut.).
$M x . \quad=$ Supramaxillare.

orb. rug. = Hornsockel.

$\mathrm{Na} . \quad=$ die in der Mitte verschmolzenen Nasalia mit dem rauhen Knochensockel fiir das Nasenhorn.

Op. o. = Opisthoticum $(=$ Paroccipitale).

$P a . \quad=$ Parietale.

Po. $\quad=$ Postorbitale + Postfrontale.

„Pr.fr. " = Lacrymale $(=$ Praefrontale, aut.).

Pr. $m x .=$ Praemaxillare.

Quj. = Quadratojugale.

Sq. $\quad=$ Squamosum.

Model of the Skeleton. Ibidem, Vol. XXXII, 1913, p. 91, - Derselbe, Crania of Tyrannosaurus and Allosaurus. Memoirs of the American Museum of Natural History; New York, Vol. I (New series), Part. 1, 1912, p. 1. 
Genyodectes. - Obere Kreide von Chubut, Patagónien. ${ }^{1}$

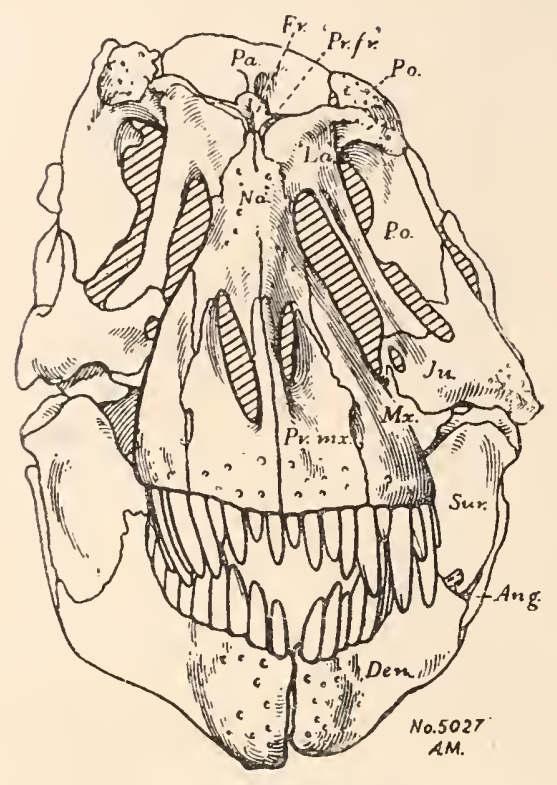

Fig. 469.

Vorderansicht des Schädels von Tyrannosaurus rex. (Nach H. F. Osborn.)

$$
\begin{aligned}
& \text { Ang. = Angulare. } \\
& \text { Den. } \quad=\text { Dentale. } \\
& \text { Fr. } \quad \text { Frontale. } \\
& \text { Ju. } \quad=\text { Jugale. } \\
& \text { "La". = Adlacrymale. } \\
& M x . \quad=\text { Supramaxillare. } \\
& \mathrm{Na} . \quad=\text { Nasale. } \\
& \text { Pa. } \quad=\text { Parietale. } \\
& \text { Po. } \quad=\text { Postorbitale }+ \text { Post- } \\
& \text { frontale. } \\
& \text {,Pr. } r^{\prime \prime} \text {. = Lacrymale (= Prae- } \\
& \text { frontale, aut.). } \\
& P r . m x .=\text { Praemaxillare. } \\
& \text { Sur. }=\text { Supraangulare. }
\end{aligned}
$$

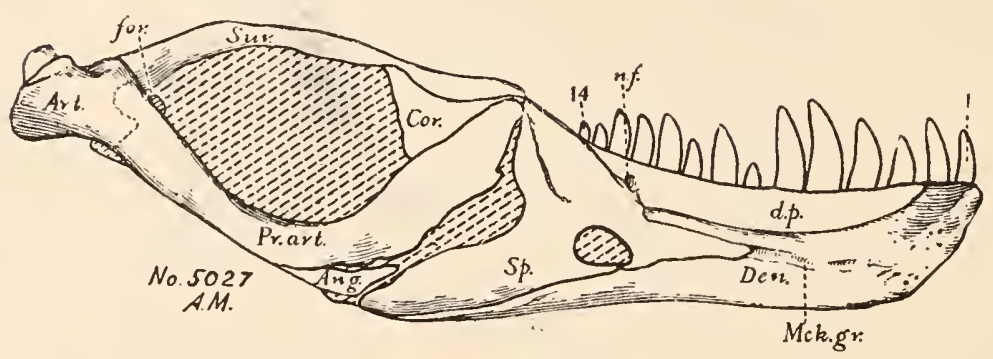

Fig. 470.

Innenansicht der linken Unterkieferhälfte von Tyrannosaurus rex, Osb., aus der oberen Kreide am Hell Creek in Montana; Nr. 5027 des American Mus. of Nat. Hist.

New York. (Nach H. F. Osborn.)

Art. $=$ Articulare.
Ang. $=$ Angulare.
Cor. $=$ Complementare.
Den. $=$ Dentale.
d. $p .=$,Supradentale" $(=$ Teil
Sp. $=$ Spleniale $)$

Art. = Articulare.

$S p .=$ Spleniale .
Pr. art. = Praearticulare.
Sur. $=$ Supraangulare.
for. $\quad$ Foramen im Supraangulare.
n. $\%$ = Gefäßloch.
Mck.gr. = Grube f. d. Meckelschen Knorpel.
I u. $I f=$ erster und vierzehnter Zahı.

\section{F. Spinosauridae.}

Im untersten Cenoman Ägyptens ist vor kurzem ein Theropode mit extrem verlängerten, an die Wirbelform der Sphenacodontiden

1 A. Smith Woodward, On some Extinct Reptiles from Patagonia, of the Genera Miolania, Dinylisia, and Genyodectes. - Proceedings of the Zoological Suciety, London 1901, p. 169. 
erinnernden Neurapophysen gefunden und von E. Stromer (1915) als Type einer neuen Gattung und Fannilie beschrieben worden. Für diese Abtrennung können nicht so sehr die verlängerten Dornfortsätze maßgebend sein, da sich solche auch bei Megalosaurus finden; aber das Gebiß zeigt einen wesentlichen Unterschied von den Megalosauriden darin, daß die unteren Zälıne (inl ganzen 15 jederseits) ausgesprochen heterodont sind (der 2.-4. sehr groß, der 1. und der 5.-10. sehr klein). Der Querschnitt der Zähne ist oval; sie sind nicht so stark komprimiert wie die Zähne der Megalosauriden und vor allenı dadurch gekennzeichnet, daß ilire Achsen senkrecht zur Kieferaclise stehen und nicht, wie bei den Megalosauriden, nach hinten gerichtet sind. Die Körpergröße muß bedeutend' gewesen sein, da der Unterkieferrest (nur das Dentale und Spleniale umfassend) $75 \mathrm{~cm}$ lang ist und einer der Rückenwirbel eine Gesanthöhe von etwa $180 \mathrm{~cm}$ erreicht. Wahrscheinlich waren die Neurapopliysen durch einen Hautkamm verbunden.

\section{Zu Fig. 471.}

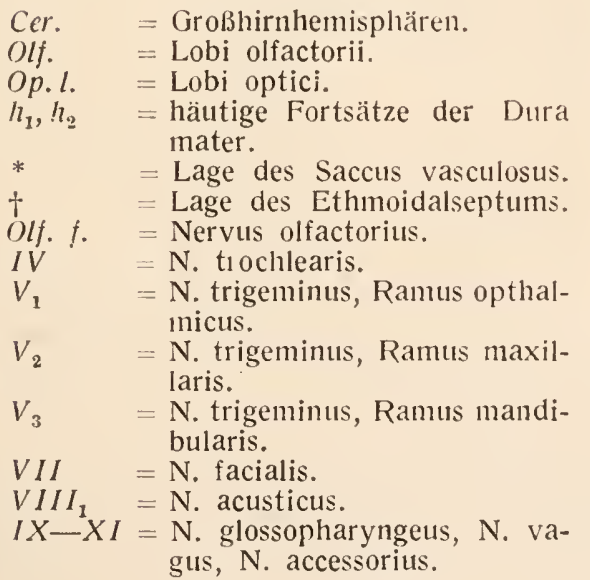

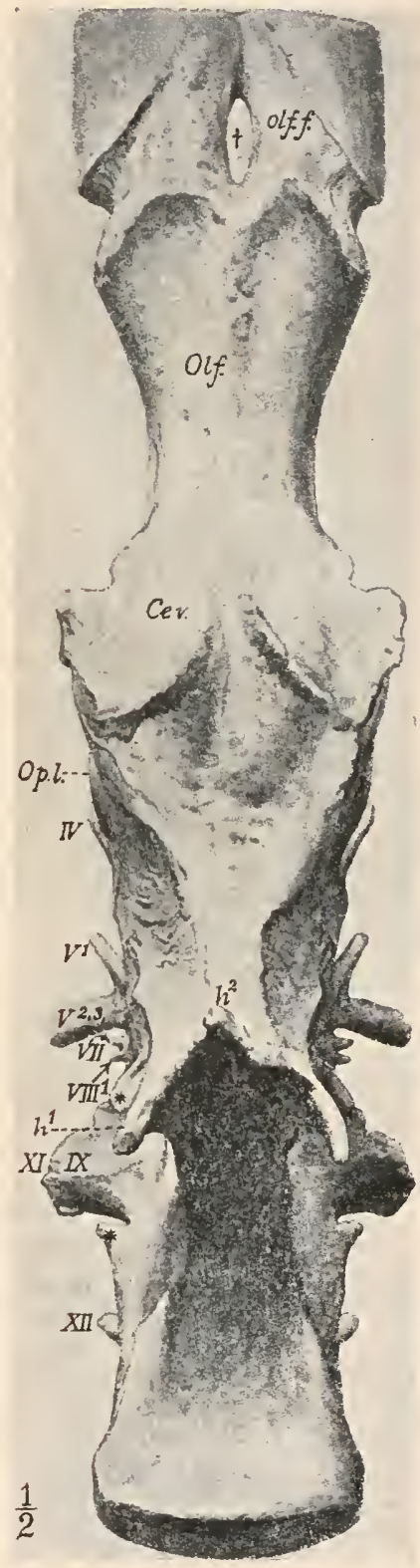

Fig. 471 .

Ausguß der Gehirnhöhle von Tyrannosaurus rex, von oben gesehen, in $1 / 2$ nat. Gr. (Nach H. F. Osborn.) 
Spinosaurus. - Cenoman Ägyptens. - Sp. aegyptiacus (Stromer, 1915) ${ }^{1}$ (Fig. 473, 474).

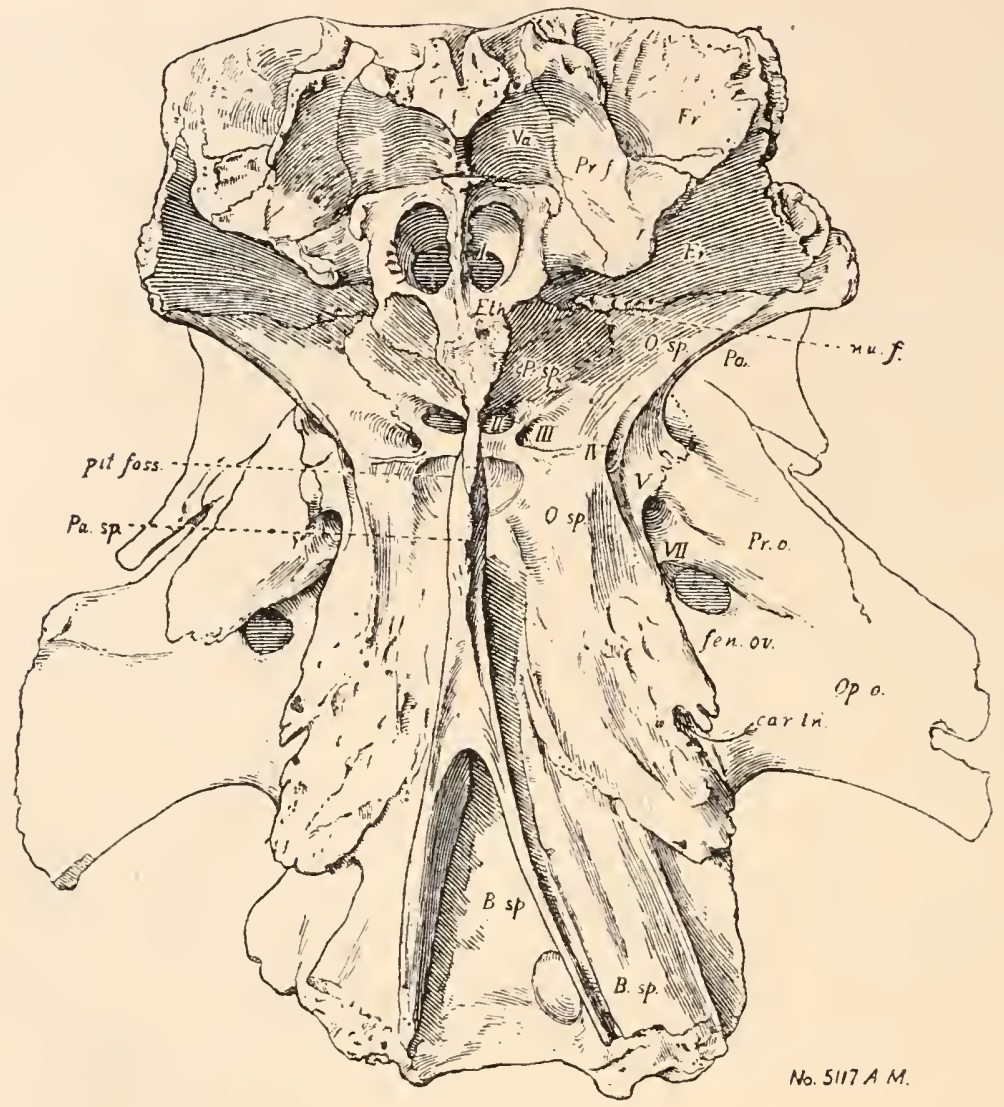

Fig. 472.

'Gaumenansicht der Schädelkapsel von Tyrannosaurus rex, aus der oberen Kreide von Montana. (Nach H. F. Osborn.)

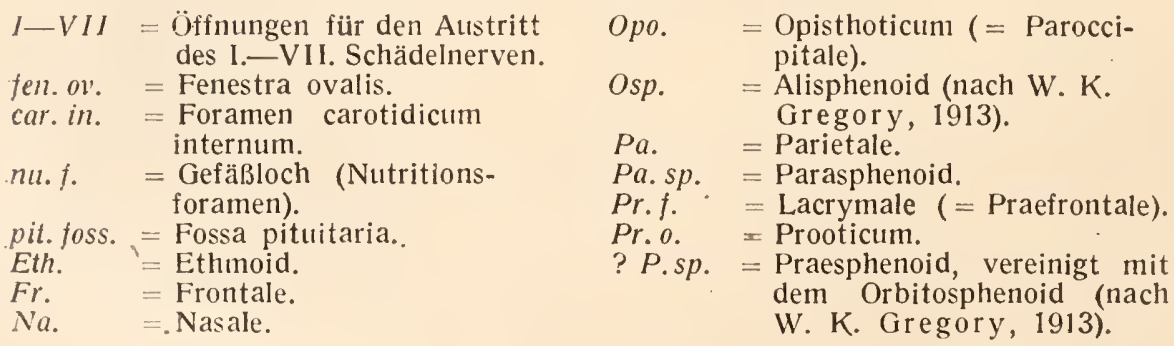

1 E. von Stromer, Ergebnisse der Forschungsreisen Prof. E. Stromers in den Wüsten Ägyptens. II. Wirbeltierreste der Baharijestufe (unterstes Cenoman). 1II. Das Original des Theropoden Spinosaurus aegyptiacus. - Abhandlungen der 


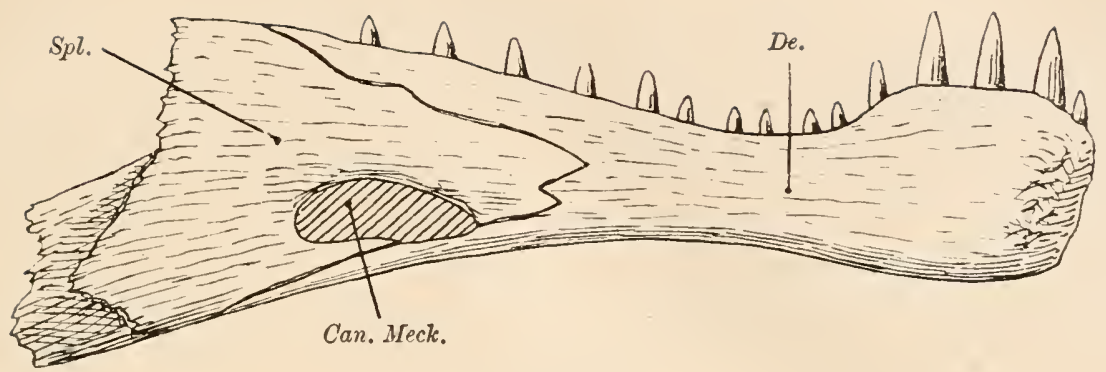

Fig. 473.

Unterkieferfragment von Spinosaurus aegyptiacus, Stromer; linker Kieferast von innen: gesehen, Zähne und Hinterende des Dentale ergänzt. Aus dem untersten Cenoman des Gebel el Dist des Baharîje-Kessels (Ägypten). 1/7 nat. Gr. (Nach E. v. Stromer.)

Fig. 474.

Spinosaurus aegyptiacus, Stromer, aus dem untersteı Cenoman des. Baharîje-Kessels in Ägypten. Brustwirbel, in $1 /{ }_{24}$ nat. Gr., von rechts gesehen.

$$
\begin{aligned}
& \text { N. }=\text { Neurapophyse. } \\
& \text { Diap. }=\text { Diapophyse. } \\
& \text { V. }=\text { Vorderfläche des Wirbelkörpers. } \\
& \text { Prz. }=\text { Praezygapophyse. } \\
& \text { Poz. }=\text { Postzygapophyse. }
\end{aligned}
$$

Kgl. Bayrischen Akademie der Wissenschaften, mat.physik. Klasse, Bd. XXVIII. München 1915, S. 1. F. von Nopcsa, Bau und Lebensweise der Dinosaurier. - Berlin 1918 (im Erscheinen). (Durch das liebenswürdige Entgegenkommen des Verfassers konnte ich in das Manuskript Einsicht nehmen.)

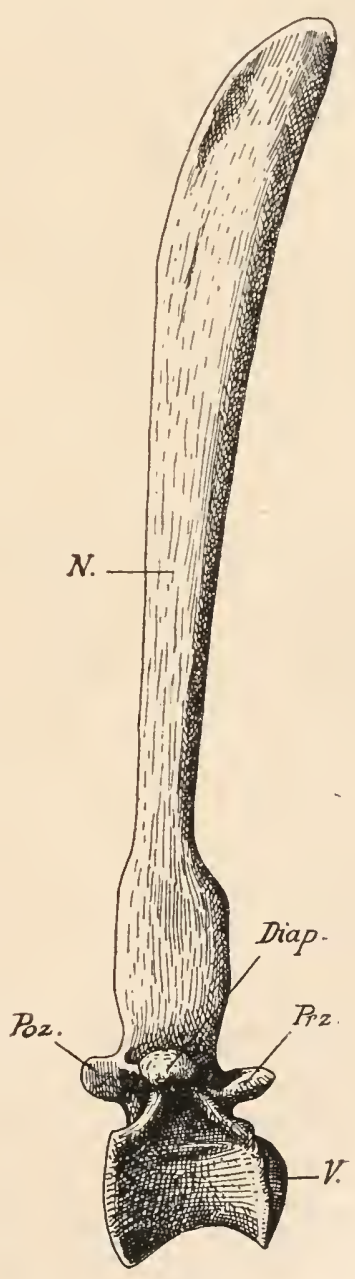




\section{Unterordnung: Sauropoda.}

Die Sauropoden umfassen die riesigsten Landwirbeltiere, die jemals gelebt laben. Diplodocus Carnegiei besaß eine Länge von über $22 \mathrm{~m}$; das Femur derselben Art erreicht eine Länge von 154,2 $\mathrm{cm}$ bei einer Humeruslänge von $95 \mathrm{~cm}$, während Brachiosaurus, der viel längere Arme als Diplodocus besaß, eine Humeruslänge von $213 \mathrm{~cm}$ aufweist, also über das Doppelte der Humeruslänge von Diplodocus. Daraus darf allerdings nicht geschlossen werden, daß Brachiosaurus etwa $40 \mathrm{~m}$ Körperlänge erreichte, weil die Hinterbeine von Brachiosaurus fast dieselbe Länge wie die Arme besessen haben. Vor kurzem ist durch E. Hennig ein riesiger Halswirbel eines Sauropoden aus den Tendaguruschichten Deutsch-Ostafrikas (ungefähr von demselben Alter wie die Atlantosaurus Beds Nordamerikas und die Wealdenbildungen Europas, d. i. Grenzschichten zwischen Jura und Kreide) abgebildet worden, der eine Länge von $1,11 \mathrm{~m}$ bei einer Höhe von $0,72 \mathrm{~m}$ erreicht und somit der größte bisher bekannte Wirbel ist.

Die Sauropoden sind aus den Pachypodosauriern, und zwar wahrscheinlich aus der Stamminruppe der Plateosauriden hervorgegangen. Sie sind jedoch nicht mehr biped gewesen, sondern sekundär zur tetrapoden Gangart zurückgekehrt, ebenso wie dies auch bei den jüngeren Ornithischiern der Fall gewesen ist, die von der bipeden Lebensweise wieder zur tetrapoden zurückgekehrt sind (Stegosauridae, Ceratopsidae, Ankylosauridae).

Der Schädel der Sauropoden ist im Verhältnis zum riesigen Körper sehr klein. Die Zähne sind lang und stiftförmig, zur räuberischen Nahrungsweise durchaus ungeeignet und stehen bei Diplodocus ähnlich wie die Zähne eines Rechens, so daß auch nicht an eine herbivore Nahrungsweise gedacht werden kann, bei der die Nahrung zermalılen wurde, wie es z. B. bei Iguanodon der Fall war. Da die Tiere, wie aus verschiedenen anderen Merkmalen hervorgeht, Wasserbewohner gewesen sind und eine Lebensweise wie die Flußpferde gefülırt haben dürften - dafür spricht auch die Verschiebung der Nasenlöcher nach hinten so dürfte die Nahrung hauptsächlich aus schwimmenden Wasserpflanzen und vielleicht auch aus Fischen bestanden haben, die mit dem Fangrechen des Gebisses erfaßt und nach dem Auslaufen des Wassers durch die Zahnlücken verschluckt wurden. Bei den primitiveren Gattungen (Morosaurus) liegen die Nasenöffnungen weiter vorn und sind durcli die Prämaxillaria getrennt, während sie bei Diplodocus weit hinten liegen und nur im vorderen Teile noch durch einen Fortsatz der Prämaxillaria getrennt werden, in hinteren Teile aber zu einer einzigen Öffnung zusammenfließen. 
Vor den Augenhöhlen liegen entweder eine oder zwei Präorbitalöffnungen jederseits. Hinter den Augenhölllen befinciet sich ein Paar kleiner oberer Temporalgruben, unter den Augenhöhlen ein Paar langgestreckter, schmaler unterer Temporalgruben. Der Schädel erhält dadurch ein merkwürdig verzerrtes Ausselıen, das durch die Verschiebung der Nasenöffnungen bei Diplodocus noch gesteigert wird.

Die Zahl der Wirbel schwankt bei den einzelnen Gattungen zwischen 10-15 im Halsabschnitt, und 10-15 im Rumpfabschnitt. Der Thorax hat meist einen schmal herzförmigen Querschnitt. Die Wirbel sind fast immer opisthocoel, besonders stark inı Halsabschnitt, wälrend die Rumpfwirbel schwächer ausgehölılt sind. Alle Präsakralwirbel sind leicht gebaut, besitzen seitliche Holılräume oder sind überlaupt von grobzelliger, kavernöser Struktur; diese Struktur findet sich auch nocl zuweilen in den Sakralwirbeln und den vordersten Schwanzwirbeln, deren Zahı bei Diplodocus wahrscheinlich 70 beträgt; der Schwanz läuft bei dieser Gattung in eine lange, dünne Peitsche aus. Die Zahl der zu einem Sacrum vereingten Wirbel, die mit dem llium in Verbindung treten, schwankt zwischen vier und fünf; die vorderen Schwanzwirbel sind mitunter procoel (bei Diplodocus).

Die Halswirbel tragen kräftige Rippen, die bei den einzelnen Gattungen (z. B. bẹi Brontosaurus und Diplodocus) sehr verschieden gestaltet sind.

Die Gliedmaßenknochen sind massiv, ihre Gelenkenden unverknöchert.

Die Carpalia und Tarsalia sind stark reduziert und im Carpus und Tarsus zu einer einheitlichen Masse verschmolzen. Die Metacarpalia sind bei Brontosaurus und Diplodocus und wahrscheinlich ebenso bei allen übrigen Sauropoden steil gestellt und ihre Gelenkflächen stelen fast senkrecht zur Achse der Knochen; das erste Metacarpale ist stets das kräftigste. Bei Diplodocus sind die Metacarpalia länger als bei Brontosaurus und sclnließen eng aneinander; dabei stehen sie in einem nach vorn konkaven Bogen unter dem. Carpus, so daß das dritte Metacarpale vorn, das erste innen und das fünfte außen unter dem Carpus steht. Vou den Fingern trägt bei Brontosaurus und Diplodocus nur der Daumen eine Krallenphalange, an den übrigen Fingern ist nur die Grundphalange erhalten, die übrigen Phalangen sind rudimentär.

Aus dem Bau der Hand geht mit voller Klarheit hervor, daß die Metacarpalia steil standen und nur mit den distalen Enden dem Boden aufruhten. Die Hand der Sauropoden ist also in funktioneller Hinsicht mit der Elefantenhand zu vergleichen.

Da die Sauropoden auf die Plateosauriden zurückgehen, so erklärt sich daraus die sehr auffallende und sonst unerklärliche Stärke des 


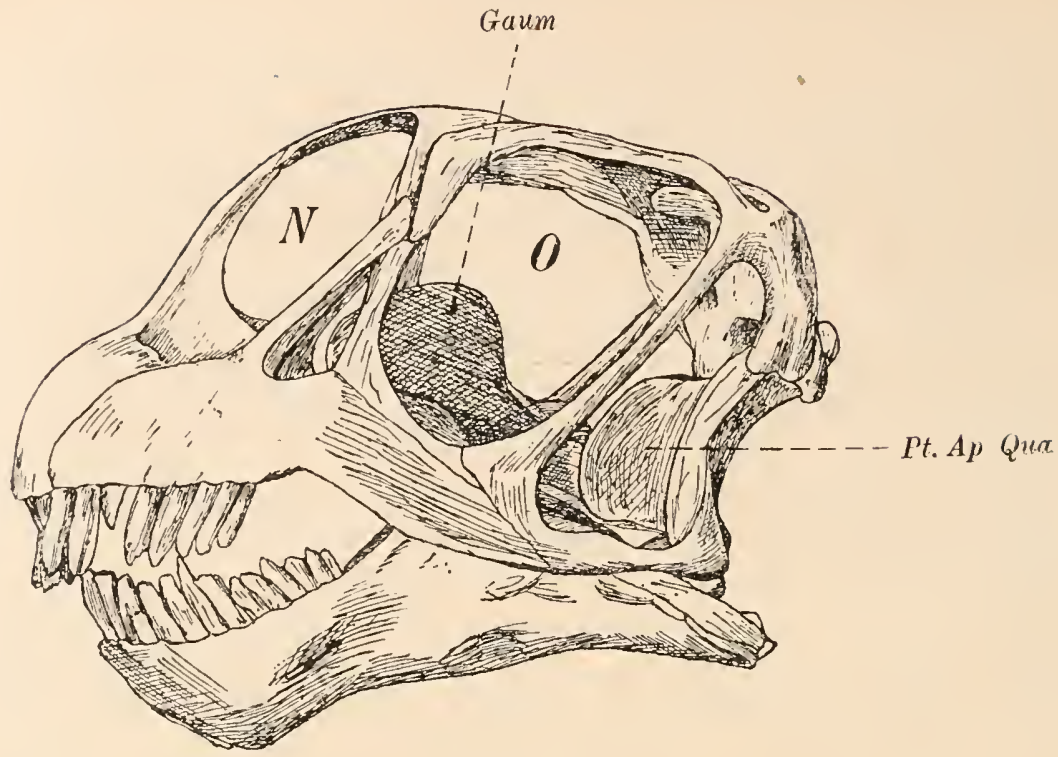

Fig. 475 .

Seitenansicht des Schädels von Morosaurus grandis aus den Atlantosaurus Beds von Wyoming, in $1 /$, nat. Gr. (Nach H. F. Osborn, umgezeichnet von J. Versluys.)

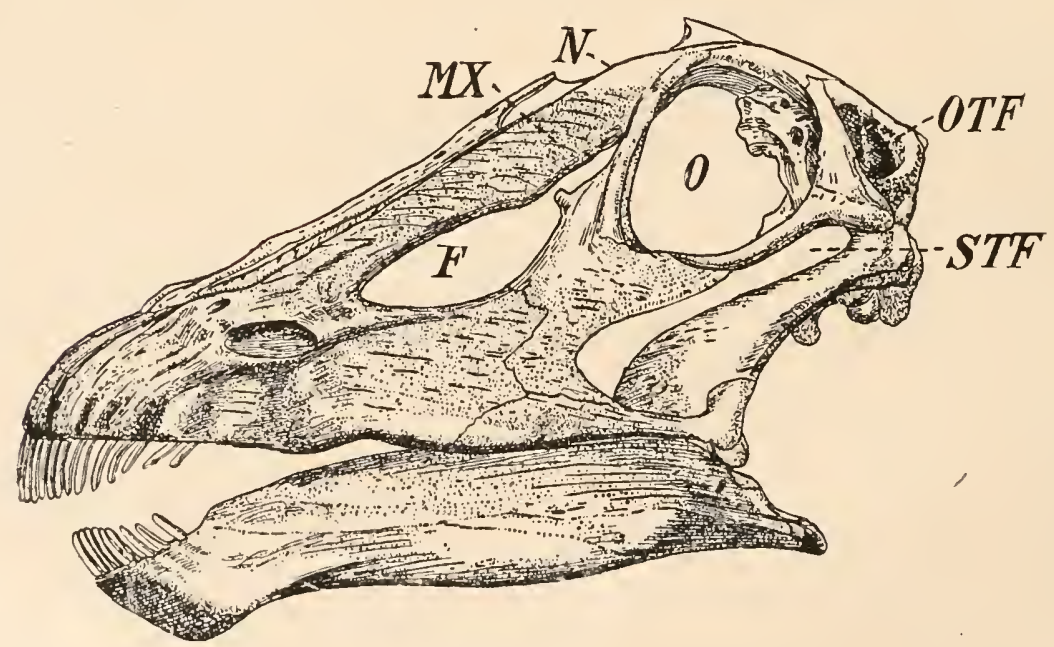

Fig. 476.

Seitenansicht des Schädels von Diplodocus longus, in $1 / 10$ nat. Gr.

(Nach W. J. Holland, umgezeichnet von J. Versluys.)
$F=$ Foramen antorbitale.
$O=$ Augenhöhle.
$M x=\begin{aligned} & \text { oberer Abschnitt des Supra- } \\ & \text { maxillare. }\end{aligned}$
$O T F=$ obere Temporalgrube.
$S T F=$ seitliche Temporalgrube
$N=$ Nasenöffnung. 
Daumens, an dem noch die schon bei den Vorfahren sehr starke Krallenphalange erhalten geblieben ist, während die übrigen Phalangen verloren gegangen sind. Die Greifhand der Plateosauriden ist bei den Sauropoden infolge ihrer Rückkehr zur tetrapoden Gangart zu einer elefantenartig funktionierenden Schreithand mit reduzierten Phalangen geworden und es ist wahrscheinlich, daß auch ein Sohlenballen vorllanden war.

Auch im Fußbau sind weitgehende Spezialisationen festzustellen. Die Stärke der Metatarsalia nimmt bei Diplodocus Carnegiei vom ersten

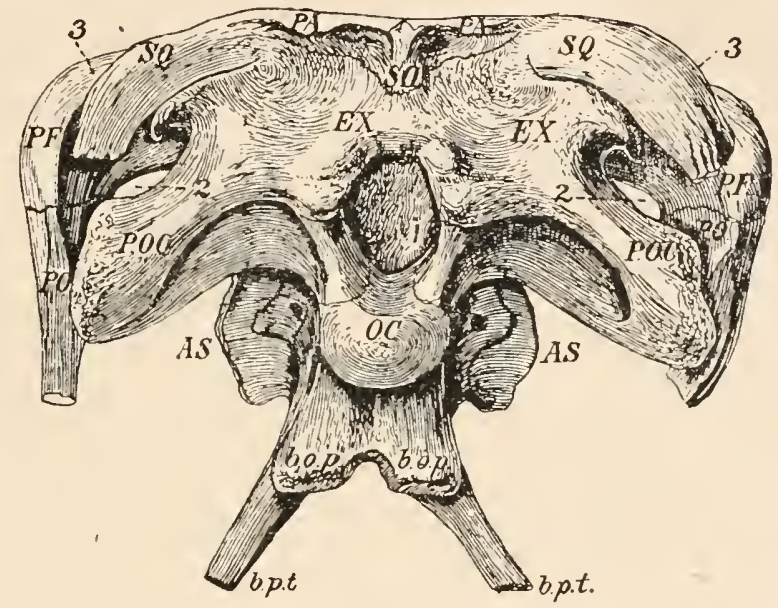

Fig. 477.

Hinterhaupt von Diplodocus Carnegiei, von hinten geseher, in $1 / 3$ nat. Gr.

Atlantosaurus Beds, Wyoming. (Nach W. J. Holland, 1906.)

Die Enden der Squamosa sind beiderseits abgebrochen.

$\begin{array}{lll}2 & =\text { Fenestra posttemporalis. } & O C=\text { Condylus occipitalis. } \\ 3 & =\text { Fenestra supratemporalis. } & P A=\text { Parietale. } \\ \text { AS } & =\text { flügelartige Knochenleiste auf } & P F=\text { Postfrontale. } \\ & \text { dem Prooticum. } & P O=\text { Postorbitale. } \\ \text { bop }=\text { Tubercultum sphenoccipitale. } & P O C=\text { Processus paroticus. } \\ b p t=\text { Processus basipterygoideus. } & S O=\text { Supraoccipitale. } \\ E x=\text { Exoccipitale. } & S Q=\text { Squamosum. }\end{array}$

Metatarsale an gegen außen konstant ab; das dritte Metatarsale ist das längste. Bei Brontosaurus excelsus tragen die drei inneren Zehen noch die Krallenphalangen und die Phalangenzahl ist normal (im ersten Zehenstrahl 2, im zweiten 3, im dritten 4), aber die beiden äußeren Zehen besitzen nur mehr Phalangenrudimente (die vierte 2, die fünfte 1). Ähnlich war der Bau des Hinterfußes bei Diplodocus. Die Metatarsalia waren zwar auch aufgerichtet, standen aber nicht so steil wie die Metacarpalia.

Aus dem Bau von Hand und Fuß geht hervor, daß die Sauropoden mit steil gestellten Gliedmaßen gingen und daß nur der Arm 


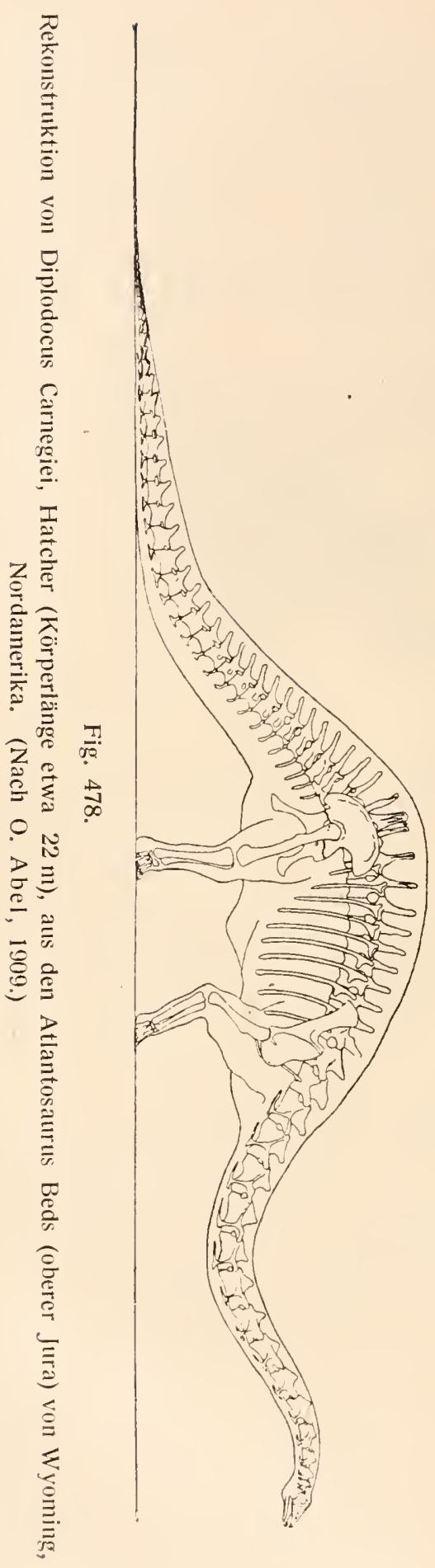

iml Ellbogengelenk stärker gębeugt war, während die Hinterbeine eine mehr säulenartige Stellung besessen haben müssen.

Die Sauropoden erscheinen mit Cetiosaurus und Dystrophaeus zuerst im mittleren Jura von England und Nordamerika. In den Atlantosaurus Beds (= Como Beds) Nordamerikas (Wyoming, Colorado usw.) sind zahlreiche Skelette und vereinzelte Skeletteile von Sauropoden gefunden worden. Sie sind aber auch in den Tendaguruschichten Deutsch-Ostafrikas in zum Teile trefflicher Erhaltung entdeckt worden (Gigantosaurus, Brachiosaurus usw.), ferner in Wealden Englands, in der Kreide von Ostindien, Madagaskar und Patagonien.

Die systematische Gruppierung der Sauropoden hat zur Aufstellung mehrerer Familien geführt, die sich aber z. T. nur durch graduelle Differenzen der in ihnen eingereihten Gattungen unterscheiden und daher vielleicht $z$. T. einzuziehen sein werden, wenin die Morphologie dieser Dinosauriergruppe genauer als bisher studiert sein wird. Einzelne Gattungen sind fast in allen Skelettteilen bekannt.

\section{F. Diplodocidae.}

Vorderbeine viel kürzer als die Hinterbeine. Zalıl der Halswirbel 15, Rückenwirbel 12, 4-5 Sakralwirbel. Vordere Rückenwirbel und Halswirbel mit gegabelten Neurapophysen, opisthocoel. Etwa 73 Scluwanzwirbel. llium mit rudimentärer hinterer Spitze. Pubis schmal, distal verdickt, Foramen 
obturatorium klein. Scapula stark verbreitert. Im Schädel von Diplodocus sind die Nasenöffnungen weit nach hinten und oben verschoben, die Nasalia hinter den Nasenöffnungen rudimentär.

Morosaurus. - Ebendaher (Fig. 475). ${ }^{1}$

Diplodocus. - Oberster Jura Nordamerikas (Fig. 476-479). ${ }^{2}$

\section{F. Atlantosauridae.}

Habitus ähnlich wie bei Diplodocus, aber im allgemeinen plumper gebaut. Halswirbel nit gegabelten Dornfortsätzen, ebenso die vorderen Rückenwirbel; Halsrippen sehr kräftig, beilförmig. Die Halswirbel und vorderen Rückenwirbel sind opisthocoel, die hinteren Rückenwirbel amphicoel. Pubis schmal, an beiden Enden verdickt.

Atlantosaurus. - Oberster Jura Nordamerikas. ${ }^{3}$

Brontosaurus. - Oberster Jura Nordamerikas (Fig. 480-481).

\section{F. Cetiosauridae.}

Vorderbeine beinahe oder ebenso lang als die Hinterbeine. Zahı der Halswirbel unter 15, Zahl der Rückenwirbel über 10. Halswirbel stark, vordere Rückenwirbel schwächer opisthocoel, hintere Rückenwirbel amphicoel, ohne gegabelte Neurapophysen; llium mit rudimentärer hinterer Spitze. Pubis durchaus plattenförmig mit großem Foramen obturatorium. Scapula am Gelenkende und am Oberende stark verbreitert. Die Fanilie unfaßt einige hochspezialisierte Gattungen.

1 H. F. Osborn, The Skeleton of Brontosaurus and Skull of Morosaurus. Nature, London, Vol. 73, 1906, p. 282.

$\mathrm{Ch}$.W. Gilmore, The Type of the Jurassic Reptile Morosaurus agilis redescribed, with a Note on Camptosaurus. - Proceedings U. S. National Museum, Vol. XXXII, Washington, 1907, p. 151.

2 J. B. Hatcher, Diplodocus (Marsh): Its Osteology, Taxonomy, and Probable Habits, with a Restoration of the Skeleton. - Memoirs Carnegie Museum, Pittsburg, Vol. I, 190I, p. 1; Ibidem, Vol. II, 1903, p. 72.

W. J. Holland, Osteology of Diplodocus, Marsh. - Ibidem, Vol. II, Nr.6, 1906 , p. 225.

O. Abel, Die Rekonstruktion des Diplodocus. - Abhandlungen der K. K. Zoologisch-Botanischen Gesellschaft in Wien, Bd. V, 3. Heft, Jena 1910 (ausführliche Literatur).

Ch. C. Mook, The Fore and Hind Limbs of Diplodocus. - Bulletin American Museum of Nat. Hist., New York, Vol. XXXVII, Art. 31, 1917, p. 815.

3 O. C. Marsh, The Dinosaurs of North America. - XV1. Annual Report of the U. S. Geological Survey, Washington, 1896, p. 166.

$4 \mathrm{~J}$. B. Hatcher, Structure of the Fore-Limb and Manus of Brontosaurus. - Annals of the Carnegie Museum, Vol. I, 1902, p. 356.

W. D. Matthew, The Mounted Skeleton of Brontosaurus in the American Museum of Natural History. Guide Leflet Nr. 18, The American Museum Journal, Vol. V, 1905, p. 1.

ก. Abel, I. c. (Literatur). 

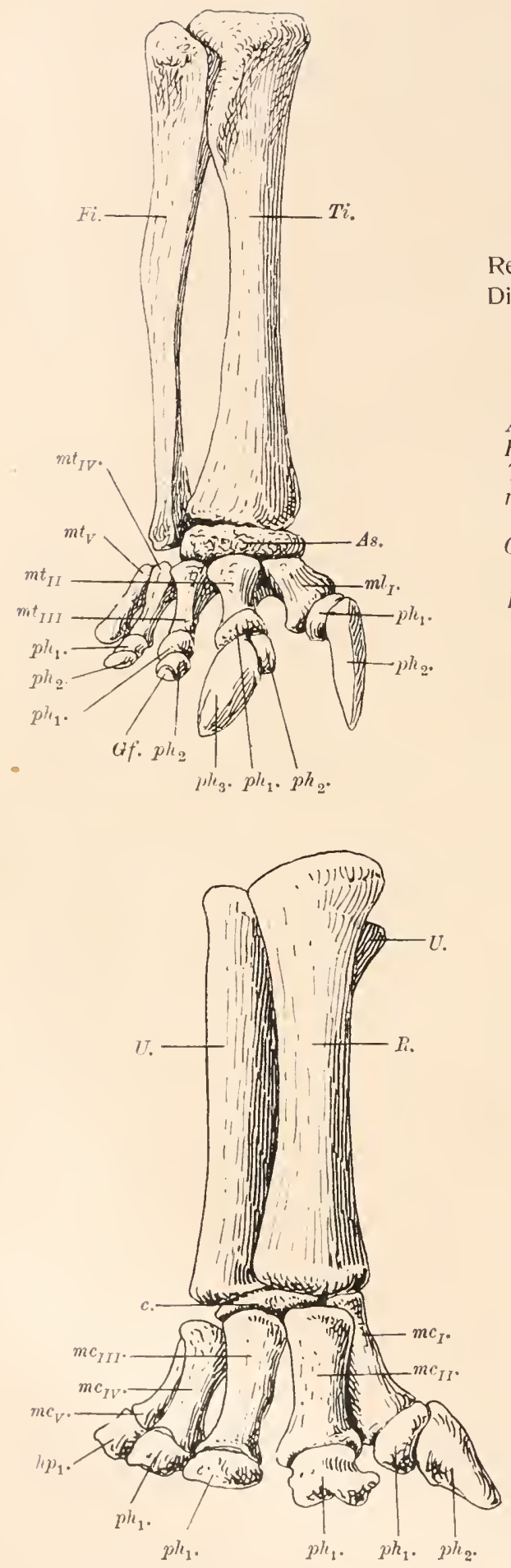

Fig. 479.

Rechter Hinterfuß und Unterschenkel von Diplodocus Carnegiei, Hatcher, aus den Atlantosaurus Beds von Wyoming. $1 / 11$ nat. Gr.

(Nach J. B. Hatcher, 1901.)

As. $=$ Astragalus .

$F i$. = Fibula.

Ti. = Tibia.

$m t_{I^{*}}, m t_{I^{\prime}}, m t_{H^{\prime}}, m t_{I^{\nu^{*}}}, m t_{V^{*}}=$ erstes bis fünftes Metatarsale.

Gi. = Gelenkfläche der zweiten Phalange der dritten Zehe.

ph. $=$ Phatangen .

Rechte Hand und Vorderarm von Brontosaurus excelsus, Marsh, aus den Atlanto. saurus Beds von Wyoming, von vortue gesehen. $1 / 10$ nat. Gr.

(Nach J. B. Hatcher.)

$U .=$ Ulna.

$R .=$ Radius

$c .=$ Carpalia (verschmolzen).

mc. $=$ Metacarpalia.

$p h$, = Phalangen. 
Dystropliaeus. - Mittlerer Jura. Nordamerika. ${ }^{1}$

Cetiosaurus. - Dogger bis Malm. England.2

Haplocanthosaurus. - Oberster Jura Nordamerikas und Kreideschichten (?) am Rio Neuquem in Südamerika. ${ }^{3}$

Brachiosaurus. - Oberster Jura Nordanerikas und DeutschOstafrikas. Arme länger als Hinterbeine, Hals sehr lang. ${ }^{4}$ Humerus bis $213 \mathrm{~cm}$ lang..

Die systematiscle Stellung von Gigantosaurus (E. Fraas) 5 und

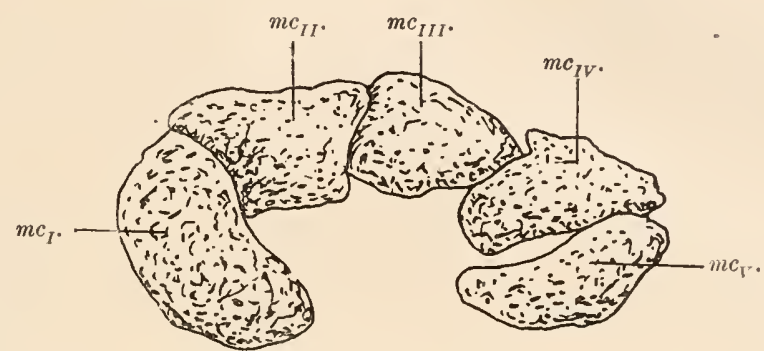

Fig. 481.

Die oberen Gelenkflächen der fünf Metacarpalia von Brontosaurus excelsus, Marsh, in natïrlicher Lage. 1/4 nat. Gr. (Nach J. B. Hatcher.) $m c_{r}-m c_{\mathrm{V}}=$ Metacarpale $\mathrm{I}-\mathrm{V}$.

1 F, von Huene, Dystrophaeus viaemalae, Cope, in neuer Beleuchtung. Neues Jahrbuch für Mineralogie usw., Beilageband XIX, I904, S. 319.

2 R. Owen, Monograph of the Fossil Reptilia of the Mesozoic Formations. Part 11. - (Genera Bothriospondylus, Cetiosaurus, Omosaurus). - Palaeontographical Society, Vol. XXIX, 1875, p. 15.

A. Smith Woodward, On Parts of the Skeleton of Cetiosaurus Leedsi, a Sauropodous Dinosaur from the Oxford Clay of Peterborough. - Proc. Zool. Soc. London, 1905, Vol. I, p. 232.

Derselbe, A Guide to the Fossil Reptiles, Amphibians and Fishes in the Department of Geology and Palaeontology in the British Museum of Natural History, 9. Edition, London, 1910, Pl. III, p. 17.

3 J. B. Hatcher, Osteology of Haplocanthosaurus etc. - Memoirs Carnegie Museum, Vol. II, Nr. I, 1903, p. 1.

F. Baron Nopcsa, Notizen ïber cretacische Dinosaurier. - 3. - Wirbel eines sijdamerikanischen Sauropoden. - Sitzungsberichte der Kaiserlichen Akademie der Wissenschaften in Wien, CXI. Bd., 1902, S. 108.

4 E. S. Riggs, Structure and Relationships of Opisthocoelian Dinosaurs. Part II. The Brachiosauridae. - Publication 94 of the Field Columbian Museum, Geological Se1ies, Vol. II, Nr. 6, Chicago, 1904, p. 229.

W. Janensch, Übersicht über die Wirbeltierfauna der Tendaguruschichten, nebst einer kurzen Charakterisierung der neu aufgefuihrten Arten von Sauropoden.- Archiv fuir Biontologie, 111. Bd., 1. Heft, 1914, S. 86.

W. D. Matthew, Dinosaurs. - New York, 1915, p. 73.

${ }^{5}$ E. Fraas, Ostafrikanische Dinosaurier. - Paläontographica, LV. Bd., 1908, p. 120 . 
Dicraeosaurus (Janensch) ${ }^{1}$ im Rahmen der Sauropoden ist noch unsicher. Beide Gattungen sind im obersten Jura Deutsch-Ostafrikas entdeckt worden. Die auch bei Dicraeosaurus gegabelten Neurapophysen der Rumpfwirbel sind etwa fünfmal so hoch als der Wirbelkörper (D. Sattleri).

\section{Ordnung: Ornithischia (= Orthopoda).}

Der wesentlichste Unterschied der Ornithischier von den Dinosauriern liegt im Bau des Beckens (vgl. oben bei den Pachypodosauriern). Hierzu treten als weitere wesentliche Differenzen: das Vorhandensein eines herbivoren, aus dichtstehenden Mahlzähnen bestehenden Gebisses, das mit Ausnahme von Hypsilophodon auf die Supramaxillaria und Dentalia beschränkt ist (bei Hypsilophodon sind auch die Prämaxillaria bezahnt), ferner das Fehlen der Bauchrippen, die Ausbildung eines Prädentale, das Vorhandensein von Hornscheiden mit schneidenden Rändern auf den Kieferenden (nit Ausnahme von Hypsilophodon), die Befestigungsart der Zähne, die in mehreren dichtgedrängten Reihen übereinanderstehen, auf der Innenseite der Oberkiefer und der Außenseite der Unterkiefer freiliegen und bei der Abkauung der obersten Zahnserie (einer oder mehreren ïbereinanderliegenden Reihen angehörig) in die Kaufläche nachrücken. Dazı kommt ferner die Reduktion der Präorbitalöffnung, welche entweder klein ist(z. B. Iguanodon) oder fehlt (z. B. Triceratops).

Ein wichtiges Merkmal des Femurs liegt in der Ausbildung eines Muskelhöckers an der Innenseite des Femurs, des Trochanter quartus. An diesem Höcker muß der Musculus caudofemoralis, der an der Unterseite des Schwanzes entspringt, in derselben Weise wie bei den Vögeln inseriert haben. Sein Vorhandensein ist als ein wesentliches Begleitmerkmal des aufrechten Ganges anzusehen. Der vierte Trochanter geht nach oben in einen Kamm über, an den der von der Unterseite des Ischiums entspringende Musculus ischiofemoralis inseriert.

In Tarsus ist meist nur die obere Reihe verknöchert (Astragalus = Tibiale und Calcaneus $=$ Fibulare). Bei den Theropoden entsendet der Astragalus ebenso wie bei den Vögeln (z. B. gut sichtbar bei Struthio) (Fig. 482) einen, lappenartigen Fortsatz nach oben, der sich an das Unterende der Tibia fest und unbeweglich anlegt und auf diese Weise einen „Tibiotarsus" bildet, wie er auch bei Pterosauriern auftritt. Dieser vogelartige Processus ascendens des Astragalus fehlt bei den Ornithischiern.

1 W. Janensch, Wirbeltierfauna der Tendaguruschichten usw., I. c. 1914, p. 98. 
Die Vorderbeine sind bei allen Ornithischiern viel kürzer als die Hinterbeine; ursprüngliclı gingen die Ornithischier auf den Hinterbeinen allein, waren also biped. Hypsilophodon war eine kletternde, wohl arborikole Type mit opponierbarem Hallux, die übrigen Ornithopoden waren zumeist terrestrische, z. T. auch aquatische Schreittiere. Anzeichen dafür, daß einzelne sich zu Springtieren ausgebildet hätten, sind aus dem Skelett der Ornithischier nicht zu entnehmen. Dagegen sind einzelne Typen sekundär zur quadrupeden Gangart übergegangen (z. B. Stegosauriden und Ceratopsiden), und zwar hat im ersten Falle die Ausbildung eines schweren Rückenpanzers, im zweiten die Ausbildung einer gewaltigen, dem Schädeldach angehörenden Nackenschutzplatte und die Entstehung schwerer Schädelzapfen den Vorderteil des Körpers

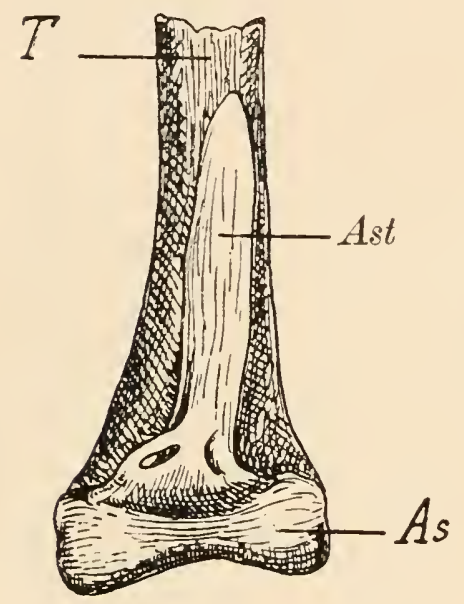

Fig. 482.

Unteres Ende der Tibia und des oberen Teiles des Tarsus (Tibiotarsus) eines jungen afrikanischen Straußes (Struthio camelus). (Nach L. Dollo.)

As $=$ Astragalus und Calcaneus.

Ast $=$ aufsteigender Ast des Astragalus. $T=$ Tibia .

buchstäblich niedergedrückt, so daß eine sekundäre Quadrupedie eintrat, die sich auch in der abgeänderten Gestalt des Beckens bemerkbar macht (das Pubis ist bei Stegosaurus fest mit dem lschium verschmolzen, so daß beide Knochen als einer funktionieren, bei den Ceratopsiden dagegen rudimentär).

Die Ornithischier müssen aus einer Ahnengruppe hervorgegangen sein, die 'von der Almengruppe der Dinosaurier verschieden ist. Die spätere Stammesgeschichte der Ornithischier ist in den Hauptzügen wenigstens so weit geklärt, daß wir die sekundär quadruped gewordenen Stegosauriden und Ceratopsiden als Formenreihen zu betrachten haben, die schon sehr frühzeitig von der Wurzel der Ornithopodiden abgezweigt sein müssen, da bei ihnen noch ein Postorbitale vorhanden ist, das den Ornithopodiden fehlt.

Wir können unter den Ornithischiern mehrere Stämme (Kalodontidae, Trachodontidae, Stegosauridae, Acanthopholidae, Ceratopsidae) unterscheiden, welche in verschiedene Unterfamilien zerfallen, die sich 
aber in verschieden hohem Grade, manchmal nur in unbedeutenden Differenzen, voneinander unterscheiden.

Die ersten Ornithischier erscheinen mit Nanosaurus agilis in der Trias von Canyon City in Colorado; dann erscheinen im unteren Lias die ersten Stegosauriden. Erst mit Beginn der Kreideformation scheint jedoch die Blütezeit der Ornithischia zu beginnen. Alle Gruppen der Ornithischier sterben in der oberen Kreide aus.

\section{F. Kalodontidae.}

Die Kalodontiden besitzen kein freies Postorbitale; es ist mit dem Postfrontale verschmolzen. Der Unterkiefer trägt einen hohen Processus coronoideus, eine Folge der herbivoren Funktion des aus dichtgedrängten Zähnen bestehenden Gebisses. Eine kleine Präorbitalöffnung ist vorhanden. Die Vorderbeine sind viel kürzer als die Hinterbeine; das Pubis ist schlank und lang. Panzerbildungen fehlen (mit Ausnahme von Hypsilophodon).

Der wichtigste Unterschied der von F. Nopcsa aufgestellten Gruppe der Kalodontiden von den Trachodontiden liegt in der ganz verschiedenen Spezialisationsrichtung des Gebisses. Bei den Kalodontiden wird im Laufe der Stammesgeschichte die Schneide der Zähne in der Weise verstärkt, daß eine einseitige, eine prächtige Ornamentierung bewirkende Anlage von Schmelzrippen einsetzt, ohne daß es zu einer wesentlichen Vermehrung der Zähne kommt. Hingegen findet bei den Trachodontiden keine Verstärkung der Schmelzschichte statt und es tritt dagegen eine außerordentliche Vermehrung der Zähne ein, so daß die Zahnmagazine einzelner Formen, wie z. B. bei Trachodon, in ganzen bis 2072 Zähne unfassen können.

F. Nopesa machte es wahrscheinlich, daß die Kalodontiden von härteren Pflanzen lebten, die sie mit ihren Gebiß zerschnitten, während die Trachodontiden von weichen Pflanzen lebten, die sie zermalmten. Die Lösung des dem Gebisse gestellten mechanischen Problems erfolgte in tmökonomischer Weise; es liegt hier, wie F. Nopesa (1915) ausfülırt ${ }^{1}$, bei den Ornithischiern jene Erscheinung vor, die ich als fehlgeschlagene Anpassungsrichtung bezeichnet habe und wofür bisher nur aus dem Kreise der Säugetiere einige Beispiele erbracht werden konnten. Derartige fehlgeschlagene Anpassungen, d. h. unvorteilhafte Reaktionen der Organismen auf die Reize der Umwelt, sind jedenfalls viel häufiger als man im allgemeinen anzunchmen geneigt ist.

1 F. von Nopcsa, Die Dinosaurier der siebenbürgischen Landestenle Ungarns. - Jahrbuch der K. Ungarischen Geologischen Reichsanstalt, XXI11. Bd., 1915, Budapest, S. 17. 
Unterfamilie: Nallosaurinae.

Nanosaurus. - Obere Trias von Canyon City in Colorado. Die unvollständigen Skelettreste liegen in schlechtem Erhaltungszustande auf einer roten Sandsteinplatte zerstreut; an besten erhalten ist der Unterkiefer und das Ilium. Ein Ornithischiermerkmal ist das Vorhandensein eines steil aufsteigenden Processus coronoideus, der hier zum ersten Male auftritt und bei anderen Reptilien unbekannt ist. Die Tibia ist lang, der Trochanter quartus kräftig, was den aufrechten Gang von Nanosaurus beweist; auch die Beckenreste sprechen für seine Ornithischiernatur. Leider gibt uns dieser Rest keinen weiteren Aufschluß über die Entstehung der Ornithischier. ${ }^{1}$

Unterfamilie: Hypsilophodontinae.

Hypsilophodon. - Wealden Englands. - In Rücken- und Schwanzabschnitt der Wirbelsäule sind Sehnenverknöcherungen vorhanden, welche die Unbeweglichkeit dieses Körperabschnittes beweisen. Füße mit opponierbarem Hallux, fünfte Zehe rudimentär. Hand funktionell dreifingerig, dritter Finger der längste; vierter Finger mit zwei rudimentären Phalangen, fünfter bis auf ein senkrecht zur Handachse abstehendes Metacarpalrudiment verkümimert. Tibia länger als Femur. Im Zwischenkiefer fünf in tiefen Alveolen eingepflanzte Zälnne jederseits, das Vorderende zahnlos und schnabelförmig zugespitzt. Mehrere gut erhaltene Skelette bekannt. Körperlänge wenig über $1 \mathrm{~m}^{2}{ }^{2}$ Das Tier ist arborikol gewesen (sekundäre Arboricolie wie beim Baumkänguruh).

Unterfamilie: Laosaurinae.

Laosaurus. - Atlantosaurus Beds Nordamerikas. - Mit Hypsilophodon verwandt, gleichfalls klein, aber im Bau von Hand und FuB sowie durch die Zahnlosigkeit der Zwischenkiefer verschieden. ${ }^{3}$

Unterfamilie: Camptosaurinae.

Camptosaurus. - Atlantosaurus Beds Nordamerikas, Wealden Englands (Fig. 483-490). ${ }^{4}$

1 F. von Huene und R. S. Lull, Neubeschreibung des Originals von Nanosaurus agilis, Marsh. - Neues Jahrbuch für Mineralogie usw., 1908, I. Bd., S. 134.

2 J.W. Hulke, An Attempt at a Complete Osteology of Hypsilophodon Foxii. - Philosophical Transactions, London, Vol. CLXXIII, 1883, p. 1035.

F. von Nopcsa, Notes of British Dinosaurs. - Part I. - Hypsilophodon. - Geological Magazine, London, 1905, p. 203.

O. Abel, Die Bedeutung der fossilen Wirbeltiere für die Abstammungslehre. In: „Die Abstammungslehre“, Jena, G. Fischer, 1911, p. 217.

O. Abel, Grundzïge der Paläobiologie d. W., 1912, p. 395.

G. Heilmann, Fuglenes Afstamning, Kobenhavn, 1916, p. 101-104.

3 O. C. Marsh, The Dinosaurs of North America. - XVI. Annual Report of the U. S. Geol. Survey, Washington, 1896, p. 199.

${ }^{4}$ Ch. W. Gilmore, Osteology of the Jurassic Reptile Camptosaurus, with a Revision of the Species of the Genus, and Descriptions of two New Species. Proceedings U. S. Nat. Mus., Vol. XXXVI, 1909, p. 197. 
Rhabdodon (= Mochlodon). - Obere Kreide von Grünbach bei Wiener-Neustadt (Niederösterreich), Siebenbürgen und Südfrankreich. ${ }^{1}$

Als die Type der Unterfamilie hat Camptosaurus zu gelten, der am besten bekannt ist. Der Gesamthabitus des Tieres erinnert an Iguanodon, aber nach O. C. Marsh sind die Arme sehr klein und die Hand ist nicht in der eigentümlichen Weise wie bei Iguanodon spezialisiert; der Schädel ist relativ klein. In die Augenhöhle ragt ein Supraorbitale, von der Grenzlinie zwischen Lacrymale und Adlacrymale entspringend, in hori-

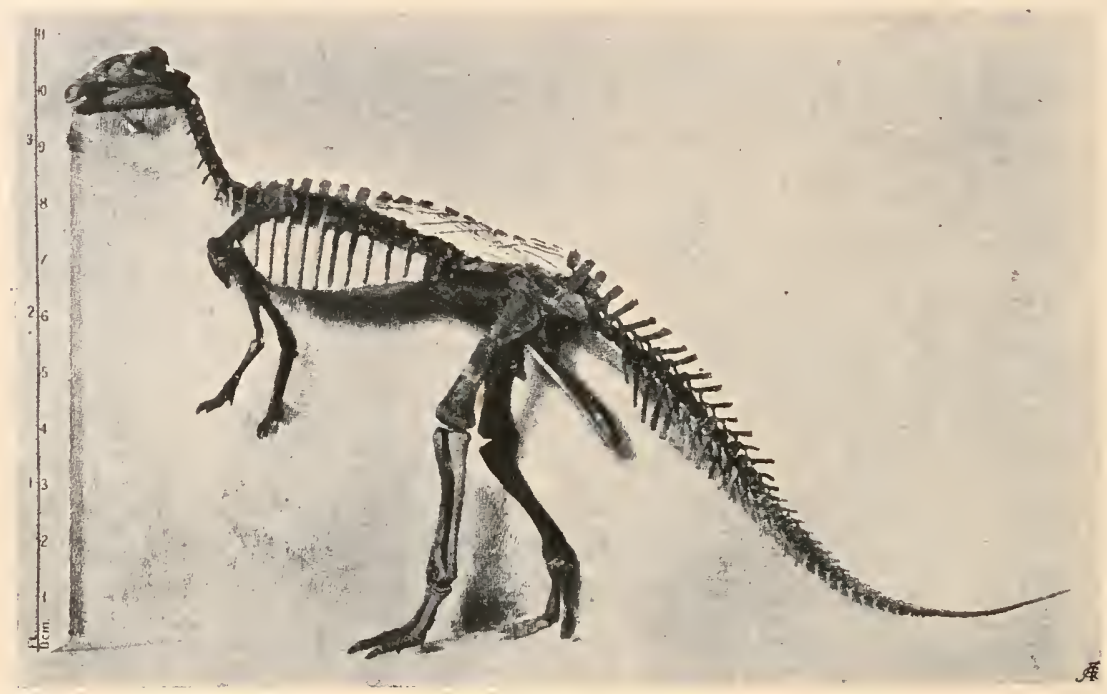

Fig. 483.

Rekonstruiertes Skelett von Camptosaurus nanus, Marsh, aus dem obersten Jura von Wyoming. Größe aus dem nebenstehenden Maßstab ersichtlich. (Nach W. D. Mat thew.) An der Seite mehrerer Rückenwirbel sind die verknöcherten Sehnen erhalten.

zontaler Richtung hinein, so daß der obere Vorderteil der Orbita abgetrennt erscheint. Die Hand zeigt im Verhalten der beiden ulnaren, rudimentären Finger zu den drei bekrallten vorderen Fingern (1., 2., 3.) auffallende Anklänge an den Handbau der Coelurosaurier (z. B. von Plateosaurus oder Gresslyosaurus), was darauf hindeutet, daß schon unter den gemeinsamen, weiter zurückliegenden Ahnen der Dinosaurier und

1 F. von Nopcsa, Dinosaurierreste aus Siebenbiirgen, II. Teil : Schädelreste von Mochlodon. - Denkschriften d. K. Akad. d. Wiss. Wien, LXXII. Bd., 1902, p. 149.

III. Teil: Weitere Schädelreste von Mochlodon. - Ibidem, LXXIV. Bd., 1904, p. 229 (Literatur).

Derselbe, Die Dinosaurier der siebenbürgischen Landesteile Ungarns. Jahrbuch d. Kgl. Ungar. Geol. Reichsanstalt, XXIII. Bd., Budapest, 1915, S. 1. 


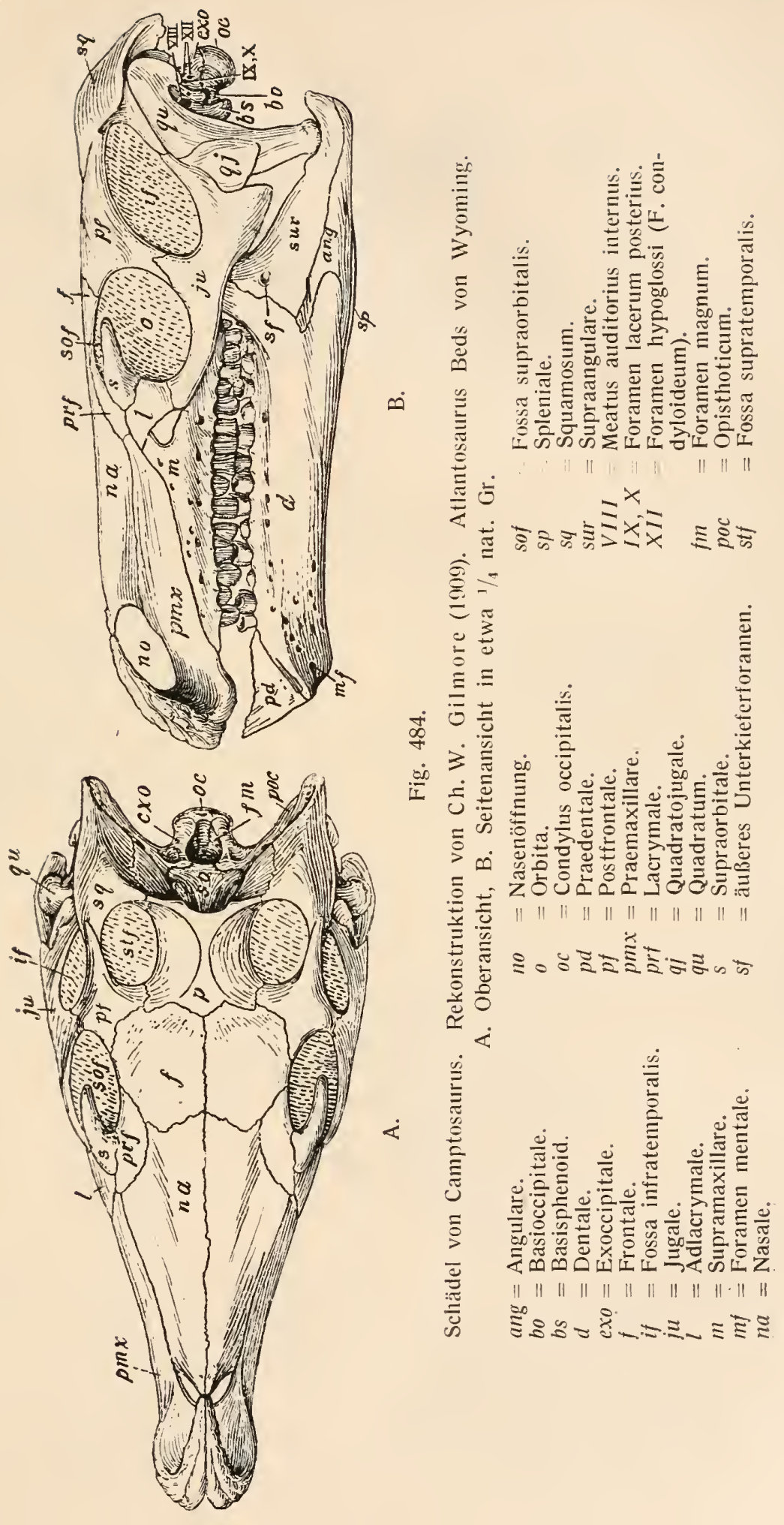




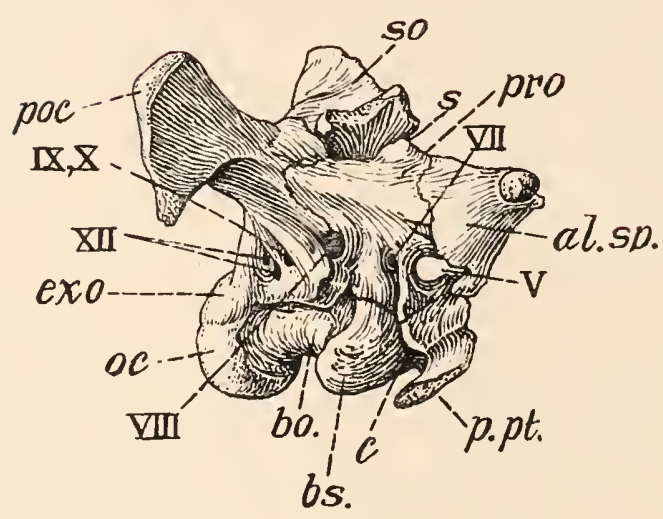

Fig. 485.

Seitenansicht des Hinterteiles des Schädels von Camptosaurus dispar, Marsh, aus den Atlantosaurus Beds (oberster Jura) von Wyoming, 3/s nat. Gr. (Nach Ch. W. Gilmore.)

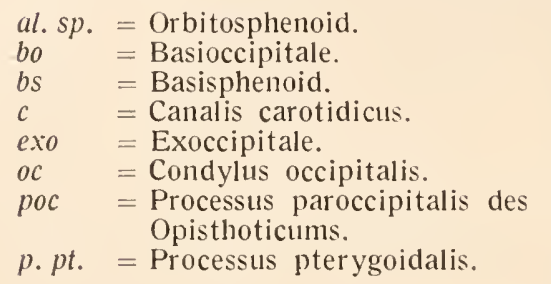
pro $=$ Prooticum.
$S=$ Nahtfläche des Supraoccipitale.
so $\quad$ : $=$ Supraoccipitale.
$V \quad=$ Foramen ovale.
$V I I=$ Foramen f. d. VII. Nerv.
$V I I I=$ Meatus auditorius internus.
$I X, X=$ Foramen lacerum posterius.
$X I I=$ Foramen $\mathrm{f}$. d. Hypoglossus und eine Vene.

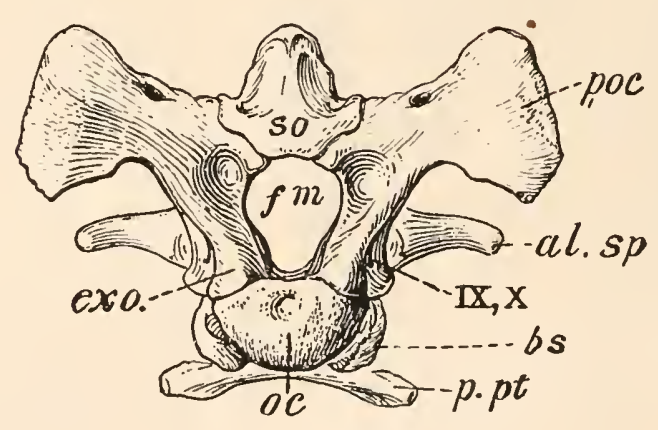

Fig. 486.

Hinteransicht des Hinterhauptes von Camptusaurus dispar, Marsh; oberer Jura von Wyoming. $3 / 8$ 11at. Gr. (Nach Ch. W. Gilmore.)
al. $s p .=$ Orbitosphenoid
bs $\quad=$ Basisphenoid
exo = Exoccipitale.
$\mathrm{fm}=$ Foramen magnum.
oc $=$ Condylus occipitalis.
poc = Opisthoticum (Processus par- occipitalis).
$p \cdot p t .=$ Pterygoidfortsatz des Basi- sphenoids.
so $=$ Supraoccipitale.
$I X, X=$ Foramen lacertin posterius. 

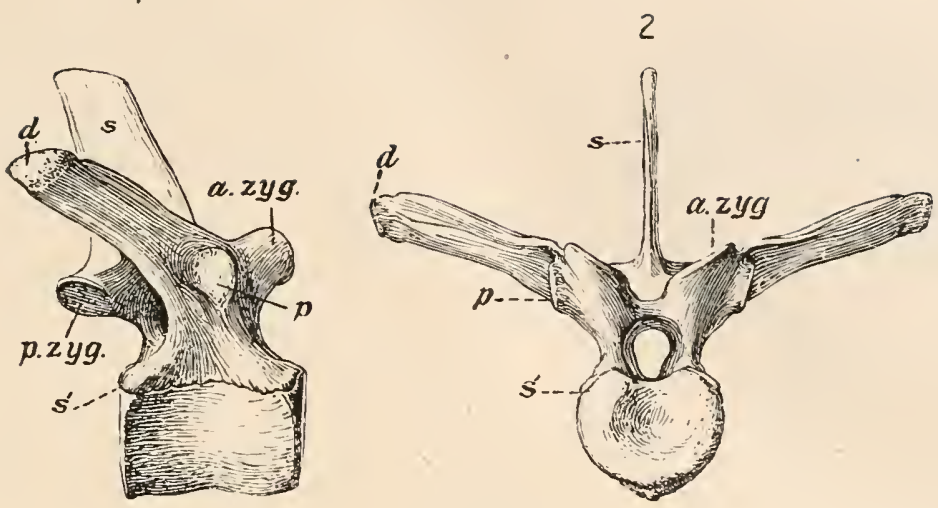

Fig. 487 A.

Dritter Dorsalwirbel von Camptosaurus Browni, Gilmore, aus den Atlantosaurus Beds von Wyoming, U. S. A., in $1 / 4$ nat. Gr. (Nach Ch.W. Gilmore.) 1. Seitenansicht von rechts, 2. Vorderansicht.
a. zyg. = Praezygapophyse.
$p=$ Parapophyse.
p. zyg. = Postzygapophyse.
$s=$ Processus spinosus.
d $=$ Diapophyse.
$s^{\prime}=$ Sutura centro-neuralis .
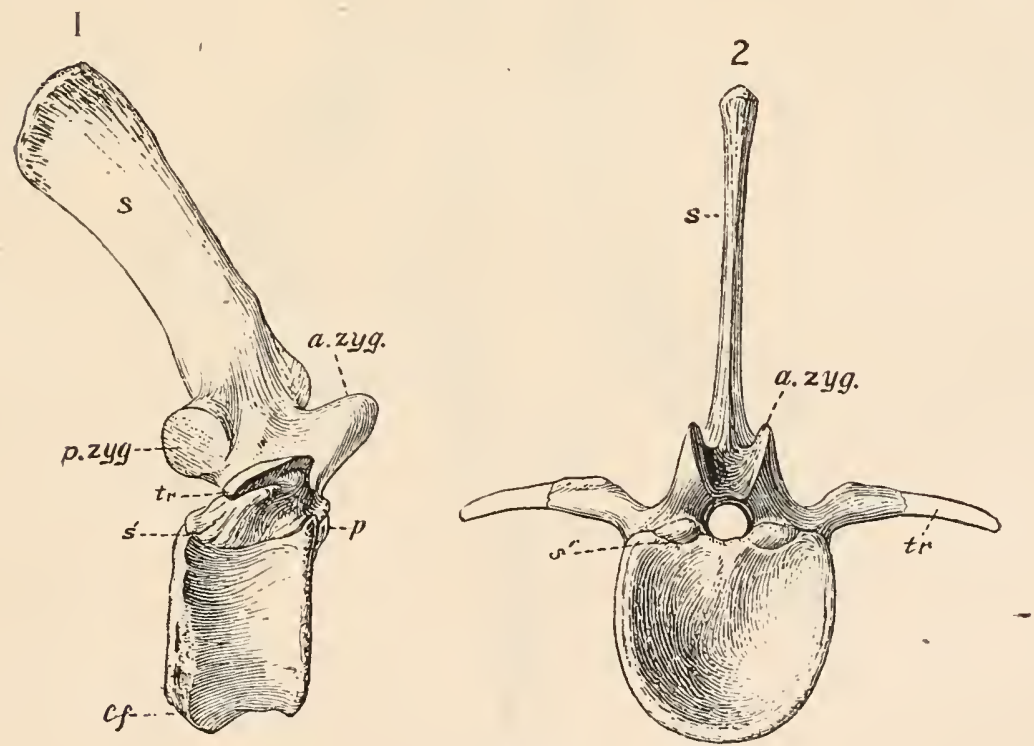

Fig. $487 \mathrm{~B}$.

Zweiter Kaudalwirbel von Camptosaurus Browni Gilmore aus dem obersten Jura von Wyoming, $1 / 4$ nat. Gr. (Nach $\mathrm{Ch}$. W. Gilmore.)

1. Ansicht von rechts, 2. Ansicht von vorne.

a. $z y g .=$ Praezygapophyse.

$s^{\prime}=$ Sutura centro-neuralis.

p. zyg. $=$ Postzygapophyse.

$c f=$ Facette f. d. Haemapophyse.

tr $\quad=$ Processus transversus.

$p=$ minutialer Fortsatz. 


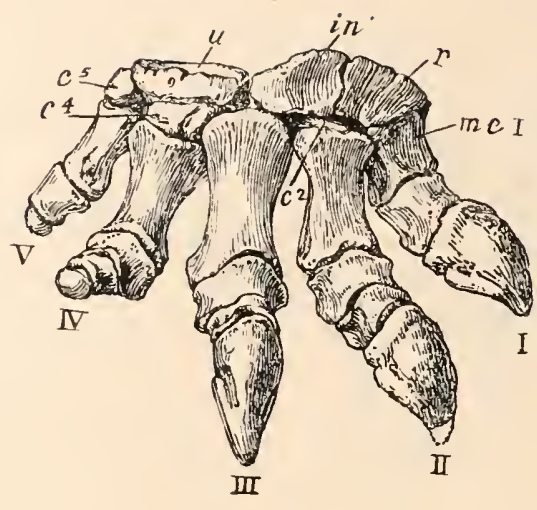

Fig. 488.

Rechter Vorderfuß von Camptosaurus dispar Marsh aus dem obersten Jura von Wyoming, $1 / 4$ nat. Gr. (Nach Ch. W. Gilmore.)

$$
\begin{array}{ll}
c_{2} & =\text { Carpale II. } \\
c_{4} & =\text { Carpale IV. } \\
c_{5} & =\text { Carpale V. } \\
\text { in } & =\text { Intermedium. } \\
r & =\text { Radiale. } \\
u & =\text { Ulnare. } \\
m c I & =\text { Metacarpale I. } \\
I-V & =\text { I. - V. Finger. }
\end{array}
$$

Die Ungualphalange des Daumens ist ergänzt.

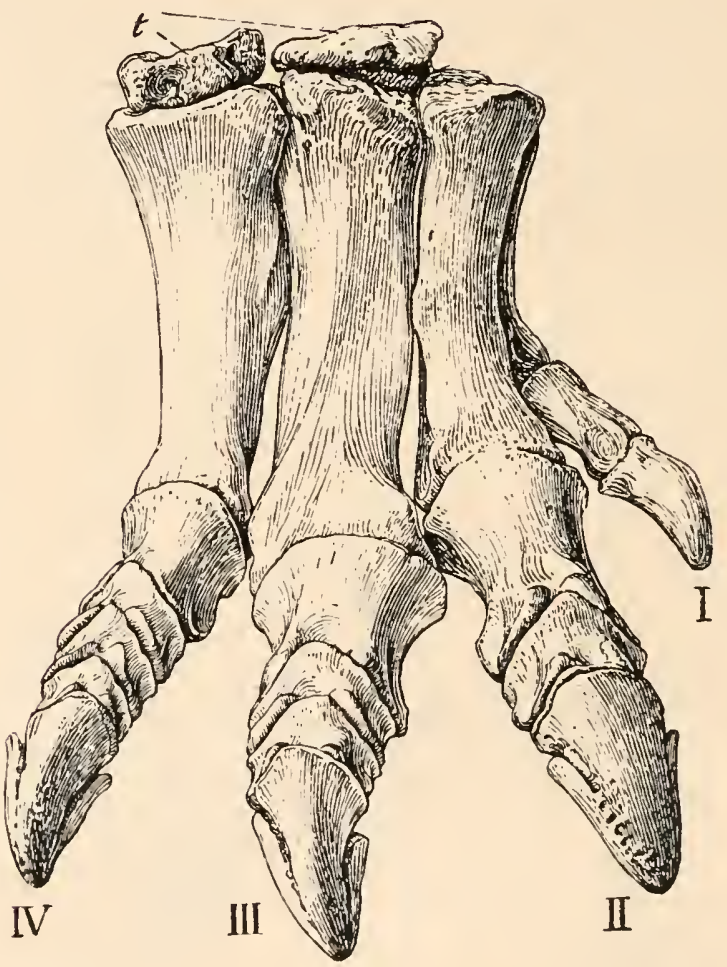

Fig. 489.

Rechter Hinterfuß von Camptosaurus dispar, Marsh, aus dem obersten Jura von Wyoming, 1/4 nat. Gr., Ind. 4277 des U. S. N. M. (Washington). (Nach Ch. W. Gilmore.)

$$
t=\text { zwei Tarsalia. } \quad I-V=1 .-\mathrm{V} \text {. Zehe. }
$$

Die Endphalangen der I., III. und IV. Zehe sind nach anderen Individuen gezeichnet und mit dem Ind. 4277 kombiniert. 
der Ornithischier derselbe Handtypus auftrat, der sich auch noch trotz aller Spezialisationen in der Vogelhand nachweisen läßt. In der Wirbelregion sind Sehnenverknöcherungen $\mathrm{zu}$ beobachten, welche schräg zu den Neurapophysenachsen verlaufen und eine Bewegung derselben fast unmöglich machen. Der Schwanz war gleichifalls starr und konnte nicht auf den Boden aufgesetzt werden, wenn das Tier schritt oder lief, sondern wurde in freier Balance gehalten.

Unterfamilie: Iguanodontinae.

Iguanodon. - Wealden von Belgien und England, Fährten im Wealden von England und Hannover. In .Bernissart (Belgien) wurden die Skelettreste von 29 Individuen, davon die Mehrzahl vollständig erhalten, auf engem Raume nebeneinander gefunden und im Museum in Brüssel aufgestellt. Die Körperlänge von Iguanodon bernissartensis erreichte $10 \mathrm{~m}$, die Höhe des aufgerichteten Tieres $5 \mathrm{~m}$ (Fig. 491-497). ${ }^{1}$

Der Schädel von Iguanodon bernissartensis ist nach den eingehenden Untersuchungen von L. Dollo sehr merkwürdig gebaut; die Augenhöhlen liegen weit hinten, die Nasenöffnungen sind sehr groß; hinter den Augenhöhlen liegt eine weite Temporalgrube, vor ihnen eine kleine Präorbitalgrube. Das Supramaxillare ist ungewöhnlich hoch, die breiten Nasalia sind stark herabgebogen und der Vorderteil des Schädels sehr stark lateral komprimiert, so daß die Schnauze sehr schmal und sehr hoch erscheint. 'Die Frontalia sind sehr breit und flacl, die oberen Temporalgruben liegen auf dem flachen Schädeldach und sind in der Seitenansicht nicht sichtbar. Die Orbita wird oben von zwei Supra-

1 L. Dollo, Première-Cinquième Note sur les Dinosauriens de Bernissart. Bulletin Mus. Roy. Hist. Nat. Belg., Vol .I, 1882, p. 161 und 205; Vol. II, 1883, p. 85 und 223; Vol. III, 1884, p. 129.

Derselbe, Note sur la présence, chez les Oiseaux, du troisième trochanter des Dinosauriens, et sur la fonction de celui ci. - Ibidem, Vol. II, 1883, p. 13.

Derselbe, L'appareil sternal de I'Iguanodon. - Revue quest. scient., Vol. XVIII 1885 , p. 664 .

Derselbe, Note sur les ligaments ossifiés des Dinosauriens de Bernissart. Archives de Biologie, Vol. VII, 1886, p. 249.

Derselbe, Sur la signification du Trochanter pendant des Dinosauriens. Bull. scientifique, Giard, Vol. XIX, 1888, p. 215.

Derselbe, Iguanodontidae et Camptonotidae. - Comptes Rendus Acad. Scienc. Paris, Vol. CVI, 1888, p. 775.

Derselbe, Les Vertébrés vivants et fossiles dans le Musée Royal d'Histoire naturelle de Belgique. - Guide lllustré des Musées de Bruxelles, édité par le Touring Club de Belgique, 1914.

Derselbe, Guide dans les Collections du Musée Royal d'Histoire Naturelle de Belgique. - Bernissart et les Iguanodons. - Bruxelles, 1897.

Derselbe, Les Allures des Iguanodons, d'après les empreintes des pieds et de la queue. - Bull. scientifique de la France et de la Belgique (Giard), T. XL, Paris 1905 , p. 1 . 
orbitalien, einem vorderen und einem hinteren begrenzt. Ein Lacrymale ist nicht nachweisbar, aber ein kleines Adlacrymale ist vorhanden; wahrscheinlich ist das Lacrymale (= Praefrontale aut.) mit einem Nachbarknochen verschmolzen. Das Jugale ist sichelförmig, selır klein und auf die untere Umfassung der Augenhöhle beschränkt, während das Quadratojugale sehr groß ist und mit dem Pterygoidalfortsatz des Quadratums in Verbindung tritt. Das Quadratum ist von einem großen - Foramen quadrati durchbohrt, wird hinten von einer herabsteigenden, langen Spange des Squamosums begrenzt und paßt in eine Grube des

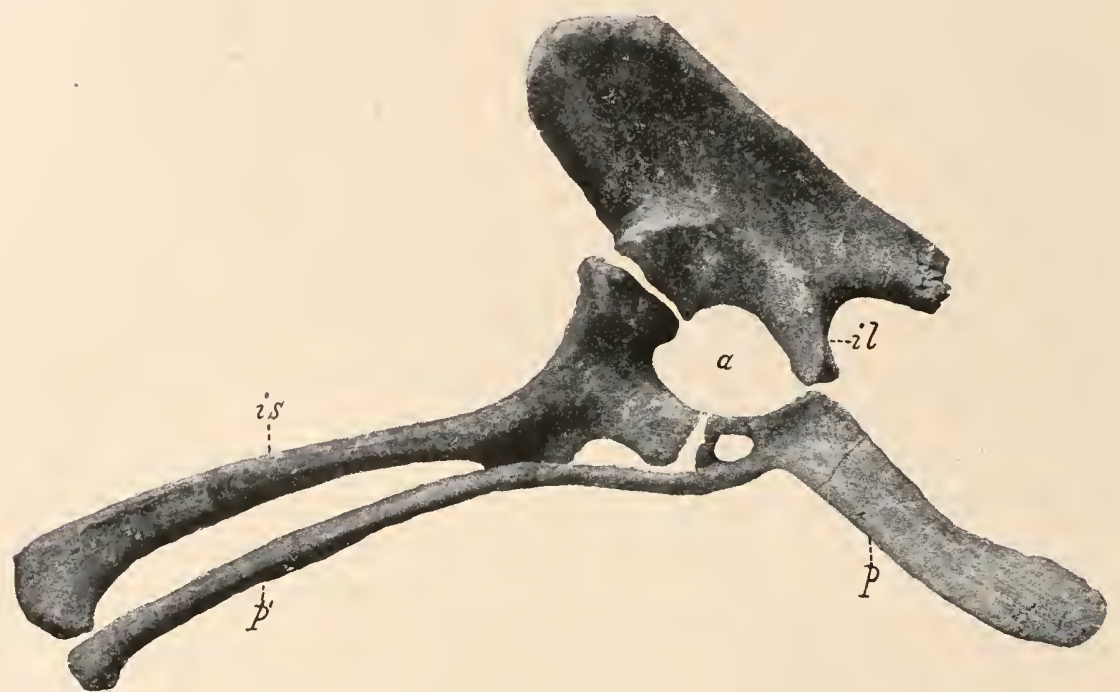

Fig. 490.

Außenansicht der rechten Beckenhälfte von Camptosaurus medius Marsh aus dem obersten Jura von Wyoming. (Nach Ch. W. GiImore.) Stark verkleinert.

$$
\begin{aligned}
& a=\text { Acetabulum. } \quad \text { is }=\text { Ischium. } \\
& \text { il = Ilium. } \quad p^{\prime}=\text { Pubis. } \\
& p=\text { Processus pseudopectinealis. }
\end{aligned}
$$

Squamosums, welche aber kaum mehr als Gelenkgrube funktionieren konnte, weil das Quadratum mit dem Quadratojugale fest verbunden war, so daß wohl keine Bewëgungen stattfinden konnten, wie dies bei Orthomerus (= Telmatosaurus) der Fall war. Der Schädel von lguanodon ist daher nach J.Versluys (1910) akinetisch gewesen. Der zwischen die Orbita und die untere Temporalgrube absteigende Ast des Postfrontale dürfte wohl das Postorbitale unfassen.

Der Unterkiefer trägt am Vorderende ein großes, zalınloses Prädentale, dessen Sclmeide am Vorderende scharfe Zacken trägt; es war wie das Vorderende des Prämaxillare jedenfalls mit einer Hornscheide bedeckt. Die Unterkieferäste schließen hinter dem Prädentalabschnitt 
eng aneinander; da somit die Zunge durch eine ovale Öffnung des Unterkiefers durchtreten mußte, hat L. Dollo das Vorhandensein einer Greif-

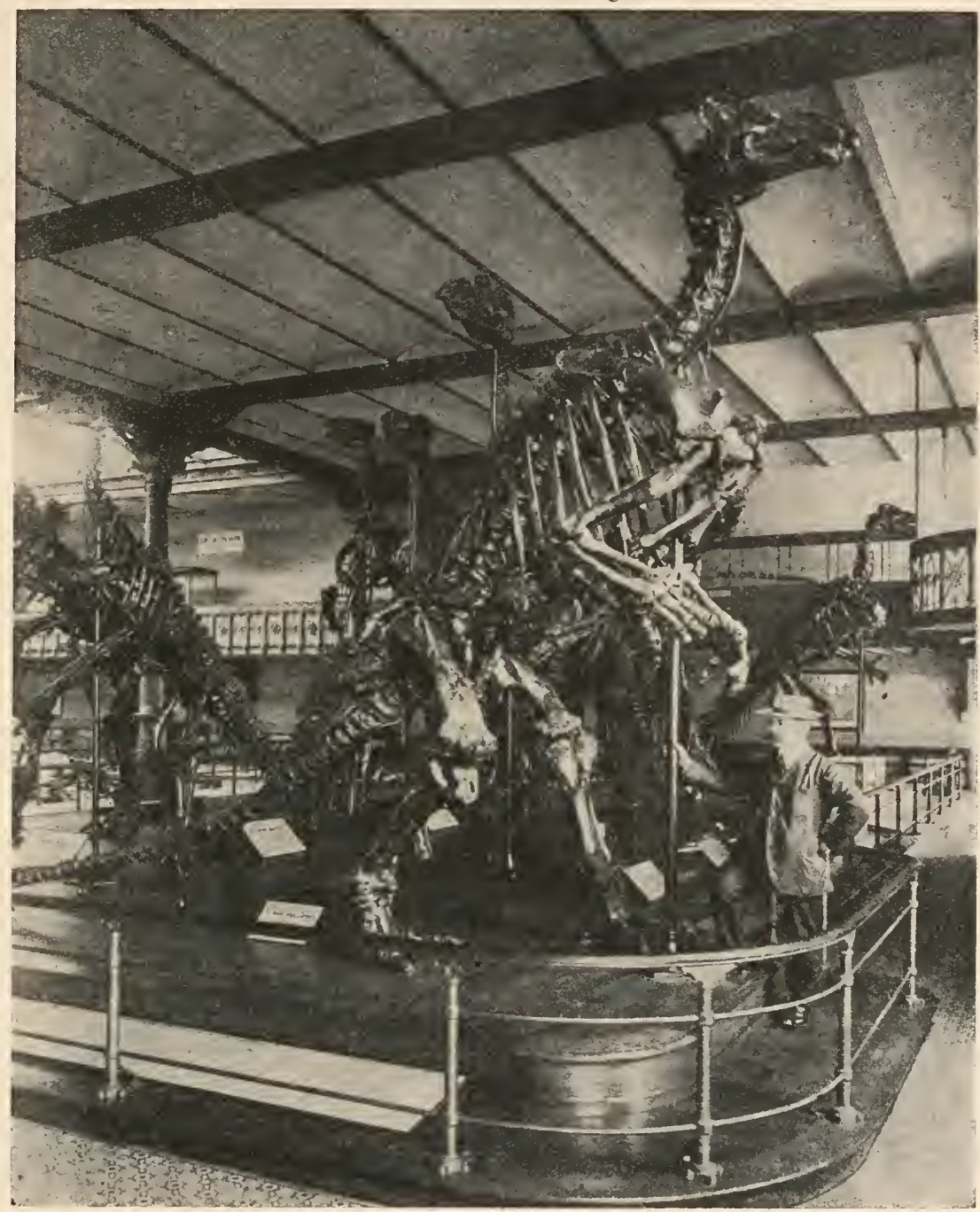

Fig. 49I.

Gruppe von neun Skeletten des Iguanodon bernissartensis, Boulenger, und einem Skelett des Iguanodon Mantelli, Owen (das kleine Skelett auf der linken Seite des Bildes, dessen Schädel durch einen Lichtfleck der photographischen Platte undeutlich ist). Die größere Art (I. bernissartensis) erreichte eine Maximallänge von $10 \mathrm{~m}$ bei einer Höhe von $5 \mathrm{~m}$. - Originale des Briisseler Museums, Wealdenton (untere Kreide) von Bernissart in Belgien. (Nach einer Photographie von L. Dollo.)

zunge nach Analogie der Giraffe für Iguanodon angenommen (vgl. O. Abel, Paläobiologie, S. 496). Es ist wahrscheinlich, daß sich Igua- 


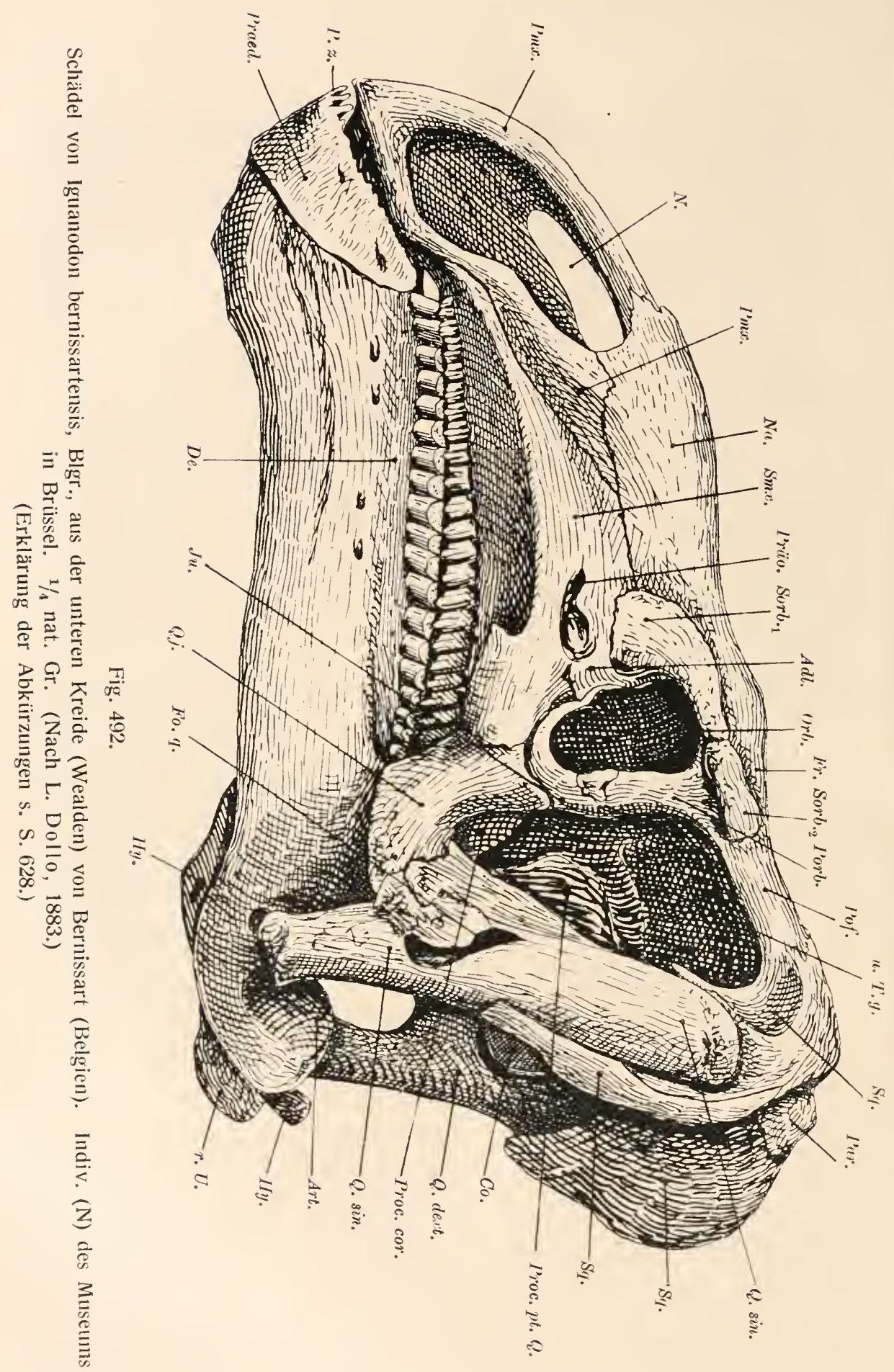




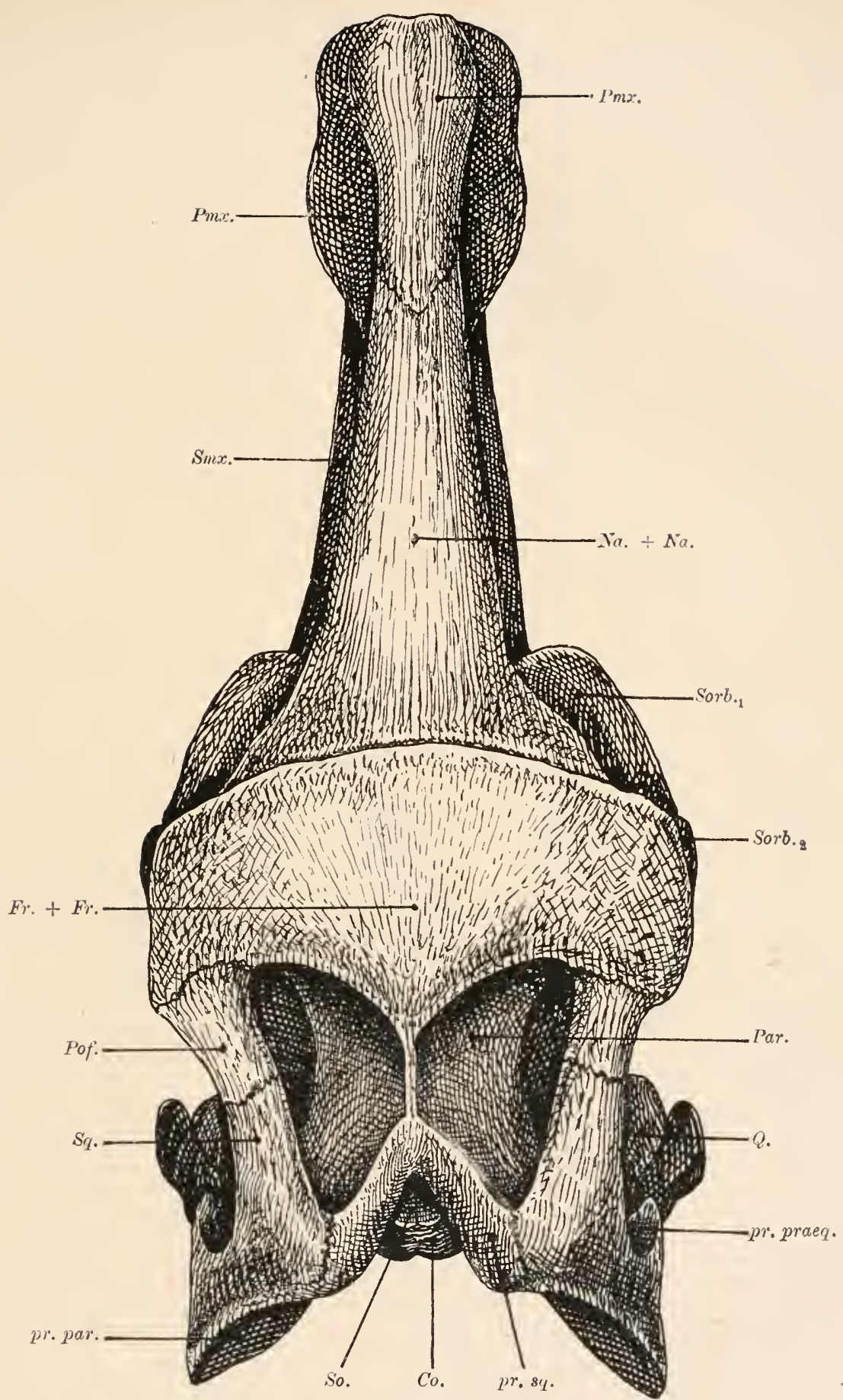

Fig. 493.

Oberansicht des Schädels von Iguanodon bernissartensis, Boulenger, aus dem Wealden von Bernissart, Belgien. 1/1 nat. Gr. (Neue Rekonstruktion auf Grundlage der Abbildung des Exemplars (N) des Museums in Brüssel durch L. Dollo, 1883.) (Erklärıng der Abkürzungen s. S. 628.) 
nodon von hochstämmigen Landpflanzen (z. B. Araukarien oder Koniferen) ernährt hat; daß in der Wealdenzeit Belgiens zahlreiche Koniferen auftraten, wird durch die reichen Funde pinusartiger Zapfen in diesen Schichten bewiesen. Der Unterkiefer besitzt einen hohen Processus coronoideus, der eine Folgeerscheinung der Pflanzennahrung und der durch sie bedingten Muskeltätigkeit der Kiefer ist. .

Die Wirbelsäule unfaßt 10 Halswirbel, 18 Rückenwirbel, 4 bis 6 Sakralwirbel und 40-50 Schwanzwirbel. Die vorderen Wirbel sind opisthocoel, die hinteren platycoel. Der Hals stand ungefähr senkrecht zur Schädelachse.

In der Hand fällt die Ausbildung des Daumens zu einem langen Stachel auf, der von der vergrößerten Krallenphalange gebildet wird. Der Daumen wurde, wie aus seiner kegelförmigen Gestalt und seiner Stellung hervorgeht, wohl als Waffe verwendet. Der fünfte Finger ist nach hinten abgespreizt. Die Phalangenzahl ist nur im ersten, zweiten und fünften Finger normal, sonst reduziert (vom ersten bis fünften Finger: 2, 3, 3, 3, 3-4).

Zı Fig. 492 auf S. 626.

$\begin{array}{ll}\text { Adl. } & =\text { Adlacrymale. } \\ \text { Art. } & =\text { Articulare. } \\ \text { Co. } & =\text { Condylus occipitalis. } \\ \text { De. } & =\text { Dentale. } \\ \text { Fo. } q . & =\text { Foramen quadrati. } \\ \text { Fr. } & =\text { Frontale. } \\ H y . & =\text { Hyoideum. } \\ \text { Ju. } & =\text { Jugale. } \\ \text { N. } & =\text { Nasenöffnung. } \\ \text { Na. } & =\text { Nasale. } \\ \text { Orb. } & =\text { Orbita. } \\ \text { Par. } & =\text { Parietale. } \\ \text { Pmx. } & \text { Praemaxillare. } \\ \text { Pof. } & =\text { Postfrontale. } \\ \text { Porb. } & =\text { Postorbitale. }\end{array}$

Praed.

Präo. $=$ Präorbitalöffnung.

Proc. cor. = Processus coronoideus

Proc. pt. Q. = Processus pterygoideus

P.z. Quadrati.

Q. dext. = rechtes Quadratum.

Q. sin. = linkes Quadratum.

Qj. $\quad=$ Quadratojugale.

r. U. $\quad=$ rechter Unterkiefer.

Simx. = Supramaxillare.

Sorb $_{1} \quad=$ Supraorbitale 1.

Sorb ${ }_{2}=$ Supraorbitale 2.

Sq. $=$ Squamosum.

ul. T.g. = untere Schläfengrube.

Zu Fig. 493 auf S. 627.

\begin{tabular}{|c|c|c|c|}
\hline$r$. & $\begin{array}{l}\text { occipitalis. } \\
\text { sin. + Frontale } \\
\text { rschmolzen). } \\
\text { n. + Nasale dext. } \\
\text { olzen). } \\
\text { llare. } \\
\text { ale. } \\
\text { paroccipital is }\end{array}$ & $\begin{array}{l}\text { pr. praeq. } \\
\text { pr.sq. } \\
\text { Q. } \\
\text { Smx. } \\
\text { So. } \\
\text { Sorb. }, \text { Sorb } \\
\text { Sq. }\end{array}$ & $\begin{array}{l}\text { squamosalis des } \\
\text { m. } \\
\text { illare. }\end{array}$ \\
\hline
\end{tabular}



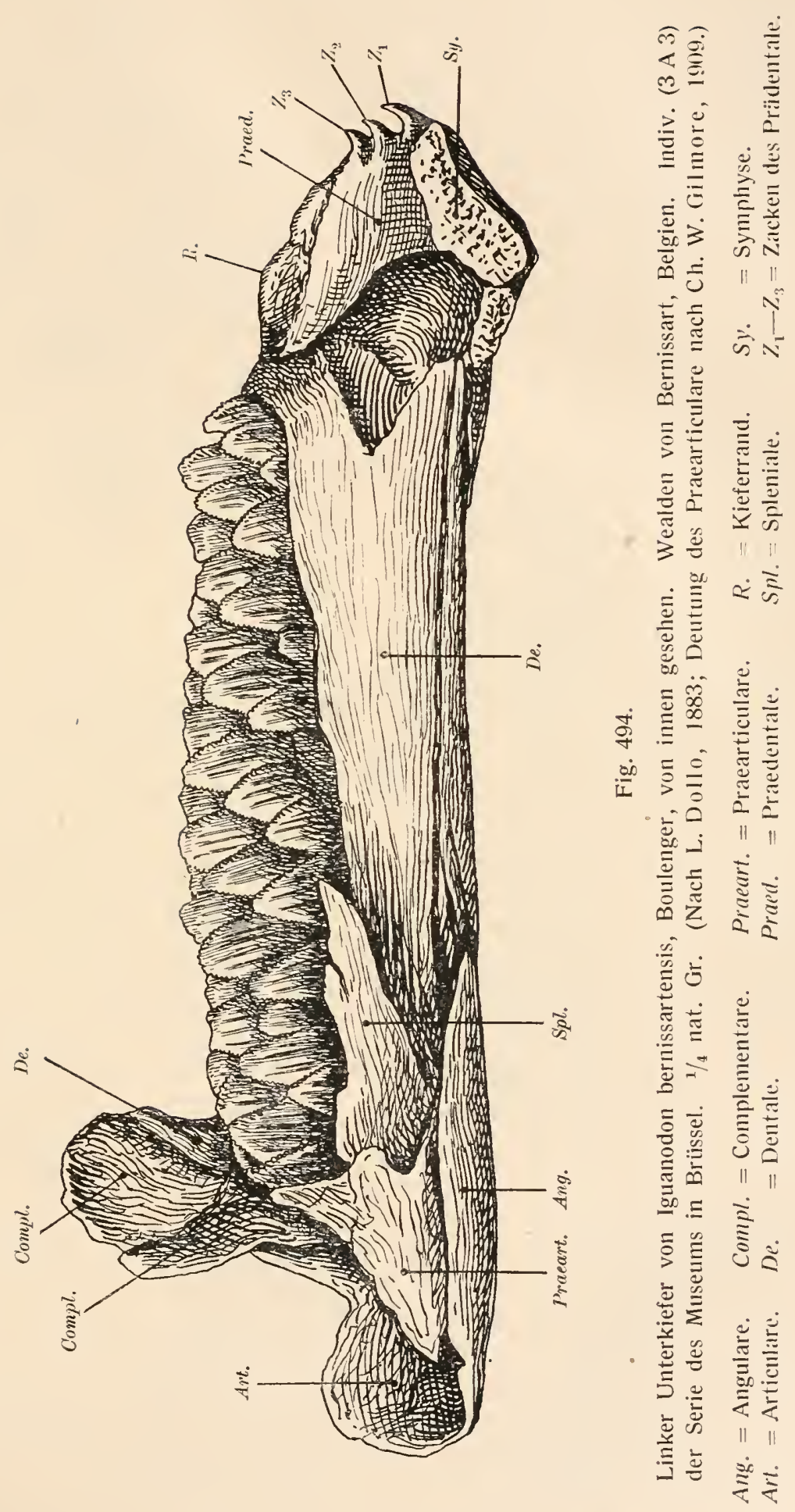

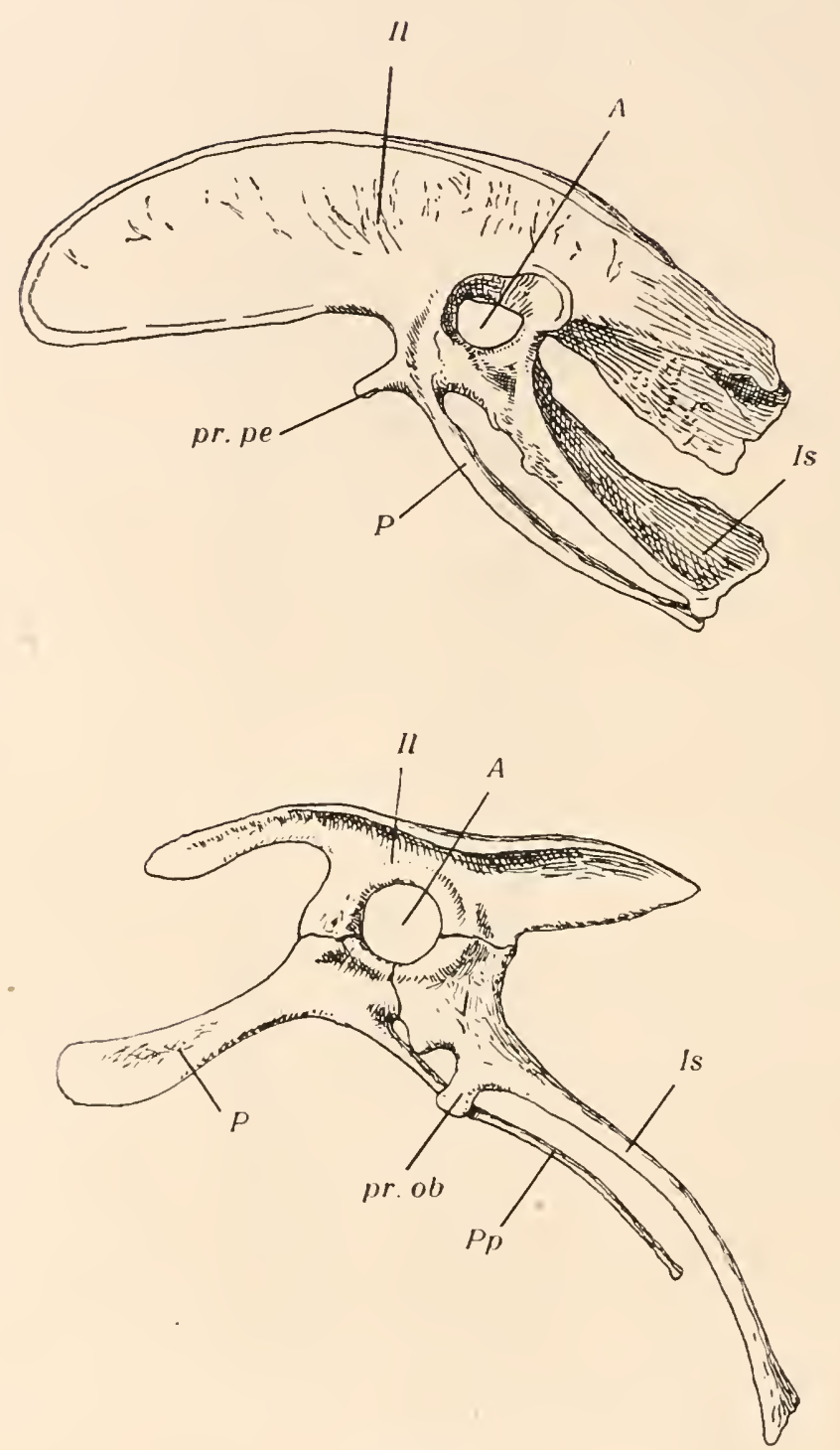

Fig. 495.

Oben: Linkes Hiiftbein von Apteryx australis, Owen (neuseeländischer Kiwi). Unten: Derselbe Knochen von lguanodon bernissartensis, Blgr., aus dem Wealden Belgiens.

Oben:

Unten:

$$
\begin{aligned}
& \text { ll = llium. } \\
& p=\text { Pubis. } \\
& \text { pr. pe. }=\text { Processus pectinealis. } \\
& \text { Is. }=\text { Ischium. } \\
& \therefore \text {. = Acetabulum. } \\
& \begin{array}{ll}
I l & =\text { Ilium. } \\
P & =\text { Processus pseudopectinealis. } \\
\text { pr. ob. } & =\text { Processus obturatorius. } \\
\text { Is } & =\text { Ischium. } \\
A & =\text { Acetabulum. } \\
P p & =\text { Pubis. }
\end{array}
\end{aligned}
$$


Reptilia.

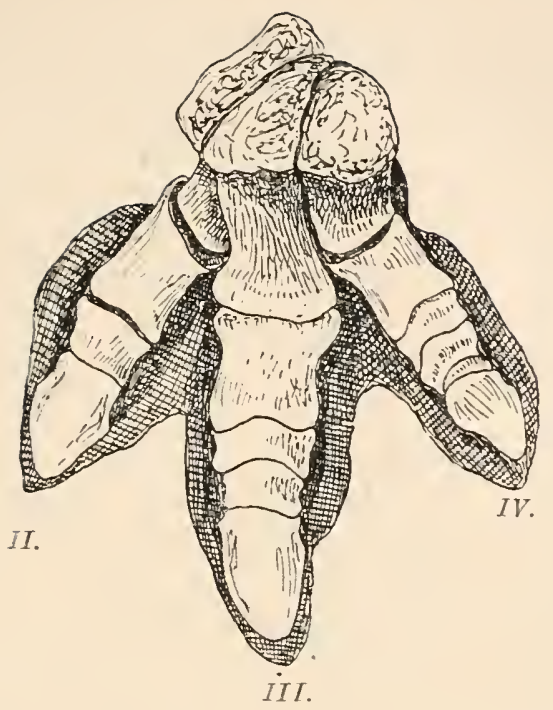

Fig. 496.

Fährte von Iguanodon mit hineingestelltem Fußskelett von Iguanodon Mantelli. $I I ., I I I ., I V .=$ zweite bis vierte Zehe. (Nach L. Dollo.)

Fig. 497.

Unterschenkel und Mittelfuß von Iguanodon bernissartensis, Boulenger. Stark verkleinert. (Nach L. Dollo.) Oben: Unterschenkel und obere Tarsa!knochen von vorne;

unten links: Mittelfu $\beta$ und untere

Tarsalknochen von vorne;

unten rechts: dieselben, von außen gesehen.

T. = Tibia.

$F$. = Fibula.

As. = Astragalus.

$C a$. $=$ Calcaneus.

$t_{1+2}, t_{3}, t_{4+5}=$ distale Tarsalknochen. $m t_{1}, m t_{2}, m t_{3}, m t_{4}=$ die vier Metatarsalknochen.
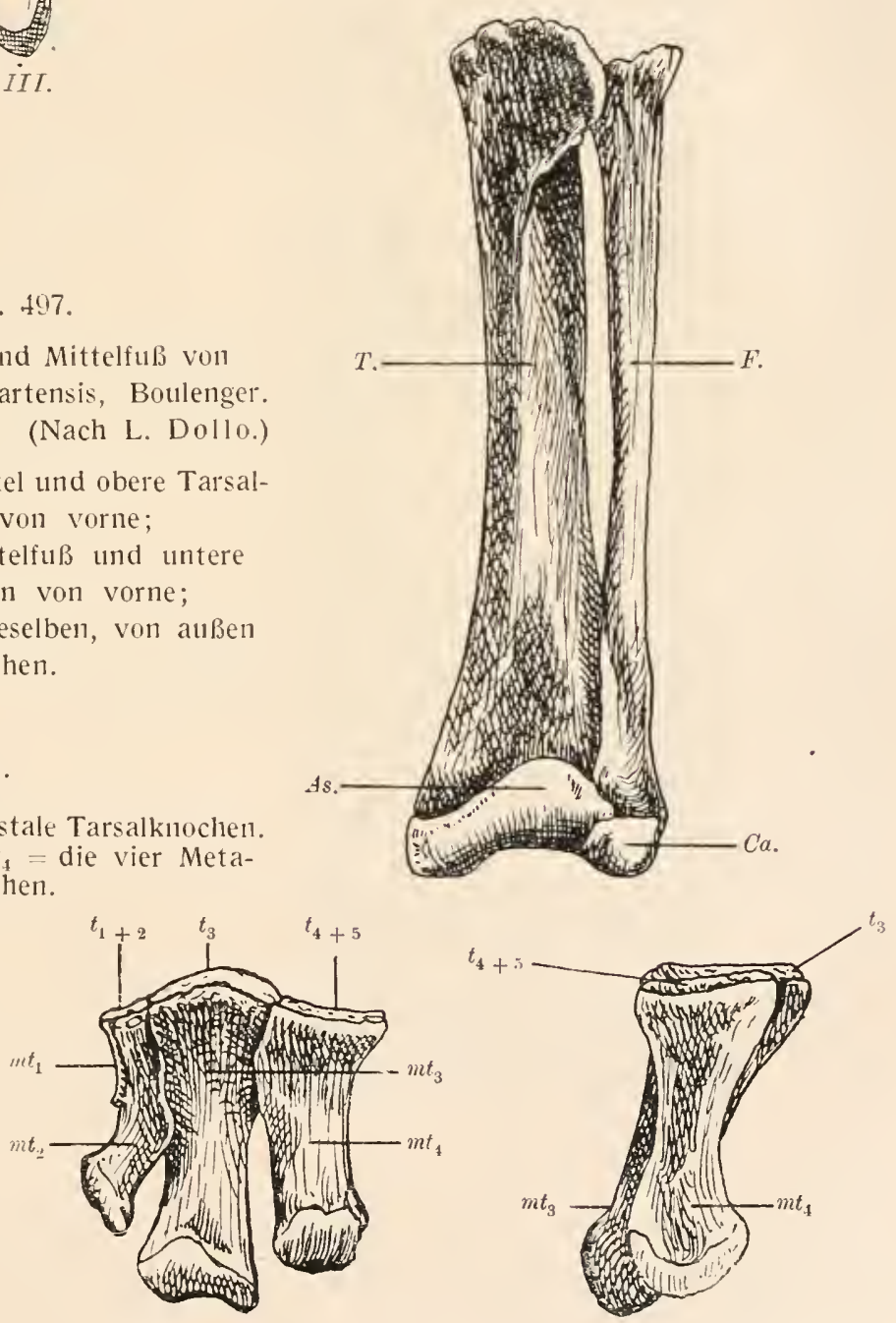
Der Hinterfuß ist sehr kräftig und dreizehig. Die fünfte Zehe fehlt gänzlich, von der ersten ist ein schwaches Metatarsalrudiment an der Seite des Metatarsale 11. erhalten. Die Phalangenzahlen der

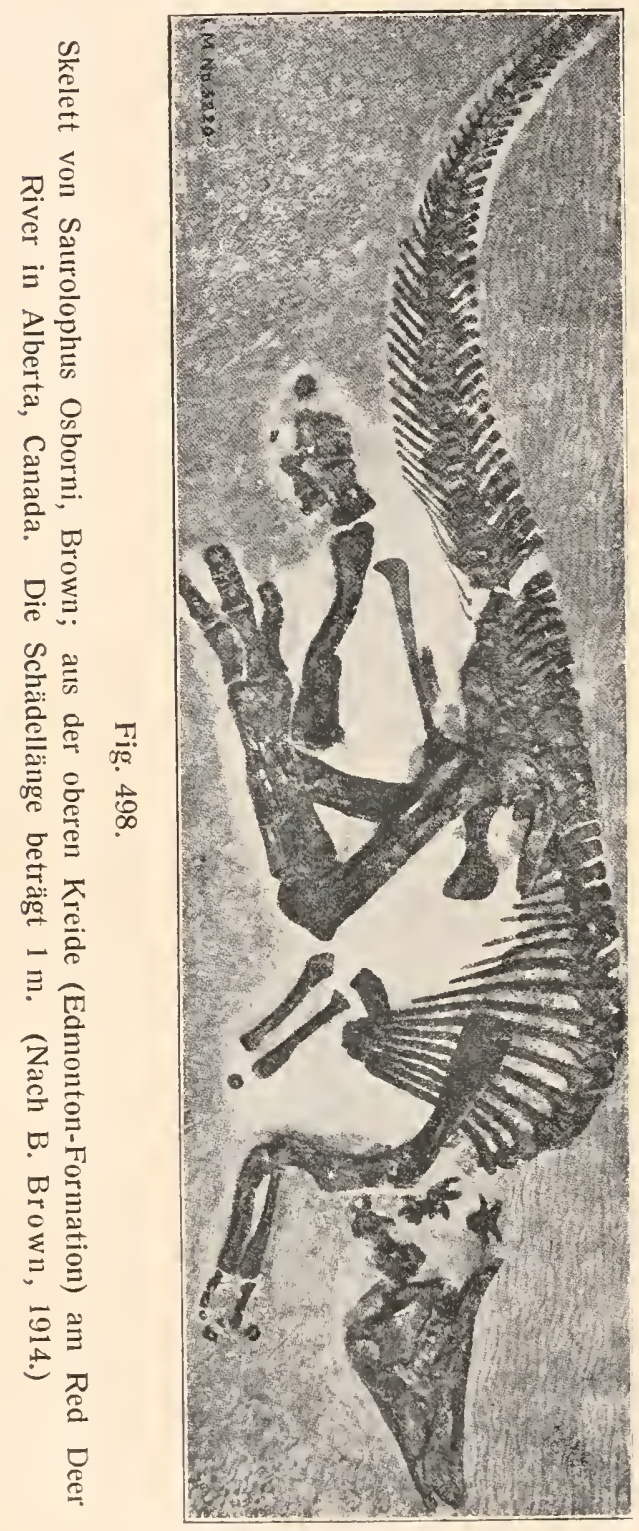
drei funktionellen Zehen sind (zweite bis vierte Zehe): 3, 4, 5 .

Die beiden gut bekannten Typen (I. Mantelli und I. bernissartensis) sind wahrscheinlich nicht Männchen und Weibchen derselben Art.

Craspedodon. - Maestrichtien Belgiens. ${ }^{1}$

\section{F. Trachodontidae.}

Auf den wesentlichen Unterschied zwischen den Trachodontiden (im Sinne F. Nopcsas, 1915) und den Kalodontiden wurde schon früher (S. 616) lingewiesen. Sie unfassen zwei Unterfamilien, die Protrachodontinen und die Trachodontinen.

Unterfamilie: Protrachodontinae.

Orthomerus. - Obere Kreide (Danien) Siebenbürgens und Maestrichtien Belgiens. Diese Gattung unterscleidet sich von der Unterfamilie der Trachodontinen, mit der sie sonst in nahen Beziehungen steht, durch die geringe Entwicklung des Zahnmagazins und das hohe Gesichtsprofil (F. v. Nopcsa, 1915). Der Schädel dürfte kinetisch gewesen sein. Eine Präorbitalöffnung felılt, ebenso felılen

1 L. Dollo, Notes d'Ostéologie herpétologique. - I. Sur une nouvelle dent de Craspedodon, Dinosaurien du Crétacé sttpérieur de la Belgique. - Annales Soc. Sci. Bruxelles, Vol. 1X, 1885, p. 309. 
die Suborbitalia. Das Quadratum ist schlank und lang, der Processus coronoideus des Unterkiefers sehr hoch. Der Schwanz muß lateral
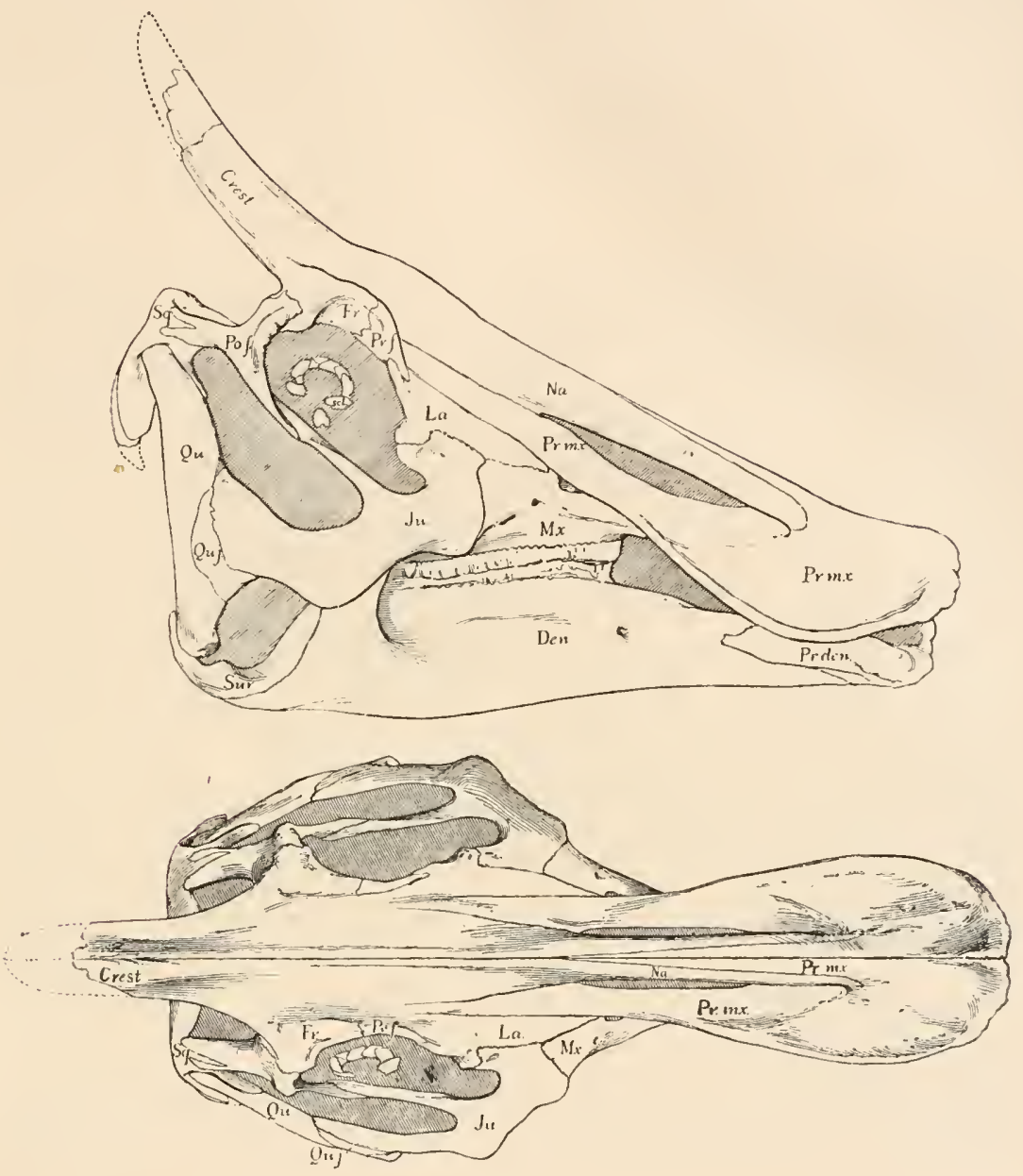

Fig. 499.

Saurolophus Osborni, Brown; ein Trachodontide aus der oberen Kreide am

Red Deer River in Montana; Schädellänge $1 \mathrm{~m}$. (Nach B. Brown, 1912.)

Oben: Schädel von rechts, unten: von oben gesehen.

$\begin{array}{llrl}\text { Crest } & =\text { Schädelkamm. } & & \text { Prden }=\text { Praedentale. } \\ D e n & =\text { Dentale. } & & \text { Prf }=\text { Lacrymale. } \\ F r & =\text { Frontale. } & & \text { Prmx }=\text { Praemaxillare. } \\ J u & =\text { Jugale. } & & Q u=\text { Quadratum. } \\ L a & =\text { Adlacrymale. } & & Q u j=\text { Quadratojugale. } \\ M x & =\text { Supraniaxillare. } & & S c l=\text { Sklerotikalring. } \\ N a & =\text { Nasale. } & & S q=\text { Squamosum. } \\ \text { Pof } & =\text { Postfrontale. } & & S u r=\text { Supraangulare. }\end{array}$

komprimiert gewesen sein, da seine Neurapophysen und Hämapophysen? ungewöhnlich hoch sind. 
Das Tier lebte in Sümpfen und seichten Gewässern und nährte sich wahrscheinlich von Sumpfpflanzen und weichen Wasserpflanzen. ${ }^{1}$

Saurolophus. - Obere Kreide von Alberta, Canada. Der Schädel trägt einen hohen Kamm, der eine ähnliche Stellung wic bei den Chamaeleodontiden besitzt und nach B. Brown (1912) aus einer gemeinsamen Verlängerung der Nasalia, Lacrymalia und Frontalia besteht.

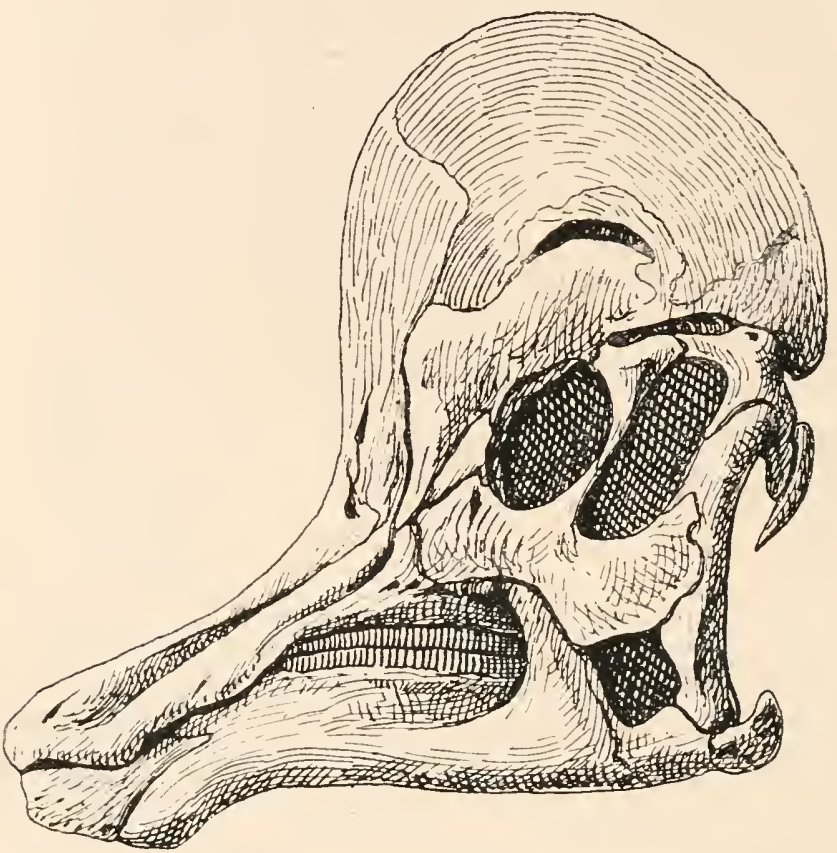

Fig. 500.

Sccliädel von Corythosaurus casuarius, Brown, aus der oberen Kreide von Alberta (Kanada). (Nach B. Brown 1914.)

Vielleicht war ein Hautkamin wie bei der lebenden Lacertiliergattung Basiliscus vorhanden. Die Schnauze ist ähnlich wie bei Trachodon, aber nicht so stark verbreitert; sie trug zweifellos einen Hornschnabel. Das kleine Auge war durch einen Sklerotikalring geschützt. Der Schädel ist 1111 lang (Fig. 498, 499). ${ }^{2}$

^ L. Dollo, Notes sur les restes de Dinosauriens rencontrés dans le Crétacé supérieur de la Belgique. - Bull. Mus. Roy. d'Hist. Nat. Belg., 11, 1883, p. 205.

F. von Nopcsa, Die Dinosaurier der siebenbiirgischen Landesteile Ungarns. - Jahrb. d. Kgl. ungar. Geol. Reichanstalt. - XXIII. Bd., 1915, S. 7.

2 B. Brown, A Crested Dinosaur from the Edmonton Cretaceous. - Bull. Am. Mus. Nat. Hist., New York, Vol. XXXI, 1912, p. 131.

Derselbe, The Skeleton of Saurolophus. Ibidem, Vol. XXX1I, 1913. 
Hypacrosaurus. - Obere Kreide von Alberta (Canada). Das etwa $11 \mathrm{~m}$ lange Tier besaß Rückenwirbel mit enorm verlängerten Neurapophysen, deren Höhe die des Wirbelkörpers um das Siebenfache übertrifft. Der Kopf besaß einen medianen, hohen Kamm. ${ }^{1}$

Corythosaurus. - Obere Kreide Nordamerikas. - Der Schädelkamm ist sehr hoch, lateral stark komprimiert und mit scharfer Kammsclmeide versehen. Er wird von den Nasalia und Frontalia gebildet

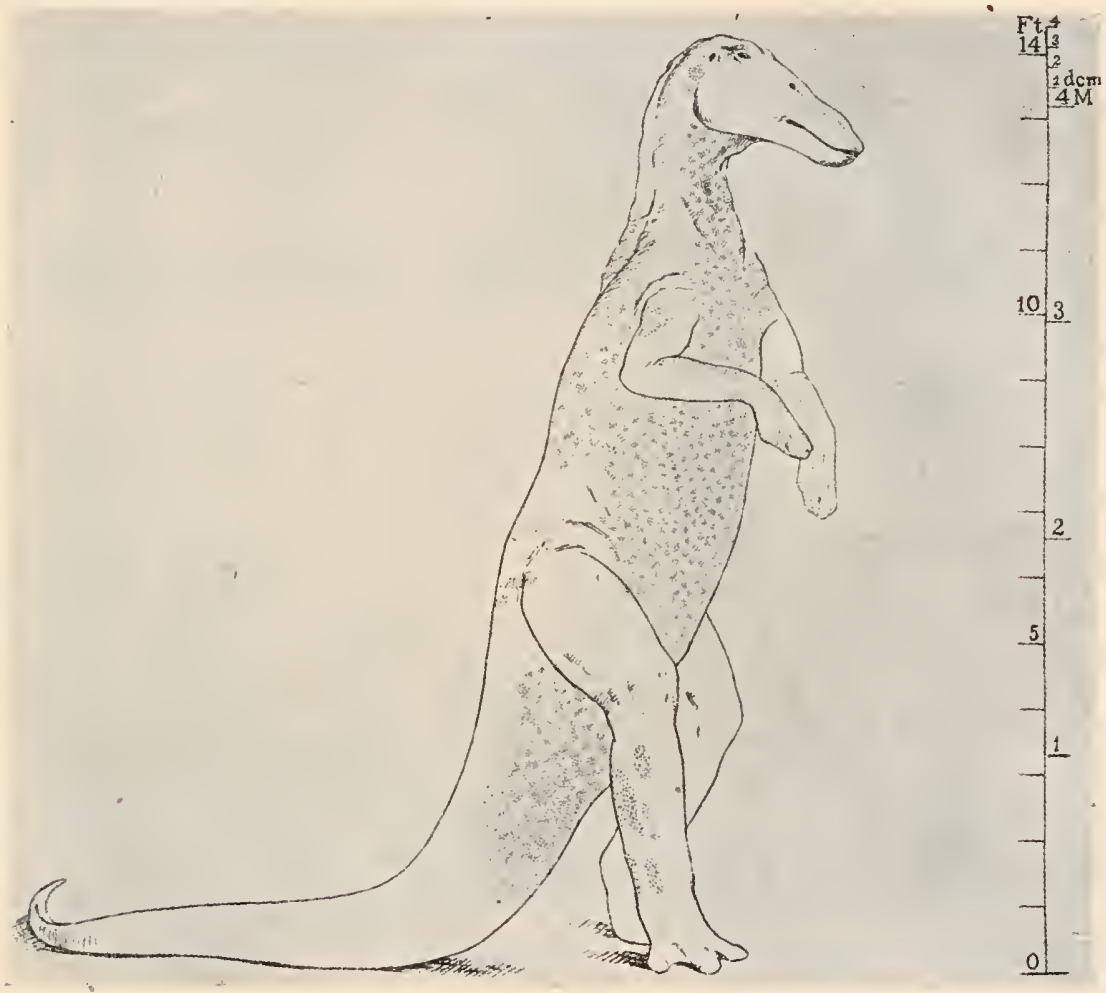

Fig. 501.

Rekonstruktion von Trachodon annectens aus der oberen Kreide von Converse County (Wyoming, Nordamerika). (Nach H. F. Osborn.)

and erimnert in der allgemeinen Form an den Hornkamm der Helmkasuare, der auf einem sclıwammigen, vom Ethmoideum, den Nasalia und Frontalia gebildeten Knochenkamm aufsitzt (Fig. 500). ${ }^{2}$

1 B. Brown, A New Trachodont Dinosaur, Hypacrosaurus. Ibidem, Vol. XXXI1, 1913.

2 B. Brown, Corythosaurus casuarius, a New Crested Dinosaur. Ibidem, Vol. XXXIII, 1914. 
Unterfamilie: Trachodontinae.

Trachodon. - Obere Kreide Nordamerikas. - Das auffallendste Kennzeichen dieses hochspezialisierten Ornithischiers ist die Schnauzenform; der Schädel ist vor den Augenhöhlen lateral stark komprimiert, erweitert sich aber weiter vorn rasch zu einer löffelartigen Schnauze, deren Form an den Schnabel einer Löffelente (Spatula) oder eines Löffelreihers (Platalea) erinnert und wohl auch in derselben Weise funktioniert hat. Die Funktion der Löffelschnauzen ist eine gründelnde

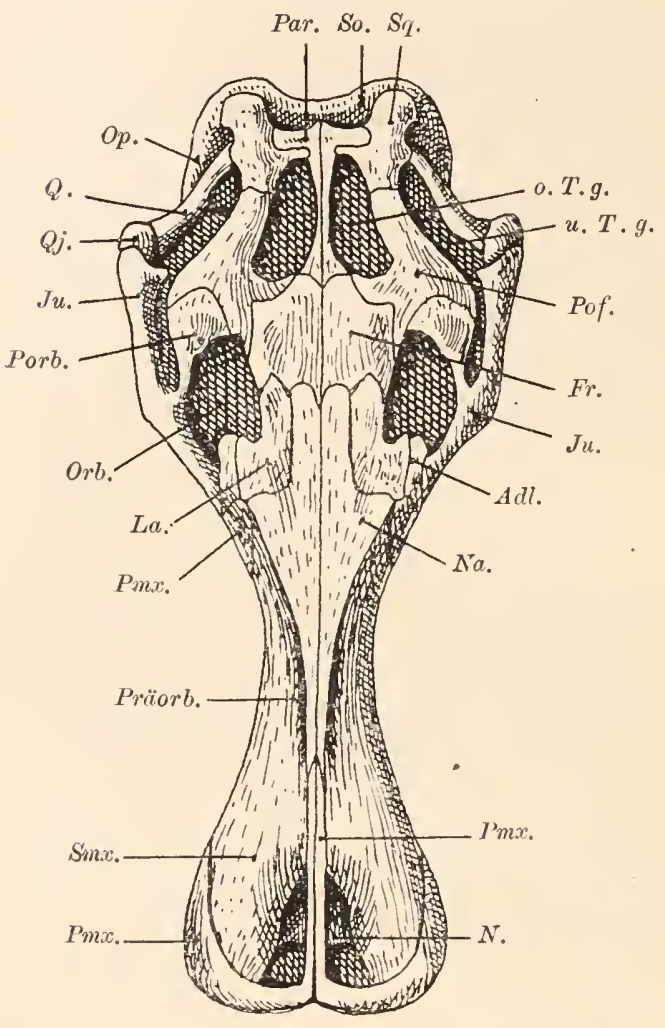

Fig. 502.

Rekonstruktion des Schädels von Trachodon mirabilis, Cope, aus der oberen Kreide Nordamerikas; Schädellänge $1,15 \mathrm{~m}$.

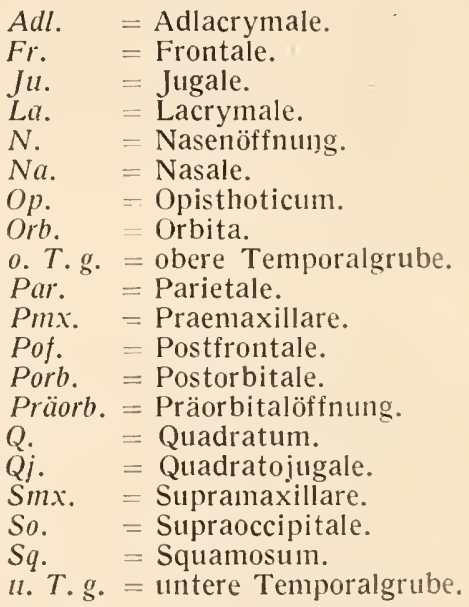

und es werden vegetabilische und animalische Stoffe aufgenommen. Bei Trachodon muß jedoch die Nahrung weitaus überwiegend vegetabilischer Natur gewesen sein, da das Gebiß eine große Zahl von Zähnen enthält, die mit Einrechnung aller Reserven in den Zahmmagazinen die enorme Ziffer von 2072 erreicht.

Die Präorbitalöffnungen sind ungewöhnlich groß, ebenso die äußeren Nasenöffnungen, während die Augenhöhlen einen viereckigen Umriß besitzen. Die Arme sind verhältnismäßig lang und scheinen viel häufiger als Körperstützen gebraucht worden zu sein als dies bei den anderen Trachodontiden der Fall war; der Datumen fehlt, die drei folgenden 
Finger (2., 3., 4.) sind funktionell, der fünfte Finger ist rudimentär. Nur der zweite Finger besitzt seine normale Phalangenzahl (3), die folgenden tragen rudimentäre Phalangen; ihre Zahl schwankt (z. B. bei T. annectens, nach L. M. Lambe, 1913) von 2-3. Die Endphalange erinnert in der Form an eine Hufphalange. Die Hand dürfte beim Schwimmen als Ruder gedient haben (Fig. 501-507). ${ }^{1}$

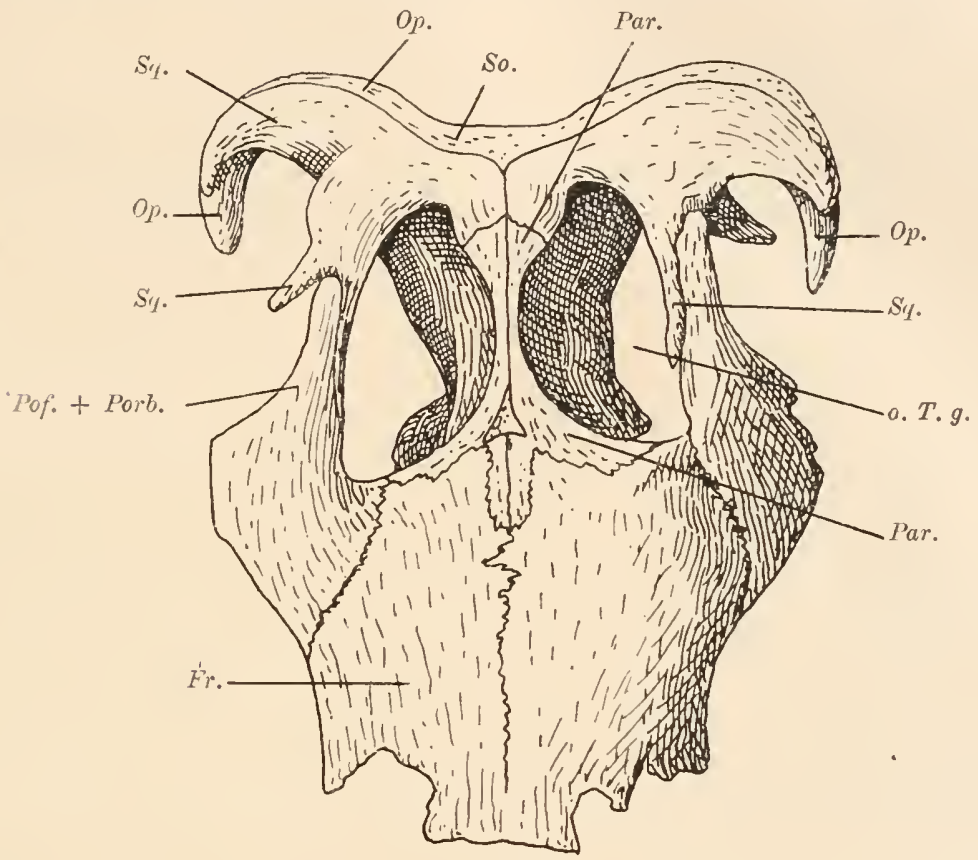

Fig. 503.

Oberansicht des hinteren Schädelabschnittes von Trachodon spec. (Nr. 427 d. Amer. Mus. Nat. Hist., New York), aus der oberen Kreide Nordamerikas, in $1 /$ nat. Gr. (Nach F. von Huene.)

Fr. $\quad=$ Frontale

Op. = Opisthoticum.

o.T.g. = obere Temporalgrube.

Par. $=$ Parietale.
Pof. + Porb. = Postfrontale + Postorbitale.

Sq. $\quad=$ Squamosum

Claosaurus. - Obere Kreide Nordamerikas. - Die Gliedmaßenknochen sind massiv, während sie bei Trachodon hohl sind; der Schädel ist im Schnauzenteil schmal. Am Sacrum beteiligen sich neun Wirbel, eine auffallend hohe Zahl. ${ }^{2}$

$1 \mathrm{H} . \mathrm{F}$. Osborn, Integument of the lguanodont Dinosaur Trachodon. Memoirs Am. Mus. Nat. Hist., New York, 1912.

B. Brown, The Osteology of the Manus in the Family Trachodontidae. Bull. Am. Mus. Nat. Hist., New York, 1912, p. 105.

2 O. C. Marsh, The Dinosaurs of North America. - XVI. Annual Report U. S. Geol. Survey, Washington, 1896, p. 219. 


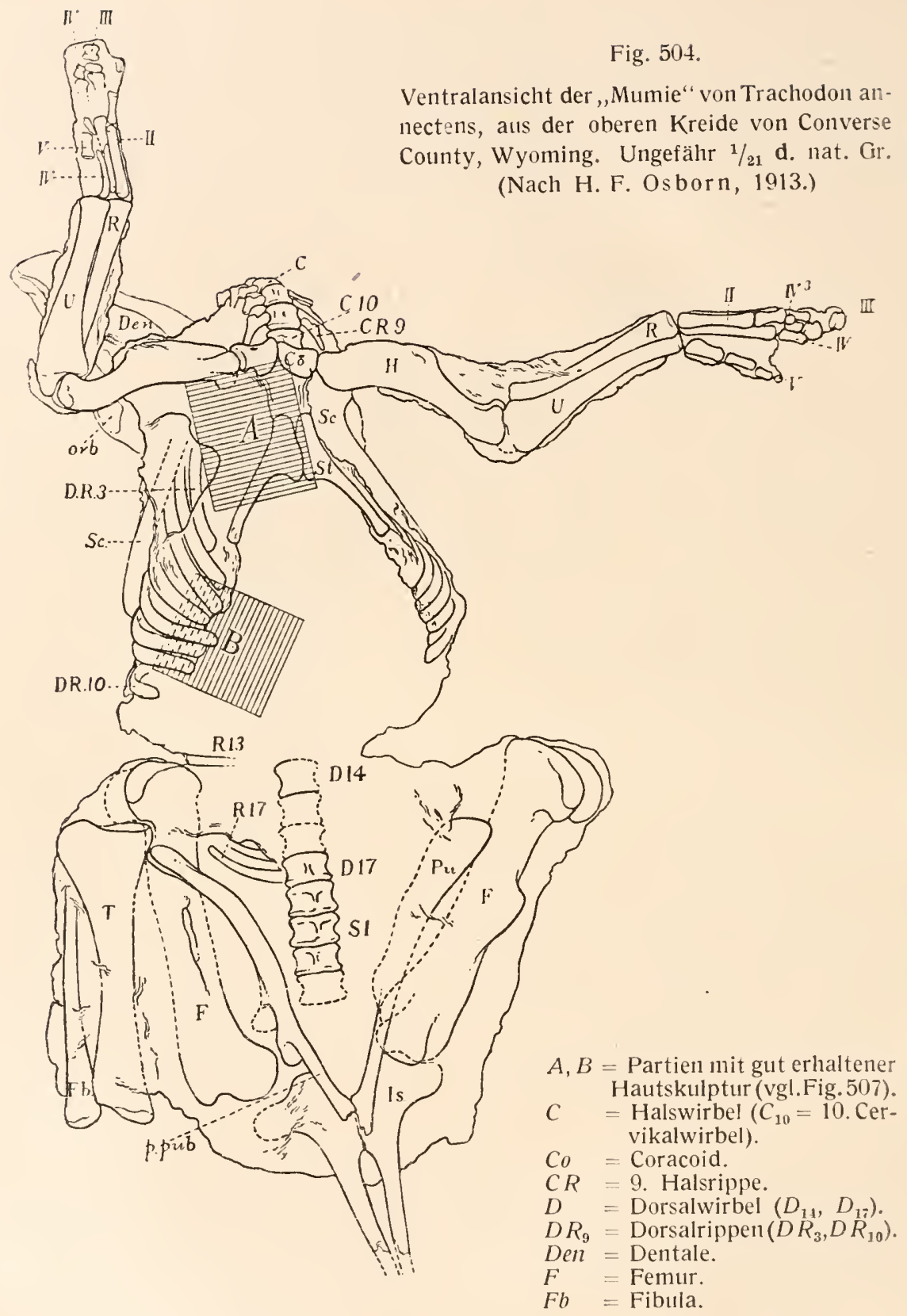

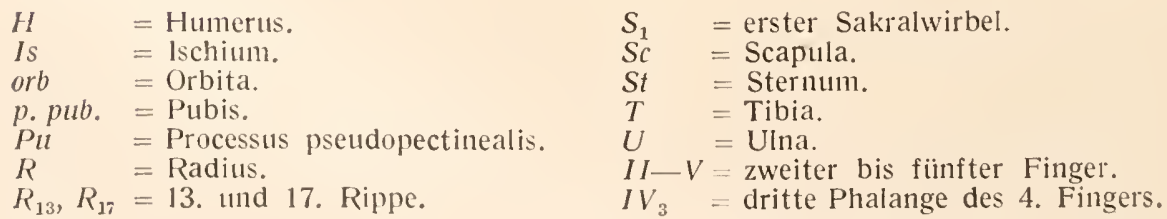




\section{F. Stegosauridae.}

Unterfamilie: Scelidosaurinae.

Von den Stegosaurinen hauptsächlich dadurch verschieden, daß bei diesen der Unterkiefer keinen Kronenfortsatz trägt, während er bei den Scelidosaurinen vorhanden ist. Die Spezialisationen der Scelidosaurinen halten sich im Vergleiche zu denen der, Stegosaurinen im allgemeinen auf einer tieferen Stufe. Der Panzer von Sce. lidosaurus, Sarcolestes und Echinodon ist noch nicht stark differenziert.

Scelidosaurus. - Unterer Lias von Charmouth in England (Dorsetshire). Körperlänge etwa $4 \mathrm{~m}$. Keine Höhlung im Sakralabsclmitt der Wirbelsäule vorhanden. ${ }^{1}$

Unterfamilie: Stegosaurinae.

Stegosaurus. - Atlantosaurus Beds (oberster Jura) Nordamerikas. ${ }^{2}$ Diese an besten bekannte Gattung mag als typischer Repräsentant der Familie gelten, obschon die übrigen Gattungen z. T. recht

1 R. Owen, Monograph of a Fossil Dinosaur (Scelidosaurus Harrisoni Owen) of the Lower Lias. Palaeontographical Society, 1875, p. 45.

2 Ch. W. Gilmore, Osteology of the Armored Dinosauria in the United States National Museum, with Special Reference to the Genus Stegosaurưs. - Smithsonian Institution, U. S. Nat. Mus., Bull. 89, 1914. (Ausführliche Literaturiubersicht, p. 127.)

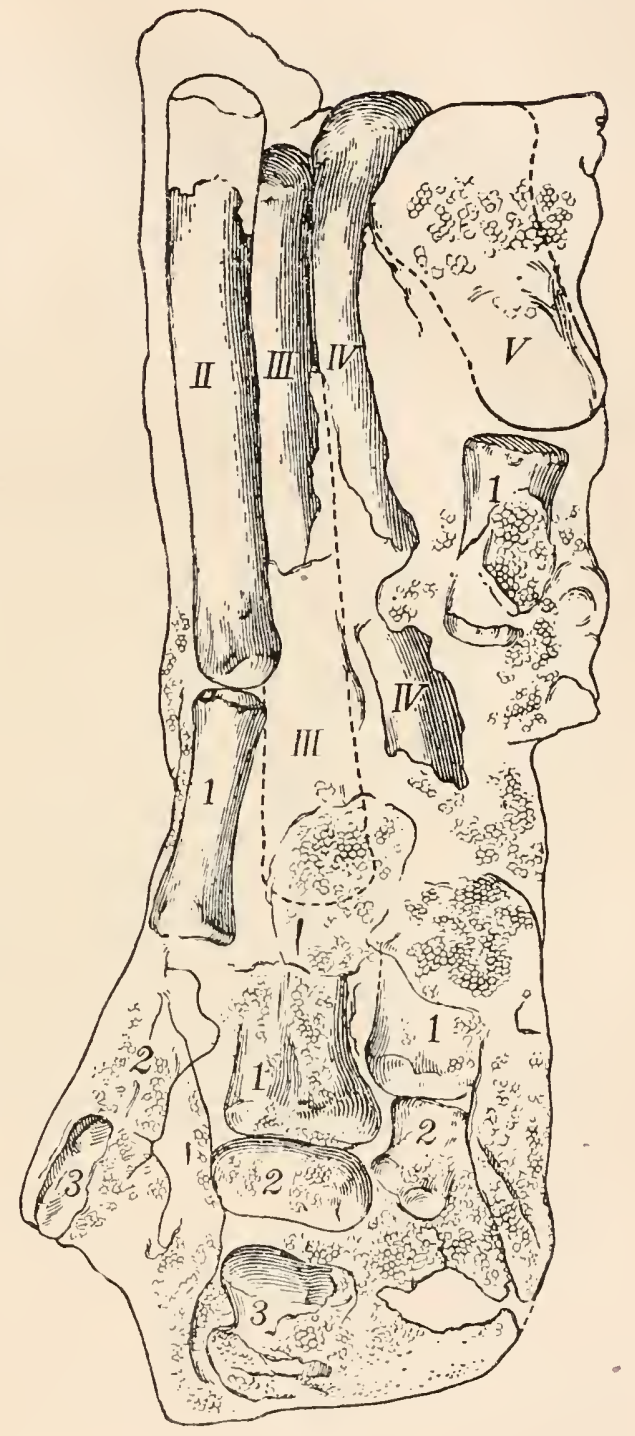

Fig. 505.

Rechte Hand von Trachodon annectens mit Abdrïcken der Hautbekleidung. 1/3 nat. Gr. (Nach H. F. Osborn.)

$I I, I I I, I V, V=$ zweites bis füntes Metacarpale.

$r, 2,3$ = erste bis dritte Phalange der Finger. 
verschiedene Spezialisationen aufweisen, die besonders die Ausbildung des Panzers betreffen (Fig. 508-511).

Von den Kalodontiden und Trachodontiden sind die Stegosauriden yor allem dadurch verschieden, daß das Postorbitale immer frei ist (bei

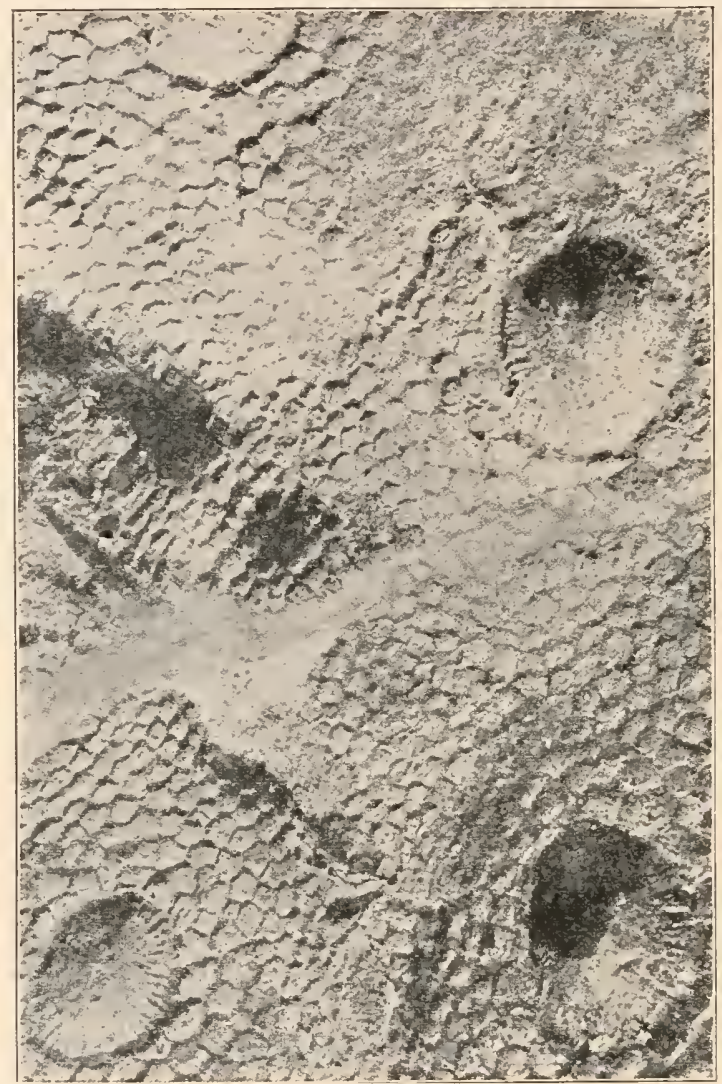

Fig. 506.

Abdruck der Haut von Trachodon marginatus, Lambe; aus der oberen Kreide (Belly-River-Formation) am Red Deer River in Kanada. Ungefähr $2 / 3$ nat. Gr. (Nach L. M. Lambe.) (Die Skulptur der Haut tritt hervor, wenn die Abbildung des Abdruckes verkehrt betrachtet wird. wobei die konkaven Stellen als Hautbuckel erscheinen.)

den erstgenannten entweder mit dem Postfrontale verschmolzen oder fehlend) und daß der Unterkiefer keinen Processus coronoideus besitzt. Alle Wirbel sind amphicoel, der Rückenmarkskanal von Stegosaurus ist im Bereiche des Sacrum zu einer geräumigen, eiförmigen Höhlung erweitert, welche eine Rückenmarksmasse enthalten haben muß, die jene des Gehirns um das Zwanzigfache übertraf. Bei jugendlichen 
Individuen ist sie relativ größer als bei erwachsenen (O. C. Marsh, 1896).

Eine Präorbitalöfnung fehlt; die Orbita wird wie bei Iguanodon von zwei Suborbitalien ïberdeckt.

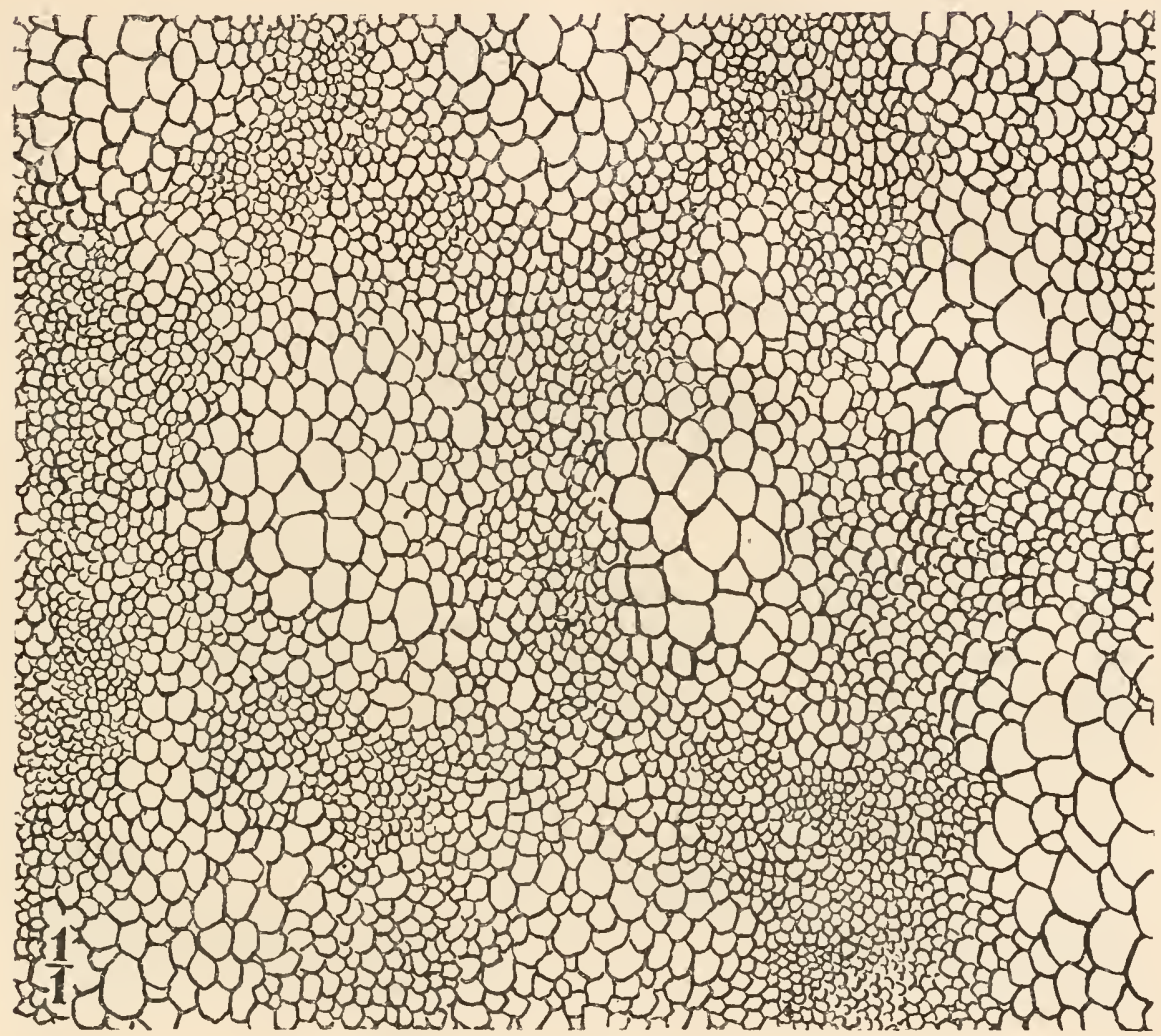

Fig. 507.

Hautskulptur von der Stelle B der ,Mumie“ von Trachodon annectens (Fig. 504), gefunden von Charles $H$. Sternberg in der oberen Kreide von Converse County in Wyoming, 1908. Nat. Gr. (Nach H. F. Osborn, 1913.)

Ein weiteres, alle Stegosauriden kennzeiclmendes Merkmal ist die Ausbildung gewaltiger Panzerplatten und Knochenstacheln, die bei deı verschiedenen Gattungen beträchtliche Form- und Größendifferenzen aufweisen. Bei Scelidosaurus besteht der Panzer aus in Längsreihen stehenden kegelförmigen Höckern und niedrigen Schildern, bei Polacanthus sind diese Kuochenplatten in der Lenden- und Sakralregion zu einem geschlossenen, großen Schild verschmolzen, während Hals, Scliwanz und Rücken hohe, spitze Knochenstacheln tragen; bei Stegosaurus war der Schwanz mit sehr langen, spitzen Stacheln in zwei 
Längsreihen bewehrt, während der Rücken durch riesige, steil in die Höhe stehende Knochenplatten geschützt war, die alternierend in einer Doppelreihe, links und rechts von den Neurapophysen, standen und auf den oberen Rippenenden und dem Ende des Wirbelquerfortsatzes aufruhten.

Die Hand zeigt nach den neuen Untersuchungen Ch. W. Gilmores (1914) eine auffallende Älnlichkeit mit jener von Diplodocus; nur der Daumen trägt noch eine Phalange, die übrigen Finger tragen an den Enden der steil gestellten, an die Metacarpalia dẹr Elefantenhand er-

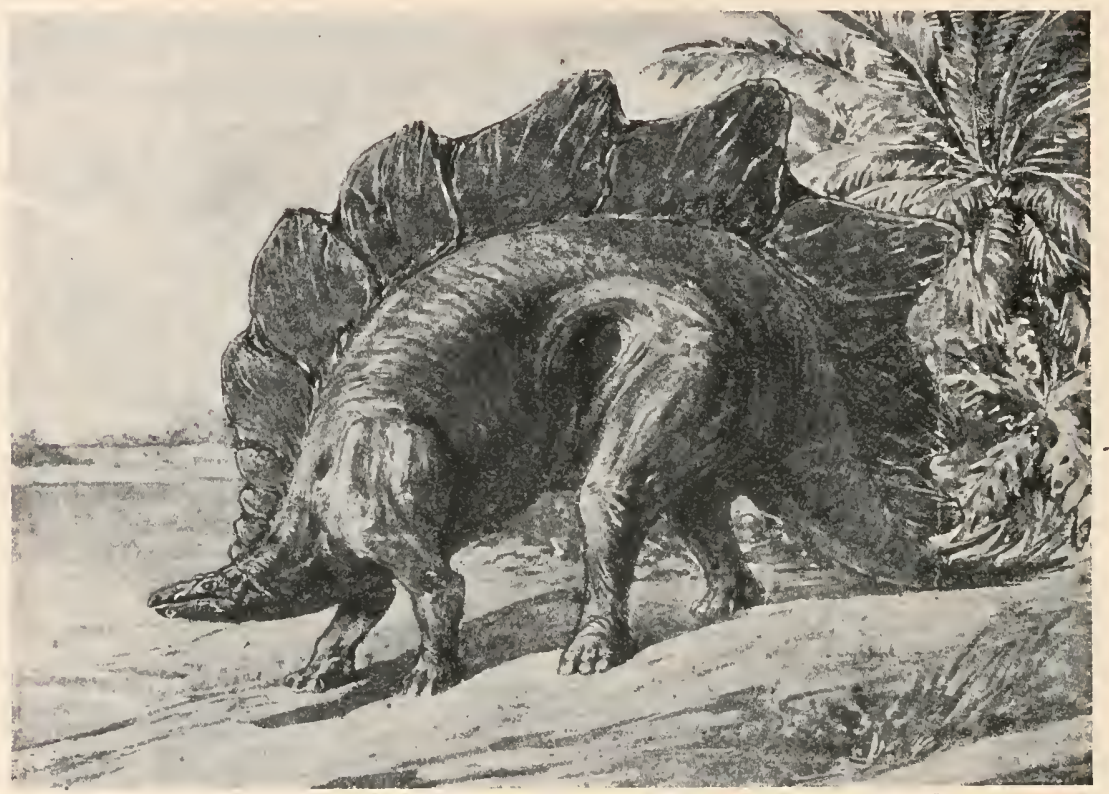

Fig. 508 .

Rekonstruktion von Stegosaurus ungulatus, Marsh, aus den Atlantosaurus Beds Nordamerikas. (Nach O. Abel.)

innernden Mittelhandknochen nur mehr je eine verkümmerte, bohnenförmige Phalange. Die Carpalia sind zu zwei großen Komplexen verschmolzen, von denen ein ulnarer und ein radialer zu unterscheiden ist. Die Reduktion der Phalangen ist hier auf einen ähnlichen Prozeß wie bei den Sauropoden, nämlich auf die sekundäre Rückkehr zur tetrapoden Lebensweise bei elefantenartiger Handhaltung und Steilstellung des Armes zurückzufülıren.

Das Becken besitzt ein Ilium mit sehr stark verlängertem vorderen Fortsatz; das Pubis ist ungewöhnlich kräftig und schließt sich eng an den Unterrand des Ischiums an, mit diesem zusammen in funktioneller 


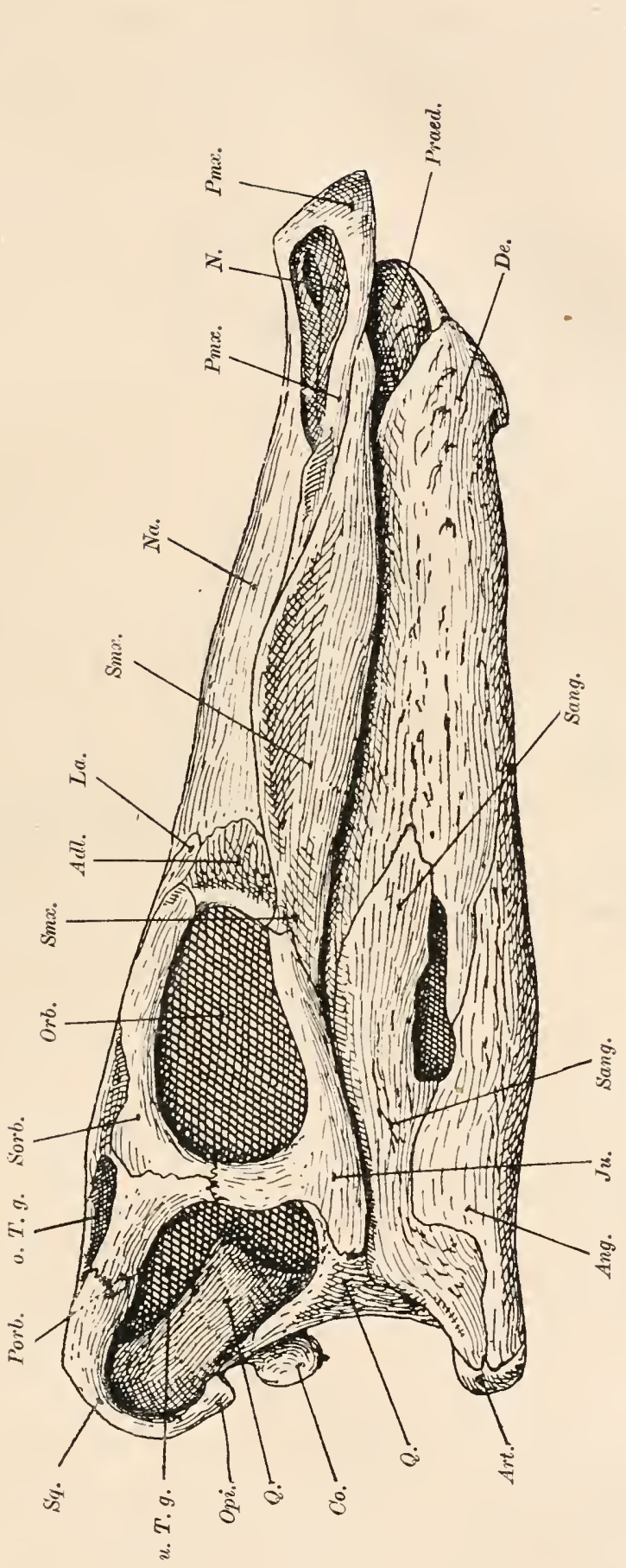

5

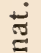

$\pi$

$\Xi \stackrel{\dot{0}}{\Xi}$

ลิ

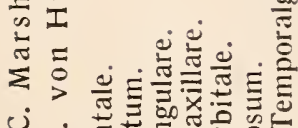

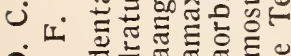

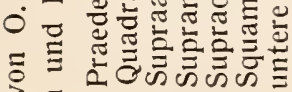

> की $\|$ || || || || || ||

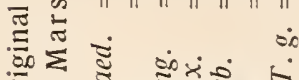

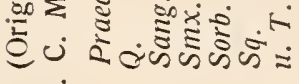

$+0$

के

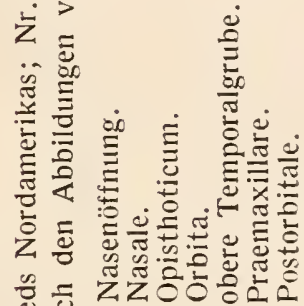

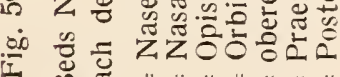

严吾

突

这这.

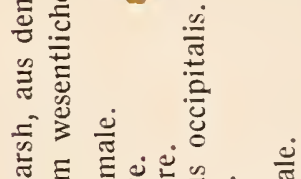

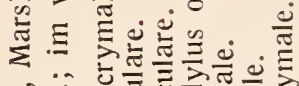

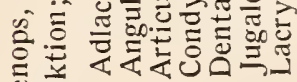

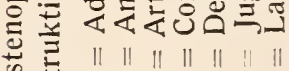

政

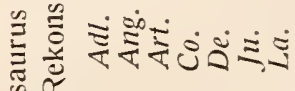

ㄴ.

蓠苛

Бे

$\frac{\bar{g}}{\frac{\pi}{5}}$ 
Hinsicht ein Beckenelement bildend (Folgeerscheinung des Aufgebens der bipeden Gangart der Vorfahren). Der Hinterfuß ist funktionell dreizehig geworden; die Endphalange ist am dritten Zehenstrahl bei einem Exemplar erhalten, die Phalangen der übrigen Zehen sind un-
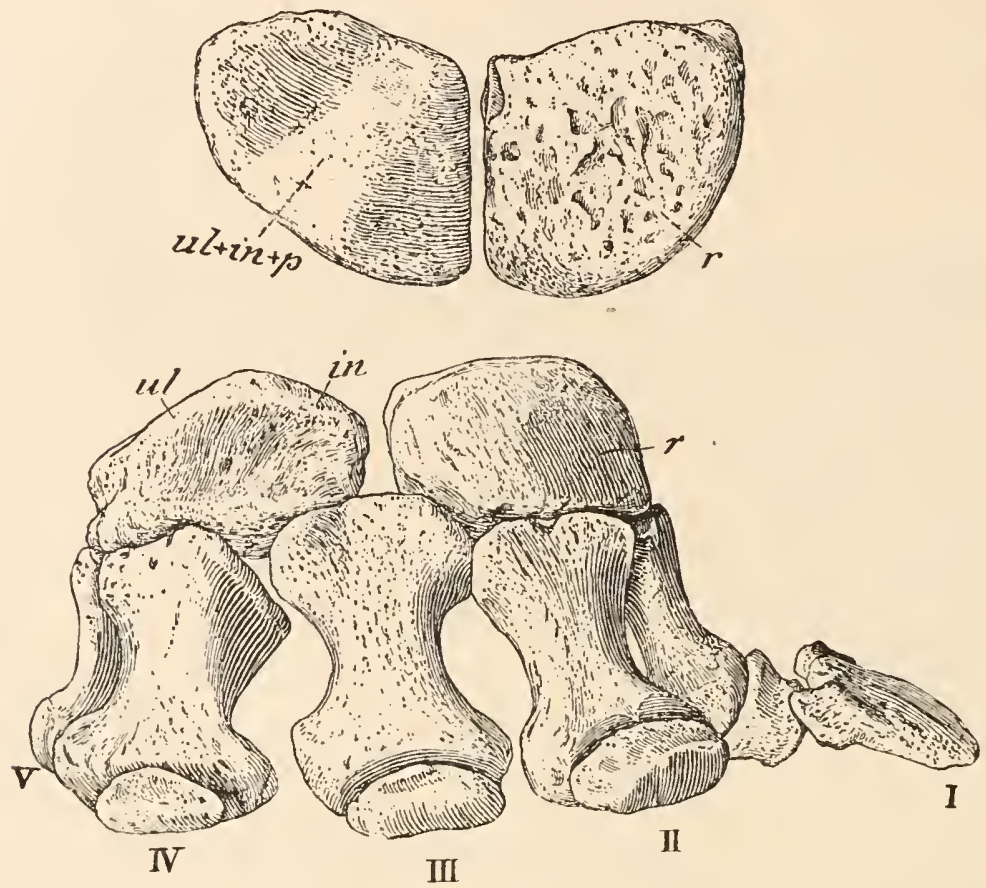

Fig. 510 .

Rechte Hand von Stegosaurus sulcatus, Marsh, aus dem oberen Jura von Como (Albany Connty, Wyoming) in Nordamerika (Atlantosaurus Beds). 1/4 nat. Gr. (Nach Ch. Wh. Gilmore.)

Oben: Dorsalansicht der beiden Carpalmassen;

Unten: Ansicht der Hand von vorne.

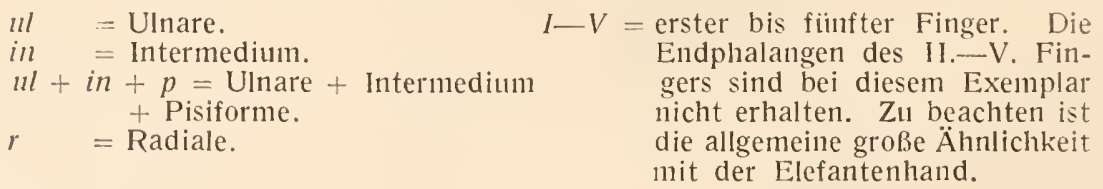

bekannt. Die drei funktionellen Zehen entsprechen der ersten bis dritten Zehe. Die Körperlänge von Stegosaurus betrug 6-9 111. - Mehrere Arten, eine auch im oberen Jura (Oxfordien) Englands.

Alle Stegosauriden sind quadruped, und zwar ist dies schon für die älteste Gattung Scelidosaurus anzunehmen. Die Ursache der sekundären Rückkehr zur tetrapoden Gangart war wohl die Ausbildung des 
schweren Rückenpanzers. Daß die Vorfahren biped waren, beweist vor allen der Bau des Beckens, da nur bei der bipeden Gangart eine unter das Ischium geschobene Spange (bei den Ornithischiern und bei den Vögeln $=$ Pubis) zur Ausbildung gekommen ist.

Kentrurosaurus. - Aus den Tendaguruschichten (OberjuraUnterkreide) Deutsch-Ostafrikas. ${ }^{1}$

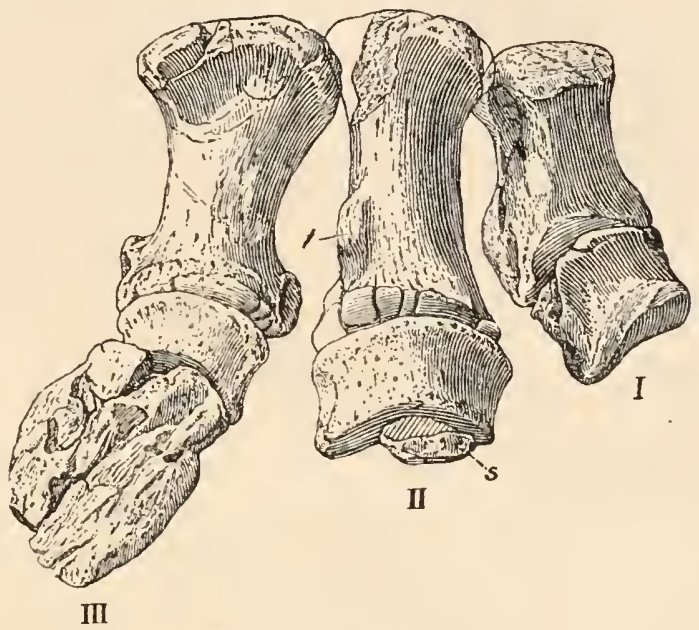

Fig. 511.

Rechter Hinterfuß von Stegosaurus sp. aus dem oberen Jura (Atlantosaurus Beds) von Wyoming (Albany County). Original im National-Museum zu

Washington. Etwa $1 / 4$ nat. Gr. (Nach Ch. Wh. Gilmore, 1914.)

$s=$ Sesambein (?).

$t=$ Höcker am II. Metatarsale.

$I, I I, I I=$ Metatarsale $\mathrm{I}-\mathrm{III}$.

\section{F. Acanthopholidae.}

Bei den Angehörigen dieser Familie, deren Selbständigkeit erst kürzlich (1915 und 1917) von F. von Nopcsa klargelegt worden ist, fehlen die oberen Schläfenöffnungen; der Schädel ist bis obeıhalb des Foramen magnum seitlich, rückwärts und oben bis zur Fronto-Nasalnaht fast kugelförmig und erinnert daher stark an den eines Vogels. Ein wesentlicher Unterschied im Vergleiche mit dem Schädel der Vögel besteht jedoch darin, daß sich nicht wie bei den Vögeln die das Hirn einschließenden Knochen, sondern die Deckknochen (Squamosa, Post-

1 E. Hennig, Kentrosaurus aethiopicus, der Stegosauride des Tendaguru. Sitzungsberichte der Gesellschaft naturforschender Freunde in Berlin, 1915, Nr. 6, S. 219 .

Derselbe, Zweite Mitteilung über den Stegosauriden vom Tendaguru. Ibidem, 1916, Nr. 6, S. 175. 
frontalia und Lacrymalia) an Baue dieser kugeligen Kapsel beteiligen. Das Foramen magnum liegt auf der Unterseite des Schädels; die Schädelbasis steht daher senkrecht zur Achse der Halswirbelsäule. Die wichtigsten Gattungen sind:

Acanthopholis. - Mittlere Kreide Englands. ${ }^{1}$

Polacanthus. - Wealden von Hastings und der Insel Wight. Die Sakral- und Lendenregion wird von einem geschlossenen, scliildartigen Panzer geschützt, während Rücken, Hals ınd Schwanz zwei Längsreihen spitzer Knochenstacheln tragen. ${ }^{2}$

Struthiosaurus. - Obere Kreide Österrèich-Ungarns (Gosaıbildungen Niederösterreichs und Siebenbürgens). Die früher mit dieser Gattung (= Crataeomus) vereinigten Reste aus der Oberkreide Südfrankreichs gehören einer anderen Gattung an, die den Ankylosaurinen (s. unten) einzureihen sein dürfte. ${ }^{3}$

\section{F. Ceratopsidae.}

\section{Unterfamilie: Ceratopsinae.}

Auch die Ceratopsiden stellen eine Gruppe der Ornithischier dar, die sekundär nach Durchlaufung der bipeden Lebensweise zur Tetrapodie zurückgekehrt ist; infolgedessen ist das Pubis funktionslos geworden, ist aber hier nicht mit dem Ischium in feste Verbindung getreten wie bei den Stegosauriden, sondern rudimentär geworden.

Die weitgehendste Spezialisation hat der Schädel der Ceratopsiden erfahren. Das Schädeldach ist nach hinten in einen riesigen Scliild ausgezogen, der wohl als Nackenschutzplatte gegen die Angriffe der großen Raubdinosaurier diente, während die gewaltigen Schädelzapfen, die sich auf den Nasenbeinen (ein medianes) und auf den Postfrontalia (jederseits eines) ausbildeten, eine wirksame Verteidigungswaffe der herbivoren, schwerfälligen Tiere darstellten.

Wir können die Entstehung des eigentüunlichen Nackenschildes bei den auf die obere Kreide Nordamerikas beschränkten Gattungen dieser Familie selır gut verfolgen. Bei der primitivsten Ceratopsidengattung Monoclonius erscheint bereits das Schädeldach nach hinten weit ausgezogen und die oberen Temporalgruben sind sehr vergrößert;

1 Th. H. Huxley, On Acanthopholis horridus, a New Reptile from the Chalk Marl. - Geol. Magazine, London, Vol. IV, 1867, p. 65.

2 J.W. Hulke, Polacantlus Foxi, a Large Undescribed Dinosaur from the Wealden Formation in the Isle of Wight. - Philosophical Transactions, London, 1881, p. 653.

F. von Nopcsa, Notes on British Dinosaurs. - Part II: Polacanthus. Geol. Magazine, Dec. V, Vol. II, 1905, p. 241.

${ }^{3}$ F. von Nopcsa, Die Dinosaurier der siebenbürgischen Landesteile Ungarns. - Jahrbuch d. Kgl. ungar. Geol. Reichsanstalt. XXIII. Bd., 1915, S. 11. 
der Außenrand ist mit stumpfen Höckern besetzt, die nach außen abstanden und wahrscheinlich von Hornkappen überzogen waren (Fig. 512).

Die weitere Spezialisation des Nackenschildes schlägt nun zwei divergente Wege ein. Der eine führt zu der extremen Type Styracosaurus albertensis, deren hinterer Schädelrand eine große Zahl von Stacheln trägt, von denen die drei hintersten durch ihre gewaltige Länge auffallen; auch auf den Nasenbeinen ist ein medianes, nach vorn steil in die Höhe stehendes Horn vorhanden. Ob über der Orbita kleine Hörner standen, ist zweifelhaft.

Bei der anderen Spezialisationsreihe, die zu Triceratops führt, schließt sich die obere Temporalgrube und ist $z$. B. bei Triceratops prorsus bereits rudimentär. Der Hinterrand des Schädeldaches ist

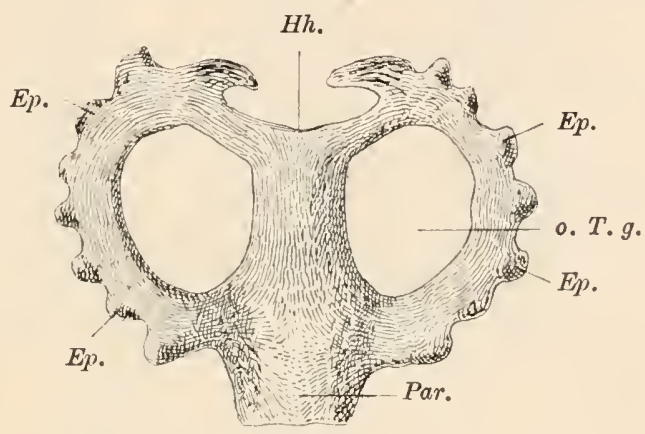

Fig. 512 .

Rekonstruktion des Hinterhauptes von Centrosaurus apertus, Lambe, aus der oberen Kreide von Alberta, Canada. 1/16 nat. Gr. (Nach L. M. Lambe, 1904.)

o. T. g. = obere Temporalgrube. $H h .=$ Hinterhaupt.

Par. $=$ Parietale.

$E p$. = Epoccipitale.

zuweilen mit Epoccipitalien (neu entstandenen Dermalplatten oder Höckern) besetzt (Fig. 512, 514, 516).

Ein Seitenzweig, der bis auf die nonocloniusartigen Ceratopsidentypen zurückgeht, ist durch die Gattung Torosaurus repräsentiert, bei der noch die oberen Temporalgruben weit offen stehen.

Die morphologische Bestimmung der Knochen, welche das Nackensclild zusammensetzen, hat große Schwierigkeiten bereitet. Die Seitenteile wurden wohl zumeist richtig als die in die Länge gezogenen Squamosa gedeutet, aber die mittleren Teile des Nackenschildes sind (so von O. C. Marsh und R. S. Lull) als Parietalia, von O. P. Hay als Supratemporalia, von Huene als-Dermosupraoccipitalia gedeutet worden. Wenn wir uns vergegenwärtigen, daß die großen Öffnungen des Schädeldaches bei Monoclonius, Centrosaurus und Styracosaurus (Fig. 512, 514) nichts anderes sind als die erweiterten oberen 
Temporalgruben, so muß der Außenrand vom Squamosum, der Hinterrand und der mittlere, beide Temporalgruben trennende Kamm aber von den Parietalia gebildet werden, wie dies auch früher zumeist angenommen wurde. Dann ist es aber nicht möglich, daß der Verschluß der oberen Temporalgrube in der zu Triceratops führenden Formenreihe durch Dermosupraoccipitalia bewirkt wurde, wie dies Huene (1911) annimmit, da die Lagebeziehungen zu den Parietalia und Squamosa eine solche Annahme verbietet. Es ist kein zwingender Grund für die Annahme vorhanden, daß die Parietalia an der Bildung des Nackenschildes keinen Anteil nehmen, und ich bin der Meinung, daß der

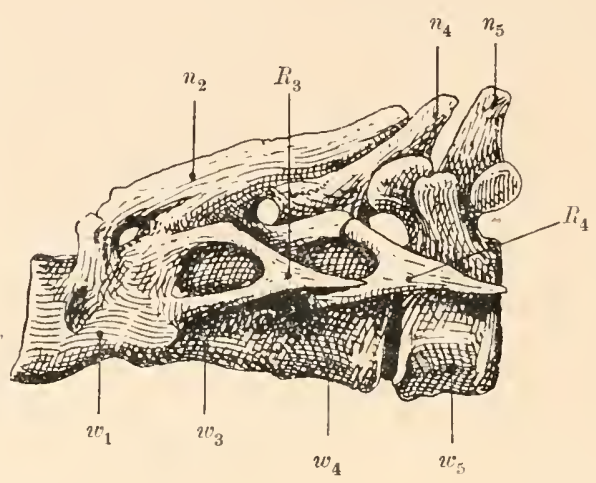

Fig. 513.

Die fünf vordersten Wirbel von Triceratops prorsus, Marsh, aus der oberen Kreide Nordamerikas. 1/s nat. Gr. (Nach O. C. Marsh.)

$\begin{aligned} w_{1}= & \text { Atlas }+ \text { zweiter Halswirbel } & n_{2}, n_{4}, n_{5}= & \text { Neurapophysen des 2., } 4 . \\ w_{3}-w_{5}= & \text { die Wirbelkörper des } 3 ., & & \text { und } 5 \text {. Wirbels. } \\ & \text { 4. und 5. Wirbels. } & R_{3}, R_{4}= & \text { dritte und vierte Halsrippe. }\end{aligned}$

Verschluß der oberen Temporalgruben in dem enorm nach hinten ausgezogenen Schädeldach gleichmäßig durch die Squamosa und die Parietalia bewirkt worden ist.

Präorbitalöffnungen sind zuweilen vorhanden, sind aber (z. B. bei Triceratops prorsus und T. serratus) sehr klein und rudimentär. Eine untere Temporalgrube ist vorhanden, aber klein.

Von überzähligen Neubildungen sind zu nennen: ein vorderes Supraorbitale (Fig. 516, Sorb.), ein Rostrale (das, vorn an die Prämaxillaria anstößt und somit dem Prädentale des Unterkiefers entspricht (Fig. 516, Ro.), ein Epijugale (Fig. 516, Epj.) an Unterrand des Quadratojugale und des Quadratums, sowie zahlreiche Epoccipitalia (Fig. 516, Epo.); sie sind ausnahmslos dermalen Ursprungs. Ebenso sind die Schädelzapfen selbständige Verknöcherungen. 


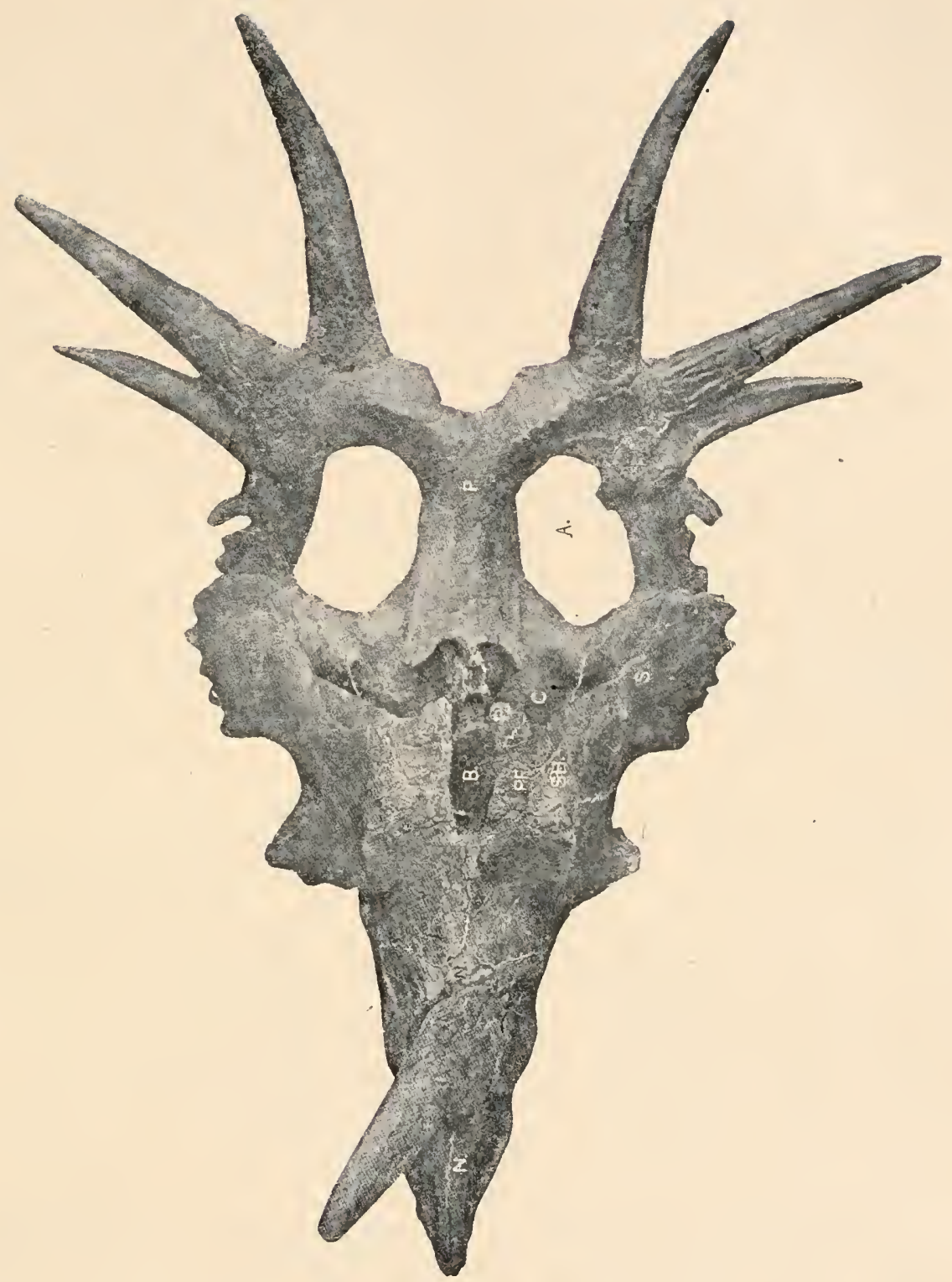

- Fig. 514.

Styracosaurus albertensis, Lambe; aus der oberen Kreide (Belly-RiverFormation) von Alberta, Canada. Schädel von oben in $1 / 12$ nat. Gr.

(Nach L. M. Lambe.)

$A$ und $B=$ Fenster $i m$ Schädeldach. $S H=$ Basis des supraorbitalen

$C=$ obere Schläfengrube.

$N=$ Nasale.

$S=$ Squamosum.

$P=$ Parietale.

$P F=$ Postfrontale. 
In Schädeldach von Triceratops befindet sich eine große runde Öffnung (Fig. 516, o.T.g.) zwischen den Postfrontalia und den Parietalia, durch welche wahrscheinlich Blutgefäße austraten, die in zwei divergierenden Rinnen gegen das Nackenschild zogen und sich hier verzweigten, wie die Rinnen auf dem abgebildeten Schädel zeigen.

Der Unterkiefer trägt einen hohen Kronenfortsatz; die Zähne stehen in einfacher Reihe; zuweilen treten bei höherem Alter zweiwurzelige auf. Das Tier war herbivor.

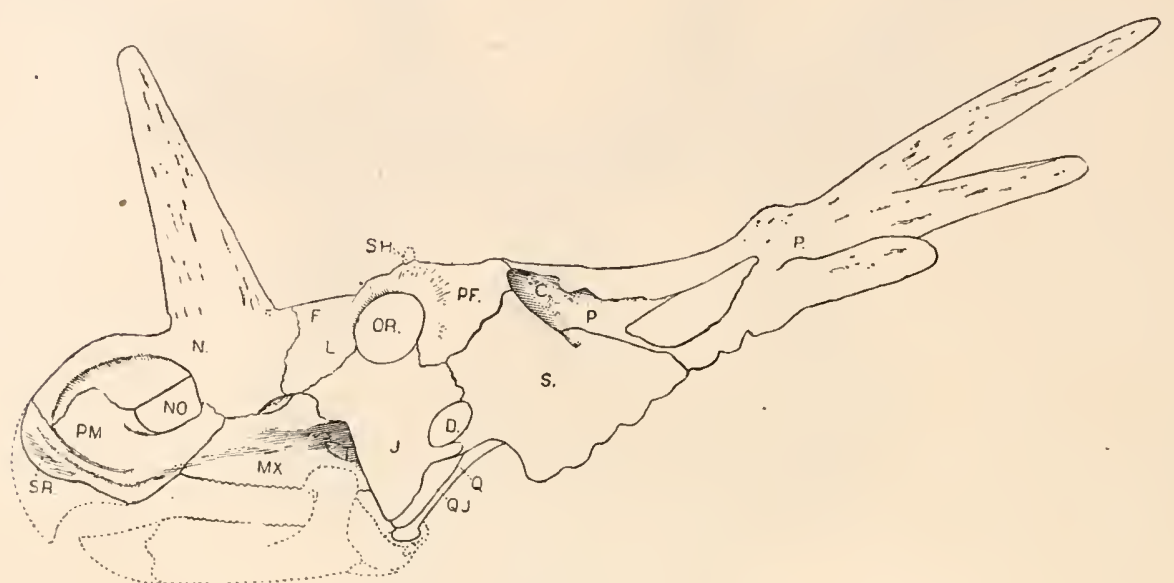

Fig. 515.

Schädel von Styracosaurus albertensis, Lambe, aus der Oberkreide von Alberta, Canada, von der Seite gesehen (dasselbe Exemplar wie Fig. 514; etwas stärker verkleinert).
C. = obere Schläfengrube.
$P F .=$ Postfrontale
D. = seitliche Schläfengrube.
Q. $=$ Quadratum.
$F$. $=$ Frontale.
J. $=$ Jugale.
L. $\quad=$ Lacrymale.
$M X .=$ Supramaxillare.
$N .=$ Nasale.
NO. = Nasenöffnung.
$P . \quad=$ Parietale.
QJ. = Quadratojugale.
$S$. $=$ Squamosum.
SH. = Basis des supraorbitalen Schädelzapfens.
$S R$. = Basis der Hornscheide der Schnauze.
$O R .=$ Orbita .

Die Wirbel sind platycoel und massiv; mehrere Halswirbel (die beiden ersten oder überhaupt die vordersten 3-4 Wirbel) sind meist verschmolzen. Daraus geht hervor, daß der Schädel nur sehr wenig bewegt werden konnte, aber er konnte jedenfalls riach unten abgebogen werden, da der Nackenschild frei und nicht, wie z. B. W. D. Matthew (1915) annahın, unter der Rückenhaut verborgen war.

Die Vorderbeine sind kürzer als die Hinterbeine und durch die starke Beugung der Arme in Ellbogengelenk steht der Vorderteil des Körpers mit dem schweren Schädel viel tiefer als die Krupp. Alle Zehen besaßen hufförmige Endphalangen. 
Monoclonius. - Tiefere Stufe der Oberkreide Nordannerikas (Judith River Beds = Belly River Beds bei Judith in Montana und an Red Deer River in Alberta, Canada). ${ }^{1}$

Centrosaurus. - Aus denselben Schichten von Alberta, Kanada (Fig. 512). ${ }^{2}$

Styracosaurus. - Ebendaher. - Der Schädel trägt einen hohen, kegelförmigen Zapfen auf den Nasenbeinen; der Hinterrand des von zwei großen Fontanellen durchbrochenen Schädeldaches ist von mächtigen Knochendornen, jederseits vier, besetzt, die von hinten nach vorne an Größe rasch abnehmen (Fig. 514, 515). Auch der Außenrand des Squamosum trägt zackige Vorsprünge. ${ }^{3}$

Ceratops. - Ebendaher und aus gleichalten Schichten am Missouri in Montana. - Weite obere Temporalgrube, Schädelzapfen klein.

Torosaurus. - Obere Stufe der Oberkreide Nordamerikas (Laramie Beds). Große obere Temporalgrube, sehr großes hinteres Hornpaar, kleines Nasenhorn.

Diceratops. - Ebendaher. - Nasenhorn fehlt.

Triceratops. - Ebendaher. - Nasenhorn und ein Paar sehr hohe, nach vorn gerichtete Hörner ober den Augenhöhlen vorhanden. Die oberen Temporalgruben sind sehr klein, rudimentär (Fig. 513, 516). ${ }^{4}$

1 L. M. Lambe, Contributions to Canadian Palaeontology, Vol. III, Part II: On Vertebrata of the Mid-Cretaceous of the North West Territory. - Geol. Survey of Canada, 1902, p. 23.

2 Derselbe, On the Squamoso-Parietal Crest of the Horned Dinosaurs Centrosaurus apertus and Monoclonius canadensis from the Cretaceous of Alberta. - Transactions Roy. Soc. Canada (2), Vol. X, Sect. 4, 1904, p. 3.

3 Derselbe, A New Genus and Species of Ceratopsia from the Belly River Formation of Alberta. - The Ottawa Naturalist, Vol. XXVII, 1913, p. 109.

4 O. C. Marsh, The Dinosaurs of North America. - 1. c., 1896, p. 206.

B. Brown, New Notes on the Osteology of Triceratops. - Bull. Am. Mus. Nat. Hist., Vol. XXII, 1906, p. 297.

Derselbe, Notes on Some Recent Additions to the Exhibition Series of Vertebrate Fossils. - Proc. U. S. Nat. Mus., Vol. XXX, Washington 1906, p. 607.

O. P. Hày, On the Skull and the Brain of Triceratops, with Notes on the Brain-Cases of Iguanodon and Megalosaurus. - Ibidem, Vol. XXXVI, 1909, p. 95.

L. Dollo, Les Dinosauriens adaptés a la Vie quadrupède secondaire. - Bull. Soc. Belge de Géol., Paléont. et d'Hydrol., Bruxelles 1905, T. XIX, p. 441.

F. Drevermann, Aus der Schausammlung: Der Triceratops. - 44. Bericht der Senckenbergischen Naturforsch. Ges. Frankfurt a. M., 1913.

F. v. Huene, Beiträge zur Kenntnis des Ceratopsidenschädels. - Neues Jahrbuch f. Mineralogie usw., 1911, II. Bd., S. 146.

Derselbe, Über die Zweistämmigkeit der Dinosaurier, mit Beiträgen zur Kenntnis einiger Schädel. - Ibidem, Beilageband XXXVII, 1914, S. 577.

F. von Nopcsa, Über Dinosaurier. - I.-III. Teil. - Centralbl. f. Mineralogie, 1917, p. 203 und 332. 


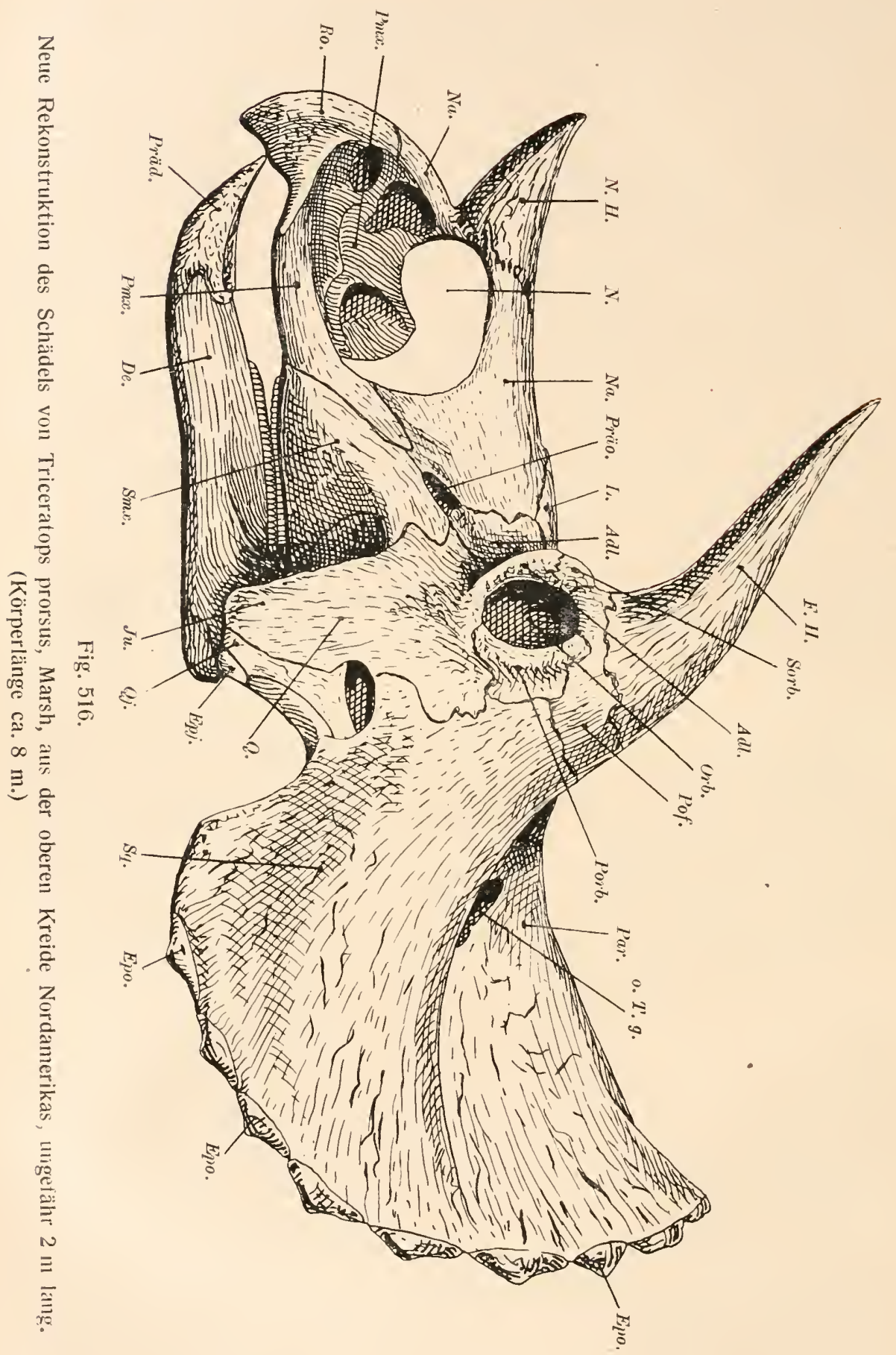


Unterfamilie: Nodosaurinae.

Die durch Ankylosaurus in der oberen Kreide Nordannerikas vertretene, selnr eigenartig spezialisierte Gruppe umfaßt wahrscheinlich auch die Gattung Hierosaurus aus der oberen Kreide Nordamerikas ${ }^{1}$ und Südfrankreichs. Der Nackenschild, der bei den Ceratopsinen eine so gewaltige Entwicklung erfährt, ist hier erst durch Nackenstacheln angedeutet. Der Körper ist nit mäclıtigen Panzerplatten bedeckt, die in ihrer Form an Ofenkacheln erinnern und in dichten Reihen stehen. Im Becken fällt die weitgehende Reduktion des Pubis und Pr. pseudop. auf, ein Seitenstück zu den Spezialisationen im Beckenbau von Stegosaurus und Triceratops, die L. Dollo als Folgeerscheinung der Rückkehr zur quadrupeden Lebensweise betrachtet; zweifellos sind die Vorfahren der Stegosauriden und Ceratopsiden, wahrscheinlich auch die der Acanthoplıoliden, biped gewesen.

Ankylosaurus. - Obere Kreide (Edmonton- und Belly-RiverFormation) von Alberta, Canada und Montana. - Die weit ausladenden Rippen sind mit den Wirbeln verschmolzen und bilden so einen tonnenförmigen Thorax. Der Schädel ist mosaikartig gepanzert gewesen. Der Schwanz endet in einen plumpen, an die Sclıwanzröhre von Glyptodon erimnernden Panzer; die Gliedmaßen waren kurz, massiv und elefantenähnlich. ${ }^{2}$

Stegopelta. - Atlantosaurus-Beds, Wyoming. ${ }^{3}$

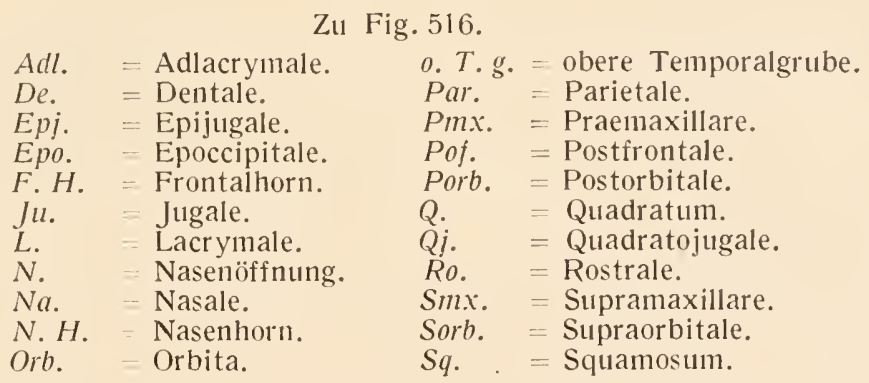

1 G. R. Wieland, A New Armored Saurian from the Niobrara. - American Journal of Science, Vol. XXV11, 1909, p. 250.

Derselbe, Notes on the Armored Dinosauria. - Ibidem, Vol. XXX1, 1911, p. 112.

F. von Nopcsa, Über Dinosaurier. - Centralblatt f. Mineralogie usw., 1917, S. 211 (iiber hierosaurusartige Panzerplatten aus Südfrankreich, die von $\mathrm{Ch}$. Depéret [Bull. Soc. Géol. France, 1900) als Crataeomus sp. erwähnt worden waren).

2 B. Brown, The Ankylosauridae, a New Family of Armored Dinosaurs from the Upper Cretaceous. - Bull. Amer. Mus. Nat. Hist.; Vol. XXIV, 1908, p. 187.

W. D. Matthew, Dinosaurs. - New York, 1915, p. 103.

${ }^{3}$ S. W. Williston, A New Armored Dinosaur from the Upper Cretaceous of Wyoming. - Science, N. S., Vol. XXII, Nr. 564, 1905, p. 503.

Roy L. Moodie, An Armored Dinosaur from the Cretaceous of Wyoming. The Kansas University Science Bulletin, Vol. V, Nr. 14, 1910, p. 257. 


\section{Ordnung: Araeoscelidia.}

In Perm von Craddocks Ranch bei Seymour in Texas ist vor einigen Jahren eine größere Zahl von Skelettresten eines Reptils entdeckt worden, das eine sehr eigentünliche Spezialisationsrichtung aufweist. S. W. Williston, der dieses Reptil unter dem Namen Araeoscelis gracilis beschrieben hat (1914), ist neuerdings (1916) geneigt, es in die Ordnung der Lepidosauria einzureihen, hat aber auch auf gewisse Ähnlichkeiten mit den Protorosauriern hingewiesen. Der allgemeine Habitus des Tieres, von dem fast das ganze Skelett in zahlreichen Individuen bekannt ist, erinnert an den einer schlanken, schmalköpfigen und langschwänzigen Eidechse mit gut entwickelten, auffallend langen Laufbeinen. Der Schädel ist jedoch so eigenartig spezialisiert, daß die Sonderstellung von Araeoscelis und ihre Abtrennung als Vertreter einer eigenen Ordnung gerechtfertigt erscheint.

Der Schädel besitzt nur ein Paar kleiner Temporalgruben; welche den oberen des Sphenodonschädels entsprechen. An Stelle der unteren findet sich eine große, dünne Knochenplatte, die sich vom Squamosum aus nach vorn weit ausdehnt und an das kleine Jugale und das Postorbitale anschließt; ein Quadratojugale fehlt, wie bei den Theriodontierı, ebenso ist (wahrscheinlich) auch kein Adlacrymale vorhanden. Die Squamosalplatte scheint mir einen sekundären VerschluBder un teren Temporalgrube darzustellen, deren ehemalige Vordergrenze durch die Nahtgrenzen des Jugale und Postorbitale gegeben ersclieint. Derartige sekundäre Verschlußplatten treten unter den Amphibien bei den Blindwülılen (z. B. Siphonops) und bei den Scliildkröten (z. B. Podocnemis einerseits und Chelone andererseits) auf. Das Quadratum liegt hinter dem Squamosum und bildet das Unterkiefergelenk in ähnlicher Weise wie bei den Eidechsen, nur mit dem Unterschiede, daß die Beweglichkeit des Schädels (Streptostylie) durch die sekundäre Verschließung der unteren Temporalgrube aufgehoben erscheint. Das Postfrontale ist sehr klein, das Tabulare gleichfalls; ein Supratemporale fehlt. Das Hinterlıaupt läßt bei den bisher vorliegenden Schädeln keine scharfen Nahtgrenzen zwischen den einzelnen Elementen erkennen; walırscheinlich ist das Supraoccipitale neben den Exoccipitalia und den Opisthotica (= Paroccipitalia) ausgebildet. Die Gaumenfläche ist mangellaft bekannt ; das Parasphenoid ist nacligewiesen. Das Transversum trägt einige kegelförmige Zälıne. Inı Supramaxillare stehén 14 stumpfkonische Zähne, deren Befestigungsart thecodont oder protothecodont ist. Auch die Pterygoidea und Palatina sind bezahnt.

Die Gliedmaßenknochen sind sehr lang, das Längenverlıältnis und die Phalangenzalıl von Hand und Fuß entspricht den Verhältnissen, die wir bei den Schieblaufextremitäten der Stegocephalen und primitiven 
Reptilien antreffen (Phalangenformel 2, 3, 4, 5, 3, längster Finger- und Zelenstralıl der vierte).

Die Wirbel (7 stark verlängerte Halswirbel, etwa 20 Thorakalwirbel, 2 Sakralwirbel und eine unbestinumte, aber jedenfalls sehr große Zahl Kaudalwirbel) sind amphicoel.
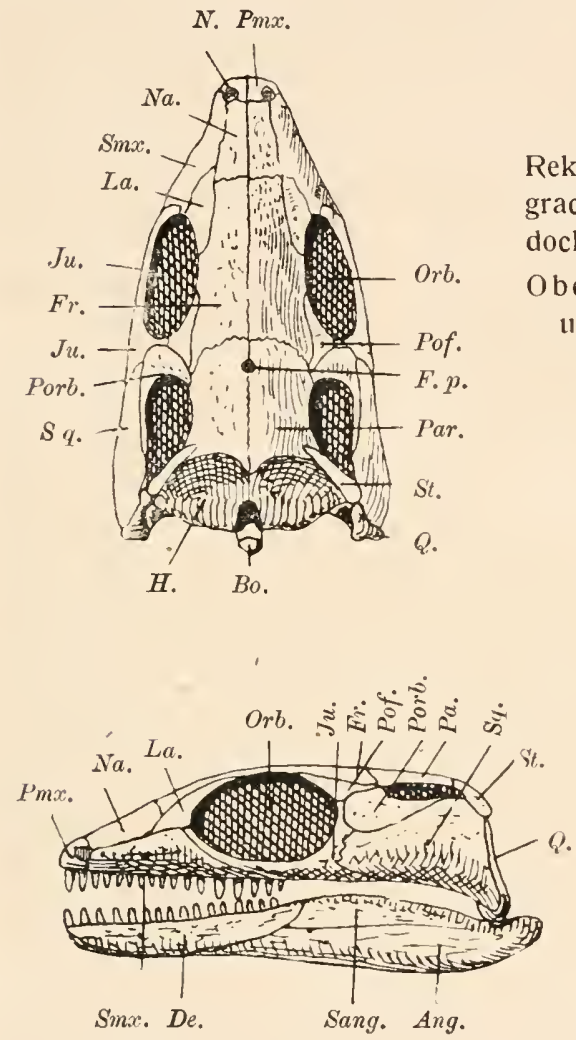

Fig. 517.

Rekonstruktion des Schädels von Araeoscelis gracilis, Wieland, aus dem Perm von Craddocks Ranch bei Seymour (Texas). Nat. Gr. Oben: Schädel von oben; unten: Schädel und Unterkiefer von der Seite gesehen.

(Nach S. W. Williston, 1914.)

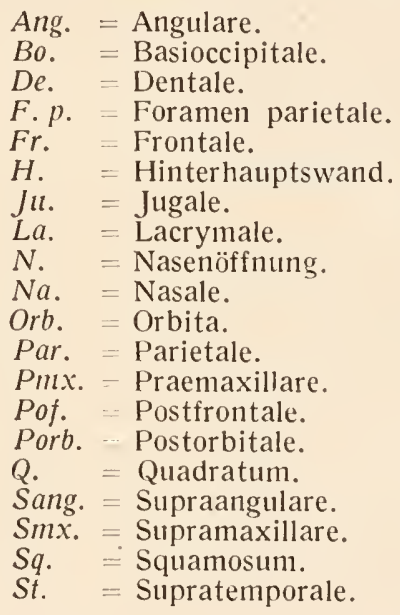

Araeoscelis. - Perm1 von Texas. - Körperlänge etwa 0,5 111 . Bauchrippen fehlen. Gliednaßenknochen hohl (Fig. 517). ${ }^{1}$

Kadaliosaurus. - Perm von Niederhäßlich bei Dresden. Schädel unbekannt; die Gliedmaßen stimmen mit denen von Araeoscelis nahezu überein. Bauchrippen vorhanden. Gliedmaßenknochen nicht hohl, sondern im lnneren spongiös. ${ }^{2}$

1 S. W. Williston, The Osteology of Some American Permian Vertebrates. Journal of Geology, Vol. XXII, 1916, p. 364.

Derselbe, Contributions to the Walker Museum, Chicago, Vol. 1, Nr. 9, p. 235.

2 S. W. Williston, I. c., Joumal of Geology, Vol. XXII, 1916, p. 396. 


\section{Ordnung: Lepidosauria (= Squamata).}

Unter den heute noch lebenden Reptilienstämmen sind die Lepidosaurier mit den artenreichen Stämmen der Lacertilier und Ophidier die einzigen, welche noch in voller Blüte stehen; die Schildkröten befinden sich trotz der großen Artenzahl unverkennbar bereits im Niedergang, wenn wir die lebenden Typen mit den fossilen vergleichen, und das gleiche gilt von den Krokodilen. Von den zahlreichen Ordnungen der fossilen Reptilien, die im Palaeozoicum und Mesozoicum in hoher Blüte standen, blieb nur Sphenodon als der letzte Vertreter der Rhynchocephalen übrig, aber auch er ist bei der isolierten Art seines Vorkommens dem sicheren Untergang geweiht.

Die Lepidosaurier sind eine alte Familie, die sich wahrscheinlich schon im Perm, zur Zeit der Hauptspaltung der Reptilienstämme, von primitiven Landreptilien abgezweigt hat; wir kennen jedoch aus dem Perm keine Reste, die mit Sicherheit den Lepidosauriern zuzuweisen wären, da die beiden Gattungen Araeoscelis und Kadaliosaurus zwar in vielen Punkten eidechsenähnlich sind, aber doch zweifellos bereits eine Seitenlinie bilden. Erst aus der Trias kennen wir einen mangelhaft erhaltenen Schädel eines Lacertiliers, den Broom als Paliguana Whitei beschrieben hat; die wesentlichen Kennzeichen des Lacertilierschädels sind schon bei dieser Form deutlich erkennbar. Von da an klafft jedoch eine große Lücke bis zum oberen Jura, aus dem einige wenige Lacertilierreste vorliegen; auch aus Kreidebildungen kennt man nur wenige Reste, die uns keinen Aufschluß über die Geschichte des Lacertilierstammes zu geben vermögen.

Dreimal haben sich im Laufe des Mesozoicums von den terrestrischen Lacertiliern Formenreihen abgezweigt, die sich an das Meeresleben angepaßt und dabei hochgradig spezialisiert haben. Das erstemal ist eine solche Abzweigung in der Trias erfolgt — die Thalattosaurier - und das zweitemal in der Unterkreide - die mit Aigialosaurus und Opetiosaurus beginnenden Mosasaurier. Die Thalattosaurier sterben noch in der Trias aus und scheinen keine sehr weite Verbreitung gellabt zu haben; denn obwohl wir marine Ablagerungen aus der Triasformation von einer großen Zahl von Fundorten kemen, so sind doch bisher die Thalattosaurier ausschließlich aus Kalifornien bekannt geworden. Dagegen sind die Mosasaurier in der oberen Kreide weit verbreitet gewesen und haben in dieser Zeit eine hohe Blüte erreicht; sie sind jedoch im oberen Senon ohne Nachkommen erloschen. Eine dritte Abzweigung von terrestrischen Lacertiliern $\mathrm{zu}$ aquatischen Typen ist gleichfalls in der Unterkreide erfolgt - die Dolichosauriden -, deren jüngste Vertreter aus der oberen Kreide Englands bekannt geworden sind. Nur die Mosasaurier haben sich zu Riesenformen entwickelt; die Thalattosaurier 
bleiben an Körpergröße beträchtlich hinter ihnen zurück und die Dolichosauriden sind überhaupt sehr klein geblieben. Von den terrestrischen, kriechenden, laufenden und schreitenden Lacertiliern sind keine besonders aberranten Seitenlinien abgezweigt, und der Lacertiliertypus ist bei diesen noch heute lebenden Formenreihen mit geringen Abweichungen stets erhalten geblieben.

Die Lacertilier haben jedoch die Tendenz, sich nicht nur mit Hilfe ihrer Extremitäten fortzuschieben, sondern die Lokomotion wird in der Regel sehr wesentlich durch die schlängelnde Bewegung des Schwanzes und überlıaupt des ganzen Körpers unterstützt. Bei weiterer Steigerung dieser schlängelnden Fortbewegungsart werden die Gliedmaßen mehr und mehr überflüssig, sie verkümmern schließlich und es kommt zur Entstehung von fußlosen Typen, die wir als Schlangentypen zu bezeichnen pflegen. Dieser Übergang vom Eidechsentypus zum Schlangentypus vollzieht sich heute bei zahlreichen Gattungen von Lacertiliern, und zwar ganz unabhängig voneinander. Auf diese Weise kommt es zum Schlangentypus unter den lebenden Eidechsen, wie er uns z. B. bei der Blindschleiche entgegentritt; derselbe Weg ist aber auch schon früher von älteren Lacertiliern eingeschlagen worden, die sich zu der Formenreihe der Ophidier oder Schlangen entwickelt haben. Obwohl die Schlangen in vieler Hinsicht als hochspezialisierte Typen zu bezeichnen sind, s, sind sie doch aller Wahrscheinlichkeit nach erst in der Kreideformation entstanden; ihr Aufblülın fällt in die Tertiärzeit und in die Gegenwart.

Die wesentlichen Merkmale der Lepidosaurier kommen vor allem im Bau des Schädels zum Ausdruck. Der Schädel ist nicht mehr eine kompakte Kapsel wie bei den Stegocephalen oder bei den ältesten Reptilien (Cotylosauriern), sondern das Schädeldach ist von vielen großen Lücken durchbrochen, so daß es nur durch ein System von Spangen zusammengehalten wird; am weitesten ist diese ,Traversenkonstruktion“, wie man den Schädeltypus der Lepidosaurier nennen kann, bei den Schlangen fortgeschritten. Diese Reduktion der Elemente der Schädelkapsel ermöglicht den übriggebliebenen Elementen eine weit größere Beweglichkeit, als dies bei einem Schädeltypus mit geringerer Lückenbildung oder gar bei einem stegalen Schädel der Fall ist. Während ursprünglich, wie die Analyse des Stegocephalenschädels und des Cotylosaurierschädels lehrt, das Quadratum unbeweglich mit den angrenzenden Knochen verbunden war und eine Bewegungsmöglichkeit der Schädelknochen ausschließlich in Unterkiefergelenk lag (akinetischer Typus), so tritt im Laufe der Spezialisierung der Reptilienstänme eine Lockerung der Verbände der Schädeldachknochen ein, wobei der Vorderteil des Schädels an einer zwischen dem Parietale und dem Supraoccipitale liegenden Biegungslinie gegen den hinteren 
gehoben werden kann (netakinetischer Typus). Bei den Vögeln liegt diese Bewegungslinie weiter vorn; lier wird der Oberkiefer an einem Scharnier gehoben, das etwa in der Mitte des Schädeldaches liegt (z. B. beim Papagei), wobei das Quadratum nach vorn gedrückt, die an ihm einlenkende lange Pterygoidspange wie eine Pleuelstange nach vorn verschoben und dadurch der Kiefer in die Höhe gerückt wird (mesokinetischer Typus). Es gibt aber außerdem noch Fälle, in denen sowohl die hintere als auch die vordere Durchbiegungslinie des Schädeldaches vorhanden ist, wo also der Schädel gleichzeitig mesokinetisch und metakinetisch ist, wie bei Tupinambis oder Uromastix (amphikinetischer Typus).

Mit dieser vergrößerten Bewegungsfreiheit der übrig gebliebenen Schädelknochen steht die Reduktion des Jochbogens, wie sie im Schädel der Lepidosaurier vorliegt, in Zusammenhang. Man kann häufig der Angabe begegnen, daß die Lepidosaurier nur die obere Temporalgrube besitzen und keine untere Temporalgrube entwickelt zeigen; dies ist falsch, denn die untere Temporalgrube ist bei allen Lepidosauriern vorhanden, nur fehlt die untere Abschlußspange, ebenso wie sie bei den Plesiosauriern sekundär verloren gegangen ist.

Diese Bewegungsfreiheit des Quadratums, die man als „,Streptostyli e" bezeichnet", ist innerhalb des Kreises der Lepidosaurier sekundär wieder reduziert worden oder sogar ganz verloren gegangen. Dies ist der Fall bei den Chamäleonen, welche (z. B. bei Chamäleon [Fig. 518]) die Biegungsfähigkeit in der hinteren Beugungslinie des Schädels verloren haben, womit auch der Verlust der Epipterygoide in Verbindung zu bringen ist; ganz starr verlıält sich der Schädel bei der Gattung Brookesia. Daß dieser Zustand sekundär ist, geht, wie J. Versluys (1912) gezeigt hat, aus der noch vorhandenen Bewegungsmöglichkeit des Quadratums bei den Chamäleonen hervor. Die Reduktion des metakinetischen Zustandes ist zweifellos eine Folgeerscheinung der eigentümlichen Art der Nahrungsaufnahme, wobei die Zunge plötzlich weit vorgeschleudert wird und die Kiefer beim Erfassen der Beute eigentlich keine Rolle mehr spielen.

Mit diesen Schädelbewegungen der Lepidosaurier und der Umformung des Kapselschädels zu einem Traversenschädel steht die eigentümliche Ausbildung des Epipterygoids (= Columella cranii) in Zusammenhang. Das Epipterygoid ist eine Verknöcherung des vom

1 J. Versluys, Streptostylie bei Dinosauriern, nebst Bemerkungen ïber die Verwandtschaft der Vögel und Dinosaurier. - Zool. Jahrb., Abt. f. Anat. ı. Ontog., XXX. Bd., 1910, S. 175 .

Derselbe, Das Streptostylieproblem und die Bewegungen im Schädel bei Sauropsiden. - Ibidem, Suppl. XV. 2. Bd. (Spengel-Festschrift), 1912, p. 545. 
Palatoquadratum aufsteigenden Astes (Processus ascendens palatoquadrati). Es ist schon bei Stegocephalen (bei Lyrocephalus, Fig. 216, und Eryops) nachgewiesen (vgl. S. 243) und findet sich weiter auch bei den primitiven Reptilien, wie den Cotylosauriern und den Theromorphen, bei Dinosauriern und Ornithischiern, bei Ichthyosauriern und Sauropterygiern; auch bei den Schildkröten ist dieser Knochen vorhanden. In diesen Fällen reicht das Epipterygoid fast immer bis zu den Parietalia hinauf, ist aber mit den Prootica nicht verbunden. Die Anlagerung der Epipterygoidea an die Seitenwand des Knorpelkraniums ist nach J. Versluys der primitive Zustand; die feste Stütze fand das Epipterygoid erst dann, als es beim weiteren Wachsen nach oben die Unter-

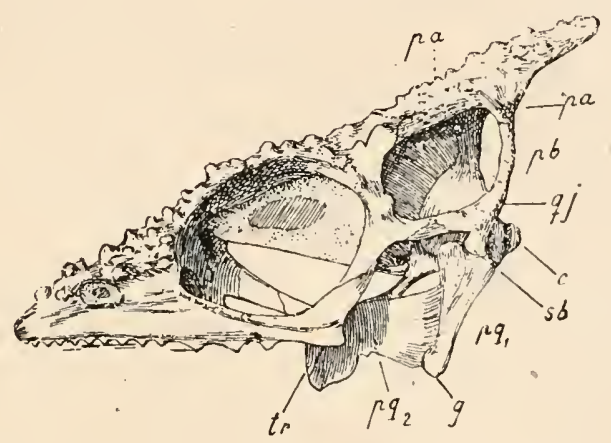

Fig. 518.

Schädel von Chamaeleo pumilus, von der Seite gesehen.

(Nach J. E. V. Boas.)

$p a=$ Parietale

$p b=$ Posttemporalbogen.

$p q_{1}=$ Quadratum.

$q j=$ Quadratojugale.

$c=$ Condylus.

$s b=$ oberer Schläfenbogen.

$p q_{2}=$ Pterygoid.

$g=$ Gelenkfläche für den Unterkiefer.

tr $=$ Transversum.

seite des knöchernen Schädeldaches e̊rreichte. So wurde dann das Epipterygoid zu dem Stützpfeiler, den es im Lepidosaurierschädel darstellt, ohne aber die Bewegungsfreiheit des Quadratums, des Pterygoids und der Kiefer irgend zu hemmen. Das Epipterygoid ist bei den Amphisbäniden, deren Schädel sekundär verfestigt worden ist und sich infolge der grabenden, unterirdischen Lebensweise wieder der Kapselform genähert hat, bedeutungslos geworden und verloren gegangen, ebenso bei den Chamläleoniden und Schlangen (Fig. 518).

Die Pariefalia sind fast immer miteinander verschmolzen, besitzen aber immer ein Parietalforamen; auch die Frontalia sind häufig verschmolzen. Das Postfrontale ist mit dem Postorbitale zu einem Postorbitofrontale verschmolzen. Ein Supraorbitale ist zuweilen vorhanden, das sich zwischen das Lacrymale und Adlacrymale 
einschiebt. Der Condylus des Hinterhauptes ist meist einfach, bei Amphisbäniden doppelt. Ein Septomaxillare ist ausgebildet.

Die Zähne verwachsen bei höherem Alter des Individuums in der Regel mit den angrenzenden Knochen, und zwar ist die Befestigungsart entweder pleurodont oder acrodont.

Die Wirbelsäule ist in einen Hals-, Thorakal-, Sakral- und Kaudalabschnitt gegliedert; der Halsabschnitt enthält bei den Dolichosauriden 13, sonst in der Regel 7, seltener 9 Wirbel; Zygosphen und Zygantrum sind zuweilen vorhanden. Die Rippen sind einköpfig.

Die Gliedmaßen sind auch bei den Formenreihen, bei denen sie zu Flossen umgeformt sind, niemals polydaktyl, und enthalten also nie mehr als 5 Finger oder Zehen; dagegen tritt bei den Mosasauriden zuweilen eine Phalangenvermehrung ein (Hyperphalangie). Bei den Lepidosauriern mit Schieb- oder Laufbeinen ist stets der vierte Fingerund Zehenstrahl der stärkste und längste, und die Phalangenformel der Hand ist in diesen Fällen 2, 3, 4, 5, 3, während im Hinterfuß die Plıalangenformel durch Hinzutreten einer Phalange in fünften Strahl in die Formel 2, 3, 4, 5, 4 abgeändert erscheint.

Der Brustgürtel umfaßt in der Regel die normalen Elemente und nur bei den Amphisbäniden ist infolge der geänderten Lebensweise das Sternum verloren gegangen. Die Scapula geht nach oben meist in ein knorpelig bleibendes Suprascapulare über.

Der Körper trägt bei den meisten Lepidosauriern hornige Schuppen; sie waren wohl auch bei den Mosasauriern vorhanden. Die Schuppen bedecken auch den Schädel.

Als die Stammgruppe der Lepidosaurier sind die Lacertilier anzusehen, wenngleich fossile Vertreter dieser Unterordnung nur sehr spärlich sind. Die älteste Lacertiliertype ist Paliguana aus der Trias der Kapkolonie.

Unterordnung: Lacertilia.

Der älteste Lacertilier ist Paliguana Whitei Broom ${ }^{1}$ aus der südafrikanischen Trias; schon bei dieser ältesten bis jetzt bekannten Art ist jedoch die untere Spange der unteren Temporalgrube bereits obliteriert, und der Schädel muß daher ebenso streptostyl (kinetiscli) gewesen sein wie bei den späteren Lacertiliern. Das Foramen parietale von Paliguana ist noch sehr groß. Im oberen Jura sind einzelne Arten gefunden worden, die sich vielleicht den Scincoiden einreihen lassen (Ardeosaurus), während andere möglicherweise den Anguiniden zuzuweisen sind (Euposaurus); auch aus dem älteren Tertiär fließen unsere

1 R. Broom, On the Skull of a True Lizard from the Triassic Beds of South Africa. - Records of the Albany Museum, Vol. I, Nr. 1, 1903. 
Kenntnisse von fossilen Lacertiliern verhältnismäßig spärlich. Häufiger werden sie im Miozän. Alle bekannten tertiären Lacertilier können unschwer den lebenden Familien eingereiht werden. Viele Namen fossiler Arten, die in der Literatur angeführt werden ${ }^{1}$ und eine verhältnismäßig gute Kenntnis der fossilen Lacertilier vortäuschen, sind auf ganz unbestimmbare Reste gegründet, die höchstens die Bestimmung der Unterordnung, aber nicht einmal die der Familie gestatten.

\section{Unterordnung: Thalattosauria.}

In der mittleren und oberen Trias Kaliforniens (Shasta County) sind Reste von Lepidosauriern gefunden worden, die eine hochgradige Anpassung an das Meeresleben aufweisen. ${ }^{2}$

Der Schäd:1 (Fig. 519) ist lang und besitzt ein spitz zulaufendes Rostrum, das aber im Vergleich zu den Ichthyosauriern kürzer und plumper bleibt. Die Nasenlöcher sind weit nach hinten bis in die Nähe der Augenhöhlen verschoben. Die Kieferknochen sind an der Oberfläche skulpturiert, was auf den Besitz eines Hautpanzers über diesen Teilen des Schädels schließen läßt. Zwei Temporalgruben sind vorhanden, die untere Abschlußspange der unteren Grube ist noch nicht verkümmert. Dies beweist, daß die Thalattosaurier von Vorfahren abstammen müssen, die siclı in diesem Punkte primitiver verhielten als Paliguana.

Ein Parietalforamen ist vorhanden.

Die Vomeres tragen niedrige Zälne, deren Krone die Gestalt von Rundbuckeln besitzt; die Pterygoide sind mit mehreren Reihen dichtstehender kegelförmiger Zähne besetzt. Dagegen sind die Supramaxillaria und der hintere Teil des Dentale nur mit wenigen stumpfen, niedrigen Buckelzähnen besetzt; nur auf den Vorderenden des Dentale und dem gegenüberstehenden Teil des Prämaxillare stehen höhere und spitzere Kegelzähne. Diese Ausbildungsart des Gebisses beweist, daß die Thalattosaurier keine Fischfresser waren, sondern durophag gewesen sein müssen; wahrscheinlich bestand ihre Nahrung aus Muscheln und anderen hartschaligen Mollusken, wie beschalten Cephalopoden u. dgl.

Die Wirbel sind amphicoel, die Dornfortsätze hoch und schlank. Die Rippen sind einköpfig; Bauchrippen waren vorhanden. Der Humerus ist stark verkürzt und distal verbreitert, Radius und Ulna etwa halb so lang als der Humerus. Die hinteren Gliedmaßen sind noch unbekannt.

1 F. von Nopcsa, Zur Kenntnis der fossilen Eidechsen. - Beiträge zur Paläontologie und Geologie Österreich-Ungarns und des Orients, XXI. Bd., 1908, S. 33 .

2 J. C. Merriam, The Thalattosauria. A Group of Marine Reptiles from the Triassic of California. - Memoirs of the California Academy of Sciences, Vol. V, Nr. 1, 1905, p. 1 . 


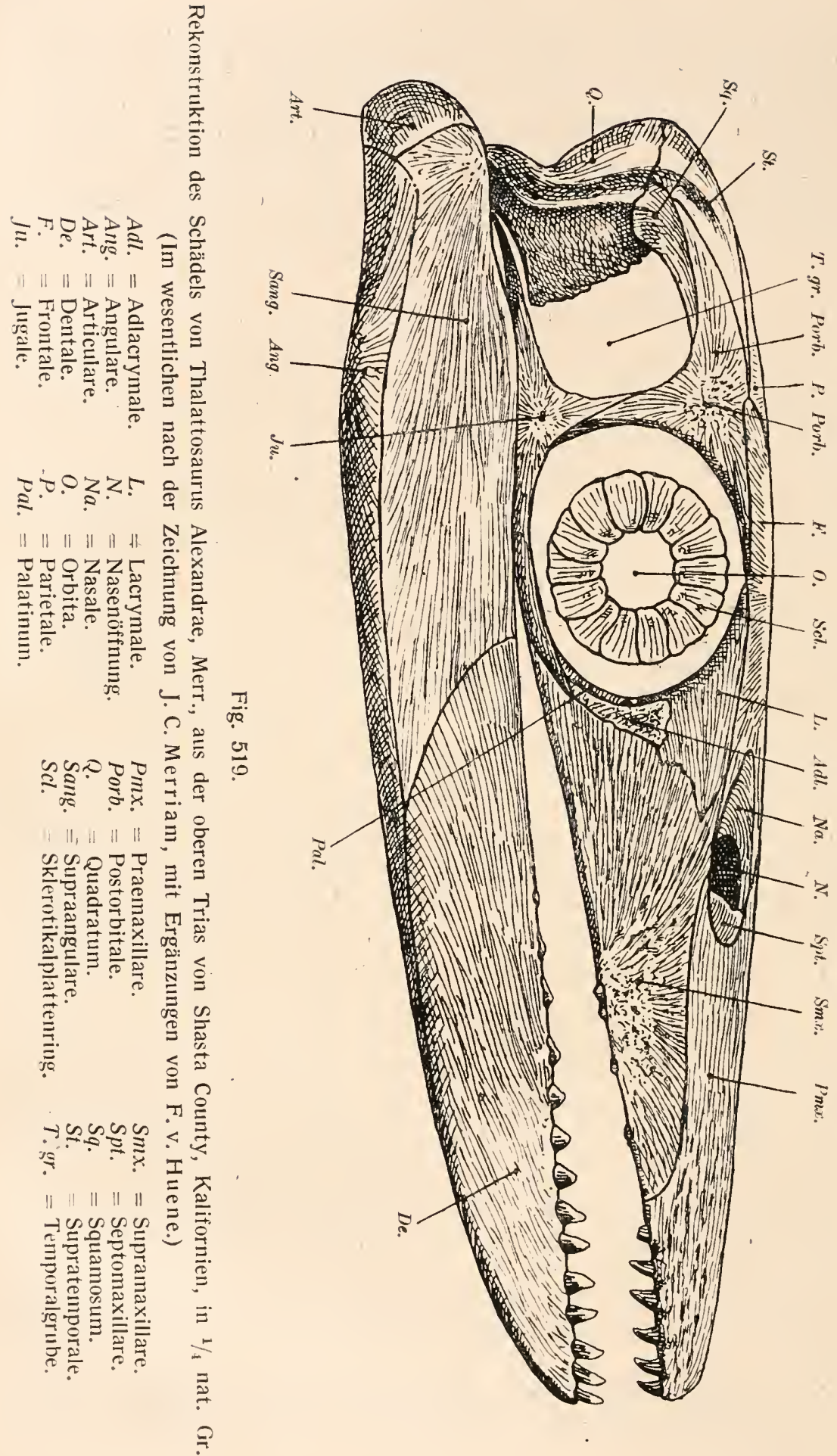


Aus dem Spezialisationsgrade der Gliedmaßen in Verbindung mit der Verschiebung der Nasenlöcher nach hinten, sowic aus dem Vorhandensein eines starken Sklcrotikalringes geht hervor, daß die Tiere Schwimmer gewesen sind, die sich wahrscheinlich in der Nähe der Kïste aufhielten, wo sie den Meeresboden nach Mollusken u. dgl. absuchten.

Das von Huene ${ }^{1}$ festgestellte Vorhandensein und die Lage des Septomaxillare sowie die Ausbildung eines Supratemporale nähern die Thalattosaurier meln den Lacertiliern als den Rhynchocephalen, und zwar ist die Ähnlichkeit mit den Varaniden einerseits und den Mosasauriern andererseits besonders groß.

Ein Quadratojugale ist bei den Thalattosauriern bis jetzt nicht nachgewiesen.

Thalattosaurus. - Trias Kaliforniens. - Die größte der drei bescluriebenen Arten ist Th. Alexandrae, der eine Körperlänge von etwa 2 m erreicht haben dürfte (Fig. 519).

Nectosaurus. - Trias Kaliforniens. - Viel kleiner als Thalattosaurus; Zähne kegelförmig, spitz, wahrscheinlich zahlreicher als bei Thalattosaurus.'

Unterordung: Dolichosauria.

Diese Gruppe umfaßt aquatisch gewordene Lacertilier aus der Verwandtschaft der Varaniden. Sie sind klein, besitzen einen langgestreckten, blindschleichenälnlichen (nicht molchförmigen!) Körper; der Schädel ist klein. Der Halsabschnitt unfaßt $13 \mathrm{Wirbel}^{2}$, die nach vorn an Größe stark abnehmen; der Rumpfabsclnnitt besteht aus 26 Wirbeln, das Sacrum aus 2 Wirbeln. Der Schwanz ist sehr lang und umfaßt bei Adriosaurus Suessi ungefähr 66 Wirbel; auf den Kaudalwirbeln stehen hohe Neurapophysen und Hämapophysen, wie dies für einen Ruderschwanz bezeichmend ist. Der walzenförmige Leib trägt noch beide Gliedmaßenpaare, aber das vordere ist viel kleiner als das hintere (ursprünglich etwa halb so lang). Unterarm- und Unterschenkelknochen durch ein weites Spatium interosseum getrennt, was auf cine breite Ruderflosse hindeutet. Nur aus dem Neokom bei Triest (Comen) und Dalmatien (Insel Lesina) sowie aus der oberen Kreide Englands bekannt.

1 F. von Huene, Über einen echten Rhynchocephalen aus der Trias von Elgin, Brachyrhinodon Taylori. - Neues Jahrbuch für Mineralogie 11sw., 1910, I1. Bd., S. 45 .

2 Diese Zahl ist das wichtigste Unterscheidungsmerkmal der Dolichosaurier von den Mosasauriern, die ausnahmslos nur sieben Halswirbel besitzen. 
Pontosaurus. - Unterkreide (Neokom) der Insel Lesina. - Verlıältnis der Länge der Vorder- zur Hinterextremität $11: 22 .{ }^{1}$ Der kleinste Dolichosauride und dem terrestrischen Lacertiliertypus am nächsten stehend.

Actaeosaurus. - Unterkreide (Neokom) von Comen. - Verhältnis der Länge der Vorder- zur Hinterextremität $11: 18 .^{2}$ Gliedmaßen bereits stärker an das Wasserleben angepaßt.

Adriosaurus. - Unterkreide von Comen (bei Triest) und Lesina (Dalmatien). - Verhältnis der Länge der Vorder-zur Hinterextremität wie 11:16.3 Die abnehmende Länge des Hinterfußes im Laufe der Stammesgeschichte der Dolichosauriden beweist eine parallele Anpassung an das Wasserleben, wie sie die Mosasaurier aufweisen, und die Ausbildung des auch bei den Rhynchocephalen (Pleurosaurus) zu beobachtenden niosasauriformen Anpassungstyps (Abel) infolge eigenartiger Bewegungsart im Wasser, wobei die Lokomotion im wesentlichen durch das Schlängeln des Körpers bewirkt wird (Fig. 520). Ein weiterer Fall konvergenter Anpassung tritt uns bei einem der jüngsten und selır hoch spezialisierten Ichthyosaurier, I. platydactylus aus der Unterkreide Norddeutschlands, entgegen.

Dolichosaurus. - Obere Kreide Englands. - Hinterer Rumpfabschnitt und Hintergliedmaßen unvollkommen bekannt. Die Gattung schließt sich in den wesentlichen Skelettmerkmalen enge an die übrigen Gattungen aus der unteren Kreide an und unterscheidet sich selır bestimmt von den ältesten Mosasauriern.*

1 A. Kornhuber, Über einen neuen fossilen Saurier aus Lesina. - Abhandlungen der K. K. Geol. Reichsanstalt in Wien, V. Bd., 4. Heft, 1873, S. 73.

F. von Nopcsa, Zur Kenntnis der fossilen Eidechsen. - Beiträge zur Paläontologie und Geologie Österreich-Ungarns u. des Orients, XXI. Bd., 1908, S. 45 (Literatur).

2 H. von Meyer, Actaeosaurus Tommasinii aus dem schwarzen Kreideschiefer von Comen an Karste. - Paläontographica, VIl. Bd., 1860, p.·223.

F. von Nopcsa, 1. c., 1908, p. 36.

${ }^{3}$ H. G. Seeley, On Remains of a Small Lizard from the Neocomian Rocks of Comen, near Trieste, preserved in the Geological Museum of the Univessity of Vienna. - Quarterly Journal of the Geological Soc. London, Vol. XXXV11, 1881, p. 52 .

F. von Nopcsa, Über die varanusartigen Lacerten Istriens. - Beiträge zur Paläontologie usw., Wien, XV. Bd., 1903, p. 32.

Derselbe, I. c., lbidem, 1908, p. 50.

4 R. Owen, Monograph of the Fossil Reptilia of the Cretaceous Formations. Palaeontugraphical Society, London, 1851-1864.

F. von Nopcsa, 1. c., 1908, p. 39 und 55 (Literatur!). 

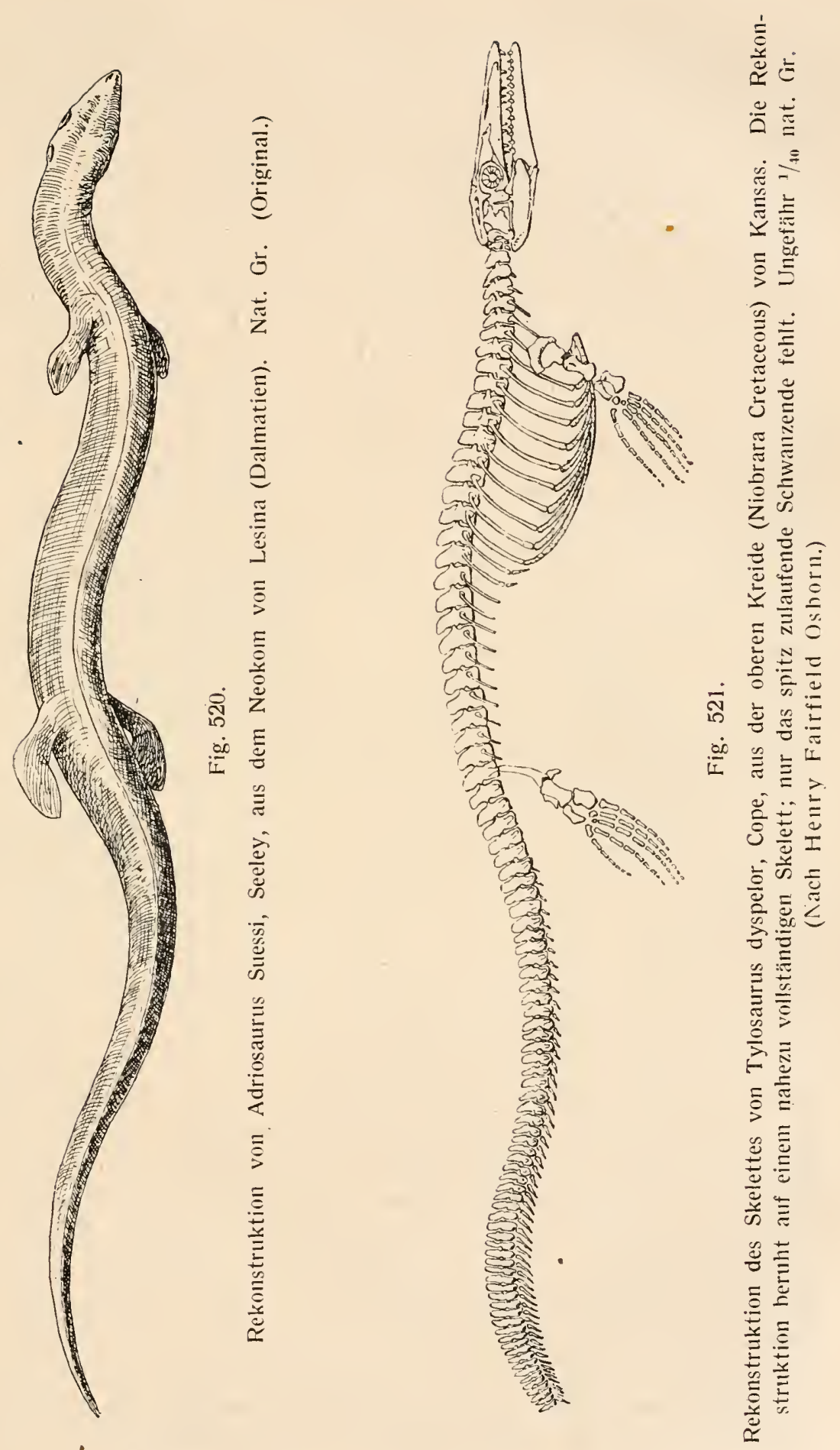
Unterordnung: Mosasauria (= Pythonomorpha).

Die Mosasaurier, deren Hauptentfaltung in die obere Kreide (Turon und Senon) fällt, waren große, langgestreckte Meeresreptilien, deren Skelett im Vergleich zu den Lacertiliern, die ihre Vorfahren sind, mancherlei durchgreifende Veränderungen infolge vorgeschrittener Anpassung an das Meeresleben erfahren hat. Die Gliedmaßen sind zu Ruderflossen umgeformt, die den schlanken, beschuppten Körper bei seiner in wesentlichen schlängelnden Lokomotion unterstützten und wohl auch als Steuerorgane dienten. Der Schwanz ist nur bei Clidastes und Tylosaurus stärker spezialisiert, indem bei diesen Formen entweder die Neurapophysen und Hämapophysen vor dem Schwanzende stärker erhöht sind, was auf den Besitz einer lanzettförmigen Terminalflosse deutet (Clidastes) oder es sind die letzten Schwanzwirbel schwach nach unten abgebogen, ohne aber den hohen Spezialisationsgrad dieser Anpassungsrichtung zu erreichen, wie er entweder bei den Geosauriden oder bei den Ichthyosauriern vorliegt (Tylosaurus). Die .Umformung der Gliedmaßen ist bei den verschiedenen Gattungen bzw. Formenreihen verschiedene Wege gegangen, so daß wir daraus entnelnmen können, daß innerhalb des Stammes der Mosasaurier verschiedene divergente Spezialisationsrichtungen vorliegen; es ist indessen bis jetzt noch nicht möglich, diese verschiedenen Stammeslinien, die sich divergent entwickelt haben, mit voller Schärfe zu trennen. Zweifellos gehört z. B. Mosasaurus einer ganz anderen Formenreihe als Platecarpus oder Clidastes an. Die Spezialisation der Flossen der Mosasaurier ist ganz eigenartig (Fig. 521) und läßt sich mit den Flossentypen der übrigen, sekundär zum Wasserleben übergegangenen Landwirbeltiere nur äußerlich vergleichen. Stets ist die Vorderseite der Hand und des Fußes stärker als die Hinterseite, was besonders durch die Verstärkung von Radius und Tibia, aber auch, z. B. bei Mosasaurus (Fig. 522), durch die ausgesprochene Verstärkung des ersten Zehenstrahls ihren Ausdruck findet. Der fünfte Zehenstrahl ist bei Mosasaurus auf das Metatarsale $V$ redıziert, während bei den übrigen Formen die fünfte Zehe funktionell war und nach hinten als Stütze und Spreize der breiten Flosse von den übrigen Fingem oder Zehen abgespreizt erscheint (z. B. bei Platecarpus). Die Carpalia und Tarsalia lassen sich, was z. B. bei den Ichthyosauriern infolge der hochgradigen Spezialisation der Flossen nicht so leicht möglich iste, mit den entsprechenden Elementen des Varanidenfußes unschwer homologisieren; es sind verschiedene Verschmelzungen, Verschiebungen und Reduktionen der Carpalia und Tarsalia zu beobachten, die bei den verschiedenen Gattungen sehr abweichend ausgebildet sind. Überzählige Phalangen kommen zuweilen vor, ảber es sind sowohl die Phalangen als auch die Meta- 
podialknochen bei weitem nicht in dem Grade wie bei den lchthyosauriern modifiziert.

Im Schädel fällt vor allem die Verschmelzung der in der Mittellinie des Schädeldaches gelegenen vorderen Knochen (z. B. Clidastes) zu einem einheitlichen Knochen auf (Praemaxillaria + Frontalia), doch bleiben die Parictalia stets von diesem Komplex getrennt, wenn sie auch untereinander verschmolzen sind. In der Mitte zwischen beiden Parietalia, deren Naht gänzlich obliteriert ist, steht ein Foramen parietale, das namentlich bei den tauchenden Gattungen (Plioplatecarpus) sehr groB, bei den Oberflächenschwimmern (Mosasaurus) kleiner ist. Die

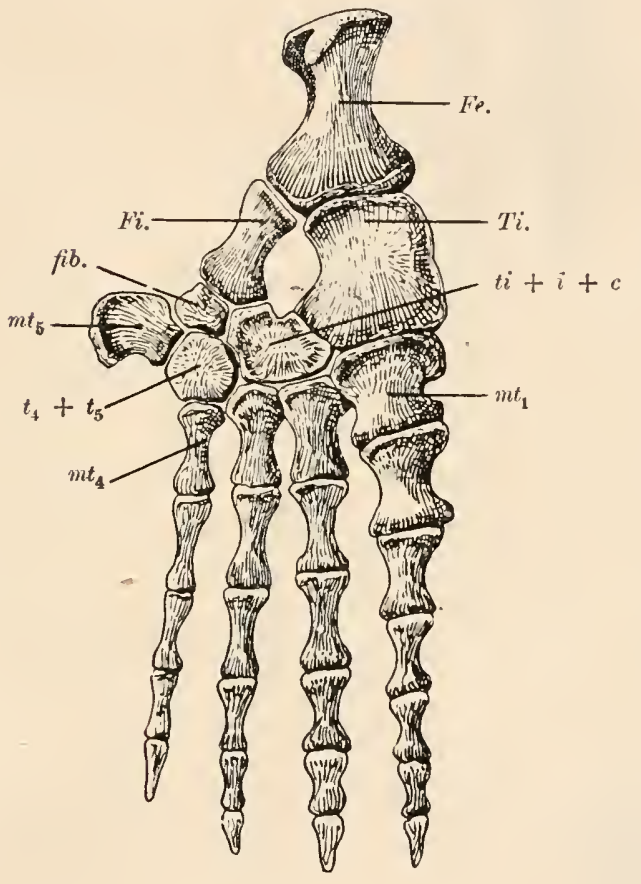

Fig. 522 .

Hinterflosse von Mosasaurus Lemonnieri, Dollo, aus der oberen Kreide Belgiens. Stark verkleinert.

(Nach L. Dollo.)

$\mathrm{Fe}$. $\quad$ Femur.

Fi. $\quad$ Fibula .

Ti. $\quad=$ Tibia.

fib. $\quad=$ Fibulare.

$t i+i+c=$ Tibiale + Intermedium + Centrale.

$t_{4}+t_{5}=$ Tarsale IV + V.

$m t_{1}=$ Metatarsale $\mathrm{I}$.

$m t_{4} \quad$ Metatarsale IV.

$m t_{5} \quad$ Metatarsale $\mathrm{V}$.

Nasalia sind rudimentär (nach Huene, 1910) und bei Tylosaurus (Fig. 523), Prognathosaurus, Mosasaurus und Leiodon nachgewiesen.

Eine weitere Eigentünılichkeit des Mosasaurierschädels ist die Gestalt des Quadratums.. Es hat hier seine bei den Lacertiliern als Hebel zur Aufwärtsbiegung des vorderen Schädelteiles dienende Funktion gänzlich eingebüßt und dient hier hauptsächlich zur Einlenkung des Artikulare des Unterkiefers; der Schädel scheint (nach J. Versluys, 1912) akinetisch gewesen zu sein. Das Quadratum war vielleicht in unbedeutenden Grenzen bewegungsfähig, aber nicht in dem Grade wie z. B. bei den Varaniden. Dagegen hat es eine sehr merkwürdige, an das Tympanicum der Cetaceen erinnernde Bullaform angenommen und besitzt eine Einbuchtung, oder ein Fenster für den äußeren Gelı̈rgang; 


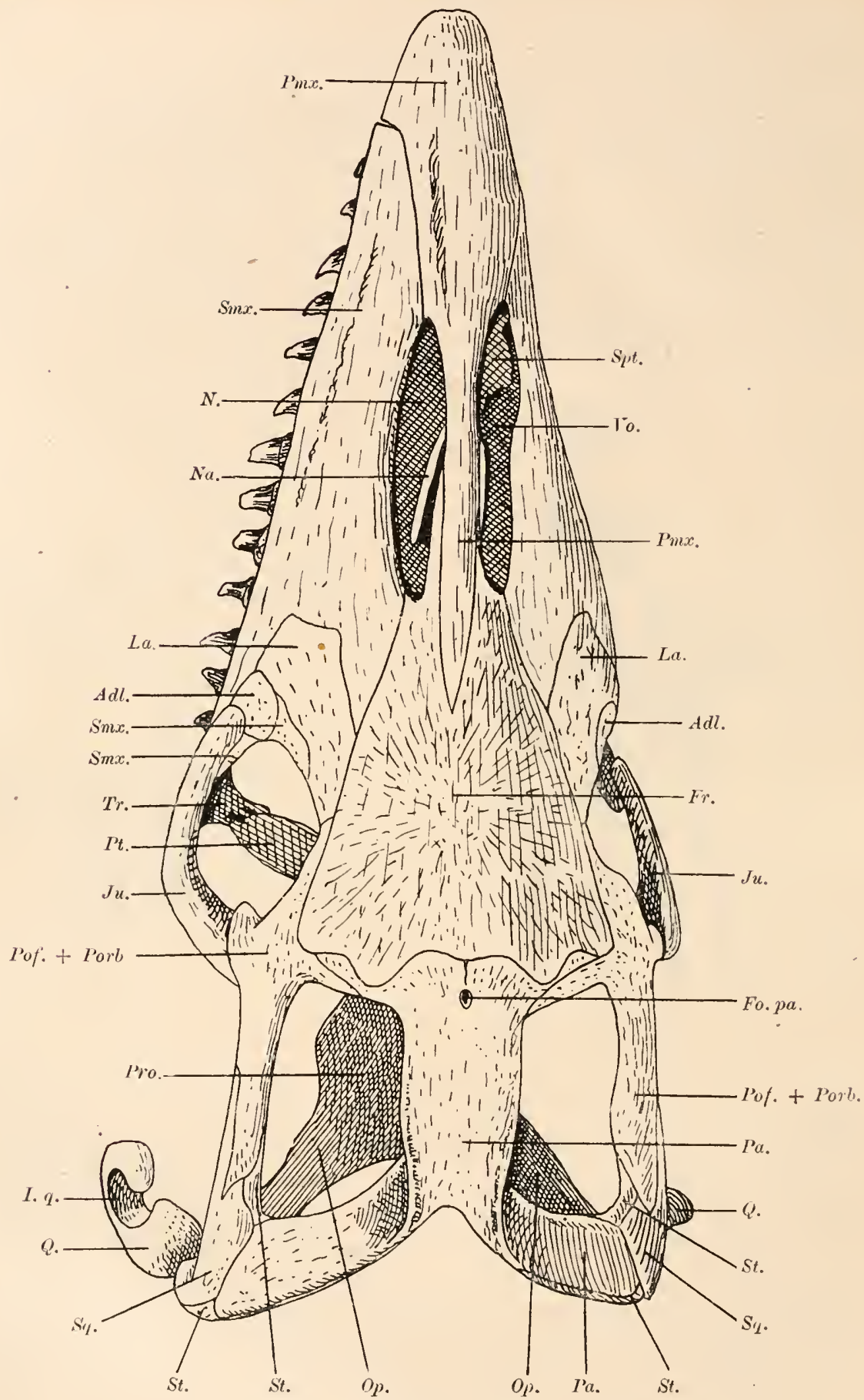

Fig. 523.

Oberansicht eines etwas verdriickten Schädels von Tylosaurus dyspelor, Cope, aus der oberen Kreide von Kansas, in $1 / 6$ nat. Gr. (Nach F. v. Huene.) 
dieses Fenster wird vom Trommelfell verschlossen, an das sich zunächst eine ursprünglich knorpelige Extracolumella anlegt (wie bei den Lacertiliern), die sich in die Columella (= Stapes) fortsetzt (Fig. 524). Der Stapes verschließt mit seiner ovalen Basalplatte die Fenestra ovalis, die sich zwischen dem Prooticum und Opisthoticum in das Innenohr öfnet. Bei einigen Mosasauriern (z. B. Mosasaurus) sind diese noch mehr an die Varaniden gemahnenden Verhältnisse der Quadratregion erhalten geblieben, aber bei anderen (z. B. Plioplatecarpus) ist die Extracolumella verknöchert und mit dem verknöcherten Trommelfell zu einer kompakten_Masse verwachsen (Fig.525). L. Dollo hat (1905) gezeigt, daß diese Modifikation der Extracolumella und die Verknöcherung des Trommelfells ein Gegenstück in der Verstärkung der analogen Elemente bei den Cetaceen findet und daß diese Veränderungen als Anpassungen an die tauchende Lebensweise von Plioplatecarpus zu erklären sind, während Mosasaurus mit häutigem Trommelfell und knorpelig gebliebener Extracolumella ein Oberflächenschwimmer gewesen sein muß.

Die äußeren Nasenöffnungen sind sehr schmal und lang und nach hinten verschoben. In ihrem Grunde liegen die Septomaxillaria.

Wie bei den Varaniden fehlt auch bei den Mosasauriern die untere Abschlußspange der unteren Temporalgrube. Das Transversum ist klein, ebenso das Epipterygoid, das bei den akinetisch gewordenen Schädel nicht mehr die Rolle wie bei den Varaniden usw. spielt. Das Postfrontale ist mit dem Postorbitale verschmolzen, wie dies auch schon bei den Varaniden der Fall ist (Postorbitofrontale). Die Augenhöhlen sind groß und durch einen Sklerotikalring verschlossen.

Eine weitere Eigentümlichkeit der Mosasaurier ist die Ausbildung eines sekundären Gelenks in der Mitte des Unterkiefers (Fig. 526). Das Dentale und Spleniale einerseits und das Angulare und Supraangulare anderseits bilden zwei Stücke, die in einem Gelenk zusammenstoßen. Das Complementare umfaßt dachreiterartig den Oberrand des Supraangulare und nimmt mit seiner Vorderspitze noch an der Gelenkbildung teil.

Zu Fig. 523.

$\begin{array}{ll}\text { Adl. } & =\text { Adlacrymale. } \\ \text { Fr. } & =\text { Frontale sin. }+ \text { Frontale } \\ & \text { dext. } \\ \text { Fo.pa. } & \text { Foramen parietale. } \\ \text { I.q. } & =\text { Incisura quadrati. } \\ J u . \quad & =\text { Jugale. } \\ \text { La. } & =\text { Lacrymale. } \\ N . & =\text { Nasenöffnung. } \\ N a . \quad & \text { Nasale. } \\ O p . \quad & \text { Opisthoticum. } \\ P a . & =\text { Parietale. }\end{array}$

Pmx.

Pof. + Porb. $=$ Postfrontale + Postorbitale.

Pro. $\quad=$ Prooticum.

Pt. $\quad=$ Pterygoid.

Q. $\quad=$ Quadratum.

Sim. $\quad=$ Supramaxillare.

Spt. $\quad=$ Septomaxillare.

Sq. $\quad=$ Squamosum.

St. $\quad=$ Supratemporale.

Tr. $\quad=$ Transversum.

Vo. $\quad=$ Vomer.

(Die Gesamtlänge des Skelettes, dem der in Fig. 523 abgebildete Schädel angehört, wird von F.v. Huene auf $7.86 \mathrm{~m}$ veranschlagt. Die sonst mit den Fr. verschmolzenen Pmx. sind hier von den ersteren noch getrennt.) 


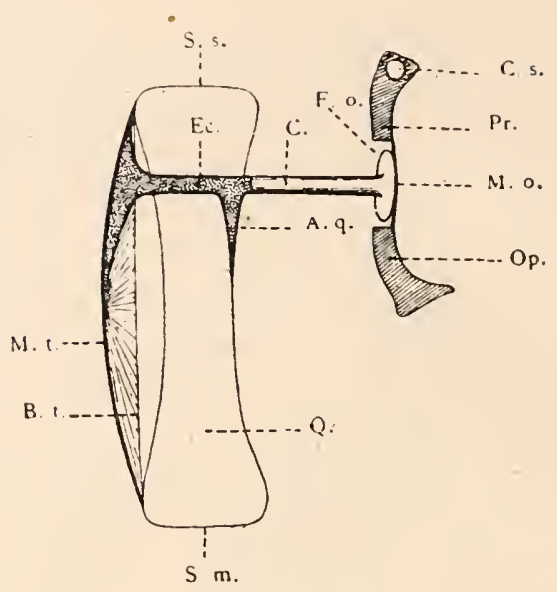

Fig. 524.

Der Gehörapparat einer Eidechse, schematisiert.

(Nach W. K. Parker, J. Versluys und L. Dollo.)
A. q. = Fortsatz der Extracolumella gegen das Quadratum.
M. o. = Membrana ovalis.
B. $t$. = Rand der tympanischen Mem-
C. $\quad$ bnöcherner Teil der Columella
M. $t$. = Membrana tympanica.
C. $s$. = Canalis semicircularis horizon- talis.
Ec. = Extracolumella (knorpelig).
F. $o$. = Fenestra ovalis.
Op. = Opisthoticum.
Pr. = Prooticum.
Q. = Quadratum.
$S m$. = Gelenkfläche gegen den
S. s. - Gelenkfläche gegen das Squamosum.
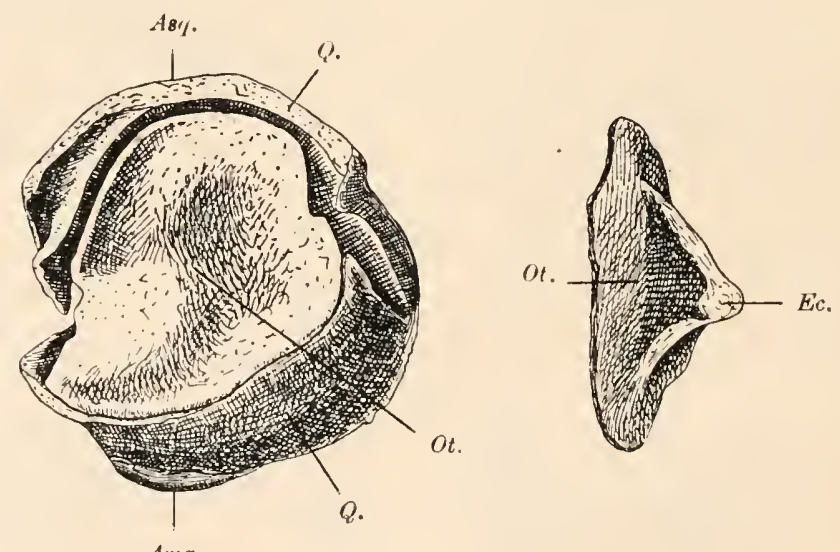

Ama.

Fig. 525.

Außenseite des rechten Quadratums (links) und Profilansicht (rechts) des rechtsseitigen Operculum tympanicum von Plioplatecarpus Houzeaui, Dollo, aus denı oberen Senon (Oberkreide) Belgiens. 1/2 nat. Gr. (Nach L. Dollo.)

Q. = Quadratum.

Ot. = Operculum tympanicum.

$E c$. = verknöcherter Abschnitt der Extracolumella, mit dem Op. tymp. verwachsen.
Asq. = Gelenkfläche gegen das Squamosum.

Ama. = Gelenkfläche gegen den Unterkiefer. 
Die Mosasaurier waren daher zum Teil furchtbare Räuber des Kreidemeeres; aber Plioplatecarpus aus dem Senon von Maestricht und Belgien weist eine erhebliche Reduktion des Gebisses auf und dürfte daher wahrscheinlich ähnlich wie Ophthalmosaurus unter den Ichthyosauriern zur Cephalopodennahrung übergegangen, also teuthophag geworden sein. L. Dollo hat (1913) einen Mosasaurier mit sehr plumpen und dicken Zähnen beschrieben (Globidens Fraasi), der jedenfalls durophag gewesen sein muß und sich vorwiegend von Echinodermen und Lamellibranchiaten genälırt haben dürfte (Fig. 527).

Die Zähne stehen sowohl auf den Kieferknochen (Praenaxillaria, Supramaxillaria, Dentalia) als auch auf den Pterygoidea. Bei den ältesten bekannten Mosasauriergattungen (Aigialosaurus, Opetiosaurus, Carsosaurus, aber auclı noch bei der senonen Gattung Prognathosaurus) waren die Pterygoidea bezahnt; sonst sind sie zahnlos. Die Zähne stehen in

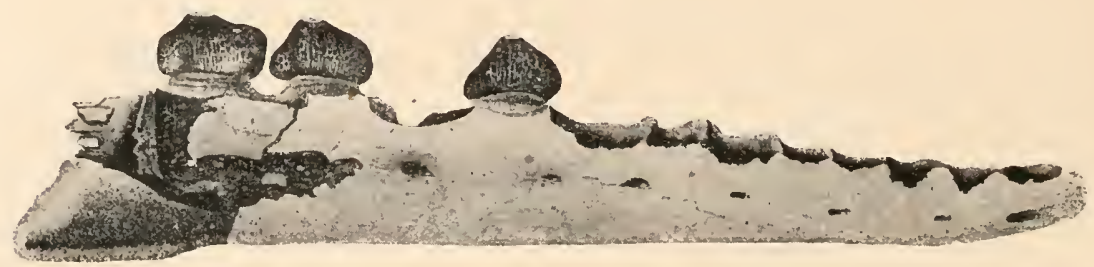

Fig. 527.

Globidens Fraasi, Dollo; ein durophager Mosasaurier aus der oberen Kreide (Maestrichtien) von Limburg in Holland. Rechtes Dentale von der Außenseite in ungefähr $1 / 2$ nat. Gr. (Nach L. Dollo, 1913.)

seichten Alveolen und sind mit den Knochen, auf denen sie sitzen, fest verwachsen. Die Ersatzzähne entwickelten sich an der Innenseite der jeweils funktionierenden Zähne in den Kiefern. Die Wurzel ist unterhalb der Krone meist beträclitlich angeschwollen (vgl. z. B. Fig. 528).

In der Wirbelsäule umfaßt der Halsabschnitt nie mehr als 7 Wirbel; die Zahl der folgenden präsakralen Wirbel sclıwankt von 20 (bei Opetiosaurus und Aigialosaurus) bis zu 39 rippentragenden +12 rippenlosen Wirbelı (also zusammen 51) bei Mosasaurus Lemomieri; dabei ist aber zu beachten, daß die Gesantsumme alle ${ }^{\circ}$ Wirbel zwischen 117 und 134 schwankt und daß Opetiosaurus (130) und Mosasaurus (134) fast dieselbe Wirbelzalıl aufweisen. Ebenso hat auch Plioplatecarpus inl ganzen 126 Wirbel, aber davon sind 7 Halswirbel, 13 Dorsalwirbel, 18 Lumbarwirbel und 88 Kaudalwirbel. Die Halswirbel sind durch das Auftreten großer, mit den Wirbelkörpern verschmolzenen Hypozentren (= Interzentren-Hypapophysen) gekennzeiclmet. Die Dorsalwirbel tragen cinköpfige Rippen; die folgenden Wirbel ohne freie Rippen 
(Lendenwirbel= Lumbarwirbel) besitzen Querfortsätze, die aus den mit den Wirbelkörper vereinigten rudimentären Rippen bestehen. Alle Wirbel sind procoel.

Der Brustgürtel ist plattig verbreitert; besonders groß ist das Coracoid. Claviculae scheinen zu fehlen.

Der Beckengürtel ist bei den jüngeren Mosasauriern frei gewesen wie bei den Walen oder den Iclithyosauriern. Nur bei den ältesten Gattungen (Aigialosaurus, Opetiosaurus) sind noch zwei Wirbel als Sakralwirbel mit den Ilimm in Verbindung getreten. Die auffallende Tatsache, daß die Wirbelzahl der älteren Gattungen mit jenter der jüngsten Gattungen nahe übereinstimnt und sich ungefähr um die Zahl 130 bewegt, wänrend die Rumpfwirbelzahl im ersten Falle 20, inı zweiten 51 beträgt, scheint mir dafür zu sprechen, daß eine Verlagerung des Beckens in der Richtung nach hinten eingetreten ist, bedingt durch die Funktion der Hinterextremitäten als Ruderflossen und Steuerapparate.

Aigialosaurus. - Neokom der Insel Lesina (Dalmatien). ${ }^{1}$

Carsosaurus. - Neokom von Comen in österreichisclıen Küstenland. ${ }^{2}$

Opetiosaurus. - Neokom der Insel Lesina ${ }^{3}$ (F g. 528).

Von den drei genannten Gattungen ist die letzgenannte an besten bekannt. Das Tier besaß einen sehr langen Schwanz und unterscheidet sich von den jüngeren Mosasauriden ausschließlich durch graduelle Differenzen, so daß es in jeder Hinsicht den Anforderungen entspricht, die an eine Ahnenform zu stellen sind. In vielen Merkmalen noch an die Varaniden erinnernd, welche zweifellos die Ahnengruppe der Mosasauriden bilden, stellt es in anderen eine Übergangsstufe zwischen den Varaniden und den jüngeren Mosasauriden dar. Unter den primitiven Merkmalen sind zu nennen: die noch durchaus an den Warantypus erinnernden Gliedmaßen mit nur wenig verkürzten Extrenitätenknochen und normaler Plralangenzahl des Lacertilierfußes, das bezahnte Pterygoid, die

1 C. Gorjanovic-Kramberger, Aigialosaurus, eine neue Eidechse aus den Kreideschichten der Insel Lesina usw. - Societas Historico-Naturalis Croatica. VII. God., Agram (Zagreb), 1892, p. 74.

2 A. Kornhuber, Carsosaurus Marchesettii, ein neuer fossiler Lacertilier aus den Kreideschichten des Karstes bei Komen. - Abhandlungen der K. K. Geol. Reichsanstalt in Wien, XV11. Bd., 1893.

${ }^{3}$ Derselbe, Opetiosaurus Bucchichi. Eine neue fossile Eidechse aus der unteren Kreide von Lesina in Dalmatien. - Ibidem, XVII. Bd., 5. Heft, 1901.

F. von Nopcsa, Über die varanusartigen Lacerten Istriens. - Beiträge zur Paläontologie und Geologie Österreich-Ungarns und des Orients, XV. Bd., 1903, S. 31. S. 33.

Derselbe, Zur Kenntnis der fossilen Eidechsen. - Ibidem, XXI. Bd., 1908, 
Verbindung des Iliums mit 2 Sakralwirbeln und das Vorhandensein von Nasalia am Ende der Nasenöffnungen, die etwa die Form, Lage und

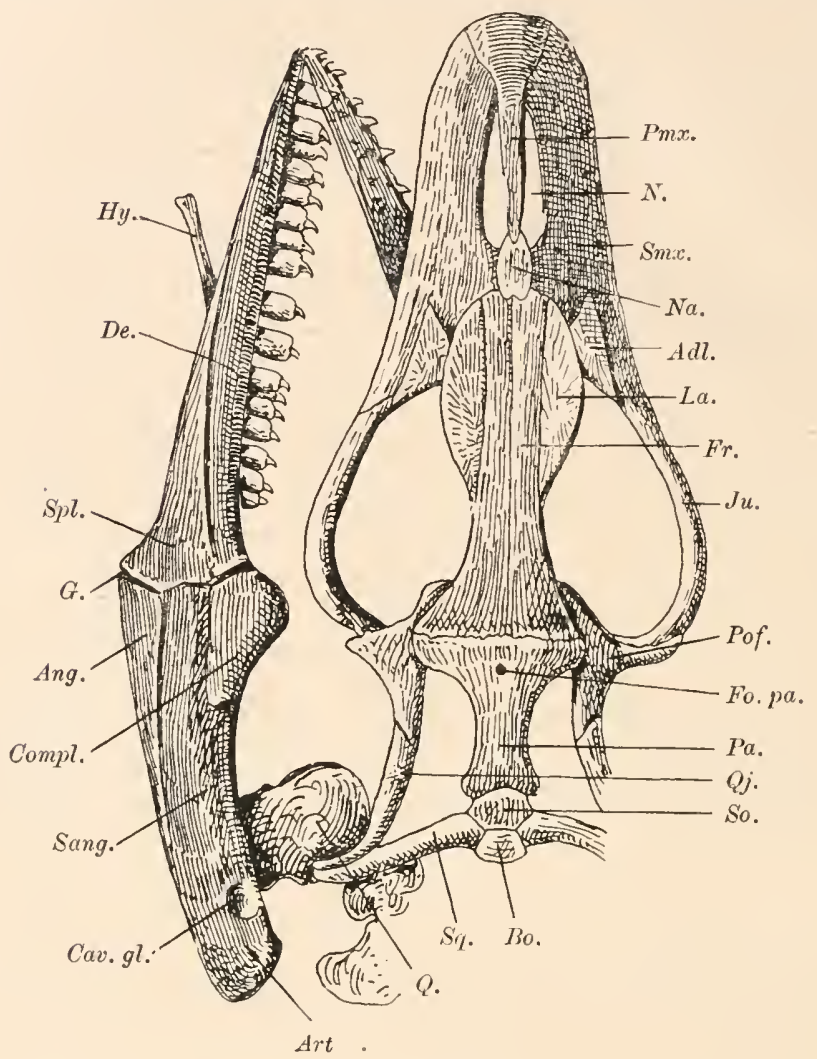

Fig. 528.

Schädel und Unterkiefer von Opetiosaurus Bucchichi, Kornhuber, aus der unteren Kreide der Insel Lesina in Dalmatien. $3 / 4$ nat. Gr. Schädeldach von oben gesehen; Unterkiefer verdrückt und verschobenl, so daß der linke Ast von der Außenseite sichtbar ist. (Mit Benuitzung der Abbildungen von $\mathrm{A}$. Kornhuber und $\mathrm{F}$. von Nopcsa gezeichnet, Original-Rekonst.)

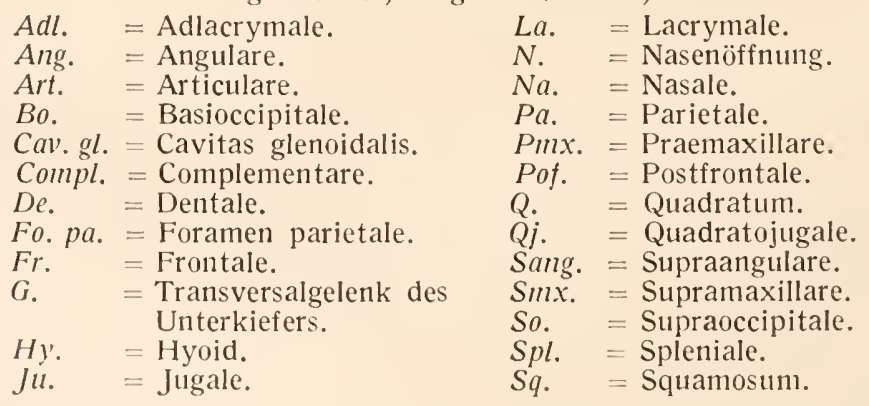

Größe der Nasalia eines Varanus besitzen. Der Aufbaı des Hinterlıauptes ist infolge der starken Verdrückung des Restes nicht klar zu erkennen. 
Mosasaurus. - Senon und Maestrichtien von Holland (Petersberg bei Maestricht), Belgien; Turon und Senon von Norddeutschland, Frankreich, Oberitalien (?), Nordamerika und Neuseeland (hier vielleicht in Cenoman1). - Diese Gattung enthält die größten Arten unter den Mosasauriern; einzelne dürften eine Länge von über $12 \mathrm{~m}$ erreicht haben; die Länge des berühınten Mosasaurus Camperi betrug ungefähr 7,50 m, wovon 1,20 $\mathrm{m}$ auf den Schädel entfallen. Die Nasalia sind frei, aber klein (wie dies schon bei Opetiosaurus und den Varaniden der Fall ist). Die Tiere müssen, wie aus ihrem Gebiß hervorgeht, furchtbare Raubtiere gewesen sein. M. Camperi (Holland), M. Lemonnieri (Belgien) und viele andere Arten $^{1}$ (Fig. 522).

Clidastes. - Turon und Senon von Nordamerika (Kansas, New Jersey, Alabana). Körperlänge durchschnittlich $4 \mathrm{~m}$. Die Wirbel besitzen, was sonst bei den Mosasauriden nur sehr selten zu beobachten ist (z. B. Platecarpus), Zygosphen und Zygantrum. Die Neurapophysen der Schwanzwirbel sind vor dem Ende des Schwanzes verlängert, ebenso die antagonistischen Hämapophysen ${ }^{2}$ (Fig. 529).

Dollosaurus. - Senon des Donetzbeckens (Rußland). Vom Schädel sind außer dem Unterkiefer nur unbedeutende Reste bekannt; dagegen liegt ein größerer Abschnitt der Wirbelsäıle vor, in der die Zygosphene deutlich entwickelt sind. Die Reste aus dem Senon des Gouvern. Saratow in den Gegenden südlich vom Ural (Turgaisk in Russ.-Asien) lassen einstweilen keine präzise Bestimmung zu., ${ }^{3}$

Platecarpus. - Turon und Senon von Nordamerika (Kansas, Wyoming, Colorado, Norddakota, Texas) und vielleicht auch in Frankreich. - Die Tiere erreichten eine Körperlänge von höchstens 5,6 m. Der Rumpf ist kürzer als bei Clidastes, was als ein primitives Merkmal anzusehen ist; ob die minutialen Zygosphenbildungen rudi-

1 Eine Liste der von L. Dollo über die Mosasaurier der belgischen Oberkreide veröffentlichten Abhandlungen ist enthalten in: L. Dollo, Les Mosasauriens de la Belgique. - Bull. Soc. Belge de Géologie, Paléontologie et d'Hydrologie, T. XVIII, Bruxelles 1904, p. 207.

Die umfangreiche Literatur iiber die Mosasaurierreste Nordamerikas ist zu finden in: S. W. Williston, Mosasaurs. - Univers. Geol. Survèy Kansas, Vol. IV, 1898 , p. 83 sowie in der Bibliographie der fossilen Wirbeltiere Nordamerikas von O. P. Hay (Bulletin Nr. 179 of the U. S. Geological Survey, Washington, 1902, p. 464 -473). - Weitere Arbeiten (bis 1910) vgl. bei F. Broili (in der Neubearbeitung der ,Grundzïge der Paläozoologie“" von K. A. von Zittel), 1911, S. 211.

2 S. W. Williston, Mosasaurs, 1. c.

O. Abel, Paläobiologie der Wirbeltiere, 1912, p. 160-162.

${ }^{3}$ N. Yakovlew, Restes d'un Mosasaurien trouvé dans le Crétacé supérieur du Sud de la Russie. - T. XX des Bulletins du Comité géologique, St. Petersburg, 1901, p. 507.

Derselbe, Notes sur les Mosasauriens. - 1bidem, T. XXIV, 1906, p. 135. 
mentär oder orimentär sind, ist fraglich. Die Augen standen lateral; das Parietalforamen ist groß. Dic Zähne sind schlank und etwas nach hinten gewendet. - Z. B. P. coryphaeus $^{1}$ (Fig. 530).

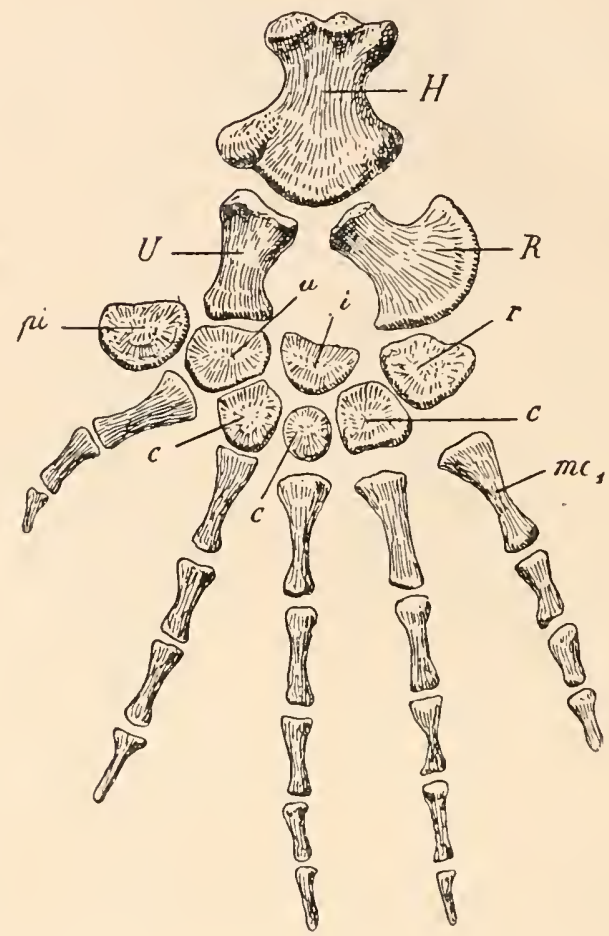

Fig. 529.

Vorderflosse von Clidastes pumilus, Marsh, aus der oberen Kreide von Kansas, $1 / 2$ nat. Gr.

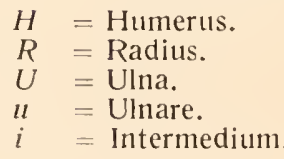

$r=$ Radiale.

$p i=$ Pisiforme.

$c=$ distale Carpalia.

$m c_{1}=$ Metacarpale $\mathrm{I}$.

1 S. W. Williston, Mosasaurs. - Univ. Geol. Surv. Kansas, Vol. IV, 1898, p. 83.

Derselbe, Editorial Notes. - Kansas Univ. Quarterly, Vol. VII, 1898, p. 235.

Derselbe, Some Additional Characters of the Mosasaurs. - Ibidem, Vol. VIII, 1899 , p. 39.

F. von Huene, Über einen Platecarpus in Tübingen. - Neues Jahrb. für Min. IIsw., 1911, Bd. II, S. 48.

S. W. Williston, A Mounted Skeleton of Platecarpus. - Journal of Geology, Vol. XVIII, Chicago 1910, p. 537.

O. Abel, Grındzüge der Paläobiologie der Wirbeltiere. - 1912, S. 161. 
Plioplatecarpus. - Senon und Maestrichtien von Holland und Belgien. - Die Gattung steht Platecarpus sehr nahe; die Körperlänge betrug etwa 5 111. Der Schädel nimmt etwa $1 / 10$ der ganzen Körperlänge ein. Ein wichtiges Merkmal ist das verknöcherte und mit der gleichfalls verknöcherten Extracolumella verwachsene Trommelfell und das auffallend große Foramen parietale; die Bezahnung war stark reduziert, was auf weichkörperige Nahrung, wahrscheinlich Cephalopodennahrung, schließen läßt (Analogie mit den zahnarmen Ichthyosauriern und Squaloceten). Die Augen sind auf die Oberseite des Schädels verschoben. P. Houzeaui (Obersenon), P. Marshi (Maestrichtien) ${ }^{\mathbf{1}}$ (Fig. 525).

Tylosaurus. - Turon und Senon von Nordamerika (Alabama, Neumexiko, Kansas, New Jersey). Körperlänge 8,5 m erreichend. Schnauze spitz, auf dem Grunde der äußeren Nasenöffnungen Septomaxillaria vorhanden, die ebenso wie bei den Varaniden zwischen dem Prämaxillare und Vomer liegen; Nasalia rudimentär. Praearticulare ungewöhnliclı lang. Die Parietalia entsenden lange laterale Flügel als hintere Abschlußspange der oberen Temporalgrube. - Z. B. T. dyspelor, T. proriger. ${ }^{2}$ (Fig. 521, 523, 526, 531).

Hainosaurus. - Obersenon Belgiens. - Das auffallendste Merkmal ist die schnabelartige Verlängerung der Praemaxillaria. ${ }^{3}$

1 L. Dollo, 'Note sur l'ostéologie des Mosasauridae. - Bulletin Mus. Roy. Mus. Hist. Nat. Belg., T. I, 1882, p. 64.

Derselbe, Nouvelle Note sur l'ostéologie des Mosasauriens. - Bull. Soc. Belge de Géologie etc., T. VI, 1892, p. 222.

Derselbe, Première note sur les Mosasauriens de Maestricht. - Ibidem, T. IV, 1890, p. 157.

Derselbe, Notes d'ostéologie erpétologique. - Annales de la Société scientifique de Bruxelles, 9e année, 1885, p. 319.

Derselbe, Les Mosasauriens de la Belgique. - Bull. Soc. Belge de Géologie usw., T. XVIII, 1904, p. 207.

Derselbe, Un nouvel opercule tympanique de Plioplatecarpus, Mosasaurien plongeur. - Ibidem, T. XIX, 1905, p. 125.

Derselbe, The Fossil Vertebrates of Belgium. - Annals of the New York Academy of Sciences, Vol. XIX, 1909, p. 103, 105.

${ }^{2}$ E. D. Cope, The Vertebrata of the Cretaceous Formations of the West. Report of the U. S. Geol. Survey, Vol. 11, 1875, p. I60 (Liodon).

J. C. Merriam, Über die Pythonomorphen der Kansaskreide. - Paläontographica, XLI. Bd., 1894, p. 1.

H. F. Osborn, A Complete Mosasaur Skeleton, Osseous and Cartilagineous. Memoirs Mus. Nat. Hist. New York, Vol. I, 1899, p. 167.

F. von Huene, Ein ganzes Tylosaurusskelett. - Geol. u. paläontol. Abhandl., N. F. Bd. VIII (G. R. Bd. XII), 1910, p. 297.

3 L. Dollo, Première note sur le Hainosaure, Mosasaurien nouveau de la Craie brune phosphatée de Mesvin-Ciply, près Mons. - BulI. Mus. Nat. Hist. Belg., T. IV, 1885 , p. 25.

Derselbe, Les Mosasauriens de la Belgique, I. c., 1904, p. 213. 
Globidens. - Oberste Kreide (Maestrichtien) von Maestricht in Holland und Alabama in Nordamerika. - Das wichtigste Merkmal dieser Gattung sind die halbkugeligen, zweifellos nur zur Verkleinerung hartschaliger Beutetiere dienenden Zähne (durophager Gebißtypus). G. alabamaensis (Alabama), G. Fraasi (Maestricht) ${ }^{1}$ (Fig. 527).

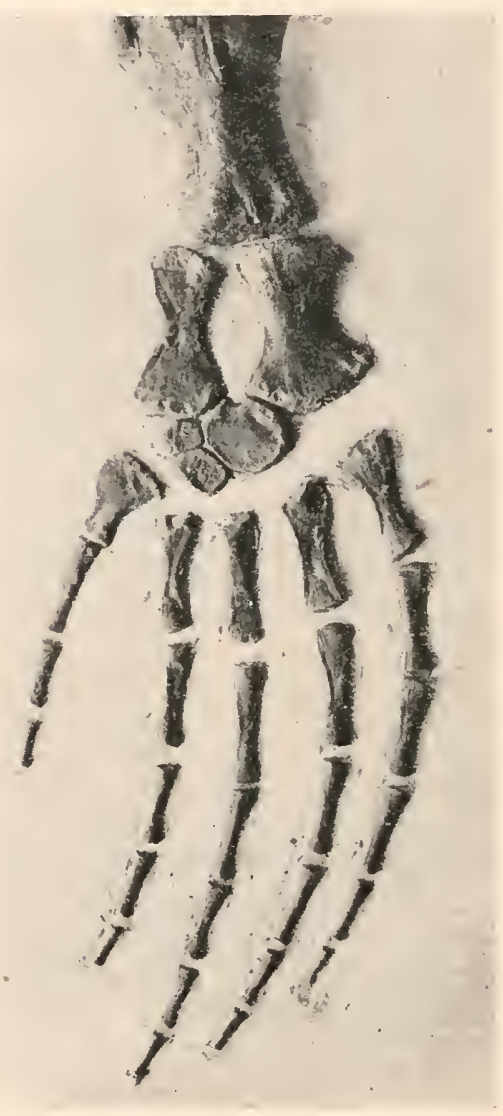

A.

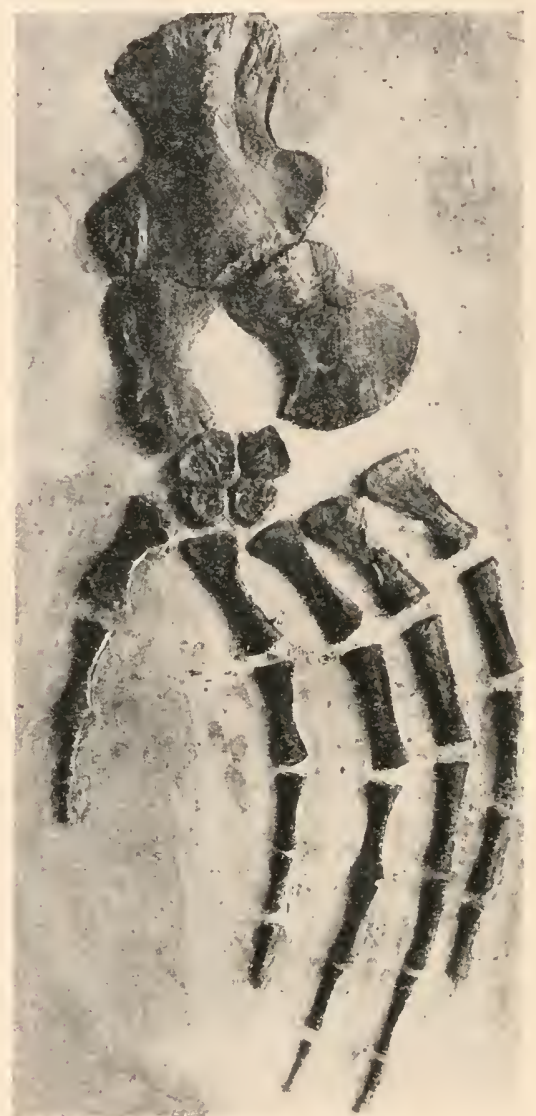

B.

Fig. 530.

A Vorderflosse, B Hinterflosse von Platecarpus abruptus, Marsh, aus der oberen Kreide (Niobrara Cretaceous) von Kansas.

(Nach zwei von S. W.Williston zur Verfügung gestellten Photographien.)

Unterordnung: Rhiptoglossa (= Chamaeleontia).

Von Clamäleoniden sind bisher nur zwei fossile Reste beschrieben worden, deren Bestimnnung übrigens zweifellaft ist; die dürftigen Reste

1 L. Dollo, Globidens Fraasi, Mosasaurien mylodonte nouveau du Maestrichtien (Crétacé supérieur) du Limbourg, et l'Éthologie de la Nutrition chez les Mosasauriens.

- Bull. Soc. Belge de Geologie usw., T. XXVIII, 1913, p. 609. 
sind aus dem Eozän von Wyoning (Chamaeleo pristinus ${ }^{1}$ ) und aus dem Eozän des Quercy in Frankreich (Prochamaeleo europaeus ${ }^{2}$ ) besclırieben worden. Sie sind olne Bedeutung für die Geschichte dieses Stammes, der einen hochspezialisierten Seitenzweig der Lacertilier bildet.

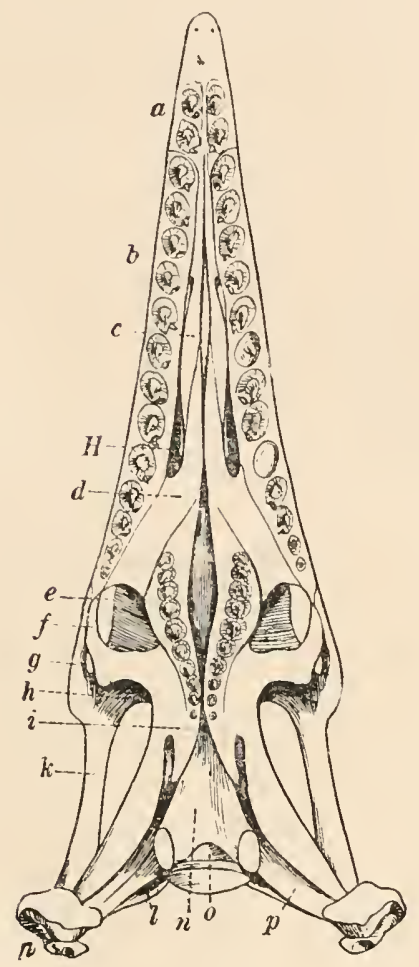

Fig. 531.

Unterseite des Schädels von Tylosaurus proıiger, Cope, aus der oberen Kreide (Niobrara Cretaceous) von Kansas, in $1 / 6$ nat. Gr. (Nach S. W. Williston.)

$H=$ Choane. Der weiße Spalt bezeichnet die Lage der oberen Nasenöffnung.

$a=$ Praemaxillare.

$b=$ Supramaxillare (die Zähne stehen auf Sockeln).

$c=$ Vomer.

$d=$ Palatinum.

$e=$ Frontale .

$f$ = Transversum.

$g=$ Jugale.

$h=$ Postfrontale.

$i=$ Pterygoid.

$k=$ Quadratojugale.

$l=$ Squamosum.

$m=$ Quadratum.

$n=$ Basisphenoid.

$o=$ Basioccipitale.

$p=$ Exoccipitale.

Unterordnung: Oplidia.

Die Schlangen bilden einen hochspezialisierten Seitenzweig der Lacertilier, dessen Abzweigung vielleicht in die Kreidezeit fällt - die ältesten Schlangenreste sind aus der mittleren Kreide bekannt vielleicht aber noch weiter zurückliegt. Der Körpertypus findet sich schon unter den Lacertiliern in verschiedenen Forntenreihen ausgebildet und es kann wohl keinem Zweifel unterliegen, daß die Vorfahren der Schlangen ein Stadium durclnlaufen haben, wie es die jetzt lebenden fußlos gewordenen oder fußlos werdenden Eidechsen repräsentieren.

1 J. Leidy, Contributions to the Extinct Vertebrate Fauna of the Western Territories. - Report U. S. Geol. Survey, Vol. 1, 1873, p. 345.

2 De Stefano, Sauri del Quercy appartenenti a la collezione Rossignol. Atti Soc. Italiana Scienze naturali, Milano 1904. - Die Grundlage der Gattung und Art besteht nur aus dem Fragment eines Dentale! 
Die Spezialisationen des Skeletts sind durch die Bewegungsart und die Art der Nahrungsaufnahme entscheidend bedingt. Mit der Bewegungsart steht der völlige oder teilweise Verlust der Gliedmaßen in Zusammenhang. Gliedmaßenreste sind in dürftigen Rudimenten nur bei wenigen lebenden Formengruppen (bei den Typhlopiden, Glauconiiden, Ilysiiden und Pythoniden) erhalten geblieben und zwar sind dies nur Reste der hinteren Gliedmaßen; die Arme sind bei keinem einzigen Ophidier auch in dürftigen Resten nachweisbar.

In der Wirbelsäule, welche bei den lebenden Arten aus höchstens 435 Wirbeln besteht (bei Python molurus), bei einer fossilen Art (Archaeophis proavus) aber die enorme Zahl von 565 Wirbeln erreicht, sind alle Wirbelkörper procoel und besitzen ein gut entwickeltes Zygosphen und Zygantrum, die als sekundäre Gelenke eine festere Verbindung zwischen den Wirbeln zur Folge haben und ebenso wie bei den Ophidiern ganz unabhängig bei den schlangenförmigen Stegocephalen entstanden sind; es sind parallele Anpassungen, hervorgerufen durcli die gleichartige Bewegungsart.

An der Unterseite der vorderen (etwa 30) Wirbelkörper der rezenten Schlangen findet sich stets ein langer, medianer Fortsatz, die ,Hypapophyse", welche zuweilen beim Hinabwürgen der Beute eine wichtige Rolle spielt; bei der Eierschlange Afrikas (Dasypeltis scabra) werden die von den weitauseinandertretenden Kiefern aufgenommenen, hinabgewürgten Eier an den die Speiseröhre durchbrechenden Unterenden der Hypapophysen vorübergeführt, wobei die Eischalen zerschnitten werden. Die Hypapophysen sind aber hier nicht, wie sonst, nach hinten, sondern nach vorn gerichtet. Bei der fossilen Gattung Archaeophis treten Hypapophysen im ganzen Rumpfabschnitt auf, sind aber an den hinteren Rumpfwirbeln (z. B. am 330.) nur mehr als Kämme entwickelt, während sie an den vorderen Rumpfwirbeln als im Profile dreieckige Platten schief nach hinten vorspringen und der hinteren Hälfte des Wirbelkörpers ansitzen. Bei den fossilen Paläophiden sind sowohl vordere als hintere Hypapophysen ausgebildet, die durch einen niederen Kamm miteinander verbunden sind (Fig. 534, v.Hy., h.Hy.). Bei derselben Familie sind auch sehr eigentünliche, paarig flügelartige Fortsätze an den oberen Bögen vorhanden, die als Pterapophysen (Fig. 534, Pt.) bezeichnet werden können; sie fehlen bei den rezenten Schlangen. An den Kaudalwirbeln treten paarig entwickelte, nach unten und außen divergierende Fortsätze auf, welche vielfach mit den Hämapophysen homologisiert worden sind, aber wahrscheinlich nicht homologe Bildungen derselben đarstellen; echte Hämapophysen oder die Basiventralia scheinen bei den Schlangen gänzlich zu fehlen. Die als Hämapophysen gedeuteten Fortsätze sind wahrscheinlich Abzweigungen der Querfortsätze. Die Rippen sind einköpfig und 
auf den Rumpf beschränkt; auf den letzten rippentragenden Wirbel folgt der erste Schwanzwirbel mit den nach unten gerichteten „Pseudohämapophysen", wie diese Fortsätze am besten zu bezeichnen sind.

Die fossilen Reste geben über die Entstehungsgeschichte des Schlangenschädels nur sehr unvollkommenen Aufschluß. Der Schädel (Fig. 532, 533 ) ist bei den lebenden Schlangen hochgradig spezialisiert und zwar ist vor allem die große Beweglichkeit des Quadratums, das im Squamosalgelenk weit nach außen gedreht werden kann, die auffallendste Eigen-

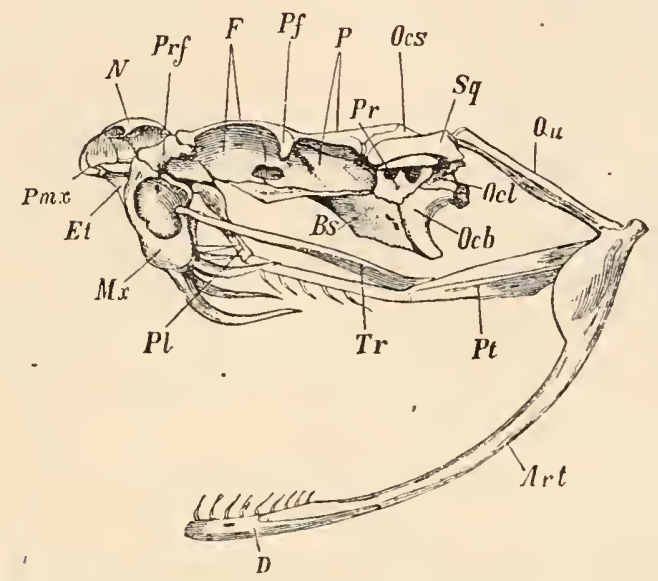

Fig. 532.

Schädel der Klapperschlange (Crotalus horridus). (Nach Claus.)

$\begin{array}{rlrl}O c b & =\text { Basioccipitale. } & & P r f=\text { Lacrymale. } \\ O c l & =\text { Exoccipitale. } & E t=\text { Ethmoideum. } \\ O s c & =\text { Supraoccipitale. } & & P l=\text { Palatinum. } \\ P r & =\text { Prooticum. } & & M x=\text { Supramaxillare } \\ B s & =\text { Basisphenoid. } & & P m x=\text { Praemaxillare. } \\ S q & =\text { Squamosum. } & & T r=\text { Transversum. } \\ P & =\text { Parietale. } & D & \text { Dentale. } \\ F & =\text { Frontale. } & & \text { Art }=\text { Articulare. } \\ P f & =\text { Postfrontale. } & & \end{array}$

tümlichkeit; diese Ausbiegungsfähigkeit des Quadratums ermöglicht es ja den Schlangen, sehr große Beutetiere hinabzuwürgen. Der Schädel ist mesokinetisch, d. h. die Biegungshinie zwischen dem vordersten Schädelabschnitt, der durch die Verschiebung der Pterygoide nach obent gedrückt wird (hierbei spielen die Transversa mit), liegt weit vorn und zwar läuft diese Linie vor der Orbita quer durch das Schädeldach durch. Dadurch kommen, wie Versluys (1912) näher auseinandersetzt ${ }^{1}$, die Zähne in eine wesentlich günstigere Stellung zum Einschlagen in das

1 J. Versluys, Das Streptostylieproblem. - Zoologische Jahrbiicher, Suppl. XV, 2. Bd., 1912, S. 640 . 
Beutetier. Ein Epipterygoid fehlt den Schlangen. Ebenso sind die Schläfenlochspangen gänzlich obliteriert, was mit der geänderten Funktion des Quadratums zusammenhängt.

Die ältesten Sclılangen treten im Cenoman Frankreichs und Portugals auf (Symoliophis); die meisten Reste, die aus der Kreide und aus dem Tertiär beschrieben worden sind, lassen kaum eine nähere syste-

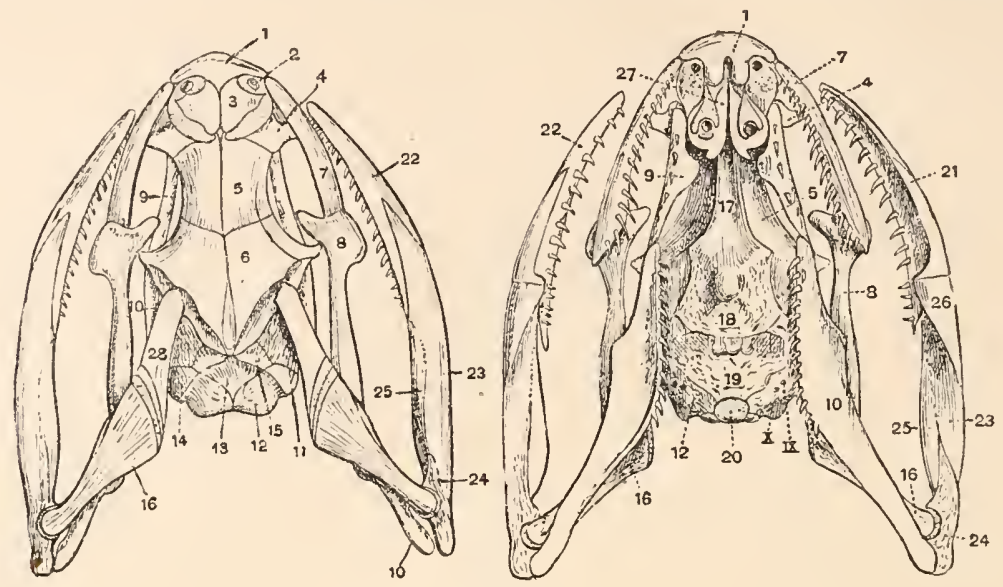

Fig. 533.

Links: Oberansicht, rechts: Unteransicht des Schädels der Ringelnatter

(Tropidonotus natrix). (Nach Parker.)

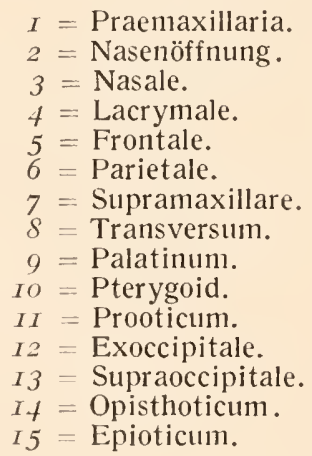

$16=$ Quadratum.

$I 7=$ Parasphenoid.

$I S=$ Basisphenoid.

$19=$ Basioccipitale.

$20=$ Condylus occipitalis.

$2 I=$ Spleniale.

$22=$ Dentale.

$23=$ Angulare.

$24=$ Articulare.

25 - Supraangulare.

$26=$ Complementare.

$27=$ Vomer.

28 = Squamosum.

$I X, X=$ Foramina für den IX. und $\mathrm{X}$. Schädelnerven.

matische Bestimmung und Zuteilung zu den zahlreichen lebenden Familien zu und geben uns daher keine Aufschlüsse über die Stammesgeschichte der Schlangen. Wichtigere Reste sind nur jene, die in den Fanilien der Paläophiden und Archäophiden vereinigt werden.

\section{F. Palaeophidae.}

Nur durch Wirbel bekannt, die aber in wesentlichen Merkmalen von jenen der lebenden Schlangenfamilien abweichen. Diese Merkmale bestehen in der Ausbildung einer vorderen und hinteren Hypapophyse, 
der Ausbildung eines Pterapophysenpaares auf der Hinterseite der Neurapophysen, großen Neurapophysen und in der allgemeinen Schmalheit der Wirbel. Es sind zum Teil riesenhafte Formen, deren Länge über $11 \mathrm{~m}$ betragen haben muß. Die seitliche Konpression der Wirbel sprîcht für einen lateral komprimierten Körper und dies ist wohl auch ein sicherer Beweis dafür, daß es wasserbewohnende Formen waren; das Vorkommen in marinen Bildungen würde den Schluß nahelegen (der freilich kein zwingender ist), daß die Paläophiden Meerschlangen waren.

Pterosphenus. - Obereozän (obere Mokattanstufe) Ägyptens und Obereozän von Alabama. - P. Schweinfurthi (Ägypten), P. Schucherti (Alabana) ${ }^{1}$ (Fig. 534).

Palaeophis. - Untereozän (London Clay) und Mitteleozän (Schichten von Bracklesham) Englands. - Mehrere Wirbeltypen, die als Grundlage verschiedener Arten betrachtet werden. ${ }^{2}$

\section{F. Archaeophidae.}

Nur durch eine Art (Archaeophis proavus) aus dem Eozän des Monte Bolca (Oberitalien) vertreten. Der Schädel läuft in eine spitze Schnauze mit relativ kurzem Unterkiefer aus, das Quadratum ist nach vorn gewendet, die Zähne schwach gekrümmt. Wirbelzahl die größte unter den Schlangen (565). Zygapophysen und Querfortsätze schwach; Hypapophysen, an allen Rumpfwirbeln vorhanden. Rippen sehr zart, stark nach hinten gerichtet. Rumpf lateral stark komprimiert. Walıscheinlich Meeresbewohner.

Archaeophis. - Eozän des Monte Bolca. ${ }^{3}$

Unter den übrigen alttertiären Schlangen wäre noclı Gigantophis aus dem Obereozän Ägyptens zu nennen, die naclı C. W. Andrews (1906) zu den Boiden gehört, während Dinilysia aus dem Untereozäı Patagoniens ${ }^{4}$ nach den Untersuchungen von A. S. Woodward (1901)

1 F. A. Lucas, A New Snake from the Eocene of Alabama. - Proceedings U. S. Nat. Mus., Vol. XXI, Nr. 1164, 1898, p. 637.

C. W. Andrews, A Descriptive Catalogue of the Tertiary Vertebrata of the Fayûm, Egypt. - London, Brit. Mus. Nat. Hist., 1906, p. 309.

W. Janensch, Pterosphenus Schweinfurthi Andrews und die Entwicklung der Palaeophiden. - Archiv für Biontologie, I. Bd., 1906, S. 311.

2 R. Owen, A History of British Fossil Reptiles. - Part II. - Palaeontographical Society, Londón, 1850, p. 77. - Pt.toliapicus aus den Untereozän von Sheppey und Pt. typhaeus aus dem Mitteleozän von Bracklesham.

W. Janensch, I. c., p. 332.

${ }^{3}$ W. Janensch, Über Archaeophis proavus Mass., eine Schlange aus dem Eozän des Monte Boica. - Beiträge zui Paläontologie Österreich-Ungarns und des Orients, XIX. Bd., 1906, p. 1.

4 A. Smith Woodward, On some Extinct Reptiles from Patagonia, of the Genera Miolania, Dinilysia and Genyodectes. - Proc. Zool. Soc. London 1901, p. 169. 


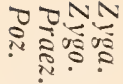

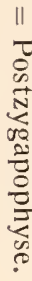

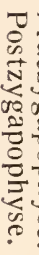

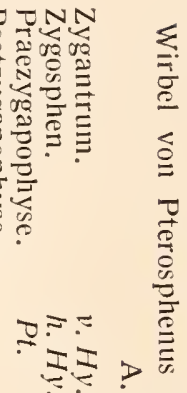

|| || ||

ㅋㅀㅀ

궁을

छ

踏

ए人

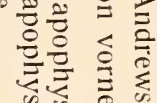

यह है

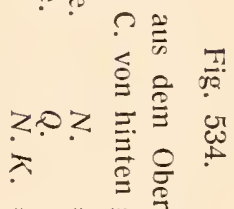

|| || ||

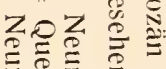

息引

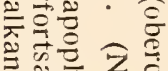

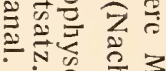

N 3

飞

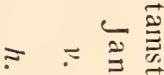

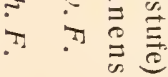

11 $\stackrel{5}{\Xi}$

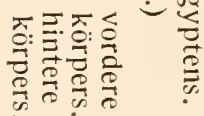

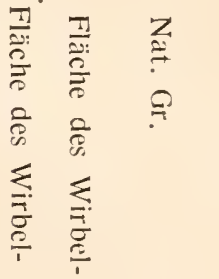
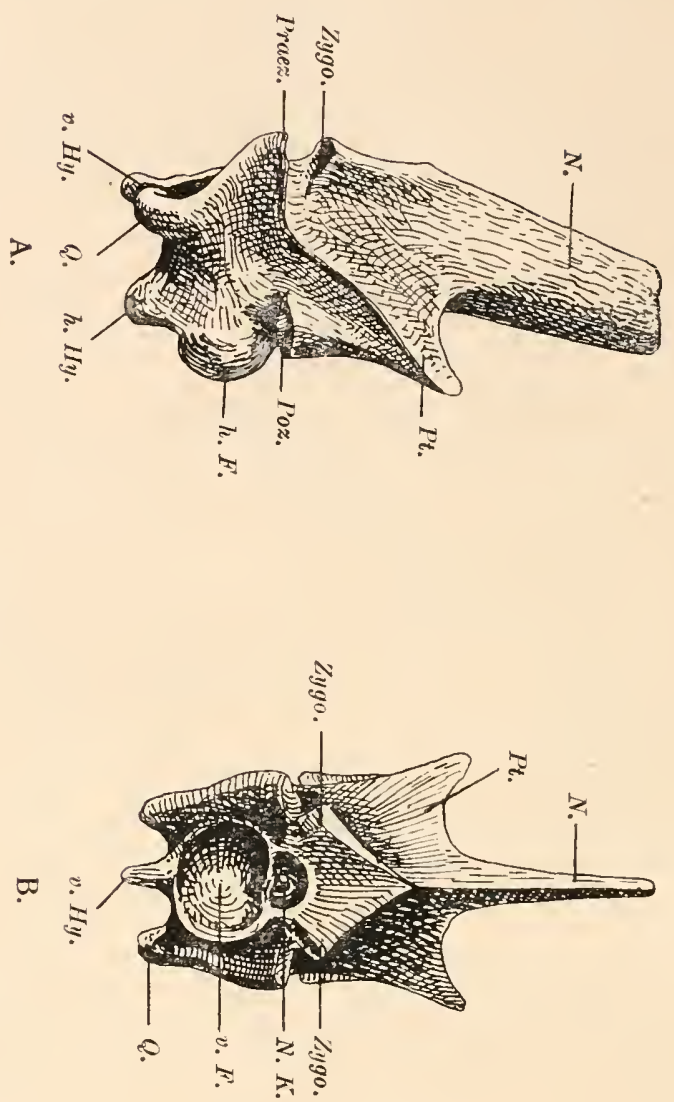

$\Omega$

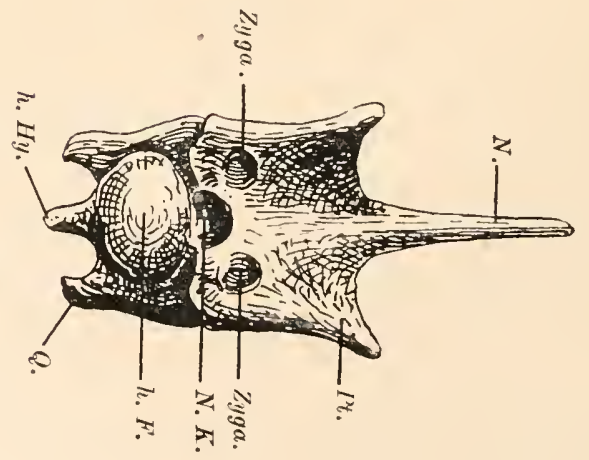


den Ilysiiden einzureihen ist; von dieser Schlange liegt ein sehr gut erhaltener Schädel vor. Heteropython euboeicus ${ }^{\mathbf{1}}$ aus dem Miozän von Kumi (Euboea) gehört zu den Pythoniden. Aus dem Miozän Europas sind verschiedene Reste bekannt, die zum Teil zu den Colubriden und Eryciden gehören mögen; die älteste Viper (Provipera) wurde im Miozän von Mosbach-Biebrich in Deutschland entdeckt. Wie schon erwähnt, sind diese Reste für die Stammesgeschichte der Ophidier ohne Belang. ${ }^{2}$

1 F. Roemer, Über Python euboeicus. - Zeitschrift der Deutschen Geolog. Ges., 1870, XX. Bd., p. 582.

${ }^{2}$ Eine Übersicht der im Museum des Jardin des Plantes aufbewahrten fossilen Schlangen gibt A. T. De Rochebrune, Révision des Ophidiens fossiles du Muséum d'Histoire naturelle. - Nouvelles Archives du Mus. Hist. Nat., Paris (2), T. III, 1880 , p. 271. 


\section{Klasse: Vögel (Aves).}

Die Vorfahren der Vögel sind in der engeren Verwandtschaft der Pseudosuchier zu suchen. Nur von solchen Formen, wie sie uns bei dieser Stammgruppe entgegentreten, kann der für die Vögel typische Handund Fußbau abgeleitet werden.

Das Federkleid ist für die Vögel ebenso bezeichnend als der Bau des Flügelskeletts. Von den fünf Fingern der normalen Reptilienhand sind in der Regel nur noch drei (bei den Formen mit reduzierten Flügeln weniger) erhalten geblieben, der erste, zweite und dritte, aber auch diese befinden sich bei den lebenden Vögeln in stark spezialisiertem und teilweise verkünmertem Zustande, während sie beim ältesten bekannten Vogel (Archaeopteryx) noch frei waren und die, normalen, von den Vorfahren ererbten Phalangenzahlen (2, 3, 4 für den 1., 2. und 3. Finger) besaßen. Der zweite Finger ist bei Archaeopteryx der längste, der dritte der schwächste, der erste der kürzeste und stärkste. Die Krallen sind ursprünglich nach vorn gewendet gewesen wie die Handfläche überhaupt und erst die Übernahme der Trägerfunktion für die Basen der Schwanzfedern, welche bei den lebenden Vögeln dem Handrücken aufruhen, hat eine Stellungsänderung des Handskelettes zur Folge gehabt.

Im Fußskelett sind die Metatarsalia der 2., 3. und 4. Zehe schon bei Archaeopteryx fest miteinander zu einem ,Laufbein“ verwachsen, während das erste Metatarsale bis auf ein Rudiment seines Distalendes verkümmert erscheint. Die erste Zehe (Hallux) ist bei vielen Vögelı vorhanden, aber bei den Laufvögeln verloren gegangen; meist ist sie nach hinten gerichtet und bildet dann den hinteren Teil einer Greifzange, mit welcher der Fuß die Äste zu umklammern vermag. Auch der Bau des Fußskelettes schließt sich an primitive Typen unter den Pseudosuchiern und den Dinosauriern an.

Die Lockerung des Verbandes zwischen den Metatarsalia der Pinguine, wie sie z. B. bei Eospheniscus Gunnari aus dem Miozän der Seymourinsel oder bein lebenden Aptenodytes Forsteri zu beobachten ist, zeigt deutlich die Merkmale eines sekundären Prozesses und darf niclit als ein prinitives, von den Alnen ererbtes Merkmal gewertet werden. Der Tarsometatarsus von Cladornis (Fig. 539) ist noch fest verschmolzen und crst in weiteren Verlaufe der Spezialisation tritt bei den Pinguinen eine Lockerung ein (Fig. 540). 
Das Becken der Vögel besitzt in der allgemeinen Form eine auffallende Ähnlichkeit mit jenem der Ornithischier. Bei Archacopteryx sind die drei Elemente des Beckens noch getrennt, auch bei den Pinguinen, die in vielen Merkmalen primitiv erscheinen; ist der Verband der drei Beckenknochen locker; doch ist es möglich, daß auch hier wie bei der teilweisen Lösung der Metatarsalia voneinander die Lockerung der Beckenelemente als eine sekundäre Ersclieinung aufzufassen ist. Die Pubes bleiben häufig von den Ischia getrennt. Der Processus pectinealis gehört dem llium an.

Der Brustschultergürtel ist entsprechend der Funktion der Arme als aktive Flügel hochgradig modifiziert. Die Claviculae verschmelzen vor dem Sternum zum Gabelbein (,Furcula") und treten sowohl mit dem Sternum als auch mit den Coracoidea in feste Verbindıng. Beim Verluste des Flugvermögens bei den Laufvögeln und gewissen insularen, flugunfähig gewordenen Typen tritt eine Reduktion der Claviculae ein. Das Sternum ist sehr groß und trägt bei den aktiven Flugvögeln einen starken Kiel oder Crista sterni (z. B. Kolibri, Taube, Rebhuhn), während es bei den flugunfähigen Vögeln verkümmert oder doch seinen Kiel verliert; bei dem sekundär zu einem passiven Flieger gewordenen Albatros (Diomedea) ist das Sternum rudimentär.

Der Unterschenkel besteht aus der kräftigen Tibia und der zumeist stark verkümmérten Fibula; die Tibia verschmilzt mit den proximalen Tarsalia zu einem „Tibiotarsus“, die distalen Tarsalia gehen mit den drei vereinigten Metatarsalia der 2. bis .4. Zehe eine feste Verbindung ein und verschmelzen zum ,Tarsometatarsus". Bei den Vögeln gibt es sonach keine freien Fußwurzelknochen mehr.

Auch die Wirbelsäule ist durch die Flugtätigkeit wesentlich beeinflußt worden. Während der Halswirbelabschnitt mit 8-25 (meist 14-15) Wirbeln sehr beweglicl ist, sind die Rückenwirbel wenig beweglich und zuweilen zu einem sakrumartigen Gebilde, dem „Notarium“, verschmolzen, das wir schon bei den Pterodactyloidea kennen gelernt haben (S. 567). In der Regel verwachsen 2-4 Dorsalwirbel untereinander zu dem Notarium (z. B. beim Truthahn, Meleagris gallipavo), bleiben aber vom Sacrum durch einen freien Wirbel getrennt. Das Sacrum umfaßt eine selır große Zahl von Wirbeln $(11-20$, z. B. bei Anas boschas 17), unter denen die beiden primären Sakralwirbel durcli die breiten und starken Sakralrippen stets kenntlich bleiben. An das Sacrum schließen sich mehrere (meist 6, mitunter 8) freie Kaudalwirbel an; den Abschluß der Wirbelsäule der lebenden Vögel bildet das ,Pygostyl“, ein Komplex aus 6-10 verschmolzenen Wirbeln, die ontogenetisch noch als getrennte Wirbel nachweisbar sind; bei den Straußen bleiben jedoch die Schwanzwirbel bis auf die vier letzten Pygostylwirbel getronnt. Auch bei Apteryx bleiben die Kaudalwirbel größtenteils frei. 
Die freien Wirbel besitzen sattelförmige Gelenke, die eine große Bewegungsfreiheit der Wirbel gestatten. Bei Archaeopteryx und Hesperornis sind die Wirbel amphicoel und das gleiche ist auch bei den Embryonen der lebenden Vögel zu beobachten. Die Kaudalwirbel sind inmer amphicoel. Bei den Pinguinen und Kormoranen treten opisthocoele Wirbel auf.

Die Rippen des Thorax besitzen meist einen nach !hinten abstehenden Fortsatz, den Processus uncinatus, der sich über die nächstfolgende hintere Rippe legt und auf diese Weise die Festigkeit des Brustkastens bedeutend erhöht. Auch die letzte Halsrippe trägt in der Regel diesen Fortsatz, den vorderen Halsrippen fehlt er.

Bauchrippen sind in der Regel vorhanden. Eine weitgehende Umformung und Spezialisierung hat der Schädel der Vögel erfahren. lm Bereiche der Schädelkapsel, welche sehr geräumig ist und sich in dieser Hinsicht unter den Reptilien mit den Compsognathiden, Rhamplorhynchoidea und Pterodactyloidea am elesten vergleichen läßt, sind die Knochennähte fast gänzlich verschwunden. Am deutlichsten sind sie bei einigen altertümlichen, in Schädelbau primitiven Laufvögelı wie beim afrikanischen Strauß (Struthio africanus) oder beim amerikanischen Strauß (Rhea americana) zu verfolgen. Auch bei den Pinguinen sind die Nahtgrenzen der Schädelknochen deutlicher sichtbar als bei der Mehrzahl der übrigen Vögel.

Das Vorderende des Schädels (Fig. 535) wird von den Praemaxillaria gebildet, die schon sehr frühzeitig miteinander verschmelzen, aber durch eine mediane Furche im hinteren, zwischen die Nasalia vorspringenden Teile ihre ehemalige Grenznaht erkennen lassen. Die Supramaxillaria verbinden sich mit den Praemaxillaria, hinten mit dem Unterende der Masalia und dem Vorderende der Jugalia.

Das Ethmoideum ist knöchern entwickelt und komnt häufig auch auf der Oberseite des Schädels zwischen den Nasalia und Frontalia zum Vorschein; die großen äußeren Nasenöffnungen münden in einen Kanal, der durch ein medianes Septum geteilt wird; es ist sehr verschieden ausgebildet. Häufig bleibt der Raum zwischen dem Ethmoideum und dem Internasalseptum unverknöchert, so daß der Schädel hier biegsam bleibt; zuweilen kommt es, wie z. B. beim Papagei (Psittacus usw.) an dieser Stelle zu einem wirklichen, als querstehendes Scharnier entwickelten Gelenk (Fig. 536) ${ }^{1}$, an welchem der Kieferteil in die Höhe

1 Dies zeigt der Schädel eines Graupapageis (Psittacus trithacus) oder von Ara und Microglossus sehr deutlich. In eine Querfurche des Hinterschädels fügt sich ein entsprechender Wulst des Schnabelteiles des Schädels ein. Obwohl J. Versluys (1910, p. 239) das Vorhandensein eines solchen Quergelenks in Abrede stellt, muß ich doch nach dem mir vorliegenden Material das Vorhandensein eines wirklichen „Gelenkes" bestätigen. 
gehoben werden kann (nesokinetischer Schädeltypus). Der Vogelschädel ist immer als ein kinetischer zu bezeichnen, aber es ist

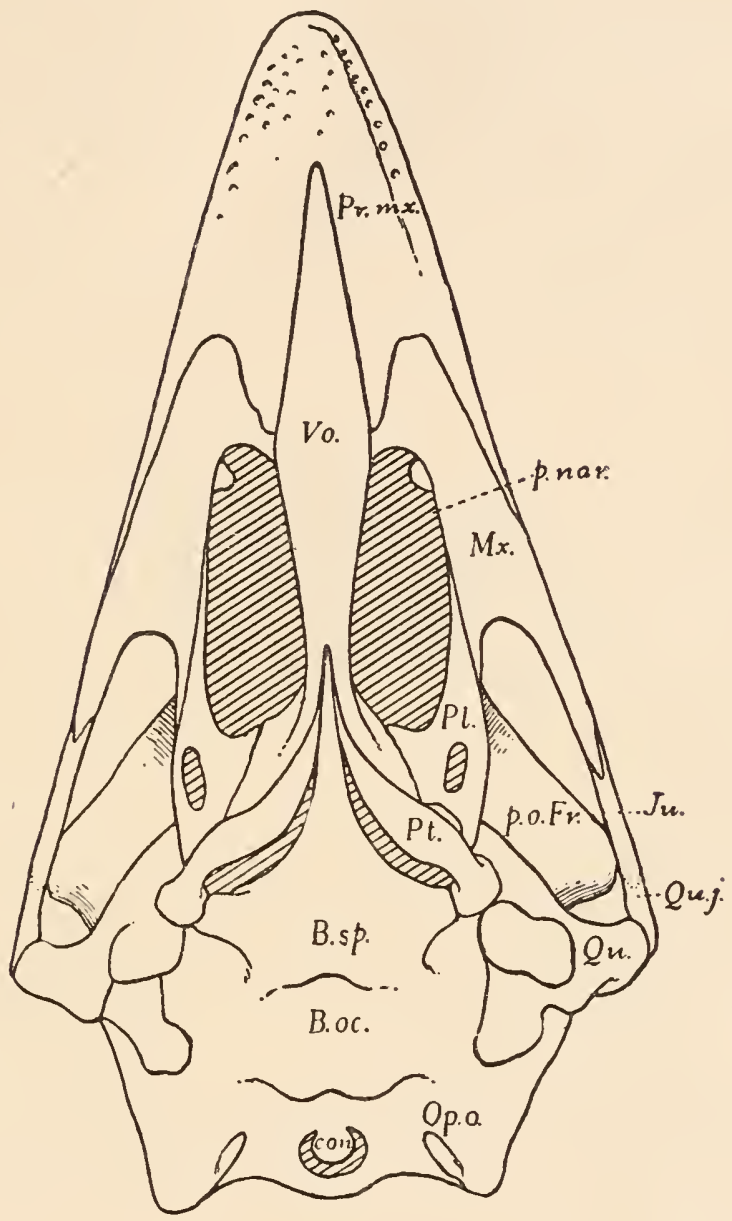

Fig. 535.

Unterseite des Schädels eines Emus (Dromaeus).

(Nach H. F. Osborn, 1912.)

B. oc. - Basioccipitale.

B. $s p$. = Basisphenoid.

conl. $=$ Condylus occipitalis (dahinter das Foramen magnum).

Ju. = Jugale.

$M x$. Supramaxillare.

Op.o. = Opistloticum.

Pl. = Palatinum.
p.o.Fr. = Processus orbitalis Frontalis.

p.nar. $=$ Choane

Pr.mx. - Praemaxillare.

Pt. $\quad=$ Pterygoid.

Qu. - Quadratum.

Quj. = Quadratojugale.

Vo. $=$ Vomer .

z. B. bei den Straußen (Struthio, ebenso aber auch bei Rhea) und bei Apteryx die Biegungsmöglichkeit der Schädelknochen sehr gering. 
Der mesokinetische Zustand des Vogelschädels ist, wie J. Versluys (1910 und 1912) gezeigt hat, von einem metakinetischen (vgl. S. 658) abzuleiten, wo die Biegungslinie zwischen den Parietalia und dem Supraoccipitale lag. Dieser Zustand ist durch das Vorhandensein eines Gelenks zwischen dem Basisphenoid und den Pterygoidea gekennzeichnet; dieses ,Basipterygoidgelenk" ist bei den primitiveren Vogeltypen (Rhea, Struthio, Apteryx, Gypogeranus usw.) noch vorhanden, unterliegt aber bei den höher spezialisierten, mesokinetisch gewordenen Schädeln der Rückbildung, und zwar scheint diese ganz unabhängig in verschiedenen Stämmen der Vögel vor sich gegangen zu sein.

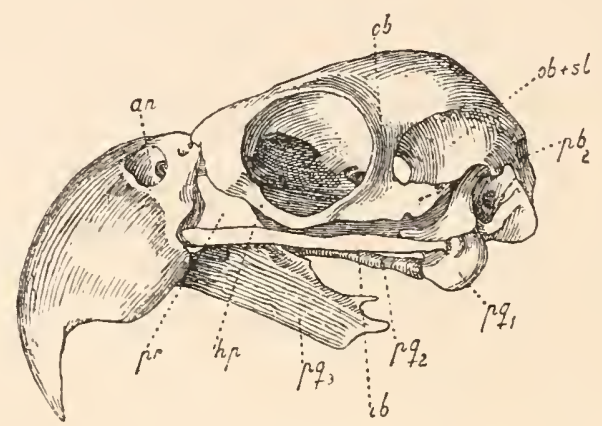

Fig. 536.

Schädel eines Papageis, von der Seite gesehen.

(Nach J. E. V. Boas.)

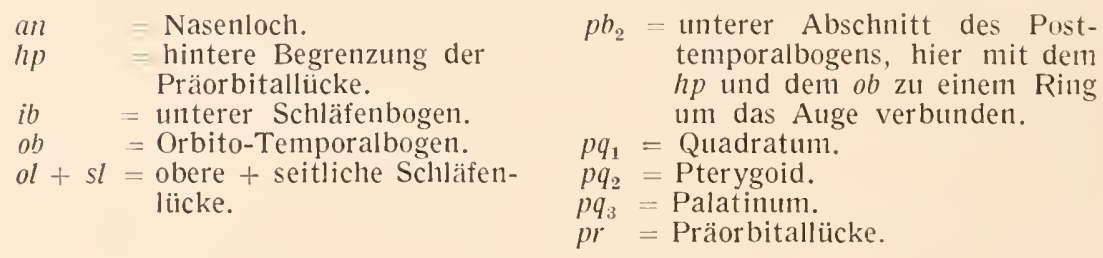

Die Ganmenregion des Vogelschädels weist bedentend mehr Verschiedenheiten als die Region der Schädelkapsel und der Oberseite auf. Besonders stark sind diese Unterschiede an den Vomeres zu beobachten. Sie sind bei den meisten Vögeln mit dem Hinterende der Palatina verbunden, bei Struthio dagegen nicht. Bei den Spechten getrennt, verschmelzen die Vomeres sonst meist in der Mittellinie.

Bei primitiveren Typen (z. B. bei Rhea) vereinigen sich die Supramaxillaria hinter den Enden der Prämaxillaria und bilden ein queres Dach über dem Gaumen am Vorderrande der Choanen. Bei den meisten Vögeln entsenden die Palatina nach linten zarte Flügel, welche mit den Pterygoidea in Verbindung treten und auf dem Basisphenoid hin und her gleiten können, wenn durch die Verschiebung des Quadratuns 
und des an ihm einlenkenden Jochbogens der vordere Teil des Schädels in die Höhe gehoben wird (nlesokinetischer Typus der Schädelbewegung). Diese Gleitbewegung auf dem Basisplenoid ist erst nach dem Aufgeben der Gelenkbewegung im Basipterygoidgelenk ausgebildet worden und der mesokinetische Zustand des Vogelschädels ist daher vom metakinetischen abzuleiten (J. Versluys, 1909 und 1912). Bei der mesokinetischen Bewegungsart, wie sie z. B. sehr deutlich beim Papagei zu beobachten ist, wird der Oberkiefer samt den Nasenkapseln dadurch gehoben, daß die Quadrata nach vorn geschoben werden; die mit ihnen gelenkenden Jochbogen übertragen die Bewegung auf den Schnauzenteil, der infolgedessen um eine Linie in die Höhe gedrückt wird, welche vor den Lacrymalia und zwischen den antorbitalen Fenstern des Schädeldaches liegt.

Mit dieser geänderten Bewegungsart der Schädelknochen steht die Reduktion der präorbitalen Knochenspange in Zusammenhang, da eine Verbindung derselben mit dem Jochbogen ein Hinaufdrücken der Kieferpartie unmöglich machen würde. Da aber die Jochbögen allein eine zu schwache Traversenverbindung des Hinterschädels mit dem Vorderschädel darstellen würden, so ist an der Schädelbasis bei den mesokinetischen Schädeltypen eine weitere Traversenbildung durch die Elemente: Quadratum-Pterygoid-Palatinum zustande gekommen, während die Palatina in Schädel der primitiveren Vögel (z. B. Rhea, Struthio, Apteryx, Crypturus usw.) mit ihren Hinterenden nicht auf dem Basisphenoid gleiten, sondern von diesem getrennt liegen, ebenso wie die Vorderenden der Pterygoidea. Im metakinetischen Schädel hat das Quadratum nur ein proximales, im mesokinetischen auch ein distales Gelenk.

Unter den Knochen des Schädeldaches sind die Frontalia stets die größten. Die Postorbitalia und Postfrontalia sind nicht mehr als selbständige Elemente erhalten und dürften mit den Frontalia vereinigt sein. Am Vorderrande der Orbita findet sich meist ein Lacrymale (= Präfrontale), auch ein Adlacrymale ist zuweilen beobachtet worden. Gelegentlich können auch am Unterrande der Augenhöhle Infraorbitalia parallel zum Jochbogen auftreten. Ein Orbitosphenoid (= Alisphenoid aut.?) ist vorhanden. Zwischen den Augenhöhlen kommt stets -ein großes Interorbitalseptum zur Ausbildung.

Der Condylus des Hinterhauptes liegt in Gestalt eines sehr kleinen, oft unregelmäßig gestalteten Knopfes auf der Unterseite des Schädels, so daß dieser mit der Achse der Halswirbelsäule einen rechten Winkel bildet.

Dem Vorderende des Basisphenoids schließt sich das Parasphenoid an.

Der Unterkiefer besteht aus sechs Elementen; zwischen dem Dentale und Spleniale bleibt häufig eine Fontanelle offen. 
Wenn in einem mesokinetischen Schädel (z. B. Papagei) der Unterkiefer beim Öffnen des Schnabels durch den Musculus digastricus herabgezogen wird, so bewegt sich das Distalende des Quadratums nach vorn und in weiterer Folge wird der Oberkiefer an der vorderen Biegungslinie des Schädels in die Höhe gehoben; daher geht beim Öffnen des Vogelschnabels durch das Herabdrücken des Unterkiefers gleichzeitig der Obeıkieferabschnitt in die Höhe, wenn der Schädel mesokinetisch ist.

Das Zungenbein ist bei den Spechten extrem verlängert und biegt sich hier über die Schädelkapsel in Rinnen der Frontalia so weit nach vorn, daß ihre Enden bis zu den Hinterenden des Zwischenkiefers reichen. Meist enden sie in einer rechtsseitig, selten in einer linksseitig gelegenen Grube neben dem Nasenloch.

Selbst im Vergleiche zu den primitiven Schädeltypen der lebenden Vögel (Rhea, Struthio usw.) erweist sich der Schädel der oberjurassischen Archaeopteryx Siemensii als primitiv, da noch eine präorbitale Knochenspange die Orbita von der Präorbitalöffnung scheidet; diese Spange besteht in ihrem oberen Teile aus dem Adlacrymale (= Lacrymale aut.), in unteren aus dem aufsteigenden Teile des Jugale (von W. Dames als „Lacrymale“, von J. Versluys als ,aufsteigender Ast des Supramaxillare" bezeichmet). Dadurclı erhält die Orbita vorn und unten eine feste Begrenzung und erinnert an die Verhältnisse, die bei den Dinosauriern vorliegen. Ebenso erweist sich der Schädel von Archaeopteryx durclı den Besitz eines geschlossenen Sklerotikalringes und die Bezahnung der Kiefer als sehr primitiv. Allerdings kommen auch bei vielen lebenden Vögeln Sklerotikalknochen vor.

Die weitverbreitete und immer von netren wiederholte Ansicht, daß den Vögeln die oberen "und unteren Temporalgruben fehlen, ist unrichtig. Bei vielen Vögeln (ich nenne nur Tetrao, Xenorhynchus, Leptopilus, Cacatua und Phasianus) ist die obere Temporalgrube vorhanden und allseits knöchern begrenzt, aber sie ist klein; die mntere Temporalgrube ist undeutlicher, die untere Abschlußspange fehlt immer und sie ist durch die Ausbreitung des Quadratums nach vorn und innen in die Tiefe der ehenaligen unteren Temporalgrube nicht so klar kenntlich als z. B. bei den Dinosauriern. Trotzdem sind beide Temporalgruben noch bej einzelnen Vogelgattungen gut nacliweisbar.

Die Stammesgeschichte der Vögel ist trotz vielfacher Bemühtungen kaum in den Hauptzügen als geklärt zu betrachten, da die diesbezüglichen Schlußfolgerungen fast ausschließlich auf der vergleichenden Anatomie der lebenden Formen beruhen und die verschiedenen fossilen Vögel, die man näher keunt, aus der Tertiärzeit stammen, also aus einer Epoche der Geschichte des Vogelstanmes, in der die Spaltung in die Hauptzweige schon vorüber war. In phylogenetischer Hinsicht sind die straußartigen Vögel von großer Wichtigkeit, da sie sich frül- 
zeitig von sehr primitiven Carinaten, d. h. flugfähigen Vögeln, abgezweigt und das Flugvermögen verloren haben. Lange Zeit hindurch sind die flugunfähig gewordenen Vogelstämme als „Ratiten“ zusammengefaßt worden, bis die Erkenntnis gereift ist, daß die Ratiten eine unnatürliche, künstliche Gruppe von Laufvögeln bilden, die viele priniltive Züge gemeinsam besitzen und anderseits durch gleichsinnige Anpassungen an das Laufen und den Verlust des Flugvermögens übereinstimmende Merkmale erworben haben. Die Vereinigung der Struthioniden, Rheiden, Dromaeiden, Aepyornithiden und Dinornithiden in die „Ordnung". Struthiones und die Gruppierung der Struthiones, der Apteryges (Kiwis) und der Crypturi zur ,Überordnung" der Dromaeognathae hat zwar den Begriff der Ratiten zu elininieren gesucht, aber ihn doch nur durch eine andere ebenso künstliche Gruppierung ersetzt. Die einzelnen Stämme weisen untereinander sehr große Gegensätze auf und das verbindende Merkmal ist nur die Konservierung vieler altertümlicher Züge, die bei diesen unabhängig entstandenen Zweigen des Vogelstammes zu beobachten ist. In vielen Punkten, wie im Schädelbau, im Baue des Schultergürtels und des Beckens, des Pygostyls usw. sind die Stämme der ,Dromaeognathae“ sehr primitiv und vermitteln uns eine Vorstellung von den Merkmalen jener Entwicklungsstufe, die auch die übrigen Vögel durchlaufen haben müssen.

\section{Unterklasse: Saururae.}

\section{Ordnung: Archaeornithes.}

Nur zwei Exemplare eines primitiven Vogels aus den oberjurassischen Plattenkalken von Solnhofen (Archaeopteryx lithographica) und Eichstäd t (Archaeopteryx Siemensii) (Fig. 537) geben uns über die Organisation der mesozoischen Vogelahmen einigen Aufschluß und füllen die große Lücke, die zwischen den Pseudosuchiern und den Vögeln klafft, wenigstens in einigen wichtigen Punkten aus. Zu den wichtigsten Unterschieden von den höher spezialisierten Ornithurae, die uns schon in der oberen Kreide (z. B. Ichthyornis) mit den fertigen Merkmalen der lebenden Vögel entgegentreten, soweit dies den Flügelbau betrifft, gehört der primitive Baı des Handskelettes von Archaeopteryx. Die Hand enthält zwar auch hier nur drei Finger, aber da schon die triadischen Pseudosuchier und Dinosaurier denselben Typus aufweisen, sind diese früher für sehr wichtig gehaltenen Gegensätze zwischen der Vogelland und der Reptilienhand viel kleiner geworden. Die drei Fingér von Archaeopteryx sind aber nicht untereinander verbunden wie bei den höheren Vögeln, sondern vollkomınen frei, bekrallt, und tragen die normale Plıalangenzahl (für den ersten bis dritten Finger 2, 3, 4). Die Finger waren nach vorn gewendet, 
so daß sich der dritte Finger unter den zweiten legte, wie dies das Berliner Exemplar von A. Siemensii aus Eichstädt deutlich zeigt (Fig. 537). Die Schwanzfedern sind in scharfen Abdrücken erlalten und zwar sind 6 Metacarpodigitales vorhanden (gegen 16 bei Struthio, 12 bei Rhea, 10 - 11 bei den meisten lebenden Carinaten), die nur in losem Zusammenhang mit den Fingern gestanden sein können. Die Gesamtzahl der Flügelschwungfedern war 16 oder 17. Die niedere Zaill der Handschwingen und ilıre lockere Verbindung mit dem Handskelett beweist,

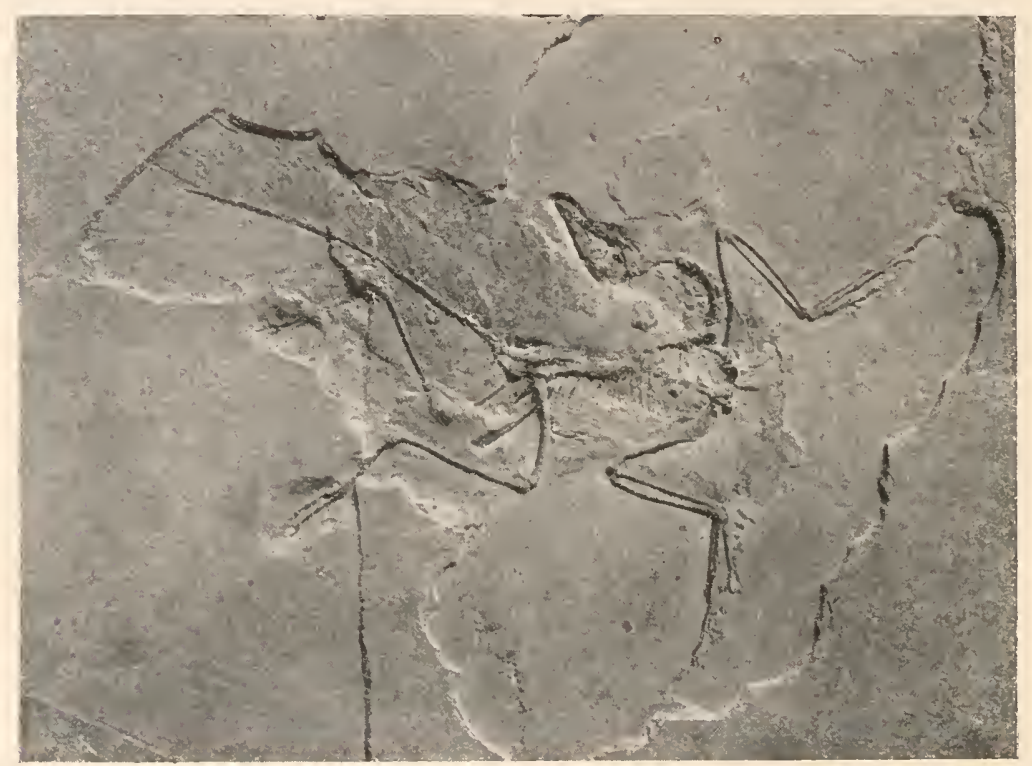

Fig. 537.

Archaeopteryx Siemensii, Dames, aus dem lithographischen Schiefer von Eichstätt in Bayern. $1 / 5$ nat. Gr. (Phot. F. Hafferl.)

daß Archaeopteryx ein schlechter Flieger gewesen sein 11uß (O. Abel, 1911 und 1912). Der Unterschenkel war zweiseitig befiedert, ebenso der lange, 20-21 Wirbel umfassende Schwanz. Dieser clürfte kaum so biegsam gewesen sein, wie in der letzten Zeit vielfach angenomm1en wurde, da Spuren von Schwanzsehnen erhalten sind, die wahrscheinlich eine Versteifung des Schwanzes ähnliclı wie bei den Rhamphorhynchoidea bewirkten. Wahrscheinlich vermochte Archaeopteryx mit Hilfe seiner freien, bekrallten Finger an Baunstänmen zu klettern, wie dies der heute lebende Hoatzin (Opisthocomus cristatus) selir geschickt und gleichfalls mit Unterstützung der bei ihn noch erhaltenen Fingerkrallen an1 1. und 2. Finger zu tun vernag. 
Ein wichtiger, bisher noch wenig gewürdigter Unterschied der Wirbelsäule von Archaeopteryx im Vergleiche zu den übrigen Vögeln liegt in der großen Beweglichkeit der Rumpfwirbel, die mit zarten, grätenförmigen Rippen ohne Processus uncinati in Verbindung treten. Der Brustkasten muß also bei Archaeopteryx nur einen sehr geringen Grad von Festigkeit besessen haben, der mit dem starken und starren Aufbau des Thorax der lebenden Vögel kaum vergleichbar ist (F. Stellwaag, 1916). Die Gesamtsumme der Wirbel beträgt etwa 50, wovon 10-11 auf den Hals, 11-12 auf den Thorax, 2 auf die Lendenregion, 6-7 auf das Sacrum und 20-21 auf den Schwanz entfallen. Die Wirbel sind amphicoel. 11-12 Paar feiner, kurzer Bauchrippen sind vorhanden.

In der Verwachsung der Schädelknochen, im Fehlen der Temporalöffnungen und denı Vorhandensein einer großen Präorbitalöffnung schließt sich der Schädel an den Typus der lebenden Vögel an, unterscheidet sich aber durch die geschlossene Spange zwischen der Orbita und der Präorbitalöffnung, einem geschlossenen Sklerotikalring und den Besitz zahlreicher, in Alveolen steckender Zälıne, deren Zahl im Oberkiefer 13 beträgt. Auch der Unterkiefer war bezahnt, doch ist die Zalıl seiner Zähne unvollständig bekannt.

Die neuerlich weitergeführte Präparation des Exemplars von Archaeopteryx lithographica im Britischen Museum zu London hat uns wichtige Aufschlüsse ïber den Bau des Beckens und des Schultergürtels gebracht. Das Pubis ist doppelt so lang als das lschium und beide Beckenhälften sind durch eine lange Sympliyse verbunden. Das nummehr freigelegte Coracoid ähnelt jenem von Hesperornis und dem der Ratiten.

\section{Unterklasse: Ornithurae.}

Bei den Ornithurae, welche alle Vögel mit Ausıahme der Saururae (Archaeopteryx) umfassen, sind wesentliche Veränderungen im Vergleiche zu Archaeopteryx eingetreten. Zwar finden sich noch in der Kreideformation einige bezahnte Gattungen (z. B. Hesperornis, Ichthyornis), aber bei den jüngeren fehlen funktionelle Zähne bereits vollständig. Bei den Embryonen der Strauße und Papageien sind rudimentäre Zahnanlagen beobachtet worden. Die zahnartigen Zacken an den Kieferrändern von Odontopteryx aus dem Untereozän Englands oder von Mergus (lebend) dürfen mit den verloren gegangenen Zähnen nur in physiologischer Hinsicht verglichen werden.

Rudimentäre Zähne hat vielleicht noch Argillornis aus dem Unter- 
cozän (Londonton) von Sheppey in England besessen, da in den hinteren Abschnitten der Kiefer seichte Alveolen sichtbar sind.

Bei allen Ornithuren ist der Schwanz reduziert, am geringsten bei den Straußen; sonst hat sich durch Verschmelzung der hinteren Kaudalwirbel das Pygostyl gebildet.

Das Handskelett ist zu einem Träger der Metacarpodigitales modifiziert worden, wobei die Metacarpalia des 2. und 3. Fingers sich vereinigten und die Grundphalange des zweiten Fingers besonders breit und flach wurde. Die Phalangen verkümmerten (am wenigsten bei Struthio). Eine eigenartige, durch die Funktion der Flügel als Ruderflossen bedingte Spezialisation weist das Armskelett der Pinguine auf.

Im Rumpfabschnitt der Wirbelsäule kam es schon frühzeitig zu einer Verfestigung des Rippenkorbes durch die Ausbildung der Processus uncinati der Brustrippen.

Mit der Reduktion des Schwanzes steht die Ausbildung eines fächerförmigen Federnsteuers im Zusammenhang; es. wird vom Pygostyl gestützt. In einigen Fällen kommt es sekundär zur Ausbildung eines langen Steuerschwanzes bei dem sekundären Drachenflug (z. B. des Fasanhalıns; O. Abel, 1910 und 1912).

$1 \mathrm{~m}$ Schädel ist die feste Verbindung der Präorbitalspange mit dem Jochbogen aufgehoben; verschiedene Veränderungen im Baue der Schädelbasis sind als Folgeerscheinungen der geänderten Bewegungsfähigkeit der Schädelknochen anzusehen, da der Schädel vom metakinetischen in den mesokinetischen Zustand übergelıt.

\section{Ordnung: Odontolcae.}

Die durcl Hesperornis vertretene Ordnung ist durch den Besitz zahlreicher, in einer Alveolarrinne eingepflanzter Zähne gekennzeichnet, die auf den Zwisclınkiefern fehlen. Die Unterkieferäste sind frei. Das Quadratum besitzt nur an Proximalende ein Gelenk. Die Beckenknochen sind an Hinterende frei.

Die einzige Gattung aus der oberen Kreide von Kansas ist durcl die gewaltige Entwicklung des Proximalendes der Patella sowie durch die weitgelıende Reduktion der Arme gekennzeichnet (nur der Humerus ist noch vorhanden). Mit dieser Reduktion der Flügel steht das völlige Verschwinden des Brustbeinkieles in Zusammenlıang. In Hinterfuß ist die vierte Zehe viel länger als die dritte, eine Erscheinung, die auf die Funktion der nit Hornschuppen bedeckten Hinterbeine als Ruderfüße hinweist, wofür auch die starke Patella spricht, die in gleicher Weise wie bei den Podicipiden (Lappentauchern) entwickelt und als eine Folge gleichartiger Funktion der Hinterbeine als Ruderfüße anzusehen ist. 
Hesperornis. - Oberkreide von Kansas. - Skelett fast vollständig bekannt. - Der Vogel war ein flugunfähiger, mariner Schwimmer. ${ }^{1}$

\section{Ordnung: Odontormae.}

Zähne nicht in einer gemeinsamen Rinne, sondern in Alveolen eingepflanzt. Unterkieferäste in der Symphyse verwachsen. Flügelknochen wie bei den jetzt lebenden Vögeln gebaut. Sternun mit hoher Crista.

lchthyornis. - Oberkreide von Kansas. - Skelett-unvollständig bekannt. Wahrscheinlich ein fischjagender, gutfliegender Meeresvogel.²

\section{Ordnung: Struthiones (Strauße).}

Laufvögel, die sich sehr frühzeitig vom Hauptstamm der Flugvögel abgezweigt und an die laufende Lebensweise in Ebenen angepaßt haben. Das Sternum hat den Kiel verloren, die Flügel sind verkümmert. Die Struthionen leben heute nur mehr in Afrika, doch sind fossile Vertreter der Gruppe aus dem Unterpliozän von Samos ${ }^{3}$ bekannt; ob ein dürftiger Rest eines Tibiotarsus, der als Eremopezus eocaenus aus dem Unteroligozän Ägyptens beschrieben wurde ${ }^{4}$, zu den Struthionen gehört, ist noch fraglich, aber wahrscheinlich. Aus Asien liegen Reste aus dem Pliozän vor. Das Ei eines straußartigen Vogels (Psammornis

1 O. C. Marsh, Odontornithes: A Monograph of the Extinct Toothed Birds of North America. - Report of the Geological Exploration of the 40 th. Parallel. Vol. VII, Washington 1880 und Memoirs of the Peabody Museum Yale College, New Haven, Vol. I, 1880.

S. W. Williston, On the Dermal Covering of Hesperornis. - Kansas University Quarterly, Lawrence, Kansas, Vol. V, 1896, p. 53.

C. W. Beebe, The Bird, its Form and Funktion. - The American Nature Series, Gruup II, Westminster 1907, Titelbild.

O. A bel, Paläobiologie, 1912, p. 244.

R. W. Shufeldt, On a Restoration of the Base of the Cranium of Hesperornis regalis. - Bulletin of American Paleontol. - Vol. V, 1915, p. 75.

Derselbe, Fossil Birds in the Marsh Collection of Yale University. - Transactions of the Connecticut Academy of Arts and Sciences, Vol. XIX, New Haven 1915, p. 1.

G. Heilmann, Fuglenes Afstamning. - Kjöbenhavn, 1916.

2 O. C. Marsh, Odontornithes, 1. c.

R. W. Shufeldt, l. c.

Verschiedene dürftige Reste, die als selbständige Gattungen und Arten aus der Oberkreide von Kansas beschrieben worden sind (z. B. Apatornis celer, Cimolopteryx rara), gestatten nicht, weitgehende phylogenetische Schlüsse aus ihnen abzuleiten.

3 R. Martin, Note on Some Remains of Struthio Karatheodoris Maj. of the Island of Samos. - Proc. Zool. Soc. London, I903, Vol. I, p. 203.

+ C. W. Andrews, A Descriptive Catalogue of the Tertiary Vertebrata of the Fayûm, Egypt. -- London 1906, p. 258. 
Rothschildi) aus dem Obereozän Südalgeriens ${ }^{1}$ ist als der älteste bisher bekannte Rest der Struthionen zu betrachten, deren Entstelıung aber wahrscheinlich noch viel weiter zurückliegt und vermutlich in das Mesozoicum fälıt.

\section{Ordnung: Aepyornithes (Madagaskarstrauße).}

Diese am nächsten mit den Straußen verwandte Ordnung umfaßt I iesige, flugunfähige Vögel, die nur aus Madagaskar bekannt sind, wo sie erst im 17. Jahrhundert erloschen zu sein scheinen. Die Eier haben mit 8,751 den sechsfachen Inhalt der Straußeneier. Der Fuß war vierzehig, bei einer Art (Aepyoinis Hildebrandti) war der Flügel ganz verkümmert. Die größten Arten erreichten eine Höhe von $5 \mathrm{~m}^{2}$

\section{Ordnung: Rheae (Nandus).}

Die auf Südanerika beschränkte Ordnung, die durch die lebende, noch sehr primitive Gattung Rhea vertreten wird, ist auch aus dem Plistozän Südamerikas (Knochenhöhlen Brasiliens) bekannt.

\section{Ordnung: Dinornithes (Moas).}

Die Ordnung ist auf Neuseeland beschränkt, wo in plistozänen Ablagerungen zahlreiche (etwa 20) Arten gefunden worden sind, die zum Teile noch mit dem Menschen zusammen gelebt haben und erst vor einigen Jahrhunderten erloschen sind. An Lagerplätzen der Maori hat man zerbrochene Eischalen gefunden und es liegen noch Wirbel mit Überresten der Bänder, Muskeln und der Haut vor; auch Federn haben sich mehrfach gefunden, so daß die Zeit des Aussterbens dieser Riesenvögel keineswegs weit zurückliegen dürfte und wahrscheinlich in das 18. Jahrhundert fällt.

Die Versuche, die Verwandtschaftsbeziehungen der Moas mit den übrigen Hauptstämmen der Vögel zu ermitteln, haben bishe1 kein durcliaus befriedigendes Ergebnis gezeitigt. Die meisten Merkmale weisen auf nähere Beziehungen zu den Apteryges oder Kiwis als zu den Kasuaren oder gar zu den übrigen altertümlichen Laufvögeln hin. Durch die Untersuchungen M. Fürbringers ${ }^{3}$ ist wohl endgültig festgestellt,

${ }^{1}$ C. W. Andrews, Note on some Fragments of the Fossil Egg-shell of a Large Strouthious Bird from Southern Algeria with some Remarks on some Pieces of the Egg-shell of an Ostrich from Northern India. - Verhandlungen des V. Internationalen Ornithologen-Kongresses in Berlin, 1910, p. 169.

${ }^{2}$ Der Tibiotarsus von Aepyornis titan ist bis $80 \mathrm{~cm}$, das Femur bis $41,5 \mathrm{~cm}$ lang.

${ }^{3}$ M. Fürbringer, Untersuchungen zur Morphologie und Systematik der Vögel usw. - Bijdragen tot de Dierkunde, 15. Afl., 2. Gedeelte, Amsterdam 1888, p. $1424-1472$. 
daß die „Ratiten“ eine unnatürliche systematische Gruppe bildeten; das Flugvermögen ist eben zu wiederholten Malen in Laufe der Stanmesgeschichte der Vögel verloren gegangen und zwar haben sich wohl schon in sehr früher Zeit, wahrscheinlich schon in der Kreide, einzelne Stänmme zu Laufvögeln und Schreitvögelı entwickelt. So bilden die Struthiones eine auf Europa, Asien und Afrika beschräıkte, selbstständig entstandene Gruppe, von der die.Aepyornithes schon in sehr alter Zeit (im frühen Eozän?) abgezweigt sein dürften; Aepyornis staht Struthio noch an nächsten. Ein ganz selbständiger, sehr alter Laufvogelstanm wird durch die südanterikanischen Nandus dargestellt, während die Gastornithiden eine zu Schreitvögeln gewordene, auf das Untereozäı Europas beschränkte Familie der Anseriformes repräsentieren. Ebenso sind auch die Kasuare und die Moas ganz unabhängig voneinander aus flugfähigen Vorfahren hervorgegangen. Ähnlıchkeiten des Skelettbaues aller dieser ,Ratiten“ sind dadurch zu erklären, daß sie schon in sehr alter Zeit, aber unabhängig voneinander, eine analoge Lebensweise angenommen liaben, wobei den divergenten Stämmen gewisse altertümliche Merkmale verblieben sind.

Für die Unterscheidung der einzelnen Gattungen und Arten finden sich Anlialtspunkte in der versclieden starken Ausbildung der in allgemeinen kräftigen Gliedmaßen, den Längenverhältnis der Gliechnaßenabschnitte (bei Dinornis z. B., Fig. 538, ist der Tarsometatarsus lang und schlank, bei Pachyornis kurz und plump), der Schnabelform und dem Fehlen oder Vorhandensein des Halluxrudimentes (bei Dinornis vorhanden, bei Pachyornis fehlend). Die größte Höhe erreichte Dinornis maximus mit einer Gesanthöhe von 3,5 m bei einer Tibiotarsuslänge von $1 \mathrm{ml}$.

\section{Ordnung: Casuarii (Kasuare).}

Die beiden noch lebenden Vertreter dieser Ordnung, Dromaeus (Fig. 535) und Casuarius, gehören der australischen Faumenregion an. Dromaeus bewohnte früher nicht nur das Hauptland Australien, sondern auch die umliegenden Inseln, ist aber heute auf Australien beschränkt. Die Kasuare besitzen eine viel weitere Verbreitung und bewohnen die papuanische Inselwelt von Ceran bis Neupommern. Im Plistozän Australiens sind dürftige Reste gefunden worden; nur Genyornis aus dem Plistozän Australiens ist vollständiger bekannt, gibt aber keinen Aufschluß über die Stammesgeschichte dieser Gruppe.

\section{Ordnung: Apteryges (Kiwis).}

Die Kiwis stellen einen frühzeitig vom Hauptstanmme der Flugvögel abgezweigten Ast dar, der mit den Casuarii in engeren verwandt- 
schaftlichen Beziehungen steht. Sie sind auf Neuseeland beschränkt und von dort auch fossil bekannt; auch diese Reste sind in phylogenetischer Hinsicht wertlos.

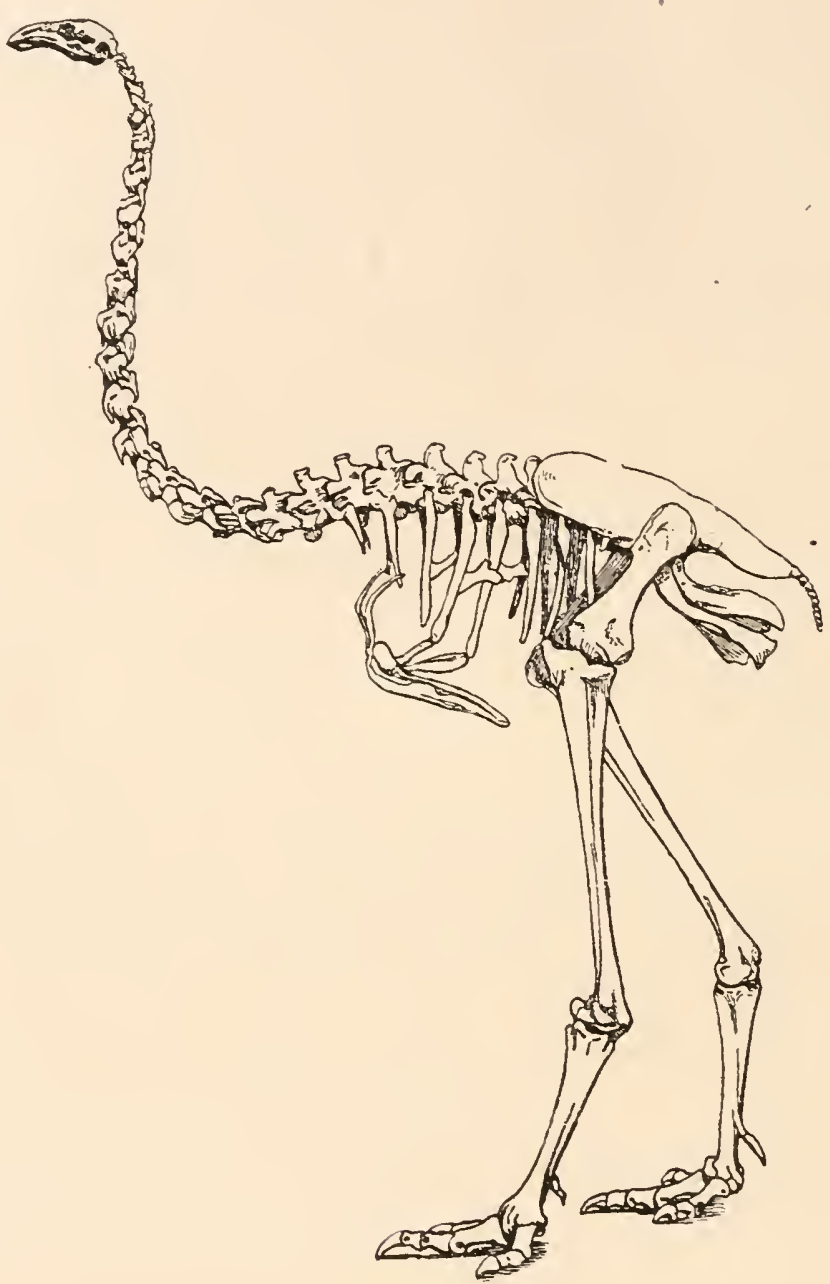

Fig. 538.

Dinornss maximus, Owen, aus dem Quartär der Sïdinsel Neuseelands, in $1 / 1$ 11 11 at. Gr. (Nach C. W. Andrews.)

IX. Ordnung: Tinamiformes (Steißhühner).

Die Steißhülmer sind leute mit etwa 65 Arten über Südanerika weit verbreitet. Sie stellen eine selir alte Gruppe dar, die in vielen osteologischen Merkmalen primitive Züge bewahrt hat. Über die Geschichte dieser Ordnung geben die dürftigen Reste von Steißhülnıern 
in den brasilianischen Höhlen (Plistozän) keinen Aufschluß. Sie sind schleclite Flieger.

\section{Ordnung: Sphenisciformes (Pinguine).}

Auch diese Gruppe hat trotz einseitiger Anpassung an das Wasserleben (Umbildung der Flügel zu Rudern, Reduktion des Federkleides usw.) viele altertümliche Züge bewahrt, wie $z$. B. die unvollkommene

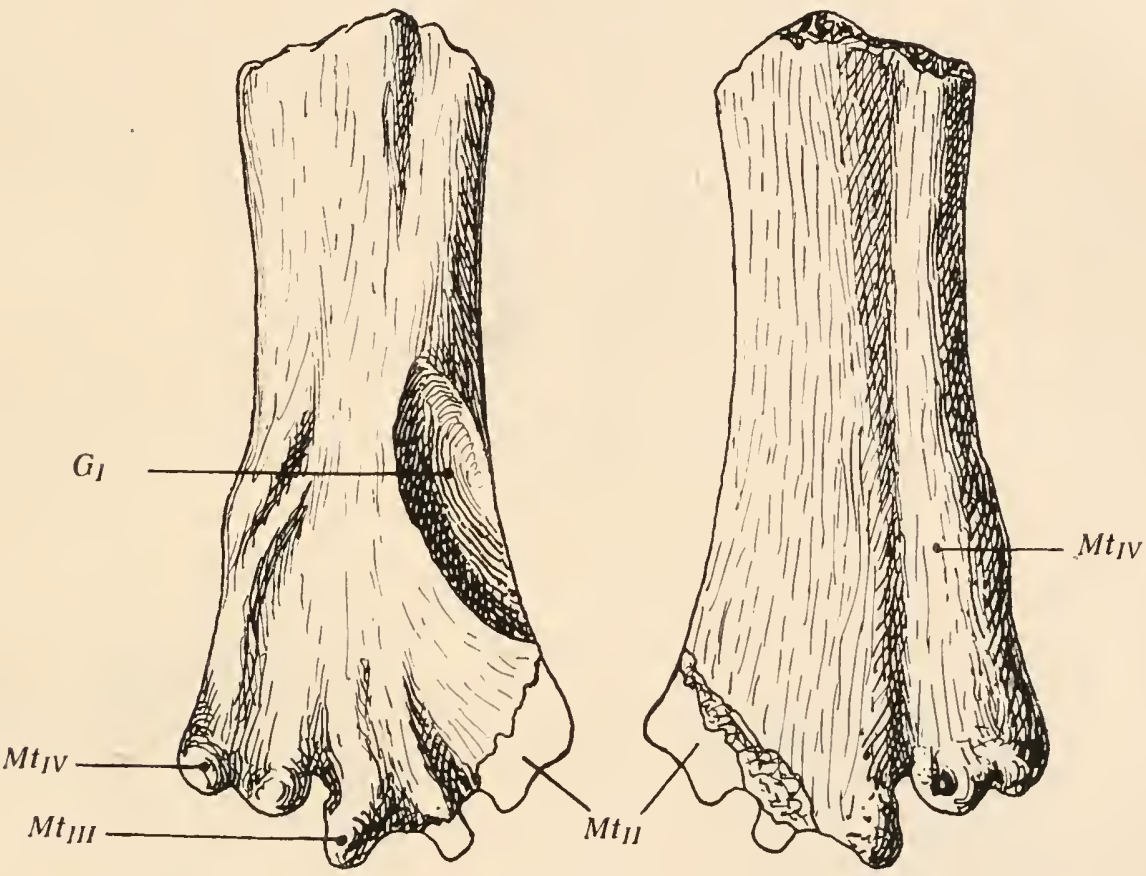

Fig. 539.

Tarsometatarsus eines fossilen Pinguins (Cladornis pachypus, Amgh.) aus dem

Untermiozän (Pyrotheriumschichten) von Südpatagonien. $2 / 3$ d. nat. Gr.

(Nach F. Ameghino.)

$\mathrm{Zu}$ beachten: Die drei Metatarsalia $\left(M t_{I I}, M t_{I I I}\right.$ und $\left.M t_{I V}\right)$ sind noch fest und ihrer ganzen Länge nach miteinander verwachsen. Die Grube $G_{I}$ ist zur Aufnanme des ersten Metatarsale bestimmt.

Verwachsung der Schädelknochen oder das einköpfige Quadratum. Dagegen ist die Lockerung der drei Metapodien des Hinterfußes sekundärer Natur (Fig. 539-540).

Die Pinguine gehören der antarktischen Faunenregion an; sie sind aus dem im Miozän der Seymourinsel und von Patagonien sowie aus dem Tertiär Neuseelands bekannt. Obwohl diese alten Formen in verschiedener Hinsicht prinitiver sind als die lebenden Typen, so sind diese 


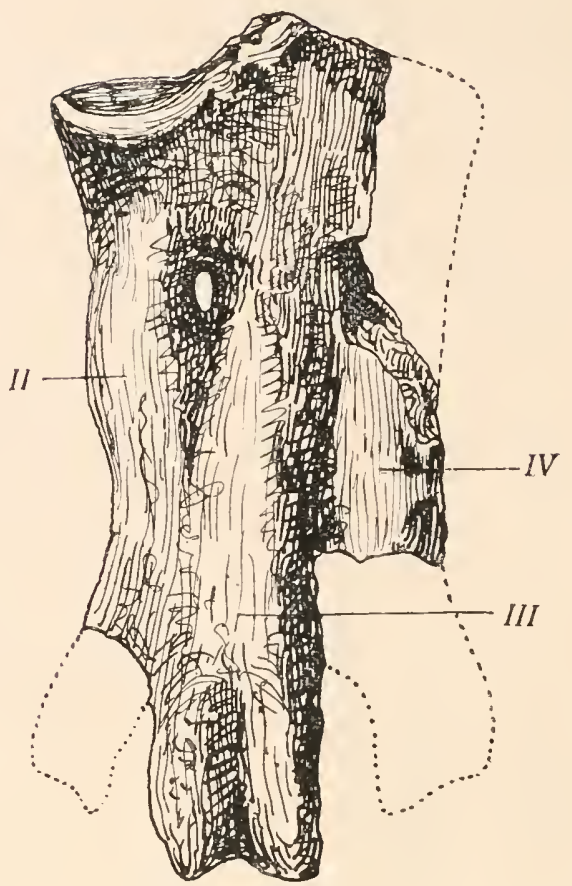

A.

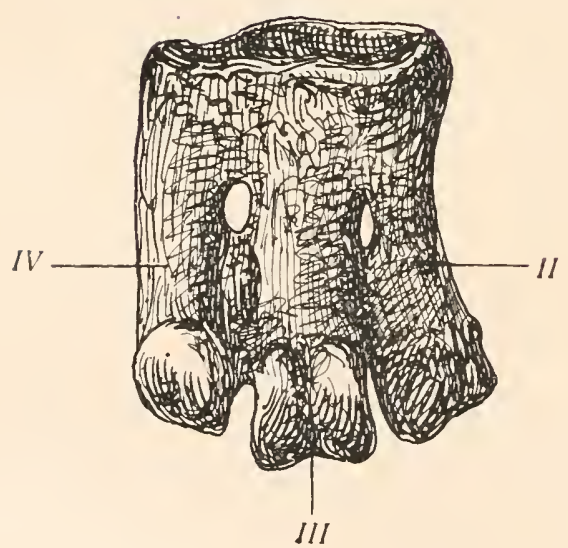

B.

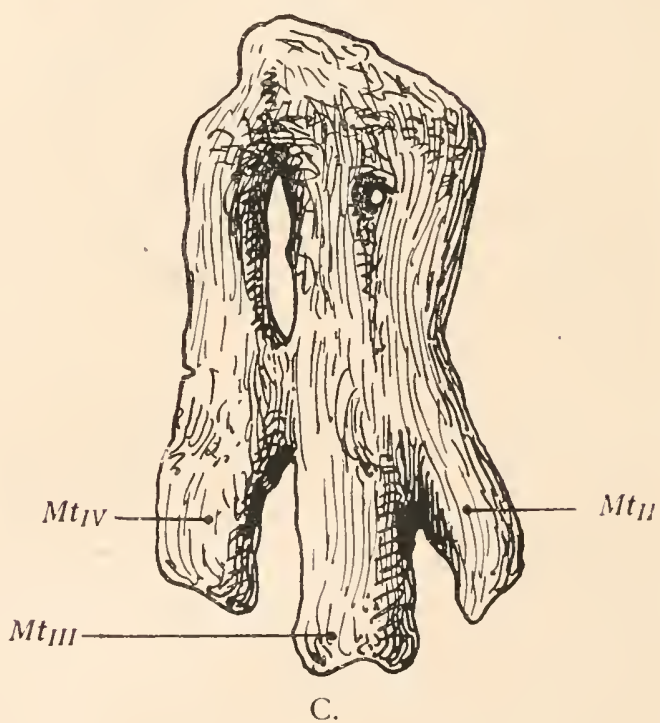

Fig. 540.

Die sekundäre Lockerung der Metatarsalia bei den Pinguinen (vgl. Fig. 539).

A. Anthropornis Nordenskiöldi, Wiman. - Miozän der Seymourinsel.

B. Eospheniscus Gumnari, Wiman. - Ebendaher.

C. Aptenodytes Forsteri; Rezent. 
Unterschiede doch nur ganz unbedeutender Natur und geben keinen Aufschinß ïber die Herkunft und das Alter dieser Ordnung. Ob Alabamornis (Eozän von Alabama) hierher grhört, ist noch fraglich.

\section{Ordnung: Colymbiformes (Tauclıvögel).}

Unfaßt die Familien der Podicipidae (Lappentaucher) und Colymbidae (Seetaucher). Die fossilen Reste (z. B. Colymbus und Podiceps im Pliozän Italiens) sind für die Vorgeschichte der Gruppe belanglos.

$\mathrm{Ob}$ die dürftigen Reste eines Vogels, den Marsh als Baptornis advenus beschrieb und die nur aus dem oberen und unteren Ende eines Tarsometatarsus bestehen, dazu ausreichen, als ein Bindeglied zwischen den Hesperornithiden der Kreide und den lebenden Colymiden betraclitet zu werden, wie dies von R. W. Shufeldt (1915) wahrscheinlich gemacht wird, erscheint mir selır fraglich.

\section{Ordnung: Procellariiformes (Sturmvögel).}

Ein fossiler Albatros (Diomedea) im Red Crag (Pliozän) Englands. Fossile Puffinusarten sind im Miozän Nordamerikas und Frankreiclıs nachgewiesen.

\section{Ordnung: Ciconiiformes (Storchvögel).}

Vertreter der drei Unterordnungen der Ruderfüßer (Steganopodes), Reilıer (Ardeae) und Störche (Ciconiae) sind aus vielen Tertiärablagerungen bekannt, lassen sich aber fast durchaus den heute noch lebenden Gattungen einreihen. Flaningos (Ploenicopterus) sind im Alttertiär und Miozän Europas gefunden worden, Pelikane (hierher Odontopteryx mit gezähnten Kieferrändern aus dem Untereozän Englands) treten im Miozän von Steinheim (Württemberg) zahlreich auf; auch von Reilhern, Störchen und Jbissen sind viele Reste bekannt, die aber gleichfalls für die Stanmesgeschichte ohne Belang sind. Ebenso verbreiten auch die dürftigen Reste eines Vogels (Scapula, Coracoid, Humerus) aus der obersten Kreide von Malmö in Schweden ${ }^{1}$, die als Scaniornis Lundgreni beschrieben wurden, kein Licht über die Vorgeschichte der Flamingos, in deren Verwandtschaft diese Art gestellt wird.

Ein für die Stanmesgeschichte der Steganopoden wichtiger Fund ist in der oberen Kreide Siebenbürgens gennacht worden; leider liegen nur wenige Reste eines Vogels vor, den C. W. Andrews ${ }^{2}$ als Elopteryx

1 W. Dames, Über Vogelreste aus dem Saltholmskalk von Limhamn bei Malmö. - Bihang till K. Svenska Vet. Akad. Handlingar, XVI. Bd., Stockholm 1890.

2 C. W. Andrews, On Some Bird Remains from the Upper Cretaceous of Transylvania. - Geol. Magazine (5), Vol. X, London 1913, p. 193. 
Nopcsai beschrieb, aber die Merkmale weisen auf enge Beziehungen zu den Kormoranen oder Scharben (Phalacrocoracidae), deren Anfänge somit bis in die Kreide zu verfolgen wären. Ob Argillornis longipennis aus dem untereozänen Londonton von Sheppey ${ }^{1}$ und dem jüngeren (mitteleozänen) Bruxellien von Etterbeek in Belgien ${ }^{2}$ zu den ${ }^{`}$ Scharben oder zu den Albatrossen gehört, ist einstweilen noch unsicher.

\section{Ordnung: Anseriformes (Gänsevögel).}

Zahlrejche fossile Arten aus dem Tertiär bekannt, die meist mit lebenden Gattungen in nähere Beziehung gebracht werden können, aber ohne phylogenetische Bedeutung sind.

Eine gänzlich erloschene Familie der Anseriformes sind die untereozänen Gastornithiden, die durch mehrere Gattungen und Arten atts dem Untereozän Frankreichs (Gastornis Edwardsi aus dem Basaleozän von Reins ${ }^{3}$ und Gastornis parisiensis aus den Tonen von Meudon bei Paris $^{1}$ ), aus dem Untereozän Belgiens (Gastornis Edwardsi aus dem unteren Landenien von Mesvin bei Mons ${ }^{5}$ ) sowie aus dem London Clay der Insel Sheppey (Dasornis londiniensis ${ }^{6}$ ) und dem Untereozän (Woolwich Beds) von Croydon in England (Gastornis Klaassenii ${ }^{7}$ ) bekannt sind. In dieselbe Gruppe gehören wahrscheinlich auch die beiden Arten Remiornis minor und R. Heberti aus dem Basaleozän von Reims. ${ }^{8}$

Die Gastornithiden waren zweifellos flugunfähige Landvögel, die beträchtliche Körpergrößen erreichten; der Oberschenkelknochen von Gastornis Parisiensis ist $31 \mathrm{~cm}$, die Tibia derselben Art $48 \mathrm{~cm}$ lang.

1 R. Owen, On Argillornis longipennis, a Large Bird of Flight, from the Eocene Clay of Sheppey. - Quart. Journ. Geol. Soc. London, Vol. XXXIV, 1878, p. 124.

${ }^{2}$ L. Dollo, The Fossil Vertebrates of Belgium. Annals N. Y. Acad. Sciences. Vol. XIX, Nr. 4, Pt. I, 1909, p. 111.

${ }^{3}$ V. Lemoine, Recherches sur les Oiseaux fossiles des terrains tertiaires inférieurs des environs des Reims. - Reims, I. Partie: 1878, 11. Partie: 1881.

${ }^{4}$ E. Hébert, Note sur le Tibia du Gastornis parisiensis. - Note sur le Femur du Gastornis parisiensis. - Comptes Rendus de l'Académie des Sciences, Paris, T. XL, 1855 , p. 579 und 1214 .

5 L. Dollo, Note sur la Présence du Gastornis Edwardsii, Lemoine, dans l'assise inférieure de l'Étage Landenien a Mesvin, près Mons. - Bull. Mus. Roy. Mus. Nat. Belg., Bruxelles, Vol. II, 1883, p. 297.

${ }^{6}$ R. Owen, On Dinornis. - Part XIV. - Transactions Zoological Society, London, Vol. VII, 1872, p. 123.

7 E. T. Newton, On the Remains of a Gigantic Species of Bird (Gastornis Klaassenii n.sp.), from the Lower Eocene Beds near Croydon. - Ibidem, Vol. XII, 1886, p. 143.

${ }^{8}$ V. Lemoine, Sur le Gastornis Edwardsi et le Remiornis (n. g.) Heberti de l'Éocéne inférieur des environs de Reims. - Comptes Rendus, Paris, Vol. XCill, I882, p. 1157. 


\section{Ordnung: Falconiformes (Raubvögel).}

Aus dem Tertiär und Quartär kennt man zahlreiche Arten, die sich an lebende Gattungen anschließen. Zu erwähnen ist der gewaltige Harpagornis aus dem Plistozän Neuseelands. Die ältesten Raubvogelreste kennt man aus dem Eozän Frankreichs (Phosphorite des Quercy).

\section{Ordnung: Opisthocomi (Hoatzine).}

Nur ein lebender Vertreter (Opisthocomus hoatzin) aus Südamerika bekannt.

XVII. Ordnung: Galliformes (Hühnervögel).

Die Hühner sind seit dem Eozän bekannt.

\section{Ordnung: Gruiformes (Kranichvögel).}

Unfaßt die lebenden Fanilien der Rallen (Rallidae), Kraniche (Gruidae), Schlangenstörche (Dicholophidae), Trappen (Otididae), Rallenkraniche (Rhinochetidae), Sonnenrallen (Eurypygidae) und Binsenrallẹn (Heliornithidae). - Die seit den Eozän, vielleicht schon aus der Oberkreide ${ }^{1}$ bekannten Rallen neigen zur Ausbildung von flugunfäligen Typen; derartige Formen sind auf der Südhemisphäre wiederholt unabhängig voneinander an weit voneinander liegenden Orten entstanden. Die. flugunfähig gewordenen Rallen sind heute fast sämtlich erloschen, nur die sehr seltene Notornis Hochstetteri lebt noch auf der Nordinsel Neuseelands. In die Nähe der Rallen gehört der gewaltige Phororhacos aus dem Miozän Patagoniens, der gleichfalls flugunfähig war, wie das verkümmmerte Flügelskelett beweist (Fig. 541); der Schädel fällt durch den gewaltigen Schnabel auf. ${ }^{2}$ Die ausgestorbene Gattung Aptornis aus dem Plistozän der Südinsel Neuseelands dürfte gleichfalls zu den Rallen gehören; sie erreichte die Größe der Dinornithiden. ${ }^{3}$ Flugunfähige Rallen lebten, zum Teil noch bis vor kurzer Zeit, auf Tristan d'Acunla, Mauritius, auf der Nordinsel Neuseelands, auf der Clataminsel, der Lord

1 Falls Telmatornis priscus, Marsh, aus der Oberkreide von Neu-Jersey, in diese Gruppe gehört. - Vgl. R. W. Shufeldt, Fossil Birds in the Marsh Collection of Yale University. (Transactions Connecticut Acad. Sci., Vol. XIX, New Haven, 1915, p. 26.) Telmatornis war ein Laufvogel.

1 C. W. Andrews, On the Extinct Birds of Patagonia. - I. - The Skull and Skeleton of Phororhacos inflatus Ameghino. - Transactions Zoological Society, Vol. XV, London 1898-1901, p. 55.

2 Derselbe, Note on a nearly complete Skeleton of Aptornis defossor, Owen.

- Geological Magazine, London 1896, p. 241. 
Howe Insel und auf den Norfolkinseln und sind an allen diesen Orten selbständig aus flugfähigen Vorfahren entstanden.

Auch die verschiedenen bis jetzt bekannten Arten der Gattung Diatryma aus dem Eozän Nordamerikas (Untereozän von Wyoning,

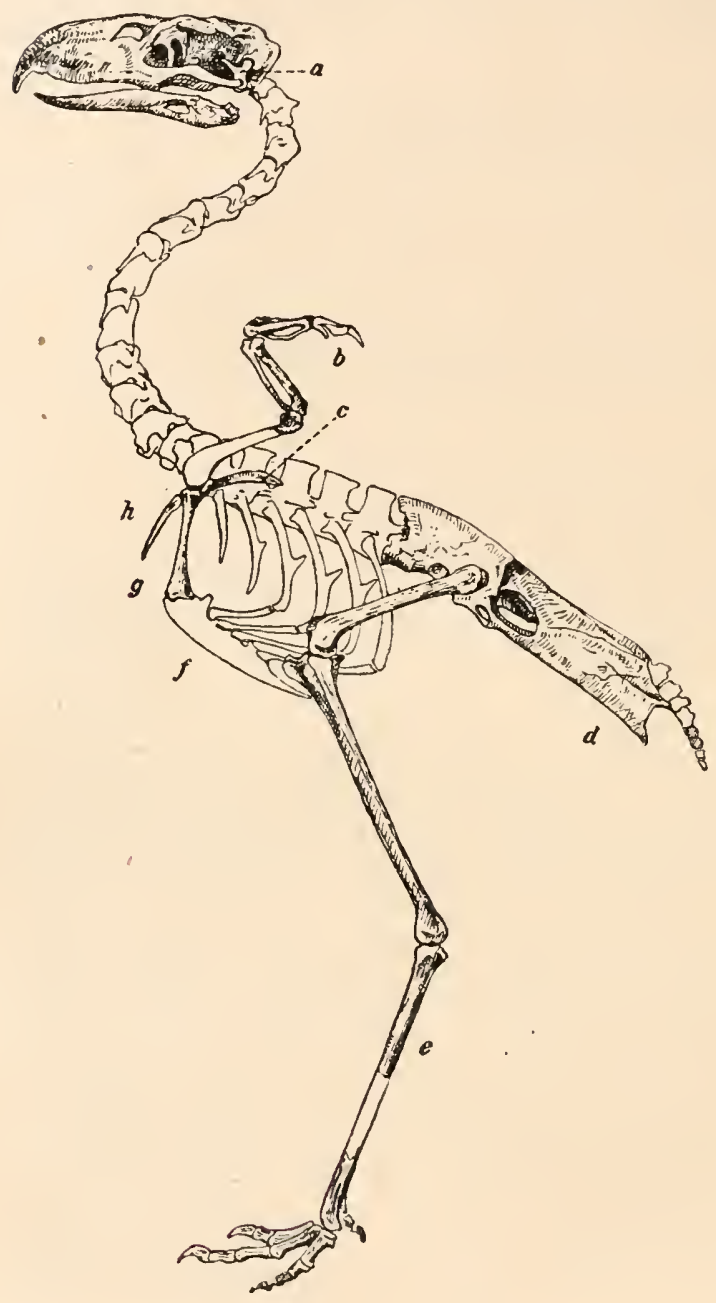

Fig. 541 .

Phororhacos inflatus, Ameghino, aus dem Obermiozän (Santacruzeno) Patagoniens. Rekonstruktion des Skelettes in etwa $1 / 12$ nat. Gr. (Nach C. W. Andrews.)

$$
\begin{aligned}
& a=\text { Quadratum. } \\
& b=\text { Arm. } \\
& c=\text { Scapula } \\
& d=\text { Becken. } \\
& e=\text { Tarsometatarsus. } \\
& f=\text { Sternum (ohne Kiel) } . \\
& g=\text { Coracoid. } \\
& h=\text { Clavicula. }
\end{aligned}
$$

New Jersey, Neumexiko) scheinen zu dem Kreise der Rallen zu'gehören. Es waren dies riesige, flugunfähige, ,straußartige“ Vögel, und R. W. Shufeldt ${ }^{1}$ nahm an, daß Diatryma ajax der größte Vogel war, der jemals lebte; indessen ist er wahrscheinlich kaum größer als Di-

1 R. W. Shufeldt, The Biggest Bird that ever lived. - Scientific American, Vol. CX, New York, 1914, p. 248. 
nornis maximus gewesen. Das 1917 von W. D. Matthew und W. Grange $r^{1}$ beschriebene Skelett von Diatryma gigantea erreichte nur 2,10 $\mathrm{m}$ Höhe. Der von O. C. Marsh ${ }^{2}$ als Barornis regens bescluiebene Rest (eine Grundphalange) gehört nach R. W. Shufeldt zur Gattung Diatryma. ${ }^{3}$ Ob Beziehungen zwischen Diatryma und den Papageien vorliegen, wie C.W. Andréws annimmt, scheint fraglich zu sein.

Die übrigen fossilen Vertreter der Ordnung sind für die Stammesgeschichte der Gruppe bedeutungslos.

XIX. Ordnung: Charadriiformes (Regenpfeifervögel).

Diese Ordnung umfaßt die Unterordnungen der echten Regenpfeifer oder Schlammläufer (Limnicolae), der Möwenvögel (Lari), der Flughühner (Pterocles) und der Taubenvögel (Columbae). Zu den letzteren gehört die erloschene Familie der Dididae (Dronten) mit dem Dodo von Mauritius (Didus ineptus) und dem Dodo der Insel Bourbon (Didus borbonicus, beide im 17. Jahrhundert ausgestorben) und mit dem Pezophaps solitarius, dem „Solitär“ der Insel Rodriguez, der im 18, Jahrhundert erlosch. Unsichere Spuren dieses Stammes erscheinen bereits in der oberen Kreide Nordamerikas.

\section{Ordnung: Cuculiformes (Kuckucksvögel).}

Für die fossilen Reste dieser Ordnung, die seit dem Eozän bekannt ist, gilt dasselbe wie für die meisten anderen Ordnungen, die wir unter den lebenden Vögeln zu unterscheiden haben: die fossilen Arten geben keinen Aufschluß über die Phylogenie der Gruppe.

Papageien treten in Miozän Frankreichs auf (Psittacus und Trogon).

\section{Ordnung: Coraciiformes (Rakenvögel).}

Aucl diese Ordnung tritt schon im Eozän auf. Die verschiedenen fossilen Vertreter sind, wie die meisten fossilen Vögel, wohl in tiergeographischer Hinsicht von Wichtigkeit, aber für die Stammesgeschichte bedeutungslos, da die meisten fossilen Arten den lebendên Gattungen einzureihen sind.

1 W. D. Matthew and W. Granger, The Skeleton of Diatryma, a Gigantic Bird from the Lower Eocene of Wyoming. - Bulletin of the American Museum of Natural History, New York, Vol. XXXVII, 1917.

2 O. C. Marsh, A Gigantic Bird from the Eocene of New Jersey. - American Journal of Science, (3), Vol. XLIV, 1894, p. 344.

${ }^{3}$ R. W. Shufeldt, Fossil Birds in the Marsh Collection of Yale University. Transactions Connecticut Acad. Sciences, New Haven, Vol. XIX, 1915, p. 37. p. 469 .

4 C. W. Andrews, A Gigantic Eocene Bird. - Geol. Magazine, London 1917, 


\section{Ordnung: Passeriformes (Sperlingsvögel).}

Seit dem Oligozän bekannt; es liegen nur wenige dürftige Reste vor. ${ }^{1}$

Für die Stanmesgeschichte der Vögel sind somit die fossilen Vertreter der Mehrzahl der 22 Ordnungen ohne tiefgreifende Bedeutung. Alles spricht dafür, daß die Spaltung der heute noch lebenden Ordnungen selır weit zurückliegt und vielleicht noch weiter zurückreicht als die Kreide. Seit dem Eozän haben sich sogar die meisten im fossilen Zustande nachgewiesenen Gattungen nur unwesentlich verändert, wenn auch einzelne Typen aberrante Seitenwege eingeschlagen haben. Wir dürfen vermuten, daß die Entfaltung des Vogelstammes vielleicht schon vor die Zeit fällt, aus der wir den ältesten fossilen Vogel, Archaeopteryx, kenmen. Bei den Untersuchungen über die Stammesgeschichte der Vögel sind wir daher fast ausschließlich auf jene Merkmale angewiesen, die sich noch heute bei den Angehörigen der einzelnen Hauptgruppen vorfinden.

$\mathrm{Da}$ in den letzten Jahren mehrere zusammenfassende Darstellungen der Vogelfaunen der europäischen Tertiär- und Quartärablagerungen erschienen sind, so haben wir durch diese sehr dankenswerten Arbeiten einen guten Einblick in die jüngere Geschiclite der europäischen Vogelwelt erhalten. Cl. Gaillard ${ }^{2}$ beschrieb die Vogelreste aus den Phosphoriten des Quercy (Eozän) Frankreichs; die jüngeren Faunen Frankreichs hat P. Paris ${ }^{3}$ in seiner Darstellung, die alle bis zum Jahre 1912 beschriebenen fossilen Vögel Frankreichs umfaß̣t, dargestellt. Vor kurzem hat L. von Ammon sämtliche Arten der europäischen Vogelfauna der jüngeren Miozänzeit (etwa 60) in einer Liste zusammengefaßt,

1 Der älteste bis jetzt bekannte Rest eines Passeriformen wurde in den (?) oligozänen Amyzonschiefern von Colorado entdeckt. - J. A. Allen, Description of a Fossil Passerine Bird from the Insect-bearing Shales of Colorado. - Bull. U. S. Geological and Geograph. Survey Territories, 1878, p. 443.

(Über das Alter der Amyzonschiefer vgl. L. M. Lambe, On Amyzon brevipinne, Cope, from the Amyzon Beds of the Southern Interior of British Columbia. Transactions of the Royal Society of Canada (2), 1906-1907, Vol. XI1, 1906, p. 151.)

2 C. Gaillard, Les Oiseaux des Phosphorites du Quercy. - Annales de l'Université de Lyon (n. sér.), Fasc. XXIII, London 1908.

${ }^{3}$ P. Paris, Oiseaux fossiles de France. - Revue Française d'Ornithologie. IV., 1912, p. 282.

${ }^{4}$ L. von Ammon, Tertiäre Vogelreste von Regensburg und die jungmiocäne Vogelweit. - Abhandlungen des naturwissenschaftl. Vereins zu Regensbuig, 12. Heft, Muinchen 1918, S. 60. 
während $\mathrm{K}$. Lambrecht ${ }^{1}$ eine tabellarische Übersicht der plistozänen Vögel Europas veröffentlichte.

Aus diesen Darstellungen ergibt sich mit voller Klarlieit, daß sich seit dem mittleren Tertiär der Charakter der Vogelwelt nur in ganz unbedeutendem Maße geändert hat. Freilich begegnen wir schon in plistozänen Ablagerungen einigen heute erloschenen Arten und die Zahl derselben nimmt zu, je weiter wir uns von der Gegenwart entfernen, aber der Gesamtcharakter der tertiären Vogelwelt ist trotzdem ein durchaus. noderner. Über die Verzweigung der verschiedenen Vogelstämme werden wir nur in mesozoischen Ablagerungen entscheidende Aufschlüsse erwarten dürfen.

1. K. Lambrecht, Díe Ausbildung und Geschichte der etropäischen Vogel-weilt. -- Aquila, Bd. XXIV, Budapest 1917; S. 191.

Demselben Autor verdanken wir die wertvollste Bibliographie der fossilen Vögel: Geschichte und Bibliographie der Paläoornithologie. - Ibidem; Bd. XXIII, . 1916 , S. 209. 


\section{Klasse: Säugetiere (Mammalia).}

\section{Unterklasse: Monotremata.}

Von den Monotremen, die zweifellos einen uralten Stanm der Säugetiere bilden, sind nur aus plistozänen Schichten Australiens Reste erhalten, welche den heute noch lebenden Gattungen Echidna und Ornithochynchus angehören und uns über die Stammesgeschichte der Monotremen keinen Aufschluß geben. Wir sind daher über die Frage nach der phylogenetischen Stellung dieser Gruppe unter den übrigen Wirbeltieren allein auf die morphologische Analyse der lebenden Typen angewiesen. Verschiedene Gesichtspunkte sprechen dafür, daß diese Gruppe schon in sehr früher Zeit, vielleicht schon in Perm, von Reptilien aus der näheren Verwandtschaft der Theriodontier abgezweigt ist und sich ganz selbständig weiterentwickelt hat. Wenn auch das Skelett der lebenden Monotremen in vielen Merkmalen noch sehr primitiv geblieben ist, so dürfen wir doch keineswegs den Schluß ziehen, daß alle jüngeren Säugetiere das Stadium der Monotremen durchlaufen haben; ebenso wie sich die Therocephalier als ein selbständiger Stamm erwiesen haben, der sich in vielen Merkmalen parallel zu den Säugetieren entwickelt hat, so werden wir auch die Monotremen als einen solchen blinden Seitenzweig ansehen dürfen, der aus Reptilien lıervorgegangen ist, ohne daß er in irgendeiner Form mit den Marsupialiern oder mit den Placentaliern zı verknüpfen wäre.

\section{Unterklasse: Marsupialia.}

Auch die Beuteltiere sind eine sehr alte Gruppe der Säugetiere. Über ihre Herkunft und Stammesgeschichte sind wir gleichfalls nur sehr ungenügend unterrichtet und die verschiedenen fossilen Reste der Marsupialier aus den mesozoischen und känozoischen Ablagerungen geben uns nur sehr unvollkommenen Aufschluß über den Zeitpunkt der Abzweigung der Beuteltiere und ihrer Spaltung in die Hauptzweige der Allotheria, Diprotodontia und der Polyprotodontia.

Man hat früher fast allgemein die Auffassung vertreten, daß die Beuteltiere das Vorstadium der Placentatiere darstellen und daß diese ausnahmslos ein Beuteltierstadium durchlaufen haben, in dem die in sehr hilflosem Zustande geborenen Jungen in einer Bruttasche an der Bauchhaut der Mutter bis zur größeren Reife verlıarrten. In neuerer Zeit sind verschiedene Bedenken gegen diese früher herrschende Anschaumng laut geworden und es scheint in der Tat, als ob die Vor- 
stellung von der unbedingten Durchlaufung einer marsupialen Vorstufe für die Placentalier nicht anzunehmen sei. Bei der sehr primitiven Gruppe der Beutelratten (Didelphiidae) ist nach Bresslau der Beutel noch heute keine fixierte Bildung und Winge hat mit guten Gründen die Meinung vertreten, daß der Beutel bei den Marsupialiern wiederholt entstanden ist.

Die Ausbildung der Marsupialier und der Placentalier ist daher möglicherweise nur als eine verschiedene Lösung der Aufgabe anzusehen, die Jungen möglichst lange ausreifen zu lassen. In der Tat ist nicht leicht einzusehen, wie eine Brücke von den Beuteltieren mit wohlausgebildetem Beutelapparat zu den placentalen Säugetieren hinüberführen könnte.

Über diese fundamentale Frage gibt uns die Paläontologie bis heute keine Auskunft. Die wenigen fossilen Marsupialier, die wir aus mesozoischen Ablagerungen kennen, bestehen fast ausschließlich aus Kieferstücken und die tertiären Reste bleiben uns über diese Frage gleichfalls die Antwort schuldig. Wir sind somit auf die Untersuchungen anderer Merkmale des Skelettes und des Gebisses angewiesen, die uns über die Beziehungen zwischen Beuteltieren und Placentatieren einen Aufschluß vermitteln können.

Das Gebiß der Beuteltiere unterscheidet sich von dem der Placentalier durchgreifend durch den Mangel eines regulären Zahnwechsels in größerem Umfange. Wir haben unter den Beuteltieren zwei verschiedene Arten des Zahnwechsels zu unterscheiden. Bei den Polyprotodontiern wird nur ein Zahn gewechselt, der in der Mitte der Backenzähne steht und früher fälschlich als $P_{4}$ bezeichnet worden ist; wir können ja nur bei den Säugetieren mit normal ausgebildetem Ersatzgebiß zwischen „Prämolaren“ des Ersatzgebisses und „Molaren“ unterscheiden, die noch zur Milchdentition gehören und nicht gewechselt werden. Dieser Ersatzzahn tritt bei den Polyprotodontiern entweder nocls vor dem Durchbruch der hintersten Zähne auf, wie bei Thylacinus oder er tritt erst spät nach deni Durclıbruch aller Zähne auf wie bei Potorous. Bei den Polyprotodontiern findet nun der Ersatz durch einen Zahn einer andern Zahngeneration als der statt, welcher die übrigen Zähne angehören, aber bei den Diprotodontiern, bei denen gleichfalls ein Zalnn gewechselt zu werden pflegt, ist dieser Ersatzzahn ein Element derselben Gencration. wie der übrigen Zähne und der Zahnwechsel vollzieht sich also hier nicht ,,vertikal“, sondern ,,horizontal“", wie dies bei den Diprotodontiern auch für die hinteren Backenzähne gilt.

Schon diese sehr verschiedene Art des Zahnersatzes muß den Gedanken nahelegen, daß das Gebiß der Beuteltiere nicht als die Vorstufe des Placentaliergebisses angesehen werden darf, sondern daß es sich hier um verschiedene Entwicklungswege hàndelt. 
Über die Frage, wie der Zalmersatz bei den fossilen Beuteltieren stattfand, geben uns die bisher vorliegenden Reste nur einen sehr unvollkommenen Aufschluß. Eine einzige jurassische Marsupialierart, Triconodon serrulla, zeigt denselben Zahnwechsel, wie er bei den Polyprotodontiern der Gegenwart zu beobachten ist. Die Gebisse der polyprotodonten Beutler aus dem Tertiär Argentiniens schließen sicli durchaus dem Typus der lebenden Beutelwölfe an und geben uns keinen befriedigenden Aufschuß über die Frage nach der Entstehung dieser Ersatzzähne. Keinesfalls können diese patagonischen Beutler als „Sparassodonta" eine Übergangsgruppe zwischen den Marsupialiern und den Placentaliern bilden ${ }^{1}$, wie in früherer Zeit angenommen worden ist (Fig. 542).

Wir werden daher zu der Annahme geführt, daß die Trennung der Beuteltiere und der Placentatiere eine sehr scharfe und durch keinen Übergang verbundene ist und daß sie schon in sehr alter Zeit erfolgt se.n muß. Wahrscheinlich fällt diese Trennung der beiden Stämm1e schon an den Anfang der Abspaltung der Säugetiere von den Reptilie11; die aller Wahrscheinlichkeit nach bereits in der Permformation stattgefunden liat.

\section{Ordnung: Allotheria.}

Die ältesten Gattungen der Beuteltiere, welche mitunter auch als Allotheria bezeichnet und von verschiedenen Forschern in die Gruppe der Monotremen eingereiht werden, sind in der Trias des Basutolandes in Südafrika (vielleicht Juraformation?) entdeckt worden. AußerdenI sind vereinzelte Reste in den Jurabildungen Englands und Nordamerikas, in den Wealdenbildungen Europas (Unterkreide) und in der oberen Kreide (Laraniebildungen) Nordamerikas gefunden worden. Die jüngsten Gattungen dieser Gruppe der Beuteltiere, welche als vollständig erloschen anzusehen ist, wurden im Untereozäı von Montana in Nordanıerika und in Untereozän Patagoniens entdeckt.

\section{F. Tritylodontidae.}

Die Gattung Tritylodon (= Triglyphus) ist in der obersten Trias Südafrikas und in gleich alten Schichten Württembergs, die gleichfalls vielleicht schon dem Lias angehören, entdeckt worden. Der Schädel von Tritylodon zeigt unverkennbare Beziehungen zu den Reptilien aus der Gruppe der Theriodontier und ist wiederliolt zu den Reptilien gestellt worden. Der Schädel fällt vor allem durch das hochspezialisierte Gebiß auf, das aus einer Reihe dicht geschlossener Backenzähne von

1 W. D. Matthew, The Relationships of the Sparassodonta. - Geol. Magazine, London (N. S.), Dec. V., Vol. IV, 1907, p. 531. 
A.

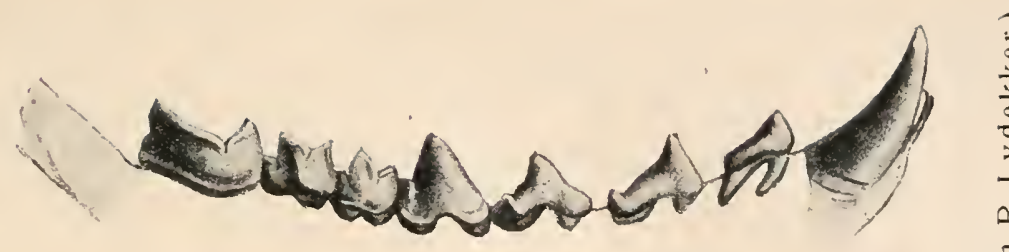

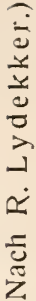

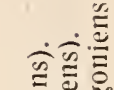
$\simeq \quad$.

ป

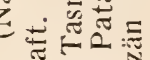

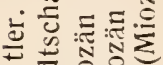

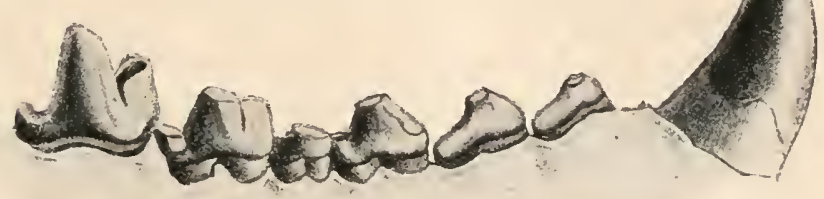

B. 1.

B. 1.

B. 1.

B. 1.

B. 1.

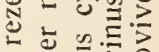
ชั

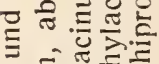

( )

I

(I) $\Xi$.

ن ษิ 10: iI

它

光

플

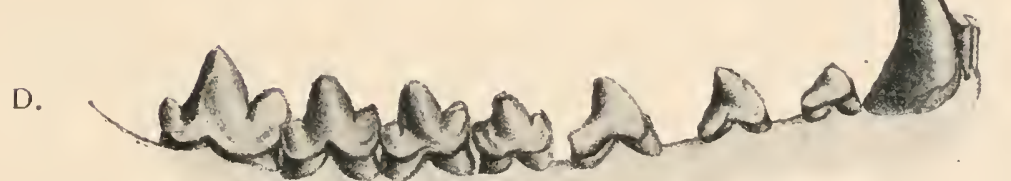

ए

志壳要

汇灾。

Љิ

\壱.

บ $\overline{0} 0_{0}^{\circ} \frac{\pi}{\pi}$

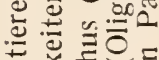

늘 롱리

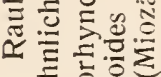

E.

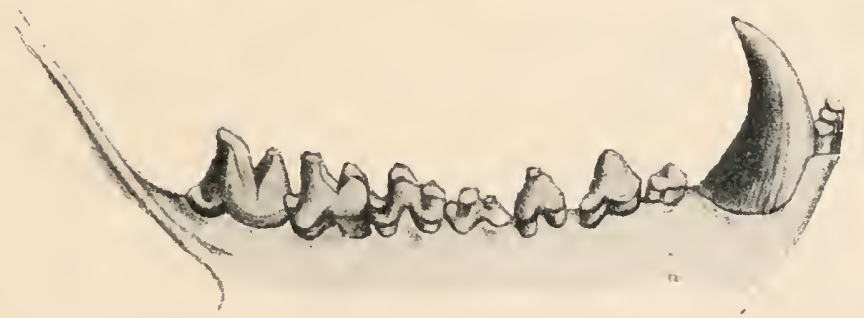

F.

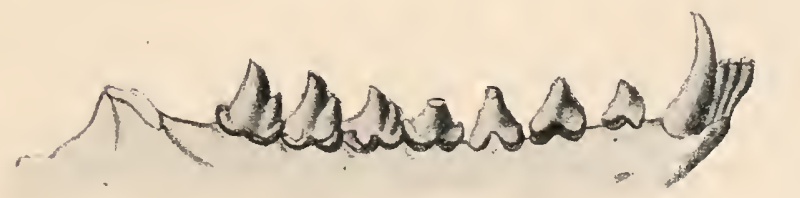

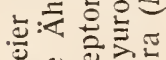

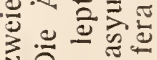

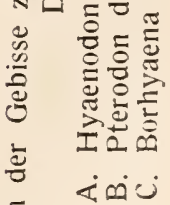


quadratischer Form besteht, die drei Höckerreihen tragen; zwischen den Backenzähnen und den stark vergrößerten lnzisiven klafft eine große Lücke. Jedenfalls ist das kleine Tier ein Pflanzenfresser gewesen. Die Schnauze zeigt eine auffallend breite, vorn abgestutzte Form.

Tritylodon. - Oberste Trias des Basutolandes (Südafrika) und Württembergs. ${ }^{1}$

\section{F. Plagiaulacidae.}

Die ersten Plagiaulaciden erscheinen in der obersten Trias Württembergs nit der nur aus vereinzelten Zähnchen bekannten Gattung Microlestes; im oberen Jura tritt die kleine Gattung Plagiaulax auf, der sich weitere Gattungen aus der oberen Kreide anschließen. Das wesentliche Kennzeichen der Plagiaulaciden besteht in der eigentümlichen Spezialisation der unteren Backenzähne, unter denen einer besonders vergrößert ist und eine scharfe Schneide trägt, die vielleicht eine spezielle Anpassung an das Zerschneiden von Pflanzenwurzeln darstellt und ein Gegenstück in der lebenden Gattung Bettongia besitzt, welche zu den Diprotodontiern gehọrt und mit den Allotherien nicht näher verwandt sein kann.

Microlestes. - Älteste Gattung der Familie. Obere Trias Württembergs und Englands. ${ }^{2}$

Plagiaulax. - Oberer Jura und Unterkreide Englands. ${ }^{3}$

Allodon. - Oberer Jura von Wyoming.

Ctenacodon. - Oberer Jura von Wyoming. ${ }^{5}$

1 R. Owen, On the Skull and Dentition of a Triassic Mammal (Tritylodon longaevus Owen) from South Africa. - Quarterly Journal Geological Society, Vol. 40, London 1884, p. 146.

H. Seeley, The Reputed Mammals from the Karroo Formation of Cape Colony. - Philosophical Transactions, London 1895, Vol. 185, p. 1027.

F. Broom, On Tritylodon, and on the Relationships of the Multituberculata.

- Proceedings Zoological Society, London 1910, p. 760.

O. Fraas, Vor der Sündfluth! - Stuttgart 1866, p. 215, Fig. 77.

M. Neumayr, Erdgeschichte. 2. Aufl., 1885, S. 182. - (Vgl. auch: Netles Jahrbuch f. Min. usw., 1884, p. 279.)

2 Th. Plieninger, Über Microlestes. - Jahreshefte des Ver. f. vaterländ. Naturkunde in Württemberg. 1847, S. 164.

${ }^{3}$ H. F. Osborn, The Structure and Classification of the Mesozoic Mammalia. - Journal of the Academy of Nat. Sci. of Philadelphia. Vol. 1X, Nr. 2, 1888, p. 215.

A. S. Woodward, On a Mammalian Tooth from the Wealden Formation of Hastings. - Proceedings Zoolog. Soc. London 1891, p. 585.

4 O. C. Marsh, Notice of New Jurassic Mammals. - American Journal 0 Science, Vol. XX1, June 1881, p. 511.

H. F. Osborn, l. c., p. 218.

${ }^{5}$ O. C. Marsh, Notice of New Jurassic Mammals. - American Journal of Science, Vol. XV111, 1879, p. 396. 
Neoplagiaulax. - Untereozän Frankreichs und Neumexikos. ${ }^{1}$ Ptilodus. - Untereozän von Montana. ${ }^{2}$

\section{F. Polymastodontidae.}

Nur durch eine einzige Gattung aus dem Untereozän Nordamerikas vertreten, die im Gesantcharakter des Gebisses an Tritylodon erinnert und wahrscheinlich dieselbe Lebensweise führte.

Polymastodon. - Puerco-Beds (unterstes Eozän) von Neumexiko. ${ }^{3}$

\section{F. Polydolopidae.}

Nur aus dem unteren Tertiär Südamerikas bekannt. Die Nahrungsweise dürfte, wie aus der eigentümlichen Differenzierung des Gebisses hervorgeht, eine ähnliche gewesen sein wie bei den Plagiaulaciden, da einzelne Zähne des Unter- und Oberkiefers zu einer hohen, im Profil dreieckigen Schneide vergrößert sind, die wahrscheinlich zum Ausheben und Absclineiden von Wurzeln diente.

Propolymastodon. - Untereozän Patagoniens. ${ }^{4}$

Polydolops. - Untereozän Patagoniens. ${ }^{5}$

Die Gruppe der Polydolopiden erlischt im Untereozän Südamerikas und findet keine Fortsetzung in den Nagetieren, wie F. Ameghino vermutet hatte.

\section{Ordnung: Diprotodontia.}

Diese Gruppe der Beuteltiere unfaßt meist Pflanzenfresser. Sie ist heute mit einziger Ausnahme der südamerikanischen Gattung Caenolestes auf Australien und die angrenzenden Inseln beschränkt. Fossile Vertreter der Ordnung kennt man aus dem Tertiär Patagoniens und aus den Plistozänbildungen Australiens; falls die sehr unvollkommen,

1 V. Lemoine, Étude sur le Neoplagiaulax. - Bulletin Soc. Géol. France, Paris (3), Vol. XI, 1883, p. 249.

E. D. Cope, Synopsis of the Vertebrate Fauna of the Puerco Series. - Transactions of the American Philosoph. Soc., Vol. XVI, 1888, p. 302.

2 J. W. Gidley, Notes on the Fossil Mammalian Genus Ptilodus, with Descriptions of New Species. - Proceedings of the U. S. Nat. Museum, Vol. 36, Washington, 1909 , p. 611.

${ }^{3}$ E. D. Cope, The Vertebrata of the Tertiary Formations of the West. Book I. - Report of the U. S. Geol. Survey of the Territories, Washington, Vol. III, I884, p. 732 .

H. F. Osborn and Ch. Earle, Fossil Mammals of the Puerco Beds, - Bull. Amer. Mus. Nat. Hist., Vol. V11, I895, p. 11.

4 F. Ameghino, Los Diprotodontes del Orden de los Plagiaulacideos y el origin de los Roedores y de los Polimastodontes. - Anales del Museo de Bueno Aires, T. IX, 1903 , p. 100.

5 lbidem, p. 141. 
nur durch einen schlecht erhaltenen Kieferrest vertretene Gattung Wyny$\operatorname{ardia}^{1}$ aus dem Tertiär (?) Australiens wirklich in die Nälıe der Phalangeriden gehört, würde dies der älteste Rest eines Diprotodontiers auf australischem Boden sein. Niemals ist außerhalb Südainerikas und Australiens auch nur der geringste Anlıaltspunkt dafür gewonnen worden, daß diese Ordnung der Beuteltiere über dieses Gebief- hinausgekommen ist.

\section{F. Caenolestidaé.}

Die lebende Gattung Caenolestes erinnert durch die Form ilırer Zahnkronen in den Backenzähnen sehı an die Zahntypen, die wir bei den Beutelratten, also unter den Polyprotodontiern antreffen; dies würde dafür sprechen, daß wir in den Diprotodontiern die Nachkommen der Polyprotodontier zu erblicken haben. Sekundär tritt im Stamme der Caenolestiden eine Spezialisation der Backenzähne auf, die in auffallender Weise an die Zahnformen der Plagiaulaciden erinnert, indem ein großer seitlich geriefter Unterkieferzalın zur Ausbildung gelangt.

Abderites. - Miozän Patagoniens. ${ }^{2}$

Caenolestes. - Lebend in Südamerika (Ecuador): ${ }^{3}$

\section{F. Phalangeridae.}

Die lebenden Beutelfüchse sind vorwiegend herbivor; nur einige sind omnivor; unter den fossilen ist eine Gattung (Tlıylacoleo) sekundär zur karnivoren Nahrungsweise übergegangen, wie aus dem Charakter des Gebisses hervorgeht. ${ }^{4}$ Die Finger und Zehen dieses großen Beutelfuchses aus den Plistozänbildungen Australiens, das eine höhlenbewohnende Lebensweise geführt haben dürfte, da seine Reste nur in Knochenlıölılen entdeckt worden sind, waren mit großen Krallen bewaffnet. Die ïbrigen Gattungen, die durch fossile Arten im Plistozän Australiens vertreten sind, bieten kein besonderes stammesgeschiclitliches Interesse dar. Einige fossile Känguruharten, für die verscliedene Gattungen errichtet worden sind, haben bedeutende Größe erreicht.

1 B. Spencer, A Description of Wynyardia bassiana, a Fossil Marsupial from the Tertiary Beds of Table Cape, Tasmania. - Proceedings Zool. Soc. London 1900, p. 776 .

${ }^{2}$ F. Ameghino, I. c., p. 87.

${ }^{3}$ O. Thomas, On Caenolestes, a still Existing Survivor of the Epanorthidae of Ameghino, and Representative of a New Family of Recent Marsiupials. - Proceedings Zoological Society, London 1895, p. 870.

P. H. Dederer, Comparison of Caenolestes with Polyprotodontá and Diprotodonta. - American Naturalist, Vol. 43, 1909, p. 614.

J. E. V. Boas, Zur Kenntnis des Hinterfußes der Marsupialier. - Biologiske Meddelelser, Kgl. Danske Videnskabernes Selskab, Kjöbenhavn, 1918, p. 19:

4 O. Abel, Grundziige der Paläobiologie der Wirbeltiere, 1912, S. 502. 
Thylacole0.-- Plistozän Australiens. ${ }^{1}$ straliens. ${ }^{2}$

Palorchestes. - Ein Riesenkänguruh aus dem Plistozän Au-

\section{F. Phascolomyidae.}

Zu den Wombaten gehört das große, ausgestorbene Beuteltier Diprotodon, das die Größe eines Nashorns erreichte und somit das größte bisher bekannte Beuteltier ist. Dieser Pflanzenfresser lebte, wie aus den Funden am Lake Callabonna hervorgeht, in den südostaustralischen Salzsümpfen und nährte sich von halophilen Pflanzen, wie der zum Teil noch erhaltene Mageninhalt beweist. Das Gliedmaßenskelett ist hoch spezialisiert und beweist, daß das Tier ein sekundär zur terrestrischen Lebensweise zurückgekehrter Phalangeride war, dessen Ahnen arborikol gewesen sein müssen, wie aus dem Reduktionsgrade der mittleren Finger und Zehen hervorgeht. Das Tier hatte Klumpfüße und kann sich daher nur unbeholfen bewegt haben.

Diprotodon. - Plistozän Australiens. ${ }^{3}$

\section{Ordnung: Polyprotodontia.}

Die ersten echten Raubbeutler erscheinen in der Trias Nordamerikas und Südafrikas., Vielleicht sind diese Formen (Dromatherium, Microconodon, Tribolodon, Karoonys) als Übergangsformen zwischen Säugetieren und Reptilien anzusehen, aber die bisher bekannten Reste sind für die Entscheidung dieser Frage unzureichend. Im oberen Jura Englands und Nordamerikas treten verschiedene Gattungen auf, die als Triconodonta zusammengefaßt wurden und insectivor gewesen sein dürften, wie aus dem Charakter ihres Gebisses zu erschließen ist. Im

1 R. Owen, On the Fossil Mammals of Australia. - Philosophical Transactions, London 1860, Vol. 149, p. 309; Vol. 156, 1866, p. 73; Vol. 161, 1871, p. 213; Vol. 172, 1883, p. 575, 639; Vol. 187b, 1887, p. 1. Ferner: Researches on the Fossil Remains of the Extinct Mammals of Australia. London 1877.

W. H. Flower, On the Affinities of Thylacoleo. - Quarterly Journal Geol. Soc. London 1868, Vol. 24, p. 307.

R. Broom, On the Affinities and Habits of Thylacoleo. - Proc. Linnean Soc. N. S. Wales 1898, Part I, p. 57.

2 R. Owen, l. c., Philosoph. Transactions, Vol. 164, 1874.

${ }^{3}$ E. C. Stirling and A. H. C. Zietz, Description of the Bones of the Manus and Pes of Diprotodon australis, Owen. - Memoirs of the Roy. Society of South Australia. - Adelaide 1899, Vol. I, p. 1.

L. Dollo, Le Pied du Diprotodon et l'Origine arboricole des Marsupiaux. Bull. Scientifique de la France et de la Belgique, Vol 33, 1900, p. 278.

R. Owen, I. c., Philos. Transactions, 1870, p. 521.

A. Smith-Woodward, On a Reconstructed Skeleton of Diprotodon in the British Museum (Nat. Hist.). - Geol. Magazine (Dec. V.), Vol. IV, 1907, p. 337. 
Eozän Patagoniens erscheinen die ersten echten Dasyuriden, erlöschen aber schon im Miozän in Südamerika und sind heute auf die australische Faunenregion beschränkt. Dic echten Beutelratten treten zuerst in der oberen Kreide Nordamerikas auf (Eodidelphis Browni), sind aus dem europäischen Eozän in einzelnen Exemplaren bekannt ${ }^{1}$ und verschwinden hier wieder im Miozän. ${ }^{2}$ Auch in Südamerika hat man in miozänen Ablagerungen Reste von Didelphiiden gefunden. ${ }^{3}$ Alle diese Reste sind für die Stammesgeschichte der Polyprotodontier nit Ausnahme der südamerikanischen Dasyuriden von sehr geringer Bedeutung und geben keinen befriedigenden Aufschluß über die Verwandtschaft der ältesten Beutelratten mit den Insektenfressern unter den Placentaliern.

\section{F. Dromatheriidae.}

Dromatherium. - Obere Trias Nordamerikas. ${ }^{4}$

Microconodoll. - Obere Trias Nordamerikas. ${ }^{5}$

Tribolodon. - Obere Trias Südafrikas. ${ }^{6}$

\section{F. Triconodontidae.}

Amphilestes. - Oberer Jura Englands. ${ }^{7}$

Triconodon. - Oberer Jura Englands ${ }^{8}$, vielleicht ( $=$ Priacodon ?) auch in Nordamerika.

1 Die Reste, die aus den alttertiären Phosphoriten des Quercy in Frankreich unter dem Namen Peratherium beschrieben wurden, lassen sich nach $\mathrm{H}$. Winge kaum von den Arten der lebenden Untergattung Grymaeomys unterscheiden und fallen jedenfalls in den durch die Gattung Didelphys gekennzeichneten Formenkreis.

2 Die letzte Didelphysart auf dem Boden Europas ist D. frequens aus dem Untermiozän von Ulm.

3 Z. B. die Gattung Microbiotherium aus dem Miozän (Santa Cruz-Schichten) Patagoniens sowie mehrere andere Reste von fraglicher systematischer Stellung.

${ }^{4}$ H. F. Osborn, On the Structure and Classification of the Mesozoic Mammalia. - Journal Acad. Nat. Sciences Philadelphia, Vol. IX, Nr. 2, 1888, p. 222 (Literatur).

${ }^{5}$ Derselbe, Ibidem, p. 223.

Derselbe, Evolution of Mammalian Molar Teeth. - New York 1907, p. 18.

${ }^{6}$ H. G. Seeley, Researches on the Structure, Organisation and Classification of the Fossil Reptilia. - Philosophical Transactions R. Soc., London 1895, p. 145. - Der Rest besteht aus einem schlecht erhaltenen Unterkiefer mit drei erhaltenen Zähnen mit dreispitziger Krone. Ob dieses Kieferfragment zu den Beuteltieren zu stellen ist, muß als fraglich bezeichnet werden. Der kleine Unterkiefer von Karroomys aus denselben Schichten ist zu schlecht erhalten, um ein sicheres Urteil iuber seine systematische Stellung zu gestatten (vgl. R. Broom, Geol. Magazine, London 1903, p. 345).

7 H. F. Osborn, On the Structure and Classification usw., 1. c., 1888, p. 193.

Derselbe, The Evolution of Mammalian Molar Teeth, 1. c. 1907, p. 21.

8 Derselbe, I. c. 1888 , p. 195 ; I. c., 1907, p. 22. 
Triacanthodon. - Oberer Jura Englands. ${ }^{1}$

Phascolotherium. - Oberer Jura Englands. ${ }^{2}$

Tinodon. - Oberer Jura von Wyoming. ${ }^{3}$

\section{F. Dasyuridae.}

Cladosictis. - Miozän von Santa Cruz, Patagonien. ${ }^{*}$

Amphiproviverra. - Miozän von Santa Cruz (Fig. 542, F). ${ }^{5}$

Prothylacinus. - Miozän von Santa Cruz (Fig. 542, E und 543).

Borhyaena. - Miozän von Santa Cruz (F g. 542, C und 544).'

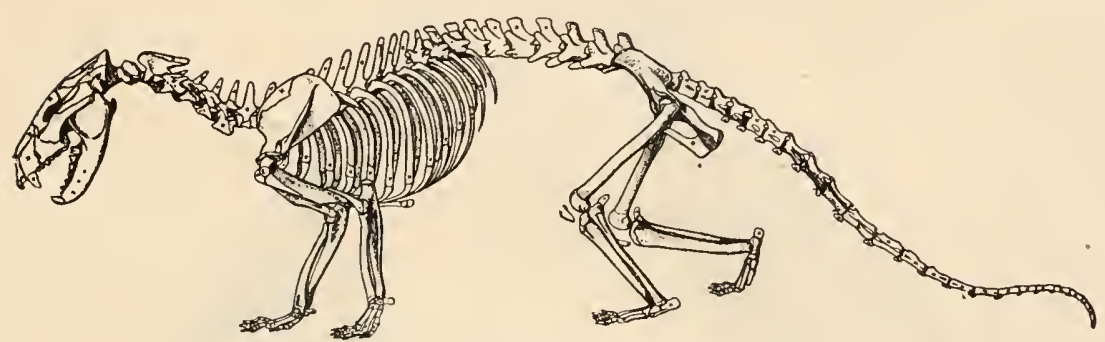

Fig. 543.

Rekonstruktion des Skelettes von Prothylacinus patagonicus, aus dem Miozän(SantaCruz-Schichten) Patagoniens. Skelettlänge etwa $140 \mathrm{~cm}$. (Nach W. J. Sinclair.)

\section{F. Didelphiidae.}

Didelphis. - Oberkreide bis zur Gegenwart. Heute auf Ämerika beschränkt, im Tertiär auch in Europa. ${ }^{8}$

\section{F. Myrmecobiidae.}

Die durch den lebenden australischen Ameisenbeutler Myimecobius

1 H. F. Osborn, I. c., 1888, p. 197; I. c., 1907, p. 22.

2 Derselbe, 1. c., 1888, p. 194; 1. c., 1907, p. 22.

3 O. C. Marsh, Additional Remarks of Jurassic Mammals. - Amer. Journ. of Science and Arts, Vol. XVIII, 1879, p. 215.

H. F. Osborn, I. c., 1888, p. 229.

4 W. J. Sinclair, The Marsupial Fauna of the Santa Cruz Beds. - Proceedings Amer. Philos. Soc., Vol. 49, 1905, p. 73.

Derselbe, Mammalia of the Santa Cruz Beds, Marsupialia. - Report Princeton Univ. Expedition to Patagonia, Vol. IV, Part 3, 1901, p. 333, PI. 1.

s lbidem, 1901 und 1905.

6 Ibidem, 1901 und 1905 (PI. I1).

7 F. Ameghino, Paleontologia argentina. - Publicaciones de la Universidad de la Plata, Nr. 2, 1904, p. 23.

8 Am bekanntesten ist das Vorkommen von Didelphisresten in den obereozänen Gipsen des Montmartre in Paris, die zuerst von G. Cuvier richtig gedeutet wurden. Die Reste wurden später in der Regel zur Gattung Peratherium gestellt, von der zahlreiche Arten unterschieden wurden (vgl. S. 718, Fußnote 1). Hierher gehört auch Microbiotherium aus dem Miozän Patagoniens (Santa Cruz-Schichten). 
vertretene Familie ist vor einigen Jahren ${ }^{1}$ auch in Nordamerika nachgewiesen worden, wo in den Fort-Union-Schichten (unterstes Eozän,

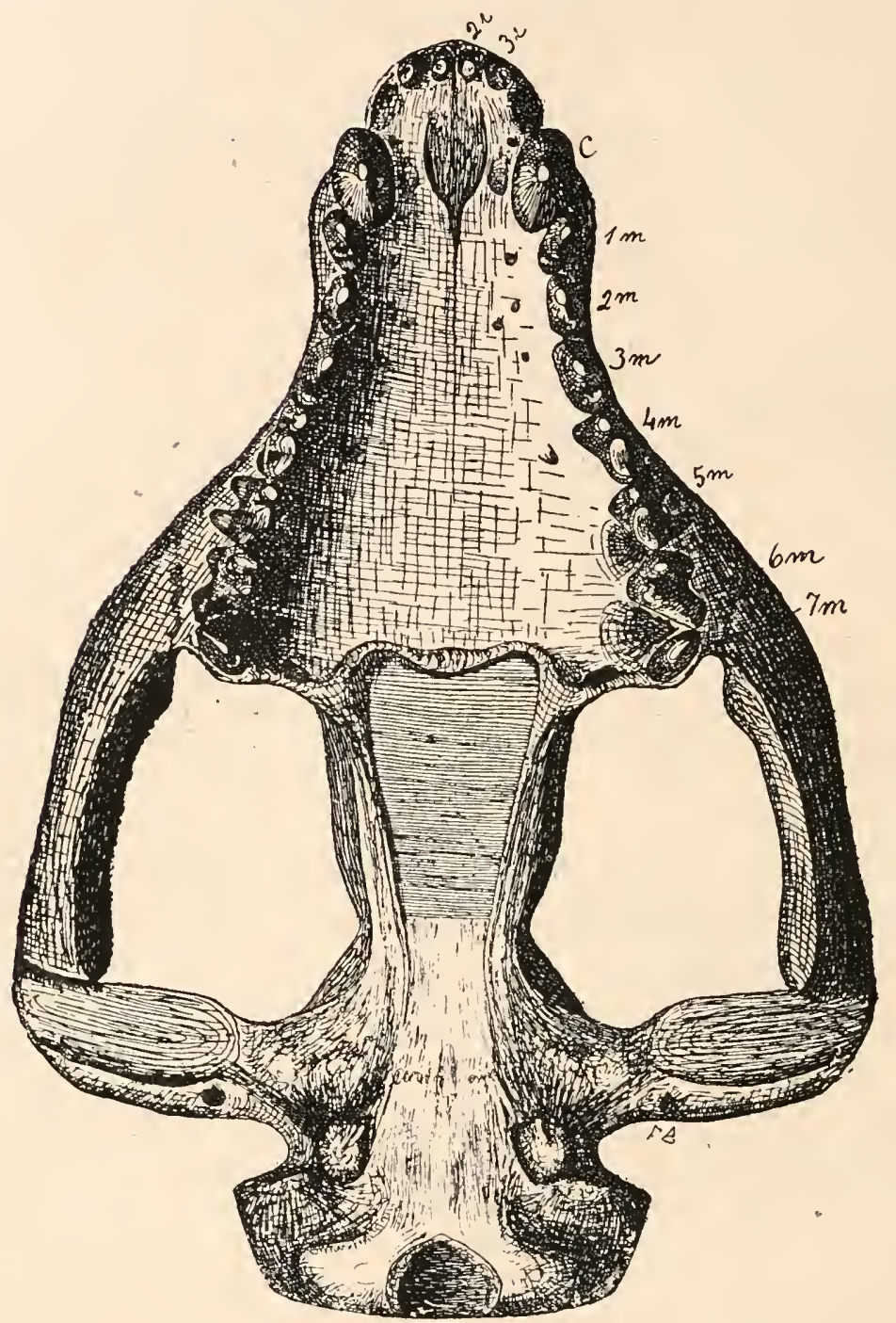

Fig. 544.

Schädel von Bo:hyaena tuberata, von der Unterseite gesehen. Aus dem Miozäı von Santa Cruz in Patagonien. $2 / 3$ nat. Gr. (Nach F. Ameghino.)

von gleichem Alter wie die Puercoschichten und Torrejonschichten) Montanas ein Unterkieferrest entdeckt wurde, den J. W. Gidley als Myrmecobioides montanensis beschrieb.

1 J.W. Gidaley, An Extinct Marsupial from the Fort Union with Notes on the Myrmecobiidae and other Families of this Group. - Proceedings U. S. Nat. Musenm, Washington, Nr. 2077, Vol. 48, 1915, p. 395. 


\section{F. Caroloameghiniidae.}

Die systematische Stellung der Gattung Caroloameghinia ist noch unsicher. Die Zahl der Schneidezähne in Unterkiefer ist jederseits vier, was auf eine Zahl von fünf oberen Schneidezähnen im Zwischenkiefer schließen läßt; dies würde für eine Einreihung der Caroloameghiniiden in die Gruppe der Polyprotodontier sprechen.

Caroloameghinia. - Untereozän (Notostylopsschichten) Patagoniens. ${ }^{1}$

\section{Unterklasse: Placentalia.}

\section{Ordnung: Pantotheria.}

Während die Monotremen kaum jemals eine besondere Bedeutung erlangt haben und nur einen armen Seitenast des Säugetierstammes darstellen, haben sich die Marsupialier wenigstens in der südlichen Hemisphäre und besonders in Australien sowie in ganzen australischen Faunengebiet zur Blüte entwickelt. Aber auch dieser Stamm bleibt weit hinter den Placentaliern zurück, der sich im Tertiär und Quartär zu einer sehr hohen Blüte entfaltet hat. Die Geschichte der Placentalier reicht wahrscheinlich bis in die Permzeit zurück, wenn uns auch über den Zeitpunkt der Abzweigung keine fossilen Reste Kunde geben. Daß die Insektenfresser.schon in der Trias vorhanden waren, ist sehr wahrscheinlich; sie dürften sich im allgemeinen Habitus kaum von den ältesten kleinen Polyprotodontiern unterschieden haben. Die Reste, welche wir aus den oberjurassischen Ablagerungen Nordamerikas kennen, und die durch gleichalterige Funde aus dem oberen Jura Englands in wesentlicher Weise ergänzt werden, können nicht dem Kreise der Insektenfresser selbst eingereiht werden, sondern sind wohl an besten als eigene Ordnung, die der Pantotheria oder Trituberculata, von den übrigen Stänmen der Placentalier abzutrennen.

Obwohl die Zahnformen dieser kleinen Säugetiere außerordentlich an die Gebißtypen der fossilen Polyprotodontier erinnern, so daß sie vielfach mit denselben vereinigt werden, so besteht doch ein Unterschied in der verschiedonen Ausbildung des Unterkieferendes. Bei den Polyprotodontiern ist an der Innenseite der unteren Unterkieferecke ein Fortsatz vorhanden, der Processus angularis; er wurde bei vielen Beuteltieren, auch bei den Diprotodontiern beobachtet und findet sich zwar auch bei anderen primitiven Säugetierstämmen, wie bei den lnsectivoren, Rodentiern und Xenarthren vor, ist aber nur bei den Beutel-

1 F. Ameghino, Les Formations sedimentaires du Crétacé supérieur et du Tertiaire de Patagonie. - Anales del Museo de Buenos Aires, T. XV (Ser. 3, T. VIII), 1906 , p. 287. 
tieren nach innen umgebogen. Er fehlt zwar auch vollständig bei Tarsipes und ist bei Myrmecobius rudinentär, aber der nach innen ungebogene Processus angularis darf doch im allgemeinen als ein bezeichnendes Merkmal der Beutler angesehen werden. Da er nun bei den Pantotherien auch vorhanden, aber nicht eingebogen ist, so betrachtet .H. F. Osborn diesen Unterschied als ein Kennzeichen dafür, daß die Pantotherien nicht den Beuteltieren, sondern den Insectivoren eingereiht werden müssen.

Über die Entstehung der Säugetiere mit Placenta geben freilich die Pantotherien keinen weiteren Aufschluß. Sie zeigen höchstens, daß der Ausgangsstanm der Placentatiere trituberkuläre, beziehungsweise trituberkulärscktoriale Backenzähne besessen haben muß und daß somit wohl alle Stämme der Placentalier auf kleine, insectivore Tiere zurückgehen. Die Zahnzahl ist bei den Pantotherien noch sehr groß und viel größer als bei den Insectivoren und den aus ihnen hervorgegangenen Stämmen, soweit nicht bei diesen sekundär eine Vermehrung der Zahnzahl erfolgt ist, wie bei den Delfinen oder beim Riesengürteltier Priodon, das bis 25 Zähne in jeder Kieferhälfte, also zusammen etwa 50 Zähne tragen kann. Bei den Pantotherien beträgt die Maximalzahl der Zähne in einer Kieferhälfte 16. Hinter dem Eckzahn können 7-13 Backenzähne stehen, während die Zahl der Schneidezähne jederseits bei den primitiveren Pantotherien vier beträgt. Schon im oberen Jura treten jedoch neben den vielzahnigen Gattungen einzelne auf, bei denen die normale Zahnzahl der Placentalier ${ }^{\circ} \mathrm{zu}$ beobachten ist (3 Schneide-, 1 Eck-, 4 Lücken- und 3 Malılzähne, also mit der Zahnformel: 3.1.4.3). ${ }^{1}$

\section{F. Amphitheriidae.}

Diese Fanilie enthält die primitivsten Gattungen aus den Stonesfieldschiclnten Englands, die dem nittleren Jura angehören. Aus dem oberen Jura sind einige weitere Gattungen bekannt, die in den Purbeckschichten gefunden worden sind.

Amphitherium. - Dogger Englands.

Amphitylus. - Dogger Englands.

Peramus. - Malm Englands.

Leptocladus. - Malm Englands.

\section{F. Amblotheriidae.}

Amblotherium. - Malm Englands.

Peraspalax. - Malm Englands.

1 Dic im folgenden angeführten Gattungen der Amphitheriidae, Amblotheriidae und Dicrocynodontidae sind von H. F. Osborn, On the Structure and Classitication of the Mesozoic Mammalia, I. c., 1888 sowie in dem Buche desselben Forschers ,On the Evolution of the Mammalian Molar Teeth", 1907, beschrieben und abgebildet, wo auch die ältere Literatur nachzusehen ist. 
Acliyrodon. - Malm Englands.

Pliascolestes. - Oberjura von Wyoming, Nordamerika.

Laodon. - Oberjura von Wyoming, Nordamerika.

Stylodon. - Oberjura von Wyoming, Nordamerika.

Asthenodon. - Oberjura von Wyoming, Nordamerika.

\section{F. Dicrocynodontidae.}

Dicrocynodon. - Oberjura von Wyoming.

Trotz der unvollkommenen Erhaltung dieser Reste - es sind fast durchaus nur die Unterkiefer und wenige Oberkieferreste bekannt sind die Pantotheria doch als sehr wichtige Dokumente aus der älteren Zeit der Geschichte des Placentalierstammes zu betrachten.

Derzeit kann nicht mit Sicherheit ermittelt werden, welche Stellung in der Stanmmesgeschichte den Säugetieren zukommt, die in dürftigen, fast nur aus isolierten Backenzähnen und Kieferfragmenten bestehenden Resten (Fig. 545) in den der oberen Kreideformation angehörenden Laramieschichten des Gebietes der Rocky Mountains in Nordamerika gefunden worden sind. Es ist möglich, dab einige derselben den Insectivoren, andere den Carnivoren und ein Teil derselben vielleicht der Stammgruppe der Ungulaten angehören. Wir verdanken die Kenntnis dieser wenigen Zälnnchen hauptsächlich der Tätigkeit der Ameisen, welche, wie R. S. Lull (1915) berichtet ${ }^{1}$, auf ihren Erdhaufen die im Gestein gefundenen kleinen Knochen und Zähne zusammentragen. . Funde vollständigerer Reste aus diesen Schichten wären für die Ermittlung der älteren Geschichte der Sängetiere von größter Bedeutung; wir dürfen hoffen, einmal in den Laramie Beds den Schlüssel zu vielen heute noch ungelösten Problemen aus der Phylogenie der Säugetiere zu finden.

\section{Ordnung: Insectivora.}

Die Insektenfresser, die sich auf das engste an die Pantotheria anschließen, sind nur durch wenige fossile Formen vertreten. Die ältesten sicher bestinmbaren Reste kennt man aus dem Eozän Europas und Nordamerikas; aus dem Tertiär Südamerikas sind nur dürftige Reste bekannt. Die geringe Körpergröße dieser Säugetiere ist wohl die Ursache ihrer seltenen Erhaltung. Diese Lücke unserer Kenntnisse über die Vorgeschichte der Insektenfresser ist um so mehr zu bedauern, als sie die Alnengruppe wahrscheinlich aller übrigen Placentalier darstellen. Vielleicht wirft gelegentlich ein glücklicher Fund in den mesozoischen Ablagerungen Nordamerikas Licht in dieses Dunkel. In Australien scheinen die lnsektenfresser seit jeher gefehlt zu haben. p. 236 .

1 R. S. Lull, Ant-Hill Fossils. - The Popular Science Monthly, Sept. 1915, 

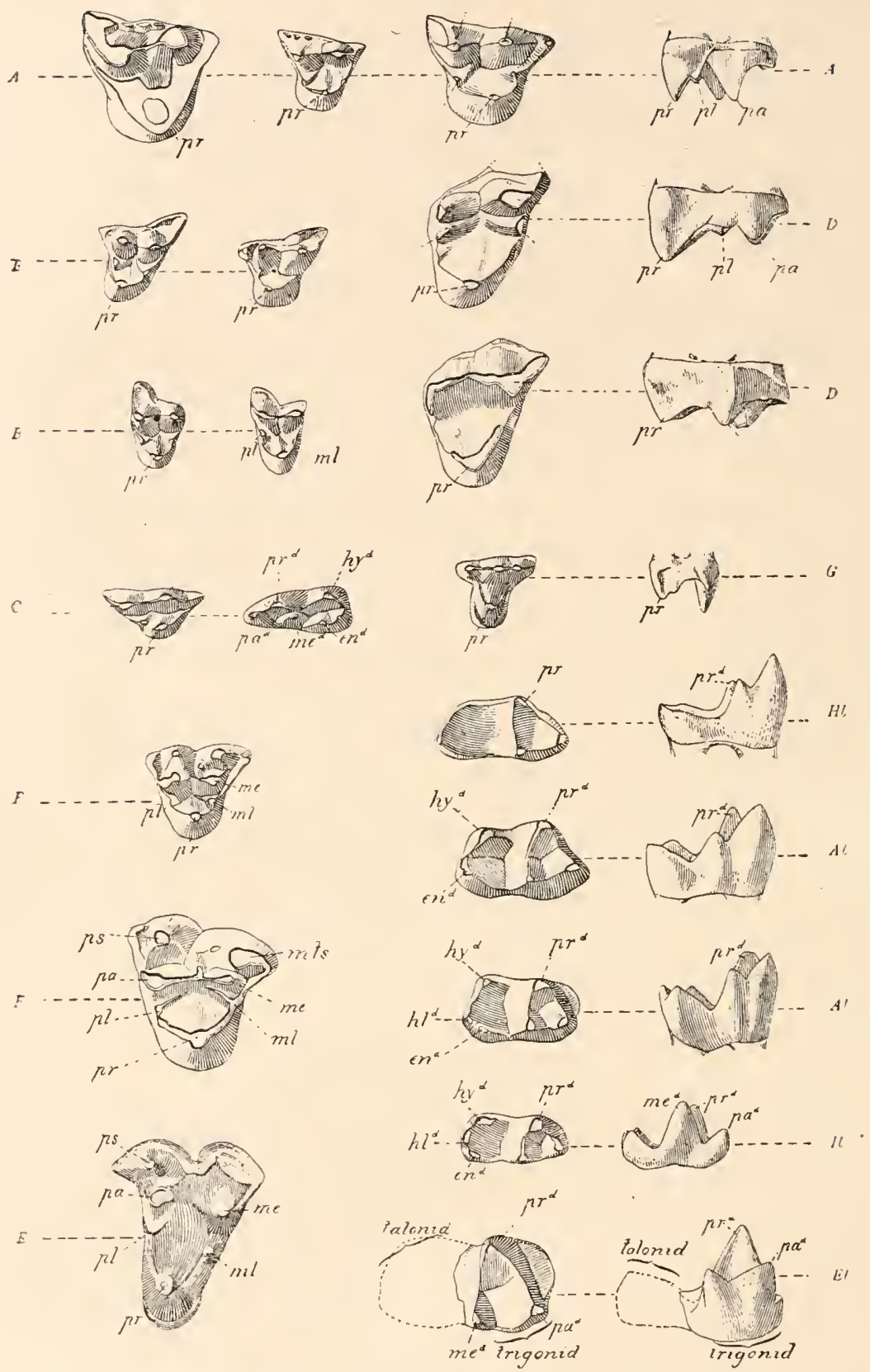

Fig. 545 .

Zähne v. Säugetieren aus den Laramieschichten d. Gebietes der Felsenberge (Rocky Moun?tains) in Nordamerika. Die Zähne zeigen den, trituberkulären" Baı. (Nach H.F.Os born.)
A. Protolambda Hatcheri (drei obere Mo-
E. Didelphops vorax. (ein recht.ob.Molar).

laren, wahrscheinlich rechtsseitige).

R. Pediomys sn. (vier obere Molaren).

C. Synconodon sexicuspis (ein oberer und

F. Ectoconodon Petersoni. (zwei obere ein unterer Molar der rechten Seite). [linke?] Molaren).

G. Gen. indet.

El. Didelphodon? (Unterer Molar.)

D. Gen, indet. (zwei linke obere Molaren).

Al., HI. und $11 .=$ Gen. indet. 


\section{Unterordnung: Dilambdodonta.}

Die Unterordnung der Dilambdodonten umfaßt alle jene Gattungen und Familien, bei denen die oberen Molaren trituberkulär sind und bei denen mitunter auch noch ein überzähliger hinterer Innenhöcker ( $\mathrm{Hy}$ pocon) zur Ausbildung gelangt, während die unteren Molaren ein kräftiges Talonid besitzen und daher einen trituberkulärsektorialen Bau aufweisen. Dieser Molarentypus leitet zu den Carnivoren und Huftieren sowie zu den Affen hinüber und es ist nach dem heutigen Stande unserer Kenntnisse über die Geschichte des Säugetierstammes wahrscheinlich, daß diese Gruppe der Insektenfresser die Stammgruppe für die höheren Säugetierordnungen bildet.

\section{F. Leptictididae.}

Diese Familie ist als gänzlich erloschen zu betrachten.

Palaeictops. - Untereozän von Wyoming. ${ }^{1}$

Leptictis. - Oligozän Nordamerikas.²

\section{F. Talpidae.}

Die Maulwürfe erscheinen zuerst im Mitteleozän und sind eine sehr konservative Gruppe, die sich einseitig spezialisiert hat.

Nyctitherium. - Mitteleozän Nordamerikas. ${ }^{3}$

Talpa. - Die ältesten Talpaarten sind aus den Miozän Europas bekannt. ${ }^{4}$

Desmana. - Lebend in Südosteuropa, lıauptsächlich im Flußgebiete des Don und der Wolga, sowie in Bokhara; fossil im Präglazial (Forest-Bed) Englands, im Plistozän Belgiens und im Postglazial von Beremend in Ungarn. ${ }^{5}$

1 E. D. Cope, The Vertebrata of the Tertiary Formations of the West. Book 1. - Report U. S. Geol. Surv. Territ., Washington 1884, I11, p. 266.

- J. Leidy, The Extinct Mammalian Fauna of Dakota and Nebraska, usw. with a Synopsis of the Mammalian Remains of North America. - Journ. Acad. Sci. Philadelphia (2), Vol. VIl, 1869, p. 345 und 408.

${ }^{3}$ W. D. Matthew, The Carnivora and Insectivora of the Bridger Basin, Middle Eocene. - Memoirs Amer. Mus. Nat. Hist., Vol. IX, Part 6, New York 1909, p. 537.

${ }^{4}$ M. Schlosser, Die Affen, Lemuren, Chiropteren, Insectivoren usw. des europäischen Tertiärs. - Beiträge zur Paläontologie und Geologie Öst.-Ung. und des Orients, VI. Bd., Wien 1887, p. 125.

5 Th. Kormos, Trois nouvelles espèces fossiles des Desmans en Hongrie. Annales Musei Nat. Hung., X1. Bd., Budapest 1913, p. 138.

Derselbe, Die suidrussische Bisamspitzmaus (Desmana moschata Pall.) im Pleistozän Ungarns. - Barlangkutatás, 11. Bd., Budapest 1914, p. 206. 
Galemys. - Lebend in Nordspanien und Nordportugal, fossil im Miozän Frankreichs, Unterpliozän und Präglazal Ungarns und Plistozän Frankreichs. ${ }^{1}$

\section{F. Soricidae.}

Protosorex. -- Oligozän Nordamerikas. ${ }^{2}$

\section{F. Erinaceidae.}

Necrogymnurus. - Obereozän Frankreichs. ${ }^{3}$

Eine ausgestorbene Gcuppe der Igel, welche durch die Gattungen Dimylus, Plesiodimylus und Cordylodon bezeichnet wird, ist nur aus dem Miozän Europas bekannt. Sie unterscheidet sich von den Talpiden durch den Bau der Molaren sehr bestimnt.

\section{F. Macroscelididae.}

Die heute auf Afrika beschränkte Familie der Rüsselspringer scheint durch die im Obereozän des Quercy in Frankreich entdeckte und durch einen Schädel belegte Gattung Cayluxotherium auch im Tertiär Europas vertreten gewesen zu sein. Diese Gatturg wurde früher von den meisten Forschern mit Necrogynnurus vereinigt, scheint aber nach neueren Untersuchungen von $\mathrm{H}$. Winge ${ }^{5} \mathrm{zu}$ den Macroscelididen zu gehören.

\section{F. Tupaiidae.}

Die in Hinterindien und im indomalayischen Archipel lebenden Spitzhörnchen (Tupaia $=$ Cladobates, Ptilocercus) sind bisher nicht in fossilen Resten bekannt.

\section{F. Galeopithecidae.}

Die durch die einzige Gattung und Art (Galeopithecus volans) in der Jetztzeit vertretene Fanilie ist zwar wahrscheinlich schon sehr frühzeitig vom Hauptstamme der Insektenfresser abgezweigt, doch geben uns keine fossilen Reste über ihre Vorgeschichte Aufschluß.

1 Th. Kormos, Trois, no:ıvelles espèces usw., 1. c., 19I3, p. 140.

Die Literatur der fossilen und lebenden Talpiden ist bei $\mathrm{H}$. Winge, Udsigt over Insektaedernes indbyrdes Slaegtskab (Vidensk. Medd. fra Dansk naturh. Foren., Bd. 68, Kjöbenhavn 1917, p. 184) nachzusehen.

2 W. B. Scott, A New Insectivore from the White River Beds. - Proc. Acad. Nat. Sci., Philadelphia 1894, p. 446.

Die Literatur ïber die fossilen und lebenden Soriciden bei H.Winge, l. c., p. 186.

${ }^{3}$ M. Schlosser, Die Affen, Lemuren usw., 1. c., S. 102.

Die Literatur iiber die lebenden und fossilen Erinaceiden bei H.Winge, l. c., 1917, p. 189.

4 Über die Grïnde der Einreihung der ,Dimyliden“ in die Familie der Erinaceiden vgl. H. Winge, 1. c., 1917, p. 146.

5 H. Winge, I. c., 1917, p. 183. 


\section{F. Adapisoricidae.}

Eine Gruppe von unsicherer systenatischer Stellung, die in manchen Merkmalen an Halbaffen erinnert.

A dapisorex. - Untereozän Frankreichs. ${ }^{1}$

\section{F. Mixodectidae.}

Auch diese Familie nimmt eine eigentümliche Zwischenstellung zwischen verschiedenen Familien ein und ist daher bald mit den Nagetieren, bald mit den Primaten und bald mit den Insektenfressern vereinigt worden. Diese Vermischung verschiedener Merkmale beweist jedenfalls, daß wir in dieser Gruppe, die leider nur durch sehr dürftige Reste vertreten ist, Formen zu erblicken haben, die entweder selbst die Ahnen einer der genannten böheren Ordnungen bilden oder doch zum mindestens der Verzweigungsstelle der Insectivoren, Primaten and Rodentier sehr nahe stehen.

Olbodotes. - Unterstes Eozän Nordamerikas (Torrejon-Beds). ${ }^{2}$

Mixodectes. - Unterstes Eozän Nordanerikas (Torrejon-Beds). ${ }^{3}$

Cynodontomys. - Untereozän (Wasatch-Beds) Nordamerikas. ${ }^{4}$

Microsyops. - Mitteleozän (Bridger-Beds) Nordamerikas. ${ }^{5}$

\section{F. Pantolestidae.}

Auch bei dieser Gruppe finden sich verschiedene Merkmale der lnsektenfresser mit jenen aus anderen Ordnungen der Säugetiere gemischt. Es liegen Ähnlichkeiten mit Paarhufern und mit Creodontiem vor, so daß die Ansichten über die systematische Stellung der Pantolestiden sehr geteilt sind. Die Gattung Pantolestes besitzt ferner große Ähnlichkeit mit den Robben, die aber vielleicht nur als Konvergenzerscheinungen infolge der Annahme der aquatischen Lebensweise zu bewerten sind. Der Schwanz von Pantolestes erinnert in Länge und Form an den der Fischottern.

1 V. Lemoine, Étude sur quelques Mammifères de petite taille de la Faune cernaysienne des environs de Reims. - Bull. Soc. Géol. de France (3), T. XIII, I $884-1885$, p. 206.

${ }^{2}$ H. F. Osborn, American Eocene Primates, and the Supposed Rodent Family Mixodectidae. - Bull. Amer. Mus. Nat. Hist., Vol, XVI, New York 1902, p. 205.

3 Ibidem, p. 206.

4 Ibidem, p. 208.

s Ibidem, p. 209.

J. L. Wortman, Studies of Eocene Mammalia in the Marsh Collection, Peabody Museum. - Amer. Journ. Sci., Philadelphia (4), Vol. XVI, p. 202.

H. G. Stehlin, Die Säugetiere des schweizerischen Eocäns. VII. Teil, 2. Hälfte. - Abh. Schweiz. Paläont. Ges., Vol. XLI, I916, p. 1503.

H. Winge, I. c., 1917, p. I75. 
Pantolestes. - Mitteleozän Nordamerikas. ${ }^{1}$

\section{F. Tillotheriidae.}

Eine durchaus einseitig spezialisierte Gruppe, die sich durch ihre bedeutende Körpergröße von den sonst durchweg kleinen Insektenfressern auffallend unterscheidet. Tillotherium erreichte die Größe eines Bären. Die Tillotheriiden werden von manchen Forschern für eine zwai aus den Insectivoren hervorgegangene, aber durchaus selbständige Ordnung der Placentalier betrachtet.

Esthonyx. - Untereozän Nordamerikas. ${ }^{2}$

Tillotherium. - Mitteleozäı Nordamerikas. ${ }^{3}$

\section{Unterordnung: Zalambdodonta.}

Diese Gruppe umfaßt einige aberrante Familien, die sich von den Dilambdodonta durch den Bau der Molaren unterscheiden; in den oberen Molaren sind die Außenhöcker verkümmert und das Talonid der unteren Molaren ist reduziert worden. Die Zalambdodonten stellen daher eine Gruppe dar, die aus den Dilambdodonten mit primitiven, trituberkulärem oberen und tuberkulosektorialen unteren Gebiß hervorgegangen ist.

\section{F. Chrysochloridae.}

Die heute auf Südafrika beschränkten Goldmulle lebten im Tertiär auch in Nordamerika.

Xenotheriun. - Oligozän Nordamerikas. ${ }^{4}$

\section{F. Centetidae.}

Die ältesten Reste der heute noch auf der Insel Cuba und auf Madagaskar lebenden Centetiden sind in den Torrejon-Beds der Vereinigten Staaten gefunden worden.

Palaeoryctes. - Unterstes Eozän von Neumexiko. ${ }^{5}$

1 W. D. Matthew, The Carnivora and Insectivora of the Bridger Basir, Middle Eocene. - I. c., 1909, p. 522.

Wahrscheinlich bildet Pantolestes den Vertreter eines Zweiges der Carnivoren und nicht der Insectivoren. Herr Hofrat B. Hatschek, der iber diese Frage mit Untersuchungen beschäftigt ist, hat mich auf die Merkmale aufmerksam gemacht, die nach seiner Auffassung die Zugehörigkeit der Pantolestiden zu den Insektenfressern ausschließen.

2 E. D. Cope, The Vertebrata of the Tertiary Formations of the West, Book 1. - Rep. U. S. Geol. Surv. Territ., Vol. III, 1884, p. 202.

3 O. C. Marsh, Principal Characters of the Tillodontia. - Amer. Journ. Sci. (3), Vol. X1, 1876, p. 249.

4 E. Douglass, The Tertiary of Montana. - Memoirs of the Carnegie Museum, Pittsburgh, Vol. 11, 1906, p. 204.

H. Winge, Udsigt over Insektaedernes indbyrdes Slaegtskab. - Vid. Medd. fra Dansk naturh. For., Bd. 68, Kjöbenhavn 1917, p. 193 (Literatur).

5 W. D. Matthew, A Zalambdodont Insectivore from the Basal Eocene. Bull. Anır. Mus. Nat. Hist., New York, Vol. XXXII, 1913, p. 307. 


\section{Ordnung: Chiroptera.}

Die fossilen Fledermäuse, welche zweifellos die Nachkommen der Insectivoren sind, gehören zum Teile der Unterordnung der Microchiropteren, zum Teile den Macrochiropteren an. Die verschiedenen Überreste, die in Tertiärablagerungen zu großen Seltenheiten zählen, können in zahlreichen Fällen auf lebende Gattungen bezogen werden; so sind aus dem Miozän die Gattungen Vespertilio, Vesperugo, Rhinolophus, Cynonycteris, aus dem Plistozän aber zahlreiche lebende Gattungen nachgewiesen. Daneben treten aber in Eozän und in jüngeren Tertiärablagerungen viele ausgestorbene Microchiropterengattungen auf. Über die Stanmesgeschichte der Fledermäuse geben diese Reste wenig Aufschluß, dagegen sind ninanche Funde von tiergeographischem Interesse, wie das Vorkommen von Vampyren, u. z. (Provampyrus) im Oligozän Ägyptens und (Necromantis) im Obereozän Frankreichs. Von der Unterordnung der Macrochiroptera ist bis jetzt nur ein einziger fossiler Vertreter, Archaeopteropus transiens aus dem Oberoligozän Oberitaliens bekannt. ${ }^{1}$

Fossile Fledermäuse sind jetzt seit dem unteren Mitteleozän (Braunkohle von Messel bei Darmstadt) ${ }^{2}$ bekannt. Sie finden sich verhältnismäßig häuf:g in den Phosphoriten des Quercy in Frankreich, aber auch an verschiedenen anderen Fundstellen alttertiärer und jungtertiärer Säugetierreste und sind in g:ößerer Zahl auch aus plistozänen Höhlen bekannt; gegen die große Artenzahl der lebenden Formen, die ungefälır 1000 betragen soll, steht die Zahıl der fossilen Arten freilich weit zurück.

\section{Ordnung: Carnivora.}

Die Carnivoren sind unnittelbar aus den Insectivoren hervorgegangen; die primitivsten Carnivorengattungen lassen sich nur selir schwer von den Insektenfressern unterscheiden. Frühzeitig spalten sich die Raubtiere in verschiedene Stämme, die zwar zum Teile sich zu hoher Blüte entfaltet haben, aber doch niemals die mannigfachen Fornverschiedenheiten erreichten, wie sie uns bei der größten Gruppe der Säugetiere, den Huftieren, entgegentreten. Gleichwohl ist die Nahrungsweise der Carnivoren doch nicht immer dieselbe, was die Art der Nahrungsaufnahme anbelangt, sondern es bestehen in dieser Hinsicht sehr erhebliche Verschiedenheiten. So ist z. B. das Gebiß der eigentümlich spezialisierten Machairodontinen durchaus von den Gebißtypen der übrigen Raubtiere verschieden und anderseits treffen wir in den

1 L. Meschinelli, Un nuovo Chirottero fossile (Archaeopteropus transiens Mesch.) delle Ligniti di Monteviale. - Atti Reale Istit. Veneto die Scienze usw., T. XLII, Parte 2a, Venezia 1903, p. 1329 (Literatur über fossile Chiropteren!)

2 P. Revilliod, Fledermäuse aus der Braunkohle von Messel bei Darmstadt. - Abhandl. d. Geol. Landesanstalt zu Darmstadt, Bd. VII, 2. Heft, 1917, p. 161. 
mehr omnivoren Bären und Dachsen wieder andere Typen an. Diese Differenzen halten sich aber doch verhältnismäßig in viel engeren Grenzen als die Unterschiede, die bei den Huftieren infolge der verschiedenartigen Nahrung auftreten. Ebenso ist auch die Unformung der. Gliedmaßen bei den oft sehr schnellfüßigen Raubtieren, die ja zum Teile selbst ein Pferd in gestrecktem Laufe einzuholen vermögen, keineswegs so weit vorgeschritten als bei den Huftieren, sondern auf verlältnismäßig tiefer Stufe stehen geblieben.

Ursprünglich waren die Raubtiere arborikole Formen von der GröBe und dem Aussehen primitiver Beutelratten und besaßen die Fähigkeit, Daumen und Großzehe den übrigen Fingern oder Zehen gegenüberzustellen oder zu ,opponieren“. Diese Fähigkeit geht erst sehr spät verloren. Bei der Spezialisation der Gliedmaßen zu Lauffüßen wird bei den Carnivoren entweder ein mesaxonischer FuB ausgebildet, d. h. der FuB wird dreizehig und die Mittelzehe wird zum Hauptträger der Extremität oder der Fuß wird paraxonisch, d. h. der Fuß bleibt vierzehig und der Druck läuft durch den dritten und vierten Finger-oder Zehenstrahl. Es kehrt also auch hier der Unterschied zwischen dem Fußtypus der „Paarhufer" und der ,Mittelhufer" (= Unpaarhufer) unter den Huftieren wieder. Diese Unterscheidung ist für die Beurteilung der verwandtscliaftlichen Beziehungen zwischen den Ungulaten und den Carnivoren von besonderer Wichtigkeit, da für die mesaxonischen Huftiere nur die mesaxonischen Carnivoren als Ahnen in Betracht gezogen werden können. Wemn einmal entweder der Weg zur Mesaxonie oder zur Paraxonie eingeschlagen war, so ist ein Wechsel dieser beiden Wege nicht mehr möglich gewesen. Dieser Gesichtspunkt darf bei den Versuchen, die Verbindungsglieder zwischen den Ungulaten und den Carnivoren aufzufinden, nicht aus den Augen gelassen werden. Schon daraus ergibt sich, daß der paraxonische Hauptstamm der Carnivoren von der Alnengruppe der mesaxonischen Ungulaten unbedingt ausgeschaltet werden muB. Da auch die Mesonyehiden paraxonischen Fußbau besitzen, so können sie gleichfalls nicht in Betracht kommen; der Fußbau der Triisodontidae ist noch unbekannt und so muß die Frage offen bleiben, ob dieser Seitenzweig der Carnivoren vielleicht die Alnengruppe der mesaxonischen Ungulaten bildet, wofür der primitive und undifferenzierte Zustand des Gebisses sprechen würde. Die mesaxonischen Pseudocreodi mit den Fanilien der Hyaenodontiden und der Oxyaeniden müssen wegen der bereits zu weit vorgeschrittenen Spezialisation des Gebisses in ein Brechscherengebiß ausgeschaltet werden. So bleibt eigentlich nur mehr die Stammgrtippe der Carnivoren selbst, die Gruppe der leider noch sehr wenig bekannten Oxyclaeniden übrig, welche die Carnivoren mit den Insectivoren verbindet und es muß die Vermutung auftauchen, ob nicht auch die Huftiere, soweit sie mesaxonisch sind, von 
mesaxonischen Carnivoren abgeleitet werden müssen. Dagegen ist es wahrscheinlich, daß die paraxonischen Huftiere oder "Paarhufer" in primitiven, aber bereits paraxonisch gewordenen Vorfahren wurzeln, wenn auch die Möglichkeit nicht auszuschließen ist, daß die Paraxonie der Paarhufer unabhängig von den paraxonischen Carnivoren erworben worden ist.

Das Gebiß wird bei den-meisten Carnivoren zu einem Brechscherengebiß ungeformt. Die Wege, auf denen das mechanische Problem der Schaffung eines solchen Brechscherenapparates gelöst wird, sind jedoch sehr verschieden. Stets muß, wenn das Gebiß zum Zerbrechen und Zerschneiden der Beute entsprechend funktionieren kann, der stärkste Zahn in Hebelwinkel, das ist möglichst weit hinten in den Kiefern liegen.

Bei den Insektenfressern liegt dẹr dritte Molar des Unterkiefers schon so weit hinten, daß er keinen Platz zur weiteren Ausdehnung nach rückwärts hat; vorne versperren ihm die vor ihm in Funktion getretenen Zähne den Weg. Ein Brechscherengebiß kann also nicht unter Heranziehung des letzten unteren Molaren gebildet werden.

Wenn dagegen der zweite untere Molar sich vergrößert, so kann er nur dann als Knack- und Scherenapparat erfolgreich funktionieren, wenn er den hinteren Zahn nicht zur Entwicklung gelangen läßt.

Noch größer kann jedoch der Zahn werden, der die Funktion der Brechschere ïbernimmt, wenn nicht der zweite, sondern der vor ihm stehende erste Molar herangezogen wird, der bei zunehmendem Größenwachstum im Laufe der Stammesgeschichte die hinter stehenden Molaren verdrängt und sich auf ihre Kosten ausdehnt.

Was im Unterkiefer mit den besprochenen drei hinteren Zähmen der Fall ist, das tritt auch im Oberkiefer, lier aber bei den vier letzten Zähnen ein, da ja die unteren Zähne immer um einen Zahn weiter vorne stehen als die oberen, so daß z. B. der erste untere Molar mit dem oberen vierten, letzten Prämolaren zusammen die Brechschere bildet. Wenn also im Unterkiefer der zweite Molar vergrößert wird, so trifft das gleiche Schicksal den oberen ersten Molaren, wenn der erste untere Molar vergrößert wird, so nimmt oben der vierte Prämolar an Größe zu.

Wir haben also drei verschiedene Wege, ım ein Brechscherengebiß aus dem prinitiven Insectivorengebiß abzuleiten. Alle diese Wege sind von den Camivoren versucht und verfolgt worden. Die Stämme, welche die Kombination $M^{2} / M_{3}$ und $M^{1} / M_{2}$ versucht haben, sind erloschen und nur ein einziger Stamm der Carnivoren ist heute noch am Leben, jener nämlich, bei dem die Lösung auf dem Wege $P^{4} / M_{1}$ durchgefülırt worden ist (Fig. 546). ${ }^{1}$

1 O. Abel, Verfehlte Anpassungen bei fossilen Wirbeltieren. - Zoolog. Jahrbiicher, Festschrift für Spengel, Supp. XV, 1. Bd., 1912, p. 597. 


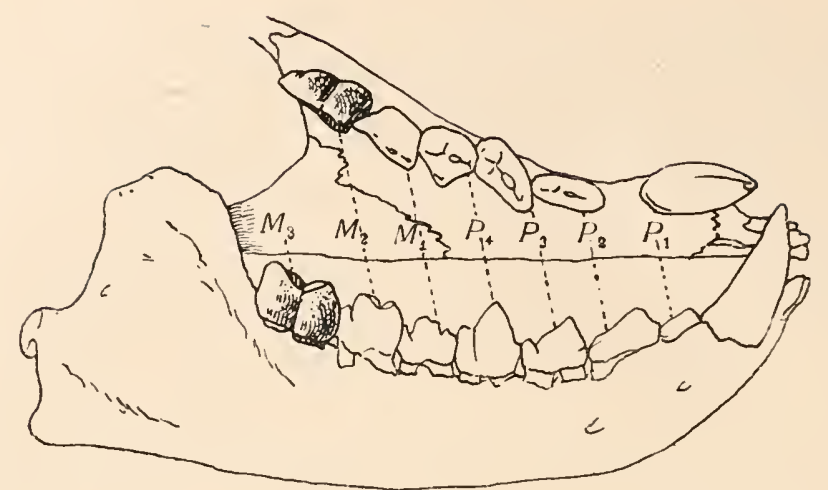

A.

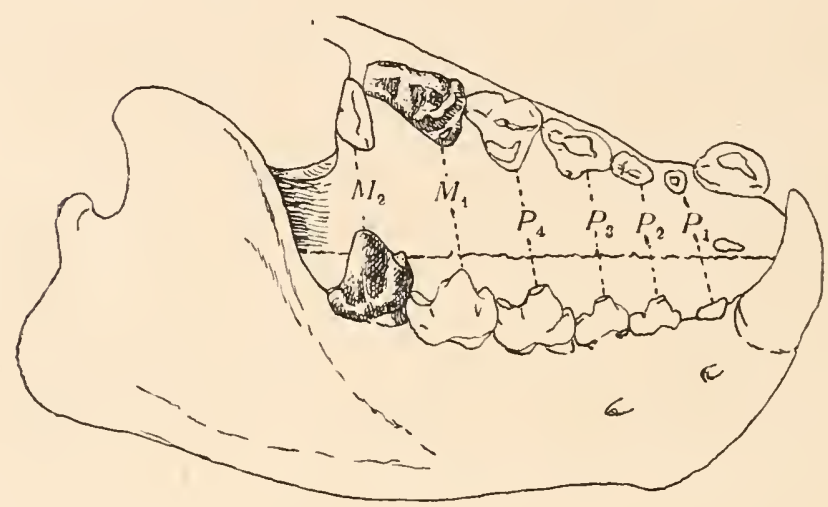

B.

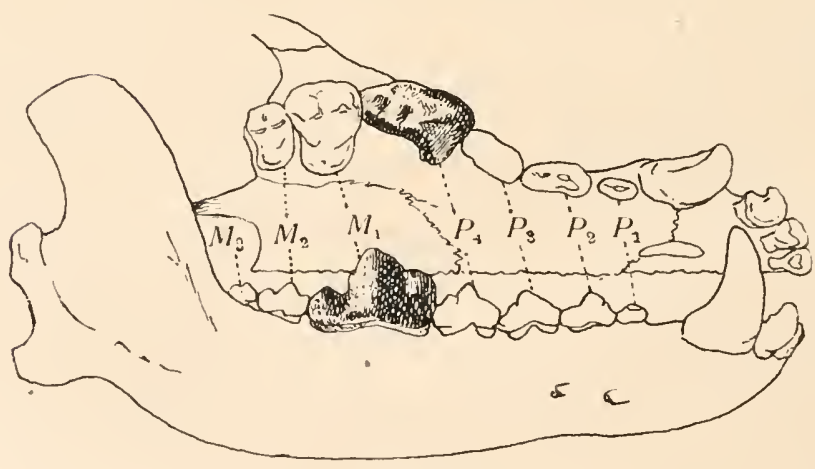

C.

Fig. 546 .

Die drei verschiedenen Wege der Ausbildung des Brechscherenapparates bei den Carnivoren.

A: Hyaenodon, B: Oxyaena, C: Wolf.

(Nach W. D. Matthew.)

$P_{1}-P_{1}=$ Praemolaren, $M_{1}-M_{3}=$ Molaren.

Die dunkel schraffierten Zähne bilden den Brechscherenapparat. 


\section{Unterordnung: Acreodi.}

Die Unterordnung der Acreodi ist als die primitivstc Gruppe der Carnivoren zu betrachten, da bei ihren Vertretern keine Andeutung: der Ausbildung eines Brechschcrengebisses zu beobachten ist.

\section{F. Oxyclaenidae.}

Einige unvollständig bekannte Arten, die sich auf die Gattungen Oxyclaenus, Chriacus, Deltatherium (Fig. 547) und Tricentes verteilen. Sie sind nur aus dem untersten Tertiär (Puercobeds und Torrejonbeds) Nordamerikas bekannt. ${ }^{1}$

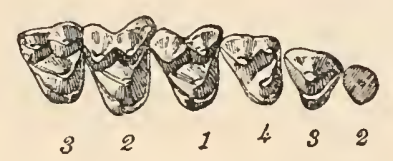

Fig. 547.

(J)ere Backenzähne von Deltatherium funcaminis, ein primitiver Carnivore aus der Gruppe der Oxyclaeniden. Torrejonschichten (Basaleozän) Nordamerikas. Nat. Gr.

Von links nach rechts: die drei Molaren $(3,2,1)$ und die drei hinteren Prämolaren (4, 3, 2). (Nach H. F. Osborn.)

\section{F. Mesonychidae.}

Hand und Fuß paraxonisch; vom untersten Eozän bis zun Obereozän in Nordamerika, vom Untereozän bis zum Mitteleozän auch in Europa.

Hyaenodictis. - Untercozän Frankreichs (Cernays bei Reims) und Belgiens (Landerien von Erquelinnes). ${ }^{2}$

Hapalodectes. - Untereozän und unteres Mitteleozän Nordamerikas. ${ }^{3}$

1 H. F. Osborn and Ch. Earle, Fossil Mammals of Puerco Beds. - Bull. Amer. Mus. Nat. Hist., New York, Vol. VII, 1895, p. 1. p. 259.

W. D. Matthew, A Revision of the Puerco Fauna. - Ibidem, Vol. IX, I897,

Derselbe, A Provisional Classification of the Fresh-Water Tertiary in the West. - Ibidem, Vol. XII, 1899, p. 28.

Ch. Earle, Relationship of the Chriacidae to the Primates. - American Naturalist, Vol. XXXII, 1898, p. 261.

2 V. Lemoine, Étude d'ensemble sur les dents de Mammifères fossiles des Environs de Reims. - Bull. Soc. Géol. France, Paris (3), T. XIX, p. 263.

L. Dollo, The Fossil Vertebrates of Belgium. - Annals New York Academy of Sciences, Vol. XIX, 1909, p. 109.

H. F. Osborn, A Review of the Cernaysian Mammalia. - Proceedings Acad. Nat. Sci. Philadelphia, 1890, p. 60.

${ }^{3}$ W. D. Matthew, The Carnivora and Insectivora of the Bridger Basin, Middle Eocene. - Memoirs Amer. Mus. Nat. Hist., New York, Vol. IX, Part VI. 1909 , p. 498. 
Pachyaena. - Untereozän von Paris, Untereozän Nordamerikas. ${ }^{1}$

Harpagolestes. - Mitteleozän und Obereozän Nordamerikas. ${ }^{2}$ Mesonyx. - Mitteleozän Nordamerikas. - Die Krallen dieses

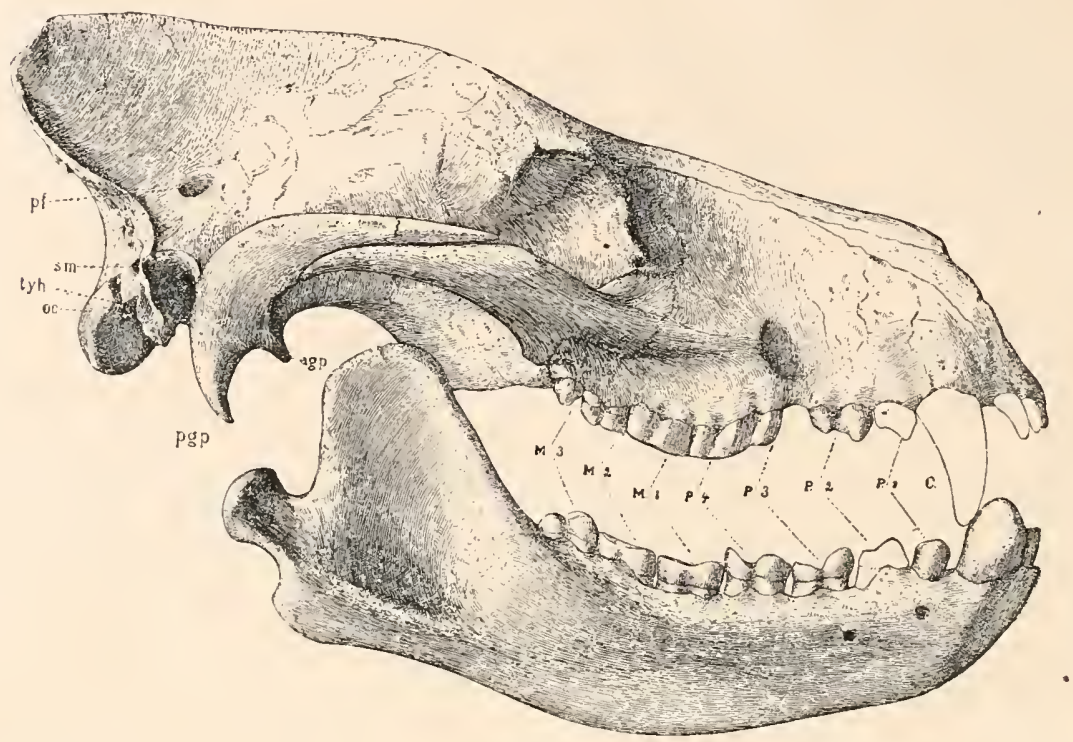

Fig. 548.

Synoplotherium vorax, Marsh, aus dem Mitteleozän (Bridger Beds) Nordamerikas. $2 / 3$ nat. Gr. (Nach J. L. Wortman.)

eigentümlich spezialisierten Raubtieres waren hufartig, breit und gespalten. ${ }^{3}$

Synoplotherium (= Dromocyon). - Mitteleozän (Bridger Beds) Nordanerikas (Fig. 548). ${ }^{+}$

\section{F. Triisodontidae.}

Nur aus dürftigen Resten bekannt.

1 Ibidem, p. 491.

E. L. Trouessart, Catalogus Mammalium, Suppl. 1904, p. 163. (Pachyaena Boulei aus dem Soissonien (Untereozän) von Vaugirard, Frankreich).

2 J. L. Wortman, Studies of Eocene Mammalia in the Marsh Collection, Peabody Museum. - Amer. Journal of Science, Vol. XII, 1901, p. 286.

W. D. Matthew, 1. c., 1909, p. 496.

W. B. Scott, On Some New and Little-Known Creodonts. - Journal Acad. Nat. Sci. Philadelphia (2), Vol. IX, 1888, p. 168.

3 W. D. Matthew, I. c. 1909, p. 493.

4 J. L. Wortman, l. c., 1901, p. 291 (Dromocyon vorax).

W. D. Matthew, 1. c., 1909, p. 492 (Synoplotherium vorax). 


\section{Unterordnung: Pseudocreodi.}

Bei den Pseudocreodi ist ein Brechscherengebiß ausgebildet, das entweder aus dem oberen zweiten Molaren und unteren dritten Molaren oder aus dem oberen ersten Molaren und unteren zweiten Molaren besteht. Der erste Typus ist bei den Hyaenodontiden, der zweite bei den Oxyaeniden ausgebildet.

\section{F. Hyaenodontidae.}

Unterfamilie: Proviverrinae.

Die wichtigste Gattung dieser Gruppe ist die kleine Gattung Proviverra, die aber ihren Namen mit Unrecht trägt; diese Gattung kann ebensowenig wie irgend ein anderer Vertreter der Pseudocreodi als ein Ahne der Fissipedier angesehen werden, zu denen die Viverriden oder Zibethkatzen gehören.

Sinopa. - Untereozän und Mitteleozän Nordamerikas (Fig. 549). ${ }^{1}$

Tritemnodon. - Mitteleozän Nordamerikas. ${ }^{2}$

Unterfamilie: Hyaenodontinae.

Diese Unterfanilie schließt sich enge an die vorangehende an und ist aus ihr hervorgegangen. Sie unfaßt die größten Raubtiere des Alttertiärs; so erreichte die weit verbreitete Gattung Pterodon die Größe eines starken Höhlenlöwen. Während Pterodon ein Landraubtier war, haben wir in Apterodon ein aquatisches Raubtier zu erblicken, das in zahlreichın Merkmalen an den ältesten bekannten Wal, Protocetus atavus, erinnert, aber nicht als dessen Alne betrachtet werden kann, da Protocetus im Mitteleozän Ägyptens auftritt, während Apterodon im Oligozän Ägyptens gefunden wurde. Immerhin ist es sehr wahrscheinlich, daß aus einer mit Apterodon nahe verwandten, aber älteren Gattung die Ordnung der Wale ilrren Ursprung genommen hat.

Hyaen odon. - Alttertiär Europas und Nordamerikas (Fig. 546, A). ${ }^{3}$

Pterodon. - Alttertiär Europas (Pariser Gips, Lignite von Débruge, Phosphorite des Quercy, Bohnerze der Schweiz und Schwabens, Eozän der lnsel Wight), Oligozän Nordamerikas und Oligozän Ägyptens. ${ }^{+}$

1 Ibidem, p. 469.

2 Ibidem, p. 474.

${ }^{3}$ M. Schlosser, Die Affen, Lemuren, Chiropteren usw. des europäischen Tertiärs. I. c., 1887, p. 173.

W. B. Scott, The Osteology of Hyaenodon. - Journ. Acad. Nat. Sci. Philadelphia, Vol. IX, 1894, p. 499.

W. B. Scott and H. F. Osborn, The Mammalia of the Uinta Formation. Transactions Amer. Phil. Soc., Vol. XVI, 1889, p. 461.

4 M. Schlosser, 1. c. p. 195.

C. W. Andrews, A Descriptive Catalogue of the Tertiary Vertebrata of the Fayûm, Egypt. - London 1906, p. 219. 

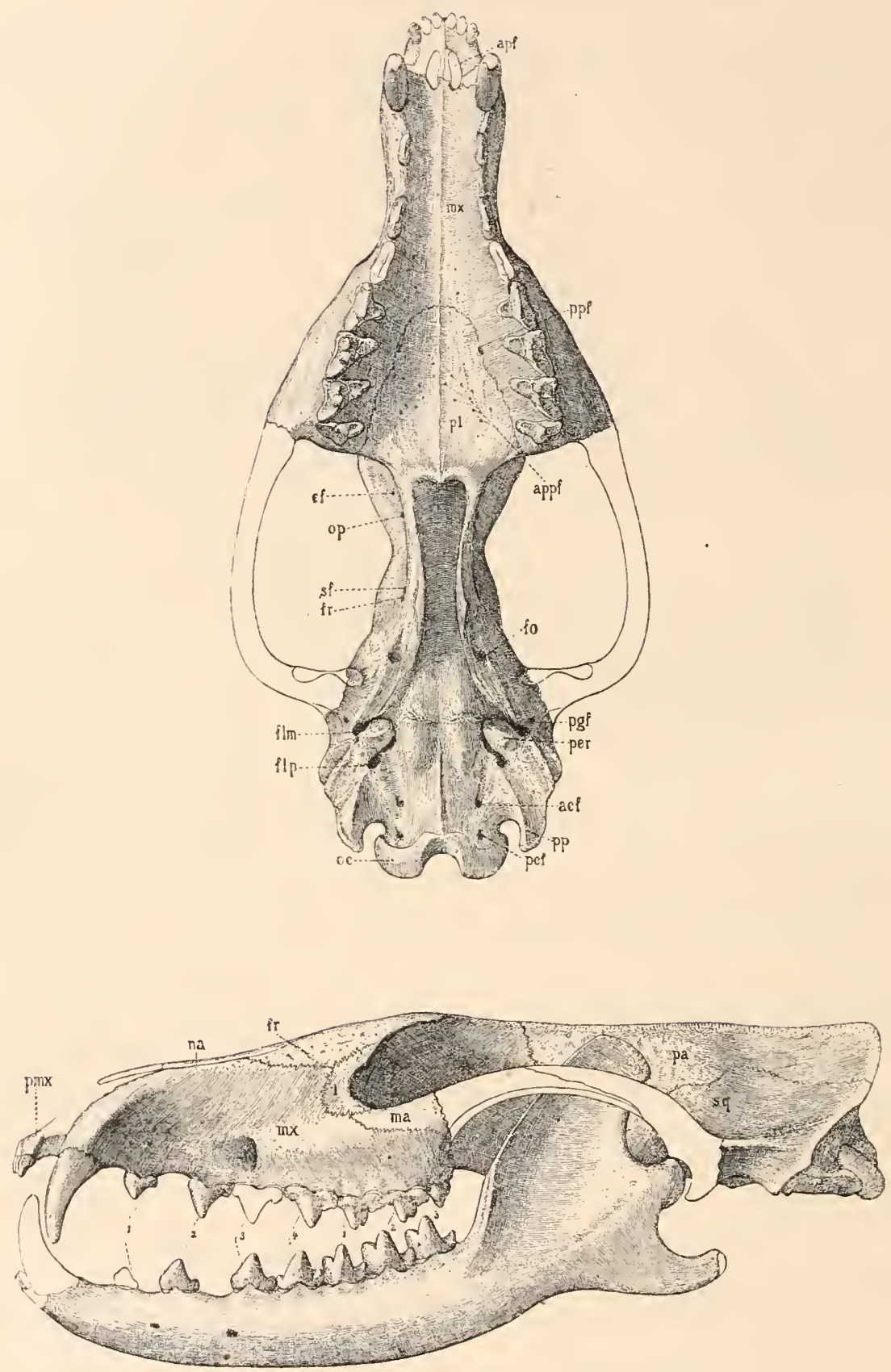

Fig. 549.

Sinopa agilis, Marsh, aus dem Mitteleozän (Bridger Beds) Nordamerikas; Schäde! von unten und von links gesehen, rekonstruiert, ungefähr in $2 / 3$ nat. Gr.

(Nach J. L. Wortman.) 
Apterodon. - Unteroligozän Ägyptens. ${ }^{1}$

\section{F. Oxyaenidae.}

Von der vorhergehenden Gruppe durch den verschiedenen Aufbau des Brechscherengebisses verschieden.

1. Unterfamilie: Limnocyoninae.

Eine Gruppe von langschuauzigen Formen.

Limnocyon. - Mitteleozän Nordamerikas. - Besonders auffallend sind bei dieser Gattung die niedrigen, gebogenen Gliedmaßen.2

Machairoides. - Mitteleozän Nordamerikas. - Der Unterkiefer erimnert im Gesamtcharakter seiner Spezialisation an die Kieferbildung der Machairodontinen, doch kann von genetischen Beziehungen in diesem Falle keine Rede sein, da ja die Elemente des Brechsclserengebisses durchaus verschieden sind. ${ }^{3}$

2. Unterfamilie: Oxyaeninae.

Auch bei den Oxyaeninen ist die Katzenähnlichkeit sehr groß, olıne daß an eine genetische Verknüpfung zwischen diesen beiden Gruppen.gedacht werden könnte. Aus der Zeit, in der man an derartige Beziehungen dachte, stammen die irreführenden Namen Patriofelis und Oxyaena.

Oxyaena. - Untereozän Nordamerikas (Fig. 546, B). ${ }^{4}$

Palaeonictis. - Untereozän Nordamerikas und Frankreichs. ${ }^{5}$

Patriofelis, - Untereozän und Mitteleozän Nordamerikas. ${ }^{6}$

Thinocyon. - Mitteleozän Nordamerikas. ${ }^{7}$

\section{Unterordnung: Eucreodi.}

Die Eucreodier sind der einzige Stamm der Raubtiere, der sich bis zur Gegenwart erhalten und es im oberen Tertiär und Quartär zu

1 Ibidem, p. 225.

H. F. Osborn, New Carnivorous Mammals from the Fayûm Oligocene, Egypt. - Bull. Amer. Mus. Nat. Hist., New York, Vol. XXV1, 1909, p. 415.

${ }^{2}$ W. D. Mat thew, ibidem, p. 433.

${ }^{3}$ W. D. Matthew, ibidem, p. 461.

4 E. D. Cope, Report upon the Extinct Vertebrata obtained in New Mexiko usw., Chapter XII; Geograph. Surv., West of the 100. Meridian. Washington 1877, p. $72,98,101,105$.

H. F. Osborn, The Huerfano Lake Basin, Southern Colorado, and its Wind River and Bridger Fauna. - Bull. Amer. Mus. Nat. Hist., Vol. IX, 1897, p. 255.

5 M. Schlosser, 1. c. p. 211.

H. F. Osborn and J. L. Wortman, Fossil Mammal of the Wasatch and Wind River Beds. Collection of 1891. - Bull. Amer. Nat. Hist., Vol. IV, 1892, p. 80.

${ }_{6}^{6}$ H. F. Osborn, Oxyaena and Patriofelis restudied as terrestrial Creodonts.

- Ibidem, Vol. X111, 1900, p. 277.

W. D. Matthew, 1. c., 1909, p. 417.

7 W. D. Matthew, I. c., 1909, p. 447.

Abe1, Die Stämme der Wirbeltiere. 
einer hohen Blüte gebracht hat. Ohne scharfe Grenzen gehen die Eucreodi in die Stämme der Arctoidea und Aeluroidea über, die man als „Fissipedier" zusammenzufassen gewohnt ist. Die-Stammgruppe der modernen Raubtiere ist die Fannilie der Miaciden, in der die Merkmale der jüngeren Raubtierstänme sozusagen noch vereinigt sind, neben den Miaciden tritt aber ein Stamm der Eucreodier auf, der keine Fortsetzung in den jüngeren Raubtieren findet und auf das Untereozän Nordamerikas und Frankreichs beschränkt gewesen zu sein scheint. Die allgemeine Ähnlichkeit des Gebißtyps zwischen den Arctocyoniden und Bären hat ebenso wie die oberflächliche Katzen- und Hyänenähnlichkeit der Oxyaeniden zu falschen Vorstellungen über genetische Beziehungen zwischen den Arctocyoniden und Bären geführt, wir wissen aber heute, daß diese Ähnlichkeiten nur als Konvergenzerscheinungen zu deuten sind und keine nähere Verwandtschaft beweisen können.

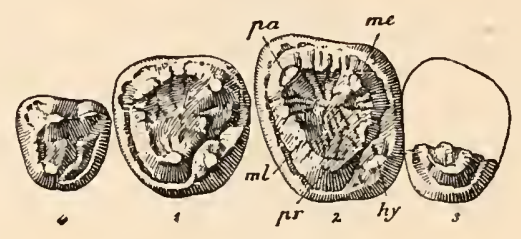

Fig. 550 .

Obere Backenzähne eines Arctocyoniden, Anacodon ursidens, aus den untereozänen Wasatch-Beds des Bighorn Valley in Wyoming. Nat. Gr. (Nach H. F. Osborn.)

Die Ähnlichkeit beruht vor allem auf der omnivoren Spezialisation des Gebisses, dessen Mahızäne breite, flache, niedrige Kronen tragen und dadurch an die flachen Bärenmolaren erinnern, aber der Bau der Krone ist, wie genauere Vergleiche gezeigt haben, doch durchaus verschieden.

\section{F. Arctocyonidae.}

Arctocyon. - Unterstes Eozän von Reims. ${ }^{1}$

Claenodon. - Unterstes Eozän (Puerco Beds und Torrejonbeds) von Neumexiko. ${ }^{2}$

An acodon. - Untereozän (Wasatch Beds) von Wyoming ${ }^{3}$ (Fig. 550).

\section{F. Miacidae.}

Bei dieser Stanmmgruppe der modernen Raubtiere tritt zum ersten

1 H. F. Osborn, A Review of the Cernaysian Mamınalia. - Proc. Acad. Nat. Sci. Philadelphia, 1890 , p. 59.

M. Schlosser, 1. c., 1887, p. 221.

H. F. Osborn, Evolution of Mammalian Molar Teeth. - New York 1907, p. 133.

${ }^{2}$ E. D. Cope, Synopsis of the Vertebrate Fauna of the Puerco Series. Transact. Amer. Phil. Soc., Vol. XV1, 1888, p. 298.

${ }^{3}$ H. F. Osborn, Evolution of Mammalian Molar Teeth, 1907, p. 133. 
Male ein Brechscherengebiß auf, das aus dem oberen vierten Prämolaren und dem untersten ersten Molaren besteht.

Unterfamilie: Miacinae.

Einzelne der in der Unterfamilie Miacinae zusammengefaßten Gattungen stehen den Hunden, andere den Bären nahe und wahrscheinlich gehen die Bären auf solche Miaciden zurück, deren Brechscherengebiß noch nicht zur Entwicklung gelangt war.

Miacis. - Untereozän bis Obereozän Nordamerikas. ${ }^{1}$

Uintacyon. - Unter- und Mitteleozän Nordamerikas. ${ }^{2}$

Oodectes. - Mitteleozän Nordamerikas. ${ }^{3}$

Vulpavus. - Oberes Untereozän und Mitteleozän Nordamerikas. ${ }^{+}$

Unterfamilie: Viverravinae.

Die zweite Gruppe der Miaciden zeigt bereits unverkennbare Beziehungen zu den Katzen und Hyänen, so daß wir also die Spaltung in die Stämme der Arctoidea und Aeluroidea bis in die Stammgruppe der Miaciden zurückverfolgen können. Hier liegt wieder ein Fall vor, der uns zeigt, wie schwer es ist, die genetischen Beziehungen zwischen den älteren und jüngeren Stämmen in einem ,System“ zum Ausdrucke zu bringen; da wir die beiden Gruppen der lebenden Raubtiere bis in die Stanmgruppe zurückverfolgen können, so sollten folgerichtig die Miacinen den Arctoidea, die Viverravinen aber den Aeluroidea angegliedert werdén. Anderseits sind aber die beiden Unterfamilien der Miaciden so wenig untereinander verschieden, daß sie sich zusammen als eine einheitliche Gruppe darstellen. Derartige Schwierigkeiten müssen überall dort auftreten, wo es uns gelungen ist, in die Geschichte der einzelnen Stämme einen genaueren Einblick zu erhalten und wo sich die Lücken schließen, welche die älteren und jüngeren Fanilien voneinander trennen.

\section{F. Viverridae.}

\section{Gruppe der Aeluroidea.}

Die Zibetlıkatzen stammen von den Viverravinen ab und sind frülı= zeitig aus Nordamerika ausgewandert. Sie sind schon seit dem Tertiär auf Eurasien und Afrika beschränkt.

Progenetta. - Miozän Europas. ${ }^{5}$

1 W. D. Matthew, 1. c., p. 362.

2 W. D. Matthew, 1. c., p. 372.

${ }^{3}$ W. D. Matthew, 1. c., p. 377.

4 W. D. Matthew, I. c., p. 379.

5 H. Filhol, Études sur les Mammifères fossiles de Sansan. - Annales des Sciences géologiques de France, T. XXI, 1891, p. 121.

Ch. Depéret, La Faune des Mammifères miocènes de la Grive-Saint-Alban (1sère). - Archives Musée Hist. Nat. Lyon, T. V, 1892, p. 34. 
C.
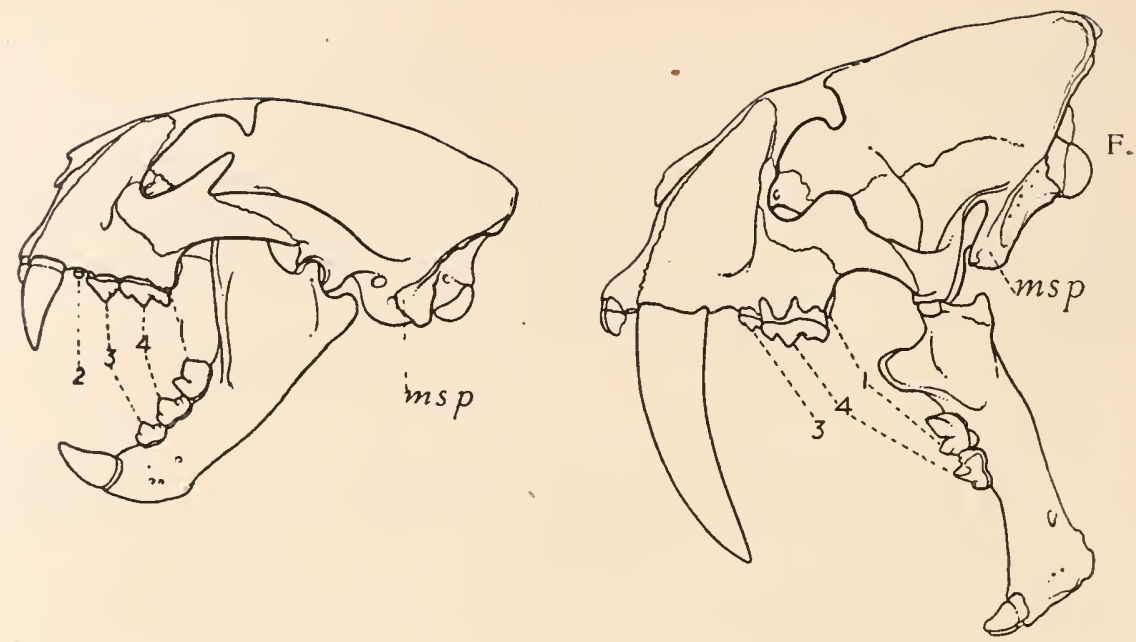

B.
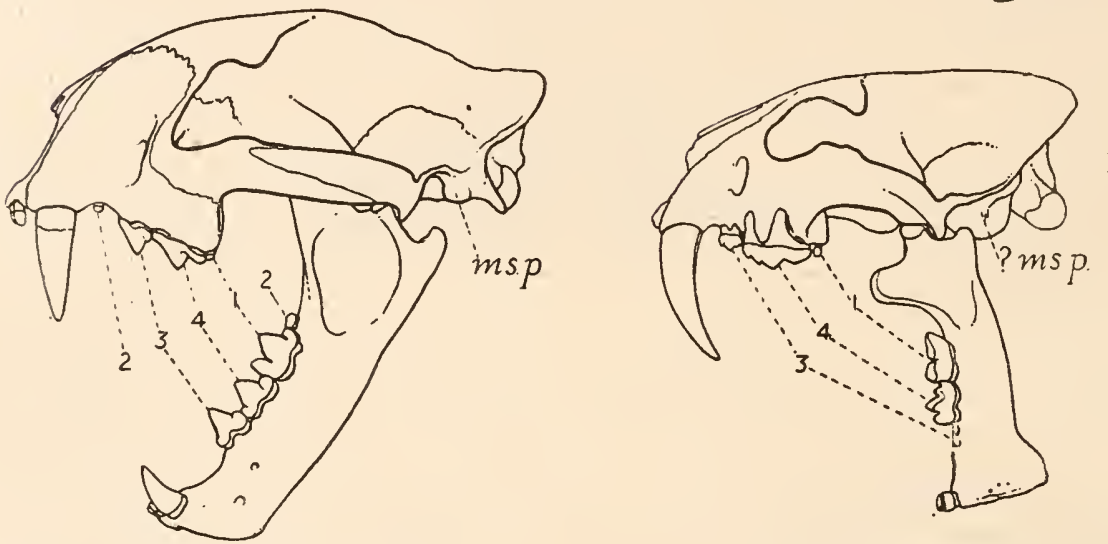

E.

A.
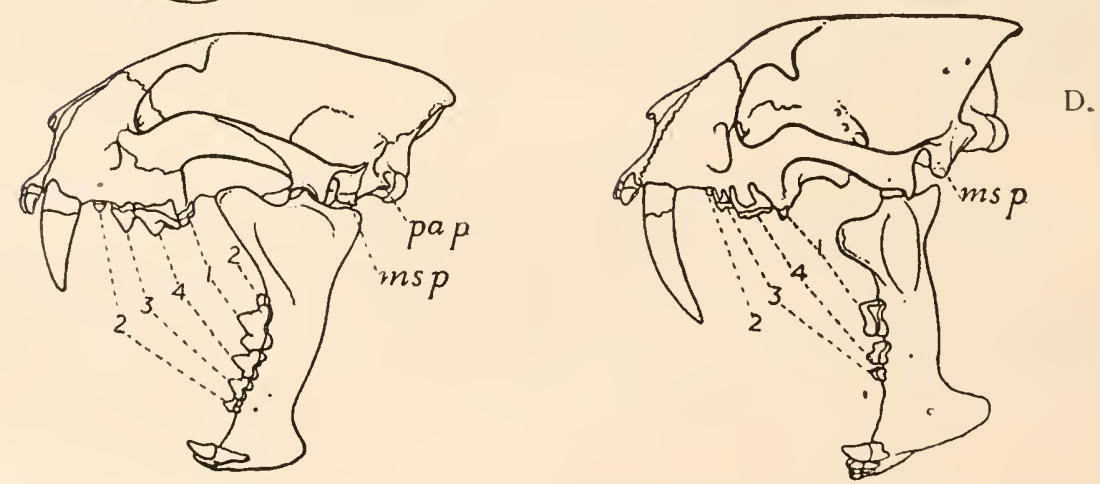

Fig. 551.

Linke Reihe: Schädel der Felinen; rechte Reihe: Schädel der Machairodontinen. (Nach W. D. Matthew.)

A: Dinictis (Oligozän Nordamerikas).

B: Nimravus (Oberoligozän tınd Untermiozän Nordamerikas).

C: Felis (vom Pliozän an).

D: Hoplophonens (Oligozïn Nordamerikas).

E: Machairodus (Miozän bis Plistozän Eurasiens).

F: Smilodon (Plistozän Nord- und Sïdamerikas). 
Ictitherium. - Unterpliozän Europas und Asiens. ${ }^{1}$

\section{F. Hyaenidae.}

Die Hyänen sind ein Seitenzweig des Stammes der Viverriden und zwar dürfte die Gattung Ictitherium oder eine nahe verwandte Gattung das Bindeglied bilden. Echte Hyänen erscheinen zuerst im Unterpliozän Europas und Asiens und sind niemals nach Amerika ausgewandert, sondern stets auf Eurasien und Afrika beschränkt geblieben; in der Eiszeit Europas lebten drei Hyänenarten: Hyaena crocuta, H. spelaea, H. striata; die letztgenannte war die häufigste. ${ }^{2}$

\section{F. Felidae.}

Von den Viverriden haben sich schon frühzeitig zwei Äste wahrscheinlich von derselben Wurzel abgezweigt, die sich jedoch getrennt entwickelten und die Unterfanilien der Felinen und der Machairodontinen bilden, welche divergente Spezialisationswege eingesclılagen haben. Die ältesten Vertreter der beiden Unterfamilien sind noch sehr wenig voneinander verschieden, aber die jüngsten Angehörigen der beiden Stämme sind außerordentlich verschieden. Diese Differenzen betreffen in erster Linie das Gebiß. Bei den Machairodontinen fällt die enorme Sperrweite der Kiefer auf, die mit der Größenzunahme des oberen Eckzahnes Hand in Hand geht. Bei den Katzen oder Felinen ist dagegen keine exzessive Vergrößerung der oberen Reißzähne oder Eckzähne zu beobachten, sondern es tritt eine umgekehrte Spezialisation ein; die oberen Eckzähne werden im Verlaufe der Stammesgeschichte der Felinen konstant kleiner, dagegen nelımen die unteren Eckzähne beständig an Größe zu. Weitere Verschiedenheiten betreffen die Höhe des Vorderund Hinterschädels in den beiden Gruppen, ferner die Stellung und Spreizung der Zehen, die Verkümmerung der Großzehe usf.

Unterfamilie: Felinae.

Din ictis.- Oligozän und Untermiozän Nordamerikas (F g.551,552). ${ }^{3}$

Nimravus. - Oberoligozän bis Untermiozän Nordamerikas und (?) Phosphorite des Quercy in Frankieich (Fig. 551, 552).

1 A. Gaudry, Animaux fossiles et Géologie de l'Attique. - Paris 1862, p. 12.

M. Schlosser, Die Affen, Lemuren usw., des europäischen Tertiärs. - Beiträge zur Geol. u. Paläont. Österreich-Ungarns u. d. Orients, VIII. Bd., Wien 1889, p. 13.

2 W. Soergel, Das Aussterben diluvialer Säugetiere und die Jagd des diluvialen Menschen. - Festschrift zur 43. Allgem. Versammlung d. Deutschen Anthrop. Ges., Weimar 1912, 2. Heft, p. 58.

${ }^{3}$ W. D. Matthew, The Phylogeny of the Felidae. - Bull. Amer. Mus. Nat. Hist., New. York, Vol. XXVIII, 1910, p. 309.

Die ältere Literatur vgl. bei O.P.H a y, Bibliography and Catalogue of the FossilVertebrata of North America. - Bull. Nr. 179 U. S. Geo'. Surv., Washington, 1902, p. 779.

4 W. D. Matthew, I. c., 1910, p. 310. 
Die Stämme der Wirbeltiere.

E.

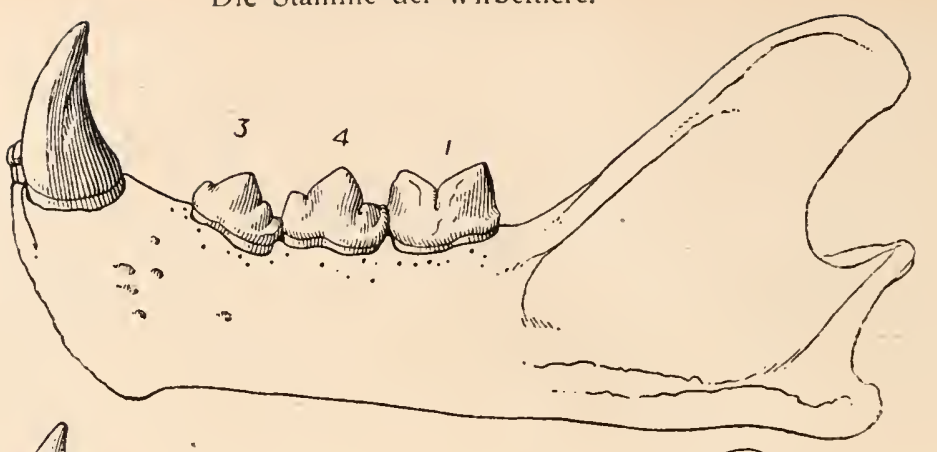

D.

c.

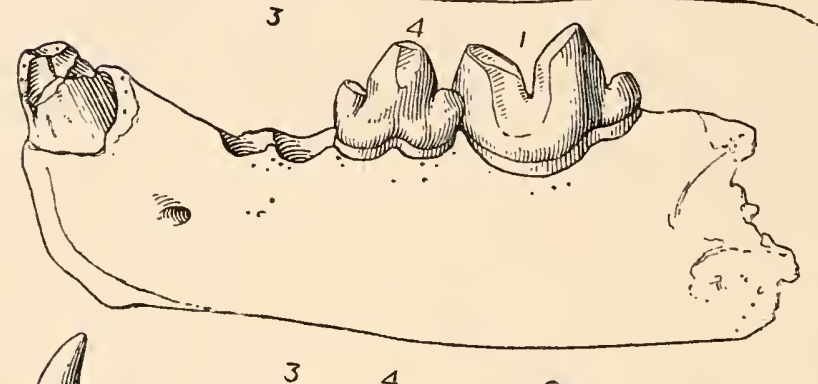

B.
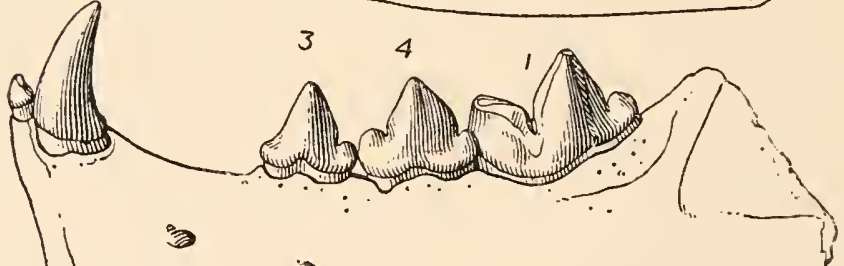

A.
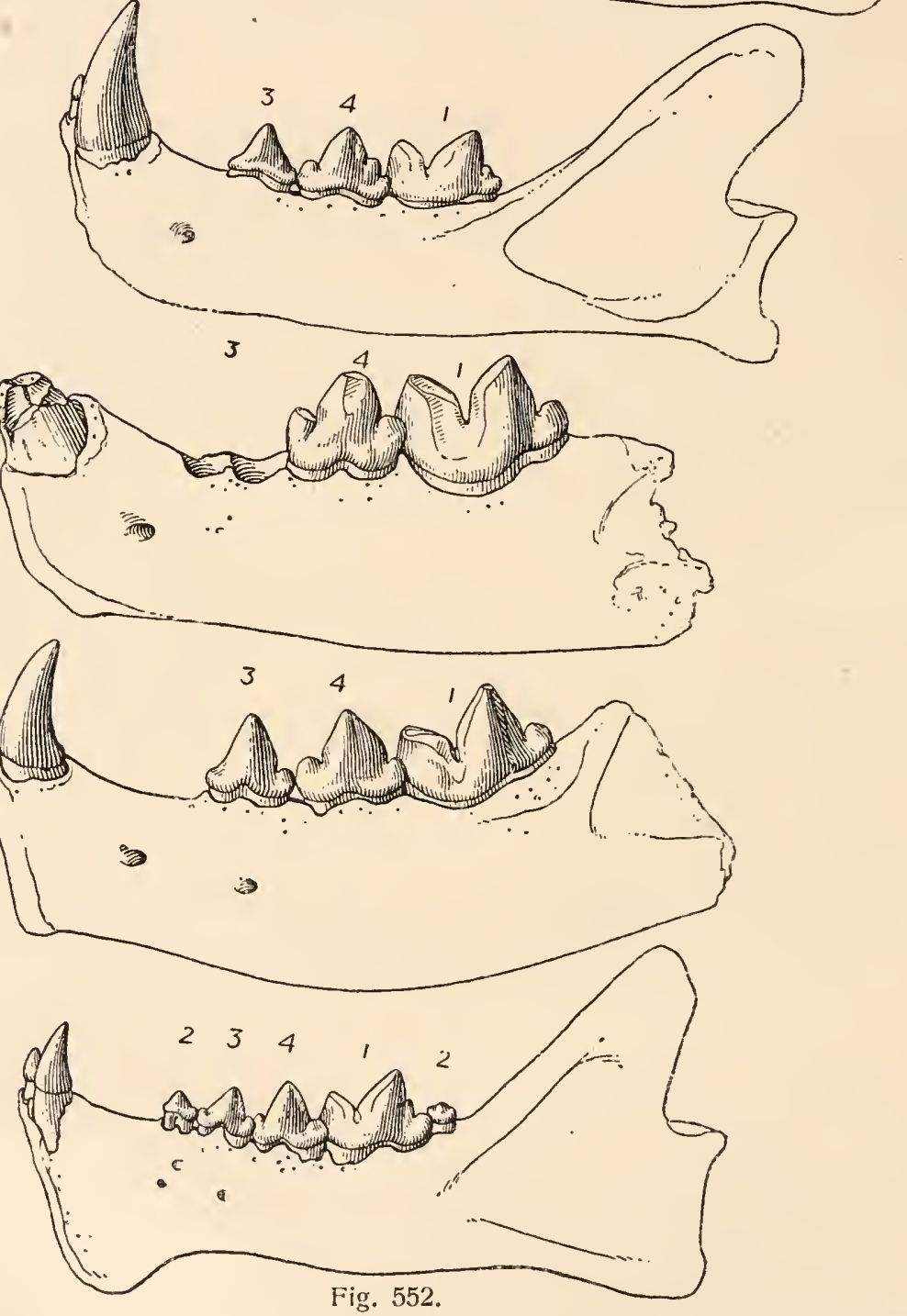

Entwicklungsreihe des Unterkiefers der Felinen. ${ }^{2} / 3$ nat. Gr. (Nach W. D. Matthew.)

A: Dinictis (Mitteloligozän).

B: Nimravus sp. (Oberoligozän).

C: Nimravus sp. (Miozän). D: Pseudailurus (Obermiozän). E: Felis (Holozän). 
Pseudailurus. - Obermiozän Europas (Fig. 552, D).

Felis. - Fossil vom Obermiozän an (Fig. 551, 552). ${ }^{1}$

Unterfamilie: Ma chairodontinae.

Hoplophoneus. - Mitteloligozän Nordamerikas (Fig. 55I, 553). ${ }^{2}$

Machairodus. - Miozän bis Plistozän Europas; im Pliozän auch in Asien (Fig. 551, 553, 554). ${ }^{3}$

Smilodon. - Plistozän Nordamerikas und Südamerikas (Fig. 551, $553,555) .{ }^{4}$

\section{Gruppe der Arctoidea.}

\section{F. Mustelidae (Marder).}

Die ältesten Marder treten im Oligozän Nordamerikas auf und erimnern zum Teile an kleine Viverriden, sind aber sicher die Nachkommen der Miacinen und nicht der Viverravinen. Die fossilen Marder schließen sich ziemlich enge an die lebenden an und stellen eine primitive Gruppe der Arctoidea dar.

\section{F. Ursidae.}

Die ältesten Bären sind urst inn Miozän Europas gefunden wordon, sind aber in älteren Ablagerungen bestimmt zu erwarten. Wahrscheinlich licgt die Stelle ihrer Entstehung nicht auf dem Boden Nordamerikas, von wo wir eine sehr große Zahl fossiler Raubtiere kennen, sondern in einem anderen Erdteil, wahrscheinlich in As.en. Die Bären erscheinen in Nordamerika sehr spät, erst in der Eiszeit, und sind dorthin wahrscheinlich aus Ostasien eingewandert. Zuletzt erreichten die Bären auch Südamerika, wo sie aber nie eine große Rolle gespielt zu haben scheinen.

Die Stammesgeschichte der Bären liegt wenigstens in ilıren letzten Abschnitten ziemlich klar zutage; von kleinen, etwa wolfgroßen Formen (Ursavus) ist die unterpliozäne Gattung Hyaenarctos abzuleiten,

1 Eine wertvolle Zusammenstellung der Literatur ïber fossile Felisarten (bis 1895) findet sich bei O. Roger, Verzeichnis der bisher bekannten fossilen Säugetiere. - Berichte d. naturw. Vereins für Schwaben und Neuburg, XXX1I. Bd., Augsburg 1896 , S. 70.

2 W. D. Matthew, The Phylogeny of Felidae, 1. c., p. 312.

3 Ibidem, p. 310.

4. lbidem, p. 315.

F. Ameghino, Sobre dos Esqueletos de Mamíferos fósiles armados recientemente en el Museo Nacional. - Anales del Museo de Buenos Aires, T. XVI, Buenos Aires, 1907 , p. 39.

F. Drevermann, Aus der Schausanimlung. Der Säbeltiger. - 42. Bericht d. Senckenberg. Mus. zu Frankfurt a. M., 1911, p. 268. 
D.

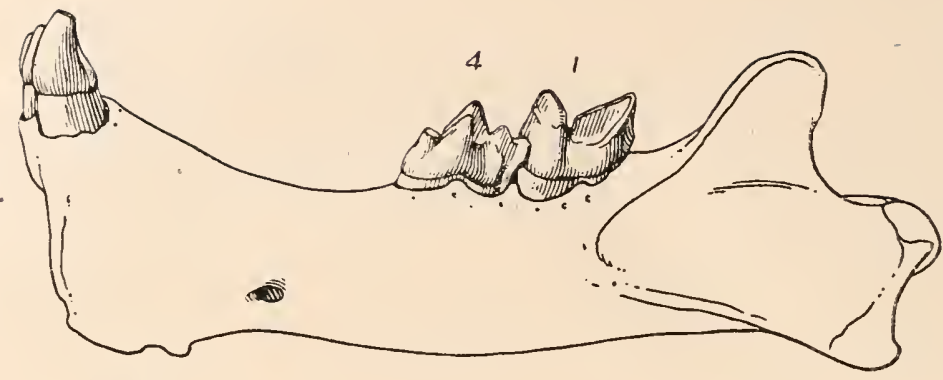

C.

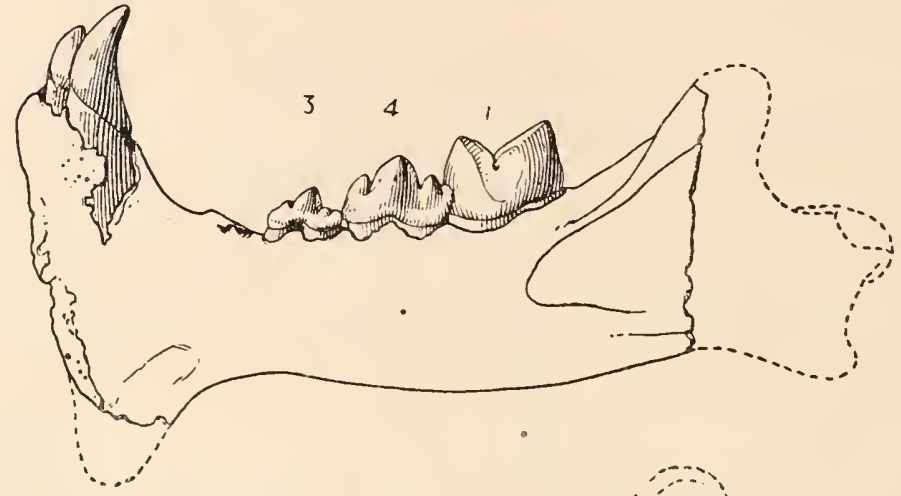

B.

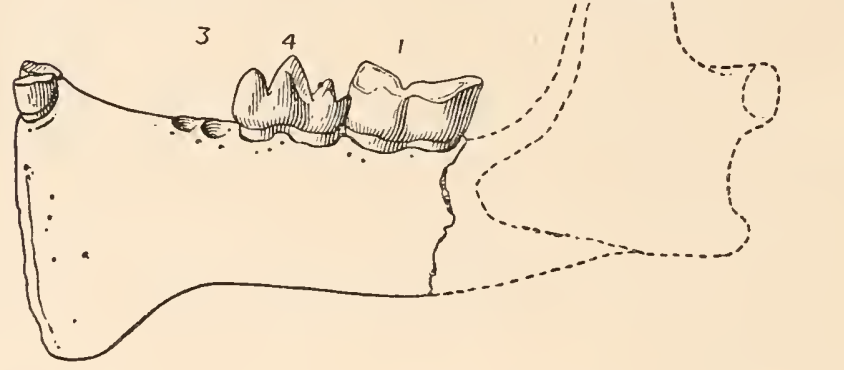

A.

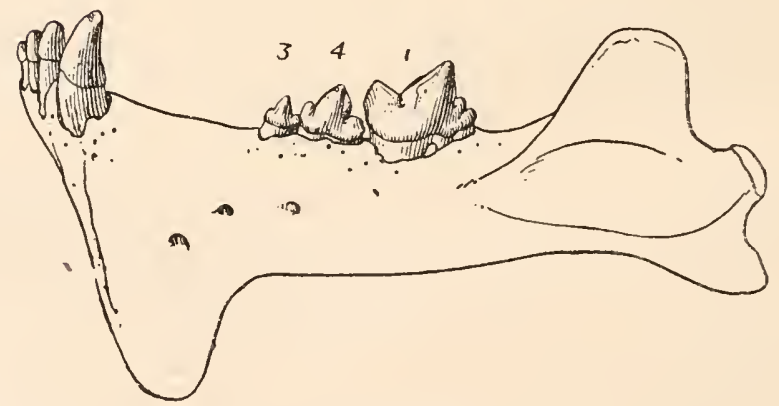

Fig. 553.

Entwicklungsreile des Unterkiefers der Machairodontinen.

$$
\text { (Nach W. D. Mattliew.) }
$$

A: Hoplophoneus (Oligozän).

B: Machairodus palınidens (Miozän).
C: Machaırodus megantereon (Pliozän). D: Smilodon (Plistozän). 
die in Eurasien weit verbreitet gewesen zu sein scieint. Aus deni oberpliozänen Ursus arvernensis (einer Varietät des Ursus etruscus) ging im älteren Plistozän Ursus Deningeri hervor, dessen Nachkomme der

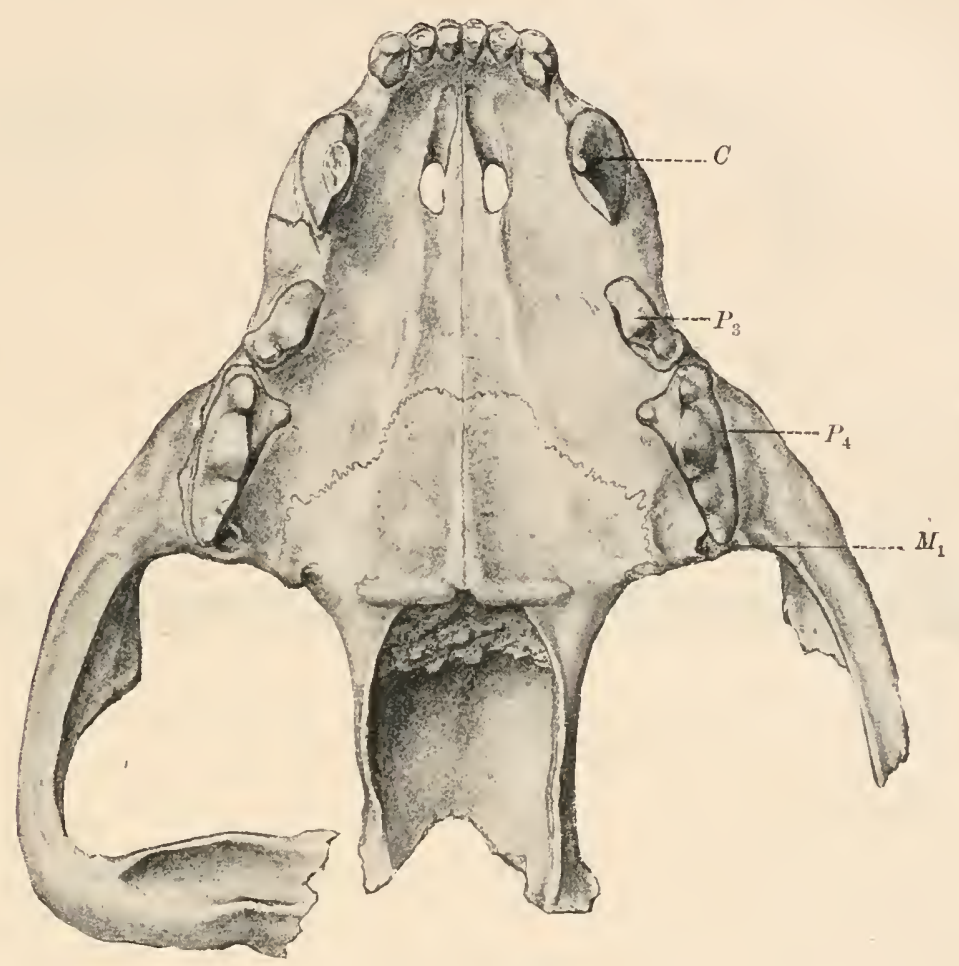

Fig. 554 .

Machairodus orientalis, Kittl, aus dem Unterpliozän von Kopran in Persien. $2 / 3$ nat. Gr. (Nach E. Kittl.)

Höhlenbär (Ursus spelaeus) ist, wälırend der braune Bär (Ursus arctos) auf den oberpliozänen Ursus etruscus zurückgeht und mit dens Höhlenbären daher in keinem direkten Verwandtschaftsverlältnisse steht.

Ursavus. - Miozän Europas. ${ }^{1}$

Hyaenarctos. - Unterpliozän Europas, Persiens, Ostindiens, Chinas. ${ }^{2}$

${ }^{1}$ M. Schlosser, Über die Bären und bärenähnlichen Formen des europäischen Tertiärs. - Palaeontographica, 46. Bd., 1899, S. 103.

Derselbe, Beiträge zur Kenntnis der Säugetierreste aus den süddeutschen Bohnerzen. - Geol. u. Paläont. Abhandl., Jena 1902 (N. F. Bd. V.), IX. Bd., p. 35.

2 A. Weithofer, Beiträge zur Kenntnis der Fauna von Pikermi bei Athen. Beiträge zur Geol. u. Paläont. Öst.-Ung. u. d. Orients, VI. Bd., 1888, p. 231. 
Ursus. - Vom Oberpliozän Europas an. ${ }^{1}$

Arctotherium. - Plistozän Nord- und Südamerikas. ${ }^{2}$

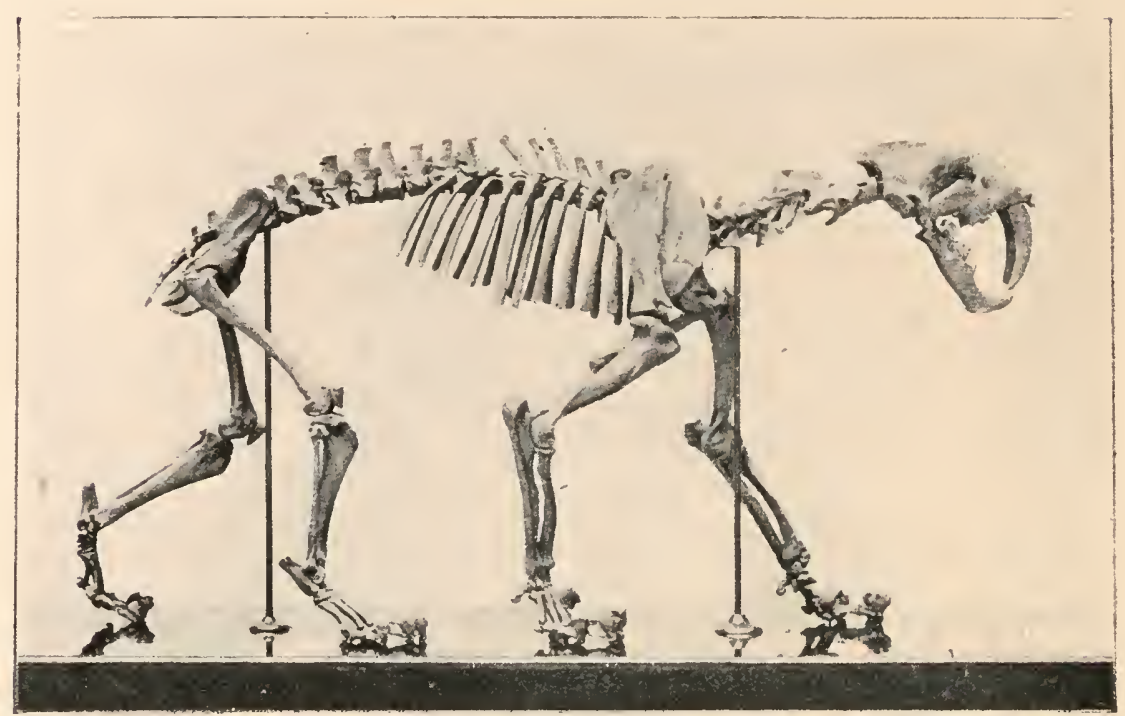

Fig. 555.

Smilodon californicus, Merriam, aus dem Plistozän Kaliforniens. (Nach F. Drevermann.)

\section{F. Procyonidae.}

Die Waschbären sind eine Gruppe nordamerikanischen Ursprungs, wo sie zuerst im Untermiozän von Colorado mit Phlaocyon ${ }^{3}$ auftreten;

1 M. Schlosser, Parailurus anglicus und Ursus Böckhi. - Mitteilungen a. d. Jahrbuch d. Ung. Geol. Anstalt, XIIl. Bd., Budapest 1900, p. 87.

W. Reichenau, Beiträge zur näheren Kenntnis der Karnivoren aus den Sanden von Mosbach und Mauer. - Abhandl. d. Hessischen Geol. Landesanstalt, IV. Bd., 2. Heft, Darmstadt 1906.

M. Schlosser, Die Bären- oder Tischoferhöhle im Kaisertal bei Kufstein. Abh. K. Bayer. Akad. d. Wiss., II. KI., XXIV. Bd., II. Abt., München I909, p. 420 (Fußnote).

W. Soergel, Das Aussterben diluvialer Säugetiere usw., 1. c., 1912, p. 47.

2 L. M. Lambe, On Arctotherium from the Pleistocene of Yukon. - The Ottawa Naturalist, Vol. XXV, 1911, p. 21.

Literatur iiber nordamerikanische Funde vgl. bei O. P. Hay, 1. c. 1902, p. 763.

F. Ameghino, Paleontologia Argentina. - Publicaciones de la Universidad de La Plata, 1904, Nr. 2, p. 40.

Derselbe, Notas sobre alcunos Mamiferos fósiles.nuevos ó poco conocidos del valle de Tarija. - Anales del Museo Nac. de Buenos Aires, T. VIII, 1902, p. 226.

${ }^{3}$ J. L. Wortman and W. D. Matthew, The Ancestry of Certain Members of the Canidae, the Viverridae and Procyonidae. - Bull. Amer. Mus. Nat. Hist., XII, New York 1899, p. 129.

H. von Ihering (Die Umwandlungen des amerikanischen Kontinentes wälurend der Tertiärzeit. - Netıes Jahrb. f. Min. usw., Beilageband XXXI1, 1911, p. 159) ver- 
später erscheinen sie auch in Europa.und Asien, wo die Gattung Ailurus noch houte im Himalaya lebt.

\section{F. Canidae.}

Die ältesten Hunde sind aus dem Obereozän Nordamerikas und Europas bekannt; ihre Geschichte hat sich hauptsächlich auf dem Boden Nordamerikas abgespielt und von hier aus hat sich der Stamm der Caniden fast über die ganze Erde verbreitet. Die älteste europäische Gattung ist Cynodictis zus dem Obereozän von Paris.

Cynodictis. - Obereozän des Montmartre (Paris), Quercy, Debruge usf. ${ }^{1}$

Amphicyon. - Oligozän und Miozän Europas, Unterpliozän Ostindiens. ${ }^{2}$

Daphaenus. - Oligozän und Miozän Nordamerikas. ${ }^{3}$

Canis. - Vom Obermiozän an (Fig. 546, C).

\section{Ordnung: Pinnipedia.}

Die fossilen Robben sind nur durch dürftige Reste vertreten; diese Funde, von denen die aus dem Obermiozän des Wiener Beckens ${ }^{4}$ die wichtigsten sind, geben uns keinen Aufschlıß über die Stammesgeschichte der Robben, da die Anpassungen der miozänen Arten bereits in allen wichtigen Merkmalen, auf der Stufe der lebenden Gattungen angelangt sind. Die Familie der Phociden (Seehunde) ist seit dem Miozän bekannt, die Fanilie der Otariiden ist durch dürftige Reste im Tertiär und Quartär Nord- und Südamerikas nachgewiesen. Die Trichechiden (Walrosse) sind erst seit den Pliozän (Belgien) bekannt und treten erst später in Holland und Nordamerika auf. Wahrscheinlich stellen die drei Familien der Pinnipedier drei verschiedene und von allem Anfang an getrennte

tritt den Standpunkt, daß Phlaocyon nicht zu den Procyoniden gehört, sondern zı den Caniden, so daß der älteste bekannte Waschbär durch Cynonasua aus den pliozänen Entrerioschichten Patagoniens repräsentiert wïrde; indessen findet sich, abgesehen von dem nordamerikanischen Phlaocyon im Untermiozän von Colorado, auch im Pliozän Siebenbürgens ein Procyonide (Parailurus). Von der südamerikanischen Herkunft der Waschbären kann kaum ernstlich die Rede sein.

1 Über die zahIreichen bisher unterschiedenen Reste verschiedener Arten dieser Gattung vgl. insbesondere: M. Schlosser, Die Affen, Lemuren nsw. des Europäischen Tertiärs. - Beiträge zıır Paläont. ı. Geol. Öst.-Ung. 11. d. Orients, VII. Bd., 1888 und VIII. Bd., 1889.

$2 M$. Schlosser, Ibidem; vgl. ferner die Literaturangaben bei $O$. Roger (Verzeichnis d. bisher bekannten fossilen Sätgetiere, 1896, p. 51) und E. L. Troulessart (Catalogus Mammalium).

3 J. B. Hatcher, Oligocene Canidae. - Memoirs of the Carnegie Museum, Pittsburgh, Vol. I, Nr. 2, 1902, p. 65.

4F. Toula, Phoca vindobonensis n. sp. von Nıßdorf in Wien. - Beiträge zur Paläontologie u. Geologie Öst.-Ung. u. d. Orients, Bd. XI, 1897, p. 47. (Literatur!) 


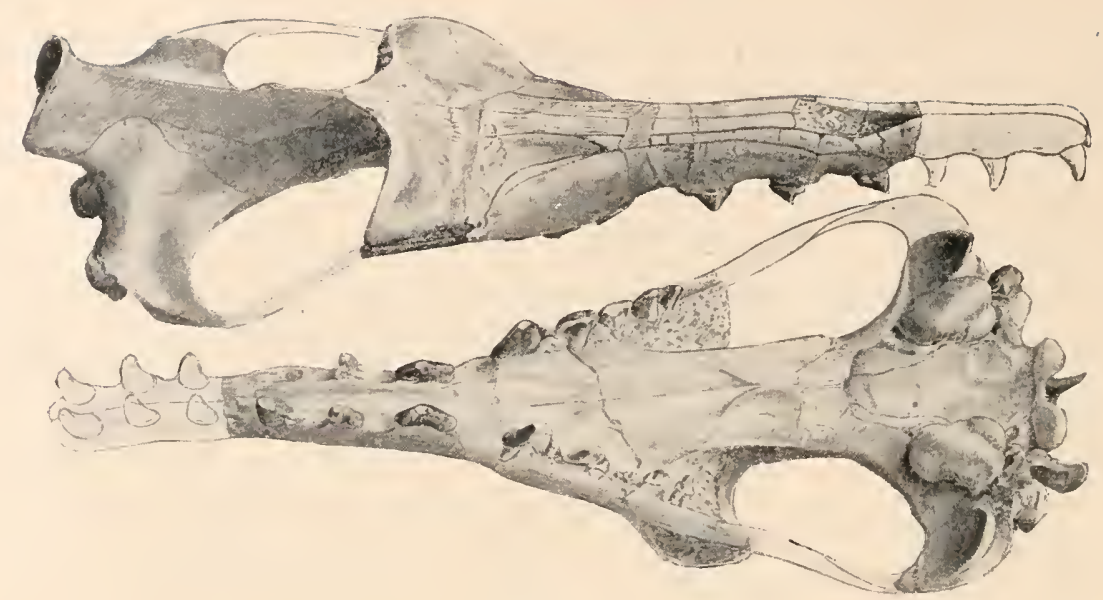

Fig. 556.

Schädel des primitivsten bis jetzt bekamnten Wales, Protocetus atavus, E. Fraas, aus dem Mitteleozän Ägyptens (untere Mokattamstufe des Mokattamberges bei Kairo). Schädellänge $60 \mathrm{~cm}$. (Nach E. Fraas.)

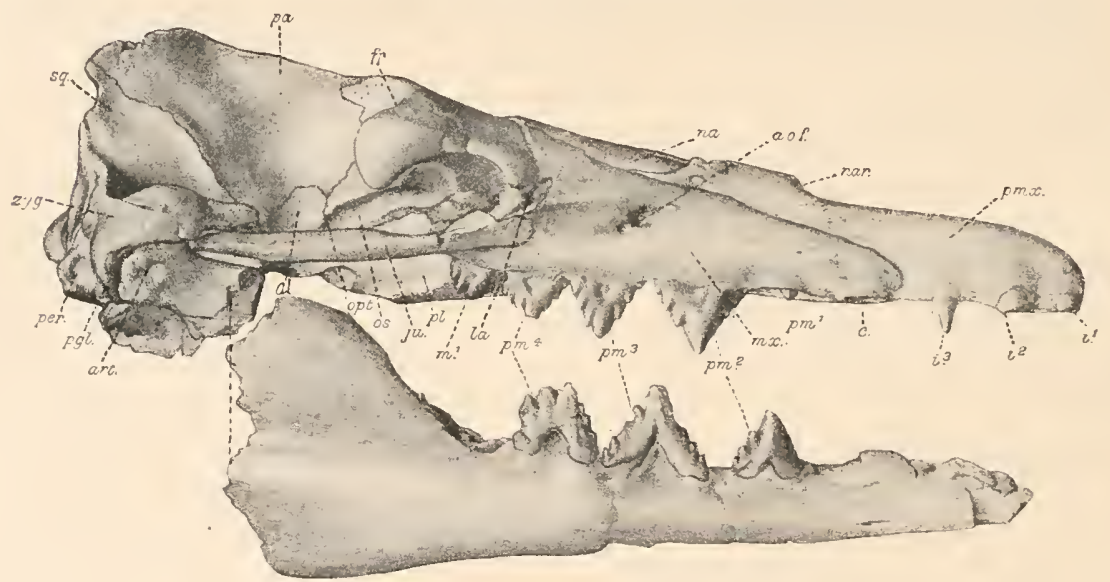

Fig. 557.

Prozeuglodon atrox Andr. Mitteleozän, Fayûm. Schädellänge $60 \mathrm{~cm}$. (Nach C. W. Andrews.)

al. $\quad=$ Alisphenoid.

a. $o . j .=$ Foramen antorbitale.

art. $=$ Unterkiefergelenk (die punktierte Linie bezeichnet die Verbindungslinie zwischen diesem Teil des Unterkiefers und dem herabgedrïickten Hauptteile desselben1).

c. $=$ Eckzahn.

cond. = Condylus occipitalis.

fr. Frontale.

$i^{1}-i^{3}=1 .-3$. Schneidezahn.

ju. $\quad$ Jugale.

la. - Lacrymale.

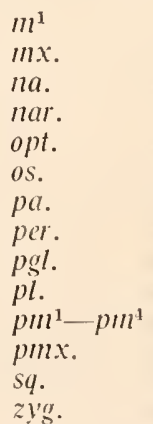

1. Molar.

- Supramaxillare. Nasale.

= Nares.

Foramen opticum. Orbitosphenoid. Parietale. Perioticum.

- Processus postglenoidalis. Palatinum. 1.-4. Prämolar. Praemaxillare. Squamosum. Processus zygomaticus. 
Stämme dar, die untereinander in keinen direkten genetischen Beziehungen stehen. Die Paläozoologie hat bisher nichts zu der Lösung der Frage nach dem Verwandtschaftsgrade der Robben mit den Carnivoren beitragen können; vielleicht stammen sie von Amphicyon ähnlichen Caniden $a b$, obwohl anderseits manche Beziehungen zu den Bären bestehen.

\section{Ordnung: Cetacea. ${ }^{1}$}

Die Wale stanmen, wie Funde im Eozän Ägyptens einwandfrei bewiesen haben, von den Raubtieren ab und zwar kommen als die Stammformen dieser frühzeitig zum Meeresleben übergegangenen Raubtiere in erster Linie die Hyaenodontiden unter den primitiven Carnivoren in Betracht, unter denen wir in Apterodon eine an das Wasserleben angepaßte Gattung kennen gelernt liaben, die sich in manchen Merkulalen den Robben nähert, aber durch langen Schwanz von dem Anpassungstypus der Robben durchgreifend unterscheidet, der durch Reduktion des Schwanzes charakterisiert ist. Die Robben sind jedenfalls nicht aus demselben Stamm wie die Wale entsprungen; wir haben gesehen, daß sie die meisten Beziehungen zu den Aictoidea aufweisen und daher jedenfalls mit den Walen nicht näher verwandt sein können.

Die Stanningruppe der Wale sind die Urwale (Archaeoceti), aus denen einerseits'die Bartenwale (Mystacoceti) und anderseits die Haizahnwale (Squaloceti) hervorgegangen sind, während die Herkunft der Delfine, welche mit einer großen Zahl von lebenden Gattungen die Gruppe der Delphinoceti bilden, bishe1 noch unaufgeklärt ist.

\section{Stammgruppe: Archaeoceti.}

Die Archaeoceten schließen sich mit der ältesten Gattung Protocetus an die Carnivoren so enge an, daß sie von E. Fraas (1904) als eine Untergruppe der Carnivoren betrachtet worden sind. In der Tat weist das Gebiß von Protocetus aus dem Mitteleozän von Kairo noch durchaus die Merkmale des Carnivorengebisses auf und bildet zweifellos die Brücke zwischen den jüngeren Archaeoceten und den Raubtieren. Aus den Archaeoceten gingen unter Vermehrung der Zähne und Vereinfachung des Kronenbaues die Squaloceti mit der Anfangsgattung Neosqualodon hervor, die wieder durch zahlreiche Zwischenglieder mit den Physeter:den, Ziphiiden und den anderen Fanilien der Squaloceti verbunden ist, wie ich diese G.uppe genannt habe. Mit den Bartenwalen werden die Archaeoceti durch die Übergangstype Patriocetus verknüpft,

1 Mit Rücksicht auf die in den Grundzïgen jetzt aufgeklärte Stammesgeschichte der Wale habe ich diesen Abschnitt reicher durch Abbildungen zu illustrieren getrachtet, ebenso wie bei den verschiedenen Hauptstammesreihen der Unpaarhufer, bei denen gleichfalls die Grundlinien ihrer Stammesgeschichte genauer festgelegt sind. 
bei der man im Zweifel sein kann, ob sie schon den Bartenwalen oder noch den Archaeoceten einzureihen ist.

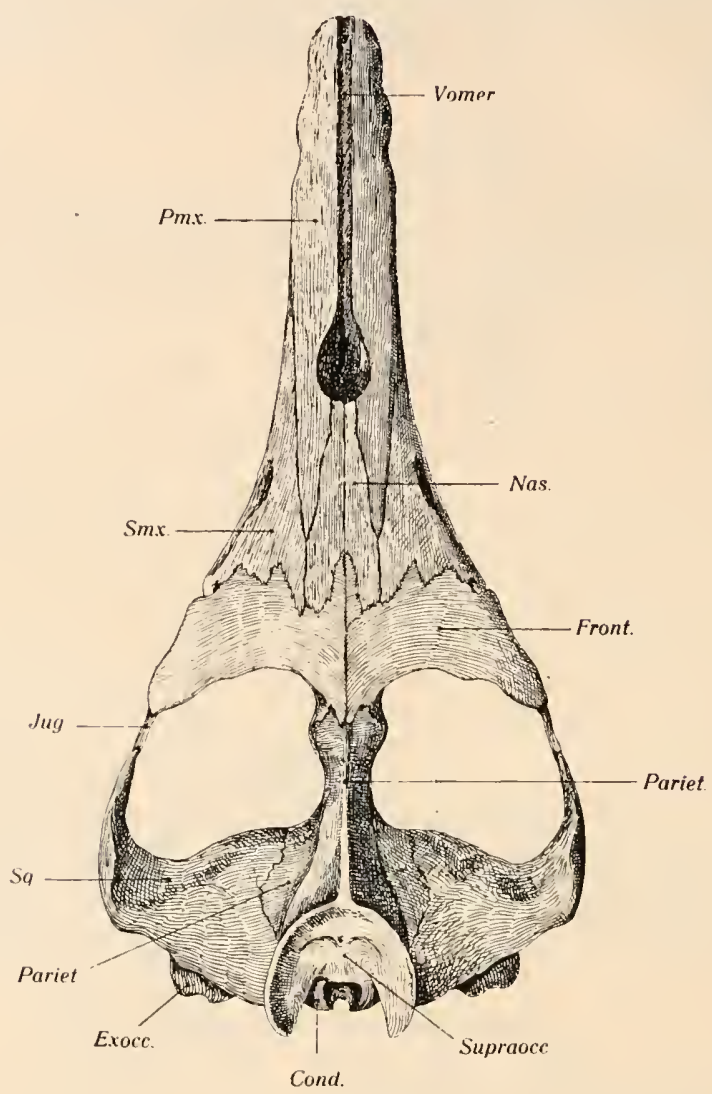

Fig. 558.

Schädel von Zeuglodon Isis, Beadnell, aus dem oberen Mitteleozän von Ägypten. Schädeliänge $119 \mathrm{~cm}$.

Cond. $=$ Condylus occipitalis.

Exocc. $=$ Exoccipitale.

Front. $=$ Frontale.

Jug. $\quad=$ Jugale.

Nas. = Nasale (davor die Nasenöffnung).
Pariet. $=$ Parietale

Pmlx. $\quad=$ Praemaxillare.

Smx. = Supramaxillare.

Sq. $\quad=$ Squamosum.

Supraocc. = Supraoccipitale.

Vomer $=$ Vomer.

Aus Protocetus ging noch im Mitteleozän über Eocetus die Gattung Zeuglodon hervor, die einen einseitig spezialisierten Seitenzweig der Archaeoceten bildet, der ohne Nachkommen erloschen ist. Die jüngsten Nachkommen dieser Gruppe sind in der Gattung Kekenodon aus dem Miozän Neuseelands und der Seymourinsel zu vereinigen. 


\section{F. Zeuglodontidae.}

Protocetus. - Mitteleozän Ägyptens ${ }^{1}$ (Fıg. 556).

Eocetus. - Mitteleozän Ägyptens. ${ }^{2}$

Prozeuglod on.—Mitteleozän (und Obereozän ?) Ägyptens ${ }^{3}$ (Fig.557).

Zeuglodon. - Mitteleozän bis Obereozän Ägyptens, Europas und Nordamerikas ${ }^{4}$ (Fig. 558, 559 A).

Kekenodon. - Miozän Neuseelands und der Seymourinsel. ${ }^{5}$

\section{F. Microzeuglodoptidae.}

Microzeuglodon. - Alttertiär des Kaukasus. Vielleicht eine Ahnenform der Squaloceti. ${ }^{6}$

\section{F. Agorophiidae.}

Agorophius. - Alttertiär (Unteroligozän?) von Südcarolina. Sicher ein Bindeglied zwischen Archaeoceten und Squaloceten ${ }^{7}$ (Fig. 560).

Prosqualodon. - Miozän Patagoniens. Vertreter einer erloschenen Seitenlinie der Archaeoceten, der durch die Reduktion des Gebisses und die sekundäre Verkürzung der Schnauze eine isolierte Stellung einnimmt ${ }^{8}$ (Fig. 561, 562).

1 E. Fraas, Neue Zeuglodonten aus dem unteren Mitteleozän vom Mokattam bei Cairo. - Geol. u. Paläont. Abhandl, Jena, Neue Folge Bd. VI (G. R. Bd. X), 1904, S. 199.

2 Ibidem, S. 21 (der Name Mesocetus wurde, weil präoccupiert, von E. Fraas, 1905, in Eocetus abgeändert).

3 C. W. Andrews, A Descriptive Catalogue of the Tertiary Vertebrata of the Fayûm, Egypt. - London 1906, p. 243.

4 W. Dames, Über Zeuglodonten aus Ägypten und die Beziehungen der Archaeoceten zu den übrigen Cetaceen, - Geol, und Paläont. Abhandl., Jena, N. F. Bd. I, 1894, S. 189.

E. von Stromer, Zeuglodonreste aus dem oberen Mitteleocän des Fajûm. Beiträge zur Geologie u. Paläontologie Österreich-Ungarns u. d. Orients, XV. Bd., Wien 1903, S. 65.

Derselbe, Die Archaeoceti des ägyptischen Eozäns. - Ebenda, XXI. Bd., Wien 1908, S. 106 (Literatur).

O. Abel, Die Vorfahren der Bartenwale. - Denkschriften d. Kais. Akademie d. Wiss., XC. Bd., Wien 1913, S. 201 (Literatur).

$5 \mathrm{~J}$. Hector, Notes on New Zealand Cetacea. - Transactions and Proceedings of the New Zealand Institute, 1880, XIII. Bd., p. 434.

C. Wiman, Über die alttertiären Vertebraten der Seymourinsel. - Wiss. Ergebisse d. Schwedischen Südpolarexpedition (Dr. O. Nordenskjöld), IIl. Bd., Stockholm 1905, S. 1.

O. Abel, Die Vorfahren der Bartenwale, 1. c., S. 211.

${ }_{6}^{6}$ O. Abel, Die Vorfahren der Bartenwale, l. c., S. 206.

7 F.W. True, Remarks on the Type of the Fossil Cetacean Agorophius pygmaeus (Müller). - Smithsonian Institution, Nr. 1694, Washington 1907, p. 1.

O. Abel, Die Vorfahren der Bartenwale, 1. c., S. 204.

${ }^{8}$ O. Abel, Cetaceenstudien, III. Teil. - Sitzungsberichte d. Kais. Akademie d. Wiss., Wien, CXXI. Bd., Abt. 1, 1912, S. 68. 


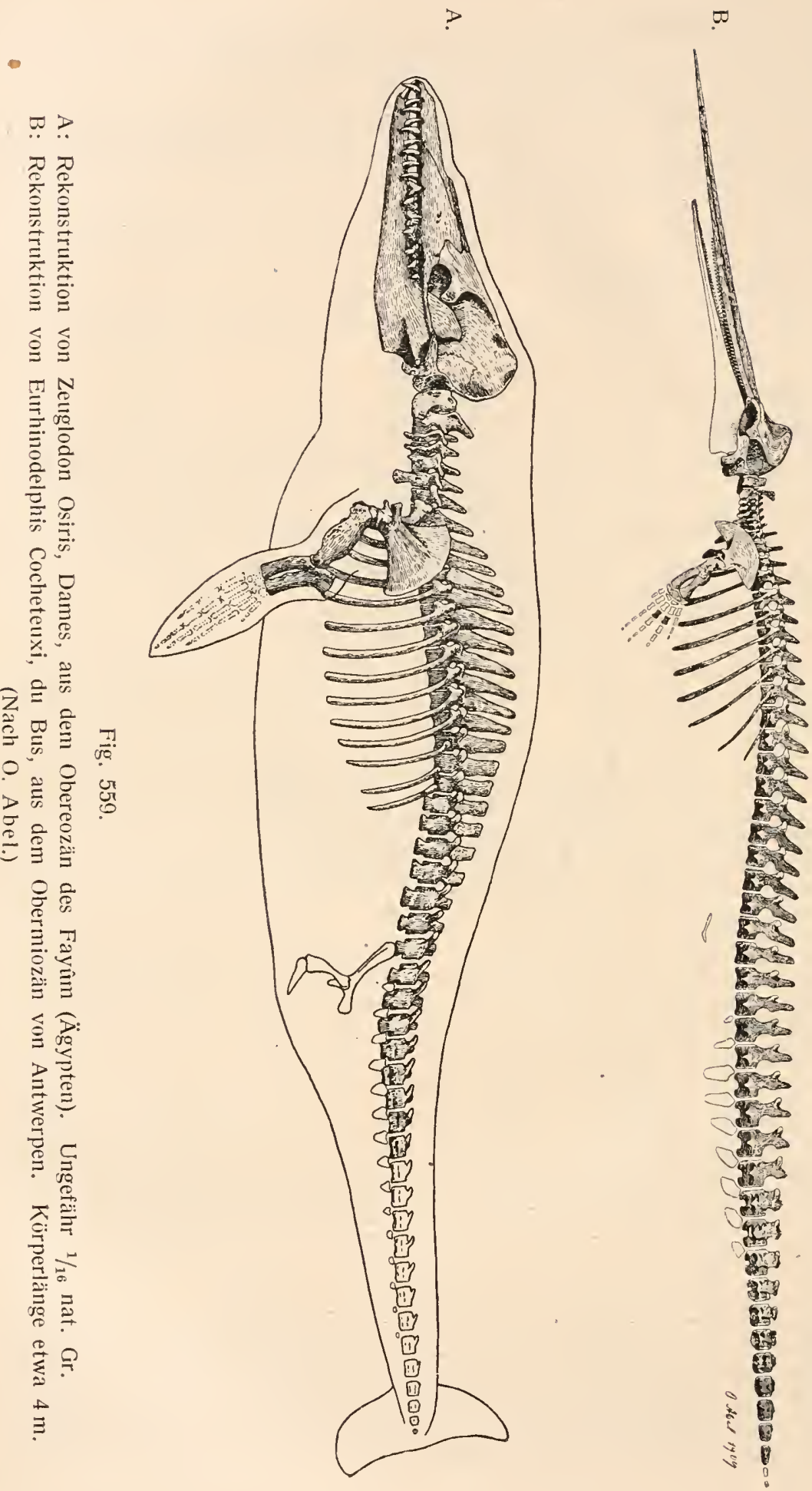




\section{F. Patriocetidae.}

Patriocetus. - Oberstes Oligozän Österreichs. Gebißformel $\frac{3.1 .4 .3}{3.1 .4 .3}$. Die sieben Backenzähne besitzen je sieben Spitzen. Daraus erklärt sich das Vorhandensein von im Maximum 53 Einzelspitzen der rudimen-

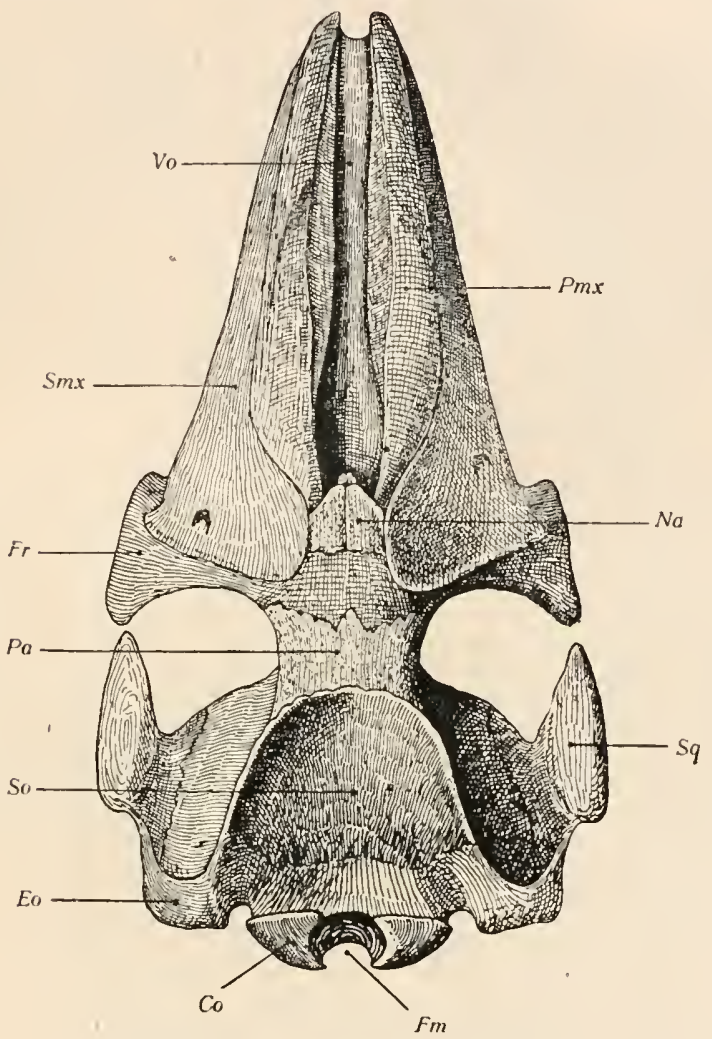

Fig. 560 .

Rekonstruktion des Schädels von Agorophius pygmaeus, Müller, aus dem Unteroligozän Nordamerikas (Südkarolina). $1 / 4$ nat Gr. (Nach O. Abel.)

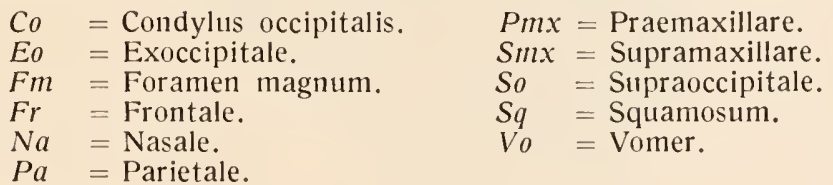

tären Zähne (Fig. 563) bei den Embryonen der lebenden Bartenwale (Fig. 564), bei denen die Backenzähne in je sieben Stücke zerfallen sind (Fig. 565), die den sieben Zacken der Backenzähne von Patriocetus entsprechen; zu diesen $49(=7 \times 7)$ Zacken treten die vier rudimentär gewordenen einspitzigen Zähne des Patriocetusgebisses hinzu, also zusammen 53 Spitzen, die Zahnzahl der Bartenwalembryonen. Im 
Schädelbau bildet Patriocetus ein vollständiges Bindeglied zwischen den Archaeoceten und Mystacoceten ${ }^{1}$ (Fig. 566, 567, 568).

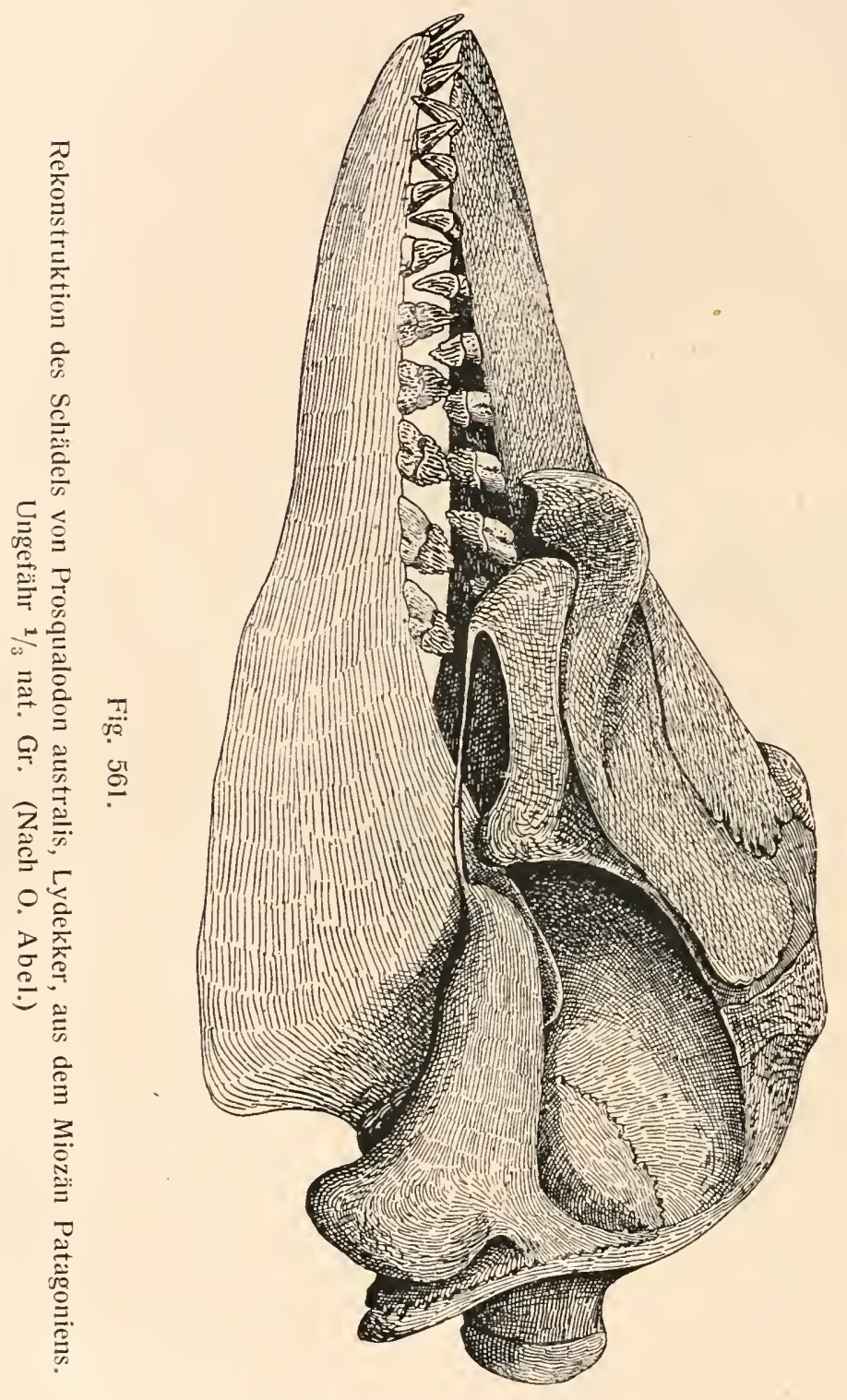

Agriocétus. - Oberstes Oligozän Österreichs² (Fig. 569).

1 O. Abel, Die Vorfahren der Bartenwale. - I. c., p. 155.

2 O. Abel, Ibidem, p. 188. 


\section{Unterordnung: Mystacoceti.}

Der Schädelbau der Bartenwale weist viel größere Älnnlichkeiten

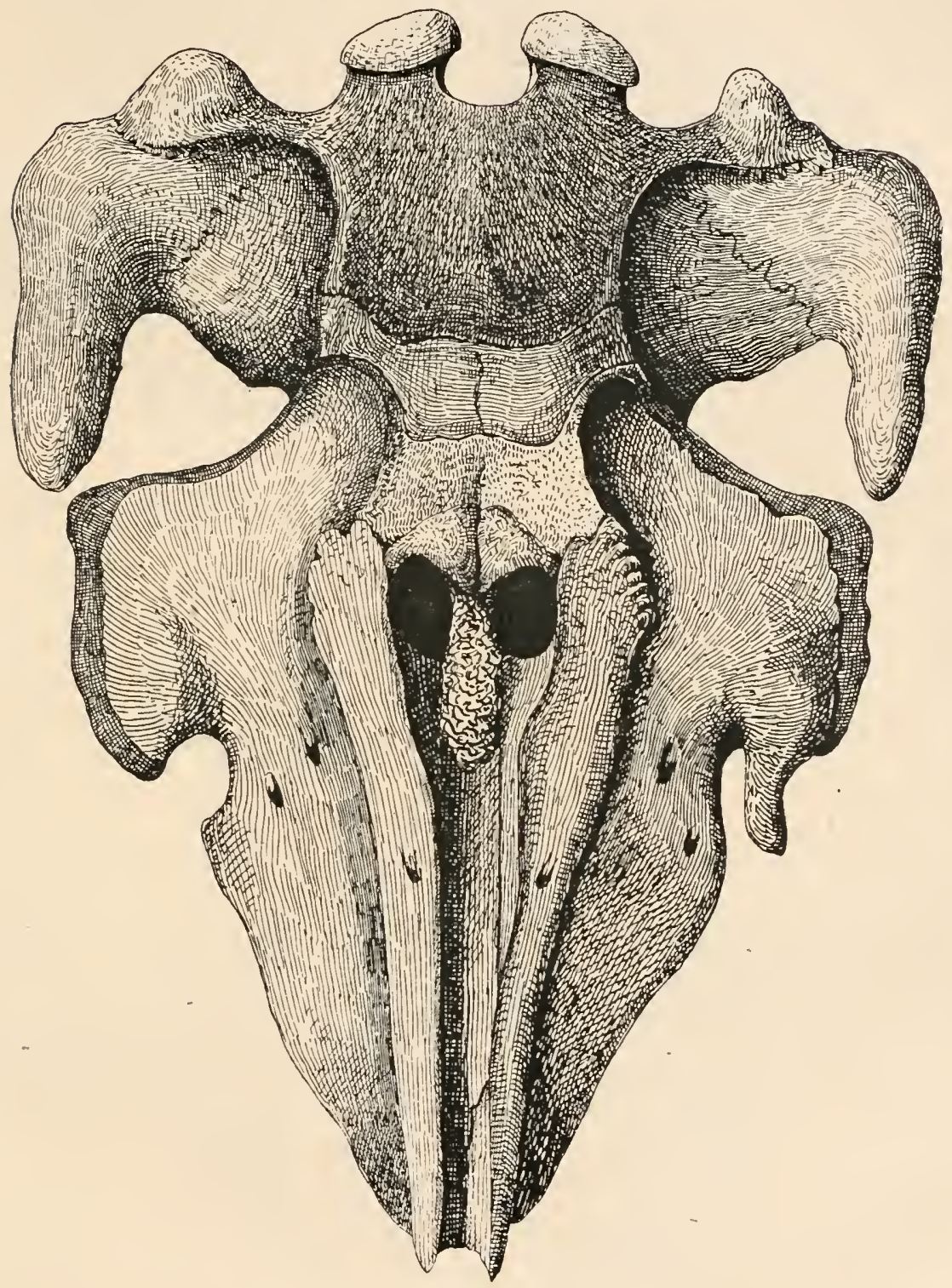

Fig. 562.

Rekonstruktion der Oberseite des Schädels von Prosqualodon australis, Lyd., aus dem Miozän Patagoniens, ungefähr in $1 / 3$ nat. Gr. (Nach O. Abel.)

mit den Archaeoceten als mit den Squaloceten oder Delphinoceten auf; als der wesentlichste Unterschied zwischen der Gruppe der "Zahnwale“ 


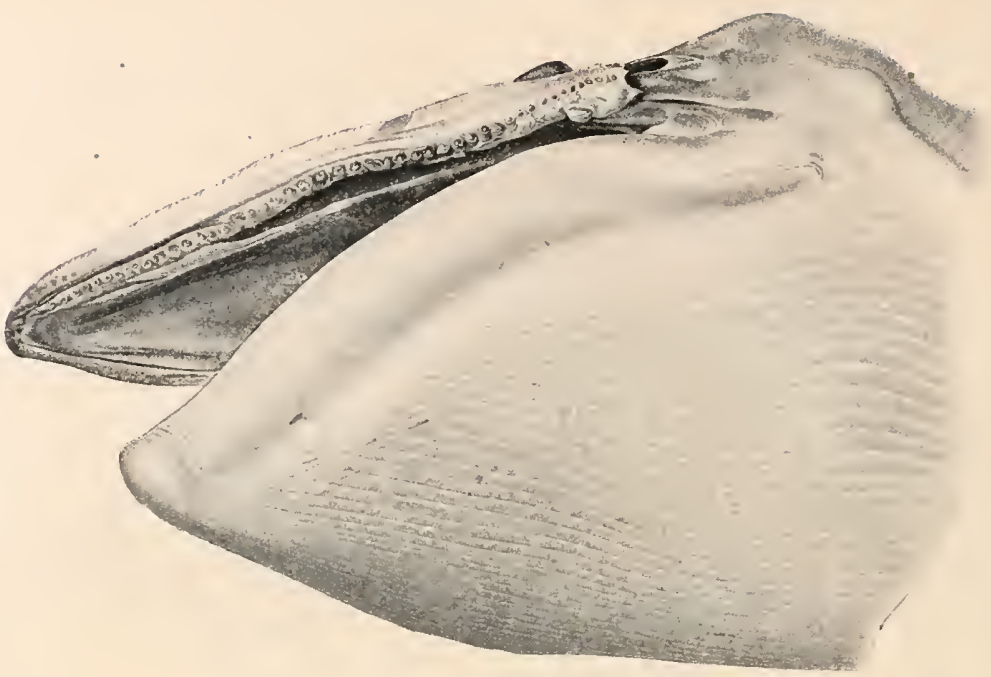

Fig. 563 .

Kopf eines Embryos von Balaenoptera physalus von $123 \mathrm{~cm}$ Länge, mit freigelegter Zahnreihe des Oberkiefers. $1 / 3$ nat. Gr. (Nach W. Kiikentha!.)

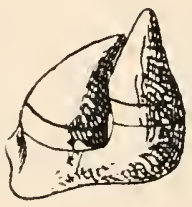

$A$

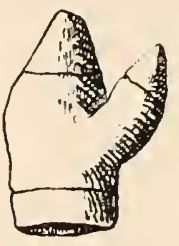

$B$

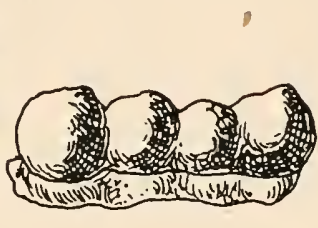

$C$

Fig. 564 .

In Teilung begriffene Zahnindividuen aus den Kiefern von Finwalembryonen.

A: ,Doppelzahn“ aus dem Oberkiefer eines $114 \mathrm{~cm}$ langen Embryos von Balaenoptera physalus, L.

B: „Doppelzahn“ eines $49 \mathrm{~cm}$ langen Embryos von Balaenoptera rostrata, Fabr.

C: Vierspitzenzahn eines $60 \mathrm{~cm}$ langen Embryos von Balaenoptera physalus, L. (Hälfte dex Zahnkrone eines Archaeocetenmolaren, der sieben Spitzen zählt).
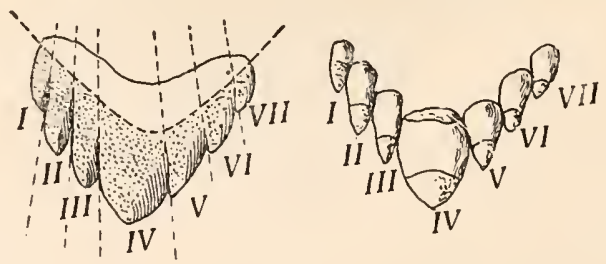

Fig. 565.

Schematische Darstellung des Teilungsprozesses eines siebenspitzigen Backenzahns vom Patriocetustypus, der bei den Balaenopteriden in sieben Einzelspitzen zerfällt. Links der intakte Backenzahn, rechts die sieben isolierten Spitzen. (Nach O. Abel, 1913.) 
und der „Bartenwale“ ist nicht die Spezialisationsdifferenz des Gebisses, sondern das Verhalten der Supramaxillaria zu betrachten, die bei den Bartenwalen ebenso wie bei den Urwalen die Stirnbeinflügel unterschieben, während die Supramaxillaria der Squaloceti und Delphinoceti die Stirnbeinflügel überschieben (O. Abel, 1913). In sehr vielen Merkmalen verhalten sich die Bartenwale primitiver als die
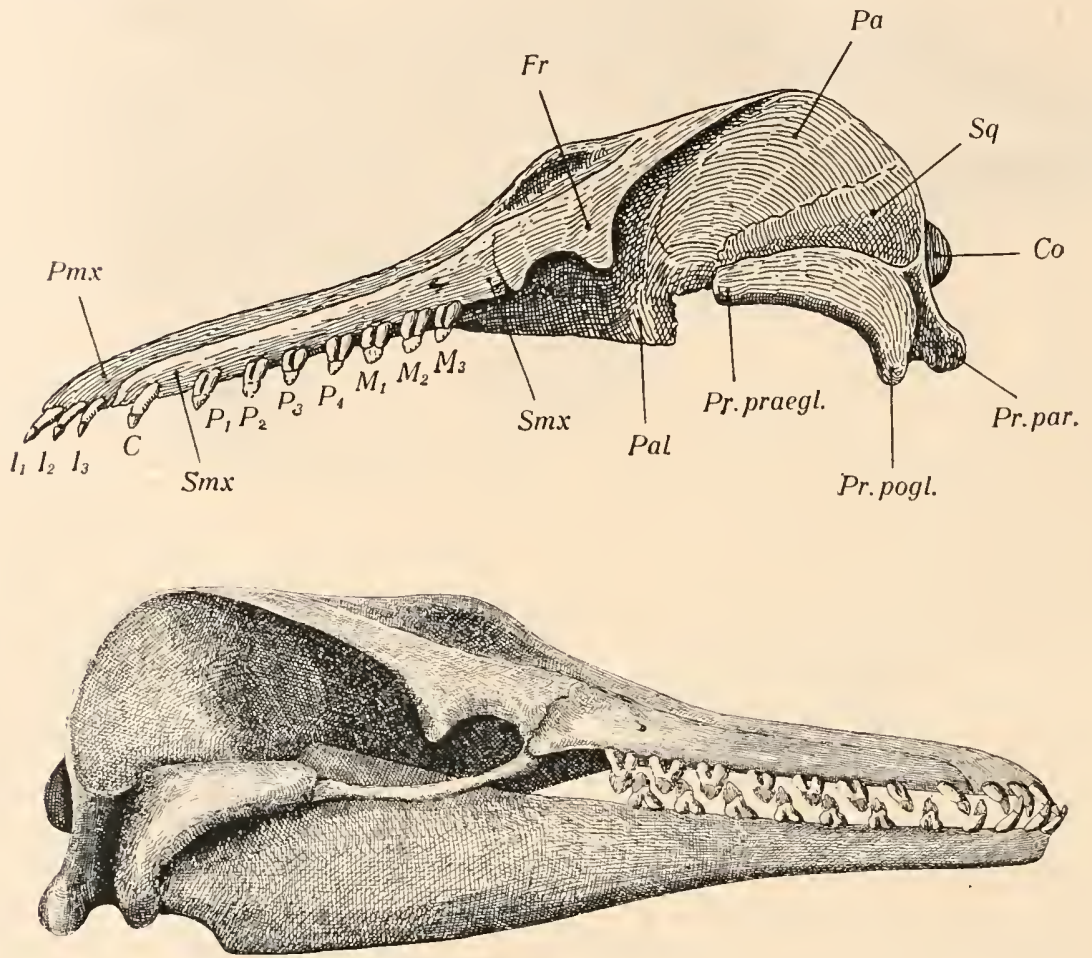

Fig. 567.

Schädel von Patriocetus Ehrlichi, van Beneden (vgl. Fig. 566).

(Nach O. Abel.)

Pr. par. $\quad=$ Processus paroccipitalis.

Pr. pogl. $=$ Processus postglenoidalis.

Pr. praegl. $=$ Processus praeglenoidalis.

C. $=$ Eckzahn .

$P_{1}-P_{4}=$ Praemolaren $(1-4)$.

$I_{1}-I_{3}=\operatorname{lnzision}(1-3)$.

$M_{1}-M_{3}=$ Molaren $(1-3)$.

(Die übrigen Abkürzungen wie in Fig. 560.)

Haizahnwale und Delfine. Die Umwandlung aus den Urwalen zu den Bartenwalen ging, wie es scheint, relativ sehr rasch vor sich und war in den Grundzügen bereits im Untermiozän abgeschlossen. Frülızeitig spalteten sich die Bartenwale in verschiedene Stänme, die sich größtenteils bis zur Gegenwart erhalten haben. Die beiden Hauptstänme sind die Furchenwale (Balaenopteridae) und die Glattwale (Balaenidae), die 
durch wichtige Spezialisationskreuzungen voneinander verschieden sind; die dritte lebende Fanilie, die der Grauwale (Rhachianectidae) nimmt eine Mittelstellung zwischen beiden ein.

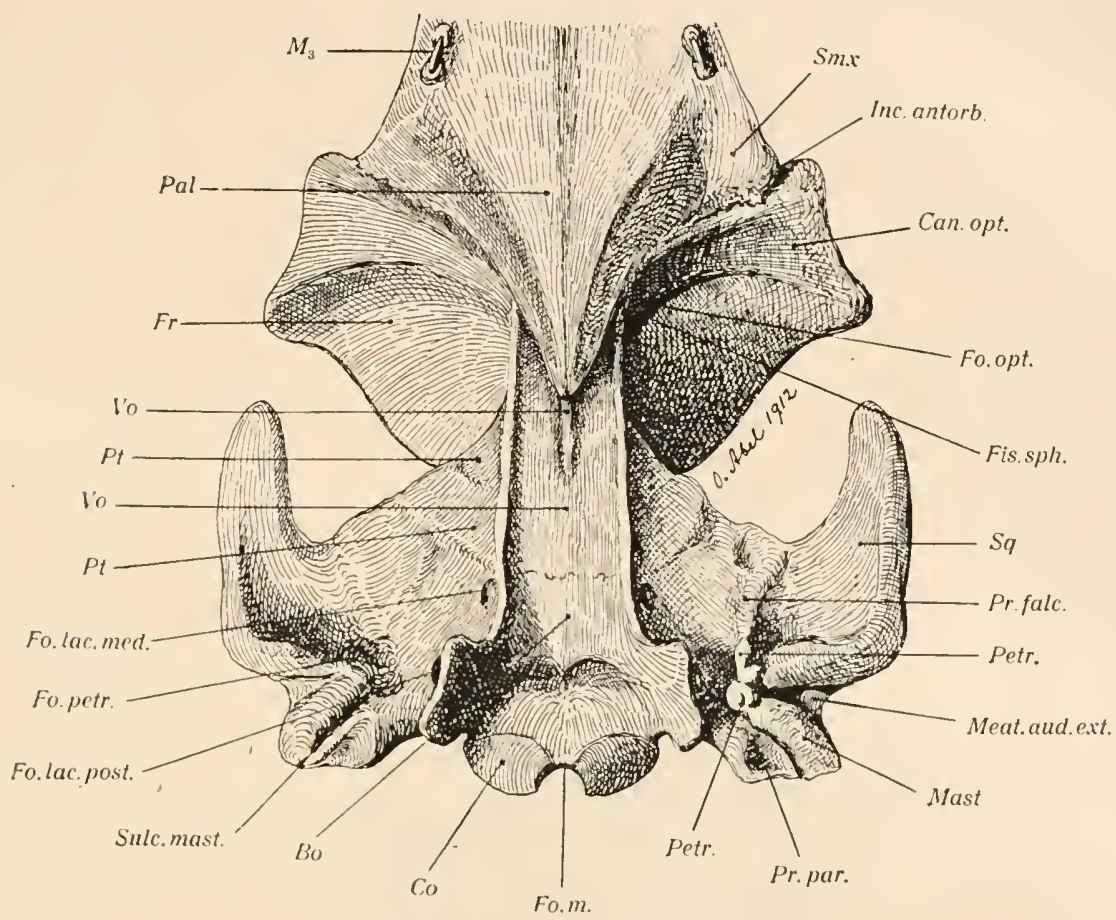

Fig. 568.

Rekonstruktion der Schädelbasis von Patriocetus Ehrlichi, van Ben. (vgl. Fig. 566 11. 567).

\begin{tabular}{|c|c|c|c|}
\hline $\begin{array}{l}\text { Bo } \\
\text { Can. opt. } \\
\text { Co } \\
\text { Fis. sph. } \\
\text { Fo. lac. med. } \\
\text { Fo. lac. post. } \\
\text { Fo. m. } \\
\text { Fo. opt. } \\
\text { Fo. petr. } \\
\text { Fr } \\
\text { Inc. antorb. } \\
M_{3}\end{array}$ & $\begin{array}{l}=\text { Basioccipitale. } \\
=\text { Canalis opticus. } \\
=\text { Condylus occipitalis. } \\
=\text { Fissura sphenoidalis. } \\
=\text { Foramen lacerum medium. } \\
=\text { Foramen lacerum pos- } \\
\text { terius. } \\
=\text { Foramen magnum. } \\
=\text { Foramen opticum. } \\
=\text { Fossa petrosi. } \\
=\text { Frontale. } \\
=\text { Incisura antorbitalis. } \\
=\text { der dritte rechte Molar. }\end{array}$ & $\begin{array}{l}\text { Mast } \\
\text { Meat. aud. ext. } \\
\text { Pal } \\
\text { Petr. } \\
\text { Pr. falc. } \\
\text { Pr. par. } \\
\text { Pt } \\
\text { Smx } \\
\text { Sq } \\
\text { Sulc. mast. } \\
\text { Vo }\end{array}$ & $\begin{aligned}= & \text { Mastoideum. } \\
= & \text { Meatus auditorius ex- } \\
& \text { ternus. } \\
= & \text { Palatinum. } \\
= & \text { Petrosum. } \\
= & \text { Processus falciformis. } \\
= & \text { Processus parocci- } \\
& \text { pitalis. } \\
= & \text { Pterygoideum. } \\
= & \text { Supramaxillare. } \\
= & \text { Squamosum. } \\
= & \text { Sulcus mastoideus. } \\
= & \text { Vomer. }\end{aligned}$ \\
\hline
\end{tabular}

\section{F. Balaenopteridae.}

Die ältesten Balaenopteriden treten bereits neben ihren Stammformen im obersten Oligozän Österreichs auf (Aulocetus linzianus) und unterscheiden sich nur in geringem Grade von den jüngeren Formen; 
die häufigste Gattung des Miozäns ist Cetotherium. Eine sehr große Zahl von Artnamen bezieht sich auf unvollständige und in morphologischer Hinsicht wertlose Reste und täuscht eine umfassende Kenntnis der fossilen Furchenwale vor, die bisher nur sehr ungenügend untersucht sind.

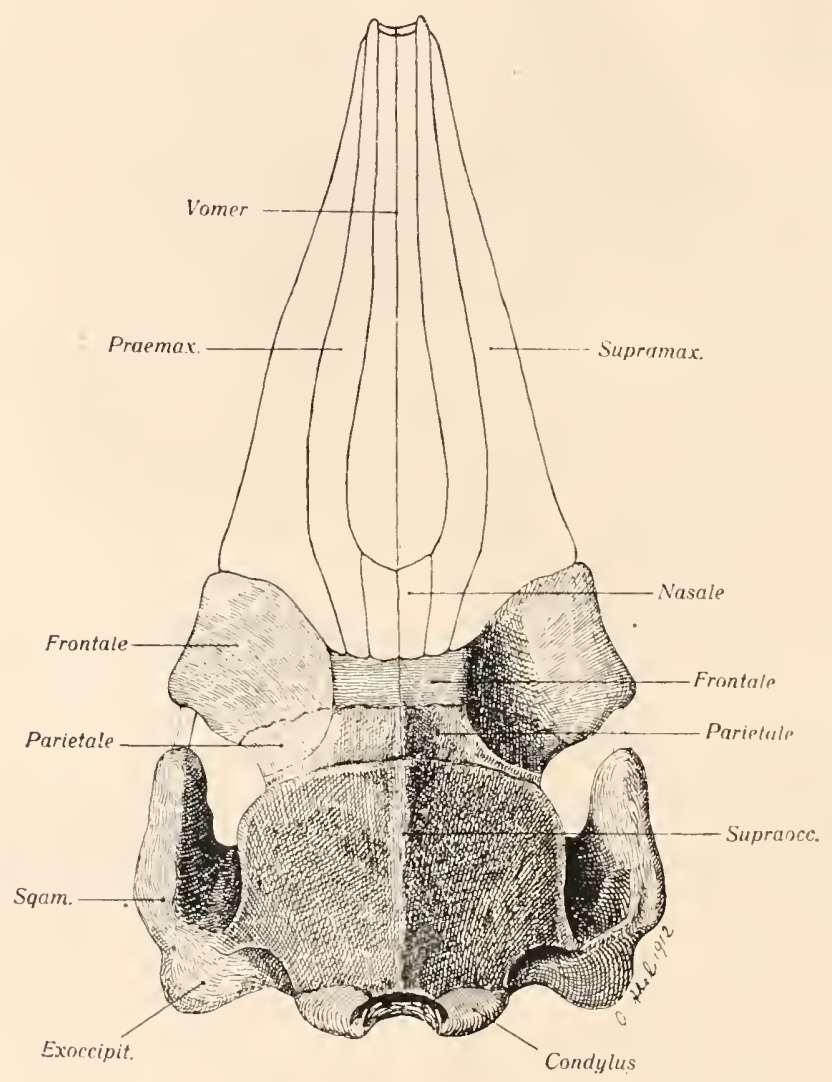

Fig. 509.

Agriocetus austriacus, Abel, aus dem obersten Oligozän von Linz (Oberösterreich) in etwa $1 / 5$ der nat. Gr. (Nach O. Abel.)

Aulocetus. - Oberstes Oligozän Österreichs. ${ }^{1}$

1 P. J. van Beneden, Recherches sur les Ossements provenant du Crag d'Anvers. - Les Squalodons. - Mémoires Acad. Roy. Belg., T. XXXV, Bruxelles. 1865 , p. 72.

Derselbe, Les Ossements fossiles du Genre Aulocète au Musée de Linz. Bull. Acad. Roy. Belg. (2), T. XL, Bruxelles, Nov. 1875, p. 357. 
Cetotherium. - Miozän Europas, Nord- und Südamerikas ${ }^{1}$ (Fig. 570).

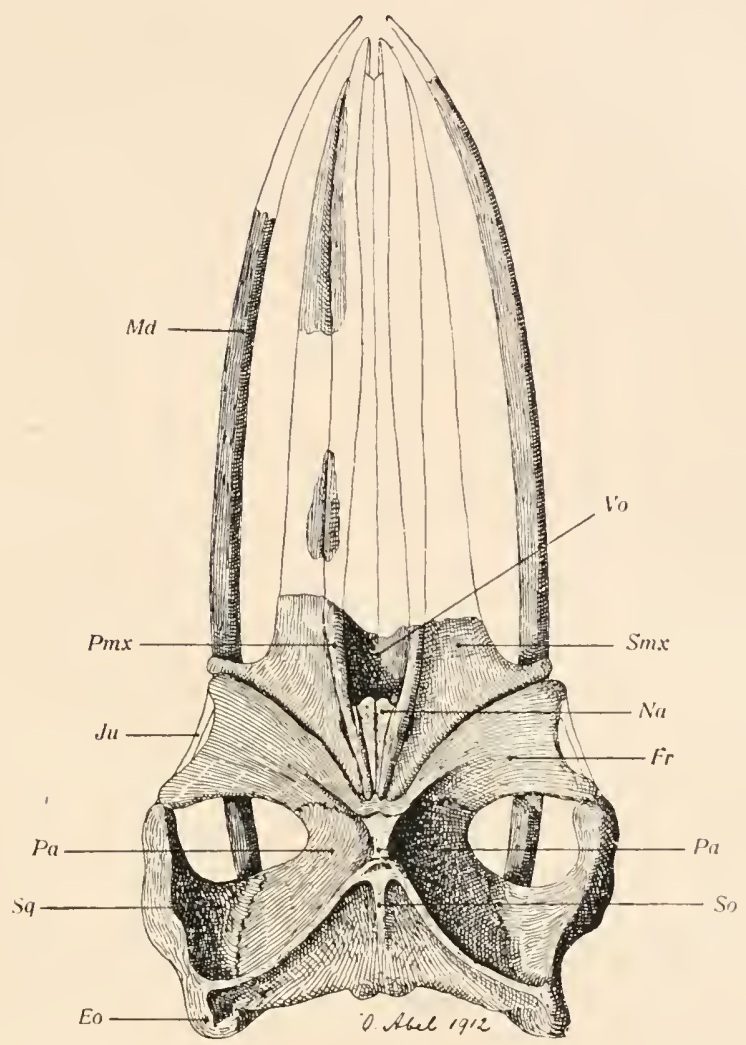

Fig. 570 .

Cetotherium Rathkei, Brdt., aus dem Miozän der Halbinsel Taman (Krim). in ungefähr $1 / 6$ nat. Gr. (Nach O. Abel.)

Pachyacanthus. - Obermiozän des Wiener Beckens. Ein ein-

1 J. F. Brandt, Untersuchungen über die fossilen und subfossilen Cetaceen Europas. - Mém. Acad. Imp. Sci. St. Pétersbourg (7), Vol. XX, 1873.

Derselbe, Ergänzungen zu den fossilen Cetaceen Europas. - Ebenda, XX1, 1874 .

R. Lydekker, Contributions to a Knowledge of the Fossil Vertebrates of Argentina: I1. Cetacean Skulls from Patagonia. - Anales del Museo de la Plata, La Plata 1893.

E. C. Case, Mammalia (of the Miocene of Maryland). Maryland Geolog. Survey, Miocene. - Baltimore 1904, p. 34-55. (Hier die ältere Literatur; vgl. auch O. P. Hay, Bibliography and Catalogue of the Fossil Vertebrata of North America. Washington 1902 , p. 598.) 
seitig spezialisierter, an Pachyostose erkrankter und degenerierter Bartenwalstanm, der sehr kleine Arten umfaßt. ${ }^{1}$

Plesiocetus. - Pliozän Europas. ${ }^{2}$

\section{F. Balaenidae.}

Die Vorgeschichte der Glattwale bzw. ihr Anschluß an die Patriocetiden, ist bisher noch dunkel. Die ersten Vertreter der lebenden Gattung Balaena treten mit den bezeichnenden Merkmalen der Gattung schon in oberen Pliozän auf (beschrieben als Probalaena, Balaenula, Balaenotus).

Balaena. - Zuerst im oberen Pliozän von Antwerpen. ${ }^{3}$

Unterordnung: Squaloceti.

\section{F. Squalodontidae.}

Diese Familie bildet zweifellos die Stanmingruppe der Physeteriden und der Acrodelphiden; die ersteren sind nach rascher Durchlaufung der bis zu Physeter führenden Anpassungsstadien seit dem oberen Miozän stehen geblieben und nicht zum Ausgangspunkt neuer Familien geworden, während die Acrodelpliden sich in weitere Familien zerspalten haben (Eurhinodelphidae und Ziphiidae).

Wesentliche Merkmale der Familie sind: die meist außerordentlich verlängerte Schnauze und das polyodonte Gebiß, das außer den drei Schneidezähnen jederseits noch bis zelnn zweiwurzelige (Neosqualodon) und mehrere einwurzelige, schneidezahnförmige Backenzälne und einen Eckzahn in jeder Kieferlıälfte besitzt. Die an die Sclnneidezähne und den Eckzahn anschließenden Zähne sind einwurzelig, die hinteren zweiwurzelig, die hintersten bei den primitiveren Foimen sogar noch dreiwurzelig; die hintes en Backenzälnne tragen am Vorder- und Hinterrand scharfe Zacken. Das Vordergebiß bildet einen Fangrechen.

1 J. F. Brandt, 1. c. (1873 und 1874). - Die Rippen und Wirbel dieser kleinen Form zeigen dieselben pathologischen Veränderungen, die bei rezenten Typen als Pachyostose oder Hyperostose beschrieben worden sind. Mit Rücksicht auf diese pachyostotischen Erscheinungen, welche insbesondere bei den fossilen Seekühen (z. B. Halitherium) sehr stark ausgebildet sind, wurde Pachyacanthus frïher vielfach als ein Angehöriger des Sirenenstammes betrachtet, doch haben meine Untersuchungen die Richtigkeit der Brandtschen Auffassung bestätigt, der diese Gattung den Walen einreihte.

2 P. J. van Beneden, La Baleine fossile du Musée de Milan. - Bull. Acad. Roy. de Belgique (2), T. XL, Bruxelles 1875.

${ }^{3}$ P. J.van Beneden, Description des ossemens fossiles des environs d'Anvers. - Annales du Musée Roy. d'Hist. Nat. de Belgique, Vol. IV-XIII, 1880-1886. 
Neosqualodo11. - Miozän Siziliens. ${ }^{1}$

Squalodon. - Miozän Europas und Nordamerikas² (Fig. 571, A).

\section{F. Physeteridae.}

Die ältesten Gattungen der Familie (z. B. Scaldicetus) haben noch ein vollständiges und vielzahniges Gebiß wie Squalodon, aber die Zähne sind vereinfacht (Kronenform mehr und mehr kegelförmig werdend, Wurzeln durch Verwachsung geschlossen; später geht der Schmelzbelàg der Krone verloren und die Wurzeln erfahren eine Verdickung). Ursprünglich stehen die Zähne im Zwischen-, Ober- und Unterkiefer (Scaldicetus), bei den Nachkommen tritt bereits die Reduktion des Zahnschmelzes ein (Physeterula), dann gehen die Zwischenkieferzähne verloren (bei Prophyseter nur in früher Jugend vorhanden) und auch die Oberkieferzälnne fallen bei höherem Alter aus (Propliyseter Dolloi), bis schließlich bei den am höchsten spezialisierten Gattungen nur mehr im Unterkiefer funktionelle Zähne vorhanden sind, eine Stufe, die schon im Obermiozän von der Gattung Placoziphius erreicht wurde und in der Gegenwart durch die Gattungen Physeter und Kogia repräsentiert wird. Der Schädel ist stark asymmetrisch, die Kiefer bilden in der Pränasalregion eine weite Wanne zur Aufnahme einer fettigen Substanz. Die Halswirbel sind (mit Ausnahme des frei bleibenden Atlas) miteinander verschmolzen, bei den älteren Gattungen nur der 2. bis 6., bei den lebenden der 2. bis 7 .

Scaldicetus. - Im Miozän und Pliozän Europas, Nordanerikas und Südamerikas. Diese Gattung verbindet die Squalodontiden mit den Physeteriden (Pottwalen) ${ }^{3}$ (Fig. 571, B).

Physeterula. - Obermiozän Belgiens, Deutsclilands und Ungarns ${ }^{4}$ (Fig. 571, C).

Prophyseter. - Obermiozän von Antwerpen ${ }^{5}$ (Fig. 572).

1 G. Dal Piaz, Neosqualodon, nuovo genere della famiglia degli Squalodontidi. - Abh. d. Schweiz. Paläont. Ges., Vol. XXX1, Genf 1904, p. 1.

2 Ein Teil der Literatur über Squalodon findet sich bei O. P. Hay, Bibliography and Catalogue of the Fossil Vertebrata of North America (Bull. 179, U. S. Geol. Surv., Washington 1902, p. 588); vgl. ferner:

G. Dal Piaz, Sopra alcuni resti di Squalodon dell' arenaria miocenica di Belluno. - Palaeontographia italica, Vol. VI, Pisa 1900, p. 303.

E. C. Case, Mammalia of the Miocene of Maryland. - Maryland Geolog. Survey (Miocene). Baltimore 1904, p. 6.

O. Abel, Les Odontocètes du Boldérien d'Anvers. - Mémoires Musée Roy. d'Hist. Nat. de Belgique, T. III, Bruxelles 1905.

3 O. Abel, Les Odontocètes usw., 1. c., p. 52 (Literatur).

4 Ibidem, p. 74.

5 Ibidem, p. 82. 

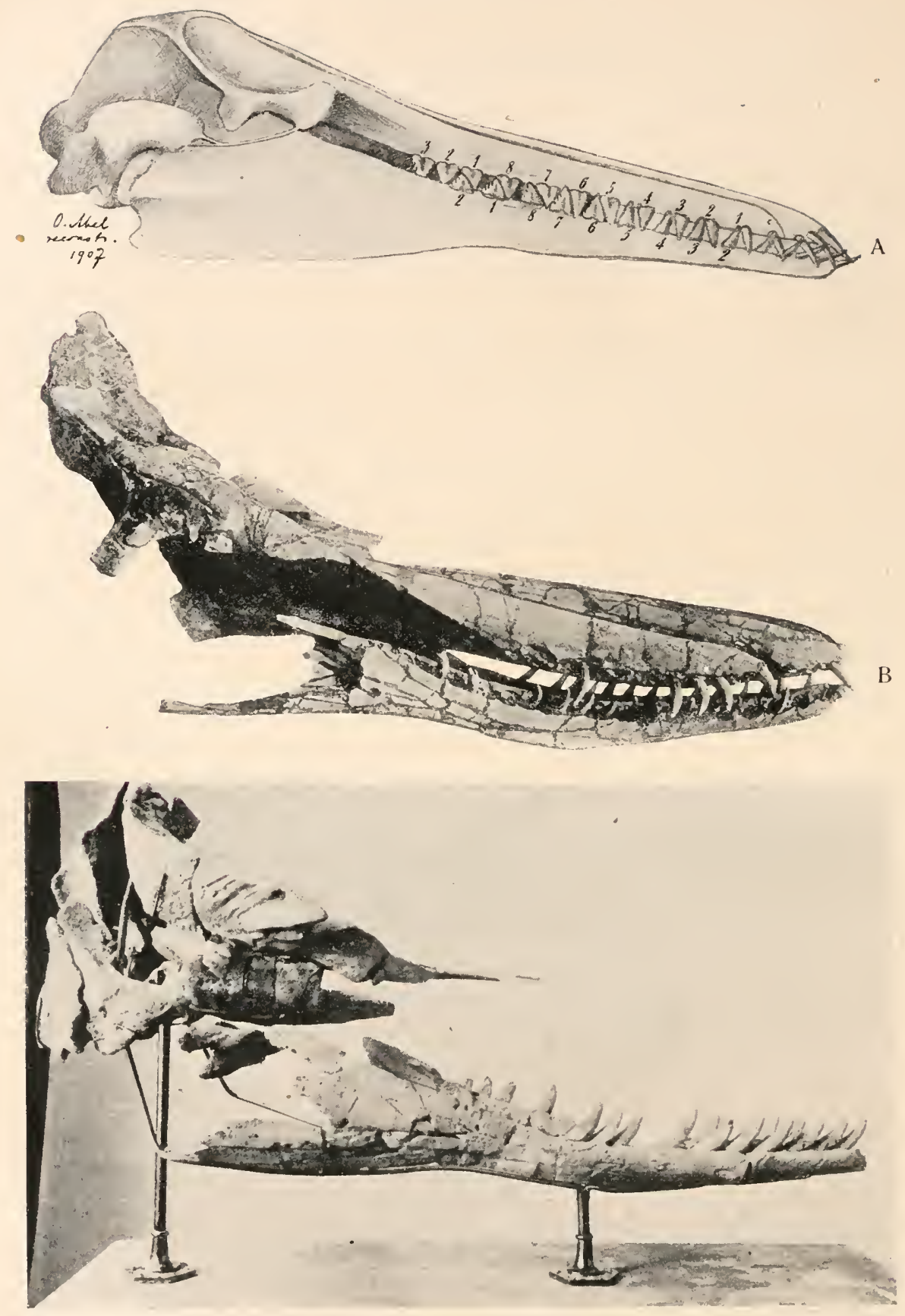

Fig. 571.

C

A: Squalodon bariensis, Jourdan, aus dem Miozän Suidfrankreichs. Etwa $1 / 10$ nat. Gr. (Nach O. Abel.)

B: Scaldicetus patagonicus, Lyd., aus dem Miozän (patagonische Stufe) von Chubut in Patagonien. Etwa 1/18 nat Gr. (Nach R. Lydekker.)

C: Physeterula Dubusii, van Ben., aus dem Obermiozän von Antwerpen. Etwa $1 / 10$ nat. Gr. (Schädellänge 1,35 $\mathrm{ml}$ ). (Nach $\mathrm{O}$. A bel.) 
Placoziphius. - Obermiozän von Antwerpen, Unterpliozän Norditaliens. ${ }^{1}$

Physeter. - Lebend (Fig. 573).

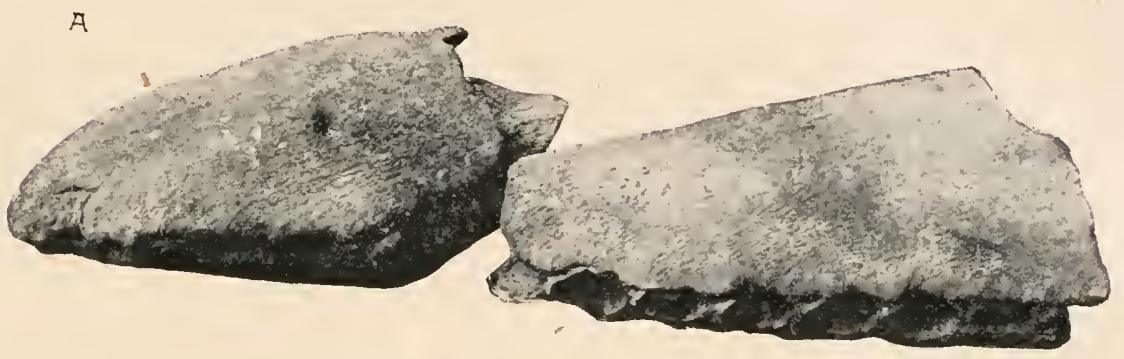

B

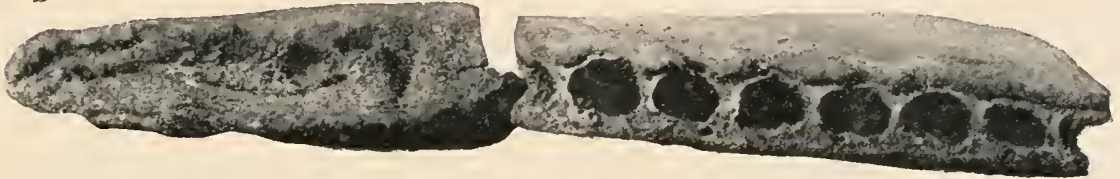

Fig. 572.

Vorderende der Schhauze eines Vorläufers des Pottwals, Prophyseter Dolloi, Abel, aus dem oberen Miozän von Antwerpen, etwa in $4 / 10$ nat. Gr. Der linke Zwischenkiefer und Oberkiefer von unten und von außen gesehen. Im Zwischenkiefer (links) noch drei, aber bereits verwachsene Alveolen der Schneidezähne sichtbar, die Alveolen des Oberkiefers im Verwachsen begriffen, also gleichfalls nicht mehr mit funktionellen Zähnen besetzt.

(Nach O. Abel.)

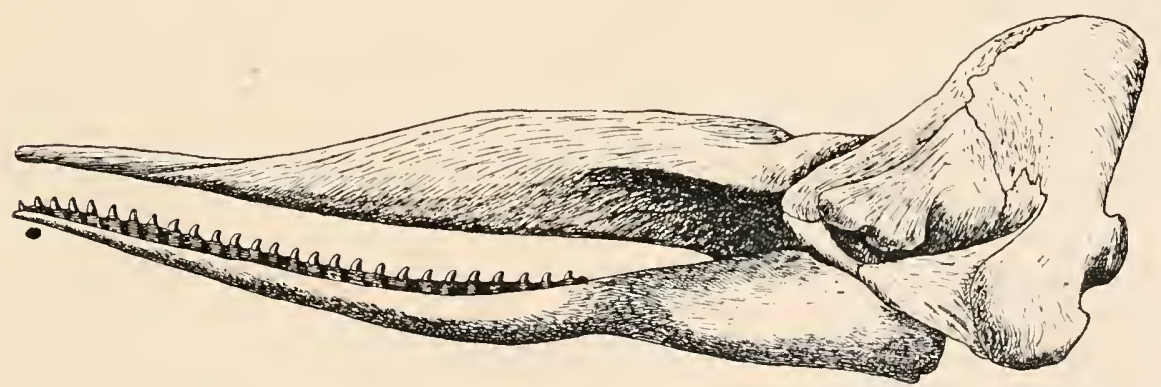

Fig. 573.

Physeter macrocephalus (Pottwal). Länge des erwachsenen Tiers bis zu $18 \mathrm{~m}$. (Nach W. H. Flower.)

Der Unterkiefer trägt beiderseits je 27 große einwurzelige Zähne, der Zwischenkiefer und Oberkiefer sind zahnlos.

1 Ibidem, p. 85. 


\section{F. Acrodelphidae.}

Diese aus den Squalodontiden hervorgegangene Familie erreicht in Miozän eine hohe Blüte, ist aber seither im Niedergang begiffen. Im Gegensatz zu den Physeteriden tritt hier eine weitere Vermehrung der Zähne ein, die erst bei einigen hochspezialisierten Gattungen rudimentär werden; aus den Acrodelphiden gingen einerseits die Ziphiiden, anderseits die Eurhinodelphiden hervor. Die Schnauzen sind mit wenigen Ausnahmen (z. B. bei Belıga und Monodon) sehr lang, in einigen Fällen sogar enorm verlängert, und in einzelnen Fällen steigt die Zahnzahl in jedem Kiefer auf 60. Die Halswirbel bleiben stets frei, die Lenden- und vorderen Schwanzwirbel sind in der Regel stark verlängert.

Acrodelphis. - Miozän Europas, Nord- und Südamerikas. ${ }^{1}$

Argyrocetus. - Miozän Südamerikas. ${ }^{2}$

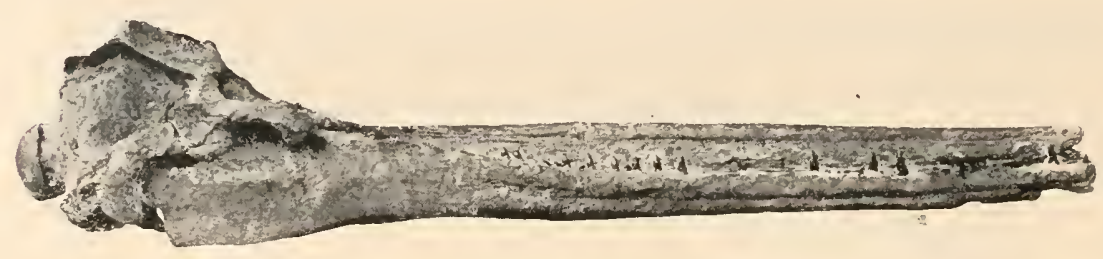

Fig. 574.

Seitenansicht des Schädels von Cyrtodelphis sulcatus, Gervais, einem langschnauzigen Zahnwal aus dem Miozän von Belluno. Schädellänge $63 \mathrm{~cm}$ (ergänzteLänge : 70-80 cm).

(Nach G. Dal Piaz.)

Cyrtodelphis. - Miozän Europas und Nordamerikas ${ }^{3}$ (Fig. 574). Saurodelphis. - Pliozän Südamerikas. ${ }^{*}$

1 Ibidem, p. 132.

2 R. Lydekker, Cetacean Skulls from Patagonia. - Anales del Museo de la Plata, Palcontologia Argentina, II, 1893.

3 O. Abel, Untersuchungen iiber die fossilen Platanistiden des Wiener Beckens. - Denkschriften d. Kais. Akad. d. Wiss., Math.-nat. Kl., LXVIII. Bd., Wien 1899, p. 839.

Derselbe, Les Dauphins longirostres du Boldérien (Miocène supérieur) d'Anvers. - Mém. Mus. Roy. Hist. Nat. Belg., T. I., Bruxelles 1901.

Derselbe, Les Odontocètes du Boldérien (Miocène supérieur) d'Anvers. Ibidem, T. III, 1905, p. 124.

F. W. True, On the Occurence of Remains of fossil Cetaceans usw.; Smithsonian Miscell. Collections, Vol. L., Part 4, Nr. 1782, Washington 1908, p. 449.

G. Dal Piaz, Di alcuni resti di Cyrtodelphis sulcatus dell' Arenaria miocenica di Belluno. - Palaeontographia italica, Vol. VIl, Pisa 1901, p. 287.

4 O. Abel, Der Schädel von Saurodelphis argentinus aus dem Pliozän Argentiniens. - Sitzungsber. Kais. Akad. d. Wiss., Math.-nat. Kl., CXVIII. Bd., Wien 1909, p. 255. 
Die letzten lebenden Ausläufer der Familie, die sich in die Unterfamilien der Acrodelphinae, Argyrocetinae, Iniinae, Beluginae und Platanistinae teilt, sind die Gattungen Beluga, Monodon, Inia, Pontoporia, Platanista.

\section{F. Eurhinodelphidae.}

Ein einseitig spezialisierter Seitenzweig, der durch die enorme Verlängerung des Zwischenkiefers gekennzeichnet ist, der ebenso wie bei Eurhinosaurus unter den Ichthyosauriern (p. 479) den Unterkiefer weit überragt und gänzlich zahnlos geworden ist. Der Stamm geht auf die Acrodelphiden zurïck.

Eurhinodelphis. - Miozän von Antwerpen tmd von Nordamerika $^{1}$ (Fig. 559, B).

\section{F. Ziphiidae.}

Aus den Acrodelphiden sind ferner die Schnabelwale oder Ziphiiden hervorgegangen; sie haben sich im Miozän zu hoher Bläte entfaltet, sind aber gegenwärtig im Niedergang begriffen.

Die ältesten Angehörigen dieser Familie besaßen noch funktionelle Zähne im Zwischen-, Oter- und Unterkiefer; später gingen die Zähnı verloren und sind bei den lebenden Gattungen nur als dürftige, im Zalınfleisch steckende Rudimente erhalten. Nur im Unterkiefer finden sich auch noch bei den lebenden Gattungen ein bis zwei Paar funktionelle, meist stark vẻrgrößerte Zähne, die als Waffen bei den Paarungskämpfen Verwendung finden, aber für die Nahrungsaufnahme (die Ziphiiden leben von weichkörperigen Cephalopoden) bedettungslos geworden sind. Sowohl die allmälliche Vergrößerung der Unterkieferzähne als auch die schrittweise sich steigernde Reduktion der übrigen Zähne läßt sich bei den einzelnen fossilen Gattungen von Stufe zu Stufe verfolgen (Fig. 578). Einzelne niozäne Ziphiiden (Choneziphitı, Mioziphitus) besitzen noch rudimentäre Alveolen im Oberkiefer (Fig. 575, 577), während bei den lebenden an Stelle dieser Alveolenreihe nur mehr eine Rinne vorhanden ist. Der Atlas ist stets mit dem Epistropheus verwachsen, die übrigen Wirbel bleiben frei.

Palae oziphius. - Obermiozän von Antwerpen ${ }^{2}$ (Fig. 578, $\mathrm{A}_{1} \mathrm{~A}_{2}$ ). Anoplonassa. - Miozän von Südcarolina ${ }^{3}$ (Fig. 578, B).

1 O. Abel, Les Dauphins longirostres du Boldérien (Miocène supérieur) d'Anvers. - Mém. Mus. Roy. Hist. Nat. Belg., T. I-II, Bruxelles 1901-1902.

Derselbe, Das Skelett von Eurhinodelphis Cocheteuxi aus dem Obermiozän von Antwerpen. - Sitzungsber. Kais. Akad. d. Wiss. Wien, CXVIII. Bd., 1909, p. 241 .

2 O. Abel, Les Odontocètes du Boldérien d'Anvers, I. c., 1905, p. 90.

3 F.W. True, Observations on the Type Specimen of the Fossil Cetocean, Anoplonassa forcipata, Cope. - Bulletin of the Museum of Compar. Zoology at Harvard College, Vol. L1., Cambridge, Mass., 1907, pp. 97. 


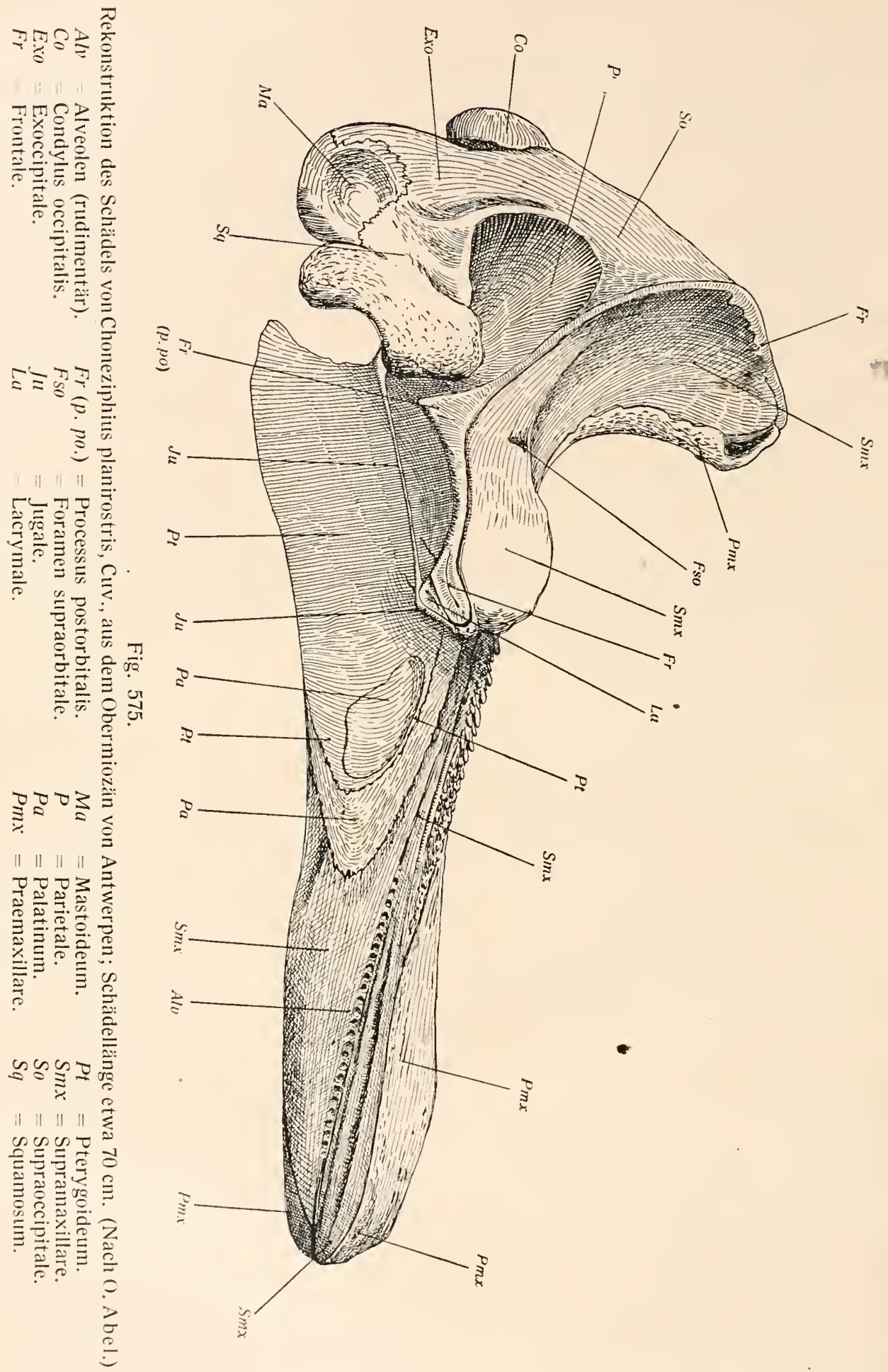




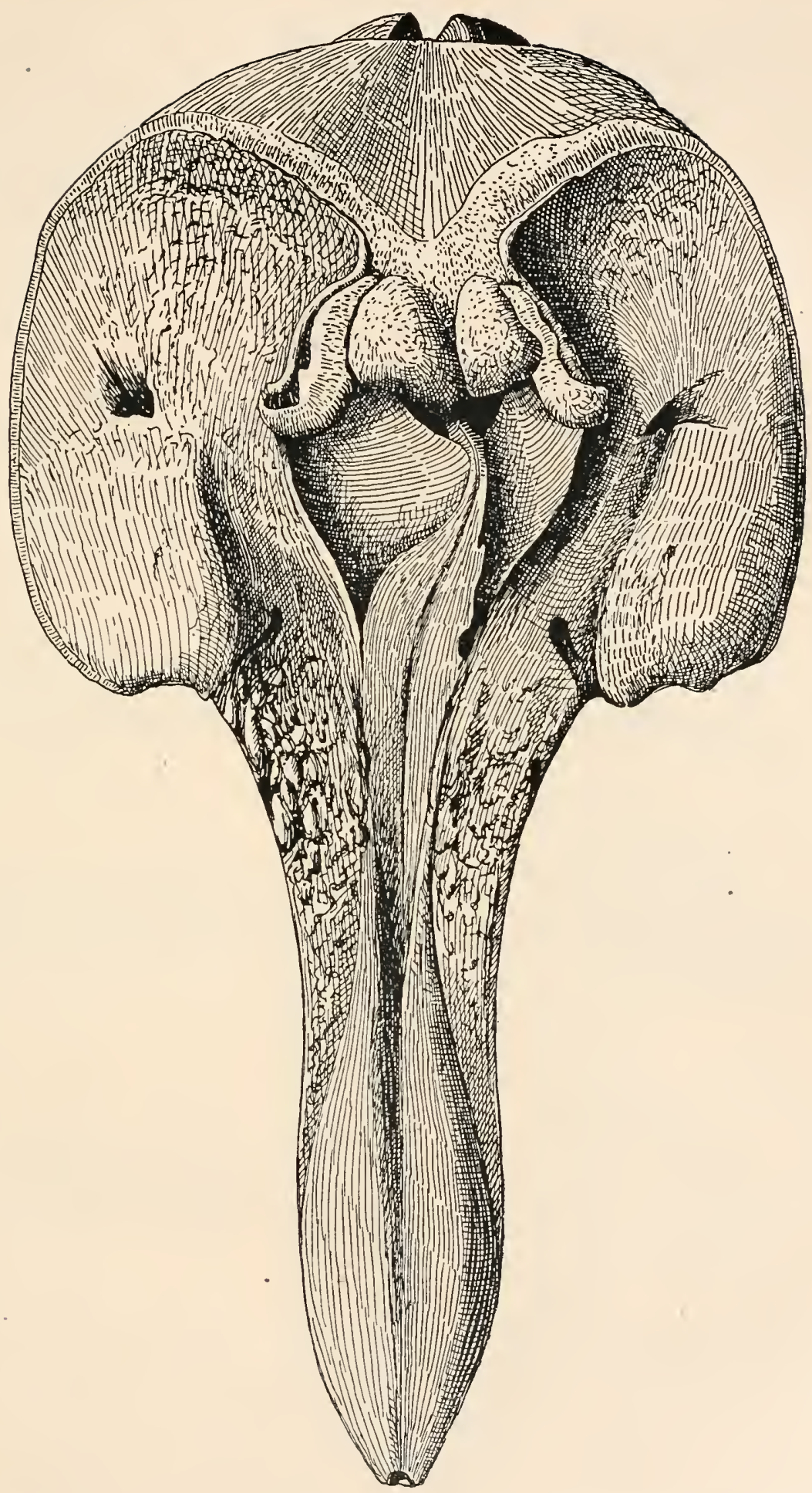

Fig. 576. Rekonstruktion des Schädels von Choneziphius planirostris, Cuv., aus dem Obermiozän von Antwerpen, von oben gesehen (vgl. Fig. 575). (Nach O. Abel.) 


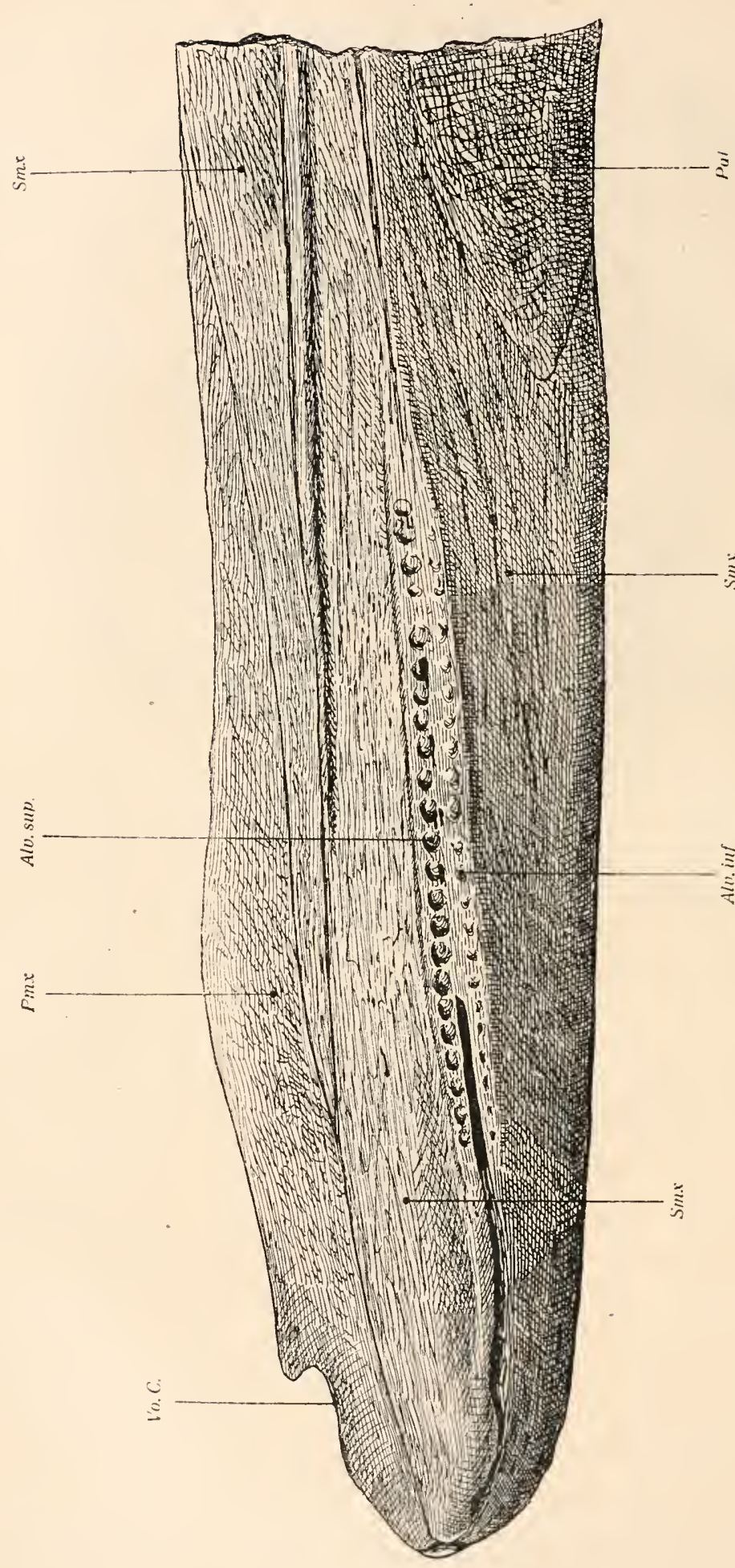

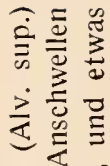

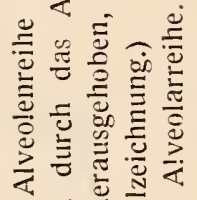

$\overline{\overline{2}} \overline{\mathrm{z}}$

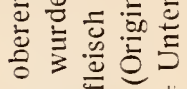

产蓄就

$\leftarrow$ 政

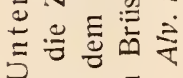

$\because$

可离芯志

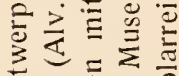

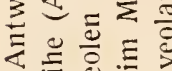

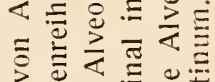

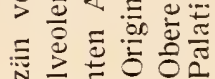

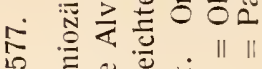

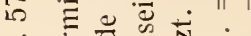

证 气

$\Xi$

च

$\stackrel{5}{5}$

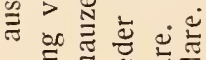

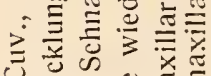

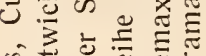

क芯导苞芯

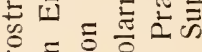

.

空艺艺艺

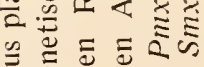

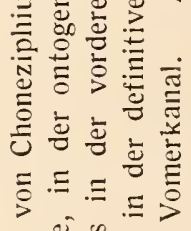

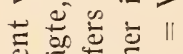

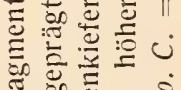

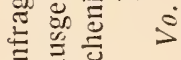

స్ స

突范芯

㻤: 

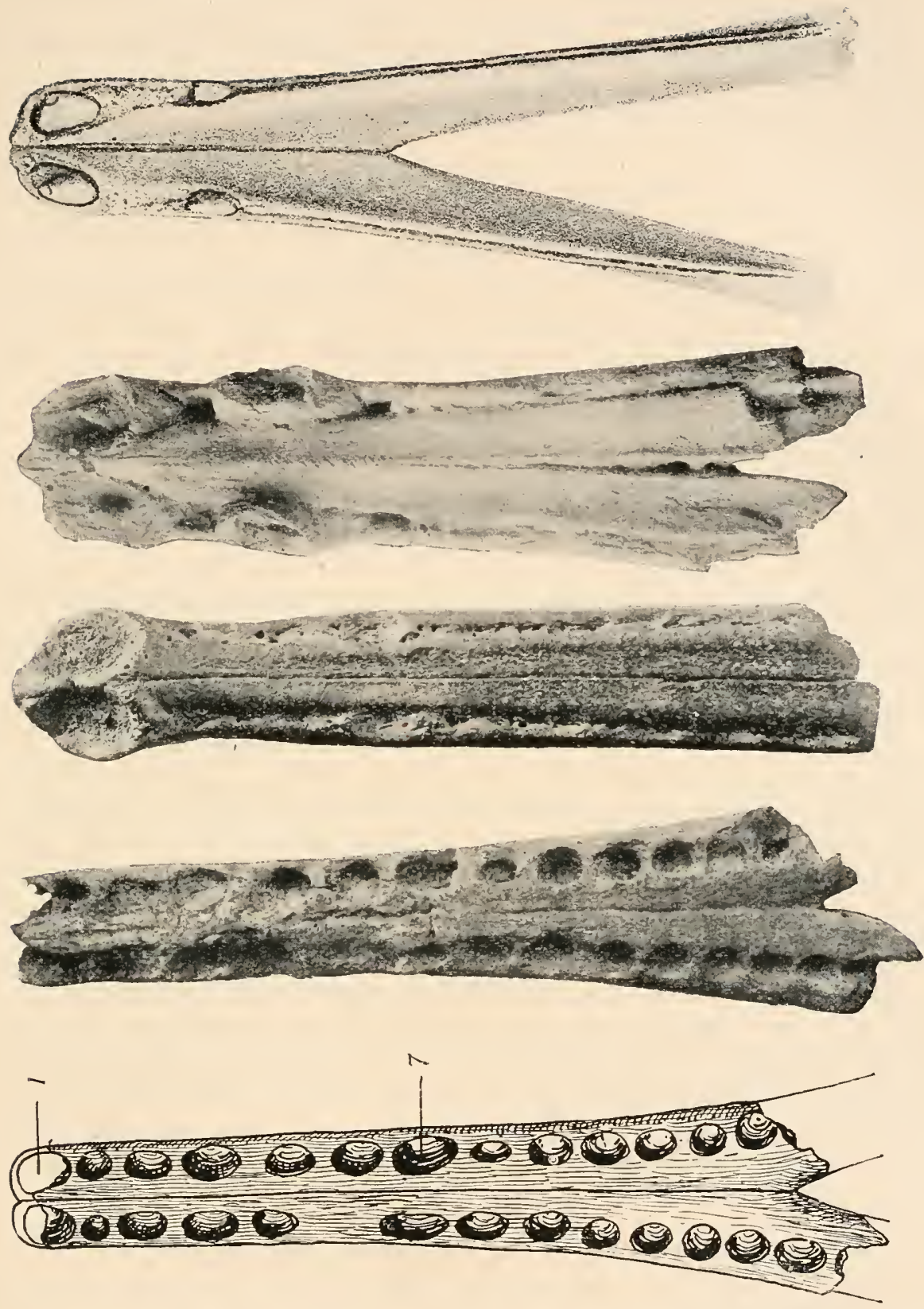

$A_{1} A_{2}$ : Palaeoziphius scaldensis, du Bus, aus dem Obermiozän von Antwerpen. ( $I$ und 7 bezeichnet die beiden vergrößerten Zahnpaare der Ausgangsform. Die übrigen Zähne stehen noch in Funktion:) $A_{2}$ : Original, $A_{1}$ : Rekonstruktion.

B: Anoplonassa forcipata, Cope. Phosphatschichten von Savannah in Georgien, Nordamerika. (Nach F. W. True.)

C: Mioziphius belgicus, Abcl. Obermiozän von Antwerpen.

D: Berardius Arnuxii. Antarktische Meere. (Nur mehr zwei Zahupaare im Unterkiefer in Funktion.) 
Mioziphius. - Obermiozän von Antwerpen ${ }^{1}$ (Fig. 578, C).

Choneziphius. - Obermiozän und Unterpliozän Europas und Nordamerikas. $^{2}$

Mesoplodon. - Vom Miozän an. ${ }^{3}$

Unterordnung: Delphinoceti.

Die primitivste Gruppe der Delfine sind die Braunfische oder Phocaeniden, die zuerst im Miozän der Krim auftreten.

Palaeophocaena. - Miozän Südrußlands. ${ }^{4}$

Protophocaena. - Obermiozän Antwerpens. ${ }^{5}$

Pithanodelphis. - Obermiozän Belgiens. ${ }^{6}$

Delphinodon. - Miozän Nordanterikas.?

Delphinus. - Vom Pliozän an.

\section{Ordnung: Xenarthra.}

Die Xenarthra bilden einen einseitig hochspezialisierten Stamm, dessen Vorgeschichte sich fast ganz auf dem Boden Südamerikas abgespielt hat. Wahrscheinlich in Nordamerika entstanden, hat sich dieser Stanm in der Tertiär- und Quartärzeit in Südamerika zu hoher Blüte entfaltet und nur nach der Wiederherstellung der Landverbindung zwischen Nord- und Südamerika in Pliozän einige Gattungen nach dem Süden Nordamerikas entsendet, wo sie aber noch im Plistozän erloschen sind. Einzelne Gattungen haben gewaltige Körpergrößen erreicht, wie Scelidotherium, Mylodon, Megatheriunı, Megalonyx, Glyptodon usw. und nur einzelne im Vergleiche zı diesen Riesen zwerghafte Formen haben sich bis in die Gegenwart gerettet.

Frülhzeitig haben sich die Xenarthren in zwei Stämme gespalten, die Hicanodonta und die Anicanodonta, deren Entstehung zwar noch nicht vollständig aufgeklärt ist, aber doch höchstwahrscheinlich aus einer Gruppe nordamerikanischer Säugetiere erfolgt ist, die als die Taen:odonta zusammingefaßt werden. Vielleicht stellt aber die Unterordnung der Taeniodonten nur eincn parallelen Ast zu cler Aln1engruppe der

3 O. Abel, Les Odontocètes du Boldérien d'Anvers. 1. c., p. 98.

2 Ibidem, p. 106.

3 Ibidem, p. 110.

4 O. Abel, Eine Stammtype der Delphiniden aus dem Miocän der Halbinsel Taman. - Jahrbuch d. k. k. Geol. Reichsanstalt, Wien, LV. Bd., 1905, p. 375.

5 O. Abe!, Les Odontocètes du Boldérien d'Anvers, 1. c., p. 139.

6 Ibidell, p. 142.

7 F. W. True, Description of a New Fossil Porpoise of the Genus Delphinodon from the Miocene Formation of Maryland. - Journal Acad. Nat. Sci. - Philadelphia (2), Vol. XV, 1912, p. 165. 
Xenarthra dar, deren Ahnen daher noch unbekannt wären, wenn sich die Ableitung von den Taeniodonten als unrichtig erweisen sollte. ${ }^{1}$

\section{Unterordnung: Taeniodonta.}

Die verschiedenen Gattungen, die in dieser Unterordnung vereinigt werden, sind namentlich aus dem untersten Eozän Nordamerikas, aber auch durch einen einzelnen Rest aus dem Eozän Europas bekannt. Man kennt Schädel und Unterkiefer mehrerer Arten sowie Wirbel und einige andere Teile des Skelettes dieser merkwürdigen Formen. Das Gebiß ist hochgradig differenziert und die Schneidezähne rudimentär; die Eckzähne sind sehr groß und die Backenzähne besitzen geteilte Wurzeln. Alle Zähne tragen noch eine Unuhüllung von Email, aber an den Eckzähnen tritt das Schmelzblech nur mehr an der Vorderseite auf, wodurch die Zähne eine gewisse Ähnlichkeit mit Nagerzähnen erhalten. Am nagerähnlichsten ist Calamodon, aber es kann von Beziehungen der Taeniodonta zu den Nagern keine Rede sein, da sie sich in anderen Merkmalen von diesen selır bestimmt unterscheiden. Die Taeniodonten treten zuerst in den Puercobildungen auf und verschwinden schon im Mitteleozän.

Die primitivste Gattung ist Onychodectes.

On ychodectes. - Puerco-Beds. - Die Zälne erhalten schon früh eine horizontale Abnützungsfläche. ${ }^{2}$

Conoryctes. - Torrejon-Beds Nordamerikas.. - Der obere letzte Molar, die Schneidezähne, cbenso die beiden vordersten Prämolaren sirt verloren gegangen. ${ }^{3}$

Wortmania. - Puerco-Becis. Obwohl älter als Conoryctes, steht diese Gattung doch auf einer höheren Stufe der Spezialisation, da der Schmelzbelag der Eckzähne reduziert ist. Außerdem ist der Schädel stark verkürzt. ${ }^{4}$

Psittacotherium. - Torrejon-Beds. - Die Eckzähne sind stark cntwickelt, aber die Schneidezähne oben und unten reduziert ${ }^{5}$ (Fig. 579).

1 Vgl. über diese Frage insbesondere: W. B. Scott, Mammalia of the Santa Cruz Beds, Reports of the Princeton University Expeditions to Patagonia, 1896 bis 1899. - Vol. V, Stuttgart 1993-1905.

2 J. L. Wortman, The Ganodonta and their Relationship to the Edentata. - Bull. Amer. Museum Nat. Hist., Vol. IX, 1897, p. 97.

3 Ibidem, p. 101.

4 Ibidem, p. 64.

E. D. Cope, Synopsis of the Vertebrate Fauna of the Puerco Series. - Transactions American Philos. Society, Vol. XV1, 1888, p. 311.

O. P. Hay, On the Names of Certain North American Fossil Vertebrates. Science (2), Vol. IX, 1899, p. 593.

5 J. L.Wortman, Psittacotherium, a Member of a New and Primitive Suborder of the Edentata. - Bull. Amer. Mus. Nat. Hist., New York, Vol.Vili, 1896, p. 259. 
Calamodon. - Untereozän Nordamerikas (Wasatch-Beds). Nur durch Unterkieferreste und Zälne bekannt. ${ }^{1}$

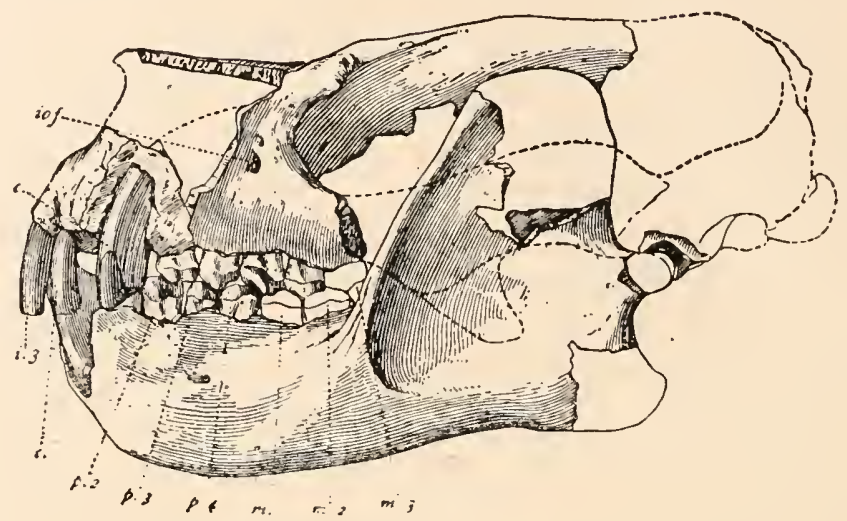

Fig. 579.

Schädel von Psittacotherium multifragum aus den Torrejonschichten von Neumexiko. Ungefähr $1 / 3$ nat. Gr. (Nach J. L. Wortman.)

Stylinodon. - Untereozän (Wind River Beds) und vielleicht noch im Mitteleozän (Bridger-Beds) Nordamerikas. Die letzte Gattung der Taeniodonta ${ }^{2}$ (Fig. 580).
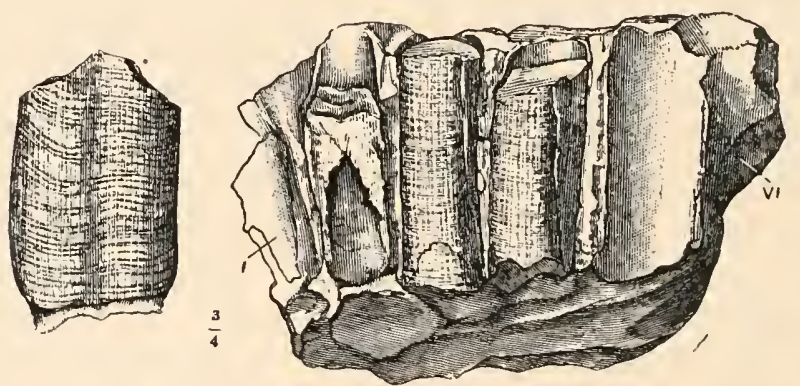

Fig. 580.

Links: Einzelner Zahn; rechts: Unterkieferfragment von Stylinodon mirus, aus dem Untereozän (Wind-River-Beds) Nordamerikas. (Nach O. C. Marsh.)

1 E. D. Cope, Report upon the Extinct Vertebrata obtained in New Mexico by Parties of the Expedition of 1874. - Chapter XI. - Geogr. Surveys West of the 100. Meridian, Vol. IV, Palacontology, Washington 1877, p. 162.

Derselbe, The Vertebrata of the Tertiary Formations of the West. - Book 1. - Report U. S. Geol. Survey Territ., Washington, Vol. 111, 1884, p. 188.

Der angeblich zu Calamodon gehörende und von L. Riitimeyer als C. europaeus beschriebene Rest aus dem Mitteleozän von Egerkingen (Schweiz) gehört nach H. G. Stehlin (Abhandl. d. Schweiz. Paläont. Ges., Bd. XLI, 1916, p. 1434) zu den Primaten und wird jetzt als Amphichiromys europaeus unterschieden.

2 J. L. Wortman, The Ganodonta, usw., I. c., 1897, p. 92. 


\section{Unterordnung: Anicanodonta.}

Die. lebenden Vertreter dieser Gruppe. sind die Ameisenbären und die Faultiere. Das Gebiß ist bei den lebenden Typen stark reduziert, bei den Myrmecophagiden sogar vollständig verloren gegangen. Die Deutung des vordersten Zahnes in den Kiefern der Baumfaultiere oder Bradypodiden ist fraglich und daher ist auch die Frage nach den Beziehungen zu den Taeniodonta einstweilen nicht zu entscheiden. Die Anicanodonta stanmen von grabenden Vorfahren ab und sogar in den hoch spezialisierten Gliedmaßen der Riesenfaultiere sind die Spuren dieser grabenden Lebensweise der Vorfahren noch mit voller Deutlichkeit zu erkennen. ln der Haut finden sich vereinzelte Knochenkerne (Fellreste sind von Grypotherium domesticum aus dem jüngeren Plistozän Argentiniens bekannt). Der Schädel der ältesten Gravigradiden war sehr langgestreckt und elinnert in der allgemeinen Form an den der Ameisenbären, aber bei den jüngeren Gattungen wird er stark verkürzt und erscheint vorne abgestutzt.

\section{F. Gravigradidae.}

Die Gravigradiden sind dic größten Vertreter der Xenarthra; Mylodon und Migatherium erreichten die Größe eines starken Elefanten. Der kräftige Sclıwanz diente bei den bipeden Formen (Mylodon, Megatherium) als Körperstütze, so daß der wuchtige Körper wie auf einem Dreifuß ruhte, wenn das Tier stand. Das Becken ist enorm vergrößert und schüsselförmig. Hand- und Fußbau beweist die Herkunft von grabenden Vorfahren. ${ }^{1}$

Unterfamilie: Megalonychinae.

Die ersten Gattungen treten im Oligozän Südanterikas auf und entwickeln sich inn Miozän zu großen Formen; die größte bekannte Gattung ist Megalonyx. Alle Megalonychinen waren tetrapod.

Hapalops. - Miozän Südamerikas. ${ }^{2}$

Eucholoeops. - Miozän Südamerikas ${ }^{3}$ (Fig. 581).

1 Die vollständigste Übersicht der Literatur ïber die fossilen Xenarthren Südameriaks findet sich in den Anmerkungen zu der Abhandlung von $\mathrm{H}$. Winge, Jordfundne og nulevende Gumlere (Edentata) fra Lagoa Santa, Minas Geraes, Brasilien. - E Museo Lundii, en Samling af Afhandlinger om de in Brasiliens Knoglehuler af Prof. Dr. P. V. Lund udgravede Dyre-og Menneskeknogler. - Kjobenhavn 1915, p. $261-313$.

2 F. Ameghino, Paleontologia Argentina. - Publicaciones de la Universidad de La Plata, 1904, p. 29.

W. D. Matthew, Ancestry of Edentates. - American Museum Journal, Vol. X11, 1912, p. 300 .

${ }^{3}$ R. Lydekker, The Extinct Edentates of Argentina. - Anales del Museo. de La Plata, Paleontologia Argentina, 111, 1894.

F. Ameghino, Paleontologia Argentina, I. c., 1904, p. 28. 
Hyperleptus. - Miozän Südamerikas. ${ }^{1}$

Megalonyx. - Pliozän und Plistozän Nordamerikas. Der vorderste Zahn aller Megalonychiden funktionierte als Eckzahn" und ist durch ein großes Diastem von den Backenzähnen getrennt. Ob er einem Eckzahn oder einem Pränolar honılog ist, bleibt einstweilen eine offene Frage ${ }^{2}$ (Fig. 582).

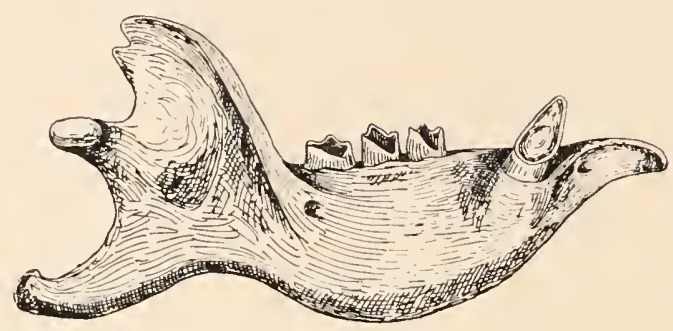

Fig. 581 .

Unterkiefer von Eucholoeops externus aus dem Miozän von Santa Cruz in Patagonien. $1 / 3$ nat. Gr. (Nach F. Ameghino.)

Unterfamilie: Mylodontinae.

Diese Gruppe unterscheidet sich von der vorhergehenden dadurch, daß die Vorderzähne nicht durch eine Lücke von den Backenzähnen getrennt und nicht vergrößert sind. Dies beweist, daß diese Unterfamilie, obwohl sie in Skelettbau nahe Beziehungen zu den Megalonychinen aufweist, doch von Anfang an von ihr getrennt gewesen sein muß und schon frühzeitig ilhre eigenen Wege gegangen ist. Dazu kommt, daß der letzte Backenzahn bei den Megalonychinen verkümmert, bei den Mylodontinen aber vergrößert ist, so daß auch in diesem Punkte eine wichtige Spezialisationskreuzung vorliegt.

Die ältesten Gattungen (z. B. Scelidotherium) waren tetrapod, die höher spezialisierten (z. B. Mylodon) biped.

Scelidotherium. - Plistozän Südamerikas ${ }^{3}$ (Fig. 583).

1 F. Ameghino, Revista Argentina de Historia Natural. - T. I, Buenos Aires 1891, p. 151.

2 J. Leidy, A Memoir on the Extinct Sloth Tribe of North America. - Smithsonians Contributions to Knowledge, 1855.

Über die Frage, ob Megalonyx noch ein Zeitgenosse des Menschen war, vgl. H. F. Osborn, The Age of Mammals, New York 1910, p. 496.

${ }^{3}$ R. Lydekker, The Extinct Edentates of Argentina, I. c.

I. Sefve, Scelidotheriumreste aus Ulloma, Bolivia. - Bull. of the Geol. Institute, Upsala. - Vol. XIII, Upsala 1915, p. 61. 


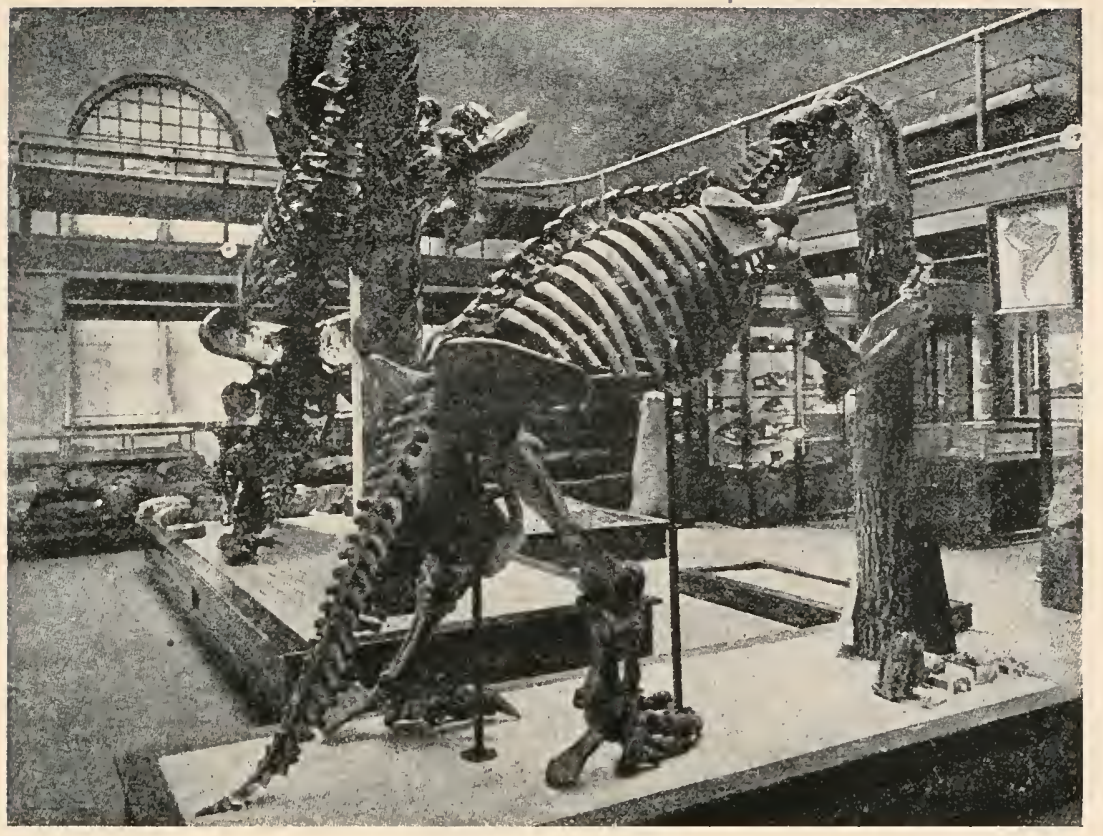

Fig. 582.

Megalonyx Jeffersoni aus dem Plistozän Nordamerikas; zwei montierte Skelette im Ohio State University Museum, Columbus, Ohio. (Photographie von C. S. Prosser; aus H. F. Osborn, 1910.)

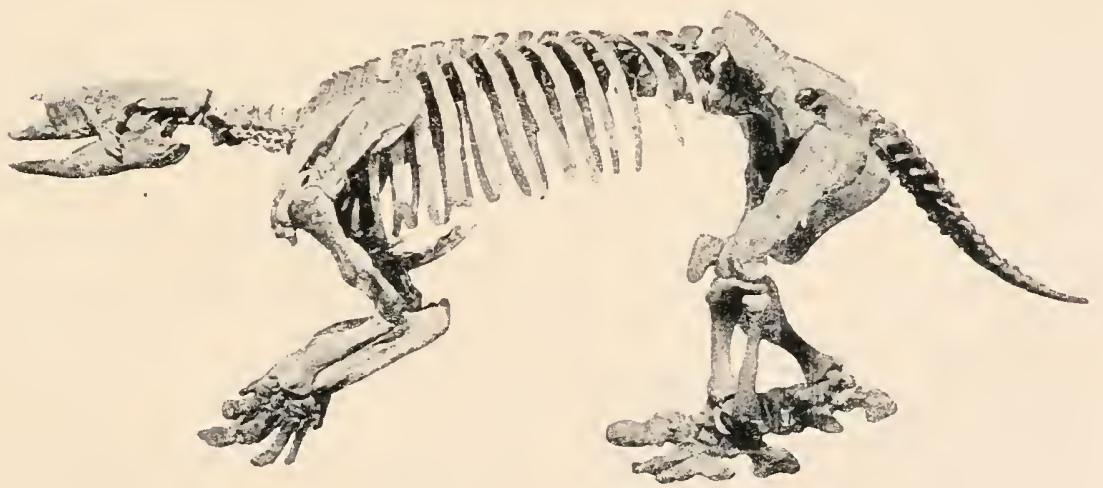

Fig. 583.

Scelidotherium leptocephalum, aus der Pampasformation Argentiniens. Stark verkleinert. (Nach R. Lydekker.) 
Mylodon. - Häufig im Plistozän Argentịniens, aber auch aus den Pliozän und Plistozän Nordamerikas bekannt ${ }^{1}$ (Fig. 584).

Grypotherium. - Plistozän Südamerikas. ${ }^{2}$

Paramylodon. - Plistozän von Nebraska und Colorado. ${ }^{3}$

Lestodon. - Plistozän Südanerikas. ${ }^{4}$

Unterfanilie: Megatheriinae.

Von den Mylodontinen durch die Kleinheit des letzten Molaren und durch die verschiedene Lage der Austrittsstelle des Alveolarkanals in den Unterkieferästen verschieden. Megatherium erreichte die Größe eines Elefanten und war biped wie Mylodon.

Megatherium. - Plistozän Südamerikas. ${ }^{5}$

\section{F. Myrmecophagidae.}

Die Ameisenbären stellen in vielen Merkmalen einon auf der Stufe der Vorfahren der Anicanodonta stehengebliebenen Typus dar, der sich

1 Die Literatur über Mylodon ist zusammengestellt von G. M. Allen, A New Mylodon. - Memoirs of the Museum of Comparative Anatomy at Harvard College, Vol. XL, Cambridge, Mass., 1913, p. 345.

- R. Owen, Description of the Skeleton of an Extinct Gigantic Sloth, Mylodon robustus, Owen usw., London 1842.

Die wichtigste Literatur über Mylodon findet sich bei: Glover M. Allen, A Ncw Mylodon. - Memoirs of the Museum of Comparative Anatomy at Harvard College, Vol. XL, Cambridge, U. S. A., 1913, p. 345.

Über die bipede Körperstellung von Mylodon vgl. O. Abel, Grundzïge der Paläobiologie, 1912, S. 261.

Über die geographische Verbreitung von Mylodou in Nordamerika vgl.: R. S. Lu11, A Pleistocene Ground Sloth, Mylodon Harlani, from Rock Creek, Texas. - American Journal of Science, Vol. XXXIX, 1915, p. 327.

2 Die Publikationen über Grypotheritm sind zusammengestellt bei H. Winge, Jordfundne og nulevende Gumlere (Edentata) fra Lagoa Santa, Minas Geraes, Brasilien. In den Schriften: „E Museo Lundii“, 1. c., Kjobenhavn, 1915, p. 310-311. Arbeiten von J. Reinhardt, H. Burmeister (1879), F. Ameghino (1889), R. Lydekker (1894), E. Loennberg, F. P. Moreno, A. Smith Woodward, R. Hauthal, S. Roth, R. Lehmann-Nitsche, E. Nordenskjoeld, Jakob (1899-1900), Philippi (1901).

Über die Ablehnung der Hypothese von der Haltung des Tieres als Haustier vgl. O. Abel, Die vorzeitlichen Säugetiere, Jena 1914, p. 105.

${ }^{3}$ B. Brown, A New Genus of Ground Sloth from the Pleistocene of Nebraska. - Bull. Amer. Mus. Nat. Hist., New York, Vol. XIX, 1903, p. 569.

T. D. A. Cockerell, A Fossil Ground Sloth in Colorado. - University Col. Studies, Vol. V1, 1909, p. 309.

${ }^{4}$ F. Ameghino, Contribucion al conocimiento de los Mamíferos fósiles de la República Argentina. - Actas de la Academia Nacional de Ciencias de la Rep. Arg. en Cordoba, T. VI, 1889.

${ }^{5}$ Die wichtigste Abhandlung iiber diese Gattung ist: R. Owen, On the Megatherium. - Part 1-V. - Philosophical Transactions, London 1851-1860.

Über den Fußbau vgl. O. Abel, Paläobiolcgie, 1912, p. 375. 
nur in einigen Punkten (z. B. Verlängerung des Schnauzenteils, Verlust des Gebisses usf.) hoch spezialisiert und einseitig weiter entwickelt hat. Die lebenden Ameisenbären sind im Begriffe, von der terrestrischen Lebensweise zur arborikolen Lebensweise überzugehen, wie Tamandua und Cycloturus zeigen. Obwohl die Myrmecophagiden eine sehr alte Gruppe der Xenarthra darstellen, so kennt man ihre Reste doch erst seit dem Plistozän.

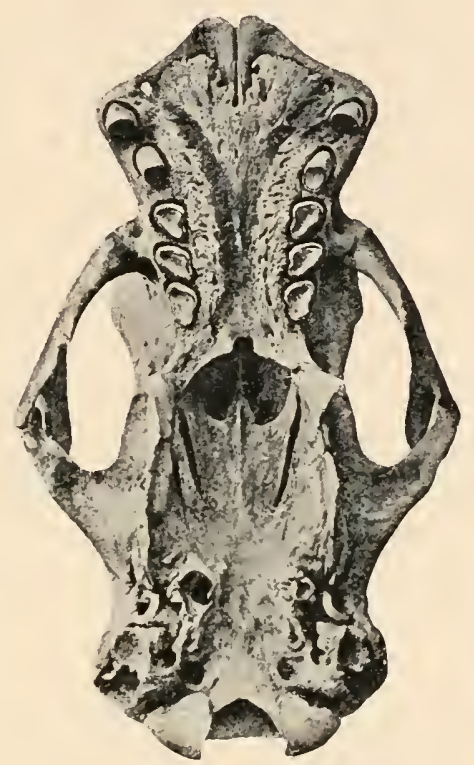

Fig. 584 .

Unteransicht des Schädels von Mylodon robustus aus der Pampasformation Argentiniens. Stark verkleinert. (Nach R. Lydekker.)

\section{F. Bradypodidae.}

Fossil erst seit dem Plistozän bekannt. Die fossilen Formen geben keinen Aufschluß über dia Stammesgeschichte der Baumfaultiere. Aus den Merkmalen des Skelettes der lebenden Typen ist jedoch mit Sicherheit der Schluß zu ziehen, daß die Vorfahren dieser Tiere ebenso wie die der lebenden Baumfaultiere terrestrische und zwar grabende Formen gewesen sind.

\section{- Unterordnung: Hicanodonta.}

Die Gürteltiere, welche die lebenden Ausläufer dieses einst sehr formenreich gewesenen Stammes bilden, sind von den Anicanodonta schon seit sehr langer Zeit getrennt und daher vielleicht als eigene Ordnung anzusehen. Der Körper ist bei den primitiveren Formen in einen aus beweglichen Ringen gebildeten Panzer eingeschlossen, der bei den 
lebenden Gattungen noch in der ursprünglichen Form erhalten geblieben, aber bei den zu beträchtlicher Größe angewachsenen ausgestorbenen Glyptodonten zu einem unbeweglichen, schildkrötenartigen Panzer verschmolzen ist. Eine Folgeerscheinung dieser Vereinigung der knöchernen Querringe zu einem geschlossenen, hoch gewölbten Rückenpanzer ist die weitgehende Verschmelzung benachbarter Wirbel zu einzelnen unbeweglichen Komplexen. Der Schädel wird bei den Glyptodonten wie bei den lebenden Gürteltieren durch einen Knochenpanzer geschützt and der Schwanz entweder in eine aus knöchernen Ringen bestehende Hülle oder in cine unbewegliche Knochenıöhre eingeschlossen, die häufig mit kräftigen Buckeln oder Stacheln bewehrt ist und als Verteidigungswaffe gedient haben dürfte.

Im Schädel fehlen die Schneide- und die Eckzähne vollständig. Die lebenden Arten sind vorwiegend herbivor und auch die fossilen Vertreter der Gruppe sind wohl zumeist Pflanzenfresser gewesen. ${ }^{1}$

\section{F. Dasypodidae.}

Mit Ausnahme der lebenden Gattung Tatusia (im südlichen Nordamerika) nur aus Südamerika bekannt. Dasypus (Fig. 585) seit dem Plistozän.

Peltephilus. - Miozän Patagoniens. Schädel mit einem Paar Hörner.

Stegotheriuns. - Miozän Patagoniens. - Schädel sehr langgestreckt, Gebiß reduziert und auf die hinteren Teile der Kiefer beschränkt. Das Tier war, nach der Ähnlichkeit mit den lebenden Ameisenbären in der Schnauzenform zu schließen, wahrscheinlich myrmecophag.

Chlamydotherium. - Plistozän Brasiliens und Argentiniens. Der Schädel fällt durch die spitze Schnauze auf. Die Wirbel sind noch getrennt, wie bei den primitiveren Formen, aber der Rückenpanzer ist vorne und hinten bereits zu einem festen Knochenschild verschnolzen und

1 Die wichtigste Abhandlung über die tertiären Dasypodiden Südamerikas ist: W. B. Scott, Dasypoda and Glyptodontia. - Reports of the Princeton University Expeditions to Patagonia, 1896-1899, Vol. V, Palaeontology. Mammalia of the Santa Cruz Beds. - Stuttgart 1903.

Die wichtigste Abhandlung über die sich um Glyptodon gruppierenden Gattungen ist: H. Burmeister, Monografia de los Glyptodontes en el Museo publico de Buenos Aires. - T. 11, 1870-1874.

Gute (photographische) Abbildungen suidamerikanischer Dasypodiden des Tertiärs ınd Quartärs veröffentlichte R. Lydekker, The Extinct Edentates of Argentina. - Palaeontologia Argentina, III, Anales del Museo de La Plata 1894.

Die Literatur iiber die fossilen Dasypodiden ist am vollständigsten zusammengestellt in H. Winge, Jordfundne og nulevende Gumlere (Edentata) fra Lagoa Santa, Minas Geraes, Brasilienl. — „E Museo Lundii“, Kjobenhavn 1915, p. 303-306. 
nur der Mittelabschnitt des Rückenpanzers besteht noch aus verschiebbaren Halbringen. Die Zähne sind durch eine äußere und innere longitudinale Rinne in einen vorderen und hinteren Pfeiler zerlegt, so daß

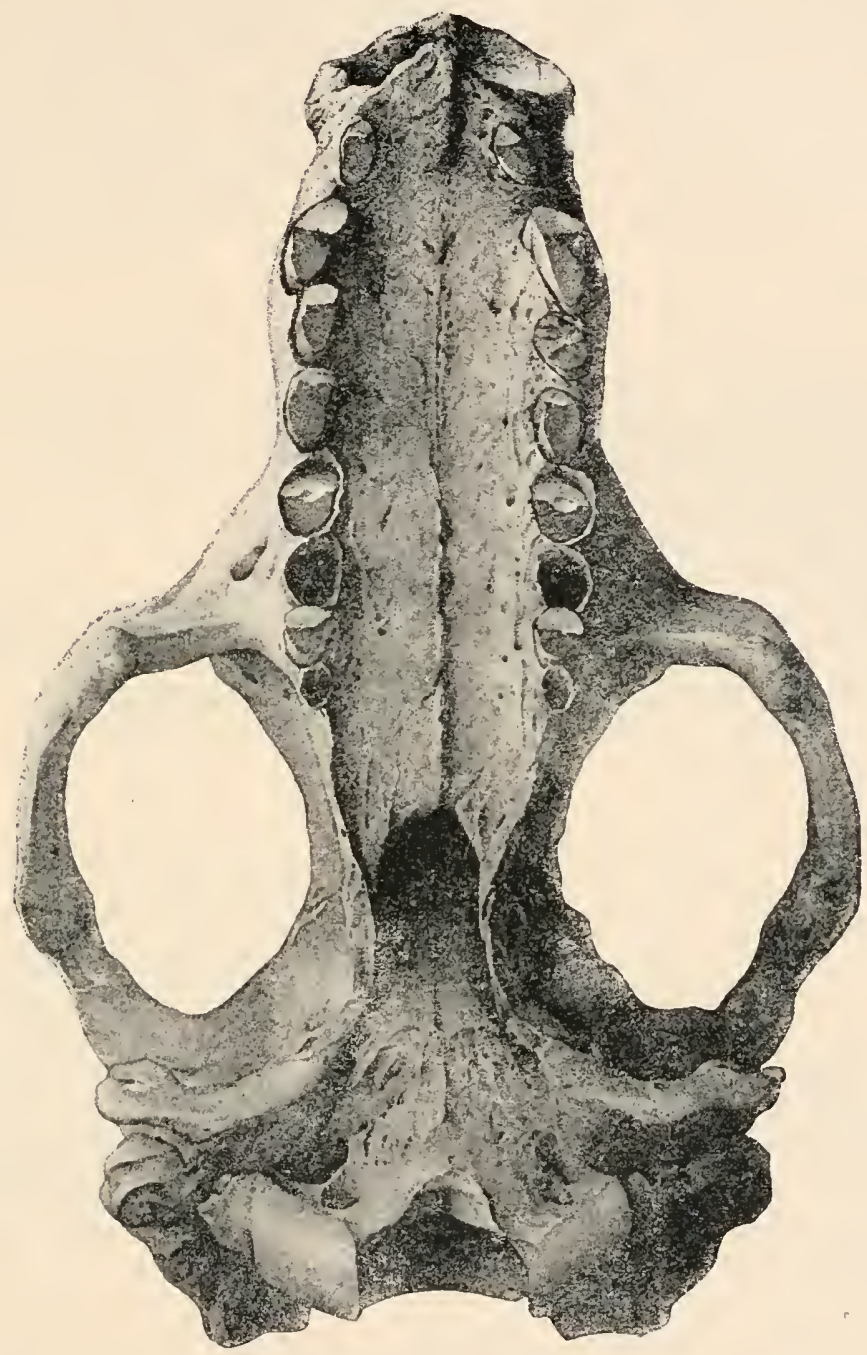

Fig. 585 .

Unteransicht des Schädels von Dasypus retusus, aus dem Plistozän (Pampasformation) Argentiniens. Verkleinert. (Nach R. Lydekker.)

die Kaufläche brillenförmig erscheint. Chlamydotherium bildet ein Übergangsglied zwischen den primitiveren Dasypodiden und den früher meist als "Glyptodonta" abgetrennten spezialisierten Typen.

Glyptodon. - Plistozän von Argentinien, Brasilien, Uruguay, Florida, Neumexiko (Fig. 586, 589, 590). 
Die sich I'm Glyptodon gruppierenden Gattungen unterscheiden sich von den primitiveren Formen namentlich durch den Besitz eines gewaltigen, geschlossenen Rückenpanzers. Das Grabvermögen ist wohl vollständig verloren gegangen gewesen, da die Hände und Füße Hufe tragen. Der Schädel ist hochgradig spezialisiert, viel höher als lang und besitzt einen zwar auch bei den anderen Xenarthren vorhandenen, aber bei den Glyptodonten enorm entwickelten Fortsatz des Jochbogens, der steil nach unten gerichtet ist. Die Gattung Glyptodon erreichte etwa $3 \mathrm{~m}$, die Gattung Doedicurus etwa $4 \mathrm{~m}$ Körperlänge.

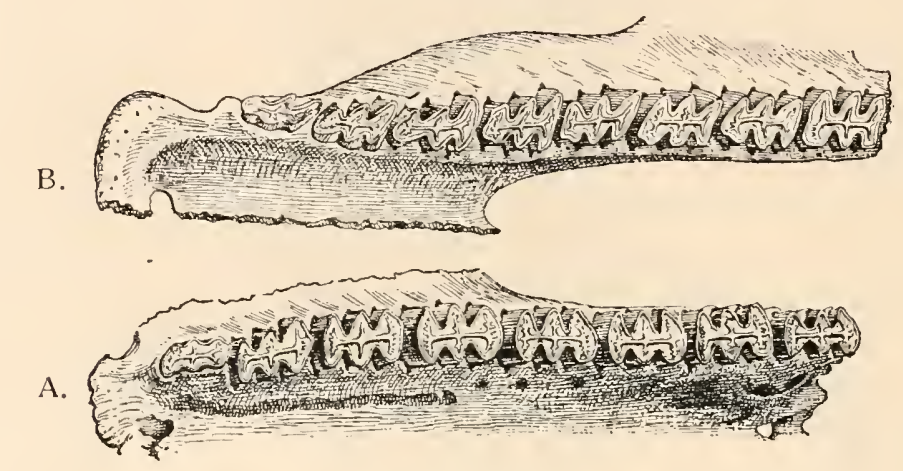

Fig. 586.

A. Backenzähne des Oberkiefers, B. Backenzähne des Unterkiefers von Glyptodon reticulatus, Owen, aus dem Plistozän (Pampasformation)

Argentiniens. Verkleinert. (Nach K. A. von Zittel.)

Brachyostracon. - Plistozän von Mexiko. Hoplophorus. - Plistozän Argentiniens und Brasiliens. Panochthus. - Plistozän Argentiniens (Fig. 588, 591). Doedicurus. - Plistozän Argentiniens.

\section{Ordnung: Tubulidentata.}

Über die Vorgeschichte der „Edentaten“ der alten Welt geben uns die wenigen fossilen Reste aus dem Tertiär Europas keinen Aufsclıluß; die Gruppe ist jedenfalls sehr alt und es wären höchstens in alttertiären Ablagerungen Afrikas prinitivere Reste zu erwarten, die uns über die nächsten Verwandten dieser Ordnung Aufschluß geben könnten. So ist die Vorgesclichte dieser Gruppe noch vollständig in Dunkel gehüllt and wir sind nicht in der Lage, sichere Beziehungen zu einer der bekannten primitiven Säugetiergruppen feststellen zu können. 


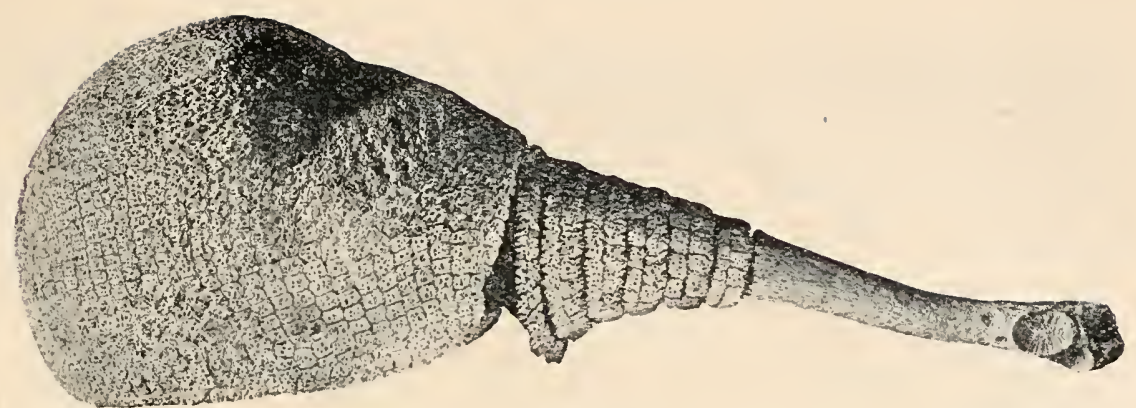

Fig. 587.

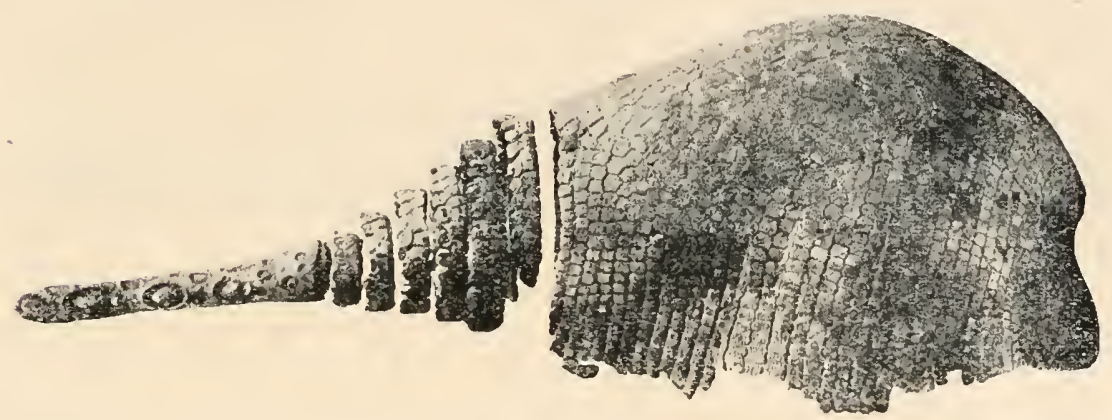

Fig. 588 .

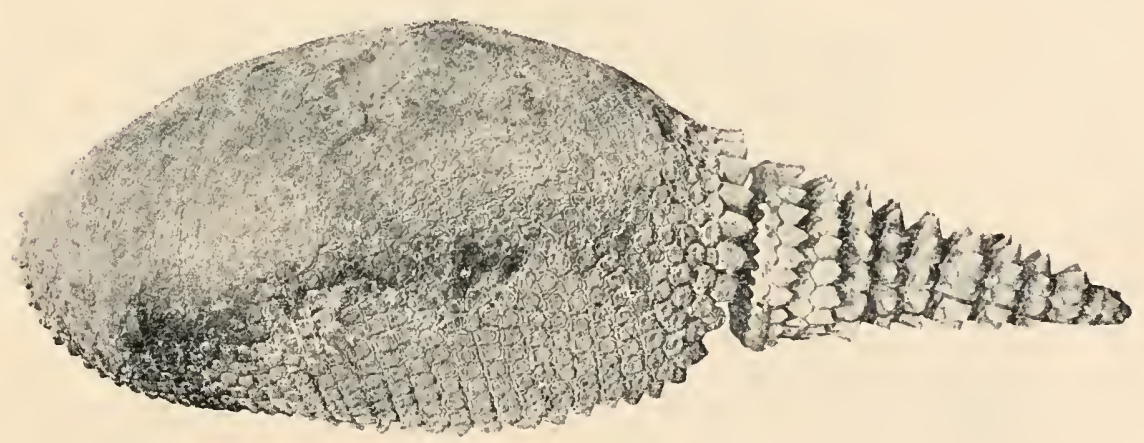

Fig. 589.

Panzer von siidamerikanischen Glyptodonten aus der Pampasformation.

Fig. 587. Doedicurus clavicaudatus.

Fig. 588. Panochthus tuberculatus.

Fig. 589. Glyptodon clavipes.

(Nach R. Lydekker.)

\section{F. Orycteropodidae.}

Die ersten Erdferkel, die heute auf Afrika beschränkt sind, treten in Obereozän und Oligozän Frankreichs auf, doch sind diese Reste sehr dürftig und gestatten nur eine beiläufige systematische Bestimmung. 


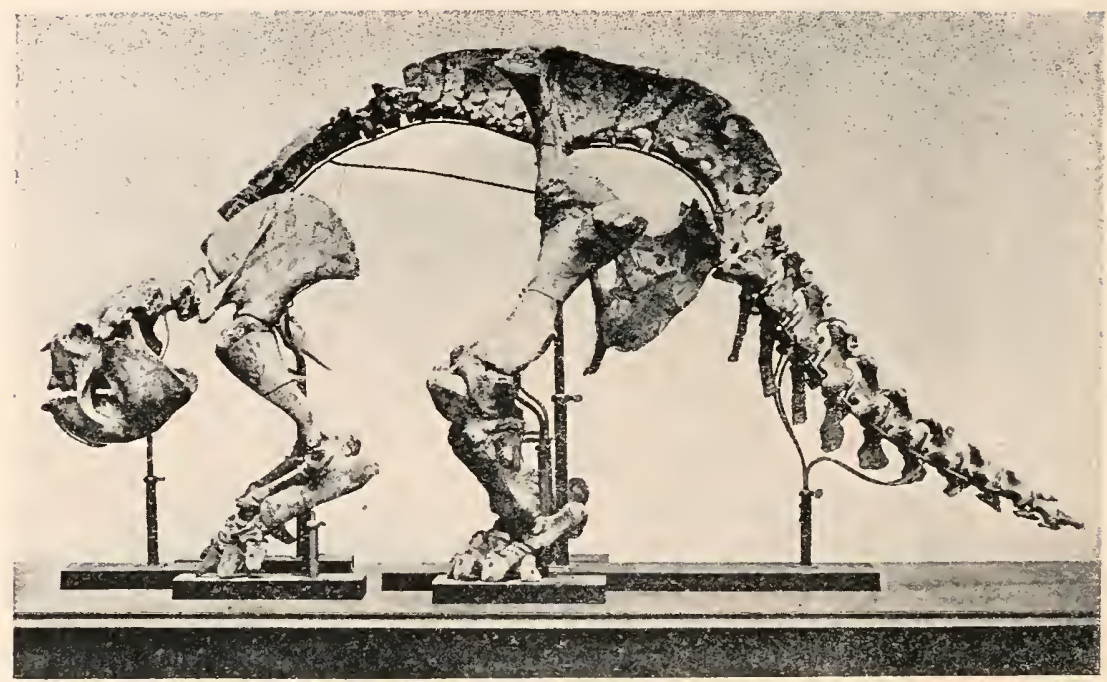

Fig. 590.

Glyptodon clavipes, aus der Pampasformation Argentiniens. Körperlänge etwa $2 \mathrm{~m}$. (Nach R. Lydekker.)

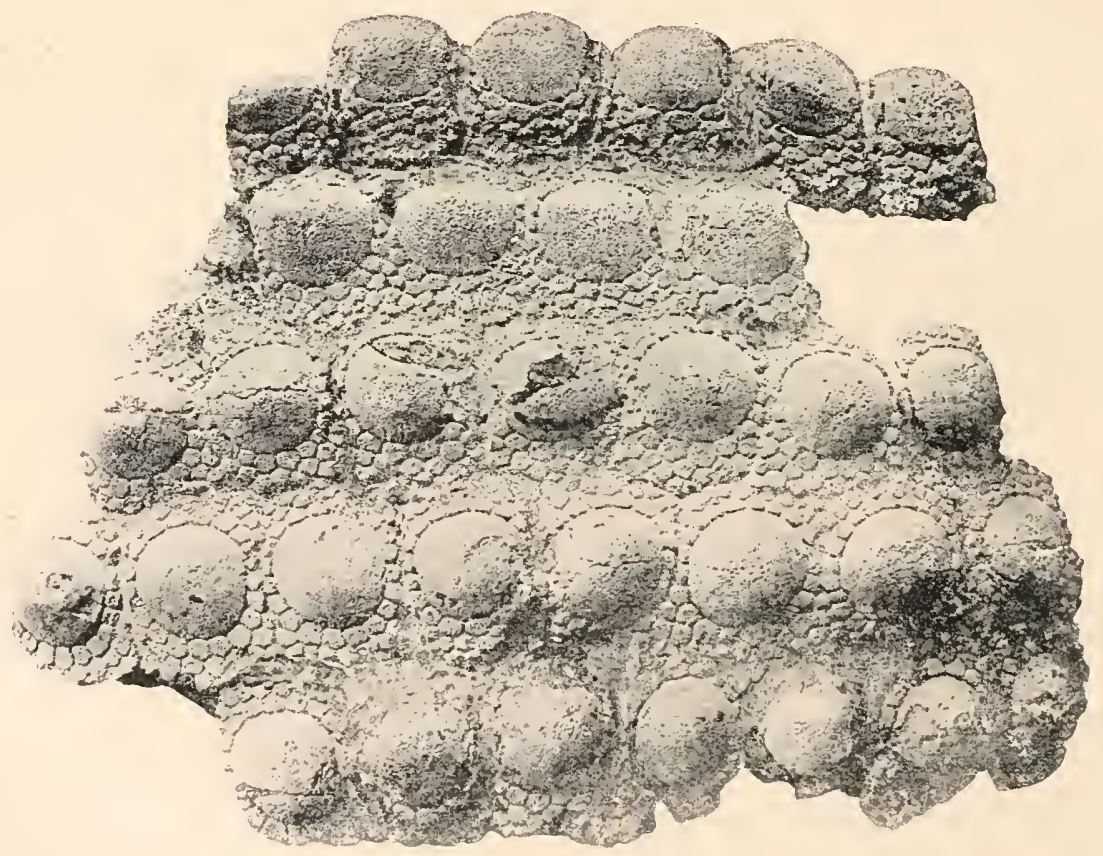

Fig. 591.

Panzerfragment von Panochthus bullifer, aus dem Quartär (Pampasformation) Argentiniens. $1 / 3$ nat. Gr. (Nach R. Lydekker.) 
Palaeorycteropus. - Obereozän oder Oligozän des Quercy in Frankreich (ein isolierter Humerus). ${ }^{1}$

Orycteropus. - Unterpliozän von Pikermi und Samos in Griechenland (Schädel- und andere Reste) und lebend in Südafrika. ${ }^{2}$

\section{Ordnung: Pholidota.}

Die hochspezialisierten Schuppentiere (Manidae), die heute einen großen Teil Afrikas, ganz Südasien sowie mehrere südasiatische Inseln (Ceylon, Hainan, Formosa, Sundainseln) bewohnen, sind durch dürftige Reste auch in tertiären Ablagerungen Europas nachgewiesen worden. Diese fossilen Vertreter der Maniden unterscheiden sich jedoch in den wenigen, bisher vergleichbaren Merkmalen nicht wesentlich von den lebenden Gattungen. Die Vorgeschichte der Pholidota, die wahrscheinlich eine sehr alte und vielleicht schon im Mesozoikum von der Stammgruppe der Säugetiere abgezweigte Gruppe darstellen, ist durch diese Fossilfunde nicht aufgeklärt worden. Wir sind daher in der Beurteilung der stammesgeschichtlichen Stellung der Pholidoten ausschließlich auf die Ergebnisse der vergleichenden Anatomie der rezenten Formen angewiesen. Da sich jedoch bei kritischer Prüfung der angeblichen morphologischen Ähnlichkciten zwischen den Pholidoten und anderen Säugetieren (z. B. den Myrmecophagiden) herausgestellt hat, daß diese Älnlichkeitın nur die Folgeerscheinungen einer übereinstimmenden Lebensweise (grabende Ameisenfresser) sind, so bleiben nur selır wenige Merkmale übrig, die uns über die verwandtschaftlichen Baziehungen der Schuppentiere zu anderen Säugetierordnungen aufklären könnten. Eine Lösung des Problems von den verwandtschaftlichen Beziehungen der Pholidoten zu den übrigen Säugetieren dürfte nur dann gelingen, wemn wir fossile Pholidoten in kretazischen Ablagerungen Afrikas finden würden, denn es scheint, daß diese Ordnung der Säugetiere afrikanischen Ursprunges ist.

\section{F. Manidae.}

Die ältesten Schuppentiere sind aus dem Obereozän und Oligozän Frankreichs bekannt.

1 H. Filhol, Observations concernant quelques Mammifères fossiles nouveaux - du Quercy. - Annales des Sciences naturelles. Zoologie et Paléontologie, T. XVI, 1894, p. 135.

F. Ameghino, Les Édentés fossiles de France et d'Allemagne. - Anales del Museo Nacional de Buenos Aires, T. XIII, 1905, p. 207.

2 C. W. Andrews, On a Skull of Orycteropus Gaudryi, Forsyth Major, from Samos. - Proceedings Zoological Society London 1896, p. 296. 
Necrodasypus. - Phosporite des Quercy (Schädelrest). ${ }^{1}$

Necromanis. - Phosphorite des Quercy (ein Humerus). ${ }^{2}$

Teutomanis. - Miozän Bayerns (Gliedmaßenreste). ${ }^{3}$

Galliaetatus. - Miozän Bayerns und vielleicht auch in miozänen Ablagerungen Frankreichs (Gliedmaßenreste). ${ }^{4}$

Manis. - Zuerst im Unterpliozän, dann im Plistozän Ostindiens; lebend in Südasien und Afrika.

\section{Ordnung: Rodentia.}

Die Nagetiere dürften schon in sehr alter Zeit von den Insektenfressern abgezweigt sein und zusammen mit diesen, den Xenarthren und Nomartlıren zu den ältesten Säugetieren gehören. Trotz dieses hohen Alters, das wir für die Nagetiere amnehmen dürfen, fällt ilıre Blütezeit nicht in das Tertiär, wie z. B. bei den Ungulaten, sondern in die Gegenwart. Daraus erklärt sich auch, daß wir keine einzige erloschene Familie der Nagetiere kennen, obwohl sehr viele fossile Gattungen und Arten bekannt sind, die zuerst im Untereozän Nordamerikas auftreten. Im Obereozän erscheinen die Rodentier in Europa, in Südamerika kennt man sie erst aus dem Oligozän, doch sind sie wahrscleinlich schon mit der ersten Einwanderung der Säugetiere im Untereozän nach Südamerika gelangt und wir dürfen mit Bestimmtheit im Untereozän Südamerikas Funde von Nagetieren erwarten.

Unterordnung: Simplicidentata.

\section{Sektion : Aplodontoidea.}

Die Unterfamilie der Ischyromyinae ist erloschen (Paramys im Eozän, Ischyromys inn Oligozän Nordamerikas).

\section{Sektion: Sciuromorpha.}

Die Unterfamilie der Theridomyinae dürfte, falls sie nicht die Alnnen der Stachelschweine umfaßt, als erloschen zu betrachten sein. Verschiedene Gattungen (z. B. Theridomys, Trechomys, Protechimys) vonı Eozän bis zu11 Miozän Europas.

1 F. Ameghino, Les Édentés fossiles de France et d'Allemagne, I. c., p. 194.

Derselbe, Encore quelques mots sur les Tatous fossiles de France et d'Allemagne. - Annales del Museo Nacional de Buenos Aires. - T. XVII. 1908, p. 93.

2 F. Ameghino, Les Édentés fossiles de France et d'Allemagne. - I. c., p. 210.

${ }^{3}$ M. Schlosser, Notizen über einige Säugetierfaunen aus dem Miozän von Württemberg und Bayern. - Neues Jahrbuch für Mineralogie usw., Beilageband XIX, 1904 , p. 499.

F. Ameghino, Les Édentés fossiles de France et d'Allemagne. - I. c., p. 215.

I Ibidem, p. 176. 
Die Unterfanilie der Mylagaulinae (gehörnte Nager aus dem Miozän und Pliozän Nordamerikas mit den Gattungen Mylagaulus, Mesogaulus, Ceratogaulus und Epigaulus) ist erloschen.

\section{Sektion: Myomorpha.}

Die Unterfamilie der Protoptychinae (Protoptychus im Obereozän Nordamerikas) ist erloschen.

Auch die Unterfamilie der Eomyinae (im Oligozän Europas und Nordamerikas) ist erloschen, alle übrigen sind am Leben.

\section{Sektion: Hystricomorpha.}

Von den zahlreichen Unterfamilien der stachelschweinartigen Nagetiere ist nur die Unterfamilie der Issiodoromyinae, die auf das europäische Oligozän beschränkt ist, erloschen.

\section{Unterordnung: Duplicidentata.}

Diese Unterordnung der Nagetiere, die durch die beiden Familien der echten Hasen oder Leporiden und der Pfeifhasen oder Lagomyiden (=Ochotontidae) in der Gegenwart vertreten ist, tritt zuerst im Oligozän auf. Die fossilen Gattungen und Arten geben keinen Aufschluß über die ältere Geschichte dieser Gruppe und sind daher in phylogenetischer Hinsicht ziemlich bedeutungslos.

\section{Überordnung: Ungulata.}

Der Kern und die Hauptmasse des Säugetierstammes wird durch die Überordnung der Ungulaten oder Huftiere repräsentiert, die sich schon im unteren Tertiär in zahlreiche Stämme zerspalten haben, die rasch divergierten und sich zu einer großen Zahı selbständiger Familien entwickelt haben.

Die Huftiere stammen von karnivoren Vorfahren ab, sind früllzeitig von der omnivoren Durchgangsstufe zur herbivoren Nahrungsweise übergegangen und haben diese mit wenigen Ausnahmen (z. B. Suiden) beibehalten. Trotzdem bietet vielleicht kein anderer Stanm der Wirbeltiere so vielgestaltige Anpassungserscheinungen des Gebisses an die Ernährungsart dar, die sich nicht nur in einer verschiedenen Gestalt und relativen Größe der Zähne, sondern namentlich in den Einzelheiten des Kronenbaues ausprägen. Ursprünglich waren die Mahlzähne niedrige Höckerzähne mit wenigen stumpfen Höckern in der Kaufläche; aber je nach der Bevorzugung von weicher, saftiger oder von harter, strohartiger Pflanzennahrung differenzierte sich die Form der Mahlzähne in sehr verschiedenen Richtungen, so daß wir folgende Mahlzalntypen unter den Huftieren je nach der Form der Kronenelemente zu unterscheiden haben: 
1. Bunodonter Typus (Höckerzahntypus). Zuerst wenige, später zahlreiche Höcker (oligobunodonte und polybunodonte Molaren). Der oligobunodonte Molarentypus ist der Ausgangspunkt für alle übrigen. - Beispiele: Hippopotamus, Sus, Hyracotherium (Fig. 592, A).

2. Lophodonter Typus (Jochzahntypus). Die Höcker vereinigen sich zu Jochen, die quer oder schräg zur Längsachse des Zahnes und des Kiefers stehen. Dadurch entsteht ein Vorjoch (Protoloph) und ein Nachjoch (Metaloph); an der Außenseite der Krone kann sich

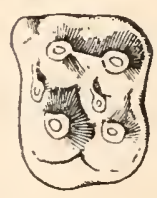

A
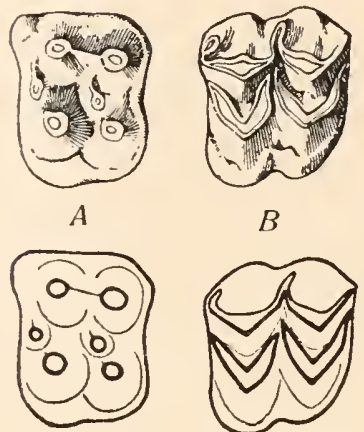

$B$
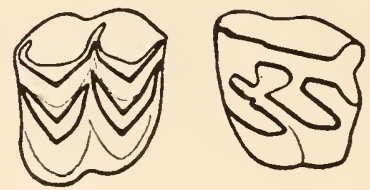

C
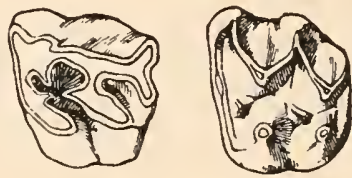

$D$
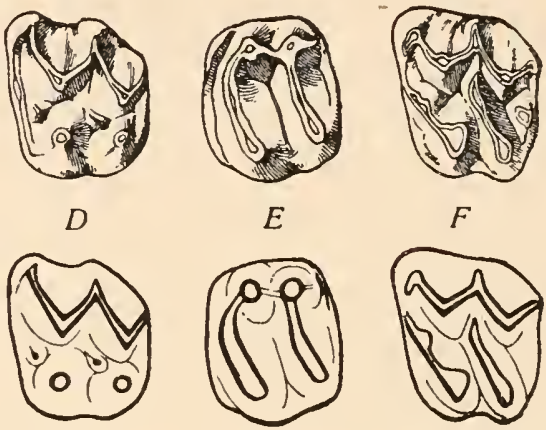

$E$
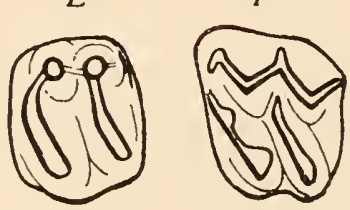

Fig. 592.

Verschiedene Mahlzahntypen der Ungulaten (obere linksseitige Molaren). Nach H. F. Osborn.

A. Bunodonter Typus (Höcker kegelförmig): Hyracotherium.

B. Selenodonter Typus (Höcker mondsichelförmig): Protoceras.

C. Lophodonter Typus (Höcker kammförmig): Rhinoceros.

D. Bunoselenodonter Typus (Höcker teils mondsichelförmig, teil kegelförmig): Palaeosyops.

E. Lophobunodonter Typus (Höcker teils kegelförmig, teils kammförmig): Tapirus.

F. Lophoselenodonter Typus (Höcker teils mondsichelförmig, teils kammförmig): Anchitherium.

ein beide Querjoche verbindendes Außenjoch (Ectoloph) entwickeln. Molarentypen mit 2 oder 3 Querjochen nennt man oligolophodont, die vieljochigen polylophodont. - Beispiele: Jochzähne mit querstehendem Protoloph und Metaloph (ohne Ectoloph) bei Dinotherium und Pyrotheriun, Unterkieferzälnne von Tapirus; Molarentypus mit Protoloph, Metaloph und Ectoloph sowie mit sekundär dazu tretenden Kämmlen, die in den Raum zwischen den drei Jochen vorspringen (Crista im Winkel zwischen Ectoloph und Protoloph, Antecrochet vom Protoloph, Crochet vom Metaloph): Rhinoceros (Fig. 592, C); diese Typen sind oligolophodont. Ein Beispicl für den polylophodonten Molarentypus sind die Mahlzähne von Elephas).

3. Selenodonter Typus. Die Höcker erhalten zuerst die Gestalt eines $V$, so daß wir zwei V-förmige Außenhöcker und in der Regel 
zwei ebenso gestaltete Innenlı̈cker zu unterscheiden haben, die durch Abrundung der lnnenspitze des $\mathrm{V}$ in eine Halbmondform mit einer mondsichelförmigen Abnutzungsfläche ïbergehen. - Beispiel: Cervus.

Außer diesen Haupttypen der Ungulatenmolaren liaben wir noch eine Anzahl von Mischtypen zu unterscheiden, die als bunoselenodont (z. B. Titanotherium, Palaeosyops (Fig. 592, D), Chalicotherium), lophobunodont (z. B. Tapirus, Fig. 592, E) und lophoselenodont (z. B. Equus, Bos) unterschieden werden (Fig. 592, F).

Der Ausgangstypus der bunodonten oberen Ungulatenmolaren ist der trituberkuläre (= trigonodonte) Molarentypus der lnsectivoren.

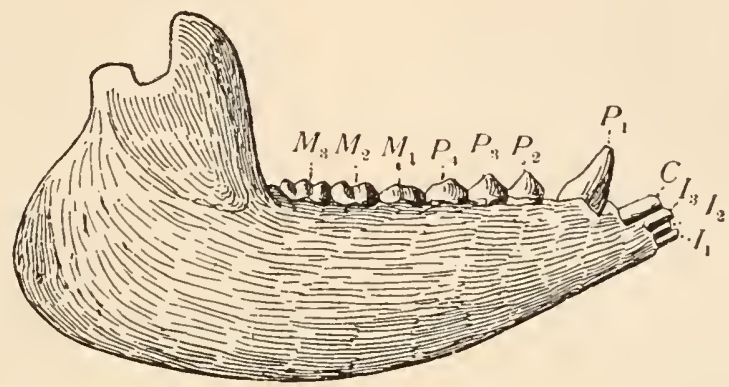

Fig. 593.

Unterkiefer von Cebochoerus minor aus den Phosphoriten des Queicy

in Frankreich; in $2 / 3$ nat. Gr. (Nach H. G. Stehlin.)

$I_{1}-I_{3}=$ Inzisiven (Schneidezähne).

C $=$ Canin (Eckzahn), in die Gruppe der Schneidezähne einbezogen und als solcher funktionierend.

$P_{1}=$ erster Prämolar, als ,Eckzahn“ funktionierend.

$P_{0}-P_{4}=$ zweiter bis vierter Prämolar.

$\bar{M}_{1}-M_{3}=$ erster bis dritter Molar.

$\mathrm{Zu}$ diesen $($ Protocon $=$ Innenhöcker, Paracon $=$ vorderer Außenhöcker, Metacon = hinterer Außenhöcker) treten noch ein vorderer Zwischenhöcker (Protoconulus) und ein hinterer Zwischenhöcker (Metaconulus) dazu, so daß wir schon frülızeitig fünf Höcker zu unterscheiden haben, die in verschiedenem Ausmaße an der Bildung des höher spezialisierten Ungulatenmolaren Anteil nehmen und zu der Entstehung ähnlicher Zahnformen auf konvergenten Wegen führen kömnen. Später tritt zuweilen noch ein hinterer Außenhöcker (Hypocon) auf, so daß der Zahı sechshöckerig wird (Fig. 602, oben).

Der bunodonte Typus der unteren Ungulatenmolaren geht auf den trituberkulärsektorialen Molarentypus der Insectivoren zurück. Hier lraben wir einen die Spitze eines (umgekehrt wie im Oberkiefer stehenden) Dreiecks bildenden Außenhöcker (Protoconid), einen vorderen Innenhöcker (Paraconid) und einen hinteren Innenhöcker (Metaconid). 


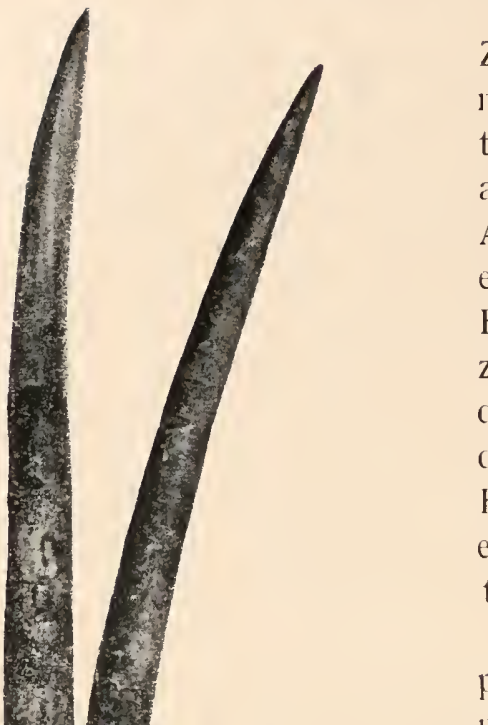

phodont geformten Ungulatenmolaren werden als Metalophid (Vorderjoch) und Hypolophid (Nachjoch) bezeichnet, ein am Hinterende ausgebildetes drittes Joch als Hypoconulid, auch wenn es als Querkanm und nicht als Höcker entwickelt ist, worauf die Beze chinung ,Conulid" schließen lassen würde.

Die oberen Eckzähne der Huftiere sind in einzelnen Stämmen stark vergrößert und dienen als Waffen (z. B. bei Suiden, Amblypoden, Hippopotaniden, Protoceratiden, Anthracotheriiden usf.), fehlen aber den meisten Huftieren entweder gänzlich oder sind rudimentär (Equus, Cervus). In anderen Gruppen sind die unteren Eckzähne in den Schneidezahnabschnitt einbezogen worden, so daß am Vorderende des Unterkiefers nicht drei, sondern vier Greifzähne jederseits in Funktion stehen, z. B. bei Cervus, Cebochoerus (Fig. 593).

Die Schneidezähne sind nur bei den Proboscidiern (Fig. 594) 
zu gewaltigen Stoßzähnen umgeformt worden; geringere Entwicklung haben sie als StoBzähne bei den Sirenen erlangt, wenngleich auch in
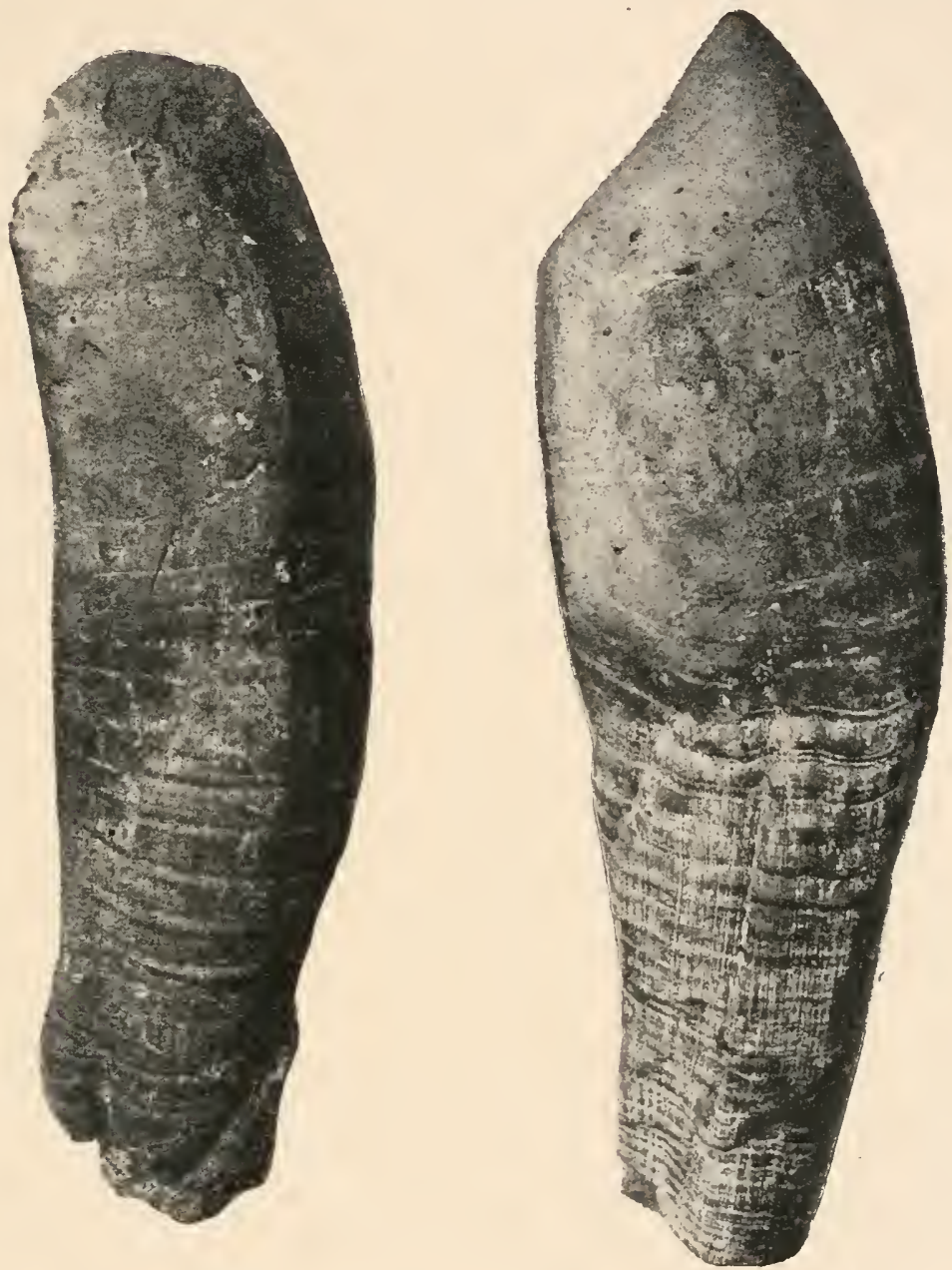

Fig. 595.

Zwei obere Stoßzähṇe von Rhytiodus Capgrandi, Lartet; aus dem Oberoligozän (Aquitanien) von Bournic im Garonnebecken, Frankreich. Länge der Zähne etwa $30 \mathrm{~cm}$. Gesamtlänge des Tieres etwa $5 \mathrm{~m}$. Originale im Jardin des Plantes in Paris.

(Orig. Phot.)

diesen Stamme mitunter kräftige Stoßzälne (z. B. bei Rhytiodus Capgrandi, Fig. 595) auftreten.

Ein bemerkenswerter Unterschied zwischen prinitiven und spezialisierten Molaren der Huftiere besteht darin, daß die Zähne der ältesten Ungulaten niedrige Kronen und Wurzeln besaßen, also ,brachyodont" waren, während im Laufe der Stammesgeschichte bei jenen 
Stämmen, die von weicher zu harter Pflanzenkost übergegangen sind, die Kronen und Wurzehn sehr hoch, ,hypselodont" oder ,hypsodont" wurden (Fig. 596). Dieser Übergang von der Brachyodontie zur Hypsodontie hat sich unabhängig in verschiedenen Stämmen, also parallel vollzogen.
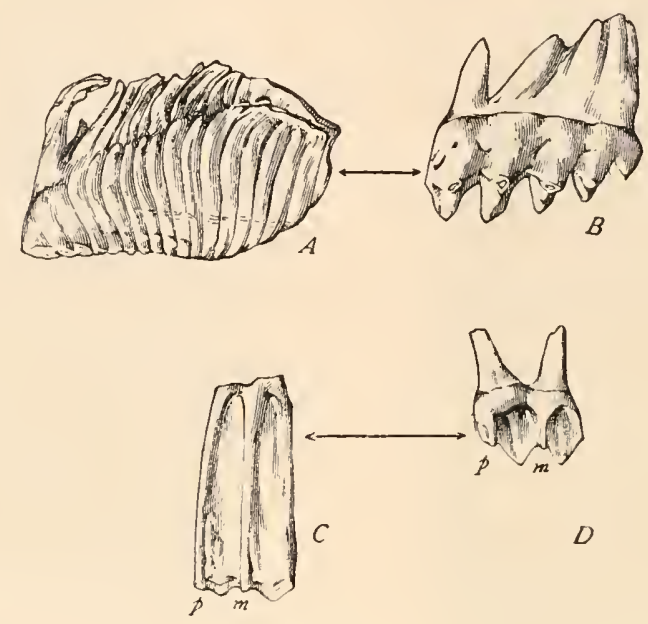

Fig. 596.

Brachyodonte und hypsodonte Molarentypen der Ungulaten.

A. Hypsodonter oder hochkroniger (spezialisierter) Typus: Elephas meridionalis.

B. Brachyodonter oder niedrigkroniger (primitiver) Typus: Mastodon americanus.

C. Hypsodonter Typus: Equus caballus.

D. Brachyodonter Typus: Anchitherium aurelianense.

Die gleichen Spezialisationserscheinungen (primitiv: brachyodont, spezialisiert: hypsodont) zeigen auch die Molaren anderer Huftierstämme; diese Spezialisation ist wiederholt unabhängig in den einzelnen Stämmen infolge Überganges von weicher

Pflanzennahrung zu harter Pflanzennahrung (Grasnahrung) erworben worden.

Die Gliedmaßen der Huftiere haben im Laufe der Stammesgeschichte eine weitgehende Unformung erfahren. Ursprünglich fünffingerig und fünfzehig (Fig. 597), werden Hand und Fuß später in zwei verschiedenen Hauptrichtungen spezialisiert, wobei entweder die Mittelzehe besonders verstärkt und zum Hauptträger der Gliedmaßen wird oder zwei Zehen (dritte und vierte) zusammen das Tragen der Körperlast übernehmen. Den ersten Typus nennen wir mesaxonisch (Fig. 598), den zweiten paraxonisch (Fig. 599). Dieser Gegensatz in der Verteilung der Körperlast auf die Finger und Zehen reicht weit zurück und wahrscheinlich stammen die Paarhufer oder Artiodactylen von einer anderen Gruppe von Vorfahren als die mesaxonischen Huftiere 
ab. Extreme der mesaxonischen Gliedmaßentypen finden wir bei den Equiden (Fig. 600) und bei den erloschenen Proterotheriiden (Fig. 598) Südamerikas; Extreme der paraxonischen Typen stellen uns die in physiologischer Hinsicht einfingerig oder monodaktyl gewordenen lebenden Hirsche, Schafe, Gazellen usw. dar, bei denen es zu einer Verschmelzung des dritten und vierten Metapodiums in ein ,Kanonenbein" gekommen ist (Fig. 599). Die beim Laufen nicht mehr den Boden berührenden Seitenzehen wurden rudimentär und in der Regel

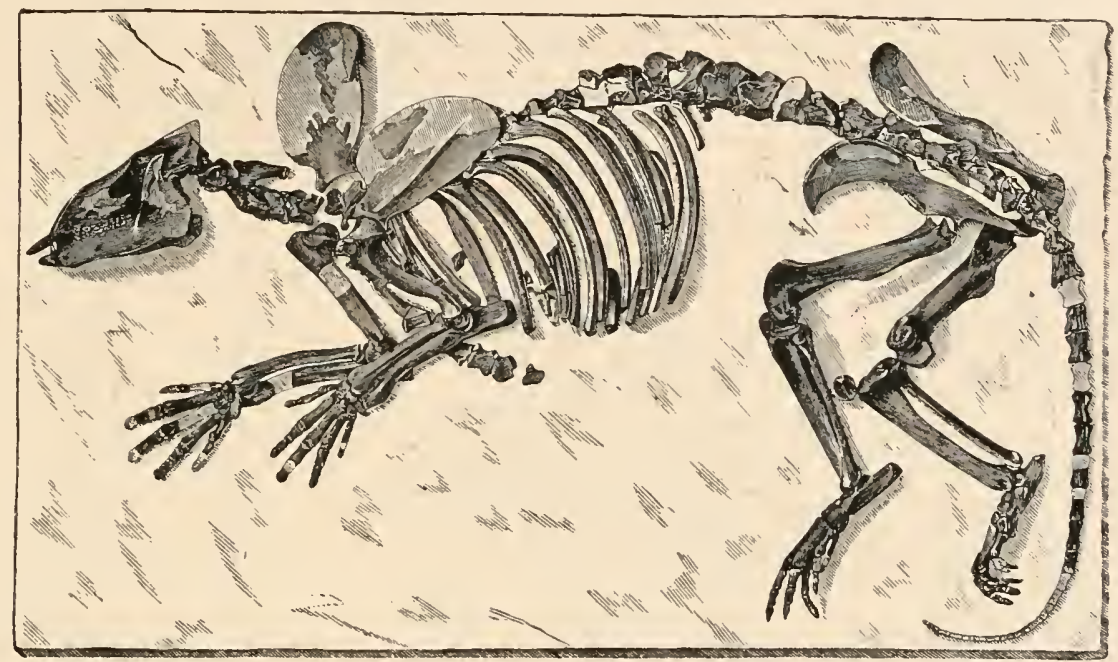

Fig. 597.

Skelett von Phenacodus primaevus, Cope, aus dem Untereozän (Wasatch Beds, Coryphodonzone) von Wyoming, das in der hier dargestellten Lage entdeckt wurde. (Nach E. D. Cope.)

zu ,Griffelbeinen“, seltener zu knopfförmigen Rudimenten umgeformt; bei den Pferden nehmen die Oberenden der Metapodien noch an der Gelenkbildung gegen Carpus und Tarsus Anteil, bei den hochspezialisierten Hirschen, Gazellen usf. sind sie aus dem Verbande mit denı Carpus und Tarsus herausgedrängt worden und daher häufig gänzlich verloren gegangen.

Ein wichtiges Spezialisationsmerkmal der Gliedmaßen der Ungulaten besteht in der Reduktion der Ulna im Unterarm und der Fibula im Unterschenkel. Nur in wenigen Gruppen findet diese Reduktion nicht statt, wie z. B. bei den Elefanten (Fig. 601) und Amblypoden, wo die Ulna kräftiger ist als der Radius, was mit der eigenartigen Stellung des Unterarms zum Oberarm und dem nach vorne durchgedrückten Ellbogengelenk zusammenhängt. 


\section{Ordnung (Stammgruppe) der Ungulaten: Protungulata.}

Die Stammgruppe der Huftiere umfaßt eine Reihe von Familien, von denen wir bereits einzelne als die Ahnengruppen jüngerer Familien ermittelt haben. Untereinander sind die Angehörigen dieser sechs

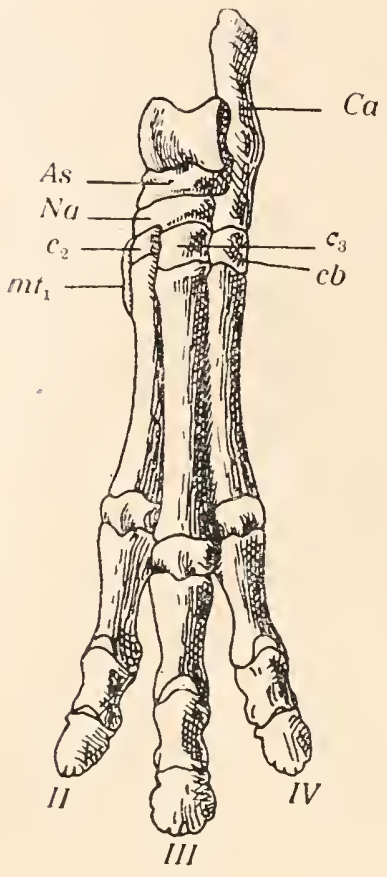

A.

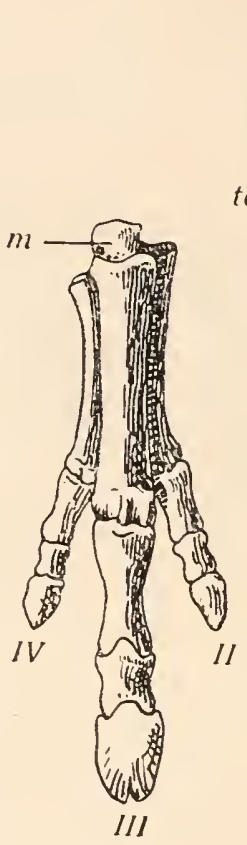

B.

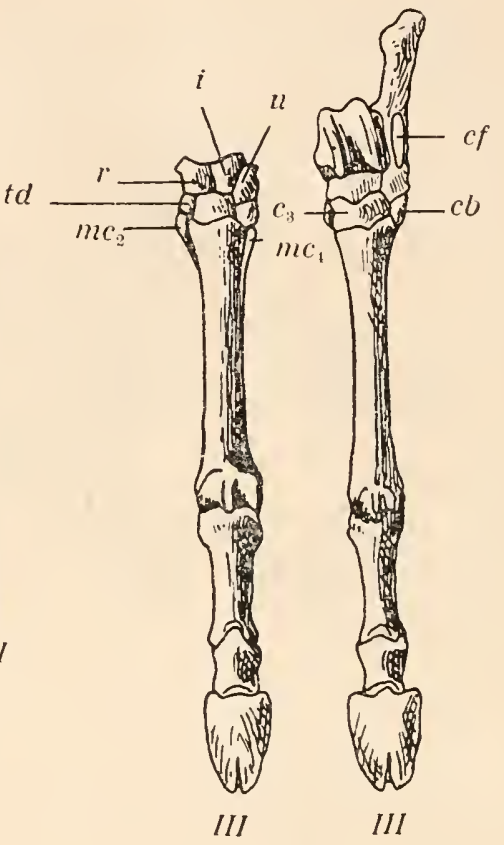

C.

Fig. 598.

A. Theosodon Lydekkeri, Amgh., Hinterfuß. Santa Cruz Beds, Patagonien. $1 / 4$ nat. Gr.

B. Proterotherium intermixtum; Hand. Ebendaher. 1/3 nat. Gr.

C. Thoatherium crepidatum; Hand und Fuß. Ebendaher. 1/3 nat. Gr. (Nach F. Ameghino.)

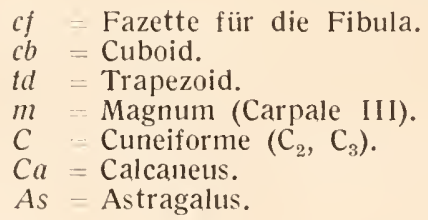

$$
\begin{aligned}
N a & =\text { Naviculare } \\
r & =\text { Radiale. } \\
i & =\text { intermedium } . \\
l l & =\text { Ulnare. } \\
m c & =\text { Metacarpalia. } \\
m t & =\text { Metatarsalia } .
\end{aligned}
$$

Fannilien noch sehr wenig verschieden; alle besitzen einen in der Gesamtform an primitive Raubtiere erinnernden Schädel mit starkem und langem Scheitelkamm, kleinem Gehirn und der Gebißformel $44\left(\frac{3.1 .4 .3}{3.1 .4 .3}\right)$; die Molaren sind zuerst oben trituberkulär, unten trituberkulärsektorial, später bunodont, und zwar tritt noch ein neuer Höcker zu den fünf 
primären (Protocon, Paracon, Metacon, Protoconulus, Metaconulus) an der hinteren Innenecke hinzu (Hypocon) (Fig. 602). Hand und Fuß

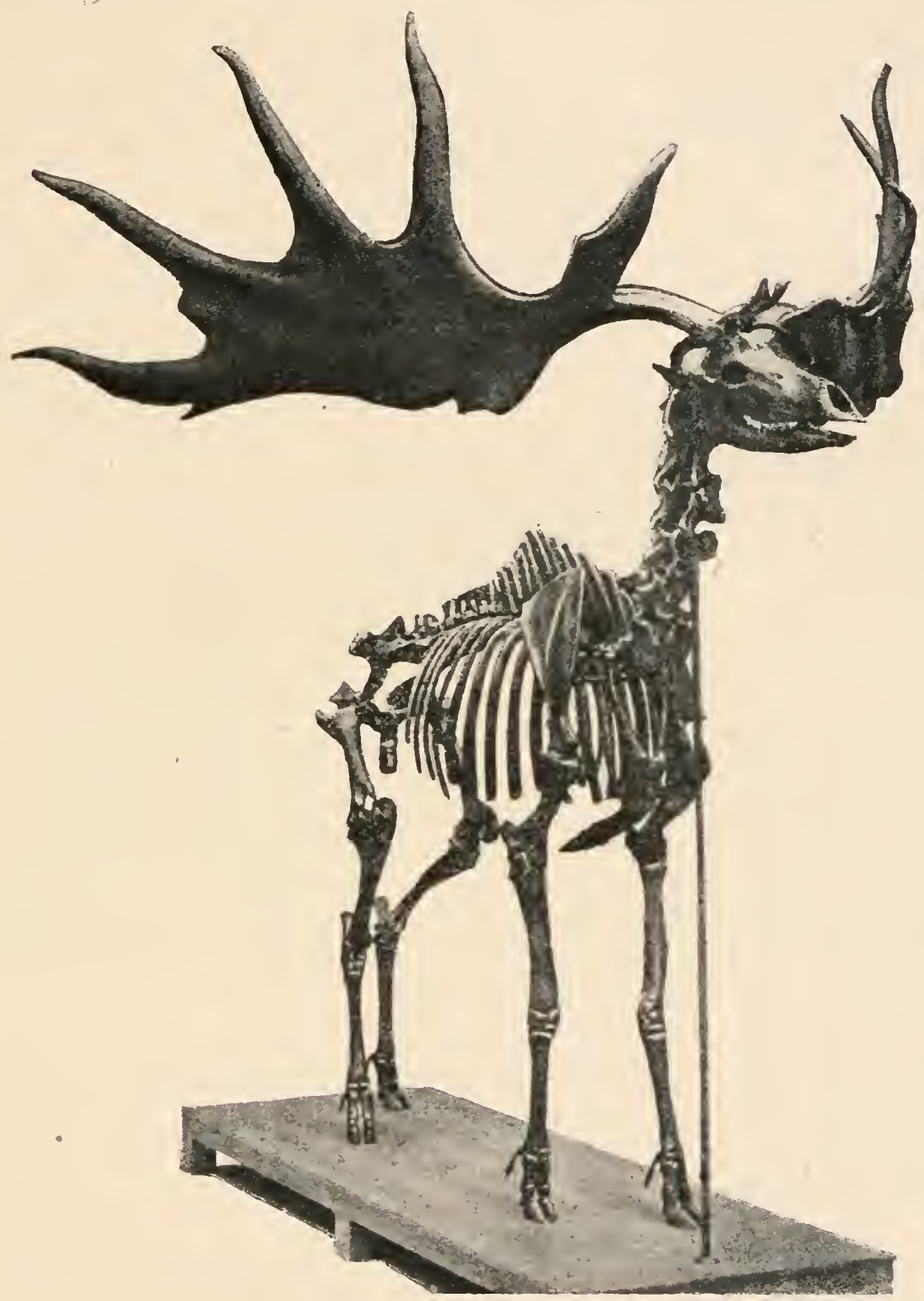

Fig. 599.

Skelett des irischen Riesenhirsches, Megaceros hibernicus, aus einem Torfmoor Irlands. (Nach F. Drevermann.)

waren fünffingerig und fünfzehig und wurden bej den primitiveren Formen mit der Sohlenfläche dem Boden aufgesetzt (plantigrader Typus), während im Laufe der Stammesgeschichte bei verschiedenen Zweigen der Protungulaten Hand und Fuß nur mehr mit den Phalangen 
und deni Unterende der Metapodien den Boden berührten (semiplantigrader oder semidigitigrader Typus), weil Hand und FuB eine steilere Stellung infolge des Überganges von der langsamen zur sclnelleren Bewegungsart erhielten. Die Fibula endet frei wie bei den Raubtieren, am Femur tritt ein Muskelhöcker, der „Trochanter tertius“ auf (heute nur mehr bei den Equiden, Rhinocerotiden und Tapiriden vorhanden). Der Gesamthabitıs erinnert an kleine, langschwänzige Raubtiere.

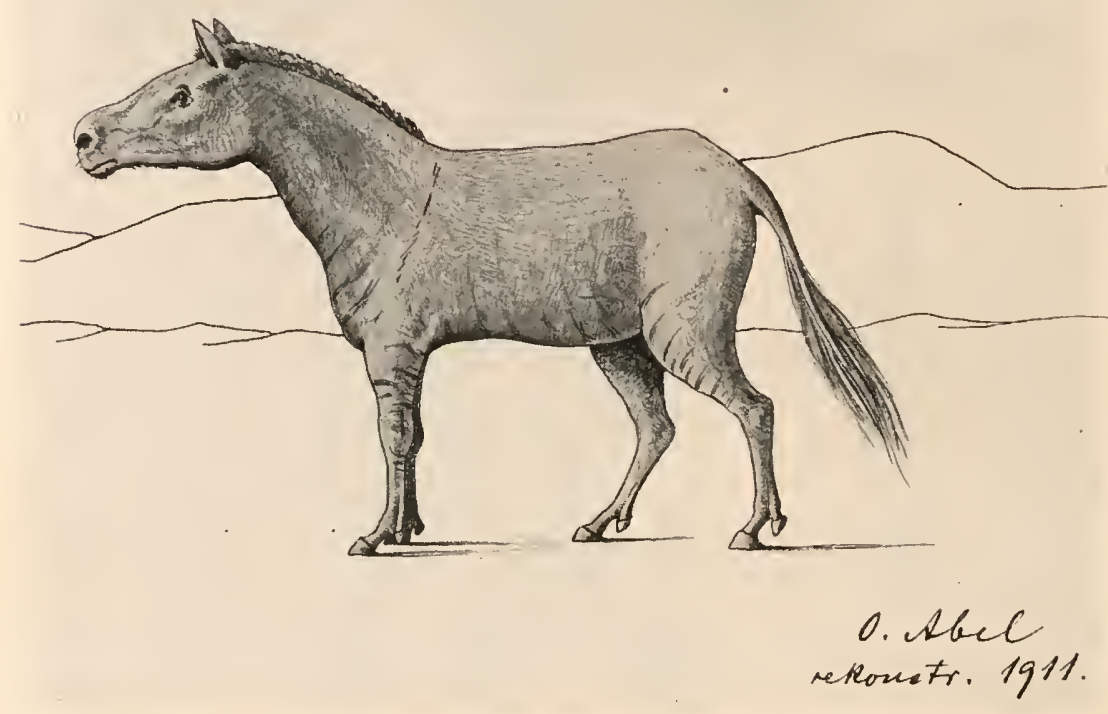

Fig. 600 .

Rekonstruktion eines dreizehigen Pferdes (Hipparion mediterraneum, Hensel) auts dem unteren Pliozän Europas.

\section{F. Mioclaenidae.}

Nur das Gebiß bekannt; die unteren Molaren erinnern an jene der Paarhufer, die oberen haben noch den Charakter von Insectivorenmolaren.

Mioclaenus. - Unterstes Eozän Nordamerikas. ${ }^{1}$

\section{F. Periptychidae.}

Obere Molaren meist dreihöckerig, selten (durch Hinzutreten des Hypocons) vierhöckerig werdend.

1 E. D. Cope, The Vertebrata of the Tertiary Formations of the West. Book I. - Report U. S. Geol. Survey, Washington, Vol. III, 1884, p. 324.

W. D. Matthew, A Revision of the Puerco Fauna. - Bull. Amer. Mus. Nat. Hist., New York, Vol. IX, 1897, p. 259. 
Periptychus. - Unterstes Eozän Nordamerikas. ${ }^{1}$

Conacodon. - Unterstes Eozän Nordamerikas. ${ }^{2}$

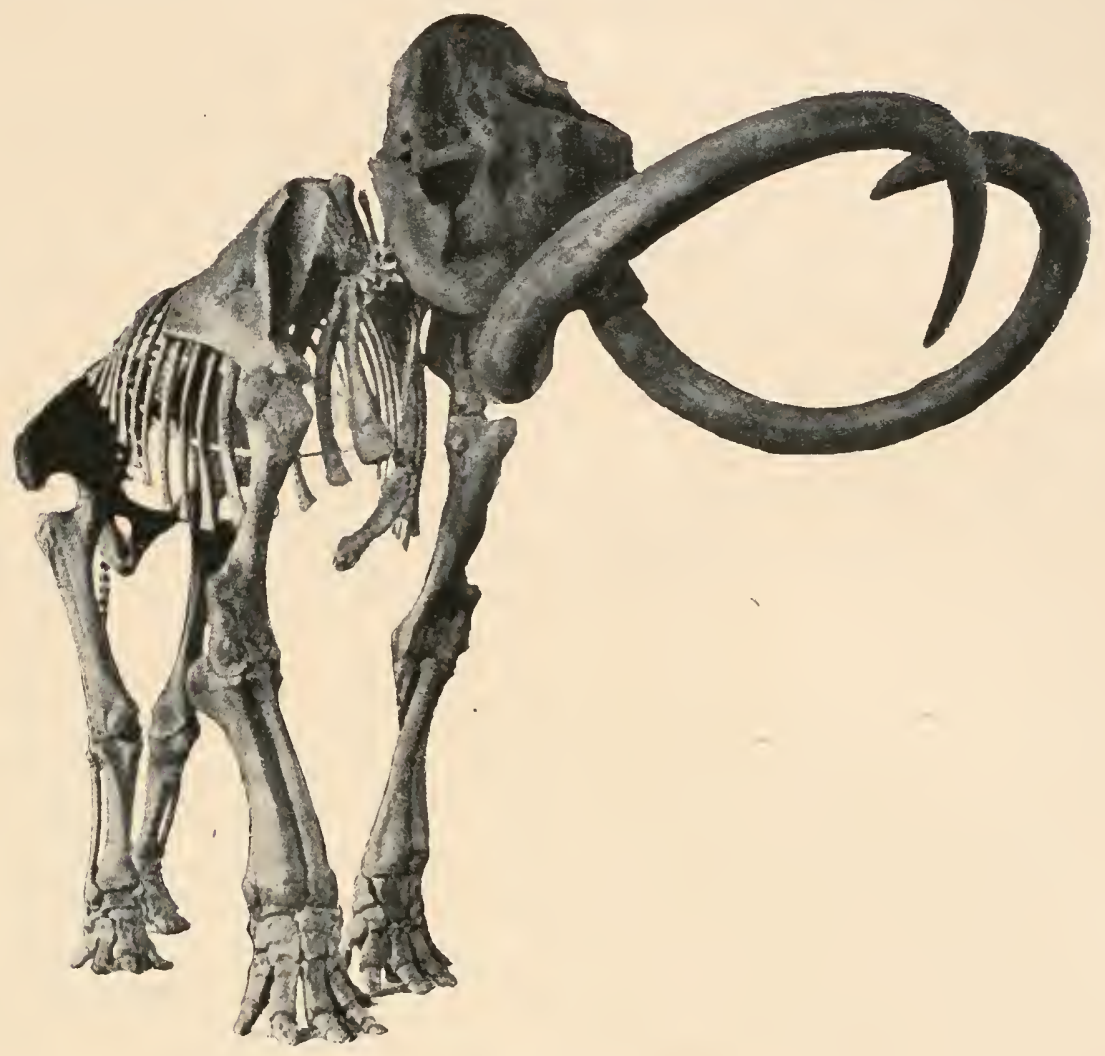

Fig. 601 .

Skelett von Elephas Columbi, Falc., aus dem juingeren Plistozän von Jonesboro, Indiana (Nordamerika), gefunden 1903. (Nach H. F. Osborn.)

(Die Arme sind bei diesem im American Museum of Natural History in New York montierten Skelette tınrichtig gestellt, da auf die Überknöchelung des Ellbogengelenkes, wie sie beim Elefanten in der Standstellung zu beobachten ist, hier keine Rïcksicht genommen wurde.)

\section{F. Pantolambdidae.}

Stammgruppe der Amblypoden. In den oberen Molaren 3 Haupthöcker und 2 Zwischenhöcker, noch ohne Hypocon, der erst später hinzu-

1 Die umfangreiche Literatur ïber diese Gattung vgl. bei O. P. Hay, Bibliography and Catalogue of the Fossil Vertebrates of North America. - Bull. Nr. 179 of the U. S. Geol. Survey, Washington, 1902, p. 693. - Abbildungen des Gebisses vgl. H. Osborn, Evolution of Mammalian Molar Teeth. New York, 1907, p. 164.

2 E. D. Cope, The Vertebrata of the Tertiary Formations of the West. Book I. - Report of the U. S. Geol. Survey of the Territories. Washington, Vol. III, 1884, p. 416, 421, 409 (hier unter dem Namen Haploconus und Anisonchus beschrieben). 
tritt; Höcker V-förmig. Schneide- und Eckzähne raubtierartig. Fast das ganze Skelett bekannt.

Pantolambda. - Unterstes Eozän (Torrejon-Beds) von - Neumexiko. ${ }^{1}$

\section{F. Phenacodontidae.}

Das Skelett der Hauptgattung Phenacodus ist vollständig bekannt.
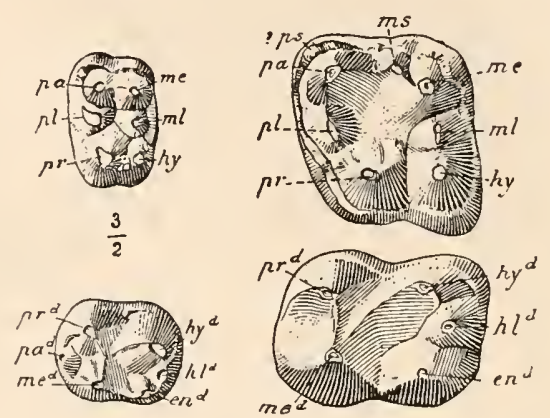

Fig. 602.

Links (oben und unten): Oberer und unterer Molar von Tetraclaenodon puercensis aus dem Basaleozän Nordamerikas (Torrejon-Beds); Rechts: oberer und unterer Molar von Phenacodus primaevus aus dem Untereozän Nordamerikas (Wasatch-Beds). Phenacodus ist von Typen wie Euprotogonia abzuleiten. (Nach H. F. Osborn.)

Die Höcker der oberen Molaren:

$p r=$ vorderer Innenhöcker (Protocon).

$p l=$ vorderer Zwischenhöcker (Protoconulus).

$p a=$ vorderer Außenhöcker (Paracon).

$h y=$ hinterer Innenhöcker (Hypocon).

$m l=$ hinterer Zwischenhöcker (Metaconulus).

$m e=$ hinterer Außenhöcker (Metacon).

$p s=$ sekundärer Außenpfeiler (Parastyl).

$m s$ = sekundärer Außenpfeiler (Mesostyl).
Die Höcker der unteren Molaren: prd $=$ vorderer (primärer) Außenhöcker (Protoconid).

pad $=$ vorderer Innenhöcker (Paraconid $).$ med $=$ hinterer (primärer Außenhöcker (Metaconid).

hyd $=$ Außenhöcker des Talonids (Hypoconid).

hld $=$ Zwischenhöcker des Talonids (Mesoconid).

end = Innenhöcker des Talonids (Entoconid).

Die Körpergröße des Tieres erreichte etwa die eines Panthers; die Bedeutung der Gruppe der Phenacodontiden, die im Torrejon von Neumexiko und Montana mit einer schlankbeinigen Form (Tetraclaenodon) beginnt, liegt darin, daß in ihr die Wurzeln der Equiden, Rhinocerotiden und Titanotheriiden zusammenlaufen. Die oberen Molaren sind durch Hinzutreten des Hypocons sechshöckerig geworden, ebenso sind die unteren schon bei Tetraclaenodon sechshöckerig, da das Talonid dreispitzig geworden ist. Der Habitus von Phenacodus erinnert noch immer an ein Raubtier, während sich die ältere Gattung Tetraclaenodon bereits melır an die ältesten Equiden (Hyracotherimm) anschließt.

1 H. F. Osborn, Evolution of the Amblypoda. - Part 1. Taligrada and Pantodonta. - Bul!. Amer. Mus. Nat. Hist. New York, Vol. X, 1898, p. 169. 
Tetraclaenodon (= Euprotogonia). - Torrejon-Beds Nordamerikas $^{1}$ (Fig. 602).

Phenacodus. - Wasatch-Beds (Untereozän) Nordamerikas ${ }^{2}$ (Fig. 597, 602).

\section{F. Meniscotheriidae.}

Obere Molaren nuit W-förmiger Außenwand, auch die unteren Molaren mit zwei V-förmigen Höckern, die dem Molarentypus der Clıalicotheriiden so ähnlich sind, daß in dieser Gruppe wahrscheinlich die Wurzel der Chalicotheriiden zu erblicken ist.

\section{F. Bunolitopternidae.}

Die Stammgruppe der'südanerikanischen Litopterna. Sie ist nur aus dem Alttertiär (Eozän und Oligozän) Patagoniens bekannt. Obere Molaren mit Hypocon, daher sechshöckerig, untere Molaren nit V-förmigen Außenhöckern und zwei kegelförmigen Innenhöckern.

Didolodus. - Notostylopsschichten (Eozän) Patagoniens. ${ }^{3}$

\section{Ordnung: Artiodactyla.}

1. Unterordnung: Hypoconifera.

Die oberen Molaren besitzen außer den 5 primären Höckern noch einen Hypocon,' der zuerst sehr klein ist, später aber erstarkt (Hyperdichobune nobilis) und durch weitere Größenzunahme aus dem dreieckigen Zahn einen quadrangulären entstehen läßt (Dichobune leporina). Die Gliedmaßen zeigen bereits Reduktionserscheinungen in den Seitenzehen. Erloschen.

\section{F. Dichobunidae.}

Dichobune. - Eozän und Mitteloligozän Mitteleuropas. ${ }^{4}$

1 W. D. Matthew, A Revision of the Puerco Fauna. - Ibiden, Vol. IX, 1897, p. 259.

H. F. Osborn, Remounted Skeleton of Phenacodus primaevus. Comparison with Euprotogonia. - Ibidem, Vol. X, 1898, p. 159.

${ }^{2}$ E. D. Cope, The Vertebrata of the Tertiary Formations usw., I. c., p. 435 sowie die beiden Arbeiten von Osborn und Matthew (l. c. supra).

${ }^{3}$ F. Ameghino, Recherches de Morphologie phylogénétique sur les Molaires supét ieures des Ongulés. - Anales del Museo Nacional de Buenos Aires, T. IX (3), 1904.

${ }^{4}$ H. G. Stehlin, Die Säugetiere des schweizerischen Eocäns. - IV. Teil. Abhandlungen der Schweiz. Palaeont. Ges., XXXIII. Bd., 1906, p. 597. Über nordamerikanische Dichobuniden aus dem unteren und mittleren Eozän Nordamerikas (z. B. Wasatchia) vgl. William J. Sinclair, A Revision of the Bunodont Artiodactyla of the Middle and Lower Eocene of North America. - Bull. Amer. Mus. Nat. Hist., New York, Vol. XXXIII, 1914, p. 267. 


\section{F. Elotheriidae.}

Elotherium (= Entelodon). - Oligozän Frankreichs, Oligozän und Untermiozän Nordanerikas. ${ }^{1}$

Dinohyus. - Oberoligozän von Nebraska. ${ }^{2}$

2. Unterordnung: Caen o theria.

Die oberen Molaren besitzen keinen Hypocon; trotzdem entsteht in Laufe der Stanmesgeschichte dieser Gruppe aus dem dreieckigen Kronenumriß ein viereckiger, indem der Protocon in die hintere Zahnlälfte rückt und der Protoconulus zum vorderen Innenhöcker des Molaren wird. Die Zahnreihe ist voliständig. Erloschen; vom Eozän bis Untermiozän in Europa.

\section{F. Caenotheriidae.}

Caenotherium. - Oligozän Frankreichs und Untermiozän Deutschlands. Kleine Tiere von der Größe und dem Aussehen des Zwergmoschushirsches. ${ }^{3}$

\section{Unterordnung: Euartiodactyla.}

Die oberen Molaren besitzen keinen Hypocon, aber auch in dieser dritten Reihe der Paarhufer entstelit eine viereckige Kronenform der oberen Molaren. Dies wird hier dadurch erreicht, daß der Protocon in die vordere Zahnhälfte rückt und den vorderen lnnenhöcker bildet, während der Metaconulus zum hinteren Innenhöcker wird und der Protoconulus verloren geht, der z. B. noch bei Cebochoerus, Pseudamphimeryx und Dacrytherium vorhanden ist. Auf diese Weise entsteht ein vierhöckeriger oberer Molar.

\section{F. Suidae.}

1. Superfamilie: Neobunodontia.

Ursprünglich mit vollem Gebiß (44 Zähne), aber später mit reduziertem Gebiß (Verlust des letzten oberen Schneidezahnes und des letzten

1 H. Filhol, Étude des Mammifères fossiles de Ronzon (Haute-Loire). Annales des Sciences géologiques, T. XII, Paris 1882, p. 190 (Literatur).

W. B. Scott, The Osteology of Elotherium. - Transactions of the American Philosophical Society, Vol. XIX, 1898, p. 273.

O. A. Peterson, A Revision of the Entelodontidae. - Memoirs of the Carnegie Museum, Pittsburgh, Vol. IV, Nr. 3, 1909, p. 4I.

2 O. A. Peterson, 1. c.

${ }^{3}$ Die Literatur ïber diese Gattung (bis 1896) hat O. Roger zusammengestellt (Berichte d. naturw. Vereins für Schwaben und Neuburg, XXXII. Bd., Augsburg 1896, S. 221).

Über die phylogenetische Stellung der Caenotheria vgl. H. G. Stehlin, Die Säugetiere des schweizerischen Eocäns. - Abhand. d. Schweiz. paläont. Ges., Vol. XXXVI, Ziirich 1910, S. 1134 . 
oberen und unteren Prämolaren). Molaren brachyodont, ursprünglich oligobunodont, später polybunodont. Eckzahn meist als „Hauer“ ausgebildet, aber mitunter sehr klein (Sus erymanthius aus dem Unterpliozän von Pikermi in Griechenland). Hand vierzehig, Fuß mitunter dreizelig.

Cebochoerus. - Mittel- und Obereozän Europas. - Der untere Eckzahn ist in den Schneidezahnabschnitt einbezogen; an seiner Stelle funktioniert der erste untere Prämolar als ,Eckzahn"1 (Fig. 593).

Choeromorus. - Obereozän Europas. ${ }^{2}$

Propalaeochoerus. - Oligozän Europas. Wahrscheinlich die Stanmingattung der späteren tertiären und quartären Schweine. ${ }^{3}$

Palaeochoerus. - Miozän Europas. ${ }^{4}$

Hyotheriun. - Miozän Europas, Unterpliozän Ostindiens. ${ }^{5}$

Listriodon. - Miozän Europas, Unterpliozän Ostindiens. ${ }^{6}$

Sus. - Zuerst im Unterpliozän von Griechenland, Deutschland, Ostindien und China.

\section{F. Hippopotamidae.}

Die Geschichte der Flußpferde ist noch durchaus dunkel; als sicher ist nur ihre nahe Verwandtschaft mit den Suiden anzusehen, deren Nachkonmen sie sein müssen, doch sind wir über die Zeit der Abzweigung der Hippopotamiden von den Suiden aus dem Grunde nicht unterrichtet, weil die ältesten bekannten Flußpferde erst in späten Tertiär (Unterpliozän Indiens) auftreten. Im Plistozän lebten Zwergarten auf einzelnen Mittelmeerinseln (Sizilien, Malta, Cypern. [Fig. 603], Kreta) und auf Madagaskar; in Liberia lebt noch heute ein Zwergflußpferd. In der Eiszeit kamen Flußpferde auch in Mitteleuropa vor, sogar in England.

\section{Superfamilie: Bunoselenodontia.}

\section{F. Anthracotheriidae.}

Die oberen Molaren besaßen vier Haupthöcker und den vorderen Zwischenhöcker (Protoconulus), die unteren waren vierhöckerig. Die

1 H. G. Stehlin, Die Säugetiere des schweizerischen Eocäns. V. Teil. Abhandl. d. Schweiz. paläontolog. Ges., Vol. XXXV, Zürich 1908, S. 691.

${ }^{2}$ H. G. Stehlin, Ibidem, p. 701.

${ }^{3}$ H. G. Stehlin, Über die Geschichte des Suidengebisses. - lbidem, Vo:. XXVI und XXVII, 1899-1900.

4 Ch. Depéret, Recherches sur la succession des Faunes des Vertébrés miocènes de la Vallée du Rhône. - Archives du Musée d'Hist. Nat. de Lyon, T. IV, 1887, p. 236.

${ }^{5}$ Die Literatur bis $1896 \mathrm{vgl}$. bei O. Roger, Berichte d. naturwiss. Vereins für Schwaben und Neuburg, XXXII. Bd., Augsburg 1896, S. 206.

${ }^{6}$ H. G. Stehlin, Über die Geschichte des Stridengebisses, 1. c., S. 483 (hier die ältere Literatur ïber diese Gattung). 
Familie lebte vom Mitteleozän bis zum Ende des Oberoligozäns in Europa $^{1}$, kamen aber in Ostindien ${ }^{2}$ noch im Miozän vor; aus dem Oligozän des Fayûm (Ägypten) sind zahlreiche Reste bekannt. ${ }^{3}$ Einzelne Reste sind im Oligozän Nordamerikas entdeckt worden. ${ }^{4}$ Erloschen.

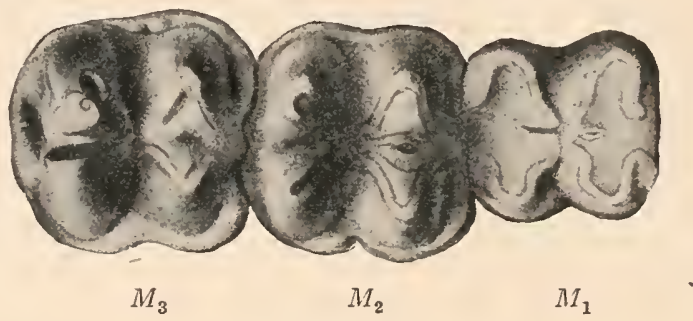

Fig. 603.

Hippopotamus minutus, aus dem Plistozän von Cypern.

(Nach C. I. Forsyth-Major.)

$M_{1}-M_{3}=$ die drei oberen Molaren, von der Kaufläche gesehen, in nat. Größe.

Anthracotherium. - Oligozän Europas und Nordamerikas. A. magnum ist als „Leitfossil“ der aquitanischen Stufe (Oberoligozän Europas) bekannt. Die Tiere waren Sumpfbewohner und erinnerten in ihrem Gesamthabitus an große Schweine ${ }^{5}$ (Fig. 604, 605).

1 W. Kowalevsky, Monographie der Gattung Anthracotherium Cuv. und Versuch einer natürlichen Klassifikation der fossilen Huftiere. - Palaeontographica, XXII. Bd., 1873, p. 133.

H. G. Stehlin, Zur Revision der europäischen Anthracotherien. - Velhandlungen der Naturforschenden Gesellschaft in Basel, XXI. Bd., Basel 1910, S. 165.

2 Guy E. Pilgrim, The Vertebrate Fauna of the Gaj Series in the Bugti Hills usw., Palaeontologia Indica, New Series, Vol. IV, 1912.

C. Forster-Cooper, New Anthracotheres and Allied Forms from Baluchistan. -- Preliminary Notice. - Annals and Magazins of Natural History (8), Vol. XII. London 1913, p. 514.

${ }^{3}$ M. Schmidt, Über Paarhufer der fluviomarinen Schichten des Fayum. Geologische und paläontologische Abhandlungen, n. F., Bd. XI (der g. Reihe XV. Bd.), Jena 1913, S. 155 (Literatur).

${ }^{4}$ W. B. Scott, The Structure and Relationships of Ancodus. - Journal Acad. Nat. Sciences, Philadelphia, Vol. IX, 1894, p. 461.

H. F. Osborn and J. L. Wortman, Fossil Mammals of the Lower Miocene White River Beds. Bull. Amer. Mus. Nat. Hist., Vol. VI, 1894, p. 222.

W. D. Matthew, Observations upon the Genus Ancodon. - Ibidem, Vol. XXVI, 1909, p. 1.

5 Die nordamerikanischen Anthracotheriiden besaßen eine abweichende Körperform, die von R. Bruce Horsefall in dem Buche von W. B. Scott: A History of Land Mammals in the Western Hemisphere. - New York, 1913, p. 371, Fig. 196 in der Rekonstruktion von Ancodus (Bothriodon) brachyrhynchus sehr gut zum Ausdrucke gebracht erscheint. Einzelne Gattungen, wie z. B. Ancodon leptorhynchus aus dem Oligozän Frankreichs fallen durch die stark verlängerte Schnauze auf. 


\section{F. Anoplotheriidae.}

Die in dieser Familie vereinigten Gattungen unterscheiden sicl durch den eigentümlichen Bau ihrer Gliedmaßen durchgreifend von allen übrigen Huftieren. Die Hand von Diplobune war, wie Funde in den oligozänen Bohnerzen von Ulm beweisen, dreifingerig, ebenso der Hinterfuß; bei Anoplotherium aus dem Obereozän Frankreiclıs war dagegen die Hand bereits höher spezialisiert und zweifingerig, während der Hinterfuß auch bei dieser Gattung dreizehig war. Dieser Gliedmaßentypus läßt sich weder mit dem der übrigen Paarhufer, noch mit dem der Unpaarhufer in engeren Vergleich ziehen. Der Hauptdruck, der sicl auf

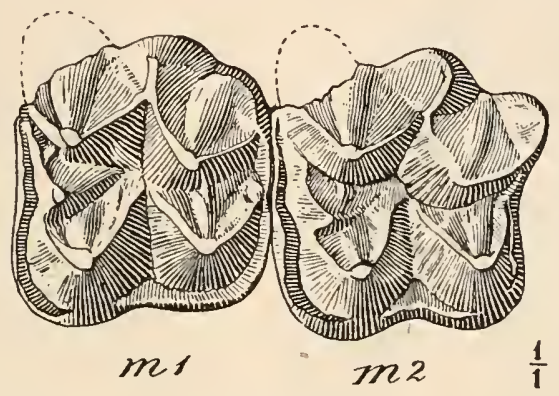

Fig. 604.

Die beiden ersten oberen linken Molaren $\left(m_{1}, m_{2}\right)$ von Anthracotherium Karense aus dem Oberoligozän (Protoceras Beds) Nordamerikas, in nat. Größe. (Nach H. F. Osborn.)

die Zehen verteilte, ging zwar bei Anoplotherium und Diplobune durch den dritten und vierten Zehenstrahl, aber der zweite Zehenstrahl, dẹr von der dritten Zehe ziemlich weit abstand, nalm noch am Tragen der Körperlast wesentlichen Anteil. M. Schlosser nimmt an, daß die drei Zehen durch Schwimmhäute verbunden waren; wenn dies der Fall gewesen sein sollte, würde der lange Schwanz als Ruderschwanz aufzufassen sein. Anoplotherium ist jedoch, wie aus der Rcduktion des zweiten Fingers zu einem knopfförmigen Rudiment hervorgeht, jedenfalls ein Landbewohner gewesen. Die Zahnreihen der Anoplotheriiden waren lückenlos, der Eckzahn ist nach Größe und Form unwesentlich von den Nachbarzähnen verschieden. Die Familie ist erloschen.

Diplobune. - Oligozän Mitteleuropas. ${ }^{1}$

Anoplotherium. - Obereozän von Paris ${ }^{2}$ und Unteroligozän (Bohnerze) Schwabens und der Schweiz.

1 H. G. Stehlin, Die Säugetiere des schweizerischen Eocäns. - Abhandl. d. Schweiz. Paläont. Ges., Vol. XXXV1, Zürich 1910, S. 937.

${ }^{2}$ H. G. Stehlin, lbidem, p. 937-963. 


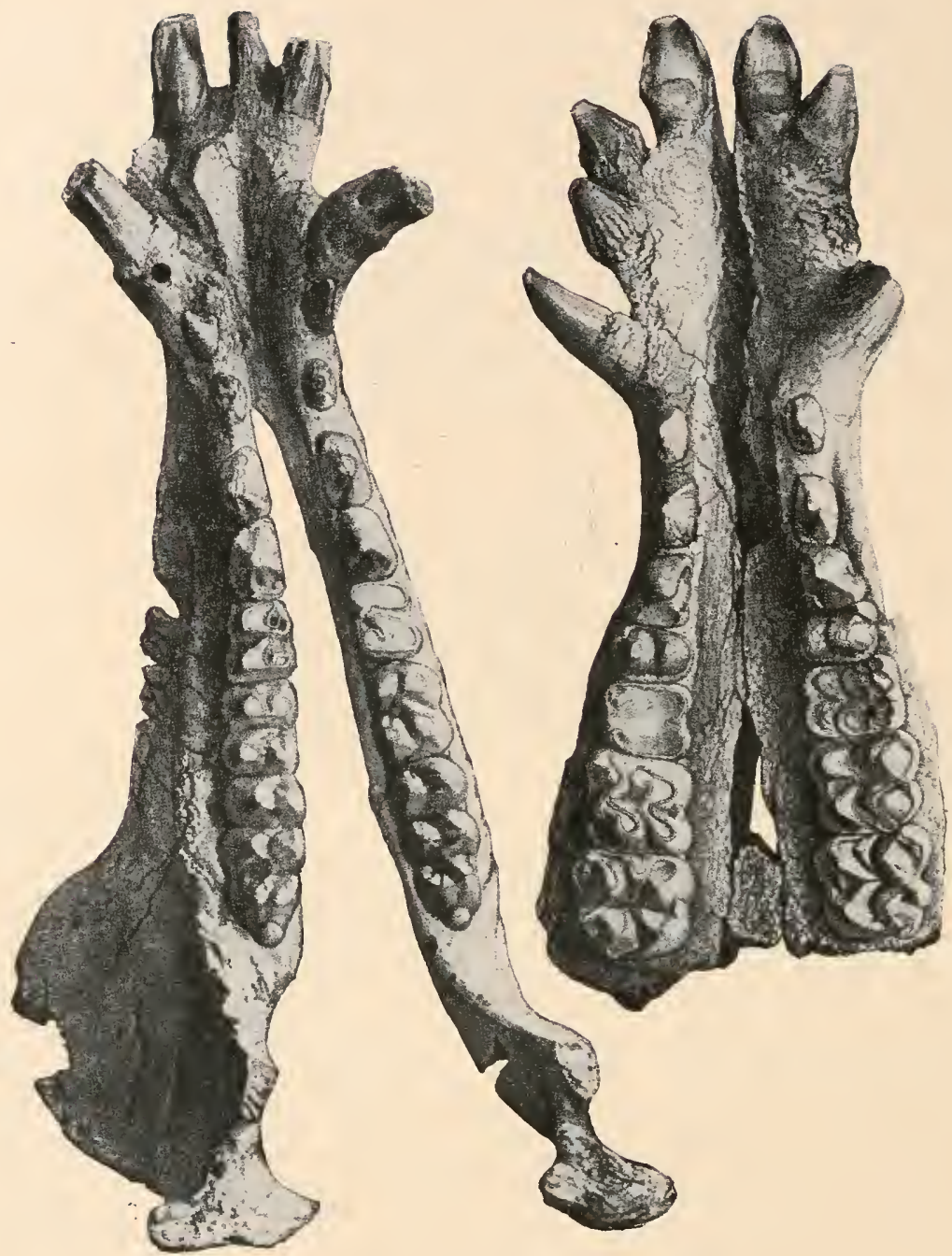

Fig. 605 .

Anthracotherium magnum (links: Unterkiefer, rechts: Oberkiefer und Zwischenkiefer) aus den oberoligozänen Ligniten von La Rochette bei Lausanne. 1/4 nat. Gr. (Nach W. Kowalevsky.)

Mixtotherium. - Eozän Frankreichs und der Schweiz, Oligozän Ägyptens (?). Der Unterkiefer dieser Gattung ist auffallend hoch und erinnert in seiner Folm an den Unterkiefer von Mycetes (Brüllaffe). ${ }^{\circledR}$

1 H. G. Stehlin, Ibidem, Vol. XXXV, 1908, p. 799.

M. Schmidt, Über Paarhufer der fluviomarinen Schichten des Fayum. Geol. u. Paläont. Abhandlungen, Jena 1913, XV. Bd., S. 259. 


\section{Superfamilie: Selenodontia.}

\section{F. Oreodontidae.}

Bei den Oreodontiden funktioniert in dem lückenlosen Gebiß der erste untere Prämolar als Eckzahn (wie bei Cebochoerus), während der Eckzahn in die Gruppe der Schneidezähne einbezogen ist.

Die Familie ist erloschen; sie scheint auf Nordamerika beschränkt gewesen zu sein, da nur aus dem Obereozän, Oligozän und Miozän der Vereinigten Staaten Reste von Angehörigen der Familie bekannt sind.

1. Subf. Agriochoerinae.

Habitus raubtierartig; Augenhöhle hinten geöffnet, Schwanz lang, Humerus mit niedriger Gelenkrolle, Zehen in Krallen endend.

Agriochoerus. - Oligozän Nordamerikas. Wahrscheinlich arborikol. ${ }^{1}$

2. Subf. Oreodontinae.

Habitus schweineartig, Jochbogen stark nach außen gebogen, Jochfortsatz des Squamosums steil in die Höhe ragend; Augenhölle hinten geschlossen, Schwanz kurz, Humerus mit hoher Gelenkrolle, Zehen in Hufe endend.

Oreodon. - Oligozän Nordamerikas (Fig. 606). ${ }^{2}$

Promerycochoerus. - Oberoligozän und Untermiozän Nordamerikas (Fig. 607). ${ }^{3}$

Leptauchenia. - Untermiozän Nordamerikas (Fig. 608). ${ }^{4}$

Ticholeptus. - Mittel- und Obermiozän Nordamerikas (Fig. 609). ${ }^{5}$

\section{F. Xiphodontidae.}

Die Xiphodontiden waren hochbeinige, schlank gebaute und daher wohl schnellfüßige Paarhufer, die im Obereozän und Oligozän Europas lebten und seither verschwunden sind. Der untere erste Prāmolar fungierte

${ }^{1}$ H. F. Osborn and J. L. Wortman, Artionyx, a New Genus of Ancylopoda. - Bull. American Museum of Nat. Hist., Vol. V, 1893, p. 1.

W. D. Matthew, A Tree Climbing Ruminant. - American Museum Journal, Vol. XI, 1911, p. 162 .

2 J. Leidy, The Extinct Mammalian Fauna of Dakota and Nebraska usw., Journal Acad. Natur. Sciences Philadelphia (2), Vol. VII, 1869, p. 94.

Ch. W. Gilmore, Notes on a New Mounted Skeleton of Merycoidodon, a Fossil Mammal. - Proceedings U. S. Nat. Museum, Washington, Vol. XXXI, Nr. 1492, Washington 1906, p. 513.

3 E. Douglass, Promerycochoerus and a New Genus of Merycoidodonts with Some Notes on other Agriochoeridae. - Annals Carnegie Museum, Pittsburgh, Vol. IV, 1907.

4 W. J. Sinclair, The Restored Skeleton of Leptauchenia decora. - Proceedings Amer. Philosoph. Society, Vol. XLIX, Nr. 195, 1910, p. 196.

5 E. Douglass, 1. c. 


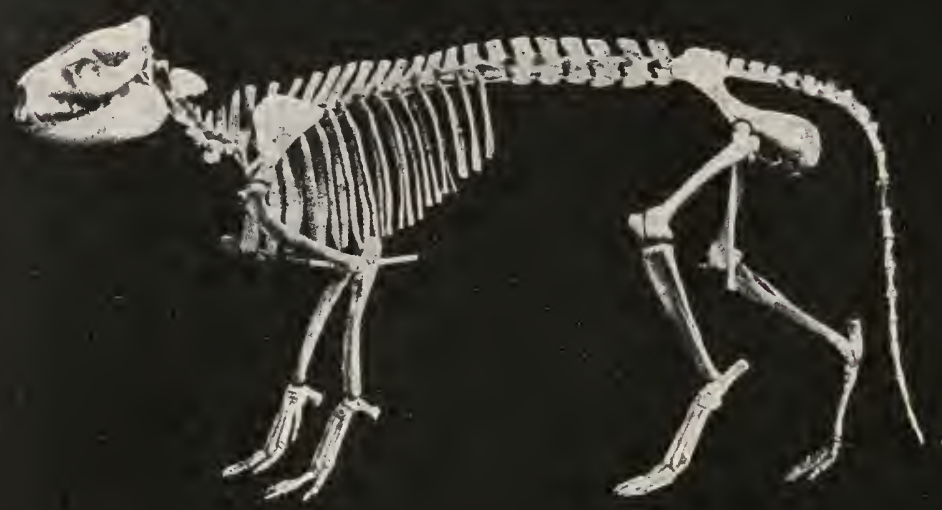

*a.

Fig. 606 .

Skelett von Oreodon gracilis Leidy, aus dem Mitteloligozän Nordamerikas.

(Nach Ch. W. Gilmore.)

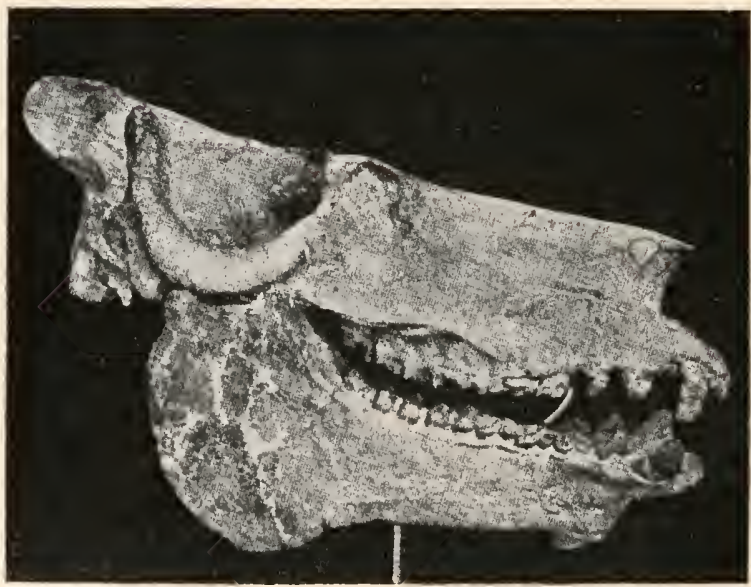

Fig. 607.

Promerycochoerus macrostegus, ein Oreodontide aus dem Oberoligozän (Upper John Day-Beds) Nordamerikas. (Nach W. D. Matthew.) 


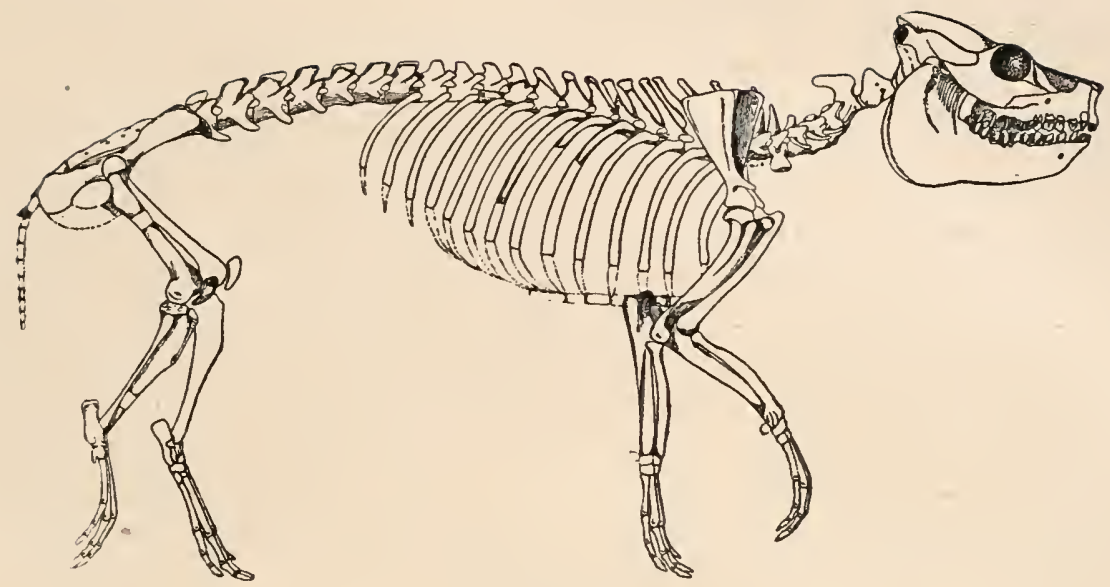

Fig. 608.

Skelett von Leptauchenia decora, ein Oreodontide aus dem Untermiozän beim Corral Draw in den Bad Lands von Süd-Dakota. Etwa $1 / 6$ nat. Gr.

(Nach W. J. Sinclair.)

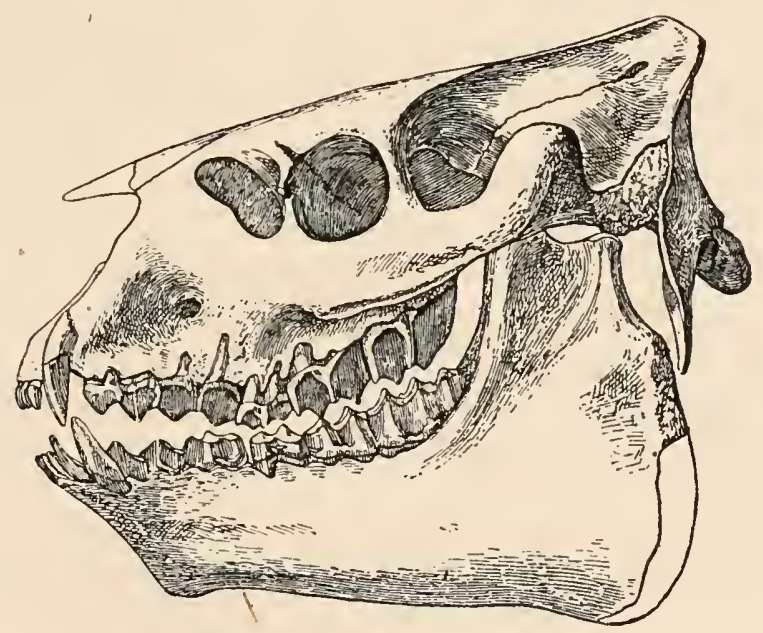

Fig. 609 .

Schädel von Ticholeptus breviceps aus dem Mittelmiozän Nordamerikas.

In $3 / 8$ nat. Gr. (Nach E. Douglass.)

wie bei den Oreodontiden als Eckzahn oder trat überhaupt ebenso wie der Eckzahn nicht aus der Zahnreihe hervor (z. B. bei Tapirulus hyracinus). Die Gliedmaßen waren zweizehig. 
Xiphodon. - Obereozän von Paris. ${ }^{1}$

Tapirulus. - Obereozän Europas. ${ }^{2}$

\section{F. Camelidae.}

Das Gebiß der zuerst im Obereozän Nordamerikas auftretenden Cameliden war ursprünglich vollständig, später ging der erste und zweite obere Schneidezahn und der zweițe obere Prämolar verloren. Laufkiele fehlen den Unterenden der Metapodien. Eckzähne als solche funktionell.

Protylopus. - Obereozän (Uinta Beds) Nordamerikas. Das Tier besaß die Größe eines Feldhasen und hatte ein lückenloses Gebiß; die Hand war vierfingerig, der Fuß aber bereits zweizehig. ${ }^{3}$

Poëbrotherium. - Oligozän (White River Beds) Nordamerikas. Inı vorderen Kieferabschnitt sind die Zälnne auseinandergerückt und die Molaren beginnen hypsodont zu werden. Ulna und Radius, bei Protylopus noch frei, sind hier bereits verwachsen. ${ }^{4}$

Protomeryx. - Untermiozän (Arikareeformation) Nordamerikas. - Die Eckzähne sind scharf, die bei den älteren Gattungen hinten geöffnete Orbita ist beinahe geschlossen, die Gliednußen werden digitigrad. ${ }^{5}$

Protolabis. - Mittelmiozän (Ticholeptuszone) bis Unterpliozän (Procameluszone) Nordamerikas. Die Molaren sind ausgesprochen hypsodont; der obere zweite Prämolar beginnt zu verkümmern. Metapodien lang, aber nicht verschmolzen. ${ }^{6}$

Procamelus. - Unterpliozän (Procameluszone und Peraceraszone) Nordamerikas. Der erste und zweite obere Schneidezahn und der zweite obere sowie der zweite untere Prämolar sind verloren gegangen, die Metapodien sind verschmolzen und bilden ein „Kanonenbein“. Von Procamelus dürfte die nach Südamerika ausgewanderte "Formenreihe abgezweigt sein, die durch das lebende Lama repräsentiert wird, während die Kamele auf Protolabis zurückgehen und sich von Nordamerika aus gegen Westen ausgebreitet haben. Die Familie der Cameliden, die in Nordamerika im Plistozän mit Camelus americanus und einigen mit den Lamas verwandten Arten der Gattung Camelops und Auchenia erlischt, ist seit dem Unterpliozän in Asien (China und Ostindien) heimisch und hat in der Eiszeit Sibirien und Südrußland erreicht. Die Gattung

1 H. G. Stehlin, Die Säugetiere d. Schweiz. Eocäns (VI. Teil). — Abh. d, Schweiz. Paläont. Ges., Vol. XXXVI, Zürich 1910, S. 964 und 1143.

${ }^{2}$ H. G. Stehlin, Ibidem, I. c., 1910, p. 1065.

3 J. L. Wortman, The Extinct Camelidae of North America, and Some Associated Forms. - Bull. Amer. Mus. Nat. Hist., New York, Vol. X, 1898, p. 104.

${ }^{4} \mathrm{~W}$. B. Scott, On the Osteology of Poëbrotherium; A Contribution to the Phylogeny of the Tylopoda. - Journal of Morphology, Vol. V, 1891, p. 1.

5 J. L. Wortman, 1. c., 1898, p.. 115.

${ }^{6}$ J. L. Wortman, 1. c. p. 122. 
Camelus dürfte über die Zwischenform Pliauchenia von Protolabis abgezweigt sein. ${ }^{1}$

\section{F. Tragulidae.}

Schon bei den ältesten Traguliden, die zuerst im europäischen Oligozän auftreten und heute durch die Gattung Tragulus vertreten sind, fehlen alle oberen Schneidezähne und der obere erste Prämolar, während erst viel später auch der erste untere Prämolar verloren geht. Der obere Canin ist säbelartig geformt, der untere funktioniert als Schneidezalnn. Die Ulna bleibt frei; bei den tertiären Formen sind zuerst noch alle Metapodien getrennt, aber bei der obermiozänen und unterpliozänen Gattung Dorcatherium verschmelzen die hinteren Metapodien zu Kanonenbeinen.

Cryptomeryx. - Phosphorite des Quercy in Frankreich (Oligozän). ${ }^{2}$

Dorcatherium. - Obermiozän und Unterpliozän von Europa, Unterpliozän Ostindiens. ${ }^{3}$ Hyaemoschus und Tragulus lebend; der letżtere schon inı Pliozän Ostindiens.

\section{F. Hypertragulidae.}

Die erloschenen Hypertraguliden waren auf Nordamerika beschränkt; sie sind nur aus dem Oligozän bekannt. Der untere Eckzahn funktionierte als Schneidezahn. Die oberen Eckzähne fehlten schon den ältesten Gattungen dieser Fanilie, welche noch geweihlos waren; bei Blastomeryx aus dem Unterpliozän von Nebraska war ein von Haut bedecktes Geweih vorhanden. Die Mittelfußknochen waren schon bei Leptomeryx verschmolzen, aber die Mittelhandknochen vereinigten sich erst bei Blastomeryx zu einem Kanonenbein.

Leptomeryx. - Oligozän Nordamerikas. ${ }^{4}$

Blastomeryx. - Miozän und Unterpliozän Nordamerikas (Fig.610). Nach Matthew soll Blastomeryx der Alne der Hirscligattung Mazama sein, die sonach in diese Familie einzureihen wäre. ${ }^{4}$

1 Die Literatur über diese Gattung (bis 1902) findet sich bei O. P. Hay, Bibliography and Catalogue of the Fossil Vertebrates of North America. - Bull. Nr. 179 of the U. S. Geological Survey, Washington 1902, p. 677.

${ }^{2}$ M. Schlosser, Beiträge zur Stammesgeschichte der Huftiere und Versuch einer Systematik der Paar- und Unpaarhufer. - Morphologisches Jahrbuch, XII. Bd., 1886 , S. 93.

3 Die Literatur über Dorcatherium (Syn.=Hyaemoschus p. p.) findet sich (bis zum Jahre 1896) bei O. Roger, Verzeichnis der bisher bekannten fossilen Säugetiere. - Berichte des naturwiss. Vereins für Schwaben und Neuburg, XXXII. Bd., Augsburg 1896, S. 225-226.

4 W. D. Matthew, Osteology of Blastomeryx and Phylogeny of the American Cervidae. - Bull. Amer. Mus. Nat. Hist., Vol. XXIV, 1908, p. 535. 


\section{F. Cervidae.}

1. Subf. Gelocinae.

Die Gruppe der durch Gelocus und verwandte Gattungen vertretenen Gelocinen wurde früher vielfach als Subfamilie der Traguliden betrachtet, aber Stehlin tritt für eine engere Vereinigung dieser Gruppe mit den Hirschen, Giraffen und Rindern ein. Bei Gelocus sind die mittleren Metapodien zu einem Kanonenbein verwachsen, während die seitlichen $z u$ oberen und unteren griffelförmigen Rudimenten ver-

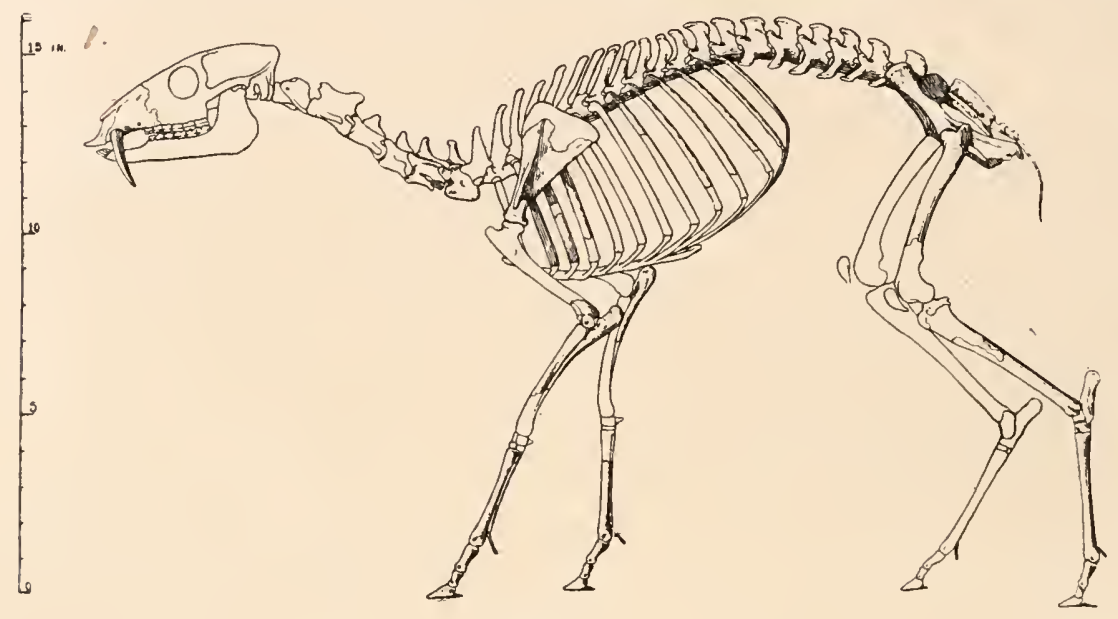

Fig. 610.

Skelett von Blastomeryx advena (rekonstruiert), aus den oberen' RosebudBeds (Miozän) der Indianer Reservation „Pine Ridge“ in Süd-Dakota.

(Nach W. D. Matthew.)

künmmert sind. Man bezeichnet jenen Reduktionstypus der Seitenfinger, bei dem nur die oberen Griffelrudimente der Seitenfinger übrig geblieben sind, als „plesiometacarpal“, jenen dagegen, bei dem nur die unteren erhalten sind, als "teleometacarpal“. Gelocus ist also gleichzeitig ,plesiometacarpal" und ,teleometacarpal“.

Gelocus. - Oligozän (vielleicht schon im obersten Eozän) Europas. ${ }^{1}$

\section{Subf. Protoceratinae.}

Dieser ausgestorbene Zweig der Hirsche ist auf Nordanerika beschränkt, wo er vom oberen Eozän bis zum oberen Oligozän lebte. Der Schädel trug mächtige, jedenfalls von Haut und Fell überzogene Schädelzapfen, die bei der ältesten Gattung Camelomeryx noch fehlten, aber bei den jüngeren mächtig entwickelt sind; ein Paar dieser Schädelzapfen

1 W. Kowalevsky, Osteologie des Genus Gelocus. - Palaeontographica, XXIV. Bd., 1876, p. 187. 
steht ober den Augenhöhlen, das vordere, zweite, auf den Oberkiefern und Stirnbeinen (Protoceras) oder auf den Nasenbeinen (Syndyoceras) und zwar haben die Männchen größere und höhere Schädelzapfen besessen.

Camelomeryx. - Obereozän Nordamerikas. ${ }^{1}$

Protoceras. - Oberoligozän Nordamerikas (Fig. 611).2

Syndyoceras. - Oberoligozän Nordamerikas. ${ }^{3}$

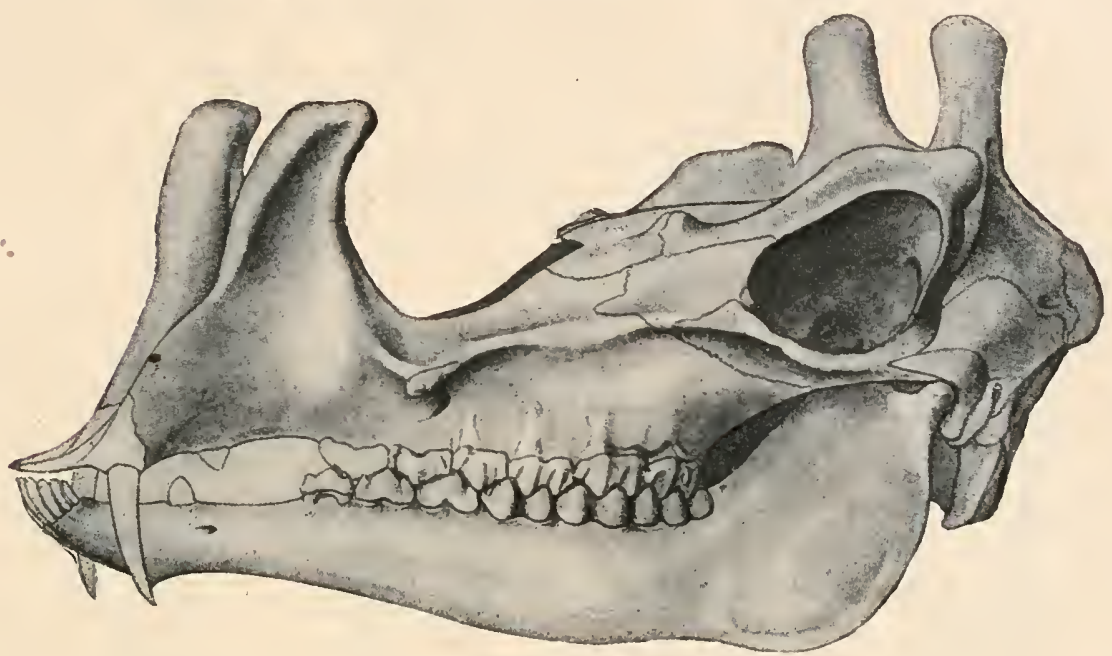

Fig. 611.

Schädel von Protoceras celer, Marsh, aus dem Oberoligozän von Süd-Dakota in Nordamerika. Ungefähr $1 / 2$ nat. Gr. (Nach O. C. Marsh.)

3. Subf. Moschinae.

Die noch lebenden Moschushirsche erscheinen zuerst im Unterpliozän Ostindiens.

4. Subf. Cervulinaé.

Die noch lebenden Muntjakhirsche lebten vom Miozän bis zum Unterpliozän in Europa.

Amplitragulus. - Miozän Europas. - Geweihlos. ${ }^{4}$

1 W. B. Scott, The Selenodont Artiodactyls of the Uinta Eocene. - Transactions of the Wagner Free Inst. Science, Philadelphia, Vol. VI, 1899, p. 67.

2 O. C. Marsh, Principal Characters of the Protoceratidae. - American Journal of Science, Vol. IV, 1897, p. 165.

${ }^{3}$ H. F. Osborn, The Age of Mammals. - New York, 1910, p. 236, 237.

4 Die Literatur iiber diese Gattung vgl. bei O. Roger, Berichte des naturwissenschaftlichen Vereins fïr Schwaben und Neuburg, XXXI1. Bd., Augsburg 1896, p. 227 sowie bei E. L. Trouessart, Catalogus Mammalium usw., 1905. 
A.

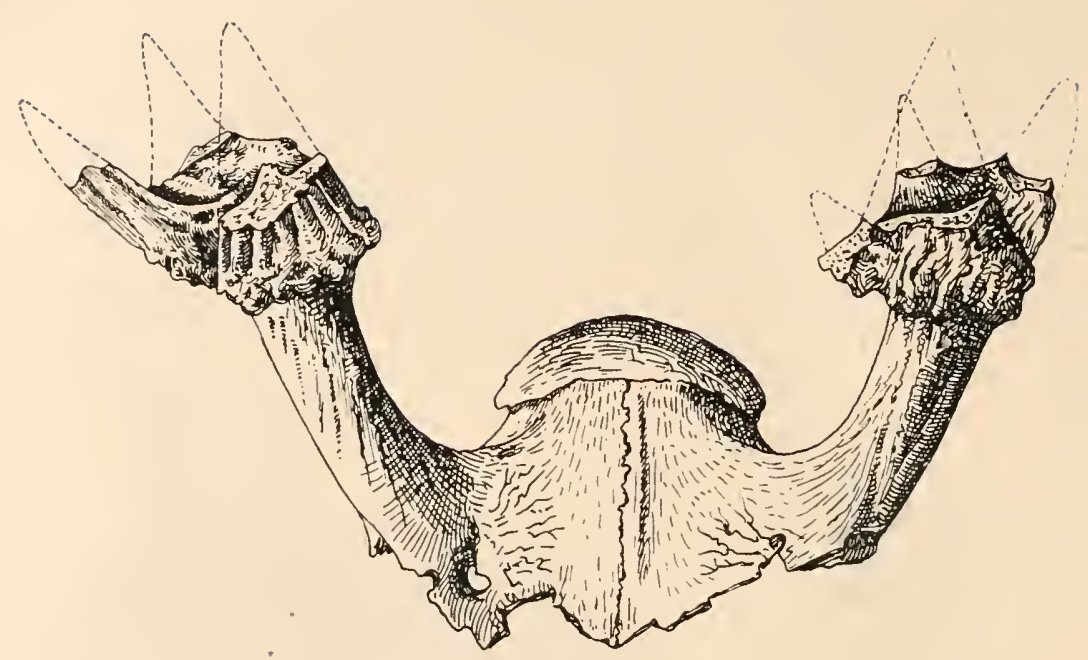

B.
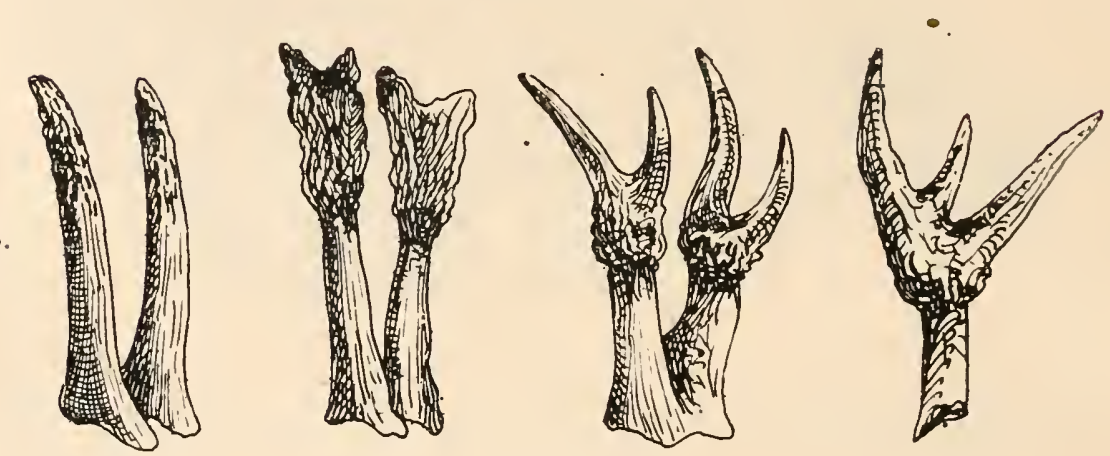

Fig. 612 .

A. Geweilı von Dicroceros elegans, Lartet, aus den Miozän Frankreichs. $3 / 5$ nat. Gr. (Nach H. Filhol.)

B. Vier Geweihe von Dicroceros furcatus, Hensel, aus dem Miozän von Steinheim in Württemberg. Alle vier Figuren in $1 / 3$ nat. Gr. (Nach O. Fraas.)

Palaeomeryx. — Miozän Europas. - Geweihlos. ${ }^{1}$

Dicroceros. - Miozän Europas, Ein zwei- bis dreisprossiges, wahrscheinlich persistentes Schädelzapfenpaar vorhanden; der Rosenstock lag hoch über dem Schädeldach (Fig. 612). ${ }^{2}$

${ }^{1}$ M. Schlosser, Beiträge zur Kenntnis der Säugetierreste aus den süddeutschen Bohnerzen. - Geologische und paläontologische Abhandlungen, Jena 1902, IX. Bd., S. 67. (Hier die wichtigste ältere Literatur.)

2 E. Kiernik, Über ein Dicrocerosgeweih aus Polen. - Bull. Acad. Sciences de Cracovie (B), Krakau 1913, S. 449 (Literatur!). 
Cervavus. - Unterpliozän Chinas. Wahrscheinlich der Stammvater der modernen Rehe und echten Hirsche (Fig. 613). ${ }^{1}$

5. Subf. Cervinae.

Der älteste Vertreter dieser Gruppe, die man als die ,echten Hirsche" bezeichnet, ist in Unterpliozän Südrußlands gefunden worden.

Procervus. - Unterpliozän von Petrovierovka in Südrußland. (Fig. 614). ${ }^{2}$

Capreolus. - Seit dem Unterpliozän (Pikerni in Attika) in Europa. ${ }^{3}$

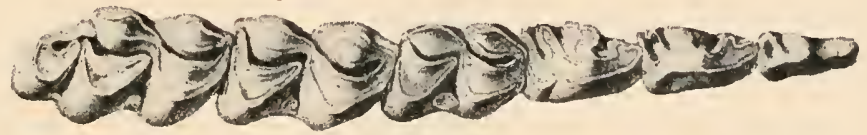

Fig. 613.

Backenzahnreihe des rechten Unterkiefers von Cervavus Oweni Koken, aus mehreren Exemplaren kombiniert. Aus den rötlichen Sanden (Pliozän der Provinzen Tientsin, Honan, Hupch (I'tschang) und Schansi in China bekannt. Nat. Gr. (Nach Max Schlosser, 1903.)

Elaphus. - Seit dem oberen Pliozän Europas bekannt. Megaceros. - Plistozän Europas (,,Riesenhirsch") (Fig. 599). ${ }^{4}$

\section{F. Giraffidae (= Camelopardalidae).}

1. Subf. Giraffinae.

Die Giraffinen stammen wahrscheinlich von großen Palaeomeryxarten des europäischen Miozäns ab, wälırend die Sivatheriinen möglicherweise von den Protoceratinen abzuleiten sind. Sollte sich diese Annahme als richtig herausstellen, so müßten beide Unterfamilien als selbstständige Familien unterschieden werden, um nicht einen Beweis für die eventuelle Behauptung abgeben $z u$ können, daß die Giraffiden ,,polyphyletischen Ursprungs" sind. Der Schädel der Giraffen ist entweder hornlos oder trägt ein bis zwei Paar Knochenzapfen. Die hinteren Knochenzapfen stehen entweder auf den Stirnbeinen allein (Okapia,

1 M. Schlosser, Die fossilen Säugetiere Chinas nebst einer Odontographie der rezenten Antilopen. - Abhandlungen der Kgl. Bayrischen Akademie der Wissenschaften, II. K1., Vol. XXI1, München 1903, S. 116.

${ }^{2}$ A. Alexejew, Nouvelle Espèce des Cerfs fossiles des Environs du village Petrovierovka. — Odessa 1913.

${ }^{3}$ W. Dames, Hirsche und Mäuse von Pikermi in Attika. - Zeitschrift der Deutschen Geol. Ges., 1883, S. 92.

4 K. Hescheler, Der Riesenhirsch. - Neujahrsblatt der Naturforschenden Gesellschaft in Zürich, 1909, 111. Stück (Literatur). 
Samotherium) oder auf den Stirnbeinen und Scheitelbeinen, während das vordere Zapfenpaar auf den Nasen- und Stirnbeinen steht.

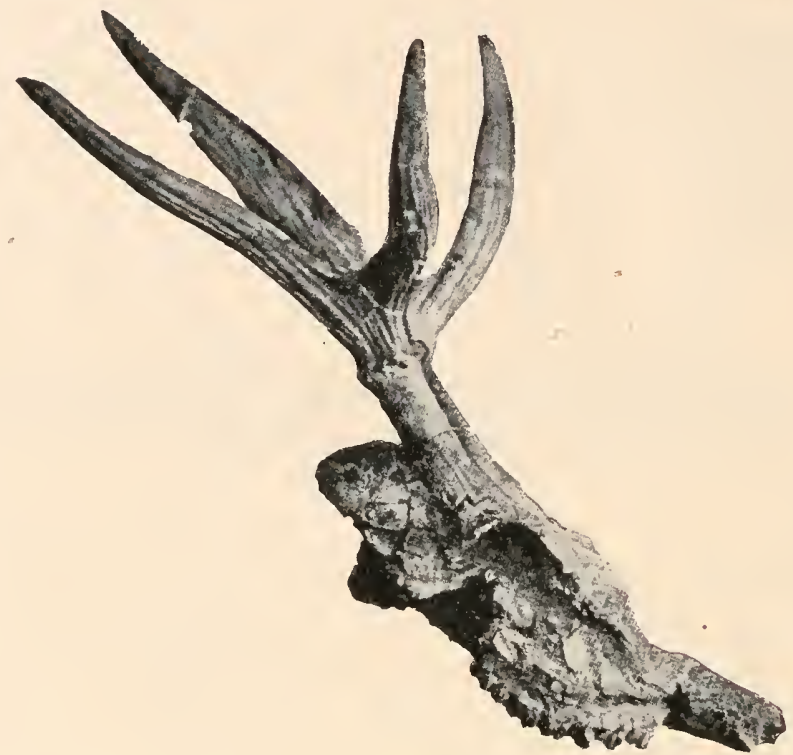

Fig. 614 .

Schädel eines jungen Exemplars (,Gablerhirsch“) von Procervus variabilis Alex. aus dem Unterpliozän von Petrovierovka in Siidrußland. $1 / 4$ nat. Gr. (Nach A. Alexejew.)

Die ersten Giraffen erscheinen im Unterpliozän Eurasiens. Helladotherium. - Unterpliozän von Griechenland, Südrußland, Ostindien und Persien. ${ }^{1}$

Samotherium. - Unterpliozän von Griechenland, Südrußland, Persien und China. ${ }^{2}$

1 A. Gaudry, Animaux fossiles et Géologie de l'Attique. Paris 1862.

Guy E. Pilgrim, The Fossil Giraffidae of India. - Palaeontologia Indica, Calcutta 1911, p. 11.

${ }^{2}$ C. I. Forsyth-Major, On the Fossil Remains of Species of the Family Giraffidae. - Proceedings Zoological Society, London 1891, p. 317.

Derselbe, On the Okapi. - Ibidem, 1902, p. 73 (Fig. 6, 9, 10, 13) und p. 348 .

E. Stromer beschreibt in den Abhandlungen der Senckenbergischen Gesellschaft zu Frankfurt a. M. (XXIX. Bd., 2. Heft, 1905, S. 118) Reste eines fossilen Giı affiden aus dem Mittelpliozän Ägyptens, die vielleicht zu Samotherium gehören. Eine gute Ưbersicht über die pliozänen Giraffiden Rußlands gibt J. Khomenko, La Faune méotique du village Taraklia dı district de Bendery. - Annuaire géologique et minéralogique de la Russie, Vol. XV, 1913, p. 107. 
Camelopardalis. - Unterpliozän von Griechenland (Pikermi und Samos), Südrußland, Persien (Maragha), (Siwalik Hills), China (Schansi und Sztschwan) und lebend (Afrika). ${ }^{1}$

2. Subf. Sivatheriinae.

Der Schädel der Sivatheriinen trug mächtige Knochenzapfen an der Grenze der Stirn- und Scheitelbeine. - Am besten bekannt ist Sivatherium. - Unterpliozän der Siwalik Hills in Ostindien und von Adrianopel (Fig.615). ${ }^{2}$

\section{F. Antilocapridae.}

In Oligozän Nordamerikas ist der bis jetzt älteste Vertreter dieser Familie gefunden worden. Die Familie ist stets auf Nordamerika beschränkt geblieben.

Hypisodus. - Oligozän (White River Beds) Nordanerikas. In den vorderen Greifzahnabschnitt des Unterkiefers sind nicht nur die drei Inzisiven, sondern auch der Eckzahn und der vorderste Prämolar einbezogen, der von dem dritten Prämolaren (der zweite fehlt) durch eine weite Lücke getrennt ist. Der Schädel war hornlos. ${ }^{3}$

Merycodus. - Mittelmiozän bis Pliozän Nordamerikas. - Der Scliädel trug ein hohes Geweih, das wahrscheinlich persistierte. ${ }^{4}$

Antilocapra. - Plistozän Nordamerikas. Lebend in Nordamerika.

\section{F. Cavicornia.}

Bei allen „Hohlhornträgern“ felılen die oberen Schneidezälne und Eckzälnne, die oberen und unteren ersten Prämolaren und zuweilen auch die oberen und unteren zweiten Prämolaren; der untere Eckzalın ist in den Greifzahnabschnitt mit einbezogen.

1 A. Gaudry, Animaux fossiles et Geologie de l'Attique. - 1. c.

Guy E. Pilgrim, The Fossil Giraffidae of India, 1. c., 1911 (Literatur).

A. Rodler und A. Weithofer, Die Wiederkäuer der Fauna von Maragha. Denkschriften der Math.-Nat. Klasse der Wiener Akademie der Wissenschaften, LVII. Bd., 1890.

M. Schlosser, Die fossilen Säugetiere Chinas. - 1. c., 1903.

2 O. Abel, Über einen Fund von Sivatherium giganteum bei Adrianopel. Sitzungsberichte der Wiener Akademie der Wissenschaften, CXIII. Bd., Wien 1904, S. 629 (Literatur!).

Guy E. Pilgrim, Fossil Giraffidae of India, I. c., 1911, p. 22.

${ }^{3}$ W. D. Matthew, The Skull of Hypisodus, the Smallest of the Artiodactyla, with a Revision of the Hypertragulidae. - Bull. Amer. Mus. Nat. Hist., New York, Vol. XVI, 1902, p. 311.

${ }^{4}$ W. D. Matthew, A Complete Skeleton of Merycodus. - Ibidem, Vol. XX, 1904, p. 101.

J. C. Merriam, A Peculiar Horn or Antler from the Mohave Miocene of California. - University of California Publications, Bull. Depart. Geology, Berkeley, Vol. VII, Nr. 16, 1913, p. 335. 
Diese Familie der Huftiere ist die weìtaus formenreichste und steht gegenwärtig in voller Blüte. Man unterscheidet zwei Unterfamilien; die erste (Aegodontia) umfaßt die Neotraginae, Gazellinae (Gazellen), Rupicaprinae (Gemsen), Ovicaprinae (Schafe und Ziegen) und Ovibovinae (Moschusochsen); die zweite (Boodontia), die wahrscheinlich von

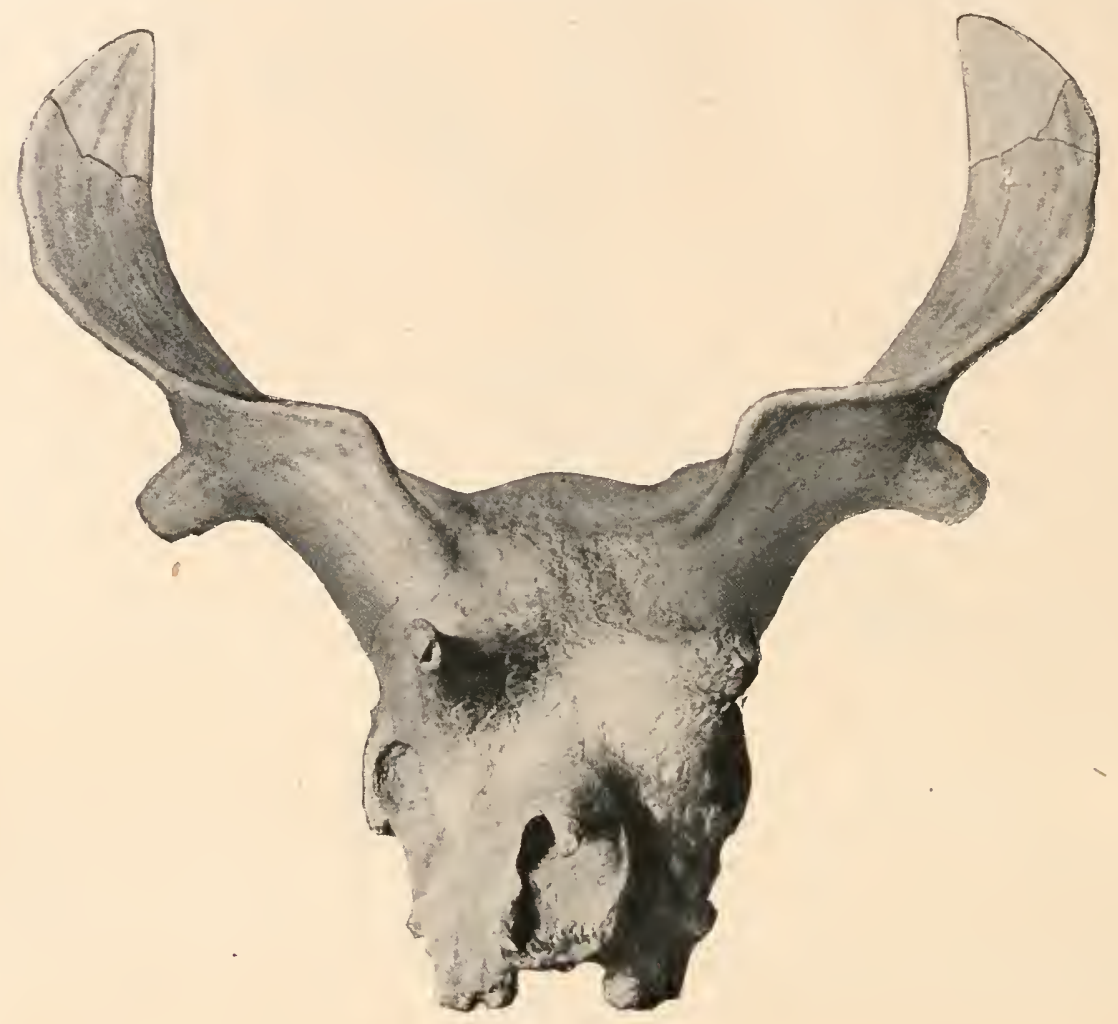

Fig. 615.

Schädel von Sivatherium giganteum, Falc. et Cautl., aus dem Pliozän der Siwalikberge in Ostindien. Die Schädelzapfen sind nach einem isoliert gefundenen Exemplar rekonstruiert und der photograph. Abbildung des Gipsabgusses des Originalschädels im Brit. Museum in London angefügt. $1 / 12$ nat. Gr. (Nach O. Abel.)

geweihlosen Hirschen der Miozänzeit abstammt, umfaßt die Unterfamilien der Pseudotraginae (ausgestorben), Cephalophinae, Bubalidinae, Hippotraginae, Cervicaprinae, Tragelaphinae und Bovinae.

\section{Ordnung: Amblypoda.}

Die Amblypoden stammen von den Pantolambdiden, einer Gruppe aus der Stammgruppe der Protungulata, ab und haben schon im unteren Eozän eine bedeutende Spezialisationshöhe erreicht. Sie sind zu dieser Zeit (Wasatch-Beds = Untereozän) die größten Landsäugetiere; im 
Mitteleozän lebten in Nordamerika einzelne Arten, welche die Größe eines Elefanten erreichten. Nur ein Seitenzweig der Amblypoden, die Coryphodontiden, ist nach Europa ausgewandert, aber auch hier bald erloschen, während die von den Coryphodontiden abgezweigten Dinoceratiden ihre Heimat niemals verlassen zu haben scheinen, da man illre Reste nur aus Nordamerika kennt.

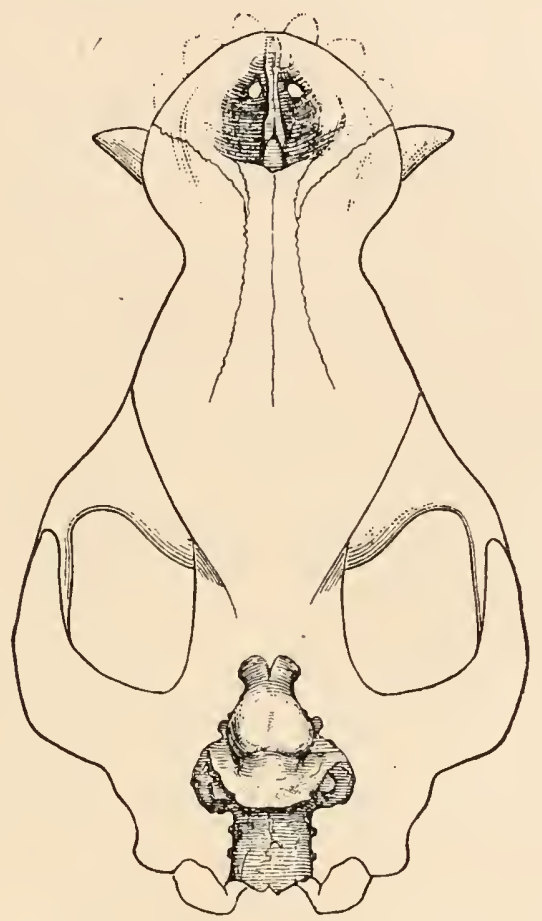

Fig. 616.

Schädel von Coryphodon hamatus mit eingezeichneter Ausfïllung des Hirnhöhlenraumes, um das Größenverhältnis zwischen Gehirn und Schädel zu zeigen. Etwa in $1 / 5$ der nat. Gr. (Nach O. C. Marsh.)

Die Gliedmaßen der Amblypoden waren ähnlich gestaltet und gebaut wie die der Elefanten. Das Gehirn blieb bei allen Amblypoden sehr klein.

\section{F. Coryphodontidae.}

Der Schädel der zu dieser Familie gehörenden Gattungen fällt besonders durch das Vorhandensein gewaltiger Eckzähne auf, die dem Schädel das Aussehen eines Raubtieres verleihen. Die Zähne stellen eine Weiterentwicklung des schon bei den Pantolambdiden zu beobachtenden Typus dar. Der Schädel war sehr groß, das Gehirn auffallend klein (Fig. 616). 
Aus dem Untereozän Nordamerikas sind zahlreiche Arten beschrieben worden.

Coryphodon. - Untereozän (Wasatch) und Mitteleozän (Wind River) Nordamerikas; Untereozän Englands und Frankreichs (Fig. 616). ${ }^{1}$

Bathyopsis. - Grenze des Untereozäns und Mitteleozäns (Basis der Wind River Beds) in Wyoming. - Unterkiefer sehr hoch. ${ }^{2}$

\section{F. Dinoceratidae.}

Schädel mit starken Knochenzapfen (zwei Paare: das vordere auf den Supramaxillaria, das hintere auf den Parietalia), sehr langen, mit Schneiden versehenen oberen Eckzähnen und einem an den Unterkiefer von Machairodus erinnernden lappenartigen Fortsatz des Unterkiefers. Die größten Formen wurden etwa 411 lang und dürften im allgemeinen Habitus selır elefantenähnlich gewesen sein; auch die Stellung der säulenförmigen Beine muß dieselbe gewesen sein wie bei den Elefanten, wofür namentlich der Größenunterschied von Hand und Fuß spricht; die Hand war weit größer und kräftiger als der Hinterfuß, was mit der Verlegung der Körperlast auf die vordere Extremität zusammenhängt. Auch bei diesen Formen ist das Gehirn außerordentlich klein geblieben.

Uintatherium (= Dinoceras). - Mitteleozän und Obereozän (obere Bridger Beds und Washakie Beds) von Wyoming. ${ }^{3}$

Loxolophodon (= Tinoceras). - Dieselbe Verbreitung wie Uintatherium. Beiden Gattungen werden zahlreiche Arten zugeteilt. ${ }^{*}$

\section{Ordnung: Hyracoidea.}

Diese sehr alte und primitive Ordnung der Huftiere ist heute auf Afrika besclıränkt. In Ägypten sind zahlreiche fossile Arten im Oligozän entdeckt worden, die sich auf mehrere Gattungen verteilen und sehr verschiedenen Zahnbau aufweisen. ${ }^{5}$ Aus dem Pliozän von Pikermi und

${ }^{1}$ Die umfangreiche Literatur ïber Coryphodon findet sich zusammengestellt bei O. P. Hay, Bibliography and Catalogue of the Fossil Vertebrates of North America. - Bull. U. S. Geol. Survey, Nr. 179, Washington 1902, p. 697.

2 O. P. Hay, 1. c., p. 700 .

H. F. Osborn, The Skull of Bathyopsis, Wind River Uintathere. - Bull. Amer. Mus. Nat. Hist., Vol. XXX11, 1913, p. 417.

3 O. C. Marsh, Dinocerata, a Monograph of an Extinct Order of Gigantic Mammals. - U. S. Geological Survey, Vol. X, Washington 1884.

O. C. Marsh, I. c.

${ }^{5}$ M. Schlosser, Beiträge zur Kenntnis der oligozänen Landsäugetiere aus dem Fayum (Ägypten). - Beiträge zur Paläontologie und Geologie Österreich-Ungarns und des Orients, XXIV. Bd., Wien 1911, S. 95. 
Samos ist eine Art der Gattung Pliohyrax bekannt geworden. ${ }^{1}$ Sowohl diesé Gattung wie jene aus dem Oligozän Ägyptens werden der Familie der Saghatheriiden eingereilıt, während von der durch die lebenden Gattungen vertretenen Fanilie der Hyraciden noch keine fossilen Vertreter bekannt sind.

\section{Ordnung: Embrithopoda.}

Diese Gruppe ist bisher nur durch eine einzige Gattung aus dem Oligozän Ägyptens bekannt, die eine höchst eigenartige Ṣpezialisation aufweist und eine ganz isolierte Stellung einnimmt; die Embrithopoden dürften aus einer Ahnenform hervorgegangen sein, die Merkmale der Hyracoidea und der Proboscidea verband, die einander sehr nahe verwandt sind und auch mit den Sirenen in engen genetischen Beziehungen stehen.

Das auffallendste Merkınal des fast vollständig bekannten Skelettes von Arsinoitherium sind die gewaltigen Protuberanzen des Schädels, die eine ganz eigenartige Stellung und Richtung aufweisen. Diese Zapfen entspringen von den Nasenbeinen und richten sich nach vorne; hinter ihnen steht noch ein Paar kleinerer Stirnzapfen. Der schwere Schädel wurde tief gesenkt getragen, so daß die Zapfen fast horizontal nach vorne abstanden'. Ebenso wie bei den Amblypoden und Proboscidiern waren die Arme kräftiger gebaut als die Hinterbaine, ebenso auch die Hände stärker und größer als die Füße.

Arsinoitherium. - Unteres Oligozän (fluviomarine Schichten) Ägyptens (Fig. 617). ${ }^{2}$

\section{Ordnung: Proboscidea.}

Die Rüsseltiere oder Proboscidier bilden eine höchst eigenartig spezialisierte Gruppe der Huftiere, deren Wurzeln noch nicht mit voller Sicherheit ermittelt werden konnten. Die ältesten Rüsseltiere erscheinen mit Moeritherium im Obereozän Ägyptens; die tertiären Vertreter dieses Stammes sprechen durch ihre geographische Verbreitung dafür, daß die ursprüngliche Heimat in Afrika zu suchen ist, von wo aus die verschiedenen Zweige zuerst naclı Europa und Asien und später auch nach Nordamerika, zuletzt sogar bis Südamerika ausgestrahlt sind. Sicher stehen die Proboscidier in engen verwandtschaftlichen Be-

1 C. I. Forsyth-Major, The Hyracoid Pliohyrax graecus from Samos and Pikermi. - Geological Magazine, 1899, p. 548.

M. Schlosser, 1. c., p. 111.

2 C. W. Andrews, A Descriptive Catalogue of the Tertiary Vertebrata of the Fayûm, Egypt. -- London 1906, p. 1. 
ziehungen zu den Sirenen und wurzeln wahrscheinlich ebenso wie diese in der Stammgruppe der Protungulata, doch fehlen heute noch die verbindenden Zwischenglieder, die im unteren Tertiär Afrikas zu suchen sein dürften.

Die weitgehendsten Spezialisationen hat das Gebiß und der Schädel der Proboscidier erfahren. Bei der ältesten Gattung Moeritherium (Fig. 618) ist es noch fast vollständig, da nur der untere dritte Schneidezahn $\left(\mathrm{I}_{3}\right)$,

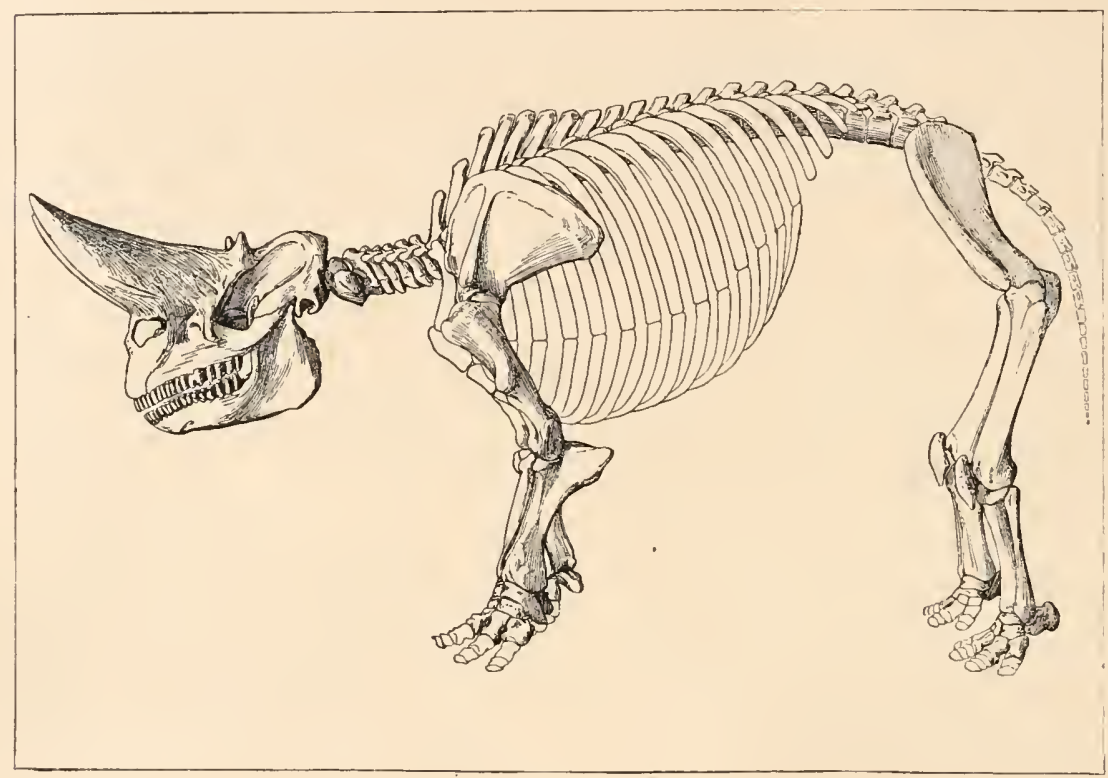

Fig. 617.

Skelettrekonstruktion von Arsinoitherium Zitteli, Beadnell, aus dem Unteroligozän von Ägypten, in $1 / 32$ nat. Gr. (Nach C. W. Andrews.)

der untere Canin, sowie der obe ${ }_{1} e$ und untere erste Prämolar $\left(\mathrm{P}^{1}\right.$ und $\left.\mathrm{P}_{1}\right)$ verloren gegangen sind, aber die übrigen Zähne noch in gleichzeitig funktionierender Reihe in den Kiefern stehєn. Die Vergrößerung des oberen und unteren zweiten Schneidezahns $\left(1^{2}\right.$ und $I_{2}$ ) zeigt bereits den Weg, den die Spezialisierung des Schneidezahnabschnittes bei den jüngeren Proboscidiern eingeschlagen hat, aber in der Schädelform und namentlich durch die weit vorne liegenden Augenhöhlen weicht Moeritherium stark von den mit Palacomastodon (Fig. 619) beginnenden jüngeren Stämmen cier Rüsseltiere ab.

Sehr frühzeitig werden die Schneidezähne auf ein oberes und ein unteres Paar reduziert; bei den Dinotheriiden bleibt nur das untere Paar $\left(\mathrm{I}_{2}\right)$ erhalten, bei den übrigen Stämmen bleiben zuerst oben und 
unten die zweiten Schneidezähne in Funktion, bis bei den echten Elefanten die unteren Stoßzähne verkümmern, ein Weg, der auch bei einigen Seitenzweigen der Mastodonten (z. B. Reihe des Mastodon arvernensis und des $M$. americanus) eingeschlagen erscheint.

Die Backenzähne erfahren bei den verschiedenen Familien der Proboscidier eine verschiedenartige Spezialisierung. Ursprünglich (Moeritherium) waren die Molaren oligobunodont (Fig. 620) oder oligolophodont; den oligolophodonten Typus behalten sie in der Fanilie der

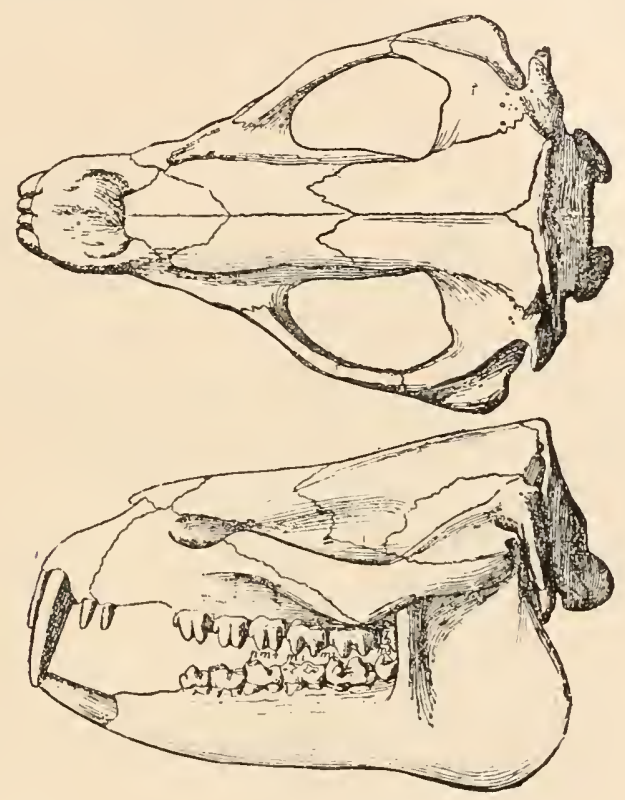

Fig. 618.

Schädel von Moeritherium Lyonsi, Andr., dem ältesten bisher bekannten Proboscidier, aus dem Eozän Ägyptens. Schädellänge $37 \mathrm{~cm}$. (Nach C. W. Andrews.)

Barytheriiden und Dinotheriiden (Fig. 621) bei, aber bei den Elephantiden treten sowohl Höckerzähne (suider Typus) als Jochzähne (tapiroider Typus) auf. Aus den oligobunodonten Backenzälınen entwickelten sich polybunodonte (Fig. 622), aus den oligolophodonten (Fig. 623) Typen polylophodonte (Fig. 624, 625). Die Zahl der Joche wächst durch Neubildung von Jochen am Hinterende der Zähne beträchtlich an und steigt beim Mammut (Elephas primigenius) bis zu einer Zahl von 27 Querjochen im létzten oberen Molaren (hyperlophodonter Typus). Diese Differenz der Kronenform ist durch eine verschiedene Funktion des Gebisses bedingt, die bei den höckerzähnigen Elephantiden im wesentlichen eine mahlende, bei den jochzähnigen eine 


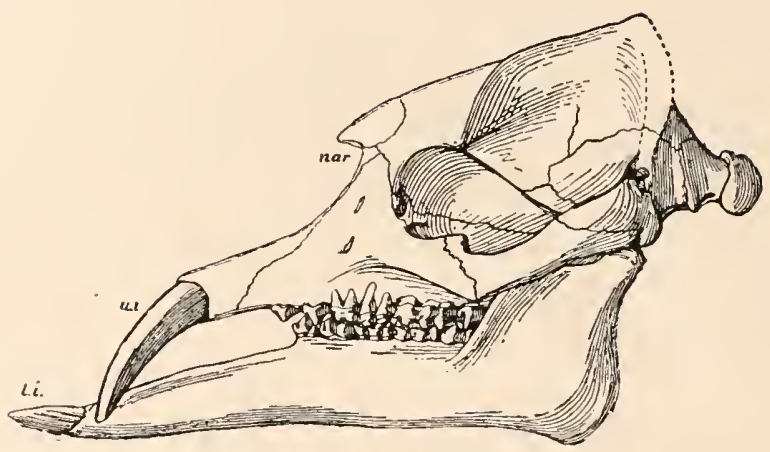

Fig. 619.

Schädel von Palaeomastodon Beadnelli, Andr., aus dem Unteroligozän Ägyptens. Etwa $1 / 12$ nat. Gr. (Nach C. W. Andrews.)

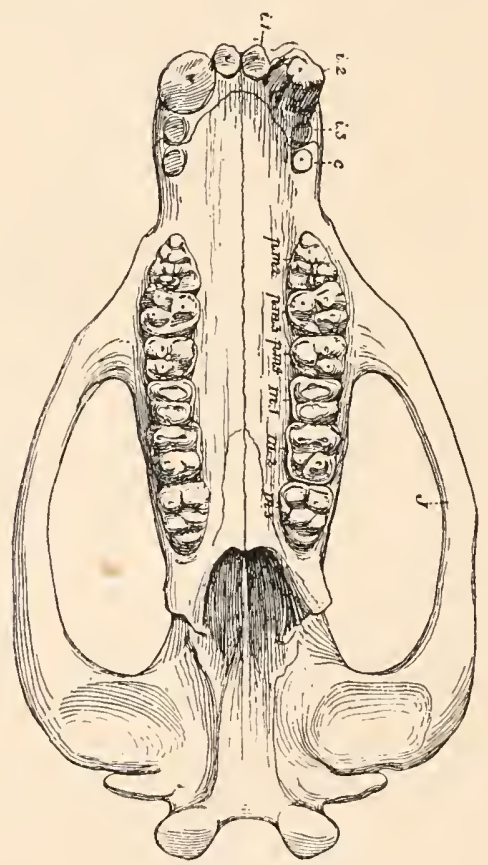

Fig. 620 .

Oligobunodonter Molarentypus der Proboscidier: Obergebiß von Moeritherium Lyonsi, Andr., von der Kaufläche gesehen (vgl. Fig. 618.) (Nach C. W. Andrews.)

quetschende war. Aus den jochzähnigen Mastodonarten sind (aus Mastodon latidens über die indische Gattung Stegodon) die echten Elefanten hervorgegangen, deren Entstehung in das Mittelpliozän fällt. 


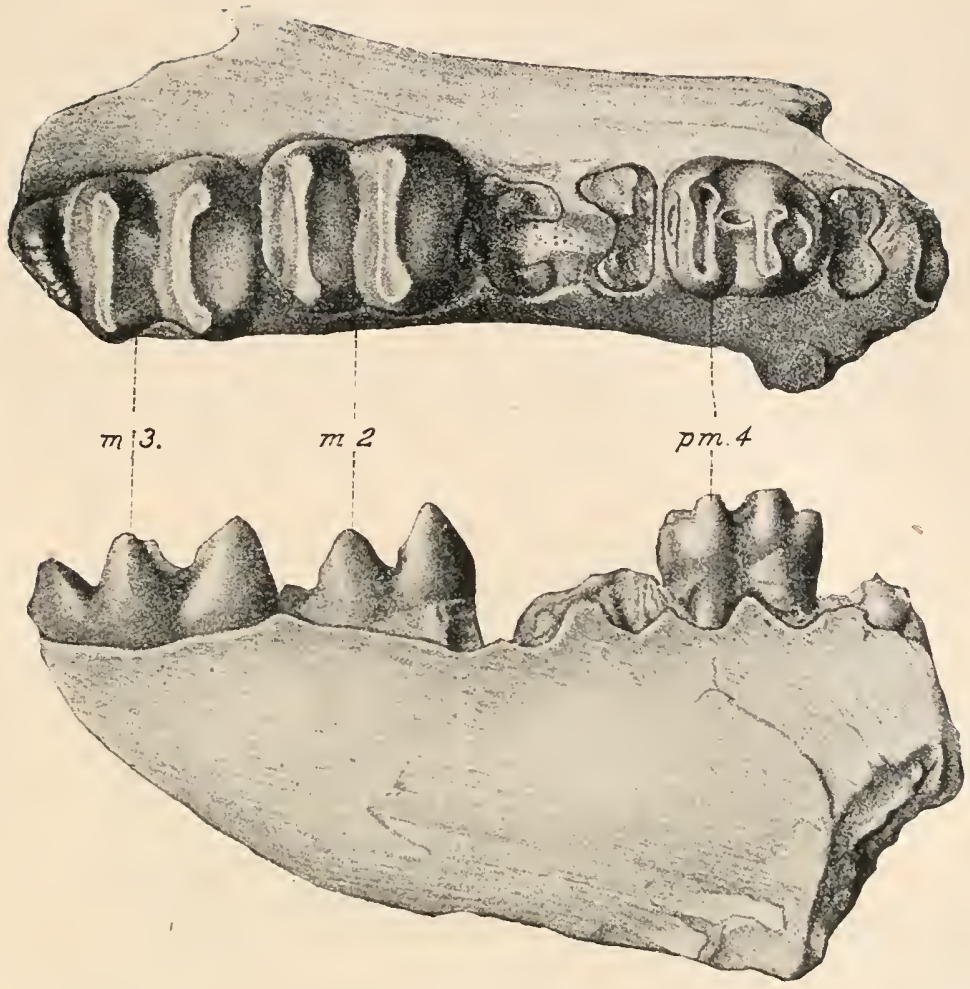

Fig. 621 .

Oligolophodonter Molarentypus der Proboscidier: Fragment des linken Unterkieferastes von Dinotherium Hobleyi, Andr., aus dem Miozän von Karungı (Ostseite des Viktoria-Nyanza) in Britisch-Ostafrika. 1/3 nat. Größe.

(Nach C. W. Andrews.)

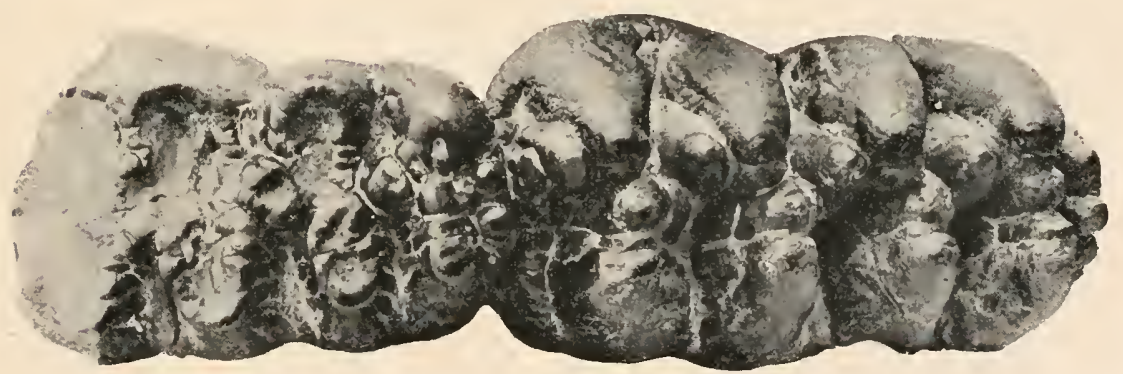

Fig. 622 .

Polybunodonter Molarentypus der Proboscidier. Die beiden vorderen Molaren $\left(M^{1}\right.$ und $M^{2}$ ) des rechten Oberkiefers von Mastodon arvernensis Croizet et Jobert aus den oberpliozänen Ligniten von Illyefalva (Szent-Királyi) in Siebenbïrgen, Original in der Sammlung des Honterusgymnasiums in Kronstadt (Siebenbïrgen). Ungefähr $2 / 3$ der nat. Gr. (Nach F. Toula, 1911.) 
Die lebende Gattung Elephas zerfällt in die Untergattungen Euelephas (E. maximus, der indische Elefant) und Loxodon (L. africanus, der afrikanische Elefant). Zu Loxodon gehört die eiszeitliche Type E. antiquus, ebenso die kleinen ,Zwergelefanten“ aus dem Plistozän der Mittelmeerinseln (Malta, Sizilien, Cypern, Kreta), zu Euelephas das Mammut (E. prinigenius). Die größte fossile Elefantenart war E. meridionalis aus dem Pliozän Süd- und Mitteleuropas, der eine Schulterhöhe von $5 \mathrm{~m}$ erreichte.

Die Größenzunahme der Backenzähne bedingt eine durchgreifende Abänderung des Zahnwechsels bei den Elephantiden. Zuerst geht (bei Moeritheriumı) der vorderste Prämolar verloren, dann folgt

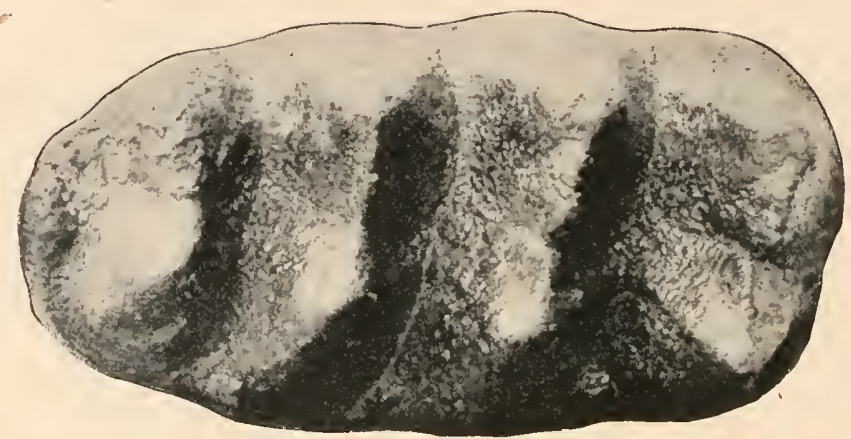

Fig. 623.

Molar von Mastodon brevidens, Cope, aus dem Oberpliozän von Montana (Nordamerika). $1 / 2$ nat. Gr. (Nach M. Pavlow.)

auch $\mathrm{P}_{2}$. Im Verlaufe der Stammesgeschichte gehen bei den Elefanten alle Prämolaren des Ersatzgebisses verloren und es bleiben nur mehr die Milchmolaren übrig, denen auch die sonst als ,bleibende“ Molaren bezeichneten Mahlzähne des fertigen Gebisses erwachsener Säugetiere angehören. Ursprünglich stehen die Backenzähne nebeneinander in einer Reihe und funktionieren gleiclızeitig. Mit dem Größenwachstum der Zähne und der Verkürzung der Kiefer ändert sich dics aber derart, daß die Molaren nacheinander in Funktion treten, so dab der jeweils abgekaute Za!n durch seinen hinteren Nachbar crsetzt und, wenn el zu unbrauchbaren Stummeln abgenützt ist, nach vorne aus der Kaufläche des Malılzahnabschnittes hinausgcdrängt wird. Mit dieser Ersatzart steht in Zusammenhang, daß die Mahlzähne zuerst anı Vorderende mit schräger Fläche angekaut werden.

Sehr eigenartig ist der Zahnbau bei den Desnostyliden, welche ich als eine Fanilie der Proboscidier betrachte; die Backenzälıne bestehen aus 12 bis 15 locker ancinandergefügten Zylindern mit dickem 


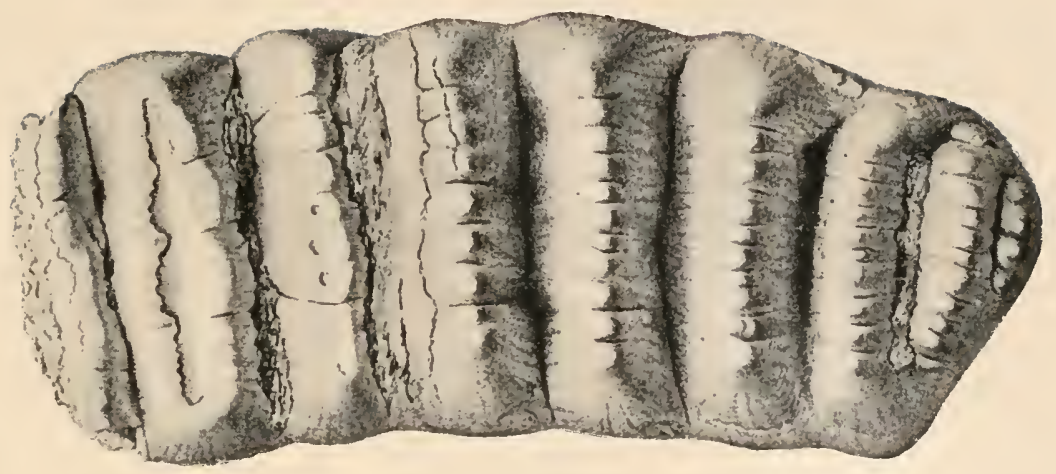

Fig. 624 .

Polylophodonter Molarentypus der Proboscidier. Linker unterer letzter Molar $\left(M_{3}\right)$ von Stegodon insignis, Falconer, angeblich aus Fokien (China). Das Alter dürfte nach Max Schlosser jünger sein als das der chinesischen Hipparionenfauna. Dieselbe Art ist aus dem Pliozän von Punjab und aus den Siwalik Hills, wahrscheinlich auch aus dem Plistozän des Narbadatales bekannt; sie ist ferner in Burma, China und Jảpan nachgewiesen worden. (Nach Max Schlosser, 1903.)
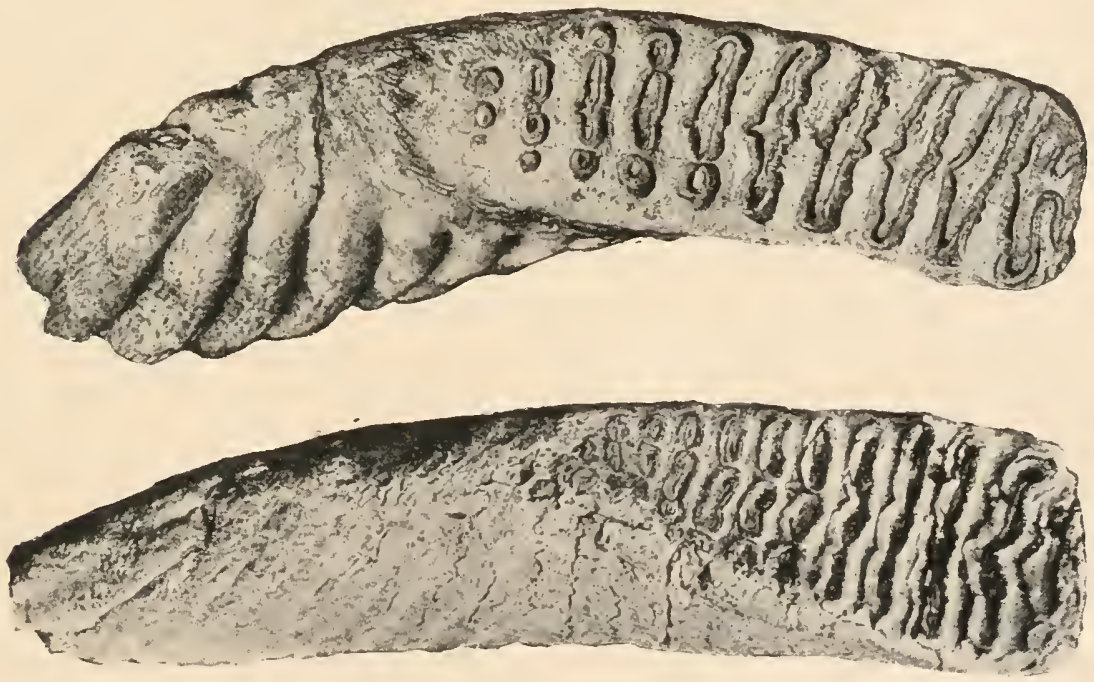

Fig. 625.

Oben: Elephas antiquus, Falconer. Dritter rechter Unterkiefermolar. Plistozän von Steinheim a. d. Murr, Wuirttemberg. Etwas kleiner als $1 / 2$ nat, Gr.

Unten: Elephas trogontherii, Pohlig. Dritter rechter Unterkiefermolar. Plistozän von Suissenborn. Ungefähr $1 / 2$ nat. Gr. (Nach W. Soergel.)

Schmelzbelag, ein Kronenaufbau, der unter den Säugetieren völlig isoliert dasteht. 
Die Extremitäten der Proboscidier differenzierten sich aus fünfzehigen Schreitbeinen zu Säulenbeinen, bei denen die Hand stärker ausgebildet erscheint als der Hinterfuß. Abweichend von den meisten übrigen Huftieren ist die Ulna im Arme der Elefanten stärker als der Radius, was mit der eigentümlichen Armstellung der Elefanten in Verbindung steht, bei denen das Ellbogengelenk nach vorne durchgedrückt und sozusagen ,,überknöchelt" erscheint.

\section{F. Moeritheriidae.}

Gebiß fast vollständig $\left(\frac{3 \cdot 1 \cdot 3 \cdot 3}{2 \cdot 0 \cdot 3 \cdot 3}\right)$. Augenhöhlen weit vorne gelegen, Backenzähne oligobunodont. Oberes und unteres zweites Schneidezahnpaar vergrößert. Größe die eines Tapirs.

Moeritlerium. - Obereozän und Unteroligozän Ägyptens (Fig. 618, 620). ${ }^{1}$

\section{F. Palaeomastodontidae.}

Gebiß stärker reduziert $\left(\frac{1 \cdot 0.3 .3}{1.0 .2 .3}\right)$. Schädelform bereits elefantenartig. Unterkiefersymphyse sehr lang, mit horizontal abstehenden, eine Schaufel bildenden Schneidezähnen. Palaeomastodon scheint nach neueren Untersuchungen eine selbständige Familie zu repräsentieren, die nicht als Vorstufe der Elephanticlen zu betrachten ist.

Palaeomastodon. - Oligrzän Ägyptens (Fig. 619)。 ${ }^{2}$

\section{F. Elephantidae.}

Gebiß noch weiter reduziert; bei den älteren Gattungen sind nocln Prämolaren vorhanden, die aber bald verloren gehen. Innerhalb der Elephantiden sind verschiedene Alnenreihen sicher festgestellt worden. Im Laufe der Stammesgeschichte erfahren namentlich der Unterkiefer, die Stcßzähne und die Schädelkapsel vielfache Veränderungen, die durch Übergänge derart verbunden sind, daß die Reihenfolge dieser Modifikationen vollkommen klar zutage liegt. So wird der bei Mastodon angustidens (Miozäı) sehr lange Schneidezahnabschnitt der Unterkiefersymphyse schon bei dem aus ihm hervorgegangenen $M$. longirostris

1 C. W. Andrews, A Descriptive Catalogue of the Tertiary Vertebrata of the Fayûm, Egypt. - London 1906, p. 99.

M. Schlosser, Beiträge zur Kenntnis der Landsäugetiere aus dem Fayum (Ägypten). - Beiträge zur Paläontologie und Geologie Österreich-Ungarns und des Orients, XXIV. Bd., Wien 1911, S. 129.

2 C. W. Andrews, 1. c. p. 130.

C. W. Andrewś, On the Skull, Mandible, and Milk Dentition of Palaeomastodon, with Some Remarks of the Tooth Change in the Proboscidia in General. Philosophical Transactions of the Royal Society, London, Vol. 199 (Ser. B), 1908, p. 393.

M. Schlosser, I. c., 1911, p. 135. 
(Unterpliozän) verkürzt und ist bei dem oberpliozänen Nachkommen von M. longirostris, M. arvernensis, rudimentär (Fig. 626), während die Länge der oberen Stoßzähne im selben Maße zunimmit (Fig. 594).

Die Mastodonten entwickelten sich aus afrikanischen Ahnenformen auf dem Boden Europas und Asiens, sind aber auch nach Amerika ausgewandert und lebten dort noch im Plistozän. Die echten Elefanten

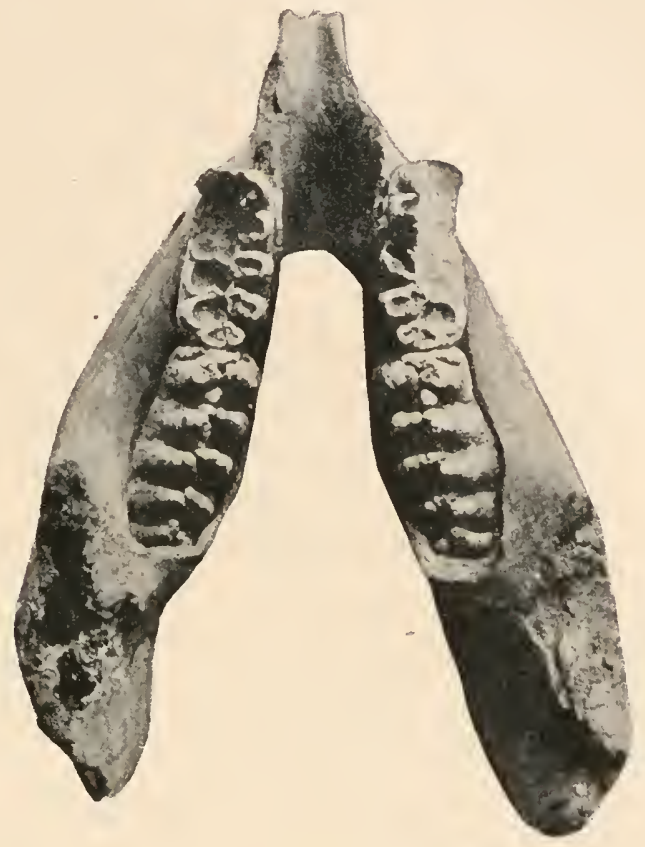

Fig. 626.

Unterkiefer von Mastodon arvernensis Croiz. et Job. aus dem Oberpliozän (Astigiano) von Cinaglio bei Asti in Oberitalien. Ungefähr 1/9 nat. Gr. (Nach G. Capellini, 1908.)

sind in Ostasien entstanden und von hier aus nach Europa, Afrika und Nordamerika ausgewandert.

Mastodon. - Von Miozän bis zum Oberpliozän in Europa und Asien; in Miozän in Nordamerika, später (nach Herstellung der Landbrücke zwischen Nord- und Südamerika im Mittelpliozän) auch nach Südamerika gelangt, wo noch im Plistozän einige Arten im Hochgebirge der Anden lebten. Auch aus dem Plistozän Südafrikas (ein einzelner Zahn) bekannt. - Zahlreiche Arten (Fig. 594, 622, 623, 626). ${ }^{1}$

1 Die Literatur iiber Mastodonten, die eine große Zahl von Arbeiten umfaßt, ist bei G. Schlesinger, Die Mastodonten des K. K. Naturhistorischen Hofmuseums. - Denkschriften des K. K. Naturhistorischen Hofmuseums in Wien, I. Bd., Wien 1917, nachzusehen. 
Stegodon. - Pliozän und Plistozän Süd- und Ostasiens (Indien bis Java, Philippinen [Mindanao] und Japan). Die Backenzähne sind

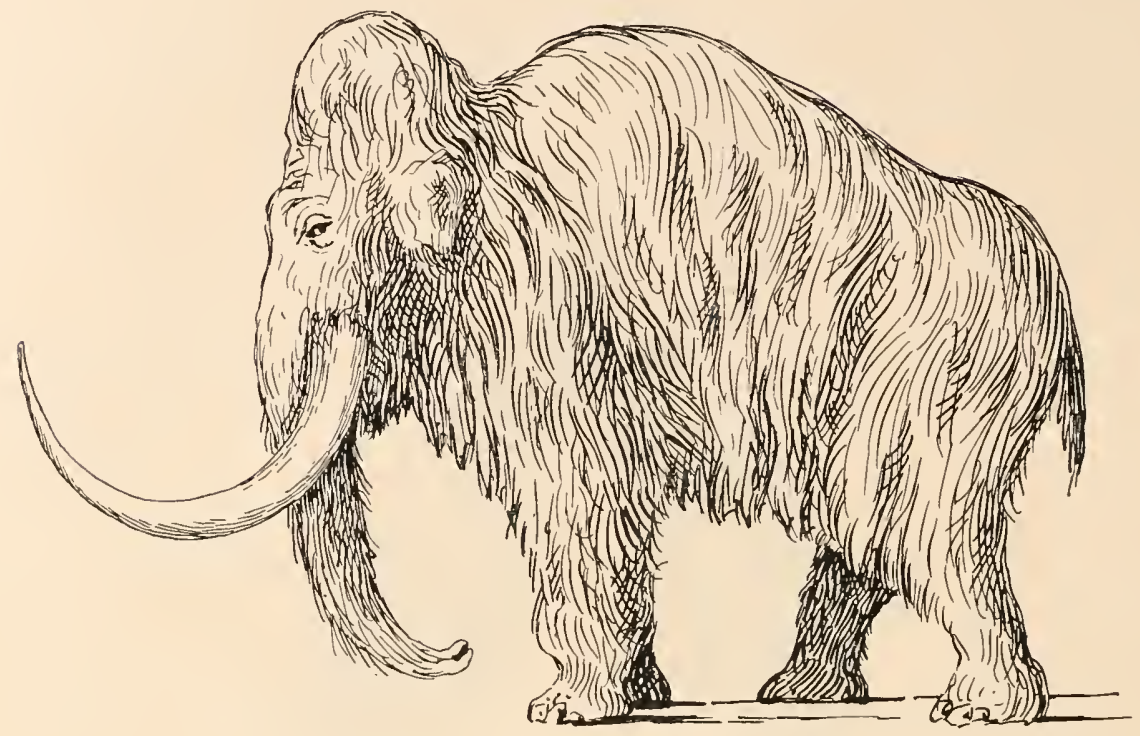

Fig. 627.

Rekonstruktion des Mammuts (mitteleuropäische Rasse), Elephas primigenius, Bl., unter Berïcksichtigung der Darstellungen des Eiszeitmenschen.

(Nach O. Abel, 1913.)

noch niedrig, aber lophodont ( 6 bis 12 Joche, zwischen ihnen beginnt sich Zement zu entwickeln). - - (Fig. 624. $)^{\mathbf{1}}$

Elephas. - Vom Oberpliozän an (Fig. 596, 601, 625, 627).²

1 W. Janensch, Die Proboscidierschädel der Trinil-Expeditionssammlung. „Die Pithecanthropusschichten auf Java“, herausgegeben von L. Selenka, Leipzig 1911 , S. 151.

H. Pohlig, Zur Osteologie von Stegodon. - Ebenda, S. 196.

W. Soergel, Stegodonten aus den Kendengschichten auf Java. - Paläontographica, Suppl.-Bd. IV, 1913, p. 1.

2 Die umfangreiche Literatur iiber fossile Elefanten ist nachzusehen bei:

O. O. Hay, Bibliography and Catalogue of the Fossil Vertebrates of North America. - Bull. U. S. Geol. Survey, Washington 1902, p. 706-714.

E. L. Trouessart, Catalogus Mammalium. - Berlin 1904.

W. Soergel, Elephas trogontherii Pohl. und Elephas antiquus Falc., ihre Stammesgeschichte und ihre Bedeutung für die Gliederıng des Deutschen Diluviums. - Paläontographica, LX. Bd., 1912, p. 112.

G. Schlesinger, Studien ïber die Stammesgeschichte der Proboscidier. Jahrbuch der K. K. Geologischen Reichsanstalt in Wien, LXlI. Bd., 1912, p. 87.

Neure Publikationen iiber eiszeitliche Elefanten sind u. a. J. Felix, Das 


\section{F. Barytheriidae.}

Eine Proboscidiergattung aus dem Obereozän Ägyptens (Barytherium) bildet den einzigen bisher bekannten Vertreter einer selbstständigen Familie, über deren Beziehungen und Stellung zu den übrigen Stämmen der Proboscidier noch wenig bekannt ist. Die oligolophodonten Backenzähne erinnern an die Dinotheriiden. Besonders auffallend sind die kräftigen Höcker an den Unterrändern des Unterkiefers und die Höhe der Kieferäste.

Barytherium. - Obereozän Ägyptens. ${ }^{1}$

\section{F. Dinotheriidae.}

Das Gebiß ist stark reduziert; die oberen Schneidezähne fehlen, dagegen ist das untere zweite Schneidezahnpaar zu steil nach abwärts gerichteten, mächtigen Hauern entwickelt und dementsprechend ist auch die Symphyse des Unterkiefers fast in rechtem Winkel zum Backenzahnabschnitt herabgebogen. Die Gebißformel ist $\frac{0.0 .2 .3}{1.0 .2 .3}$. Die Backenzähne sind zweijochig mit Ausnahme des dreijochigen oberen und unteren ersten Molaren. Der Zahnwechsel ist normal.

Dinotherium. - Zuerst in Untermiozän von Karungu an Viktoria-Nyanza; in Mittelmiozän Europas und Ostindiens durch kleine, im Unterpliozän durch zum Teil riesige Arten vertreten (D. gigantissimum im Unterpliozän Rumäniens). Aus jüngeren Schichten sind keine Vertreter bekannt (Fig. 621, 628). ${ }^{2}$

Mammut von Borna. - Veröffentlichungen des städtischen Museums für Völkerkunde in Leipzig, 1912. - W. O. Dietrich, Elephas primigenius Fraasi, eine schwäbische Mammutrasse. - Jahreshefte des Vereins für vaterländische Naturkunde in Württemberg, LXVIII. Bd., 1912, S. 42. - Derselbe, Elephas antiquus Recki aus dem Diluvium von Deutsch-Ostafrika. - Berlin 1916.

1 C. W. Andrews, A Descriptive Catalogue of the Tertiary Vertebrata of the Fayum, Egypt, 1. c., p. 172.

2 Die ältere Literatur über Dinotherium findet sich bei K. A. Zittel, Handbuch der Paläozoologie, IV. Bd., 1893, S. 454. Über die beiden ziemlich vollständigen Skelette von Dinotherium, deren eines bei Franzensbad (Böhmen) entdeckt wurde (es befindet sich im naturhistorischen Hofmuseum in Wien), während das zweite in Mânzati in Rumänien ausgegraben und im Bukarester Museum aufgestellt wurde, liegen einstweilen nur ungenügende Mitteilungen vor.

Über Dinotherienreste aus Ostafrika berichtet C. W. Andrews, On A New Species of Dinotherium (Dinotherium Hobleyi) from British East Africa. - Proceedings Zoological Society, London 1911, p. 943. (Vgl. unsere Figur 621, p. 823.)

Vgl. über Dinotherium auch die Literaturangaben in Trouessart, Catalogus Mammalium, Berlin 1899-1904, sowie O. Roger, Verzeichnis der bisher bekannten fossilen Säugetierreste, Augsburg 1896, S. 158. 


\section{F. Desmostylidae.}

Nur eine einzige Art (Desmostylus hesperus) aus dem Miozän (?) von Japan und dem Pliozän (?) oder Plistozän Kaliforniens und Oregons in Nordamerika bekannt. Der Schädelbau weicht nicht nur von dem der übrigen Proboscidier ab, sondern steht auch unter allen übrigen

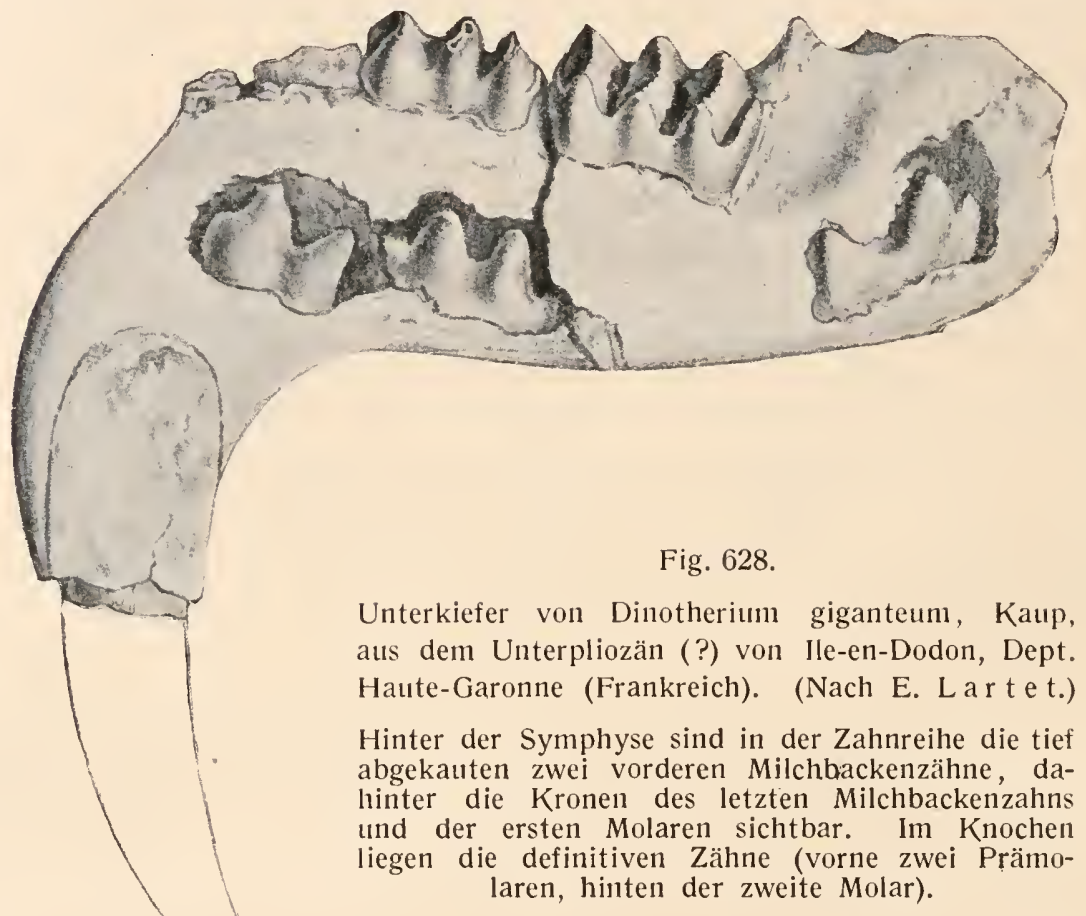

Säugetieren ganz isoliert. Die Unterkiefer tragen zwei, die Zwischenkiefer einen Stoßzahn jederseits; alle Stoßzähne sind nach vorne gerichtet und erinnern etwas an die Stoßzahnformen der Flußpfende. Die hypsodonten Molaren bestehen aus locker aneinandergefügten Zylindern (12-15), die in zwei longitudinalen Reihen stehen. Die Sclnauze ist schmal und schlank.

Desmostylus. - Miozän (?) bis Plistozän (?) Japans, Oregons und Kaliforniens (Fig. 629, 630). ${ }^{1}$

1 S. Yoshiwara and J. I wasaki, Notes on a New Fossil Mammal. - Journal of the College of Science, Imperial University, Tokyo, Japan. Vol. XVI, Art. 6, 1901.

H. F. Osborn, A Remarkable New Mammal from Japan. Its Relationship to the Californian Genus Desmostylus, Marsh.- Science, N.S., Vol. XVI, 1902, Nr.409, p.713.

O. C. Marsh, Notice of A New Fossil Sirenian from California. - Amer. Journal of Science (3), Vol. XXXV, 1888, p. 94.

O. Abel, Die vorzeitlichen Säugetiere. Jena 1914, S. 212. 
Fig. 629.

Schädel von Desmostylus hesperus, Marsh, aus dem Miozän (?) Japans (vgl. Fig. 630), in $1 / 5$ nat. Gr.)

(Nach S. Yoshiwara und J. Iwasaki.)

$\mathrm{Fr}=$ Frontale.

$\mathrm{Na}=$ Nasale.

Pmx $=$ Praemaxillare.

$M x$ = Supramaxillare.

$M d=$ Unterkiefer.

Up $I=$ oberer Inzisiv.

Lo $I_{1}=$ erster unterer-Inzisiv.

Lo $I_{2}=$ zweiter unterer Inzisiv.

$P m_{1}=$ Wurzel des ersten unteren Prämolaren.

$P m_{.}=$Wurzel des zweiten unteren Prämolaren.

$M=$ Berührungsfläche des unteren Molaren am Unterkieferknochen.
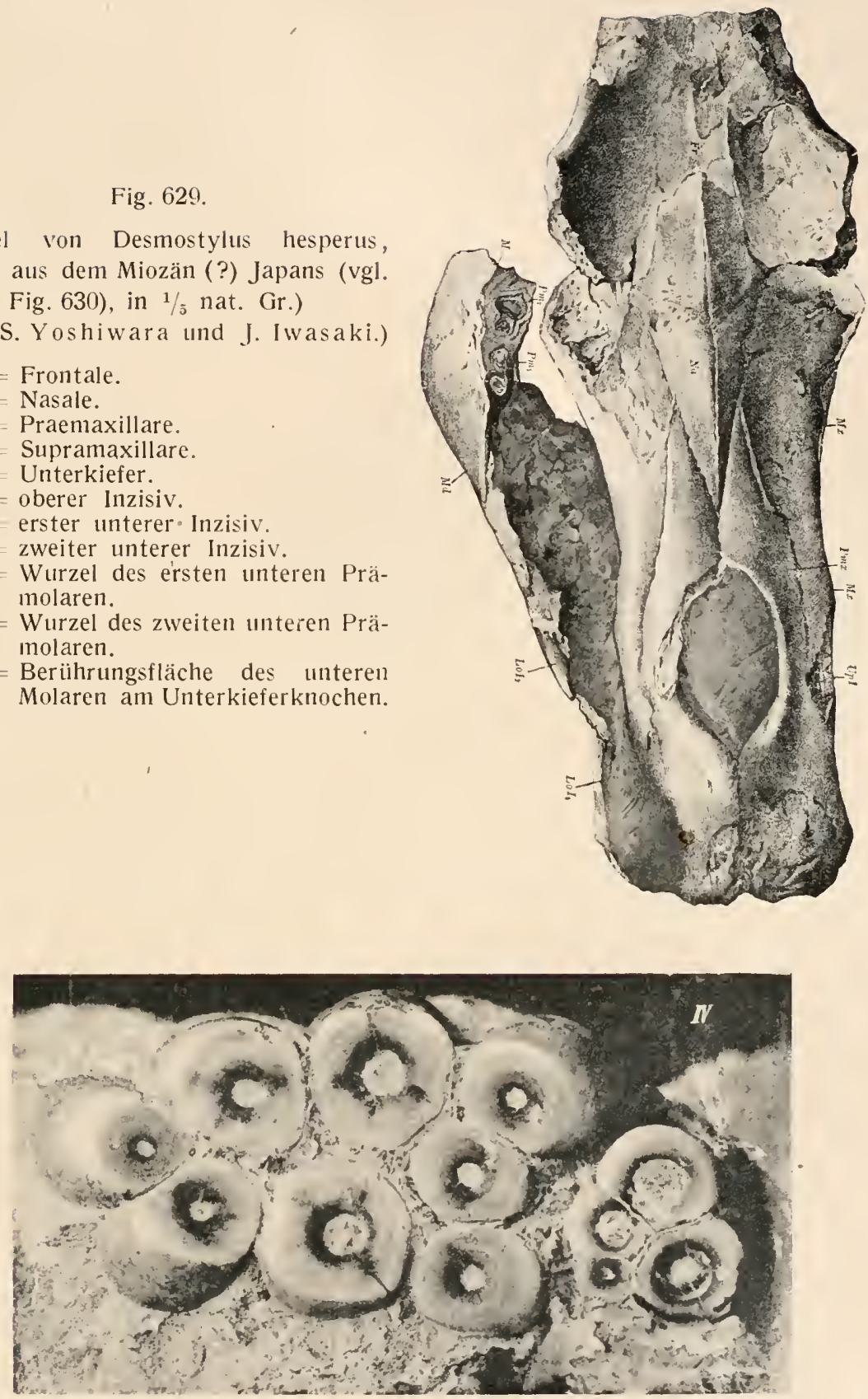

Fig. 630 .

Zwei obere Backenzähne (der rechte letzte Prämolar, in der Figur rechts, und der rechte erste Molar, in der Figur links) von Desmostylus hesperus, Marsh, aus dem Miozän (?) von Togari in der Provinz Mino, Japan, von der Kaufläche gesehen. Nat. Gr. (Nach S. Yoshiwara und J. Iwasaki.) 


\section{Ordnung: Sirenia.}

Die Seekühe stehen in engen verwandtschaftlichen Beziehungen zu den Proboscidiern, haben sich aber bereits sehr frühzeitig. wahrscheinlich im frühesten Tertiär, von ihnen getrennt und sind schon im Mitteleozän an das Wasserleben angepaßt gewesen. Ursprünglich noch mit vollständigem Gebiß $\left(\frac{3.1 .4 .3}{3.1 .4 .3}\right)$, verlieren die Sirenen bei weiter fortschreitender Entwicklung zuerst die Prämolaren und Eckzähne des Ersatz-

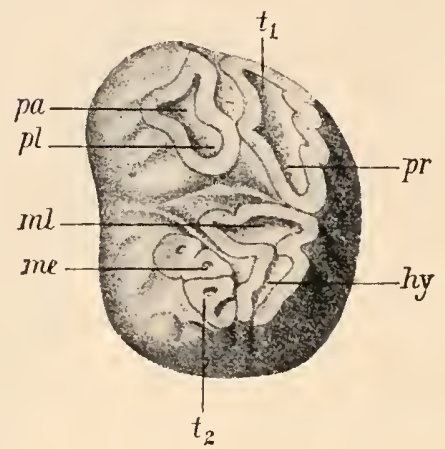

Fig. 631 .

Rechter oberer letzter Molar von Metaxytherium Krahuletzi, Dep., aus dem Miozän von Gauderndorf in Niederösterreich. Nat. Gr. (Nach O. Abel, 1904.)

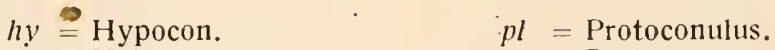

$$
\begin{aligned}
& \dot{m e}=\text { Metacon. } \quad p r=\text { Protocon } . \\
& m l=\text { Metaconulus. } \quad t_{1}=\text { vorderer Talon. } \\
& p a=\text { Paracon. } \quad t_{2}=\text { hinterer Talon. }
\end{aligned}
$$

gebisses $^{1}$ sowie die Schneidezähne bis auf einen Stoßzahn (der erste Schneidezahn) des Zwischenkiefers, der aber auch bei der Gruppe der Manatiden und bei der hochspezialisierten Gattung Rhytina unter den Halicoriden verloren geht.

Die Molaren sind bei den ältesten Gattungen sehr einfach gebaut und haben diesen primitiven Bau noch bei der lebenden Gattung Manatus bewahrt; es sind sechshöckerige Molaren, die noch den Protungulatentypus rein ausgeprägt zeigen. Bei den Halicoriden werden die ursprünglich V-förmigen Höcker sehr frühzeitig (schon bei Prototherium Veronense aus dem Mitteleozän Oberitaliens) höckerförmig und nehmen den Charakter von polybunodoniten oder suiden Molaren an (z. B. Halitherium, Metaxytherium (Fig. 631), Felsinotherium). Die Prämolaren waren schon bei der ältesten Gattung (Eotherium) einwurzelig und kegel-

1 O. Abe1, Die Milchmolaren der Sirenen.- Neues Jahrbuch für Mineralogie usw., II. Bd., 1906, S. 50 . 
förmig, trugen aber noch fünf Höcker (eine Hauptspitze und vier in zwei Reihen geordnete Höcker an der Hinterwand), die sich später (bei Halitherium) in perlschnurartig gekörnte Kämme auflösen. Die Unterdrückung der Prämolaren beginnt schon bei den eozänen Formen. Der Unterkiefer der Halicoriden ist im Symphysenabschnitt stark herabgebogen und bei den jüngeren Halicoriden zahnlos, ebenso bei den Manatiden.

Die aufeinanderfolgenden Spezialisationsstufen des Gebisses, des Schädelbaues, der Beckenreduktion usf. sind bei den tertiären Halicoriden in geschlossener Reihe zu verfolgen. ${ }^{1}$ Das Skelett ist durch das Auftreten von „Pachyostose" der Rippen und Wirbel 2, zum Teil auch der Schädelknochen und Gliedmaßenknochen, besonders gekennzeichnet (Fig. 632, 633); bei dieser Modifikation der Skelettstruktur verschwinden die Haversischen Kanäle vollständig. Die Arme sind als Flossen ausgebildet, die Hinterbeine bei Eotherium noch funktionell, bei allen übrigen Sirenen funktionslos (Fig. 632).

Die Sirenen sind in der Mittelmeerregion entstanden, haben sich dort im Tertiär zu hoher Blüte entfaltet, sind aber in Mittelmeergebiet ebenso wie an der atlantisclien Küste Europas noch im Jungtertiär erloschen; im Mittelmeer haben sie sich noch bis zum Oberpliozän erlaalten. Von diesen Hauptstamm sind schon sehr frühzeitig, jedenfalls schon inı frühen Eozän, die Halicorinen (mit Halicore und Rhytina) nach Osten in das Rote Meer, den Indischen und Stillen Ozean ausgewandert, während die Manatiden den Weg nach Westen eingeschlagen und die Küsten des Atlantischen Ozeans (Westafrika und Ostküste Südamerikas) sowie einige große Ströme dieser Gebiete besiedelt haben. Die Stellersche Seekuh, die schon bei ilırer Entdeckung durch Steller auf die Behringsinsel beschränkt gewesen zu sein scheint, ist dort in XVIIl. Jahrhundert ausgerottet worden.

\section{F. Halicoridae.}

Unterfamilie: Halitherinae.

Eotherium. - Mitteleozän Ägyptens (Fig. 633, 634, 637 I). ${ }^{3}$

1 O. Abel, Die Sirenen der mediterranen Tertiärbildungen Österreichs. Abhandlungen der K.K. Geologischen Reichsanstalt in Wien, XIX. Bd., 2. Heft, Wien 1904.

2 Die Pachyostose ergreift zuerst den vorderen Teil des Körpers und schreitet von da allmählich nach-hinten fort; bei Eotherium (Fig. 633) ist erst der vordere Teil des Thorax pachyostotisch, der hintere besteht noch aus normal gestalteten Rippen und Wirbeln. Schon bei den obereozänen Sirenen ist auch der hintere Teil des Thorax von der Pachyostose betroffen worden, so daß sämtliche Rippen und Wirbel gleichartig verdickt erscheinen.

3 O. Abel, Die eozänen Sirenen der Mittelmeerregion. Erster Teil: Eotherium aegyptiacum. - Paläontographica, LIX. Bd., 1912, p. 289. 
Prototherium. - Mitteleozän Oberitaliens. ${ }^{1}$

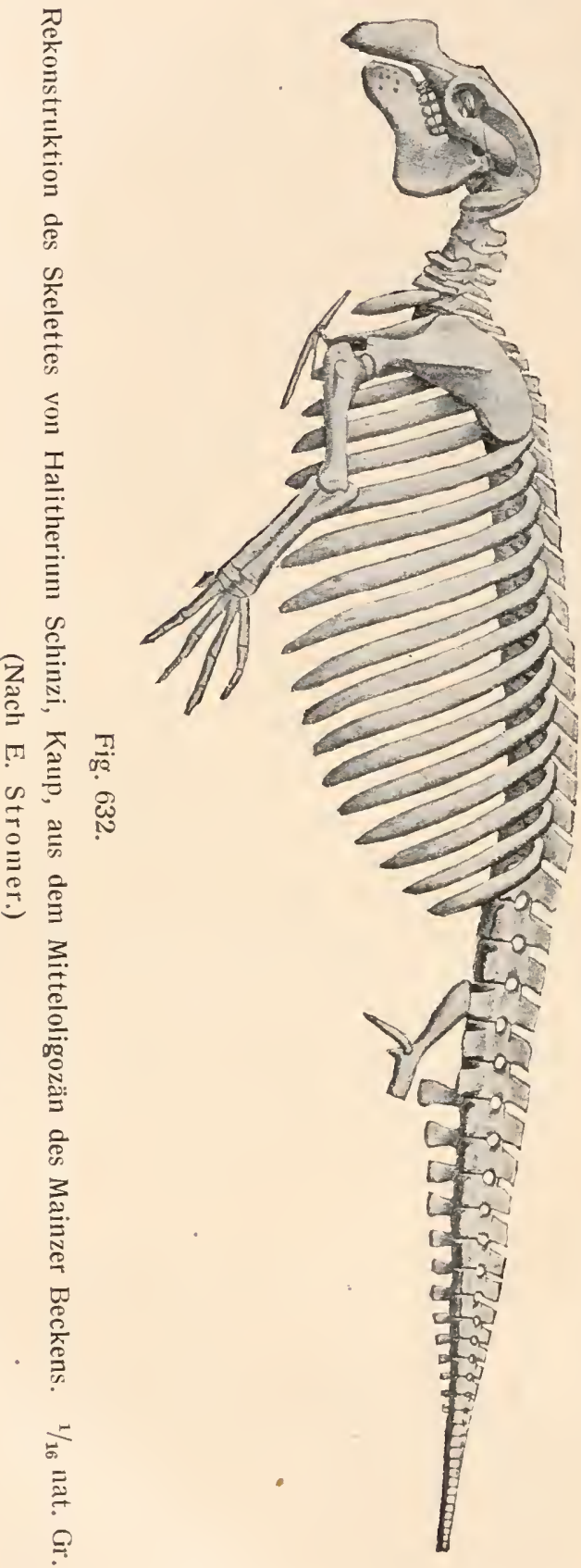

Eosiren. - Obereozän Ägyptens (Fig. 637 II). ${ }^{2}$

Halitherium.-Oligozän Mittelęuropas (Fig. 632, 637 III, 638). ${ }^{3}$

Met a xy the r i um. Miozän Mitteleuropas und Südeuropas (Fig. 637 IV, 631, 639). ${ }^{4}$

Felsino therium.-Oberpliozän Oberitaliens (Fig. 635, $636) .^{5}$

Rhy ti o dus. - Miozän Frankreichs (Fig. 595). ${ }^{6}$

${ }^{1}$ A. de Zigno, Sirenii fossili trovato nel Veneto. - Memorie delle Istituto Veneto, Vol. XVIII, ParteIII, Venezia 1875 , p. 445.

${ }^{2}$ C. W. Andrews, A Descriptive Catalogue of the Tertiary Vertebrata of the Fayûm, Egypt. London 1906, p. 198.

O. Abel, l. c., 1912, p. 300.

${ }^{3}$ R. Le psius, Halitherium Schinzi, die fossile Sirene des Mainzer Beckens.-Abhandlungen des Mittelrheinischen Geol. Vereins, I. Bd., Darmstadt 1881-1882, S. 1.

O. Schmidtgen, Neue Beiträge zur Kenntnis der hinteren Extremität von Halitherium Schinzi Kaup. - Zoologische Jahrbücher, Suppl. XV, Jena 1912, S. 457.

${ }^{4}$ O. Abel, 1. c., 1904 (Literatur!).

${ }^{5}$ G. Capellini, Sul Felsinoterio, Sirenoide halicoreiforme etc., Memorie dell' Accademia delle Scienze dell' Istituto di Bologna (3), T. 1, 1872, p. 1.

${ }^{6}$ E. Delfortrie, Découverte d'un Squelette entier de Rhytiodus dans le Falun Aquitanien. - Actes de la Soc. Linnéenne de Bordeaux, Vol. XXXIV, 1880, p. 131.

E.Lartet, Note sur deux nouveaux Siréniens fossiles des terrains tertiaires du bassin de la Garonne. -- Bull. de la Soc. Géol. de Fr., Vol. XXIIl, Paris 1866, p. 673. (Die in Fig. 595 abgebildeten Zähne sind Originalabbildungen nach den im 
Unterfamilie: Halicorinae.

Halicore. - Lebend im Roten Meer, Indik und Pacifik (Fig. $637 \mathrm{~V}, \mathrm{VI}$ ).

Rhytina. - Auf der Behringsinsel im XVIIl. Jahrhundert ausgerottet. ${ }^{1}$

Unterfamilie: Miosireninae.

Protosiren. - Mitteleozän Ägyptens (Fig. 640-642).²

Archaeosiren. - Obereozän Ägyptens. ${ }^{3}$

Miosiren. - Miozän Belgiens. ${ }^{4}$

\section{F. Manatidae.}

Prorastomus. - Obereozän von Jamaika. ${ }^{5}$

Manatherium. - Oligozän Belgiens. ${ }^{6}$ Die Stellung eines 1915 bei Juana Diaz (Porto Rico) gefundenen Unterkiefers ${ }^{7}$ ist noch unsicler.

Jardin des Plantes, Muséum d'Histoire naturelle zu Paris, aufbewahrten Resten. Das geologische Alter ist auf der zugehörigen Etikette als ,Faluns de l'Étage de Bazes [Miocène moyen]" angegeben.)

1 J. F. Brandt, Symbolae Sirenologicae. - Mémoires de l'Académie Imp. St. Pétersbourg (7), T. XII, 1869.

O. Abel, 1. c., 1904, S. 180.

L. von Lorenz, Das Becken der Stellerschen Seekuh. Abhandlungen der K. K. Geologischen Reichsanstalt in Wien, XIX. Bd, 3. Heft, 1904, S. 1.

E. Buechner, Die Abbildungen der nordischen Seekuh (Rhytina gigas Zimm.) mit besonderer Berücksichtigung neu aufgefundener handschriftlicher Materialien in Sr. Maj. höchsteigener Bibliothek zu Sarskoje Selo. - Mém. Acad. Imp. Sci. St. Pétersbourg (7), T. XXXVIII, Nr. 7, 1891.

L. Stejneger, Contributions to the Natural History of the Commander Islands. - Proceedings U. S. Nat. Museum, Washington 1883, Vol. VI, p. 58; 1884, Vol. VII, p. 181.

Derselbe, Skeletons of Steller's Sea-Cow preserved in the Various Museums. - Science, 1893, Vol. XX1, p. 81 .

2 O. Abel, i. c., 1904, p. 214.

Derselbe, Die Stammesgeschichte der Meeressäugetiere. - Meereskunde, I. Jahrgang, 4. Heft, Berlin 1907, S. 29.

(Die Abbildungen Fig. 640-642 sind Originalphotographien nach den im Museum zu Kairo aufbewahrten Schädelresten von Protosiren Fraasi, die von Andrews zuerst unter dem Namen Eotherium aegyptiacum (?) beschrieben worden waren.)

3 O. Abel, 1. c., 1912, p. 307.

4 L. Dollo, Première Note sur les Siréniens de Boom. - Bull. Soc. Belge de Géol., Paléontologie et d'Hydrologie, T. III, Bruxelles 1890, p. 415.

5 R. Owen, On the Fossil Skull of a Mammal (Prorastomus sirenoides, Owen) from the Island of Jamaica. - Quarterly Journal of the Geol. Soc., London, Vol. XI, 1885, p. 54I.

Derselbe, On Prorastomus sirenoides. - Ibidem, Vol. XXXI, 1875, p. 559.

${ }^{6}$ C. Hartlaub, Manatherium Delheidi. - Zoologische Jahrbiicher, I. Bd., 1886 , S 369.

7 W. D. Matthew, New Sirenian from the Tertiary of Porto Rico, West Indies.Annals of the New York Academy of Sciences, Vol. XXVII, New York, 1916, p. 23. 


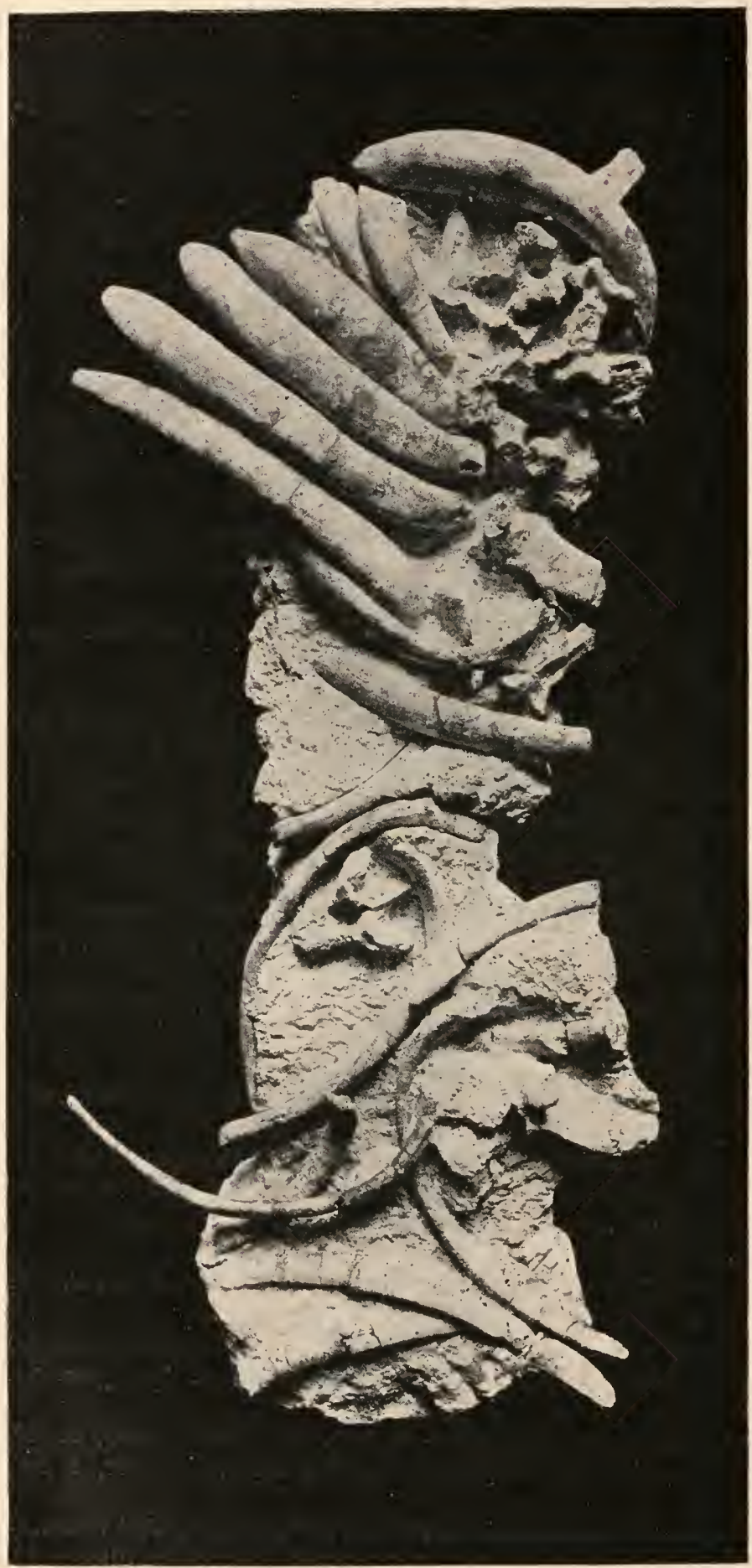

Fig. 633.

Rumpfskelett von Eotherium aegyptiacum Ow., aus dem Mitteleozän des Mokattam bei Kairo, stark verkleinert. Im vorderen Teile des Rumpfes (in der Figur oben) sind die Rippen stark pachyostotisch verdickt, im hinteren Teile dagegen normal.

(Original.) 

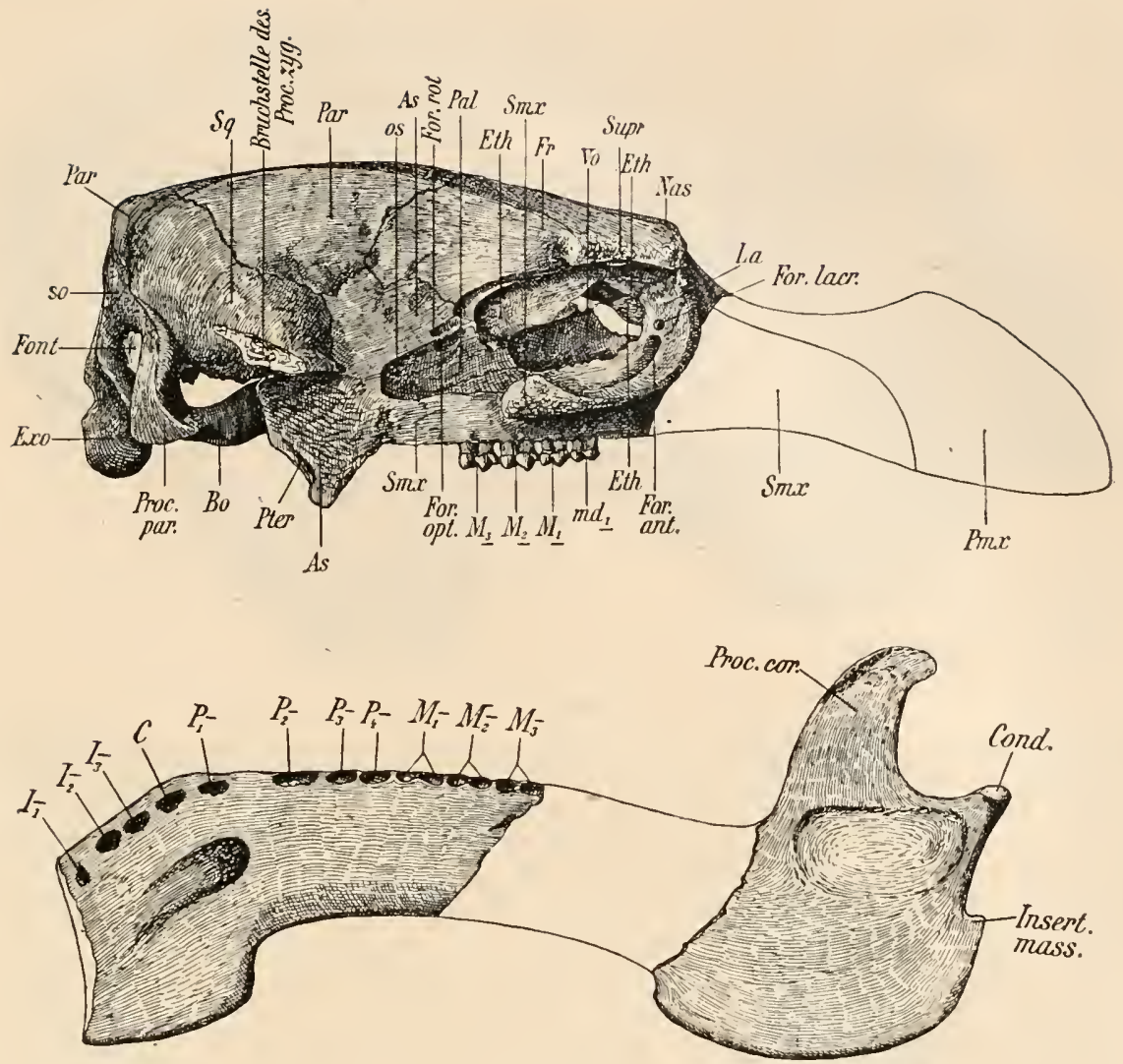

Fig. 634.

Schädel von Eotherium aegyptiacum, Owen, aus der unteren Mokattamstufe (Mitte!eozän) des Mokattam bei Kairo. Schädel von rechts, Unterkiefer von links gesehen. Ungefähr $1 / 3$ nat. Gr. (Nach O. A bel.)

$\begin{array}{ll}\text { As } & =\text { Alisphenoid. } \\ \text { Bo } & =\text { Basioccipitale. } \\ \text { Eth } & =\text { Ethmoidale. } \\ \text { Exo } & =\text { Exoccipitale. } \\ \text { Font } & =\text { Facies Fonticulimastoidei. } \\ \text { For. ant. } & =\text { hintere Miindung des Ca- } \\ & \text { nalis infraorbitalis. } \\ \text { For. } \text { lacr. } & =\text { Foramen lacrymale. } \\ \text { For. opt. } & =\text { Foramen opticum. } \\ \text { For. rot. } & =\text { Foramen rotundum. } \\ \text { Fr } & =\text { Frontale. } \\ M_{1} M_{2} M_{3}= & \text { erster, zweiter und dritter } \\ & \text { Molar. } \\ m_{1} & =\text { letzter (bleibender) Milch- } \\ & \text { molar. } \\ \text { La } & =\text { Lacrymale (bei den jün- } \\ & \text { geren Sirenen rudimentär). } \\ \text { Nas } & =\text { Nasale (bei den jüngeren } \\ & \text { Sirenen rudimentär). } \\ \text { os } & =\text { Orbitosphenoid. }\end{array}$

$\begin{array}{ll}\text { Pal } & =\text { Palatinum. } \\ \text { Par } & =\text { Parietale. } \\ \text { Pmx } & =\text { Prämaxillare. } \\ \text { Proc. par. } & =\text { Processus paroccipitalis. } \\ \text { Pter } & =\text { Pterygoid. } \\ \text { Sinx } & =\text { Supramaxillare. } \\ \text { so } & =\text { Supraoccipitale. } \\ \text { Sq } & =\text { Squamosum. } \\ \text { Supr } & =\text { Supraorbitalrand des } \\ \text { Vo } & \text { Frontale. }\end{array}$

Unterkiefer:

$I_{1} I_{2} I_{3} \quad$ = Inzisiven.

$C_{1} \quad=$ Canin.

$P_{1} P_{2} P_{3} P_{4}=$ Prämolaren.

$M_{1} M_{2} M_{3}=$ Molaren.

Proc. cor. $=$ Processus coronoideus.

Cond $=$ Condylus des Unterkiefers.

Insert. Mass. = Insertionsstelle des Musculus inasseter. 


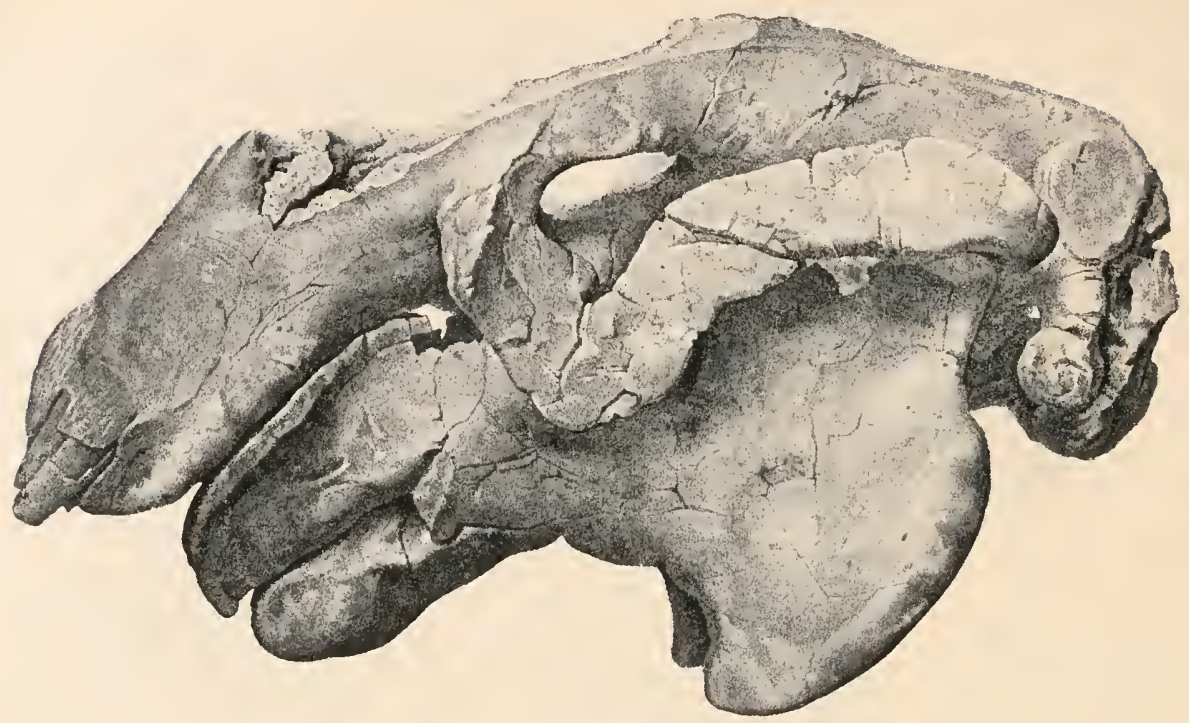

Fig. 635 .

Felsinotherium Forestii, Capellini, aus dem Oberpliozän von Riosto bei Bologna, Oberitalien; Schädel von links gesehen. Schädellänge $54 \mathrm{~cm}$. (Nach G. Ca pellini.)

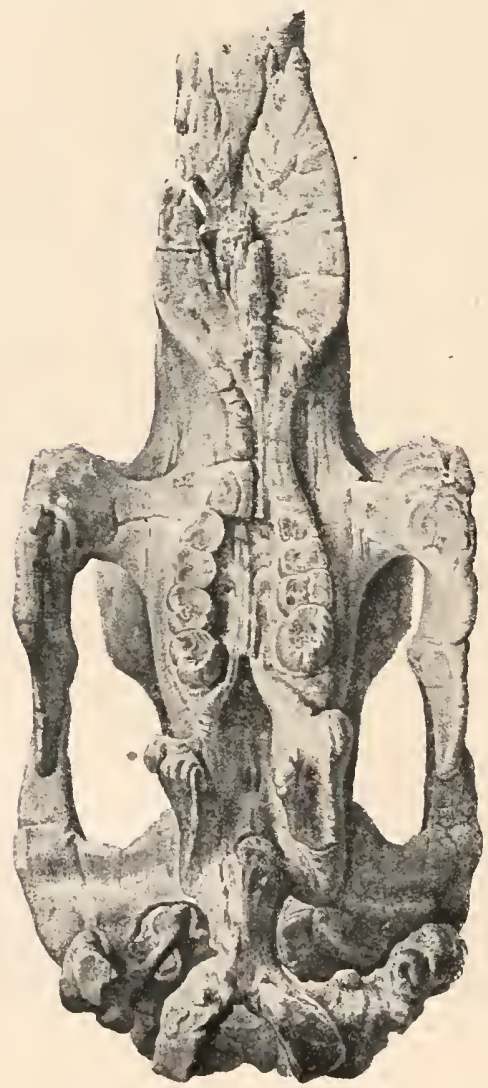

Fig. 636.

Felsinotherium Forestii, Cap., aus dem Oberpliozän von Riosto bei Bologna (vgl. Fig. 635); Schädel von unten gesehen. Das Ersatzgebiß ist bis auf einen Stoßzahn des Zwischenkiefers jederseits unterdrüickt und die Milchmolaren bleiben bis zu ihrer völligen Abnützung neben den drei bleibenden Molaren im Oberkiefer stehen; im rechten Oberkiefer des abgebildeten Exen1plars sind noch zwei, im linken nur mehr ein Stummel des letzten Milchmolaren in Funktion.

(Nach G. Capellini.) 
Er scheint einem Manatiden anzugehören, ebenso wie die dürftigen Reste aus dem marinen Miozän, Pliozän und Plistozän Nordamerikas. ${ }^{1}$

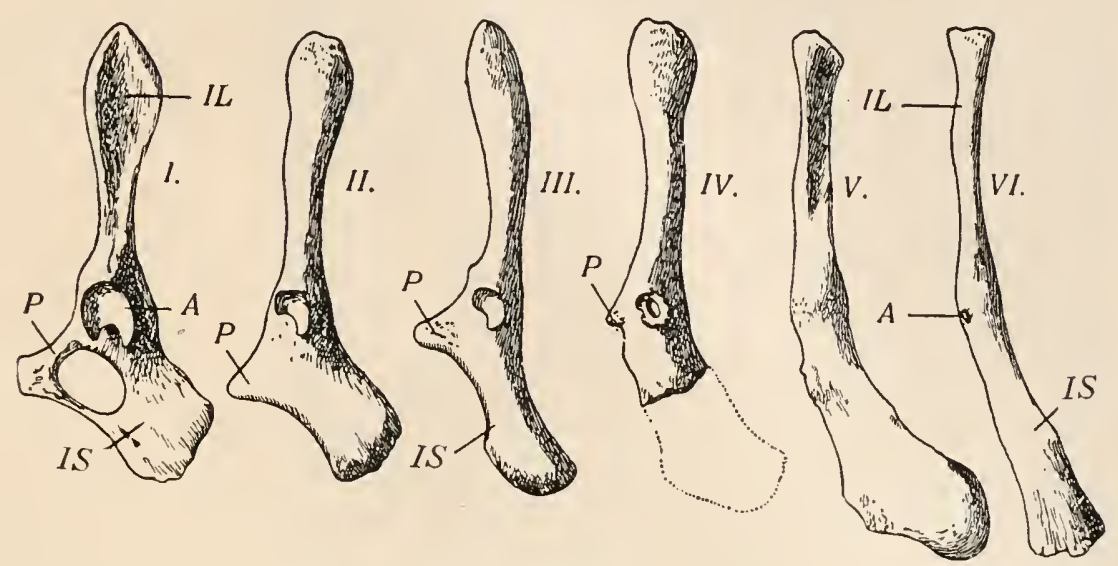

Fig. 637.

Die stufenweise Verkümmerung des Hüftbeins inı Laufe der stammesgeschichtlichen Entwicklung der Halicoriden (stark verkleinert). Besonders deutlich tritt die Reduktion des Pubis $(P)$ in Erscheinung, das bei der ältesten und primitivsten Gattung (Eotherium) noch das Hiiftbeinloch (Foramen obturatorium) vorne umrandet, bei der nächst höher stehenden Form (Eosiren) aber bereits verkümmert erscheint und von da ab schrittweise abnimmt, bis es bei einzelnen Exemplaren von Metaxytherium Krahuletzi (vgl. Fig. 639) nur mehr als sehr kleiner Höcker vorhanden ist oder bei anderen Exemplaren derselben Art ganz verschwindet. Bei Halicore (Fig. V und V1) ist das Pubis bereits gänzlich verloren gegangen, so daß das Hïftbeinrudiment nur mehr aus dem Ilium und Ischium besteht. Gleichzeitig geht auch das Acetabulum seiner Reduktion und schließlich dem völligen Schwunde entgegen, wie Fig. V zeigt, während es sehr selten (Fig. V1) noch als kleines Grübchen die ehemalige Stelle der Gelenkpfanne andeutet. (Nach O. Abel.)

1. Eotherium, Mitteleozän Ägyptens.

11. Eosiren, Obereozän Ägyptens.

11I. Halitherium, Oligozän Mitteleuropas.

IV. Metaxytherium, Miozän und Pliozän Mittel- und Südeuropas.

V. Halicore dugong, Gegenwart, Indopacifischer Ozean.

VI. Halicore tabernaculi, Gegenwart, Rotes Meer.
$A=$ Acetabulum.
$I L=$ llium.
$I S=$ Ischium.
$P=$ Pubis.

Manatus. - Vielleicht schon im Jungtertiär Nordamerikas ${ }^{2}$ und Südamerikas fossil; lebend an der Ostküste Südamerikas und an der Westküste Afrikas.

1 Die Literatur über diese Reste ist nachzusehen bei O. P. Hay, Bibliography and Catalogue of the Fossil Vertebrates of North America, 1902, p. 583.

2 E. C. Case in: Maryland Geological Survey, Miocene, Baltimore 1904, p. 56, PI. XXVI, Fig. 1. 


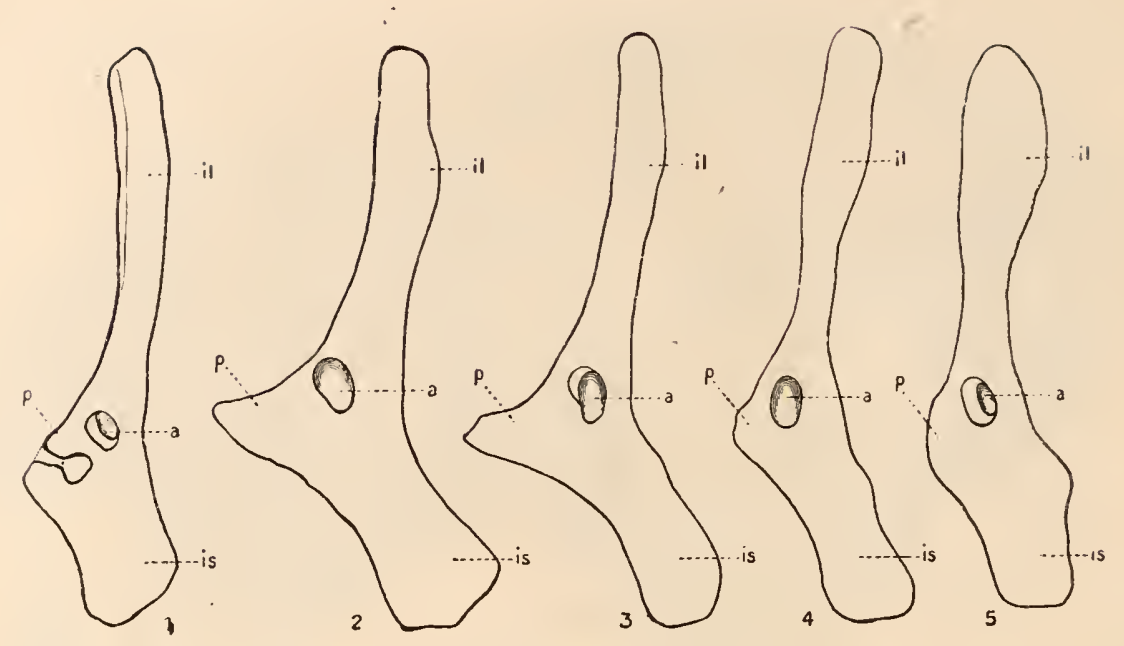

Fig. 638.

1-5: Linke Hüftbeine von Halitherium Schinzi aus dem Mitteloligozän des Mainzer Beckens. (Nach O. Schmidtgen.) Ein Vergleich der fünf Beckenrudimente zeigt die große Variabilität dieser rudimentären Bildungen. Von Wichtigkeit ist die Art des Rudimentärwerdens des Hüftloches (Foramen obturatorium), das, wie Fig. 1 lehrt, nicht durch Obliteration der unteren Hüftlochspange, sondern durch Ausfiillung der Öffnung mit Knochenmasse verschwindet, wodurch sich die auffallende Breite dieser Region im Hüftbein Fig. 2 erklärt; ein analoger Fall scheint bei dem in Fig. 637, II abgebildeten Hüftbeinrudiment von Eosiren vorzuliegen.

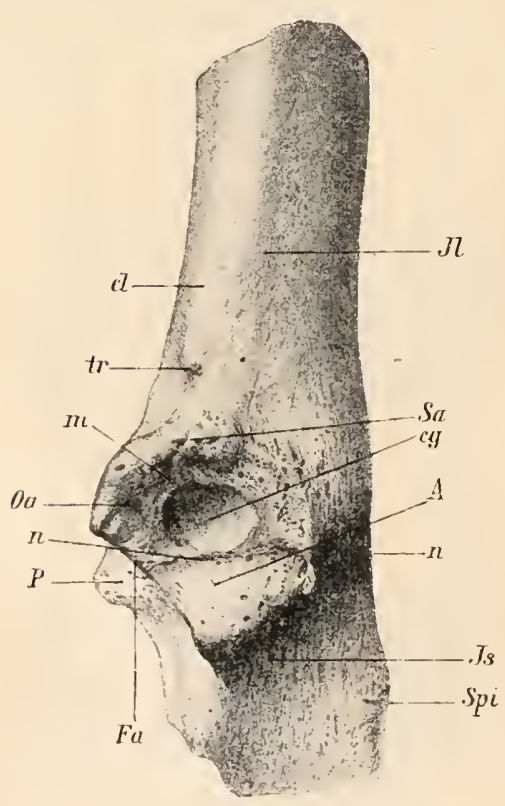

Fig. 639.

Linkes Hüftbeinrudiment von Metaxytherium Krakuletzi, Dép., aus dem Miozän von Eggenburg in Niederösterreich, von außen gesehen. Ungẹfähr $4 / 5$ nat. Gr:

(Nach O. Abel, 1904.)
$A=$ Acetabulum.
$c g=$ Gelenkfläche für den Kopf des Oberschenkels.
$F a=$ Fossa acetabuli.
$I l=$ llium.
$P=$ Pubis.
Is = Ischium. 
Fig. 640 .

Schädel von Protosiren Fraasi (vgl. Fig. 641) alls dem Mitteleozän von Kairo, von unten gesehen, in etwa $1 / 2$ nat. Gr.

Original im Museum von Kairo.

(Orig.-Phot.)

Das Gebiß ist hier noch vollständig und umfaßt 3 l., 1 C. $4 \mathrm{P}$. und $3 \mathrm{M}$. im erwachsenen Z11stande.

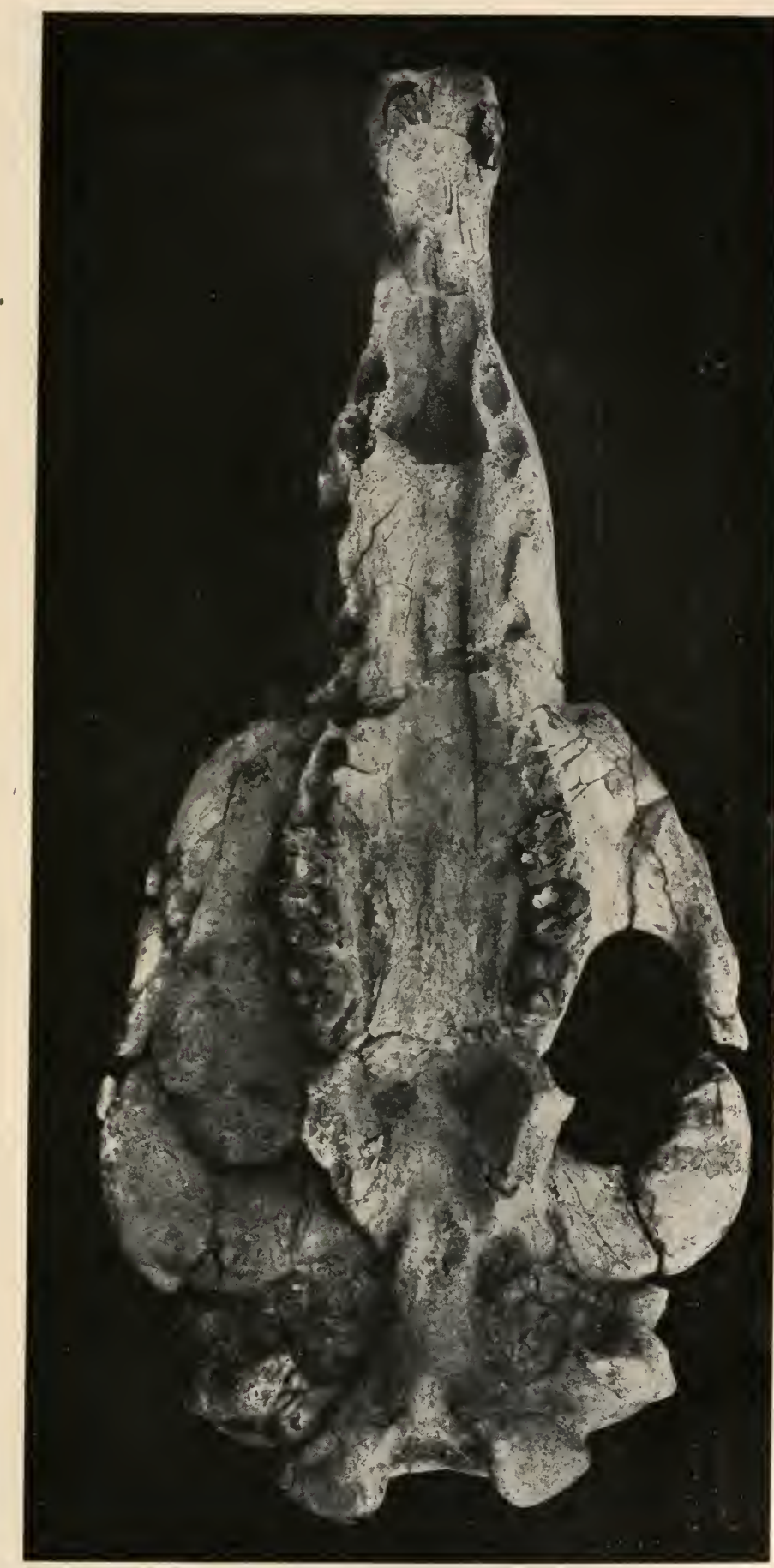




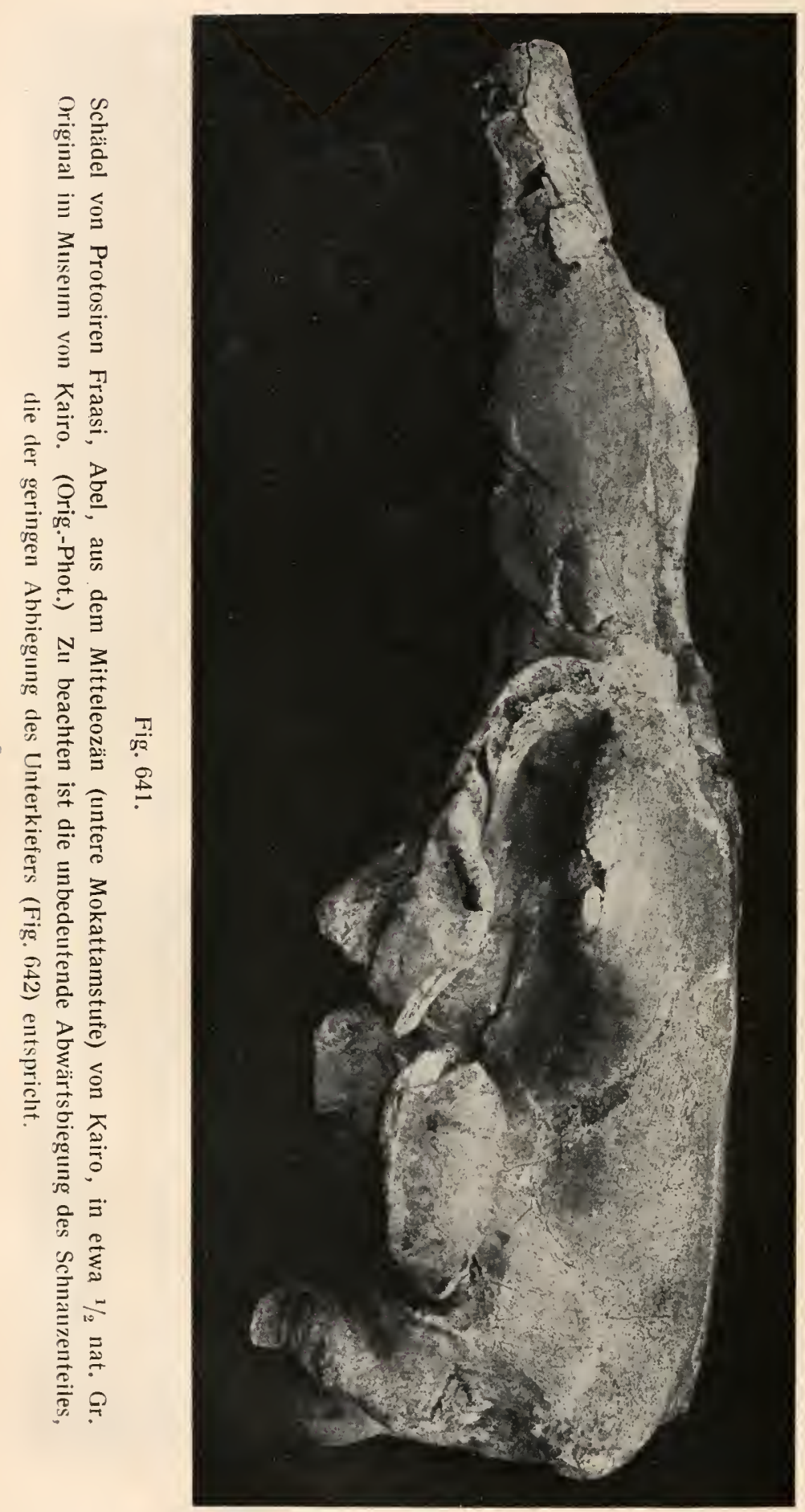



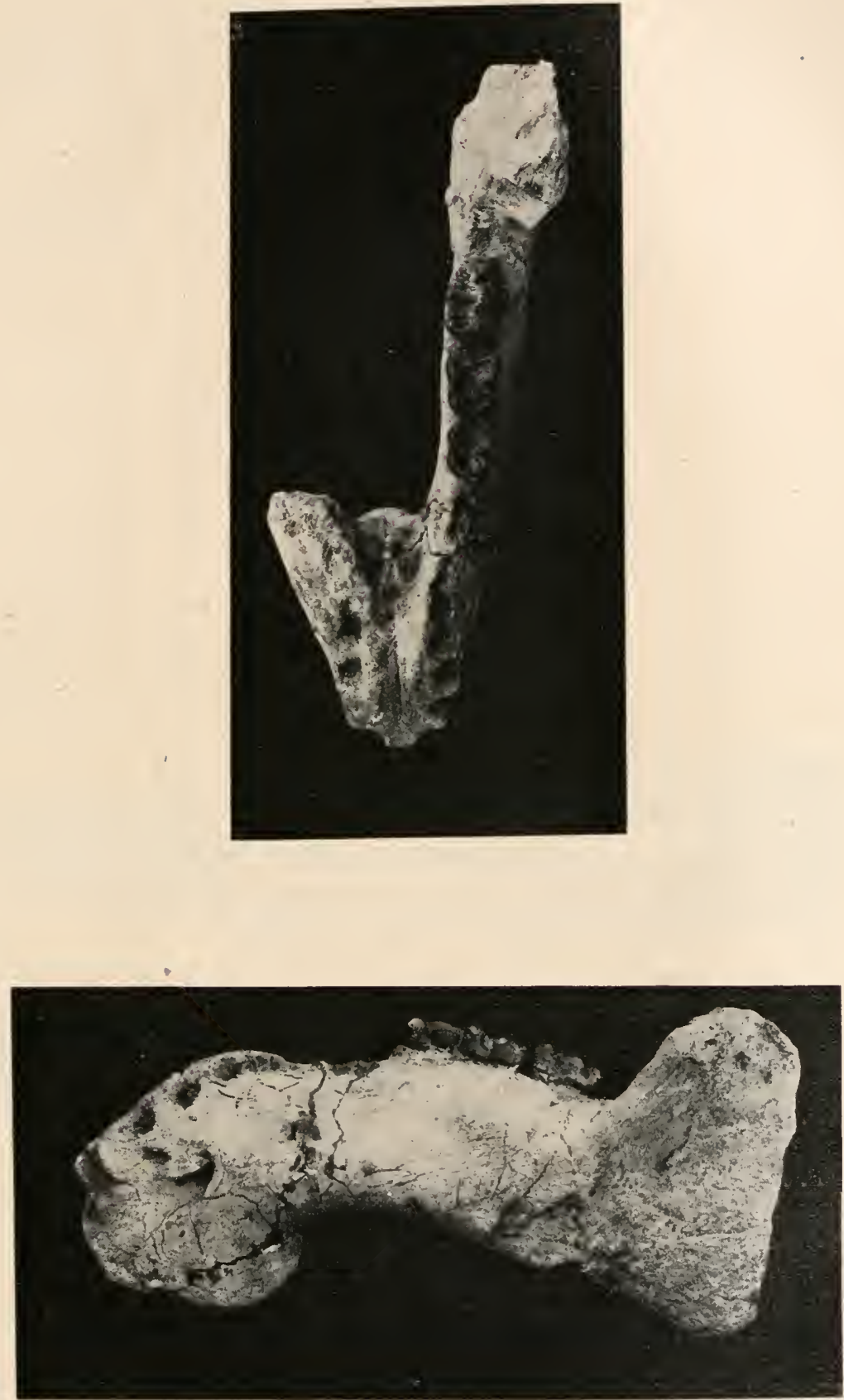

Fig. 642 .

Protosiren Fraasi, Abel, aus dem unteren Mitteleozän des Mokattam bei Kairo. Unterkiefer von oben und von der Seite, in etwa $1 / 2$ nat. Gr. Original im Museum von Kairo. (Orig.-Phot.) 


\section{Ordnung: Pyrotheria.}

Die Pyrotheria bilden mit den Notoungulata und Litopterna eine auf Südamerika beschränkte Gruppe der Huftiere, die sich aus primitiven Protungulaten entwickelte, die inı unteren Eozän aus Nordamerika nach Südamerika. eingewandert sind. Sie stellen durchaus selbständige Stämme dar, die in keinen Beziehungen zu den Ungulatenordnungen der übrigen Erdteile stehen und sind vollständig erlosclien, nachdem sie im Tertiär eine hohe Blüte erreicht haben, die in der Ausbildung zahlreicher differenter Gattungen zum Ausdrucke kommt.

Die erste Gruppe dieser südamerikanischen Huftiere ist auf das Tertiär Patagoniens beschränkt und war schon bei der Wiederherstellung der Landbrücke zwischen Nord- und Südamerika im Mittelpliozän ausgestorben. Die Pyrotherien waren große Tiere, die eine Größe wie die lebenden. Elefanten erreicht habèn; sie sind von F. Ameghino für einen Seitenzweig der Proboscidier gehalten worden, mit denen sie jedocl in keinen verwandtschaftlichen Bezieluungen stehen. Auch zu den diprotodonten Beuteltieren hat man Beziehungen zu finden geglaubt, aber auch diese Vermutung hat sich als irrig erwiesen. ${ }^{2}$

Das auffallendste Merkmal der Pyrotherien liegt in denı Längenverhältnis der Gliedmaßenabschnitte, deren proximale Teile (Humerus und Fenur) die distalen (Unterarm und Unterschenkel) fast um das Doppelte an Länge übertreffen, ein ganz eigenartiges Verhalten. ${ }^{3} \mathrm{~lm}$ kurzen Schädel liegen die Augenhöhlen über dem vierten Prämolaren; oben und unten war je ein Paar Stoßzähne vorhanden.

Die Pyrotheria nehmen unter den Ungulaten eine ganz isolierte Stellung ein. Unter den Protungulaten sind bis heute keine Formen bekannt, mit denen sie in nähere Beziehungen gebracht•werden könnten.

Carolozittelia. - Untereozän Patagoniens (Fig. 643). ${ }^{4}$

Pyrotherium. - Untermiozän Argentiniens (Fig. 644, 645). ${ }^{5}$

1 F. Ameghino, Linea filogenetica de los Proboscideos. - Anales del Museo Nacional de Buenos Aires (3), T. VIII, 1902, p. 19.

2 F. Ameghino, Le Pyrotherium n'est pas parent du Diprotodon. - Anales del Museo Nacional de Buenos Aires (3), T. VIII, 1902, p. 223.

${ }^{3}$ A. Gaudry, Fossiles de Patagonie. Étude sur une Portion du Monde Antarctique. - Annales de Paléontologie, T. 1, Fasc. 3, Paris 1906, p. 101.

4 F.Ameg hi no, Les Formations sédimentaires du Crétacé supérieur et du Tertiaire du Patagonie etc. - Anales del Museo Nacional de Buenos Aires (3), T. XV,1 906, p. 329.

5 F. Ameghino, lbidem, p. 331.

Eine Rekonstruktion des Schädels nach einem Schädelskelett im Museum des Amherst College Mass., deren Bearbeitung durch F. B. Loomis erfolgte (1914), hat W. B. Scott mitgeteilt (A History of Land Mammals in the Western Hemisphere. - New York 1913, Fig. 243, p. 486).

C. A meghino, Le, ,Pyrotheriım“, l'étage Pyrothéréen et les Couches à Notostylops. Une réponse à Mr.Loom is.—Boletin de la Soc. „Physis“, T. I, Buenos Aires 1914, p. 446. 


\section{Ordnung: Notoungulata.}

Die Notoungulaten umfassen die Mehrzahl der südamerikanischen Ungulaten; sie sind vom Eozän bis zum Plistozän bekannt.

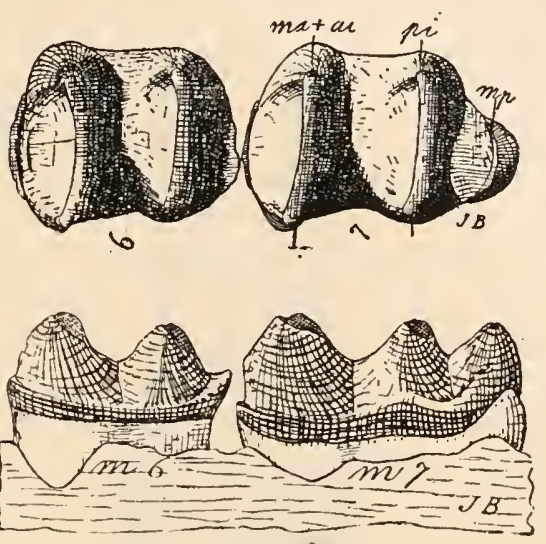

Fig. $64 \hat{3}$.

Die beiden letzten Backenzähne des Unterkiefers von Carolozittelia tapiroides, Ameghino, aus dem unteren Eozän (Notostylopsschichten) Patagoniens. Nat. Gr. (Nach F. Ameghino.)

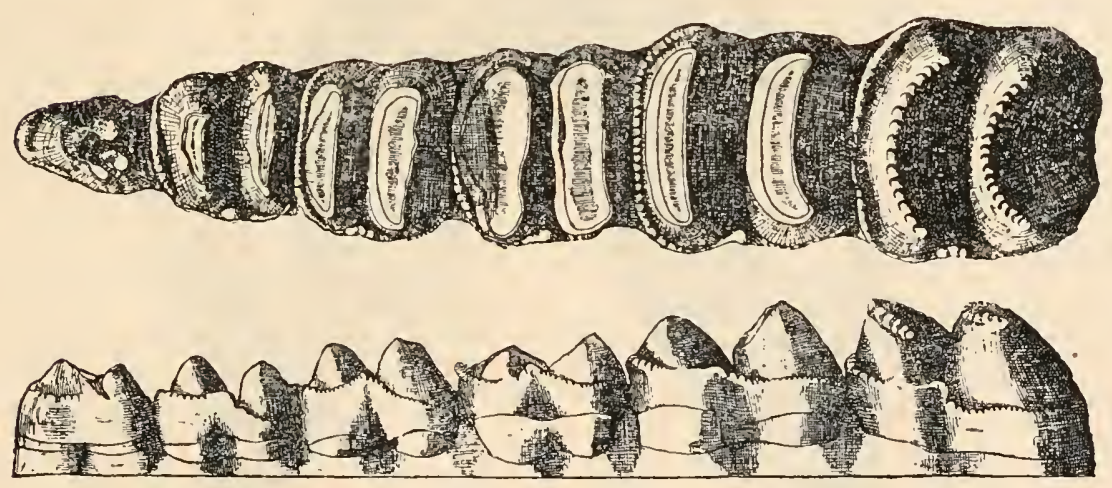

Fig. 644.

Obere Backenzähne von Pyrotherium Sorondoi, Amgh., aus den Pyrotheriumschichten (Grenzschichten des Oberoligozäns und Untermiozäns) Patagoniens, ungefähr in $1 / 3$ der nat. Gr. Oben: Ansicht von der Kaufläche, unten: Seitenansicht.

(Nach F. Ameghino.)

Das Gebiß ist fast immer vollständig, oft sind die Schneidezähne als „Stoßzähne" entwickelt; Hörner oder Geweihe fehlen und nur bei den Toxodontiden ${ }^{1}$ sind schwache Schädelprotuberanzen in der Stirnregion

1 F. Ameghino, Les Toxodontes à Cornes. - Anales del Museo Nacional de Buenos Aires (3), T. XVI, 1907, p. 49. 
oder auf den Zwischenkiefern vor der Nasenöffnung zu beobachten, die aber erst in einer Zeit auftreten, in der die Verbindung mit Nordamerika hergestellt war und sich der Strom der Raubtiere, die bis dahin in Südamerika gänzlich gefehlt hatten, über das Land ergossen hatte.

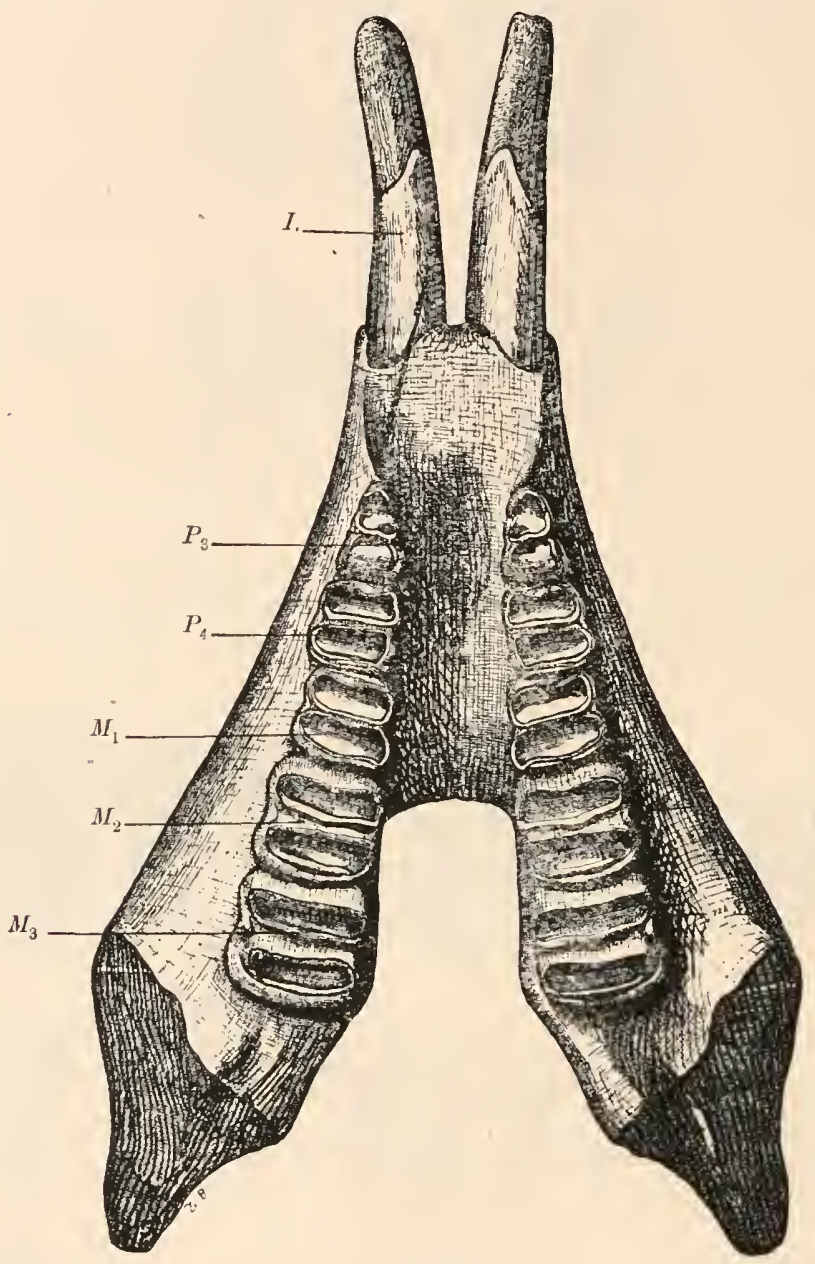

Fig. 645 .

Unterkiefer von Pyrotherium Sorondoi, Amgh., aus den Pyrotheriumschichten Patagoniens (vgl. Fig. 644). (Nach F. Ameghin 0.)

Ursprünglich waren die Zähne brachyodont, sind aber auch hier ebenso wie bei den nordamerikanischen und altweltlichen Ungulatenstänmen, wohl infolge gleichsinnigen Nahrungsweclisels (Übergang von weicher zu harter Pflanzennahrung) hypsodont geworden. Der Kronenbau der Backenzähne ist durchaus eigenartig und von allen anderen Backenzahnformen der Huftiere verschieden; einem langen AuBenjoch 
schließt sich ein schrägstehendes, stark zurückgebogenes Vorjoch an, zuweilen auch ein kurzes, gerades Nachjoch. Dieser Zahntypus ist von einem trituberkulären bzw. tuberkulosektorialen Typus abzuleiten. Die weiteren Spezialisationen der Backenzähne der Notoungulaten bestanden in der Ausbildung sekundärer Schmelzfalten (ähnlich wie in den Nashornmolaren). Im Gegensatz zu diesen Spezialisationen der oberen Backenzähne waren die unteren aus zwei lialbmondförnigen Falten aufgebaut, deren vordere sich an einen Innenhöcker anlegt.

Unter den Notoungulaten unterscheiden wir vier Stämme: die Typotheria, Toxodontia, Entelonychia und Astıapotherioidea.

\section{Unterordnung: Typotheria.}

Das Gebiß dieser Gruppe, die von Eozän bis zum Plistozän lebte, ist fast inmer vollständig. Die vordersten Inzisiven sind vergrößert. Das Vordergebiß gelıt ohne scharfe Grenze in das Mahlgebiß über. Die Molaren waren bei den älteren Typen brachyodont, bei den jüıgeren hypsodont.

\section{F. Notopithecidae.}

Diese Fanilie bildet die Stanngruppe der Interatheriiden und Hegetotheriiden und ist nur aus dem Eozän und Oligozän Patagoniens bekannt. Die Zähne waren brachyodont.

Notopithecus. - Eozän (Notostylopsschichten) Patagoniens. ${ }^{1}$

Guielnoscottia.- Oligozän (Astraponotusschichten) Patagoniens.²

\section{F. Interatheriidae.}

Die Molaren entwickeln sich aus brachyodonten zu hypsodonten Typen. Die Unterschenkelknochen bleiben getrennt.

Protypotherium. - Miozän (Santa Cruzschichten) Patagoniens. ${ }^{3}$ Interatherium. - Miozän (Santa Cruzschichten) Patagoniens. ${ }^{+}$

\section{F. Hegetotheriidae.}

Obere Schneidezähne selır eigenartig spezialisiert. Der erste ist schaufelförmig, groß und nach innen gebogen, die beiden vorderen

1 F. Ameghino, Paleontologia Argentina. - Publicaciones de la Universidad de La Plata, Nr. 2, La Plata 1904, Fig. 66, p. 74.

2 F. Ameghino, Recherches de Morphologie phylogénétique sur les Molaires supérieures des Ongulés. - Anales del Museo Nacional de Buenos Aires (3), T. IX, Buenos Aires 1904, Fig. 451, p. 340.

${ }^{3}$ W. J. Sinclair, Mammalia of the Santa Cruz Beds. Part I. - Typotheria. - Reports of the Princeton University Expeditions to Patagonia, 1896-1899, Vol. VI, Palaeontology, Part I (Typotheria of the Santa Cruz Beds). Princeton, N. J., 1909, p. 13.

4 Ibidem, p. 47. 
Schneidezahnpaare des Unterkiefers meißelförmig. Die beiden Unterschenkelknochen waren verwachsen.

Hegetotherium. - Miozän Patagoniens. ${ }^{1}$

Pacliyrukhos. - Miozän Patagoniens. ${ }^{2}$

\section{F. Typotheriidae.}

In dieser Familie vereinige ich außer den Typotheriiden nocl die Archaeopitheciden, Henricoosborniiden, Pantostylopiden und Archaeohyraciden. Die Archaeohyraciden sind die Ahnen von Typotherium, d:e Archaeopitheciden die Ahnen der Archaeohyraciden; diese Gattungen gehen ohne scharfe Grenzen ineinander über. Die primitivsten Vertreter cer Familie hatten die Größe von Kaninchen und ein vollständiges Gebiß. Die Typotheriiden lebten vom Eozän bis zum Plistozän.

Henricoosbornia. - Eozän Patagoniens. ${ }^{3}$

Archaeohyrax. - Oligozän und Miozän Patagoniens. ${ }^{4}$

Typotherium. - Plistozän Patagoniens. ${ }^{5}$

\section{Unterordnung: Toxodontia.}

Nur in Südamerika vom Oligozän bis zum Plistozän. Das Vordergebiß ist eigenartig spezialisiert; der untere dritte Schneidezahn ist stark vergrößert und schleift an der Hinterseite des oberen zweiten Schneidezahns. Die Tiere übertrafen mit ihren jüngsten Gattungen (Toxodon) (Fig. 646) die Größe der lebenden Nashörner. Der Schmelzbelag der ursprünglich brachyodonten, später hypsodonten Backenzähne wird allmählich rudinentär, und zwar geht er entweder auf der Vorderund Hinterseite oder auf der Innen- und Hinterseite der Kronen verloren, während eine Zementschicht die Krone umkleidet, die eine meist stark gekrümmte Achse besitzt. ${ }^{6}$

\section{F. Acoelodidae.}

Wahrscheinlich die Stammgruppe der übrigen Familien. Die Grenzen dieser Fanilie gegen die primitiveren Typotheriiden sind keineswegs scharf, so daß die Herkunft der Typotheria und Toxodontia aus einer gemeinsamen Wurzel sehr wahrscheinlich ist.

Acoelodus. - Eozän Patagoniens.?

1 Ibidem, p. 67.

2 Ibidem, p. 85.

3 F. Ameghino, Paleontologia Argentina, 1. c., 1904, p. 75.

Derselbe, Morphologie phylogénétique etc., 1. c., 1904, p. 341, Fig. 456.

* Derselbe, Les formations sédimentaires du Crétacé supérieur et du Tertiaire de Patagonie. - Anales del Museo Nacional de Buenos Aires (3), T. XV, 1906, p. 308.

${ }^{5}$ P. Gervais, Remarques sur le Typotherium. - Zoologie et Paléontologie générales, Paris 1867-1869, p. 134.

${ }^{6}$ R. Lydekker, A Study of the Extinct Ungulates of Patagonia. - Paleontologia Argentina, La Plata 1883, Part. II.

7 F. Ameghino, Morphologie phylogénétique, 1. c., p. 305. 


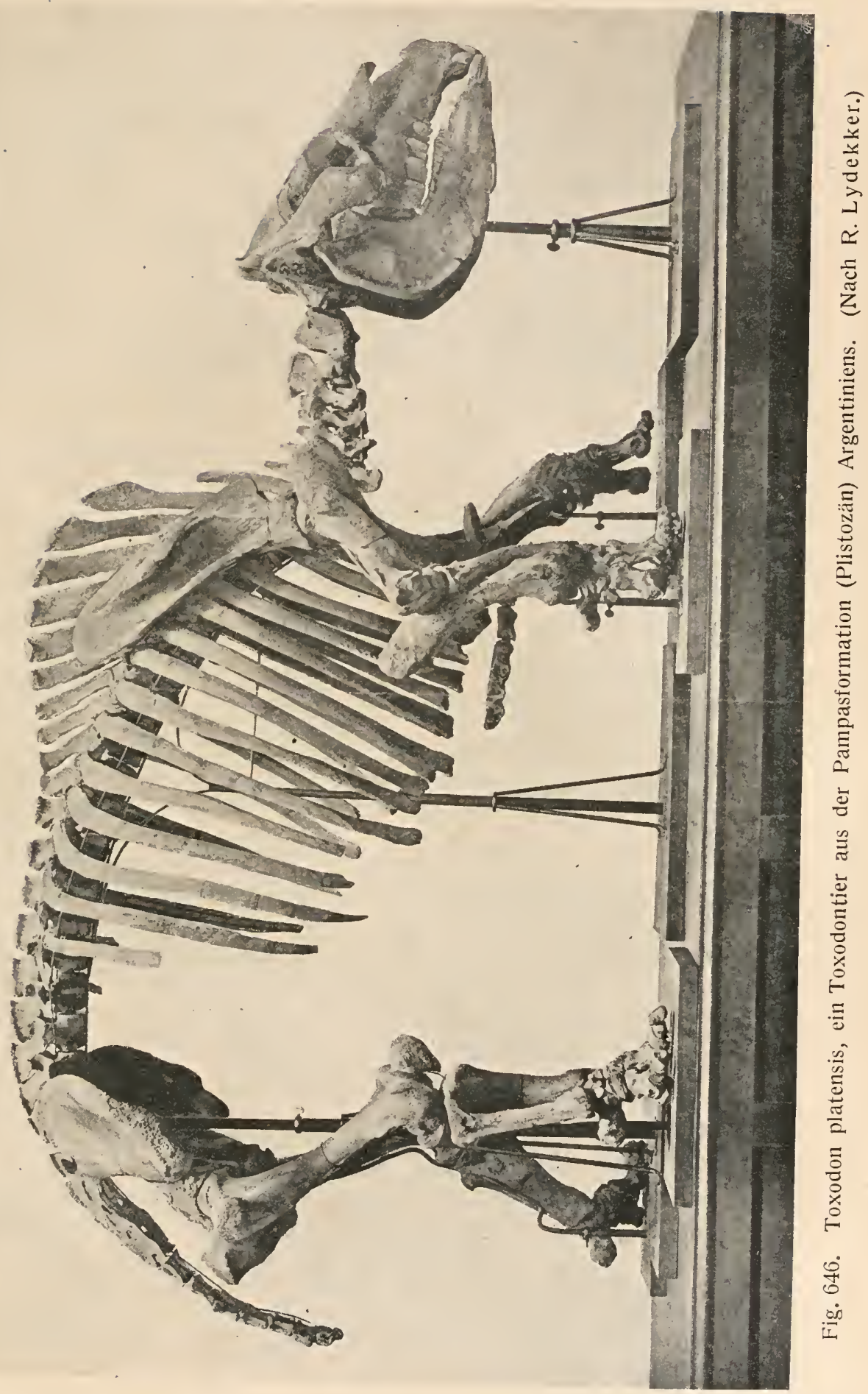


F. Notohippidae.

Morphippus. - Miozän Patagoniens. ${ }^{1}$

\section{F. Nesodontidae.}

Nesodon. - Miozän Patagoniens. ${ }^{2}$

\section{F. Toxodontidae.}

Toxodon. - Pliozän (?) und Plistozän Patagoniens (Fig. 646). ${ }^{3}$

3. Unterordnung: Entelonychia.

Die Tiere erreichten die Größe von Nashörneın. Die Endphalangen waren zurückziehbar. Die Bezahnung ist älnlich wie bei den Toxodontiern. Alle Molaren bleiben brachyodont. Vom Eozän bis zum Miozän.

\section{F. Notostylopidae.}

Notostylops. - Eozän Patagoniens. ${ }^{*}$

\section{F. Isotemnidae.}

1sotemnus. - Eozän Patagoniens. ${ }^{5}$

Pleurostylodon. - Miozän Patagoniens. ${ }^{6}$

\section{F. Leontiniidae.}

Leontinia. - Miozän Patagoniens. ${ }^{\top}$

\section{F. Homalodontotheriidae.}

Homalodontotherium. - Miozän Patagoniens. ${ }^{8}$

\section{Unterordnung: Astrapotherioidea.}

Diese Unterordnung läuft wahrscheinlich mit den Entelonychiern in einer gemeinsamen Wurzel zusanmen, hat aber eigenartige Spezialisationswege eingeschlagen, da die oberen Eckzähne als mächtige Hauzähne und die Molaren nashornartig entwickelt sind. Die Backenzälııe sind brachyodont geblieben.

1 F. A reghin 0, Palaeontologia Argentina, I. c., 1904, p. 62.

2 R. Lydekker, I. c.

A. Gaudry, Fossiles de Patagonie. Les Attitudes de quelques Animaux. Annales de Paléontologie, T. I, Paris 1906, p. 1. (Vgl. insbesondere Fig. 53, p. 29). Über die sekundäre Plantigradie von Nesodon, nach Durchlaufung eines digitigraden Ahnenstadiums, vgl. O. A bel, Grundzüge der Paläobiologie, 1912, p. 227.

3 R. Lydekker, I. c.

${ }^{4}$ F. Ameghino, Paleontologia Argentina, 1. c., Fig. 38, p. 54.

5 Derselbe, Morphologie phylogénétique etc., Fig. 177, p. 144.

${ }^{6}$ Ibiden, Fig. 228, p. 175 usw.

7 Derselbe, Paleontologia Argentina, 1. c., Fig. 42, p. 58.

8 Ibidem, p. 55-57. 


\section{F. Albertogaudryidae.}

Diese eozäne Familie umfaßt die Ahnen der Astrapotheriidae. Albertogaudrya. - Eozän Patagoniens. ${ }^{1}$

\section{F. Astrapotheriidae.}

Vom Eozän bis zum Miozän.

Proplanodus. - Eozän Patagoniens. ${ }^{2}$

Astraponotus. - Oligozän Patagoniens. ${ }^{3}$

Astrapotheriull1. - Miozän Patagoniens. ${ }^{4}$

\section{F. Trigonostylopidae.}

Von Eozän bis zum Oligozän.

Trigonostylops. - Eozän Patagoniens. ${ }^{5}$

Pseudostylops. - Oligozän Patagoniens. ${ }^{6}$

\section{Ordnung: Litopterna.}

Ebenso wie die Pyrotheria und Notoungulata sind auch die Allgehörigen dieser Ordnung auf Südamerika beschränkt geblieben. Aus bunodonten Protungulaten, und zwar aus der der Fanilie der Phenacodontiden nahestehenden Familie der Bunolitopterniden entstanden, haben sie rasch eigene Entwicklungswege eingeschlagen, die durch die Macraucheniiden und Proterotheriiden repräsentiert werden. Die Adiantiden sind nur aus dürftigen Resten bekannt, die eine große Ähnlichkeit mit jenen der Proterotheriiden besitzen. Von den zahlreichen Arten und Gattungen, die F. Anteghino unterschied, sind fast nur isolierte Molaren bekannt. ${ }^{\top}$

\section{F. Macraucheniidae.}

Die Macraucheniiden schließen sich den Bunolitopterniden an, haben aber bereits im Baue der Molaren, des Schädels und der Gliedmaßen Spezialisationen erfahren. Besonders auffallend ist die Verlängerung

1 F. Ameghino, Les Formations sédimentaires etc., I. c., Fig. 142, 144, p. 321.

2 Derselbe, Notices préliminaires sur des Mammífères nouveaux des terrains crétacés de Patagonie. Boletin de la Academia nacional de Ciencias de Cordoba, Buenos Aires, T. XVII, 1902, p. 20.

${ }^{3}$ Derselbe, Morphologie phylogénétique etc., l. c., p. $192 \mathrm{ff}$.

4 R. Lydekker, Paleontologia Argentina, I. c.

A. Gaudry, Fossiles de Patagonie, I. c., 1906.

W. B. Scott, A History of Land Mammals in the Western Hemisphere. New York 1913, p. 508ff. (Rekonstruktion des Schädels von Astrapotherium.)

5 F. Ameghino, Morphologie phylogénétique, I. c., p. $100 \mathrm{ff}$.

Ibidem; p. 282.

- W. B. Scott, Litopterna of the Santa Cruz Beds. - Report of the Princeton University Expedition to Patagonia, 1896-1899, Vol. VII, Princeton-Stuttgart 1910.

Derselbe, A History of Land Mammals in the Western Hemisphere, 1913, p. 489 . 
des Unterarms inı Verhältnis zum Oberarm $(100: 155=3: 2$ bei Macrauchenia patagonica), das schon bei Theosodon angebahnt erscheint (100:124). Im allgemeinen pflegt bei den Huftieren mit mesaxonischen Gliedmaßen der Oberarm länger oder gleichlang wie der Unterarm (Radius) zu sein, nur bei Hippidium ist der Humerus etwas kürzer als der Radius. Diese eigentümliche Verlängerung des Unterarms scheint (nach I. Sefve, 1914) danit zusammenzuhängen, daß Macrauchenia auf sumpfigem Boden lebte und die drei Zehen weit gespreizt hielt, um ein Einsinken in das Moor zu verhindern; darum ist auch bei den Macraucheniiden keine weitere Reduktion der Zehen und Finger eingetreten, die dagegen bei den Proterotheriiden zur Ausbildung einfingeriger Typen (z. B. Thoatherium crepidatum) gefühnt hat, einer Spezialisation, die mit jener der Pferdegliedmaßen eine überraschende Ähnlichkeit aufweist. Die für laufende Tiere notwendige Verlängerung der distalen Gliedmaßenabschnitte ist bei den Macraucheniiden deshalb fast ausschließlich auf den Unterarm übertragen worden, weil die drei Zehen zur Schaffung einer breiten Trittfläche dienten und die Seitenzehen nicht entbehrt werden konnten. Für die aquatische Lebensweise scheint mir aber auch die Lage der äußeren Nasenöfnungen zu sprechen, die bei Macrauchenia weit nach hinten verschoben waren; außerdem muß, wie aus den Gruben hinter den Nasenöffnungen zu schließen ist, ein Rüssel vorhanden gewesen sein.

Theosodon. - Miozän Patagoniens (Fig. 598 A). ${ }^{1}$

Macrauchenia. - Plistozän Argentiniens und Boliviens, Vorderund Hinterfuß dreizehig (Fig. 647). ${ }^{2}$

\section{F. Proterotheriidae.}

Die Spezialisationen der Proterotheriiden haben eine andere Richtung als die der Macraucheniiden. Die Reduktion der Seitenzehen schreitet von einem Ausgangstypus wie Theosodon weiter fort und führt zur Einzeligkeit (Thoatherium); die Nasenöffnungen bleiben an Vorderende des ebenso wie bei den Macraucheniiden im allgemeinen pferdeförmigen, langen und schmalen Schädels liegen. Die Molaren erinnern in ihrer Form an jene der Unpaarhufer.

Diadiaphorus. - Miozän und Pliozän Patagoniens. ${ }^{3}$

Proterotherium. - Miozän Patagoniens (Fig. 598 B). ${ }^{4}$

Thoatherium. - Miozän Patagoniens (Fig. 598 C). ${ }^{5}$

1 Ibidem, Vgl. ferner A. Gaudry, 1. c., 1906.

2 Ibidem. Ferner: I. Sefve, Über eine netse Art der Gattung Macrauchenia aus Ulloma, Bolivien. - Bull. Geol. Instit. of Upsala, Vol. XII, Upsala 1914, p. 205.

${ }^{3}$ F. Ameghino, Paleontologia Argentina, 1. c., 1904, p. 69.

${ }^{4}$ W. B. Scott, 1. c. und F. Ameghino, Paleontologia Argentina, p. 69.

5 Ibidem.

F. Ameghino, Paleontologia Argentina, 1904, p. 70. 


\section{F. Adiantidae.}

Durch ungenügend bekannte und vielleicht mit den Proterotheriiden zu vereinigende Reste vertreten.

Adiantus. - Miozän Patagoniens. ${ }^{1}$

Proadiantus. - Miozän Patagoniens. ${ }^{2}$

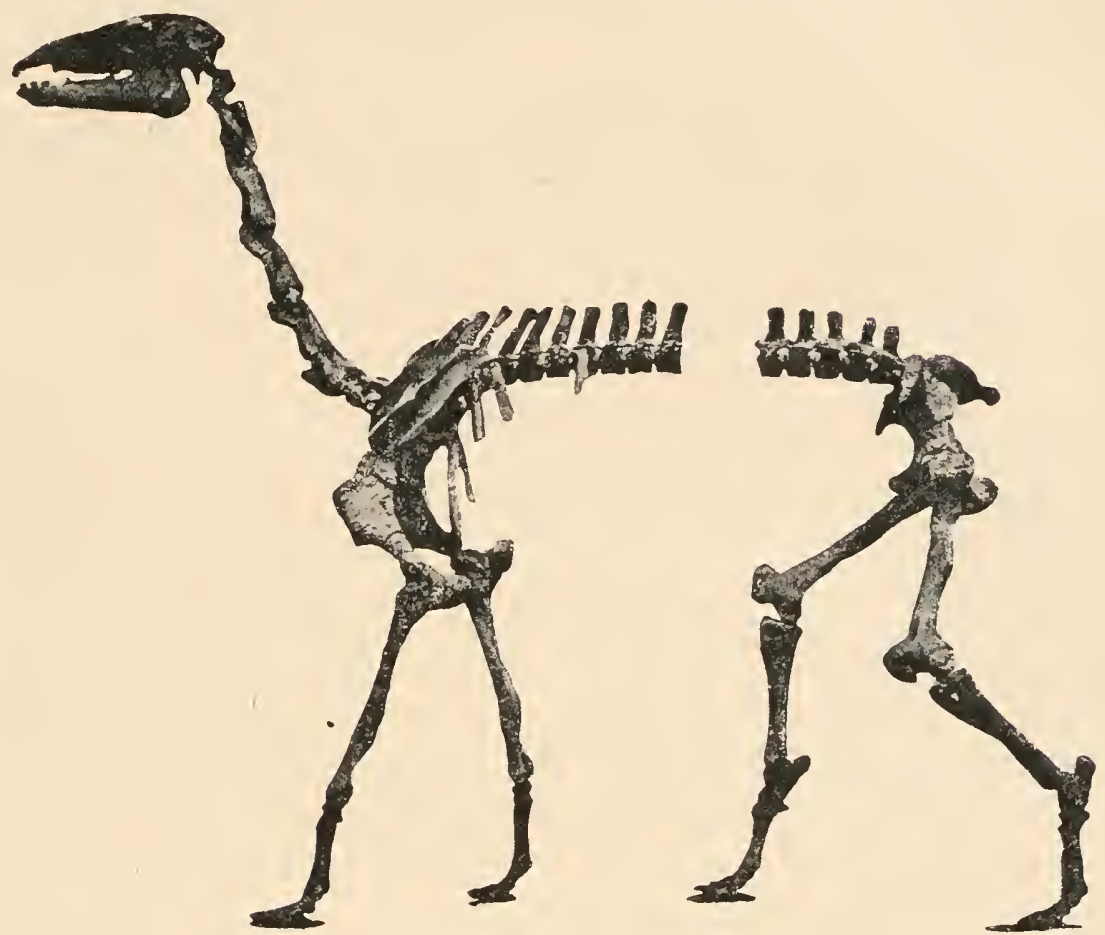

Fig. 647.

Macrauchenia patagonica, Owen, aus dem Plistozän (Pampasformation) Argentiniens, ein Wassertier. (Nach R. Lydekker.)

\section{Ordnung: Perissodactyla.}

Die Unpaarhufer oder Perissodactylen sind aus den Phenacodontiden hervorgegangen und lassen sich daher bis in die Stammgruppe der Protungulaten zurückverfolgen. Im Eozän besaßen noch alle Vertreter der sich später in vier Stämme (Tapiridae, Rhinocerotidae, Equidae und die erloschenen, tertiären Titanotheriidae) spaltenden Unpaarhufer geschlossene Zahnreihen und erst später traten Reduktionen ein, die am weitesten bei den Rhinocerotiden vorgeschritten sind. Die Zähne waren bei den primitiveren Formen brachyodont und wurden später bei den Equiden und Rhinocerotiden unabhängig voneinander hypsodont, während

1 F. Ameghino, Morphologie phylogénétique, p. 92.

2 Derselbe, Les Formations sédiméntaires etc., 1906, p. 345. 
die Tapiriden und Titanotheriiden keine hypsodonten Molaren bekommen haben. Die Verfestigung der Zahnkronen, die beim Zerreiben harter Pflanzennahrung (besonders Gramineen) stark in Anspruch genommen werden, erfolgte bei den Equiden und bei den Rhinocerotiden auf ganz verschiedenen Wegen, doch kam es in beiden Stämmen zur Ausbildung von Zement in den Vertiefungen der Krone, die durch sekundäre Schmelzfalten, Kämme, Pfeiler usw. verfestigt wurden. In den Gliedmaßen sind niemals Verschmelzungen der Karpal- und Tarsalelemente wie bei den Paarhufern zu beobachten. Am weitesten spezialisiert ist Fuß und Hand der Equiden, die einfingerig geworden sind wie die löchst-spezialisierten Proterotheriiden. Die schrittweise zunelımende Verkümmerung der Seitenfinger und Seitenzehen bei den verschiedenen Tertiärpferden ermöglicht es, die Geschichte dieser Anpassung an das Laufen auf hartem Boden bis in ihre Einzelheiten zu verfolgen. Die beiden seitlichen Metapodien (II. und IV.) sind aber noch beim lebenden Pferde in Form langer, distal zugespitzter Griffel vorhanden, deren Oberende an der Gelenkbildung gegen den Carpus oder Tarsus teilnimmt und daher noch in Funktion steht; sie sind also wohl funktionslos in bezug auf die Trittfläche, aber nicht funktionslos in bezug auf die Tragfläche am Oberende des Metapodialabschnittes und unterliegen daher keiner weiteren Reduktion mehr, sondern verbinden sich fest mit den zum alleinigen Träger des Körpers gewordenen dritten Metapodium in Fuß und Hand. Am Femur aller Unpaarhufer ist der dritte Trochanter (Trochanter tertius), ein Muskelansatz, stark entwickelt.

\section{F. Tapiridae.}

Die Tapire leben heute im tropischen Südamerika und in Südasien, besaßen aber in Tertiär eine viel weitere Verbreitung; sie erscheinen im Eozän und lebten bis zum Pliozän in Europa, bis zum Plistozän in Nordamerika und traten im Plistozän auch in China auf.

1. Unterfamilie: Lophiodontinae.

Nur aus dem Eozän bekannt. Durch den Molarenbau von den Tapirinen scharf geschieden.

Lophiodon. - Eozän Europas. ${ }^{1}$

2. Unterfamilie: Tapirinae.

Homogalax. - Untereozän von Wyoning. ${ }^{2}$

$1 \mathrm{Ch}$. Depéret, Études paléontologiques sur les Lophiodon dı Minervuis. Archives du Muséum d'Histoire naturelle de Lyon, T. 1X, 1903, p. 1.

H. G. Stehlin, Die Säugetiere des Schweizerischen Eozäns. - Abhandlungen der Schweizerischen paläontologischen Gesellschaft, Vol. XXX, Zürich 1903, p. 74.

2 J. L. Wortman, Species of Hyracotherium and Allied Perissodactyls from the Wasatch and Wind River Beds of North America. - Bull. Amer. Mus. Nat. Hist., Vol. VIl], 1896, p. 89.

Der Name Homogalax wurde von O.P.Hay 1903 aufgestellt (für Systemodon p.p.). 
Protapirus. - Oligozän Europas. ${ }^{1}$

Tapirus. - Vom Obermiozän (Österreichs) an. ${ }^{2}$

\section{F. Rhinocerotidae.}

Die Nashörner umfassen vier frühzeitig voneinander getrennte Stänme, die Hyracodontinae, Amynodont nae, Rhinocerotinae und Elasmotheriinae.

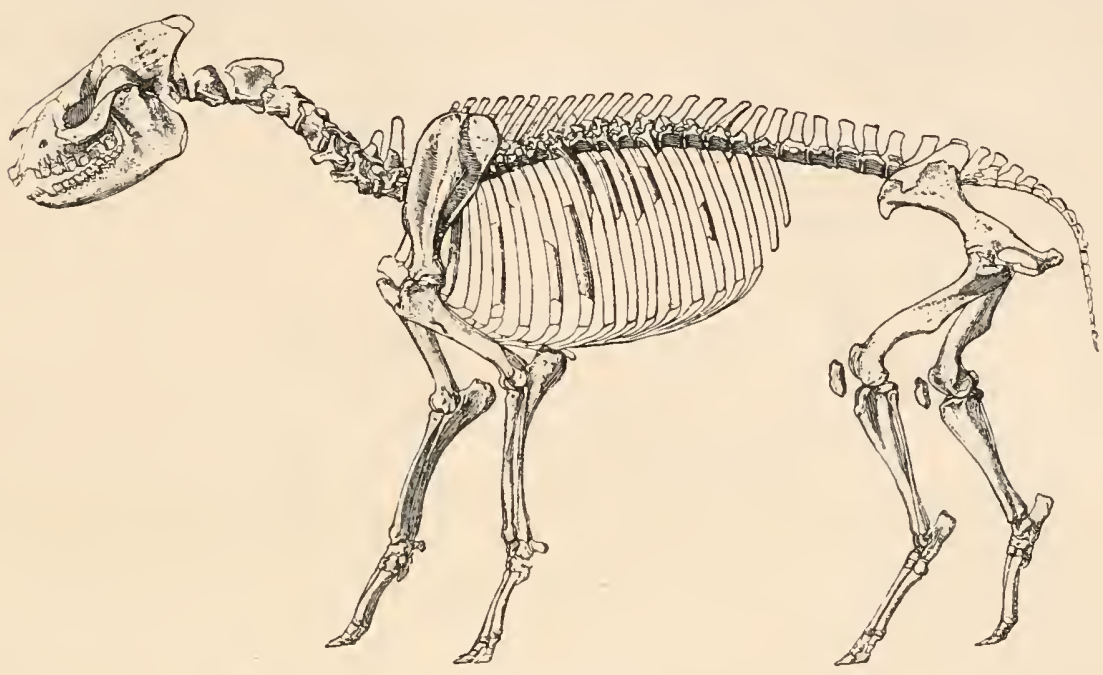

Fig. 648.

Rekonstruktion von Hyracodon nebrascensis, Leidy, aus dem Oligozän Nordamerikas. (Nach W. B. Scott, 1895.)

1. Unterfamilie: Hyracodontinae.

Hochbeinige, zartgebaute Formen, die sehr an die ältesten Pferde erinnern und jedenfalls schnellfüßige Tiere gewesen sind. Sie sind nur aus dem Eozän und Oligozän Nordamerikas bekannt und erloschen. Hyrachyus. - Mittel- und Obereozän von Wyoning. ${ }^{3}$

Hyracodon. - Oligozän Nordamerikas (Fig. 648). ${ }^{4}$

1 H. Filhol, Recherches sur les Phosphorites du Quercy. - Annales des Sciences géologiques, Vol. VIII, 1877, p. 131.

2 Der älteste bisher bekannte Tapir (Tapirus Telleri) ist im Miozän der Steiermark gefunden worden. - V Vl. darüber: A.Hofmann, Die Fauna von Göriach. - Abhandlungen der K. K. Geologischen Reichsanstalt in Wien, XV. Bd., Wien 1893, S. 47.

Im Pliozän Europas sind die Tapire nicht selten. Sie fehlen jedoch in ausgesprochenen Steppengebieten wie in Samos oder in Gegenden, die den Charakter der stärker bewaldeten Buschsteppe besaßen.

3 Die Literatur über diese Gattung ist nachzusehen bei O. P. Hay, Bibliography and Catalogue of the Fossil Vertebrata of North America, Washington, l. c., 1902, p. 638.

${ }^{4}$ W. B. Scott, Die Osteologie von Hyracodon, Leidy. - Festschrift zum 70. Geburtstage von Carl Gegenbaur, 1I. Bd., 1895, S. 353. 
2. Unterfamilie: Amynodontinae.

Eine einseitig spezialisierte und erloschene Gruppe der Rhinocerotiden, die nordamerikanischen Ursprungs ist, wo sie im Obereozän mit

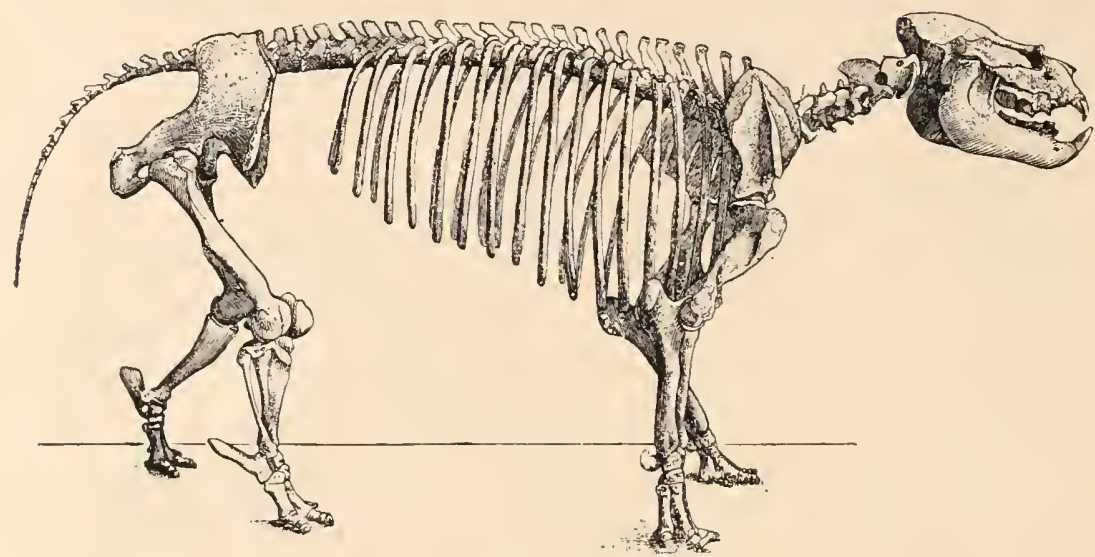

Fig. 649.

Rekonstruktion des Skelettes von Metamynodon planifrons, ein Amynodontine aus dem Oligozän Nordamerikas. (Nach H. F. Osborn und J. L. Wortman.)

Amynodon auftritt; sie wandert im Oligozän in Europa ein, erlischt aber hier ebenso wie in Nordamerika noch zur selben Zeit.

Amynodon. - Obereozän Nordamerikas. ${ }^{1}$

Metamynodon. - Oligozän Nordamerikas (Fig. 649). ${ }^{2}$

Cadurcotherium. - Oligozän Frankreichs (Fig. 650). ${ }^{3}$

${ }^{1}$ W. B. Scott and H.F. Osborn, On the Skull of the Eocene Rhinoceros, Orthocynodon, and the Relation of this Genus to other Members of the Group. Princeton College, Bulletin Nr. 3, 1883, p. 1.

H. F. Osborn, The Mammalia of the Uinta Formation. Part III. The Perissodactyla. Transactions of the American Philosophical Society, Vol. XVI, 1890 (I 889 ), p. 508.

M. Pavlow, Note sur un nouveau crâne d'Amynodon. - Bull. de la Soc. des Naturalistes de Moscou, Nr. 1, 1893, p. 1.

${ }^{2}$ W. B. Scott and H. F. Osborn, Preliminary Account of the Fossil Mammals from the White River Formation, contained in the Museum of Comparative Zoology. - Bull. Mus. Comparative Zool., Vol. X111, 1887, p. 165.

H. F. Osborn and J. L. Wortman, Perissodactyls of the Lower Miocene White River Beds. - Bull. Amer. Mus. Nat. Hist, Vol. VII, 1895, p. 373.

H. F. Osborn, The Extinct Rhinoceroses. - Memoirs of the American Museum of Nat. Hist., New York, Vol. 1, Part 3, 1898, p. 75.

${ }^{3}$ F. Roman, Le Cadurcotherium de l'Isle-sur-Sorgues. - Archives de Musée d'Hist. Nat. Lyon, T. X, 1908.

Derselbe, Sur un Acerotherium des Collections de l'Université de Grénoble et sur les Mammifères du Stampien des Environs de l'Isle-sur-Sorgues (Vaucluse). - Annales de l'Université de Grenoble, T. XXIV, Nr. 2, Paris-Grenoble 1912, p. 9. 


\section{Unterfamilie: Rhinocerotinae.}

Die lebenden Nashörner bilden die letzten Ausläufer eines einst sehr formenreichen und blühenden Stammes, dessen Blüte in die obere Tertiärzeit fällt. Ein Kennzeichen der jüngeren Gattungen sind die Nasenhörner, die jedoch den älteren fehlten (Aceratherium). Die oberen Molaren wurden in Laufe der Stammesgeschichte durch die Ausbildung von Kämmen und Leisten, die in das Innere der von drei Jochen (Protoloph, Metaloph und Ectoloph) gebildeten Krone vorspringen (Antecrochet, Crochet und Crista) kompliziert (Fig. 651). Die ursprünglich von den Molaren formverschiedenen Prämolaren wurden im Laufe

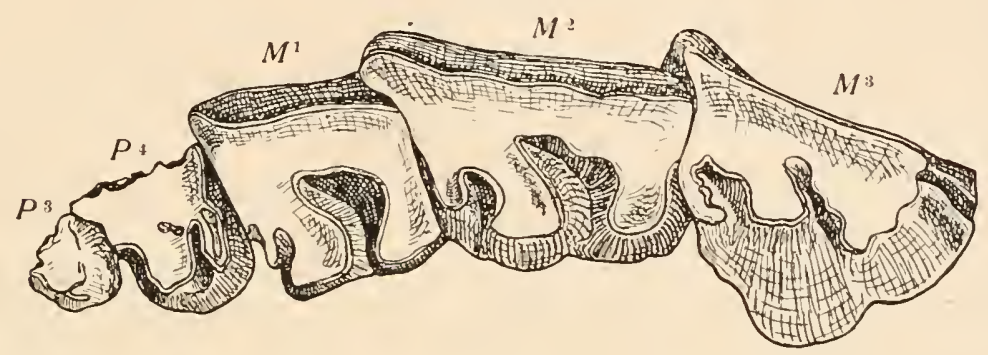

Fig. 650 .

Die fünf letzten linksseitigen oberen Backenzähne $\left(P_{3}-M_{3}\right)$ von Cadurcotherium Nouleti aus dem Oligozän von Isle-sur-Sorgues (Vaucluse) in Frankreich. $1 / 2$ nat. Gr. (Nach F. Roman.)

der Stammesgeschichte imnter mehr molarenähnlich (,molariform"); dabei wurden die ursprünglich brachyodonten Zähne allmählich hypsodont. Im Unterkiefer verdrängt das allmählich immer größer werdende zweite Schneidezahnpaar das immer kleiner werdende erste schrittweise ganz. Die unteren $l_{3}$ verkünmern schon frühzeitig; die oberen $1^{3}$ gehen später verloren. Stets bleibt der Hinterfuß dreizehig und verharrt heute noch auf dem schon im Oligozän erreichten Ausbildungsstadium. Die Hand ist bei den jüngeren Gattungen und Arten dreifingerig; bei den älteren war sie noch vierfingerig.

Die ersten Rhinocerotinen erscheinen im Mitteleozän Europas, nehmen aber schon im Oligozän Europas und Nordamerikas an Häufigkeit zu und erreichen im Miozän und Pliozän in Eurasien eine hohe Blüte, während sie in Nordamerika allmählich verschwinden. In der Eiszeit erreichten einzelne Arten (z. B. Coelodonta antiquitatis $=$ Rhinoceros tichorhinus, und Coelodonta Merckii) eine weite Verbreitung in Europa und Nordasien.

Prohyracodon. - Mitteleozän Siebenbürgens. ${ }^{1}$

1 A Koch, Prohyracodon orientalis, ein neues Ursäugetier aus den mittel- 
Trigonias. - Oligozän Nordamerikas. ${ }^{1}$

Leptaceratherium. - Oligozän Nordamerikas (Fig. 652). ${ }^{2}$

Meninatherium. - Oberoligozän Österreichs. ${ }^{3}$

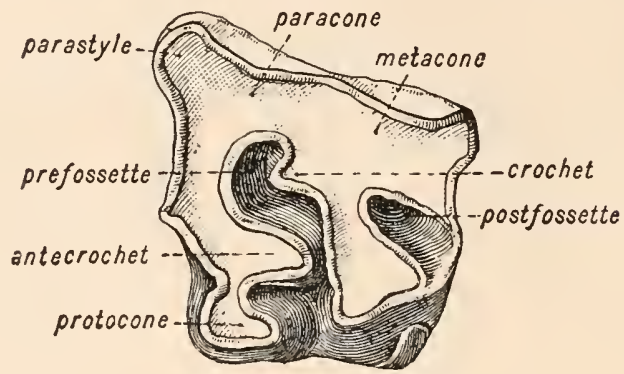

Fig. 651 .

Oberer linker Molar von Teleoceras sp. in $1 / 2$ nat. Gr.

(Nach H. F. Osborn.)

Protaceratherium. - Oligozäı Mitteleuropas (Fig. 653). ${ }^{4}$

Aceratheriu11. - Oberoligozän bis Pliozän Europas und Asiens. ${ }^{5}$

Diceratherium. - Oligozän und Miozän Nordamerikas und Europas. ${ }^{6}$

eocänen Schichten voll Siebenbürgen. - E Museo nationali hungarico, Budapest, Vol. XX, 1897, p. 481.

O.Abel, Kritische Untersuchungen über die paläogenen Rhinocerotiden Europas. Abhandl. der K. K. Geolog. Reichsanstalt in Wien, XX. Bd., 3. Heft, Wien 1910, S. 24.

1 F. A. Lucas, A New Rhinoceros, Trigonias Osborni, from the Miocene of South Dakota. - Proceedings of the U.S. National Museun,, Washington, Vol. XXIII, Nr. 1207, 1900, p. 221.

J. B. Hatcher, Some New and Little Known Fossil Vertebrates. - Annals of the Carnegie Museum, Pittsburgh, Vol. I, 1901, p. 135.

2 H. F. Osborn, The Extinct Rhinoceroses. - I. c., 1898, p. 132.

3 O. Abel, Kritische Untersuchungen über die paläogenen Rhinocerotiden Europas. - 1. c., 1910, S. 26.

W. Teppner, Ein Beitrag zur näheren Kenntnis von Meninatherium Telleri, Abel. - Carniola, 4. Heft, 1914, S. 1.

4 O. Abel, Kritische Untersuchungen usw., 1. c., S. 15.

${ }^{5}$ Die Literatur iiber Funde der zahIreichen Aceratheriumreste aus Europa und Asien ist sehr umfangreich. Die wichtigste Literatur ist nachzusehen bei H. F. Osborn, The Extinct Rhinoceroses, 1. c., ferner in der Abhandlung desselben Autors: Phylogeny of the Rhinoceroses of Europe. - Bull. Amer. Mus. Nat. Hist., Vol. XIII, 1900, p. 229; O. Abel, Krit. Untersuchungen über die paläogenen Rhinocerotiden Europas, 1910; F. Roman, Les Rhinocéridés de l'Oligocène d'Europe, I. c., 1911.

- O. C. Marsh, Notice of New Tertiary Mammals. - Part IV. - Amer. Journal of Science (3), Vol. IX, 1875, p. 242.

O. Abel, Kritische Untersuchungen über die paläogenen Rhinocerotiden Europas, 1. c., 1910, S. $6,9$.

O. A. Peterson, A Mounted Skeleton of Diceratherium Cookei. - Annals of the Carnegie Museum, Pittsburgh, U. S. A., Vol. VII, 1911. 
Teleoceras. - Miozän Nordamerikas (Fig. 651). ${ }^{1}$

Ceratorhinus. - Inı Miozän Europas zuerst auftretend, lebend in Sumatra.

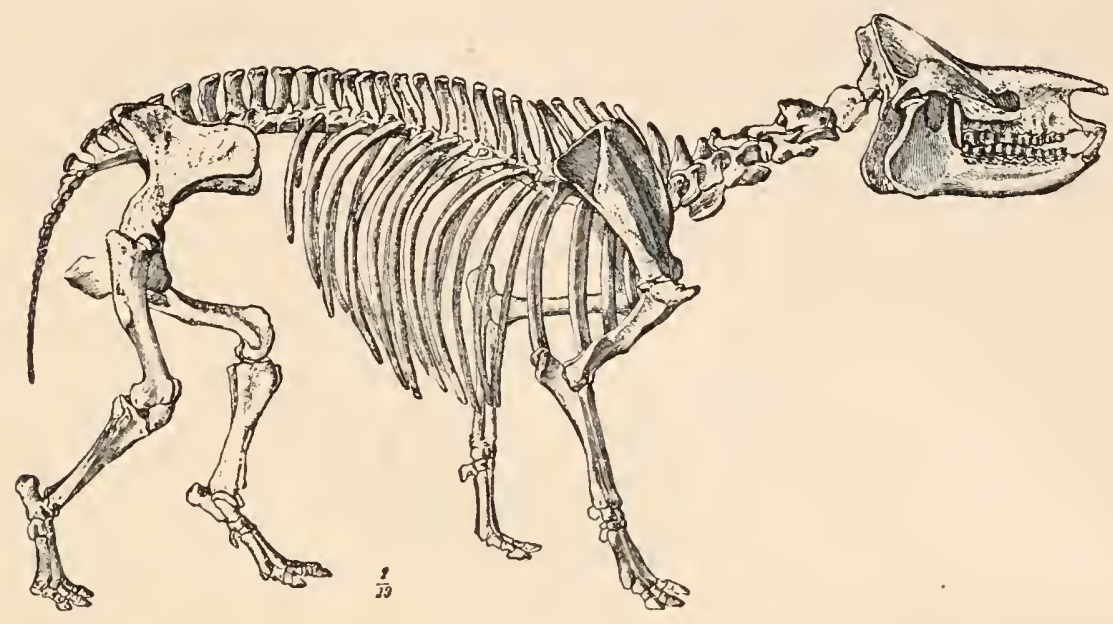

Fig. 652 .

Rekonstruktion des Skelettes von Leptaceratherium tridactylum, Osborn, ein oligozäner Rhinocerotine aus den Protoceras Beds (Oberoligozän) von SüdDakota, Nordamerika. (Nach H. F. Osborn und J. L. Wortman.)

Rhinoceros. - Houte in Südindien lebend, erscheint zuerst in Unterpliozän Ostindiens.

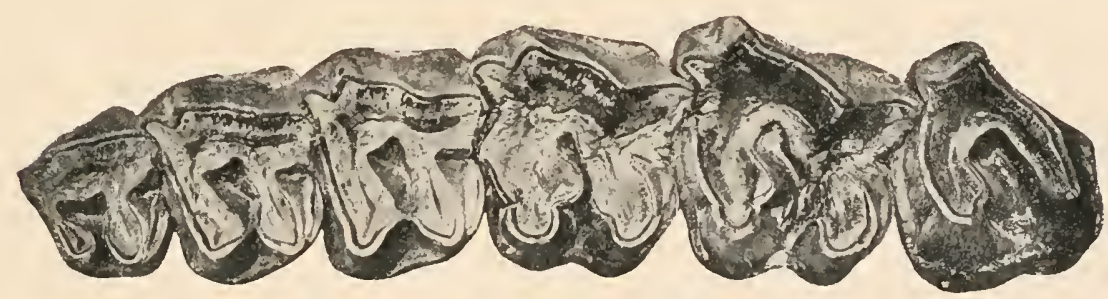

Fig. 653.

Linke obere Backenzahnreihe von Protaceratherium minutum Cuvier aus dem oberen Stampien (Mitteloligozän) von Auzon bei Alais (Dep. Gard, Frankreich). Original in der Sammlung der Universität Lyon. Ungefähr $2 / 3$ nat. Gr. (Nach F. Roman, 1911.)

Diceros. - Lebend in Afrika, fossil inn Unterpliozän von Eurasien. Coelodonta. - Lebend in Afrika, fossil aus plistozänen Ablagerungen Eurasiens bekannt.

1 J.B.Hatcher, On a Small Collecrion of Vertebrate Fossils from the Loup Fork Beds of North Western Nebraska etc. - American Naturalist, Vol. XXVII1, 1894, p. 241.

H. F. Osborn, The Age of Mammals: New York 1910, Fig. 127, p. 252; Fig. 161, p. 349. 
4. Unterfamilie: Elasmotherimae.

Nur eine einzige aberrante Gattung (Elasmotherium) bekannt ${ }^{1}$ (Fig. 654), deren Beziehungen zu den übrigen Rhinocerotiden noch unaufgeklärt sind. Wahrscheinlich repräsentiert sie das Endglied eines

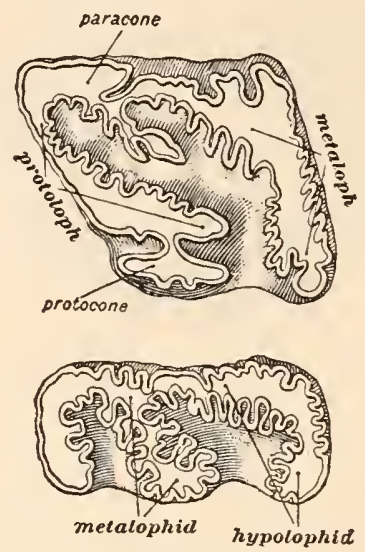

Fig. 654 .

Oberer und unterer Molar von Elasmotherium sibiricum aus der Eiszeit Sibiriens. $4 / 9$ nat. Gr. (Nach A. Gaudry und M. Boule.)

im Alttertiär abgezweigten Astes des Rhinocerotidenstammes. ${ }^{2}$ Elasmotherium sibiricum ist im Plistozän Südrußlands, an Kaspisee und Sibirien, aber auch im Rheintal und in Sizilien gefunden worden.

\section{F. Equidae.}

Die Geschichte der Equiden, welche auf die Phenacodontiden zurückgehen und mit diesen durch die kleine Gattung Hyracotherium aus dem Untereozän Englands verknüpft sind (diese Form schließt sich am nächsten

1 J. F. Brandt, Mitteilungen über die Gattung Elasmotherium, besonders den Schädelbau derselben. Mémoires de l'Académie $1 \mathrm{mp}$. Sciences St. Pétersbourg (7), Vol. XXVI, Nr. 6, 1876.

A. Gaudry et M. Boule, Materiaux pour l'Histoire des Temps quaternaires. 3. Fasc., Paris 1888.

Die wichtigsten Kennzeichen dieser Gattung sind die starke Kräuselung des Schmelzes in den Molaren sowie der Verlust des vorderen Nasenhorns, während das hintere Horn zwischen den Augen auf den Stirnbeinen stand und von einem gewaltigen Knochensockel getragen wurde.

2 Osborn hat (Science, N. S. O., Vol. IX, Nr. 214, 1899, p. 161) die Ansicht vertreten, daß Elasmotherium der Nachkomme des unterpliozänen Aceratherium incisivum sei, was jedoch kaum möglich sein dürfte. Die Heimat dieses hochspezialisierten Rhinocerotiden sind jedenfalls die Steppen Zentralasiens gewesen; es war an Grasnahrung angepaßt, was vor allem aus der hochgradigen Hypsodontie der MoIaren hervorgeht. In Europa scheint das Tier auch in der Eiszeit nur als sehr seltener Gast aufgetreten zu sein. 
an Tetraclaenodon an), hat sich hauptsächlich auf dem Boden Nordamerikas während der Tertiärzeit abgespielt, während in Europa sechs Stämme inı Alttertiär eine hohe Blüte erreichten, aber rasch nacheinander ausstarben. Die lebenden Equiden gehen ausnahmslos auf nordamerikanische Ahnen zurück, aber die Pferde starben in der Neuen Welt schon im Plistozän aus und wurden erst nach der Entdeckung Amerikas wieder in Nordamerika und Südamerika eingeführt. Die südamerikanischen Equiden des Plistozäns gehören einer durchaus selbständigen Seitenlinie der Pferde an.

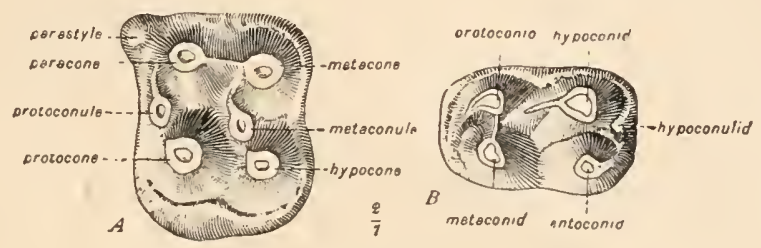

Fig. 655 .

Links: oberer, Rechts: unterer Molar von Hyracotherium leporinum aus dem Untereozän (London Clay) Englands, in 2/1 nat. Gr. - Beide Zähne zeigen den primitiven Ausgangstypus der Molaren der Unpaarhufer; aus dem Höckerzahn mit 6 Höckern im Oberkiefer und 4 Höckern im Unterkiefer entstehen in Laufe der Stammesgeschichte' die verschiedenen, hochgradig spezialisierten Zahntypen, wie sie z. B. die lebenden Nashörner und Pferde aufweisen.

(Nach R. Owen, aus H. F. Osborn.)

Die Reduktion der Seitenfinger und Seitenzehen sowie die Spezialisation des Gebisses, daneben aber auch die Schädelmerkmale geben uns eine sehr klare Übersicht über die Veränderungen der Equiden inı Laufe ihrer Stammesgeschichte, die in den Hauptzügen völlig geklärt ist. Nur über den Verwandtschaftsgrad einzelnei Gattungen bestehen noch unwesentliche Meinungsverschiedenheiten.

Hyracotherium. - Untereozän Europas (Fig. 655, 656 A). ${ }^{1}$

Eohippus. - Unteres Untereozän Nordamerikas (Fig. 657 a). ${ }^{2}$

Protorohippus. - Oberes Untereozän Nordamerikas. ${ }^{3}$

Orohippus. - Mitteleozän Nordamerikas (Fig. 657 b). ${ }^{4}$

Epilıippus. - Obereozän Nordamerikas. ${ }^{5}$

1 Die ältere Literatur ïber Hyracotherium ist nachzusehen bei H. G. Stehlin, Die Säugetiere des Schweizerischen Eozäns. 111. Teil. - Abhandlungen der Schweiz. Paläont. Ges., Vol. XXX11, 1905, S. 552.

2 O. P. Hay, Bibliography and Catalogue of the Fossil Vertebrata of North America. - Bull. 179 of the U. S. Geol. Survey, Washington 1902, p. 608.

3 lbidem, p. 610.

4 Ibidem, p. 611.

5 Ibidem, p. 612. 
Mesohippus. - Unteroligozän und Mitteloligozän Nordamerikas (Fig. 656 D und Fig. 657 c). ${ }^{1}$
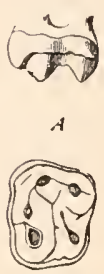
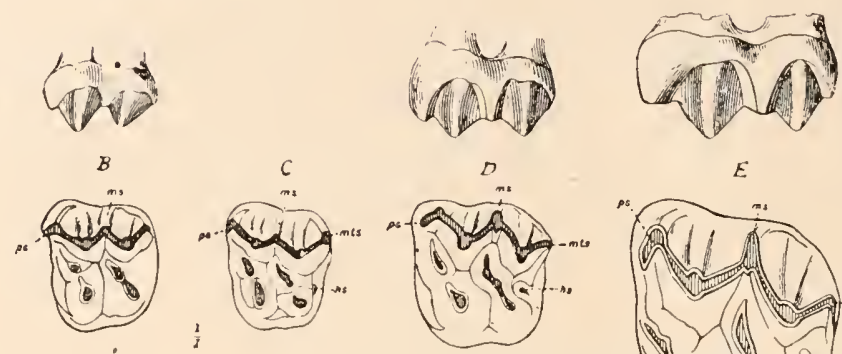

$E$

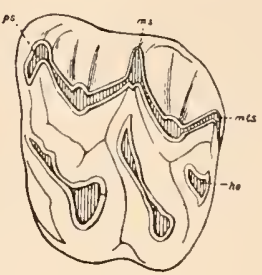

Fig. 656.

Verschiedene Molarentypen tertiärer Equiden.

A: Hyracotherium (Untereozän Europas).

B: Pachynolophus (Mittel- und Obereozän Europas).

C: Anchilophus (Mittel- und Obereozän Europas).

D: Mesohippus (Unter- und Mitteloligozän Nordamerikas).

E: Anchitherium (Miozän Europas bis Pliozän Ostasiens).

(Nach H. F. Osborn.)

Miohippus. - Oberoligozän Nordamerikas (Fig. 657 d). ${ }^{2}$

Anchitherium. - Untermiozän Nordamerikas, Miozän Europas. Lebte noch im Unterpliozän in China. A. ist der Nachkomme von Mesohippus; es ist ohne Nachkommen erloschen (Fig. 658, 656 E). ${ }^{3}$

1 Miohippus wird von einigen Autoren mit Mesohippus vereinigt. Die Arten aus dem Unter- und Mitteloligozän Nordamerikas erweisen sich jedoch in verschiedenen Merkmalen primitiver und rechtfertigen daher die Unterscheidung beider ,Gattungen“ als zwei aufeinanderfolgende, wenn auch direkt verbundene Entwicklungsstufen. Zı den wichtigsten Unterschieden beider Gattungen gehört die stärkere Reduktion des fünften Fingers bzw. des fünften Metacarpale bei Miohippus im Vergleiche zu Mesohippus, die etwas kompliziertere Beschaffenheit der Molarenkronen und die bedeutendere Körpergröße. Darüber ist zu vergleichen: R. S. Lull, The Evolution of the Horse Family. - Guide no. I of the Peabody Museum of Natural Histor y, Yale University, New Haven (Reprinted of the Amer. Journal of Science, Vol. XXIII, March 1907).

Außer der bei O. P. Hay angegebenen Literatur (1. c., S. 612) sind iiber diese wichtige Gattung folgende Arbeiten nachzusehen:

E. Douglass, New Vertebrates from the Montana Tertiary. - Annals Carnegie Museum, Vol. I1, Nr. 2, 1903, p. 161.

H. F. Osborn, New Oligocene Horses. - Bull. Mus. Nat. Hist. New York, Vol. XX, 1904, p. 167.

L. M. Lambe, On the Tooth-Structure of Mesohippus Westoni (Cope). The American Geologist, Vol. XXXV, April 1905, p. 243.

2 H. F. Osborn, The Age of Mammals, 1910, p. 227, 230.

3 O. P. Hay, 1. c., p. 614 (Literatur bis 1902).

M. Schlosser, Die fossilen Säugetiere Chinas usw. - Abhandl. Bayr. Akad. d. Wissenschaften, München, Cl. Il, XXII. Bd., 1903. 


\section{Parahippus. - Untermiozän Nordamerikas. ${ }^{1}$ \\ Merychippus. - Mittel- und Obermiozän Nordamerikas. ${ }^{2}$}
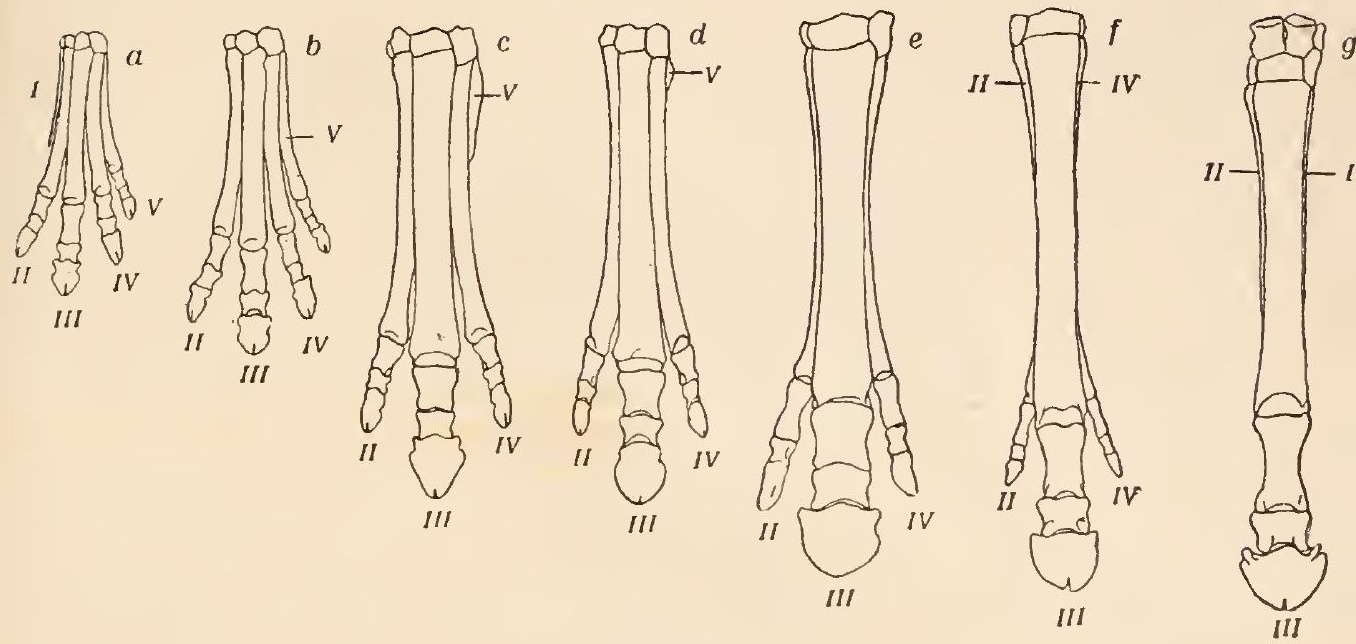

Fig. 657.

Die phylogenetische Entwicklung der Pferdehand, welche die schrittweise erfolgende Reduktion der Seitenfinger zeigt (die Finger I, II, IV und V verkümmern und nur der III. Finger bleibt als ,Lauffinger“ in Funktion). - Diese Stufenreihe, welche nur nordamerikanische Vertreter der Equiden umfaßt, repräsentiert nicht die Ahnenreihe der nordamerikanischen Equiden, da Hypohippus jünger ist als Neohipparion und Protohippus und einem von Mesohippus abzweigenden blind endigenden Seitenast angehört. - (Zusammengestellt von O. Abel, 1912.)

a) Eohippus pernix. - Wasatch Beds (Untereozän).

b) Orohippus agilis. - Bridger Beds (Mitteleozän).

c) Mesohippus celer. - White River Beds (Unteroligozäı).

d) Miohippus anceps. - John Day Beds (Oberoligozän).

e) Hypohippus equinus. - Deep River Beds (Mittel- und Obermiozän).

f) Neohipparion Whitneyi. - Arikaree Beds (Untermiozän).

g) Protohippus pernix. - Arikaree Beds (Untermiozän).

(Fig. a-d nach O. C. Marsh, e-g nach R. S. Lull.)

Protohippus. - Obermiozän bis Unterpliozän Nordamerikas (Fig. $657 \mathrm{~g})^{3}$

Neohipparion. - Obermiozän bis Unterpliozän Nordamerikas (Fig. $657 \mathrm{f}){ }^{+}$

1 Über die Beziehungen von Parahippus zu den nächstverwandten Formen vgl. H. Winge, Jordfundne og nulevende Hovdyr (Ungulata) fra Lagoa Santa, Minas Geraes, Brasilien. - Med Udsigt over Hovdyrenes Indbyrdes Slaegtskab. E Museo Lundii. Kjöbenhavn 1906, p. 226.

${ }^{2}$ H.F. Os born, Palaeontology.- Encyclopaedia Britannica, 1911, p.584, Pl. 111.

${ }^{3}$ R. S. Lull, l. c., p. 18 (nebst der anderen oben zitierten Literatur).

${ }^{4}$ H. F. Osborn, Palaeontology, 1. c., 1911, Pl. IV.

W. B. Scott, A History of Land Mammals in the Western Hemisphere. 1913, p. 298. 
Hipparion. - Pliozän Europas und Asiens. Nachkomme von Parahippus; es lebt in den heutigen Pferden fort. Zahlreiche Arten (Fig. 600, 659). ${ }^{1}$

Pliohippus. - Das erste einzehige Pferd Nordanerikas. Die Hauptverbreitung fällt in das obere Pliozän. ${ }^{2}$

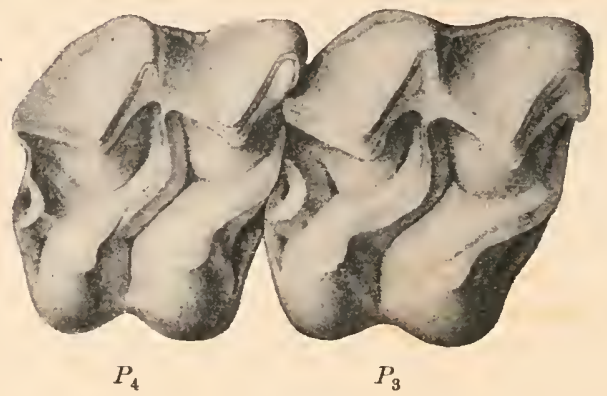

Fig. 658.

Rechter oberer dritter und vierter Prämolar $\left(P_{3}\right.$ und $\left.P_{4}\right)$ von Anchitherium Zitteli Schlosser aus den roten Tonen von Schansi in China (Pliozän). Nat. Gr. (Nach M. Schlosser, 1903.)

Neohippus. - Die der Gattung Equus ähnlichsten Vertreter der Equiden in der Eiszeit Nordamerikas. Nur nach Südanerika ausgewandert, wo die Gattung noch in der Eiszeit erlischt. ${ }^{3}$

Hippidium. - Plistozän Südamerikas. ${ }^{4}$

Onohippidium. - Plistozän Südamerikas. ${ }^{5}$

Parahipparion. - Plistozän Südamerikas. ${ }^{6}$

1 Die ältere Literatur (bis 1902) bei O. P. Hay, I. c., p. 619.

M. Schlosser, Die fossilen Säugetiere Chinas, 1. c., p. 78.

O. Antonius, Untersuchungen ïber den phylogenetischen Zusammenhang zwischen Hipparion und Equus. - Zeitschrift für induktive Abstammungs- und Vererbungslehre. XX. Bd., 4. Heft, Berlin 1919, S. 273.

2 J.W. Gidley, Revision of the Miocene and Pliocene Equidae of North America. - Bull. Amer. Mus. Nat. Hist. New York, Vol. XXIII, 1907, p. 865.

3 Der Name Neohippus ist von mir (Handwörterbuch d. Naturwissenschaften, VII1. Bd, p. 754 und in ,Die vorzeitlichen Säugetiere“, Jena 1914, S. 248) für die auf dem Boden Nordamerikas entstandenen, der Gattung Equus ähnlichen Arten aufgestellt worden. Vgl. dazı O. Antonius, 1. c., p. 294. Zu dieser Gattung gehören: Neohippus fraternus, N. complicatus, N. occidentalis, N. pectinatus und vielleicht noch einige andere Arten, über deren Unterschiede von Arten der Gattung Equus noch nichts Genaueres bekannt ist. Sicher ist es, daß die typischen Neohippusarten sich nicht in rezente Equiden fortsetzen, sondern gänzlich erloschen sind. Die Gattung Equus ist nicht amerikanischen, sondern eurasiatischen Ursprungs und geht auf die Gattung Hipparion zuriick.

4 I. Sefve, Die fossilen Pferde Südamerikas. - Kungl. Svenska Vetenskapsakademiens Handlingar. - XLVIII. Bd., Nr. 6, Upsala und Stockholm 1912, p. 28.

5 Ibidem, p. 81 .

6 Ibidem, p. 95 (= Hyperhippidium, Sefve, 1910). 
Equus. - Zuerst in Oberpliozän Italiens (Fig. 662).

Die europäischen Equidenstänmme des Alttertiärs, die vollständig erloschen sind, zweigten wahrscheinlich von Hyracotherium ab und spalteten sich in sechs Zweige, deren bedeutendste die Stammesreihen der Palaeotheriumarten und der Plagiolophusarten sind (beide vom Mitteleozän bis zum Unteroligozän Europas): ${ }^{1}$

Diese sechs „Palaeohippiden“-Stänme des europäischen Eozäns, die bereits im Mitteleozän auftreten, sind durch folgende Gattungen gekennzeichnet:

1. Pachynolophus (endet im Obereozän) (Fig. 656 B).

2. Lophiotherium (eńdet im Obereozän).

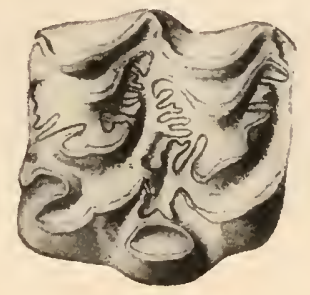

Fig. 659 .

Rechter oberer dritter Prämolar (Ersatzzahn des zweiten Milchmolaren) von Hipparion Richthofeni Koken, aus den pliozänen, roten Tonen von Schansi in China. - Nat. Gr. (Nach M. Schlosser, 1903.)

3. Propalaeotherium (endet in Obereozän).

4. Plagiolophus (endet im Unteroligozän).

5. Palaeotherium (endet im Unteroligozän) (Fig. 660).

6. Anchilophus (endet im Obereozän) (Fig. 656 E).

\section{F. Titanotheriidae.}

Die Fanilie ist nordanerikanischer Herkunft und erscheint dort zuerst im Eozän, erlischt aber schon im Oligozän. Aus. Europa sind nur sehr seltene Reste von Titanotheriiden bekannt. Die größten Arten erreichten die Größe eines Elefanten. Da das Gebiß brachyodont ist und auch sonst nur unbedeutende Kronenspezialisationen zeigt, so scheinen diese Tiere eine weiche Pflanzenkost bevorzugt zu haben. Die ältesten Typen waren hornlos wie die primitiven Rhinocerotiden, doch treten bei den jüngeren Gattungen mächtige, knöcherne Schädelprotuberanzen auf, die besonders bei den Männchen kräftig ausgebildet waren. Die Gliedmaßen waren plump und elefantenartig, die Hand war größer als der Fuß und zwar war die Hand vierzehig und der Fuß dreizehig.

1 H. G. Stehlin, Die Säugetiere des Schweizerischen Eozäns. - Kritischer Katalog der Materialien. - Abhandlungen der Schweizerischen Paläontologischen Gesellschaft, Vol. XXX, 1903, p. 1; Vol. XXX1I, 1904; Vol. XXXII, 1906, p. 447. 


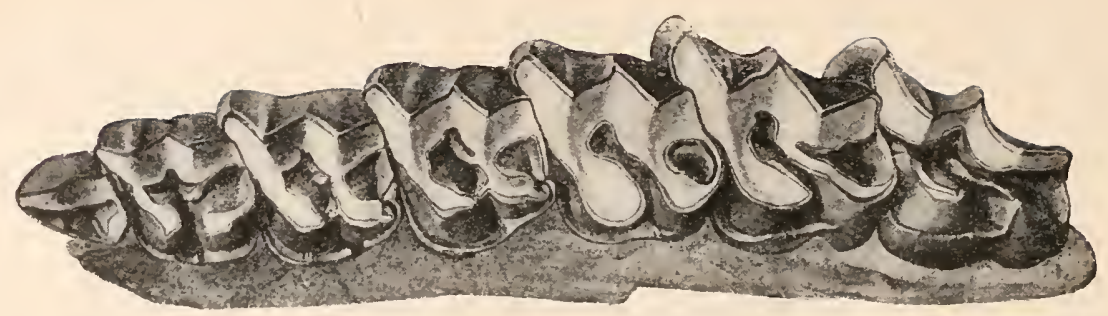

Fig. 660 .

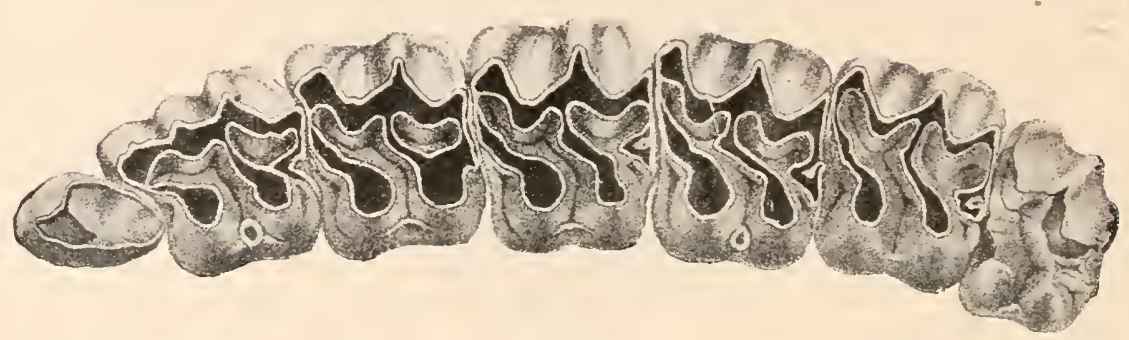

Fig. 661.

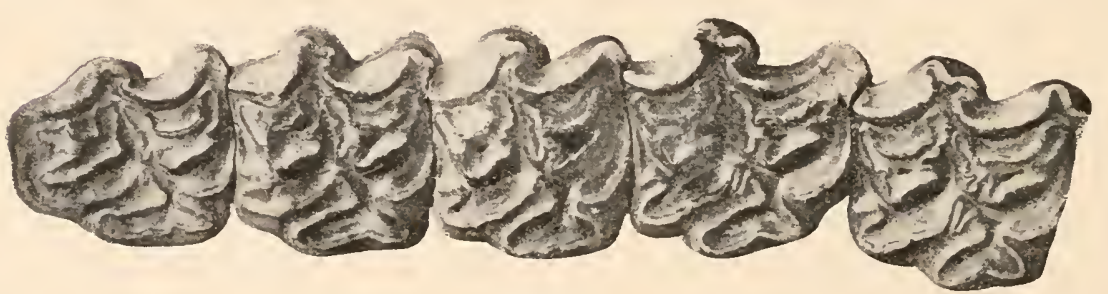

Fig. 662 .

Vergleich der Molarenformen bei einem eozänen (Fig. 660), einem miozänen (Fig. 661) und einem plistozänen (Fig. 662) Equiden, um die Differenzierung der Backenzähne zu zeigen. Bei Palaeotherium (Fig. 660) und Anchitherium (Fig. 661) sind die Unterschiede bei weitem geringer als zwischen Anchitherium und Equus (Fig. 662); die Reihe, welche mit der rezenten Gattung Equus endet, geht nicht auf Anchitherium zurïck, sondern diese Gattung stirbt ohne Nachkommen im Pliozän Ostasiens aus, nachdem sie zuerst im Untermiozän Nordamerikas aufgetreten war und sich im Miozän über Eurasien weit verbreitet hatte. Sie wird von den Hipparionen im unteren Pliozän abgelöst, die gleichfalls auf amerikanische Ahnen zurückgehen.

Dargestellt sind die Backenzähne des linken Oberkiefers folgender Arten:

Fig. 660. Palaeotherium Renevieri, Stehlin. - Oberstes Eozän (Ludien) aus der Gegend von Mormont bei La Sarraz in der Schweiz. (Nach H. G. Stehlin.) - Nat. Gr.

Fig. 661. Anchitherium aurelianense, Cuvier. - Miozän von Steinheim in Württemberg. (Nach O. Fraas.) - Nat. Gr.

Fig. 662. Equus Abeli, Antonius. - Plistozän (Löss) von Heiligenstadt in Wien. (Nach O. Antonius.) - 1/4 nat. Gr. 


\section{Unterfamilie: Palaeosyopinae.}

Die Palaeosyopinen sind die Vorläufer der Titanotheriinen und schließen sich enge an die Protungulata an, mit denen sie durch die Protungulatenfamilie der Phenacodontiden verknüpft sind. Die Grenze zwischen den Palaeosyopinen und den Phenacodontiden ist eine durchaus künstliche und unnatürliche. Die Gliedmaßen waren hoch und sclılank, der Gesanithabitus erinnert an die ältesten Pferde (z. B. Eohippus).

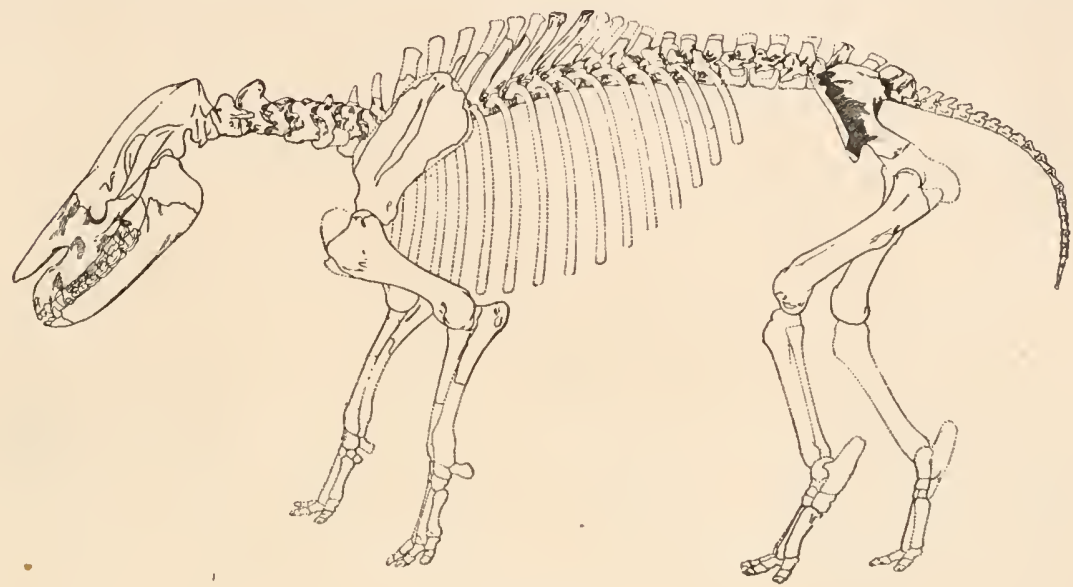

Fig. 663.

Skelettrekonstruktion des Titanotheriiden Dolichorhinus hyognathus, Scott and Osborn, aus dem Eozän (Uinta-Beds) Nordamerikas. - Ungefähr $1 / 20$ nat. Gr. (Nach H. F. Osborn.)

Palaeosyops. - Mitteleozän Nordamerikas (Fig. 664 A). ${ }^{1}$

Manteoceras. - Mitteleozän Nordamerikas (Fig. 664 B). ${ }^{2}$

Dolichorhinus. - Obereozän Nordamerikas (Fig. 664 C, 663). ${ }^{3}$

2. Unterfamilie: Titanotheriinae.

Unter den Titanotheriinen sind vier divergente Stämme zu unterscheiden, die im Oligozän Nordamerikas durch zahlreiche Arten vertreten sind: ${ }^{4}$

1 H. F. Osborn, New or Little Known Titanotheres from the Eocene and Oligocene. - Bull. Amer. Mus. Nat. Hist. New York, VoI. XXIV, 1908, p. 599.

2 Ibidem, p. 606.

3 Ibidem, p. 611.

${ }^{4}$ H. F. Osborn, The Four Phyla of oligocene Titanotheres. - Ibidem, Vol. XVI, 1902, p. 91. (Hier die ältere Literatur.)

Derselbe, Biological Conclusions drawn from the Study of the Titanotheres. - Science (N. S.), Vol. XXXIII, Nr. 856, 1911, p. 825.

Derselbe, The Continous Origin of Certain Unit Characters as Observed by a Paleontologist. - Harvey Lectures, Series 1911-1912, Philadelphia 1912, p. 178. Eine umfassende Monographie iber die Titanotheriiden Nordamerikas, von H. F. Osborn, ist in Vorbereitung. 
I. Titanotheriumstamm.

II. Megaceropsstamm (Fig. 665, 666).

1II. Symborodonstamm (Fig. 667).

IV. Brontotheriumstamm.

\section{XII: Ordnung: Ancylopoda.}

Die Ancylopoda bilden einen sehr eigentümlich spezialisierten Seitenzweig der Ungulaten, der gleichfalls in den Protungulaten wurzelt. Da er auf die Familie der Meniscotheriiden zurückverfolgt werden kann,
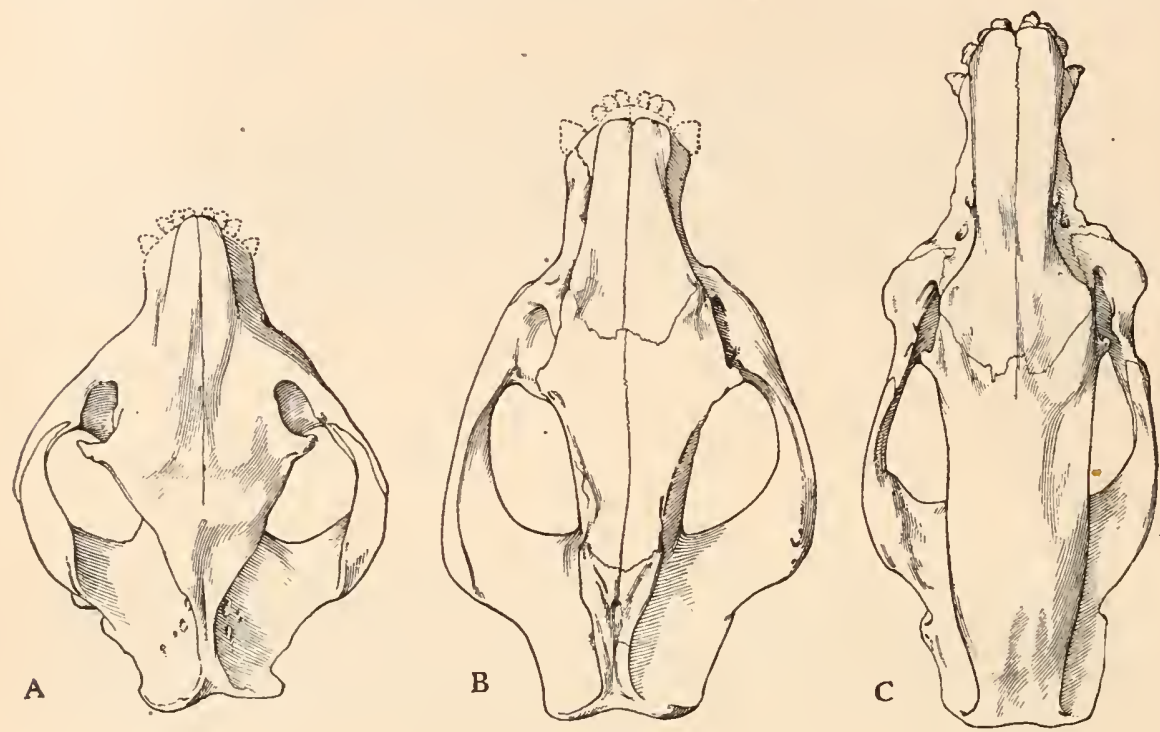

Fig. 664.

Schädelformen der nordamerikanischen Palaeosyopinen. (Nach H. F. Osborn.)

A: Palaeosyops maior, aus dem Mitteleozän Nordamerikas (untere Bridger-Beds).

B: Manteoceras manteoceras, aus dem Mitteleozän Nordamerikas (obere Bridger-Beds).

C: Dolichorhinus cornutus, aus dem Obereozän (Eobasileuszone der Washakie-Beds) Nordamerikas.

die schon im ältesten Tertiär von den Phenacodontiden getrennt ist (die Molaren besitzen schon bei Meniscotherium eine W-förmige Außenwand und erinnern dadurch an die Molaren der ältesten Sirenen), so ist die Aufstellung der Ancylopoda als eigene, von den Perissodactylen abzutrennende Ordnung genügend begründet. Das Gebiß der Chalicotheriiden, der einzigen Familie dieser Ordnung, zeigt die Merkmale der Titanotheriidenmolaren, aber die unteren Molaren sind nicht aus drei Halbmonden aufgebaut wie bei den Titanotheriiden, sondern nur aus zwei Halbmonden. Die Gliedmaßen endeten in je drei Finger oder Zehen mit gewaltigen, zurückziehbaren Scharrkrallen; die Endphalangen sind ebenso wie bei den grabenden Xenarthren tief gespalten. 
Die Verknüpfung der Scharrkrallen mit den an weiche Pflanzenkost adaptierten Molaren rechtfertigt den Schluß, daß die Tiere Steppenbewohner waren, wofür auch das Vorkommen in typischen Steppenfaunen spricht; ihre Nahrung bestand wahrscheinlich hauptsächlich aus weichen Pflanzenwurzeln (Zwiebeln und Knollen) und vielleicht auch aus sukkulenten Pflanzen. ${ }^{1}$

\section{F. Chalicotheriidae.}

Eomoropus. - Mitteleozän Nordamerikas. ${ }^{2}$

Schizotherium. - Oligozän Europas. ${ }^{3}$

Moropus. - Miozän Nordamerikas ${ }^{4}$ (Fig. 668, 669).

Macrotherium. - Miozän Europas. ${ }^{5}$

Chalicotherium. - Unterpliozän Europas; der letzte Vertreter im Plistozän Chinas. ${ }^{6}$

\section{Ordnung: Primates.}

Die Ordnung der Primaten und ihre Vorgeschichte hat seit jeher das berechtigte Interesse wegen der Frage nach der Herkunft des Menschen und des Grades seiner Verwandtschaft mit den verschiedenen Stänmen und Familien der Affen in Anspruch genommen. So ist es begreiflich, daß über die Beziehungen der einzelnen Stämme der lebenden Primaten zu den verhältnisnıäßig zahlreichen fossilen Formen viele Untersuchungen angestellt worden sind, die jedoch zu sehr abweichenden Ergebnissen geführt haben.

Mehr und mehr hat sich die Erkenntnis gefestigt, daß wir unter den Primaten zwei große Stämme zu unterscheiden haben, welche zwar in einer gemeinsamen Wurzel zusammenlaufen, aber schon seit sehr langer Zeit nebeneinander herlaufen, nämlich der Stamm der Lemuroidea oder Prosimier (Halbaffen) und der Anthropoidea oder echten Affen, dem die Familie der Menschen oder Hominiden angehört.

1 O. Abel, Die vorzeitlichen Säugetiere. - Jena 194, p. 254.

2 H. F. Osborn, Eomoropus, An American Eocene Chalicothere. - Bull. Am. Mus. Nat. Hist., Vol. XXXII, 1913, p. 261.

$3 \mathrm{H}$. Filhol, Observations concernant quelques Mammifères fossiles nouveaux de Quercy. - Annales des Sciences naturelles (Zool.), T. XV1, 1894, p. 141.

4 W. J. Holland and O. A. Peterson, The Osteology of the Chalicotheroidea. - Memoirs of the Carnegie Museum, Vol. 111, Nr. 2, Pittsburgh 1914, p. 189 (Literatur).

5 P. Gervais, Zoologie et Paléontologie françaises, 1. édit., T. I, Paris 1859 , p. 169 .

6 J. J. Kaup, Description des Ossements fossiles de Mammifères inconnus jusqu'à présent etc., 2. Heft, Darmstadt 1833, p. 4.

M. Schlosser, Die fossilen Säugetiere Chinas. - Abh. d. Bayr. Akad. d. Wiss., München 1903, p. 75. 
Die untere Grenze der Lemuroidea ist noch nicht sichergestellt, da über die Einreihung gewisser Gattungen aus dem unteren Tertiär noch große Meinungsverschiedenheiten bestehen. Einzelne Forscher be-

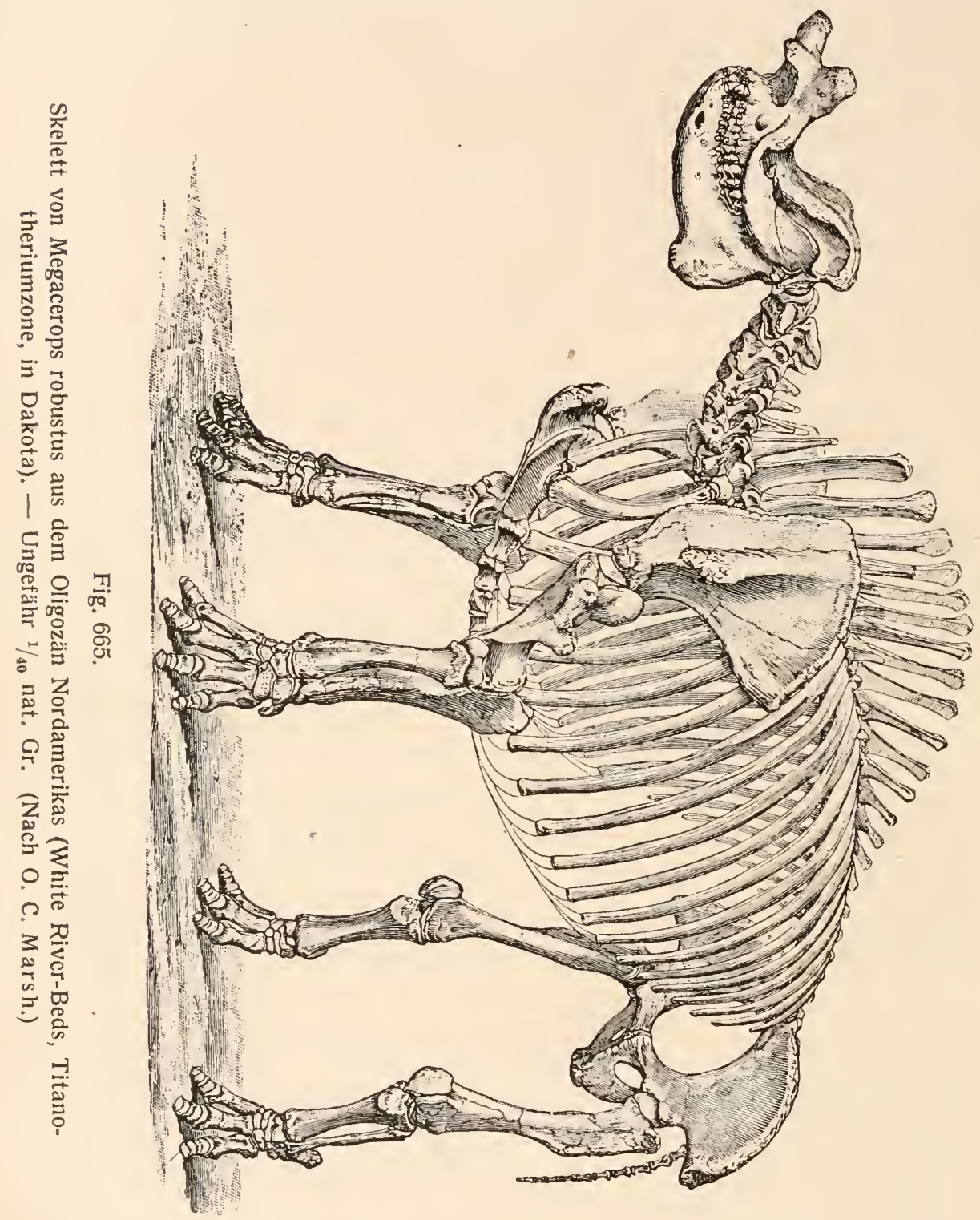

trachten die Mixodectiden und die Hyopsodontiden als Prinlaten, andere reihen diese Fanilien in die Ordnung der Insectivoren ein. Aller Wahrscheinlichkeit nach wurzeln die Primaten in den Insectivoren, aber es ist heute noch nicht möglich, dlese Fäden zu näher verfolgen, welche die beiden großen Ordnungen verbinden. 


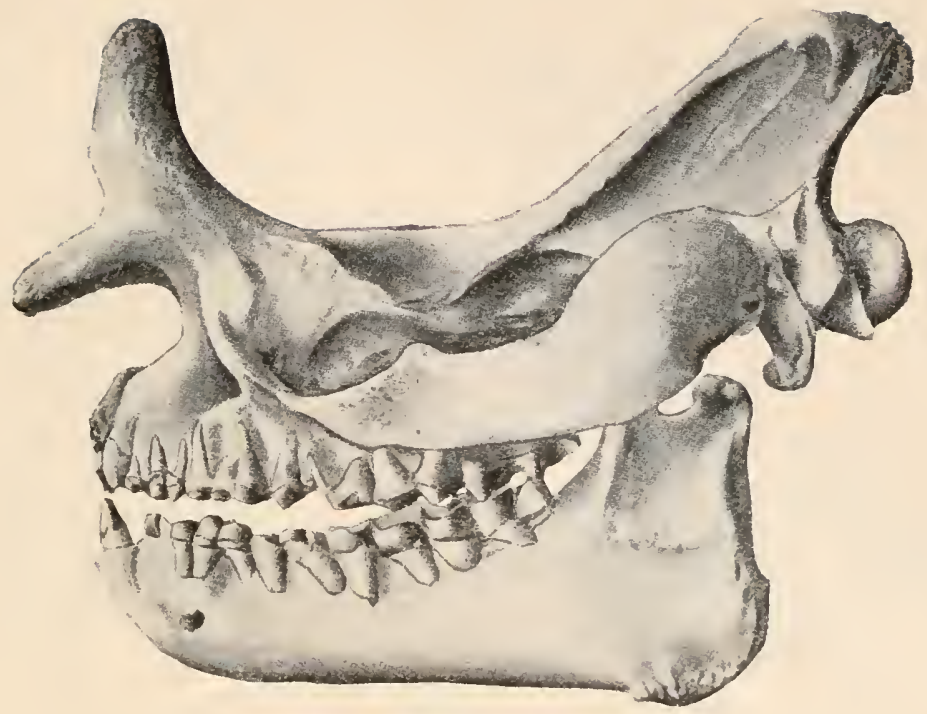

Fig. 666.

Megacerops bicornutus, Osborn, aus dem Oligozän Nordamerikas. 1/s nat. Gr. (Nach H. F. Osborn.)

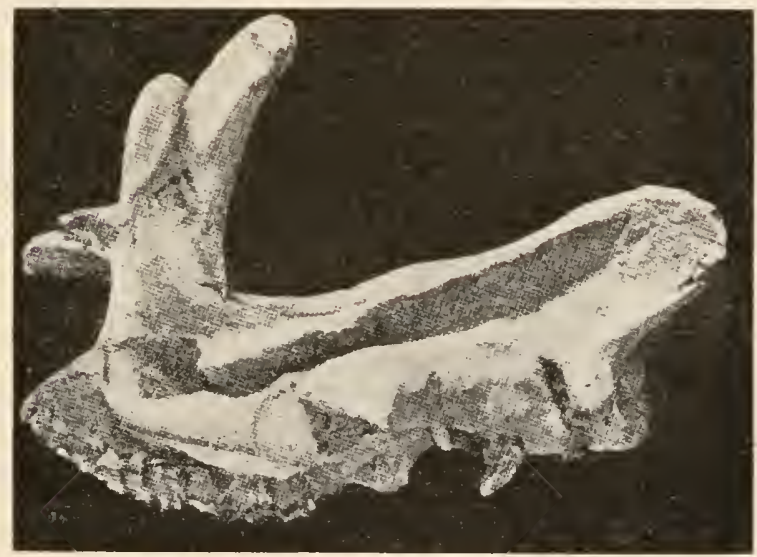

Fig. 667.

Symborodon Copei, Osborn, ein Titanotheriide aus dem Oligozän (mittlere Titanotherium-Beds) von Süd-Dakota, Nordamerika. 1/10 nat. Gr. (Nach H. F. Osborn.)

Sehen wir von der Frage nach der Herkunft und dem Zeitpunkt der Abzweigung der Primaten einstweilen $a b$, so wendet sich unser Interesse zunächst der Frage zu, wie die weitere Geschichte des Primatenstammes verlaufen ist und in welchen Beziehungen die Lemuroidea zu den Anthropoidea stehen. 

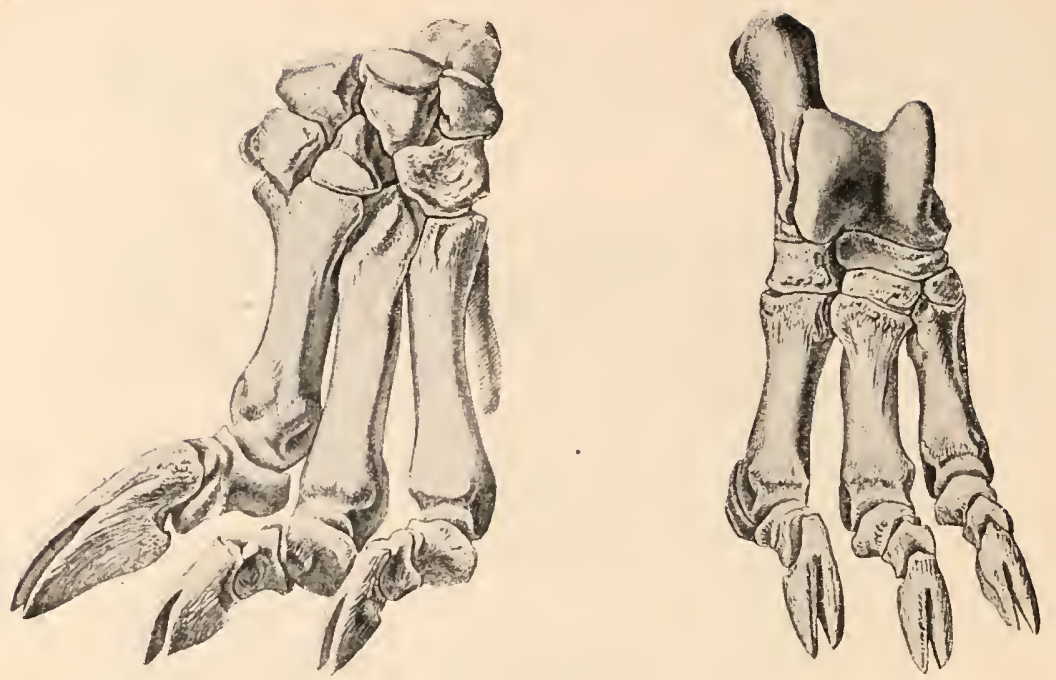

Fig. 668 .

Rechte Hand und rechter. Hinterfuß von Moropus elatus, Marsh, aus dem Untermiozän (Lower Harrison Beds) von Nebraska, Nordamerika; beide Figuren in ungefähr $1 / 6$ nat. Gr. (Nach W. J. Holland und O. A. Peterson.)

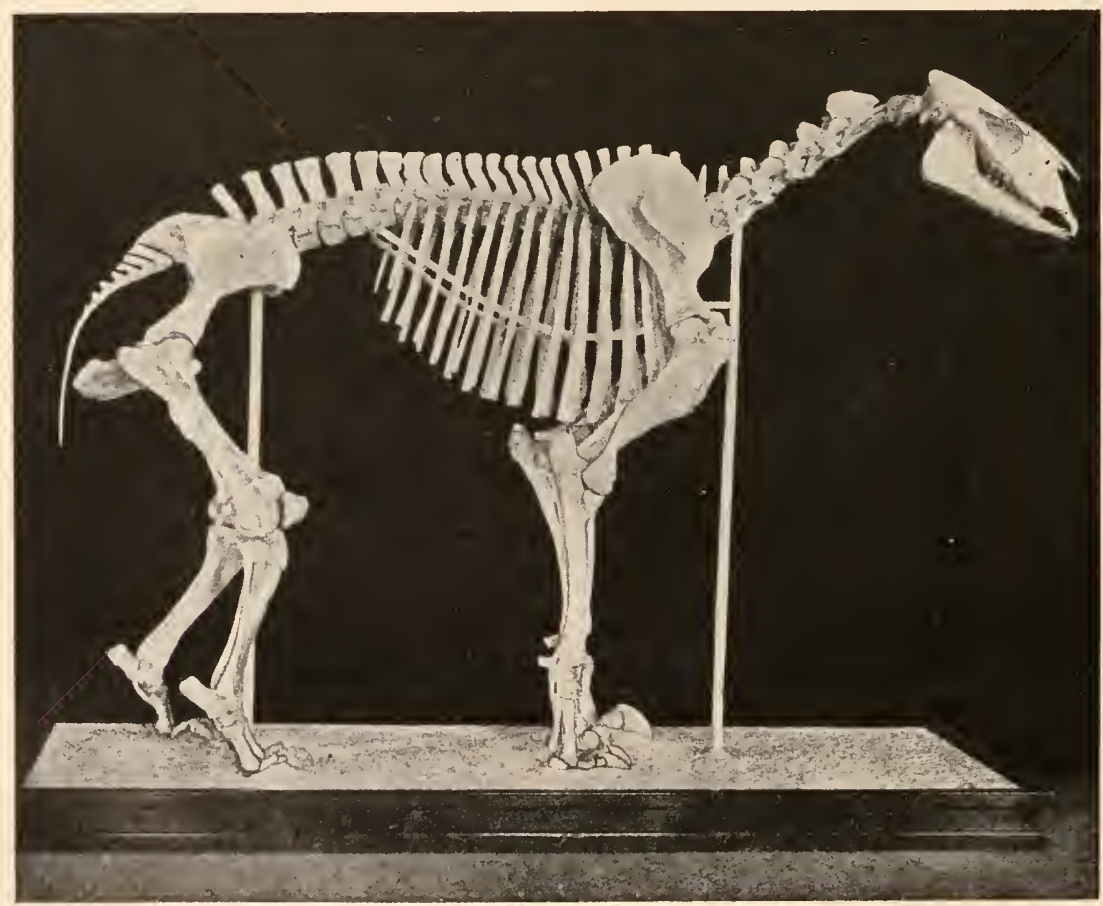

Fig. 669.

Moropus elatus Marsh. Untermiozän Nordamerikas. Ungefähr $1 / 30$ nat. Gr. (Nach W. J. Holland und O. A. Peterson.) 
Die Halbaffen unterscheiden sich in einigen Merkmalen von den Anthropomorphen, von denen folgende besonders hervorgehoben werden mögen. Der Schädel fällt durch die enorme Größe der Augenhöhlen auf, was mit dem nächtlichen Leben der Tiere zusammenhängt; bei den primitiveren Formen stehen die Augenhöhlen noch lateral, bei den spezialisierteren Formen frontal.

Das Vordergebiß ist bei den beiden Hauptstämmen der Primaten sehr verschieden gebaut. Bei den Affen ist es, worauf H. G. Stehlin ${ }^{1}$ (1916) besonders aufmerksam gemacht hat, ,normal“, d. h. die oberen und unteren Schneidezähne greifen in typischer Weise ineinander, die Eckzähne sind steil eingepflanzt und stark entwickelt, während die Inzisiven kleiner als die Caninen sind. Die Gebißformen der Halbaffen weichen dagegen vom Typus der echten Affen sehr stark ab. Einen selbständigen Typus bildet Chironlys, das bekannte „Fingertier" Madagaskars, dessen Vordergebiß oben und unten nur ein einziges permanent wachsendes und dadurch an Nagerinzisiven erinnerndes Zahnpaar besitzt. Die unteren Zähne scheinen den Eckzähnen oder Caninen, die oberen den ersten oder zweiten lnzisiven zu entsprechen.

Bei den übrigen Halbaffen sind die unteren Schneidezähne sehr schräge in den Kiefern eingepflanzt und besitzen eigentümlich verlängerte, pfriemenartige Kronen, die zusammen eine Art Kanm bilden. Dagegen sind die oberen Inzisiven sehr häufig steil gestellt und tragen schaufelförmige Zahnkronen; mitunter werden sie rudimentär und gehen zuweilen vollständig verloren. Der obere Eckzahn steht nicht wie bei den Affen dem unteren Eckzahn als Antagonist gegenüber, sondern dem hinter ihm in die Zahnreihe des Oberkiefers eingreifenden ersten Prämolaren des Unterkiefers, der die Rolle eines Caninen übernommen hat. Der untere Eckzahn ist ganz anders geformt.

Wenn die von Stehlin dargelegten Unterschiede des Vordergebisses auf Richtigkeit beruhen, was nach den vorliegenden Untersuchungsmaterial der Fall zu sein scheint, so kann das Affengebiß nicht vom Halbaffengebi $\beta$ abgeleitet werden. Wir werden zu der Schlußfolgerung geführt, daß diese beiden Stänme seit sehr langer Zeit voneinander getrennt sind und in einer gemeinsamen Stammgruppe zusammenlaufen, welche ein normales, wenig differenziertes Vordergebiß besessen haben, aus dem sich einerseits das Vordergebiß der Affen und anderseits das Gebiß der Halbaffen divergent entwickelte.

Daß die lebenden Lemuren als Ahnen der Affen nicht in Betracht kommen können, zeigt auch die bei ihnen weitgehende Spezialisation von Hand und FuB, die bei den Lemuroidea in hohem Grade die durch

1 H. G. Stehlin, Die Säugetiere des schweizerischen Eozäns. VII. Teil, zweite Hälfte. - Abhandlungen der Schweizerischen Paläont. Gesellschaft, Vol. XLI, Zürich 1916, S. 1527. 
das arborikole Leben bedingten Unformungen in Gestalt der Bildung einer Greifzange aufweisen, während Hand und Fuß der Affen und ganz besonders der Hominiden auf einer viel tieferen, primitiveren Entwicklungsstufe stehen geblicben sind und sich im Verlaufe der Stammesgeschichte der Affen in ganz anderer Richtung als bei den Halbaffen entwickelt haben. Auch hier müssen wir annehmen, daß sich die Spaltung der beiden Hauptstämme zu einer Zeit vollzogen hat, in der Hand und Fuß noch nicht in die Spezialisationsrichtung der Halbaffen gelangt war, sondern noch im allgemeinen primitivere Zustände bewahrt hatte.

Schon diese Gesichtspunkte müssen uns davor warnen, zwischen den Halbaffen und Affen nach engeren genetischen Beziehungen zu suchen. Daß primitivere Gattungen der Lemuroidea eine größere Ähnlichkeit mit den Affen aufweisen als höher spezialisierte, ist ganz begreiflich und eben auf Rechnung der Entstelıung beider Stämme aus einer gemeinsamen Stammgruppe zu setzen.

Von den Halbaffen und Affen der Tertiärzeit liegen leider in derMehrzahl der Fälle nur dürftige Kieferfragmente, seltener vollständigere Schädclreste vor. ${ }^{1}$ Schon im unteren Eozän Nordamerikas treten Primatcnreste auf und ebenso erscheinen auch bereits in untersten Eozän Europas einige Vertreter der Primaten; aus dem Eozän sind relativ zahlreiche Reste bekannt, die ausschließlich der Gruppe der Lemuroidea angehören. ${ }^{2}$ Erst im Unteroligozän Ägyptens treten uns die ersten echten Affen entgegen (Propliopithecus ${ }^{3}$ und Parapithecus). ${ }^{4}$

1 Von Adapis parisiensis sind (aus den Phosphoriten des Quercy in Frankreich) etwa 20 Schädel bekannt, von Necrolemur antiquus (aus denselben Schichten) 6 Schädel.

2 Eine Zusamn.enstellung der nordamerikanischen und europäischen eozänen Primaten findet sich bei Stehlin (1. c., S. 1543), wo auch die ältere Literatur iuber die eozänen Primaten nachzusehen ist. Weitere Abhandlungen über diesen -Gegenstand, die aus neuerer Zeit stammen, sind:

W. K. Gregory, On the Relationship of the Eocene Lemur Notharctus to the Adapidae and to other Primates. - On the Classification and Phylogeny of the Lemuroidea. - Bull. Geological Society of North-America, Vol. XXVI, 1915, p. 419.

Derselbe, Studies of the Evolution of the Primates. - 1J. Phylogeny of Recent and Extinct Anthropoidea with Special Reference to the Origin of Man. Bull. Amer. Mus. Nat. Hist., New York, Vol. XXXV, 1916, p. 258.

Th. A rldt, Zur Stammesgeschichte der Halbaffen und Menschenaffen. Die Naturwissenschaften, V. Jahrgang, 19. Januar 1917, 3. Heft, S. 39.

O. Abel, Die alttertiären Primaten Europas. - Ebenda, V1. Jahrgang, 10. Mai 1918, p. 281, und 17. Mai 1918, p. 295.

${ }^{3}$ M. Schlosser, Beiträge zur Kenntnis der oligozänen Landsäugetiere aus dem Fayum (Ägypten). - Beiträge zur Paläontologie und Geologie Österreich-Ungarns und des Orients, XXIV. Bd., Wien 1911, S. 52.

4 Ebenda, S. 58.

E. Werth, Parapithecus, ein primitiver Menschenaffe. - Sitzungsberichte der Ges. Naturforschender Freunde, Berlin, Jahrgang 1918, Nr. 9, S. 327. 
Die systematische Gruppierung der eozänen Primaten ist bisher noch in manchen Punkten sehr strittig. Sicher ungrenzt sind heute nur die eozänen Gruppen der Adapiden, Notharctiden, Necrolemuriden und der Plesiadapiden; die ältesten Reste, die wir bis heute kennen, gehören den Plesiadapiden an, die durch zwei Arten aus dem untersten Eozän von Reims vertreten sind. Dazu kommt noch die Gruppe der Anaptomorphiden, die höheren Schichten des Untereozäns Nordamerikas angehört.

\section{Unterordnung: Lemuroidea.}

\section{F. Notharctidae.}

Die Notharctiden beginnen im Untereozän Nordamerikas mit der Gattung Pelycodus, die durch verschiedene Arten aus dem Wasatch, Wind River und Bridger vertreten ist und somit vom Untereozän bis zum Obereozän reiclıt; aus ilır ist die Gattung Notharctus hervorgegangen, die vom Wind River bis zum Oberbridger lebte. Die Gattung Pelycodus besitzt eine lange Schnauze und freie Unterkieferäste; das Gebiß ist durch das Vorhandensein eines orimentären Hypocons in den oberen dreieckigen Molaren gekennzeichnet, während bei Notharctus die Molaren durch das Wachstum des Hypocons einen quadratischen Umriß erhalten haben. Außerdem ist die Schnauze von Pelycodus kürzer geworden und die Unterkieferäste sind miteinander in einer Symphyse verschmolzen. $\mathrm{Ob}$ und inwieweit Beziehungen zu Protadapis bestehen, ist noch eine offene Frage.

\section{F. Plesiadapidae.}

Diese Fanilie, die zuweilen mit den lnsectivoren und zuweilen mit den Primaten vereinigt wurde, wird jetzt neuerdings (H. G. Stehlin, 1916) wieder den Lemuroidea eingereiht.

Plesiadapis. - Untereozän (Thanétien, Sparnacien, Yprésien) Europas.

\section{F. Anaptomorphidae.}

Die Anaptomorphiden erscheinen im Untereozän Nordamerikas (Wind River) und verschwinden wieder im Mitteleozän (Unterer Bridger). Neben der Gattung Anaptomorphus erscheinen mehrere Gattungen und Arten von einstweilen unsicherer systematischer Stellung.

\section{F. Necrolemuridae.}

In dieser Familie vereinigt Stehlin (1916) die Gattungen Necrolemur und Microchoerus, von denen die erste dem Mitteleozän und Obereozän, die zweite dem Obereozän Europas angehört. Die Herkunft und Verwandtschaft dieser Gruppe ist gleichfalls einstweilen nicht aufgeklärt. 


\section{F. Adapidae.}

Diese Familie umfaßt mehrere Gattungen, die sich noch am ehesten mit den heute noch lebenden Lemuriden verknüpfen lassen und zwar wären solche Beziehungen zwischen Adapišs und den Lemurinen einerseits und zwischen Anchomomys, Omonys und Pronycticebus sowie den Nycticebinen anderseits festzustellen. Die bisherigen Untersuchungen sind aber über das Stadium der Vermutungen noch nicht hinausgegangen und die systematische und genetische Stellung dieser Gattungen bleibt einstweilen unsicher. Von der Gattung Adapis sind aus dem oberen Eozän Frankreichs und der Schweiz gut erhaltene, fast vollständige Schädel bekannt. Auch von Pronycticebus liegen vollständigere Reste vor. Die Stellung der Gattung Protadapis aus dem Eozän Europas. ist unsicher.

\section{F. Lemuridae.}

Die große Familie der lebenden Halbaffen ist vielleicht durch Adapis mit den älteren Gattungen der Halbaffen verknüpft, doch sind wir auch hier noch nicht zu einer sicheren Erkenntnis der genetischen Zusammenhänge gelangt. Im Plistozän Madagaskars fanden sich Lemurenreste von zum Teil sehr ansehnlicher Größe wie der stattliche Megaladapis, der die Größe eines Schimpansen erreichte. ${ }^{\mathbf{1}}$

Die oberen Schneidezähne fehlen bei Megaladapis gänzlich. Bei einer zweiten, etwas kleineren Gattung sind dagegen die oberen Schneidezähne mit Ausnahme eines Paares noch vorhanden (Palaeopropithecus).

\section{F. Archaeolemuridae.}

Nur aus dem Plistozän Madagaskars bekannt. ${ }^{2}$

Archaeolemur. - Plistozän Madagaskars.

Bradylemur. - Plistozän Madagaskars.

Hadropithecus. - Plistozän Madagaskars.

\section{F. Chiromyidae.}

Das lebende Fingertier Madagaskars (Chiromys madagascariensis) stellt einen sehr merkwürdig und einseitig spezialisierten Zweig des Primatenstammes dar. Im Eozän Nordamerikas und Europas treten verschiedene Primaten aus der Gruppe der Lemuroidea auf, die eine gleichsinnige Spezialisation des Vordergebisses zeigen, aber es ist einstweilen noch ungewiß, ob diese gleichsinnig spezialisierten Formen wirklich als die Ahnen von Chiromys anzusehen sind oder nur Vertreter paralleler Entwicklungsreihen darstellen.

1 L. von Lorenz, Megaladapis Edwardsi G. Grandidier. - Denkschriften der Akad. d. Wiss., Wien 1905, LXXVII. Bd., p. 451.

2 G. Grandidier, Recherches sur les Lémuriens disparus etc. - Notıvelles Archives dı Muséım (4), T. VII, Paris 1905, p. 1. 


\section{F. Tarsiidae.}

Von dieser lebenden Familie, die durch den Gespensteraffen (Tarsius) repräsentiert wird, ist noch kein fossiler Vertreter bekannt.

\section{Unterordnung: An thropoidea.}

Die ältesten echten Affen sind erst vor einigen Jahren im Unteroligozän Ägyptens entdeckt worden. Sie sind als sehr primitive Formen anzusehen und können als die Vertreter der Ahnengruppe der höheren Primaten betrachtet werden. Von den beiden Gattungen Propliopithecus und Parapithecus liegen zwar nur Unterkieferreste vor, aber diese sind sehr charakteristisch und gestatten eingehendere Vergleiche mit den höheren Primaten. Beide Gattungen besitzen sehr kleine Zähne, die noch nicht sehr stark differenziert sind, und zwar sind die Schneidezähne und der Eckzalın ungefähr gleichgroß. Der vorderste Prämolar ist bereits verloren gegangen.

Diese kleinen Affen aus dem Unteroligozän Ägyptens schließen sich an die alttertiäre Gruppe der Anaptomorphiden noch am nächsten an. Auch dies spricht dafür, daß wir in den Lemuroidea und Anthropoidea zwei Stämme zu erblicken haben, die in einer gemeinsamen Wurzel zusammenlaufen und sich schon frühzeitig gespalten liaben. Aus Propliopithecus und Parapithecus oder doch zum mindesten aus ihnen sehr nahestehenden Formen sind die Anthropomorphen und die Hominiden abzuleiten.

F. Ameghino hat seinerzeit einigen fossilen Affen aus dem Miozän von Santa Cruz in Patagonien eine große Bedeutung für die Stammesgeschichte der Affen zuschreiben wollen. Dieser Auffassung ist von allen Seiten energisch widersprochen worden und wir können heute mit Bestimmitheit feststellen, daß diese südamerikanischen Tertiäraffen der lebenden Familie der Cebiden angehören (Honunculus, Anthropops und Eudiastatus). Von fossilen Hapaliden ist in brasilianischen Knochenhöhlen eine Hapaleart gefunden worden. Sicher sind die Affen Südamerikas schon seit dem Eozän von den altweltlichen Affen getrennt und seinerzeit mit der ersten Welle der aus Nordamerika im unteren Eozän nach Südamerika ausgewanderten Säugetiere nach Südamerika gelangt, wo sie sich zu der Gruppe der Platyrrhinen entwickelt haben, die aus der Alnenreihe der altweltlichen Affen vollkommen auszuschalten ist.

Die Hundsaffen oder Cynopitheciden sind zuerst aus unterpliozänen Ablagerungen bekannt. Man hat Reste von Gattungen, die zweifellos dieser Familie angehören, inı Unterpliozän Griechenlands (Mesopithecus) und Ostindiens gefunden und sie sind außerdem aus dem Mittelpliozän Ägyptens und dem Oberpliozän Europas, Algiers und Ostindiens be- 
kannt. Von der Gattung Macacus sind im Quartär Europas verschiedene Reste entdeckt worden.

Die Menschenaffen sind, wie schon erwähnt, durch die im Unteroligozän Ägyptens aufgefundene Gattung Propliopithecus seit einigen Jahren nunmehr auch aus dem Alttertiär bekannt, nachdem man früher nur aus miozänen Ablagerungen und jüngeren Bildungen Europas und Ostindiens Vertreter dieses Stammes gekannt hatte. Die Spaltung der Mcnschenaffen oder Simiiden und der Menschen oder Hominiden fällt jedenfalls in eine frühe Zeit des Tertiärs und kann sich nur auf dem Boden der alten Welt vollzogen haben. Im Miozän ist diese Spaltung bereits vollzogen gewesen und es ist sogar möglich, daß die Spaltung zwischen den Simiiden und den Hominiden in eine ältere Stufe des Alttertiärs als Unteroligozän fällt.

Die Gattung Homo selbst ist erst aus dem Plistozän bekannt und obwohl es nach dem heutigen Zustande unserer Forschungen über die Herkunft und Verwandtschaftsstellung der Hominiden unter den Primaten als sicher anzusehen ist, daß die Hominiden eine sehr alte und einseitig entwickelte Gruppe der Primaten darstellten, so fehlt uns doch bis jetzt jede Kenntnis über den Verlauf dieser Entwicklung im Alttertiär. Bei dem außerordentlichen Fortschritte, den die Erforschung der Stammesgeschichte der Wirbeltiere in den letzten Jahrzehnten aufzuweisen hat, ist aber zu hoffen, daß uns in nicht zu ferner Zeit auch über diese Frage fossile Funde die allein entscheidenden Dokumente in die Hände geben werden und zu einer Beantwortung jener Probleme führen, die uns von den verschiedenen Fragen der Phylogenie seit jeher am meisten gefesselt haben. 


\section{Morphologisches Register.}

Abdominale Ventralen 154.

Abdominalia (= Abdominalscuta) 390.

Abdominalscuta (der Schildkröten) 376.

Acetabulum (der Stegocephalen) 257.

Acetabulum, Reduktion bei den Sirenen 839.

Acromion (der Schildkröten) 391.

Adlacrymale, Homologie 36.

- (der Stegocephalen) 237.

- (der Cotylosaurier) 333.

- (der Pelycosaurier) 353.

- (der Vögel) 691, 692.

Adnasale (der Teleostomen) 49.

Adoccipitale (der Teleostomen) 58.

Akinetischer Schädeltypus 657.

Akrodonte Zahnbefestigung 248.

Akromegalie 579.

Alisphenoid (der Teleostomen) 43.

Alisphenoid, Homologie 36.

- (bei Amphibien noch nicht nachgegewiesen) 243.

-.- (bei Sphenodon) 445.

- (? der Vögel) 691.

Alveolen 248.

Amphicoeler Wirbeltypus 28, 232.

Amphikinetischer Schädeltypus 658.

Amphiplatyane Wirbelform 232.

Amphistylie des Kiefergelenks 109.

Analia (= Analscuta) 390.

Analscuta (der Schildkröten) 376.

Angulare (der Teleostomen) 51 .

- (der Stegocephalen) 245.

Angularplatte (der Antiarchi) 88.

Anisodontie 356.

Annulus tympanicus (der Anuren) 317.

Antecrochet 788 .

Anterodorsolaterale (der Arthrodiren) 100. Anteroventrolaterale(der Arthrodiren)100. Anteroventromedianum (der Arthrodiren) 100.

Antorbitalia (der Teleostomen) 48.
Aorta, Lage zur Wirbelsäule 22.

Apertura intermaxillaris 252.

Arcualia 22.

Armschilder (der Schildkröten) 376.

Articulare (der Stegocephalen) 246.

- (der Teleo tomen) 51.

- (der Therocephalier) 419.

Astragalus (= Tibiale), der Anuren 320.

- $(=$ Intermedium + Tibiale + Centrale), der Cotylo aurier 337.

Atlas (von Ophiacodon) 365.

Augenhöhle (der Stcgocephalen) 248.

Außenskelett der Wirbeltiere 17, 31.

Autostylie des Unterkiefers 109.

- - wiederholt unabhängig entstanden 93, 109.

Axis (= Epistropheus) von Ophiacodon 365.

Basibranchiale 55.

Basibranchiost gale 55 .

Basidorsalia (allgemeines) 23.

Basihyale (der Teleostomen) 55 .

Basilaire (der Telcostomen) 57.

Basilare (der Teleostomen) 57.

Basioccipitale, Entstehung 31.

- Knorpelknochen 20.

- (der Teleostomen) 40.

- (der Stegocephalen) 240.

Basipterygoidgelenk (der Vögel) 690.

Basisphenoid (der Teleostomen) 40.

- (der Stegocephalen) 240.

Basiventralia (allgemeines) 24.

- (der Tetrapoden) 224.

Bauchrippen (der Reptilien) 261.

- (der Schildkröten) 377.

- (von Lariosaurus) 484, 488.

- (von Placodus) 512.

- (von Teratosaurus) 588, 590.

Bauchschild (der Schildkröten) 375.

Bauchschilder (der Schildkröten) 376. 
Becken (der Stegocephalen) 257.

Belegknochen (allgemeines) 21.

- (der Stegocephalen) 233, 234.

Bogenelemente der Wirbel 22.

Bogenwirbelzentren 26, 27.

Bogenzentren 27.

Brachialia (= Brachialscuta) 390 .

Brachialscuta (der Schildkröten) 376.

Brachyodonte Backenzähne 791 .

Branchiostegalia 55.

Brustschilder (der Schildkröten) 376.

Bunodonter Molarentypus 788.

Bunoselenodonte Molaren 789.

Calcaneus (= Fibulare), der Anuren 320.

- (der Cotylosaurier) 337.

Canalis carotidicus 620 .

- cartilaginis Meckelii 244.

- Fallopii (der Stegocephalen) 253.

- interorbitalis 29 .

- primordialis (des Unterkiefers) 244.

- semicircularis 670 .

Caninen, der Therocephalier 422.

Capitulum costae (der Stegocephalen) 259.

Carapax (der Schildkröten) 375.

Carpalia, proximale, sekundär verlängert bei Krokodilen 538.

Carpus (der Cotylosaurier) 337.

Cartilago Meckelii 245.

Cavitas glenoidalis (= Armgelenk) der Schildkröten 391.

- - (der Plesiosaurier) 498.

Cavum oticale 250.

- tympani (von Triassochelys) 379.

Centrale (der Arthrodiren) 100.

Centroparietale (der Stegocephalen) 235.

Ceratobranchiale (der Acanthodier) 149.

- (der Teleostomen) 55.

Ceratobranchialia (bei Lysorophus) 328.

Ceratohyale (der Teleostomen) 55.

Cerebellum 61.

Chevron Bones 227.

Choanen (der Stegocephalen) 248.

Chondropalatinum (der Teleostomen) 41.

Chorda dorsalis 21 .

- tympani 67 .

Chordascheide 25.

Chordawirbelzentren 26.

Circumorbitalia (der Teleostomen) 35, 47.

Claspers 110.

Claustrum (ossiculum Weberianum) 56.

Clavicula (der Stegocephalen) 254.

- (der Teleostomen) 53.

- (der Cotylosaurier) 336.

- der Pelycosaurier 354.

Cleithrum (der Teleostomen) 53.

- (der Stegocephalen) 255.
Cleithrum (der Cotylosaurier) 336, 338, $340,341$.

- (der Schildkröten) 377, 386.

- fehlt den Poliosauriden 362.

Coccyx 313.

Coeliane Wirbelform 232.

Coelocyrteane Wirbelform 232.

Coeloplatyane Wirbelform 232.

Collare (der Arthrodiren) 96.

Columella auris (= Stapes) der Stegocephalen 243, 251.

- - (= Stapes) der Anuren 317.

- - (= Stapes) von Triassochelys 387.

- - (= Stapes) der Mosasaurier 669.

- cranii (= Epipterygoideum) der Stegocephalen 243.

- - (der Lepidosaurier) 658.

Complementare (der Teleostomen) 54.

- (der Stegocephalen) 246.

- (der Pelycosaurier) 353, 366.

-, fehlt den Ichthyosauriern 460 .

Condylus occipitalis der Stegocephalen, Bau 240.

_ - , doppelt bei den Stegocephalen 240 .

- -, doppelt bei den Therocephaliern $420,423$.

_ -, doppelt bei den Amphisbäniden 660.

Coracoid (der Stegocephalen) 255.

- (der Cotylosaurier) 336.

Cornutalplatte (der Pteraspiden) 84.

Coronoid (der Teleostomen) 54.

- (= Complementare) der Stegocephalen 246.

- (= Complementare) der Pelycosaurier $353,366$.

-- fehlt den Ichthyosauriern 460.

Costae (der Stegocephalen) 259.

- dorsales 24.

- ventrales 24.

Costalia (der Schildkröten) 375, 377.

Costalscuta (der Schildkröten) 376.

Costoide 537.

Crista (der Nashornmolaren) 788.

- sterni (der Vögel) 687.

Crochet 788 .

Cuboideum 794.

Cuneiformia (= Tarsalia distalia) 794 .

Cyrteane Wirbelform 232.

Cyrtocoeliane Wirbelform 232.

Darmrohr 29.

Deckknochen (Allgemeines) 20.

- des Fischschädels (Allgemeines) 32.

- (der Stegocephalen) 233, 234.

Dendrodonte Zahnstruktur 160. 
Dentale (der Teleostomen) 52.

- (der Stegocephalen) 244.

- (der Therocephalier) 419, 422.

Dentin (der Stcgocephalenzähne) 246.

Dentinschuppen der Osteostraci 69.

Dermarticulare (der Teleostomen) 54.

Dermethmoideum medianum (der Teleostomen) 51.

Dermopalatinum (der Teleostomen) 41.

Dermosupraoccipitale (der Stegocephalen) $31,234$.

- (der Cotylosaurier) 333.

- (der Pelycosaurier) 354, 356, 362.

Diapophyse (Wirbelfortsatz) 259.

Diastema 356.

Distales Ende eines Knochens 256.

Doppelwirbel (bei Tetrapoden) 224.

Dornfortsatz, oberer 23.

- unterer 24.

Dorsale Arcualia 23.

Dorsalrippen 24.

Dorsomedianum (der Arthrodiren) 100.

Ductus pneumaticus 219.

Ectethmoideum (der Teleostomen) 46. Ectoloph 788.

Ectopterygoid (der Teleostomen) 41.

- (= Transversum' der Stegocephalen) 239.

(fehlt bei Pelycosauriern) 353.

- (= Transversum) von Tyrannosaurus 600.

Elastica interna 27.

Elle (der Stegocephalen) 256.

Email (der Stegocephalenzähne) 246.

Embolomerer Wirbeltypus (der Tetrapoden) 224.

Entoconid 790.

Entomella (der Cheloniidea) 395.

Entoplastron (der Schildkröten) 376.

Entopterygoideum (der Teleostomen) 41.

Ephippische Wirbelform 232.

Epibranchialia (der Teleostomen) 55.

- (bei Lysorophus) 328.

Epicoronoid (= Complementare) der

Stegocephalen 246.

- (der Pelycosaurier) 353, 366.

Epider malbildungen 17.

Epidyse 79.

Epihyale (der Teleostomen) 55.

Epihyomandibulare 149.

Epijugale (der Ceratopsiden) 648.

Epioticum (der Teleostomen) 44, 58, 59.

- (der Arthrodiren) 94, 101.

- (der Stegocephalen) 243.

Epiphyse 61.

Epiphysenöffnung 79.
Epiplastra (der Schildkröten) 376.

Epipterygoid, Homologie 36.

- (der Stegocephalen) 243.

- (der Cotylosaurier) 333.

- (der Pelycosaurier) 353.

- (von Ceratosaurus) 598.

- (der Lepidosaurier) 658, 659.

-, fehlt bei den Amphisbäniden 659.

-, fehlt bei den Chamäleoniden 658,659 .

- fehlt bei den Schlangen 659, 682.

Epipubis (der Urodelen) 326.

- (der Krokodile) 537.

Episternum (der Anuren) 320.

Epistropheus (= Axis) von Ophiacodon 365.

Epithekale Hautknochen (der Schildkröten) 377, 393.

Epoccipitalia (der Ceratopsiden) 648.

Ersatzgebiß, bei den höher spezialisierten

Sirenen unterdrïickt 832, 838.

Ersatzknochen (allgemeines) 20.

- (der Stegocephalen) 233, 239.

Ethmoidalia (der Stegocephalen) 240.

Ethmoidalkamm von Corythosaurus 635.

Ethmoideum laterale (der Teleostomen) 46.

- medianum (der Telcostomen) 51.

Ethmonasale (bei Lepidosteus) 43.

Exoccipitale, Knorpelknochen 20.

- (der Teleostomen) 40.

- (der Stegocephalen) 240.

Extracolumella 669.

Extralateralplatte (der Antiarchi) 88.

Extramandibulärer Stachel (der Acanthodier) $149,150$.

Extraoccipitalplatte (der Antiarchi) 90.

Extrascapulare (der Teleostomen) 44.

Facies Fonticuli Mastoidei 837.

Fangzahnlöcher (der Stegocephalen) 252.

Fazialgrube 249.

Felsenbein (= Epioticum) der Stegocephalen 243.

Femoralia (= Femoralscuta) 390.

Femoralscuta (der Schildkröten) 376.

Femur (der Stegocephalen) 257.

-, bei Pyrotherium doppelt so lang als der Unterschenkel 844.

Fenestra basitemporalis 249 .

- (= Fossa) infratemporalis 619.

- internasalis 249.

-.- jugalis $593,599$.

- mediopalatinalis 249 .

- orbitotemporalis 350 .

- oticalis 243.

- ovalis (der Stegocephalen) 251.

- - (der Anuren) 317. 
Fenestra palatinalis 249, 496.

- - anterior (bei Thaumatosaurus) 496.

- - lateralis $369,496$.

_. mediana 519.

- - posterior (bei Thaumatosaurus)

496.

- posttemporalis 249.

- praeorbitalis (der Stegocephalen) 249.

- pteroccipitalis 250.

- (= Fossa) supraorbitalis 619 .

- vestibuli (der Theriodontier) 423.

Fersenhöcker (der Anuren) 320.

Fibula (der Stegocephalen) 257.

Fibulare (der Stegocephalen) 257.

Fingerknöchel (der Stegocephalen) 256.

Firstschuppen 82.

Fissura sphenoidalis 759 .

Fontanelle (des Plastrons der Cheloniidea) 392.

Foramen abducens 60 .

- accessorium 60.

- antorbitale 748 .

- carotidicum 29.

- condyloideum 60.

- - (der Theriodontier) 428.

- entepicondyloideum (der StegocephaIen) 256.

- - (der Theriodontier) 423.

- für den Eintritt der Chorda tympani 671.

- glossopharyngeum 60.

- hypoglossi 619.

- infrascapulare 391.

- interclaviculare 499.

- intertympanicum 574.

- lacerum anterius 60.

- - medium (von Patriocetus) 759.

- posterius 60 .

- _ - (der Theriodontier) 428.

_ _ - (von Patriocetus) 759.

- magnum (der Stegocephalen) 252.

- mentale 619.

- obturatorium (der Stegocephalen) 257.

_ _ (der Cotylosaurier) 336.

- _ (der Pseudosuchier) 531.

- - (der Sirenen) 840.

- oculomotorium 60.

- olfactorium 60.

- opticum 60.

— - (der Stegocephalen) 253.

— orbitonasale 29.

- ovale 60.

- parietale (der Stegocephalen) 252.

- - (der Reptilien) 61.

- - (der Mosasaurier) 667.

- - (fehlt bei den Pantyliden) 341.

- pineale (der Arthrodiren) 100.
Foramen postnuchale 399 (Fig. 310), 400

(Fig. 311).

- prooticum 60.

- - (der Stegocephalen) 253.

- quadrati 252.

- - (bei Iguanodon) 624.

- rotundum 60 .

- stylomastoideum 60 .

- suborbitale 550 .

- supracoracoideum, bei Triassochelys 391.

— - der Pelycosaurier 355.

- supraglenoideum, der Pelycosaurier 355.

- supraorbitale 768 .

- transversarium 534, 546, 548, 550.

- trochleare 60.

Fossa infratemporalis (= Fenestra infratemporalis) 619.

- petrosi 759 .

- pituitaria (bei den Stegocephalen 241.

- supraorbitalis (= Fenestra supraorbitalis) 619.

- supratemporalis (= Fenestra supratemporalis) 619.

Fovea pro capitulo costae 259.

- pro tuberculo costae 259.

Frontale, Hautknochen 20.

- (der Stegocephalen) 234.

- (der Arthrodiren) 94.

- (der Teleostomen) 46.

- posterius (der Teleostomen) 57, 58.

- posticum (der Teleostomen) 57.

Frontalia, Homologie 33.

- mit Praemaxillaria verschmolzen (bei Mosasauriern) 667.

Frontoparietale ( = Frontale + Parietale, der Anuren) 316.

Fulkren 82.

Furcula (der Vögel) 687.

Fußwurzel (der Stegocephalen) 257.

Gabelbein (der Vögel) 687.

Ganoin 159.

Ganoinschuppen 154.

Gastrozentraler Wirbeltypus 227.

Gaumen, sekundärer, der Therocephalier $420,422$.

- sekundärer, der Krokodile 534, 546, 55 ?.

Gaumengrube (der Stegocephalen) 249.

Gaumenschläfengrube (derStegocephalen) 249.

Gelenkpfanne des Beckens (der Stegocephalen) 257.

Glandula pituitaria 61 .

Glossobranchiale 55 . 
Glossohyale (der Teleostomen) 55.

Goniale (= Praearticulare) der Stegocephalen) 244.

Griffelbeine 793.

Gürtelbein (der Anuren) 317.

Gulare laterale (der Teleostomen) 53.

- medianum (der Teleostomen) 53.

- ventrale (der Teleostomen) 53.

Gularscuta (der Schildkröten) 376.

\section{Hämalbogen 24.}

Hämapophyse 24.

Hämapophysen (der Tetrapoden) 227.

Halbwirbel 213.

Hallux (der Vögel) 686.

Hauptwirbel 228.

Hautknochen (allgemeines) 20.

- (der Stegocephalen) 233, 234.

Hautpanzerbildungen 17 .

Hautrippen 206.

Hautzähne 32.

- der Osteostraci 69.

Haversische Kanäle in den Knochen, Verlust bei den Sirenen 833 .

Heterozerkie 115.

Hinterhauptbeine 239.

Hinterhauptsloch (der Stegocephalen) 252.

Hinterhirn 61.

Höckerzalıntypus 788 .

Holospondyler Wirbeltypus 226 .

Hiiftbeinloch (der Stegocephalen) 257.

Humerus (der Stegocephalen) 256.

_, bei Pyrotherium doppelt so lang als der Unterarm 844.

Hyoidapparat 30 .

Hyomandibulare (der Teleostomen) 51. Hyoplastra (der Schildkröten) 376.

Hyostylie 109.

Hypantrum 232.

Hypapophysen, vordere und hintere (bei den Schlangen) 680.

Hyperlophodonter Molarentypus 821 .

Hypobranchiale 55 .

Hypocon 789.

Hypoconid 790.

Hypoconulid 790.

Hypodyse (des Stegocephalenschädels) 241.

Hypohyale (der Teleostomen) 55.

Hypolophid 790 .

Hypophyse 61.

— abnorm vergrößert 578, 579.

- (der Dinosaurier) 579.

Hypophysengrube (bei Placochelys) 510. Hypoplastra (der Schildkröten) 376.

Hyposphen 232.

Hyposphenoideum (der Teleostomen) 58.
Hypozentrum (der Tetrapoden) 224.

-, der Ichthyosaurier 463.

- der Pelycosaurier 354, 361.

-, der Mosasaurier 672.

-, fehlt im hinteren Teile der Wirbelsäule bei Deuterosauriern 373.

Hypselodonte (= hypsodonte) Backenzähne 792 .

Ilium, der Vögel und Ornithischier 578. Incisura antorbitalis (von Patriocetus) 59. - oticalis (der Stegocephalen) 251.

_- (bei Seymouria) 333.

Incus 56.

Infradentale (der primitiven Teleostomen). 52.

Infraoperculum 50.

Infraorbitale (der Vögel) 691.

Infraorbitalkanal (des Seitenliniensystems) 270.

Infrapharyngeale 56 .

Infrapostzygapophysen 231 .

Infrapräzygapophysen 231 .

Infraventralia 25.

Infrazygapophysen 232 .

Infundibulum 61 .

Innenskelett 17, 31 .

Intercalare (der Teleostomen) 44.

- (der Stegocephalen) 236.

Intercalarium(ossiculum Weberianum) 56 . Intercentra pleuralia 224 .

Interclavicula (der Stegocephalen) 253.

- (der Cotylosaurier) 336.

- , der Pelycosaurier 354.

- (der Schildkröten) 376.

Intercoronoid (der Stegocephalen) 244.

Interdorsalia 23.

- (der Tetrapoden) 224 .

Interfrontale 242.

Intergularscutum (der Schildkröten) 376.

Interliyale (der Teleostomen) 55.

Interkalarknochen 234.

Interkaudalscuta (Proterochersis) 376.

Intermedium (der Stegocephalen) 257.

Internasale (der Stegocephalen) 234.

- (von Micropholis) 282.

Internasofrontale 242 .

Interoperculum 50.

Interorbitalseptum (der Vögel) 691.

Interparietale (der Reptilien) 236.

Intersquamosum (bei Gephyrostegus) 236.

Intertemporale (der Stegocephalen) 236.

- (bei Seymouria vorhanden) 342 .

Interventralia (allgemeines) 24 .

- (der Tetrapoden) 224.

Intervertebralmasse 225 .

Interzentrum (der Tetrapoden) 224. 
Interzentrum, der Pelycosaurier 354, 361.

-, der Iclithyosaurier 463.

-, fehlt im hinteren Teile der Wirbelsäule bei Deuterosauriern 373.

Intranasale (der Stegocephalen) 237.

- (der Anuren) 317.

Inzisiven, der Therocephalier 422.

Ischium (der Stegocephalen) 257.

—, der Ornithischier 577.

Jochbogen der Therocephalier 422 .

Jochzahntypus 788 .

Jugale (der Stegocephalen) 237.

- (der Arthrodiren) 94.

- (der Teleostomen) 50.

Jugulare Ventralen 154.

Jugularia (der Teleostomen) 53.

\section{Kammplatten 261.}

Kanonenbein 793.

Kaudalscuta (von Proterochersis) 376.

Kehlplatten (der Schildkröten) 376.

Keilbeine 240.

Kieferbogen 30 .

Kieferplatten der Asterolepiden 89.

Kiemenbögen 30 .

Kiemendeckel 49.

Klavikularplatten (der Schildkröten) 376.

Knorpelknochen (allgemeines) 20.

- (der Stegocephalen) 233, 239.

Kommissuren der Schleimkanäle 271.

Kosmin 159.

Kostalplatten (der Schildkröten) 375 .

Ktenoidschuppen 155.

Labyrinthodonte Zahnstruktur 160.

Lacrymaie, Homologie 36.

- (der Stegocephalen) 237.

_., der Dinosaurier 593.

—, der Vögel 691, 692.

- der Sirenen 837.

„Lacrymalia“ (der Arthrodiren) 94.

Längenverhältnis der Gliedmaßenabschnitte, Abweichungen 844, 852.

Laterale Occipitalplatte (der Antiarchi)88.

Lateralkanal (des Seitenliniensystems) 270.

Laterăllinienknochen (der Teleostomen) 49.

Lateralliniensystem (der Amphibien) 269.

Lateralplatte (,Frontale") bei Neoceratodus 34 .

Lateralplatten (der Antiarchi) 88.

Lateralscuta (der Schildkröten) 376.

Latipinnater Flossentypus 465.

Laufbein (der Vögel) 686.

Lauffinger (der Petalodontiden) 135.

Lepidotrichia 154, 158.
Lepospondyler Wirbeltypus 226.

Ligamentum ethmopalatinum 29.

- longitudinale 23.

- praespiraculare 29.

Lippenknorpel 30.

Lobus olfactorius 61.

- opticus 61.

Longipinnater Flossentypus 465.

Lophobunodonte Molaren 789.

Lophodonter Molarentypus 788.

Lophoselenodonte Molaren 789.

Magnum (= Carpale 111) 794 (Fig. 598).

Malleus 56.

-, Homologie 36.

Mandibularbärtel 45 .

Mandibulare 149.

Marginale (der Arthrodiren) 100, 101.

Marginalplatten (der Schildkröten) 376.

Marginalscuta (der Schildkröten) 376 .

Mastoideum (Homologie) 32.

- (der Teleostomen) 57.

- (der Wale) 759, 768.

Maxillare (der Teleostomen) 50, 51.

Meatus auditorius externus (äußerer Gchörgang) 759.

- - - (der Theriodontier) 423, 428.

- - internus (innerer Gchörgang) 60.

Meckelscher Knorpel 51, 245.

Medianplatte, vordere (,Ethmoid") im Schädeldach von Neoceratodus 34 .

Membrana ovalis 670 .

- tympani (der Stegocephalen) 251.

- tympanica (der Theriodontier) 428.

- - (der Lepidosaurier) 670.

Mentale Ventralen 154.

Mentomandibulare (der Teleostomen) 54.

- (der Stegocephalen) 246.

Mento-Meckelian Bone 54.

Merapophysen 537.

Mesaxonisches Gliedmaßenskelett 730 , 792.

Mesethmoideum (der Teleostomen) 51.

Mesoconid 790.

Mesokinetischer Schädeltypus 658.

Mesoplastron (der Schildkröten) 409.

Mesopterygiales Radiale 111.

Mesopterygium (der Pleuropterygier) 111.

Mesopterygoideum (der Teleostomen) 41.

Metacarpalia (der Stcgocephalen) 256.

Metacon 789.

Metaconid 789 .

Metaconulus 789 .

Metacoracoid (der Stegocephalen) 255.

- (der Cotylosaurier) 336.

Metakinetischer Schädeltypus 658.

Metaloph 788. 
Metalophid 790.

Metapterygiales Radiale 111.

Metapterygium 111.

Metapterygoideum (der Teleostomen) 41.

Mittelhandknochen (der Stegocephalen) 256.

Molaren 711 .

- , der Therocephalier 422.

Mundhöhlenschuppen 32.

Musculus abductor indicis longus (der Anuren) 320 .

- adductor mandibulae posterior longus 315 .

- ambiens 578 .

- caudofemoralis 614 .

- digastricus 692.

- ischiofemoralis 614 .

- masseter, Insertionsstelle 419, 837.

- pterygoideus 315 . rhomboideus 315 .

- temporalis $315,419$.

Myodoma (Augenmuskelkanal) 39.

Nachhirn 61.

Nackenschild der Ceratopsiden 646.

Nahtknochen 235.

Naris (der Stegocephalen) 248.

Nasale (der Arthrodiren) 94

- (der Teleostomen) 48.

- (der Stegocephalen) 234.

- geht bei den höher spezialisierten Sirenen verloren 837.

Nasalia, Homologie 33.

--, variable Ausbildung bei Krokodilen $543,544,545$.

Nasenöffnıngen (der Stegocephalen) 248.

- , ihre Lage bei aquatischen Tetrapoden 267.

- ihre Lage bei Lonchorhynchus 248, 267.

- der Therocephalier 421.

-, bei den Ichthyosauriern nach hinten verschoben 454.

_- ihre Lage bei den Mesosauriern 452.

- , ihre Lage bei den Phytosauriern 515.

- ihre Lage bei den Krokodilen 515, 533,534 .

-, ihre Lage bei Diplodocus 606, 608, 611.

- - ihre Lage bei Macrauchenia 852.

—, äußere, miteinander verschmolzen (bei Krokodilen) 533.

Nasofrontale 242.

Naviculare 794

Neokraniale Nerven 62.

Nervenrohr 21, 25, 29.

Nervus abducens 60 .
Nervus accessorius 60,62 .

- acusticus 60.

- facialis 60 .

- glossopharyngeus 60 .

- hypoglossus 60.

_ - Entstehung aus drei Spinalnerven 30 .

- lateralis 62.

- maior 270.

- oculomotorius 60.

- olfactorius 60.

- opticus 60 .

- quintus 60.

- trigeminus 60 .

- trochlearis 60 .

- vagus 60.

Neuralbogen 23.

Neuralplatten (der Schildkröteı) 375.

Neurapophyse (allgemeines) 23.

- (der Tetrapoden) 222.

Neuschädelnerven 62.

Notarium 567.

- (der Vögel) 687.

Notozentraler Wirbeltypus 227.

Nuchalplatte (der Schildkröten) 375.

Nuchalscutum (der Schildkröten) 376.

Oberarmknochen (der Stegocephalen) 256.

Oberschenkelknochen (der Stegocephhalen) 257.

Occipitale basilare (der Teleostomen) 4i, $57,58,59$.

- extermum (der Teleostomen) 44, 57, 58,59 .

- inferius (der Teleostomen) 57.

- laterale (der Teleostomen) 40,57,58,59.

- - (der Stegocephalen) 240.

- medianum (der Arthrodiren) 100.

- superius (der Arthrodiren) 94.

- - (der Teleostomen) 44, 57, 58, 59.

Occipitalia (der Tetrapoden) 239.

Occipitalkommissur (bei Polypterus) 271.

Occipitalplatte (der Antiarchi) 88.

Occipitalregion der Schädelkapsel 30.

Ohrengrube (der Stegocephalen) 250.

Ohrenschlitz (der Stegocephalen) 251.

Ohrknochen 239.

Olecranon ulnae (der Theriodontier) 423.

Oligobunodonte Molaren 788.

Oligolophodonte Molaren 788.

Operculare (der Teleostomen) 54.

_ (= Spleniale der Stegocephalen) 244.

Operculum (der Teleostomen) 49.

- (der Anuren, nicht $=$ dem der Teleostomen) 317.

- (der Urodelen; nicht homolog dem Ó. der Teleostomen) 324. 
Operculum tympanicum (der Mosasaurier) 670.

Opisthocoele Wirbelform 232.

Opisthoticum, Homologie 38.

- (der Teleostomen) 44, 58, 59.

- (der Stegocephalen) 243.

- (der Cotylosaurier) 333.

- (der Araeoscelidia) 654.

Oralplatten (bei Tremataspis) 80.

Orbita (der Stegocephalen) 248.

Orbitale posterius (der Teleostomen) 57.

Orbitosphenoid, Homologie 36.

- (der Teleostomen) 43.

- (der Vögel) 691.

Orbitotemporalöffnung (der Procolophonia) 350.

Os coccygeum (der Anuren) 318.

- en ceinture (der Anuren) 317.

- - V 227.

- innominatum (der Teleostomen) 57.

- Wormianum 234.

Ossicula Weberiana 56.

Otica 239.

Otikalschlitz (der Stegocephalen) 251.

- (bei der Reptilgattung Seymouria) 333.

Pachyostose der Rippen, bei Mesosauriern 453.

_- - bei Sauropterygiern 453, 487.

Pachyostotische Knochen 833.

Paläokraniale Nerven 62.

Palatinum (der Teleostomen) 41.

— der. Stegocephalen) 239.

Palato-Pterygo-Quadratbogen 29.

- -Pterygoideum 34.

Panzer der Osteostraci, Entstehung 69. Parabasale (= Parasphenoideum) 238.

Paracon 789.

Paraconid 789.

Paraphyse 61 (Fig. 28).

Parapophyse 23.

- (der Stegocephalen) 259.

Parasphenoid, Homologie 36.

- (der Teleostomen) 41, 58, 59.

- (der Stegocephalen) 238.

-, mit den Nachbarknochen bei Ichthyophis verwachsen 331.

- (der Araeoscelidia) 654.

- (fehlt bei den Säugetieren) 435 .

Parasphenoidallücke (der Plesiosaurier) 491.

Paraxonisches Gliedmaßenskelett 730,792. Parethmoideum (der Teleostomen) 46.

Parietalauge 61.

- (der Stegocephalen) 252.

Parietale, Hautknochen 20.

-, Homologie 33.
Parietale (der Teleostomen) 45.

- (der Stegocephalen) 234.

Parietalöffnung (der Stegocephalen) 252.

Parietalorgan 61 .

- (der Stegocephalen) 252.

Paroccipitale (der Teleostomen) 57, 59.

- (= Opisthoticum) der Stegocephalen 243.

- (der Schildkröten) 384.

- (der Araeoscelidia) 654.

Patella (bei Hesperornis) 696.

Pectoralia (= Pectoralscuta) 390.

Pectoralscuta (der Schildkröten) 376.

Perennibranchiater Zustand 329.

Perichordales Bindegewebe 27, 28.

Perilymphatische Gefäße, Austrittsstelle, am Stegocephalenschädel 241, 253.

Perioticum 748.

Perisquamosum (der Ceraterpetontiden) 299.

Petrosal (der Teleostomen) 57.

Petrosum (der Teleostomen) 43, 57.

- (der Wale) 759 (Fig. 568, Petr.).

Phalangen (der Stegocephalen) 256.

Pharyngobranchiale 55.

Phyllospondyler Wirbeltypus 226.

Physocliste Schwimmblase 219.

Physostome Schwimmblase 219.

Pineale (der Arthrodiren) 101.

Pinealorgan 60.

- (der Stegocephalen) 252.

Pisiforme (im Carpus der Cotylosaurier) 337.

Plakoid chuppen $32,80$.

Plantigradie 795 .

Plastron (der Schildkröten) 375.

Platyane Wirbelform 232.

Platycoele (= platycoeliane) Wirbelform 232.

Platyhippische Wirbelform 232.

Plectrum (der Anuren) 317.

Plesiometacarpaler Gliedmaßentypus 810.

Pleuralrippe 23.

Pleuroccipitale (der Teleostomen) 58, 59.

Pleurodontie 248.

Pleurozentren (der Tetrapoden) 224.

Polybunodonte Molaren 788.

Polylophodonte Molaren 788.

Posterodorsolaterale (der Arthrodiren) 100.

Posteroventrolaterale (der Arthrodiren). 100.

Posteroventromedianum (der Arthrodiren) 100.

Postfrontale (der Teleostomen) 45, 57, $58,59$.

- (der Arthrodiren) 94.

- (der Stegocephalen) 237. 
Postfrontale (der Dinosaurier) 593.

Postmedianplatte (der Antiarchi) 88.

Postnasale (= Adlacrymale) 237.

Postoccipitale (der Teleostomen) 45.

Postorbitale (der Arthrodiren) 100.

- (der Teleostomen) 47.

- (der Stegocephalen) 237.

- (der Cotylosaurier) 333.

- (der Pelycosaurier) 353.

- (der Dinosaurier) 593.

_, bei den Stegosauriden frei 640 .

Postorbitalfortsatz (der Acantlodier 150.

Postorbitofrontale 637, 659, 669.

Postparietale (der Stegocephalen) 234, 236.

Postpubis 577.

Postspiraculare (der Teleostomen) 47.

Postspleniale (der Stegocephalen) 245.

Posttemporale (der Teleostomen) 44.

Posttemporalgruben des Schildkrötenschädels 380,381 .

Postzygapophysen 229.

Praeangulare ( $=$ Postspleniale der Stegocephalen 245 .

Praearticulare (der Stegocephalen) 244.

- (der Pelycosaurier) 353.

- (der 1chthyosaurier) 460.

- (bei lguanodon) 629.

Praecoracoid (der Stegocephalen) 255.

- (fehlt den Schildkröten) 377.

Praecoronoid (der Stegocephalen) 244.

Praedentale (der Teleostomen) 54.

- (bei Aspidorhynchus) 212.

- (der Ornithischier) 578.

Praeethmoideum (der Teleostomen) 51.

Praefrontale, Homologie 36, 237.

- (der Arthrodiren) 101.

- (der Teleostomen) 46.

- (= Lacrymale der Säugetiere). 48.

Praehallux (der Anuren) 320.

Praemandibulare 149, 150.

Praemaxillare (der Teleostomen) 51.

- (der Stegocephalen) 239.

Praemaxillaria, mit den Frontalia verschmolzen (bei Mosasauriern) 667.

Praerıedianplatte (der Antiarchi) 88.

Prämolaren 711.

- Reduktion bei den Elephantiden 824.

- bei den Sirenen 832, 833.

Praeoperculare (von Neoceratodus) 34.

- anterius (der Teleostomen) 54.

- posterius (der Teleostomen) 54.

Praeoperculum 50.

Praepalatoquadratum 149, 150.

Präorbitalöffnung (der Labyrinthodontiden) 283.

- der Parasuchier 514, 517.

- der Pseudosuchia 525.
Präorbitalöffnung der Teleosauriden 539.

- bei Thoracosaurus 553.

- bei Libycosuchus 551.

- der Rhamphorhynchoidea 557, 558.

- der Pterodactyloidea 565.

- des Dinosaurierschädels 593.

- der Kalodontiden 616, 623.

- der Ceratopsiden 648, 652, 653.

Praepalatoquadratum (der Acanthodier) 149.

Praeparictale (der Reptilien) 236.

Praepubis (der Krokodile) 537.

- (der Rhamphorhynchoidea) 560.

Praespiraculare (der Teleostomen) 47.

Praesymphyseale (der Teleostomen) 54.

Praesymphysealknochen (bei Aspidorhynchus) 212.

Praevomer (= Vomer) $36,239,420,422$, 435.

Praezygapophysen 229.

Primordialcranium 29.

Proatlas (von Ophiacodon) 365.

Processus acromialis scapulae (der Schildkröten) 377.

- angularis (des Unterkiefers) 721.

- articularis des Prooticums (für das Metapterygoid) 52.

- ascendens astragali 614.

- palatoquadrati 659 .

- basipterygoideus 609.

- coronoideus (der Theriodontier) 419, 428.

- - der Ornithischier 578, 617.

_- fehlt bei den Stegosaurinen 639, 640.

- cultriformis des Parasphenoids 238.

- ethmopalatinus (bei Notidanus) 111.

- falciformis 759 .

- obturatorius 630 .

- odontoideus des Epistropheus (bei

Ophiacodon) 365.

- orbitalis frontalis (der Vögel) 689.

- paroccipitalis (des Opisthoticums der Ornithischier) 620.

- paroticus 574, 609.

- paroccipitalis des Exoccipitale 758 .

- pectinealis 577,587 .

— postglenoidalis 748 .

- postorbitalis (bei Notidanus) 111.

- - (der Acanthodier) 149, 150.

- - (der Wale) 768.

- posttympanicus (der Theriodontier) 428.

- praeglenoidalis des Squamosums 758.

- praequadraticus squamosi 628 .

- pseudopectinealis 577,578 .

- pterygoidalis (der Ornithischier) 620. 
Processus pterygoideus quadrati 628.

- squamosalis parietalis 628 .

- transversi (der Anurenwirbel) 319.

- uncinati costarum 260.

- uncinatus (der Vogelrippe) 688, 695.

- zygomaticus des Squamosums 748.

Procoele Wirbelform 232.

Prooticum (der Teleostonien) 43.

- (der Stegocephalen) 243.

Propterygiales Radiale 111.

Propterygium 111.

Prosquamosum, Homologie 36.

- (der Stegocephalen) 236.

Protocon 789.

Protoconid 789.

Protoconulus 789.

Protoloph 788.

Protothekodontie 248.

Proximales Ende eines Knochens 256.

Pseudohämapophysen (der Schlange) 681.

Pseudopulpa 160.

Pseudostegaler Schädelbau 332, 382.

Pseudotemporalgrube (der Stegocephalen) 251, 252, 287.

Pseudozentraler Wirbeltypus 225.

Pseudozentrum 226.

Pterapophysen (der Schlangen) 680.

Pteroccipitallïcke 250.

Pteroticum 34, 38.

- (der Teleostomen) 44.

Pterygoidalfortsatz des Quadratums (von Morosaurus) 608.

-_ - - (von lguanodon) 624, 626, 628.

Pterygoideum (der Teleostomen) 41.

- (der Stegocephalen) 239.

Pterygopodien 18, 112.

Pubis (der Stegocephalen) 257.

- (der Krokodile) 537.

- (der Dinosaurier und Ornithischier) 577.

— Reduktion bei den Sirenen 839, 840.

-, bei den Ceratopsiden rudimentär 646 , 653.

Pulpa 247.

Pygalplatten (der Schildkröten) 375.

Pygalscutum (der Schildkröten) 376.

Pygostyl (der Vögel) 687.

Quadratojugale (der Arthrodiren) 94.

- (der Cotylosaurier) 333.

- (der Stegocephalen) 236.

- (der Pelycosaurier) 353.

- (fehlt m. A. von Delphinognathus bei den Theriodontiern) 415 .

- (fehlt bei den Araeoscelidia) 654.

Quadratum, Homologie 36.

- (der Teleostomen) 51.
Quadratum (der Stegocephalen) 243.

- bei den Theriodontiern rudimentär $415,421,422$.

- (von Iguanodon) 624 .

- (von Trachodon) 633.

- (der Lepidosaurier) 658.

- (bei den Säugetieren noch nicht nachgewiesen) 32.

-, Streptostylie 658.

Querfortsätze der Anurenwirbel 319.

Radiale 322.

Radialia 45.

- (der Haifischflossen) 111.

Radius (der Stegocephalen) 256.

Ramus buccalis (des Nervus facialis) 270.

- mandibularis (des Nervus facialis) 271.

_ ophthalmicus (des Nervus facialis) 270.

- oticalis (des Nervus facialis) 270.

Rhachitomer Wirbeltypus 222.

Ringwirbel 26.

Ringzentren 159.

Rippen (der Fische) 24, 25.

- (der Stegocephalen) 259.

-, mit den Wirbeln verschmolzen bei Anuren 319.

- mit den Wirbeln versclimolzen bei

Deuterosauriern 374.

Rocher (der Teleostomen) 57.

Rostrale (der Arthrodiren) 100, 101.

- (der Ceratopsiden) 648.

Rostralia (der Teleostomen) 51.

Rostralplatte (der Pteraspiden) 84.

Rostrum (des Haifischschädels) 29.

- sphenoidale 574.

Rückensaite 21.

Rückenschild (der Schildkröten) 375.

Rüickgrat 17.

Saccus vasculosus 240 .

Sakralrippen, Homologie $: 37$.

Sakralwirbel (der Stegocephalen) 260.

Sanduhrwirbeltypus 226.

Scaphium (Ossiculum Weberianum) 56.

Scapula (der Cotylosaurier) 336.

Scapulare (der Stegocephalen) 255.

Schädeldach 31 .

Schaltknochen 234.

Scheitelloch 61 .

- (der Stegocephalen) 252.

Schenkelschilder (der Schildkröten) 376.

Schienbein (der Stegocephalen) 257.

Schläfenöffnung, untere (der Stegocephalen) 249.

_, hintere (der Stegocephalen) 249.

Schleimkanäle (des Fischschädels) 62.

- (der Amphibien) 269. 
Schmelz (der Stegocephalenzähne) 246.

Schnittwirbel 222, 226.

Schuppen (der Knochenfische) 156.

Schuppenreihen, Verlauf und Richtung in der Schwanzregion der Teleostomen 184.

- (der Stegocephalen) 261.

Scleroparietale 34 .

Scleroticalia (der Stegocephalen) 237.

Seitenlinie der Fische 62.

Seitenorgan (der Antiarchi) 90.

Selenodonter Molarentypus 788.

Sella turcica (des Stegocephalenschädels) 241.

Semidigitigradie 796 .

Semilunarplatten (der Antiarchi) 89.

Semiplantigradie 796 .

Septomaxillare (der Teleostomen) 51.

- (der Stegocephalen) 237.

- (der Anuren) 317.

- (der Cotylosaurier) 333.

- (der Pelycosaurier) 353. (der Lepidosaurier) 660. (der Mosasaurier) 669.

Septum ethmoidale (bei Tyrannosaurus) 603.

_ interorbitale (bei Chimaera) 112.

- - (der Vögel) 691.

Sesambeine 21, 465, 566, 568, 645.

Siebbeine 240.

Sklerotikalring der Tremataspiden 80 .

- der Arthrodiren 94.

der Acanthodier 150.

- der Teleostomen 48.

- der Stegocephalen 237.

-, von Galechirus 431.

-, bei Ichthyosauriern 454 .

- von Euparkeria 526.

- der Gensauriden 543, 546.

- der Ornithocheiriden 570, 575.

-, bei Saurolophus 634 .

- bei Thalattosauriern 663 .

- bei Mosasauriern 669.

, bei Archaeopteryx 692.

Speiche (der Stegocephalen) 256.

Sphenethmoideum (der Stegocephalen) 241.

Sphenoidalia 240.

Sphenoideum basilare (der Teleostomen) 57.

- principale (der Teleostomen) 57.

Sphenoticum (der Teleostomen 44, 58, 59 .

- (der Stegocephalen) 243.

Spinale (der Arthrodiren) 95.

Spinalnerven 30,62 .

Spiracula (bei Tremataspis) 79, 80 .

- (der Elasmobranchier) 108.
Spiraculare (der Teleostomen) 46.

Spleniale (der Teleostomen) 54.

- (der Stegocephalen) 244.

- der Pelycosaurier 353, 354.

Squama ossis occipitis (der Teleostoment)

57.

- temporis (der Teleostomen) 57.

Squamosum (der Teleostomen) 44.

- (der Stegocephalen) 236.

Stapes 56.

- (der Stegocephalen) 243, 251.

- (der Anuren) 317.

- (von Triassochelys) 387.

- (der Mosasaurier) 669.

Stegaler Schädelbaı 332, 333.

Stereospondyler Wirbeltypus 224.

Sternalrippen (der Reptilien) 261.

Sternum (der Anuren) 320.

Stirnorgan der Frösche 313.

Streptostylie des Quadratums 658 .

Stylohyale (der Teleostomen) $\mathbf{5 5 .}$

Submarginalscuta (der Schildkröten) 376 , 387.

Suboperculum 49.

Suborbitalia (der Teleostomen) 47.

- (= Supraorbitalia) von iguanodon 623.

- (= Supraorbitalia) bei Stegosaurus $641,643$.

Sulcus intermedius (zwischen Tibia und

Fibula der Anuren) 320.

- mastoideus 759 .

Supermaxillare (der Teleostomen) 50.

Supraangulare (der Teleostomen) 54.

- (der Stegocephalen) 246.

Suprabasidorsalia 23.

Supraclavicula (der Arthrodiren) 96.

- (der Telcostomen) 53, 96.

Supradentale (bei Tyramnosaurıs) 602.

Suprainterdorsalia 23.

Supramaxillare (der Stegccephalen) 239.

Supramaxillaria, Verhalten zu den Frontalia bei den Walen 758 .

Supraoccipitale, Entstehung 31.

- (der Teleostomen) 44, 57, 58, 59.

- (der jüngeren Actinopterygier) 35.

- (der Stegocephalen) 240.

- (der Wale) 750.

Supraorbitale (der Teleostomen) 48.

- (von Iguanodon) 623, 624, 626.

- (der Ornithischier) 618, 619, 648.

- (der Lepidosaurier) 659.

Supraorbitalkanal (des Seitenliniensystems) 270.

Supraorbitalkommissur 271.

Suprapharyngeale (bei Gadus) 55.

Suprascapulare (von Archegosaurus) 255.

- (der Anuren) 319. 
Suprascapulare (bei Triassochelys) 377.

- (der Lepidosaurier) 660.

Supratemporale, Homologie 36.

- (der Teleostomen) 44.

- (der Arthrodiren) 94, 101.

- (der Stegocephalen) 236.

- (der Cotylosaurier) 333.

- der Pelycosaurier 354, 356.

- (der Mosasaurier) 668 (Fig. 523, St).

- (der Thalattosaurier) 663.

- medianum (bei Acipenser sturio) 45.

Sutura centro-neuralis 621 .

Symplecticum (der Teleostomen) 51 .

Tabulare (der Cotylosaurier) 333.

-, der Pelycosaurier 354, 356, 366.

- (der Aracoscelidia) 654.

Talonid 790 .

Tarsalia (der Stegocephalen) 257.

Tarsometatarsus (der Vögel) 687.

Tarsus (der Stegocephalen) 257.

- (der Cotylosaurier) 337.

Tegaler Schädeltypus (von Chelonia) 382.

Tektospondyle Wirbelzentren 26 .

Teleometacarpaler Gliedmaßentypus 810 .

Temporalgruben, seitliche, fehlen den Stegocephalen 233.

- _, wiederholt unabhängig entstanden 355.

—, sekundär verschlossen $332,373,382$, 654.

- hintere (der Stegocephalen) 249.

-, obere, der Ceratopsiden 647, 648, 650, 651.

- seitliche, von Palaeohatteria 360.

_ _ , der Deuterosaurier 373.

-, untere, der Ceratopsiden 648, 650.

-, seitliche, der Ichthyosaurier 373, 471, 472.

—, seitliche, fehlen den Apoden 332.

— - , fehlen den Cotylosauriern 333.

Temporalregion der Anuren 314.

- der Gymnophionen 332.

- von Ophiacodon 364.

- der Schildkröten 373, 382.

- der Theriodontier 415, 420.

- der Parasuchia 514, 517.

- der Pseudosuchia 525.

- der Krokodile 536.

- von Araeoscelis 373, 654.

- der Lepidosaurier 658.

- der Schlangen 682.

- der Vögel 692.

Tentakelöffnung (bei Drepanaspis) 81.

Temnospondyler Wirbeltypus 226.

Temporale (der Teleostome) 57.

Terminalflosse (der Osteostraci) 70.
Terminalflosse (der Cladodontiden, heterocerk) 115 .

- (bei den Ichthyotomi nur von der Caudalis gebildet) 117 .

- (hochspezialisiert bei den Trygonidae) 128.

- (der Teleostomen) 156.

- (der Actinopterygii) 184.

Theca (der Schildkröten) 374.

Thekale Hautknochen (der Schildkröten) 377, 393.

Thekodontie 248 .

Thorakale Ventralen 154.

Tibia (der Stegocephalen) 257.

Tibiale (der Stegocephalen) 257.

Tibiotarsus (der Ornithocheiriden) 570.

- (der Ornithischier) 614.

- (der Vögel) 687.

Trabeculare (der Acanthodier) 149, 150.

Transpalatinum (= Transversum) 239.

Transversum (der Stegocephalen) 239.

-, der Therocephalier 420.

—, fehlt bei den Cotylosauriern 336.

- (fehlt bei Pelycosauriern) 353.

- (der Araeoscelidia) 654.

- (der Mosasaurier) 669.

Trapezoid (= Carpale 11) 794.

Trichter 61.

Trigonodonter Molarentypus 789.

Tripus (ossiculum weberianum) 56 .

Trituberkulärer Molarentypus 789.

Trituberkulärsektoriale Molaren 789 .

Trochanter quartus 614 .

- tertius 796, 854.

Trommelfell (der Stegocephalen) 251.

Tuberculum costae (der Stegocephalen) 259.

- sphenoccipitale 609.

Türkensattel (des Stegocephalenschädels) 241.

Turbinated Bone 237.

Tympanicum, Homologie 36 .

Ulna (der Stegocephalen) 256.

Unterkiefergelenk, sekundäres, der Therocephalier 419.

— - der Mosasaurier 669.

Urohyale (der Teleostomen) 55.

Urostyl, 313.

Urschädelnerven 62 .

Viszeralbögen 29,30 .

Ventrale Arcualia 24

Ventralrippen (der Fische) 24.

- (der Reptilien) 261.

Vertebralscuta (der Schildkröten) 376.

Vollwirbel 226. 
Vomer, Homologie 36.

-, ursprünglich paarig, später verschmolzen 40.

- (der Teleostomen) 41.

- (der Stegocephalen) 239.

- (der Säugetiere, Homologie) 422, 435.

Wadenbein (der Stegocephalen) 257.

Wangengrube (der Stegocephalen) 249.

Wirbelkörper 25.

Wirbeltheorie 31 .

Wirbelzahl, höchste, bei den Stegocephalen $262,307$.

_- - bei den Coeciliiden 262.

_ - bei den Schlangen 680 .

Xiphiplastra (der Schildkröten) 376.

Xiphisternum (der Anuren) 320.
Zahnknochen (allgemeines) 31.

- (der Stegocephalen) 233, 238.

Zement (der Stegocephalenzähne) 246.

Zentralia (im Tarsus der Stegocephalen) 257.

Zentrum des Wirbels 25.

Zungenbeinapparat 30 .

Zungenbeinbogen 30 .

Zwischenwirbel 228.

Zygaler Schädelbau 333.

Zygantrum 230.

- (bei den Lepidosauriern) 660.

Zygosphen 230.

- (bei den Lepidosauriern) 660.

Zykloidschuppen 155, 159.

Zyklospondyle Wirbelzentren 26, 27. 


\section{Übersicht}

\section{der Familien und Unterfamilien, Ordnungen und Unter- ordnungen, Klassen und Unterklassen.}

Acanthodei 147.

Acanthodidae 151.

Åcanthopholidae 645.

Acanthopterygii 157.

Acanthostomatidae 296.

Aceraspidae 3.

Acipenseridae 197.

Acoelodidae 848.

Acreodi 733 .

Acrodelphidae 766 .

Actinopterygii 183.

Adapidae 876.

Adapisoricidae 727.

Adiantidae 853.

Aegodontia 816.

Aeluroidea 739.

Aepyornithes 698 .

Aëtosauridae 529.

Aglossa 322.

Agorophiidae 751.

Agriochoerinae 805 .

Aistopoda 297.

Albertogaudryidae 851 .

Allophagi 585.

Allotheria 712 .

Amblotheriidae 722 .

Amblypoda 816.

Amiidae 212.

Amphichelyidae 411 .

Amphignathodontidae 324 .

Amphistiidae 216.

Amphitheriidae 722.

Amphinmidae 330.

Amynodontinae 856.

Anacanthini 157.

Anaptomorphidae 875 .

Anaspida 65.

Anclisauridae 595.

Ancylopoda 868.

Anguindiae 660.
Anicanodonta 775 .

Anoplotheriidae 803 .

Anseriformes 704 .

Anthracotherijdae 801.

Anthropoidea 877.

Anthropomorpha 877.

Antiarchi 86.

Antilocapridae 815.

Anura 311.

Aplodontoidea 786 .

Apoda 332.

Apodes 157.

Aptera 5.

Apteryges 699.

Araeoscelidia 654.

Archaeoceti 749.

Archaeochelyidae 409.

Archaeohyracidae 848.

Archaeolemuridae 876 .

Archacophidae 683.

Archaeopithecidae 848.

Archaeornithes 693.

Archegosauridae 272.

Arcifera 322.

Arctocyonidae 738.

Arctoidea 743.

Ardeae 703.

Arthrodira 92.

Arthrothoraci 100.

Artiodactyla 799 .

Aspidorhynchidae 211.

Aspidosauridae 280 .

Asterolepidae 88.

Astrapotheriidae 851.

Astrapotherioidea 850.

Ateleaspidae 3.

Atlantosauridae 611.

Atoposauridae 549.

Aves 686.
Balaenidae 762 .

Balaenopteridae 759 .

Barytheriidae 829.

Belonorhynchidae 194.

Birkeniidae 68.

Bolosauridae 349 .

Boodontia 816.

Bovinae 816.

Bradypodidae 779 .

Branchiosauridae 295.

Brevirostres 536.

Bubalidinae 816 .

Bufonidae 323.

Bunolitopternidae 799 .

Bunoselenodontia 801.

Caenolestidae 716 .

Caenotheria $\$ 00$.

Caenotheriidae 800.

Camelidae 808.

Camelopardalidae 813.

Camptosaurinae 617.

Canidae 747.

Captorhinidae 346 .

Carchariidae 121.

Carettochelyidae 414 .

Carnivora 729.

Caroloameghiniidae 721 .

Caseidae 364.

Casuarij 699.

Catosteomi 157.

Cavicornia 815.

Cebidae 877.

Centetidae 728.

Cephalaspidae 73 .

Cephalophinae 816.

Ceraterpetontidae 297.

Ceratopsidae 646.

Ceratopsinae 646 .

Cervicaprimae 816 . 
Cervidae 810.

Cervinae 813.

Cetacea 749.

Cetiosauridae 611.

Cetomorpha 5 .

Cetorhinidae 123.

Chalicotheriidae 869 .

Chamaeleonidae 678 .

Chamaeleontia 678.

Champsosauridae 449.

Charadriiformes 707 .

Chelonia 374.

Cheloniidae 399.

Cheloniidea 389.

Chelydridae 389.

Chimaeridae 143.

Chiromyidae 876.

Chiroptera 729.

Chirothricidae 216.

Chlamydoselachidae 120 .

Chondrostei 156 .

Chondrosteidae 195.

Chrysochloridae 728.

Ciconiae 703.

Ciconiiformes 703.

Cinosternidae 389 .

Cladodontidae 115.

Clepsydropidae 356 .

Coccosteidae 99.

Cochliodontidae 133.

Coeciliidae 332.

Coelacanthidae 167.

Coelolepidac 72 .

Coeluridae 581 .

Coelurosauria 580.

Colubridae 685.

Columbae 707.

Colymbiformes 703 .

Compsognathidae 581 .

Coraciiformes 707 .

Coryphodontidae 817 .

Cotylosauria 333.

Cricotidae 293.

Crocodilia 533.

Crocodilidae 550.

Crossopterygii 158.

Cryptodira 386.

Crypturi 693.

Ctenodontidae 180.

Ctenothrissidae 216.

Cuculiformes 707 .

Cyclostomata 63.

Cynopithecidae 877.

Cystignathidae 324 .

Dasypodidae 780 .

Dasyuridae 719.
Delphinoceti 772 .

Dercetidae 216.

Dermatemydidae 389.

Dermochelyidae 404.

Desmostylidae 830 .

Deuterosauria 372.

Diadectidae 339.

Dichobunidae 799.

Dicholophidae 705.

Dicrocynodontidae 723.

Dicynodontia 435.

Dicynodontidae 440.

Didelphiidae 719.

Dididae 707.

Dilambdodonta 725 .

Dinichthyidae 100.

Dinocephalia 431.

Dinocephalidae 432.

Dinoceratidae 818.

Dinornithes 698.

Dinosauria 576.

Dinotheriidae 829.

Diplodocidae 610.

Dipneusti 171.

Diprotodontia 715 .

Dipteridae 175.

Dissorophidae 278.

Dolichosauria 663.

Drepanaspidae 80.

Dromaeognathae 693.

Dromasauria 431.

Dromasauridac 431.

Dromatheriidae 718.

Duplicidentata 787 .

Edaphosauridae 367.

Edestidae 136.

Elasmobranchii 104.

Elasmosauridae 502.

Elasmotheriinae 860.

Elephantidae 826.

Elginiidae 347.

Elotheriidae 800.

Embolomeri 292.

Embrithopoda 819.

Enchodontidae 216.

Entelonychia 850.

Equidae 860.

Erinaceidae 726 .

Erycidae 685.

Eryopidae 277.

Euartiodactyla 800.

Eucreodi 737.

Eurhinodelphidae 767.

Eurypygidae 705.
Falconiformes 705 .

Felidae 741.

Felinae 741.

Galeopithecidae 726 .

Galliformes 705 .

Gastornithidac 704.

Gastrocentrophori 308.

Gavialidae 553.

Gazellinae 816.

Gelocinae 810.

Gemuendinidae 129.

Geosauridae 543.

Giraffidae 813.

Giraffinae 813.

Glanconiidae 680.

Glyptodonta 781 .

Goniopholidae 546.

Gravigradidae 775 .

Gruidae 705.

Gruiformes 705.

Gymnarthridae 345 .

Gymnophiona 332.

Halicoridae 833.

Halicorinae 835.

Halitheriinae 833.

Hallopidae 581.

Hapal.dae 877.

Hap'omi 157.

Hegetotheriidae 847.

Heliornithidae 705 .

Hemiphractidae 324.

Henricooshorniidae 848.

Heterodontidae 121.

Heteromi 157.

Hicanodonta 779.

Hippopotamidae 801.

Hippotraginac 816.

Holoptychiidae 163.

Holostei 156.

Homalodon totheriidae 850 .

Hominidae 878.

Homosteidae 100.

Hyaenidae 741 .

Hyaenodontidae 735 .

Hyaenodontinae 735 .

Hylaeobatrachidae 329 .

Hylidac 324.

Hylonomidae 309.

Hypertragulidae 809 .

Hypoconifera 799.

Hypsilophodontinae 617.

Hyracidae 819.

Hyracodontinae 855 .

Hyracoidea 818.

Hystricomorpha 787. 
Ichthyosauria 453.

Ichthyotomi 116.

Iguarodontinae 623 .

Ilysiidae 680 .

Insectivora 723 .

Interatheriidae 847.

Ischyromyinae 786 .

Isotemnidae 850.

Issiodoromyinae 787 .

Kalodontidae 616 .

Labyrinthodontidae 282.

Lacertilia 660.

Lagomyidae 787.

Lamnidae 122.

Laosaurinae 617.

Lari 707.

Lasaniidae 68.

Lemuridae 876.

Lemuroidea 875 .

Leontiniidae 850.

Lepidosauria 656.

Lepidosirenidae 177.

Lepidosteidae 215.

Leporidae 787.

Leptictididae 725 .

Leptolepidae 216.

Limnerpetontidae 309.

Limnicolae 707.

Limnocyoninae 737.

Limnoscelidae 338.

Litopterna 851.

Longirostres 536 .

Lophiodontinae 854.

Lytolomidae 397.

Machairodontinae 743 .

Macraucheniidae 851 .

Macrocliroptera 729 .

Macrorhynchidae 546 .

Macroscelididae 726 .

Macrosemiidae 204.

Malacopterygii 157.

Mammalia 710 .

Manatidae 835.

Manidae 785.

Marsupialia 710 .

Megalonychinae 775 .

Megalosauridae 595 .

Megatheriinae 778.

Meniscotheriidae 799 .

Mesonychidae 733.

Mesosauria 452.

Mesosauridae 453.

Mesosuchia 534.
Miacidae 738.

Miacinae 739 .

Microbrachidae 308.

Microchiroptera 729.

Micropholidae 281.

Microzeuglodontidae 751 .

Mioclaenidae 796.

Miolaniidae 412.

Miosireninae 835.

Mixodectidae 727 .

Moeritheriidae 826.

Molgophidae 307.

Monotremata 710 .

Mosasauria 666.

Mustelıdae 743.

Mylagaulinae 787 .

Myliobatidae 128 .

Mylodontinae 776 .

Mylostomidae 102.

Myomorpha 787.

Myriacanthidae 142 .

Myrmecobiidae 719.

Myrmecophagidae 778 .

Mystacoceti 755 .

Myxinidae 63 .

Nanosaurinae 617.

Necrolemuridae 875 .

Neobunodontia 800.

Neotraginae 816 .

Nesodontidae 850 .

Nodosaurinae 653.

Notharctidae 875 .

Nothosauridae 484.

Notidanidae 120.

Notohippidae 850.

Notopithecidae 847.

Notostylopidae 850 .

Notoungulata 845 .

Nyctosaurinae 571.

Ochotontidae 787.

Odontolcae 696.

Odontormae 697.

Oligopleuridae 215.

Onychodontidae 166.

Ophiacodontidae 364.

Ophiderpetontidae 304.

Oplidia 679.

Opisthocomi 705.

Opisthomi 157.

Oreodontidae 805 .

Oreodontinae 805 .

Ornithischia 614.

Ornithocheiridae 570.

Ornithodesmidae 567.
Ornithopodidae ( $=$ Kalodontidae) 615 .

Ornithosuchidae 528.

Ornithurae 695.

Orthopoda 614.

Orycteropodidae 783 .

Ostariophysi 157.

Osteolepidae 161.

Osteostraci 69.

Otariidae 747.

Otididae 705 .

Ovibovinae 816.

Ovicaprinae 816.

Oxyaenidae 737.

Oxyaeninae 737.

Oxyclaenidae 733 .

Pachycormidae 214.

Pachypodosauria. 584.

Palaeobatrachidae 322.

Palaeohatteriidae 360 .

Palaeohippidae 865.

Palaeomastodontidae 826.

Palaeoniscidae 186.

Palaeophidae 682.

Palacorhynchidae 216 .

Palaeosyopinae 867.

Pantolambdidae 797.

Pantolestidae 727.

Pantostylopidae 848.

Pantotheria 721 .

Pantylidae 341.

Parasita 5.

Parasuchia 513.

Pareiasauridae 348.

Pariotichidae 346.

Passeriformes 708 .

Paterosauridae 326.

Patriocetidae 753.

Pediculati 157.

Pelobatidae 324.

Pelycosauria 352.

Pelycosimiidae 513.

Percesoces 157.

Periptychidae 796.

Perissodactyla 853.

Petalodontidae 135.

Petromyzodontidae 63.

Phalacrocoracidae 704.

Phalangeridae 716 .

Phaneroglossa 322.

Phaneropleuridae 175.

Phascolomyidae 717.

Phenacodontidae 798.

Plilegethontiidae 307.

Phocaenidae 772.

Phocidae 747. 
Pliolidophoridae 208.

Pholidopleuridae 211.

Pholidosauridae 546 .

Pholidota 785.

Phyllospondyli 294.

Physeteridae 763.

Physoclisti 219.

Physostomi 219.

Phytophagi 585.

Phytosauridae 515.

Pinnipedia 747.

Pipidae 322.

Placentalia 721 .

Placodontia 504.

Plagiaulacidae 714 .

Plagiosauridae 288.

Plagiostomi 118.

Plateosauridae 590.

Platyrrhini 877.

Platysomidae 190.

Platysternidae 389.

Plectognathi 157.

Plesiadapidae 875.

Plesiochelyidae 410 .

Plesiosauridae 489.

Plethodidae 216.

Pleuracanthidae 118.

Pleurodira 406.

Pleuropterygii 110.

Pleurosauridae 446.

Pleurosternidae 411.

Pliosauridae 503.

Podicipidae 696.

Podokesauridae 580.

Poliosauridae 361 .

Polycotylidae 503.

Polydolopidae 715.

Polymastodontidae 715 .

Polyodontidae 196.

Polyprotodontia 717.

Polypteridae 170.

Praedentata 576.

Primates 869.

Pristidae 124.

Pristiophoridae 123.

Proboscidea 819.

Procellariiformes 703.

Procolophonia 350.

Procyonidae 746 .

Proostea 147.

Propleuridae 397.

Prosimia 869.

Proteidae 332.

Proterosuchidae 526.

Proterotheriidae 852.

Protoceratinae 810.

Protoptychinae 787.
Protorosauria 451.

Protostegidae 397.

Protosyngnathidae 216 .

Protrachodontinae 632.

Protungulata 794.

Proviverrinae 735 .

Psammodontidae 135.

Pseudocentrophori 297.

Pseudocreodi 735.

Pseudosuchia 524.

Pseudotraginae 816.

Pteranodontinae 571.

Pteraspidae 82.

Pterocles 707.

Pterodactylidae 566.

Pterodactyloidea 563

Pterolepidae 69.

Pterosauria 554.

Ptychodontidae 139.

Ptyctodontidae 103.

Ptyonidae 304.

Pycnodontidae 205.

Pyrotheria 844.

Pythonidae 680.

Pythonomorpha 666.

Rajidae 126.

Rallidae 705 .

Ratitae 693, 699.

Rhachitomi 271.

Rhamphorhynchoidea 554 .

Rheae 698.

Rhinidae 124.

Rhinobatidae 126.

Rhinocerotidae 855 .

Rhınocerotinae 857 .

Rhinochetidae 705.

Rhinodontidae 123.

Rhiptoglossa 678 .

Rhizodontidae 163.

Rhynchocephalia 443.

Rhynchosauridae 446.

Rodentia 786.

Rupicaprinae 816.

Saghatheriidae 819 .

Salamandridae 330 .

Sauranodontidae 448.

Sauravidae 344 .

Saurischia 576.

Saurodontidae 216 .

Sauropoda 606.

Sauropterygia 481 .

Saururae 693.

Scelidosaurinae 639.

Scincoidae 660.
Sciuromorpha 786 .

Scleromochlidae 532 .

Scylliidae 121.

Selenodontia 805.

Selenosteidae 100.

Semionotidae 197.

Seymouriidae 342 .

Simiidae 878.

Simplicidentata 786 .

Sirenia 832.

Sirenidae 332.

Sivatheriinae 815 .

Soricidae 726.

Sparassodonta 712 .

Sphenacodontidae 356 .

Sphenisciformes 701 .

Sphenodontidae 444 .

Sphyrnidae 122.

Spinacidae 123.

Spinosauridae 602.

Squaloceti 762 .

Squalodontidae 762 .

Squamata 656.

Steganopodes 703 .

Stegosauridae 639 .

Stegosaurinae 639.

Stephanospondylidae 340 .

Struthiones 697.

Suidae 800 .

Symbranchii 157.

Taeniodonta 773 .

Talpidae 725 .

Tamiobatidae 133.

Tapiridae 854.

Tapirinae 854.

Tarrasiidae 163.

Tarsiidae 877.

Teleosauridae 539.

Telcostei 156, 219.

Teleostomi 153.

Temnospondyli 271 .

Temnothoraci 100 .

Testudinata 374 .

Testudinidae 389 .

Thalassemydidae 397 .

Thalattosauria 661 .

Theridomyinae 786 .

Theriodontia 415 .

Therocephalia 416 .

Therophagi 585 .

Theropoda 591 .

Tillotheriidae 728 .

Tinamiformes 700 .

Titanichthyidae 100 .

Titanotheriidae 865 .

Titanotheriinae 867 . 
Tomognathidae 216.

Torpedinidae 126.

Toxochelyidae 397 .

Toxodontia 848.

Toxodontidae 850 .

Trachelosauridae 482 .

Trachodontidae 632 .

Trachodontinae 636 .

Tragelaphinae 816 .

Tragulidae 809.

Tremataspidae 78 .

Trematopsidae 278.

Triassochelyidae 386 .

Trichechidae 747.

Triconodonta 717 .
Triconodontidae 718 .

Trigonostylopidae 851 .

Triisodontidae 734 .

Trimerorhachidae 275.

Trionychidae 414 .

Trionychoidea 414 .

Tritylodontidae 712 .

Trygonidae 126.

Tubulidentata 782 .

Tupaiidae 726.

Typhlopidae 680.

Typotheria 847.

Typotheriidae 848 .

Ungulata 787.
Urodela 324.

Ursidae 743 .

Viverravinae 739 .

Viverridae 739.

Xenarthra 772.

Xenopodidae 322.

Xiphodontidae 805 .

Zalambdodonta 728 .

Zanclodontidae 588.

Zatrachydae 281 .

Zeuglodontidae 751 .

Ziphiidae 767. 


\section{Verzeichnis der Gattungsnamen.}

(Die fettgedruckten Seitenzahlen bezeichnen die Stellen der Abbildungen.)

Abderites 716 .

Abramis 191.

Acanthias 26.

Acanthodes 148, 149, 150, 151, 152.

Acanthodopsis 150, 152.

Acanthopholis 646.

Acanthorhina 141, 142, 143, 144.

Acanthostoma 238, 239, 249, 206.

Aceraspis 3, 70, 73, 77.

Acentrophorus 197, 199.

Aceratherium 857, 858, 860.

Achyrodon 723.

Acichelys 398.

Acipenser 22, 23, 35, 41, 45, 51, 64, 108, 195, 197.

Acoelodus 848.

Acrobates 556 .

Acrodelphis 766 .

Acrodus 121.

Acrosaurus 446.

Actaeosaurus 664.

Actinodon 256, 273.

Adap is 874,876 .

Adapisorex 727.

Adiantus 853.

Adocus 401.

Adriosaurus 664, 665.

Aelurosuchus 424.

Aepyornis 698, 699.

Aetheolepis 198, 200, 201.

Aetosaurus 524, 525, 528, 529, 530, 531, $532,539$.

Agorophius 751, 753.

Agriocetus 754, 760 .

Agriochoerus 805.

Aigialosaurus 656, 672, 673.

Ailurus 747.

Alabamornis 703 .

Albertogaudrya 851 .

Aletodus 106.
Alligator 536, 539, 546, 553 .

Alligatorellus 549 .

Alligatorium 546, 549 .

Allodon 714 .

Allopleuron 391.

Allosaurus 593, 596, 597, 598.

Alopecias 122.

Alopecodon 417, 426.

Aloposaurus 416, 426.

Alytes 323.

Amblotherium 722.

Amblydectes 573 .

Amtlypterus 188, 189.

Antlystoma 268.

Amia 24, 32, 37, 38, 39, 40, 41, 43, 44, $45,46,47,48,49,50,51,52,53,108$, $212,214,225$.

Amphibamus 263, 309.

Amphichiromys 774 .

Amphicyon 747.

Amphilestes 718 .

Amphioxus 25.

Amphipnous 155.

Amphiproviverra 713, 719.

Amphitherium 722.

Amphitragulus 811.

Amphitylus 722 .

Amphiuma 18, 262, 264, 267, 308, 326.

Amynodon 856.

Anabas 155.

Anacodon 738.

Anaptomorphus 875 .

Anarosaurus 489, 490.

Anas 687.

Anaschisma 243, 252, 283, 285.

Anchilophus 862, 865.

Anchisauripus 593.

Anchisaurus 527, 593, 595, 596.

Anchitherium 788, 792, 862, 864, 866.

Anchomomys 876 . 
Ancodon 802.

Ancodus 802.

Andrias 326, 330.

Animasaurus 340.

Ankylosaurus 577, 653.

Anodontacanthus 117.

Anomosaurus 510.

Anoplonassa 767, 771.

Anoplotherium 803.

Anthracosaurus 224, 284.

Anthracotherium 802, 803, 804.

Anthropops 877.

Anthropornis 702 .

Antilocapra 815.

Apatornis 697.

Aphaneramma 235, 267, 283, 285.

Aphelosaurus 451.

Aptenodytes 686, 702 .

Apterodon 735, 737.

Apteryx 630, 687, 689, 690, 691 .

Aptornis 705 .

Ara 688

Aracoscelis $366,373,504,654,655,656$.

Archaeohyrax 848.

Archaeolemur 876.

Archaeophis $680,683$.

Archaeopteropus 729 .

Archaeopteryx 586, 686, 687, 688, 692, $693,694,695$.

Archaeosiren 835 .

Archaeoteuthis 83.

Archaeotriton 331.

Archegosaurus 223, 224, 228, 253, 254, 255, 256, 257, 260, 265, 266, 269, 272.

Archelon 391, 395, 399, 401, 402, 403.

Arctocyon 738.

Arctotherium 746 .

Ardeosaurus 660.

Argillochelys 404.

Argillornis 695, 704.

Argyrocetus 766.

Aristosuchus 581 .

Arsinoitherium 819, 820 .

Ascaphus 311.

Aspidorhynchus 54, 211, 212, 214.

Aspidosattrus 260.

Asthenocormus 215.

Asthenodon 723.

Asterolepis 90, 91, 92.

Astraponotus 851.

Astrapotherium 851.

Atcleaspis 3, 70, 71, 73, 74, 77 .

Atlantosaurus 611.

Atoposaurus 546, 549.

Auchenaspis 76, 77, 78.

Auchenia 808.

Aulocetus 759, 760 .
Baëna 411, 412.

Balaena 762 .

Balaenoptera 756.

Balaenotus 762 .

Balaenula 762 .

Baptornis 703.

Barytherium 829.

Bathyopsis 818 .

Batrachiderpeton 239, 298, 301, 302, 303.

Bauria 418, 419, 422, 427.

Bdellostoma 29, 64 .

Belodon 268, 519, 520, 521, 522.

Belone 195 .

Belonorhynchus 195.

Belonóstomus 211, 212.

Beluga 766, 767.

Benthobatis 129 .

Berardius 771.

Bernissartia 534, 546, 548, 549.

Bettongia 714 .

Birkenia 65, 66, 68, 69.

Blastomeryx 809, 810 .

Bolbodon 333.

Bolosaurus 349.

Bombinator 227, 228, 318, 321 .

Borhyaena 713, 719, 720.

Bos 789.

Bothriodon 802 .

Bothriolepis 87, 89, 90, 91, 92.

Bothriopsis 174.

Brachauchenius 502, 503.

Brachiosaurus 578, 606, 610, 613.

Brachycephalus 260, 261.

Brachydirus 95, 102.

Brachyostracon 782 .

Brachyrhinodon 444.

Bradylemur 876.

Bradypus 570.

Brancasaurus 499.

Branchiosaurus 226, 238, 249, 259, 264, 266, 269, 295.

Breviceps 265, 267.

Broiliellus 251, 280.

Brontosaurus 578, 607, 609, 611, 612, 613.

Brontotherium 868.

Brookesia 658.

Bufo 314, 315, 323.

Cacatua 692.

Cacops 233, 252, 254, 255, 256, 258, 260, 261, 262, 265, 266, 279, 280.

Caenolestes 716 .

Cadurcotherium 856, 857.

Caenotherium 800.

Caiman 538, 553.

Calamodon 773,774 . 
Calamoichthys $158,171$.

Callorhynchus 106, 141, 143, 145, 146, 147.

Calyptocephalus Gayi $314,315$.

Camelomeryx 810, 811.

Camelopardalis 815 .

Camelops 808.

Campodus 54, 121.

Camptosaurus $577,617,618,619,620$, $621,622,624$.

Campylognathus 558, 562.

Canis 732, 747.

Capitosaurus 224, 234, 236, 237, 239, 243, 250, 252, 287.

Capreolus 813.

Captorhinus 333, 347.

Carcharias $110,121$.

Carcharodon 122.

Cardiocephalus 345,346 .

Caroloameghinia 721 .

Carolozittelia 844, 845.

Carsosaurus 672, 673.

Casea 366, 368.

Casuarius 699.

Catopterus 189.

Caturus 213.

Cayluxotheriun 726 .

Cebochoerus 789, 790, 800, 801, 805.

Centrophorus 123.

Centrosaurus 647, 651.

Cephalaspis $69,70,71,73,74,75,76$, $77,78$.

Ceraterpeton 258, 262, 263, 297, 298, 299.

Ceratochelys 413 .

Ceratodus 159, 182, 183.

Ceratogaulus 787.

Ceratohyla $314,317$.

Ceratophrys 260, 261, 314, 315, 324 .

Ceratops 651.

Ceratoptera 132.

Ceratorhinus 859 .

Ceratosaurus 597, 598.

Cervavus 813.

Cervus $789,790$.

Cestracion 93, 121.

Cetiosaurus 610 .

Cetorhinus 123 .

Cetotherium 760, 761 .

Chalicotherium $789,869$.

Chamaeleo 658, 659, 679 .

Champsosaurus 450 .

Clieiracanthus 153.

Cheirodus 54, 190, 191, 193, 194, 208.

Cheirolepis $184,186,187,189$.

Chelodina 381.

Chelonia $19,332,380,382,395,404$, 654.
Chelonides 397, 398.

Chelydosaurus 224, 272.

Chelys 412.

Chenopı osopus 267, 311.

Chilonyx 333.

Chimaera $30,112,140,143,145,147$.

Chimaeropsis 142.

Chiromys $873,876$.

Chirotherium 268, 283, 579, 580.

Chitracephalus 398, 399.

Chlamydo elache 26, 107, 120.

Chlamydotherium 780,781 .

Choeromus 801.

Choloepus 570.

Chondrenchelys 117, 118.

Chondrosteus $195,196$.

Choneziphius 767, 768, 769, 770, 772.

Chorophilus 266.

Chriacus 733.

Cimoliasaurus 493, 500, 501, 503.

Cimolopteryx 697.

Cinosternum 384.

Cistecephalus $440,442,443$.

Cladobates 726.

Cladodus 112, 113, 114, 115, 116, 148.

Cladornis 686, 701 .

Cladoselache $115,116$.

Cladosictis 719 .

Claencdon 738.

Clic osaurus 737.

Cleithrolepis 209, 210.

Clepsydrops 356.

Clidastes 666, 675, 676 .

Climatius 18, 148, 149, 151.

Coccolepis 186, 187, 188, 189, 190, 191.

Coccosteus 93, 94, 95, 96, 97, 98, 99, 100.

Cochliodus 134, 136.

Coelacanthus 167, 168.

Coelodonta 857, 859.

Coelodus 207.

Coelurus 581.

Colobodus 201.

Colossochelys 395 .

Colymbus 703 .

Compsognathus 581, 582.

Conacodon 797.

Congosaurus 543, 553.

Conoryctes 773 .

Cordylodon 726 .

Coryphodon 817,818 .

Corythosaurus 634,635 .

Craspedochelys 411 .

Craspedodon 632.

Crataeomus 646.

Creosaurus 598 .

Cricotus 225, 228, 246, 257, 268, 293.

Criorhynchus 573 . 
Crocodilus 267, 535, 539, 546, 550, 552.

Crossopholis 196, 197.

Crossotelus 260.

Crotalus 681 .

Cryptobranchus 324,330 .

Cryptocleidus 493, 497, 498, 501, 503.

Cryptocynodon 440, 441.

Cryptomeryx 809.

Crypturus 691.

Ctenacanthus 121.

Ctenacodon 714 .

Ctenodus 33, 34, 36, 180, 181.

Ctenosaurus 370 .

Cyamodus 504, 507, 508, 513.

Cyathaspis $71,84,86$.

Cyclanorbis 377 .

Cyclobatis 126 .

Cycloderma 377.

Cyclotosaurus 239, 242, 243, 250, 252, 287, 291, 292.

Cycloturus 779 .

Cymbospondylus 473, 475.

Cynodict is 747 .

Cynodontomys 727 .

Cynognathus 417, 418, 419, 420, 421, $425,427,428$.

Cynonycteris 729 .

Cynonasua 747.

Cyprinus $44,49,51$.

Cyrtodelphis 766 .

Dacosaurus 544, 546.

Dacrytherium 800.

Dapedius 156, 198, 202, 203, 218.

Daphaenus 747.

Dasornis 704.

Dasyceps 249, 281.

Dasypeltis 680 .

Dasypus 780,781 .

Dawsonia 238, 239.

Deinosuchus 550 .

Deltatherium 733.

Delphinodon 772.

Delphinognathus 415, 431, 432, 433.

Delphinus 772.

Deltodus 134, 136.

Deltoptychius 134, 136.

Dendrodus 161, 164.

Dermatonotus 260.

Dermochelys 392, 393, 395, 406, 407.

Desmana 725.

Desmospondylus 265, 266.

Desmostylus 830, 831 .

Deuterosaurus 372, 373, 374, 375 .

Diadectes 266, 333, 338, 339, 340, 350 .

Diadectoides 340.
Diademodon $416,420,421,422,423$ $425,427,428,429$.

Diasparactus 266, 340, 341.

Diatryma 706, 707.

Diceratherium 858.

Diceratops 651.

Diceratosaurus 253, 254, 258, 299, 300 .

Diceros 859.

Dichobune 799.

Dicraeosaurus 614.

Dicroceros 812.

Dicrocynodon 723.

Dictyopyge 187, 189.

Dicynodon 236, 435, 436, 438, 439, 440, 443.

Didelphis 422, 719 .

Didelphodon 724 .

Didelphops 724.

Didolodus 799 .

Didus 707.

Didymaspis $71,73,74,78$.

Diemyctilus 324.

Dimetrodon 356, 357, 358, 359, 360, 367, 368,374 .

Dimorphodon 557, 560, 561.

Dimylus 726.

Dinichthys 96, 98, 100, 101, 102.

Dinictis $740,741,742$.

Dinilysia 683.

Dinoceras 818.

Dinohyus 800.

Dinomylostoma 103.

Dinornis 699, 700 .

Dinotherium 788, 823, 829, 830.

Diomedea 571, 687, 703.

Diplacanthus 148, 150, 152.

Diplobune 803.

Diplocaulus 230, 231, 239, 248, 249, 252, 259, 262, 297, 298, 299, 303, 304, 305, 306.

Diplocynodon 546, 553.

Diplodocus 232, 578, 585, 606, 607, 608, $609,610,611,612,642$.

Diplognathus 102.

Diplopterus 162.

Diplovertebron 225, 294.

Diplurus 167, 168.

Diprotodon 717.

Dipterus 33, 34, 36, 159, 160, 175, 176, $177,178,180$.

Dissorophus 256, 260, 261, 266, 280.

Distoechurus 556.

Doedicurus 782,783 .

Dolichorhinus 867, 868.

Dolichosaurus 664 .

Dolichosoma 231, 233, 262, 266, 307, 308. 
Dollopterus 200.

Dollosaurus 675.

Dorcatherium 809.

Dorygnathus 562.

Dorypterus 190, 194.

Draco 571.

Drepanaspis $70,71,80,81,82$.

Dromaeus 689, 699.

Dromatherium 717, 718 .

Dromocyon 734

Dryptosaurus 599.

Dyoplax 532.

Dyrosaurus 539, 543.

Dystrophaeus 610, 613 .

\section{Echidna 710.}

Echinodon 639.

Ectoconodon 724.

Ectostereorhachis 163.

Edaphodon 145, 147.

Edaphosaurus 367, 368, 369, 370.

Edestus 137, 138, 167.

Eifelosaurus 444.

Elaphus 813.

Elasmodectes 145.

Elasmodus 145, 147.

Elasmosaurus 482, 489, 493, 500, 502.

Elasmotherium 860.

Eleplas 8, 788, 792, 797, 821, 824, 825, 828.

Elginia 347, 348, 349, 412.

Elonichthys 189 .

Elopteryx 703.

Elotherium 800.

Emyda 414.

Emys 380, 381, 391.

Endothiodon 436, 440.

Entelodon 800.

Eobatrachus 323.

Eocetus 751.

Eochelone 401, 404.

Eodidelphys 718.

Eohippus 861, 863, 867.

Eomoropus 869.

Eosauravus $338,345$.

Eosiren 834, 839.

Eospheniscus 686, 702.

Eotherium 833, 836, 837, 839.

Epigaulus 787.

Epihippus 861.

Equus 8, 789, 790, 792, 864, 865, 866.

Erpetosuchus 527.

Eryops 223, 235, 237, 238, 240, 241, $243,245,248,251,253,254,255,256$, 262, 265, 276, 277, 278, 332, 659.

Erythrosuchus 512, 513, 514, 515.

Esoterodon 440, 441, 442.
Esthonyx 728.

Euchirosaurus 260, 273.

Eucholoeops 775, 776.

Eudiastatus 877.

Euelephas 824.

Eugnathus 213, 214.

Eukeraspis 71, 73, 74, 76, 78 .

Euparkeria 525, 526, 527, 528, 529.

Euphanerops 66.

Euposaurus 660.

Euprotogonia 798, 799.

Eurhinodelphis 479, 752, 767.

Eurhinosaurus 471, 475, 479.

Eurycormus 213, 225.

Eurynotus 190, 191, 192.

Eurypteryg jus 459, 462, 463, 465, 466, $471,475,476$.

Eurysternum 398, 399.

Euskelosaurus 588.

Eusthenopteron 158, 159, 165, 166.

Euthynotus 215.

Exococtus 210.

Felis $740,742,743$.

Felsinotherium 834, 838.

Gadus $41,47,49,50,51,52,55,56$, $108,160,270$.

Galechirus 431.

Galemys 726.

Galeopithecus 726.

Galepus 236, 430, 431 .

Galesaurus 417, 421, 422.

Galeus 121.

Galliaetatus 786 .

Ganodus 145, 147.

Gastornis 704 .

Gavialis 267, 546, 554 .

Gelocus 810 .

Gemündina 129, 133, 134.

Genyodectes 602 .

Genyornis 699.

Geoemyda 383.

Geosaurus 267, 533, 546, 547, 548.

Gephyrostegus 236, 310 .

Gigantophis 683.

Gigantopterus 210, 211.

Gigantosaurus 610, 613 .

Globidens 672, 678.

Glyptodon 772, 781, 782, 783, 784

Glyptolaemus 159 .

Glyptolepis 164, 165 .

Glyptopomus 53, 161, 162, 167.

Glyptops 411 .

Gomphognathus $422,427$.

Gonatodus 53, 54, 189.

Gondwanosaurus 243. 
Goniopholis 534, 546, 548, 549 .

Gordonia 236, 437, 440, 443.

Gorgonops 236, 433, 434, 435, 438.

Graphiurus 168.

Gresslyosaurus 585, 586, 588, 589, 618 .

Grymaeomys 719.

Grypotherium 775, 778.

Guielmoscottia 847.

Gymnarthrus 240, 333, 345, 346.

Gymnobelideus 556 .

Gypogeranus 690 .

Gyrodus 205, 207.

Gyrolepis 189.

Gyroptychius 164, 165.

Gyrosteus 195, 196.

\section{Hadropithecus 876 .}

Hainosaurus 677.

Halicore 833, 835, 839.

Halitherium 833, 834, 839, 840.

Hapalodectes 733 .

Hapalops 775 .

Hallopus 581.

Haplocanthosaurus 613.

Harpagolestes 734 .

Harpagornis 705 .

Harriotta 141, 143.

Hatteria 443, 445.

Hegetotherium 848.

Heliarchon 331.

Helicoprion 138, 139, 167.

Helladotherium 814.

Henricoosbornia 848 .

Heptanchus 120.

Hesperornis 688, 695, 696, 697.

Heterodontus 93, 109, 111, 121, 136.

Heteropython 685.

Heterosteus 98, 102.

Hierosaurus 653.

Hipparion 796, 864, 865 .

Hippidium 864.

Hippopotamus 788, 801, 802.

Histiophorus 214.

Holaspis 84.

Holoptychius 159, 161, 163, 164, 274.

Homalodontotherium 850 .

Homo 422, 878.

Homoeosaurus 446.

Homogalax 854.

Homosteus 102.

Homunculus 877.

Hoplophoneus 740, 743, 744.

Hoplophorus 782.

Hoplopteryx 218.

Howesia 448.

Hyaemoschus 809 .

Hyaena 741.
Hyaenarctos 745 .

Hyaenodictis 733 .

Hyaenodon 713, 732, 735 .

Hybodus 119, 121.

Hydromedusa $379,380,381$.

Hydropelta 398.

Hydropessum 209, 210, 211.

Hyla 266.

Hylaeobatrachus 326, 328, 330.

Hylaeochampsa 534, 546, 550.

Hylonomus 228, 266, 309, 345.

Hyotherium 801 .

Hymenochirus 318.

Hypacrosaurus 635.

Hyperdichobune 799.

Hyperhippidium 864.

Hyperleptus 339, 776.

Hyperodapedon 446, 447.

Hypisodus 815.

Hypohippus 863.

Hypsilophodon 614, 615, 616, 617.

Hypsocormus 215.

Hyrachyus 855.

Hyracodon 855 .

Hyracotherium 788, 798, 860, 861, 862 .

Ichthyophis 266, 331, 332 .

Ichthyornis 693, 695, 697.

Ichthyosaurus 8, 19, 268, 459, 460, 461, $469,471,481,664$.

Ictitherium 741 .

Idiochelys 398.

Iguanodon 577, 587, 614, 618, 623, 624, $625,626,627,628,629,630,631,632$, 641 .

Inia 767.

Inostranzewia 427.

Interatherium 847.

Ischnacanthus $150,152,153$.

lschyodus 144, 145, 146.

Ischyromys 786 .

Isodectes $345,346,347$.

Isotemnus 850 .

Janassa 135, 136, 137.

Kadaliosaurus 655, 656 .

Karoomys 717, 718.

Kekenodon1 750, 751.

Kentrurosaurus 645 .

Kogia 763.

Koiloskiosaurus 351, 352, 354.

Labidosaurus 347.

Labyrinthodon 224 .

Laelaps 599.

Lamna 26, 27, 120, 122. 
Lanarkia $70,72,73,75$.

Laodon 723.

Laosaurus 617.

Lariosaurus 483, 484, 485, 488, 489.

Lasanius 29, 65, 66, 67, 68, 69 .

Latonia 324.

Leidyosuchus 552 .

Leiodon 667.

Leontinia 850.

Lepidoblepliaron 269.

Lepidosiren $64,97,113,172,176,177$, $183,185$.

Lepidosteus $35,43,47,51,52,54,64$, 108, 195, 215, 216, 248.

Lepidotus 156, 198, 200, 201, 202, 203.

Leptaceratherium 858, 859.

Leptauchenia $805,806$.

Leptictis 725 .

Leptocladus 722.

Leptodactylus 324.

Leptomeryx 809.

Leptomylus 147.

Leptopilus 692.

Lestodon 778.

Libycosuchus 550, 551 .

Limnerpeton 309 .

Limnocyon 737.

Limnoscelis 266, 335, 336, 337, 338, 339.

Liognathus 102.

Lissoprion 138, 139.

Listriodon 801.

Lonchodectes 573.

Lonchorhynchus 243, 248, 266, 267, 268, 283, 285, 288, 289.

Lophiodon 854 .

Lophiotherium 865.

Loxodon 824.

Loxolophodon 818.

Loxomma 224, 247, 248, 249, 283, 284.

Lycosaurus 426.

Lycosuchus 417, 424, 425.

Lyrocephalus 287, 289, 659 .

Lysorophus 221, 269, 326, 327, 328, 329.

Lystrosaurus 236, 436, 438, 439, 440, $442,443$.

Lytoloma 399, 401.

Macacus 878.

Machairodus $\mathbf{7 4 0}, \mathbf{7 4 3}, \mathbf{7 4 4}, \mathbf{7 4 5}, 818$.

Machairoides 737.

Macrauchenia 852, 853.

Macropetalichthys 94, 102.

Macropoma 35, 42, 47, 167, 169.

Macrosemius 204.

Macrotherium 869.

Manatherium 835.

Manatus 839 .
Manis 786.

Manteoceras 867, 868.

Mastodon 790, 792, 821, 822, 823, 824, $826,827$.

Mastodonsaurus 161, 224, 228, 239, 247, 252, 257, 260, 283, 287, 292.

Mawsonia 169.

Mazama 809.

Megacerops 868, 870, 871.

Megaceros 795, 813 .

Megaladapis 876 .

Megalichthys 165, 166, 247.

Megalneusaurus 500.

Megalobatrachus 267, 324.

Megalonyx 772, 773, 775, 776, 777.

Megalosaurus 595, 597.

Megalotriton 330 .

Megalurus 213, 214.

Megaptera 115.

Megatherium 772, 773, 775, 778.

Melanerpeton 226, 253, 296.

Meleagris 687.

Menaspis 134, 135.

Meninatherium 858.

Menobranchus 261.

Mergus 690.

Merriamia 462, 473, 474, 476.

Merychippus 863.

Merycodus 815 .

Merycoidodon 805 .

Mesacanthus 148, 150, 152.

Mesocetus 751.

Mesodon 205, 206, 207.

Mesogaulus 787.

Mesohippus 862, 863.

Mesonyx 734 .

Mesopithecus 877.

Mesoplodon 772 .

Mesorhinus 513, 516, 517, 518, 519.

Mesosaurus 268, 452, 453, 472.

Mesturus 35, 42, 207.

Metamynodon 856.

Metaxytherium 834, 839, 840.

Metopias 224, 252, 256, 257, 258, 260, 287, 290.

Metoposaurus 260.

Metriorhynchus 232, 267, 542, 544, 545, 546.

Miacis 739.

Micraspis 3, 70, 73, 77, 78 .

Micrerpeton 62, 271, 295, 296.

Microbiotherium 718, 719 .

Microbrachis 228, 229, 308, 309.

Microchoerus 875.

Microconodon 717, 718.

Microdon 205, 207.

Microglossus 688 . 
Microleptosaurus 489.

Microlestes 714 .

Micropholis 234, 242, 281.

Microsyops 727.

Microzeuglodon 751 .

Mioclaenus 796.

Miohippus 862, 863.

Miolania $412,413,414$.

Miosiren 835.

Mioziphius 767, 771, 772 .

Mixodectes 727.

Mixosaurūs $461,464,465,472,473,474$, 475.

Mixtotherium 804.

Mochlodon 618.

Moeritherium 174, 819, 820, 821, 822, $824,826$.

Molge 249, 266, 325, 331 .

Molgophis 259, 260, 307.

Moloch 347.

Monoclonius 646, 647, 651 .

Monodon 766, 767.

Moropus 869, 872.

Morosaurus 606, 611.

Morphippus 850.

Mosasaurus 666, 667, 669, 672, 675.

Moschognathus 433.

Moschops 433.

Muraenosaurıs 492, 495, 497, 502.

Mustelus 110.

Mycterosaurus 363, 364.

Mycterosuchus 542, 543.

Mylagaulus 787.

Myliobatis 128, 131, 132, 133.

Mylodon 772, 773, 775, 776, 778, 779 .

Mylostoma 102, 103.

Myriacanthus 141, 142, 143.

Myrmecobius $719,722$.

Mystriosaurus 540, 542.

Mystriosuchus 520, 521, 522, 523, 536. Myxine 64.

Nanosaurus $616,617$.

Naosaurus 356, 367, 368, 370, 371, 372.

Narcine 126.

Necrodasypus 786.

Necrogymnurus 726 .

Necrolemur 875.

Necromanis 786 .

Necromantis 729 .

Nectosaurus 663.

Necturus 62, 244, 246, 276, 295.

Neoceratodus 34, 158, 159, 172, 173, 174, $176,177,178,182,183,250$.

Neohipparion 863.

Neohippus 864.

Neoplagiaulax 715 .
Neosqualodon $749,762,763$.

Nesodon 850.

Neusticosaurus 487.

Neustosaurus 544 .

Nimravus 740, 741, 742.

Notagogus 204.

Notharctus 875 .

Nothosaurus 485, 486, 487, 488, 489.

Notidanus 107, 109, 111, 117, 120.

Notopithecus 847.

Notornis 705.

Notostylops 850 .

Notosuchus 534, 546, 548, 549.

Nyctitherium 725 .

Nyctodactylus 571 .

Nyctosaurus 571, 572, 573.

Odontaspis 121, 122, 123.

Odontopteryx 695, 703.

Oestocephalus 229, 230, 266, 304.

Okapia 813.

Olbodotes 727.

Oligochelone 404.

Oligopleurus 215.

Omomys 876.

Onohippidium 864 .

Onychodectes 773.

Onychodus 167.

Oodectes 739.

Opetiosaurus 656, 672, 673, 674, 675 .

Ophiacodon 257, 266, 355, 360, 364, 365, $366,367$.

Ophiderpeton 259, 260, 266, 304 .

Ophiocephalus 155.

Ophthalmosaurus 465, 467, 468, 471, $480,481,672$.

Opsithocomus 694, 705.

Opisthoctenodon 440, 441, 442.

Oreodon 805, 806.

Ornithocheirus 570, 571, 572, 573.

Ornithodesmus 558, 565, 567, 570.

Ornitholestes 583.

Ornithomimus 583.

Ornithorhynchus 710 .

Ornithosuchus 525, 526, 527, 528, 529.

Orohippus 861, 863 .

Orthomerus 624. 632 .

Orthophya 331.

Orycteropus 785.

Osteolaemus 552.

Osteolepis 158, 161, 162.

Osteophorus 241, 273.

Osteopygis 399, 401.

Osteorhachis 213, 214.

Otocryptis 264, 525, 533.

Oxyaena 732, 737.

Oxyclaenus 733. 
Oxyglossus 324 .

Oxyosteus 96, 101.

Oxyrhina 109, 122.

Pachyacanthus 761 .

Pachyaena 734.

Pachycormus 215.

Pachynolophus 862, 865.

Pachyornis 699.

Pachyosteus 95, 97, 102.

Pachyrhynchus 401.

Pachyrukhos 848.

Palaeaspis $84,86$.

Palaedaphus 178, 180.

Palaeictops 725 .

Palaeobalistum 207.

Palaeobatrachus 322.

Palacochoerus 801.

Palaeohatteria 360, 361, 539.

Palaeomastodon 820, 822, 826.

Palaeomeryx 812, 813.

Palaeomylus 104.

Palaeonictis 737 .

Palaeoniscus 187, 189.

Palaeophis 683.

Palaeophocaena 772.

Palaeopropithecus 876.

Palaeorycteropus 785 .

Palaeoryctes 728 .

Palaeospinax 26.

Palaeospondylus 64, 98, 99, 106.

Palaeosyops 788, 789, 867, 868 .

Palaeoteuthis 83 .

Palaeotherium 865, 866.

Palaeoziphius 767, 771.

Paliguana 656, 660, 661 .

Palorchestes 717 .

Panochthus 782, 783, 784.

Pantolambda 798.

Pantolestes 727, 728.

Pantosaurus 500.

Pantylus 342, 343, 344.

Parabatrachus 163.

Paracestracion 121.

Parahipparion 864.

Parahippus 863.

Parailurus 747.

Paramylodon 778 .

Paramys 786 .

Paramyxine 64.

Parapithecus 874, 877.

Parasuchus 522.

Pareiasaurus 348, 350 .

Parexus 150, 152.

Pariotichus 346.

Partanosaurus 489.
Patriocetus 584, 749, 753, 754, 756, 757, 758, 759.

Patriofelis 737 .

Pediomys 724.

Pelagosaurus 542.

Pelion 221, 260, 296.

Pelobates 265, 313, 314, 315, 318, 324.

Peloneustes 497, 498.

Pelophilus 324.

Pelosaurus 226, 258, 264, 295, 296.

Peltephilus 780.

Peltopleurus 209, 211.

Peltostega 252, 253, 287.

Pelycodus 875.

Peramus 722.

Peraspalax 722.

Peratherium 718, 719.

Perca 217.

Periptychus 797.

Perleidus 189.

Petalodus 136.

Petauroides 556.

Petaurus 556.

Petrobates 345.

Petromyzon 64.

Pezophaps 707.

Phaneropleuron $33,34,36,174,176,181$.

Phanerosaurus 341.

Pharyngolepis 66, 69.

Phascolestes 723.

Phascolotherium 719 .

Phasianus 692.

Phenacodus 793, 798, 799.

Phlaocyon $746,747$.

Phlegethontia 230, 232, 307.

Ploca 19, 747.

Phocaena 115.

Phoenicopterus 703.

Pholidophorus 210.

Pholidop!eurus 208, 209, 211.

Pholidosaurus 534, 546, 548.

Phororhacos 706 .

Phrynosoma 347.

Phyllomedusa 265, 266.

Physeter 25, 762, 763, 765.

Physeterula 763, 764 .

Phytosaurus 268, 517, 519, 520, 521, 522, 536.

Pinguin 18, 19.

Pipa 318, 227, 228.

Piratosaurus 503.

Pithanodelphis 772.

Placochelys 504, 505, 508, 509, 510, 511, $512,513$.

Placodus 504, 505, 506, 507, 508, 510, $512,513$.

Placoziphius 763, 765. 
Plagiaulax 714.

Plagiolophus 865 .

Plagiosaurus 224, 288, 290, 291.

Plagiosternum 289, 292, 293.

Platalea 636.

Platanista 767.

Platax 191.

Platecarpus 666, 675, 676, 677, 678.

Platemys 412.

Plateosaurus 577, 584, 586, 588, 590, 591, 592, 594, 618.

Platychelys 411.

Platyhystrix 281 .

Platysomus 192, 193, 194, 209.

Plesiadapis 875.

Plesiocetus 762.

Plesiochelys 411.

Plesiodimylus 726.

Plesiosaurus 8, 482, 491, 493, 494, 495, 497, 498, 499, 500.

Pleuracanthus 117, 118.

Pleuropholis 208, 211.

Pleuroplax 136.

Pleurosaurus 446, 664.

Pleurosternum 411, 412.

Pleurostylodon 850.

Pliauchenia 809.

Pliohippus 864.

Pliohyrax 819.

Plioplatecarpus 667, 669, 670, 672, 677.

Pliosaurus 482, 498, 503.

Podiceps 703.

Podocnemis 382.

Podokesaurus 581.

Poëbrotherium 808.

Poecilodus 136.

Polacanthus 17, 641, 646.

Poliosaurus 363.

Polycotylus 500, 503.

Polydolops 715.

Polymastodon 715 .

Polyodon 54, 197.

Polypterus 25, 35, 44, 46, 47, 51, 62, 108, 158, 170, 171, 240.

Polysemia 330 .

Polysphenodon 446, 447.

Pontoporia 767.

Pontosaurus 664.

Porichthys 269.

Potorous 711.

Priodon 722.

Pristerodon 440, 441.

Pristiophorus 123.

Pristis 124.

Proadiantus 853.

Probalaena 762.

Procamelus 808.
Procervus $813,814$.

Prochamaeleo 679.

Procolophon 281, 350, 35 i.

Procompsognathus 581.

Proganochelys 376, 377, 384, 387, 393.

Progenetta 739.

Prognathosaurus 667, 672.

Prohyracodon 857.

Promerycochoerus 805, 806.

Proneusticosaurus 485, 487, 488, 489.

Pronycticebuss 876.

Propalaeochoerus 801.

Propalaeotherium 865 .

Propappus 348.

Prophyseter 763, 765.

Proplanodus 851.

Propleura 401.

Propliopithecus 874, 877, 878.

Propolymastodon 715 .

Propristis 124, 125.

Propterus 204.

Prorastomus 835.

Prosqualodon 751, 754, 755.

Protaceratherium 858, 859.

Protadapis 875.

Protapirus 855.

Protechimys 786 .

Proterochersis 376, 384, 385, 409, 410.

Proterosuchus 526, 527.

Proterotherium 794, 852.

Proteus 262, 263, 264, 266, 326.

Prothylacinus 713, 719.

Protitanichthys 99.

Protoceras 788, 811.

Protocetus 735, 748, 749, 750, 751.

Protohippus 863.

Protolabis 808, 809.

Protolambda 724 .

Protomeryx 808.

Protopelobates 323 .

Protophocaena 772.

Protopterus 64, 172, 176, 177, 183, 185.

Protoptychus 787.

Protorohippus 861.

Protorosaurus 451, 452, 539.

Protosiren 835, 841, 842, 843.

Protosorex 726.

Protosphargis 399, 403, 404.

Protostega 403.

Prototherium 834.

Protylopus 808.

Protypotherium 847.

Provampyrus 729 .

Provipera 685.

Proviverra 735.

Prozeuglodon 748, 751.

Psammochelys 387. 
Psammodus 135.

Psammornis 697.

Psephodus 134, 136.

Psephophorus 395, 405, 406.

Psephurus 197.

Psettus 191.

Pseudailurus 742, 743.

Pseudamphimeryx 800.

Pseudochirus 556 .

Pseudosphargis 406.

Pseudostylops 851.

Psittacotherium 773, 774.

Psittacus 688, 707.

Pteranodon 565, 566, 571, 573, 574, 575.

Pteraspis 70, 71, 82, 83, 84.-85.

Pterichthys 88, 89, 90, 91, 92, 94.

Pterodactylus 556, 565, 566, 567, 568, 569.

Pt erodon 713, 735.

Pt rolepis 29, 65, 66, 69 .

Pteroplatea 128, 130.

Pteroplax 285.

Pterosphenus 683, 684.

Ptilocercus 726.

Ptilodus 715.

Ptychodus 139.

Ptyctodus 104.

Ptyonius 229, 230, 231, 266, 304 .

Pycnodus 206, 207.

Pygopterus 189.

Pyrotherium 788, 844, 845, 846.

Python 680, 685.

Pyxicephalus 265, 267.

Racophorus 266.

Raja 126, 128.

Rana 237, 246, 266, 268, 312, 313, 314, $315,316,318,319,321,322,323,324$.

Redfieldius $187,189$.

Remiornis 704.

Rhabdodon 618.

Rhamphodus 94, 95, 103, 104, 105.

Rhamphorhynchus 556, 558, 560, 561, $562, \mathbf{5 6 3}, \mathbf{5 6 4}, 573$.

Rhea 688, 689, 690, 691, 692, 694, 698.

Rhina $26,27,110,124,126,127$.

Rhinobatus $126,128$.

Rhinoceros 8, 788, 857, 859 .

Rhinodon 123.

Rhinolophus 729.

Rhinophrynus 267.

Rhizodopsis 44, 160, 166, 186.

Rhopalodon 372, 373, 374 .

Rhynchodus 104.

Rhyncholepis 66, 69.

Rhynchosaurus 448.

Rhytina $439,833,835$.
Rhytiodus 791, 834 .

Rhizodu 165.

Ricnodon 242.

Rutiodon 522.

Saccobranchus 155 .

Sagecephalus 437, 443.

Sagenodus 181, 182.

Salamandra 263, 266.

Salmo 39-55, 46, 48.

Saltopus 580 .

Samotherium 814.

Sandalodus 134.

Sarcolestes 639 .

Sauranodon 448, 449.

Sauravus 345.

Saurichthys 105.

Saurodelphis 766 .

Saurolophus $632,633,634$.

Scaldicetus 763,764 .

Scaloposaurus 424.

Scaniornis 703.

Scaphaspis 83.

Scapherpeton 330 .

Scaphognathus 558, 562 .

Scaphonyx 513, 515.

Scaumenacia $33,34,36,174,176,179$, $180,181$.

Scelidosaurus 639, 641, 644.

Scelidotherium 772, 776, 777.

Schizotherium 869.

Scincosaurus 181, 230, 263, 266, 299, $301,302$.

Sclerocephalus 252, 272, 273.

Scleromochlu: 52b, 527, 532, 533.

Sclerorhynchus 124 .

Sclerosaurus 352.

Scomber 115.

Scylacosaurus $418,419,420,421,424$.

Scyllium 26, 29, 107, 108, 121.

Scymnosuchus 420, 426, 434.

Scymnus 26.

Seeleya 263.

Selache 123.

Selenosteus 100, 102.

Sellosaurus 584, 591.

Semionotus 198, 199, 200.

Sesamodon 429, 430.

Seymouria 220, 266, 333, 334, 344, 345.

Shastasaurus $474,476$.

Simoedosaurus 451 .

Simolestes 482, 499.

Simosaurus 485, 486, 487, 489.

Sinopa 735, 736.

Siphonops 242, 654.

Siredon 244, 246.

Siren 18, 263, 267. 
Sivatherium 815,816 .

Smilodon 740, 743, 744, 746 .

Sontiochelys 399 .

Spathiurus 215.

Spatula 636.

Sphenacodon 356.

Sphenosaurus 224.

Sphenodon 360, 443, 444, 445, 656.

Spliyrna 122.

Spinax 123.

Spinosaurus 602, 603, 604, 605.

Squalodon 763, 764 .

Squaloraja 141, 142, 143.

Squatina 124.

Squilla 87.

Stagonolepis 519 .

Stegochelys 386 .

Stegodon 822, 825, 828.

Stegomus 525, 526, 532.

Stegosaurus 17, 577, 615, 639, 640, 641, $642,643,644,645,653$.

Stegotherium 780 .

Steneosaurus 232, 536, 541, 542.

Stenometopon $448,449$.

Stenopterygius $454,455,456,457,458$, $459,460,461,469,470,471,475,476$, $477,478,479$.

Stephanospondylus $340,341,342$.

Stereocyclops 237, 260.

Stereosternum 452, 453, 472, 487.

Streblodus 134.

Streptospondylus 232 .

Struthio 614, 615, 688, 689, 690, 691, 692, 694, 696, 699.

Struthiosaurus 646.

Stylinodon $\mathbf{7 7 4}$.

Stylodon 723.

Styracosaurus 647, 649, 650, 651 .

Sus 788,801 .

Symborodon 868, 871 .

Symoliophis 682 .

Synconodon 724 .

Syndyoceras 811 .

Synodontis 35, 45.

Synoplotherium $\mathbf{7 3 4}$.

Systemodon 854 .

Talpa 725 .

Tamandua 779 .

Tamiobatis 133 .

Tanystrophaeus 581 .

Tapinocephalus 425, 431, 433.

Tapirulus 807,808 .

Tapirus 788, 789, 855.

Tarrasius 163 .

Tarsipes 722 .

Tarsius 877.
Tatusia 780 .

Teleoceras $\mathbf{8 5 8}, 859$.

Teleosaurus 267, 543.

Telerpeton 351, 352, 353.

Telmatosaurus 624 .

Teratosaurus $585,588,590$.

Terrapene 382, 383.

Tertrema 285.

Testudo 382, 383, 389, 390, 394, 395.

Tetrabelodon (= Mastodon p. p.) 13.

Tetraceratops $360,361$.

Tetraclaenodon 798, 799, 861 .

Tetragonolepis 198, 204.

Tetrao 692.

Teutomanis 786 .

Thalassemys 396, 397, 398, 411.

Thalassochelys 404 .

Thalattosaurus 268, 661, 662, 663.

Thaumatosaurus 495, 496, 497.

Thecodontosaurus 588 .

Thelodus 30, 67, 70, 72, 73, 75 .

Theosodon 794,852 .

Theridomys 786 .

Theromus 423 .

Theropleura 364 .

Thinocyon 737 .

Thoatherium 794, 852.

Thoracopterus 210.

Thoracosaurus 553 .

Thunnus 115 .

Thursius 162 .

Thyestes 71, 73, 74, 76, 77, 78 .

Thylacinus 711, 713 .

Thylacoleo 716, 717 .

Thyrsidium 226, 304.

Titanotherium 868.

Titanichthys 98, 100, 102.

Ticholeptus 805, 806.

Tillotherium 728 .

Tinoceras 818 .

Tinodon 719 .

Tomistoma 546, 553, 554, 555.

Toretocnemus 474

Torosaurus 651.

Torpedo 126.

Toxochelys 395, 399, 400, 401.

Toxodon 848, 849, 850 .

Toxoprion 137, 138.

Trachodon 616, 635, 636, 637, 638, 639, 640,641 .

Trachelosaurus 483.

Trechomys 786 .

rremataspis $71,78,79,80$.

Trematops 233, 249, 252, 256, 257, 258, 278, 279.

Trematosaurus 238, 241, 252, 270, 285.

Triacanthodon 719 . 
Triassochelys $374,375,376,377,378$, $381,382,384,385,386,387,388,389$, $390,391,392$.

Tribelesodon 561.

Tribolodon 717, 718.

Tricentes 733 .

Triceratops 577, 614, 647, 648, 650, 651, 652.

Tricleidus 497.

Triconodon 712, 718 .

Triglyphus 712 .

Trigonostylops 851 .

Trimerorhachis $220,222,236,237,244$, 252, 274, 275, 332 .

Trinacromerum 482, 499, 502, 503, 504 .

Trionyx 381, 414.

Trissolepis $186,189$.

'Tristichopterus 164, 165.

Tritemnodon 735 .

Tritylodon 712, 714, 715 .

Trogon 707.

Tropidonotus 682 .

Trygon 126, 128, 130, 131.

Tupaia 726.

Tupinambis 658 .

Tylosaurus 665, 666, 667, 668, 671, 677, 679.

Typhlomolge 267.

Typotherium 848.

Tyrannosaurus 578, 585, 591, 593, 599, $600,601,602,603,604$.
Udenodon 435, 436, 439, 440, 441, 443.

Uintacyon 739 .

Uintatherium 818.

Undina 158, 159, 167, 169.

Urocordylus 229, 263, 266, 304 .

Urolophus 128.

Uromastix 658 .

Uronemus 174, 175, 176, 181.

Ursavus 745 .

Ursus 746 .

Varanops 360, 362.

Varanosaurus 352, 362, 363, 472.

Vespertilio 729 .

Vesperugo 729.

Vulpavus 739.

Wasatchia 799.

Wortmania 773

Wynyardia 716 .

Xenopus 227, 265.

Xenorhynchus 692.

Xenotherium 728 .

Xiphodon 808.

Zanclodon 584, 585, 588.

Zatrachys 237, 238, 239, 248, 249, 281, 282.

Zeuglodon 750, 751, 752. 


\section{Autorenregister.}

Agassiz, L. 63.

Albrecht, P. 537.

Alcock, A. 129.

Alexejew, A. 813, 814.

Allen, G. M. 778 .

-, J. A. 708 .

Allis, E. P. 37, 39, 40, 44.

Alth, von A. 84

Alton, E. de 542 .

Ameghimo, C. 844.

Ameghino, F. 183, 701, 715, 716, 719, $720,721,745,746,775,776,778,785$, $786,749,799,844,845,846,847,848$, $850,851,852,853,877$.

Ammon, L. von 144, 146, 271, 446, 546. 549, 562, 563, 708.

Andreae, A. 446.

Andrews, C. W. 394, 467, 468, 471, 777, $480,492,495,498,499,501,534,542$, $543,544,54$ ๖, 546, 550, 552, 553, 554, $683,697,698,700,703,705,706,707$, $735,748,751,785,819,820,821,822$, $823,826,829,834$.

Antonius, O. 864, 866.

Arldt, Th. 874

Assmann, P. 212.

Atthey, Th. 152, 180, 181, 284, 285.

Auer, E. 541, 542, 543.

Auinger, M. 11.

Bassani, F. 561.

Bater, F. 461, 463.

Baur, G. 62, 236, 360, 476, 477.

Beasley, W. L. 598.

Beebe, C. W. 697.

Boas, J. E. V., 61, 249, 250, 251, 313, $314,315,316,317,334,382,659,716$. Boule, M. 860 .

Boulenger, G. A., 157, 413, 446, 447, 448, 449, 477, 489.

Branca, W. 468.
Brandt, J. F. 761, 762, 835, 860.

Branson, E. B. 101, 285, 346.

Bresslau, E. 711.

Bridge, T. W. 59, 78, 155, 269.

Broili, F. 231, 234, 236, 242, 273, 275 , $280,287,329,347,362,458,463,464$. $465,473,477,483,505,506,507,512$, 567,675 .

Brongniart, Ch. 118.

Bronn, H. G. 542.

Broom, R. 168, 182, 189, 209, 210, 211 , $234,235,236,238,239,240,241,244$, 245, 274, 276, 277, 281, 282, 287, 294. $342,348,349,350,351,356,357,368$, $369,370,416,417,419,420,422,423$, $424,425,426,427,428,429,430,431$, $432,433,440,442,443,448,526,527$. $529,656,660,714,717,718$.

Brown, B. $450,576,632,633,634,635$, $637,651,653,778$.

Browne, M. 196.

Bruch, C. 39, 46, 57.

Brühl, C. B. 45, 57, 58.

Buckley 152, 162.

Buechner, E. 835.

Burckhardt, R. 446.

Burmeister, H., 285, 542, 778, 780.

\section{Canu 8.}

Capellini, G. 403, 559, 555, 790, 827, $834,838$.

Case, E. C., 256, 271, 277, 281, 294, 305, $311,326,329,338,339,340,341,345$, $346,347,348,349,356,358,359,360$, $362,363,364,365,366,367,368,370$, $371,372,374,761,763,839$.

Claus 681 .

Claypole, E. W. 86, 116.

CockereIl, T. D. A. 778.

Cole, F. J. 50.

Conybeare, W. D. 495. 
Cope, E. D. 87, 165, 197, 207, 236, 237, $266,304,307,309,330,412,476,553$, $581,677,715,725,728,737,738,773$, $774,793,796,797,799$.

Credner, H. 295, 296, 309, 361.

Cuvier, G. 57, 719.

Dacqué, E. 9, 10.

Dal Piaz G. 763, 766.

Dames, W. 446, 489, 692, 703, 751, 813.

Darwin, Ch. 2, 8, 11 .

Davis, J. W. 118.

Dawson, J. W. 309, 345.

Dean, B. 86, 98, 100, 102, 115, 116 , $120,140,141,142,143,158,170,217$.

Dederer, P. H. 716.

Deecke, W. 489.

Delfortrie, E. 834.

Depéret, Ch. 739, 801, 854.

Deslongschamps-Eudes, J. A., 542, 543.

Dietrich, W. O. 829 .

Doederlein 12.

Dollo, L. $82,104,154,155,171,174$, $175,176,178,184,197,208,220,328$, $330,395,399,401,404,406,414,451$, $543,549,615,623,635,626,627,629$, $631,632,634,651,653,667,669,670$, $672,675,677,678,704,717,733,835$.

Duuglass, E. 728, 805, 807, 862.

Drevermann, F. 127, 285, 470, 484, 510, $513,540,542,651,745,746,795$.

Earle, Cl1. 715, 733.

Eastman, C. R. 93, 101, 102, 103, 104 , $109,133,168,189,207$.

Eaton, G. F. 573, 574, 575.

Egerton, P. G. 152.

Emerson, K. B. 532.

Etheridge, R. 414.

Fejerváry, A. M. von 260, 319.

Felix, J. 828.

Fillol, H. 739, 785, 800, 812, 855, 869.

Finney, M. 329.

Fischer, E. 483.

Flower, W. H. 717, 765.

Forster-Cooper, C. 802.

Forsyth-Major, C. 1. 802, 814, 819.

Fraas, E. 125, 142, 144, 242, 243, 287 , $290,291,292,293,387,393,396,398$, $399,409,410,411,454,457,458,460$, $461,463,469,476,477,479,494,495$, $496,498,500,519,521,522,530,531$. $532,546,547,548,581,588,589,591$, $613,749,751$.

Fraas, O. 525, 532, 567, 714, 812, 866.
Fritsch, A. 189, 261, 275, 294, 296, 299. $302,304,309,370,372$.

Fuirbringer, M. 698.

Gadow, H. 222, 226, 227, 318.

Gaillard, C. 708.

Gaudry, A. 273, 274, 741, 814, 815, 844, $851,852,860$.

Gaupp, E. 237, 238, 246, 313, 317, 318.

Gegenbaur, C. 31, 59, 111, 246.

Geikie, A. 162.

Gervais, P. 848, 869.

Gidley, J. W. 207, 715, 720, 864.

Gilmore, Ch. W. 552, 611, 617, 619, 620, $621,622,624,629,639,642,644,645$, $805,806$.

Goethe, J. W. von 31 .

Goette, A. 377.

Goodrich, E. S. 22, 23, 27, 33, 37, 38, $39,40,41,42,43,44,45,49,50,52$, $53,55,59,70,78,100,143,158,214$, 216.

Gorjanovič-Kramberger, K. 200, 201, 673.

Grabbe, A. 412.

Grandidier, G. 876.

Granger, W. 707.

Grassi, B. 56.

Gray, J. E. 185.

Gregory, W. K. 36, 423, 425, 428, 430, 874.

Gïnther, A. 34, 182.

Hafferi, F. 694.

Hallmann, E. 57.

Hancock, A. 152, 180, 181, 284, 285.

Hartlaub, C. 835.

Harvie-Brown 152, 162.

Hasse, C. 27, 110, 120.

Hatcher, J. B. 585, 611, 612, 613, 747, $858,859$.

Hatschek, B. 728.

Hauff, B. 479.

Haug, E. 182.

Haughton, S. H. 242, 285.

Hauthal, R. 778.

Hay, O. P. $67,138,163,180,189,401$, $411,477,597,598,647,651,741,746$, $761,773,797,809,818,828,839,854$, $855,861,862$.

Hébert, E. 704.

Heckel, J. J. 207.

Hector, J. 751 .

Heilmann, G. 524, 526, 527, 528, 529, $578,617,697$.

Hennig, E. 200, 202, 205, 207, 606, 645.

Hertwig, O. 233, 244. 
Hertwig, R. 9 .

Hescheler, K. 813.

Hoernes, R. 11.

Hoffmann, 92.

Hofmann, A. 855.

Holland, W. J. 549, 550, 608, 609, 611, $869,872$.

Hollard, M. 57.

Hooley, R. W. 549, 567, 570, 571, 573. Horsefall, R. B. 802.

Howes, G. B. 445.

Howse, 237.

Hubrecht, 112.

Huene, F. von 234, 241, 253, 274, 277, $281,292,305,327,329,352,353,354$, $356,360,370,373,374,375,422,443$, $444,449,452,464,468,471,472,473$, $474,508,512,513,514,515,517,519$, $520,522,524,525,528,529,530,537$, $538,560,571,572,576,578,580,581$, $582,583,584,585,589,590,591,595$, $596,613,617,637,643,647,651,662$, 663, 667, 668, 671, 677.

Hulke, J. W. 549, 646.

Hussakof, L. 33, 99, 101, 147, 165, 179, $181,207$.

Huxley, Th. H. $31,53,58,162,281$, 283, 284, 304, 308, 446, 519, 534, 646.

Ihering, H. von 746 .

lwasaki, J. 830, 831 .

Jaekel, O. 8, 9, 34, 65, 67, 75, 76, 77, $78,79,80,86,87,88,92,93,94,95$, $96,97,99,101,102,104,105,112,113$, $116,118,131,134,135,137,143,146$, $147,149,152,164,165,200,223,226$, $236,237,255,258,272,275,285,286$, $288,289,291,299,300,301,309,310$, $370,374,375,376,377,378,379,381$, $382,385,386,387,388,389,390,391$, $392,408,436,437,441,443,444,446$, $447,462,469,475,477,485,486,489$, $490,508,509,510,511,512,512,517$, $519,537,558,566,585,586,588,589$, $591,592$.

Jaffé, G. 548.

Jakob 778.

Janensch, W. 613, 614, 683, 684, 828.

Kail, J. A. 553.

Karpinsky, A. 138, 139.

Kaup, J. J. 542, 869.

Khomenko, J. 814.

Kiacr, J. 3, 66, 69, 70, 77.

Kiernik, E. 812.

KittI, E. 745.
Klein, von 58.

Kner, R. 168.

Knight, W. C. 183.

Koch, A. 857.

König, F. 479, 562 .

Köstlin, O. 57.

Koken, E. 71, 99, 119, 489, 553.

Koninck, L. G. de 178.

Kormos, Th. 725, 726.

Kornhuber, A. 664, 673, 674.

Kowalevsky, W. 802, 804, 810.

Kiikenthal, W. 756.

Lambe, L. M. 189, 552, 583, 599, 637, $640,647,649,650,651,708,746,862$.

Lambrecht, K. 709.

Lartet, E. 834.

Laube, G. C. $330,331$.

Lankester, E. R. 76, 78, 100, 151.

Lartet, E. 830.

Lebedinsky, N. G. 587.

Lehmann-Nitsche, R. 778.

Leidy, J. 503, 679, 725, 776, 805.

Lemoine, V. 451, 704, 715, 727, 733.

Lepsius, R. 834.

Leriche, M. 78, 82, 83, 86, 122, 123, 136, 146, 202.

Linné $6,9,10,12$.

Lindström, G. 86.

Loennberg, E. 778 .

Loomis, F. B. 532, 844.

Lorenz, L. von $835,876$.

Lortet, L. 398, 449, 549.

Lucas, F. A. 683, 858.

Ludwig, R. 553.

Lull, R. S. $581,595,647,723,778,862$, 863.

Lund, P. V. 775.

Lydekker, R. 386, 404, 412, 477, 494, $713,761,764,766,775,776,777,778$, $779,780,781,783,784,848,849,850$, 851,853 .

Maack, G. A. 398, 411.

Mc Gregor, J. H. 452, 453, 520, 522, 523.

Mc Murrich, J. P. 58.

Marsh, O. C. $183,529,532,562,583$, $596,598,611,617,618,637,643,647$, $648,651,697,703,707,714,719,728$, $811,817,818,830,858,863,870$.

Martin, R. 697.

Matthew, W. D. 360, 361, 584, 585, 611, $613,618,650,653,707,712,725,728$, $732,733,743,737,739,740,742,743$, $744,746,775,796,799,802,805,806$, $809,810,815,835$. 
Mawson, J. 169.

Mehl, M. G. 267, 311.

Mehnert, E. 587.

Merriam, J. C. 462, 473, 474, 475, 661, $662,677,815$.

Meschinelli, L. 729 .

Meyer, H. von 241, 242, 273, 275, 330, $331,332,398,405,519,549,562,567$, 664 .

Miall 234.

Moodie, R. L. 62, 221, 261, 271, 296, $305,309,653$.

Mook, Ch. C. 611.

Moreno, F. P. 778.

Morton, H. G. 579.

Müller, J. 44.

Negri, A. 414.

Neumayr, M. 10, 11, 12, 714 .

Newberry, J. St. 102, 104, 165, 166, 167.

Newton, E. T. 147, 167, 348, 349, 350, 437, 443, 526, 528, 529, 562, 704.

Nopcsa, F. von 524, $443,576,578,579$, $580,583,605,613,616,617,618,632$, $634,645,646,651,653,661,664,673$, 674.

Nordenskjöld, E. 778 .

-, O. 751 .

0ertel, W. 398, 401.

Oldham, Th. 183.

Oken, L. 31.

Osborn, H. F. 370, 503, 535, 583, 584, $596,597,598,599,600,601,602,603$, $604,608,611,635,637,638,639,641$, $665,677,689,714,715,718,719,722$, $724,727,733,735,737,738,776,777$, $788,797,798,799,802,803,805,811$, $818,830,856,858,859,860,861,862$, $863,867,868,869,871$.

Owen, R. 57, 121, 161, 247, 412, 413, $422,423,425,439,440,458,476,477$, $494,549,557,561,613,639,664,683$, $704,714,717,778,835,861$.

Pander, Ch. H. 104, 161, 177, 178.

Paris, P. 708.

Parker, G. H. 269.

Parker, W. K. 48, 58, 670, 682.

Patten, W. 78, 79.

Paul, C. M. 10.

Pavlow, M. 824, 856.

Peterson, O. A. 800, 858, 869, 872.

Philippi, E. 146, 778.

Pilgrim, Guy E. 802, 814, 815.

Plate, L. 12.

Plieninger, F. 562, 567, 574.

A bel, Stämme der Wirbeltiere.
Plieninger, Th. 714.

Pohlig, H. 828.

Pomel, A. 553.

Pompecki, J. F. 330.

Portis, A. 398.

Power, 268.

Powrie, J. 151, 152.

Priem, F. 202, 207.

Prosser, C. S. 777.

Quenstedt, F. A. 243, 459.

Rabl, C. 380, 381, 382, 383, 384.

Redlich, K. A. 553.

Reichenau, W. 746.

Reinhardt, J. 778.

Reis, O. M. $142,147,148,149,150,152$. 168, 169, 194, 195, 212.

Repossi, E. 473.

Revilliod, P. 72?.

Reynolds, S. H. 29, 47, 59, 107, 108, $111,112,121,537,538$.

Riabinin, A. 501.

Ridewood 557.

Riggs, E. S. 613.

Rochebrune, A. T. de 685.

Rodler, A. 815.

Roemer, F. 685.

Roger, O. 743, 747, 800, 801, 809, 829.

Rogers, A. W. 424.

Rohon, J. V. 79, 165.

Roman, F. 856, 857, 858, 859.

Roth, S. 778.

Ruetimeyer, L. 398, 411, 774.

SagemehI, M. 38, 56, 59.

Schaninsland, H. 24, 63.

Schellwien, E. 198, 200.

Schlesinger, G. 827, 828.

Schlosser, M. 725, 726, 735, 738, 741, $745,746,747,786,803,809,812,813$, $815,818,819,325,826,862,864,865$ ، 869,874 .

Schmidt, F. 78.

-, M. 802, 804.

Schmidtgen, O. 834,840 .

Schroeder, H. 236, 287.

Schwarz, H. 229, 230, 231， 259，261, 302, 304, 307, 308, 309.

Scott, W. B. 726, 734, 735, 773, 780, $800,802,808,811,844,851,852,855$, $856,863$.

Seeley, H. G. $182,350,373,405,422$, $423,425,451,487,537,561,571,581$, $664,714,718$.

Sefve, 1. $776,852,864$.

Semon, R. 172, 173, 183, 185.

Sherborn, C. D. 152. 
Shufeldt, R. W. 58, 697, 703, 705, 706, 707.

Siebenrock, F. 59.

Sinclair, W. J. 719, 799, 805, 807, 847.

Skuphos, Th. 489.

Smith, B. 96.

Soergel, W. 741, 746, 825, 828 .

Sollas, J. B. J. 98, 99, .443.

Sollas, W. J. 98, 99, 443, 494.

Spencer, B. 716.

Spener, Ch. M. 451.

Stache, G. 399.

Stannius, H. 57.

Stappenbeck, R. 341, 342.

Stefano, G. die 330, 679.

Stehlin, H. G. 727, 774, 789, 799, 800, $801,802,803,804,808,854,861,865$, $866,873,874,875$.

Stejneger, L. 835.

Steller 833.

Stellwaag, F. 695.

Sternberg, Ch. H. 641.

Stirling, E. C. 717.

Stromer, Freiherr v. Reichenbaclı E. 74, $93,119,170,171,183,198,453,477$, $550,551,559,562,604,605,751,814$, 834.

Swinnerton, H. H. 237, 445.

Talbot, M. 581 .

Teller, F. 182.

Teppner, W. 414, 858.

Thévenin, A. 274, 296, 543.

Thiollière V. 207.

Thomas, O. 556, 716 .

Thomson, A. 185.

Toula, F. 553, 747, 823.

Traquair, R. H. $54,62,65,68,71,72$, $73,80,81,83,86,88,89,91,92,97$. $98,99,102,106,112,114,116,118$, $129,131,134,152,153,162,163,164$, $165,166,167,175,180,181,187,188$, $189,190,191,192,193,194,196,200$, 202, 204, 206, 207, 210, 211.

Trouessart, E. L. 734, 747, 811, 828, 829. True, F.W. 751, 766, 767, 771, 772.

Valenciennes, M. 57.

Van Beneden, P. J. 178, 760, 762.

Versluys, J. 350, 377, 406, 458, 574, $593,598,608,624,658,659,667,670$, $681,688,690 ; 691,692$.

Voelker, H. 406, 407.

Volz, W. 487, 489.

Vries, de H. 10.

Vrolik, A. J. 58.
Waagen, W. 9, 10, 11.

Wagner, A. 204, 542, 562, 567, 583.

Wanderer, K. 562.

Watson, D. M. S. 242, 244, 281, 284, $285,301,302,303,362,415,419,420$, $421,422,423,425,427,429,433,434$, $435,436,438,439,443,548$.

Weber, M. 269.

Wegner, Th. 499.

Weithofer, A. $745,815$.

Werner, F. 266, 311.

Werth, E. 874.

Whiteaves, J. F. 165, 166.

Wiedcrsheim, R. 59.

Wieland, G. R. 232, 399, 400, 401, 402, $403,653$.

Willcox, M. A. 216.

Williston, S. W. 181, 182, 207, 223, 225, $244,254,256,258,274,275,276,277$. $278,279,280,281,294,305,300,311$. $327,328,329,335,336,337,339,340$, $341,342,343,344,345,346,347,348$, $349,355,356,360,361.362,363,364$. $365,360,367,368,370,451,499,500$, $502,503,504,571,572,574,653,654$. $655,675,676,697$.

Wiman, C. $235,243,253,277,285,287$, 288, 289, 292, 461, 464, 465, 473, 702, 751 .

Winge, H. 711, 718, 726, 727, 728, 775, $778,780,863$.

Winkler, T. C. 403, 562, 567.

Woodward, A. S. $42,43,66,74,75,76$, $78,83,118,124,133,134,136,139$, $142,143,145,146,147,148,151,152$, $158,162,167,169,177,182,183,189$, $190,195,196,200,201,202,203,204$, $207,214,218,285,287,292,298,299$, $350,412,413,419,425,448,458,515$, $532,549,561,597,602,613,683,714$, 717,778 .

Wortman, J. L. 727, 734, 736, 737, 746, $773,774,802,805,808,854,856,859$.

Wright, R. R. 56.

Wyman, J. 221, 296.

Yakovlew, N. 675.

Yoshiwara, S. 830, 831.

Zietz, A. H. C. 717 .

Zigno, A. de 834.

Zittel, K. A. von 71, 99, 142, 152, 169 . $217,226,285,330,386,398,458,459$, $479,488,549,562,567,583,675,782$, 829. 
14 

